\title{
All101 l10109
}

NATL INST OF STANDARDS \& TECH R.IC.

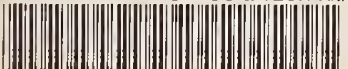







National Bureau of Standards

Library. E-01 Admin. Bidg.

OCT 1 198?

191018

QC

160

PUBILCATIONS
OF THE NATIONAL
BUREAUJ OF STANDARDS

457

\section{U.S. DEPARTMENT OF COMMERCE}

NBS SPECIAL PUBLICATION 305/SUPPIEMENT 11

\section{CATALOG}
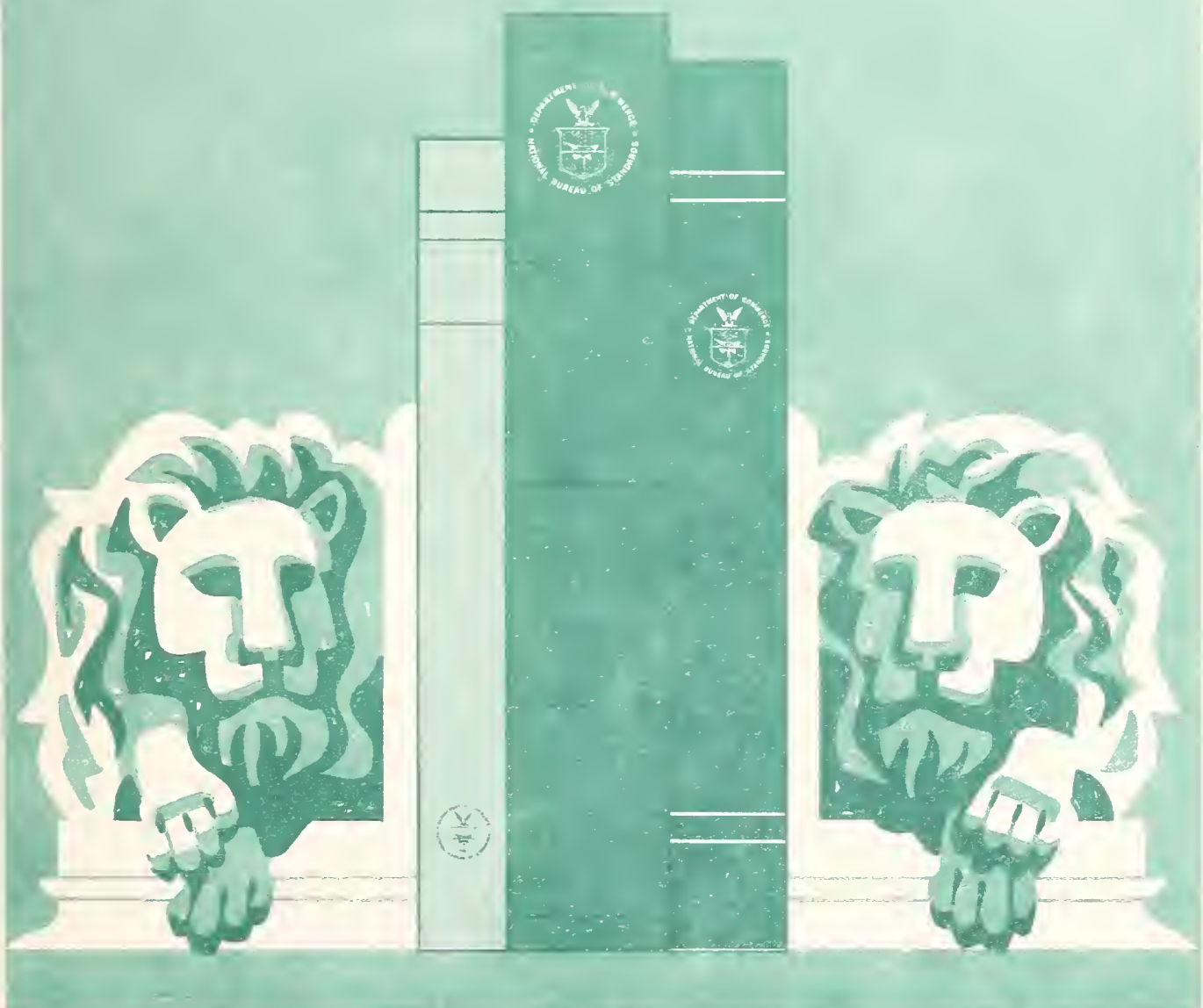


\section{NATIONAL BUREAU OF STANDARDS}

The Nicicna! Bureau of Standards' was established by an act of Congress on March 3, 1901. The Bureau's verall goal is to strengthen and advance the Nation's science and technology and facilitate their effective application for public benefit. To this end, the Bureau conducts research and provides: (1) a basis for the Nation's physical measurement system, (2) scientific and technological services for industry and government, (3) a technical basis for equity in trade, and (4) technical services to promote public safety. The Bureau’s technical work is perrormed by the National Measurement Laboratory, the National Engineering Laboratory, and tre Institute for Computer Sciences and Technology.

THE NATIONAL MEASUREMENT LABORATORY provides the national system of physical and chemical and materials measurement; coordinates the system with measurement systems of other nations and furnishes essential services leading to accurate and uniform physical and chemical measurement throughout the Nation's scientific community, industry, ind commerce: conducts materials research leading to improved methods of measurement, standards, and data on the properties of materials needed by industry, commerce, educational isstitutions, and Government: provides advisory and research services to other Government yencies; develops, produces, and distributes Standard Reference Materials; and provides calibration services. The Laboratory consists of the following centers:

Absolute Physical Quantities ${ }^{2}$... Radiation Research — Thermodynamics and Molecular Science — Analytical Chemistry - Materials Science.

THE NATIONAL ENGINEERING LABORATORY provides technology and technical ser:ices to the public and private sectors to address national needs and to solve national roblems; conducts research in engineering and applied science in support of these efforts; builds and maintans competence in the necessary disciplines required to carry out this research and lechnical service; develops engineering data and measurement capabilities; provides engineering measurement traceability services; develops test methods and proposes sngineering standards and code changes; develops and proposes new engineering practices: und develops and improves mechanisms to iransfer results of its research to the ultimate user. The Laboratory consists of the following centers:

Applied Mathematics - Electronics and Electrical Engineering- - Mechanical Encineering ald Process Technology - Building Technology - Fire Research Consumer Product Technology — Field Methods.

THE INSTITUTE FOR COMPITER SCIENCES AND TECHNOLOGY conducts research and provides scientific and technical services to aid Federal agencies in the selection, requisition. application, and use of computer technology to improve effectiveness and sconomy in Government operations in accordance with Public Law $89-306$ (40 U.S.C. 759), relevant Executive Orders, and other directives; carries out this mission by managing the Federal Information Processing Standards Program, developing Federal ADP standards guidelines, and managing Federal participation in ADP voluntary standardization activities; En ides scientific and technological advisory services and assistance to Federal agencies; and provides the technical foundation for computer-related policies of the Federal Government. the Institute consists of the following centers:

Programming Science and Technology - Computer Systems Engineering.

He. dq arters and Laboratorses at Gaithersburg, MD, unless otherwise noted:

7uling ddress Washington, DC 20234.

Sune divisions within the center are located at Boulder, CO 80303. 


\section{Publications of the National Bureau of Standards}

1979 Catalog

\section{A Compilation of Abstracts and Key Word and Author Indexes}

Betty L. Burris and Rebecca J. Morehouse, Editors

Technical Information and Publications Division

National Bureau of Standards

Washington, D.C. 20234

\section{Dedicated with Appreciation \\ to \\ WILLIAM REEVES TILLEY}

Who retired in February 1980 as Chief of the NBS Technical Information and Publications

Division after 34 years of service to the

National Bureau of Standards

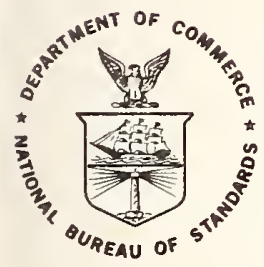

U.S. DEPARTMENT OF COMMERCE, Philip M. Klutznick, Secretary Luther H. Hodges, Jr., Deputy Secretary Jordan J. Baruch, Assistant Secretary for Productivity, Technology and Innovation NATIONAL BUREAU OF STANDARDS, Ernest Ambler, Director 


\section{Library of Congress Catalog Number: 48-47112}

\section{National Bureau of Standards Special Publication 305 Supplement 11}

To Accompany National Bureau of Standards Special Publication 305; and its Supplements 1 through 10 Nat. Bur. Stand. (U.S.), Spec. Publ. 305 Suppl. 11, 615 pages (Feb. 1980)

CODEN: XNBSAV

Issued February 1980 


\section{PREFACE}

NBS research and technical service activities cover a wide range of subjects in physics, chemistry, engineering, mathematics, and computer sciences. These are related to the specific program areas listed on the inside cover of this catalog. Publications are an important way to communicate the results of these diverse activities to the equally diverse audiences served by the Bureau. In 1979, over 37,000 pages were published by NBS in 1,000 papers. These appeared in the Bureau's own publications series and in non-NBS journals, books, and proceedings.

All papers are cited by full title, author(s), place of publication, abstract, and key words. Permuted author and key word indexes facilitate use of the listings, as does the edge index on the back cover. Citations for papers published in the Bureau's formal program are organized by NBS publications series. NBS-authored papers in non-NBS media are cited separately in numerical sequence. In addition, for the convenience of specialists, the titles of all NBS publications for 1979, categorized by major primary subject area, are listed in a special section.

NBS papers published by the U.S. Government Printing Office are sold in paper copy by the Superintendent of Documents, and in microcopy by the National Technical Information Service (NTIS). The NBS Federal Information Processing Standards Publications (FIPS PUBS) and National Bureau of Standards Interagency Reports (NBSIR's) are sold only by NTIS, both in paper and microcopy form. This issue also contains information on previous NBS catalogs and on the availability of NBS papers published in past years. Also included for completeness are those NBS papers published prior to 1979 but not reported in previous issues of this annual catalog. Like NBS catalogs since 1966 this 1979 compilation has been produced by means of computer-assisted photocomposition. This is the third annual supplement issued since the publication of an 11-year consolidated NBS publications catalog covering the period 1966-76. This consolidation, Special Publication 535, Volumes 1 and 2 are cited on page 9 .

W. R. Tilley

Chief, Technical Information and Publications Division

February 1980 


\section{CONTENTS}

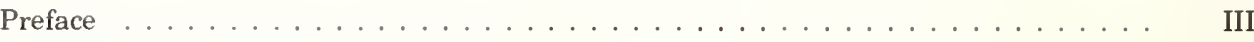

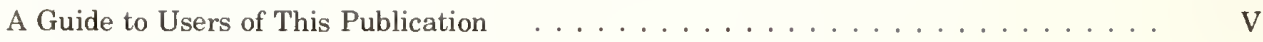

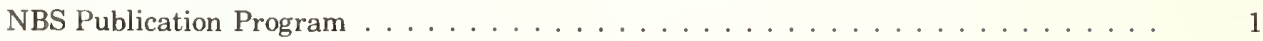

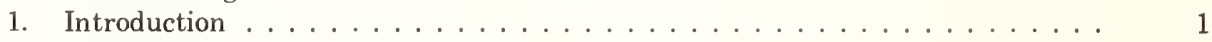

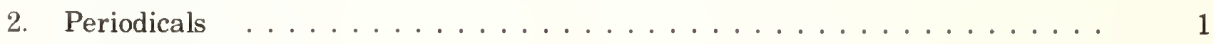

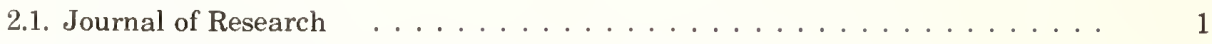

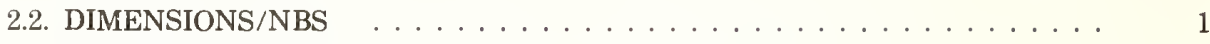

2.3. Journal of Physical and Chemical Reference Data (JPCRD) . . . . . . . . . 1

3. Nonperiodicals ... . . . . . . . . . . . . . . . . . . . . . . . . . . . . . . . 1

3.1. NBS Interagency Reports . . . . . . . . . . . . . . . . . . . . . . . . . . . . 2

3.2. Grantee/Contractor Reports and NBS Patents . . . . . . . . . . . . . . . . . 2

3.3. NBS Bibliographic Subscription Services . . . . . . . . . . . . . . . . . . . . . . 3

3.4. Papers Published by Others . . . . . . . . . . . . . . . . . . . . . . . . . . 3

4. Purchase Procedures and Document Availability . . . . . . . . . . . . . . . . . . . . . . .

4.1. Purchase Procedures ... . . . . . . . . . . . . . . . . . . . . . . . . . . . 3

4.2. Announcements of NBS Publications . . . . . . . . . . . . . . . . . . . 4

4.3. Catalogs of NBS Publications ... . . . . . . . . . . . . . . . . . . . . . 4

4.4. Functions of Depository Libraries in the United States . . . . . . . . . . . . . . . 5

4.5. Functions of U.S. Department of Commerce District Offices . . . . . . . . . 5,

4.6. Availability of NBS Publications . . . . . . . . . . . . . . . . . . . . . . . . 6

A. Periodical Subscription Rates . . . . . . . . . . . . . . . . . . . . . 6

B. Superseded NBS Reference Publications . . . . . . . . . . . . . . . . . . . 6

C. Price Lists for Nonperiodicals . . . . . . . . . . . . . . . . . . . . . . . . . 8

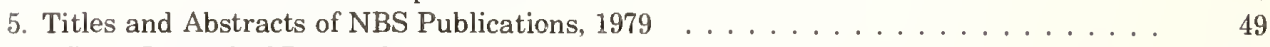

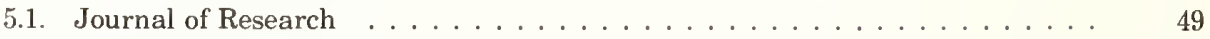

5.2. Journal of Physical and Chemical Reference Data . . . . . . . . . . . . . . . . 53

5.3. DIMENSIONS/NBS, article titles only . . . . . . . . . . . . . . . . . . . 57

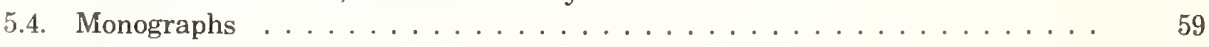

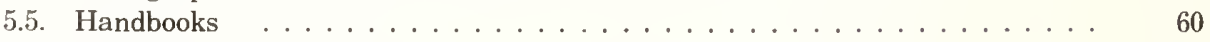

5.6. Special Publications ... . . . . . . . . . . . . . . . . . . . . . . . . . . . . . . . . . .

5.7. Applied Mathematics Series . . . . . . . . . . . . . . . . . . . . . . . . . . . 144

5.8. National Standard Reference Data Series . . . . . . . . . . . . . . . . . . . . . . . 145

5.9. Building Science Series . . . . . . . . . . . . . . . . . . . . . . 146

5.10. Federal Information Processing Standards Publications . . . . . . . . . 148

5.11. Voluntary Product Standards . . . . . . . . . . . . . . . . . . . . . . . 149

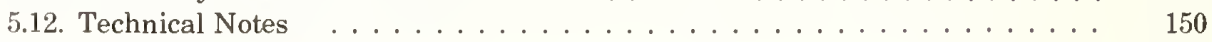

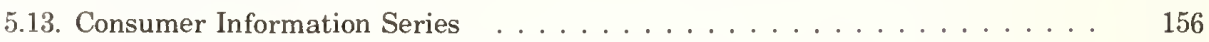

5.14. NBS Interagency Reports . . . . . . . . . . . . . . . . . . . . . . . . . . . . . . . . . . . . . . . . . . . . . . . .

5.15. Grantee/Contractor Reports and NBS Patents . . . . . . . . . . . . . . . 181

6. Titles and Abstracts of Papers Published in Non-NBS Media, 1979 . . . . . . . 195

7. Listing of NBS Papers by Major Subject Areas . . . . . . . . . . . . . . . . . . . . . . . . . . . . . . . . . .

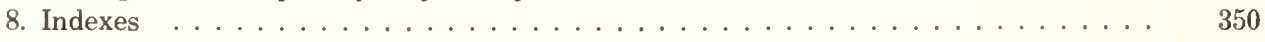

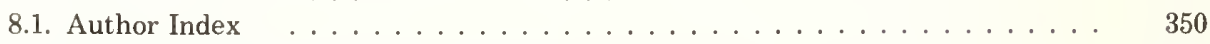

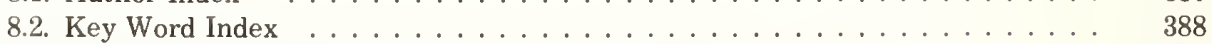

Appendix A. List of Depository Libraries in the United States . . . . . . . . . . . 590

Appendix B. List of District Offices of the U.S. Department of Commerce . . . . . . . 604 


\section{A GUIDE TO USERS OF THIS PUBLICATION}

In addition to the usual author index, a subject index is provided in the form of a permuted key word index. In this type of index the key words in each publication or paper are arranged by shifting each group of key words along the horizontal printing line so that each key word in turn has an opportunity to appear alphabetically. The user is thus able to locate papers of interest through the subject-related words in the key word index.

The index symbols used in the author and key word indexes are explained in the following three tables. These tables also give the pages on which the abstracts of the various publication series begin.

\section{SYMBOLS FOR NBS PUBLICATIONS}

A. Symbols for the Periodicals

\begin{tabular}{|c|c|c|c|c}
\hline \hline \multirow{2}{*}{} & \multicolumn{2}{|c|}{ Index Symbol } & \multicolumn{1}{c|}{ Issue Date } & $\begin{array}{c}\text { Page } \\
\text { Number }\end{array}$ \\
\cline { 2 - 4 } & Vol. & No. & 1979-Bimonthly & \\
& J. Res. 84 & 1 & January-February & 49 \\
J. Res. 84 & 2 & March-April & 49 \\
NBS Journal & J. Res. 84 & 3 & May-June & 50 \\
& J. Res. 84 & 4 & July-August & 50 \\
& J. Res. 84 & 5 & September-October & 51 \\
& J. Res. 84 & 6 & November-December & 52 \\
\hline
\end{tabular}

\begin{tabular}{|c|c|c|c|c|c|c|}
\hline & & & \multicolumn{2}{|c|}{ Index Symbol } & \multirow{2}{*}{$\begin{array}{c}\text { Issue Date } \\
\\
1979 \\
1979 \\
1979 \\
1979\end{array}$} & \multirow{2}{*}{$\begin{array}{c}\begin{array}{c}\text { Page } \\
\text { Number }\end{array} \\
\\
53 \\
53 \\
55 \\
56\end{array}$} \\
\hline \multicolumn{3}{|c|}{$\begin{array}{c}\text { Journal of Physical } \\
\text { and } \\
\text { Chemical Reference Data }\end{array}$} & $\begin{array}{l}\text { Vol. } \\
\text { JPCRD } 8 \\
\text { JPCRD } 8 \\
\text { JPCRD } 8 \\
\text { JPCRD } 8\end{array}$ & $\begin{array}{c}\text { No. } \\
1 \\
2 \\
3 \\
4\end{array}$ & & \\
\hline & \multicolumn{2}{|c|}{ Index Symbol } & \multicolumn{3}{|c|}{ Issue Date } & $\begin{array}{c}\text { Page } \\
\text { Number }\end{array}$ \\
\hline DIMENSIONS/NBS & $\begin{array}{l}\text { Vol. } \\
\text { DIM/NBS } 63 \\
\text { DIM/NBS } 63 \\
\text { DIM/NBS } 63 \\
\text { DIM/NBS } 63 \\
\text { DIM/NBS } 63 \\
\text { DIM/NBS } 63 \\
\text { DIM/NBS } 63 \\
\text { DIM/NBS } 63 \\
\text { DIM/NBS } 63 \\
\text { DIM/NBS } 63\end{array}$ & $\begin{array}{c}\text { No. } \\
1 / 2 \\
3 \\
4 \\
5 \\
6 \\
7 / 8 \\
9 \\
10 \\
11 \\
12\end{array}$ & \multicolumn{3}{|c|}{$\begin{array}{l}\text { 1979-10 issues per year } \\
\text { January/February } \\
\text { March } \\
\text { April } \\
\text { May } \\
\text { June } \\
\text { July/August } \\
\text { September } \\
\text { October } \\
\text { November } \\
\text { December }\end{array}$} & $\begin{array}{l}57 \\
57 \\
57 \\
57 \\
57 \\
57 \\
58 \\
58 \\
58 \\
58\end{array}$ \\
\hline
\end{tabular}


B. Symbols for the Nonperiodicals

\begin{tabular}{l|l|c}
\hline \hline \multicolumn{1}{c|}{ NBS Nonperiodical Series } & \multicolumn{1}{|c|}{ Index Symbol } & Page Number \\
\hline Monographs & Monogr. & 59 \\
Handbooks & H & 60 \\
Special Publications & SP & 61 \\
Applied Mathematics Series & AMS & 144 \\
National Standard Reference Data Series & NSRDS & 145 \\
Building Science Series & BSS & 146 \\
Federal Information Processing Standards & FIPS PUBS & 148 \\
Publications & & 149 \\
Voluntary Product Standards & PS & 150 \\
Technical Notes & TN & 156 \\
NBSumer Information Series & CIS & 157 \\
Grantee/Contractor Reports and Patents & NBSIR & 181 \\
\hline
\end{tabular}

C. Symbols for the Papers Published by Non-NBS Media (1979)

\begin{tabular}{c|c|c}
\hline \multicolumn{1}{c|}{ NBS Papers Published by Others } & Index Symbol & Page Number \\
\hline $\begin{array}{l}\text { Professional Journals, Books, Book Chapters, } \\
\text { Proceedings, etc. }\end{array}$ & $\begin{array}{l}\text { Five-Digit numbers, } 18318 \\
\text { through 19048 }\end{array}$ & 195 \\
\hline
\end{tabular}

SAMPLE

ENTRIES

FOLLOW 


\section{CATALOG ENTRIES: HOW TO READ THEM}

\section{A. Abstracts-Sample Entries}

NBS publication series and series number (also the index symbol)

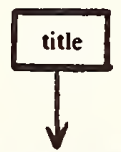

Monogr. 25. Section 16. Standard x-ray diffraction powder patterns. Section 16-Data for 86 substances, M. C. Morris, H. F. McMurdie, E. H. Evans, B. Paretzkin, J. H. de Groot, C. R. Hubbard, and S. J. Carmel, Nat. Bur. Stand. (U.S.), Monogr. 25. Sec. 16, 190 pages (Oct. 1979) SN003-003. 02128-8.

Key words: crystal structure; integrated intensities; lattice constants; peak intensities; powder patterns: reference intensities; standard; $x$-ray diffraction.

key words (as indexed in this catalog)
Standard $x$-ray diffraction patterns are presented for 87 substances. Fifty-nine of these patterns represent experimental data and 28 are calculated. The experimental $x$-ray powder diffraction patterns were obtained with an $x$-ray diffractometer. Ali d-values were assigned Miller indices determined by comparison with computed interplanar spacings consistent with space group extinctions. The densities and lattice constants were calculated and the refractive indices were measured whenever possible. The calculated $x$-ray powder diffractiun patterns were computed from published crystal structure data. Both peak height and integrated intensities are reported for the calculated patterns.

\section{Example of NBS published paper}

arabic number

index symbol

key words

(as indexed in

this catalog)

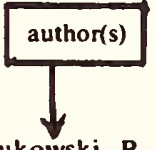

18625. Bukowski, R. W., Custer, R. L. P., Bright, R. G., Fire alarm communications, Chapter 19 in Handbook of Building Security Planning and Design, P. S. Hopf, Ed., pp. 19-1-19. 27 (McGraw-Hill Book Co., New York, NY, 1979).

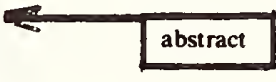

bibliographic citation: publisher, publication medium, no. of pages, date of publication
SD $/ \stackrel{\text { GPO stock }}{ }$ number or NTIS number

Key words: control units; fire alarm systems; fire detectors: high-rise communication systems; multiplex systems; NFPA standards; residential fire detector; sprinkler supervisory devices.

The operation and use of all current types of fire alarm and communication systems is discussed. This includes the differences between and operating features of local, auxiliary, remote station, proprietary, and central station systems, highrise communication systems and residential fire detection devices. A discussion of commonly used fire detectors is given including operation, installation and application considerations. indicating devices, sprinkler supervisory devices, maintenance. reliability and code/standard compliance is also covered.

\section{Example of NBS paper published in non-NBS media}




\section{B. Key Words-Sample Entries}

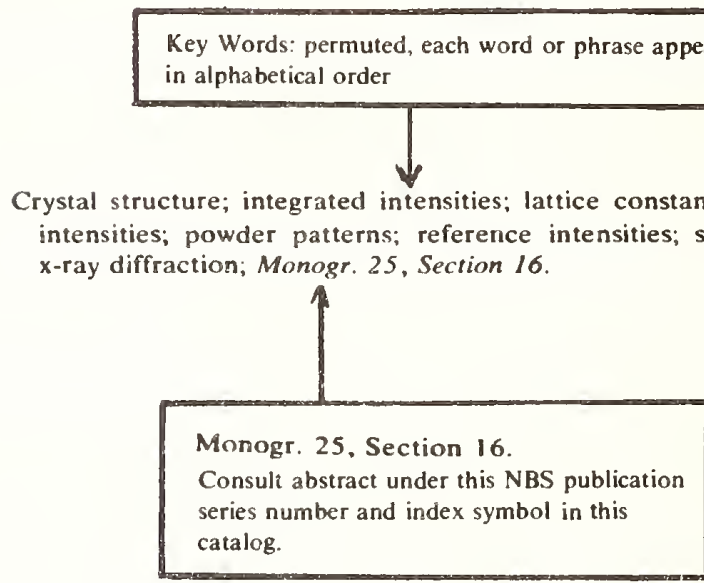

\section{Example of NBS published paper}

Key Words: permuted, each word or phrase appears in alphabetical order

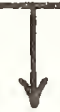

Control units; fire alarm systems; fire detectors; nigh-rise communication systems; multiplex systems; NFPA standards; residential fire detector; sprinkler supervisory devices; 18625 .

Consult abstract under this arabic number in this catalog

\section{Example of NBS paper published in non-NBS media}




\section{Authors-Sample Entries}

Authors: permuted.

in alphabetical order

Morris, M. C., McMurdie, H. F., Evans, E. H., Paretzkin,

B., de Groot, J. H., Hubbard, C. R., Carmel, S. J., Monogr.

25 , Section 16.

Monogr. 25. Section 16.

Consult abstract under this NBS publication series number and index symbol in this catalog.

\section{Example of NBS published paper}

Authors: permuted, in alphabetical order

Bukowski, R. W., Custer, R. L. P., Bright, R. G., 18625.

Consult abstract under this arabic number in this catalog

Example of NBS paper published in non-NBS media 


\section{NBS PUBLICATION PROGRAM}

\section{INTRODUCTION}

The formal publications of the National Bureau of Standards-some 1,000 papers in 1979are the primary way of communicating the results of NBS programs to its varied technical audiences, and the general public. Publications are a major end product of the Bureau's efforts. These take the form of the Bureau's three periodicals, its ten nonperiodical series, interagency reports, and articles in the journals of professional organizations and technological associations.

This annual catalog, Publications of the National Bureau of Standards, lists the 1979 output of papers documenting the results of the $\mathrm{Bu}$ reau's current programs. The various media in which these papers appeared are as follows:

\section{PERIODICALS}

\subsection{JOURNAL OF RESEARCH}

The National Bureau of Standards Journal of Research, a bimonthly, reports NBS research and development in those physical and engineering disciplines where the Bureau is active. These include physics, chemistry, engineering, mathematics, and computer sciences. Papers cover a broad range of subjects, with major emphasis on measurement methodology and on the basic technology underlying standardization. Also included from time to time are survey articles on topics closely related to the Bureau's technical and scientific programs. As a special service to subscribers, each issue contains complete citations for all recent NBS publications. Papers published during 1979 in the Journal are reported in this catalog.

Board of Editors:

Churchill Eisenhart,

Executive Editor (Mathematics)

John W. Cooper (Physics)

Donald D. Wagman (Chemistry)

Andrew J. Fowell (Engineering)

Joseph O. Harrison (Computer Science)

Howard J. M. Hanley (Boulder Labs.)

\subsection{DIMENSIONS/NBS}

This magazine is published to inform both the technical expert and the interested layperson of the latest advances in science and technology, with primary emphasis on the work at NBS. The magazine highlights and reviews such issues as energy research, fire protection, building technology, metric conversion, pollution abatement, health and safety, and consumer product performance. In addition, it reports the results of Bureau programs in measurement standards and techniques, properties of matter and materials, engineering standards and services, instrumentation, and automatic data processing.

The table of contents for each issue in 1979 is listed in Section 5.3. pages 57 and 58. Issued monthly.

Editors: Juli Chappell, Gail Porter, and Barbara Plocinik

\subsection{JOURNAL OF PHYSICAL AND CHEMI- CAL REFERENCE DATA (JPCRD)}

This Journal is published quarterly by the American Chemical Society and the American Institute of Physics for the National Bureau of Standards. The Journal provides critically evaluated physical and chemical property data, fully documented as to the original sources and the criteria used for evaluation. Critical reviews of measurement techniques assess the accuracy of available data in a given technical area. The principal source for the Journal is the National Standard Reference Data System (NSRDS). The Journal is not intended as a publication outlet for original experimental measurements normally reported in the primary research literature, nor for descriptive or primarily theoretical review articles. (See also Section 1.3. National Standard Reference Data Series.)

\section{NONPERIODICALS}

These ten categories of nonperiodical publications are listed in this catalog:

MONOGRAPHS-major contributions to the technical literature on various subjects related to the Bureau's scientific and technical activities.

HANDBOOKS-recommended codes of engineering and industrial practice (including safety codes) developed in cooperation with interested industries, professional organizations, and regulatory bodies. 
SPECIAL PUBLICATIONS-include proceedings of conferences sponsored by NBS, NBS annual reports, and other special publications such as wall charts, pocket cards, and bibliographies. Special subject-matter subseries include Semiconductor Measurement Technology (SP400-), Standard Reference Materials (SP260- ), Precision Measurement and Calibration (SP300-), Law Enforcement Technology (SP480- ), and Computer Science and Technology (SP500-).

\section{APPLIED MATHEMATICS SERIES-math-} ematical tables, manuals, and studies of special interest to physicists, engineers, chemists, biologists, mathematicians, computer programmers, and others in scientific and technical work.

NATIONAL STANDARD REFERENCE DATA SERIES-provides quantitative data on the physical and chemical properties of materials, compiled from the world's literature and critically evaluated. Developed under a worldwide program coordinated by NBS, under authority of National Standard Data Act (Public Law 90-396). This series supplements the JPCRD, see also Section 2.3.

\section{BUILDING SCIENCE SERIES-disseminates} technical information developed at the Bureau on building materials, components, systems, and whole structures. The series presents research results, test methods, and performance criteria related to the structural and environmental functions and the durability and safety characteristics of building elements and systems.

TECHNICAL NOTES-studies or reports complete in themselves but restrictive in their treatment of a subject. Like monographs but not so comprehensive in scope or definitive in treatment of the subject area. Often serve as a vehicle for final reports of work performed at NBS under the sponsorship of other Government agencies. Special subject-matter subseries include Optical Radiation Measurements (TN594- ) and Self Calibrations Manual for Optical Radiation (TN910- ).

VOLUNTARY PRODUCT STANDARDS-developed under procedures published by the U.S. Department of Commerce in Part 10, Title 15, of the Code of Federal Regulations. The standards establish nationally recognized requirements for products, and provide all concerned interests with a basis for common understanding of the characteristics of the products. The National Bu- reau of Standards administers the Voluntary Product Standards program as a supplement to the activities of the private sector standardizing organizations.

FEDERAL INFORMATION PROCESSING STANDARDS PUBLICATIONS (FIPS PUBS)publications in this series make up the Federal Information Processing Standards Register. The register serves as the official source of information in the Federal Government regarding standards issued by NBS pursuant to the Federal Property and Administrative Services Act of 1949 as amended, Public Law 89-306 (79 Stat. 1127), and as implemented by Executive Order 11717 (38 FR 12315, dated May 11, 1973) and Part 6 of Title 15 CFR (Code of Federal Regulations). FIPS PUBS may be purchased from the National Technical Information Service, Springfield, VA 22161.

CONSUMER INFORMATION SERIES-practical information, based on NBS research and experience, on areas of interest to the consumer. Easily understandable language and illustrations provide useful background knowledge for shopping in today's technological marketplace.

\subsection{NBS INTERAGENCY REPORTS}

A special series of interim or final reports on work performed by NBS for outside sponsors (both Government and non-government). In general, initial distribution is handled by the sponsor; public distribution is by the National Technical Information Services, Springfield, VA 22161 , in paper copy or microfiche. (See pages 10 to 48 for price lists.)

\subsection{GRANTEE/CONTRACTOR REPORTS AND NBS PATENTS}

Grantee/contractor reports are prepared by non-NBS persons or organizations working under grant or contract from the National Bureau of Standards. Those contract reports not incorporated into the formal NBS publication series are available directly from the National Technical Information Service (NTIS), Springfield, VA 22161 , in paper copy or microfiche unless otherwise stated. When ordering a report from NTIS you must order it by the "COM, PB, AD, or N" number as indicated. 
Patents-are obtained on NBS inventions with high commercial potential, to establish Government ownership of the patent rights. The patents are then made available for the grant of nonexclusive licenses to all qualified applicants. A limited exclusive license may be granted under a particular patent if it appears some period of exclusivity is necessary as an incentive for the investment of risk capital. For information on licensing any of the NBS held patents, write to the Office of the Legal Adviser, National Bureau of Standards, Washington, DC 20234. Copies of patents may be obtained from the U.S. Patent and Trademark Office, Washington, DC 20231, for 50 cents each.

\subsection{NBS BIBLIOGRAPHIC SUBSCRIPTION SERVICES}

The Cryogenic Data Center of the National Bureau of Standards, Boulder, CO has developed specialized bibliographies to provide interested audiences with information on latest developments in certain specialized fields. These issuances, together with subscription information, are listed as follows:
CRYOGENIC DATA CENTER CURRENT AWARENESS SERVICE (Publications and Reports of Interest in Cryogenics). A literature survey issued biweekly. Annual subscription: Domestic, \$25; Foreign, $\$ 30$.

LIQUEFIED NATURAL GAS. A literature survey issued quarterly. Annual subscription: $\$ 20$.

\section{SUPERCONDUCTING DEVICES AND MATE-}

RIALS. A literature survey issued quarterly. Annual subscription: $\$ 30$.

Send subscription orders and remittances for the preceding bibliographic services to the National Bureau of Standards, Cryogenic Data Center (736), Boulder, CO 80303.

\subsection{PAPERS PUBLISHED BY OTHERS}

Many significant contributions by NBS authors are published in other journals. Up-to-date listings of these articles are carried regularly in the Journal of Research, along with selected abstracts. A complete listing is published annually in NBS SP305, along with abstracts, key words, and author/subject indexes.

\section{PURCHASE PROCEDURES AND DOCUMENT AVAILABILITY}

\subsection{PURCHASE PROCEDURES}

Publications of the Bureau are available from the Superintendent of Documents, U.S. Government Printing Office, Washington, DC 20402, at the prices listed in this publication. However, prices are subject to change without notice. You may also order through the U.S. Department of Commerce District Office nearest you (see Appendix B for list of District Offices of the U.S. Department of Commerce). Microfiche copies of all recent NBS publications, and paper copies of many nonperiodicals, may be ordered through the National Technical Information Service, U.S. Department of Commerce, Springfield, VA 22161. Note that three of the nonperiodical series are available only from NTIS; these are FIPS PUBS, NBS Interagency Reports (NBSIR's), and Grantee/Contractor Reports (GCR's).
This section includes price lists of available publications, plus instructions on how to acquire reprints of articles by NBS authors, and how to get out-of-print material.

How To Make Remittances. Remittances for publications for which individual sales or subscription prices are shown should be mailed to Superintendent of Documents, U.S. Government Printing Office, Washington, DC 20402, by money order or check. Master Charge and VISA are also accepted. Be sure to give your credit card number and expiration date on all orders. Postage stamps will not be accepted. Publications cannot be mailed before remittances are received. Foreign remittances should be made either by international money order, draft on an American or Canadian bank or UNESCO coupons. 
The letter symbol, publication number, full title of the publication, SD stock number MUST be given when ordering. The Superintendent of Documents allows a discount of 25 percent on orders of 100 or more copies of one publication, when mailed to a single address.

Persons who make frequent purchases from the Superintendent of Documents may find a deposit account convenient. Deposits of $\$ 50$ or more are accepted, against which orders may be placed without making individual remittances or first obtaining quotations. Order blanks are furnished for this purpose. After the order has been processed, the order itself is returned, showing the publications supplied, explanations regarding those not sent, the amount of charge, and the balance on deposit.

No charge is made for postage on documents sent to points in the United States and its possessions. In computing foreign postage, the charge is approximately one-fourth of the current selling price of the publication. The charge is to cover the special handling required to comply with the customs and international mailing regulations.

How To Make Remittances to NTIS. Orders for publications purchased from the National Technical Information Service (NTIS) must be accompanied by postal money order, express money order, or check made out to the NTIS and covering total cost of the publications order. NTIS also accepts charges to American Express, VISA, or Master Charge. You may also establish an NTIS deposit account by contacting them for this service. All inquiries or orders should be addressed to: National Technical Information Service, Springfield, VA 22161.

SD and NTIS order forms are included at the end of this publication for your convenience in ordering.

\subsection{ANNOUNCEMENTS OF NBS PUBLICA- TIONS}

The National Bureau of Standards and the agencies mentioned below regularly issue the following official announcements dealing with NBS publications.

DIMENSIONS/NBS. Issued monthly by the National Bureau of Standards. In addition to publishing technical news of the Bureau, this periodical announces selected new publications in an NBS series. Available from the Superintendent of Documents, U.S. Government Print- ing Office, Washington, DC 20402. Annual subscription, $\$ 11 ; \$ 13.75$ foreign. Single copies, $\$ 1.10$ domestic; $\$ 1.40$ foreign.

NBS JOURNAL OF RESEARCH. The Journal carries a listing of all NBS Publications as issued. See Section 4.6. for subscription information.

Monthly Catalog of United States Government Publications. Issued by the Superintendent of Documents, U.S. Government Printing Office, Washington, DC 20402. Annual subscription, with consolidated annual index, $\$ 45 ; \$ 56$ foreign.

Selected List of U.S. Government Publications. Issued monthly by the Superintendent of Documents. Each list is arranged by subject, with annotations, prices, and order form. May be obtained free from the U.S. Government Printing Office, Superintendent of Documents, Mail List Section, Stop SSOM, Washington, DC 20402.

Commerce Publications Update. Biweekly announcement of publications of the Department of Commerce. Lists titles and prices of National Bureau of Standards publications, as well as those of other offices of the Department of Commerce. Contact the Editorial Policy and Review Division, Office of Publications, U.S. Department of Commerce, Washington, DC 20230, for information on how to receive this listing.

NBS Publications Newsletter. This newsletter is issued approximately six times a year. It presents full citations, including abstracts and availability information, for NBS papers announced during the report period. Its primary audience includes librarians, documentalists, and science information specialists. However, other NBS audiences also find it useful as a guide to new NBS publications.

Contact: Editor, NBS Publications Newsletter, Technical Information and Publications Division, National Bureau of Standards, Washington, DC 20234.

\subsection{CATALOGS OF NBS PUBLICATIONS}

These catalogs list the titles of all NBS publications through December 31, 1979. The catalogs are available from the Superintendent of Documents, U.S. Government Printing Office, Washington, DC 20402, unless otherwise stated, or may be consulted in a library which maintains sets of National Bureau of Standards publications. 
Circular 460: Publications of the National Bureau of Standards 1901 to June $30,1947.375$ pages including subject and author indexes. Brief abstracts are included for the period January 1, 1941 to June 30, 1947

Supplement to Circular 460: Publications of the $\mathrm{Na}$ tional Bureau of Standards, July 1, 1947 to June 30, 1957. 373 pages, including subject and author indexes

Miscellaneous Publication 240: Publications of the National Bureau of Standards, July 1, 1957 to June 30, 1960. First NBS Catalog to include Titles of Papers published in Outside Journals 1950 to 1959,391 pages including subject and author indexes.

Supplement to Miscellaneous Publication 240: Publications of the National Bureau of Standards published by NBS, July 1960 through June 1966; published by others, 1960 through 1965. 740 pages, including subject and author indexes

Special Publication 305: Publications of the National Bureau of Standards, published by NBS, July 1966 through December 1967; published by others, 1966-1967. 223 pages, a citation of titles and abstracts, with key words and author indexes................

Supplement 1 to Special Publication 305: Publications of the National Bureau of Standards, 1968 through 1969. 497 pages, a citation of titles and abstracts, with key words and author indexes....

Supplement 2 to Special Publication 305: Publications of the National Bureau of Standards, 1970. 378 pages, a citation of titles and abstracts, with key words and author indexes

Supplement 3 to Special Publication 305: Publications of the National Bureau of Standards, 1971. 342 pages, a citation of titles and abstracts, with key words and author indexes

Supplement 4 to Special Publication 305: Publications of the National Bureau of Standards, 1972.449 pages, a citation of titles and abstracts, with key words and author indexes

Supplement 5 to Special Publication 305: Publications of the National Bureau of Standards, 1973. 349 pages, a citation of titles and abstracts, with key words and author indexes

Supplement 6 to Special Publication 305: Publications of the National Bureau of Standards, 1974. 523 pages, a citation of titles and abstracts, with key words and author indexes

Supplement 7 to Special Publication 305: Publications of the National Bureau of Standards, 1975. 595 pages, a citation of titles and abstracts, with key words and author indexes

Supplement 8 to Special Publication 305: Publications of the National Bureau of Standards, 1976.728 pages, a citation of titles and abstracts, with key words and author indexes

Supplement 9 to Special Publication 305: Publications of the National Bureau of Standards, 1977.601 pages, a citation of titles and abstracts, with key words and author indexes

Supplement 10 to Special Publication 305: Publications of the National Bureau of Standards, 1978.679 pages, a citation of titles and abstracts, with key words and author indexes

Supplement 11 to Special Publication 305: Publications of the National Bureau of Standards, 1979. 615 pages, a citation of titles and abstracts, with key words and author indexes.

\subsection{FUNCTIONS OF DEPOSITORY LIBRAR- IES IN THE UNITED STATES}

The Superintendent of Documents, U.S. Government Printing Office, is authorized by law to furnish Government publications to designated depository libraries.

Under Provisions of Title 44 of the United States Code, certain libraries are designated depositories for Government publications. Through them, Federal Government documents are made available to residents of every State, the District of Columbia, Guam, Puerto Rico, and the Virgin Islands. Distribution to the libraries is made by the Superintendent of Documents.

It is sometimes impossible to obtain desired publications by purchase from the Superintendent of Documents. Stocks may have been exhausted or the document may be permanently out of print. The depositories provide a valuable service by keeping such publications permanently available. Every Government publication cannot be consulted at all depository libraries. Designated Regional Depositories are required to receive and retain one copy of all Government publications made available to depository libraries either in printed or microfacsimile form. All other libraries are allowed to select the classes of publications best suited to the interest of their particular clientele.

These libraries are now receiving selected publication series of the National Bureau of Standards for general reference use. Whether a given library has a copy of a particular publication can be determined by inquiring at the library.

\subsection{FUNCTIONS OF U.S. DEPARTMENT OF COMMERCE DISTRICT OFFICES}

-Available by purchase from the National Technical Information Service, Springfield, VA 22161. See Price List for ordering numbers. Note: All citations in NBS SP305 and its Supplements 1 through 8 have been accumulated into NBS SP535, Volumes 1 and 2 (see Notice, page 9).

\section{U.S. Department of Commerce District Offices} provide ready access at the local level to the services of the Department of Commerce and its reports, publications, statistical statements, and surveys. Most District Offices serve as official sales agents of the Superintendent of Documents, U.S. Government Printing Office, making available for purchase locally a wide range of Government business publications. The reference library maintained by each District Office contains many Government and private publications, periodicals, directories, reports, and other reference materials. 


\subsection{AVAILABILITY OF NBS PUBLICATIONS}

\section{A. PERIODICAL SUBSCRIPTION RATES}
Periodical
Domestic ${ }^{1}$
Foreign $^{2}$
Journal of Research of the National Bureau of Standards:
Effective July 1977 issued bimonth- ly as single section. Separate Sec- tions $\mathrm{A}$ and $\mathrm{B}$ discontinued with the June 1977 issues. Paper cov- ers ..................................................
Bound volume (1 volume per year), blue buckram ...................................
DIMENSIONS/NBS, issued 10 times per year.

\section{$\$ 13 \quad \$ 16.25$}
(3)
(3)
$\$ 11 \quad \$ 13.75$
NOTE-Send order, with remittance, to Superintendent of Documents, U.S. Government Printing Office, Washington, D C $2040 \%$
"United States and its possessions.
${ }^{2}$ Foreign price includes the cost of the publication and postage.
${ }^{3}$ Prices of the bound volumes vary. The Superintendent of Documents will furnish prices on request.

\section{B. SUPERSEDED NBS REFERENCE PUBLI- CATIONS}

NBS publications not listed in the price lists are out of print and are not available from the Superintendent of Documents. Many can be consulted at libraries. Also, in many cases, photoduplicated copies can be purchased from the Library of Congress. For full information concerning this service, write to the Photoduplication Service, Library of Congress, Washington, DC 20540.

Certain NBS Publications are out of print because they have been replaced or partially replaced, by material issued by other organizations. In this connection NBS is able to offer the following information:

Circular 410, National Standard Petroleum Oil Tables. Information in this Circular has been incorporated in the American Edition-ASTM Petroleum Measurement Tables issued as PCN12-4125-10-12 by the American Society for Testing and Materials, 1916 Race Street, Philadelpha, PA 19103. Available at $\$ 30,20$ percent discount to ASTM members. Tables 5 and 7 of the ASTM Petroleum Measurement Tables may also be purchased from the ASTM in separate reprint form at $\$ 2.25$ and $\$ 2$ per copy respectively.

Circular 438, Static Electricity. The National Fire Protection Association, 60 Batterymarch Street, Boston, MA 02110, has issued a publication by the same title, available from them as NFPA Publication 77, $\$ 3.50$.

Circular 499, Nuclear Data. Replaced by Atomic Data and Nuclear Data Tables, published by Academic Press, 111 Fifth Avenue, New York, NY 10003. Available bi-monthly for $\$ 63$.
Circular 547, Section 1, Precision Laboratory Standards of Mass Laboratory-Weights. Information in this Circular has been incorporated in the ANSI/ASTM E 617-78. Standard Specification for Laboratory Weights and Precision Mass Standards issued by the American Society for Testing and Materials, 1916 Race Street, Philadelphia, PA 19103, Attn.: Sales, for $\$ 4$.

Circular 576, Automotive Antifreezes. For information on this subject consult American National Standards Institute, 1430 Broadway, New York, NY 10018.

Circular 577 and Supplement, Energy Loss and Range of Electrons and Positrons. These have been superseded by NASA Special Publication 3012, available from the National Technical Information Service, Springfield, VA 22161, as $\mathrm{N} 65-12506$, at $\$ 10$ hardcopy and $\$ 3.50$ microfiche and N67-14099, at $\$ 6$ hardcopy and $\$ 3.50$ microfiche.

Miscellaneous Publication 179, American Standard Building Code Requirements for Minimum Design Loads in Buildings and Other Structures. The American National Standards Institute, 1430 Broadway, New York, NY 10018, has issued a publication on this subject. Available from them as A58.1-1972, at $\$ 9.75$.

Miscellaneous Publication 187, Directory of Commercial and College Laboratories. A new Directory of Testing Laboratories, issued as STP 333D, is published by the American Society for Testing and Materials, 1916 Race Street, Philadelphia, PA 19103 , at $\$ 3.75$.

NBS Handbook 28, Parts 1, 2, and 3, Screw Thread Standards. Federal Government responsibility for screw thread standards has been transferred to the General Services Administration (GSA). Standards will be promulgated by the GSA as Federal Standard 28. Technical questions should be addressed to Directorate of Engineering and Standardization, Defense Logistics Agency (DISC), 700 Robbins Ave., Philadelphia PA 19111, telephone (215) 697-3325. Questions regarding administration of the program should be addressed to Standards Control and Support Division, General Services Administration (Federal Supply Service), attn: FMHS, Washington, DC 20406, telephone (703) 557-7595.

Handbook 30, National Electrical Safety Code (also H81 and its Supplements and H110-1). All 
NBS publications on this subject have been superseded by National Electrical Safety Code, 1977 edition, issued by the American National Standards Institute, 1430 Broadway, New York, NY 10018. Available from them as ANSI C2-1977, at $\$ 6.50$.

Handbook 46, Code for Protection Against Lightning. A United States of America Standards Institute Code for Protection Against Lightning (NFPA-78-1977) is available from the American National Standards Institute, 1430 Broadway, New York, NY 10018, at $\$ 5.25$, as ANSI/NFPA78-1977.

Handbook 48, Control and Removal of Radioactive Contamination in Laboratories. Reprints of this Handbook can be purchased as NCRP Report 8 at $\$ 4$ from NCRP Publications, P.O. Box 30175 , Washington, DC 20014.

Handbook 49, Recommendations for Waste Disposal Phosphorus-32 and Iodine-131 for Medical Users. Reprints of this Handbook can be purchased as NCRP Report 9 at $\$ 4$ from NCRP Publications, P.O. Box 30175, Washington, DC 20014.

Handbook 53, Recommendations for the Disposal of Carbon-14 Wastes. Reprints of this Handbook can be purchased as NCRP Report 12 at $\$ 4$ from NCRP Publications, P.O. Box 30175, Washington, DC 20014.

Handbook 55, Protection Against Betatron-Synchrotron Radiations up to 100 Million Electron Volts, February 26, 1954 has been combined with NBS Handbook 97. Available as NCRP Report 51, Radiation Protection Design Guidelines for 0.1-100 MeV Particle Accelerator Facilities from NCRP Publications, P.O. Box 30175, Washington, DC 20014 , at $\$ 7$.

Handbook 58, Radioactive Waste Disposal in the Ocean. Reprints of this Handbook can be purchased as NCRP Report 16 at $\$ 4$ from NCRP Publications, P.O. Box 30175, Washington, DC 20014.

Handbook 59, Permissible Dose from External Sources of Ionizing Radiations. Reprints of this Handbook can be purchased as NCRP Report 39 at $\$ 6$ per copy from NCRP Publications, P.O. Box 30175, Washington, DC 20014.

Handbook 63, Protection Against Neutron Radiation up to $30 \mathrm{MeV}$. Reprints of this Handbook can be purchased as NCRP Report 38 at $\$ 6$ per copy from NCRP Publications, P.O. Box 30175, Washington, DC 20014.

Handbook 65, Safe Handling of Bodies Containing Radioactive Isotopes. Reprints of this Handbook can be purchased as NCRP Report 37 at $\$ 6$ per copy from NCRP Publications, P.O. Box 30175, Washington, DC 20014.

Handbook 69, Maximum Permissible Body Burdens and Maximum Permissible Concentrations of Radionuclides in Air and in Water for Óccupational Exposure. Reprints of this Handbook can be purchased as NCRP Report 22 at $\$ 4$ per copy from NCRP Publications, P.O. Box 30175, Washington, DC 20014.

Handbook 71, Specifications for Dry Cells and Batteries. Available as ANSI C18.1-1979 from the American National Standards Institute, 1430 Broadway, New York, NY 10018, at \$6.25.

Handbook 73, Protection Against Radiations from Sealed Gamma Sources (Supersedes H54). Reprints of this Handbook can be purchased as NCRP Report 40 at $\$ 6$ per copy from NCRP Publications, P.O. Box 30175, Washington, DC 20014.

Handbook 74, Building Code Requirements for Reinforced Masonry. The American National Standards Institute, 1430 Broadway, New York, NY 10018 has issued a publication on this subject. Available from them as ANSI/NBS Handbook H74-1960 (R1970), at $\$ 4.50$.

Handbook 75, Measurement of Absorbed Dose of Neutrons and of Mixtures of Neutrons and Gamma Rays. Reprints of this Handbook can be purchased as NCRP Report 25 at $\$ 4$ per copy from NCRP Publications, P.O. Box 30175, Washington, DC 20014.

Handbook 76, Medical X-ray Protection Up to Three Million Volts. Now available as NCRP 33. Purchase from NCRP Publications, P.O. Box 30175, Washington, DC 20014, at $\$ 5$.

Handbook 80, A Manual of Radioactivity Procedures. Reprints of this Handbook are available as NCRP Report 58, for paper copy at $\$ 12$, and Buckram at $\$ 14$. For more information write to NCRP Publications, P.O. Box 30175, Washington, DC 20014. 
Handbook 81 and Its Supplements, Safety Rules for the Installation and Maintenance of Electric Supply and Communication Lines (also H30 and H110-1). All NBS publications on this subject have been superseded by National Electrical Safety Code, 1977 Edition, issued by the American National Standards Institute, 1430 Broadway, New York, NY 10018. Available from them as ANSI C2-1977, at $\$ 6.50$.

Handbook 84, Radiation Quantities and Units. Reprints of this Handbook can be purchased as ICRU Report 33 at $\$ 7$ per copy from ICRU Publications, P.O. Box 30165, Washington, DC 20014.

Handbook 86, Radioactivity. Reprints of this Handbook can be purchased as ICRU Report 10C, Radioactivity at $\$ 4$ per copy from ICRU Publications P.O. Box 30165, Washington, DC 20014.

Handbook 88, Radiobiological Dosimetry. Reprints of this Handbook can be purchased as ICRU Report 30, Quantitative Concepts and Dosimetry in Radiobiology at $\$ 10$ per copy from ICRU Publications, P.O. Box 30165, Washington, DC 20014.

Handbook 89, Methods of Evaluating Radiological Equipment and Materials. Reprints of this Handbook can be purchased as ICRU Report 10F at $\$ 3$ per copy from ICRU Publications, P.O. Box 30165, Washington, DC 20014.

Handbook 96, Inspection of Processed Photographic Record Films for Aging Blemishes. Reprints of this Handbook can be purchased as $\mathrm{PH}$ 1.28-1976 at $\$ 5.50$ per copy from the American National Standards Institute, 1430 Broadway, New York, NY 10018.

Handbook 97, Shielding for High-Energy Electron Accelerator Installations. July 1, 1964, has been combined with NBS Handbook 55. Available as NCRP Report 51, Radiation Protection Design Guidelines for 0.1-100 MeV Particle Accelerator Facilities from NCRP Publications, P.O. Box 30175 , Washington, DC 20014 at $\$ 7$.

Handbook 102, ASTM Metric Practice Guide. Available as ANSI/ASTM E380-76 from the American National Standards Institute, 1430 Broadway, New York, NY 10018, at \$4.

Handbook 110-1, National Electrical Safety Code. Part 1. Rules for Installation and Mainte- nance of Electric Supply and Communication Lines (also H30 and $\mathrm{H} 81$ and its Supplements). All NBS publications on this subject have been superseded by National Electrical Safety Code, 1977 Edition, issued by the American National Standards Institute, 1430 Broadway, New York, NY 10018. Available from them as ANSI C2-1977 at $\$ 6.50$.

Technical Note 938, Recommended Practice for the Use of Metric (SI) Units in Building Design and Construction, has been superseded by ASTM E 621-78, Standard Practice of the Use of Metric (SI) Units in Building Design and Construction. It is available from the American Society for Testing and Materials, 1916 Race Street, Philadelphia, PA 19103. Price $\$ 5$.

\section{PRICE LISTS FOR NONPERIODICALS}

The lists on the following pages give the numbers and prices of all NBS publications issued from 1901 through 1979 which are still in print. Items in boldface are the 1979 publications in this supplement. The prices shown supersede prices in previous catalogs of NBS publications. Prices are those in effect the date this publication went to press. Prices are subject to change without notice, and the prices charged on your order will be those in effect as of the date your order is processed. Except for the Federal Information Processing Standards Series and the National Bureau of Standards Interagency Reports, which are only available by purchase from the National Technical Information Service, Springfield, VA 22161, publications may be ordered from the Superintendent of Documents, U.S. Government Printing Office. SD order forms are included at the end of this publication.

For availability and price of Patents see page 2.

Publications not listed are out of print. In such cases, your nearest depository library may still have a copy of that item. (See Section 4.4 and Appendix A.) Some NBS publications may be purchased from the National Technical Information Service. (See Section 4.1.)

Publications shown as available from NTIS are represented by the NTIS Price schedule in effect at the time of purchase. NTIS prices as of this date are given below. Again, prices are subject to change. 
The current dollar equivalent for each code is shown in the schedule below. Orders must list the accession number(s) and be accompanied by the total dollar amount from the current schedule.

Customers in Canada, U.S., and Mexico please use this price schedule; other addressees write for Folder PR-360-4.

\begin{tabular}{|c|c|c|c|c|c|}
\hline & $\begin{array}{r}\$ 3.50 \\
5.00 \\
6.00 \\
7.00 \\
8.00 \\
9.00 \\
10.00 \\
11.00 \\
12.00 \\
13.00 \\
14.00 \\
15.00 \\
16.00 \\
17.00 \\
18.00 \\
19.00 \\
20.00 \\
21.00 \\
22.00 \\
23.00 \\
24.00 \\
25.00 \\
26.00 \\
27.00 \\
28.00 \\
*\end{array}$ & 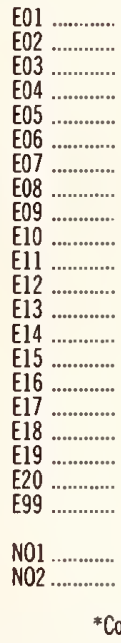 & $\begin{array}{r}\$ 5.50 \\
6.50 \\
8.50 \\
10.50 \\
12.50 \\
14.50 \\
16.50 \\
18.50 \\
20.50 \\
22.50 \\
24.50 \\
27.50 \\
30.50 \\
33.50 \\
36.50 \\
39.50 \\
42.50 \\
45.50 \\
50.50 \\
60.50 \\
* \\
30.00 \\
50.00 \\
\\
\\
\end{array}$ & 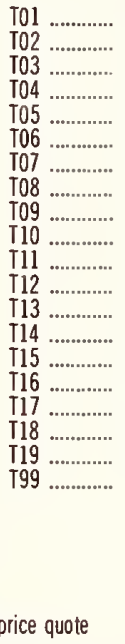 & $\begin{array}{r}110.00 \\
125.00 \\
210.00 \\
300.00 \\
360.00 \\
420.00 \\
480.00 \\
540.00 \\
600.00 \\
660.00 \\
720.00 \\
780.00 \\
840.00 \\
900.00 \\
960.00 \\
1,020.00 \\
1,080.00 \\
1,140.00 \\
1,200.00 \\
*\end{array}$ \\
\hline
\end{tabular}

PRICES EFFECTIVE JANUARY 1,1980

\section{NOTICE}

NBS Special Publication 535, Catalog of NBS Publications, 1966-1976. Volumes 1 (2 parts) and 2 (2 parts). Consolidated reprint of citations, abstracts, and key words from NBS SP 305, and its Supplements 1-8.

For sale in sets only by the Superintendent of Documents, U.S. Government Printing Office, Washington, DC 20402 as follows: Order by SD Stock No. Sold in sets only as follows:

SP 535. Volume 1. SD Stock No. 003-003-02010-9. Price $\$ 23.75$.

SP 535. Volume 2. SD Stock No. 003-003-02011-7. Price $\$ 21.25$.

(Add 25 percent for other than U.S. mailing.)

This compilation is updated through 1979 by the present supplement and two previous annual supplements, see page 5 . 
NBS PUBLICATIONS

CIRCULARS

\begin{tabular}{|c|c|c|c|c|c|c|}
\hline No. & & Price & No. & Price & No. & Price \\
\hline $\begin{array}{r}74 \\
402 \\
410 \\
438 \\
440 \\
\\
447 \\
453 \\
460 \\
460 \\
470 \\
488 \\
488\end{array}$ & $\begin{array}{l}(\text { PB264-261) } \\
\\
\text { \& Suppl. } \\
\text { (PB262-014) } \\
\text { (PB258-782) } \\
\text { (PB192-338) } \\
\text { (PB259-278) } \\
\text { Suppl. } \\
\text { (PB259-279) } \\
\text { (COM75-10206) } \\
\text { Sec. 1 \& 2 } \\
\text { (PB252-093) } \\
\text { Sec. 3, 4 \& 5 } \\
\text { (PB252-094) }\end{array}$ & $\begin{array}{l}* * \\
* \\
* \\
* \\
* * \\
* * \\
* * \\
* * \\
* * \\
* * \\
* * \\
* *\end{array}$ & 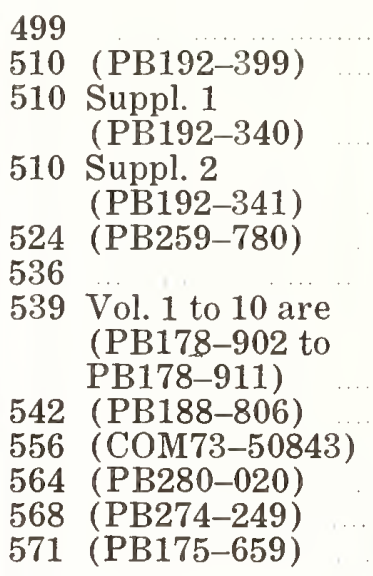 & $\begin{array}{l}* \\
* * \\
* \\
* \\
* * \\
* \\
.55\end{array}$ & $\begin{array}{ll}574 & \text { (PB272-292) } \\
576 & \\
577 & \text { \& Suppl } \\
579 & \text { (PB168-350) } \\
582 & \text { (COM75-10277) } \\
589 & \text { (PB188-296) } \\
593 & \text { (COM75-10234) } \\
596 & \text { (PB172-059) } \\
602 & \text { (COM73-10504) }\end{array}$ & $\begin{array}{r}* * \\
* \\
* \\
* * \\
* * \\
* * \\
* * \\
* * \\
* *\end{array}$ \\
\hline
\end{tabular}

* See page 6 for additional information.

**Available from the National Technical Information Service ; use "PB", "COM" or NBS publication identification if no specific NTIS number is assigned. Available in Microfiche for $\$ 3.50$; consult NTIS for paper copy price. 


\begin{tabular}{|c|c|c|c|c|c|c|c|c|}
\hline \multicolumn{2}{|c|}{ No. } & Price & \multicolumn{2}{|l|}{ No. } & Price & \multicolumn{2}{|l|}{ No. } & Price \\
\hline & (PB1 & 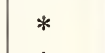 & 52 & & * & 113 & Vol. 3 (PB192-746) & 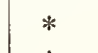 \\
\hline & Vol. 1 & $*$ & & (PI & * & 116 & & * \\
\hline & $\begin{array}{l}\text { (COM71-01000-1) } \\
\text { Vol. } 2\end{array}$ & $\begin{array}{l}* \\
*\end{array}$ & & $\begin{array}{l}(\mathrm{COM} 75-10244) \\
(\mathrm{PB} 193-909)\end{array}$ & * & 117 & $\begin{array}{l}3-003- \\
-0)\end{array}$ & \\
\hline & (COM71-01000-2) & $*$ & 60 & (COM75-10053) & * & 118 & (PB194-751) & \\
\hline & $\begin{array}{l}\text { 887) } \\
10503) \ldots \ldots . . . .\end{array}$ & $\begin{array}{l}* \\
*\end{array}$ & & (COM74-10737) & * & 119 & (COM71-50201) & $*$ \\
\hline & (PB186-237) & $*$ & $\begin{array}{l}66 \\
67\end{array}$ & $\begin{array}{l}(\mathrm{COM} 75-10245) \\
(\mathrm{PB} 186-426)\end{array}$ & * & & $00749-8)$ & .85 \\
\hline 10 & $\begin{array}{l}(\text { COM75-10235) } \\
(\text { PB172-156) }\end{array}$ & $\begin{array}{l}* \\
*\end{array}$ & 68 & (COM71-00692) & * & 121 & (COM75-10169) & * \\
\hline & (PB192-874) & * & 70 & $072)$ & * & 124 & $(\mathrm{C}$ & * \\
\hline 20 & $\begin{array}{l}(\mathrm{PB} 195-221) \\
(\mathrm{PB} 183-992)\end{array}$ & * & $\begin{array}{l}70 \\
70\end{array}$ & Vol. 2 (PB189-714) & * & 125 & $01177-1$ & 4.55 \\
\hline $\begin{array}{l}2: \\
25\end{array}$ & $\begin{array}{l}\text { (PB183-992) } \\
\text { Sec. } 1 \text { (PB178-429) }\end{array}$ & * & 70 & $\begin{array}{l}\text { Vol. } 3 \\
\text { (COM74-10794) }\end{array}$ & * & 125 & Sup. 1 (SN003-003- & 05 \\
\hline & Sec. 2 (PB 1 & $*$ & 70 & $\begin{array}{l}\text { Vol. } 4 \\
\text { (COM74-10795) }\end{array}$ & $*$ & & (SN003-003 & \\
\hline 25 & $\begin{array}{l}\text { Sec. } 4 \\
\text { Sec. } 4 \ldots\end{array}$ & $*$ & 70 & Vol. 5 & & & & 2.10 \\
\hline & $\begin{array}{l}\text { Sec. } 5 \\
\text { Sec } 6\end{array}$ & $\begin{array}{l}* \\
*\end{array}$ & & (COM74-10796) & * & 127 & $\begin{array}{l}\text { (COM72-5 } \\
00982-2)\end{array}$ & \\
\hline 25 & $\begin{array}{l}\text { Sec. } 6 \\
\text { Sec. } 7\end{array}$ & $*$ & 73 & $\begin{array}{l}\text { (PB186-427) } \\
\text { (PB186-432) }\end{array}$ & $\begin{array}{l}* \\
*\end{array}$ & 128 & (COM & * \\
\hline & Sec. 8 (PB194-872). & $*$ & 74 & (PB195-213) & 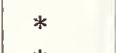 & $\begin{array}{l}129 \\
130\end{array}$ & (COM73- & $*$ \\
\hline & (COM72-50002) & * & $\begin{array}{l}75 \\
76\end{array}$ & $(\mathrm{CO}$ & * & & $01120-7)$ & 1.10 \\
\hline & $\begin{array}{l}\text { Sec. } 10 \\
\text { (COM72-51079) }\end{array}$ & * & 77 & (PB & * & 131 & $\begin{array}{l}\text { (SN003-003- } \\
01076-6)\end{array}$ & 10.70 \\
\hline & $\begin{array}{l}\text { Sec. } 11 \text { (COM74- } \\
50183 \text { ) }\end{array}$ & * & $\begin{array}{l}80 \\
82\end{array}$ & $\begin{array}{l}(\text { PB257-342) } \\
(\text { PB189-659) }\end{array}$ & * & & (SN003-003- & 1580 \\
\hline 25 & $\begin{array}{l}\text { Sec. } 12 \text { (SN003- } \\
003-01376-5 \text { ) }\end{array}$ & $1:$ & $\begin{array}{l}83 \\
84\end{array}$ & $\begin{array}{l}\text { (COM75-10246) } \\
\text { (COM72-10513) }\end{array}$ & * & 133 & (COM74-50309) & $\begin{array}{c}10.00 \\
* \\
*\end{array}$ \\
\hline & Sec. 13 (S) & & 85 & (CC & * & $\begin{array}{l}134 \\
135\end{array}$ & (COM73-50840) & * \\
\hline 25 & $\begin{array}{l}\text { 003-01629-2) } \\
\text { Sec. } 14 \text { (SN003- }\end{array}$ & & $\begin{array}{l}86 \\
88\end{array}$ & $\begin{array}{l}\text { (COM75-10046) } \\
\text { (SN003-003-- }\end{array}$ & & 136 & (S) & \\
\hline & $003-0$ & 2.75 & 80 & $00354-9)$ & 1.05 & & $01160-6)$ & .50 \\
\hline & $86-1)$ & 4.00 & $\begin{array}{l}89 \\
91\end{array}$ & $\begin{array}{l}\text { (AD700-466) } \\
\text { (PB266-262) }\end{array}$ & * & $\begin{array}{l}137 \\
138\end{array}$ & (COM73-50960) & * \\
\hline & Sec. 16 (SN003- & 500 & 92 & & & $\begin{array}{l}108 \\
139\end{array}$ & (SN003-003- & \\
\hline 2 & $(\mathrm{~PB} 172-178)$ & & 93 & (COM73-10008) & $*$ & & 0131' & 1.35 \\
\hline 30 & (PB1 & * & $\begin{array}{l}94 \\
96\end{array}$ & $(\mathrm{~N} 6$ & & & 01202 & 9.20 \\
\hline $\begin{array}{l}31 \\
34\end{array}$ & (COM75-10045) & * & 98 & & 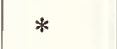 & & (SN003-003- & \\
\hline & M71-00 & * & 99 & & & & & 5. \\
\hline 34 & Vol. 2 & * & $\begin{array}{l}100 \\
101\end{array}$ & & * & 142 & $\begin{array}{l}\text { (SN003-003- } \\
01290-4)\end{array}$ & 5.45 \\
\hline $\begin{array}{l}56 \\
39\end{array}$ & $\begin{array}{l}\text { (COI } \\
(\mathrm{COI}\end{array}$ & * & $\begin{array}{l}101 \\
102\end{array}$ & & * & 143 & (SN003-003- & \\
\hline 40 & (CO & $*$ & 103 & & * & & & 1.10 \\
\hline 41 & (PB1 & * & 104 & & * & 144 & (SN003-003- & 5 \\
\hline $\begin{array}{l}42 \\
43\end{array}$ & (COM72-10377) & * & 105 & & & 145 & Pt. 1 (COM75. & \\
\hline & (COM73-10636) & * & $\begin{array}{l}106 \\
107\end{array}$ & & * & & & * \\
\hline 43 & $\begin{array}{l}\text { Vol. } 2 \\
\text { (COM73 }\end{array}$ & $*$ & 109 & (AD6 & * & & $\begin{array}{l}\text { Pt.2 (COM75 } \\
10756)\end{array}$ & * \\
\hline 45 & (PB1 & & & & & 146 & (COM75-509 & $*$ \\
\hline 46 & $(\mathrm{~PB}$ & * & 112 & & * & 147 & (S & \\
\hline $\begin{array}{l}47 \\
48\end{array}$ & (COM71-00691) & * & 113 & Vol. 1 & & & $01412-5$ & 2.1 \\
\hline 49 & (COM72-10380) & * & & $\begin{array}{l}\text { Vol. } 2 \text { (SN0 } \\
00304-2)\end{array}$ & 1.65 & & $\begin{array}{l}\text { Sup. } 1 \text { (SN003-003 } \\
01754-0)\end{array}$ & 1. \\
\hline
\end{tabular}


MONOGRAPHS (Continued)

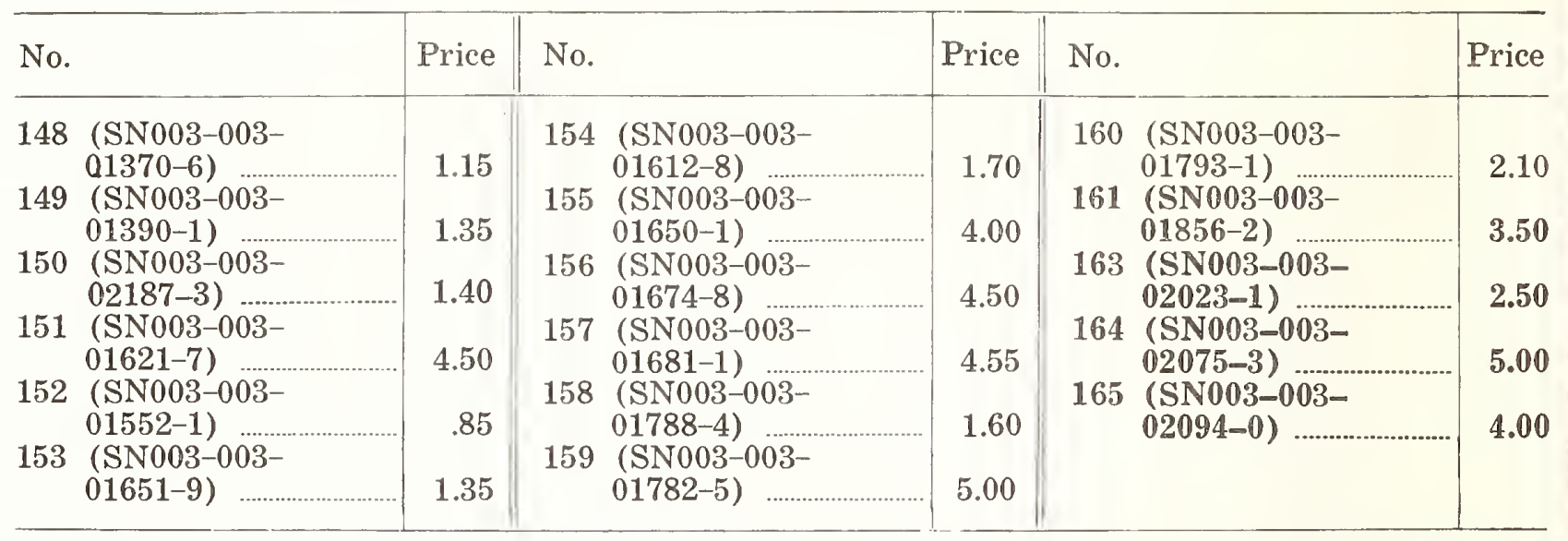

*Aväilable from the National Technical Information Service; use "PB", "AD", "N", "COM", or NBS publication identification if no specific NTIS number is assigned. Available in Microfiche for $\$ 3.00$; consult NTIS for paper copy price.

\section{MISCELLANEOUS PUBLICATIONS}

\begin{tabular}{|c|c|c|c|c|c|}
\hline No. & Price & No. & Price & No. & Price \\
\hline $\begin{array}{l}179 \\
187 \\
211(\mathrm{COM} 73-10871) \\
240 \\
240 \text { Suppl } \\
256 \text { (PB285-882) } \\
260-1 \text { (COM74-11061) } \\
260-2 \text { (COM74-11063) } \\
260-3 \text { (COM74-11060) } \\
260-4 \text { (COM74-11059) } \\
260-5 \text { (PB168-068) } \\
260-6 \text { (COM74-11068) } \\
260-7 \text { (COM74-11067) } \\
260-8 \text { (COM74-11066) } \\
260-9 \text { (COM74-11065) } \\
260-10 \text { (COM74-11064) } \\
\end{array}$ & $\begin{array}{l}* \\
* \\
* * \\
* * \\
* * \\
* * \\
* * \\
* * \\
* * \\
* * \\
* * \\
* * \\
* * \\
* * \\
* * \\
* *\end{array}$ & $\begin{array}{l}260-11 \\
260-12 \\
260-13\end{array}$ & $\begin{array}{l}* * \\
* * \\
* * \\
* * \\
* \\
* \\
* \\
* * \\
* \\
* \\
* * \\
8.50 \\
* * \\
* *\end{array}$ & $\begin{array}{l}287 \\
291 \\
292 \\
294 \\
\text { This series name was } \\
\quad \text { changed to Special } \\
\text { Publications beginning } \\
\text { With SP295 }\end{array}$ & $\begin{array}{l}* * \\
* * \\
* * \\
* *\end{array}$ \\
\hline
\end{tabular}

* See page 6 for additional information.

**Available from the National Technical Information Service; use "AD", "PB", "COM", or NBS publication identification if no specific NTIS number is assigned. Available in Microfiche for $\$ 3.50$; consult NTIS for paper copy price. 


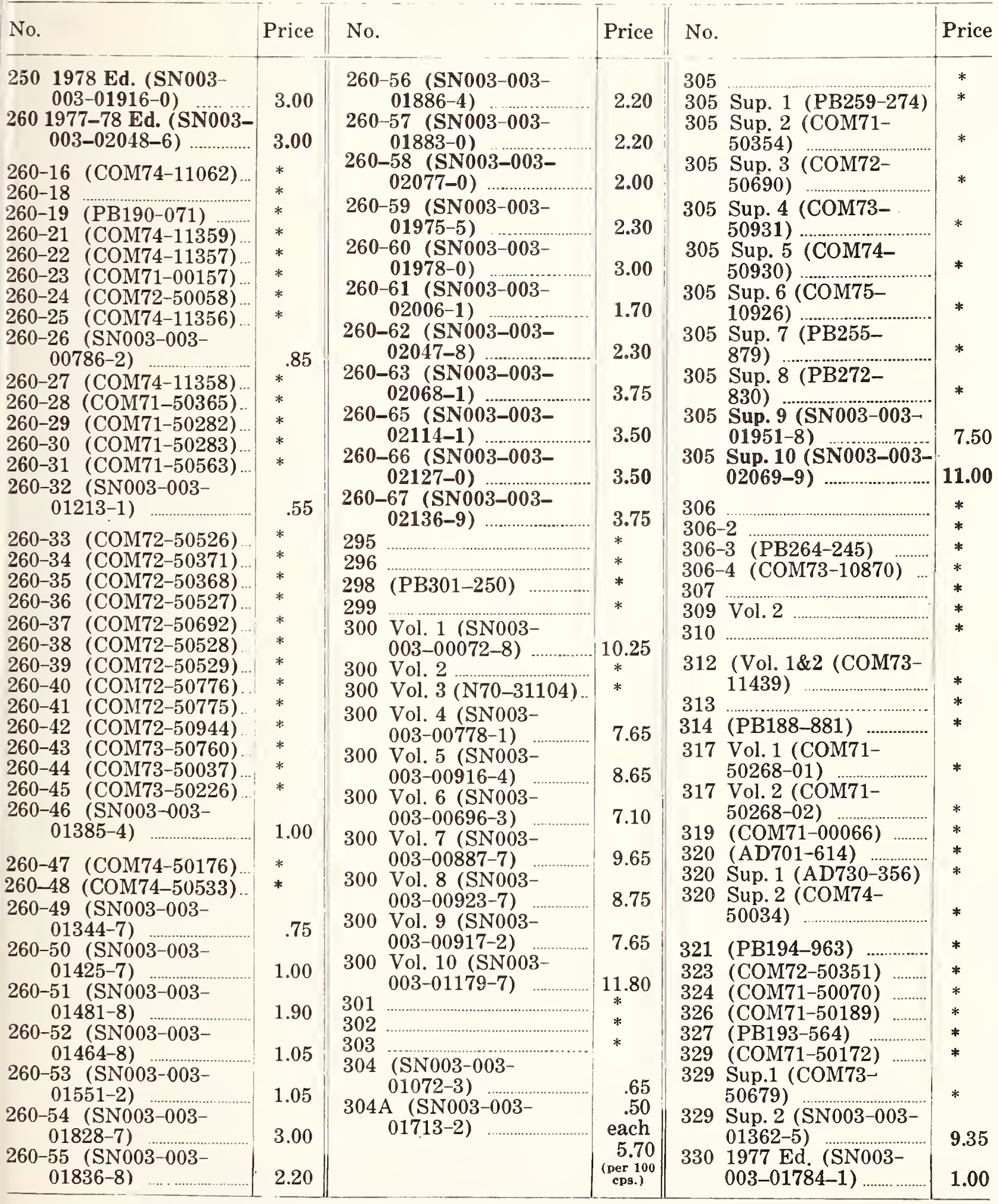

*Available from the National Technical Information Service, use "AD", "PB", "N", "COM", or NBS publication identification if no specific NTIS number is assigned. Available in' Microfiche for $\$ 5.00$; consult NTIS for paper copy price. 
SPECIAL PUBLICATIONS (Continued)

\begin{tabular}{|c|c|c|c|c|c|}
\hline No. & Price & No. & Price & No. & Price \\
\hline 1 & & 356 (SN & & 378 (c & * \\
\hline $2($ PB194-959) & * & $357 \stackrel{0093}{\text { (SN }}$ & 2.05 & 380 (S & 2,10 \\
\hline 33 (PB194-585) & * & 0092 & 5.40 & $380-1$ & 2.10 \\
\hline 34 (COM74-11482) & $*$ & 359 (COM72-50057) & & 01 : & 2.75 \\
\hline 336 (SN003-003- & $*$ & $\begin{array}{l}361 \text { Vol. } 1 \text { (COM72- } \\
\text { 10309) }\end{array}$ & * & 381 (COM73-50932) & $*$ \\
\hline $337 \begin{array}{l}00688-2) \\
(\text { COM71-00182) }\end{array}$ & $\begin{array}{l}9.70 \\
*\end{array}$ & 361 Vol. 2 (COM72- & * & $\begin{array}{l}382 \begin{array}{l}\text { (SN003-003- } \\
01176-2)\end{array} \\
\text {........... }\end{array}$ & 3.30 \\
\hline 338 (COM74-10736) & * & 362 (SN003-003- & & 383 (SN003-003- & \\
\hline $\begin{array}{ll}339 & \text { (COM71-50080) } \\
343 & \text { (COM71-50398) }\end{array}$ & $*$ & 0100 & 1.15 & 01171-1) & 2.10 \\
\hline 345 (SN003-003- & & $\begin{array}{l}363 \text { (COM72-50676) } \\
363-1 \text { (SN003-003-- }\end{array}$ & * & $\begin{array}{l}384 \text { Rev. } 1976 \text { (SN003- } \\
003-01670-5)\end{array}$ & \\
\hline $\begin{array}{r}0088 \\
345-1\end{array}$ & 2.70 & $01673-0$ ) & 2.50 & 385 (COM74-50307) & \\
\hline $\begin{array}{l}345-1 \text { (SN003-003- } \\
00731-5)\end{array}$ & 1.70 & $\begin{array}{l}364 \text { (COM72-50746) } \\
365 \text { (SN003-003- }\end{array}$ & * & $\begin{array}{c}386 \text { (SN003-003 } \\
01593-8)\end{array}$ & \\
\hline $\begin{array}{l}345-2 \text { (SN003-003- } \\
00824-9)\end{array}$ & 3.20 & $01068-5)$ & .60 & 387 & \\
\hline $\begin{array}{c}345-3 \text { (SN003-003- } \\
00859-1)\end{array}$ & 1.75 & 366 (SN00: & 2.80 & $\begin{array}{l}388 \text { (COM } \\
389 \text { Super }\end{array}$ & $*$ \\
\hline $\begin{array}{c}345-4 \quad(\text { SN003-003- } \\
00825-7)\end{array}$ & 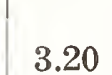 & $366-2$ & & 390 (CO & Fe \\
\hline $\begin{array}{c}345-5 \text { (SN003-003- } \\
00898-2)\end{array}$ & 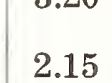 & $\begin{array}{r}015 \\
366-3(\end{array}$ & 1.35 & $\begin{array}{l}391 \text { (SN003-0 } \\
01260-2)\end{array}$ & 2.5 \\
\hline 345-6 (SN003-003- & & 02007 & 2.75 & $\begin{array}{c}392 \text { (SN003-00 } \\
01272-6)\end{array}$ & $1.0^{\circ}$ \\
\hline $\begin{array}{l}345-7 \text { (SN003-003- } \\
00864-8)\end{array}$ & 1.75 & 368 Rev. 1976 & $\begin{array}{r}.35 \\
\text { each }\end{array}$ & $\begin{array}{l}393 \text { (COM74-50350) } \\
394 \text { (COM74-50523) }\end{array}$ & ${ }^{*}$ \\
\hline $\begin{array}{c}345-8 \text { (SN003-003- } \\
00895-8)\end{array}$ & 2.10 & ) ....... & 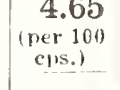 & 395 (SN003-003- & \\
\hline $345-9$ (COI & * & $\begin{array}{r}369 \text { (SN } \\
0112\end{array}$ & 1.85 & $\begin{array}{r}396-1 \\
012\end{array}$ & 1. \\
\hline $\begin{array}{c}345-10 \text { (SN003- } \\
00879-6)\end{array}$ & 3.05 & $370 \begin{array}{l}\text { (SN003-003- } \\
01057-0)\end{array}$ & & 396-2 (SN003-003- & \\
\hline $\begin{array}{l}\text { 345-11 (SNO03-003- } \\
00835-4 \text { ) }\end{array}$ & 2.70 & 371 (COM73-50245) & & $396-3(\mathrm{PH}$ & \\
\hline $\begin{array}{l}\text { 345-12 (SN003-003- } \\
00865-6)\end{array}$ & 2.00 & 0142 & 1.45 & $\begin{array}{l}396-4 \text { (SN003-00: } \\
01572-5)\end{array}$ & 1.6 \\
\hline 346 (COM71-50147) & $*$ & $\begin{array}{l}372 \text { (SN00 } \\
01059-\end{array}$ & 2.0 & $\begin{array}{c}398 \text { (SN003-003- } \\
01331-5)\end{array}$ & \\
\hline 347 (COM7 & $*$ & $\begin{array}{l}373 \text { (COM72-51036) } \\
374 \text { (SN003-003- }\end{array}$ & & $\begin{array}{c}399-1 \text { (SN003-003- } \\
01339-1)\end{array}$ & \\
\hline $\begin{array}{ll}348 & \text { (COM72-50763) } \\
349 & \text { (COM72-50807) }\end{array}$ & $*$ & & 5.20 & $399-2$ & \\
\hline 350 (CON & $*$ & 375 (COM73-5 & & & \\
\hline $\begin{array}{l}351 \text { (SN003-00 } \\
01027-8)\end{array}$ & & 1979 Ed. & .60 & $\begin{array}{r}399-3 \quad \text { (SN } \\
01334\end{array}$ & \\
\hline $\begin{array}{ll}352 & \text { (COM75-10291) } \\
353 & \text { (COM71-50364) }\end{array}$ & & & $\begin{array}{r}9.90 \\
(\operatorname{per} 100\end{array}$ & $\begin{array}{ll}400-1 & (\text { COMi74-50305) } \\
400-2 & (\text { COM74-50089) }\end{array}$ & \\
\hline $\begin{array}{ll}354 & (\text { COM72-50808) } \\
355 & (\text { COM71-50385) }\end{array}$ & $*$ & 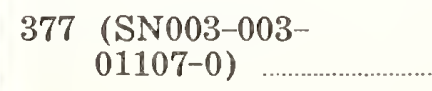 & .85 & 400-3 (COM74-50138) & * \\
\hline
\end{tabular}

"Available from the National Technical Information Service, use "PB", "COM", or NBS publication identification if no specific NTIS number is assigned. Available in Microfiche for $\$ 3.50$; consult NTIS for paper copy price.

**Superseded by NBS LC1070, free upon request from the Technical Information and Publications Division, National Bureau of Standards, Washington, DC 20234. 
SPECIAL PUBLICATIONS (Continued)

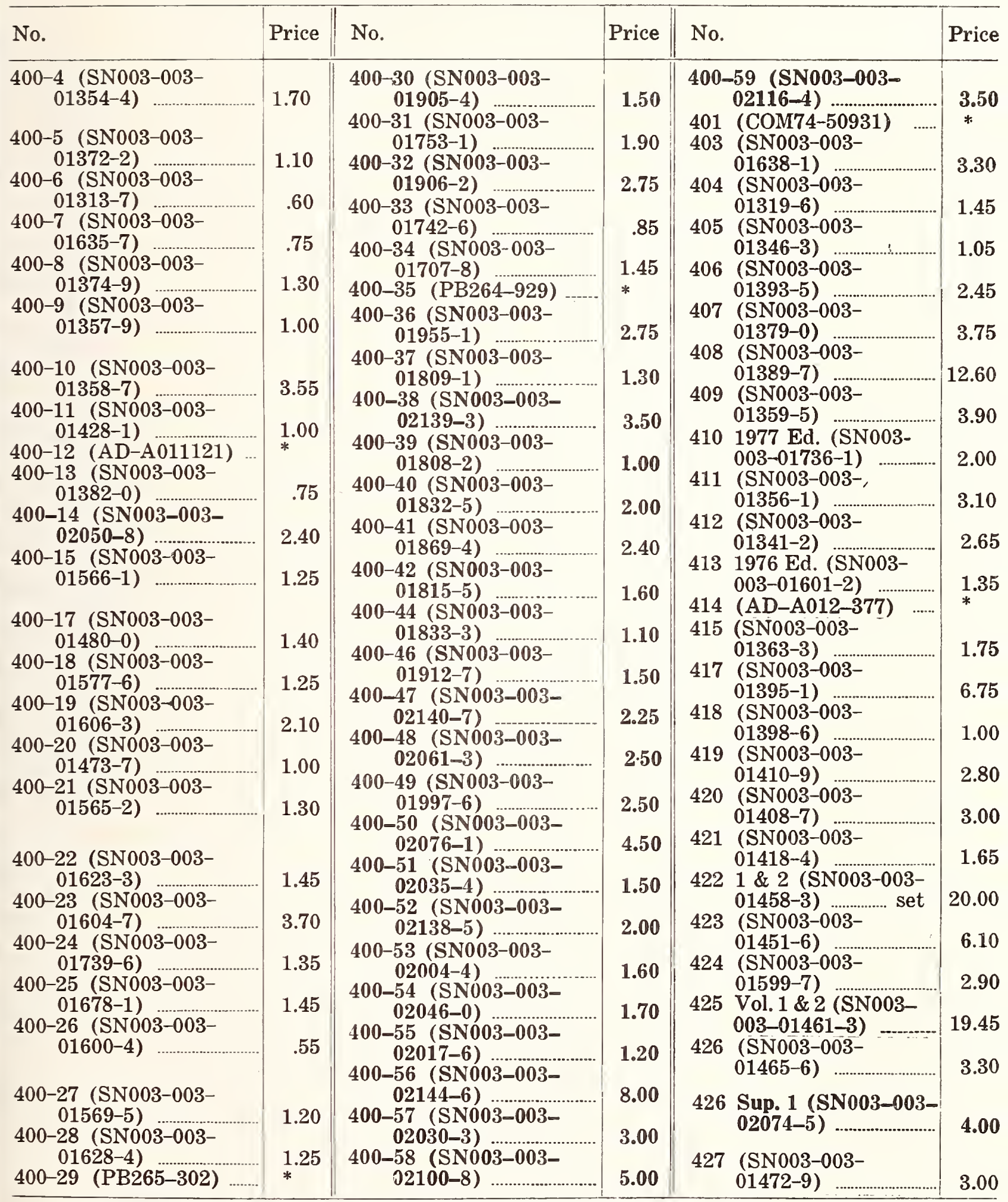

*Available from the National Technical Information Service, use "AD", "PB", or "COM" number when ordering. Available in Microfiche for $\$ 3.50$; consult NTIS for per copy price. 
SPECIAL PUBLICATIONS (Continued)

\begin{tabular}{|c|c|c|c|c|c|c|}
\hline No. & & Price & No. & Price & No. & Price \\
\hline 428 & $\begin{array}{l}\text { Pts. 1, } 2 \text { \& 3(SN003- } \\
003-01541-5)\end{array}$ & \multirow{3}{*}{$\begin{array}{r}28.50 \\
1.95 \\
.35\end{array}$} & 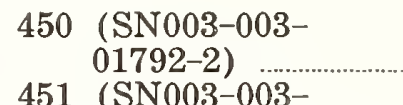 & 4.75 & \multirow{5}{*}{ 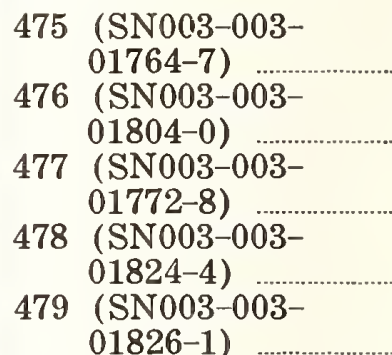 } & \multirow{3}{*}{$\begin{array}{l}2.80 \\
1.40 \\
6.25\end{array}$} \\
\hline 429 & $\begin{array}{l}(\mathrm{SNO03-003-} \\
01463-0)\end{array}$ & & $\begin{array}{l}451 \text { (SN003-003- } \\
01662-4)\end{array}$ & 3.00 & & \\
\hline 430 & $\begin{array}{l}\text { (SN003-003- } \\
01542-3)\end{array}$ & & $\begin{array}{l}452 \text { (SN003-003- } \\
01664-1)\end{array}$ & 2.65 & & \\
\hline 431 & $\begin{array}{l}\text { (SN003-003- } \\
01608-0)\end{array}$ & \multirow{3}{*}{$\begin{array}{r}11.00 \\
.60 \\
3.50\end{array}$} & $\begin{array}{l}453 \text { (SN003-003- } \\
01700-1)\end{array}$ & \multirow[b]{2}{*}{$\begin{array}{l}0.00 \\
1.65\end{array}$} & & \multirow{2}{*}{$\begin{array}{l}2.00 \\
3.75\end{array}$} \\
\hline 432 & $-003-$ & & $\begin{array}{l}454 \text { (SN003-003- } \\
01666-7)\end{array}$ & & & \\
\hline 433 & $-003-$ & & $\begin{array}{c}455 \text { (SN003-003- } \\
01699-3)\end{array}$ & 4.45 & $480-1$ (S & \\
\hline 434 & (SNO & & 456 (PB262-111) & & 0172 & 3.00 \\
\hline 435 & (SNOO & & $01685-3)$ & 1.80 & $\begin{array}{c}480-2 \text { (SN003-003- } \\
01723-0)\end{array}$ & 2.75 \\
\hline & $\begin{array}{l}0160 \\
\text { (SN }\end{array}$ & 5.60 & $\begin{array}{c}457-1 \text { (SN003-003- } \\
01802-3)\end{array}$ & 2.20 & $\begin{array}{l}480-3 \text { (SN003-003- } \\
01744-2)\end{array}$ & 2.50 \\
\hline & $\begin{array}{l}0155 \\
\text { (SN }\end{array}$ & 4.25 & $\begin{array}{l}457-2 \text { (SN003-003- } \\
01962-3)\end{array}$ & 3.25 & $\begin{array}{c}480-4 \text { (SN003-003-- } \\
01745-1 \text { ) }\end{array}$ & 2.75 \\
\hline & 0155 & 1.05 & 457-3 (SN003-003- & 0.20 & $480-5(\mathrm{SN}$ & 2.10 \\
\hline 438 & (SNO & & 0209 & 4.00 & 01747 & 2.20 \\
\hline & $003-$ & & 4080168 & 1.30 & $\begin{array}{c}480-6 \text { (SN003-003- } \\
01748-5)\end{array}$ & 2.20 \\
\hline $39-$ & $03-003-$ & & $\begin{array}{c}459 \text { (SN003-003- } \\
01686-1)\end{array}$ & 3.40 & $\begin{array}{c}480-7 \text { (SN003-003- } \\
01766-3)\end{array}$ & 2.40 \\
\hline & $\begin{array}{l}0205 \\
\text { (SN0 }\end{array}$ & 1.40 & $\begin{array}{c}460 \begin{array}{l}\text { (SN003-003- } \\
01737-0)\end{array}\end{array}$ & 8.10 & $\begin{array}{l}480-8 \text { (SN003-003- } \\
01735-8 \text { ) }\end{array}$ & \\
\hline & 0170 & 3.25 & 461 (PB263-200) & $*$ & & \\
\hline 441 & (SN & & $\begin{array}{l}\text { (SN003-003- } \\
01729-9)\end{array}$ & 4.60 & $\begin{array}{r}480-12 \\
02012-5)\end{array}$ & 1.60 \\
\hline & $-003-$ & & $\begin{array}{ll}463 & \text { (SN003-003- } \\
01701-9) & \\
& (\mathrm{PR} 75-008)\end{array}$ & $\begin{array}{l}3.35 \\
*\end{array}$ & $\begin{array}{l}480-13 \text { (SN003-003- } \\
01818-0)\end{array}$ & 2.00 \\
\hline 443 & $\begin{array}{l}\text { (SN003-003- } \\
01633-1 \text { ) }\end{array}$ & 4 & 464 (PB268-008). & & $\begin{array}{c}480-14 \text { '(SN003-003- } \\
\text { 02098-2) }\end{array}$ & 4.00 \\
\hline 444 & $\begin{array}{l}\text { (SN003-003- } \\
01588-1 \text { ) }\end{array}$ & & 400 (SNO17-4) & 5.25 & & \\
\hline $445-$ & $\begin{array}{l}-1 \text { (SNO03-003- } \\
01632-2)\end{array}$ & 1.20 & $\begin{array}{l}467 \\
01716-7) \\
468 \text { (SN003-0...... }\end{array}$ & 1.20 & $\begin{array}{r}480-15 \text { (SN } \\
01837-6\end{array}$ & 3.00 \\
\hline 446 & $003-$ & & $469 \stackrel{01760-4)}{(\text { SN003-003- }}$ & 3.0 & $\begin{array}{c}480-16 \text { (SNO03-003- } \\
01901-1)\end{array}$ & 3.50 \\
\hline $446-$ & $\begin{array}{l}-1 \text { (SN003-003- } \\
01846-5)\end{array}$ & & & 1.05 & $\begin{array}{c}480-17 \text { (SN003-003- } \\
01857-1 \text { ) }\end{array}$ & 3.00 \\
\hline $446-$ & $\begin{array}{l}-2(\text { SNO03-003- } \\
02021-4)\end{array}$ & 3 & $\begin{array}{c}470 \text { (SN003-003- } \\
01762-1)\end{array}$ & 5.60 & $\begin{array}{l}480-18 \text { (SN003-003- } \\
01786-8)\end{array}$ & 0 \\
\hline 447 & $\begin{array}{l}\text { (SN003-003- } \\
01654-3)\end{array}$ & 1.0 & $\begin{array}{c}471 \text { (SN003-003- } \\
01806-6)\end{array}$ & 3.75 & $\begin{array}{c}480-19 \text { (SN003-003- } \\
01773-6 \text { ) }\end{array}$ & 2.10 \\
\hline 448 & $\begin{array}{l}\text { (SN003-003- } \\
01663-2)\end{array}$ & 1.90 & $\begin{array}{c}472 \begin{array}{l}\text { (SN003-003- } \\
01767-1)\end{array}\end{array}$ & 2.00 & $\begin{array}{l}480-20 \text { (SN003-003- } \\
01904-6 \text { ) }\end{array}$ & 2.20 \\
\hline 449 & $\begin{array}{l}\text { (SN003-003- } \\
01677-2)\end{array}$ & 2.00 & 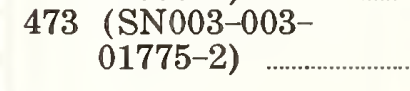 & 6.00 & $\begin{array}{l}480-21 \text { (SN003-003- } \\
01777-9 \text { ) }\end{array}$ & 1.00 \\
\hline
\end{tabular}

*Available from the National Technical Information Service; use "PB" number when ordering. Available in Microfiche for $\$ 3.50$; consult NTIS for paper copy price. 
SPECIAL PUBLICATIONS (Continued)

No.

480-22 (SN003-003$01774-4)$

480-24 (SN003-00301868-6)

480-25 (SN003-00301855-4)

480-26 (SN003-00301821-0)

480-27 (SN003-00301838-4)

480-28 (SN003-00301925-9)

480-29 (SN003-00301919-4)

480-30 (SN003-00302071-1)

480-31 (SN003-00301932-1)

480-32 (SN003-00301950-0)

480-33 (SN003-00302073-7)

480-34 (SN003-00301961-5)

480-35 (SN003-003-

480-36 (SN003-00302085-1)

480-38 (SN003-00302149-1)

481 (SN003-00301783-3)

482 (SN003-00301800-1)

483 (SN003-00301822-8)

484 Vol. 1 \& 2 (SN003003-01845-7)

485 (SN003-00301812-1)

486 (SN003-00301827-9)

487 (SN003-00301829-5)

488 (SN003-00301831-7)

489 (SN003-00301830-9)

490 (SN003-00301841-4)

491 (SN003-00301849-0)

Price No.

1.00

492 (SN003-00301858-9)

493 (SN003-00301847-3)

3.00

.90

494 (SN003-00301844-9)

496 Vol. 1 \& 2

(SN003-003-

01895-3)

1.50497 (SN003-003-

01884-8)

2.20498 (SN003-003-

01943-7)

1.10

499 (SN003-00301870-8)

1.75

.90

500-1 (SN003-00301724-8)

2.75

500-2 (SN003-00301726-4)

500-3 (SN003-00301725-6)

2.00

.90

500-4 (SN003-00301756-6)

500-5 (PB265-117)

2.30

1.50

500-6 (SN003-00301757-4)

500-7 (SN003-00301780-9)

4.25

1.40

2.50

2.75

12.25

500-8 (SN003-00301771-0)

500-9 (SN003-00301770-1)

500-10 (SN003-00301787-6)

500-11 (SN003-00301785-7)

2.00

500-12 (SN003-00301797-3)

500-13 (SN003-00301807-4)

2.10

5.25

3.00

3.00

3.00

3.25

500-14 (SN003-00301823-6)

500-15 (SN003-00301814-7)

500-16 (SN003-00301817-1)

500-17 (SN003-00301843-1)

500-18 (SN003-00301839-2)

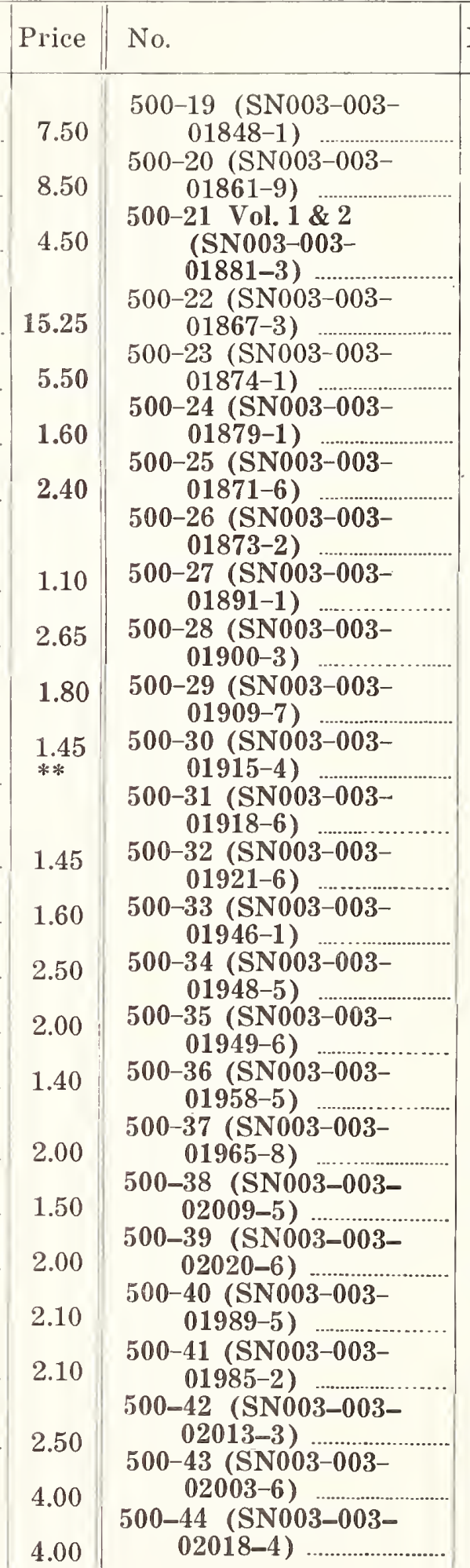

Price

4.00

1.60

6.00

3.25

4.25

2.20

2.40

1.40

3.00

2.20

1.60

3.00

2.40

2.30

1.40

3.25

2.20

1.10

1.50

2.40

2.75

4.00

6.00 
SPECIAL PUBLICATIONS (Continued)

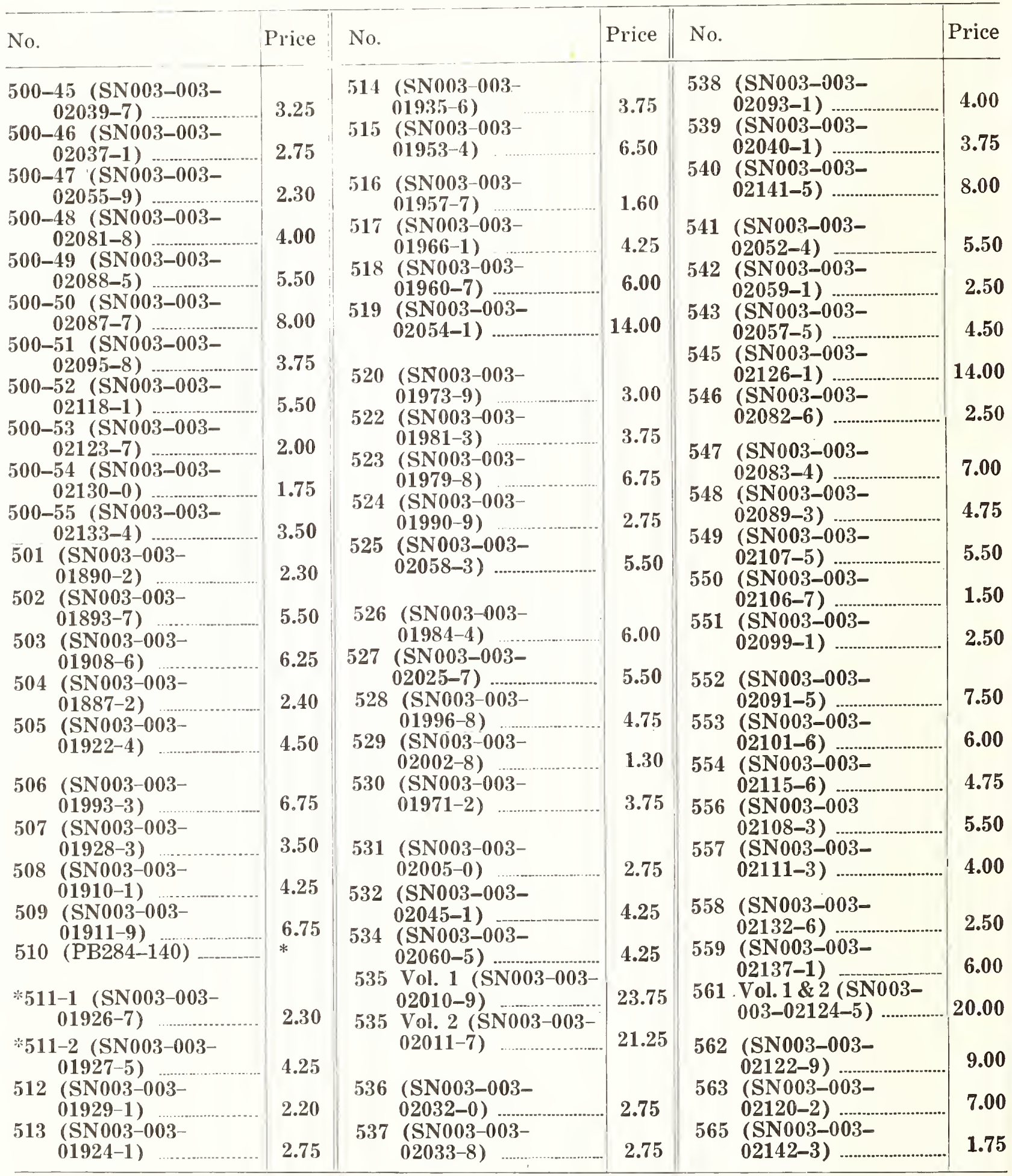

*NBS GCR 78-122 accompanies this publication, it is available from the National Technical Information Service as PB 279-430, price $\$ 21.50$.

**Available from the National Technical Information Service; use "PB" number when ordering. Available in Microfiche for $\$ 3.50$; consult NTIS for paper copy price. 
HANDBOOKS

\begin{tabular}{|c|c|c|c|c|c|c|}
\hline \multicolumn{2}{|c|}{ No. } & \multirow{3}{*}{\begin{tabular}{|l|} 
Price \\
$*$ \\
$*$ \\
$*$
\end{tabular}} & No. & \multirow{2}{*}{\begin{tabular}{|l|} 
Price \\
$\underset{*}{1.30}$
\end{tabular}} & No. & \multirow{2}{*}{$\begin{array}{r}\text { Price } \\
.90\end{array}$} \\
\hline & 1969 (Pt. 1.) & & 86 (SN003-003- & & $114 \begin{array}{l}\text { (SN003-003- } \\
01377-3)\end{array}$ & \\
\hline & 1957 (Pt. 3) & & 87 (PB248-564) & & 115 (SN003-003- & \\
\hline & & & 88. & $\begin{array}{l}* \\
*\end{array}$ & 115 Sup. 1 (SN003- & 2.90 \\
\hline 44, & $1979 \mathrm{~F}$ & & $90(\mathrm{~PB}$ & $* *$ & $116 \stackrel{003-}{\text { (SN }}$ & 2.2 \\
\hline & $003-0$ & $\begin{array}{l}6.00 \\
*\end{array}$ & 91 (SN & 1100 & $01456-7)$ & 1.10 \\
\hline 48 & & $*$ & 92 (SN003-003- & 11.00 & $117 \begin{array}{l}\text { (SN003-003- } \\
01563-6)\end{array}$ & .7 \\
\hline $\begin{array}{l}49 \\
51\end{array}$ & $(s$ & * & $94 \stackrel{00136-8)}{(\text { COM73-10635) } \ldots \ldots \ldots . . . .}$ & $\underset{* *}{2.10}$ & 118 (SN003-003- & 27 \\
\hline 53 & & $*^{.60}$ & & * & 119 (SN003-003- & \\
\hline 55 & & $*$ & $\begin{array}{l}90 \\
97\end{array}$ & $*$ & $01646-2)$ & 5.10 \\
\hline $\begin{array}{l}57 \\
58\end{array}$ & (PB248-218) & * & 98 (COM72-10619) & $\begin{array}{l}* * \\
* *\end{array}$ & $\begin{array}{c}120 \begin{array}{l}\text { (SN003-003- } \\
01667-5)\end{array} \\
. . . . .\end{array}$ & .70 \\
\hline 59 & & * & 100 & $* *$ & 121 (SN003-003- & 3. \\
\hline 63. & & & 101 & ** & 122016 & \\
\hline 64 & (COM73-10872) & ** & 102 & ${ }^{*} *$ & $\begin{array}{l}\text { IZ2 } \\
01750-7)\end{array}$ & 2.60 \\
\hline $\begin{array}{l}60 \\
69\end{array}$ & & * & $\begin{array}{l}105-1 \\
105-2(\text { COM72-50707) } \\
\text { (COM71-50065) }\end{array}$ & $* *$ & 123 (SN003-003- & 9 \\
\hline $\begin{array}{l}71 \\
72\end{array}$ & & * & 105-3 (SN003-0 & & & \\
\hline 12 & 00123 & 1.30 & & 1.20 & 0181 & 1.60 \\
\hline $\begin{array}{l}73 \\
74\end{array}$ & 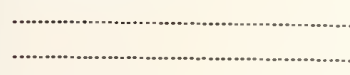 & & $107 \begin{array}{l}\text { Rev. } 1978 \text { (SN003- } \\
003-02064-8 \text { ) }\end{array}$ & 1.30 & $\begin{array}{l}125 \begin{array}{l}\text { (SN003-003- } \\
01972-1)\end{array}\end{array}$ & 6.25 \\
\hline $\begin{array}{l}75 \\
76\end{array}$ & & * & 109 (COM72-50183 & $* *$ & $126 \begin{array}{l}\text { (SN003-003- } \\
01903-8)\end{array}$ & \\
\hline 80 & & 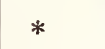 & $110-1$ & $*$ & 127 (SN) & \\
\hline 81 & & * & 111 Rev. 77 (SN003- & & 0191 & 1.1 \\
\hline 81 & Suppl. 2 & $*$ & $003-01917-\varepsilon$ & 1.00 & 128 (SN003-003- & \\
\hline $\begin{array}{l}84 \\
85\end{array}$ & (SN003-003- & & $\begin{array}{ll}112 & \text { (COM } \\
113 & \text { (SN0 }\end{array}$ & & $129 \stackrel{020}{\mathrm{C} I}$ & \\
\hline & $00131-7)$ & 2.20 & 012 & 2.15 & & 1.75 \\
\hline
\end{tabular}

*See page 6 for additional information.

**Available from the National Technical Information Service, use "PB", "COM", or NBS publication identification if no specific NTIS number is assigned. Available in Microfiche for $\$ 3.50$; consult NTIS for paper copy price. 


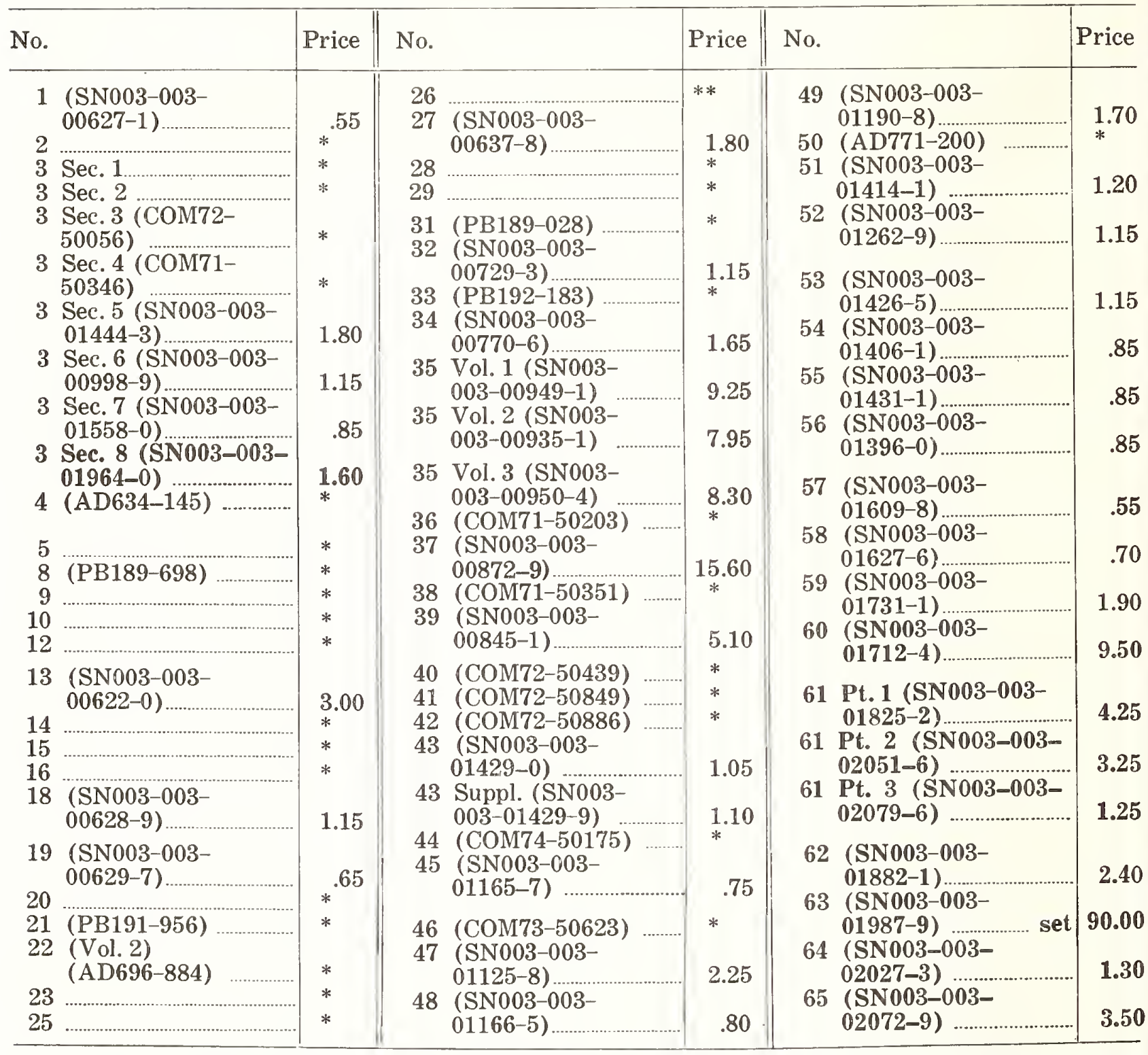

*Available from the National Technical Information Service, use "AD", "PB", "COM", or NBS publication identification if no specific NTIS number is assigned. Available in Microfiche for $\$ 3.50$; consult NTIS for paper copy price.

**Superseded by the Journal of Physical and Chemical Reference Data, Vol. 6, Supp. 1; available from the American Chemical Society, 1155 16th St., N.W., Washington, DC 20036. 


\begin{tabular}{|c|c|c|c|c|c|c|}
\hline No. & & Price & No. & Price & No. & Price \\
\hline & 0046) & ${ }^{*}$ & $41(\mathrm{CO}$ & * & $69(\mathrm{~S}$ & \\
\hline & (PB & * & $42(C$ & * & & 4.60 \\
\hline & Pt. 1 (COM72- & $x^{*}$ & 43 (COM75-10173) & * & 70 (SN003-003- & \\
\hline 3 & 105 & $*$ & $44 \begin{array}{l}\text { (SN003-003- } \\
01071-5)\end{array}$ & .65 & 01437 & 1.55 \\
\hline 4 & $\ldots \ldots$ & * & 45 (COM73-50725) & $*$ & $\begin{array}{l}71 \text { (SN) } \\
0145\end{array}$ & 2.25 \\
\hline & Pt. 2 & * & 46 (COM73-50188) & * & 72 (SN003-003- & 180 \\
\hline 7 & & * & 48 (SN003-003- & & 73 (SN003-003- & 1.80 \\
\hline 8 & (COM73-10487) & * & $01212-2)$ & 4.85 & $01479-6)$ & 1.25 \\
\hline & (PB19: & * & 49 (COM74-50353) & * & 74 (SN & $1=5$ \\
\hline 10 & & $*$ & & & 0147 & 1.55 \\
\hline $\begin{array}{l}11 \\
12\end{array}$ & & * & $51 \stackrel{01282-3)}{\text { (SN003-003- }}$ & .55 & $\begin{array}{r}75 \cdot \text { (SN0 } \\
02029\end{array}$ & 3.00 \\
\hline 13 & & * & $01267-0)$ & 90 & 76 (SN003-003- & \\
\hline 14 & 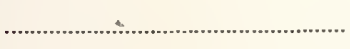 & * & 52 (COM74-50537) & $x^{2}+2+2$ & 0164 & 1.45 \\
\hline 15 & & * & 53 (SN003 & & 77 (SN003-003- & 235 \\
\hline 16 & & $*$ & 54 (SN & & 78 (SA & 2. \\
\hline $\begin{array}{l}17 \\
18\end{array}$ & & * & 0130 & 1.25 & 0153 & 1.25 \\
\hline 19 & $(1$ & * & 55 (COM74-51188) & * & $79 \begin{array}{l}\text { (SN003-003- } \\
01546-6)\end{array}$ & 1.1 \\
\hline 20 & (PB1 & $*$ & 56 (SNO03-003 & 2.35 & $80 \mathrm{GN}$ & \\
\hline 21 & (PB1 & $*$ & 57 (SNO03-003- & & $02183-1)$ & 1.15 \\
\hline 23 & . & * & 01364 & 1.20 & 81 (SNO03-00: & \\
\hline 24 & $x_{-1}$ & * & of $01349-8)$ & 2.00 & 82 (SN003-003- & \\
\hline $\begin{array}{l}25 \\
26\end{array}$ & (PB188-789) & $*$ & 59 (SN003-003- & & 02185-7) & .50 \\
\hline 27 & (PB191-304). & * & (SNOO3-003- & & $01592-0)$ & .5 \\
\hline & $(\mathrm{PE}$ & * & ou $01352-8)$ & & 84 (SNO03-003- & \\
\hline 29 & (PB1 & * & 61 (COM75-10473) & & $85 \stackrel{016}{(S)}$ & 3.50 \\
\hline $\begin{array}{l}30 \\
31\end{array}$ & $\begin{array}{l}(\mathrm{COM} 71-00141) \\
(\mathrm{PB} 193-601)\end{array}$ & $*$ & 62 (SN003-003- & 1.90 & 85 (SNU03-003- & 2.2 \\
\hline 32 & (COM71-50078) & * & 63 (SN003-003- & & 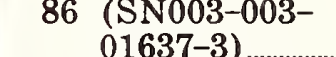 & $1.0+2>-1$ \\
\hline $\begin{array}{l}33 \\
34\end{array}$ & $\begin{array}{l}\left(\mathrm{COM}^{r}\right. \\
\left(\mathrm{COM}^{\prime}\right.\end{array}$ & * & & 70 & 87 (SN003-003- & \\
\hline 35 & (CC & ${ }^{*}$ & $01360-9)$ & 1.35 & 88 (SNM03-01642-0) & \\
\hline & $\begin{array}{l}\text { (SNO } \\
0085\end{array}$ & & $\begin{array}{l}65 \text { (SN003-003- } \\
01394-3)\end{array}$ & & 01693-4) & .65 \\
\hline 37 & (SN003-003- & & 66 (SN003-003- & & 01706 & . \\
\hline & (CO & * & 01417-6) & $2.1+3+2,-1$ & $90($ (PB257-581) & \\
\hline 39 & (COM72-50068) & * & $01468-1)$ & 1.20 & 10165 & 1.40 \\
\hline & $\begin{array}{l}\text { (SN003-003- } \\
00940-7)\end{array}$ & 3.95 & $\begin{array}{l}68 \text { (SN003-003- } \\
01419-2) \ldots . . . . . .\end{array}$ & 1.25 & $\begin{array}{l}92 \text { (SN003-003- } \\
\text { 01692-6) }\end{array}$ & .70 \\
\hline
\end{tabular}


BUILDING SCIENCE SERIES (Continued)

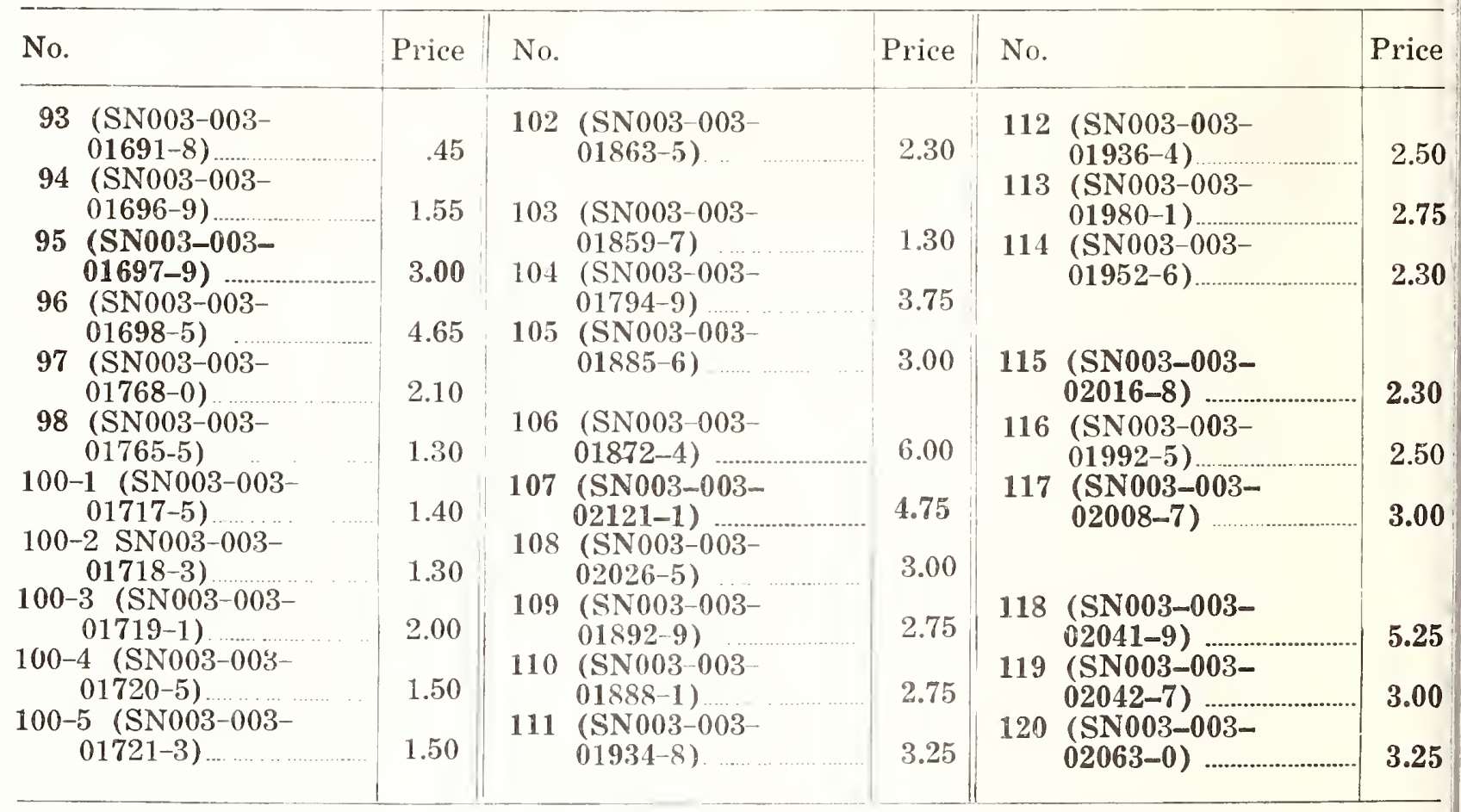

*Available from the National Technical Information Service; use "PB", "COM" or NBS Publication identification if no specific NTIS number is assigned. Available in Microfiche for $\$ 3.50$; consult NTIS for paper copy price. 


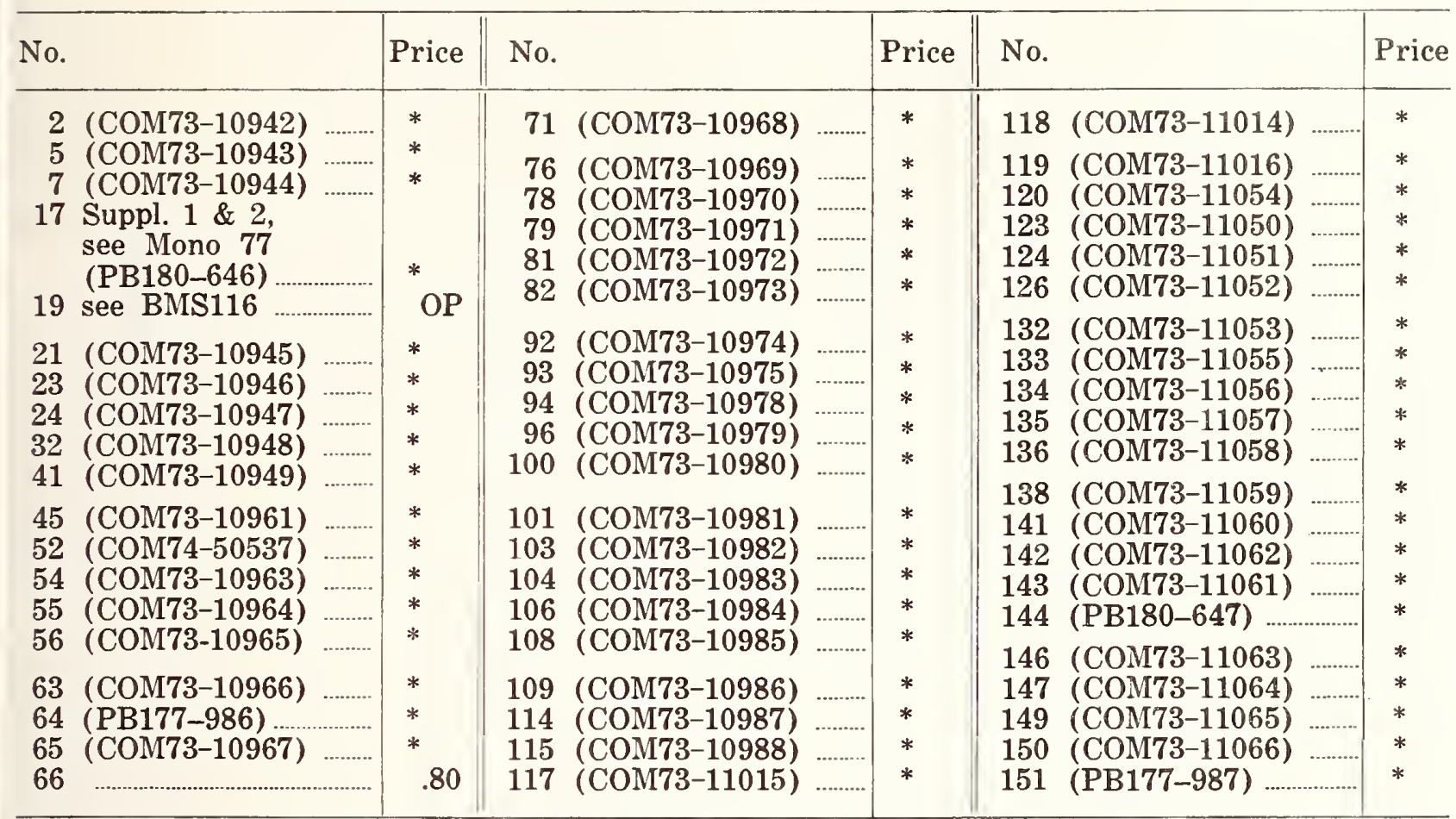

*Available from the National Technical Information Service, use "PB" or "COM" number when ordering. Available in Microfiche for $\$ 3.50$; consult NTIS for paper copy price.

\section{VOLUNTARY PRODUCT STANDARDS}

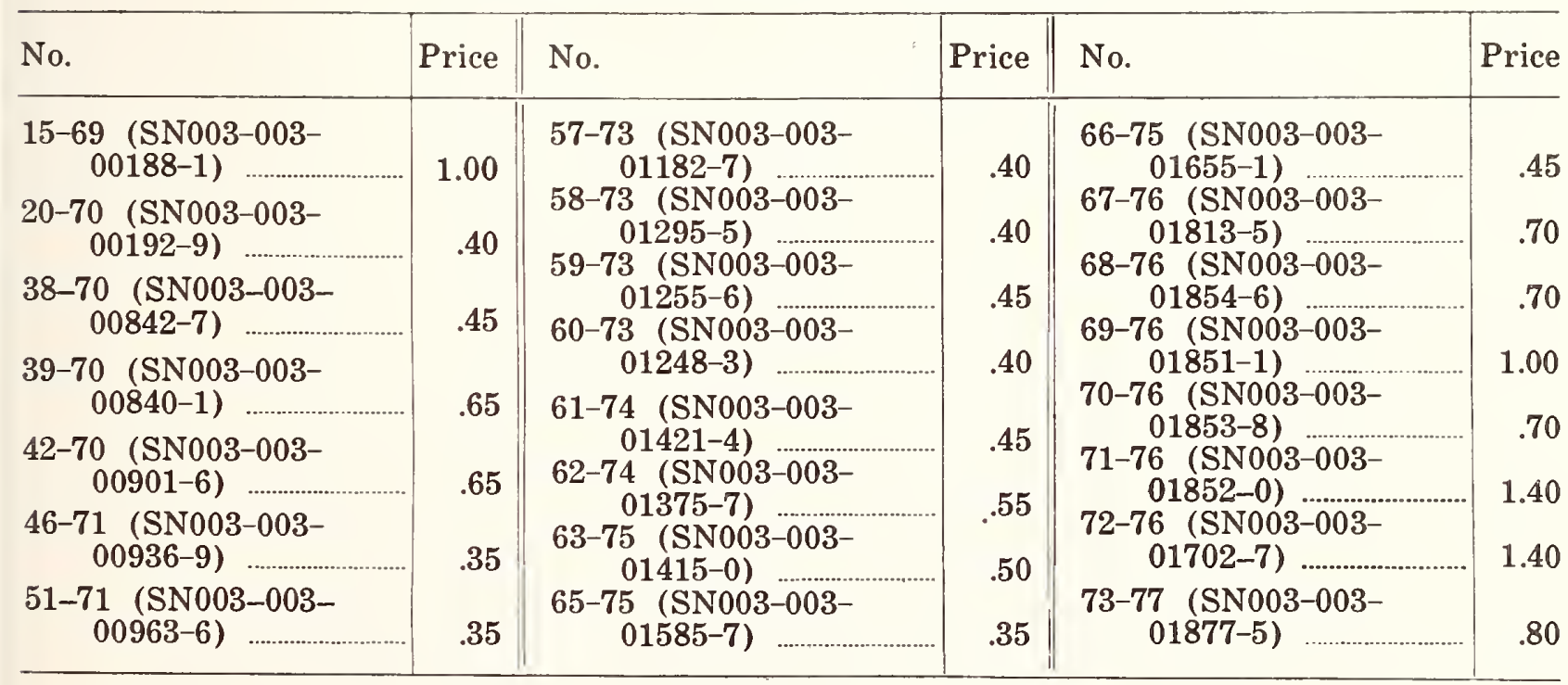


FEDERAL INFORMATION PROCESSING STANDARDS SERIES

\begin{tabular}{|c|c|c|c|c|c|c|c|c|}
\hline \multirow[b]{2}{*}{ No. } & \multicolumn{2}{|c|}{$\begin{array}{c}\text { Single Copy Price } \\
\text { Paper Copy } \\
\end{array}$} & \multirow[b]{2}{*}{ No. } & \multirow{2}{*}{\multicolumn{2}{|c|}{$\begin{array}{l}\text { Single Copy Price } \\
\text { Paper Copy } \\
\text { Domestic Foreign }\end{array}$}} & \multirow[b]{2}{*}{ No. } & \multicolumn{2}{|c|}{$\begin{array}{c}\text { Single Copy Price } \\
\text { Paper Copy }\end{array}$} \\
\hline & Domestic & & & & & & & Foreign \\
\hline 0 & 5.00 & 10.00 & $22-1$ & 5.00 & 10.00 & 43 & 7.00 & 14.00 \\
\hline & 5.00 & 10.00 & 23 & 5.00 & 10.00 & 44 & 5.00 & 10.00 \\
\hline & 5.00 & 10.00 & 24 & 6.00 & 12.00 & 45 & 7.00 & 14.00 \\
\hline $3-1$. & 5.00 & 10.00 & 25 & 5.00 & 10.00 & 46 & 5.00 & 10.00 \\
\hline & 5.00 & 10.00 & 26 & 5.00 & 10.00 & 47 & 6.00 & 12.00 \\
\hline 5-1. & 5.00 & 10.00 & 27 & 5.00 & 10.00 & 48 & 5.00 & 10.00 \\
\hline $6-2$. & 6.00 & 12.00 & 28 & 5.00 & 10.00 & 49 & 5.00 & 10.00 \\
\hline & 5.00 & 10.00 & 29 & 5.00 & 10.00 & 50 & 6.00 & 12.00 \\
\hline $8-4$ & 5.00 & 10.00 & 30 & 5.00 & 10.00 & 51 & 6.00 & 12.00 \\
\hline & 5.00 & 10.00 & & & & 52 & 5.00 & 10.00 \\
\hline 10-2 & 6.00 & 12.00 & 31 & 8.00 & 16.00 & 53 & 5.00 & 10.00 \\
\hline $11-1$ & 11.00 & 22.00 & 32 & 8.00 & 16.00 & 54 & 5.00 & 10.00 \\
\hline $12-2$. & 12.00 & 24.00 & 33 & 6.00 & 12.00 & 55 & 16.50 & 33.00 \\
\hline 13 & 5.00 & 10.00 & 34 & 5.00 & 10.00 & 56 & 5.00 & 10.00 \\
\hline 14 & 5.00 & 10.00 & 35 & 6.00 & 12.00 & 57 & 6.00 & 12.00 \\
\hline 15 & 5.00 & 10.00 & 36 & 5.00 & 10.00 & 58 & 5.00 & 10.00 \\
\hline $16-1$ & 5.00 & 10.00 & 37 & 5.00 & 10.00 & 59 & 5.00 & 10.00 \\
\hline $17-1$. & 5.00 & 10.00 & 38 & 7.00 & 14.00 & 64 & 6.00 & 12.00 \\
\hline 18-1. & 5.00 & 10.00 & 39 & 5.00 & 10.00 & 65 & 6.00 & 12.00 \\
\hline 19 & 5.00 & 10.00 & 40 & 7.00 & 14.00 & 66 & 6.00 & 12.00 \\
\hline 20 & 5.00 & 10.00 & 41 & 5.00 & 10.00 & 67 & 6.00 & 12.00 \\
\hline $21-1$ & 20.50 & 41.00 & $42-1$ & 6.00 & 12.00 & & & \\
\hline
\end{tabular}

All FIPS are available from the National Technical Information Service. 
APPLIED MATHEMATICS SERIES

\begin{tabular}{|c|c|c|c|c|c|c|}
\hline \multicolumn{2}{|l|}{ No. } & Price & No. & Price & No. & Price \\
\hline & See AMS25 & * & 23 (PB175-967) & $*$ & 45 (COM74-10639) & $*$ \\
\hline & (PB194-385) & $*$ & 24 (PB175-816) & $*$ & 46 (PB186-429) & $*$ \\
\hline & (PB251-959) & $*$ & 25 & $*$ & 47 (PB251-902) & * \\
\hline 4 & (PB251-962) & $*$ & 26 (PB178 & $*$ & 48 (PB176-119) & * \\
\hline & (COM73-10501) & $*$ & 27 (AD694-116) & $*$ & 49 (PB251-903) & $*$ \\
\hline & (PB251-862) & $*$ & 28 (AD695-952) & * & 50 (PB176-520) & $*$ \\
\hline & (PB251-863) & $*$ & 29 (AD695-953) & $*$ & 51 (PB248-467) & $*$ \\
\hline 8 & (PB251-864) & $*$ & 30 (PB175-817) & $\%$ & 52 (PB251-904) & $\begin{array}{l}* \\
*\end{array}$ \\
\hline 9 & (COM73-10498) & $*$ & 31 (COM74-11112) & $*$ & 53 (PB186-430) & * \\
\hline 10 & (PB251-960) & $*$ & 32 (COM73-10499) & $*$ & $\begin{array}{l}54 \text { (COM73-11111) } \\
55 \text { (SN003-003- }\end{array}$ & \\
\hline & $(\mathrm{AD} 702-411)$ & $*$ & 33 (PB175-818) & $*$ & $\begin{array}{l}\text { (DNOU3-0 } \\
00279-8)\end{array}$ & 12.65 \\
\hline 12 & (PB184-887) & $\%$ & 34 (SN003-003- & & 56 (PB190-608) & $*$ \\
\hline 13 & (PB251-865) & $*$ & $00272-1)$ & 4.70 & 57 (PB266-263) & $*$ \\
\hline & $\begin{array}{l}\text { (SN003-003- } \\
00270-4)\end{array}$ & & 35 (PB251-103) & & 58 (AD700-470) & * \\
\hline & $(\mathrm{PB} 251-866)$ & 11.70 & 36 (PB251-871) & $*$ & 59 (SN003-003- & \\
\hline & (PB251-867) & $\%$ & $\begin{array}{l}37 \\
38\end{array}$ & $*$ & $\begin{array}{l}00282-8) \\
60\end{array}$ & \\
\hline 17 & (PB251-868) & $*$ & 39 (PB251-901) & $*$ & $00283-6)$ & 1.45 \\
\hline 18 & (PB175-819) & $*$ & 40 (PB186-428) & $*$ & 61 (PB188-790) & \\
\hline & (PB175-815) & * & 41 (PB176-521) & $*$ & 62 (SN003-003- & \\
\hline 20 & (PB251-870) & & 42 (PB175-819) & $*$ & 00993-8) & 1.20 \\
\hline & (PB178-392) & $*$ & 43 (PB176-127) & $*$ & 63 (SN003-003- & \\
\hline & (PB192-337) & $*$ & 44 (AD698-954) & $*$ & 00988-1) ..... & 3.45 \\
\hline
\end{tabular}

*Available from the National Technical Information Service; use "PB", "AD", "COM", or NBS publication identification if no specific NTIS number is assigned. Available in Microfiche for $\$ 3.50$; consult NTIS for paper copy price. 
CONSUMER INFORMATION SERIES

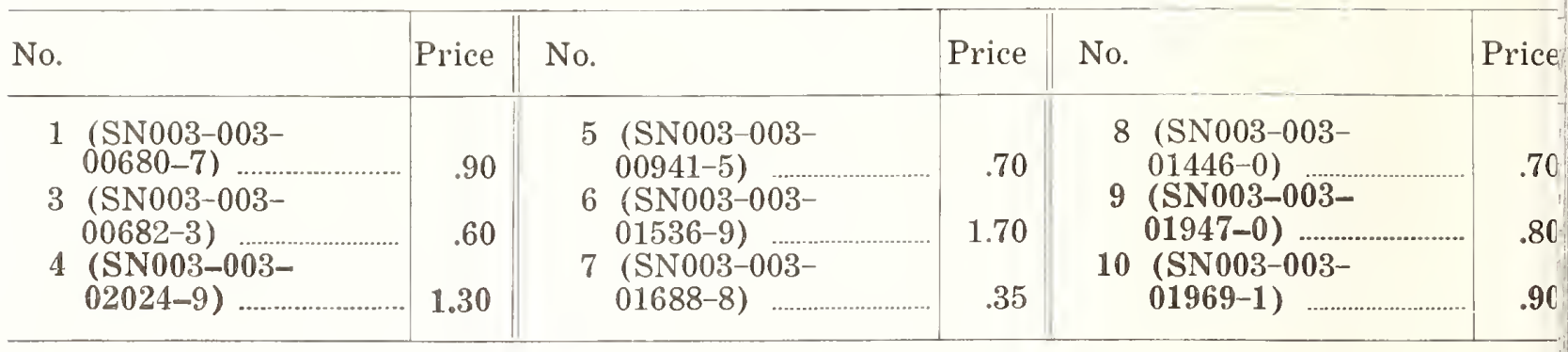

TECHNICAL NOTES

\begin{tabular}{|c|c|c|c|c|c|}
\hline No. & Price & No. & Price & No. & Price \\
\hline $1 \quad(\mathrm{~PB} 151-360)$ & * & 18-19 (PB195-218) & $*$ & $40-9$ (PB189-933) & * \\
\hline 2 (PB151-361) & $*$ & $18-20(\mathrm{~PB} 168-044)$ & $*$ & $40-10($ PB189-934) & * \\
\hline $2-2(\mathrm{~PB} 151-361-2)$ & * & $18-21$ (PB195-219) & $*$ & 40-11 (PB189-935) & $*$ \\
\hline 3 (PB151-362) & $*$ & $18-22(\mathrm{~N} 661-3994)$ & $*$ & 40-12 (PB189-936) & $*$ \\
\hline 4 (PB151-363) & * & 18-23 (COM74-10437) & $*$ & $40-13(\mathrm{~PB} 151-399-13)$ & * \\
\hline 5 (PB151-364) & $*$ & 18-24 (COM74-10438). & $*$ & $41 \quad(\mathrm{~PB} 151-400)$ & * \\
\hline $6(\mathrm{~PB} 151-365)$ & * & $18-25$ (COM74-10473) & $*$ & 42 (PB151-401) & $*$ \\
\hline $7(\mathrm{~PB} 151-366)$ & $*$ & 18-26 (COM74-10439) & $*$ & 43 (PB151-402) & $*$ \\
\hline 8 (PB151-367) & $*$ & 19 (PB151-378) & $*$ & 44 (PB151-403) & $*$ \\
\hline 9 (PB151-368) & * & 20 (PB151-379) & $*$ & 45 (PB151-404) & $*$ \\
\hline 10 (PB151-369) & $*$ & $21(\mathrm{~PB} 151-380)$ & $*$ & $46 \quad(\mathrm{~PB} 151-405)$ & $*$ \\
\hline 11 (PB151-370) & $*$ & 22 (PB151-381) & * & 47 (PB151-406) & $*$ \\
\hline 12 (PB151-371) & * & 23 (PB151-382) & * & 48 (PB151-407) & $*$ \\
\hline 13 (PB151-372) & $*$ & 24 (PB151-383) & * & 49 (PB151-408) & $*$ \\
\hline 14 (PB151-373) & $*$ & 25 (PB151-384) & * & 50 (PB151-409) & * \\
\hline 15 (PB151-374) & $*$ & $26(\mathrm{~PB} 151-385)$ & $*$ & 51 (PB161-552) & $*$ \\
\hline $16(\mathrm{~PB} 151-375)$ & $*$ & 27 (PB151-386) & $*$ & 52 (PB161-553) & $*$ \\
\hline 18 (PB151-377) & * & 28 (PB151-387) & $*$ & 53 (PB161-554) & $*$ \\
\hline $18-2(\mathrm{~PB} 151-377-2)$ & $*$ & 29 (PB151-388) & $*$ & 54 (PB161-555) & * \\
\hline $18-3$ (PB151-377-3) & $*$ & 30 (PB151-389) & $*$ & 55 (PB161-556) & $*$ \\
\hline $18-4$ (PB151-377-4) & * & 31 (PB151-390) & * & 56 (PB161-557) & $*$ \\
\hline $18-5$ (PB151-377-5) & $*$ & 33 (PB151-392) & $*$ & 57 (PB161-558) & $*$ \\
\hline 18-6 (PB151-377-6) & $*$ & 34 (PB151-393) & $*$ & 58 (PB161-559) & $*$ \\
\hline 18-7 (PB151-377-7) & $*$ & 35 (PB151-394) & $*$ & 59 (PB161-560) & $*$ \\
\hline 18-8 (PB151-377-8) & * & 37 (PB151-396) & * & 60 (PB161-561) & * \\
\hline 18-9 (PB151-377-9) & * & 38 (PB151-397) & $*$ & 61 (PB161-562) & * \\
\hline $18-10(\mathrm{~PB} 151-377-10)$ & * & 39 (PB151-398) & * & 62 (PB161-563) & $*$ \\
\hline $18-11$ (PB151-377-11) & $*$ & $40-1$ (PB151-399-1) & $*$ & 63 (PB161-564) & $*$ \\
\hline $18-12$ (PB151-377-12) & $*$ & 40-2 (PB151-399-2) & * & 64 (PB161-565) & $*$ \\
\hline $18-13$ (PB151-377-13). & * & 40-3 (PB151-399-3) & 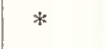 & 66 (PB161-567) & $*$ \\
\hline 18-14 (PB195-273) & * & $40-4 \quad(P B 151-399-4)$ & * & 67 (PB161-568) & * \\
\hline $18-15$ (PB195-215) & $*$ & $40-5$ (PB151-399-5) & $*$ & 68 (PB161-569) & * \\
\hline $18-16(\mathrm{~PB} 195-216)$ & $*$ & $40-6$ (PB151-399-6) & $*$ & 69 (PB161-570) & * \\
\hline $18-17$ (PB195-217) & * & 40-7 (PB151-399-7) & $*$ & 70 (PB161-571) & * \\
\hline 18-18 (PB168-058) & $*$ & $40-8$ (PB189-932) & * & $71 \quad(\mathrm{PB161}-572)$ & * \\
\hline
\end{tabular}

*Available from the National Technical Information Service; use "PB", "N", or "COM" num. ber when ordering. Available in Microfiche for $\$ 3.50$; consult NTIS for paper copy price. 


\begin{tabular}{|c|c|c|c|c|c|}
\hline No. & Price & No. & Price & No. & Price \\
\hline 72 (PB161-573) & $*$ & $120 \mathrm{~A} \quad(\mathrm{~PB} 190-611)$ & $*$ & 196 (COM73-10483) & $*$ \\
\hline 73 (PB161-574) & $*$ & 121 (PB161-622) & * & 197 (AD419-866) & $*$ \\
\hline 74 (PB161-575) & $*$ & $122(\mathrm{~PB} 161-623)$ & & 199 (AD683-408) & * \\
\hline 75 (PB161-576) & $*$ & $\begin{array}{l}122(\mathrm{~PB} 161-623) \\
123(\mathrm{~PB} 161-624)\end{array}$ & $*$ & 200 (N64-14272) & $*$ \\
\hline 76 (PB161-577) & $*$ & 124 (PB161-625) & * & $201 \quad$ (PB182-539) & * \\
\hline 77 (PB161-578) & $*$ & 125 (PB161-626) & * & 204 (PB184-118) & $\begin{array}{l}* \\
*\end{array}$ \\
\hline $78 \quad(\mathrm{~PB} 161-5$ & * & 128 (PB161-629) & $*$ & 205 (COM73-10634) & . \\
\hline 80 (PB161-581) & * & 129 (PB161-630) & $*$ & $206-1$ (COM73-10684) & $*$ \\
\hline 81 (PB161-582) & $*$ & $129 \mathrm{~A}$ & $*$ & 206-2 (COM73-10685) & * \\
\hline 82 (PB161-583) & $*$ & $\begin{array}{l}130 \\
131 \text { (PB161-632) }\end{array}$ & $*$ & 206-3 (COM73-10686) & $*$ \\
\hline 83 (PB161-584) & $*$ & 132 (PB161-633) & * & $206-5$ (COM73-10688) & $*$ \\
\hline $\begin{array}{ll}84 & (\mathrm{~PB} 161-585) \\
85 & (\mathrm{~PB} 161-586)\end{array}$ & * & 133 (PB161-634) & * & 207 (COM73-10689) & $*$ \\
\hline 86 (PB161-587) & * & 134 (PB161-635) & $*$ & 209 (PB168-043) & * \\
\hline 87 (PB161-588) & $*$ & $\begin{array}{ll}135 & (\mathrm{~PB} 161-636) \\
136 & (\mathrm{~PB} 161-637)\end{array}$ & $*$ & 210 (PB189-930) & * \\
\hline 88 (PB161-589) & $*$ & 137 (PB161-638) & $*$ & 214 (PB189-931) & $*$ \\
\hline 89 (PB161-590) & $*$ & $61-639)$ & * & 215 (PB188-808) & $*$ \\
\hline $\begin{array}{l}90(\mathrm{P}=\mathrm{B} 161-591) \\
91 \quad(\mathrm{~PB} 161-592)\end{array}$ & * & 139 (PB161-640) & $*$ & 217 (PB189-103) & $*$ \\
\hline (1) & & 140 (PB161-641) & $*$ & 218 (PB188-809) & * \\
\hline 92 (PB161-593) & * & 141 (PB191-729) & $*$ & 219 (PB186-279) & $*$ \\
\hline & * & 142 (PB161-643) & * & 220 (COM74-11077) & * \\
\hline $\begin{array}{l}94 \quad(\mathrm{~PB} 161-595) \\
95 \text { (PB161-596) }\end{array}$ & * & 143 (PB161-644) & $*$ & 221 (COM71-00690) & * \\
\hline 96 (PB161-597) & * & 146 (PB161-647) & $*$ & 223 (PB168-051) & * \\
\hline 97 (PB161-598) & $*$ & 147 (PB161-648) & $*$ & 224 (PB184-119) & * \\
\hline 98 (PB186-280) & * & $\begin{array}{l}148 \text { (PB161-649) } \\
151\end{array}$ & $*$ & $\begin{array}{l}225 \text { (AD614-056) } \\
226 \text { (PB168-042) }\end{array}$ & * \\
\hline 99 (PB186-431) & $*$ & 101 (IDA151- & & 227 (PB184-473) & $*$ \\
\hline $\begin{array}{l}100(\mathrm{COM} 74-10393) \\
100-\mathrm{A}\end{array}$ & * & $\begin{array}{l}154 \text { (PB172-217) } \\
154 \mathrm{~A} \text { (PB182-435) }\end{array}$ & $*$ & $228(\mathrm{~PB} 191-\overline{1} \overline{1} 1)$ & * \\
\hline 101-1 (AD687-820) & * & 160 & $*$ & 229 (PB188-805) & * \\
\hline 101-2 (AD687-821) & * & 163 (COM7 & & 231 (COMT2-1058 & * \\
\hline 102 (PB161-603) & * & $164(\mathrm{~N} 63-$ & $*$ & $232(\mathrm{~N} 65-29825) \ldots$ & $*$ \\
\hline $\begin{array}{ll}106 & \text { (PB161-607) } \\
107 & \text { (PB161-608) }\end{array}$ & $*$ & $\begin{array}{l}165 \text { (AD401-044) } \\
166 \text { (PB181-454) }\end{array}$ & $*$ & 234 (COM73-10485) & $*$ \\
\hline 108 (PB16 & $*$ & $172(\mathrm{PI}$ & $*$ & 235 (COM73-10481) & $*$ \\
\hline 109 (PB161-610) & * & 173 (COM75-10523) & * & 236 ( AI & $*$ \\
\hline 110 (PB161-611) & $*$ & $174(\mathrm{CO}$ & * & 237 (COM75-10166 & * \\
\hline 111 (PB161-612) & $*$ & 177 (COM72-10514) & * & 245 (PB184-177 & $*$ \\
\hline 112 (PB161-613) & $*$ & 178 (PB190-917) & $*$ & 249 & $*$ \\
\hline 113 (PB161-614) & * & 179 (PB190-610) & * & 252 (AD612-812) & $*$ \\
\hline 114 (PB161-615) & $*$ & 180 (COM75-10083) & $*$ & 253 (PB184-176) & * \\
\hline 115 (PB161-616) & $*$ & 182 (COM75-10283) & $*$ & 255 (AD614-257) & * \\
\hline 116 (PB161-617) & $*$ & 183 (COM75-10052) & $*$ & $260 \quad(\mathrm{~PB} 168-041)$ & $*$ \\
\hline 117 (PB161-618) & * & 187 (PB188-807) & * & 262-A (COM73-1 & $*$ \\
\hline 118 (PB161-619) & * & 191 (PB182-538) & & 263 (COM75-10167) & $*$ \\
\hline 119 (PB161-620) & $*$ & 194 See NSRDS1 & .55 & 266 (PB195-214) & $*$ \\
\hline 120 (PB161-621) & $*$ & 195 (COM73-10418) & & 267 (AD628-586) & $*$ \\
\hline
\end{tabular}

*Available from the National Technical Information Service, use "AD", "PB", "N", "COM", or NBS publication identification if no specific NTIS number is assigned. Available in Microfiche for $\$ 3.50$; consult NTIS for paper copy price. 
TECHNICAL NOTES (Continued)

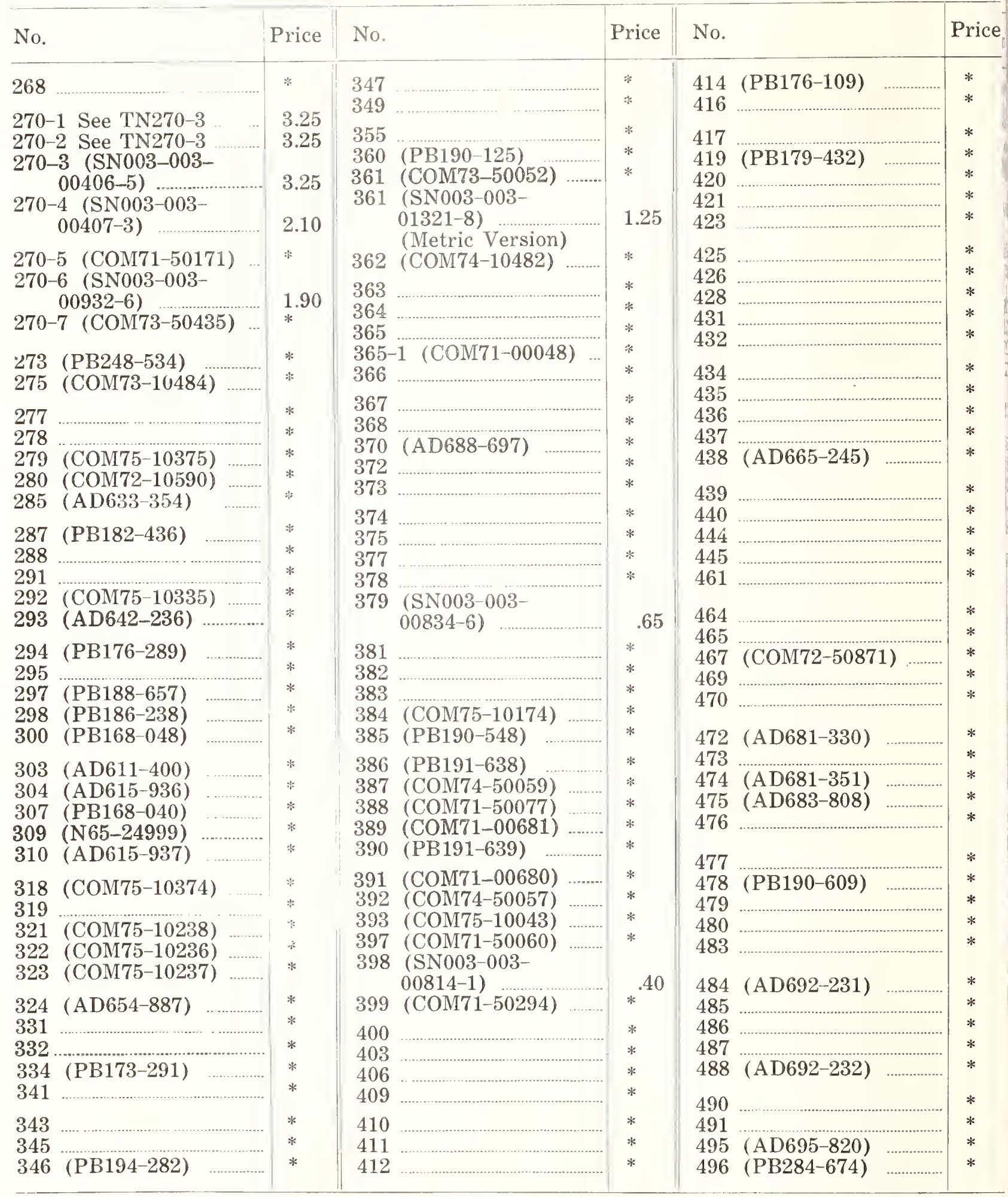

*Available from the National Technical Information Service, use "PB", "AD", "N", "COM", or NBS publication identification if no specific NTIS number is assigned. Available in Microfiche for $\$ 3.50$; consult NTIS for paper copy price. 
TECHNICAL NOTES (Continued)

\begin{tabular}{|c|c|c|c|c|c|c|}
\hline No. & Price & No. & Price & No. & & Price \\
\hline 497 (AD695-821) & $*$ & $569(\mathrm{C}$ & & 604 & & \\
\hline $98(\mathrm{~S}$ & & $\begin{array}{ll}570 & (\text { COM71-50075) } \\
572 & (\text { COM7...... }\end{array}$ & * & & & \\
\hline 0059 & .65 & 573 (COM71-50227) & $*$ & 606 & $\begin{array}{l}\text { (COIV7 1-50332) } \\
(\mathrm{COM} 71-50325)\end{array}$ & \\
\hline $\begin{aligned}498-1)(5 \\
0077\end{aligned}$ & .60 & 575 (COM75-10280) & $*$ & 607 & (AD734-035) & \\
\hline $\begin{array}{c}498-2 \text { (SN003-003- } \\
00686-6)\end{array}$ & & 577 (COM71-50264) & 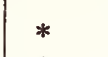 & & ) ....................... & \\
\hline $500($ PB191-352) & $*$ & 578 (COM75 & * & 610 & 9) & $*$ \\
\hline 3 & * & $\begin{array}{ll}579 & (\mathrm{COM} 75-10184) \\
584 & (\mathrm{COM} 71-50635)\end{array}$ & * & 613 & $\begin{array}{l}(\text { COM72-50205) } \\
(\text { COM72-50020) }\end{array}$ & * \\
\hline 10 & * & 585 (COM72-50066) & $*$ & 614 & $(\mathrm{C}$ & * \\
\hline & $*$ & & & 615 & (COM72-50 & \\
\hline $\begin{array}{l}513(\mathrm{AD} \\
515 \text { (SN }\end{array}$ & * & $\begin{array}{l}589(\text { COM72-50061) } \\
590(\text { COM...... }\end{array}$ & * & 616 & $\dot{(S N 003-}$ & 1.0 \\
\hline 006 & .65 & Ј91 (COM75-10168) ............ & $*$ & 617 & & \\
\hline 517 & & 592 (SNO0 & & 618 & (CC & $*$ \\
\hline $\begin{array}{l}519(\mathrm{~PB} 1 \\
520(\mathrm{AD}\end{array}$ & * & $593(\mathrm{COI}$ & & $\begin{array}{l}619 \\
620\end{array}$ & $\begin{array}{l}(\mathrm{CC} \\
(\mathrm{CC}\end{array}$ & * \\
\hline 522 (PB191-024) & $*$ & $594-$ & & 621 & (a & \\
\hline 523 (PB191-057) & * & $594-2(\mathrm{C}$ & * & & & 1.1 \\
\hline $524(\mathrm{~PB} 1$ & $*^{*}$ & 594-3 (COM & $*$ & 622 & & * \\
\hline $25(\mathrm{~PB}$ & $*$ & $\begin{array}{l}594-4 \text { (CUM73-50224) } \\
594-5 \text { (SN003-003- }\end{array}$ & 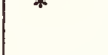 & 623 & & * \\
\hline( & * & $00159-7)$ & .5 & 624 & $(\mathrm{C}$ & * \\
\hline 529 (PB1 & $*$ & & & 625 & & * \\
\hline 530 (COM7 & * & $\begin{array}{c}\text { 594-6 (SN003-003- } \\
01253-0)\end{array}$ & & & & \\
\hline $\begin{array}{r}532 \text { (SN } \\
0077\end{array}$ & & 594-7 & & 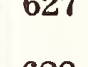 & 011 & $1 .($ \\
\hline 533 (PB192-875) & & & & 629 & (CON & \\
\hline $4(\mathrm{~PB}$ & * & $594-8(\mathrm{C}$ & & 631 & (COI & * \\
\hline $\begin{array}{lll}535 & (\mathrm{~PB} 193-794) \\
536 & (\mathrm{~PB} 192-953)\end{array}$ & * & $\begin{array}{r}594-9 \\
013\end{array}$ & 1.10 & 632 & & \\
\hline $3(\mathrm{C}$ & * & $\begin{array}{r}594-10 \\
014\end{array}$ & 8 & 633 & 9) & $\begin{array}{l}* \\
*\end{array}$ \\
\hline $4(\mathrm{P})$ & & & & 635 & (COM & $*$ \\
\hline $\begin{array}{ll}7 \\
0\end{array}$ & & 594-11 & & 637 & 82) .................... & * \\
\hline $551(\mathrm{CC}$ & * & $594-12$ & & 638 & $(C$ & \\
\hline $552(\mathrm{~S}$ & & 594-13 & & 640 & $(\mathrm{C}$ & \\
\hline 00 & $2 E$ & 01 & .40 & 641 & 0281) & $*$ \\
\hline (P & & $595(\mathrm{C}$ & & 643 & (COM & 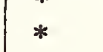 \\
\hline $\begin{array}{ll}505 \\
557(\mathrm{C}\end{array}$ & $*$ & 596 (S & & 644 & (COM73-50972) & * \\
\hline $558(\mathrm{C}$ & & & & & & \\
\hline & * & 598 (A & t & 646 & (C & $*$ \\
\hline $2(\mathrm{C}$ & * & $599(\mathrm{CO}$ & * & 647 & $(\mathrm{C}$ & * \\
\hline $563(\mathrm{C}$ & $*$ & 600 (COM71-50297) & * & 648 & is & \\
\hline $566(\mathrm{C}$ & $*$ & $602(\mathrm{~S}$ & & & & .2 \\
\hline 568 (A) & * & 00 & .55 & 649 & $171 / 4-50$ & \\
\hline
\end{tabular}

*Available from the National Technical Information Service, use "PB", "AD", “COM", or NBS publication identification if no specific NTIS number is assigned. Available in Microfiche for $\$ 3.50$; consult NTIS for paper copy price. 


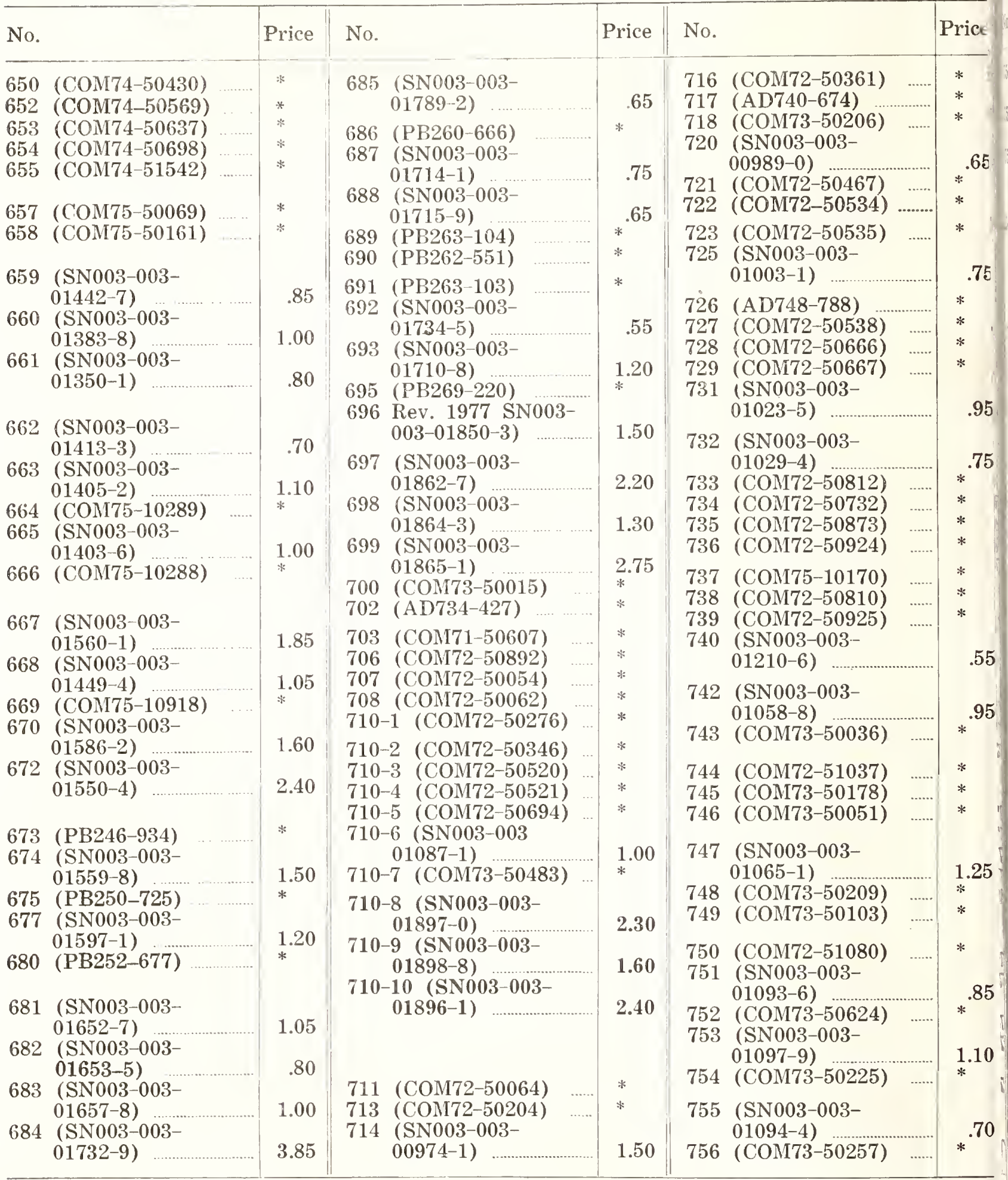

*Available from the National Technical Information Service, use "PB", "AD", or "COM" number when ordering. Available in Microfiche for $\$ 3.50$; consult NTIS for paper copy price. 
TECHNICAL NOTES (Continued)

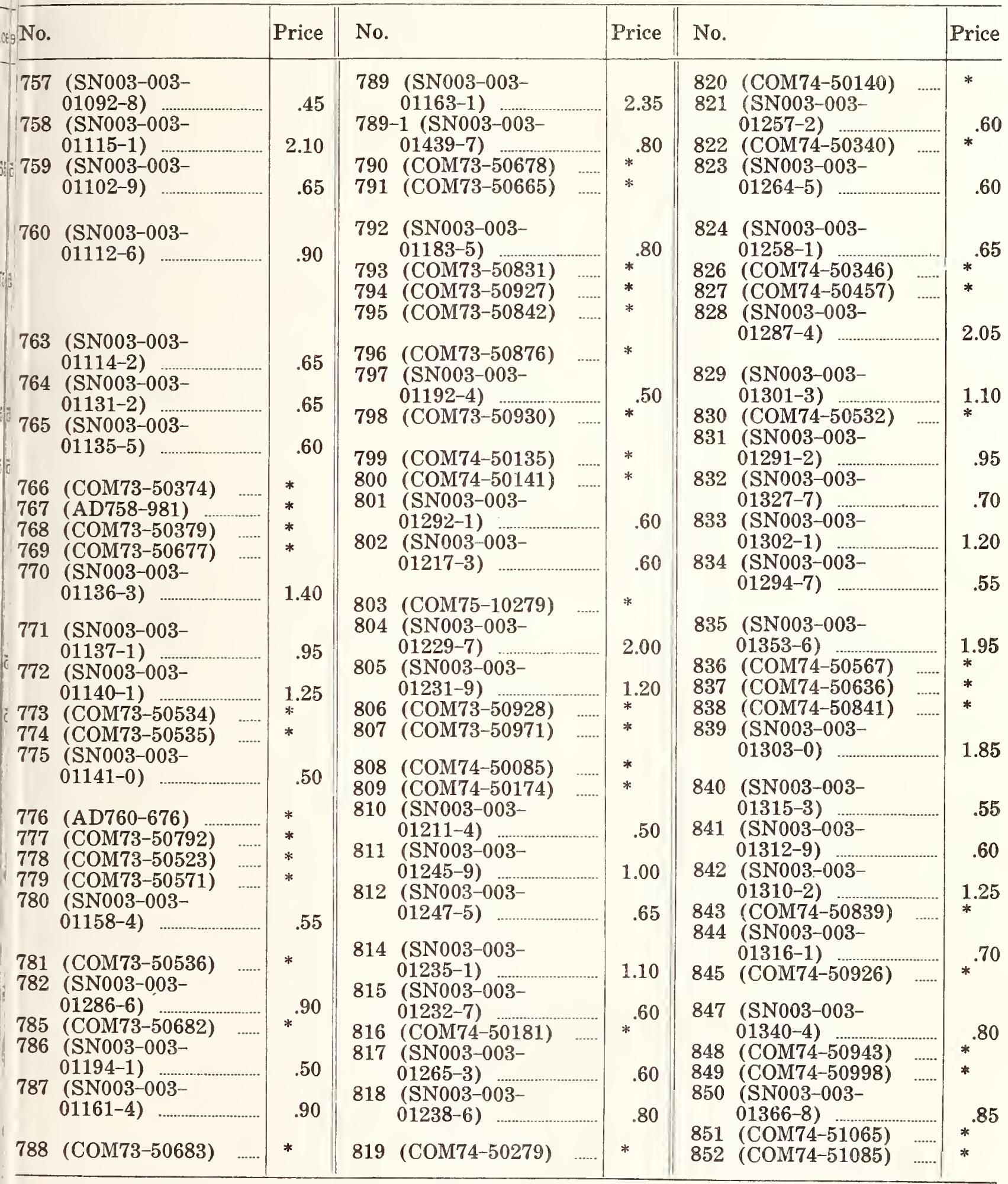

*Available from the National Technical Information Service, use "AD", or "COM" number when ordering. Available in Microfiche for $\$ 3.50$; consult NTIS for paper copy price. 


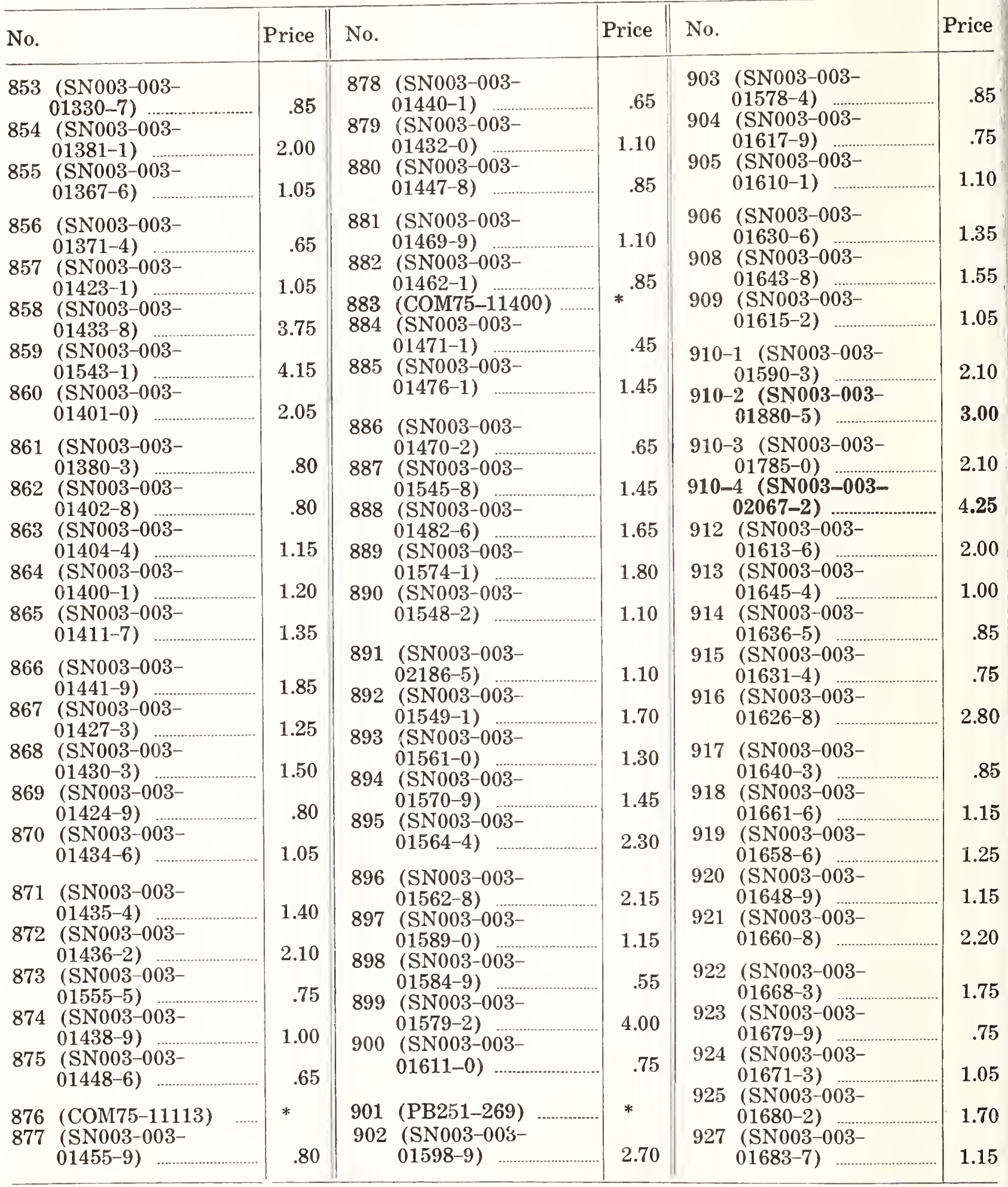

*Available from the National Technical Information Service; use "PB" or "COM" number when ordering. Available in Microfiche for $\$ 3.50$; consult NTIS for paper copy price. 
TECHNICAL NO'TES (Continued)

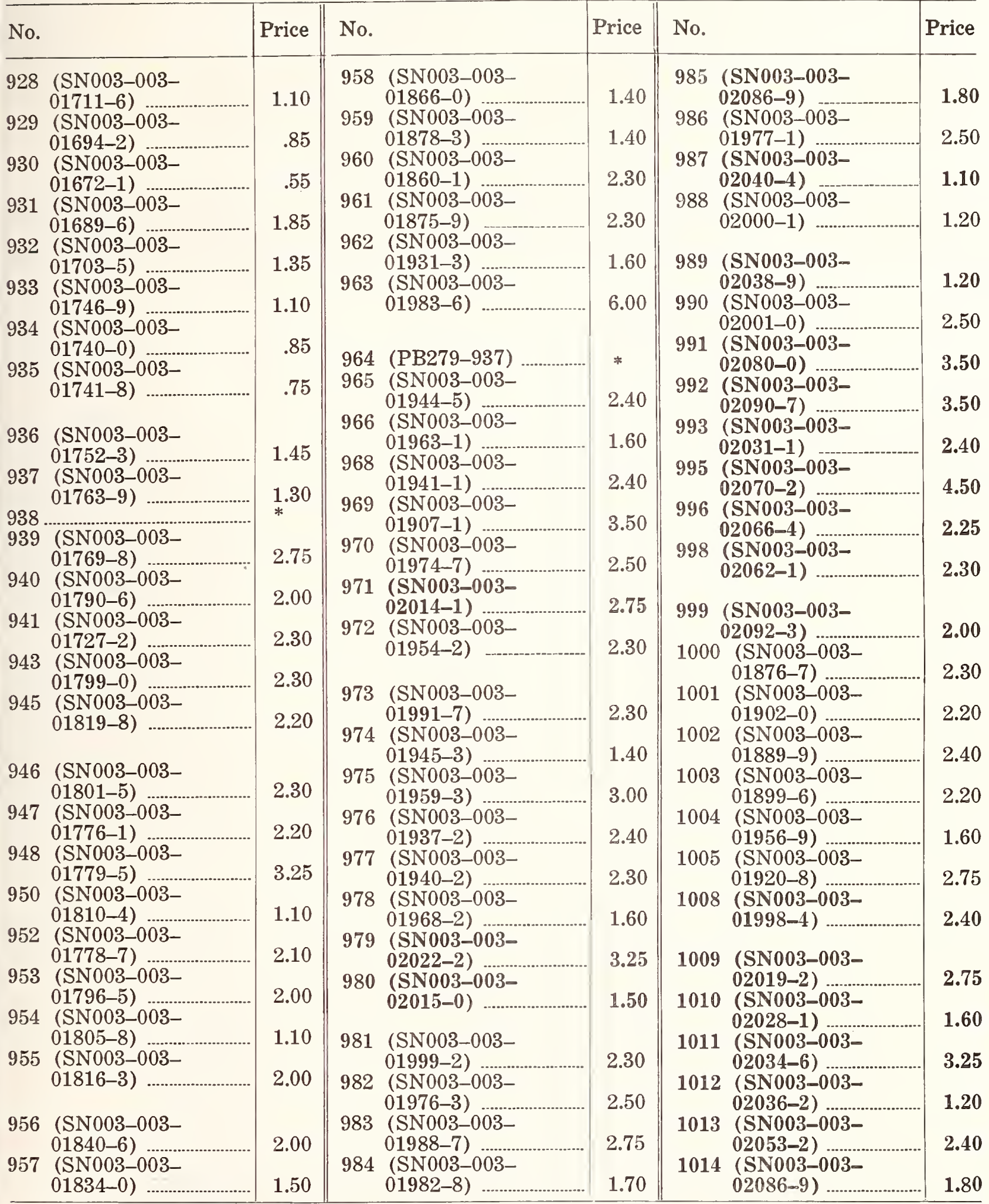

*See page 6 for additional information. 
TECHNICAL NOTES (Continued)

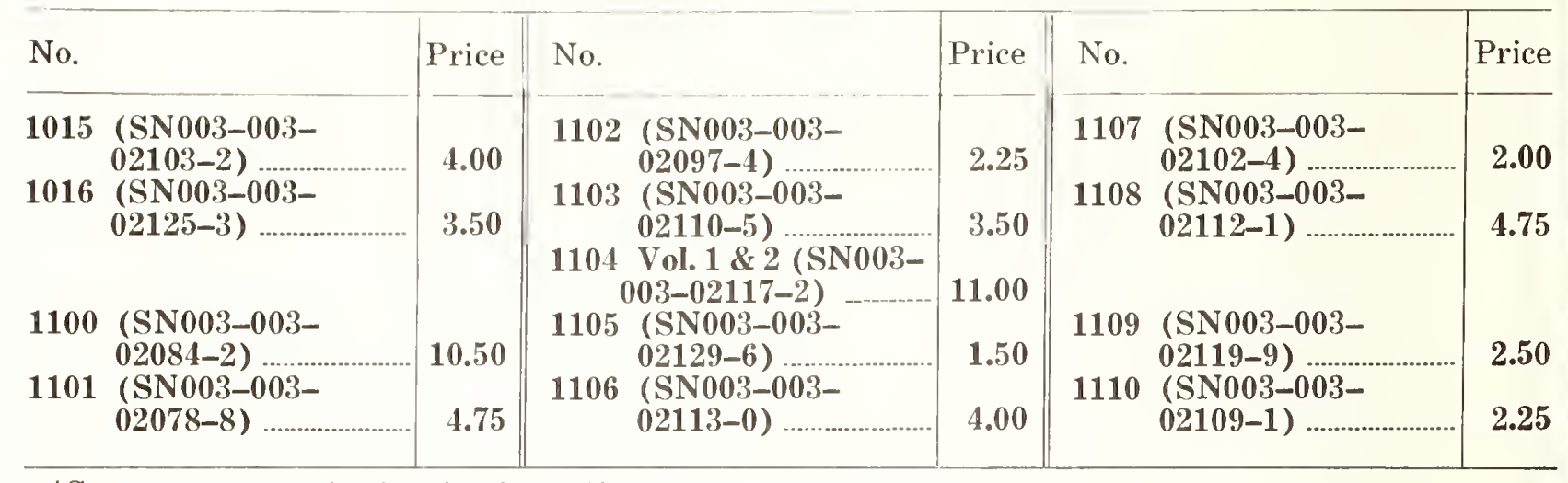

* See page 6 for additional information. 
These reports are available by purchase from the National Technical Information Service, Springfield, VA 22161. Those items in boldface denote the publications cited in this supplement. The prices are those in effect as of the date this publication went to press. When ordering, use the "AD", "PB", "N" or "COM" number. The prices quoted are for paper copy domestic, add $\$ 2.25$ additional for foreign mailing. Microfiche are available for $\$ 2.25$ per set. Prices are subject to change without notice.

\begin{tabular}{|c|c|c|c|}
\hline No. & Price & No. & Price \\
\hline $\begin{array}{ll}73-101 & (\text { COM73-10867) } \\
73-102 & (\text { COM73-10856) } \\
73-105 & (\text { COM73-10858) } \\
73-106 & (\text { PB273-940) } \\
73-108 & (\text { COM74-10701) }\end{array}$ & $\begin{array}{l}\mathrm{A} 05 \\
\mathrm{~A} 04 \\
\mathrm{~A} 03 \\
\mathrm{~A} 04 \\
\mathrm{~A} 02\end{array}$ & 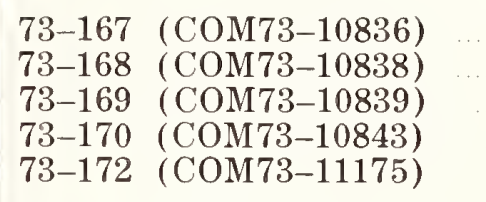 & $\begin{array}{l}\mathrm{A} 02 \\
\mathrm{~A} 03 \\
\mathrm{~A} 02 \\
\mathrm{~A} 03 \\
\mathrm{~A} 05\end{array}$ \\
\hline $\begin{array}{ll}73-109 & (\text { COM74-10701-01) } \\
73-110 & (\text { COM73-11191) } \\
73-112 & (\text { COM74-10702-03) } \\
73-113 & (\text { COM74-10702-01) } \\
73-114 & (\text { COM74-10702-02) }\end{array}$ & $\begin{array}{l}\text { A05 } \\
\text { A07 } \\
\text { A04 } \\
\text { A13 } \\
\text { A13 }\end{array}$ & $\begin{array}{ll}73-173 & (\text { COM73-10844) } \\
73-175 & (\text { COM74-10395) } \\
73-176 & \text { (AD761-197) } \\
73-177 & \text { (COM75-10336) } \\
73-180 & \text { (COM74-10130) }\end{array}$ & $\begin{array}{l}\mathrm{A} 03 \\
\mathrm{~A} 04 \\
\mathrm{~A} 03 \\
\mathrm{~A} 03 \\
\mathrm{~A} 03\end{array}$ \\
\hline $\begin{array}{ll}73-115 & (\text { PB226-907) } \\
73-116 & (\text { COM73-10859) } \\
73-119 & (\text { AD757-789) } \\
73-121 & (\text { COM73-10860) } \\
73-123 & (\text { PB275-435) }\end{array}$ & $\begin{array}{l}\text { A04 } \\
\text { A04 } \\
\text { A04 } \\
\text { A06 } \\
\text { A04 }\end{array}$ & $\begin{array}{ll}73-182 & (\text { COM73-11284) } \\
73-183 & (\text { COM73-11177) } \\
73-184 & (\text { COM73-11110) } \\
73-185 & (\text { COM73-11287) } \\
73-187 & (\text { PB221-188) }\end{array}$ & $\begin{array}{l}\text { A05 } \\
\text { A04 } \\
\text { A05 } \\
\text { A03 } \\
\text { A04 }\end{array}$ \\
\hline $\begin{array}{ll}73-125 & (\text { COM73-11189) } \\
73-126 & (\text { COM73-10854) } \\
73-127 & (\text { COM73-10857) } \\
73-128 & (\text { AD 760-150) } \\
73-129 & (\text { COM73-10853) }\end{array}$ & $\begin{array}{l}\text { A04 } \\
\text { A06 } \\
\text { A05 } \\
\text { A04 } \\
\text { A05 }\end{array}$ & $\begin{array}{ll}73-188 & (\mathrm{~PB} 221-183) \\
73-189 & (\mathrm{COM} 73-11173) \\
73-190 & (\mathrm{COM} 73-10813) \\
73-191 & (\mathrm{~PB} 221-695) \\
73-192 & (\text { COM73-19832) }\end{array}$ & $\begin{array}{l}\text { A05 } \\
\text { A03 } \\
\text { A02 } \\
\text { A02 } \\
\text { A02 }\end{array}$ \\
\hline $\begin{array}{ll}73-131 & (\text { COM73-10863) } \\
73-132 & (\text { PB222-300) } \\
73-135 & (\text { COM73-10840) } \\
73-136 & (\text { PB273-995) } \\
73-138 & (\text { COM73-10868) }\end{array}$ & $\begin{array}{l}\mathrm{A} 04 \\
\mathrm{~A} 07 \\
\mathrm{~A} 03 \\
\mathrm{~A} 02 \\
\mathrm{~A} 03\end{array}$ & $\begin{array}{ll}73-196 & (\mathrm{~PB} 273-941) \\
73-197 & (\text { COM74-10468) } \\
73-198 & (\text { COM74-11289) } \\
73-199 & (\text { COM74-10129) } \\
73-200 & (\text { COM74-10478) }\end{array}$ & $\begin{array}{l}\text { A03 } \\
\text { A04 } \\
\text { A02 } \\
\text { A06 } \\
\text { A03 }\end{array}$ \\
\hline $\begin{array}{ll}73-140 & (\text { COM73-10842) } \\
73-141 & (\text { COM73-10841) } \\
73-144 & (\text { PB220-849) } \\
73-145 & (\text { COM75-10541) } \\
73-146 & (\text { COM73-10989) }\end{array}$ & $\begin{array}{l}\text { A02 } \\
\text { A03 } \\
\text { A07 } \\
\text { A03 } \\
\text { A04 }\end{array}$ & $\begin{array}{ll}73-201 & (\text { COM73-11221) } \\
73-202 & (\text { COM74-10479) } \\
73-203 & (\text { See NBSIR 74-439 } \\
& \text { COM74-10724) } \\
73-206 & (\text { COM73-11262) }\end{array}$ & $\begin{array}{l}\text { A05 } \\
\text { A03 } \\
\text { A06 } \\
\text { A06 }\end{array}$ \\
\hline $\begin{array}{ll}73-147 & (\text { AD759-737) } \\
73-148 & (\text { COM73-10855) } \\
73-151 & (\text { COM73-10866) } \\
73-152 & (\text { AD } 914-258) \\
73-153 & (\text { AD758-730) }\end{array}$ & $\begin{array}{l}\text { A03 } \\
\text { A05 } \\
\text { A02 } \\
\text { A07 } \\
\text { A02 }\end{array}$ & $\begin{array}{ll}73-207 & (\text { AD769-266) } \\
73-208 & \text { (COM74-10127) } \\
73-209 & \text { (COM 74-10469) } \\
73-210 & (\text { COM74-11767) } \\
73-211 & (\text { COM74-10950) }\end{array}$ & $\begin{array}{l}\text { A07 } \\
\text { A03 } \\
\text { A11 } \\
\text { A10 } \\
\text { A08 }\end{array}$ \\
\hline $\begin{array}{ll}73-154 & (\text { COM73-10865) } \\
73-156 & (\text { COM73-11286) } \\
73-157 & (\text { COM74-10394) } \\
75-159 & (\text { COM73-11174) } \\
73-160 & (\text { PB243-540) }\end{array}$ & $\begin{array}{l}\mathrm{A} 02 \\
\mathrm{~A} 04 \\
\mathrm{~A} 03 \\
\mathrm{~A} 02 \\
\mathrm{~A} 03\end{array}$ & $\begin{array}{ll}73-212 & (\text { COM74-11909) } \\
73-213 & \text { (COM74-11771) } \\
73-214 & \text { (COM74-11239) } \\
73-215 & \text { (COM74-11010) } \\
73-216 & (\text { COM74-11011) }\end{array}$ & $\begin{array}{l}\text { A07 } \\
\text { A07 } \\
\text { A06 } \\
\text { A06 } \\
\text { A07 }\end{array}$ \\
\hline $\begin{array}{ll}73-161 & (\text { PB225-310) } \\
73-163 & \text { (COM74-10542) } \\
73-164 & \text { (COM73-10834) } \\
73-165 & \text { (COM73-10837) } \\
73-166 & \text { (COM73-10835) }\end{array}$ & $\begin{array}{l}\mathrm{A} 04 \\
\mathrm{~A} 06 \\
\mathrm{~A} 03 \\
\mathrm{~A} 02 \\
\mathrm{~A} 02\end{array}$ & $\begin{array}{ll}73-217 & \text { (COM74-10470) } \\
73-218 & \text { ( COM75-10144) } \\
73-219 & (\text { PB273-939) } \\
73-220 & (\text { PB222-437) } \\
73-221 & (\text { COM73-11113) }\end{array}$ & $\begin{array}{l}\text { A03 } \\
\text { A03 } \\
\text { A03 } \\
\text { A02 } \\
\text { A05 }\end{array}$ \\
\hline
\end{tabular}


NBS INTERAGENCY REPORTS (Continued)

\begin{tabular}{|c|c|c|c|}
\hline No. & Price & No. & Price \\
\hline 73-223 (COM73-11220) & A05 & 73-318 (N73-27390) & A09 \\
\hline $73-228$ (PB222-425) & $\mathrm{A} 02$ & 73-320 (COM73-11971) & $\mathrm{A} 02$ \\
\hline $73-231$ (PB224-645) & A03 & $73-322$ ( COM73-11464) & $\mathrm{A} 03$ \\
\hline 73-232 (PB273-947) & A 03 & 73-326 (COM73-11465) & $\mathrm{A} 02$ \\
\hline $73-233$ (COM74-11770) & A04 & $73-329$ (COM74-10608) & A05 \\
\hline 73-234 (COM74-10128) & $\mathrm{A} 03$ & $73-330 \quad$ (COM74-10609) & A04 \\
\hline 73-239 (PB273-962) & A02 & $73-331$ (COM74-10238) & A05 \\
\hline $73-240$ (COM74-10986) & $\mathrm{A} 03$ & 73-335 (COM74-11051) & A05 \\
\hline $73-242$ (PB224-654) & A03 & 73-338 (COM73-11660) & A03 \\
\hline $73-244$ (AD-A003-900) & $\mathrm{A} 04$ & 73-339 (COM73-11985) & A13 \\
\hline 73-246 (COM74-10989) & $\mathrm{A} 02$ & 73-341 (COM74-10885) & $\mathrm{A} 03$ \\
\hline $73-248$ (COM74-10474) & A05 & 73-342 (COM73-11978) & A13 \\
\hline $73-251 \quad(\mathrm{~PB} 224-688)$ & $\mathrm{A} 03$ & 73-343 (COM75-10282) & A05 \\
\hline $73-252$ (AD775-082) & A12 & 73-344 (COM74-10749) & A03 \\
\hline 73-254 (COM74-10987) & A02 & $73-345$ (COM74-10239) & A04 \\
\hline 73-256 (COM75-11443) & $\mathrm{A} 02$ & 73-346 (COM74-10240) & $\mathrm{A} 03$ \\
\hline 73-257 (COM75-11444) & $\mathrm{A} 02$ & 73-347 (COM74-10674) & $\mathrm{A} 04$ \\
\hline 73-258 (COM75-11445) & $\mathrm{A} 02$ & 73-348 (COM74-10241) & A03 \\
\hline 73-259 (COM75-11446) & $\mathrm{A} 02$ & 73-349 ( COM74-11374) & $\mathrm{A} 04$ \\
\hline 73-260 (COM75-11440) & $\mathrm{A} 02$ & 73-351 (COM74-10784) & $\mathrm{A} 04$ \\
\hline 73-261 (COM75-11441) & $\mathrm{A} 02$ & 73-402 ( COM74-10472) & $\mathrm{A} 07$ \\
\hline 73-262 (COM75-10370) & $\mathrm{A} 04$ & $73-403$ (COM74-10016) & A07 \\
\hline 73-263 (PB225-284) & $\mathrm{A} 04$ & 73-404 (PB230-952) & $\mathrm{A} 03$ \\
\hline 73-264 (PB243-541) & $\mathrm{A} 02$ & 73-405 (COM74-10131) & $\mathrm{A} 02$ \\
\hline 73-265 (COM73-11453) & $\mathrm{A} 04$ & $73-406$ (COM74-11352) & $\mathrm{A} 02$ \\
\hline $73-266$ (PB225-286) & $\mathrm{A} 03$ & 73-407 (COM74-11078) & $\mathrm{A} 05$ \\
\hline 73-267 (COM73-11955) & $\mathrm{A} 04$ & $73-412$ ( COM74-10512) & A03 \\
\hline 73-268 (AD768-303) & A03 & $73-413$ ( COM74-10750) & $\mathrm{A} 04$ \\
\hline 73-273 (PB243-542) & A02 & 73-414 (COM74-10866) & A03 \\
\hline 73-275 (COM74-10126) & $\mathrm{A} 04$ & $73-415$ (COM75-11448) & A09 \\
\hline $73-277$ (PB225-278) & $\mathrm{A} 04$ & $73-416$ (COM74-10511) & $\mathrm{A} 04$ \\
\hline $73-280 \quad(\mathrm{AD} 782-094)$ & A06 & 73-417 (COM74-10477) & A03 \\
\hline 73-281 (AD782-028) & A06 & 73-418 (COM74-11783) & A07 \\
\hline 73-287 (COM73-11928) & $\mathrm{A} 02$ & $73-420$ (COM74-11092) & $\mathrm{A} 04$ \\
\hline 73-288 ( COM73-11861) & $\mathrm{A} 04$ & $73-421$ (COM74-11224) & $\mathrm{A} 03$ \\
\hline 73-289 (COM74-10475) & A03 & 73-422 ( COM74-11240) & $\mathrm{A} 04$ \\
\hline 73-290 (COM74-10974) & $\mathrm{A} 02$ & 73-423 ( COM74-11722) & A08 \\
\hline $73-291$ (PB272-376) & A03 & 73-424 (COM74-10867) & $\mathrm{A} 02$ \\
\hline $73-294$ (AD787-327) & A04 & $74-355$ (N74-30195) & A04 \\
\hline 73-295 (COM74-10471) & A02 & 74-357 (COM74-10551) & A04 \\
\hline 73-297 (AD772-066) & $\mathrm{A} 02$ & 74-359 (AD780-596) & $\mathrm{A} 24$ \\
\hline 73-299 (PB243-543) & $\mathrm{A} 03$ & 74-361 (COM74-11222) & $\mathrm{A} 04$ \\
\hline 73-301 (COM73-10762) & A03 & 74-363 (COM74-11053) & A07 \\
\hline 73-302 (COM73-10869) & A05 & 74-364 (COM74-11208) & A05 \\
\hline 73-303 (AD759-374) & A04 & 74-365 (COM74-11375) & $\mathrm{A} 03$ \\
\hline 73-304 (COM74-10281) & A05 & 74-366 (COM74-11076) & $\mathrm{A} 05$ \\
\hline 73-308 (COM73-10761) & A03 & 74-369 (COM74-11688) & A03 \\
\hline 73-309 (COM73-11981) & A05 & $74-371$ (COM74-11567) & A04 \\
\hline '73-312 ( COM73-11893) & $\mathrm{A} 03$ & $74-372$ (AD/A006-037) & A05 \\
\hline 73-316 (COM73-11954) & A05 & $74-374$ (N75-22407) & A04 \\
\hline
\end{tabular}




\begin{tabular}{|c|c|c|c|c|}
\hline \multicolumn{2}{|l|}{ No. } & \begin{tabular}{|c|} 
Price \\
A04
\end{tabular} & No. & \multirow{2}{*}{$\begin{array}{r}\text { Price } \\
\text { A06 } \\
\text { A02 } \\
\text { A05 } \\
\text { A05 } \\
\text { A02 }\end{array}$} \\
\hline $\begin{array}{l}74-375 \\
74-377 \\
74-378 \\
74-379 \\
74-380\end{array}$ & $\begin{array}{l}(\text { COM74-11657) } \\
(\text { COM74-11449) } \\
(\text { COM74-11450) } \\
(\text { PB247-658) } \\
(\text { COM74-11686) }\end{array}$ & $\begin{array}{l}\text { A04 } \\
\text { A03 } \\
\text { A04 } \\
\text { A03 } \\
\text { A06 }\end{array}$ & $\begin{array}{ll}74-488 & (\text { COM75-10088) } \\
74-493 & (\text { PB243-545) } \\
74-495 & \text { (COM74-11575) } \\
74-496 & \text { (COM74-11576) } \\
74-497 & \text { (COM74-11269) }\end{array}$ & \\
\hline $\begin{array}{l}74-381 \\
74-382 \\
74-387 \\
74-388 \\
74-389\end{array}$ & $\begin{array}{l}(\text { COM75-10522) } \\
(\text { AD783-433) } \\
(\text { COM74-11643) } \\
(\text { COM74-11687) } \\
(\text { COM74-11717) }\end{array}$ & $\begin{array}{l}\text { A04 } \\
\text { A10 } \\
\text { A03 } \\
\text { A07 } \\
\text { A08 }\end{array}$ & $\begin{array}{ll}74-499 & (\mathrm{COM} 74-11378) \\
74-500 & (\mathrm{~PB} 265-694) \\
74-501 & (\mathrm{COM} 75-10131) \\
74-506 & (\mathrm{COM} 44-11632) \\
74-507 & (\mathrm{AD} / \mathrm{A} 000-343)\end{array}$ & $\begin{array}{l}\text { A03 } \\
\text { A05 } \\
\text { A02 } \\
\text { A05 } \\
\text { A03 }\end{array}$ \\
\hline $\begin{array}{l}74-390 \\
74-391 \\
74-393 \\
74-394 \\
74-395\end{array}$ & $\begin{array}{l}(\text { COM74-11718) } \\
(\text { COM74-10258) } \\
(\text { COM75-10768) } \\
(\text { COM75-10126) } \\
(\text { COM75-10161) }\end{array}$ & $\begin{array}{l}\text { A06 } \\
\text { A03 } \\
\text { A13 } \\
\text { A03 } \\
\text { A03 }\end{array}$ & $\begin{array}{ll}74-509 & (\text { COM74-11377) } \\
74-510 & (\text { AD782-793) } \\
74-511 & \text { (COM74-11448) } \\
74-514 & \text { (COM75-10102) } \\
74-515 & \text { (COM74-11498) }\end{array}$ & $\begin{array}{l}\text { A02 } \\
\text { A03 } \\
\text { A02 } \\
\text { A04 } \\
\text { A09 }\end{array}$ \\
\hline $\begin{array}{l}74-396 \\
74-398 \\
74-426 \\
74-430 \\
74-432\end{array}$ & $\begin{array}{l}(\text { COM74-11766) } \\
(\text { COM75-10130) } \\
(\text { COM74-11074) } \\
(\text { COM74-10724) } \\
(\text { COM74-10751) }\end{array}$ & $\begin{array}{l}\text { A03 } \\
\text { A15 } \\
\text { A06 } \\
\text { A06 } \\
\text { A04 }\end{array}$ & $\begin{array}{ll}74-516 & (\text { COM74-11384) } \\
74-517 & (\text { COM74-10470) } \\
74-518 & (\text { PB239-633) } \\
74-519 & (\text { PB238-284) } \\
74-520 & (\text { COM74-11480) }\end{array}$ & $\begin{array}{l}\text { A04 } \\
\text { A03 } \\
\text { A05 } \\
\text { A03 } \\
\text { A07 }\end{array}$ \\
\hline $\begin{array}{l}74-434 \\
74-438 \\
74-439 \\
74-442 \\
74-443\end{array}$ & $\begin{array}{l}(\text { COM74-11079) } \\
(\text { COM74-10980) } \\
(\text { COM74-10985) } \\
(\text { AD787-743) } \\
(\text { COM74-11003) }\end{array}$ & $\begin{array}{l}\mathrm{A} 02 \\
\mathrm{~A} 03 \\
\mathrm{~A} 02 \\
\mathrm{~A} 03 \\
\mathrm{~A} 02\end{array}$ & $\begin{array}{ll}74-521 & (\text { COM75-10187) } \\
74-522 & (\text { COM75-10080) } \\
74-523 & (\text { COM75-11126) } \\
74-524 & (\text { COM74-11568) } \\
74-525 & (\text { AD782-564) }\end{array}$ & $\begin{array}{l}\mathrm{A} 04 \\
\mathrm{~A} 02 \\
\mathrm{~A} 02 \\
\mathrm{~A} 03 \\
\mathrm{~A} 02\end{array}$ \\
\hline $\begin{array}{l}74-444 \\
74-449 \\
74-451 \\
74-452 \\
74-454\end{array}$ & $\begin{array}{l}(\text { COM74-10548) } \\
(\text { COM75-10049) } \\
(\text { COM74-11385) } \\
(\text { PB204-486) } \\
(\text { COM74-10988) }\end{array}$ & $\begin{array}{l}\mathrm{A} 03 \\
\mathrm{~A} 03 \\
\mathrm{~A} 02 \\
\mathrm{~A} 06 \\
\mathrm{~A} 02\end{array}$ & $\begin{array}{ll}74-526 & (\text { COM75-10087) } \\
74-527 & \text { (COM74-11720) } \\
74-529 & \text { (COM74-11495) } \\
74-530 & (\text { COM75-10041) } \\
74-533 & (\text { PB238-573) }\end{array}$ & $\begin{array}{l}\text { A04 } \\
\text { A04 } \\
\text { A04 } \\
\text { A03 } \\
\text { A06 }\end{array}$ \\
\hline $\begin{array}{l}74-455 \\
74-456 \\
74-457 \\
74-458 \\
74-461\end{array}$ & $\begin{array}{l}(\text { COM74-10865) } \\
(\text { COM74-11793) } \\
(\text { COM74-11792) } \\
(\text { AD776-337) } \\
(\text { PB246-623) }\end{array}$ & $\begin{array}{l}\text { A03 } \\
\text { A02 } \\
\text { A05 } \\
\text { A02 } \\
\text { A03 }\end{array}$ & $\begin{array}{ll}74-535 & \text { (COM74-11659) } \\
74-537 & \text { (COM74-11577) } \\
74-539 & \text { (COM74-11574) } \\
74-541 & \text { (COM75-10618) } \\
74-542 & \text { (COM75-10081) }\end{array}$ & $\begin{array}{l}\text { A05 } \\
\text { A02 } \\
\text { A05 } \\
\text { A03 } \\
\text { A03 }\end{array}$ \\
\hline $\begin{array}{l}74-464 \\
74-465 \\
74-466 \\
74-467 \\
74-469\end{array}$ & $\begin{array}{l}(\text { COM74-10785) } \\
(\text { COM75-10417) } \\
(\text { COM74-10700) } \\
(\text { COM74-11754) } \\
(\text { PB234-348) }\end{array}$ & $\begin{array}{l}\text { A05 } \\
\text { A04 } \\
\text { A21 } \\
\text { A04 } \\
\text { A04 }\end{array}$ & $\begin{array}{ll}74-543 & \text { (COM74-11772) } \\
74-544 & \text { (COM74-11525) } \\
74-545 & \text { (COM74-11656) } \\
74-550 & \text { (COM74-11721) } \\
74-551 & \text { (COM74-11658) }\end{array}$ & $\begin{array}{l}\text { A07 } \\
\text { A03 } \\
\text { A04 } \\
\text { A05 } \\
\text { A06 }\end{array}$ \\
\hline $\begin{array}{l}74-470 \\
74-471 \\
74-473 \\
74-474 \\
74-477\end{array}$ & $\begin{array}{l}(\text { PB232-629) } \\
(\text { COM74-10981) } \\
(\text { COM74-11719) } \\
(\text { AD778-340) } \\
(\text { COM74-11784) }\end{array}$ & $\begin{array}{l}\text { A05 } \\
\text { A02 } \\
\text { A04 } \\
\text { A03 } \\
\text { A03 }\end{array}$ & $\begin{array}{ll}74-552 & (\text { COM74-11644) } \\
74-553 & \text { (COM75-10058) } \\
74-554 & \text { (COM74-10703) } \\
74-555 & (\text { COM74-10704) } \\
74-556 & \text { (COM74-10703) }\end{array}$ & $\begin{array}{l}\text { A05 } \\
\text { A04 } \\
\text { A03 } \\
\text { A03 } \\
\text { A05 }\end{array}$ \\
\hline $\begin{array}{l}74-479 \\
74-481 \\
74-482 \\
74-486 \\
74-487\end{array}$ & $\begin{array}{l}(\text { PB239-420) } \\
(\text { COM74-11794) } \\
(\text { COM75-10147) } \\
(\text { AD780-705) } \\
(\text { COM74-10886) }\end{array}$ & $\begin{array}{l}\text { A07 } \\
\text { A04 } \\
\text { A10 } \\
\text { A04 } \\
\text { A23 }\end{array}$ & $\begin{array}{ll}74-557 & \text { (COM75-11439) } \\
74-561 & \text { (COM75-10413) } \\
74-564 & \text { (COM74-11726) } \\
74-567 & \text { (COM74-11631) } \\
74-568 & \text { (COM74-11578) }\end{array}$ & $\begin{array}{l}\text { A03 } \\
\text { A03 } \\
\text { A04 } \\
\text { A13 } \\
\text { A04 }\end{array}$ \\
\hline
\end{tabular}




\begin{tabular}{|c|c|c|c|}
\hline No. & Price & No. & Price \\
\hline $\begin{array}{l}74-569 \text { (AD/A002-289) } \\
74-572 \text { (COM74-11791) } \\
74-577-1 \text { (COM74-11723) } \\
74-577-2 \text { (COM74-11724) } \\
74-578 \text { (COM74-11765) }\end{array}$ & $\begin{array}{l}\text { A03 } \\
\text { A04 } \\
\text { A09 } \\
\text { A14 } \\
\text { A02 }\end{array}$ & $\begin{array}{ll}75-652 & (\mathrm{COM} 75-11399) \\
75-653 & (\mathrm{~PB} 248-097) \\
75-654 & (\mathrm{COM} 75-10367) \\
75-658 & (\mathrm{AD} / \mathrm{A} 007-445) \\
75-659 & (\mathrm{AD} / \mathrm{A} 008-538)\end{array}$ & $\begin{array}{l}\mathrm{A} 05 \\
\mathrm{~A} 03 \\
\mathrm{~A} 02 \\
\mathrm{~A} 03 \\
\mathrm{~A} 03\end{array}$ \\
\hline $\begin{array}{ll}74-580 & (\mathrm{~PB} 248-465) \\
74-581 & (\mathrm{COM} 75-10127) \\
74-582 & (\mathrm{COM} 74-11645) \\
74-583 & (\mathrm{AD} / \mathrm{A} 003-900) \\
74-586 & (\mathrm{COM} 75-10525)\end{array}$ & $\begin{array}{l}\mathrm{A} 02 \\
\mathrm{~A} 03 \\
\mathrm{~A} 03 \\
\mathrm{~A} 05 \\
\mathrm{~A} 02\end{array}$ & $\begin{array}{ll}75-660 & (\text { COM75-10669) } \\
75-661 & (\text { COM75-10763) } \\
75-662 & (\text { COM75-10420) } \\
75-664 & (\text { AD } / A 007-447) \\
75-665 & (\text { COM75-10421) }\end{array}$ & $\begin{array}{l}\mathrm{A} 03 \\
\mathrm{~A} 03 \\
\mathrm{~A} 02 \\
\mathrm{~A} 03 \\
\mathrm{~A} 03\end{array}$ \\
\hline $\begin{array}{ll}74-588 & (\text { COM75-10040) } \\
74-590 & (\text { COM75-11434) } \\
74-594 & (\text { PB243-546) } \\
74-591 & (\text { COM75-10101) } \\
74-595 & (\text { COM75-10057) }\end{array}$ & $\begin{array}{l}\mathrm{A} 03 \\
\mathrm{~A} 02 \\
\mathrm{~A} 02 \\
\mathrm{~A} 02 \\
\mathrm{~A} 02\end{array}$ & $\begin{array}{ll}75-666 & (\mathrm{COM} 75-11381) \\
75-667 & (\mathrm{~PB} 241-267) \\
75-672 & (\mathrm{COM} 75-10338) \\
75-673 & (\mathrm{COM} 75-10921) \\
75-675 & (\mathrm{COM} 75-10686)\end{array}$ & $\begin{array}{l}\mathrm{A} 03 \\
\mathrm{~A} 03 \\
\mathrm{~A} 03 \\
\mathrm{~A} 03 \\
\mathrm{~A} 03\end{array}$ \\
\hline $\begin{array}{ll}74-596 & (\text { COM75-10209) } \\
74-597 & \text { (COM75-11069) } \\
74-600 & \text { (AD/A008-935) } \\
74-601 & \text { (PB273-948) } \\
74-602 & \text { (COM75-10048) }\end{array}$ & $\begin{array}{l}\mathrm{A} 03 \\
\mathrm{~A} 03 \\
\mathrm{~A} 09 \\
\mathrm{~A} 02 \\
\mathrm{~A} 03\end{array}$ & $\begin{array}{ll}75-676 & (\mathrm{COM} 75-10697) \\
75-677 & (\mathrm{COM} 75-10516) \\
75-678 & (\mathrm{~PB} 248-687) \\
75-679 & (\mathrm{COM} 75-10419) \\
75-680 & (\mathrm{COM} 75-10423)\end{array}$ & $\begin{array}{l}\text { A05 } \\
\text { A04 } \\
\text { A04 } \\
\text { A03 } \\
\text { A06 }\end{array}$ \\
\hline $\begin{array}{ll}74-605 & (\text { COM75-10464) } \\
74-606 & \text { (COM75-10340) } \\
74-608 & (\text { COM75-10056) } \\
74-610 & (\text { COM75-10073) } \\
74-612 & (\text { COM75-10414) }\end{array}$ & $\begin{array}{l}\mathrm{A} 03 \\
\mathrm{~A} 05 \\
\mathrm{~A} 02 \\
\mathrm{~A} 03 \\
\mathrm{A0} 2\end{array}$ & $\begin{array}{ll}75-682 & (\text { COM75-10524) } \\
75-685 & \text { (COM75-10690) } \\
75-687 & \text { (COM75-11137) } \\
75-688 & \text { (COM75-11222) } \\
75-689 & (\text { COM75-11190) }\end{array}$ & $\begin{array}{l}\text { A02 } \\
\text { A05 } \\
\text { A07 } \\
\text { A06 } \\
\text { A04 }\end{array}$ \\
\hline $\begin{array}{ll}74-613 & (\text { COM75-10059) } \\
74-614 & \text { (COM75-11013) } \\
74-618 & (\text { COM75-11014) } \\
74-619 & (\text { COM75-10047) } \\
74-620 & (\text { PB246-622) }\end{array}$ & $\begin{array}{l}\mathrm{A} 03 \\
\mathrm{~A} 03 \\
\mathrm{~A} 02 \\
\mathrm{~A} 02 \\
\mathrm{~A} 02\end{array}$ & $\begin{array}{ll}75-690 & (\text { COM75-11207) } \\
75-691 & \text { (COM75-11015) } \\
75-692 & \text { (PB250-385) } \\
75-693 & (\text { COM75-11194) } \\
75-696 & (\text { COM75-10527) }\end{array}$ & $\begin{array}{l}\text { A05 } \\
\text { A05 } \\
\text { A06 } \\
\text { A02 } \\
\text { A05 }\end{array}$ \\
\hline $\begin{array}{ll}74-621 & (\text { COM75-10422) } \\
74-623 & (\text { COM75-10210) } \\
74-624 & (\text { COM75-10412) } \\
74-625 & (\text { PB243-547) } \\
74-626 & (\text { COM75-10411) }\end{array}$ & $\begin{array}{l}\mathrm{A} 03 \\
\mathrm{~A} 05 \\
\mathrm{~A} 03 \\
\mathrm{~A} 03 \\
\mathrm{~A} 02\end{array}$ & $\begin{array}{ll}75-697 & (\text { COM75-10920) } \\
75-699 & (\text { COM75-11016) } \\
75-700 & \text { (COM75-11280) } \\
75-701 & (\text { COM75-11282) } \\
75-702 & (\text { COM75-11433) }\end{array}$ & $\begin{array}{l}\mathrm{A} 04 \\
\mathrm{~A} 03 \\
\mathrm{~A} 04 \\
\mathrm{~A} 02 \\
\mathrm{~A} 03\end{array}$ \\
\hline $\begin{array}{ll}74-627 & (\text { COM75-10134) } \\
74-628 & (\text { COM75-10514) } \\
74-629 & (\text { COM75-11281) } \\
74-631 & (\text { COM75-10208) } \\
74-632 & (\text { PB246-554) }\end{array}$ & $\begin{array}{l}\mathrm{A} 02 \\
\mathrm{~A} 02 \\
\mathrm{~A} 03 \\
\mathrm{~A} 02 \\
\mathrm{~A} 05\end{array}$ & $\begin{array}{ll}75-703 & (\text { COM75-11278) } \\
75-705 & (\text { COM75-11277) } \\
75-706 & (\text { PB248-640) } \\
75-707 & (\text { COM75-11017) } \\
75-708 & (\text { COM75-10817) }\end{array}$ & $\begin{array}{l}\mathrm{A} 03 \\
\mathrm{~A} 03 \\
\mathrm{~A} 02 \\
\mathrm{~A} 03 \\
\mathrm{~A} 02\end{array}$ \\
\hline $\begin{array}{ll}74-633 & (\text { COM75-10691) } \\
74-634 & \text { (COM75-10685) } \\
74-635 & (\text { COM75-10276) } \\
75-637 & (\text { COM75-10055) } \\
75-638 & (\text { AD } / A 011-485)\end{array}$ & $\begin{array}{l}\mathrm{A} 04 \\
\mathrm{~A} 03 \\
\mathrm{~A} 04 \\
\mathrm{~A} 02 \\
\mathrm{~A} 04\end{array}$ & $\begin{array}{ll}75-710 & (\text { COM75-11030) } \\
75-711 & \text { (COM75-10689) } \\
75-712 & \text { (COM75-11070) } \\
75-713 & (\text { COM75-11134) } \\
75-715 & \text { (COM75-11208) }\end{array}$ & $\begin{array}{l}\text { A02 } \\
\text { A04 } \\
\text { A03 } \\
\text { A04 } \\
\text { A02 }\end{array}$ \\
\hline $\begin{array}{ll}75-639 & (\mathrm{AD} / \mathrm{A} 005-410) \\
75-641 & (\mathrm{COM} 75-11209) \\
75-647 & (\mathrm{COM} 75-10418) \\
75-649 & (\mathrm{~PB} 241-237) \\
75-651 & (\mathrm{COM} 75-11211)\end{array}$ & $\begin{array}{l}\mathrm{A} 02 \\
\mathrm{~A} 05 \\
\mathrm{~A} 03 \\
\mathrm{A02} \\
\mathrm{A} 05\end{array}$ & $\begin{array}{ll}75-716 & (\mathrm{COM} 75-11210) \\
75-718 & (\mathrm{COM} 75-10750) \\
75-719 & (\mathrm{~PB} 251-410) \\
75-721 & (\mathrm{~PB} 246-864) \\
75-722 & (\mathrm{~PB} 248-641)\end{array}$ & $\begin{array}{l}\text { A08 } \\
\text { A03 } \\
\text { A03 } \\
\text { A03 } \\
\text { A03 }\end{array}$ \\
\hline
\end{tabular}




\begin{tabular}{|c|c|c|c|c|c|}
\hline No. & & & Price & No. & Price \\
\hline $\begin{array}{l}75-723 \\
75-728 \\
75-729 \\
75-730 \\
75-731\end{array}$ & $\begin{array}{l}(\mathrm{COM} 75-10753) \\
(\mathrm{AD} / \mathrm{A} 014-830) \\
(\mathrm{PB} 246-858) \\
(\mathrm{AD} / \mathrm{A} 018-451) \\
(\mathrm{COM} 75-11071)\end{array}$ & & $\begin{array}{l}\mathrm{A} 04 \\
\mathrm{~A} 03 \\
\mathrm{~A} 03 \\
\mathrm{~A} 03 \\
\mathrm{~A} 03\end{array}$ & $\begin{array}{ll}75-794 & (\mathrm{~PB} 247-203) \\
75-795 & (\mathrm{~PB} 246-866) \\
75-796 & (\mathrm{~PB} 247-656) \\
75-797 & (\mathrm{COM} 75-11465) \\
75-801 & (\mathrm{~PB} 252-044)\end{array}$ & $\begin{array}{l}\mathrm{A} 03 \\
\mathrm{~A} 04 \\
\mathrm{~A} 02 \\
\mathrm{~A} 02 \\
\mathrm{~A} 08\end{array}$ \\
\hline $\begin{array}{l}75-732 \\
75-733 \\
75-734 \\
75-735 \\
75-736\end{array}$ & $\begin{array}{l}(\text { COM75-11022) } \\
(\text { COM75-11139) } \\
(\text { COM75-11212) } \\
(\text { PB256-295) } \\
(\text { COM75-11018) }\end{array}$ & $\ldots$ & $\begin{array}{l}\mathrm{A} 02 \\
\mathrm{~A} 02 \\
\mathrm{~A} 03 \\
\mathrm{~A} 07 \\
\mathrm{~A} 02\end{array}$ & $\begin{array}{ll}75-804 & (\text { COM75-10395) } \\
75-805 & \text { (PB252-971) } \\
75-806 & (\text { COM75-10368) } \\
75-807 & \text { (COM75-10396) } \\
75-809 & (\text { COM75-10989) }\end{array}$ & $\begin{array}{l}\text { A03 } \\
\text { A03 } \\
\text { A04 } \\
\text { A05 } \\
\text { A03 }\end{array}$ \\
\hline $\begin{array}{l}75-737 \\
75-738 \\
75-739 \\
75-740 \\
75-741\end{array}$ & $\begin{array}{l}(\text { COM75-11472) } \\
(\text { COM75-11279) } \\
(\text { COM75-11189) } \\
(\text { COM75-11127) } \\
(\text { COM75-11136) }\end{array}$ & & $\begin{array}{l}\text { A03 } \\
\text { A03 } \\
\text { A02 } \\
\text { A03 } \\
\text { A03 }\end{array}$ & $\begin{array}{ll}75-810 & (\mathrm{COM} 75-10919) \\
75-812 & (\mathrm{AD} / \mathrm{A012}-889) \\
75-814 & (\mathrm{COM} 75-11132) \\
75-816 & (\mathrm{AD} / \mathrm{A001}-250) \\
75-818 & (\mathrm{~PB} 245-439)\end{array}$ & $\begin{array}{l}\text { A06 } \\
\text { A03 } \\
\text { A04 } \\
\text { A04 } \\
\text { A03 }\end{array}$ \\
\hline $\begin{array}{l}75-742 \\
75-744 \\
75-745 \\
75-746 \\
75-747\end{array}$ & $\begin{array}{l}(\text { PB248-744) } \\
(\text { COM75-11072) } \\
(\text { PB347-657) } \\
(\text { COM75-11432) } \\
(\text { COM75-11131) }\end{array}$ & & $\begin{array}{l}\mathrm{A} 04 \\
\mathrm{~A} 02 \\
\mathrm{~A} 03 \\
\mathrm{~A} 04 \\
\mathrm{~A} 03\end{array}$ & $\begin{array}{ll}75-819 & (\mathrm{~PB} 258-554) \\
75-820 & (\mathrm{~PB} 246-436) \\
75-822 & (\mathrm{~PB} 46-933) \\
75-823 & (\mathrm{~PB} 246-658) \\
75-825 & (\mathrm{~PB} 258-913)\end{array}$ & $\begin{array}{l}\text { A06 } \\
\text { A04 } \\
\text { A03 } \\
\text { A05 } \\
\text { A04 }\end{array}$ \\
\hline $\begin{array}{l}75-748 \\
75-750 \\
75-751 \\
75-755 \\
75-757\end{array}$ & $\begin{array}{l}(\mathrm{COM} 75-11031) \\
(\mathrm{PB} 249-934) \\
(\mathrm{AD} / \mathrm{A} 017-626) \\
(\mathrm{PB} 248-642) \\
(\mathrm{PB} 248-914)\end{array}$ & & $\begin{array}{l}\text { A05 } \\
\text { A03 } \\
\text { A03 } \\
\text { A03 } \\
\text { A03 }\end{array}$ & $\begin{array}{ll}75-827 & (\mathrm{~PB} 247-938) \\
75-828 & (\mathrm{~PB} 249-041) \\
75-829 & (\mathrm{~PB} 248-855) \\
76-844 & (\mathrm{~PB} 264-300) \\
75-900 & (\mathrm{~PB} 250-859)\end{array}$ & $\begin{array}{l}\mathrm{A} 02 \\
\mathrm{~A} 09 \\
\mathrm{~A} 03 \\
\mathrm{~A} 04 \\
\mathrm{~A} 03\end{array}$ \\
\hline $\begin{array}{l}75-760 \\
75-761 \\
75-763 \\
75-766 \\
75-767\end{array}$ & $\begin{array}{l}(\mathrm{AD} / \mathrm{A} 016-843) \\
(\mathrm{COM} 75-11377) \\
(\mathrm{COM} 75-11276) \\
(\mathrm{COM} 75-11376) \\
(\mathrm{PB} 246-879)\end{array}$ & & $\begin{array}{l}\mathrm{A} 10 \\
\mathrm{~A} 06 \\
\mathrm{~A} 10 \\
\mathrm{~A} 04 \\
\mathrm{~A} 03\end{array}$ & $\begin{array}{ll}75-901 & (\mathrm{~PB} 246-860) \\
75-902 & (\mathrm{~PB} 249-539) \\
75-903 & (\mathrm{~PB} 246-859) \\
75-908 & (\mathrm{~PB} 247-270) \\
75-909 & (\mathrm{~PB} 246-863)\end{array}$ & $\begin{array}{l}\mathrm{A} 03 \\
\mathrm{~A} 03 \\
\mathrm{~A} 03 \\
\mathrm{~A} 02 \\
\mathrm{~A} 02\end{array}$ \\
\hline $\begin{array}{l}75-768 \\
75-769 \\
75-770 \\
75-771 \\
75-772\end{array}$ & $\begin{array}{l}(\mathrm{PB} 247-943) \\
(\mathrm{PB} 246-978) \\
(\mathrm{COM}-15-1370) \\
(\mathrm{AD} / \mathrm{A} 017-626) \\
(\mathrm{PB} 246-861)\end{array}$ & & $\begin{array}{l}\text { A03 } \\
\text { A11 } \\
\text { A03 } \\
\text { A03 } \\
\text { A04 }\end{array}$ & $\begin{array}{ll}75-910 & (\mathrm{~PB} 248-646) \\
75-913 & (\mathrm{~PB} 248-911) \\
75-914 & (\mathrm{~PB} 275-158) \\
75-915 & (\mathrm{~PB} 249-775) \\
75-916 & (\mathrm{AD} / \mathrm{A019-648)} \\
75-917 & (\mathrm{~PB} 247-655)\end{array}$ & $\begin{array}{l}\text { A06 } \\
\text { A03 } \\
\text { A03 } \\
\text { A02 } \\
\text { A05 } \\
\text { A02 }\end{array}$ \\
\hline $\begin{array}{l}75-774 \\
75-775 \\
75-778 \\
75-779 \\
75-781\end{array}$ & $\begin{array}{l}(\text { COM75-11364) } \\
(\text { PB248-864) } \\
(\text { PB246-435) } \\
(\text { PB249-935) } \\
(\text { AD/A015-630) }\end{array}$ & & $\begin{array}{l}\mathrm{A} 04 \\
\mathrm{~A} 04 \\
\mathrm{~A} 04 \\
\mathrm{~A} 06 \\
\mathrm{~A} 02\end{array}$ & $\begin{array}{ll}75-918 & (\mathrm{~PB} 251-412) \\
75-920 & (\mathrm{~PB} 248-913) \\
75-923 & (\mathrm{~PB} 250-767) \\
75-924 & (\mathrm{~PB} 248-686) \\
75-925 & (\mathrm{PB256}-622)\end{array}$ & $\begin{array}{l}\text { A05 } \\
\text { A03 } \\
\text { A02 } \\
\text { A05 } \\
\text { A03 }\end{array}$ \\
\hline $\begin{array}{l}75-782 \\
75-784 \\
75-785 \\
75-786 \\
75-787\end{array}$ & $\begin{array}{l}(\mathrm{PB} 248-643) \\
(\mathrm{PB} 246-862) \\
(\mathrm{PB} 246-345) \\
(\mathrm{PB} 251-411) \\
(\mathrm{AD} / \mathrm{A} 016-844)\end{array}$ & & $\begin{array}{l}\text { A03 } \\
\text { A04 } \\
\text { A03 } \\
\text { A04 } \\
\text { A04 }\end{array}$ & $\begin{array}{ll}75-926 & (\mathrm{~PB} 257-467) \\
75-927 & (\mathrm{~PB} 255-809) \\
75-928 & (\mathrm{~PB} 283-169) \\
75-929 & (\mathrm{~PB} 261-498) \\
75-930 & (\mathrm{~PB} 258-250)\end{array}$ & $\begin{array}{l}\text { A06 } \\
\text { A04 } \\
\text { A04 } \\
\text { A03 } \\
\text { A04 }\end{array}$ \\
\hline $\begin{array}{l}75-788 \\
75-789 \\
75-790 \\
75-791 \\
75-793\end{array}$ & $\begin{array}{l}(\mathrm{PB} 250-843) \\
(\mathrm{PB275}-159) \\
(\mathrm{PB} 250-848) \\
(\mathrm{PB} 253-229) \\
(\mathrm{PB} 247-538)\end{array}$ & & $\begin{array}{l}\text { A03 } \\
\text { A03 } \\
\text { A16 } \\
\text { A04 } \\
\text { A04 }\end{array}$ & $\begin{array}{ll}75-931 & (\mathrm{~PB} 261-030) \\
75-932 & (\mathrm{~PB} 257-425) \\
75-933 & (\mathrm{~PB} 248-982) \\
75-935 & (\mathrm{~PB} 299-158) \\
75-937 & (\mathrm{~PB} 65-614)\end{array}$ & $\begin{array}{l}\text { A03 } \\
\text { A04 } \\
\text { A04 } \\
\text { A05 } \\
\text { A02 }\end{array}$ \\
\hline
\end{tabular}


NBS INTERAGENCY REPORTS (Continued)

\begin{tabular}{|c|c|c|c|}
\hline No. & Price & No. & Price \\
\hline $\begin{array}{ll}75-938 & (\mathrm{~PB} 264-290) \\
75-939 & (\mathrm{~PB} 274-643) \\
75-940 & (\mathrm{~PB} 276-020) \\
75-941 & (\mathrm{~PB} 269-535) \\
75-942 & (\mathrm{~PB} 256-644)\end{array}$ & $\begin{array}{l}\text { A05 } \\
\text { A03 } \\
\text { A06 } \\
\text { A04 } \\
\text { A04 }\end{array}$ & $\begin{array}{ll}76-983 & (\mathrm{~PB} 251-213) \\
76-984 & (\mathrm{~PB} 262-020) \\
76-985 & (\mathrm{~PB} 250-755) \\
76-986 & (\mathrm{~PB} 250-858) \\
76-987 & (\mathrm{~PB} 250-857)\end{array}$ & $\begin{array}{l}\text { A03 } \\
\text { A07 } \\
\text { A04 } \\
\text { A04 } \\
\text { A03 }\end{array}$ \\
\hline $\begin{array}{ll}75-943 & (\mathrm{~PB} 258-914) \\
75-944 & (\mathrm{~PB} 258-372) \\
75-945 & (\mathrm{~PB} 264-258) \\
75-946 & (\mathrm{~PB} 280-564) \\
75-947 & (\mathrm{PB276}-494)\end{array}$ & $\begin{array}{l}\text { A05 } \\
\text { A03 } \\
\text { A05 } \\
\text { A07 } \\
\text { A04 }\end{array}$ & $\begin{array}{ll}76-988 & (\mathrm{~PB} 254-469) \\
76-990 & (\mathrm{~PB} 251-769) \\
76-991 & (\mathrm{AD} / \mathrm{A} 021-255) \\
76-992 & (\mathrm{AD} / \mathrm{A} 021-295) \\
76-993 & (\mathrm{~PB} 253-227)\end{array}$ & $\begin{array}{l}\text { A05 } \\
\text { A02 } \\
\text { A02 } \\
\text { A04 } \\
\text { A03 }\end{array}$ \\
\hline $\begin{array}{ll}75-948 & (\mathrm{~PB} 274-049) \\
75-949 & (\mathrm{~PB} 274-048) \\
75-950 & (\mathrm{~PB} 250-664) \\
75-951 & (\mathrm{~PB} 249-094) \\
75-952 & (\mathrm{~PB} 248-910)\end{array}$ & $\begin{array}{l}\text { A03 } \\
\text { A07 } \\
\text { A03 } \\
\text { A03 } \\
\text { A03 }\end{array}$ & $\begin{array}{ll}76-994 & (\mathrm{~PB} 263-100) \\
76-996 & (\mathrm{~PB} 251-998) \\
76-997 & (\mathrm{~PB} 254-298) \\
76-998 & (\mathrm{~PB} 253-228) \\
76-999 & (\mathrm{~PB} 268-130)\end{array}$ & $\begin{array}{l}\text { A09 } \\
\text { A03 } \\
\text { A05 } \\
\text { A03 } \\
\text { A05 }\end{array}$ \\
\hline $\begin{array}{ll}75-953 & (\mathrm{~PB} 256-219) \\
75-954 & (\mathrm{~PB} 253-242) \\
75-955 & (\mathrm{~PB} 248-685) \\
75-956 & (\mathrm{~PB} 247-654) \\
75-957 & (\mathrm{~PB} 250-769)\end{array}$ & $\begin{array}{l}\mathrm{A} 03 \\
\mathrm{~A} 03 \\
\mathrm{~A} 08 \\
\mathrm{~A} 02 \\
\mathrm{~A} 02\end{array}$ & $\begin{array}{ll}76-1000 & (\mathrm{~PB} 251-219) \\
76-1002 & (\mathrm{~PB} 257-469) \\
76-1003 & (\mathrm{~PB} 251-211) \\
76-1005 & (\mathrm{~PB} 273-120) \\
76-1007 & (\mathrm{~PB} 252-021)\end{array}$ & $\begin{array}{l}\text { A04 } \\
\text { A04 } \\
\text { A02 } \\
\text { A04 } \\
\text { A04 }\end{array}$ \\
\hline $\begin{array}{ll}75-958 & (\mathrm{~PB} 248-743) \\
75-960 & (\mathrm{~PB} 249-774) \\
75-961 & (\mathrm{~PB} 257-466) \\
75-962 & (\mathrm{PB2} 47-639) \\
75-966 & (\mathrm{~PB} 250-768)\end{array}$ & $\begin{array}{l}\mathrm{A} 02 \\
\mathrm{~A} 04 \\
\mathrm{~A} 11 \\
\mathrm{~A} 02 \\
\mathrm{~A} 02\end{array}$ & $\begin{array}{ll}76-1008 & (\mathrm{~PB} 251-218) \\
76-1010 & (\mathrm{~PB} 250-654) \\
76-1011 & (\mathrm{~PB} 259-641) \\
76-1012 & (\mathrm{~PB} 257-197) \\
76-1013 & (\mathrm{~PB} 256-130)\end{array}$ & $\begin{array}{l}\mathrm{A} 03 \\
\mathrm{~A} 03 \\
\mathrm{~A} 03 \\
\mathrm{~A} 04 \\
\mathrm{~A} 03\end{array}$ \\
\hline $\begin{array}{ll}75-967 & (\mathrm{~PB} 251-413) \\
75-968 & (\mathrm{~PB} 250-845) \\
75-971 & (\mathrm{~PB} 249-776) \\
75-972 & (\mathrm{~PB} 259-630) \\
75-973 & (\mathrm{PP} 249-255)\end{array}$ & $\begin{array}{l}\mathrm{A} 02 \\
\mathrm{~A} 03 \\
\mathrm{~A} 03 \\
\mathrm{~A} 05 \\
\mathrm{~A} 04\end{array}$ & $\begin{array}{ll}76-1014 & (\mathrm{~PB} 251-414) \\
76-1015 & (\mathrm{~PB} 249-530) \\
76-1016 & (\mathrm{~PB} 254-177) \\
76-1017 & (\mathrm{~PB} 251-917) \\
76-1018 & (\mathrm{~PB} 257-779)\end{array}$ & $\begin{array}{l}\text { A02 } \\
\text { A13 } \\
\text { A04 } \\
\text { A03 } \\
\text { A04 }\end{array}$ \\
\hline $\begin{array}{ll}75-974 & (\mathrm{~PB} 249-777) \\
75-975 & (\mathrm{~PB} 253-113) \\
75-976 & (\mathrm{~PB} 248-986) \\
75-977 & (\mathrm{~PB} 251-220) \\
76-833 & (\mathrm{~PB} 250-846)\end{array}$ & $\begin{array}{l}\mathrm{A} 06 \\
\mathrm{~A} 03 \\
\mathrm{~A} 03 \\
\mathrm{~A} 03 \\
\mathrm{~A} 03\end{array}$ & $\begin{array}{ll}76-1019 & (\mathrm{~PB} 251-944) \\
76-1020 & (\mathrm{~PB} 258-256) \\
76-1021 & (\mathrm{~PB} 257-101) \\
76-1022 & (\mathrm{~PB} 259-628) \\
76-1023 & (\mathrm{~PB} 256-191)\end{array}$ & $\begin{array}{l}\text { A02 } \\
\text { A03 } \\
\text { A04 } \\
\text { A02 } \\
\text { A02 }\end{array}$ \\
\hline $\begin{array}{ll}76-834 & (\mathrm{~PB} 250-666) \\
76-836 & (\mathrm{~PB} 254-459) \\
76-837 & (\mathrm{~PB} 261-709) \\
76-839 & (\mathrm{~PB} 252-013) \\
76-840 & (\mathrm{~PB} 258-324)\end{array}$ & $\begin{array}{l}\mathrm{A} 03 \\
\mathrm{~A} 03 \\
\mathrm{~A} 07 \\
\mathrm{~A} 08 \\
\mathrm{~A} 03\end{array}$ & $\begin{array}{ll}76-1024 & (\mathrm{~PB} 255-876) \\
76-1025 & (\mathrm{~PB} 251-753) \\
76-1027 & (\mathrm{~PB} 253-243) \\
76-1028 & (\mathrm{~PB} 251-415) \\
76-1029 & (\mathrm{~PB} 261-199)\end{array}$ & $\begin{array}{l}\text { A04 } \\
\text { A05 } \\
\text { A03 } \\
\text { A02 } \\
\text { A03 }\end{array}$ \\
\hline $\begin{array}{ll}76-841 & (\mathrm{~PB} 256-319) \\
76-842 & (\mathrm{~PB} 258-331) \\
76-846 & (\mathrm{~PB} 258-327) \\
76-847 & (\mathrm{~PB} 265-007) \\
76-848 & (\mathrm{~PB} 261-996)\end{array}$ & $\begin{array}{l}\mathrm{A} 03 \\
\mathrm{~A} 02 \\
\mathrm{~A} 03 \\
\mathrm{~A} 09 \\
\mathrm{~A} 14\end{array}$ & $\begin{array}{ll}76-1030 & (\mathrm{~PB} 263-633) \\
76-1031 & (\mathrm{~PB} 253-932) \\
76-1034 & (\mathrm{~PB} 254-460) \\
76-1037 & (\mathrm{~PB} 253-933) \\
76-1038 & (\mathrm{~PB} 251-918)\end{array}$ & $\begin{array}{l}\text { A03 } \\
\text { A02 } \\
\text { A05 } \\
\text { A03 } \\
\text { A02 }\end{array}$ \\
\hline $\begin{array}{ll}76-850 & (\mathrm{~PB} 266-945) \\
76-851 & (\mathrm{~PB} 263-124) \\
76-979 & (\mathrm{~PB} 248-992) \\
76-980 & (\mathrm{~PB} 250-849) \\
76-982 & (\mathrm{~PB} 248-699)\end{array}$ & $\begin{array}{l}\mathrm{A} 04 \\
\mathrm{~A} 02 \\
\mathrm{~A} 02 \\
\mathrm{~A} 10 \\
\mathrm{~A} 15\end{array}$ & $\begin{array}{ll}76-1039 & (\mathrm{~PB} 254-047) \\
76-1040 & (\mathrm{~PB} 254-178) \\
76-1041 & (\mathrm{~PB} 257-086) \\
76-1043 & (\mathrm{~PB} 254-347) \\
76-1046 & (\mathrm{~PB} 256-476)\end{array}$ & $\begin{array}{l}\text { A03 } \\
\text { A02 } \\
\text { A04 } \\
\text { A06 } \\
\text { A06 }\end{array}$ \\
\hline
\end{tabular}


NBS INTERAGENCY REPORTS (Continued)

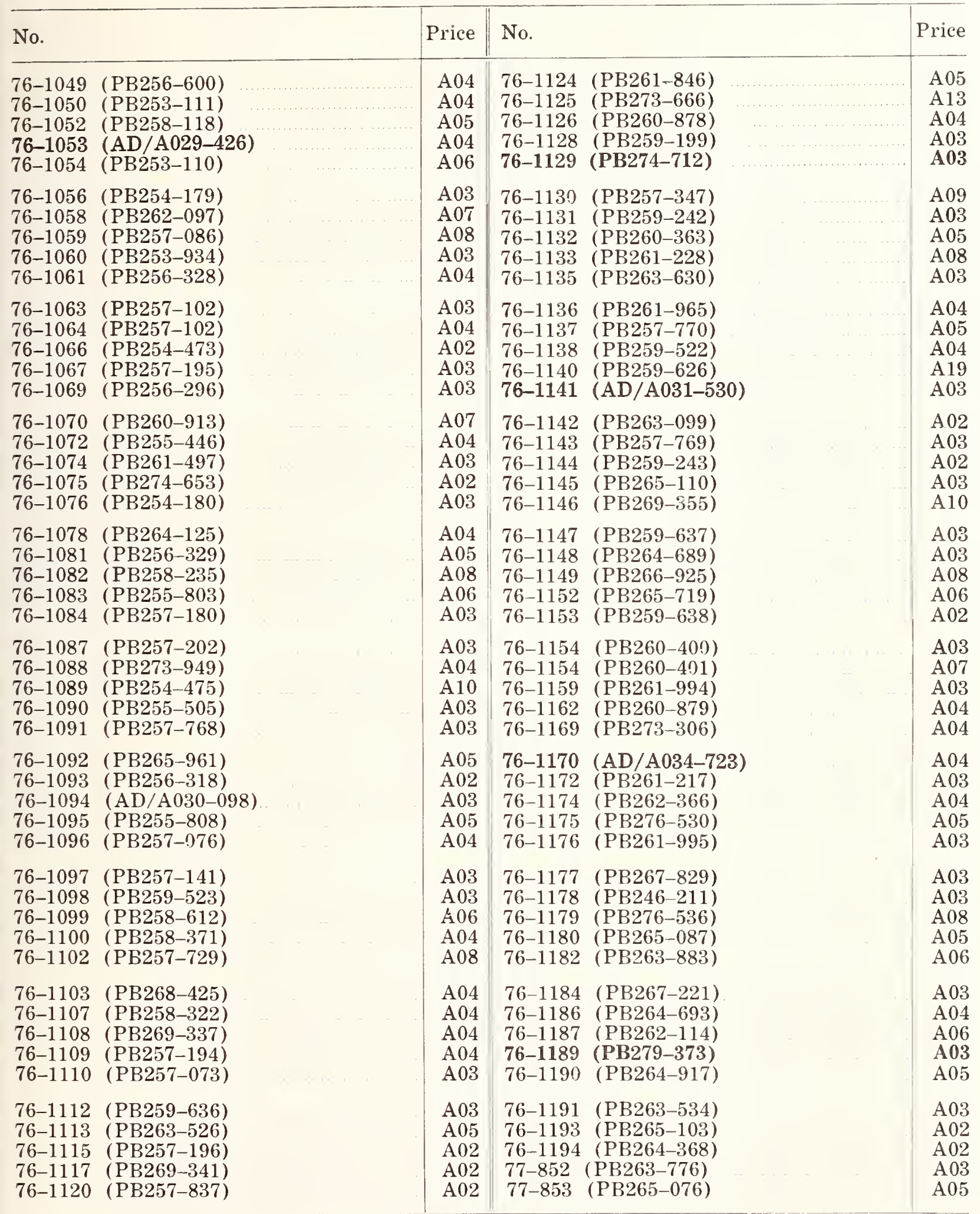


NBS INTERAGENCY REPORTS (Continued)

\begin{tabular}{|c|c|c|c|}
\hline No. & Price & No. & Price \\
\hline $\begin{array}{ll}77-855 & (\mathrm{~PB} 265-076) \\
77-856 & (\mathrm{AD} / \mathrm{A} 038-725) \\
77-857 & (\mathrm{~PB} 266-944) \\
77-858 & (\mathrm{~PB} 272-358) \\
77-859 & (\mathrm{~PB} 274-186)\end{array}$ & $\begin{array}{l}\mathrm{A} 02 \\
\mathrm{~A} 03 \\
\mathrm{~A} 03 \\
\mathrm{~A} 02 \\
\mathrm{~A} 03\end{array}$ & $\begin{array}{ll}77-1249 & (\mathrm{~PB} 269-345) \\
77-1250 & (\mathrm{~PB} 268-150) \\
77-1251 & (\mathrm{~PB} 269-531) \\
77-1253 & (\mathrm{~PB} 268-424) \\
77-1254 & (\mathrm{~PB} 269-354)\end{array}$ & $\begin{array}{l}\text { A05 } \\
\text { A05 } \\
\text { A06 } \\
\text { A06 } \\
\text { A04 }\end{array}$ \\
\hline $\begin{array}{ll}77-860 & (\mathrm{~PB} 272-355) \\
77-861 & (\mathrm{~PB} 274-057) \\
77-862 & (\mathrm{~PB} 274-058) \\
77-863 & (\mathrm{AD} / \mathrm{A} 046-831) \\
77-866 & (\mathrm{~PB} 274-456)\end{array}$ & $\begin{array}{l}\text { A11 } \\
\text { A03 } \\
\text { A04 } \\
\text { A08 } \\
\text { A03 }\end{array}$ & $\begin{array}{ll}77-1256 & (\mathrm{~PB} 269-845) \\
77-1257 & (\mathrm{~PB} 271-973) \\
77-1259 & (\mathrm{~PB} 268-873) \\
77-1269 & (\mathrm{~PB} 268-112) \\
77-1261 & (\mathrm{~PB} 270-867)\end{array}$ & $\begin{array}{l}\text { A03 } \\
\text { A03 } \\
\text { A06 } \\
\text { A04 } \\
\text { A04 }\end{array}$ \\
\hline $\begin{array}{ll}77-867 & (\mathrm{~PB} 276-047) \\
77-868 & (\mathrm{~PB} 274-457) \\
77-1195 & (\mathrm{~PB} 263-771) \\
77-1196 & (\mathrm{~PB} 274-647) \\
77-1197 & (\mathrm{~PB} 268-081)\end{array}$ & $\begin{array}{l}\text { A04 } \\
\mathrm{A} 03 \\
\mathrm{~A} 08 \\
\mathrm{~A} 03 \\
\mathrm{~A} 02\end{array}$ & $\begin{array}{ll}77-1262 & (\mathrm{~PB} 269-346) \\
77-1263 & (\mathrm{~PB} 273-946) \\
77-1264 & (\mathrm{~PB} 272-475) \\
77-1265 & (\mathrm{~PB} 271-097) \\
77-1270 & (\mathrm{~PB} 269-518)\end{array}$ & $\begin{array}{l}\text { A03 } \\
\text { A03 } \\
\text { A07 } \\
\text { A03 } \\
\text { A04 }\end{array}$ \\
\hline $\begin{array}{ll}77-1202 & (\mathrm{~PB} 276-652) \\
77-1203 & (\mathrm{~PB} 287-805) \\
77-1207 & (\mathrm{~PB} 264-427) \\
77-1208 & (\mathrm{~PB} 264-286) \\
77-1209 & (\mathrm{~PB} 269-866)\end{array}$ & $\begin{array}{l}\mathrm{A} 02 \\
\mathrm{~A} 02 \\
\mathrm{~A} 02 \\
\mathrm{~A} 06 \\
\mathrm{~A} 03\end{array}$ & $\begin{array}{ll}77-1271 & (\mathrm{~PB} 280-107) \\
77-1272 & (\mathrm{~PB} 271-758) \\
77-1273 & (\mathrm{~PB} 276-004) \\
77-1274 & (\mathrm{~PB} 269-847) \\
77-1275 & (\mathrm{~PB} 270-523)\end{array}$ & $\begin{array}{l}\text { A05 } \\
\text { A08 } \\
\text { A03 } \\
\text { A08 } \\
\text { A03 }\end{array}$ \\
\hline $\begin{array}{ll}77-1210 & (\mathrm{~PB} 264-297) \\
77-1211 & (\mathrm{~PB} 285-452) \\
77-1212 & (\mathrm{~PB} 265-697) \\
77-1213 & (\mathrm{~PB} 265-102) \\
77-1214 & (\mathrm{~PB} 269-878)\end{array}$ & $\begin{array}{l}\text { A04 } \\
\text { A03 } \\
\text { A04 } \\
\text { A07 } \\
\text { A10 }\end{array}$ & $\begin{array}{ll}77-1276 & (\mathrm{~PB} 270-855) \\
77-1277 & (\mathrm{~PB} 269-965) \\
77-1278 & (\mathrm{~PB} 270-868) \\
77-1279 & (\mathrm{~PB} 279-863) \\
77-1282 & (\mathrm{~PB} 273-575)\end{array}$ & $\begin{array}{l}\text { A09 } \\
\text { A02 } \\
\text { A03 } \\
\text { A03 } \\
\text { A03 }\end{array}$ \\
\hline $\begin{array}{ll}77-1215 & (\mathrm{~PB} 269-534) \\
77-1217 & (\mathrm{~PB} 264-691) \\
77-1218 & (\mathrm{~PB} 264-666) \\
77-1219 & (\mathrm{~PB} 264-692) \\
77-1221 & (\mathrm{~PB} 264-919)\end{array}$ & $\begin{array}{l}\mathrm{A} 11 \\
\mathrm{~A} 03 \\
\mathrm{~A} 06 \\
\mathrm{~A} 03 \\
\mathrm{~A} 04\end{array}$ & $\begin{array}{ll}77-1286 & (\mathrm{~PB} 276-473) \\
77-1287 & (\mathrm{~PB} 273-576) \\
77-1289 & (\mathrm{~PB} 297-463) \\
77-1290 & (\mathrm{~PB} 272-064) \\
77-1291 & (\mathrm{~PB} 271-744)\end{array}$ & $\begin{array}{l}\text { A02 } \\
\text { A04 } \\
\text { A07 } \\
\text { A07 } \\
\text { A04 }\end{array}$ \\
\hline $\begin{array}{ll}77-1222 & (\mathrm{~PB} 265-089) \\
77-1225 & (\mathrm{~PB} 270-856) \\
77-1227 & (\mathrm{~PB} 267-608) \\
77-1228 & (\mathrm{~PB} 265-950) \\
77-1229 & (\mathrm{~PB} 265-477)\end{array}$ & $\begin{array}{l}\mathrm{A} 03 \\
\mathrm{~A} 08 \\
\mathrm{~A} 02 \\
\mathrm{~A} 03 \\
\mathrm{~A} 02\end{array}$ & $\begin{array}{ll}77-1293 & (\mathrm{~PB} 271-745) \\
77-1294 & (\mathrm{~PB} 272-507) \\
77-1295 & (\mathrm{~PB} 275-170) \\
77-1297 & (\mathrm{~PB} 273-899) \\
77-1298 & (\mathrm{~PB} 271-974)\end{array}$ & $\begin{array}{l}\text { A09 } \\
\text { A04 } \\
\text { A03 } \\
\text { A12 } \\
\text { A03 }\end{array}$ \\
\hline $\begin{array}{ll}77-1230 & (\mathrm{~PB} 269-344) \\
77-1231 & (\mathrm{~PB} 267-780) \\
77-1232 & (\mathrm{~PB} 265-672) \\
77-1233 & (\mathrm{~PB} 265-436) \\
77-1234 & (\mathrm{~PB} 267-828)\end{array}$ & $\begin{array}{l}\mathrm{A} 04 \\
\mathrm{~A} 04 \\
\mathrm{~A} 04 \\
\mathrm{~A} 04 \\
\mathrm{~A} 03\end{array}$ & $\begin{array}{ll}77-1299 & (\mathrm{~PB} 297-641) \\
77-1300 & (\mathrm{~PB} 273-171) \\
77-1301 & (\mathrm{~PB} 279-218) \\
77-1302 & (\mathrm{~PB} 275-173) \\
77-1303 & (\mathrm{~PB} 274-331)\end{array}$ & $\begin{array}{l}\text { A03 } \\
\text { A05 } \\
\text { A05 } \\
\text { A02 } \\
\text { A04 }\end{array}$ \\
\hline $\begin{array}{ll}77-1235 & (\mathrm{~PB} 273-634) \\
77-1236 & (\mathrm{~PB} 268-902) \\
77-1237 & (\mathrm{~PB} 267-281) \\
77-1239 & (\mathrm{~PB} 269-281) \\
77-1240 & (\mathrm{~PB} 266-238)\end{array}$ & $\begin{array}{l}\text { A03 } \\
\text { A03 } \\
\text { A03 } \\
\text { A11 } \\
\text { A02 }\end{array}$ & $\begin{array}{ll}77-1304 & (\mathrm{~PB} 272-478) \\
77-1305 & (\mathrm{~PB} 272-500) \\
77-1306 & (\mathrm{~PB} 276-531) \\
77-1307 & (\mathrm{~PB} 273-175) \\
77-1308 & (\mathrm{~PB} 273-589)\end{array}$ & $\begin{array}{l}\text { A03 } \\
\text { A04 } \\
\text { A03 } \\
\text { A06 } \\
\text { A09 }\end{array}$ \\
\hline $\begin{array}{ll}77-1241 & (\mathrm{~PB} 272-945) \\
77-1243 & (\mathrm{~PB} 269-517) \\
77-1244 & (\mathrm{~PB} 270-854) \\
77-1246 & (\mathrm{PB268}-389) \\
77-1247 & (\mathrm{PB280}-182)\end{array}$ & $\begin{array}{l}\text { A03 } \\
\text { A08 } \\
\text { A04 } \\
\text { A05 } \\
\text { A07 }\end{array}$ & $\begin{array}{ll}77-1309 & (\mathrm{~PB} 274-334) \\
77-1310 & (\mathrm{~PB} 272-690) \\
77-1312 & (\mathrm{~PB} 274-330) \\
77-1313 & (\mathrm{~PB} 273-944) \\
77-1314 & (\mathrm{~PB} 273-\mathbf{3 0 5})\end{array}$ & $\begin{array}{l}\text { A03 } \\
\text { A02 } \\
\text { A03 } \\
\text { A04 } \\
\text { A06 }\end{array}$ \\
\hline
\end{tabular}


NBS INTERAGENCY REPORTS (Continued)

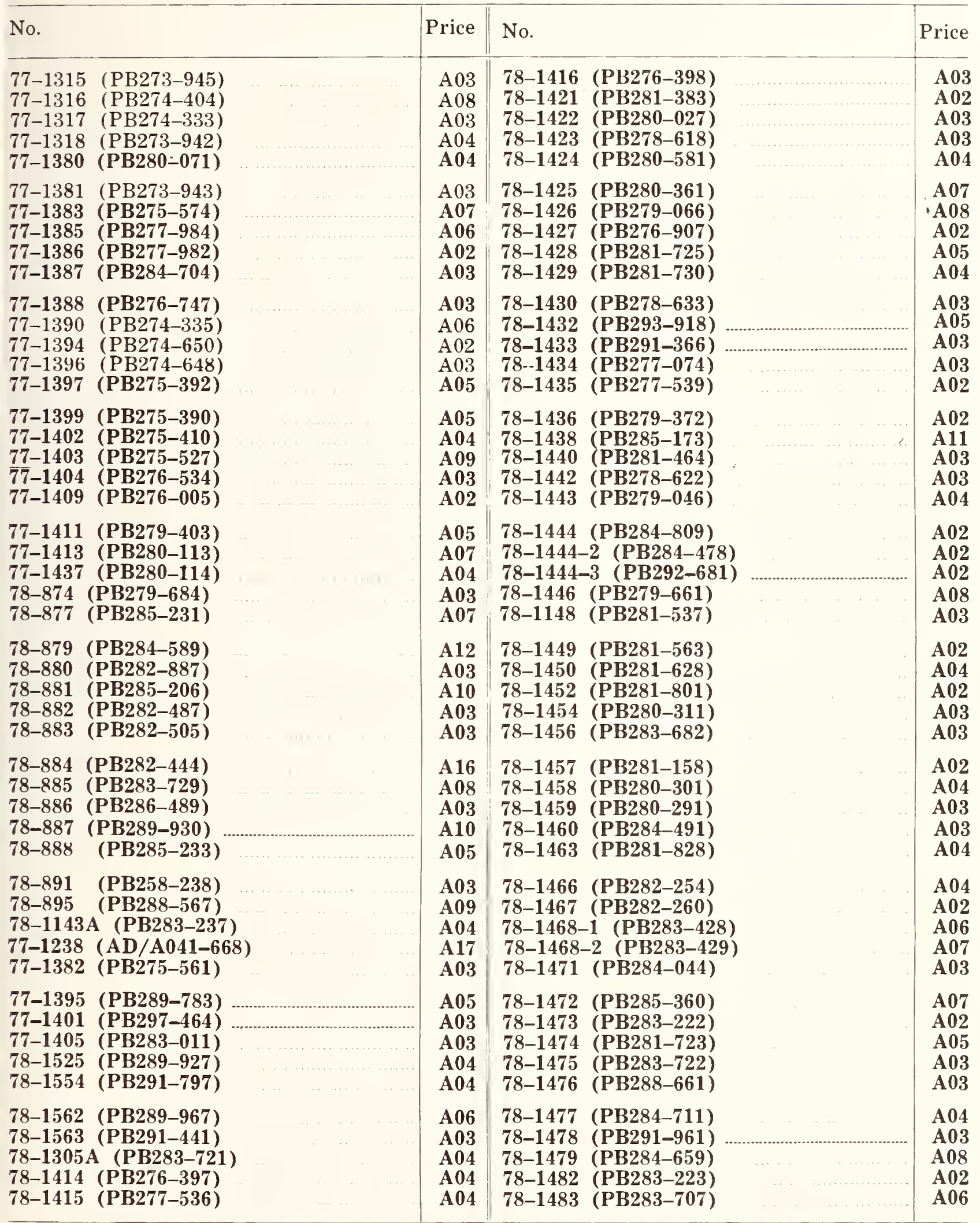


NBS INTERAGENCY REPORTS (continued)

No.

$\begin{array}{ll}78-1484 & (\mathrm{~PB} 284-044) \\ 78-1485 & (\mathrm{~PB} 284-864) \\ 78-1486 & (\mathrm{~PB} 283-708) \\ 78-1487 & (\mathrm{~PB} 282-406) \\ 78-1488 & (\mathrm{~PB} 283-881) \\ 78-1490 & (\mathrm{~PB} 284-819)\end{array}$

78-1493 (PB287-861)

Supp. to NBSIR 76-1140

78-1494 (PB290-160)

78-1495 (PB286-096)

78-1496 (PB295-431)

78-1497 (PB285-186)

78-1499 (PB284-492)

78-1500 (PB284-495)

78-1501 (PB298-052)

78-1502 (PB287-870)

78-1503 (PB284-685)

78-1504 (PB284-462)

78-1505 (PB291-987)

78-1507 (PB290-491)

78-1508 (PB284-959)

78-1509 (PB291-241)

78-1512 (PB287-510)

78-1513 (PB287-519)

78-1514 (PB289-272)

78-1520 (PB289-961)

78-1521 (PB296-148)

78-1522 (PB291-426)

78-1524 (PB291-410)

78-1526 (PB291-930)

78-1528 (PB287-405)

78-1530 (PB291-844)

78-1531 (PB291-444)

78-1532 (PB282-772)

78-1534 (PB286-933)

78-1535 (PB289-729)

78-1537 (PB288-857)

78-1539 (PB289-803)

78-1541 (PB287-936)

78-1542 (PB287-410)

78-1543 (PB289-484)

78-1544 (PB287-496)

78-1545 (PB291-409)

78-1547 (PB292-284)

78-1548 (PB288-793)

78-1549 (PB288-762)

78-1552 (PB288-804)

78-1553 (PB288-763)

P

Price
A03
A02
A04
A03
A03
A03

A03

A03

$\mathrm{A} 03$

A03

$\mathrm{A} 03$

A04

$\mathrm{A} 04$

A07

A03

A10

A02

A02

A03

A03

A05

$\mathrm{A} 03$

$\mathrm{A} 02$

A 07

A04

A03

A04

A02

A10

A04

A08

A06

$\mathrm{A} 03$

$\mathrm{A} 03$

$\mathrm{A} 03$

A03

A05

A 05

A05

A06

A03

A02

A05

A04

A03

$\mathrm{A} 03$

$\mathrm{A} 03$
No.

78-1555 (PB292-273)

78-1556 (PB294-880)

78-1557 (PB289-755)

78-1558 (PB293-556)

78-1559 (PB288-730)

78-1564 (PB291-959)

78-1568 (PB289-813)

78-1569 (PB299-654)

78-1571 (PB291-889)

78-1573 (PB289-913)

78-1575 (PB291-988)

78-1576 (PB291-335)

78-1577 (PB293-170)

78-1581 (PB291-946)

78-1584 (PB298-264)

78-1586 (PB292-600)

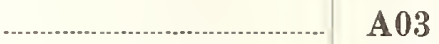

A05

A06

A02

A04

A04

$\mathrm{A} 03$

A04

79-1588 (PB293-159)

78-1590 (PB290-679)

79-1591 (PB294-846)

79-1591-2 (PB298-063)

79-1591-3 (PB298-064)

79-1595 (PB293-487)

79-1596 (PB295-039)

79-1599 (PB292-967)

79-1604 (PB296-321)

79-1605 (PB296-207)

79-1606 (PB296-324)

79-1607 (PB298-555)

79-1608 (PB296-951)

79-1609 (PB299-288)

79-1612 (PB299-361)

79-1613 (PB299-576)

79-1615 (PB80-105-141)

79-1618 (PB80-116-502)

79-1619 (PB80-118-508)

79-1620 (PB80-120-066)

79-1621 (PB80-118-193)

79-1700 (PB297-765)

79-1703 (PB292-753)

79-1705 (PB295-642)

79-1706 (PB293-498)

79-1707 (PB292-743)

79-1709 (PB294-926)

79-1710 (PB298-622)

78-1712 (PB296-326)

79-1713 (PB295-063)

79-1714 (PB297-631)

79-1716 (PB295-357)
$\mathrm{A} 03$

A04

A02

A02

$\mathrm{A} 02$

A04

A02

A05

A03

A02

A03

A02

A03

A 21

A09

A04

A03

A04

A06

A03

A08

A02

A03

A17

A05

A04

A08

A03

A08

A09

A03

A03 
NBS INTERAGENCY REPORTS (Continued)

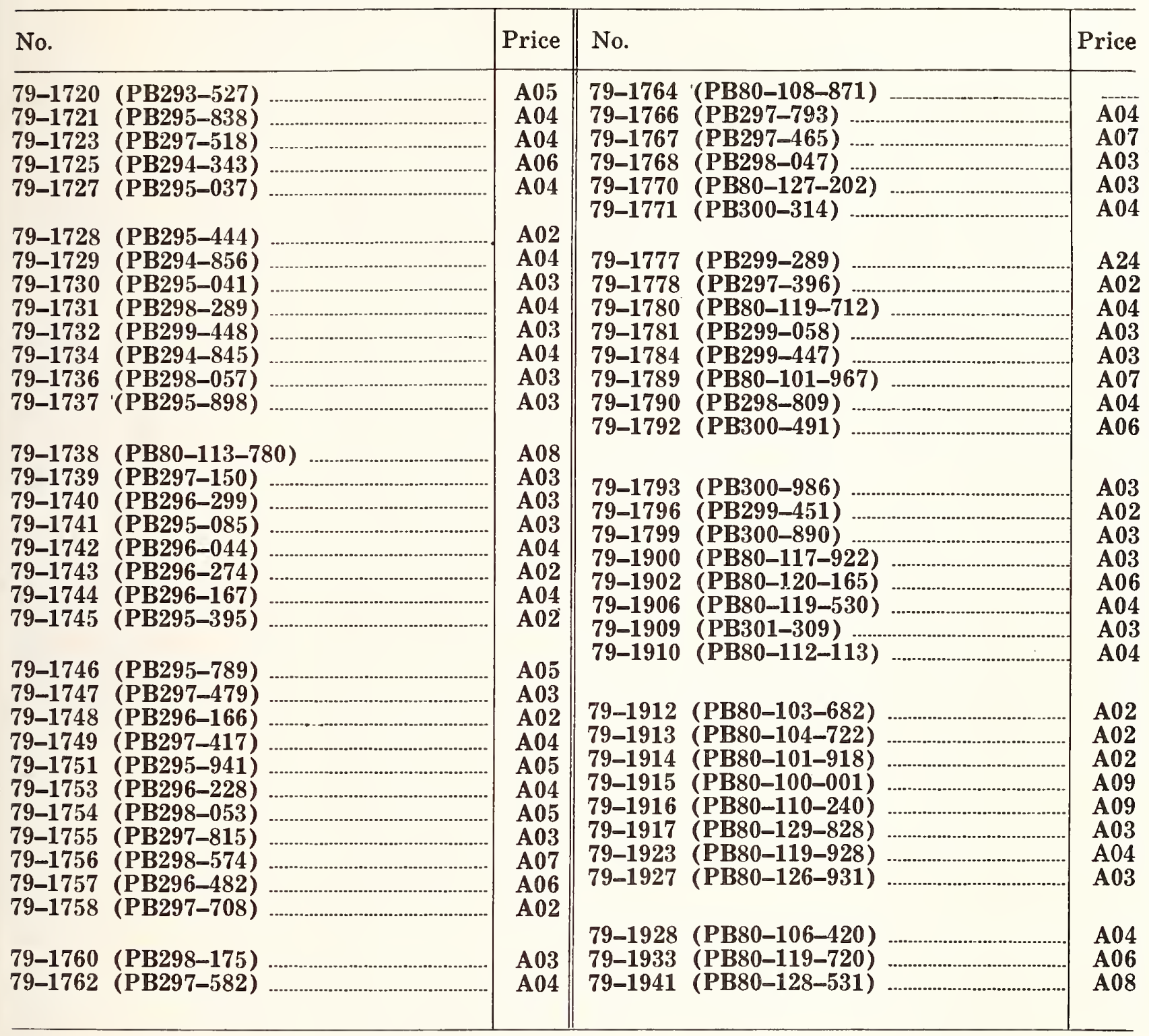




\begin{tabular}{|c|c|c|c|c|}
\hline No. & & Price & No. & Price \\
\hline $\begin{array}{l}73-1 \\
73-2 \\
73-3\end{array}$ & $\begin{array}{l}(\mathrm{PB} 192-365) \\
(\mathrm{PB194-614}) \\
(\mathrm{COM} 71-00605)\end{array}$ & $\begin{array}{l}\text { A03 } \\
\text { A05 } \\
\text { A10 }\end{array}$ & $\begin{array}{ll}76-57 & (\mathrm{PB250}-573) \\
76-58 & (\mathrm{~PB} 256-291) \\
76-59 & (\mathrm{~PB} 256-639)\end{array}$ & $\begin{array}{l}\text { A06 } \\
\text { A07 } \\
\text { A10 }\end{array}$ \\
\hline $\begin{array}{l}73-4 \\
73-5 \\
73-6 \\
73-7 \\
73-8\end{array}$ & $\begin{array}{l}(\text { COM73-10323) } \\
(\text { COM73-10951) } \\
(\text { COM73-10959) } \\
(\text { COM73-10958) } \\
(\text { COM73-10954) }\end{array}$ & $\begin{array}{l}\text { A04 } \\
\text { A08 } \\
\text { A04 } \\
\text { A04 } \\
\text { A10 }\end{array}$ & $\begin{array}{ll}76-60 & (\mathrm{~PB} 253-588) \\
76-61 & (\mathrm{~PB} 253-553) \\
76-63 & (\mathrm{~PB} 256-440) \\
76-64 & (\mathrm{~PB} 255-445) \\
76-69 & (\mathrm{~PB} 254-276)\end{array}$ & $\begin{array}{l}\text { A05 } \\
\text { A05 } \\
\text { A06 } \\
\text { A05 } \\
\text { A06 }\end{array}$ \\
\hline $\begin{array}{l}73-9 \\
73-10 \\
73-11 \\
73-12 \\
73-13\end{array}$ & $\begin{array}{l}(\text { COM73-10953) } \\
(\text { COM73-10952) } \\
(\text { PB242-597) } \\
(\text { COM73-10955) } \\
\text { (COM73-10957) }\end{array}$ & $\begin{array}{l}\text { A03 } \\
\text { A08 } \\
\text { A12 } \\
\text { A06 } \\
\text { A05 }\end{array}$ & $\begin{array}{ll}76-70 & (\mathrm{~PB} 254-748) \\
76-71 & (\mathrm{~PB} 254-751) \\
76-72 & (\mathrm{~PB} 256-190) \\
76-73 & (\mathrm{~PB} 257-424) \\
76-74 & (\mathrm{~PB} 256-771)\end{array}$ & $\begin{array}{l}\text { A04 } \\
\text { A04 } \\
\text { A06 } \\
\text { A08 } \\
\text { A03 }\end{array}$ \\
\hline $\begin{array}{l}73-14 \\
73-15 \\
73-16 \\
73-17 \\
73-18\end{array}$ & $\begin{array}{l}(\text { COM73-10950) } \\
(\mathrm{PB} 242-582) \\
(\text { COM73-11265) } \\
(\text { COM74-10932) } \\
(\text { COM73-11783) }\end{array}$ & $\begin{array}{l}\text { A04 } \\
\text { A15 } \\
\text { A04 } \\
\text { A07 } \\
\text { A03 }\end{array}$ & $\begin{array}{ll}76-75 & (\mathrm{~PB} 261-201) \\
76-76 & (\mathrm{~PB} 261-200) \\
76-77 & (\mathrm{~PB} 257-767) \\
76-78 & (\mathrm{~PB} 257-836) \\
76-79 & (\mathrm{~PB} 259-127)\end{array}$ & $\begin{array}{l}\text { A03 } \\
\text { A06 } \\
\text { A05 } \\
\text { A06 } \\
\text { A03 }\end{array}$ \\
\hline $\begin{array}{l}73-19 \\
73-21 \\
74-22 \\
74-23 \\
74-24\end{array}$ & $\begin{array}{l}(\text { COM74-10481) } \\
(\text { COM74-10722) } \\
(\text { COM74-10934) } \\
\text { (COM74-10929) } \\
(\text { COM74-10983) }\end{array}$ & $\begin{array}{l}\mathrm{A} 04 \\
\mathrm{~A} 07 \\
\mathrm{~A} 16 \\
\mathrm{~A} 02 \\
\mathrm{~A} 05\end{array}$ & $\begin{array}{ll}76-80 & (\mathrm{~PB} 259-126) \\
77-82 & (\mathrm{~PB} 263-882) \\
77-83 & (\mathrm{~PB} 265-228) \\
77-84 & (\mathrm{~PB} 267-278) \\
77-85 & (\mathrm{~PB} 267-233)\end{array}$ & $\begin{array}{l}\text { A04 } \\
\text { A17 } \\
\text { A06 } \\
\text { A06 } \\
\text { A14 }\end{array}$ \\
\hline $\begin{array}{l}74-25 \\
74-26 \\
74-27 \\
74-28 \\
74-29\end{array}$ & $\begin{array}{l}(\text { COM74-11075) } \\
\text { (COM74-11633) } \\
(\text { COM75-10143) } \\
(\text { PB176-912) } \\
(\text { PB176-913) }\end{array}$ & $\begin{array}{l}\text { A07 } \\
\text { A06 } \\
\text { A06 } \\
\text { A12 } \\
\text { A04 }\end{array}$ & $\begin{array}{ll}77-86 & (\mathrm{~PB} 272-882) \\
77-87 & (\mathrm{~PB} 268-132) \\
77-88 & (\mathrm{~PB} 268-131) \\
77-89 & (\mathrm{~PB} 268-517) \\
77-90 & (\mathrm{~PB} 269-489)\end{array}$ & $\begin{array}{l}\text { A10 } \\
\text { A04 } \\
\text { A06 } \\
\text { A08 } \\
\text { A09 }\end{array}$ \\
\hline $\begin{array}{l}74-30 \\
74-31 \\
74-32 \\
75-33 \\
75-34\end{array}$ & $\begin{array}{l}(\text { COM74-11732) } \\
(\text { COM74-11733) } \\
\text { (COM75-10039) } \\
(\text { COM75-10133) } \\
(\text { COM75-10128) }\end{array}$ & $\begin{array}{l}\mathrm{A} 03 \\
\mathrm{~A} 02 \\
\mathrm{~A} 04 \\
\mathrm{~A} 11 \\
\mathrm{~A} 04\end{array}$ & $\begin{array}{ll}77-91 & (\mathrm{~PB} 268-904) \\
77-92 & (\mathrm{~PB} 273-166) \\
77-93 & (\mathrm{~PB} 271-980) \\
77-94 & (\mathrm{~PB} 271-755) \\
77-95 & (\mathrm{~PB} 272-883)\end{array}$ & $\begin{array}{l}\text { A05 } \\
\text { A04 } \\
\text { A09 } \\
\text { A14 } \\
\text { A07 }\end{array}$ \\
\hline $\begin{array}{l}73-35 \\
75-36 \\
75-37 \\
75-38 \\
75-40\end{array}$ & $\begin{array}{l}(\text { COM75-10341) } \\
(\text { PB261-144) } \\
(\text { PB261-145) } \\
(\text { PB261-021) } \\
(\text { COM75-10696) }\end{array}$ & $\begin{array}{l}\text { A05 } \\
\text { A16 } \\
\text { A06 } \\
\text { A05 } \\
\text { A03 }\end{array}$ & $\begin{array}{ll}77-97 & (\mathrm{~PB} 272-069) \\
77-98 & (\mathrm{PB280}-\mathbf{7 4 6}) \\
77-99 & (\mathrm{~PB} 273-977) \\
77-100 & (\mathrm{PB284-517}) \\
77-101 & (\mathrm{~PB} 284-\mathbf{5 0 0})\end{array}$ & $\begin{array}{l}\text { A06 } \\
\text { A05 } \\
\text { A12 } \\
\text { A04 } \\
\text { A06 }\end{array}$ \\
\hline $\begin{array}{l}75-42 \\
75-43 \\
75-44 \\
75-45 \\
75-46\end{array}$ & $\begin{array}{l}(\mathrm{COM} 75-10805) \\
(\mathrm{AD} / \mathrm{A} 016-782) \\
(\mathrm{COM} 75-10991) \\
(\mathrm{PB} 257-835) \\
(\mathrm{PB} 247-235)\end{array}$ & $\begin{array}{l}\text { A24 } \\
\text { A06 } \\
\text { A10 } \\
\text { A02 } \\
\text { A09 }\end{array}$ & $\begin{array}{ll}77-102 & (\mathrm{~PB} 273-165) \\
77-103 & (\mathrm{~PB} 273-174) \\
77-104 & (\mathrm{~PB} 276-102) \\
77-105 & (\mathrm{~PB} 275-083) \\
77-106 & (\mathrm{~PB} 275-155)\end{array}$ & $\begin{array}{l}\text { A03 } \\
\text { A06 } \\
\text { A04 } \\
\text { A04 } \\
\text { A03 }\end{array}$ \\
\hline $\begin{array}{l}75-47 \\
75-48 \\
75-50 \\
75-51 \\
76-54\end{array}$ & $\begin{array}{l}(\mathrm{PB} 247-236) \\
(\mathrm{PB} 248-781) \\
(\mathrm{PB} 247-939) \\
(\mathrm{PB} 247-483) \\
(\mathrm{PB} 251-682)\end{array}$ & $\begin{array}{l}\text { A17 } \\
\text { A09 } \\
\text { A07 } \\
\text { A15 } \\
\text { A05 }\end{array}$ & $\begin{array}{ll}77-107 & (\mathrm{~PB} 275-524) \\
77-108 & (\mathrm{~PB} 278-634) \\
77-109 & (\mathrm{~PB} 275-576) \\
77-110 & (\mathrm{~PB} 278-648) \\
77-111 & (\mathrm{~PB} 278-643)\end{array}$ & $\begin{array}{l}\text { A09 } \\
\text { A03 } \\
\text { A05 } \\
\text { A05 } \\
\text { A05 }\end{array}$ \\
\hline $\begin{array}{l}76-55 \\
76-56\end{array}$ & $\begin{array}{l}(\mathrm{PB} 250-571) \\
(\mathrm{PB} 250-572)\end{array}$ & $\begin{array}{l}\mathrm{A} 04 \\
\mathrm{~A} 04\end{array}$ & $\begin{array}{ll}77-112 & (\mathrm{~PB} 278-644) \\
77-116 & (\mathrm{~PB} 276-549)\end{array}$ & $\begin{array}{l}\text { A02 } \\
\text { A06 }\end{array}$ \\
\hline
\end{tabular}


GRANTEE/CONTRACTOR REPORTS (Continued)

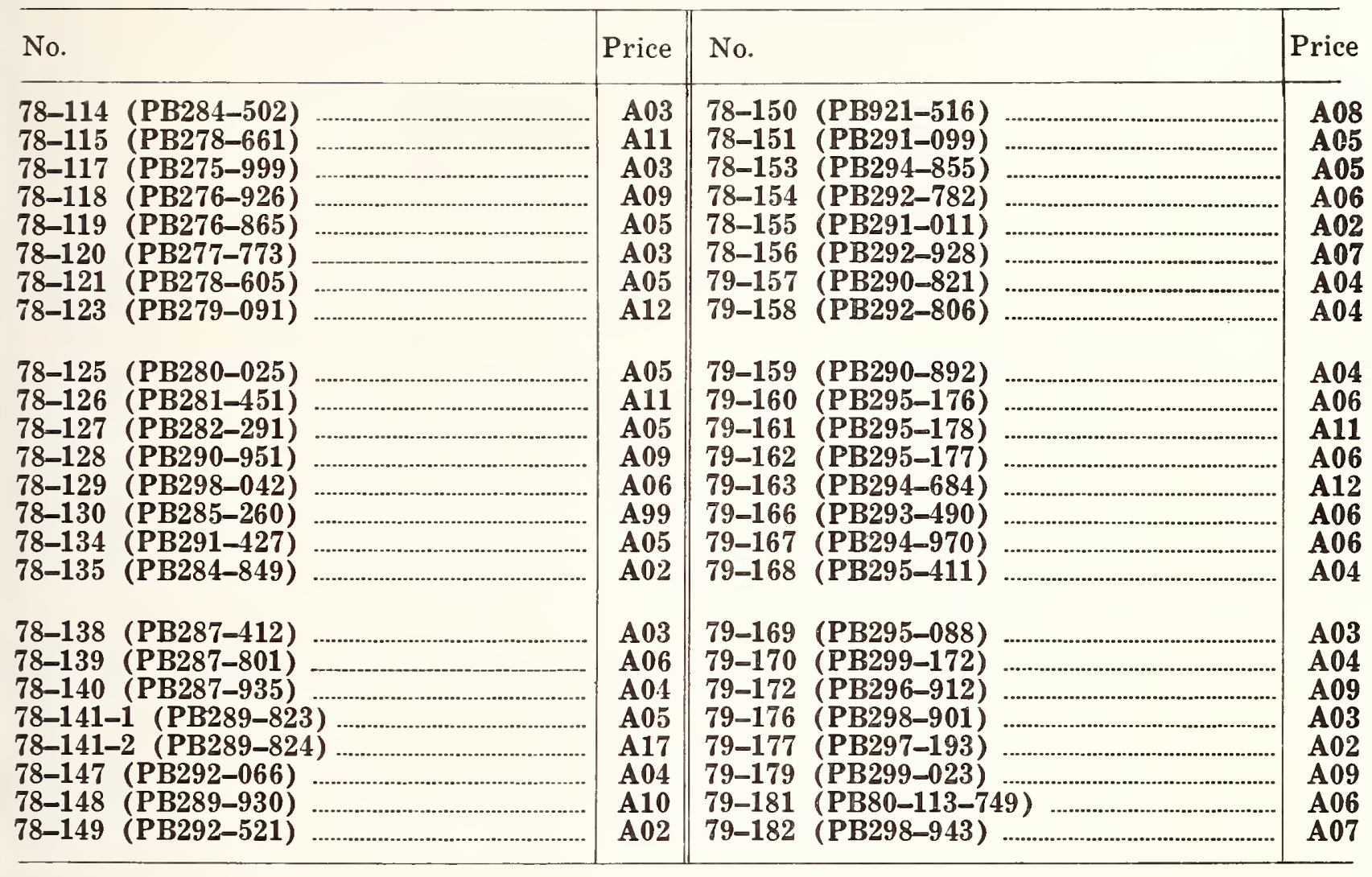


EXPERIMENTAL TECHNOLOGY INCENTIVES PROGRAM REPORTS

No.

\begin{tabular}{|c|c|}
\hline Price & No. \\
\hline A12 & $76-31 \quad(\mathrm{~PB} 264-390)$ \\
\hline A08 & 76-32 (PB264-391) \\
\hline A06 & 76-33 (PB264-392) \\
\hline A02 & 76-34 (PB263-275) \\
\hline $\mathrm{A} 04$ & 76-35 (PB263-273) \\
\hline
\end{tabular}

Price

73-01 (COM73-11373)

73-02 (COM73-11375)

73-03 (COM73-11374)

73-04 (COM74-10256)

73-05 (COM74-10257)

73-06 (COM74-10258)

73-07 Vol. 1 (COM74-10939)

73-07 Vol.2 (COM74-10940)

75-01 (COM75-11369)

76-03 (PB251-266)

76-04 (PB251-683)

76-05 (PB253--108)

76-06 (PB253-918)

76-07 (PB262-123)

76-08 (PB254-078)

76-09 (PB252-488)

76-10 (PB253-260)

76-11 (PB253-115)

76-12 (PB254-996)

76-13 (PB253-475)

76-14 (PB253-476)

76-15 (PB253-477)

76-16 (PB256-129)

76-17 (PB254-233)

76-18 (PB256-642)

76-19 (PB256-643)

76-22 (PB257-884)

76-23 (PB258-991)

76-24 (PB258-093)

76-25 (PB264-386)

76-26 (PB259-998)

76-27 (PB260-523)

A03 77-36 (PB264-393)

$\mathrm{A} 05$ 77-37 (PB268-162)

A14 77-38 (PB272-700)

A11

A12

A17

A05

A03

A12

A06

A10

A07 77-39 (PB273-950)

A04 78-40 (PB285-288)

A15 78-41 (PB285-289)

A03 78-42 (PB285-290)

A09 78-43 (PB285-291)

A99 78-44 (PB285-292)

A03 78-45 (PB285-293)

A03 78-46 (PB285-294)

A03

A07

A09

A05

A05

A08

A10

A08

A03 78-47 (PB285-295)

A06 78-49 (PB290-164)

A06

A19 78-50 (PB289-886)

A03 78-51 (PB291-826)

A03 78-52 (PB291-827)

A03 78-53 (PB287-932)

A11 78-57 (PB292-851)

A10 78-58 (PB292-852)

A04

A05

A03

A07

A06

A02

A07

A03 78-58A (PB292-853)

A03 78-59 (PB292-770)

A20 78-60 (PB292-783)

A03 79-62 (PB300-835)

A11 79-63 (PB297-499)

A05 79-64 (PB298-446)

A03 79-65 (PB298-631)

A03 79-66 (PB299-006)

A08

A08

A04

A06

A08

A06

A09

A06

76-28 (PB264-387)

76-29 (PB264-388)

76-30 (PB264-389)

A08 79-67 (PB289-352)

A10 79-70 (PB300-770)

A06 79-71 (PB300-846)

A10

A06

A09 


\section{TITLES AND ABSTRACTS OF NBS PUBLICATIONS, $1979^{1}$}

\subsection{PAPERS FROM THE JOURNAL OF RESEARCH OF THE NATIONAL BUREAU OF STANDARDS, VOLUME 84, JANUARY-DECEMBER 1979}

\section{January-February 1979}

Diffusion coefficients of the $45 \mathrm{~S}$ and $50 \mathrm{~S}$ states of the large ribosomal subunit of $E$. coli by quasielastic light scattering, $C$. C. Han, I. N. Serdyuk, and H. Yu, J. Res. Nat. Bur. Stand. (U.S.), 84, No. 1, 1-8 (Jan.-Feb. 1979).

Key words: diffusion coefficient; $E$. coli ribosomal subunit; quasielastic light scattering; $45 \mathrm{~S}$ and $50 \mathrm{~S}$.

The transitional diffusion coefficients of the $45 \mathrm{~S}$ and $50 \mathrm{~S}$ states of the large ribosomal subunit of $E$. coli were determined from the spectral distributions of quasielastically scattered light with a $5 \mathrm{~mW}$ He-Ne laser as the source. The spectral analysis was performed by directly Fourier transforming the photocurrent and fitting to double-Lorentzian profile via a non-linear regression routine. A small amount (about $1 \%$ ) of strongly scattering contaminants required the double-Lorentzian profile in order to extract the diffusion coefficients of the principal components. The results are: $D_{20}{ }^{\circ}, w(45 S)=(1.79 \pm 0.12) \times 10^{-7}$ $\mathrm{cm}^{2} / \mathrm{sec}$, and $\mathrm{D}_{20^{\circ}}, \mathrm{w}(50 \mathrm{~S})=(1.91 \pm 0.06) \times 10^{-7} \mathrm{~cm}^{2} / \mathrm{sec}$, the latter being in accord with those reported in the literature. The transition from the $50 \mathrm{~S}$ state to the $45 \mathrm{~S}$ state is not attended by a change in its molecular weight if the partial specific volumes are assumed to be the same.

System for assessing eye injury potential of propelled objects, $R$.

E. Berger, J. Res. Nat. Bur. Stand. (U.S.), 84, No. 1, 9-19 (Jan.-Feb. 1979).

Key words: eye injury; impact; ocular contusion; projectiles; propelled objects; test methods; toy safety.

A test system is proposed to evaluate the ocular injury potential of propelled objects. The object in question is fired into a thin rubber pad, and the force of impact and the rise time are measured. For a set of test projectiles, the response of the system was shown to correlate with the likelihood of injury, as predicted by a mathematical model. The response was further related to ocular injury tolerance curves which were generated by the math model using data from impact injuries to real eyes.

Enhancing Fortran to aid manipulation of large structured matrices, H. J. Greenberg and J. E. Kalan, J. Res. Nat. Bur. Stand. (U.S.), 84, No. 1, 21-47 (Jan.-Feb. 1979).

Key words: data pooling; data structures; mathematical programming; matrices; name generation; operations research; programming languages; sparse matrices.

This paper presents, for wider discussion by the technical community, suggested means for enhancing (ANS) FORTRAN in order to accommodate the needs of operations research analysts in programming tasks involving large, structured or sparse matrices. Such needs frequently arise in connection with large-scale optimization problems. Most of the text deals with fundamental concepts and descriptions of syntax, but related data structures are also treated. Proposed new capabilities include exploitation of repeated values among matrix entries,

${ }^{1} T$ The various NBS publications series are grouped under subheadings within this section. If a particular publications series is sought, consult the table of contents or the edge index on the back cover space-saving "quasi-dynamic storage allocation," and easy setup for construction of large matrices from smaller ones (with the actual construction deferable until and if the need arises).

Cutting the d-cube, J. Lawrence, J. Res. Nat. Bur. Stand. (U.S.), 84, No. 1, 49-53 (Jan.-Feb. 1979).

Key words: cube; geometry; hyperplane.

Some problems concerned with cutting faces of the cube with affine or linear spaces are considered. It is shown that through any d-3 points of $R^{d}$ there passes a hyperplane which cuts all the facets of the d-cube. Furthermore, it is shown that if $m<d-1$ and $d^{\prime}<d-[(m+1) / 3]$, then no $m$-dimensional affine subspace of $R^{d}$ cut all the $d^{\prime}$-dimensional faces of the cube.

\section{March-A pril 1979}

A novel method for analyzing silver sediment with high precision, R. S. Davis and V. E. Bower, J. Res. Nat. Bur. Stand. (U.S.), 84, No. 2, 157-160 (Mar.-Apr. 1979).

Key words: controlled potential; coulometry; electrochemical equivalent of silver; electrochemistry; Faraday; potentiostat; silver; silver analysis.

A technique has been devised which is sufficiently accurate to aid in an electrochemical determination of the Faraday constant using the silver coulometer. The technique is used to recover the silver residue which falls from the anode during operation of the silver coulometer. In contrast to previous efforts at recovery, which involved weighing of the silver residue, the method here described is to convert the silver atoms to ions and then to plate the silver onto a cathode held at constant potential with respect to a reference electrode. The current involved in the electrolysis is integrated electronically. An overall standard deviation of $5 \mu \mathrm{g}$ is achieved for samples' ranging in size from $400 \mu \mathrm{g}$ to $1.8 \mathrm{mg}$.

Psychrometric wet elements as a basis for precise physico-chemical measurements, R. G. Wylie, J. Res. Nat. Bur. Stand. (U.S.), 84, No. 2, 161-177 (Mar.-Apr. 1979).

Key words: convective heat transfer; convective mass transfer; emissivity of water; evaporation coefficient; humidity measurement; monomolecular film; psychrometer; psychrometry; radiative heat transfer; temperature depression; water vapor measurement; wet bulb; wet element.

Under appropriate conditions, psychrometric wet elements of simple design can be highly reproducible in behavior. A temperature depression of $10 \mathrm{~K}$ can be reproducible from element to element within $2 \mathrm{mK}$. The properties of a wet element can be determined very accurately by direct comparisons with other wet elements in a common airstream. Comparisons with one specially developed type show the effects of practical waterretaining coverings. Comparisons with another type, which simulates the fully calculable flat-plate system, then give the behavior in absolute terms.

A cotton-yarn covering increases the psychrometer coefficient $A$ by only 0.2 percent. The departure of the flow around a cylinder from laminar boundary-layer flow increases it by 0.7 percent. 
The background and theory are outlined. The detailed behavior of a cotton-yarn covered cylinders is deduced from element comparisons; and their absolute value of $A$ obtained as a function of diameter, airspeed, and the temperature, pressure and water content of the airstream. The dependence of $A$ on these parameters is essentially simple. The work leads to a large increase in the accuracy of water vapor measurements and to new methods of measuring some other physico-chemical quantities.

Non-free groups generated by two parabolle matrices, R. J. Evans, J. Res. Nat. Bur. Stand. (U.S.), 84, No. 2, 179-180 (Mar.-Apr. 1979).

Key words: free groups; matrix groups; roots of unity.

In 1974, M. Newman conjectured that for any root of unity $\zeta$, the matrix group generated by $\left(\begin{array}{ll}1 & \zeta \\ 0 & 1\end{array}\right)$ and $\left(\begin{array}{ll}1 & 0 \\ \zeta & 1\end{array}\right)$ is non-free. This conjecture is proved here.

\section{May-June 1979}

Enthalples of solution of the nucleic acid bases. 5. Adenine in aqueous hydrochloric acid, aqueous sodium hydroxlde, methanol, and ethanol, M. V. Kilday, J. Res. Nat. Bur. Stand. (U.S.), 84, No. 3, 231-240 (May-June 1979).

Key words: adenine; enthalpy of dissociation; enthalpy of protonation; enthalpy of reaction; enthalpy of solution; nucleic acid bases; solution calorimetry; thermochemistry.

The two preceding papers in this series described the results of measurements of the enthalpies of solution in water for some of the bases of the nucleic acids. In this work the enthalpies of solution or reaction of adenine (Ade), $\mathrm{C}_{5} \mathrm{H}_{5} \mathrm{~N}_{5}$ or 6-amino purine, in other solvents are reported.

Sample preparation in ion-chromatography, W. F. Koch, J. Res. Nat. Bur. Stand. (U.S.), 84, No. 3, 241-246 (May-June 1979).

Key words: conductivity; ion-chromatography; ionexchange; liquid chromatography; oil; oyster.

lon-chromatography, a relatively new technique in analytical chemistry, has already shown great promise toward solving complex trace analysis problems, in particular the speciation and quantitation of anions. It is especially attractive to the field of microanalysis. The method of sample preparation, however, is crucial in order to realize this capacity. Existing microanalytical methods nearly always must be modified to be compatible with ion-chromatography, and often, more extensive sample cleanup is required than is needed for "single species" methods. These considerations have been applied to the determination of chloride and bromide in waste oil, and to the analysis of oyster tissue. Pretreatment with polystyrene resin and ion-exchange resin is discussed.

Miniaturization of normal-state and superconducting striplines, R. L. Kautz, J. Res. Nat. Bur. Stand. (U.S.), 84, No. 3, $247-$ 259 (May-June 1979).

Key words: copper; niobium; stripline; superconductivity; surface impedance.

The properties of normal-state and superconducting striplines are calculated as a function of miniaturization. For normal conductors the Reuter-Sondheimer theory is applied in order to account for the effects of finite film thickness and mean free path. For superconductors the Mattis-Bardeen theory is used in order to include effects due to the energy gap. Calculations for three example conductors, copper at $295 \mathrm{~K}$ and $4.2 \mathrm{~K}$ and niobium at $4.2 \mathrm{~K}$, examine the attenuation, dispersion, and characteristic impedance of striplines as a function of frequency and dielectric thickness. Simulations of pulse transmission are used to evaluate the utility of the example striplines for high-speed digital applications.

\section{July-August 1979}

Enthalpies of solution of $\mathrm{KBr}, \mathrm{KI}, \mathrm{KIO}_{3}$, and $\mathrm{KIO}_{4}$ in $\mathrm{H}_{2} \mathrm{O}, \mathrm{M}$. E. Efimov, G. N. Klevaichuk, V. A. Medvedev, and M. V. Kilday, J. Res. Nat. Bur. Stand. (U.S.), 84, No. 4, 273-286 (July-Aug. 1979).

Key words: endothermic solution reactions; enthalpy of solution; $\mathrm{KBr}, \mathrm{K} 1, \mathrm{KIO}_{3}, \mathrm{KIO}_{4}$; solution calorimetry; thermochemistry; tris(hyd roxymethyl)aminomethane.

Enthalpy of solution measurements of four potassium salts in $\mathrm{H}_{2} \mathrm{O}$ were made in either an adiabatic or an isoperibol calorimeter or both (see p. 273 for table summarizing the measured and recommended values).

The value for $\mathrm{KlO}_{4}$ has been corrected for the hydrolysis of the periodate ion. The $\Delta C_{p}=-(82.5 \pm 4.3) \mathrm{J} \cdot \mathrm{mol}^{-1} \cdot \mathrm{K}^{-1}$ for the unhydrolysed reaction. For the reaction of $\mathrm{KBr}$ in $\mathrm{H}_{2} \mathrm{O}, \Delta C_{p}$ was measured as $-(166.6 \pm 7.2) \mathrm{J} \cdot \mathrm{mol}^{-1} \cdot \mathrm{K}^{-1}$ in the temperature range $298 \mathrm{~K}$ to $319 \mathrm{~K}$.

Measurements with the isoperibol calorimeter are also reported for the endothermic reaction of tris(hydroxymethyl)aminomethane, SRM 724a, in aqueous $\mathrm{NaOH}\left(0.05 \mathrm{~mol} \cdot \mathrm{L}^{-1}\right)$.

Comparisons of measurements by different calorimeters on the same samples reveal unidentified calorimetric errors for endothermic reactions which are greater than the imprecision of the measurements.

A preliminary study of the fluid mechanics of liquid penetrant testing, S. Deutsch, J. Res. Nat. Bur. Stand. (U.S.), 84, No. 4, 287-292 (July-Aug. 1979).

Key words: defect geometry; fluid elasticity; liquid penetrant testing; Rideal-Washburn equation; surface tension.

Some aspects of the fluid mechanics of liquid penetrant testing are considered. Penetration is represented by surface tension driven flow into defects of small defect width to depth ratio. Defect width is chosen so that both gravitational and non-continuum effects may be ignored. Penetration time is found to follow a Rideal-W ashburn relation, in which:

$$
t \sim\left(I^{2} \mu\right) /(\gamma R \cos \theta)
$$

where $t$ is time, $l$ defect depth, $\mu$ the dynamic viscosity, $\gamma$ the surface tension, $R$ the defect width and $\theta$ the contact angle. The proportionality constant, however, is shown to be strongly dependent on defect geometry and penetrant application procedure. The effect of slight fluid elasticity is shown to be negligible.

Exact coefficients of the limit cycle in Van der Pol's equation, A. Deprit and D. S. Schmidt, J. Res. Nat. Bur. Stand. (U.S.), 84, No. 4, 293-297 (July-Aug. 1979).

Key words: algebra by computer; differential equations; mathematical software; non-linear oscillations.

A program generator to manipulate automatically Poisson series over the field of rational numbers is applied to develop the limit cycle of Van der Pol's equation in the powers of the small parameter. The results indicate that the recurrence relations in what Melvin calls the algorithm of the shifted phase are stable.

Tensile behavior of some mathematical models of paper networks, J. C. Smith, J. Res. Nat. Bur. Stand. (U.S.), 84, No. 4, 299-318 (July-Aug. 1979). 
Key words: mathematical modeling, network; network, tensile properties; paper, interfiber bonding; paper, low-density handsheets; paper, pulp characterization; paper, tensile testing.

The tensile behavior of a thin web-like paper network was simulated by two simple mathematical models. The mesh distortion, drop in tensile force and energy loss resulting from breakage of a network junction were calculated. These results were used to formulate two parameters for characterizing interfiber adhesion: a parameter averaging the network energy losses incurred in a series of bond breaks when the network is elongated and a parameter averaging the force drops. The effect of mesh size, local bond adhesive force, and size and shape of the specimen network were calculated. These results based on model studies were used to interpret behavior observed in an actual paper network.

A class of double integrals involving Gaussian and trigonometric factors, D. M. Fradkin, J. Res. Nat. Bur. Stand. (U.S.), 84, No. 4, 319-326 (July-Aug. 1979).

Key words: definite integrals; double integrals; error functions; Fourier transforms; radiation reaction.

The five parameter double integral $\int_{0} \infty d y \exp \left(-p^{2} y^{2}\right) \sin (\beta y$ $+\theta$ ) times $\int_{0}^{\nu} d x \exp \left(-x^{2}\right) \cos (\epsilon \beta x+\phi)$ is evaluated in terms of Fourier transforms of $\exp \left(-x^{2}\right) \operatorname{erfc}(\alpha x)$. Some new expressions for these transforms are obtained.

\section{September-October 1979}

A high precision load cell mass comparator, R. M. Schoonover, J. Res. Nat. Bur. Stand. (U.S.), 84, No. 5, 347-351 (Sept.Oct. 1979).

Key words: constant loading; force; high precision; highprecision weighing; load cell; mass; mass comparator; mass difference; strain-gage; substitution weighing; weighing; weights.

Described here is a simple mechanical method used to fabricate a high precision mass comparator using a bonded strain gage load cell. Results indicate that a standard deviation of less than $0.0003 \%$ is readily attainable, and the device works well for objects normally considered too unwieldy for large high-precision balances.

Molecular interpretations of modulus and swelling relations in natural rubber cross-linked by dicumyl peroxide, L. A. Wood, J. Res. Nat. Bur. Stand. (U.S.), 84, No. 5, 353-358 (Sept.Oct. 1979).

Key words: cross-linking of rubber; dicumyl peroxide; elasticity theory of rubber; modulus of rubber; MooneyRivlin constants; rubber elasticity theory; rubber, natural; swelling of rubber network.

A survey of published experimental work on the modulus of natural rubber cross-linked by dicumyl peroxide permits a comparison with the results and molecular interpretations obtained in recent NBS work [J. Res. NBS 76A, No. 1, 51 (1972), 77A, No. 1, 171 (1973) and 80A, No. 3, 451 (1976)]. Excellent agreement was found among values of the shear modulus $G$ at the same cross-linking when the cross-linking is calculated from the amount of decomposed dicumyl peroxide. The types of deformation included torsion as well as uniaxial extension and compression. $G$ increases linearly with cross-linking (except at the lowest degrees) with a slope from 5 to 15 percent greater than that predicted by the simple statistical theory. Data of Mullins demonstrated that at each degree of cross-linking the value of $G$ is intermediate between $2 C_{1}$ and $2\left(C_{1}+C_{2}\right)$ where
$C_{1}$ and $C_{2}$ are the Mooney-Rivlin constants. Measurements of equilibrium swelling at a given degree of cross-linking are in reasonable agreement with each other. However the entropy components of the modulus and the sub-chain density calculated from swelling measurements are appreciably greater than those calculated from cross-linking or from direet mechanical measurements. They increase linearly with cross-linking. It is concluded that the number of sub-chains effective in limiting swelling is greater than that effective in direct mechanical measurements.

Theory of flow-induced fibril formation in polymer solutions, $\mathbf{J}$. D. Hoffman, J. Res. Nat. Bur. Stand. (U.S.), 84, No. 5, 359 384 (Sept.-Oct. 1979).

Key words: core fibril; cumulative stress; flow-induced crystallization; nucleation theory; polyethylene; polymer fiber; shish; volume strain.

A treatment of the formation of a basic core fibril (shish) of the type that is generated by flow-induced crystallization of a polymer from solution is given that features the concept of cumulative strain. Multiple nucleation acts by flow-elongated molecules produce an empbryonic fibril that is a connected set of bundlelike nuclei. Surface stress resulting from repulsion of the quasi-random coil chains in the amorphous zone between the nuclei or crystallites builds up at the bundle ends as the nuclei mature, leading ultimately to a high end surface free energy, and to volume strain in the crystallites comprising the core fibril. The theory leads to a stable (or metastable) fibril diameter $a_{s}$ and mean characteristic length $l_{g}$ with a fixed axial ratio, and predicts why the diameter does not grow further even in a medium that is supersaturated with polymer. The predicted dependence of $a_{a}, l_{b}$, and the axial ratio, on undercooling is in approximate agreement with experiment. The lattice expansion in the crystal resulting from volume strain is also in fair accord with experiment. The effect of annealing, including the commonly encountered case where the volume strain relaxes to give normal lattice dimensions, but with a high end surface energy still remaining, is noted. The effect of volume strain and the distribution of core fibril lengths about $l$, on the melting behavior is calculated. The theory can reproduce crystallinity versus temperature data on polyethylene fibrils. This procedure yields an independent value of $l_{\mathrm{g}}$. The overall treatment implies that the core fibril is a set of concatenated and substantially extended-chain crystallites with bundlelike ends and a somewhat expanded lattice when unannealed and under tension, the molecular connections between the crystallites consisting of short amorphous ciliary bridges. It is suggested that prolonged annealing at high temperatures can remove a substantial number of the amorphous zones.

Observations of surface changes in platinum crucibles, C. P. Saylor, E. Wichers, and J. I. Hoffman, J. Res. Nat. Bur. Stand. (U.S.), 84, No. 5, 385-394 (Sept.-Oct. 1979).

Key words: contrast augmentation of reflecting surfaces; double-diaphragm; faces (crystal) on platinum crucibles; hematite forming on platinum; iron as alloy in platinum; platinum ware; surface of platinum influenced by method heating.

lon which has been in solid solution in a platinum crucible will cause iron determinations in analyses to become high. Likewise the iron, oxidizing to ferric oxide during ignition, segregates along the boundaries between platinum crystals. It causes embrittlement and eventual crumbling of the crucible.

During these studies it was observed that after heating in an electric muffle furnace the surface of a crucible was covered by tiny crystallographic faces. When, however, heating to the same temperature was-carried out in a gas flame the facets almost smoothed out of existence. 
lsolonic isotope exchange with hydroxylapatite and the dilution effect, D. N. Misra, J. Res. Nat. Bur. Stand. (U.S.), 84, No. 5, 395-406 (Sept.-Oct. 1979).

Key words: dilution effect, at same $\mathrm{pH}$ and concentration; hydration shell, role of; hydroxylapatite, at different $\mathrm{pHs}$; isotopic exchange, isoionic; recrystallization, role of; surface layer, role of.

Isoionic isotope exchange data of ${ }^{45} \mathrm{Ca}^{2+}$ and ${ }^{32} \mathrm{PO}_{4}{ }^{3-}$ in a saturated solution with hydroxylapatite at $25^{\circ} \mathrm{C}$, collected by Avnimelech, have been reinterpreted on the basis that the processes consisted of three pools: hydration shell, surface layer and "recrystallization of crystallites." These processes are regarded as strictly separable. This theoretically allows: (i) a quantitative evaluation of the constants involved in the processes; (ii) an estimation of the exchange capacities of hydration and surface layers (fast pools) which may be $\mathrm{pH}$-dependent; and (iii) a determination of the isoionic exchange rate constants. The constants are essentially the same for $\mathrm{Ca}^{2+}$ and $\mathrm{PO}_{4}{ }^{3-}$ at a given $\mathrm{pH}$ if the cross-sectional areas of the ions are taken as $23 \AA^{2}$ and $33 \AA^{2}$ respectively; they, perhaps, increase linearly with the hydrogen ion concentration of the solutions.

The effects of three consecutive abrupt dilutions of the radioactive ions without changing the concentrations (or $\mathrm{pH}$ ) of the nonradioactive components of the solution are predictable by a mathematical model based on the complete reversibility of the two fast pools and the kinetics of the irreversible third pool.

\section{November-December 1979}

Molecular dynamics study of liquid rubidium and the LennardJones fluid, R. D. Mountain and S. W. Haan, J. Res. Nat. Bur. Stand. (U.S.), 84, No. 6, 439-446 (Nov.-Dec. 1979).

Key words: intermediate scattering function; LennardJones liquid; liquid rubidium; molecular dynamics; radial distribution function; transverse current correlation function; velocity autocorrelation function

Molecular dynamics calculations were made for three thermodynamic states of a model of liquid rubidium and for two states of the Lennard-Jones fluid in order to investigate the influence of density, temperature and interatomic potential on the spectra of density fluctuations in these fluids. Here the results for the intermediate scattering function, the radial distribution function, the velocity autocorrelation function of the transverse momentum autocorrelation function are presented in tabular form. The procedures employed in this study are discussed and the major features of these functions are described.

Room temperature poling of poly(vinylidene fluoride) with deposited metal electrodes, J. M. Kenney and S. C. Roth, J. Res. Nat. Bur. Stand. (U.S.), 84, No. 6, 447-453 (Nov.-Dec 1979).

Key words: dielectric strength; electrets; piezoelectricity; polarization; poling procedures; polymers; poly(vinylidene fluoride); pyroelectricity; transducers.

High values of pyroelectric and piezolectric activity in fullyelectroded films of poly(vinylidene fluoride) were obtained by "conventional" (non-corona) poling at room temperature with sufficiently high fields. The avoidance of breakdown while obtaining high activity requires an understanding of the time dependence of both breakdown and activity. Time-to-breakdown as a function of field, and room-temperature pyroelectric activity (7-14 days after poling at $23.5^{\circ} \mathrm{C}$ ) as a function of poling time and field were obtained for $25-\mu \mathrm{m}$ biaxially stretched films with evaporated aluminum electrodes. The highest activities were obtained by poling at the highest fields and poling to breakdown. A pyroelectric activity of $36 \mu \mathrm{CK}^{-1} \mathrm{~m}^{-2}$ was measured two weeks after poling with a nominal field of 550 $\mathrm{MVm}^{-1}$ for a nominal poling time of $10 \mathrm{~s}$ (reduced by multiple brcakdown). The highest activity obtained with no apparent breakdown ( $31 \mu \mathrm{CK}^{-1} \mathrm{~m}^{-2}$ ) was measured a week after poling with a field of $400 \mathrm{MVm}^{-1}$ for $10 \mathrm{~s}$. These values are comparable with the highest that have been reported for this material using any poling temperature or using corona poling.

Generators for discrete polynomial $L_{1}$ approximation problems, P. Domich, J. Lawrence, and D. Shier, J. Res. Nat. Bur. Stand. (U.S.), 84, No. 6, 455-488 (Nov.-Dec. 1979).

Key words: algorithm testing; approximation; computational experiment; least absolute deviation; polynomial approximation; test problems.

Polynomial approximation problems represent a class of specially structured problems which are frequently encountered in empirical curve-fitting. Two generators for creating such problems have been developed, implemented and used in the testing of discrete $L_{1}$ approximation codes. Both generators permit automatic generation of problems with specified characteristics and (for one generator) having known, unique and controllable solutions

A graph coloring algorithm for large scheduling problems, F. T. Leighton, J. Res. Nat. Bur. Stand. (U.S.), 84, No. 6, 489-506 (Nov.-Dec. 1979).

Key words: algorithm; chromatic number; color function; graph; graph coloring; heuristic; interchange; random test graphs; scheduling; time complexity.

A new graph coloring algorithm is presented and compared to a wide variety of known algorithms. The algorithm is shown to exhibit $O\left(n^{2}\right)$ time behavior for most sparse graphs and thus is found to be particularly well suited for use with large-scale scheduling problems. In addition, a procedure for generating large random test graphs with known chromatic number is presented and is used to evaluate heuristically the capabilities of the algorithms discussed. 


\subsection{PAPERS FROM THE JOURNAL OF PHYSICAL AND CHEMICAL REFERENCE DATA, VOLUME 8, JANUARY-DECEMBER 1979}

This journal is published quarterly by the American Chemical Society and the American Institute of Physics for the National Bureau of Standards. The objective of the Journal is to provide critically evaluated physical and chemical property data, fully documented as to the original sources and the criteria used for evaluation. Critical reviews of measurement techniques, whose aim is to assess the accuracy of available data in a given technical area, are also included. The principal source for the Journal is the National Standard Reference Data System (NSRDS). The Journal is not intended as a publication outlet for original experimental measurements such as are normally reported in the primary research literature, nor for review articles of a descriptive or primarily theoretical nature.

\section{Volume 8, No. 1}

Energy levels of titanium, Ti I through $\mathrm{Ti} \times \mathrm{xx}$, $\mathrm{C}$. Corliss and J. Sugar, J. Phys. Chem. Ref. Data 8, No. 1, 1-62 (1979).

Key words: atomic energy levels; atomic spectra; titanium.

The energy levels of the titanium atom in all of its stages of ionization, as derived from the analyses of atomic spectra, have been critically compiled. In cases where only line classifications are reported in the literature, level values have been derived. Term designations, experimental $g$-values, and ionization energies are included. Calculated percentages of the two leading components of the eigenvectors of the levels are given.

The spectrum and energy levels of the neutral atom of boron (B 1), G. A. Odintzova and A. R. Striganov, J. Phys. Chem. Ref. Data 8, No. 1, 63-68 (1979).

Key words: atomic energy levels; atomic spectra; boron.

The published data on the spectrum of the neutral atom of boron are compiled and presented. In one table 164 lines in the range $36010-993 \AA$ are listed with their intensities and classifications. A second table gives 92 levels with the numerical values of the energy.

Relativistic atomic form factors and photon coherent scattering cross sections, J. H. Hubbell and 1. Qverb $\phi, J$. Phys. Chem. Ref. Data 8, No. 1, 69-106 (1979).

Key words: atomic form factor; coherent scattering; cross sections; gamma rays; photons; Rayleigh scattering; tabulations; $x$ rays.

Tabulations are presented of relativistic Hartree-Fock atomic form factors $F(x, Z)$, for values of $x(=\sin (\theta / 2) / \lambda$ from 0.01 to $10^{9} \AA^{-1}$, for all elements $Z=1$ to 100 . For $Z=1, F(x, Z)$ is given by the exact expression of Pirenne. For $Z=2$ to $98, x$ $=0.01$ to $2.0 \AA^{-1}$, the tabulated values are those of Cromer and Waber given in the International Tables for X-Ray Crystallog-' raphy (Vol. IV, 1974), based in part on the work of Doyle and Turner. For $Z=21$ to $92, x=2.2$ to $6.0 \AA^{-1}$, the present tables are based on the values of Doyle and Turner and additional values $(Z=44,60,68$, and 74$)$ as given by $\phi$ verb $\phi$. For $Z=$ 3 to $20, x=2.2$ to $45 \AA^{-1}$, and $Z=21$ to $92, x=6.2$ to $45 \AA^{-1}$ the tables are interpolated from values given for 36 elements by $\phi$ verb $\phi$, extended to $x=10^{9} \AA^{-1}$ using $\emptyset$ verb $\phi$ 's corrections to the Bethe-Levinger $K$-shell expression. The remainder of the table is filled in by interpolation and extrapolation, guided for high $x$-values by the Bethe-Levinger result. Tables of relativistic coherent (Rayleigh) scattering cross sections, obtained by numerical integration of the Thomson formula weighted by $F^{2}(x, Z)$, are presented for all elements $Z=1$ to 100 , for photon energies $100 \mathrm{eV}(\lambda=124 \AA=12.4 \mathrm{~nm})$ to $100 \mathrm{MeV}$ $(\lambda=0.000124 \AA=12.4 \mathrm{fm}$ ). Departures from the nonrelativistic coherent scattering cross sections tabulated in $J$. Phys. Chem. Ref. Data 4, 471 (1975) are less than $1 \%$ for $Z$ $\leqslant 20$. However for a high $Z$ element such as lead, for example, the relativistic coherent scattering cross section is systematically higher by less than $0.4 \%$ below $1 \mathrm{keV}$, by $8 \%$ at $100 \mathrm{keV}$ and by $13 \%$ above $1 \mathrm{MeV}$.

Microwave spectra of molecules of astrophysical interest. XIV. Vinyl cyanlde (Acrylonltrile), M. C. L. Gerry, K. Yamada, and G. Winnewisser, J. Phys. Chem. Ref. Data 8, No. 1, 107. 124 (1979).

Key words: interstellar molecules; microwave spectra; molecular parameters; radio astronomy; rotational transitions; vinyl cyanide.

The available data of the microwave spectrum of vinyl cyanide are critically reviewed and tabulated. Molecular data such as rotational constants, centrifugal distortion constants, hyperfine coupling constants, dipole moments, and structural parameters are tabulated. Rotational transitions from $400 \mathrm{MHz}$ to $200 \mathrm{GHz}$, which are likely to be of interest to radio astronomy, are calculated and tabulated along with their estimated 95\% confidence limits.

Molten salts: Volume 4, Part 4. Mixed halide melts, G. J. Janz, R. P. T. Tomkins, and C. B. Allen, J. Phys. Chem. Ref. Data 8, No. 1, 125-302 (1979).

Key words: bromides; chlorides; data compilation; density; electrical conductance; fluorides; halides; iodides; molten salt mixtures; standard reference data; surface tension; viscosity.

Data on the electrical conductance, density, viscosity, and surface tension of mixed halide melts have been systematically collected and evaluated. Results are given for eighty-five binary mixtures over a range of compositions and temperatures.

\section{Volume 8, No. 2}

Atomic radiative and radiotionless yields for $K$ and $L$ shells, $M$. O. Krause, J. Phys. Chem. Ref. Data 8, No. 2, 307-328 (1979).

Key words: atomic properties; Auger yield; Coster-Kronig yield; effective fluorescence yield; fluorescence yield; $K$ shell; $\boldsymbol{L}$ shell; non-radiative yield; partial level width; radiative yield.

The available body of information on (a) fluorescence, Auger, and Coster-Kronig yields, (b) radiative and radiationless transition rates, (c) level widths, (d) $x$-ray and Auger line widths, (e) $x$-ray and Auger spectra, and (f) Coster-Kronig energies has been used to generate an internally consistent set of values of atomic radiative and radiationless yields for the $K$ shell $(5 \leqslant Z \leqslant 110)$ and the $L$ subshells $(12 \leqslant Z \leqslant 110)$. Values of fluorescence yields $\omega_{k}, \omega_{1}, \omega_{2}, \omega_{3}$, Coster-Kronig yields $f_{1}$, $f_{1,2}, f_{1,3}, f_{1,3}, f_{2,3}$. Auger yields $a_{K}, a_{1}, a_{2}, a_{3}$, and effective fluorescence yields $v_{1}$ and $v_{2}$ are presented in tables and graphs. 
Estimatcs of uncertainties are given. Updated and expanded graphs of partial and total widths of $K, L_{1}, L_{2}$, and $L_{3}$ levels are presented as well as a referencc list of papers publishcd since about 1972

Natural widths of atomic $K$ and $L$ levels, $K \alpha$ x-ray lines and several $K L L$ Auger lines, M. O. Krausc and J. H. Oliver, J. Phys. Chem. Ref. Data 8, No. 2, 329-338 (1979).

Key words: Auger effect; Auger line width; $K$ shell; level width; linc width; $L$ shell; natural width; $x$-ray line width

Semi-empirical values of the natural widths of $K, L_{1}, L_{2}$ and $L_{3}$ levels, $K \alpha_{1}$ and $K \alpha_{2}$ x-ray lines, and $K L_{1} L_{1}, K L_{1} L_{2}$ and $K L_{2} L_{3}$ Auger lines for the elements $10 \leqslant Z \leqslant 110$ are presented in tables and graphs. Level width $\Gamma_{i}\left(i=K, L_{1}, L_{2}, L_{3}\right)$ is obtained from the relation $\Gamma_{i}=\Gamma_{k, 1} / \omega_{i}$, using the theorctical radiative rate $\Gamma_{H, t}$ from Scofield's relativistic, relaxed Hartree-Fock calculation and the fluorescence yield $\omega_{i}$ from Krause's evaluation. $\mathrm{X}$-ray and Auger line widths are calculated as the sums of pertinent level widths. This tabulation of natural level and line widths is internally consistent, and is compatible with all relevant experimental and theoretical information. Present semiempirical widths, especially those of $K \alpha_{1}$ and $K \alpha_{2}$ x-rays, are compared with measured widths. Uncertainties of semi-empirical values are estimated.

Electrical resistivity of alkali elements, T. C. Chi, J. Phys. Chem. Ref. Data 8, No. 2, 339-438 (1979).

Key words: alkali elements; cesium; electrical resistivity; francium; lithium; magnetic flux density dependence; potassium; pressure dependence; rubidium; sodium; temperature dependence.

This paper presents and discusses the available data and information on the electrical resistivity of alkali elements (lithium, sodium, potassium, rubidium, cesium, and francium) and contains recommended reference values (or provisional or typical values). The compiled data include all the experimental data available from the literature and cover the temperature dependence, pressure dependence, and magnetic fiux density dependence. The temperature range covered by the compiled data is from cryogenic temperatures to above the critical temperature of the elements. The recommended values are generated from critical evaluation, analysis, and synthesis of the available data and information and arc given for both the total electrical resistivity and the intrinsic electrical resistivity. For most of the elements, the recommended values cover the temperature range from $1 \mathrm{~K}$ to $2000 \mathrm{~K}$.

Electrical resistivity of alkaline earth elements, T. C. Chi, J. Phys. Chem. Ref. Data 8, No. 2, 439-498 (1979).

Key words: alkaline earth elements; barium; beryllium; calcium; electrical resistivity; magnesium; radium; strontium; temperature depcndence.

This paper prcsents and discusses the available data and information on the electrical resistivity of alkaline earth elements (beryllium, magnesium, calcium, strontium, barium, and radium) and contains recommended or provisional reference values. The compiled data include all the experimcntal data available from the literature. The temperature range covered by the compiled data is from cryogenic temperatures to above the melting temperature of the elernents. The recommended values are generated from critical evaluation, analysis, and synthesis of the available data and information and are given for both the total electrical resistivity and the intrinsic electrical resistivity. For most of the elements, the recommended values cover the temperature range from $1 \mathrm{~K}$ to $1000 \mathrm{~K}$.
Vapor pressures and boiling points of selected halomethanes, $A$ P. Kudchadker, S. A. Kudchadker, R. P. Shukla, and P. R. Patnaik, J. Phys. Chem. Ref. Data 8, No. 2, 499-518 (1979).

Key words: Antoine equation; enthalpy of vaporization; halomethanes; vapor pressure-boiling point data; Wagner equation.

This critical review is a study of the vapor pressure-boiling point data from the triple point to the critical point for $\mathrm{CH}_{4-a} \mathrm{X}_{a}(\mathrm{X}=\mathrm{Br}, 1)$ and $\mathrm{CH}_{4-\alpha+b+c+d}, \mathrm{~F}_{a} \mathrm{Cl}_{b} \mathrm{Br}_{c} \mathrm{l}_{d}$ halomethanes. The available data are carcfully analyzed and the "best" data selected. The sclection procedure is discussed. Uncertainties in the selected temperatures and pressures are reported. The selected data were fitted to the Antoine equation for data up to $1500 \mathrm{~mm} \mathrm{Hg}$ pressure and the Wagner equation for data up to the critical point. Antoine constants for nineteen compounds and the Wagner constants for five compounds are reported. The enthalpy of vaporization at $298.15 \mathrm{~K}$ and at the normal boiling point have been computed.

Ideal gas thermodynamic properties of selected bromoethanes and iodoethane, S. A. Kudchadker and A. P. Kudchadker, J. Phys. Chem. Ref. Data 8, No. 2, $519-526$ (1979).

Key words: bromoethanes; ideal gas thermodynamic properties; internal rotation; iodoethane; potential barrier heights; symmetric top; torsional frequencies.

The available molecular parameters, fundamental frequencies, potential barrier heights, torsional frequencies, and standard enthalpies of formation at $298.15 \mathrm{~K}$ for selected bromoethanes and iodoethane containing one symmetric-top group have been critically evaluated and recommended values sclected. The chemical thermodynamic properties in the ideal gas state at one atmosphere pressure using the rigid-rotor harmonic-oscillator approximation have been calculated for $\mathrm{CH}_{3} \mathrm{CH}_{2} \mathrm{Br}, \mathrm{CH}_{3} \mathrm{CHBr}_{2}, \mathrm{CH}_{3} \mathrm{CBr}_{3}, \mathrm{C}_{2} \mathrm{Br}_{6}$, and $\mathrm{CH}_{3} \mathrm{CH}_{2} \mathrm{l}$. The internal rotational contributions have been obtained from the partition function formed by the summation of internal rotation energy levels.

Thermodynamic properties of normal and deuterated naphthalenes, S. S. Chen, S. A. Kudchadker, and R. C. Wilhoit, J. Phys. Chem. Ref. Data 8, No. 2, 527-536 (1979).

Key words: enthalpy of formation; ideal gas thermodynamic properties; molecular structure; normal and deuterated naphthalenes; vibrational assignments.

Structural and spectroscopic data and the standard enthalpy of formation at $298.15 \mathrm{~K}$ for $\mathrm{C}_{10} \mathrm{H}_{8}, \alpha-\mathrm{C}_{10} \mathrm{H}_{4} \mathrm{D}_{4}, \beta-\mathrm{C}_{10} \mathrm{H}_{4} \mathrm{D}_{4}$ and $\mathrm{C}_{10} \mathrm{D}_{8}$ were reviewed. The selected values were utilized to calculate the ideal gas thermodynamic properties in the temperaturc range 0 to $1500 \mathrm{~K}$, using the rigid rotor and harmonic oscillator model. The comparison between the third law entropies and the spectroscopically calculated entropies of $\mathrm{C}_{10} \mathrm{H}_{8}$ was studied. The agreement is satisfactory within the experimental uncertainties.

Microwave spectra of molecules of astrophysical interest. XV. Propyne, A. Bauer, D. Boucher, J. Burie, J. Demaison, and A. Dubrulle, J. Phys. Chem. Ref. Data 8, No. 2, 537-558 (1979).

Key words: interstellar molecules; line strengths; microwave spectra; molecular constants; propyne; radio astronomy; rotational transitions.

The microwave spcctrum of propyne is critically reviewed for information applicable to radio-astronomy. Molecular data such as the derived rotational constants, centrifugal distortion parameters, hyperfine coupling constants, electric dipole mo- 
ment, and molecular structurc are tabulated. The observed rotational transitions are presented for the astronomically interesting isotopic forms and the lowest lying vibrational state of propync. Calculated rotational transitions are presented for the ground vibrational statc of ${ }^{12} \mathrm{CH}_{3}{ }^{12} \mathrm{C} \equiv{ }^{12} \mathrm{CH},{ }^{13} \mathrm{CH}_{3}{ }^{12} \mathrm{C} \equiv{ }^{12} \mathrm{CH}$, ${ }^{12} \mathrm{CH}_{3}{ }^{13} \mathrm{C} \equiv{ }^{12} \mathrm{CH}$ and ${ }^{12} \mathrm{CH}_{3}{ }^{12} \mathrm{C} \equiv{ }^{13} \mathrm{CH}$, and for the vibrationally excited state $\nu_{10}$ of ${ }^{12} \mathrm{CH}_{3}{ }^{12} \mathrm{C} \equiv{ }^{12} \mathrm{CH}$.

A correlation of the viscosity and thermal conductivity data of gaseous and liquid propane, P. M. Holland and H. J. M. Hanley, J. Phys. Chem. Ref. Dara 8, No. 2, 559-576 (1979).

Key words: correlated data; critical point enhancement; data evaluation; propane; thermal conductivity; viscosity.

Data for the viscosity and thcrmal conductivity of gaseous and liquid propane have been evaluated and represented by empirical functions developed in previous work. Tables of values are presented for the range $140-500 \mathrm{~K}$ for pressures to $50 \mathrm{MPa}(\approx 500 \mathrm{~atm})$. The viscosities are estimated to have uncertainties of about $\pm 5 \%$, with corresponding uncertainties of the thermal conductivities of about $\pm 8 \%$. It is stressed that the data base should be improved. As in our work with other fluids, the anomalous contribution to the thermal conductivity in the vicinity of the critical point is included.

\section{Volume 8 , No. 3}

Microwave spectra of molecules of astrophysical interest. XVI. Methyl formate, A. Bauder, J. Phys. Chem. Ref. Data 8, No. 3, 583-618 (1979).

Key words: internal rotation; interstellar molecules; line strengths; methyl formate; microwave spectrum; radio astronomy; rotational transitions.

The microwave spectrum of methyl formate is critically reviewed for information applicable to radio astronomy. The review is based on new laboratory measurements in the frequency range from $8 \mathrm{GHz}$ to $58 \mathrm{GHz}$. Molecular data such as the derived rotational constants, centrifugal distortion parameters, internal rotation parameters, electric dipole moment and molecular structure are tabulated. Since the primary objective is to provide microwave spectral transitions applicable to radio astronomy observations, the review encompasses only the ground state rotational spectrum of the most abundant isotopic form of methyl formate, $\mathrm{H}^{12} \mathrm{C}^{16} \mathrm{O}_{2}{ }^{12} \mathrm{CH}_{3}$. While all measured transitions are included, the predicted transitions were limited to $J \leqslant 12$ in the range of $900 \mathrm{MHz}$ to $250 \mathrm{GHz}$.

Molecular structures of gas-phase polyatomic molecules determined by spectroscopic methods, M. D. Harmony, V. W. Laurie, R. L. Kuczkowski, R. H. Schwendeman, D. A. Ramsay, F. J. Lovas, W. J. Lafferty, and A. G. Maki, J. Phys. Chem. Ref. Data 8, No. 3, 619-722 (1979).

Key words: bond angles; bond distances; gas-phase polyatomic molecules; gas-phase spectroscopy; microwave spectroscopy; molecular conformation; molecular spectroscopy; molecular structure; molecules; structure.

Spectroscopic data related to the structures of polyatomic molecules in the gas phase have been reviewed, critically evaluatcd, and compiled. All reported bond distances and angles have been classified as equilibrium $\left(r_{e}\right)$, average $\left(r_{z}\right)$, substitution $\left(r_{s}\right)$, or effectivc $\left(r_{o}\right)$ parameters, and have been given a quality rating which is a measure of the parameter uncertainty. The surveyed literature includes work from all of the areas of gas-phase spectroscopy from which precise quantitative structural information can be derived. Introductory material includes definitions of the various types of parameters and a description of the evaluation procedure
Critically evaluated rate constants for gaseous reactions of several electronically excited species, K. Schofield, J. Phys. Chem. Ref. Data 8, No. 3, 723-798 (1979).

Key words: activation energies; electronically excited states; evaluation; gaseous interactions; molecular correlations; quenching; radiative lifetimes; rate constants; reactive channels; recommended data; rclaxation processes; review.

An extensive evaluation is presented of the available gas phase chemical kinetic rate constants for the interactions of the low lying electronic states of several atoms and molecules with numerous collision partners. These include the following excited states: $C\left(2^{1} D_{2}, 2^{1} S_{0}\right), \quad N\left(2^{2} D_{3 / 2,5 / 2}, 2^{2} P_{1 / 2,3 / 2}\right), \quad P\left(3^{2} D_{3 / 2}\right.$. $\left.{ }_{5 / 2}, 3^{2} \mathrm{P}_{1 / 2,3 / 2}\right), \mathrm{S}\left(3^{1} \mathrm{D}_{2}, 3^{1} \mathrm{~S}_{0}\right), \quad \mathrm{Se}\left(4^{3} \mathrm{P}_{0}, 4^{1} \mathrm{D}_{2}, 4^{1} \mathrm{~S}_{0}\right), \quad \mathrm{Te}\left(5^{3} \mathrm{P}_{1,0,} 5^{1} \mathrm{D}_{2}\right.$,

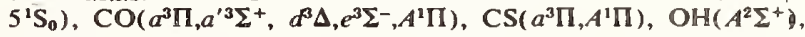
$\mathrm{OD}\left(A^{2} \Sigma^{+}\right), \quad \mathrm{O}_{2}\left(c^{1} \Sigma_{u}^{-}, C^{3} \Delta_{u}, A^{3} \Sigma_{u}{ }^{+}, B^{3} \Sigma_{u}^{-}\right), \quad$ and $\mathrm{S}_{2}\left(a^{1} \Delta_{g}, b^{1} \Sigma_{g}{ }^{+}, A\right.$ $\left.{ }^{3} \Sigma_{u}{ }^{+}, B^{3} \Sigma_{u}{ }^{-}\right)$. Wherever possible, recommended values are suggested. Much of the data refers only to room temperature. To facilitate the evaluation, collision-free radiative lifetimes often have been required. These also have been evaluated and are presented. The mechanisms of the interactions and the various potential kinetic channels are discussed. These include such processes as chemical reactions, electronic quenching to the ground electronic state, electronic cross relaxation to an adjacent excited state, and for molecules, vibrational and rotational relaxation processes within the excited state. A complete coverage of the literature published prior to 1978 has been attempted.

A review, evaluation, and correlation of the phase equilibria, heat of mixing, and change in volume on mixing for liquid mixtures of methane + ethane, M. J. Hiza, R. C. Miller, and A. J. Kidnay, J. Phys. Chem. Ref. Data 8, No. 3, 799-816 (1979).

Key words: binary mixtures; data correlation; excess volumes; heat of mixing; liquid-vapor equilibria; methane + ethane.

The available experimental data for liquid equilibria, heat of mixing, and change in volume on mixing for the methane + ethane system have been reviewed and where possible evaluated for consistency. The derived properties chosen for analysis and correlation were liquid mixture excess Gibbs energies, Henry's constants, and $\mathrm{K}$ values. Data sets, selected on the basis of the consistency tests applied, we re correlated as functions of temperature and composition to provide internally consistent sets of property values suitable for engineering design calculations.

Energy levels of aluminum, Al i through Al xIII, W. C. Martin and R. Zalubas, J. Phys. Chem. Ref. Data 8, No. 3, 817-864 (1979).

Key words: aluminum; atomic energy levels; atomic spectra; electron configurations; ionization potentials.

Energy level data are given for the atom and all positive ions of aluminum $(Z=13)$. These data have been critically compiled, mainly from published material on measurements and analyses of the optical spectra. We have derived or recalculated the levels for a number of the ions. In addition to the level value in $\mathrm{cm}^{-1}$ and the parity, the $J$ value and the configuration and term assignments are listed if known. Leading percentages from the calculated eigenvectors are tabulated wherever available. Ionization energies are given for all spectra.

Energy levels of calcium, $\mathrm{Ca}$ I through $\mathrm{Ca} \mathbf{x x}, \mathrm{J}$. Sugar and $\mathrm{C}$. Corliss, J. Phys. Chem. Ref. Data 8, No. 3, 865-916 (1979).

Key words: atomic energy levels; atomic spectra; calcium energy levels. 
The energy levels of the calcium atom in all of its stages of ionization, as dcrived from the analyses of atomic spectra, have bcen critically compiled. In cases where only line classifications are reported in the literature, level values have been derived. Electron configurations, term designations, J-values, experimental $g$-values, and ionization energies are included. Calculated percentages of the two leading components of the eigenvectors of the levels are given.

Simplification of thermodynamic calculations through dimensionless entropies, K. S. Pitzer and L. Brewer, J. Phys. Chem. Ref. Data 8, No. 3, $917-920$ (1979).

Key words: dimensionless entropies; thermodynamic functions.

The advantages of using thermodynamic quantities divided by the gas constant $(H / R, G / R$, etc.) in calculations are described. It is recommended that thermodynamic tables be presented in this form, so that the entries are either dimensionless or in units of kelvins.

\section{Volume 8 , No. 4}

Evaluated activity and osmotic coefficients for aqueous solutions: Iron chloride and the bi-univalent compounds of nickel and cobalt, R. N. Goldberg, R. L. Nuttall, and B. R. Staples, J. Phys. Chem. Ref. Data 8, No. 4, 923-1004 (1979).

Key words: activity coefficient; cobalt; critical evaluation; electrolyte; excess Gibbs energy; iron; nickel; osmotic coefficients; solutions; thermodynamic properties.

A critical evaluation of the mean activity and osmotic coefficients in aqueous solutions of iron chloride, nickel chloride, perchlorate, and nitrate and twenty-nine bi-univalent compounds of cobalt at $298.15 \mathrm{~K}$ is presented. Osmotic coefficients were calculated from direct vapor pressure measurements, from isopiestic measurements, from freezing point depression measurements, and from vapor pressure osmometry measurements. Given are empirical coefficients for three different correlating equations, obtained by a weighted least squares fit of the experimental data, and tables consisting of the activity coefficients of the compounds, the osmotic coefficients and activity of water, and the excess Gibbs energy of the solution as functions of the molality for each electrolyte system. The literature coverage is through the computerized version of Chemical $\mathrm{Ab}$ stracts of April 1979.

Evaluated activity and osmotic coefficients for aqueous solutions: Bi-univalent compounds of lead, copper, manganese, and uranium, R. N. Goldberg, J. Phys. Chem. Ref. Data 8, No. 4, 1005-1050 (1979).

Key words: activity coefficient; copper; critical evaluation; electrolyte; excess Gibbs energy; lead; manganese; osmotic coefficients; solutions; thermodynamic properties; uranium.

A critical evaluation of the mean activity and osmotic coefficients in aqueous solutions of twelve bi-univalent compounds of lead, copper, manganese and uranium at $298.15 \mathrm{~K}$ is presented. Osmotic coefficients were calculated from direct vapor pressure measurements, from isopiestic measurements and from freezing point depression measurements. Activity coefficients were calculated from electromotive force measurements on galvanic cells without transference. Given are empirical coefficients for three different correlating equations, obtained by a weighted least squares fit of the experimental data, and tables consisting of the activity coefficients of the compounds, the osmotic coefficients and activity of water, and the excess Gibbs energy of the solution as functions of the molality for each electrolyte system. The literature coverage is through the computerized version of Chemical Abstracts of April 1979.
Microwave spectra of molecules of astrophysical interest. XV Dimethyl ether, F. J. Lovas, H. Lutz, and H. Dreizler, J. Ph. Chem. Ref. Data 8, No. 4, $1051-1108$ (1979).

Key words: dimethyl ether; internal rotation; interstel molecules; microwave spectrum; radio astronomy; ro tional transitions.

The microwave spectrum of dimethyl et (methoxymethane) is critically reviewed and supplemen through calculations which include the contributions of inter rotation and centrifugal distortion in the molecular Hamilt an. The primary objective of this review is to pror microwave spectral transitions applicable to molecular radio tronomy for the ground vibrational state rotational spectrun the most abundant isotopic form of dimethyl ether, ${ }^{12} \mathrm{CH}_{3}$ ${ }^{12} \mathrm{CH}_{3}$. While all measured rotational transitions are incluc the predicted transition frequencies were limited to $\mathbf{J} \leqslant \mathbf{I}$ : the range $1 \mathrm{GHz}$ to $300 \mathrm{GHz}$. In order to provide a comp summary of the laboratory studies on dimethyl ether, the rI tional constants of the less abundant isotopic species excited torsional siates are also tabulated and all reported $\mathrm{r}$ tional studies are referenced.

Energy levels of potassium, $\mathbf{K}$, through $\mathbf{K}$ xIX, $C$. Corliss : J. Sugar, J. Phys. Chem. Ref. Data 8, No. 4, $1109-1$ (1979).

Key words: atomic energy levels; atomic spectra; potassi energy levels.

Data on the energy levels of the potassium atom in all of stages of ionization, as derived from the analyses of atol spectra, have been critically compiled. In cases where only 1 classifications are reported in the literature, level values $h$ : been derived. Electron configurations, term designations, values, experimental $g$-values, and ionization energies are cluded.

Electrical resistivity of copper, gold, palladium, and silver, $\mathbf{R}$. Matula, J. Phys. Chem. Ref. Dala 8, No. 4, 1147-12 (1979).

Key words: copper; critical evaluation; data analysis; di compilation; data evaluation; data extraction; data synth is; electrical resistivity; elements; gold; metals; molı metals; palladium; precious metals; reference data; silv solid statc physics; transport properties.

In this work, recommended values for the electrical resistiv as a function of temperature from the cryogenic region to $\mathrm{w}$ beyond the melting point are given for bulk pure copper, go palladium, and silver. In addition to the total electrical resisti ty values for the solid state, intrinsic electrical resistivity valt are presented from cryogenic temperatures to the melti point. The values are corrected for the change in geometry $d$ to thermal expansion. Thc recommendations are based theoretical considerations and on the experimental data fou in the open literature. That available experimental di together with information pertaining to the specimen char: terization and measurement conditions are included in $t$ work. The methods of data evaluation and other consideratic used in arriving at the recommendations are described. For 1 solid state, an interpolation scheme is given to aid in the det mination of values between those supplied in the tables; for liquid state, equations are given. 


\subsection{DIMENSIONS/NBS, ARTICLE TITLES ONLY}

This monthly magazine is published to inform scientists, engineers, businessmen, industry, teachers, students, and consumers of the latest advances in science and technology, with primary emphasis on the work at NBS.

DIMENSIONS/NBS highlights and reviews such issues as energy research, fire protection, building technology, metric conversion, pollution abatement, health and safety, and consumer product performance. In addition, DIMENSIONS/NBS reports the results of Bureau programs in measurement standards and techniques, properties of matter and materials, engineering standards and services, instrumentation, and automatic data processing.

\section{January-February 1979}

DIM/NBS 63, No. 1/2, 1-28 (1979).

Key words: analytical chemistry; ion-chromatography; law enforcement standards; materials properties; measurement science; science students; SRM; titanium alloy.

Good as Gold?, S. Washburn

Frontiers of Measurement Science, M. Baum

Getting Federal Research to the Grass Roots, G. Lindsteadt

Seeing the Human Side of Science, S. Liberman

Government and Industry Officials Discuss EMI Problems, F. McGehan

New Method for Assessing Building Code Benefits and Costs, M. Heyman

Predicting Materials Properties of Polymers, C. Hans

Tungsten Concentrate Standard Reference Material

New Analytical Chemistry Technique Being Used at NBS: IonChromatography, w. Koch

Conferences

Publications

News Briefs

\section{March 1979}

DIM/NBS 63, No. 3, 1-28 (1979).

Key words: appropriations; fusion diagnostics; gravity waves; laser-interferometer; microwave measurements; non-destructive evaluation; pipe welds; standard; $x$-ray image.

Microwave Measurements on Snowpacks, F. McGehan

NBS Budget Request, S. Washburn

Casting Light on Nature's Ways, F. McGehan

Measurement Services for Ultrasonic Non-Destructive Evaluation, D. Eitzen

National Load Standard Being Revised, M. Heyman

X-Ray Image Magnification Technique Developed, M. Kuriyama

Evaluating Pipeline Welds, L. Mordfin

Fusion Diagnostics: Spectrum of Molybdenum lon Determined, J. Reader

Conferences

Publications

News Briefs

\section{April 1979}

DIM/NBS 63, No. 4, 1-24 (1979).
Key words: computer interface standards; computers; cryogenic temperature; energy; energy savings; industrial robots; network services; SRM's.

Giving a Robot the Eye, M. Baum

Arabian Days and Nights at NBS, M. Heyman

Summer Energy-Saving Tips, M. Heyman

Government Adopts Three Computer Interface Standards, S. Lichtenstein

Cryogenic Temperature Reference Device, $\mathbf{R}$. Soulen

A Methodology for Selecting Interactive Computer Services, $\mathbf{S}$. Mamrak

River Sediment and Urban Particulate SRM's

Conferences

Publications

News Briefs

May 1979

DIM/NBS 63, No. 5, 1-28 (1979).

Key words: aluminum SRM's; computer systems;'electron microscopy; group decisions; properties of steam; space; stirling refrigerators.

Impossibility of Group Decisions, C. Johnson

Space Behaves as Einstein Expected, D. Orr

Colder Than Cold, K. Armstrong

Small Computer Systems Excluded from Interface Standards, S.

Lichtenstein

A Powerhouse at NBS: Properties of Steam, A. L. Sengers

Standard Reference Material for Scanning Electron Microscopy Reissued, D. Ballard

Two Aluminum SRM's Available

Conferences

Publications

News Briefs

\section{June 1979}

DIM/NBS 63, No. 6, 1-32 (June 1979).

Key words: building rehabilitation; energy measurements; energy-related inventions; environment; precision power; radioactivity; Raman microprobe; solar energy; toxic substances.

Cities in Renaissance, G. Lupton

Keeping Tabs on Toxicity, M. Heyman

WANTED: Better Energy Ideas, S. Lieberman

NBS Publishes Updated Survey of State Solar Energy Legislation, M. Heyman

Characterizing South Pole Aerosols with the Raman Microprobe, W. C. Cunningham and $W$. Zoller

Units of Measurement for Radioactivity, L. Barbrow

Precision Power and Energy Measurements, F. L. Hermach

Conferences

Publications

News Briefs

July/August 1979 
Key words: computer network; computer standards; fire safety; gamma-ray spectroscopy; matrix-isolation; metric conversion; satellite system.

Common Sense Approach to Metric Conversion, J. Odom

Fire Safety for Health Care Facilities, M. Heyman

Einstein's Theories and a New Satellite System, C. Smith

NBS Seeks Proposals for Computer Standards Development and for Systems Security Program, S. Lichtenstein

New Computer Network for NBS, R. J. Carpenter, J. Sokol, Jr., and J. E. Malcolm

Scientific Tools for the Art World: Autoradiography and Ganma-Ray Spectroscopy, D. Garrett

Matrix-Isolation Raman Spectroscopy, D. S. King and J. C. Stephenson

Conferences

Publications

News Briefs

\section{September 1979}

DIM/NBS 63, No. 9, I-32 (1979).

Key words: calibrations; energy; fluid mixtures; light; liquefied natural gas; measurements; microwaves; super spring, ultraviolet radiation.

Happy Anniversary, NBS/Boulder

Radar to the Rescue, F. P. McGehan

Accurate Measurement of Ultraviolet Radiation, J. L. Linsky

Liquefied Natural Gas: An Energy Alternative, G. Porter and K. Higgins

Assessing LNG Tank Volume Calibrations, K. Higgins and $\mathbf{M}$. Baum

First Direct Frequency Measurement of Visible Light Reported, K. M. Evenson, D. A. Jennings and F. R. Petersen

Generic Technique for Accurately Predicting the Thermophysical Properties of Fluid Mixtures, N. Olien

Super Spring, J. E. Faller and R. L. Rinker

Conferences

Publications

News Briefs

\section{October 1979}

DIM/NBS 63, No. 10, I-36 (1979).

Key words: cardiac pacemakers; computer standards; fire safety; molybdenum; network measurement; semiconductors; SRM's; standards.

Fighting Fire with Fire Research, M. Heyman

The New, Improved Computer Standards Program, S. Radack

A Little Less Witchery, a Little More Craft, M. Baum

Science on Safety's Side, S. Lieberman

Neutron Radiography of Cardiac Pacemaker Batteries, D. Garrett

The Network Measurement Instrument, M. D. Abrams

Molybdenum Temperature Standard Reference Material

Two Total Protein Standards Available

Conferences

Publications

News Briefs

\section{November 1979}

DIM/NBS 63, No. 11, 1-36 (1979).

Key words: Alaskan pipeline; computers; corrosion; fire safety; gyromagnetic ratio; paper; photometric calibrator; safety tips; solar energy; toxic chemicals; ultra-black coating.
Meeting Mother Nature on Her Own Turf, G. Porter

The Precisely Precessing Proton, M. Baum

Fire Safety Tips for Wood-Burning Appliances, S. Liberman

Tenth Anniversary of NBS-TAPPI Collaborative Reference Paper Program, Dr. Lashof

NBS Announces Four Computer Interface Standards, S. Radack

New Photometric Calibrator Performs Direct Measurement, D. Swyt

Girth Weld Standards for Alaskan Natural Gas Pipeline, $\mathbb{R}$. Reed

"Ultra-Black" Coating for High Absorptance of Solar Energy, C. Johnson

Conferences

Publications

News Briefs

\section{December 1979}

DIM/NBS 63, No. 12, 1-32 (1979).

Key words: chemical degradation; coal conversion; coal gasifier; computers; data; metric; refractory concrete; resource conservation and recovery.

Protecting Citizens' Rights, S. Radack

Once Is Not Enough, G. Porter

Guidelines for the Use of Modernized Metric System

Refractory Concrete Strength Measured Under Simulated Usage, E. Fuller

Chemical Degradation of Refractory Liners in Coal Gasifier Systems, F. Mauer

Data Centers Established to Aid Coal Conversion Industry, R. Dobbyn

Conferences

Publications

Index

News Briefs 


\subsection{MONOGRAPHS}

Major contributions to the technical literature on various subjects related to the Bureau's scientific and technical activities.

Monogr. 25, Section 16. Standard x-ray diffraction powder patterns. Section 16-Data for 86 substances, M. C. Morris, $H$. F. McMurdie, E. H. Evans, B. Paretzkin, J. H. de Groot, C. R. Hubbard, and S. J. Carmel, Nat. Bur. Stand. (U.S.), Monogr. 25, Sec. 16, 190 pages (Oct. 1979) SN003-003$02128-8$.

Key words: crystal structure; integrated intensities; lattice constants; peak intensities; powder patterns; reference intensities; standard; $x$-ray diffraction.

Standard x-ray diffraction patterns are presented for 87 substances. Fifty-nine of these patterns represent experimental data and 28 are calculated. The experimental $x$-ray powder diffraction patterns were obtained with an x-ray diffractometer. All d-values were assigned Miller indices determined by comparison with computed interplanar spacings consistent with space group extinctions. The densities and lattice constants were calculated and the refractive indices were measured whenever possible. The calculated $x$-ray powder diffraction patterns were computed from published crystal structure data Both peak height and integrated intensities are reported for the calculated patterns.

Monogr. 163. Measurement assurance for gage blocks, C. Croarkin, J. Beers, and C. Tucker, Nat. Bur. Stand. (U.S.), Monogr. 163, 78 pages (Feb. 1979) SN003-003-02023-1.

Key words: calibration; gage blocks; length; measurement assurance; measurement process control; systematic error; uncertainty.

This monograph is intended for those who need to know on a continuing basis the uncertainty of their gage block calibration procedure. A general discussion of the philosophy of measurement assurance is given first. Then three levels of measurement assurance programs are outlined showing how control over the measurement process can be maintained and how the offset (or systematic error) from the unit of length maintained by the National Bureau of Standards can be made negligible.

Monogr. 164. Electromagnetic boundary-value problems based upon a modification of residue calculus and function theoretic techniques, J. P. Montgomery and D. C. Chang, Nat. Bur. Stand. (U.S.), Monogr. 164, 183 pages (June 1979) SN003003-02075-3.

Key words: closed systems; electromagnetic problems; functional theoretic techniques; modified residue calculus; open systems; remote sensing.

The solution of a number of electromagnetic problems, in both closed and open systems, using the modified residue calculus and functional theoretic techniques is presented.

The solutions start with known closed region problems and then are extended to new closed region problems and finally to several open region problems.

Specific problems considered for the closed region are: 1) the trifurcated waveguide; 2) the dielectrically loaded trifurcated waveguide; 3 ) the $\mathrm{N}$-furcated waveguide; 4 ) the dielectrically loaded $\mathrm{N}$-furcated waveguide; 5) determination of the Eigenvalues of ridged waveguide; and 6 ) scattering by a dielectric stop.
Open region problems considered are: 1) a parallel plate radiating into a homogeneous half-space; 2) a finite phased array; 3) remote sensing of the earth using parallel plate waveguides; 4) a flanged wave-guide radiating into a half-space; 5) scattering by a thick semi-infinite plane; and 6) radiation from a slot in a waveguide wall.

Some suggested extension of the techniques to other types of problems is also included.

Monogr. 165. An institutional plan for developing national standards with special reference to environment, safety, and health, B. W. Steiner, Nat. Bur. Stand. (U.S.), Monogr. 165, 24 pages (Sept. 1979) SN003-003-02094-0.

Key words: energy standards; environmental standards; safety and health standards; standards development.

This plan was commissioned to provide a framework for the development of all essential non-nuclear energy-related, environmental, safety, and health (ES\&H) standards for the private sector to coincide with the commercialization of new energy technologies. The development of such standards in the United States is a subset of the development of technological standards. Such standards consist of two basic types: "limit standards," which establish system performance criteria and "compliance measurement standards," which establish methods for the demonstration of compliance with "limit standards." The system addressed in this report encompasses four basic elements: (1) Hazards, (2) Limit Standards, (3) Evidence of Compliance, and (4) Compliance Measurement Standards. The unabridged version of the standards development process contains 39 discrete steps, each of which consists of intermediate stages. These are described here in the context of ten essential standards management functions. Some essential components in a comprehensive system, such as the voluntary standards bodies, already exist. However, to carry out many of the other functions effectively, new organizations would be required. The operation of the entire process is described in terms of a hypothetical example. 


\subsection{HANDBOOKS}

Rccommended codes of engineering and industrial practice (including safety codes) developed in cooperation with interested industries, professional organizations, and regulatory bodies.

H44, 1979 Edition. Specifications, tolerances, and other kechnical requirements for weighing and measuring devices, $H$. F. Wollin, Ed., Nat. Bur. Stand. (U.S.), Handb. 44, 1979 Edition, 213 pages (Dec. 1979) SN003-003-02143-1.

Key words: length-measuring devices; liquid-measuring devices; measures; scales; specifications; taximeters; tolerances; volume-measuring devices; weighing devices; weights.

This Handbook supersedes National Bureau of Standards Handbook 44, Fourth Edition, published in 1971 and includes amendments to the Handbook through 1978 that were subsequently published in the form of replacement sheets. It also includes the amendments that were adopted by the 64th $\mathrm{Na}$ tional Conference on Weights during its annual meeting on July 22-27, 1979, in Portland, Oregon. This edition was developed by the Committee on Specifications and Tolerances of the $\mathrm{Na}$ tional Conferenee on Weights and Measures, with the assistance of the Office of Weights and Measures of the National Bureau of Standards.

The National Bureau of Standards has a statutory responsibility for "cooperation with the states in securing uniformity of weights and measures laws and methods of inspection." This Handbook is published in partial fulfillment of that responsibility.

HI05-3. Specifications and tolerances for reference standards and field standard weights and raeasures. 3. Specifications and tolerances for graduated neck type volumetric field standards, B. C. Keysar, Nat. Bur. Stand. (U.S.), Handb. 105-3 Revised, 23 pages (Mar. 1979) SN003-003-02044-3.

Key words: bottom loading; field standard provers; field standards; field standard test measures; provers; specifications; standards; test measures; tolerances; vapor recovery.

These specifications and tolerances are recommended as minimum requirements for standards used in the field by State and local weights and measures officials and others in quantity determinations of liquid commodities.

H 107, Revised. American National Standard N43.1; Radiological safety in the design and operation of particle accelerators. (ANSI N43.1-1978), E. H. Eisenhower, Chairman, ANSI Subcommittee N43, Nat. Bur. Stand. (U.S.), Handb. 107 Revised, 24 pages (May 1979) SN003-003-02064-8.

Key words: accelerator design; accelerator operation; health physics; particle accelerators; radiation measurements; radiation protection; standard.

This American National Standard provides the basic considerations essential to the safe operation of a particle accelerator. It applies principally to particle accelerators with primary energies less than $100 \mathrm{MeV}$. It considers the characteristics of and controls for radiations as they affect accelerator design, operating procedures, and exposure evaluation. The section on radiation protection design criteria includes radiation shielding considerations and the use of safety systems. Operational health physics requirements are treated extensively, and radiation measurements are discussed in terms of the types of radiation that may be produced and proper techniques for monitoring. The final section, on dose assessment, includes basic exposure considerations such as maximum permissible dose and dose equivalent.

H128. Vibration isolation: Use and characterization, J. C. Snowdon, Nat. Bur. Stand. (U.S.), Handb. 128, 129 pages (May 1979) SN003-003-02065-6.

Key words: antivibration mounting; damping; dynamic properties; industrial engineering; isolation; machinery and equipment; mechanical impedance; mechanical vibrations; noise control; transmissibility; vibration isolation; vibrations.

The results of a search and critical evaluation of the literature pertinent to both the use and the characterization of the performance of antivibration mountings for the control of noise and vibration are described. First to be discussed are the static and dynamic properties of rubberlike materials that are suited for use in antivibration mountings. This is followed by analyses of the simple (one-stage) mounting system and its subsequent, impaired performance when second-order resonances occur either in the isolator (wave effects) or in the structure of the mounted item itself (nonrigid supporting feet). A discussion is then given to the performance of the compound or two-stage mounting system which possesses superior isolation properties for high frequencies. Next, the four-pole parameter technique of analysi" is described and applied, in general terms, to the characterization of the performance of an antivibration mounting with wave effects for both the cases where either the supporting foundation or mounted item are nonrigid. The adopted methods for the direct measurement of antivibration-mounting performance are described, followed by an explanation of how this same experimental determination of transmissibility can also be made using an indirect measurement technique based upon four-pole parameter analysis considerations. Finally, recommendations for future work in various areas of research on antivibration mountings are given.

H129. American National Standard N538; Classification of industrial ionizing radiation gauging devices. (ANSI N5381979), E. H. Eisenhower, ANSI Subcommittee N43-3.2, Nat. Bur. Stand. (U.S.), Handb. 129, 29 pages (Oct. 1979) SN003-003-021 35-1.

Key words: device safety performance classification; gauges; gauging devices; ionizing radiation; radiation measurements; radiation safety; standard.

This American National Standard applies to the radiation safety aspects of gauging devices, commonly called gauges, which use sealed radioactive sources or $x$-ray tubes for the determination or control of thickness, density, level, interface location, or qualitative or quantitative chemical composition. This standard establishes a system for classification of gauging devices based on performance specifications relating to radiation safety. In addition to specific tests for both use conditions and accident conditions, guidelines for other safety features and considerations are presented. This standard does not apply to the measurement performance of gauging devices. 


\subsection{SPECIAL PUBLICATIONS}

lnclude proceedings of conferences sponsored by NBS, NBS annual reports, and other special publications appropriate to this grouping such as wall charts, pocket cards, and bibliographies.

SP260, 1979-80 Edition. NBS Standard Reference Materials Catalog-1979-80 Edition, R. W. Seward, Nat. Bur. Stand. (U.S.), Spec. Publ. 260, 1979-80 edition, 107 pages (Apr. 1979) SN003-003-02048-6.

Key words: analysis; certification; characterization; composition; properties; research materials; special reference materials; standard reference materials.

This Catalog lists those Standard Reference Materials (SRM's), Research Materials (RM's), and Special Reference Materials (GM's) that are available from the National Bureau of Standards (NBS), and those that are soon to be available. The Catalog describes these materials as to their certified characterization, unit size, and type, as well as providing ordering information. Prices for these materials are listed separately in annual supplements to this Catalog.

SP260-58. Standard reference materials: SRM 1470: Polyester film for oxygen gas transmission measurements, J. D. Barnes and G. M. Martin, Nat. Bur. Stand. (U.S.), Spec. Publ. 260 58, 43 pages (June 1979) SN003-003-02077-0.

Key words: gas transmission rate; manometric technique; oxygen; permeability; poly(ethylene terephthalate); standard reference material; temperature coefficient; time-lag.

This report presents information which should be of interest to users of NBS Standard Reference Material 1470. This SRM takes the form of $23 \mu \mathrm{m}$ thick sheets of poly(ethylene terephthalate) film. The gas transmission rates of these films with respect to oxygen gas have been carefully analyzed. We describe where the film comes from, how it is packaged, and how it should be conditioned prior to measuring. The steps which were taken to characterize a random sample of sheets from the production lot of the SRM are discussed in detail. The gas transmission rates and the time-lags of 22 films were measured using a state-of-the-art electronic manometric permeation facility. The temperature dependence of the permeability was determined over the temperature range $288 \mathrm{~K}$ to $310 \mathrm{~K}$. A small pressure effect was found which is thought to be an artifact. The statistical measures which were derived from the data are discussed in detail. It is concluded that the largest source of variability is from one sample to another with a coefficient of variation amounting to 4 percent. A brief discussion of units for expressing permeabilities is given. Effects due to thermal conditioning ("aging") and outgassing are discussed.

SP260-62. Standard reference materials: SRM 768: Temperature reference standard for use below $0.5 \mathrm{~K}, \mathrm{R}$. J. Soulen, Jr. and R. B. Dove, Nat. Bur. Stand. (U.S.), Spec. Publ. 260-62, 47 pages (Apr. 1979) SN003-003-02047-8.

Key words: $\mathrm{AuAl}_{2} ; \mathrm{AuIn}_{\mathbf{2}} ; \mathrm{Be}$; cryogenic temperature scale; fixed points; lr; superconductivity; thermometry; $W$.

Cryogenic temperature scales are now available (viz., the newly created EPT-76 [1]) which are quite accurate and which extend deep into the cryogenic region (as low as $0.5 \mathrm{~K}$ ). It is the region below $0.5 \mathrm{~K}$ where no formal scale exists which is of concern here. By developing a compact device which pro- vides five reference temperatures from $0.015 \mathrm{~K}$ to $0.21 \mathrm{~K}$, the authors hope to provide a lingua franca by which experimental results from different laboratories involving the parameter temperature may be meaningfully compared.

Such a device, designated SRM 768, is now available and consists of a self-contained assembly of coils and five samples which can be used to provide in situ temperature calibration. Simple room temperature electronics readily permit the observation of the five narrow and highly reproducible superconducting phase transitions. These phase transitions have been assigned temperature values by means of fundamental thermometers used at the National Bureau of Standards. Provided that care is exercised in reducing the magnetic field acting upon the device, the user can confidently expect to achieve a temperature reproducibility and traceability to the NBS temperature scale of $\pm 0.3 \mathrm{mK}$.

SP260-63. Standard reference materials: A reference method for the determination of potassium in serum, R. A. Velapoldi, $R$. C. Paule, R. Schaffer, J. Mandel, L. A. Machlan, and J. W. Gramlich, Nat. Bur. Stand. (U.S.), Spec. Publ. 260-63, 104 pages (May 1979) SN003-003-02068-1.

Key words: clinical analysis; clinical chemistry; definitive method; electrolytes; flame atomic emission spectroscopy; reference method; semiautomated pipetting; serum potassium analysis; statistical analysis.

Guided by a committee of experts in clinical chemistry, a reference method was established for the determination of serum potassium based on flame atomic emission spectroscopy (FAES). Its accuracy was evaluated by comparing the values obtained by use of the method in 12 laboratories against the results obtained by a definitive analytical method based on isotope dilution-mass spectrometry (IDMS). Seven serum pools with potassium concentrations in the range 1.319 to 7.326 $\mathrm{mmol} / \mathrm{L}$ were analyzed. Manual and semiautomated pipetting alternatives were tested using sample sizes of 5.0 and $0.25 \mathrm{~mL}$, respectively.

The laboratories used several different FAES instruments. The results showed that the standard error for a single laboratory's performance of the procedure ranged from 0.049 to $0.063 \mathrm{mmol} / \mathrm{L}$ with a maximum bias of $0.065 \mathrm{mmol} / \mathrm{L}$ over the range of concentrations studied. These values were within the accuracy and precision goals that had been set by the committee. The results from the two pipetting techniques were similar. The calibration curve data showed excellent linearity over the total concentration range, with 20 of 22 curves having standard deviations of fit of $0.075 \mathrm{mmol} / \mathrm{L}$ or less.

With appropriate experimental design, the reference method may be used to establish the accuracy of field methods as well as to determine reference sodium values for pooled sera.

SP260-65. Standard reference materials: Micro-homogeneity studies of NBS standard reference materials, NBS research materials, and other related samples, R. B. Marinenko, K. F. J. Heinrich, and F. C. Ruegg, Nat. Bur. Stand. (U.S.), Spec. Publ. 260-65, 84 pages (Sept. 1979) SN003-003-02114-1.

Key words: digital periodic integrator; electron microprobe; homogeneity; standard reference materials; steel.

A simple routine technique for studying homogeneity in the micrometer range with the electron microprobe has been 
developed. For graphic display, a digital periodic integrator is used. In conjunction with scalers and a stcpping motor on the sample stagc, traces similar to industrial control charts based on a comparison of the experiment with the expected (Poisson) counting statistics are quickly obtained. A computer program has been developed to numericaliy evaluate sample homogenei. ty.

Several Standard Reference Materials (SRMs) have bcen tested. These include the iron and steels (SRMs 661-664, 461. and 463), the gold-copper and gold-silver alloys (SRMs 481 and 482 ), the tungsten-20 percent molybdenum alloy (SRM 480), cartridge brass (SRM 478), the iron-chromium-nickel alloy (SRM 479a). A Research Material, Glasses for Microanalysis ( $R M-30)$, has also been tested.

SP260-66. Standard reference mgterials: Didyminum glass filters for calibrating the wavelergth scale of spectrophotometers-SRM 2009, 2010, 2013, and 2014, W. H. Venable, Jr. and K. L. Eckerle, Nat. Bur. Stand. (U.S.), Spec. Publ. $260-$ 66, 85 pages (Oct. 1979) SN003-003-02127-0.

Key words: bandwidth; didymium glass filtcr; passband centroid; spectrophotometer; transmittance; wavelength standard.

This publication presents the use of didymium glass filters as Standard Reference Materials (SRM). The standard reference materials are labeled 2009, 2010,2013 and 2014 depending on size and method of calibration. The certification and uncertainties are also discussed. An appendix with background material and terminology is included. Wavelengths of minimum transnuttance and inflection points in the transmittance curve are certified to be at specified wavelength and provide a convenient method of calibrating the passband centroid of spectrophotometers with bandwidths between 1.5 and $10.5 \mathrm{~nm}$.

SP260-67. Standard reference materials: A reference method for the determination of chloride in serum, R. A. Velapoldi, R. C. Paule, R. Schaffer, J. Mandel, T. J. Murphy, and J. W. Gramlich, Nat. Bur. Stand. (U.S.), Spec. Publ. 260-67, 97 pages (Nov. 1979) SN003-003-02136-9.

Key words: amperometry; chloride analysis; clinical analysis; clinical chemistry; coulometry; definitive method; electrolytes; reference method; serum chloride analysis; statistical analysis.

Guided by a committee of experts in clinical chemistry, a reference method was established for the determination of serum chloride based on a coulometric titration-amperometric end-point determination (C-A). Its accuracy was evaluated by comparing the values obtained by use of the method in 14 laboratories against the results obtained by a definitive analytical method based on isotope dilution-mass spectrometry (IDMS). Seven serum pools with chloride concentrations in the range 79.2 to $116.8 \mathrm{mmol} / \mathrm{L}$ were analyzed. Micro- and macropipetting alternatives were tested using sample sizes of 0.010-0.100 and $5.0 \mathrm{~mL}$, respectively.

The laboratories used several different C-A instruments. The results showed that the standard error for a single laboratory's performance of the procedure was approximately $1.0 \mathrm{mmol} / \mathrm{L}$ with a maximum bias of $0.5 \mathrm{mmol} / \mathrm{L}$ over the range of concentrations studied. These values are within the accuracy and precision goals that had been set by the committee. The results from the micro- and macropipetting techniques were similar. The calibration curve data showed excellent linearity over the total concentration range, with 12 of 14 curves having standard deviation of fit of less than $0.80 \mathrm{mmol} / \mathrm{L}$.

With appropriate experimental design, the reference method may bc used to establish the accuracy of field methods as well as to determine reference chloride values for pooled sera.
SP305. Supplement 10. Publications of the National Bureau of Standards 1978 Catalog. A compilation of abstracts and key word and author indexes, B. L. Burris and R. J. Morehouse Eds., Nat. Bur. Stand. (U.S.), Spec. Publ. 305, Suppl. 10, 679 pages (June 1979) SN003-003-02069-9.

Key words: abstracts, NBS publications; key words; publications.

This 10th supplement to Special Publication 305 of the National Bureau of Standards lists the publications of the Bureau issued bctween January 1-December 31, 1978. It includes an abstract of each publication (plus some earlier papers omitted from Special Publication 305 Supplement 9), key-word and author indexes; and general information and instructions about NBS publications.

SP376. Ruler: $15 \mathrm{~cm} / 6 \mathrm{in}$, with metric-customary units and equivalent, Nat. Bur. Siand. (U.S.), Spec. Publ. 376, both sides (Reissued Jan. 1979) SN003-003-01080-4.

Key words: centimeter; conversion; customary units; inch; metric units.

This ruler provides metric linear measure $(15 \mathrm{~cm})$ and customary-unit linear equivalents (approximately 6 inches) plus conversion formula for effecting changes from customary to metric units.

SP400-14. Semicondactor measurement technology: Thermal resistance measurements on power transistors, S. Rubin and F. F. Oettinger, Nat. Bur. Stand. (U.S.), Spec. Publ. 400-14, 69 pages (Apr. 1979) SN003-003-02050-8.

Key words: current crowding; die attachment evaluation; junction temperature; measurement technology; power transistors; semiconductor devices; thermal characterization; thermal resistance; transistors.

A brief description of the idealized concept of thermal resistance is given along with the problems and pitfalls encountered in applying the concept to power transistors. In addition, the advantages and disadvantages of various electrical techniques for measuring junction temperature (thermal resistance) are described, and a preferred technique, in which the forward-biased emitter-base junction is used as the temperature-sensitive parameter, is usable on all types of bipolar transistors. The measurement procedure is relatively simple and lends itself to industrial measurements as well as for referee purposes. The power inter ruption circuitry is also relatively fast and simple since only one device terminal is switched. The preferred technique that was developed for measuring the thermal resistance of power transistors has been adopted as EIA Recommended Standard RS-313-B on Thermal Resistance Measurements of Conduction Cooled Power Transistors, dated October 1975.

SP400-38. Semiconductor measurement technology: Progress report, Octoher 1, 1976 to March 31, 1977, W. M. Bullis, Ed., Nat. Bur. Stand. (U.S.), Spec. Publ. 400-38, 95 pages (Nov. 1979) SN003-003-02139-3.

Key words: auger electron spectroscopy; die attachment; electrical properties; electronics; hermeticity; indiumdoped silicon; infrared reflectance; in tegrated circuits; linewidth measurements; oxidation; photolithography; photovoltaic method; power-device grade silicon; radioisotope leak test; resistivity variations; resistors, sheet; scanning acoustic microscope; semiconductor materials; semiconductor process control; silicon; silicon dioxide; silicon-on-sapphire; sodium contamination; test patterns; test structures; thermally stimulated current and capacitance; 
transistors; ultraviolet reflectance; VCE(SAT); x-ray photoelectron spectroscopy.

This progress report describes NBS activities directcd toward he development of methods of measurement for semiconducor materials, process control, and devices. Both in-house and zontract efforts are included. The emphasis is on silicon device echnologies. Principal accomplishments during this reporting period included (1) refinement and extension of the analysis of he nondestructive, photovoltaic method for measuring radial esistivity variation of silicon slices; (2) development of a Jonor-addition technique for testing for the presence of $\mathbf{X}$ evels in indium-doped silicon; (3) development of a precision, wet chemical etching procedure for use in conjunction with $\mathrm{x}$ ay photoelectron spectroscopy for profiling silicon dioxide-silcon interfaces; (4) completion of thermodynamic calculations f equilibrium sodium density in oxidation atmospheres concained in polycrystalline silicon tubes; (5) initial extensions of he line-width measurement procedure to partially transparent and reflecting specimens and to submicrometer dimensions; and 6) completion of the development of a test pattern for characerizing a large-scale-integration, silicon-on-sapphire process. Also reported is other ongoing work on materials characterizaion by electrical and physical analysis methods, materials and procedures for wafer processing, photolithography, test patterns, and device inspection and test proccdures. Supplementary data concerning staff and publications are included as appendices.

SP400-47. Semiconductor measurement technology: The theoretical and experimental study of the temperature and dopant density dependence of hole mobility, effective mass, and resistivity in boron-doped silicon, S. S. Li, Nat. Bur. Stand. (U.S.), Spec. Publ. 400-47, 50 pages (Nov. 1979) SN003003-02 140-7.

Key words: boron-doped silicon; dopant density; effective mass; hole mobility; ionized impurity scattering mobility; lattice scattering mobility; neutral impurity; resistivity; scattering mechanisms; scattering mobility; $\rho$-type silicon.

Theoretical expressions for computing resistivity and conductivity mobility of holes as functions of dopant density and temperature have been derived for boron-doped silicon. The model is applicable for dopant densities from $10^{13}$ to $3 \times 10^{18} \mathrm{~cm}^{-3}$ and temperatures between 100 and $400 \mathrm{~K}$.

Using a three-band [i.e., heavy-hole, light-hole, and spin-orbit split ( $\mathrm{SO}$ ) bands] model, the hole mobility was calculated by properly combining the contributions from scattering by lattice phonons, ionized impurities, and neutral impurities. In addition, the effects of hole-hole (h-h) scattering and nonparabolicity of the light-hole band were taken into account in the mobility formulation.

To verify our theoretical calculations, resistivity measurements on nine boron-doped silicon slices with dopant densities from $4.5 \times 10^{14}$ to $3.2 \times 10^{18} \mathrm{~cm}^{-3}$ were performed for $100 \leqslant$ $T \leqslant 400 \mathrm{~K}$, using a planar four-probe square-array test strueture. Agreement between our calculated and measured resistivity values was within 6 percent over the entire range of dopant density and temperature studied here. Excellent agreement (within \pm 5 percent) between our calculated hole mobility values and those of Thurber et. al was obtained for $N_{A} \leqslant 10^{18}$ $\mathrm{cm}^{-3}$. These discrepancies are attributed to Wagner's neglect of the effect of deionization of boron impurities at higher dopant densities (i.e., he assumed hole density equal to the total boron density).

Finally, formulations for the density-of-states effective mass, conductivity effective mass, and Hall effective mass are described, and the results are applied to the calculations of hole masses in boron-doped silicon for $10^{14} \leqslant N_{A} \leqslant 10^{18} \mathrm{~cm}^{-3}$ and $50 \leqslant T \leqslant 500 \mathrm{~K}$.
SP400-48. Semiconductor measurement technology: Spreading resistance analysis for silicon layers with nonuniform resistivity, D. H. Dickey and J. R. Ehrstein, Nat. Bur. Stand. (U.S.), Spec. Publ. 400-48, 72 pages (May 1979) SN003-003-020613.

Key words: dopant profiles; resistivity; resistivity profiles; semiconductor; silicon; spreading resistance.

A simple mathematical algorithm is developed for the calcu. lation of resistivity depth profiles from spreading resistance measurements on sectioned silicon device structures. It is applicable to structures consisting of one or more layers of the same or differing conductivity types. The algorithm accounts for modification of the sampling volume of the spreading resistance probes due to nearby variations in depth of specimen resistivity whether resulting from graded dopant distribution or electrical boundaries, either insulating or conducting.

The algorithm is based on limiting case one- and two-dimensional models of the conduction between the probes. Compared with the traditional spreading resistance analysis algorithm based on the three-dimensional boundary value solution of Schumann and Gardner, the present work offers greatly enhanced execution times even with a microcomputer, making real time analysis for process control possible.

An experiment to test the accuracy of one of the limiting models used is described. Profiles of a number of diffused layers generated from spreading resistance measurements analyzed by this algorithm are compared with profiles obtained on replicate specimens using another electrical technique. In addition, computer experiments are used for simple layer models to compare results based on this algorithm with results from the Schumann-Gardner approach.

SP400-50. Semiconductor measurement technology: Reliability technology for cardiac pacemakers III-A workshop report. Report of a Workshop held at the National Bureau of Standards, Gaithersburg, MD, Oct. 19-20, 1977, H. A. Schafft, Ed., Nat. Bur. Stand. (U.S.), Spec. Publ. 400-50, 134 pages (June 1979) SN003-003-02076-1.

Key words: automated testing; batteries; cardiac pacemakers; contamination; corrosion; electrostatic-induced damage; hermeticity; hybrid dcvices; leak testing; measurement technology; microcalorimetry; moisture; nondestructive testing; pacemaker leads; process control; reliability; semiconductor devices; welding.

The workshop, third in a series, served as a forum for pacemaker manufacturers and other interested parties to address technical questions relevant to the enhancement and assurance of cardiac pacemaker reliability. Extended summaries are provided of 27 talks and of eight sets of group encounter discussions on the following topic areas: microcalorimetric measurements to evaluate nondestructively batteries used in pacemakers; qualification procedures, end-of-life prediction, and neutron radiography interrogation of lithium-based batteries; measurement of moisture; moisture effects on the reliability of pacemakers and components; electrostatic-induced damage to semiconductor devices; procurement of high reliability semiconductor components; automated testing of pacemakers; actuarial analyses of lead and pacemaker failures; pacemaker case welding processes; surface contamination measurements; corrosion and accelerated tests for metallic materials; and conformal coatings for pacemaker applications.

SP400-51. Semiconductor measarement technology: A production-compatible microelectronic test pattern for evaluating photomask misalìggreregat, T. J. Russell and D. A. Maxwell, Nat. Bur. Stand. (U.S.), Spec. Publ. 400-51, 32 pages (Apr. 1979) SN003-003-02035-4. 
Key words: contact resistor; cross bridge sheet resistor; electrical alignment resistor; semiconductor; silicon; test pattern; test structures; visual alignment.

Microelectronic test pattern NBS-15 is composed of several potentiometric, production-compatible electrical alignment resistor test structures, visual alignment indicator test structures, cross bridge sheet resistors, and contact resistor test structures. The pattern was originally designed as a study vehicle for the electrical alignment resistor, but it was also demonstrated that, when stepped over an entire wafer, the pattern is suitable for use in evaluating misalignment which may result from photomask generation, photomask exposure, or other fabrication processes. This report summarizes the test structures that are included in the pattern and contains explanation of how each of the structures is measured.

SP400-52. Semiconductor measurement technology: An automated photovoltaic system for the measurement of resistivity variations in high-resistivity circular silicon slices, $D$. $L$. Blackburn, Nat. Bur. Stand. (U.S.), Spec. Publ. 400-52, 41 pages (Nov. 1979) SN003-003-02138-5.

Key words: automation; bulk photovoltaic effect; computer control; homogeneity; measurement method; nondestructive testing; photoconductivity; power devices; resistivity variation.

This report describes an automated photovoltaic system for nondestructive measurement of resistivity variations of high-resistivity circular silicon slices. The computer-based system for making the measurements is described, detailed construction diagrams are given to facilitate reproduction of the system, and a listing of the computer program for controlling the system is given. Comparisons between resistivity profiles determined using the automated photovoltaic system and the four-probe technique indicate that the photovoltaic system is adequate for production screening and incoming inspection of high-resistivity float-zoned silicon slices.

SP400-54. Semiconductor measurement technology: A reverseblas safe operating area transistor tester, D. W. Berning, Nat. Bur. Stand. (U.S.), Spec. Publ. 400-54, 43 pages (Mar. 1979) SN003-003-02046-0.

Key words: base drive circuit; electronic circuits; inductive load; nondestructive; protection circuit; reverse bias; safe operating area; second breakdown; switching power transistor; tester; transistor.

This is a construction guide for a reverse-bias safe operating area (RBSOA) transistor tester for npn switching transistors. Principles of operation for various circuits in the tester are discussed, as well as those of the complete system. System specifications are given. Extensive construction notes are given with hints on chassis layout. Complete circuit schematics are given with additional detail pertaining to power supply and grounding interconnections. Mechanical drawings of the tester enclosure are given. Photographs are included as additional help in building the tester. Special components such as the collector load inductor are described. Finally, a section on the use of the tester includes waveforms generated by a typical test that would be made on a transistor with this equipment.

SP400-55. Semiconductor measurement technology: A wafer chuck for use between -196 and $350{ }^{\circ} \mathrm{C}, \mathrm{R}$. Y. Koyama and M. G. Buehler, Nat. Bur. Stand. (U.S.), Spec. Publ. 400-55, 24 pages (Jan. 1979) SN003-003-02017-6.

Key words: deep level measurements; defect mapping; hot/cold wafer chuck; thermally stimulated measurements; thermal wafer chuck; variable temperature; wafer chuck.
This report describes the design and characterization of a variable-temperature wafer apparatus for use in the detection of electrically active defects which produce deep levels in the band gap of silicon. In its present form, the wafer chuck can heat and cool wafers as large as $51 \mathrm{~mm}$ in diameter over the temperature range from -196 to $350{ }^{\circ} \mathrm{C}$; heating rates as high as $7^{\circ} \mathrm{C} / \mathrm{s}$ have been achieved. The uniformity of the temperature across the chuck under static conditions is estimated to be better than $\pm 0.4{ }^{\circ} \mathrm{C}$. Construction details of the chuck are given in an appendix. The use of this apparatus is illustrated by wafer mapping the gold defect density in diodes fabricated across a silicon wafer.

\section{SP400-56. Semiconductor measurement technology: Comprehen- sive test pattern and approach for characterizing SOS technology, W. E. Ham, Nat. Bur. Stand. (U.S.), Spec. Publ. 400-56, 370 pages (Dec. 1979) SN003-003-02144-6.}

Key words: comprehensive process characterization; design rules; intradie parametric integrity; LSI circuits; mask alignment tolerances; modular test programs; parametric yield limitazions; performance limitations; photomask performance; process control; test patterns; test structures; total process integration.

This report contains detailed information concerning a comprehensive approach to parametric process characterization for IC processes. This includes defining the general areas of importance, devising structures which are sensitive to these areas, devising methods for testing the structures, documenting the structures, tests, and results, producing suitable data reduction and presentation schemes, and considering the implementation of the methods in a practical sense. Proper methods for automatically testing some of these structures are explored. Seven divisions were created for the general types of test structure: (1) individual structures of nominal dimensions, (2) closely spaced identical structures, (3) structures of various sizes, (4) series and parallel combinations of structures, (5) structures especially sensitive to lithographic properties, (6) basic circuit building blocks, and (7) small area test circuits.

A test pattern, compatible primarily with silicon on sapphire rechnology, which integrates into a single mask set (6 levels) test structures to measure the properties of each of these basic divisions, was created and partially tested. This concept of total integration is shown to be valuable for determining causes and effects of many kinds with the use of only a small number of test wafers. An attempt was made to use computer-aided techniques as much as possible. These found application in mask making (the masks would have been much more difficult to create without the computer), documentation (where computer line drawings were used as the basic drawings), testing (where a standardizable building block approach was implemented), and finally, the traditional use of the computer for data reduction and presentation. The test pattern contains 175 individually identified test structures and has approximately 1250 electrical access pads for each chip. The chip dimensions are 258 by $258 \mathrm{mil}(6.553 \times 6.553 \mathrm{~mm})$. All of these structures are documented with cross sections and line drawings. A discussion of the intended uses of the structures, of their peculiarities, and samples of actual test results for many of the structures are included. A "small-signal" approach to testing, data analysis, and test structure design was used in several cases. For the test structure design, the small-signal approach is particularly useful with respect to physical structure sensitivity. For the testing, it finds traditional applications in the measurement of slopes while in the data analysis differences in identically acquired data from different wafers are frequently the desired information.

Results from a limited use of the pattern on a sampling of wafers from a few lots indicated that contact resistance effects 
and deposited oxide pin holes were much more important than previously thought. Alignment measurements between photomasking levels were obtained with an accuracy of \pm 250 $\AA$. The closely spaced and nominally identical structures are shown to be especially valuable for determining the nature of the individual measurements and for providing some of the best clues to the causes of the observed variations.

The uses of the overall approach include processing facility comparisons using structures with understandable outputs, detecting the least controlled parts of the process, providing a solid base on which to define circuit design rules, and predicting parametric yield loss to be expected due to circuit designprocess incompatibility.

SP400-57. Semiconductor measurement technology: DISTRIB $\mathbb{\text { , }}$ an impurity redistribution computer program, D. Gilsinn and R. Kraft, Nat. Bur. Stand. (U.S.), Spec. Publ. 400-57, 130 pages (Feb. 1979) SN003-003-02030-3.

Key words: diffusion; electronic technology; impurity distribution; material transport; segregation; semiconductor technology.

This report provides documentation of a computer program which calculates the redistribution of impurities in silicon during a single oxidation step. The documentation provides: (1) a physical and mathematical description of the redistribution process, (2) a detailed description of the discretization of the appropriate partial differential equations, and (3) a complet description of the FORTRAN program for computing the solution.

SP400-58. Semlconductor measurement technology: NBS/DOE workshop, stabllity of (thin fllm) solar cells and materials, D. E. Sawyer and H. A. Schafft, Eds., Nat. Bur. Stand. (U.S.), Spec. Publ. 400-58, 181 pages (Aug. 1979) SN003-00302100-8.

Key words: accelerated tests; failure mechanisms; failure modes; photovoltaics; reliability; semiconductors; solar cells; stability; testing; thin films.

A workshop was held to discuss what needs to be done to achieve and measure long term stability of terrestrial solar cells using thin film materials and device technologies. Under this theme, researchers in the field and invited speakers from related device technologies presented papers and took part in discussions related to solar cells of the following three material groupings: (1) $\mathrm{Cu}_{2} \mathrm{~S} /[\mathrm{CdZn}] \mathrm{S}, \mathrm{Cu}$-ternaries/CdS, $1 \mathrm{nP} / \mathrm{CdS}$, and amorphous $\mathrm{Si}$; (2) polycrystalline, metal-insulator-semiconductor (MIS), and conducting-oxide $\mathrm{Si}$; and (3) polycrystalline and antireflection-coated metal-oxide-semiconductor (AMOS) GaAs. This workshop report contains the 18 papers presented and the reports of three discussion groups; it also includes a section on the highlights of these papers and reports. The many needs identified by the workshop participants can be organized into two general areas of work to be done. One area of work is in the development of an improved understanding of cell operation and of component structures of these cells. The other is in the development of an improved measurements base. These proceedings include the following papers (indented):

The importance of thln film solar cell stability, D. L. Feucht, SP4OO-58, p. 12 (Aug. 1979).

Status of the DOE photovoltaic performance criteria and standards project, L. M. Magid, SP400-58, p. 13 (Aug. 1979).

The stabllity and reliabillty of $\mathrm{CdS} / \mathrm{Cu}_{2} \mathrm{~S}$ solar cells, J. D. Meakin and J. E. Phillips, SP400-58, pp. 17-29 (Aug. 1979).
Stability and ternary chalcopyrite photovoltalc devices, $\mathbf{L}$. L. Kazmerski, SP400-58, pp. 30-40 (Aug. 1979).

Stability of thin film polycrystalline sillicon solar cells, T. L. Chu, S. S. Chu, E. D. Stokes, C. L. Lin, and R. Abderrassoul, SP400-58, pp. $41-47$ (Aug. 1979).

Reliability studies on MIS and transparent oxlde-SI solar cells, W. A. Anderson and J. K. Kim, SP400-58, pp. 48-56 (Aug. 1979).

Stability of conducting oxide/SI heterostructure solar cells, S. L. Frank, M. L. Andren, and R. L. Anderson, SP400-58, pp. 57.62 (Aug. 1979).

Unique problem areas in M-I-S solar cell structures, $\mathbf{J}$. Fonash, G. Fishkorn, and T. E. Sullivan, SP400-58, pp. $63-$ 68 (Aug. 1979).

Reliability testing of GaAs AMOS solar cells, R. J. Stirn, SP400-58, pp. 69-75 (Aug. 1979).

Stability of thin fillm gallium arsenide solar cells, S. S. Chu, T. L. Chu, H. T. Yang, and E. D. Stokes, SP400-58, pp. 7681 (Aug. 1979).

Stability studies of amorphous sillicon solar cells, D. E. Carlson, SP4OO-58, pp. 82-85 (Aug. 1979).

Silicon cell space program experience, P. A. 1les, SP4O0-58, pp. 86-94 (Aug. 1979).

Reliability concerns and life test procedures for concentrator solar cells, W. V. McLevige, SP400-58, pp. 95-101 (Aug. 1979).

Some reliabihity problems in integrated circuits-Thelr detection, definition, ard remedy, J. W. Adolphsen, SP400-58, pp. 102-109 (Aug. 1979).

Tests for instabilities in silicon integrated clrcults, C. W. Green, SP400-58, pp. $110-125$ (Aug. 1979).

Real-time controls for reliability assurance, S. Kukunaris, SP400-58, pp. 126-127 (Aug. 1979).

Interdiffusion and interface problems relating to thin film photovoltaic devices, L. L. Kazmerski, SP400-58, pp. 128-143 (Aug. 1979).

Corrosion and its control, R. P. Frankenthal, SP400-58, Pp. 144-145 (Aug. 1979).

Terrestrial silicon array field and test experience, $R$. G. Ross, Jr., SP400-58, pp. 146-149 (Aug. 1979).

Methodology for designing accelerated aging tests for predỉcting life of photovoltaic artrays, $R$. E. Thomas and G. B. Gaines, SP4OO-58, pp. 150-159 (Aug. 1979).

SP400-59. Semiconductor measurement technology: Nondestructive tests used to insure the integrity of semiconductor devices, with emphasis on acoustic emisslon techniques, G. G. Harman, Nat. Bur. Stand. (U.S.), Spec. Publ. 400-59, 72 pages (Sept. 1979) SN003-003-02116-4.

Key words: acoustic emission; beam lead devices; electronic devices; hermeticity; hybrids; nondestructive tests; semiconductor: tape-bonded devices.

The discussion is divided into two major sections. The first consists of an introduction to device assembly techniques and problems followed by a review of six important nondestructive tests used during and after device packaging to insure the 
mechanical integrity of completed electronic devices. Most of these tests are called out in the military testing standard, MILSTD-883 and are generally classified as screcns. The first section concludes with a brief introduction to the economic and other factors that result in the choice of one screen over another and to production line statistical sampling (LTPD) appropriate to special high reliability device lots such as thosc used for space flight.

The second section begins with an introduction to acoustic emission, the status of theory as it can be applied to microelectronics. Then the published papers that have applied $\mathrm{AE}$ as a nondestructive test in electronics applications will be reviewed. Finally, passive AE techniques are applied to establishing the mechanical bond integrity of beam lead, flip chip, and tapebonded integrated circuits as well as components in hybrid microcircuits.

SP426. Supplement 1. Bibliography of low energy electron and photon cross section data (January 1975 through December 1977), J. W. Gallagher, J. R. Rumble, Jr., and E. C. Beaty, Nat. Bur. Stand. (U.S.), Spec. Publ. 426, Suppl. I, 115 pages (June 1979) SNO03-003-02074-5.

Key words: atom; collision cross section; detachment; dissociation; elastic scattering; electron; excitation; ion; ionization; molecule; photon; positron.

A bibliography of original reports of measurements or calculations of electron, positron and photon cross sections for atoms, small molecules, and their ions is presented. A detailed index to the bibliography facilitates retrieval of cross section data for specific processes and associated atomic or molecular species. A comprehensive author index is included. The bibliography covers the calendar years 1975-1977. This work supplements a previous bibliography which covered the literature through 1974.

SP439-1. Center for building technology: A perspective-1979, M. Olmert, Nat. Bur. Stand. (U.S.), Spec. Publ. 439-1, 31 pages (May 1979) SN003-003-02056-7.

Key words: building research; criteria; energy; engineering; industry construction; measurement techniques; standards.

The mission of the Center for Building Technology is threefold. They are 1) advance building technology by providing technical and scientific bases for criteria and standards that improve the usefulness, safety, and economy of buildings; 2) facilitate, for the public benefit, the implementation of improved building technology by providing technical assistance to all sectors of the building community; and 3) develop improved techniques by which the end-users in buildings, communities and industrial processes conserve energy. This report presents an overview of the Center for Building Technology's research areas through its accomplishments and ongoing projects.

SP446-2. Building technology project summaries 1977-1978, M. Olmert and N. Raufaste, Eds., Nat. Bur. Stand. (U.S.), Spec. Publ. 446-2, 108 pages (Jan. 1979) SN003-003-02021-4.

Key words: building research; building technology; codes; criteria; project summaries; standards; technical bases.

The Center for Building Technology provides the technical and scientific bases for criteria and standards that improve the usefulness, safety, and economy of buildings while conserving building materials and energy. The Center's activities support the building technology program of the Federal, State and local government; assists design professions, building officials and the research community by developing design criteria that improve buildings; and assists manufacturers of building products by developing criteria for evaluating innovative building materials. This report summarizes the Center's projects for calendar year
1977. It enables individuals to get a clear impression of CBT research activities.

SP457-3. Building technology publications 1978-Supplement 3,

J. R. Debelius, Ed., Nat. Bur. Stand. (U.S.), Spec. Publ. $457-$

3, 106 pages (July 1979) SN003-003-02096-6.

Key words: abstracts; Center for Building Technology; key words; publications.

This report presents the National Bureau of Standards' (NBS) Center for Building Technology (CBT) publications for 1978. It is a supplement to Special Publication 457, Building Technology Publications 1965-1975, and covers the period from January 1, 1978 to December 31, 1978. It includes an abstract of each NBS publication, titles and abstracts of papers published in non-NBS media, key word and author indexes, and general information and instructions on how to order CBT publications.

This report provides the primary means of communicating the results of CBT programs to its varied technical audiences, as well as to the general public. Publications constitute a major end product of CBT's efforts and in 1978 appeared in several NBS publication series (Building Science Series, Technical Notes, Special Publications, Handbooks, and NBS Interagency Reports).

SP480-12. Communication systems guide, W. W. Scott, Jr., Nat. Bur. Stand. (U.S.), Spec. Publ. 480-12, 36 pages (Jan. 1979) SN003-003-02012-5.

Key words: communication systems; equipment selection; law enforcement; public safety.

Recently many law enforcement agencies, in response to increased funding, have expanded and improved communication capabilities. Such efforts involve additional communications equipment. This guideline was prepared to assist the communication systems manager in choosing communications equipment with desirable attributes such as reliability, low cost, and effectiveness. General topics include communication systems, equipment, cost considerations, and suppliers. Emphasis is on the important operational and support communication sub-systems and include topics ranging from computer-aided dispatch centers to voting receivers. References are listed for the reader who desires additional information on these topics.

SP480-14. Selection and application guide to commercial intrusion alarm systems, A. H. Sher and G. N. Stenbakken, Nat. Bur. Stand. (U.S.), Spec. Publ. 480-I4, 40 pages (Aug. 1979) SN003-003-02098-2.

Key words: alarm; burglar alarm; guidelines holdup alarm; intrusion alarm.

This set of guidelines outlines a procedure to help the person who must buy an alarm system to protect a store or business establishment to make a wise selection. The procedure takes him through the following considerations: (1) The type of threat (what is the protection for?), (2) the types of protection (what methods are available?), (3) the types of sensors (which characteristics are desirable?), (4) the mode of alarm (how is the alarm signal to be transmitted?) and, (5) the types of services (how do the police find out an alarm has been sounded?).

SP480-30. Juror response to prerecorded videotape trials, E. M: Robertson, Nat. Bur. Stand. (U.S.), Spec. Publ. 480-30, 28 pages (June 1979) SNOO3-003-02071-1.

Key words: civil trials; courtroom procedures; juror attitudes; prerecorded videotaped trials; PRVTT; trials, PRVTT; videotaped trials. 
This report is an analysis of the responses to an attitudinal questionnaire returned by 278 jurors who had participated in prerecorded videotaped (PRVTT) civil trials conducted in Ohio during 1975 and 1976. These trials differ from ordinary trials in two major respects: (1) The witnesses' testimony had been prerecorded for trial presentation and (2) the judge is not present during the videotape presentation.

The responses indicated a gensrally favorable reaction to the use of PRVTT. As an illustration, the respondents indicated (by a 2.4 to 1 ratio) a preference for a PRVTT over an ordinary trial in a civil suit in which they were a litigant. In contrast, there was an even split in indicated preference in the case of a criminal trial in which they were the accused.

SP480-33. Guide to high speed patrol car tires, A. C. Lewis and E. Lewis, Jr., Nat. Bur. Stand. (U.S.), Spec. Publ. 480-33, 42 pages (1979) SN003-003-02073-7.

Key words: braking traction; cornering traction; driving traction; endurance; maintenance; operation; purchasing; pursuit tires; safety; tread wear.

Tests were conducted on various sizes and construction of pursuit tires to measure performance in the areas of tread wear, endurance, braking, driving and cornering traction. The results of these tests are presented to give police departments information needed to help them select replacement tires to meet their particular needs.

This guide will also help them provide the care necessary for maximum safety, tire life and performance.

SP480-36. Some psychophysical tests of the conspicuities of emergency vehicle warning lights, G. L. Howett, Nat. Bur. Stand. (U.S.), Spec. Publ. 480-36, 24 pages (July 1979) SN003-003-02085-1.

Key words: color, lights; conspicuity, lights; effective intensity; emergency lights; intensity, effective; lights, flashing; lights, warning; perception, visual; peripheral vision; vehicles, emergency; visibility, lights; visual perception.

This is a report of some exploratory studies aimed at evaluating the conspicuities (attention-attracting powers) of a group of commercial warning lights meant for use on emergency vehicles. The main experiment used a novel technique of conspicuity matching. Each observer, in turn, fixated straight ahead and viewed two flashing lights peripherally, one located $20^{\circ}$ to the left of the fixation point, and one $20^{\circ}$ to the right. One of the two lights was always a reference light whose intensity could be adjusted by the observer until the two lights appeared equally conspicuous. All the lights were thereby ranked on a single scale of conspicuity, based on the adjustable-light intensities. There was a good correlation $(r=0.90)$ between these ranks and the measured effective intensities of the lights. Another, very brief, pilot experiment ranked some of the lights according to the number of degrees into the left side of the visual field that the flashes could still be seen. This disappearance-angle rank also correlated well $(r=0.86)$ with conspicuity rank. Problems encountered and suggestions for future improvements are discussed.

SP480-38. The role of behavioral science in physical security. Proceedings of the Third Annual Symposium, May 2-4, 1978, J. J. Kramer, Ed., Nat. Bur. Stand. (U.S.), Spec. Publ. $480-$ 38, 110 pages (Dec. 1979) SN003-003-02149-1.

Key words: adversary characteristics; animal research; behavioral science; biosensors; computer analysis; ergonomics; human engineering; human factors; human motivation; human reliability; personnel selection; physical security; physiological psychology; sensory capability; terrorism; threat analysis; training.
This document contains the proceedings of the third annual symposium on, "The Role of Behavioral Science in Physical Security," held in May 1978. The symposium provided a forum for the exchange of information between specialists in physical security and behavioral science through the presentation of eight papers and four structural workshops: Human Sensory Capabilities/Limitations; Human Engineering of the Workplace; Human Motivation, Attitudes, Error/Reliability; Personnel Selection, Placement, Training. The symposium concluded with a summary and synthesis of the results of the workshops and a panel discussion on new research thrusts. These proceedings include the following papers (indented):

Biosensor for assessment of defender performance capability, T. E. Bevan, SP480-38, pp. 1-6 (Dec. 1979).

Neurophysiological operant and classical condition methods in rats in the detection of explosives, S. Weinstein, C. Weinstein, and R. Nolan, SP480-38, pp. 7-16 (Dec. 1979).

Link analysis of threats and physical safeguards, D. H. Harris, SP480-38, pp. 17-22 (Dec. 1979).

An overview of the M.A.I.T. analysis system (machine analysis of the internal threat), J. R. NiCastro, B. Woolson, and J. Glancy, SP480-38, pp. 23-28 (Dec. 1979).

Strategies of counter-nuclear terrorism: Theory and decision on the frontiers of law enforcement and criminal justice, $L$. R. Beres, SP480-38, pp. 29-46 (Dec. 1979).

Potential application of computer-based crisis management aids to problems of physical security, S. J. Andriole and J. A. Daly, SP480-38, pp. 47-74 (Dec. 1979).

Brain wave and biochemical research findings, $K$. Montor and D. Afdahl, SP480-38, pp. $75-80$ (Dec. 1979).

Psychological deterrence in robberies of banks and its application to other institutions, W. D. Tiffany and J. M. Ketchel, SP480-38, pp. 81-88 (Dec. 1979).

SP500-38. Computer science \& technology: Findings of the standard benchmark library-Study group, D. M. Conti, Nat. Bur. Stand. (U.S.), Spec. Publ. 500-38, 57 pages (Jan. 1979) SN003-003-02009-5.

Key words: benchmarking; benchmark library; selection of ADP systems; standard benchmarks; synthetic benchmarks; workload characterization; workload definition.

This report presents the findings of a Government-industry study group investigating the technical feasibility of standard benchmark programs. As part of its investigation, the study group reviewed earlier efforts to develop and use standard benchmark programs. Several issues dealing with the implementation, maintenance, cost/benefit, and acceptability of standard benchmarks emerged as a result of this review. The problems encountered by the study group, notably the lack of an accepted definition of "representativeness," prevented it from arriving at a definitive statement on feasibility. However, several areas were identified as topics requiring further investigation and are presented in this report.

SP500-39. Computer science \& technology: Computer model documentation: A review and an approach, S. I. Gass, Nat. Bur. Stand. (U.S.), Spec. Publ. 500-39, 89 pages (Feb. 1979) SN003-003-02020-6.

Key words: computer; computer model; documentation; documentation procedures; model; model documentation. 
Recent studies and surveys have concluded that, in general, the documents produced to support the understanding and use of computer models are inadequate. This paper describes the issues and concerns of computer model documentation and proposes an approach for the development of adequate documentation. First, a number of documentation studies and reports are reviewed, including software documentation guidelines and model documentation procedures. Then, based on the relationship between the phases of the model life cycle and documentation information needs, a set of documents is proposed and described.

The author takes a highly critical view of the past and present inadequate state of documentation procedures for computer models. The attention of computer model sponsors and developers must be directed to this area. Otherwise, the author feels, there will be an unfortunate decline in the use of decision models as aids in the analysis of importanit policy issues. The course of action recommended in this report is an extreme position as to the total information and number of documents required to produce adequate documentation. The author calls for the capturing of all information generated during a model's life cycle. Further research is needed to adapt this extreme position to the realities of cost, resources, model complexity, and model use.

SP500-42. Computer science \& technology: A survey of remote monitoring, G. J. Nutt, Nat. Bur. Stand. (U.S.), Spec, Publ. 500-42, 34 pages (Jan. 1979) SN003-003-02013-3.

Key words: diagnostic testing; performance assurance; performance evaluation; remote monitoring; system security testing.

This report describes remote monitoring in the application areas of performance evaluation, diagnostic testing, performance assurance and system security testing. The evolution of remote monitoring is briefly reviewed and, then, remote monitors are categorized into seven classes. Several example systems are discussed for each classification, along with their capabilities in each application area. The views presented in this report represent only those of the author, an independent consultant, and should not be construed as a policy statement of NBS or any other organization.

SP500-44. Computer science \& technology: A methodology for the selection of interactive computer services, S. A. Mamrak and P. D. Amer, Nat. Bur. Stand. (U.S.), Spec. Publ. 500-44, 82 pages (Jan. 1979) SN003-003-02018.

Key words: comparison of computers; computer measurement; computer selection; computer services; ranking and selection; selection methodology.

This publication addresses the comparison and selection of remote access interactive computer services. The comparison methodology presented relies prineipally on the statistical analysis of measurement data obtained from the interaction between a computer service and a user. One of the most important properties of the mcthodology is that it incorporates confidence statements about the probability of having made a correct selcction. Experimental data are presented to illustrate an application of the methodology, and serve as a basis for a discussion of the cost and appropriateness of using the methodology in various procurement efforts.

SP500-45. Computer science \& technology: Computer peripheral memory systern forecast, R. B. J. Warnar, P. J. Calomeris, and S. A. Recicar, Nat. Bur. Stand. (U.S.), Spec. Publ. 500-45, 147 pages (Apr. 1979) SN003-003-02039-7.

Key words: beam-addressables; cartridges; cassettes; core memories; disks; drums; floppy disks; laser beams; magnetic bubbles; masstapes; solid state memories; video disks.
This document describes and forecasts computer peripheral memory technologies as displayed by U.S. research and manufacturing facilities. Specifically, both technical and economic criteria are discusscd. The presented peripheral memories include contemporary and emerging systems, all of which are compared in graphs, tables, and decision trees. The document contains an extensive bibliography (in ANSI format) to support certain main points that are supplemented by information supplied by the Institute for Computer Sciences and Technology (ICST) resources. Additional information and verification was received from private interviews with various U.S. technical experts and equipment manufacturers.

SP500-46. Computer science \& technology: Computers in the Federal Govermment: A compilation of statistics-1978, M. M. Gray, Nat. Bur. Stand. (U.S.), Spec. Publ. 500-46, 95 pages (Apr. 1979) SN003-003-02037-1.

Key words: ADP costs; Federal acquisition dates; Federal ADP statistics; Federal ADP work-years; Federal Government computers; Federal minicomputers; statistics.

This report presents data on the status of computer technology in the Federal Government. It is an extension and update of "Computers in the Federal Government: A Compilation of Statistics" (NBS SP 500-7), June 1977. The report contains a combination of existing statistics based on these sources. Data is included on numbers of computers installed in the Federal Government, dollar value of computers installed, numbers of computers installed by agency, Federal ADP costs by agency, Fedcral computers by acquisition date, and Federal ADP workyears. A detailed analysis is presented for Federal computers classifying the computers into three major categories, general purpose computers, special computers and minicomputers. Federal computers are compared with U.S. computers in the same categories.

SP500-47. Computer science \& technology: Data base reorganization-Principles and practice, G. H. Sockut and R. P. Goldberg, Nat. Bur. Siand. (U.S.), Spec. Publ. 500-47, 51 pages (Apr. 1979) SN003-003-02055-9.

Key words: data base; data base management; file maintenance; reformatting; reorganization; restructuring.

Data base reorganization can be defined as changing some aspect of the way in which a data base is arranged logically and/or physically. This paper contains tutorials and surveys. It introduces the basic concepts of reorganization, including why it is performed. Many examples of types of reorganization are described and are classified into logical/physical levels. The paper then covers pragmatic issues such as reorganization strategies, a survey of several commercial reorganization facilities, case studies, and data base administration considerations. Finally, several research efforts are surveyed.

SP500-48. Computer science \& technology: Measurement of interactive computing: Mettodology and application, I. W. Cotton, Nat. Bur. Stand. (U.S.), Spec. Publ. 500-48, 111 pages (June 1979) SN003-003-02081-8.

Key words: computer performance evaluation; human factors; interactive computing; man-machine interaction; performance measurement; timesharing.

This dissertation addresses the measurement of interactive computing, including both the computer system providing service and the users demanding and receiving it. The focus is on the performance of the user and the system in individual interaction sessions (rathcr than on the performance of the system under varying conditions of load). A new measurement tool developed at the National Burcau of Standards is employed to record a large number of individual interactive ses- 
sions over a period of three years. The basic data of interest are the number and rate of characters sent by user and system, and latencies or delays prior to and during transmission by either party. These data are fit to a model of user-computer interaction which distinguishes between stimuli from the user, acknowledgements from the system (which only indicate that a service request has been received) and responses from the system (which contain meaningful information).

Analysis of the data consists of grouping according to two independent criteria: 1 ) maximum operating line speed of the terminal (either 10, 15 or 30 characters per second); and 2) type of application (for each individual service request). The data are grouped according to these criteria and cumulative frequency distributions are computed for each of 14 parameters of the model. Non-parametric tests are used to determine the significance of differences in the distributions of different sets of data.

The methodology itself is the major contribution of the study, providing, as it does, a quantitative way to investigate a variety of phenomena associated with interactive computing. The most interesting specific finding from the data collected is the increase in output data length as the terminal speed increases.

SP500-49. Computer science \& technology: Modeling and measurement techniques for evaluation of design alternatives in the implementation of database management software, $D$. $R$. Deutsch, Nat. Bur. Stand. (U.S.), Spec. Publ. 500-49, 244 pages (July 1979) SN003-003-02088-5.

Key words: analytic models; database management; model validation; performance evaluation; performance measurement; predictive modeling; set-processing; simulation; software design.

The substantial costs associated with building complex hardware/software systems make the traditional development approach of implementation followed by several iterations for modification and enhancement unacceptable for building modern database management systems. Mechanisms for determining gross feasibility prior to the commitment of resources for major software development efforts are required. An integrated approach combining the development of a limited but well-structured DBMS prototype with the use of high-level measurement and predictive modeling techniques for evaluating design alternatives in the implementation of database management software is proposed as an alternative to the traditional development-enhancement spiral.

Using a prototype for a set-theoretic implementation of a database management system with a relational user interface as an object, this research demonstrated that proposed DBMS designs can be evaluated through the use of performance prediction models based on prototype implementations and associated measurement systems.

SP500-50. Computer science \& technology: Computers, personnel administration, and citizen rights, A. F. Westin, Nat. Bur. Stand. (U.S.), Spec. Publ. 500-50, 465 pages (July 1979) SN003-003-02087-7.

Key words: citizen rights; computers; computer utilization; confidentiality; data systems; personnel administration; personnel practices; personnel records; privacy; record-keeping practices; relevant information; security.

This report investigates the impact of computers on citizen rights in the field of personnel record-keeping. Part 1 traces the changing patterns of employment and personnel administration in America from the 19th century to the present. Part 2 examines the trends in computer use in personnel administration starting with payroll processing in the mid 50s to the present day Human Resources Information Systems. The effect of orrends on citizen rights are highlighted in eight profiles ( 3 indepth) of Federal Government and business organizations and a discussion of non-Federal Government and non-profit organizations in Part 3. Part 4 compares the overall effects of computer technology against the effects of current personnel administration policies (organizational and legislative) on the four key dimensions of employee rights; relevance of data collected, employee access to records, confidentiality of data collected, and disclosure of data to third parties. Part 5 discusses policy alternatives for observing fair employee information practices. An extensive bibliography (52 pages) of material compiled and used by the project in preparing this report is appended.

SP500-51. Computer science \& technology: Recommendations for database management system standards, J. Berg, Chaitman, Nat. Bur. Stand. (U.S.) Spec. Publ. 500-51, 99 pages (Aug. 1979) SN003-003-02095-8.

Key words: database; data-description; data-dictionary; data-directory; data-manipulation; DBMS; languages; query; standards.

In March 1977, F1PS Task Group 24 initiated a study of the need for database standards within the Federal Government. The voluntary participants from several Federal agencies considered the actions of other standards bodies; reviewed the alternative to Federal standards; examined the issues of standards adoption, timing, and impact on technology; developed a method for justifying standards, and attempted to anticipate likely database technology advancements.

TG-24 recommended standards in certain specific technical areas, concluded that standards were premature in others, and emphasized the need for certain guidelines.

This final report of TG-24 contains the recommendations for standards and guidelines as well as the assumptions, benefits, and costs considerations used to justify the recommendations.

SP500-52. Computer science \& technology: Computer performance evaluation users group (CPEUG). Proceedings of the Fifteenth Meeting held at San Diego, CA, Oct. 15-18, 1979 , J. E. Weatherbee, Ed., Nat. Bur. Stand. (U.S.), Spec. Publ. 500-52, 240 pages (Oct. 1979) SN003-003-021 18-1.

Key words: computer performance evaluation; computer performance measurement; computer performance prediction; computer system acquisition; conference proceedings; CPE in auditing; hardware monitoring; CPEUG; installation management; on-line system evaluation; prediction methods; queuing models; simulation; software monitoring; workload definition.

The Proceedings record the papers that were presented at the Fifteenth Meeting of the Computer Performance Evaluation Users Group (CPEUG 79) held October 15-18, 1979, in San Diego, California. With the theme "The Expanding Scope of CPE," CPEUG 79 focused on changes in CPE techniques that will occur in an era of increased use of distributed processing techniques. The program was divided into two parallel sessions with one session devoted to the presentation of technical papers on previously unpublished work and the other devoted to tutorials and case studies. The technical papers fall into one of two general categories, (1) application of CPE in installation management and (2) methods and tools of CPE as a technical discipline, and are presented in the Proceedings in their entirety. Summaries of several of the tutorials and case studies are also presented in the Proceedings. These proceedings include the following papers (indented):

Data processing information utilization-An audit perspective, M. J. Thibault, SP5OO-52, pp. 3-8 (Oct. 1979). 
Key words: ADP auditors; audit; data center; data processing; information utilization.

This paper outlines an audit approach used to evaluate ADP support of the user population and covers subjects such as (i) measurement of user satisfaction, (ii) data center responsiveness to user information requirements, and (iii) distribution methods for computer based information, i.e., on-line availability vs. hardcopy distribution. The paper's intent is to show that audit disciplines can disclose user needs. Specific review methods, sampling criteria and actual audit results are presented supporting this premise. Through user oriented reviews non data processing professionals can be effective ADP auditors.

Auditing an IMS system, C. L. Gausche and W. J. Schwinden, SP500-52, pp. 9-19 (Oct. 1979).

Key words: auditing; capacity planning; computer performance evaluation; Information Management System (IMS); management reporting; performance analysis; structured approach.

This paper provides a structured approach to data collection, analysis, and reporting when conducting a performance audit of an IBM Information Management System (IMS). Performance auditing, analogous to the traditional definition of an operational audit, is concerned with: verifying planned results of a change, developing a current baseline, and reporting this data in management usable terms. The approach of the paper is to provide the performance auditor with information concerning: a performance auditing procedure, various data collection tools, applications of performance analysis techniques, and how gathered data and subsequent analysis can be structured into a logical flow. The performance audit steps are amplified by using a case study. A reporting format, used extensively by Boeing Computer Services (BCS) Company, is also included.

Applications and limitations of the cost-value technique for competitive computer selection, R. E. Barbour, Jr., J. O. Holcombe, C. S. Harris, and W. C. Moncrief, $S P 500-52$, pp. $25-$ 36 (Oct. 1979).

Key words: computer evaluation; computer performance; computer procurement; computers; eomputer selection; cost-value; cost-value technique; EDP selection; evaluation methodology; performance evaluation; procurement.

The cost-value technique, as proposed by E. O. Joslin in Computer Selection, was investigated in a simulated DOD system procurement exercise. The cost-value technique was found to be favorable over less formalized and rigorous approaches such as specification fulfillment, cost only, cost-effectiveness selection, etc. The cost-value method requires detailed research on the part of both the decisionmaker and the end user into the needs and intended applications of the system prior to issuance of a Request for Proposals (RFP). They must analyze and define all aspects of system applications and segregate these into mandatory and desirable features, assigning a dollar value to each. With a more thorough definition of system requirements, the system proposals are driven more by the purchaser's needs than by "marketing assumptions" made to enhance the vendor's "product. In order for any system to be considered for selection under this method, the system must meet all mandatory features. Qualifying systems are then judged on the basis of their cost-value relative standing in meeting the desirable features. This approach provides to all vendors the criteria for selection, thus establishing a fair and competitive basis for system proposals. Proposal relevancy is therefore encouraged with respect to organizational needs. The selection experiment showed that employing the cost-value technique in a real market environment was subject to several difficulties not common to other techniques. The problems encountered and the limitations of the technique will be discussed in the context of competitive computer procurement.

Computer selection: To measure or not to measure, $S$. A. Mamrak, SP500-52, pp. 37-52 (Oct. 1979).

Key words: computer measurement; computer procurement; computer selection; decision theory.

Measurement phases of a computer selection process are costly and time-consuming. A decision must be made prior to measurement whether the data obtained will be worth more to the decision maker than the cost of conducting the measurement experiment. This paper illustrates how statistical decision theory can be applied to answer that cost/value question.

Benchmarking interactive systems: Modeling the application, C. R. Spooner, SP500-52, pp. 53-64 (Oct. 1979).

Key words: benchmarking; computer performance measurement; distributed processing; interactive systems; kernels; modeling; real-time; simulation; synthetic programs.

A benchmarking methodology has been developed that applies to competitive procurements for dedicated interactive applications, where the hardware and at least some of the operating system are to be off-the-shelf, but where a suitable implementation of the application does not yet exist. The methodology was developed by The MITRE Corporation under the sponsorship of the Federal Aviation Administration (Contract DOT-FA79WA-4184). It consists of preparing a model of the proposed application in the form of a set of modules of synthetic code, and requiring each of the competing vendors to run the model on his proposed system. The vendor provides two items: a package that interfaces his operating system to the buyerprovided model, and a separate benchmark driver (hardware plus software). The driver reads artificial messages off a buyer-provided scenario tape and delivers them in real-time. Having time-starnped the corresponding responses, it writes them to an output tape for subsequent analysis. The model is written in a very high level language, from which it is translated automatically by software into High Order Language for delivery to vendors.

This paper describes the modeling of the application. The model is not intended to measure the vendor's design or programming skills, but it must drive the hardware in approximately the same manner as would his eventual implementation. It must do this for all cornpeting configurations, even though none of them are known when the benchmark is being developed. After briefly summarizing the overall benchmark approach, the paper shows how the application is modeled in terms of abstract components whose implementation can be vendor-dependent, with a topdown approach being taken to the functional requirements for the application. Relevent considerations are discussed in the text of the paper.

Methodology for establishing a computer performance management system: A case study, G. H. Goodman, SP50O52, pp. 69-77 (Oct. 1979)

Key words: capabilities; methodology; needs; Performance Management System (PMS).

The first steps in establishing a computer performance management system are critical to success. Lack of atten- 
tion to organizational and management needs are as likely to lead to failure as lack of attention to technical details. This paper prcsents a methodological framework which is intended to assist those who are establishing a CPM capability. Techniques are suggested to enable the individual to assess the needs of his or her own organization, and to design a performance management system to meet those needs.

Naval laboratories' quality of service standards, J. S. Dodds, SP500-52, pp. 79-86 (Oct. 1979).

Key words: availability standards; batch processing; calibration programs; computer standards; interactive processing; quality of service; response time; turnaround time.

This paper summarizes the objectives, history and status of user quality of service standards that are being developed by the Naval Laboratories for their general purpose computer centers. The problem includes social, economic and technical challenges. Standards must be relevant to the users, non-competitive with other evaluation processes, economically applied and consistent among the different computer architectures installed at each Laboratory. Each standard currently being used will be presented along with the rationale for the standard.

Computer system migration planning through benchmark performance evaluation, A. Mukherjee, A. K. Jain, and B. A. Ketchledge, SP500-52, pp. 89-104 (Oct. 1979).

Key words: benchmark performance data; empirical models; IBM 168-3; IBM 3033; migration guidelines; migration planning.

This paper presents the development of a program which provides guidelines for migration from an IBM 168-3 to an IBM 3033. This program, based on the Bell System 3033 benchmark performance data, consists of analytical and empirical models. The benchmark consisted of several real and synthetic job streams, which were run on the 168-3 and the 3033 under an MVS Operating System. The migration guidelines are in terms of (i) key 3033 system performance measures, (ii) gross configuration tuning information, and (iii) execution times for batch job steps. Furthermore, a component of this program can be uscd as a capacity planning aid for an existing 3033 system.

An optimal sample size allocation scheme for benchmark design, S. K. Tripathi, K. D. Gordon, and A. K. Agrawala, SP500-52, pp. 105-111 (Oct. 1979).

Key words: benchmarking; clustering; perforınance evaluation; stratified sampling.

A major problem in benchmark design is the selection of the jobs to compose the benchmark. In this paper, stratified sampling is applied to the problem. The strata in the job population are identified by clustering the jobs on the basis of job features. The clusters are then viewed as strata. Within a stratum, jobs are selected by simple random sampling. The question of how many jobs to select from each stratum is addressed in this paper. An extension of Neyman's result on the optimal allocation of sample points among strata to the multidimensional case is used. The technique is then applied to a real workload, and the results are examined.

Computer workload forecasting, J. E. McNeece, SP500-52, pp. 113-120 (Oct. 1979).

Key words: computer workload; data requirements; documentation cycle; forecast; projections; sensitivity analysis.
Experience has shown that the successful initiation of computer workload forecasting is directly dependent upon the quality of the data furnished by users to the requesting organization. Inaccurate data almost inevitably causes delays in the documentation cycle. The purpose of this paper is to serve as a guide for performing the analysis required to forecast workload requirements. Application of the methodology suggested herein should significantly reduce the risk of inaccurate or misleading projections.

A simulation model of JES output processing, H. P. Artis, SP500-52, pp. 123-127 (Oct. 1979).

Key words: data collection; JES output; job entry subsystem; model design; model selection; remote work stations; simulation model.

The design and implementation of a discrete simulation model of the 1BM Job Entry Subsystem (JES2 and JES3) output processing is presented. This model was developed for sizing printers at remote stations and at the central site.

Design for performance, M. J. Kirrene and M. G. Spiegel, SP50O-52, pp. 129-140 (Oct. 1979).

Key words: audit; capacity planning; financial applications; long-range planning; management control; measurement; modeling; on-line system design; performance evaluation; performance management; prototyping; remote terminal emulation; system testing.

Expensive on-line systems are difficult to justify to top management-unless your competitors or contemporaries are using them to advantage.

In 1971, AVCO Financial Services (AFS), a subsidiary of the AVCO Corporation, set out to construct an on-line system for its consumer credit operation. Funding was approved in 1972 and the design project formally began in January 1973. The first pilot branch office was converted in November 1975, and the conversion of the last branch occurred in May 1977. This is a history of how major strategic performance decisions were successfully made for AVCO's on-line system. AVCO's process of strategic performance decision-making, "design for performance," encompasses present ideas about capacity planning and performance evaluation.

AFS employed a variation of the conventional approach to the system design methodology - a process of prototyping the system and its interface with the organization in every design phase to focus on the performance issues.

Quantitative methods in computer perforamance evaluation, A. K. Jain, SP500-52, pp. 143-145 (Oct. 1979)

The application of clustering technigues to computer performance modeling, T. C. Hartrum and J. W. Thompson, SP500-52, pp. 147-161 (Oct. 1979).

Key words: cluster analysis; computer modeling; computer performance; empirical models; modeling; performance modeling; workload characterization.

The performance of a given computer system is to a large extent dependent upon its workload. A fairly standard approach to workload modeling is to define the workioad by the amount of computer resources each job consumes. If each resource is considered to be one element in an ordered set, then a job's workload requirement can be represented as an $\mathrm{n}$-dimensional vector $\mathrm{X}=\left(\mathrm{x}_{1}, \mathrm{x}_{2}, \ldots, \mathrm{x}_{n}\right)$ where, for example $x_{1}=C P U$ time, $x_{2}=$ central memory used, and so forth. By applying vector distance measurements the workload can be partitioned into clusters of "similar" jobs based on their nearness in n-space. This ap- 
proach has been applied to describc workloads more accurately than by the aggregate resource usage of all jobs taken together. This paper investigates the possibility of extending the clustering technique to modcling and predicting computer performance. If one hypothesizes that performance is a function of resource consumption, then one should be able to determine a predictable range of performancc for each cluster. This paper presents the results of the application of this technique to the workload characterization of a Cyber 74 computer and the subsequent investigation of the relationship between a job's turnaround time and its workload cluster.

Performance comparison measures for computer systems, 1. Dzelzgalvis, SP500-52, pp. 163-176 (Oct. 1979).

Key words: comparison measures; evaluation process; performance measures; performance ratings; response time; system design tradeoffs; thruput measures.

The need for performance ratings of computer systems is as fundamental as the measures of horsepower, calories, watts, etc. Yet the computer system performance measures that are of sufficient quality to quantify and evaluate reasonable the differences of systems of differing architectures, design, and operating systems are hard to find. That does not mean that comparisons are not made. In fact, comparisons are made quite frequently; however, the quality and value of the results is at best questionable. It will be shown that the classical performance measures of cycle time and MIPS never were accurate measures and with today's added complexity and clever system design tradeoffs, these measures can be downright distortions and/or invcrsions of the facts. The measures of thruput and response time/turn around time are the real candidates for computer system performance measurement; however, their proper evaluation can be a tedious and costly undertaking. In addition, due to the complexity of the evaluation process, these measures are prone to error and biases which can quickly destroy their quality as proper measures to be used in a comparison. This paper focuses on he evaluation process of the response time and thruput measures, identifies the potential pitfalls, suggests some useful approaches to their proper evaluation, and identifies key problems yet to be resolved.

Event driven capacity planning, S. W. Cox, SP500-52, pp. 179-192 (Oct. 1979).

Key words: capacity planning; hardware monitors; modeling; performance evaluation; performance prediction; simulation; validation; workload characterization; workload management.

Accurate performance prediction for capacity planning has historically been hindered by inadequate workload descriptions. Present techniques often rely on accounting information without considering its sufficiency as a basis for performance prediction. Further, the performance reports generated for capacity planning often force the analyst to take sizable intuitive steps in reaching his conclusions. As a result, planning decisions must be based on predictions of unknown accuracy and sensitivity to error.

A performance prediction system for capacity planning is under development. The important events of system/workload interaction are recorded and used to drive an efficient hardware/software simulation model. After each workload has been traced, the model can predict performance under a wide variety of loads, mixes, and configurations. For a small but diverse domain of demand paging environments, accurate response time predictions have been achieved.
A FORTRAN synthetic program for benchmarking, P. M. Fleming and A. C. Rucks, SP500-52, pp. 193-199 (Oct. 1979).

Key words: benchmarking; performance evaluation; synthetic program; workload mapping.

Benchmarking is a generally accepted and essential element in the competitive procurement of computer systerhs. A benchmark workload consists of a set of application programs, synthetic programs, or a combination of these designed to be representative of expected system workload. A benchmark workload developed from application programs is unacceptable because it (1) is potentially biased in favor of the incumbent vendor, (2) may not be truly representative, and (3) may contain data that is subject to privacy and security restrictions. A benchmark workload constructed from synthetic programs does not suffer from these limitations. The basis for employing synthetic benchmarks is well established; however, previous synthetic programs have failed to provide a means to test system capacity through the execution of a reasonable variety of programming functions. The FORTRAN Synthetic overcomes this disadvantage of previous synthetics by providing a set of programming functions which test a wide range of system capabilities. The Synthetic is modular in structure to provide representativeness and control of instruction mixes; parameter driven to provide control of processing time; and provides a means of controlling memory usage. The structure of the FORTRAN Synthetic and the process of workload mapping is presented.

The NBS Network Measurement Instrument, M. D. Abrams and D. C. Neiman, SP5O0-52, pp. 201-211 (Oct. 1979).

Key words: computer; computer communications; computer performance measurement; data measurement; measurement; performance measurement.

The NBS Network Measurement Instrument (NM1) represents the third generation implementation of an approach to the measurement of interactive computer networks, teleproeessing systems, and network services which focuses on the service delivered to users rather than on the internal operating efficiency of the system. The information obtained aids users in the quantitative evaluation of such systems and services. The performance measures and measurement conditions are described. The applicability of the stimulus-acknowledgement-response model to interactive asynchronous, character synchronous (e.g., bisync), and bit synchronous (e.g., SDLC and ADCCP) communication is discussed. The NMI is presented in terms of its functions, statistical capabilities, architecture, and communications protocol state transitions.

Performance analysis of a saturated system-A case study, N. Lennon and W. P. Bond, Jr., SP50O-52, pp. $215-218$ (Oct. 1979).

Key words: inventory management; on-line; performance; response time; saturated system; transaction processor.

This paper describes some recent experiences that the authors have had in attempting to gather decision-making data from an on-line system which was totally saturated, and for which minimal performance measurement tools were provided. The case study presented illustrates the limited use of data resulting from post facto measurement techniques. An attempt has been made to illustrate the type and quality of results which can be expected under these circumstances. 
Teleprocessing transaction thruput performance, B. Irwin, SP500-52, pp. 219-226 (Oct. 1979).

Key words: input lockout; mathematical modeling; queuing models; race conditions; TCAM data flow; teleprocessing.

Financial industries are dependent on Teleprocessing systems to execute their daily transactions. Unacceptable Teleprocessing performance can, and does, impede the expected flow of line of business transactions, thus degrading the anticipated level of work units for that line of business. This paper is an analysis of TCAM's tuning parameter: BUFFER DELAY VALUE. The analysis develops a mathematical characterization of TCAM's BUFFER DELAY VALUE which describes the race conditions inherent in TCAM logic. Such race conditions potentially degrade Teleprocessing transaction throughput. The analysis resulted in a TCAM modification to search a table of BUFFER DELAY VALUES, where each value corresponds to a number of stations currently active on the line. The instantaneous optimal DELAY VALUE generated by this table acts to optimize line utilization and prevents station input transaction line lockouts.

Methodology for performance evaluation and capacity planning, A. O. Allen, SP500-52, p. 227 (Oct. 1979).

Key words: analytic queueing theory models; capacity planning; performance evaluation.

In this tutorial we summarize a methodology taught at the Los Angeles IBM Systems Science Institute in a class called Performance Evaluation and Capacity Planning.

Benchmarking with remote terminal emulation, T. F. Wyrick and R. E. Youstra, SP500-52, pp. 229-230 (Oct. 1979).

Planning and implementing remote teleprocessing services: Management perspectives of the TSP, R. L. DeMichiell and G. L. Underwood, SP500-52, pp. 231-232 (Oct. 1979).

Key words: competitive negotiated procurement; computer management; remote teleprocessing; statement of work; teleprocessing services program; timesharing.

This tutorial addresses a competitive negotiated procurement of remote timeshare services under the Teleprocessing Services Program (TSP). The guidelines provided by the Department of Transportation and the General Services Administration governing the U.S. Coast Guard have resulted in the implementation of timesharc services for the U.S. Coast Guard Academy. A final comprehensive report culminated a rather extensive effort.

It is the intention here to discuss many aspects of the procurement from the perspective of the personnel involved in the various phases of the process. The relevant issues will be examined and some reference literature on the general subject will complement the two main thrusts of the presentation: (1) to identify and clarify the procedures and options, and (2) to provide practical, locally-derived guidelines for future implementation of the program.

Although the guidelines are general in nature, they were derived from a detailed analysis of the events which recently were experienced by the authors. The completion of the negotiation for a five-year systems life procurement under TSP resulted in a savings in excess of half a million dollars.

Selection and evaluation of instructional time-sharing services-(A tutorial outline), R. T. Close and R. A. Kambeitz, SPSOO-52, pp. 233-234 (Oct. 1979).
Key words: benchmarking; cost analysis; evaluation; procurement; technical analysis; time-sharing; TSP.

The U.S. Coast Guard Academy has completed a multiyear procurement of instructional time-sharing services using the General Services Administration Teleprocessing Services Program (TSP). This fully competitive procurement included extensive technieal and cost evaluations and adhered to Department of Transportation and Coast Guard directives for data processing contracts. The technical evaluation included an on-site operational capability demonstration with benchmarking. The final ranking of vendors used a point scoring system which included both the technical and cost analyses.

Tutorial on benchmark construction, H. Letmanyi, SP50052, pp. 235-240 (Oct. 1979).

Key words: benchmark construction process; benchmark validation; competitive evaluation; tutorial; vendor systems; workload requirements.

This tutorial will provide participants with a detailed overview of the benchmark construction process-the steps involved and the tools that can be employed to construct a benchmark. This tutorial is recommended for those who have an interest in constructing benchmarks for use in the competitive evaluation of vendor systems.

A brief review of the ADP system evaluation and selection process within the Federal Government will first be given to identify how the benchmark construction proccss fits into the total selection process. Next, the tutorial will discuss in a step-by-step fashion those tools and techniques which can be used to analyze existing workloads, project future workloads, and represent work load requirements via benchmarks. The importance of having definite objectives and goals prior to constructing a benchmark, as well as the need for benchmark validation and documentation will also be discussed. An outline of the topics to be covered in the tutorial follows.

Using accounting log data in performance reporting, J. P. Bouhana, SP500-52, pp. 241-243 (Oct. 1979).

Key words: accounting logs; performance evaluation; workload characterization.

This tutorial summary outlines several topics pertinent to using a computer system's accounting log file as a basis for performance rcporting. Some major topics are a log's organization and contents, the types or reports and displays which can be generated, and the problems encountered in using $\log$ data. It is concluded that although accounting logs have an understandably principal orientation toward accounting, they can be effectively used for performance reporting and for operations reporting as well.

SP500-53. Computer science \& techwology: Technology mssessment: $A D P$ installation performance measurement and reporting, C. B. Wilson, Nat. Bur. Stand. (U.S.), Spec. Publ. 50053, 37 pages (Sept. 1979) SN003-003-02123-7.

Key words: computer performance evaluation (CPE); computer performance management (CPM); installation management; installation performance management; performance measurement and reporting; resource management; standard performance measures.

This report compares the current status of ADP installation performance measurement and reporting in the Federal ADP community with the best practices as found in the Federal and private sectors and described in the literature. The comparison reveals that more effort could be expended by Federal sites in 
the area of computer performance management. The principal obstacles to more and better performance programs are perceived to be the lack of needed measures on many systems and the magnitude of the effort involved in accessing and analyzing the measures which are available. The report discusses several underlying causes for these obstacles and makes three recommcndations which could partially relieve the situation: (1) development of standard performance measures, (2) development of a Government-wide data base for normative performance ranges, and ( 3 ) development of statistical computer performance evaluation techniques.

SP500-54. Computer science \& technology: A key notarization system for computer networks, M. E. Smid, Nat. Bur. Stand. (U.S.), Spec. Publ. 500-54, 35 pages (Oct. 1979) SN003-003$02130-0$.

Key words: cryptography; digital signatures; encryption; identifiers; key management; key notarization.

A cryptographic, key notarization system is proposed for computer networks to protect personal (nonshared) files, to communicate securely both on and off-line with local and remote users, to protect against key substitution, to authenticate system users, to authenticate data, and to provide a digital signature capability using a nonpublic key encryption algorithm. The system is implemented by addition of key notarization facilities which give users the capability of exercising a set of commands for key management as well as for data encryption functions. Key notarization facilities perform notarization which, upon encryption, seals a key or password with the identities of the transmitter and intended receiver.

SP500-55. Computer science \& technology: Selection of data entry equipment, S. A. Recicar, Nat. Bur. Stand. (U.S.), Spec. Publ. 500-55, 77 pages (Nov. 1979) SN003-003-02133-4.

Key words: application; character set; computer interface; cost; data entry; edit; operator speed; record size; transaction volume; transfer speed; validate; verify.

This publication provides information to be used by Federal organizations in the selection of data entry equipment. It serves as a supplement to the Federal Information Processing Standards Publication (FIPS PUB) 67, "Guideline for Selection of Data Entry Equipment." The objective is to make available information that could lead to the selection of more efficient and economical data entry systems. This report provides information about economic and general operational considerations, steps to be followed in acquisition and training, and other factors pertinent to data entry equipment selection. Equipment profiles for the different data entry methods are also provided.

SP519. Trace organic analysis: A new frontier in analytical chemistry. Proceedings of the 9th Materials Research Symposium held at the National Bureau of Standards, Gaithersburg, MD, Apr. 10-13, 1978, H. S. Hertz and S. N. Chesler, Eds., Nat. Bur. Stand. (U.S.), Spec. Publ. 519, 788 pages (Apr. 1979) SN003-003-02054-1.

Key words: drug analysis; food toxicants; hormones; neurotransmitters; nutrients; organic pollutants; trace organic analysis.

Researchers in diverse areas must currently perform critical analyses on minute quantities of organic compounds in various matrices. It was the aim of this Symposium to bring together these scientists to discuss their common problems and to explore current and impending technology for organic analyses. Emphasis was placed on the total analysis, from collecting the sample through interpreting the results, rather than upon the measurement only.
The Proceedings consist of a series of invited papers by experts as well as particularly appropriate contributed papers. Topics covered in thc Proceedings are as follows: Sampling and Sample Handling for Trace Organic Analysis, State-of-the-Art Analytical Systems, Analytical Techniques on the Horizon, Analysis of Nutrients, Analysis of Organic Pollutants and Their Metabolitcs in the Ecosystem, Analysis of Drugs in Body Fluid, Analysis of Food Toxicants, and Analysis of Hormones and Neurotransmitters. These proceedings include the following papers (indented):

Statistical sampling and environmentaI trace organic analysis, H. H. Ku, SP5 19, pp. 1-6 (Apr. 1979).

Key words: environmental measuremcnts; modeling; sampling schemes; statistical sampling.

In the field of analytical chemistry, statistical sampling traditionally did not play a prominent role. Samples were usually drawn, or composited, from fairly homogeneous material and the characteristic of interest determined. The results were averaged and claimed to represent the value of the property desired. This procedure has been used in manufacturing and industrial processing for some time, and has shown to be satisfactory for the purpose. For example, in determining percent carbon in steel, only one preliminary grab sample from a melt is taken and analyzed to give the carbon content representing the whole 160 tons.

Once the chemists ventured from manufactured goods with controlled composition to natural products, the variability of the properties among samples began to pose a problem. In determining the sucrose content of a shipload of raw sugar, samples were taken systematically every 300 tons while unloading. The average of the 90 or so samples in a shipload is considered to be "the sucrose content" of the whole shipload by definition. Where the buyer and seller can agree on a specified procedure, the purpose is served.

In environmental measurements, or in analysis of low level contaminants, time and space added dimensions to the statistical sampling problem. Coupled with difficulties in extraction and measurements in trace organic analysis, the problem is indeed formidable. Any knowledge as to sources of variability and pattern of variability, however, would be helpful in dealing with the sampling problems.

It is suggested that the design of a proper statistical sampling scheme depends almost entirely on the purpose for which the results are going to be used. Hence, without an explicit and defined purpose for an undertaking, the design of the sampling scheme cannot be formulated for efficient data collection and for the correct interpretation of results.

Sample preparation for environmental trace organic analysis, F. C. McElroy, T. D. Searl, and R. A. Brown, SP519, pp. 7-18 (Apr. 1979).

Key words: gas chromatography; gas chromatography/mass spectrometry; preconcentration techniques; sample preparation; ultraviolet spectrometry.

This paper covers the handling of markedly different sample types, namely gas (ambient air, stack gas), water, and solid wastes. Emphasis will focus upon the sample preparation for the measurement of EPA's priority pollutants exclusive of pesticides and some specialty byproducts.

For gas samples, toxic compounds are present in the gaseous and particulate phases. Volatile components are concentrated by passing the gas through solvent, carbon, or porous polymer resins. They are quantitatively dissolved and introduced into the instrument. After removal of particulates by filtration or cyclonic action, the nonvolatile 
toxics are measured by GC/MS, GC with and without specific detectors, or HPLC.

In the analysis of water, volatile compounds of low solubility are removed by nitrogen sparging, trapped and analyzed as mentioned above. Nonvolatiles such as polynuclear aromatic hydrocarbons, PCB's, or phenols are adsorbed on porous polymer resins or solvent extracted. The resulting organic concentrate is analyzed in the samc manner as particulates.

Solid wastes are simpler in that the toxics are already present in a concentrated form. Volatiles are determined by simply heating the sample in the instrument. Nonvolatile organics are dissolved by solvent in Soxhlet or ultrasonic extractors. Following extensive cleanings the pollutants are determined.

It is convenient and desirable to employ intcrnal standards for quantitation purposes. These may consist of 1) a representative organic known to be absent in the sample to be analyzed, or 2) a compound especially labeled with a halogen, deuterium or ${ }^{14} \mathrm{C}$ atom.

Analysis of water for chlorinated hydrocarbon pesticides and PCB's by membrane filters, D. A. Kurtz, SPS19, pp. 19. 32 (Apr. 1979).

Key words: cellulose triacetate filters; gas chromatography; pesticide residues; sampling.

Pesticide residues in water have been analyzed through the use of cellulose triacetate membrane filters. As a chemisorption separation method DDT analogs, mirex, aldrin, and PCB mixtures have been separated from water by absorption to these filters. Recovery of these compounds has been achieved through elution with diethyl ether. Filters were cleaned before use with diethyl ether.

Adsorption of $p, p$.-DDT, $p, p$.-DDE and Aroclor mixtures 1242 and 1254 were found to be $98-99 \%$ complete. Maximum loading studied at this time has been $385 \mathrm{ng} / \mathrm{cm}^{2}$ for DDT analogs and $1650 \mathrm{ng} / \mathrm{cm}^{2}$ for Aroclor -1254 .

Recovery from membrane filters of these compounds ranged from 69 to $113 \%$. p,p.-DDT analogs ( $p, p .-\mathrm{DDT}$, $p, p$. TDE, and p,p.-DDE) at charge levels of 60,300 , and $1500 \mathrm{ng}$ were recovered from 68 to $89 \%$. Mirax at 300 and $7500 \mathrm{ng}$ charge was recovered at $97-113 \%$. Aroclor mixture 1242 at charge levels of 400,2000 , and $10,000 \mathrm{ng}$ and Aroclor mixture 1254 at similar levels were recovered at $89-112 \%$ and $83-84 \%$, respectively

The recovery of DDT analogs and mirex were found to be similar from water whose $\mathrm{pH}$ was 2 and 7 but at $\mathrm{pH}$ 12 it dropped to almost zero.

The importance of this new chemisorption separation method is seen by its convenience of operation. Separations can be done in the field and filters stored easily. A high degree of concentration can be achieved.

Application of liquid and gas chromatographic techniques to a study of the persistence of petroleum in marine sediments, R. G. Riley and R. M. Bean, SPS19, pp. 33-40 (Apr. 1979).

Key words: gas chromatography-mass spectrometry; glass capillary chromatography; high pressure liquid chromatography; hydrocarbon persistence; infrared spectroscopy; petroleum hydrocarbons; sediment analysis.

A technique employing high-pressure liquid chromatography (HPLC) and glass capillary chromatography has been used to monitor the long-term persistence of petroleum in marine sediments. Petroleum in sediments was studied using Prudhoe Bay crude (PBC) as the host oil, as part of a combined chemistry/biology study of the impact of oil on marine ecosystems.
Total monoaromatic-diaromatic hydrucarbon concentrations in extracts of oil polluted sediments were analyzed by HPLC on series coupled columns containing Durapak oxypropionitrile on Porasil C. Chromatographic separation of the extracts produced a saturated fraction and a monoaromatic-diaromatic fraction which was approximately $80 \%$ resolved as determined by the separation of model compounds. The quantitative analysis of the summation of the monoaromatic-diaromatic componcnts was performed with a calibration curve prepared from a PBC aromatics fraction isolated by an ASTM method. Infrared analysis of carbon tetrachloride extracts of the same sediments provided total oil concentrations as complementary information to the HPLC analysis. More detailed compositional information on individual saturate and aromatic hydrocarbons in oil contaminated sediments was provided by glass capillary chromatography.

The above methods were applied to a study of the persistence of PBC in two types of sediments that were exposed to conditions which simulated possible environmental pollution situations. In a laboratory experiment, a finetextured sediment containing PBC oil was monitored periodically over a period exceeding 1 year after deposition in a continuous-flow seawater bioassay apparatus. Similarly, the fate of PBC in a field experiment involving a coarse beach sediment located in an intertidal zone was studied. The persistence of PBC in both sediment systems is discussed in terms of total oil concentration, concentrations of hydrocarbons and hydrocarbon classes, and some of the physical, chemical, and biological parameters which affect the degree of persistence.

The use of a fluorescence detector in high performance liquid chromatographic routine analysis of polycyclic aromatic hydrocarbons in environmental pollution and occupational health studies, B. S. Das and G. H. Thomas, SPS19, pp. 4156 (Apr. 1979).

Key words: environmental pollution; fluorescence; high performance liquid chromatography; occupational health; picogram; polycyclic aromatic hydrocarbons; selectivity; sensitivity; specificity; trace analysis.

A routine method for trace analysis of nine major polycyclic aromatic hydrocarbons (PAH) by high performance liquid chromatography (HPLC) with fluorescence dețection is described. The fluorimetric detection involves a deuterium light source and excitation wavelengths below $300 \mathrm{~nm}$. Careful selection of excitation and emission wavelengths gives a high degree of selectivity and specificity in fluorescence detection and permits complete analysis of individual PAH in a multi-component mixture. The extremely high sensitivity in fluorescence detection has reduced minimum detectable concentration of the PAH close to subpicogram levels, e.g., benzo(a)anthracene 0.19 $\mathrm{pg}$, benzo(k)fluoranthene $0.11 \mathrm{pg}$, benzo(a)pyrene 0.34 pg. The sensitivity is found to be strongly influenced by the amount of water present in the PAH solution to be analyzed. The HPLC-fluorescence system allows the use of dilute solutions, thus eliminating the usual clean-up procedures associated with trace analysis. The application of the method for the analysis of PAH in environmental, process and occupational health samples is discussed.

Study of organometal speciation in water samples using liquid chromatography with electrochemical detection, W. A. MacCrehan, R. A. Durst, and J. M. Bellama, SP519, pp. 5763 (Apr. 1979).

Key words: electrochemical detection; liquid chromatography; methylmercury; organometals; water preconcentration. 
A new measurement technique for trace organometal analysis employing liquid chromatography with electrochemical detection is described. Important considerations in the optimization of sensitivity and selectivity of this detection approach are discussed.

A column preconcentration for methyl- and ethylmercury from water samples is outlined.

An automatic sampler, a master analytical scheme, and a registry system for organics in water, A. W. Garrison, J. D. Pope, A. L. Alford, and C. K. Doll, SP519, pp. $65-78$ (Apr. 1979)

Key words: accumulators; analysis of organics in water; automatic sampler; master analytical scheme; non-purgeable organics; organic pollutant; purgeable organics; WaterDROP.

A three-phase analysis program for organics in water is described. In the first phase, a prototype automatic sampler was constructed to sample and concentrate organic compounds from dilute systems, including finished drinking water. The sampler collects and seals up to 26 "grab" samples for analysis of purgeable organics and concentrates up to 14 samples on various accumulators, such as $\mathrm{XAD}$ resins, for analysis of non-purgeable volatiles and perhaps non-volatiles. Samples are collected according to preset sampling frequencies, sequences, flow rates, and collection periods. The sample water is exposed only to Teflon and glass components. The sampler control circuits are AC or DC powered; valving and switching mechanisms are pneumatically operated using bottled gas. The sampler is refrigerated to $4{ }^{\circ} \mathrm{C}$ and is capable of unat tended operation for up to 7 days in a remote location.

The wide distribution of organics in water emphasizes the need for development of a master analytical scheme that will serve as a general protocol for analytical surveys in which all volatile organic compounds above a specified level in any type of water are identified and quantified. In the second phase, such a scheme, which incorporates modern GC-MS-computer analytical techniques, is currently being developed by the U.S. Environmental Protection Agency (EPA), and should be available in early 1980. In developing the scheme, emphasis will be on comparison, selection, and optimization of techniques for sampling, extraction, cleanup, and separation of all gas chromatographable organics in water. A computer program for quantification will be based upon internal standards selected for each major functional group and volatility class of organics, and upon predetermined recovery and detector response data obtained using several model compounds from each class. The scheme will be tested and improved using samples of surface water, drinking water, and industrial and municipal effluents.

In the third phase, a comprehensive data collation and retrieval system for organics in water will be developed by the EPA. This system, called the Distribution Register of Organic Pollutants in Water (WaterDROP), will include a means for continual updating and dissemination of new in formation on organics identified in water. WaterDROP will include various chemical and geographical descriptors for each compound, as well as data on concentration, source, analytical method, etc. The data base will reside in computer storage to allow interactive data retrieval by a remote operator and will, in addition be available in a slightly abbreviated cross-indexed printed version. WaterDROP will be searchable by several parameters to locatc compounds of particular interest to analytical chemists, epidemiologists, enforcement groups, and others.
Identification and quantitation of aromatic hydrocarbon metabolites in marine biota, L. C. Thomas, W. D. MacLeod, Jr., and D. C. Malins, SP519, pp. $79-86$ (Apr. 1979).

Key words: high-pressure liquid chromatography; marine biota; metabolites; polynuclear aromatic hydrocarbons.

Many marine organisms metabolize polynuclear aromatic hydrocarbons by adding oxygen directly to the aromatic rings. Typical chemical species resulting from such oxygenations arc epoxides, dihydrodiols, phenols, and quinones. A variety of conjugates may be formed in subsequent reactions.

Separations of a number of conjugated and non-conjugated metabolites were achieved by high-pressure liquid chromatography (HPLC). The analytical procedures employ an internal standard of metabolites obtained from the urine of rats exposed to radio-labcled naphthalene. By use of the intcrnal standards it was possible to identify metabolites in fish tissues, regardless of whether the compounds were structurally identified, and obtain recovery data on those metabolites that were common to both tissue extracts.

Techniques to purify radiolabeled aromatic hydrocarbons by HPLC and to quantitate hydroxylated and conjugated metabolites of naphthalene are described.

The trace-level determination of organics by high-pressure liquaid chromatography, R. W. Edwards, K. A. Nonnemaker, and R. L. Cotter, SP519, pp. 87-94 (Apr. 1979).

Key words: extraction; herbicides; high pressure liquid chromatography; organics in water; pesticides.

High-pressure liquid chromatography holds great promise as a tool for the rapid, trace-level determination of multi-residue samples of organics in water. Because of the great versatility available in selecting mobile phase/stationary phase combinations, many organic compounds can be collected and determined by HPLC without the concommitant problems of extraction, derivatization, clean-up, etc., that plague other methods. In addition, HPLC can be used as a tool to fractionate multi-residue samples of organics into smaller fractions, for further study.

This paper will discuss several applications of HPLC to the analysis of organics in a number of matrices.

One application to be discussed is the analysis of pentachlorophenol in waste effluents. This HPLC method is rapid, requiring no derivatization of the $\mathrm{PCP}$, specific for PCP and can determine PCP in the low ppb range.

Another application is the multi-residue determination of chlorphenoxy acid herbicides in drinking water. Contrary to the gas-chromatographic method, which requires several hours per sample, the HPLC requires only minutes, and determines the herbicides in the low $\mathrm{ppb}$ range.

A third application that will be discussed is the isolation of a single pesticide metabolite from a soil extract containing a wide-array of organic components.

Co-condensation with $n$-pentane. A new route to concentration of atmospheric pollutants, D. J. Freed, SP519, pp. 95-99 (Apr. 1979).

Key words: air sampling; co-condensation; gas chromatography; trapping.

An air sampling system has been developed in which gaseous $n$-pentane is introduced into the air stream during collection of the analytical sample. The gases are mixed and then passed through a cold trap maintained at liquid nitrogen temperature during which time the pentane vapor 
is condensed to the solid. Trace organic constituents of the sampled air stream are trapped in the matrix of solid pentane and thereby concentrated. Flow rates of pentane in the range 5 to $50 \mathrm{~cm}^{3} / \mathrm{min}$ have allowed the collection of up to 1 gram of solid pentane for sampling times of up to 1 hour. Depending on the flow rate of the sampled air stream and the original concentration of the gaseous pollutant, concentration factors of up to three orders of magnitude are achieved. As an example, an air stream containing 1 ppm by volume of benzene was sampled at a flow rate of $100 \mathrm{~cm}^{3} / \mathrm{min}$ together with a pentane stream flow rate of $10 \mathrm{~cm}^{3} / \mathrm{min}$ for a total period of 10 minutes. This resulted in the collection of approximately $100 \mathrm{mg}$ (150 microliters) of solid pentane. This was allowed to warm to room temperature and subsequently analyzed by gas chromatography. The trapping efficiencies for a number of common atmospheric pollutants have been measured and all are greater than $90 \%$. The technique is of particular value in the case of reactive materials or those which react with the commonly used charcoal tubes. Other factors and possible interferences are discussed.

Analysis of organic ambient aerosols, E. S. Macias, K. S. Kumar, and M. K. Hoffman, SP519, pp. 101-107 (Apr. 1979).

Key words: air pollution; ambient aerosols; computer controlled gas chromatography/mass spectrometry; GRALE; organic analysis; reflectance.

Methods for the determination of organic compounds in atmospheric aerosols are described. The amount of carbon in organic compounds is determined from the difference between the total carbon content of the aerosol determined by the gamma ray analysis of light elements technique and the elemental carbon (soot) content determined by reflectance. The detailed composition of the organic species in the aerosol is determined by gas chromatography-mass spectrometry.

Polynuclear aromatic hydrocarbons associated with coal combustion, L. Sucre, W. Jennings, G. L. Fisher, O. G. Raabe, and J. Olechno, SP519, pp. 109-120 (Apr. 1979).

Key words: coal combustion products; glass capillary gas chromatography; high pressure extraction; polynuclear aromatic hydrocarbon.

Samples of coal tar exudate, coke and stack fly ash from coal combustion were subjected to several extraction procedures, including a novel high-pressure liquid $\mathrm{CO}_{2}$ extraction. Extracts were analyzed on wall coated open tubular (WCOT) glass capillary columns; selected extracts were also subjected to GC/MS analysis utilizing a glass capillary as the inlet to the mass spectrometer, and a number of polynuclear aromatic hydrocarbons were identified on the basis of computer-matched fragmentation patterns, supported by retention data.

Diurnal and spatial variations of organic aerosol constituents in the Los Angeles Basin, B. R. Appel, E. M. Hoffer, E. L. Kothny, S. M. Wall, M. Haik, and R. L. Knights, SP519, pp. 121-129 (Apr. 1979).

Key words: diurnal variations; elemental carbon; mass spectroscopy; organic aerosol constituents; primary organic carbon; sampling errors; secondary organic carbon; solvent extraction; spatial variations.

Two-hour and 14-hour hi-vol aerosol samples were collected simultaneously at Pasadena, Pomona and Riverside, California on 4 successive days in July 1975. Simultaneous ozone and visibility measurements were made for correla- tion with aerosol constituents. Samples were analyzed for primary $\left(C_{p}\right)$, secondary $\left(C_{s}\right)$, and elemental carbon $\left(C_{e}\right)$ by selective solvent extraction-carbon analysis. In addition, high resolution mass spectroscopy was used to provide detailed analysis of organic constituents and to evaluate the selective extraction procedure. The composition of the carbonaceous material at the three sites was found to be similar with $C_{s} / C_{p} \geqslant 2$. The $C_{e}$, as estimated by insoluble carbon, was the most abundant carbon form. Adipic and glutaric acids were among the more abundant aerosol constituents of probable secondary origin. Elevated morning levels of $C_{8}$, dicarboxylic acids and acid nitrates as well as low morning $\mathrm{Br} / \mathrm{Pb}$ ratios gave evidence of the retention of secondary organic aerosol from preceding days. Cyclic olefins appear to be the principal secondary organict aerosol precursor. Primary organics show evidence of a motor vehicle origin plus additional unidentified sources. Comparison between 2-hour and 14-hour samples reveals evidence of both loss of organics by volatilization and increased collection efficiency for organics with increased particle loading.

Trace analysis in respiratory carcinogenesis, D. Hoffmann, K. D. Brunnemann, 1. Schmeltz, and E. L. Wynder, SP519, pp. 131-141 (Apr. 1979 ).

Key words: aza-arenes; hydrazines; nitroalkanes; nitrosamines; sidestream smoke; thermal energy analyzer; tobacco smoke; vinyl chloride.

Carcinogenic polynuclear and N-heterocyclic aromatic hydrocarbons are found in urban air in traces of $10^{-8}$ to $10^{-8} \mathrm{~g} / \mathrm{m}^{3}$. Their quantitative determination is made by using ${ }^{14} \mathrm{C}$-labelled internal standards in distributions between solvent pairs, followed by GLC and/or HPLC separations and identification by UV and MS. Volatile carcinogens in tobacco smoke include hydrazines $\left(2-4 \times 10^{-8}\right.$ $\mathrm{g} / \mathrm{cig}$ ), vinyl chloride ( 0.6 to $2 \times 10^{-8} \mathrm{~g} / \mathrm{cig}$ ), certain nitroalkanes $\left(10^{-7}\right.$ to $\left.10^{-8} \mathrm{~g} / \mathrm{cig}\right)$ and $\mathrm{N}$-nitrosamines $\left(10^{-9}\right.$ to $10^{-8}$ $\mathrm{g} / \mathrm{cig}$ ). Development and application of specific analytical methods for the quantitative analyses will be presented. The highly reactive hydrazines are derivatized in the smoke trap with pentafluorobenzaldehyde; vinyl chloride is derivatized by bromination. The derivatives of the trace compounds, as well as the nitroalkanes, are enriched by chromatography and analyzed by GLC with a ${ }^{63} \mathrm{Ni}-\mathrm{ECD}$. Volatile and nonvolatile $\mathrm{N}$-nitrosamines are determined by GLC with a thermal energy analyzer (TEA) or by HPLC/TEA, respectively (detection limit $10^{-10} \mathrm{~g}$ ).

During cigarette smoking significantly greater quantities of carcinogenic $\mathrm{N}$-nitrosamines are formed in-between puffs, than are produced in the mainstream during puffing. Therefore, it was suspected that smoke polluted indoor environments would reflect these contaminants. Analyses of various indoor atmospheres revealed concentrations up to $2 \times 10^{-7} \mathrm{~g} / \mathrm{m}^{3}$ of $\mathrm{N}$-nitrosamines depending on the degree of tobacco smoke pollution. A portable collection device and analytical methods for the determination of these other indoor pollutants will be described.

A new approach to the trace analysis of mono- and dihalogenated organics, an analysis of methyl chloride in the atmosphere, E. P. Grimsrud and D. A. Miller, SP519, pp. 143151 (Apr. 1979).

Key words: carrier gas doping; electron capture detector; methyl chloride; monochlorinated organics.

The intentional addition of oxygen to the nitrogen carrier gas of a constant-current Electron Capture Detector $(E C D)$ is shown to provide a useful extension of ECD 
analysis capabilities. The ECD sensitivity to compounds having few and particularly only one chlorine atom is greatly increased. As an example of this use, an analysis of methyl chloride in ambient air is reported. Oxygen doping is also shown to be useful for compound identification in ECD analyses, since the magnitude of the response enhancements caused by the addition of a definite amount of oxygen to the carrier gas varies greatly with compound type and is reproducible for a given compound. A systematic study of oxygen doping for the ECD analysis of $\mathrm{CH}_{3} \mathrm{Cl}, \mathrm{CH}_{2} \mathrm{Cl}_{2}, \mathrm{CHCl}_{3}, \mathrm{CCl}_{4}$, and $\mathrm{CH}_{3} \mathrm{Br}$ along with the accompanying effects on baseline frequency and noise is reported from which the selection of oxygen concentration and detector temperature can be made to cause the most favorable signals from sample components.

Analytlcal facilties for the analysis of trace organic volatiles In ambient alr, R. B. Denyszyn, J. M. Harden, D. L. Hardison, J. F. McGaughey, and A. L. Sykes, SP519, pp. 153-159 (Apr. 1979).

Key words: complete analysis scheme; gas chromatography; hydrocarbons; permanent gas analysis; trace organics in air.

During the past 4 years the Research Triangle Institute has developed state-of-the-art capabilities for the analyses of wide varieties of organic volatiles in ambient air. The facility in which analyses are carried out is described and the philosophies and criteria utilized in developing the methodology are discussed in this paper. In particular, the instrumental approach, GC column selections, and sampling methodology are specified. RTI capabilities include 5 gas chromatographs with 1 I detectors, which have been modified to accommodate analyses ranging from $\mathrm{ppm}$ to ppt levels. Analyses can be performed on hydrocarbons ranging from $\mathrm{C}_{1}-\mathrm{C}_{12}$, halocarbons, sulfur-containing compounds, and photochemical byproducts such as ethyl nitrate and peroxyacetyl nitrate. Calibration procedures, generation of accurate standard materials, and quality control programs associated with ambient monitoring programs are also discussed.

Analysis of trace levels of petroleum hydrocarbons in marine sediments using a solvent/slurry extraction procedure, D. W. Brown, L. S. Ramos, A. J. Friedman, and W. D. MacLeod, Jr., SP519, pp. 161-167 (Apr. 1979).

Key words: extraction; hydrocarbons; marine; petroleum; sediments.

A solvent slurry technique for the extraction of hydrocarbons in marine sediments has been developed based on dewatering with methanol and extraction on a ball-mill tumbler with 2:1 dichloromethane/methanol. After filtration and preliminary chromatographic cleanup, the extract was fractionated into saturated and unsaturated hydrocarbons using column adsorption chromatography. Both fractions were analyzed by gas chromatography with high resolution glass capillary columns. The procedure affords quantitation of individual hydrocarbons at part-perbillion levels in sediments.

Automatic analysis of organic pollutants in water via GC/MS, D. Beggs, SP519, pp. 169-173 (Apr. 1979).

Key words: gas chromatography/mass spectrometry; microcomputer; routine analysis; trace organics in water.

The use of gas chromatograph/mass spectrometer (GC/MS) systems for the routine analysis of organic pollutants in water samples has grown significantly during the last few years. However, these systems have had several disadvantages; namely, the need for a highly skilled operator and the need for elaborate sample preparation prior to analysis. A GC/MS system will be described which eliminates these disadvantages.

The recent development of microcomputer controlled GC/MS systems allows simplification of operation for routine analysis. The ability to preprogram gas chromatograph and mass spectrometer conditions as well as to format data output reduces the need for operator attention. The instrument is programmed to automatically tune itself and set up proper GC and mass spectrometer conditions. The instrument will accept raw water samples and automatically prepare those samples for analysis. The subsequent data acquisition and data analysis is carried out automatically. A final report is prepared without the need for operator attention. Several analysis schemes which demonstrate these automatic techniques will be shown.

In addition, results of a real time qualitative and quantitative analysis scheme will be shown. This system automatically defines qualitatively and quantitatively organic compounds as they elute from the GC column. The sensitivity of this method will be demonstrated down to the 60 parts-per-trillion level.

A simple, sensitive method for the quantitative analysis of carbon tetrachloride and chloroform in water at the parts-perbillion level, G. Brozowski, D. Burkitt, M. Gabriel, J. Hanrahan, E. McCarthy, and J. Smith, SP519, pp. $175-179$ (Apr. 1979).

Key words: carbon tetrachloride; chloroform; drinking water analysis; gas chromatography; parts per billion.

A chromatographic method has been developed and applied to the quantitative analysis of carbon tetrachloride and chloroform in drinking water at the ppb level. The method is simple and rapid with a turnaround time of 20 minutes or less. It is also largely interference free.

Analysis of tire cord emissions, D. Richton, J. Scott, J. S. Smith, A. F. Weston, and C. Werwick, SP519, pp. 181-184 (Apr. 1979).

Key words: emissions; gas chromatography; tensilization; thermogravimetric analysis; tire cord; tire cord dip; tire cord finish.

Current concern over industrial emissions has led us to study emissions produced by dipped tire cords when they are tensilized. Thermogravimetric analysis and gas chromatographic analysis have been used to study tensilization emissions. A simple device has been designed to produce emissions on a laboratory scale.

Trace organic analysis of wastewater by liquid chromatography, H. F. Walton and G. A. Eiceman, SP519, pp. 185-190 (Apr. 1979).

Key words: liquid chromatography; trace enrichment; wastewater analysis.

In the "trace enrichment" method, 1-2 liters of the water to be analyzed are pumped through a column containing reverse-phase, octadecyl-silica bonded packing. This packing retains hydrophobic, weakly-polar solutes while allowing highly polar and ionized solutes to pass. After loading the column, distilled water is passed, followed by a linear water-to-methanol gradient. The absorbed solutes are released in decreasing order of their polarity. The ultraviolet absorbance of the effluent is recorded.

The technique has been applied to treated wastewaters, tap waters and natural waters. Characteristic chromato- 
grams are obtained that depend on the $\mathrm{pH}$ of the water that is loaded; the lower is the $\mathrm{pH}$, the more is the absorption and subsequent release of humic acids and weak acids of low molecular weight. The effects of various kinds of wastewater treatment are noted; for example, reverse osmosis removes humic acids and ionized compounds, but allows less-polar nonionic compounds to pass; carbon treatment removes humic acids and solutes of low polarity, but not ionic compounds and solutes of intermediate polarity.

Effluent fractions are collected, concentrated, and examined by ultraviolet spectroscopy, as well as liquid chromatography on porous polymer gels and capillary gas chromatography followed by mass spectrometry. Certain compound classes have been identified, such as phthalate esters and phenol ethers of the type R. $C_{6} \mathrm{H}_{4} \cdot \mathrm{OR}$.. A "flush peak" appearing when the column is flushed with distilled water following the loading step indicates the presence of carboxylic acids; its origin will be discussed.

Analysis of soil and sediment to determine potential pesticlde contamination of a water supply impoundment, $F$. Amore, SP519, pp. 191-203 (Apr. 1979).

Key words: carbamates; gas chromatography; organochlorides; pesticides; sediment and water.

Analysis of soil, sediment, and water for insecticides, miticides, and fungicides was carried out to assess the potential for contamination of a water supply impoundment. The drainage area which feeds the impoundment is primarily agricultural with land in orchards or row crops. The impoundment is the source of water for a community of approximately 25,000 .

An analytical method was developed to allow for the determination of eleven pesticides in a single extract. The compounds were chosen from about 25 compounds known to have been used in the area. The compounds selected were those most extensively used and/or known to be persistent. The compounds determined were the organochlorides: lindane, dieldrin, endrin, DDT and metabolites, and kelthane; the organophosphates: malathion, parathion, and guthion; the carbamates: folpet and captan; and tetradifon.

All of these compounds were determined by gas chromatograph with an electron capture detector after extraction. Using an OV-17/QF-1 column all compounds except captan and folpet could be detected separately, although kelthane and malathion were poorly resolved as were p,pDDE and dieldrin.

The soil and sediment samples were extracted with acetone. The pesticides were flooded out of the acetone and extracted with 10 percent diethyl ether in petroleum ether. The water samples were extracted with 1:1 methylene chloride:hexane mixture. The detection limits using the method were $0.004 \mu \mathrm{g}$ lindane per gram of soil or sediment; $0.009 \mu \mathrm{g}$ DDE, DDD, DDT, dieldrin, endrin; $0.04 \mu \mathrm{g}$ kelthane, malathion, parathion, captan/folpet; 0.08 $\mu \mathrm{g}$ tetradifon; and $4 \mu \mathrm{g}$ guthion using $50 \mathrm{~g}$ of air-dried soil or sediment. For the water samples the sensitivity was about a factor of 100 lower using $500 \mathrm{~mL}$ of water and concentrating the final extract to $5 \mathrm{~mL}$.

Soils contained primarily dieldrin and DDE, while sediment contained dieldrin and DDD. None of the pesticides were detected in water. Recoveries were on the order of 75 to 95 percent for all compounds from both clay-like and humus-type soils.

Confirmatory studies were carried out using flame photometric detector, $p$-values, and saponification.

The method proved to be efficient, simple, and straightforward in providing reliable results. The method could be easily run on a routine basis by a tcchnician after minimal training.

Sampling and analysis of beta-chloroethers in the environment, P. L. Sherman, A. M. Kemmer, L. Mctcalfe, H. D. Toy, and G. E. Parris, SP519, pp. 205-212 (Apr. 1979).

Key words: air; environment; gas chromatography/mass spectrometry; sampling; sediment; trace analysis; water; $\boldsymbol{\beta}$ chloroethers.

Under contract with the U.S. Environmental Protection Agency, Office of Toxic Substances, Monsanto Research Corporation has developed and successfully utilized methods for the sampling and analysis of trace levels of $\beta$-chloroethers in the environment. The six compounds analyzed in this study were: 2-chloroethylethyl ether, 2chloroethylvinyl ether, bis(2-chloroethoxy) methane, and 1,2 bis(2-chloroethoxy) ethane. The methods for the sampling, workup, and analysis of air, water, soil, and sediment samples collected in the vicinity of potential producers and users are discussed in this paper.

A statistical study of atmospheric sampllng for an enclosed inhabited environment, H. G. Eaton, F. W. Williams, J. R. Wyatt, J. J. DeCorpo, F. E. Saalfeld, D. E. Smith, and T. L. King, SP519, pp. 213-218 (Apr. 1979).

Key words: aging; analysis; atmosphere; sampling.

Maintaining the quality of an enclosed inhabited environment, such as in the nuclear-powered submarine, requires monitoring of the atmosphere by various sampling procedures. One type of sampling procedure is grab sampling, whereby atmosphere samples are obtained essentially instantaneously in evacuated fiasks. However, in many instances these samples cannot be analyzed for days or months. An extensive statistically based program was conducted on selected contaminants to determine the effect of time (shelf life) on the samples. In addition, a parallel study was conducted in the grab sampling technique to determine if there was a difference in flask preparation.

Although this study did not reveal any differences in flask preparation, it did reveal that the samples do have a shelf life. For all contaminants evaluated except the refrigerants and methane, a statistically significant exponential time decay is present in the shelf life of a contaminant.

Development of an aqueous polynuclear aromatic hydrocarbon standard reference material, W. E. May, J. M. Brown, S. N. Chesler, F. Guenther, L. R. Hilpert, H. S. Hertz, and S. A. Wise, SP519, pp. 219-224 (Apr. 1979).

Key words: dynamic coupled-column liquid chromatography; extractor column; generator column; polynuclear aromatic hydrocarbon; standard reference material.

The National Bureau of Standards currently issues over 900 Standard Reference Materials (SRM's), with various groups being represented, such as: clinical laboratory standards, trace element standards, nuclear materials, glass viscosity standards, rubber materials, color standards, and coating thickness standards. We are now endeavoring to add to this list an additional group, namely trace organic chemical Standard Reference Materials.

The first SRM from this new group of materials will be an aqueous polynuclear aromatic hydrocarbon (PAH) Standard Reference Material. There are several problems associated with the preparation, storage and handling of aqueous solutions of PAH that previously prevented the development of this SRM. Now, through the use of a dynamic coupled-column liquid chromatographic method 
developed in this laboratory, we have been able to circumvent these problems. The use of this technique for the preparation and certification of an aqueous PAH SRM will be discussed.

New column technology in the analysis of organics in water by gas chromatography, R. Mindrup, Jr., SP519, pp. 225-229 (Apr. 1979).

Key words: aqueous organics; phenols; volatile organics, Carbopack C/0.2\% Carbowax 1500 .

Recently EPA issued a protocol on the analysis of 114 organic pollutants in water. The proposed method of analysis is by gas chromatography using selective columns and detectors. The organic pollutants are concentrated from water samples by solvent extraction or purge and trap techniques. The volatile pollutants, which are purged and trapped, are analyzed on a 80/100 Carbopack C/0.2\% Carbowax 1500 column. Base-neutrals and pesticides are extracted from water with methylene chloride and analyzed on a $1 \%$ SP-2250 column. The pesticides and Aroclors are analyzed with selective detectors such as electron capture or Hall conductivity. The analysis of phenols has been improved with the use of a new deactivated phase, SP-1240 DA, instead of the EPA recommendation of Tenax.

Sampling methods for trace organic analysis in foods, W. Horwitz and J. W. Howard, SP519, pp. 231-242 (Apr. 1979).

Key words: analysis; analytical food chemistry; errors; sampling.

The operation of sampling permits a small, conveniently handled portion to provide information as to the condition or composition of a large lot. How well the small portion represents the large portion is a function of the nature of the sampling operation, number of units in the sample, and the homogeneity of the parent lot. Many of the problems in analytical food chemistry at $\mu \mathrm{g}$ and $\mathrm{mg}$ per $\mathrm{kg}$ levels involve a very heterogeneous distribution of toxic compounds, causing the sampling error to be very much greater than the analytical error. In such a situation it does little good to improve the precision of the method of analysis, because the improvement is simply "swamped out" by the magnitude of the sampling error. More reliable results can only be obtained by taking and analyzing more and/or larger samples.

The role of sample preparation in nutritional labeling analysis, H. G. Lento, SP5 19, pp. 243-248 (Apr. 1979).

Key words: composite sampling; nutritional analysis; nutritional labeling; sample preparation.

The broad spectrum of food products requiring analysis for nutritional labeling and the ubiquitous nature of many of the substances being determined has created many diverse problems for the food scientist. Among these is the need to obtain from rather large representative lots, products prepared in such a manner so as to guarantee uniformity of the sample and the integrity of their nutrients which are by their very nature highly reactive and most labile. The problem is compounded by the fact that in the final actual analysis minute quantities of the original sample must be analyzed by using semi-micro and even micro methods with the same precision and accuracy demanded by macro techniques. This paper will discuss some of the diversified products encountered by the food analyst in his daily routine and the special techniques and equipment which must be utilized to handle such samples. Also stressed will be the importance of sample preparation and how good sample handling techniques can be used to minimize the loss of nutrients and sampling errors which, unless corrected, are greatly amplified as a consequence of nutritional labeling.

Nutrient analyses of foods: A reexamination, K. K. Stewart, SP519, pp. 249-255 (Apr. 1979).

Key words: nutrient analysis; nutrition; standard reference materials.

One of the key areas in the rapidly expanding field of human nutrition is the quantitative analysis of nutrients in foods. Contrary to popular belief, the nutrient analysis of foods is not routine, and much research is needed to obtain accurate and precise data on the nutrient composition of foods. This paper presents an overview of the analytical aspects of the chemical analysis of food nutrients, emphasizing the organic chemical nutrients (trace and otherwise), and evaluates the state of current nutrient data, the public health problems associated with certain nutrients, and the analytical methodology. Rapid, inexpensive, specific analytical procedures for trace compounds in complex matrices and certified standards and standard reference materials are needed to acquire the required nutrient data.

Measurement of the trace amounts of vitamin $B_{12}$ present in various foods by a new radiometric microbiologic technique, M. Chen and P. A. McIntyre, SP519, pp. 257-265 (Apr. 1979).

Key words: foods; radiometric microbiological assay; vitamin $B_{12}$.

A simple, sensitive and reliable radiometric microbiological assay was developed for the assay of vitamin $B_{12}$ content in foods. The evolution of ${ }^{14} \mathrm{CO}_{2}$ by $L$. leichmannii from $\mathrm{L}$ (guanido ${ }^{14} \mathrm{C}$ ) arginine was shown to be directly proportional to the amount of cyanocobalamin added to the usual assay medium. The assay requires less technical time than the standard turbidimetric assay and is semi-automated. Comparison of the vitamin $\mathbf{B}_{12}$ content of a variety of foods by this radiometric assay and the standard microbiological assay gave an $r$ value of 0.96 . Recovery experiments using cyanocobalamin gave good results with foods of animal origin. Recovery from foods of vegetable or grain origin were significantly lower. Reproducibility on a variety of foods and replicate samples of the same foods by the radiometric technique was satisfactory. This simplified radiometric microbiological assay combines the biologic specificity of the microorganism with the precision and automation of measuring a physical event as the end point (quantification of ${ }^{14} \mathrm{CO}_{2}$ evolved from a label substrate).

Gas liquid chromatographic analysis of pantothenates and panthenol, A. J. Sheppard and W. D. Hubbard, SP519, pp. 267-269 (Apr. 1979).

Key words: gas/liquid chromatography; panthenol; pantothenates; pharmaceutical preparations.

Gas Liquid Chromatographic (GLC) methods are described for the analysis of calcium and sodium pantothenates and panthenol in pharmaceutical preparations. In one method the acetate derivatives are prepared using a pyridine: acetic anhydride mixture. The residue is dissolved in chloroform and injected onto a column packed with $2 \%$ neopentyl glycol sebacate. In a second method trimethyl silyl ester-ethers of the pantothenate compounds are prepared using a mixture of silylating agents. GLC column packings of $5 \% \mathrm{SE}-30$ and $3 \% \mathrm{OV}-1$ were used. The application of these methods to pharmaceutical preparations is discussed. 
Quantitative analysis of simple carbohydrates in foods, B. W. Li and K. K. Stewart, SP519, pp. 271-278 (Apr. 1979).

Key words: carbohydrates; fructose; galactose; gas-liquid chromatography; glucose; lactose; liquid chromatography; maltose; raffinose; ribose; stachyose; sucrose; sugar analysis.

Liquid Chromatography and gas-liquid chromatography methods were developed to separate the mono-, di-, tri-, and tetrasaccharides commonly found in foods. The liquid chromatography system uses an anion-exchange column to separate the common food sugars as borate complexes. Sugars in the column eluate are quantified colorimetrically by reaction with p-hydroxybenzoic acid hydrazide subsequent to hydrolysis with sulfuric acid. In the gas-liquid chromatography system, the peracetylated aldononitriles or trimethylsilylated oximes of sugars are chromatographed on a column packed with either $3 \%$ SP 2250 or $3 \%$ OV17.

Preparation and extraction of samples for two chromatography procedures and derivatization for gas-liquid chromatography are discussed. The combination of the two chromatography systems for the determination of sugars in foods appears to be very useful. One or both of these analytical systems will allow the sugar content of foods to be determined in detail.

Determination of vitamins $\mathbf{E}$ and $\mathrm{K}$ in foods and tissues using high performance liquid chromatography, J. N. Thompson, G. Hatina, and W. B. Maxwell, SP5 19, pp. 279-288 (Apr. 1979).

Key words: high performance liquid chromatography; phylloquinone; tocopherols; tocotrienols; vitamin $\mathrm{E}$; vitamin $\mathrm{K}$.

Foods and tissues were extracted with hot isopropanol and acetone. Low polarity lipids, including vitamins $E$ and $K$, were obtained by addition of hexane, then water, to the filtered extract. Tocopherols $(\alpha, \beta, \gamma$, and $\delta)$ and tocotrienols were separated by high performance liquid chromatography (HPLC) on LiChrosorb Si60 in hexane containing either $0.2 \%$ isopropanol or $5 \%$ diethyl ether. High sensitivity and specificity were obtained by using a fluorometric detector. Vegetable oils, margarines, meat, liver, grains, milk, plants and complete meals were successfully analysed by this method. In the analysis for vitamin $\mathbf{K}$, lipids were first filtered through a short column of hydroxyalkoxypropyl Sephadex (HAPS). Triglycerides were reduced in some samples (milk, vegetable oils) by low pressure chromatography in hexane on a long column of HAPS $(120 \mathrm{~cm} \times 1 \mathrm{~cm})$. Crude or purified lipids were then chromatographed on a preparative HPLC column ( 25 $\mathrm{cm} \times 1 \mathrm{~cm}) 5 \mu$ LiChrosorb $\mathrm{Si} 60$ in hexane containing $0.03 \%$ isopropanol. A fraction containing phylloquinone was collected and rechromatographed on a LiChrosorb Reverse Phase column ( $25 \mathrm{~cm} \times 3.2 \mathrm{~mm}$ ) using a 30 minute gradient of $15 \%$ water in methanol to methanol. Phylloquinone levels $(\mu \mathrm{g} / \mathrm{g})$ were measured in a variety of foods including peas $(0.36)$, cabbage $(0.46)$, spinach (2.44), green beans $(0.47)$, lettuce (1.95) and cow's milk $(0.018)$.

Current status of lipoxidase method for determining 9,12. di-cis-polyunsaturated fatty acids, A. J. Sheppard and W. D. Hubbard, SP519, pp. 289-295 (Apr. 1979).

Key words: fats; lipoxidase; oils; PUFA; 9,12-di-cis-polyunsaturated fatty acids.

The enzyme lipoxidase isolated from the soybean exhibits a specificity for the cis, cis-methylene interrupted configuration in a straight carbon chain. MacGee in 1959 reported the development of a procedure for measuring cis, cis-methylene interrupted polyunsaturated fatty acids based on lipoxidase. The Canadian Food and Drug Directorate modified the MacGee method and adopted the modified procedure for legal use. The United States Food and Drug Administration through the Association of Official Analytical Chemists (AOAC) and others through the International Union of Pure and Applied Chemistry have been studying collaboratively either the MacGee method or individualized versions of the MacGee Method. After a number of collaborative attempts, the AOAC in 1977 completed a satisfactory study. The method has been adopted as an "official interim first action method" by the AOAC. Five oleo-margarine stocks in blind duplicates were analyzed by 17 laboratories located in the United States, Canada, England, Australia, The Netherlands, and Sweden. The method that is being adopted is limited to the official assays of fats and oils and does not include general food extracts. A collaborative study of the additional modifications of the basic method so that food extracts may be analyzed is planned.

Trace analysis in agricultural products. Methods for hydrazines, carbamates, N-nitrosodiethanolamine and other compounds, 1. Schmeltz, K. D. Brunnemann, and D. Hoffmann, SP5I9, pp. 297-309 (Apr. 1979).

Key words: carbamates; chemical ionization; electron-capture; hydrazines; maleic hydrazide; mass spectroscópy; nitrosamines; nitrosodiethanolamine; silylation; thermal energy analyzer (TEA); tobacco.

Agricultural crops are often exposed to chemical agents such as growth regulators, herbicides and pesticides. As a result of processing and other factors, these chemical agents undergo degradative reactions which lead to compounds considered toxic, carcinogenic or otherwise hazardous. Such compounds, however, are present in trace quantities and their analyses and/or monitoring require specialized techniques. Hydrazines, for example, have been found in tobacco and mushrooms. In the case of the former, the presence of hydrazine may be related to the use of the chemical suckering agent, maleic hydrazide. Determination of both the hydrazine and its suspected precursor is facilitated by reaction with a halogenated acylating or alkylating agent, and subsequent use of electron-capture gas chromatography. In addition, hydrazine has been determined by mass-fragmentographic techniques, and most recently thermal energy analysis (TEA) has been proposed for its determination.

A number of $\mathrm{N}$-nitrosamines have been shown to result from the reaction of various pesticides and nitrite. $N$ nitrosodiethanolamine, for example, arises from the reaction of nitrite and diethanolamine (found in certain pesticide formulations) or triethanolamine; this nitrosamine is difficult to determine because of its polarity. In this case, therefore, the analytical scheme involves methanol extraction, column chromatography and trimethylsilylation, followed by combined gas chromatography-mass spectroscopy. A ${ }^{14} \mathrm{C}$-internal standard is also included to monitor the analytical scheme. We can now analyze $N$ nitrosodiethanolamine by HPLC/TEA as well.

Other chemical compounds likely to be found in agricultural products in trace quantities as the result of pesticide application (or processing) are carbamates and halogenated hydrocarbons. The former require solvent partition and column chromatography prior to gas chromatography/mass spectroscopy. Chemical ionization mass spectroscopy is especially helpful here. Halogenated hydrocar- 
bons may be determined by electron-capture gas chromatography; however, in the case of vinyl chloride, prior reaction with $\mathrm{Br}_{2}$ facilitates the analysis.

Supported by National Cancer Institute Grant CA 17613 and by USDA Contract ARS No. 12-14-1001-607.

Criteria for purity of food additives used in biological tests. Experience with saccharin and Amaranth (FD\&C Red No. 2), B. Stavric, D. R. Stoltz, and R. Klassen, SP519, pp. 311-319 (Apr. 1979).

Key words: Amaranth; Ames test; criteria for purity; food additives; mutagenicity; naphthylamines; saccharin; saccharin impurities; Salmonella typhimurium.

The presence of traces of certain impurities in food additives used for various biological tests could significantly influence the results of biological testing and give an erroneous impression of the toxicity of the food additive. After a brief review of the literature, the authors summarize their results about the chemical purity of saccharin and Amaranth samples used in biological tests. Criteria for establishing and identifying the purity of chemicals used in biological tests are suggested.

Advances in the analysis of natural food toxicants, $D$. L. Park and A. E. Pohland, SP5 19, pp. 321-331 (Apr. 1979).

Key words: food toxicants; mycotoxins; review; seafood toxins.

An overview of the latest developments in analytical methods devised specifically for the detection of selected naturally occurring food toxicants-mycotoxins, natural plant toxins and seafood toxins-is presented. Special emphasis is placed upon the need for careful attention to sampling and sample preparation, the types of analytical techniques available for qualitative detection and quantitation, the need for confirmative techniques, and the requirement for high quality standard materials.

Analysis of potato for glycoalkaloid content by radioimmunoassay (RIA), R. P. Vallejo and C. D. Ercegovich, SP519, pp. 333-340 (Apr. 1979).

Key words: potato alkaloids; radioimmunoassay; solanidine; solanine.

Radioimmunoassay ( RIA) provides a means of combining the specificity of immunology with the sensitivity of radiochemistry to efficiently and economically analyze for toxicants in food. The underlying principle of RIA is that of competitive binding. The basic methodology of RIA requires suitable antiserum as the source of specific antibodies, radiolabeled tracer, and a means of measuring precise quantities of reactants, separating the tracer that is bound to the antibodies from that which is not and quantification of the radioactive fraction(s). An antiserum highly specific for solanidine, the aglycone of the potato glycoalkaloid solanine, a potent cholinesterase inhibitor, has been produced in rabbits after immunization with a solanidine hemisuccinate-bovine serum albumin conjugate. The RIA procedure which utilizes such antiserum and dihydrosolanidine $-{ }^{3} \mathrm{H}$ has a high degree of reliability and is capable of detecting as little as $150 \mathrm{pg}$ of solanidine in a potato sample. This RIA procedure greatly reduces the amount of sample preparation, use of costly organic solvents, and increases the number of analyses per unit of time in comparison to conventional chemical methods of analysis for the total glycoalkaloid content in potato.

Analysis of kepone ${ }^{R}$ in biological samples, N. Mady, D. Smith, J. Smith, and C. Wezwick, SP519, pp. 341-343 (Apr. 1979).
Key words: analysis; biologicál; gas chromatography; Kepone $^{R}$; partition chromatography; parts per billion.

A simple, rapid and quantitative method for the analysis of Kepone ${ }^{R}$ in biological samples is presented. The sample is extracted with ethyl ether. After removal of the solvent, the residue is placed on a Florisil-based partition column and lipophilic materials are eluted with hexane. Kepone ${ }^{R}$ is eluted with methanol-toluene and analyzed by gas chromatography using electron capture. Recoveries are 80$105 \%$.

Progress in the automation of extraction and cleanup procedures for detecting trace amounts of pesticides in environmental samples, M. E. Getz, G. W. Hanes, and K. R. Hill, SP519, pp. 345-353 (Apr. 1979).

Key words: continuous flow system; environmental analysis; pesticides; synthetic carbonaceous resins.

The discovery of a class of reusable adsorptive silica gels and the recent development of an effective commercial module for continuous evaporation to dryness have opened new possibilities for the eventual complete automation of pesticide residue analysis.

Appropriate modules were assembled to index, blend, extract, pump, filter, partition, concentrate, and chromatograph (cleanup) fortified samples of vegetable, animal, or mineral material according to conventional schemes for residue analysis. The liquid effluent from this system was then collected by a fraction collector for residue determination by gas chromatography or alternatively, in favorable cases, the pesticide residues were measured directly by means of a moving-wire/element selective (chlorine, phosphorus, or nitrogen) detector. The standard peristaltic pump used in AutoAnalyzer systems was found to provide sufficient pressure to give adequate solvent flow rates through silica gel cleanup columns. The performance and usable lifetimes of either charcoal or silica gel columns under continuous-flow solvent gradient systems (step gradient or linear gradient) were evaluated. The efficacy of the entire automatic extraction and cleanup system was tested using fortified samples selected to present specific problems such as alfalfa and tomato (pigments), beef fat (lipids), soil, and water. Although the results show that automated extraction and cleanup systems for pesticide residue and analysis are now both feasible and practical, much development work yet remains to optimize such systems for routine regulatory analysis.

Method of aflatoxin analysis, S. Nesheim, SP519, pp. 355372 (Apr. 1979).

Key words: aflatoxin analysis; food and feed analysis; methods; preparation; sampling.

A "State of the Art" summary of methods for the analysis of foods and feeds for aflatoxins is presented. Included are: preparation, distribution and handling of standards, sample preparation, technique and solvents for extraction, toxin separation, detection and quantitation by techniques including two dimensional thin layer chromatography and high performance liquid chromatography, and a discussion of method limitations, problems, precision and accuracy. Also included is a bibliography of aflatoxin methodology covering the last 5 years.

Trace organic sampling in the clinical area, B. Halpern, SP519, pp. 373-379 (Apr. 1979).

Key words: blood samples; clinical sampling of infants; clinical trace organic sampling; Guthrie blotters. 
Since the blood volume of a newborn is only about 270 $\mathrm{mL}$ and the clinical state of a sick infant may have to be monitorcd several times a day it is essential that the quantity of blood used for clinical analysis be kept to a minimum (preferably $<10 \mu \mathrm{L}$ per test). The collection of blood by venipunctures is practical in older children, but heel or finger punctures are the most efficient and least traumatic for obtaining blood from infants. Heel pricks must be performed carefully and a free flow of blood is essential to avoid contamination with tissuc fluid and to prevent hemolysis of the specimen. Variability attributable to collection factors may be minimized by reducing the number of individuals who are allowed to collect blood. At present, there is no mechanical device that can ensure reproducibility of specimen collection. Sample identification can also cause problems as it is impossible to attach a label directly to a capillary blood tube. A convenient way of manipulating, transporting, storing, and identifying blood samples from newborns is to spot the blood onto filter paper (Guthrie blotters). The dried blood spots can then be punched out to deliver a fixed volume $(5.5 \mu \mathrm{L})$ for clinical analysis. It is possible to selectively remove metabolites such as the fatty acids, cholesterol, and the amino acids or drugs from the filter paper by a sequential solvent extraction. These extracts can then be analyzed by conventional means, or more conveniently by a fast and more sensitive direct mass spectrometric technique. The new method has already been applied successfully, to confirm abnormals from a genetically oriented screening program using the duplicate blood spots from Guthrie blotters.

Sample preparation for clinical trace organic analysis, K. $\mathbf{H}$. Dudley, SP519, pp. 381-390 (Apr. 1979).

Key words: clinical chemistry; drug analysis; gas chromatography; internal standards; methylation; sample preparation.

An overview is presented of some common error sources in analytical methods and of knowledge which has contributed to the design of more reliable drug assays. Factors related to the initial state of the biological specimen, which can cause significant interferences and errors in measurements, are reviewed. The principle of the distribution law is utilized to explain the efficient extraction of acidic and basic drugs from media in which the drugs are largely in the ionic form. Extraction schemes which eliminate interferences by fatty acids in gas-liquid chromatographic (GLC) methods, are discussed. The internal standard method in GLC assays is reviewed. Ground rules for the selection of an internal standard and the need for selecting multiple, appropriate internal standards for the simultaneous determination of multiple drugs by GLC are also reviewed. Some factors important to the design and practice of intra-laboratory quality control of a drug assay are explained.

Measurement of catecholamines and their metabolites in tissue and physiological fluids using reverse-phase liquid chromatography with electrochemical detection, L. J. Felice, C. S. Bruntlett, R. E. Shoup, and P. T. Kissinger, SP519, pp. 391397 (Apr. 1979).

Key words: catecholamines; electrochemical detection; liquid chromatography; phenolic metabolites.

Liquid chromatography with electrochemical detection (LCEC) has proven to be a very versatile tool in the neurosciences. A number of laboratories have now adopted this technique as the principal means of investigation of catecholamines and their acidic (DOPAC, HVA, VMA), neutral (MHPG, etc.), and basic (3-MT, NM, M) mctabolites. The LCEC approach has also been used to assay the activity of enzymes responsible for the synthesis and catabolism of the catccholamines. Urine, blood, spinal fluid, tissue slices, and tissue homogenates are the usual samplc matrices of interest.

Quantitative analysis of melatonin in human plasma by negative chemical ionization mass spectrometry, S. P. Markey and A. J. Lewy, SP519, pp. 399-404 (Apr. 1979).

Key words: human plasma; melatonin; negative chemical ionization mass spectrometry.

A quantitative assay for melatonin in I $\mathrm{mL}$ of human plasma has been developed using gas chromatographynegative chemical ionization mass spectrometry. Extracted melatonin, along with a tetradeuterated internal standard can be measured from $1-100 \mathrm{pg} / \mathrm{mL}$ derivatized as the pentafluoropropionyl ester.

A candidate definitive method for the determination of total cholesterol in serum, R. Schaffer, E. White V, L. T. Sniegoski, and A. Cohen, SP519, pp. $405-410$ (Apr. 1979).

Key words: cholesterol; gas chromatography/mass spectrometry; isotope dilution; serum.

An isotope dilution-mass spectrometry method for the determination of total cholesterol was developed. Cholesterol, isotopically labeled with deuterium at C-25 to C-27, was added to serum samples. After an alkaline treatment to hydrolyze esters of cholesterol, the cholesterol was isolated from the serum and converted into the trimethylsilyl derivative for analysis by GC/MS. The ratio of the unlabeled to labeled cholesterol TMS ether in the entire GC peak was measured in the mass spectrometer by focusing alternately on the molecular ions at $\mathrm{m} / \mathrm{e} 458$ and 465 , and summing both signals. Duplicate GC/MS isotopic ratio measurements were bracketed by duplicate measurements of standard mixtures containing comparable proportions of SRM cholesterol and cholesterol- $d_{7}$. To ensure stability of measurement, the duplicate measurements of standard mixture or of sample had to agree within $1 \%$, and these duplicate measurements of sample and standard had to be repeated again on another day. The weight ratio of the isotopic forms in a sample was obtained by linear interpolation between the bracketing standard mixtures whose compositions were accurately known. An overall relative standard deviation of 0.33 percent was obtained for the measurement of total cholesterol in five different serum pools that were analyzed as described on four different occasions.

The determination of neurologically important tryptophan metabolites in brain cerebrospinal fluid, G. M. Anderson, W. C. Purdy, and S. N. Young, SPS19, pp. $411-418$ (Apr. 1979).

Key words: brain; cerebrospinal fluid; fluorescence flow cell; liquid chromatography; tryptophan metabolites.

The compounds tryptophan (TRP), 5-hydroxyindoleacetic acid (5-HIAA), indoleacetic acid (IAA), and indolepropionic acid (IPA) have been determined in human and rat CSF. Absolute detection limits of 5-25 pg have been obtained using a liquid chromatographic-fluorometric method. TRP and 5-HIAA are quantitated by the direct injection of 1-20 $\mu \mathrm{L}$ of CSF. IAA and IPA are determined by injection of $50 \mu \mathrm{L}$ of CSF. IAA is determined in rat brain after homogenization and centrifugation by direct injection of supernatant. The fluorometric system is discussed in a signal/noise context, the limiting noise is seen to be photon shot noise. Several neurochemical studies are presented illustrating the utility of the method. 
Applications of the mitrogen detector to the analysis of steroid hormones and related compounds by gas chromatography, J. P. Thenot and A. Hung, SP519, pp. $419-427$ (Apr. 1979).

Key words: gas chromatography; nitrogen-phosphorus; selective detection; steroid hormones.

The linearity and sensitivity of the nitrogen-phosphorus (N/P) detector was assessed with quinolinc as a model compound. It was found that the selectivity ratio, hydrocarbon to quinoline, was approximately 1 to 5000 . Direct comparison of a flame ionization with a N/P detector was made possible by splitting the effluent stream at the end of a capillary column. The N/P detector was found only 4 times more sensitive than the flame ionization detector for steroid derivatives $\mathbf{O}$-methyloxime tri-methylsilyl (MO-TMS). Methods for removing the reagents are described as well as other means to prepare nitrogen containing-derivatives (enamines). The possibility of using phosphorous containing derivatives is also discussed

Analysis of neutral lipids by high-performance liquid chro matography and nephelometric detection, S. L. Smith, J. W. Jorgenson, and M. Novotny, SP519, pp. $429-436$ (Apr. 1979).

Key words: cerebrospinal fluid; detector; high-performance liquid chromatography; light-scattering; lipids; nephelometry; oils; reversed-phase; serum.

A nephelometric detector, developed for high-performance liquid chromatography, has been applied to the sensitive detection of nonpolar lipids. By utilizing reversedphase chromatography for the separation of cholesterol, cholesterol esters, and triglycerides, the distribution of these lipids in physiological fluids can be determined. Procedures have also been developed for the determination of the fatty acid composition of individual triglycerides in plant oils. The current detection limit is $0.5 \mu \mathrm{g}$ for lipid solutes, and the response linearity of thc system has been extended to approximately $100 \mu \mathrm{g}$.

The determination of anabolic steroids in human body fluids, H. W. Dürbeck, C. G. B. Frischkorn, I. Büker, B. Scheulen, and B. Telin, SP5 19, pp. 437-445 (Apr. 1979).

Key words: anabolic steroids; clean-up; contamination; dianabol; gas chromatography-mass spectrometry ( $\mathrm{gc} / \mathrm{ms})$; gas liquid chromatography (glc); gc/ms interface; high performance liquid chromatography (hplc); inert columns; metabolism; methandienone; urine.

For the determination and identification of synthetic anabolic steroids in human body fluids some simple and generally applicable screening procedures have been developed employing HPLC, GLC and capillary GC/MS as basic instrumental techniques.

This paper discusses steroids with a tertiary hydroxy group at $\mathrm{C}-17$ and their detection in urine by improved GLC and capillary GC/MS methods.

For reasons of analytical accuracy and precision, a variety of important aspects and problems concerning clean-up and instrumentation have to be considered: (1) Sampling, sample stabilization and storage; (2) problems and sources of contamination; ( 3 ) problems of derivatization and their solution; (4) preparation of inert packed columns; and (5) GC/MS coupling of glass capillary columns.

Recent findings of pharmacokinetic and metabolic studies after oral administration may be summarized as follows:
(1) Steroids with a tertiary hydroxy group at C-17 and no other hydroxy group present in the molecule are normally excreted in their unconjugated form;

(2) For the same type of steroids the rate of metabolism is more rapid than their excretion. A drug is therefore only detectable via its metabolites;

(3) Without knowing the major metabolites of each anabolic compound a reliable drug administration regimen seems to be impossible; and

(4) The date of sampling is of great importance since all metabolites are totally excreted within a few days after the last drug application.

Development of a standard reference material for antiepilepsy drugs in serum, D. J. Reeder, D. P. Enagonio, R. G. Christensen, and R. Schaffer, SP519, pp. 447-453 (Apr. 1979).

Key words: antiepilepsy drugs in serum; serum matrix; standard reference material (SRM).

This paper describes one of the procedures developed in the process of producing and certifying an anticonvulsant drugs-in-serum Standard Reference Material (SRM). Four drugs, diphenylhydantoin, ethosuximide, phenobarbital, and primidone are used in the serum standards.

A human serum base is prepared from pooled human plasma. Methods for removing and testing for interferences are described. Uniformity of dispersed sample size is also tested.

Drugs added to the serum matrix are quantitated by gas chromatography using internal standards and bracketing techniques, and by liquid chromatography using calibration standards. The SRM will be supplied as a set of three samples, each having different concentration levels of the four drugs. A serum bank is also included.

Potentiometric titration of microgram amounts of penicillamine using ion selective electrodes, S. M. Donahe, G. E. Janauer, T. D. Zucconi, and C. Lewkowicz, SP519, pp. 455459 (Apr. 1979).

Key words: clinical chemistry; ion selective electrodes; penicillamine; potentiometric titration.

Over the last 20 years penicillamine (PA) has seen application in the treatment of Wilson's Disease, Cystinuria, and hcavy metal poisoning. Recently it has shown promise as an effective therapeutic agent in the treatment of rheumatoid arthritis (RA). However, its mode of action in RA therapy is not known. To aid in more effectively monitoring patients treated with this investigational drug and to provide a tool for studying the fundamental aspects of PA therapy, we have sought to develop a sensitive analytical procedure applicable to physiological fluids.

That PA is a strong metal chelating agent is the basis of its use in the treatment of heavy metal poisoning and Wilson's Disease. Very strong complexes are formed with $\mathrm{Hg}^{2+}, \mathrm{Cu}^{2+}$, and $\mathrm{Pb}^{2+}$. This same characteristic was exploited in developing our analytical procedure.

The method utilizes an automatic titration system equipped with a first derivative mode for the recorder. The sample is maintained at a constant $\mathrm{pH}$ (usually 9) using a Tris buffer. lonic strength is adjusted by addition of sodium perchlorate solution. Typically, the sample is titrated with a standard solution of lead perchlorate (analyzed with EDTA ). Initially $\mathbf{P A}$ will complex $\mathbf{P b}^{2+}$ as it is added to the system. When all available PA is complexed, excess titrant will add free $\mathrm{Pb}^{2+}$ to the solution. $\mathrm{Pb}^{2+}$ is detected by a lead specific electrode referenced to a double junction reference electrode containing a solution of sodium nitrate 
in the outcr chamber. A first derivative endpoint is recorded. Less than $0.2 \mu \mathrm{g} \mathrm{PA} / \mathrm{mL}$ can be determined.

Detection and quantitative determination of tricyclic anthepressants and benzodiazepines in serum and plasma by hlgh performance liquid chromatography, C. Hesse, SP519, pp. 461-468 (Apr. 1979).

Key words: benzodiazepines; clinical use; derivatization; quaternary two-phase systems; serum; uv-detection; tricyclic antidepressives.

Development and some applications of a liquid chromatographic method for the determination of most of the tri- and tetracyclic antidepressives in use is presented. Detection limits range from 5 to $50 \mathrm{ng}$ per sample. Routine application to the determination of Maprotiline in serum shows that patients can profit from this kind of therapy control.

The identification of odoriferous compounds formed by cital ejaculate in collagen sponge contraceptives, C. D. Eskelson, S. Y. Chang, T. Chvapil, and M. Chvapil, SP519, pp. 469-476 (Apr. 1979).

Key words: butylamine; collagen sponge; contraceptive device; gas chromatography; mass spectrometry; propylamine.

The study analyzed the molecular mechanism of the formation of malodor related to the retention and decomposition of ejaculate in collagen sponge (CS) used as an intravaginal contraceptive barrier method. Parallel studies were done in vitro with sponges soaked with semen and incubated at $37^{\circ} \mathrm{C}$ in a moist atmosphere. Gas samples from the vials containing CS used intravaginally or CS soaked with semen were analyzed by gas chromatographic and mass spectrometric methods. These analyses indicated that propylamine and butylamine were present in the gas samples analyzed. When ejaculate was incubated in vitro in sealed vials, not only were butylamine and propylamine detected, but also propanol. The incubation of radioactive polyamines with ejaculate and the isolation of radioactive products by derivatization and recrystallization to constant specific activity indicates that propylamine is derived from the spermine and spermidine in ejaculate, and that butylamine is derived from the putrescine contained in ejaculate.

It is concluded that the polyamines are converted to simple aliphatic amines by ejaculate enzymes and that the aliphatic amines are responsible, in part, for the malodor associated with collagen sponge worn postcoitally for several days by sexually active women.

The assay of triamterene in human blood by ion-pair extraction and high performance liquid chromatography, S. Sved and J. A. A. Sertié, SP519, pp. $477-480$ (Apr. 1979).

Key words: clinical analysis; fluorescence detection; liquid chromatography; triamterene assay.

The potent diuretic, triamterene ( $T$ ), is often used in cardiac patients in conjunction with quinidine. It is metabolized in the body and appears in the urine mainly in the form of the sulfate ester of the hydroxylated drug. Most methods of assay of $T$ in blood take advantage of its strong fluorescence, but difficulties may arise from interference by its metabolites or quinidine. This paper describes an assay which is highly specific and very rapid. Plasma or whole blood $(0.5 \mathrm{~mL})$ is acidified with perchloric acid, extracted with methylisobutyl-ketone and an aliquot of the organic phase passed on HPLC using silica gel with dichloromethane-hexane-methanol-perchloric acid
(57:35:8:0.1) as mobile phase. The fluorescence detector is set at $350 \mathrm{~nm}$ excitation (monochromator) and above $470 \mathrm{~nm}$ emission (sharp cut filter). Recovery after a single extraction was 88.6 percent, and the calibration curve was linear from $1-1000 \mathrm{ng} / \mathrm{mL}$ (slope: 0.59 , intercept: 0.06 ) with a C.V. of 3.9 percent over the entire range. The method was used for one non-fasted human volunteer given $50 \mathrm{mg} \mathrm{T}$. The profile showed a peak at $3 \mathrm{~h}$ both for plasma (16.2 ng/mL) and whole blood $(20.3 \mathrm{ng} / \mathrm{mL})$, declining to 6.1 and $10.8 \mathrm{ng} / \mathrm{mL}$ at $7.6 \mathrm{~h}$ for plasma and blood, respectively.

The gas chromatographic measurement of dextromethorphan levels in human plasma, J. E. O'Brien, $O$. N. Hinsvark, W. R. Newman, L. P. Amsel, J. E. Giering, and F. E. Leaders, Jr., SP519, pp. 481-485 (Apr. 1979).

Key words: antitussive; dextromethor phan; gas-liquid chromatography; human plasma; nitrogen-sensitive detector.

A highly sensitive method for the determination of plasma levels of the antitussive, dextromethorphan (DM), is described. Following the administra-tion of a therapeutic dose $(30 \mathrm{mg})$ of dextromethorphan hydrobromide $(\mathrm{DM} \cdot \mathrm{HBr}$ ), plasma levels of intact drug can be expected to be low due to rapid and ex-tensive demethylation. To reliably and accurately measure such levels, an ultra-sensitive means of determining the concentration was developed. A preliminary extraction with hexane, a backwash into acid, a final basic extraction into hexane with subsequent measurement by a gas chromatograph equipped with a nitrogen sensitive detector provided the required selectivity, sensitivity and speed of analysis. Less than 5 minutes of instrument time was required to reliably measure $1 \mathrm{ng} \mathrm{DM} / \mathrm{mL}$ of plasma. Plasma levels of $\mathrm{DM}$ were determined from human subjects receiving $30 \mathrm{mg}$ orally every 6 hours for a I-week period.

Chromatographic methods in organic trace analysis: Current situation and perspectives of future progress, $M$. Novotny, SP519, pp. 487.499 (Apr. 1979).

Key words: ancillary methods; bonded phases; chromatographic preconcentration; detector sensitivity; gas chromatography; glass capillary columns; high-performance liquid chromatography; LC microcapillary columns; selcctive detectors.

Gas chromatography and high-performance liquid chromatography now belong among the most important methods of trace organic analysis. The analytical aspects of the column efficiency, detection sensitivity and ancillary techniques are reviewed for both methods. Future methodological directions are indicated.

Flow injection analysis-A new approach to quantitative measurements, J. Ruzicka and E. H. Hansen, SP519, pp. 501 507 (Apr. 1979).

Key words: automation; continuous analysis; controlled dispersion; flow injection analysis.

The reason for automation of chemical analysis should not only be a necessity to analyze a large number of samples, but also less apparent advantages of automated sample handling, i.e., better reproducibility, instant availability of analytical result, and new opportunities for innovation. The continuous flow analysis is in comparison to batch approach closest to this ideal as it is easily programmable, yet its conventional form based on air segmentation is aimed to meet the first two goals, but certainly not the rest of them. It is the nonhomogeneity of the carrier stream, segmented by air, which causes pulsation and irregular move- 
ments of the liquids in the system, which requires a "steady state" readout to be taken if sufficient reproducibility of the measurement is to be achieved.

The new method of continuous flow analysis is based on an entirely different approach and utilizes three principles: 1) sample injection, 2) controlled dispersion, and 3) reproducible timing. In the absence of air, the sample zone, injected into a carrier stream of reagent will disperse on its way towards the detector. This process of zone dispersion can be used (rather than unselectively retarded by air bubbles, for various analytical purposes. Following the principles of chemical reactor engineering and the theory of laminar flow in narrow tubes, limited, medium, or large dispersion can he achieved. This allows a new approach to design of analytical methods hased on spectrophotometric, fluorescence, nephelometric, voltammetric, and ion-selective electrode measurement. As the flow system is miniaturized, the sample has a dwell time in it between 3 to $30 \mathrm{~s}$ which makes the readout instantly available.

Emphasis will be given on explaining the theory of the dispersion and its relation to the flow conditions in the system. The ways to utilize the dispersion patterns for analytical purposes will be illustrated by examples of methods from clinical, agricultural, and pharmaceutical analysis

Ion-pair HPLC of drugs and related organic compounds, G Schill and K. G. Wahlund, SP5 19, pp. 509-523 (Apr. 1979).

Key words: amino acids; barbiturates; carboxylic acids; catecholamines; conjugates; detection sensitivity; dipeptides; drugs; HPLC; ion-pair adsorption; ion-pair chromatography; ion-pair partition; metabolites; psychotropic amines; selectivity; sulphonamides.

The principles for high performance liquid chromatography (HPL.C) based on ion-pair distribution are indicated. lon-pair HPLC can be performed in straight phase mode with an organic mobile phase and an aqueous stationary phase and in reversed phase mode with an aqueous mobile phase and a non-polar surface or liquid as the stationary phase. The retention can be regulated by the kind and concentration of the counter ion added to the aqueous phase.

The design and preparation of stable systems for ion-pair HPLC is indicated and the influence of the composition of the phases on the separating efficiency and selectivity is demonstrated.

Straight phase systems for separation of amines, amino acids and dipeptides as well as anionic compounds (carboxylates, sulphates, sulphonates, sulphamates, conjugates of glycine and glucuronic acid) are demonstrated. By use of counter ions with high UV-absorbance, down to a few nanograms of non-absorbing compounds can be detected

Reversed phase systems are given for separation of psychotropic amines (e.g., imipramine, amitriptyline, fluphenazine, zimelidine) and their metabolites, catecholamines and related phenylethylamine derivatives (e.g., adrenaline, dopamine), sulphonamides, barbituric acids and their metabolites, amino acids, dipeptides and metabolites of biogenic amines (phenylacetic, mandelic and indoleacetic acid derivatives).

Bio-selective membrane electrodes, G. A. Rechnitz, SP5/9, pp. 525-532 (Apr. 1979).

Key words: bio-selective membrane electrodes; bio-sensors; enzymes; immunoelectrodes; trace organic electrochemistry.
In order to prepare membrane electrodes with response and selectivity to biological molecules or species, other than simple ions or gases, it is necessary to modify conven. tional potentiometric membrane electrodes with additional components selected to "mediate" hetween bischemica! and electrochemical processes. Such mediation can he as simple as $\mathrm{pH}$ huffering to ionize a neutral biological sub. stance or extraordinarily complicated as in the case of sequential enzymatic conversions or immunochemical sieps.

Although much of the current research involves enyme electrodes, we should recogni\%e that enzymes are only one class of possible biological materials which could be used as mediators on membrane electrodes. Indeed, it is possible to construct a hierarchy of mediator categories.

The lecture will consider several approaches to the mediation problem including extrapolations to the future based on high explorative, unpublished work currently in progress in the author's laboratory. Such work includes the use of hapten electrodes for monitoring immunoreactions and the direct employment of intact micro-organisms to develop a "living" membrane electrode.

Recent developments in homogeneous immunoassay techniques, D. S. Kabakoff, SP519, pp. 533-539 (Apr. 1979).

Key words: drug assay; EMIT $^{R}$ fluoroimmunoassay fluorescence immunoassay; homogeneous enzyme immu. noassay; immunoassay.

Immunoassay techniques, based on the specific recogni. tion of antigens by antibodies, are increasingly used in the measurement of analytes of clinical interest. During the past decade, a number of immunoassays have heer developed which do not require physical separation of free and bound labeled analyte prior to quantitation. These homogeneous immunoassay techniques may be furthei classified according to the type of molecule used as the reaction indicator or label. The review describes assay: employing free radicals, fluorescent molecules, chemilu. minescent molecules, enzyme cofactors, and enzymes. The EMIT $^{R}$ homogeneous enzyme immunoassay technique representing the homogeneous immunoassay method ir widest use, is described in detail.

Analytical systems for trace organic analysis, H. M. Mc Nair, SP519, pp. 541-546 (Apr. 1979).

Key words: analytical systems; atomic absorption; gas chro matography; liquid chromatography; mass spectrometry trace organic analysis.

An overview of instrumental systems capable of trace or ganic analysis will be presented. A simple statement o operating principle will be followed by emphasis on specia techniques available for trace work. Factors to be con sidered in the evaluation include detectivity (M.D.Q.) sample size required, type of detector response (universa or selective) and availability. Advantages and limitation will be presented. Systems which will be discussed will in clude: MS, GC/MS, GC, LC, AA, NMR, fluorescence radiochemical and electrochemical systems.

Selective detection in chromatographic analysis, L. S. Ettre SP519, pp. 547-585 (Apr. 1979).

Key words: detector design; gas chromatography; liqui chromatography; selective detection.

While being the best separation technique, chromatog raphy also excels in sensitivity: traces present in concentra tions at the parts-per-billion-1:109-level or lower can b detected. However, at such low levels, positive identific: 
tion is difficult since a large number of compounds may emerge from the column within a short retention time range.

The solution of this problem is to use substance-selective detection, i.e., detectors which respond only to certain types of compounds. In this way, two goals are achieved simultaneously: one has information on the chemical nature of the compound present and, at the same time, interferences of co-emerging compounds of dissimilar chemical nature are eliminated.

Although selective detection is not new in chromatography-after all the colored bands of Tswett already compound identification-its real evolution started in the early 1960 s, in gas chromalography as an answer to the requirement of detecting trace quantities of halogenated pesticides. The electron capture and coulometric detectors have been developed to fulfill this need. Based on new requirements a number of other detectors were also developed in the last 15 years, providing e.g., selective detection of phosphorus, sulfur and nitrogen containing compounds. Most recently spectroscopic detectors based on the principles of IR and UV spectroscopy and applying on-the-fly detection techniques further extended our possibilities for selective detection.

In liquid chromatography the widely used variable wavelength UV detectors also provide selective detection since the absorptivity of different compounds-even within one class-varies widely. In addition to these, a number of other detectors have been introduced to further enhance selectivity. From these the use of fluorescence is probably the most important: such systems may provide even better sensitivity than the highly selective and sensitive GC detectors.

Automation of trace organic analysis, D. A. Burns, SP519, pp. 587-600 (Apr. 1979).

Key words: automation; clinical chemistry; environmental chemistry; gas chromatography; liquid chromatography.

As analysts' workloads rise in response to increasing regulation, and as minimum detectable levels of organic substances decrease with improvements in detectors, the need for automation becomes more apparent. Although start-up costs may seem appreciable, the ultimate benefits of automation generally include lower cost per sample and increased precision as human resources (expensive and subjective) are diminished.

The technique of choice depends upon the structure of the analyte and the accompanying interferants. For low molecular weight substances (especially those containing halogen, nitrogen, or sulfur) GC is a likely candidate. And gaining rapidly in popularity is HPLC with its potential for pre- or post-column derivatization to greatly enhance sensitivity via UV or fluorescent tags. Where levels are especially low, instruments are available to perform continuous sample concentration. For larger molecules, the principle of the immune reaction can lead to biological amplification as in radioimmunoassay ( $R I A$ ) and enzyme-labeled antibody (ELA) schemes, and automated instruments currently exist for both of these very sensitive techniques.

Applications for the automation of trace organic analyses are found in clinical chemistry (e.g., trace drugs in biological fluids), in the food industry (e.g., aflatoxins in peanuts), and in environmental area (e.g., pesticides in water). Examples of such automation will be cited, along with factors which should be considered before undertaking any program to introduce total or partial automation into an analytical facility.
Electron capture negative ion chemical ionization mass spectrometry, D. F. Hunt and F. W. Crow, SP519, pp. 601-607 (Apr. 1979).

Key words: chemical ionization; electron capture; gas chromatography-mass spectrometry; negative ions.

The utility of the electron capture negative ion chemical ionization technique for quantitating organic compounds by conventional GC-MS selected ion monitoring methodology is discussed. Detection of dopamine, amphetamine, and $\Delta^{9}$ tetrahydrocannabinol derivatives at the attomol $\left(10^{-18} \mathrm{~g}\right)$ level is reported.

Mixture analysis by mass spectrometry, R. G. Cooks, SP519, pp. 609-625 (Apr. 1979).

Key words: mass-analyzed ion kinetic energy spectrometry; MIKES; mixture analysis; trace analysis.

Trace analysis is considered from general principles with emphasis on the contrasting procedures of chromatography/spectroscopy and mass spectroscopy/spectroscopy. The latter, embodied in the MIKES technique, uses the mass spectrometer in both its mass transport and its compound identification roles, The effects of chemical noise on detection limits in chromatographic and non-chromatographic techniques are emphasized. Alternatives to massanalyzed ion kinetic energy spectrometry (M1KES) for direct analysis of mixtures by sequential ion separation and identification are systematized. Studies using MIKES in conjunction with a variety of methods of ion formation and various ion dissociation processes are reviewed. The technique of single reaction monitoring is presented and examples of its use are covered.

The use of negative chemical ionization in conjunction with MIKES for mixture analysis is explored. It is shown that both positive and negative secondary ions may usefully be detected, and that a systematic ion chemistry underlies these MIKE spectra. Applications of CI/MIKES to metabolites in urine, preservatives in foodstuffs, drug preparations and to natural products are covered. Examples of isomer identification are given, including some which employ high energy ion/molecule reactions other than the usual collision-induced dissociation process. New. developments involving pyrolysis/MIKES, improvements in the quantitative accuracy of the methodology, alternative instrumentation, and extensions of the method to the study of hitherto intractable biological materials are foreseen.

Organic secondary ion mass spectrometry, A. Benninghoven, SP519, pp. 627-635 (Apr. 1979).

Key words: amino acids; drugs; nonvolatile organic compounds; organic trace detection; peptides; pharmaceuticals; secondary ion mass spectrometry; sputtering; structural information; vitamins.

Secondary ion mass spectrometry (SIMS) provides information on the chemical composition of a solid surface by mass analysis of sputtered ions. Applying extremely small primary ion current densities, the analysis of a single monolayer becomes a vailable (static SIMS). This technique has been applied to metal supported organic compounds such as amino acids, peptides, drugs, pharmaceuticals, vitamins, etc. From virtually all these compounds "parentlike" molecular ions of the general composition $(\mathbf{M}+\mathbf{H})^{+}$ and/or $(\mathrm{M}-\mathrm{H})^{-}$are emitted with high secondary ion yields in the range of 0.1 .

Experimental detection limits below $10^{-9} \mathrm{~g}$ were found. The technique offers promising applications in the field of trace detection and analysis, structural investigation, sur- 
face reaction studies etc. of high molecular weight organic compounds. It is applicable, without any restriction, to nonvolatile material.

The wire transport LC/MS system, R. P. W. Scott, SP519, pp. 637-645 (Apr. 1979).

Key words: liquid chromatography/mass spectrometry; pesticides; vitamin $\mathrm{A}$; wire transport.

The two basic types of interface for LC/MS systems will be described and the characteristics of these interfaces that can affect column performance will be discussed in detail. The design of direct inlet systems developed by McLafferty will then be described and the results obtained from this device given. The wire transport interface system developed by Scott et al., will also be discussed, together with the results obtained using it in conjunction with high efficiency microparticulate columns. Finally, the modified form of wire transport system devised by McFadden et al. and utilizing a belt transport system will be described, and the results obtained from the Finnegan LC/MS system utilizing the belt transport interface given.

Techniques for combined liquid chromatography-mass spectrometry, M. L. Vestal, SP519, pp. 647-654 (Apr. 1979).

Key words: laser ionization; laser vaporization; liquid chromatography; liquid chromatography/mass spectrometry.

High pressure liquid chromatography (HPLC) has recently become established as a powerful separation technique with many environmental and biomedical applications. HPLC is especially valuable for polar, involatile, or thermally unstable compounds not amenable to gas chromatography. The most serious obstacles to further rapid development of HPLC appear to be problems associated with the versatility, selectivity, and sensitivity of available detectors. The combination of mass spectrometry with HPLC is an obvious possible solution to these detector problems, but the technical problems involved in the LC-MS interface are substantially more difficult than those encountered in the analogous development of GC-MS.

This paper presents a review of the current status of combined LC-MS systems and focuses on techniques which have demonstrated capabilities for trace organic analysis not amenable to GC-MS. Several successful approaches to LC-MS interfacing are described and the demonstrated performances of the various techniques are compared. Selected examples are given of applications of combined LC-MS systems to trace organic analysis of environmental and biomedical samples.

Atmospheric pressure ionization mass spectrometry, D. I. Carroll, I. Dzidic, R. N. Stillwell, and E. C. Horning, SP519, pp. 655-671 (Apr. 1979).

Key words: atmospheric pressure ionization; bioanalytical systems; mass spectrometry; negative ions; positive ions.

Atmospheric pressure ionization mass spectrometry differs in several significant ways from conventional mass spectrometry. The ionization of samples occurs in a small reaction chamber at atmospheric pressure, negative as well as positive ions are detected, and the source does not contain a heated filament. Samples can be introduced in organic solvents by direct injection or in the effluent stream from a liquid chromatographic column, as well as in the usual ways. Very short-lived, as well as very long-lived, ions have been detected, and subpicogram sensitivity of detection has been achieved for both positive and negative ions. Ionization occurs through a sequence of ion molecule reactions, or through electron attachment. Current studies are concerned with negative ion mass spectrometry and with conditions for attaining high sensitivity of detection in bioanalytical studies.

${ }^{252}$ Cf-plasma desorption mass spectrometry (PDMS) of antibiotic molecules, R. D. Macfarlane, SP519, pp. 673-677 (Apr. 1979).

Key words: charge transfer; chlorophyll; erythromycin; fast reactions; fission track; ion-dipole; $\beta$-endorphin; ${ }^{252} \mathrm{Cf}$.

The use of mass spectrometry for the analysis of antibiotic molecules is mainly to confirm the molecular weight of a structure deduced by NMR or x-ray analysis. The chemistry of Cf-plasma desorption mass spectrometry (PDMS) makes it possible to produce molecular ions of the molecule by initiating fast chemical reactions in solid films. The fission track formed by the passage of a high energy heavy ion affords a means of exciting an ensemble of molecules at solid-state density in times on the order of $10^{-16} \mathrm{~s}$. Reactions that occur depend on the nature of the inter-molecular interactions and can include electron transfer (hedamycin), proton transfer (erythromycin) and ion-dipole attachment ( $\beta$-endorphin). Reaction products can be desorbed from the solid surface by the shock wave that follows the initial excitation. Although the application is in mass spectrometry of biomolecules, PDMS may be another approach to the study of solid state organic photochemistry.

Recent advances in synchronous luminescence spectroscopy for trace organic analysis, T. Vo-Dinh, R. B. Gammage, A. R. Hawthorne, and J. H. Thorngate, SP519, pp. 679-684 (Apr. 1979).

Key words: cresol; luminescence spectrometry; organic pollutants monitoring; synchronous excitation spectroscopy.

The use of the synchronous excitation technique and second-derivative luminescence spectroscopy for monitoring organic pollutants is reported. The combination of these two methods can significantly improve the selectivity of luminescence spectroscopy.

A nalysis of individual polychlorinated biphenyls (PCBs) and their hepatic microsomal metabolites by HPLC-MS, P. Dymerski, M. Kennedy, and L. Kaminsky, SP519, pp. 685690 (Apr. 1979).

Key words: cytochrome P-450; liquid chromatographymass spectrometry; PCB metabolism; polychlorinated biphenyls.

The new technique of liquid chromatography interfaced mass spectrometry (LCMS) was applied to reactant and product identification in the in vitro metabolism of 2-, 3-, and 4-chlorobiphenyl by hepatic microsomal cytochrome P-450. Individual monochlorinated biphenyl (MCB) isomers were purified and quantitated by HPLC with a reverse-phase $C_{18}$ column (67.5\% water/acetonitrile solvent mixture). This system proved to be ineompatible with LCMS and therefore a normal phase Porasil column method $(0.5 \%$ methanol/methylene chloride solvent mixture) was developed. The direct introduction of LC effluent into the mass spectrometer (via interface) supported the purity of the reactant materials. Analysis of the metabolized mixtures identified, in addition to several nonchlorinated interferents, a monohydroxychlorobiphenyl and, at trace levels, a dihydroxychlorobiphenyl for each of the three MCBs. A second monohydroxychlorobiphenyl product was also identified in the metabolism of 3chlorobiphenyl with a significantly different retention time from the other products. Kinetic analysis of the metabolism 
of the three MCBs showed that, for the production of the monohydroxylated product, 4-chlorobiphenyl has a $V_{\max }$ significantly greater than those of the other two MCBs, while 3-chlorobiphenyl has a significantly lower $\mathbf{K}_{m}$.

Sub-part-per-trillion detection of organics in aqueous soluton by laser induced molecular fluorescence, J. H. Richardon, S. M. George, and M. E. Ando, SP5 19, pp. 691-696 Apr. 1979).

Key words: fluorescence; organics in water; pulsed laser.

Pulsed laser irradiation has been demonstrated to be a superior excitation source for fluorescence analysis. Three different configurations have been compared experimentally, and the superior system used as the excitation source in the trace analysis of several organics in aqueous solutions. In favorable cases sub-part-per-trillion detection limits can be achieved.

Analysis of polymer outgassing as studied by plasma chromatography-mass spectroscopy, T. W. Carr, SP519, pp. 697703 (Apr. 1979).

Key words: epoxy polymer; plasma chromatography-mass spectroscopy; polymer outgassing.

The plasma chromatograph-mass spectrometer has been utilized to analyze the trace level organic species which were outgassed from epoxy polymers. Direct measurements of such compounds as hexahydrophthalic anhydride (HHPA), ethyl cellosolve acetate, and 2,6-ditertbutyl para cresol (BHT) in complex mixtures are demonstrated.

Liquid chromatography with electrochemical detection. State of the art and future directions, P. T. Kissinger, C. S. Bruntlett, K. Bratin, and J. R. Rice, SP519, pp. 705-712 (Apr. 1979).

Key words: cell design; electrochemical detection; liquid chromatography; oxidation; reduction.

Over the last 5 years our laboratory has invested a great deal of effort in the development of reliable amperometric detectors for trace organic analysis by liquid chromatography. As a result of this work commercial detectors are now available which exhibit excellent sensitivity and selectivity at minimum cost. Electrochemical detectors provide the instrumentation of choice for a number of important assays where they easily out perform optical detectors.

At present, reverse-phase chromatography offers the greatest compatibility with electrochemical detection due to the polar nature of the mobile phase. The fact that $\mathrm{pH}$, ionic strength, and solvent composition are important variables for both chromatography and electrochemistry implies the need for compromise in most cases. Likewise the choice of stationary phase and column length enters into the overall optimization process. The relatively recent use of hydrocarbon phases intentionally modified by hydrophobic bonded solvents (e.g., pentanol) and/or polar lipids (e.g., octyl sulfate) brings great flexibility to reverse-phase separations and therefore further enhances the utility of electrochemical detection.

The choice of electrode (glassy carbon, carbon paste, amalgamated gold) and cell geometry play an important role in optimizing the performance of an electrochemical detector for ultimate sensitivity and linear range.

Modification of conventional gas chromatographic inlets for the use of glass capillary columns, L. S. Ramos, D. W. Brown, R. G. Jenkins, and W. D. MacLeod, Jr., SP519, pp. 713-718 (Apr. 1979).
Key words: capillary columns; gas chromatography; hydrocarbons

A conventional packed column gas chromatographic inlet has been adapted to accommodate glass capillary columns. This simple inlet design requires only five inexpensive, readily obtainable parts, and is applicable to most existing gas chromatographs. The system has performed well with non-polar compounds as well as many polar compounds in both split or splitless injection modes. Temperature programmed operation is routine with the system, and either a manual or automatic sample injection configuration is possible. Reproducibility of individual measurements and linearities of response were determined using internal reference standards. Chromatograms from complex environmental samples demonstrate performance of the system.

Trace organic analysis using second-derivative uv-absorption spectroscopy, A. R. Hawthorne, J. H. Thorngate, R. B. Gammage, and T. Vo-Dinh, SP519, pp. 719-722 (Apr. 1979).

Key words: absorption spectroscopy; derivative spectroscopy; PNA analysis; trace organic analysis.

Second-derivative uv-absorption spectroscopy is discussed as a method of trace organic analysis. Various ways of obtaining a second-derivative spectrum are presented, along with examples of improved selectivity between compounds due to the enhanced resolution of the technique. The effect of sample turbidity on direct absorption and on second-derivative absorption spectra is also discussed.

On the analytical potential of micro-Raman spectroscopy in the trace characterization of polynuclear aromatic hydrocarbons, E. S. Etz, S. A. Wise, and K. F. J. Heinrich, SP519, pp. 723-729 (Apr. 1979).

Key words: laser-Raman microprobe; liquid chromatograph-Raman spectrometer interface; micro-Raman spectroscopy; organic microanalysis; PAH microsamples; (PAHs); polynuclear aromatic hydrocarbons; Raman spectra; trace organic analysis.

The results of a feasibility study are reported aimed at evaluating the analytical potential of micro-Raman spectroscopy (MRS) in the trace characterization of solid organic pollutants. In these experiments, a laser-Raman microprobe developed at the NBS has been used to obtain vibrational Raman spectra of microsamples of polynuclear aromatic hydrocarbons (PAHs). The spectra were obtained with $514.5 \mathrm{~nm}$ (green), $568.2 \mathrm{~nm}$ (yellow), and $647.1 \mathrm{~nm}$ (red) excitation from an $\mathrm{Ar} / \mathrm{Kr}$ ion laser to specifically examine potential measurement difficulties arising from sample heating (due to radiation absorption) and sample fluorescence. The PAHs were invcstigated as single microparticles, generally of size $2-10 \mu \mathrm{m}$, and include representative compounds of the 3-ring (e.g., anthracene, phenanthrene), 4-ring (e.g., chrysene, pyrene, fluoranthene) and 5-ring (e.g., benzo[a]pyrenc) systems. The Raman spectra of these organic solids are highly characteristic of crystal lattice (external) and molecular (internal) vibrations. They can therefore form a basis for the positive identification of the compounds in this class. A detection limit (with the Raman microprobe in its present state of development) of $10-100 \mathrm{pg}$ is indicated for many of these environmentally significant hydrocarbons. These results demonstrate a considerable analytical potential of the MRS technique for application as a sensitive and specific method for the detection and identification of 
trace level PAHs separated by chromatographic procedures.

Combined glass capillary-column gas chromatography and mixed charge exchange-chemical ionization mass spectrometry of isomeric polycylic aromatic hydrocarbons, M. L. Lee, D. L. Vassilaros, W. S. Pipkin, and W. L. Sorensen, SP519, pp. 731-738 (Apr. 1979).

Key words: capillary-column; charge exchange; chemical ionization; gas chromatography; mass spectrometry; polycyclic aromatic hydrocarbons.

Glass capillary-column gas chromatography combined with mixed charge exchange-chemical ionization mass spectrometry is used to differentiate between isomeric polycyclic aromatic hydrocarbons found in Utah air particulate matter. A reagent-gas mixture of methane and argon is used to produce unique mass spectra for isomers eluted within the methylphenanthrene/anthracene and the methylfluoranthene/pyrene regions of the chromatogram.

New concepts of quantitation in headspace gas analysis by stripping and trapping components in a closed circuit, J. Novăk, J. Janák, and J. Goliās, SP519, pp. $739-746$ (Apr. 1979).

Key words: equilibration trapping; gas chromatography; headspace gas stripping; standard-addition calibration; trace analysis; trapping column.

A theoretical analysis of the method of stripping and trapping components in a closed circuit was carried out. Alternatives involving the discontinuation of the stripping and trapping process either before the frontal zone of a component under determination starts breaking through the trapping column or after the component reaches a state of equilibration within the system are specified. Equations relating the amount of a solute component accumulated in the trapping column and the initial total amount of the component in the system analyzed were derived for both of the above alternatives. The standard-addition technique is shown to be a universal means of quantitation in headspace gas trace analysis by the method studied.

Error estimates in total organic elemental content passive personal samplers, J. G. Montalvo, Jr., SP519, pp. $747-752$ (Apr. 1979).

Key words: ambient concentration; compute and limit; error; sampler response factors; total elemental content passive personal samplers; total organic chlorine; weighted diffusion coefficient.

The development of specific passive personal samplers for each volatile organic form of an element will become more complex, ultimately leading to a common monitor which can detect any or all organic forms of that element. Such a device is introduced here as a total organic elemental content passive personal sampler. The goal of this paper is to show how to compute and limit the ambient concentration error attributed to molecular diffusion approximations for total organic elemental content passive samplers. Some of the implications of data collected by this approach are discussed. For example, calculations of the anticipated error in determining total organic chlorine levels (TOCI) at a vinyl chloride plant in known workplace situations indicated the maximum error between monitor and ambient concentration values due to diffusion assumptions would bc less than $11 \%$. The total organic elemental contcnt sampler error depends upon the value of the weighted diffusion coefficient used to convert the mass of element collected to ambient concentration. The error is calculated from the following equation derived for $n$ species:

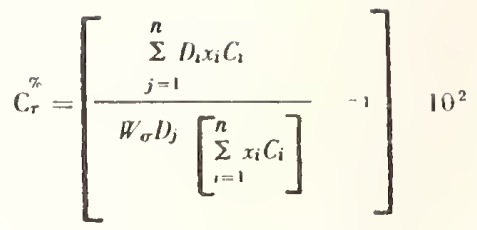

where $C_{\ell} \%=$ error in ambient total organic elemental content, $D_{i}=$ diffusion coefficicnt of the $i$ form of the element, $x_{i}=$ number of equivalents per molecule for the $i$ species, $C_{i}=$ ambient total organic elemental concentration of the $i$ form of an element, $W_{0}=$ weighting factor of the occupational situation on the diffusion coefficient of the $j$ species of the element, and $D_{j}$ $=$ diffusion coefficient of the $j$ species. Unfortunately, the value of the weighted diffusion coefficient tends to be nonideal in occupational exposure situations, because the relative concentrations of the different organic volatile forms of an element diffusing into the sampler are variable. Since it is not possible to calculate an exact weighted diffusion coefficient, an error will exist between sampler and ambient concentration values. These calculations are examples of what could be accomplished with total elemental content passive samplers. The methods of approach should also be applicable to other occupational situations where there is a need for more comprehensive exposure data. It is hoped that this paper will stimulate development of this novel concept in personal sampling.

Concerted trace organic analysis in industrial research, $\mathrm{S}$. A. Liebman and E. J. Levy, SP519, pp. 753-760 (Apr. 1979).

Key words: Fourier transform infrared; gas chromatography; modular organic analysis system; pyrolysis; trace organic analysis.

The three primary analytical fields utilized in the conduct of trace (submicrogram) organic studies are spectroscopy, chromatography, and thermal analysis. It is within each of these specialities, developed with state-ofthe-art computer capabilities, that the field has advanced to its present level. Complex problem-solving is seldom accomplished with a single analytical tool, even with the sophisticated instrumentation available to most researchers. Thus, the interaction of the organic analysts with organic and physical chemists, chemical and instrument engineers, and computer specialists provides a wide range of cooperative efforts in basic and applied industrial chemical research.

The modular unit incorporates a variety of sample injection modes (gas, liquid, solids, pyrolyzer) with an on-line concentrator trap, and an analytical separation column with stop-flow valving to direct effluent peaks into an online functional group or elemental reactor system. The simultaneous determination of $\mathrm{C}, \mathrm{H}, \mathrm{N}, \mathrm{O}$ and certain heteroatoms is achieved by microchemical conversions to diagnostic products which are separated on a second internal chromatographic column to aid in peak identification. Outline of the equipment design and engineering will be presented and its adaptation to diverse applications in trace organic analysis.

Diffusion tubes as a primary standard for OSHA-type calibration, F. J. Debbrecht, D. T. Daugherty, and E. M. Neel, SPS19, pp. 761-769 (Apr. 1979).

Key words: diffusion tubes; OSHA; primary standards.

The technique of diffusion tubes is presented as a means of generating dynamically a primary standard of a material 
in a flowing air stream that can be used for calibration. The entire technique of diffusion tubes is discussed including both the theoretical and empirical data obtained from typical diffusion tubes. An instrument is described to incorporate diffusion tubes in the development of these dynamic standards. The use of dynamic standards generated from diffusion tubes is used for the calibration of charcoal tubes. This mode of calibrating charcoal tubes is compared with the recommended way of calibration.

Methods for the organic analysis of the Mighei; a reputedly contaminated meteorite, P. H. Buhl, SP519, pp. 771-775 (Apr. 1979).

Key words: abiotic synthesis; carbonaceous chondrite; chemical evolution; meteorite; Mighei.

Of the various classes of meteorites, the Type I and II carbonaceous chrondrites are the least metamorphosed and contain the largest fraction of extractable organic compounds. Since recently fallen Type I and II carbonaceous chondrites are rare, occurring at $\sim 5-10$ year intervals, it is desirable to be able to use older fallen meteorites to add to the specimens available for analysis. However the older specimens, usually preserved in museum collections, were considered contaminated and unsuitable for organic analysis.

A sampling technique was developed and applied to a fragment of the supposedly contaminated Mighei Type II carbonaceous chondrite which fell in Russia in 1889 . Using GC and GC-MS methods, protein and nonprotein amino acids were identified. Equal amounts of the diastereomers of alanine, $\alpha$-aminobutyric, norvaline, $\beta$-aminoisobutyric, aspartic and $\alpha$-aminoadipic acids were found. This distribution is not found in naturally occurring terrestrial materials, thus the asymmetric amino acids are shown to be indigenous to the meteorite and not the result of contamination. The analysis of the Mighei demonstrates that older fallen meteorites can be used to study indigenous organic compounds. This makes additional and varied specimens of these rare meteorites available for prebiotic studies of organic processes of the early solar system which may have led to chemical evolution.

The use of a novel gas chromatographic detection system for the analysis of trace halo-organics, J. D. Lupton, S. C. Havlicek, and P. R. Loy, SP519, pp. $777-782$ (Apr. 1979).

Key words: electron capture detector; gas chromatography; halo-organics; ionization detector; porous anode.

A novel ionization (electron capture) gas chromatographic detector is described. The new design features an open cell, an anode-to-cathode gas flow and a porous anode. These features greatly reduce recirculation in the detector which in turn means that polar solvents may be injected without loss of the ability to detect trace quantities of halo-organics. The new detector design is also remarkably tolerant to highly impure samples and can be used at low flows. The desirable properties of electron capture type detectors, such as selectivity, linearity of response and extreme sensitivity are retained. A number of practical applications are described.

Use of polymer supported functional groups for the selective concentration of organic compounds, R. J. Kostyla, T. H. Mourey, R. Cohen, M. E. Merritt, K. Simmons, R. LaFaucia, G. Limentani, D. N. Washburn, and S. Siggia, SP519, pp. 783-787 (Apr. 1979).

Key words: affinity chromatography; environmental analysis; functional group analysis.
The objective of this research has been the preparation and characterization of chemically modified solid supports containing specific functional groups for the separation and/or concentration of selective classes of organic compounds. These resins derive their high selectivity and strong affinity from specific chemical reactions between the polymer supported functional group and the solute.

A proposal for implementing a reference collection of humic and fulvic acids, R. L. Malcolm and P. MacCarthy, SP519, pp. $789-792$ (Apr. 1979).

Key words: aquatic humus; fulvic acid; humic acid; humic substances; reference collection of humic substances; reference samples; soil organic matter.

Four humic and fulvic acids from a mineral soil, an organic soil, a geologic deposit, and from a stream water are proposed as international reference samples of natural organic matter. The acids will be extracted and isolated by the best present technology to insure well-humified, representative, ash-free preparations for geochemical research. A proposed isolation procedure is outlined using $\mathrm{XAD}-8$, an uncharged acrylic resin. An international committee of scientists will oversee all aspects of the establishment of the reference collection.

The need to establish a reference collection of humic substances, P. MacCarthy and R. L. Malcolm, SP519, pp. 793796 (Apr. 1979)

Key words: fulvic acid; humic acid; humic substances; reference collection of humic substances; soil organic matter; standard humic materials.

Humic substances constitute an ubiquitous class of natural organic matter occurring in soils, sediments and natural waters. These materials are found in concentrations ranging from trace to macroscopic levels, and they play an important role in many agricultural, environmental and geochemical processes. Fundamental and applied research on humic substances is hampered by the fact that presently there is no objective mechanism for the interlaboratory comparison of experimental data on humic substances. A proposal to remedy this situation through the establishment of an international stockpile of standard humic materials. is discussed; the potential benefits of this program to research on humic substances are outlined.

Analysis of $4.5 \mathrm{~mol} / \mathrm{L}$ sulfuric acid for organic compounds leached from battery separators, E. C. Laird and S. B. Hanna, SP519, pp. 797-802 (Apr. 1979).

Key words: battery; chromatography; sulfuric acid; trace organics.

Organic compounds present at $\lambda 10 \mu \mathrm{g} / \mathrm{mL}$ in $4.5 \mathrm{~mol} / \mathrm{L}$ $\mathrm{H}_{2} \mathrm{SO}_{4}$ were separated, identified, and quantitated. These compounds were solubilized from lead-acid battery separators, made of phenol-formaldehyde resin-impregnated cellulose, by the action of $4.5 \mathrm{~mol} / \mathrm{L} \mathrm{H}_{2} \mathrm{SO}_{4}$ at $75{ }^{\circ} \mathrm{C}$ for 20 h. Separation techniques include: steam distillation, ionexchange, TLC, GC, centrifugation, chemical precipitation, paper chromatography and reverse phase HPLC. Identification and quantitation involved the use of GC, IR, NMR, UV-visible and "total carbon" analysis. Glucose, formaldehyde, acetic acid, and formic acid are among the many products found in the leach acid.

Analysis of trace plant constituents, N. Mandava, SP519, pp. 803-807 (Apr. 1979).

Key words: abscisic acid; gas chromatography; liquid chromatography; plant constituents. 
The isolation and identification of trace plant constituents such as N,N-dimethyltryptophan, $m$-hydroxyphenylacetic acid, and $5 \beta$-cholanic acid were achieved by microanalytical methods. Two methods for analysis of abscisic acid in the plant tissue are described.

GC-ECD assay after sample work-up: Nomenclature for standards, and some poirsts of practice, E. Reid, SP5/9, pp. 809-810 (Apr. 1979).

Key words: chromatography/column packings (GC); electron-capture detection; evaporation; nomenclature; sample work-up; standards.

For trace-organic assays where spiked-in standards are put through the whole procedure, a nomenclature is advocated to reduce present-day diversity and ambiguity, especially where the end-step is GC, HPLC or TLC. The reliability of such assays, e.g., for basic drugs in blood, can be improved by measures to deal with problems such as adsorptivity.

SP525. Ultrasonic tissue characterization 11. A collection of reviewed papers based on talks presented at the Second International Symposium on Ultrasonic Tissue Characterization held at the National Bureau of Standards, Gaithersburg, MD, June 13-15, 1977, M. Linzer, Ed., Nat. Bur. Stand. (U.S.), Spec. Publ. 525, 339 pages (Apr. 1979) SN003-003-020583.

Key words: absorption; attenuation; computerized tomography; Doppler; impedance; medical diagnosis; microscopy; pattern recognition; scattering; signal processing; tissue characterization; tissue parameters; ultrasound, velocity.

The Second International Symposium on Ultrasonic Imaging and Tissue Characterization was held at the National Bureau of Standards on June 13-15, 1977. The meeting was cosponsored by the National Bureau of Standards, the National Science Foundation, and the National Institutes of Health. This volume contains extended and reviewed papers based on 43 of the 53 talks presented at the Symposium. Topics covered include techniques for measurement of ultrasonic tissue parameters, the dependence of tissue properties on physical and biological variables (e.g., ultrasonic frequency, temperature), mechanisms of ultrasonic tissue interactions, propagation through bone and skull, tumor Doppler signatures, computerized tomography, signal processing and pattern recognition, and tissue phantoms. A survey of velocity and attenuation data in mammalian tissue is included in an appendix. These proceedings include the following papers (indented):

Elements of tissue characterization. Part I. Uhtrasonic propagatior properties, R. L. Johnston, S. A. Goss, V. Maynard, J. K. Brady, L. A. Frizzell, W. D. O'Brien, Jr., and F. Dunn, SP525, pp. 19-27 (Apr. 1979).

Key words: absorption; amino acids; attenuation; frequency; mammalian tissues; polypeptides; proteins; tissue characterization; ultrasonics; velocity.

Tissues can be characterized ultrasonically by their attenuation, absorption, and velocity, all of which correlate well with the presence of the major tissue components of water, and protein, particularly, collagen. This correlation is examined in solutions of biologically important molecules and in a number of tissues and organs. It is shown that tissues can be grouped according to similar ultrasonic propagation properties, physiological functions, and concentration of elementary constituents. The role of collagen in determining ultrasonic properties of normal and pathological tissues is discussed.
Absorption of sound in tissues, E. L. Carstensen, SP525, pp. 29-36 (Apr. 1979)

Key words: absorption of ultrasound; macromolecular relaxation; relaxation phenomenon; ultrasonic tissue absorption.

In spite of extensive applications of ultrasound in diagnosis, therapy and even surgery, there a re still many problems to be solved in the basic physics of sound propagation in tissues. Absorption of longitudinal ultrasonic waves occurs primarily at the macromolecular level. There is evidence to indicate that this absorption can be profoundly modified by macromolecular interaction. The specific structural or chemical relaxation mechanisms responsible for the absorption are unknown. Microscopic inhomogeneities may lead to certain forms of relative motion viscous losses or thermal absorption. Macroscopic inhomogeneities in tissue affect sound propagation and can lead to artifacts in certain methods of measurement of tissue absorption. Shear waves are not important in the soft tissues of the body.

Mechanisms of ultrasomic attenuation in soft tissue, $\mathbf{M}$. O'Donnell and J. G. Miller, SP525, pp. 37-40 (Apr. 1979).

Key words: inhomogeneities; inhomogeneity thermal losses; mechanisms; viscous relative motion.

Ultrasonic loss mechanisms which arise from the microscopically inhomogeneous nature of soft tissue are investigated over the frequency range $\sim 1$ to $\sim 10 \mathrm{MHz}$. Contributions to the ultrasonic attenuation due to viscous relative motion losses and thermal losses are shown to exhibit an approximately linear dependence on frequency. Numerical estimates of the attenuation arising from these mechanisms are compared with the results of experiments for a representative substance in each of three attenuation categories: low (blood), medium (heart), and high (skin). Inhomogeneity losses can account for $\sim 60$ percent of the attenuation observed in heart and skin, and thus may contribute a non-negligible fraction to the attenuation observed in most soft tissue.

Elements of tissue characterization. Part II. Untrasonic propagation parameter measurements, S. A. Goss, R. L. Johnston, V. Maynard, L. Nider, L. A. Frizzell, W. D. O'Brien, Jr., and F. Dunn, SP525, pp. 43-51 (Apr. 1979).

Key words: ultrasonic absorption; ultrasonic attenuation; ultrasonic instrumentation; ultrasonic measurements; ultrasonic spectroscopy; ultrasonic tissue characterization; ultrasonic tissue parameters; ultrasonic tissue signature; ultrasonic velocity.

Methods employed at the Bioacoustics Research Laboratory of the University of Illinois for the determination of ultrasonic propagation properties of biological media are described, with attention devoted to attenuation, absorption and velocity measurements of both longitudinal and shear ultrasonic waves. These include systems specifically for the ultrasonic characterization of soft tissues and for solutions of biologically significant macromolecules. Each method is presented in terms of theory, limitations, applicability, and possible sources of error. Important new techniques from other laboratories are also discussed.

A device for measuring ultrasonic propagation velocity in tissue, B. D. Sollish, SP5 25, pp. 53-56 (Apr. 1979).

Key words: propagation velocity; reflection technique; solids; tissue; ultrasound. 
This paper discusses a device capable of measuring propagation velocity in tissue, both excised and in vivo. The device produces a 4-digit decimal readout of propagation velocity in the specimen relative to that in water. As presently constituted the device is capable of 1 velocity measurement per second, with one additional second required for printout of the result.

The theory of the device is described, and experimental results are presented for solids and soft tissues.

Measurement of the temperature dependence of the velocity of ultrasound in soft tissues, T. Bowen, W. G. Connor, R. L. Nasoni, A. E. Pifer, and R. R. Sholes, SP525, pp. 57-61 (Apr. 1979).

Key words: non-invasive temperature monitoring; soft tissue; temperature dependence; ultrasound velocity; zero crossing detection.

The velocity of $5 \mathrm{MHz}$ ultrasound is being measured in tissue samples in order to evaluate the feasibility on noninvasive monitoring of temperature distributions produced during hyperthermia treatments. By employing a pulsed-ultrasound technique in which the time of the first zerocrossing of the received signal is recorded, the velocity measurements are insensitive to reflections and to changes of attenuation. Results in the 35 to $45^{\circ} \mathrm{C}$ range for fresh canine tissues, such as kidney, liver, and muscle, indicate that the rate of velocity change with temperature is correlated with the magnitude of the ultrasonic velocity, but the relationship appears to be altogether different for tissue fat. The results give encouragement to carry out the more extensive measurements, particularly in vivo, which would be needed to determine feasibility of an ultrasonic temperature monitoring system.

Ultrasonic attenuation in normal and ischemic myocardium, M. O'Donnell, J. W. Mimbs, B. E. Sobel, and J. G. Miller, SP525, pp. 63-71 (Apr. 1979).

Key words: ischemic injury; myocardial infarction; ultrasonic attenuation.

The ultrasonic attenuation coefficient of dog myocardium was measured in vitro over the frequency range 2 to $10 \mathrm{MHz}$. Changes in the attenuation of normal myocardium were measured as a function of time after excision at fixed temperatures. Results of measurements made on tissue maintained at $35^{\circ} \mathrm{C}$ revealed progressive changes in the attenuation as a function of time, presumably indicative of tissue degradation. Results of measurements at $\mathbf{1 9 . 5}$ ${ }^{\circ} \mathrm{C}$, however, showed no significant changes in attenuation up to 4 hours following excision. The temperature dependence of the attenuation was measured over the range $\sim 20$ ${ }^{\circ} \mathrm{C}$ to $\sim 37^{\circ} \mathrm{C}$, yielding the result that the attenuation coefficient at $37{ }^{\circ} \mathrm{C}$ is about 20 percent lower than that at 20 ${ }^{\circ} \mathrm{C}$. The attenuation coefficient was measured in vitro at $\sim 20{ }^{\circ} \mathrm{C}$ in hearts from dogs previously subjected to coronary occlusion and sacrificed at intervals ranging from 15 minutes to 3 days following occlusion. Results of these measurements indicate a modest decrease in the attenuation of ischemic tissue measured at 15 minutes, 1 hour, 6 hours and 24 hours, and an increase in attenuation of ischemic regions studied 3 days following occlusion.

Acoustic microscopic analysis of myocardium, D. E. Yuhas and L. W. Kessler, SP525, pp. 73-79 (Apr. 1979).

Key words: acoustic microscopy; anisotropy; attenuation; elastic microstructure; infarct; interferogram; myocardium; phase cancellation; velocity.
Acoustic microscopy can be employed to measure variations in the ultrasonic attenuation and velocity over spatial dimension of tens of micrometers. Knowledge of the interactions at this fine-structure level provides a more complete understanding of the response of tissues at diagnostic frequencies. In this article we investigate the ultrasonic characteristics of formalin-fixed infarcted and normal myocardium at the microscopic level. The elastic microstructure of normal tissues is found to be uniform over spatial dimensions of hundreds of micrometers. The attenuation coefficient $\alpha$, at $100 \mathrm{MHz}$, ranges from 37 to $68 \mathrm{~cm}^{-1}$ while the velocity varies less than $\pm 20 \mathrm{~m} / \mathrm{s}$. Acoustic anisotropy, attributed to muscle fiber orientation, is found to be a primary source of attenuation variability. The elastic microstructure in the zones of infarction is very distinct from that in normal zones. With infarction, variations in the attenuation ranging from 38 to $100 \mathrm{~cm}^{-1}$ occur over dimensions of hundreds of micrometers. Accompanying this variability in attenuation is a wide distribution of velocity. The most highly attenuating regions in the infarcted tissue show localized increases in the velocity of more than $75 \mathrm{~m} / \mathrm{s}$. Such large variations in sonic velocity are sufficient in magnitude to be an important source of phase cancellation in low frequency attenuation measurements. Additionally, the $100 \mathrm{MHz}$ data indicate that the frequency dependence of the attenuation coefficient observed in the 1 to $10 \mathrm{MHz}$ range for infarcted and normal myocardium may not hold in the 10 to $100 \mathrm{MHz}$ frequency interval.

Acoustic properties of normal and abnormal human brain, F. W. Kremkau, C. P. McGraw, and R. W. Barnes, SP525, pp. 81-84 (Apr. 1979).

Key words: attenuation; brain tumor; clot; hemorrhage; hydrocephalus; impedance; infarct; speed; ultrasonic.

Attenuation and propagation speed at 1,3, and $5 \mathrm{MHz}$ and specific acoustic impedance at $2 \mathrm{MHz}$ were measured in vitro in 10 tissue samples from 8 abnormal human brains. The results were compared to values resulting from a study of 5 normal human brains reported elsewhere. Conclusions from literature review are that attenuation is lower in gliobastoma than in normal brain and attenuation, propagation speed and impedance are higher in meningioma than in normal brain. Conclusions from the data of the present study are that subarachnoid hemorrhage appears acoustically normal; infarcts have normal attenuation but increased speed; clots, intracerebral hemorrhage, and metastases have increased attenuation and speed; hydrocephalic brain has very low attenuation and low speed. In general, it appears that abnormal conditions produce increases in all three acoustic properties studied.

Frequency dependent attenuation of malignant breast tumors studied by the Fast Fourier transform technique, E. K. Fry, N. T. Sanghvi, F. J. Fry, and H. S. Gallager, SP525, pp. 85-91 (Apr. 1979).

Key words: attenuation of areola; attenuation of breast tissue; attenuation of malignant tumors; breast cancer detection; breast carcinoma; breast examination techniques; FFT techniques for breast; histology of breast tumors; signal processing for tissue; $x$-ray examination of breast.

The work discussed in this paper comprises one aspect of an experimental design concerned with the use of multidiscipline examination methods to provide detailed information on the interaction of normal and malignant breast tissues with a high frequency sound field. The complete experimental design included $x$-ray and needle biopsy ex- 
amination of the breast of a patient prior to mastectomy, followed by: $x$-ray examination of the excised breast (the malignant tumor remained intact in the excised breast); ultrasound visualization and FFT studies of the formalinfixed, excised breast specimen; x-ray examination of 0.5 $\mathrm{cm}$ thick, whole breast sections of the tissue; and, finally, sectioning and histological staining of the primary malignant tumor region and other tissue areas of interest. Emphasis is given in this preliminary report to a study of attenuation of the sound beam as a function of frequency for specific tissue paths (i.e., from skin to back surface of the excised breast), which included (1) the malignant tumor, (2) the nipple and (3) the areola.

For the tissue path which included the malignant tumor, the FFT studies indicate that the attenuation for the full range of frequencies studied ( 1.1 to $4.4 \mathrm{MHz}$ ) was greater than that of any other area of the breast. A significant result of the investigations reported in this paper is the determination that this analytical technique is feasible and can yield data on malignant and normal regions of breast tissue which correlate with the ultrasound visualization imaging information and with the tissue structure information as revealed by histological examination.

Correlation of ultrasonic attemuation with connective tissue content in breast cancers, T. Kobayashi, SP525, pp. 93-99 (Apr. 1979).

Key words: attenuation; breast cancer; cancer; connective tissue; differential diagnosis; medullary carcinoma; papillary carcinoma; scirrhous carcinoma; shadowing; ultrasound.

In recent years, ultrasonic techniques have been applied to the diagnosis of breast cancer. Various characteristics suggestive of tumor pathology have been determined. In this paper, some of these signs, such as the acoustic middle shadow and the complete disappearance of the distal limit of the tumor mass echo, are correlated with the connective tissue content of various breast cancers. Because of the high acoustic impedance of connective tissue relative to the other tissues, tumors rich in connective tissue are believed more strongly to attenuate the ultrasonic waves and thus to cause shadows in the tissues beyond them.

The attenuation of selected soft tissue as a fanction of Irequency, D. H. Le Croissette, R. C. Heyser, P. M. Gammell, J. A. Roseboro, and R. L. Wilson, SP525, pp. 101-108 (Apr. 1979).

Key words: attenuation; tissue properties; transmission; ultrasound.

Measurements of attenuation versus frequency have been made on pancreas, kidney, fat and liver specimens of hog tissue. Hogs were of the "Berkshire" variety and the tissue obtained from a slaughterhouse. The measurements were taken under controlled conditions of temperature and formalin fixing to determine the effects of aging and fixing on the tissue. A swept-frequency transmission system was used operating over the range of about 1.5 to $9.5 \mathrm{MHz}$. The curves show the changes occurring in fresh tissue as a result of several days of aging at refrigerator temperatures $\left(5^{\circ} \mathrm{C}\right)$ and the effects of fixing the tissue in formalin immediately post-mortem or after several days of $5{ }^{\circ} \mathrm{C}$ storage. All measurements were made at $37^{\circ} \mathrm{C}$.

Clinical spectrum analysis techniques for tissue characterization, F. L. Lizzi and M. E. Elbaum, SP525, pp. $111-119$ (Apr. 1979).

Key words: clinical ultrasound; ocular tumor; power spectra; Rayleigh scattering; ultrasonic spectrum analysis.
A spectrum analysis system is being used in a clinical measurement program to examine the reflectance characteristics of intraocular structures. The on-line system computes power spectra descriptive of echoes returned from well-defined tissue segments chosen by the examiner. Clinical data are digitized for subsequent post-processing and cataloguing. This paper presents an overview of the theoretical analysis used to formulate system design and to guide data interpretation. The analysis accounts for stochastic tissue architectures and treats the specific illumination conditions employed in the system. The paper also discusses system parameters as related to observable tissue characteristics and presents typical test data and clinical spectra for several pathologic conditions.

Tissue characterization in vivo by differential attenuation measurements, S. Lévi and J. Keuwez, SP525, pp. 121-124 (Apr. 1979)

Key words: characterization; differential attenuation; tumor; ultrasound.

A practical ultrasound method has been applied for the differentiation in vivo of pelvic tumors. This method has the advantage of being applicable during usual ultrasonic examination and does not require information about the tissues involved, nor the surrounding tissues.

The method is based upon the fact that the ultrasonic attenuation increases with frequency; the comparison of the echoes from the posterior and anterior boundaries of the tumor leads to a coefficient of differential attenuation. This coefficient has been determined in examinations of 95 gynecological patients; the organs and tumors explored were normal uteri, leiomyomas and ovarian cysts. The values of the coefficient of differential attenuation obtained for these three categories of tissue are sufficiently separated, which enables us to make a differentiation.

Statistical estimation of the acoustic attenuation coefficient slope for liver tissue from reflected ultrasonic signals, R. Kuc, M. Schwartz, N. Finby, and F. Dain, SP525, pp. 125-132 (Apr. 1979).

Key words: computer processing; estimation theory; liver attenuation; spectral analysis; statistical modeling; ultrasonic tissue characterization.

The acoustic attenuation coefficient measured in $\mathrm{dB} / \mathrm{cm}$ is known to increase linearly with frequency for liver tissue. The slope of this linear function, denoted by $\beta$, has been shown by other investigators to be an indicator of tissue state. $\beta$ is usually measured from the change in the log spectrum experienced by an acoustic pulse when it is transmitted through the tissue. This paper presents research in estimating $\beta$ from the reflected signals which are currently used in the clinical environment to generate diagnostic images. The reflected signals from internal tissue structures (in liver-the vascular and biliary systems) are distorted by the irregular reflector shapes. By modeling the roughness of the typical acoustic reflector, the distribution of the received spectra can be derived and the 95 percent confidence limits for the measured $\beta$ can be calculated. The confidence limits are presented in terms of the tissue size and average reflector density. Experimental results using the reflected signals from in vitro refrigerated and formalin-fixed liver sections are presented.

An ultrasonic tissue signature for the lung surface, $T$. L. Rhyne, SP525, pp. 135-141 (Apr. 1979).

Key words: detection of lung disease; frequency signature; statistical scattering; tissue signature; ultrasonic scattering; ultrasound. 
The normal lung surface is modeled as a statistically rough surface composed of the air-containing alveolar sacs at the periphery. The ultrasonic reflection (scatter) from the rough surface is analyzed as a random process and a frequency signature, which depends upon alveolar sac radii statistics, is prcdicted for the reflectance. Pulse-echo ultrasonic instrumentation for the measurement of the absolute reflectance from the lung surface is presented. Lung reflectance data confirming the lung surface frequency signature is presented for humans. Applications of the model are discussed to the detection of pulmonary embolism, atelectasis, pulmonary edema, and chronic lung disease.

Angle scan and frequency-swept ultrasonic scattering characterization of tissue, R. C. Waag, P. P. K. Lee, R. M. Lerner, L. P. Hunter, R. Gramiak, and E. A. Schenk, SP525, pp. 143-152 (Apr. 1979).

Key words: angular scattering; characterization of tissue; optical correlation; scattering; swept-frequency diffraction.

Ultrasonic wave interference has been applied to characterize tissue by measuring scattered wave intensity as a function of frequency and angle. A theory of acoustic wave propagation and scattering in an inhomogeneous medium has been employed to show that received ultrasound may be expressed in terms of medium refractive index variations via a Fourier transform. Using a computer-based system, measurements were made on model targets and post-mortem liver specimens. Model studies demonstrate that regular scatterer spacing can be inferred from measured diffraction data by Fourier inversion and that scattering differences can be observed from random media consisting of particles of different average sizes. Scattering from liver indicates there is significantly more energy scattered at small angles than is backscattered. Correlation of ultrasound scattering with structure observed through a microsocpe has been obtained by computing the diffraction pattern of the two-dimensional optical transmittance images acquired through a microscope-TV chain attached to the computer. Average particle sizes of the model random media determined by Fourier analysis that exhibited diffraction rings of the digitized cross-sections yielded scattering predictions which were in agreement with measured acoustic data.

Quantitative measurements of scattering of ultrasound by heart and liver, J. M. Reid and K. K. Shung, SP525, pp. 153156 (Apr. 1979).

Key words: absorption; attenuation; heart; liver; scattering; scattering cross-section.

Quantitative backscattering measurements have been made using the substitution method used to measure the scattering properties of blood previously. We have obtained preliminary experimental values for the backscattering coefficients of liver and myocardium, fully corrected for equipment and transducer parameters as well as attenuation of the scattering tissue. Results show that scatter ${ }^{2}$ ing for both liver and myocardium is an increasing function of frequency up to $10 \mathrm{MHz}$. This increase indicates that the tissue elements responsible for the scattering must be less than 30 micrometers in diameter. The level of scattering from liver tissue indicates that if it isotropic scattering the scattering loss is large enough to account for about 28 percent of the total attenuation reported at $10 \mathrm{MHz}$ frequency.

Dependence of ultrasound backscatter from human liver tissue on frequency and protein/lipid composition, M. Freese and E. A. Lyons, SP525, pp. 157-163 (Apr. 1979).
Key words: backscatter frequency dependence; cirrhosis; composition-dependent scattering; fatty liver; stochastic scattering; tissue characterization; ultrasonic tissue scattering; ultrasound attenuation; ultrasound diagnosis.

The dependence of ultrasonic volume backscatter on frequency, lipid and protein content in normal and fatty human (post-mortem) liver tissue was investigated with a view towards the possible development of a noninvasive quantitative diagnostic test for fatty liver. Mean values of the backscatter coefficient, its range and frequency dependence were determined for normal liver in the 1 to $5 \mathrm{MHz}$ range and for fatty liver at frequencies of 2.25 and 3.56 $\mathrm{MHz}$. The results indicate that frequencies below about 2 $\mathrm{MHz}$ should bc avoided for quantitative measurements of the backscatter in liver. Although the measurements revealed considerable variation in the backscatter levels of normal liver, the backscatter levels in moderately and severely fatty liver were significantly greater than the normal range. Simple linear correlation of the backscatter magnitude with the lipid content for 21 samples (10 normal, 8 fatty, 1 cirrhotic, 2 other abnormal) yielded a value of 0.94 , significant at the 1 percent level.

Ultrasound backscattering from blood: Hematocrit and erythrocyte aggregation dependence, $M$. Hanss and $M$. Boynard, SP525, pp. 165-169 (Apr. 1979).

Key words: blood erythrocytes aggregation; blood hematocrit; ultrasound backscattering from blood.

The ultrasound back-scattering of blood has been shown to be increased when the erythrocytes sedimentation rate is high. Moreover, in this case, temporal fluctuations of the back-scattered intensity have been also demonstrated. To explain these results, a simplified theory of ultrasound back-scattering by blood is presented. The model of the blood structure used is: the erythrocytes are associated to form spherical transient aggregates having the same cell number, $m$. The acoustic wave is scattered by these clusters called "scattering units." The scattered intensity is calculated for one scattering unit taking a spherical elastic model, then for a blood unit volume, when the hematocrit $H$ is very low. It is found that the back-scattered intensity is proportional to $\mathbf{H}$ and to $\mathrm{m}$. When $\mathbf{H}$ is not negligible, a simplified statistical theory is proposed. The main result is that the back-scattered intensity is still proportional to $\mathrm{m}$ but that it passes through a maximum value when $\mathrm{H}$ get near 0.3. An explicit relation between the mean relative value of the intensity fluctuation, $H$ and $m$ is given. Therefore, the aggregation state of blood can in principle be determined through ultrasound scattering studies. Further theoretical developments are in progress so as to take into account the distribution of the number of erythrocytes in each kinetic units and the variation of this number with $\mathbf{H}$.

Tumour detection by altrasonic Doppler blood-flow signals, P. N. T. Wells, M. Halliwell, R. A. Mountford, R. Skidmore, A. J. Webb, and J. P. Woodcock, SP525, pp. 173-176 (Apr. 1979).

Key words: blood flow; breast cancer; diagnosis; Doppler; screening; ultrasonics.

An in situ cancer is avascular and harmless. Vascularisation is necessary before a tumour is potentially capable of rapid growth. Distinctive continuous-wave ultrasonic Doppler signals have been obtained transcutancously from malignant breast tumours. Similar signals have been detected from abdominal malignancy, by means of a pulsed Doppler. These signals may form the basis of a practicable method of screening for breast cancer, and of improving the accuracy of cancer diagnosis. 
A theory relating sonic velocity to mineral content in bone, S. Lees and C. L. Davidson, SP525, pp. 179-187 (Apr. 1979).

Key words: bone; collagen; crosslinking modification; curvelinking; hydroxyapatite; sonic velocity.

Bony tissues consist primarily of mineral hydroxyapatite (HAP) crystallites embedded in a matrix of a much softer material, collagen. Currey and others suggested that bone is a two-phase composite, like mineral filled plastics, but the known laws of mixtures give at best a crude approximation of the observed elastic properties of bone. We have investigated the problem by measuring the ultrasonic velocity in mineral filled particulate composites as a function of the mineral concentration.

It was found that the ultrasonic velocity can be predicted for some mineral filled plastics by applying the Reuss formalism to the longitudinal elastic modulus, indicating that these are families of Reuss solids in some sense. Other mineral filled plastics do not seem to obey this rule, the ultrasonic velocity being greater than predicted. Bone appears to belong to this latter class of particulate composites.

The literature indicates that in certain situations the mineral filler affects the plastic matrix, giving the plastic constituent a higher modulus. A maximum longitudinal modulus is ultimately attained so that two Reuss formalism bounds can be obtained, the lower one calculated from the modulus of the unfilled plastic, the upper using the maximum modulus. The ultrasonic velocities of a system of fluorapatite (FAP) filled epoxy was found to lie between such bounds.

Currey and his successors assumed bone collagen has the same elastic properties as tendon collagen and that these are invariant with respect to contained HAP. The literature shows the contrary, that bone collagen, even when demineralized, is more highly cross linked than any other collagen. Moreover, the literature indicates that HAP crystallites are chemically bonded to the collagen molecules.

It is postulated that bone collagen is stiffened because HAP crystallites form on the intermolecular cross links, encasing them and making their effective lengths very short. It is shown that the sonic velocity for bone can be bounded by two Reuss formalism curves in the same manner as for FAP epoxy.

Ultrasonic properties and microtexture of human cortical bone, H. S. Yoon and J. L. Katz, SP525, pp. 189-196 (Apr. 1979).

Key words: anisotropy; dispersion; elasticity; human bone; microhardness; microstructure; piezoelectricity; thermodynamics; ultrasound; viscoelasticity; wave propagation.

The wave propagation in human cortical bone (dried) was investigated, using an ultrasonic pulse transmission method at room temperature. Firstly, it has been found that the symmetry of human cortical bone is consistent with the hexagonal system, based on the ultrasonic velocity measurement and microscopic observations. The five independent elastic stiffnesses were determined at $5 \mathrm{MHz}$, and they are (in GPa): $c_{11}=23.4 \pm 0.31, c_{33}=32.5 \pm 0.44, c_{44}$ $=8.71 \pm 0.13, c_{12}=9.06 \pm 0.38, c_{13}=9.11 \pm 0.55$.

Secondly, this study shows that bone filters and polarizes ultrasonic waves. Thirdly, since, in a piezoelectric medium such as bone, the wave propagation (or elastic stiffnesses) is modified by the piezoelectric coupling, the piezoelectric contribution or "stiffening" was calculated for bone, employing the piezoelectric and dielectric constants of bone reported in the literature. Compared with the corresponding values of two well-known piezoelectric materials, $\alpha$ quartz (single crystal) and "poled" barium titanate ceramic (polycrystalline), it has been found that the piezoelectric "stiffening" in bone is negligible. Finally, the sound velocities were measured over the frequency range of $I$ to 5 $\mathrm{MHz}$ for the transverse mode and of 2 to $10 \mathrm{MHz}$ for the longitudinal mode. For all the eight independent modes the ultrasonic velocities are found to increase with increasing frequency, implying that bone is viscoelastic even at these high frequencies.

Attenuation and dispersion of ultrasound in cancellous bone, J. E. Barger, SP525, pp. 197-201 (Apr. 1979).

Key words: attenuation; dispersion; skull bone; sound speed; ultrasound.

Measurements of the insertion loss and insertion phase shift for ultrasound transmitted through sections of cancellous bone from human skull are reported as functions of frequency over the range extending from $0.3 \mathrm{MHz}$ to 3.0 $\mathrm{MHz}$. The frequency dependence of insertion loss and of phase speed are both found to be caused principally by scattering of sound by the blood and fat filled interstices in the bone matrix. Independent scattering measurements made at all observation angles confirm the scattering phenomenon. It is concluded that both the high attenuation and the significant dispersion at frequencies above about $1 \mathrm{MHz}$ will limit the ability to characterize brain tissue by its backscatter at these high frequencies. Also, most reported sound speeds in cancellous bone have been calculated from the time-of-flight of broad-band pulses, and are therefore group speeds. These group speeds will exceed the phase speeds by about 15 percent in magnitude.

Transkull transmission of axisymmetric focused ultrasonic beams in the 0.5 to $1 \mathrm{MHz}$ frequency range: Implications for brain tissue visualization, interrogation, and therapy, F. J. Fry, SP525, pp. 203-208 (Apr. 1979).

Key words: axisymmetric; beams; focal thermal flaw; skull transmission; ultrasound.

In order for ultrasound to become a practical clinical technique for diagnosis of many intracerebral diseases in the adult human, it has been necessary to answer questions concerning insertion loss of skull, temporal and spatial characteristics of beams operating in the 0.5 to $1.0 \mathrm{MHz}$ range (the requisite frequency is a function of the particular adult skull) have a maximum single pass skull insertion loss of nearly $10 \mathrm{~dB}$ ( $20 \mathrm{~dB}$ for a pulse echo system) which can be handled with present techniques to provide adequate signal strength from normal and pathological features of brain. In this frequency range, for skulls in our studies, the appropriately selected frequency is unchanged after double pass skull transmission, the $6 \mathrm{~dB}$ beam width is increased by a maximum of 40 percent and the beam focus is shifted laterally by a maximum of $3 \mathrm{~mm}$. Resolution of string targets or live brain targets has been demonstrated to be in the 2 to $3 \mathrm{~mm}$ range at $1 \mathrm{MHz}$ and at 0.5 $\mathrm{MHz}$ it appears that 4 to $6 \mathrm{~mm}$ resolution can be achieved.

A high intensity focused ultrasonic beam ( $1 \mathrm{MHz}$ ) has been transmitted through an excised adult skull and used to produce a focal thermal flaw in lucite. This simulation test indicates that the induction of transkull focal lesions in live adult brain may now be possible.

Some advances in acoustic imaging through skull, S. W. Smith, D. J. Phillips, O. T. von Ramm, and F. L. Thurstone, SP525, pp. 209-218 (Apr. 1979). 
Key words: brain scanning; echoencephalography; neurology; phase compensation.

Previous attempts to image the adult brain through the skull using diagnostic ultrasound have resulted in images of poor lateral resolution and limited dynamic range. The skull can be modeled as an acoustic lens whose attenuation increases rapidly above the $1 \mathrm{MHz}$ and whose thickness variations introduce phase aberrations on the order of several wavelengths across the transducer aperture. Statistical analysis of skull thickness data indicate that an electronic sector scanner using a $1 \mathrm{MHz}$ linear array transducer is less sensitive to these effects of the skull than traditional pulse echo systems operating at higher frequencies. Representative ultrasound tomograms of the brain are shown. In addition, water tank experiments are described in which the skull phase aberration, $\phi(x)$, was measured on line and removed by incorporating a compensating phase variation, $-\phi(x)$, into the transmit and receive timing of a digitally controlled real time phased array imaging system. Preliminary results show that the lateral resolution of the imaging system is restored in both the transmit and receive modes.

Characterization of in vivo breast tissue by ultrasonic timeof-flight computer tomography, G. H. Glover, SP525, pp. 221-225 (Apr. 1979).

Key words: breast cancer; computerized tomography; mammography; time-of-flight; tissue characterization; ultrasonic imaging; ultrasound.

The use of ultrasonic time-of-flight (TOF) computed tomography for characterization of tissue in live breasts is reported. Quantitative distributions of the refractive index within a tomogram of the specimen were obtained by reconstruction from $5 \mathrm{MHz}$ TOF projection data. Fifteen breast cancer patients and five asymptomatic volunteers were scanned during the clinical feasibility study. The results indicate that young, dense breasts have wide variation in the refractive index distributions. In older subjects, however, various lesions are found to have distinctive indices. Histograms of the reconstructions show differences between pathological and normal breasts.

Variation of acoustic speed with temperature in various excised human tissues studied by ultrasound computerized tomography, B. Rajagopalan, J. F. Greenleaf, P. J. Thomas, S. A. Johnson, and R. C. Bahn, SP525, pp. 227-233 (Apr. 1979).

Key words: aperture synthesis; computed tomography; Doppler; fluid flow; high resolution; reconstruction; temperature reconstruction; ultrasound.

Variation of acoustic speed as a function of temperature was measured in fresh excised human liver, psoas muscle, spleen, spinal cord, kidney and fat, parenchyma and muscles associated with female breasts. Tissues were encased in rubber finger cots and suspended in a temperature controlled bath. A prototype clinical ultrasound breast scanner was used to obtain data required to reconstruct distributions of acoustic speed within two-dimensional planes through the tissue specimens over a temperature range of 20 to $40{ }^{\circ} \mathrm{C}$. Quantitative images (printer listings of acoustic speed) of $64 \times 64$ pixels were used to obtain averages of up to 16 speed measurements within the image of each tissue. The acoustic speed in most tissues increased monotonically with temperature following the behavior of water. Acoustic speed of fat showed an anomalous decrease in acoustic speed around $34^{\circ} \mathrm{C}$ suggesting possible phase transition.
High spatial resolution ultrasonic measurement techniques for characterization of static and moving tissues, S. A. Johnson, J. F. Greenleaf, B. Rajagopalan, R. C. Bahn, B. Baxter, and D. Christensen, SP525, pp. 235-246 (Apr. 1979).

Key words: aperture synthesis; computed tomography; Doppler; fluid flow; high resolution; reconstruction; temperature reconstruction; ultrasound.

Clinical and pathology-based arguments are presented for the need for higher resolution ultrasound images. The theoretical foundation and experimental characteristics of a high resolution, sampled aperture, reflection technique termed "synthetic focus" imaging are given. It is shown by theory and simulation that such synthetic focus images may be corrected for attenuation and refraction effects and thereby approach one-half wavelength resolution. The similarity between synthetic focus and seismic migration techniques is discussed. An example of a high resolution, seismic processed (i.e., migrated) image obtained from real data at medical ultrasound frequencies is shown. Synthetic focus imaging theory is extended to moving coordinate systems and the effect of Doppler shift effects on echo pulse shape is discussed. A generalized wide aperture Doppler imaging theory is presented which suggests further improvements in signal-to-noise ratio, spatial resolution and flow velocity over narrow aperture systems is possible. A new computed tomographic flow measurement and reconstruction technique based on transmission measurements is presented. This technique permits imaging the three flow velocity components and temperature of homogeneous fluids in a three-dimensional domain.

A comprehensive ultrasonic tissue analysis system, $M$. Linzer, S. I. Parks, S. J. Norton, F. P. Higgins, D. R. Dietz, R. W. Shideler, T. H. Shawker, and J. L. Doppman, SP525, pp. 255-259 (Apr. 1979).

Key words: annular array; breast cancer; chirp signals; imaging; opto-acoustic; pulse compression; sensitivity; signal averaging; signal processing; tissue characterization; tomography; transducers; ultrasonics.

A progress report on the development of a comprehensive system for ultrasonic tissue characterization is presented. Major elements of the program include computerized tomography studies, particularly for breast cancer detection; opto-acoustic visualization of ultrasonic fields, for testing of new imaging schemes, studies of propagation through inhomogeneous media, in vitro measurements, and transducer calibration; electronic focusing, especially annular array imaging; sensitivity enhancement, using digital signal averaging and pulse compression techniques; computer and chirp waveform techniques for compensation of frequency-dependent attenuation; the SonoChromascope, a digital device for real-time acquisition, processing, and display of B-scan images; and computer-based image processing.

Theoretical analysis of instantaneous power spectra as applited to spectra-color ultrasonography, W. D. Jennings, E. Holasek, and E. W. Purnell, SP525, pp. 261-266 (Apr. 1979).

Key words: instantaneous power spectra; color-coded Bscan; spectra-color ultrasonography (SCU); spectrum analysis; ultrasonic spectroscopy.

Spectra-color ultrasonography (SCU), a technique for two-dimensional (B-mode) display of ultrasonic spectral data, has been analyzed theoretically. The analysis includes the use of an instantaneous power spectrum calculated 
from broadband gated echo spectra produced by an analog spectrum analyzer. The results of the analysis indicate that additional signal processing factors must be added to the $\mathrm{SCU}$ system as it was originally designed. With the inclusion of these modifications, the SCU scan represents a true low resolution instantaneous spectral analysis of ultrasonic echo waveforms. An experiment was performed to test the theoretical equations we have developed relating SCU to an instantaneous spectral analysis. The comparison of the SCU signals and the computed SCU equivalent based on an instantaneous power spectrum is presented.

Identification of tissue parameters by digital processing of real-time ultrasonic clinical cardiac data, L. Joynt, D. Boyle, H. Rakowski, R. Popp, and W. Beaver, SP525, pp. 267-273 (Apr. 1979).

Key words: clinical cardiac data; digital processing; Fast Fourier Transform; frequency spectra; in vivo; microprocessor-controlled data acquisition; myocardial infarction; real-time; tissue characterization; ultrasound diagnosis.

A study to assess the feasibility of obtaining diagnostically useful tissue characterization information by digitally processing clinical cardiac data is described. Normal subjects, myocardial infarction, IHSS, and amyloid patients were studied. The data acquisition system used to record data from a real-time scanner is also described. Significant changes in the RF signals and frequency spectra as the heart moves were noted over very short time intervals, indicating the need for a dynamic tissue characterization measure. Wide variation in the spectral characteristics of the signals from the normal population were found. Behavior of the spectra for the Ml patient data were noted wich differentiated them from the other subjects.

Dynamic autocorrelation analysis of A-scans in vivo, J. C. Gore, S. Leeman, C. Metreweli, N. J. Plessner, and K. Willson, SP525, pp. 275-280 (Apr. 1979).

Key words: A-scan; correlation analysis; temporal changes.

A realistic tissue model has been analysed to indicate the information that may be derived from autocorrelation studies of in vivo A-scan echograms, as well as to show some of the limitations of such techniques. Although many of these difficulties are not easily overcome when considering single, or even averaged, realisations of the autocorrelation function ( $A C F$ ), an analysis of the time course of the $A C F$ is less subject to such objections.

Several potentially useful clinical applications of such temporal changes are being investigated. These include measurements of echoes from within heart muscle throughout the cardiac cycle as a possible indicator of cardiac disease; similar variations in echoes from the stomach wall during gastric emptying are demonstrated, and a relationship to contractile state is postulated.

Results are also presented which indicate that the perfusion of tissues with blood may be assessed by this technique, and, on a different physiological time scale, changes in the placenta throughout pregnancy have been investigated. The technique is being extended to the study of the response of malignant tumours to treatment.

Computer spectral analysis of ultrasonic $\mathbf{A}$ mode echoes, D. E. Robinson, SP525, pp. 281-286 (Apr. 1979).

Key words: acoustic; computer processing; digital acquisition; digital signal processing; pulse-echo techniques; spectrum analysis; ultrasonics.
Tissue attenuation as a function of frequency measured by the effect on the power density spectrum of the echo off glass shadowed by the tissue sample is shown to give results comparable to those published previously. A method of measuring attenuation within tissue by comparison of the scattered echoes from shallow and deep scatterers is investigated and shown to have limitations. An asscssment of properties of the scatterers from investigation of the spectral properties of the echoes from a scattering region is suggested.

Cepstral signal processing for tissue signature analysis, $J$. Fraser, G. S. Kino, and J. Birnholz, SP525, pp. 287-295 (Apr. 1979).

Key words: attenuation; B-scan; cepstrum; computer; convolution; de-convolution; liver; power spectrum; signal processing; tissue characterization; tissue parameters; ultrasound.

The reflected signal received by an ultrasonic transducer is modeled as a convolution of a transducer response with a reflection function for the target region. Cepstral analysis translates that signal into a domain where those components interact additively rather than through convolution and where separation can be accomplished with simple bandpass filtering operations. The cepstral transform of the pulse echo signal also provides direct access to any periodic behavior of reflectors arising from their spacing. As an example of these capabilities, the technique is used experimentally to describe the characteristic spacing of macrostructural reflecting elements in the pig liver in vitro and to determine the frequency dependent attenuation behavior of normal human liver in vivo.

Recognition of patterns in ultrasonic sectional pictures of the prostate for tumor diagnosis, W. von Seelen, A. Gaca, E. Loch, W. Scheiding, and G. Wessels, SP525, pp. 297-302 (Apr. 1979).

Key words: pattern recognition; prostate tumors; ultrasound.

We examined the prostate with ultrasonics to diagnose tumorous alterations of the organ. We scanned directly from the abdominal wall through the filled bladder (transvesical). The research is aimed at: 1) improvement and mathematical preparation of the ultrasonic pictures to assist the physician in his diagnosis; and 2) ascertainment of significant parameters which allow the classes "normal prostate," "adenoma" and "carcinoma" to be distinguished in screening examinations. The results show that with ultrasonics, adenomas and carcinomas are recognizable in 96 percent of the examined patients and can be differentiated from normal prostate tissue. The palpation finding was used as a reference in most cases.

Recent developments in obtaining histopathological information from ultrasound tissue signatures, K. Preston, Jr., M. J. Czerwinski, M. L. Skolnik, and D. E. Leb, SP525, pp. 303313 (Apr. 1979).

Key words: picture processing; signal analysis; ultrasound.

Statistical, signal-analytic techniques may be applied to ultrasonic pulse-echoes received from organs of the human body. Simultaneous tissue biopsies of these organs may be sectioned, stained, and measured by the computerized optical microscope using various image-analytic techniques. This paper reports some preliminary work along these lines as related to the kidney and liver. 
Damage and death in tissues and associated changes in their mechanical properties, L. Weiss, SP525, pp. 317-322 (Apr. 1979).

Key words: cell detachment; mechanical properties; tissue damage; tissue death.

Mechanical effects of tissue damage associated with artefactual change during examination, and that developing naturally during tumor development, have been demonstrated by a quantitated cell detachment test. Although the precise relationship between this semi-destructive test of tissue properties and ultrasonic, nondestructive tests is uncertain, it appears feasible to consider the following points in studies of the interaction of ultrasound with tissue specimens: a) thin specimens should be examined quickly to avoid anoxic and hypoxic damage; b) note must be made of the heterogeneities within solid tumors, particularly those produced by necrosis; c) degenerative changes in a tumor and surrounding non-malignant tissues may act as image-enhancers.

A human abdominal tissue phantom, P. D. Edmonds, Z. Reyes, D. B. Parkinson, R. A. Filly, and H. Busey, SP525, pp. 323-326 (Apr. 1979).

Key words: gelatin; human abdominal tissues; phantom.

The objective of this work was to determine the feasibility of constructing a phantom that would simulate human abdominal tissues when interrogated by advanced B-scan diagnostic ultrasound equipment operating 2.25 and 3.5 $\mathrm{MHz}$. Satisfactory results were obtained with gelatin based components having dispersed scatterers and embedded sponge, plastic tubes and rubber bulbs filled with saline solution. Stability of the gelatin was achieved by addition of a stabilizing agent, a preservative and impervious coatings to prevent water evaporation.

Tissue simulators for diagnostic ultrasound, R. C. Eggleton and J. A. Whitcomb, SP525, pp. 327-336 (Apr. 1979).

Key words: tissue signature; tissue simulators; training phantoms; ultrasonic phantoms.

Factors are presented related to the design, construction and use of phantoms to replace human patients or subjects in the development, testing, clinical training and promotion of ultrasonic diagnostic equipment. Materials are described which match the acoustic properties of tissue. Realistic echograms can be obtained by scanning properly configured phantoms using such materials.

The phantoms may be simple geometric test patterns, sections of human torso or complete human torsos simulating dynamic cardiovascular and respiratory movements to evaluate the real-time systems.

Tissue equivalent test objects for comparison of ultrasound transmission tomography by reconstruction with pulse echo ultrasound imaging, P. L. Carson, L. Shabason, D. E. Dick, and W. Clayman, SP525, pp. 337-340 (Apr. 1979).

Key words: computed tomography-ultrasonic; diagnosis-ultrasonic; tissue equivalent test objects and phantoms; ultrasonic tissue characterization; ultrasound imaging.

Tissue equivalent materials have been investigated for evaluation and comparison of pulse echo ultrasound imaging and ultrasound transmission tomography by reconstruction (UTTR). Investigations have centered primarily on various urethane polymers and $3 \mathrm{M}$ Reston Brand Flotation Pad material. Attenuation coefficients of the urethane polymers still are somewhat too high, and thus initial test objects or "phantoms" have been constructed from the flotation pad material. One phantom chosen to simulate several characteristics of human breast tissue consists of an annulus of unaltered flotation pad material surrounding a center region in which scattering polystyrene microspheres are embedded. Contrasting material such as polyethylene rods can be inserted between the inner and outer areas of the phantom. The UTTR technique clearly delineates polyethelene rods in the phantom as small as $.6 \mathrm{~mm}$ in diameter. The scattering at 2.2 to $3.5 \mathrm{MHz}$ nominal frequency exhibits a pulse echo appearance, similar to that of liver tissue, and causes only approximately a 5 percent increase in the attenuation coefficient of the pure flotation pad material.

Data of the velocity and attenuation of ultrasound in mammalian tissues-A survey, R. J. Parry and R. C. Chivers, SP525, pp. 343-360 (Apr. 1979).

Key words: attenuation; mammalian tissues; ultrasound; velocity.

A compilation of the reported values of velocity and attenuation of ultrasound in mammalian tissues is presented to give a clear picture of the state of knowledge and enable it to be assessed. In the twenty years since the last such compilation, the progress in estimating the relative contributions of the animal species, tissue condition, temperature and frequency at which measurements were made and the method of measurement to the observed variation has been small. It is hoped that this compilation will both be of practical use and also encourage the establishment of a stronger body of fundamental information for the application of ultrasound in medicine and biology.

SP527. Footwear technology symposium-Manufacturing a competitive advantage. Proceedings of the Footwear Technology Symposium held at the National Bureau of Standards, Gaithersburg, MD, June 1-2, 1978, M. H. King, Ed., Nat. Bur. Stand. (U.S.), Spec. Publ. 527, 348 pages (Feb. 1979) SN003-003-02025-7.

Key words: computer-aided design and manufacture (CAD/CAM); footwear industry; fragmented industries; government-industry cooperation; imports; innovation; leather; manufacturing technology; materials development; shoes; technology transfer.

The Footwear Technology Symposium, hosted by the National Bureau of Standards, was held in Gaithersburg, Maryland on June 1 and 2, 1978. Approximately 220 people participated representing the manufacturing, supplier and retailing segments of the footwear industry, as well as federal officials concerned with assistance to the industry. The objective of this symposium was to assess manufacturing technologies which could be adapted or developed to provide a competitive advantage for the U.S. footwear industry, and to develop a specific plan for activities that would be appropriate for government and industry cooperation. The meeting was part of a three-year Department of Commerce Program to help restore the growth and vitality of the domestic footwear industry. Initial sessions presented technical and evaluative information as an input to the subsequent working group discussions of footwear industry representatives. Government staff described the results of their assessment of the problems and opportunities of the industry. To stimulate constructive dialogue, five private research organizations presented ideas and recommendations for future footwear technological development resulting from Commerce Department sponsored studies. The major new technologies and processes presented addressed materials development, leather technologies, customfitting and computer assistance in shoe 
design and manufacture (CAD/CAM). In other presentations, the President of the American Footwear Industry Association shared his concerns, a leading footwear designer explored design, marketing and the technology interfaces, and representatives of technologically advanced industries, (aerospace, automobiles, communications) shared their views on manufacturing technologies and applications to footwear industry problems. Preliminary symposium results were evidence of industry enthusiasm and support for government-industry cooperative activities, interest in establishing a footwear center to provide industry-wide technical assistance, and a desire to assess computer-aided design and manufacture (CAD/CAM). Reports by the consulting firms on new technologies and business strategies for the footwear industry arc included as appendices. These proceedings include the following papers (indented):

Manufacturing a competitive advantage, J. Baruch, SP527, pp. 3-6 (Feb. 1979).

Gemerall accoumting office perspective, F. Haynes, SP527. pp. 7-10 (Feb. 1979)

Fitting technology into the picture, M. King, SP527, pp. 13 20 (Feb. 1979).

Techmology reviews, A. D. Little, SP527, pp. 21-50 (Feb. 1979).

The potential of new technology, F. Daley, SP527, pp. 51 59 (Feb. 1979).

A matter of irust, S. Harman, SP527, pp. 73-77 (Feb. 1979).

Industry response, R. M. Ansin, SP527, pp. 79-80 (Feb. 1979).

lndustry view, F. A. Meister, SP527, pp. 83-86 (Feb. 1979).

Relating technologies to the amarketplace, B. Levine, SP527, pp. 87-91 (Feb. 1979).

Symposinam integration and future directions, J. Baruch, SP527, pp. 95-97 (Feb. 1979).

SP532. Report of the 63d National Conference on Weights and Measures 1978, H. F. Wollin, L. E. Barbrow, and A. P. Heffernan, Nat. Bur. Stand. (U.S.), Spec. Publ. 532, 323 pages (Feb. 1979) SN003-003-02045-1.

Key words: consumer affairs; education; electromagnetic interference; electronic devices; International Organization of Legal Metrology; measurement assurance; metrication; model laws and regulations; national type approval; packaging and labeling; specifications and tolcrances; vapor recovery; weights and measures.

This is a report of the proceedings (edited) of the Sixty-Third National Conference on Weights and Measures, sponsored by the National Bureau of Standards, held in Washington, DC, July 9-14, 1978, and attended by State, county, and city weights and measures officials, and representatives of the Federal Government, business, industry, and consumer organizations.

Major issues discussed at this Conference included metric conversion in the United States; problems relating to the quantity fill, labeling, and inspection of packaged commodities; requirements covering the design and performance of new weighing and measuring technology; and recommendations for improvement in weights and measures administration. These proceedings include the following papers (indented):
Electromagnetic interference-A problem of growing concern, C. K. S. Miller, SP532, pp. 1-12 (Feb. 1979).

A practical approach to the EMI-RFI problem in the field, F. L. Platt, SP532, pp. 13-16 (Feb. 1979).

Laboratory metrology-Its goals and needs, R. C. Egnew, SP532, pp. 17-19 (Feb. 1979).

National Food Processors Association solid content weight labeling program, A. W. Matthys, SP532, pp. 20-23 (Feb. 1979).

An industry perspective on packaging regulations, $R$. W. Miller, SPS32, pp. 24-28 (Feb. 1979).

Measurements in the United Kingdom market place, F. L. N. Samuels, SP532, pp. 29-41 (Feb. 1979).

Food labeling-The next step, E. Williams, SP532, pp. 4247 (Feb. 1979).

Measurement assurance-The future of legal metrology, A. O. McCoubrey, SP532, pp. 48-54 (Feb. 1979).

Experience in program evaluation, D. Guensler, SP532, pp. 55-58 (Feb. 1979).

Cost-benefit performance auditing-A tool for weights and measures program improvement, C. H. Vincent, SP532, pp. 59-60 (Feb. 1979).

Cost-benefit performance auditing - A tool for weights and measures program improvement, $R$. Lockridge, SP532, pp. 61-65 (Feb. 1979).

Application of quantity of contents requirements to packaged seafoods, I. D. Sackett, Jr., SP532, pp. 66-71 (Feb. 1979).

Pressure measurement-A new activity for weights and measures, C. R. Tilford, SP532, pp. $72-77$ (Feb. 1979).

Net weight assurance $-A$ responsibility for both government and industry, S. J. Butler, SP532, pp. $118-124$ (Feb. 1979).

SP534. Utility and use of large-scale mathematical models. Proceedings of a Workshop held at the National Bureau of Standards, Gaithersburg, MD, Apr. 28-29, 1977, S. 1. Gass, Ed., Nat. Bur. Stand. (U.S.), Spec. Publ. 534, 217 pages (May 1979) SN003-003-02060-5

Key words: documentation; energy; evaluation; guidelines; implementation; large-scale; management; mathematical models; policy analysis; software; standards; transfer.

The Workshop on the Utility and Use of Large-Scale Mathematical Models, held at the National Bureau of Standards, Gaithersburg, Maryland (A pr. 28-29, 1977), was a "first" in its purpose: to examine the problem of how to improve the use and utility of large-scale mathematical models in the Federal Government. The Workshop speakers addressed specific problem areas of concern, including: the present status of model use in DOD and non-DOD applications; issues facing developers; problems of model implementation; transfer and development in the energy field; model assessment and evaluation; use in analysis; comparison of models; management of the modeling process; model software and documentation; guidelines, standards and management improvement activities. This proceedings volume presents the papers and much of the discussion presented at the Workshop, along with a summary of directions for needed research. These proceedings include the following papers (indented): 
The workshop issues, S. I. Gass, SP534, pp. 3-7 (May 1979).

Review of the DOD modeling effort and modeling as a profession, G. D. Brewer, SP534, pp. 9-14 (May 1979).

Review of the non-DOD modeling effort, G. Fromm, SP534, pp. 15-21 (May 1979).

Issues facing model developers I, S. Bonder, SP534, pp. 2344 (May 1979).

Issues facing model developers II, D. Meadows, SP534, pp. 45-50 (May 1979).

Issues facing model developers III, D. Maxim, SP534, pp. 51-55 (May 1979).

Issues facing model developers IV, A. Pugh III, SP534, pp. 57-59 (May 1979).

Model implementation, R. Larson, SP534, pp. 61-92 (May 1979).

Implementation of emergency service deployment models in operating agencies, J. M. Chaiken, SP534, pp. 93-106 (May 1979).

The PTI experience, J. Barrett, SP534, pp. 107-110 (May 1979).

The FEA project independence model experience, $H$. Greenberg, SP534, pp. 111-122 (May 1979).

The EPRI/NBER energy model assessment project, D. Kresge, SP534, pp. 123-135 (May 1979).

The energy modeling forum, W. Hogan, SP534, pp. $137-$ 161 (May 1979).

Models in the policy process: A framework, B. Crissey, SP534, pp. 163-175 (May 1979).

Strategies in the model management, J. Mulvey, SP534, pp. 177-193 (May 1979).

Software requirements for an improvement in transfer and adaptability of models, S. Dickhoven, SP534, pp. 195-203 (May 1979).

SP536. Selected papers dealing with regulatory concerns of building rehabilitation, P. W. Cooke, Ed., Nat. Bur. Stand. (U.S.), Spec. Publ. 536, 93 pages (Feb. 1979) SN003-00302032-0.

Key words: adaptive reuse; building codes; buildings; building safety; code enforcement; construction; fire safety; housing; preservation; regulations; rehabilitation.

This publication consists of a collection of six papers common to the subject of rehabilitation and preservation of existing buildings and how our present system of regulating construction for the public benefit presents various barriers that must be more fully understood in order that rational solutions can be developed and implemented. The papers have been reprinted from the Proceedings of previous national conferences dealing with building regulatory research held under the joint sponsorship of NBS and the National Conference of States on Building Codes and Standards. This publication includes the following papers (indented):

Building codes: Preservation and rehabilitation, R. J. Kapsch, SP536, pp. 1-16 (Feb. 1979).
Key words: adaptive reuse; architecture; building codes; building regulations; building safety; construction; performance; preservation; rehabilitation; renovation.

There has been a large rise in interest in the last ten years in building reuse, rehabilitation and preservation projects. This trend is expected to continue in the foreseeable future. Such projects pose difficulties for the building regulatory system since many of these buildings were originally constructed prior to the existence of building codes. Most of these buildings do not meet modern levels of building regulation and application of building regulations to them poses difficulties as these regulations are essentially designed for new construction. The potential impact of these regulations includes the increase of project costs and damage to the fabric of the building intended to be preserved. Yet safety and health must be achieved in existing buildings as well as new. This paper summarizes studies and other activities that are presently being conducted by a number of organizations on this subject. One such study conducted by NBS has indicated that numerous State and local jurisdictions and model code organizations are adopting historic building waiver clauses and similar regulations as a partial answer to this problem. The National Trust for Historic Preservation sponsored the first national conference, in 1974, on this question and is currently cooperating with NBS in a study of the effectiveness of selected historic building waiver clauses. The National Endowment for the Arts has sponsored a grant that would identify tradeoffs that could be used in building regulations. NBS has also sponsored a study, reported in a separate paper in these Proceedings, on how a standard designed for existing buildings might be structured and formatted. NBS is also studying, for the Department of Housing and Urban Development, technological aspects of neighborhood conservation, including the role of building regulations. As of this writing, no final or definitive answer has been developed for the problem of achieving contemporary levels of safety and health in existing buildings.

Information structure of building codes and standards for the needs of existing buildings, B. Smith, SP536, pp. 17-53 (Feb. 1979).

Key words: building codes and standards; building code structure; existing buildings; historic preservation; performance attributes; performance evaluation.

With the increased occurrence of rehabilitation and preservation projects, the problem of code compliance for these buildings is growing in magnitude. We are no longer dealing with isolated historic buildings, but with both entire historic districts and an ever increasing number of recycled, adaptively used buildings. The problem of code compliance for these projects frequently causes the destruction of the historic integrity of the building, the replacement of serviceable materials and, at the same time, increases project costs. The compliance problems may stem from the organization and format of the model codes which are based on new construction materials and techniques. This study examines the present organization and format of the three model codes, and develops a decision flow chart which analyzes how these model codes are used. The regulatory problems facing rehabilitation and preservation projects are then reviewed. From this investigation, a proposed decision process, based on the needs of rehabilitation and prescrvation projects is developed. Such a decision process could be used if and when building regulations are developed for the unique needs of these type projects. 
Contractor understanding relative to rehab costs, R. S. Harrington, SP536, pp. 55-61 (Feb. 1979).

Key words: building codes; community development; construction costs; contractors; housing; rehabilitation; standards.

The nature of rehabilitation, with its nonvisible elements and its potential for self-help, makes it extremely difficult to accurately estimate the costs involved. The uncertainty is passed on by the Contractor in the fees he charges. Uncertainty exists, as well, in the standards for accomplishing the work at hand. Specifications are normally cumbersome, Work Write-Ups lacking in detail. Therefore understanding is diminished, and costs rise, while quality falls below standards.

With the pending increase in neighborhood code rehabilitation projects, there is the need to increase the supply of competent contractors interested and experienced in rehab. This requires both a method for offering standardization of specifications and work-write-ups with more detail, and the ability to assure a steady flow of work into bidding channels

The role of fire prevention and control in building construction and regulations, W. H. McLain, SP536, pp. 63-74 (Feb. 1979).

Key words: building codes; control measures; fire codes; fire safety; governmental actions; life safety; regulation; risk assessment; societal goals.

Fire prevention and control is an important feature of the modern building codes. Building set-back limits, structural design, and limitations on interior finish materials are among the building design parameters that reflect the public need for fire safety. Historically, codes have been developed to reduce mass urban fires and to limit property damage from the structural collapse of single building units. For example, a standard time-temperature curve has been developed and widely used (ASTM E 119) for classification of building structural components in terms of a firetime rating. More recently, there has developed an increased concern about life safety. Smoke and toxic gas produced by materials subjected to fire exposures are being evaluated and in some cases form part of a developing set of new regulations. The implementation of these new regulations poses a number of difficult problems to the local code regulatory and enforcement officials. An analysis is made of some of the alternative approaches which may be considered to aid the local building official in this important area of control.

Rehabilitation as an instrument in meeting housing need: Can it really work?, J. Heron, SP536, pp. 75-81 (Feb. 1979).

Key words: decision criteria; demolition; housing needs; physical condition rehablitation.

There is an increasing trend in city planning toward rehabilitating older buildings and conserving neighborhoods that might have become slums, but the rehabilitation process is slow and unreliable. Few builders are interested in rehabilitation, most preferring new construction in the suburbs. A major question is: can the rehabilitation process be changed to attract more builders and become a highvolume business?

The suggested answer is that criteria to identify buildings needing rehabilitation and to specify what repairs necd to be made must be developed, using the cumulative knowledge of builders who have done such work and the insight of people involved in building regulation. These criteria should deal with the fundamental structural and safety characteristics of buildings, to provide a yardstick for selecting the right buildings and deciding how much work is required.

Building codes and historic preservation in Savannah Georgia, M. Rosenthal, SP536, pp. 83-93 (Feb. 1979).

Key words: barriers; building codes; code enforcement; historic district; historic preservation; regulations; rehabilitation; safety.

The City of Savannah has the largest registered urban historical district in the United States. Over 900 structures have been restored or are awaiting restoration. Building code barriers that once existed were overcome through cooperation and communications with results that satisfy the intent of code criteria while also maintaining the integrity of historic preservation. The experience gained in Savannah suggests that code compliance responsibilities in historic preservation projects resis jointly with designers, preservationists, owners and builders as well as code enforcement personnel. Recommendations include the need for guidelines in the use of codes for dealing realistically with building rehabilitation projects.

SP537. A bibliography of sources of experimental data leading to thermal properties of binary aqueous electrolyte solutions, D. Smith-Magowan and R. N. Goldberg, Nat. Bur. Stand. (U.S.), Spec. Publ. 537, 89 pages (Mar. 1979) SNo03-00302033-8.

Key words: apparent molal heat capacity; aqueous systems; bibliography; electrochemistry; electrolytes; enthalpy of dilution; heat capacity; relative apparent molal enthalpy; salt solutions; thermochemistry; vapor pressure.

Contained herein is a bibliography of sources of experimental data that can be used to calculate either relative apparent molal enthalpies or apparent molal heat capacities for aqueous electrolyte solutions. The data types included are calorimetric heat capacity measurements, enthalpies of solution as a function of molality, enthalpy of dilution measurements, electromotive force measurements as a function of temperature, and vapor pressure measurements as a function of temperature. Approximately 900 references to the primary literature are included.

SP538. National Bureau of Standards: A national resource for science and technology, M. Heyman, Nat. Bur. Stand. (U.S.), Spec. Publ. 538, 86 pages (July 1979) SN003-003-02093-1.

Key words: basic research; computer; energy conservation; environmental quality; industrial productivity; materials utilization; measurement capabilities; medical aids; product safety; public health and safety; science and technology transfer; standards.

This report highlights key accomplishments of the National Bureau of Standards during fiscal year 1978. NBS is the Nation's central reference laboratory for measurements in the physical sciences and engineering. The Bureau is a source of reference materials, data, standards, and technical guidelines needed to improve measurement techniques; it is also an independent government source for objective and technical research.

This year's report includes summaries of NBS research on basic measurement improvemert, electromagnetic interference, medical aids, consumer product safety, fire, building technology, muclear safeguards, and energy. It details work on corrosion and other materials research, semiconductor technology, automation and computers, and environmental research. Also listed are the services and special programs which NBS offers, a 
revicw of NBS funds and facilities, and a summary of important legislation affecting NBS.

SP539. Metrology in industry and government: How to find out who needs what services. Proceedings of a Regional Seminar held at the Korea Standards Research Institute, Dae Jeon, Korca, Sept. 27-28, 1978, H. S. Peiser, R. C. Sangster, and W. Jung, Eds., Nat. Bur. Stand. (U.S.), Spec. Publ. 539, 165 pages (Apr. 1979) SN003-003-02040-1

Key words: developing countries; industrializing countries; Korea; measurements; metrology; physical standards; seminar; South Asia.

A regional seminar sponsored by the Korea Standards Research Institute, the National Bureau of Standards, and the U.S. Agency for International Development was held at the new K-SRI Laboratories at Daeduk near Dae Jeon in the Republic of Korea on September 27-28, 1978. The participants representing most of the countries in the South Asian and Western Pacific Region discussed the importance of providing services in measurement science and technology (metrology) to governmental and industrial organizations in the region. The consensus was that a need for a central national capability in metrology existed in countries at all levels of development, and that central organization could be a focal point for intra- and international cooperation, which alone could lead to compatibility of measurements, a prerequisite for quality control for all kinds of products in domestic and international markets. Australia and New Zealand had established a group of accredited test laboratories to disseminate the accuracies inherent in the national measurement system. Industry was increasingly aware that metrology was essential to development, but the specific needs at appropriate accuracies needed to be established by surveys. The Korean Government strongly supported the establishment of metrological services as is well illustrated by the new K-SRI Iaboratories. These proceedings include the following papers (indented):

Quantitative measurement is the basis for all science and technology-But are we aware of the need for metrology?, $\mathrm{H}$. S. Peiser, SP539, p. 17 (Apr. 1979).

Quantitative measurement, the basis for all science and technology, H. S. Peiser, SP539, pp. 19-22 (Apr. 1979).

Importance of national capability in metrology for industrial development-The Indian experience, A. R. Verma, SP539, pp. 23-28 (Apr. 1979).

Quantitative measurement as a basic framework for science and technology, S. Takata, SP539, pp. 29-32 (Apr. 1979).

The need for quantitative measurement in Hong Kong, $\mathrm{H}$. K. Lam, SP539, pp. 33-34 (Apr. 1979).

National measurement capabilities for industrial development in Korea, J. W. Choi, SP539, pp. 37-41 (Apr. 1979).

Development of metrology capabilities in step with industry needs-A New Zealand experience, M. C. Probine, SP539, pp. 43-66 (Apr. 1979).

Implementing metrology for developing industrialization, $\mathrm{H}$. Kartowisastro, SP539, pp. 67-78 (Apr. 1979).

Assessment of the requirement of industries/institutions for services in the field of standards, A. Ghani, SP539, pp. 79. 90 (Apr. 1979).

A national capability in metrology is essential to industrial development, M. Z. Hashim, SP539, pp. 91-93 (Apr. 1979).
The National Measurement Laboratory and Australian manufacturing industry, W. R. Blevin, SP539, pp. 97-100 (Apr. 1979).

A study of the National Measurement System in Korea-An interim report: How we approached it and what we found, $W$. Jung, SP539, pp. 101-112 (Apr. 1979).

But is industry aware of its dependence on metrology?, $\mathrm{H}$. L. K. Goonetilleke, SP539, pp. 113-116 (Apr. 1979).

The National Metrology and Calibration Service for Industry in Thailand, C. Vashrangsi, SP539, pp. 117-124 (Apr. 1979).

SP540. Fire research and safety. Proceedings of the Third Joint Panel Conference of the U.S.-Japan Cooperative Program in Natural Resources held at the National Bureau of Standards, Gaithersburg, MD, Mar. 13-17, 1978, M. A. Sherald, Ed., Nat. Bur. Stand. (U.S.), Spec. Publ. 540, 729 pages (Nov. 1979) SN003-003-02141-5.

Key words: building fires; conferences; fire detection; fire investigations; fire models; fire research; fire retardants; flame retardants; human behavior; smoke; toxic gascs; toxicity.

The Third Joint Panel Meeting of the United States-Japan Panel on Natural Resources (UJNR), Fire Research and Safety, was held at the National Bureau of Standards in Gaithersburg, MD, from Mar. 13-17, 1978. The meeting consisted of in-depth technical sessions on detection and smoke properties, modeling of fire, and toxicity of fire gas. Progress reports briefly covered human behavior, building systems, and smoke control. This proceedings includes the technical papers presented at the meeting along with the ensuing discussion and the summary reports prepared by each session chairman.

The first meeting of UJNR Panel on Fire Research and Safety was held in Washington, DC, from Apr. 7-8, 1976, where the current activities in the United States and Japan on fire research and safety were introduced. After this exchange, the following 6 topics were selected for initial cooperation: toxicity, building systems, human behavior, smoke control, detection and smoke properties, and modeling of fire. These proceedings include the following papers (indented):

Smoke detector design and smoke properties, R. W. Bukowski and G. W. Mulholland, SP540, pp. 1-45 (Nov. 1979).

False alarm of smoke detectors, J. Miyama and A. Watanabe, SP54O, pp. 46-53 (Nov. 1979).

Researches in smoke properties in Japan, F. Saito, Chairman, SP540, pp. 54-101 (Nov. 1979).

Human behavior, J. L. Bryan, SP54O, pp. $115-133$ (Nov. 1979).

Human Behavior, S. Horiuchi and T. Jin, SP540, pp. 134137 (Nov. 1979).

Current U.S. systems activities in fire safety design, H. E. Nelson, SP540, pp. 138-147 (Nov. 1979).

Present status of research on fire safety systems for buildings, K. Kawagoe and Y. Morishita, SP540, pp. 148-161 (Nov. 1979).

Smoke control, I. Benjamin, SP540, pp. 162-165 (Nov. 1979).

Smoke control, T. Wakamatsu, SP54O, pp. 166-169 (Nov. 1979). 
Subprograms: A state-of-the-art review, J. de Ris, SP540, pp. $110-208$ (Nov. 1979).

Mathematical modellng of enclosed fires-A review of current U.S. research, C. D. MacArthur, SP540, pp. 209-232 (Nov. 1979).

Basic problems in physlcal understanding of compartment fire, Y. Hasemi, SP54O, pp. 233-263 (Nov. 1979).

A model on flre spread in small scale building, T. Tanaka, SP54O, pp. 264-355 (Nov. 1979).

Statistical analysis of fire spread process in houses, $Y$. Morishita, SP54O, pp. 356.381 (Nov. 1979).

Experimental study of compartment fires using model boxes, F. Saito, SP540, pp. $382-447$ (Nov. 1979).

Research on evaluation of relative toxicities of combustion products of various materials, $K$. Kishitani and $S$. Yusa, SP54O, pp. 453-484 (Nov. 1979).

Research on evaluation of toxicities of combustion gases generated during fires, K. Kishitani and K. Nakamura, SP54O, pp. 485-519 (Nov. 1979).

On the acute toxiclties of the combustion products of various fibers, with special reference to blood cyanlde and $\mathbf{P o}_{2}$ values, K. Yamamoto, SP54O, pp. 520-527 (Nov. 1979).

Factors accelerating the gas toxicity in a fire, F. Saito, SP540, pp. 528-548 (Nov. 1979).

Biological testing in fire toxicology, P. W. Smith and C. R. Crane, SP540, pp. 549-565 (Nov. 1979).

Recent test results from the FAA/NAFEC cabin fire safety program, C. P. Sarkos, SP54O, pp. 589-623 (Nov. 1979).

Brief comments on fire research at the U.S. Bureau of Mines, R. F. Chainen, SP540, pp. 624-625 (Nov. 1979).

Instrumentation for the size determination of submicron particulates systems by sideway llght scattering method and the characteristics of smokes from polymerized materials in fire, T. Handa, K. Suda, T. Nagashima, K. Kaneko, T Yamamura, Y. Takahashi, H. Suzuki, and F. Saito, SP540, pp. 626-7II (Nov. 1979).

Technical session on detection and smoke properties, J. Miyama, SP540, p. 713 (Nov. 1979).

Progress report session on human behavior, building systems and smoke control, G. Bates, Jr., SP54O, pp. 714-715 (Nov. 1979).

Technical session on fire modeling, H. Emmons, SP540, p. 716 (Nov. 1979).

Tecthnical session on toxiclty, A. Watanabe, SP540, p. 717 (Nov. 1979).

SP541. Laser induced damage in optical materials: 1978. Proceedings of a Symposium Sponsored by: National Bureau of Standards, American Society for Testing and Materials, Office of Naval Research, Department of Energy, Defense Advanced Research Project Agency, NBS Boulder, CO, Sept. 12-14, 1978, A. J. Glass and A. H. Guenther, Eds., Nat. Bur. Stand. (U.S.), Spec. Publ. 54I, 362 pages (Dec. 1978) SNO03-003-02052-4.

Key words: laser damage; laser interaction; optical components; optical fabrication; optical materials and properties; thin film coatings.
The Tenth Annual Symposium on Optical Materials for High Power Lasers (Boulder Damage Symposium) was held at the National Bureau of Standards in Boulder, Colorado, from 12 14 September 1978. The Symposium was held under the auspices of ASTM Committee F-1, Subcommittee on Laser Standards, with the joint sponsorship of NBS, the Defense Advanced Research Project Agency, the Department of Energy, and the Office of Naval Research. About 175 scientists attended the Symposium, including representatives of the United Kingdom, France, Canada, Japan, West Germany, and the Soviet Union. The Symposium was divided into sessions concerning the Measurement of Absorption Characteristics, Bulk Material Properties, Mirrors and Surfaces, Thin Film Damage, Coating Materials and Design and Breakdown Phenomena. As in previous years, the emphasis of the papers presented at the Symposium was directed toward new frontiers and new developments. Particular emphasis was given to materials for use from $10.6 \mu \mathrm{m}$ to the uv region. Highlights included surface characterization, thin film-substrate boundaries, and advances in fundamental laser-matter threshold interactions and mechanisms. The scaling of damage thresholds with pulse duration, focal area, and wavelength were also discussed. In commemoration of the Tenth Symposium in this series, a number of comprehensive review papers were presented to assess the state of the art in the various facets of laser induced damage in optical materials. Alexander J. Glass of Lawrence Livermore Laboratory and Arthur H. Guenther of the Air Force Weapons Laboratory were cochairpersons of the Symposium. The Eleventh Annual Symposium is scheduled for 30-31 October 1979 at the National Bureau of Standards, Boulder, Colorado. These proceedings include the following papers (indented):

Discussion of a theory of analysis of rate calorimetry which includes coating absorption, N. C. Fernelius and G. T. Johnston, SP541, pp. 7-12 (Dec. 1978).

Key words: coating optical absorption; laser calorimetry theory; optical calorimetry theory; surface optical absorption.

A simplified method of analyzing laser rate calorimetry on samples with absorbing coatings is presented. Special cases of rate calorimetry are shown to agree with previously derived cases. Results are given for samples with dissimilar faces in which the temperature rise and the reflected power in both orientations to the laser beam are measured. A computer program was written to reduce data. A sample case shows that the output requires the reflected and transmitted powers to be measured to three significant figures for meaningful results.

Absorption coefficient of $\mathrm{NaF}$ by attenuated total reflection spectroscopy, D. L. Burdick, SP541, pp. 13-18 (Dec. 1978).

Key words: absorption coefficient; sodium fluoride film; total internal reflection; 0.65 to 3.0 microns.

Attenuated total reflection (ATR) spectroscopy has been employed to measure the absorption coefficient of $\mathrm{NaF}$ films from the visible to $3 \mu \mathrm{m}$. A 1 -mm-thick ZnSe ATR plate (50-mm long) was coated on two sides with $\mathrm{NaF}$ (0.55- and $0.57-\mu \mathrm{m}$-thick films). By coating half the width of the ATR plate, "sample-in/sample-out" measurements could be performed to reduce substrate effects. The spectra reveal a strong water band in NaF peaking at $2.95 \mu \mathrm{m}$ with a peak absorption coefficient at $165 \mathrm{~cm}^{-1}$ relative to the substrate. Scattering effects are noted at shorter wavelengths, and it is estimated that $7 \AA$ of water are adsorbed onto the bare ATR plate.

Laser calorimetric measurement of two photon absorption, M. Bass, E. W. Van Stryland, and A. F. Stewart, SP541, pp. 19-23 (Dec. 1978). 
Key words: CdSe; CdTe; internal reflections; laser calorimeter; linear absorption; Nd:YAG laser; two photon absorption.

A laser calorimeter has been used to measure two photon absorption in solids. This new technique provides greater sensitivity than is possible in nonlinear transmission measurements. The two photon absorption coefficients of $\mathrm{CdTe}$ and CdSe at $1.06 \mu \mathrm{m}$ using $\sim 16 \mathrm{nsec}$ (FWHM) pulses are $0.13 \pm 0.04 \mathrm{~cm} / \mathrm{MW}$ and $0.050 \pm 0.014 \mathrm{~cm} / \mathrm{MW}$ respectively.

A comparison of bulk and surface absorptions in $\mathrm{NaCl}$ and $\mathrm{KCl}$ between 9.2 and $10.8 \mu \mathrm{m}, \mathrm{H}$. Vora, M. C. Ohmer, and T. G. Stoebe, SP54I, pp. 24-32 (Dec. 1978).

Key words: absorption; $\mathrm{KCl} ; \mathrm{NaCl}$; tuneable laser calorimetry; 9.2 to $10.6 \mu \mathrm{m}$.

Tunable $\mathrm{CO}_{2}$ laser calorimetry has been used to study the wavelength dependence of optical absorption at 16 different wavelengths between 9.2 and $10.85 \mu \mathrm{m}$ in $\mathrm{NaCl}$ and $\mathrm{KCl}$. Samples prepared on a small scale using the reactive atmosphere process (RAP) growth, as well as samples cut from large diameter ingots prepared commercially for highpower $\mathrm{CO}_{2}$ laser windows, have been investigated. A differentiation between the bulk and surface absorption has been made in several cases using long bar samples. The measured bulk absorption in the best RAP-grown $\mathrm{NaCl}$ crystal is intrinsic over the entire wavelength range from 9.2 to $10,85 \mu \mathrm{m}$, showing bulk absorption values near 9 $\times 10^{-4} \mathrm{~cm}^{-1}$ at $10.6 \mu \mathrm{m}$ and $1.4 \times 10^{-4} \mathrm{~cm}^{-1}$ at $9.2 \mu \mathrm{m}$. The best $\mathrm{KCl}$ shows bulk absorption values near $9 \times 10^{-5} \mathrm{~cm}^{-1}$ at $10.6 \mu \mathrm{m}$ and $4 \times 10^{-5} \mathrm{~cm}^{-1}$ at $9.2 \mu \mathrm{m}$; these values are above the expected intrinsic limit due to residual absorption caused by the presence of at least two bulk impurities, possibly $\mathrm{ClO}_{3}^{-}$and $\mathrm{ClO}_{2}^{-}$.

A $1.06 \mu \mathrm{m}$ laser absorption calorimeter for optical coatings, T. H. Allen, J. H. Apfel, and C. K. Carniglia, SP541, pp. 33-36 (Dec. 1978).

Key words: absorption; calorimetry; optical coatings.

We describe a laser calorimeter for measuring the absorption of an optical coating deposited on a thin disc. The sample with diameter $2.54 \mathrm{~cm}$ and thickness between 0.02 to $0.13 \mathrm{~cm}$ is irradiated with 6 watt $\mathrm{CW} \mathrm{Nd:YAG} \mathrm{laser.}$ The temperature of the coated disc is compared to that of a reference disc using the thermistors in mechanical contact with the samples. Measurements are made under vacuum ( 100 torr) to reduce temperature variations caused by convection. The calorimeter was evaluated by measuring coated and uncoated discs of various thicknesses with absorptances from $9 \times 10^{-6}$ to $5 \times 10^{-3}$. These measurements demonstrated a repeatability of $\pm 2 \%$ at an absorptance level of $1 \times 10^{-4}$ and a sensitivity for a $0.04 \mathrm{~cm}$ thick substrate of $3.8 \times 10^{5} \mu \mathrm{V} /$ watt. The lower absorption limit of the calorimeter is $2 \times 10^{-6}$. The results of measurements on polished, uncoated fused silica discs with thicknesses from 0.04 to $0.13 \mathrm{~cm}$ show a surface absorptance of $6 \times 10^{-6}$ and a bulk value of $5 \times 10^{-5} / \mathrm{cm}$.

Measured thin film absorption at the air-film interface, the film bulk, and the film-substrate interface, P. A. Temple, D. L. Decker, T. M. Donovan, and J. W. Bethke, SP541, pp. $37-42$ (Dec. 1978).

Key words: absorption coefficient; adiabatic calorimetry; $\mathrm{As}_{2} \mathrm{Se}_{3}$; interface absorption; laser calorimetry; $\mathrm{NaF}$; thin film absorption; water absorption; wedged film.
A measurement technique is described where the absorption introduced by the addition of a single-layer thin film is separated into three parts: absorption (a) within the bulk of the film; (b) at the air-film interface; and (c) at the film-substrate interface. The technique employs a scanning adiabatic calorimeter to measure substrates which are partially coated on the entrance surface with films of continuously varying thickness. By measuring the absorption on the bare substrate and at various film thicknesses, we have unambiguously determined the film-bulk absorption coefficient. We have also measured the combined absorption due to the two film interfaces. 1t will be shown that, in some cases, it is possible to distinguish between air-film interface absorption and film-substrate interface absorption and determine the magnitude of each. Data will be presented for 2.9 and $2.7 \mu \mathrm{m}$ for films made of $\mathrm{NaF}$ and $\mathrm{As}_{2} \mathrm{Se}_{3}$ on $\mathrm{CaF}_{2}$. These films show the presence of impurities in the film and/or at the film interfaces. The relative magnitude of absorption in the three regions will be discussed.

Photoacoustic spectroscopy studies of thin film coatings on laser windows, N. C. Fernelius and D. A. Walsh, SP54I, pp. 43-49 (Dec. 1978).

Key words: absorption edge; $\mathrm{CaF}_{2} ; \mathrm{KCl}$; optical absorption coefficient; optoacoustic spectroscopy; $\mathrm{PbF}_{2}$; photoacoustic spectroscopy; TII; ZnSe.

Photoacoustic spectroscopy (PAS) studies have been, made of TII and graded $\mathrm{PbF}_{2}-\mathrm{Tl} 1$ coatings on $\mathrm{KCl}$. Wavelength dependent PAS studies on the TIl absorption edge indicate impurities in T11 in the graded coating and/or the existence of cubic T1l layers. PAS wavelength studies were made on a solid $\mathrm{ZnSe}$ window and various $\mathrm{ZnSe}$ coatings on $\mathrm{CaF}_{2}$. Wavelength dependent studies show poorer stoichiometry as the coating gets thinner. Frequency dependent PAS studies at $440 \mathrm{~nm}$ on the solid and thin film ZnSe all showed a signal dependence of $\mathrm{S}=\mathrm{Af}^{-1}$. Theoretical calculations based on the Rosencwaig-Gersho theory show that these results are consistent if $\beta$ is greater than $500 \mathrm{~cm}^{-1}$ for $\mathrm{ZnSe}$ at $440 \mathrm{~nm}$.

Piezo-optic coefficients of some neodymium doped laser glasses and single crystals of $\mathrm{CaF}_{2}, \mathrm{BaF}_{2}$ and $\mathrm{SrF}_{2}, \mathrm{R}$. $\mathrm{M}$. Waxler, A. Feldman, and D. Horowitz, SP54I, pp. 50-54 (Dec. 1978)

Key words: $\mathrm{BaF}_{2} ; \mathrm{CaF}_{2}$; laser glass; photoelasticity; piezobirefringence; piezo-optic constants; $\mathrm{SrF}_{2}$; stress-optical coefficient.

The piezo-birefringence coefficients of one neodymium doped phosphate laser glass and three neodymium doped fluorophosphate laser glasses have been measured at $0.6328 \mu \mathrm{m}$ and $1.15 \mu \mathrm{m}$. All of the piezo-optic constants have been obtained for two of the glasses. The piezo-optic coefficients, $\mathrm{q}_{11}, \mathrm{q}_{12}$ and $\mathrm{q}_{44}$, of $\mathrm{CaF}_{2}, \mathrm{BaF}_{2}$, and $\mathrm{SrF}_{2}$ have been measured at $0.6328 \mu \mathrm{m}, 1.15 \mu \mathrm{m}$, and $3.39 \mu \mathrm{m}$. The coefficients were obtained by interferometric and polarimetric techniques.

Refractive index of strontium fluoride, M. J. Dodge, SP541, pp. $55-58$ (Dec. 1978).

Key words: alkaline earth fluorides; refractive index; strontium fluoride.

The refractive index, relative to air, of fusion-cast strontium fluoride was determined from $0.2138 \mu \mathrm{m}$ to 11.475 $\mu \mathrm{m}$ by means of the minimum-deviation method. Measurements were made on a precision spectrometer at a controlled room temperature near $20^{\circ} \mathrm{C}$. The experimental 
data were fitted to a Sellmeier-type dispersion equation which permits refractive index interpolation within several parts in $10^{-5}$. The index of $\mathrm{SrF}_{2}$ is compared graphically with that of $\mathrm{BaF}_{2}$ and $\mathrm{CaF}_{2}$.

The development of fluorides for high power laser optics, $J$. F. Ready, H. Vora, R. A. Skogman, K. M. Leung, and E. Bernal, SP54l, pp. 59-64 (Dec. 1978).

Key words: fluorides; forging; laser windows; lithium fluoride; mechanical properties; optical properties; ultraviolet transmission.

The development of improved optical materials with low nonlinear refractive index and good vacuum ultraviolet transparency is needed for future laser systems to heat fusion targets. This program has produced lithium fluoride windows through isostatic forging of single crystalline material. For reductions around $60 \%$, forging yields finegrained material with considerably increased yield strength and fracture energy. The ultraviolet transparency of the material is not degraded by the forging.

This paper will describe the improvement of yield strength and fracture energy as a function of forging parameters. It will discuss measurements of optical homogeneity, optical scattering and visible and ultraviolet transmission for both the original material and the forged material.

Optical properties of $\mathrm{KCl}$ forged between optically polished dies, R. H. Anderson and J. M. Bennett, SP541, pp. 65-69 (Dec. 1978).

Key words: alkali halides; backward scattering; forward scattering; grain boundaries; isostatic forging; optical figure; optical homogeneity; single crystal; Talystep traces.

Plano-plano and plano-concave $\mathrm{KCl}$ optical elements have been isostatically forged using a two-step forging process in a closed die. No optical polishing was required for the finished surfaces. The initial forging was performed between teflon sheets, the sample was then water polished, and the final forging was done between optically figured fused quartz or pyrex dies. Forgings were typically done in the 200 to $275{ }^{\circ} \mathrm{C}$ temperature range in a helium atmosphere at $29.65 \mathrm{MN} / \mathrm{m}^{2}$ (4000 psi). Measurements on the finished samples include optical figure, homogeneity, internal strain, total integrated forward and backscattering, surface texture (Nomarski microscopy), and surface roughness. The results of these measurements are compared with similar measurements on optically polished single-crystal and press-forged $\mathrm{KCl}$ samples.

Bulk optical properties of fine grained forged calcium fluoride, R. H. Anderson, R. A. Skogman, J. F. Ready, and J. M. Bennett, SP541, pp. $70-77$ (Dec. 1978).

Key words: calcium fluoride; forging; laser windows; optical properties; scattering.

Single crystals of $\mathrm{CaF}_{2}$ having $\langle 111\rangle,\langle 100\rangle,\langle 112\rangle$. and $\langle 113\rangle$ orientations have been routinely isostatically forged in a helium atmosphere at $750{ }^{\circ} \mathrm{C}$. The crystals were deformed 60 percent to ensure a uniform grain size of less than $15 \mu \mathrm{m}$. A fine cloudiness of "veiling" occurs when the forging is done below the recrystallization temperature of about $800{ }^{\circ} \mathrm{C}$ for $\mathrm{CaF}_{2}$. Nomarski micrographs show that voids are distributed within the bulk of the forgings. Polariscope photographs show internal stress. Total integrated forward scattering measurements have been made on the sample immersed in a cell containing index matching fluid to eliminate scattering from the sample surfaces. These measurements show variations cannot be definitely correlated with the positions of veils in the $\mathrm{CaF}_{2}$.

CW laser damage in $A R$ coated alkaline earth fluorides at $3.8 \mathrm{\mu m}, \mathrm{J}$. A. Detrio and R. D. Petty, SP541, pp. 78-85 (Dec. 1978).

Key words: antireflection coatings; calcium fluoride; $\mathrm{cw}$ laser damage; DF laser; fusion cast; laser damage; laser window; single crystal; strontium fluoride.

We have measured the damage threshold of AR coated $\mathrm{SrF}_{2}$ and oriented single crystals of $\mathrm{CaF}_{2}$ using a cw chemical laser operating at approximately $3.8 \mu \mathrm{m}$. The samples were irradiated for three seconds up to a total power of $8.4 \mathrm{~kW}$. The specimens all failed at a power density of 22 $\mathrm{kW} / \mathrm{cm}^{2}$ over a $0.3 \mathrm{~cm}^{2}$ area. The failure mode was not catastrophic and is believed to consist of plastic deformation due to compressive loading in the center of the irradiated region on the exit surface. The surface absorption is the dominant contributor to the failures. A novel statistical approach to defining the damage threshold and assessing the confidence level of the data was used.

Lattice absorption, phonon assignments, and image spoiling properties of CVD $\mathrm{ZnS}$ in the infrared, C. Klein, B. diBenedetto, R. Donadio, T. Kohane, and J. Pappis, SP54l, pp. 86-97 (Dec. 1978).

Key words: characteristic phonons; chemical-vapor deposition; image spoiling; infrared imaging; lattice absorption; zinc sulfide.

Chemical-vapor-deposited zinc sulfide (CVD ZnS) has been established as a highly promising material for advanced infrared imaging applications and is attracting attention as a potential window material at HF/DF laser wavelengths. The present contribution concerns work that has been carried out in the context of assessing the optical characteristics of CVD-ZnS blanks, particularly with regard to: (a) lattice absorption. Careful examination of transmission traces at wavelengths up to $25 \mu \mathrm{m}$ indicates that multiphonon processes dominate at frequencies below 1000 $\mathrm{cm}^{-1}$; peak-absorption assignments in terms of zone-boundary phonons have been made on the basis of best available inelastic neutron-scattering results for zincblende $\mathrm{ZnS}$. (b) Temperature dependence. Absorption coefficients at temperatures up to $600 \mathrm{~K}$ have been investigated in light of spectral transmittance and emittance measurements supplemented by calorimetric data at $\mathrm{HF}, \mathrm{DF}, \mathrm{CO}$, and $\mathrm{CO}_{2^{-}}$ laser wavelengths. (c) Image spoiling. Line-spread functions in conjunction with index-inhomogeneity maps demonstrate that wavefront distortions resulting from the presence of a CVD-ZnS window do not inject any detectable degradation in contrast transmittance.

Laser induced damage in fluoride glasses: A status report, S. E. Stokowski, D. Milam, and M. J. Weber, SP54l, pp. 99-108 (Dec. 1978).

Key words: damage thresholds; fluoroberyllate glass; fluorophosphate glass; inclusions; pulse duration.

Bulk and surface damage thresholds of fluorophosphate and fluoroberyllate glasses have been measured for 1-ns 1064-nm laser pulses. For crystal-free samples, threshold values for fluoride glasses are comparable to those measured in optical quality fused silica and borosilicate glasses. However, for many samples investigated the presence of solid inclusions results in low damage thresholds. Some examples of solid inclusions are shown and discussed. Surface damage thresholds in FK-51 fluorophosphate glass are uniformly high and exhibit an approximate square root dependence on pulse duration in the range of 0.1-1.0 ns. 
Liquids for high repetition rate glass laser systems, J. M Rinefierd, S. D. Jacobs, D. C. Brown, J. A. Abate, O. Lewis, and H. Appelbaum, SP541, pp. 109-121 (Dec. 1978).

Key words: Abbé value; coolants, $\mathrm{dn} / \mathrm{dT}$; index matching liquids; neodymium glass lasers; nonlinear refractive index: thermal conductivity; viscosity

We present physical properties data for a number of liquids currently heing used for cooling and/or index matching of components in high peak power, low repetition rate $\mathrm{Nd}$ :glass laser systems. Liquids examined include saturated water solutions of $\mathrm{ZnCl}_{2}$ and $\mathrm{ZnBr}_{2}$, TCP. hen\%ene, DMSO, glycerol, ethylene glycol, FC-104, DowCorning 710, and Cargille 5040) and 5610. Thermal properties (conductivity, diffusivity), mechunical properties (viscosity, density), chemical properties ( $\mathrm{pH}$, materials compatibility), and optical properties (refractive index Abbé value, nonlinear index, dn/dT, optical transparency) are tabulated and compared to projected liquid properties requirements for high repetition rate systems.

Physical and optical properties of surfaces generated by diamond-turning on an advanced machine, D. L. Decker and D. J. Grandjean, SP541, pp. 122-130 (Dec. 1978 ).

Key words: absorption; diamond-turning; scattered light; surface roughness.

A superprecision, two-axis, air-static bearing, diamondturning machine of advanced design has been previously described at this conference and is now operational. The microtopography and other physical characteristics of surfaces turned by this machine will be examined in detail. Some effects of machining parameters will be briefly discussed. The ability of this machine to turn surfaces with very small slope errors $\left(<10^{-3}\right)$ and small rms roughness $(\sim 10 \AA)$ is discussed with relation to the resulting optical absorption, scattering, and laser damage resistance. The characteristics of the machine which permit these high quality surfaces are identified, and some projections are given to the future application of diamond-turned optics at near infrared or visible wavelengths.

Optical and metallurgical characterization of molybdenum laser mirrors, S. M. Wong, G. Krauss, and J. M. Bennett, SP541, pp. 132-163 (Dec. 1978).

Key words: laser mirror; metallurgical characterization; microstructures; molybdenum; optical characterization.

A study has been performed to determine the correlation between the microstructure, metallurgical processing, and surface finish of eight specially selected molybdenum (Mo) specimens from various sources. Samples of bar and plate stock produced from pure Mo either arc-cast or pressed and sintered, and TZM ( $\mathrm{Ti}-\mathrm{Zr}-\mathrm{Mo})$ Mo alloy were examined in the form of optically polished 1 1/2-inch- (3.86$\mathrm{cm}-$ ) diameter discs. Metallurgical characterization included hardness measurements, grain size and shape determinations from polished and etched sections, scanning electron microscopy, and Auger electron spectroscopy. Optical characterization consisted of measurements of total integrated scattering, $\mathrm{rms}$ roughness, height distribution functions, and autocovariance. In some cases, the surface roughness of as-polished mirror surfaces could be directly related to grain structure and substructure as revealed by etching. These observations and their implications for the selection of Mo starting stock to be used in the production of low-scatter laser mirrors will be discussed.

1064-nm laser damage thresholds of polished glass surfaces as a function of pulse duration and surface roughness, D. Milam, SP541, pp. 164-167 (Dec. 1978).
Key words: BK-7 glass; fused silica; laser dismage; polished surfaces; pulse duration dependence of damage; surface roughness.

Laser damage thresholds were measured for four polished glass surfaces, using linearly polarized 1064-nm pulses with durations of $0.17 \mathrm{~ns}, 1.0 \mathrm{~ns}, 1.6 \mathrm{~ns}$, and $3.2 \mathrm{~ns}$. Thresholds scaled approximately as the square root of pulse duration, hut were insensitive to variations in surface roughness when the roughness was $<25 \AA$ rms. Careful cleaning increased the damage threshold at 3.2 ns by removing particulates.

Large giant and free-running laser pulse energy and power densities through optical fibers, M. J. Landry, SP54I, pp. $168-189$ (Dec. 1978).

Key words: free-running laser pulses; giant laser pulse; optical fiber damage; pulsed $\mathrm{Nd}^{3+}$ laser damage; single and multiple element fibers; surface threshold damage.

The surface threshold damage levels (STDL) and coupling efficiencies, $\epsilon$, (ratio of output-to-input energy) have heen determined for single and multiple optical fibers of five manufacturers. For giant laser pulses of 30 nsec duration, the largest STDL's were ohserved in American Optical Company fibers for single and multiple laser shots with values of 48.2 and $31.6 \mathrm{~J} / \mathrm{cm}^{2}$, respectively. For freerunning laser pulses of $100 \mu \mathrm{sec}$ duration, the largest STDL was observed in Corning Glass Works fibers for single laser shots with a value of $4.66 \mathrm{~kJ} / \mathrm{cm}^{2}$. For multiple laser shots increased energy caused the initial damage sites in the binding or fiber cladding materials to increase in size and cause new sites in these materials at lower STDL's than for single laser shots. The giant laser pulses caused the most severe surface damage. There is no evidence to suggest that the observed decrease in $\epsilon$ was caused by other than the increase in damage to the input surface of the fibers.

Ultraviolet damage resistance of laser coatings, B. E. Newnam and D. H. Gill, SP541, pp. 190-202 (Dec. 1978).

Key words: damage thresholds; electric fields; laser damage; nanosecond pulses; pulsewidth dependence; standing waves; thin-film coatings; two-photon absorption; ultraviolet wavelength scaling.

The damage resistance of several thin-film materials used in ultraviolet laser optics was measured at $266 \mathrm{~nm}$ and 355 $\mathrm{nm}$. The coatings included single, quarter-wave ( $Q W$ ) layers of $\mathrm{NaF}, \mathrm{LaF}_{3}, \mathrm{MgF}_{2}, \mathrm{ThO}_{2}, \mathrm{Al}_{2} \mathrm{O}_{3}, \mathrm{HfO}_{2}, \mathrm{ZrO}_{2}, \mathrm{Y}_{2} \mathrm{O}_{3}$ and $\mathrm{SiO}_{2}$, plus multilayer reflectors composed of some of these materials. The substrates were uv-grade fused silica. Single-shot thresholds were obtained with 22-ns and 27-ns (FWHM) pulses at 266 and $355 \mathrm{~nm}$, respectively. One of the samples had previously been tested using 20-ps pulses, providing a pulsewidth comparison.

At $266 \mathrm{~nm}$ the coating with the highest damage threshold was a QW layer of NaF at $10.8 \mathrm{~J} / \mathrm{cm}^{2}(450$ $\mathrm{MW} / \mathrm{cm}^{2}$ ), whereas for a maximum reflector of $\mathrm{Al}_{2} \mathrm{O}_{3} / \mathrm{NaF}$ the value was $3.6 \mathrm{~J} / \mathrm{cm}^{2}\left(154 \mathrm{MW} / \mathrm{cm}^{2}\right)$. At $355 \mathrm{~nm}$ the QW layer of NaF could not be damaged at $38 \mathrm{~J} / \mathrm{cm}^{2}$ ( 1390 $\left.\mathrm{MW} / \mathrm{cm}^{2}\right)$, and the threshold of the maximum reflector was $12.2 \mathrm{~J} / \mathrm{cm}^{2}\left(470 \mathrm{MW} / \mathrm{cm}^{2}\right)$.

The results were analyzed to determine correlations with standing-wave electric fields and linear and two-photon absorption. Scaling relationships for wavelength, refractive index and atomic density, and pulsewidth were found.

Multithreshold evaluation of 100 -nsec pulsed laser damage to coating materials at $2.7-$ and $3.8-\mu \mathrm{m}$ wavelengths, J. O. 
Porteus, T. M. Donovan, J. L. Jernigan, and W. N. Faith, SP54l, pp. 202-211 (Dec. 1978).

Key words: absorption; antireflection coatings; damage thresholds; impurities; laser-induced damage; thermal damage.

In this time and wavelength regime optical coatings typically fail from thermal damage. Unlike catastrophic damage resulting from dielectric breakdown, one finds disparity among the thresholds for one or more of the following damage characteristics: delamination, cracking, flow, erosion, perforation, ion emission, and light emission. Comparison of the different thresholds provides useful information on how damage proceeds, and how the absorbed energy is distributed in the coating layer. Comparison of multithreshold damage data at the two different wavelengths permits evaluation of the importance of impurities which absorb preferentially at one of the wavelengths, such as water. Comparing thresholds at the two wavelengths after $\mathrm{N} / \mathrm{l}$ conditioning provides detection of preferentially absorbing impurities which are laserdesorbed. Complementary information may be obtained from laser calorimetry. The following materials, prepared as single-layer, antireflection coatings, were evaluated: $\mathrm{NaF}, \mathrm{SiO}_{x}, \mathrm{Al}_{2} \mathrm{O}_{3}, \mathrm{ZnS}, \mathrm{As}_{2} \mathrm{~S}_{3}$, and Si. Samples of the first three were prepared in ultra-high vacuum, in addition to the usual standard vacuum preparation. Thresholds are expressed in terms of the theoretical energy per unit area in the coating layer in order to permit a practical intercomparison of materials for multilayer coating design.

Multithreshold damage measurements on $\mathrm{As}_{2} \mathrm{~S}_{3}, \mathrm{As}_{2} \mathrm{Se}_{3}$, and NaF at HF and DF wavelengths, T. M. Donovan, J. O. Porteus, J. L. Jernigan, and E. J. Ashley, SP541, pp. 212-217 (Dec. 1978).

Key words: absorption; arsenic selenide; arsenic trisulfide; defects; laser damage; sodium fluoride.

We previously reported on the deposition, absorption, and $\mathrm{CO}_{2}$-laser damage threshold for $\mathrm{As}_{2} \mathrm{~S}_{3}, \mathrm{As}_{2} \mathrm{Se}_{3}$, and $\mathrm{NaF}$ coatings. It was shown that the damage threshold was much lower for coated than uncoated substrates and that the mechanism for damage was different in the coatings than in the substrates. We speculated that the damage in the coatings was related to the presence of micron-sized crystalline defects distributed in the amorphous chalcogenide matrix. In this paper we report the results of damage measurements on these materials at 2.8 and $3.8 \mu \mathrm{m}$ and identify two operating damage processes: "uniform" damage, which we associate with the amorphous chalcogenide matrix, and "selective" damage, which we associate with the crystalline defects. For single-layer films, we find that $N / 1$ conditioning generally produces an increase in the damage thresholds. The wavelength dependence of multithreshold results in single-layer coatings of $\mathrm{As}_{2} \mathrm{~S}_{3}$ and $\mathrm{NaF}$ suggests that improvement in threshold results from the thermal desorption of contaminating layers of water at 2.7 $\mu \mathrm{m}$. However, for a dielectrically enhanced reflector containing quarter-wave layers of $\mathrm{As}_{2} \mathrm{Se}_{3}$ and $\mathrm{NaF}, \mathrm{N} / 1$ conditioning promoted crystallite growth which resulted in a definite deterioration of $\mathrm{N} / 1$ thresholds.

TEM investigation of effects of a barrier layer on damage to $\mathbf{1 . 0 6 4 \mu}$ Ar coatings, C. K. Carniglia, J. H. Apfel, G. B. Carrier, and D. Milam, SP541, pp. 218-225 (Dec. 1978).

Key words: antireflection coatings; electron microscopy; laser damage; optical coatings; thin films.
Silica/titania 4 layer AR coatings on BK-7 glass, with and without a half-wave silica barrier layer, have been damaged at $1.064 \mu$ by 150 ps laser pulses. The damage sites have been examined by TEM replica techniques at a magnification of 70,000 . The size of the damage sites appears to be "quantized." Most sites consist of a $1 \mu$ nucleus which leads to a $3 \mu$ crater in a fully developed site. The mechanical properties of the films appear to play a role in the morphology of the damage sites. The titania layers seem to fracture while the silica layers seem to melt or tear. A series of micrographs of near threshold damage sites shows the development of the sites from a rupture which appears to occur at or near the substrate surface. Evidence of heating in the substrate is also present, although it is difficult to pinpoint the exact starting point of the damage mechanism.

Optical techniques for the determination of pulsed laser damage in thin films, T. W. Walker, A. H. Guenther, and P. E. Nielsen, SP541, pp. 226-234 (Dec. 1978).

Key words: laser damage; optical probe technique; radiation scattering; thin films.

Two techniques, to determine the occurrence of pulsed laser induced damage in thin film dielectric coatings, were compared and evaluated against normally employed methods. One of the new techniques utilized near back scattered radiation from the damaging pulse and proved to be as sensitive as the best existing optical probe method while being experimentally facile. The second new method recorded a time delayed probe pulse which was reflected from the thin film damage site. This method appears to be more sensitive to a local index of refraction change in the thin film rather than increased reflectance/scattering from the damage site. Preliminary test results show that most of the morphological damage occurs after the damaging pulse has passed.

A statistical analysis of absorptive laser damage in dielectric thin films, A. B. Budgor and K. F. Luria-Budgor, SP541, pp. 235-248 (Dec. 1978).

Key words: laser damage; probability; statistical analysis; thin films; Weibull distribution.

The Weibull distribution arises as an example of the theory of extreme events. It is commonly used to fit statistical data arising in the failure analysis of electrical components and in DC breakdown of materials.

This distribution is employed to analyze time-to-damage and intensity-to-damage statistics obtained when irradiating thin film coated samples of $\mathrm{SiO}_{2}, \mathrm{ZrO}_{2}$, and $\mathrm{Al}_{2} \mathrm{O}_{3}$ with tightly focused laser beams. The data used is furnished by Milam. The fit to the data is excellent; we often obtain least squared correlation coefficients greater than 0.9 .

It is found almost universally that statistical models of breakdown, such as the lucky electron theory, oversimplify the damage process by neglecting nonlinear interactions and anisotropies induced by impurities. Thus, the fundamental intensity I relation on pulse length $t_{p}$ often deviates from the classical $t_{p}^{-1 / 2}$ dependence resulting from 2photon absorption without diffusion, or from linear absorption with diffusion, to dependencies as high as $t_{p}{ }^{-0.22}$ for the former to $t_{p}-\mathbf{0 . 4 4}$ for the latter. This fact, coupled with the experimental nonobservability of higher than 2-photon absorption seems to imply that the avalanche mechanism is the most likely initiator of the plasma requisite for lattice meltdown.

Statistical confidence bands for material survivability as a function of laser intensity and pulse length can be con- 
structed; this lends high practical utility to the Weibull distribution as an engineering diagnostic tool.

New coating materials for IR laser optical components, $R$. C. Pastor, J. A. Harrington, L. E. Gorre, and R. K. Chew, SP541, pp. 249-256 (Dec. 1978).

Key words: infrared laser windows; materials purification; reactive atmosphere process (RAP) chemistry; thin film coating materials.

Six materials $\left(\mathrm{LaF}_{3}, \mathrm{PrF}_{3}, \mathrm{CeF}_{3}, \mathrm{BiF}_{3}, \mathrm{KGaF}_{4}\right.$, and $\left.\mathrm{BiI}_{3}\right)$ were prepared and optical evaluated for use as thin film coating materials at 3.8 and $9.27 \mu \mathrm{m}$.

Improved $\mathrm{PbF}_{2}$ coatings for the infrared, $\mathrm{P}$. Baumeister, $\mathrm{G}$. P. Arnold, and D. F. Edwards, SP541, pp. 257-258 (Dec. 1978).

Key words: antireflection coatings; CdSe; coating substrate; damage resistant; $\mathrm{Ge} ; \mathrm{PbF}_{2}$; pulsed $\mathrm{HF}$ laser.

A technique is described for reproducibly depositing single layer $\mathrm{PbF}_{2}$ antireflection coatings for $\mathrm{CdSe}$ that have a damage threshold of about $50 \mathrm{MW} / \mathrm{cm}^{2}$ for $2.87 \mu \mathrm{m}$ laser radiation. This is an 8 -fold increase in damage resistance over coatings made by other methods. These same coatings applied to $\mathrm{Ge}$ have a damage threshold of about 22 $\mathrm{MW} / \mathrm{cm}^{2}$. The coated $\mathrm{Ge}$ value is less probably due to the index mismatch between the $\mathrm{PbF}_{2}$ and the Ge.

Graded index coatings of cubic thallium iodide (TII) and lead fluoride $\left(\mathrm{PbF}_{2}\right)$, T. J. Moravec and R. A. Skogman, SP541, pp. 259-265 (Dec. 1978).

Key words: graded index; lead fluoride; polymorphism; thallium iodide; thin films.

We present a new technique for producing graded index films from alternating very thin layers of two materials. During deposition the thickness of the layers is adjusted so that the resulting average index matches the index of the profile for that total thickness. This method shows great promise for making films with any desired complicated index profile in a very straightforward manner. Results are presented for graded index AR films near $10 \mu \mathrm{m}$ made from TlI and $\mathrm{PbF}_{2}$. The $10.6 \mu \mathrm{m}$ absorption of these films was similar to that of discrete, multilayer AR films composed of the same materials.

The alternating layer method also takes advantage of the polymorphism of TII in thin layers to produce films in the cubic phase. We show by $x$-ray and optical measurements that each TlI layer possesses the $\mathrm{CsCl}$ structure at room temperature. It thus appears that each layer of TII is ignorant of the existence of the previous layer of TII due to the layer of buffer material $\left(\mathrm{PbF}_{2}\right)$.

Simple expressions for calculating the effect of volume or interface absorption in thin films on the performance of high reflectance or antireflectance multilayer coatings, H. E. Bennett and D. K. Burge, SP541, pp. 266-277 (Dec. 1978).

Key words: absorption; antireflectance coatings; high reflectance coatings; interface absorption; multilayer films; scattering.

Approximate closed-form expressions are developed for predicting the effect of volume and interface absorption in thin films on the performance of quarter-wave multilayer coatings. For highly reflecting coatings on dielectric substrates the volume absorption expressions are equivalent to those obtained by Sparks using a perturbation approach. The results are extended to metal substrates by introducing the concept of a generalized substrate index. An approxi- mate expression for scattering losses for high reflectance coatings is included. Multiple quarter-wave antireflectance coatings are also analyzed using admittance theory. A technique for experimentally separating and determining interface and volume absorption in single-layer films has recently been reported. The expressions developed in this paper make it possible to predict the performance of high reflectance and antireflectance multilayer stacks from these single-film measurements without recourse to a computer.

Simplified description of dielectric reflectors, $M$. Sparks and M. Flannery, SP541, pp. 278-287 (Dec. 1978).

Key words: asymmetric absorptance; damage thresholds; dielectric reflectors; electric-field distribution; high-power; reflectance; spectral absorptance; theory.

The spectral reflectance, $R(\omega)$, of a quarter-wave reflector is quite asymmetric in general as a result of absorption. The maximum electric field $E$ in an infinite stack is in the center of the high-index (low-index) layer at the lowfrequency (high-frequency) end of the high-reflection band. Thus, the absorptance minimum of a stack having much greater absorption in the high-index material occurs at $\omega>\omega_{\sigma_{0}}$ (band center). Operation at $\omega>\omega_{c}$ could increase the damage resistance if the high-index material is easily damaged. At $\omega_{c}$, E decays rapidly. As $\omega$ departs from $\omega_{c}$ in an infinite reflector, $E$ penetrates deeper into the coating, with no decay at the band edges. The peak-topeak distance in an infinite dielectric stack is constant for all frequencies in the band. By using the continuity of $E$ and $\mathrm{dE} / \mathrm{dz}, \mathrm{E}$ can be obtained from $\mathrm{E}=0$ at the metallic substrate or, in an infinite stack, from $E=0$ at the reflector surface for $\omega=\omega_{c}$ or $E=0$ in the center of the highor low-index layer at the band edges. Simple closed-form approximations for the spectral absorptance and the phase of $E$ are accurate and sufficient for present applications.

Electric fields near coated surfaces: Application to damage protection, H. B. Rosenstock, SP541, pp. 288-295 (Dec. 1978 ).

Key words: damage threshold; electric fields; internal reflection; protective coatings.

Damage to transparent materials from intense light pulses usually begins at the exit surface. This is usually explained by "constructive" interference between incident and reflected waves: The total electric field may exceed the threshold for damage only upon reflection from the exit surface. However, in case of a surface coated with a thin film, interference may either increase or decrease the total electric field. Details depend on the optical constants, thickness, and wavelengths. A film designed to provide protection against excessive electric fields at one wavelength may not do so at other wavelengths. Also, attempts to minimize the field in the material proper may entail novel problems in the film, in which the damage mechanism may be an absorptive one.

Computer simulation of laser damage morphology in the alkali-halides, P. Kelly, D. Ritchie, P. Bräunlich, and A. Schmid, SP541, pp. 296-298 (Dec. 1978).

Key words: alkali-halides; laser pulse; pico-second; picosecond laser pulse.

A numerical model of the spatio-temporal behaviour of a pico-second laser pulse has been developed which allows the study of the interaction of macroscopic photons with electrons in an alkali-halide lattice. Trajectories of the photons are computed. Gradients in the refractive index 
change the direction of the photons and this can lead to focusing or defocusing of the pulse. Rotational symmetry is assumed for both the pulse and background. Results obtained to date will be presented.

The relative role of impsct and multiphoton ionization mechanisms in laser indaced damage of transparent dielecArics, B. G. Gorshkov, A. S. Epifanov, and A. A. Manenkov, SP541, pp. 299-302 (Dec. 1978).

Key words: damage threshold; electron avalanche; frequency and pulse width dependencies of the critical field; multiphoton ionization.

The results of a theoretical analysis of the electron avalanche process at high frequencies of the electromagnetic field are presented. The dependence of the avalanche rate on radiation intensity and of the critical field on frequency are obtained for nanosecond and picosecond pulse durations. The relative role of electron avalanche and multiphoton ionization in laser damage of transparent dielectrics is discussed and it is shown that it is strongly influenced by the pulse widths.

Theory of laser damage in dielectric solids, S. Brawer and W. L. Smith, SP541, pp. 303-304 (Dec. 1978).

Key words: conduction band (CB) electrons; dielectric solids; electrons, conduction band (CB); laser damage.

In this theory a new approach to the interaction of conduction band (CB) electrons with damaging radiation is considered. We assume band gaps grearer than $4 \mathrm{eV}$ and radiation frequencies greater than $1 \mathrm{eV}$. Two processes are required for damage. First, the incident radiation rapidly excites a few "primer" electrons from trap levels to the bottom of the CB. Next these primer electrons can either cause enough energy to be absorbed to cause damage without avalanche, or they can trigger an electron avalanche and subsequent damage. In either case a mechanism for the excited-state absorption process is required.

Laser-induced damage in semiconductors, Y. K. Danileiko, A. A. Manenkov, and A. V. Sidorin, SP54l, pp. 305-308 (Dec. 1978).

Key words: laser induced breakdown; laser-induced damage threshold; nonequilibrium carriers; semiconductors, Ge, Si, GaAs.

The laser-induced bulk breakdown in Ge, Si and GaAs crystals at the $10.6 \mu \mathrm{m}, 2.76 \mu \mathrm{m}$, and $2.94 \mu \mathrm{m}$ radiation wavelengths of the pulsed $\mathrm{CO}_{2}, \mathrm{Ca}_{2} \mathrm{~F}: \mathrm{Er}^{3+}$ and $\mathrm{YAG}: \mathrm{Er}^{3+}$ lasers is investigated. Generation of free carriers has been observed and their kinetics studied by the $\mathrm{dc}$ and microwave photoconductivity measurement techniques. In Si and GaAs, the laser-induced bulk damage has been observed and the damage threshold measured. In $\mathrm{Ge}$, the damage was not observed due to a self-defocusing effect associated with the negative contribution of nonequilibrium electrons in the refractive index. Mechanisms of free carrier generation and laser-induced damage are discussed.

Frequency dependence of breakdown fields in single-crystal $\mathrm{NaCl}$ and $\mathrm{KCl}, \mathrm{M}$. J. Soileau, M. Bass, and E. W. Van Stryland, SP541, pp. 309-317 (Dec. 1978).

Key words: breakdown fields; $\mathrm{KCl}$; $\mathrm{NaCl}$; spot-size dcpendence.

In this paper new observations of the breakdown fields in single-crystal $\mathrm{NaCl}$ and $\mathrm{KCl}$ are reported. Measurements were made of the wavelength and focal spot radius depen- dence of breakdown fields in $\mathrm{NaCl}$ and $\mathrm{KCl}$ at optical frequencies. The measurements at different focal spot radii were used to establish empirical scaling laws for these two materials over the range of focal spot radii studied. Correct application of these scaling laws gives directly comparable fields at all frequencies. The results indicate little dispersion in breakdown fields over the wavelength range of 10.6 to $0.53 \mu \mathrm{m}$. The ratio of the $\mathrm{NaCl}$ and $\mathrm{KCl}$ breakdown fields are found to depend on frequency and this implies that extrinsic phenomena were being probed by these experiments.

Investigation of surface breakdowil mechanism in IR-optical materials, V. I. Kovalev and F. S. Faizullov, SPS41, pp. 318 326 (Dec. 1978).

Key words: adsorbed water; breakdown mechanism; frequency and time dependence of breakdown thresholds; IR window materials; $\mathrm{NaCl}$; pressure; pulsed TEA $\mathrm{CO}_{2}$ laser surface breakdown; spot size; surface absorption; transmitted pulse.

It has been found that with a decrease in ambient gas pressure, there takes place a decrease of surface breakdown threshold in IR-optical materials under TEA $\mathrm{CO}_{2}$ laser radiation. To explain this fact, a new mechanism of the breakdown has been proposed, which is connected with evaporation of adsorbed water. The breakdown stage has been experimentally investigated and a theoretical analysis has been performed. The dependence of the surface breakdown in $\mathrm{NaCl}$ on ambient gas pressure, spot size, frequency and time have been studied. The dependence on the quantity of adsorbed water (surface absorption) has been studied as well. The breakdown thresholds have been measured with a calibrated, photon drag detector by the amplitude of the transmitted pulse. The results obtained are in good agreement with the proposed model.

SP542. Possible contributions of cement and concrete technology to energy conservation, G. Frohnsdorf, P. W. Brown, and J. R. Clifton, Nat. Bur. Stand. (U.S.), Spec. Publ. 542, 76 pages (May 1979) SN003-003-02059-1.

Key words: cement; concrete; energy. saving opportunities; research needs.

A workshop on Possible Contributions of Cement and Concrete Technology to Energy Conservation by the Year 2000 was held at the National Bureau of Standards on October 3 and 4,1977 . The purpose of the workshop was to identify and record ideas on possible contributions of cement and concrete technology to energy conservation in the near term and by the Year 2000. This included consideration of current technology as well as areas in which technological advances might be realized.

The workshop was divided into working groups on cement composition, cement production, blending materials, concrete production, efficient use of concrete, and institutional factors. The essential results from the six working groups were statements of Energy-Saving Opportunities, Research Needs, and Unresolved Issues. The statements, which are the major part of this report, are presented without critical analysis. They suggest, however, that there are a large number of possible opportunities which should be evaluated for their ability to contribute to energy conservation in the cement and concrete industries.

SP543. The technological knowledge base for industrializing countries. Proceedings of the NBS/AID UNCSTD Seminar held at the National Bureau of Standards, Gaithersburg, MD, Oct. 16-17, 1978, R. C. Sangster, Ed., Nat. Bur. Stand. (U.S.), Spec. Publ. 543, 239 pages (Apr. 1979) SN003-00302057-5. 
Key words: Africa; Asia; developing countries; industrialization; Latin America; management; measurement; metrology; quality control; standards; technology transfer; UN Conference on Science and Technology for Development (UNCSTD).

The National Bureau of Standards held a two-day seminar to explore needs for the technological knowledge base for industrializing countries and procedures for acquiring and applying it, in the areas of measurement capabilities and services required by technological industry, national and international standards that must be satisfied by industrializing nations, knowledge required for industrial quality control, knowledge required to enable a country to acquire commercial industrial technology, and managerial responsibilities and technical knowledge. The Proceedings are background material for preparation of U.S. positions at the UN Conference on Science and Technology for Development in Vienna, August 1979. Cosponsors included the Office of Science and Technology, Dept. of Commerce; U.S. Coordinator for the UN Conference, Dept. of State; and the Agency for International Development. The 97 registrants came from Argentina, Barbados, Brazil, Egypt, Guyana, India, Indonesia, Jordan, Kenya, Korea, Lesotho, Mexico, Pakistan, Panama, Philippines, Saudi Arabia, Singapore, South Africa, Sudan, Switzerland, Taiwan, Tanzania, Tunisia, Turkey, and many public and private organizations in the U.S. Key words used to summarize the conclusions were: local realities; industrialization; import, adapt, and innovate; complexity; technology assessment; indigenous capabilities; metrology, standardization, and quality control; survey projects; instrumentation; international standardization; existing plant; access to industrial technology; management; organizational climate; the human resource; the UN. All are important and need attention/support. These proceedings include the following papers (indented)

Expanding horizons: Technological knowledge for industria! takeoff, H. I. Fusfeld, SP543, pp. 24-28 (Apr. 1979).

Korean measurement capabilities: Past and present, J. W. Choi, SP543, pp. 34-39 (Apr. 1979).

On the National Standards System in Korea, D. H. Kim, SP543, pp. 41-44 (Apr. 1979).

Experience of a major U.S. firm in a newly industrializing country, R. Coria, SP543, pp. 46-50 (Apr. 1979).

Electronics metrology in Argentina, H. F. Mazza, SP543, pp. 53-54 (Apr. 1979).

Programs of IPT, J. C. Waeny, SP543, pp. 55-57 (Apr. 1979).

Standardization and measurement services in Indonesia, $M$. E. E. Gandhi, SP543, pp. 58-61 (Apr. 1979).

Present status of electronic measurement standards and calibration services in India, K. Chandra, SP543, pp. 62-63 (Apr. 1979).

Siandardization in the developing nations, A. Fadlalla, SP543, pp. 65-72 (Apr. 1979).

The international standards picture, R. B. Belford, SP543, pp. 73-76 (Apr. 1979).

Towards standardization in Guyana, L. Lawrence, SP543, pp. 78-86 (Apr. 1979).

Standardization in Panama, M. F. de Chan, SP543, pp. 8788 (Apr. 1979).
Standardization as seen im Tanzania, T. Rajaraman, SP543, pp. 89.93 (Apr. 1979).

Views on standardization, J. E. Owino-Okwero, SP543, pp. 94-98 (Apr. 1979).

Progress of standardization in the Sudan, A. G. Suliman, SP543, pp. 99-100 (Apr. 1979).

Standardization In Tunisia, R. Bouhalila, SP543, pp. I01105 (Apr. 1979).

Standardization in Saudi Arabia, K. Y. Al-Khalaf, SP543, pp. 106-107 (Apr. 1979).

Standardization in Jordå, R. B. Halteh, SP543, pp. 108 110 (Apr. 1979).

Establishing a quality confrol system In an industriallzing country, K. S. Stephens, SP543, pp. 113-132 (Apr. 1979).

High technology quality control in a newly industriallzing society, L. K. Tatt, SP543, pp. 134-141 (Apr. 1979).

On providing the tech nological knowledge base for industrializing Barbados, J. L. Tudor, SP543, pp. 144-147 (Apr. 1979).

Certification and quality control problems in Ghana, A. O. Nitoro, SP543, pp. 148-149 (Apr. 1979).

United States preparations for the United Nations conference on science and technology for development, $J$. Wilkowski, SPS43, pp. 151.155 (Apr. 1979 ).

A survey of development efforts in Turkey, T. G. Somer, SP543, pp. 163-172 (Apr. 1979).

Experience of an industrializing mation in deployment of technical knowledge to meet national needs, M. M. Qurashi, SP543, pp. 173-190 (Apr. 1979).

Management principles in industrialization, J. A. Slater, SP543, pp. 192-193 (Apr. 1979).

Remarks prepared for the NBS/AID UNCSTD seminar: The technological knowledge base for industrializing countries, I. S. Djermakoye, SP543, pp. 196-198 (Apr. 1979).

Knowledge required to emable a country to acquire commercial industrial technology - Experience of a country with an interzasediate economy, A. P. de Castro, SP543, pp. 199-208 (Apr. 1979).

The role of technology megotiators, R. J. Radway, SP543, pp. 209-214 (Apr. 1979).

A public interest point of view of science and technology for development, J. Gudaitis, SP543, pp. 21 6-217 (Apr. 1979).

SP545. Contributions to color science, D. B. Judd and D. L. MacAdam, Ed., Nat. Bur. Stand. (U.S.), Spec. Publ. 545, 760 pages (Sept. 1979) SNO03-003-02126-1.

Key words: color; colorimetry; color spacing; color vision; Deane Judd; selected writings; spectrophotometry.

This book is a collection of fifty-seven papers written by Deane B. Judd, a staff member of the National Bureau of Standards from 1926 to 1969 , and an internationally recognized authority on color. The contents of this collection include some of the major contributions of Dr. Judd to such areas as the measurement and specification of color, spectrophotometry, color appearance and spacing, and color vision. Each paper is 
preceded by an introduction which provides general commentary on the article and explains the terminology used. Some introductions also direct the reader to related articles in the collection and point out significant developments, such as international agreements, which were based on Judd's work. A list of the more than 200 articles written by Dr. Judd is included in an appendix.

SP546, 1979 Edition. Catalog of Federal metrology and calibration capabilities, K. O. Leedy, Nat. Bur. Stand. (U.S.), Spec. Publ. 546, 1979 Edition, 52 pages (June 1979) SN003-00302082-6.

Key words: calibration; Federal Government; laboratory; measurement; metrology; precision; test equipment.

This publication lists Federal laboratories involved in metrology and calibration. Included is the name of a person at each laboratory to contact for more information as well as the laboratory telephone number and address. The capabilities of each laboratory are indicated in a tabular listing by agency. To provide geographical distribution, the laboratories are listed by States. In addition, the laboratories are shown on a map by coded number. Other references are described.

SP547. MFPG-Detection, diagnosis, and prognosis. Proceedings of the 28th Meeting of the Mechanical Failures Prevention Group, held at San Antonio, TX, Nov. 28-30, 1978, T. R. Shives and W. A. Willard, Eds., Nat. Bur. Stand. (U.S.), Spec. Publ. 547, 368 pages (July 1979) SN003-00302083-4.

Key words: bearing analysis; condition monitoring; engine diagnosis; failure detection; failure diagnosis; failure prevention; maintenance; performance monitoring.

These proceedings consist of a group of twenty-five submitted papers from the 28th meeting of the Mechanical Failures Prevention Group which was held in San Antonio, TX, Nov. 28-30, 1978. The central theme of the proceedings deals with detection, diagnosis, and prognosis as related to mechanical failure prevention. Special emphasis is on aerospace applications, land based applications, marine applications and industrial applications. These proceedings include the following papers (indented):

Space shuttle diagnostics, D. J. Webb, SP547, pp. 3-16 (July 1979).

Key words: automatic monitoring; failure annunciation; malfunction procedures; manned spaceflight failures; redundancy management; training for diagnosis.

The Space Shuttle Orbiter employs an elaborate onboard failure diagnosis system. Failure detection, accomplished in a variety of ways by the vehicle's data processing system, provides aural and visual cues to the flight crew on vehicle anomalies. In some cases, redundancy management is automatically performed to compensate for the failure. The flight crew then refers to a comprehensive body of malfunction procedures, developed by mission control center personnel, to analyze the detailed symptoms, identify the scope of the failure, and reconfigure the vehicle for safe continuation of the mission. Operational verification of the diagnosis system and training in its use by the flight crew and mission control center personnel is accomplished by classroom instruction and simulation experience. Examples and philosophy of the diagnosis system design and the responsibilities of the flight crew and mission control are discussed.

Multispectral scanner on LANDSAT, S. M. Gritton and A. B. Marchant, SP547, pp. 17-30 (July 1979).
Key words: crosstrack scan; carth imagery; ERTS; LANDSAT; multispectral scanner; reflective optics.

The multispectral scanner (MSS) is described; it is an instrument onboard the earth resources satellite that was formerly called ERTS, but is now referred to as LANDSAT Since July 1972, three scanncrs have been launched that have provided tens of thousands of pictures of the earth. The scanning mechanisms that produces these pictures has proven to be extremely reliable and repeatable. After the first scanner was turned off after five years of operation in orbit, the scan mirror had accumulated 90 million cycles and was still performing flawlessly. The design approach that was taken in order to achieve reliability is discussed as well as the scan monitor that serves both to provide a correction signal for data processing on the ground and as a diagnostic device to detcct impending trouble.

Drivetrain bearing analysis, T. C. Belrose and D. Board, SP547, pp. 31-35 (July 1979).

Key words: aircraft diagnostics; bearing; condition monitoring; diagnostic equipment; shock pulse.

The U.S. Army has recognized for some time the need for improved condition monitoring and diagnostic equipment for hclicopter drivetrain systems. Recent studies have confirmed that an unacceptably high false removal rate exists on many helicopter drivetrain components and that "phenomenal savings" would accrue to the Army by improving the diagnostic effectiveness. There have been several attempts at developing cost effective, affordable and reliable equipment. It now appears that such a system exists. It is the Small Portable Analyzer Diagnostic Equipment (SPADE). The equipment has been undcr development for several years and is currently in a Development Test at Ft. Rucker and an Operational Test at Ft. Hood. The purpose of this paper is to briefly review the program, the equipment characteristics and to review in detail the results of the Contractor Demonstration Phase.

Light helicopter detection, diagnosis and prognosis objectives and applications, H. G. Smith and R. E. Rohtert, SP547, pp. 36-57 (July 1979).

Key words: detection; diagnosis; prognosis.

The need for obtaining adequate diagnostic data on aircraft and helicopters and the processing thereof for practical utilization has long been recognized by both the airlines and the military. The implications in regard to flight safety, operational availability of the vehicle, and maintenance and logistics economics are too tremendous to ignore. The techniques for obtaining and processing such diagnostic information have been the subject of considerable experimental research and development over the past several years. The advent of reliable miniaturized transducers as well as data processors/computers has now made onboard diagnostics a current technical feasibility for even a light helicopter such as the Hughes 500D.

Data projected to be measured and processed include engine condition, gearbox condition, vibration levels, rotor hub and swashplate bearings condition, and flight structural envelope exceed ance.

Detection, diagnosis and prognosis (DD\&P) applications that either have been, or are being, considered by Hughes Helicopters in regard to its 500D light helicopter are: 1) Use of the recently developed and FAA certified onboard computer system; 2) Installation of a system for providing a quantitative display in the cockpit in the event of tail rotor imbalance; 3 ) Development of an engine data recording and analysis system with the objective of establishing 
criteria and method for substantially extcnding the time between overhaul (TBO) on all engine components; (4) Sampling and analysis of oil from main transmission and tail rotor gearbox at regular intervals with the objective of developing criteria and technique for extending the TBO.

Gas turbines and millimeter-wave radar, N. B. Kramer, SP57, pp. 58-62 (July 1979).

Key words: advanced sensors; Doppler millimeter radar; gas turbine monitoring; remote motion detection; static displacement measurement; vibration measurement.

The Doppler Effect is widely used for detection and analysis of remote moving objects via radar, sonar and beacon systems. Doppler radar at millimeter wavelengths has been used to measure vibration amplitude and frequency in physically confined systems at short ranges. Methods for calibration of the radar for accurate vibration amplitude and static displacements have been worked out in principle. Limited testing has been done on an operating gas turbine proving the feasibility of the millimeter radar technique.

Some background to support the Doppler radar technique is presented. However, the principal point to be made is that in the last several years, significant advances have been made in extending the frequency range of practical millimeter hardware to $100 \mathrm{GHz}$ and above and in building extremely tiny and simple radar sensors to operate at these frequencies. This means that sensors for a wide variety of applications can be tailored to exact requirements and produced at low cost. Practical considerations for gas turbine measurements include probe design and transmission and absorption of millimeter radiation in various materials and gases.

Improving vehicle life-cycle reliability by prognostic maintenance management through geriometry, R. G. Salter, SP547, pp. 65-77 (July 1979).

Key words: geriometry; life cycle reliability; on-vehicle computing instrumentation; prognostic maintenance management.

Land vehicle life cycle reliability is a topical subject. The military is recognizing the necessity to survive the peacetime environment in order to improve combat readiness. Government intervention in the automotive world increases on behalf of energy, the environment, and the consumer. This intervention forces the implementation of revolutionary designs and technology while insisting on concurrent reductions in consumer maintenance problems and costs. Automobile first costs are showing the effects.

On-vehicle computing instrumentation technology now offers new capabilities to fight the battle through prognostic maintenance management (PMM). Prognosis enables the selection of the best time for maintenance while reducing inspection requirements, vehicle breakdowns and secondary failures. A PMM program enables an improved user confidence while maximizing the productivity of scarce maintenance resources.

On-vehicle microdata systems enable two prognostic techniques: (1) the automation of condition trend analysis, and (2) a new capability-geriometric accounting-the cumulative recording of stress energy and cylic stress functions which contribute to wear and fatigue damage.

Some homework is required, however-on-vehicle data acquisition sufficient to identify the service parameters to monitor and the necessary maintenance criteria expressed in terms of these parameters. In a practical sense, a bootstrap program is required in which an initial system design will provide for both an operational PMM program as well as the acquisition of data with which to improve both the hardware and the software of the evolving system. We are now in a position to design such an initial system.

Motor vehicle fault detection and diagnosis, J. J. Innes, SP547, pp. 78-97 (July 1979).

Key words: diagnosis; emissions inspections; fault detection; fuel economy; motor vehicle.

Motor vehicle diagnostic inspection demonstration projects conducted by the National Highway Traffic Safety Administration under Title 1 II of the Motor Vehicle Information and Cost Savings Act indicate that high volume diagnostic inspections can result in greater safety, improve fuel economy, and reduce the number of faulty and unnecessary repairs and the amount of motor vehicle pollutants. The projects conducted periodic safety and emissions inspections for a period of 15 months. They provided direct experience and documentation of the benefits and costs of diagnostic motor vehicle inspection.

Diagnosis of combat vehicle systems using simplified test equipment, T. E. Fitzpatrick, R. E. Hanson, and F. W. Hohn, SP547, pp. 98-110 (July 1979).

Key words: combat vehicles; diagnostic connector assembly; fighting vehicle systems; generic DCA; Hull systems; simplified test equipment for internal combustion engines; turret systems; vehicle maintenance.

In response to the current requirement to improve both the efficiency and the effectiveness of U.S. Army vehicle maintenance, the U.S. Army Tank-Automotive Research and Development Command has developed Simplified Test Equipment for Internal Combustion Engines (STE/ICE). Although the STE/ICE system has been developed for applicability across the entire Army vehicle fleet, this paper describes the STE/ICE application to combat vehicles only. Because of the complexity of combat vehicle systems and attendant problems associated with test accessibility, maintenance training and documentation, combat vehicle maintenance represents the most demanding challenge to the U.S. Army vehicle combat service support mission.

This paper discusses the STE/ICE application to Combat Vehicle Hull systems. A specific vehicle application is described as an example of STE/ICE test capability within the framework of the standard vehicle diagnostic connector interface definition.

A newly developed extension of STE/ICE test capability to Turret Systems is also presented. This extension demonstrates that test of the entire Combat Vehicle with a single test system is possible.

The STE/ICE System, capable of hull system test of the existing combat vehicle fleet, and its demonstrated suitability for turret test extension provides a basis for conclusions relative to test system and vehicle design approaches for enhanced combat vehicle maintenance.

Automated vehicular test equipment, L. T. Carter, SP547, pp. 111-126 (July 1979).

Key words: automated test and diagnostics; automotive test and diagnostics; vehicle test and diagnostics.

Motor vehicles are becoming increasingly more complex as radically new vehicle systems are being incorporated as standard equipment with each new model year. Government regulation of vehicle performance is having a significant impact upon the design and maintenance of these vehicles. Ever-increasing fuel costs are becoming a tremendous incentive to keep vehicles in an optimum state of 
tune to reduce fuel consumption and minimize pollution. These situations have combined to form a formidable challenge to the automotive repair industry. To meet this challenge, the automotive repair industry will have to define a revised approach to vehicle test and diagnostics. Any new approach must be cost effective, minimize dependence on mechanic's skill and experience while increasing the quality of diagnosis and subsequent repair; it must be adaptable to new vehicle systems with minimum test equipment obsolescence; and it must be compatible with Government regulations and provide acceptable service to the customer. One such approach to vehicle test and diagnosis which is described in this paper, involves one piece of self-contained computerized test equipment-Autosense ${ }^{R}-$ which performs both the test and diagnosis.

The acoustic valve leak detector-A new tool for fluid systems maintenance, J. G. Dimmick and J. W. Dickey, SP547, pp. 129-152 (July 1979).

Key words: acoustic emission; failure detection; preventive maintenance.

The operations, limitations and successful applications of a portable, non-intrusive instrument currently in use by the U.S. Navy to detect internal leakage through shipboard steam, water, hydraulic and high-pressure air valves are described. The Acoustic Valve Leak Detector (AVLD), developed by the David W. Taylor Naval Ship R\&D Center, listens for the ultrasonic emissions characteristic of internal valve leakage. The AVLD is being used for troubleshooting, for overhaul planning, and in a sytematic preventive maintenance monitoring program.

Pielstick engine diagnostics, A. Genot, SP547, pp. 153-166 (July 1979).

Key words: crankshaft displacement; medium speed diesel engine; piston ring wear; turbocharging monitoring.

In order to improve engine reliability and reduce maintenance expenses on ships, S.E.M.T. has developed a monitoring and diagnostic system for medium speed diesel engines used in marine propulsion. The system was designed to monitor ship's engines automatically, and without manual intervention, while underway. The aim was both to prevent failures and to perform maintenance only when necessary. The Pielstick Engine Diagnostic system automatically monitors wear of the piston top ring, main bearing alignment and shell wear, pressure charging circuit fouling condition, and exhaust gas temperatures. The use of the system will result in the extension of piston on-line time between inspections, in the elimination of alongside monitoring of the shafting, and in the improvement of the operating environment of the engine. The economical justification will be extended engine life while eliminating unnecessary labor and engine outages.

This paper describes the monitoring arrangement, including data acquisition and processing, with results from both land tests and a seagoing vessel.

Machinery condition analysis for maintenance planning-The aircraft carrier experience, M. D. Dougherty, SP547, pp. 167-175 (July 1979).

Key words: aircraft carrier; condition analysis; machinery; maintenance; monitoring; repairs; vibration.

In 1970, Machinery Condition Analysis (MCA) began to replace the more traditional methods of planning the overhaul of aircraft carrier machinery. These traditional methods included overhauling all machines, opening each machine up and inspecting to see what was wrong, or running until failure. None of these methods, however, was particularly conservative in either money or time, and MCA was intended to take a more objective look at high cost, mission critical machines, and identify which ones were most in need of overhaul.

This paper addresses the evolution of MCA at PERA (CV), the process as it is conducted today, and the varied uses of its results. Particularly addressed are the benefits derived from the program and the possible expansion of the program in the future.

Diesel engine analyzer: Past experience and future plans, $H$. W. Rethmann, SP547, pp. 176-190 (July 1979).

Key words: automatic test system; diesel engine analyzer.

A computer-automated diesel engine analyzer system with four test cells was developed in 1973-74 for use at the Long Beach Naval Shipyard. As originally designed, the system performed fully automatic final testing of nine specific type diesel engines or manual testing of any diesel engines which could be fit into one of the four test cells. The nearly four years of operation has proven many of the original design concepts, as well as revealed some areas where changes were neerled if the full potential of the system was to be realized. Operation of the automated diesel engine analyzer has also stirred the imaginations of both the original designers and the test system operators as to how the existing system might be augmented to perform final test after overhaul on equipments other than diesel engines. This paper gives a brief description of the system as originally constructed and implemented. It points out those facets of original design that have proven to be helpful in updating and modifying the system to perform the task at hand. It also points out areas where major changes will be made both in hardware and software to take advantage of the experience gained over the several years of testing, as well as those required to cope with changing Navy test requirements. The final portion of the paper deals with augmentations that will be made to the system to test shipboard air compressors. The description of a proposed fifth engine test cell for testing large diesel engine subsytems is also included.

Fiber optics for bearing performance monitoring, G. J. Philips, SP547, pp. 191-199 (July 1979).

Statistical techniques for automating the detection of anomalous performance in rotating machinery, K. R. Piety and T. E. Magette, SP547, pp. 203-231 (July 1979).

Key words: automated surveillance; rotating machinery monitoring; statistical detection algorithm; vibrational signatures.

We have assessed the level of technology utilized in automated systems that monitor industrial rotating equipment and the potential of alternative surveillance methods. We conclude that changes in surveillance methodology would upgrade ongoing programs and yet still be practical for implementation. We formulated an improved anomaly recognition methodology and implemented these methods on a minicomputer system. The effectiveness of our monitoring system was evaluated in laboratory tests on a small rotor assembly, using vibrational signals from both displacement probes and accelerometers. Time and frequency domain descriptors are selected to compose an overall signature that characterizes the monitored equipment. Limits for normal operation of the rotor assembly are established automatically during an initial learning period. Thereafter, anomaly detection is accomplished by applying an approximate statistical test to each signature descriptor. As 
demonstrated over months of testing, this monitoring system is capable of detecting anomalous conditions while exhibiting a false alarm rate below $0.5 \%$.

Vibration analysis method for detection of abnormal movement of material in a rotary dissolver, C. M. Smith, D. N. Fry, and W. T. King, SP547, pp. 232-249 (July 1979).

Key words: monitor system; rotary dissolver; signature analysis; vibration analysis.

Vibration signals generated by the movement of simulated nuclear fuel material through a three-stage, continuous, rotary dissolver were frequency analyzed to determine whether these signals contained characteristic signal patterns that would identify each of five phases of operation in the dissolver and, thus, would indicate the proper movement of material through the dissolver. This characterization of the signals is the first step in the development of a system for monitoring the flow of material through a dissolver to be developed for reprocessing spent nuclear fuel. Vibration signals from accelerometers mounted on the dissolver roller supports were anlayzed in a bandwidth from 0 to $10 \mathrm{kHz}$. The analysis established that (1) all five phases of dissolver operation can be characterized by vibration signatures; (2) four of the five phases of operation can be readily and directly identified by a characteristic vibration signature during continuous, prototypic operation; (3) the transfer of material from the inlet to the dissolution stage can be indirectly monitored by one of the other four vibration signatures (the mixing signature) during the prototypic operation; (4) a simulated blockage between the dissolution and exit stages can be detected by changes in one or more characteristic vibration signatures; and (5) a simulated blockage of the exit chute can not be detected.

Monitoring inlet steam valves of PWR $900 \mathrm{MW}$ turbogenerators, A. Jaudet and J. C. Sol, SP547, pp. 250-279 (July 1979).

Key words: detection procedures; mechanical failures; steam-valves; turbine operational safety; turbogenerators.

A study of the reliability of overspeed protection systems for turbines associated with nuclear rcactors, confirms the essential role of steam valves in the general reliability of these systems, and consequently in the operational safety of the units.

Over and above the obvious reasons concerning operational safety, an improvement in investigation and diagnostic methods clearly provides beneficial spin-off in terms of equipment availability.

Assessment of turbine operational safety, and more particularly evaluation of the risks generated by non-closure of steam-valves, has led to a concentration of interest about three functional characteristics: steam movement quality; seal-tightness; "general condition."

Each of these characteristics can be subject to specific mechanical failures for which detection procedures exist, and which are described in this paper.

In application of these principles, examples of the technological solutions (including automatic surveillance system) adopted for monitoring the steam-valves of the units of the $900 \mathrm{MW}$ standard are described, together with the first operating results for these methods and this equipment.

An approach to monitoring existing utility turbogenerators, S. Doughty, SP547, pp. 280-285 (July 1979).

Key words: rotating equipment; vibration monitoring; vibration signal processing.
A three stage program of minicomputer based, continuous monitoring development and application is currently in progress on several large turbogenerators. The first stage is a period of planning the primary development effort in terms of review of existing vibration sensors, selection of additional sensors, and identification of operating parameters which influence vibration. The second stage involves gathering data in many different operating states in order to develop a vibration comparison algorithm which removes the effects of the operating state. In the final stage, the machine is monitored quasi-continuously with the intent of detecting progression of failure modes as changes in the vibration response of the machine.

Enhancing machinery protection through automated diagnostics, J. L. Frarey, SP547, pp. 286-295 (July 1979).

Key words: automatic diagnostics; digitized data; spectrum analyzers; steady state mode; tolerance vibration levels.

Shaker Research Corporation under contract to Electric Power Research Institute, has installed an automated vibration monitor system in Northeast Utilities Millstone II Nuclear Power Plant. The objective of the program is to demonstrate that the system can provide insight into the condition of critical pumps and thus guide the planned maintenance during scheduled shutdowns. To provide this insight, the system must be capable of processing a large amount of vibration data and based on the results, draw conclusions about the condition of the unit. Both aspects of the system will be discussed.

Report on industry/joint services project task group 1-d, J. P. Wright, SP547, pp. 299-302 (July 1979).

Key words: military systems; non-electronic equipment; testing.

Recognition by the armed services of a need for definition in Automatic Test Arena led to the establishment of first a Navy/Indusiry project and later to the establishment of a Tri Service/Industry project. The Tri Service project, started in the last quarter of 1976, included numerous committee meetings, a general meeting in January of 1977 and a major working symposium in April of 1977. The symposium attendance was 860 with an approximate $60 / 40$ ratio of industry/DOD attendance. The project included a specific task group to deal with the application of Automatic Test Techniques and Equipments to the testing of non-electronic equipments.

The non-electronic testing group, chaired by Donald $\mathbf{A}$. Prue of Hamilton Standard, presented a series of findings regarding the application of automatic testing to non-electronic equipments. These findings include the recommendation for: Equipment failure mode analysis; Equipment designed for testability; Standardization of test interfaces.

The implications of these recommendations in terms of acquisition costs were recognized by the group and the need for an effective means of demonstrating cost effectivity was established.

A polymer sensor for monitoring ball-bearing condition, $\mathbf{S}$. Edelman, J. M. Kenney, J. F. Mayo-Wells, and S. C. Roth, SP547, pp. 303-314 (July 1979).

Key words: bearing noise; failure prevention; machinery noise; noise signature; non-destructive evaluation; piezoelectric polymer; spectrum analysis; strain gage.

Noise spectra have been used frequently in the past to detect faulty bearings and to provide some indication of how the faults worsened with time. Usually accelerometers or microphones were used to detect the noise spectrum. 
This paper describes how the use of piczoclectric polymer scnsors couple with spectrum analyzcrs now available makc this tcchnique morc uscful. Improvement in accuracy and rcproducibility, lower cost, greater conveniencc, and specd arc potential benefits.

An instrumentation technique to evaluate spectra for engine diagnostics, T. Carolan, SP547, pp. 315-322 (July 1979).

Key words: gatcd frequency analysis; Gaussian window; impulsive complex signals; linear averaging; rcciprocating; records after trigger; tape loop; time signal; time window.

This paper describes a method of using a digital frequency analyzer as a "sliding time gate" when analyzing complex time signatures (e.g., as those produced by reciprocating machines). To isolate individual events such as valves opening and closing, firing and exhaust pulses, rather than take a composite frequency analysis of the complete engine signature produced during one rotation, implies a triggered, movable, variable width window which can be used to view each occurrence. Timing can be with reference to any arbitrary occurrence during a cycle, but a known reference such as Top Dead Center (TDC) is normally used. An integral part of any flexible Digital Narrow Band Analyzer should be the settable After Trigger Recording facility allowing the memory contents to be locked at any time relative to an incoming trigger pulse. If the incremental settings available on the After Trigger Recording are sufficiently small, this will enable the memory length to be used as a window to look at any part of the incoming time signal. A triggerable Gating System with variable delay and window length will also be described. The results gathered from using the technique on a marine diesel engine will be presented.

The direct reading ferrograph, D. P. Anderson, SP547, pp. 323-329 (July 1979).

Key words: ferrography; machine condition monitoring; oil analysis; oil sampling; wear; wear particles.

The principle of operation, design, calibration, and a ficld application are discussed for the direct reading ferrograph, a system for rapid on-site monitoring of wear in oillubricated machinery. The principle of operation is the magnetic precipitation of wear particles from an oil sample within a glass tube. Light attenuation measurements at two cross sections of the glass tube provide a measure of large and small wear particles present in the oil sample. Oil samples resulting in high severity of wear indices may be further scrutinized by analytical ferrography. Calibration of the direct reading ferrograph was performed with known weight concentration samples of ferrous wear particles generated in a gear box. Comparison of direct reading ferrograph data to spectrometric data for the same oil samples is made. A typical field application and results are discussed.

An advanced real-time oill debris monitor, T. E. Tauber, SP547, pp. 330-344 (July 1979).

Key words: aircraft component failure; condition monitoring; debris monitoring; diagnostic techniques; failure detection; lubrication system monitoring.

Diagnostic methods based on oil sampling tend to disregard the fact that particles larger than 200 microns are reliable indicators of incipient failure. This is confirmed by the success of diagnostic mcthods which utilize visual inspection of lube system filters and of magnetic chip collectors. Apart from the morphology of such particles, these methods rely on correlating the particle size and quantity with data obtained from previous experience.
TEDECO has developed an in-line centrifugal oil monitor which separates debris particles above 100 micron from the oil stream and deposits them on a magnetic sensor. Each particle is counted individually in accordance with its mass, magnetic susceptibility and shape. Digital circuitry registers and stores each event and permits calculation of debris production rates. The debris is retained and easily accessiblc for visual inspection.

A number of such systems are currently undergoing field evaluation on an Air Force TF-39 engine, on a Navy LM2500 engine and on a Westland Lynx helicopter transmission.

A similar system tested during the Army AIDAPS program on a transmission implanted with defective parts confirmed the soundness of this diagnostic approach.

A practical approach to aircraft system component malfunction diagnosis, F. E. Bishop, SP547, pp. 345-357 (July 1979).

Key words: accumulator; analog; centralized; check-out system; dessicant; discrete; displacement; fiber optics; filters; flight critical; flow; fluid; go-no-go; ground readout; hydraulic; IMACS; instantaneous diagnosis and analysis; level; maintenance oriented; malfunction detection; monitoring; onboard; patented; pressure; pumps; reservoirs; sensors; tailorable; temperature.

Aircraft fluid system component failures and the associated costs of unscheduled maintenance and loss of operational readiness can be reduced significantly with proper system monitoring. The author describes a multifunction monitoring system built into the aircraft that will provide a signal at one central location when the maximum allowable limit has been reached for the system and/or component function being monitored. The appropriate maintenance action can then be implemented or scheduled for a convenient time without interrupting the operational service of the aircraft. This concept would give a go-nogo signal and not require interpretation or special training. Another fcature is that the monitoring is performed by ground personnel at pre-flight or post-flight chcckout. The benefits of a system incorporating instant diagnosis and analysis of fluid system component malfunctions are increased system operating utility, reliability, and safety along with reduced logistic support and reduced maintenance and operating costs.

SP548. Summer attic and whole-house ventilation. Proceedings of a Workshop held at the National Bureau of Standards, Gaithersburg, MD, July 13, 1978, M. H. Reppert, Ed., Nat. Bur. Stand. (U.S.), Spec. Publ. 548, 153 pages (July 1979) SN003-003-02089-3.

Key words: attic ventilation; energy conservation; solar absorptance of roofing materials; whole-house ventilation.

These are the proceedings of the Summer Attic and WholeHouse Ventilation Workshop sponsored by the National Bureau of Standards in collaboration with the Department of Energy and the attic ventilation industry. The purpose of the Workshop was to provide a forum for technical discussion to assess summer energy savings that might be achieved from the use of static and powered attic ventilation and wholehouse ventilation equipment. Papers on experimental and mathematical model studies relating to attic and whole-house ventilation were presented. In addition, a paper on roof solar absorptance and its effect on the cooling requirement of a residence was presented.

After each paper was presented, participants of the Workshop were given an opportunity to question the speaker concerning his paper. The resulting questions and responses are 
included at the end of each of the papers. These proceedings include the following papers (indented):

Solar reflectivity of common roofing materials and its influence on the roof heat gain of typical southwestern residences, J. A. Reagan and D. M. Acklam, SP548, pp. 1-13 (July 1979).

Measurement of attic temperatures in Florida, T. 1. Wetherington, Jr., SP548, pp. 15-24 (July 1979).

Forced ventilation for cooling attics in summer, G. S. Dutt and D. T. Harrje, SP548, pp. 25-38 (July 1979).

Effect of powered attic ventilation on ceiling heat transfer and cooling load in two townhouses, R. A. Grot and C. I. Siu, SP548, pp. 39-56 (July 1979).

Attic ventilation research conducted by Arkansas Power and Light Company, F. B. Clark, SP548, pp. 57-72 (July 1979).

Ventilating residences and their attics for energy conservation-An experimental study, D. M. Burch and S. J. Treado, SP548, pp. 73-104 (July 1979).

Analysis of attic ventilation test, D. Brewster and T. Arkfeld, SP548, pp. 105-117 (July 1979).

A model for predicting the thermal performance of ventilated attic-ceiling-roof combinations, B. A. Peavy, SP548, pp. 119-149 (July 1979).

SP549. Proceedings of the National Conference on Regulatory Aspects of Building Rehabilitation. Proceedings of a Conference held at the National Bureau of Standards, Gaithersburg, MD, Oct. 30, 1978, S. A. Berry, Ed., Nat. Bur. Stand. (U.S.), Spec. Publ. 549, 220 pages (Aug. 1979) SN003-00302107-5.

Key words: building; code administration; codes; evaluation; existing buildings; performance standard.

This document contains the edited Proceedings of the $\mathrm{Na}$ tional Conference on Regulatory Aspects of Building Rehabilitation held Oct. 30, 1978, at the National Bureau of Standards.

it contains a total of 18 presented papers, all of which address the subject of rehabilitation-currently a critical issue in the Nation's effort to revitalize its cities and house its citizens.

Public sector, as well as private sector programs and experiences toward achieving this goal are covered in one general and three technical sessions. These proceedings include the following papers (indented):

Public programs for housing rehabilitation, A. Rechler, SP549, pp. 19-21 (Aug. 1979).

HUD rehabilitation guideiines, R. J. Kapsch, SP549, pp. 2327 (Aug. 1979).

Appiication of Article 22 of the Massachusetts State Building Code, P. Folkins, SP549, pp. 33-38 (Aug. 1979).

Impact of new construction orient ed codes on building rehabilitation, R. P. Kuchnicki, SP549, pp. 39-42 (Aug. 1979).

Code requirements for existing buildings: $A$ new approach, K. M. Schoonover, SP549, pp. 43-50 (Aug. 1979).

A "professional practice" approach to the rehabilitation process, W. E. Lewis, SP549, pp. 71-84 (Aug. 1979).

A fire evaiuation system for heaith care facilities, H. E. Nelson, SP549, pp. 85-102 (Aug. 1979).
Rehabllitation standards: What are they? Who is to develop, maintain, and enforce them?, B. A. Cummings, SP549, pp. 103-106 (Aug. 1979).

Rehabiiitatlon, performance and the 'real world' of the code official, J. Stein, SP549, pp. I19-123 (Aug. 1979).

An architect's view of rehabilitation regulation, F. A. Stahl, SP549, pp. 125-129 (Aug. 1979).

Administration of a rehabllitation code in a major city, $\mathrm{C}$. C. Lederer, SP549, pp. 131-134 (Aug. 1979).

SP550. A bibilography on the corrosion and protection of steel in concrete, E. Escalante and S. Ito, Nat. Bur. Stand. (U.S.), Spec. Publ. 550, 24 pages (Aug. 1979) SN003-003-02106-7.

Key words: bridge deck; concrete; corrosion; corrosion of steel; rebar corrosion; reinforced concrete.

This is a bibliographic list of references of published papers, reports, and talks about the corrosion of steel in concrete and related subjects. The references are presented in two forms: 1) a subject index divided into six major subheadings including reviews, factors affects corrosion, measurement techniques, protection techniques, concrete design, and related fields, and 2 ) an author index in alphabetical form. A total of 394 references are listed covering the period from 1964 to November 1978.

SP551. Proceedlngs of the 1978 Electromagnetic Interference Workshop. Proceedings of a Workshop held at the National Bureau of Standards, Gaithersburg, MD, Nov. 2-3, 1978, M. G. Arthur, Ed., Nat. Bur. Stand. (U.S.), Spec. Publ. 551, 57 pages (July 1979) SNO03-003-02099-1.

Key words: electromagnetic bioeffects; electromagnetic compatibility; electromagnetic immunity; electromagnetic interference; electromagnetic radiation; electromagnetic susceptibility; electronic smog; home entertainment electronics; industrial electronics; medical electronics; microwave electronics; nonionizing radiation; radiation hazards; radio regulations; radio standards; $\mathrm{RFi}$; spectrum management; standardization organizations; telecommunications; TVi; vehicular electronics.

This report is a summary of the overview talks and session discussions at the 1978 Electromagnetic Interference Workshop, held at the National Bureau of Standards, Gaithersburg, Maryland, on November 2 and 3, 1978. These discussions addressed the following questions: What are the significant Electromagnetic Interference (EMI) problems? How serious are they? Which should be tackled first? What solutions are practical? Who is responsible for solutions? What new standards or changes in present voluntary standards are needed? What is needed for progress? Impacted areas featured at the workshop included communications, transportation, consumer products, industrial, and medical. Workshop speakers and attendees represented a broad segment of decision-makers in both industry and government. These proceedings include the following papers (indented):

The extent of today's EMI problems and prioritizing EMI problems, C. M. Kendall, SP55I, pp. 3-4 (July 1979).

Biologlcai electro-magnetic interference (BEMI), D. R. Justesen, SPS5I, pp. 5-6 (July 1979).

FCC activities regulating electromagnetic interference, $A$. W. Paul and J. Krauss, SP551, pp. 7-9 (July 1979).

EMI/EMC iegistation In the 95th and 96th Congresses, $\mathrm{C}$. L. Jackson, SP551, pp. 10-11 (July 1979). 
Voluntary standardization for electromagnetic compatibility, R. M. Showers, SP55I, pp. 12-19 (July 1979).

What is needed for progress in EMC?, H. M. Schlicke, SP551, pp. 20-22 (July 1979).

Communications working group summary, J. P. Murray, SP551, pp. 23-26 (July 1979).

Transportation working group summary, R. J. Wasko, SP551, pp. 27-28 (July 1979).

Consumer products working group summary, W. T. Collins, SP551, pp. 29-31 (July 1979).

Industrial working group summary, G. H. Hagn, SP551, pp. 32-37 (July 1979).

Medical working group summary, J. C. Toler, SP5.51, pp. 38-41 (July 1979).

Plemary session IV summary "The Last, Last Word", M. G. Arthur, SP551, pp. 42-44 (July 1979).

SP552. Research and innovation ing the building regulatory process. Proceedings of the $3 \mathrm{~d}$ Annual NBS/NCSBCS Joint Conference held in Annapolis, MD, Sept. 12, 1978, in conjunction with the Eleventh Annual Meeting of the National Conference of States on Building Codes and Standards, Inc. (NCSBCS), P. W. Cooke, Ed., Nat. Bur. Stand. (U.S.), Spec. Publ. 552, 358 pages (July 1979) SN003-003-02091-5.

Key words: administrative procedures; building codes; building regulations; buildings; construction; economic impacts; environmental considerations; innovative practices; regulatory research; standards development.

The third NBS/NCSBCS Joint Conference on Research and Innovation in the Building Regulatory Process was held in Annapolis, MD, on September 12, 1978. The proceedings of the Joint Conference include the opening remarks, the Keynote Address and the 24 papers presented at the technical sessions dealing with various aspects of building regulatory research and innovative administrative application of building codes and standards. The eight technical sessions were organized around the following themes: Regulatory Aspects of Fire Safety; Standards Development Activities and the Building Regulatory Process; Accommodating Provisions for the Elderly and Handicapped in Building Regulations; Implementation of Energy Conservation Building Regulations at the State Level; Application of Computers and Information Systems for Building Regulation and Construction; Energy Conservation, Solar Energy and the Built Environment; issues Concerning the Intent, Formulation and Economic Impact of Regulations; Metrication, Industrialized Buildings and Complex Structures.

In addition, three other research papers covering Lighting, Tax Shelters, Resource Zoning, and Land Use Planning are also included. These proceedings include the following papers (indented)

A defensible technique for determining code equivalency in buildings, G. N. Berlin, SP552, pp. 13-27 (July 1979).

Key words: building fires; equivalency; evaluation; fire safety; models; research; standards; systematic procedure

New materials, construction methods, and contents are rapidly changing the nature and magnitude of the fire problem in the United States. These changes often provide a situation that is not covered explicitly in existing codes or that requires amendments to allow their installation. In some cases, these changes in construction or materials provide a safer environment. It is desirable to take advantage of these changes and to encourage similar advances within the framework of the codes. An important step in that direction is the development of rigorous procedures for objectively evaluating the equivalency of such changes to the accepted standards.

A systematic procedure for measuring the hazards of building fires has been developed as part of a project funded by the Department of Housing and Urban Development. This procedure, called the "Building Firesafety Model" incorporates data derived from actual fire tests to describe the rate of fire growth, the likelihood of entrapment, and estimates of structural damage.

It is expected that this tool will assist government officials, architects and engineers in evaluating the design (or rehabilitation) of buildings with regard to the level of fire safety. Such a tool could potentially be used to evaluate the comparative levels of fire safety implied by compliance with codes and to identify voids in fire test data. In addition, the model can be used for evaluating the allocation of fire service resources and pre-fire tactical planning.

The liability of municipalities and municipal officials for negligeance in the regulation of buildings, V. Brannigan, SP552, pp. 29-37 (July 1979).

Key words: duty; liability; municipal corporations; negligence; sovereign immunity; tort.

Building and fire codes and inspections have spawned lawsuits charging both cities and individuals with negligence. This paper explores the development of municipal liability, the elements of a negligence action, and specific defenses and immunities which are available to a city and individual. Special attention will be given to high risk activities of municipalities.

Buildings engineer emergency response team, S. S. Koren, SP552, pp. 39-44 (July 1979).

Key words: crisis; flood recovery effort; missing link; rebuilding.

Code enforcement embraces the cycle of ConstructionCrisis-Reconstruction

Baltimore County has added a code enforcement team to its emergency forces. This allows both staff assistance to other county emergency forces as well as immediate participation in the reconstruction phase.

The development and implementation of building standards in France, I. Martinez, SP552, pp. 45-56 (July 1979).

Key words: building standards; foreign building standards; French building standards; French standards system; marking and certification: types of French standards.

The systems available today in the U.S. for developing standards are being subjected to much scrutiny and criticism. Many of the organizations involved in the standardization process are striving for better ways to produce standards. Attempts are being made to make the process more dynamic, more representative for general interest groups and better able to handle revisions and updatings.

One way to obtain a wide perspective of the options available is to examine standards development practices in other countries. It is difficult to find a foreign country that has a well-developed standards promulgation system and enough points in common with the U.S.-in the economic, political, geographic, and technological areas-to be used as a reference.

The French standards system, discussed here, does not coincide exceptionally well with the U.S. system. However, a study of the procedures used in France might give some 
insight and suggest diffcrent ways of approaching the problem. Hopefully, interesting elcments and specific rclevant procedures which might be adaptcd to U.S. practices will emerge.

A case history of the integrity of the National Electrical Code, D. J. MacFadyen, SP552, pp. 57-78 (July 1979).

Key words: appeals process; consensus standards; electrical distribution systems; flat conductor cable; National Electrical Code; technological innovation.

A new system for surface-mounted branch-circuit building wiring is being commercialized that holds substantial promise for flexibility and cost-effectiveness. This system is based on the flat conductor cable technology developed by the National Aeronautics and Space Administration for aerospace use. NASA sponsored a project to commercialize flat cable-based building wiring systems, which included a NASA contractor and a consortium of twelve major American corporations.

One of the most critical aspects of making advanced wiring systems available to the public is the development of code provisions to allow their use. The process of establishing a new National Electrical Code Article 328 permitting flat conductor cable wiring systems involved use of every procedural step available in the Code-making regulations of the National Fire Protection Association. Unfounded technical objections and procedural irregularities on the part of opponents to the new technology necessitated the use of every protest and appeals process available under those regulations. It was only at the highest level of the Code-making organization-the NFPA Board of Directors - that the final favorable action was taken on the basis of proper technical justification.

The adoption of Article 328 as an amendment to the 1978 National Electrical Code was a victory, not only for the public and the proponents of the Code change, but also for the NFPA and the whole concensus approach to Code making. The checks, balances, and recourses in the system were shown to be adequate to assure that the Code change was ultimately resolved on technical merit.

Federal Government activities relative to the development of voluntary consensus standards, D. R. Mackay, SP552, pp. 7993 (July 1979).

Key words: consensus standards; Federal policies; Federal voluntary standards policy; voluntary standards; voluntary standards system.

Federal government agencies have been involved in voluntary standards activities for many years and have made significant contributions to the development of consensus standards covering many product areas. This involvement of Federal agencies has strengthened the voluntary standards system and has tended to reduce the need for government regulations.

The policy established by one Federal regulatory agency-the Consumer Product Safety Commission-regarding the involvement of its staff in the development of voluntary standards is discussed in this paper along with the criteria that have been imposed on the staff in an attempt to reduce the appearance of any conflict of interest between these activities and the agency's regulatory responsibilities.

The philosophy and requirements of the proposed circular published by the Office of Management and Budget is also described in this paper. The restrictions on Federal agency involvement in voluntary standards activities and the objectives of this proposed uniform Federal agency policy are discussed.
The paper also presents a summary of the voluntary standards activities of several Federal regulatory agencies and compares the similarities as wcll as the differences of some Fcderal agency policies and programs.

The formulation of sensible regulations for accessible rehabilitation housing, A. E. Osterberg, SP552, pp. 95-100 (July 1979).

Key words: accessible; disabled; housing; regulations.

In order to achieve better housing alternatives for America's elderly and disabled populations, sensible regulations covering accessibility are necessary. A more accessible housing market could help reverse the present rise in thc number of dependent care settings. The regulation of new construction in terms of accessibility will soon be easier with the publication of the American National Standards Institute, Inc. (ANS1) standard on accessibility for the physically disabled. While the document is expected to be comprehensive in terms of new construction, the same standards may not be appropriate in regards to the adaptation of existing housing. Additional research on adaptation is neccssary in order to formulate guidelines for making existing housing units accessible for wheelchair bound individuals.

The new research should include a study of a variety of existing housing units which have been adapted and modified by disabled users to become more accessible. Methods for programming designs of housing projects with future adaptations in mind need to be explored. Until these new research findings become available, regulatory officials will have little to guide them in regulating housing adaptations.

Designing for access to, movement within, and egress from building and sites: Effective research for more reasonable regulation, F. I. Stahl, SP552, pp. 101-113 (July 1979).

Key words: architectural barriers; building design; building site planning; environmental psychology; evaluation; fire escape; human research; measurement; pedestrian movement; regulation; safety; standards.

This paper discusses needs for a more complete and effective technical basis for design standards impacting occupants' access to, movement within, and egress from buildings and building sites. It is suggested that a major cause of injury and death from fire, and of inconvenience and psychological stigmatization to physically handicapped persons, results (even in code-complying buildings and sites) from adherence to design regulations narrowly founded upon physical and engineering principles alone. This paper recommends that psychological aspects of dangerous and stressful situations guide the development of standards for emergency egress facility design, and that such therapeutic objectives as "normalization" guide development of barrier-free design regulations. Finally, this paper outlines particular programmatic themes and research tasks, and discusses the role of the National Bureau of Standards in improving the technical basis for egress and accessibility design regulations.

Communication techniques in building code implementation, T. J. Rosenberg, SP552, Pp. I15-120 (July 1979)

Key words: accessibility standards; building codes; code administration; communication; physically handicapped; public awareness; public relations.

Communication is essential in any process of change. Occasionally, when a building code is altered, changes are made which substantially influence users of the built en- 
vironment. This is certainly true of building code specifications regarding accessibility for physically handicapped persons.

North Carolina pioneered the development of code requirements for accessibility. Since implementation of the fundamental provisions in 1973, the State has embarked on a vigorous educational campaign to increase understanding of environmental barriers, needs of disabled people, laws and codes. This project has included the production of illustrated handbooks, brochures, manual and automatic slide presentations, radio and television announcements and newspaper articles.

This report explains the selection and development of appropriate media for presentation to audiences including the building community, owners, consumers and others. The techniques are pertinent to other areas of concern, such as energy efficiency in buildings, which affect a wide spectrum of interests.

A summary of Kentucky's experience in implementing a statewide energy code, J. R. Groves, Jr., SP552, pp. 121-130 (July 1979).

Key words: design professionals; energy audits; energy codes; Kentucky Fire Marshal's office; lighting and thermal efficiency standards; local governments; new construction plans review; training and education.

In the near future, every state will have to adopt some form of energy code. Compatibility with existing codes and code enforcement procedures will be a major consideration in the adoption and implementation process. Public Law 94-163 made funds available to states for the adoption of a five part energy conservation program. Of primary significance where codes and standards are concerned are the lighting and thermal provisions of that plan. To implement those provisions has called for the adoption of an energy code.

For many states, the energy code represents one of if not the most all inclusive code application and enforcement effort in the area of code enforcement. Especially in those primarily rural states where building code applications has been limited to the more urban areas, the adoption of a uniform energy code which applies to all new buildings including single family residences has posed special problems.

Energy conservation in building codes and standards, R. W. Lisle, SP552, pp. 131-140 (July 1979).

Key words: building official; energy code; energy efficient; enforcement; implementation and effective $U$ value; on-site construction.

Many states have recently adopted energy model codes and standards or are considering the adoption of such regulations.

This paper explains what has happened in New Mexico since the adoption of an energy model code two years ago. (September 10, 1976.) The implementation of the code in the real world of on-site construction projects has revealed several special problems with enforcement and/or interpretation of the code. The effective $U$ values being developed and implemented in New Mexico are adding a new perspective to the traditional understanding of the thermal conductance characteristics of building envelopes. lt may be more cost-effective to paint a south facing wall a dark color than to add insulation.

Implementation of energy conservation standards, $J$. T. Quinn, SP552, pp. 141-151 (July 1979).
Key words: education; energy utilization codes; illustrated handbook; legislation; thermal envelope criteria; thermal performance criteria.

Energy conservation in new buildings is one area where a code will affect virtually all aspects of the building construction. It is an area that can create confusion, misunderstanding and even resentment over a short time span. This can be further heightened when the code is implemented in areas where no code enforcement previously existed.

Chapter XXXII "Efficient Energy Utilization in New Buildings" of the North Carolina State Building Code was by necessity implemented over a short time frame, and enforced without exception across the state. The Engineering and Building Codes Division of the North Carolina Department of Insurance used its previous experience in new code implementation, the research presented by NCSBCS, ERDA, and DOE, and some innovative ideas of its own to bring this code into reality across the state, and it is hoped this experience may be of some benefit to other states as energy conservation codes are implemented by those states.

The uses of an integrated data base in municipal computer assisted regulatory systems, N. S. Remmer, SP552, pp. 153165 (July 1979).

Key words: computer facilities; integrated data base; municipal governments; regulatory.

Computer based systems are becoming more prevalent as the basic means of administrative and financial control of municipal governments. With the availability of computer hardware or the access to computational facilities well established in most cases, the consideration of the additional uses for the municipality of such facilities becomes important.

Two of the many areas receiving considerable attention at this time relate to building regulatory functions and housing inspection functions. Several cities have already instituted departmental programming for use in normal administrative and control functions. The system in Chicago for the building department has already been reported at the 1976 NBS Conference. The Boston Housing Inspection Department has incorporated the use of the computer extensively for their daily operational functions. Many other cities are in the process or have recently installed systems to computerize one or more aspects of their housing or building regulatory functions.

The City of Worcester, population of about 180,000, has been studying for almost two years the potential for a system that would not only provide computerization of normal building and housing inspection administrative and control function, but could provide a base for many interrelated functions, and process specialized data for many coordinated municipal programs.

The size of the city precludes the availability of separate computer facilities for each department. Therefore, the study developed requirements based on a central computer and interdepartmental accessibility of data and results. By looking at a coordinated system, it became apparent that many benefits could be derived for a choice of proper initial hardware and careful software considerations. Studies by departmental personnel and interns from Clark University indicated the following as some examples of potential use: 1) Correlation between housing inspection abatement notices and building or demolition permit issuances. 2) Evaluation of potential arson sites based on coordination of housing inspections and building inspection records and outstanding tax and water bills. 3) Evaluation of overall 
ncighborhood physical characteristics to determine blight arcas, potcntial blight areas and establish the boundaries of such arcas. 4) Coordination of Fire Dept. building data and building and housing data.

In addition, there is the potential for coordination of municipal programs involving many other functions and intcgrated programs involving the building inventory or its infrastructure.

The results of the studies so far indicate that while the normal control and administration functions of computer programs, such as used in Chicago and Boston, have great potential, the readily available spinoffs from the data base and information have even more important potential for municipal planning and control of all city programs relating to buildings and their infrastructure.

Exploiting the computer to control the application of design criteria to construction, R. E. Larson, SP552, pp. 167-183 (July 1979).

Key words: design criteria; guide specifications; habitability criteria; Computer-Aided Engineering and Architectural Design System (CAEADS).

The U.S. Army Corps of Engineers is sponsoring the development of a Computer-Aided Engineering and Architectural Design System (CAEADS) to aid the programmer, planner, designer, and constructor of facilities. One of the basic objectives of CAEADS is to provide for systematic application of design and habitability criteria that are the counterpart of building codes and standards adopted by federal, state, and municipal agencies. This paper will describe the overall conceptual design of CAEADS and then go into some detail on the specific system features that deal with criteria.

Construction labor demand system: An overview, W. F. Hahn, SP552, pp. 185-196 (July 1979).

Key words: building trades; construction industry; forecasting; labor information systems; manpower projections; modelling.

Currently under development by the Department of Labor is an extensive modelling effort designed to provide accurate forecasts at a local level of future construction levels and on-site labor requirements. The Construction Labor Demand System (CLDS) is a computerized management information system that provides continuously updated forecasts for local regions, for specific types of construction, and for precise construction trades.

Actual construction project information is the nucleus of the CLDS system. Information on hundreds of thousands of current and planned projects are included in CLDS. Each project is time-phased to completion and estimates generated of the associated craft requirements.

Forecasts of construction initiations are accomplished through econometric modelling. Initiation forecasts are transformed into pseudo-projects within CLDS and pseudoprojects are combined with hard project data for the generation of forecasts of construction activity.

A conversion subsystem translates construction activity into demand for labor. Over 200 conversion profiles translate activity levels into time-phased flows of requirements by occupation.

Proposed criteria for establishing energy consumption standards for existing buildings, R. R. Somers $11, T$. C. Scott, and L. S. Fletcher, SP552, pp. 197-209 (July 1979).

Key words: conservation; energy cost; existing buildings; regulation; retrofit; standards.
Rising energy costs recently have compelled many municipalities and industries to undertake energy conservation programs in the hopes of reducing energy expenditures. The current lack of government and industrial standards specifying acceptable levels of energy use by existing structures, however, makes it difficult for these organizations to determine if their facilities are wasting fuel. This paper proposes that standards be established for the overall energy efficiency of existing buildings in terms of quantities which can be computed readily from available data, without need for elaborate computer programs and/or engineering analyses. The paper discusses the type of standards needed to meet these objectives, techniques for formulating the standards, and facility classifications (based upon building functions) for which guidelines should be developed. By being able to pinpoint buildings using excessive energy without costly or time-consuming analyses, government and business groups can direct conservation efforts and funding to the most inefficient facilities, where conservation programs will be of the greatest value.

Proposed solar energy leglslation likely to affect the buildlng regulatory process, R. J. Smith, SP552, pp. 211-216 (July 1979).

Key words: building regulation; energy conservation; legislation; solar energy.

A number of researchers have identified and discussed numerous legal barriers to the effective utilization of various types of solar energy. Much of the literature also makes specific recommendations for legislation directed at removal of these barriers to solar utilization. This paper discusses the context in which the legislation has been drafted, the key features of the legislation, and their potential effect on the building regulatory process. The objective is to give state and local building regulatory officials and code administrators an overview of what sorts of legislation may be introduced at the state and local level so that they may be better prepared to deal with both the legislative proposals, and their implementation.

Critical performance standards for passive solar buildings, J. K. Holton, SP552, pp. 217-224 (July 1979).

Key words: passive solar systems; performance standards; system classification.

An outline of a limited number of performance standards and evaluation criteria for passive solar buildings is presented. Three levels of criteria are described which are intended to categorize these into a few most needed criteria concerning basic thermal performance, health and safety, and two levels of additional criteria that are thought desirable to assess long term usefulness of passive installations. Status of development of the criteria is also discussed.

A case for more rational and explicit building regulations, H. M. Markman, SP552, pp. 225-247 (July 1979).

Key words: building codes; code enforcement; fire prevention codes; fire safety; master planning; regulation; standards.

Building regulations are unique in that they are as much a statement of social attitudes and policies as they arc of engineering and technology. To be responsive to one concern is not enough. The consensus of the literature on the Beverly Hills Supper Club Fire in Southgate, Kentucky, was that the codes as written are adequate and that this incident should have not occurred. The fault was said to lie in the improper enforcement of the applicable codes. 
While this statement may be true, the broader social and policy issucs wcre nowhere addressed.

Safety is a relative rather than absolute concept. No safety is obviously not acceptable; total safety is not affordable, if possible at all. To date, the building regulatory community has fixed the level of safety with minimal input or interest from the public at large. But inflation, the increasing cost of regulation, and the resistance to excessive government spending will lead to greater public interest in the regulatory process. Regulations will be scrutinized as to their necessity, effectiveness, and utility as a means of efficiently allocating protection costs between the public and private sectors.

The challenge for the building regulatory community is to recognize and meet this growing public concern.

Formulation and expression analysis of standards and regulations, J. W. Melin and R. L. Tavis, SP552, pp. 249-266 (July 1979).

Key words: decision tables; formulation analysis; information networks; regulations; standards.

A systematic technology for the translation of a standard, building code, regulation or specification into a graphical network and decision tables is presented. This technology leads to a clear concise expression which aids in the understanding of the document. It may also be used to improve the clarity, consistency, completeness of the provisions. A brief example is used to illustrate the process of using the technology.

Life-cycle benefit-cost analysis of housing safety regulations, J. L. Walters, SP552, pp. 267-282 (July 1979).

Key words: building codes; building regulations; costbenefit analysis; life-cycle analysis; safety regulations.

Increasingly the public is demanding that proposed building safety regulations be justified by evidence that they generate benefits commensurate with their costs. This paper discusses a methodology developed by the author to assess the life-cycle costs and benefits of performance standards for increased safety in the home. The methodology was developed, under contract with the Department of Housing and Urban Development, for the assessment of the life-cycle costs and benefits of proposed performance standards for mobile homes. However, with appropriate modifications, it can be applied to the analysis of virtually any building regulations for increased safety.

The need for life-cycle analyses of building regulations is being increasingly acknowledged, and some excellent efforts have been made to develop comprehensive practical methodologies, but not all of the fundamental issues have been addressed at this time. Therefore, this paper focuses principally on fundamental conceptual issues. A secondary purpose is to describe the basic methodology for actually measuring the costs and benefits of regulatory options.

Regulatory implications of adopting a metric building code for the Province of Alberta, Canada, A. J. M. Aikman, SP552, pp. 283-291 (July 1979).

Key words: building codes; construction; metric.

With the notable exception of the United States and Canada the majority of the world's countries use the metric system of measurement. Canada is now converting to the metric system on a voluntary basis. The period of conversion is spread over a number of years with each section of the economy establishing its own targets. The construction industry established January 1,1978 as the date to begin using metric measurements. The Province of Alberta is experiencing a rapid and smooth transition from footpound units to SI (metric) units and the construction industry is in the forefront.

The Alberta Construction Association receives major credit for its educational programmes and government has co-operated fully by responding to the industry's requirements rather than by dictating its own ideas. The province introduced a metric building code in April 1978 with no opposition because it was supported by all groups involved in construction.

An approach to third party approval for industrialized housing, C. M. Edwards, SP552, pp. 293-309 (July 1979).

Key words: agencies; approval process; evaluation; industrialized housing products; inspection; regulation; third party.

The Commonwealth of Pennsylvania a few years ago found themselves in a unique position of trying to determine which agencies were qualified to represent the state for the evaluation and inspection of industrialized housing products to be sold in the state. This paper is a summary of the experience of Pennsylvania in this area. The use of Third Party agencies was not created by Pennsylvania, but it is believed that the approach used by Pennsylvania deviated from previous practices at the time.

It is the hope of the writer of this paper that by summarizing the Pennsylvania experience, others will be stimulated to refine the approval process for selection and use of third party agencies.

Structural inspection of complex structures, C. G. Cooper and G. P. Berson, SP552, pp. 311-320 (July 1979).

Key words: code enforcement; county building code; critical structures program; expense; inspection requirements; pre-construction conference.

This paper provides a look at what a local county government, burdened with the responsibility of inspecting all new construction, has done to insure quality construction, proper inspection and code compliance for large or complex structures, with a minimum of expense to the tax payers.

Lighting and building codes for energy conservation, M. S. Millet, J. R. Bedrick, G. S. Spencer, and G. B. Varey, SP552, pp. $321-335$ (July 1979).

Key words: building codes; building performance simulation; computer applications; energy conservation; illumination standards; lighting distribution simulation; visual performance.

The role of lighting within the purpose of building codes is discussed. A review is made of the continuing controversy over the visual performance criteria being used as the basis for IES (Illuminating Engineering Society) recommended levels of illumination. These levels are the present design procedure base levels for the ASHRAE 90-75 and NCSBCS Code for Energy Conservation lighting power budget procedure. The third section of the paper lists the objectives of an energy-conserving building code for lighting and compares the NCSBCS code with a lighting power budget approach recommended for Seattle by the Citizens' Task Force on an Energy-Conserving Building Code, on which the author serves. The final issue discussed is an alternative for the future, a performance standard. Thorough evaluation of lighting alternatives for energy conservation will require detailed analysis, such as computer simulation, that looks at the interaction of the building components and systems. A lighting computer program which has been developed at the University of Washington 
to predict illumination levels from daylight and from artificial light sources is described briefly, and its inclusion in a larger building performance simulation outlined.

Tax shelter in construction: Public objectives and private incentives, U. P. Gauchat, SP552, pp. $337-346$ (July 1979).

Key words: building; private interests; public objectives; taxation; tax incentives.

Building as an activity is strongly conditioned by both the taxation system and the building regulatory mechanism. Since both of these systems represent public commitments and funds, it is reasonable to assert that the ensuing consequences should, whenever possible, be mainly in the public interest. The main purpose of the regulatory system is to protect the public by maintaining adequate health and safety standards. An ostensible goal of the incentives as related to building is to further public objectives by encouraging specific activities perceived to be of societal value, which are not adequately covered by a free market situation. It is felt that current tax incentives in building, however, are not always in the public interest, but rather serve private interests instead.

It is felt that some conceptual changes in the building process and pattern of ownership could best combine the intent of the regulatory and taxation systems with public interest objectives. It is suggested that the tax incentives in building could be designed to draw distinctions between those aspects of building which are market-related (and hence in the private interest) and those portions which are health and safety oriented (and hence in the public interest). It is futher suggested that tax incentives in building bear a direct relationship to the degree of public utility involved.

The implications of this proposition are examined in the light of increasing economic pressures to produce large quantities of housing efficiently and economically.

Resource zoning and land use planning: An examination of urban infrastructures, U. P. Gauchat and D. L. Schodek, SP552, pp. 347-360 (July 1979).

Key words: infrastructure; land use; resource zoning; urban; zoning regulations.

Buildings cater to the full array of human activities. They are disposed over the landscape in a range of patterns and densities. Each pattern not only designates spatial arrangements of building masses, but also sponsors a series of mostly invisible supply and distribution networks.

Existing infrastructures, particularly in urban areas, tend to be old, badly maintained and often in less than excellent condition. Each network has a maximum carrying capacity which is determined by the type of system and its state of repair. While it is possible to envision far more technologically advanced infrastructure systems than we now possess, the extent of the investment in our current systems is so vast as to mitigate against any radical changes in the forseeable future. Land use policies therefore must more directly begin to face the issue of how best to cope with an infrastructure system of a fixed or even declining quality and capacity.

The capacity of existing infrastructure systems, particularly of water and sewerage, can be a determining factor in imposing density and other land use constraints. Thus, many typical city zoning ordinances are directly or indirectly influenced by the character of the existing infrastructure. Zoning regulations based mainly on these considerations may not, however, be the most socially or economically advantageous.
This paper proposes an approach to land use planning involving the concept of Resource Zoning. This type of zoning draws a clear distinction between ordinances that relate to social goals and those that relate to constraints imposed by the existing infrastructure. It is felt that the idea of Resource Zoning would not only prove valuable in the context of land use planning but could also provide the necessary incentive for the development of innovative practices in the design of service systems for individual buildings.

SP553. Water supply and drainage in buildings. Proceedings of an International Symposium, National Academy of Sciences, Washington, DC, Sept. 28-30, 1976, L. S. Galowin and J. R. Debelius, Eds., Nat. Bur. Stand. (U.S.), Spec. Publ. 553, 232 pages (Aug. 1979) SN003-003-02101-6.

Key words: building water systems; CIB; international plumbing research; plumbing and drainage; U.S. research in plumbing.

This report contains the papers presented at the International Symposium on Water Supply and Drainage convened on September 28-30, 1976 at the National Academy of Sciences, Washington, DC, and conducted by the U.S. National Committee for the International Council for Building Research, Studies and Documentation (CIB) Counterpart Commission W-62. The meeting provided the opportunity to exchange information and identify general needs and common perspectives of plumbing in on-going research applications and practices in the United States and other countries. These proceedings include the following papers (indented):

Water requirements and procedures for estimating the demand for water in buildings, $R$. V. Benazzi, L. Guss, R. Orend, R. S. Wyly, and T. P. Konen, SP553, pp. 3-13 (Aug. 1979).

Protecting water quality in buildings, G. Williams, T. P. Konen, F. Liposki, J. R. Myers, L. Nielsen, W. Mikucki, and W. Staton, SP553, pp. 15-19 (Aug. 1979).

Water and water-related conservation in buildings, A. J. Fowell, A. Bransdorfer, P. Fletcher, R. J. Orend, H. J. Pavel, and G. H. Williams, SP553, pp. 21-31 (Aug. 1979).

Hydraulies of gravity drainage systems, R. S. Wyly, R. V. Benazzi, T. P. Konen, R. R. Manfredi, and L. S. Nielsen, SP553, pp. 35-51 (Aug. 1979).

Performance concepts for water supply and drainage systems in buildings, L. S. Galowin, W. J. Downing, L. S. Nielsen, M. J. Orloski, and R. S. Wyly, SP553, pp. 53-70 (Aug. 1979).

Alternative concepts for transporting and treating wastes within buildings, T. P. Konen, R. S. Bevans, W. J. Boegly, D. Savitsky, and C. Cole, SP553, pp. $71-77$ (Aug. 1979).

CIB W-62 purpose, methodology and fields of work, $K$. Ovesen, SP553, pp. 81-88 (Aug. 1979).

Siandardization structure in Europe, F. Perrier, SP553, pp. 89-99 (Aug. 1979).

Certification and agreement system in Europe, D. Trinkler, SP553, pp. 101-108 (Aug. 1979).

Research laboratories with CIB interest, R. Hanslin, C. D. J. Webster, and V. Nielsen, SP553, pp. 109-128 (Aug. 1979). 
Cost benefit of plumbing: Large frimge benefits for sanitary installations by thorough malysis of system, T. Rosrud, SP553, pp. 131-135 (Aug. 1979).

Economic water supply design based on performance requirements, E. Olsson, SP553, pp. 137-159 (Aug. 1979).

Production, transport and use of thot water, F. Perrier, SP553, pp. 161-173 (Aug. 1979).

Performance requirements for taps: A consensus from Scandinavia, V. Nielsen, SP553, pp. $175-192$ (Aug. 1979).

Code structure and standardization in the United States, $M$. Snyder, SP553, pp. 193-205 (Aug. 1979).

Potential savings from using reduced-size venting in the United States, H. Marshall, $\mathbb{R}$. Ruegg, and $\mathbb{R}$. Wyly, SP553, pp. 207-225 (Aug. 1979).

SP554. Proceedings of a conference on neutrons from electron medical accelerators. Proceedings of a Conference held at the National Bureau of Standards, Gaithersburg, MD, Apr. 9-10, 1979, H. T. Heaton II and R. Jacobs, Eds., Nat. Bur. Ständ. (U.S.), Spec. Publ. 554, 172 pages (Sept. 1979) SN003-00302115-6.

Key words: dosimetry; high energy radiotherapy beams; leakage; measurement techniques; medical accelerators; neutrons; relative biological effect; shielding techniques; standards.

These proceedings are the compilation of 18 papers presented at the Conference on Neutrons from Electron Medical Accelerators held in Gaithersburg, $M D$, on April 9 and 10 , 1979. The topics addressed include: properties of high energy beams for radiotherapy, regulations, biological interpretation, physical measurements and calculations, and neutron reduction techniques. These proceedings include the following papers (indented):

Unwanted meutron contribution to megavoltage $x$-ray and electron therapy, J. S. Laughlin, A. Reid, L. Zeitz, and J. Ding, SP554, pp. 1-14 (Sept. 1979).

Key words: accelerators; betatrons; electrons; megavoltage; neutrons; therapy; $x$ rays.

The significance of megavoltage $x$-ray and electron therapy and their development is briefly outlined and illustrative plans presented. Early and recent measurements of photoneutron fluence present in the x-ray beam, and outside the $\mathrm{x}$-ray beam but also incident on a patient, have been reviewed. The variation of incident neutron production with $\mathrm{x}$-ray energy, as well as that of the dose in the patient due to internally produced photoneutrons, has been estimated.

Advantages and properties of high energy photon bearms, $H$. E. Johns, SP554, pp. 15-21 (Sept. 1979).

Key words: betatrons; cobalt units; dose buildup; linacs; patient survival.

A brief history of the development of high energy machines-cobalt 60 units, betatrons and linacs is presented. The properties and advantages of these machines are discussed. The large increase in cure rate resulting from the use of these machines in the treatment of cancer of the cervix is presented. Instead of worrying about neutrons, we should be dealing with the properties of these beams. They should be designed to give as small an entrance dose as possible and the peak dose should be placed as far below the skin as possible. These parameters are much more important than neutron leakage. Ways of improving these beams by altering the flattening filter and other components are described. Problems arising from the use of very large half body fields are discussed. With very large fields, surface doses become large and the buildup properties of the beam disappear. Ways of improving these fields are dealt with. It is suggesed that regulatory agencies should be more concerned with beam improvements than with neutron leakage which is not a problem. The hope is expressed that with CT scanning and the possible improvements in beam direction and dose calculations, a further dramatic increase in cure rate will result.

Scattered radiation relative to leakage radiation in high energy x-ray beams, J. A. Rawlinson, SP554, pp. 25-28 (Sept. 1979).

Key words: dose; leakage; medical accelerator; neutrons; scatter; $x$ rays.

It has been common practice recently to limit the neutron leakage reaching the patient outside the useful beam to $0.1 \%$ in rems of the dose on the central axis. This value appears to be based on earlier recommendations regarding $\mathrm{x}$-ray leakage. It is shown by comparison to the dose received by the patient due to photon scatter that this value is unnecessarily low.

International standards for medical accelerators, G. R. Higson, SP554, pp. 29-32 (Sept. 1979).

Key words: accelerators; IEC; interlocks; leakage; radiation; safety; standards.

The International Electro-technical Commission is engaged in a major programme for the development of standards for medical electrical equipment. A standard for the radiation safety of electron medical accelerators will soon be published. The main features of this standard are described and some of the background to them is discussed.

State regulations for medical accelerators, C. H. Smith, SP554, pp. 33-35 (Sept. 1979).

Key words: accelerators; leakage radiation; regulations; SSRCR; state.

The "Suggested State Regulations for the Control of Radiation" includes a section regarding medical accelerators. The provisions of that section are reviewed.

The RBE of neutrons, H. H. Rossi, SP554, pp. 37-40 (Sept. 1979 ).

Key words: meutrons; radiotherapy; RBE.

The RBE of neutrons is not only a function of energy but more importantly a function of absorbed dose. A combination of experimental and theoretical findings permits at least a fair estimate of the dependence of neutron $R B E$ on both of these factors. It would appear that in radiotherapy with high voltage electron accelerators neutrons have a minimal biological effect on the treatment volume but that they may be an important and perhaps a biologically dominant factor in leakage radiation.

Risk of cancer based on promotion from cytotoxicity, T. D. Jones, D. G. Jacobs, J. A. Auxier, and G. D. Kerr, SP554, pp. 41-56 (Sept. 1979).

Key words: cell-proliferation; cell-turnover; cytotoxicity; homeostasis; promotion; RBE; risk. 
Cytotoxicity is reviewed as a basis of risk assessment for environmental cancers. Linear relations of several cancers to organ-specific cell-surviving fractions have led to the practical assumption that cytotoxicity can stimulate cell proliferation which may permit altered cells to become tumors. Furthermore, an insult which retards cell proliferation or selectively blocks or destroys transformed cells may decrease tumor incidence. This simple assessment model for cancer growth seems to be unique because it requires no assumptions about the number of initiating events per cell, bases the increased demand for proliferation on cytotoxicity estimates by mathematical analyses of in vivo and in vitro irradiation of cells, and also assumes that the exact number of neoplastic cells, their death rate, and the repair rate, are of secondary importance. The significant point appears to be that a sufficient quantity of altered cells exist in order to respond to the proliferation stimulus from normal or enhanced cell turnover. The use of this model for extrapolation to spontaneous cancer incidence in a population is discussed. Many investigators suggest that cancers occur linearity with low dose; however, carcinogenic response based on linearity with cytotoxicity does not seem inconsistent with linearity at low dose, and furthermore this relation seems to hold to saturated cellkilling levels. Cytotoxicity may also provide a common basis for comparing risk from ionizing insults with risk from chemical insults; relating risk in different organisms (over a wide insult range) to an experimental determination at a single insult level; summing risk to different tissues; and estimating risk for partial body or nonuniform irradiation.

Clinical tradeoff: The maximum probability of uncomplicated cure, L. Cohen, SP5 54, pp. 57-61 (Sept. 1979).

Key words: instantaneous optimization; radiation therapy; uncomplicated cure.

Any new procedure intended to yield more effective tumor control in clinical radiation therapy carries the concomitant risk of more severe acute and remote side effects. The effective gain or trade-off can then be evaluated in two ways. One is an instantaneous optimization function (cure-rate minus complication-rate) determining the probability of uncomplicated cure, which can presumably be maximized by judicious choice of technique. Consideration of long-term effects however suggests that a different optimization algorithm, integrating the total expectation of disease-free person-years is more realistic. It can be shown that even if higher energy radiation leads to a small increase in the rate of local control, or in the time to recurrence in uncontrolled cases, these gains would effectively offset the risk of induced neoplasia or similar remote complications.

Dependence of radiation-induced neoplastic transformation in vitro upon radlation quality and repair, $A$. Han and $M . M$. Elkind, SP554, pp. 63.73 (Sept. 1979).

Key words: carcinogenesis; neutron; repair; survival; transformation; $\mathrm{x}$ ray.

$\mathrm{C} 3 \mathrm{H} / 10 \mathrm{~T} 1 / 2$ mouse embryo cells grown in culture were irradiated with single or fractionated doses of fission-spectrum neutrons from the JANUS reactor or with $50-\mathrm{kV} x-$ rays; survival and frequencies of neoplastic transformation were measured and the relative biological effectiveness (RBE) for each end point was estimated. As expected, for both survival and transformation, RBE's depend upon level of effect, being higher for small than for large doses. Changes in transformation frequencies following $x$-ray dose fractionation indicate appreciable repair of both sublethal and subtransformation damage. Results of fractionation of the fission-spectrum neutron dose suggest repair of the first-dose subtransformation damage and no repair of sublethal damage. The observed results for the induction of neoplastic transformation in $\mathrm{C} 3 \mathrm{H} / 10 \mathrm{~T} 1 / 2$ cells are qualitatively similar to data for tumor induction in animals.

Neutron sources and their characteristics, R. C. McCall and W. P. Swanson, SP554, pp. 75-86 (Sept. 1979).

Key words: accelerator; neutron fluence; photoneutrons.

The significant sources of photoneutrons within a linearaccelerator treatment head are identified and absolute estimates of neutron production per treatment dose are given for typical components. It is found that the high- $Z$ materi, als within the treatment head do not significantly alter the neutron fluence but do substantially reduce the average energy of the transmitted spectrum. Reflection of neutrons from the concrete treatment room contribute to the neutron fluence, but not substantially to the patient integral dose, because of a further reduction in average energy. The ratio of maximum fluence to the treatment dose at the same distance is given as a function of electron energy. This ratio rises with energy to an almost constant value of $2.1 \times 10^{5}$ neutrons $\mathrm{cm}^{-2} \mathrm{rad}^{-1}$ at electron energies above about $25 \mathrm{MeV}$. Measured data obtained at a variety of accelerator installations are presented and compared with these calculations. Reasons for apparent deviations are suggested. Absolute depth-dose and depth-doseequivalent distributions for realistic neutron spectra that occur at therapy installations are calculated, and a rapid falloff with depth is found. The ratio of neutron integral absorbed dose to leakage photon absorbed dose is estimated to be 0.04 and 0.2 for 14 and $25 \mathrm{MeV}$ incident electron energy, respectively. Possible reasons are given for lesser neutron production from betatrons than from linear accelerators. Possible ways in which neutron production can be reduced are discussed.

Mixed photon-neutron field measurements, R. Nath, K. W. Price, and G. R. Holeman, SP554, pp. 87-97 (Sept. 1979).

Key words: high energy $x$-ray radiotherapy machine; mixed photon-neutron field dosimetry; neutron leakage.

High energy $x$-ray radiotherapy machines produce neutrons by photonuclear reactions which present a potential radiation hazard to the personnel and patient. A series of measurements of the neutron flux and spectrum from a $25 \mathrm{MV} x$-ray linear accelerator, inside and outside the treatment room, have been performed using a multisphere spectrometer, Nemo dosimeter, and activation detectors. These results are compared with other mixed photonneutron field measurements for the same machine using an argon/propane ionization chamber, moderated gold foil, silicon diode, track-etching detectors, and Monte Carlo calculations illustrating some of the experimental difficulties which are encountered in an accurate measurement of the neutron contamination of a high energy photon beam.

Neutron contamination in the primary beam, P. H. McGinley and M. Sohrabi, SP554, pp. 99-107 (Sept. 1979).

Key words: activation; detectors; dose; fast; neutrons; track.

In this work the absorbed dose due to neutrons was measured at points inside and outside of a $10 \times 10 \mathrm{~cm}$ photon beam for several medical treatment units (Varian Clinac18, Allis-Chalmers $25 \mathrm{MeV}$ betatron, and Brown Boveri 45 $\mathrm{MeV}$ betatron). The neutron dose was evaluated using a 
moderated activation detector, solid state track detectors, and by the fast neutron activation of phosphorous. For the linac it was found that the maximum neutron dose at the beam center was $0.004 \%$ the photon dose and maximum values of $0.054 \%$ and $0.08 \%$ were observed for the AllisChalmers betatron and the Brown Boveri betatron.

Neutron production from electron accelerators used for medical purposes, E. J. Axton and A. G. Bardell, SP554, pp. 109-123 (Sept. 1979).

Key words: dose-equivalent; electrons; kerma; multisphere; photon; photoneutrons; radiotherapy; spectrometry.

Measurements have been made of the photoneutron production in and out of the photon and electron beams produced by the SL75-20 linear accelerator installed at Addenbrookes Hospital, Cambridge. The in-beam neutron dose-equivalent to the patient per treatment rad in water is estimated at $4.38 \mathrm{mrem}$ in the photon mode and 0.249 mrem in the electron mode. The present results confirm less accurate measurements published earlier by the same authors, based on a prototype accelerator of this type. Similar measurements on a $33 \mathrm{MV}$ Brown Boveri betatron published at the same time should be reduced by $25-30 \%$ to obtain the neutron dose-equivalent to the patient from externally generated neutrons, although the published values were probably a truer representation of the total patient dose-equivalent.

Survey of European measurements on photoneutron production from electron accelerators used for medical purposes, E. J. Axton and A. G. Bardell, SP554, pp. $125-127$ (Sept. 1979).

Key words: dose-equivalent; electrons; kerma; multispheres; photoneutrons; photons; radiotherapy; spectrometry.

Brief details are presented of European work on problems associated with neutron production from electron accelerators used for medical purposes. For completeness, the earlier references which have already received citation in the literature have been included.

Neutron leakage from current machines, P. R. Almond, SP554, pp. 129-138 (Sept. 1979).

Key words: betatrons; detectors; dosimetry; leakage; linear accelerators; neutrons.

A survey has been made of published, and unpublished reports during the last ten years, of neutron leakage measurements around medical linear accelerators. The review involved seventeen different studies involving fourteen different types of machines, six betatrons and eight linear accelerators with measurements reported on twenty-eight different machines. It was found that as the energy increases, the neutron leakage increases and is a maximum at around $25 \mathrm{MV}$ and then remains constant. The target appears to be the main source of neutrons. In a treatment room, the neutrons can be identified as fast primary neutrons, fast scattered neutrons from the walls and a constant background of thermal neutrons. The neutron dose in the photon beam is approximately four times higher than 50 $\mathrm{cm}$ from the beam edge. At greater distances, the neutron dose becomes constant. Due to the large number of variables in the different reports, it is possible to draw definite conclusions. It is recommended that standards be established for neutron leakage measurements.

Design criteria for photon beam exits on high energy medical accelerators to minimize neutron production, L. Taumann, SP554, pp. 139-144 (Sept. 1979).
Key words: beam quality; neutron production; photon beam exit.

The major components of the photon beam exit of a medical linear accelerator are discussed from the viewpoint of beam quality and neutron production. It is pointed out that the optimization of the beam quality also leads to a minimum in the neutron production.

Neutron leakage characteristics related to room shielding, E. Tochilin and P. D. LaRiviere, SP554, pp. 145-154 (Sept. 1979).

\section{Key words: gamma rays; neutron leakage rates.}

A systematic study of neutron leakage rates has been made over a range of $x$-ray energies $10-19 \mathrm{MeV}$ in one of Varian's test cells. Leakage was evaluated at one meter and in the patient plane. Measurements were presented of neutron and gamma ray leakage in the concrete test cell, together with door shielding calculations. The information allows scaling of neutron leakage to other size rooms and $x$-ray energies extending to $25 \mathrm{MV}$. The neutron activation of concrete and its contribution to treatment room dose was investigated. Gamma rays from radiative capture in concrete and their influence on leakage through the exit door were also examined.

SP556. Measurements and standards for recycled oil-II. Proceedings of a Conference held at the National Bureau of Standards, Gaithersburg, MD, Nov. 29-30, 1977, D. A. Becker and H. A. Hurd, Eds., Nat. Bur. Stand. (U.S.), Spec. Publ. 556, 212 pages (Sept. 1979) SN003-003-02108-3.

Key words: engine oil; fuel oil; hydraulic oil; industrial oil; lubricating oil; oil specifications; petroleum standards; petroleum test methods; recycled oil; re-refined oil; used oil; waste oil.

This publication is a formal report of the second Conference on Measurements and Standards for Recycled Oil, held at the National Bureau of Standards on November 29 and 30, 1977. There were seven sessions on specific subject areas, with a total of 32 presentations. The subject areas were as follows: (1) The Existing Situation, (II) Environmental Considerations, (III) Nonlubricating End Uses, (IV) Legislation and Studies, (V) Evaluation of Re-refined Engine Oils, (VI) Additional Recycled Oil Activities, and (VII) A panel discussion on the topic: "What Data Base is Required to Establish the "Substantial Equivalency' on Re-refined Motor Oils to Virgin Motor Oils." Included in this report are invited talks given and a summary of the discussion following session VIl. These proceedings include the following papers (indented):

Conference objectives and the NBS recycled oil program, D. Becker, SP556, pp. 5-8 (Sept. 1979).

The curren status of the re-refining industry, D. Ekedahl, SP556, pp. 9-13 (Sept. 1979).

A limited integrated assessment of the waste oil re-refining industry, S. Liroff, SP556, pp. 15-20 (Sept. 1979).

A survey of metals in oil: Occurrence and significance for reuse of spent automotive lubricating oils, T. Coyle and A. Siedle, SP556, p. 23 (Sept. 1979).

Speciation of metals in used oils: Recent progress and environmental implications of molecular lead compounds in used crankcase oils, F. Brinckman and W. Blair, SP556, pp. 25-38 (Sept. 1979). 
The analysis of some residual fuel and waste lubricating oils by a high-performance liquid chromatographic procedure, W. May and J. Brown, SP556, pp. 39-44 (Scpt. 1979).

Current EPA views on ambient air lead standards, J. Cooper, SP556, p. 47 (Sept. 1979).

An updated look at the fuel potential of waste automotive oil, P. Spawn and P. Fennelly, SP556, pp. 49-55 (Sept. 1979).

The burning of used oil as a fuel in cement manufacture, J. Armstrong and L. MacDonald, SP556, pp. 57-64 (Sept. 1979).

Industrial oils used as fuel, J. Swain, Jr., SP556, pp. 65-70 (Sept. 1979).

Runoff of oils from rural roads treated to suppress dust, $F$. Freestone, SP556, pp. 71-86 (Sept. 1979).

Test procedures for recycled oil used as burner fuel, J. Comeford, SP556, pp. 87-92 (Sept. 1979).

Recent Federal and State legislative developments in used oil recycling, W. Irwin and K. Heimann, SP556, pp. 95-100 (Sept. 1979).

EPA activities in waste oil management, $H$. Kaufman, SP556, pp. 101-104 (Sept. 1979).

The role of the FTC in recycled oil labeling, $C$. Aldhizer, SP556, pp. 105-106 (Sept. 1979).

Used oil recycling program issues: The Department of Energy, D. Ellerbe, SP556, pp. 107-108 (Sept. 1979).

Utilization of used oil: Energy conservation aspects, G. Mascetti, SP556, pp. 109-113 (Sept. 1979).

The EPA/DOD investigation of re-refined engine oil, $T$. Bowen, SP556, pp. 117-122 (Sept. 1979).

Iowa re-refined oil fleet test, $D$. Ulrichson and $D$. Yake, SP556, pp. 123-132 (Sept. 1979).

Phillips recycled oil program, R. Linnard, SP556, pp. 133 137 (Sept. 1979).

The system of used oil regulation in the Federal Republic of Germany, F. Irouschek, SP556, pp. 139-140 (Sept. 1979).

Testing and use of re-refined engine oils in Europe, D. Becker, SP556, pp. 141-144 (Sept. 1979).

Waste oil recycling utilizing solvent pretreatment, $C$. Thompson and W. Whisman, SP556, pp. 147-151 (Sept. 1979).

API activities in used oil, B. Hutchings, SP556, pp. 153-155 (Sept. 1979).

Voluntary test method and specification standards (ASTM) for petroleum products from waste (used) oill, P. Strigner, SP556, pp. 157-158 (Sept. 1979).

Establishing substantial equivalency for motor oils, J. Comeford, SP556, pp. 161-163 (Sept. 1979).

Activities of the SAE Fuel and Lubricants Technical Committee, C. Schwarz, SP556, pp. 165-166 (Sept. 1979).

Some views on substantial equivalency, J. Creedon, SP556, pp. 167-170 (Sept. 1979).
Field experiences with re-refined motor oils, R. Pedall, SP556, pp. 171-173 (Sept. 1979).

An approach to qualification of re-refined engine oil under military specifications, T. Bowen, SP556, pp. $175-177$ (Sept. 1979).

Performance testing is the key to engine oil quality, D. Stehouwer, SP556, pp. 179-182 (Sept. 1979).

Re-refined oil in our future, R. Bjorndal, SP556, pp. 183184 (Sept. 1979).

SP557. Chemical kinetic data needs for modeling the lower troposphere. Proceedings of a Workshop held at Reston, VA, May 15-17, 1978, J. T. Herron, R. E. Huie, and J. A. Hodgeson, Eds., Nat. Bur. Stand. (U.S.), Spec. Publ. 557, 105 pages (Aug. 1979) SNO03-003-02111-3.

Key words: aldehydes; aromatics; chemical kinetics; data needs; free radicals; modeling; $\mathrm{NO}_{x}$; olefins; $\mathrm{SO}_{x}$; troposphere.

This is a report of the proceedings of a workshop on chemical kinetic data needs for modeling the lower troposphere, held at Reston, Virginia, May 15-17, 1978. The mecting, sponsored by the Environmental Protection Agency and the National Bureau of Standards, focused on six key problem areas in tropospheric chemistry: reactions of olefins with hydroxyl radicals and ozone, reactions of aldehydes, free radical reactions, reactions of oxides of nitrogen, reactions of aromatic compounds, and reactions of oxides of sulfur.

The report includes a summary and list of major recommendations for further work, review papers, discussion summaries, contributed comments, recommendations, and an attendance list. These proceedings include the following papers (indented):

An evaluation of chemical kinetic data meeds for modeling the lower troposphere: Reactions of olefins with hydroxyl radical and with ozone, H. Niki, SP557, pp. 7-14 (Aug. 1979).

Key words: hydroxyl; kinetics; olefin; ozone; review; troposphere.

Needs for improved kinetic and mechanistic data for the reactions of olefinic hydrocarbons with hydroxyl radical and with ozone have been evaluated from the view point of modeling the chemistry of the lower troposphere. Research priorities for removal of various uncertainties in these reactions have been discussed briefly.

Tropospheric chemistry of aldehydes, A. C. Lloyd, SP557, pp. 27-46 (Aug. 1979).

Key words: aldehyde; free radical; photolysis; reactions; review; troposphere.

This paper presents a survey of the current published literature on aldehydes, and to a lesser extent, the other oxygenated hydrocarbons, as related to their role in modeling the troposphere. Sources, ambient levels, photochemistry, and free radicals, reactions of these substances are treated.

Organic free radicals, D. M. Golden, SP557, pp. 51-61 (Aug. 1979).

Key words: alkoxyl; kinetics; radicals; review; troposphere.

The role of free radicals in the chemistry of the lower troposphere is reviewed. Methods of predicting and estimating kinetic parameters are discussed with particular reference to alkoxyl radical decomposition, isomerization, and reaction with oxygen. Data needs, accuracy and priorities are considercd. 
Tropospheric chemistry of nitrogen oxides-A summary of the status of chemicaI kinetic data, R. A. Cox, SP557, pp. 71-79 (Aug. 1979).

Key words: nitrates; nitrites; nitrogen oxides; photolysis; reactions; review; tropospheric chemistry.

This paper is a review of the tropospheric chemistry of nitrogen oxides. The important atmospheric reactions and the photolysis of these compounds are discussed and problem areas are emphasized.

Reactions of aromatic compounds in the atmosphere, D. G. Hendry, SP557, pp. 85-91 (Aug. 1979).

Key words: aromatics; free radicals; mechanism; reactions; tropospheric chemistry.

This paper is a review of the tropospheric chemistry of aromatic compounds. The reactivity of aromatic compounds is discussed and rate constants for their reactions with $\mathrm{OH}$ are tabulated. The reaction mechanisms are discussed in detail.

SO ${ }_{x}$ chemistry, J. G. Calvert, SP557, pp. 99-100 (Aug. 1979).

Key words: kinetics; photochemistry; review; sulfur dioxide; troposphere.

An evaluation has been made of the existing kinetic data related to the elementary, homogeneous reactions of $\mathrm{SO}_{2}$ within the troposphere. A set of recommended values of the rate constants for these reactions is presented. The results show that the direct photooxidation of $\mathrm{SO}_{2}$ by way of the electronically excited states of $\mathrm{SO}_{2}$ is relatively unimportant for most conditions which occur within the troposphere. The oxidation of $\mathrm{SO}_{2}$ within the natural troposphere is expected to occur largely by way of reactions 39,31 , and 33 , with reaction 39 being the dominant path: $\mathrm{HO}+\mathrm{SO}_{2}(+\mathrm{M}) \rightarrow \mathrm{HOSO}_{2}(+\mathrm{M})$ (39); $\mathrm{HO}_{2}+\mathrm{SO}_{2}$ $\rightarrow \mathrm{HO}+\mathrm{SO}_{3}$ (3I); $\mathrm{CH}_{3} \mathrm{O}_{2}+\mathrm{SO}_{2} \rightarrow \mathrm{CH}_{3} \mathrm{O}+\mathrm{SO}_{3}$ (33). For certain special conditions within the troposphere the oxidation of $\mathrm{SO}_{2}$ by way of the products of the ozone-olefin reaction may be significant. Also the reaction of $O\left({ }^{3} \mathrm{P}\right)$ with $\mathrm{SO}_{2}$ may contribute somewhat to the $\mathrm{SO}_{2}$ removal in $\mathrm{NO}_{2}$-rich, $\mathrm{O}_{2}$-deficient stack gases in sunlight during the early stages of dilution of the plume.

The complete paper upon which most of the talk was based is: "Mechanism of the Homogeneous Oxidation of Sulfur Dioxide in the Troposphere," by Jack G. Calvert, Fu, Su, Jan W. Bottenheim, and Otto P. Strausz which appeared in the Preprint Volume I, Plenary Papers, International Symposium on Sulfur in the Atmosphere, July, 1977, and which was presented at the Symposium on September 7-14, 1977, Dubrovnik, Yugoslavia. The paper has been published in Atmospheric Environment, 12, 197 (1978).

SP558. Efficient allocation of research funds: Economic evaluation methods with case studies in building technology, H. E. Marshall and R. T. Ruegg, Nat. Bur. Stand. (U.S.), Spec. Publ. 558, 56 pages (Dec. 1979) SN003-003-02132-6.

Key words: benefit-cost analysis; building technology; economic impacts; economics; efficiency; payback; plumbing; roofing; shingles; venting.

Public and private administrators of research programs are concerned with maximizing the payoffs from their research investments; that is, with allocating their limited budgets most efficiently. Benefit-cost, rate-of-return, payback, and other evaluation methodolgies are examined for their usefulness in helping administrators to decide whether to accept or reject research projects leading directly to applications; to plan the scale of these research projects; and to identify priorities among alternative research investments, all of which may be profitable. Data needs for applying these evaluation methodologies are outlined. The net-benefits and rate-of-return methodologies are applied to two case studies involving research in the Center for Building Technology (CBT) of the National Bureau of Standards. The first deals with a heavier asphalt shingle for roofing, and the second deals with reducedsize venting in plumbing. The case studies show high payoffs in these two areas of research, both for society as a whole and and for CBT's contribution in undertaking the research. Recommendations from the study are that research funds be allocated on the basis of anticipated payoffs determined through these evaluation techniques, and that benefit and cost data for evaluating new technologies be collected.

SP559. Time and frequency users' manual, G. Kamas and S. L. Howe, Eds., Nat. Bur. Stand. (U.S.), Spec. Publ. 559, 256 pages (Nov. 1979) SN003-003-02137-1

Key words: frequency calibration; high frequency; LoranC; low frequency; radio broadcasts; satellite broadcasts; standard frequencies; television color subcarrier; time and frequency calibration methods; time calibration; time signals.

This manual has been written for the person who needs information on making time and frequency measurements. It has been written at a level that will satisfy those with a casual interest as well as laboratory engineers and technicians who use time and frequency every day. It gives a brief history of time and frequency, discusses the roles of the National Bureau of Standards, the U.S. Naval Observatory, and the International Time Bureau, and explains how time and frequency are internationally coordinated. It also explains what time and frequency services are available and how to use them. It discusses the accuracies that can be achieved using the different services as well as the pros and cons of using various calibration methods.

SP561, Vols. 1 and 2. Characterization of high temperature vapors and gases. Proceedings of the loth Materials Research Symposium held at the National Bureau of Standards, Gaithersburg, MD, Sept. 18-22, 1978, J. W. Hastie, Ed., Nat. Bur. Stand. (U.S.), Spec. Publ. 561/1, 800 pages; 561/2, 901 pages (Sept. 1979) SNO03-003-02124-5.

Key words: combustion; equilibrium; high temperature; isolation; lasers; mass spectrometry; matrix; modeling; vapors.

This book is based on the proceedings of the 10th Materials Research Symposium, held at the National Bureau of Standards, Gaithersburg, MD, Sept. 18-22, 1978. The symposium was sponsored by the National Measurement Laboratory (formerly Institute for Materials Research). Modern technology increasingly requires materials and processes to function at high temperatures-a condition where the vapor, gaseous or plasma phase becomes significant. Characterization of such atmospheres, or components thereof, is a challenging problem requiring adaptation of existing and development of new experimental and theoretical techniques. The aim of the symposium was to assess the state-of-the-art and future directions and characterization methods for high temperature vapors including, where appropriate, gases and, to a lesser extent, plasmas. In order to prevent, as far as possible, serious omissions of important new or improved techniques, a number of papers not delivered at the Symposium were solicited for inclusion in this publication. A total of eighty-six papers (invited and contributed) or chapters representing nine countries are contained 
in these volumes. The discussion, which followed most of the delivered papers, is also included. These proceedings include the following papers (indented):

The effusion method at age 69: Current state of the art, E. D. Cater, SP561/1, pp. 3-38 (Sept. 1979).

General theoretical angular number distribution functions of Knudsen flow through the following single and double-slipic orifice geometries: Circular, rectangular, and cylindrical, F. Miller, SP561/1, pp. 39-65 (Sept. 1979).

Automatic data acquisition by the torsion-effusion method, J. G. Edwards, SP561/1, pp. 67-81 (Sept. 1979).

Application of laser pulse heating for the study of high temperature vapors, phase transitions and equation of state, $\mathbb{R}$. W. Ohse, J. F. Babelot, L. Cercignani, P. R. Kinsman, K. A. Long, J. Magill, and A. Scotti, SP561/1, pp. 83-109 (Sept. 1979).

A high temperature transpiration apparatus for the study of the atmosphere above viscous incongruently vaporizing melts, D. M. Sanders and W. K. Haller, SP561/1, pp. 111-123 (Sept. 1979).

Vaporization thermodynamics and kinetics of hexagonal silicon carbide, R. G. Behrens and G. H. Rinehart, SP561/1, pp. 125-141 (Sept. 1979).

A very accurate pyrometer for general laboratory use, $E$. $K$. Storms and B. A. Mueller, SP561/1, pp. 143-151 (Sept. 1979).

Operation of near ideal heat pipes, L. A. Melton, SP561/1, pp. 153-166 (Sept. 1979).

Attainment of chemical equilibrium in effusive beam sources of the heterogeneous reaction type, D. L. Hildenbrand, SP561/1, pp. 171-179 (Sept. 1979).

Thermodynamic and physico-chemical behavior of the interactions between Knudsen-effusion-cells and the systems under investigation. Analysis by high temperature mass spectrometry, C. Chatillon, M. Allibert, and A. Pattoret, SP561/1, pp. 181-210 (Sept. 1979).

Characterization of high temperature vapors by angular distribution mass spectrometry, R. T. Grimley and J. A. Forsman, SP561/1, pp. $211-229$ (Sept. 1979).

The high temperature vaporization and thermodynamics of the titanium oxides. XIV. Relative ionization cross-sections of Ti, TiO, and $\mathrm{TiO}_{2}$, R. I. Sheldon and P. W. Gilles, SP561/1, pp. 231-234 (Sept. 1979).

Congruent, vaporization and thermodynamics in the praseodymium-sulfur system, E. D. Cater, B. H. Mueller, and J. A. Fries, SP561/1, pp. 237-262 (Sept. 1979).

Vapor pressure measurements of potassium over $\mathrm{K}_{2} \mathrm{O}-\mathrm{SiO}_{2}$ solutions by a Knudsen effusion mass spectrometric method, E. R. Plante, SP561/I, pp. 265-281 (Sept. 1979).

Mass spectrometric investigation of vapor species over liquid germanium dioxide, T. Sasamoto, M. Kobayashi, and T. Sata, SP561/1, pp. 283-286 (Sept. 1979).

Mass spectrometric determination of atomization energies of inorganic molecules and their correlation by empirical models of bonding, K. A. Gingerich, SP561/1, pp. 289-300 (Sept. 1979).
High pressure molecallar beam mass spectrometric sampling of high temperature molecules, C. A. Stearns, F. J. Koh1, G. C. Fryburg, and R. A. Miller, SP561/I, pp. 303-354 (Sept. 1979).

Transpiration mass spectrometry of high temperature vapors, D. W. Bonnell and J. W. Hastie, SP561/I, pp. $357-$ 408 (Sept. 1979).

In situ analysis of minor gaseous species in crystal growth ambients using anolecular beam mass spectrometry, H. Dun, B. L. Mattes, and D. A. Stevenson, SP561/1, pp. 411-428 (Sept. 1979).

Molecular beam mass spectrometric sampling of minor species from coal dust-air flames, F. T. Greene, J. E. Beachey, and T. A. Milne, SP561/1, pp. $431-442$ (Sept. 1979).

The use of flames as media for the study of ion-molecule thermochemistry, W. J. Miller, SP561/1, pp. 443-456 (Sept. 1979).

Mass spectrometric determination of negative and positive bon concentrations in coal-fired MHD plasmas, $J$. Wormhoudt and C. E. Kolb, SP561/1, pp. 457-476 (Sept. 1979).

Mass spectrometric sampling of condensed system flames, O. P. Korobeinichev and A. G. Tereshenko, SP561/1, pp. 479-491 (Sept. 1979).

Matrix isolation studies of high temperature species, $\mathbf{R}$. $H$. Hauge and J. L. Margrave, SP561/1, pp. $495-509$ (Sept. 1979).

The characterization of high temperature molecules using matrix isolation and isotope fine structure, J. S. Ogden, SP561/1, pp. $511-520$ (Sept. 1979).

Matrix isolation of high temperature species and matrix perturbation effects, F. W. Froben, SP561/1, pp. 523-527 (Sept. 1979).

Matrix isolation study of the vibrational and electronic spectra of PO and HPO, M. Larzilliere and M. E. Jacox, SP561/1, pp. 529-543 (Sept. 1979).

ESR matrix isolation of $\mathrm{AlH}^{+}$formed during the high temperature vaporization of $\mathrm{Al}_{2} \mathrm{O}_{3}$, L. B. Knight, Jr., R. L. Martin, and E. R. Davidson, SP561/1, pp. 545-555 (Sept. 1979).

Matrix isolation studies of magnesium and iron atom reactions with water, R. H. Hauge, S. E. Gransden, J. W. Kauffman, and J. L. Margrave, SP561/1, pp. $557-566$ (Sept. 1979).

Photoselective bimetallic aggregation: A new route to bimetallic clusters, W. E. Klotzbucher and G. A. Ozin, SP561/1, pp. 567-585 (Sept. 1979).

Transition-metal molecules and Walsh's rules-Rationalization of optical and ESR data, W. Weltner, Jr., SP561/1, pp. 587-594 (Sept. 1979).

The determination of the molecular shapes of 'high temperature' species, 1. Beattie and D. A. Greenhalgh, SP561/1, pp. 597-606 (Sept. 1979).

Raman spectroscopy in high temperature chemistry, M. C. Drake and G. M. Rosenblatt, SP561/1, pp. 609-646 (Sept. 1979).

Resonance Raman spectra of metal halide vapor complexes, G. N. Papatheodorou, SP561/1, pp. 647-678 (Sept. 1979). 
Infrared spectral measurements of species in a high temperature flow tube, M. E. Gersh and C. E. Kolb, SP561/1, pp. 679-693 (Sept. 1979).

Rotational spectroscopy of high temperature molecules, $\mathrm{T}$. Torring and E. Tiemann, SP561/1, pp. 695-709 (Sept. 1979).

Modern high-temperature electron diffraction, $\mathrm{V}$. P. Spiridonov and E. Z. Zasorin, SP561/1, pp. $711-755$ (Sept. 1979).

Photoionization mass spectrometry and photoelectron spectroscopy of high temperature vapors, J. Berkowitz, SP561/I, pp. 757-769 (Sept. 1979).

The photoelectron spectroscopic characterization of vapors over heated inorganic solids, R. A. Bowling, T. W. Lassiter, D. O. Vick, and G. K. Schweitzer, SP56//1, pp. 771-789 (Sept. 1979).

$A b$ initio molecular orbital studies of some high temperature metal halide complexes, L. A. Curtiss, SP561/1, pp. 791-801 (Sept. 1979).

New optical diagnostic techniques for temperature and species concentration measurements in flames, J. R. McDonald, A. P. Baronavski, L. Pasternack, S. Lamont, and A. B. Harvey, SP561/2, pp. 817-831 (Sept. 1979).

Laser-absorption methods for characterizing high temperature gases, W. C. Gardiner, Jr., SP561/2, pp. 835-846 (Sept. 1979).

Near-resonance Rayleigh scattering and atomic flame Fuorescence spectroscopy, C. Chan and J. W. Daily, SP561/2, pp. 847-853 (Sept. 1979).

Laser induced reactions of lithium in flames, C. H. Muller III, K. Schofield, and M. Steinberg, SP56I/2, pp. 855-864 (Sept. 1979).

Opto-galvanic spectroscopy: A new look at atoms and molecules, K. C. Smyth, P. K. Schenck, W. G. Mallard, and J. C. Travis, SP561/2, pp. 865-882 (Sept. 1979).

$\mathrm{SiCl}_{2}$ fluorescence as a chemical vapor deposition reactor probe, T. O. Sedgwick and G. U. Arbach, SP56I/2, pp. 885896 (Sept. 1979).

Raman scattering of the gaseous phase at high temperature, R. Hillel, J. Bouix, and A. Machaelides, SP561/2, pp. 899 911 (Sept. 1979).

Diagnostic techniques in combustion MHD flows, S. A. Self, SP561/2, pp. $915-941$ (Sept. 1979).

CARS diagnostic investigations of flames, A. C. Eckbreth and R. J. Hall, SP561/2, pp. 943-972 (Sept. 1979).

Comparison of thermocouple, gas sampling and Raman measured temperatures in an afterburning turbojet engine plume, W. M. Roquemore and P. O. Yaney, SP561/2, pp. 973-1023 (Sept. 1979).

Use of thermocouples for gas temperature measurements in gas turbine combustors, R. R. Dils and P. S. Follansbee, SP561/2, pp. 1027-1070 (Sept. 1979).

Moving thermocouple measurements of heat transfer in hot gases, L. W. Hunter, C. H. Hoshall, C. Grunfelder, and R. M. Fristrom, SP561/2, pp. 1071-1078 (Sept. 1979).
Application of the two line atomic fluorescence technique to the temporal measurement of small volume flame temperatures, J. Bradshaw, J. Bower, S. Weeks, K. Fujiwara, N. Omenetto, H. Haraguchi, and J. D. Winefordner, SP561/2, pp. 1079-1102 (Sept. 1979).

A comparison of spectroscopic flame temperature measurements: Na-D line reversal, rotational and vibrational Raman, and $\mathrm{OH}$ absorption spectroscopy, M. C. Drake, L. H. Grabner, and J. W. Hastie, SP561/2, pp. 1105-1134 (Sept. 1979).

Optical diagnostics in CVD reactors, G. H. Miller, A. J. Mulac, and P. J. Hargis, Jr., SP561/2, pp. 1135-1151 (Sept. 1979).

Laser-generated opto-acoustic pulses in an atmospheric pressure flame, W. R. Anderson, J. E. Allen, Jr., T. D. Fansler, and D. R. Crosley, SP561/2, pp. 1153-1167 (Sept. 1979).

Measurement of rotational distributions within $\mathrm{OH}\left(\mathbf{A}^{2} \Sigma^{+}, \mathbf{v}^{\prime}\right.$ $=0$ ) in flames, M. A. DeWilde and D. R. Crosley, SP561/2, pp. 1171-1179 (Sept. 1979).

Rotational dependence of transition probabilities in the $\mathrm{OH}$ A-X band system, I. L. Chidsey and D. R. Crosley, SP561/2, pp. 1181-1191 (Sept. 1979).

Chemical processes in high Reynolds number turbulent diffusion flames, D. E. Jensen, SP561/2, pp. $1195-1220$ (Sept. 1979).

Modeling study of flame structure in low-pressure, laminar, pre-mixed methane flames, J. R. Creighton and C. M. Lund, SP561/2, pp. 1223-1244 (Sept. 1979).

Predictive modeling of diborane oxidation, W. M. Shaub and M. C. Lin, SP561/2, pp. 1249-1261 (Sept. 1979).

New computational algorithms for chemical kinetics, D. T. Pratt, SP561/2, pp. 1265-1279 (Sept. 1979).

Measures of effectiveness and mechanisms for chemical and physical inhibition of quenched and adiabatic premixed flames, J. J. Reuther, SP561/2, pp. 1281-1312 (Sept. 1979).

Influence of water vapor on hydrogen combustion, $A$. Feugier, SP561/2, pp. 1315-1325 (Sept. 1979).

Inhibition on the propagation of flame, T. Inomata, S. Okazaki, T. Moriwaki, and M. Suzuki, SP561/2, pp. 1327 1337 (Sept. 1979).

Measurements of some elementary hyd rocarbon reactions at high temperatures, P. Roth and T. H. Just, SP561/2, Pp. 1339-1352 (Sept. 1979).

The wall-less reactor. A technique for the study of gas phase oxidations and pyrolyses of hydrocarbons, J. E. Taylor, SP561/2, pp. 1353-1358 (Sept. 1979).

Studies of the elementary reaction kinetics of high-temperature species using optical measurement techniques, A. Fontijn, SP561/2, pp. 1359-1370 (Sept. 1979).

Diffusion of carbon dioxide at high temperatures, J. R. Ferron, D. L. Kerr, and A. U. Chatwani, SP561/2, pp. 13731402 (Sept. 1979).

The combustion of pulverized coals-An assessment of research needs, D. R. Hardesty and J. H. Pohl, SP561/2, pp. 1407-1449 (Sept. 1979) 
Transport, thermodynamic and kinetic aspects of salt/ash deposition rates from combustion gases, D. E. Rosner, K. Seshadri, J. Fernandez de la Mora, G. Fryburg, F. Kohl, C. Stearns, and G. Santoro, SP561/2, pp. 1451-1474 (Sept. 1979).

The modeling of modern high pressure arc lamps, R. J. Zollweg, SP561/2, pp. 1477-1494 (Sept. 1979).

The future of gas transport reactions, V. P. Orlovskii, SP561/2, pp. 1497-1506 (Sept. 1979).

New molecules involved in chemical transport reactions: Gaseous halide complexes, H. Schafer, SP561/2, pp. 15071515 (Sept. 1979).

Metal halide-Group III halide vapor complexes with emphasis on aluminum chloride, $H$. A. Oye and D. M. Gruen, SP561/2, pp. 1517-1537 (Sept. 1979).

Formation of chromates from the reaction of alkali chlorides with $\mathrm{Cr}_{2} \mathrm{O}_{3}$ and oxygen, C. Hirayama and C. Y. Lin, SP561/2, pp. $1539-1547$ (Sept. 1979).

Catalytic reactions studies by a matrix isolation technique: Decomposition of $\mathbf{H C O O H}$ on Pt, D. Tevault and M. C. Lin, SP56I/2, pp. $1551-1568$ (Sept. 1979).

Reference data for high temperature systems, L. N. Gevantman, H. J. White, Jr., and D. R. Lide, Jr., SP56I/2, pp. 1571-1579 (Sept. 1979).

Evaluation and compilation of the thermodynamic properties of high temperature species, M. W. Chase, J. R. Downey, and A. N. Syverud, SP561/2, pp. 1581-1594 (Sept. 1979).

Dimensional analysis of partition functions for ionic molecules: Thermodynamic properties of vapors, D. J. Frurip and M. Blander, SP561/2, pp. 1597-1609 (Sept. 1979).

Thermodynamics of non-rigid molecules at high temperature, P. Ip and H. L. Strauss, SP56I/2, pp. $1611-1618$ (Sept. 1979).

Graph theory prediction of the pressure second virial coefficients of some hydrocarbons, fluorocarbons, and their mixtures, W. Brostow, SP561/2, pp. 1619-1638 (Sept. 1979).

Mechanisms of oxidation and hot corrosion of metals and alloys at temperatures of 1150 to $1450 \mathrm{~K}$ under flow, E. A. Gulbransen and G. H. Meier, SP561/2, pp. 1639-1682 (Sept. 1979).

Potassium seed activities in open cycle MHD systems: Predictions using a multiphase multicomponent solution model, $\mathrm{C}$. C. Hsu and C. E. Johnson, SP561/2, pp. 1683-1704 (Sept. 1979).

Computer modeling of gas-condensed phase equilibria: Present status and some future needs in science and technology, M. Blander, SP56I/2, pp. 1707-1715 (Sept. 1979).

SP562. The science of ceramic machining and surface finishing 11. Proceedings of a Symposium held at the National Bureau of Standards, Gaithersburg, MD, Nov. 13-15, 1978, B. J. Hockey and R. W. Rice, Eds., Nat. Bur. Stand. (U.S.), Spec. Publ. 562, 524 pages (Oct. 1979) SN003-003-02122-9.

Key words: abrasion; ceramic machining; ceramics; effects of machining on ceramic properties; hardness; surface characterizations; surface finishing.
This volume presents the proceedings of the Second Symposium on the Science of Ceramic Machining and Surface Finishing held at the National Bureau of Standards in Gaithersburg, MD, on November 13-15, 1978. The symposium was jointly sponsored by the Air Force Office of Scientific Research, the American Ceramic Society, the Office of Naval Research, and the National Bureau of Standards. The purpose of the symposium was to review reccnt progress by discussion of current problems and research efforts. The proceedings contain forty of forty-three research papers, together with floor discussions, presented at the Symposium. Specific topics covered include: 1 ) mechanisms of abrasive machining and surface finishing; 2) technology of machining and surface finishing; 3 ) characterization of machined surfaces; and 4) effects of machining on the properties of ceramics. Also included is an edited discussion on hardness and its relation to machining. These proceedings include the following papers (indented):

Abrasive wear in ceramics: An assessment, A. G. Evans, SP562, pp. 1-13 (Oct. 1979).

Key words: abrasive wear; ceramics; fracture; plastic penetration; thermal stresses.

The mechanisms of material removal during abrasive wear have been examined, and preliminary analyses presented. Primary emphasis has been placed on the lateral fracture mechanism, in an attempt to elucidate both its realm of importance and the concomitant material removal rates. Thermal stresses induced by plastic penetration have also been shown to be a potential source of material removal, especially at low levels of the normal force.

Nucleation of median and lateral cracks around Vickers indentations in soda-lime glass, J. T. Hagan, M. V. Swain, and J. E. Field, SP562, pp. 15-20 (Oct. 1979).

Key words: crack nucleation; fracture; median, radial and lateral cracks; plastic indentations; residual stresses; shear flow lines.

The median, radial and lateral cracks that form around Vickers indentations in soda-lime glass have been studied. Cross sections of the plastic indentations have revealed a system of intersecting flow lines in the deformed zone directly beneath the indenter; these flow lines lie close to the elastic shear trajectories beneath a pointed indenter and also around a radially expanding cylinder. It is suggested that the nucleation of both the median (radial) and lateral cracks arise from the inhomogeneous nature of the subsurface deformation. The nucleation of the bulk median crack occurs at the intersection point of two limiting flow lines and is therefore similar to crack nucleation from a pile of dislocations at an obstacle, or the interaction of dislocations on two intersecting slip planes. The radial cracks are nucleated from the interaction of similar flow lines that develop on the sample surface and around the indentation. The lateral cracks appear to form as shear cracks along the flow lines and are propagated by the unloading residual stresses. The interaction of the flow lines may also be responsible for the powdering or crushing of material that occurs at high indenter loads.

Fragmentation and damage penetration during abrasive machining of ceramics, H. P. Kirchner, R. M. Gruver, and D. M. Richard, SP562, pp. 23-42 (Oct. 1979).

Key words: abrasive machining; ceramics; contact stress; damage penetration; fracture mechanics; fragmentation; glass; grinding; impact; silicon nitride; strength; stress intensity factor. 
Mechanisms of fragmentation and damage penetration during abrasive machining of ceramics were investigated using indentation fracture mechanics. Specimens of glass and hot pressed silicon nitride were damaged by controlled scratching and single point diamond grinding. Vertical and horizontal forces acting on the material were measured for various diamond shapes, set depths and wheel speeds. The damage was characterized by optical and scanning electron microscopy. Cracks, similar to those formed by static contact and particle impact, were observed. The vertical forces were correlated with the extent of damage yielding results consistent with those expected based on indentation fracture mechanics.

Initially, the penetration of damage was analyzed in terms of point contact loading. This analysis resulted in improved understanding of the effect of diamond shape on the variations of the forces and damage penetration which were manifested by variations in the dimensionless contact constant $\chi$. Subsequently, the results were analyzed in terms of line contact loading which allowed the results for hot pressed silicon nitride and various diamond shapes to be represented by a single value of $\chi$.

Single-point scratches as a basis for anderstanding grindimg and lapping, A. Broese van Groenou, N. Maan, and J. B. D. Veldkamp, SP562, pp. 43-59 (Oct. 1979).

Key words: ceramics; chipping; crack formation; fracture toughness; friction; hardness; liquid softening; oxides; scratching; size effect; specific energy.

Considering grinding as a multi-scratch process we have used single-point, low-speed, scratch experiments with pyramidal diamonds in an attempt to understand such quantities as the force ratio and the specific energy in terms of the shape of the diamond and of the properties of the workpiece, here ferrites, glasses and various oxides. The force ratio is found to be dominated by the geometry of the diamond, while the interface friction is small. The specific energy for groove formation is determined by the Vickers hardness. A depth dependence ("size effect") occurs with the harder materials. Moreover, scratch experiments yield information on the resistance of cracking on a microscopic scale and therefore give some idea of the relative strength of the grain boundaries with respect to the grains. A liquid environment of e.g. n-alcohols does not have a pronounced influence on the force ratio and the specific energy for grooving, in contrast to water. Experiments made with a loose particle between a binder material (brass, pitch, steel) and an oxide or a metal shows that the particle motion depends on its shape and on the hardness of the two materials. Rolling occurs where the hard ness values are about equal. For a spherical particle a high load favours rolling, deforming both materials to a moderate extent. Sharp particles behave in an irregular manner and scratch both materials. Finally, scratching is a useful means of testing the homogeneity of materials.

Experiments on hightspeed grinding of ferrites and glasses, A. Broese van Groenou and $\mathbb{R}$. Brehm, SP562, pp. 61-74 (Oct. 1979).

Key words: chipping; ferrites; glass melting; grinding; grinding model; high-speed grinding; pyrex; size effect.

At wheel speeds of $60-100 \mathrm{~m} / \mathrm{s}$ measurements have been made on a horizontal-spindle grinder with a nickel-plated diamond wheel. The grinding force components are unique functions of the continuum chip thickness $h_{e q}=a_{v o} / v_{g}$, over a large range of the depth of cut a, the workpiece speed $v_{v o}$ and the given range of wheelspeed $v_{g}$. The $v_{s}$ de- pendence is different for those glasses where melting occurs. Where a specific energy can be determined, it shows a dependence on the depth of diamond penetration. This "size effect" is strong in the case of low-toughness materials. The energy data are compared with those obtained for grooving in low-speed scratching experiments. Deviations occur where groove formation is accompanied by heavy chipping. Finally, for brittle materials, the requirements of a grinding model are considered, with emphasis on the amount of chipping and the diamond distribution on the grinding wheel. In this model the specific energy is a characteristic of the grinding system and not of the workpiece alone.

Effect of workpiece properties on grinding forces in polycrystalline ceramics, B. G. Koepke and R. J. Stokes, SP562, pp. 75-91 (Oct. 1979).

Key words: chip formation; grinding forces; surface condition; surface grinding.

Grinding forces have been measured on a number of polycrystalline ceramics and correlations between the forces and workpiece properties have been attempted in an effort to gain insight into mechanisms of chip formation. The closest correlations were with a parameter related to the indentation fracture characteristics of each workpiece. This suggests that a major mechanism of chip formation during multipoint abrasive machining of ceramics is fracture resulting from the plastic indentation of the workpiece by the abrasive grains. Grinding forces during up and down grinding were different but both correlated with the indentation fracture parameter when the comminution characteristics of the chips during down grinding were accounted for.

Glass grimding mechanisms and influence on the finished surface and strength, S. Malkin and M. Huerta, SP562, pp. 93-106 (Oct. 1979).

Key words: glass, grinding; strength; surface damage.

Mechanisms for grinding of glass were investigated and related to the finished surface morphology and fracture strength. The abrasive-glass interaction was found to involve flow into chips for grinding with silicon carbide abrasive, and flow followed by concoidal fracture for grinding with diamond abrasive. Much less energy was required for grinding with diamond, since much less of the material being removed is deformed. Grinding conditions causing more flow were generally found to give less surface damage and higher fracture strengths after grinding.

The fine grinding of glass and ceramic material using conventional grinding wheels, E. D. Doyle and S. K. Dean, SP562, pp. 107-114 (Oct. 1979).

Key words: abrasive machining; chip formation; fine grinding; glass; ceramics; material removal.

The fine grinding of glass and ceramic material, using standard silicon carbide and aluminum oxide grinding wheels was studied.

Transparent glass surfaces were produced by both grinding wheels using wheel depths of cut of less than $1 \mu \mathrm{m}$. Electron microscopy of the glass grinding debris produced with the silicon carbide wheel showed that the glass was removed by a chip-formation process, leaving a finely grooved surface. On the ohter hand, the aluminum oxide wheel removed glass by a ploughing process, whereby the appearance of the ground surface on a micro-scale was relatively rough. Surface quality of fine ground glass was found to be dependent on the type of cutting fluid used. 
The silicon carbide grinding wheel produced a smooth surface finish on an alumina workpiece. The mechanism of material removal was predominantly by chip formation. Some wear debris was also produced as a result of a chemical reaction between the wheel and the workpiece in the region of rubbing contact. Alumina workpieces could not be ground with aluminum oxide grinding wheels due to high frictional interactions.

Some observations on environmental effects when diamond drilling, G. A. Cooper, SP562, pp. 115-137 (Oct. 1979).

Key words: diamond drilling; drilling; drilling additives; Rehbinder effect; rock fracture; surface chemistry; wear.

During the forties, the Russian scientist P. A. Rehbinder presented evidence to show that when drilling in rock, the addition of certain chemicals to the flushing liquid had the effect of markedly increasing the rate of penetration. He explained the effect by supposing that the rock was softened or made more brittle by the additive, and hence was more easily drilled.

Results which have been published subsequently have been contradictory and have shown that, inter alia, the rock may be either hardened or softened by the additive. It is significant that even though the original work dates from thirty years ago, there has as yet been no commercial exploitation of the so-called Rehbinder effect.

The present report describes an investigation of the effects of some additives recommended in the literature on the speed of diamond drilling in marble and granite. It is found that at the speeds of penetration common in commercial practice, none of the additives has any effect on the rate of penetration. By contrast, however, they have a very significant effect on the wear of the diamonds. It is this effect which is now thought to be at the root of Rehbinder's observations, and it may well explain the conflicting results obtained by different groups of workers.

Having established this explanation, one then asks how the environment influences the wear of the diamonds. The process is almost certainly chemical, rather than mechanical, and related to frictional heating. Three possible effects of the environment are then possible: 1) the heat generated during cutting is reduced by the environment, 2) the efficiency by which it is carried away is improved, or 3 ) the chemical nature of the additive can influence the wear of the diamond. Work described shows that any or all of these influences can be significant.

The effect of chemical environments on the fracture of ceramic surfaces, R. E. Cuthrell, SP562, pp. $139-145$ (Oct. 1979).

Key words: acoustic emission; chemomechanical effects; environmental effects; fracture of brittle materials; hydrogen embrittlement; Rehbinder effects; Westwood effects.

Environmental effects on the deformation and fracture of a variety of materials during drilling/grinding and four point bending to failure have been traced to embrittlement by hydrogen. The extent of embrittlement is determined by the availability of hydrogen in the drilling fluid or in the gaseous environment in an ultrahigh vacuum chamber $\left(10^{-10}\right.$ Torr $)$. The hydrogen availability is in turn dependent on its binding in liquids (ionic, covalent, ion paired in media of low dielectric constant) or by the blocking effect of adsorbed carbon monoxide in the vacuum chamber. These hydrogen effects were shown in drilling rates, maximum strain to fracture, acoustic emission amplitude (energy) distributions accompanying fracture, and scanning electron microscope photomicrographs of the fractured surfaces. The embrittling effect appears to be universal, affecting in varying degree the behavior of ceramics, glasses, single crystal minerals, polycrystalline materials, semiconductors, refractory coatings, rocks, and metals containing brittle phases (organic solids may be exceptions).

Some results on the wear of a hronze-bonded grinding wheel, A. Broese van Groenou, SP562, pp. 147-155 (Oct. 1979).

Key words: bronze binder; diamonds; erosion; grinding; wear.

Small parts of a diamond grinding tool have been in. vestigated in a grinding apparatus where the tool is fixed whereas the workpiece material, here a $\mathrm{MnZn}$ ferrite, moves at $20 \mathrm{~m} / \mathrm{s}$. The wear of the bronze hinder, and of the diamonds can be measured on plastic replicas: Apart from an estimate of the average $G$ value it is possible to study locally the erosion of the binder and the wear of the diamonds. Two areas of erosion are distinguished: the region between the diamonds and the zone in front of a diamond. For a dozen diamonds it is found that the average erosion rate is proportional to the removal rate of the workpiece, whereas the local rate of increase of zone depth is about twice as fast. For this type of wheel the conditions for self-sharpening can be formulated. For a nickelplated wheel the wear was too small to be measureable.

New concepts on surface finishing and its application to ceramics-Recent progress in ultra-fine finishing in Japan, $O$. Imanaka and M. Okutomi, SP562, pp. 157-169 (Oct. 1979).

Key words: damaged layer; elastic emission machining; environmental effect; hydrate; hydration polishing; mechanochemical polishing with soft powder; pre-existing defect; sapphire; solid state reaction; water vapor; working unit.

This paper outlines the ultra-fine finishing techniques developed in Japan. First, mechanical behavior of a crystal is considered in connection with the "working unit," that is, a bit of stock removal or the range of stress field induced in the working zone. Since the defects pre-existing in the stressed part affect the microscopic deformation or fracture of the material, importance of the working unit as a basic concept in machining or fine finishing should be emphasized. As an attempt to realize ultra-fine finishing by minute elastic fracture of the lattice size order, the study on "Elastic Emission Machining" is described. Chemical phenomena in abrasive machining process are also dealt with; these have led the development of mechanochemical finishing techniques, e.g., "mechanochemical polishing of a hard crystal with a softer powder," and "hydration polishing." Polishing characteristics for the latter method are somewhat detailed. Additionally, fine finishing techniques of ceramics by electron beams and ion beams are reviewed.

Mechanism and application of the "mechanochemical polishing method using soft powder", N. Yasunaga, N. Tarumi, A. Obara, and O. Imanaka, SP562, pp. 171-182 (Oct. 1979).

Key words: high pressure; high temperature; mechanochemical polishing; quartz crystal; sapphire; Si single crystal.

Polishing mechanisms of the mechanological polishing method using soft powders are discussed by estimating the reaction rates at interfacial contact points from static reaction experiments of mixed powder. Considering the case of 
polishing sapphire by $\mathrm{SiO}_{2}$ powder, reaction process of $\alpha$ $\mathrm{Al}_{2} \mathrm{O}_{3}-\mathrm{SiO}_{2}$ powder was examined at high pressures $(36,50$ kbar) and high temperatures $\left(630 \sim 1230^{\circ} \mathrm{C}\right)$ which were supposed to be generated at real contact points in polishing operation. The following are the main results obtained. (1) Reaction ratcs for kyanite formation at high pressures were much higher than those for mullite formation at atmospheric pressure. (2) The theoretical polishing rate estimated from these reaction rates approximately coincides with the one measured in the actual processing of sapphire by $\mathrm{SiO}_{2}$ powder. (3) Polishing of sapphire could proceed only by mechanochemical reactions at contact points.

Mechanochemical polishing of $\mathrm{Si}$ single crystals and quartz crystals were tried in order to extend the applicability of this surface finishing method to other hard materials besides sapphire. It was disclosed that damage-free mirror surface could be obtained by mechanochemical polishing using powders such as $\mathrm{BaCO}_{3}, \mathrm{CaCO}_{3}$ etc. for $\mathrm{Si}$ single crystals and $\mathrm{Fe}_{3} \mathrm{O}_{4}, \mathrm{MgO}$ etc. for quartz crystals.

Extesded discussion: Hardness and its relation to machinimg, R. W. Rice and A. G. Evans, SP562, pp. 185-188 (Oct 1979).

Key words: load application factors; load hardness; load rate; machining; translational motion.

During the conference, a number of questions arose about hardness and its relation to machining. As a consequence, time was set aside for a general discussion; A. G. Evans volunteered to present some specific considerations on this subject as an aid in focusing this discussion. The following note, subsequently preparcd by $\mathbf{R}$. W. Rice and A. G. Evans, represents a summary of both his specific considerations and the general group discussion. Basically, three issues were addressed: 1) the meaning and technique of hardness measurements; 2) the appropriate hardness/load values to use in machining considerations; and, 3 ) the relevance of hardness to multipoint machining.

Optimization of multistage grinding operations: Tợe choice of consecutive removal rates, A. Broese van Groenou, SP562, pp. 191-199 (Oct. 1979).

Key words: grinding; grinding damage; lapping; polishing; polishing times.

The optimum choice of removal rates is determined in a model for multistage grinding on the basis of remedying the damage introduced in the previous stage. A set of second order difference equations is derived from the relation between the depth of damage $d$ and removal rate $\mathrm{Z}$, written in the form $d=a Z^{m}$. The boundary conditions are the shape error in the workpiece $\mathrm{d}_{o}$ and the final, acceptable, depth of damage $d_{e}$. The solution shows that the minimum total time is achieved when the number of stages increases; more than three or five stages are ineffective both as regards the constant duration of each stage and the optimum duration. In contradistinction to normal practice, the first stage-to be optimum-should ensure a high removal rate over a short period of time. The following rates are one order of magnitude smaller and last longer. A map with time contours is given for three-stage grinding; a shallow minimum is found which allows wide margins for choosing removal rates.

Grimding stone, comarete and ceramics with conted abrasives, R. C. Lokken and E. J. Duweil, SP562, pp. 201-207 (Oct. 1979).

Key words: abrasives; ceramics; coated abrasives; grinding; stone.
Silicon carbide coated abrasives grind stone or ccramics most efficiently when run dry and at high speeds. This high energy process appears to heat the surface layer of the workpiece to temperatures which make "chip formation" easy. However, neither the ground surface of the workpiece nor the coated abrasive is thermally damaged to any significant degree. Dry dust collection may be an attractive alternative to the removal of wet debris in water lubricated operations.

Turbine component machining development, D. W. Richerson and M. W. Robare, SP562, pp. 209-220 (Oct. 1979).

Key words: as-machined material strength; dimensional tolerances; profile grinding; silicon nitride; ultrasonic machining.

Various machining methods that have been evaluated to produce ceramic turbine components from high-strength ceramic materials are discussed. These machining methods are compared in terms of economics, dimensional tolerances, surface finish, and strength of the resulting product. Special emphasis is on the machining methods developed for fabrication of rotor blades from hot-pressed silicon nitride $\left(\mathrm{Si}_{3} \mathrm{~N}_{4}\right)$

Machinability studies on MACOR ${ }^{T M}$ glass-ceramic, D. G. Grossman and D. L. Taylor, SP562, pp. 221-229 (Oct. 1979).

Key words: Corning code 9658; glass-ceramic; machinable; MACOR $^{T M}$.

MACOR ${ }^{T M}$ glass-ceramic is a class of ceramic material which lends itself to conventional machiring tools and equipment. This machinability is attributed to the unique microstructure which consists of a highly interlocked array of plate-like mica crystals dispersed in a glassy matrix. The machining of this material is tunlike machining ductile metals and this paper makes some comparisons of the energy requirements, cutting forces and tool wear in turning and drilling operations.

Effects of vgrious polishing media and techniques on the surface firnuish asod behavior of laser glasses, R. L. Landingham, A. W. Casey, and R. O. Lindahl, Sp562, pp. 231 244 (Oct. 1979).

Key words: laser glass; particle characterization; polishing compounds; subsırface defects; surface contamination; surface preparation.

The advance of high-power laser technology is dependent on the rate of advancement in laser glass forming and surface preparation. The threshold damage of glass surfaces continues to be a weak link in the overall advancement of laser technology. Methods were developed and used in the evaluation of existing glass surface preparation techniques. Modified procedures were evaluated to reduce surface contamination and subsurface defects. Polishing rates were monitored under controlled polishing conditions (purity, pH, particle size distribution, particle concentration, etc.). Future work at LLL for this ongoing investigation are described.

The fabrication of alumina tooth roots by fiamond contour grianding, G. L. Messing, L. G. McCoy, and C. R. Hassler, SP562, pp. 247-254 (Oct. 1979).

Key words: alumina; diamond contour grinding; flexure strength; prosthetic device; serrated surface design; tooth roots. 
To determine if the process of fabricating alumina tooth roots by diamond contour grinding significantly reduces the strength of the tooth root, flexure strengths were determined for four different grinding conditions. The grinding conditions studied were grinding direction (longitudinal or transverse) and the sintered state of the alumina during grinding (bisque or fully sintered). Only for one condition (transversely ground, sintered alumina), did the grinding process lead to the strength-limiting flaw. For the other conditions the strength limiting flaw was entirely intrinsic (i.e., pores) or an interaction of a pore with surface damage from grinding.

Simultaneous finishing of both surfaces of hemispherical domes, R. Gentilman, F. Cooke, and P. Miles, SP562, pp. 255-260 (Oct. 1979).

Key words: dome finishing; finishing technique; hemispherical domes; oxides; sapphire; two-surface lapping; two-surface polishing.

The high cost of finishing durable oxide materials is the major factor limiting their use as infrared domes for future missiles. A novel technique has been developed for lapping and polishing both surfaces of hemispherical domes simultaneously. The technique, which halves finishing time and costs, has been successfully demonstrated for sapphire and glass.

Abrasionless machining methods for ceramics, R. F. Firestone, SP562, pp. 261-281 (Oct. 1979).

Key words: ceramics; chemical milling; electric discharge machining; electron beam machining; glass; hydrodynamic machining; ion beam machining; water jet cutting.

Abrasionless machining methods for ceramic materials are reviewed with extensive references to the recent literature. These methods offer significant advantages over traditional abrasive machining methods since they are not limited by the hardness of the ceramic and easily machine delicate or complex parts.

Shaping silicon compound ceramics with a continuous wave carbon dioxide laser, S. M. Copley, M. Bass, and R. G. Wallace, SP562, pp. 283-292 (Oct. 1979).

Key words: laser; shaping; silicon compound ceramics.

Results are presented on the use of a high power continuous wave carbon dioxide laser to shape workpieces of $\mathrm{Si}_{3} \mathrm{~N}_{4}$, SiAlON and $\mathrm{SiC}$. Several shaping operations have been investigated in the turning configuration including grooving, threading and the production of convex and concave surfaces. A straightforward analysis is presented, which predicts the feed and beam power corresponding to a specific surface roughness grade and effective material removal rate.

Optical and surface physical characteristics of diamondmachined infrared windows, D. L. Decker, D. J. Grandjean, and J. M. Bennett, SP562, pp. 293-303 (Oct. 1979).

Key words: diamond single-point machining; dielectrics; infrared optical components; laser damage; optical properties.

This paper presents the results of the diamond turning of surfaces of a wide range of single-crystal and polycrystalline infrared window materials, including $\mathrm{Ge}$, $\mathrm{CaF}_{2}, \mathrm{MgF}_{2}, \mathrm{SrF}_{2}, \mathrm{KCl}$, and $\mathrm{GaAs}$. These surfaces were obtained from an advanced air-bearing, diamond-turning machine recently brought to an operational state at the Naval Weapons Center. The surface characterization per- formed includes a wide range of optical and surface physical examination including an analysis of scattered and absorbed light, and a surface microtopographic examination by diamond profilometry, phase contrast interference (Nomarski), and scanning electron microscopy. These data are compared with earlier results and are related to the characteristics of the Naval Weapons Center diamondturning machine and to the machining parameters. A companion paper at this conference discusses the laser damage resistance of these surfaces with implications for their usc in laser applications.

Electrochemical grinding and surface damage for cemented carbides, S. Malkin and R. Levinger, SP562, pp. 305-315 (Oct. 1979).

Key words: ccmented carbides; electrochemical grinding; grinding; tungsten carbide.

The electrochemical grinding process (ECG) for WC-Co cemented carbides is shown to be governed by differences in electrochemical dissolution rates into the two phases. An electrochemical analysis indicates that the initial electrochemical etching rate into the cobalt phase is much faster than into the WC. This facilitates mechanical removal during ECG but produces a damaged surface weakened by partial cobalt depletion. The degrce of surface damage is quantitatively measured as the reduction in mechanical grinding resistance as a function of depth below the finished surface.

A new ultra-fine polishisg technique for sapphire, T. Sugita, S. Kawakami, and O. Imanaka, SP562, pp. 317-323 (Oct. 1979).

Key words: crystallographic integrity; electron diffraction images; hydrated layer; ion microprobe mass spectrometer; roughness; sapphire; ultra-fine polishing; water; $x$-ray photoelectron spectrometer.

A new method of ultra-fine polishing for sapphire oriented with the polishing surface parallel to the (0001) plane is proposed, and the nature of the polished surface is analyzed. Experimental polishing is performed in water using a pin-on-disk machine with a tool disk made of sintered alumina. The sapphire is remarkably polished by friction action causing removal of the surface asperities; the polishing rate is significantly decreased as the smoothed surface is formed. Roughness of the polished surface is less than Rmax of $200 \AA$. Behavior of friction is very stable in comparison with specimen worked in air. A high crystallographic integrity of the surface polished in water is confirmed from electron diffraction images. Analyses of the surface with $\mathrm{x}$-ray photoelectron and ion microprobe mass spectrometers indicate the presence of a very thin hydratcd layer which acts as an anti-friction agent preventing the damage of the nonhydrated substrate.

Fine polishing of sapphire crystals, M. Ikeda, A. Yamada, Y. Kokaji, and S. Kimura, SP562, pp. 325-333 (Oct. 1979).

Key words: damaged layer; fine polishing; sapphire; silicon; solid state reaction; wear debris.

A new method for polishing sapphire crystals has been developed which is based on a chemical reaction at the contact area between surfaces of solids to be polished and a polishing disc. Special features of this method are as follows: (1) A scratch-free and smooth surface is produced on the basis of reaction between silicon oxide and alumina. (2) The worked layer left in a subsurface polished is so thin as not to be detected with a Berg-Barrett method. (3) Use of a rigid polishing disc results in a highly flat finished 
surface. (4) Since no abrasive particles are used, a clean working environment is maintained.

Surface characterization of optical materials, H. E. Bennett, SP562, pp. 337-350 (Oct. 1979).

Key words: Auger spectroscopy; corrosion films; ESCA; impurities; microroughness; optical microscopy; polishing defects; scattered light; SIMS; stylus instruments.

A complete description of the surfaces of optical materials involves their topography, presence of particulates, crystallinity and degree of disorder at the surface, impurities in the vicinity of the surface, stoichiometry at the surface, and surface films. The most direct method for observing small surface imperfections is by using electron or optical microscopy. Often transmission electron microscopy using replication has too high a lateral resolution and too low a depth resolution to ivestigate imperfections of greatest optical interest. Surprisingly, optical interference microscopy has one to two orders of magnitude higher depth resolution than electron microscopy, and techniques such as differential interference contrast, sometimes called Nomarski microscopy, are extremely useful in evaluating surfaces qualitatively. For quantitative results, stylus techniques and interometry using fringes of equal chromatic order are very useful and give results in good agreement with those obtained by scattered light measurements. Total integrated scattering provides a simple noncontact method for determining the rms height of surface irregularities and may be applied in various surface roughness determinations. Evaluating the roughness of ball bearings is one example.

Surface impurities and stoichiometry at the surface also affect the performance of optical materials. Impurity atoms in concentrations as low as 0.001 monolayer can be detected using Auger spectroscopy. There is a danger however, of disturbing the surface with the high energy electrons required to produce the Auger electrons unless very low electron currents are used. This problem is alleviated by using electron spectroscopy for chemical analysis (ESCA), which depends on photoemission induced by $x$ ray or vacuum ultraviolet irradiation rather than on electron bombardment. ESCA is also more sensitive to molecular forces than is Auger spectroscopy, so that compounds as well as the atomic constituents can often be detected. Even more sensitive is secondary ion mass spectroscopy. In many cases, surface impurity levels in the $10^{-6}$ range can be detected using this technique. Surface films also affect the optical properties of materials, often significantly. Their growth can be monitored using ellipsometry, which is insensitive to roughness introduced by the film and is sensitive to changes in average film thickness of a fraction of a monolayer. A new surface evaluation technique being developed is high fluence diagnostics and multithreshold analysis. Most of the techniques discussed are applicable to nonoptical surfaces as well as optical surfaces, and should be used more widely in analyses of surfaces produced by ceramic machining.

The nature of strength controlling machining flows in ceramics, R. W. Rice and J. J. Mecholsky, Jr., SP562, pp. 351-378 (Oct. 1979).

Key words: brittle failure; flaw populations; flaws; fractography; fracture origins; grinding; machining; polishing; sanding; strength-size effects.

The nature of machining flaws introduced in a variety of glass, single crystal, and especially polycrystal bodies are reported, based on fractographic determination of such flaws as the source of mechanical failure. Particular attenuation is given to grinding where the anisotropy of strength due to the direction of grinding relative to the tensile axis is shown to be due primarily to a dual population of flaws of differing shapes. One set of flaws form $\sim$ perpendicular and another $\sim$ parallel to the grinding direction. The latter flaws are typically substantially more elongated and often larger than the former and thus give lower strengths for stressing perpendicular to the direction of grinding. Sawing, sanding, and polishing are also shown to result in similar dual flaw populations. The character of flaws are examined as a function of the type of material and machining, as well as specimen size and shape. The latter suggests a limited strength-size effect due to machining flaws. However, the key findings are that machining flaws do not vary greatly with typical variations of machining or material parameters, e.g., composition, grain size, or hardness.

Acoustic surface wave measurements of surface cracks in ceramics, B. T. Khuri-Yakub, A. G. Evans, and G. S. Kino, SP562, pp. 379-392 (Oct. 1979).

Key words: acoustic surface wave; ceramic; surface characterization; surface crack; turbine blade.

Acoustic surface wave techniques for detecting and characterizing surface cracks in ceramics have been devised. The techniques have been demonstrated to detect cracks at least as small as $60 \mu \mathrm{m}$ in depth, on polished samples. The crack detectability was diminished by surface grinding, because of a background effect attributed to the backscattering from surface microcracks. Preliminary experiments conducted on turbine blades indicated that the techniques can be applied to components of complex shape.

Characterization of surface damage in ceramics using selected area electron channeling, J. Lankford and D. L. Davidson, SP562, pp. 395-404 (Oct. 1979).

Key words: electron channeling; plasticity; subsurface damage; surface damage.

The technique of selected area electron channeling has been applied to the problem of characterizing subsurface plastic damage introduced during ceramic machining and polishing operations. The surfaces of ceramics spanning a wide range in hardness were prepared under controlled grinding and polishing conditions. Subsurface regions of sectioned specimens were subjected to electron channeling analysis, enabling the boundaries of the subsurface damage (plastic) zones to be mapped out. It was determined that under conditions of constant applied load, the depth of damage during polishing is inversely proportional to the square root of the hardness; this finding is in good agreement with predictions based on indentation theory.

Y-denection modulated secondary electron images in the evaluation of ceramic surface finish, L. P. Cook, E. N. Farabaugh, and C. D. Olson, SP562, pp. 407-415 (Oct. 1979).

Key words: ceramic; scanning electron microscope; secondary electron emission; silicon; surface roughness; $y$-deflection modulation.

Variations in secondary electron emission intensity as a function of surface topography have been examined for single crystal silicon surfaces of three different roughnesses. It is possible to calibrate absorbed current, and under carefully controlled conditions, to calibrate secondary emission for quantitative study of surface angu- 
lar variation. Such data can be statistically processed to give information on surface slopes analogous to that obtained from profilometry. The agreement between profilometer and preliminary SEM data appears to be good for the roughest of the silicon surfaces. The utility of this as a general method for the examination of ceramic surfaces is suggested for instances where specimen charging can be properly eliminated.

Latent scratches on optical glasses that appear after cleaning, T. Izumitani, E. Miyade, S. Adachi, and S. Harada, SP562, pp. 417-425 (Oct. 1979).

Key words: cleaning; chemical durability; glass surface: latent scratch; optical glass; polishing.

The latent scratch which appears on polished optical glass surfaces was studied. The latent scratch, as the word implies, can be hardly detected in polishing process, but becomes evident after cleaning or after antireflection coating. The appearance of the latent scratch is affected by (1) the polisher, (2) the polishing grains, (3) the mechanical condition of the polishing, and (4) the glass property. And it is also affected by the corrosion power of the cleaning solution. It is concluded that the latent scratches are the scratches which are formed as undetectable fine scratches in the polishing process and grow to the detectable size in cleaning process. On the basis of this fact, a method of preventing latent scratches was suggested.

Machining flaws and the strength grain size behavior of ceramics, R. W. Rice, SP562, pp. 429-452 (Oct. 1979).

Key words: brittle failure; flaw sizes; grain size dependence of strength; strength.

A model for the strength-grain size dependence of ceramics failing from machining flaws is presented based on the observation that the size of machining flaws (C) shows little or no dependence on grain size. Two regimes of behavior are seen. At finer grain sizes, little or no strength dependence on grain size $(G)$ exists because flaws are $>$ G. For large $G$, the significant decrease of strength with increasing $G$ is attributed to a transition from polycrystalline to either lower single crystal or grain boundary (i.e. bicrystal) fracture energies was the $\sim$ constant (C) becomes significantly less than the $G$ as $G$ increases. The transition between the two regimes is when $C$ and $G$ are similar. Extensive analysis of strength-grain size data, and more limited directly correlated fractographic data support the proposed model. Spontaneous cracking in noncubic materials is shown to support the model, but not be an alternate explanation for the transitions seen in machined $\mathrm{Al}_{2} \mathrm{O}_{3}$ or $\mathrm{BeO}$. This analysis also further supports the observation that machining flaws do not vary greatly with typical variations in machining parameters.

Surface machining effects on the strength distributions of aluminas, T. E. Easler, T. A. Countermine, R. E. Tressler, and R. C. Bradt, SP562, pp. $455-462$ (Oct. 1979). removal rate; Weibull function.

Three microstructurally different, dense polycrystalline aluminas were machined with 400 -grit diamond at two different rates of surface removal. Flexural strengths were measued in four-point bending under toluene and the strength distributions analyzed by two-parameter Weibull statistics. Effects of edge-bevelling on the distributions were also examined. Machined surfaces and the bevelled and non-bevelled sample edges were examined by SEM. For all of the materials, the lesser rate of surface removal was less severe in edge chipping, and yielded higher average strengths and increased values of the Weibull parameters, $\mathrm{m}$ and $\sigma_{0}$.
Effect of sarface finish on the strength of hot pressed silicon nitride, C. A. Andersson and R. J. Bratton, SP562, pp. 463474 (Oct. 1979).

Key words: finishes; flexure; fracture; fracture mechanics; grinding; silicon nitride; strength; surface.

Statistical flexural strenghts of hot pressed silicon nitride, Norton NC 132, were determined as functions of the stress axis to hot pressing direction, the coarseness of grinding and the stress axis to grinding orientation. The higher strengths of the material tested perpendicular to the hot pressing direction rather than parallel to it can be attributed to a proportional difference in the critical stress intensities between the directions. Coarser grinding media introduces larger flaws and reduces strength. Finally, transverse grinding produces stress concentrating grooves, effedtively deeper cracks and possibly wider ones which reduce the applied stress necessary to cause propagation.

The effect of surface finishing on the strength of commercial hot pressed $\mathrm{Si}_{3} \mathrm{~N}_{4}, \mathrm{C}$. C. Wu and K. R. McKinney, SP562, pp. 477-481 (Oct. 1979).

Key words: fracture origin; fracture strength; machining of ceramics; oxidation and degradation; silicon-nitride.

Effects of diamond grit size on the as-ground and oxidized strength of commercial hot-pressed $\mathrm{Si}_{3} \mathrm{~N}_{4}$ were studied. Finer grit sizes gave higher as-ground strengths. Prolonged high temperature oxidation negates effect of machining on strength.

Surface condition and strength of silicon carbide-Silicon materials, T. J. Whalen and $\mathbb{L}$. L. Terner, SP562, pp. 483488 (Oct. 1979).

Key words: coatings; SiC; strength; surfaces.

The measured strength of SiC-Si materials with as-silicided ground, and ground and polished surfaces was determined. The influence on strength of $\mathrm{SiC}$ and nickel coatings and the geometry of test specimens was studied.

The effect of grinding and polishing on the strength of annealed soda-lime-sillica glass, $\mathbb{R}$. Bowles, SP562, pp. 489-500 (Oct. 1979).

Key words: defects; etching; glass; grinding; polishing; strength.

As part of the continuing studies sponsored by the Procurement Executive, Ministry of Defence (UK), recent work at British Glass Industry Research Association has aimed at assessing the defects generated in glass during its working under conventional grinding and polishing procedures.

The assessment has been mainly based upon mechanical strength property measurements of lath specimens typically $150 \times 25 \times 3.5 \mathrm{~mm}$ either at specific stages of processing or after a controlled sequence of operations designed to produce a state of minimum surface damage.

The strength of laths was determined under four point flexure test, at a nominal stress rate of $5 \mathrm{MPa} / \mathrm{s}$ under normal ambient conditions of temperature and humidity.

The resulting fracture stress data was calculated on simple bending theory after bonded strain gauge tests indicated its adequacy under observed deflections to fracture. Group statistics were largely calculated assuming normal distribution theory but tests on aggregated groups of specimens were also examined by Weibull distribution theory to determine the probability of fracture under relatively lower stresses. 
Surface flaw effects on crack propagation from subsonic water drop impact, Y. M. Ito and M. Rosenblatt, SP562, pp. 501-511 (Oct. 1979).

Key words: crack activation; numerical simulation; subsonic water drop impact; surface flaws.

The effects of surface flaws on ceramic target damage from subsonic water drop impacts are investigated using numerical code simulations based on fundamental wave propagation and fracture mechanics concepts. The water drop impact generates a tensile stress wave with a steep near-surface gradient. As a consequence of this steep stress gradient, crack activation is dependent on the depth of surface flaws. In addition, a relatively large flaw can perturb the stress field such that crack activation in its vicinity is suppressed.

Surface characteristics of diamond-machined ceramic surfaces evaluated by high fluence diagnostics, M. J. Soileau, J. O. Porteus, and D. L. Decker, SP562, pp. 513-518 (Oct. 1979).

Key words: ceramic surfaces; diamond single-point machining; high fluence; laser irradiation.

Ceramic surfaces prepared by precision diamondmachining are compared with surfaces prepared by conventional polishing. Comparison is made on the basis of high fluence diagnostics. The results indicate that the diamond-machined surfaces have as high or higher failure resistance under high fluence loading as surfaces prepared using conventional techniques. Failure of both diamondmachined and polished surfaces are strongly dependent upon surface structure and surface contamination. These findings indicate that diamond-machining is an attractive alternative for generating optical surfaces on ceramic materials.

SP563. MFPG-Advanced composites: Design and applications. Proceedings of the 29th Meeting of the Mechanical Failures Prevention Group, held at the National Bureau of Standards, Gaithersburg, MD, May 23-25, 1979, T. R. Shives and W. A. Willard, Eds., Nat. Bur. Stand. (U.S.), Spec. Publ. 563, 304 pages (Oct. 1979) SN003-003-02120-2.

Key words: advanced composites; applications of composites; composites; composite structures; design using composites; fiber composites; fiber glass; filament wound composites.

These proceedings consist of a group of thirty one submitted entries (twenty one papers and ten abstracts) from the 29 th meeting of the Mechanical Failures Prevention Group which was held at the National Bureau of Standards in Gaithersburg, MD, May 23-25, 1979. The subject of the symposium was the design and application of advanced composites. Special emphasis was directed to aerospace, aircraft, automotive, marine, and industrial applications and design. Failure modes in advanced composites were also discussed. These proceedings include the following papers (indented):

Characterization and application of advanced composite materials, M. Waddoups, SP563, p. 3 (Oct. 1979).

Key words: aircraft structural cemponents; composite materials; linear elastic materials; tensile fracture.

A technical understanding of the structural characteristics of composite materials and the critical issues in aircraft structural component development have been simultaneously generated. It is established that the strengthening concept, structural characteristics, and fabri- cation techniques are distinct from metals. These differences and the resultant structural implications are the subject of this lecture.

For practical purposes, composites are linear elastic. Tensile failure modes are brittle fracture governed, and compressive failure modes are micro and macro stability governed. Even though composites have no classical ductility, they are surprisingly tough materials. In most fullscale structures currently developed, tensile fracture constitutes the critical strength failure mode.

While generally tensile fracture governs strength, an equivalent-to-crack coalescence and monotonic growth in tension are not observed in composites (except glass-fiberreinforced plastics). In fact, tension-dominated cracking is not of serious consequence in advanced laminates. Weak plane (intralaminar and interlaminar) flaw propagation, predominantly in compressive and shear loadings, yields the lift limiting failure modes for composites. When modeled as strain-energy release-rate-driven flawgrowth processes, different growth rates and initial strengths generate competing failure modes in full-scale structures.

Simple structural forms that control the life-limiting failure processes will become the rule for successful structures. Only on stiffness critical or fairing type of structure will the complex shape moldability advantages of composites be used.

Because of the scale effects in the fracture process zone and the ability to react significant out-of-plane loads, simple mechanical fastening will dominate highly loaded, strength-critical structure. Secondary adhesive bonding will not be very successful in highly fracture critical structure.

Physical and mechanical response of graphite/polyimide materials to long term exposure in a space environment; material preparation and control testing, J. H. Powell, SP563, pp. 4-16 (Oct. 1979).

Key words: cocured and precured laminates; exoatmospheric exposure of composites; Long Duration Exposure Facility (LDEF); polyimide composite stability in space; polyimide/graphite mechanical properties; ultrasonic inspection.

Graphite/polyimide (Gr/PI) composite laminates are currently being prepared for deployment on NASA Langley Research Center's Long Duration Exposure Facility (LDEF). The experiment is intended to provide scientific and engineering design information on the response of Gr/PI composites to an actual exoatmospheric environment. Material systems to be exposed are a bismaleimide Pl (Hexcel F-178) on Thornel 300 graphite fibers and a condensation PI (Monsanto Skybond 703) on HT-S graphite fibers, including both "precured" and "cocured" laminates. Initial physical characteristics determined on both exposure and simultaneously processed control panels include flatness, microcracking, void content, dry weight, and general appearance. Mechanical tests performed to date (on control panels only) are the basis for strength and elastic properties in tension, compression, and (rail) shear at ambient and elevated temperatures. Following in-space exposure of test panels and return to earth, identical physical and mechanical determinations will be made. Data generated before and after exposure will be compared to identify any changes in physical or mechanical characteristics, particularly any unexpected changes. The ultimate output of the experiment will be either confirmation of predicted material behavior or the basis for revised prediction methods.

Effects of room-temperature aging on composite prepregs, H. C. Nash, C. F. Poranski, Jr., and R. Y. Ting, SP563, pp. 17-21 (Oct. 1979). 
Kcy words: aging of polymer; composite; fiber; mechanical properties; moisture; prepreg.

Prepreg materials of organic-matrix composites have very limited shelf-life, even under the required cold-storage conditions. A prepreg aging study has been carried out by storing prepreg materials at room temperature under three different controlled humidity levels. Exposed samples were examined periodically by proton NMR spectroscopy, and unidirectional 16-ply laminates were fabricated. Prepreg appearance, curing behavior, and laminate propcrtics were found to change with prepreg out-time.

Application of instrumentall techniques to the study of the cure of phthalocyanine/graphite composites, R. Y. Ting, SP563, pp. 25-31 (Oct. 1979).

Key words: cure; dielectric analysis; DSC; graphite-fiber; polyphthalocyanine; prepreg; TGA; V/STOL

Work on resin evaluation in the NRL V/STOL aircraft program is directed toward the development of high temperature resins for application as potential composite matrix materials. As successful prepregging of the polyphthalocyanine/graphite-fiber system has recently been demonstrated, the processability of this material is now under study. Instrumental techniques including differential scanning calorimetry (DSC), thermogravimetric analysis (TGA) and dynamic dielectric analysis are employed to examine the thermal properties of unidirectional prepregs and the fabrication of unidirectional laminates. Results of these studies have led to the development of a cure cycle for this new resin system.

Molsture diffusion analysis for composite microdamage, $C$. L. Leung and D. H. Kaelble, SPS63, pp. 32-46 (Oct. 1979).

Key words: diffusion coefficents; iteration; moisture profile modeling; nondestructive evaluation; statistical estimation.

Because of their favorable performance characteristics, advanced composites using graphite fibers as reinforcement are increasingly being used in aerospace and commercial applications. There has been much concern, however, about the extent and mechanisms of strength degradation of these composites when exposed to moisture for long periods of time. In this paper, methods to obtain directional diffusion coefficients, i.e., $D_{x}, D_{y}$ and $D_{z}$ for the principal axis of a unidirectional fibrous composite are described by moisture absorption and effusion measurements. Additionally, analytical models have been developed to calculate, using the previously established diffusion coefficients, the moisture profile of the composite after periods of moisture exposure. The feasibility of the integration of the effusion rate measurement, moisture profiling, and strength prediction into a computer-aided analyzer for composite microstructure damage or defect is discussed.

Recent work on techniques and applications of moisture barriers to graphite epoxy composites, J. F. Haskins, SPS63, pp. 47-56 (Oct. 1979).

Key words: advanced composites; dimensional stability; eutectic coating; graphite/epoxy; moisture barrier; space optics.

A number of space systems such as Thematic Mapper, MAGSAT and other space optical devices require that the components be dimensionally stable during both ground and space operation. It has been found that certain graphite/epoxy composite laminates can provide extremely low coefficient of thermal expansion $\left(\alpha<0.05 \times 10^{-6}\right.$
in./in.F) and because of this are ideally suited to optical benches, telescopc housings, and mirror substructures. Howevcr, the epoxy must be protected from moisture because it is hygroscopic and does change dimcnsions as it absorbs or dcsorbs moisture. Typically it may change as much as 100 microinches/inch over a period of several months when exposed to high relative humidity. This becomes a problem becausc most of the equipment will be manufactured, assembled, and operated in a humid environment before it is launched into space. Holding the humidity at low level lessens this problem but does not eliminate it.

A real advance in optical equipment for use in space can be made if graphite/epoxy can be sealed from moisture without substantially changing its weight and coefficient of expansion. The objective of this work was to test the effectiveness, develop inspection procedures, and check the reliability of a moisture barrier developed previously at General Dynamics Convair Division.

This paper gives the results of a critical evaluation of the effectiveness and reproducibility of the eutectic coating. Fifteen-inch long graphite/epoxy coated specimens were used to study processing variables, inspection techniques, and dimensional changes due to moisture pickup.

In-service ultrasonic inspection system for composites, $F$. $H$. Chang, J. R. Bell, A. H. Gardner, C. P. Fisher, and G. P. Handley, SPS63, p. 59 (Oct. 1979).

Key words: composite structures; flaw simulation; semi-automated ultrasonic inspection; ultrasonic inspection system.

Advanced composite structures are presently used on high performance U.S. Air Force aircraft to save weight and increase performance. These structures are often difficult to inspect because of their complex/multi-bondline construction and because of the general lack of experience in the inspection of composite structures in the field environment. Ultrasonic techniques have generally been employed for the detection of service induced discontinuities such as disbonds and delaminations. They are not considered cost effective for inspection of large areas for small flaws or for monitoring areas containing known small flaws for propagation during service, primarily because of the lack of flaw position locating and permanent inspection result recording devices. An ultrasonic technique was developed under an AFML contract to record the position and flaw indication in a permanent manner and minimize operator dependence to obtain a high level of inspection reliability. The technique is simple to apply in the field environment by personnel without advanced training. In the program, specimens representing typical composite structures and containing implanted flaws simulating service induced or production type defects were fabricated. Improvements were made to the state-of-the-art ultrasonic inspection techniques to detect these defects. A follow-on program is being conducted to establish the producibility of the semi-automated ultrasonic inspection system for aircraft composite structure, based on the preliminary design developed in the previous contract, to provide a complete inspection system from inception to obsolescence.

Design considerations for graphite-epoxy laminates of low thermal expansivity, D. D. Smith, SP563, pp. 60-71 (Oct. 1979).

Key words: advanced composite materials; graphite-epoxy laminate design; laminate design sensitivities; thermal expansion. 
The development of graphite-epoxy laminate designs tor spacc missions requiring structural components with near zero coefficient of thermal cxpansion (CTE) is examined. The selcction of fiber systems and laminate designs is approached by evaluating CTE scnsitivities to material and process variabilitics. Uniaxial and biaxial thermal stability laminates are considered. From this design approach. material and process specification tolerances can be determined to control laminate CTE within design objectives. Design examples are presented to illustrate this laminate design approach

Aircraft composite materials selection and application, V. I Reneau, SP563, pp. 72-79 (Oct. 1979)

Key words: aircraft; composites; design allowables.

Composite aircraft structure requires proof of safety and durability similarly to metallic structure. The proofs of structural analysis methods, reliable material properties, and of assembly methods are similar to those rcquired for meta! structure. The effects of environment, time and fatigue damage are different than for metal and must bc compcnsated for when design properties (allowables) are developed. Design allowables arc not as readily available for composites as for metals and frequently must be obtaincd by testing

Composite structures in rotors and propellers, D. F Thompson, SP563, pp. 80-88 (Oct. 1979).

Kcy words: blade acroelastic behaviour; blade manufacturc and quality control; composite propcllers and rotors; failsafe blade design; propeller fatigue bchaviour; propeller materials requirements.

A variety of composite rotor blade and propeller dcsigns are reviewed. Desirable blade composite material qualities are cnumcrated. Various failsafc dcsign features are shown for propeller blades. Multiple load path design features are discussed. Some manufacturing and quality control aspects of composite blade construction are discussed. Composite material properties versus cost factors are discussed.

Development of a library module for the analysis of advanced composite materials, K. T. Knoll, SP563, pp. 91-107 (Oct. 1979).

Key words: advanced composite materials; composite materials analysis; orthotropic materials; programmable calculators; solid state software.

Because of their orthotropic nature, advanced composite materials present some special problems to the engineer. The rclation between the elastic constants of an orthotropic material is more complex than that of an isotropic material. In addition, composites exhibit coupling between normal and shear deformations as well as between bending and stretching load responses. The more complicated behavior of advanced composites is usually handled using techniques of matrix mathematics, but the required bookkeeping often overwhelms the isotropic-trained engineer who is used to working with fewer terms and less complicated equations. This paper discusses the development of a module, designed to be used with the Texas Instru. ments T1-58 and T1-59 desktop calculators which can be used to handle much of the required "bookkeeping." Given such input as the elastic constants of a single ply of composite material, the stacking sequence of a laminate, and the applied loads (or strains), the module will output desired information such as the physical properties of a laminate, the strains (or loads) in both the whole laminate and the individual plies, and the values of the laminate properties as the laminate is rotated. The module will also provide "strength ratios" for particular laminate and load vector to indicate how close the material is to failure. It is hoped that this module will make the analysis and use of advanced composites seem less formidable to both research and developmental engineers.

Structural SMC-Materia!, process and performance review, R. B. Jutte, SP563, pp. 108-129 (Oct. 1979).

Key words: glass fiber reinforcement; polyester resin; structural sheet molding compound.

Sheet molding compound (SMC) has been used for functional or fascia automotive parts such as front and rear pancls for scveral years. When properly formulated, processed, and molded, SMC has a potentially substantial role in the manufacture of more structurally demanding automotive parts.

Through variations in the materials, equipment and processing techniques, different types of SMC can be produced. These are random fiber SMC (SMC-R); continuous fiber SMC (SMC-C); and directional fiber SMC (SMC-D).

Representative formulations show how static mechanical properties are dependent upon glass content, glass orientation, and on the test temperature.

Based on equivalcnt performance, these systems are lighter in weight than steel and arc generally less costly, on a material basis, than aluminum.

Development of a graphite-epoxy spacecraft precision wounting platform, K. S. Budlong and A. W. Sheffler, SP563, "p. 130 (Oct. 1979).

Key words: composite design; graphite-epoxy; Precision Mounting Platform; resonant frcquency.

A wide variety of spacecraft applications require structure which is ultralight in weight while satisfying tight stiffness (resonant frequency) criteria, along with critical pointing accuracy and thermal distortion rcquirements. This paper presents the design, analysis, and test of a graphite-epoxy precision mounting platform intended to replace the current aluminum platform being flown on an Air Force satellite program.

The Precision Mounting Platform (PMP) provides an instrument mounting surface which is defined and controlled for each instrument to within $0.0 \mathrm{i}$ degree. It maintains a mutual alignment of the instruments to within 0.003 degree through the full range of thermal gradients occurring on orbit. While the aluminum PMP uses active thermal controls to minimize thermal gradients and maintain alignment, the composite design takcs full advantage of the near zero coefficient of thermal expansion of the GY70/X30 graphite-epoxy, thus eliminating active control. The ultra-ligh stiffness of the composite is also critical in maintaining the resonant frequency range defined by overall spacecraft dynamics for the aluminum PMP. The graphiteepoxy PMP provides in addition a weight savings of 32 percent while fulfilling all the requirements of a direct replacement for the current aluminum version.

Design analysis of automotive composite structures, M. F. Kowalski, D. S. Fine, and R. K. Herrman, SP563, p. 133 (Oct. 1979).

Key words: automotive structures; composite material; composite material analysis program; Tsai-Wu tensor polynomial lamina strength failure criterion.

Advanced composite matcrials offer potential for structural mass reduction in automotive structures due to their 
high strength-to-weight ratios. In addition, they provide styling freedom to reduce aerodynamic drag forces and part consolidation advantages for vehicle system design. Consequently, they may play an increasing role in the reduction of fuel consumption in the next generation of automobiles.

Traditionally, prevention of mechanical failure has been a key automotive design goal. This is necessitated because our products are often subjected to abuse for lack of required periodic inspections and maintenance. Failures lead to product liability claims, high warranty repair costs, and dissatisfied customers. Failure prevention is difficult because of the wide variety of operating conditions and environments our product experiences, and because the product must be produced by a mass production technology at a cost our customers can afford. Considering the fact that there are over 15,000 parts in an average automobile, our components must be designed for very high reliability.

Because of the nature of advanced composite materials, particularly their anisotropy and their multiple failure modes, the design and analysis procedures currently employed to minimize failure on metal structures are not adequate for composite structures. In anticipation of the need to address the automotive design possibilities of composite materials, a study has been conducted to determine what modifications are needed in the existing finite element structural analysis procedures. It has been found that a composite material analysis program, SQ5, now widely used in the aerospace industry, offers potential for automotive structural analysis.

SQ5 is based on classical laminate plate theory and can be used in two modes. The first is an input pre-processor to compute equivalent orthotropic properties from a laminate description. The second is an output post-processor to predict first ply failure and safety margins from laminate strength data. The program has been modified to employ the interactive Tsai-Wu tensor polynomial lamina strength failure criterion. Limited comparisons have been performed with theoretical solutions, based on classical laminate plate theory, and with test data for static and dynamic response of composite panels. Predicted failure loads have also been compared with measurements.

Fiberglass reinforced plastics use in transportation vehicles, R. D. Pistole, SP563, p. 134 (Oct. 1979).

Key words: fiberglass composites; fiberglass reinforced plastics.

The use of Fiberglass Reinforced Plastics (F.R.P.) in ground vehicles has steadily increased in recent years.

In 1975 one of F.R.P.'s largest penetrations into exterior passenger car panels was grille opening panels or front headers. This use was cost effective due to the consolidation of many metal parts by one F.R.P. molded panels.

Today, with the need for lighter weight automobiles to improve fuel economy, F.R.P. is again the answer with its additional advantages.

One piece truck hoods are becoming more popular as they too turn to fiberglass composites. Many new truck designs utilizing F.R.P. are appearing on our highways.

The manufacturing of F.R.P. car and truck components will be discussed in this presentation.

Designing automotive components with continuous fiber composites, H. T. Kulkarni and P. Beardmore, SP563, pp. 135-151 (Oct. 1979).

Key words: automotive component design; continuous fiber composite materials; fabrication; finite element stress analysis; front end; graphite; part integration; wheel.
The primary characteristics of continuous graphite fiber reinforced plastics as structural materials are high specific strength and modulus and exceptional fatigue strength. All these properties are a function of fiber orientation in the individual layers and the lay up sequence. The advantages of continuous fiber reinforced composites relative to the conventional chopped fiber systems currently utilized in automobiles lies in the ability to apply these composites in major load/stiffness critical components. The application of a composite materials design methodology to prototype automotive components is described. Examples of different types of components are given, specifically wheel and body structures. Both the design and the fabrication of these structures in composite materials are described and any specific problems are outlined.

Fabrication of large composite spars and blades, $O$. Weingart, SP563, pp. 155-172 (Oct. 1979).

Key words: composite materials; filament winding; large composite structures; rotor blades; wind turbine.

A national wind energy program has been established to develop the technology necessary to enable wind energy systems to be cost-competitive with conventional power generation systems and capable of rapid commercial expansion for producing significant quantities of electrical power. Wind Turbine Generators being developed under this program will require rotor diameters of up to $300 \mathrm{ft}$.

Because of the considerable extension in the technology required to design and construct blades of this size, it was highly desirable to establish an early technology base. To that end, the Department of Energy, through NASA-Lewis Research Center has awarded several contracts for the design, fabrication and test of large low-cost wind turbine blades built of composite materials.

This paper describes SCl's fabrication of a 20,000 lb. one piece, composite spar for a $150 \mathrm{ft}$. long developmental blade. Also discussed are a recent $\mathrm{SCl}$ design study of a composite blade for the $300 \mathrm{ft}$. diameter Mod-2 Wind Turbine, and a new SCI contract from DOE/NASA for design and possible fabrication of low cost composite blades for the $125 \mathrm{ft}$. diameter Mod-OA Wind Turbine.

The effect of fiber orientation on the design parameters of reinforced and filled thermoplastic compounds, P. J. Cloud and R. T. Alvord, SP563, p. 173 (Oct. 1979).

Key words: fiber reinforced; thermoplastics.

To determine the limiting design stress and modulus value which can be substituted into Hookeian stress-strain equations to enable the engineer to safely design with discontinuous fiber reinforced injection moldable thermoplastics.

Quality assurance of manufactured components, R. D. Margolis, SP563, p. 174 (Oct. 1979).

Key words: adhesive bond integrity; control testing; sonic testing device.

This paper describes progress to date on a joint effort of Rockwell Plastics and Ford Motor Company to apply nondestructive testing techniques in the quality control testing of adhesive bonded plastic truck hood assemblies. The program involves selection of a suitable sonic testing device to measure adhesive bond integrity along with laboratory trials to establish procedures and measure the instrument's flaw detection capabilities. In addition, several plant trials are underway to test the instrument's viability in an industrial environment and provide a data base for establishing quality control specifications. 
Degradation data of Keviar pressure vessels, W. D. Humphrey, SP563, pp. 177-197 (Oct. 1979).

Kcy words: degradation; epoxy resins; Kevlar 49; moisture; one-tenth scale motor case; S-glass; temperature effects; watcr boil.

Recent hydroburst tests of Kevlar/epoxy composite pressure vessels showed losses in strength when subjected to extended periods of high temperature and high humidity. These pressure vessels had served to monitor the aging characteristics of Rocket Motor Cases during Engineering Development tests. Since Kevlar was a relatively new material replacing fiberglass in this application, it was considered important that these results be verified in a controlled experiment utilizing accelerated aging methods.

To measure these effects, two series of tenth-scale models of Rocket Motor Cases were fabricated, which included two different rcsin systems and two very different design concepts. The accelerated degradation of Kevlar composites from high temperature and humidity was evaluated by means of water boil tests for periods of up to ten days.

Hydroburst tests of these aged vessels showed Kevlar to have much less degradation than fiberglass. Actual values were determined to be dependent on the resin system used and also dependent upon the drymess of the composite at the time of test. Wet composites acted as if a plasticizer was added to the resin system and in the configuration tested actually regains virgin strength.

Deslgn assurance of a leak failure mode for cossiposite overwrapped metal tankage, W. W. Schmidt, SP563, pp. 198-207 (Oct. 1979).

Key words: composite materials; critical flaw size; cyclic fatigue life; filament wound tankage; leakage failure mode; linear elastic fracture mechanics; metal liner.

Assuring a leakage failure mode requires that the outer composite shell be designed such that its minimum cyclic fatigue life is approximately an order of magnitude greater than that of the metal liner. This requires making an accurate fatigue life prediction for both the composite shell and metal liner. It is further possible to determine the critical flaw size for unstable crack growth within the metal liner by application of fracture mechanics principles. A semiempirical formula has been developed for this purpose since the stresses induced in the metal liner upon initial pressurization exceed the yield strength of the liner material in all cases, which violates a basic assumption of linear elastic fracture mechanics. It is often found that the critical flaw depth is greater than the thickness dimension of the metal liner. In these instances, leakage will occur prior to unstable crack growth. For designs in which unstable crack growth can occur, a dynamic analysis has been developed. This analysis provides a means of assessing the magnitude of shock induced stresses in the composite shell due to the sudden loss of the liner's load carrying capability. Details of these design procedures are provided.

Composite materials in recreatlonal equiprient, D. Ratchford, SP563, p. 208 (Oct. 1979).

Key words: composites; durability; flexural characteristics; rccreational equipment; strength-to-weight ratio.

The general requirements of materials for recreational equipment are discussed, these being high strength-toweight ratio, fatigue resistance, the ability to store and release energy, durability, aesthetic acceptability, and manufacturing capability.
It is developed, by engineering analysis, that composites of glass fibers, graphite fibers, or their combination, bonded into a resinous matrix of thermo-setting polyester or epoxy are uniquely suited to these purposes. These composites have extremely high strength-to-weight ratio, excellent durability and excellent fatigue characteristics, all unaitered through wide environmental extremes. Additional advantages are that the flexural characteristics of the material can be designed, through stress-directed fibers, to suit the purpose; and that glass fibers are nonyielding, i.e., yield and ultimate strength are the same, meaning that lower safety factors can be used. Such composites are ideally suited for handling, for the storage and release of energy and for the durability required of rough treatment.

An important and large scale application is limbs for bows used in archery. Design parameters would be light weight, high strength, fatigue resistance and quick energy release.

The limbs may be solid FRP composites, or FRP composites in the form of "backing" which is laminated to wood cores. In either case the limb is formed to a taper in order to minimize weight and to reduce inertia and present a low profile to wind resistance upon release. Load requirements are almost purely flexural, therefore fiber orientation is $100 \%$ parallel to the longitudinal axis of the limb. Glass or graphite fiber content is usually in the order of $70 \%$. The limb has a flexural strength of approximately $150,000 \mathrm{psi}$, and a flexural modulus of $5.5 \times 10^{6} \mathrm{psi}$. High heat-distortion resins are used so that the bow can be stored in automobile trunks where temperatures can go above $150^{\circ} \mathrm{F}$. An aesthetically attractive, abrasive-resistant finish is usually applied to the limb.

Additional applications in archery are bows molded entirely in one piece, and arrow shafts.

Holographic nondestructive evaluation of spherical kevlar/epoxy pressure vessels, D. M. Boyd and B. W. Maxfield, SP563, pp. $211-212$ (Oct. 1979).

Key words: composites; holography; interferometers; matrix crazing; nondestructive testing; pressure vessels.

Three spherical kevlar/epoxy pressure vessels were evaluated using holographic interferometry. The holographic interferograms provide information on the failure modes, displacement profile, and possible fiber damage. The holograms show a symmetric anisotropic displacement pattern even though the vessels failed due to a leak in the aluminum mandrels. The presence of a biconvex fringe pattern found during the testing of vessel three is believed to indicate matrix crazing. This information would be useful for burst-type failure analysis. Holographic interferometry has been shown to supply information on the characteristics of kevlar/epoxy pressure vessels under stress.

The Alr Force "Manufacturing Cost/Design Guide (MC/DG)", B. R. Noton and D. L. Shunk, SP563, pp. $226-$ 227 (Oct. 1979).

Key words: airframe structure; cost-trade comparisons; manufacturing technologies; structural performance/cost trade-offs.

The purpose of the MC/DG is to enable designers at all levels to conduct, firstly, urgently needed, quick, simple, cost-trade comparisons of manufacturing processes, and, secondly, structural performance/cost trade-offs on both components and subassemblies. The $\mathrm{MC} / \mathrm{DG}$ will consist of two volumes-"Airframe Structure" and "Manufacturing Technologies." The MC/DG is being developed for the Air Force by a team consisting of Battelle's Columbus Labora- 
tories (BCL) and the following aerospace companies: General Dynamics Corporation, Fort Worth Division; Grumman Aerospace Corporation; Lockheed-California Company; Northrop Corporation, Aircraft Group; Rockwell International Corporation, Los Angeles Division.

Tensile strength and failure modes of boron-epoxy composite with a notch, C. E. S. Ueng, SP563, pp. 228-238 (Oct. 1979).

Key words: boron-epoxy; edge cracks; failure modes; finite element method; tensile strength.

The purpose of this paper is to study the tensile strength and failure modes of boron-epoxy composites with an edged notch. Through the use of finite element crack program, both heterogeneity and orthotropy of material properties are brought into consideration in this paper. For comparison purposes, tension tests of actual composite samples with notches are also performed. Notch insensitivity and the failure modes are discussed. The fracture toughness of the test material is also determined. The results obtained here are important for further understanding of the failure of unidirectional boron-epoxy advanced composites.

Failure criteria for composites under complex loading, P. W. Mast, L. A. Beaubien, D. R. Mulville, S. A. Sutton, R. W. Thomas, J. Tirosh, and I. Wolock, SP563, p. 241 (Oct. 1979).

Key words: bonded joints; composites; failure criteria; inplane loads.

Studies are in progress to develop failure criteria for composites and bonded joints under a broad range of inplane loads. Criteria for predicting the conditions under which a defect will grow in composites structural components, in such applications as Naval high performance craft, will be demonstrated. Validity of a new technique for determining failure criteria for composites has been verified in laboratory tests.

Failure analysis of an idealized composite damage zone, $\mathrm{C}$. T. Herakovich and D. A. O'Brien, SP563, pp. 242-254 (Oct. 1979).

Key words: compression; failure; finite elements; graphiteepoxy; interlaminar stresses; laminated composites; stress concentrations; tension; tensor polynomial.

First failure of finite width laminates with an idealized composite damage zone is analyzed through the use of a linear elastic finite element stress analysis and the tensor polynomial failure criterion. Crossply and angleply $[ \pm 45]_{s}$ laminates are analyzed under tension and compression loading. It is shown that a boundary layer exists near the damage zone which is very similar to the boundary layer which has been shown previously to exist along free edges. Comparisons are made between predicted initial failure of damaged and undamaged laminates. Transverse tension is the dominate mode of failure fo: tensile loading, but compressive loading leads to a variety of failure modes depending upon the laminate configuration.

Interlaminar failure in epoxy based composite laminates, $A$. S. Wang, F. W. Crossman, and G. E. Law, Jr., SP563, pp. 255-264 (Oct. 1979).

Key words: delamination mechanisms; energy release rate; finite element method; free-edge stresses; graphite epoxy composites; interlaminar cracks; stability of cracks; virtual crack closure.
One of the common failure modes in fibrous composite laminates involves interlaminar cracks which cause delamination. Several questions arise in the course of a delamination analysis. Notably these include (a) how is a delamination initiated? (b) under what condition will a delamination grow? and (c) what determines the stability of a delamination growth? Owing to the unusual complexity of composite laminate systems, there appears no simple way to answer these questions satisfactorily.

In this paper, a method is developed based on the energy principle of the classical linear fracture mechanics, in order to describe the various aspects of the delamination mechanisms. Specifically, free-edge induced delamination failure in some epoxy based composite laminates are investigated employing this method. And, the results obtained are compared with experiments. It will be shown that the energy method predicts well free-edge delamination in laminates under uniaxial tension, including the initiation, the growth and the growth stability of the delamination.

Current developments in advanced composites for maval ship application, J. J. Kelly and H. H. Vanderveldt, SP563, pp. 267-275 (Oct. 1979).

Key words: composites; hydrofoils; maintenance requirements; naval ship application.

The reasons for and the limitations on the use of composites for ship applications are described. The current exploratory development program in advanced composites for Navy ship applications emphasizes high performance craft such as hydrofoils. The future program will complete these efforts and stress broader applications for composites. Development of fire resistant composites, survivable structural concepts and materials which reduce maintenance requirements will be emphasized.

Environmental effects on thber reinforced organic matrix composites, M. Silvergleit, A. B. Macander, F. A. Brauer, and H. P. Edelstein, SP563, pp. 276-285 (Oct. 1979).

Key words: advanced composites; cavitation erosion; extended immersion; flammability; glass reinforced plastics; graphite epoxy; impact; marine environment.

A review is presented on the effects of the marine environment on fiber reinforced organic matrix composites. In addition to the effects of extended immersion in seawater on composite properties, the limiting utility of composites due to cavitation erosion, flammability and smoke spread evolution and damage due to impact are discussed. In general, high quality, low void content glass reinforced plastics (GRP) and graphite epoxy composites retain over 90\% of their initial strength after three years immersion in seawater. Organic matrix composites, which are subjected to high speed fluid flow are degraded by erosion due to the collapse of the cavitation cloud, however, erosion resistance "can be improved by using elastomeric or thin metallic overlays. With the exception of polyimides, organic matrix composites have poor resistance to flammability and emit large quantities of dense smoke. Impact resistance of composites is a function of fiber/resin properties and composite orientation. Incorporation of high toughness flexible matrices and/or high strength, low modulus fibers will increase composite impact resistance.

Composite technology for marine application, W. P. Couch, SP563, pp. 286-298 (Oct. 1979).

Key words: advanced composites; advanced ships; elastic properties; fatigue tests; nondestructive tests; structural analysis; ultimate strength. 
Under the sponsorship of the Naval Sea Systems Command (NAVSEA 035), the David W. Taylor Naval Ship Researeh and Dcvelopment Center (DTNSRDC) has been eonducting a program to assess the eurrent technology status of advanced composites, and to determine the feasibility of application to marinc structures. The approach bcing utilized to aehieve this objective involves a cootdinated struetures/materials eommunity effort seeking input from private industry and other government ageneies. As a result of feasibility studies performed by the MeDonnell Douglas Astronauties Company and the Grumman Aerospace Corporation and a review of high payoff areas for structural application of advanced composites by the Naval Ship Composites Community, the hydro-foil strut/foil system was selected as the primary structural element to evaluate the use of advanced composites for advaneed naval ship structures. Two subcomponents were seleeted for this evaluation; a foil test component (tapered box beam), and a hydrofoil eontrol flap. Coneurrently, analytical methods incorporating composite mechanics developed by the acrospace composites program are reviewed, modified and utilized when applicable to determine the struetural behavior for marine, load-carrying eomponents. In addition, preliminary design studies are conducted on other naval ship struetures to determine the feasibility of composite eonstruetion. The following text describes the eurrent effort under investigation related to the four program subtasks: box beam validation, foil flap validation, analytieal methods and design application studies.

SP565. A history of walkway slip-resistance research at the National Bureau of Standards, S. C. Adler and B. C. Pierman, Nat. Bur. Stand. (U.S.), Spec. Publ. 565, 36 pages (Dee. 1979) SN003-003-02142-3.

Key words: frietion; measurement; referenee standards; safety research; walkway slip-resistanee.

This report summarizes NBS researeh in the area of walkway and shoe slip-resistanee measurement sinee 1924 and outlines current aetivities that will provide a technical basis for slip-resistance measurement. The work of Sigler, Hunter, Boone and Brungraber represents the historie perspective. Current activities in data base development and identifieation of standard rcference surfaces eontribute to a rational basis for quantitative slip-resistance criteria for building eodes and standards. Proposed future researeh thrusts inelude personal factors such as human biokinetie and perceptual variables, as well as environmental factors such as lighting in the built environment. This research will eontribute to the development of new intervention strategies to reduce deaths and injuries due to slips and falls.

\subsection{APPLIED MATHEMATICS SERIES}

Mathematical tables, manuals, and studies of special interest to physicists, engineers, chemists, biologists, mathematicians, eomputer programmers, and others engaged in scientific and teehnical work.

No publieations issued in this series during this period. 


\subsection{NATIONAL STANDARD REFERENCE DATA SERIES}

Provides quantitative data on the physical and chemical properties of materials, compiled from the world's literature and critically evaluated. Developed under a worldwide program coordinated by NBS. Program under the authority of National Standard Data Act (Public Law 90-396).

NSRDS-NBS3, Section 8. Selected tables of atomic spectra. A: Atomic energy levels-Second edition. B: Multiplet tables. O vi, O vil, O vill, C. E. Moore, Nat. Stand. Ref. Data Ser., Nat. Bur. Stand. (U.S.), 3, Sec. 8, 31 pages (Jan. 1979) SN003-003-01964-0.

Key words: atomic energy levels, O vI-O vili; atomic spectra, O vI-O viI; multiplet tables, O vI-O vIII; oxygen, spectra, O vi-O vill; spectra, O vI-O vill; wavelengths, $O$ vi-O vilI.

The present publication is the eighth Section of a series being prepared in response to the need for a current revision of two sets of the author's tables containing data on atomic spectra as derived from analyses of optical spectra. As in the previous Sections, Part A contains the atomic energy levels and Part B the multiplet tables. Section 8 includes these data for $\mathrm{O} v \mathrm{vI}, \mathrm{O}$ VII, and $O$ VIII, thereby completing the spectra of oxygen. The form of presentation is described in detail in the text to Section 1.

NSRDS-NBS61, Part I1. Physical properties data compilations relevant to energy storage. II. Molten salts: Data on single and multi-component salt systems, G. J. Janz, C. B. Allen, N. P. Bansal, R. M. Murphy, and R. P. T. Tomkins, Nat. Stand. Ref. Data Ser., Nat. Bur. Stand. (U.S.), 6I, Part II, 442 pages (Apr. 1979) SN003-003-02051-6.

Key words: corrosion; data compilation; electrochemical energy storage materials; molten salts; physical properties; safety and hazards; thermal energy storage materials; thermal properties; thermodynamic properties; transport properties.

The present work provides selected data with value judgements for a set of 49 salt systems of interest as candidate materials for thermal energy storage sub-systems and for electrochemical energy storage systems. The physical properties assessed are: melting points; phase diagrams; eutectic compositions; density; surface tension; viscosity; electrical conductivity; diffusion constants for ions; heat of fusion; heat capacity; volume change on fusion; vapor pressure; thermal conductivity (liquid and solid); and cryoscopic constant. The status of corrosion studies in the form of annotated bibliographic summaries, and salient observations on safety and hazards are also reported. A summarizing series of tables is provided as index to the data-gaps status for this set of candidate materials.

NSRDS-NBS61, Part 111. Physical properties data compilations relevant to energy storage. III. Engineering properties of single and polycrystalline sodium beta and beta"-alumina, G. R. Miller and D. G. Paquette, Nat. Bur. Stand. Ref. Data Ser., Nat. Bur. Stand. (U.S.), 6I, Part III, 19 pages (June 1979) SN003-003-02079-6.

Key words: battery application; engineering properties data; evaluated data; polycrystalline; single crystal; sodium beta alumina; sodium beta double prime alumina.
A review of the properties of the two dimensional superionic conductors of the sodium beta alumina family is presented, with emphasis on the variability of properties with composition and processing. Processing methods, including methods of distributing additives, may strongly influence engineering properties of these substances through changes in microstructures. Described are common methods of measurement of properties with generally accepted ranges of property values. The need to compromise in the design of devices requiring several coincident optimal properties is, at this time, a necessary ingredient in the use of these materials as device components.

NSRDS-NBS64. Rate coefficjents for ion-molecule reactions. Organic ions other than those containing only $\mathbf{C}$ and $\mathbf{H}, \mathbf{L}$. W. Sieck, Nat. Stand. Ref. Data Ser., Nat. Bur. Stand. (U.S.), 64, 27 pages (Feb. 1979) SN003-003-02027-3.

Key words: chemical kinetics; data evaluation; gas phase ion-molecule reactions; mass spectrometry; organic molecules; rate coefficients.

A compilation is presented of all experimentally determined bimolecular and termolecular rate coefficients for the reactions of organic ions (other than those containing only $\mathbf{C}$ and $\mathbf{H}$ ) with neutral molecules in the vapor phase. The literature covered is from 1960 to the present, and both positive and negative ions are considered. Five hundred and seventy-seven separate reaction-partners are tabulated, and experimental conditions are specified wherever possible. Preferred values are suggested for a number of these processes.

NSRDS-NBS65. Rate constants for reactions of inorganic radicals in aqueous solution, A. B. Ross and P. Neta, Nat. Stand. Ref. Data. Ser., Nat. Bur. Stand. (U.S.), 65, 62 pages (June 1979) SN003-003-02072-9.

Key words: aqueous solution; carbonate radical; chemical kinetics; halogen radical anions; nitrate radical; oxyanion radicals; phosphate radical; photolysis; radiolysis; rates; selenium radicals; sulfate radical; thiocyanate radical anion.

Rate constants have been compiled for reactions of various transient inorganic radicals produced by radiolysis or photolysis in aqueous solution. Data are included for the carbonate radical, sulfate radical, phosphate radical, nitrate radical and other nitrogen-, sulfur- and selenium-containing radicals, and the halide and pseudohalide radicals $\mathrm{Cl}_{2}^{-}, \mathrm{Br}_{2}^{-}, \mathrm{l}_{2}^{-}$, and $(\mathrm{SCN})_{2}{ }^{-}$. The radicals react with other inorganic ions, as well as aliphatic, aromatic and heterocyclic compounds. 


\subsection{BUILDING SCIENCE SERIES}

Disseminates technical information developed at the Bureau on building materials, components, systems, and whole structures. The series presents research results, test methods, and performance criteria related to the structural and environmental functions and the durability and safety characteristics of building elements and systems.

BSS75. Building research at the National Bureau of Standards 1968-1974, N. Gallagher, Ed., Nat. Bur. Stand. (U.S.), Bldg. Sci. Ser. 75, 126 pages (Mar. 1979) SN003-003-02029-0.

Key words: building technology; Center for Building Technology; history of building research.

This report details the progress of building research at the Center for Building Technology from the year 1968 to 1974. Starting with the backlog of needed research in building techniques, components, and materials that faced researchers in the 60 's, this history covers the evolution of the performance concept for building specifications, cooperation with states and codes-generating organizations, and specific technical accomplishments. The report continues with discussions of programs involving the building community, research on the needs of the building users, and technology transfer. A special chapter is devoted to energy conservation in buildings and how CBT's test methods and other programs-including solar-were pressed into this vital national struggle.

BSS95. The development of an improved compression test method for wall panels, C. W. C. Yancey and L. E. Cattaneo, Nat. Bur. Stand. (U.S.), Bldg. Sci. Ser. 95, 108 pages (Feb. 1979) SN003-003-01697-7

Key words: compression; eccentric loading; flat-end; kern; loading rate; pin-end; test method; wall panels; walls.

An experimental and analytical investigation of the primary factors involved in the testing of prototype wall panels under axial compression loading is reported. The objective of the investigation was to develop a method of testing wall specimens that incorporates the best features of ASTM Standard Method E 72 while at the same time incorporating improvements in the areas of deficiency in the Standard. Twenty-five laboratory tests were conducted on samples composed of five types of wall panel construction. The panels were tested to failure under either of two different eccentricities of load, while being supported with one of two types of idealized end conditions. Selected test results and detailed descriptions of the laboratory procedures used are presented. A computer-aided analytical study of the variables affecting the degree of uniformity of loading was conducted. Equations based on the analogy of beams supported on elastic foundations were used in the analysis. A study of the statistical parameters commonly used to interpret test results was conducted to establish useful guidelines for predicting structural performance on the basis of small sample test results. A compression test method applicable to traditional and innovative wall constructions is presented. The principal additions in the revised test method are as follows: (a) a provision for variable eccentricity, (b) a procedure for selecting a load distribution assembly which will be compatible with the test-panel.

BSS107. Soil and rock anchors for mobile homes-A state-ofthe-art report, W. D. Kovacs and F. Y. Yokel, Nat. Bur. Stand. (U.S.), Bldg. Sci. Ser. 107, 164 pages (Oct. 1979) SN003-003-02121-1.
Key words: anchors; mobile home foundations; soil anchors; soil mechanics; wind upset.

Available anchor hardware is surveyed and evaluated and pull-out capacity data are compared with hypotheses for predicting anchor pull-out capacity based on soil mechanics principles. The evidence suggests that our ability to predict anchor pull-out capacity by soil mechanics principles is inadequate, and that there is a need for the standardization of test procedures and soil classification and for further test data. Suggestions for future research are presented.

BSS I 15. Fire safety for high-rise buildings: The role of communications, R. A. Glass and A. 1. Rubin, Nat. Bur. Stand. (U.S.), Bldg. Sci. Ser. 115, 47 pages (Apr. 1979) SN003-00302016-8.

Key words: buildings; communications systems; fire safety; high-rise; model codes; people movement; systems design.

This literature survey reviews the communications requirements for fire safety in buildings from the standpoint of the building occupant and the control operator. It traces the development of the problem of communications in buildings and the specialized needs that exist today.

An examination is made of the purposes of a communications system in buildings as well as some of the psychological design requirements necessary for such a system.

The communications requirements of the building occupants are also covered, with emphasis on the types of information communicated by signals and the integration of those signals into an overall system design.

Personnel requirements for staffing a control center are also discussed, along with common problems in several operational communications systems.

Detailed examples of communications systems are provided. Portions of several model codes which cover communications systems are presented. Suggested areas for future research on fire safety in buildings are identified.

BSS I 17. Experimental verification of a standard test procedure for solar collectors, J. E. Hill, J. P. Jenkins, and D. E. Jones, Nat. Bur. Stand. (U.S.), Bldg. Sci. Ser. II7, 126 pages (Jan. 1979) SN003-003-02008-7.

Key words: measurement; solar collector; solar energy; solar radiation; standards; standard test; testing.

A proposed procedure for testing and rating solar collectors based on thermal performance was published by the National Bureau of Standards (NBS) in 1974. Subsequently, the American Society of Heating, Refrigerating, and Air Conditioning (ASHRAE) developed a modified version of the NBS procedure which was adopted in early 1977 as ASHRAE Standard 93-77. A test facility for water-heating and air-heating collectors has been built at NBS and was used to support the development of Standard 93-77. The purpose of this report is to describe the recently adopted test procedure, the NBS test facility, and the tests that were conducted to support the development of the procedure.

BSS 1 18. Extreme wind speeds at 129 stations in the contiguous United States, E. Simiu, M. J. Changery, and J. J. Filliben, Nat. Bur. Stand. (U.S.), Bldg. Sci. Ser. 118, 318 pages (Mar. 1979) SNO03-003-02041-9. 
Kcy words: building (codes); probability distribution functions; statistical analysis; storms; structural engineering; wind prcssure; wind speeds.

The purpose of this report is to present information on recorded and predicted wind speeds at 129 airport stations in the contiguous United States at which reliable records are available over a number of consecutive years. This information is provided to serve as basic documentation from which appropriate decisions can be made on values of design wind speeds to be specified in building codes and standards or on specific projects. Included in the report are: recorded wind speeds and anemometer elevations; predicted wind speeds based on probability distributions of the largest values; estimates of the sampling errors inherent in the predicted wind speeds; a description of the statistical procedure used in the analysis of the data; and a discussion of the results of the analysis.

BSS119. Economic evaluation of windows in buildings: Methodology, R. T. Ruegg and R. E. Chapman, Nat. Bur. Stand. (U.S.), Bldg. Sci. Ser. 119, 118 pages (Apr. 1979) SN003-003-02042-7.

Key words: building economics; daylighting; economic analysis; energy conservation; engineering economics; lifecycle costs; solar heat gain; thermal efficiency; window; window management.

This study, which is one part of a National Bureau of Standards interdisciplinary project on windows, is aimed at improving the cost-effectiveness of window selection and use in buildings. It develops and illustrates a life-cycle costing evaluation model and computer program for assessing for alternative window systems the net dollar impact of acquisition, maintenance and repair, heating and cooling energy gains and losses, and artificial lighting and daylighting tradeoffs. The method is applicable to the evaluation of many different window sizes, designs, accessories, and uses, both for new and existing residential and commercial buildings. Two step-by-step examples of evaluating selected window alternatives in a residence and in an office building in Washington, D.C., serve to illustrate the application of the method.

A companion report, A Regional Economic Assessment of Selected Window Systems, presents the results of eight additional residential case studies and eight additional commercial case studies. While the emphasis of this report is on the method of evaluation, the companion report focuses on summarizing the results of a regional analysis in a form that will be convenient for use by building owners, operators, designers, financiers, and builders, those whose interest centers on the actual implementation of research results.

BSS 120. Guidelines for stair safety, J. Archea, B. L. Collins, and F. I. Stahl, Nat. Bur. Stand. (U.S.), Bldg. Sci. Ser. 120, 129 pages (May 1979) SN003-003-02063-0.

Key words: accidents; architectural design; architectural psychology; architectural research; building codes; building design; building regulatory standards; floor covcrings; home safety; safety standards; stair safety; stairway design.

This report summarizes information and research in the area of stair use and provides design guidelines for improving stair safety. These guidelines are directed toward seven major categories of stairway design and construction: (1) structural integrity and quality of stairs, (2) physical attributes of stair surfaces, (3) appearance of stair surfaces, (4) handrails, (5) physical attributes of the surrounding stairway environment, (6) appearance of the surrounding stairway environment, and (7) signs and symbols.
In general, the recommendations offered in this report derive from thc premise that stairway accidents are caused by human perceptual errors, which are frequently triggered by some flaw in the design or construction of stairways themselves. Evidence dcscribing the severity and frequency of residential stairway hazards, and supporting premises underlying design guidelines were obtained from epidemiological, experimental, exploratory, and survey research sources. General directions for future investigation are suggested. 


\subsection{FEDERAL INFORMATION PROCESSING STANDARDS PUBLICATIONS}

Publications in this series collectively constitute the Federal Information Processing Standards Register. Register serves as the official source of information in the Federal Government rcgarding standards issued by NBS pursuant to the Federal Property and Administrative Services Act of 1949 as amended, Public Law 89-306 (79 Stat. 1127), and as implemented by Executive Order 11717 (38 FR 12315, dated May 11, 1973) and Part 6 of Title 15 CFR (Code of Federal Regulations). This series is available only from the National Technical Information Services, Springfield, VA 22161 . See page 24 for price list.

FIPS PUB 58. Representations of local time of the day for information interchange, $\mathrm{H}$. McEwen, Standards Coordinator, Nat. Bur. Stand. (U.S.), Fed. Info. Process. Stand. Publ. (FIPS PUB) 58,4 pages (Feb. 1979).

Key words: American National Standard Representation for Calendar Date and Ordinal Date for Information interchange; meridian designators; separators; sequencing; time elements; timekeeping systems; time representations.

This FIPS PUB announces the adoption of American $\mathrm{Na}$ tional Standard X3.43-1977, Representations of Local Time of the Day for Information Interchange. This standard provides the means for representing local time of the day to facilitate the interchange of information among data systems.

FIPS PUB 59. Representations of universal time, local time differentials, and United States time zone references for information interchange, H. McEwen, Standards Coordinator, Nat. Bur. Stand. (U.S.), Fed. Info. Process. Stand. Publ. (FIPS PUB) 59, 4 pages (Feb. 1979).

Key words: American National Standard Representation for Calendar Date and Ordinal Date for Information Interchange; local time differentials; meridian designator; time differential factor; time zone references; Uniform Time Act of 1966; universal time.

This FIPS PUB announces the adoption of American National Standard X3.51-1975, Representations of Universal Time, Local Time Differentials, and United States Time Zone References for Information Interchange. This standard provides the means for representing universal time, local time differentials, and U.S. time zone references to facilitate interchange of information among data systems.

FIPS PUB 64. Guidelines for documentation of computer programs and automated data systems for the initiation phase, B. Leong-Hong, Standards Coordinator, Nat. Bur. Stand. (U.S.), Fed. Info. Process. Stand. Publ. (FIPS PUB) 64, 54 pages (Aug. 1979)

Key words: automated data systems; computer programs; cost/benefit analysis; documentation; documentation content guidelines; feasibility study; FIPS guidelines; initiation phase; project request; software.

These guidelines provide a basis for determining the content and extent of documentation for the initiation phase of the software life cycle. Content guidelines are given for the following document types: Project Request Document, Feasibility Study Document, and Cost/Benefit Analysis Document.

The guidelines are intended to be a basic reference and a checklist for general use throughout the Federal Government to plan and evaluate documentation practices.
FIPS PUB 65. Guideline for automatic data processing risk analysis, S. K. Reed, Standards Coordinator, Nat. Bur. Stand. (U.S.), Fed. Info. Process. Stand. Publ. (FIPS PUB) 65, 27 pages (Aug. 1979).

Key words: ADP availability; annual loss exposure; application system vulnerability; computer security; data confidentiality; data integrity; data security; physical security; procedural security; risk analysis; risk assessment; systems security.

This document presents a technique for conducting a risk analysis of an ADP facility and related assets. Risk analysis produces annual loss exposure values based on estimated costs and potential losses. The annual loss exposure values are fundamental to the cost effective selection of safeguards for the security of the facility. An ADP facility of a hypothetical government agency is used for an example. The characteristics and attributes of a computer system which must be known in order to perform a risk analysis are described and an example is given of the process of analyzing some of the assets, showing how the risk analysis can be handled.

FIPS PUB 66. Standard Industrial Classification (SIC) codes, $\mathbf{H}$. McEwen, Standards Coordinator, Nat. Bur. Stand. (U.S.), Fed. Info. Process. Stand. Publ. (FIPS PUB) 66, 23 pages (Aug. 1979).

Key words: computers; data processing; Federal Information Processing Standards Publication; industries; representations and codes; Standard Industrial Classification.

This standard provides classifications, short titles, and codes for representing industries. The general concept of an industry is one of a group of establishments with similar economic activities. The SIC codes, initially developed by the Office of Managcment and Budget, are currently being maintained and published by the DOC Office of Federal Statistical Policy and Standards, the organization to which this function has been transferred. Their implementation in Federal ADP systems will avoid unnecessary and costly incompatibilities in the collection, processing and dissemination of data.

FIPS PUB 67. Guideline for selection of data entry equipment, Nat. Bur. Stand. (U.S.), Fed. Info. Process. Stand. Publ. (FIPS PUB) 67, 23 pages (Sept. 1979).

Key words: data entry; economic considerations; keyboard; keypunch; optical character recognition; optical mark sensing; source data entry.

This publication provides a guideline to be used by Federal agencies in the selection of data entry equipment. The objective is to make available information that will assist in the selection of more efficient and economical data entry systems. The guideline provides information about economic and general operational considerations, steps to be followed in acquisition and training, and other factors pertinent to data entry equipment selection. 


\subsection{VOLUNTARY PRODUCT STANDARDS}

Developed under procedures published by the Department of Commerce in Part 10, Title 15, of the Code of Federal Regulations. The purpose of the standards is to establish nationally recognized requirements for products, and to provide all concerned interests with a basis for common understanding of the characteristics of the products. The National Bureau of Standards administers the Voluntary Product Standards program as a supplement to the activities of the private sector standardizing organizations.

No publications issued in this series during this period. 


\subsection{TECHNICAL NOTES}

Studies or reporis which are complete in themselves but restrictive in their treatment of a subject. Analogous to monographs but not so comprehensive in scope or definitive in treatment of the subject area. Often serve as a vehicle for final reports of work performed at NBS under the sponsorship of other Government agencies.

TN910-4. Self-study marmal on optical radiation measurements: Part 1-Concepts, chapters 7, 8, and 9, F. E. Nicodemus, Ed., Nat. Bur. Stand. (U.S.), Tech. Note 910-4, 134 pages (June 1979) SN003-003-02067-2.

Key words: aperkure/aperture-image pair; aperture pair; calibration; convolution; deconvolution; geometrical-optics radiometry; inversion; measurement-beam geometry; relative spectral responsivity; slit-scattering function; slit-scattering function corrections; spectral line radiometry; spectroradiometer characterizations; spectroradiometry; vignetting.

This is the fourth in a series of Technical Notes (910-) entitled "Self-Study Manual on Optical Radiation Measurements." It contains Chapters 7, 8, and 9 of this Manual. Additional chapters will continue to be published, similarly, as they are completed. The Manual is a comprchensive tutorial treatment of the measurcment of incoherent radiation that is complete enough for self instruction. Detailed chapter summaries make it also a convenient authoritative reference source.

The manner in which the spectral responsivity of a spectroradiometer containing a nonochromator varies with wavelength is treated in Chapter 7 . The nature and characteristics of this function, how it is dctermined, and the effects it has on spectroradiometric measurements are discussed in detail. The traditional, indirect determination, involving the slitscattering function, is shown to be highly inaccurate except for wavelengths in the ccntral portion of the function. An introduction to the mcasurement of spectral line radiation is also presented.

Deconvolution, discussed in Chapter 8 , is the numerical process of recovering an improved spectral distribution from spectroradiometric measurenents incvitably smeared spectrally by the spectral-responsivity function of the radiometer. A simple, iterative technique, which is extensively used, will be completely satisfactory in almost all radiometric situations. A more sophisticated technique, which is founded on a sounder thcoretical basis, should succeed in many of the few remaining instances where the simpler technique fails. Examples of computer programs for the two techniques are given in an appendix. Both are applied to a simple illustrative numerical examplc with brief mention of some of the sources of difficulty and the limitations of deconvolution. Finally, we touch on the qucstion of errors and describe a couple of useful measures of accuracy.

The physical definition of measurement beams, including the integration limits in the mcasurement equation, is treated in Chapter 9 in terms of geometrical-optics quantities and concepts. The usual definitions of geometrical optics are extended to situations where defining the measurement beam may not involve the imaging of any source. The importance of aperture pairs or equivalent aperture/aperture-image pairs, in defining measurement beams without vignetting, is developed. Also discussed are entrance pupils as receiving apertures in radiometry (their positions and dimensions), diffusers, vignctting, and the effects of beam geometry on overall instrument radiance and irradiance responsivities. The treatment is in terms of simple, ideal, gcometrical optics, with sharp image and shadow boundaries, and only passing mention is made of perturbations caused by imperfect imaging, aberrations, scattering, and diffraction.

TN971. Guidelines for cost-effective lead paint abatement, R. E. Chapman and J. G. Kowalski, Nat. Bur. Stand. (U.S.), Tech. Note 971, 88 pages (Jan. 1979) SN003-003-02014-1.

Key words: abatement; building economics; building materials; economic analysis; housing; lead-based paint; lead poisoning.

Public and private concern about the potential for lead poisoning in children due to the ingestion of lead-based paint chips has rcsulted in a Federally sponsored program to develop technologies by which the Icad-based paint hazard may be eliminated from the nation's housing. Through this program lead-based paint abatement techniques were tested in field deleading operations conducted in Boston, Massachusetts. The major focus of the program was on the collection of data on the direct costs of labor, materials and special equipment associated with these abatement techniques. Data were also collected on contractors' bids so that markup ratios could be calculated

This report provides an overview of the statistical analysis of these direct cost data by abatement technique and building component (i.e, walls, doors and frames, windows and frames, and misccllaneous trim). An overview of the statistical analysis of the markup ratio is also included. Cost models are developed for each abatement technique which identify the key factors which affect direct cost and markup. Guidelines are given so that these models can be used by municipal officials and building owners to estimate deleading costs as well as provide input to policy evaluation and formulation.

TN979. Lead paint abatement costs: Some technical and theoretical considerations, R. E. Chapman and J. G. Kowalski, Nat. Bur. Sland. (U.S.), Tech. Note 979, 153 pages (Feb. I 979) SN003-003-02022-2.

Key words: abatement; building economics; building materials; cost estimation; econometric models; economic analysis; housing; lead-based paint; lead poisoning

Public and private concern about the potential for lead poisoning in children due to the ingestion of lead-based paint chips has resulted in a Federally sponsored program to develop technologies by which the lead-based paint hazard may be eliminated from the nation's housing. The nature and design of the Experimental Hazard Elimination Program (EHEP) is thought to be unique in that it permitted the costs of the alternative lead paint abatement techniques to be rigorously analyzed.

The focus of this rcport is on the design, implementation and analysis of EHEP and the cost information it produced. Statistical analyses which permitted the development of econometric models capable of estimating abatement technique costs and expected contractor markup are described. Structural equations relating changes in the valucs of certain key factors to variations in direct cost and contractor markup are also presented. Guidelines, including a national deleading cost estimate, are given so that these econometric models can be used by municipal officials and building owners to estimate deleading costs as well as provide input to policy evaluation and formulation. 
TN980. Historic preservation incentives of the 1976 Tax Reform Act: An economic analysis, S. F. Weber, Nat. Bur. Stand. (U.S.), Tech. Note 980, 32 pages (Fcb. 1979) SN003-00302015-0.

Key words: adaptive rcuse; buildings; dcmolition; economics; historic preservation; life-cycle costing; redevelopment; rehabilitation; tax incentives.

The Tax Reform Act (TRA) of 1976 includes several provisions which affect the financial position of owners of incomeproducing historic buildings. This report analyzes the effect of the TRA on the after-tax cost of two basic alternatives facing the owner: (1) rehabilitate the structure; or (2) demolish it and redevelop the site. A life-cycle minimization model was developed, programmed in BASIC language, and applied in an after-tax comparison of six alternative situations representing rehabilitation and redevelopment both before and after the TRA. Under the assumptions of the model used in this analysis, the TRA has made the rehabilitation option significantly more attractive than previously. The former tax bias in favor of demolition and redevelopment has been reversed. Until now, this information on the life-cycle tax advantages of rehabilitating historic buildings has been unavailable. This report will help corporate investors make cost-effective decisions regarding historic preservation of nonresidential buildings and provide policy makers with information on the effectiveness of these tax incentives. The approach utilized could be adapted to analyze incentives for other types of building rehabilitation.

TN985. Fire effects on reinforced concrete members, B. Ellingwood and J. Shaver, Nat. Bur. Stand. (U.S.), Tech. Note 985 , 42 pages (Aug. 1979) SN003-003-02104-1.

Key words: concrete (reinforced); fire load; fire resistance; fire tests structural engineering; temperature; thermal analysis.

Fire ratings for structural assemblies in the U.S. are currently measured by endurance of or temperature rise in components subjected to a standard test. Analytical procedures show considerable promise for alleviating the extensive testing required, and for placing fire resistant structural design on a limit states basis. In this study, thermal and structural analyses for reinforced concrete members are validated using experimental data. Temperature distributions computed in reinforced concrete members for several realistic fire exposures are examined and compared to the distributions measured in a standard test. Parameter studies show the effect of typical variations in thermal diffusivity, emissivity and conductivity. Structural responses for the different fire exposures are also briefly compared.

TN987. A servo controlled electro-optic modulator for $\mathrm{cw}$ laser power stabilization and control, J. B. Fowler, M. A. Lind, and E. F. Zalewski, Nat. Bur. Stand. (U.S.), Tech. Note 987, 16 pages (Apr. 1979) SN003-003-02049-4.

Key words: laser power modulator; laser power stabilizer; photodetector characterization; radiometric instrumentation.

Two simple designs for a low cost laser stabilization system are presented. The systems described are capable of stabilizing the power output of a cw laser line to better than $.05 \%$ from $D C$ to $100 \mathrm{kHz}$ in the 350 to $1150 \mathrm{~nm}$ spectral range.

TN989. A low-velocity airflow calibration and research facility, L. P. Purtell and P. S. Klebanoff, Nat. Bur. Stand. (U.S.), Tech. Note 989, 21 pages (Mar. 1979) SN003-003-02038-9.

Key words: airflow; calibration; facility; laser optics; low velocity; mine ventilation; velocity standard.
A low-velocity airflow facility suitabic for the calibration of wind speed measuring instruments and research in aerodynamics is described. The flow facility is of the opcn-return type with a test section 20 feet (6.1 meters) long, and nominally 3 $\times 3$ feet $(0.91 \times 0.91 \mathrm{~m})$ in cross section. Special attention was given to obtaining an air stream with a high degree of spatial uniformity and low turbulence with excellent speed control over the range from 3 to 1000 meters ( 10 to 3300 feet) per minute. Laser-optical methods with appropriate signal processing electronics are employed to establish a primary standard for the measurement of very low velocities. A crossedbeam dual-scattcring laser-optical system is used that can operate with either forward or backscattering, and in a frequency shifted Bragg cell mode, or in a non-frequency shifted optical beam-splitter block mode. Detailed performance characteristics of the flow facility and the laser velocity standard are presented.

TN991. COMPF2-A program for calculating post-flashover fire temperatures, V. Babrauskas, Nat. Bur. Stand. (U.S.), Tech. Note 991, 76 pages (June 1979) SN003-003-02080-0.

Key words: computer programs, fire protection; fire protection; fire resistance; fire tests; fire walls; safety engineering, fires.

COMPF2 is a computer program for calculating the charactcristics of a post-flashover fire in a single building compartment, based on fire-induced ventilation through a single door or window. It is intended both for performing design calculations and for the analysis of experimental burn data. Wood, thermoplastic, and liquid fuels can be treated. In addition to the capability of performing calculations for compartments with completely determined properties, routines are included for calculating fire behavior by an innovative variable abstraction method. A comprehensive output format is provided which gives gas temperatures, heat flow terms, and flow variables. The documentation includes input instructions, sample problems, and a listing of the program. The program is written in Fortran and constitutes an improved version of an earlier program, COMPF.

TN992. An investigation of gir-infiltration characteristics and mechanisms for a townhouse, S. J. Treado, D. M. Burch, and C. M. Hunt, Nat. Bur. Stand. (U.S.), Tech. Note 992, 36 pages (Aug. 1979) SN003-003-02090-7

Key words: air infiltration, residential; air permeability of houses; energy conservation; pressurization technique; tracer-gas technique.

Air infiltration measurements using a tracer-gas technique and the pressurization technique were performed on a threebedroom townhouse having a gas-fired, forced-air furnace system, in order to quantify the amount of air infiltration due to various mechanisms. These mechanisms include combustion and draft-diverter air requirements, air leakage from supply-air ducts, and air leakage through the solid parts of the building envelope as well as air leakage through cracks around windows and doors. A thermographic survey was also performed in conjunction with pressurization of the structure, in an attempt to identify specific leaks. An apparatus for measuring the air permeability of building materials was used to analyze the significance of air permeation through solid building elements. Based on the findings of the study, general guidelines are presented for reducing air infiltration in residences.

TN993. Optical materials characterization-Final technical report, February 1, 1978-September 30, 1978, A. Feldman, D. Horowitz, R. M. Waxler, and M. J. Dodge, Nat. Bur. Stand. (U.S.), Tech. Note 993, 71 pages (Feb. 1979) SN003-00302031 - 1 . 
Key words: $\mathrm{Al}_{2} \mathrm{O}_{3} ; \mathrm{As}_{2} \mathrm{~S}_{3}$ glass; $\mathrm{BaF}_{2} ; \mathrm{CaF}_{2} ; \mathrm{CdF}_{2}$; chalcogenide glass; elastic compliances; elastic constants; elastooptic constants; fused silica; $\mathrm{Ge}$; hot forged; $\mathrm{KBr} ; \mathrm{KCl}$; $\mathrm{KCl}: \mathrm{Kl}$; LiF; $\mathrm{MgF}_{2}$; $\mathrm{NaCl}$; $\mathrm{NaF}$; piezo-optic constants; refractive index; $\mathrm{SiO}_{2}, \mathrm{SrF}_{2}$; thermal expansion coefficient; thermo-optic constant; $\mathrm{ZnS} ; \mathrm{ZnSe}$.

Data obtained as part of the Optical Materials Characterization Program are summarized in this report. Room temperature values of refractive index as a function of wavelength are presented for the following materials: commercially grown $\mathrm{KCl}$, reactive atmosphere processed (RAP) $\mathrm{KCl}, \mathrm{KCl}$ nominally doped with $1.5 \% \mathrm{Kl}$, hot forged $\mathrm{CaF}_{2}$, fusion cast $\mathrm{CaF}_{2}, \mathrm{CaF}_{2}$ doped with $\operatorname{Er}(0.001 \%$ to $3 \% \mathrm{Er}), \mathrm{SrF}_{2}$, chemical vapor deposited (CVD) ZnSe (2 specimens), and ZnS (CVD, 2 specimens). Data for the thermo-optic constant (dn/dT) and the linear thermal expansion coefficient are given for the following materials over the temperature range $-180{ }^{\circ} \mathrm{C}$ to 200 ${ }^{\circ} \mathrm{C}: \mathrm{Al}_{2} \mathrm{O}_{3}, \mathrm{BaF}_{2}, \mathrm{CaF}_{2}, \mathrm{CdF}_{2}, \mathrm{KBr}, \mathrm{KCl}, \mathrm{LiF}, \mathrm{MgF}_{2}, \mathrm{NaCl}, \mathrm{NaF}$, $\mathrm{SrF}_{2}, \mathrm{ZnS}$ (CVD), and $\mathrm{ZnSe}$ (CVD). The piezo-optic constants of the following materials are presented: $\mathrm{As}_{2} \mathrm{~S}_{3}$ glass, $\mathrm{CaF}_{2}$, $\mathrm{BaF}_{2}, \mathrm{Ge}, \mathrm{KCl}$, fused $\mathrm{SiO}_{2}, \mathrm{SrF}_{2}$, a chalcogenide glass (Ge $33 \%$, As $12 \%$, Se $55 \%$ ) and $\mathrm{ZnSe}$ (CVD).

TN995. NBS Reactor: Summary of activities-July 1977 to June 1978, F. J. Shorten, Ed., Nat. Bur. Stand. (U.S.), Tech. Note 995, 147 pages (May 1979) SN003-003-02070-2.

Key words: activation analysis; crystal structure; diffraction; isotopes; molecular dynamics; neutron; neutron radiography; nondestructive evaluation; nuclear reactor; radiation.

This report summarizes all those programs which depend on the NBS reactor. It covers the period from July 1977 through June 1978. The programs range from the use of neutron beams to study the structure and dynamics of materials through nuclear physics and neutron standards to sample irradiations for activation analysis, isotope production, radiation effects studies, neutron radiography and nondestructive evaluations.

TN996. Mechanical properties of adobe, J. R. Clifton and F. L. Davis, Nat. Bur. Stand. (U.S.), Tech. Note 996, 45 pages (May 1979) SN003-003-02066-4.

Key words: adobe; adobe soil; compressive strength; creep; flexural strength; mechanical properties; moisture; nondestructive testing; preservation.

Relationships between the compressive strength and creep, and the moisture contents of adobe were investigated. Moisture was found to have a deleterious effect on these mechanical properties of adobe, its severity increasing with increasingly higher relative humidities and higher moisture contents. It was concluded that rain and ground water would have a greater deleterious effect on the mechanical properties of adobe than high relative humidities.

The physicochemical properties of adobe, mix proportions, drying conditions, and shrinkage of specimens were also found to influence the compressive strength of adobe. Procedures for preparing, curing and testing of adobe specimens are given.

A nondestructive test method, based on measuring the penetration resistance of adobe, was found to give reliable predictions of the compressive strength and moisture content of adobe specimens.

TN998. Impact of building regulations on rehabilitation-Status and technical needs, J. G. Gross, J. H. Pielert, and P. W. Cooke, Nat. Bur. Stand. (U.S.), Tech. Note 998, 50 pages (May 1979) SN003-003-02062-1.

Key words: building code; building research; code administration; existing buildings; model codes; preservation; regulation; rehabilitation; renovation.
This report presents the results of a study of the impact of regulations on building rehabilitation and includes a discussion of the activities of the Building Rehabilitation Technology Program of the Center for Building Technology. Particular activities discussed relative to existing buildings include: (a) development of the technical bases for regulations and an improved regulatory process, (b) development of new technology and evaluation tools, and (c) development of responsive and costeffective decision tools. A new code concept is outlined which could be a replacement for the "25-50 percent" rule presently in codes for new construction. This rule often controls the amount of work that may be required in the rehabilitation of existing buildings. The status of existing code documents for buildingrehabilitation is provided along with an overview of other publications which discuss the impact of building regulations on rehabilitation.

TN999. A study of the dynamic flue-gas temperature and offperiod mass flow rate of a residential gas-fired furnace, $C$. Park, W. J. Mulroy, and G. E. Kelly, Nat. Bur. Stand. (U.S.), Tech. Note 999, 41 pages (July 1979) SN003-003-02092-3.

Key words: automatic stack damper; flue-gas temperature profile; gas-fired furnace; off-period mass flow rate; partload performance; seasonal efficiency.

The flue-gas temperature and mass flow rate through a gasfired furnace were studied in the laboratory. Temperature profiles were measured under cycling conditions and compared with profiles predicted mathematically using data obtained while the furnace was cooling down from steady-state operation and warming up from equilibrium. The mass flow rates at various flue-gas temperatures were measured using both a vane anemometer and a tracer-gas technique, and these results are compared with the mass flow rate predicted by the theoretical equations. The effect on the off-period flow rate of automatic stack dampers having different sized damper openings was experimentally determined. Theoretical equations are presented for predicting the effectiveness of a stack damper as a function of the ratio of the area of the damper to the area of the stack and a system friction factor.

TN1008. Antennas and the associated time domain range for the measurement of impulsive fields, R. A. Lawton and A. R. Ondrejka, Nat. Bur. Stand. (U.S.), Tech. Note 1008, 68 pages (Nov. 1978) SN003-003-01998-4.

Key words: antenna; conical transmission line; impulse response; impulsive fields; standards; TEM horn antenna.

This report describes the construction and evaluation of a TEM horn antenna designed at NBS to be used as a transfer standard to generate and measure impulsive electromagnetic fields. Our purpose in the evaluation was to analyze the different electrical field generation and measurement techniques thoroughly enough to determine the major sources of error and establish a standard of impulsive field strength having a well established statement of accuracy.

The evaluation of this horn was done in two independent ways; by placing the horn in the field of a conical transmission line and by a three antenna intercomparison. The two methods were found to agree within $\pm 3 \mathrm{~dB}$ over the range of 0.6 to 5 $\mathrm{GHz}$. Part of this disagreement is due to the assumption of far field conditions, and an experimental technique is described which determines the frequency range over which this assumption is valid.

TN1009. Laser beam profile measurements using spatial sampling, Fourier optics, and holography, E. G. Johnson, Jr., Nat. Bur. Stand. (U.S.), Tech. Note 1009, 96 pages (Jan. 1979) SN003-003-02019-2. 
Key words: amplitude; beam profile; cross correlation; digital sampling; Fourier optics; holography; laser; laser parameters; laser pulse; optical processing; phase; precision measurements; wave front.

Using appropriate holography, lenses, mirrors, and a twodimensional array of small holes to sample the electric field of a laser pulse, we demonstrate a technique for beam profile measurements at a preselected observation plane. This method can measure the amplitude and phase of a laser pulse at each preselected sampling point on a transverse observation plane. Subject to constraints, these measurements can provide separated visual images of the temporal pulse shapes for the amplitude and phase at each of the sampled electric fields. This paper describes the basic concepts for beam profile measurements via holography and uses pictures generated by a prototype system for illustration.

This unit may be calibrated by using a cw laser beam of the same wavelength as the carrier or a Q-switched laser pulse. Therefore, a user can make beam profile measurements of a laser pulse in real time. This technique requires appropriate scaling of the lenses and mirrors, and uses a different hologram to allow the unit to work optimally for each wavelength.

We define the potential limits and virtues of the holographic method. In addition, we define limits and virtues of other beam profile techniques such as the two-pinhole scanning method and the Hartmann plate method.

Finally, we indicate possible directions for eventual commercial and scientific exploitation of the holographic method. The technique can be used for near- and far-infrared wavelengths and, with appropriate changes in the optics, for visible wavelengths.

TNI010. Measurement of pulsed-laser power, $M$. Young and R. A. Lawton, Nat. Bur. Stand. (U.S.), Tech. Note 1010, 40 pages (Feb. 1979) SN003-003-02028-1.

Key words: attenuators; calibration; laser; neodymium laser; peak power; power meter; pulsed laser; Q-switched; risetime; speckle; waveform.

We describe calibrating several optical-pulse power meters to an accuracy of about $8 \%$ or better. The meters are designed for Q-switched neodymium lasers with peak powers in excess of a few megawatts and pulses longer than five or ten nanoseconds. Combined with a fast oscilloscope or a transient digitizer, the meters display the time-domain waveform of the laser emission and thereby allow determination of parameters such as transition duration (risetime, falltime), duration and peak power. We discuss calibrating the meters by both pulsed and cw methods, and show why each method is useful as a check on the other. We treat in some detail the effect of speckle on the use of diffusers as attenuators in power meters such as ours.

TN1011. Construction of a large transverse electromagnetic cell, W. F. Decker, W. A. Wilson, and M. L. Crawford, Nat. Bur. Stand. (U.S.), Tech. Note 1011, 92 pages (Feb. 1979) SN003-003-02034-6.

Key words: electromagnetic susceptibility testing; structural design and fabrication procedures; transverse electromagnetic (TEM) cell.

In support of the electromagnetic interference studies underway in the Electromagnetic Fields Division of the National Bureau of Standards, a 2.8 meter transverse electromagnetic (TEM) cell was constructed by the Instrument Shops Division of the NBS Boulder Laboratories.

The cell requirements, design concepts, and fabrication procedures were developed through the coordination of both the Electromagnetic Fields Division personnel and the Instru- ment Shops Division personnel. This paper provides the sequential procedure used to fabricate this cell, in conjunction with a complete set of detail and assembly drawings used to illustrate the complete fabrication process. The purpose of this publication is to provide documented information sufficient for any outside vendor, with the proper facilities, to construct a similar TEM cell.

TN1012. Calibrating a six-port reflectometer with four impedance standards, C. A. Hoer, Nat. Bur. Stand. (U.S.), Tech. Note 1012, 24 pages (Mar. 1979) SN003-003-02036-2.

Key words: calibration; impedance; reflection coefficient; reflectometer; six-port.

This report is a theoretical study showing how four terminations of known impedance can be used to calibrate a six-port reflectometer for measuring other terminations of unknown inpedance. The equations for obtaining the calibration constants are exact but nonlinear, requiring an iterative solution. Several ways are described for using these constants to calculate the impedance of terminations being measured with the six-port reflectometer.

TN1013. Using a TEM cell for EMC measurements of electronic equipment, M. L. Craw ford and J. L. Workman, Nat. Bur. Stand. (U.S.), Tech. Note 1013, 72 pages (Apr. 1979) SN003-003-02053-2.

Key words: measurement procedures; susceptibility and emission measurements; transverse electromagnetic cell.

This publication describes the physical design and electrical evaluation of pertinent parameters which influence the use and operation of a transverse electromagnetic (TEM) cell. Detailed, step by step procedures are given for using a TEM cell for performing either radiated EM susceptibility testing or for measuring radiated EM emissions from electronic/electro-mechanical equipment. These measurement procedures provide guidelines to potential users and also indicate precautions to observe to minimize problems often encountered when performing EMC measurements and hence to enhance the cell's usefulness. Where available, a brief error analysis associated with the measurement technique is included.

TN1014. Electromagnetic interference (EMII) radiative measurements for automotive applications, J. W. Adams, H. E. Taggart, M. Kanda, and J. Shafer, Nat. Bur. Stand. (U.S.), Tech. Note 1014, 48 pages (June 1979) SN003-003-02086-9.

Key words: mobile-radio; near-field strength levels; vehicular electromagnetic environment; vehicular near-zone electric fields; vehicular near-zone magnetic fields; worst-case EM fields.

This report describes the measured results of the electromagnetic (EM) environment encountered by three different-sized vehicles exposed to a selection of $\mathrm{CB}$ and mobile radio transmitters and broadcast stations. The vehicle in these situations is immersed in the near field of the radiating signals and the measured data is near-field data. This report gives measured data of electric and magnetic fields measured independently. The purpose of the report is to identify the EM environmental conditions under different circumstances in order to estimate EMC testing criteria for vehicles and their electronic systems.

TN1015. Design of a reflection apparatus for laser beam profile measurements, E. G. Johnson, Jr., Nat. Bur. Stand. (U.S.), Tech. Note 1015, 124 pages (July 1979) SN003-003-021032.

Key words: beam profile; calibrated system; holography; irradiance; laser diagnostics; phase front. 
Measurement of both the irradiance and phase front (the bcam profile) in rcal timc from the output of a laser has intcrest for control of that beam and for efficient energy and economic design of the source and the resulting optical systems. The National Bureau of Standards (NBS) has begun a program to build a unit that can measure, at numerous wavelengths from $1.06 \mu \mathrm{m}$ to $10.6 \mu \mathrm{m}$, a selected spatial sample of the beam profile. This device would have the following features: (1) The different carrier wavelengths use the same apparatus by changing two mirrors. (2) The beam profile is sampled simultaneously with no time-shift distortions. (3) The output data streams documenting the sampled beam profile are continuous and are distorted only by the finite number and the time constants of the detectors. (4) The phase-front information is generated before the detectors create the data streams. (5) The apparatus uses mirrors and a reflection hologram that is computer generated. (6) The unit is calibrated piecewise over the range of relative phase and irradiances for each pair of neighboring sampling holes which are $5 \mathrm{~mm}$ apart. (7) The resulting calibrated unit can measure profiles near $10 \mathrm{~cm}$ in diameter with phase-front variations of less than 5 wavelengths. (8) The expected response time for measurements as controlled by the electronics is of the order of several tens of nanoseconds.

The design analysis reported here includes: (1) the theory which uses Fourier optics concepts with off-axis reflections and rough surfaces to provide the basis for accurate computer simulation of laser beams; (2) the program, BEAM, which generates the expected behavior of the apparatus under variation of laser wavelength, physical dimensions for curvatures, hologram structure, and changes in positions of the various components; (3) the simulation results which demonstrate the expected characteristics for the apparatus; and (4) the key element in the apparatus, namely the reflection hologram, which requires discussion of the design, construction, and testing of this element.

The Hartmann plate method is described briefly so that a comparison between it and the holographic method can be made. The comparison shows why the holographic method is best for a standard for irradiance and phase-front measurements.

TN1016. A standard for $\mathrm{rf}$ modulation factor, M. G. Arthur and G. R. Reeve, Nat. Bur. Stand. (U.S.), Tech. Note 1016, 92 pages (Sept. 1979) SN003-003-02125-3.

Key words: amplitude modulation; instrument landing system (ILS); measurement instrumentation; measurement standard; modulation; modulation factor; modulation meter; Newton-Raphson method; percent modulation; signal generator; vhf omnidirectional radio range ( $V O R$ ).

A modulation factor standard has been developed to support the Federal Aviation Administration's requirements for a measurement capability for the ILS and VOR navigation systems. The standard consists of both a precision modulation meter and a stable amplitude-modulated signal source. Although designed primarily for ILS and VOR signals, it has general purpose capabilities within an if range of $10 \mathrm{MHz}$ to $500 \mathrm{MHz}$ and an af range of $20 \mathrm{~Hz}$ to $20 \mathrm{kHz}$. Measurement uncertainty is less than 0.11 percent modulation below 90 percent modulation for ILS/VOR tones of $90 \mathrm{~Hz}$ and above, and is somewhat greater than $30 \mathrm{~Hz}$. Included are a circuit description and an error analysis.

TN1100. Analysis of tentative seismic design provisions for buildings, J. R. Harris, S. J. Fenves, and R. N. Wright, Nat. Bur. Stand. (U.S.), Tech. Note 1100, 599 pages (July 1979) SN003-003-02084-2.

Key words: building codes; buildings; building standards; classification; decision tables; earthquake-resistant design; information networks; nctwork; seismic design; systems analysis.

This report presents the results of a thorough study of the internal logic of the Tentative Provisions for the Development of Seismic Regulations for Buildings developed by the Applied Technology Council. The methods of analysis employed in the study provide objective measures of clarity, completeness, and consistency and an alternative form in which to examine the technical validity of the provisions. These methods include decision logic tables for examining individual provisions, information networks for representing the precedence among provisions, and classification of the provisions to study their scope and arrangement. A formal representation of the provisions is presented by the data items, decision tables, networks, and classification systems developed in the study. An index and several alternate arrangements of the provisions are also included. Opportunities for improvement of the tentative provisions are identified and discussed, and considerations for their future development and implementation within various national standards are highlighted.

TN1 101. Decision analysis of strategies for reducing upholstered furniture fire losses, S. G. Helzer, B. Buchbinder, and F. L. Offensend, Nat. Bur. Stand. (U.S.), Tech. Note 1101, 155 pages (June 1979) SNO03-003-02078-8.

Key words: building fires; cost-benefit analysis; costs; decision analysis; fire losses; furniture; hazard analysis; probability; residential buildings; sensitivity analysis; smoke detectors; standards; upholstered furniture.

Decision analysis is used to evaluate alternative strategies for reducing residential upholstered furniture fire losses. Three alternatives are evaluated: no-action, mandatory smoke detector installation, and the proposed upholstered furniture standard under consideration by the Consumer Product Safety Commission. Quantitative models are developed to assess fire losses and cost under each alternative. The alternatives are evaluated on the basis of minimizing the total cost plus loss to society over time. Subject to the assumptions set forth in the report, the analysis shows that the detector alternative and the proposed standard are essentially equivalent and preferred to the no-action alternative. The proposed standard is more effective in saving lives, whereas the detector alternative is less costly to implement. The sensitivity of the results to key assumptions and input parameters is tested. The results are shown to be particularly sensitive to the cost of the proposed standard, the loss of life value assignment, and the upholstered furniture replacement pattern.

TN1102. Large scale integration digital testing-Annotated bibliography, 1969-1978, T. F. Leedy, Nat. Bur. Stand. (U.S.), Tech. Note 1102, 44 pages (Aug. 1979) SN003-00302097-4.

Key words: electronics; integrated circuit; large scale integration; memory; microprocessor; testing.

This annotated bibliography covers articles published in the field of semiconductor device testing. The bibliography contains (1) entries divided into six economics of testing, (2) monolithic circuit testing, (3) the testing of subsystems of large scale integrated circuits such as microcomputer boards and memory arrays, (4) various test strategies used to locate a defective LSI circuit, (5) test equipment available for LSI testing, and (6) various measurement methods that may be of interest to the test engineer.

TN1 103. Full-scale burning behavior of upholstered chairs, V. Babrauskas, Nat. Bur. Stand. (U.S.), Tech. Note 1103, 86 pages (Aug. 1979) SN003-003-02110-5. 
Key words: chairs; compartment fires; fire tests; flammability; furnishings; upholstered furniture.

A test program was conducted to determine the fire behavior of a variety of upholstered chairs subjected to a flaming ignition. Major variables were materials and construction of chairs, room ventilation, and type of ignition sources. A total of 16 types of traditional and modern design chairs were tested in a full-scale, otherwise unfurnished room. A folded up newspaper at the seat area was used as the standard ignition source. Room tenability criteria were based on smoke, concentrations of gaseous combustion products, and heat flux. One or more tenability criteria were exceeded for 14 chairs, in times ranging from 100 $\mathrm{sec}$ to $650 \mathrm{sec}$; two chairs burned without exceeding any of the tenability criteria. A review is included of previous upholstered furniture experiments using flaming ignition sources and of existing or proposed small-scale standard tests.

TN1 104, Vols. 1 and 2. The FCC public message services policy change: An ETIP evaluability assessment report, J. Bell, S. Kirby, R. G. Weiss, and S. Watson, Nat. Bur. Stand. (U.S.), Tech. Note 1104/1, 232 pages, 1104/2, 110 pages (Sept. 1979) SN003-003-02117-2.

Key words: administrative experimentation; economic deregulation; evaluability assessment; evaluation; Experimental Technology Incentives Program; Federal Communications Commission; regulatory experimentation; regulatory policy; technology innovation; telecommunications.

This document is a report of work in progress toward evaluating effects of the recent decision of the Federal Communications Commission to open public message services to competition. It is one product of the Regulatory Processes and Effects Project of the Center for Field Methods (ETIP). The broader project, described elsewhere, is attempting to analyze the effects of changes in regulatory processes on industrial innovation. The joint ETIP/FCC project will involve measuring whether the FCC policy change leads to increases in competition, technological innovation, and public benefit.

The first two chapters provide an introduction and synopsis. Chapter II examines the setting in which the decision occurs in terms of historical developments, industry trends, and views held by various observers. Chapter IV describes the: Commission's mandate for regulation, process for implementing this mandate in terms of regulations and operations, and current industry status. The fifth chapter describes the evaluation logic. The last chapter is an assessment which shows that there are many choices to be made to target the evaluation. A glossary of terms and bibliography are included. Seven appendices are bound separately.

TN1 105. A 20 bit + sign, relay switched D/A converter, T. M. Souders and D. R. Flach, Nat. Bur. Stand. (U.S.), Tech. Note 1105, 21 pages (Oct. 1979) SN003-003-02129-6.

Key words: digital-to-analog converter; high resolution; multirange; R-2R ladder; relay switching; self-calibration; twenty bits + sign; voltage output.

A multirange, 20-bit + sign, voltage output d/a converter is described. The converter exhibits less than $1 \mathrm{ppm}$ (of full scale range) linearity error, and temperature coefficients of gain, offset and linearity of less than $0.5 \mathrm{ppm} /{ }^{\circ} \mathrm{C}$. The design is based on the R-2R ladder network in the current steering mode, using miniature latching relays with mercury wetted contacts for switching. Ten buffered, temperature-controlled unsaturated standard cells comprise the voltage reference.

Techniques with design details are presented for minimizing errors due to relay thermal emf's, for implementing a selfcalibration of linearity errors, and for obtaining optional coding formats. Calibration techniques are discussed and representative calibration data are presented.

TN1 106. Frame C: A compact procedure for quantitative energy-dispersive electron probe $x$-ray analysis, $R$. L. Myklebust, C. E. Fiori, and K. F. J. Heinrich, Nat. Bur. Stand. (U.S.), Tech. Note 1106, 111 pages (Sept. 1979) SN003-003-021130 .

Key words: computer program; energy dispersive detector; multichannel analyzer; peak overlap; quantitative electron probe microanalysis; $x$-ray continuum; $x$-ray spectrum.

A data evaluation procedure (FRAME C) for carrying out quantitative electron probe microanalysis with a lithium-drifted silicon detector was developed for use with a small computer. The procedure consists of a background correction calculated from two selected background regions of interest, a simple method of resolving overlapping peaks, and the matrix corrections for characteristic radiation ( $\mathrm{ZAF}$ ). To save computation time, small groups of adjacent channels (regions of interest) in the multi-channel analyzer rather than individual channels are used for the calculations. The method for computing the overlap factors is described. Examples of several types of analyses are presented.

TN1107. The use of aerial infrared thermography to compare the thermal resistances of roofs, D. M. Burch, Nat. Bur. Stand. (U.S.), Tech. Note 1107, 38 pages (Aug. 1979) SN003-003-02102-4.

Key words: aerial flyovers; aerial infrared thermography; energy conservation; roof heat-loss survey.

The paper investigates whether a comparative roof survey using aerial infrared thermography can be used to rank the roofs of residential and commercial buildings according to their thermal resistance. Mathematical models are presented for predicting the apparent radiance temperatures of these roof systems. These models are used to investigate the differences in apparent radiance temperature between roofs having various thermal resistances. These predicted differences are then compared with predicted differences in apparent radiance temperature caused by typical variations in roof emittance, local outdoor temperature, and local wind speed throughout the macroclimate. The transmission characteristics of the atmosphere are reviewed, and the required dew-point spread for preventing dew or frost formation on a roof is examined.

TN1108. SPEED2, a computer program for the reduction of data from automatic data acquisition systems, R. D. Peacock and J. M. Smith, Nat. Bur. Stand. (U.S.), Tech. Note 1108 , 153 pages (Sept. 1979) SN003-003-021 12-1.

Key words: computer program; data acquisition systems; data reduction; plotting.

The voluminous amount of data that can be collected by automatic data acquisition systems requires the use of a digital computer for the reduction of data. A general purpose computer program for the reduction of data collected by automatic data acquisition systems is presented. The program is written with the ability to accept data from a number of different data acquisition systems, with the ability to check the correctness of data included. Through the use of FORTRAN computer programming, the data can be converted to meaningful scientific and engineering units. The data can then be presented in tabular, printer plot or ink pen plot form.

The program is documented, and detailed instructions for its use, with examples, are presented. The use of SPEED2 requires some knowledge of FORTRAN programming language and the executive control language for the computer system in use. 
TNI109. Characterization of electrical ignition sources within television receivers, G. J. Rogers and D. D. Evans, Nat. Bur. Stand. (U.S.), Tech. Note 1109, 60 pages (Oct. 1979) SN003-003-021 19-9.

Key words: electrical failure; fire containment; ignition; television fire.

The ignition of television receivers initiated by electrical failures in the circuitry was examined by studying four receivers. They were: two black and white portables, a color portable, and a color console receiver. Selected locations within the circuitry were stressed by introducing full or partial short circuits to simulate the failure of electronic components. The temperatures and increased power dissipation generated by short-circuited components were recorded. Although component temperatures greater than $500{ }^{\circ} \mathrm{C}$ were achieved, no flaming ignition sources were generated.

For comparative purposes the energy release rate of the ignition source specified in the UL 1410 test procedure was measured. Supplemental measurements on the operating temperatures of chassis components under varying ventilation conditions were also made.

TN1110. NBS interagency transducer project 1951-1979-Art overview, P. S. Lederer, Nat. Bur. Stand. (U.S.), Tech. Note 1110, 45 pages (Aug. 1979) SN003-003-02109-1.

Key words: dynamic calibration; evaluation; interagency transducer project; performance characteristics; telemetry; transducer.

Between 1951 and 1979, the National Bureau of Standards was engaged in a continuing project to study the performance of sensory transducers, primarily those used in telemetry. This project has been supported by agencies of the Defense Department and NASA. This report provides a brief description of the background and history of the project, of its objectives, of some of the techniques and specialized facilities developed and used, and of some of the publications that have been issued from the project.

\subsection{CONSUMER INFORMATION SERIES}

Practical information, based on NBS research and experience, covering areas of interest to the consumer. Easily understandable language and illustrations provide useful background knowledge for shopping in today's technological marketplace.

CIS4, Revised 1978. Corrosion, E. L. R Corliss, Nat. Bur. Stand. (U.S.), Consum. Inf. Ser. 4, 31 pages (Revised 1978) SN003-003-02024-9.

Key words: audition; communications; hearing; hearing aids; selection of hearing aids; speech communication.

A consumers information publication containing information on hearing aids including selection, use, and maintenance.

CIS9, Revised 1979. Facts about hearing and hearing aids, J. Kruger and S. Halpin, Eds, Nat. Bur. Stand. (U.S.), Consum. Inf. Ser. 9, 12 pages (Revised June 1979) SN003-003-019470 .

Key words: corrosion; crevice corrosion; galvanic corrosion; inhibitors; pitting corrosion; rust; stress corrosion.

This document explains what corrosion is, how it affects certain metals and, how to prevent it. 


\subsection{NBS INTERAGENCY REPORTS}

A special series of interim or final reports on work performed by NBS for outside sponsors (both government and non-government). In general, initial distribution is handled by the sponsor; public distribution by the National Technical Information Service (NT1S), Springfield, VA 22161, in paper copy or microfiche form unless otherwise stated. When ordering this series from NTIS you must order it by the "COM, PB, or AD" number listed at the end of each entry.

NBSIR 75-935. The National Measurement System tor electricity, N. B. Belecki, B. L. Dunfee, and O. Petersons, 86 pages (Sept. 1978). Order from NTIS as PB299158.

Key words: calibrations; dissemination of units; electrical measurements; eleçtric power measurements; electrotechnology; impact of measurements; measurement technology assessment; National Measurement System; standards.

The National Electrical Measurement System, by which all measurements of electrical quantities are made in the U.S., is reviewed. This overview, based on the results of a four-year study, details the organizational structure of the system; the technical aspects of realizing, maintaining, dissemination and using the units for measurements; and the economic characteristics of its basic industry, the instrumentation industry, and the system's user constituency. Documentary standards and the organizations producing them are discussed, concluding with a survey of presently adopted documents. Its two major components, the electronics subset and the electric power subset, are defined, described, and contrasted. Major technical, management, and logistics problems facing the system are delineated. An in-depth view of the Electricity Division, which supplies the measurement base of the system, is given. Finally, recommendations for technical and management action by NBS in a number of areas are given.

NBSIR 77-1289. The measurement of wind loads on a full-scale mobile home, R. D. Marshall, 132 pages (Sept. 1977). Order from NTIS as PB297463.

Key words: aerodynamics; building; codes and standards; full-scale testing; mobile homes; wind loads.

An experimental investigation of wind loads acting on a fullscale mobile home is reported. The objectives of the investigation were (1) the direct measurement of surface pressures and overall drag and lift forces, (2) the formulation of recommended loads for the design of mobile homes and their anchoring systems to resist forces due to wind and (3) the measurement of deflections and the identification of failure modes with application of simulated wind loads.

Measurements were obtained for a variety of wind speeds and relative wind directions using a mobile home with nominal plan dimensions of 12 by $60 \mathrm{ft}$ ( 3.7 by $18.3 \mathrm{~m}$ ). Wind speeds were measured at five levels ranging from 3 to $18 \mathrm{~m}$ and the mean velocity profiles were found to be best described by a power law with exponent $\alpha=0.18$. Extreme negative pressure fluctuations were found to occur on the end walls and along the perimeter of the roof. The resonant component of response of the mobile home to drag and lift forces is negligible for basic wind speeds up to $90 \mathrm{mph}(40 \mathrm{~m} / \mathrm{s})$ and the average maximum lift loads are not strongly influenced by the presence or absence of skirting.
Recommended design loads are based on the average maximum event in a time interval of 1000 seconds and are tabulated for assumed basic wind speeds of 70 and $90 \mathrm{mph} \mathrm{(31}$ and $40 \mathrm{~m} / \mathrm{s}$ ) and a moderately open wind exposure.

NBSIR 77-1298. Power lawn mowers: Ease of pulI, V. J. Pezoldt and J. J. Persensky, 32 pages (June 1977). Order from NTIS as PB271974.

Key words: consumer products; human factors; hịman performance; lawn mowers; psychophysics; safety; standards.

This study was designed to provide objective information about the subjective judgement of "easy to pull" as it relates to the effort required to restart manual pull-start power lawn mowers. Seventy-four lawn mower users performed a total of more than 10,000 pulls on two simulated pull-start mechanisms. The peak forces applied in the pulls were associated with the subjects' judgements about the ease or difficulty of the pulls. These data were used to generate sample distributions of the maximum forces judged easy and the minimum forces judged hard. While not providing a definitive answer to the question of what is easy to restart, the data generated in the study provide a practical basis upon which an upper force limit for easy to restart can be based.

NBSIR 77-1 299. Power lawn mowers: Time-to-blade access, $A$. M. Ramey and J. J. Persensky, 22 pages (May 1977). Order from NTIS as PB297641.

Key words: consumer product; human factors; lawn mowers; reaction time; safety; standards.

This document is the final report for the Consumer Product Safety Commission of an investigation of time-to-blade access for walk-behind power mowers. The problem studied was: "How long after the dead-man control is released should a lawn mower blade be allowed to rotate?" The Human Factors Section at NBS performed this empirical study of operator movement time to determine an ergonomically sound recommendation for blade stopping time.

One hundred participants were tested using a reaction time device designed to measure mower users' approach times to various areas of potential blade contact. The test apparatus permitted measurement of both reaction time-or time to release a simulated dead-man control at the onset of a cue light and, more importantly, movement time-or the time from the release of the dead-man control to activation of one of five switches in the blade access area.

Analysis of the data reveal no statistically significant differences in reaction time as a function of movement distance. As expected, however, movement time does increase linearly as movement distance increases. The range of average movement times observed was from 0.6 to 3.3 seconds. The median movement time at the shortest and longest distances were 1.4 and 2.2 seconds respectively. An inspection of percentile information for movement time suggests a blade-stopping time of 0.7 seconds in order to protect the maximum number of people.

Recommendations for needed further research are discussed.

NBSIR 77-1401. Processing and characterization of NBS standard polyethylene for use as a negative control material, $A$. J. Bur, 32 pages (Jan. 1978). Order from NTIS as PB297464. 
Key words: biomaterials; negative control; polyethylene; processing sheets and rods; surface characterization; surface contamination.

This work was initiated in order to fulfill a need for a polymer which can serve as a negative control material for biocompatibility studies involving new polymer implant materials. Two large batches of well-characterized polyethylene resin are the sources of the candidate negative control material. The original polyethylene resin, in pellet form, was processed into sheets and rods and examined for surface contaminants and uniformity. Surface observations consisted of measurements of contact angle, attenuated total reflectance infra-red absorption and secondary ion mass spectroscopy (SIMS). Bulk measurements consisted of density, differential scanning calorimetry, and transmission infra-red spectroscopy. All of the measurements, except SIMS, indicated that the material was uniform and typically polyethylene with no macroscopic contamination. The SIMS measurement, which is a sensitive analytical tool for detecting low levels of elemental contamination, showed significant differences between the types of contamination on the surfaces of the starting material and the rype of contamination on the processed sheet and rod. The method of processing was also significant because the extruded rod showed much more contamination than did the compression molded sheet. The surfaces of the rod were found to contain metallic oxides and several other metals which were not present in the unprocessed polyethylene. It is concluded that close attention must be paid to the method of processing and that only a sensitive analytical tool such as SIMS can be used to detect surface contamination and the differences between these samples.

NBSIR 78-887. Development and evaluation of an LNG s\&mpling measurement system, W. R. Parrish, J. M. Arvidson, and J. F. LaBrecque, 200 pages (July 1978). Order from NT1S as PB289938.

Key words: custody transfer; density; gas analysis; gas chromatography; heating value; hydrocarbon; liquefied natural gas; phase equilibrium; pipelines; sampling.

This report describes the development and evaluation of procedures and components for sampling and analyzing LNG from flowing streams. Laboratory and field test results showed the total uncertainty in the computed heating value of samples taken with the recommended sampling system could be routinely within \pm 0.3 percent; this included the \pm 0.1 percent uncertainty in analysis by gas chromatography. Three sample probes and two vaporizer designs were considered. Of the ten operating variables considered, six were found to be important in sampling. Test results were used to establish recommended design and operating criteria.

NBSIR 78-1432. Automation of the ion energetics data center, R. Thompson, W. Webb, and H. M. Rosenstock, 84 pages (Dec. 1977). Order from NTIS as PB293918.

Key words: abstract; appearance potential; archival tape; computer program; data base; data base management; empirical molecular formula; GPSDC; ion energetics; ionization potential.

The Ion Energetics Data Center is engaged in the compilasion, evaluation and dissemination of experimental information on gaseous ion energetics. Outputs include bibliographic and tabular information on ionization potentials, appearance potentials, electron affinities and heats of formation of gaseous positive and negative ions. The operation of the data center is discussed. This operation has recently been automated by the development of a set of computer programs, called 1ONPACK, which minimize the manual effort required for the numerous file manipulations and editing steps necessary to produce the data center output. The functions of the programs are outlined and the associated operating procedures are described in detail. Full documentation of the programs is presented in a separate report.

NBSIR 78-1433. Low velocity performance of a bronze bearing vane anemometer, L. P. Purtell, 23 pages (Feb. 1978). Order from NTIS as PB291366.

Key words: airflow; anemometer; laser velocimeter; low velocity; performance; vane anemometer; wind tunnel.

Performance of a bronze bearing vane anemometer is evaluated over the speed range of 64 to 690 feet per minute including starting speed and stopping speed. The tests were performed in the NBS Low Velocity Airflow Facility which provides a uniform flow of low turbulence and utilizes a laser velocimeter as the velocity standard.

\section{NBSIR 78-1444-3. Semiconductor technology pro- gram-Progress briels, W. M. Bullis, Ed., 16 pages (Oct. 1978). Order from NTIS as PB292681.}

Key words: electronics; integrated circuits; measurement technology; microelectronics; semiconductor devices; semiconductor materials; semiconductor process control; silicon.

This report provides information on the current status of NBS work in measurement technology for semiconductor materials, process control, and devices. Results of both inhouse and contract research are covered. Highlighted activities include: determination of resistivity-dopant density relationships in silicon; measurement of ion-implanted dopant profiles by spreading resistance; optical measurement of line widths on chrome photomasks, iron-oxide photomasks, and silicon wafers; additional data on sulfur impurity levels in silicon; conduct of a workshop on stability of thin film solar cells; analysis of leakage currents in gated diode test structures; calculations of the radiation dose incurred by oxide layers during $x$-ray and e-beam lithographic steps; correlation of selected electrical parameters on commercial rectifier diode wafers; and availability of a test pattern for determining alignment between mask levels. In addition, brief descriptions of new and selected ongoing projects are given. The report is not meant to be exhaustive; contacts for obtaining further information are listed. Compilations of recent publications and publications in press are also included.

NBSIR 78-1478. A universal set of tést data for computer implementations of elementary mathematical functions, $D$. W. Lozier, 29 pages (May 1978). Order from NTIS as PB291961.

Key words: elementary function testing; Fortran library test data; Fortran library testing; mathematical function testing; test data for elementary functions; test data for mathematical functions.

A short table of values of 20 mathematical functions commonly found in computer libraries is given. The data was chosen to sample the functions throughout the range of a typical floating-point arithmetic. Computer implementations can be tested by comparing computed function values against the tabular values. A discussion on how to interpret the test results is included, for both decimal and non-decimal implementations.

NBSIR 78-1494. Test procedures for the determination of the gross calorific value of refuse and refuse-derived-fuels by oxygen bomb calorimetry. Summary of the 1977 fiscal year results, D. R. Kirklin, D. J. Mitchell, J. Cohen, E. S. Domalski, and S. Abramowitz, 35 pages (Dec. 1978). Order from NTIS as PB290160. 
Key words: bomb calorimetry; gross calorific values; refuse-derived-fuels; sample characterization; test procedures.

Gross calorific values have been determined for refusederived-fuels (RDF) from two manufacturers, Teledyne National and Combustion Equipment Associates. Test procedures used are modifications of those used for coal and coke. The calorific values (moisture- and ash-free basis) obtained for Teledyne National RDF ranged from 24.51 to $25.20 \mathrm{MJ} \mathrm{kg}^{-1}$ ( 10539 to $10835 \mathrm{Btu} \mathrm{lb}^{-1}$ ) with a standard deviation of 0.8 percent. The calorific values (moisture- and ash-free basis) of Combustion Equipment Associates ECO-FUEL 11 RDF ranged from 21.93 to $22.16 \mathrm{MJ} \mathrm{kg}^{-1}$ (9427 to $9528 \mathrm{Btu}^{\mathrm{lb}} \mathrm{b}^{-1}$ ) with a standard deviation of 0.4 percent. Results of 23 laboratory samples are presented at various stages of sample preparation which were derived from single field samples from each of the two sources. Calorimetric results based on an equilibrated laboratory sample are presented along with some semi-quantitative spectrochemical results. The results indicate that the techniques of oxygen bomb calorimetry can be successfully applied to a non-homogeneous refuse stream after considerable processing to prepare a "homogeneous" refuse-derived-fuel (RDF).

NBSIR 78-1496. Preliminary data on the field performance of storage-type residential water heaters, R. A. Grot and L. S. Galowin, 27 pages (Apr. 1979). Order from NTIS as PB295431.

Key words: energy usage; load profiles; water heaters.

The early results of a field experiment for determining the performance of gas and electric residential storage water heaters are presented. Energy requirements for hot water supply and hot water consumption and usage pattern data are presented and analyzed using statistical techniques in order to display average load curves and the variation about the average. It is shown that the daily energy usage of these water heaters is approximately a linear function of the energy content of the drawn daily water consumption. This fact allows a simple procedure to be used for evaluating the effects of retrofit actions on the performance of the water heater.

NBSIR 78-1501. Quantified occupant-use factors affecting energy consumption in residences, $R$. E. Clark and S. R. Hastings, 143 pages (July 1979). Order from NTIS as PB298052.

Key words: appliance energy consumption; energy consumption of residences; lighting energy consumption; occupant factors; residential air conditioning; service hot water; space heating; ventilation.

Predicting energy consumption for a building requires three types of data: climatic data, component performance data, and occupant-use data. Historically, few data on occupant use of a building have been collected, and the data which are collected are not easily referenced. Consequently, it is common for energy analysts to establish values for occupant variables merely on the basis of their own personal experience. In response to this dilemma, this report assembles residential energy-use-data, as could be found, from field metering studies, surveys, utility company estimates, and government sponsored statistical projections. From these data the authors have determined recommended occupant-use values based on their analysis and judgments. These "recommended values" represent the best judgment of the present authors, but are not to be interpreted as "NBS recommended" values. Data, and assessment of their validity for input in models for predicting energy consumption, are organized into six groups by energy end-use: (1) heating, (2) service hot water, (3) appliances, (4) lighting, (5) air conditioning, and (6) ventilation. The use of more soundly derived values for occupant-use variables will result in a better correlation between the energy use predicted for buildings being designed today and the actual energy use of the buildings when occupied.

NBSIR 78-1505. Characteristics of helicoid anemometers, J. M. McMichael and W. G. Cleveland, 17 pages (Aug. 1978). Order from NT1S as PB291987.

Key words: air; anemometer; helicoid anemometer; lag; overspeeding error; rotary anemometer; unsteady flow.

An experimental study of the overspeeding error for helicoid anemometers in periodic air flows is described. The ranges of amplitude and frequency for which a simple nonlinear model for the dynamic response of such instruments remains valid are presented. It is shown that the model is valid for typical atmospheric applications of such instruments. A simple method is presented whereby the effects of inertial lag and nonlinearity may be taken into account in obtaining measurements of alongwind power spectra in the atmosphere.

NBSIR 78-1507. Some thoughts on electrical connections, J. Rabinow, 35 pages (Aug. 1978). Order from NTIS as PB290491.

Key words: aluminum wiring; electrical connections; pressure terminals; wire creep.

This report is a subjective and personal statement of my experiences and thoughts regarding electrical connections, in general, and aluminum wiring for homes, in particular. It is not a statement of official position of the National Bureau of Standards (NBS). It is entirely possible that other members of the NBS staff may not agree with many statements made in this report. It is based on some considerable experience and where the ideas expressed are not based on such experience, I hope this is clearly indicated.

My conclusions are that present day technology of electrical distribution wiring in residences is not in keeping with good engineering practices available today. This is true relative to both copper and aluminum wiring.

NBSIR 78-1509. An algorithm and basic conputer program for calculating simple coal gasification equilibria, W. S. Horton, 83 pages (Aug. 1978). Order from NTIS as PB291241.

Key words: BASIC; carbon dioxide; carbon monoxide; coal gasification; COLGAS; hydrogen; interactive computer program; methane; minimization of Gibbs energy; phase rule; simultaneous chemical equilibria; water.

Calculation of the equilibrium composition for the gases $\mathrm{CH}_{4}$, $\mathrm{CO}, \mathrm{CO}_{2}, \mathrm{H}_{2}$, and $\mathrm{H}_{2} \mathrm{O}$ is treated by minimizing the Gibbs energy, G. Minimization is constrained by the conservation of chemical elements. With the use of Lagrangian multipliers, the minimum is found by setting the partial derivatives of $G$ with respect to the amount of each substance equal to zero. The resulting non-linear equations are solved iteratively by the Newton-Raphson method. This algorithm is implemented with an interactive computer program written in the BASIC language named COLGAS. The aim of this work was to provide people who test materials in coal-gasification-like atmospheres an easy way to obtain the equilibrium composition of their gas mixtures. A knowledge of computer programming is not required in order to use the program. A listing of the program is given and also six sample computer calculations. The phase rule is applied to the $\mathrm{C}-\mathrm{H}-\mathrm{O}$ system and two ternary diagrams are shown illustrating the condensation of solid carbon and liquid water.

NBSIR 78-1521. French schools-A report of the U.S. team visit to France from November 13 to 23,1977, P. Driscoll, Coor- 
dinator, 42 pages (Mar. 1979). Order from NTIS as PB296148.

Key words: building technology; France/NBS cooperative program; French schools.

By June 1970, the National Bureau of Standards and the Centre Scientifique et Technique du Batiment had effectively begun a cooperative program in building technology. The purpose of this program was to increase jointly the French and United States capability to develop building sciences and technology; seek answers to significant building problems; and reduce costly and wasteful duplication of parallel national efforts. This collaboration has provided opportunities for representatives of both nations to exchange ideas, skills, information and techniques in attacking problems of particular mutual interest. These opportunities have included the exchange of selected literature, with translations of main papers and publications; the exchange of long-term interns working in the organization of the other country on subjects requiring special facilities; work by one organization for the benefit of the other not as well equipped, either in staff or in equipment; and-the exchange of missions of experts from one country to the other to study special work. It is precisely this exchange of missions of experts, to study specific work, that produced the report which follows.

NBSIR 78-1526. Annual conference on fire research, C. Huggett, Ed., 217 pages (Dec. 1978). Order from NTIS as PB291930.

Key words: combustion products; fire hazards; fire modeling; fire research; human behavior in fires.

This report contains extended abstracts of grants and contracts for fire research sponsored by the Center for Fire Research, National Bureau of Standards and descriptions of the internal programs of the Center for Fire Research.

NBSIR 78-1539. Mathematical models for selecting catalogs of standard-sized items, D. R. Shier, 80 pages (Sept. 1978). Order from NTIS as PB289803.

Key words: catalog; dynamic programming; iterative procedure; models; optimization; stability; standards.

This report identifies and discusses various mathematical models for selecting a "best" catalog of standard sizes. A survey of existing models for continuous and discrete versions of the catalog selection problem is presented. The advantages and disadvantages of such models are assessed with regard to both range of applicability and computational feasibility. This evaluation shows that a frequently-advocated iterative procedure may produce erroneous results and identifies another approach as the most promising. Various refinements and extensions are then proposed for this latter (discrete) model and its associated solution technique (dynamic programming). In particular, a multidimensional version of the catalog selection problem is formulated and analyzed. Areas for further investigation, and unresolved issues, are also discussed.

NBSIR 78-1545. Low velocity performance of a high speed vane anemometer, L. P. Purtell, 23 pages (Sept. 1978). Order from NTIS as PB291409.

Key words: airflow; anemometer; laser velocimeter; low velocity; performance; vane anemometer; wind tunnel.

Performance of a high speed vane anemometer is evaluated over the speed range of 43.4 to 741 feet per minute including starting speed and stopping speed. The tests were performed in the NBS Low Velocity Airflow Facility which provides a uniform flow of low turbulence and utilizes a laser velocimeter as the velocity standard.
NBSIR 78-1547. Methodology for choosing test parameters to evaluate protective headgear, R. E. Berger and N. J. Calvano, 77 pages (Nov. 1978). Order from NTIS as PB292284.

Key words: headform; headgear; head injury; helmet; impact; test method.

The effects of changing test variables (headform, impact velocity, impact surface, impact site) on output parameters (peak acceleration, severity index) were studied. Twelve football helmets representing six different types of energy absorbing systems were used in the test. Results show good correlation between metal and humanoid headforms during top impacts but poor correlations when helmets were impacted on the back. Correlation between impact surfaces was high. Peak acceleration correlated well with severity index.

NBSIR 78-1555. A system for fire safety evaluation of health care facilities, H. E. NeIson and A. J. Shibe, 146 pages (Nov. 1978). Order from NTIS as PB292273.

Key words: automatic sprinklers; building codes; building construction; Delphi Method; fire safety; health care facilities; hospitals; interior finishes; Life Safety Code; nursing homes; risk analysis; safety equivalency; safety evaluation; smoke detection.

A quantitative evaluation system for grading health care facilities in terms of fire safety is described. The system can be used to determine how combinations of widely accepted fire safety equipment and building construction features may provide a level of safety equivalent of that required by the widely accepted Life Safety Code of the National Fire Protection Association. The system will provide flexibility to both the designer of new facilities and to the renovator of existing health care facilities.

Three major concepts form the basis for code equivalency: a. Occupancy Risk - the number of people affected by a given fire, the level of fire they are likely to encounter, and their ability to protect themselves; b. Building Safety Features-the ability of the building and its fire protection systems to provide measures of safety commensurate with the risk; c. Safety Redundancy-in-depth protection, through the simultaneous use of alternative safety methodologies such as containment, extinguishment, and people movement methodologies. The design of the complete fire safety system is intended to ensure that the failure of a single protection device or method will not result in a major failure of the entire system.

In this system, equivalency is judged to exist when the total impact of the occupancy risk factors and the compensating building safety features produce a level of safety equal to or greater than that achieved by rigid conformance to the explicit requirements of the NFPA Life Safety Code. In this evaluation, safety performance is gauged both in terms of overall safety impact and depth of redundance.

NBSIR 78-1556. Kitchen range energy consumption, J. V. Fechter and L. G. Porter, 68 pages (Mar. 1979). Order from NTIS as PB294880.

Key words: appliance; cooking; efficiency; energy; human factors; kitchen ranges; labeling; stoves; test methods.

In support of the national appliance energy conservation program, the National Bureau of Standards (NBS) has been developing, evaluating, and recommending standard methods for measuring appliance energy efficiency. This report describes a study where 58 non-professional cooks prepared 21 standard meals each on kitchen ranges, and compares the results with a laboratory test method which does not utilize such cooks. Ten different ranges were tested-five gas and five electric. The results are (1) the rank order (least to most efficient) cor- 
relations between laboratory measured efficiency and energy used by cooks were not significantly different, (2) the cooking practices of the 58 cooks were sufficiently alike that no major modification to the laboratory test method was required, (3) homemakers showed greater variability in energy use than did laboratory tests with the same ranges, (4) energy consumption labels on appliances should include information about that variability, and (5) evaluation of range efficiencies could be done with only three to five energy intensive meals.

NBSIR 78-1558. Development of hydrogen and hydroxyl contamination in thin silicon dioxide thermal films, S. Mayo and W. H. Evans, 39 pages (Mar. 1979). Order from NTIS as PB293556.

Key words: dry oxidation of silicon; hydrogen contamination; hydroxyl contamination; semiconductor device fabrication; silicon; silicon dioxide; thermal oxidation of silicon.

Hydrogen and hydroxyl incorporation into thin silicon dioxide films thermally grown on silicon in dry oxygen atmospheres contained in resistance-heated fused silica or polycrystalline silicon tubes is analyzed. The mechanisms leading to incorporation of these impurities in the film are discussed in terms of trace water and hydrocarbon contamination in the oxygen used, room ambient humidity permeation through the fused silica tube, the silicon wafer preparation prior to oxidation, and other environment factors. The most significant reactions occurring the water-silica-silicon system during wafer oxidation at temperatures in the range from $800{ }^{\circ} \mathrm{C}$ to $1200{ }^{\circ} \mathrm{C}$ are discussed. It is shown that, during the oxidation period required to grow a $100-\mathrm{nm}$ thick silicon dioxide film on a $<100>$ silicon wafer in nominally dry oxygen containing water contamination in the ppm range, the introduction of hydrogen and hydroxyl contamination into the oxide film can be explained in terms of the water-silica interaction. The use of polycrystalline silicon oxidation tubes is discussed with reference to the inherent water gettering action of silicon at oxidation temperatures.

NBSIR 78-1564. Tabulation of published data on electron devices of the U.S.S.R. Through December 1976, C. P. Marsden, 137 pages (Dec. 1978). Order from NTIS as PB291959.

Key words: electron devices; electron tubes; semiconductors; U.S.S.R.

This tabulation includes data on U.S.S.R. electron devices as collected from publications, mostly handbooks published by the various ministries and institutes of the U.S.S.R. Information is given on all active devices ranging from receiving to microwave devices, semiconductor devices, and miscellaneous devices such as photographic flash tubes and thermistors.

NBSIR 78-1569. End-of-year-report. Micromechanical properties of beryllium and other instrument materials, B. W. Christ, R. S. Polvani, and R. J. Hocken, 42 pages (Oct. 1978). Order from NTIS as PB299654.

Key words: beryllium; dimensional stability; gyroscope; instrument materials; microcreep; micromechanical properties.

This research program was initiated on October 1, 1977. It is sponsored by the Office of Naval Research. The objective of the program is to evaluate and understand the micromechanical properties of beryllium and other instrument materials for use in gryoscopes, so that dimensional stability can be improved. Improved dimensional stability is expected to lessen the need to periodically align gyroscopes in service.

NBSIR 78-1571. Sprinkler-vent and spray nozzle systems for fire protection of openings in fire resistive walls and
ceilings-The state-of-the-art and a plan for future research work, J. G. O'Neill, 29 pages (Jan. 1979). Order from NTIS as PB291889.

Key words: automatic sprinkler; building code; smoke movement; spray nozzle; stairway protection; ventilated stair.

A review of literature was conducted to determine the stateof-the-art of automatic sprinkler, sprinkler-vent and spray nozzle methods of protecting openings in fire resistive assemblies. A review of nationally used model building codes and standards indicated that they have varying provisions for these types of systems. Generally, the use of these systems is only applied to escalator openings in fully sprinklered buildings. Previous experimental work, however, demonstrated that these systems can also be effective in preventing passage of heat and smoke through other types of openings in structural assemblies.

An outline of a planned research project and a description of the test facility are given. The project will develop design parameters for sprinkler-vent and spray nozzle methods for protecting stairways and other openings through floor ceiling assemblies. Results from this project may suggest improvements to current codes and standards involving these systems and possibly permit their wider use in unsprinklered buildings.

NBSIR 78-1573. Properties and interactions of oral structures and restorative materials, J. M. Cassel, 94 pages (Dec. 1978). Order from NTIS as PB289913.

Key words: accelerator; alloy; base metal; casting; composite; cyanoacrylate; dental alloy; initiator; resin; wear.

To improve the storage stability of dental composite resin systems, alternative catalyst systems to the commonly used benxoyl peroxide-tertiary amine are being developed. Increased storage stability is attainable with organic peresters or hydroperoxides but requires more efficient accelerators than the presently used amines. Ascorbic acid or ascorbyl palmitate offer promise as useful accelerators which give good biocompatibility. To develop more reactive amine accelerators with perhaps less toxicity than those currently in use, pdimethylamino-phenylacetic acid (or ester derivatives) and dimethylaminoglutethimide were synthesized and shown to yield composite restorative specimens of good mechanical strength and color stability. A wide range of cyanoacrylates from the simplest, 2-ethyl cyanoacrylate, to the more complex type such as viscous isoamyl product have been examined for their capacity to achieve and retain bonding between acrylic resin and dentin. Very high initial bond strengths were achieved with isobutyl-2-cyanoacrylate on dentin pretreated with dilute acid but a one-month thermal cycling test in water indicated the bonding was not sufficiently stable. Initial pin on disc wear measurements with a synthetic hydroxyapatite pin have shown promise.

A pattern modification to reduce variability in the alloy castability test has been developed. Variations in the number of firing cycles and amount of condensation of green porcelain have been shown to cause significant differences in dimensional characteristics on cooling of fused dental porcelain.

NBSIR 78-1575. Erosion by solid particle impact, A. W. Ruff and S. M. Wiederhorn, 103 pages (Jan. 1979). Order from NTIS as PB291988.

Key words: abrasives; ceramics; erosion; impact; metals; particle erosion; wear.

A review of the methods and findings associated with solid particle impact erosion of metals and ceramics is presented. Modern theories of particle erosion and critically reviewed experimental observations are brought together and compared. 
Conclusions regarding the present state of understanding of erosion are given.

NBSIR 78-1576. Final Report-Proximity-vision system for protoflight manipulator arm, J. S. Albus, 22 pages (Aug. 1978). Order from NTIS as PB291335.

Key words: depth image; proximity sensor; robot vision; teleoperator vision; wrist-mounted TV.

The NBS Proximity-Vision System consists of two separate but complementary subsystems: 1) A solid-state TV camera with $128 \times 128$ resolution elements mounted on the manipulator wrist. Coordinated with this camera is a high intensity strobe flash system with optics which project a thin fan-shaped plane of light into the region viewed by the camera. 2) A pair of close-range infra-red proximity sensors mounted in the fingertips.

The system is built for a manually controlled teleoperator. However, the design is also suitable for computer image analysis in the control of an autonomous robot manipulator.

NBSIR 78-1577. Data bases available at the National Bureau of Standards Library, D. Cunningham, 53 pages (Mar. 1979). Order from NTIS as PB293170.

Key words: bibliographic data bases; computerized data bases; information storage and retrieval systems; librariesautomation; machine-readable-bibliographic data.

An alphabetical listing of data bases available on-line at the National Bureau of Standards (NBS) Library is listed by either acronym or full title of the data base. Other additional information includes description of the data base, period of coverage, producer(s), corresponding hard copy, principal sources and vendors. A general subject and a cross reference index to the data bases is also supplied.

NBSIR 78-I581. Annual Report 1978. Office of nondestructive evaluation, H. Berger and L. Mordfin, Eds., 58 pages (Jan. 1979). Order from NTIS as PB291946.

Key words: acoustic; annual report; eddy currents; inspection; magnetic particles; nondestructive evaluation; penetrants; radiography; statistics; ultrasonics; visual-optical tests.

This report summarizes the activities of the National Bureau of Standards (NBS) Nondestructive Evaluation (NDE) Program. It emphasizes activities over the Fiscal Year, 1978. However, since this is the Program's first Annual Report, some material is included to summarize activities since the Program was formally instituted in June 1975.

NBSIR 78-1584. Submarine compartment fire-Study-fire performance evaluation of hull insulation, $B$. T. Lee and $J$. $N$. Breese, 49 pages (May 1979). Order from NTIS as PB298264.

Key words: combustion products; fire barrier coatings; fire growth; flame spread; foam insulation; heat release; interior finish; laboratory fire tests; material ignitability; submarine compartment.

Certain foam rubber materials which are currently used to insulate the interior of submarines are shown to possess a serious fire risk potential. Flame spread tests often do not adequately reflect the fire hazard potential of these materials. It is shown that compartment fire testing is the only satisfactory method of evaluating these kinds of materials at the present time.

Fire barrier coatings for protecting these hull insulations are also investigated. Two candidate coatings are found to prevent full fire involvement of an insulated compartment following a moderately large flame exposure and at the same time meet the
Navy's elasticity requirement for submarine application. The study includes comparisons of model and prototype compartment fire behavior and demonstrates the practicality of using quarter-scale fire tests for screening compartment finish materials.

NBSIR 78-1586. Fire safety guidelines for vehicles in a Downtown People Mover system, R. D. Peacock, 57 pages (Jan. 1979). Order from NTIS as PB292600.

Key words: emergency communications; emergency evacuation; fire detection; fire safety; fire suppression; mass transportation; material flammability; people movers; smoke.

The results of a study to formulate fire safety guidelines to be required for vehicles used in Downtown People Mover (DPM) systems for the movement of people in a congested urban area are presented. Through a review of the design features of existing people mover vehicles and systems, and a review of proposed new systems, fire scenarios are developed and guidelines suggested to minimize the fire risk to passengers.

Methods and criteria, based on established test procedures, are proposed for assessing the flammability and smoke generation of interior finish and furnishing materials. Fire and smoke detection and suppression equipment are recommended, along with proposed guidelines for emergency evacuation provisions and emergency communication requirements.

An extensive bibliography of flammability in fixed guideway transit systems is included.

NBSIR 78-1590 (NASA). Loose-particle detection in microelectronic devices, J. S. Hilten, P. S. Lederer, J. F. Mayo-Wells, and C. F. Vezzetti, 73 pages (Jan. 1979). Order from NTIS as PB290679.

Key words: acoustic emission; co-shock; couplant; detection; electronic package; impact noise; microcircuit device; particle detection; particle impact noise detection; PIND; pre-shock; seeded specimens; transducer.

The work described constitutes an evaluation of the test procedures and apparatus specified in MIL-STD-883, Test Method 2020, Particle Impact Noise Detection Test. The major experimental effort described-a comparison of procedures and apparatus-is based on the use of specially prepared specimen device packages known either to have or not to have a particle present. Other experimental efforts reported include characterization of the accelerations imparted to a specimen device by pre- and co-shock apparatus, a brief study of the effectiveness of couplant materials in transmitting mechanical energy to the specimen device, and a comparison of the output signal level from four different ultrasonic detection transducers under otherwise identical test conditions. As part of the plan of work, 252 of the specially prepared devices, representing six package types, were characterized (as containing particles or not) by several test procedures in order to provide a set of specimens for use by the sponsor in a proposed interlaboratory evaluation of PIND testing. Problems associated with this effort are discussed. Results of the work are presented, together with conclusions and recommendations for further work. A result of interest is that the acceleration imparted by the single sample of the pre-test shock apparatus tested is on the order of 1.5 times the maximum specified by the Test Method.

NBSIR 78-1712. Report to AID on an NBS/AID workshop on standardization and measurement services, H. S. Peiser, C. C. Raley, and P. M. Odar, Eds., 156 pages (May 1979). Order from NTIS as PB296326.

Key words: AlD; assistance; developing economies; foreign relations; industrializing nations; international relations; LDC's; measurement services; standardization. 
From October 1-18, 1977, a Workshop was held at the National Bureau of Standards, Gaithcrsburg, and at selected universities, research institutes, standards developing organizations, tcst centers, and industrial companies, under the sponsorship of AID. The object of the Workshop was to give standards officials of industrializing nations insight into the standards and mcasurement systems of the United States and the role of thc National Bureau of Standards, so that these officials might consider what parts of the U.S. system might usefully be adapted to conditions in their home countries. An exchange of standardization experience in each of the participant's countries was presented by delivered papers which are reproduced here. Countries represented included Argentina, Bangladesh, Bolivia, Egypt, Ghana, Indonesia, Iran, Kenya, Korea, Phillipines, and Thailand. In addition, there were representatives from the Arab Organization for Standardization and Metrology and the International Organization for Standardization.

NBSIR 79-1588. Interlaboratory evaluation of the attic floor radiant panel test and smoldering combustion test for cellulose thermal insulation, J. R. Lawson, 38 pages (Feb. 1979). Order from NTIS as PB293159.

Key words: attic floor radiant panel; cellulose thermal insulation; critical radiant flux; flame spread; smoldering combustion; test methods.

An interlaboratory test program was conducted to provide estimates of repeatability and reproducibility of fire tests for cellulose loose fill insulation. The test methods evaluated were for critical radiant flux, using the Attic Floor Radiant Panel, and for smoldering combustion; they were based on Federal Specification HH-I-515D. Seven commercially manufactured cellulose thermal insulations marketed for residential use were evaluated by each procedure. An additional set of four replicate hardboard specimens were tested by each participant using the Attic Floor Radiant Panel. Nine laboratories conducted the Attic Floor Radiant Panel test, and ten conducted tests for smoldering combustion. The testing was conducted during the month of June 1978. The participating laboratories were surveyed prior to testing in order to ensure conformance to the critical details of the test apparatus and procedures.

The between-laboratory coefficient of variation for critical radiant flux ranged from 13 to 30 percent with an average for seven insulation materials of 21 percent. Estimated precision levels of repeatability and reproducibility for the Attic Floor Radiant Panel test when compared to other standard flame spread tests and materials are favorable. Data from the Smoldering Combustion test was evaluated on a pass/fail basis with agreement by nine of ten laboratories for six of the seven materials tested. Seven of ten laboratories also agreed on the seventh material.

Based on work of this study, there is reasonable assurance that results from different laboratories evaluating the same material for compliance with Federal Specification HH-I-515D will be consistent.

NBSIR 79-1591. Semiconductor technology program-Progress briefs, W. M. Bullis, Ed., 12 pages (Jan. 1979). Order from NTIS as PB294846.

Key words: electronics; integrated circuits; measurement technology; microelectronics; semiconductor devices; semiconductor materials; semiconductor process control; silicon.

This report provides information on the current status of NBS work on measurement technology for semiconductor materials, process control, and devices. Results of both inhouse and contract research are covered. Highlighted activities include studies of: laser annealing of low-fluence implants in sil- icon; analysis techniques for spreading resistance profiling measurements; Hall effect measurements in two-layer structures; incorporation of hydrogen and hydroxyl impurities in silicon dioxide films; an integrated gated-diode electrometer test structure; defect-density profiling by constant-capacitance deep-level transient spectroscopy; and a spatial integrity test pattern for electrical measurement of intra- and inter-die line-width variations. In addition, brief descriptions of new and selected ongoing projects are given. The report is not meant to be exhaustive; contacts for obtaining further information are listed. Compilations of recent publications and publications in press are also included.

\section{NBSIR 79-1591-2. Semiconductor technology pro- gram-Progress briefs, W. M. Bullis, Ed., 12 pages (Mar. 1979). Order from NTIS as PB298063.}

Key words: electronics; integrated circuits; measurement technology; microelectronics; semiconductor devices; semiconductor materials; semiconductor process control; silicon.

This report provides information on the current status of NBS work on measurement technology for semiconductor materials, process control, and devices. Results of both inhouse and contract research are covered. Highlighted activities include studies of: process-induced radiation damage; resistivity-dopant density relationships in silicon; spreading resistance measurements; spreading resistance profiling; cross-bridge sheet resistor test structure; PIND test; and moisture infusion into hermetic packages and conduct of a workshop on power semiconductor devices. In addition, brief descriptions of new and selected on-going projects are given. The report is not meant to be exhaustive; contacts for obtaining further information are listed. Compilations of recent publications and publications in press are also included.

\section{NBSIR 79-1591-3. Semiconductor technology pro- gram-Progress briefs, W. M. Bullis, Ed., 12 pages (June 1979). Order from NTIS as PB298064.}

Key words: electronics; integrated circuits; measurement technology; microelectronics; semiconductor devices; semiconductor materials; semiconductor process control; silicon.

This report provides information on the current status of NBS work on measurement technology for semiconductor materials, process control, and devices. Results of both inhouse and contract research are covered. Highlighted activities include studies of: reverse-bias second breakdown, an integrated gated-diode electrometer, random fault measurements, pattern generator positional accuracy, intrachip linewidth variation, transient upset in TTL circuits, photoresist sensitometry, optical linewidth measurements, spreading resistance profiling, model spreading resistance data, silicon resistivity SRMs, and sheet resistance measurements. In addition, brief descriptions of new and selected on-going projects are given. The report is not meant to be exhaustive; contacts for obtaining further information are listed. Compilations of recent publications and publications in press are also included.

NBSIR 79-1595. CMOS/SOS test patterns for process evaluation and control: Annual report, March 1 to November 1, 1978 , L. W. Linholm, 53 pages (Jan. 1979). Order from NT1S as PB293487.

Key words: CMOS/SOS; process control; process metrology; silicon gate; test patterns; test structures.

The National Bureau of Standards in collaboration with the Jet Propulsion Laboratory, Pasadena, CA, and RCA, Somerville, NJ, has designed a CMOS/SOS test pattern, NBS-16, and 
the necessary measurement techniques. $\mathrm{RCA}$ is required to process one test pattern wafer with each CMOS/SOS wafer lot being fabricated for the radiation hardened microprocessor chip set. Each test pattern is to be tested at NBS and JPL and recommendations for improvements made to the Air Force Avionics Laboratory (AFAL), the Air Force Materials Laboratory (AFML), and RCA. A second generation test pattern will be designed later based on information and experience obtained from the first. To date, the NBS- 16 test pattern has been designed, a pattern generator tape has been delivered to RCA, and the testing hardware and software has been developed. A program schedule and a description and illustration of each test structure are found in the appendices.

NBSIR 79-1596. Studies of flammability test procedures for curtains and drapes, D. E. Hopkins and J. F. Krasny, 25 pages (Mar. 1979). Order from NTIS as PB295039.

Key words: curtains; drapes; fabrics; fire; flammability; international; self-extinguishment; ships; standards.

The Intergovernmental Maritime Consultative Organization (IMCO) is in need of a simple, relevant flammability test method for the curtain and drapery fabrics used aboard ships. Two methods for measuring self-extinguishment of fabrics upon removal of the flame were compared. One was proposed by the United States' representative to IMCO, the other was an adaptation of a recently proposed method of the International Standards Organization (ISO). The effects of variations of the proposed test methods (changes in the ignition flame characteristics, bottom edge or surface ignition, and in the specimen suspension) were also investigated. In general, the relative ranking of the fabrics was not changed, though the individual afterflame time and char length results were affected by some of these variables. The advantages and disadvantages of the two proposed test methods are discussed and an improved method is recommended.

NBSIR 79-1599. Microphone windscreen performance, R. N. Hosier and P. R. Donavan, 85 pages (Jan. 1979). Order from NTIS as PB292967.

Key words: acoustics; flow; insertion loss; microphone; porous sphere; sphere; spheres; wind noise; windscreen; windscreen performance; windscreens.

Measurements were made of the wind-induced noise and acoustic insertion loss of ten microphone windscreens. Eight of these were reticulated polyester spheres of varying porosity. The other two were the metal cage type typically used in long term outdoor noise monitoring. The measurements were made under laboratory conditions for normal and grazing flow incidence at wind speeds up to $14 \mathrm{~m} / \mathrm{sec}$. The data show that the windscreens are very different in the amount of wind-induced noise reduction they provide, with some achieving more than $25 \mathrm{~dB}$. In general the foam windscreens provided more windinduced noise reduction than the cage windscreens; however, the cylindrical cage windscreen performed better than any of the foam windscreens for normal flow incidence. The insertion loss measurements proved difficult to make because of the small insertion losses encountered. However, data for grazing flow and normal acoustic incidence show no strong velocity dependence for any of the windscreens tested. Examination of the wind-induced noise spectra provided significant insight into the noise generating mechanisms associated with flow around a porous sphere. Effects of inflow turbulence, self-generated turbulence, mean flow, flow through the sphere, and flow incidence angle were identified. Test results are provided in the form of curves and tables for easy use in evaluating potential wind noise levels in outdoor measurements.
NBSIR 79-1604. A comparison of centrifuge and freezing calorimeter methods for measuring free water in snow, $R$. N. Jones, 43 pages (May 1979). Order from NTIS as PB29632l.

Key words: centrifuge; comparison of measurement methods; free water; freezing calorimeter; hydrology forecasting; microwave remote sensing; snow.

In using microwave measurements in hydrological studies of snowpack or avalanche prediction, the presence of free water in the snow has a strong influence on observed data because it affects the dielectric characteristics. Although several methods are in use for determining the percent of free water in snow, there is very little information in the literature as to how well the various methods agree. This paper reports on a comparison of two popular methods; namely, the centrifuge and the freezing calorimeter. Results from measurements over a two-month period in the Colorado mountains in the winter of 1978 indicate serious disagreement between these two methods. Some reasons for the disagreement are presented and verified. This raises some important questions pertaining not only to what the two methods actually measure, but also which methods may be appropriate for particular applications.

NBSIR 79-1605. A theoretical study of unbalanced ground effects on receiving dipoles, $M$. T. Ma, 5 pages (May 1979). Order from NTIS as PB296207.

Key words: dipole antenna; ground effect; unbalanced system.

Balanced ground effects on the performance of some antenna systems are relatively well known and can be taken into account by the design engineer. Unbalanced ground effects on a measuring system are, however, more complicated and make a thorough understanding difficult. In this report, specific ground effects on the calibration of a dipole antenna with an arbitrary inclination angle with respect to the ground are analyzed by means of a theoretical model. Numerical results representing this undesired effect are also included.

NBSIR 79-1606. A variational expression for the scattering matrix of a coaxial line step discontinuity and its application to an over moded coaxial TEM cell, 1. Sreenivasiah and D. C. Chang, 47 pages (May 1979). Order from NTIS as PB296324.

Key words: coaxial transmission line; cut-off frequency; equivalent circuit; modal analysis; scattering matrix; step discontinuity; TEM-cell; variational formulation

A step discontinuity in a coaxial transmission line, where one of the sections is large enough to support both TEM and $\mathrm{TM}_{01}$ modes, may be modeled as a 3-port junction. A variational expression for the $(3 \times 3)$ scattering matrix of such a junction is obtained in simple closed form. The scattering matrix, so obtained, is used to analyze the tansmission characteristics of a coaxial TEM cell beyond the cutoff point of the $\mathrm{TM}_{01}$ mode. Finally, an equivalent circuit, along with the expressions for the circuit parameters, is given for the general case where the number of propagating modes in each section is finite but arbitrary.

NBSIR 79-1607. Producing slush oxygen with an auger and measuring the storage characteristics of slush hydrogen, $R$. $O$. Voth and P. R. Ludtke, 41 pages (Mar. 1979). Order from NT1S as PB298555.

Key words: cryogenic; hydrogen; oxygen; scraping auger; slush; slush production; slush storage.

Part 1. Producing Slush Oxygen With An Auger: An auger rotating inside a brass tube refrigerated with liquid helium was 
used to produce liquid-solid (slush) mixtures of oxygen. The auger produced small particles of solid oxygen so that the resulting mixture could be transferred and sorted. The auger could produce slush continuously in an appropriate system, and it could produce slush at pressures higher than the triple point pressure of the oxygen.

Part 2. Storage Characteristics of Slush Hydrogen: Three long term storage tests were conducted on an Apollo hydrogen vessel. The vessel was filled to 88 percent with normal boiling point liquid hydrogen then the pressure rise rate to $17.6 \mathrm{bar}$ and the venting rate at 17.6 bar were measured. The two other tests were similar except the vessel was filled with slush hydrogen. In one of these tests, the slush was mixed to eliminate thermal stratification. Filling with slush instead of liquid hydrogen increased the storage time before venting by 1.08 to 1.17 times and increased the mass loaded by 1.11 to 1.13 times.

NBS1R 79-1608. Attenuation measurements on optical fiber waveguides: An interlaboratory comparison among manufacturers, G. W. Day and G. E. Chamberlain, 35 pages (May 1979). Order from NTIS as PB296951.

Key words: attenuation; fiber optics; interlaboratory comparison; measurements; optical communications; quality control.

In late 1978, the National Bureau of Standards invited U.S. manufacturers of optical fiber waveguide to participate in an interlaboratory comparison of attenuation measurements. Seven manufacturers performed four different measurements on each of two fibers. The range of results was typically 1 to $1.5 \mathrm{~dB} / \mathrm{km}$ for fibers with 3 to $7 \mathrm{~dB} / \mathrm{km}$ nominal attenuation. This report contains the results and an analysis based on additional data taken by NBS.

NBSIR 79-1609. Materials studies for magnetic fusion energy applications at low temperatures-II, F. R. Fickett and R. P. Reed, Eds., 495 pages (June 1979). Order from NTIS as PB299288.

Key words: alloys; fiberglass; mechanical properties; nonmetallics; physical properties; stainless steel.

The reports presented here summarize the work of the low temperature materials research project for the second year of the program. The various projects are outlined and the research results are presented. The major thrust of the measurements has been the evaluation of the low temperature mechanical and physical properties of stainless steel base metal and welds, with particular emphasis on the nitrogen strengthened stainless steels. Aluminum alloys have received some consideration also. Work has been done on the production of nonmetallics, primarily industrial laminates for low temperatue applications and on the measurement of their properties at cryogenic temperatures. The second NBS/DOE Vail workshop was held in October 1978. A brief description is given of that program.

NBSIR 79-1612. Isobutane: Provisional thermodynamic functions from 114 to $700 \mathrm{~K}$ at pressures to $700 \mathrm{bar}, \mathrm{R}$. D. Goodwin, 191 pages (July 1979). Order from NTIS as PB299361.

Key words: densities; enthalpies; entropies; equation of state; internal energies; isobars; isobutane; isochores; isotherms; Joule-Thomson inversion; latent heats of vaporization; melting line; orthobaric densities; specific heats; speeds of sound; vapor pressures.

Thermophysical properties of isobutane are tabulated at integral temperatures along isobars over the entire range of fluid states. Results for the compressed liquid, from the triple- to the boiling-point, have been estimated by use of the highly constrained, nonanalytic equation of state, because experimental $\mathrm{P}-\rho$ - $\mathrm{T}$ data are lacking in this region.
NBSIR 79-1613. Radar absorber measurement techniques at frequencies above $20 \mathrm{GHz}, \mathrm{N}$. S. Nahman, C. M. Allred, J. R. Andrews, C. A. Hoer, and R. A. Lawton, 70 pages (Aug. 1979). Order from NTIS as PB299576.

Key words: dielectrics; frequency-domain measurements; magnetic materials; microwaves; millimeter waves; permeability measurements; permittivity measurements; radar absorbers; time-domain measurements.

New methods for implementing automatic permittivity/permeability measurements of radar absorber materials for applications primarily above $20 \mathrm{GHz}$ and into the millimeter wave region to about $100 \mathrm{GHz}$ are discussed. A brief review of the state-of-the-art of dielectric and magnetic material measurements is given. Automated time domain and frequency domain methods are considered including time domain automatic network analyzers, correlation measurement systems using noise signal sources, and six-port network analyzers.

NBSIR 79-1615. Dispersion and attenuation characteristics of modes in a TEM-cell with a lossy dielectric slab, J. C. Tippet and D. C. Chang, 37 pages (Aug. 1979). Order from NTIS as PB80-105141.

Key words: attenuation; coupled integral equations; dispersion; lossy dielectric slab; modes considerations; TEM-cell.

Dispersion and attenuation characteristics of the dominant mode in a TEM cell, loaded with a lossy dielectric slab, are investigated. It is shown that, while the insertion of the lossy material can indeed lower the Q-factor of the higher-order modes, the attenuation of the dominant mode also increases drastically as frequency increases. Correction to that effect must be taken before measurements in the cell are used to correlate those taken in a free-space environment.

NBSIR 79-1618. Helium research in support of superconducting power transmission, D. E. Daney, 61 pages (Oct. 1979). Order from NTIS as PB80-116502.

Key words: cable cool-down; cool-down helium; liquid helium; superconducting power transmission; thermal cycling; thermal stress.

During FY 78, the NBS Thermophysical Properties Division program of supporting research for Superconducting Power Transmission Line (SPTL) development focused on three tasks: 1) Numerical computation of SPTL cool down by both single stream and counter flow methods. 2) Experimental modeling of counterflow SPTL cool down. 3) Thermal cycling of lengths of lead-sheathed model cable destined for testing in the BNL 5th Ave. facility.

The preparation of computer codes and numerical computation of SPTL cool down were completed and the results are given in Section 3. These calculations confirm our original intuitive judgment that cool-down times for the counterflow arrangement can be long-twenty days or more.

Greater than anticipated computer run times and costs required a reduction of effort on experimental modeling of counterflow cool down. Consequently, completion of this task will be delayed until FY 79.

Two sections of cable underwent extensive thermal cycling, and the results of these tests are given in Section 1. The complex structure of the cable leads to unusual (although reproducible) load vs time curves.

Funding limitations required postponement until FY 79 of the experimental evaluation of heat flow sensors as a means of non-intrusive vacuum indication for SPTL vacuum envelopes. This task together with experimental modeling of cool down will form the heart of our program in FY 79. 
NBSIR 79-1619. Quality assarance program for the NBS C, K, and $Q$ laser calibration systems, W. E. Case, 101 pages (Aug. 1979). Order from NTIS as PB80-118508.

Key words: calorimetry; laser beamsplitter system; laser calibration system; laser measurements; laser power calibration.

This report is a detailed procedure of how to set up and operate a Measurement Assurance Program (MAP) for a laser power and energy calibration facility. Items such as traceability, methods of self-checking measurement consistency, computer documentation and statistical analysis are discussed.

NBSIR 79-1620. Time domain pulse measurements and computed freguency responses of optical communications components, J. R. Andrews and M. Young, 35 pages (Sept. 1979). Order from NTIS as PB8()-120066.

Key words: avalanche photodiode; FFT; fiber optics; frequency response; impulse response; laser; photodiode.

The purpose of this report is to demonstrate the application of the NBS Automatic Pulse Measurement System (APMS) to measuring the pulse responses of optical communications components and to computing their impulse and frequency responses. For example we describe measurement of the properties of two glass fibers and an avalanche photodiode using both a pulsed GaAs laser diode $(\lambda=0.9 \mu \mathrm{m})$ and a mode locked, Nd:YAG laser $(\lambda=1.06 \mu \mathrm{m})$. All measurements were performed in the time domain; frequency domain data were obtained from the time domain data by using the Fast Fourier Transform (FFT). The impulse response was obtained by deconvolution.

NBSIR 79-1621. Normel butane: Provisional thermodynamic functions from 135 to $700 \mathrm{~K}$ at pressures to $700 \mathrm{bar}, \mathrm{R}$. D. Goodwin, 171 pages (Sept. 1979). Order from NTIS as PB80-118193.

Key words: densities; enthalpies; entropies; equation of state; internal energies; isobars; isochores; isotherms; JouleThomson inversion; latent heats of vaporization; melting line; n-butane; orthobaric densities; specific heats; speeds of sound; vapor pressures.

Thermophysical properties of n-butane are tabulated at integral temperatures along isobars over the entire range of fluid states. Resulis for the compressed liquid, from the triple- to the boiling-point, have been estimated by use of the highly-constrained, nonanalytic equation of state, because experimental $\mathbb{P}-\rho-\mathbb{T}$ data are lacking in this region. Only available, published physical properties data are used in this work.

NBSIR 79-1700. Fire performance guidelines for shipboard interior finish, B. T. Lee and W. J. Parker, 24 pages (June 1979). Order from NTIS as PB297765.

Key words: compartment fires; fire tests; flame spread; heat release rate; ignition; interior finish; passive fire protection; potential heat; smoke.

The present Navy fire performance requirements given in Military Standard 1623B (SHIPS) for shipboard interior finish provide a means for selecting fire safe materials. However, a recent evaluation of the Navy fire safety requirements along with an experimental berthing compartment fire study have suggested more rational design rules $N$ w guidelines are recommended to update this standard with improved fire risk critera.

NRSIR 79-1703. The tamely development of enviraratental, safety, and health standards for energy lechnologies, B. W. Steiner, 40 pages (Jan. 1979). Order from NTIS as PB292753.
Key words: energy standards; environmental standards; safety and health standards; standards development.

The Division of Operational and Environmental Safety (OES) was established in the spring of 1977 as a division of the former Energy Research and Development Administration. As one of its first tasks, OES commissioned the National Bureau of Standards to develop a comprehensive plan for the development of non-nuclear energy-related environmental, safety, and health standards for the Department of Energy. The objective was to provide assurance that the exploitation of new energy technologies by the private sector would not be hindered by the absence in the private sector of (1) all necessary environmental, safety, and health standards; or (2) the ability to comply with them. A detailed plan was submitted to the Division in September 1977.

During the preparation of that report it became clear that the effort commissioned by the OES was representative of a broad transformation with great significance for the standards development process in the United States. The present report consists of a paper describing that transformation in the role of standards, its significance, and the broad implications.

NBS1R 79-1705. State solar encrgy legislation of 1977: A review of statures relating to buildings, R. M. Eisenhard and L. A. Santucci, 396 pages (Feb. 1979). Order from NTIS as PB295642.

Key words: buildings; design; energy; legislation; solar; standards; State.

This report reviews State legislation on solar energy, as applied to buildings, which was enacted in 1977. Acts involve tax incentives, sun rights, standards for solar units, and State support of promotion of solar research, solar demonstrations, and solar loans. The Acts arc identified and abstracted, and responsible State agencies and officials identified. The Acts, supporting forms and other documents are included in the Appendices.

NBSIR 79-1706. CSA weatherization demonstration project Plan, R. Crenshaw, R. Clark, R. Chapman, R. Grot, and M. Godette, 81 pages (Mar. 1979). Order from NTIS as PB293498.

Key words: Community Services Administration; heating balance point analysis; low-income residences; marginal cost/benefit analysis in weatherization; optimum weatherization retrofit combinations; thermal analysis of residences.

This report comprises the plan of a research and demonstration effort to determine the fraction of energy that may be saved by installing weatherization retrofits in poor peoplcs' homes throughout the United States. Two broad groups of weatherization retrofits are considered for application in each dwelling: 1) "architectural," those affecting the building shell; and 2) "mechanical," those affecting space heating and service hot water systems. The optimum combination of weatherization options is defined as that set of retrofits which maximizes net savings (the difference between savings in fuel usage and the cost of the retrofits) over 20 years for a particular house and climatic environment. The retrofits will be selected through present-value benefit/cost analysis. The savings will be established through analysis of utility billings and fuel delivery records before and after weatherization. The report presents the background of the demonstration, the research tasks associated with the demonstration, a description of the diagnostic tests to be used, the rationale for economic decisions, the tests for evaluating mechanical systems, and the calculation methods used in selecting architectural options. 
NBSIR 79-1 707. Impact attenuation performance of surfaces installed under playground equipment, B. M. Mahajan and W. B. Beine, 53 pages (Feb. 1979). Order from NंTIS as PB292743.

Key words: head injury criterion; impact; peak acceleration; performance; playground surfaces; test method.

This report describes a test method and a suggested criterion for evaluating the impact attenuation performance of playground surfacing materials intended to protect against head injury due to falls. Several types of surfacing materials have been tested and the results are included. These results indicate that some surfacing materials impart peak accelerations below this criterion for fall distances up to 10 feet while others exceed the criterion for relatively short fall distances.

NBSIR 79-1709. Description of the data acquisition and instrumentation systems: Jersey City total energy project, C. Bulik, W. G. Rippey, C. W. Hurley, and D. E. Rorrer, 160 pages (Mar. 1979). Order from NTIS as PB294926.

Key words: data acquisition system; digital tape recorder; fuel measurement; instrumentation; total energy; transducers; weather station.

Under the sponsorship of the Department of Housing and Urban Development (HUD), the National Bureau of Standards (NBS) gathered engineering data on an operating diesel total energy plant which supplies all electrical power, hot water, and chilled water to a 485 unit apartment/commercial building complex in Jersey City, New Jersey. Engineering data was continuously collected from April 1975 to December 1978 by a data acquisition system (DAS) which recorded the outputs from approximately 200 sensors located in the plant and site buildings.

This report describes the design and operation of the instrumentation system and the data acquisition system used to monitor the total energy plant and certain utility services to the site buildings. The report contains a description of the types, characteristics and locations of instruments used to measure physical variables. The capabilities and operational modes of the data acquisition system components are described in detail. The report also contains a brief description of the total energy plant and site, instrument costs, data processing procedures and some of the instrumentation problems encountered.

NBSIR 79-1710. Electrical injuries-A literature review, Y. C. Wu, 36 pages (Feb. 1979). Order from NTIS as PB298622.

Key words: arc burn; contact burn; current threshold; electrical injury; electrolyte shift; heat effect; injury mechanism; injury statistics; mouth burn; specific electrical effect.

This report reviews and discusses the frequency, severity and mechanisms of the electrical injury as reported in the literature. Detailed national statistics on the frequency and severity of specific types of electrical injury are not available, however, limited data from the literature and from a survey of a few randomly selected hospitals are summarized and presented. The mechanisms of injury involve the physical and physiological parameters of the electrical source and the human body. These parameters are discussed according to known principles.

Injury to the human body, initiated by the flow of electrical current, is the consequence of disturbance, change or destruction of physiological entities such as nerves, blood vessels, organs, muscles and bones. For interpreting the electrical injury phenomena two theories exist in the literature. One theory suggests that electrical injury is thermal in nature and is caused by the Joulean heat $\left(l^{2} R\right)$ resulting from current flow through the body. The other theory suggests that injury is caused by specific electrical effects such as electrolyte shifts that are induced by the current flow. Evidence to support or dispute both theories was found in the literature. Due to the lack of quantitative data, however, the validity of these theories can only be assessed qualitatively.

NBSIR 79-1713. Final report on the "BFTRES/Version 1" computer simulation of emergency egress behavior during fires: Calibration and analysis, F. 1. Stahl, 179 pages (Mar. 1979). Order from NTIS as PB295063.

Key words: architectural research; building fires; computeraided design; environmental psychology; fire research; fire safety; human performance; modeling technique; programming; sensitivity analysis; simulation.

This report documents computer simulation experiments designed to calibrate and analyze BFIRES, a computer program which simulates building occupants' egress behavior during fires. This report demonstrates that emergency egress behavior under certain specified conditions can be systematically conceptualized, and simulated through the use of a digital computer. Important findings concerning the calibration and sensitivity of BFIRES are also discussed. In particular, it is shown that: (a) a variety of general egress situations may be simulated through the application of BFIRES; (b) every such event is unique, and is defined by the set of user-supplied input parameter values which describe the building, the threat, and the occupants; (c) BFIRES may be used in simulated environments of known (or desired) spatial dimension, and events of known (or desired) temporal duration; and (d) BFIRES simulation outcomes are sensitive to variations in a number of parameters of immediate interest to the building design and regulatory communities.

NBSIR 79-1714. Fire buildup in shiploard compartments-Characterization of some valinerable spaces and the status of prediction analysis, B. T. Lee and W. J. Parker, 45 pages (May 1979). Order from NTIS as PB297631.

Key words: fire growth; fire statistics; flame spread; fuel load survey; heat release; interior finish; laboratory fire tests; material ignitability; prediction model; shipboard spaces.

A review of shipboard fire incidents in the Navy over the past six years was made to determine the spaces of greatest vulnerability to fire and the most common sources of ignition in these areas. Some of these compartment spaces are characterized with regard to their furnishing and interior finish materials. Their fire loads are specified. The various factors which determine the extent and rate of fire build up in a compartment are discussed in terms of a simplified prediction model. Although substantial progress has been made in developing a prediction model for room fire development, a satisfactory treatment of flame spread on combustible interior finish materials along with a better understanding of the effect of the fire environment on fire buildup are needed. Meanwhile, criteria for choosing fire safe materials must continue to rely on existing laboratory fire tests. The application of laboratory fire tests on ignition, flame spread, and heat release rate to control the use of interior frnish materials aboard ship is explored. Test data on ignition, flame spread, and heat release rate of typical shipboard materials are provided.

NBS1R 79-1716. Possible fïre and electric shock hazards from hot lamps in miniature Christmas tree light strings and decorations, P. M. Fulcomer, 34 pages (Mar. 1979). Order from NT1S as PB295357.

Key words: electric shock; fire; flaming ignition; glowing ignition; hazard; ignition temperature; lamp surface tem- 
perature; melting temperature; miniature Christmas lights; plastic insulating material; polyethylene; series-constructed.

Failure to replace burned out lamps in series-constructed miniature Christmas light strings, or replacement with lamps of incorrect voltage rating, can lead to very high power dissipation by some or all of the lamps in the series string. Hot spot surface temperatures as high as $470^{\circ} \mathrm{C}$ were measured for lamps subjected to simulation of the above conditions. Additional testing showed that contact with surface temperatures above $390^{\circ} \mathrm{C}$ can cause glowing ignition, within two minutes, of cellulose material (e.g., tissue paper, decorative cotton) of ten found in the vicinity of Christmas light strings, and can cause flaming ignition in some samples of absorbent, untreated cotton. Furthermore, the hot spot surface temperature of normally operating lamps (no excessive power dissipation) can, particularly if the filament is off center, be higher than the melting temperature of some commonly used plastic insulating materials such as polyethylene. Contact between a hot lamp and insulating material can thus cause a shock hazard due to exposure of current carrying parts. Light string design and performance requirements that would prevent these hazards are discussed in the report.

This report is based on work funded by the Consumer Product Safety Commission as part of its program for develop. ment of a mandatory standard for miniature light sets.

NBSIR 79-1720. Mobile home fire studies: Summary and recommendations, E. K. Budnick and D. P. Klein, 94 pages (Mar. 1979). Order from NTIS as PB293527.

Key words: ASTM E-84 Tunnel Test; construction standard; fire growth; fire tests; flame spread; flashover; impact assessment; interior finish; kitchen fires; life safety; mobile homes; room fires.

Since 1974, a major research project has been ongoing at the National Bureau of Standards to investigate various aspects of fire growth and spread in typical single-wide mobile homes. The objective of this project is to provide recommendations for possible changes to the Federal Mobile Home Construction and Safety Standard promulgated in June, 1976 by the Department of Housing and Urban Development. These changes are intended to provide an improved level of fire safety in mobile home construction.

This report provides a summary of the important findings from previously reported parts of the project which involved the conduct of full-scale fire tests in the kitchen, corridor, living room and bedroom areas of typical mobile homes. Also included in this summary are the findings from a previously unreported series of full-scale living room tests, which are discussed in some detail in Appendix A.

This report describes the rationale upon which the overall experimental approach was based, and provides a series of recommendations, some in the form of design options, for possible changes to the standard. $\dot{A}$ limited impact assessment is included to provide a relative measure of the potential impact of each of three design options for flame spread requirements for interior wall and ceiling materials. This assessment is based on the likely effect of each option on fire severity, and does not include an economic analysis.

NBSIR 79-1721. Report to AID on an NBS/AID course on weights and measures services, H. S. Peiser, C. C. Raley, and A. D. Tholen, Eds., 64 pages (Apr. 1979). Order from NTIS as PB295838.

Key words: AID; assistance; developing economies; foreign relations; industrializing nations; international relations; measures; weights; weights and measures.
During the period June 25 to July 14, 1978, a course on weights and measures was held at the National Bureau of Standards, Gaithersburg, Maryland, in Harrisburg, Pennsylvania, and Richmond, Virginia, under the sponsorship of AID. The object of the course was to give weights and measures officials of industrializing nations insight into the weights and measures systems of the United States and the role of the National Bureau of Standards, so that these officials might consider what parts of the U.S. system might usefully be adapted to conditions in their home countries. An exchange of experience in each of the participant's countries was presented by delivered papers which are reproduced here. Countries represented included Argentina, Ecuador, Indonesia, Jamaica, Jordan, Keṇya, Korea, Morocco, Panama, Philippines, and Sudan.

NBSIR 79-1723. Standard procedure for use of thermoluminescence dosimetry in radiation-hardness testing of electronic devices, J. C. Humphreys and S. E. Chappell, 74 pages (Mar. 1979). Order from NTIS as PB297518.

Key words: electronic devices; electrons; photons; radiation hardness; standard practice; thermoluminescence dosimeters.

A standard recommended practice for the use of thermoluminescence dosimetry (TLD) systems has been developed. It is intended for the use of facilities that are engaged in the radiation-hardness testing of electronic components and systems. The practice has been written in the form of an ASTM standard for determination of absorbed dose in a medium as a result of photon or electron irradiation. It covers various aspects of TLD systems such as performance testing, dose calibration, and use procedures and precautions. A selected bibliography of TLD characteristics is included.

NBSIR 79-1725. Phase II final report. Computerized site security monitor and response system, R. T. Moore, R. J. Carpenter, A. W. Holt, A. L. Koenig, and R. B. J. Warnar, 118 pages (Mar. 1979). Order from NTIS as PB294343.

Key words: central unit; computerized; detection; electronic lock; exclusion area; forced entry deterrent systems; guard control station; higher headquarters; perimeter station; remote unit; response force; triply redundant central computer.

The Computerized Site Security Monitor and Response System (CSSMRS) is conceived as an integrated, state-of-theart, computer-based system to enhance and improve the overall physical security of storage sites for nuclear weapons and materials. This would result from the interconnection of all site security systems, including intrusion detection equipment, duress alarms, guard radio and telephone systems, guard activity sensors, access control equipments, meteorological and environmental sensors, and deterrent systems to a distributed processing network of computers. These would be expected to provide timely, accurate, and unambiguous information about the site security status or the progress of an attack or intrusion attempt. To the extent that is feasible, appropriate response initiatives would be preprogrammed into the system. Changes in site security status and the resulting response actions would be automatically reported up-channel to higher command levels and backup and reserve forces would be automatically called out in the event of certain identifiable threat situations, particularly those in which continued survival of local guard forces might be doubtful.

NBSIR 79-1727. Group homes for the developmentally disabled: Case histories of demographics, household activities, and room use, A. M. Ramey-Smith and J. V. Fechter, 66 pages (Apr. 1979). Order from NTIS as PB295037. 
Key words: demographics; developmental disabilities; fire protection; group homes; household activities; room use.

This document is the final report to the National Bureau of Standards' Center for Fire Research as part of their support to the Developmental Disability Office of the U.S. Department of Health, Education and Welfare. The objective of the present study was to obtain case history information on a sample of group homes for the developmentally disabled. Survey techniques were used to compile summary data on residents' room use and activities, the group home facilities, and demographics of the supervisors and residents. Data are presented for room use and activities of developmentally disabled residents and these data are compared to results available for the normal population. Summary data describe characteristics of the group homes, supervisors, and residents. Recommendations are presented regarding fire safety for developmentally disabled residents of group homes.

NBSIR 79-1728. A low-cost method for measuring air infiltration rates in a large sample of dwellings, $\mathbf{R}$. A. Grot, 14 pages (Apr. 1979). Order from NTIS as PB295444.

Key words: air infiltration; air sample bags; energy conservation; retrofit; sulfur hexafluoride; tracer gas; weatherization.

A method for collecting air infiltration data in a large sample of dwellings is presented. The method consists of a tracer gas dilution technique employing air sample bags which are analyzed in a central laboratory. The method will be applied to a Community Services Administration optimal weatherization demonstration in approximately 300 dwellings on 16 sites throughout the United States. The method will yield air exchange rates under typical heating season condition for each dwelling in the demonstrations. Preliminary data on air infiltration rates in low-income housing in Portland, Maine are presented.

NBSIR 79-1729. Pedestrian movement on ramps-A preliminary investigation, G. E. Turner and B. L. Collins, 62 pages (Mar. 1979). Order from NTIS as PB294856.

Key words: building circulation; building ramps; pedestrian circulation; pedestrian flow; pedestrian movement; pedestrian ramps; ramps.

The research described in this report was a preliminary investigation of pedestrian movement characteristics on two specific building ramps. Variables of pedestrian movement such as speed, flow, and area were studied, as well as the relationships between these variables. In addition, the specific measurements of speed, flow and area were compared with similar measurements determined by other researchers not only for ramps, but also for stairs and level surfaces. Finally, suggestions were made for additional research into the characteristics of pedestrian movement on various elements of the building circulation system.

NBSIR 79-1730. Protecting adobe walls from ground water, J.

R. Clifton and F. Davis, 29 pages (Mar. 1979). Order from NTIS as PB295041.

Key words: adobe building materials; chemical grouts; damp course membrane; metallic membrane; permeability; preservation technology.

Two methods for creating impervious membranes in existing adobe walls were investigated. They were the injection of chemical grouts and installation of a metallic membrane. Chemical grouting was unsuccessful because of the low permeability of the tested adobe materials. The metallic membrane did prevent the migration of moisture in the adobe un- derneath the membrane, weakening the adobe. Further, soluble salts migrated to the surface of the wet adobe. Alternative methods for protecting adobe structures from ground water and runoff water are discussed, including the installation of effective drainage systems and upgrading the foundations.

NBSIR 79-1731. A review of fire incidents, model building codes, and standards related to wood-burning appliances, $R$. D. Peacock, 60 pages (May 1979). Order from NTIS as PB298289.

Key words: accident investigations; chimneys; coal; creosote; fire departments; fire safety; heating equipment; maintenance; stoves; wood.

As a part of the Department of Energy program to advance the technology for the utilization of fuel wood as an alternate energy source for applications ranging from single-family dwellings to apartment complexes and small industries, a review is presented of fire incidents and fire deaths attributable to wood-burning appliances. Initiated to establish accident patterns and to determine the risks involved with the use of woodburning equipment, the survey represents a compilation of approximately 11,800 fire incidents including injuries and deaths associated with solid fuel burning appliances. In addition, a review of model building codes and of test methods currently used to test or certify wood-burning equipment is included to identify priorities for future research in wood-burning safety.

NBSIR 79-1732. Computer analysis of energy requirements in single-family residences: A limited rase study of the effects of envelope design, W. L. Carroll and J. P. Barnett, 31 pages (July 1979). Order from NTIS as PB299448.

Key words: building energy consumption analysis; computerized building energy analysis; cooling load calculation; energy conservation; heating load calculation; NBSLD analysis of residences; residential energy conservation; thermal mass effect in buildings.

A number of design variations of a typical one-story singlefamily residence were analyzed to determine annual heating and cooling energy requirements. The National Bureau of Standards Load Determination computer program, NBSLD, was used to accomplish the analysis. Design details for each of the residence variations are described in detail. Annual heating and cooling energy requirement calculations are presented and discussed. The results show only a small dependence on the thermal mass of the building envelope for the two climates studied (Washington, D.C. and Orlando, Florida). The thermal properties of the windows had a greater effect. Concluding the report are technical generalizations based on the present study, and recommendations for further work in order to produce a definitive study of the effect of selected building design parameters on energy consumption.

NBSIR 79-1734. Guide to technical services and information sources for ADP managers and users, S. M. Radack, 50 pages (Apr. 1979). Order from NTIS as PB294845.

Key words: ADP information sources; ADP management; ADP policies; ADP services; automatic data processing; computer services; Federal Information Processing Standards; Federal standards.

This publication contains brief descriptions of technical services and resources available to Federal ADP managers and users from other agencies in the U.S. Government. The names, addresses and telephone numbers of the agencies providing computer-related services and information are included. Subject areas covered include ADP standards, reports, management, performance evaluation, training, magnetic media, software, security and technical assistance. Also included is infor- 
mation about Federal Information Processing Standards, Federal Standards for data communications, OMB policy guidance for ADP, procurement regulations, and GSA regional services. Federally sponsored ADP users' groups are listed. Sources are given for the documents and publications are cited.

NBSIR 79-1736. Evaluation of hand-held infrared thermometers for wall thermal resistance determinations, S. J. Treado and D. M. Burch, 26 pages (July 1979). Order from NTIS as PB298057.

Key words: infrared thermometers; in situ evaluation of insulation; R-value measurement by spot radiometer; thermal resistance of walls.

Hand-held infrared (IR) noncontact surface thermometers from two manufacturers were tested to evaluate their effectiveness in measuring surface temperatures for the determination of the thermal resistance of walls. Two phases of the test were performed, first a laboratory test of a wood-frame wall, followed by a field test of a brick veneer wood-frame wall. During both phases of testing, additional measurements of thermal resistance were made for comparative purposes, using multijunction thermopiles and heat flow meters. An error analysis of the thermal resistance measurement procedure utilizing IR surface thermometers was also performed.

NBSIR 79-1737. Testing of pebble-bed and phase-change thermal energy storage devices according to ASHRAE Standard 94-77, D. E. Jones and J. E. Hill, 48 pages (May 1979). Order from NTIS as PB295898.

Key words: ASHRAE Standard 94-77; Glauber's salt; latent heat storage; pebble bed; phase-change unit; solar energy storage; thermal energy storage device.

The American Society of Heating, Refrigerating, and Air Conditioning Engineers (ASHRAE) has recently adopted ASHRAE Standard 94-77-Methods of Testing Thermal Storage Devices Based on Thermal Performance. Experiments have been completed at the National Bureau of Standards in which a $7 \mathrm{~m}^{3}\left(250 \mathrm{ft}^{3}\right.$ ) pebble-bed and a similarly-sized $264 \mathrm{MJ}$ $(250,000$ Btu $)$ phase-change unit utilizing sodium sulfate decahydrate, both using air as the transfer fluid, were tested in accordance with this Standard. A description of the test procedure, test apparatus, and detailed test results is given. Some problems were encountered in using the Standard for these kinds of thermal energy storage devices, and modifications to the Standard are recommended based on these experiments.

NBSIR 79-1738. EVACNET: Prototype network optimization models for building evacuation, R. L. Francis and P. B. Saunders, 164 pages (Oct. 1979). Order from NTIS as PB80113780.

Key words: building evacuation; high-rise building design; network flow.

This report presents the results of a pilot project conducted to explore how the evacuation and "evacuability" of buildings can be analyzed with the aid of mathematical network flow optimization models. As a research vehicle, Building 101, an eleven-floor building located on the Gaithersburg, MD, campus of the National Bureau of Standards, has been studied; mathematical models pertinent to evaluating that building under a number of different circumstances have been developed and solved on the computer.

NBSIR 79-1739. Tests on the performance of automatic fire detectors in health care occupancies-A preliminary report, $R$. W. Bukowski, 29 pages (Apr. 1979). Order from NTIS as PB297150.
Key words: corridors; escape; fire detectors; full-scale tests; heat detectors; hospitals; ionizaton detectors; mattresses; nursing homes; photoelectric detectors.

The paper reports the results of the first series of eight fullscale fire tests to evaluate the response of automatic fire detectors in health care occupancies to flaming ignition mattress fires. Comparisons were made between three types of detectors (ionization, photoelectric, and heat) installed in the patient room versus in the corridors.

For the fire scenario selected (flaming ignition of bedding and mattress), the results indicated that the ionization-type detectors in the patient room provided the maximum time for escape. The maximum time period available for either rescue of a non-ambulatory patient in the room of origin or for use of the corridor past the room of origin as a means of escape averaged only about five minutes. The times available for escape or rescue were based on the time provided between detector alarm and the time that one of several criteria selected for occupant tenability was exceeded.

NBSIR 79-1740. The influence of polymer membrane properties on the performance of dissolved oxygen sensors, J. D. Barnes, 33 pages (June 1979). Order from NTIS as PB296299.

Key words: diffusion; dissolved oxygen; mathematical model; oxygen; oxygen sensor; permeation; polarographic sensor; polymer membrane.

This report examines polarographic dissolved oxygen sensors using a polymer membrane in order to design experiments aimed at minimizing the contribution of the polymer membrane to instabilities observed during the testing of these sensors. A mathematical model is presented which links the transport properties of the membrane layer and the electrolyte layer to the overall performance of the sensor. The confounding effects of other elements of the measuring system are so severe that the most satisfactory experiments are those which directly measure the transport properties of the polymer membrane. In view of other uncertainties found in the polarographic method for measuring dissolved oxygen it is unlikely that processes in the polymer membrane make an important contribution to the observed instabilities. A critical examination of the effect of membrane permeance on sensor performance should be undertaken so that optimum choices of membrane materials can be made.

NBSIR 79-1741. Physical testing of polymers for use in circulatory assist devices, R. W. Penn and G. B. McKenna, 45 pages (July 1978). Order from NTIS as PB295085.

Key words: additive damage; biaxial fatigue; biomaterials; circulatory assist devices; fatigue of polymers; mechanical testing.

The concept of linear additive damage has been used to relate sinusoidal fatigue data with creep failure time data on two polymers. Deviations of fatigue data from predictions made from creep failure time data were found to be in opposite directions for a glassy and a semicrystalline polymer. Further work will extend this study to elastomers and candidate biocompatible materials. Specimens of Avcothane 51, obtained from rejected intra-aortic balloons, reflection spectroscopy, as well as by optical microscopy. Significant differences were observed between the two surfaces of the intra-aortic balloon similar to those which had been previously reported.

Optical microscopy has revealed circular features near the surface of the balloon wall which were are tempted to characterize as regions of segregated PDMS on a much grosser scale than has been previously reported.

We have prepared carefully controlled samples of an NBS standard butyl rubber and distributed test specimens to other investigators involved in physical testing of polymers for use in 
circulatory assist devices. This material has mechanical properties similar to candidate biocompatible materials and may be useful as an interlaboratory standard and for test method development.

Preliminary design and construction of a biaxial fatigue test cell has been completed. Fatigue experiments on butyl rubber using this device have indicated that only minor modifications will be necessary before initiation of fatigue testing on candidate biomaterials. A multiposition test station for these cells is being assembled.

NBSIR 79-1742. Recent improvements to the ASTM-type uItrasonic reference block system, D. J. Chwirut, 54 pages (Apr. 1979). Order from NTIS as PB296044.

Key words: calibration; diffusion bonding; measurement assurance program; reference blocks; standards; ultrasonics; variability.

Recent activities aimed toward improving the ASTM-type ultrasonic reference block system are described. On the aluminum block system (ASTM E 127 and NBS TN 924), efforts were focused on better definition of the measurement equipment (transducer and instrument), the implementation of a Measurement Assurance Program and Loaner Block Service, and modeling of the distance-amplitude relationship. It is shown that a large increase in the precision of reference block readings is easily achievable by implementing simple changes and controls in the measurement procedure. On steel and titanium blocks (e.g. ASTM E-428), efforts were directed toward quantifying the extent of reproducibility possible among blocks fabricated by both conventional drilling and by diffusion bonding. Reasonable reproducibility is achieved by both, with the diffusion-bonding process offering both advantages and disadvantages.

NBSIR 79-1743. Standards for photovoltaic energy conversion systems, H. A. Schafft, 18 pages (May 1979). Order from NT1S as PB296274.

Key words: batteries; photovoltaic energy conversion; power conditioning; power systems; solar cells; standards; test methods.

This report provides the results of a search for existing domestic standards and related documents for possible application in the development of a standards base for photovoltaic energy conversion systems. The search resulted in locating about 150 test methods, recommended practices, standards, solar-thermal performance criteria, and other standards-related documents. They are listed by topic areas in the appendix. The listing was prepared to assist those involved in developing performance criteria for photovoltaic systems and in identifying methods to test system performance against these criteria. It is clear from the results of the search that few standards are directly applicable to terrestrial solar photovoltaic systems and that much standards development is required to support the commercialization of such systems.

NBSIR 79-1744. The development of test structures for characterization of the fabrication and performance of radiationhardened CCD imagers, G. P. Carver and M. G. Buehler, 54 pages (May 1979). Order from NT1S as PB296167.

Key words: CCD; electrical test structure; gated diode; generation lifetime; integrated gated-diode electrometer; integrated test structure; leakage current; MOSFET dc profiler; surface recombination.

A set of production-oriented parametric test structures has been proposed for use in the evaluation of the radiationhardened processes for radiation-hardened CCD imagers. The proposed test structures specified in this report include ad- vanced test structures which were developed during this program, improved versions of existing NBS test structures, and various other commonly used test structures. Some of the designs for test structures were modified for compatibility with the radiation-hardened processes and with radiation testing. Procedures are described for testing the test structures using high-speed computer-controlled data acquisition techniques.

Two of the test structures developed for this program represent new and unique test vehicles which allow the determination of relevant physical parameters which are difficult to obtain by other methods.

NBS1R 79-1745. Fire research publications, 1978, N. H. Jason, 17 pages (Apr. 1979). Order from NTIS as PB295395.

Key words: arson; bibliographies; building fires; compartment fires; fabric flammability; fire detection systems; fire tests; flammability tests; human behavior; plastics; polymers; smoke; smoke detectors; subway fires; toxicity; upholstered furniture.

"Fire Research Publications, 1978" is a supplement to the previous edition: 1969-72 (NBS1R 73-246, NT1S Order No. COM-74-10989, \$3.25); 1973 (NBSIR 74-51 I, NTIS Order No. COM-74-1 1448, \$3.25); 1974 (NBSIR 75-736, NT1S Order No. COM-75-11018,\$3.25); 1975 (NBS1R 76-1120, NTIS Order No. PB-257837, \$3.50); 1976 (NBSIR 77-1277, NTIS Order No. PB-269965, \$3.50); 1977 (NBSIR 78-1504, NTIS Order No. PB-284462, $\$ 4.00$ ).

Only publications prepared by members of the Center for Fire Research (CFR), by other National Bureau of Standards (NBS) personnel or external laboratories under contract or grant from CFR are cited. Articles published in NBS house organs also are cited.

NBSIR 79-1746. Mathematical modeling and new experiments on durability of paper: A progress report, J. T. Fong, I. K. Fong, E. E. Toth, and E. L. Graminski, 83 pages (Apr. I1, 1979). Order from NT1S as PB295789.

Key words: computer graphics; data base management; data retrieval; durability; fatigue; interactive system; mathematical modeling; paper; paper fiber; report retrieval; scientific data.

As a necessary step towards the modeling of the microstructural changes of paper due to environmental and mechanical loadings, a computer-aided data file for a collection of 47 NBS reports (1953-1976) is created. Using an in-house experimental database management system (COLL1N) as implemented on an NBS computer (DEC PDP-10), a mini-data bank for the 47 technical reports is set up with the following searchable parameters: (a) report number, (b) author's name, (c) keyword, (d) test sample label, and (e) primary test variable. Each search will yield a complete record containing all the searchable information as well as ( $f$ ) title of report, ( $g$ ) citation, (h) the abstract, and (i) the so-called secondary test variable. To obtain quantitative information from any specific report for some combinations of sample labels and test variables for which experimental data were reported, a data tape is prepared and implemented for retrieval on a leased mini-computer graphical system (Tektronix 4051 with printer 4641 and plotter 4662). The operating system using the computer language BAS1C is general enough to assist any scientist or engineer to create a personal data file at a reasonable cost. 1t is clearly demonstrated that no prior training in the use of a computer is necessary for the implementation of this project.

During this reporting period, experiments on relating the quantity of water in the cellulose walls of pulp fibers to the cross-sectional morphology of fibers in paper were in progress. A brief discussion of this aspect of work is included in this report. 
NBSIR 79-1747. Stairwell pressurization systems, 1. A. Benjamin and J. H. Klote, 31 pages (June 1979). Order from NTIS as PB297479.

Key words: bottom injection; multiple injection; smoke candle test; smoke control; stairwell pressurization; top injection; tracer gas test.

The use of stairwell pressurization systems has grown in the U.S. over the past few years. However, there are no accepted design procedures for the systems. The paper discusses several of the designs now being used in the U.S., with some of the assumptions used for design of the systems. In particular, single and multiple injection systems are discussed. A report is made on field tests on two systems. The testing is part of a continuous program to evaluate alternate systems, in an attempt to establish design recommendations for the future.

NBSIR 79-1748. Detection of phosphorus in epitaxial silicon by EPR, T. T. Chang, 16 pages (May 1979). Order from NTIS as PB296166.

Key words: electron paramagnetic resonance; epitaxial silicon; Hall-effect measurements; phosphorus in silicon.

Electron paramagnetic resonance (EPR) spectroscopy has been used to identify phosphorus in an epitaxial layer of silicon. The concentration of phosphorus atoms was estimated using a ruby standard sample (NBS SRM 2601) to establish a calibration for the spectrometer. The concentration obtained with EPR is in satisfactory agreement with the concentration obtained from Hall-effect data on the same specimen.

NBSIR 79-1749. Full-scale fire tests with automatic sprinklers

in a patient room, J. G. O'Neill and W. D. Hayes, Jr., 52 pages (June 1979). Order from NTIS as PB297417.

Key words: health care facilities; hospitals; mattresses; smoke movement; sprinkler systems.

The Center for Fire Research is conducting a research program to examine the use of automatic sprinklers in patient rooms of health care facilities. This is an interim report of eight full-scale fire tests in which the effectiveness of automatic sprinklers was measured in terms of fire control and overall life safety. These fire tests simulated the scenario in which mattresses with bedding constituted the burning items.

Analysis of test results indicate that prior to sprinkler operation, smoke obscuration reached critical levels in the burn room doorway and adjacent corridor such that rescue of patients in the burn room and the use of the corridor as an exit way would have been seriously impeded. Immediately following sprinkler operation, there was total obscuration from floor to ceiling throughout the corridor and lobby area.

For several tests, a privacy curtain was installed between the sprinkler head and the bed and, despite the shielding action of the curtain, the overall cooling of the sprinkler spray prevented the fire from spreading to the combustible wall finish. However, the shielding action delayed extinguishment and the carbon monoxide concentrations increased significantly. In these cases it was estimated that the carboxyhemoglobin level for a patient in an adjacent bed would reach levels considered hazardous. In other tests where the privacy curtain was not installed and this shielding did not occur, the estimated hazardous threshold was not reached.

NBSIR 79-1751. Custody transfer systems for LNG ships: Tank survey techniques and sounding tables, R. H. F. Jackson, R. S. Collier, S. Haber, and P. V. Tryon, 85 pages (May 1979). Order from NTIS as PB295941.

Key words: accuracy; cryogenic; error estimation; liquefied natural gas; LNG; marine; mathematical modeling; mea- surement; photogrammetric; precision; ship cargo; statistical analysis; strapping; survey.

Static measurements of liquefied natural gas (LNG) for custody transfer purposes require an accurate and precise knowledge of the container volume and the volume-height relationship. The extremely low temperatures of LNG (less than $150^{\circ} \mathrm{K}$ ) preclude in situ surveys; however, the increasing value of the cargo requires more precise and accurate measurements than previously used for bulk marine cargoes.

A description and assessment of the application of photogrammetric techniques to the ambient temperature survey of a 35-meter diameter spherical aluminum container are presented. Sample sounding tables (height-volume) are calculated, and an estimate of error is given.

NBSIR 79-1753. Radiation-induced acoustic cavitation; Threshold vs temperature for some liquids, $M$. Greenspan and C. E. Tschiegg, 54 pages (May 1979). Order from NTIS as PB296228.

Key words: acoustic cavitation; cavitation; cavitation threshold vs temperature; radiation-induced cavitation; temperature dependence of cavitation threshold; threshold.

Neutron thresholds at various temperatures were measured for methanol, ethanol, 1-propanol, 2-propanol, n-pentane, diethyl ether, fluorocarbon 113 and fluorocarbon 11 , and fission thresholds were similarly measured for water, 1-propanol and 2-propanol. The work was done in 1969, but not reported then because the project had not been completed owing to the pressure of other duties. However, there seems to be a revival of interest in this sort of thing and we have been persuaded to work up and publish the data, such as it is. So here goes.

NBSIR 79-1754. A linearized finite difference computation of

fluid heating in an enclosure, R. G. Rehm, M. R. Cordes, H. R. Baum, and J. Lewis, 76 pages (May 3, 1979). Order from NTIS as PB298053.

Key words: buoyant convection; finite-difference computations; fire in an enclosure; heat addition; hyperbolic, elliptic equations; initial, boundary-value problem; linearized equations; partial differential equations.

In an earlier paper, approximate equations of motion were derived which are applicable to nondissipative, very nonadiabatic, buoyant flows of a perfect gas. In the present paper, these approximate equations are in a form in which they can be integrated by finite difference techniques. The nonlinear equations are made dimensionless, specialized to two dimensions and linearized. Finite difference approximations, using central differences in space and leapfrog in time, are made to the linearized equations. To start the computation, a first-order scheme is used for the initial time step. The dependent variables are density, the horizontal and vertical velocity components and pressure, and these variables are defined at various positions within a grid cell. The computer time required for various size computations and the accuracies obtained are reported.

At each time step, a large sparse system of linear algebraic equations, the finite difference approximation to the elliptic equation for the pressure, must be solved. A hybrid method, combining the interactive algorithm called conjugate gradients with a fast direct method for solving Poisson's equation, is used to solve the algebraic system efficiently and accurately. Examples of computations of the flow fields induced by heating are presented and discussed.

NBSIR 79-1755. Fire accident simulations with apparel fabrics, A. W. Meierhoefer, E. Braun, J. F. Krasny, and R. D. Peacock, 31 pages (June 1979). Order from NTIS as PB297815. 
Key words: accident; apparel; burn injury; clothing; fabric flammability; fabrics; fire; garments; heat transfer; injury potential; simulation.

The objective of the work described here was to continue earlier garment burn simulations and to establish further background for the estimation of the relative burn injury potential of flammable apparel fabrics. The apparatus used was the Apparel Fire Modeling Apparatus (AFMA). The AFMA is a semicylinder almost completely covered with heat sensors. It simulates part of a human leg or torso. Fabrics can be burned on the AFMA in the free-hanging mode or can be brought into contact with its surface after a small amount of heat is sensed by the AFMA. The burn injury potential of the fabrics can be evaluated by such heat transfer characteristics as the total heat transferred to the AFMA and the area of the AFMA which would be susceptible to a second-degree burn, as well as the rate of increase of this injury area. The results are related to fiber content, and weight and construction of the fabrics. The fabrics used were selected from a series used in the Cooperative Program on Apparel Flammability sponsored by the American Textile Manufacturers Institute.

NBSIR 79-1756. Measurement techniques for high power semiconductor materials and devices: Annual report, October 1, 1977 to September 30, 1978, F. F. Oettinger, Ed., 144 pages (June 1979). Order from NTIS as PB298574.

Key words: d-c transmission; deep level measurements; energy conservation; measurement methods; power-device grade silicon; resistivity variations; silicon; spreading resistance measurements; thermally stimulated measurements; thyristor materials measurements; thyristor measurements.

This annual report describes NBS activities directed toward the development of measurement methods for semiconductor materials and devices which will lead to more effective use of high power semiconductor devices in applications for energy generation, transmission, conversion, and conservation. It responds to national needs arising from rapidly increasing demands for electricity and the present crisis in meeting longterm energy demands. Emphasis is on the development of measurement methods for thyristors and rectifier diodes.

The major tasks under this project are (1) to evaluate the use of thermally stimulated current and capacitance measurements and other deep level measurement techniques as a means for characterizing lifetime controlling or leakage source defects in power grade silicon material and devices, and (2) to develop procedures to enable spreading resistance measurements of thyristor starting material and layer profiles to be made on a reliable basis.

NBSIR 79-1757. Data reduction processes for the Jersey City total energy project, D. E. Rorrer, W. G. Rippey, and Y. L. Chang, 117 pages (May 1979). Order from NTIS as PB296482.

Key words: computerized processing; data editing; data flow; data processing; data reductions; raw data conversion to engineering units; total energy; total energy data flow.

The major processes used in the reduction of the data obtained from the Jersey City, New Jersey, Total Energy Site are discussed. These discussions begin with the acquisition of the raw engineering data and carry through to the final data presentation in a form from which the summary performance reports of the Total Energy Site are produced.

The major functions of the Jersey City total energy data editing and conversion software program developed by the $\mathrm{Na}$ tional Bureau of Standards are described in some detail. Included are descriptions of the command structure, overall data flow, data editing, data conversions, error processing, and the creation of data output tapes for use in further analysis. The more important subroutines which are used to handle the individual operations are also discussed. The equations used in the calculation of engineering units are described, along with their derivations where appropriate.

The report assumes that the reader has a basic familiarity with computer and engineering terminology.

NBSIR 79-1758. The calibration of a roundness standard, C. P. Reeve, 22 pages (June 1979). Order from NTIS as PB297708.

Key words: least squares circle; least squares estimation; polar graph; restraints; roundness standard; spindle error; standard deviation; stylus.

For the past decade the National Bureau of Standards has been making high precision roundness measurements using an algorithm which allows the spindle out-of-roundness to be separated from the true profile of the workpiece. The algorithm requires multiple traces on a roundness measuring instrument, and the resulting redundancy provides an estimate of the measurement precision. The primary purpose of this paper is to describe in detail the mathematical model used for this measurement process. Some related topics are discussed briefly and an example is given.

NBSIR 79-1760. Evaluation of safety symbols, B. L. Collins'and B. C. Pierman, 38 pages (June 1979). Order from NTIS as PB298175.

Key words: communication; evaluation methods; fire safety; hazard warnings; pictograms; safety information; standardization; symbols.

The increasing use of symbols to convey fire safety information nonverbally is described. In addition, the trend toward international standardization of symbols is discussed for transportation and other systems. The need for further research on symbols is discussed in terms of the advantages and disadvantages of symbol use. Advantages include rapid and accurate communication without the barriers of verbal language. Disadvantages include the too rapid proliferation of different symbols and inappropriate or misleading application. Furthermore, the failure to evaluate the understandability of each symbol is cited as a major problem. A case study which documents some of the advantages and disadvantages of a set of proposed fire-safety symbols is presented. Finally, areas for further research on symbol evaluation are discussed.

NBSIR 79-1762. ResidentiaI solar data center-Data resources and reports, P. M. Christopher and J. E. Krzewick, 68 pages (June 1979). Order from NTIS as PB297582.

Key words: automatic data processing; data base; residential buildings; solar data center; solar energy systems; solar heating and cooling.

The Residential Solar Data Center (SDC) is responsible for the establishment and operation of a computerized data base containing non-instrumented residential data collected from the DOE/HUD Solar Heating and Cooling Demonstration Program. This document includes a summary of the history and background of the SDC and it's role in the Demonstration Program, a list of the computer reports which are available and sample pages of representative reports, a description of the data files which comprise the solar data base, a description of the interactive access to the solar data base, a set of figures showing the amount of data on the computer, and a list of other Solar Data Center publications. 
NBSIR 79-1764. Image pattern recognition in industrial inspection, G. J. Vanderbrug and R. N. Nagel, 48 pages (Sept. 1979). Order from NTIS as PB80-108871.

Key words: automation; image processing; inspection; manufacturing; pattern recognition; robotics; vision systems.

Most manufacturing processes require a visual inspection of some aspect of the process. In the most straight forward applications, a vision system is used to inspect for part completeness, or to check for flaws in the manufacturing product. In more sophisticated use of vision systems the inspection task may be secondary to tasks such as part location, identification, or determining part orientation. In general these tasks are important when the vision system is used in conjunction with a robot manipulator. In robot systems, vision is needed to allow the robot to acquire, manipulate, and inspect parts without the need for elaborate fixturing, or complex part delivery systems. The labor cost of manual inspection, and the high cost of special purpose part delivery systems for robots have led many manufacturers to investigate vision systems for use in manufacturing. Digital image processing and pattern recognition are providing the basis for a growing number of attempts to achieve an automated vision system.

This paper begins with a brief historical perspective on image processing and pattern recognition. Next a series of state of the art examples of visual inspection systems, and then robot vision systems is presented. The paper contains a list of other areas in manufacturing for the application of vision systems, and concludes with an assessment of the future of vision systems in manufacturing.

NBSIR 79-1766. Studies on the photodegradation of poly (methyl anethacrylate), M. Abouelezz and $\mathbb{P}$. F. Waters, 52 pages (June 1979). Order from NTIS as PB281828.

Key words: degradation; IR; photodegradation; poly (methyl methacrylate); UV; visible.

When poly (methyl methacrylate), PMMA, is exposed to sunlight, it gradually degrades and, after long-term exposures, may be unable to perform its intended functions. While the photodegradation of PMMA has been studied extensively using radiation sources below $300 \mathrm{~nm}$, natural sunlight at the earth's surface does not extend below $292 \mathrm{~nm}$. This study was performed in order to examine the effect of the radiation from the upper part of the ultraviolet, UV, and the visible regions on PMMA and to identify the mechanism(s) of degradation induced by the radiation.

Thin films of PMMA were irradiated in air with upper UV, upper UV-visible, upper UV-visible-near infrared and 436 and $546 \mathrm{~nm}$ radiation. Exposure to either the upper UV or visible radiation caused degradation of the polymer. The data show that both random scission and unzipping of the polymer chain are operative in the degradation. Unzipping becomes increasingly important with incident radiation of increasing wavelength.

NBSIR 79-1767. NBS: Properties of electronic materials, J. R. Manning, 137 pages (June 1979). Order from NTIS as PB297465.

Key words: convection; heat capaçity measurement; $\mathbf{P b}-\mathrm{Sn}$ off-eutectic alloys; phase diagram of $\mathrm{K}_{2} \mathrm{O} \cdot \mathrm{Fe}_{2} \mathrm{O}_{3}$ system; solidification; surface tension of liquid gallium; thermodynamic properties.

The report describes NBS work for NASA in support of NASA's Materials Processing in Space Program covering the period April 2, 1978 to April 1, 1979.
The results obtained are given in detailed summaries in the body of the report. Briefly, in Task I-Surface Tensions and their Variations with Temperature and Impurities-measurements of the surface tension $\gamma$ of liquid gallium were made in vacuum by the sessile drop technique as a function of temperature $\mathrm{T}$ and, in the range $100^{\circ} \mathrm{C}$ to $750^{\circ} \mathrm{C}$, it was found that $\mathrm{d} y / \mathrm{dT}=-0.068 \mathrm{~mJ} / \mathrm{m}^{2}{ }^{\circ} \mathrm{C}$. In Task 2 -Solutal Convection and Liquid Diffusion Coefficients-samples of offeutectic Pb-rich $\mathrm{Pb}-\mathrm{Sn}$ were directionally solidified, and the macrosegregation and changes in microstructure along the length of the sample, attributed to solutal convection, were measured. In Task 3-A Thermochemical Study of Corrosion Reactions in Oxide Materials-phase relationships in the $\mathrm{K}_{2} \mathrm{O}$ $\mathrm{Fe}_{2} \mathrm{O}_{3}$ system were investigated up to $1600^{\circ} \mathrm{C}$ with major corrosion of the platinum containers being avoided, perhaps because of the small amount of $\mathrm{Fe}^{+2}$ in the specimens. In Task 4-Thermodynamic Properties of Refractory Inorganic Materials as Functions of Temperature-methods of determining heat capacities in reactive liquid samples levitated at high temperatures, especially by use of freely-cooling spherical samples, were analyzed.

NBSIR 79-1768. Performance of plastic packaging for hazardous materials transportation. Part IV. Standardizing permeation measurements, J. D. Barnes, G. M. Martin, and F. L. McCrackin, 48 pages (June 1979). Order from NTIS as PB298047.

Key words: effective carbon atom number; hazardous materials; packaging; plastics; standardization; transportation.

This report describes experiments which confirm the essential features of the "permachor" method for estimating the permeability of polyethylene to various liquids. The variables controlled in these experiments were temperature, resin, and alkane chain length. A statistical analysis based on the Linear Model revealed that the data could be described by a function of the form:

$$
\mathrm{G}(\mathrm{T}, \sigma, \mathrm{n})=\exp [\mathrm{X}(\mathrm{T}, \sigma)+\mathrm{B}(\mathrm{T}, \boldsymbol{\sigma}) \times \mathbf{H}(\mathrm{n})],
$$

where $\mathrm{G}(\mathrm{T}, \sigma, \mathrm{n})$ is the transmission rate of lading $\mathbf{n}$ through resin $\sigma$ at temperature $T$ and $B, X$, and $H$ are empirically determined functions. The broader implications of this result with respect to possible standard artifacts for use in permeability testing are described. A concept we have called the "effective carbon atom number" is introduced as a means of correlating data. Once the effective carbon atom number of a liquid is known from measurements on one kind of polyethylene, it should be possible to predict what its permeability performance will be in containers made from different polyethylenes. Procedures are presented for implementing a standard-based system for measuring effective carbon atom numbers of various liquids and using this information to make permeability performance predictions. The major advantage of such a system is that it minimizes the number of tests which must be made using full-scale containers.

NBSIR 79.1770. The potential for erergy savings with water conservation devices, R. L. Palia, Jr., 32 pages (Sept. 1979). Order from NTIS as PB $80-127202$.

Key words: energy; energy consumption; grey water; heat recovery; recycling; residential; wastewater treatment; water; water conservation; water heating; water usage.

With the use of residential water saving devices, substantial decreases in water consumption may be realized. Perhaps of even greater significance, however, are the resultant reductions in water-related energy requirements-for water supply, wastewater treatment, and water heating. 
Through a survey of water-related energy use, a relationship between water usage and energy consumption is developed. Results obtained indicate that energy requirements for water heating far exceed those for water supply and wastewater treatment. Based on estimates of residential water consumption with and without water conserving products, the potential for energy savings is assessed. Reduction in household water heating energy consumption of about 35 percent are predicted with the use of "conventional" water saving products. Also considered in this study are the energy saving potentials of grey water recycling and grey water heat recovery systems.

NBSIR 79-1771. An investigation of preferences for various types of energy cost feedback, A. Ramey-Smith and J. L. Gagnon, 72 pages (Aug. 1979). Order from NTIS as PB300314.

Key words: attitudes; consumer preference; energy; energy cost; feedback; feedback meters.

The present study addressed the issue of consumer preferences for various types of energy cost feedback for individual consumers. Its purpose was to provide human factors recommendations to DOE related to the performance characteristics of energy cost feedback devices for use by DOE in testing energy cost feedback meters. Simulation and interview techniques were used to provide consumer reaction to cumulative, instantaneous, and projected feedback presented as dollar and cent values. A majority of participants indicated a preference for cumulative feedback types. All types of cumulative feedback are easily understood, accurate in reflecting actual energy consumption and suitable to several uses. Hourly instantaneous feedback was considered useful for monitoring energy use of individual appliances. All participants having two energy sources in their home expressed a preference for having feedback presented as separate cost figures rather than as a total cost. Recommendations for feedback types as well as some performance characteristics of energy cost feedback meters for further testing by DOE are discussed.

NBSIR 79-1777. A compendium of gas phase basicity and proton affinity measurements, K. N. Hartman, S. Lias, P. Ausloos, H. M. Rosenstock, S. S. Schroyer, C. Schmidt, D. Martinsen, and G. W. A. Milne, 563 pages (July 1979). Order from NTIS as PB299289.

Key words: data compilation; ion thermochemistry; proton affinity; proton transfer equilibrium.

Literature values of experimental measurements, calculations and estimations of gas phase basicities and proton affinities are presented. Where appropriate they are recalculated to common values for the proton affinity of ammonia and the heat of formation of the proton. The annotated information is ordered by molecular formula following the Hill System. Indices are given to permit location of information of by numerical value of the measurement(s), the compound formula, name and synonym, and CAS Registry Number. The literature coverage is essentially complete through 1977 .

NBSIR 79-1778. A perspective of a workshop on stability of (thin film) solar cells and materials, H. A. Schafft and D. E. Sawyer, 16 pages (July 1979). Order from NTIS as PB297396.

Key words: accelerated tests; failure mechanisms; failure modes; photovoltaics; reliability; semiconductors; solar cells; stability; testing; thin films.

The results of a workshop on the Stability of (Thin Film) Solar Cells and Materials are reviewed from a measurements perspective. Solar cells of the following three material groupings were considered at the workshop: (1) $\mathrm{Cu}_{2} \mathrm{~S} /[\mathrm{CdZn}]$ $\mathrm{S}$, Cu-ternaries/CdS, InP/CdS, and amorphous $\mathrm{Si}$; (2) polycrystalline, MIS, and conducting-oxide $\mathrm{Si}$; and, (3) polycrystalline and AMOS GaAs. Considering the relative state of immaturity of these developing cells and the goal for high reliability and stability, two general areas of work are recommended. One is to develop an improved understanding of cell operation and of component structures of these cells. The other is to develop an improved measurements base. Specific needs and recommendations are provided.

NBSIR 79-1780. Post-occupancy evaluation: A case study of the evaluation process, J. Elder, G. E. Turner, and A. I. Rubin, 67 pages (Aug. 1979). Order from NTIS as PB80-119712.

Key words: building evaluation; design process; man/environment research; post-occupancy evaluation; questionnaire; user needs.

Within the past decade, growing numbers of architects, educators, building users and researchers have begun to question the state-of-the-art of building design. The most common complaint is that buildings do not adequately fulfill the needs of their users. This report addresses the problem by examining the need to identify, develop and apply user information as an integral part of the design process.

The study reported here was conducted for GSA at the Richard H. Poff Courthouse and Federal Building in Roanoke, Virginia. This was a limited study examining: (1) the design process, (2) the information available to those making design decisions, (3) how that information was used and (4) the effects of selective design decisions. In addition, design problems of particular interest to GSA were considered from the viewpoint of several groups involved with the design and use of the building-GSA, the architect, the building manager, the agencies and the employees.

NBSIR 79-1781. Field performance of residential refrigerators and combination refrigerator-freezers, Y.M. L. Chang and R. A. Grot, 46 pages (July 1979). Order from NTIS as PB299058.

Key words: combination refrigerator-freezer field data; daily load profiles; energy consumption; field measurments; hourly load profiles; refrigerator field data; usage profiles.

Evaluation of the performance of household refrigerators and combination refrigerator-freezers was undertaken in a field experiment to determine the effect of room environment and occupant-usage habits on energy consumption of these appliances. This report presents the results of such an experiment in ten townhouses at Twin Rivers, N.J. One-door manual defrost and two-door frost-free models of various sizes were studied. Energy consumption, kitchen temperature, ref rigerator temperature and door openings were measured for each model by data acquisition systems located in the townhouse basements. Both daily and hourly averages and variations about the average for each variable were calculated to determine occupant-usage patterns.

Statistical techniques were utilized to obtain the effect of parameters on energy consumption of these appliances by linear regression of both one- and two-parameter models.

It was found that for a given model the temperature difference between the kitchen and the refrigerator (either main or freezer section) had the most effect on energy consumption, with a lesser, though still important, contribution from the door openings.

In addition, the normalized energy consumption of each model, in different combinations of variables, was calculated from its regression coefficients and the overall average values of parameters from the measurements. The results of these normalized values turned out to be within $5 \%$. Therefore, their mean values could be considered as the typical energy con- 
sumption for each refrigerator or combination, under usage conditions.

The linear relationship among the combination refrigeratorfreezers according to their physical sizes indicated an increasc of about $0.55 \mathrm{kWh}$ per day for each additional cubic foot increase in volume. Energy conscrvation by using a manualdefrost refrigerator was predicted at approximately $40 \%$ from the available measurements and other related laboratory test results.

NBSIR 79-1784. Interaction of blood proteins with solid surfaces, R. E. Dehl and W. H. Grant, 47 pages (Aug. 1979). Order from NTIS as PB299447.

Key words: adsorption; biomaterials; blood proteins; ellipsometry; polymer adsorption; protein adsorption; protein chromatography; radiolabeled proteins.

The purpose of this investigation is to help develop methods of characterizing the surface properties of implant materials for use in the cardiovascular system. These properties are related to the ultimate success or failure of an implant in vivo. The investigation during the current reporting period has been chiefly concerned with the amount of protein deposited on implant material surfaces. Ion exchange treatment of radiolabeled proteins has been found to lead to much greater accuracy and reliability of adsorption measurements. Results are reported for the quantitative adsorption of labeled proteins thus purified onto well characterized test surfaces, and onto the surfaces of materials supplied by contractors to the NHLBI Biomaterials Program. The effect of the label $\left({ }^{125} 1\right.$ vs. $\left.{ }^{14} \mathrm{C}\right)$ on adsorption of proteins was studied. Hydrophobic and hydrophilic oxidized silicon surfaces were used to demonstrate that the adsorption of $\gamma$-globulin, measured by ellipsometry, and serum albumin, measured by radiolabeled protein, both are significantly affected by charge interactions between the surface and the protein.

NBSIR 79-1789. Economic analysis of insulation in selected masonry and wood-frame walls, S. R. Petersen, 137 pages (Sept. 1979). Order from NT1S as PB80-101967.

Key words: building economics; energy conservation; insulation; life-cycle cost analysis; masonry construction; space heating and cooling requirements; thermal mass.

This report provides a life-cycle cost-benefit analysis of several alternative methods for insulating 8 in $(200 \mathrm{~mm})$ concrete masonry walls in new single-family residences. In addition, a cost-benefit analysis for insulation in wood-frame walls is provided, consistent with the assumptions used in the masonry wall analysis. A dynamic load simulation model, NBSLD, was used to calculate the heating and cooling requirements for a 1176 square foot $\left(110 \mathrm{~m}^{2}\right)$ house with different levels of thermal resistance for both wall types in eight geographic locations. These data are used to calculate the reduction in annual heating and cooling requirements due to several different types of insulation in the cores and furring spaces of the masonry wall and the cavities of the wood-frame wall.

Economic analysis is applied to determine estimates of lifecycle savings from insulation for different locations and furnace types in order to determine the most cost-effective insulation level. In general it is found that the maximum economically justifiable level of insulation in the masonry wall is considerably lower than for the wood-frame wall because of the significantly higher cost of insulating masonry walls.

NBSIR 79-1790. A comparison of American and European ultrasonic testing standards, S. Golan, 73 pages (Aug. 1979). Order from NTIS as PB298809.

Key words: evaluation; international; standardization; standard recommended practice; synopsis; ultrasonic standards; ultrasonic testing.
In this work twenty-seven general ultrasonic standards from eleven countries and international organizations were reviewed. Thirty-seven ultrasonic product standards from five countries werc studied to evaluate the utilization of the general ultrasonic standards, i.e., to what extent the procedures outlined in the general standards are applied by the product standards.

NBSIR 79-1792. International activities-The fiscal year 1978 survey of international programs at NEL, S. Kramer and $\mathbf{M}$. Olmert, Ed., 121 pages (Aug. 1979). Order from NTIS as PB300491.

Key words: engineering; international cooperation; international research; international standards; National Bureau of Standards (NBS); National Engineering Laboratory (NEL); technology transfer.

This report presents a survey of a major phase of the international activities of the National Engineering Laboratory (NEL), NBS, for the Fiscal Year 1978.

There are a number of media through which international activities are conducted. The first of these is the formal visit by one or more NEL staffers to a foreign research organization or conference. The second category covers visits by foreign government scientists and research institutions to the NBS facilities. Other media include exchange visits and the hosting of overseas guest workers at NBS. Although this report covers only the first category, some significant and gratifying contributions to international technical progress are detailed here.

The report is organized by countries, international organizations and conferences. NEL professional staff involved in these activities are readily identified. The report is intended to serve as a directory and reference document for all those who seek information on the international activities of the National Engineering Laboratory, NBS.

NBSIR 79-1793. Privacy as information management: A social psychological and environmental framework, S. T. Margulis, 28 pages (Sept. 1979). Order from NT1S as PB300986.

Key words: architectural psychology; bibliography; buildings; communication; cost; human characteristics; personal control; physical environment; privacy.

A social-psychological and environmental framework for a theory of privacy is summarized. The framework focuses on the management of information the loss of which would or could have costly consequences for the target of the information. Key concepts, such as information, communication, personal control, cost, and barrier, are defined and discussed. Particular emphasis is placed on influence of the objective physical environment on privacy.

NBSIR 79-1796. Preliminary findings concerning the validity of "BFIRES": A comparison of simulated with actual fire events, F. I. Stahl, 22 pages (Aug. 1979). Order from NTIS as PB299451.

Key words: architectural research; building fires; computeraided design; computer simulation; environmental psychology; fire research; fire safety; human performance; modeling technique; simulation.

This report presents preliminary findings regarding the validity of BFIRES/VERSION I, a computer program developed at the National Bureau of Standards to simulate egress movement by building occupants during fires. A computer simulation experiment was conducted in order to compare outcomes from BFIRES runs with data selected from an archival file summarizing actual fire results. Findings from this experiment suggest that BFIRES is capable of reproducing such important fire outcomes as loss-of-life indices and numbers of persons ultimately escaping. In addition, patterns of egress behavior produced by 
BFIRES were compared with those found in the literature, with professional opinions, and with impressions gathered from anecdotal accounts. With few exceptions, these comparisons illustrate agreement between simulations and other data sources.

NBSIR 79-1799. Performance of a packaged solar space-heating system used with a mobile home, D. E. Jones and J. E. Hill, 44 pages (Sept. 1979). Order from NTIS as PB300890.

Key words: mobile home; packaged solar space-heating system; rating; standards; testing.

As part of a continuing program to develop test methods for solar heating equipment, NBS is now developing a standard test procedure for packaged solar space-heating systems similar to test procedures now used for solar collectors and thermal storage devices, and now under development for packaged solar water-heating systems. As a first step, a mobile home, which was previously tested for thermal performance in an environmental chamber, was equipped with a packaged solar space-heating system using air-heating collectors and pebblebed storage. The system was fully instrumented and data were collected over the 1977-78 heating season at the NBS site in Gaithersburg, MD. The performance of the system was determined and various methods of correlating performance were explored.

NBSIR 79-1900. Bibliography on the voluntary standards system and product certification, C. Chapman, 28 pages (Oct. 1979). Order from NTIS as PB80-117922.

Key words: bibliography; buildings; certification; economics of standards; legal aspects of standards; product certification; product liability; regulation; standards system; voluntary standards.

This bibliography lists references accumulated by the NBS Office of Engineering Standards in the course of its research into the workings of the voluntary standards system and the economic and legal effects of standards. The first portion of the bibliography lists references alphabetically by author. The second portion groups references by subject. Subject categories include: standards system reform, regulatory use of standards (buildings, safety, environment), certification and laboratory accreditation, solar heating and cooling, product liability, and international and foreign.

NBSIR 79-1902. Economic aspects of fire safety in health care facilities: Guidelines for cost-effective retrofits, R. E. Chapman, P. T. Chen, and W. G. Hall, 118 pages (Nov. 1979). Order from NTIS as PB80-120165.

Key words: applied economics; building codes; building economics; economic analysis; fire safety; health care facilities; hospitals; life safety; mathematical programming; nursing homes; renovation.

This study focuses upon one aspect of the fire safety problem in health care facilities; the use of the Fire Safety Evaluation System developed by the Center for Fire Research at the $\mathrm{Na}$ tional Bureau of Standards for determining equivalence to the Life Safety Code. The Life Safety Code, a voluntary code developed by the National Fire Protection Association, is currently the most widely used guide for identifying the minimum level of fire safety in buildings. Using the Fire Safety Evaluation System as a basis, this study develops a computerized procedure which permits the least-cost means of achieving compliance to the Life Safety Code in health care facilities to be identified. Since each of the parameters used in the Fire Safety Evaluation System has a unique value which corresponds to strict compliance, it is possible to quantify the cost savings attributable to the use of the Fire Safety Evaluation System over strict compliance to the Life Safety Code. Preliminary stu- dies conducted by the National Bureau of Standards of a prototypical hospital have concluded that the use of this computerized procedure can result in cost savings of 50 percent or more over those associated with strict compliance to the Life Safety Code.

NBSIR 79-1906. The evacuation of non-ambulatory patients from hospital and nursing home fires: A framework for a model, J. Archea and S. T. Margulis, Ed., 65 pages (Nov. 1979 ). Order from NTIS as PB80-119530.

Key words: building codes; building evaluation; elderly; fire safety; handicapped occupants; health care facilities; nursing homes; user needs.

This report is directed toward the problem of evacuating dependent, non-ambulatory persons from fires in nursing homes and other health care facilities. It deals only with those behavioral and building factors that bear on the activities that follow directly from a decision to evacuate patients from a fire zone in a nursing home or similar facility. The examination is based on the rejection of the model which is the basis for current life safety regulations because it assumes independent occupant mobility. This assumption does not apply to dependent, non-ambulatory persons. The major objective of the report is to identify those factors that must be considered in order to determine the ideal performance of a hospital or nursing home evacuation system for non-ambulatory patients when all components or persons in that system act as they are designed or trained to act. These factors are presented as part of an analysis of evacuation as a five phase process: manpower supply phase, patient preparation phase, patient removal phase, rest and recovery phase, and manpower resupply phase. Research findings are reviewed and a research agenda is proposed.

NBSIR 79-1909. Measurement techniques for solar cells, Quarterly Report: April 1 to June 30, 1978, D. E. Sawyer, H. K. Kessler, and H. A. Schafft, 27 pages (Oct. 1979). Order from NT1S as PB301309.

Key words: device measurements; laser scanning; light-biasing; metallization; ohmic contacts; reliability; semiconductor measurements; sheet resistance; solar cells; solar cell stability.

This is the quarterly report of the work in a program on solar cell measurement technique development and other services which was performed in the period from April 1 to June 30, 1978. The objectives of the program are to assist the DOE thinfilm photovoltaic effort by developing solar cell device and material measurement techniques using the NBS-developed laser flying-spot scanner, by assisting DOE in organizing and hosting appropriate workshops and symposia, and by providing general consultation and liaison services.

The technique proposed last quarter employing cell forwardbiasing during scanning to reveal cell defects was implemented. Using an electrical current source, cell cracks and metallization regions disconnected from the cell output electrode have been readily revealed. The mathematical analysis work supporting the experimental scanning of cells has been extended to more realistic cell geometries than the one-dimensional one previously treated. Developments in scanner equipment and ancillary techniques include the completion of the high-intensity isolation source for forward-biasing cells with light during scanning, an improvement in coupling biased and scanned cells to the display-screen electronics, and an increase in the cell scanning area.

The workshop on Stability of (Thin Film) Solar Cells and Materials was held May 1-3, 1978 at the National Bureau of Standards, Gaithersburg, MD. 
NBSIR 79-1910. Purely buoyant diffusion fames: Some experimental results, B. J. McCaffrey, 5 I pages (Oct. 1979). Order from NTIS as PB80-112113.

Key words: buoyancy; diffusion flames; fire entrainment; flame oscillations; plume; scaling.

Measurements of temperature and velocity using thermocouples and an impact probe were made in the near field of a purely buoyant diffusion flame produced by a porous refractory burner. Based on time-averaged center line value of $\mathrm{V}$ and $\Delta \mathrm{T}$ together with photographic records the flame can be conveniently divided into three distinct regimes: (1) a continuous flame region, starting from the surface of the burner with $V$ equal to zero at the surface and rising with the height above the burner, 2 , to the $1 / 2$ power. $\Delta \mathrm{T}$ is constant over this regime. Higher up is (2), an intermittent regime, with pulsating flame $(\sim 3 \mathrm{~Hz})$ exhibiting approximately constant $V$ and $\Delta T$ falling with $\mathrm{z}$ to the first power. Still higher is (3) the plume region which is, most of the time, free of flames with $V \sim z^{-1 / 3}$ and $\Delta \mathrm{T} \sim \mathrm{z}^{-5 / 3}$ as predicted by conventional plume theory. Throughout the three regimes and indistinguishable among these is the consistency of the buoyance relation, $V / \sqrt{2 g z}$ $\overline{\Delta \mathrm{T} / \mathrm{T}}_{o}$ which has a value of approximately 0.9 , a factor 2.5 times previous estimates in the flame region and confirming the recent correlation measurements of $\mathrm{Cox}^{1}$. Different heat release rates, Q, can be scaled to a "universal" fire if the length is normalized as $z / Q^{2 / 5}$ and the velocity scale as $V / Q^{1 / 5}$. The flame regime is thus independent of $Q$.

In the radial direction for time-averaged quantities only the plume region appears reasonably Gaussian. The data in the flame and intermittent regimes do not fall as rapidly as that dictated by a Gaussian distribution. In all three regimes the velocity profile is wider than the temperature profile.

Large scale, low frequency $\Delta p$ fluctuations are about $35 \%$ of the time-averaged signal on the center line throughout the three regions. Radially the fluctuating to time-averaged signal ratio rises from the center line value and approaches $100 \%$ in the wings. Elementary spectral analysis indicates that most of this energy is concentrated in a narrow band centered around $3 \mathrm{~Hz}$.

Implications of these results for flame entrainment calculations and heat release rates will be discussed.

NBSIR 79-1912. Temperature measurement on operating surface mounted lighting fixtures, P. M. Fulcomer, 24 pages (Sept. 1979). Order from NTIS as PB80-103682.

Key words: branch circuit wiring; electrical junction box; hazardous temperatures; load current; overlamping; surface mounted incandescent lighting fixture; thermal insulation; thermocouple.

Potentially hazardous temperatures may result from adding thermal insulation in the attic above mounted incandescent lighting fixtures and/or operating these fixtures with lamps of higher wattage than specified. This study was concerned with the range of temperatures generated (1) within the fixture, (2) within the electric junction box associated with the fixture and (3) on the adjoining ceiling and attic surfaces.

Test results indicate that the addition of minimal insulation (equivalent to $\mathrm{R} 11$ ) over a surface mounted lighting fixture which contains two or more rated lamps, is likely to cause normal household branch circuit supply wiring associated with the fixture to operate above its specified $60^{\circ} \mathrm{C}$ temperature rating. Overlamping (using lamps of higher wattage than specified for the fixture) and/or additional load current flowing through the branch circuit wire will cause even higher supply wire temperatures.

With all three conditions present (i.e., insulation over the fixture, overlamping, and an additional 15 ampere load current flowing through the supply wire), the tests indicate that the temperature of associated branch circuit wiring will exceed 80 ${ }^{\circ} \mathrm{C}$ for a one lamp fixture and $100{ }^{\circ} \mathrm{C}$ for fixtures with two or more lamps.

NBSIR 79-19/3. Temperature measurement on operating recessed lighting fixtures, P. M. Fulcomer, 23 pages (Sept. 1979). Order from NTIS as PB80-104722.

Key words: branch circuit wiring; electrical junction box; hazardous temperatures; load current; protective barrier; recessed incandescent lighting fixture; thermal insulation; thermocouple.

Potentially hazardous temperatures may result from adding thermal insulation in the attic above recessed incandescent lighting fixtures. The National Electric Code for 1978 specifies that "...thermal insulation shall not be installed within three inches of a recessed fixture enclosure, wiring compartment or ballast and shall not be so installed above the fixture as to entrap heat and prevent the free circulation of air..." The purpose of this investigation was to determine the effectiveness of various protective barriers in maintaining the requisite threeinch spacing and in preventing over-temperature conditions when loose-fill insulation is installed around recessed lighting fixtures.

For the devices tested, the results indicate that properly installed open-top barriers are sufficient to allow the fixture and associated branch circuit wiring to operate within specified ratings. However, a barrier closed at the top by any method, can cause branch circuit wiring, the external surface of the barrier and/or parts of the fixture to operate at temperatures above those designated as "safe."

NBSIR 79-1914. Assessment of the quality of pulp fibers by short span tensile analysis, E. L. Graminski and K. Bonin, 22 pages (Oct. 1979). Order from NTIS as PB80-101918.

Key words: fiber length distribution; fiber strength; interfiber bonding; recycled pulps; short span tensile analysis; zero span tensile.

Fiber strength is an important factor in paper strength, but despite its importance fiber strength is rarely assessed as it involves the tedious and time consuming testing of single fibers. In the recycling of paper, especially of the abundant low grades of waste paper, the question of fiber quality always arises. The inability to monitor fiber quality of recycled pulp, especially from low grade waste paper has led to the practice of utilizing this pulp only for low grade papers regardless of the actual quality of the pulp fibers. Unfortunately, there is a limited demand for Iow grade papers. Increased utilization of low grade waste paper could be enhanced if the fiber quality of the recycled pulps could be monitored routinely. As the strength of fibers is affected by defects that are randomly distributed among and within fibers it appeared a short span tensile test might provide a means for assessing fiber quality. In short span tensile testing of fibrous webs the load at the break declines as the span increases. The rate of decline is partly controlled by the fiber length distribution. Since the probability of locating defects in fibers increases with increasing span lengths the rate of decline in web strength with increasing span lengths should be a function of fiber quality for a specific fiber length distribution, all things being equal. The results of this investigation indicate that the rate of decline in web strength with increasing span length is indeed a function of fiber quality. It appears that the test method could be used to monitor fiber quality routinely.

NBSIR 79-1915. Investigation of the effects of heating and air conditioning on the performance of smoke detectors in mobile homes, R. W. Bukowski, 181 pages (Oct. 1979). Order from NTIS as PB80-100001. 
Key words: detection time; detector location; fire tests; gas detectors; kitchen fires; mobile homes; smoke detectors; tenability limits; upholstered furniture.

Since its original promulgation in June 1976, the U.S. Department of Housing and Urban Development's Federal Mobile Home Construction and Safety Standard has required the installation of at least one smoke detector to protect the mobile home occupants. The location of the smoke detector was based on earlier tests in a mobile home conducted by NBS in 1976.

Because of the limited scope of the earlier NBS tests and subsequent improvements in the design of smoke detectors and the construction of mobile homes, a new series of tests was conducted to evaluate the influences of the operation of central forced-air heating and air conditioning systems on the performance of smoke detectors representative of those which are currently being installed. The tests were conducted with upholstered chairs in smoldering and flaming fire modes, representing key residential fire death scenarios. Tests were conducted in both summer and winter weather conditions. The effects of detector location (wall or ceiling and position within the bedroom corridor) and the effects of open and closed bedroom doors were also investigated.

The report concludes that, for the scenarios examined, a properly functioning ionization or photoelectric smoke detector mounted near the ceiling on the inside or outside wall at the living room end of the corridor should provide an alarm in sufficient time for occupant escape.

NBSIR 79-1916. Third annual conference on fire research, I. M. Martinez, Ed., 188 pages (Oct. 1979). Order from NTIS as PB80-1 10240.

Key words: chemistry of fire; combustion products; fire hazards; fire modeling; fire research; human behavior in fires; physics of fire; toxicity of combustion products.

This report contains extended abstracts of grants and contracts for fire research sponsored by the Center for Fire Research, National Bureau of Standards, as well as descriptions of the internal programs of the Center for Fire Research.

NBSIR 79-1917. Solar energy systems-Standards for rubber hose, R. D. Stiehler and J. L. Michalak, 36 pages (Nov. 1979). Order from NTIS as PB8()-129828.

Key words: hose; hose specifications; rubber hose; solar energy systems.

A study of commercial rubber hose was made to develop standards for hose used in solar energy systems. Twelve hoses were evaluated by cycling between temperatures of about 100 ${ }^{\circ} \mathrm{C}$ and temperatures as low as $-40{ }^{\circ} \mathrm{C}$ during a period of about seven months. Laboratory tests for bursting strength, compatibility with metals, compression set, ozone resistance, and water vapor transmission were also made.

The results of this study and tests are presented. Based on these findings, a standard for rubber hose used in solar energy systems is proposed.

NBSIR 79-1923. Residential solar data center grant reports, $P$. M. Christopher and M. J. Aronoff, 74 pages (Oct. 1979). Order from NTIS as PB80-119928.

Key words: automatic data processing; computer reports; grant data; residential buildings; solar database; solar energy system; solar heating and cooling.

The Residential Solar Data Center project staff in the Center for Building Technology, National Bureau of Standards, is responsible for the establishment and operation of a computerized database containing non-instrumented residential data generated by the Solar Heating and Cooling Demonstration
Program sponsored by the Department of Energy and the Department of Housing and Urban Development (HUD). This document includes computer reports of data contained in the Grant file, one of six computer files comprising the database. These reports contain data recorded on applications submitted to HUD by organizations or individual builders applying for grants to build solar energy systems in new and/or existing homes. To date, approximately 450 grants have been awarded in the first four award cycles.

NBSIR 79-1927. Recovery from soft errors in triplicated com. puter systems operating in Iock-step, A. L. Koenig and A. W. Holt, 28 pages (Nov. 1979). Order from NTIS as PB80-126931.

Key words: fault tolerant computer; soft errors; TMR; triply modular redundant.

A Triply Modular Redundant (TMR) computer system operating in clocked lock-step is being investigated for an application requiring a Mean Time Between Failure of five years. No mechanical memories are used; this allows comparison of the outputs of the three computers to be made each clock period. The most novel contribution is the method of recovery from soft errors, such as those produced by lightning strokes or alpha particles. Data are provided on the uptime history of an experimental system, which uses three commercial microcomputers.

NBSIR 79-1928 (NBS). NBS library handbook for NBS staff, N. H. Knight, 76 pages (1979). Order from NT1S as PB80106420 .

Key words: library policy; library procedures; library services.

This publication describes NBS Library services, policies, resources, and lists personnel.

NBSIR 79-1933. Evaluation of a multimegavolt impulse measurement system, R. E. Hebner, Jr., D. L. Hillhouse, and R. A. Bullock, 102 pages (Nov. 1979). Order from NTIS as PB80-1 19720.

Key words: divider; Duhamel's integral; high voltage; impulse; pulse measurements; response time; step response; transients.

The calibration of a $4.5 \mathrm{MV}$ impulse divider was evaluated by measuring both the input and output waveforms and the response of the divider to a low voltage step. The measured output was compared to an output calculated from the step response and the measured input waveform using Duhamel's Integral. The validity of the approach for this large measurement system was demonstrated for the specific waveforms studied.

NBSIR 79-1941. Table of recommended rate constants for chemical reactions occurring in combustion, F. Westley, 169 pages (Nov. 1979). Order from NTIS as PB80-128531.

Key words: Arrhenius parameters; combustion; decomposition; free radicals; hydrocarbons; hydrogen; nitrogen; organic compounds; oxidation; oxygen; oxygenated; rate constant; sulfur.

A table of recommended rate constants for gas phase chemical reactions occurring in combustion is presented. Specifically, it gives in tabular form the values of the parameters for the modified Arrhenius equation $k=A T^{B} \exp (-E / R T)$. The table covers reactions occurring in the combustion, oxidation and decomposition of aliphatic saturated or unsaturated $C_{1}$ to $C_{10}$ hydrocarbons, alcohols, aldehydes, ketones, thiols, ethers, peroxides, amines, amides and their free radicals, as well as the reactions of $\mathrm{O}, \mathrm{O}_{2}, \mathrm{H}, \mathrm{H}_{2}, \mathrm{OH}, \mathrm{H}_{2} \mathrm{O}, \mathrm{H}_{2} \mathrm{O}_{2}, \mathrm{~N}, \mathrm{~N}_{2}, \mathrm{NO}, \mathrm{N}_{2} \mathrm{O}$, $\mathrm{NO}_{2}, \mathrm{~N}_{2} \mathrm{O}_{4}, \mathrm{~N}_{2} \mathrm{O}_{5}, \mathrm{~S}, \mathrm{~S}_{2}, \mathrm{SH}, \mathrm{SO}, \mathrm{SO}_{2}, \mathrm{SOH}$, NS, with each 
other. The tablc includes approximately 170 first order reactions 760 second ordcr reactions and 50 third order reactions There are 1805 entrics covcring about 1100 distinct chemical rcactions. These recommendations have been taken from eleven evaluations and critical reviews published between 1970 and 1976. The papers examined by the evaluators extend from the nineteen fifties up to-and including- 1975. 


\subsection{GRANTEE/CONTRACTOR REPORTS AND NBS PATENTS}

Grantee/contractor reports are prepared by non-NBS persons or organizations working under grant or contract from the $\mathrm{Na}$ tional Bureau of Standards. Those contract reports not incorporated into the formal NBS publication series are available directly from the National Technical Information Service (NT1S, Springfield, VA 22161) in paper copy or microfiche form unless otherwise stated. When ordering a report from NTIS you must order it by the "COM, PB, AD, or N" number as indicated.

Patents are legal documents which fully describc inventions in return for the right for 17 years to exclude others from making, using, or selling the inventions. They are obtained on NBS inventions of high commercial potential in order to establish Government ownership of the patent rights. The patents are then made available for the grant of nonexclusive licenses to all qualified applicants. A limited exclusive license may be granted under a particular patent, however, if it appears that some period of exclusivity is necessary as an incentive for the investment of risk capital. For information on licensing any of the following patents, write to the Office of the Legal Adviser, National Bureau of Standards, Washington, DC 20234. Copies of patents may be obtained from the U.S. Patent and Trademark Office, Washington, DC 20231 for 50 cents each.

NBS-GCR-78-127. Comparison of tape drive interface characteristics, Auerbach Associates, Inc., 75 pages (June 15, 1978). Order from NT1S as PB282291.

Key words: computer magnetic tape drives; computer tape controllers; group coded recording; interface electrical characteristics; interface functional characteristics; magnetic tape drives; NRZ1 recording; phase encoded recording; tape drive characteristics.

This report describes and compares the various characteristics of the interface between computer tape drives and their controllers for 9-track tape drives operating at 75 inches per second or more, using the 800 bpi NRZI, 1600 bpi Phase Encoding and 6250 bpi Group Coded Recording methods. It presents the results of an investigation conducted for the $\mathrm{Na}$ tional Bureau of Standards in support of the possible development of a Federal Information Processing Standard for the device level interface. Through textual descriptions and an extensive series of tables, the various functional and interface electrical characteristics of the tape drives are compared.

It was concluded that the drives reviewed could be placed in one of two general types, those with explicitly defined signal lines and those with multiplexed signalling between drive and controller. Within each of these types there is a substantial degree of commonality among drives but also important differences. At the electrical signal and physical interface level there are also significant differences of a detailed engineering nature among the drives.

NBS-GCR-78-128. Environments of fire detectors-Phase II: Effect of ceiling configuration. Volume I. Measurements, G. Heskestad and M. A. Delichatsios, 180 pages (June 1978). Order from NTIS as PB290951.

Key words: beams; ceiling height; detectors; fire detectors; fire growth; heat detectors; room fires; smoke detectors; spacing; velocity.

This report describes Phase II of a sustained research program to map ceiling environments to which fire detectors are exposed. Phase 1, reported previously, concerncd flat, horizontal ceilings of large extent. Phase 11 extends ceiling measurements of temperature, velocity and optical density to six different beam configurations in extensive, horizontal ceilings. As in Phase I, the response times of variously located sets of fire detectors were measured (three types of hcat detectors, an ionization detector and a photoelectric smoke detector). A total of 21 fire tests were conducted. The reduced data are presented in two tables, one listing detector response times and the other listing environmental data. Analysis of the data is presented in a second volume (Volume II).

\section{NBS-GCR-78-129. Environments of fire detectors-Phase II: $\mathbb{E}$ f- fect of celling conflguration. Volume II. Analysis, G Heskestad and M. A. Delichatsios, 112 pages (June 1978). Order from NTIS as PB284042.}

Key words: beams; ceiling height; detectors; fire detectors; fire growth; heat detectors; room fires; smoke detectors; spacing; velocity.

This volume contains an analysis of experimental data presented in Volume I on 1) the ceiling environment generated by flaming fires under extensive beamed ceilings and 2)/the response to this environment by various types of fire detectors. Data on gas temperatures, gas velocities and optical densities have been presented in readily usable form for each of six beam configurations. These data have been converted to "reduced" forms which allow predictions to be made of the environmental variables for any combination of ceiling height and fire growth rate. The experimental response of fire detectors was generally found to conform with available response theories. With the aid of these theories and the data on the "reduced" variables, optimum spacing configurations of fire detectors have been determined as a function of ceiling height for each beam configuration. It is cautioned that the resulting spacing configurations pertain to large, unobstructed beamed ceilings and may be overly conservative in many practical situations.

NBS-GCR-78-134. Development of measurement techniques for
monitoring chemical purity of materials used in digital IC
processing, J. Stach, M. B. Das, and R. E. Tressler, 88 pages (Sept. 1978). Order from NTIS as PB29 1427.

Key words: boron nitride; Cl-doped glasses; diffusion in silicon; integrated circuit processing; kinetics of oxide growth; oxidation of silicon; semiconductor processing; silicon; silicon dioxide; thermally stimulated measurement; thermal oxidation; $\mathrm{Zn}$-doped glasses.

The report is in two principal parts: 1 . The transport of impurities from specially prepared boron nitride diffusion sources onto silicon slices was investigated. The sources were of varying degrees of purity. No transport was detected by thermally stimulated capacitance and current measurements having an estimated detection limit of $10^{11} \mathrm{~cm}^{-3}$. Zinc, one of the more probable contaminating impurities, was introduccd in excess and detected down to a level of $2 \times 10^{13} \mathrm{~cm}^{-3}$.

11. The kinetics of silicon thermal oxidation in the presence of chlorine, from $\mathrm{HCl}$ gas or from trichloroethylene vapor, were studied using the SOLGAS computer program. Calculated data are presented to show the equilibrium partial pressurcs of the various chemical species in the diffusion furnace atmosphere as a function of temperature in the range 800 to 
$1300{ }^{\circ} \mathrm{C}$ for a variety of mixtures of gases. Experimental work was also done; parabolic rate coefficients, index of refraction, etch rate, and stored charge measurements are presented.

NBS-GCR-78-135. An exploration of non-sampling error in fire incident surveys, M. A. McDaniel, L. Bickman, P. Edelman, and E. Herz, 24 pages (Dec. 1977). Order from NTIS as PB284849.

Key words: fire departments; fire incidence; fire reporting; fire victims; human behavior; statistical sampling; surveys.

Non-sampling error in fire incident surveys is a potential problem for fire and human behavior research. The present report was prepared in an effort to examine fire victims' reporting biases concerning fire incidents. The telephone numbers of household fire victims in a midwestern city, during the months of September 1975 through August 1976, were obtained from the fire department. Also a sample of telephone numbers in the same area was randomly generated. All eligible and cooperative respondents were asked a series of questions concerning whether they experienced a fire during the target interval and, if they had a fire, they were questioned about it. Approximately one-half of the respondents who, according to fire department records, had had a fire failed to report it to the interviewer. Results indicated that respondents who had more serious fires, reported the incident to the interviewer significantly more often than respondents who had less serious fires. Also fires which occurred later in the 12 month reference period (i.e., closer to the time of the interview) were more often reported to the interviewer than those which occurred earlier in the reference period. Several analyses indicated that, in most cases, the fire reporters' responses agreed with fire department records concerning the characteristics of the fire incident; however, total agreement was seldom found. In addition, it was found that fire reporters tend to be similar to fire-nonreporters in terms of demographic characteristics and most survey responses although some statistically significant differences were obtained.

NBS-GCR-78-138. Human behavior in fire-A bibliography, J. L. Bryan, 23 pages (Aug. 1978). Order from NTIS as PB287412.

Key words: bibliographies; building fires; escape; evacuation; fires; high rise buildings; hospitals; human behavior; nursing homes.

This bibliography was originally prepared for the Third Joint Panel Meeting, United States-Japan Natural Resources Panel on Fire Research at the Center for Fire Research, National Bureau of Standards, March 13-17, 1978. The bibliography was revised as the result of additional literature reviews during $\mathrm{Au}-$ gust, 1978. The previously developed bibliographies of Dr. Leonard Bickman, Fire and Human Behavior Research Center, Applied Social Psychology Program, Loyola University; Fred I. Stahl and John Archea of the Center for Building Technology, National Engineering Laboratory, National Bureau of Standards; J. L. Pauls of the Division of Building Research, National Research Council of Canada; and Dr. Tadahisa Jin, Fire Research Institute, Fire Defense Agency, Ministry of Home Affairs, Japan were valuable sources of citations.

NBS-GCR-78-140. An examination and analysis of the dymamics of the human behavior in the fire incident at St. Joseph's Hospital, Philadelphia, PA, on August 10, 1977, J. L. Bryan and P. J. DiNenno, 62 pages (May 31, 1978). Order from NTIS as PB287935.

Key words: breathing apparatus; death; evacuation; fires; flashover; hospitals; human behavior; nursing staff; patients; room fires.
The fire incident at St. Joseph's Hospital on August 10, 1977 was detected by the nursing staff at approximately 8:45 p.m., at which time the fire had obtained a post flashover development in the area of origin, a bathroom on the second floor. The 130 year old, four-story building of ordinary construction had 171 patients. The fire extended from the second floor to the ceiling of the third floor through a pipe chase and the wall stud spaces.

The fire department was notified automatically with the activation of the local fire alarm system within the facility at 8:48 p.m. through an auxiliary system arrangement with the public fire alarm system. The seven nursing staff assigned to the area of fire origin evacuated a total of thirty-four patients in a period of 6 to 7 minutes, with twenty-two of these patients being evacuated in less than three minutes. At the time of fire department arrival on the fire floor, all the patients had been evacuated from the fire area with the exception of two male patients. The fire department personnel using breathing apparatus removed both patients. One patient could not be revived, while the other died approximately one week later.

Total evacuation of the hospital was accomplished by the staff, fire and police department personnel, with assistance from some citizens. The 171 patients were evacuated in a time period from 16 to 19 minutes.

NBS-GCR-78-141-1. Solar building regulatory study. Volume I, J. Greenberg, 93 pages (Nov. 1978). Order from NTIS as PB289823.

Key words: codes and standards; solar energy; solar heating and cooling; solar model code; solar regulatory provisions; solar regulatory requirements.

The reports contained in Volumes $\mathbf{I}$ and Il represent studies and recommendations prepared under contract for the National Bureau of Standards (NBS) with funding provided by the Department of Energy (DoE). These reports document the results of an important project oriented toward obtaining the views of organizations representing diversified interests within the building community regarding: (1) the need for a solar regulatory system; and (2) the form such a system should take if indeed a solar regulatory system were recommended. The work was conducted under the leadership and coordination of NBS with the various participants providing their in puts and recommendations in various stages during the conduct of this project.

NBS-GCR-78-141-2. Solar building regulatory study. Volume II, J. Greenberg, 385 pages (Nov. 1978). Order from NTIS as PB289824.

Key words: codes and standards; solar energy; solar heating and cooling; solar model code; solar regulatory provisions; solar regulatory requirements.

The reports contained in Volumes I and II represent studies and recommendations prepared under contract for the National Bureau of Standards (NBS) with funding provided by the Department of Energy ( DoE). These reports document the results of an important project oriented toward obtaining the views of organizations representing diversified interests within the building community regarding: (1) the need for a solar regulatory system; and (2) the form such a system should take if indeed a solar regulatory system were recommended. The work was conducted under the leadership and coordination of NBS with the various participants providing their inputs and recommendations in various stages during the conduct of this project.

NBS-GCR-78-147. Review of smoke particulate properties data for burning natural and synthetic materials, C. P. Bankston, R. A. Cassanova, E. A. Powell, and B. T. Zinn, 61 pages (May 1978). Order from NTIS as PB29 2066. 
Key words: combustion; flaming combustion; flexible foams; optical density; particle size; polypropylene; polyurethane foams; polyvinyl chloride; pyrolysis; rigid foams; smoke; smoldering; weight loss; wood.

This report comprises a catalogue of smoke particulate properties data which were taken in the Combustion Products Test Chamber at the Georgia Institute of Technology through October 1, 1977. Results of smoke tests conducted under a variety of environmental conditions are presented for the following natural and synthetic materials: Douglas fir (wood), polyvinyl chloride (PVC), rigid and flexible polyurethane foams, and polypropylenes. Comparisons are provided which illustrate the effects of material variables, radiant heating rate (nonflaming), type of combustion (flaming vs. nonflaming), ventilation gas composition, and ventilation gas temperature upon smoke properties. The smoke particulate properties which have been tabulated are: fraction of sample weight loss which becomes particulate matter, particle mass median diameter and standard deviation, maximum optical densities at $633 \mathrm{~nm}$ and $458 \mathrm{~nm}$, volume-surface mean particle diameter at maximum optical density, and plots of the cumulative particle mass-size distribution.

NBS-GCR-78-148. Effectiveness of program validation methods for scientific programs, W. E. Howden, 110 pages (Dec. 1978). Order from NTIS as PB289930.

Key words: program testing; scientific programs; software errors; software validations.

This report describes the results of an investigation of the effectiveness of different software validation techniques. The investigation involved two types of activities. The first included a survey of software validation methods and of previous studies of effectiveness. The second involved a project in which each of the errors in a collection of scientific programs was carefully analyzed to determine which validation method would have been most useful in preventing the error from occurring.

The report contains five sections, in addition to an appendix.

Each section consists of a paper which was written to cover a specific topic. The first two papers are surveys of previous studies of dynamic and static analysis. The third paper is a survey of previous studies of the effectiveness of software validation methods. The fourth and fifth papers describe the results of the analysis of the errors in the scientific programs studies in the project.

The errors that were analyzed occur in 50 programs in edition five of the IMSL Scientific Subroutine Library. All errors were corrected in edition six. The errors are described in IMSL maintenance and recipient's letters.

The dynamic analysis method which was most effective in discovering the IMSL errors was a form of functional testing which was developed during the research project. The details of the method are contained in the paper in section four. The paper compares the method with the more widely studied kind of testing-structured testing.

NBS-GCR-78-149. Analysis of fire reports on file in the Massachusetts State Fire Marshal's Office relating to wood and coal heating equipment, J. W. Shelton, 9 pages (Nov. I978). Order from NTIS as PB292521.

Key words: accident investigations; chimneys; coal; creosote; fire departments; fire safety; heating equipment; maintenance; stoves; wood.

An analysis of solid-fuel related fires reported by local fire departments to the Massachusetts State Fire Marshal's Office from late 1977 through June 1978 indicates that of the fires attributed to specific causes, roughly $3 / 4$ were attributed to unsafe installations, and about $1 / 4$ were attributed to unsafe operation/maintenance. In less than 2 percent of the fires was the cause attributed to defects or poor design in the heating appliance itself. Thus, to the extent that the local fire department reports are complete and reliable, it appears that attention to installation, operation and maintenance is what has the most potential for reducing fires.

NBS-GCR-78-I 50. UNDSAFE-II-A computer code for buoyan turbulent flow in an enclosure with the rmal radiation, $K$. V. Liu and K. T. Yang, 172 pages (July 15, 1978). Order from NTIS as PB291516.

Key words: buoyant flow; compartment fires; computer programs; corridor fires; fire models; fire spread; room fires; thermal radiation; turbulence.

This report describes a numerical computer code known as UNDSAFE-I for predicting the flow, temperature and pressure fields in a simple two-dimensional rectangular enclosure due to a volumetric heat source. A variety of conditions such as location, extent, strength of the heat source and extended outside free boundary region as well as various thermal boundary conditions along the ceiling and the floor of the enclosure. Physical effects taken into account in this code include strong buoyancy, compressibility, turbulence and thermal radiation. The code is fully documented and explained in this report in terms of input data and format as well as available output options. A complete numerical example is presented.

NBS-GCR-78-151. One dimensional radiation model for surfaces and non-homogeneous gases and soot, V. K. Liu and J. R. Lloyd, 96 pages (Mar. 6, 1978). Order from NTIS as PB291099.

Key words: fire models; heat transfer; room fires; smoke; soot; thermal radiation.

This report presents a detailed description of the one dimensional radiation model which is currently employed in the UNDSAFE code. The model includes surface, soot and gas radiation with adiabatic boundaries for the enclosure. Interactions between gas and soot radiation are accounted for as well as the effect of overlapping bands in the gaseous radiation. The soot radiation model does not consider scattering and the gas radiation model includes the 2.7 and $6.3 \mu \mathrm{m}$ bands for $\mathrm{H}_{2} \mathrm{O}$ and the 2.7 and $4.3 \mu \mathrm{m}$ bands for $\mathrm{CO}_{2}$. The overlap of the 2.7 $\mu \mathrm{m}$ bands is accounted for. Samples of the results of calculations for three limiting cases including no radiation in the calculation, surface and heavy soot radiation only in the calculation, and surface and gase ous radiation only in the calculation are presented to demonstrate the model.

NBS-GCR-78-153. The architect's access to information, C. H. Burnette, 97 pages (Mar. 1979). Order from NTIS as PB294855.

Key words: access to information; architect; information format; information sources; technical information; technology application.

The purpose of this report is to provide an overview and some insight into the circumstances which constrain and influence architects when they must obtain information during the course of the design and construction process. It is intended for those outside the profession who wish to understand the conditions which influence the use of the information they provide to architects, and for architects who would consider the nature and context of their difficulties in obtaining information as they need it. While some avenues of progress and change are indicated, this report does not propose detailed solutions and improvements to be sought in the media, forms and channels of access or dissemination nor is it entirely an explanation of the systems which exist. It is, rather, a brief guide to the major 
features of the problems and to the nature of their effects. A second report in this series will prescnt exemplary formats and guidelines for the successful delivery of information to architects. An extensive bibliography is attached.

NBS-GCR-78-154. Making information useful to architects, C. H. Burnette, IOI pages (Dec. 1978). Order from NTIS as PB292782.

Key words: access to information; architect; information format; information sources; technical information; technology application.

The purpose of this report is to present rationales, practical formats and dissemination guidelines to foster the successful delivery of information to practicing architects by those in commerce, government, research organizations and trade or professional associations who produce and supply information useful to them. This report is intended as a complement to "Architect's Access to Information: Constraints on the Architect's Capacity to Seek, Obtain, Translate and Apply Information." It presents a comprehensive spectrum of exemplary practices in such a way as to provide a coordinated basis for both informal and formal actions to improve the delivery of information to architects. It is, therefore, an independent explanatory critique of the state of the art of current practice intended as a useful reference for those considering the structure, content, form and delivery of information services. A bibliography is included.

NBS-GCR-78-155. Extended range MIS C(V) measurement: A technique for monitoring semiconductor device processing, A. M. Goodman, 18 pages (Jan. 1979). Order from NTIS as PB291011.

Key words: extended-range capacitance and conductance measurements; high-voltage $\mathrm{C}(\mathrm{V})$ and $\mathrm{G}(\mathrm{V})$ measurements; semiconductor device measurements; silicon-on-sapphire measurements.

Equipment has been developed which allows the straightforward implementation of extended-range MIS $C(V)$ and $G(V)$ measurements for a variety of applications at applied-bias voltage magnitudes as large as $25 \mathrm{kV}$. This report briefly summarizes the objectives and the resulting accomplishments leading to the development of the apparatus. It also provides corrections and additions to previously published documents to aid in the construction and operation of the apparatus.

NBS-GCR-78-156. Home safety guidelines for architects and builders, D. Alessi and M. Brill, 126 pages (Dec. 1978). Order from NTIS as PB292928.

Key words: accident avoidance; accidents in the home; door accidents; home accidents; home safety; safety in the home; stair accidents; stair safety; window accidents; window safety.

This document has its goal the analysis, organization and presentation of state-of-the-art information on home accidents and ways to reduce their frequency and/or severity. It is intended to be used in the design and rehabilitation of dwellings and its primary users are intended to be architects, followed by homebuilders, product designers and homeowners.

The National Electronic Injury Surveillance System (NEISS) of the U.S. Consumer Product Safety Commission (CPSC), collects and organizes accident data according to product, frequency, severity of injury and on age and sex of accident victims. These data are statistically representative of accidents occurring nationwide, as are the injury costs associated with each accident type.

Using this substantial and elegant data base, several sophisticated analyses of accidents involving the fixed architec- tural elements of homes, such as stairs, floors, bathtubs and showers, doors, and windows have recently been undertaken under the sponsorship of various government agencies. This series of analyses has resulted in a much clearer picture of how accidents involving these housing elements occur and of their associated costs to the nation. This document brings together these research findings as a guide to design and construction.

NBS-GCR-79-I57. The psychology of firesetting: A review and appraisal, R. G. Vreeland and M. B. Waller, 58 pages (Dec. 1978). Order from NTIS as PB290821.

Key words: abnormal psychology; arson; arsonists; firesetters; human behavior; literature reviews; pyromaniacs.

Despite a rather large and diverse literature on firesetting, relatively little is understood about its determinants. This situation exists partly because of the enormous difficulties in carrying out systematic, well-controlled research studies on firesetting. Legal difficulties in accessing samples of arsonists, the manner of legal disposition of arson cases, and the fact that relatively few arsonists are apprehended makes it likely that research samples will be narrow and biased; it is not surprising that conclusions have often been contradictory and comparisons betwcen groups have been extremely difficult. A further problem is that previous attempts at classification of firesetters have usually been based arbitrarily upon one aspect of the act, such as the firesetting motive, while other, potentially more important, distinguishing features may have been overlooked. After reviewing previous attempts at classifying firesetters, the present study organizes current knowledge about the characteristics of firesetters into four major categories: antecedent environmental conditions, organismic variables, actual firesetting behavior, and the consequences of firesetting. Understanding a firesetter's behavior requires an assessment of each of these categories, and types of firesetters may eventually be defined by clusters or patterns of characteristics rather than by a single, overriding feature. This approach is also useful in that it has theoretical implications as well as implications for prevention and treatment strategies.

\section{NBS-GCR-79-158. Techniques for the preparation and analysis} of standard silicon semiconductor specimens for the ion microprobe mass analyzer, G. Larrabee and R. Dobrott, 62 pages (Jan. 1979). Order from NTIS as PB292806.

Key words: dopant analysis; impurity analysis; ion microprobe mass analyzer (IMMA); microdot reference specimens; secondary ion mass spectroscopy (SIMS); silicon sputtering.

A technique was developed to prepare sodium-, phosphorus-, arsenic-, antimony-, and gold-doped silic on and silicon dioxide reference specimens using ion-implantation techniques. The implants were done in small islands or microdots of various sizes to simulate geometries encountered in semiconductor integrated circuits. The number of dopant atoms per unit area was determined by neutron activation analysis. The reference specimens were applied to methods development and calibration of the ion microprobc mass analyzer (IMMA). IMMA detection limits were expcrimentally determined. A model for experimentally determining the parameters governing detection limits was developed.

NBS-GCR-79-159. An examination and analysis of the dynamics of the human behavior in the fire incident at the Kensington Gardens Nursing Home on January 1, 1978, J. L. Bryan and P. J. DiNenno, 67 pages (June 30, 1978). Order from NTIS as PB290892.

Key words: chairs; doors; evacuation; fire departments; fire fighters; nursing homes; patients; room fires; smoke; upholstered furniture. 
The fire incident at the Kensington Gardens Nursing Home on January 1, 1978 was detected by the nursing staff at approximately 9:56 a.m., at which time the fire consisted of preflashover state in patient room 250 . The fire apparently originated in an upholstered chair from discarded smoking materials or matches by the room's occupant. The fire consumed the chair, spread to sheets on an adjacent bed, and the privacy curtains hanging between the beds. The fire was confined to the room of origin and did not achieve flashover. The two story building consisted of an original section of ordinary construction, erected in 1937, and a new addition of protected noncombustible construction which was six years old.

The fire department was notified at 9:59 a.m. by telephone. Housekeeping and nursing personnel assigned to the second floor, west wing, detected the fire in patient room 250 and immediately closed the door to this fire room. Other patient room doors in the fire zone were then closed, and three patients were evacuated from the fire zone before the corridor became untenable from smoke migration. The housekeeping staff directed arriving fire department personnel up the exterior stairway to the fire zone. The fire department personnel removed four male patients from patient rooms within the fire zone. The seven patients in the fire zone were evacuated by the staff and the fire department in approximately ten minutes from the time of fire detection. The closing of the door to the fire involved room, and the closing of the patient room doors appeared to be critical adaptive actions in this fire incident.

NBS-GCR-79-160. Reliability modeling of smoke detectors, $H$. C. Rickers, 110 pages (Mar. 1979). Order from NTIS as PB295176.

Key words: component screening; electronic component reliability; failure analysis; failure models; failure rates; reliability; residential buildings; smoke detectors.

This report presented the results of a study to evaluate current reliability prediction methods for electronic devices and determine which of these methods can be best applied to residential smoke detectors. In addition, data collection efforts were initiated to establish a basis for more realistic reliability prediction models for the components employed in residential smoke detectors. This failure rate data was collected from smoke detector manufacturers, component manufacturers, and manufacturers of other electronic equipment employing similar devices used at similar stress levels in residential type environments. The study found that Fault Tree Analysis (FTA) and Failure Mode Effects and Criticality Analysis (FMECA) techniques together with failure rate models for individual components, modified to better agree with the actual data, provides the best approach. A handbook was then prepared which includes the modified component models and data in the forms of parts stress analysis prediction techniques, a description of how to conduct the FTA and FMECA procedures, and a discussion of component screening and test techniques. This handbook is available in two parts as NBS-GCR-79-161 and NBS-GCR-79-162.

NBS-GCR-79-161. Residential smoke detector reliability handbook. Section 1: Parts stress analysis, H. C. Rickers, 226 pages (Feb. 1979). Order from NTIS as PB295178.

Key words: component screening; electronic component reliability; failure analysis; failure models; failure rates; reliability; residential buildings; smoke detectors.

This Residential Smoke Detector Reliability Handbook is designed to provide a means for the accurate prediction of smoke detector failure rates in a residential environment. The methodology developed by which a smoke detector critical failure rate can be determined is divided into three major sec- tions. Section 1.0 contains the parts stress reliability prediction techniques for each major generic component type currently being used in residential smoke detectors, or exhibiting the potential for being in future designs. Section 2.0 through the application of FMECA and/or FTA techniques, presents the guidelines for the determination of those components, and their associated failure modes, which are considered critical to the audible warning capabilities of the detector. The process of applying the predicted failure rates of Section 1.0 to the FMECA/FTA guidelines of Section 2.0 will result in a critical failure rate for residential smoke detectors; i.e., the rate at which failures that will not trigger the audible alarm circuitry may occur, thus negating the protective characteristics of the unit. Finally, Section 3.0 discusses methods of screening for the predominant failure modes of those electronic components characterized as most critical to smoke detector operation, to efficiently detect and eliminate infant mortality failures.

NBS-GCR-79-162. Residential smoke detector reliability handbook. Section 2: System reliability evaluation techniques. Section 3: Component screening/test techniques, H. C. Rickers, 103 pages (Mar. 1979). Order from NTIS as PB295177.

Key words: component screening; electronic component reliability; failure analysis; failure models; failure rates; reliability; residential buildings; smoke detectors.

This Residential Smoke Detector Reliability Handbook is designed to provide a means for the accurate prediction of smoke detector failure rates in a residential environment. The methodology developed by which a smoke detector critical failure rate can be determined is divided into three major sections. Section 1.0 contains the parts stress reliability prediction techniques for each major generic component type currently being used in residential smoke detectors, or exhibiting the potential for being in future designs. Section 2.0 through the application of FMECA and/or FTA techniques, presents the guidelines for the determination of those components, and their associated failure modes, which are considered critical to the audible warning capabilities of the detector. The process of applying the predicted failure rates of Section 1.0 to the FMECA/FTA guidelines of Section 2.0 will result in a critical failure rate for residential smoke detectors; i.e., the rate at which failures that will not trigger the audible alarm circuitry may occur, thus negating the protective characteristics of the unit. Finally, Section $\mathbf{3 . 0}$ discusses methods of screening for the predominant failure modes of those electronic components characterized as most critical to smoke detector operation, to efficiently detect and eliminate infant mortality failures.

NBS-GCR-79-163. A theoretical rationalization of a goaloriented systems approach to building fire safety, J. Watts, 266 pages (Feb. 28, 1978). Order from NTIS as PB294684.

Key words: barrier analysis; compartment fires; compartments; fault tree analysis; fire models; fire protection engineering; probability statistics; systems analysis; systems safety; walls.

The Goal Oriented Systems Approach to Building Fire Safety developed by the U.S. General Services Administration is presently the only probabilistic methodology for fire protection evaiuation in use in the United States. Th is paper describes and analyzes the GSA approach and formulates a more scientific procedure by synthesizing GSA concepts with additional probability theory. Discussion of systems analysis and modeling concepts emphasizes the need for probabilistic considerations of fire safety. The revised model, identified by the hyphenated expression: Goal-Oriented, simplifies data requirements through parameter estimation techniques. The new approach is consistent with the GSA model for several example cases. A 
demonstrated advantage of the new methodology is the facility for sensitivity analysis of alternative fire protection strategies.

NBS-GCR-79-167. Behavioral and physical characteristics of developmentally disabled individuals, C. J. Overboe and Y. Y. Wang, 109 pages (Mar. 1979). Order from NTIS as PB294970.

Key words: ambulatory people; autism; cerebral palsy; deafness; developmentally disabled; epilepsy; fire safety; group homes; handicapped; mental retardation.

A vast body of scientific research exists with regard to the conditions considered as the developmental disabilities. The purpose of this report is twofold. First, it describes the consensus of available research on the functioning capacities of developmentally disabled persons. Second, it represents an effort to present the information in a concise and usable format. The goal of the study is to provide a baseline of information to assist planners, consultants and decision-makers in determining realistic requirements for life safety in community-based group homes for the developmentally disabled.

The paper is divided into three major sections. The first part provides an overview of the concept of developmental disabilities and discusses its prevalence. A section on the individual characteristics of mental retardation, cerebral palsy, epilepsy and autism is included. The second major part contains two sections. One describes the characteristics found in the current population of group home residents. The next section provides information on individuals presently residing in institutions for the mentally retarded and the developmentally disabled who may form part of the future population in community housing. The last major part provides a summary of descriptive data regarding severely retarded individuals.

NBS-GCR-79-168. Human fatalities from unwanted fires, W. G. Berl and B. M. Halpin, 64 pages (Dec. 1978). Order from NTIS as PB295411.

Key words: alcohol intoxication; autopsy; building fires; cigarettes; death; fire investigations; fire statistics; pathology; toxic gases.

World-wide demographic information on human fire fatalities is reviewed. Particualr emphasis is given to the physical causes and medical consequences of fire fatalities in the State of Maryland, USA, during 1972-1977. The analysis and conclusions are based on investigations of 463 fire deaths. The importance of toxic gases as the cause of death, of cigarettes as one of the principal ignition sources and of alcohol as an important contributing factor is discussed.

The widely differing fire fatality rates among the various States of the U.S. are correlated by means of Ignition and Potentiating Indices which are based, in turn, on a variety of physical, social and economic factors that are responsible for the frequency of unwanted ignition and the likelihood of a fatal outcome.

NBS-GCR-79-169. Critical evaluation of data for a standard ergonomics reference data system (SERDS), W. H. Teichner and E. Williams, 37 pages (Jan. 1979). Order from NTIS as PB295088.

Key words: anthropometry; data base; engineering psychology; ergonomics; evaluation; human engineering; human factors; human performance; standard reference data.

This report discusses quality control procedures appropriate for a Standard Ergonomics Reference Data System (SERDS). Suggested procedures include maintaining and utilizing existing centers of excellence in specific areas of ergonomics to perform the critical reviews of published research and also produce handbooks of suggested data collection methodologies. Methodology handbooks would serve not only to maintain quality control for data accepted into SERDS, but would also improve the quality of ergonomic research in general if the suggested methodologies became standard practice for researchers. Problems of data validity, reliability, and sensitivity are discussed. Without reaching any final conclusion because the system is not yet established, suggestions are made to include foreign language experts in evaluation center staffs; to use different quality control levels as a function of the type of ergonomic data being collected; to plan on reconsidering acceptable quality control levels as the amount and quality of data improves in a given area of ergonomics; and to include formal advisory boards to review SERDS operation and quality control procedures. Coding schemes for categorizing data and querying the system are also suggested.

NBS-GCR-79-170. Investigation of moisture measurements, failure rate and leak rate and a study of moisture infusion, $R$. L. Sulouff, 57 pages (Aug. 1979). Order from NT1S as PB299172.

Key words: accelerated stress test; capillary leaks; corrosion failure; hermeticity; moisture infusion; oxide moisture sensors.

A preliminary study of the relationships between moisture infusion, leak size, and device reliability has been completed. Two sets of experiments were conducted. In one, packages constructed with a controlled leak and an oxide-type moisture sensor were placed in a controlled humidity environment and the water vapor content measured as a function of time. The packages tested had leak sizes in the range between $10^{-9}$ and $10^{-5} \mathrm{~atm} \cdot \mathrm{cm}^{3} / \mathrm{s}$. The second experiment was a $5,000-\mathrm{h}$ life test in which 186 packages, each of which contained unpassivated 741 operational amplifier chips, were subjected to an atomosphere with 85 -percent relative humidity at $85^{\circ} \mathrm{C}$. In this case, the packages had measured leak sizes between $10^{-9}$ and $10^{-3}$ $\mathrm{atm} \cdot \mathrm{cm}^{3} / \mathrm{s}$. The results exhibited a great amount of scatter, both because of the primitive nature of the measurement methods available for use in this type of experiment and because of the large variability in both water vapor infusion and the reactions of water vapor on device surfaces. Nevertheless, it can be safely concluded that present leak rate limits for large packages are not low enough to insure that the maximum permissible moisture level will not be exceeded during a reasonable service life.

NBS-GCR-79-172. Standards systems in Canada, the UK, West Germany, and Denmark: An overview, D. Hemenway, 195 pages (Apr. 1979). Order from NT1S as PB296912.

Key words: antitrust; Canada; certification; Denmark; economics of standards; government policy; international standards; laboratory accreditation; standards systems; United Kingdom; West Germany.

This report provides an overview of the voluntary standards systems of Canada, the UK, West Germany, and Denmark. The immediate purpose is to identify areas where further research might be useful. Ultimately, the aim is to gain a better understanding of national standards systems in other highly industrialized countries. Based on interviews and other research, the author discusses these aspects of the four standards systems: (1) history; (2) organization and finances; (3) standards development; (4) certification and accreditation; (5) international standards work; (6) consumer and labor participation; (7) metric conversion; (8) antitrust aspects; (9) research into economic impacts; (10) the government's use of standards and its role in standards work; and (11) other activities. The author concludes that further research is needed into standards 
systems of these and additional countries-for example, Australia, Japan, and Sweden.

NBS-GCR-79-176. Fire protection design standards for buildings and construction, Nat. Committee of the Council of Ministers USSR on Building Construction (GOSSTROY USSR), 36 pages (Sept. 1970). Order from NTIS as PB298901.

Key words: building design; buildings; construction materials; evacuation; exits; fire endurance; fire protection; stairways; standards.

SNiP Chapter II-A.5-70 "Fire Protection Standards for the Design of Buildings and Structures" has been developed by TsNII promzdaniy [Central Scientific Research Institute for Industrial Buildings], Promstroyproyekt [Department of Industrial Building Design] of Gosstroy USSR, TsNIIEP zhilishcha Gosgrazhdanstroy [Central Scientific Research Institute of Experimental Design of Residential Buildings, Department of Public Buildings], and VNIIPO MVD SSSR [All-Union Scientific Research Institute of Fire Protection, Ministry of the Interior, USSR]. This Chapter Supercedes SNiP II-A.5-62 "Fire Protection Requirements. Principles of Design."

NBS-GCR-79-177. Investigations of surface flashover mechanisms, J. E. Thompson, 18 pages (June 1979). Order from NTIS as PB297193.

Key words: breakdown; electro-optics; gas-solid interface; KDP; Pockels effect; space charge.

This report describes the following activities: (1) analysis of the transverse Pockels effect relevant to the measurements to be made; (2) construction of the test cell and power supplies for vacuum/solid interface measurements; (3) construction of the polarization analyzer; (4) preliminary Pockels effect measurements in KDP; (5) measurement of the special electric field distribution in KDP for dc and pulsed excitation; (6) electrical flashover tests of $\mathrm{KDP}, \mathrm{LiNbO}_{3}$, and Plexiglas; and (7) estimation of the surface electric fields for pulsed excitation.

NBS-GCR-79-179. An evaluation of planning and training for fire safety in health care facilities-Phase two, L. Bickman, E. Herz, P. Edelman, and D. Rivers, 179 pages (Aug. 1979). Order from NTIS as PB299023.

Key words: evacuation; fire doors; fire drills; fire extinguishers; fire safety; health care facilities; hospitals; human behavior; nursing homes; nursing staff; training.

Training for fire emergencies has always been assumed to appropriately affect knowledge and behavior. This assumption has not been systematically tested until now. Six nursing homes in Evanston, Illinois, were matched and randomly assigned to experimental and comparison groups. A quasi-experimental pretest-posttest research design was employed to evaluate the impact of training on knowledge (assessed with paper and pencil surveys) and behavior (drill observational assessments) of nursing home staff. Results indicated that training augmented knowledge in the experimental group, as expected. Various threats to the internal and external validity of the design, such. as selection biases, sample attrition and pretesting by treatment interaction effects were ruled out, on a statistical basis, as plausible alternative explanations for the training effect. The results of the fire drill behavior analyses indicated a measurable impact of training on the overall behavior of the experimental group during the post-training fire drills. Several events, or procedures, that should take place during a fire emergency were evaluated on the basis of a content-related scheme and a time-related scheme. Specific behaviors of staff members during the drills were discussed. This study demonstrated that a modest investment in training produced changes in both knowledge and behavior. However, the impact of the training was not as strong as anticipated. A more detailed study of the various types of training is strongly recommended.

NBS-GCR-79-I81. Snow and ice accumulation at solar collector installations in the Chicago metropolitan area, R. B. Corotis, C. H. Dowding, and E. C. Rossow, 109 pages (Oct. 1979). Order from NTIS as PB80-1 13749.

Key words: building; ice; load; roof; roof load; snow; solar collector; structural engineering.

This report presents observations and data concerning snow and ice on eighteen flat plate solar collector installations in the Chicago area. The data was collected in February and March of 1979 , following a record snowfall in January. Nearly all of the installations were on the roofs of buildings, and about half were mounted flush with the roof. The remainder were mounted on racks at an angle to the roof. Sketches and photographs of the buildings and snow accumulation, weather data for the entire winter, and comments of the owners are included, as well as a technique for the extraction of linear measurements from the photographs. A significant observation was that the loss of operation of the solar collectors due to snow covering the collector exceeded two months at several sites. This is apparently due to the heavy snowfall, extreme cold, and lack of manual snow removal capability. Other observations and recommendations concerning functional and structural problems are included in the report.

NBS-GCR-79-182. Comparison of high speed printer interface characteristics, Calculon Corp, I 44 pages (July 31, 1979) Order from NTIS as PB298943.

Key words: cable interface; computer; controller; control units; hammer drive; input/output bus; interface; interface signals; 1/O interface bus; line printer; print controller; printer.

This report describes and compares the characteristics of the interface between various high speed printers and their control units, for line printers operating at 600 lines per minute and above. It presents the results of an investigation conducted for the National Bureau of Standards in support of the possible development of a Federal Information Processing Standard for the high speed printer device to controller interface. Through textual descriptions and an extensive series of tables, the functional and electrical interface characteristics of the various printer mechanisms are compared.

It is concluded that the high speed printers considered could be placed into three general types according to their arrangement of hammer drive signals, i.e., those with individual hammer drive signals, those with coded hammer address signals, and those which include a line buffer and control electronics within the printer and therefore accept coded data signals representing successive characters in the line to be printed.

Among each of these three types of printers, only the third type exhibits significant commonality of interface among the various printers and suppliers.

NBS-GCR-ETIP 78-40. Subsidies, capital formation, and technological change: Municipal watewater treatment facilities. Volume 1, Charles River Associates Inc., I50 pages (Sept. 1978 ). Order from NTIS as PB285288.

Key words: capital formation; economic growth; municipal wastewater treatment facilities; public sector efficiency; subsidies; technological change.

This volume is one of seven case studies conducted under the project Subsidies, Capital Formation, and Technological Change (Volume eight summarizes the policy-relevant findings). The 
tools of microeconomic analysis are applied to assess the responsiveness of both the supplier and the user of the subsidized product or service. Particular attention is given to the effects of the subsidies on eapital formation and technological changc, but general efficiency effects are also considered.

The analysis is confined to the single most important program in this area, namely federal grants to assist in the construction of municipal waste treatment plants as calfed for in the 1972 Water Quality Amendments.

NBS-GCR-ETIP 78-41. Subsidies, capital formation, and technological change: Mass transit. Volume 2, Charles River Associates Inc., 196 pages (Sept. 1978). Order from NTIS as PB285289.

Key words: capital formation; economic growth; mass transit; public sector efficiency; subsidies; technologieal change.

This volume is one of seven casc studies conducted under the project Subsidies, Capital Formation, and Technological Change (Volume eight summarizes the policy-relevant findings). The tools of microeconomic analysis are applied to assess the responsiveness of both the supplier and the user of the subsidized product or service. Particular attention is given to the effeets of the subsidies on capital formation and teehnological change, but general efficiency effects are also considered.

Because the bulk of the stimulus to technological change in the transit industry represents a secondary impact, the main focus of this study is on the ways in whieh the subsidies affect the demand for inputs into the provision of transit service.

NBS-GCR-ETIP 78-42. Subsidies, capital formation, and technological change: First generation muclear power plants. Volume 3, Charles River Associates Inc., 97 pages (Sept. 1978). Order from NTIS as PB285290.

Key words: eapital formation; economic growth; nuclear power plants; public sector efficiency; subsidies; technological change.

This volume is one of seven case studies conducted under the project Subsidies, Capilal Formation, and Technological Change (Volume eight summarizes the policy-relevant findings). The tools of microeconomic analysis are applied to assess the responsiveness of both the supplicr and the user of the subsidized product or service. Particular attention is given to the effects of the subsidies on capital formation and technological change, but general efficiency effects arc also considered.

This study identifies the principal forms of government aid to the first-generation nuclear power plants to attempt an assessment of the contribution of each form of aid to the attainment of eeonomical nuclear power and to analyze the more important economie effects of the subsidies, particularly what effects there may have been on capital formation and technologieal ehange in the electric utilities and nuclear components indus. tries.

NBS-GCR-ETIP 78-43. Sübsidies, capital formation, and technological change: Maritime transport. Volume 4, Charles River Associates Ine., 86 pages (Sept. 1978). Order from NTIS as PB285291.

Key words: capital formation; economie growth; maritime transport; public sector effieieney; subsidies; technologieal ehange.

This volume is one of seven ease studies conducted under the project Subsidies, Capital Formation, and Technological Change (Volume eight summarizes the policy-relevant findings). The tools of microeconomic analysis are applied to assess the responsiveness of both the supplier and the user of the subsidized product or service. Particular attention is given to the effects of the subsidies on capital formation and technological ehange, but general efficiency effects are also considered.

The analysis assesses the impact of the subsidies on the achievement of the goals of national security and several economic objectives.

NBS-GCR-ETIP 78-44. Subsidies, capital formation, and technological change: Primary scientific and technical journal publishing. Volume 5, Charles River Associates Inc., 172 pages (Sept. 1978). Order from N'TIS as PB285292.

Key words: eapital formation; economic growth; journal publishing; publie sector efficiency; subsidies; technological ehange.

This volume is one of seven ease studies conducted under the project Subsidies, Capital Formation, and Technological Change (Volume eight summarizes the policy-relevant findings). The tools of mieroeconomic analysis are applied to assess the responsiveness of both the supplier and the user of the subsidized product or service. Particular attention is given to the effects of the subsidies on capital formation and technological change, but general efficiency effects are also considered.

This study examines the economic effeets of subsidization on the publication of primary scientific and technieal journals. The major subsidy programs are described and their effects assessed on resource allocation, income distribution and technological ehange.

NBS-GCR-ETIP 78-45. Subsidies, capital formation, and technological change: Health facilities. Volume 6, Charles River Assoeiates Inc., 212 pages (Sept. 1978). Order from NTIS as PB285293.

Key words: eapital formation; eeonomic growth; health facilities; public sector efficiency; subsidies; technological change.

This volume is one of seven case studies conducted under the project Subsidies, Capital Formation, and Technological Change (Volume eight summarizes the policy-relevant findings). The tools of microcconomic analysis are applied to assess the responsiveness of both the supplier and the user of the sub. sidized produet or service. Particular attention is given to the effects of the subsidies on eapital formation and technological change, but general efficiency effects are also considered.

This study focuses on the Hospital Construction Act of 1946 (the Hill-Burton Act). It analyses the effects of the Act on resource allocation, market structure, investment by hospitals, and the diffusion of technology. The research relies predominantly on information already available in the literature, but some original quantitative research is undertaken.

NBS-GCR-ETIP 78-46. Subsidies, capital formation, and technological change: Local air transport. Volume 7, Charles River Associates Ine., 171 pages (Sept. 1978). Order from NTIS as PB285294.

Key words: eapital formation; economie growth; local air transport; public sector efficiency; subsidies; technological ehange.

This volume is one of seven ease studies conducted under the projeet Subsidies, Capital Formation, and Technological Change (Volume eight summarizes the poliey-relevant findings). The tools of mieroeconomic analysis are applied to assess the responsiveness of both the supplier and the user of the subsidized product or serviee. Particular attention is given to the effects of the subsidies on capital formation and technologieal ehange, but general efficieney effeets are also considered.

Subsidies for loeal air transport are analyzed to determine their effects on output levels which in turn may affect aireraft stoek levels and eonsequently the level and rate of eapital investment including embodied technological ehange. 
NBS-GCR-ETIP 78-47. Subsidies, capital formation, and technological change: Summary and conclusions. Volume $\mathbf{8}$, Charlcs Rivcr Associates lnc., 114 pages (Sept. 1978). Order from NTIS as PB285295.

Kcy words: capital formation; economic growth; public sector efficiency; subsidies; technological change.

This volume summarizes findings and conclusions from seven case studies (volumes one through seven) of the microeconomic impacts of Federal subsidies on the U.S. economy. The case studies provided a cross section of recipient industries and industry segments, industries which supply the recipients, and the industries or consumers who purchase their output. Particular attention is given to the effects of the subsidies on capital formation and technological change. From these case studies, general relationships among subsidies, capital formation, and technological change are inferred. Policy guidelines are developed.

The study found that these relationships are intertwined with the relationships among subsidies, accompanying regulations, and the output and factor mix in the subsidized industry. The subsidies altered the quantity and quality of output in most of the industries studied. In several instances they also altered the mix of factors of production (capital and labor) used to produce this output. These effects of the subsidies in turn altered to varying degrees the rate and direction (or type) of capital formation and technological change in the subsidized industries and their supplying industries.

NBS-GCR-ETIP 78-49. The influence of defense procurement and sponsorship of research and development on the development of the civilian electronics industry, J. M. Utterback and A. E. Murray, 56 pages (Jan. 1979). Order from NTIS as PB290164.

Key words: Experimental Technology Incentives Program; impact of government on industry; procurement experiments; procurement policy; research and development policy; technological change.

As part of its research program on the commercial impacts of government procurement, the Experimental Technology Incentives Program of the National Bureau of Standards conducted a study of the influence of Department of Defense procurement and sponsorship of research and development on the development of the civilian electronics industry. The goals of the study were to identify the means through which government purchasing and R\&D sponsorship may have affected the industry and to discuss the implications for procurement policy experimentation by the Program. Available literature was reviewed and interviews were conducted with industry and government executives. Results have been divided into impacts on technology, which appear to be mostly indirect, and impacts on economics and manpower which are more direct. Characteristics of the industry that may have conditioned the effect of the government actions are also discussed.

NBS-GCR-ETIP 78-50. Assessing the results of the portable oxygen generator experiment, N. B. McEachron and E. G. Woodward, 79 pages (Oct. 1977). Order from NTIS as PB289886.

Key words: Experimental Technology Incentives Program; portable oxygen generator experiment; procurement policy; two-step prototype procurement; Veteran's Administration.

This report is the result of an exploratory evaluation of the portable oxygen generator (POG) procurement experiment conducted by the Veteran's Administration (VA) under the sponsorship of the Experimental Technology Incentives Program (ETIP) of the National Bureau of Standards. The report is intended for use by procurement policymakers within and outside the VA and ETIP who are concerned with improving procurement practices. The SRl overall assessment is that the VA attempted through this experiment to substantially improve the state of the art for supplying oxygen to chronic obstructive pulmonary disease patients, and that for the most part such an improvement did not occur. However, this attempt has provided useful lessons for the appropriate role of two-step prototype procurement (TSPP) and for the appropriate processes by which specifications should be developed.

NBS-GCR-ETIP 78-51. Assessing the results of the LCC water heater experiment. Volume I: Main report, N. B. McEachron, D. C. Hall, and L. F. Lewis, 50 pages (Sept. 1977). Order from NTIS as PB291826.

Key words: commercial impacts; Experimental Technology Incentives Program; Federal Supply Service; life cycle costing; procurement of water heaters; technological change.

This report presents an exploratory evaluation of the commercial impact of experiments using a life cycle costing (LCC) strategy in the procurement of water heaters; the experiments were conducted by the Federal Supply Service (FSS) and the Experimental Tcchnology Incentives Program (ETIP). The purpose of the evaluation was to answer three questions: I) What was industry's response to the procurement by FSS, in terms of technological changes in water heaters supplied and subsequently commercialized? 2) How appropriate have FSS methods been for measuring the value of these product changes to the government as user? 3) If the procurement strategy were altered in various ways, what would be the likely changes in these commercial impacts?

NBS-GCR-ETIP 78-52. Assessing the results of the LCC water heater experiment. Volume II: Appendices, N. B. McEachron, D. C. Hall, and L. F. Lewis, 139 pages (Sept. 1977). Order from NTIS as PB291827.

Key words: commercial impacts; Experimental Technology Incentives Program; Federal Supply Service; life cycle costing; procurement of water heaters; technological change.

This report presents an exploratory evaluation of the commercial impact of experiments using a life cycle costing (LCC) strategy in the procurement of water heaters; the experiments were conducted by the Federal Supply Service (FSS) and the Experimental Technology Incentives Program (ETIP). The purpose of the evaluation was to answer three questions: 1) What was industry's response to the procurement by FSS, in terms of technological changes in water heaters supplied and subsequently commercialized? 2) How appropriate have FSS methods been for measuring the value of these product changes to the government as user? 3 ) If the procurement strategy were altered in various ways, what would be the likely changes in these commercial impacts?

NBS-GCR-ETIP 78-53. Taxonomy of incentive approaches for stimulating innovation, J. Booth, Z. Cook, and A. R. Ferguson, 103 pages (Aug. 1978). Order from NTIS as PB287932.

Key words: air pollution-regulatory policy; economic incentives; Federal funding of civilian R\&D; regulatory policy; subsidy policy; technological innovation.

This report consists of a taxonomy of incentive approaches for stimulating technelogical innovation in the private sector with an example of how the table can be used. The example used is the need to spur new technology for stationary air pollution abatement. 
NBS-GCR-ETIP 78-57. Management of Federal R\&D for commercialization-Executive summary, N. B. McEachron, H. S. Javitz, D. S. Grecn, J. D. Logsdon, and E. Milbergs, 19 pages (Sept. 1978). Order from NTIS as PB292851.

Key words: commcrcialization; empirical investigation; ETIP; Federal civilian R\&D; implementing; management practices; technological change.

This document is the exccutive summary of an empirical investigation of federal civilian $R \& D$ management practices, conducted by SRI International for the Experimental Technology Incentives Program (ETIP), National Bureau of Standards. The report is addressed to federal civilian policymakcrs and $R \& D$ managers responsible for planning, developing, and implementing $\mathbf{R} \& \mathbf{D}$ programs whose results are intended for eventual commercialization by the nonfederal private sector.

The management of federal R\&D intended for commercialization must consider issues of commercial acceptability as well as technical success. It is with these management issues that this report is concerned. Specifically, the purposes of the study was to: Describe current policies and practices of federal agencies regarding the management of federally funded R\&D intended for nonfederal application. Develop a set of empirically grounded recommendations for policies and practices that would improve the commercialization of fcderally funded R\&D results.

NBS-GCR-ETIP 78-58. Management of FederaI R\&D for commercialization-Final report, N. B. McEachron, H. S. Javitz, D. S. Grecn, J. D. Logsdon, and E. Milbergs, 143 pages (Sept. 1978). Order from NTIS as PB292852.

Key words: commercialization; empirical investigation; ETIP; Federal civilian R\&D; implementing; management practices; technological change.

This document is the final report of an empirical investigation of federal civilian R\&D management practices, conducted by SRI International for the Experimental Technology Incentives Program (ETIP), National Bureau of Standards. The report is addressed to federal civilian policy makers and R\&D managers responsible for planning, developing, and implementing $R \& D$ programs whose results are intended for eventual commercialization by the nonfederal private sector.

The management of federal $R \& D$ intended for commercialization must consider issues of commercial acceptability as well as technical success. It is with these management issues that this report is concerned. Specifically, the purposes of the study was to: Describe current policies and practices of federal agencies regarding the management of federally funded $R \& D$ intended for nonfederal application. Develop a set of empirically grounded recommendations for policies and practices that would improve the commercialization of federally funded R\&D results.

NBS-GCR-ETIP 78-58A. Management of Federal R\&D for commercialization-Appendices: Supporting documentation, N. B. McEachron, H. S. Javitz, D. S. Green, J. D. Logsdon, and E. Milbergs, 175 pages (Dec. 1978). Order from NTIS as PB292853.

Key words: commercialization; empirical investigation; ETIP; Federal civilian R\&D; implementing.

This document is the supporting documentation of an empirical investigation of federal civilian R\&D management practices, conducted by SRI International for the Experimental Technology Incentives Program (ETIP), National Bureau of Standards. The report is addressed to federal civilian policymakers and R\&D managers responsible for planning, developing, and implementing R\&D programs whose results are intended for eventual commercialization by the nonfederal private sector.
NBS-GCR-ETIP 78-59. A real-time case history of ETIP Project 67 -Integrated utility system application, J. G. Taylor and L. Q. C. Lamar III, 151 pages (Mar. 1978). Order from NTIS as $\mathrm{PB} 292770$.

Key words: case study; cogeneration; demonstration project; ETIP; evaluation; information intervention; integrated utility systems.

The major purpose of this report is to provide the real-time case history of ETIP Project 67-Integrated Utility System (IUS) and to provide the information that would permit lessons learned to be derived that, in turn, would be applicable to other ETIP projects.

The Office of Facilities Engineering and Property Management (OFEPM) of the Department of Health, Education and Welfare initiated discussions with ETIP in 1973 to undertake a feasibility study and conceptual design of the Modular Integrated Utilities System (MIUS) for university/medical complexes. These discussions resulted in OFEPM submitting a proposal to ETIP in March 1974 requesting funds for the MIUS Application Project and the transfer of $\$ 220,000$ by ETIP to OFEPM in June 1974. The IUS concept is on-site integration of five basic utility subsystems that serve building complexes: electrical power generation; heating and cooling; water supply; sewage treatment; and solid waste disposal.

An A\&E firm was contracted to conduct another feasibility and conceptual design study for an IUS at a town/university/medical complex.

NBS-GCR-ETIP 78-60. An international study of economic benefits attributable to $R \& D$, by source and sector of performance, R. U. Ayres, J. Lewis, and S. D. Collier, 71 pages (June 1978). Order from NTIS as PB292783.

Key words: economic performance; production/consumption; public and private R\&D.

This study reports evidence found in a study performed for the Experimental Technology Incentives Program on the nature of the interrelationships between public and private $R \& D$ and economic performance comparing the historical records of various countries.

NBS-GCR-ETIP 79-62. Balancing the objectives of clean air and economic growth: Regulated markets in emission reductions, W. A. Foskett, D. M. Klaus, and J. Haberle, 103 pages (June 1979). Order from NTIS as PB300835.

Key words: administrative experimentation; Environmental Protection Agency; evaluability assessment; Experimental Technology Incentives Program; industrial pollution regulation; market mechanism; offset policy; regulatory policy; technological innovation.

This document reports work in progress toward the evaluation of implementation and effects of market mechanisms for regulation of major stationary sources of air pollution. It is one product of the Regulatory Processes and Effects Project of the Center for Field Methods (ETIP). The broader project, described elsewhere, is attempting to analyze the effects of changes in regulatory processes on industrial innovation. The joint ETIP/EPA project will involve/measure whether regulated markets in emission reductions can balance the objectives of clcan air and economic growth by stimulating continual technological innovation in pollution control.

The first chapter introduces and synopsizes the report. The second chapter describes the context in which market mechanisms are being introduced. The third chapter discusses the underlying logic of various market mechanisms and an operating prototype of a market mechanism. The fourth chapter discusses potential effects of market mechanisms on air 
pollution rcgulation. The fifth chapter rcports expectations associated with EPA's introduction of a prototype market mcchanism offset policy. Chaptcr six describes the general direction of continuing work on this particular project.

NBS-GCR-ETIP 79-63. Environmental regulation in theory and praetice: EPA's process of setting best praetieable eontrol technology standards, W. A. Magat, L. P. Gianessi, and W. Harrington, 175 pages (Dec. 1978). Order from NTIS as PB297499.

Key words: administrative experimentation; best practicable technology; clean water regulation; Environmental Protection Agency; evaluability assessment; evaluation; Experimental Technology Incentives Program; regulatory experimentation; regulatory policy; rulemaking; technological innovation.

This document is a report of work carefully laying out the rulemaking process that had been used at EPA to prepare a large number of highly technical regulations in the clean water area. It is one product of the Regulatory Processes and Effects Project of the Center for Ficld Methods (ETIP). The broader project, described elsewhere, is attempting to analyze the effects of changes in regulatory processes on industrial innovation. Under a subcontract to the project, Resources for the Future has carefully examined and laid out the steps that were followed to convert the legislative mandate into actual writing and issuance of permits.

Section 1 introduces the study of rulemaking and some of the reasons for carrying it out. Section 2 covers the "Best Practicable Technology" rulemaking process in detail. Section 3 contains a review of much expert literature and its applicability here. Section 4 discusses a methodology for continuing the project. Much supporting material is contained in an appendix.

ETIP's next steps to build on this work would be to expand it in a similar level of detail into industry and industrial effects and to work from both the industrial and rulemaking domains simultaneously.

\section{NBS-GCR-ETIP 79-64. Regulatory administrative experiment} manual, J. N. Nay and J. Waller, 114 pages (June 1979). Order from NTIS as PB298446.

Key words: administrative experimentation; evaluability ássessment; evaluation; experimental methods; Experimental Technology Incentives Program; regulation; regulatory oversight; regulatory processes and regulatory effects; regulatory reform; social science; technological innovation.

This document is an interim repository of material related to methods and processes for carrying out regulatory administrative experiments. It is one product of the Regulatory Processes and Effects (RPE) Project of the Experimental Technology Incentives Program (ETIP). The broader project, described in greater detail elsewhere, is attempting to analyze the effects of changes in regulatory processes on industry and industrial innovation. The development and testing of methods and processes for carrying out this work is onc of several related aspects of the RPE project.

The first two chapters provide an introduction to ETIP, the specific program involved, and the RPE project. Chapter III describes Evaluability Assessment, one of the methods used in this work. Chapter IV outlines the general approach to carrying out the work. The last chapter is an outline for reporting on interim progress of experimental situations. Two appendices are included.

NBS-GCR-ETIP 79-65. The regulatory processes and effects project, J. N. Nay and W. Frederick, 183 pages (June 1979). Order from NTIS as PB298631.
Key words: administrative experimentation; Environmental Protection Agency; evaluability assessment; evaluation; Experimcntal Tcchnology Incentives Program; Federal Communications Commission; Federal Trade Commission; Food and Drug Administration; Interstate Comnierce Commission; rcgulation; regulatory processes and regulatory effects.

This document is a summary of progress on the Center for Field Method's (ETIP) Regulatory Processes and Effeets Project (RPE). The RPE project is working to analyze the effects of changes in regulatory processes on industrial innovation. The approach used in this work has several aspects. One is to assist in the examination, development, conduct, and assessment of actual changes in regulation implemented by regulatory agencies. A second is to develop methods and processes for carrying out such regulatory administrative experiments. A third aspect is to assist in institutionalization of thesc methods when appropriate

Chapter I provides an overview of the project. Chapter II contains brief descriptions of each of ten regulatory situations included in the first year's work. The regulatory contexts and experimental changes are described together with a report on progress, implications of the work to datc, and a listing of possible next steps. The final chapter describes implications for the future RPE project work. A number of detailed reports on specific regulatory situations are referenced in Chapter II.

The Regulatory Processes and Effects project is conducted under the direction of ETIP and includes people from the regulatory agencies, The Urban Institute, The Performance Development Institute, and consultants.

NBS-GCR-ETIP 79-66. An exploration of regulatory ineentives for innovation: Six ease studies, J. Booth and $\mathrm{Z}$. Cook, 110 pages (Aug. 1979). Order from NTIS as PB299006.

Key words: administrative experiment; anti-trust regulation; economic incentive; environmental regulation; innovation; regulatory reform; technological changes.

This document is an overview and synthesis of six feasibility explorations of changes in Federal regulation which might stimulate industrial innovation. Each case looks at a specific regulatory situation to identify a change which could be experimentally implemented in the present system to gage actual impacts on industrial innovation. These changes include compliance delays, effluent taxes and anti-trust exemptions. Because the underlying regulations have changed in some cases since the studies were completed, epilogues update the current regulatory situation.

From the individual cases a number of generalizations are drawn. These include: a critique of regulation by technical standard (including firm/industry response), a summary of standard-setting reforms, and a discussion of the general obstacles to implementing economic incentives.

NBS-GCR-ETIP 79-67. Impaets of government regulations on the iron and steel industry, I. Gutmanis, 210 pages (Aug. 1978). Order from NTIS as PB289352.

Key words: capital for mation; Experimental Technology Incentives Program; regulatory impact; rescarch and development; steel industry; technology.

This study examines the effects of the growth of government regulation of the steel industry and the contribution of those regulations to the recent lack of innovation in that industry. The study considers the position of the U.S. Steel Industry in both domestic and world markets and suggests a number of protective remedies that should be considered under the Trade Act of 1974. The study finds that government regulation of depreciation and investment tax credits have inhibited capital 
formation and subscquent technological change. A number of rcgulatory alternatives are listed which could encourage and aid in acquisition of capital.

The study addrcsses the impact of environmental regulations and provisions of the Internal Revenue Service Code that bear on cost and funding of treatment equipment. Here again, rccommendations are suggested for government action.

The major recommendation that rises from consideration of the impact of OSHA regulations on the steel industry is that OSHA should consider broader use of performance standards.

Finally, the report recommends actions that the government could take to encourage research and development in the steel industry.

NBS-GCR-ETIP 79-70. Overview report: Experiment in computer applications for regulatory agencies, Temple, Barker \& Sloanc, Inc. (NBS contact: Darlene Carver), 115 pages (Sept. 1979). Order from NTIS as PB300770.

Key words: computer program; economic performance; electric utilities; Experimental Technology Incentives Program; productivity; regulatory commission; regulatory policy; technological innovation.

This overview undertaken by ETIP was one of several projects designed to learn about regulatory influences upon innovation. These policy experiments were developed in both state and federal situations.

This report presents an overview of research into methods for improving the electric utility regulatory process conducted under Project No. 76 of the Experimental Technology Incentives Program (ETIP), National Bureau of Standards, U.S. Departinent of Commerce. More detailed reports on the results of the research may be found in separate volumes which are referenced in this overview.

The purpose of the Project was to provide improved analytical and managcrial techniques for use in the electric utility regulatory process to learn how technological innovation could be promoted among regulated industries. Computerized tools that would reduce the time required for various analyses undertaken in rate cases and in other regulatory decision problems were developed. The study also considered the need for improvements in the quality and scope of analysis. A secondary emphasis was on managerial and administrative procedures in regulatory commissions.

Four specific areas were addressed in this study. The first area was regulatory lag. This area included: managerial and administrative issues that contribute to regulatory lag; and methods for handling routine calculations required in determining rates. The second area was rate design. The third area was performance evaluation and factor productivity analysis. The final area was long-range planning.

NBS-GCR-ETIP 79-71. An evaluation design concept for regulatory reform: The waiver of efficacy data, H. D. Ojha, T. V. Renda, J. E. Harrison, and J. H. Perwak, 182 pages (Sept. 1979). Order from NTIS as PB300846.

Key words: administrative experimentation; Environmental Protection Agency; evaluation design; Experimental Technology Incentives Program; pesticide policy; regulatory policy; regulatory reform; technological innovation.

This report presents an evaluation design concept aimed at supporting the Office of Pesticide Programs of the U.S. Environmental Protection Agency in implementing one of its recently adopted regulatory reform efforts-the efficacy data waiver. It documents the policy and administrative settings as well as the evaluation problem associated with the waiver and its implementation. This report also marks the beginning of an experiment evaluation design phase of a larger joint project between EPA and the Experimental Technology Incentives Program of the National Bureau of Standards Center for Field Methods. The whole project is aimed at improving pesticide regulation so as to improve the environment for technological innovation.

The purpose of this project, as an administrative experiment, has been to develop and evaluate a change in the policy or process of pesticide regulation which could improve the environment for technological innovation. It has proceeded through several stages involving background investigations of pesticide regulations, effects on industry, stakeholders' views, and administrative and regulatory processes. At the present stage, the project is focused on documenting an evaluation design concept which can be used in subsequent phases by OPP to evaluate the efficacy data waiver policy implementation.

U.S. Patent $4,139,933$. Method for fabricating a scanning electron microscope micrometer scale, D. B. Ballard, F. Ogburn, and J. P. Young, 6 pages (Feb. 20, 1979).

Key words: electrodeposited metal layers; gold-nickel layers; micrometer scale; scanning electron microscope scale.

A microscopic length scale typically about $50 \mu \mathrm{m}$ long and graduated in several intervals ranging from $1 \mu \mathrm{m}$ to $20 \mu \mathrm{m}$. The scale is useful in calibrating the magnification of scanning electron microscopes (SEMs) and other electron imaging instruments. The scale comprises alternating layers of two metals deposited on a substrate. The two metals have substantially/different electron emission coefficients to provide contrasting emission signals when scanned by an electron beam. One of the metals, preferably gold, is deposited in uniform layers about 40-80 nm thick. The other metal, preferably nickel, is deposited in several layers ranging from $1 \mu \mathrm{m}$ or so thick near the substrate to $20 \mu \mathrm{m}$ thick in the outermost layer. The resultant multilayer composite is cut into one or more samples and each sample is mounted on edge. The exposed edge is ground and metallographically polished and a microscopic indentation is made in the substrate near the first gold layer. The indentation defines a reference region, and the distances between the first gold layer and the subsequent gold layers in the reference region are measured. The measurement is made using a similar sample which was previously calibrated with the aid of a polarizing layer interferometer.

U.S. Patent 4,140,393. Birefringent crystal thermometer, T. C. Cetas, 9 pages (Feb. 20, 1979).

Key words: aligned sheet polarizer; birefringent crystal; optical analyzer; polarized light; probe thermometer; temperature sensitive parameter.

This invention relates to the use of a birefringent crystal as the sensing element in a probe thermometer constructed of certain basic optical components utilized in three separate modes. Thus, all of the modes of the invention are directed to a probe thermometer which uses the temperature dependence of the birefringence of certain single crystals as the temperature sensitive parameter. One such crystal is a $\mathrm{Y}$-cut single crystal of $\mathrm{LiTaO}_{3}$. Alternative crystals having adequate sensitivity in the desired temperature range may be constructed from $\mathrm{LiNbO}_{3}$ or $\mathrm{BaTiO}_{3}$. Polarized light propagates through the crystal in two modes, the ordinary ray and the extraordinary ray, which have indices of refraction $n^{\circ}$ and $n^{e}$. For $\mathrm{LiTaO}_{3}$ at room temperature, $n=2.2, B=n^{e}-n^{o}=0.004$, and $d B / d T=4.4 \times 10^{-5} /{ }^{\circ} \mathrm{C}$. The intensity of light passed through a sandwich of aligned sheet polarizer, crystal, and optical analyzer is a function of B and hence also is temperature dependent. A thermometer probe is constructed by bonding this sandwich to a bundle of optical fibers along with a dielectric mirror so that the sensor 
will be at the probe tip. The probe has been constructed for use in the presence of intense electromagnetic fields and also designed to eliminate the possible hazard of an electrical leakage back to the subject.

U.S. Patent 4,143,520. Cryogenic refrigeration system, J. E. Zimmerman, 8 pages (Mar. 13, 1979).

Key words: low input power cyclic cryogenic refrigerator; multi-stage displacer; Stirling machine; superconducting quantum interfering devices (SQUID).

A simply' constructed low input power cyclic cryogenic refrigerator suitable for cooling superconducting quantum interfering devices (SQUID) and similar instruments is provided. A Stirling machine having a multistage displacer and a piston as its only essential moving parts, with helium gas as the working fluid, achieves and maintains a temperature of substantially 8.5 ${ }^{\circ} \mathrm{K}$. The working cylinder and displacer are separated by a tube and are fitted together precisely at steady-state operation rather than at room temperature. The displacer preferably is made of nylon and its cylinder of an epoxy-glass composite to provide the nearly optimum clearance required to maintain the $8.5^{\circ} \mathrm{K}$ temperature for continuous periods on the order of several weeks.

U.S. Patent 4,146,848. Frequency stabilizing system and method for beam type device, H. W. Hellwig, S. Jarvis, Jr., and D. J. Wineland, 10 pages (Mar. 27, 1979).

Key words: beam type device; frequency stabilizing system; microwave interaction regions; microwave signals.

Frequency stabilization of a beam type device is disclosed that is particularly well suited for avoiding cavity phase shift problems. A beam generator provides a molecular or atomic beam that is directed through a pair of spaced and separate interaction regions to a detector. The two interaction regions, such as cavities, provide independent regions into which different signals are injected with the injected signals being derived from an oscillator such as a crystal oscillator. The signal coupled to the interaction regions may be varied according to a general equation. The first signal may also be coupled into one of the interaction regions at a frequency substantially the same as the resonance frequency of the particles in the beam directed through the cavity, while the signal coupled to the other cavity may be caused to vary above and below the resonance frequency. At the detector, the envelope of the pattern impressed on the beam is detected and a correction signal derived therefrom with the correction signal then being coupled as a feedback signal to the oscillator for frequency stabilization thereof.

U.S. Patent 4,148,586. Apparatus for galvanic detection of optical absorptions, R. B. Green, R. A. Keller, G. G. Luther, P. C. Schenck, and J. C. Travis, 7 pages (Apr. 10, 1979).

Key words: opto-galvanic effect; predetermined frequency; spectroscopic and analytic determinations; variable wavelength monochromatic light.

An apparatus and method for utilizing the opto-galvanic effect to perform spectroscopic or analytic investigations of atomic or molecular species. A sample of the substance to be analyzed is vaporized in an alytical flame, gas discharge tube, high temperature furnace or the like, and the vapor is irradiated with chopped or pulsed variable wavelength monochromatic light. The electrical .resistance of the vapor is monitored as the frequency of the radiation is tuned through one or more electronic transition frequencies of the substance. The resistance spectrum resembles the optical absorption spectrum of the species in the vapor. The opto-galvanic effect may also be used to frequency lock a laser to a transition frequency of a substance in a gas discharge cell.
U.S. Patent 4,152,074. Inverse fourth power photometric calibrator, D. A. Swyt, 6 pages (May 1, 1979).

Key words: inverse fourth power; light flux; photometric calibrator.

A photometric calibrator is disclosed wherein a known and continuously variable amount of light flux received at a detector is linearly proportional to the inverse fourth power of thc optical path length between the detector and a primary, quasipoint source of the light flux. The calibrator includes a secondary, quasi-point light flux source wherein the total flux emitted thereby is proportional to the flux received thereby over a quasi-point detecting area located at some distance, $d$, from the primary source. The detector is located at an equal distance d from the secondary source.

\section{U.S. Patent 4,158,944. Rotary blade coupling for lawn mower,} J. Rabinow, 9 pages (June 26, 1979).

Key words: brake; coupling device; cutting blade; deadman's handle; disconnect element; lawnmower; motor shaft.

This invention relates to a coupling device and especially a coupling device operable by a dead-man's handle on a lawnmower. When used in a lawnmower the coupling device couples the motor shaft to the cutting blade. A spool has a hole in it that surrounds the shaft. A rotary connecting device normally couples the spool to the shaft so that the spool and shaft rotate together. A disconnect element and brake are operated when the dead-man's handle is released to disconnect the spool from the shaft and subsequently stop the spool. The cutting blade has a central hole through which the spool passes. The blade is in frictional contact with the flanges of the spool and is rotated thereby.

\section{U.S. Patent 4,165,183. Fringe counting interferometric system for high accuracy measurements, J. L. Hall and S. A. Lee, 15 pages (Aug. 21, 1979)}

Key words: counting and control circuitry; fringe counting interferometric method and apparatus; Michelson interferometer; phase locked oscillators; retroreflectors.

A fringe counting interferometric method and apparatus is disclosed. The apparatus comprises a fringe-counting Michelson interferometer employing a velocity-stable carriage means for translating the two comer-cube retroreflectors, two phase locked oscillators and counting and control circuitry. Fringe intensity signals are counted for both a reference and unknown beam, and high accuracy is obtained by multiplying reference beam fringe signals by a fixed integral multiplier employing a phase-lock circuit. In comparing the unknown wavelength with the reference, the convenience of direct readout in wavelength units arises from the use of a high resolution preset counter.

U.S. Patent 4,166,229. Piezoelectric polymer membrane stress gage, A. S. DeReggi and S. Edelman, 5 pages (Aug. 28, 1979).

Key words: acoustic waves; piezoelectric polymer; preset tensile stress; pressure variations.

Apparatus and method for detecting pressure variations because of acoustic waves by modulating a preset tensile stress in a stretched thin sheet of a piezoelectric polymer. The modulation is provided by the changing stress caused by an impinging acoustic signal or the like. The piezoelectric polymer sheet under a preset tension acts effectively as a membrane resulting in a high output combined with a high resonance frequency and a wide operating frequency range. 
U.S. Patent 4,168,441. Picosecond pulse generator utilizing a Josephson junction, D. G. McDonald and R. L. Pcterson, 6 pages (Scpt. 18, 1979).

Key words: ac current; high frequency oscillator; Josephson junction; picosecond pulse generator.

A picosecond pulse gencrator for producing pulses having widths in the order of $10^{-12}$ seconds utilizes a Josephson junction that has an external load resistor connected in shunt therewith by a balanced transmission line. The Josephson junction is driven by a high frcquency oscillator, and the $\mathrm{AC}$ current, $I_{1}$, flowing through it is adapted to have its amplitude varied with respect to $I_{r}$, the critical current of the junction. As the value of $1_{1} / I_{r}$ exceeds one and increases, first a single and then an increasing number of picosccond pulses are produced during each half cycle of the high frequency oscillator.

U.S. Patent 4,173,442. Apparatus and method for determination of wavelength, J. J. Snyder, 14 pages (Nov. 6, 1979).

Key words: Fizeau-type interferometer; fringe-pattern; spatial period; wavelength of light

An apparatus and method for determining the wavelength of light such as monochromatic radiation from a laser source. The apparatus comprises a Fizeau-type interferometer, photoelectric means for receiving the interference fringe pattern produced in the interferometer, means for determining the spatial period and phase of the fringe pattern, and means for calculating from the spatial period and phase the wavelength of the radiation. 
Reprints from the journals listed in this section may often be obtained from the authors. See page 3 for additional information.

18318. Hartman, A. W., Piezoelectric inchworm operation in a vacuum, Opt. Eng. 17, No. 6, 645-646 (Nov.-Dec. 1978).

Key words: high vacuum; interferometry; piezo-electric positioner.

An "inchworm"-type piezoelectric displacement device has been tested for operation in a vacuum. Comparative data are given for its operation at two pressures ( 1 atmosphere and $10^{-6}$ to $10^{-7}$ torr), three loads $(0,8,15 \mathrm{~N})$, and four speeds in the range 0.5 to 50 micrometers per second. The results are such that the device is now being applied successfully to drive an $\mathrm{X}-\mathrm{Y}$ stage in a scanning electron microscope (SEM).

18319. McNeil, J. R., Johnson, W. L., Collins, G. J., Persson, K. B., Franzen, D. L., Laser action in sputtered metal vapors, Proc. IXth Int. Conf. on Quantum Electronics, Amsterdam, The Netherlands, June 14-18, 1976, pp. 162-163 (North-Holland Publishing Co., Amsterdam, The Netherlands, 1976).

Key words: Cu Il; cw laser action.

We have obtained $\mathrm{cw}$ laser action on twenty-eight transitions of $\mathrm{Cu}$ II spanning the wavelength region from $2486 \AA$ to 7988 $\AA$ and on four transitions of $\mathrm{Ag} 11$ in the vísible region. Threshold currents for the $2500 \AA$ transitions of $\mathrm{Cu} 11$ are typically $6 \mathrm{~A}$ and $10 \mathrm{~mW}$ of $\mathrm{cw}$ output power was obtained at 10 $A$, the limit of our d.c. power supply.

18320. Miller, C. K. S., Millimeter wave metrology capabilities at NBS, Proc. 1974 Millimeter Waves Techniques Conf., San Diego, CA, Mar. 26-28, 1974, 11 pages (Naval Electronics Laboratory Center, San Diego, CA, 1974).

Key words: millimeter waves; standards.

This paper is a brief survey paper of the millimeter wave metrology capabilities of the Electromagnetics Division of the National Bureau of Standards, Boulder, Colorado. The measures and quantities covered include power, attenuation, impedance, noise, and antenna gain. The basis for the metrology capabilities are briefly sketched to identify the reference standards used, the transfer system, measurement techniques, and accuracy of the final measurement process. Calibration services offered are identified. A few comments are made about millimeter wave flanges and the precise measurement of amplifier noise. This paper gives an overview of the state of precise millimeter wave measurement capabilities at NBS and refers liberally to recent publications that detail these capabilities.
18321. Robertson, B., Application of maximum entropy to nonequilibrium statistical mechanics, Proc. Maximum Entropy Formalism Conf., Cambridge, MA, May 2-4, 1978, R. D. Levine and M. Tribus, Eds., pp. 289-320 (The MIT Press, Cambridge, MA, 1978).

Key words: correlation functions; equations of motion; maximum entropy; nonequilibrium statistical mechanics; nonequilibrium thermodynamics; projection operator.

This paper reviews the use of the maximum entropy formalism (MEF) on an isolated system that may be arbitrarily far from thermodynamic equilibrium. Information for one instant of time is collected because it gives the entire equilibrium thermodynamic formalism for a system far from equilibrium. In particular, the MEF entropy is then a suitable expression for the thermodynamic entropy for a nonequilibrium system. The MEF yields a general expression for a projection operator. This is used with the Liouville equation to derive an exact expression for the nonequilibrium statistical density. This immediately gives exact closed equations of motion for the time dependence of the expectations that appear as constraints in the MEF. The equations are integrodifferential equations whose kernels are generalizations of rate-rate time-correlation functions. The equations are also written using flux operators satisfying conservation equations, and the memory-retaining nonlocal generalizations of the equations of nonequilibrium thermodynamics are obtained. The kernels in these equations are flux-flux time-correlation functions. The appearance of the projection operator in the correlation functions has important consequences for their asymptotic time dependence. References to specific applications of the formalism and to related work are given.

18322. Sawyer, D. E., Solar cell measurement technique development and other services, Proc. Photovoltaics Program Semi-Annual Review Advanced Materials, R\&D Branch, Golden, $\mathrm{CO}, \mathrm{Oct} .4-6,1977$, pp. $708-713$ (Available as Dept. of Energy CONF-771051 from National Technical Information Service, Springfield, VA 22161, 1978).

Key words: laser scanner; measurement development; photovoltaics; reliability; solar arrays; solar cells; workshops.

The development of solar cell measurement techniques using a laser scanner is a major portion of a new program which will be initiated for ERDA. The other portion is to assist ERDA with supportive activities such as helping organize workshops and symposia and hosting these events.

18323. Waclawski, B. J., Gadzuk, J. W., Herbst, J. F., uv photoemission for rare gases implanted in Ge, Phys. Rev. Lett. 41, No. 8, 583-586 (Aug. 21, 1978).

Key words: amorphous germanium; binding energy shifts; extra-atomic screening; implants; ion bombardment; raregases; relaxation energy; ultraviolet photoelectron spectroscopy.

The first ultraviolet photoemission spectra of the valence electrons of rare-gas atoms, implanted by ion bombardment into an amorphous Ge matrix, are presented here. The posi- 
tions of the peaks in the observed spectra are shifted relative to gas-phasc spectra, consistent with a final-state screeningenergy shift which varies inversely with the radius of the particular implant, as predicted by a linear-response relaxation model described herein.

18324. Yokel, F. Y., Guidelines for housing construction in mine subsidence areas, Proc. Int. Conf. on Evaluation and Prediction of Subsidence, Pensacola Beach, FL, Jan. 1978, S. K. Saxena, Ed., pp. 129-139 (American Society of Civil Engineers, New York, NY, 1978).

Key words: foundation design; geotechnical engineering; housing construction; mine subsidence; mining; site development; standards; structural design.

Suggested guidelines for the construction of housing in mine subsidence areas are outlined and discussed. The guidelines deal with site evaluation, site development, and housing construction.

18325. Blanchard, D. B., Marrison, S. H., Trace element profiles and ratios determined by irstrumenta! neutron activation analysis for fine paper identification, J. Forensic Sci. 23, No. 4, 679-686 (1978).

Key words: analysis; clay; forensic; INAA; paper; trace elements.

Investigation into the use of (INAA) instrumental neutron activation analysis for determination of trace element profiles and ratios of clay filled fine papers for forensic purposes. First part of investigation directed toward determining if clays varied substantially in their trace-element profiles. Second part ascertained that resultant trace-element profiles and respective elemental ratios of clay filled papers could serve as a "fingerprint" of a specific piece of paper for forensic purposes.

18326. Fong, J. T., Uncertainties in fatigue life prediction and a rational definition of safety factors, Nucl. Eng. Des. 51, 4554 (1978).

Key words: corrosion fatigue; design; engineering judgment; factor of safety; fatigue; mathematical modeling; nuclear engineering; reliability; risk; safety factor; sampling; Weibull distribution.

To cope with uncertainties in mechanical and structural design, engineers exercise their judgment through the use of safety factors based on service experience and laboratory data on relevant design parameters. Using the problem of fatigue life prediction as a vehicle, the relationship between the size of a safety factor and the associated risk and cost-benefit estimates of the engineering judgment based on new technical information, is demonstrated. The subtle influence of the choice of a distribution function for a given set of data is exhibited by comparing the gaussian with the three-parameter Weibull fits of a set of fatigue life data on 6061-T6 aluminum. A system of ranking the importance of different sources of uncertainties based on an analysis of service data is proposed along with an example to "refine" the system using up-to-date laboratory and field measurements. The concept of a rational definition of safety factors as a tool for engineers who design under uncertainty is discussed.

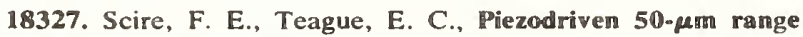
stage with subnanometer resolution, Rev. Sci. instrum. 49, No. 12, $1735-1740$ (Dec. 1978).

Key words: flexure pivots; linear positioning; micromanipulator; optical microscope stage; piezoelcctric drives; scanning stage; SEM microscope stage; submicrometer positioning instrumentation; TEM microscope stage.
A micropositioning stage has becn developed for use with optical and electron microscopes in the accurate measurement of fine lines used by the microelectronics industry and microscopic objects such as biological cells, air pollution particles, and asbestos fibers. The stage combines a piezoelectric driving elemenț and flexure pivoted lever arms to achicve a compact, vacuum compatible device with a resolution of $0.001 \mu \mathrm{m}$ or less over a range of $50 \mu \mathrm{m}$.

18328. Siedle, A. R., Bodner, G. M., Garber, A. R., Wright, R. F., Todd, L. J., A high-resolution ${ }^{11} B$ NMR stendy of the $\left[\left(\mathrm{B}_{10} \mathrm{H}_{12}\right)_{2} \mathrm{Ni}\right]^{2-}$ ion, J. Magn. Reson. 31, 203-206 (1978).

Key words: boron hydride; metalloborane; nickelaborane; nuclear magnetic resonance.

The $70.6-\mathrm{MHz}{ }^{11} \mathrm{~B}$ NMR spectrum of $\left[\left(\mathrm{B}_{10} \mathrm{H}_{12}\right)_{2} \mathrm{Ni}\right]^{2-}$ has been assigned: $\delta_{11 B}, 10.1\{\mathrm{~B}(5,7,8,10)\} ; \sim 8\{\mathrm{~B}(1$ or 3$)\} ; 0.4$ $[\mathrm{B}(3$ or 1$)] ;-4.1[\mathrm{~B}(6,9)] ;-21.7[\mathrm{~B}(2,4)]$.

18329. Abbundi, R., Rhyne, J. J., Sweger, D. M., Segnan, R., Magnetic relaxation phenomena in Dy-Sc alloys, Phys. Rev. B 18, No. 7, 3313-3317 (Oct. 1, 1978).

Key words: hyperfine fields; magnetic relaxation; magnetism; Mössbauer; rare earths; spin glass.

Neutron-scattering and magnetization experiments on $R_{x} S_{c_{1-}}$ ( $R=\mathrm{Gd}, \mathrm{Tb}, \mathrm{Ho}$, and $\mathbb{E r}$ ) alloys have given anomalous results for the concentration dependence of the magnetic-ordering temperature. In contrast to conventional theoretical arguments and to data on other rare-earth alloys, these systems require large rare-earth concentrations $(15 \% \leqslant x \leqslant 39 \%)$ for the onset of long-range magnetic order to occur. The work which we report here deals with the investigation of the $\mathrm{Dy}_{x} \mathrm{Sc}_{1-x}$ system in the concentration range $0.02 \leqslant x \leqslant 0.75$. The Mössbauer effect was used to examine the magnetic hyperfine interaction at the ${ }^{161}$ Dy nuclei both as a function of temperature and concentration. Neutron scattering on the samples containing $<35$-at.\% Dy indicated no long-range magnetic order at $T=4.2 \mathrm{~K}$. However, each of the alloys investigated, including the 2-at.\% Dy alloy which was the lowest concentration measured, exhibits a well-defined magnetic hyperfine splitting at this temperature. The magnitude of this splitting is $45 \pm 0.5 \mathrm{~cm} / \mathrm{sec}$ and corresponds to a field approximately equal to that found in pure Dy metal, and is independent of the Dy concentration contained in the alloy. The observed magnetic hyperfine lines for the alloys in the lower Dy concentration region $(\leqslant 25 \%)$ are relaxation broadened with increasing temperature, while the overall splitting remains essentially indcpendent of temperature. These spectra are analyzed in terms of an electronic-spin-relaxation model for an effective spin-1/2 system.

18330. Armstrong, G. T., Cezairliyan, A., Calorimetry, Chapter in Kirk-Othmer Encycl. Chem. Technol., 3d Ed. 4, 449-474 (John Wiley and Sons, Inc., New York, NY, 1978).

Key words: bomb calorimetry; drop calorimetry; electromagnetic power calorimetry; energy mcasurement; enthalpy measurement; entropy measurement; fuels, heating values; gas-flow calorimetry; heat capacity measurement; heat measurements; levitation calorimetry; microcalorimetry; radiation calorimetry; solution calorimetry.

Calorimetry is defined on the basis of its historical origins and in terms of the first law of thermodynamics. The technological and scientific applications of calorimetry are described: fuel technology, the properties of materials (heat capacities, internal energies, enthalpies, entropies, Gibbs energies), changes during reaction, thc calorimetry of physical processes (radioactive decay, electromagnetic radiation), the application to process design, and industrial process control. Calorimetric instruments are discussed in terms of the theoreti- 
cal basis of calorimetry, optional modes of operation, and kinds of processes to be measured. Calorimeters for reacting systems and their principles are described: bomb calorimeters, continuous-flow gas-combustion calorimeters, solution calorimeters and microcalorimeters. Calorimeters for nonreacting systems are described: including isothermal (Bunsen) calorimeter, isoperibol calorimeter, adiabatic calorimeter (low temperature and medium temperature), receiving calorimeter (using conventional furnace or levitation), high-sneed calorimeter, and modulation calorimeter. Trends are discussed. A reading list of 19 entries and a bibliography of 96 entries are provided.

18331. Ausloos, P., Lias. S. G., Proton affinity of dichlorocarbene, J. Am. Chem. Soc. 100, No. 14, 4594-4595 (July 5, 1978).

Key words: dichlorocarbene; heat of formation; ionmolecule reactions; proton affinity; proton transfer reaction.

It is demonstrated that the recently reported value for the proton affinity of $\mathrm{CCl}_{2}$ determined through the well known bracketing technique is too high by approximately 14 $\mathrm{kcal} / \mathrm{mole}$. The assignment of a value for this proton affinity was based on the observation or nonobservation of proton transfer from $\mathrm{CCl}_{2} \mathrm{H}^{+}$to selected bases of known proton affinity $\left(\mathrm{CCl}_{2} \mathrm{H}^{+}+\mathrm{B} \rightarrow \mathrm{CCl}_{2}+\mathrm{BH}^{+}\right)$. It is shown that in some experiments described in the recent study, exothermic proton transfer reactions were in competition with energetically more favorable reaction channels which strongly predominated, usually to the exclusion of proton transfer. This letter expands our earlier exhaustive study of proton transfer and competing reactions of $\mathrm{CCl}_{2} \mathrm{H}^{+}$to include the bases used by Levi, Taft, and Hehre ( $J$. Am. Chem. Soc. 99, 8454 (1977)). All reaction channels as well as rate constants have been determined, and some of our earlier measurements have been refined.

18332. Ausloos, P., Lias, S. G., Reactions of $\mathrm{NO}_{2}{ }^{+}$and solvated $\mathrm{NO}_{2}{ }^{+}$ions with aromatic compounds and alkanes, Int. J. Chem. Kinet. X, 657-667 (1978).

Key words: aromatic substitution; association ions; charge transfer; ethyl nitrate; ion-molecule reactions.

The rate constants and modes of reaction of $\mathrm{NO}_{2}{ }^{+}$and $\mathrm{C}_{2} \mathrm{H}_{5} \mathrm{ONO}_{2} \mathrm{NO}_{2}{ }^{+}$with aromatic compounds and alkanes have been determined in a pulsed ion cyclotron resonance mass spectrometer. Both ions undergo competing charge transfer and subsitution reactions $\left(\mathrm{NO}_{2}{ }^{+}+\mathrm{M} \rightarrow \mathrm{MO}^{+}+\mathrm{NO} ; \quad \mathrm{C}_{2} \mathrm{H}_{5} \mathrm{O}\right.$ $\mathrm{NO}_{2} \mathrm{NO}_{2}{ }^{+}+\mathrm{M} \rightarrow \mathrm{MNO}_{2}^{+}+\mathrm{C}_{2} \mathrm{H}_{5} \mathrm{ONO}_{2}$ ) with aromatic molecules. In both cases, the probability that a collision results in charge transfer increases with increasing exothermicity of that process. The $\mathrm{C}_{2} \mathrm{H}_{5} \mathrm{ONO}_{2} \mathrm{NO}_{2}{ }^{+}$ion docs not undergo charge transfer with molecules having an ionization potential greater than about $212 \mathrm{kcal} / \mathrm{mol}(9.2 \mathrm{eV})$; this observation leads to an estimate of $13 \mathrm{kcal} / \mathrm{mol}$ for the binding energy between $\mathrm{NO}_{2}{ }^{+}$ and $\mathrm{C}_{2} \mathrm{H}_{5} \mathrm{ONO}_{2}$. The importance of the substitution reaction depends on the number of substituents on the aromatic ring and the molecular structure, and, in the case of $\mathrm{C}_{2} \mathrm{H}_{5} \mathrm{ONO}_{2} \mathrm{NO}_{2}{ }^{+}$ ions, on the energetics of the competing charge transfer process. Both $\mathrm{NO}_{2}{ }^{+}$and $\mathrm{C}_{2} \mathrm{H}_{5} \mathrm{ONO}_{2} \mathrm{NO}_{2}{ }^{+}$undergo hydride transfer reactions with alkanes. For both these ions, $k$ (hydride transfer) $/ k$ (collision) increases with increasing exothermicity of reaction, but in both cases the rate constants of reaction are unusually low when compared with other hydride transfer reactions of comparable exothermicity which have been reported in the literature. This is interpreted as evidence that the attack on the alkane preferentially involves the nitrogen atom (where the charge is localized) rather than one of the oxygen atoms of $\mathrm{NO}_{2}{ }^{+}$.

18333. Unassigned.
8334. Durst, R. A., Sources of error in ion-selective electrode potentiometry, Chapter 5 in Ion-Selective Electrodes in Analytical Chemistry, H. Freiser, Ed., Vol. 1, 311-338 (Plenum Publishing Corp., New York, NY, 1978).

Key words: electrodes; electrodes, ion-selective; electrodes, reference; errors; ion-selective electrodes; sensors, chemical; standards.

While the advantages and unique features of ion-selective electrodes are widely known and anpreciated, the potential sources of error are numerous and the analyst must be aware of these pitfalls in order to be able to minimize their effects. The causes of these errors are almost as varied as the sensors and samples, but several common sources can be identified: interferences, and/or fouling of the indicator electrode, sample matrix effects, reference electrode instability, and improper calibration of the measurement system. These sources of error are discussed in some detail with suggestions for overcoming or minimizing the inroblems and their analytical effects.

These sensors can be a useful and convenient means for the analysis of a wide variety of ionic, molecular and gaseous species, but only if the sources of error are recognized and eliminated. More than any other modern analytical technique, ion-selective electrode potentiometry require a sound knowledge of solution chemistry in order to achieve maximum effectiveness.

18335. Hudson, R. P., NBS standards for pressure, temperature, and humidity, (Proc. Air Quality Meteorology and Atmospheric Ozone, Boulder, CO, July 3 I-Aug. 6, 1977), Am. Soc. Testing Mater. Spec. Tech. Publ. 653, A. L. Morris, R. C. Barras, Eds., pp. 13-26 (1978).

Key words: humidity; ozone; pressure; standards; temperature; vacuum.

A summary is presented of the metrological activities in the Heat Division of the National Bureau of Standards, covering the calibration and other service activities in temperature, pressure, and humidity, together with a description of some representative examples of related current research and developmental work.

18336. Kusuda, T., Use of simulation models of buildings in assessing energy conservation strategies, Proc. Symp. Energy Conservation Strategies in Buildings: Comfort, Acceptability, and Health, New Haven, CT, Jan. 25, 1978, J. A. J. Stolwijk, Ed., pp. 143-156 (J. B. Picrce Foundation Laboratories, Hartford, CT, 1978).

Key words: heating and cooling load; hybrid computer; NBSLD; thermal comfort.

A comprehensive treatment of building heat transfer processes is employed by the National Bureau of Standards Heating and Cooling Load Calculation program NBSLD to study the effect of various building parameters upon the resulting heating and cooling load and thermal comfort of occupants, in order to evaluate energy conservation strategies. The basis of the computation is the detailed solution of simultaneous heat balance equations at all of the interior surfaces of a room or space. Transient heat conduction through the exterior walls and in the interior structures is handled by using conduction transfer functions. The use of heat balance equations, although more time consuming than the conventional load calculation procedures, avoids the vagueness and uncertainties inherent in the latter. In addition, it is more accurate for a specific building design. Also mentioned in this paper is use of a hybrid computing system whereby simultaneous transfer of air, moisture and heat in and through the building can be studied more efficiently than by the conventional digital computer 
18337. Lias, S. G., Ausloos, P., Ionization energies of organic compounds by equilibrium measurements, J. Am. Chem. Soc. 100, No. 19, pp. 6027-6034 (1978).

Key words: aromatic compound; charge transfer equilibria; entropy change; ion cyclotron resonance; ionization energy.

The determination of the equilibrium constants for a number of charge transfer equilibria has generated a scale of relative values of $\Delta G^{\circ}$ for the charge transfer reactions. The factors contributing to $\Delta S^{\circ}$ for these reactions were elucidated by carrying out experimental determinations of the entropy changes for some of the equilibria. The values of $\Delta H^{\circ}$ were used to generate a scale of relative ionization energies of 41 organic compounds and NO. Standardization of the scale using the spectroscopically determined values of the ionization potentials of $\mathrm{NO}$, benzene, and furan was accomplished by calculating the relationship between adiabatic ionization potentials and the "enthalpies of ionization" measured in these experiments. The spectroscopically determined IPs of six of the compounds were reproduced in this way, thus verifying the technique.

18338. Lindstrom, R. M., Fleming, R. F., Optimized measurement of aluminum in high-purity silicon, Proc. Nuclear Methods in Environmental and Energy Research, Columbia, MO, Oct. 10-13, 1977, pp. 90-98 (Technical Information Center, U.S. Department of Energy, Washington, DC, 1978).

Key words: activation analysis; cadmium ratio; east neutron reactions; interfering nuclear reactions; optimization of analysis; silicon; trace analysis.

Measurement of small quantities of aluminum in silicon of semiconductor or solar grade is complicated by production of ${ }^{28} \mathrm{Al}$ by an $(n, p)$ reaction on the matrix, in competition with the $(\mathrm{n}, \gamma)$ reaction on the trace aluminum sought. In selecting the optimum irradiation facility, the conflicting requirements of high thermal flux for the greatest signal and of low fast flux for the smallest interference must be balanced. The present work outlines a simple experimental procedure for assessing and correcting for interferences. No explicit knowledge of fast fluxes or cross sections is required; these are often poorly known. The procedure is generally applicable to other cases of competing reactions.

18339. Peavy, B. A., A note on response factors and conduction transfer functions, (Proc. Symp. American Society of Heating and Air-Conditioning Engineers Annual Meeting, Atlanta, GA, Jan. 29-Feb. 2, 1978), ASHRAE Trans. 84, Pt. 1, 688 . 690 (1978).

Key words: computer time; conduction-transfer functions; dynamic heat transfer; thermal response factors.

The thermal response factor technique for calculating dynamic heat conduction through walls, floors, and roofs is utilized in many computer programs for determining building heating and cooling loads. Considerable computation time and computer memory space are devoted to the use of this technique, and it is advantageous to reduce the time and space required.

Reduction in computation time and computer memory space can be achieved by the use of the zeroth through fifth-order conduction-transfer functions. Computation time can be reduced by about one-half, and it is possible to reduce the memory space to one-fourth of that presently used in the computer program NBSLD.

18340. Shold, D. M., Rebbert, R. E., The photochemistry of methyl chloride, J. Photochem. 9, $499-517$ (1978).

Key words: chloride; methyl; methyl chloride; photochemistry
Methyl chloride and $\mathrm{CH}_{3} \mathrm{Cl}-\mathrm{CD}_{3} \mathrm{Cl}, \mathrm{CH}_{3} \mathrm{Cl}-\mathrm{Br}_{2}$ and $\mathrm{CD}_{3} \mathrm{Cl}-\mathrm{HI}$ mixtures have been photolyzed at 163.3, 147.0 and $123.6 \mathrm{~nm}$ in the gas phase and methyl chloride has also been photolyzed at $147.0 \mathrm{~nm}$ in the liquid phase. Over this range of wavelengths, there are four principal primary processes:

$$
\begin{gathered}
\mathrm{CH}_{3} \mathrm{Cl}+h v \rightarrow \mathrm{CH}_{3}+\mathrm{Cl} \\
\quad \rightarrow \mathrm{CH}_{2} \mathrm{Cl}+\mathrm{H} \\
\rightarrow \mathrm{CH}_{2}+\mathrm{HCL}(\text { or } \mathrm{H}+\mathrm{Cl}) \\
\rightarrow \mathrm{CHCl}+\mathrm{H}_{2}(\text { or } 2 \mathrm{H})
\end{gathered}
$$

At $163.3 \mathrm{~nm}$, process (1) is almost exclusively responsible for the photodecomposition. However, at shorter wavelengths processes (2), (3) and (4) increase while process (1) decreases in importance. At all wavelengths these four processes account for a total quantum yield of 0.75-1.0.

18341. Armstrong, R. W., Wu, C. C., Farabaugh, E. N., Crystal subgrain misorientations via $x$-ray diffraction microscopy, Adv. X-Ray Anal. 20, 201-206 (1977).

Key words: $\mathrm{Al}_{2} \mathrm{O}_{3}$; Berg-Barrett; Lang; misorientation contrast; $\mathrm{x}$-ray topography; Zn.

The "misorientation contrast" which occurs at boundaries marking the relative displacement of adjacent subgrain reflections in $\mathrm{x}$-ray diffraction images is shown by a stereographic projection method of analysis to be useful for deciphering $\mathrm{x}$-ray images obtained by the Berg-Barrett and Lang techniques. Experimental results are given for subgrain structures observed in $\mathrm{Zn}$ and $\mathrm{Al}_{2} \mathrm{O}_{3}$ crystals.

18342. Carpenter, B. S., Mapping and detecting elements selectively by the Nuclear Trace Technique, Proc. Int. Conf. on Nuclear Methods in Environmental and Energy Research, Columbia, MO, Oct. 10-13, 1977, pp. 136-143 (Available as Department of Energy CONF-771072 from National Technical Information Service, Springfield, VA 22161, 1978).

Key words: alpha tracks; biomedical; boron; fission tracks; geochronology; geology; lithium; nitrogen; silicon devices; trace analysis; uranium

The nuclear track technique (NTT) has been routinely used to determine trace concentrations of uranium, boron and lithium in a variety of matrices, as well as macro-concentrations (e.g. $\geqslant 500 \mu \mathrm{g} / \mathrm{g}$ ) of nitrogen in steels and biological materials. In addition to the trace element determinations, the NTT has found significant applications in geology as a viable method for geochronology and geothermometry. Aside from the analytical and geological applications, the NTT is being used to micromap the location, distribution and behavior of dopants, such as boron, lithium, oxygen and uranium, in various materials. This is particularly the case in the semiconductor and biomedical areas, since no convenient long lived radioactive nuclides of these elements exist.

18343. Gills, T. E., Gallorini, M., Greenberg, R. R., The determination of selected toxic elements in biological matrices using Tadiochemical activation arralysis, Proc. $3 d$ Int. Conf. on Nuclear Methods in Environmental and Energy Research, Columbia, MO, Oct. 10-13, 1977, pp. 597-609 (Available as Department of Energy CONF-771072 from National Technical Information Service, Springfield, VA 22161, 1978).

Key words: radiochemical; selectivity; sensitivity; toxic elements.

Neutron activation analysis, coupled to improved or modified radiochemical procedures, was used in the analysis of several selected toxic elements in biological matrices. These procedures proved effective in achieving maximum sensitivities 
and accuracies for the following elements: $\mathrm{Hg}, \mathrm{Se}, \mathrm{As}, \mathrm{Sb}$ and $\mathrm{Cd}$. This paper describes the application of thesc radiochemical procedurcs and their use at the National Bureau of Standards in the Standard Reference Material certification program.

18344. Schenck, P. K., Mallard, W. G., Travis, J. C., Smyth, K. C., Absorption spectra of metal oxides using optogalvanic spectroscopy, J. Chem. Phys. 69, No. 11, $5147-5150$ (Dec. 1, 1978).

Key words: light absorption; metal oxides; molecular absorption; opto-galvanic spectroscopy; uv irradiation.

The absorption spectra of neutral flame species may be detected by measuring current changes induced by photon irradiation at wavelengths corresponding to electronic transitions. This paper presents the first results using this optogalvanic spectroscopy to study molecular absorption. Numerous transitions have been detected for $\mathrm{ScO}, \mathrm{YO}$, and $\mathrm{LaO}$ in the 360 $630 \mathrm{~nm}$ wavelength region. The most extensive data have been obtained for LaO, where we observe a total of at least four electronic states and 18 sequences. Five of the sequences have not been seen in previous emission studies.

18345. Tippet, J. C., Chang, D. C., A new approximation for the capacitance of a rectangular-coaxial-strip transmission line, IEEE Trans. Microwave Theory Tech., pp. 602-604 (Sept. 1976).

Key words: EMC measurements; radiation resistance; rectangular coax; shielded strip line; TEM cell.

The method of conformal transformation is used to obtain the exact capacitance of a rectangular-coaxial-strip transmission line. An approximate form, which includes the edge-interaction capacitance of the strip, is obtained and is shown to reduce in an appropriate limit to a form obtained by other authors.

18346. Hellwig, H., Evenson, K. M., Wineland, D. J., Time, frequency and physical measurement, Phys. Today, pp. 23-30 (Dec. 1978).

Key words: atomic clocks; frequency standards; frequency synthesis; fundamental constants; length standards; physical measurement systems; review article; speed of light; time standards.

Frequency, time, and wavelength measurements of precision have been brought about by fundamental advances in spectroscopy. These include: Sub-Doppler techniques, the stabilized laser, and the extension of direct frequency measurements to the near infrared region of the spectrum. In fact, significant changes in our system of physical measurements are taking place. This article attempts to focus on several of these developments, which, we feel, are likely to substantially impact many areas of science, technology and physical measurement.

18347. Himes, V. L., Hubbard, C. R., Mighell, A. D., 3a,6adimethylglycouril $\{3 \mathrm{a}, 6 \mathrm{a}$-dihydro-3a,6a-dimethylimidazo [4,5d]imidazole-2,5(1H,6H)-dione \}, Acta Cryst. B34, 3102-3104 (1978).

Key words: biomedical standard; diacetylurea; molecular structure; urea; urea determination; x-ray diffraction.

$\mathrm{C}_{6} \mathrm{H}_{10} \mathrm{~N}_{4} \mathrm{O}_{2}, M_{r}=170.17$, orthorhombic, $\mathrm{Cmcm}, a=7.357$ (2), $b=10.836$ (5), $c=10.180$ (6) $\AA ; Z=4, D_{c}=1.389, D_{m}$ $=1.39 \mathrm{~g} \mathrm{~cm}^{-3}$ (flotation); final $R=0.040$ (463 reflections with $I>3 \sigma l)$. Crystallographic symmetry requires the molecule to have point symmetry $2 \mathrm{~mm}$. In the molecule are two planar fivemembered rings with a $65.0^{\circ}$ angle between the plane normals of the rings. Each molecule is hydrogen bonded to four neighboring molecules by eight $\mathrm{N}-\mathrm{H}$... O hydrogen bonds $\left[d_{N \ldots o}=2.869(2) \AA\right]$.
18348. Barnes, J. D., Assessing permeation performance of industrial plastic shipping containers, Proc. 36th Annual Technical Conf. Society of Plastics Engineers, Washington, DC, Apr. 24-27, 1978, pp. 824-826 (Society of Plastics Engineers, Greenwich, CT, 1978).

Key words: compatibility; permachor; permeation; plastic containers; polyethylene; standards.

This paper presents a proposal for a standards-based measurement system for predicting the permeation performance of industrial plastic shipping containers. The scheme is based on early work which demonstrates that there is a systematic way (known as the "pcrmachor") to characterize the tendency of a given molecular species to permeate polyethylene. It is possible to establish a scale for calibrating a permachor measuring system and to establish standardized conditions for making the measurements.

If such a system were operational, it would be expected that the measurements required to establish compatibility between a lading and a shipping container could be carried out more economically and with greater confidence. The number of holding tests of individual ladings in large shipping containers would also be much reduced under the proposed scheme.

18349. Becker, D. A., Envirronmental sample banking-research and methodology, Proc. Symp. on Trace Substances in Environmental Health-X, Columbia, MO, June 8-10, 1976, D. D. Hemphill, Ed., pp. 353-359 (University of Missouri, Columbia, MO, 1976).

Key words: analytical techniques; contamination; environment; retrospective; sample storage; trace analysis.

The National Bureau of Standards (NBS), in coopcration with the Environment Protection Agency and the National Science Foundation, is engaged in a research program establishing methodology for environmental sample banking. This program is aimed toward evaluating the feasibility of a $\mathrm{Na}$ tional Environment Specimen Bank (NESB).

The capability for retrospective chemical analyses to evaluate changes in our environment would provide uscful information. Much of this information could not be obtained using data from previously analyzed samples. However, to assure validity for these stored samples, they must be sampled, processed and stored under rigorously evaluated, controlled and documented conditions. Such conditions must also be specific for the various components of interest.

The program currently under way in the NBS Analytical Chemistry Division has 3 main components. The first is an extension survey of available literature concerning problems of contamination, losses and storage. The components of interest includc trace elements, pesticides, other trace organics (PCBs, plasticizers, etc.), radionuclides and microbiological species. This survey has been completcd and the limited and often contradictory information will be outlined. An important output of this effort has been the development of suggested "guidelines" for sampling, cleaning and storage techniques. These guidelines are being circulated through the scientific community for comment and suggestions.

The second component is an experimental evaluation of contamination and losses during sampling and sample handling. Of particular interest here is research into container cleaning methodology for trace elements, with respect to adsorption, desorption, leaching and partial dissolution by various sample matrices.

The third component of this program is an evaluation of existing methodology for long-term sample storage. Techniques under investigation include lyophilization, low-temperature (oxygen-plasma) ashing, air drying and freezing (at $-20^{\circ} \mathrm{C}$ and at $-70^{\circ} \mathrm{C}$ ), including evaluation of an optimum storage container for the different trace substances. 
This program is a concerted effort to bring together many aspects of sampling, sample handling and storage. The results seem to be useful not only for sample banking purposes but to the general trace substance analytical community as well.

18350. Becker, D. A., Lafleur, P. D., LeRoy, A., Spontaneous deposition radiochemlcal separation for platlnum determination in biological materials, Proc. Int. Nuclear and Atomic Activation Analysis Conf. and Nineteenth Annual Meeting on Analytical Chemistry in Nuclear Technology, Gatlinburg, TN, Oct. 14-16, 1975, I page (American Nuclear Society, Hinsdale, IL, 1976).

Key words: biological materials analysis; environmental materials analysis; neutron activation analysis; noble metals analysis; platinum determination; radiochemical separation; spontaneous deposition technique.

The use of platinum and possibly other noble metals in motor vehicle emission control systems has recently been made public. The method developed and described is capable of quantitatively determining gold, platinum, and palladium in a wide variety of biological and environmental matrices. The analytical procedure entails wet-ashing with nitric-perchloric acids with carriers, redissolving the residue in aqua regia, and then plating out on silver metal powder. This technique is also currently being evaluated for possible use in simultaneous determination of additional noble metals.

18351. Biétry, J., Sacré, C., Simiu, E., Mean wind profiles and change of terrain roughness, J. Struct. Div., Am. Soc. Civ. Eng. 104, No. ST10, Proc. Paper 14099, 1585-1593 (Oct. 1978)

Key words: aerodynamics; boundary layer; loads (forces); roughness; structural analysis; tall buildings; wind pressure.

Information is presented on the wind structure in established flow over terrains with various roughness characteristics (open water, open terrain, suburban terrain, towns, centers of large cities). Based on recent results of theoretical and experimental meteorological studies a simple procedure is then proposed, enabling the designer to assess the effect upon the mean wind profile of a roughness change upwind of the structure under consideration. The procedure, which is approximate but adequate for structural engineering purposes, is then illustrated in a numerical example.

18352. Bowman, R. C., Jr., Carter, G. C., Chabre, Y., Nuclear

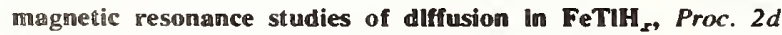
Int. Congress on Hydrogen in Metals, Paris, France, June 611, 1977, 8 pages (Pergamon Press, Paris, France, 1977).

Key words: diffusion; energy; hydrides; hydrogen storage; nuclear magnetic resonance; nuclear spin relaxation.

Proton NMR of $\mathrm{FeTiH}_{x}$ has been studied for $\mathrm{x}$ values in the $\beta$ and $\gamma$ hydride phases. Knight shifts, linewidths, spin-lattice relaxation times, and spin-spin relaxation times have been measured and a temperatule of sudden hydrogen loss has been observed. Activation energies have been deduced from these measurements.

\section{Unassigned.}

18354. Belanger, B. C., The role of NBS In traceabllity to national standards for advanced measurement systems, Proc. Industry/Joint Services Automatic Test Conf. and Workshop on Advanced Test Technology Management and Support, San Diego, CA, Apr. 3-7, 1978, pp. 295-296 (National Security Industrial Association, Washington, DC, 1978).

Key words: automated test equipment; measurement assurance; traceability.
NBS's role in traceability to national standards for automated test equipment (ATE) is described. The meaning of traceability vis-a-vis $\mathrm{ATE}$ is discussed.

18355. Ehrlich, M., Soares, C. G., Jackson, B., Lanoue, P., Influence of source configuration on spectral composition of gamma-ray beams from ${ }^{60} \mathrm{Co}$ teletherapy units, Int. J. Appl. Radiat. Isot. 29, 741-747 (1978).

Key words: atomic number; cobalt-60 photons; configuration; plug; scattered photons; sleeve; source capsule; source pellets; spacer; spectra; spectrometry.

Measurements were made of the photon spectra of simulated ${ }^{60} \mathrm{Co}$ teletherapy beams. Various source configurations and source environments of practical interest were employed for this purpose. The sources consisted of activated cobalt pellets packed into steel capsules. Several combinations of capsule diameters and heights of pellet layers were used. The spacer materials filling the remaining capsule volume were chosen to be of high, intermediate, or low atomic number. The capsules could be inserted, one at a time, into a compartment of either tungsten or brass, simulating the central section of popular commerical ${ }^{60} \mathrm{Co}$ teletherapy units. There also was some choice in the atomic number of the structural elements holding the capsules in place in the compartment. The largest contribution of scattered photons was found to occur when the materials close to the source pellets had atomic numbers in the vicinity of 30 .

18356. Nyyssonen, D., Optical linewidth measurements on wafers, SPIE Semin. Proc. 135, $115-119$ (1978).

Key words: mensuration; microdensitometry; microlithography; micrometrology; microscopy; partially coherent imaging.

An optical scanning microscope system for accurate measurement of linewidth on wafers is described. The development of this system in both theory and experiment parallels the treatment of transmitted light measurements on see-through photomasks as previously described. Threshold equations for determining edge location have been developed which include corrections for contrast phase. In reflected light, the wavelength dependence of these parameters due to thin film interference requires a much narrower spectral bandwidth. In addition, other light losses dictate the use of laser illumination. Control of the spatial coherence of the laser is discussed. A comparison of theoretical and experimental results is given along with a comparison of reflected and transmitted light measurements.

18357. Watson, R. E., Bennett, L. H., Electron factors in the occurrence of sigma and structurally related transition metal alloy phases, Scr. Metall. 12, $1165-1170$ (1978).

Key words: alloy phases; electronegativity; electron factors; electron vacancies; Laves phase; sigma phase; transition metal.

The sigma phase, a complex structure occurring in many transition metal systems, is of considerable practical and theoretical interest. Its presence can cause a normally ductile high performance steel or superalloy to embrittle and fail in service. There are a number of structurally related phases, some of which have properties which are of interest for other reasons. For example, the Al5 structure includes the highest transition temperature superconductors, such as $\mathrm{Nb}_{3} \mathrm{Sn}$, while the $\mathrm{CaCu}_{5}$ structure includes $\mathrm{LaNi}_{5}$ which is an excellent hydrogen storage alloy, and $\mathrm{SmCo}_{5}$ which is an extremely useful hard magnet. The stability of the $\sigma$ phase has generally been discussed in terms of electron and size factors. This note concentrates on the role of electron factors, and uses a pair of 
electronic coordinates derived from fundamental microscopic theory for a structural map of these alloy systems.

18358. Berger, M. J., Planned compilatlon of stopping power and range data, Proc. Sixth Symp. on Microdosimetry, Brussels, Belgium, May 22-26, 1978, J. Booz and H. G. Ebert, Eds., I, 639-649 (Harwood Academic Publishers, Ltd., London, England, 1978).

Key words: $\alpha$-particles; electrons; heavy ions; international commission on radiation units and measurements; protons; stopping power.

In recent years there has been a steady accumulation of new information about the penetration of charged particles through matter. The ICRU has appointed a committee that is charged with the task of digesting this new information and of preparing an up-to-date compilation of stopping-power and range data for electrons, protons and heavy ions, with emphasis on the needs of medical physics and radiobiology. The purpose of this talk is to indicate the plans, priorities and initial activities of the committee, and to discuss some recent development in stopping-power research which will facilitate the committee's task.

18359. Callcott, T. A., Arakawa, E. T., Ederer, D. L., Emission and absorption x-ray edges of Li, Phys. Rev. B 16, No. 12, 5185-5192 (Dec. IS, 1977).

Key words: core hole lifetime; core hole relaxation; $K \mathbf{x}$ ray absorption spectrum; $\boldsymbol{K}$ x-ray emission spectrum; many body effects; rhonon interactions.

The $K$ x-ray emission edge of $\mathrm{Li}$ is measured between 85 and $490 \mathrm{~K}$ and analyzed to obtain the temperature dependences of the edge position and of a Gaussian edge-broadening function. Full width at half-maximum edge widths range from $0.22 \pm$ $0.05 \mathrm{eV}$ at $85 \mathrm{~K}$ to $0.38 \pm 0.05 \mathrm{eV}$ at $440 \mathrm{~K}$. Edge positions shift from $54.81 \pm 0.02 \mathrm{eV}$ at $85 \mathrm{~K}$ to $54.86 \pm 0.02 \mathrm{eV}$ at 440 $\mathrm{K}$ and to $54.91 \pm 0.02 \mathrm{eV}$ after melting. Emission and absorption spectra measured with the same spectrometer establish a $0.10 \pm 0.02 \mathrm{eV}$ separation between the emission and absorption edges. These results are compared with recent theories describing incomplete lattice relaxation about the core hole. We conclude that for a core-hole life time of 0.016 to $0.030 \mathrm{eV}$ the theories give a satisfactory explanation of the premature peak in the emission spectra. We suggest also that phonon-core-hole interactions provide the dominant edge-broadening mechanism, and that many-body effects are small.

18360. CaswelI, R. S., Coyne, J. J., Influence of nuclear data on calculations of neutron energy deposition, Proc. Third Symp. on Neutron Dosimetry in Biology and Medicine, Neuherberg/Müchen, Federal Republic of Germany, May 23-27, 1977, G. Burger and H. G. Ebert, Eds., pp. 29-43 (Commission of the European Communities, DirectorateGeneral, Scientific and Technical Information Management, Bâtiment Jean Monnet, Luxembourg, 1978).

Key words: kerma factors; neutron cross section; neutron energy deposition; nuclear data; nuclear reactions; secondary particle spectra.

It is often assumed that if one has a set of evaluated neutron cross sections such as ENDF/B-IV, that it is then possible to determine physical properties of the neutron energy deposition process, such as kerma factors and secondary particle spectra, unambiguously. While this is true for some elements, it is not true for others. In the case of kerma factor calculations, nart of the calculational problem caused by lack of data can be side-stepped by use of the relation: (kerma) $=$ (energy available)-(energy carried off by secondary neutrons)-(energy carried off by gamma rays). In all cases the energy available is known. n elastic scattering the scattered neutron energy is known (if the angular distribution is known) and there are no gamma rays. For ( $n$, charged particle) reactions with cross sections given to known final states the second term is zero and the third term is determined by the cross section. In other reactions, such as $\left(n, n^{\prime} \alpha\right)\left(n, n^{\prime} p\right)$, and $\left(n, n^{\prime} 3 \alpha\right)$, the kerma factor is very sensitive to information about the outgoing neutron energy (direct reaction versus boil-off reaction), and to the final states assumed (i.e. energy carried off by gamma rays). We will discuss some "global" assumptions made in kerma factor calculations-uniform assumptions based on reasonable nuclear physics used when specific data is not available. In the case of secondary particle spectra, the above simplifying relation usually does not work since energy distributions of all secondary charged particles are needed. Here the choice of nuclear reaction mechanisms is crucial. Examples will be given of alternatives and choices made for specific nuclides.

In the higher energy regions where evaluated cross sections are not available, there are several ways to go. One is essentially an extrapolation of data at lower energies using what guides (total cross sections, optical model calculations) are available. A second method is the use of optical model and nuclear statistical model cross sections to produce the complete set of data needed. A third model is the use of the Intranuclear Cascade Model (INC). Results of some of these methods will be compared.

18361. Cavallo, L., Ehrlich, M., Hutchinson, J. M. R., Tracea* bllty in ionizing radiation measureanents systems, Proc. Int. Symp. on National and International Standardization of Radiation Dosimetry, Atlanta, GA, Dec. 5-9, 1977, IAEA-SM$222 / 18,1,65-87$ (International Atomic Energy Agency, Vienna, Austria, 1978).

Key words: dose; ionizing; radioactivity; standards; testing; traceability.

There are many demands for traceability to the national radiation measurements systems (NRMS) stemming from groups such as the regulatory agencies, state health laboratories, commercial suppliers of radioactive materials and their customers, hospitals and their patients. The United States National Bureau of Standards supervises and administers measurements assurance programmes for radiation therapy departments, the radiopharmaceutical industry, federal agencies charged with radiation and radioactivity monitoring and surveillance, and for manufacturers and users of radioactivity standards, and administers to the radioactivity measurements assurance programme of the College of American Pathologists. These efforts are described and the results are tabulated.

18362. Durst, R. A., Potential pitfalls in the use of ion-selective electrode-reference electrode pairs, Paper in Theory, Design, and Biomedical Applications of Solid State Chemical Sensors, D p. 155-163 (CRC Press, Inc., West Palm Beach, FL, 1978).

Key words: electrodes, errors; electrodes, ion-selective; electrodes, reference; ion-selective electrodes; reference electrodes; sensors, chemical.

lon-selective electrodes have demonstrated unique features for the measurement of a variety of ionic and gaseous species. While the advantages of these electrodes are widely known and appreciated, it is usually not until one is actually using these sensors that the problems and pitfalls become apparent and may result in serious errors and considerable aggravation. The causes of these problems are almost as varied as the sensors and the samples, but several common sou rces can be identified: interferences and/or fouling of the electrode, sample matrix effects, reference electrode instability, and improper calibration of the measurement system. These pitfalls are discussed in 
some detail with suggestions for overcoming or minimizing the problems and their associated errors.

These sensors can be a useful and convenient means for the dctermination and monitoring of selected species, but only if thc potential pitfalls are recognized and eliminated. More than any other modern analytical technique, ion-selective electrodes require a sound knowledge of solution chemistry in order to achieve the maximum effectiveness of these sensors.

18363. Holton, J. K., Interfacing building design and solar energy research and standards, Proc. Joint Conf. 1976 of the American Section of the Int. Solar Energy Society and the Solar Energy Society of Canada, Winnipeg, Canada, Aug. I520, 1978, pp. 74-82 (American Section of the Int. Solar Energy Society, Cape Canaveral, FL, 1978 ).

Key words: building research; NBS solar standards projects; solar energy.

An extensive program of solar energy research and standards development has been undertaken by the National Bureau of Standards in support of the national effort to expedite the introduction of solar usage. The communication between researchers and the building community, who will utilize the products of this research, is of critical importance for effective conduct of this program. This paper examines a number of the programs being conducted at NBS, identifies the intended user groups, and describes some of the paths of communication that are being used. 1t is hoped that a clearer understanding of the research/user linkage will lead to more effective communication between those working in the field.

18364. Keller, R. A., Travis, J. C., Recent advances in analytical laser spectroscopy, Paper in Analytical Laser Spectroscopy, N. Omenetto, Ed., Chapter 8, 493-538 (John Wiley \& Sons, Inc., New York, NY, 1979).

Key words: atomic flame fluorescence; intracavity absorption; isotope analysis; laser analysis; laser fluorescence; laser spectroscopy; microfluorescence; saturation spectroscopy; tunable laser.

A review of new, potentially analytical applications of lasers is presented. Topics include: description of laser properties, direct absorption measurement, frequency modulation, intracavity absorption, fluorescence measurements, saturation spectroscopy, isotope analysis, CARS, flame fluorescence, condensed phase fluorimetry, energy state population distribution, and microfluorescence.

18365. Tewksbury, S. K., Meyer, F. C., Rollenhagen, D. C., Schoenwetter, H. K., Souders, T. M., Terminology related to the performance of $\mathrm{S} / \mathrm{H}, \mathrm{A} / \mathrm{D}$, and $\mathrm{D} / \mathrm{A}$ circuits, IEEE Trans. Circuits Syst. CAS-25, No. 7, $419-426$ (July 1978).

Key words: analog-to-digital converter; digital-to-analog converter; IEEE subcommittee; performance specifications; sample/hold circuit; standards; terminology.

A review of terminology, often misunderstood or misused, concerning the performance of sample-and-hold $(\mathrm{S} / \mathrm{H})$ circuits, analog-to-digital (A/D) converters, and digital-to-analog (D/A) converters is presented. Although a set of general definitions is presented, definitions consistent with the needs of users and with the measurement capabilities of manufacturers are not easily obtained. The definitions presented have been selected by the authors from among definitions suggested by members of the Subcommittee on $A / D$ and D/A Converters of the IEEE Network Applications and Standards Committee. It is hoped that others interested in the problem of terminology will submit their opinions to one of the authors before any final recommendations are made by the Subcommittee.
8366. Younger, S. M., Wiese, W. L., Systematic trends for the oscillator strengths of resonance transitions in the $\mathrm{Cu}$ and $\mathrm{Zn}$ isoelectronic sequences, Phys. Rev. A 18, No. 5, 2366-2368 (Nov. 1978).

Key words: Cu sequence; oscillator stength; $\mathrm{Zn}$ sequence.

Ncw systematic trend curves for the oscillator stengths of the $4 s-4 p$ resonance transitions of $\mathrm{Cu}$ - and $\mathrm{Zn}$-like ions have been derived from a critical analysis. This analysis takes into account recent theoretical results as well as a simulation study of cascade effects in beam-foil experiments which showed that the currently available experimental data for high ions may be too low by as much as $40-70 \%$. The new analysis yields reliable interpolated data for many ions within the $\mathrm{Cu}$ and $\mathrm{Zn}$ isoelectronic sequences.

18367. Chang, S. J., Zapas, L. J., Several relations for comparison of a general rate fluid and the BKZ fluid, Proc. VIIth Int. Congress of Rheology, Gothenburg, Sweden, Aug. 23-27, 1976, C. Klason and J. Kubát, Eds., pp. 566-567 (Tages-Anzeiger/Regina-Druck, Zurich, Switzerland, 1976).

Key words: BKZ fluid; constitutive equation; non-linear flow histories; rate fluid; simple shear.

In the framework of a general rate fluid and a BKZ fluid the stress components for a shearing flow history can be obtained from a knowledge of the behavior in other flow histories. In some cases the two fluids are indistinguishable. To avoid specialized forms of either fluid we obtained a set of rheological relations (relations which are independent of the material properties) for two flow histories, stress relaxation after shear and suddenly applied steady shear. It is found that the relations are identical for the two fluids only in shear rates in the range of a second order fluid.

18368. Christ, B. W., Smith, J. H., Brady, C. H., Analyzing fire extinguisher failures, Met. Prog. 114, No. 8, 28-32 (Dec. 1978).

Key words: circumferential tearing; fire extinguisher; hydrostatic pressure testing; intergranular cracking stainless steel; sensitized metal.

Hydrostatic pressure testing and metallographic examination was carried out on stainless steel inverting type fire extinguishers to determine the cause of failures by circumferential tearing at the dome end of the extinguishers. Intergranular cracking of sensitized metal, perhaps over a period of 15-20 years, seemed to be the cause of these failures.

18369. Kaufman, V., Sugar, J., Analysis of the spectrum of four-times-ionized lutetium (Lu v), J. Opt. Soc. Am., 68, No. 11, 1529-1541 (Nov. 1978).

Key words: energy levels; lutetium; spectrum; wavelengths.

Spectra of Lu obtained with a sliding spark discharge at peak currents of 50-500 A were recorded with a $10.7 \mathrm{~m}$ normal incidence spectrograph in the range of 500-2100 $\AA$. Intercomparison of spectra revealed a distinct separation of Lu III, IV, and $v$, the first two of which have already been analyzed. The present work contains an interpretation of $\mathrm{Lu} \mathrm{V}$ in which 419 lines are classified as transitions among 136 energy levels of the $4 f^{13}, 4 f^{12} 5 d, 4 f^{12} 6 s$, and $4 f^{12} 6 p$ configurations. Calculated energy levels and eigenvectors, obtained with fitted values for the radial integrals, are given.

18370. Olsen, H. A., Maximon, L. C., High-frequency limit of bremsstrahlung, Phys. Rev. A 18, No. 6, 2517-2522 (Dec. 1978 ). 
Key words: atomic screening effects; bremsstrahlung high frequency limit; bremsstrahlung spectrum tip; continuum $x$ rays; Coulomb field; non-relativistic bremsstrahlung.

It is shown that, contrary to common belief, the. bremsstrahlung cross section vanishes at the high-frequency limit for a neutral atom. The Sommerfeld finite value at the upper limit is valid only for atomic fields falling off as $r^{-1}$ for large distances, i.e., for ionized atoms. The behavior of the cross section at the high-frequency limit is closely connected to the position of bound states close to the continuum limit for the atom. An explicit calculation is performed for a particular screened atomic field. It is shown that the resonances in the bremsstrahlung cross section close to the high-frequency limit found experimentally by Liefield $e t a l$., can be explained as final-state resonance scattering.

18371. Seltzer, S. M., Hubbell, J. H., Berger, M. J., Some theoretical aspects of electron and photon dosimetry, Proc. National and International Standardization of Radiation Dosimetry, Atlanta, GA, Dec. 5-9, 1977, IAEA-SM-222/05, II, 3-43 (International Atomic Energy Agency, Vienna, Austria, 1978).

Key words: absorbed dose; attenuation coefficient; detector response functions; dosimetry; electrons; foil transmission; photons; stopping power; transport theory.

The dosimetry standardization programme at the National Bureau of Standards (NBS) has a number of theoretical components. These include the compilation of standard cross-section data sets, the theoretical analysis of detector response to various radiations, the spectral and directional characterization of radiation sources, and the determination of absorbed-dose distributions in irradiated media. This paper describes recent results, with emphasis on photon and electron dosimetry. A discussion is given of some recent developments pertaining to photon attenuation coefficients and electron stopping powers. Response functions are presented for intrinsic germanium detectors (used to measure the output of diagnostic $\mathrm{X}$-ray machines) and for sodium iodide detectors (used to measure the spectral characteristics of one of the NBS ${ }^{\circ 0} \mathrm{Co}$ irradiation facilities). As examples of source characterization, calculations are described pertaining to the passage of high-energy electron beams through foils. Consideration is given to thin foils used to spread the electron beam, and to thick foils used as bremsstrahlung converters. The results include the energy spectra and angular distributions of the transmitted electrons and emergent bremsstrahlung photons. An example of the calculation of absorbed-dose distributions is given for irradiation of a carbon phantom by a ${ }^{\circ 0} \mathrm{Co}$ gamma-ray beam.

18372. Alperin, H. A., Pickart, S. J., Rhyne, J. J., Small-angle neutron scattering from rare-earth iron alloys (Extended Abstract), J. Appl. Cryst. 11, 648-649 (1978).

Key words: amorphous alloys; magnetic partides; magnetism; neutron scattering; rare earths; small angle scattering.

Small angle neutron scattering (SANS) has been used to investigate the onset of magnetic order and some aspects of the magnetic microstructure in a series of bulk amorphous rareearth iron alloys prepared by dc rapid sputtering.

18373. Cahn, J. W., Allen, S. M., A microscopic theory for domain wall motion and its experimental verification in Fe-Al alloy domain growth kinetics, J. Phys. (Paris), Colloq. C7, 38, No. 12, C7-51-C7-54 (Dec. 1977).

Key words: alloys; antiphase domains; critical behavior; domain growth; domain walls; ordering; surface mobility.
A microscopic theory for curved antiphase domain wall motion in ordered structures leads to a prediction that velocity is proportional to mean curvature. Unlike previous models, the velocity is not proportional to domain wall free energy. Experimental results on domain growth in ordered $\mathrm{FeAl}$ alloys over a range of temperatures, times and compositions, are consistent with the theory. In the vicinity of the critical temperature where domain wall free energy tends to zero, domain growth is not slowed.

18374. Steenbergen, C., Rush, J. J., Neutron scattering study of the methyl-group reorientations and the low temperature phase transition in $\left(\mathrm{CH}_{3}\right)_{2} \mathrm{SnF}_{2}, J$. Chem. Phys. 70, No. 1, 5056 (Jan. 1, 1979).

Key words: activation energy; methyl group; neutron scattering; potential barrier; quasielastic scattering; reorientation; residence time; tunneling.

The reorientation of the methyl groups in solid $\left(\mathrm{CH}_{3}\right)_{2} \mathrm{SnF}_{2}$ has been investigated by neutron quasielastic scattering. It is found that a phase transition occurs in the solid at about 70 $\mathrm{K}$, which might be of second order. The shape of the measured quasielastic lines can be described by instantaneous threefold jumps of the methyl groups. From the derived residence times as a function of temperature below the phase transition, an activation energy $E_{a} / k_{B}=250 \mathrm{~K}$ and a residence time at infinite temperatures $\tau_{0}=0.10 \mathrm{ps}$ have been determined. Above the phase transition the activation energy is at least a factor 2 smaller.

18375. Breiter, D. N., Roush, M. L., Trace element characterization of thin polymer films by proton-induced $x$-ray emission spectrometry, Macromolecules 10, No. 4, 868-870 (Aug. 1977).

Key words: copper; iron; plastic; polymer; proton-induced $\mathrm{x}$-ray fluorescence; thin films; trace element analysis; trace element concentrations; zinc.

Proton-induced x-ray fluorescence is a particularly wellsuited technique for the simultaneous quantitative analysis of trace elements in thin polymer films. Since the sample is thin and of low atomic number, matrix effects due to proton energy loss and $\mathrm{x}$-ray self absorption are small. Sensitivities are sufficient to allow for the $5-10$ minute analysis of films of $1 \mathrm{mg} / \mathrm{cm}^{2}$ areal density for iron, copper and zinc at concentration of several $\mathrm{ng} / \mathrm{cm}^{2}$.

18376. Chang, S. S., Automated adiabatic calorimetric system for heat capacity measurement, Proc. 7th Symp. on Thermophysical Properties, Gaithersburg, MD, May 10-12, 1977, pp. $75-82$ (The American Society of Mechanical Engineers, New York, NY, 1977).

Key words: adiabatic calorimetry; automated calorimetry; calorimetry; heat canacity; measurement automation; $\mathrm{p}$ Terphenyl; thermodynamic nroperties; $\lambda$-type transition.

A fully automated adiabatic calorimetric system for heat capacity measurements from 2 to $380 \mathrm{~K}$ is described. The system includes both automatic analog adiabatic shield control and automatic digital data acquisition and experimental control. The system incorporates a self-balancing, high resolution potentiometric system as the main instrument. The automated system is capable of making continuous, unattended calorimetric measurements over long periods of time. The precision of the heat capacity measurements is about $0.02 \%$ when the temperature increment of each measurement is greater than $1 \mathrm{~K}$. For higher temperature resolutions the precision of the present system is apparently limited by an uncertainty of $0.2 \mathrm{mK}$ in the estimation of the temperature increment. 
18377. Chang, S. S., Heat capacity and thermodynamic propertles of solld synthetic sapphlre, $\alpha-\mathrm{Al}_{2} \mathrm{O}_{3}$, Proc. 7 th Symp. on Thermophysical Properties, Gaithershurg, MD, May 10-12, 1977, pp. 83-90 (The American Society of Mechanical Engineers, New York, NY, 1977).

Key words: alumina; aluminum oxide; calorimetry; corundum; enthalpy; heat capacity; sapphire; specific heat; standard reference materials; thermodynamic properties.

Heat capacity of the National Bureau of Standards calorimetric Standard Reference Material 720, synthetic Sapphire ( $\alpha$ $\mathrm{Al}_{2} \mathrm{O}_{3}$ ), for heat capacity and enthalpy, has been measured from 8 to $375 \mathrm{~K}$ with a fully-automated adiabatic calorimeter. By combining the results from this work and those from NBS high-temperature drop calorimetry on the same sample, thermodynamic functions of $\alpha-\mathrm{Al}_{2} \mathrm{O}_{3}$, from 0 to $2250 \mathrm{~K}$, based entirely on NBS experimental measurements on SRM 720, are derived.

18378. Cohen, J., Methodology of product life testing, Proc. 27 th Meeting of the Mechanical Failures Prevention Group, Gaithershurg, MD, Nov. 1-3, 1977, T. R. Shives and W. A. Willard, Eds., pp. 31-41 (National Bureau of Standards, Gaithersburg, MD, May 1978).

Key words: consumer products; reliability engineering; testing methodology; useful life.

A methodology was formulated for estimating, through laboratory testing, useful life and associated performance of colısumer products. Excerpts from two key parts-concepts of reliability engineering and procedure to guide the formulation of tests-are given here. Criteria for assessing tests are presented.

18379. Durst, R. A., Cali, J. P., Recommended reference materials for realization of physicochemical properties, Pure Appl. Chem. 50, E. F. G. Herington, Ed., $1485-1517$ (1978).

Key words: activity coefficient; hydrogen ion activity; ionic activity; ionic activity scales; $\mathrm{pD} ; \mathrm{pD}$ scale; $\mathrm{pH} ; \mathrm{pH}$ scales; potentiometric ion activity.

This report is a survey and compilation of $\mathrm{pH}$ and ionic activity reference materials in use throughout the world. An introductory section discusses the differences in the national $\mathrm{pH}$ scales and provides a brief review of the equations which define these operational scales. The major part of this report tabulates the reference materials (composition and values as a function of temperature) used to realize the $\mathrm{pH}$ scales presently being employed in Germany, Hungary, Japan, Poland, Rumania, USSR, UK, and the USA. Data sheets are also included for the $\mathrm{PD}$ and ionic activity reference materials used in the United States. This report was prepared under the auspices of the IUPAC Commission 1.4 Subcommittee on Calibration and Test Materials.

18380. Joseph, J. T., Hybl, A., Flynn, J. H., Differentlal scanning calorimetry studies of some analogs for the lipid component of biological membranes, Chem. Phys. Lipids 22, 239-243 (1978).

Key words: benzyl substituted diglycerides; differential scanning calorimetry; heat of fusion; lecithins; lipids; melting temperature; metastable states; phenyl substituted diglycerides; phospholipids; polymorphism; recrystallization temperature.

The melting behavior of members of newly synthesized series of rac-1,2-diglycerides with substituted phenyl groups or a benzyl group on the 3 -position was investigated with differential scanning calorimetry (DSC). Solution crystallized samples had single melting temperatures, higher than those of the quenched or annealed specimens. Quenched samples exhibited polymorphic behavior; some melted and recrystallized during slow heating. This behavior is similar to that of lecithins and suggests that X-ray diffraction studies of the substituted diglycerides may be useful for understanding membrane structure and functions.

18381. Treado, M. J., Diamond, J. J., Taggart, H. E., Jones, $\mathbb{R}$. N., Saulsbury, L. F., Workman, J. L., NILECJ standard for body-worn FM transmitters, NILECJ-STD-0214.00, 20 pages (U.S. Department of Justice, Law Enforcement Assistance Administration, National Institute of Law Enforcement and Criminal Justice, Washington, DC, Dec. 1978).

Key words: body-worn transmitters; communications equipment; FM transmitters; law enforcement equipment; standards; surveillance; undercover equipment.

This is a voluntary national standard that establishes minimum performance requirements and methods of test for body-worn FM transmitters used by law enforcement personnel in undercover operations. The standard specifies the test equipment needed, the test methods, and the minimum performance requirements necessary for satisfactory performance.

18382. Wang, F. E., Mitchell, M. A., Sutula, R. A., Holden, J. R., Bennett, L. H., Crystal structure study of a new compound $\mathrm{LI}_{5} \mathrm{~B}_{4}$, J. Less-Common Met. 61, 237-251 (1978).

Key words: crystal; diffraction; $\mathrm{Li}_{5} \mathrm{~B}_{4}$; neutron powder; structure; $x$ ray.

A study has been made of the crystal structure of $\mathrm{Li}_{5} \mathrm{~B}_{4}$ by $x$-ray, neutron powder diffraction techniques and NMR (nuclear magnetic resonance) measurements. The crystal structure thus determined is rhombohedral (R3) in its short-range ordered state and bcc (123) in its statistically disordered (longrange) state.

The boron atomic arrangement consists of a coplanar triangular cluster of four boron atoms which are situated at the vertices and the center of the triangle. This boron atomic arrangement has no precedent either in metal-borides or boronhydrides. There is a strong indication that: 1) electrons on the boron atoms at the vertices partially transferred (approx. 1.3 electrons) to the boron atom at the center of the triangle in $\left.\mathrm{Li}_{5} \mathrm{~B}_{4}, 2\right)$ the amount of electron transfer increases with temperature rise.

Lithium atoms on the other hand, cluster in a bitetrahedral form (two tetrahedrons sharing a common face) with five lithium atoms occupying the vertices. This lithium atomic arrangement is in part similar to the hexagonal structure of lithium at low temperature.

18383. Watson, R. E., Bennett, L. H., A Mulliken electronegatlvity scale and the structural stability of simple compounds, J. Phys. Chem. Solids 39, $1235-1242$ (1978).

Key words: alloys; electronegativity; electronic configuration; $s-p$ binding; structural stability.

A new electronegativity scale is derived, in the spirit of Mulliken's original scheme, in terms of neutral atom spectroscopic data. The effect of changing the atomic configuration for $\mathbf{C}$ from covalent $\left(s p^{3}\right)$ to metallic $\left(s^{2} p^{2}\right)$ is considered. Structural stability maps are presented for non-octet non-transition metal compounds, and for two classes of transition metal-non-transition-metal compounds.

18384. Anderson, W. E., Davis, R. S., Dissipation factor measurements on dielectric materials at liquid helium temperatures, Proc. Conf. on Electrical Insulation and Dielectric Phenomena, Gaithersburg, MD, Nov. 3-6, I975, pp. 151-156 (National Academy of Sciences, Washington, DC, 1978). 
Key words: cryogenic; dielectric loss; dissipation factor; high voltage; low temperature polymer.

The designers of high voltage superconducting a.c. cables need accurate dissipation factor measurements of proposed insulating materials. A technique for making these measurements at high voltage using a current comparator bridge is described. Dissipation factor data at $60 \mathrm{~Hz}$ and $4.2 \mathrm{~K}$ is presented for several polymers. The estimated uncertainty in the dissipation factor is $\pm 5 \times 10^{-6}$.

18385. Chi, J., Kelly, G. E., A method for estimating the seasonal performance of residential gas and oil-fired heating systems, ASHRAE Trans. 84, Part 1, 405-420 (1978).

Key words: boiler; combustion; energy; furnace; gas-fired; heating; oil-fired; rating; space-heating; testing.

An evaluation nrocedure is described for estimating the seasonal efficiency of a gas or oil-fired furnace which is located in an indoor heated space and uses conditioned air for combustion and draft control. It involves carrying out the following four tasks: 1 ) measuring the flue gas temperature and $\mathrm{CO}_{2}$ concentration during steady-state operation; 2) obtaining information on the shape of the flue gas temperature-vs-time curves as a unit cools-down and warms-up from steady-state conditions; 3) assigning appropriate values to various factors which describe the off-period air flow rate through the flue and stack, the degree of furnace oversizing, and the effect of furnace operation on infiltration, and 4) carrying out the calculation procedure described herein to determine the various on-period and off-period losses and the seasonal efficiency of a furnace or boiler operating in any given climatic region. Several examples are worked out to illustrate the nature of this simplified procedure.

18386. Unassigned.

18387. Goldman, D. T., Managing research, Phys. Today, Letter to the Editor 32, No. 1, 94-95 (Jan. 1979).

Key words: management; research.

18388. Horwitz, A. B., Leone, S. R., Laser-excited resonant isotopic $V \rightarrow V$ energy transfer: $\mathrm{H}^{35} \mathrm{Cl}-\mathrm{H}^{37} \mathrm{Cl}, \mathrm{H}^{79} \mathrm{Br}-\mathrm{H}^{81} \mathrm{Br}$, $\mathrm{D}^{35} \mathrm{Cl}-\mathrm{D}^{37} \mathrm{Cl}$, and $\mathrm{D}^{79} \mathrm{Br}-\mathrm{D}^{81} \mathrm{Br}$, J. Chem. Phys. 69, No. 12 , $5319-5328$ (Dec. 15, 1978).

Key words: hydrogen halides; isotopes; laser; vibrational energy transfer.

An isotopically selective transverse discharge chemical laser coupled with infrared fluorescence techniques is used to measure vibration-to-vibration energy transfer rates between $v=1$ levels of the isotopic species $\mathrm{H}^{35} \mathrm{Cl} \leftrightarrow \mathrm{H}^{37} \mathrm{Cl}, \mathrm{H}^{79} \mathrm{Br} \leftrightarrow \mathrm{H}^{81} \mathrm{Br}$, $\mathrm{D}^{35} \mathrm{Cl} \leftrightarrow \mathrm{D}^{37} \mathrm{Cl}$, and $\mathrm{D}^{79} \mathrm{Br} \leftrightarrow \mathrm{D}^{81} \mathrm{Br}$. The measured rate constants are $k_{\mathrm{HCl}}=(1.91 \pm 0.04) \times 10^{-11}, k_{\mathrm{HBr}}=(1.50 \pm 0.06) \times$ $10^{-11}, k_{D C l}=(1.18 \pm 0.08) \times 10^{-11}$, and $k_{D B r}=(8.34 \pm 0.17) \times$ $10^{-12} \mathrm{~cm}^{3}$ molecule ${ }^{-1} \mathrm{sec}^{-1}$. All of the processes are nearly resonant and the rates for the hydrogenated species are on the order of one-tenth gas-kinetic. The rates for $\mathrm{DCl}$ and $\mathrm{DBr}$ are found to be 1.6 and 1.8 times slower than the corresponding hydrogen halides. Direct comparison of the results with theoretical predictions for such resonant energy transfer nrocesses shows disagreement, indicating that further development of theoretical methods for these systems is desirable.

18389. McCann, K. J., Flannery, M. R., Elastic scattering and rotational excitation in ion-molecule collisions. II. $\mathrm{Li}^{+}-\mathbf{H}_{2}$ and $\mathrm{H}^{+}-\mathrm{H}_{2}$ collisions, J. Chem. Phys. 69, No. 12, 5275-5287 (Dec. 15, 1978).

Key words: ion-molecule collisions; rotational excitation; semiclassical treatment.
A general semiclassical treatment of elastic scattering and of rotational excitation in ion-molecule collisions is presented. When the orbits associated with the different channels corresponding to the internal modes do not differ significantly, simplification occurs and the internal degrees of freedom can then be coupled to the relative motion via the introduction of an optical potential (which in turn depends on the transition amplitudes). Total energy is consequently conserved. An expression is derived for the inelastic scattering amplitude which acknowledges various interference effects and possible rainbow scattering. With all phase-information supressed, the procedure, when compared with the full quantum-mechanical results, reproduces the background elastic and inelastic scattering in $\mathrm{Li}^{+}-\mathrm{H}_{2}$ and in $\mathrm{H}^{+}-\mathrm{H}_{2}$ collisions. Restoration of the phases, particularly of the eikonal or action phases associated with the different classical paths that contribute to a specified scattering angle, produces the interference oscillations present in the differential cross section for scattering angles less than the rainbow angle. The method, when compared with the full quantal procedure, is remarkably efficient and accurate.

\section{Unassigned.}

18391. Sachse, W., Golan, S., The scattering of elastic pulses and the non-destructive evaluation of materials, Proc. American Society of Mechanical Engineers Winter Annual Meeting, San Francisco, CA, Dec. 10-15, 1978, pp. 11-31 (American Society of Mechanical Engineers, New York, NY, 1979).

Key words: acoustic; crack; defects; elastic solid; pulses; scattering; ultrasonic.

This paper is a review of the results of experiments and their interpretation of the scattering of bulk ultrasonic pulses from various smooth and crack-like obstacles imbedded in an elastic solid. The scattering by circular and elliptical cylinders and multiple inclusions possessing a wide range of acoustic properties and crack-like defects of various sizes and orientations is described. For the smooth obstacles, it is shown that both arrival-time and spectral analysis of the scattered signals contain information regarding the characteristics of the scatterer and either can be used to characterize such obstacles. For the crack-like scatterers, the time-delays of various signals scattered by the crack are measured relative to reference signals from the specimen surfaces from which the crack size can be ascertained.

18392. Celotta, R. J., Swanson, N., Kurepa, M., Electron scattering from ozone, Proc. Int. Conf. on the Physics of Electronic and Atomic Collisions, Paris, France, July 21-27, 1977, pp. 656-657 (Commissariat a L’Energie Atomique, Paris, France, 1978).

Key words: electron scattering; energy loss; excited states; negative ions; ozone; resonances.

We present recent electron scattering measurements in ozone which (1) resolve vibrational structure in the energy loss range of 1.3-2.4 eV and (2) exhibit resonances in the incident energy range of $0.9-1.9 \mathrm{eV}$.

18393. Hanson, D. W., Davis, D. D., Cateora, J. V., Microprocessor-based satellite-controlled clock, Proc. of the NBS-IEEE Microcomputer-Based Instrumentation Conf., Gaithersburg, MD, June 12-13, 1978, pp. 83-86 (Institute of Electrical and Electronics Engineers, Silver Spring, MD, 1978).

Key words: clock; GOES; microprocessors; satellite; synchronization; time.

As a demonstration of the usefulness of the NBS-sponsored time signals from two U.S. weather satellites, NBS designed and 
built a "Satellite-Controlled Clock." The initial design used random logic requiring nearly 80 packages of TTL logic. With the advent of microprocessors, the clock was redesigned using a four bit microprocessor and a scientific calculator chip.

Today, commercial versions of the NBS-designed clock are available and are finding use in the electric power industry, radio and television broadcasting, defense, communications, and geophysical monitoring.

The evolution of the satellite-controlled clock from random logic to commercial products using eight bit microprocessors are discussed in some detail.

18394. Hord, J., Hydrogen safety: Am annotated bibliography of regulations, standards and guidelines, Proc. World Hydrogen Energy Conf., Zurich, Switzerland, Aug. 21-24, 1978, T. N. Veziroglu and W. Seifritz, Eds., pp. 2247-2248 (Pergamon Press Inc., Elmsford, NY, 1978).

Key words: codes; guidelines; hydrogen; regulations; safety; standards.

Current federal regularions applicable to the manufacture and maintenance of hydrogen equipment and to the distribution of gaseous and liquid hydrogen in the United States are summarized and presented in a table of regulatory. references. A similar table of references is presented for nonmandatory standards and guidelines pertinent to hydrogen safety and hydrogen facilities/equipment specifications. These two tables concisely summarize the best available information that has been published in industry, universities and government agencies for the safe production, storage and handling of hydrogen.

18395. Parrish, W. R., Arvidson, J. M., LaBrecque, J. F., Evaluation of LNG sampling-measurement systems for custody transfer, Proc. American Gas Association Operating Section Transmission Conf., Montreal, Quebec, Canada, May 8-10, 1978 and Distribution Conf., Denver, CO, May 22-24, 1978, pp. T-236-T-242 (American Gas Association, Arlington, VA, 1978).

Key words: custody transfer; density; gas analysis; gas chromatography; heating value; liquefied natural gas; sampling.

This paper describes the results of a systematic evaluation of equipment and procedures for sampling and determining composition of liquefied natural gas (LNG) from flowing streams. Laboratory and field test results show that the precision of the computed heating values of samples taken with the recommended sampling-measurement system could be within \pm 0.30 percent; of this, $\pm \mathbf{0 . 0 6}$ percent is due to the random error in the composition analysis by gas chromatography. The accuracy of the composition measurement depends upon the accuracy of the gas analysis. The paper describes the recommended system and the proper operating conditions.

18396. Parrish, W. R., Brennan, 3. A., Siegwarth, J. D., LNG custody transfer research at National Bureau of Standards, Proc. American Gas Association Operating Section Transmission Conf., Montreal, Quebec, Canada, May 8-10, 1978 and Distribution Conf., Denver, CO, May 22-24, 1978, pp. T243-T-249 (American Gas Association, Arlington, VA, 1978).

Key words: cryogenic densimeter; custody transfer; density; flowmetering; liquefied natural gas; sampling.

This paper outlines the current activities of the National $\mathrm{Bu}$ reau of Standards which relate to the custody transfer of liquefied natural gas. The paper describes the results of the thermophysical properties work, including the LNG density project. The paper summarizes the results of the flowmeter and densimeter tests. It discusses briefly the results of the LNG Sampling Measurement Project.
18397. Reite, M., Edrich, J., Zimmerman, J. T., Zimmerman, J. E., Human magnetic auditory evoked fields, Electroencephalogr. Clin. Neurophysiol. 45, 114-117 (1978).

Key words: auditory evoked response; magnetoencephalography; SQUID magnetometer.

Several laboratories have demonstrated that both visual and somatosensory magnetoencephalographic (MEG) averaged evoked fields (AEF) are more localized in their scalp distribution than are their more conventional EEG evoked potential counterparts (Brenner et al. 1975; Teyler et al. 1975; Brenuer et al. 1978; Reite and Zimmerman 1978; Zimmerman). In this report, we present the first evidence of $M E G$ auditory evoked fields. Our data indicate that they, too, are highly localized in their scalp distribution.

18398. Taggart, H. E., Shafer, J. F., Testing of electronic industries association land-mobile communication antenna gain standards at the National Bureau of Standards, IEEE Trans. Veh. Technol. VT-27, No. 4, 259-264 (Nov. 1978).

Key words: antenna; communications; land-mobile; standards.

The Electronic Industries Association has a published standard, EIA RS-329A, Minimum Standards for Land-Mobile Communications Antennas, Dec. 1975. This standard details the minimum performance requirements and the test methods for evaluating the performance of fixed and base station antennas at frequencies from 25 to $1000 \mathrm{MHz}$. Also included in this standard are the specifications for a set of standard antennas for use in various frequency bands. The EIA Antenna Committee, TR8.11, requested the National Bureau of Standards to calibrate the gain of some of these antenna standards. Two antennas were calibrated in the $450-512 \mathrm{MHz}$ band, and two antennas in the $800-900 \mathrm{MHz}$ band. This paper describes in detail the techniques used throughout the measurement program, the results, and the measurement uncertainties.

Two basic methods of measuring the gain of the EIA antennas were employed during this calibration. The three-antenna technique was used at some frequencies, and the standard field technique was used at other frequencies. Both techniques are described. The NBS antennas used for the measurements were standard-gain pyramidal, horn antennas.

The antenna range used for the measurement is described. This is a vertical range using nonmetallic towers and hardware, thus providing essentially free-space conditions in which reflections and multipath problems are minimized.

The measurements were made in terms of absolute power gain, i.e., referenced to an isotropic radiator. These results are discussed and also compared to the gain figures listed in EIA standard RS-329A.

18399. Boettinger, W. J., Burdette, H. E., Kuriyama, M., X-ray magnifier, Rev. Sci. Instrum. 50, No. 1, 26-30 (Jan. 1979).

Key words: asymmetric diffraction; dynamical diffraction; microradiography; radiography; radiology; real-time radiography; resolution; $x$-ray image magnifier.

A method for the magnification of $\mathrm{x}$-ray radiographic images is described and demonstrated. This magnifier employs two successive asymmetric diffractions of an $x$-ray beam from highly perfect silicon crystals. The two diffractions magnify the beam in two perpendicular directions. A device with a magnification of $25 \times$ is demonstrated for $\mathrm{Cu} \boldsymbol{K}_{a}$ radiation. This device preserves and sometimes improves the resolution inherent in the radiographic technique. The $x$-ray magnifier is particularly useful in circumventing the relatively poor spatial resolution of electro-optical imaging systems needed for real-time observations. Basic limits on magnification and resolution using this method are described. 
18400. Coursey, B. M., Hutchinson, J. M. R., Lucas, L. L., Mann, W. B., Matsumura, T., Noyce, J. R., Radioactivity standards for environmental monitoring, J. Radioanal. Chem. 43, $451-460$ (1978).

Key words: low-level; measurements; radioactivity; standards; traceability.

The low-level radioactivity laboratory in the Radioactivity Section of the National Bureau of Standards, and its work in producing standards for monitoring in the environment, are described.

18401. Heydemann, P. L. M., Generation and measurement of pressure, Proc. NATO Summer School for High Pressure, Corfu, Greece, Sept. 26-Oct. 7, 1977, H. Kelm, Ed., pp. $1-49$ (D. Reidel Publishing Company, Boston, MA, 1978).

Key words: calibration; high pressure; high pressure chemistry; pressure generator.

This is a review of methods used to establish the primary pressure scale, of transfer gages and of the most common fixed points on the pressure scale. The major types of pressure generators and some important components like pumps, electrical feedthroughs and windows will be discussed. The review is generally limited to the hydrostatic environment.

18402. Kingston, H. M., Barnes, I. L., Brady, T. J., Rains, T. C., Champ, M. A., Separation of eight transition elements from alkali and alkaline earth elements in estuarine and seawater with chelating resin and their determination by graphite furnace atomic absorption spectrometry, Anal. Chem. 50, No. 14, 2064-2070 (Dec. 1978).

Key words: chelating resin; graphite furnace atomic absorption; sea water; separation; trace element analysis; water analysis.

A method is described for determining $\mathrm{Cd}, \mathrm{Co}, \mathrm{Cu}, \mathrm{Fe}, \mathrm{Mn}$, $\mathrm{Ni}, \mathrm{Pb}$, and $\mathrm{Zn}$ in seawater using Chelex 100 resin and graphite furnace atomic absorption spectrometry. The $\mathrm{pH}$ of the seawater is adjusted to 5.0 to 5.5 and then passed through a Chelex 100 resin column. Alkali and alkaline earth metals are eluted from the resin with ammonium acetate and then the trace elements are eluted with two $5-\mathrm{mL}$ aliquots of $2.5 \mathrm{M}$ $\mathrm{HNO}_{3}$. The difficulties previously encountered with resin swelling and contracting have been overcome. By careful selection of the instrumental conditions, it is possible to determine subnanogram levels of these trace elements by graphite furnace atomic absorption spectrometry. The proposed method has been shown to separate quantitatively the elements desired from the alkali and alkaline earth metals and has been applied in the analysis of trace elements in estuarine water from the Chesapeake Bay and seawater from the Gulf of Alaska.

18403. Mielenz, K. D., Refraction correction for fluorescence spectra of aqueous solutions, Appl. Opt. 17, No. 18, 28752876 (Sept. 15, 1978).

Key words: aqueous solutions; fluorescence spectra; refractive index, uv, visible and ir; water.

A closed expression is given for the refractive index of water at $20{ }^{\circ} \mathrm{C}$ for the wavelength region $0.235 \mu \mathrm{m}$ to $1.028 \mu \mathrm{m}$. This expression is accurate to \pm 0.0001 , and can be used for the refraction correction of fluorescence emission spectra of aqueous solutions.

18404. Barnes, J., Fanconi, B., Critical review of vibrational data and force field constants for polyethylene, J. Phys. Chem. Ref. Data 7, No. 4, 1309-1321 (1978).
Key words: force field refinement; lattice dynamics; $n$-alkanes; non-bonded potential functions; polyethylene; vibrational data.

The results of a critical review of vibrational data, their assignments, and force field constants of polyethylene and the related homologous series of $\boldsymbol{n}$-alkanes are presented. The vibrational frequencies derived from Raman spectroscopy, infrared spectroscopy, and neutron inelastic scattering were collected from the literature. We have reviewed the vibrational band assignments starting from the comprehensive treatment of the $n$ alkanes by Schachtschneider and Snyder and including subsequent reassignments. Theoretical calculations of the vibrational frequencies were reviewed with emphasis on the various models used for molecular structure and force fields. Lattice dynamical calculations of polyethylene were performed using a valence force field for intramolecular interactions and a force field derived from a nonbonded atom-atom potential function for intermolecular interactions. The molecular and lattice structural parameters were taken from $x$-ray and neutron diffraction studies of polyethylene and selected $n$-alkanes. A refinement procedure was carried out by the method of least squares on intramolecular force field constants and on parameters of a phenomenological nonbonded atom-atom potential energy function. The resulting force field constants and associated standard deviations are presented.

18405. Currie, L. A., Envirommental radiocarbon measure. ments, Proc. of the First Conf. on Radiocarbon Dating with Accelerators, Rochester, NY, Apr. 20-21, 1978, H. E. Gove, Ed., pp. $372-390$ (University of Rochester, Rochester, NY. 1978).

Key words: accelerator mass spectrometry; anthropogenic and natural carbonaceous species; atmospheric gases and particles; environmental pollutants; fossil fuels; low-level counting; radiocarbon.

Measurements of the ${ }^{14} \mathrm{C} /{ }^{12} \mathrm{C}$ ratio in environmental carbonaceous species can provide a unique indication of natural vs anthropogenic (fossil fuel) origin. Because of the low concentrations of atmospheric gases and particles which contain carbon, convenient sample sizes are limited to tens of milligrams of carbon. An assessment of the measurement feasibility, using $10 \mathrm{mg}-\mathrm{C}$ samples and Accelerator Mass Spectrometry and Low-Level Counting is given, together with the kinds of .environmental problems which might be studied. Preliminary lowlevel gas-proportional counting results, are given for atmospheric particulate samples containing 5-10 mg-C.

18406. Cuthill, J. R., ASTM Committee $E-42$ on surface analysis: Its history, scope, activities, and objectives, Am. Soc. Test. Mater., Stand. News, 6, No. 2, 8-11, 59-60 (Feb. 1978).

Key words: ASTM Committee E-42; Auger electron spectroscopy; electron spectroscopy; ESCA; secondary ion mass spectroscopy; surface analysis.

The history, purpose, scope, activities, aims, and objectives of ASTM Committee E-42 on Surface Analysis are summarized. The organization of $\mathrm{E}-42$ is given and specific examples of activities are described including the symposia that have either been held already or will be held in the near future. The use of "surface" and "analysis" are defined in terms of the scope of E-42. An estimate of the number of surface analysis instruments in the United States, and a distribution of industrial representation at our organizational meeting is presented to show both the magnitude and the breadth of interest in surface analysis.

18407. Cooper, J. W., Åberg, T., Shaking processes in $\beta$-decay, Nucl. Phys. A298, 239-252 (1978). 
Key words: beta decay; rearrangement; shake-off; shakeup.

A discussion of theoretical treatments of atomic rcarrangement processes accompanying $\beta$-decay is presented. A schematic model for $\mathrm{K}$-shell ejection or excitation is developed and the expected accuracy of this model and other theoretical treatments using approximate wave functions is discussed. Comparison with experimental evidence reveals that there is some evidence of direct processes but that uncertainties in calculations exist for low energy processes.

18408. Davis, G. T., DeReggi, A. S., Broadhurst, M. G., Nonuniform poling and pyroelectric response in a PVDF-TFE copolymer, Proc. 1977 Annual Report Conf. on Electrical Insulation and Dielectric Phenomena, Colonie, NY, Oct. 17-20, 1977, pp. 209-213 (National Academy of Sciences, Washington, DC, 1979).

Key words: blocking electrode; charge motion; polarization; poly(vinylchloride); poly(vinylidenefluoride); pyroelectric response; thermal pulse; vinylidenefluoridetetrafluoroethylene copolymer.

The transient pyroelectric response following a thermal pulse reveals that dipole alignment in a poled film of vinylidenefluoride-tetrafluoroethylene copolymer is non-uniform across its thickness. Charge migration on a time scale of minutes occurs within the unpoled region of the film after a step-change in temperature. The time constant for the charge motion becomes longer at lower temperatures and depends upon the poling history of the sample. Non-uniform poling is attributed to a non-uniform electric field within the polymer film resulting from the motion of charges under the influence of the voltage applied during the poling process. Poly(vinylidenefluoride) becomes poled much more uniformly and shows no evidence for charge motion following a stepchange in temperature. The effect of charge motion and redistribution of electric field is demonstrated by the reduced pyroelectric response from poly(vinylchloride) poled with mica as a blocking electrode.

18409. Braun, W., Herron, J. T., Tsang, W., Churney, K., High intensity infrared laser irradiation calorimetry: Direct-determination of heat input to chlorodifluoromethane and ethyl acetate, Chem. Phys. Lett. 59, No. 3, $492-497$ (Dec. I, 1978).

Key words: calorimetry; infrared; kinetics; laser chemistry; mechanisms; multiphoton; thermochemistry; unimolecular dissociation.

The heat absorbed when chlorodifluoromethane $\left(\mathrm{CF}_{2} \mathrm{HCl}\right)$ and ethyl acetate were irradiated with a pulsed infrared $\mathrm{CO}_{2}$ TEA laser was measured using a laser cálorimeter. The measurements show that $\mathrm{CF}_{2} \mathrm{HCl}$ at high pressure ( $>10$ torr) was completely thermally equilibrated during the laser pulse, while at low nressure $(<2$ torr) this system deviated considerably from thermal equilibrium. Ethyl acetate, however, was found to be non-thermal over the entire pressure range studied ( 0.5 to 20 torr). Implications of these observations to infrared induced unimolecular decompositions and molecular energy transfer are discussed.

18410. Davis, R. W., Moore, E. F., Mattingly, G. E., Miller, R. W., Numerical solutions for turbulent, swirling flow through target flowmeters, Proc. American Society of Mechanical Engineers 1978 Winter Annual Meeting, San Francisco, CA, Dec. $10-15,1978,78-W A / F M-4,1-11$ (American Society of Mechanical Engineers, New York, NY, 1978).

Key words: flowmeter; fluid dynamics; mathematical modeling; numerical modeling; pipe flows; turbulence modeling.
The turbulent incompressible flow through axisymmetric target flowmeters is modeled using the two-equation $\mathrm{k} \epsilon$-turbulence model developed at Imperial College, London. A variety of target disk diameters are examined through a range of Reynolds numbers for different inlet axial velocity profiles. The effects of swirling inlet flow are also tested, as are the effects of different target disk thicknesses. The results indicate that target flowmeter performance can be markedly affected by variations in inlet axial velocity profile and swirl distribution. A comparison between computed and experimental flow coefficients is made.

18411. Misra, D. N., Bowen, R. L., Mattamal, G. J., Surface area of dental enamel, bone, and hydroxyapatite: Chemisorption from solution, Calcif. Tiss. Res. 26, 139-142 (1978).

Key words: bone; chemisorption; enamel; hydroxyapatite; surface area.

The surface areas of three different samples of hydroxyapatite, samples of deproteinized bone, and samples of whole and deproteinized enamel were determined by adsorption of an adduct (the diglycidyl ether of bisphenol A with N-phenylglycine) from methylene chloride solution. In all cases, the surface areas of these samples agree well with those obtained by the BET $\left(\mathrm{N}_{2}\right)$ method.

18412. Tsang, W., Walker, J. A., Braun, W., Herron, J. T., Mechanisms of decomposition of mixtures of ethyl acetate and isopropyl bromide subjected to pulsed infrared laser irradiation, Chem. Phys. Lett. 59, No. 3, 487-491 (Dec. 1, 1978).

Key words: infrared laser; kinetics; mechanisms; modeling; multiphoton; unimolecular dissociation.

The infrared laser induced decomposition of mixtures of ethyl acetate and isopropyl bromide has been studied. The ratio of the yields of products ethylene and propylene, arising from the unimolecular decomposition reactions: ethyl acetate $\rightarrow$ ethylene + acetic acid, and isopropyl bromide $\rightarrow$ propylene + hydrogen bromide, were measured as a function of the ratio of ethyl acetate to isopropyl bromide and pressure of added helium. The results indicate clearly that in these systems nonequilibrium behavior is found up to the highest pressures used (about one atmosphere). A two level kinetic model is suggested which qualitatively explains the observations.

18413. Callcott, T. A., Arakawa, E. T., Ederer, D. L., $\mathbf{L}_{23}$ soft$\mathrm{x}$-ray emission and absorption spectra of $\mathrm{Na}$, Phys. Rev. B 18 , No. 12, 6622-6630 (Dec. 15, 1978).

Key words: absorption spectra; core excitation; emission spectra; lattice relaxation; many body effects; sodium.

The $\mathbf{L}_{23}$ soft $x$-ray emission (SXE) and soft $x$-ray absorption (SXA) edges have been measured. SXE edges were measured at temperatures between $85 \mathrm{~K}$ and $380 \mathrm{~K}$ and analyzed to obtain edge positions and widths. The widths increase from $\Gamma_{S x E}$ $=100 \mathrm{meV}$ at $85 \mathrm{~K}$ to $150 \mathrm{meV}$ at $320 \mathrm{~K}$ and to $180 \mathrm{meV}$ above the melting point at $380 \mathrm{~K}$. Both SXE and SXA edges were measured at $100 \mathrm{~K}$ with the same spectrometer and the data were analyzed to obtain values of the edge widths $\left(\Gamma_{S X E}\right.$ $=100 \mathrm{meV}, \Gamma_{S X A}=64 \mathrm{meV}$ ), of the many body peaking parameter $\left(\alpha_{S X E}=0.15, \alpha_{S X A}=0.24\right)$, of the gap between the edges $\left(E_{o}=74 \mathrm{meV}\right)$ and of the excess width of the emission edge $\left[(\Delta \gamma)^{2}=\Gamma_{S X E}^{2}-\Gamma^{2}{ }_{S X A}=5900(\mathrm{meV})^{2}\right]$. The values of $E_{p}$ and $(\Delta \gamma)^{2}$ were used in the partial lattice relaxation theory of C. O. Almbladh to obtain a value of the core hole lifetime broadening $\left(\Gamma_{2 P}=10 \mathrm{meV}\right)$. We conclude that structure in the transition density of states, many body effects, and lattice relaxation all have important effects on the edge structure, and suggest that rounding of the SXE edge by partial relaxation accounts for the smaller peaking parameter obtained from the SXE data as compared to the SXA data. 
18414. Cumbo, J. E., Michaclis, R. E., Production, characterization, and certification of NBS-SRM 64c, high-carbon ferrochromium, Electr. Furn. Conf., Proc. 35, 52-56 (1977).

Kcy words: composition; high-carbon fcrrochromium; homogeneity testing; preparation; processing; standard refcrcnce material.

18415. Ellingwood, B., Leyendecker, E. V., Approaches for design against progressive collapse, J. Struct. Div., Proc. Am. Soc. Civ. Eng. 104, No. ST3, Proc. Paper 13610, 413-423 (Mar. 1978).

Key words: abnormal loads; buildings (codes); probability theory; progressive collapse; reliability; structural engineering.

A progressive collapse is a chain reaction type of failure which follows damage to a relatively small portion of a structure. Progressive collapse constitutes an unacceptable hazard in many buildings, and thus procedures for its control should be incorporated in building standards. Design strategies for reducing the risk of initial failure and for controlling the amount of damage that occurs are presented and their relative advantages are discussed. Design criteria are given for the reduced loads to be carried by a damaged structure.

18416. Ehrlich, M., Seltzer, S. M., Bielefeld, M. J., Trombka, J. I., Spectrometry of a ${ }^{60} \mathrm{Co}$ gamma-ray beam used for instrument calibration, Metrol. 12, 169-179 (1976).

Key words: calibration source; collimation system; datareduction technique; low-activity replacement source; measurement technique; scatter contribution; source capsule; source housing; spectrometry results; ${ }^{60} \mathrm{CO}$ gamma-ray beam.

Measurements were made of the spectrum of one of the collimated ${ }^{60} \mathrm{Co}$ gamma-ray beams employed in the instrumentcalibration program of the National Bureau of Standards. The high-activity calibration-source capsule was replaced by one of low activity and identical geometry. The contributions to the spectrum by the scatter from the low-activity replacement source, the housing, and the collimation system were isolated by means of supplementary measurements in free air carried out on the replacement source and on a scatter-free source. Depending on collimator setting, the scatter contribution below $1 \mathrm{MeV}$ was found to be between 13 and 19 percent of the total number of photons in the beam. A description is given of the measurements and of the technique for data reduction. Detailed spectral results are presented.

18417. Erickson, N. E., ESCA studies of the clean Si (111) surface, Phys. Scr. 16, 462-465 (1977).

Key words: angular study; electron spectroscopy for chemical analysis (ESCA); silicon; surface; XPS

The angular variation of elastically scattered electrons excited by $\mathrm{x}$-rays from various electron levels of silicon and surface or near surface impurity atoms of nickel and gold are reported. The valence band profile of the Si (111) surface is presented as a function of electron take-off angle. Evidence is presented that the $\mathrm{Si}(2 p)$ binding energy is dependent on the crystal surface geometrical ordering. A discussion of some of the implications of these studies is presented.

18418. Escalante, E., Iverson, W. P., The protection of steel piles by nonmetallic coatings in sea water, Mater. Perform. 17, No. 10, 9-15 (Oct. 1978).

Key words: corrosion of steel; corrosion protection; nonmetallic coatings; offshore corrosion; saltwatcr corrosion; seawater corrosion.
Polyamide and polyamine cured coal tar epoxy systems, one with Al oxide armor, one polyvinylidenc chloride, one phenolic mastic, and one glass flake filled polyester system were evaluatcd after 6 years on carbon steel $\mathrm{H}$-pilings embedded in the ocean floor ncar shore. Data are given on the overall and extent of protection in atmospheric (above high water), splash, submerged, and buried zones. Thicknesses ranged from 5 mils of the polyvinylidene chloride to the 34 mils of the glass flake filled polyester. Ratings, based on a synthesis of polarization, pitting attack, and flange thickness data are as follows in a decreasing order of rcsistance: polyester glass flake, phenolic mastic, polyamide cured coal tar epoxy, polyamide cured coat tar epoxy with Al oxide, polyamine cured coal tar epoxy, and polyvinylidene chloride. These are interim results in a.15 year program involving 23 coating systems and cathodic protection.

18419. Ho, J. C., King, G. B., Fickett, F. R., Low temperature specific heat of two stainless steels, Cryogenics 18, No. 5, 296 298 (May 1978).

Key words: heat capacity; low temperature alloy; specific heat; stainless steel.

Specific heat values between 2 and $20 \mathrm{~K}$ are reported for the two stainless steels AISI 304 and 1SI 304L. Measurements were made by standard adiabatic calorimetry. The results suggest that the thermal properties are roughly comparable to AISI $310 \mathrm{~S}$, but the absence of magnetic clusters implies that they are more appropriate for low temperature work.

18420. MacCrehan, W. A., Durst, R. A., Measurement of organomercury species in biological samples by liquid chromatography with differential pulse electrochemical detection, Anal. Chem. 50, No. 14, 2108-2112 (Dec. 1978).

Key words: biological samples; electrochemical detection; liquid chromatography; metal speciation; organomercury cations.

A new measurement approach for organomercury cations is described employing liquid chromatography with electrochemical detection. Special considerations in constructing apparatus to optimize reductive electrochemical measurement are outlined. The added selectivity of the differential pulse mode of detection is demonstrated. A charge-neutralization reversephase separation of methyl-, ethyl-, and phenylmercury cations has been developed. The limit of detection for methylmercury is $2 \mathrm{ng} / \mathrm{g}$ or $40 \mathrm{pg}$ ( $190 \mathrm{fmol} / 20 \mu \mathrm{L}$ sample). Methylmercury is determined by the technique in two research materials-tuna fish and shark meat.

18421. Watson, R. E., Bennett, L. H., Transition metals: $d$-band hybridization, electronegativities and structural stability of intermetallic compounds, Phys. Rev. B 18, No. 12, 6439-6449 (Dec. 15, 1978).

Kcy words: electroncgativities; hybridization; structural stability; transition elcments.

An electroncgativity scale is dcrived for the noble and transition mctals, bascd on their electron-band theory description. The tendency of $d$-band electron and hole states to hybridize is used to estimate the propensity for a particular metal to gain or lose $\dot{d}$-electron count and this, in turn, is used to provide the basis of the electronegativity scale. Overall agreement of this scale with Miedema's and Pauling's electronegativity is remarkably good, granted the widely divcrgent bases of the three scalcs. The results, combined with an average electron vacancy count, are then used in structural maps of transition-metaltransition-metal alloy sy'stems. 
18422. Cahn, J. W., Monotectic composite growth, Metall. Trans. A 10A, 119-121 (Jan. 1979).

Key words: composite growth; contact angle; disjoining pressure; monotectic; multicomponent; wetting.

The theoretical factors in monotectic composite growth are reexamined. Perfect wetting to the solid by the monotectic liquid occurs whencver the monotectic temperature is close to the critical temperature. According to Chadwick, composite growth is impossible whenever such perfect wetting occurs. However, since the disjoining pressure is expected to be small, composite growth may instead be determined by the critical velocity necessary to overcome the disjoining pressure. Experience that high velocities are needed to form monotectic composites tends to support this alternate proposal. Applied pressure and ternary additions are suggested as additional ways for altering the factors that mediate composite growth.

18423. Danos, M., SU4 in muclear structure, Próc. $3 d$ Int. Conf. on Clustering Aspects of Nuclear Structure and Nuclear Reaction, Winnipeg, Manitoha, Canada, June 19-23, 1978, pp. 4868 (American Institute of Physics, New York, NY, 1978).

Key words: alpha-particles; correlations; mass formula; nuclear; quartets; reactions; spectroscopy; SU4.

The presence of quartets-the more physical term for SU4 structures-is demonstrated for nuclei throughout the table. A very strong indication for quartets is the validity of a mass formula based on SU4. This formula achieves with fewer parameters the classical liquid drop terms then turns out to have at least as good a fit to the data as the usual Weizsäcker formula. The physical reasons for quartetting are presented; possible forms of the quartet correlations, different for different regions of the Table, are discussed.

18424. Escalante, E., Iverson, W. P., The protection of steel piles by selected coatings in a natural sea water environment, Proc. 10th Annual Offshore Technology Conf., Houston, TX, May 8-11, 1978, OTC 3190, pp. 1215-1222 (OTC, Houston, TX, 1978).

Key words: coating protection; pile corrosion; protection of steel; salt water corrosion; sea water corrosion; steel corrosion.

Six types of coatings are evaluated on their ability to protect steel piles in offshore conditions. These coatings, made up of a single system metal pigmented paint and 5 two system nonmctallic coatings on metal filled primers, are described in detail. These nrotective coatings have displayed good to excellent resistance to deterioration in a sea water environment. A brief discussion of the corrosion of bare steel piles serving as controls is included.

The electrochemical techniques used to evaluate the coating deterioration in situ, and the physical measurements made on the piles after removal are briefly described. The results found on these systems in the first six years of a fifteen year program are presented.

18425. Hunt, B. J., Richtmyer, T. E., Hill, J. E., Franklin, E. A., Testing of water tanks for thermal storage according to ASHRAE Standard 94-77, ASHRAE Trans. 85, Part I, PH79-5, No. 1, 20 pages (1979).

Key words: ASHRAE Standards; evaluation of test procedure; solar heating components; standard test procedure; thermal storage tests; water tank thermal storage.

The National Bureau of Standards proposed a standard test procedure for rating thermal storage devices in mid-1975. Early in 1977, the American Society of Heating, Refrigerating, and
Air Conditioning Engineers (ASHRAE) adopted ASHRAE Standard 94-77, "Methods of Testing Thermal Storage Devices Based on Thermal Performance," which is based substantially on the NBS procedure. In order to evaluate the Standard, NBS has conducted an experiment in which a $1.9 \mathrm{~m}^{3}$ (500 gal) water tank, built as part of a residential solar heating and cooling system, was tested in accordance with this Standard. A description of the test apparatus, tcst procedure, and detailed test results are given. It was found that there were no major problems encountered in using the Standard for this kind of thermal storage device. In addition, suggestions are made for minor modifications in the Standard.

18426. Inguscio, M., Strumia, F., Evenson, K. M., Jennings, D. A., Scalabrin, A., Stein, S. R., Far-infrared $\mathbf{C H}_{3}$ F Stark laser, Opt. Lett. 4, No. 1, 9-11 (Jan. 1979).

Key words: far-infrared; laser; methyl fluoride; Stark.

A rectangular metal-dielectric far-infrared waveguide laser has been operated on the individual Stark components of $\mathrm{CH}_{3} \mathrm{~F}$ by the application of an electric field across the laser medium. The results agree well with theoretical predictions.

18427. Ku, H. H., Treatment os counting data, Chapter 7 in $A$ Handbook of Radioactivity Measurements Procedures, National Council on Radiation Protection and Measurements, Rcport No. 58, 271-298 (NCRP, Washington, DC, Nov. 1, 1978).

Key words: precision; radioactivity measurements; statistical design of experiment; statistical terms and formulas; statistics; systematic error; uncertainty.

This section on statistics is prepared for the revision of NBS Handbook 80, A Manual of Radioactivity Procedures, to be issued as a report by the National Council on Radiation Protection and Measurements. The original section on the treatment of counting data has been retained with modifications. Four new sub-sections: (1) statistical models of a measurement process, (2) statistical terms and formulas, (3) statistical design of experiment, and (4) precision, systematic error, and uncertainty, have been added.

18428. Liu, S. T., Hill, J. E., A proposed technique for correlating the performance of solar domestic water heating systems, ASHRAE Trans. 85, Part 1, No. 2516, 13 pages (1979).

Key words: computer; hot water; measurement; rating; solar; standards; testing.

A theoretical study was conducted to determine how experimental data might be collected on solar domestic water heating systems over a short period of time and then used to characterize the performance of the system. The analysis involved stimulating typical state-of-the-art systems using the computer program TRNSYS. The simulations and associated analyses were succesful in indicating a method of correlating the fraction of the hot water load supplied by solar energy with the primary indcpendent variables governing the system performance. Actual test data for a commercially available system were then used to substantiate the value of the correlation.

18429. Raufaste, N. J., Jr., Olmert, K. M., Case study: NBS' Center for Building Technology, Words 7, No. 3, 34-37 (Feb.Mar. 1979).

Key words: Center for Building Tcchnology; manuscripts; word processing center; word processing equipment.

Word Processing Centers (WPC) are more and more being created in business and government as a way of coping with large typing loads. However, making the transition from the idea of a WPC to one that is fully operational is difficult. This paper presents the Center for Building Technology's experience in this transition. 
18430. Stahl, F. 1., Exit emergency: A blueprint for design standards research, The Construction Specifier, pp. 65-7.7 (Feb. 1979).

Key words: architcctural barriers; building design; building sitc planning; environmental psychology; evaluation; fire escape; human research; mcasurement; pedestrian movement; regulation; safety; standards.

Needs for a more complete and effective technical basis for design standards impacting occupants' access to, movement within, and egress from buildings and building sites are discussed. It is suggested that a major cause of injury and death from fire, and of inconvenience and psychological stigmatization to physically handicapped persons, results (even in codecomplying buildings and sites) from adherence to design regulations which are narrowly founded upon physical and engineering principles alone. This paper recommends that psychological aspects of dangerous and stressful situations guide the development of standards for emergency egress facility design, and that such therapeutic objectives as "normalization" guide development of barrier-free design regulations. Finally, this paper outlines particular programmatic themes and research tasks, and discusses the role of the National Bureau of Standards in improving the technical basis for egress and accessibility design regulations.

18431. Wang, F. W., Dynamic flow birefringence and flow dichroism of block-copolymer molecules in solution with application to the free-draining limit, Macromolecules 11, No. 6 , 1198-1205 (Nov.-Dec. 1978 ).

Key words: bead-spring model; block copolymer; flow birefringence; flow dichroism; polymer dynamics; RouseZimm theory; solution properties.

The dynamic flow birefringence and the flow dichroism of block-copolymer molecules in solution have been calculated by modifying the bead-spring model theory of $\mathrm{Zimm}$ to take into account the existence of dissimilar segments in block copolymers. The expressions for the birefringence and the dichroism properties have been found to be the same as those for homopolymers except that the contributions of normal modes are weighted by generally different factors. Some calculated results in the free-draining limit are given to illustrate how the inhomogeneity in segmental optical properties is expected to affect the flow birefringence and the flow dichroism.

18432. Fishbane, P. M., Horn, D., Meshkov, S., Spin forces in charmonium spectroscopy, Phys. Rev. D 19, No. 1, 288-290 (Jan. 1, 1979).

Key words: charmonium; particle spectroscopy; quarks; selection rules; spin forces; tensor force.

The observed $\psi^{\prime}(3.68)-\psi^{\prime \prime}(3.77)$ structure in $e^{+} e^{-}$annihilation implies the existence of a tensor-force effect in charmonium spectroscopy. We show that the magnitude of the effect is consistent with an analysis of ${ }^{3} P$, levels using a phenomenological Hamiltonian linear in both $\overrightarrow{\mathrm{L}} \cdot \overrightarrow{\mathrm{S}}$ and $S_{12}$, the tensor force. Adding a linear $\sigma_{1} \cdot \sigma_{2}$ term one can account for all known charmonium levels below $4 \mathrm{GeV}$ and predict the location of the rest of the spectrum, in particular the ${ }^{\prime} P_{1}$ state at $3.27 \mathrm{GeV}$.

18433. Howell, B. F., McCune, S., Schaffer, R., Lactate-topyruvate or pyruvate-to-lactate assay for lactate dehydrogenase: A re-examination, Clin. Chem. 25, No. 2, 269-272 (1979).

Key words: enzyme assay; influence of inhibitor on lactate dehydrogenase assay; lactate dehydrogenase assay; lactate to pyruvate reaction; pyruvate to lactate reaction; spectrophotometric enzyme assay.
As good linearity can now be obtained for the pyruvate to lactatc assay for lactate dehydrogenase (E.C.1.1.1.27) as with the lactate to pyruvate assay. In addition, there are significant advantages to the pyruvate to lactate reaction: (a) a greater change in optical density per unit time which allows more accurate spectrophotometric readout, (b) a need for lower reactant concentrations which significantly reduces the cost per assay, (c) the use of only solid reagent materials for assay solution preparation, and (d) a greater stability of reagents once they are placed in solution.

18434. Turgel, R. S., Oldham, N. M., High-precision audiofrequency phase calibration standard, IEEE Trans. Instrum. Meas. IM-27, No. 4, 460-464 (Dec. 1978).

Key words: calibration; digital waveform synthesis; phase angle; phase measurement; phase meter; waveform generator.

A high precision standard for the calibration of audio frequency phase meters has been designed using a microprocessor to generate the test signals. The accuracy is better than 0.01 degree over a frequency band from dc to $5 \mathrm{kHz}$ and decreases to 0.1 degree at high audio frequencies.

18435. Van Blerkom, D., Castor, J. I., A simple estimate of the effect of a thick circumstellar dust shell on photospheric line profiles, Astrophy. J. 227, No. 2, 543-547 (Jan. 15, 1979).

Key words: circumstellar dust; line formation; radiation transfer; stellar atmospheres.

A star embedded in an cptically thick dust shell may have a line spectrum that closely resembles the spectrum of some unobscured star; e.g. VY CMa (shrouded) and $\alpha$ Her (unshrouded). This implies that the surface temperatures of the two stars are nearly equal, but since one is subject to a backwarming effect, the distribution of temperatures with depth in the respective atomospheres are dissimilar. We find that effective temperatures and absorption line strengths are reduced in shrouded stars below the values that obtain in their unshrouded counterparts. For models of VY CMa that yield grain temperatures at the inner boundary of the dust shell consistent with observation, the reduction in strength of a visible line is small ( $\Sigma 15 \%$ ). Thus, the spectral distribution of $\alpha$ Her may be used as an approximation to that of VY CMa before it is scattered by the dust, without the necessity of first correcting for backwarming.

18436. Kurylo, M. J., Laufer, A. H., Evidence for atom exchange in $\mathrm{OH}$ reactions with carbonyl compounds: ${ }^{18} \mathrm{OH}+$ $\mathrm{CO}_{2} \rightarrow{ }^{18} \mathrm{OCO}+\mathrm{OH} ; \quad{ }^{18} \mathrm{OH}+\mathrm{CO} \rightarrow{ }^{18} \mathrm{OC}+\mathrm{OH}, \quad J$. Chem. Phys. Lett. to Ed. 70, No. 4, 2032-2033 (Feb. 15, 1979).

Key words: carbon dioxide; carbon monoxide; carbonyl; exchange; hydroxyl; kinetics; mechan ism; photochemistry.

The reactions between $\mathrm{OH}$ and both $\mathrm{CO}_{2}$ and $\mathrm{CO}$ have been investigated using ${ }^{18} \mathrm{O}$ as a tracer. Evidence for exchange was observed. The properties of the intermediate adducts are discussed.

18437. Williams, E. R., Olsen, P. T., A method to measure magnetic fields accurately using Ampere's law, IEEE Trans. Instrum. Meas. IM-27, No. 4, 467-469 (Dec. 1978).

Key words: Ampere's law; dimensional metrology; fundamental constants; gyromagnetic ratio of proton; magnetic fields; Maxwell's equations; solenoids.

A proposed method to measure magnetic fields is described, and a simple demonstration of the new method has been performed. A derivation of the equation used to calculate the field is presented, and some of its implications are discussed. The 
objective of further experiments is to apply the technique to the measurcment of the gyromagnetic ratio of the proton $\left(\gamma_{p}\right)$ to an accuracy near 1 part in $10^{\mathrm{A}}$, using a precision solenoid whose departures from ideal are small

18438. Miller, E. B., Eitzcn, D. G., Ultrasonic transducer characterization at the NBS, IEEE Trans. Sonics Ultrason. SU26, No. 1, 28-37, 63-64 (Jan. 1979).

Key words: acoustic theory; calorimetry; electroacoustic method; medical applications; metrology; NDE; radiation force; transducer characterization; ultrasonics.

Four methods for characterizing ultrasonic transducers are reviewed. These methods have been or are being developed at the National Bureau of Standards (NBS) for characterizing the performance of ultrasonic devices operating into a water load. The nominal frequency range for the methods considered here is 0.5 to $30 \mathrm{MHz}$, which corresponds to devices used in nondestructive testing, medicine, and animal science. The principles upon which these methods are based are electrical measurements related to the equivalent circuit of a quartz transducer, a thermal equivalent calorimetric method, a measurement of total radiation force, and an electroacoustic method involving sampling the acoustic field of a directive device. It is helpful to thoroughly understand the physical theory which applies to each measurement method so that appropriate methods can be developed and analyzed for errors or uncertainties. Studies of errors and their basis constitute an important part of measurement science or "metrology," and metrology is a principal intercst of the National Bureau of Standards. Consistent with this interest, and to provide continuity among the measured quantities, linear and second-order acoustic relationships are tabulated in terms of the pressure and particle-velocity variables for lossless fluids. This provides an outline which interrelates measured quantities and suggests other derived quantities, or measurements, that may also be of interest. A formally economical method for obtaining such nonlinear acoustic relationships is outlined briefly in the Appendix. This provides the basis for the brief analyses which pertain to the radiation force method and to the scanning technique in the body of the paper. Aspects of the treatment of radiation force appear to be novel. References are given which relate to more fundamental theory and to more extensive intercomparison of methods and consideration of errors.

18439. Ackerhalt, J. R., Eberly, J. H., Shore, B. W., Statistical broadening and population loss in strongly excited three-levet systems, Phys. Rev. A 19, No. 1, 248-263 (Jan. 1979).

Key words: coherent excitation; dressed atoms; inhomogeneous broadening; intensc laser; multiphoton dissociation; multiphoton ionization; Rabi frequency; statistical broadening; three-level system.

We study the effects of statistical broadening and population loss on the dynamics of strongly excited thrce-level quantum systems. The results of both analytic and numerical treatments of the three-level Schrödinger-equation are displayed. In order to allow for statistical broadening, solutions are required for arbitrary detuning of the two very intense monochromatic lasers The most efficient statistically averaged population depletion occurs when the Rabi frequency of the second transition is greater than that of the first.

18440. Natrella, M. G., Statistics in specifications, ASTM Stand. News 7, No. 1, 10-11, 40 (Jan. 1979).

Key words: conformance; sampling; specifications; statistical methods; statistics.

This article, one of a series in ASTM Standardization News describing the work of ASTM Committec E-11, is a discussion of the role of statistics in relation to specifications. It briefly considcrs the questions of what specification requirements are, what they apply to, how they are arrived at, how they are interpreted, and how statistics can help in the various stages of this process.

18441. Dick, C. E., Soares, C. G., Motz, J. W., X-ray scatter data for diagnostic radiology, Phys. Med. Biol. 23, No. 6, 1076-1085 (1978).

Key words: diagnostic radiology; scatterer thickness; scatterer to image plane separation; tissue equivalent phantoms; $x$-ray beam diameter; $x$-ray energies of 30 to $70 \mathrm{keV}$; $\mathrm{x}$-ray scatter.

The ratio of the scattered to the total $x$-ray fluence (scatter fraction) at the centre of the image plane for $x$-rays transmitted through polystyrene phantoms has been measured for $\mathrm{x}$-ray energies of 32 and $69 \mathrm{keV}$, x-ray beam diameters from 4 to 40 $\mathrm{cm}$, phantom thicknesses from 5 to $30 \mathrm{~cm}$ and phantom-toimage-plane separations from 0.3 to $40 \mathrm{~cm}$. The experimental values for this ratio have less than a $10 \%$ variation for these two $x$-ray energies and the experimental data show good agreement with Monte Carlo calculations and available exnerimental results for low atomic number materials. Based on these results, simple curves are generated which give estimates $( \pm 10 \%)$ of the scatter fraction for all combinations of the geometric parameters encountered in diagnostic radiology.

18442. MacDonald, W. M., Dressler, E. T., O'Connell, J. S., Photopion production in the Fermi-gas model, Phys. Rev. C 19, No. 2, 455-464 (Feb. 1979).

Key words: beryllium; differential cross section; Fermi gas; lithium; optical potentials; photopion; pion.

Differential and total cross sections for $(\gamma, \pi)$ reactions in nuclear matter are calculated using the single particle $\gamma N \pi$ amplitudes recently proposed for nuclear calculations. The effect of the Pauli principle on the pion spectrum and angular distribution is examined. Optical potentials for the nucleons and pions are introduced to investigate the influence of the nuclear medium on photopion production. The total photoabsorption cross section is computed and compared with recent data on lithium and beryllium.

18443. Laufer, A. H., Bass, A. M., Photochemistry of acetylene. Biomolecular rate constant for the formation of butadiyne and reactions of ethynyl radicals, J. Phys. Chem. 83, No. 3, 310313 (1979).

Key words: acetylene; butadiyne; ethynyl; hydrogen; mechanism; photoche mistry; radicals; rate constant.

The vacuum-ultraviolet flash photolysis of acetylene has been investigated and the mechanisms and rate constant for butadiyne production have been measured. The major photolytic decomposition path 'deduced is $\mathrm{C}_{2} \mathrm{H}_{2}+h v \rightarrow \mathrm{C}_{2} \mathrm{H}+\mathrm{H}$. A minor channel corresponding to $\mathrm{C}_{2} \mathrm{H}_{2} \rightarrow \mathrm{C}\left({ }^{3} \mathrm{P}\right)+\mathrm{CH}_{2}\left(\widetilde{\mathrm{X}}^{3} \Sigma_{\mathrm{g}}{ }^{-}\right)(6)$ was also suggested. Evidence suggests that butadiyne is formed in a first-order process: $\mathrm{C}_{2} \mathrm{H}+\mathrm{C}_{2} \mathrm{H}_{2} \rightarrow \mathrm{C}_{4} \mathrm{H}_{2}+\mathrm{H}$ (2). The rate of (2) was determined by monitoring butadiyne concentration spectroscopically and a rate constant, $k_{2}=3.1 \pm 0.2 \times 10^{-11} \mathrm{~cm}^{3}$ molecule ${ }^{-1} \mathrm{~s}^{-1}$, determined. Addition of $\mathrm{H}_{2}$ reduces the yield of $\mathrm{C}_{4} \mathrm{H}_{2}$ by the reaction $\mathrm{C}_{2} \mathrm{H}+\mathrm{H}_{2} \rightarrow \mathrm{C}_{2} \mathrm{H}_{2}+\mathrm{H}$ (8) and a ratio $k_{\mathrm{B}} / k_{2}=4.9 \times 10^{-3}$ was obtained. The photolysis of $\mathrm{CF}_{3}-\mathrm{C}_{2} \mathrm{H}$ was briefly investigated.

18444. November, L. J., Toomre, J., Gebbie, K. B., Simon, G. W., The height variation of supergranular velocity fields determined from simultaneous OSO 8 satellite and groundbased observations, Astrophys. J. 227, No. 2, 600-613 (Jan. $15,1979)$ 
Key words: convection; solar; solar atmospheric motions; supergranules.

Simultancous satellite and ground-based observations of supergranular velocities in the Sun were made using the University of Colorado UV Spectrometer on OSO 8 and the Sacramento Peak Observatory diode array instrument. We compare our observations of the steady Doppler velocities seen toward the limb in the middle chromosnhere and the photosphere: the observed $\mathrm{Si}$ it $\lambda 1817$ and $\mathrm{Fe}$ । $\lambda 5576$ spectral lines differ in height of formation by about $1400 \mathrm{~km}$.

The striking results of these observations are that supergranular motions are able to penetrate at least 11 density scale heights and that, in doing so, the motion increases from about $800 \mathrm{~m} \mathrm{~s}^{-1}$ in the photosphere to at least $3000 \mathrm{~m} \mathrm{~s}^{-1}$ in the middle chromosphere. Further, a distinct change appears to occur in the flow structure: whereas the horizontal component of the velocity predominates in the low photosnhere, suggesting strong braking of vertical momentum, the motions higher in the atmosphere are more isotropic. These observations imply that supergranular velocities should be evident in the transition region.

The strong horizontal shear layers in supergranulation must produce turbulence and internal gravity waves. These smaller scale motions have bearing on chromospheric heating and nonthermal line broadening.

18445. Dickens, B., Computer program to implement automated factor-jump thermogravimetry, Thermochim. Acta 29, $57-85$ (1979).

Key words: activation energy; computer automation; computerized thermogravimetry; computer program; polymer degradation; polymer oxidation; thermogravimetry.

The paper describes a computer program written to implement the factor-jump method on a thermogravimetry apnaratus automated with an in-laboratory minicomputer. The ñrogram is written almost entirely in FORTRAN and constitutes a system of seven overlays. It determines activation energies during the course of the experiment and provides active feedback to pursue desired precision in experimental quantities and in the activation energy. The program is modular and can probably adapt to situations other than the apnaratus and technique for which it was originally designed.

18446. McCann, K. J., Flannery, M. R., Multistate semiclassical orbital treatment of $\mathrm{Li}^{+}-\mathrm{H}_{2}$ and $\mathrm{H}^{+}-\mathrm{H}_{2}$ collisions, Chem. Phys. Lett. 60, No. 3, 523-527 (Jan. 15, 1979).

Key words: elastic scattering; ion-molecule collisions; rotational excitation; semiclassical orbital; theory.

A semiclassical orbital description of elastic scattering and of rotational excitation in ion-molecule collisions is presented. Specific account is taken of interference effects between the classical trajectories that contribute to a given scattering angle, and of rainbow scattering. Excellent agreement with full quantal differential cross sections is obtained.

18447. Dickens, B., Experiences in developing an automated factor-jump method of thermogravimetry, Thermochim. Acta 29, 87-113 (1979).

Key words: activation energy; automated thermogravimetry; computer automated thermogravimeter; factor-jump thermogravimetry; polymer degradation; thermogravimetry.

We have recently provided details of an anparatus and computer programs to implement the factor-jump method of thermogravimetry. This paper describes the refinement of the technique to the present status of quasi-automatic routine operation. The procedure was worked out using samples of polymethyl-methacrylate, polystyrene and polyurethane polymers. The activation energies obtained are measured to 0.2 $\mathrm{kcal}^{\mathrm{mole}} \mathrm{e}^{-1}$ in favorable cases. This is adequate for diagnosis of changes in mechanism but may sometimes be inadequate for scaling temperature accelerated tests to room temperature.

18448. Schroeder, L. W., Mathew, M., Cation ordering in $\mathrm{Ca}_{2} \mathrm{La}_{8}\left(\mathrm{SiO}_{4}\right)_{8} \mathrm{O}_{2}, J$. Solid State Chem. 26, 383-387 (1978).

Key words: cation distribution; cation ordering; inıpurities; oxyapatite.

The distribution of $\mathrm{La}^{3+}$ and $\mathrm{Ca}^{2+}$ over the cation sites in $\mathrm{Ca}_{2} \mathrm{La}_{\mathrm{H}}\left(\mathrm{SiO}_{4}\right)_{8} \mathrm{O}_{2}$ was determined by single-crystal $\mathrm{x}$-ray diffraction. $\mathrm{Ca}_{2} \mathrm{La}_{8}\left(\mathrm{SiO}_{4}\right)_{6} \mathrm{O}_{2}$ has the apatite structure, and all available evidence indicates that the space group is $P 6_{3} / m$, thus precluding a completely ordered structure. The $6 h$ lattice sites are occupied by $\mathrm{La}^{3+}$ : In contrast, the $4 f$ sites are occupied equally by $\mathrm{La}^{3+}$ and $\mathrm{Ca}^{2+}$ ions. Consideration of the properties of the $\mathrm{La}^{3+}$ and $\mathrm{Ca}^{2+}$ ions suggests that this distribution is thermodynamically favored for this composition. A simple Ising model suggests ordered columns. These would not be precluded by space group $P 6_{3} / m$, if the correlation between adjacent columns were random.

18449. Smyth, K. C., Bentz, B. L., Bruhn, C. G., Harrison, W. $W$. The role of penning ionization of the minor species in a neon hollow cathode discharge, J. Am. Chem. Soc. 101, No. 4, 797-799 (Feb. 14, 1979).

Key words: carbon; copper; hollow cathodes; mass spectrometry; neon; nitrogen; Penning effect.

Using a tunable dye laser, a neon hollow cathode discharge was irradiated at wavelengths corresponding to $1 s_{n} \rightarrow 2 p_{n}$ neon transitions, and thereby the neon metastable atom population was perturbed. At these wavelengths, changes were detected in both the voltage across the discharge and in the ion signals for the various neon species, as well as for minor (including sputtered) species in the discharge. Attention is focused on the several possible ionization mechanisms for the minor species. Our results suggest that Penning ionization by metastable neon atoms plays the most important role at low discharge currents, but only a minor role at high currents.

18450. Dickens, B., Automation of factor-jump thermogravimetry for active computer control, Thermochim. Acta 29, $41-56$ ( 1979).

Key words: activation energy; degradation apparatus; factor-jump thermogravimetry; polymer degradation; polymer oxidation; programmed temperature control; thermogravimetry.

A scheme of automation of a thermogravimetry apparatus is described which was developed with the factor-jump method in mind. Temperature, pressure and flow rates of two gases are controlled; all components except the furnace are commercially available. This paper describes the details of the automation scheme and provides data on the quality of its performance. The scheme includes a mini-computer; if no feedback is required, a recording computer terminal can be used instead.

18451. Galloway, K. F., VLSI processing, radiation, and hardening, IEEE Trans. Nucl. Sci. NS-25, No. 6, 1469-1472 (Dec. 1978 ).

Key words: E-beam lithography; integ rated circuits; ion implantation; plasma etching; radiation damage; radiation hardening; VLSI processing; $x$-ray lithogranhy.

Procegs-induced radiation damage to silicon dioxide films is expected to be commonplace for VLS! circuit fabrication. This might be expected to be most serious for the production of 
radiation-hardened VLSI. In this paper, the oxide damage due to ion processing is reviewed and the radiation levels associated with advanced lithographic techniques are estimated. Implications for radiation-hardened VLSI circuits are considered.

18452. Cutkosky, R. D., A new switching technique for binary resistive dividers, IEEE Trans. Instrum. Meas. IM-27, No. 4, $421-422$ (Dec. 1978).

Key words: binary divider; divider network; guarded divider; resistive divider; self calibration; voltage divider.

A binary resistive divider network has been found which utilizes $N$ cascaded DPDT reversing switches plus one SPDT switch for an $N$-bit divider. The network features a simple and accurate method for internal calibration. With a fixed divider input voltage the power dissipated in each resistive element is independent of switch setting.

18453. Cutkosky, R. D., A programmable phase-sensitive detector for automatic bridge applications, IEEE Trans. Instrum. Meas. IM-27, No. 4, $401-402$ (Dec. 1978).

Key words: a-c detector; automatic bridge; detector; high resolution detector; phase sensitive detector; programmable detector.

A phase-sensitive detcctor is dcscribed which features programmable gain, digital output, and a resolution of $0.02 \mu \mathrm{V}$. The instrument suppresses harmonic sensitivity through the usc of analog circuitry which multiplies the signal by constant amplitude sine and cosine waves derived from an external reference of arbitrary voltage and frequency.

18454. Shields, J. Q., Absolute measurement of loss angle using coroidal cross capacitor, IEEE Trans. Instrum. Meas. IM-27, No. 4, 464-466 (Dec. 1978).

Key words: capacitor; cross capacitor; dielectric; dissipation factor; loss angle; microphonic coupling; phase angle; surface films.

An absolute measurement of loss angle has recently been completed at NBS. The measurement utilized a special toroidal cross capacitor in which the effects of dielectric films are greatly attenuated. The resulting unit of loss angle has an estimated uncertainty of $0.02 \mu \mathrm{rad}$ at an optimum frequency of $1592 \mathrm{~Hz}$.

18455. Field, B. F., A fast response low-frequency voltmeter, IEEE Trans. Instrum. Meas. IM-27, No. 4, 368-372 (Dec. 1978).

Key words: ac voltage measurement; low frequency; microcomputer.

A sampling voltmeter implemented with a microprocessor has been developed to perform as a true rms voltmeter and waveform analyzer. The instrument measures to 0.1 percent accuracy the true rms voltage of approximately sinusoidal inputs at voltages from $2 \mathrm{mV}$ to $10 \mathrm{~V}$ and frequencics from 0.1 to $120 \mathrm{~Hz}$. The major feature of the instrument is fast response time, with a total autoranging, settling, and measurement time of two signal periods for frequencies below $10 \mathrm{~Hz}$.

18456. Tsai, D. H., The virial theorem and stress calculation in molecular dynamics, J. Chem. Phys. 70, No. 3, 1375-1382 (Feb. 1, 1979).

Key words: equilibrium; homogeneous system; hydrostatic pressure; internal stress; internal virial; molecular dynamics; Monte Carlo method; periodic boundaries; pressure; stress calculation; virial theorem of Clausius.
In molecular dynamics, the pressure in a homogeneous system in equilibrium may be calculated by two different methods. The first is based on the virial theorem of Clausius and gives the pressure at the boundary of the system. The second is based on the notion of stress, which is the sum of the appropriate components of the interatomic forces intercepted by an area, and of the components of momentum flux across the area, averaged over the area and over time. We show by means of a detailed comparison of the forces involved that the two methods are equivalent in the thermodynamic limit. In a small system with arbitrary boundary conditions, the neglect of a part of the interactions between the system and the wall results in some error in the pressure calculated by the virial method. In the special case of a system with periodic boundaries, there is no external "wall," and the internal pressures calculated by the two methods are the same. However, with comparable effort in computation, the stress method makes more efficient use of the data and yields a result of greater precision than does the virial method. In a system not in equilibrium or not homogeneous, the stress method remains valid but the virial method leads to ambiguous results. These considerations indicate that the method of stress calculation is more general than the virial method.

18457. Sengers, J. V., Moldover, M. R., Critical phenomena experiments in space?, Z. Flugwiss. Weltraumforsch 2, 371-379 (1978).

Key words: critical phenomena; critical-point universality; fluids; gravity effects; materials science; spacelab.

Earth-bound experiments near the critical point of fluids are severely affected by the presence of the earth's gravitational field. Some estimates of the gravitational limitations are presented and it is indicated how these limitations could be reduced by performing critical phenomena experiments in an orbiting laboratory. Because of the "universal" features of critical phenomena, such experiments will contribute to our understanding of the nature of critical-point phase transitions in a large number of systems, including solids as well as fluids.

18458. Koyama, R. Y., Phillips, W. E., Myers, D. R., Liu, Y. M., Dietrich, H. B., The energy levels and the defect signature of sulfur-implanted silicon by thermally stimulated measurements, Solid-State Electron. 21, No. 7, 953-955 (July 1978).

Key words: decp level measurements; defect center characterization; defect density; ion implantation; silicon; sulfur; sulfur energy level in silicon; thermally stimulated capacitance; thermally stimulated current.

Two energy levels of sulfur in the upper half of the energy gap of silicon were obtained by isothermal transicnt capacitance and thermally stimulated current measurements on samples prepared by sulfur implantation and high-temperature annealing. The measured energy levels are in good agreement with two levels for sulfur introduced by a closed-tube diffusion but disagree with one of two levels measured for implanted sulfur after low-temperature annealing.

18459. Bender, P. L., Faller, J. E., Levine, J., Moody, S., Pearlman, M. R., Silverberg, E. C., Possible high-mobility LAGEOS ranging station, (Proc. 1977 Symp. on Recent Crustal Movements, Tricste, Italy, June 20-24, 1977), Paper in Tectonophysics, C. A. Whitten, R. Green, and B. K.) Meade, Eds., 52, 69-73 (Elsevier Scientific Publ. Co., Amsterdam, The Netherlands, 1979).

Key words: continental drift; geophysics; ranging; tectonic motions.

distortion-of-plate;

A relatively low-cost system for determining both the vertical and horizontal coordinates of several dozen points per year 
with an accuracy of ahout $2 \mathrm{~cm}$ appears feasible. One approach considered is to use a suhnanosecond pulse length laser with a few millijoules per pulse output energy and to employ single photoelectron detection of the returned signal. The single photoelectron approach has been thoroughly tested in the Lunar Laser Ranging Experiment. With a laser average power of ahout $50 \mathrm{~mW}$, a 30 -cm diameter transmit-receive aperture. 10 are sec pointing accuracy and a heam divergence of 20 arc sec, the expected returned signal level is ahout 70 pulses in a 3-min interval. If the differences between the observed ranges and those calculated from a reasonably good LAGEOS ephemeris over a 3-min interval are considered, the expected standard deviation of the mean is $<0.7 \mathrm{~cm}$.

The calibration procedure used in lunar ranging appears capable of reducing any bias due to the photomultiplier or timing system to $0.5 \mathrm{~cm}$. The other main error source we have considered for the measured optical transit time is a possihle difference in arrival time in different parts of the far field pattern because of laser mode structure. This effect needs to be checked experimentally, but we expect it to be $0.5 \mathrm{~cm}$ or less for a laser pulse length of about $200 \mathrm{psec}$. Based on these error estimates, simulations for one week of observations from the high-mobility station have been carried out for us at the $\mathrm{Na}$ tional Geodetic Survey. When a refraction model error of $0.15 \%$ was used, the uncertainty of the high-mobility station position with respect to a reference station $500 \mathrm{~km}$ away was found to be $2.4 \mathrm{~cm}$ or less in each coordinate. After the gravity-field uncertainties have been reduced, the station location accuracy will be improved further and the limitation of measuring with respect to a regional reference station can be relaxed.

18460. Blackburn, D. L., Larrabee, R. D., Automated photovoltaic technique for nondestructively measuring resistivity variations of high resistivity silicon slices, (Proc. Topical Conf. on Characterization Techniques for Semiconductor Materials and Devices, Seattle, WA, May 21-26, 1978), Chapter in Electrochemical Society, P. A. Barnes and G. A. Rozgonyi, Eds., 78-3, 168-179 (Electrochemical Society, Princeton, NJ, 1978).

Key words: electrical measurements; resistivity; semiconductors; silicon.

An automated, nondestructive photovoltaic technique for measuring the resistivity variation of high resistivity slices is described. The physics of the bulk photovoltaic effect is reviewed, an improved mathematical analysis of the bulk photovoltaic effect due to a small light spot on a large circular slice is discussed, the computer-controlled measurement system is described, and comparisons between photovoltaic and fourprobe resistivity profiles on float-zoned silicon slices with average resistivity between 10 and $150 \Omega \cdot \mathrm{cm}$ are given.

18461. Bowen, R. L., Adhesive bonding of various materials to hard tooth tissues XV1II: Synthesis of a polyfunctional surface-active comonomer, J. Dent. Res. 58, No. 3, $1101-1107$ (Mar. 1979).

Key words: acrylates; adhesion, dental; bonding; coupling agent; dental; monomers; resins; surface-active comonomers.

A facile synthesis regimen was developed for the preparation of a resin that, apparently, has the characteristics of a polyfunctional surface-active comonomer. The first reaction involves the addition of acrylic acid to half of the epoxy groups of a commercial diglycidyl ether of bisphenol A oligomer. The product is then reacted stoichiometrically with the amino groups of lithium o-aminobenzoate in a protic, mixed solvent containing stabilizers and catalysts. Preliminary qualitative tests of the product were favorable. Further analytical procedures and test- ing will he required to determine if it meets the criteria for improving adhesion by a chemical mechanism.

18462. Bowman, C. D., Eisenhauer, C. M., Gilliam, D. M., Photofission effects in reactor pressure vessel dosimetry, Proc. Second ASTM-EURATOM Symp. on Reactor Dosimetry, Palo Alto, CA, Oct. 3-7, 1977, pp. 575-582 (Available as NUREG/CP-()(O)4 from National Technical Information Service, Springfield, VA 22161, 1978).

Key words: dosimetry; fast neutrons; photofission; photoneutrons; pressure vessel; reactor; threshold detectors.

Experiments and calculations hoth suggest that serious backgrounds from photofission are present when threshold fission foils are used as spectral indices for fast neutron intensity and spectrum measurements in pressure vessel dosimetry. The prohlem might be resolved hy a measurement of the higher energy $\gamma$-ray spectrum and intensity by means of induced activity from $(\gamma, n)$ reactions.

18463. Buehler, M. G., Microelectronic test patterns for use in procuring LSICs, Proc. Industry/Joint Services Automatic Test Conf. and Workshop on Advanced Test Technology Management Acquisition Support, San Diego, CA, Apr. 5, 1978, pp. 233-235 (American Electronics Association, Palo Alto, CA, Apr. 1978 ).

Key words: integrated circuit; process validation wafer (PVW); reliability; silicon; test pattern; transistor gain.

The complexity of today's integrated circuits requires new procedures for evaluating the performance of emerging fabrication processes and for insuring that reliability is built into mature components. One approach, currently being developed at NBS, involves the Process Validation Wafer (PVW) concept which is use ful in assessing the merits of a new technology and in establishing the base-line performance of an existing process. One key to built-in reliability is parameter uniformity. This is illustrated by a wafer map showing the variability in bipolar transistor gain across a silicon wafer.

18464. Burnett, E. D., NBS hearing aid test procedures and test results of FY 78 hearing aids, Paper in Handbook of Hearing Aid Measurement 1979, IB 11-68, 324 pages (Veterans Administration, Washington, DC, Mar. 1979).

Key words: anthropometric manikin; free-field measurements; hearing aids; hearing aid tests; orthotelephonic response.

This report discusses the current test procedures used by NBS to evaluate the electro-acoustic properties of hearing aids. It includes the technical and practical reasons for performing the various tests in the manner described and in certain cases presents ideas and preliminary test methods for the evaluation of special-purpose hearing aids. However, the specific details of the electronic equipment used to perform the tests are not described.

Data for hearing aid testing for the Veterans Administration for their use in Fiscal Year 1978 are presented. The methods used are those previously agreed upon with the Veterans Administration.

18465. Calvano, N. J., Wakamiya, S., Dobbyn, R. C., Technical Coordinators, The ballistic resistance of police body armor, NILECJ-STD-0101.01, 17 pages (U.S. Department of Justice, Law Enforcement Assistance Administration, National Institute of Law Enforcement and Criminal Justice, Washington, DC, Dec. 1978).

Key words: armor, body; ballistic deformation; ballistic penetration; body armor; bullet proof vests. 
This standard is for personncl armor intended to protect the torso against gunfire. It establishes methods of test for ballistic penetration and deformation of body armor. The standard provides for five levels of protection, designated as 22 LR-38 Spec., lower velocity 357 Mag.-9 mm, higher velocity 357 Mag.-9 mm, high velocity rifle, and armor-piercing rifle.

18466. Colwell, J. H., A solid-dielectric capacitive pressure transducer, (Proc. 6th AIRAPT Conf., Boulder, CO, July 25 29, 1977), Paper R-8 in High-Pressure Science and Technology, K. D. Timmerhaus and M. S. Barber, Eds., 1, 798-804 (Plenum Press, New York, NY, 1979).

Key words: adiabatic heating; $\mathrm{As}_{2} \mathrm{~S}_{3}$; automatic bridge; $\mathrm{Bi}_{12} \mathrm{GeO}_{20} ; \mathrm{CaCO}_{3} ; \mathrm{CaF}_{2} ;$ capacitance measurement; evaporated electrodes; pressure transducer; temperature dependence.

We are developing a direct-reading pressure transducer that uses the change in capacitance with hydrostatic pressure of solid-dielectric capacitors. The transducer should be capable_sof reproducing the accuracy and long-term stability of the piston gauge at pressures of 14-700 $\mathrm{MPa}(2,000-100,000 \mathrm{psi})$. The large temperature dependence of earlier devices based on this principle have been largely overcome by using two selected capacitors of different materials in opposite arms of the measuring bridge.

18467. Crissman, J. M., Internal friction study of polycrystalline n-paraffins, J. Appl. Phys. 45, No. 10, $4190-4203$ (Oct. 1974).

Key words: audio frequencies; impurities; internal friction; isomers; low temperatures; $n$-paraffins; polycrystals; relaxation process; Young's modulus.

Recent measurements have shown that mechanical relaxation peaks commonly observed in $n$-paraffins are absent in single crystals of $n$-eicosane $\left(C_{20} H_{42}\right)$. This work has now been extended to include polycrystalline samples of several highly pure long-chain hydrocarbons. Internal friction data obtained for a variety of $n$-paraffins, pure or otherwise, have revealed no lowtemperature $\gamma$ relaxation. Moreover, the $\alpha$ relaxation peak is suppressed completely by purification. In attempts to induce an $\alpha$ or $\gamma$ loss peak, several dilute mixtures of other $n$-paraffins in pure $\mathrm{C}_{20} \mathrm{H}_{42}$ have been examined. Only the addition of oddnumbered shorter chains induced loss peaks. On the other hand, the presence of a branched impurity, in this case the $\mathrm{C}_{20} \mathrm{H}_{42}$ isomers 2-methylnonadecane and 10-methylnonadecane, did induce loss peaks, one of which correlates very well to the $\alpha$ process found in as-received $\mathrm{C}_{20} \mathrm{H}_{42}$. It is proposed here that isomer impurities are an important factor in the mechanics of many of the loss processes in long-chain hydrocarbons observed both mechanically and dielectrically.

18468. Crissman, J. M., Zapas, L. J., Dynamic mechanical behavior of polyethylene during creep to failure in uniaxial extension, J. Appl. Phys. 48, No. 10, 4049-4051 (Oct. 1977).

Key words: failure criteria; loss factor; nonlinear creen; polye thylene.

Dynamic mechanical measurements in torsion superposed on large uniaxial creep strains have been obtained on two types of polyethylene resins. At creep strains of about $10 \%$ it is observed that $\tan \delta$ goes through a minimum and rises sharply thereafter.

18469. Deslattes, R. D., Rydberg values for $x$ - and $\gamma$-rays, (Proc. Int. Conf. on X-ray and XUV Spectroscopy, Sendai, Japan, Aug. 28-Sept. 1, 1978), Jap. J. Appl. Phys. Suppl. 17, Part 2, 1-6 (1978).
Key words: encrgy levels; exotic atoms; interferometry; $x$ rays.

An improved connection chain has been established between the hydrogen Rydberg (i.e., H Balmer $\alpha$ ) and $\gamma$-ray lines to which mesic $x$-ray transitions are compared. This new $\gamma$-ray scale, together with improved comparisons between muonic spectra and the $\gamma$-ray lines, appears to have resolved the longstanding problem of vacuum polarization in high $Z$ muonic atoms. It now becomes of interest to turn to high $Z$ electronic spectra where accurate relativistic calculations are recently available. Direct re-measurement of these spectra is underway; meanwhile, however, there are already some results available. This report describes the $\mathrm{H}$ Balmer $\alpha$ to $\gamma$-ray comparisons and summarizes the results of initial comparisons between re-evaluated $\mathrm{x}$-ray transition energies and those which follow from recent relaxed-orbital relativistic Hartree-Fock-Slater calculations.

18470. Durst, R. A., Reference materials for $\mathrm{pH}$ and blood gases, (Proc. Workshop on Blood $\mathrm{pH}$ and gases, Utrecht, The Netherlands, June 5-6, 1978), Paper in Blood $p H$ and Gases, A. H. J. Maas, Ed., Session 1II, pp. 81-87 (University Press, Utrecht, The Netherlands, Mar. 1979).

Key words: acid-base status of blood; blood gases; blood $\mathrm{pH}$; carbon dioxide; oxygen; $\mathrm{pH}$.

This paper is an extended abstract of a talk presented at the Workshop on $\mathrm{pH}$ and Blood Gases in Utrecht, The Netherlands on June 6,1978 . The full publication will eventually appear as an IFCC Recommendation on Quantities related to $\mathrm{pH}$ and Blood Gases, Part 3. Reference Materials.

18471. Eisenhart, C., Contribution to invited discussion of "Francis Ysidro Edgeworth, Statistician", by Stephen M. Stigler, J. Roy. Stat. Soc. Ser. A (General) 141, Pt. 3, 317-318 (1978).

Key words: binomial test; chi-squared test; Francis Ysidro Edgeworth (1845-1926); goodness of fit; Sir Francis Beaufort (1774-1857).

It is pointed out that Sir Francis Beaufort (1774-1857), Hydrographer of the Admiralty and originator of the Beaufort Wind Scale, was both grand-uncle and uncle of F. Y. Edgeworth, and it would be interesting to know to what extent the former influenced the latter's development. It is noted also that the latter's test of goodness-of-fit to a particular hypothetical distribution, $\mathrm{H}_{O}$, can be arranged so as to be the best possible binomial test in small samples, or chi-squared test in large samples, relative to a single completely specified alternative distribution, $\mathrm{H}_{1}$, when $\mathrm{H}_{o}$ is also completely specified.

18472. Faller, J. E., Rinker, R. L., Zumberge, M. A., Plans for the development of a portable absolute gravimeter with a few parts in $10^{9}$ accuracy, (Proc. 1977 Symp. on Recent Crustal Movements, Trieste, Italy, June 20-24, 1977), Paper in Tectonophysics, C. A. Whitten, R. Green, and B. K. Meade, Eds., 52, 107-116 (Elsevier Scientific Publ. Co., Amsterdam, The Netherlands, 1979).

Key words: earthquake; fundamental "constant"; geophysics precision measurement; gravity.

Successful development of a few parts in $10^{9}$ portable $g$ apparatus (which corresponds to a height sensitivity of about 1 $\mathrm{cm}$ ) would have an impact on large areas of geodynamics as well as having possible application to earthquake prediction. Furthermore, the use of such an instrument in combination with classical leveling or extraterrestrially determined height data would yield information on internal mass motions. The plans for the development of such an instrument at JlLA using 
the method of free fall will be given. The proposed interferometric method uses one element of an optical interferometer as the dropped object. Recent work has resulted in substantial progress towards the development of a new type of longperiod $(T>60 \mathrm{sec}$ ) suspension for isolating the reference mirror (corner cube) in the interferometer. Improvements here over the isolation methods previously available, together with state-of-the-art timing and interferometric techniques, are expected to make it possible to achieve a few parts in $10^{9}$ accuracy with a field-type instrument.

18473. Flannery, M. R., McCann, K. J., Systematic trends in the inelastic cross sections and form factors for $n l \rightarrow n^{\prime} l$ ' direct collisional transitions, J. Phys. B 12, No. 3, 427-445 (1979).

Key words: collisional transitions; highly excited Rydberg states; population of angular momentum states.

Certain theoretical predictions are presented for the preferential population of final states with angular momentum $l^{\prime}$ in collisions involving an initially excited atom. Varying $l^{\prime}$, we find that the maxima of both the inelastic form factors and cross sections for the $n l \rightarrow n^{\prime} l^{\prime}$ transitions in hydrogen, induced by collision with electrons and heavy particles, in general oscillate on a background which rises as $l^{\prime}$ is increased, until they both attain a pronounced peak at a unique value $l_{\text {max }}^{\prime}$ which is strongly dependent on only the inital principal quantum number $n$ and which is fairly insensitive to changes in $l$ and $n^{\prime}$. An expression for $l_{\max }^{\prime}$ is derived. For $l^{\prime}>l^{\prime}{ }_{\max }$, the form factors and associated cross sections exhibit a dramatic decline, resulting in negligible population of those states. The predictions differ from those suggested by the Bethe high-energy asymptotic limit which favours dipole transitions, and assume significance in situations where excited states are important as in laser modelling, astrophysical and fusion plasmas, and in laboratory studies of excited Rydberg states. For heavy-particle $\left(n l \rightarrow n^{\prime} l^{\prime}\right)$ collisional transitions the additional undulations which appear in the cross sections over a wide energy range are predicted and explained.

18474. Gallagher, A., Far-wing line broadening, Acta Phys. Pol. A54, No. 6, $761-765$ (1978).

Key words: line broadening; line shapes.

Some of the history and applications of the quasi-static theory of line broadening are discussed, as is its relationship to molecular radiation theory. Interaction potentials of alkalinoble gas diatomic pairs in the ground and first excited state, obtained from application of this theory, are given.

18475. Garvey, R. M., Hellwig, H. W., Jarvis, S., Jr., Wineland, D. J., Two-frequency separated oscillating fields technique for atomic and molecular beam spectroscopy, IEEE Trans. Instrum. Meas. IM-27, No. 4, 349-354 (Dec. 1978).

Key words: atomic beams; atomic frequency standards; cavity phase shift; Ramsey envelope; Ramsey separated oscillating fields; two frequency separated oscillating fields.

We report on a novel method to reduce the effects of cavity phase shift upon atomic beam interrogation in Ramsey cavity configurations. Two distinct cavities driven at different frequencies are employed to produce a cavity phase shift which advances (or recedes) at a constant rate.

18476. Geist, J., Applications of absolute radiometers, Proc. IOth Annual Electro-Optics Laser 78 Conf., Boston, MA, Sept. 19-21, 1978, pp. 277-284 (Industrial and Scientific Conference Management, Inc., Chicago, 1L, 1978 ).
Key words: absolute radiometers; blackbody measurements; chemical actinometry; second harmonic gencration; solar radiation measurements.

The history of the application of absolute radiometers in science and technology is reviewed. The current growth of applications is described, and a possible role as the primary standard for all radiometric measurements is investigated.

18477. Geist, J., Quantum efficiency of the $p-n$ junction in silicon as an absolute radiometric standard, Appl. Opt. 18, No. 6, 760-762 (Mar. 15, 1979).

Key words: absolute detector; absorption coefficient; dead layer model; external; internal quantum efficiency; silicon.

An investigation has been performed which shows that the absolute external quantum efficiency of a silicon detector can be accurately predicted by a simple model over a broad region , of the spectrum. In the visible beyond $600 \mathrm{~nm}$ the accuracy of this calculation exceeds that of direct radiometric measurement of the external quantum efficiency, hence it should be possible to use silicon as an absolute detector in this spectral region. Using a good thermal detector, one can then "bootstrap" a silicon based calibration down into the blue or ultraviolet region of the spectrum.

18478. Greenberg, R. R., Gallorini, M., Gills, T. E., Cadmium analysis by radiochemical neutron activation analysis, Environ. Health Perspec. 28, 1-4 (Feb. 1979).

\section{Key words: cadmium; neutron activation; radiochemistry,}

Radiochemical neutron activation analysis (RNAA) has been routinely used at the National Bureau of Standards to analyze $\mathrm{Cd}$ in a variety of environmentally inportant matrices. The method used to separate $\mathrm{Cd}$ from other neutron-activated products is solvent extraction. Zinc diethyldithiocarbamate $\left[\mathrm{Zn}(\mathrm{DDC})_{2}\right.$ ] in chloroform will quantitatively extract $\mathrm{Cd}$ from an aqueous solution over a $\mathrm{pH}$ range from 1 to 12 . In addition to the extraction of $\mathrm{Cd}, \mathrm{Zn}(\mathrm{DDC})_{2}$ will also extract $\mathrm{Cu}$, which can interfere with the $\mathrm{Cd}$ analysis by producing a high background level of radiation. This can be avoided by first extracting with $\mathrm{Bi}(\mathrm{DDC})_{3}$ in chloroform which removes $\mathrm{Cu}$, but not $\mathrm{Cd}$. Copper concentrations can, therefore, be determined in addition to $\mathrm{Cd}$.

This two extraction radiochemical separation procedure is very versatile and is often used as part of a larger multi-element analysis scheme. One such scheme involves the use of an inorganic-ion exchanger, Hydrated Manganese Dioxide (HMD), to retain $\mathrm{As}, \mathrm{Sb}, \mathrm{Se}$, and $\mathrm{Cr}$ prior to extraction. The eluted fraction is then extracted with $\mathrm{Bi}(\mathrm{DDC})_{3}$ to remove $\mathrm{Cu}$, and then with $\mathrm{Zn}(\mathrm{DDC})_{2}$ to remove $\mathrm{Cd}$.

18479. Greenspan, M., Piston radiator: Some extensions of the theory, J. Acoust. Soc. Am. 65, No. 3, 608-621 (Mar. 1979).

Key words: baffled piston radiator; piston radiator; radiation of sound; ultrasonic radiator.

Those results of the theory of the baffled, uniform-piston radiator that can be calculated exactly are extended to some other cases, especially the simplest case of a simply supported radiator, the simplest case of a clamped-edge radiator and a Gaussian radiator. It is also shown that from the solution to a problem with boundary conditions framed in terms of velocity, the solution to a corresponding problem, having boundary conditions framed in terms of pressure, can be obtained very easily.

18480. Han, C. C., Concentration dependence of the diffusion coefficient of polystyrene at theta-condition, Polymer Notes 20 , 259-261 (Feb. 1979). 
Key words: polymers; polystyrene at theta-condition; theta temperaturc.

Despitc many experimental and theoretical studies, the concentration depcndence of diffusion cocfficient, $k_{D}$, of polymers at their theta-conditions still remain an unscttled problem. Many investigators found experimentally that $k_{n}$ has a negative value; furthermore, Cantow found that the diffusion coefficient $D$ is independent of the concentration at theta temperature. Meanwhile, theorctical investigations have been carried out by Yamakawa and Imai and also by Pyun and Fixman. The Pyun and Fixman (P-F) approach uses a spherical model instead of the more realistic beads and spring model which was employed by Yamakawa and Imai (Y-I). But it has been pointed out by Pyun and Fixman that Yamakawa's earlicr approach is incorrect due to the approximation made by assuming independent inter- and intra-molecular distributions and consequently resulting in the neglect of correlations due to the intermolecular interactions. In the later work of Yamakawa, a negative concentration dependence of $D$ was introduced through the change of coordinate system from actual polymer velocity to the drift velocity. Even though this model leads to a different magnitude for the $k_{D}$ than the one obtained from P-F model, nonetheless both theories predict a negative and molecular weight independent $k_{n}$ at the theta condition.

18481. Hardy, S. C., The motion of bubbles in a vertical temperature gradient, J. Colloid Interface Sci. 69, No. 1, 157-162 (Mar. 15, 1979)

Key words: air bubbles; bubbles, air; viscous silicon oil.

The motions of air bubbles in a viscous silicone oil in response to buoyancy and Marangoni forces have been studied. The Marangoni forces are produced by establishing a temperature gradient in the oil which generates a surface tension gradient over the bubbles. From the thermal gradients required to balance the buoyancy and Marangoni forces, the temperature dependence of the surface tension, $\gamma^{\prime}$, is found to be $-0.055 \mathrm{~mJ} / \mathrm{m}^{2} \mathrm{~s}$. This is in agreement with an independent measurement of $\gamma^{\prime}$ using the pendant drop technique.

18482. Hudson, R. P., The 1978 Nobel Prize in Physics, Science 202, 960-962 (Dec. 1, 1978 ).

Key words: low temperature physics; Nobel Prize.

The career of P. L. Kapitsa, 1978 Nobel Laureate in Physics, is summarized.

18483. Hunter, C., Stellar hydrodynamics of thin disk galaxies, Astrophys. J. 227, 73-92 (Jan. 1, 1979).

Key words: galaxies; stellar dynamics; structurehydrodynamics.

A closed systcm of six stellar hydrodynamic equations is derived for describing the dynamics of perturbed motions of thin disk galaxies in which the motion is primarily circular. These hydrodynamic equations can be solved exactly in the special case of the uniformly rotating Maclaurin disk. This solution is consistent with Kalnajs's exact solution of the collisionless Boltzmann equation for this disk, and describes the important barlike modes exactly. More generally, the stellar hydrodynamic equations provide a feasible method for calculating large-scale modes of oscillation of disk galaxies, and help elucidate the diffcrences between stellar and gaseous disks.

18484. Jewett, K. L., Brinckman, F. E., Bellama, J. M., Infuence of environmental parameters on transmethylation between aquated metal ions, Chapter 11 in Organometals and Organometalloids. Occurrence and Fate in the Environment, ACS Symposium Series No. 82, pp. $158-187$ (S1S/ACS, Washington, DC, 1978).
Key words: activation paramcters; aqueous transmethylation; chloride complexes; environment; formation constants; ionic mechanisms; kinetics; methylmercury; methyltin; NMR; primary salt effect; speciation.

The transmethylation reaction between trimethyltin and mercury (II) species in water, was examined under varying conditions of temperature, ionic strength, and chloride ion concentrations to establish the influence of environmental parameters on the rate and pathways for the reaction. A computer program, CHEMSPECIES, was developed to apply available formation constants in calculating net and relative concentrations of reactant methyltin and $\mathrm{Hg}^{2+}$ species, as well as product ions and molccules formed, during course of kinetic runs. Input data included observed $\mathrm{pH},\left[\mathrm{Cl}^{-}\right]$, and [mcthylmetal species] observable by proton NMR. Bimolecular total reaction rates $\mathbf{k}_{\mathbf{2}}$ (obs) were observed for all runs. Direct extension of BrфnstedDebye-Hückel concepts for ion-molecule reactions in water, provided a coherent estimation of concurrent individual reaction rates for six biomolecular pathways all contributing to $k_{2}$ (obs). These individual rate constants could be applied to transmethylation at diverse ion strengths using simple correction factors consistent with modern theory and reasonable views on the nature of principal reaction pairs. Prospects for encountering such reactions mechanisms in natural waters are briefly discussed.

18485. Kaufman, V., Hagan, L., Spectrum and energy levels of singly ionized aluminum (Al II), J. Opt. Soc. Am. 69, No. 2, 232-238 (Feb. 1979).

Key words: aluminum; energy levels; ionization energy; wavelengths.

New wavelength measurements in the spectrum of singly ionized aluminum ( $8640-683 \AA$ ) have been combined with some previous observations to re-evaluate all of the known energy levels of that ion. The designations of the previously known $3 p 3 d^{3} D^{0}$ and ${ }^{3} p^{0}$ terms have been changed and newly found terms have been identified as $3 p 3 d^{3} D^{0}$ and $3 p^{21} S$. The ionization energy is $151862.7(4) \mathrm{cm}^{-1}$ or $18.82873(5) \mathrm{eV}$.

18486. Kautz, R. L., Attenuation in superconducting striplines, IEEE Trans. Magn. 15, No. 1, 566-569 (Jan. 1979).

Key words: dielectric losses; superconducting losses; superconducting microcircuit; superconducting striplines.

Measurements of the $\mathrm{Q}$ of stripline resonators yield values for the attenuation of $\mathrm{Nb}-\mathrm{Nb}_{2} \mathrm{O}_{5}-\mathrm{Pb}$ striplines typical of those used in superconducting microcircuits. At $4 \mathrm{~K}$ the attenuation between 50 and $500 \mathrm{MHz}$ is proportional to frequency and probably results from dielectric losses. Near the transition temperature of $\mathrm{Pb}$, the attenuation begins to show the frequencysquared dependence associated with superconducting losses.

18487. Kessler, E. G., Jr., Deslattes, R. D., Henins, A., Wavelength of the $W K \alpha_{1}$ x-ray line, Phys. Rev. A 19, No. 1, 215-218 (Jan. 1979).

Key words: gamma rays; precision wavelength; silicon latticc spacing; tungsten $x$ rays; $x$-ray wavelength ratios.

The wavelength of the $K \alpha_{1}$ linc from an electron-bombarded natural $W$ anode has been mcasured in terms of that of an $\mathbf{I}_{2}$ stabilized HeNe laser. This visible laser is a reference point for current Rydberg determinations and for the present-day definition of length. The resulting wavelength value, namely $0.20901349 \AA(0.90 \mathrm{ppm})$ (energy $=59.319233 \mathrm{keV})$ appears to resolve historical inconsistencies in the $\mathrm{x}$-ray route to $\gamma$ wavelengths. 
18488. Kimhleton, S. R., Data sharing protocois: Structure, requirements and interrelationships, $\operatorname{Prox}$ COMPSAC 78, IEEE Compuser Society's Second Int. Computer Software and Application Conf., Chicago, IL, Nov. 13-16, 1978, pp. 270276 (IEEE Service Center, Piscataway, NJ, Nov. 1978).

Key words: communications; computers; data bases; networks; operating systems; protocols

Computer networks provide the basic mechanism for accessing programs and data. Effective use of networks requires appropriate protocols to preserve the meaning of data heing transmitted hetween heterogeneous systems. Currently existing protocols were developed to support the requirements of scientists and engineers. Information processing support, for example remote database access, requires substantially more sophisticated protocols. This paper describes a spectrum of data sharing protocols, identifies the need for a Structure Transport Protocol (STP), describes the nature of an STP, and discusses its utilization in the context of remote database access.

18489. Kraft, R., Finite difference techniques for diffusion and redistribution problems with segregation-type boundary conditions, (Proc. AICA Int. Symp. on Computer Methods for Partial Differential Equations, Lehigh University, Bethlehem, PA, June 17-19, 1975), Paper in Advances in Computer Methods for Partial Differential Equations, R. Vichnevetsky, Ed., pp. 328-333 (AIC, Department of Computer Science, Rutgers University, New Brunswick, NJ, 1975 ).

Key words: algorithm, finite-difference; finite-difference; integral form, conservation of mass principle; mass principle.

Finite-difference techniques and a particular finite-difference algorithm, derived from the integral form of the conservation of mass principle, are given for a one-dimensional diffusion problem in a composite domain with segregation-type boundary conditions specified at a moving interfacial boundary.

18490. Lindstrom, R. M., Harrison, S. H., Harris, J. M., Accurate calibration of gold film standards by neutron activation and gravimetry, J. Appl. Phys. 49, No. 12, 5903-5908 (Dec. 1978 ).

Key words: accuracy and precision; gold films; gravimetry; neutron activation analysis; Rutherford backscattering; standards.

A set of evaporated gold films on silicon substrates has been prepared for use as standards in the measurement of film thickness by Rutherford backscattering. The mass of gold in the films was determined independently by gravimetry and by instrumental neutron activation. The area was measured with an optical comparator; film uniformity was assayed by backscattering. Systematic errors in the single-element comparator method of activation analysis have been assessed and either eliminated or compensated, with the result that the single-sample agreement in mass between the two methods was $0.3 \%$ and the mean relative bias was below the random errors, also $0.3 \%$.

18491. Mathew, M., Schroeder, L. W., Crystal structure of a struvite analogue, $\mathrm{MgKPO}_{4} \cdot 6 \mathrm{H}_{2} \mathrm{O}$, Acta. Cryst. B35, $11-13$ (1979).

Key words: crystal structure; magnesium phosphate; potassium phosphate; struvite analogue

The struvite analogue, $\mathrm{MgKPO}_{4} \cdot 6 \mathrm{H}_{2} \mathrm{O}$, crystallizes in the orthorhombic space group $P m n 2$, with $Z=2$. The cell of $a=$ $6.873(2), b=6.160$ (2) and $c=11.087$ (3) $\AA$, obtained in this study by a least-squares fit of thirty $\pm 2 \theta$ values, is in good agreement with that reported on JCPDS powder diffraction file card 20-685. Our structure determination shows that $\mathrm{MgKPO}_{4} \cdot 6 \mathrm{H}_{2} \mathrm{O}$ is isostructural with struvite, $\mathrm{MgNH}_{4} \mathrm{PO}_{4} \cdot 6 \mathrm{H}_{2} \mathrm{O}$, and that the suhstitution of $\mathrm{NH}_{4}{ }^{+}$hy the smaller $\mathrm{K}^{+}$produces only minor structural changes. The $\mathrm{K}^{+}$ion is loosely coordinated to four water molecules at the hase and more tightly to a $\mathrm{PO}_{4}$ oxygen at the apex of a tetragonal pyramid. The packing of the $\mathrm{Mg}^{2+}, \mathrm{K}^{+}$and $\mathrm{PO}_{4}^{2-}$ ions occurs in planes approximately parallel to the ( 101$)$ and (0)11) planes, which provides a structural hasis for the ohservation that crystals grown in aqueous solutions occur as irregular tetrahedra hounded hy the $(101),(\overline{1} 01),(011)$ and $(0 \overline{1} 1)$ planes.

18492. Mills, R., Velapoldi, R. A., Technical Coordinators, Chemical spot test kits for preliminary identification of drugs of abuse, NILECJ-STD-0604.00, 19 pages (U.S. Department of Justice, Law Enforcement Assistance Administration, National Institute of Law Enforcement and Criminal Justice, Washington, DC, Dec. 1978).

Key words: chemical spot tests; color tests; drugs of ahuse; field test kits; sensitivity; specificity.

This is a performance standard for field testing kits that use chemical spot tests for the preliminary identification of drugs of abuse. Performance requirements and methods of test are given for such attributes as specificity, sensitivity, color development, and labeling.

18493. Milton, H. J., Our metric future. An analysis of metrication's impact upon construction specifications, Constr. Specifier 32, No. 2, 36-47 (Feb. 1979).

Key words: construction specifications; conversion approaches; dimensional coordination; metrication; SI; stages in metrication.

The paper examines some of the background considerations in metrication for the construction community, highlights some of the changes that will need to be made, examines different approaches to conversion, and suggests adaptive strategies for the construction specifications sector during the transitional period.

18494. Misakian, M., Kotter, F. R., Discussion of F 78 169-5, "Analysis of the proximity effects in electric field measurements", IEEE Trans. Power Appar. Syst. PAS-97, No. 6, 2175-2176 (Nov./Dec. 1978).

Key words: electric field measurements; instrumentation; measurement procedures; observer proximity effects; power transmission lines; Russian measurement technique.

18495. O'Connell, J. S., Electroproduction and decay of giant resonances, Comments Nucl. Part. Phys. 8, No. 5, 151-156 (1979).

Key words: alpha particle; dipole giant resonance; electroproduction; nickel; photon; photoproduction; quadrupole giant resonance.

The experimental technique of comparing electro and photoproduction of nuclear reactions to determine the multipolarity of the absorbed electromagnetic quanta is reviewed. The results for three isotopes of nickel $(A=58,60,62)$ show the isoscalar electric quadrupole giant resonance decays predominantly by alpha particle emission.

18496. O'Connell, J. S., MacDonald, W. M., Dressler, E. T., Photopion production in the Fermi gas model, (Proc. Int. Symp. on Photopion Nuclear Physics, Rensselaer Polytechnic Inst., Troy, NY, Aug. 10-12, 1978), Paper in Photopion Nuclear Physics, P. Stoler, Ed., pp. 381-384 (Plenum Publishing Corp., New York, NY, 1979). 
Key words: beryllium; differential cross section; Fermi gas; lithium; optical potentials; photopion; pion.

Differential and total cross sections for $(\gamma, \pi)$ reactions in nuclear matter are calculated using the single particle $\gamma \mathrm{N} \pi$ amplitudes recently proposed for nuclear calculations. Optical potentials for the nucleons and pions are introduced to investigate the influence of the nuclear medium on photopion production. The total photoabsorption cross section is computed and compared with recent data on lithium and beryllium.

18497. Paffenbarger, G. C., The contributions to dental science of Robert J. Nelsen (Introductory remarks), (Callahan Memorial Award of the Ohio Dental Association, Columbus, Ohio, Sept. 23, 1978 ), J. Am. Coll. Dent. 46, No. 1, 57-59 (Jan. 1979).

Key words: Callahan Memorial Award; dental handpiece; dental materials; dental radiography; dental research; Nelsen, Robert J.

Dr. Robert J. Nelsen, the present Executive Officer of the American College of Dentists, was the recipient of the Callahan Memorial Award in 1978. The presentation of the Award included the benefit/cost ratio $(27,000)$ of his invention of the turbine contra-angle dental handpiece in 1953 while he was a Research Associate of the American Dental Association at the National Bureau of Standards. The money saved by the use of the turbine contra-angle handpiece for the year 1978 would educate and set up in practice the equivalent of over 9,000 dentists. As it costs about $\$ 100,000$ to educate a dentist beyond high school, and to set up a practice, approximately 1 billion dollars would be saved. Dr. Nelsen's research work in dental radiography and in dental materials, together with his administrative positions, are reflected in the introduction.

18498. Raymer, M. G., Carlsten, J. L., Pichler, G., Comparison of collisional redistribution and emission line shapes, $J$. Phys. $B$ Lett. to Ed. 12, No. 4, L1 I9-L124 (1979).

Key words: collisional line broadening; collisional redistribution; resonance fluorescence.

We have studied collisional redistribution of near-resonance radiation in thallium vapour caused by collisions with argon buffer gas. We spectrally resolved electronic Raman scattering and collision-induced fluorescence, both to the weakly populated metastable $6^{2} \mathbf{P}_{3 / 2}$ level in thallium. Thus we partially avoided the problem with radiative trapping encountered in previous experiments. By measuring the total collision-induced fluorescence as a function of the incident laser frequency, we obtained the absolute collisional redistribution line shape. We have compared this line shape with the emission line shape measured by Cheron, Scheps and Gallagher.

18499. Reader, J., Acquista, N., Spectrum and energy levels of four-times ionized zirconium ( $\mathrm{Zr} \mathrm{V}$ ), J. Opt. Soc. Am. 69, No. 2, 239-253 (Feb. 1979).

Key words: spectra; ultraviolet; wavelengths; zirconium.

The spectrum of zirconium was observed in the region from 200 to $2670 \AA$ with a sliding-spark discharge on the $10.7-\mathrm{m}$ normal- and grazing-incidence spectrographs at NBS. About 580 lines were assigned to $\mathrm{Zr} \mathrm{V}$. From these observations the energy level system of $\mathrm{Zr} \mathrm{V}$ ( $\mathrm{Kr} \mathrm{I}$ isoelectronic sequence, ground state $4 s^{2} 4 p^{6}{ }^{1} S_{0}$ ) has been extended to the complete $4 s^{2} 4 p^{5} 5 s, 6 s, 7 s, 5 p, 4 d, 5 d, 4 f, 5 g$, and $4 s^{4} p^{6} 4 d$ configurations and the nearly complete $4 s^{2} 4 p^{5} 6 \mathrm{~d}$ and $6 \mathrm{~g}$ configurations. About 330 lines have been classified. All observed configurations have been theoretically interpreted. The energy parameters determined by least-squares fits to the observed levels are compared with Hartree-Fock calculations. The ionization energy derived from the $4 p^{5} \mathrm{ng}, \mathrm{n}=5,6$ levels is $648050 \pm 60 \mathrm{~cm}^{-1}(80.349 \pm$ $0.007 \mathrm{eV}$ ).

18500. Reader, J., Luther, G., Acquista, N., Spectrum ant energy levels of thirteen-times ionized molybdenum (Mo XIV) J. Opt. Soc. Am. 69, No. 1, 144-149 (Jan. 1979).

Key words: energy levels; ions; molybdenum; pulsed laser spectra; wavelengths.

The spectrum of Mo XIV was observed with a low-in ductance spark and a laser-produced plasma in the region from 70 to $630 \AA$ on the $10.7-\mathrm{m}$ grazing-incidence spectrograph at NBS. From the identification of 35 lines, a system of 22 energy levels was determined. The level system ( $\mathrm{Cu} I$ isoelectronic sequence, $\left.3 d^{10} n l\right)$ includes the series $n s(n=4-6), n p(n=4$. $6)$, $n d(n=4,5), n f(n=4-6)$, and $n g(n=5-7)$. The observed energy levels are compared with Hartree-Fock calculations. The ionization energy is determined from the $\mathrm{ng}$ series $(n=5$ 7) to be $2440600 \pm 300 \mathrm{~cm}^{-3}$ ( $\left.302.60 \pm 0.04 \mathrm{eV}\right)$.

18501. Richmiond, J. C., Evaluation of solar absorbers, reflectors and transmitters-Physical reflectance standards, Proc. 1979 Conf. of the 25th Annual Tech. Meeting Learning to Use Our Environment, Seattle, WA, Apr. 30-May 2, 1979, pp. 26 (Institute of Environmental Sciences, Mt. Prospect, IL, 1979).

Key words: diffuse reflectance standards; solar absorptance; solar optical properties; solar reflectance; solar transmittance; spectral reflectance standards; terrestrial solar irradiance.

The classical method of evaluating solar optical properties of materials (reflectance, absorptance and transmittance) is to measure the spectral property of interest (absorptance is taken as one minus reflectance) under conditions of directional irradiation and hemispherical collection, and compute the solar property as the weighted average spectral property, with the solar spectral irradiance as the weighting function. Integrating sphere reflectometers are almost universally used for measuring spectral directional-hemispherical reflectance. Such instruments defined, for accuracy, on the use of calibrated reference standards of absolute directional-hemispherical reflectance. Terrestrial solar spectral irradiance varies widely with changes in the path length of the sun's rays through the atmosphere. There is no generally accepted terrestrial solar spectral irradiance distribution. This paper briefly describes the work now in progress by the Solar Optical Materials Program Planning Committee of the Department of Energy to recommend for adoption a standard terrestrial solar spectral distribution and to make available, through the Office of Standard Reference Materials of the National Bureau of Standards, calibrated reference standards of spectral directional-hemispherical reflectance and of specular spectral reflectance.

18502. Rowan, W: L., Roberts, J. R., Electron-impact ionization-rate coefficients for lithiumlike nitrogen and oxygen, Phys. Rev. A 19, No. 1, 90-98 (Jan. 1979).

Key words: electron impact ionization; ionization cross section; ionization rate coefficient; lithiumlike ions, ionization of: $\mathrm{N}^{+4} ; \mathrm{O}^{+5}$; rate coefficient.

The electron-impact ionization-rate coefficients for lithiumlike nitrogen and oxygen are obtained from the time evolution of spectral lines emitted by a hot plasma. The plasma is produced in a $37-\mathrm{kJ}$ theta pinch. Laser scattering diagnostics indicate that $N_{e} \approx 4 \times 10^{15} \mathrm{~cm}^{-3}$ and $k T_{e} \approx 80 \mathrm{eV}$ during the time of principal interest. Under these conditions, the ionization-rate for lithiumlike nitrogen is $(7.4 \pm 2.2) \times 10^{-10} \mathrm{~cm}^{3} \mathrm{~s}^{-1}$, and that for lithiumlike oxygen is $(4.1 \pm 1.2) \times 10^{-10} \mathrm{~cm}^{3} \mathrm{~s}^{-1}$. The rate coefficients measured here and all other measure- 
ments of lithiumlike ionization rate coefficients are compared to calculations of the ground-state ionization-rate coefficient and the total-ionization-rate coefficient.

18503. Schoenwetter, H. K., A high-speed low-noise 18-bit dIgltal-to-analog converter, IEEE Trans. Instrum. Meas. IM27, No. 4, 413-417 (Dec. 1978).

Key words: A/D converters; D/A converters; data acquisition; data converters; dynamic measurements; settling time.

An 18-bit digital-to-analog converter (DAC) with a full-scale current output of $100 \mathrm{~mA}$ and a compliance voltage range of $\pm 12 \mathrm{~V}$ has been designed for use as a precision voltage output DAC. The output noise and settling time of the new design are considerably lower than obtainable from conventional design approaches. An accurate method of measuring settling time also is described.

18504. Siedle, A. R., Velapoldi, R. A., Erickson, N., Surface formation of cuprous benzotriazole, Inorg. Nucl. Chem. Lett. 15. No. 14, 33-36 (1979).

Key words: benzotriazole; charge transfer; copper; luminescence; microspectrofluorimetry; photoluminescence; spectrofluorimetry; surface analysis; tetrazole.

Intense, visible luminescence, attributed to charge transfer excited states, was observed in $\mathrm{Cu}(1)$ complexes of benzotriazole but not in the $\mathrm{Cu}$ (II) analogues. Microspectrofluorimetry was used to characterize cuprous benzotriazole, a surface phase formed from bulk copper and benzotriazole in dichloromethane.

18505. Souders, T. M., A bridge circuit for the dynamic characterization of sample/hold amplifiers, IEEE Trans. Instrum. Meas. IM-27, No. 4, 409-413 (Dec. 1978).

Key words: amplifier, sample/hold; bridge circuit; circuit bridge; dynamic characterization of sample/hold amplifier.

A transformer bridge technique is described for measuring the dynamic performance of sample/hold amplifiers (S/H's). The technique accurately measures dynamic gain errors, signal delay, aperture time delay and jitter, and acquisition time. These parameters are of particular importance to simultaneous data acquisition. The bridge is self-calibrating, and the voltage and time resolution are primarily limited only by the oscilloscope which serves as a detector.

18506. Sugar, J., Kaufman, V., Identification of $5 g$ and $6 g$ terms and revised ionization energies in the $Y b$ II $4 f^{14} n l$ isoelectronic sequence, J. Opt. Soc. Am. 69, No. 1, 141-143 (Jan. 1979).

Key words: energy levels; hafnium; ionization energies; lutetium; osmium; rhenium; tantalum; tungsten; wavelengths; ytterbium.

The $5 f-5 g$ transitions in Lu III through Os VIII and the $5 f-6 g$ transitions in Hf Iv through W VI were identified and used to

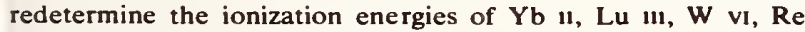
VII, and Os VIII. Complete line-lists and energy levels are given for the one-electron spectra Hf Iv, W VI and Os vilı.

18507. Sugar, J., Lucatorto, T. B., Mcllrath, T. J., Weiss, A. W., Even-parity autoionizing states in neutral sodium (350$400 \AA$ ), Opt. Lett. 4, No. 4, $109-111$ (Apr. 1979).

Key words: autoionizing states; laser-excitation technique; neutral sodium; sodium, neutral.

A recently developed laser-excitation technique has been used in the first photoabsorption studies of the even-parity $2 p^{5} 3 s 3 p$ and $2 p^{5} 3 s 4 p$ autoionizing levels of $\mathrm{Na} 1$. The observed- vel values are compared, where applicable, with those previously obtained by ejected-electron spectroscopy of collisionally excited $\mathrm{Na}$, and the identifications are confirmed by ab initio calculations.

18508. Wiese, W. L., Younger, S. M., Theoretical simulation of beam foil decay curves for resonance transitions of heavy ions, J. Phys. 2, No. 40, Cl-146-Cl-148 (Feb. 1979).

Key words: atomic decay curve simulation; atomic transition probabilities; beam-foil spectroscopy; cascades in atomic decay; exponential fitting; Kr VIll.

We have made a theoretical study of the influence of cascades on heavy ion beam-foil lifetimes, concentrating on the resonance line of $\mathrm{Kr}$ Vlll. Using theoretical data for the lifetimes and initial populations of excited states, we have constructed deaay curves simulating beam-foil excitation conditions. The theoretical decay curve producing the best fit with experimental decays yielded the same lifetime as the experiments when subjected to the same cascade analysis, but customary exponential fitting techniques were not able to extract the theoretical primary lifetime actually used in its construction.

18509. Piermarini, G. J., Forman, R. A., Block, S., Viscosity measurements in the diamond-anvll pressure cell, Proc. $6 \mathrm{ih}$ AIRAPT Int. High Pressure Conf., Boulder, CO, July 25-29, 1977, pp. 860-864 (Plenum Press, New York, NY, 1979).

Key words: diamond-anvil; glass transition; high pressure; hydrostaticity; liquids; pressure cell; viscosity.

The viscosity of liquids can be measured in the diamondanvil pressure cell utilizing a falling-ball method and the ruby technique for pressure measurement. The pressure dependence of the viscosity of a $4: 1$ mixture (by volume) of methanol:ethanol has been determined. The accuracy of the technique has been estimated from measurements made on a fluid of known viscosity.

18510. Kessler, E. G., Jr., Jacobs, L., Schwitz, W., Deslattes, R. D., Precise $\boldsymbol{\gamma}$-ray energies from the radioactive decay of ${ }^{170} \mathrm{Tm}$ and ${ }^{169} \mathrm{Yb}$, Nucl. Instrum. Methods 160, 435-437 (1979).

Key words: crystal diffraction; gamma-ray energies; thulium; ytterbium.

Precise energy values for ten standard $\boldsymbol{\gamma}$-ray reference lines produced in the radioactive decay of ${ }^{170} \mathrm{Tm}$ and ${ }^{169} \mathrm{Yb}$ have been measured relative to an optical standard. These measurements, which have an uncertainty of about $0.5 \mathrm{ppm}$ for the more intense lines, provide precise $\gamma$-ray standards in the 63 $307 \mathrm{keV}$ range. Measurements on ${ }^{169} \mathrm{Yb}$ lines constrained by the Ritz principle satisfy the combination principle within the measurement uncertainty.

18511. Han, C. C., McCrackin, F. L., Molecular weight and polydispersity measurements of polystyrene by quasielastic light scattering, Polym. 20, 427-432 (1979).

Key words: diffusion; diffusion coefficient; light scattering; polydisperse; polydispersity; polystyrene; quasielastic light scattering; SRM-706; standard reference material.

The molecular weight and polydispersity of a polydisperse polystyrene sample was measured by quasielastic light scattering. The molecular weight distribution of the polymer was represented by the Schultz distribution. The weight average molecular weight and polydispersity of distribution was adjusted until the quasielastic light scattering spectra calculated for the distribution agreed with the measured spectra. The calculation was repeated using the logarithmic normal distribution for the polymer. The calculated value of the weight average molecular 
weight is accurate and insensitive to the assumed molecular distribution function. However, the calculated values of the polydispersity are only of fair accuracy. Thus quasielastic light scattering gives values of the weight average molecular weight at least as accurate as elastic light scattering and gives a crude estimate of the polydisnersity of the polymer.

18512. Brown, D. W., Lowry, R. E., The radiation-indaced copolymerization of tetraftuoroethylene and styrene at high pressure, J. Polym. Sci. 17, $759-768$ (1979).

Key words: copolymerization; polymerization; pressure; radiation; styrene; tetrafluoroethylene.

The radiation-induced copolymerization of tetrafluoroethylene (A) and styrene (B) was studied in bulk and in perfluorotoluene at $22{ }^{\circ} \mathrm{C}$ at autogenous pressure and 260 and $510 \mathrm{MPa}$. The reactivity ratio for addition to A-ended radicals, $r_{A}$, is effectively zero at the two lower pressures and is in the range $0.002-0.008$ at $510 \mathrm{MPa}$. The other reactivity ratio, $r_{B}$, is 6 at autogenous pressure and also at 260 and 510 $\mathrm{MPa}$ if the $\mathrm{A}$ content of the charge is less than $50 \%$. If the $\mathrm{A}$ content is greater than $95 \%, r_{B}$ appears to be 100 at pressures of 260 and $510 \mathrm{MPa}$. The apparent variation in $r_{B}$ cannot be explained by invoking a penultimate unit effect for B-ended radicals. Polymerization rates scatter somewhat, but all rates are quite small when the $A$ content of the charge is in the range $95-99.8 \%$. Polymers containing as much as $66 \%$ A appear to be inherently benzene soluble but frequently contain some gel because of radiation-induced crosslinking after their formation. No very high polymers were formed that contained more than a few percent $\mathrm{A}$, even at high pressure. Features that complicated the study were immiscibility of the liquid monomers, extreme variation of the monomer-copolymer compatibility with charge composition, and freezing of $B$ at high pressure.

18513. Anderson, W. E., Davis, R. S., Petersons, O., Moore, W. J. M., An international comparison of high voltage capacitor calibrations, IEEE Trans. Power Appar. Syst. PAS-97, No. 4, 1217-1223 (July/Aug. 1978).

Key words: calibration; Clausius-Mossotti equation; compressed-gas capacitor; high voltage; standards; sulfur-hexafluoride.

The suitability of a commercially available, compressed-gasinsulated, high voltage capacitor for precise measurement of ac voltages has been examined by national laboratories in the U.S.A. and Canada. The voltage, temperature, and pressure dependences and the mechanical stability of the capacitor were determined. It was found that by taking proper precautions the device is competitive with other methods. As a result of this research, it was also found that high voltage capacitance measurements at the two laboratories involved are in agreement.

18514. Bright, R. G., Technical developments of domestic fire detectors, (Proc. Int. Fire, Security and Safety Exhibition and Conf., London, England, Apr. 24-28, 1978), Fire Surveyor Mag. 74, 9-16 (Aug. 1978).

Key words: detection; fires; home fires; residential smoke detectors; smoke detectors

A review of some of the more significant technical developments in residential smoke detectors, in the past four years is presented. In addition, some of the problems experienced, as well as forecasts of possible future technical developments, are also given.

18515. Castor, J. I., Lamers, H. J. G., An atlas of theoretical P Cygni profiles, Astrophys. J. Suppl. Ser. 39, No. 4, 481-51 I (Apr. 1979).
Key words: line profiles; P-Cygni lines; radiative transfer; resonance lines; stars; stellar winds.

An atlas of theoretical P Cygni-type line profiles is presented. The profiles are calculated assuming resonance scattering and using the Sobolev approximation. The exnanding envelope is characterized by two functions; the optical depth $\tau(v)$ and th velocity law $v(r)$. The velocity law, the process of line formation, and the accuracy of the theoretical line profiles are discussed. The effect of collisional excitation is discussed and is found not to be important in most UV resonance lines, except in a star with a very high rate of mass loss and a small wind velocity. We describe a simple procedure to correct for the nresence of underlying photospheric profiles, and show that the simple addition of the calculated P Cygni profile and photospheric nrofile can give very wrong results. We also describe a fairly simple procedure for calculating the shape of partly overlanping doublet lines. The accuracy of the information that can be derived from a comparison between observed and theoretical P Cygni profiles is discussed critically.

18516. Collins, L. A., Norcross, D. W., Schmid, G. B., Electron collisions with highly polar molecules: Integrated and momentum transfer cross sections and conductivity integrals for KOH and CsOH, J. Phys. B 12, No. 6, $1019-1030$ (1979).

Key words: cross sections; electron collisions; molecules; momentum-transfer; polar molecules; scattering theory.

We report close-coupling calculations of the total integrated and momentum transfer cross sections for the scattering of electrons from $\mathrm{KOH}$ and $\mathrm{CsOH}$ in the energy range 0.01 to 10 $\mathrm{eV}$. A cut-off dipole potential is used to account for the longrange interaction. We nominally chose the cut-off radius $\boldsymbol{R}_{c}$ such that the potential has a minimum in the vicinity of the nucleus nearest to the centre-of-mass (COM) of the molecule. No explicit account is taken of the short-range interactions. The results for the total integrated and momentum transfer cross sections exhibit oscillations about a mean value, with an amplitude of approximately $1 \%$, and $10 \%$, respectively, of the mean. The choice of a different value for $\boldsymbol{R}_{c}$ in additional calculations for $\mathrm{KOH}$ led to results for the mean value and amplitude which were virtually identical for $k^{2} \ll 1 /\left(2 R_{c}\right)^{2}$. A simple semi-quantitative understanding of this behaviour is presented in the context of Fabrikant's effective-range theory (ERT). This leads to concise analytical expressions for the velocity-averaged momentum transfer cross section and mobility that also oscillate within an envelope not greater than that of the momentum transfer cross section itself, and are very insensitive to the choice of $R_{c}$. We also present analytical expressions for the interaction parameters (conductivity integrals) which may be used for calculating electrical properties of gas mixtures according to the popular algorithm of Demetriades and Argyropoulos. A comparison of the predictions of our expressions with the previous best estimates for these parameters as reported by Spencer and Phelps is given.

18517. Davis, S., Assessment of fire hazards from furniture, Proc. Int. Fire, Security and Safety Exhibition and Conf., IFSSEC'78, London, England, Apr. 24-28, 1978, 30 nages (Victor Green Publ. Ltd., London, England, 1978).

Key words: bedding; beds; compartment fires; firesafety engineering; fire tests; health care facilities; hospitals; mattresses; prisons.

A test program was conducted to assess the hazards of institutional mattresses when subjected to a sustained flaming ignition source. This report gives results on full-scale room burns of ten different mattress types. Tenability and rapid flame spread notential criteria were applied in a hazard assessment which showed a wide range of behavior among mattresses now being used in institutions. 
18518. Dodge, W. R., Hayward, E., Moscati, G., Wolynec, E., Electrodisintegration of ${ }^{238} \mathrm{U}$, Phys. Rev. C 18, No. 5, 24352437 (Nov. 1978).

Key words: electrodisintegration; proton spectrum; ternary fission; $\alpha$-particles; $\alpha$-spectrum; ${ }^{238} \mathrm{U}$.

A search has been made for $\alpha$-particles that might stem from an isoscalar E2 giant resonance in ${ }^{238} \mathrm{U}$ near $9 \mathrm{MeV}$. Using 40 $\mathrm{MeV}$ electrons the spectra of protons and $\alpha$-particles emitted in the electrodisintegration of ${ }^{238} \mathrm{U}$ were measurcd. Peaks in the proton spectrum indicated that the target has an oxygen contamination. The less intense $\alpha$-spectrum contains $\alpha$-particles resulting from the electrodisintegration of ${ }^{15} \mathrm{O}$, a group that probably stems from ternary fission, and a higher energy feature which may be attributed to the electrodisintegration of ${ }^{238} \mathrm{U}$. The integrated ${ }^{238} \mathrm{U}(\mathrm{e}, \alpha)$ cross section is less than $1 \%$ of a recently suggested value.

18519. Filliben, J. J., Dataplot-An interactive system for graphics, Fortran function evaluation, and linear/non-linear fitting, Proc. 1978 Statistical Computing Section of the American Statistical Association, San Diego, CA, Aug. 14-17, 1978 , pp. 344-353 (American Statistical Association, Washington, DC, 1978).

Key words: computing system; dataplot; fitting; graphics; interactive graphics; regression; software; transformation.

Dataplot is a high-level language that was developed in response to data analysis problems encountered at the National Bureau of Standards. The language is very powerful, very flexible, and very fast to use-especially in an interactive environment. The system combines the best features of the 3 kernal operations of data analysis-graphics (continuous or discrete), data transformations, and linear/non-linear fitting into one language. Many of the features in dataplot are singularly unique and unmatched by any other interactive system in existence. Features of the system include: Interactive fortran expression evaluation for transformations plotting/fitting, continuous/discrete plots, single/multi-trace plots, single/multi-function plots, labelled/unlabelled plots, linear/log-scale plots, linear/non-linear fittings, interactive analyses, subset analysis, distributional summary plots, data analysis plots, control charts, probability plots, ( 24 distributions), times series plots, complex demodulation plots, exact rational function fitting, least squares smoothing, random number generation ( 24 distributions), data manipulation capabilities, probability function calculations, elementary statistics (18 statistics), format-free 1/O, diversible graphics output, and a desk calculator mode.

18520. Hayward, E., The electrodisintegration of ${ }^{58} \mathrm{Ni}$, Proc. $4 \mathrm{th}$ Seminar on Electromagnetic Interactions of Nuclei at Low and Medium Energies, Moscow, USSR, Dec. 13-15, 1977, pp. 125 139 (1979).

Key words: electric quadrupole; electrodisintegration; electron energy; giant resonance; virtual photons; ${ }^{58} \mathrm{Ni}$.

The electrodisintegration of ${ }^{58} \mathrm{Ni}$ into protons and $\alpha$-particles has been studied. The yield curves as a function of electron energy have been obtained and a few points measured with a Tantalum radiator interposed. Using the electric dipole and electric quadrupole virtual photon spectra, these yields can be interpreted as resulting from compact E1 and E2 giant resonances. Alpha particle emission is the dominant mode of decay of the isoscalar $\mathrm{E} 2$ resonance at $16.5 \mathrm{MeV}$, while the protons are emitted only by the electric dipole giant resonance at $19 \mathrm{MeV}$. This technique represents a powerful new tool for determining giant resonance multipolities.

18521. Hayward, E., Nuclear elastic scattering of photons, Proc. 4th Seminar on Electromagnetic Interactions of Nuclei at Low and Medium Energies, Moscow, USSR, Dec. 13-15, 1977, pp. 185-199 (1979).

Key words: coherent scattering; Delbrück scattering; elastic scattering; giant resonance; tensor polarizability; Thomson scattering.

Nuclear elastic scattering in the energy region of the electric dipole giant rcsonance is reviewed. The interference of the coherent nuclear scattering with Rayleigh, Delbrïck, and nuclear Thomson scattering is pointed out. The tensor polarizability of the deformed and vibrational nuclei is pointed out and the results of the experiments that use neutron capture $\boldsymbol{\gamma}$-rays and $\mathrm{Ge}(\mathrm{Li})$ detectors are summarized.

18522. Hayward, E., Dodge, W. R., Patrick, B. H., Some experiences using a positron annihilation beam, Nucl. Instrum. Methods 159, 289-299 (1979).

Key words: positron annihilation-in-flight; quasi-monoenergetic photons; sodium iodide spectrometer; $15.1 \mathrm{MeV}$ branching ratio.

The NBS positron annihilation-in-flight facility is described, along with the procedure for the calibration of the positron beam energy. Details are also given of a large Nal(TI) spectrometer used with the annihilation photon beam. Response functions of this spectrometer for photons of 15 and $31 \mathrm{MeV}$ have been measured using a photon tagging scheme based on the detection of the annihilation photons in coincidence. The variation in response function caused by the presence of absorbers in front of the spectrometer has been investigated. The response function measured at $15 \mathrm{MeV}$ is compared with that obtained by resonance fluorescence of the $15.1 \mathrm{MeV}$ level in ${ }^{12} \mathrm{C}$ and, from the latter data, the branching ratios for the decay of the $15.1 \mathrm{MeV}$ level to the ground state and the excited states at 4.44 and $7.66 \mathrm{MeV}$ have been extracted.

18523. Horton, W. S., An examination of five preferred orientation functions, Carbon 17, 153-155 (1979).

Key words: Bacon function; Bragg function; Ergun function; graphite materials; Lorentz function; preferred orientation function; pyrolitic graphite; Ruland function; $x$-ray diffraction.

Five funetions for describing the preferred orientation of graphite-like materials were examined. Their relative behavior for various degrees of orientation were compared, particularly with respect to the ease of discriminating among them experimentally. The results obtained when data were fitted by a nonlinear least squares method were used for a practical comparison. It was found that a constant term is required to allow for base line effects and some unoriented material. For careful evaluation of functions it is necessary to assume that the angle for maximum x-ray reflection intensity was set with some error. Among the five functions compared, the Bragg function fitted the comparison data best. However, if zero slope is required $90^{\circ}$ away from the reference axis, this function is ineligible. In that case the Bacon and Ergun functions were equally good. Systematic trends in some of the data were related to sample preparation. The standard deviation for measuring the orientation parameter by fitting a function in this manner was from 0.4 to $3 \%$.

18524. Johnson, C. R., Leighton, F. T., Robinson, H. A., Sign patterns of inverse-positive matrices, Linear Algebra and Appl. 24, $75-83$ ( 1979).

Key words: Hadamard product; inverse-positive matrix; matrix sign patterns; positive matrix. 
We illentify the sign palterns which occur among the real, nonsingulat, entrywise nonyero matrices whose inverses are entrywise positive

18525. Kiniscilik, J., Herger, H., McGogney, C, Thuber pilings: Mushtenunce und inspection summury of a panei discussion,

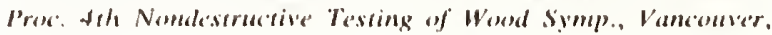
WA, dus. 28-30, 197s, Pp. 155-159) (Washington State Univ., Engineering Extension Service, Pullmin, WA, 1979).

Key words: acoustics; bridges; creosote; harbor facilities; imspection; matutenance; matine borers; nondestructive testing; pilings; timber

The panel discussion concerned with montenance and inspection of timber pilings attracted about 100 people (incluting ten who registered only for this event) to a lively evening session. Timber pilings ace nsed in brilge structures and for harbor and uavigational lacitities. The fopic lor discussion was the inspection and maintenance of these pilings in order to prevent lailures such as the collipse of the Coos Bay bridge in Oregon in 1977 due to damige cansed by marine borers.

18526. LaVilla, R. E., Double-vacuncy transitions la the copper $\kappa \beta_{1, i t}$ enutssion spectrum, Phys. Rev, A 19, No, 2, $717-720$ (Feb. 1979).

Key words: copper $K \beta$; double vacancy; emission spectum; Hatree-Fock calculations; x-ray cmission.

The $\beta^{\prime}$ and $\beta^{\prime \prime}$ satellites in the measured $C$ u $\kappa^{\prime} \beta_{1,3}$ emission spectrum alte shown to be due to the double-vacancy transitions

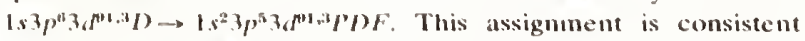
with an earlier analysis of a highly resolved $\mathrm{Cu} K \mathrm{~K}_{1,2}$ spectrum. The $M_{3}$ and $M_{3}$ level wilths are estimated to be $1.68 \mathrm{eV}$, in agreencut with $2.0 \pm 0.3 \mathrm{eV}$ and $1.6 \pm 0.3 \mathrm{eV}$, respectively, lirou photoelectron spectroscopy, and a calculated width of 2.0 eV. Comparison of the calculated doubte-vacancy transition uray with the neighboring elements $30 \leqslant Z \leqslant 32$ suggest a similat identification to the $\beta^{\prime}$ and $\beta^{\prime \prime}$ satettites in their $\kappa \beta_{1,3}$ specetra

18527. Klose, 1. Z., Mean Iffe of the t. ${ }^{2} S_{1 / 2}$ resonauce level in Al, llys. Rev. A 19, No. 2,678-681 (Feb. 1979).

Key worts: Al 1; ahminum; delayed coincidence; $f$-value; imprisonment; laser; lifetime; mean life; oscillator strength.

The mean life of the $+s^{2} S_{1 / 2}$ resonance level in $\mathrm{Al}, \mathrm{h}$ hs been measured at seven different vapor densities using a tuable dye haser for excitation atnd a method of delayed coincidence for detection. The lifetime values, obtained by exciting the level with ratiation at the resonance wavelength of $3944.01 \AA$ and observing its decay hy means of the transition at $3961.52 \mathrm{~A}$. increase with increasing vapor density. This vapor-density dependence was interpreted ans being due to the imprisomment of the $3962-1$ ratiation. Imprisonment theory at low densities was upplied to the experimental data to yield the following results: $\tau_{0}=6.7 \mathrm{~s} \pm 0.00 \mathrm{~ns}, f_{3224}=0.115 \pm 0.001$, and $f_{3 \mathrm{BN}+2}=0.116 \pm$ 0.001 . Experimental and theoretical results of other workers are presented for comparison with the results of the present work.

18528. Linsky, J. L., Haisch, B. M., Outer utmospheres of cooi stars. I. The shurp division into solar-type and non-solar-type sturs, Astrophys. J. 229, No, 1, L27-L32 (Apr, 1, 1979).

Key words: emission lines, stars; late-type stars; stellar chromospheres; stellar coronte; stellar winds: ultraviolet speerra

IUE short-waclength (1175-2000 $A)$ spectra of late-type stars stearly indicate wo separate and distinct groups of stars. The solar-type group shows spectral lines formed at tempera- tures of $5 \times 10^{3}-2 \times 10^{5} \mathrm{~K}$, indicative of chromospheres, transition regions, and by implication unseen coronae at hotter temperatures. The non-solar-type group shows lines formed at temperatures wo hotter that 10,000$)-20,000 \mathrm{~K}$, indicative of chromospheres only. We interpret this acute change in character of the outer atmospheres of stars on either side of the shitp divicting line between the two groups as due either to the absence of hot material resulting from the rapid onset of large stellar winds, a hypothesis recently suggested on theoretical grounds by Mullan, or to very low transition-region densities, as suggested by a model stellar wind corona we have calculated for Arcturus.

18529. McAuliti, R. C., Lentner, K. J., Moore, W. J. M., Schuster, G., An international comparison of power measurements at $120 \mathrm{~V}, 5 \mathrm{~A}$, and $60 \mathrm{~Hz}, I E E E$ Trans. Instrum. Meas. 27. No. 4, 445-449) (Dec. 1978).

Key words: electro-dynamic wattmeters; energy measurements; energy standards; international comparisons; metrology; power measurements; precise clectrical measurements; TDM wattneters; thermal wattmeters; transfer standards.

An international comparison of ac power measurements between metrology laboratories at the Physikalisch-Technische Bundesanstalt-Institut Berlin, (PTB(IB)), the Electrosystems Division of the National Bureau of Standards (NBS), and the Division of Electrical Engineering at the National Research Conncil of Camada (NRC(EE)) is described. The three calibration systems, each of different design and developed independently, are discussed, and estimates of the systematic uncertainties are given. The transler standard was a recently developed thermal wattmeter of high stability. No laboratory differed by more than \pm 15 parts per million ( $p$ pm) from the average, with reference to apparent power at unity and 0.5 power factors. lead, and lag. This is consistent with the error limits estimated by each of the participants.

18530. McCrackin, F. L., Monte Carlo calcuiations of the unuber of ways to pack nonoverlapping rods on a square lattice, J. Chem. Phys. 69. No. 12, $5419-5423$ (Dec. 15, 1978).

Key words: configurations of rods; Monte Carlo; orientation entropy; packing of rods; square tattice; theories of liquid crystals.

The number of configurations of nonoverlapping rods on a square lattice is computed for various packing fractions and orientations of the rods. From the number of configurations, the entropies of the configurations are computed and compared with the results of approximate formulas of DiMarzio that are much used in statisticat-mechanical theories of liquid crystats. For rods of three latice sites, our calculations and Dimarzio's formulas agree to within $0.5 \%$ for packing fractions less than 0.5. Some catculations for rods of ten lattice sites also showed good agresment.

18531. Niegele, D., Yoon, D. Y., Broadhurst, M, G., Formatiou of a new crystal form $\left(\alpha_{p}\right)$ of poly(vinyidene fluoride) under electric field, Macromolecules 11, No, 6, 1297-1298 (Dec. 1978).

Key words: phase change piezoelectric polymers; polarization; polyvinylidene 17uoride; $x$-ray diffaction; $\alpha$ phase.

Polyvinylidene films were prepared in the $\alpha$ crystal form by stretching at $145^{\circ} \mathrm{C}$. The $\mathrm{x}$-raly diffraction spectra of films which were subjected to an electric field of $1500 \mathrm{kV} / \mathrm{cm}$ at room temperature were compared to those of films which were not subjected to changes are consistent with the assumption that the electric field changes the normally anti potar $\alpha$ phase into a polar phase having the same chain conformation and unit celt dimensions. 
18532. Olsen, H. A., Maximon, L. C., Effect of resonance scattering in the high frequency limit of bremsstrahlung, Phys. Lett. 69A, No. 2, 90-92 (Nov. 27, 1978).

Key words: atomic screening effects; bremsstrahlung high frequence limit; bremsstrahlung spectrum tip; continuum $x$ rays; Coulomb field; non-relativistic bremsstrahlung.

It is shown that the resonances in the bremsstrahlung cross section close to the high-frequency limit found experimentally by Liefield et al. can be explained as final state resonance scattering.

18533. Russell, T. J., Maxwell, D. B., Reimann, C. T., Buehler, M. G., A microelectronlc test pattern for measuring unlformity of an integrated clrcult fabrlcation technology, (Proc. Government Microcircuit Application Conf., Monterey, CA, Nov. 1978), Solid State Tech. 22, No. 2, pp. $71-74$ (Feb. 1979).

Key words: bipolar process; contact resistor; cross bridge sheet resistor; electrical alignment resistor; integrated circuits; linewidth; photolithography; sheet resistance; silicon; test pattern; test structure; TTL.

Dopant density, device and circuit parameters, and randomfault densities across a wafer are important considerations in integrated circuit processing. The application of process validation wafers to evaluate silicon fabrication technologies is being studied in terms of the uniformity of these parameters across the wafer. This concept is illustrated by measurements of selected test structures on the NBS-7 test pattern which was designed to assess a junction-isolated transistor-transistor logic process. Use of this pattern for identifying fabrication nonuniformities is demonstrated by means of wafer maps of values of key parameters.

18534. Schubert, E., Schuck, A., Jung, K., Geltman, S., Triple differential cross sections for the electron impact ionization of helium at $35 \mathrm{eV}$ collision energy, J. Phys. B 12, No. 6, 967 978 (1979).

Key words: angular; Born approximation; correlations; electron impact; electrons; helium; ionization; secondary.

In a coincidence experiment with coplanar geometry, angular correlations of the two outgoing electrons have been studied for the ionisation of helium atoms by electrons with an impact energy $10.5 \mathrm{eV}$ above the first ionisation threshold. The measured angular dependencies of the triple differential cross section are compared with calculated results of the Coulomb-projected Born approximation including exchange. The measured data as well as the calculated ones do not show the features that have been found at medium and high impact energies. The momentum transfer $K_{0 a}$ looses its importance as a means of classification. For these low-energy collisions the amplitudes of direct scattering, exchange scattering and electron capture are of similar size and only the direct scattering amplitude has the momentum transfer vector $K_{o a}$ as a symmetry axis (in the Born approximation). Therefore the angular dependence of the triple differential cross section are no longer symmetrical with respect to the momentum transfer. Rapid variations of the angular distributions for different scattering angles $\theta_{a}$ of one of the two outgoing ionisation electrons indicate interference of the different scattering amplitudes. Moreover, the measurements demonstrated that the angular correlations for fixed scattering angle $\theta_{a}$ are independent of the ratio of the energies of the two emerging electrons. All other predictions of threshold theories are not valid in this energy range.

18535. Wolynec, E., Dodge, W. R., Hayward, E., Decay modes of giant resonances in ${ }^{5 R} \mathrm{Ni},{ }^{\circ 0} \mathrm{Ni}$, and ${ }^{62} \mathrm{Ni}$, Phys. Rev. Lett. 42 , No. 1, 27-30 (Jan. 1, 1979).
Key words: electric quadrupole; electrodisintegration; giant resonance; nickel isotopes; virtual photons.

The $(e, p)$ and $(e, \alpha)$ cross sections for targets of ${ }^{8 R} \mathrm{Ni},{ }^{\infty 0} \mathrm{Ni}$, and ${ }^{62} \mathrm{Ni}$ have been measured in the electron energy range 16 . 50 $\mathrm{MeV}$. They have been analyzed using the DWBA EI and E2 virtual photon spectra. Protons are emitted primarily following $\mathrm{E}_{1}$ absorption but $\alpha$ emission results from a combination of $E 1$ and $E 2$ absorption. The $E 2$ isoscalar giant resonance decays predominantly by $\alpha$ emission for these nuclei.

18536. Cali, J. P., Measurement compatlbility in clinlcal chemistry, CAMLT/Newsline 4, No. 6, 4-5 (The California Association for Medical Laboratory Technology, Oakland, CA, June $1978)$.

\section{Key words: clinical chemistry; reference material.}

Measurement compatibility is assured when all laboratories in a network do accurate analysis, i.e., analyses free of systematic error and that are precise. To accomplish this agreement on measurement units, the use of reference materials and reference methods is required. Reference materials useful in clinical chemistry laboratories and available from the National Bureau of Standards are cited.

18537. Peacock, R. D., A revlew of flre Incldents related to wood-burning appliances, Proc. Wood-Heating Seminar IV, Portland, OR, Mar. 21-24, 1979, pp. 43-66 (Wood Energy Institute, Camden, ME, 1979).

Key words: accident investigations; ćhimneys; coal; creosote; fire departments; fire safety; heating equipment; maintenance; stoves; wood.

As a part of the Department of Energy program to advance the technology for the utilization of fuelwood as an alternate energy source for applications ranging from single-family dwellings to apartment complexes and small industries, a review is presented for fire incidents and fire deaths attributable to wood-burning appliances. Initiated to establish accident patterns and to determine the risks involved with the use of woodburning equipment, the survey represents a compilation of approximately 11,800 fire incidents including injuries and deaths associated with solid fuel burning appliances.

18538. Sweger, D. M., Travis, J. C., An application of infrared lasers to the selective detection of trace organic gases, Appl. Spectrosc. 33, No. 1, 46-51 (1979).

Key words: $\mathrm{CO}_{2}$ laser; derivative spectra; infrared analysis; spectral coincidences; Stark modulation; Stark spectroscopy; trace gas analysis.

For molecules possessing a permanent electric dipole moment the Stark effect may be used to perturb the molecular energy levels and to "tune" some absorption lines into coincidence with fixed frequency lasers. The same perturbation may also be used to modulate the absorption and allow the use of sensitve ac detection techniques. In this paper we report quantitative results for four organic gases of industrial importance: vinyl chloride, vinylidene chloride, acrylonitrile, and methanol. All have overlapping absorption bands in the $\mathrm{CO}_{2}$ laser region. Because of the modulation techniques used, the observed signal as a function of electric field is the first derivative of the absorption line profile, and the peak-to-peak intensity of the derivative is the measured analytical signal. The analytical curve is a straight line over several orders of magnitude in concentration. In all cases, parts per million or sub-parts per million concentrations of the gases in air and/or nitrogen have been measured using a $\mathrm{CO}_{2}$ laser. The paper will include a discussion of interferences and selectivity of the technique. 
18539. Cali, J. P., NBS nuclear medicine and clinica! chemistry-Standard reference materials, (Proc. Symp. on Standardization, Performance and Quality Control in Nuclear Medicine, Gaithersburg, MD, June 12-14, 1975), Paper in Chapter 16 in Quality Control in Nuclear Medicine, Radiopharmaceuticals, Instrumentation, and in Vitro Assays, B. A. Rhodes, Ed., pp. 150-153 (The C. V. Mosby Company, St. Louis, MO, 1977)

Key words: accuracy; compatibility; radioactivity reference materials; standard reference materials.

Since 1967, NBS has been deeply involved in a program dedicated to the improvement of the reliability of measurements in clinical chemistry. NBS views its role in this highly complex and interactive measurement network as that of providing the "well-characterized" reference materials, called Standard Reference Materials (SRM's), and reference methods whereby measurements can be placed on an accuracy basis. When measurements are accurate, that is, are free of systematic error and also precise-with the end-use requirements-then the measurements so made are compatible, i.e., they agree.

NBS has now produced, certified, and issued 20 SRM's for use in clinical chemistry. These range from SRM's used in the measurement of cholesterol, bilirubin, and electrolytes, among others, to glass filter and quartz cuvettes for the calibration of spectrophotometers. Another half dozen are within a year or so of issuance.

To date there exists only one reference method-that for the determination of calcium in serum. However, NBS, in collaboration with other Government agencies, professional societies, and standards bodies, will issue another 6-7 reference methods within the next year or two. These include methods for lead in blood, five additional electrolytes in serum, and a method for glucose.

18540. Holdeman, L. B., Soulen, R. J., Jr., Finnegan, T. F., Peters, P. N., Superconducting properties of iridium thin films, J. Phys. Colloq. C6, Suppl. 8, Pt. 39, C6-608-C6-609 (Aug. 1978).

Key words: energy gap; iridium; Josephson junction; low$\mathrm{T}_{c} ;$ microwaves; thin-film; tunneling.

We have prepared superconducting thin films of iridium from which we have fabricated Dayem-type microbridges and Al$\mathrm{Al}_{2} \mathrm{O}_{3}$-Ir tunnel junctions that have I-V characteristics typical of these types of Josephson devices. Using the $\mathrm{Al}-\mathrm{Al}_{2} \mathrm{O}_{3}-$ Ir tunnel junctions, we have measured the temperature dependence of the superconducting energy gap of thin-film iridium.

18541. Moldover, M. R., Sengers, J. V., Gammon, R. W., Hocken, R. J., Gravity effects in fluids near the gas-liquid critical point, Rev. Mod. Phys. 51, No. 1, 79-99 (Jan. 1979).

Key words: critical point; gravity effects; phase transition.

The presence of a gravitational field leads to both practical and fundamental limits of the resolution in critical phenomena experiments in fluids near the gas-liquid critical point. We present equations that yield estimates of the gravitational limitations in a variety of critical phenomena experiments for a large number of fluids and as a function of the magnitude of the gravitational field. Various strategies for improving the resolution of such experiments are discussed, including procedures that remove a fluid from thermodynamic equilibrium (e.g., stirring). A comparison is made between the gravitational limitations in earth-bound experiments and those at the microgravitational levels that may become accessible in an orbiting laboratory.
18542. Brown, D. W., Lowry, R. E., Molecular weight standards from sulfonation of polystyrene, J. Polym. Sci., Polym. Chem. Ed. 17, 1039-1046 (1979).

Key words: polystyrene; sodium (polystyrene sulfonate); sulfonation; sulfur trioxide; triethyl phosphate.

Polystyrene was sulfonated with sulfur trioxide-triethyl phosphate complexes in dichloroethane, the object being to prepare polystyrene sulfonates substantially free of sulfone links between polymer chains. Variations in the sulfone content with reaction conditions were conveniently followed by exclusion chromatography, the sulfone peak appearing at about twice the molecular weight of the main peak. The desired products were obtained from polystyrcnes with molecular weights between 1.I $\times 10^{5}$ and $8.7 \times 10^{5}$ by using (at -20 to $+25^{\circ} \mathrm{C}$ ) a $5: 1$ excess of a 1.5:1 complex, the last at a concentration of $0.5 \mathrm{M}$. Completely soluble polystyrene sulfonate was also obtained from polystyrene of molecular weight $2.05 \times 10^{6}$. Requirements for the successful use of the 1.5:1 complex include careful purification of the dichloroethane and, if $2 \mathrm{~g}$ or more polystyrene is to be sulfonated, formation of the complex at $-20{ }^{\circ} \mathrm{C}$. A method is given for measuring the sulfonating capability of the reagent before adding the polymer.

18543. Eisenhart, C., On the transition from "Student's" $z$ to "Student's" t, Am. Stat. 33, No. 1, 6-10 (Feb. 1979).

Key words: distribution of regression coefficients; R. A. Fisher; Student's $t$; Student's z; Student (W. S. Gosset, 1876-1937; t-transformation of correlation coefficient.

The change from the $z$ of "Student's" 1908 paper to the $t$ of present day statistical theory and practice is traced and documented. It is shown that the change was brought about by the extension of "Student's" approach, by R. A. Fisher, to a broader class of problems, in response to a direct appeal from "Student" for a solution to one of these problems.

18544. Unassigned.

18545. Akcasu, A. Z., Han, C. C., Molecular weight and temperature dependence of polymer dimensions in solution, Macromolecules 12, No. 2, 276-280 (Mar.-Apr. 1979).

Key words: hydrodynamic radius; light scattering; molecular weight dependence; polystyrene; radius of gyration; temperature dependence.

The molecular weight $\left(M_{w}\right)$ and temperature $(T)$ dependence of the radius of gyration $\left(\mathbb{R}_{G}\right)$ and hydrodynamic radius $\left(R_{H}\right)$ of a polymer in a dilute solution are investigated. The theoretical predictions are compared with experimental results of polystyrene in various solvents as functions of $M_{w}$ and $T$. It is found that the existing data fall in a region of values where $R_{H}$ cannot be represented by a simple power law $R_{H} \sim N^{\boldsymbol{v}^{\prime}}$, whereas most of the data on $R_{G}$ satisfy $R_{G} \sim N^{v}$. It is concluded that a power law fit to data would yield a $\nu^{\prime}\langle\nu$ in this region, even though the theory predicts $\nu^{\prime}=\nu$ in the asymptotic region. The quantitative aspects of the blob theory are also discussed and compared in some cases to the modified Flory theory.

18546. Brugel, E. W., Wallerstein, G., Separate spectra of the visual components of MWC 349, Astrophys. J. 229, No. 1, L23-L25 (Apr. 1, 1979).

Key words: emission line stars; emission nebulae; star formation.

Observations of MWC 349 show that the two components of this visual binary have grossly different spectra. The brighter star shows numerous permitted and forbidden emission lines, reminiscent of $\eta \mathrm{Car}$ and $\mathrm{LkH \alpha} 101$, superposed on a weak continuum. The fainter star shows emission only at $\mathrm{H} \alpha$, which 
is much weaker than $\mathrm{H}_{\alpha}$ emission in the bright component, and a continuum that is stronger than that of the primary at $\lambda 7000$. It is probably an early-type emission-line star. The strong continuum of the secondary, and the plethora of weak emission lines in the primary, account for part of the anomalously high continuum relative to the hydrogen emission lines that has previously been ascribed to a preplanetary disk. In light of these facts the general nature of the system is discussed.

18547. Danielson, B. L., Optical fiber phase discriminator, Appl. Opt. 17, No. 22, 3665-3668 (Nov. 15, 1978).

Key words: delay line; discriminator; fiber optics; phase discriminator.

Phase discriminators are devices widely used at if and microwave frequencies to convert phase, or frequency, changes to amplitude changes. They find widespread use in generating audio feedback signals for frequency stabilization of oscillators and in angle demodulation applications. This paper demonstrates that similar devices, with similar functions, can be constructed in the visible region using optical fibers as delay-line elements. The operating principles of an optical-fiber delay-line phase discriminator are discussed. The sensitivity is shown to be proportional to the fiber propagation-delay time. A device working at $0.6328 \mu \mathrm{m}$ is described and compared with predictions.

18548. Van Degrift, C. T., Bowers, W. J., Jr., Wildes, D. G., Pipes, P. B., A small gas thermometer for use at low temperatures, (Proc. 15th Int. Conf. on Low Temperature Physics, Grenoble, France, Aug. 23-29, 1978), J. Phys. 6, Suppl 8, No. 39, C6-1173-C6-1174 (Aug. 1978).

Key words: gas thermometer; low temperature; temperature scale; thermometry; tunnel diode oscillator.

A small constant volume gas thermometer utilizing a selfcontained tunnel diode oscillator is described. It has a sensitivity of $0.2 \mathrm{mK}$ and is highly linear between 0.71 and $10 \mathrm{~K}$.

18549. Soulen, R. J., Jr., A superconductive device to provide reference temperatures below $0.5 \mathrm{~K}$, (Proc. 15th Int. Conf. on Low Temperature Physics, Grenoble, France, Aug. 23-29, 1978), J. Phys. 6, Suppl. 8, No. 39, C6-1166-C6-1168 (Aug. 1978).

Key words: $\mathrm{AuAl}_{2} ; \mathrm{AuIn}_{2}$; Be; Ir; superconductivity; supercooling; temperature fixed points; $W$.

We have developed a device containing five superconductive materials W, Be, Ir, $\mathrm{AuAl}_{2}$ and $\mathrm{Auln}_{2}$ which provides reference temperatures at $0.015 \mathrm{~K}, 0.024 \mathrm{~K}, 0.0975 \mathrm{~K}, 0.159 \mathrm{~K}$ and $0.204 \mathrm{~K}$ respectively. The reproducibility of three devices each containing these five superconductors was found to vary from 0.1 to $0.4 \mathrm{mK}$ except for Be where it was $1 \mathrm{mK}$.

18550. Schooley, J. F., Superconductive fixed points for temperatures above $0.5 \mathrm{~K}$, (Proc. 15 th Int. Conf. on Low Temperature Physics, Grenoble, France, Aug. 23-29, 1978), J. Phys. 6, Suppl. 8, No. 39, C6-1169-C6-1170 (Aug. 1978).

Key words: cryogenics; fixed points; pure materials; superconductivity; temperature scale; thermometry.

A tempcrature fixed point device incorporating samples of the elements $\mathrm{Cd}, \mathrm{Zn}, \mathrm{Al}, \mathrm{ln}$ and $\mathrm{Pb}$ has been available from the NBS for several years. This paper describes current efforts to reduce the temperature uncertainties of the NBS devicc below the present one milli-kelvin level. It also notes that efforts to produce narrow transition widths in samples of $\mathrm{Nb}, \mathrm{V}_{3} \mathrm{Ga}$ and $\mathrm{Nb}_{3} \mathrm{Sn}$ have resulted in widths of $9 \mathrm{mK}, 40 \mathrm{mK}$ and $17 \mathrm{mK}$, respectively.
18551. Streit, G. E., Wclls, J. S., Fehsenfeld, F. C., Howard, C. J., A tunable diode laser study of the reactions of nitric and nitrous acids: $\mathrm{HNO}_{3}+\mathrm{NO}$ and $\mathrm{HNO}_{2}+\mathrm{O}_{3}, J$. Chem. Phys. 70, No. 7, 3439-3443 (Apr. 1979).

Key words: chemical kinetics; environmental measurements; nitric acid; nitrous acid; ozone; rate constants.

This study of the reactions of nitrous and nitric acids demonstrates a new application of tunable diode laser technology. The diode laser is used for the direct detection of $\mathrm{HNO}_{2}$ and $\mathrm{HNO}_{3}$ in a chemical kinetic system. We have established an upper limit for the rate constant for $\mathrm{HNO}_{3}+\mathrm{NO} \rightarrow \mathrm{HNO}_{2}+\mathrm{NO}_{2}\left[k_{1}\right.$ $\leqslant(3.4 \pm 2) \times 10^{-22} \mathrm{~cm}^{3} /$ molecule.s] and have confirmed that nitrous acid is a product of this reaction. We have also established an upper limit for the rate constant for $\mathrm{HNO}_{2}+\mathrm{O}_{3}$ $\rightarrow \mathrm{HNO}_{3}+\mathrm{O}_{2}\left[k_{4} \leqslant(4.5 \pm 3) \times 10^{-19} \mathrm{~cm}^{3} /\right.$ molecules $]$.

18552. Read, D. T., Metallurgical effects in niobium-titanium alloys, Cryogenics 18, No. 10, 579-584 (Oct. 1978).

Key words: electrical properties; low temperatures; mechanical properties; metallurgical properties; niobiumtitanium; physical properties; superconductors.

The effects of metallurgical treatments on some of the physical, metallurgical, and mechanical properties of commercial purity Nb-34-wt.\%Ti, Nb-45-wt.\%Ti, and Nb-55-wt.\%Ti, were studied by measuring properties of annealed and metallurgically processed materials at both room and cryogenic temperatures. Processing strengthens all three materials, but significantly changes the electrical resistivity of only Nb-55-wt.\%Ti. The behavior of the electrical resistivity of Nb-55-wt.\%Ti upon deformation at $76 \mathrm{~K}$ suggests the occurrence of a systematic transformation (twinning or martensitic phase transformation).

18553. Rainwater, J. C., Evaluation of frequency sums for the free energy of superfluid 'He, Phys. Rev. B 18, No. 7, 3728 3729 (Oct. 1, 1978).

Key words: frequency sums; Rainer and Serene; superfluid ${ }^{3} \mathrm{He}$.

The three frequency sums which appear in the theory of Rainer and Serene to determine the free energy of superfluid ${ }^{3} \mathrm{He}$ are evaluated here, two analytically and the third to within one part in $10^{-6}$. A sign error has been found in the previously reported value of one of the sums.

18554. Masters, L. W., Seiler, J. F., Roberts, W. E., Development of standards for evaluating solar absorptive coatings, (Proc. Division of Organic Coatings and Plastics Chemistry at the American Chemical Society/Chemical Society of Japan Chemical Congress, Honolulu, Hawaii, Apr. 1-6, 1979), Paper in Organic Coatings and Plastics Chemistry 40, 507-510 (American Chemical Society, Washington, DC, 1979).

Key words: absorptive coatings; accelerated laboratory tests; durability; outdoor exposure; solar collectors; standard test methods.

Absorptive coatings used in solar heating and cooling systems absorb energy from the sun and convert it to thermal energy. It is essential that coatings used for this purpose be durable for extended periods of time. However, the environment in which absorptive coatings are used can cause rapid degradation. For example, the temperature at the coating surface can reach 250 ${ }^{\circ} \mathrm{C}$ or higher under collector stagnation conditions. Likewise, exposure to moisture, ultraviolet (uv) radiation and other factors can also induce degradation. Numerous problems in solar energy systems have clearly shown the need for standards by which solar absorptive coatings can be evaluated. The Center for Building Technology of the National Bureau of Standards 
is performing research, under Department of Energy sponsorship, to develop draft standards for absorptive coatings. The standards will be submitted to the American Society for Testing and Materials (ASTM) for consideration as consensus standards. Fourteen selective and nonselective absorbers have been evaluated in laboratory and field tests to obtain data needed to prepare the draft standards. The laboratory tests have emphasized thermal stability, moisture stability, uv stability and compatibility with substrates. Field tests, in which coatings are exposed to stagnation conditions in three different climates, are also being performed. Absiorptance $(\alpha)$ and emittance (e) are measured hefore and after the laboratory and field exposures. The data obtained, the test methods used and two interim test method standards prepared as result of the research are discussed.

18555. Marshak, H., Soulen, R. J., Jr., Measurement of thermodynamic temperatures using noise and nuclear orientation thermometers, (Proc. 15th Int. Conf. on Low Temperature Physics, Grenoble, France, Aug. 23-29, 1978), J. Phys. 6, Suppl. 8, No. 39, C6-1162-C6-1163 (Aug. 1978).

Key words: comparison measurements; Germanium resistance thermometer; Josephson junction noise thermometer; low temperature scale; ${ }^{3} \mathrm{He} /{ }^{4} \mathrm{He}$ dilution refrigerator; ${ }^{80} \mathrm{CO} \gamma$-ray thermometer.

We have compared ${ }^{60} \mathrm{CO} \gamma$-ray anisotropy and Josephson junction noise thermometers from $0.011 \mathrm{~K}$ to $0.05 \mathrm{~K}$ and have obtained agreement to within $\pm 0.5 \%$.

18556. Mangum, B. W., Bowers, W. J., Jr., Two practical magnetic thermometers for use below $30 \mathrm{~K}$, (Proc. 15 th Int. Conf. on Low Temperature Physics, Grenoble, France, Aug. 23-29, 1978 ), J. Phys. 6, Suppl. 8, No. 39, C6-1175-C6-1176 (Aug. 1978).

Key words: $\mathrm{Gd}\left(\mathrm{PO}_{3}\right)_{3}$; low temperature thermometry; magnetic susceptibility; magnetic thermometers; $\mathrm{Nd}\left(\mathrm{C}_{2} \mathrm{H}_{\mathrm{s}}\right.$ $\left.\mathrm{SO}_{4}\right)_{3} \cdot 9 \mathrm{H}_{2} \mathrm{O}$ : thermometry.

We have measured the magnetic susceptibility of $\mathrm{Gd}\left(\mathrm{PO}_{3}\right)_{3}$ (GP) and of $\mathrm{Nd}\left(\mathrm{C}_{2} \mathrm{H}_{5} \mathrm{SO}_{4}\right)_{3} \cdot 9 \mathrm{H}_{2} \mathrm{O}$ (NES) over the range 2 to $27 \mathrm{~K}$ and found these salts to be good magnetic thermometers, although NES is less suitable for accurate work over this entire range. By fitting the magnetic data to recently calculated temperatures $\left(T_{a r}\right)$ determined acoustically by Plumb and Catalan, a magnetic temperature scale is developed and it is compared to other scales.

18557. Bussey, H. E., Dielectric measurements of lunar soil, (Proc. Tenth Lunar and Planetary Science Conf., National Aeronautics and Space Administration, Lyndon B. Johnson Space Center, Houston, TX, Mar. 19-23, 1979), Abstract in Lunar and Planetary Science, Part 1, 140-142 (Lunar and Planetary Institute, Houston, TX, 1979).

Key words: dielectric constant; dielectric loss; lunar soil; microwave; profile effect on permittivity; temperature variation of permittivity

The dielectric constant and loss of lunar soil is given at + $100^{\circ}$, and $-100^{\circ} \mathrm{C}$, and over the frequency range 0.2 to 18 $\mathrm{GHz}$. The soil had been exposed to air of 40 to 0 relative humidity. Therefore the loss was not typical of lunar conditions. A tentative conclusion is that a nonlinear packing density of the soil sample, $17 \mathrm{~cm}$ long in a coaxial line sample holder, resulted in artificial periodic variations of the apparent permittivity and loss. The permittivity was approximately $3.9 \pm 0.1$ at $0.2 \mathrm{GHz}$ and $3.7 \pm 0.1$ at $18 \mathrm{GHz}$, at $25^{\circ} \mathrm{C}$ and a packing density of $1.85 \mathrm{~g} / \mathrm{cm}^{3}$. The average derivative of permittivity with respect to temperature was $0.014 \%$ per degree celsius. The derivative of the loss tangent was approximately 0.000025 per degree.
18558. Levenson, M. D., Eesley, G. L., Polarization selective optical heterodyne detection for dramatically improved sensitivity in laser spectroscopy, Appl. Phys. 19, No. I, 1-17, (1979).

Key words: laser spectroscopy; noise, laser sources; nonlinear spectroscopy; optical heterodync; spectroscopy, laser.

The noise characteristic of availabie laser sources limits the sensitivity of many types of nonlinear spectroscopy. We show how to maximire the sensitivity by optimizing the strength of a local oscillator wave in a heterodyne detection scheme without altering the amplitude of the wave heing detected. The intensity profile of the optimum local oscillator closely matches that of the incident probe wave, but the optimum intensity is much less than that of the probe under realistic conditions. A general signal-to-noise analysis applicable to all nonlinear spectroscopy techniques is presented along with specific applications to coherent Raman spectroscopy, two-photon absorption, saturation spectroscopy, and optical coherent transient techniques. A simple optimization procedure employing polarization selection rules is described. Detailed culculations are performed for the case of TEM $_{\boldsymbol{6}}$ waves interacting via a third-order nonlinear susceptibility and for the case where the sample is simultaneously probed at many different frequency combinations.

\section{Unassigned.}

18560. Kasen, M. B., Composite laminate applications in magnetic fusion energy superconducting magnet systems, ICCM/2 Proc. Int. Conf. on Composite Materials, 2d, Toronto, Ontario, Canada, Apr. 16-20, 1978, B. R. Norton, R. A. Signorelli, K. N. Street, and L. N. Phillips, Eds., pp. 1493-1507 (Metallurgical Society of the AIME, Warrendale, PA, 1978).

Key words: advanced composites; composite materials; cryogenics; industrial laminates; magnetic fusion energy; superconducting magnets.

Potential composite applications span the range from industrial laminates to advanced composites. Service conditions are unusually demanding, as materials must function predictably over a 20-year lifetime at 4.2 kelvin while subject to neutron and gamma radiation. Laminate components must also withstand occasional warming to room temperature. Presently, industrial laminates of the NEMA/ASTM G-10 or G-11 types are most frequently proposed for electrical and thermal insulation. This reflects the low cost, ready availability and successful use of such materials in existing small superconducting magnets. However, the more stringent demands of MFE systems requires the development of component-specified industrial laminates, thoroughly tested under radiation and cryogenic conditions. Present designs do not make structural use of advanced composite laminates. However, the combination of high modulus, low thermal and electrical conductivity make such materials attractive substitutes for stainless steel in some components of superconducting magnets. Advanced-composite metal-matrix technology has an important role to play in understanding the effects of cyclic stress on the current-carrying ability of the metallic superconducting composite.

18561. Kamper, R. A., Status of RF and microwave calibration services at NBS, NCSL Newsletter 18, No. 3, 40 (Dec. 1978).

Key words: calibrations; measurements; microwaves; radiofrequency; standards.

This brief note describes the present status of $\mathrm{rf}$ microwave calibration services at NBS, and gives a schedule for restoration of some services that had been temporarily closed down. 
18562. Jennings, D. A., Petersen, F. R., Evenson, K. M., Frequency measurement of the $260-\mathrm{THz}(1.15-\mu \mathrm{m}) \mathrm{He}-\mathrm{Ne}$ laser, Optic's Lett. 4, 129-130 (May 1979).

Key words: frequency; He-Ne laser; nonlinear optics; I.15 $\theta \mathrm{m}$.

Absolute infrared frequency measurement has been extended to 2ho THz with the measurement of the strong $1.15-\mu \mathrm{m}$ laser line in "Ne. The frequency was synthesized in nonlinear crystals of $\mathrm{CJGeAs}_{2}$ and $\mathrm{Ag}_{\mathrm{g}} \mathrm{As} \mathrm{S}_{\text {; }}$ from stabilized $\mathrm{CO}_{2}$ lasers and the $1.5-\mu \mathrm{m}$ laser line in ${ }^{21} \mathrm{Ne}$. The measured frequency is $\nu^{201}$.s. $1.15 \mu m=260.103284(30)$ ) TH\%.

18563. Ellerbruch, D. A., Jesch, R. L., Jones, R. N., Bussey, H. E., Boyne, H. S., Electromagnetlc scatterlng propertles of soils and snow, Proc. $12 \mathrm{th}$ Int. Symp. on Remote Sensing of Environment, Ann Arbor, MI, Apr. 20-26, 1978, 11, 957-474 (Environmental Research Institute of Michigan, Ann Arbor, MI, 1978).

Key words: electromagnetic measurement; snow depth; soil moisture.

The electromagnetic scattering properties of soils and snow are being measured in situ under natural environmental conditions. A physical analysis is done at each test site to determine the physical properties of the sample for correlation with its electromagnetic signature.

18564. Diller, D. E., LNG thermophysical properties data and custody transfer, GASTECH 78, Proc. Int. LNG/LPG Conf. and Exhibition, 6th, Monte-Carlo, Monaco, Nov. 7-10, 1978, 1, Session 2A, Presentation 1, 1-16 (GASTECH Exhibitions, Ltd., Rickmansworth, England, 1978).

Key words: composition; custody transfer; density; flow rate; LNG; mixtures; specific heating value; tank capacity tables; thermophysical properties; total heating value.

Developments in LNG thermophysical properties data research are reviewed. NBS projects on the PVT, thermodynamic and transport properties of pure LNG components; on the phase equilibria and orthobaric liquid densities of mixtures of LNG components; and on predictive calculation methods for the thermophysical properties of commercial LNG compositions, are discussed.

Developments in LNG custody transfer measurement research are reviewed, with emphasis on accurate methods for determining LNG composition, density, specific heating value, ship tank capacity tables, liquid level and flow rates for LNG custody transfer. The uncertainties in the determination of the heating value of large quantities of LNG in tanks and pipelines are discussed.

18565. Danos, M., Development of approaches and present status of the giant multipole resonance theory, Proc. $4 \mathrm{th}$ Seminar on Electromagnetic Interactions of Nuclei at Low and Medium Energies, Moscow, USSR, Dec. 13-15, 1977, pp. 321 (Nauka, Moscow, 1979).

Key words: giant resonances; hydrodynamic model; isoscalar resonances; isovector resonances; photonuclear physics; shell model.

A survey of the present status of the theory of photonuclear giant resonances is presented. The first level of understanding photonuclear processes is completed. The next level of understanding is spotty and contradictory. A direction for future development of theories is indicated.

18566. Bussey, H. E., Open circuited coaxial resonator for high sensitivity dielectric measurements, application to lunar soil 70051-20, (Proc. 10th Lunar and Planetary Science Conf.,
National Aeronautics and Space Administration, Lyndon B. Johnson Space Center, Houston, TX, Mar. 19-23, 1979), Abstract in Lunar and Planefary Science, Part 1, 169-171 (Lunar and Planetary Institute, Houston, TX, 1979).

Key words: cavity resonance; coaxial line resonator; dielectric constant; dielectric loss; lunar sample; temperature variation of dielectric parameters of soil.

This three page paper summarizes a sensitive ( $1 \mathrm{~g}$ sample) coaxial line cavity resonator method under vacuum conditions and $\pm 100{ }^{\circ} \mathrm{C}$ which was developed for measurements of dielectric constant and loss of powders, liquids, and solid coaxial samples. The intended frequency range was $550 \mathrm{MH}$. fundamental, plus harmonics to $2750 \mathrm{MHz}$. The frequencies and $\mathrm{Q}$ 's of the successive resonances were obtained by measuring the reflection coefficient versus stepped frequency of the 1-port cavity using an Automatic Network Analyzer programmed to skip from one resonance to the next. Results of the first three harmonics were reliable, giving permittivity $=2.15^{D}$ with a density $p$ of $1.6 \mathrm{~g} / \mathrm{ml}$ and a loss tangent $=p \times(0.01) 38$ both at 23 ${ }^{\circ} \mathrm{C}$. The sample was dried by heating in vacuum. The change with temperature from 173 to $373 \mathrm{~K}$ was obtained. Results at higher harmonics were erroneous, apparently due to a coaxial bead type of resonance near $5 \mathrm{GH}$.

18567. Daney, D. E., Ludtke, P. R., Jones, M. C., An experimental study of thermally-Induced flow oscillatlons in supercritical helium, J. Heat. Transfer 101, No. 1, 9.14 (Feb. 1979).

Key words: density wave oscillations; flow ościllations; flow stability; liquid helium; superconducting power transmission lines; supercritical helium.

The density wave stability boundary has been experimentally determined for supercritical helium flowing in a long ( $L=185$ $\mathrm{m})$, heated channel of high aspect ratio $\left(\mathrm{L} / \mathrm{d}=4.6\left(1(3)^{4}\right)\right.$. A pressure drop ratio and the fluid expansion ratio correlate the oscillation inception point data.

The growth of enthalpy (temperature) perturbations in a heated channel has been experimentally verified. During the density wave oscillation, the channel exit temperature and inlet mass flow were observed to be in phase, and the oscillation period was close to twice the fluid transit times. All three observations agree with a simple incompressible flow model. Oscillation amplitudes as great as $11 \mathrm{~K}$ and 100 percent of inlet flow were observed.

18568. Newbury, D. E., Microanalysis in the scanning electron microscope: Progress and prospects, (Proc. Ann. Intl. Scanning Electron Microscopy Conf., Washington, DC, Apr. 16-20, 1979), Scanning Electron Microsc. 11, 1-20 (Scanning Electron Microscopy, Inc., O'Hare, IL, 1979).

Key words: Auger electron spectroscopy; cathodoluminescence; ion scattering spectrometry; laser microprobe mass analyzer; laser Raman microprobe; microanalysis; secondary ion mass spectrometry; $x$-ray microanalysis.

Many techniques of analysis are available for the characterization of a sample on the micrometer scale in the scanning electron microscope. Directly available as a result of the electron bombardment are x-rays, Auger electrons, and long wavelength electromagnetic radiation (cathodoluminescence). Auxiliary excitation sources which can be added to the SEM for analysis include energic ion beams for secondary ion mass spectrometry and ion scattering spectrometry, $x$-rays for $x$-rayinduced characteristic $x$-ray emission ( $x$-ray fluorescence), and monochromatic photons from laser sources for Raman spectroscopy and mass spectrometry. The information available from these techniques includes elemental and molecular com- 
position, structural information from crystals, and a variety of semiconductor properties. The information can be obtained from regions with lateral dimensions of the order of $1 \mu \mathrm{m}$ and with depth resolutions ranging from one atom layer to several micrometers. Qualitative and quantitative analysis can be carried out for all çhemical elements, with relative errors in the best cases being less than five percent, and with limits of detection in the range $1-100 \mathrm{ppm}$ under optimum conditions. No one technique provides all of the information required for total characterization of a sample, and combinations of techniques are required.

18569. Brauer, G. M., Termini, D. J., Jackson. J. A., Durability of the bond between mimeralized tissues and potential adhesives, (Proc. 176th National Meeting of the Americian Chemical Society, Miami, FL, Sept. 11-14,1978), ACS Symp. Series 95, Durability of Macromolecular Materials, R. K. Eby, Ed., Paper 27, 393-410 (American Chemical Society, Washington, DC, 1979).

Key words: adhesion; bonding to mineralized tissues; bone; dentin; hydrolytic stability of honds; isobutyl 2-cyanoacrylate; mineralized tissue; 2 -cyanoacrylate esters.

The strength of adhesive joints between bone-bone and dentin-poly(methyl methacrylate) decreases on prolonged storage in water. With 2-cyanoacrylate esters debonding is greatly reduced by increasing the length of the ester group. Thermocycling tests give the same ranking for the decrease in the adhesive bond strength as those of the long-term isothermal storage studies.

The bonding of 2-cyanoacrylates to mineralized tissues in an aqueous environment appears to be superior to that of other adhesives. The higher homologues of 2-cyanoacrylates may be useful clinically where an intermediate-term bone adhesive is desired. The isobutyl ester is the most effective 2-cyanoacrylate for bonding dentin to acrylic resin. Pretreatment of the dentin with dilute acid, addition of 2-cyanoacrylate polymer to the adhesive or application of the protective coating to the bonded surface increases the hydrolytic stability of the bond.

18570. Bowman, C. D., Research applications of a high power induction linac, (Proc. Fifth Conf, on the Applications of Small Accelerators in Research and Industry, North Texas State Univ., Denton, TX, Nov. 6-8, 1978, J. L. Duggan, I. L. Morgan, Eds.), IEEE Trans. on Nucl. Sci. NS-26, No. 1, Part 2 of Two Parts, 1426-1431 (IEEE Nuclear and Plasma Sciences Society, New York, NY, Feb. 1979).

Key words: activation analysis; electron beams; induction accelerator; ion acceleration; nuclear research; radiation processing

An induction linac offers a number of previously unexploited advantages for research and practical application. It possesses an inherent capability for high pulsed beam currents, large aperture, simple phasing conditions, arbitrary accelerated particle mass, simple multiplexing capability, and high power conversion efficiency. An accelerator is described with the following parameters: pulsed current -2000 amps, energy-36 MeV, repetition rate $-180 \mathrm{pps}$, and pulse width-60 ns. As an electron accelerator the facility would be a very intense source of pulsed neutrons or $\gamma$-radiation. Two possible alternative power systems exist based either on multiple spark-gap switches or on magnetic compression methods. The capability of the facility will be reviewed for programs in neutron scattering for materials science, neutron nuclear science, photonuclear physics, photonuclear activation analysis, radiation processing, and other research. Neutron production targets capable of handling the full $750 \mathrm{keV}$ of beam power will be described.
18571. Dulik, D. M., Evaluation of commercial and newly. synthesized amine accelerators for dental composites, J. Dent. Res. 58, No. 4, 1308-1316 (Apr. 1979).

Key words: amine accelerators; composite restorative resin; dimethylaminoglutethimide; dimethylaminophenylacetic acid and esters; properties of composites; tertiary aromatic amines.

The characteristics of newly synthesized tertiary aromatic amines as accelerators for restorative resins have been evaluated. Comparison of the composites prepared with these and presently used accelerators indicate that resins formulated with 4-N,N-dimethylaminophenylacetic acid, its methyl ester or N,Ndimethylaminoglutethimide have properties generally better than comparahle resins prepared with commercially used amines.

18572. Wiese, W. L., Atomic transition probabilities and lifetimes, Chapter 25 in Progress in Atumic Spectroscopy, Part B, W. Hanle and H. Kleinpoppen, Eds., pp. | | (1)-1155 (Plenum Puhl. Corp., New York, NY, 1979).

Key words: atomic transition prohabilities; literature survey; oscillator strengths.

A survey of the new atomic transition prohability literature, covering the period late 1975 to late 1978, is given.

18573. Baughcum, S. L., Leone, S. R., Free radical studies by excimer laser altraviolet photolysis, (Proc. 22d Int. Tech. Symp. and Instrument Display, University of Arizona, Tucson, AZ, Aug. 4-5, 1978), Laser Spectrosc. 158, 29.32 (1978)

Key words: infrared emission; laser; methylene iodiode; methyl iodiode; photodissociation; radical.

A promising new technique for studying vibrational and lowlying electronic states of radicals has been developed. Infrared emission from vibrationally excited radicals is observed following ultraviolet photolysis of several small polyatomics with a rare gas-halide excimer laser. Strong emission from the $\mathrm{C}-\mathrm{H}$ stretches of the $\mathrm{CH}_{2} \mathrm{l}$ radical is directly detected following photolysis of $\mathrm{CH}_{2} \mathrm{I}_{2}$ at $248 \mathrm{~nm}$. Photolysis of $\mathrm{CH}_{2} \mathrm{I}_{2}$ at $308 \mathrm{~nm}$ and $\mathrm{CH}_{2} \mathrm{l}$ at $248 \mathrm{~nm}$ does not produce excitation of the C-H stretches in the radicals generated. In all three cases, strong emission from excited $I *\left({ }^{2} P_{1 / 2}\right)$ atoms is observed. With the techniques described, infrared fluorescence is monitored as a function of both wavelength and time, allowing information to be obtained about the initial vibrational state distribution of radicals following photolysis. Subsequent vibrational deactivation, energy transfer, and reaction kinetics may also be studied. By using low resolution, continuously variable interference filters, measurements of the gas phase vibrational frequencies of the radical can be obtained, since the temporal resolution allows radical emission to be readily distinguished from that of the present molecules.

18574. Bender, P. L., Geodesy-Trends and prospects, Proc Conf. 17th IEEE Conf. on Precision and Control Including Symp. on Adaptive Processes, San Diego, CA, Jan. 10-12, 1978 , pp. $455-457$ (The Institute of Electrical and Electronics Engineers, Piscataway, NJ, 1978).

Key words: distance measurements; earthquakes; geodesy; geophysics; instrumentation; satellites; tectonics.

A report with the above title recently has been completed by the Committee on Geodesy of the National Research Council. The Committee included members from the fields of geodesy, geophysics, physics and engineering, and the chairman was Professor William M. Kaula of UCLA. An important part of the 
charge to the Committee was to review and make recommendations concerning scientific and technological advances in modern geodesy and related fields, and planning for spaceborne instrumentation pertinent to geodesy in the 1980's. Some of the recommendations of the Committee in the areas of crustal movement measurements and needs for the development of new geodetic instruments are discussed briefly

18575. Demkov, Y. N., Ostrovskii, V. N., Solov'ev, E. A., Twostate approximation in the adiahatic and sudden-perturhation limits, Phys. Re'. A 18, No. 5, 2089-2096 (Nov. 1978)

Key words: adiabatic perturbation theory; elastic scattering phase shifts; pseudocrossing; sudden-perturbation limit;

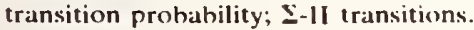

The properties of the two-state approximation are considered from the point of view of atomic collision theory in the limit of large and small values of a characteristic collision time $T$. For large $T$ (the adiabatic limit) asymptotically exact expressions are obtained for the elastic-scattering phase shifts and for the nonadiabatic transition probability due to the pseudocrossing of terms. This approximation is carried out under fairly general assumptions about the Hamiltonian, enabling us to consider such processes as transitions between $\Sigma$ - $\Pi$ terms caused by rotation of an internuclear axis. Such general problems of the adiabatic approximation as the applicability of adiabatic perturbation theory, the introduction of a dynamical basis, and the properties of the electronic wave functions in the pseudocrossing region are discussed. For small $T$ (the suddenperturbation limit) the evolution operator to zeroth and first order in $T$ is calculated. We introduce a general and unamhiguous definition of an adiabatic basis as a basis of eigenvectors of the evolution matrix to zeroth order in $T$.

18576. Demkov, Y. N., Kunasz, C. V., Ostrovskii, V. N., United-atom approximation in the problem of $\Sigma$ - $\Pi$ transitions during close atomic collisions, Phys. Rev. A 18, No. 5, $2097-$ 2106 (Nov. 1978).

Key words: adiabatic limit; atomic collisions; quasimolecule terms; sudden perturbation limit; transition probability; unified atom approximation; $\mathbf{\Sigma}-\Pi$ transition.

We consider a very simple approximation, in which the splitting of the energy of a $P$ state in a united atom into $\Sigma$ and $\Pi$ quasimolecular terms for small internuclear distances $R$ depends quadratically on $R$, and the colliding atoms pass one another along a straight or a hyperbolic trajectory. In this case the transition probability for a given scattering angle or impact parameter depends on only one parameter-the Massey parameter. This probability is computed numerically along with the elastic scattering phase shifts. Approximate formulas are obtained for both the adiabatic limit (in which the parameter is large and the flight is slow) and the sudden-perturbation limit for which the parameter is small, the flight is fast, and the process reduces to a sudden rotation of the internuclear axis. We also obtain, in the adiabatic case, the first term in the expansion of the factor in front of the exponential. In the intermediate range of the parameter, simple analytic approximations, ensuring transition to the limiting cases, are proposed. Analytic expressions for the total transition cross sections are obtained in the limits of large and small collision velocities. The results of the calculations are applicable to $\Sigma-\Pi$ transitions of electrons and holes in both outer and inner shells for close collisions in a broad energy range, where, owing to a scale transformation, all cases reduce to one. Reasonable agreement is found with other more complicated calculations for the collisions of specific atoms.

18577. Daywitt, W. C., An error analysis for the measurement of satellite EIRP using a calibrated radio star, IEEE Trans. Instrum. Meas. IM-27, No. 3, 253-258 (Sept. 1978).
Key words: error analysis; G/kT, EIRP; G/T, precision measurements; radio star; satellite communications.

An outline for the derivation of equations employed in a measurement and error analysis of satellite EIRP using a calibrated radio star is presented. A table showing analysis results at $7.55 \mathrm{GH}$ using Cassiopeia $A$ for a satellite at $12^{\circ}$ elevation angle is given. The quadrature sum of the systematic errors appearing in the table is 10.1 percent. Also presented is a curve of the systematic errors as a function of elevation angle showing a 7.3-percent minimum at high elevation angles.

18578. Crawford, M. L., Workman, J. L., Asymmetric versus symmetric TEM cells for EMI measurements, Proc. 1978 IEEE Int Symp. on Electromagnefic Compathility, Allania, (iA, June 20-22, 1978, pp. 204-210 (The Institute of Electrical and Electronics Engineers, Piscataway, NJ, 1979).

Key words: electromagnetic compatibility; measurements; transverse electromagnetic transmission cells.

This paper discusses the option of designing a transverse electromagneiic (TEM) transmission cell with an off-set septum as a multipurpose chamber for performing electromagnetic interference (EMI) measurements. The design and electrical performance characteristics of such a cell are given and compared with a similar sized symmetric cell.

18579. Crawford, M. L., Comparison and selection of techniques for measuring $\mathrm{EM}$ radiated emissions and susceptibility of large equipment, (Proc. 3d Symp. and Technical Exhibition on Electromagnetic Compatibility, Rotterdam, The Netherlands, May 1-3, 1979), Paper in Electromagnetic Com. patibility 1979, T. Dvorak, Ed., pp. $115-122$ (May 1979).

Key words: electromagnetic; rudiated emissions; susceptibility measurements.

This paper gives an overview of a number of techniques that could be used for measuring electromagnetic radiated emissions or susceptibility of large equipment. Each technique is assessed relative to operational and measurement parameters. Six techniques are selected as being optimum for specific applications.

18580. Cascaval, C. N., Florin, R. E., Pyrolysis gas chromalography of some fluorine-containing poiymers, $J$. Fluorine Chem. 13, 65-70 (1979).

Key words: isobutene copolymers; pyrolysis gas chromatography; random scission; tetrafluoroethylene copolymers; 1,3,3,3-tetrafluoropropene polymer; 3,3,3-trifluoropropene copolymers; $3,3,4,4,5,5,5$-heptafluoropentene-1 polymer.

Pyrolysis gas chromatography of the polymers of 1,3,3,3tetrafluoropropene, 3,3,4,4,5,5,5-heptafluoropentene-1 and of the copolymers of tetrafluoroethylene with the above and with $3,3,3$-trifluoropropene and with isobutene in all instances gave only 3 to $19 \%$ of volatiles below $C_{16}$, distributed among many peaks. This and the absence of significant char indicate predominantly a random scission mechanism of decomposition.

18581. Carlson, A. D., Patrick, B. H., Measurements of the ${ }^{235} U$ fission cross section in the $\mathrm{MeV}$ energy region, Proc. Int. Conf. on Neutron Physics and Nuclear Data for Reactors and Other Applied Purposes, Harwell, United Kingdom, Sept. 25-29, 1978 , pp. 880-886 (Publications de L'OCDE, Paris, France, 1979).

Key words: fission cross section; linac; neutron flux determination; proton telescope; standard cross section; ${ }^{235} \mathrm{U}(\mathrm{n}, \mathrm{f})$. 
Measurements of the energy dependence of the ${ }^{2: 5} U$ neutron fission cross section have been made from 1 to $20 \mathrm{MeV}$ at the NBS neutron time-of-flight facility. These data were measured relative to the hydrogen scattering cross section with an annular proton telescope. The error for these shape measurement is $2-3 \%$ throughout the entire energy region.

18582. Brown, L. D., ibers, J. A.. Siedle, A. R., Iridium (I) and rhodlum (I) complexes of henzotriazole. Structure of bistiriphenylphosphine) carbonyl (benzotriazenido) iridium (I), Inorg. (hem. 17. No. 11, 3026-30130)(1978).

Key words: benzotriazenides: iridium (i) complexes; organometallic benzotriazenides; rhodium (i) complexes; thallium benzotriazenide.

Thallium benzotriazenide has been prepared from benzotriazole, thallium (1) acetate, and triethylamine in ethanol. The compound serves as a convenient starting material for the synthesis of organometallic benzotriazenides, it reacts with $\left[\operatorname{Ir}(\mathrm{CO})(\right.$ acetone $\left.)\left(\mathrm{PPh}_{3}\right)_{2}\right]\left[\mathrm{PF}_{6}\right]$ to yield the tetramer $\left[\operatorname{lr}(\mathrm{BTA})(\mathrm{CO})\left(\mathrm{PPh}_{3}\right)\right]_{4}$, where $\mathrm{Ph}=$ phenyl and $\mathrm{BTA}=$ benzotriazenido. A similar reaction with $\mathrm{RhCl}(\mathrm{CO})\left(\mathrm{PPh}_{3}\right)_{2}$ yields the hexamer $\left[\mathrm{Rh}(\mathrm{BTA})(\mathrm{CO})\left(\mathrm{PPh}_{3}\right)\right]_{k}$. Direct reaction of TI(BTA) with $\operatorname{lrCl}(\mathrm{CO})\left(\mathrm{PPh}_{3}\right)_{2}$ yields ir $(\mathrm{BTA})_{2}(\mathrm{CO})\left(\mathrm{PPh}_{3}\right)$ $\mathrm{Tl} \cdot \mathrm{C}_{4} \mathrm{H}_{*} \quad$ A methanol solution of this material rapidly changes color from violet to yellow and from this solution the compound $\operatorname{lr}(\mathrm{BTA})(\mathrm{CO})\left(\mathrm{PPh}_{3}\right)_{2}$ is obtained. On the basis of an $\mathrm{x}$ ray crystal structure, the $\operatorname{Ir}$ atom in $\operatorname{Ir}(\mathrm{BTA})(\mathrm{CO})\left(\mathrm{PPh}_{3}\right)_{2}$ is coordinated by trans $P$ atoms, the CO ligand, and the BTA ligand in nearly a square-planar arrangement. Despite the symmetric nature of the $\mathrm{N}_{3}$ portion of the BTA ligand, the ligand is coordinated to the ir atom through atom N(1). The ligand makes an angle of approximately $78^{\circ}$ with the $\operatorname{Ir}(\mathrm{CO}) \mathrm{P}_{2}$ plane. The compound crystallizes with four molecules in space group $C_{2 h}{ }^{5}-P 2_{1} / n$ of the monoclinic system in a cell of dimensions $a$ $=13.508(3) \AA, \quad b=20.225(4) \AA, \quad c=13.372(3) \AA$, and $\beta=$ $103.36(1)^{\circ}$. The structure has been refined by full-matrix leastsquares methods to a final $R$ index of 0.035 for 199 variables, based on 6321 observations.

18583. Brown, W. E., Schroeder, L. W., Ferris, J. S., Interlayering of crystalline octacalcium phosphate and hydroxylapatite, J. Phy.s. Chem. 83, No. 11, 1385-1388 (1979).

Key words: bone; hydroxylapatite; interlayering; octacalcium phosphate; tooth; x-ray diffraction.

Hydroxylapatite (OHAp), $\mathrm{Ca}_{10}\left(\mathrm{PO}_{4}\right)_{6}(\mathrm{OH})_{2}$, and octacalcium phosphate (OCP), $\mathrm{Ca}_{8} \mathrm{H}_{2}\left(\mathrm{PO}_{4}\right)_{6} \cdot 5 \mathrm{H}_{2} \mathrm{O}$, form interlayered mixtures in which some of their h00 x-ray diffraction peaks interact to form combination peaks. Calculations reveal that the $d_{200}(O C P)-d_{100}(O H A p)$ peak shifts toward lower spacings from $9.34 \AA$, the $d_{200}$ of OCP, to $8.16 \AA$, the $d_{100}$ of OHAp, as the $\mathrm{Ca} / \mathrm{P}$ ration increases from 1.33 to 1.67 . The $\mathrm{d}_{500}(\mathrm{OCP})-$ $\mathrm{d}_{2100}(\mathrm{OHAp})$ and the $\mathrm{d}_{700}(\mathrm{OCP})-\mathrm{d}_{300}(\mathrm{OHAp})$ combination peaks shift to higher spacings as the $\mathrm{Ca} / \mathrm{P}$ ratio of the interlayered mixture increases. The calculated shifts in the $d_{200}(O C P)-d_{100}(O H A p)$ peak are corroborated by experimental data in the literature. Although shifts in the $x$-ray diffraction peaks are common in clays, this is the first time this phenomenon has been observed in calcium phosphates; it provides a new approach to the study of tooth and bone mineral in their formative stages when OCP is most likely to be present.

18584. Bender, P. L.; Some U.S. views on scientific opportunities in ocean and earth dynamics, European Space Agency Workshop, Schloss Elmau, Germany, Jan. 16-21, 1978, S. Hieber and T. D. Gueyene, Eds., pp. 19-23 (European Space Agency, Paris, France, 1978)
Key words: crustal movements: earth rotation; geodynamics; gravity field; ocean current; plate tectonics; polar motion.

Some of the areas of ocean dynamics and earth dynamics in which ESA participation would be strongly welcomed by earth scientists in the U.S. are discussed in this paper. The topics covered are ocean currents, tectonic plate motions, crustal movements in seismic zones, earth rotation and polar motion, and mapping of the gravity field. Cooperative international efforts in applying space techniques to these fields are likely to yield highly valuable scientific results, which later can be applied to practical problems in many countries. Particular needs for increased European participation are apparent in the laser tracking of SEASAT $A$, in setting up an international geodynamic control network, in developing accurate but inexpensive methods for detecting crustal movements at many points in seismic zones, in monitoring UT 1 and polar motion by both laser ranging and long baseline radio interferometry, and in developing a new gravity field mapping mission.

18585. Bowman, C. D., Schrack, R. A., The infiuence of vihrations of gas molecules on neutron reaction cross sections, Proc. Int. Conf. on Nentron Physics and Nuclear Data for Reacoss and Other Applied Purpeses, Ilarwell, United Kingdom, Sept. 25-29, 1978, pp. 736-741 (Publications de L'OCDE, Paris, France, 1979).

Key words: Doppler effect; fission; gas target; molecular vibrations; neutron reactions; ${ }^{2: 3} \mathrm{U}$.

The change in molecular vibration energy upon absorption of a neutron by a nucleus bound in a free molecule can influence resonance shape and other aspects of neutron reaction cross sections. A formalism is developed for centrosymmetric molecules such as $U F_{6}$ and applied to the shape of the $6.67 \mathrm{eV}$ resonance in ${ }^{238} \mathrm{U}$. The ratio of the resonance shape for ${ }^{23 *} \mathrm{UF}_{\mathrm{H}}$ gas and for solid $\mathrm{U}_{3} \mathrm{O}_{8}$ has been measured and compared with the calculation. Reasonable agreement is obtained indicating the validity of the calculation and the necessity to include vibration effects to avoid large errors in measurements and calculations on gas-containing systems

18586. Paffenbarger, G. C., Rupp, N. W., Patel, P. R., Dimensional change of dental amaigam and a suggested correlation between marginal integrity and creep, J. Am. Dent. Assoc. 99, 3I-37 (July 1979)

Key words: creep; dental amalgam; dimensional changes; extrusion of restorations; marginal fracture; zinc effect.

Amalgams made from Micro Alloy, New True Dentalloy and Dispersalloy, on which the re is adequate extant clinical testing, showed large expansion when stored in air at $60^{\circ} \mathrm{C}$ and much less or no expansion at 37 and $23^{\circ} \mathrm{C}$. Zinc free amalgam had very small expansions or shrinkages at 60,37 and $23{ }^{\circ} \mathrm{C}$. Thus zinc appears to promote diffusion in hardened amalgam. Dimensional changes were usually less proportionally on the diameter than on the lengths of $8 \times 4 \mathrm{~mm}$ unrestricted cylinders. Amalgam confined in cylindrical cavities extruded less than the unrestricted cyclinders. The extrusion from the cavities was proportional to the creep values of the amalgams. Thus it is suggested that the apparent correlation of the marginal integrity of clinical amalgam restorations with creep of the amalgams, as demonstrated by Mahler et al. in 1970 (J. Dent. Res. $49: 1452,1970$ ) may he caused by the relative resistance of the amalgams to deformation caused by expansion of the three foregoing amalgams.

18587. Kusuda, T., Hunt, C. M., McNall, P. E., Radioactivity (radon and daughter products) as a potential factor in building ventilation, $A S H R A E$ J. 21, No. 7, 30-34 (July 1979). 
Key words: energy conservation design; indoor radiation; radon in buildings; ventilation and radon concentration.

Awareness has developed in the United States, particularly within the last five years, that traces of radioactive radon gas and its daughter products are present in varying amounts in the indoor air. Some of the existing literature on the subject is briefly reviewed and discussed. It is recommended that further attention be given to quantify radon concentration data pertinent to the environmental health aspects of ventilation requirements from the standpoint of indoor air quality consistent with building energy conservation.

18588. Paabo, M., Birky, M. M., Womble, S. E., Analysis of hydrogen cyanide in fire environments, J. Combust. Toxicol. 6, 99-108 (May 1979).

Key words: combustion products; gas analysis; gas chromatography; hydrogen cyanide.

A sensitive method for the direct gas chromatographic determination of environmental hydrogen cyanide resulting from the combustion or thermal degradation products of nitrogen containing polymeric materials is described. The gas chromatographic method utilizes an alkali flame (or thermionic) detector in conjunction with a Porapak $\mathbf{Q}$ column. The range of detection was 5-400 ppm $\mathrm{HCN}$ with an estimated uncertainty of \pm $5 \mathrm{ppm}$. The lower detection limit was about 50 picograms $\mathrm{HCN}$ ( $1 \mathrm{ppm}$ per $50 \mu \mathrm{l}$ injection).

18589. Newbury, D. E., Myklebust, R. L., Monte Carlo electron trajectory simulation of beam spreading in thin foil targets, (Proc. 2d Cornell Meeting on Analytical Electron Microscopy, Ithaca, NY, July 24-26, 1978), Ultramicrosc. 3, 391-395 (North-Holland Publ. Co., Amsterdam, The Netherlands, 1979).

Key words: analytical electron microscopy; microanalysis; Monte Carlo electron trajectory simulation; spatial resolution; thin foils; $x$ rays.

The spatial resolution of $x$-ray microanalysis of thin foils is limited by beam spreading caused by elastic scattering of electrons. A simple analytical model with a single scattering approximation which has been used by other workers to calculate the magnitude of beam spreading is reviewed. Monte Carlo electron trajectory simulation techniques are developed to study beam spreading. Equations are given to calculate the three major parameters of a Monte Carlo simulation: step length between scattering points, elastic scattering angle, and azimuthal angle, Monte Carlo results compare well with analytical model calculations for thin films. For thick films, Monte Carlo values of beam spreading are $10 \%$ to $40 \%$ less than corresponding analytical model values. Beam tailing and the effects of specimen inclination can also be studied by Monte Carlo simulation.

18590. Linsky, J. L., High resolution spectrograph for the space telescope, (Proc. Society of Photo-Optical Instrumentation Engineers, Tucson, AR, Jan. 29-Feb. 1, 1979), SPIE 172 Instrumentation in Astronomy III, 254-263 (1979).

Key words: galactic astronomy; space astronomy; stellar astronomy; ultraviolet spectroscopy.

We are developing a High Resolution Spectrograph (HRS) for ultraviolet astronomy with the Space Telescope. The instrument will provide a spectral resolution of $\approx 1.2 \times 10^{5}$ over a nominal wavelength range of $110-320 \mathrm{~nm}$, together with a spatial resolution of about 0.25 arc seconds. The two detectors will consist of 512-element Digicons with cesium telluride and cesium iodide photocathodes, respectively. Photoelectrons in transit between the photocathodes and the diodes within the
Digicons can be deflected in two axes with 12-bit resolution. This feature facilitates a design that emphasizes reliability since (once a hermetic seal is opened in orbit), only two moving parts, a grating carrousel and a shutter, are required for regular operation of the HRS. The instrument will be controlled by a computer in the spacecraft. The scientific objectives of the HRS investigation relate to interstellar matter in our own and nearby galaxies, physical processes of stellar mass loss and mass transfer, chemical abundances, bright quasars and Seyfert galaxy nuclei, and solar system phenomena.

18591. Behrens, J. W., Schrack, R. A., Bowman, C. D., Resonance neutron radiography using a position-sensitive proportional counter, (Proc. Am. Nuclear Society Annual Meeting, Atlanta, GA, June 3-7, 1979), Trans. Am. Nucl. Soc. 32, 207-208 (American Nuclear Society, Hinsdale, 1L, 1979).

Key words: linac; neutrons; position-sensitive detector; radiography; time-of-flight technique.

This paper describes progress at NBS in the development of resonance neutron radiography as a laboratory reference method for measurements for safeguarding nuclear fuel. To demonstrate and test the method a broad energy spectrum of neutrons and a linear position-sensitive proportional counter were used with time-of-flight techniques to determine the distribution of solder between two silver-brazed metal disks and to measure the thickness of the braze.

18592. Murat, K., Katriel, J., The lowest triplet state of the biexciton may be bound, Phys. Lett. 71A, No. 1, 143-145 (Apr. 16, 1979).

Key words: biexcitons; Haken's Hamiltonian; polar crystals.

Using Haken's Hamiltonian and a simple variational wavefunction, the $\left(1 \sigma_{a}, 1 \sigma_{u}\right)^{3} \Sigma_{u}$ state of the biexciton in a polar crystal is found to be stable with respect to dissociation into two ground-state excitons, for a certain range of (realistic) material parameters, unlike the corresponding state in the $\mathbf{H}_{2}$ molecule.

18593. Wiese, W. L., Atomic processes for magnetic fusion research and their data status, (Proc. IX int. Symp. on Physics of lonized Gases, Dubrovnik, Yugoslavia, Aug. 28 Sept. 2, 1978), Paper in The Physics of lonized Gases, R. K. Janev, Ed., pp. 661-696 (Institute of Physics, Beograd, Yugoslavia, 1979).

Key words: atomic data; data availability; dielectronic recombination rates; excitation rate coefficients; ionization rate coefficients; magnetic fusion research; transition probabilities; wavelengths.

The role of atomic collision and radiation processes in magnetic fusion research is discussed, using the coronal plasma model as a guide. The data needs and priorities with respect to the type of atomic quantity, chemical element and stage of ionization are reviewed. The status of our knowledge for such atomic data is surveyed, and some of the problems in acquiring them are pointed out. It is shown that reliable atomic data for highly ionized species are very scarce. A few examples for the impact of atomic physics on fusion research are cited.

18594. Weidner, V. R., Hsia, J. J., NBS reference hazemeter: Its development and testing, Appl. Opt. 18, No. 10, 1619. 1626 (May 15, 1979).

Key words: collimation; haze; hazemeter; integrating sphere; linearity; scattering.

A research hazemeter has been developed by the Radiometric Physics Division of the National Bureau of Standards for the quantitative analysis of light scattering by optical materials. The 
instrument is designed to measure percentage haze as set forth in the prescribed conditions recommended in ASTM Test Method D 1003. The hazemeter has several special features which make it possible to vary the geometrical conditions of the collimated light bcam and the integrating sphere detector system for detailed studies of light scattering. Light scattering associatcd with the instrument source and collimating optics has been reduced to less than $0.1 \%$ of the total light beam by using a diffraction limited off-axis parabolic mirror to collimate the hazemeter light beam. The source optics provide a collimated light beam of approximately $6800 \mathrm{~K}$. The detector is a silicon cell photodiode with a $V(\lambda)$ window. This combination gives the system a response corresponding to the visual luminosity function. The detector nonlinearity and instrumental errors associated with the accuracy of the integrating sphere geometry have been analyzed. The over-all uncertainty in percentage haze has been reduced to $\pm 0.2 \%$, and light scattering of less than $0.5 \%$ can readily be measured.

18595. Warner, B., Apsidal motion and evolution of cataclysmic variables, Acta Astron. 28, No. 3, 303-326 (1978).

Key words: binary stars; cataclysmic variables.

Interpreted as apsidal motion, the cyclical orbital period changes of UX UMa and RW Tri indicate highly centrally condensed structures for the secondaries of these systems, suggesting that they are in Case $B$ mass transfer. The consequences are explored of loss of angular momentum (via the accretion disc) from cataclysmic variables, both with and without mass loss from the white dwarfs. Illustrations are given of the resulting mass-radius relationship for the secondaries, and of the change in orbital period during evolution. The observed absence of high-luminosity secondaries (which occur in conservative evolution) is thereby explained.

18596. McNalt, P. E., Jr., The relation of thermal comfort to learning and performance: $A$ state-of-the-art report, (Proc. ASHRAE Semiannual Meeting on HVAC-Human Factors, Philadelphia, PA, Jan. 28-Feb. 2, 1979), Paper PH-79-9, No. 2 in ASHRAE Trans. 85, Pt. 1, 759-767 (June 1979).

Key words: air-conditioning; comfort; education; environment; human factors; research; school.

The results of several research projects are summarized. These projects have attempted to relate thermal comfort, learning and productivity. They show indications of positive correlation (optimal comfort appears to result in maximum learning, etc.) but these are not well supported by commonly accepted experimental statistics. The problem seems to rest in quantifying highly variable individual human motivation as other experimental conditions are varied. This seems particularly true in the usually employed experiments of a few hours' duration on many human subjects. On the other hand, investigating longterm effects of fatigue and motivation over many weeks is expensive and time-consuming, and control of the subjects when they are not under the experimental conditions has been minimal in studies of this type up to the present time.

18597. Molino, B. B., Hilsenrath, J., Beyond data retrieval: An outline of the unique data analysis features of the NBS Omnidata system, Proc. Eighteenth Annual Tech. Symp. on Information Systems-Effectiveness for the User, Gaithersburg, MD, June 21, 1979, pp. 159-165 (The Washington DC Chapter of the Association for Eomputing Machinery, Washington, DC, June 1979).

Key words: Boolean search system; computer programs; curve fitting; data analysis; data base management; data retrieval; file handling; graphic analysis; IMS information retrieval; KWOC indexing; least-squares; linear regression; MIS; plotting; statistical analysis.
Omnidata is an interactive, general-purpose system for data retrieval, data analysis, and data file maintenance. The system is specifically designcd so that individuals with little or no background in computers are able to search data files, do analysis on these files, and prepare ad hoc or periodic reports. At the same time, the system provides the computer professional and data-base administrator with tools for proper maintenance of those data bases under his control. This wide spectrum of functions of varying complexity is provided by the modularity of the system. In addition to the 'usual' capabilities of a data management system-searching, reporting, sorting, updating-there are close to 40 distinct modules to provide detailed statistical and graphical analysis, data manipulation, and file management.

Discussion will include descriptions of some of these unique data manipulation and analysis modules, including AGGREGATE, CROSSTAB, DISTRIBUTE, SURVEY, and TALLY. Also included will be a discussion of how Ominidata interfaces with the OMNITAB statistical and plotting programs.

18598. Harter, w. G., Galbraith, H. W., Patterson, C. W., Energy level cluster analysis for $E\left(\nu_{2}\right)$ vibration rotation spectrum of spherical top molecules, J. Chem. Phys. 69, No. 11, 4888-4895 (Dec. 1, 1978).

Key words: Born-Oppenheimer approximation; high-resolution spectra; level clusters; Raman spectra; rotation-vibration spectra; symmetry analysis.

The theory of level clusters, originally developed for ground state $\left(A_{1}\right)$ and weakly coupled infrared active $\left(F_{2}, \nu_{3}\right)$ excited states, is extended to include the Raman-active $(E)$ states of vibration-rotation. Simple approximate formulas are given for the eigenvalue spectrum of the dominant second order vibration-rotation Hamiltonian and the results are compared with exact computer reductions.

18599. Harter, W. G., Patterson, C. W., Galbraith, H. W., Centrifugal and Coriolis effects on level cluster patterns for $T\left(\nu_{3}\right)$ rovibrational bands in spherical top molecules, J. Chem. Phys. 69, No. 1, 4896-4907 (Dec. 1, 1978).

Key words: Born-Oppenheimer approximation; centrifugal; Coriolis; frame transformation relations; level cluster; spherical tops; symmetry analysis.

Fundamental $T\left(\nu_{3}\right)$ type high- $J$ rovibrational fine structure is derived for a range of values of the Coriolis and $[2 \times 2]^{4}$ centrifugal constants. The theory of level clusters is developed further. Correlations are made between cluster states corresponding to well separated $P^{+}, Q^{0}$, and $R^{-}$branches, and the opposite casc in which $\Pi_{ \pm}$and $\Sigma_{0}$ labels are appropriate.

18600. Hoer, C. A., Calibrating two six-port reflectometers with an unknown length of precision transmission line, Proc. 1978 IEEE MTT-S Int. Microwave Symp. Digest, Ottawa, Canada, June 27-29, 1978, pp. 176-178 (The Institute of Electrical and Electronics Engineers, Piscataway, NJ, 1978).

Key words: calibration; current; impedance; network analyzer; power; reflection coefficient; reflectometer; scattering parameters; six-port; voltage.

This paper describes a technique for calibrating a pair of 6 port reflectometers for measuring the complex reflection coefficient of 1-port devices, or the scattering parameters of reciprocal 2-port devices. The operations in the calibration consist of connecting the two 6-ports together, connecting each 6-port to a calibration circuit consisting of two unknown terminations and a leveling loop, and then connecting the standard. The standard can be one termination whose complex impedance is known, or a length of precision transmission line whose crosssectional dimensions are known. The length and loss of the line 
are not required. The solution for the constants which characterize each 6-port is closed, requiring no iteration.

18601. Hoer, C. A., Performance of a dual six-port automatic network analyzer, Proc. IEEE MTT-S 1979 Int. Microwave Symp. Digest: The World of Microwates, Orlando, FL, Apr. 30-May 2, 1974. IEEE (at. No. 74(I/1434.9 MTT-S, 3 pages (The Institute of Electrical and Electronics Engineers, Piscataway. NJ, 1979).

Key words: calibration: current; impedance; network analyzer; power; reflection coefficient; reflectometer; scattering parameters; six-port; voltage.

The precision, accuracy, and stability of an experimental dual 6-port automatic network analyzer operating in the $2.18 \mathrm{GH} \%$ range are given. Accuracy of 0.001 in reflection coefficient and $0.003 \mathrm{~dB}$ in attenuation have heen maintained at $3 \mathrm{GH} \%$ over a 10 week period without recalibration.

18602. Johnson, C. R., Beine, W. B., Wang, T. J., Right-left asymmetry in an eigenvector ranking procedure, J. Math. Psychol. 19, No. 1, 61-64 (Feb. 1979).

Key words: decision analysis; decisions; eigenvectors; management; multiple-attribute decisions; ordering; paired comparisons; prioritization; project selection; ranking; resource allocation; weighting multiple criteria.

A suggestion for the prioritization of alternatives using the Perron-Frobenius right eigenvector of a pairwise comparison matrix has recently been made by $T$. Saaty. We note that use of the left eigenvectors is equally justified (as long as order is reversed). The purpose of this note is to point out that the resultant prioritizations may disagree even when the comparisons are "nearly consistent."

18603. Soulen, R. J., Jr., Noise thermometry using Josephson junctions, (Proc. 5th Int. Conf. on Noise, Bad Nauheim, Fed. Rep. of Germany, Mar. 13-16, 1978), Paper in Noise in Physical Systems, D. Wolf, Ed., pp. $249-259$ (Springer-Verlag, Berlin, Germany, 1978).

Key words: Johnson noise; Josephson junctions; noise thermometry; resistive SQUIDS; temperature measurement.

Two methods for measurement of temperature using Johnson noise are reviewed and compared. The temperature scale developed with each is assessed.

18604. Marshak, H., Turrell, B. G., $\gamma$-ray emission from oriented nuclei in a multiaxis nuclear spin system: ${ }^{166 m} \mathbf{H o}^{165}$ Ho, Solid State Commun. 30, No. 11, 677-681 (1979).

Key words: atomic magnetic structures; conical spin structure; decay of ${ }^{166 \mathrm{~m}} \mathrm{Ho}$; nuclear orientation; nuclear spin system; ${ }^{166} \mathrm{Ho}^{165} \mathrm{Ho}$

A new method is proposed to measure multiaxis nuclear spin structures using $\boldsymbol{\gamma}$-ray emission from oriented radioactive nuclei. This method, which depends only on angular momentum theory, is presented for helical spin structures. The atomic magnetic structure can also be obtained when the nuclear magnetism is produced by hyperfine interaction. Measurements on ${ }^{166 m} \mathrm{Ho}$ in a single crystal of ${ }^{165} \mathrm{Ho}$ metal show that the spin axes form a single cone with a half-angle of $80.4 \pm 0.4^{\circ}$.

18605. Kventsel, G. F., Katriel, J., Exact solutions for infiniterange spin Hamiltonians, J. Appl. Phvs. 50, No. 3, 1820-1821 (Mar. 1979).

Key words: ferromagnetism; magnetization equation; spin Hamiltonians; spinodal point; spin-phonon coupling.
The closed form magnetization equation, $s=\sigma \cdot \mathrm{B}_{\mu}-\boldsymbol{\beta} \cdot \boldsymbol{\sigma} \partial$ $\mathrm{H} / \partial \mathrm{s}]$, is shown to be valid for any infinite range spin Hamiltonian $\|=\mathrm{N} \cdot \mathrm{H}(\mathrm{s})$, where $\mathrm{N}$ is the number of particles, each with elementary spin $\sigma, s=S / N, S$ being the total spin, and $B_{r}$ is Brillouin's function. This equation is used to investigate the following problems: (i) determination of the class of Hamiltonians with a spinodal point at $\mathrm{O}^{\circ} \mathrm{K}$; (ii) spin-phonon coupling, quadratic in the lattice displacements. Magnetostriction of this form may lead to shift of the critical temperature, change of the order of the phase transition, decrease of the paramagnetic spinodal temperature up $t$ ) $\mathrm{O}^{\circ} \mathrm{K}$ and renormalization of the phonon spectrum; (iii) singlet-ground-state ferromagnetism, exhibiting various types of phase-transitions, including heat magnetization.

18606, Pasachoff, J. M., Linsky, J. L., Haisch, B. M., Boggess, A., IUE and the search for a lukewarm corona, $\$$ ky and Telesconpe 57, No. 5, 438-443 (May 1979).

Key words: satellites; space astronomy; stars, chromospheres; stars, coronae; stars, late-type; stars, winds; ultraviolet spectra.

Since January 1978 , a new telescope in orhit has allowed the world's astronomers to take giant steps toward understanding stars, planets, nebulae, quasars, and other objects by studying their ultraviolet spectra. The International Ultraviolet Explorer (IUE) has coupled significant advances in the instrumentation aloft with interactive capabilities in the control room below in order to allow astronomers to guide and update their projects while the observations are heing made. We describe in detail the capabilities of this system.

18607. Kilmer, R. D., Cadoff, M. A., Mathews, D. E., Shoemaker, C. O., Jr., Effects of load, inflation pressure and tire deflection on truck tire noise levels, DOT HS 803874,48 pages (Department of Transportation, National Highway Traffic Safety Administration, Washington, DC, Jan. 1979).

Key words: acoustics; noise measurement; noise (sound); tire noise; transportation noise; truck

SAE Recommended Practice J57a-Sound Level of Highway Truck Tires-specifies that the tests be made using tires inflated to the maximum inflation pressure and loaded to the maximum load as specified by the Tire and Rim Association (T\&RA). However, if local load limits preclude the use of the maximum rated load, tests may be conducted using lower loads if the inflation pressure is adjusted either to maintain constant tire deflection or according to the T\&RA load/inflation pressure tables. Whether these alternate load/inflation pressure conditions result in similar sound levels is an important question. This report presents acoustic data that allows evaluation of the equivalency of these alternate conditions. In addition, laboratory data on the relationships between load, inflation pressure, and tire deflection are presented. On the basis of these data, for tire loads greater than 70 to 75 percent of the maximum rated load, smaller variations of the measured sound level were observed when constant inflation pressure was maintained than when the inflation pressure was adjusted. This is convenient since this essentially represents the typical in-service case where the load varies between trips but the tire inflation pressure is maintained at a constant value.

18608. Wineland, D. J., Laser-to-microwave frequency division using synchrotron radiation, J. Appl. Phys. 50, No. 4, 25282532 (Apr. 1979).

Key words: $\mathrm{CO}_{2}$ laser; frequency comparison; frequency multiplication; frequency synthesis; laser frequency measurement; Penning trap; speed of light. 
Calculations are made 10 demonstrate the feasibility of obtaining one-step frequency division from optical or infrared laser frequencies to a subharmonic in the microwave spectral region. The cyclotron orbit of a single relativistic electron in a Penning trap is driven with a Gaussian laser heam focused to a spot diameter $\sim \lambda$; the laser suhharmonic frequency is measured from the electron synchrotron radiation. The uncertainty in orhit dimensions is limited to $\lambda / 2$ hy radiative cooling and the technique of motional sidehand excitation.

18609. Harter, W. G., Patterson, C. W.. Theory of hyperflne and superfine levels in symmetrlc polyatomlc molecules. Trigonal and tetrahedral molecules: Elementary spln-1/2 cases In vibronic ground states, P/hys. Rev. $A$ 19, No. 6, 2277-230)3 (June 1979).

Key words: high resolution spectroscopy; hyperfine structure; level clusters; saturation absorption spectra; superfine structure; symmetry analysis; tahleau calculus.

A simple approximate scheme for treating molecular hyperfine structure is developed by taking account of energy-level clusters. Unitary tableau and frame transformation techniques are reintroduced. Model Hamiltonians for $X Y_{3}$ and $X Y_{4}(X$ spin-zero, $Y$ spin-1/2) molecules are developed and solved in cluster bases wich are appropriate for highly excited rotational states. Two cases emerge: Case (1) for which hyperfine splittings are smaller than the "superfine" cluster splittings and case (2) for which superfine splittings are negligible or zero. The problem of correlating energy levels and states between cases (1) and (2) is solved. Since the $X Y_{4}$ problem in the elementary cluster bases reduces to $(2 \times 2)$ matrices at the worst, the physical interpretation of solutions is not difficult.

18610. McHenry, H. I., Naranjo, S. E., Read, D. T., Reed, R. P., Low-temperature fracture properties of a USSR aluminum-6\% magnesium alloy, (Proc. 2d Int. Cryogenic Materials Conf., Boulder, CO, Aug. 3-5, 1977), Paper K-3 in Advances in Cryogenic Engineering, K. D. Timmerhaus, R. P. Reed, and A. F. Clark, Eds., 24, $519-528$ (Plenum Press, New York, NY, 1978).

Key words: aluminum alloys; crack propagation; cryogenics; fatigue; fracture; low temperature tests; mechanical properties.

Aluminum alloy $5083-0$ ( $\mathrm{Al}-4.5 \mathrm{Mg}$ ) is widely used in the United States as a construction material for liquefied natural gas (LNG) containers and other cryogenic applications. In the USSR, aluminum alloy AMg6-0 ( $\mathrm{Al}-6 \mathrm{Mg}$ ) has been developed for similar applications. As a part of the U.S.-USSR LNG materials exchange program, NBS was asked to evaluate the fracture properties of the AMg6 alloy supplied by the USSR and to compare the results with those obtained previously on the 5083-0 alloy. The results of fatigue crack growth and fracture toughness tests are summarized in this paper.

18611. Tobler, R. L., Low temperature fracture behavior of a Ti-6Al-4V alloy and its electron beam welds, Am. Soc. Test. Mater. Spec. Tech. Publ. 65I, pp. 267-294 (1978).

Key words: electron beam welding: fatigue (materials); fracture properties; low temperature tests; mechanical properties; titanium; titanium alloys.

The effects of electron beam welding on the fracture hehavior of a recrystallization annealed, extra-low-interstitial $\mathrm{Ti}-6 \mathrm{Al}-4 \mathrm{~V}$ alloy have been investigated at temperatures in the ambient-to-cryogenic range. Plane strain fracture toughness $\left(K_{l c}\right)$ and subcritical crack growth parameters were measured using compact specimens 10 to $25.4 \mathrm{~mm}$ thick. These parameters can be used to predict the safe operating lifetimes of cryogenic pressure vessels and other welded Ti-6Al-4V structures.
At intermediate stress intensity factors and within the data scatter for replicate tests, the growth rates of fatigue cracks sited in the fusion and heat-affected zones of electron beam weldments were temperature insensitive and nearly equivalent to rates for the hase metal. However, electron heam welding introduced a zone of low fracture toughness at the heat-affectedzone/fusion-\%one houndary. The $K_{t,}$ value for this houndary 7.one at liquid nitrogen temperature $(76 \mathrm{~K})$ was $51 \mathrm{MPa} / \mathrm{m}^{1 / 2}$, 16 percent lower than the hase metal. The hase metal fracture toughness increases hetween 4 and $295 \mathrm{~K}$, with an ahrupt transition to higher $K_{, r}$ values occurring at temperatures between 76 and $125 \mathrm{~K}$. Static load cracking, temperature effects, and specimen orientation effects on the fracture hehavior of this titanium alloy are central topics of discussion.

18612. McHenry, H. I., Read, D. T., Begley, J. A., Fracture mechanles analysis of pipellne glrthwelds, $A \mathrm{~m}$. Srs. Tess. Mater. Specs. Tech. Publ. 668, pp. 632-642 (1979).

Key words: carhon-manganese steel; fracture mechanics; fracture toughness; pipeline; weld flaws; weldments.

Size limits for surface flaws in pipeline girthwelds are calculated on the hasis of fracture mechanics analysis. Parameters for the analysis were selected from data on a 1.22-m-diameter ( 48 in.), 12 -mm-thick ( 0.46 in.) pipe welded hy the shielded metal-arc process. The minimum fracture toughness of the welds as determined hy the crack opening displacement (COD) method was 0.1 and $0.18 \mathrm{~mm}(0.004$ and 0.007 in.), depending on the flaw location. The yield strength of the welds was 413 $\mathrm{MPa}(60 \mathrm{ksi})$. Because the toughness to yield strength ratio was high, elastic-plastic fracture mechanics analysis methods were required to determine critical flaw sizes. Four approaches were employed: (1) a critical COD method based on the ligamentclosure-force model of Irwin; (2) the COD procedure of the Draft British Standard Rules for Derivation of Acceptance Levels for Defects in Fusion Welded Joints: (3) a plastic instability method based on a critical net ligament strain developed by Irwin; and (4) a semi-empirical method that uses plastic instability as the fracture criterion developed by Kiefner on the basis of full-scale pipe rupture tests. Allowable flaw sizes determined by the Draft British Standard method are compared with the critical flaw sizes calculated using critical-COD and plastic instability as the respective fracture criteria. The results for both axial- and circumferential-aligned flaws vary significantly depending on the analysis model chosen. Thus, experimental work is needed to verify which model most accurately predicts girthweld behavior.

18613. Allen, S. M., Cahn, J. W., A microscopic theory for antiphase boundary motion and its application to antiphase domain coarsening, Acta Met. 27, $1085-1095$ (1979).

Key words: alloys; antiphase domains; critical behavior; domain growth; domain walls; ordering; surface mobility.

A microsciopic diffusional theory for the motion of a curved antiphase boundary is presented. The interfacial velocity is found to be linearly proportional to the mean curvature of the boundary, but unlike earlier theories the constant of proportionality does not include the specific surface free energy, yet the diffusional dissipation of free energy is shown to be equal to the reduction in total boundary free energy. The theory is incorporated into a model for antiphase domain coarsening. Experimental measurements of domain coarsening kinetics in FeAl alloys were made over a temperature range where the specific surface free energy was varied by more than two orders of magnitude. The results are consistent with the theory; in particular, the domain coarsening kinetics do not have the temperature dependence of the specific surface free energy.

18614. Cahn, J. W., Kikuchi, R., Ground state of f.c.c. alloys with multiatom interactions, Acta Met. 27, $1329-1336$ (1979). 
Key words: face centered cubic; ground state; interfaces: multi-ion interactions; ordered alloys; statistical mechanics.

The ground state of a binary f.c.c. alloy with nearest neighbor interactions and tetrahedral multiatom interactions (characterized by two parameters $\alpha$ and $\beta$ ) is derived and presented in a chart which shows classification of phases in the space of $\alpha$ and $\beta$. Where non-stoichiometric phases can occur, the phase houndaries at $T=0$ are computed using the tetrahedron approximation of the cluster variation method. Duality of the composition and the chemical potential is emphasized and results are presented and/or interpreted in the dual approaches.

18615. Hust, J. G., Kirby, R. K., Standard reference materials for thermophysical properties, (Proc. 2d Int. Cryogenic Materials Conf., Boulder, CO, Aug. 3-5, 1977), Puper D-3 in Advances in Cryogenic Engineering, K. D. Timmerhaus, R. P. Reed, and A. F. Clark, Eds., 24, 232-239 (Plenum Press, New York, NY, 1978).

Key words: electrical resistivity; enthalpy; specific heat; standard reference materials; thermal conductivity; thermophysical properties.

The National Bureau of Standards has prepared over 50 certified Standard Reference Materials (SRM's) for use in the area of thermophysical properties of solids. The properties that have been certified include elasticity, electrical resistivity, emittance, specific heat, thermal conductivity, thermal expansion, vapor pressure, and both defining and secondary fixed points of the International Practical Temperature Scale, IPTS-68. The materials, stocked by NBS-OSRM, whose property(ies) have been certified include aluminum, copper, gold, iron, tungsten, several high-temperature alloys, alumina, silica, and several glasses.

A discussion is presented of those SRM's most applicable to low-temperature measurements. The significance of SRM's to the national measurement system is discussed along with desirable qualities of SRM's and their applications. The work in progress and future plans of this program are also presented.

18616. Schramm, R. E., Kasen, M. B., Fiberglass-epoxy in a conical superconducting field magnet support, (Proc. $2 \mathrm{~d}$ Int. Cryogenic Materials Conf., Boulder, CO, Aug. 3-5, 1977), Paper E-3 in Advances in Cryogenic Engineering, K. D. Timmerhaus, R. P. Reed, and A. F. Clark, Eds., 24, 271-278 (Plenum Press, New York, NY, 1978).

Key words: composites; fiberglass; mechanical porperties; modulus; strength; superconducting motor.

A conical fiberglass-epoxy field magnet support was designed for use in a 2.2-MW (3000-hp) superconducting motor. The cone design was based upon cryogenic static mechanical property data published by Toth et al. for a type $1581 \mathrm{~S}$-glass/E787 epoxy resin composite. The cone tested in this program, however, was fabricated with type $1581 \mathrm{~S}$-glass cloth in an epoxy resin system known as NASA Resin 2. To check the material properties against design criteria, flat panels of composites of the glass cloth were tested with both types of resin. All tests were run to failure in tension, compression, and shear at $350,295,76$, and $4 \mathrm{~K}$. The parameters measured .were moduli, strengths, failure strains, and Poisson's ratios. Another objective was the measurement of the cone's axial spring constant at 295 and $76 \mathrm{~K}$ as a function of axial compressive force up to $89 \mathrm{kN}(20,000 \mathrm{lb})$. Because the component EMPOL 1040 in the NASA Resin 2 formulation is known to decrease the composite strength above room temperature, the cone was also tested at $350 \mathrm{~K}$.
18617. Johnson, W. W., Jones, M. C., Measurements of axial heat transport in helium 11 with forced convection, (Proc. $2 \mathrm{~d}$ Int. Cryogenic Materials Conf., Boulder, CO, Aug. 3-5, 1977), Paper G-6 in Advances in Cryogenic Engineering, K. D. Timmerhaus, R. P. Reed, and A. F. Clark, Eds., 24, $363-$ 370 (Plenum Press, New York, NY, 1978).

Key words: axial heat transport; forced convection; heat transmission; helium II; mutual friction.

An experiment was performed that allowed measurements of the effect of forced convection on the axial heat transport of He-ll contained in a long tube. The apparatus allowed the pressure difference and temperature difference across the tuhe to be adjusted independently, and both the resulting heat flow and net fluid flow to be measured. The two-fluid model can be used to display the separate contributions of 'internal convection' and ordinary convection to the heat transport. The results show that, in the limit of large temperature differences and fluid velocities, the hehavior is approaching that of a classical fluid; this allows the extrapolation of these results, with reasonable confidence, to conditions (suitahle for some applications) where forced convection would allow at least ten times the heat transport of 'internal convection' alone.

18618. Verdier, P. H., Monte Carlo studies of lattice-model polymer chains. IV. Equilibrium dimensions and distributions in Rouse coordinates, J. Chem. Phys. 70, No. 12,5708.5713 (June 15, 1979).

Key words: distributions in chain dimensions; equilibrium chain dimensions; excluded volume; lattice-model chains; polymer chain dimensions; random-coil chain dimensions; Rouse coordinates.

Distributions in the squares of the seven lowest Rouse coordinates for simple lattice models of polymer chains of up to 64 beads, with and without excluded volume, have been obtained by dynamical simulation on a digital computer. The expansion of the mean-square values of the coordinates is found to depend primarily, though not entirely, upon the ratio of the number of beads in the chain to the index of the Rouse coordinate. The distribution functions for the squares of the Rouse coordinates for chains both with and without excluded volume constraints are close to Gaussian with the sole exception of the lowest Rouse coordinate for chains with excluded volume, which exhibits a pronounced depletion at small values. This depletion is very similar to that previously observed in distributions in the square of end-to-end length.

18619. Sparks, L. L., Magnetic field effect on thermal conductivity of selected metals, (Proc. 2d Int. Cryogenic Materials Conf., Boulder, CO, Aug. 3-5, 1977), Paper D-2 in Advances in Cryogenic Engineering, K. D. Timmerhaus, R. P. Reed, and A. F. Clark, Eds., 24, 224-231 (Plenum Press, New York, NY, 1978).

Key words: aluminum alloy; copper; low temperature; magnetothermal conductivity; nickel alloy; stainless steel; thermal conductivity.

The behavior of thermal conductivity in the presence of magnetic fields has been experimentally determined for eight alloys and for two copper specimens $(R R R=107$ and 1520). The data were taken for $0 \leqslant H \leqslant 6366 \mathrm{kA} / \mathrm{m}$ ( $80 \mathrm{k0e}$ ) and $5 \leqslant T$ $\leqslant 20 \mathrm{~K}$. A summary of results is presented which indicates that (1) the decrease in conductivity is large (up to 80\%) for the copper specimens and somewhat smaller (up to $50 \%$ ) for aluminum alloy, (2) the $\mathrm{Fe}-\mathrm{Ni}$ alloys are only slightly affected (up to $8 \%$ ), (3) the effect on stainless steel S31000 (AISI 310) is approximately twice that of $\$ 30400$ (AISI 304), and (4) the Ti-6Al-4V alloy shows a reasonably small percentage effect, but 
the largest difference with temperature of all of the materials tested. The relative importance of the magnetothermal effect compared to that of thermal history and material variability is discussed.

18620. Flynn, J. H., Dickens, B., Application of new kinetic techniques to the lifetime prediction of palymers from weight lows dutu, (Proc. Symp. 176 th National Meeting of the American Chemical Society, Miami, FL, Sept.11-14, 1978), ACS Symp. Seriess 95, Durahility of Macromoleswlar Materials, R. K. Eby, Ed., Paper 7, 97-115 (American Chemical Society, Washington, DC, 1979).

Key words: aging of polymers; degradation of polymers; error propagation; factor-jump method; heating rate; lifetime prediction; polystyrene; polyurethane; thermogravimetry; weight-loss kinetics.

As more and more polymeric materials are used both in the replacement of other materials and by the creation of new applications, the study of their expected lifetimes assumes greater and greater importance. It is more economical to plan for replacement of defective parts than to suffer an unexpected failure which may occur under inhospitable, inconvenient or even dangerous conditions. Philosophies of how to assess lifetimes fall into several schools. These include: evaluation of experience with the materials under actual service conditions, acceleration of the aging process by increasing one or more degradation factors above their normal levels and assessing the degradation rate by monitoring the first appearances of degradation under service-like conditions.

We have chosen to examine the applicability to lifetime prediction of four methods of thermogravimetry. Although one can argue that many useful properties of polymers may disappear before weight loss occurs, it is worthwhile to examine the role of thermogravimetry in lifetime prediction because the technique can be applied to any condensed phase sample, soluble or not, in almost any geometric form. Further, thermogravimetry is simple, convenient, and, in some modes of application, fairly fast. The hardware is rugged, reliable and stable. Finally, the process which results in the volatilization of small fragments if often closely related to the process which results in the loss of desired properties.

18621. Tobler, R. L., McHenry, H. I., Reed, R. P., Fracture mechanics parameters for an iron- $13 \%$ chromium-19\% manganese stainless steel and its welds at cryogenic temperatures, (Proc. 2d Int. Cryogenic Materials Conf., Boulder, CO, Aug. 3-5, 1977), Paper K-7 in Advances in Cryogenic Engineering, K. D. Timmerhaus, R. P. Reed, and A. F. Clark, Eds., 24, 560-572 (Plenum Press, New York, NY, 1978 ).

Key words: crack propagation; fatigue; fracture resistance; low temperature tests; mechanical porperties; stainless steel.

As part of the USA/USSR Science \& Technology exchange program on the properties of $L N G$ containment materials, fatigue crack growth rates and fracture toughness tests at selected temperatures between $295 \mathrm{~K}$ and $4 \mathrm{~K}$ were conducted on an $\mathrm{Fe}-13 \% \mathrm{Cr}-19 \% \mathrm{Mn}-0.2 \% \mathrm{~N}$ austenitic stainless steel from the USSR. Compact specimens (18.4 mm thick) and threepoint bend specimens ( $12.5 \mathrm{~mm}$ thick) were used in testing the normalized base metal and submerged arc welds. The fatigue crack growth resistance decreases as temperature is decreased from 295 to $4 \mathrm{~K}$. Fracture toughhness also decreases, with $J_{\text {Ic }}$ values ranging from 255 to $50 \mathrm{kJm}^{-2}$ between $295 \mathrm{~K}$ and $4 \mathrm{~K}$. The effects of welding are discussed, and specimen orientation is shown to be one of the most significant factors governing the fatigue crack growth resistance of the butt welds. For TS orientation, crack growth rates are higher in the HAZ and for TL orientations crack growth rates are lower in the HAZ, compared to the base metal.

18622. Ekin, J. W., Fatigue and stress effects in NbTi and $\mathrm{Nb}_{;} \mathrm{Sn}$ multifilamentary superconductors, (Proc. $2 \mathrm{~d}$ Int. Cryogenic Materials Conf., Boulder, CO, Aug. 3-5, 1977), Paper F-I in Advances in Cryogenic Enginecring. K. D. Timmerhuus, R. P. Reed, and A. F. Clark, Eds., 24, 306-316 (Plenum Press, New York, NY, 1978).

Key words: critical current; critical current degradation; multifilamentary $\mathrm{Nb}_{s} \mathrm{Sn}$; multifilamentary $\mathrm{NbTi}$; superconductiors.

In situ $4 \mathrm{~K}$ measurements of the effects of fatigue and static stress are reported on multifilamentary $\mathrm{NbTi}$ and $\mathrm{Nb}_{\mathbf{s}} \mathrm{Sn}$ wire conductors. A hydraulic-feedback loading system permitted measurement of $J_{c}(H, \epsilon, N)$ while the specimen was under cyclic tensile stress. As many as $2.5 \times 10^{\text {s }}$ load cycles have heen obtained at frequencies ranging from 1 to $15 \mathrm{H} \%$.

The results show that in NbTi:Cu composites fatigue degradation of the matrix is the primary effect. The residual resistance ratio of the copper starts to rapidly degrade at peakto-peak cyclic strain amplitudes greater than $0.4 \%$. In $\mathrm{Nb}_{3} \mathrm{Sn}$ composites, on the other hand, static stress degradation of the critical current is the primary effect. It is shown that the widely varying results previously reported for this effect may be accounted for by different amounts of residual compressive prestress in the individual specimens from the thermal contraction of the bronze matrix. When normalized, the results show the critical current starts degrading when the $\mathrm{Nb}_{3} \mathrm{Sn}$ reaction layer experiences about $0.2 \%$ to $0.3 \%$ tensile strain. Thus, zero stress in an energized magnet could be accomplished by halancing the tensile hoop stress of the Lorentz force against the compressive prestress of the bronze matrix.

18623. Myers, D. R., Roitman, P., Mayo, S., Electrical characterization of low-dose ion-implanted silicon annealed with microsecond laser pulses, (A1P Conf. Proc. No. 50, Materials Research Society, Boston, MA, Nov. 27-Dec. 1, 1978, Series Editor: H. C. Wolfe), Paper in Laser-Solid Interactions and Laser Processing-1978, S. D. Ferris, H. J. Leamy, J. M. Poate, Eds., pp. 563-568 (American Institute of Physics, New York, NY, 1979).

Key words: energy densities; ion-implanted silicon; laser pulses; power densities; thermal anneals.

Silicon wafers implanted with low doses $\left(\sim 10^{12} \mathrm{~cm}^{-2}\right)$ of either boron or phosphorous ions were annealed with a dye laser and the results compared to those obtained from identically implanted, thermally annealed wafers. The laser was tuned to a wavelength of $600 \mathrm{~nm}$ and had a pulse duration of I $\mu$ s with a roughly triangular waveform peaked at approximately 230 ns. Energy densities of the laser pulse were varied from 0.7 $\mathrm{J} / \mathrm{cm}^{2}$ to $2.8 \mathrm{~J} / \mathrm{cm}^{2}$ in five stages. The thermal anneals were performed at $700{ }^{\circ} \mathrm{C}$ or $800{ }^{\circ} \mathrm{C}$ for $30 \mathrm{~min}$ in dry nitrogen. Examination of electrical activation of the annealed areas using capacitance-voltage (C-V) profiling on Schottky barrier structures indicated significant boron activation for the laser-annealed areas, with peak dopant concentrations 25 to $100 \%$ of those obtained from thermal annealing alone. Subjecting thermally annealed, boron-implanted wafers to laser pulses resulted in profiles identical to those of the boron-implanted wafers that had been only laser annealed. In the phosphorous-implanted wafers, areas in which laser irradiation was sufficient to cause electrical activation exhibited dopant segregation at the surface similar to zone refining. At the highest power densities examined, surface morphology characteristic of laser melting and regrowth could be detected by Nomarski interference microscopy. Examination of the phosphorous-implanted wafers 
using the scanning electron microscope indicated the presence of electrically active defect structures in both the unannealed and thermally annealed areas, hut no defect structures could he detected in the areas that had clearly melted. These results imply that temperatures near or above the melting point of silicon must be obtained during laser annealing to activate boron or phosphorous implanted into silicon at low doses and suggest that the melting Juring laser annealing appears to have removed distinct electrically active defect structures from the implanted regions.

18624. Kahler, R. L., An electronic ratio error set for current transformer calibrations, IEEE Trans. "'l Instrum. Meas, Sheor Papers IM-28, No. 2, $162-164$ (June 1979).

Key words: current comparators; current ratios; current transformers; current transformer testing; electronic ratio error set; transformer calibrations.

A direct-reading electronic ratio error set for current transformer calibrations is described. It is capable of generating direct and quadrature error currents from 1 ppm to 5 percent of transformer secondary currents up to $10 \mathrm{~A}$. The uncertainty is less than 1 percent of the generated current. The set features electronic display of the direct and quadrature components with three digits each and is direct reading at 50, 60, and 400 $\mathrm{Hz}$.

18625. Bukowski, R. W., Custer, R. L. P., Bright, R. G., Fire alarm communications, Chapter 19 in Handbook of Building Security Planning and Design, P. S. Hopf, Ed., pp. 19-1-1927 (McGraw-Hill Book Co., New York, NY, 1979).

Key words: control units; fire alarm systems; fire detectors; high-rise communication systems; multiplex systems; NFPA standards; residential fire detector; sprinkler supervisory devices.

The operation and use of all current types of fire alarm and communication systems is discussed. This includes the differences between and operating features of local, auxiliary, remote station, proprietary, and central station systems, highrise communication systems and residential fire detection devices. A discussion of commonly used fire detectors is given including operation, installation and application considerations. Indicating devices, sprinkler supervisory devices, maintenance, reliability and code/standard compliance is also covered.

18626. Chabay, I., Rosasco, G. J., Kashiwagi, T., Speciesspecific Raman spectroscopic measurements of concentration fluctuations in unsteady flow, J. Chem. Phys. 70, No. 9, 41494154 (May 1, 1979).

Key words: concentration fluctuations; fast Fourier transforms; Fourier transform analysis; mixing in turbulent flow; noise spectrum; Raman spectroscopy; turbulence.

Concentration fluctuations of specific chemical species in unsteady mixed gas flow were studied ty fast Fourier transform (FFT) analysis of Raman intensity. Average concentration and the amplitude and frequency distribution of fluctuations about that average (at a specific Raman shift) can be determined by the FFT/Raman technique. The fluctuation spectra can be modeled to yield information on the lifetimes, periodicity, amplitudes, and the statistical distribution of these in unsteady or turbulent motion. A simple burner with a concentric outer air sheath and inner $\mathrm{CH}_{4}$ jet was used in the preliminary experiments for both cold gas and flame studies. Interference from flame emission (uncorrelated to Raman scattering) was minimized by chopping the Raman exciting beam and observing the FFT signal near the chopper frequency. Peak height at the chopper frequency indicates average concentration, while the sidebands around this frequency contain information on the fluctuations in concentration of the species under observation. With the present system, fluctuations in the frequency range of ()- $\mathrm{l} \mathrm{kH} /$ having an amplitude of $5 \%$ of the average concentration of certain species whose average partial pressure is as little as $1 \%$ of atmospheric pressure could be measured. The fluctuations are observed from sampling volumes as small as $\sim 10^{-4}$ $\mathrm{mm}^{*}$ at any position in the flow. Improvements in the technique and extensions to other systems are discussed.

18627. Haynes, W. M., Measurements of the orthoharic liquid densities of argon (100-120 K) and ethylene (105-200 K), Cryesgentics 18, No, 10, 621-623 (Oct. 1978).

Key words: argon; comparisons; correlation; ethylene; experimental; magnetic suspension; orthobaric liquid density; tables.

Orthobaric liquid densities of argon $(100)$ to $120 \mathrm{~K})$ and ethylene ( 105 to $200 \mathrm{~K}$ ) have been measured using a magnetic suspension densimeter. A correlation of the present results has been used to make comparisons with experimental data from other investigations.

18628. Dougherty, H. T., Estin, A. J., Morgan, W. L., Woodruff, J. J., The orbiting standards platform, Proc: 1978 Antenna Applications Symp., Univ. of $I L$, Urhana-Champaign, IL, Sept. 20-22, 1978, pp. 1 -9 (Sept. 1978).

Key words: antenna gain; antenna pattern; antenna polarization; large aperture antenna metrology; satellite communications metrology.

Startling growth in satellite communication has placed new burdens on measurement of performance of these systems. The Orbiting Standards Platform is a combination satellite signal source and field strength meter which will enable one to make highly accurate truly far field measurements of large aperture antenna gain, pattern, sidelobes, and polarization as well as system G/T and EIRP. These measurements may be used to initially characterize earth station equipment and for the subsequent monitoring of its performance. This is a report on a study just completed on the feasibility of the OSP.

18629. Nyyssonen, D., Jerke, J. M., Optical linewidth measurement-A basic understanding, Proc. Microelectronics Measurement Technology Seminar, San Jose, CA, Feb. 6-7, 1979, pp. $251-266$ (1979).

Key words: linewidth measurement; microlithography; micrometrology; optical microscopy.

Optical systems used for micromeasurement of linewidths on integrated circuit photomasks and wafers have shown measurement differences as large as $1.0 \mu \mathrm{m}$. Modeling of the diversity of measurement methods used for edge detection has shown that these measurement differences may be attributed to both differences in the optical images formed by different microscope systems and differences in edge detection criteria. New techniques developed at NBS for accurate edge detection and calibration of optical linewidth measurement systems are discussed.

19630. Ledbetter, H. M., Elastic constants at low temperatures: Recent measurements on technological materials at NBS, (Proc. 2d Int. Cryogenic Materials Conf., Boulder, CO, Aug. 3-5, 1977), Paper A-9 in Advances in Cryogenic Engineering, K. D. Timmerhaus, R. P. Reed, and A. F. Clark, Eds., 24, 103-119 (Plenum Press, New York, NY, 1978).

Key words: aluminum alloys; copper alloys; elastic constants; iron alloys; nickel alloys; stainless steels; Young's modulus. 
Low-temperature $(4-300 \mathrm{~K}$ ) elastic constants determined experimentally at NBS during the last four years are reviewed. Forty-seven technological materiats were studied, including: aluminum alloys, cupro-nickels, titanium-niohium superconducting alloys, copper-base precipitation-hardening alloys, invar, inconels, maraging steel, nickel steels, stainless steels, nitronics, and the composites-fiberglass/epoxy, NbTi/Cu epoxy, $\mathrm{NbTi} / \mathrm{Cu}$, and $\mathrm{B} / \mathrm{Al}$. Elastic constants discussed primarily are: Young's modulus, the shear modulus, the bulk modulus, and Poisson's ratio.

18631. Kasen, M. B., Composite materials for cryagenic structures, (Proc. 2d Int. Cryogenic Materials Conf., Boulder, CO, Aug. 3-5, 1977), Paper A-5 in Advarces in Ciryogenic Engineering, K. D. Timmerhaus, R. P. Reed, and A. F. Clark, Eds., 24, 63-73 (Plenum Press, New York, NY, 1978).

Key words: advanced-fiber composites; cryogenics; industrial laminates; low-pressure laminates; metal-matrix composites; polymer matrices.

Composite laminates and aggregates are already playing a significant role as structural materials in cryogenic technology. A much wider usage is anticipated as additional data and experience are obtained. Concretes, and to a certain extent industrial high-pressure laminates, will see increased usage in massive installations due to favorable cost factors. Some industrial laminates and low-pressure glass-reinforced laminates will serve for intermediate-sized structures where their non-magnetic character and insulation qualities offer advantages over metallic structures. The high-modulus, low-pressure composites will see increasing usage as their cost decreases and as their cryogenic performance becomes better understood. The ability of such composites to match or exceed the strength and modulus of stainless steel suggests that their usage will substantially increase as alloying elements become scarce and more expensive. For the present, high-modulus composites will be selectively used for critical components where a nonmetallic, strong, stiff, low-thermal conductivity material is required to adequately perform specific critical tasks.

18632. Penn, D. R., Effect of bound hole pairs on the $d$-band photoemission spectrum of Ni, Phys. Rev. Lett. 42, No. 14, 921-925 (Apr. 2, 1979).

Key words: $d$-band of $\mathrm{Ni}$; excitons; photoemission; satellite and band narrowing

It is shown that the spectral density of the $\mathrm{Ni} d$ electrons contains a peak due to excitations of bound hole pairs. The spectral density is observed directly in photoemission experiments which show a satellite peak below the bottom of the $d$ bands. The observed peak exhibits a strong resonance as a function of photon energy and this behavior is also explained by the present theory.

18633. Sawyer, D. E., Kessler, H. K., Schafft, H. A., Solar cell measurement technique development and other services, Proc. Phorovoltaics Advanced Materials Review Meeting, Vail, CO, Oct. 24-26, 1978, pp. 41-50 (Jan. 1979).

Key words: device measurements; laser scanning; metallization; ohmic contacts; reliability; semiconductor measurements; solar cells; solar cell stability; workshops.

This is a summary of work performed in the period Sept. 15, 1977-Sept. 30, 1978. The objectives of the program are to assist the DOE thin-film photovoltaic effort by developing solar cell device and material measurement techniques using the NBS-developed laser flying-spot scanner, and by assisting DOE in organizing and hosting appropriate workshops and symposia and providing general consultation and liaison services.
A new technique is set forth which employs forward-hiasing solar cells during scanning to spatially map cell operating and locate certain cell defects such as cracks, and poor emitter ohmic contacts. This technique has been applied with success (1) a variety of solar cell types including tat-plate Si, GaAs concentrator, GaAs MIS, Cds/Cu.2 , and polycrystalline Si. Equipment has been constructed and ancillary techniques have been developed for effective cell scanning and quantification of scanning results. Cells with diameters up to $10 \mathrm{~cm}$ may now be scanned without any change in scanner adjustment. A novel, low-noise high-intensity light source for biasing cells optically has been completed

Other project activities, which include planning, organizing. and conducting workshops are outlined in the text.

18634. Schafft, H. A., Perfurmance criteria for photovoltaic power conditioning, control, and storage, Pros: U.S. DOE

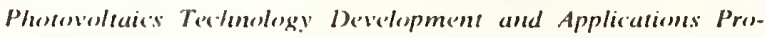
grain Review Conf., Arlingem, VA, Nov. 7-9, 1978, pp. 2$39-2-51$ ( 1978$)$.

Key words: performance criteria; photovoltaics; power conditioning; power control; solar energy; storage.

As part of an effort managed by the Solar Energy Research Institute for the development of preliminary performance criteria and test standards for photovoltaic systems, two subcommittees-one on Power Conditioning, Control, and Cabling. and one on Storage-met on June 22-23, 1978 in Vail, CO, to make initial identifications of performance criteria. This paper reports on the highlights of and directions taken by these two subcommittees.

18635. Schreiber, B., Pella, P. A., Application of anionexchange resin-loaded filters to the $\mathrm{x}$-ray fluorescence determination of sulfate, Anal. Chem. 51, No. 6, 783-784 (May 1979).

Key words: anion exchange; filter paper; fuel oil; spectrometry; sulfate; $x$ ray.

A method for the determination of sulfate by enrichment with SB-2 strongly basic anion exchange paper followed by $x-$ ray fluorescence spectrometry is presented. Enrichment is performed by passing the sample solution through the filters several times. After washing, filters are equilibrated in a barium solution resulting in the stoichiometric uptake of $\mathrm{Ba}$ by the sulfate, and the $\mathrm{Ba} \mathrm{L}_{k} \mathrm{x}$-ray line is measured. Optimum parameters are established for quantitative enrichment and measurement of amounts of $10-1000 \mu \mathrm{g} \mathrm{S}$.

18636. Stalick, J. K., Siedle, A. R., Mighell, A. D., Hubbard, C. R., A novel bimetallic sulfur cluster. Crystal and molecular structure of a dimer of bis[methyldiphenylphosphinesil ver]tetrathiotungsten, $\left[\left(\mathrm{C}_{6} \mathrm{H}_{5}\right)_{2} \mathrm{PCH}_{3}\right]_{4} \mathrm{Ag}_{4} \mathbf{W}_{2} \mathrm{~S}_{8}, J$. Am. Chem. Soc. 101, No. 11, 2903-2907 (May 23, 1979).

Key words: crystal structure; mechanism of formation; molecular compound; silver-sulfur-tungsten cluster; synthesis; x-ray diffraction.

The title compound, 1 , is formed from $\left[\left(\mathrm{C}_{6} \mathrm{H}_{5}\right)_{2} \mathrm{PCH}_{3}\right]_{4}$ $\mathrm{Ag}_{2} \mathrm{WS}_{4}$ (II) with loss of phosphine in polar solvents. The crystal and molecular structure of $\mathbf{I}$ has been determined from three-dimensional x-ray data collected by counter methods. The molecular compound I crystallizes in the monoclinic space group $P 2_{1} / n$ with $Z=2$ and cell dimensions $a=11.901$ (4) $\AA$, $b=12.233$ (5) $\AA, c=20.375(10) \AA, \beta=92.25(3)^{\circ}$. The observed and calculated densities are 2.04 and $2.08 \mathrm{~g} / \mathrm{cm}^{3}$, respectively. The structure has been refined to a final $R$ factor on $F$ of 0.049 for 2096 observed reflections. The structure of 1 consists of a 12-atom cluster containing four silver atoms, two tungsten atoms, and six sulfur atoms; the cluster possesses a 
crystallographic center of symmetry. Based on "iP NMR data for 11 and the structures of the closely related $\left[\left(\mathrm{C}_{6} \mathrm{H}_{5}\right)_{2} \mathrm{PCH}_{\mathrm{i}}\right]_{2}$ $\mathrm{Au}_{2} \mathrm{MS}_{4}$ compounds $(\mathrm{M}=\mathrm{Mo}, \mathrm{W})$, a mechanism for the formation of 1 from 11 is proposed.

18637. Swartyendruber, L. J., Carter, G. C., Kahan, D. J., Read, M. E., Manning, J. R., Numerical physical property data for metal hydrides utilized for hydrogen storage, (Proc. 2d World Hydrogen Energy Conf., Zurich, Swit\%erland, Aug. 21-24, 1978), Paper in Iydroge'n Encrgy System, T. N. Veziroglu and W. Seifritz., Eds., 4, 1973-2111) (Pergamon Press, Oxford, England, 1978).

Key words: compilation; energy storage; intermetallic compound; phase diagrams; physical properties.

Physical property data are presented for three intermetallic compounds which are considered primary candidate materials for safe hydrogen storage in stationary and mobile applications. The materials are $\mathrm{FeTi}, \mathrm{LaNi}_{5}$, and $\mathrm{Mg}_{2} \mathrm{Ni}$. The properties cover equilibrium dissociation pressures, van't Hoff equation parameters, heats of reaction, reaction rates, diffusion, thermal conductivities, heat transfer coefficients, hydride densities, lattice parameters and expansion upon hydriding, and phase diagrams.

18638. Brauer, G. M., Kumpula, J. W., Termini, D. J., Davidson, K. M., Durability of the bond between bone and various 2-cyanoacrylates in an aqueous environment, J. Biomed. Mater. Res. 13, 593-606 (1979).

Key words: adhesion; bioadhesive bond strength; bone; cyanoacrylate; hydrolytic stability.

The durability of the bond strength developed between 2cyanoacrylate esters and bone has been determined by aging specimens in water. One-day bond strength of the isobutyl and isomeric amyl 2-cyanoacrylates varied from 6.2 to $7.2 \mathrm{MPa}$. The strength of the bond decreased on storage or on thermocycling in water. Hydrolytic stability increased with increasing length of the alkyl ester group. After a six-month storage in water the various amyl 2-cyanoacrylates retained from $70 \%$ to $73 \%$ of their one-day bond strength. Pretreatment of the bone surface prior to application of the adhesive did not prove beneficial. The cured 2-cyanoacrylate can be removed from the substrate surface by appropriate solvents. Thus, it is not bonded covalently to bone. The bond strength, especially of the isobutyl and amyl 2-cyanoacrylates to bone in an aqueous environment, appears to be superior to other adhesives. Provided these monomers are biocompatible, they may be useful clinically where an intermediate-term adhesion is desired.

18639. Barnes, J. D., Martin, G. M., McCrackin, F. L., Performance of plastic packaging for hazardous materials transportation, DOT Report No. DOT/MTB/OHMO-77/5, 48 pages (Available from the National Technical Information Service, Springfield, VA 22161, June 1979).

Key words: effective carbon atom number; hazardous materials; packaging; plastics; standardization; transportation.

This report describes experiments which confirm the essential features of the "permachor" method for estimating the permeability of polyethylene to various liquids. The variables controlled in these experiments were temperature, resin, and alkane chain length. A statistical analysis based on the Linear Model revealed that the data could be described by a function of the form:

$$
G(T, \sigma, n)=\exp [X(T, \sigma)+B(T, \sigma) \times H(n)],
$$

where $\mathrm{G}(\mathrm{T}, \sigma, \mathrm{n})$ is the transmission rate of lading $\mathbf{n}$ through resin $\sigma$ at temperature $T$ and $B, X$, and $H$ are empirically determined functions. The broader implications of this result with respect to possihle standard artifacts for use in permeability testing are described. A concept we have called the "effective carhon atom numher" is introduced as a means of correlating data. Once the effective carbon atom number of a liquid is known from measurements on one kind of polyethylene, it should he possihle to predict what its permeability performance will he in containers made from different polyethylenes. Procedures are presented for implementing a standard-hased system for measuring effective carhon atom numhers of various liquids and using this information to make permeahility performance predictions. The major advantage of such a system is that it minimizes the number of tests which must be made using full-scale containers.

18640. Andrews, J. R., Measurements on pulses and pulse transmission media, circuits and components. Time-domain measurements, Paper in Review of Radio Science 1975-1977, p. 9 (Aeronomy Lahoratory, Department of Electrical Engineering, University of Illinois, Urbana, IL, 1978).

Key words: automation; laser; ascilloscope; picosecond; pulse; pulse measurement; time domain measurement.

This is a short review, including references, of the advances in the state of the art in time domain measurements. Both electrical and optical measurements are discussed.

18641. Atkinson, G. H., Parmenter, C. S., Tang, K. Y., Modeto-mode vibrational energy flow in $S_{1}$ benzene. $V$ - $V$ resonant energy transfer, microscopic reversibility, and the role of level degeneracies, J. Chem. Phys. 71, No. 1, 68-72 (July 1, 1979).

Key words: benzene; energy transfer; vibrational energy transfer.

The pattern of mode-to-mode vibrational energy flow from the level $\nu_{B}{ }^{\prime}=522 \mathrm{~cm}^{-1}$ in the $S_{1}$ state of benzene has been studied with OCS as a collision partner. OCS has a near resonant bending vibration $\nu_{2}^{\prime \prime}=520 \mathrm{~cm}^{-1}$. V-V transfer to this bend of OCS is efficient, requiring only ten collisions. However, a $T, R$ $\rightarrow V$ transfer from OCS adding $\nu_{16}{ }^{\prime}=237 \mathrm{~cm}^{-1}$ to the $\nu_{6}^{\prime}$ benzene fundamental is even more efficient. Since other $V-T, R$ transfers are also fast, the $V-V$ resonance does not dominate vibrational energy flow pattern from the initially excited benzene level. As with other added gases energy flow is governed by strong propensity rules which can be expressed simply in terms of final level degeneracies, vibration quantum changes, and energy exchange between $V$ and $T, R$ degrees of freedom. Measurements of $V-T, R$ transfer rates from other $S_{1}$ benzene levels with added $\mathrm{CO}$ have been used to demonstrate microscopic reversibility and to show the control of transfer rates by the degeneracies of the final level. OCS also quenches the $S_{1}$ electronic state of benzene with a rate constant $k=(1.1$ $\pm 0.1) \times 10^{\mathrm{A}}$ Torr $^{-1} \mathrm{~s}^{-1}$ for destruction of the $S_{1}$ state with a 300 $\mathrm{K}$ Boltzmann distribution of vibronic levels.

18642. Barger, R. L., Bergquist, J. C., English, T. C., Glaze, D J., Resolution of photon-recoil structure of the $6573 . \AA$ calcium line in an atomic beam with optical Ramsey fringes, Appl. - Phys. Lett. 34, No. 12,850-852 (June 15, 1979).

Key words: calcium; optical Ramsey fringes: photon-recoil structure; saturated absorption.

The photon-recoil of the Ca $6573-\AA$ line have been resolved using the three-zone optical Ramsey interference technique with an atomic beam. Linewidths as narrow as $3 \mathrm{kHz}$ HWHM (line $Q$ of $8 \times 10^{10}$ ) are reported for zone separations up to 7 
$\mathrm{cm}$. An indication of the light-shift-induced contraction of the recoil splitting predicted by $\mathbf{C}$. J. Bordé is obtained. Techniques are discussed which should lead to an optical wavelength/frequency standard with an accuracy of better than $10^{-14}$

18643. Blaha, J. J., Etz, E. S., Cunningham, W. C., Molecular analysis of microscopic samples with a Raman microprobe: Applications to particle characterization, (Proc. Ann. Intl. Scanning Electron Microscopy Conf, Washington, DC, Apr. 16-20, 1979), Scanning Electron Microsc. 11, 93-102 (Scanning Electron Microscopy, Inc., O’Hare, IL. 1979).

Key words: atomospheric aerosols; materials sampling; mineralogy; molecular analysis; particle analysis; power plant emissions; Raman microprobe; Raman spectroscopy; urban dusts; vibrational analysis.

A laser-Raman microprobe, developed at the National Bureau of Standards, is used to analyze individual microscopic particles in several investigations. Results are discussed for the detection and identification of the major compounds present in urban airborne dusts and in atmospheric aerosol particles collected at the South Pole. In related studies the.microprobe has been applied to the molecular characterization of fly ash particles from power plants with emphasis on the analysis of stack particulates from an oil-fired power plant. A discussion of the identification of calcium-bearing microcrystals as part of a feed utilization study for cattle is presented. In micromineralogical studies performed with the Raman microprobe, a number of common sheet and chain silicates have been investigated to determine possible spectral differences between their fibrous and nonfibrous morphologies. No unique differences could be found between spectra of the different morphologies of the same mineral; however, each mineral had a unique and characteristic spectrum.

The usefulness of the Raman spectroscopic technique as a complement to the methods of electron and ion beam microanalysis is indicated. The discussion of results indicates the unique information that can be obtained through the use of the Raman microprobe.

18644. Bowen, R. L., Compatibility of various materials with oral tissues. I: The components in composite restorations, (Proc. Composites in Dentistry Symp. Celebrating the 50th Anniv. of Cooperation Between the ADA and NBS in Dental Research 1928-1978, held in conjunction with the 56th General Session of the Int. Assoc. for Dental Research, Washington, DC, Mar. 15, 1978, W. E. Brown, R. L. Bowen, G. C. Paffenbarger, and D. F. Taylor, Eds.), J. Dent. Res. 58, No. 5, 1493-1503 (May 1979).

Key words: benzoyl peroxide; composite resins; dental materials; glass compositions; methacrylate monomers; polymerization accelerators; reinforcing fillers; silane coupling agents.

The components used in formulating state-of-the-art composite restorative materials are discussed in qualitative terms. Brand names of contemporary composites are not given, and care has been taken to avoid the revealing of trade secrets or the favoring of one over another.

There are at least eight categories of ingredients used in contemporary composites: a dimethacrylate monomer, a comonomer to adjust viscosity, a stabilizer to prevent premature polymerization, a stabilizer to diminish subsequent discoloration, a polymerization initiator, a polymerization accelerator, an inorganic reinforcing filler, and the resin. For some composite formulations, a photoinitiator is used in place of the polymerization accelerator and, perhaps, the polymerization initiator. For most of these categories, there are alternative compounds that can be used; proprietary composites contain various combinations. Certain widely-used compounds have been selected here to exemplify members of each category.

The responses of dental pulps in the teeth of monkeys to eight typical compounds is currently being studied and will be reported in Part 11.

18645. Carter, G. C., Bennett, L. H., Kahan, D. J., Cuthill, J. R., Chafe, H. D., Gray, A. G., Langer, E. L., Baker, H., The American Society for Metals and National Bureau of Standards Alloy Data Center's joint program for compilation of alloy phase diagrams, Proc. Sixth Intl. Codata Conf., Sicily, Italy, May 22-25, 1978, B. Dreyfus, Ed., pp. 235-237 (Pergamon Press, New York, NY, 1979).

Key words: alloy data center; alloy phase diagrams; American Society for Metals; data compilation; phase diagrams.

The American Society for Metals (ASM) and the National Bureau of Standards (NBS) are cooperating in a major new project to help create a worldwide data program for alloy phase diagrams. The proposed data program will be designed to offer bibliographic and evaluated numerical data on phase diagrams, and on phase characterization for binary and multicomponent alloy systems.

The plan to create the new data program has been made in response to numerous requests for more readily accessible, complete and up-to-date information on phase diagrams.

The combined ASM/NBS data project is intended to coordinate, internationally, critical phase diagram compilation efforts in order to minimize unnecessary duplication of effort. The resulting "Data Program for Alloy Phase Diagrams" is designed to update the available bibliographic information and evaluated data on phase diagrams and to keep them updated, so that users will have quick access to the most currently available information on specific alloy systems.

The availability of reliable alloy phase diagrams has been of some concern to the NBS Alloy Data Center, and a preliminary effort, concerned with international coordination of on-going evaluation projects, and centralization of bibliographic data, has already been initiated, as renorted at the previous CODATA conference. This report describes the formation of a joint program launched between the American Society for Metals and the National Bureau of Standards to produce such a centralized bibliographic alloy phase diagram file, and to produce a series of reliable critical compendia of phase diagram data: comprehensive coverage is sought for all binary diagrams, to provide an overdue update of the Hansen-ElliottShunk series; extensive coverage is sought for multicomponent alloy phase diagrams with first emphasis on subsets treating most urgent needs.

18646. Cava, R. J., Roth, R. S., Characterization of modulated structures in $\mathrm{ABO}_{4+x}$ phases, (AIP Conf. Proc. No. 53, Symp. on Modulated Structures, Kailua Kona, HI, Mar. 26-30, 1979, Series Editor: H. C. Wolfe), Paper in Modulated Structures-1979, J. M. Cowley, J. B. Cohen, M. B. Salamon, B. J. Wuensch, Eds., Sec. 7, pp. 361-363 (American Institute of Physics, New York, NY, 1979).

Key words: incommensurate lattice; lanthanum niobate; modulàted structure; nonstoichiometry; two-dimensional modulated structure.

The fergusonite structure type has been shown to alter to a phase with a modulated structure with addition of excess oxygen. The reciprocal lattice must be characterized by 5 indices. The characteristics of the modulation vary dramatically with oxygen excess.

18647. Danielson, B. L., Day, G. W., Franzen, D. L., Propagation measurements in multimode optical waveguides, Proc. 
First Fiber Optics and Communications Expositoon, Chicago, IL, Sept. 6-8, 1978, pp. 205-207 (Information Gatekeepers, Inc., Brookline, MA, 1978)

Key words: attenuation measurements; fiber optics; freyuency response measurements; measurements; review.

This talk provides an overview of the difficulties associated with adequate propagation measurements. Work at NBS and other laboratories is reviewed.

18648. Day, G. W., Measurement problems in multimode optical waveguides, Proc. $1978 \mathrm{Intl}$. Conf. on Communications, Toronto, Canada, Junc 4-7, 1978,1 , 6.6.l (Institute of Electrical and Electronics Engineers, New York, NY, 1978).

Key words: communication systems; fiber optics; measurement; optical communications; review.

This paper is primarily a review of problems associated with propagation measurements in multimode optical waveguides. Emphasis is placed on techniques which are of maximum use to the communication system designer.

18649. Dickson, G., Physical and chemical properties and wear, (Proc. Composites in Dentistry Symp. Celebrating the 50th Anniv. of Cooperation Between the ADA and NBS in Dental Research 1928-1978, held in conjunction with the 56th General Session of the Int. Assoc. for Dental Research, Washington, DC, Mar. 15, 1978, W. E. Brown, R. L. Bowen, G. C. Paffenbarger, and D. F. Taylor, Eds.), J. Dent. Res. 58, No. 5, 1535-1543 (May 1979).

Key words: amalgam; composites; dental materials; dimensional changes; physical properties; thermal expansion; wear; wear tests.

Composite restorative materials undergo shrinkage on hardening which may be approximately compensated for by the expansion that occurs as the material absorbs water in the oral environment. Dimensional changes continue to occur with changes in temperature and with the mechanical forces applied by opposing teeth. The thermal expansions of composite materials are much larger than those of tooth structures and thus tend to produce mechanical stresses in a restoration which is confined in a cavity or is adhering to tooth structure. Clinical observations indicate that composites wear more rapidly than do amalgams. The pattern of wear of a composite does not follow the contours of the opposing tooth surface but approaches more nearly the loss of a uniform thickness layer from the surface. It is thought that both stresses resulting from external forces applied to the restoration and stresses developed internally as a result of the large differences in the thermal expansions of the components of the material contribute to the wear of composites. Of the various types of wear test methods developed, it appears that a method involving the sliding of enamel against the composite specimen, perhaps with accompanying tensile cycling, may offer the greatest possibility of providing a rapid procedure for predicting the clinical wear resistance of composite materials.

18650. Engen, G. F., An overview of the six-port measurement technique, Proc. 1978 IEEE MTT-S Intl. Microwave Symp. Digest, Ottawa, Canada, June 27-29, I978, J. Y. Wong, Ed., pp. 174-175 (Institute of Electrical and Electronics, New York, NY, 1978).

Key words: automatic network analyzer; microwave; microwave measurement; six-port.

The advent of digital technology and the automatic network analyzer has had a major impact on the evolving microwave metrology. The six-port measurement technique provides an al- ternative method for implementing the automatic network analyzer, which yields significant advantages. This paper will review the major features of this measurement approach.

18651. Engen, G. F., Calihrating the six-port reflectometer, Iren. 1978 IEEE MTT-S Intl. Microwave Symp. Digest, O)tawa, Canada, Junc 27-29, 1978, J. Y. Wong, Ed., pp. 18218.3 (Institute of Electrical and Electronics Engineers, New York, NY, 1978).

Key words: calibration; microwave measurements; reflectometer; six-port.

Because complex heterodyne methods may he replaced by simple amplitude detectors, the six-port technique promises to have a major impact on the next generation of automatic network analyzers. This projection, however, is predicated upon the existence or development of calibration techniques which permit one to conveniently and accurately obtain the parameters which characterize the six-port.

This paper describes a numher of substantial refinements to a previously descrihed procedure which is based upon the use of sliding terminations.

18652. Engen, G. F., Calibrating the six-port reflectometer by means of sliding terminations, IEEE Trans. Microwave Therory Tech. MTT-26, No. 12, 951-957 (Dec. 1978)

Key words: automation; microwave; microwave measurements; reflectometer; six-port.

The six-port technique promises to have a major impact on the next generation of automatic network analyzers because complex heterodyne methods may be replaced hy simple amplitude detectors. This projection, however, is predicated upon the existence or development of calibration techniques which permit one to conveniently and accurately obtain the parameters which characterize the six-port. This paper describes a number of substantial refinements to a previously described procedure which is based upon the use of sliding terminations.

18653. Engen, G. F., Hoer, C. A., Speciale, R. A., The application of "thru-short-delay" to the calibration of the dual sixport, Proc. 1978 IEEE MTT-S Intl. Microwave Symp. Digest, Ottawa, Canada, June 27-29, 1978, J. Y. Wong, Ed., pp. 184. 185 (Institute of Electrical and Electronics Engineers, New York, NY, 1978).

Key words: automatic network analyzer; microwave; microwave measurement; six-port.

In a companion paper, in this digest, a scheme for reducing the (single) six-port calibration problem to that of an equivalent four-port reflectometer has been described. This now makes it possible to apply existing four-port calibration schemes. One such method is the "thru-short-delay" (TSD) procedure. This paper briefly outlines this calibration approach.

18654. Faller, J. E., Rinker, R. L., Zumberge, M. A., Plans for the development of a portable absolute gravimeter: A tool for studying non-tidal variations in gravity, (Proc. Non-Tidal Variations in Gravity and Methods of Their Study Conf., Trieste, Italy, June 20-24, 1977), Boll. Geofis. Teor. Appl. 20, No. 80, 355-361 (Dec. 1978 ).

Key words: earthquake; fundamental constant; geophysics; gravity; precision measurement.

The availability of a few parts in $10^{9}$ absolute gravimeter would impact large areas of geodynamics as well as having possible application to earthquake prediction. The use of such an instrument in combination with classical leveling or extraterrestrially determined height data would also yield information on internal mass motions. The plans for the development of 
such an instrument at JILA using the method of free fall are discussed

18655. Fickett, F. R., Investigation of a practical superconductor with a copper matrix, INCRA Project No. 255 Annual R'mort, 44 pages (International Copper Research Association, Inc., New York. NY, Jan. 19781.

Key words: alloy; copper; low temperatures; niobium; precipitate: superconductor: tin.

The production of superconducting wires by a variety of "insitu" techniques is described and referenced to an extensive bibliography. Alloy methods involving copper, niobium and tin appear to be the most promising for the production of inexpensive, high-field superconductors of commercial interest.

18656. Fickett, F. R., Investigation of a practical superconductor with a copper matrix, INCRA Project No. 255A Annual Report, 64 pages (International Copper Research Association, Inc., New York, NY, Dec. 1978).

Key words: alloy; copper; electrical property; niobium; superconductor; tin.

In-situ preparation of complete $\mathrm{Nb}_{3} \mathrm{Sn}$ superconducting composite materials may offer a new and relatively inexpensive solution to the problems associated with production of high field superconductors. We have studied several approaches to the production of wires from a single melt. The alloying techniques and the electrical and magnetic properties of the resulting wires are given. A number of the wires show promise but are not yet competitive with commercial superconductors.

18657. Fish, G. E., Rhyne, J. J., Sankar, S. G., Wallace, W. E., Effect of hydrogen on sublattice magnetization of Laves-phase rare earth iron compounds, (Proc. 24th Conf. on Magnetism \& Magnetic Materials, Cleveland, OH, Nov. 14-17, 1978), J. Appl. Phys. 50, No. 3, 2003-2005 (Mar. 1979).

Key words: hydrides; Laves phase; magnetic properties; neutron scattering; rare earth compounds.

We have used elastic neutron scattering to examine the effect of hydriding on the sublattice magnetization of the Laves-phase compounds $\mathrm{RFe}_{2}$ for $\mathrm{R}=\mathrm{Ho}$ and $\mathrm{Er}$. On addition of hydrogen or deuterium a stable phase of composition about $R F e_{2} D_{3.5}$ is formed. The pure compounds $\mathrm{RFe}_{2}$ are ferrimagnetic, with the $\mathrm{R}$ moment equal to the free ion value and $\mathrm{Fe}$ moment of $\sim$ $1.6 \mu_{H}$. The bulk Curie temperatures $T_{r}$ of the hydrides and deuterides are considerably lower than the corresponding $\mathrm{RFe}_{2}$ values (e.g., $440 \mathrm{~K}$ for $\mathrm{ErFe}_{2} \mathrm{D}_{3.5}$ versus $574 \mathrm{~K}$ for $\mathrm{ErFe}_{2}$ ). The 10) K R moment is also significantly reduced in the deuterides (4.4 and $5.2 \mu_{H}$ versus 9 and $10 \mu_{H}$ for $\mathrm{Er}$ and $H o$ in $\mathrm{RFe}_{2}$ ) and drops steadily with increased temperature, reaching zero below $\mathrm{T}_{r}$ in the case of $\mathrm{E}_{\mathrm{r}}$. The Fe moment remains nearly constant with temperature until just below $T_{r}$ where it drops rapidly to zero; in $\mathrm{ErFe}_{2} \mathrm{D}_{3.5}$ and $\mathrm{HoFe}_{2} \mathrm{D}_{3.5}$ its magnitude is 1.6 $\mu_{H}$, and $1.9 \mu_{H}$, respectively. These results indicate that the exchange interactions involving the $\mathrm{R}$ atoms are markedly weakened in the hydrides. The distortion of the local anisotropy field due to random site occupancy of $H$ and the weak exchange coupling of $R$ produces a "fanning" of the $R$ moment which reduces the spatially averaged moment measured in the neutron experiment.

18658. Caswell, R. S., Coyne, J. J., Energy deposition spectra for neutrons based on recent cross section evaluations, Proc. Sixth Symp. on Microdosimetry, Brussels, Belgium, May 22 26, 1978, J. Booz and H. G. Ebert, Eds., II, 1159-1171 (Harwood Academic Publishers, Ltd., London, England, 1978).
Key words: energy deposition spectra; microdosimetry parameters; neutron cross section evaluations; single-event energy.

Improved neutron cross section evaluations, such as ENDF/B-IV and the now-emerging ENDF/B-V, are making possible the calculation of improved microdosimetric energy deposition spectra for secondary particles resulting from neutron interactions in tissue, especially in the neutron energy range $10-20 \mathrm{M}=\mathrm{V}$. Nuclear reactions with more than wo particles in the final state are included, in addition to the ${ }^{\prime 2} \mathrm{C}(1,9,3$ a) reaction previously considered. Examples of sigle-cient energy deposition spectra are shown and compared with other calculations and experimental measurements. Microdosimetry parameters. such as $y_{11}$ and $y^{*}$ which are derived from the spectra are also presented. Some calculated spectra are presented for inhomogeneous Rossi spherical proportional counters (wall and gas of differing composition).

18659. Paretzke, H. G., Berger, M. J., Stopping power and energy degradation for electrons in water vapor, Proc: Sixth Symp. on Microdesimetry, Brussels, Belgium, May 22-26, 1978 , J. Boo\% and H. G. Ebert, Eds., II, 749-758 (Harwood Academic Publishers, Lid., London, England, 1978).

Key words: electron energy loss; energy degradation; lowenergy stopping power.

This paper is concerned with electron energy loss and degradation phenomena in water vapor at energies below a few keV where the Bethe theory is no longer applicable. There is practically no experimental information on low-energy stopping power and on degradation spectra in gases, so that these quantities must be obtained by calculation. The required cross sections for the ionization and excitation of water molecules are not well known, and various assumptions and extrapolations have to be made in order to obtain input data which include all the important processes and all energies of interest. Three such data sets for water vapor are available which are based on somewhat different assumptions and approximations. One set has been published by Olivero, Stagat and Green and the other two sets are from more recent analysis made by us. We compare in this paper various quantities derived from these data sets, in order to obtain an indication how sensitively the stopping-power and energy degradation calculations depend on the cross section input.

18660. Coyne, J. J., $\overline{\mathbf{W}}_{n}$, computed from recent nuclear data and $\mathrm{W}$ measurements, Proc. Sixth Symp. on Microdosimetry, Brussels, Belgium, May 22-26, 1978, J. Booz and H. G. Ebert, Eds., 11, 699-706 (Harwood Academic Publishers, Ltd., London, England, 1978).

Key words: initial spectra; ion pair energy; nuclear data; secondary charged particles.

Initial spectra of secondary charged particles produced by neutrons with energies varying from $60 \mathrm{keV}$ to $20 \mathrm{MeV}$ have been calculated. The most recent nuclear data evaluations have been used. ENDF/B-IV for hydrogen, nitrogen and oxygen and a preliminary version of ENDF/B-V for carbon. Many reactions with more than two particles in the final state are now included. In addition to the ${ }^{12} \mathrm{C}\left(\mathrm{n}, \mathrm{n}^{\prime}\right) 3 \alpha$ reaction, which was used in previous calculations, the reactions (n,n.p), $\left(n, n^{\prime} \alpha\right)$, $(n, 2 \alpha)$ and $(n, 2 n)$ have been calculated. Recent measurements of the average energy per ion pair, $\bar{W}$, for protons and other heavy ions have been combined with these initial spectra to derive a value for $\bar{W}_{n}$ as a function of neutron energy. Preliminary results of these calculations will be presented and comparisons with previous calculations of $\bar{W}_{n}$ will be presented. 
18661. Katriel. J., On the divergence of perturbation theory for anharmonic oscillators, Phys. Lett. 72A, No. 2, $94-96$ (June 25,1979 ).

Key words: anharmonic oscillators; singular perturbation theory

(ieneralized Bose operators are used to reduce the general anharmonic oscillator into an harmonic oscillator with a frequency which depends on the strength of the anharmonicity $(\lambda)$ and on the quantum number. The analytic properties of the energy levels as functions of $\lambda$ are very transparently exhibited.

18662. Franzen, D. L., Danielson, B. L., Day, G. W., A simple first positive system nitrogen laser for use in optical fiber measurements, IEEE J. Quantum Electron. QE-14, No. 6, 41)2404 (June 1978).

Key words: laser; optical fibers.

A near infrared laser operating on several transitions of the first positive system of $\mathrm{N}_{2}$ was developed for measurements associated with optical fibers. The laser features a simple, longitudinal, segmented design giving pulsewidths of 60 to $80 \mathrm{~ns}$ full width at half maximum (FWHM) and peak powers of over 600$)$ $W$ in the 0.86 to $0.89 \mu \mathrm{m}$ region in addition to significant output near 1.04 and $1.23 \mu \mathrm{m}$. Backscatter-reflection returns from optical fibers have been obtained using the laser.

18663. Giffard, R. P., Michelson, P. F., Soulen, R. J., Jr., Low frequency impedance and noise properties of an $\mathrm{r}$ biased resistive SQUID, (Proc. 1978 Applied Superconductivity Conf., Pittsburgh, PA, Sept. 25-28, 1978), IEEE Trans. Mag. 15, No. 1, 276-279 (Jan. 1979)

Key words: Josephson junction; noise; point contacts; SQUID.

A noise thermometer consisting of a non-hysteretic resistive SQUID has been used for unusually precise measurements of the low frequency Josephson linewidth of a heavily shunted point-contact. The results agree with theories appropriate for weak links, and support the contention that the pair fluctuation noise calculated for tunnel junctions is not present in pointcontacts.

18664. Grohmann, K., Zapf, T. L., An international comparison of inductive voltage divider calibration methods between 10 kHz and $100 \mathrm{kHz}, \mathrm{Met}$. 15, 69-75 (1979).

Key words: calibrations; inductive voltage dividers; international comparison; measurements; voltage dividers; voltage ratio.

A comparison of methods used for the calibration of inductive voltage dividers at the National Bureau of Standards and the Physikalisch-Technische Bundesanstalt is presented in the frequency range between $10 \mathrm{kHz}$ and $100 \mathrm{kHz}$. The error determinations performed on three transportable test dividers using two different calibration procedures agree well within the measurement uncertainty of $\pm 3 \cdot 10^{-7}$. making evident the lack of systematic errors in both methods.

18665. Guildner, L. A., Kostkowski, H. J., Evans, J. P., Appraisal of interpolation instruments for the International Practical Temperature Scale from 630.74 to $1064.43{ }^{\circ} \mathrm{C}$, Metrologia 15, 1-4 (1979).

Key words: instruments: International Practical Temperature Scale; interpolation; interpolation instruments; temperature scale from 630.74 to $1064.43^{\circ} \mathrm{C}$.

A better interpolating instrument has long been needed to replace the standard platinum-10\% rhodium/platinum thermocouple for the International Practical Temperature Scale. In this paper we compare the characteristics of the high temperature platinum resistance thermometer and the photoelectric spectral pyrometer with those of the standard thermocouple and conclude that the resistance thermometer is the better replacement, in terms of both accuracy and convenience.

18666. Hamilton, C. A., Harris, R. E., Sullivan, D. B., Highspeed superconducting electronics, (Proc. Government Microcircuit Applications Conf., Monterey, CA. Nov. 14-16, 1978), (;)MAC 1978 Digest of Papers V11, 29-32 (1979).

Key words: high speed logic; Josephson computer; Josephson junction; microstriplines; superconductivity.

Superconducting electronics is an emerging technology which offers significant performance advances in digital computers and high-speed instruments. These advantages include low dissipation. high speed and packing density, and dispersionlcss transmission lines.

18667. Horwit\%, A. B., Leone, S. R., Versatile, isotopically specific hydrogen halide TEA pin laser, R'v. Sci. Instrum. 50, No. 7.811-816 (July 1979).

Key words: electronic discharge; hydrogen halides; isotopes; laser; TEA laser

A practical, easily constructed design for a laboratory hydrogen/deuterium halide chemical TEA laser is presented. Typical output energies in excess of $50 \mathrm{~mJ} / \mathrm{pulse}$ broudband and $5 \mathrm{~mJ} /$ pulse on single lines are easily obtained. Isotopically specific oscillation on the $v=1 \rightarrow 0$ band of single isotopes of $\mathrm{H}^{35} \mathrm{Cl}-\mathrm{H}^{37} \mathrm{Cl}, \mathrm{D}^{35} \mathrm{Cl}-\mathrm{D}^{37} \mathrm{Cl}, \mathrm{H}^{79} \mathrm{Br}-\mathrm{H}^{43} \mathrm{Br}$, and $\mathrm{D}^{79} \mathrm{Br}-\mathrm{D}^{41} \mathrm{Br}$ is demonstrated. The ease of conversion from one laser species to the next and the flexible design provide a highly versatile device for laboratory problems in chemical and physical dynamics. Major advances in the development of laboratory $\mathrm{HCl}$ and $\mathrm{HBr}$ chemical TEA lasers are also reviewed.

18668. Hust, J. G., Graphite as a standard reference material, (Proc. 15th Intl. Thermal Conductivity Conf,, Ottawa, Ontario, Canada, Aug. 24-26, 1977), Paper in Thermal Conduclivity 15, V. V. Mirkovich, Ed., pp. 161-167 (Plenum Press, New York, NY, 1978).

Key words: characterization; density; electrical resistivity; graphite; Lorenz ratio; reference materials; thermal conductivity.

The Cryogenics Division (Boulder, $\mathrm{CO}$ ) in conjunction with the Office of Standard Reference Materials (Gaithersburg, MD) of the National Bureau of Standards has been investigating graphite as a potential, extended temperature range, Standard Reference Material (SRM). A large number of isotropic, finegrained graphite rods in various diameters have been obtained for homogeneity and stability investigations. Electrical resistivity and density measurements have been performed on numerous rods at temperatures from 4 to $300 \mathrm{~K}$. Thermal conductivity measurements have been performed on thirteen specimens at about $20{ }^{\circ} \mathrm{C}$. These measurements show that transport property variations both between and within these rods is relatively large (approximately $10 \%$ ). However, a correlation between these variables is shown to exist which will allow the calculation of thermal conductivity from simple and inexpensive electrical resistivity and density measurements to within about $\pm 2 \%$.

18669. Kikuchi, R., Cahn, J. W., Theory of interphase and antiphase boundaries in f.c.c. alloys. Actu Mot. 27. 13.37-1.353 (1979).

Key words: equilibrium antiphase domain (APB) boundaries; f.c.c. alloys: interphase (IPB) boundaries; secondorder transitions. 
Equilibrium antiphase domain (APB) and interphase (IPB) boundaries in the $\mathrm{Cu}-\mathrm{Au}$ system are examined theoretically using the cluster variation method with multiatom interactions whose magnitudes were previously obtained from a fit of the phase diagram. The IPB energy between equilibrium disordered l.c.c. and ordered $\mathrm{Cu}_{3} \mathrm{Au}$ phases is strongly temperature (and hence composition) dependent, heing much higher for the

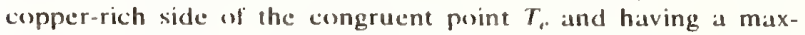
imum on that side at about $0.95 T_{7}$. The IPB energies are only slightly anisotropic. The APB energies at constant chemical potential decrease monotonically with increasing temperature; at constant non-stoichiometric composition they increase at low temperature to a maximum well below the disordering temperature. Near the congruent point, the APB undergoes one or more second-order surface phase transitions in which an interfacial layer-resembling the inhomogeneous $\mathrm{Cu}-\mathrm{Au}\left(L \mathrm{I}_{0}\right)$ phase develops within the boundary. The APB with (//k0) orientation (in our notation) should be perfectly wet by the disordered phase at the disordering temperature for that particular composition.

18670. Komarek, E. L., Advantages of the six-port reflectometer for $\mathbf{r} /$ microwave power measurement in operational systems, (Proc. Government Microcircuit Applications Conf., Monterey, CA, Nov. 14-16, 1978), 1978 GOMAC Digest of Papers VII, 39-42 (Nov. 1978).

Key words: microwave measurements; microwave power; microwave systems; power monitor; reflectometers; six-port reflectometers.

All methods have errors associated with them but because the six-port is completely calibratable, it is suggested as the most accurate uption available to the microwave system designer. The three-port power monitor, four-port reflectometer and six-port reflectometer are reviewed and an example is used to illustrate the magnitude of maximum possible errors associated with each method. Also included in this paper is a suggested configuration of the six-port reflectometer suitable for integration into an operational microwave system.

18671. Lin, H. M., Seuver, M., Tang, K. Y., Knight, A. E. W., Parmenter, C. S., The role of intermolecular potential well depths in collisiory-induced state changes, J. Chem. Phys. 70, No. 12,5442-5457 (June 15, 1979).

Key words: collisions; cross sections; intermolecular potential; state changes; well depths.

A relationship is developed from two distinct theoretical approuches to correlate the rate constants $k_{M}$ or cross sections $\sigma_{M}$ for a series of added gases $M$ which collisionally induce a state transformation $A^{*} \rightarrow B$. The correlation derived from theory is

$$
\ln \sigma_{M}=\ln C+\epsilon_{A-M} / k T,
$$

where $C$ is a constant and $\epsilon_{A_{-M}}$ is the intermolecular well depth between $A^{*}$ and $M$. We observe that experimental data can be described by a related correlation

$$
\ln \sigma_{M}=\ln C+\beta\left(\epsilon_{M \cdot M} / k\right)^{1 / 2},
$$

where $\beta$ is a constant and $\epsilon_{M M}$ is the well depth between pairs of $\mathrm{M}$ molecules. This correlation is shown to be general. It works for electronic state deactivation in atoms, intersystem crossing and internal conversion in $S_{1}$ polyatomics, rotational and also vibrational relaxation in $S_{1}$ polyatomics, predissociation in diatomics and polyatomics, and vibrational relaxation in a free radical as well as in a molecular ion. The theory is appropriate only when attractive forces dominate the interaction. and this seems consistent with the experimental data. The correlation thus provides a simple means to distinguish between attractive and repulsive interactions. The correlation also reveals that collision partners do not substantially modify the intrinsic $S_{1}-T$ mixing during collision-induced intersystem crossing.

18672. Mighell, A. D., Hubbard, C. R., Cohen, A., 2-ethoxy1,7,9-triethyl-7,9-dihydro- $1 H$-purine-6,8-dione; a tetraethyl derivative of uric acid, $A(1 /$. Crist. B35, 128()$-1282$ (1979).

Key words: biological assay: crystal structure; single crystal; uric acid derivative; uric acid determination; x-ray dilfraction

$\mathrm{C}_{13} \mathrm{H}_{201} \mathrm{~N}_{4} \mathrm{O}_{3}, \quad M_{r}=280 \cdot 33$; monoclinic, $P 2_{1} / n ; \quad a=$ $15 \cdot 491(6), b=4 \cdot 794(2), c=19 \cdot 597(5) \AA, \gamma=95 \cdot 26(3)^{\circ}, Z=$ $4, D_{c}=1 \cdot 285, D_{m}=1.28 \mathrm{Mg} \mathrm{m}^{-3}$ (flotation); final $R=0.048$ ( 852 reflections). Uric acid was ethylated and four isomers of tetraethyluric acid were isolated. One isomer, m.p. 387.2-38 $7 \cdot 7 \mathrm{~K}$, was analyzed.

18673. Mighell, A. D., Huhbard, C. R., Harris, J., Stalfa, J. A., Zervos, C., S-carboxymethyl-1.-cysteine, Acra Cryst. B35. $1258-1261(1979)$.

Key words: amino acid derivative; crystal structure; $S$-carboxymethyl-1. - cysteine; single crystal; x ray; zwitterion.

$\mathrm{C}_{5} \mathrm{H}_{9} \mathrm{NO}_{4} \mathrm{~S}$, monoclinic, $P 2_{1}, a=10 \cdot 290(4), h=7 \cdot(1) 39(1)$, ، $=5 \cdot 093(1) \AA, \beta=95 \cdot\left(19(2)^{\circ}, Z=2, \rho_{c}=1 \cdot 62, \rho_{b}=1 \cdot 60 \mathrm{Mg}\right.$ $\mathrm{m}^{-3}$ (flotation). The structure has been determined by direct methods and refined to $R=0.021$ for 720 independent reflections. The compound exists as a zwitterion. Two carboxyl groups in adjacent molecules are involved in a hydrogen bond with $\mathrm{O}-\mathrm{H} \cdots \mathrm{O}=2 \cdot 548(2) \AA$. The $\mathrm{H}$ atom in this bond was found to be covalently bonded to the carboxyl group in the carboxymethyl moiety. The $-\mathrm{NH}_{3}{ }^{+}$group is involved in three hydrogen bonds.

18674. Mountain, R. D., Model study of fluctuations and switching in amorphous semiconductors, J. Non-Cryst. Solids 33. 149-157 (1979).

Key words: fluctuation; master equation; noise spectrum; nonequilibrium; stationary states; switching; threshold switching.

The model developed by $\mathrm{Ma}$ for the initiation of threshold switching is used as the basis for a master equation description of the fluctuation spectrum of the number of carriers. The system size expansion is used to derive explicit expressions for the fluctuation spectrum in terms of the parameters of the model. It is shown that the study of the power spectra of current fluctuations about stationary states is a useful way of investigating the physical mechanisms responsible for switching.

18675. O'Connell, J. S., Schoch, B., Electromagnetic coincidence experiments, Proc. June Workshop in Intermediate Energy Electromagnetic Interactions With Nuclei, Cambridge. MA, June 13-24, 1977, 34 pages (1979).

Key words: coincidence experiments; electromagnetic; neutrons; photons; pions; protons.

Counting rate estimates are made for photon and electron induced nuclear reactions in which two products are detected in time coincidence. Measurements to be made with a $100 \%$ duty factor electron accelerator are discussed and classified as to their relative scientific interest and feasibility.

18676. Paffenbarger, G. C., Fifty years of cooperative research between the American Dental Association and the Nationa' Bureau of Standards: A historical perspective 1928-1978 (Proc. Composites in Dentistry Symp. Celebrating the 50)t Anniv. of Cooperation Between the ADA and NBS in Denta Research 1928-1978, held in conjunction with the 56t General Session of the Int. Assoc. for Dental Research 
Washington, DC, Mar. 15, 1978, W. E. Brown, R. L. Bowen, G. C. Paffenbarger, and D. F. Taylor, Eds.), J. Dent. Res. 58, No. 5, 1486-1492 (Maly 1979).

Key words: American Dental Association; dental history; dental instruments; dental materials; dental research: National Bureau of Standards.

In April 1928 there began a conperative research program on dental materials and instruments between the National Bureau of Standards and the American Dental Association that continues in 1978 . During this 50 years the research has invented new dental materials and instruments, has improved existing materials, has formulated specification and certification programs for dential materials, hals developed quality control methods for manufacturers, and has trained many teachers and researchers in the science of dental materials for many institutions. The work has had a substantial effect in professional, educational and trade circles in dentistry. Its cost to benefit ratio is 1 to many thousands of dollars. In this 25 minute review the failures, the misjudgments and the false steps have not only been neglected they have been ignored.

18677. Parmenter, C. S., Seaver, M., A method to estimate intermolecular potential well depths for species in both ground and excited electronic states, J. Chem. Phys. 70, No. 12, 5458-5462 (June 15, 1979).

Key words: excited states; ground state; intermolecular potential; molecules; well depths.

The relationship $\ln \sigma_{M}=\ln C+\left[\left(\epsilon_{A}{ }^{*}{ }^{*}\right)\left(\epsilon_{M M}\right)\right]^{1 / 2} / \mathrm{kT}$ correlates the cross sections $\sigma_{M}$ for a state change $A^{*} \rightarrow$ B induced by a series of added $M$ gases with the intermolecular potential well depths for $A^{*} \ldots A^{*}$ pairs and $M \ldots M$ pairs. This correlation is used with literature data concerning $A^{*} \rightarrow B$ to deduce $\epsilon_{A}{ }^{*}{ }_{A}{ }^{*}$ for electronically excited atoms ( $\mathrm{Na}, \mathrm{Ne}, \mathrm{Ar}, \mathrm{Xe}$ ) and electronically excited molecules $\left(\mathrm{I}_{2}, \mathrm{SO}_{2}, \mathrm{CH}_{3} \mathrm{OH}\right.$, glyoxal, propynal, benzene). The well depths are generally observed to exceed the ground state values by factors of 2-10. Large well depths are also observed for sec-butyl radicals and for the $\mathrm{C}_{5} \mathrm{H}_{9}{ }^{+}$ion with high vibrational excitation. The correlation also provides an alternate means to measure ground state well depths $\epsilon_{M . M}$. In cases where secure comparisons are available, the well depths so derived usually lie within $20 \%$ of values found from transport measurements or virial coefficients. The correlation seems a useful alternative to empirical estimating procedures when data from conventional methods are not available.

18678. Peterson, R. L., Analog-to-digital conversion with a SQUID: Conditions for a countable pulse train, J. Appl. Phys. 50, No. 6, 4231-4239 (June 1979).

Key words: A/D converter; Josephson junction; SQUID; superconducting electronics; superconductivity.

A superconducting loop containing a Josephson junction develops voltage pulses when it admits and expels magnetic flux quanta, and thus may be used as an A/D converter. We here develop and discuss several conditions which must be satisfied for the generation by the SQUID of an unambiguously countable pulse train, from which the analog signal can be faithfully reconstructed. These conditions can be satisfied over a broad range of realizable values of inductance and resistance. The capacitance, however, must be carefully controlled. The results of simulations are also presented, illustrating the various ways in which the pulse trains are affected.

18679. Radebaugh, R., Ultralow-temperature physics in Japan, Off. Nav. Res. (Tokyo) Sci. Bull. 3, No. 2, 1-6 (Apr.-June 1978).
Key words: cryogenics; dilution refrigerators; helium 3; Japan; millikelvin research; nuclear coolin : $_{\text {: }}$ Pomeranchuk refrigerators; solid $\mathrm{He}^{3}$; superfluid $\mathrm{He}^{3}$; symposium.

This paper traces the progress of ultralow-temperature (ULT) physics in Japan from about 1970 to 1977. Ultralow temperatures are defined as those below $1 \mathrm{~K}$. The progress is based on visits to various laboratories during this period of time. Laboratories at Tohoku University, University of Tokyo, and Osaka City University are discussed in some detail. The paper points out that in 1970 Japan was behind many other countries in the field of ULT physics but rapid progress has brought them up to an equal plane. Suggested reasons for the rapid progress are given. The paper also gives a summary of the recent International Symposium on Physics at Ultralow Temperatures held in Hakone, Japan, Sept. 5-9, 1977.

18680. Radebaugh, R., Lawless, W. N., Siegwarth, J. D., Morrow, A. J., Feasibility of electrocaloric refrigeration for the 4.15 K temperature range, Cryogenie:s 19, No. 4, 187-208 (Apr. 1979).

Key words: beryllium; ceramics; cryogenics; dielectric-constant; electrets; electrocaloric effect; entropy; ferroelectrics; glass-ceramics; heat switches; magneto-thermal conductivity; polarization; potassium tantalate; refrigeration; specific heat; strontium titanite

The feasibility of a solid state type of refrigeration, which utilizes the electrocaloric effect in certiin dielectric materials, has been investigated. The study was limited to the temperature range where the refrigerato- would absorb heat from a load at about $4 \mathrm{~K}$ and reject heat to a reservoir at about $15 \mathrm{~K}$. Heat switches would be required for such a refrigerator and two types were studied. One type was a multiple-leaf contact switch, the other a magnetothermal switch of single crystal beryllium. Many electrocaloric materials were studied but none was found with a sufficiently large reversible electrocaloric effect for a practical refrigerator. The largest effects were seen in a $\mathrm{SrTiO}_{3}$ ceramic, followed by a $\mathrm{KTaO}_{3}$ single crystal. Temperature reductions of about $0.3 \mathrm{~K}$ at $10 \mathrm{~K}$ were observed during depolarization from fields of $20 \mathrm{kV} \mathrm{cm} \mathrm{cm}^{-1}$. A theoretical model, based on the electret behaviour of impurity-vacancy dipoles is postulated to interpret the anomalous dielectric behaviour of the materials investigated. Another theoretical model, based on the lattice dynamics of displacive dielectrics, is postulated to explain the observed temperature changes seen in such materials. The model points out that at $4 \mathrm{~K}$ the entropies of di: piacive type materials are probably too low for practical refrigcration. An investigation of certain order-disorder dielectrics is suggested.

18681. Read, D. T., Ekin, J. W., Powell, R. L., Clark, A. F., Definitions of terms for practical superconductors. 3. Fabrication, stabilization and transient losses, Cryogencis 19, No. 6, 327-332 (June 1979).

Key words: critical parameters; definitions; flux phenomena; Josephson phenomena; stabilization; superconductors; terminology.

The definitions of terms used in describing the phenomenology and measurement practices of practical superconductive materials are proposed. The definitions cover the subject categories of: 1. fundamental states and flux phenomena; 2 . critical parameters; 3. fabrication, stabilization, and transient losses; and 4. Josephson phenomena. It is intended that these terms will become the basis for the development of standard measurement practices and responses are invited.

18682. Rhyne, J. J., Fish, G. E., Sankar, S. G., Wallace, W. E., Magnetic properties of Laves-phase rare earth hydrides. 
(Proc. Conf. Physics of Mctallic Rare-Earths, Saint-Pierre-deChartrcuse, France, Scpt. 4-7, 1978), J. Phys. 40, No. C-5, C5-209-C5-210 (May 1979).

Key words: hydrides; intermetallic compounds; Laves phasc; magnctism; neutron scattering; rare earths.

Neutron scattering results show that the introduction of hydrogen into $\mathrm{RFe}_{2}$ compounds ( $\mathrm{R}=\mathrm{Tm}, \mathrm{Ho}$, and $\mathrm{Er}$ ) significantly lowers the overall Curie temperaturc and produces a reduced $0 \mathrm{~K}$ moment on the rare earth sitc. The rare earth spins disorder at a tempcrature lowcr than the bulk $T_{c}$ in $\mathrm{ErFe}_{2} \mathrm{H}_{3.5}$. The $\mathrm{O} \mathrm{K}$ iron sublattice moment in $\mathrm{ErFe}_{2} \mathrm{H}_{3.5}$ is essentially the same as that found in the non-hydride compounds and remains nearly constant to approximately $0.8 T_{c}$.

18683. Richards, P. L., Shen, T. M., Harris, R. E., Lloyd, F. L., Quasiparticle heterodyne mixing in SIS tunnel junctions, Appl. Phys. Lett. 34, No. 5, 345-347 (Mar. 1, 1979).

Key words: Josephson junctions; microwave receivers; microwaves; mixers; superconductivity; tunnel junctions.

The rapid onset of quasiparticle tunneling current in superconductor-insulator-supcrconductor (Josephson) junctions at voltages above $2 \Delta / e$ is being used for millimeter-wave heterodyne mixing. Junctions with a $2-\mu \mathrm{m}$ diameter and $R_{N}=$ $50 \Omega$ have little capacitive shunting at the signal frequency of $36 \mathrm{GHz}$. Because there is no series resistance, residual capacitance can be tuned out. Double sideband conversion efficiencies of 0.32 and mixer noise temperatures as low as $T_{M} \leqslant$ $7 \mathrm{~K}=4 h v / k$ have been observed. The results are compared with shot-noise-limited mixer theory. Photon-assisted tunneling effects are seen which indicate the approach to photon-noiselimited operation.

18684. Rupp, N. W., Clinical placement and performance of composite resin restorations, (Proc. Composites in Dentistry Symp. Celebrating the 50th Anniv. of Coopcration Between the ADA and NBS in Dental Research 1928-1978, held in conjunction with the 56th General Session of the Int. Assoc. for Dental Research, Washington, DC, Mar. 15, 1978, W. E. Brown, R. L. Bowen, G. C. Paffenbarger, and D. F. Taylor, Eds.), J. Dent. Res. 58, No. 5, 1551-1557 (May 1979).

Key words: curing shrinkage; glaze; margin staining; roughness; wear.

Composite resins should be used for esthetic restoration of Class III, IV and V cavities, and not for load bearing areas nor the distal of cuspids. Defects other than gradual wear and color shift in the material can be controlled by careful placement, finishing and glazing.

18685. Sangster, R. C., R\&D for developing countries: I-The role of industrial $\mathrm{R} \& \mathrm{D}$, Res. Manage. XXII, No. 3, 34-38 (May 1979).

Key words: appropriate téchnology; industrialization; industrial R\&D; LDC's; less developed countries; light capital technology; science and technology for development; U.N. Conference on Science and Technology for Development; UNCSTD.

Science and technology for international development are under intense scrutiny at this time, in connection with preparations for the 1979 U.N. Conference on Science and Technology for Development and creation of the U.S. Foundation for Technological Cooperation. The nrimary need for industrialization of the less developed countries (LDC's) is technology. This technology needs to be "appropriate" to the LDC economies, often "intermediate" between pre-industrial technology and advanced Western technology, and "light capital" in nature. The ovcrwhelming need is technology for employment. Usually, only "technology transfer" is discussed when looking at LDC needs, although the U.S. academic scientific community has becn substantially involved, also. The U.S. industrial R\&D community has had little involvement in this field. Yct it is this community that provides most of the new technology for U.S. development, and it spcnds $70 \%$ of U.S. R\&D $\$$ and $37 \%$ of the world-wide R\&D expenditures. Participation by the industrial $R \& D$ community in providing technology and science for use in development of the LDC's could be rewarding for all parties involved. Linkage mechanisms need to be created to couple this R\&D capability with LDC needs. Existing mechanisms can be expanded to include greater industrial participation. Industry can take a lead to make contact-with the LDC's. Governmental actions can assist this process.

18686. Schaefer, J. C., Chabay, I., Generation of enhanced coherent anti-Stokes Raman spectroscopy signals in liquidfilled waveguides, Opt. Lett. 4, No. 8, 227-229 (Aug. 1979).

Key words: coherent anti-Stokes Raman spectroscopy (CARS); liquid-filled dielectric waveguide; optical waveguide; phase-matched propagation in waveguide; Raman spectroscopy of liquids; signal enhancement of coherent Raman process.

We have demonstrated enhancement of coherent anti-Stokes Raman spectroscopy signals in liquid benzene contained in dielectric waveguide capillaries with angular phase-matching conditions. Enhancement factors as high as 130 were observed relative to a single crossing. These were measured for capillaries of various cross sections as a function of length. The maximum enhancement we observed was in a $50-\mu \mathrm{m} \times 50-\mu \mathrm{m} \times$ $292-\mathrm{mm}$ capillary with a sample volume of $0.75 \mu \mathrm{l}$. Signals increased steadily with capillary length and showed the same dependence on pump-beam crossing angle (phase-matching conditions) as in bulk samples.

18687. Schrack, R. A., Bowman, C. D., Chemical and temperature effects on thermal ${ }^{235} \mathrm{U}$ fission, Proc. Intl. Conf. on Neutron Physics and Nuclear Data for Reactors and Other Applied Purposes, Harwell, United Kingdom, Sept. 25-29, 1978, pp. 742-745 (Publications De L'Ocde, Paris, France, 1979).

Key words: chemical effects; delayed neutrons; Einstein model; fission; temperature effects; thermal; ${ }^{235} \mathrm{U}$.

Theoretical and exnerimental checks have been madc to look for reported chemical dependence in the yield of delayed neutrons from thermal ncutron induced fission in ${ }^{235} \mathrm{U}$. No significant chemical dependence arising from phonon transfer is predicted using an Einstein model of the lattice phonon distribution. Two types of experimental tests were made. In the first, the fission fragment yield was compared for thermal neutron induced fission in $\mathrm{U}_{3} \mathrm{O}_{4}$ and $\mathrm{UO}_{2}$. In the second experiment the delayed neutron yield from samples of $\mathrm{U}_{3} \mathrm{O}_{3}$ and $\mathrm{UO}_{2}$ irradiated in a thermal neutron field was compared. Neither experiment showed a difference in yield for the two chemical states of uranium.

18688. Simiu, E., Scanlan, R. H., Flutter of a plate-like member in horizontal fluctuating flow, Eng. Struct. 1, No. 4, 207-210 (July 1979).

Key words: aerodynamic stability; aeroelasticity; fluctuating flow; flutter; suspended-span structures; time-dependent loads.

A procedure is presented for determining the mean flutter velocity of a symmetrical plate with a vertical and a torsional degrec of freedom in a flow with periodic horizontal fluctuations. Expressions of the self-excited forces based on a generalized Theodorsen-type model are used. The resulting flutter mo- 
tion is described by a system of generalized Mathieu-Hill equations to which the stability criteria of the theory of dynamic systems with periodic coefficients are applied. A numerical example is given for a plate with mechanical characteristics comparable to those of a suspension bridge in a flow with fluctuations comparable to those occurring in natural winds. It is found that the cffect of such fluctuations upon the value of the mean flutter velocity is negligible. This suggests that in investigating the aerodynamic stability of a suspension bridge with characteristics similar to those dealt with in the paper, it is pcrmissible to neglect the cffect of the horizontal fluctuations of the flow. Recently obtained cxperimental results are quoted which tend to confirm this result.

18689. Smith, E. W., Giraud, M., Temperature dependence of rotational linewidths in $\mathrm{HCl}$ perturbed by argon, J. Chem. Phys. Lett. to Ed., 70, No. 4, 2027.2028 (Feb. 15, 1979).

Key words: $\mathrm{HCl}-\mathrm{Ar}$; rotational linewidths; temperature dependence; theoretical and experimental comparison; vibrational cffect.

The temperature dependence of several rotational linewidths in $\mathrm{HCl}$ pcrturbed by argon is studied. Comparison of theoretical and cxperimental data indicate that there may be a vibrational cffect (i.e. an increase in halfwidth due to distortion of the molecular potential curves for higher vibrational levels) which is strongest at low temperatures.

18690. Stanley, H. R., Bowen, R. L., Folio, J., Compatibility of various materials with oral tissues. II: Pulp responses to composite ingredients, (Proc. Composites in Dentistry Symp. Celebrating the 50th Anniv. of Cooperation Between the ADA and NBS in Dental Research 1928-1978, held in conjunction with the 56 th General Session of the Int. Assoc. for Dental Research, Washington, DC, Mar. 15, 1978, W. E. Brown, R. L. Bowen, G. C. Paffenbarger, and D. F. Taylor, Eds.), J. Dent. Res. 58, No. 5, 1507-1517 (May 1979).

Key words: chemical composition; composite resins; dental materials; primates; pulp response; toxicology.

In their present commercial formulations, composite restorative materials cause significant inflammation of dental pulp tissues unless special protective measures are taken by the dentist. The literature lacks reports delineating the pulp-irritating potential of individual ingredients of composite restorative materials. Eight components, used in formulating dental composite restorative materials, were placed, individually, against the pulpal walls of Class $\mathrm{V}$ cavities in Macaca irus primate tecth, and covered with gold foil and then ZOE fillings. After 21 days, the teeth were prepared for histological appraisal of the dental pulps. Each ingredient, individually, was apparently innocuous, not producing an average degree of inflammation greater than 1 on a scale of 0 to 4 . No abscesses or lesions predominating in leukocytes occurred. Interaction effects (especially benzoyl peroxide initiator and amine accelerators) should be studied next.

18691. Stein, S. R., Manney, C. M., Jr., Walls, F. L., Gray, J. E., Besson, R. J., A systems approach to high performance oscillators, Proc. 32d Ann. Symp. on Frequency Control, Atlantic City, NJ, Mav 3/-June 2, 1978, pp. 527-530 (U.S Army Electronics Research \& Development Command, Washington, DC, 1978).

Key words: long term frequency stability; oscillator systems; quartz crystal oscillator; short term frcquency stability.

The purpose of this paper is to show how systems composed of multiple oscillators and resonators can achieve superior performance compared to a single oscillator. Experimental results are presented for two systems based on quartz crystals which provide state-of-the-art stability over a much wider range of averaging times than has been previously achieved. Onc system has achieved a factor of five improvement in noise floor compared to all previously reported results.

18692. Stein, S. R., Turneaure, J. P., Superconducting resonators: High stability oscillators and applications to fundamental physics and metrology, Proc. Conf. on Future Trends in Superconductive Electronics, San Diego, CA, Mar. 27-28, 1979, pp. 192-213 (Apr. 1979).

Key words: high stability oscillators; superconducting cavity stabilized oscillator; supcrconducting oscillators; superconducting resonators.

Superconducting oscillators have achieved better frequency stability than any other device for averaging times of 10 l.c.s. to 1000 l.c.s. This high stability results from the use of solid niobium resonators having $Q$ factors greater than $10^{10}$. Such oscillators have direct applications as clocks and spectrally pure sources. They may also be used for accurate measurements of many physical quantities and to perform a variety of experiments on fundamental constants, relativity, and gravity waves.

18693. Stein, S. R., Walls, F. L., Composite oscillator systems for meeting user needs for time and frequency, Proc. $10 \mathrm{th}$ Ann. Precise Time and Time Interval Applications \& Planning Meeting, Washington, DC, Nov. 28, 1978, pp. 22-28 (Naval Research Laboratory, Washington, DC, 1978).

Key words: frequency lock loop; frequency stability; navigation; oscillator systems; phase lock loop; position location; spectral purity.

Frequency standards are used in most navigation and position location systems to provide a long term memory of either frequency, phase, or time epoch. From a systems point of view, the performance aspects of the frequency standard can be weighed against other systems characteristics, such as overall performance, cost, size, and accessibility. A number of areas of navigation and position location are very briefly reviewed from this point of view. The theory of phase lock and frequency lock systems is outlined in sufficient detail that one can casily predict total oscillator system performance from measurements on the individual components. As an example, details of the performance of a high spectral purity oscillator phased locked to a long term-stable oscillator are given. Results for several systems, including the best system stability that can be obtained from present commercially available $5-\mathrm{MHz}$ sources, is shown.

18694. Tippet, J. C., Chang, D. C., Characteristic impedance of a rectangular coaxial line with of fset inner conductor, IEEE Trans. Microwave Theory Tech. MTT-26, No. 11, 876-883 (Nov. 1978).

Key words: capacitance; rectangular coaxial line; transmission lines.

The singular-integral-equation technique is used to derive the capacitance and, hence, characteristic impedance of a rectangular coaxial line with a zero-thickness inner conductor. The position of the inner conductor is arbitrary, but its orientation is assumed to be parallel to the top and bottom walls of the outer conductor. Simplc yet very accurate formulas for the capacitance and characteristic impedance are found in terms of complete elliptic integrals.

18695. Tobler, R. L., Reed, R. P., Fatigue crack growth resistance of structural alloys at cryogenic temperatures, (Proc. 2d Int. Cryogenic Materials Conf., Boulder, CO. Aug. 3-5, 1977), Paper A-7 in Adyunces in Cryogenic Engineering, K D. Timmerhaus, R. P. Reed, and A. F. Clark. Eds., 24, 82. 90) (Plenum Press, New York. NY, 1978 ). 
Key words: crack propagation; fatigue; low temperature tests; nickel alloys; stainless steels; steels; superalloys; titanium alloys.

Fatigue crack growth rate data at selected temperatures including 295,76 , and $4 \mathrm{~K}$ are presented for a variety of titanium alloys, stainless steels, and $\mathrm{Fe}-\mathrm{Ni}$ alloys. The results correlate well with crystal structure. Compared to their behavior in a room temperature air environment, stable austenitic face-centered cubic alloys exhibit improved fatigue crack growth resistance at low temperatures. Hexagonal close-packed titanium alloys show temperature-insensitive behavior. Temperature effects on the fatigue crack growth resistance of body-centered cubic Fe-Ni alloy steels are moderate, except below the fracture transition temperature range where fatigue crack growth rates are drastically accelerated.

18696. Walls, F. L., Howe, D. A., A passive hydrogen maser frequency standard, Proc. 32d Ann. Symp. on Frequency Control, Atlantic City, NJ, May 3l-June 2, 1978, pp. 492-498 (U.S. Army Electronics Research \& Development Command, Washington, DC, 1978).

Key words: amplitude modulation; cavity. pulling; cavity servo; dielectrically loaded cavity; frequency stability; second-order Doppler shift phase modulation; spin exchange; temperature coefficient; time dispersion; wall shift.

Basic principles, circuit details, and measurements on a passive hydrogen maser frequency standard are presented. The perturbations to the output frequency are discussed and it is shown that the temperature coefficient of the microwave cavity is negligible in this system. Thus the fractional change in the output frequency is about $10^{-13} / \mathrm{K}$ determined by the second order Doppler shift and the wall shift $\left(10^{-14} / \mathrm{K}\right.$ is possible). A temperature stability of only $.1 \mathrm{~K}$ is required in order to maintain a frequency stability of $1 \times 10^{-14}$. Long term stability and reproducibility are expected to be improved over other designs because of this greatly reduced sensitivity to changes in temperature and temperature gradients. Measurements indicate a frequency stability of $\sigma y(\tau)=2 \times 10^{-12} \mathrm{t}^{-1 / 2}$ for $10 \mathrm{~s}<\mathrm{t}<4 \times$ $10^{5} \mathrm{~s}$. Frequency stability at several days is the best ever reported for a single device. The design of a small passive hydrogen maser using a dielectrically loaded cavity is described. Similar frequency stability is expected for the small maser.

18697. Walls, F. L., Wineland, D. J., Drullinger, R. E., New possibilities for frequency standards using laser cooling and detection of stored ions, Proc. $32 d$ Ann. Symp. on Frequency Control, Atlantic City, NJ, May 31-June 2, 1978, pp. 453-459 (U.S. Army Electronics Research \& Development Command, Washington, DC, 1978).

Key words: Ba ions; frequency stability; frequency standard; ion temperature; laser induced cooling; $\mathrm{Mg}$ ions; optical \& microwave double resonance; stored ions; systematic effects.

Techniques for storing $-10^{4}$ to $10^{5}$ ions for periods of hours to days are described in detail. Ion dynamics and detection techniques are also covered. Experimental data is presented demonstrating that ions stored in a room temperature Penning style ion trap using dc electric and magnetic fields can be cooled to near ZERO Kelvin using a suitable laser. This cooling technique, which is applicable to very many atomic and molecular ions, can reduce fractional frequency shifts due to the second order Doppler effect to smaller than $10^{-15}$. This cooling, coupled with the other attractive features of ion storage, promises to make possible frequency standards with stabilities in the $10^{-16}$ to $10^{-18}$ range with accuracies of order
$10^{-15}$ or better. One possible candidate for a microwave frequency standard is described. The projected fractiona frequency stability is $\sigma_{\nu}(\tau)=4 \times 10^{-15} \tau^{-1 / 2}$ for $16 \mathrm{~s}<\tau<10^{4} \mathrm{~s}$

18698. Wineland, D. J., Howe, D. A., Mohler, M. B., Hellwig H. W., Special purpose ammonia frequency standard-A feasibility study, IEEE Trans. Instrum. Meas. 28, No. 2, 122 132 (June 1979).

Key words: acceleration insensitive oscillator; ammoni microwave absorption; atomic clock; cavity frequency sta bilization; digital demodulator; frequency-lock servo frequency standard; inversion transition in ammonia; precision.

We have investigated the feasibility of a special purpose frequency standard based on microwave absorption in ammonia gas $\left(\mathrm{N}^{15} \mathrm{H}_{3}\right)$. Such a device would potentially fill a need in certain communications and navigation applications for an oscillator which has medium stability, greater accuracy $\left(\sim 10^{-9}\right)$ than that provided by crystal oscillators, but a cost significantly smaller than that of more sophisticated atomic frequency stan-y dards. A device was constructed using a stripline oscillator near$0.5 \mathrm{GHz}$ whose multiplied output was frequency-locked to the absorption of the 3-3 line in $\mathrm{N}^{15} \mathrm{H}_{3}(\sim 22.8 \mathrm{GHz})$. Output between 5 and $10 \mathrm{MHz}$ was provided by direct division from the $0.5-\mathrm{GHz}$ oscillator. Observed stability was $2 \times 10^{-10}$ from 10 to $6000 \mathrm{~s}$, and reproducibility (accuracy) is estimated to be \pm $2 \times 10^{-9}$. The unique features of this device, which include: 1) high-performance stripline oscillator, 2) digital servo techniques, 3 ) unique oscillator-cavity servo, 4) pressure shift compensation scheme, and 5) acceleration insensitivity, are discussed. Areas for further study are noted.

18699. Wineland, D. J., Walls, F. L., Drullinger, R. E., Highresolution spectroscopy by radiative cooling of bound resonant absorbers, (Proc. 10th Ann. Quantum Electronics Conf., Atlanta, GA, May 30, 1978), J. Opt. Sci. Am. 68, 648 (1978).

Key words: Doppler-free spectroscopy; frequency standard; high resolution spectroscopy; ion storage; laser spectroscopy; Mössbauer effect; optical pumping; optical spectroscopy; radiation pressure; radiative cooling.

A method for obtaining high resolution spectra of bound resonant absorbers is discussed. The Doppler width and Doppler frequency shifts are nearly eliminated by cooling the absorbers using radiation pressure. Experiments to test this principle use $\mathrm{Mg}^{+}$ions which are contained in a Penning ion trap. Theoretical and experimental details are discussed.

18700. Zimmerman, J. E., Cryocoolers for superconductive electronics, (AIP Conf. Proc. No. 44, Conf. on Future Trends in Superconductive Electronics, Charlottesville, VA, Mar. 2325, 1978, Series Editor: H. C. Wolfe), Paper in Future Trends in Superconductive Electronics, B. S. Deaver, Jr., C. M. Falco, J. H. Harris, S. A. Wolf, Eds., Sec. 7, pp. 412-420 (American Institute of Physics, New York, NY, 1979).

Key words: cryocoolers; Josephson devices; refrigeration; SQUID; superconductive electronics.

Superconductive electronic devices are generally operated and will continue to be operated in liquid-helium cryostats. Appropriate small closed-cycle cryocoolers for these devices do not exist. Development of cryocoolers, including efficient use of conventional gas refrige ration cycles and innovative thoughts on new and unconventional methods, could greatly enhance the usefulness of small-scale superconductive electronics. Large cryocoolers are already well-developed and can be adapted to the requirements of large-scale systems, such as computers, requiring a watt or more of refrigeration. 
18701. Zimmerman, J. E., Sullivan, D. B., Superconducting devices, Paper in McGraw-Hill Yearbook of Science and Technology, pp. 378-380 (McGraw-Hill Book Company, New York, NY, 1979).

Key words: digital elcctronics; magnetometry; quantum interference; superconductivity

The history of the SQUID is reviewed with emphasis on recent developments.

18702. Williams, E. R., Olsen, P. T., New measurement of the proton gyromagnetic ratio and a derived value of the finestructure constant accurate to a part in $10^{7}$, Phys. Rev. Lett. 42, No. 24, 1575-1579 (June 11, 1979).

Key words: electron anomalous moment; fine-structure constant; fundamental constant; magnetic fields; proton gyromagnetic ratio; quantum electrodynamic theory.

A new value for the fine-structure constant has been obtained from a new measurement of the gyromagnetic ratio of the proton. The result, $\gamma_{p}^{\prime}(\text { low })_{N B S}=2.67513229(57) \times 10^{8} \mathrm{~s}^{-1}$ $\mathrm{T}_{\text {NB. }}{ }^{-1}(0.21 \mathrm{ppm})$, is used to derive $\alpha^{-1}=137.035963(15)$ $(0.11 \mathrm{ppm})$. This value of $\alpha^{-1}$ is $(0.33 \pm 0.14) \mathrm{ppm}$ less than the value of $\alpha^{-1}$ derived from measurements of the anomalous magnetic moment of the electron, $a_{e}$, and its current best quantum electrodynamics theoretical estimate.

18703. Didion, D. A., Kelly, G. E., New testing and rating procedures for seasonal performance of heat pumps, ASHRAE J., pp. 40-44 (Sept. 1979).

Key words: heat pumps; part-load evaluation; standards for heat pumps; testing procedures for heat pumps.

Current testing and rating procedures for heat pumps have served industry and the consumer well for many years. These steady-state (SS) full-load evaluation procedures allow for the capacity determination needed for sizing the unit to the building loads. They also serve as an efficiency evaluation for comparing the relative merits of various units. However, with the need for energy conservation, and with increasing energy costs, buildings and their equipment have come to require a lifecycle-cost analysis instead of the traditional first-cost approach. In order to provide a better estimate of operational costs, the heat pump industry needs a more comprehensive evaluation technique to obtain data during part-load, cyclic operation. Although the wide variety of types of heat-pump installations and climates makes field performance impractical as a basis for this cost analysis, laboratory part-load simulation can increase the input for a reasonable testing investment.

18704. Bickford, N. A., Fleming, R. F., Silicon irradiation facilities at the NBS reactor, (Proc. Neutron Transmutation Conf., Columbia, MO, Apr. 23-26, 1978), Paper in Neutron Transmutation Doping in Semiconductors, J. M. Meese, Ed., pp. 165-170 (Plenum Publ. Corp., New York, NY, 1979).

Key words: NBS reactor; neutrons; silicon irradiation; thermal fluxes.

A program of silicon irradiation is being carried out at the National Bureau of Standards $10 \mathrm{MW}$, heavy water moderated reactor. The facility, which operates on a 40 day round-theclock cycle, can provide a wide range of neutron fluxes with an equally wide range of cadmium ratios.

18705. Brungraber, R. J., Adler, S. C., Technical support for a slip-resistance standard, (Proc. American Society for Testing and Materials Symp. on Walkway Surfaces: Measurement of Slip Resistance, Denver, CO, June 30, 1977), Am. Soc. Test. Mater. Spec. Tech. Publ. 649, pp. 40-48 (1978).
Key words: ASTM; bathtubs; CPSC; performance test; showers; slip-resistance.

In the spring of 1975, ASTM Subcommittee F15.03.01 on Specifications and Test Methods for Slip Resistance of Bathing Facilities, requested technical assistance from the Building Safety Section (BSS) of the National Bureau of Standards (NBS) in developing a performance test for establishing quantitatively an acceptable level of slip resistance for bathtubs and shower bases. Close cooperation between the subcommittee members and the BSS staff, coupled with financial supnort from the Consumer Product Safety Commission (CPSC), resulted in the development of a performance test which anproximates the conditions that are likely to occur on bathtub or shower base surfaces, is reliable and repeatable, and discriminates adequately between currently available bathtub and shower base materials.

18706. Harter, W. G., Patterson, C. W., Asymptotic eigensolutions of fourth and sixth rank octahedral tensor operators, $J$. Maih. Phys. 20, No. 7, 1453-1459 (July 1979).

Key words: asymptotic eigensolutions; high resolution spectra; spectral clusters; spherical top molecules; 4th and 6th rank octahedral tensor.

Qualitative and quantitative features of high quantum rotational spectra are discussed by appealing to geometrical and topographical representations of the tensor operators. Approximate formulas are derived for level-cluster energies. The approximate conditions for the occurrence of "anomalous" fourfold clusters are given.

18707. Gregory, D., Dunn, G. H., Phaneuf, R. A., Crandall, D. $\mathrm{H}$., Absolute cross sections for $2 s-2 p$ excitation of $\mathrm{N}^{4+}$ by electron impact, Phys. Rev. A 20, No. 2, $410-420$ (Aug. 1979).

Key words: crossed beams; cross sections; electron impact; excitation, $2 s-2 p ; \mathrm{N}^{4+}$.

Absolute cross sections have been measured for $1 s^{2} 2 s^{2} S_{1 / 2}$ $1 s^{2} 2 p^{2} P_{1 / 2,3 / 2}$ excitation of lithiumlike $\mathrm{N}^{4+}$ by electron impact. For this process, which has a threshold at $10 \mathrm{eV}$, relative cross sections measured at several energies between 4 and $52 \mathrm{eV}$ were normalized to a single absolute measurement taken at $15.5 \mathrm{eV}$. Similar data for Li-like $\mathrm{C}^{3+}$ have been previously reported and are presented for comparison. In both cases, allowing for the experimental electron energy spread, the measurements agree within experimental uncertainties with published Coulomb-Born and close-coupling calculations over the entire experimental energy range. Rate coefficients as a function of electron temperature are also presented for the $\mathrm{N}^{4+}$ transition.

18708. Braun, E., Krasny, J. F., Peacock, R. D., Stratton, A., NBS activities in apparel flammability, Proc. Ninth Annual Meeting of the Information Council on Fabric Flammability, New York, NY, Dec. 11, 1975, pp. 263-271 (Dec. 1975).

Key words: apparel; extinguishability; fabrics; flammability; garments; hazard; heat transfer; ignitability; standard; test.

This paper gives a brief overview of apparel flammability research activities of NBS and development of an apparel flammability test. Research consists of programs to explore: heat transfer during free burning and after contact is made between the burning fabric and a simulated body; ease of extinguishment; and optimization of fabric specimen configuration. Based on the results of this research and the general literature, a test concept was developed which strives for balance between simulation of real-life garment fires and test simplicity and reproducibility. A cylindrical specimen is suspended from a circular plate and ignited above its bottom edge. Time-to-ignite and heat transfer to the plate and a cylinder inside the specimen are measured. 
Typical results and possible criteria for dividing the fabrics into classes according to time-to-ignite and heat transfer are discussed. Fabrics which are hard to ignite and/or transfer little heat would be in a class which could be used in all garments. Fabrics which are easily ignited and/or transfer more heat could be used; e.g., in slacks and underwear, i.e., garments which cover only part of the body and could be expected to fit tightly.

18709. Braun, W., Herron, J. T.. Tsang. W., Churney, K., High Intensity Infrared laser irrudiation culcorimetry: Direct-deter. mination of heat Input to chlorodlfluoromethane and ethyl acetate, Chem. Phys. Letl. 59. No. 3, $492-497$ (Dec. 1, $1978)$.

Key words: calorimetry; infrared; kinetics; laser chemistry; mechanisms; multiphoton; thermochemistry; unimolecular dissociation.

The heat absorbed when chlorodifluoromethune $\left(\mathrm{CF}_{2} \mathrm{HCl}\right)$ and ethyl acetate were irradiated with a pulsed infrared $\mathrm{CO}_{2}$ TEA laser was measured using a laser calorimeter. The measurements show that $\mathrm{CF}_{2} \mathrm{HCl}$ at high pressure ( $>10$ torr) was completely thermally equilibrated during the laser pulse, while at low pressure $(<2$ torr) this system deviated considerably from thermal equilibrium. Ethyl acetate, however, was found to be non-thermal over the entire pressure range studied ( 0.5 to 20 torr). Implications of these observations to infrared induced unimolecular decompositions and molecular energy transfer are discussed.

18710. Rosenberg, L., Coulomb scattering in a faser field, Phys. Rev. A 20, No. 2, 457-464 (Aug. 1979).

Key words: multiphoton transitions; scattering in an external field; stimulated bremsstrahlung

The problem of scattering by a local potential in the presence of an intense radiation field is studied for the case where the potential is Coulombic at great distances. The effect of the Coulomb tail on the asymptotic dynamics is accounted for here through a modification of the form of the wave functions which describe the time evolution of the system in initial and final states. This is in analogy with previous treatments of field-free Coulomb scattering. Starting from the time-dependent picture, the author obtains a time-independent formulation of the problem and then applies it to the derivation of a lowfrequency approximation. In the simplest version of this approximation the transition amplitude is represented as the product of a known field-dependent factor (a Bessel function) and the physical field-free scattering amplitude, thus generalizing an earlier result of this type derived for the case of a shortrange potential.

18711. Rosenberg, L., Generalized low-frequency approximation for scattering in a laser field. 11, Phys. Rev. A 20, No. 1, 275280 (July 1979).

Key words: free-free transitions; low-frequency approximation; multiphoton effects; scattering in laser field.

A time-independent formulation of the problem of scattering in an intense radiation field is used as the basis for a derivation of a low-frequency approximation in which field-free scattering amplitudes enter into the determination of transition amplitudes in the presence of the field. A single-mode field of arbitrary polarization is assumed and the scatterer is represented by a local, short-range potential. In the present derivation the dipole approximation for the field is not assumed. As a result, recoil corrections to earlier versions of the low-frequency approximation are obtained in explicit form. The low-frequency approximation for bremsstrahlung in the absence of a background field, derived some time ago by Low and others, appears as a limiting case of the result obtained here.
18712. Tsang, W., Walker, J. A., Braun, W., Herron, J. T. Mechanisms of decomposition of mixtures of ethyl acetate and isopropyl bromide subjected to pulsed infrared laser irradiation, Chem. Phys. Lett. 59, No. 3, $487-491$ (Dec. 1, 1978).

Key words: infrared laser; kinetics; mechanisms; modeling; multiphoton; unimolecular dissociation.

The infrared laser induced decomposition of mixtures of ethyl acetate and isopropyl hromide has heen studied. The ratio of the yields of products ethylene and propylene, arising from the unimolecular decomposition reactions: ethyl acetate $\rightarrow$ ethylene + acetic acid, and isopropyl hromide $\rightarrow$ propylene + hydrogen hromide, were measured as a function of the ratio of ethyl acetute to isopropyl bromide and pressure of added helium. The results indicate clearly that in these systems nonequilibrium hehavior is found up to the highest pressures used (ahout one atmosphere). A two level kinetic model is suggested which qualitutively explains the ohservations.

18713. Mopsik, F. I., Khoury, F., Kryder, S. J., Bolz., L. H., The dieiectric loss of polypropylene films and polypropylene-polyurethane laminates at cryogenic temperatures, (Proc. ICMC Symp. on Nonmetallic Materials and Composites at Low Temperatures, Munich, W. Germany, July 10-11, 1978), Paper in Nonmetallic Materials and Composites at Low Temperatures, A. F. Clark, R. P. Reed, G. Hartwig, Eds., pp. 85. 96 (Plenum Press, New York, NY, 1979).

Key words: cryogenic temperature; dielectric loss; polymer films; polymers; polypropylene; polyurethane; superconducting power cable; $\tan \delta$.

Dielectric loss measurements were made on six commercial polypropylene films as well as on polypropylene-polyurethane laminates from $4.2 \mathrm{~K}$ to $323 \mathrm{~K}$ at $100 \mathrm{~Hz}$ and $1 \mathrm{KHz}$. Loss peaks were observed in the polypropylene films at $<4.2 \mathrm{~K}, 30 \mathrm{~K}$, and $125-150 \mathrm{~K}$. The magnitudes of the peaks varied among these films. The $<4.2 \mathrm{~K}$ peak is attributed to the presence of antioxidant in the polypropylene. The magnitude of the dielectric loss in the polypropylene films in the temperature range of interest for use of this polymer as electric insulation in superconducting $\mathrm{AC}$ cables depends on the relative magnitudes of the $<4.2 \mathrm{~K}$ and $30 \mathrm{~K}$ peaks whose respective high temperature tail and low temperature tail overlap in the temperature range at which the cables will be operated, namely 6-9K. The polypropylenepolyurethane laminates exhibit a broad loss peak at $150 \mathrm{~K}$ which is due to the polyurethane. The results of experiments carried out to determine the relative contributions of the polypropylene and polyurethane layers to the dielectric loss of the laminates in the range $4.2 \mathrm{~K}-10 \mathrm{~K}$ are discussed.

18714. Albus, J. S., Mechanisms of planning and problem solving in the brain, Math. Biosci. 45, 247-293 (1979).

Key words: brain mechanisms; cognition; goal seeking; intelligeace; motor behavior; neural modeling; perception; planning; problem solving; robot control.

Classical AND/OR goal, or task, decomposition techniques are generalized to deal with the problem of sensory-interactive goal-directed behavior in biological organisms. A neurophysiological model is described which demonstrates the capacity to learn, to generalize, to compute multivariate mathematical functions, and to decompose input commands into sequences of output commands in a context-sensitive manner. Evidence is presented that clusters of neurons with such properties are arranged in hierarchical structures in the brain so as to produce AND/OR task compositions. At the lowest levels in the motor system these clusters transform coordinates and compute servo functions. At the middle levels they decompose input commands into sequences of output commands which 
give rise to behavior patterns. Mechanisms by which feedback can alter these decomposition sequences to compensate for perturbations and uncertainties in the cnvironment are described. At the highest levels of the hierarchy there are goal selecting and cvaluating mechanisms. It is argued that in higher mammals these upper levels of the motor hierarchy are the mechanisms of planning and problem solving.

18715. Hoffman, J. D.. On the formation of polymer fibrils by flow-induced crystallization. Pelymer 20, No. 9, 1071-1077 (Sept. 1979).

Key words: crystallization theory; extended chain fibrils; flow-induced crystallization; polymer crystallization; shish kebabs.

A theory of the formation of the core fibril ('shish') that is produced by flow-induced crystallization in undercooled polymer solutions is given. Multiple nucleation cvents on a flow-elongated molecule produce an embryonic fibril that is a connected set of bundle-like nuclei. End surface stress resulting from the repulsion of the 'amorphous' chains in the regions hetween these nuclei builds up cumulatively as the nuclei mature, leading ultimately to volume strain in the body of cach crystallite in the core fibril. This causes the diameter and length of the crystallites to be limited in a thcrmodynamic sense. The dependence of this diameter and length are calculated in terms of the driving force for the crystallization. Annealing and melting cffects are discussed. The theory leads to a thin $(\sim 150$ to $\sim 500 \AA$ A ) core fibril that is a set of concatenated and substantially cxtended-chain crystallites of stable diameter that is interrupted at long intervals $(\sim 1000$ to $\sim 3000) \AA$ ) by short and highly strained amorphous regions. Most of the chain molecules pass through these amorphous zones from one crystallite to another. Expanded lattice spacings are predicted for the crystallites comprising the core fibril under certain circumstances.

18716. Ledbetter, H. M., Dynamic elastic modulus and internal friction in fibrous composites, (Proc. ICMC Symp. on Nonmetallic Materials and Composites at Low Temperatures, Munich, W. Germany, July 10-11, 1978), Paper in Nonmetallic Materials and Composites at Low Temperatures, A. F. Clark, R. P. Reed, G. Hartwig, Eds., pp. 267-28I (Plenum Press, New York, NY, 1979).

Key words: aramid-epoxy; boron-aluminum; boron-epoxy; composites; clastic constants glass-epoxy; internal friction; Young's modulus.

Longitudinal, transverse, and crossply Young's moduli determined dynamically in this study provide useful comparisons with previously determined static moduli. Dynamic internal friction tends to relate inversely to dynamic modulus in the studied materials, which include: boron-aluminum, boron-epoxy, glass-epoxy, graphite-epoxy, and aramid-epoxy. The experimental arrangement consisted of a Marx three-component oscillator at frequencies between 30 and $90 \mathrm{kHz}$. The graphite-epoxies show regular temperature behavior and a relatively small pcrcentage change in Young's modulus between room tempcrature and $76 \mathrm{~K}$.

18717. Kasen, M. B., Cryogenic applications of composite technology, (Proc. ICMC Symp. on Nonmetallic Materials and Composites at Low Temperatures, Munich, W. Germany, July 1()-11, 1978), Paper in Nonmetallic Materials and Composites at Low Temperatures, A. F. Clark, R. P. Reed, G. Hartwig, Eds., pp. $317-337$ (Plenum Press, New York, NY, 1979).

Key words: aramid fiber; composite applications; composites; concrete; cryogenics; epoxy resins; glass fiber; graphite fiber.
The present applications of composite materials in U.S. cryogenic technology is reviewed. Particular attention is paid to identifying the reasons for selecting a specific composite for a given application and to assessing performance. Future applications are discussed with cmphasis on the technological progress required to implement composite materials use. The rcview includes concrete aggregates as well as laminates.

18718. Ekin, J. W., Schramm, R. E., Clark, A. F., Effect of strain on epoxy-impregnated superconducting composites, (Proc. ICMC Symp. on Nonmetallic Materials and Composites at Low Tempcratures, Munich, W. Germany, July 10$11,1978)$, Paper in Nonmetallic Materials and Composites at Low Temperatures, A. F. Clark, R. P. Reed, G. Hartwig, Eds., pp. 301-308 (Plenum Press, New York, NY, 1979).

Key words: cpoxy; epoxy-impregnated magnets? superconductor; training superconducting magnet.

Mechanical property data are reported for three epoxy materials of the type used to impregnate superconducting solenoids: a filled cpoxy, a flexibilized cpoxy, and a low viscosity cpoxy suitable for vacuum impregnation. Impregnated superconducting test rings were also constructed using each type of epoxy. The critical current and training behavior of each composite ring was then measured as a function of hoop stress applied to the ring and correlated with the tensile properties of the corresponding epoxy. The ultimate strain, $\epsilon_{u}$, of the epoxy impregnate was a primary controlling factor in the superconducting performance of cach composite ring. Af strains below $\epsilon_{u}$, both critical-current degradation and training were negligible. At strains near $\epsilon_{u}$, however, training became a serious problem with 5 to 10 quenches required to reach full critical current. These data would indicate that the training behavior of potted superconducting magnets is associated with a process involving relief of stress concentration within the epoxy impregnant.

18719. Sparks, L. L., Cryogenic foam insulations: Polyurethane and polystyrene, (Proc. ICMC Symp. on Nonmetallic Materials and Composites at Low Temperatures, Munich, W. Germany, July 10-11, 1978), Paper in Nonmetallic Materials and Composites at Low Temperatures, A. F. Clark, R. P. Reed, G. Hartwig, Eds., pp. 165-205 (Plenum Press, New York, NY, 1979).

Key words: cellular plastic; low temperature; mechanical properties; polystyrene; polyurethane; thermal insulation; thermal properties.

The need for and diverse use of low temperature thermal insulations has increased dramatically in the last 20 years. Widespread use of cryogenic temperatures in industry and acrospace endeavors and, more recently, the need to transport and store large volumes of LNG are primarily responsible. Two materials being used extensively in these applications are the expanded plastics polyurethane (PU) and polystyrene (PS). These cellular plastics are excellent thermal insulators with measured values of apparent thermal conductivity at a mean temperature of $112 \mathrm{~K}$ being 0.013 to $0.016 \mathrm{~W} / \mathrm{m} \cdot \mathrm{K}$ for $\mathrm{PU}$ and 0.010 to $0.016 \mathrm{~W} / \mathrm{m} \cdot \mathrm{K}$ for $\mathrm{PS}$. The effect of aging and conditions of aging are critical factors in determining the ultimate conductivity. The major component of the overall conductivity, gas conductivity, is affected by pcrmeation of gases through the cell walls. The reasonably high strength to density ratio for PU and PS at room temperature, 10 to $16 \mathrm{~Pa} / \mathrm{kg} / \mathrm{m}^{3}$ compared to $\sim 110$ for aluminum alloys and $\sim 130$ for stainless steels, allows these insulations to be self-supporting and to lend structural support to the system. The thermal, elastic, and mechanical properties are functions of several nonindependent parameters such as density, cell size, composition, and method of 
processing. The properties of these expanded plastics are also anisotropic. The large variations found in existing data reflect these complex dependences. Expected behavior and experimentally determined data are discussed for the following properties: Tensile, compressive, and shear strengths and the associated moduli, thermal conductivity, linear thermal expansion, specific heat, and thermal diffusivity. Temperatures below $300 \mathrm{~K}$ are considered

18720. Belanger, B. C., Kieffer, L. J., The NBS role in quality assurance for physical measurements, Proc. Nat. Conf. on Quality Assurance of Environmental Measurements, Denver, CO, Nov, 27-29,1978, pp. 18-22 (1979).

Key words: environmental measurements; Measurement Assurance Programs; quality assurance.

While the layman may think of environmental measurements primarily in terms of chemical and/or biological measurements, accurate measurements of quantities such as clectromagnetic radiation, ionizing radiation, optical and ultraviolet radiation, temperature, flow, noise, etc.. are becoming increasingly important to environmental scientists. For many years, NBS has provided calibration services for a wide variety of physical measurement quantities for those who need traceability to national standards. In recent years, requirements for higher accuracy and more rigorous quantification of measurement uncertainty have lead NBS to develop so-called "Measurement Assurance Programs" or "MAP's," to provide a higher confidence level in the adequacy of the measurement accuracy for the intended application. This paper reviews those physical measurement services and MAP's that should be of interest to those concerned with accurate environmental measurements.

18721. Benjamin, 1. A., A firesafety evaluation system for health care facilities, (Proc. Intl. Fire Safety in Hospitals Symp., Paris, France, Apr. 4-5, 1978), Fire J. 73, No, 2, 52-55, $95-$ 96 (Mar. 1979).

Key words; fire hazards; fire protection; fire safety; health care facility: smoke development.

In the United States today, there are about 16,000 nursing homes (homes for elderly) and 7,000 hospitals. Some of these facilities do not meet current standards for firesafety, and therefore require upgrading. In an effort to aehieve economical retrofit systems and minimize disruption to the operation of the facility, authorities having jurisdiction have granted waivers of firesafety regulations. These waivers have been based on the use of alternate protection means to provide equivalency to the regulations. The difficult decision as to what constitutes equivalency has been left to the various local jurisdictions, and, therefore, there has been a lack of uniformity across the country in terms of what may be waived and what constitutes an adequate alternative to provide the required level of safety.

18722. Berlin, V. N., Administrative experimentation: A methodology for more rigorous "muddling through", Manage. Sici. 24, No. 8, 789-799 (Apr. 1978).

Key words: administrative experimentation; managerial decision-making; methodology

Administrative experimentation is described as a more rigorous approach to the "muddling through" style of managerial decision making. It includes a class of heuristics for obtaining feedback on management decisions in what amounts to a continuous trial and error process. A manager on his own, a manager-consultant team. or a manager-researcher team can implement these heuristics in a variety of settings to serve a varicty of purposes. A case study describing one application of this approach is presented.
18723. Bagoz7i, R. P., Ives, W. R., Nahman, N. S., Determination of the dielectric relaxation time in a Debye binary liquid by pulse measur ements, (Proc. XVI General Assembly of the Intl. Union of Radio Science, Ottawa. Canada. Aug. 26, 1969). Paper in Progress in Radio Science, 1966-1969, J. A. Lane, J. W. Findlay, C. E. White, Eds., 2, 257-265 (International Union of Radio Science, Brussels, Belgium, 19711.

Key words: dielectric measurements; dielectric relaxation time; time-domain; transmission lines

The dispersive properties of a lossy coaxial transmission line were used to deduce the Debye relaxation time for dilute solutions of (polar) 2-heptanone in (non-polar) normal heptane. The step responses of a liquid filled coaxial line were measured and compared with the Debye model in order to deduce the relaxation time $\tau$. Over the concentration range of 0.1 to 1.1 molal, I $\mathrm{kHz}$ capacitance measurements showed that the static dielectric constant varied linearly with increasing concentration from 1.98 to 2.54 ; also, the deduced relaxation time varied from 1.36 to 5.4 picoseconds.

18724. Bertocci, U., Photopotentials on copper and copper alloy electrodes, J. Electrochem. Soc. 125, No. 10, $1598-1602$ (Oct. 1978).

Key words: aluminum; copper; copper alloys; nickel; oxide films; photopotentials.

The effect of white light illumination on the current-potential relationships of pure copper and of $\mathrm{Cu}-\mathrm{Ni}$ and $\mathrm{Cu}-\mathrm{Al}$ alloys in neutral solutions was examined, both under galvanostatic and potentiostatic eonditions. The results obtained show that the photoresponse is only weakly affected by the addition of alloying elements to copper, but that it is influenced by the method of formation of the oxide film on the metal surface. Depending on whether or not the $\mathrm{Cu}_{2} \mathrm{O}$ film was formed by reaction with a copper solution, the amplitude of the signal response could be strongly affected and the sign of the photopotential at open cireuit reversed, indicating a change in the nature of the majority carriers. Polarization of the electrode can also vary the photoresponse, but its rapid following of the potential does not support the view that the structure of the oxide film is altered. Impedance measurements on electrodes under illumination and in the dark indicate that the charge-transfer reactions, rather than the resistivity of the oxide film, are affected by light.

18725. Bertocci, U., Mullen, J. L., Laboratory corrosion studies on tinned copper concentric neutral wires, Mater. Perform. 18, No. 6, 24-31 (June 1979)

Key words: copper concentrie neutrals; corrosion: corrosion tests; electrochemical measurements; potentiodynamic scans.

Long term corrosion tests, potentiodynamic scans and eurrent potential measurements have been carried out on copper concentric neutral ( $\mathrm{CCN}$ ) wires in various environments, simulating the eonditions that could be encountered in the field. The effect of different ions in the electrolyte, including chloride, of the presence of oxygen and of the superposition of an a.c. signal were investigated. The influence of these conditions on causing pitting corrosion are examined and discussed.

18726. Florin, R. E., Electron spin resonance spectra of polymers during fluorination, $J$. Fhorine Chem. 14, 253-262 (1979)

Key words: electron spin resonance; fluorination of polymers; free radicals: peroxy radicals; transition metal fluorides. 
ESR spectra characteristic of peroxy radicals appeared rapidly in all of eleven hydrogen-containing polymers examined when treated with dilute fluorine. These radicals presumably result from the reaction of hydrocarbon and fluorocarbon radicals, existing at undetectably low steady-state concentrations, with the oxygen impurity content of commercial fluorine. In poly(vinylidene fluoride) films of thickness 11 and $58 \mu \mathrm{m}$ the radical contents were nearly proportional to surface area rather than volume, in agreement with earlier reports of a shallow depth of penetration. Some polymers exhibited also or exclusively a broad spectral component, varying in character with the polymer; examples are polystyrene, polyethylene, poly(vinyl chloride), poly(vinylidene chloride), polyoctafluoropentadiene, polyhexafluoropropene, and a fluorinated graphite. The broad spectral component did not react with ordinary radical scavengers such as propylene and oxygen, and is probably not due to a fluorocarbon radical but to unknown transition metal fluorides.

18727. Hebner, R. E., Jr., Annestrand, S., Evaluation of calibration techniques for multimegavolt impulse dividers, Proc. Third Intl. Symp. on High Voltage Engineering, Milan, Italy, Aug. 28-3I, 1979, 42.18, pp. 1-4 (Associazione Elettrotecnica ed Elettronica Italiana, Milan, Italy, Aug. 1979).

Key words: divider; high voltage; impulse; lightning impulse; pulse calibration; ramp response; step response.

The calibration of a $4.5 \mathrm{MV}$ impulse divider was evaluated by measuring both the input and output waveforms and the response of the divider to a low voltage step. The measured output was compared to that which was found from a Duhamel's integral calculation using the input waveform and the measured response to a step. The validity of this approach for this large measurement system was demonstrated for the specific waveforms studied.

18728. Cook, R. K., Proctor, T. M., A standing-wave tube as an absolutely known source of sound power, J. Acoust. Soc. Am. 65, No. 6, 1542-1555 (June 1979).

Key words: absolute sound power source; particle velocity; plane wave; sound intensity; sound power; standing wave tube.

An open ended standing-wave tube has been examined as an absolute sound power (ASP) source, having an absolutely known radiated sound power. The ASP source can serve as an acoustical instrument, principally in reverberation chambers, for three purposes. The first is for calibration of the presently used arrays of microphones for measurement of total radiated sound power by steady sources. The second is for measurement of the influence of acoustical diffusion devices, such as moving vanes, on the radiated power of a source. A third application is to the steady-state measurement of the total cross section for sound absorption. The power measurement scheme makes use of concurrent measurements of sound pressure, both amplitude and phase, at two separate points inside the tube and on its axis. From these, the time-averaged product (Umov vector) of the particle velocity and pressure can be obtained. The product gives accurately both the sound intensity within the tube and the radiated power from the open end. Optimum accuracy for measurement of intensity is achieved by large microphone separations (one-quarter wavelength). Comparison of indicated sound power radiated from the tube with the usual sound power measurements done in both an anechoic and a reverberant environment are made.

18729. Paffenbarger, G. C., Rupp, N. W., Patel, P. R., Linear dimensional change of copper-rich dental amalgam, J. Am. Dent. Assoc. 99, 468-471 (Sept. 1979).
Key words: amalgam; creep; dental; dimensional change; dispersion type alloy; high copper; single alloy.

Clinical observations show that the dimensional ability of amalgam materials partly affects the extrusion of restorations. Data reported give linear expansions for seven copper-rich amalgams aged in air at 60,37 , and $23 \mathrm{C}$ for a maximum of $105( \pm 2)$ weeks.

18730. deGraaf, L. A., Rush, J. J., Livingston, R. C., Flotow, H. E., Rowe, J. M., Study of hydrogen diffusion in vanadium and tantalum hydride by quasielastic thermal neutron scattering, Proc. Intl. Meet. on Hydrogen in Metals, Kernforschungsanlage Julich, Germany, Mar. 20-24, I972, pp. 301-312 (Mar. 1972).

Key words: diffusion; quasielastic scattering; tantalum hydride; vanadium hydride; $\alpha$ phase; $485 \mathrm{~K}$.

The diffusion of hydrogen in vanadium and tantalum has been studied by quasielastic thermal neutron scattering. Neutron line widths associated with diffusion broadening have been determined at $485^{\circ} \mathrm{K}$ for $\mathrm{VH}_{0.198}$ and $\mathrm{VH}_{0.570}$ and at several temperatures between $295^{\circ}$ and $613{ }^{\circ} \mathrm{K}$ for $\mathrm{TaH}_{0.15}$. These measurements cover a range of momentum transfers ( $Q$ ) for elastic scattering up to $4.1 \AA^{-1}$. This is much larger than the momentum transfers obtained in our earlier cold-neutron experiments, where no conclusive comparison was possible between data and proposed models involving diffusive jumps between octahedral and tetrahedral sites. The line width results for $\alpha-\mathrm{VH}_{\mathbf{0 . 5 7}}$ are compared with these models and with a model allowing occupation of multiple sites. Although no complete agreement was obtained, this comparison leads to the conclusion that jumps between tetrahedral sites seem to be predominant in the diffusion process. Differences in the line width behaviour for $\mathrm{VH}_{0.20}$ and $\mathrm{VH}_{0.57}$, and the fact that the measured widths at large $Q$ increase rapidly with $Q$ rather than approaching an asymptotic value as predicted by the theory, are discussed. The tantalum hydride width curves are compared to the $\mathrm{VH}_{x}$ results and to the same models. It is suggested that the observed line width behavior and the large Debye-Waller factors found in the present and previous neutron experiments on $\mathrm{VH}_{x}$ are connected with the relative magnitudes of diffusion relaxation time and the jump time between sites.

18731. Clark, F. O., Lovas, F. J., Johnson, D. R., Dimethyl ether in orion, Astrophys. J. 229, 553-559 (Apr. 15, 1979).

Key words: dimethyl ether transitions; high-resolution spectra; Orion Nebula.

Seven new dimethyl ether transitions have been observed in emission from the direction of the Orion Nebula. Dimethyl ether has also been detected in Sgr B2 in weak emission from two rotational transitions. The observed high-resolution spectra from several of the Orion transitions exhibit well-resolved splittings due to internal motions in the molecule. All of the Orion signals are quite narrow $\left(\langle\Delta V\rangle \approx 2.3 \mathrm{~km} \mathrm{~s}^{-1}\right)$ and centered near $\left\langle V_{L S R}\right\rangle=6.6 \mathrm{~km} \mathrm{~s}^{-1}$. Laboratory measurements of the rest frequencies of these same transitions are presented, along with the calculated relative intensities of the internal rotor split components.

18732. Danos, M., Rafelski, J., Singularities in quanturn field theory, II Nuovo Cimento 49A, No. 3, 326-367 (Feb. 1, 1979).

Key words: Feynman integrals; quantum field theory; singularities; $S$-matrix.

The short-range behaviour of certain Feynman integrals reveals mathematical properties which are not those of either functions or distributions-they contain terms which are more 
singular than distrihutions and possess inherent amhiguitics Two classes of singularities cxist: To the first onc helong all those singularities which have a physical mcaning in the sense that in a convergent (regularized) quantum ficld theory they contrihute to ohservahle quantities, frequently as renormalization constants. Most of the singularities of the second, the spurious type, violate the symmetries of the Lagrangian. We demonstrate that they are associated with ccrtain mathematical difficulties of unregularized theorics. Much of our analysis deals with the isolation of singularities of this type and with the study of the properties of the singular products of distrihution. We argue that the four-dimensional intcgration leading to the $S$ matrix in the perturhation cxpansion must be carried out over an open domain which leaves out the contrihutions from singularities of the contact type, that is terms proportional to $\delta^{4}(x-$ y).

18733. Harrjc, D. T., Grot, R. A., Instrumentation for monitoring energy usage in buildings at twin rivers, Paper in Energy and Buildings, 1, 293-299 (Elsevier Sequoia S. A., Lausanne-The Netherlands, 1977/1978).

Key words: air infiltration; buildings; data acquisition; energy; instrumentation; measurement; thermography; Twin Rivers Project; weather station.

The measurement systems used at Twin Rivers for detcrmining energy usage are descrihed. These include a weather station, three different systems for the measurement of temperatures and cnergy-related cvents in a house, automated devices to measure the air infiltration rate, and infrared thermography, Each of these systems played a role in assessing the actual usage of cnergy in individual buildings, in identifying the factors that determinc energy consumption, and in checking the accuracy of theoretical models for predicting the cnergy performance of dwellings.

18734. Waterstrat, R. M.. Haenssler, F., Müller, J., Nb-Si A 15 compounds produced by liquid quenching, J. Appl. Phys. 50 , No. 7, 4763-4766 (July 1979).

Key words: intermetallic compounds; liquid quenching; metastahle phases; niobium-silicon alloys; splat-cooling: supcrconductivity.

A metastahle A I5-typc structure has bcen obtained in binary Nb-Si alloys containing $18.8 \pm 0.5$ at $\% \mathrm{Si}$ by very rapid quenching (splat cooling) from the liquid state. Supcrconducting onsct temperatures $\left(T_{i}\right)$ of about $4 \mathrm{~K}$ wcre measured on these samples. The relatively low $T_{r}$ values can be a result of the nonstoichiometric (Nh-rich) composition, residual antisite disorder, or other types of defect structures. Ternary additions such as Sn, Pt, or Ir seem to improve the stoichiometry of the A 15 phase and a $T_{r}$ of $13 \mathrm{~K}$ was ohtained for the analyzed composition $\mathrm{Nh}_{75} \mathrm{Si}_{16} \mathrm{Sn}_{4}$.

18735. Goodwin, K. E., Schleter, J. C., Maltese, M. D. K. Diversion Path Analysis Handbook Vol. 1, Methodology: Vol. 2, Example; Vol. 3, Computer Program 1; Vol. 4, Computer Program 2, DOE HCP/D60/0-OI/I, 157 pages; $D O E$ HCP/D6010-01/2, 287 pages; DOE HCP/D6010-01/3, 194 pages; DOE HCP/D6010-01/4, 123 pages (Available from the National Technical Information Service, Springfield, VA 22161, Nov. 1978).

Kcy words: analysis; diversion of nuclear materials; diversion path analysis; material accounting; material control; nuclear material safeguards; safeguards.

Anticipating that many pcople with varying interests and backgrounds will have an interest in the Diversion Path Analysis (DPA) methodology, an cffort has been made to structure the DPA Handhook so that cach reader can best utilize those scetions which pertatin to him. The DPA Handhook, thereforc, is divided into four volumes. Volume 1 provides a description of the methodology and its implementation while Volume 2 sets forth the results and complete documentation of an example DPA. Volumes 3 and 4 provide information on two computer programs that have been written to assist in assembling and analyzing the data resulting from a DPA.

Volume I contains a hrief cxecutive summary, a chapter explaining the basic concepts hchind the DPA methodology, and a chapter which details the steps necessary to implemcnt DPA at a facility. There are also several appendices which provide additional detailed information necessary cither to understand or to implement the methodology.

Volume 1 provides, in Chapter 1 , an explanation of the DPA methodology, intended principally to scrve the needs of management. It relates: (1) the purpose of DPA: (2) the scopc of a typical analysis; (3) the type of personnel needed to perform the analysis; and (4) a general description of the five basic steps for performing an analysis. Chapter 2 contains the details of implementing the methodology. It is intended primarily for use by the DPA team and contains numerous cross references to Volume 2, the cxample DPA. This chapter gives the step-by-step procedurcs necessary to insure a thorough analysis.

Volume 2, the cxample DPA, a plutonium bar to button conversion process, illustrates typical results ohtained for a hypothetical process and dcmonstrates the type of documentation rccommended for a completed DPA. It is divided into two parts, the workpaper documentation and the summary documentation. The DPA team should give carcful attention to the cxample as it serves to answer numerous questions on the fine points of the analysis.

In Volumes 3 and 4, two computer programs are descrihed. DPA Computer Program 1 (Volume 3 ) assemhles data derived for vulnerabilities and DPA Computer Program 2 (Volume 4) provides statistics on modifications. Tahles produced by these programs assist the DPA team in establishing findings and recommendations.

It is recommended that the DPA team carcfully read and study all volumes of the DPA Handhook bcfore starting their first analysis.

18736. Wiese, W. L., Martin, G. A., Atomic transition probabilities, Section D. General Chemical in CRC Handhook of Chemistry and Physics, 59/h Edition, R. C. Weast, Ed., pp. DI 12-D140 (CRC Prcss, Inc., 2255 Palm Bcach Lakes Blvd. West Palm Beach, FL, 1978-1979),

Key words: atomic transition probabilities; clectric dipole lines; multiplets; singly ionized spcctra.

These tables were prepared under the auspices of the Committee on Line Spectra of the Elements of the National Academy of Sciences - National Research Council. They contain critically cvaluated atomic transition probabilities A for about 4000 selected lines of clements from hydrogen to nickel. The material is largely for neutral and singly ionized spcçtra, but includes a number of prominent lines of more highly charged ions.

18737. Wiese, W. L., Konjevic, N., Regularities in plasmabroadened line widths. (Proc. IX Int. Symp. on Physics of Ionized Gases, Duhrovnik, Yugoslavia, Aug. 28-Sept. 2, 1978). Paper in The Physic:s of lonized Gases, R. K. Janev, Ed.. pp. 257-260 (Institute of Physics, Beograd, Yugoslavia, 1978)

Key words: atomic spectra; nitrogen; oxygen; plasmabroadening; singly ionized oxygen: stark broadening.

Certain regularities in plasma-hroadened line widths are cxpccted on account of the atomic structure involved. A search 
for such regularities is reported, which was concentrated on those within a given spectrum. i.e., the behavior of line widths in multiplets and transition arrays. Several examples are presented, and it is shown that variations of line widths of supermultiplets follow regular patterns closely correlated with the positions of perturbing cnergy levels and the strengths of relevant interactions.

18738. Blackburn, D. L., Berning, D. W., Some effects of base current on transistor switching and reverse-bias second breakdown, (Proc. Intl. Electron Devices Meeting, Washington, DC, Dec. 4-6, 1978), Technical Digest 1978, pp. 671-675 (Institute of Electrical and Electronics Engineers, New York, NY, 1978).

Key words: device characterization; nondestructive testing; safe operating area, reverse-bias; second-breakdown, reverse-bias; transistors, power switching.

Some experimental observations of the switching characteristics and second breakdown susceptibility of high-voltage, fast-switching power transistors are discussed. A unique test circuit is described which permits devices to be taken into reverse-bias second breakdown many times with little or no apparent degradation. Evidence for the constriction of emitter current to the centers of the cmitter fingers during the time associated with the extraction of stored charge is presented, three modes of reverse-bias second breakdown are shown, and reverse-bias safe-operating-area limits which have been nondestructively determined are shown.

18739. Cuthill, J. R., Kahan, D. J., Bennett, L. H., Chafe, H D., Gray, A. G., Langer, E. L., Baker, H., Joint program of American Society for Metals and National Bureau of Standards for compilation of alloy phase diagrams, Proc. $\mathrm{V}_{t} / \mathrm{l} \mathrm{In}$ teramerican Conf. on Materials Technology, Sao Paulo, Brazil, Nov. 6-10, 1978, pp. 149-152 (Southwest Research Institute, San Antonio, TX, 1979).

Key words: alloy phase diagrams; applications; ASM/NBS data program; compilations; computer data bank; computer display.

A recent NBS Workshop revealed the need for both new as well as evaluation of existing alloy phase diagram data in solving problems in many fields of metallurgy, including a majority of the topics which this conference is addressing.

We are embarking on a program of compiling and assessing alloy phase diagram data to address these needs. The program will have four primary outputs: [1] comprehensive compilation of critically evaluated binary diagrams, [2] compilation of ternary and higher-order diagrams, [3] quarterly bulletin of provisional diagrams, and [4] on-line computer data bank of bibliographic and phase diagram data.

18740. Unassigned.

18741. Callcott, T. A., Arakawa, E. T., Ederer, D. L., The soft $x$-ray emission and absorption spectra of simple metals, (Proc. Intl. Conf. on X-Ray and XUV Spcctroscopy, Sendai, Japan, 1978), Jpn. J. Appl. Phys. 17, Suppl. 17-2, 149-153 (1978).

Key words: aluminum; beryllium; core hole lifetime; lattice relaxation; lithium; magnesium; sodium; soft $x$-ray absorption spectra; soft $x$-ray emission spectra.

The soft $x$-ray cmission and absorption spectra of simple metals provide information about transition density of states, many body effects and lattice relaxation dynamics. We find that many body effects are negligible for the $K$ spectra of lithium and beryllium, but play an important role at threshold for the $L_{2.3}$ spectra of sodium, magnesium, and aluminum. Many body threshold exponents may be derived from the data for these materials. Lattice relaxation processes are found to have an important cffect on the emission edges of sodium and lithium. The shapc width and separation of these materials have been analyzed to obtain core hole lifetimes.

18742. Sweeting, L. M., Coxon, B., Varma, R., Conformational analysis of peracetylated hexononitriles, Carhohydr. Res. 72, $43-55$ ( 1979$)$.

Key words: acyclic sugars; chemical shifts; conformation; coupling constants; hexononitriles; iterative analysis; proton nmr spcctroscopy; shift reagents.

The conformations of six peracetylated hexononitriles in solution have been investigated by Fourier-transform, proton n.m.r. spectroscopy at $90 \mathrm{MHz}$, with iterative analysis and simulation of many of the spectra. The conformation of tetra$O$-acetyl-L-arabinononitrile has been re-examined by the same methods. A shift reagent [Eu(fod) $)_{3}-d_{30}$ ] and spectra at 220 $\mathrm{MHz}$ were used to improve spectral dispersion, where necessary. For practically all of the derivatives studied, the vicinal, proton-proton coupling-constants are consistent with a zigzag conformation in which the cyano group lies in the plane of the other carbon atoms of the chain, unless this conformation contains a parallel 1,3-interaction of substituents. Other conformers that are also consistent with the coupling constants observed are discussed, including rotamers about chain-terminal, carbon-carbon bonds.

18743. Walker, J. A., Tsang, W., Thermal decomposition of hexamethylethane in a flow system, Intl. J. Chem. Kinet. XI, $867-882$ (1979).

Key words: activation cnergy; $A$-factor; comparative rate; flow system; heat of formation; hexylmethylethane; $t$-butyl radical; unimolecular decomposition.

Hexamethylethane has been decomposed in a flow system in the temperature range of $700-900 \mathrm{~K}$. The mechanism involves carbon-carbon bond cleavage at the most highly substituted position and rapid formation of isobutene from the $t$-butyl radical. The rate expression is

$$
k\left(\left({ }_{l} \mathrm{C}_{4} \mathrm{H}_{9}\right)_{2} \rightarrow 2 \ell \mathrm{C}_{4} \mathrm{H}_{9}\right)=10^{17.4} \exp (-36,000 / T) \mathrm{sec}^{-1}
$$

and is completely consistent with deductions from radical buffer, shock-tube, and direct recombination studies. Of special importance is experimental evidence for large decreases of the $A$ factor with increasing temperature and a high heat of formation for the $t$-butyl radical, $\Delta H_{\mathcal{N}}\left(t \mathrm{C}_{4} \mathrm{H}_{\mathrm{y}} \text {. }\right)_{: 000}=52.7 \pm 6 \mathrm{~kJ}$.

18744. Chwirut, D. J., Eitzen, D. G., Toward the development of improved reference fatigue cracks for use in ultrasonic nondestructive evaluation, Int. Adv. Nondestruct. Test 6, 179-197 (1979).

Key words: compact tension specimen; crack; crack, wellcharacterized; destructive evaluation; fatigue flaw evalua. tion; fracture mechanics; standards; technique development.

A rationale for the development of well-characterized fatigue cracks for use as standards for advanced ultrasonic flaw evaluation systems is presented. The primary parameters affecting the ultrasonic response from fatigue cracks are reviewed. A loading program to generate controlled cracks and to minimize the cffccts of some of these parameters is described. As determined by these techniques, measured crack lengths are accurate within a few percent. The specimens are being uscd as test objects in the development of a new tcchnique for flaw evaluation by ultrasonics, radiography, and penetrants.

18745. Earl, W. L., VanderHart, D. L., Observations in solid polyethylenes by carbon-13 nuclear magnetic resonance with 
magic angle sample spinning, Macromolecules 12, No. 4, 762 767 (July-Aug. 1979)

Key words: conformation; crystallinity; NMR; polyethylene; resolution: sample spinning; solids; 13 ,

It is shown that the "1:C NMR resonance lines of the crystalline component (CC) and the noncrystalline component (NCC) in polyethylene (PE) are chemically shifted from one another. This usually produces an upfield shoulder on the CC resonance line in a "cross-polarization with magic angle sample spinning" (CPMASS) cxpcriment. Two pcaks were resolved in a low crystallinity, high molecular weight sample, the NCC pcak being $2.36 \pm 0.1 \mathrm{ppm}$ upfield from the $\mathrm{CC}$ pcak. The chemical shift of the $\mathrm{CC}$ pcak was measured against cxternal $\mathrm{Me}_{4} \mathrm{Si}$ to be $34.06 \pm 0.26 \mathrm{ppm}$. Measurements of the chemical shifts of liquid $n-\mathrm{C}_{17} \mathrm{H}_{36}$ and cyclohexane relative to external $\mathrm{Me}_{4} \mathrm{Si}$ were also made, and the chemical shift trends are discussed in terms of trans and gauche conformational cffects on the chemical shift. Transverse relaxation times, $T_{2 r}$, were measured for various samples; the natural $T_{2 c}$ broadened full width at half-height for the CC pcak ranged from 1.00 to $26 \mathrm{~Hz}$ with a resonant proton dccoupling field, $\nu_{1 H}$, of $64 \mathrm{kHz}$. The corresponding natural line width for the NCC peak was measured to be 14 $\pm 4 \mathrm{~Hz}$, and it is presumed that this width is determined by molecular motion. The NCC pcak has a substantial line width contribution from isotropic chemical shift dispersion. The capability of the CPMASS technique for resolving closely spaced, wcak resonances was tested using a branched and a radiation cross-linked linear PE. Only methyl groups are completely resolved with a second resonance partially resolved in the cross-linked sample. It is noted that the CPMASS technique docs not yield true relative intensities for the NCC and CC resonances.

18746. Candela, G. A., Haines, R. A., A method for determining the region of superparamagnetism, Appl. Phys. Lett. 34, No. 12, 868-870 (June I5, 1979).

Key words: blocking temperature; magnetic; particles; supcrparamagnetic particles

A simple procedurc which determines the coercive force as a function of temperature has bcen developed for superparamagnetic materials having a particle-size distribution. This procedure accurately determines the region where superparamagnetism occurs, and it has been used to obtain the first cxpcrimental vcrification of the Bean-Livingston coercive-force tcmperature rclation.

18747. Atkinson, G. H., Parmenter, C. S., The $260 \mathrm{~nm}$ absorption spectrum of benzene: Vibronic analysis, J. Mol. Spectrosc. 73, $52-95$ (1978).

Key words: absorption analysis; absorption spectrum; benzenc; rotational contours of absorption bands.

The supporting details for assignment of band maxima (see paper 1) in the one-photon ${ }^{1} B_{2 u} \leftarrow{ }^{1} A_{1 \text { u }}$ absorption spectra of benzene vapor arc given. By the criteria of band separations and Franck-Condon intensities, maxima are first sorted into $\nu_{1}$ progressions (Table II). The progressions are then assigned by systematic search for allowed first-, sccond-, and third-order Hcrzberg-Teller transitions as set forth in Table 11 of Paper 11. Much attention is given to vibrational angular momentum as it affects band contours and component splittings. Over $90 \%$ of the intensity is assigned and a consistent pattern of HerzbergTeller activity is found. Both the list of modes observed to be active in vibronically inducing the transition $\left(\nu_{4}, \nu_{3}, \nu_{6}, \nu_{7}, \nu_{9}\right.$. $\left.\nu_{10}, \nu_{11}, \nu_{15}, \nu_{17}\right)$ and the relative intensities of various types of transitions found in absorptuon match well that seen in SVL fluorescence. Third-order transitions are comparatively few in number, but are cquivalent in intensity to many sccond-order transitions. Variation in the separation between progression members suggests that small (and unidentified) pcrturbations of upper state vibronic levels arc ubiquitous. Rcvised or new values of nine fundamentals in the ${ }^{1} B_{2 u}$ state and two in the ${ }^{1} A_{1}, \prime$ state are given (Table IV). Some of the cxcited and ground state anharmonic constants $\chi_{i}{ }^{\circ}, \chi_{i, i}{ }^{\prime \prime}, \chi_{i j}{ }^{\prime \prime}, g_{t, i}$, and $g_{i j}$ arc deduced for $\nu_{33}, \nu_{6}, \nu_{16}, \nu_{11}, \nu_{16}$, and $\nu_{17}$ (Table V).

18748. Cali, J. P., The role of reference materials in the analytical laboratory, Fresenius Z. Anal. Chem. No, 297, pp. 1-3 (1979)

Key words: analytical laboratory; ccrtified reference materials; measurement; mcasurement compatibility; reference materials; standard reference materials.

The importance of rcference materials (RM) in today's highly technological society is discussed with regard to their use in the analytical laboratory. How measurement compatibility is achieved through the use of RM's is shown. Formal definitions of both RM's and Certified Rcference Materials (CRM), using ISO terminology are given. Six questions are posed as a guide for the analyst considering the use of CRM's for his work. Finally, six major uses of RM's in the analytical laboratory arc outlined.

18749. Atkinson, G. H., Parmenter, C. S., The $260 \mathrm{~nm}$ absorption spectrum of benzene: Remeasured band positions and refined assignments, J. Mol. Spectrosc: 73, 20-30 (1978).

Key words: absorption analysis; absorption spcctrum; benzene.

The positions and intensities of most of the band maxima in the ${ }^{1} B_{2 u} \leftarrow{ }^{\prime} A_{1 " \text {, }}$ absorption system of benzene vapor have been remeasured at $300 \mathrm{~K}$. Particular attention has been given to the mcasurement of the positions of component maxima which are present on account of vibrational angular momentum splitting. Weak $\mathrm{O}_{2}$ absorptions included in the original listings of benzene band maxima have been identified. Assignments of the benzene maxima are given. They offer some revision and substantial extension of prcvious assignments. The general basis and specific details of assignments are given in papers II and III.

18750. Atkinson, G. H., Parmenter, C. S., The $260 \mathrm{~nm}$ absorption spectrum of benzene: Selection rules and band contours of vibrational angular momentum components, J. Mol. Specirosc. 73, 31-51 (1978).

Key words: absorption selection rules; benzene; HcrzbergTcller theory; rotational contours of absorption bands; vibrational angular momentum.

The role of vibrational degencracies and vibrational angular momcntum in the $260 \mathrm{~nm}$ absorption spectrum of benzene is further examined. Degcnerate Herzberg-Teller terms are set down through third order with specific identification of vibrational symmetries capable of inducing itensities (Table II). These terms provide a basis for predicting the $\Delta \pi$ sclection rules, the signed vibrational angular momentum selection rules, and the vibrational angular momentum component cnergy splittings for all vibronic transitions. A ncw parameter, $\chi$, is developed which can be used to predict the rotational band contour of any vibronic component transition. These developments underlie the systematic reexamination of assignments which is given in Paper 1 Il of this series.

\section{Unassigned.}

18752. Ackcrson, B. J., Hanley, H J. M., Transport properties of a binary mixture at the gas-liquid critical point, $A m$. Phys. Soc. Bull. 23, 315 (1978). 
Key words: binary mixture at the gas-liquid critical point; gas-liquid critical point: Rayleigh light scattering.

Experimental Rayleigh light scattering mcasurements were made on a $70 \%$ (molar) methane-30\% cthane mixture close to the gas-liquid critical point. The rate of decay for both concentration and entropy fluctuations were determined together with the critical temperature, eritical pressure and the dielectric constant. The decay rate of the concentration fluctuations showed anomalous behavior similar to that found at a consolute point, as expected. The dccay rate of the entropy tluctuations, however, appeared well-behaved or, at most. weakly anomalous. A one-fluid model was used to estimate quantitatively the decay rate (thermal diffusivity) for the entropy fluctuations. Agrement between theory and experiment is excellent

1875.3. Anderson, R. C., Henry, R. C. Moos, H. W., Linsky, J. L.. Ultraviolet observations of cool stars. VIII. Interstellar matter toward procyon, Astrophyx. J. 226, No. 3, 883-887 (Dec. 15, 1978).

Key words: deuterium; interstellar medium: Lyman-alpha.

The profile of the chromospheric $L \alpha$ emission line of the F5 lV-V star Procyon ( $\alpha \mathrm{CMi}, d=3.5 \mathrm{pc}$ ) has been measured using the high-resolution Princeton spectrometer aboard NASA : Copernicus satellite. L $\alpha$ absorption lines of interstellar deuterium and hydrogen are distinctly present. The average number density of interstellar hydrogen along the line of sight is found to be $0.11 \pm 0.02 \mathrm{~cm}^{-3}$, similar to the densities that have been found in the directions of the stars $\epsilon$ Eri, $\epsilon$ lnd, and $\alpha$ Cen A. These stars are all within $3.5 \mathrm{pc}$ of the Earth. The ratio of deuterium to hydrogen in the direction of Procyon is found to be $1.3(+1.2,-0.5) \times 10^{-5}$.

18754. Anderson, R. J. M., Kohler, B. E., Stevenson, J. M., The effects of strong excitation-phonon coupling on mixed crystal spectra: Diphenylmethylene in benzophenone, J. Chem. Phys. 71, No. 4, 1559-1563 (Aug. 15, 1979).

Key words: diphenylmethylene; lineshape; low temperature; mixed crystal optical spectra.

We present low temperature absorption and emission spectra of diphenylmethylene in benzophenone. Although the spectra are broad at temperatures greater than $\sim 20 \mathrm{~K}$, considerable structure appears at lower temperatures. The spectra and their temperature dependence arc readily explained by a large excitation-phonon coupling which is expected for this type of mixed-crystal system.

18755. Armstrong. G. T. King, R. C., Fluorine flame calorimetry. Chapter 15 in Combustion Calorimetry, S. Sunner, M. Mănssion, Eds.. 1, 333-359 (Pergamon Press, Oxford. England, 1979).

Key words: calorimetry, gas flow; chlorine thermochemistry: flame calorimetry; fluorinaceous; oxidizer; thermochemistry of fluorine compounds.

Procedures and instruments for fluorine flame calorimetry are reviewed in their application to thermochemical measuremonts. Gaseous fluorine and fluorinaceous oxidizers are made to react with a reducer (often hydrogen) in a constant pressure flame in a calorimetric reaction vessel and the products are effluent as gases in the one-phase procedure. In the two-phase procedure gaseous products are dissolved in water to form aqueous hydrofluoric acid or other hydrohalic acid solutions depending on the composition of the oxidizer.

Inaccuracies in the method amount to about 0.1 percent, with the largest contribution to the uncertainty being unidentified corrosion reactions involving the metals of the reaction vessels. The method has been applied successfully to establishing the enthalpy of formation of aqueous hydrofluoric and hydrochloric acids, three chlorine fluorides, trifluoramine oxide, oxygen difluoride and other fluorinaceous substances.

18756. Bcrtocci, U., Mullen, J. L., Corrosion induced by an alternating voltage. A comparison between theoretical predictions and experimental results. (Proc. Int. Corrosion Forum Devoted Exclusively to the Protection and Performance of Materials, Atlanta, GA, Mar. 12-16, 1979), Paper 242 in Corrosion/79, pp. 242/1-242/11 (NACE. Publications Dept., P.O. Box 986, Katy, TX, 1979 ).

Key words: alternating current; alternating voltage; comparison between theoretical and experimental results; copper; corrosion; hydrogen evolution.

After summarizing the theoretical predictions for the current response to an alternating voltage of an electrode under charge-transfer control, the experimental results obtained for the hydrogen evolution reaction on a copper electrode are reported. The results show that the current-potential curves obtained for the d.c. component of the current as well as some of the harmonic components of the periodic current are in good agreement with the values calculated from the theoretical model. The predictions concerning the cffect of varying the modulating signal amplitude and frequency are also verified experimentally. The experimental results begin to deviate from the predicted ones when the amplitude exceeds thc potential range where only charge-transfer is significant, and when the ohmic drop resistance becomes large with respect to the other circuit elements.

18757. Buehler, M. G., Limitations and applications of the dc MOSFET dopant profile method, (Proc. Topical Conf. on Characterization Techniques for Semiconductor Materials and Devices, Seattle, WA. May 1978), Paper in Semiconductor Characterization Techniques, P. A. Barnes, G. A. Rozgonyi, Eds., 78-3, 241-252 (The Electrochemical Society, Inc., Princeton, NJ, 1978).

Key words: electrical measurements; profiles; semiconductors; sílicon.

Dopant profiles can be determined from dc measurements on a four-terminal surface-channel MOSFET. The region from about three Debye lengths from the oxide-silicon interface to a maximum depth, limited by the avalanche breakdown in silicon, can be profiled by this method. Within three Debye lengths of the surface, the depletion approximation fails, and in this region the profile has a characteristic dip $\mathrm{w}$.hich is easily recognized. Other limitations include effects due to the field dependence of the channel mobility, short channel effects, and the lack of parallelism of the depletion edge with the interface. The method is illustrated by dopant profiles of bulk wafers, implanted layers, and a diffused laycr. The dopant densities covered by these profiles vary from $6 \times 10^{14} \mathrm{~cm}^{-3}$ to $2 \times 10^{14}$ $\mathrm{cm}^{-3}$.

18758. Cahn, J. W., Balluffi, R. W., On diffusional mass transport in polycrystals containing stationary or migrating grain boundaries, Scr. Metall. 13, No. 6, 499-502 (1979).

Key words: diffusion; grain boundaries; Harrison classification; lattice diffusion; migrating boundaries; polycrystals; thin films.

Mass transport in polycrystalline materials is classified according to whether grain boundaries are stationary or not, whether there is time for lattice diffusion and whether there is time for multiple interactions between diffusing species and grain boundaries. 
18759. Cahn, J. W., Pan, J. D., Ballufti, R. W.. Diffusion induced grain boundary migration, Sir. Mo'lall, 13, No, 6, 503$5(19(1979)$.

Key words: diffusion; grain houndaries: Harrison classification; lattice diffusion; migrating houndaries; polycrystals; thin films.

Diffusion induced grain houndary migration had been ohserved in three systems. The results in three additional systems are reported, suggesting that this may be a widespread phenomenon for low tcmpcrature diffusion. The theoretical problems posed by the observations are discussed.

18760. Carpcnter, R. J., Sokol, J., Jr., Rosenthal, R., A microprocessor-based local network node, (Proc. Seventeenth IEEE Computer Society Int. Conf. COMPCON Fall 78, Washington, DC, Sept. 5-8, 1978), IEEE Caralog $\mathrm{No} .78 \mathrm{CH}$ 1388-8C, pp. 104-110) (Institute of Electrical and Electronics Engincers, Inc., New York, NY, 1978).

Key words: hroadcast; coaxial; communication; contention; data; digital; cthernet; local; microprocessor; network; serial.

Along with the growth and development of national and international computer networks, there has been a more recent parallel growth in the field of local area networks. Background is given on a time division multiple access cahle local network with adaptive resource allocation through a fully distributed contention-type control system. There is no central control cquipment. Details arc given on the microprocessor-based node which allows a wide variety of terminals, microprocessors, minicomputers, and larger mainframes on one campus or in a building complex to be fully interconnected by a common coaxial cahle. The node or Terminal Interface Equipment (TIE) is partitioned to allow cfficient modular expansion for single or multiple-user network connection. Provision is made for data encryption where required.

18761. Cavallo, L. M., Golas, D. B., Mann, W. B., The traceability program for radiopharmaceuticals at the United States National Bureau of Standards, A. N. Z. Nuclear Medicine Newsletter, pp. 15-16 (1979).

Key words: radioactivity; radiopharmaceuticals; traceahility.

Through various Acts of Congress and Rules and Regulations pcrtaining thereto, the nuclear industry in the United States is required to conduct its operations in such a manner that its measurements are in reasonable conformity with the standards of radioactivity maintained by the National Bureau of Standards (NBS).

18762. Clark, A. F., Ekin, J. W., Radebaugh, R., Read, D. T., The development of standards for practical superconductors, IEEE Trans. Mag. 15, No. 1, 224-227 (Jan. 1979).

Key words: critical current; definitions of tcrms; measurement techniques; standards; superconductors.

The program to develop standard measurement practices for practical superconductors includes the generation of uniform definitions of terms, the development of standard measurement techniques, and comparisons of these measurements using standard refercnce materials. The initial sets of definitions have heen published and their development will be described. Responses will be solicited on terms whose definitions are still in development or are controversial. The progress in the development of standard mcasurement techniques for critical current, transient losses and critical temperature will bc discussed. The different techniqes will be compared and the ex- perimental parameters which must be carefully controlled will be enumerated.

18763. Collings, E. W., Ledhetter, H. M.. Sound velocity anomalies near the spin glass trnsition in an austenitic stainless steel alloy, Phys, Lelt. 72A, No. I, 53-56 (June II. 19791 .

Key words: Dehye temperature; iron alloy; magnetic susceptihility; spin-glass. sound velocity.

A cusp in the magnetic susceptibility temperature dependence of a commercial manganese austenitic stainless steel alloy, attributable to spin-glass condensation, is accompanied by anomalies in the temperature dependences of both longitudinal and transverse ultrasonic wave velocities.

18764. Coxon, B., Hough, L., Revision, by proton, carbon-13, and nitrogen-15 n.m.r. spectroscopy, of the structure assigned a bis(hexopyranosyl)-amine derivative, Carhollydr. Res. 73 , 47.57 (1979).

Key words: bis(hexopyranosyl)amine; carhon-13; conformational analysis; nitrogen-15 coupling constants; nitrogen15 n.m.r. spectroscopy; proton; proton coupling; structural analysis.

Structural analysis of the acetylated, minor product of the reaction of methyl 2,3-anhydro-4,6- $\mathrm{O}$-henzylidene- $\alpha$-D-mannopyranoside with ammonia by high-field proton- and ${ }^{1: C} \mathrm{C}$ n.m.r. spectroscopy, and also ${ }^{15}$ N-n.m.r. spectroscopy, has shown that this acetyl derivative is bis(methyl 2-O-acetyl-4.6$O$-henzylidene-3-deoxy- $\alpha$-D-altropyranosid-3-yl)amine, and not the $N$-acetyl derivative reported previously. The configuration and conformation of the bis(altropyranosid-3-yl)amine derivative have been determined, and its unusually large $J_{15.1 /}$ coupling constant is discussed.

18765. Crissman, J. M., Zapas, L. J., Creep failure and fracture of polyethylene in uniaxial extension, Polym. Eng. Sci. 19, No. 2, 99-103 (Mid-Feb. 1979).

Key words: additivity of damage; cold drawn; crack growth: fracture; molecular weight distrihution; necking: polyethylene; uniaxial creep.

It is shown that under conditions of uniaxial creep the fracture of high density polyethylene can be categorized as one of three types, depending upon the magnitude of the applied load, molecular architecture, and environment. When subjected to relatively large loads, the specimens nech and then fracture almost immediately. At the other extreme of very small initial loadings, the specimens fracture in a brittle fashion through crack formation and growth. In the intermediate range of loadings the specimens neck and, depending upon the molecular weight and molecular weight distribution, may then elongate substantially before fracture. It is shown that the uniaxial creep behavior for the region where drawing occurs, when plotted in terms of isochrones, represents a type of phase diagram, one boundary of which descrihes the fracture envelope. In addition. expcriments employing different constant rate of loading histories are described and an addivitiy of damage criterion used to predict the time to failure under constant load conditions, and vice versa.

18766. Crissman, J M.. Zapas, L. J., Lifetime behavior of polyethylene bars in uniaxial extension in various chemical environments. (Proc. Symp. 176th Meeting of the American Chemical Society. Miami, FL, Sept. 11-14, 1978), ACS Simp. Series 95. Durability of Macrumolectular Materials. R. K. Eby, Ed., Paper 20, 289-299 (American Chemical Society, Washington, DC, 1979). 
Key words: crack growth: failure; polycthylene; solvent: stress-cracking agent; uniaxial creep

The uniaxial creep behavior of linear and branched polyethylene is examined in the presence of various environments. It is demonstrated that it is possible to use either a solvent or surface active type of stress-cracking agent as a means of accelerating fracture. In the case of a surface active stresscracking agent a superposition principle has been applied in order to separate out one mechanism, that arising from bond rupture and erack formation. A proper description of this mechanism should be valuable as a means of predicting long time behavior under conditions where the applied load may be very small.

18767. Crissman, J. M., Zapas, L. J., Mechanical behavior of a highly oriented polyethylene rod, J. Polym. Sci. 15, 16851693 (1977).

Key words: dynamic mechanical; high pressure cxtrusion; oriented polyethylene; relaxation process; stress relaxation; torsion pendulum.

Dynamic mechanical and single step stress relaxation data are presented for a highly oriented linear polyethylene rod as produced by a high pressure extrusion technique. The results indicate that both major relaxation processes normally observed in unoriented polyethylene are virtually absent in torsion, whereas they are present in flexure. Stress relaxation in torsion data show a very highly nonlinear behavior when compared to similar data for an unoricnted polyethylene rod.

18768. Cummings, A. L., Coxon, B., Layer, H. P., Hocken, R. J., Improved $100^{\circ} \mathrm{S}$ point and pol, Proc, 1978 Technical Session on Cane Sugar Refining Research, Washington, DC, Sept. 17-19,1978, pp. 191-204 (U.S. Dept. of Agriculture, P.O. Box 19687, New Orleans, LA, 1979).

Key words: laser application; pol; polarimetry; saccharimetry; sugar analysis; sugar scale; wavelength.

A newly constructed polarimeter, and highly purified suerose were used to redetermine the hundred degree point of the saccharimeter scale at $546 \mathrm{~nm}$ wavelength. The rcsult differs from previously reported results by 140 to $500 \mathrm{ppm}$. In addition to the low pressure mercury discharge lamp, lasers at 546 $\mathrm{nm}$ and $633 \mathrm{~nm}$ wavelengths have been advantageously employed as polarimeter light sources. Lasers improved the sensitivity, accuracy and reproducibility of measurements and decreased the measurement time. These and related investigations open the door to future improvements in the determination of the pol of technical sugars.

18769. Danos, M., Gillet, V., Relativistic field theory of nuclei, Chapter 21 in Me'sons in Nuclei, M. Rho, D. Wilkinson, Eds., III, 841-865 (North-Holland Publ. Co., Amsterdam, The Netherlands, 1979).

Key words: composite system; ficld quantization; interacting quantum fields; relativistic field theory; relativistic hamiltonian; relativistic stationary states.

The concepts and basic principles needed in a fully relativistic description of the stationary states of composite systems in quantum field theory are given. Their connection with the more common time-dependent interaction picture treatment are elucidated. Also, as illustration, some of the $\mathrm{cx}-$ pressions encountered in the actual performance of the calculations are derived in detail.

18770. Jenkins, J. P., Hill, J. E., Testing of water-heating collectors according to ASHRAE Standard 93-77, (Proc. Int. Solar Energy Society 1978 Meeting, New Dclhi, India, Jan. 16-21,
1978). Paper in SUN: Mankind's Future Source of Energy, F deWinter, M. Cox, Eds., 2, $1021-1028$ (Pergamon Prcss, New York, NY, 1978).

Key words: ASHRAE Standard 93-77; solar collectors; water-hcating collectors.

A proposed procedure for testing and rating solar collectors was published by the National Bureau of Standards (NBS) in 1974. In carly 1977, the American Society of Heating, Refrigerating and Air-Conditioning Engineers (ASHRAE) adopted ASHRAE Standard 93-77 which is a modified version of the NBS procedure. A tcst facility for water-heating colleetors has been built at NBS in accordance with this Standard. The purpose of this paper is to briefly explain the recently adopted test procedure, describe the NBS test facility, and to give typical test results for collectors commercially available in the United States.

18771. Kasen, M. B., High-pressure industrial laminates for cryogenic applications, Compos. Tech. Rev. Research Briefs, 1 , No. 3, 17 (1979).

Key words: eryogenics; glass-epoxy; industrial laminates; mechanical properties; physical properties; radiation properties.

A research brief describing NBS/industry efforts to provide industry with a commercial source of high-pressure industrial laminates having predictable mcchanical and physical properties at eryogenic temperatures.

18772. Kranbuehl, D. E., Verdier, P. H., Simulation of the relaxation of random-coil polymer chains by lattice models with excluded volume: The effect of bead movement rules, $J$. Chem. Phys. 71, No. 6, 2662-2670 (Sept. 15, 1979)

Key words: computer simulation; end-to-end length; entanglement effects; excluded volume cffects; lattice-model polymer chains; polymer chain dynamics; random-coil polymer chains; relaxation times; self-entanglement effeets.

Earlier work showed that excluded volume constraints lengthen the long relaxation times of lattice-model polymer chains using single-bead elementary motions by a factor proportional to about the first power of chain length. This paper reports the extension of this work to chains employing doublebead clementary motions and to chains $\mathrm{cm}$ ploying random mixtures of both kinds of motion. For pure two-bead motion, the chain-length dependence of the lengthening of rclaxation time is essentially identical with that previously obtained for pure single-bead motion. For models using both kinds of move, this chain-length dependence is suppressed at shorter chain lengths. However, for ehains longer than about 30 beads, contrary to the prediction of Deutch and others, the lengthening of the relaxation time by excluded volume again becomes proportional to about the first power of chain length. Other studies that have not exhibited this first power dependence have cither examined relaxation from highly nonequilibrium configurations or have not cmployed sufficiently long chains for the effect to be observed

18773. Geist, J., Lind. M. A., Schaefer, A. R., Zalewski, E. F. A laser based characterization facility for silicon photocell studies, Proc. Workshop Terrestrial Phomowoltaic Measurements-11, Baton Rouge, LA, Nov. 10-12. 1976, pp. 223-231 (Available as NASA CP-2010 from the National Tcchnical Information Service, Springfield, VA, 1976).

Key words: absolute radiometry; detector; electrically calibrated detectors; laser power measurements: pyroelectric detectors; radiometry: silicon cell: silicon detector; silicon photodetector. 
A laser-based facil, 'ty for characterization of photocells, and some studies performed on it are described with cmphasis towards results of the greatest interest to the silicon solar cell community.

18774. Geist, J., Lind, M. A., Schaefer, A. R., Zalewski, E. F., A new approach to spectral radiometry based on opto-electronics, Proc. $7 \mathrm{l} h \mathrm{Im}$. Sump. of the Technical Committee on Photon-Detectors, Braunschweig, Federal Republic of Germany, May 17-21, 1976, pp. 149-167 (1976).

Key words: absolute radiometry; detector; clectrically calibrated detectors: laser power measurements; pyroelectric detectors; radiometry; silicon cell; silicon detector; silicon photodetector.

Progress in developing a new approach to radiometry based on electro-optical technology is discussed. A feasibility experiment that demonstrates and motivates the new approach is described. The laser-based, characterization facility that plays a central role in the new approach, including the clectrically calibrated pyroelectric radiometer that provides the absolute radiant power measurements, and recent investigations of silicon photovoltaic detectors that were performed on the facility arc all described Alternatives for extending the wavelength range of the new approach are also discussed.

18775. Haynes, W. M., McCarty, R. D., The density of liquefied natural gas, Proce. 58th Gas Processors Association Ann. Conventien, Denver, CO, Mar. 19-21, 1979, pp. 10-16 (Gas Processors Assoc, Tulsa, OK, 1979).

Key words: comparisons; correlation; custody transfer; density; experimental; extended corresponding states method; hard sphere model; Klosek-McKinley method; liquefied natural gas ( $L N G$ ); magnctic suspension densimeter.

A project has been carried out at the National Bureau of Standards to provide a means for the accurate determination of the density of liquefied natural gas (LNG) that would serve as a basis for equitable custody transfer of this valuable commodity.

A magnetic suspension densimeter was used to obtain a consistent set of density data for LNG components and their mixtures with a total uncertainty in density of less than $0.1 \%$. These data were used to opímize and test mathematical models for LNG density calculations. A description of the apparatus, data, uncertainties, experimental procedures, etc., is presented here.

Three mathematical models for the calculation of LNG densities have been optimized, tested, and compared. These models are an extended corresponding states model, a hard sphere model, and an empirical model due to Klosek and McKinley

It is believed that the final objective of this project, which was to produce one or more mathematical models that could be used to predict the density of a given LNG within $0.1 \%$ of its true value from an input of pressure, temperature, and composition, has been achieved

18776. Hord, J., How safe is hydrogen?, Proc. Hydrogen for Energy Distribuion Symp., Chicagen, IL, July 24-28, 1978, pp. 613-643 (Institute of Gas Technology, Chicago, IL, Jan. $1979)$.

Key words: cxplosion; fire, hydrogen; procedures; regulations; research needs; safety; standards.

Just mention hydrogen and the subject of safety will arise. In this symposium, the safety features of hydrogen are systematically reviewed and compared with those of methane and gasoline. Intercomparisons with coriventional fuels are necessary for us to assess the relative safety of hydrogen fuel. The degrec or extent of fuel hazards and damage potenial are not easily expressed in indisputable terms; therefore, technical data are usually tompered with experienced judgment to evaluate the relative safety of different fuels. Thus, the safety history of each fuel in varied applications, as well as the experience of cach safety analyst will influence safety judgments. Obviously, hydrogen can be safer than conventional fuels in some applications and more hazardous in other applications, and controversies over the rclative safety of fucls will always exist.

The fire characteristics of hydrogen, methane and gasoline are different but do not substantially favor any one of these fuels; however, the risks due to fuel-air explosions in confined spaces are greatest for hydrogen. Gasoline appears to be the casiest and pcrhaps the safest fuel w storc because of its lower volatility and narrower flammable and detonable limits. All three fuels are safely stored and used in industry today.

The basic technical data, available to the safety analyst, will be reviewed in this symposium. In addition, practical procedures, guidelines, standards, and regulations (applicable to the handling, storage and distribution of hydrogen) will be presented. Analyzical and experimental research needs, relative to hydrogen safety, arc defined and a state-of-the-art summary of hydrogen safety is given.

Specifically, the following aspects of hydrogen safety will be addressed: safety procedures (handling, combustible gas detectors, $H_{2}$ fire detectors, etc.); physical, chemical and combustion properties; leakage characteristics (flow mode, diffusion, buoyancy); ignition sources (weak and strong); fire and explosion hazards (fireball size and duration, thermal radiation, explosive potential, vapor cloud yields, overpressure, shrapnel, hazard summary charts), and mandatory and voluntary codes.

18777. Jeffery, S., Fife, D., Deutsch, D., Sockut, G., Architectural considerations for federal database standards, (Proc. Eightcenth IEEE Computer Society Int. Conf. COMPCON Spring 79, San Francisco, CA, Feb. 26-Mar. 1, 1979), IEEE Catalsg No, 79 CH/393-8C, pp. 139-143 (Institute of Electrical and Electronics Engineers, Inc., New York, NY, 1979).

Key words: database management; standardization

Planning is underway for federal government-wide standardization of database management systcms (DBMS). This paper discusses the objectives of database management standardization, and basic considerations in developing federal standards in this field. After a brief review of the current possibilities for standards, the opportunities for near-term NBS action are described. The paper indicates specific studies NBS is planning.

18778. Didion, D. A., New testíng and rating procedures for seasonal periformance of heat pumps, Proc. Carrier litt. Symp. on Heat Punps and Space Conditioning in the 1990's, Syracuse, NY, Feb, 2-3, 1979, pp. $37-47$ (Carrier Corp. Syracuse, NY, Sept. 1979)

Key words: heat pumps: part-load evaluation; standards for hcat pumps; testing procedures for heat pumps

Current testing and rating procedures for heat pumps have served industry and the consumer well for many years. These steady-state (SS) full-load evaluation procedures allow for the capacity detcrmination ncedcd for sizing the unit to the building loads. They also serve as an efficiency cvaluation for comparing the relative merits of various units. However, with the need for energy conservation, and with increasing cncrgy costs. buildings and their cquipment have come to requirc a lifecycle-cost analysis instead of the traditional first-cost approach. In order to provide a better estimate of operational costs, the hcat pump industry needs a more comprehensive evaluation technique to obtain data during part-load, cyclic operation. Although the wide vartety of types of heat-pump installations 
and climates makes field performance impractical as a basis for this cost analysis, laboratory part-load simulation can increase the input for a reasonable investment.

Part-load laboratory evaluation offers two added benefits; a more accurate estimate of energy usage on an absolute basis, hence a better comparison between heat pumps and other equipment, needed at least for the heating mode; and encouragement to manufacturers to develop a more efficient product, since they can get more credit for their innovations.

18779. Eisenhower, E. H., Report of the National Bureau of Standards' survey of state measurement needs, (Proc. 9th Ann. Nat. Conf. on Radiation Control-Mecting Today's Challenges, Scattle, WA, June 19-23, 1977), HEW Publication (FDA) 78-8054, pp. $117-126$ (U.S. Department of Health. Education, and Welfare, Public Health Scrvice, Food and Drug Administration, Bureau of Radiological Health, Rockville, MD, Apr. 1978).

Key words: calibrations; measurements; radiation; radiation control; radiation measurcments; radiation protection; radiation safety; standards; states.

This paper presents a summary of the results of an NBS survey of radiation measurement needs and capabilities in state radiation control programs. The survey was funded by Congress in fiscal year 1975. Survey mechanisms consisted of a questionnaire and on-site visits to 16 state programs. The questionnaire was distributed to all 58 members of the Conference of Radiation Control Program Directors, of which 38 responded. Some impressions received during the visits are presented. Responses to some of the more significant qucstions asked in the questionnaire are summarized. State needs as pcrceived by a task force of state personnel are also presented, in the form of recommendations for action. A limited NBS program which has been initiated in response to the discovered needs is described. Questions and problems which require further consideration are identified

18780. Ekin, J. W., Strain dependence of the critical current and critical field in multifilamentary $\mathrm{Nb}_{3} \mathrm{Sn}$ composites, $I E E E$ Trans. Magn. 15, No. 1, 197-200 (Jan. 1979).

Key words: critical-current; critical-field; degradation; multifilamentary strain; $\mathrm{Nb}_{3} \mathrm{Sn}$; stress; superconductor

High-J. multifilamentary $\mathrm{Nb}_{3} \mathrm{Sn}$ superconductors with widely varying amounts of prestrain and critical field values can be characterized fairly accurately by a single normalized critical field-strain relationship. Such is relationship permits first order prediction of critical-current dcgradation at arbitrary magnetic ficld magnitudes knowing only two parameters for any conductor, the prestrain and the maximum critical field. Some of the conductor-fabrication factors affecting the paramcters are considered.

18781. Ekin, J, W., Braginski, A. 1.. Effect of strain on the critical current of $\mathrm{Nb}_{3} \mathrm{Ge}$, IEEE Trans. Magn. 15, No. I, 509-51। (Jan. 1979),

Key words: critical-current; degradation: $\mathrm{Nb}_{3} \mathrm{Ge}$; strain; stress; supcrconductor

The strain dependence of the critical-current density has been determined for compositc tapes of $\mathrm{Nb}_{3} \mathrm{Ge}$ prepared by chemical vapor deposition. For $\mathrm{Nb}_{3}$ Ge layers 3-4 $\mu \mathrm{m}$ thick deposited on a nickcl-molybdenum-iron alloy substrate, the critical current monotonically increases when uniaxially strained to about $0.6 \%$. This strain corresponds almost exactly to the compressive strain that would be introduced into the $\mathrm{Nb}_{3} \mathrm{Ge}$ by the substratc due to thermal contraction during cooldown after reaction. The increase in critical current was relatively small, about $61 / 2 \%$ at $7 \mathrm{~T}$ and $51 / 2 \%$ at $4 \mathrm{~T}$. At higher
Tain, the critical current decreased rapidly, falling by more than $50 \%$ at a strain of $10.9 \%$, for cxample. For $\mathrm{Nb}_{3} \mathrm{Gc}$ deposited on a tantalum substrate, however, the critical current monotonically decreased, falling by more than $50 \%$ at a strain of $0.4 \%$. The results indicate that $\mathrm{Nb}_{3} \mathrm{Gc}$ can withstand considerable compressive strain (at least $0.6 \%$ ), but fractures at tensile strains of only $0.1 \mathrm{to}(0.2 \%$

18782. Epstein, G. L., Reader, J., Spectrum and energy levels of triply ionized lanthanum (La IV), J. Opt. Sisc. Am. 69, No. 4. 511-520 (Aрr. 1979).

Key words: energy levels; lanthanum; spectra; spectroscopy; triply-ionized; ultraviolet; wavelengths.

The spectrum of La IV has been observed in a sliding spark discharge with the NBS 10.7-m normal incidence vacuum spectrograph and the NBS $10.7-\mathrm{m}$ Eagle spectrograph in air. A total of 368 lines have been observed in the region from 300 to $5000 \AA$. About 190 lines have been classified as transitions between 49 energy levels. All levels of the $5 p^{6}, 5 p^{5} 5 d, 6 s, 6 d$, and $7 s$ configurations as well as half of the levels of the $5 p^{5} 4 f$ configuration have been located. Because of the greatly contracted $4 f$ orbital, the lowest cxcited configuration is $5 p^{5} 4 f$. All configurations have been theoretically interpreted. The cnergy parameters detcrmined from least-squares fits to the observed levels are compared with Hartree-Fock calculations. Some new measurements for La 111 are presented that confirm the 1967 results of Odasbasi.

18783. Epstein, M. S., Zander, A. T., Direct determination of barium in sea and estuarine water by graphite furnace atomic spectrometry, Anal. Chem. 51, No. 7,915-918 (June 1979).

Key words: atomic absorption; atomic emission; barium; graphite furnace; seawater; wavelength modulation.

Seawater samples from the Gulf of Alaska and estuarine water samples from the York River in Virginia near the Chesapcake Bay are directly analyzed for barium concentration using graphite furnace atomic emission spectrometry. The accuracy of the method is cvaluated by a correlation of results with data from analyses using line source and wavelength-modulation continuum-source atomic absorption spectrometry and graphite furnace atomization, as well as the analysis of a standard reference water sample. Interferences in the analysis and techniques used to overcome them are discussed.

18784. Stahl, F. 1., Conway, D., Goglia, M. R., Muman behavioral considerations in the planning and design of passive solar systems for commercial facilities: An exploratory study of the effects of sun and shade, Proc. $4 t h$ National Passive Solar Conference, Kansas Cily, MO, Ocl. 3-5, 1979, pp 26-29 (Oct. 1979).

Kcy words: cnvironmental psychology; field methodology; passive solar systems; pedestrian behavior; psychology of retailing; retail facilities.

An exploratory study was conducted to determine whether alterations in sun and shad̄e patterns (which may result from certain passive solar retrofit designs) influence windowshopping and other behaviors on rctail streets. Pedestrians werc observed at two urban locations. The hypothesis that in cool weather pedestrians prefer the sunny (rather than shady) side of retail streets was partially supported by the data. The hypothesis that durations of window-shopping and other relevant behaviors would be greater on the sunny side was not supported.

18785. Flynn, D. R., Regulation of new products noise emission, Chapter 41 in Handbook of Noise Control, 2d Edition, pp 41-1-41-8 (McGraw-Hill Inc., Ncw York. N): Jan. 1979). 
Key words: acoustics; environmental noise; noise; noise emission; regulations; sound.

This publication is a short book chapter for The Handbook of Noise Control, Second Edition (McGraw-Hill). A description is given of existing and pending Federal regulations on the noise emission from new products.

18786. Birnbaum, G., Bose, T. K., Comparison of dielectric and refractive virial coefficients and collision induced absorption bands, J. Chem. Phys. 71, No. 1, 17-19 (July 1, 1979).

Key words: $\mathrm{CH}_{4}$; collision induced bands; $\mathrm{CO}_{2} ; \mathrm{C}_{2} \mathrm{H}_{4}$; dielectric virial coefficients; refractive virial coefficients; $\mathrm{SF}_{i \mathrm{i}}$.

The second dielectric virial coefficient minus the second refractive virial coefficient is equal to the Kramers-Kroning contributions arising from the far-infrared and infrared pressure induced absorption bands due to bimolecular interactions. The usefulness in comparing such results is illustrated for $\mathrm{CO}_{2}$, $\mathrm{C}_{2} \mathrm{H}_{4}, \mathrm{CH}_{4}$, and $\mathrm{SF}_{63}$. It is shown that for $\mathrm{SF}_{6}$ there may be as yct unmeasured collision induced bands and for $\mathrm{C}_{2} \overrightarrow{\mathrm{H}}_{4}$ the farinfrared collision induced absorption is anomalously large.

18787. Farmer, B. L., Eby, R. K., Energetics of methyl branches in hydrocarbon crystals, Polym. 20, 363-366 (Mar. 1979).

Key words: calculations; ccll dimensions; crystal; defect; encrgy; hydrocarbon; methyl-branch; structure

Semi-empirical energy calculations are reported for methyl branched hydrocarbon molecules in orthorhombic and monoclinic crystalline arrays of linear molecules. The 19 molecules in the array are flexible and twenty methylene units long. Two modes of packing the defect molecule in the crystals are found and for each the mechanical relaxation criterion of there being two or more sites available to the molecule is met. However, there is no significant relaxation strength because the differences in site cnergies are too large. This results for all cases because the unfavorable orientation of the molecular stem in one of the sites makes the energy too much greater than in the other site which has a favorable orientation. The defect energies show that methyl branches could be incorporated in the crystals in at least one of the cases. For that case, the unit cell dimensions are comparable to those found experimentally for the same methyl group concentration. Drawings showing the molecular distortion are presented.

18788. Feinberg, R. B., Characterization of incidence algebras, Discrete Math. 17, 47-70 (1977).

Key words: coalgebra; direct limit; faithful distributive module; generating function; incidence algebra; inverse limit; orthogonal idempotents; quasi-order; topological algebra.

We develop an internal characterization of the incidence algebra of a lower finite quasi-ordered set and dualize it to obtain a characterization of the corresponding coalgebra. The algebra characterization consists of (wo axioms concerning the homomorphic images of the algebra and another axiom stipulating the cxistence of a faithful module over the algebra which has a distributive lattice of submodules.

18789. Feinberg, R. B., Faithful distributive modules over incidence algebras, Pac, J. Marh. 65, No. 1, 35-45 (1976).

Key words: autimorphism; cyclic module; faithful distributive module; incidence algebra; multiplicative function; quasi-ordered set; topological algcbra.

Let $Q$ be a lower finite quasi-ordered set and let $I(Q)$ be the incidence algebra of $Q$ over a field $K$, In this paper we deter- mine all faithful distributive modules over $/(Q)$ and relate the result to the structure of the outer automorphism group of the algebra. In the case when () is finite we also determine all left ideals $L$ of $I(Q)$ such that $/\left(Q_{2} /(Q) / L\right.$ is a faithful distributive module over $I(Q)$.

18790). Fiori, C. E.. Newbury, D. E., Artifacts observed in energy-dispersive $x$-ray spectrometry in the scanning electron microscopy, (Proc. I th Annual Scanning Electron Microscopy Conf.. Los Angeles, CA, Apr. 17-21, 1978), Scanning Electron Microsc. I, 401-422 (1978).

Key words: artifacts; clcctron probe microanalysis; energydispersive $\mathrm{x}$-ray spectrometry; microanalysis; qualitative analysis; scanning electron microscope.

X-ray spectra obtained with a lithium-drifted silicon detector attached to a scanning electron microscope often contain artifacts which limit the accuracy of qualitative and quantitative analysis. Three categories of artifacts are rccognized: (1) artifacts which originate during the physical process of $x$-ray detection; (2) artifacts associated with the signal processing chain; and (3) artifacts which arise from the environment of the sample and detector. Artifacts in these categories include: (1) silicon $x$-ray escape peaks, peak broadening, and peak distortions; (2) dcad-time effects, the formation of sum peaks, and anomalous background signals; and (3) detector microphony, excitation by stray radiation of regions which are remote from the beam impact point, and cffects on x-ray intensities caused by contamination. Recognition of these artifacts is required for accurate qualitative analysis of unknowns, particularly of low intensity signals. A procedure is described for qualitative analysis based on the known properties of the family of x-ray lines for each element as well as the artifacts which can be observed. The implications of the presence of spectral artifacts on the accuracy of quantitative analysis is also discussed

18791. Fisher, G. B., Madey, T. E., Yates, J. T., Jr., Ultraviolet photoemission studies of formaldehyde and related molecules adsorbed on Ru(110), J. Vac. Sci. Technol. 15, No. 2, 543547 (Mar./Apr. 1978)

Key words: adsorption; chemisorption; formaldchyde; ruthenium; surface chemistry; ultraviolet photoemission spectroscopy.

The adsorption of formaldehyde $\left(\mathrm{H}_{2} \mathrm{CO}\right)$, hydrogen, and carbon monoxide on Ru(110) has been studied using angle-integrated ultraviolet photoemission spectroscopy (UPS) and temperature programmed desorption (TPD). The UPS spectra for low exposures of $\mathrm{H}_{2} \mathrm{CO}$ at $80 \mathrm{~K}$ indicate that $\mathrm{H}_{2} \mathrm{CO}$ dissociates to a substantial degree. These spectra are compared with UPS spectra for the sequential adsorption of hydrogen and $\mathrm{CO}$. Whereas thcre are similarities between these spectra, the differences in the UPS, work function change, and TPD results are sufficient to suggest that a portion of the dissociated $\mathrm{H}_{2} \mathrm{CO}$ may exist as a surface molecular complex containing $\mathbf{H}$ and CO. This is apparently the first rcported cxample, based on a UPS study, of an oxygen-containing organic molecule which dissociates upon adsorption on a metal surface at $80 \mathrm{~K}$. For high exposures at $80 \mathrm{~K}$, adsorption of a condensed layer of molecular $\mathrm{H}_{2} \mathrm{CO}$ is observed.

18792. Fleming, R., Spiegel, V., Measurement of threshold reaction cross section ratios in fission neutron fields, Proc. $2 d$ ASTM-EURATOM Symp. on Reactor Dosimerry: Dosimery Methods for Fuels. Cladding, and Siructural Materials, Palo Alto, CA, Oct. 3-7, 1977, 2, pp. $953-957$ (Available as NUREG/CP-0004 from the National Technical Information Service, Springfield, VA, Oct. 1977). 
Key words: Californium; cross sections; fission spectrum; neutron: threshold reaction; uranium.

Direct measurement of ratios of cross sections were carried out in both ${ }^{262} \mathrm{Cf}$ and ${ }^{235} \mathrm{U}$ fission spcctra. The rcsults for the reactions. ${ }^{5 x} \mathrm{Ni}(\mathrm{n}, \mathrm{p})^{5 x} \mathrm{Co}$ and ${ }^{54} \mathrm{Fe}(\mathrm{n}, \mathrm{p})^{5+} \mathrm{Mn}$ arc presented and compared with calculations based on the ENDF/B-IV data file.

18793. Fowell, A. J.. Clothes dryer air exchange, Proc. Conf. on Major Home Appliance Technology for Energy Conservation, West Lafayette, IN, Feh. 27-Mar. I, 1978, D. R. Tree, G. E. Courville, V. O. Haynes, H. Phillips, Eds., pp. 168-170 (Available as Conf-780238 from the National Technical Information Service, Springfield, VA, 1978).

Key words: appliance; clothes dryer; efficiency; cnergy conservation; heat recovery; lint; pcrformance; venting.

The opportunity for reducing the energy used in the clothes drying process is presented by utilizing periods of no heat or reduced heat drying coupled with provision for indoor or outdoor operation of the dryer inlet and exhaust. The selection of the mode of operation is dependent on the time of year and build up of humidity in the house. The results of a pilot study on a clothes dryer coupled to the outdoors for both intake and exhaust are presented.

18794. Franklin, A. D., Young, K. F., Discussion on the paper Ionic conductivity of some lithium silicates and aluminosilicates, by I. D. Raistrick, C. Ho, and R. A. Huggins, J. Elecirochem. Soc. 124, No. 6, $871-872$ (June 1977).

Key words: clectrode polarization; equivalent circuits; ionic conduction; lithium aluminosilicates; lithium silicate.

It is shown that the impedance data of Raistrick et. al. ( $\mathrm{J}$. Electrochem. Soc. 123, 1469, 1976) can be well represented by an equivalent circuit in which grain boundary effects are represented by a modified Cole-Cole distribution of impedance, and electrode effects by a similar distribution of admittance. Physical models are discussed

18795. Unassigned.

18796. Geist, J., Frontiers in optical radiation measurements, Proc. Electro-Optical Systems Design Conf.-1976 Int. Laser Exposition, New York, NY, Sept. 14-16, 1976, pp. 281-284 (1976).

Key words: clectrically calibrated detector; optical radiation measurements; primary standards; standard source.

Recent progress in optical radiation measurements is reviewed with emphasis on very recent progress in areas currently undergoing significant development. By its nature the paper must rely on some cxtent on unpublished material.

18797. Domalski, E. S., From the history of combustion calorimetry, Chapter 18 in Combustion Calorimetry, S. Sunner, M. Månsson, Eds., 1, 401-428 (Pergamon Press, Oxford, England, 1979).

Key words: benzoic acid; calihration; combustion bombs; comhustion calorimetry: historical survey; prominent calorimetrists.

The history of combustion calorimetry is surveyed from, the early part of the 19 th century to its current state of development. Advances in calorimetric apparatus and techniques are presented; these are concurrent with improvements found in the precision and accuracy of the comhustion data obtained from calorimetric investigations. A chronology of the use of benzoic acid as a calibration standard is given particular cmphasis. Contributions by prominent calorimetrists are identified. This presentation of the history of combustion calorimetry is not a highly-detailed study of this branch of physical chemistry, but is an attempt to highlight significant phases of development over the past one hundred years. A bibliography containing 172 references is provided

18798. Dressler, E.. Single nucleon operators in pion photoproduction from nuclei, Proc. June Workshop in Intermediate Energy Electromagnetic Interactions with Nuclei. MIT, Boston, MA, June 13-24, 1977, Report No. COO-3069. 677. pp. 147-I54 (William H. Bates Linear Accelerator Laboratory and the Laboratory for Nuclear Science, Massachusetts Institute of Technology, Boston, MA, 1977).

Key words: electroproduction; non relativistic operators; nuclear photoproduction; photoproduction; pions; pseudovector coupling.

By studying photoproduction of pions from nuclei, it is possible to obtain important information about the single nucleon photoproduction operators. For example, photoproduction of $\pi^{+}$from deuterium depends on parts of the single nucleon operator which are insignificant in the $\gamma+\mathbf{P} \rightarrow \pi+\mathrm{n}$ cross section.

18799. Lam, L. K., Schearer, L. D., Laser initiated afterglow in a high pressure $\mathrm{K}-\mathrm{Kr}$ mixture, Chem. Phys. Lett. 60, No. 1. 130-134 (Dec. 15, 1978).

Key words: collisional excitation; collisional radiative recombination; laser induced plasma; optical emission; photoionization; Potassium-Krypton mixtures; resonant multiphoton ionizations.

The potassium atoms in a K-Kr mixture ( $[\mathrm{K}]=6 \times 10^{14} \mathrm{~cm}^{-3}$ : $\left.[\mathrm{Kr}]=2 \times 10^{19} \mathrm{~cm}^{-3}\right)$ are ionized with a $140 \mu$ joule, $4 \mathrm{nsec}$ laser pulse in a resonant 2 photon absorption via the $K(5 p)$ level. The optical emission spectra in the afterglow of the laser pulse is monitored as a function of time. A fast initial decay of the fluorescence $(\sim 20 \mathrm{nsec})$ due to collisional excitation of the potassium by the hot photoelectrons and a slow decay tail ( $\sim 10 \mu \mathrm{sec})$ due to collisional-radiative recombination is observed.

18800. Eisenhower, E. H., NBS radiation measurement assurance activities, (Proc. 8th Ann. Nat. Conf. on Radiation Control-Radiation Benefits and Risks: Facts, Issues, and Options, Springfield, IL, May 2-7, 1976). HEW Publication (FDA) 77-802/, pp. $391-397$ (U.S. Department of Health, Education, and Welfare. Public Health Service, Food and Drug Administration, Bureau of Radiological Health, Rockville, MD, Apr. 1977).

Key words: measurement assurance; measurement consistency; measurement system; national standards; radiation; radiation control; radiation measurements; traceability.

The role of the National Bureau of Standards as the national reference laboratory for radiation measurements is descrihed, as well as the organizational structure and concepts for measurement traceability. Present NBS radiation mcasurement assurance programs are described briefly. Intended future measurement assurance activities are described gcnerally, particularly those of interest to state radiation control programs.

18801. Levenson, M. D.. Coherent optical transients observed by polarization switching, Chem. Plyys. Lett. 64, No. 3, 495498 (July 15, 1979).

Key words: coherent optical transients; $\mathrm{I}_{2}$; polarization switching. 
A transient signal analogous to the optical free induction decay is observed when a laser beam tuned to an absorption line of $I_{\text {. }}$ is switched from left to right circular polarization. The polarization transient amplitude decays at a rate equal to twice the usual transverse decay rate, and can be detected with sensitivity similar to that achieved in polarization spectroscopy.

18802. McHenry, H. I. Fitness for purpose evaluation of defects in pipeline girthwelds, Proc. Siructural Integrity Technology Conf., Washington, DC, May 9-11, 1979, J. P. Gallagher, T. W. Crooker, Eds., pp. $39-44$ (American Society of Mechanical Engineers, New York, NY, 1979).

Key words: carbon-manganese steel; fatigue; fatigue cracks; fracture mechanics; fracture toughness; pipeline; weld flaws; weldments.

Fracture-mechanics principles are used to calculate allowable-flaw-size curves according to guidelines set by OPSO. All flaws are considered to be surface cracks. Initially, the curves are calculated by determining the largest flaw that would not grow through the pipe thickness during thirty years of worstcase operation. The curves are then modified by incorporating safety factors contained in the OPSO documents. This procedure defines accept and reject regions on a flaw-length versus flaw-depth plot. Curves defining these regions are developed using four distinct elastic-plastic fracture-mechanics methods: a critical crack-opening-displacement model, the Draft British Standard method, a plastic-instability model, and a semi-empirical model. Maximum stress, worst-case fatigue, and minimum toughness are assumed in all models. Separate sets of curves are developed for planar flaws, for non-planar flaws, and for arc burns.

18803. Mosselman, C., Churney, K. L., Calibration of combustion calorimeters, Chapter 3 in Combustion Calorimetry, $\mathrm{S}$. Sunner, M. Månsson, Eds., 1, 35-55 (Pergamon Press, Oxford, England, 1979).

Key words: calorimeters; combustion; combustion calorimeters; electrical calibration equipment.

The theory and design of combustion calorimeters has been reviewed in terms of recent improvements in the precision of the measurement theory of isoperibol calorimeters. Calculation of the adiabatic temperature rise is discussed in terms of the linear approximation for treatment of the temperature-time data of rating periods. Practical considerations dealing with the validity of a proper execution of calibration experiments using either a reference substance, whose energy of combustion is known, or electrical calibration equipment are outlined.

18804. Rosenbaum, J., Larson, E., Hoblitt, R., Fickett, F. R., A convenient standard for low-field susceptibility calihration, Rev. Sci. Instrum. 50, No. 8, 1027-1029 (Aug. 1979).

Key words: calibration; iron oxide; magnetic property; magnetometer; powders; susceptibility.

Finely ground mixtures of magnetic iron oxide and glass provide a convenient calibration standard of moderate accuracy $(\sim 5 \%)$ for low-field $(<0.5 \mathrm{kA} / \mathrm{m})$ magnetic susceptibility measurements. The use of powders allows fabrication of standards of nearly any shape and size. For our mixtures, which range from 0.063 to $11.8 \%$ iron oxide by weight, the susceptibility values vary from $2.65 \times 10^{-7} \cdot$ to $5.77 \times 10^{-5} \mathrm{~m}^{3} / \mathrm{kg}$, and are nearly linear with iron oxide concentration.

18805. Siegwarth, J. D., LaBrecque, J. F., Younglove, B. A., Test of densimeters for use in the custody transfer of LNG, Proc. 53d Int. Scluol of Hydrocarbon Measurement, Norman. OK, Apr. 1/-13, 1978, pp 385-390 (1978).
Key words: cryogenic; densimeters; density reference system; liquid methane; LNG.

The NBS cryogenic fluids density reference system has been used to evaluate three basic types of densimeters: the vibrating element type, the dielectric cell type and the displacement type. These meters were used to measure densities in liquid methane and liquid methane mixtures with ethane, propane, normal butane, and nitrogen. Measurements were made over the density range from 400 to $480 \mathrm{~kg} / \mathrm{m}^{3}$, temperatures from 108 to $130 \mathrm{~K}$, and pressures from 1 to 3 bar. A hundred measurements were made at various densities, temperatures, pressures and compositions.

18806. Travis, J. C., Schenck, P. K., Turk, G. C., Mallard, W G., Effect of selective laser excitation on the ionization of atomic species in flames, Anal. Chem. 51, No. 9, 1516-1520 (Aug. 1979)

Key words: enhanced ionization theory; flame spectroscopy; ion production; laser enhanced ionization; laser spectroscopy; optogalvanic effect.

Laser enhanced ionization of atomic species in flames, also known as the optogalvanic effect, has been used as the basis for a new spectrometric technique. A simple model is formulated here to help explain the production of electron-ion pairs by the combination of optical and collisional processes. The model yields an analytical expression for the relative enhanced ionization sensitivity of a given transition of any element, and also predicts possible sources of bias in spectrometric applications. The theoretical function is fitted to experimental data by the least-squares adjustment of two parameters. The fitted function may be used, with appropriate caution, to predict the potential LEI sensitivity of further elements and transitions in a similar flame. The model should provide a durable foundation for the further development of methodology and instumentation for atomic spectrometry by laser snhanced ionization in flames.

18807. Zapas, L. J., Crissman, J. M., Stress-strain-time diagrams, including failure envelopes, for high-density polyethylenes of different molecular weight, (Proc. Symp. 176th Meeting of the American Chemical Society, Miami, FL, Sept. 11-14, 1978), ACS Symp. Series 95, Durahility of Macromolecular Materials, R. K. Eby, Ed., Paper 21, 301-309 (American Chemical Society, Washington, DC, 1979).

Key words: creep; instability; polyethylene; viscoelastic.

The behavior in uniaxial loading under creep for three samples of linear polyethylene of different molecular weight is examined. Stress-strain-time diagrams, including failure envelopes are presented and compared to a phenomenological description of the instability of viscoelastic bars.

18808. Lucatorto, T. B., Mcllrath, T. J., Roberts, J. R., Capillary array: A new type of window for the vacuum ultraviolet, Appl. Opt. 18, No. 14, 2505-2509 (July 15, 1979).

Key words: differential pumping across capillary arrays; focused vacuum ultraviolet; heat-pipe oven use in the vacuum ultraviolet; multichannel capillary arrays; vacuum ultraviolet spectroscopy; vacuum ultraviolet windows.

Experiments with optical radiation often require separation of a region of relatively high pressure from a lower pressure region while allowing transmission of radiation between regions. When working with vacuum ultraviolet radiation (VUV) the problem is made more difficult by the small number of transparent materials, there being no bulk materials which transmit at shorter wavelengths than the $1050 \AA$ cut off of LiF. In this paper we report the successful use of glass capillary arrays combined with differential pumping to sustain large pressure 
differences with exccllent transmission of radiation throughout the VUV region.

18809. Brauer, G. M., Petrianyk, N., Termini, D. J., Storage stability of dental composites, J. Dent. Res. 58, No. 8, 1791 1800 (Aug. 1979).

Key words: amine accelerators; degradation of benzoyl peroxide; dental composites; restorative dental resins; shelf-life of composites; storage stability.

Composites made from powder-liquid constituents and subjected to elevated temperatures during storage are more stable than those employing pastes. The decomposition of the benzoyl peroxide ingredient is mainly responsible for the increased setting time and the decreased mechanical properties of the resulting composite.

18810. Greiner, G., Menzel, D., Klein, R., Field-induced redistribution processes in adsorption layers of hydrogen on ruthenium. Surf. Sci. 84, 129-140 (1979).

Key words: adsorption; field emission; field-induced redistribution; hydrogen; ruthenium.

The field-induced cffects in hydrogen layers on ruthenium field emitters, which had been observed before, have been investigated in more detail in two laboratories. Raising the field causes an unusual increase of emission, due to a decrease of work function, on certain planes and vicinals (mostly on and around the $\{110\}$ ) of the Ru field emitter. The extent, rate of appcarance, and disappearance, of this cffect depend on field, coverage and temperature. It is shown that the cause is mainly the removal of hydrogen from these areas. However, all earlier reports on similar effects in other systems have shown the opposite sign of the dependence on the direction of the electric field. The discussion of possible mechanisms shows that no fully satisfactory explanation can be given at present.

18811. Lucatorto, T. B., Mcllrath, T, J., Mehlman, G., Timeresolved measurements of the far $\mathrm{UV}$ output of a BRV source, Appl. Opt. 18, No. 17, 2916-2917 (Sept. 1, 1979).

Key words: far ultraviolet; light pulse shape; vacuum spark.

The temporal behavior of the BRV-type vacuum spark source was studied at two wavelengths ( 300 to $600 \AA)$. The position of the peak output was measured rclative to the maximum spark current and values for the pulse width obtained.

18812. Hord, J., Parrish, W. R., Economics of hydrogen, Chapter 1 in Hydrogen: Its Technology and Implications, $\mathrm{K}$. E. Cox, K. D. Williamson, Jr., Eds., 5, 3-48 (CRC Press, Boca Raton, FL, 1979).

Key words: cost; economics; hydrogen; production; storage; transmission.

The costs of producing, transmitting and storing hydrogen are presented in this chapter. Production methods considered are steam-reformation and partial oxidation of methane, coal gasification, partial oxidation of fuel oil, water electrolysis and hybrid thermochemical-electrolysis. The costs of compressing, liquefying, slushing and solidifying hydrogen gas are also outlined. Modes of hydrogen transmission considered are overland and underwater gas pipelines, overland liquid pipelines, compressed gas or liquid by highway, railway, or sea, and metal hydrides by highway or railway. Hydrogen storage options considered are underground caverns for compressed gas, low pressure gas holders, metal hydride, high pressure compressed gas in steel cylinders, and dewars for liquid. Potential by-product cost credits are reviewed and examples of hydrogen-system cost analyses are given.
18813. Arp, V., Computer analysis of quench transients in forced-flow cooled superconductors for large MHD magnets, Proc: Superconducting MHD Magnet Design Conf., Massaclusetts Inst, of Teclt., Cambridge, MA, ().t. 18-19, 1978, pp. 411-432 (May 1979).

Key words: forced flow; helium; stability; superconductor; transient flow; transient heat transfer.

This paper reports preliminary results and conclusions from a recent numerical analysis of force-cooled superconducting system response to a thermal pcrturbation. The analysis differs from previous published analyses of such systems in that no approximations are used in the helium hydrodynamics (for one dimension). As a result, the analysis predicts that a thermal perturbation will cause rapid pressure and flow variations moving at sonic velocity within the coolant channel; such variations were not predicted by earlier analyses. These rapid flow variations, and the consequent fluid turbulence, may provide an important heat transfer mechanism even when the helium is initially at rest or only in laminar flow. Such a result may be the qualitative explanation for the recent experimental observations at ORNL and MIT of high superconductor stability under zero flow conditions. Computed results are presented for superconducting geometries representative of those under experimental study at MIT.

18814. Larsen, E. B., Techniques for producing standard EM fields from $10 \mathrm{kHz}$ to $10 \mathrm{GHz}$ for evaluating radiation monitors, Proc. 1978 Symp. on Electromagnetic Fields in Biological Systems, Orlawa, Canada, June 28-30, 1978, pp. 96-112 (1979).

Key words: antcnna gain calculation; field strength calibration; pyramidal horn antenna; rf radiation monitor; standard electromagnetic field.

The approach used at NBS for evaluating rf radiation monitors is to generate a calculable field and then immerse the probe being calibrated in this known field. The optimum instrumentation depends on the frequency and required accuracy. Up to $300 \mathrm{MHz}$ a TEM cell is used, which is a large rectangular "coaxial" transmission line. At these low frequencies, only the principal wave (TEM mode) propagates through the cell and uniform electromagnetic fields are established. Both $\mathrm{E}$ and $\mathrm{H}$ field strengths can be calculated in terms of power, plate spacing and the cell characteristic impedance. In the 300 to 1000 $\mathrm{MHz}$ range a series of rectangular waveguide transmission lines is used. Power is transmitted through the guide to a matched resistive load. Operation is restricted to the $T E_{11}$ mode in which the $\mathrm{E}$ and $\mathrm{H}$ fields can be calculated approximately in terms of the frequency, guide dimensions and power flow. Calibrating fields above $500 \mathrm{MHz}$ are generated in an anechoic chamber by a series of standard-gain pyramidal horns. Intense fields can be produced close to the antenna aperture even with low power transmitters. Simple equations are given for accurately calculating these near-zone fields, as determined empirically from the results of numcrical integrations on a computer. The procedure involves a simple computation of the intensity produced by an in-phase aperture and then using algebraic equations to calculate near-zone correction factors. These gain reduction factors depend on frequency, horn dimensions and the distance to the fieid point. The above approach was checked experimentally and the worst case disagreement was $0.5 \mathrm{~dB}$.

18815. Younglove, B. A., Thermodynamic properties of nitrogen gas from sound velocity measurements, Proc. IsI InI. Symp. on Cryogenic Wind Tunnels, Southampton, England, Apr. 3-5, 1979, pp. 16.1-16.6 (1979).

Key words: density; gas; nitrogen; sound velocity; thermodynamic properties; virial coefficients. 
Thermodynamic properties of nitrogen gas have been calculated from $80 \mathrm{~K}$ to $350 \mathrm{~K}$ and at pressures to 10 bar from sound velocity measurements and cxisting P-V-T data using multiproperty fitting techniques. These new data are intended (1) improve cxisting predictive capability of the equation of state in the low density rcgion needed for use with the NASA-1 Langley National Transonics Facility.

18816. Moody, S. E., Levine, J., Design of an extended-range, three-wavelength distance-measuring instrument, Tecionophysic's 52, 77-82 (1979).

Key words: atmospheric propcrties; distance measurement; geodesy; instrumentation; multiwavelength techniques; tectonics.

We describe an extension of current multiwavelength Electromagnetic Distance Measurement (EDM) techniques which should allow the range of multiwavelength measurements to be extended to approximately $50 \mathrm{~km}$. The basic modification needed is the replacement of the retro-reflector commonly used by an active station containing lasers and a microwave source. Because the system will always be operated as a full threewave-length instrument, accuracies of about $5 \cdot 10^{-\mathrm{K}}$ at $50 \mathrm{~km}$ should be obtainable on a routine basis under reasonably clear weather conditions.

18817. McGehan, F. P., Interpreting the scientific paper for the trade press, Proc. 26th Int. Technical Communication Conf., Los Angeles, CA, May 16-19, 1979, pp. M-115-M-1 17 (May $1979)$.

Key words: audience; feature article; news release; publication announcement; scientist-author; technical communicator; technical paper; trade press.

The technical communicator serves as a valuable liaison between the scientific institution and the world of trade and technical publications. When sifted through the communicator's skillful hand, the scientist's technical work can reach larger audiences and have greater impact than publication only in an archival journal.

The communicator must be familiar with the needs of trade and technical publications editors in order to advise the scientist-author. An up-to-date mailing list of trade and technical publications is a valuable aid to the communicator. This specialized knowledge can mean the difference between success and failure in obtaining exposure for an agency's technical output.

Once the publications have been targeted, then it is the job of the communicator to reach those publications through announcements, technical news releases and specialized articles. These releases should be based on technical reports and/or discussions with the bench scientists.

18818. Stubenrauch, C. F., Some recent near-field measurements at NBS, Proc: 1979 Antenna Applications Symp., Urhana-Champaign, $1 L$, Sept. 26-28, 1979, pp. 1-25 (Sept. $1979)$.

Key words: antenna mcasurements; cylindrical scanning; far field; near field; planar scanning.

Three topics relating to recent near-field scanning work at NBS are discussed. These are: a planar scan of a large microstrip phased array, rcsults of measurements made using cylindrical scanning, and measurements of the far sidelobe region of an antenna using a hybrid planar-cylindrical scanning system. Results of these measurements are presented and discussed.

18819. Hebner, R. E., Jr., Misakian, M., Temperature dependence of the electro-optic Kerr coefficient of nitrobenzene, $J$. Appl. Ihys. 50, No. 9, 6016-6017 (Sept. 1979).
Key words: electrical measurements: electro-optics; Kerr coefficient; Kerr effect; nitrobenzene; pulse measurement.

The Kerr coefficient of nitrobenzene was measured over the temperature range 285-340 K. To within experimental error, the data indicate that the Kerr coefficient can be expressed as a quadratic function of reciprocal temperature. Fitting the data to this quadratic function yields an equation which can be used to correct the response of a pulse-voltage measuring system based on the Kerr effect for variations in the ambient tempcrature.

18820. Boyne, H. S., Ellerbruch, D. A., Microwave measurements of snow stratigraphy and water equivalence, Proc. $47 \mathrm{th}$ Annual Western Snow Conf., Sparks, NV, Apr. 18-20, 1979, pp. 20-26 (1979).

Key words: microwave remote sensing; snowpack-water equivalence; snow stratigraphy.

This paper reports on a study of electromagnetic surface and subsurface scattering properties of snow using an FM-CW radar system operating in the frequency range 8-12 GHz. The scattering properties are interpreted and compared with the measured physical properties of snow such as density, stratigraphy, hardness, and equivalent moisture content. The electromagnetic scattering properties are measured in situ under natural environmental conditions, and the physical analysis is done at each test site to correlate the physical properties of the sample with its electromagnetic signature. Correlation between the electromagnetic and physical properties of snow are discussed. In particular, it is shown that there is a simple relationship between the "optical" depth of the snowpack and the snowpack-water equivalence, where the "optical" depth, $\sqrt{E \mathbf{d}}$, is the product of the square root of the average dielectric constant, $\epsilon$, and the physical depth, d, of the snowpack.

18821. Frenkiel, F. N., Klebanoff, P. S., Huang, T. T., Grid turbulence in air and water, Plys. Fluids 22, No. 9, 16061617 (Sept. 1979).

Key words: correlations; grid-turbulence; higher-order moments; hot-wire anemometry; probability distributions; small-scale turbulence.

An experimental comparison of grid turbulence performed in a wind tunnel and in a water tunnel is described. The measurements were made in the initial stage of decay with mesh Reynolds numbers ranging from 12800 to 81000 . Hot-wire and hot-film instrumentation combining analog and digital computing methods were used to measure higher-order correlations of the longitudinal component of turbulent velocity and highcrorder moments of longitudinal turbulent velocity gradients. A comparison of the latter is obtained for an increase in Reynolds number without having to alter the flow geometry. Apart from the intrinsic interest of such measurements in water, the results show the non-Gaussian character of the turbulent fluctuation and compare the behavior of higher-order moments of turbulent velocity gradients to theoretical considerations for the small scale turbulent structure.

18822. Jones, M. C., Arp, V. D., Review of hydrodynamics and heat transfer for large helium cooling systems, Cryogenics 18, No. 8, 483-490 (Aug. 1978).

Key words: ac generators; heat transfer; helium; hydrodynamics; large magnets; power transmission; review; superconductors.

This paper is a review of recent expcrimental results and computational methods needed for the fluid engineering aspects of helium cooling systems for power applications. The discussion is illustrated by three different applications: large magnets; 
power transmission lines and ac generators. An attempt is made to) put recent rcsearch into pcrspective, considering the requirements of cach application, and problems in need of further rescarch are pointed out.

18823. Lcvine, J., Strain-tide spectroscopy, Geophys. J. R. Astron. Soc. 54, 27-41 (1978).

Key words: core rcsonance; free wobble; laser strainmeter; ocean load; preferred frame; spatial anisotropy; strain tides.

We have used two years of strain-tide data to study the response of the Earth to the diurnal and semidiurnal tidal excitations. Our results show that there is significant structure in the response of the Earth to tidal excitations near one cycle/sidereal day. This structure agrees with the resonance behaviour predicted from calculations of the forced elasticgravitational response of an elliptical, rotating earth with a liquid outer core. The data can also be used to test for possible preferred frames and spatial anisotropies. We find that upper bounds on the parameterized post-Newtonian (PPN) parameters which characterize these effects are $\alpha_{2} \leqslant 0.007$ and $\zeta_{w} \leqslant$ 0.005 . We also infer that there is a significant frequency dependence to the ocean load near one cycle/day and that the coherence between strain and barometric pressure fluctuations are significant at periods longer than a few days.

18824. Kusch, P., Hessel, M. M., An analysis of the $B^{1} \Pi_{u^{-}} X^{1} \Sigma^{+}$, band system of $\mathrm{Na}_{2}, J$. Chem. Phys. 68, No. 6, 2591-2606 (Mar. 15, 1978).

Key words: collisional excitation; dissociation energy; Dunham coefficients; Franck-Condon factors; laser fluorescence; molecular sodium; potential curves.

A critical analysis of the $B^{1} \Pi_{u^{-}} X^{1} \Sigma_{i j}{ }^{+}$band system of the $\mathrm{Na}_{2}$ molecule has been made. The body of data on which the present analysis is based is much more extensive than that used in any previous analysis. The data for the analysis were obtained by a laser-induced fluorescence technique in which many collisionally induced satellite fluorescence series were observed in addition to the directly excited series. We have found the coefficients in a Dunham expansion that replicates the frequencies of 12591 lines that originate in 1297 different $v^{\prime}$, $J^{\prime}$ lcvels with an r.m.s. deviation between the observed and calculated frequencies of $0.011 \mathrm{~cm}^{-1}$. The frequencies of the lines that appear in the present analysis are poorly replicated by use of the Dunham coefficients found by earlier workers. The RKR potential curves, for both the $B$ and $X$ states and the FranckCondon factors for transitions between the two states, have been found. In contrast to previous analyses, the theoretical centrifugal distortion coefficients, calculated from the rotationless RKR potential, agree closely with those directly found in the present analysis. The dissociation energies have been found to be $5988 \mathrm{~cm}^{-1}$ for the $X$ state and $3116 \mathrm{~cm}^{-1}$ for the $B$ state. The maximum of the potential barrier of the $B$ state lies about $474 \mathrm{~cm}^{-1}$ above the ${ }^{2} P_{3 / 2}+{ }^{2} S_{1 / 2}$ levels to which the $B$ state dissociates.

18825. Greer, S. C., Liquid-liquid critical phenomena, Acc. Chem. Res. 11, $427-432$ (Nov. 1978).

Key words: binary-liquid mixture; consolute point; critical exponent; critical phenomena; critical solution point; liquid-liquid critical point; renormalization group theory; scaling theory; universality hypothesis.

The theories and experiments on liquid-liquid critical phenomena arc rcviewed and compared. It is found that the expcriments confirm the scaling and renormalization group theories.
18826. Hellwig, H., Stein, S. R., Walls, F. L., Kahan, A., Relationships between the performance of time/frequency standards and navigation/communication systems, Proc. 10th Precision Time and Time Interval Planning Meeting, Washingun, $D C$, Nov. 28, 1978, pp. 37-5I (1979).

Key words: clocks: communication; frequency standards; navigation; stability; time.

Oscillators and clocks have moved beyond individual instrument applications and are now being used as critical elements of large scale electronic systems. The need for developing advanced time and frequency standards arises from increasingly more sophisticated DOD and civilian missions and functions in navigation, surveillance, identification and communication.

In these systems, time and frequency standards are employed to provide some desired performance or to be the central signal source for most systems functions. It is often not clear what frequency stability or accuracy is really needed. Often, a better clock or oscillator could simplify the system, or improve the performance of the system; in other cases, a different system design may lead to a reduction in the performance demands on the frequency or time standard.

This paper discusses the relationship between system performance and clock or oscillator performance. Our approach will be basic, pointing out some tradeoffs such as short term stability versus bandwidth requirements; frequency accuracy versus signal acquisition time; flicker or frequency and drift versus resynchronization time; frequency precision versus communications traffic volume; spectral purity versus bit error rate, and frequency standard stability versus frequency selection and adjustability. Our aim is to give the system designer and manager a better grasp of the benefits and tradeoffs of using precise frequency and time signals at various levels of precision and accuracy.

18827. Hinkley, J. A., Han, C. C., Mozer, B., Yu, H., Chain deformations in rubber, Macromolecules 11, No. 4,836-838 (July-Aug. 1978).

Key words: affine network; neutron scattering; phantom network; polybutadiene; rubber elasticity; uniform network.

Small angle neutron scattering measurements were pcrformed on mixtures of poly(butadiene- $\mathrm{d}_{6}$ ) at $3 \%$ or less in polybutadiene and on uniform networks containing $3 \%$ deuterated chains over the range of extension ratios $1 \leqslant \lambda \leqslant 1.55$. The chain dimensions of poly (butadiene- $d_{6}$ ) in the mixtures and in the unstrained networks $(\lambda=1)$ are found to be the same within the experimental uncertainty. The increase of the chain dimension with extension ratio is in qualitative accord with that predicted for the affine deformation of crosslink junctions.

18828. Hagan, L., Atomic spectra reports, reports of observatories of Astronomical Society, Bull. Am. Astron. Soc. 7, No. 1, $165-169$ (1975); 8, No. 1, $210-214$ (1976); 9, No. 1, 189193 (1977).

Key words: atomic line shapes; atomic spectra; atomic transition probabilities; bands, molecular; energy levels: energy levels, atomic; line shapes, atomic; molecular bands; molecular spectra; rotational constants.

Research at the National Bureau of Standards in spectroscopy pertinent to astronomy is summarized. Publications on atomic spectra, atomic transition probabilitics and line broadcning, and molecular spectra are refercnced and work in progress is discussed.

18829. Grot, R. A., Field performance of gas and electric water heaters, Proc. Major Home Appliance Technology for Energy Conservation, West.Lafayetle, IN, Feb. 27-Mar. 1, 1978, pp. 
110-120 (Available as CONF-780238 from the National Technical Information Service, Springfield, VA 22161, 1978).

Key words: cnergy field measurements; hot water heaters; hot water usage; residential water use.

The results of a field cxperiment for assessing the pcrformance of gas and clectric residential storage water heaters are presented. Energy requircments for hot water supply, hot water consumption and usage pattern data are presented and analyzed using statistical techniques in order to obtain average load curves and variations from the average. The effects of various retrofit measures such as wrapping the water heater with additional insulation and reducing the hot water temperature are assessed under actual usage conditions.

18830. Hoffman, J. D., Materials failure and materials research policy, (Proc. Symp. 176th Meeting of the American Chemical Society, Miami, FL, Sept. 11-14, 1978), AC'S Symp. Series 95. Durubility of Macromolecular Materials, R. K. Eby, Ed., Paper 1, 1-10 (American Chemical Society, Washington, DC, 1979).

Key words: lifetime prediction; materials durability; materials failure.

Several examples of failure in metals, ceramics, and polymeric materials are described to illustrate the need for increased understanding of the associated areas of lifetime prediction and materials durability. Examples of NBS studies of predictive testing are discussed in terms of the scientific problems which underlie such efforts. Recent national activities related to materials research policy are reviewed.

18831. Gubernatis, J. E., Krumhansl, J. A., Thomson, R. M., Interpretation of elastic-wave scattering theory for analysis and design of flaw-characterization experiments: The longwavelength limit, J. Appl. Phys. 50, No. 5, 3338-3345 (May 1979).

Key words: flaws in crystals; NDE; ultrasonic scattering.

Recently, the results of a gcneral theory of the scattering of clastic waves from a flaw embedded in an isotropic medium were shown in the far-field limit to be compactly represented by a single vector, the $f$ vector. Studying the $f$ vector is thus a way to investigate systematically the dependence of the scattering on the polarization of the incident mode, scattering angle, changes in material parameters, and shape. In the longwavelength limit the $f$ vector is exactly determinable and exhibits significant features of the flaw. We discuss longwavelength scattering results for volume flaws and idealized cracks and compare some of the results with those of the Born approximation, which has already been calibrated by comparison to exact calculations and experiment.

18832. Gutman, D., Braun, W., Tsang. W., Comparison of the thermal and infrared laser induced unimolecular decompositions of allylmethylether, ethylacetate, and isopropylbromide, J. Chem. Pltys. 67, No. 9, 4291-4296 (Nov. 1, 1977).

Key words: aliylmethylether; bromide; ethylacetate; isopropyl; laser; non-equilibrium; pyrolysis; rclaxation; thcrmal decomposition

The thermal and the infrared laser-induced unimolecular decompositions of three molecules, allylmethylether, cthylacetate, and isopropylbromide, have been studied. The thermal decompositions were studied using a single-pulse shock tube and the laser-induced reactions using a $0.63 \mathrm{~cm}$ i.d. gas cell with $\mathrm{NaCl}$ windows with radiation at $9.28 \mu$ from a $\mathrm{Lu}$ monics 203 TEA laser and modest energy fluences $\left(4.5 \mathrm{~J} / \mathrm{cm}^{2}\right)$.
In both studies the molecules were used in pairs (allylmethylether with ethylacetate and isopropylbromide with ethylacetate) so that relative unimolecular ratc constants could bc accurately determined. Although the products produced in the thermal [where equilibrium kinetics holds) and laser-induced reactions werc identical, the rclative rate constants showed variations. In the system in which only one reactant absorbed the laser light (ethylacetatc in the mixturc with isopropylbromide) the ratio of unimolecular rate constants almost reached the thermal value of this ratio at the highest pressures studied ( 50 torr), but the decomposition of the pumped reactant bccime dominant in the laser expcriments at the lowest pressures ( 2 torr). A closer adherence to thc "thermal" rate constants werc observed in the analogous study of the decomposition of the two molecules which both absorbed the laser light (allylmethylether with ethylacetate). Details of the expcrimcnt, the data obtained, and the cxtent to which multiphoton decomposition of large molecules occur under these "mild" conditions are discussed.

18833. Hitlhouse, D. L., Portable system calibrates CCVTs, Electr. World 189, No. 12, 44-46 (June 15, 1978).

Key words: CCVT; compact; field calibration; high accuracy; modular capacitive divider; portable system; truckmounted.

A prototype field calibration system has been developcd. The system contains a high voltage transfer standard divider made up of CCVT capacitor modules, a current comparator bridge, a high voltage standard capacitor, and a resonant power supply which are transported and opcrated from a closed calibration truck. The modular divider is assembled and connected to the CCVT bus for the calibration. The system is compact, requires only a two-man crew plus utility operating crews, and can be set up and taken down quickly on site.

18834. Wagner, H. L., Dillon, J. G., A specification method for ultra high molecular weight polyethylene for implant use, $J$. Bismed. Mater. Res. 13, $821-824$ (1979).

Key words: intrinsic viscosity; molecular weight; polyethylene; shear rate; ultra high molecular weight polyethylene; viscosity number.

Several unusual difficulties which occur in the measurement of the viscosity number of ultra high molecular weight polyethylene (UHMWPE) are examined and a suggested procedure is outlined for its determination. Because of the dependence on shear rate, there is no simple way at present to relate this quantity to limiting viscosity number (or intrinsic viscosity) or to molecular weight. We recommend for routine purposes a single point measurement in a viscometer of standard dimensions, without any attempt to relate the results quantitatively to molecular weight.

18835. Alperin, H. A., Gillmor, W. R., Pickart, S. J., Rhyne, J. J., Magnetization and neutron scattering measurements on amorphous $\mathrm{NdFe}_{2}$, J. Appl. Phys. 50, No. 3, 1958-1960 (Mar. 1979).

Key words: amorphous materials; domains; magnetism; phasc transitions; rare earths; small angle neutron scattering.

A bulk sputtered sample of $\mathrm{NdFe}_{2}$ was investigated by magnctization and neutron scattering measure ments and compared to similar previous measu rements for heavy rare-earth alloys. The amorphous structure was found here to be more open but in all other respects the results were found to agree qualitatively with the results for $\mathrm{TbFe}_{2}$ and $\mathrm{HoFe}_{2}$. Magnetic ordering from the neutron measurements was observed below $\mathrm{T}_{r}=305$ $\mathrm{K}$ with a net moment of $1.3 \mu_{k} /$ atom at $\mathrm{T}=\mathrm{O}$. The coercive force increased to $11.4 \mathrm{kOe}$ at $5 \mathrm{~K}$. 
18836. Howard, C. P., Utensil interface for electric ranges, Proc; Major Home Appliance Technology for Encrgy Conservation, West Lafayctle, IN, Fe'b. 27-Mar. I, 1978, pp. 9-10) (Available as CONF-780238 from the National Tcchnical Information Service, Springfield, VA 22161, 1978).

Kcy words: appliances; cooking utensils; cncrgy conservation; energy cfficiency; ranges and ovens.

An cvaluation of utcnsil interface for clectric ranges as a function utensil and surface unit designs is presented. Suggestions are made for improving utensil and surface until design to improve the interface.

18837. Howard, C. P., Instrumentation opportunities in appliance energy conservation, Proc. Major Home Appliance Technology for Energy Conservation, West Lafayette, IN, Feh. 27-Mar. 1, 1978, pp. 196-197 (Available as CONF-780238 from the National Tcchnical Information Service, Springfield, VA $22(61,1978)$

Key words: appliances; cnergy conservation; energy instrumentation; cnergy rate; cnergy use.

The potential for energy conservation by providing cnergy ratc and energy use instrumentation on major household appliances for consumer utilization is cxamined. Those appliances which can be rcadily instrumented are identified.

18838. Diller, D. E., NBS research on LNG thermophysical properties data and custody transfer measurement methods, Proc. Storage and Transfer of LNG Conf., Boumerdes, Algeria, Apr. 4-5, 1978, pp. 125-130 (Institute of Gas Technology, Chicago, IL, 1978).

Key words: composition; custody transfer; density; flow rate; LNG; mathematical models; mixtures; spccific heating value; tank capacity tables; thermophysical propcrties data; total heating value.

Developments in LNG thermophysical propertics data research at NBS are rcviewed and discussed. These include projects on thc PVT, thermodynamic, clectromagnetic and transport properties of pure LNG components; and on the liquid-vapor cquilibrium properties and orthobaric liquid densitics of mixtures of LNG components.

Developments in LNG custody transfer measurement research are rcviewed, with emphasis on accurate methods for dctermining LNG composition, density, specific heating value, flow rate and ship tank capacity tables for LNG custody transfer. The uncertainties in the determination of the total heating value of large quantities of LNG in tanks and pipelines are discussed.

18839. Ayres, T. R., Linsky, J. L., Garmire, G., Cordova, F., A search for coronal soft $x-r a y$ emission from cool stars with HEAO) 1, Astrophys. J. 232, No. 2, L117-L120) (Sept. 1, 1979).

Key words: stars, coronae; stars, flare; stars, supcrgiants; $x$-ray, sources.

We summarize a search of the $H E A O$ / A-2 cxpcriment allsky survey for coronal soft $x$-ray cmission from a sample of active chromosphere G-M stars including six dwarfs, eight giants, four supergiants, and 10 dMe flare stars. Point sources were detccted ncar the positions of several of the stars on our list. However, of these, only the flare stars BY Draconis (dMOe) and AD Leonis (dM3.5e) appear to be likely candidates for the detected $x$-rays.

18840. Brill, R. H., Yandsaki, K., Barnes, I. L., Rosman, K. J. R., Diaz, M.. Lead isotopes in some Japanese and Chinese glasses, Ars Orientalis 11, 87-109 (1979).
Key words: Chinese glass; galena ores; glass; Japanese glass; lead; lead isotopes.

Lead isotope ratios have been mcasured in a number of Japanesc glasses or glass-like materials, in a few Chincse glasses and in galena orc samples from well defined arcas in Japan. Mcasurable differences found in the ore samples indicate the possibility of identifying sources of lead in ancicnt glass, pottery, bronze, ctc., and thus the possiblc site of manufacture. A particular sct of "Mara" glasses from the first half of the eighth century A.D. has been identified

18841. Hutchinson, J. M. R., Schima, F. J., Coursey, B. M., Decay of ${ }^{121} \mathbf{S n}^{m}$, Phy.s. Rev. C 18, No. 1, $408-413$ (July (978).

Key words: coincidence counting; decay probability; isomeric transition; liquid scintillation counting; photon counting; radioactivity; ${ }^{121} \mathrm{Sn}^{m}$ decay scheme.

${ }^{121} \mathrm{Sn}^{m}$ has becn found to decay by a highly converted isomeric transition to ${ }^{12}{ }^{1} \mathrm{Sn}^{\circ}$ with a branching fraction of 0.776 \pm 0.020 . The $K$-shell internal-conversion coefficient $\alpha_{\kappa}$ for the $37.2-\mathrm{keV}$ transition in $\mathrm{Sb}$, has becn found to be $9.45 \pm 0.33$.

18842. Jacox, M. E., Matrix isolation study of the vacuum ultraviolet photolysis of methyl cyanide. Vibrational and electronic spectra of the CNC free radical, J. Mol. Spectrosc. 71, $369-385(1978)$.

Key words: CCN; CNC; far infrared spcctrum; HCCN; infrared spectrum; interferometer; matrix isolation; methyl cyanide; ultraviolct spectrum; vacuum ultraviolet photolysis.

Visiblc-ultraviolet spectra of $\mathrm{CH}_{3} \mathrm{CN}$ deposited in an argon matrix at $14 \mathrm{~K}$ with concurrent $1216-\AA$ photolysis show prominent absorptions of $\mathrm{CN}$ and $\mathrm{CNC}$ and weak absorptions of $\mathrm{CCN}$. The far infrared spectra of deposits made using similar experimental conditions show a peak at $134 \mathrm{~cm}^{-1}$ which has tentatively been assigned to the lowest frequency component of the bending fundamental of ground-state CNC, split by strong Renner-Teller interaction. Detailed isotopic substitution studies have confirmed the assignment of a prominent absorption at $1453 \mathrm{~cm}^{-1}$ and of its satellite at $1461 \mathrm{~cm}^{-1}$ to the previously unidentificd antisymmetric stretching fundamental, $\nu_{3}^{\prime}$, of CNC. The stretching force constant for this molecule is estimated to lic between 8.0 and $8.5 \times 10^{2} \mathrm{~N} \cdot \mathrm{m}^{-1}$ and the stretching-interaction force constant between +2.5 and $+3.0 \times 10^{2} \mathrm{~N} \cdot \mathrm{m}^{-1}$. Consideration of the photoprocesses important in these cxperiments suggests that CNC is formed primarily by photodissociation of $C C N$ and cage recombination of the resulting $\mathrm{C}+\mathrm{CN}$.

18843. Kelley, E. F., Hebner, R. E., Jr., Time evolution of the electric field associated with breakdown phenomena in liquids, (Proc. Conf. on Electrical Insulation and Dielectric Phenomena, Whitc Haven, PA, Oct. 1979), 1979 Annual Report of Conf. on Electrical Insulation and Dielectric Phenomena, pp. 203-211 (1979).

Key words: electrical breakdown; high speed photography; Kcrr effect; liquid breakdown; nitrobenzene; partial discharges; streamers; transient phenomena.

This paper describes electro-optic measurements of the electric field distribution in the vicinity of prebreakdown structures in nitrobenzene. The measurements indicate that the prebreakdown structures are conducting. This conclusion was reached by modeling the structurcs as conducting spheres and observing that the fringc patterns calculated using the model spheres are well correlated with those photographed during breakdown. 
18844. Hsia, J. J. Venable, W. H. Jr. NBS capabilities for reflectance and transmittance measurements, Proc. Seminar om Testing Solar Energy Materials and Systems. Gaithershurg. MD. May 22-24, 1978, pp. 258-260) (1978).

Key words: reflectance; standard reference materials; transmittance.

A description is given of the current and planned NBS measurement capabilities for reflectance and transmittance measurements of interest to engineers of solar energy collection and conversion devices. Details to be included are spectral ranges, instrument geometries, and estimated uneertainties in the data. Related Standard Reference Materials are also described

\section{Unassigned.}

18846. Holdeman, L. B., Trapped-flux spin-down torques on a spherical superconducting gyroscope, J. Appl. Phys. 49, No. 3, $951-954$ (Mar. 1978)

Key words: gyroscope; ralativity; space; supereonducting; torque; trapped flux.

Magnetic flux trapped in the rotor of a superconducting gyroscope can cause the rotor to lose energy through dissipation in a readout loop encompassing the rotor and by the generation of eddy currents in the support electrodes. These losses are ealeulated and shown to be negligible for the rotor in the gyroscope-relativity experiment, a proposed satellite experiment which is to test predictions of the theory of general relativity

18847. Jacox, M. E., The stabilization and spectra of free radicals and molecular ions in rare gas matrices, Rev. Chem. Intermediates 2, 1-36 (1978).

Key words: charge transfer; excited argon atoms; free radicals; infrared speetra; matrix isolation; molecular ions; photochemistry; ultraviolet spectra.

Characteristics of the infrared and ultraviolet spectra of molecules isolated in rare-gas matrices are reviewed, and the roles played by the eage effect and by secondary photodecomposition in determining the products observed in matrix isolation experiments are discussed. The use of charge transfer processes to obtain molecular anions trapped in an argon matrix is considered, and the results of experimental studies of the spectra of molecular anions are summarized. The use of argon atoms exeited in a microwave discharge for the production of free radicals and molecular ions on collision with small molecules is revicwed, with emphasis on the processes which are important in these discharge experiments.

18848. Franzen, D. L., Day, G. W., LED source for determining optical detector time response at $1.06 \mu \mathrm{m}$, Rev. Sci. Insirum. 50, No. 8, 1029-1031 (Aug. 1979)

Key words: detectors; light emitting diode.

A gallium indium arsenide light emitting diode (LED) is investigated as a source for determining optical detector time response at $1.06 \mu \mathrm{m}$. To obtain either impulse or step shaped waveforms, the diode is driven by a charged transmission line switched by a transistor operating in the avalanche mode. A pulse with a 2.5-ns full width at half-maximum and a step with a 3-4-ns transition time are produced at repetition rates to 1 $\mathrm{kHz}$. The effects of wavelength change during the pulse (chirping) are discussed and evaluated.

18849. Engen, G. F., Hoer, C. A.. "Thru-load delay": An improved technique for calibrating the dual six-port, (Proc. Conf. The World of Microwaves, Orlando, FL. Apr. 30-May
2. 1979), IEEE MTT-S 1979 International Micronave Simposium Digest, p. 53 (Available as IEEE Cat. No. 79CHI439. 9 MTT-S from Institute of Elcetrical and Electronics Engineers, Now York, NY. 1979).

Key words: automatic network analyzer; ealibration; microwave measurement; six-port.

In some carlier papers the use of a "thru-short-delay" technique for calibrating the dual six-port was described. Another scheme required only a length of precision transmission line and a calibration circuit. The better features of these two somewhat different approaches have now been combined and the requirement for cither a known short, or a "calibration circuit" eliminated. This paper will discuss this new procedure and also describe its application in a practical dual six-port system.

18850. Lynn, J. W., Shelton, R. N., Neutron scattering studies of crystal field excitations in (RE) $\mathrm{Mo}_{6} \mathrm{Se}_{4}, J$. Appl. Plys. 50, No. 3, 1984-1986 (Mar, 1979).

Key words: Chevrel-phase; coexistence; crystal ficld; magnetic superconductor; neutron scattering; rare earth.

Neutron inclastic scattering measurements have been made to determine the crystal field levels of the rare earth ions in the ternary superconductors $\mathrm{Tb}_{1.2} \mathrm{Mo}_{6} \mathrm{Se}_{\mathrm{K}}, \mathrm{Ho}_{1.2} \mathrm{Mo}_{6} \mathrm{Se}_{\mathrm{H}}$ and $\mathrm{ErMo}_{6} \mathrm{Se}_{\mathrm{H}}$. The results show that the lifting of the free-ion angular momentum degeneracies can be adequately understood on the basis of a crystalline electric field with cubic symmetry. In each ease the determined ground state possesses a magnetic moment. The situation found in these selenide materials contrasts with the sulfide materials in which no crystal field excitations have been observed over a wide range of energies.

1885 I. Wlodawer, A., Segrest, J. P., Chung, B. H., Chiovetti, R., Jr., Weinstein, J. N., High-density lipoprotein recombinants: Evidence for a bicycle tire miceile structure obtained by neutron scattering and electron microscopy, FEBS Lett. 104, No. 2, $231-235$ (Aug. 1979).

Key words: electron microscopy; high-density lipoproteins; neutron scattering.

High-density lipoprotein recombinants were studied by neutron low-angle scattering and electron microscopy. The shape of molecules was discoidal, with the diameter $100 \AA$ and thickness $33 \AA$. Analysis of models based on radii of gyration of recombinants containing both hydrogerated and deuterated lipids shows that best agreement between the neutron and microscopic results can be obtained by postulating separation of protein from polar lipid heads, with protein on the outside of the recombinants.

18852. Shaulov, A., Bell, M. 1.. Smith, W. A., Direct measurement of pyroelectric figures of merit of proper and improper ferroelectrics, J. Appl. Pliss. 50, No. 7, 4913-49l9 (July 1979).

Key words: ferroelectrics; figures of merit; improper ferroelectrics; pyroelectric detectors; pyroelećtric vidicons; terbium molybdate; triglycine sulfate.

A direct method is described for measuring the figures of merit which characterize the performance of pyroelectric materials as infrared vidicon targets or point detectors. The results of experiments earried out as a function of temperature on a proper ferroelectric, triglycine sulfate, and an improper ferroelectric, terbium molybdate, are compared with the predictions of the appropriate thermodynamic theories. It is shown that within the family of rare-earth molybdates isomorphic to terbium molybdate there exists an optimum value for the figure of merit relevant to pyroelectric vidicon performance. 
18853. Linsky, J. L., Worden, S. P.. McClintock, W., Robertson. R. M. Stellar model chromospheres. X. High-resolution, absolute flux profiles of the $\mathrm{Ca} \| \mathrm{H}$ and $\mathrm{K}$ lines in stars of spectral types FO-M2, Astrophys. J. Suppl. Ser. 41, No. 1. 47-74 (Sept. 1979).

Key words: Ca 11 cmission, stars: chromospheres, stars: circumstellar shells; emission line, stars; late-type stars.

We prcsent $120 \mathrm{~mA}$ resolution spectra of the cores and wings of the $\mathrm{Ca} \| \mathrm{H}$ and $\mathrm{K}$ lines in 43 stars covering a wide range of spectral type and luminosity class. These spectra were obtained with the KPNO $4 \mathrm{~m}$ cchelle spectrograph and blue image tube, and are calibrated in absolute surface flux units using Willstrop's narrow-band photometry and the Barnes and Evans relations for stellar angular diameters. We estimate an uncertainty of $\pm 15 \%$ in our flux scales. We derive chromospheric radiative loss rates in the $\mathbf{H}$ and $\mathrm{K}$ lines, and discuss trends in these loss rates with effective temperature for dwarfs, giants, and supergiants. We compare these loss rates with similar rates for the $\mathrm{Mg} \mathrm{II} h$ and $k$ lines, and discuss the doublet line ratios for $\mathbf{H}$ and $\mathbf{K}$. The monochromatic surface fluxes for different features in the $\mathrm{H}$ and $\mathrm{K}$ lines are presented. From the surface fluxes at $K_{1}$ we derive the radiation temperature $T_{k}\left(K_{1}\right)$ . The $T_{H}\left(\mathrm{~K}_{1}\right) / T_{\text {eff }}$ ratio is lower in giants than in dwarfs, as predicted by partial redistribution calculations, and this ratio appears to be an empirical age indicator among dwarfs. Asymmetries in the $\mathrm{K}$ line profile provide evidence for a solar-type supergranulation flow pattern in F5-K5 dwarfs and perhaps also in $G$ and carly $K$ supergiants. Measurements of line widths at $H_{1}, K_{1}$, and $K_{2}$ are presented, together with FWHM data for the $H$ and $K$ lines. We find rough agreement between the measured $K_{1}$ widths and the gravity and chromospheric heating rate dependences in the scaling law proposed by Ayres. Finally, we present data on emission lines in the wings of $H$ and $K$, and discuss chromospheric radiative loss rates in the $\mathrm{H} \epsilon$ line compared with loss rates in the $\mathrm{H}$ and $\mathrm{K}$ lines.

18854. Frohnsdorf, G., Clifton, J. R., Brown, P. W., History and status of standards relating to alkalies in hydraulic cements, (Proc. American Society for Testing and Materials Symp. on Cement Standards-Evolution and Trends, St. Louis, MO, Dec. 7. 1977), Am. Sioc. Test. Mater. Spec. Tech. Puhl. 663, pp. 16-34 (1978)

Key words: alkalies; cement; history; standards.

The evolution of ASTM standards relating to alkalies, specifically sodium and potassium, in portland and blended hydraulic cements is described. The standards include analytical methods for the determination of alkalies in cements, optional specification limits for alkalies in portland cements for use with aggrcgates that may be deleteriously reactive, and tests for potential alkali reactivity of aggregates. Some shortcomings of the standards are mentioned, and, where they do not treat portland and blended cements in comparable ways, this fact is pointed out. Finally, changes which might be made in the standards to make them responsive to national nceds for conservation of energy and materials arc suggcsted.

18855. Hagan, L., Modelling ultraviolet radiation sources and the upper atmosphere-Critical data needs, Proc: $6 / \mathrm{h} / \mathrm{llll}$. Conf. 'm CODATA, Sania Flavia. Ilaly. May 22-25. 1978, B Drcyfus, Ed., pp. 73-76 (Pergamon Press, New York, NY. 1979).

Key words: atomic energy levels; atomic spectra; atomic transition probabilities: clectron cross scctions: fusion plasmas; lasers; molecular bands; molecular spectra; reaction rate constants; upper atmosphere.
Ultraviolet (UV) radiation is important in the fields of controlled thermonuclear fusion rcsearch, the dcvelopment of short wavclength lasers, the study of inadvertent modification of the upper atmosphere by pollutants. and in the study of the safety of UV radiation sources used in industry and mcdicine. Theoretical models are needed for many UV sources. The mostly non-thermal nature of high tcmperaturc plasmas requires consideration of detailed atomic and ionic processes governing the ionization and excitation. Reactions in the stratosphere between atmospheric pollutants and ozone rcduce the ozone concentration and allow increased UV radiation from the Sun to reach the Earth. References to compilations of atomic and molecular data needed to model UV sources and reactions are summarized. Future needs for critical data and compilations are discussed.

18856. Kanda, M., A "TEM" horn with continuously tapered resistive loading for picosecond pulse measurements, Proc. $3 d$ Symp. \& Tech. Exhihition on Electromagnetic Compatihility. Rotterdam. The Netherlands, May 1-3, 1979, pp. 67-70 (1979).

Key words: antenna gain; broadband antenna; directivity; FFT; method of mcasurements; non-dispersive; rcsistive loading; TEM horn: time domain measurement.

For dircctional reception or transmission of picosecond pulses with minimal distortion, a short TEM horn with resistive loading was developed, and found to be broadband and nondispersive. Theoretical computations with the moment method and FFT were compared with time domain measurements.

18857. Jenkins, R., Hubbard. C. R., A preliminary report on the design and results of the second round robin to evaluate search/match methods for qualitative powder diffractometry, (Proc. Twenty-Seventh Ann. Conf. on Applications of X-ray analysis, Denver, CO, Aug. 1-4, 1978), Paper in Advances in X-ray Analysis, G. J. McCarthy, C. S. Barrett, D. E. Leyden. J. B. Newkirk, C. O. Ruud, Eds., 22, $133-142$ (Plenum Press, New York, NY, 1979).

Key words: qualitative $x$-ray powder diffractometry; round robin; search/match methods.

Six computer synthesized data sets, each representing a mixture, and one physical mixture were prepared and widely distributed in order to study the various search/match methods and factors which affect their success. A total of 67 .returns were received representing eight countries and three search mcthods. The participants were primarily from industrial laboratories. The average score exceeded $90 \%$. The Hanawalt search method yielded the best overall score. Use of thc Frequently Encountered Phascs subfile decreased the search time by about $40 \%$ and marginally increased the success rate. For the physical mixture the $\Delta d / d$ and $\Delta l / I$ values were measured to be about $2 / 1000$ and $40 \%$ respectively. Use of an internal standard improved the d-values by a factor of 2 and resulted in better search/match performance

18858. Ruff, A. W., Wiederhorn, S. M., Erosion by solid particle impact, Treatise Mater. Sci. Technol. 16, 69-126 (1979).

Key words: abrasives; ceramics; crosion: impact; metals; particle erosion: wear

A review of the methods and findings associated with solid particle impact crosion of metals and ceramics is presented. Modern theories of particle erosion and critically reviewed experimental observations arc brought together and compared. Conclusions rcgarding the present state of understanding of erosion are given. 
18859. Harris, R. E., Hamilton, C. A., Fast supereondueting instruments, (Proc. 44th AIP Conf. on Future Trends in Superconductive Elcctronics, Charlottesvillc, VA, Mar. 23-25, 1978). Paper in Future Trends in Superconductive Electronics. B. S. Deaver, Jr., C. M. Falco, J. H. Harris, S. A. Wolf, Eds., pp. 448-458 (American Institute of Physics, New York, NY. 1978).

Key words: clectronics; instruments; integrated circuits: Josephson junctions; measurements; superconductivity.

The emerging tcchnology for fabricating superconducting integrated circuits offers the possibility of remarkable new instruments. The advantagcs of this form of electronics are high device spced and low dissipation, combined with lossless, dispersionless, properly terminated transmission lines. A number of possible new instruments are presented. It is shown that a small group can successfully fabricate the supcrconducting integrated circuits rcquired for these new instruments.

18860. Iverson, W. P., Brinckman, F. E., Mierobial metabolism of heavy metals, Chapter 8 in Water Pollution Microhiology, R. Mitchell, Ed, 2, 201-232 (John Wiley \& Sons, Inc., New York, NY, 1978).

Key words: arsenic; bio-transformation; cadmium; food chain; lead; mercury; metal; methylation; microbial tolcrance; microorganism; plasmid; tin.

Our current understanding of the transformations of metals and mctalloids by, and the cffects of metals and metalloids on, microorganisms is reviewed with 200 references. Microbial transformations of several technologically prominent toxic metal systems, including arsenic, mercury, cadmium, lead and tin are discussed, in greater detain with respect to inorganic and organometallic ions. The implications of these transformations to the general problem of metal pollution, particularly in aquatic environments, are described. The cffect of metal stress, plasmid transfer, and mctal tolerance on bacteria is considered.

18861. Costain, C. C., Daams, H., Boulanger, J. S., Hanson, D W., Kelpczynski, W. J., Two-way time transfers between NRC/NBS and NRC/USNO via Hermes (CTS) satellite, Proc. lOth Annual PTTl Conf., Washington, DC, Nov. 28-30, 1978, pp. $585-600(1978)$.

Key words: Hermes/CTS; international time comparison; precise time transfer; satellite; time; time scales

Two-way time transfers via the Hermes (CTS) satellite between NRC, Ottawa and NBS, Boulder and between NRC and USNO, Washington, DC, began oncc a week in July 1978. At each station the differences wcre measured between the local UTC scconds pulse and the remote UTC pulse received by satellite. The difference between the readings, if station dclays are assumed to be symmetrical, is two times the difference hetween the clocks at the two ground station sites. Over a 20-minute pcriod, the precision over the satellite is hetter than I $\mathrm{ns}$. The timc transfer from NRC to the CRC satellite terminal near Ottawa and from NBS to the Denver HEW terminal are still subject to larger uncertainties which are being examined. The absolute measurc of UTC differences also depends on the measurement of station delays, which in present circumstances will be difficult to carry out

18862. Fechter, J. V., Jr., Generic approaches to product improvement researeh, $C P$ New's 4 , No. 1, 12-20) (Oct. 1978).

Key words: data banks; data bascs; crgonomics; human factors; product research

The National Bureau of Standards neither regulates nor produces consumer products, but it is hcavily involved with research aimed at improving product performance and safety Congressional mandates have given NBS the responsibility for providing technical support to regulatory agcncies, such as the Consumer Product Safety Commission and the Federal Energy Administration. In this role NBS analyzes product safety hazards, inefficient appliance designs, and other product characteristics.

In the Human Factors Section, much product research involves studying hww peoplc use consumer products. What functions does the product scrve-both manufacturer-intended functions and consumer-intented functions? Do either of these conflict with safe use? Can consumers do what the product design assumes.

Rather than restrict the answers to these questions to spccific products, Section research attempts to produce generic answers whenever possible. As a result, the same information may bc useful to regulatory agcncies, manufacturers, and consumers.

Spccific cxamples of Section studies are discussed wherc generic, rather than specific, information was sought. The relationship between this approach and the Scction's long term goal of developing an Ergonomics Data Base is also presented.

18863. Hastings, S. R., Daylighting-Confliets and synergies of architectural solutions, Proc. 1979 Topical Solar Glazing Conf., Pomona, NJ, June 22-23, 1979, pp. F-21-F-24 (June 1979).

Key words: daylighting; energy conservation; fenestration; solar energy; windows.

Dcsign solutions which enhance daylighting may enhance or detract from a window's performance of other functions. Five energy control functions and five non-energy functions of windows arc defined. The inherent conflicts and synergies between daylighting and other window functions are cxamined. Various design or hardware solutions to minimize conflict and/or improve overall performance are discussed. Daylighting solutions need not compromise other window functions, given the multitude of design or hardware options available today.

18864. Wells, J. S., Sams, R. L., Lafferty, W. J., The high resolution infrared speetrum of the $\nu_{1}$ band of $\mathrm{HOCl}, J . \mathrm{Mol}$. Spectrosc. 77, $349-364$ (1979).

Key words: air pollutants; chlorine sink; high resolution IR spectra; hypochlorous acid; large A-value molecules; stratospheric HOCl.

The $\nu_{1}$ bands of $\mathrm{HO}^{35} \mathrm{Cl}$ and $\mathrm{HO}^{37} \mathrm{Cl}$ have been recorded. Both the $A$ - and $B$-typc rotational transitions of these hybrid bands have been completely assigned, and spectroscopic constants have been obtained for both the ground and upper state. The ratio of the clectric dipole moment derivatives $\left(\partial \mu_{t} / \partial\right.$ $\left.Q_{1}\right) /\left(\partial \mu_{t s} / \partial Q_{1}\right)$ has been found to be $0.985 \pm 0.05$ for $\nu_{1}$.

18865. Reed, R. P., Yushchenko, K. A., Low temperature US/USSR material and weld properties for LNG applications-Part 1, Proc. $7 / h$ Inl. Cryogenic Engineering Conf., London, England, July 4-7, 1978, pp. 474-486 (IPC Science and Technology Press, Surrey, England, 1978).

Kcy words: aluminum alloys; ferrous alloys; fracture mechanics; LNG; low temperature; mechanical properties.

Both the USA and the USSR have large material needs for liquefied natural gas (LNG) storage, sea transportation, and possibly, pipelines. Alloys currently considered for these applications are the aluminum alloys $\mathrm{Al}-4.4 \mathrm{Mg}$-USA designated 5083 and Al-6Mg USSR designated AMg-6 and the stecls Fe9Ni (USA-ASTM A-553), Fe-5Ni (USA-ASTM A-645) and $\mathrm{Fe}-13 \mathrm{Cr}-19 \mathrm{Mn}$ (USSR-O3X13Al19). A joint USA/USSR program to cvaluate structural materials for LNG usc has been conducted as a result of the mutual concerns of both countries 
for sufc and cconomical LNG structures. This program consists of the exchange of the three USA and the two USSR alloys fracture and mechanical property mcasurements at low temperatures of the exchanged alloys in both countries and analysis of the data.

18866. (ireenherg. R. R. Trace element characterlzatlon of the NBS urban partlculate matter Standard Reference Materlal by Instrumental neutron actlvatlon analysis, Anal. ( $\%^{\prime}(\mathrm{m} .51, \mathrm{No})$. 12, 2004-2006 (Oct. 1979)

Key words: error analysis; instrumental analysis; multielement analysis; neutron activation analysis; SRM; trace clements; urban particulate.

The Urban Particulate Matter, SRM 1648, recently prepared by the National Bureau of Standards, with partial support from the Environmental Protection Agency, has been analyzed by instrumental neutron activation analysis (INAA) for 32 elements. Special attention has been given to reducing and evaluating the analytical errors. SRM 1632, Trace Elements In Coal, was also analyzed and the results were compared with literature and NBS certified values.

18867. Hessel, M. M., Vidal, C. R., The $B^{1} \Pi_{u^{-}}-X^{1} \Sigma_{g}{ }^{+}$band system of the ${ }^{7} \mathbf{L i}_{2}$ molecule, J. Chem. Phys. 70, No. 10, 44394459 (May 15, 1979).

Key words: dissociation energy; Franck-Condon factors; laser spectroscopy; lithium molecule; molecular spectroscopy; potential curves.

The laser induced fluorescence and absorption spectra of the $B^{1} \Pi_{u}-X^{1} \Sigma_{a}+$ band system of the $\mathrm{Li}_{2}$ molecule has been photographed at high resolution and high dispersion. Over 14,000 spectral lines have been assigned to this band system for a wide range of rotational quantum numbers $(\mathrm{J}=0-80)$ and vibrational quantum numbers $\left(v^{\prime}=0-14\right.$ and $\left.v^{\prime \prime}=0-20\right)$. Using a Dunham type analysis, we have obtained the molecular constants for both states and have fitted about 9000 non-overlapping lines with an r.m.s. error of $0.012 \mathrm{~cm}^{-1}$. The $B^{\prime} \Pi_{u}$ lambda doubling constants, including the centrifugal distortion lambda doublet splitting, have been determined. Quantum mechanical potential curves have been generated for this system using a novel variational procedure and Franck-Condon factors for different rotational quantum numbers have been determined over the range of vibrational levels observed. Excellent agreement has been achieved for the centrifugal distortion terms $\mathbf{D}_{v}, \mathbf{H}_{x}$ and $\mathbf{L}_{v}$ which were obtained from the least squares fit of the assigned lines and those calculated from the quantum mechanical rotationless potential. Levels above the $2^{2} P_{1}+2^{2} S_{1 / 2}$ dissociation limit have been observed and a maximum for the barrier in the $B^{1} \Pi_{u}$ potential of $410 \pm 50 \mathrm{~cm}^{-1}$ above this atomic level was found. The dissociation energy, $\mathbf{D}_{e}$ ", of the $X^{1} \Sigma_{f}$ state was found to be $8620 \pm 100 \mathrm{~cm}^{-1}$. A review of the literature on the $\mathrm{Li}_{2}$ molecule is given.

18868. Reader, J., Acquista, N., Spectrum and energy levels of ten-times ionized yttrium ( $\mathrm{Y} \times 1)$, J. Opt. Soc. Am. 69, No. 9 , 1285-1288 (Sept. 1979).

Key words: energy levels; ion; ionization energy; spectrum; wavelengths; yttrium.

The spectrum of $\mathrm{Y}$ XI was observed with a low-inductance vacuum spark and a laser-produced plasma in the region from 70 to $630 \AA$ on the $10.7-\mathrm{m}$ grazing-incidence spectrograph at NBS. From the identification of 40 lines, a system of 29 energy levels was determined. The level system ( $\mathrm{Cu}$ " isolectronic sequence, $\left.3 d{ }^{10} n l\right)$ includes the series $n s(n=4-7), n p(n=$ $4-6)$, $n d(n=4-6), n f(n=4-7)$, and $n g(n=5-8)$. The $4 f^{2} F$ term is inverted. The observed levels are compared with Hartree-Fock calculations. The ionization energy is determined from the $n g$ scrics $(n=5-8)$ to be $1660000 \pm 200 \mathrm{~cm}^{-1}$ $(205.82 \pm 0.03 \mathrm{cV})$.

18869. Jacox, M. E., The reaction of $F$ atoms with methane in an argon matrlx, (hem. Ihys. 42, 133-148 (1979).

Key words: F-atom production; F-atom reactions; $\mathbf{H}$-atom abstraction; hydrogen honding; hydrogen fuoride; infrared spectrum; matrix isolation; methane; methyl fluoride; methyl radical.

A microwave discharge through an $\mathrm{Ar}_{\mathrm{C}} \mathrm{CF}_{4}$ or $\mathrm{Ar}_{\mathrm{N}} \mathrm{NF}_{3}$ sample flowing through an $\mathrm{Al}_{2} \mathrm{O}_{3}$ tube provides a suitable source of $\mathrm{F}$ atoms for studies of the infrared spectra of the products of their reaction with $\mathrm{CH}_{4}$ trapped in an argon matrix at $14 \mathrm{~K}$. Prominent infrared absorptions of isolated $\mathrm{CH}_{3}$ and $\mathrm{HF}$ appeared in these experiments. The further reaction of $\mathrm{F}$ atoms in the solid deposit leads to the stabilization of the $\mathrm{H}_{3} \mathrm{C} \ldots \mathrm{H}-$ $F$ complex, for which two infrared absorptions have been identified. Detailed isotopic studies of this complex are presented. Secondary reaction of $\mathrm{F}$ atoms with $\mathrm{CH}_{3}$ isolated in solid argon leads to the stabilization of $\mathrm{CH}_{3} \mathrm{~F}$, while the corresponding reaction with $\mathrm{H}_{3} \mathrm{C}$...H-F leads to the appearance of the $\mathrm{H}_{3} \mathrm{C}-\mathrm{F}$...H-F complex, for which isotopic data are also presented.

18870. Reader, J., Corliss, C. H., Line spectra of the elements, Section E. General Physical Constants in CRC Handhook of Chemistry and Physics, 60th Edition, R. C. Weast, Ed., pp. E217-E349 (CRC Press, Inc., 2255 Palm Beach Lakes Blvd., West Palm Beach, FL, 1978-1979).

\section{Key words: elements; emission; spectra.}

Tables of the outstanding spectral lines of all neutral, sing!y ionized, doubly ionized, triply ionized, and quadruply ionized atoms for which data are available are given. Listed are lines that appear in emission from the vacuum ultraviolet to the far infrared. These lines have been selected from much larger lists in such a way as to include the stronger observed lines in each spectra region. In a few cases prominent monoxide band heads are also given.

18871. Sullivan, D. B., Holdeman, L. B., Soulen, R. J., Jr., The future of superconducting instruments in metrology, (Proc. 44th AlP Conf. on Future Trends in Supercorductive Electronics, Charlottesville, VA, Mar. 23-25, 1978), Paper in Future Trends in Superconductive Electronics, B. S. Deaver, Jr., C. M. Falco, J. H. Harris, S. A. Wolf, Eds., pp. 171-181 (American Institute of Physics, New York, NY, 1978).

Key words: Josephson effect; metrology; noise thermometry; SQUID's; standards; superconductivity.

Superconductivity has played a major role in the development of useful new methods for standards and measurements, particularly for dc and high-frequency instruments and for thermometry. In this paper we speculate on future activities in this field including the development of commercial instruments, the improvement of devices for standards laboratories and the adaptation of some of these systems to small refrigerators.

18872. Hebner, R. E., Hillhouse, D. L., Kotter, F. R., Discussion on $F 77$ 696-8 "Transient measurement techniques in EHV systems", by R. Malewski and G. R. Nourse, IEEE Trans. Power Appar. Syst. 97, No. 3, 901 (May/June 1978).

Key words: current measurement; electric transmission; electro-optic systems; high voltage; pulse measurement; voltage measurement.

18873. Choi, C. S., Prince, E., 1,2,3-triaminoguanidinium nitrate by neutron diffraction, Acta Cryst. B35, 761-763 (1979) 
Key words: crystal structure; hydrogen bond; neutron diffraction; rigid body motıon, triamınoguanidinım nitrate.

$\mathrm{CH}_{4,} \mathrm{~N}_{63}{ }^{+} \cdot \mathrm{NO}_{33}{ }^{-}$, orthorhomhic, Phem, $a=8 \cdot 389, b=12 \cdot 684$, $c=6.543 \AA$ A $, Z=4, D_{m}=1.60, D_{i}=1.594 \mathrm{Mg} \mathrm{m}^{-3}$. The structure is made up of an infinite thrce-dimensional network of $\mathrm{N}-\mathrm{H} \cdots \mathrm{O}$ hydrogen bonds linking the 1,2,3triaminoguanidinium ions to the nitrate 1ons. The librational motions of the nitrate ion have a particularly large amplitude about an axis which is close to the perpendicular to the plane of the ion.

18874. A rmstrong, L., Jr., Eherly, J. H., Laser bandwidth effect on two-photos two-channel ionisation in caesium. J. Pleys. B. Lett. to Ed. 12, No. 10, L291-L296 (1979).

Key words: cesium; laser bandwidth; lasers; multiphoton ionisation.

We have considered the influence of finite laser bandwidth on the theory of coupled-channel two-photon ionisation of caesium. The results of a detailed model calculation suggest that the cxistence of laser bandwidth may well explain the discrepancy between theory and experiment. In this short note we sketch our approach to the problem and summarize our findings

18875. Brillet, A., Hall, J. L., Improved laser test of the isotropy of space, Phys. Rev. Lett. 42, No. 9, 549-552 (Feb. 26, 1979)

Key words: isotropy of space; Michelson-Morley experiment; special relativity; stabilized lasers.

Extremely sensitive readout of a stable "etalon of length" is achieved with laser frequency-locking techniques. Rotation of the entire clectro-optical system maps any cosmic directional anisotropy of space into a corresponding frequency variation. We found a fractional length change $\Delta l / l=(1.5 \pm 2.5) \times 10^{-15}$, with the expected $P_{2}(\cos \theta)$ signature. This null result represents a 4000 -fold improvement on the best previous measurement of Jaseja et al

18876. Basri, G. S., Linsky, J. L., Bartoe, J. D. F., Brueckner, G., Van Hoosier, M. E., Lyman-alpha rocket spectra and models of the quiet and active solar chromosphere based on partial redistribution diagnostics, Astrophys, J. 230, No. 3, 924-949 (June 15, 1979).

Key words: L $\alpha$ emission; sun, atmosphere; sun, chromosphere; sun, plage; ultraviolet, spectra.

We present $\mathrm{L} \alpha$ line profiles ohtained with O."8 spatial resolution and $50 \mathrm{m \AA}$ spectral resolution during the first rocket flight of the NRL High Resolution Telescope and Spectrograph (HRTS) instrument. Absolute intensity $\mathrm{L} \alpha$ profiles were obtained for network and cell regions in the quiet Sun, umhral and penumbral regions of a sunspot, two plages, and a quiescent prominence off the limb. We find that cospatial, simultaneous $\mathrm{H} \alpha$ and $\mathrm{L} \alpha$ intensities are not well correlated and that the $\mathrm{L} \alpha$ core and wings exhibit only weak limb brightening, consistent with predictions of our partial redistribution (PRD) line transfer calculations. The smallest structures seen in the $\mathbf{L} \alpha$ wings are prohahly unresolved at $O . " 8$, but the smallest structures seen in the core are $\sim 1.8$. Unequal red and blue $\mathbf{L} \alpha$ pcak intensities arc interpreted as flow velocities near 20,000 $\mathrm{K}$ using a comoving two-level PRD code which conserves mass flux. We find on a statistical basis outflow in plage regions, downflows in the network, and $\sim 15 \mathrm{~km} \mathrm{~s}^{-1}$ outflow in a "minihole" region which is dark in $\mathrm{L} \alpha$ and $C$ iv $\lambda 1548$.

We use a five-level-plus-continuum non-LTE computer code for hydrogen which treats $L \beta$ and $H \alpha$ in the complete redistrihution (CRD) approximation, and $L \alpha$ explicitly as a PRD transition. L $\alpha$ is computed taking into account the frequency dependence of the incoherence fraction following the nonimpact regime Stark hroadening calculations of Cooper. We find that the Vernazza-Avrett-Loeser model leads to $\mathbf{L} \alpha$ profiles which (1) are 35\% too faint, (2) cxhihit too much self-reversal near line center, (3) show considerably flatter wings than our observed mean quiet Sun profile, and (4) limb-darken in the wings. We propose a new mean quiet Sun chromosphere model consistent with the observed $\mathrm{L} \alpha$ integrated intensity, the Lyman continuum slope, and the millimeter continuum. Our model predicts Lyman continuum and $\mathrm{Ca}$ "I intensities somewhat lower than observed and $\mathrm{Mg}$ II intensities a factor of 2 lower than observed. We also present preliminary models to match representative $L \alpha$ profiles for bright and dark points in the quiet Sun and bright regions in plages. The plage and bright points models predict negative contrast in $\mathrm{H} \alpha$ at $\Delta \lambda \geqslant 0.43 \AA$ and $0.22 \AA$, respectively, consistent with ohservations. This computed negative contrast is a natural consequence of increased $\mathrm{H} \alpha$ opacity in the plage chromosphere, which results in a mapping of photospheric temperatures onto $l(\Delta \lambda)$ at larger values of $\Delta \lambda$ in plages.

18877. Gallagher, A., Metal vapor excimers, Chapter 5 in Topics in Applied Plyysics, C. K. Rhodes, Ed., 30, 135-174 (Springer-Verlag, Berlin, Germany, 1979).

Key words: excimer lasers; excimer molecules; metal atoms.

In this chapter we consider diatomic excimer molecules ( $A B$ ) in which a Group I, II, or III metal atom is the radiative species $(A)$. Group II metal atoms can play the role of a noble gas $(B)$, since they have ' $S_{0}$ ground states and have predominantly repulsive interactions with ground-state atoms. Thus Group II and VIII atoms will be included in the class of " $B$ " atoms and we have divided the discussions of specific systems into the six cases of Group I, II, or III atoms paired with Group II or VIII atoms.

18878. Hsu, N. N., Hardy, S. C., Experiments in acoustic emission waveform analysis for characterization of $A E$ sources, sensors and structures, (Proc. Winter A nnual Meeting of the American Society of Mechanical Engineers, San Francisco, CA, Dec. 10-15, 1978), Paper in Elastic Waves and NonDestructive Testing of Materials, Y. H. Pao, Ed., AMD-29, 85-106 (American Society of Mechanical Engineers, New York, NY, 1978).

Key words: acoustic cmission; capacitive transducer; signal analysis; simulated acoustic emission; time-domain deconvolution; transient elastic wave propagation.

While industrial acoustic emission (AE) applications and instrumentation developments have progressed well in recent years, the precise interpretation of AE signals remains a problem. In this paper, we review various signal processing techniques which have been used to characterize the detected signals and then report a simple expcrimental system consisting of a large plate, a mechanical step-impulse simulator, and a capacitive transducer. The transfer function of the plate can he theoretically computed; thus it provides a basis for detailed analysis. The transfer function of the capacitive transducer is shown to be true displacement measurements. The system is used to determine unknown sources in terms of force-times functions explicitly through a time-domain deconvolution algorithm. The system also provides means to characterize sensors and structures. Finally, we compare the spectral and direct time-domain analyses and discuss their limitations.

18879. Jacox. M. E. Matrix isolation study of the interaction of excited argon atoms with methyl cyanide. Vibrational and electronic spectra of ketenimine, Chem. Phys. 43, 157-172 (1979). 
Key words: charge transfer: cyanomethyl radical; cxcited argon atoms; force constants; infrared spectrum; ketenimine; matrix isolation; methyl cyanide; ultraviolet spectrum; vacuum ultraviolet photolysis.

When methyl cyanide mixed with an excess of argon is codeposited at $14 \mathrm{~K}$ with a beam of argon atoms that has been excited by a low power microwave discharge, infrared and ultraviolet absorptions of several previously unidentified products appear. The most prominent set of absorptions is assigned to ketenimine, previously tentatively identified as the product of the reaction of $\mathrm{NH}$ with $\mathrm{C}_{2} \mathrm{H}_{2}$ in an argon matrix. Using a molecular geometry resulting from a recent ab initio calculation and a valence force field with four interaction constants, it has been possible to obtain a satisfactory least-squares force constant fit to the infrared data for seven isotopic species of ketenimine. Two electronic band systems are also reported for ketenimine, which is photodissociated by $2537-\AA$ radiation. The mechanism by which ketenimine is formed may involve an initial electron transfer from excited argon to methyl cyanide. Spectroscopic data are also considered for the other products, one of them tentatively identified as $\mathrm{CH}_{2} \mathrm{CN}$, which differ in their behavior on mercury-arc photolysis of the sample.

18880. Turk, G. C., Travis, J. C., DeVoe, J. R., O'Haver, T. C., Laser enhanced ionizaton spectrometry in analytical flames, Anal. Chem. 51, No. 12, 1890-1896 (Oct. 1979).

Key words: analytical flame spectroscopy; flame ionization; flame spectroscopy; laser enhanced ionization; laser spectroscopy; opto-galvanic effect; trace metal analysis; tunable dye laser.

A new variety of analytical atomic flame spectrometry called laser enhanced ionization (LEl) has been developed. The method relies on the enhanced rate of thermal ionization of the analyte element following photoexcitation with a dye laser tuned to an appropriate transition wavelength. This enhanced ionization rate can be electrically measured directly in the flame, and therefore no optical detection system is required. Detection limits have been measured for 18 elements, showing order-of-magnitude superiority over other flame based spectroscopic methods in many cases. A variety of types of transitions have been successfully utilized, including ground state transitions, thermally excited state transitions, low transition probability transitions, and a two-photon transition. The strong dependence of LEI sensitivity on the ionization potential of the analyte clement and the energy of the laser populated excited state is discussed. Other topics discussed include interference problems cncountered and the application of LEI to the analysis of real samples.

18881. Rhyne, J. J., Fish, G. E., Sankar, S. G., Wallace, W. E., Magnetic properties of Laves-phase rare earth hydrides, $J$. Phys. C5, 40, Suppl. 5, C5-209-C5-210 (May 1979).

Key words: hydrides; intermetallic compounds; Laves phase; magnetism; neutron scattering; rare earths.

Neutron scattering results show that the introduction of hydrogen into $\mathrm{RFe}_{2}$ compounds ( $R=T m, H o$, and $E_{r}$ ) significantly lowers the overall Curie tempcrature and produces a reduced $\mathrm{O} K$ moment on the rare earth site. The rare carth spins disorder at a temperature lower than the bulk $T_{r}$ in $\mathrm{ErFe}_{2} \mathrm{H}_{3.5}$. The $\mathrm{O} \mathrm{K}$ iron sublattice moment in $\mathrm{ErFe}_{2} \mathrm{H}_{3.5}$ is essentially the same as that found in the non-hydride compounds and remains nearly constant to approximately $0.8 T_{\text {r }}$

18882. Katzke, S. W., Software certification-Fact or fancy?, Proc. Seventh Annual Conf. of The Society for Computer Medicine on Effective Performance in the Dynamic Health Care Environment, Las Vegas, NV, Nov. 9-11, 1977, Invited
Paper 3.4, N. S. Hill, Ed., pp. I-II (The Society for Com puter Medicine, Minneapolis, MN, Dec. 1977),

Key words: design specifications; requirements definition; software certification; software development; software reliability; software validation.

Software certification is an approval or an endorsement by some designated authority that there is an acceptable level of confidence that the software, when used in its intended environment, will satisfy its critical specifications.

This paper discusses the future possibility of certifying software by defining software certification, validation and reliability, by explaining the factors that make software certification difficult, and by considering new technological developments that enhance the possibility of limited certification. It concludes that relatively small pieces of software that implement tritical functions can be certified, provided that emerging technological developments prove practical and that the developments are used throughout the entire software development life cycle.

18883. Spiegel, V., Eisenhauer, C. M., Grundl, J. A., Martin, G. C., Jr., Reaction rate measurements and integral cross sections using the NBS ${ }^{252} \mathrm{CF}$ fission neutron indoor irradiation facility, Proc. $2 d$ ASTM-EURATOM Symp. on Reactor Dosimetry: Dosimetry Methods for Fuels, Cladding, and Structural Malerials, Palo Allo, CA, Oct. 3-7, 1977, 2, 959-967 (Available as NUREG/CP-0004 from the National Technical Information Service, Springfield, VA, Oct. 1977)

Key words: Californium; dosimetry; fission neu, ons; iron cross section; nickel cross section; reaction rates.

A fission source of ${ }^{252} \mathrm{Cf}$ has been developed especia, $v$ for integral cross section determinations and reaction rate calı, rations at the National Burcau of Standards (NBS). An irradiation program has been successfully completed utilizing the NBS ${ }^{252} \mathrm{Cf}$ standard fission spectrum indoor facility and the radioactivity counting laboratory at General Electric Company, Valecitos Nuclear Center (VNC). Certified fission neutron fluences for two irradiations of aluminum, iron, nickel, titanium, ${ }^{235} \mathrm{U},{ }^{234} \mathrm{U}$, and ${ }^{237} \mathrm{~Np}$ dosimeters were $6.6 \times 10^{12}$ and 1.6 $\times 10^{13} \mathrm{n} / \mathrm{cm}^{2}$. The cross sections reported are- ${ }^{5 \mu} \mathrm{Ni}(\mathrm{n}, \mathrm{p})^{5 \mathrm{rr}} \mathrm{Co}$, ${ }^{27} \mathrm{Al}(\mathrm{n}, \alpha)^{24} \mathrm{Na}, \quad{ }^{46} \mathrm{Ti}(\mathrm{n}, \mathrm{p})^{46} \mathrm{Sc}, \quad{ }^{47} \mathrm{Ti}(\mathrm{n}, \mathrm{p})^{47} \mathrm{Sc}, \quad{ }^{4 H} \mathrm{Ti}(\mathrm{n}, \mathrm{p})^{4 \pi} \mathrm{Sc}$, ${ }^{54} \mathrm{Fe}(\mathrm{n}, \mathrm{p})^{54} \mathrm{Mn}, \quad{ }^{23 \pi} \mathrm{U}(\mathrm{n}, \mathrm{f})^{140} \mathrm{Ba},{ }^{23.5} \mathrm{U}(\mathrm{n}, \mathrm{f})^{140} \mathrm{Ba}$, and ${ }^{237} \mathrm{~Np}(\mathrm{n}, \mathrm{f})^{\prime}$ ${ }^{40} \mathrm{Ba}$.

This report describes the methods and results of this program. Reaction-rate cross sections inferred from the radioanalysis if the activation detectors include corrections for all nearby and remote scattering materials.

18884. Gilliam, D. M., Helmer, R. G., Greenwood, R. C., Rogers, J. W., Heinrich, R. R., Popek, R. J., Kellogg, L. S., Lippincott, E. P., Hansen, G. E., Zimmer, W. H., "Reference and standard benchmark field consensus fussion yields for U.S. reactor dosimetry programs", Proc. $2 d$ ASTMEURATOM Symp. on Reactor Dosimetry: Dosimetry Methods for Fuels, Cladding, and Structural Materials, Palo Alto, CA, Oct. 3-7, 1977, 3, 1289-1306 (Available as NUREG/CP-0004 from the National Technical Information Service, Springfield, VA, Oct. 1977).

Key words: activation analysis; benchmark fields; dosimetry; fission yields; measurements; neutrons; $\mathrm{Np}-237$; Pu-239; U-235; U-238.

Measured fission product yields are reported for three benchmark neutron fields- the BIG-10 fast critical assembly at Los Alamos, the CFRMF fast neutron cavity at INEL, and the thermal column of the NBS Research Reactor. These measurements were carried out by participants in the Interlaboratory LMFBR Reaction Rates (ILRR) program. Fission product 
generation rates were determined by post-irradiation analysis of gamma-ray cmission from fission activation foils. The gamma counting was performed by Ge(Li) spectrometry at INEL, ANL, and HEDL: the sample sent to INEL was also analyzed by $\mathrm{Naf}(\mathrm{Tl})$ spcctrometry for $\mathrm{Ba}-140$ content. The fission rates were determined by means of the NBS Double Fission Ionization Chamber using thin deposits of cach of the fissionable isotopes. Four fissionable isotopes were included in the fast neutron field measurements; these were U-235, U-238, Pu-239, and $\mathrm{Np}-237$. Only U-235 was included in the thermal neutron yield mcasurements. For the fast neutron fields, consensus yields were determined for thrce fission product isotopes- $\mathrm{Zr}$ 95, Ru-103, and Ba-l40. For these fission product isotopes, a separately activated foil was analyzed by each of the three gamma counting laboratories. For the thermal neutron fiel $i$, ia consensus value for the Cs-137 yield was also obtained. S:119sidiary fission yields are also reported for other isotopes which were studied less intensively (usually by only onc of the participating laboratories). Comparisons with EBR-11 fast reactor yields from destructive analysis and with ENDF/B recommended values arc given.

18885. Katriel, J., Explicit expressions for the coefficients in Boson series expansions of arhitrary spin operators, Phys. Status Solidi Short Notes B93, K177-K179 (1979).

Key words: Boson cxpansions; Holstein-Primakoff representation; spin opcrators.

A generalization of the Holstein-Primakoff representation of spin operators in terms of Boson operators has been proposed by Agranovich and Toshich. We present a closed form expression of this representation which enables a derivation of the corresponding normal-ordered expansion for arbitrary spin

18886. Birnbaum, G., The shape of collision broadened lines from resonance to the far wings, J. Quant. Spectrosc. Radiat. Tranfer 21, 597-607 (1979).

Key words: $\mathrm{CO}_{2}$; far wings; infrared wings; line shape; model correlation function; pressure broadening.

A line shape for collision-broadened lines applicable from the rcsonance region to the far wings is developed. An empirical correlation function is used to represent the known short and long time behavior of the true correlation function and to interpolate the unknown intermediate time regime. The resulting spcctral shapc is a simple analytic function which reduces to $\mathrm{cs}$ scntially the Van Vleck-Weisskopf equation when $\left|\omega-\omega_{0}\right| \tau_{2}=$ 1 , but which smoothly assumes an cxponential behavior in the far wings where $\left|\omega-\omega_{11}\right| \tau_{2} \gg 1$. The time parameter. $\tau_{2}$. is a measure of the duration of collision and is related to the mean squared torque produced in bimolecular collisions. The effect of overlapping lines, also variations in the model correlation function on the line shape are considered. The theory is applied to the absorption in the high-frequency far wing of the $4.3 \mu$ band in $\mathrm{CO}_{2}$.

18887. Knab, L. 1., Moody, R. C., Glulam design criteria for temporary structures, J. Struct. Div., Am. Soc. Civ. Eng. 104, No. ST9, Proc. Paper 14031, $1485-1494$ (Sept. 1978).

Key words: bridges; buildings; design criteria; gluedlaminated timber; safety; tcmporary structures; wood.

If temporary structures having lives of 2-5 ycars are designed using criteria for permanent structures with lives of 50-75 years, overly conservative designs can result. This paper presents a systematic, rational basis for developing critcria for glued-laminated timber temporary bridges and buildings. Second moment reliability theory, which rcquires estimates of the mean and coefficient of variation of resistance and load, is used to compute mcasures of safety, called safety index values.
These index values are computed for permanent and tcmporary structural elements. Allowable stresses for temporary structures are determined by choosing corresponding safcty index values which will provide adequate safety relative to the safety of permanent structures, while reflecting the temporary nature of the structures. Examples of how allowable flexural stresses are developed for bridges and buildings are given.

18888. Marshall, H. E., Petersen, S. R., Economics and the selection and development of energy standards for buildings, Energy and Buildings 2, 89-99 (1979).

Key words: buildings; conservation; criteria; design; economics; efficiency; cnergy; energy budget; equity; lifecycle cost; optimal; standard

Energy-conservation standards for new buildings will play a major role in federal and state conservation policies in the coming decade. This article discusses economic-efficiency considerations that can be incorporated into the selection and development of such standards. Three types of energy budgcts- fixed cnergy budgets, partially variable cnergy budgets, and economically efficient cnergy budgets (EEEB)-are cxamined for use as standards. Economic-efficiency criteria are presented for use in selecting an appropriate energy budget. An illustrative cxample shows the potential dollar losses in life-cycle terms from failing to apply an EEEB. Research and operational requirements for developing and implementing an energy budget are described. Three cnergybudget standards are evaluated in terms of economic efficiency, administrative fcasibility, equity, and consistency in design requirements. An EEEB appears optimal in that it ranks highest overall with respect to the four criteria. Failure to begin research for, and development of, EEEBs now would impose unnecessary social costs in the form of extra expenses to achieve any chosen target levels of energy conservation in buildings.

18889. Koch, W. F., Complication in the determination of nitrite by ion chromatography, Anal. Chem. 51, No. 9, 15711573 (Aug. 1979).

Key words: ion-chrom atography: nitrite; nitrite solutions; oxidation

A serious problem in the determination of nitrite by ionchromatography has been discovered. Evidence is presented to show that the problem is due to ion-exclusion and oxidation of nitrite on the suppressor column. Partial remedy can be achieved by deaeration of the eluent. It is suspected that a similar problem exists for all weak acids and/or easily oxidizable anions, such as sulfite.

18890. Knab, L. I., Numerical aid to reduce construction injury losses, J. Constr. Div., Am. Sro. Civ. Eng, 104, No. C04, Proc. Paper 14213.437-445 (Dec. 1978).

Key words: construction; cost effectiveness; hazard; injuries; loss prevention; risk; safety.

In the construction industry, the rate of work-related injuries and deaths is two or more times the national rate for all industries. This paper develops a rational method which quantitatively rates construction risks, using risk scorcs. The scores, which are computed for each workmen's compensation classification, are based on insurance premiums and injury cause-cost analysis. In addition the method numerically ranks the relative cost effectiveness of corrective actions which are taken to reduce risks. The cost effectiveness ranking is determined from the risk score, the cost and the degree of effectiveness of the corrective action. Use of the method can improve the efficiency of evaluating risks and allocating resources to minimize the risks. The mcthod presented is considered only a first step. The uses 
limitations. and further development of the method are presented.

18891. Kimbleton. S. R., Data sharing protocols: Structure, requirements and interrelationships, (Proc. Second IEEE Computer Society Int. Conf. COMPSAC 78, Chicago, IL, Nov. 13-16, 1978), IEEE Catalog No. 78CH1338-3C, pp. 270-276 (Institute of Electrical and Electronics Engineers, Inc., New York, NY, 1978).

Key words: communications; computers; databases; networks; operating systems; protocols.

Computer networks provide the basic mechanism for accessing programs and data. Effective use of networks requires appropriate protocols to preserve the meaning of data being transmitted between heterogeneous systems. Currently cxisting protocols were developed to support the requirements of scientists and engineers. Information processing support, for $\mathrm{cx}$ ample remote database access, requires substantially more sophisticated protocols. This paper describes a spectrum of data sharing protocols, identifies the need for a Structure Transport Protocol (STP), describes the nature of an STP, and discusses its utilization in the context of remote database access.

18892. Eberly, J. H., Extended two-level theory of the exponential index of multiphoton processes, Phys. Rev. Lelt. 42, No. 16, 1049-1052 (Apr. 16, 1979).

Key words: absorption; cesium; cxponential index; ionization; multiphoton; Rabi frequency; Star shift; two-level model.

We give a non-perturbative expression for the $r$-photon-resonant, $(r+p)$-photon ionization rate of an atom. From this expression the cxponential index $\mathrm{K}$ is derived. A comparison with experimental data of Morellec et al. appears satisfactory.

18893. Eberly, J. H., ONeil, S. V., Coherence versus incoherence: Time-independent rates for resonant two-photon ionization, Phys. Rev. A 19, No. 3, $1161-1168$ (Mar. 1979).

Key words: bandwidth; coherence; dynamic rate; incoherence; ionization; linear rate; multiphoton; rate approximation; saturable rate.

We study three ways in which two-photon ionization, at high light intensitics and near an intermediate-state resonance, may be described. We calculate the instantaneous ionization rate, the total ion count, and a saturable rate constant. We find that the total ion count, which is the experimentally interesting quantity in most cases, is very closely modelled by our saturable rate constant. The instantaneous ionization rate bears no useful relation to the total ion count in many cases. In comparing these three descriptions of ionization we have included the effects of detuning from resonance, finite light bandwidth, finite intermediate-state lifetime, and light intensity; we have varied all of these parameters independently over several orders of magnitude. Our conclusions are in good agreement with, and cxtend the findings of, Ackerhalt and Shore.

18894. Hastings, S. R., Passive solar design for urban commercial environments, (Proc. 4th Nat. Passive Solar Conf., Kansas City, MO, Oct. 3-5, 1979), Paper in Proceedings of the 4th National Passive Solar Conference, G. Franta, Ed., 4, Section 3, 303-306 (American Section of the International Solar Energy Society, Inc., Newark, DE, 1979).

Key words: application; buildings; commercial; daylighting; energy; environments; heating; passive; solar; suburban; urban.

To investigate the passive use of solar energy in urban commercial cnvironments five generic cnvironments and five pas- sive solar configurations have been defined. Common solar energy issues are summarized here. Two of the five generic environments are then examined regarding energy use characteristics, passive solar configurations, and constraints.

18895. Ware, R. H., Bender, P. L., Noise reduction techniques for use in determining local geomagnetic field changes, $J$. Geomag. Geoelectr. 30, 533-537 (1978).

Key words: conductivity anomalies; carthquake prediction; geomagnetism; induced currents; magnetometers.

We recently have made measurements of the difference in total field $\Delta F(t)$ over a $16 \mathrm{~km} \mathrm{~N}-\mathrm{S}$ path near Boulder, and find the behavior quite different from that observed for an E-W path. The present accuracy of our narrow line rubidium magnetometcrs is about $0.01 \gamma$. The N-S variations appear to correlate mainly with variations in $H$ rather than $D$, and may bc associated with cither gradients of cxternal ficlds or current in shallow conductivity anomalies. Morc recently we have set up our three magnetometers on a straight E-W line so that the "second difference" can be measured, and a transfer function from field component variation to the second difference can be determined. We plan to use a generalization of this approach for analyzing USGS tectonomagnetic data from California.

18896. Early, J., Discussion on the paper "A mechanism of intergranular fracture during high-temperature fatigue," by $B$. Min and R. Raj, (Proc. American Society for Testing and Materials Symp. on Fatigue Mechanisms, Kansas City, MO, May 22-24, 1978), Am. Soc. Test. Mater. Spec. Tech. Publ. 675, pp. 585-587 (1979).

Key words: critical strain ratc; fatigue; grain boundary sliding; high temperature; intergranular fracture; stainless steel.

The phenomenological model described in this paper is a further step in the process of separating the macroscopic failure mode categories of transgranular failure and intergranular failure from the qualitative description of mechanical behavior, such as ductile failure and brittle failure. By focusing on local deformation conditions, the model extrapolates discrete microscopic behavior to average macroscopic behavior which can be tested in the laboratory. Several questions are raised, however, concerning not only the particular model proposed in this paper but also the relationship of this model to other elevated fracture models.

18897. Forester, D. W., Koon, N. C., Schelleng, J. H., Rhyne, J. J., Spin-glass and magnetic blocking transitions in amorphous $\mathrm{YFe}_{2}$, Solid State Commun. 30, No. 4, 177-180 (1979).

Key words: amorphous magnetism; Mössbauer effect; rare earths; spin freezing; spin glasses; susceptibility.

Low field dc magnetic susceptibility measurcments on amorphous $\mathrm{YFe}_{2}$ show a distinct cusp-like peak at $\mathrm{T}_{\text {s.f. }}=58 \mathrm{~K}$. This result, together with carlier Mössbauer and neutron scattering measurcments, indicates that a true thermodynamic spinglass transition occurs at $T_{\text {s.G. }}$. In addition, susceptibility and coercive field data are presented which strongly suggest a magnetic freezing or blocking temperature near $T=20 \mathrm{~K}$. This is the first time these two magnetic phenomena have been observed in the same magnetic system.

18898. Rhyne, J. J., Lynn, J. W., Luborsky, F. E., Walter, J. L., Spin excitations in amorphous transition-metal boron glasses, J. Appl. Plys. 50, No. 3, 1583-1 585 (Mar. 1979).

Key words: amorphous alloys; magnetic properties; neutron scattering; spin waves; transition-metal glasses. 
Magnetic inelastic neutron seattering studies have been performed on ribbon speeimens of amorphous $\mathrm{Fe}_{\mathrm{k}: 3} \mathrm{~B}_{16,5} \mathrm{Si}_{0.5}$ and $\mathrm{Fe}_{201} \mathrm{Ni}_{\mathrm{tin}_{11}} \mathrm{~B}_{13} \mathrm{P}_{1}$. The samples were prepared from isotopically enriched $\mathrm{B}$ to reduce the neutron absorption. The Curie temperatures for the two materials are $613 \mathrm{~K}$ and $410 \mathrm{~K}$ respectively, and the room temperature saturation magnetizations $4 \pi \mathbf{M}_{5}$ are $16.0 \mathrm{kG}$ and $5.1 \mathrm{kG}$. In the $\mathrm{Fe}_{20,0} \mathrm{Ni}_{6,10} \mathrm{~B}_{19} \mathrm{P}_{1}$ speeimen, welldefined spin waves were observed at room temperature for neutron wave-veetor transfers in the range $q=0.06 \AA^{-1}$ to $q$ $=0.20 \AA^{-1}$. After correcting for instrumental resolution, the data obeyed a quadratic dispersion law with spin stiffness $D=$ $80 \mathrm{meV}-\AA^{2}$. Spin waves in the $\mathrm{Fc}_{\mathrm{x} ; \mathrm{i}} \mathbf{B}_{16,5} \mathrm{Si}_{10.5}$ amorphous alloy exhibited a $\mathrm{D}=125 \mathrm{meV}-\mathrm{A}^{2}$ consistent with the higher $\mathrm{T}_{r}$ of this alloy.

18899. Allan, D. W., Hellwig, H., Time deviation and time prediction error for clock specification, characterization, and application, Proc: IEEE 1978 Position Location and Navigation Symp., San Diego, CA, Nov. 6-9. 1978, pp. 29-36 (Institute of Eleetrieal and Electronics Engineers, Inc., New York, NY, 1978).

Key words: clocks; frequeney drift; frequeney stability; navigation; oscillator; position location; time dispersion; time error; time error measure; time prediction error.

The characterization of oscillators and elocks in terms of frequency fluctuations as a function of averaging time, $\sigma_{v}(\tau)$ is now well understood and documented. However, a need still exists to deseribe a time deviation measure $x(t)$. We show the dependence of such a deviation measure and the error of predietion of this measure on praetical maeasurement eonstraints, on systematic eharacteristies, as well as on $\sigma_{r}(\tau)$. We develop models which allow eloek characterization from insufficient data. For example, when statistically significant data are eonstrained to the short term region it is still possible to extrapolate into the long term.

Finally, we summarize the state-of-the-art of eloeks and oseillators in terms of $x$ and show the obvious importance of these measures to properly choosing, measuring, specifying, or using elocks and oseillators for position location or navigation applieations.

18900. Sehaefer, A. R., Geist, J., Spatial uniformity of quantum efficiency of a silicon photovoltaic detector, $A p p l . O p t .18$, No. 12, 1933-1936 (June 15, 1979).

Key words: dead layer model; external; internal; quantum efficieney; refleetance; response; silieon deteetor; spatial position dependence.

In the course of investigating the spatial uniformity of response of a silieon detector, an extensive experiment was eonducted to examine the eorrelation between changes in reflectance, internal and external quantum efficiency as a funetion of position and wavelength on the detector. The sensitivity of the technique was tested and demonstrated in several ways. The examined detector was found to be suitably uniform for absolute radiometric purposes, and the small changes observed in external quantum efficiency ean be easily aceounted for by the dcad layer model

18901. Eisenhauer, C. M., Gilliam, D. M., Grundl, J. A., Spiegel, $V$., Utilization of standard and reference neutron fields at NBS, Proc. $2 d$ ASTM-EURATOM Symp. on Reactor Dosimetry: Dosimetry Methods for Fuels, Cladding, and Structural Materials, Pato Alto, CA, Oct. 3-7, 1977, 3, 1177-1191 (Available as NUREG/CP-0004 from the National Technical Information Service, Springfield, VA, Oct. 1977).

Key words: benehmark; fission spectrum; foils; neutron fields; scattering corrections; sensitivity.
Several neutron fields whose absolute intensity and speetrum are known suffieiently well to serve as calibration facilities for reactor dosimetry are now operational at NBS. These include a fission-neutron spectrum generated by a small point souree of ${ }^{252} \mathrm{Cf}\left(\phi \sim 1.5 \times 10^{7} \mathrm{n} / \mathrm{cm}^{2}\right.$ see at $5 \mathrm{~cm}$ distance), an intermediate-energy standard neutron field (ISNF) at the center of a spherical eavity in the thermal eolumn of the NBS reactor ( $\phi$ $\left.\sim 10^{9} \mathrm{n} / \mathrm{cm}^{2}-\mathrm{sec}\right)$, and a near-1/E spectrum in the same location with about twice that flux. For the ${ }^{252} \mathrm{Cf}$ facility we will diseuss reeent investigations such as intercomparison of souree strength with other laboratories, response of integral detectors in this speetrum, and cvaluation of the differential spectrum For the ISNF facility we will describe the facility and discuss some preliminary integral measurements.

\section{Unassigned.}

18903. Hogben, D., OMNITAB 78, (Proe. Intl. Assoc. for Statistical Computing Exhibition held at the 4lst Session of the International Statistical Institute, New Delhi, India, 1977). Chapter II in A Comparative Review of Statistical Software, I. Franeis, Ed., pp. 197-208 (1979).

Key words: capabilities; case of learning and using; installation; language; maintenanee; numerical analysis; $O M-$ NITAB 78; portability; poster; reliability; statistical eomputing section; worksheet.

This poster gives an overview of the OMNITAB 78 generalpurpose statistical computing system. The basic design of OMNITAB is deseribed. The main features and types of instruetions are listed. The portability of OMNITAB is explained with a deseription of the types of eomputers on which OMNITAB ean be installed. The ease of learning and using OMNITAB is explained with a diseussion of the user's manual and training required. The reliability of OMNITAB is diseussed with aceuraey, maintenanee and updating. The poster concludes with a set of references and an cxample of a "typical" set of instructions.

18904. Layer, H. P., Acoustooptic modulator intensity servo, Appl. Opt. 18, No. 17, 2947-2949 (Sept. 1, 1979).

Key words: acoustooptic; intensity; laser; modulator; noise; servo eontrol.

A device has been eonstrueted that combines optical isolation and amplitude noise reduction by the use of a servo controlled aeoustooptic intensity modulator. The isolation can, in prineiple, be perfect while the noise reduction can be significant up to about $100 \mathrm{kHz}$ and as large as $80 \mathrm{~dB}$ at low frequeney. This performanee is accomplished by applying negative feedback around an acoustooptic modulator, serving the intensity of the Bragg diffraeted beam to a eonstant value.

18905. Kirby, R. K., Standard reference materials for thermophysical properties, Proc. $7 / /$ Symp. on Thermophysical Properties, Gaithershurg, MD, May 10-12, 1977. A. Cezairliyan, Ed., pp. 949-965 (The American Society of Meehanical Engineers, New York, NY, 1977).

Key words: calorimetry; elasticity; electricill resistivity; emittance; measurement system; standard reference materials; temperature; thermal eonduetivity; thermal expansion; thermal properties; vapor pressure; viseosity.

The National Bureau of Standards has prepared over 70 certified referenee materials for use in the area of thermophysical properties of solids ineluding those that define fixed and secondary-referenee points of the International Practical Temperature Scale of 1968 . These reference materials are deseribed in detail. The procedures that the Office of Standard Reference Materials follows in eertifying these materials are also deseribed. Standard Reference Materials (SRM's) can be used 
to develop test methods and to calibrate mcasurement equipment thereby insuring the compatibility of measurements among laboratories and assuring the long-term integrity of quality control in manufacturing processes. Used in these ways SRM $:$ form an important part of the national measurement system.

18906. Penner, S., High duty-cycle accelerators and new experimental possibilities. (Proc. Nuclear Physics with Electromagnetic Interactions, Mainz, Germany, June 5-9, 1979), Paper in Lecrure Notes in Plyssics, J. Ehlers, K. Hepp. R. Kippenhahn, H. A. Weidenmüller, J. Zittart7, Eds., 108, 99-113 (Springer-Verlag, Berlin, Germany, 1979).

Key words: coincidence cxperiments; correlations in nuclei; ew accelerators; clectronuclear physics; high duty-cycle.

New typcs of nuclear physics cxperiments are made possible by clectron accelerators with $\mathrm{cw}$ beams. Experiments not feasible with present day accelerators will contribute greatly to our understanding of two-body correlations and the role of nucleon resonances in nuclei. It will be possible to study neutron wave functions in nuclei with accuracy comparable to what is now possible only for photons. Better methods for studying the giant resonances will also become feasible. Accelerator possibilities for achieving the goal of $\mathrm{cw}$ electron beams are discussed. Some considerations of how high an energy might be needed are given.

18907. Sachse, W., Hsu, N. N., Ultrasonic transducers for materials testing and their characterization, Chapter 4 in Physical Acoustics XIV, 277-405 (Academic Press, Inc., New York, NY, 1979).

Key words: characterization, transducers; propagating, bulk waves; transducers, angle beam; transducers, contact; transducers, immersion; transducers, ultrasonic; transduction, ultrasonic; ultrasonic; ultrasound.

The paper is a comprehensive review of ultrasonic transducers which are being used for materials testing and flaw detection. Emphasis is placed on the characterization of these transducers.

The scopc of this review is four-fold: (1) to consider the ultrasonic transducer coupled to various test media as an element in an ultrasonic system; (2) to survey the various methods of ultrasound transduction; (3) to summarize some of the techniques by which the characteristics of a transducer are modified; and (4) to review the techniques for transducer characterization. The emphasis is on transduction devices of bulk waves propagating in solids including contact, immersion and angle beam transducers.

18908. Hellwig, H., Microwave time and frequency standards, Radio Science 14, No. 4, $561-572$ (July-Aug. 1979).

Kcy words: atomic clocks; cesium standards; crystal oscillators; frequency standards; hydrogen standards; rubidium standards; time and frcquency; timekeeping.

Today's time and frequency standards which are in active use ranging from the definition of the second to spacecraft applications are all based on atomic resonances in the microwave region controlling high-performance quartz crystal oscillators. The present status of these standards will be presentcd focusing in particular on cesium, hydrogen, and rubidium devices, as well as on new quartz crystal standards. A coherent picture of their physical principles and limitations is given based on the common attempt to reduce perturbations and Doppler effects. The sharpness of the resonance line is linked to the flicker noise stability limit of the various standards, and some speculation is made on where and how much further improvements may occur. It is demonstrated how new design concepts and new physical methods most likely will significantly improve the accuracy, stability, and practical usefulness of time and frequency standards.

18909. Johnson, C. R., Hadamard products of matrices, Linear and Multilinear Algebra 1, 295-307 (1974).

Key words: closure; $D$-stability; diagonal matrix: field of values; Hadamard product; inclusion theorem; Kronecker product; numerical radius; spectrum; stable matrix.

The entry-wise product of arbitrary $n \times n$ complex matrices is studied. The principal tools used include the Kronecker product, field of values and diagonal multiplications. Inclusion theorems for the field of values and spectrum are developed in the gcneral case and refined in special cases. These arc employed to obtain inequalities involving the real parts of the characteristic roots and the numerical radius, and previously known results are found to be special cases of several of the theorems. In addition, the case of positive stable matrices is considered and a new class of nonnegative stable matrices is introduced, studied and related to $D$-stability.

18910. Jednaćak-Bisćan, J., Mikac-Dadić, V., Pravdić, V., Haller, W., Surface conductivity of glass at the solid/liquid interface, J. Colloid Interface Sci. 70, No. I, 18-27 (1979).

Key words: conductivity: electric conductivity; electrokinetics; glass-surface; surface conductivity.

The electrokinetic phenomenon of surface conductivity was studied for capillaries of pure fused silica and of a borosilicate glass, in water, dilute aqueous solutions of $\mathrm{HCl}$ and $\mathrm{NaCl}$, in methanol and acetonitrile. Measurements were done in the temperature range between 5 and $30^{\circ} \mathrm{C}$ by a dc linear voltage sweep technique at a rate of $0.2 \mathrm{~V} / \mathrm{sec}$ or less, and with applied polarization voltages up to $\pm 40 \mathrm{~V}$. Surface conductivity was calculated from the total specific conductivity measured by two bright platinum electrodes at the mouths of the capillary and from the specific bulk conductivity of the liquid medium measured by a separate pair of Pt electrodes at the same temperature. Absolute values of the surface conductivity were between $10^{-9}$ and $10^{-10} \mathrm{ohm}^{-1}$. Energies of activation were calculated from the slopes, $S$, of $\log \kappa$ vs $1 / T$ curves, observed within a temperature range from 5 to $30^{\circ} \mathrm{C}$. The cnergies $E$ defined as $S=E / k$ wcre: $45-55 \mathrm{~kJ} /$ mole for the borosilicate glass, and 25 $34 \mathrm{~kJ} / \mathrm{mole}$ for fused silica in water, in aqueous solutions, and in methanol. In acetonitrile they wcre $105 \mathrm{~kJ} / \mathrm{mole}$ for borosilicate glass and $59 \mathrm{~kJ} / \mathrm{molc}$ for fused silica. The results were interpreted on the basis of the assumption that protonic conductivity is the predominant mode of surface charge transfer, with the rotation of water molecules in the first liquid layer as the rate-determining step

18911. Spal, R., Kahn, A. H., Eddy currents in a conducting cylinder with a crack, J. Appl. Plivs. 50, No. 10, 6135-6138 (Oct. 1979).

Key words: crack detection; eddy cur rents; non-destructive cvaluation

We report calculations for the impedance of a long solenoid which surrounds a cylinder of conducting material containing a radial surface crack of constant depth. The calculation is accomplished by solving for the longitudinal ac magnetic field in the interior of the "cracked" cylinder in terms of an infinite series of cylindrical Bessel functions. All the coefficicnts in the series are determined in principle by boundary-condition requirements and the most significant terms are obtained numerically by truncation of the series. The rcsulting impedance is calculated for a wide range of values of the ratios of crack depth to radius and radius to skin depth. The results are tabulated in a form useful for nondestructive testing purposes. 
18912. Ederer, D. L., Lucatorto, T. B., Mehlman, G., Photoahsorption spectrum of $\mathrm{Mg} 1$ in the range $226-170 \mathrm{~A}(54.70 \mathrm{eV})$, J. Opt. Soc. Am. 69, No. 4, $520-524$ (Apr. 1979).

Key words: autoionization; core-excited states; magnesium; photoabsorption-spectrum; synchrotron radiation.

The photoabsorption spectrum of $\mathrm{Mg}$ I has been observed in the spcctral region 226-170 $\AA$ (54-70 cV) using synchrotron radiation as a background source. The one-electron excitation levels associated with the series $1 s^{2} 2 s^{2} 2 p^{6} 3 s^{21} S_{0} \rightarrow 1 s^{2} 2 s^{2} 2 p^{5}\left[{ }^{2} P\right.$ :a/2, $1 / 2 s^{2} n s, n d$ were observed as well as 29 two-and three-electron excitation resonances. A critical analysis of the one-electron cxcitation spcctrum was made and classifications for all the multiple clcctron excitations have been suggested on the basis of their quantum defects to known limits in $\mathrm{Mg} \mathrm{II}$.

18913. Harris, H., Olszewski, E. W., Wallerstein, G., The binary cepheid AU Peg, Astron. J. 84, No. 10, 1598-1602 (Oct. $1979)$.

Key words: AU Pcg; binary cepheids; cepheids; population Il cepheids.

.A photometric and spectroscopic study of the Type II cepheid AU Pegasi indicates it is a member of a binary with a period $\leqslant 50$ days. Constraints on the orbit indicate the companion is likely to be more massive than AU Peg and may be a compact object. The light curve, pulsation-velocity curve, and spectrum of AU Peg are consistent with its cepheid nature. However, the colors are peculiar and the large period changes remain to be explained.

18914. Sanders, A. A., National standards of a powerful sort, Opt. Spectra, pp. 45-49 (Aug. 1979).

Key words: calorimeter; laser; laser MAP; laser measurements; laser power and energy; NBS standards; standards.

Some basic principles of laser calorimeters are discussed. The calorimeter measurement system maintained by NBS as $\mathrm{Na}$ tional standards for laser power and energy measurements is presented. Measurement services provided by these systems are outlined and techniques are discussed for pcrforming documented traceable laser power measurements. The importance of linearity and spatial responsivity uniformity of transfer standards is shown

18915. Day, G. W., Fiber measurements: Quality and cost, (Proc. Intl. Conf. on Communications, Boston, MA, June 1014, 1979), Paper in ICC 79 Conference Record 1, 10.4.110.4.3 (1979).

Key words: attenuation; fiber optics; frequency response: measurements.

Several points which should be considered by groups writing standard measurement procedures for optical fiber waveguides are discussed. These include the quality of measurements now attainable, the factors limiting that quality, the prospect for improvement, and the cost of measurements. Some of the points are illustrated with data from measurement comparisons.

18916. Baird, K. M., Evenson, K. M., Hanes, G. R., Jennings, D. A., Petersen, F. R., Extension of absolute-frequency measurements to the visible: Frequencies of ten hyperfine components of iodine, Opt. Lett. 4, No. 9, 263-264 (Sept. 1979 ).

Key words: frequency ma surements; iodine; laser; visible.

Direct-frequency measurements have been extended into the visible rcgion of the clectromagnetic spectrum. The visible frequencies were synthesized by generating the second harmonic of the rccently measured $260-\mathrm{THz}{ }^{20} \mathrm{Ne}, 1.15-\mu \mathrm{m}$ laser with a $\mathrm{LiNbO}_{3}$ crystal. The absolute frequencies of ten hyperfine components of ${ }^{127} \mathrm{I}_{2}$ near $520 \mathrm{THz}$ are reported.
917. Saykally, R. J., Evenson, K. M.. Ohservation of pure rotational transitions in the $\mathrm{HBr}^{+}$molecular ion hy laser magnetic resonance, Phys. Rev. Lett. 43, No. 7, 515-5I8 (Aug. 13, 1979).

Key words: $\mathrm{HBr}^{+}$laser magnetic resonance; molecular ions.

A molecular ion $\left(\mathrm{HBr}^{+}\right)$has becn observed for the first time by laser magnetic resonance spectroscopy. Pure rotational transitions have been detected with five different far-infrared laser lines. Assignment of the hyperfine patterns has produced values for the magnetic hypcrfine constants.

18918. Unassigned

18919. Saykally, R. J., Evenson, K. M., Laser magnetic resonance measurement of the $2^{3} P_{2}-2^{3} P_{1}$ splitting in atomic oxygen, J. Chem. Phys. 71, No. 4, 1564-1566 (Aug. 15, 1979).

Key words: atomic oxygcn; glow discharge; laser magnetic resonance.

Thc $J=2 \rightarrow 1$ fine-structure splitting in the ground state of atomic oxygen has bcen measured by laser magnetic rcsonance employing an intracavity de glow discharge to generate the atom. The splitting, observed with the $63.1 \mu \mathrm{m}$ laser line of ${ }^{1:} \mathrm{CH}_{3} \mathrm{OH}$ pumped by a $\mathrm{CO}_{2}$ laser, is $158.30298(7) \mathrm{cm}^{-1}$.

18920. Schneeberger, T. J., Linsky, J. L., McClintock, W., Worden, S. P., Chromospheric emission lines in the red spectrum of AD leonis. II. Physical conditions in flares, Astrophys. J. 231, No. I, 148-151 (July 1, 1979).

Key words: cmission line stars; flare stars; late-type stars; stellar chromospheres; stellar coronae.

Simultaneous photometry and time-resolved spectra of the dMe flare star AD Leo has been used to deduce flare temperatures, electron densities, and dimensions. Photometric results for two qualitatively different flares yield cstimates of the differences in physical properties between these flares. Flares on AD Leo are hotter and denser than their solar counterparts, and spike-like flares occupy smaller volumes than longer-lived flares. An upper limit to the flare $\mathrm{x}$-ray luminosity is set at $L_{x}$ $<4 \times 10^{23} \mathrm{ergs} \mathrm{s}^{-1}$.

18921. Patterson, C. W., Galbraith, H. W., Krohn, B. J., Harter, W. G., Energy level clusters for $\boldsymbol{y}_{2}+\nu_{3}$ type combination bands of tetrahedral molecules, J. Mol. Spectrosc. 77, No. $3,457-473$ (1979).

Key words: combination bands; high resolution spectroscopy; level clusters; spherical top molecules.

Clustering of tetrahedral levels is shown to occur in $\nu_{2}+\nu_{3}$ type combination bands of spherical top molecules due to Coriolis and vibrational anharmonic interactions. Cluster correlation diagrams are shown for cases where the vibrational splitting is both large and small compared to the Coriolis splitting, and cluster approximations are given for both cases.

18922. Mango, S. A., Bohlin, J. D., Glackin, D. L., Linsky, J. L., The solar XUV He 1 and He $\|$ emission lines. I. Intensities and gross center-to-limb behavior, Astrophys. J. 220, No. 2, 683-691 (Mar. 1, 1978).

Key words: sun, chromosphere; sun, spectra: sun, transition region; ultraviolet, spectra.

We derivc the center-to-limb variation of the He $\| \lambda 304$ and $\lambda 256$ lines and He 1 入584 and $\lambda 537$ lines for differcnt solar features, but averaged over the chromospheric supergranulation structure. The general trend is for limb brightening in quiet-Sun regions, limb neutrality in unipolar magnetic regions (UMR), and limb darkening in polar coronal holes. The center-to-limb 
hehavior in these optically thick emission lines indicates collisional excitation and decreasing transition-region tempcrature gradients with respect to optical depth in the sequence quict Sun $\rightarrow$ UMR $\rightarrow$ coronal hole.

18923. Norcross, D. W.. Addendum to "Photoabsorption by cesium". Phys. R('v. A 20. No. 3, 1285-1286 (Sept. 1979).

Key words: oscillator strengths; photoabsorption.

The results of earlier calculations are used to ohtain oscillator strengths for high principal-series transitions in cesium, in terms of the coefficients in an interpolation formula for principal quantum numbers $17<n<x$

18924. Powell, C. J., Erickson, N. E., Madey. T. E., Results of a joint Auger/ESCA round rohin sponsored by ASTM Committee E-42 on surface analysis, Part 1. ESCA results, $J$. Electron Spectrose. Relat. Phenom. 17,361-403 (1979).

Key words: binding cnergics: coppcr; ESCA; gold; relative intensities; round robin; $x$-ray photoelectron spcctroscopy

We report results of a round rohin involving hinding-energy (BE) and relative-intensity measurements on high-purity samples of gold and cooper by $x$-ray photoclectron spcctroscopy. These results werc ohtained on 38 different instruments manufactured by 8 companies. We found that the spread in reported $B E$ values was typically greater than $2 \mathrm{cV}$ while the spread in intensity ratios from cleaned samples was typically a factor of ten. We have analyzed the observed trends and have developed a procedure to show thc contributions of systematic crrors, random errors, and mistakes on BE and intensity measurements made with different individual instruments. This procedure, which leads to a plot of instrumental response as a function of electron cncrgy. can be used by any user to compare the pcrformance of this instrument with those reported here and to monitor performance as a function of timc. At least part of the ohserved spreads in the reported BE and intensity data can be ascribed to erratic instrumcntal pcrformance. The results of this round robin clearly demonstrate the need for improved calihration methods and opcrating procedurcs to cnsure that data of known accuracy can be obtained routinely.

18925. Tachibana, K., Phelps, A. V., Excitation of the $C^{3} \Pi_{b}$ state of $\mathbf{N}_{2}$ by low energy electrons, J. Chem. Phys. 71, No. R. 3544-3546 (Oct. 15, 1979),

Key words: drift tuhe; elcctrons; cxcitation; low cnergy; nitrogen: rate coefficicnts.

Electron cxcitation rate coefficients for $\mathrm{N}_{2}$ are important to the development of models of $\mathrm{N}_{2}$ lasers, gas discharges and ionospheric phenomena and in determining electron collision cross sections. Although cross sections for thc cxcitation of the $\mathrm{N}_{2}\left(\mathrm{C}^{3} \mathrm{II}_{4}\right)$ state have heen measured by a number of authors, there are only a few measurcments of cxcitation rate coefficients. This Note presents measurements of this excitation rate coefficient obtained using the drift tuhe technique uscd for $\mathrm{O}_{2}\left(h^{1} \Sigma_{,}{ }^{+}\right)$molecules and $\mathrm{N}_{2}\left(A^{3} \Sigma_{u}{ }^{+}\right)$molecules. We also recommend a set of clectron- $\mathrm{N}_{2}$ collision cross scctions.

18926. Kelch, W. L.. Linsky, J. L.. Worden. S. P., Stellar model chromospheres. IX. Chromospheric activity in dwarf stars, Astrophys. J. 229, No. 2. 7(30)-712 (Apr. 15, 1979).

Key words: Ca u emission, stars; chromosphercs, stars; emission line, star: late-type, ultraviolet: spectra.

High-resolution $\mathrm{Ca}$ ॥ $\mathrm{K}$ linc profiles are used to derive photospheric and lower chromospheric models of cight mainscquence stars of spectral typcs FO through MO. These stars exhibit different degrecs of chromospheric activity as indicated hy their chromospheric radiative losses. Plane-parallel homogeneous models are computed on the hasis of partial redistribution diagnostics. We find that the morc active stars generally have steeper temperature gradients in their lower chromospheres and may he hotter in the temperature minimum region than other quiet-chromosphere stars of similar spcctral type. Computations of $\mathrm{H} \alpha$ profiles for 6I Cyg B (dM(1)) and EQ $V \operatorname{Vir}(\mathrm{dK} 7 \mathrm{e})$, using models derived from the $\mathbf{K}$ line analysis, correctly predict $\mathrm{H} \alpha$ absorption from $6 \mathrm{I} \mathrm{Cyg} \mathrm{B}$ and $\mathrm{H} \alpha$ cmission from EQ Vir. Thus the dMc star phenomenon can be simply cxplained by enhanced chromospheric tempcrature gradients, presumably duc to enhanced nonradiative heating rates which imply magnetic fields. Comparing $\mathrm{K}$ line observations of all dwarf and subgiant stars analyzed in this series, we find that the $K_{1}$ cmission width $\left(\Delta \lambda_{k 1}\right)$, indicative of the mass column density at the tcmperature minimum, is systematically grcater in thc active-chromosphere stars. This suggests that the temperature minimum moves outward to lower values of mass column density with decreasing nonradiative heating in the lower chromosphere. Previous work has suggcsted that this occurs as stars cvolve. We also find that the separation of the $K_{2}$ cmission features decreases with increasing nonradiative heating. Both this narrowing of $K_{2}$ and the broadening of the base of the $K$ emission with greater activity agree qualitatively with the theoretical scaling arguments of Ayres. Finally, we find that the chromospheric radiative losses for all the dwarfs analyzed in this series confirm the trends with cffective tempcrature originally presented by Linsky and Ayres.

18927. Theodosiou, C. E.. Armstrong, L., Jr., Two-photon ionisation of caesium, J. Phys. B Lett. (1) Ed. 12, No. 3, L87. L91 (1979).

Kcy words: cesium; ionization; pcrturbation theory; second-order pcrturhation theory; two-photon ionization.

We study the time dependence of the two-photon ionisation rate for atomic caesium calculated using a sudden approximation. We show that for pulse lengths similar to ones used in the measurements by Granneman and Van der Wiel second-order pcrturbation theory gives results different from those obtained with our model. Finally we utilize molecular data to rcsolve the discrepancy still outstanding between theory and cxperiment

18928. Harter, W. G., Layer, H. P., Petersen, F. R., Evidence of tumbling multiplets in saturation absorption spectra of $\mathrm{SiF}_{+}$, Opt. Lett. 4, No. 3, 90)-92 (Mar. 1979).

Key words: high resolution spectroscopy; level clusters: saturation absorption spectroscopy; spherical top molecules.

Some implications of tumbling quartets, triplets, and doublets seen in high-resolution spherical-top spectra are discussed. Somc of the first observed cluster splittings are shown in $\mathrm{SiF}_{+}$ spectra and compared with the predictions of the quantum theory of clusters. Further potentially interesting spectroscopic cxpcriments are proposed.

18929. Horwitz, A. B., Le one, S. R., Temperature dependence of resonant isotopic vibrational energy transfer in $\mathrm{H}^{35} \mathrm{Cl}$ $\mathrm{H}^{37} \mathrm{Cl}, \mathrm{J}$. Chem. Phys. 70, No. I1, 4916-4923 (June 1, 1979).

Key words: hydrogen halides; isotopes: temperature dependence; vibrational cnergy transfer.

The resonant vibration-to-vibration energy transfer process, $\mathrm{H}^{35} \mathrm{Cl}(\nu=1)+\mathrm{H}^{37} \mathrm{Cl}(\nu=0) \rightarrow \mathrm{H}^{35} \mathrm{Cl}(\nu=0)+\mathrm{H}^{37} \mathrm{Cl}(\nu=1)+$ $\Delta E=2.1 \mathrm{~cm}^{-1}$ has been investigated over the temperature range 192-632 $\mathrm{K}$ by use of an isotopically selective transverse discharge chemical laser and infrared fluorescence techniques. The transfer probahility shows a temperature dependence of $P_{t}$ $\sim T^{-1.6}$ over the range studied. This dependence is similar to those observed for a number of other near-resonant processes, 
but differs from current theoretical predictions for resonant vibrational energy transfer. It is shown that a model based on a statistical distribution of rotational states resulting after a long-lived collision is useful in understanding the parameters which must be important in resonant vibrational energy transfer.

18930. Saylor, C. P., Refractometry of fluids in microscopic tuhes, Appl. Opt. 18, No. 6. 802-808 (Mar. 15, 1979 ).

Key words: fluids; noxious fluids; refractive index; refractive index tuhes.

Fluid filling a tube immersed in a medium that matches the index of the tube acts as a cylindrical lens. Because of geometrical aherrations, the focal length cannot be used directly for an accurate determination of refractive index. By ohserving the focal position with a microscope that has an aperture regulating diaphragm in the back focal plane, the ambiguity can be removed. The diaphragm restricts the observing light to two beams of cqual and opposite obliquity. With unpolished tubes accuracy is about as good as with an Abhe refractometer, a few units in the fourth decimal place.

\section{Unassigned.}

18932. Penner, S., Galejs, A., Transport calculations for very high current beams, (Proc. 1979 Particle Accelerator Engineering and Technology, San Francisco, CA, Mar. 12-14, 1979), IEEE Trans. Nuc\%. Sci. NS-26, No. 3, Pt. I, 30863089 (June 1979).

Key words: beam transport; high current beams; numerical simulation; particle accelerators; space charge forces.

A computer program has been developed to calculate the effect of the transverse space charge forces on a particle beam. The method is to divide the beam into a large number, $M$, of "heamlets," and compute the force on each beamlet hy summing over the forces due to all the others. $M \geqslant 1000$ is needed to make spurious collisional cffects negligihle. To the space charge forces, we add the forces due to the physical components of the system such as quadrupoles, solenoids or accelerating gaps. Using this program we have verified the prediction that at high current, certain perturbations of the K-V distributions are unstable. In a FODO line tuned to $90^{\circ}$ phase advance per cell at zero current, with the phase advance depressed to $30^{\circ}$. hy space charge, we found that the rms cmittance of a perturhed $\mathrm{K}-\mathrm{V}$ distribution grows by a factor of 2 in $\sim 40$ cells, and then remains stable, although no longer having the $\mathrm{K}-\mathrm{V}$ form. For thin-lens focusing, this result is in good agreement with Haber's calculation. The use of finite quadrupoles rather than thin lenses has remarkably little effect.

18933. Krauss, M., Neumunn, D. B., Charge overlap effects in dispersion energies, J. Chem. Phys. 71, No, 1, 107-112 (July 1, 1979).

Key words: Bc; dispersion; excited states; He; interaction energy; overlap.

Charge overlap effects in dispersion energies are calculated using frequency dependent atomic polarizabilities. The dispersion energy is expanded in the usual multipole interaction series but the dispersion coefficients are found to be given as a product, $C\left(L_{1,}, L_{n}\right) \times\left(L_{, 1}, L_{n}, R\right)$ where $C\left(L_{.1}, L_{n}\right)$ is the usual coefficient for nonoverlapping fragments and $\chi$ is called a damping function which equals one asymptotically. Damping functions have been calculated for $\mathrm{He}\left(I^{1} S\right)-\mathrm{He}\left(1^{1} S\right)$, Be( $\left.1^{1} S\right)$ $\mathrm{Be}\left(\mathrm{I}^{\prime} S\right)$, and combination of $\mathrm{He}\left(2^{3} .5\right), \mathrm{He}\left(2^{1} S\right), \mathrm{He}\left(1^{1} S\right)$, and $\mathrm{H}\left(\mathrm{I}^{2} S\right)$. The results are used to analyze qualitatively the extent of the dispersion contribution to the energy of interactions at cither the equilibrium separation or the critical distance for orbiting collisions.
8934. Krauss, M., Neumann, D., Variational calculation of dynamic polarizabilities, Chem. Phys. Le't, 52, No, 3, 6()()$-$ 602 (Dec. 15, 1977).

Key words: frequency dependent polarizability; helium is state; molecular electronic structure; van der Waals coefficient.

The finite field method of ohtaining static multipole polarizabilities is extended to the calculation of dynamic polarizabilities. The first-order frequency dependent wavefunction is ohtained variationally using a trial function, $\lambda(\omega) \psi_{1}(0), \psi_{1}(0)$ is the first-order wavefunction ohtained in the static calculation. The results are applied to the approximation of the dynamic polarizahility at imaginary frequencies. These are then used to calculate the coefficients for the inverse power-series representation of the interatomic potential cnergy. The method has been applied to two simple cases, hydrogen and helium. For hydrogen the present method yields results close to the exact values for the static dipole polarizahility and the dipole-dipole van der Waals coefficient, $C_{t}$. In the case of helium a simple Hartree-Fock function was pcrturbed but the results are still encouraging with the dipole-dipole van der Waals coefficicnt, $C_{6}$, calculated to within $7 \%$ of the accurate value.

18935. Krauss, M., Neumarin, D. B.. The ${ }^{5} \Pi_{u^{-5}} \Sigma_{1}{ }^{+}$transition in N. Mol. Phys. 37, No. 6, 1661-1671 (1979).

Key words: energy curve; cxcited state; $N_{2}$; radiative transition; ${ }^{5} \Pi_{u} ; 5 \Sigma_{u}+$.

Accurate electronic energy curves and wavefunctions of the $1^{5} \Pi_{u}$ and $1^{5} \Sigma_{u}{ }^{+}$states of $N_{2}$ have been calculated using the multi-configuration self-consistent-field (MC-SCF) method. The ${ }^{5} \Pi_{u}$ state was predicted by Mulliken who suggested it was important in $\mathrm{N}_{2}$ afterglow emissions. The calculated $R_{e}$ and $D_{\infty}$ of the ${ }^{5} \Pi_{u}$ state are in reasonable accord with estimates of Carroll and Mulliken based on predissociation behaviour of the $C^{n} \Pi_{u}$ state.

The vertical transition energy, ${ }^{5} \Pi_{u^{-}} \Sigma_{\Sigma_{g}}{ }^{+}$, is calculated to be about $1.8-1.9 \mathrm{eV}$. The calculated transition probahility is zero asymptotically but increases rapidly to shorter distances as the atoms overlap. At $R=1.6 \AA$ the transition probability is about $2 \times 10^{5} \mathrm{~s}^{-1}$ or a lifetime of $5 \mu \mathrm{s}$ for the ground vihrational level. The large and rapidly varying transition prohability is a consequence of the difference in s-p mixing in the molecular orbitals of the two states. The dominant contributions to the transition probability arise from the non-orthogonality of the MC-SCF molecular orbitals of the two states.

18936. Krauss, M., Mies, F. H., Electronic structure and radiative transitions of excimer systems, Chapter 2 in Topics in Applied Physics, C. K. Rhodes, Ed., 30, 5-46 (Springer-Verlag, Berlin, Germany, 1979').

Key words: electronic structure; energy curves; excimer; gain; radiative transition.

The electronic structure and radiative transitions of excimer molecules are reviewed. Diatomic systems are briefly analyzed for rare gas-rare gas, rare gas with Group I through VIl, and Group II-Group II atomic interactions in terms of the energy curve and transition moment behavior. The gain cross section for these systems is also proportional to a continuum line shape factor which is the Franck-Condon factor for a bound to continuum transition. The line line shape factor analyzed in terms of two limiting cases where the ground state repulsive curve is flat or steep at the transition.

18937. Sengers, J. V., Dielectric constant of water and steam, Mech. Eng. 101.44-45 (Sept. 1979). 
Key words: dielectric constant of water; interpolating equation dielectric: steam: table-dielectric constant of water: thermophysical properties of water; water.

The International Association for the Properties of Steam has adopted a recommended interpolating equation to represent the static dielectric constant of water substance in a substantial range of temperatures $\left(0{ }^{\circ} \mathrm{C}-550^{\circ}\right)$ and pressures (0-50) MPa). A description of this recommended equation is presented.

18938. Hillhouse, D. L.. Petersons. O., Sze, W. C., A prototype system for on-site calibration of coupling capacitor voltage transformers (CVVTs), (Proc. IEEE Power Engineering Society Summer Meeting. Los Angeles, CA, July 16-21, 1978), IEEE Trans. Power Appar. Syst. PAS-98, No. 3, $1026-$ 1036 (May/June 1979).

Key words: CCVT; compact: field calibration; high accuracy; portable system; truck-mounted.

In recent ycars, the coupling capacitor voltage transformer (CCVT) has come into wide use for $0.3 \%$ accuracy extra-high voltage (EHV) revenue metering in interties between utilities. Considerable user experience raised doubts as to its adequacy for this application and suggested the need for periodic calibration. Since the CCVT is permanently installed, this calibration must be done on-site.

A prototype field calibration system for CCVTs has been developed. The system contains a high voltage transfer standard divider made up of CCVT capacitor modules, a current comparator bridge, a high voltage standard capacitor, and a resonant power supply which are transported and operated from a closed calibration truck. The modular divider is assembled and connected to the CCVT bus for the calibration. The system is compact, requires only a two-man crew plus utility operating crews, and can be set up and taken down quickly on site.

System accuracy is $0.05 \%$ and 0.3 milliradians. It has successfully undergone two complete field tests in which a total of six CCVTs and six PTs were calibrated. Feasibility of a considerably simpler and less costly system has been demonstrated.

18939. Henningsen, J. O., Petersen, J. C., Petersen, F. R., Jennings, D. A., Evenson, K. M., High resolution spectroscopy of vihrationally excited ${ }^{13} \mathrm{CH}_{3} \mathrm{OH}$ by frequency measurement of FIR laser emission, J. Mol. Spectrosc. 77, 298-309 (1979).

Key words: $C^{13}$ methanol; FIR laser; laser frequency measurements.

High resolution spectroscopic data on vibrationally excited ${ }^{13} \mathrm{CH}_{3} \mathrm{OH}$ have been obtained by combining the technique of optically pumped FIR lasers with accurate frequency measurements. The frequencies of 20 torsion-rotation transitions in the $C-O$ stretch fundamental were measured and spectroscopically assigned. From these measurements, ${ }^{13} \mathrm{CH}_{3} \mathrm{OH}$ molecular constants were determined.

18940. Allun, D. W., A review of flicker noise frequency instabilities in precision frequency standards. Proc. Symp. on $1 / f$ Fluctuations, Tokyo, Japan, July 11-13,1977, pp. 158-172 (Institute of Electrical Engineers of Japan, Tokyo, Japan, 1977).

Key words: clock's rms time errors: flicker noise; frequency modulation; frequency reference; precision oscillators.

Flicker noise has limited the performance of precision oscillators since their advent as a technological tool. Flicker noise in its common usage is defined as a noise process which has a spectral density which is inversely proportional to the Fourier frequency $f\left(S_{\nu}(f)=h_{2} / f\right)$ where $y(t)$ is a time varying process whose fluctuations are being characterized, $h_{-1}$ is the proportionality constant (noise level).
8941. Johnson, C. R. An inclusion region for the field of values of a doubly stochastic matrix based on its graph, Aequationes Math. 17. 305-310) (1978).

Key words: doubly stochastic matrix; eigenvalues; field of values; graph; longest circuit; permutation matrix.

It is known that an eigenvalue $\lambda=u+i v$ of a nonnegative, row stochastic $n-b y-n$ matrix $A$ satisfies

$$
u+|v| \tan \pi / n \leqslant 1,
$$

and it has been conjectured that $n$ may be replaced by $m \leqslant$ $n$ where $m$ is the length of the longest circuit (with no repeated nodes or edges) in the graph of $\mathbf{A}$. We show that when $\mathbf{A}$ is doubly stochastic this conjecture is correct not only for the eigenvalues of $\mathrm{A}$ but also for all elements of the field of values of $A$.

18942. Henderson, M. M.. Technology's help in putting information to work, Bull. Am. Sric. Inf. Sci. 6, No. 1, 32-35 (Oct. 1979).

Key words: American Society of Information Science; computer technology library science; information science.

Computer, telecommunications, and microform technologies combine to facilitate information handling today. The development of these technologies, their current trends and their impact on information handling tasks are briefly reviewed here. (This paper is to be included in a special issue of the Bulletin of ASIS which attempts an overview of the information handling field. The issue will appear at the time of the White House Conference on Libraries and Information Science and will be distributed to Conference attendees. Since the attendees will vary widely in their knowledge and familiarity with the scope of information technology, the individual papers for the special issue are written in an easy tutorial style.)

18943. Tobler, R. L., Reed, R. P., Tensile and fracture behavior of a nitrogen-strengthened, chromium-nickel-manganese stainless steel at cryogenic temperatures, Am. Soc. Test. Mater. Spec. Tech. Publ. 668, pp. 537-552 (1979).

Key words: crack propagation; cryogenics; fracture; low temperature tests; martensitic transformations; mechanical properties; stainless steel alloys.

J-integral fracture and conventional tensile properties are reported for an electroslag remelted Fe-2l Cr-6Ni-9Mn austenitic stainless steel that contains 0.28 percent nitrogen as an interstitial strengthening element. Results at room (295 K), liquidnitrogen ( $76 \mathrm{~K}$ ), and liquid-helium ( $4 \mathrm{~K}$ ) temperatures demonstrated that the yield strength and fracture toughness of this alloy are inversely related and strongly temperature dependent. Over the investigated temperature range, the yield strength tripled to $1.24 \mathrm{GPa}(180 \mathrm{ksi})$ at $4 \mathrm{~K}$. The fracture toughness, as measured using 3.8 -cm-thick ( 1.5 i.) compact specimens, decreased considerably between 295 and $4 \mathrm{~K}$. During plastic deformation at $295 \mathrm{~K}$ the alloy undergoes slight martensitic transformation, but at 76 and $4 \mathrm{~K}$ it transforms extensively to martensites. The amount of body-centered cubic (bcc) martensite formed during tension tests was measured as a function of elongation.

18944. King, D. S., Schenck, P. K., Laser-excited galvanic spectroscopy, Laser Focus, pp. 50, 52, 54, 56, and 57 (Mar. 1978).

Key words: laser excited galvanic spectroscopy: lasers, bandwidth determination of; lasers. frequency locking of; lasers, wavelength calibration of; optogalvanic effect: trace metal detection. 
The new spectroscopic and analytical technique, laser excited galvanic spectroscopy is presented. Applications of this technique to wavelength calibration and bandwidth determination of tunable lasers, frequency stabilization of $\mathrm{cw}$ dye lasers. and analytical determinations of trace metal in aqueous solution are described.

18945. Mauer, F. A., Robbins, C. R., X-ray powder diffraction measurements in reactive atmospheres at $1000{ }^{\circ} \mathrm{C}$ and $7 \mathrm{MPa}$ (1000) PSIG), Paper in Advances in X-ray Analvis, G. J. McCarthy, Ed., 22, 19-30 (Plenum Publ. Corp., New York, NY, 1979).

Key words: coal gasification; high pressure; high temperature; measurement method; powder diffraction; reactive atmosphere.

Studies of changes in the flexural strength and phase composition of castable refractories are being carried out in simulated coal gasification reactor cnvironments. This paper describes a pressure vessel in which $x$-ray diffraction measurements can be made by an energy dispersive method while the specimen is being heated to temperatures as high as $1000{ }^{\circ} \mathrm{C}$ in atmospheres containing $\mathrm{H}_{2} \mathrm{O}, \mathrm{CO}_{2}, \mathrm{CO}, \mathrm{H}_{2}, \mathrm{CH}_{4}, \mathrm{NH}_{3}$, and $\mathrm{H}_{2} \mathrm{~S}$ at pressures up to $7 \mathrm{MPa}(1000 \mathrm{psig})$.

18946. Kruger, J., Fundamental aspects of the corrosion of melallic implants, Am. Soc. Test. Mater. Spec. Tech. Puhl 684, pp. 107-127(1979).

Key words: corrosion; crevice corrosion; galvanic corro sion: implants; implants passivity.

The corrosion of metals in the aqueous environments of body fluids involves the setting up of electrocitemical corrosion cells. The corrosion produced by these cells is controlled by thermodynamic and kinetic factors. The thermodynamic factors determine the corrosion tendencies; the kinetic factors determine the rate. Galvanic corrosion is affected by both thermodynamic and kinetic factors and occurs when two metals with widely differing potentials are placed in contact with each other. Other forms of corrosion depcnd more directly on factors controlling the rate of corrosion. For most alloys used in implants the corrosion rate is mainly dependent on the protective properties of the thin passive films that exist on the surfaces of these alloys. The quality of the protection afforded by passive films is related to their ability to resist chcmical breakdown by damaging species and, once broken down, their ability to reform rapidly (repassivate). The interplay between breakdown and repassivation is important in determining the susceptibility of metallic implants to pitting, crevice corrosion, stress corrosion, corrosion fatigue, intergranular corrosion, and fretting corrosion.

18947. Faller, J. E., Rinker, R. L., Zumberge, M. A., Progress on the development of a portable absolute gravimeter, (Proc. Conf. Bureau Gravimetrique International, Paris, France, May 1979), Bull. d'lnf. 44, 1-B-4-1-B-11 (Universite P. et M. Curi, 75230 Paris Cedex 05, France, 1979).

Key words: fundamental constants; geodynamics: geophysics: instrumentation.

At the Joint Institute for Laboratory Astrophysics we are developing an absolute gravimeter using the method of free fall. Our goal is to devise an easily portable apparatus that has a 1-3 $\mu$ gal sensitivity and which requires less than half a day per measurement (including set up) to obtain that accuracy. Significant progress toward this goal has been made.

18948. Kelleher, D. E., Konjevic, N., Wiese, W. L., Test for ion dynamic dependence of plasma red shifts in neutral hydrogen, Pliys. Revi, A 20, No. 3,1195-1196 (Sept. 1979).
Key words: deuterium; hydrogen; ion dynamic effect: plasma line shift; spectral lines; Stark broadening.

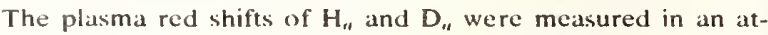
mospheric-pressure wall-stabilized arc, which was opcrated in argon with a small admixture of either hydrogen or deuterium. The measurements have yielded, within the experimental uncertainties, the same red shifts for $H_{n}$ and $D_{n}$ i.e, zero mass dependence.

18949. Roszman, L. J., Dielectronic recomhination rate of Mo xxxit, Phys. Rev. A 20, No. 3, 673-676 (Sept. 1979).

Key words: atomic physics; dielectronic rccombination: highly ionized; impurity; molybdenum; plasma.

The total rate of dielectronic recombination of Mo xxxill to form Mo xxxll is computed by means of the fundamental atomic physics of the process and atomic data calculated for this problem. Agreement with a simple analytic expression sug gested by Burgess for the total rate is good in the temperature range 1.()-6.0 keV, but poor below $1.0 \mathrm{keV}$. Considerable disagreement exists with the analytic expression when the details of the process are examined

18950. Victor, G. A., Constantinides, E. R., Double photoionization and doubly charged ions in the thermosphere, Geophys. Res. Lell. 6, No, 6, 519-522 (June 1979).

Key words: double photoionization; doubly charged ions; ionosphere: $\mathrm{O}^{++}$; photoionization; thermosphere.

We show that a plausible cross section for double photoionization of atomic oxygen,

$$
\mathrm{h} \nu(\lambda<254 \AA)+\mathrm{O} \rightarrow \mathrm{O}^{++}+2 \mathrm{e}
$$

yields the dominant source mechanism for $\mathrm{O}^{++}$in the thermosphere. With this large source, harmony is obtained between the measured $\mathrm{O}^{++}$concentrations and the large $\left(\mathrm{k} \sim 10^{-9} \mathrm{~cm}^{3}\right.$ $s^{-1}$ ) measured sink (by charge exchange with molecular species) at altitudes above about $250 \mathrm{~km}$.

18951. Danos, M., Rafelski, J., Higher-order effects in fermitype charged current theory of weak interactions: Semi-leptonic neutral currents, Phys. Lett, 73B, No. 3, 313-316 (Feb. 27, 1978)

Key words: atomic parity mixing; charged currents; fermi theory; neutral currents; neutrino scattering; weak interaction.

In a convergent field theory rescattering graphs lead to neutral-current effects of the observed magnitude if the effective cut-off momentum is $\sim G^{-1 / 2} \approx 300 \mathrm{GeV}$. A perturbation expansion is justified owing to the value $f=0.18$ of the resulting expansion parameter

18952. Brillet, A., Hall, J. L., An improved test of the isotropy of space using laser techniques, Proc. Fourlh Int. Conf, on Laser Spectroscopy, Roltach-Egern, Germany, June 11-15, 1979, H. Walther, K. W. Rothe, Eds., pp. 12-20 (SpringerVerlag, New York, NY, Oct. 1979).

Key words: isotropy of space; Michelson-Morley expcriment; special relativity; stabilized lasers.

This paper describes a new laser version of the MichelsonMorley experiment, in which we achieved a sensitivity $\Delta \mathrm{c} / \mathrm{c}=$ $(1.5 \pm 2.5) \times 10^{-15}$. This appears to constitute the most precise test of special relativity yet realized.

18953. Leuchs, G., Smith, S. J., Walther, H., High resolution spectroscopy of Rydberg states, Proc. Fourih lin. Conf. on Laser Spectroscopy, Romach-Egern, Germany, June 11-15, 
1979. H. Walther, K. W. Rothe, Eds., pp. 255-263 (SpringerVerlag, New York, NY, Oct. 1979).

Key words: angular distributions; field ionization; laser spectroscopy; multiphoton processes: photoionization: quantum beats; sodium atom.

Quantum beat measurements of the fine structure of the sodium "D states for $n=21$ to $n=31$ are reported. These highlying states were populated by a resonant two-step excitation using linearly polarized dye lasers pumped simultaneously by a nitrogen laser. They were detected by applying a voltage pulse across the atom beam immediately after excitation and detecting the cmitted field electrons. In this paper it is also shown that in the absence of an electric field, the cxcitation of $6 \mathrm{D}$ to IOD states can be detected by observing the photoelectron due to absorption of a third photon. Angular distributions of photoelectrons $I(\theta)$ with respect to the direction of laser polarization, measured in a plane perpendicular to the laser beam axis, were found to contain cven powers of $\cos \theta$ up to $\cos ^{6 i} \theta$ depending quite sensitively on the intermediate states in the three-step process. This could provide a basis for detecting microwave resonances between high-lying states.

18954. Hogben, D., Pcavy, S. T., OMNITAB 78 plotting capability, Proc. Compater Science and Statistics: 12th Ann. Symp. in the Interface, University of Waterlow, Oniario, Canada, May 10-11, 1979, J. F. Gentleman, Ed., pp. 413-417 (1979).

Key words: box plots; CALCOMP; computing system; confidence cllipse; OMNITAB 78; plots; portability plots; residuals; statistical plots; statistics; stem-and-leaf displays.

OMNITAB 78 is an integrated programming language and statistical software system, particularly suitable for physical and engineering scientists. This paper gives a brief description of OMNITAB 78 and then describes its extensive plotting capability, which includes plots with easy to read scales, plots of varying sizes, multiple plots per page, and CALCOMP plots. Histograms, stem-and-leaf displays, probability plots and four statistical plots on one page are routinely used for statistical analysis. A regression instruction automatically prints four plots of standardized residuals on one page. For a straight line regression, a $95 \%$ confidence cllipse for the slope and intercept is printed. The instruction which produces a oneway analysis of variance prints box plots. Nine cxamples are described showing many of the plots which can be casily obtained using OMNITAB 78 .

18955. Smith, S. J., Hogan, P. B., Laser bandwidth and intensity effects in multiphoton ionization of sodium, Proc. Fourth IIIt. Conf. on Laser Spectroscopy, Rottach-Egern, Germany, June 11-15, 1979, H. Walther, K. W. Rothe, Eds., Pp. 360)367 (Springer-Verlag, New York, NY, Oct. 1979).

Key words: ac Stark effect; double optical resonance; laser bandwidth effects; multiphoton ionization.

Recently there has been interest in the development of theoretical methods for incorporating the effects of finite laser bandwidth in the treatment of the ac Stark effect in the twolevel atom approximation, and in the extension of this model to approximate descriptions of "weak probe" double resonance cxperiments. In this puper we briefly describe some expcrimental observations which have played a role in motivating recent developments in the mathematical framework for treating finite lascr bandwidth effects in phase diffusion models and, more recently, in chaotic field models which include the cffects of amplitude fluctuations.

18956. Wacker, P. F.. Plane-radial scanning techniques with probe correction; natural orthogonalities with respect to sammation on planar measurement lattices, (Proc. 1979 Int.
IEEE/AP-S Symp., Seattle, WA, June 18-22, 1979), Paper in 1979 International Symposinm Digest: Antenuas and Propagatiom, 7y CH1456-3 AP, 2, 561-564 (IEEE Antennas and Propagation Society, University of Washington. Seattle, WA, (979)

Key words: aliasing; Bravais lattices; Fast Fouricr "Transform"; near-field scanning; orthogonalities; planeradial scanning; probe correction; space groups.

Plane-radial scanning has the advantage that it requires only a linear probe transport (with azimuthal rotation of the transducer-under-test), yet it is wcll suited to highly-directional transducers. (The word "transducer" is used instead of "antenna" since the treatment applies to a wide variety of mathematically-linear physical systems, e.g., EM or acoustic.) For transducers many wavelengths across, highly efficient data processing is needed, requiring (Hermitian) orthogonalities with respect to summation on the measurement lattice; further, these should be natural orthogonalities so that time-consuming orthogonalization (e.g., Gram-Schmidt orthogonalization) can be avoided. (As will be seen, the orthogonalities are implemented by the highly-efficient Discrete Fast Fourier "Transform.") Moreover, in cxpressing the fields as linear combinations of basis functions, cxact global solutions of the pertinent differential cquation(s) (Maxwell's in the EM case) make much more cffective use of the data than ad hoc basis functions, since no data are wasted in dctermining information available from the equation(s). Furthermore, for both accurate measurement and for non-ideal (c.g., directional) probes, correction for the pattern of the probe is required. This in turn requires addition theorems (like Graf's addition theorem for Bessel functions) which pcrmit the rcexpansion of the field of the probe at each and cvery measurement point in terms of the test-transducer coordinate system. Note that the orthogonalities required for the probe correction case are not between the basis functions or modes (as in the ideal probe case) but between the transformation coefficients in the addition theorcms. For both the ideal probe and probe correction cases, the lattice must provide the required orthogonalities. Assuming that the properties of the medium are invariant under certain translations, rotations, and/or reflections, we will determine all the lattices providing natural orthogonalities for any type of planar scanning involving cxact solutions of a linear system.

18957. Read, D. T., Reed, R. P., Toughness, fatigue crack growth, and tensile properties of three nitrogen-strengthened stainless steels at cryogenic temperatures, (Proc. Symp. 107th AlME Ann. Meeting, Denver, CO, Mar. 2, 1978), Paper in The Metal Science of Stainless Steels, E. W. Collings, H. W. King, Eds., pp. 92-121 (Metallurgical Society of the American Institute of Mechanical Engineers, Warrendale, PA, 1979).

Key words: cryogenic; fatigue; fracture; high-strength; lowtemperature; mechanical properties; nitrogen; nitrogenstrengthened; stuinless steel; tensile properties; toughness.

Fracture toughness, fatigue crack growth rate, and tensile property data for the nitrogen-strengthened stainless steels at 295,76 , and $4 \mathrm{~K}$ have been obtained. These materials were tested to investigate their suitability as structural materials for cryogenic service. The materials tested were nitrogenstrengthened Fe-18Cr-3Ni-13Mn, Fe-2lCr-12Ni-5Mn, and Fe19Cr-9Ni-2Mn. Toughness measurements cmployed $\mathbf{J}$-integral, plane strain critical stress intensity, and crack-opening-displacement tests. It was found that the nitrogen-strengthened austenitic stainless steels gcnerally exhibit lower toughness at 4 $K$ than the widely used 300 -series stainless steels. Of the nitrogen-strengthened steels tested to date. Fe-18Cr-3Ni-13Mn is the strongest and least tough, and $\mathrm{Fe}-19 \mathrm{Cr}-9 \mathrm{Ni}-2 \mathrm{Mn}$ is the 
toughest and least strong. Fatigue crack growth rates at $4 \mathrm{~K}$ in the nitrogen-strengthened stainless stcels were found to be generally higher than or comparable to rates for previously tested stainless stecls. Fe-1 $8 \mathrm{Cr}-3 \mathrm{Ni}-13 \mathrm{Mn}$ had rates significantly above previously tested materials, cspccially at high stress intensity range levels. Four Kclvin crack growth rates for $\mathrm{Fe}$ $19 \mathrm{Cr}-9 \mathrm{Ni}-2 \mathrm{Mn}$ and $\mathrm{Fe}-21 \mathrm{Cr}-12 \mathrm{Ni}-5 \mathrm{Mn}$ fell approximately in the mid-range of previous data for austenitic stainless steels at $4 \mathrm{~K}$. All studied materials cxhibited high strengths at cryogenic temperatures. After being strained to failure at 4 and $76 \mathrm{~K}$, Fe-18Cr-3Ni-13Mn and Fc-19Cr-9Ni-2Mn cxhibited some ferromagnetism, indicating that martensitic transformations had occurred; $\mathrm{Fe}-21 \mathrm{Cr}-12 \mathrm{Ni}-5 \mathrm{Mn}$ exhibited no ferromagnetism.

18958. Abraham, J. L., Etz. E. S., Molecular microanalysis of pathological specimens in situ with a laser-Raman microprobe, Sci. 206, 716-718 (Nov. 9, 1979)

Key words: biological microanalysis; biological tissue; foreign bodies; histological sections; implant materials; microanalysis; molecular microanalysis; pathological tissue; Raman microprobe; Raman spcctra; Raman spectroscopy.

A laser-Raman microprobe has bcen used to identify microscopic inclusions of silicone polymer in standard paraffin sections of lymph node. This cxamplc of organic chcmical microanalysis in situ in pathological tissue rcpresents an extension of microunalytical capabilities from clemental analysis, performed with clectron and ion microprobes, to compoundspccific molecular microanalysis.

18959. Unassigned

18960. Han, C. C., Molecular weight and temperature dependence of intrinsic viscosity of polymer solutions, Polymer 20. 1083-1086 (Sept. 1979).

Kcy words: hydrodynamic radius; intrinsic viscosity; polymer dimensions in solution; polystyrene; radius of gyration; temperature and molecular wcight dependence.

The molecular weight and tempcrature dependence of the intrinsic viscosity of polymer solutions have been predicted by combining the calculated radius of gyration, $R_{6,}$, and hydrodynamic radius, $R_{n}$, with either the static empirical approach of Mandelkern-Flory or the dynamic argument of Weilldes Cloizeaux. It is found that cxperimental results can be successfully represented by the dynamic model for a range of five decades of molecular weight and temperature. The discrepancy betwcen the calculated and cxperimental data at $N=N$, rcveals the crudeness of the discontinuity at the temperature cut-off assumed by current temperature blob theory.

18961. Sealabrin, A., Evenson, K. M., Additional cw FIR laser lines from optically pumped $\mathbf{C H}_{2} \mathbf{F}_{2}$, Opt. Lett. 4, No, 9, 277279 (Sept. 1979).

Key words: $\mathrm{CH}_{2} \mathrm{~F}_{2}$, FIR; optically pumped; wavelength.

Twenty-five new, $\dot{c} w$, FIR lines from $\mathrm{CH}_{2} \mathrm{~F}_{2}$, optically pumped by a $\mathrm{CO}_{2}$ laser, have been found, using a variablecoupling, open-structure resonator. Accurate wavelength measurements have been made on the 47 known $\mathrm{CH}_{2} \mathrm{~F}_{2}$ lines. The new lines arc fairly uniformly distributed over a wide range, from 105 to $1448 \mu \mathrm{m}$

18962. Frederick, N. V., Haynes, W. M., Differential capacitance sensor as position detector for a magnetic suspension densimeter, Rev. Sci. Instrum. 50, No. 9, 1154-1155 (Sept. 1979).

Key words: capacitance sensor; densimeter; magnetic suspension; position detector.
A differential capacitance sensor has been used in the servosystem of a magnetic suspension densimeter to detect the position of a magnetic buoy. This typc of sensor has not previously been used in this application. Its design, performance, and advantages arc described

18963. Etz, E. S.. Raman microprobe analysis: Principles and applications, Scanning Electron Microsc. Pt. I, pp. 67-82 and 92 (1979).

Key words: biological microanalysis; microanalysis; micromineralogy; microsampling; molecular analysis; organic microanalysis; Raman microprobe; Raman spectra; Raman spectroscopy

The principles of normal (spontaneous) Raman scattering spectroscopy are cxtended to molecular analysis with laserRaman microprobes. These instruments furnish information on the identity of the principal molecular constituents of microsamples and their distribution in the solid phasc. From the vibrational Raman spectrum, additional information on the structural order (c.g., crystalline or glassy state) of the sample is obtained. Instrumentation developed for Raman microprobe analysis is described and the pcrformance of these systems demonstrated by cxamples of measurement. Considerations on the use of these microprobes are limited to qualitative analysis. The analytieal applications of micro-Raman spcctroscopy are surveyed. Specific cxamples arc presented from the study of (i) airborne dust particles, (ii) trace organic pollutants, (iii) fluid inclusions in minerals, and (iv) thin sections of biological tissues. Sample requircments, methods of sample preparation and choice of measurement conditions are set forth to illustrate optimum analysis procedures. The cxamples given indicate the unusual advantages of the technique, offering molecular specificity, structural discernment, relatively simple spectral fingerprints, and generally pieogram sensitivity. Chief limitations of the method arise from the inherent weakness of the Raman cffect, the possibility of localized sample heating, spectral interferences from fluorescence, and the lack of quantitation.

18964. Powell, J. W., Economic evaluation of passive solar designs for urban environments, Proc. $4 t h$ Nat. Passive Solar Conf., Kansas City, MO, Oct. 3-5, 1979, pp. 1-5 (American Section of the International Solar Energy Society, Newark, DE, 1979)

Key words: commercial; cconomics; cvaluation; feasibility; passive; rehabilitation; retrofit; solar.

This paper outlines an economic model for evaluating passive solar designs for commereial buildings and applies the model in several case studies of retrofit systems. Taking into account tax cffects, incentive programs available to urban rchabilitation projects, and non-thermal as well as thermal benefits of selccted passive solar encrgy systems for space heating, the cvaluations show that these systems are eost effective over a wide range of conditions.

18965. Eisenhauer, C., Model for diffusion of a pencil beam of electrons: Angular distribution, Trans. Am. Nucl. Soc. 32, 649-650 (June 1979).

Key words: charged particle; electron; cnergy deposition; Monte Carlo; multiple scatter; tracklength.

An approximatc one-parameter analytic cxpression is developed to describe the two-dimensional tracklength distribution due to multiple scatter of narrow bcam of chargc particles. Predictions are compared with distributions calculated by the Monte Carlo method for two typcs of one-velocity scattering kernels. The analytic model is then applied to electrons of 10 , 1 , and $0.1 \mathrm{MeV}$ in water and $1 \mathrm{MeV}$ in lead, by introducing the clectron range as a cut-off parameter. A correction func- 
tion is generated by comparing energy deposition determined Irom a rigorous Monte Carlo calculation with predictions of the model. The correction function is found to be slowly varying differing from unity by less than $40 \%$. Thus, variations in energy deposition density of three orders of magnitude or more can be expressed by the product of an analytic expression and a slowly-varying tabulated correction function.

18966. Etz, E. S., Blaha, J. J., Laser-Raman microprobe analysis of particles in pollution studies, (Proc. American Nuclear Society 1979 Winter Meeting, San Francisco, CA, Nov, 11 15, 1979), Trans. Am. Nucl. Soc. 33, $241-242$ (Nov, 1979).

Key words: microanalysis: particle analysis; pollution studies; power plants: Raman microprobe; Raman spectroscopy: vibrational spectra.

The paper (a 600-word abstract, including two figures and selected literature references) refers to ongoing work at the National Bureau of Standards in the application of Raman microprobe spectroscopy to the molecular analysis of single particles in pollution particulate samples. Results of NBS research in the analysis of particles from power plant emissions are presented. Discussed are the chief attributes and limitations of Raman microanalysis as well as instrumentation developed at NBS and elsewhere.

18967. Reno, R. C., Swartzendruber, L. J., Bennett, L. H., Positron annihilation study of defects in titanium, NDT Int., pp. 224-227 (Oct. 1979).

Key words: defects; Doppler broadening; hardness: positron annihilation; titanium.

Positron annihilation linewidth measurements have been used to study defect behaviour in titanium samples which were first cold-worked and then annealed at temperatures ranging up to $850{ }^{\circ} \mathrm{C}$. The line width for a highly deformed high purity (0.9998) sample showed a gradual increase with increasing annealing temperature up to recrystallization temperature, above which there was a rapid increase. In contrast, a commercially pure $(0.9984)$ sample deformed by $20 \%$ displayed a smooth increase in linewidth over the entire annealing range. Hardness measurements correlate reasonably well with the overall trend of the positron lineshape parameter, but the positron annihilation measurements reveal defect changes that occur at temperatures too low to give any observed changes in hardness.

18968. Warner, B, E., Persson, K. B., Collins, G. J., Metalvapor production by sputtering in a hollow-cathode discharge: Theory and experiment, J. Appl. Ply.s. 50, No, 9, 5694-5703 (Sept. 1979).

Key words; charge transfer; hollow cathode discharge; metal vapor production; sputtering.

Laser action in singly ionized metal atoms has been obtained when a rare gas is excited in a metal hollow cathode. The required metal-vapor density is produced by discharge sputtering from the cathode and the excitation of upper levels occurs via a charge-transfer reaction of the type $B^{+}+M \rightarrow\left(M^{+}\right)^{*}+$ $B+\Delta E$. We present a unified discharge-sputtering theory which describes the metal density created in the hollow cathode, including both the current and spatial dependence. The predictions of this model are then compared to the measured dependence of metal-vapor density with current, spatial position, and buffer-gas pressure, Discharge conditions which support laser oscillation are emphasized. Agreement between theory and experiment is good.

18969. Hudson. R. P.- Note on the dependence of AC magnetic susceptibility on the magnitude of the measuring field, J. Low Temp. Phys. 36, Nos. 5/6, $511-519$ (1979).
Key words: low temperatures; magnetic susceptibility; magnetic thermometry; paramagnetic relaxation.

Ac measurements of susceptibility are analyzed to investigate the effect of a finite measuring field, the effect arising from the interplay of the spin-lattice relaxation time, and the measuring frequency. The analysis constitutes an at tempt at rather more rigor than that of a recent discussion by Dawber, Finn, and Kiymac. The consequences for precision magnetic thermometry with cerous magnesium nit rate are summarized.

18970. Myklebust, R. L., Newbury, D. E., The use and abuse of a quantitative analysis procedure for energy-dispersive $\mathbf{x}$ ray microanalysis, Proc. Fourteenth Ann. Microheam Analysis Society/1979 Conf., San Antonio, TX, Aug. 13-17, 1979, pp. 231-237 (San Francisco Press, Inc., San Francisco, CA, 1979).

Key words: electron probe microanalysis; energy dispersive $x$-ray microanalysis: energy dispersive $x$-ray spectrometry; quantitative analysis; scanning clectron microscopy; $x$-ray microallalysis.

FRAME C, a procedure for quantitative energy dispersive $\mathrm{x}$-ray microanalysis, is capable of high relative accuracics when the proper required analytical conditions are observed. Evaluation of the errors introduced by poor spectral quality (poor statistics, high deadtime counting, and errors in the energy calibration), uncertainty in user-supplied parameters (beam energy, $x$-ray emergence angle, and background selection), and specimen roughness reveals that average relative errors increase by factors of 2 to 20 . The most significant errors are introduced by surface roughness.

18971. Etz, E, S., Blaha, J, J., Investigations into the critical measurement aspects of Raman microprobe analysis, Proc. Fourteenth Ann. Microheam Analysis Society/1979 Conf., San Antonio, TX, Aug. 13-17, 1979, pp. 173-184 (San Francisco Press, Inc., San Francisco, CA, 1979).

Key words: laser excitation; microanalysis; microparticle analysis; microprobe resolution; microsample heating; optical detection; Raman microprobe; Raman spectra; Raman spectroscopy

In the course of NBS research in Raman microprobe analysis experiments have been performed to hetter define the critical measurement aspects of micro-Raman spectroscopy. Discussed are several experimental criteria and their relationship to successful molecular microanalysis. Spatial resolution of the probe measurement is discussed in terms of effective sampling volume determined by the design of the NBS microprobe. Effects of laser-induced sumple heating and optical breakdown of microsamples are illustrated by examples from the analysis of environmental particies. Spectral interferences from sample fluorescence are illustrated for microparticulate polynuclear aromatic hydrocarbons. Measurement problems arising from the chemical reactivity of microparticles are discussed with reference to sample modifications observed for hygroscopic particles. The question of weak signal measurements is examined from the point of view of the potential benefits to be derived from the application of optical multichannel analyzers as detection devices. Several areas requiring further experimental investigations are identified for the further enhancement of the field.

18972. Misra, D. N., Bowen, R. L., Reaction of anthranilic acid with cupric ion-containing hydroxyapatite surface, Paper in Surface Contamination. K. L. Mittal, Ed.. 2, 983-991 (Plenum Publ. Corp., New York, NY, 1979).

Key words: anthranilic acid; chemisorption: cupric anthranilate: cupric ion-containing hydroxyapatite: reaction kinetics; surface reaction. 
Equal amounts of anthranilic acid (o-aminobenzoic acid) are irreversihly adsorhed on hydroxyapatite surface with or without pretreatment of the surface with cupric ions. Cupric ions enhance the strength of the bonding between anthranilic acid and the hydroxyapatite surface by effecting chemisorption of the acid molecules at their sites. This result, in itself, is of considerahle interest to the chemistry of adhesion; but it is also shown that the chemisorption process is followed by a desorption of cupric anthranilate molecules and the formation of its crystals as a separate phase. A kinetic analysis of the latter process is of interest, because it is consistent with a model in which the rate is controlled by the concentration of the unreacted cupric ions remaining on the surface of the hydroxyapatite.

18973. Marinenko, R. B., Heinrich, K. F. J., Ruegg, F. C., Microhomogeneity studies of NBS standards, Proc. Fourteenth Ann. Microbeam Analysis Society/1979 Conf., San Antonio, TX, Aug. 13-17, 1979, pp. 221-226 (San Francisco Press Inc., San Francisco, CA, 1979).

Key words: digital periodic integrator; electron microprohe; homogeneity; standard reference materials; standards.

A simple routine technique for studying homogeneity in the micrometer range with the electron microprohe has been developed. For graphic display, a digital periodic integrator is being used. In conjunction with scalers and a stepping motor on the sample stage, traces similar to industrial control charts based on a comparison of the experiment with the expected (Poisson) counting statistics are quickly obtained. A computer program has been developed to numerically cvaluate sample homogeneity.

Several Standard Reference Materials (SRM's) have been tested. These include the iron and steels (SRM's 661-664, 461, and 463), the gold-copper and gold-silver alloys (SRM's 481 and 482), the tungsten-molybdenum alloys (SRM 480), cartridge brass ( $S R M 478$ ), the iron 3-percent silicon alloy (SRM 483 ), and the iron-chromium-nickel alloy (SRM 479a). The Research Material, Glasses for Microanalysis (RM-30), has also been tested.

18974. Laufer, A. H., Photochemistry of bromoacetylene. Formation of $\mathrm{HBr}$ and quenching of excited $\mathrm{Br}\left(\mathcal{4}^{2} \mathrm{P}^{0}{ }_{1 / 2}\right), J$. Phys. Cleem. 83, No. 21, 2683-2686 (1979).

Key words: bromine atoms; bromoacetylene; excited state; hydrogen bromide; photochemistry mechanism; thermochemistry.

The photolysis of $\mathrm{C}_{2} \mathrm{HBr}$ has been investigated in the region above $155 \mathrm{~nm}$ by the flash photolysis-kinetic spectroscopy technique. Primary processes which involve the formation of both $\operatorname{Br}\left(4^{2} \mathrm{P}_{3 / 2}^{0}\right)$ and $\operatorname{Br}\left(4^{2} \mathrm{P}_{1 / 2}^{n}\right)$ have been observed. Rate constants for the quenching of excited $\operatorname{Br}\left(4^{2} \mathrm{P}_{1 / 2}^{0}\right)$ to the ground state $\operatorname{Br}\left(4^{2} \mathrm{P}_{3 / 2}^{\prime \prime}\right)$ by $\mathrm{M}$ where $\mathrm{M}=\mathrm{He}, \mathrm{C}_{2} \mathrm{HBr}, \mathrm{CF}_{4}$, and $\mathrm{D}_{2}$ have been determined and found to be equal to $8 \pm 3 \times 10^{-16}, 3.7$ $\pm 1.6 \times 10^{-12}, \quad 1.9 \pm 0.5 \times 10^{-13}, \quad$ and $2.8 \pm 0.8 \times 10^{-13} \mathrm{~cm}^{3}$ molec $^{-1} \mathrm{~s}^{-1}$, respectively. $\mathrm{HBr}$ has been observed as a secondary product and its rate of formation has been monitored and a mechanism for its formation suggested. The probability of another primary process $\mathrm{C}_{2} \mathrm{HBr}+\mathrm{h} \nu \rightarrow \mathrm{H}+\mathrm{C}_{2} \mathrm{Br}$ (6) is discussed. The heats of formation of several $\mathrm{C}-\mathrm{Br}$ species required for mechanistic considerations are derived.

18975. Istvan, E. J., New issues confronting the information systems planner, Infosystems 26, No, 6, 54, 58, 60, 62 and 67 (June 1979).

Key words: computer-telecommunications convergence; computer trends; information age; information as a resource; information revolution; social issues in information: telecommunication trends; transborder data flows.

Today's MIS planner faces a staggering array of new technological developments out of the computer and communications "revolution." Not only must he be concerned with cost effectiveness trade-offs or poorly understood competing technologies, but he also must be sensitive to society's favorable acceptance of or negative reaction to the widescale use of these technologies. His concerns must now encompass issues of freedom of information, privacy, property rights in information, protection of information, and the suhtleties of differences between information pertaining to persons and that pertaining to corporate personalities. Some of the new technical possibilities, their potential social implications, and evolving trends in attempting to bring "regularization" to this milieu is discussed.

18976. Small, J. A., Newbury, D. E., Myk lehust, R. L., Analysis of particles and rough samples by FRAME P, a ZAF method incorporating peak-to-background measurements, Proc. Fourteenth Ann. Microbeam Analysis Society/1979 Conf., San An(onio, TX, Aug. 13-17, 1979, pp. 243-246 (San Francisco Press, Inc., San Francisco, CA, 1979).

Key words: electron prohe analysis; peak-to-background ratios; quantitative analysis; rough surfaces; $x$-ray microanalysis.

The ideal specimen for electron probe microanalysis has the form of a bulk solid with a flat, polished surface. When samples are analyzed which deviate from this condition, such as small particles or specimens with rough surface topography, large errors in the composition calculated from a ZAF method can arise, frequently exceeding $50 \%$ relative. Moreover, normalization of the results by forcing the sum of the clements to $100 \%$ can sometimes actually increase the relative errors.

Providing instrumental conditions are kept constant, the $x$ ray intensities measured on a flat, bulk sample vary for compositional reasons only. In the case of a particle or rough surface, however, geometrical factors including size and shape of the sample relative to the electron interaction volume and $\mathrm{x}$ ray emergence angle can also strongly affect the measured signals. Recently, a new method for compensation of the geometrical effects has been independently suggested by Small et al. and Statham and Pawley. This method is based on the observation that to a first approximation the ratio of a characteristic x-ray peak to the continuum intensity of the same energy for a flat, bulk target is equivalent to the ratio from a particle or rough surface of the same composition.

18977. Reinhold, T. A., Wind interaction of neighboring tall buildings, Proc. ASCE Third Engineering Mechanics Division Specialty Conf., Sept. I7-19, 1979, Austin, TX, pp. 179-182 (American Society of Civil Engineers, New York. NY, 1979).

Key words: aerodynamics; boundary layers; dynamic response; interference effects; tall buildings; wind loads; wind tunnels.

A wind-tunnel investigation into the influence of an upstream structure on the dynamic wind loads acting on a square-section tall building is described. The test configurations studied and the types of data obtained are presented. Results are discussed and some important ohservations are summarized.

The paper contains a listing of reports which contain more detailed information concerning the tests and results.

18978. Newbury, D. E., Myklehust, R. L., Monte Carlo calculations of absolute $\mathrm{x}$-ray generation from solid targets, Proc. Fourteenth Ann. Microheam Analysis Society/l979 Conf., San Antomio, TX, Aug. 13-17, 1979, pp. $51-53$ (San Francisco Press, Inc., San Francisco, CA, 1979). 
Key words: characteristic x-ray yield; electron probe microanalysis; inner shell ionization cross section; Monte Carlo electron trajectory simulation; scanning electron microscopy; $x$-ray yield.

Monte Carlo electron trajectory calculations of the absolute characteristic yield $x$-ray generated in solid targets bombarded by electrons with energies in the rangc $5-25 \mathrm{keV}$ are reportcd. Four different cross sections for inner shell ionization have been tested: Bethe (Mott-Massey), Green-Cosslett, Fabre, and Worthington-Tomlin. Comparison of the calculated absolute $x$ ray yield with recent experimentally determined values reveals differences of a factor of two or more for some of the cross sections. In general, the Bethe (Mott-Massey) gives the closest correspondence to the experiment.

18979. Newbury, D. E., The influence of instrumental sensitivity variations on quantitative analysis by secondary ion mass spectrometry, Proc. Fourteenth Ann. Microheam Anulysis Sirciety/1979 Comf., San Antonio, TX, Aug. 13-17, 1979, pp. 335-337 (San Francisco Press, Inc., San Francisco, CA, $1979)$

Key words: elemental analysis; ion microprobe mass analyzer; local thermal equilibrium model; microanalysis; secondary ion mass spectrometry; surface analysis.

Physical models of ion emission used for quantitative analysis in secondary ion mass spectrometry compensate for matrix effects but ignore instrumental cffects. Studies of relative elemental sensitivity factors measured by various SIMS instruments reveal a strong influence of instrumental factors on measured secondary ion signals. Analysis with the local thermal equilibrium (LTE) model produces compositional errors which follow the trends observed in the relative sensitivity factors, If a low rclative sensitivity factor is measured, LTE analysis will generally underestimate the composition. A modified analytical approach balsed on relative sensitivity factors modified by matrix correction factors is proposed.

18980. Bright, D., Chabay, I., Measuring aerosol particles, Chemlech, pp. 694-699 (Nov. 1979).

Key words: aerosol size measurement; calibration of particle sizing instruments; Doppler shift spectrometer; light scattering; optical particle sizing; particle size standards.

Optical methods of aerosol particle size measurement are reviewed. Basic concepts of light scattering are outlined as the basis for understanding the many specific optical techniques. Problems of calibration and intercomparison of techniques are discussed and a new instrument, the particle Doppler shift spectrometer, which specifically addresses those problems is described. A table which lists techniques grouped according to physical effect employed and cites references and size range is given along with a representative bibliography.

18981. Hutchinson, J. M. R.. International Committee for Radionuclide Metrology ICRM Newsletter: Report of the Woods Hole Conference on the Development of Naturally Contaminated Radioactivity Standards, (Proc. Symp. Int. Committee on Radionuclide Metrology (ICRM), Woods Hole. MA, Oct. 1977), Paper in Environment International 2, No. 1. 49-50 (Pergamon Press, Oxford, England, 1979).

Key words: environment; ICRM: natural matrix; radioactivity; standards; Woods Hole.

The recommendations of the Woods Hole Conference on the development of "natural matrix" radioactivity standards are summarized.
18982. Casciani, F. S., Et7, E. S., Raman microprobe study of hiological mineralization in situ: Enamel of the rat incisor, Proc. Fourcenth Ann. Microbeam Analysis Society/1979 Conf. San Antonio, TX, Aug. 13-17, 1979, pp. 169-172 (San Francisco Press, Inc., San Francisco, CA, 1979).

Key words: biological microanalysis; biological tissue; dental studies; enamel: mineralizing tissue; Raman microprobe; Raman spectra; Raman spectroscopy; tissue sections; tooth.

The NBS laser-Raman microprobe is used in a study of the mineralization process in enamel of the rat incisor. In microprobe mcasurements on thin (10 $\mu \mathrm{m}$ thickness) scctions of the mincralized biological tissue, vibrational Raman spectra are obtained from microscopic regions $(6-20 \mu \mathrm{m}$ lateral resolution) which are characteristic of the major inorganic and organic components of the tissue. The interpretation of these spectra permits the identification of the mineral phases and any changes in both concentration and distribution of the mineral during the early stages of enamel development. The spectra of mineralizing enamel and mature enamel show the development of biological apatite $\left(\mathrm{Ca}_{10}\left(\mathrm{PO}_{4}\right)_{6}(\mathrm{OH})_{2}\right)$ as reflected in the Raman scattering intensity changes for the strong $\sim 960 \mu \mathrm{m}^{-1}$ phosphate Raman band. These changes in the apatite content of the tissue are followed over a lateral distance of $30 \mu \mathrm{m}$ from the ameloblast-enamel junction to the dentino-enamel junction. This type of information has heretofore not been available by any other probe technique and provides new insights in to the process of biological mineralization.

18983. Turk, G. C., Mallard, W. G., Schenck, P. K., Smyth, K. C., Improved sensitivity for laser enhanced ionization spectrometry in flames by stepwise excitation, Anal. Chem, 51, No. 14, 2408-2410) (Dec. 1979).

Key words: enhanced ionization; ionization spectrometry; LEl; stepwise excitation; tunable dye lasers.

The cnhanced rate of thermal ionization of excited state atoms produced by the absorption of laser radiation forms the basis for a recently developed method of analytical flame spectrometry called laser enhanced ionization (LEI). Detection sensitivity for a particular element is strongly dependent on the energy gap between the excited state being populated and the ionization limit of the element, with sensitivity increasing as the gap narrows.

This paper describes the use of two tunable dye lasers, pumped by a single $\mathrm{N}_{2}$ laser, to populate high lying. atomic levels by stepwise excitation using two atomic lines connected by a common intermediate level. Closer proximity of the excited state to the ionization limit is thus achieved and sensitivity is improved accordingly. Sensitivities and detection limits were measured for scven elements using both single and dual laser excitation. Enhancements of sensitivities resulting from the use of the second laser ranging from one to three orders of magnitude were observed.

18984. Loebenstein, W, V., How to balance chemical equations, J. Wash. Acad. Sci. 69, No. 1, 7-11 (1979).

Key words: algebraic method; balancing equations; chemical equations; equation balancing.

It has been shown that an algebraic method may always be used to balance chemical equations. The method is equally applicable to REDOX reactions, complex organic reactions, ionic reactions, etc. It is not necessary to determine the oxidation numbers of the elements which comprise the various molecules. nor is there any advantage to be gained by doing so. In rare instances more than one "correct" solution can be found for the balanced equation. When this occurs, the method reveals 
the fact that it is the result of independent chemical processes taking place simultaneously.

18985. Brauer, G. M., Jackson, J. A., Termini, D. J., Bonding of acrylic resins to dentin with 2-cyanoacrylate esters, J. Dent. Re.s. 58, No. 9, 1900-1907 (Sept. 1979).

Key words: adhesive; honding to dentin; dental adhesive; dentin; durahility of dentin acrylic hond; isohutyl 2cyanoacrylate; pretreatment of dentin; 2-cyanoacrylate csters.

Strength and durahility of the dentin-acrylic resin joint cemented with 2-cyanoacrylate esters were studied. Maximum adhesion is ohtained with isobutyl 2-cyanoacrylate after 1\% acid pretreatment of the dentin. Hydrolytic stability is somewhat improved by addition of polymer to the adhesive or coating around the joint.

18986. Jenkins, J. P., Hill, J. E., A comparison of test results for flat-plate water-heating solar collectors using the BSE and ASHRAE procedures, Proc. ASME Winter Ann. Meesing, New York, NY, Dec. 2-7, 1979, 79-WA/Sol-4, pp. 1-13 (American Society of Mechanical Engineers, New York, NY, 1979).

Key words: collector efficiency; comparison German BSE vs ASHRAE 93-77 procedures; flat-plate solar collectors; German Bundesverhand Solarenergie; solar collector testing; water-heating solar collectors.

The German Bundesverhand Solarenergie (BSE) Working Group recently adopted and puhlished a procedure for testing solar collectors based on thermal performance. Research facilities for testing flat-plate water-heating collectors have been built at NBS in accordance with the BSE procedure and the existing ASHRAE Standard 93-77. The purpose of this paper is to describe the BSE test procedure and compare experimental test results with those obtained using the existing ASHRAE Standard 93-77. Included is a description of the collector test facilities at NBS and the results ohtained from testing five commercially available flat-plate water-heating collectors using both procedures.

18987. Straty, G. C., Younglove, B. A , Compact capacitor for wide-range dielectric constant measurements on small amounts of fluids, Rev. Sci. Instrum. 50, No. 10, $1309-1310$ (Oct. $1979)$

Key words: capacitor; density; dielectric constant; oxygen.

A stable parallel-plate capacitor of unusually simple design is described which is suitable for wide-range dielectric constant measurements on fluids.

18988. Unassigned.

18989. Soures, C. G., Ehrlich, M. Concerning $\mathrm{Li}_{2} \mathrm{~B}_{4} \mathrm{O}_{7}$ thermoluminescence dosimeters, Med. Phys. Commun. 6, No. 4, 312 (July/Aug. 19749.

Key words: fading; Harshaw Chemical Company; relative humidity; storage; Studsvik AB Atomenergi, Sweden; thermoluminescence dosimeters.

We have compared two commercially available types of lithium borate thermoluminescence dosimeters, one obtained from the Harshaw Chemical Company and the other from Studsvik, AB Atomenergi, Sweden. Differences between the samples of the two types were apparent mainly in their long-term storage characteristics. The Studsvik samples exhibited more fading under ambient laboratory conditions than the Harshaw samples, while the Harshaw samples were influenced more adversely by storage at high relative humidities. From these results one might conclude that a superior dosimeter could be obtained if the Harshaw powder were distrihuted in a matrix similar to that used by Studsvik.

18990. Ku, H. H., A biography of "Youden, W. J.", International Encyclopedia of Statistics, W. H. Kruskal, J. M. Tanur, Eds., pp. 1257-1261 (The Free Press, Division of MacMillan Publ. Co., Inc., New York, NY, 1978).

Key words: statistics; Youden plot; Youden ruggedness test; Youden squares; Youden, W. J.

This is a 2,000-word biography of Dr. W. J. Youden prepared for a volume of statistics and statistics-related articles and biographies selected from the International Encyclopedia of the Secial Sciences. Dr. Youden was a memher of the Applied Mathematics Division, National Bureau of Standards, from 1948-1965, and a guest worker until his death on March 31, 1971 .

18991. Krasny, J. F., Braun, E., Peacock, R., Synthesis of a general apparel flammability standard, Proc. 10th Annual litformation Council on Fabric Flammability Meeting. New York, NY, Dec. 8-9, 1976, pp. 171-184 (1976).

Key words: apparel; burn injury; ease of ignition; fahrics; fire; flammability tests; garments; heat transfer; standards.

NBS has recently submitted a draft of a general apparel flammability standard to the Consumer Product Safety Commission. If accepted by the Commission, proposed in the Federal Register, and issued in final form, this standard would replace $C S 191-53$, the present general wearing apparel standard. It is based on the Mushroom Apparel Flammahility Tester (MAFT) concept. The paper describes in detail the work on which this apparatus and the standard are based: analysis of burn accidents collected in FFACTS, work under grant at the University of Maryland and MIT, and experimental work at NBS and in other lahoratories.

18992. Ehrlich, M., Criteria for testing personnel dosimetry performance, (Proc. Annual Meeting American Nuclear Society, Atlanta, GA, June 4-7, 1979), Trans. Am. Nucl. Soc. 32, 657$658(1979)$.

Key words: American National Standards Institute; Health Physics Society Standards Committee; mandatory testing program; peer review; personnel dosimetry; processors; standard; trial use and comment.

In the summer of 1978, the Draft American National Standard, Criteria for Testing Personnel Dosimetry Performance was puhlished for one year of trial use and comment. Inasmuch as this standard is to form the basis for a mandatory testing program of the performance of all U.S. suppliers of personneldosimetry services, it is important that comments and suggestions be received by the work group of the Health Physics Society Standards Committee that developed the document prior to its final adoption as the hasis for such a test program. A brief outline is given of the contents of the standard for the purpose of stimulating peer reaction.

18993. Ashby, N., Allan, D. W., Practical implications of relativity for a global coordinate time scale, (Proc. 19th General Assembly of URSI, Helsinki, Finland, Aug. 1-4, 1978), Radio Science 14, No. 4, 649-669 (American Geophysical Union, Washington, DC, July/Aug. 1979).

Key words: coordinate time; portable clocks; relativity; synchronization; time scales.

Frontiers of technology now need synchronization between remote clocks to an accuracy of about a nanosecond. Rate changes arising from the velocity and gravitational potential of a transported clock used for synchronization of a nctwork must 
be accounted for. In addition one eannot assume the earth is an inertial frame-i.e. not spinnning. If classieal Einstein synchronization were used where from the midpoint between two elocks of $\mathbf{A}$ and $\mathbf{B}$ one simultaneously sends light pulses to $A$ and $B$ to synchronize them, then two problems arise: first, the synchronization process will not be transitive: i.e., if $A$ is synehronized with $\mathbf{B}$, and $\mathbf{B}$ with $\mathbf{C}$ then $\mathbf{A}$ will not neeessarily be synehronized with $C$. Seeond, starting at a point on the equator and transporting a portable elock eastward (westward), while establishing a synchronized eoordinate time grid on the way will result in a diseontinuity upon returning to the original points of $-200 \mathrm{~ns}(200 \mathrm{~ns})$; minus $(-)$ means the portable clock will be late. This paper will diseuss the use of a eoordinate elock network eonstrueted on the earth's surface which does not have these problems, i.e., synehronization is transitive, and there is no discontinuity. This may be done by adjusting cloeks to read coordinate time on an underlying non-rotating inertial frame. The theoretieal and praetical implieations of setting up such a coordinate cloek network using either electromagnetie signals (e.g., lasers, Loran C) or portable eloeks will be diseussed. It will be shown how this network may be applied in making UTC or any other global seale more useful for stateof-the-art navigation and communieation systems.

18994. Unassigned.

18995. Martín, W. C., Working Group 4: Strueture of atomie spectra. A. Compilations and bibliographies on energy levels, wavelengths, and line elassifieations, Trans. of the Internalional Astronomical Union Vol. XVIIA-Part I. Reports on Astronomy, E. A. Müller, Ed., Commission 14, Fundamental Spectroscopic Data, pp. 56-60 (D. Reidel Publ. Co., Dordrecht, Holland, 1979).

Key words: astrophysieal speetra; atomic data compilatíons; atomie energy levels; atomie speetroseopy; atomie wavelengths.

Reeent eompilations, bibliographies, reviews, and researeh papers on atomie energy levels and speetra of astrophysical interest are summarized ( 93 referenees).

18996. Younger, S. M., Collision strengths and Gaunt factors for highly ionized atoms of the eopper isoelectronie sequency, J. Quant. Spectrosc. Radiat. Transfer 22, 155-159 (1979).

Key words: Born approximation; eopper isoeleetronie sequence; Coulomb-Born approximation; distorted wave approximation; effeetive Gaunt faetor; eleetron impaet excitation eollision strength.

Collision strengths have been eomputed in three approximations for eleetron-impaet excitation of the $4 s-4 p$ resonance transition of ions in the eopper isoeleetronie sequenee. Good agreement is observed between distorted wave and CoulombBorn results at energies from two to twenty times threshold. In this range $g$ is close to unity and a slowly varying funetion of energy. An analytic fit was made to the distorted wave data, and an cffective Gaunt faetor $g$ was derived with the form $g$ $=A+B / x+C \ln (x)$, where $A, B$, and $C$ are functions of $Z$, and wherc $x$ is the ratio of the ineident eleetron's energy to the excitation cnergy.

18997. Younger, S. M., Wiese, W. L., An assessment of the effective Gaunt faetor approximation, J. Quant, Spectrose. Radiat. Transfer 22, 161-170 (1979).

Key words: effeetive Gaunt factor; electron eollision theory; electron eorrelation; eleetron exeitation eollision strength; electron exeitation eross seetion; highly ionized atoms.
Based on eomparisons with reeent theoretical data, it is shown that the effective Gaunt faetor for $\Delta n=0$ transitions in alkali-like ions is within $25 \%$ of unity in most cases and is a slowly varying funetion of energy. A more eomplex energy dependenee is noted for some non-alkali-like spectra, and especially for $\Delta n \neq 0$ exeitations. A method for the approximation of important eorrelation effeets in the target is diseussed for transitions of the type $n s^{21} S-n s n p$ ' $P$ ".

18998. Younger, S. M., Diagrammatie many-body perturbation theory applied to highly ionized atoms of the copper isoeleetronic sequence, Phys. Rev. A 20, No. 3, 951-963 (Sept. 1979).

Key words: eopper isoleetronie sequence; diagrammatie perturbation theory; eleetron eorrelation; ionization energies; line strengths; many-body interaetion; many-hody perturbation theory; oscillator strengths.

Many-body diagrammatic perturbation theory has been applied to the ealeulation of ionization energies and multiplet strengths for two highly ionized atoms of the eopper isoeleetronie sequence. A unified Hartree-Foek zeroth-order Hamiltonian the eigenfunetions of which inelude both open- and elosed-shell orbitals has been eonstrueted for systems with a single open shell. Correlation energies for the exeited $4 p$ states as well as the ground $4 s$ states of $\mathrm{Kr}$ Vill and Mo xiv were eomputed by means of individual basis sets generated for eaeh state. The distribution of the $3 l-4 l^{\prime}$ eorrelation energy among seeond- and higher-order terms differed significantly for the two ions. In Mo XIV, most of the eorrelation energy was coneentrated in seeond-order, with small third-order effeets. In $\mathrm{Kr}$ vil1, however, seeond-order results were substantially ehanged by higher-order diagrams, partieularly in the ease of the $4 p$ state. Correlated multiplet strengths for the $4 s{ }^{2} S-4 p$ i $P$ resonance transition were computed, ineluding first-order eorreetions to the Hartree-Foek zeroth-order wave funetions for both initial and final states. The results of these ealculations are in exeellent agreement with those of reent multieonfiguration Hartree-Fock ealeulations.

18999. Young, M., Conference on optieal seattering standards, (Proc. Standards for Seattering from Optieal Surfaces Conf., Boulder, CO, Feb. 6-7, 1979), SPIE J. 181, 133-134 (1979).

Key words: optieal scattering; optical surface quality; seattering; standards; surface roughness.

This paper is a report on a eonferenee, Standards for Seattering from Optieal Surfaees, that was held February 6 and 7 , 1979, at the National Bureau of Standards, in Boulder, CO. Approximately 50 seientists attended and heard a dozen invited papers and a panel diseussion. The visitors agreed, among other things, that national physieal standards are needed. There was also general agreement that NBS should eonsider providing measurement services (such as well eharacterized surfaces) based on a state-of-the-art facility for precision scattering measurements and calibrations.

19000. Yin, L. I., Seltzer, S. M., The Lixiseope: A pocket-size x-ray imaging system, Phys. Med. Biol. 23, No. 5, 993-997 (1978).

Key words: imaging; low-dose; low-intensity; mieroehannel plate; radiography; $x$ ray.

This note deseribes a low-intensity $x$-ray imaging deviee with the aeronym Lixiseope. This deviee was originally eoneeived for use in $x$-ray astronomy where single-photon visualisation is required; however, the extension of its eapabilities to medieal and dental radiography soon beeame evident. The high sensitivity and large gain of the Lixiseope make it possible to reduee the patient dose by $\sim 10^{3}$ in eertain diagnostic 
procedures as compared to conventional practice. Such cxtensive dose reduction not only allows safe fluoroscopic cxaminations, but also cnables the use of radioactive sources in lieu of $x$-ray machines. Furthermore, because the Lixiscope produces a visible-light output imagc, it can be casily recorded on fast instant-processing films or used in conjunction with any other image recording and processing devices. As will be shown, the small format of the Lixiscope in conjunction with a minute radioactive source provides a truly portable, nearly pocket-size fluoroscopic system

19001. Scltzer, S. M., X-ray source characteristics and detection efficiencies of prototype Lixiscopes, (Proc. Lixiscope Conf, NASA Goddard Space Flight Center, Greenbelt, MD, July 27-28, 1978), NASA Conf. Puhl. 21/2, Preliminary Applications and Evaluation Results, pp. 11-14 (NASA Goddard Space Flight Center, Greenbelt, MD, 1978).

Key words: Csl; detection cfficiency; Lixiscope; radioactive $\mathrm{x}$-ray source; rare-earth scintillator screen; ${ }^{125} \mathrm{I}$; ${ }^{153} \mathrm{GD}$.

Important components used in the prototypc Lixiscope (lowintensity $x$-ray-imaging scope) are the radioactive $x$-ray source and. the scintillator screen. Calculatcd data are given pertinent to the spectra and intensity of x-rays cmitted by the commercially available ${ }^{125} 1$ and ${ }^{153}$ Gd finite, encapsulated sources used. Detcetion cfficiencies for a rare-earth and a Csl scintillator screen are compared.

19002. Loevinger, R., Dose equivalent unit, Health Phys. Lett. (1) Ed. 37, 602-603 (Oct. 1979).

Key words: absorbed dose; dose cquivalent; gray; sievert: unit.

In answer to a previous letter, it is cxplained that thcre is no logieal conflict in using the name "gray" for the joule per kilogram for the physical quantity absorbed dose, and the name "sievert" for the joule por kilogram for the weighted physical quantity dose cquivalent.

19003. Kusuda, T., Bean, J. W., Comparison between a simplified daylighting calculation procedure and a comprehensive interreflection model calculation procedure, (Proc. Third Int. Symp. Use of Computers for Environmental Engincering Relatcd to Buildings, Alberta, Canada, May 10-12, 1978), CNRC Publ. 17376, pp. 569-578 (National Research Council of Canada, Ottawa KIA OR6, Canada, 1978 ).

Key words: daylighting; cnergy calculation; energy consumption; fenestration; heating and cooling load; solar heat gain

A simplified calculation methodology for daylighting was developed as a subroutine to the annual cnergy calculation of buildings. Several sets of sample calculations were performed to compare the rcsults of the simplified calculation with those obtained by a rigorous multiple interreflection model called GLIM (General Lighting Interreflcction Model) for a sample office module with different ratios of window to exterior wall area.

The simplified daylight calculation procedure then was uscd to determine the cffect of daylight utilization on annual heating and cooling energy consumption on NBSLD, National Bureau of Standards heating and cooling load calculation program. The calculation includes the reduction of light heat gain and clcctric power demand as a result of daylight utilization.

19004. Kayser, R. F., Jr., Raveche, H. J., Equivalence of integral equations in the molecular theory of fluids, Plisica 97A, 399-409 (1979).

Key words: BBGKY; corrclation functions; Kirkwood-Salsburg; Maycr-Montroll.
It is proven that, under physically rcasonable conditions, the correlation functions satisfying the BBGKY cquations for an infinite system are also solutions of the Maycr-Montroll and Kirkwood-Salsburg cquations. The relation betwen these correlation functions and the probability distributions for finding a fixcd number of particles in a given finite rcgion of an infinite system is investigated. The Gibbsian nature of these probability distributions is shown to depend on the rangc of the intermolccular forces.

19005. Hellwig, H., Precise time and frequency, (Proc. Symp 19th Gencral Assembly of URSI on Time and Frequency, Helsinki, Finland, Aug. 1-4, 1978), Plyys. Teclinol. 9, 266-267 (1978).

Key words: communication; frequency; frequency standards; navigation; time; time dissemination.

The article entitled "Precise Time and Frcquency," is a brief summary of the Symposium on Time and Frequency, 19th General Assembly of URS1, 1-4 August 1978, Helsinki, Finland.

19006. Unassigned.

19007. Giampapa, M. S., Linsky, J. L., Schneeberger, T. J., Worden, S. P., Chromospheric emission lines in the red spectrum of $\mathrm{AD}$ Leonis, I. The nonflare spectrum, Astrop/rys. J. 226, No. 1, 144-150 (Nov. 15, 1978).

Key words: flarc stars; helium; x-ray cmission.

High-resolution red (5300-7300 $\AA$ ) spectra of the flarc star AD Leonis were obtained with the Kitt Peak $4 \mathrm{~m}$ echelle spectrograph system at a spectral resolution of $0.22 \AA$ at $\mathrm{H} \alpha$. A series of time-trailed plates with 5 hours integration in total were averaged together to obtain a representation of the star's nonflaring spcctrum with high signal-to-noise ratio. The He I $\lambda 5876$ triplet line and $\lambda 6678$ singlet line appear in emission with measured cquivalent widths of $0.312 \pm 0.016 \AA$ and $0.058 \pm 0.029$ $\AA$, respcctively. The corresponding triplet-to-singlet line flux ratio is 3.7 , close to the ratio of the level statistical weights. We argue that the $\mathrm{He}, \mathrm{l}$ lines are not produced by recombination and cascade following photoionization by $\lambda<504 \AA$ coronal photons, but are instead collisionally cxcited. We suggest that these lines arc formed in a gcometrically thin chromospheric layer at $20,000-50,000 \mathrm{~K}$ with a column density of $n_{e} i \approx 6 \times$ $10^{14} \mathrm{~cm}^{-3}$. The sodium D cmission lines $(\lambda 5890, \lambda 5896)$ are found to bc stellar in origin, with measured FWHM of $0.7 \AA$ for both lincs, and the Ho line has a FWHM of $1.4 \AA$. No other chromospheric cmission lines were found in this spectral region.

19008. Casciani, F. S., Etz, E. S., Newbury, D. E., Doty, S. B., Raman microprobe studies of two mineralizing tissues: Enamel of the rat incisor and the embryonic chick tibia, Scanning Electron Microsc, Pt. II, pp. 383-391 (1979).

Key words: biological microunalysis; biological mineralization; bone; dental studies; dentin; cnamel; microanalysis; mincralizing tissue; Raman microprobe; Raman spectroscopy.

The laser-Raman microprobc dcveloped at the National Bureau of Standards has been applied to the study of the mineralization process in rat incisor cnamel and cmbryonic chick tibia. Cryostat sections were prepared from fresh frozen tissues and allowed to air dry. In these mineralizing tissues two forms of phosphorus compounds have been observed: (1) an inorganic phase identified as apatitic phosphate and (2) an organic phosphate. The distribution of these components from the mincralizing front to regions of higher mineralization has becn determined with a spatial resolution of $-15 \mu \mathrm{m}$. The studies suggest the cxistencc of a carbonatc, with a Raman hand 
corresponding to that of the mineral huntite, $\mathrm{Mg}_{3} \mathrm{Ca}\left(\mathrm{CO}_{3}\right)_{4}$, and found in regions of low phosphate mineral content.

19009. Wood, H. M., Kimbleton, S. R., Access control mechanisms for a network operating system, Prex. 1979 Nat. Compuler Conf., New York, NY, Junce 6, 1979, pp. $821-829$ (June 1979).

Key words: access control; computer networking; computer security; network operating systems.

While research and development are still ongoing in the Network Operating Systems (NOS) area, it is vital to ensure that requirements for the security and integrity of data are well specified and that mechanisms for achicving the needed levels of systems protection are included in the design of the NOS. This will ensure that subsequent production versions of NOSs ineorporate such mechanisms-thus charting a course away from otherwise inevitable "retrofit security" situation

This paper addresses the problem of incorporating access control mechanisms into a general-purpose NOS. The varying requirements and motivations for security in an NOS environment are briefly explored. Mechanisms for controlling NOS access (logon) and data access in the National Bureau of Standards Experimental Network Operating System (XNOS) are then described.

19010. Meshkov, S., Introductory remarks-Quark flavors, Paper in New Frontiers in High-Energy Plyscis 14, Studies in the Natural Sciences, A. Perlmutter, L. F. Scott, Eds., pp. 221-226 (Plenum Press, New York, NY, 1978).

Key words: flavor; hadron; quark; spectroscopy; spcctrum; structure.

The question of where the next quark flavor $n$ should occur is discussed. It is guessed that it will have a mass of 14-15 GeV by extrapolating from lower heavy quark mass ratios. The corresponding $\vec{n} \mathbf{n}$ vector meson would have a mass of $30 \mathrm{GeV}$. The excitation spectrum of quarks is contrasted with that of the hydrogen atom. The possibility of regarding flavor as an excitation of some new degree of frcedom in the system is also discussed.

19011. Dyer, C. S., Trombka, J. I., Seltzer, S. M., Calculation of radioactivity induced in scintillator materials during spaceflight, (Proc. 1977 Winter Meeting American Nuclear Society, San Francisco, CA, Nov, 27-Dec. 2, 1977), Trans. Am. Nucl. Soc. 27, 195-196 (1977).

Key words: radioactivity; scintillator materials during spaceflight; spaceflight.

19012. McElroy, W. N., Doran, D. G., Gold, R., Lippincott, E. P., Schiffgens, J. O., Simons, R. L., Morgan, W. C., Grundl, J. A., McGarry, E. D., Kam, F. B. K., Swank, J. H., Odette, G. R., Standardization of dosimetry and damage analysis work for U.S. LWR, FBR and MFR development programs, Proc. 2d ASTM-EURATOM Symp. on Reaclor Dosimerry: Dosimetry Methods for Fuels, Cladding, and Structural Materials, Pale Alto, CA, Oct. 3-7, 1977, 1, 17-60) (Available as NUREG/CP-()(0)4 from the National Technical Information Service, Springfield, VA, Oct. 1977).

Key words: damage analysis; dosimetry standardization; fast breeder reactors; light water reactors.

The results of neutron cnvironmental characterization and damage analysis work for reactor fuels and materials programs for (1) Light Water Reactors (LWR), (2) Fast Breeder Reactors (FBR), and (3)-Magnetic Fusion Reactors (MFR) will be discussed in the sessions and workshops of this Second ASTMEURATOM Symposium. The accuracy requirements for vari- ous measured/calculated exposurc and correlation parameters associated with current dosimetry and damage analysis procedures and practices depend on the accuracy necds of reactor development cfforts in testing, design, safety, operations, and surveillance programs. Present state-of-the-art aecuracies are estimated $t o$ be in the range of \pm 2 to $30 \%(1 \sigma)$, depending on the particular parameter. There now appears to be international agrcement, at least for the long term, that most reactor fuels and materials programs will not be able to accept an uncertainty greater than about $\pm 5 \%(1 \sigma)$. In order to achieve such an accuracy routinely, however, it will be necessary to work towards a better level of accuracy, namely 2 to $5 \%$ $(\mid \sigma)$. International development, standardization, and application of reactor "benchmark field" and "test region" validated and calibrated dosimetry and damage analysis procedures and data will be csiscntial for the achievement of this common goal accuracy objective. In this regard, the current status of dosimetry and damage analysis standardization work within the U.S. for LWR, FBR and MFR is reviewed in this paper.

19013. Fabry, A., Grundl, J. A., McElroy, W. N., Lippincott, E. P., Farrar, H. IV, Status report on dosimetry benchmark neutron field development, characterization and application, Proc, $2 d$ ASTM-EURATOM Symp. on Reactor Dosimetry: Dosimetry Methods for Fuels, Cladding, and Structural Materials, Pals Als, CA, Oct. 3-7, 1977, 3, 141-1175 (Available as NUREG/CP-0004 from the National Technical Information Service, Springfield, VA, Oct. 1977).

Key words: benchmark neutron field development; dosimetry mcthods; fission cross sections; reactor dosimetry.

This report attempts to present a brief, but comprehensive review of the status and future directions of benchmark neutron field development, characterization and application in perspective with two major objcctives of reactor dosimetry: 1) fuel fission rate and burn-up passive monitoring; 2) correlation of materials irradiation damage cffects and projection to commercial power plants.

The report focuses on the Light Water Reactor and Fast Breeder Reactor program needs.

Current interfaces between dosimetry, reactor physics, cross section metrology, solid state research and metallurgy are highlighted through a tentative classification of the benchmark fields and its justification.

A summary is given of indications draw $n$ regarding the accuracy of fundamental fission cross sections, of dosimetry sensor nuclear data, of hclium production assessment, of dosimetry fission yields, and of some other nuclear cross sections, on the basis of integral measurements in selected benchmark neutron fields. The ENDF/B IV data files are used as reference for the discussions. The success of this benchmark field approach to reactor dosimetry must not hide its present limitations and it is tried to adopt throughout a critical attitude to this respect, so as to delineate the areas where improvements are most needed.

19014. Rahn, F. J., Serpan, C. Z., Fabry, A., McElroy, W. N., Grundl, J. A., Debrue, J., Trends in light water reactor dosimetry programs, Proc. 2d ASTM-EURATOM Symp. on Reactor Dosimetry: Dosimetry Metusds for Fuels, Cladding, and Structural Materials, Palo Alto, CA, Oct. 3-7, 1977, 3, 1069-1091 (Available as NUREG/CP-0004 from the National Technical Information Service, Springfield, VA, Oct. 1977).

Key words: dosimetry programs; light water reactors; nuclear reactors; reactor dosimetry

Dosimetry programs and techniques play an cssential role in the continued assurance of the safety and reliability of com- 
ponents of light water reactors. Primary concern focuses on the neutron irradiation embrittement of reactor pressure vessels and methods by which the integrity of a pressurc vessel can be predicted and monitored throughout its servicc life. Research in these areas requires a closely coordinated program which integrates the elements of the calculational and material sciences, the development of advanced dosimetric techniques and the use of benchmarks and validation of these methods. This paper reviews the status of the various international efforts in the dosimetry area.

19015. Lapides, J. R., Crannell, C. J., Crannell, H., Hornyak, W. F., Seltzer, S. M., Trombka, J. I., Wall, N. S., Measurements of $15.11-\mathrm{MeV} \gamma$-ray flux produced in the reactions ${ }^{12} \mathrm{C}\left(\mathrm{p}, \mathrm{p}^{\prime}\right)^{12} \mathrm{C}^{* 115.11}$ Me' $\left.{ }^{\prime}\right)$ and ${ }^{16} \mathrm{O}\left(\mathrm{p}, \mathrm{p}^{\prime} \alpha\right)^{12} \mathrm{C}^{* 115.11}$ Mer', (Proc. Symp. on Gamma Ray Spectroscopy in Astrophysics, NASAGoddard Space Flight Center, Grcenbelt, MD, Apr. 28-29, 1978), NASA Teclnical Memorandum 79560, 13 pages (Available from the National Technical Information Service, Springfield, VA, June 1978).

Key words: cosmic source; preliminary; proton intêtactions; relative measurements; ${ }^{12} \mathrm{C} \gamma$-rays; ${ }^{16} \mathrm{O} \gamma$-rays.

The flux of $15.11-\mathrm{MeV} \gamma$ rays relative to the flux of 4.44$\mathrm{MeV} \gamma$ rays, which are cmitted from the corresponding states of ${ }^{12} \mathrm{C}$, are a sensitive measure of the spcctrum of cxciting particles in solar flares and other cosmic sources. Emission of 15.11-MeV $\gamma$ rays may result not only from the direct excitation of ${ }^{12} \mathrm{C}$ but also from the interaction ${ }^{16} \mathrm{O}\left(\mathrm{p}, \mathrm{p}^{\prime} \alpha\right)^{12} \mathrm{C}^{* 115.11}$ M.1. Although the cross sections for the direct reaction has bcen studied extensively, the cross section for the spallation interaction with ${ }^{16} \mathrm{O}$ is not reported in the literature. Preliminary measurements have demonstrated the feasibility of measuring the production of $15.11-\mathrm{MeV} \gamma$ rays by proton interactions with "O using the University of Maryland cyclotron facility. For both carbon and oxygen targets the flux of $15.11-\mathrm{MeV} \gamma$ rays is being measured relative to the flux of $4.44-\mathrm{MeV} \gamma$ rays. The $\gamma$-raly emission from de-excitation of the Giant Dipole Resonances also is being measured

19016. Weber, S. F., Tax incentives for historic preservation: An economic analysis, J. Real Estate Tax. 7, No. 1, 31-49 (Fill 1979)

Key words: adaptive reuse; buildings; demolition; cconomics; historic preservation; life-cycle costing; redevelopment; rehabilitation; tax incentives.

The Tax Reform Act of 1976 contains a number of provisions which affect the financial position of owners of incomeproducing historic buildings. Prior tax law tended to penalize historic preservation by allowing more rapid acceleration of depreciation schedules for new buildings and by pcrmitting demolition costs to be deducted in the year in which they occur. TRA provided a more favorable tax cnvironment for historic preservation by moving these tax pcnalties. The effect of the tax changes depends on the type of building (residential versus nonresidential) and on the legal form of ownership TRA 's tax incentives for the prcservation of certified historic buildings were expanded by technical corrections cnacted as part of the Revenue Act of 1978. This article analyzes the cffect of the historic preservation provisions of both tax acts on the after-tax cost of two basic alternatives facing corporate owners of nonresidential historic buildings: (1) Rchabilitate the structure; or (2) demolish it and redevelop the site.

19017. Wilson, W. K., Parks, E. J., An analysis of the aging of paper: Possible reactions and their effects on measurable properties, Restaurator 3, 37-61 (1979).
Key words: accelerated aging, aging: aging of cellulose: aging of paper; cellulose; cellulose aging; natural aging; paper; paper aging; tests for paper

Various reactions that celluiose can undergo are reviewed in relation to their bearing on the aging of paper. The principal rcactions of cellulose are hydrolysis, oxidation, crosslinking, changc in lateral order in the bonding area, and, during accclerated aging, thermal decomposition. The effects these various reactions might have on tests that are available for evaluating changes that occur during the aging of paper are reviewed. Some spccial examples of these reactions that occur during natural aging, because of special composition characteristics of the paper, are discussed. Suggestions are made concerning most sensitive tests for use in detecting changes in paper. and tests, regardless of sensitivity, available for determining what happens during aging. Some general guidelines regarding specifications for permanent record papers are discussed

19018. Krause, R. F., Jr., Fuller, E. R., Jr., Compressive, tensile, pipe-bonding strengths, and permeability of selected cementing-materials for hot-dry-rock wells, Progress Report No. 10. Cementing of Geothermal Wells, July-Sept. 1978, BNL 50943 UC-66C (Geothermal Energy, Drilling Texhnology-TID-4500), pp. 139-147 (Brookhaven National Laboratory, Upton, NY, 1978)

Kcy words: cementing-materials; compressive strength; hotdry-rock well; permeability to water; pipe-bonding strength; tensile strength

Comprcssive and tensile strength data for five cementingmaterials, which are candidates for cementing hot-dry-rock wells, were obtained after 40 and 176 hour exposure to water in an autoclave at $195^{\circ} \mathrm{C}\left(383^{\circ} \mathrm{F}\right)$ and $21 \mathrm{MPa}(3000 \mathrm{psi})$. Additional tests will be conducted after extended exposure of four and eight weeks to similar conditions; these exposures are presently two weeks underway

In addition, an apparatus is under eonstruction, and specimens are being prepared, to measure at ambient laboratory conditions the shear bond strength of the interface between a cementing-materials and a steel rod, and the permeability to water of a cementing-materials. We also plan to investigate the effect that thermal cycling between autoclave conditions and ambient laboratory conditıons will have on these properties.

19019. Lee, S. A., Helmcke, J., Hall, J. L., Illigh resolution twophoton spectroscopy of $\mathbf{R} b$ Rydberg levels, (Proc. Fourth int. Conf. on Laser Spectroscopy, Rottach-Egern, Federal Republic of Germany, June 11-15, 1979), Paper in Laser Spectroscopy, H. Walther, K. W. Rothe, Eds., IV. 130-14I (Springer-Verlag, New York, NY, Oct. 1979).

Key words: laser spectroscopy; optical Ramscy effect; resonance line shape analysis; Rydberg atoms; two photon spectroscopy.

In this paper we report on our investigation of the interesting features; and problems, associated with ultrahigh resolution two-photon spectroscopy, using a frequency controlled dye laser to study the $5^{2} S-n^{2} S$ transitions in rubidium. The optical Ramsey tcchnique of sepirated interactions is used to reduce transit broadening. Narrow resonances of $17 \mathrm{kHz}$ full width half maximum are observed.

19020. Krause, R. F, Jr., Thermodynamics of vaporization of molybdenum pentafluoride, Proc. Symp. on High Temperature Metal Halide Chemistry, The Electrochemical Society Meeting. Princeton, NJ. Oit. 9-14, 1977, Proceedings Volume 78-1, 199-209 (1978).

Key words: enthalpy and entropy of vaporization: cntrainment method; melting temperature; molybdenum pentafluoride; vapor density; vapor pressure. 
The $\Delta H^{\circ}$ and $\Delta S^{\circ}$ at $298.15 \mathrm{~K}$ for $2 \mathrm{MoF}_{54}\left(\mathrm{MoF}_{3}\right)_{2}(\mathrm{~g})$ were evaluated as $66.79 \mathrm{~kJ} / \mathrm{mol}$ and $133.53 \mathrm{~J} \cdot \mathrm{K}^{-1} \mathrm{~mol}^{-1}$, respectively. These values were derived from vapor density data which were obtained by the entrainment method at 343,363 , and $383 \mathrm{~K}$. The vapor pressure of $\mathrm{MoF}_{5}$ ligomers over the liquid was measured by a static method at 373 and $392 \mathrm{~K}$ with an uncertainty several times that of the vapor density. Combination of these two properties indicates a mean extent of association of about (wo. These properties were measured in and corrected for the presence of $\mathrm{MoF}_{6}(\mathrm{~g})$, which was added to suppress sample disproportionation. Special care was taken to prepare samples by reaction of $\mathrm{Mo}(\mathrm{c})$ and $\mathrm{MoF}_{\mathrm{H}}(\mathrm{g})$ with vacuum manipulation. Melting curves of temperature against time established the melting temperature at zero impurity to be $318.82 \mathrm{~K}$, the enthalpy of fusion to be $6.1 \mathrm{~kJ} \cdot \mathrm{mol}^{-1}$, and the cryoscopic impurity of the sample to be 0.15 mole per cent. Combination of the above values of $\Delta H^{o}$ and $\Delta S^{o}$, of approximate values of $S^{o}$ for the monomer and dimer gases, and of the published $\Delta H f^{\circ}$ values for the monomer gas and for the solid indicates that the proportion of oligomers other than the dimer is negligible within the estimated uncertainties.

19021. Young, M., Continuous-wave (mode-locked) dye laser with unfolded cavity, Appl. Opt. $18, \mathrm{No}, 19,3212$ (Oct. I, 1979).

Key words: dye laser; laser cavity; mode locked dye laser; passive mode locking; picosecond pulses; Rhodamine 6G.

I have used a catadioptic cavity (rather than a folded cavity) to produce 5 ps pulses with a passively mode locked, R6G dye laser.

19022. Olien, N. A., Present and future sources of fluid property data, Proc. American Society of Mechanical Engineers Winter Annual Meeting. New York, NY, Dec, 2-7, 1979, Paper No. 79-WA/HT-19, 7 pages (American Society of Mechanical Engineers, New York, NY, 1979).

Key words: chemical processing; engineering calculations; equation of state; fluid properties; prediction; standard reference data; synthetic gas.

Fluid Property calculations for the design and operation of large process systems require that the data used by the engineer be in a computer compatible form. This in turn places complex demands on those of us in the data generation and correlation field. The responsibility of the producers of data, i.e., experimentalists, theorists or correlators, to the ultimate users of the data such as design engineers is discussed, because the efficient transfer of data from the originator to the ultimate user is absolutely essential.

The specific requirements for data in the future will be for "black box" type computer-compatible routines to calculate broad ranges of thermophysical properties for pure fluids and mixtures. Although calculational packages are very useful tools, reliance on them by the uninformed can lead to costly design errors and there is some evidence that the cxistence of the packages may tend to reduce future research in fluid properties. Generic solutions to the future data requirements of the chemical process and energy industries will place heavy reliance on theoretical approaches. Illustrations of the future data requirements of specific industries are given as examples.

19023. Sanchez, I. C., Phase transition behavior of the isolated polymer chain, Macromolecules 12, 980-988 (Sept.-Oct. 1979).

Key words: collapse transition; fluctuations; mean field approximation; ternary interactions; theta point: virial coefficients.
A mean field theory of chain dimensions is formulated which is very similar to the van der Waals theory of a simple fluid. In the limit of infinite chain length, the chain undergoes a Landau-type sccond-order phase transition. For finite chains, the transition is pseudo-second order. At low temperatures, the chain is in a condensed or globular state, and the mean square gyration radius $\left(S^{2}\right)$ varies at $r^{2 / 3}$ where $r$ is proportional to chain length. At high temperatures, the chain is in a gaslike or coil state where $\left(\mathrm{S}^{2}\right)$ varies as $\mathrm{r}^{6 / 5}$. In the globular state, fluctuations in $\left(\mathrm{S}^{*}\right)$ are very small, whereas they are very large in the coiled state. A characteristic feature of the theory is that ternary and higher order intramolecular interactions are approximated. At high temperatures, only binary interactions are important, but at low temperatures, many of the higher order terms contribute. An important conclusion of this study is that a polymer chain does not obey ideal chain statistic at the $\Theta$ tempcrature. Although the second virial coefficient vanishes at $\theta$, the third virial coefficient does not; its presence is responsible for the perturbation of the chain statistics. For an infinite chain, $\boldsymbol{\theta}$ and the second-order phase-transition temperature are identical. For finite chains, the pseudo-second-order transition temperature is less than $\theta$. When generalized to d dimensions, the theory yields at low temperatures $\left(S^{2}\right)^{d / 2} \sim r$ for all $d$ and at high temperatures $\left(S^{2}\right) \sim r^{6 /(l+2)}, d<4$, and $\left(S^{2}\right) \sim r, d>4$.

19024. Grundl, J., DeLeeuw-Gierts, G., Workshop Chairmen's Report "Utilization of Benchmark Neutron Fields". Proc. $2 d$ ASTM-EURATOM Symp. in Reacior Dosimetry: Dosimeiry Methods for Fuels, Cladding, and Structural Materials, Pals) Alto, CA, Oct. 3-7, 1977, 2, 981-982 (Available as NUREG/CP-0004 from the National Technical Information Service, Springfield, VA, Oct. 1977).

Key words: benchmark fields; benchmark testing; neutron fields; nuclear data; reactor dosimetry.

19025. Trevino, S. F., An observation of one-dimensional reorientation and tunnel splitting of the ground and first excited state in a low barrier system: Solid nitromethane, $J$. Chem. Phys. 71, No. 4, 1973-1974 (Aug. 15, 1979).

Key words: crystal structure; neutron scattering; nitromethane; rotation; tunneling.

In this Communication, we report the complete characterization of the structural and dynamical properties of a simple one dimensional rotor with the lowest known barrier to rotation in the solid state.

19026. Rush, J. J., Quasielastic neutron scattering and high resolution spectroscopy, NSF Workshop Present Needs and Future Trends in Neutron Crystallograply and Spectroscopy, Argonne National Laboratory. Argonne, IL, Nov. 15-17, 1978, Paper 14, pp. 71-75 (National Science Foundation, Washington, DC, 1979).

Key words: condensed phases; diffusion mechanisms; inelastic scattering; neut ron scattering; orientational disorder; rotational dynamics.

A brief introduction is given to the application of highresolution neutron inelastic scattering to study of diffusive and rotational bchavior in condensed phases and for studies of ultra-low energy transitions (e.g., tunnel splittings) in solids. Illustrative examples of such applications are discussed.

19027. Choi, C. S., Prask, H. J., Trevino, S. F., Nondestructive investigation of texture by neutron diffraction. $J$. Appl. Crist 12, 327-331 (1979).

Key words: metal texture; neutron diffraction: nondestructive testing; pole figure: texture of copper shaped charge liner: texture of $\mathrm{Ni}-\mathrm{W}$ alloy. 
Texture measurement as a function of depth with a collimated thermal neutron bcam is demonstrated for a "two-laycr plate' geometry sample with preliminary results for a copper cone.

19028. Zajonc, A., Gallagher, A., Electron excitation of Li $S$ and D states, Phys. Rev. A 20, No. 4, 1393-1397 (Oct. 1979).

\section{Key words: clectron cxcitation; lithium}

Electron-impact cxcitation of the $\mathrm{Li} 3 S, 4 S, 3 \mathrm{D}$, and $4 \mathrm{D}$ states have been measured from threshold to 1200 -eV impact cnergy. The intensities of cmission lines from these states have been measurcd rclative to the $2 P-2 S$ resonance line, and cross sections arc obtained by normalizing to the resonance-line cross section and correcting for branching ratios. Cascade corrcctions to these total cross sections have been made at the higher energies, using available Born cross sections. The resulting direct cross sections show a uniform convergence at high cnergy to available Born cross sections and to $E^{-1}$ behavior. At lower cnergies the $S$ - and $D$-state cross sections have very different forms: the $S$ states rise abruptly at threshold and drop rapidly past a narrow pcak, while the $D$ states rise gradually to a very broad maximum. Comparisons are made to available cross section calculations.

191029. Hanson, D. W., Davis, D. D., Cateora, J. V., NBS time to the Western Hemisphere by satellite, Radio Sci. 14, No. 4, 731-740 (July-Aug. 1979).

Kcy words: broadcast; coordinated universal time; synchronous satellite; time code; Western Hcmisphere.

As a complement to the present time and frequency services of WWV, WWVH, and WWVB, the National Bureau of Standards (NBS) is now providing a satellite-disseminated time code using the Geostationary Operational Environmental Satcllites (Goes) of the National Oceanic and Atmospheric Administration (NOAA). The time code is referenced to the NBS time scale, giving coordinated universal time (UTC). In addition to the usual information of day of year, hours, minutes, seconds, and the UTl correction the time code contains the satellite's current position for use in path delay calculations. The time signals arc relayed to the cntire Western Hemisphere from two gcostationary satellites on a full-time basis except during brief pcriods of solar cclipses occurring during the vernal and autumnal equinoxes. The time code, originally intended for use by environmental monitoring platforms, is easily accessible by anyone using rclatively simple, commercially available equipment. Physically small antennas $(30 \mathrm{~cm} \times 30 \mathrm{~cm} \times 1 \mathrm{~cm})$ are typical. The gcneration, satellite relay, and recovery of these signals is discussed. Results obtained with commercial receiving cquipment are included.

19030. Glinka, C. J., Rowe, J. M., Libowitz, G. G., Maeland, A., Neutron crystal-field spectroscopy of CeD $\mathrm{D}_{2.12}, J$. Phys. $C$ 12, 4229-4236 (1979).

Key words: cerium dihydride; crystal-field splitting; inclastic ncutron scattering; magnetic properties of rare earth alloys; metal hydrides; rare-earth hydrides.

The crystal-field splitting of the ${ }^{2} \mathrm{~F}_{5 / 2}$ ground state of $\mathrm{Ce}^{3+}$ in $\mathrm{CeD}_{2.12}$ has been studied by inelastic neutron scattering. A singlc crystal-field transition, consistent with a cubic cnvironment for the Ce ion, is observed at an cnergy of $20 \mathrm{meV}$. Low-temperature measurements of the quasielastic scattering in a magnctic field, however, cannot be explained in terms of crystalfield cffects alone.

19031. Koon, N. C., Rhyne, J. J., Excited state spin waves in ErFe $_{2}$, Solid Stale Commun. 26, 537-540 (1978).
Key words: crystal fields; Laves phase; magnetic materials; neutron scattering; rare carths; spin waves.

Neutron inclastic scattering mcasurements on ErFe, reveal an unusual doubling of the two lowest cnergy spin wave branches over a widc temperature range. Crystal ficld calculations suggest that one member of cach doublet is associated with transitions from the ground state of $\mathrm{Er}^{3+}$ to the first cxcited statc, while the other is associated with transitions between excited states. The gapless acoustic mode appcaring at high tempcratures is identified as a propagating cxcited state spin wave.

19032. Brenner, D., Modified multimeter measures precise voltage ratios, Electron. Design 27, No. 21, 162-163, 165 (Oct. 11, 1979).

Key words: dc voltage ratio measurement; digital voltagc ratio instrument errors; digital voltmeter for ratio measurement; voltage ratio measurement.

The article describes how a singlc wiring change can cnable many dual-slope digital voltmeters to measure voltage ratios. A short discussion of rcsulting instrument crrors is also presented, along with casily implemented tcchniques to correct for these crrors. As a demonstration, an inexpcnsive 19999 count digital multimeter was thus modified and used, with thc result that voltage ratio measurements were not more than two counts (i.e., $0.01 \%$ of full scale) in error. The crrors increased however, when the voltage that was the denominator of the ratio was too small (for the demonstration meter, less than about $8 \%$ of full scale).

19033. Bennett, W. S., Taggart, H. E., Characterization of a CISPR/VDE far-field EMI test site with ground screen, Proc. Electromagnetic Compatihility Symp., Rotterdam, The Netherlands, May 1979, pp. 507-513 (1979).

Key words: antennas; CISPR; ground screen; measurements; standards; VDE

The complex problem of measuring radiated EMI in the farfield is further complicated when measuring in close proximity of the earth. Because of rcflections from the carth's surface, measured radiation from a system under test is a combination of both direct and reflected clectromagnetic waves. If the ground plane is a highly conductive ground screen, and the reflection coefficients approximate thosc values associated with a perfect conductor, the incident and reflectcd signals should be predictable and agree with theoretical values. A test site at the National Bureau of Standards which meets all criteria spccified by CISPR and VDE was used to pcrform a series of measurements whereby measured data were compared to theoretical data with the following conclusions. The presence and composition of a ground plane significantly affect far-field EMl measurements at frcquencies from 30 to $1000 \mathrm{MHz}$. Range correction factors vary significantly over a highly conductive ground screen from those of free space; however, they are stable and well-dcfined. Measured responses to horizontally-polarized signals over a conductive ground scrcen are repcatable, and the measured results agree well with theoretical rcsults. Measured responses to vertically-polarized signals over a conductive ground screen are erratic and often are not repeatable to within $10 \mathrm{~dB}$.

19034. Kanda, M., A braodband, isotropic, real-time, electricfield sensor (B1RES) using resistively loaded dipoles for EMI measurements, Proc. 1979 IEEE Int. Symp. on Electromagnetic Compatihility, San Diego, CA, Oct. 9-11, 1979, pp. 423428 (Institutc of Elcctrical and Electronics Engineers, Inc., New York, NY, 1979).

Key words: broadband; dynamic range; Hermitian mag nitude; isotropicity; isotropic, rcal-time, clectric-field sensor (IRES); resistively loaded dipole; tangential sensitivity. 
A broudband, isotropic, real-time, electric-field sensor (BIRES) developed by the National Bureau of Standards (NBS) consists of three resistively loaded dipoles mounted orthogonally to each other. It has the capability of measuring frequency, polatization, magnitude, and phase information of the incident electromagnetic (EM) field. The typical tangential sensitivity of the BIRES is 13 to $16 \mu \mathrm{V} / \mathrm{m}$ with a typical usable dynamic range of 125 to $144 \mathrm{~dB}$ for various bandwidths in the frequency range of $10 \mathrm{MHz}$ to $1 \mathrm{GH}$. The isotropic response of the BIRES is obtained by arithmetically calculating the Hermitian magnitude of the incident elcctric ficld, and its variation is found to be less than $\pm 1 \mathrm{~dB}$.

19035. Kanda, $M$., The characteristics of a traveling-wave linear antenna with a nonlinear load, Proc. Symp. Int. Union of Rudio Science National Radio Science Meet, Seatlle, WA, June 18-22, 1979, pp. 314 (University of Washington, Seattlc, WA, 1979).

Key words: Fast Fourier transform; linear load; NcwtonRaphson interation methods; nonlinear load; time-domain measurements; time-stcpping finitc-difference technique; transient; traveling-wave antcnna.

This paper discusses the characteristics of a traveling-wave, linear antenna with a nonlinear load. The theoretical tcchnique used for analyzing the antenna is the time-stepping, finite-diffcrence cquation method with the Newton-Raphson technique. Differential equations arc solved using the time-stepping, finitedifference equation method, whereas the nonlinear cffect is trcated by the Newton-Raphson iteration technique.

19036. Rowc, J. M., Rush, J. J., Hinks, D. G., Susman, S, Neutron scattering study of the dynamics of $(\mathrm{KCN})_{6.5}(\mathrm{KBr})_{1.5}$, Phys. Rev. Lell, 43, No, 16, 1158-1161 (Oct. 15, 1979),

Key words: coupled modes; dynamics; KCN-KBr; neutron seattering; phasc transition; rotation-translation eoupling.

Our carlier measurcments on pure $\mathrm{KCN}$ and $(\mathrm{KCN})_{6.25}(\mathrm{KBr})$ 0.75 have bcen cxtended to mixed crystals of $(\mathrm{KCN})_{0.5}(\mathrm{KBr})_{11.5}$. From a comparison of the obscrved neutron scattering line shapcs to those predicted by a simplc cxtension of the theory used to describe pure $\mathrm{KCN}$, it is concluded that this theory does not deseribe the mixed systems correetly. This Letter suggests that the current rcsults may be indicative of the formation of a "glass" phase at low tempcratures in thcse mixed systems.

19037. Santoro, A., Roth, R. S., Minor, D., Neutron powder diffraction study of tantalum tungstate, $\mathrm{Ta}_{2} \mathbf{W O} \mathrm{O}_{\mathrm{s}}$, Acta Cryst. B35, 1202-1205 (1979).

Kcy words: ionic conductors; ncutron diffaction; powder method; profile refinement; tantalum tungstate; thcrmal expansion.

$\mathrm{Ta}_{2} \mathrm{WO}_{\mathrm{H}}$, orthorhombic, Phcm, $a=3.8762(2), \quad b=17.716$ (1), $c=16.684$ (1) $\AA$. The strueture was studied by profile analysis. Contrary to previous conclusions based on $x$-ray diffraction data, it was found that the compound crystallizes with the symmetry of spaec group Phem and is isostructural with Nb.2. WO.

19038. Collard, J. J., The search for a safe police tire, The Police Chief XL.VI, No. 12, 30-34 (Dec. 1979).

Kcy words: high speed pcrformance; high speed tires; police tircs; pursuit tires; tirc maintenance; traction performance; tread wear.

Tires form one of the major subsystems of an automobile. In 1976, the International Association of Chiefs of Police conducted a survey of 379 police agcncies to learn what their most serious tire problems wcrc. These and other important data and information on tread wear, high speed and traction performance and maintenanee were published in NBS Spccial Publication 480-33 entitled, "Guide to High Speed Patrol Car Tires"

19039. Smid, M. E., A key notarization system for computer networks, (Proc. National Tclccommunications Conf., Washington, DC, Nov, 27-29, 1979), Paper in NTC 1979 Conference Record 3, 43.3.1-43.3.5 (Available from IEEE Publishing Scrviccs, New York, NY, as IEEE Catalog Number 79CH1514-9, 1979).

Key words: cryptography; digital signatures; cncryption; identifiers; key management; kcy notarization.

A cryptographic, key notarization system (KNS) is proposed for eomputer nctworks to protect personal (nonshared) files, to communicatc securely both on and off-line with local and remote users, to protect against kcy substitution, to authenticate system users, to authenticate data, and to provide a digital signaturc capability using a nonpublic key encryption algorithm. The system is implemented by the addition of key notarization facilities (KNF's) which give uscrs the capability of cxcreising a set of commands for key management as well as for data cncryption functions. Kcy notarization facilities perform notarization which, upon cncryption, seals a key or password with the identities of the transmitter and intended recciver.

19040. Plumb, H. H., Besley, L. M., Stabilities of germanium thermometers at $20 \mathrm{~K}$ and below, Proc. ISA-78 Nat. Conf. and Exhibit, Philadelphia, PA, Oct. 15-19, 1978, pp. 19-25 (Instrument Society of America, Pittsburgh, PA, 1978).

Key words: germanium thermometers; low temperature; rhodium-iron thermometry; thermal cycles to low temperatures.

Gcrmanium thermometers have been widely used in the last fifteen ycars both for engineering application and in precision thcrmometry measurcments that have led to the development of and comparison of international tempcrature scales. For the most precise investigations it has been necessary that the expcrimentalists carefully select thermometers and continue intercomparisons to ensure that the thermometers' calibrations are maintained. This paper describes such selection and monitoring processes within the authors' laboratories.

19041. Wood, H. M., Women and minorities in the computer professions, Proc, 1979 Nat. Computer Conf, New York, NY, June 6, 1979, pp. $419-424$ (June 1979).

Key words: employment; equal employment opportunity; labor foree; minorities in computing; women in computing.

It is assumed that, while full cquity has not been achieved by women and minorities in computer-related professions, their cmployment status is better and conditions are morc favorable for full-utilization of skills due to the relative youth of the ADP field. As the Federal Govërnment has been involved in computers since thcir beginnings, and has been a leader for equal employment opportunity (EEO) and affirmative action, recruitment is reasonable to assume that employment opportunities should be bctter in the Federal sector than in other sectors of the labor force.

This paper examines statisties coneerning the status of women and minorities in computer-related professions, both in the private work force and in the Federal Government. U.S. and Federal seientifie labor force statistics are presented in order to establish a framework for assessing the relative status of computer-related fields.

The focus of this report is on labor market experience (c.g., employment and unemployment rates, relative salaries). Studies 
addressing ascriminallum, societal, cultural and other employment and unilizatton-relited lactors are relerenced.

19042. Biallhuwshi, S I:., King, D. S., Steplenson. J. C., The gass polanse laser inalued fluoresecence spectroscopy of clilorofluoronatliylene, $J$. (\%em, Phys. 71, No, 10, 4(1)10-40)14 (Nov. 15, 1979).

Key words: chlorolluoromethylene: lluorescence; laser spectroscopy; multiploton dissociation; radicals; vibronic specerosicopy.

The CFCl ractical has been produced in the gas phase by both IR multiphoton photolysis of $\mathrm{C}_{2} \mathrm{~F}_{3} \mathrm{Cl}$ and He metastable reaction with $\mathrm{C}_{2,} \mathrm{~F}_{12} \mathrm{Cl}$. Single vibronic level fluorescence and excitation spectrat taken of this species have yielded sufficient information to determine certain vibronic constants. The excited statc was found to have an origin of $r_{n}=2528.3 \pm 5 \mathrm{~cm}^{-1}$ with vibrational frequencies: $\omega_{2}^{\prime}=394 \pm 3 \mathrm{~cm}^{-1}$ and $\omega_{i 1}^{\prime}=739 \pm 5$ $\mathrm{cm}^{-1}$. In the grount state, the vibrational frequencies were formd $(0)$ be: $\omega_{3}^{\prime \prime}=118 \pm 10 \mathrm{~cm}^{-1}, \omega_{2}^{\prime \prime}=448 \pm 6 \mathrm{~cm}^{-1}$, and $\omega_{: 1}$ $=750 \pm 6 \mathrm{~cm}^{-1}$. The rotational structure of the vibronic bands Is similar to those of band transitions of a near prolate top, and the electronic transition has been tentatively iclentificd as $\bar{A}^{\prime} A^{\prime \prime}$ $\leftarrow X^{\prime} A^{\prime}$ by analogy to similar $C_{2}$ transitions. The radiative. lifetime of the excited stite, $\tau_{r}=700 \pm 10 \mathrm{nsec}$, was found to be independent of the rovibronic excitation frequency. The chatuge in the major rotitional constant was found to be $A^{\prime}-$ $A^{\prime \prime}=1.8 \pm 0.2 \mathrm{~cm}^{-1}$.

19043. Marshiall, H. E., Ruegg, R. T., Life-cycle costing guide for energy conservation in lonildiugs, Cbipter 9 in Energy Comservation Through Building Design, pp. 162-181 (McGraw Hill Book Co., New York, NY, 1979).

Key words: building design; cost; energy conservation; energy stanclarts; fenestration; life-cycle costing; retrofitting; solar.

Architects, engineers, building operators and owners, and others who make decisions about tbe design and use of buildings need cost information about alternative energy conservation atesigns for old and new buildings. Specifically, they need to know the cost over time from introducing energy conserving techniques as compared to the cost savings over time from reduced energy bills. Life-cycle costing of energy conservation alternatives in buildings can be applied at the working level to reduce the owning and operating costs of buildings, to reduce encrgy consumption. and to encourage the optimal retrofit of old and design of new buildings with respect to rising fuel costs. This article provides practicing architects, architectural students, and others interested, in the design process an overview of state-of-the-art methods for estimating the lifecycle cost ( $L C C$ ) of alternative energy conservation techniques and a description of selected applications of LCC metbods to energy conservation in buildings.

Retrofitting existing fesidential buildings for energy conservation is examined in LCC terms. The design of envelope features and subsystems for energy conservation in new buildings is explored in the context of LCC analysis. Finally, energy standards for buildings are examined in the LCC context to show why varying climates and fucl prices must be considered in developing economically efficient standards.

19044. Weber, S. F.. Cast effectiveness of energy conservation investments in new United States residences, Proc. Second Int. ClB symp. an Energy Conseriation in the Buitt Entirmment, Copenhagen, De'umark. May 28-June 1, 1979. pp. I-10 (Maly 1979).

Key words: building envelope; cost effectiveness; economics: energy conservation; internal rate of return: lile-cycle costing: marginal analysis; optimal design; residential buildings: sparce cooling: space heating.

This paper assesses the cost effectiveness of selected energy conservation investments in new single-family residences in the U.S. Alternative investment levels in the four major components of the building envelope are evaluated: (1) atties: (2) walls; (3) floors; and (4) windows. The analysis is conducted for five cities of widely diverse climate conditions and lor the major forms of energy used for heating and cooling in the U.S. For each investment level the internal rate of return (IRR) is calculated on an incremental basis, that is, in comparison with the next lower level of investment for that component. This marginal IRR is uscd to rank alternative levels of investment for all four components so that economically optimal envelope designs can be selceted for each city and energy type.

19045. Chapman, R. E., Cont-effective methods for achieving compliance to fire safety codes, Fire J. 73, No. 5, 3()-39, 123 (Sept. 1979).

Key words: alpplied economics; building codes; building economics; cconomic analysis; fire safety; health care facilities; hospitals; life safety; mathematical programming; nursing homes; renovation.

The identification of cost-effective levels of fire safety in health care facilities is a major concern to hospital administrators, fire safety engineers and public policy makers. The probibitive costs of strict compliance to the prescriptive provisions of the Life Safety Code in hospitals and nursing homes has led to the development of an cquivalency methodology, the Fire Safety Evaluation System. The equivalency methodology provides a means for identifying how combinations of several widely accepted fire safety systems can be used to produce a level of safety equal to that of the prescriptive provisions of the Life Safety Code. Three topics are described briefly in this paper. They are (1) the Fire Safety Evaluation System; (2) a computerized version of the Fire Safety Evaluation System which permits the least-cost mcans of achieving compliance to the Life Safety Code to be identified; and (3) an indication of the cost-siaving potential of the Fire Safety Evaluation System based on a case study of a typical general hospital.

19046. Romanov, V. P., Candela, G. A., Roth, R. S., Swartzendruber, L. J., Magnetic properties and hyperfine interactions in the $\boldsymbol{\beta}^{\prime \prime \prime}$ phase of potassium ferrite, $J$, Appl. Phys. 50, No. 10, 6455-6458 (Oct, 1979 ).

Key words: conductivity; exchange interaction; ferrite; hyperfine field; magnetism; phase diagram; potassium.

The hyperfine field structure and magnetic susceptibility in the temperature range 5-295 K was measured for the $\beta^{\prime \prime \prime}$ phase of potassium ferrite. Results show that this new phase bals an antiferromagnetic ordering similar to the $\beta$ phase. The hyperfine-interaction parameters bave been determined and are compared with those found in magnetite, $\beta$-phase potassium ferrite, and barium hexaferrite.

19047. Watson, R. E., Bennett, L. H., Heats of farmation of transition-metal alloys, Pliss. Rer. Lett, 43, No, 15, 1130 1134 (Oct. 8. 1979).

Key words: d-electron energy band parameters; d-electron transfer; heats of formation: transition metal alloys.

This Letter proposes a scheme for obtaining the d-electron energy-band parameters to be used in a simple anilytic inodel of the alloy heat of lormation. $\Delta / /$. The scheme employs, as an intermediate step, the equalization of the local chemical potentials of the two sites. Calculations for $3 d, 4 d$, and $5 d$ metal alloys yield $\Delta H$ in accord with experimental trends, but, unlike 
surlier estimates, with $d$ charge transfer in the direction indicated by experiment

19048. Berger, P. W., Sprague, P. A., Zurkowski, P., Library and information services for improving organizations and professions, Proc. White Howse Conf. on Lihrary and Information Services-Dialogues on the Future of Library and Information Services, Wastington, DC, Nov. 15-19, 1979, Cassette 2 Side I (Staff of the White House Conference on Library and Information Services, Washington, DC, 1979).

Key words: information services; libraries. 
This section provides a listing of 1979 papers organized by primary subject matter as follows:

Acoustics and Sound

Analytical Chemistry

Atomic and Molecular Studies

Building Technology

Computer Science and Technology

Consumer Information and Protection

Electromagnetic Metrology

Electronic Technology

Energy Conservation and Production

Engineering, Product and Information Standards

Environmental Studies: Pollution Measurement

Failure Analysis

Fire Research

Fluids: Liquids, Gases and Plasmas

General Theoretical Chemistry and Physics

Health and Safety

Instrumentation and Experimental Methods

Lasers and Their Applications

Low Temperature Science and Engineering

Mathematical and Statistical Methods

Measurement Science and Technology:

Policy and State-of-the-Art Surveys

Measurement Science and Technology:

Physical Standards and Fundamental Constants

Mechanics: Design, Testing and Measurement

Metrology: Physical Measurements
Nuclear Physics and Radiation Technology

Operations Analysis and Applications

Processing and Performance of Materials

Properties of Materials: Electronic, Magnetic and Optical

Properties of Materials: Structural and Mechanical

Properties of Materials: Thermodynamic and Transport

Standard Reference Data

Standard Reference Materials

Surfaces and Interfaces

Thermodynamics and Chemical Kinetics

Technology Incentives

Other Subjects of General Interest

It permits users of this catalog to scan the Bureau's output by major subject category. The user should bear in mind that a paper is listed once by major subject even though it might well contain other secondary subject matters of interest. The keyword index permits the reader to determine the overall context of a paper, and provides an excellent secondary reference source.

The categories currently in use for classifying NBS publications are listed below and are followed by a listing of each paper by category. Full citations (including key-words and abstracts) will be found under the appropriate publication series, which is included in the paper title. Also of use will be the key-word index (mentioned above) and the author index. 
Pope, A. L. Allord, and C. K. Doll, SP519, Pp. 65-78 1 Apr 1979).

Identification and quartitation of a romatic hydrocarbon metaholites in marine biota, L. C. Thomas, W. D. MacLeod, Jr., and D. C. Malins, SP519. pp. 79-86 (Apr. 1979).

The trace-level determination of organics by high-pressure liquid chromatography, R. W. Edwards, K. A. Nonnemaker. and R. L. Cotter, SP519, pp. 87-94 (Apr. 1979).

Co-condensation with n-pentane. A new route to concentration of atmospheric pollutants, D. J. Freed, SP5 19. pp. 95-99 (Apr. 1979).

Analysis of organic ambient aeroswols, E. S. Macias, K. S. Kumar, and M. K. Hollman, SP5/4, pp. 101-107 (Apr. 19791.

Polynuclear aromatic hydrocarbons assuciated with coal combustion, L. Sucre, W. Jennings, G. L. Fisher, O. G. Raabe, and J. Olechno, S1P5/9, pp. 109-120 (Apr. 1979).

Diurnal and spatial variations of orgaric aerosol constituents in the Los Angeles Basin, B. R. Appel, E. M. Hoffer, E. L. Kothny, S. M. Wall, M. Haik, and R. L. Knights, SP519, pp. 121-129 (Apr. 1979).

Trace analysis in respiratory carcinogenesis, D. Hoffmunn, K. D. Brunnemann, 1. Schmeltz, and E. L. Wynder, SP519, pp. 131-141 (Apr. 1979).

A new approach to the irace analysis of mono- and dihalogenated organics, an analysis of methyl chloride In the atmosphere, E. P. Grimsrud and D. A. Miller, SP519, pp. 143151 (Apr. 1979).

Analytical facilities for the analysis of trace organic volatiles in ambient air, R. B. Denyszyn, J. M. Harden, D. L. Hardison, J. F. McGaughey, and A. L. Sykes, SP5/9. pp. 153-159 (Apr. 1979).

Analysis of trace levels of petroleum hydrocarbons in marine sediments using a solvent/slurry extraction procedure, D. W. Brown, L. S. Ramos, A. J. Friedman, and W. D. MacLeod, Jr., SP519, pp. 161-167 (Apr. 1979).

Automatic analysis of organic pollutants in water via GC/MS, D. Beggs, SP519, pp. 169-173 (Apr. 1979).

A simple, sensitive method for the quantitative analysis of carbon tetrachloride and chloroform in water at the parts-perbillion level, G. Brozowski, D. Burkitt, M. Gabriel, J. Hanrahan, E. McCarthy, and J. Smith, SP519. pp. 175-179 (Apr. 1979).

Analysis of tire cord emissions, D. Richton. J. Scott, J. S. Smith, A. F. Weston, and C. Wezwick, SP519, pp. 181-184 (Apr. 1979).

Trace organic analysis of wastewater by liquid chromatography, H. F. Walton and G. A. Eiceman, SP519, pp. $185+190$ (Apr. 1979).

Analysis of soil and sediment to determine potential pesticide contamination of a water supply impoundment, $F$. Amore, SP519, pp. 19!-203 (Apr. 1979).

Sarapling and analysis of beta-chloroethers in the environment, P. L. Sherman, A. M. Kemmer, L. Metcalfe, H. D. Toy, and G. E. Parris. SP519. pp. 205-212 (Apr. 1979).

A statistical study of atmospheric sampling for an enclosed inhabited environment, H. G. Eaton, F. W. Williams, J. R. Wyatt, J. J. DeCorpo. F. E. Saalfeld, D. E. Smith, and T. L. King, SP519. pp. 213-218 (Apr. 1979).

Development of an aqueous polynuclear aromatic hydrocarbon standard reference material, W. E. May, J. M. Brown, S. N. Chesler, F. Guenther, L. R. Hilpert, H. S. Hertz, and S. A. Wise. SP519. pp. 219-224 (Apr. 1979). 
New column technology in the analysis of organics in water by gas chromatography. R. Mindrup. Jr.. SP. 19 . pp. 225-229 (Apr. 1979).

Sampling methods for trace organic analysis in foods, $W$. Horwit/ and J. W. Howard, SP5/9. pp. 231-242 (Apr. 1979).

The role of sample preparation in nutritional labeling analysis, H. G. Lento, SP5/9. pp. 243-24X (Apr. 1979).

Nutrient analyses of foods: $A$ reexamination, K. K. Stewart. SP5 19. pp. 249-255 (Apr. 1979)

Measurement of the trace amounts of vitamin $B_{1: 2}$ present in various foods hy a new radiometric microhiologic technique, $M$ Chen and P. A. Mclntyre, SP5/\%, pp. 257-265 (Apr. 1979).

Gas liquid chromatographic analysis of pantothenates and panthenol, A. J. Sheppard and W. D. Huhbard. SP5/9. pp. 267-269 (Apr. 1979)

Quantitative analysis of simple carbohydrates in foods, B W. Li and K. K. Stewart, SP5/4, pp. 271-27X (Apr. 1979).

Determination of vitamins $E$ and $K$ in foods and tissues using high performance liquid chromatography, J. N. Thompson. G. Hatina, and W. B. Maxwell, SP5/9, pp. 279-288 (Apr. 1979).

Current status of lipoxidase method for determining 9,12di-cis-polyunsaturated fatty acids, A. J. Sheppard and W. D. Hubhard, SP519, pp. 289-295 (Apr. 1979).

Trace analysis in agricultural products. Methods for hydrazines, carbamates, $\mathrm{N}$-nitrosodiethanolamine and other compounds, I. Schmeltz, K. D. Brunnemann, and D. Hoffmann, SP519, pp. 297-369) (Apr. 1979)

Criteria for purity of ford additives used in biological tests. Experience with saccharin and Amaranth (FD\&C Red No. 2), B. Stavric, D. R. Stoltz, and R. Klassen, SP5 19, pp. 311-319 (Apr. 1979).

Advances in the analysis of natural food toxicants, D. L. Park and A. E. Pohland, SP5 19, pp. 321-331 (Apr. 1979).

Analysis of potato for glycoalkaloid content by radioimmunoassay (RIA), R. P. Vallejo and C. D. Ercegovich, SP5/4. pp. 333-340) (Apr. 1979).

Analysis of kepone" in biological samples, N. Mady, D. Smith. J. Smith, and C. Wezwick, SP519, pp. 341-343 (Apr. 1979).

Progress in the automation of extraction and cleanup procedures for detecting trace amounts of pesticides in environmental samples, M. E. Getz, G. W. Hanes, and K. R. Hill, SP519, pp. 345-353 (Apr. 1979 ).

Method of aflatoxin analysis, S. Nesheim. SP519, pp. 355372 (Apr. 1979)

Trace organic sampling in the clinical area, $B$. Halpern. SP514, pp. 373-379 (Apr. 1979).

Sample preparation for clinical trace organic analysis, $K . \mathbf{H}$. Dudley. SP514.pp. 381-390 (Apr. 1979).

Measurement of catecholamines and their metabolites in tissue and physiological fluids using reverse-phase liquid chromatography with electrochemical detection, L. J. Felice, C. S. Bruntlett, R. E. Shoup, and P. T. Kissinger. SP519. pp. 391 397 ( Apr. 1979).

Quantitative analysis of melatonin in human plasma by negative chemical ionization mass spectrometry, S. P. Markey and A. J. Lewy. SP519. pp. 399-404 (Apr. 1979).

A candidate definitive method for the determination of total cholesterol in serum, $R$. Schaffer. E. White V, L. T. Sniegoski, and A. Cohen, SP5 19. pp. 405-410 (Apr. 1979).

The determination of neurologically important tryptophan metabolites in brain cerebrospinal fluid, G. M. Anderson. W. C. Purdy, and S. N. Young. SP519. pp. 411-418 (Apr. 1979).

Applications of the nitrogen detector to the analysis of steroid hormones and related compounds by gas chromatography, J. P. Thenot and A. Hung. SP5/9. pp. $419-427$ (Apr. 1979).
Analysis of neutral lipids hy high-performance liquid chro)matography and nephelometric detection, S. L. Smith, J. W. Jorgenorn. and M. Novotny. SP5/9. pp. 429-436 (Apr. 1979).

The determination of anabolic steroids in human hody fluids, H. W. Durbeck, C. G. B. Frischkorn, I. Buker. B. Scheulen, and B. Telin, SP5/9, pp. 437-445 (Apr. 1979).

Development of a standard reference material for antiepilepsy drugs in serum, D. J. Reeder, D. P. Enagonio, R. G. Christensen, and R. Schaffer, SP519. pp. 447-453 (Apr. 1979).

Potentiometric titration of microgram amounts of penicillamine using ion selective electrodes, S. M. Donahe, G. E. Janauer, T. D. Zucconi, and C. Lewkowicz, SP5/9: pp. 455459 (Apr. 1979)

Detection and quantitative determination of tricyclic antidepressants and benzodiazepines in serum and plasma by high performance liquid chromatography, C. Hesse. \$15/9, pp. 461-46x (Apr. 1979).

The identification of odoriferous compounds formed by coital ejaculate in collagen sponge contraceptives, C. D. Eskelson, S. Y. Chang, T. Chvapil, and M. Chvapil, SPs/9. pp. 469-476 (Apr. 1979).

The assay of triamterene in human blood by ion-pair extraction and high performance liquid chromatography, $S$. Sved and J. A. A. Sertie, SP5/4, pp. 477-480 (Apr. 1979).

The gas chromatographic measurement of dextromethorphan levels in human plasma, J. E. O'Brien, $O$. N. Hinsvark, W. R. Newman, L. P. Amsel, J. E. Giering, and F. E. Leaders, Jr., SP519, pp. 4K1-485 (Apr. 1979).

Chromatographic methods in organic trace analysis: Current situation and perspectives of future progress, $M$. Novotny, SP519, pp. 487-499 (Apr. 1979).

Flow injection analysis-A new approach to quantitative measurements, J. Ruzicka and E. H. Hansen, SP5/4, pp. 501507 (Apr. 1979)

Ion-pair HPLC of drugs and related organic compounds, $G$ Schill and K. G. Wahlund, SP519, pp. $509-523$ (Apr. 1979).

Bio-selective membrane electrodes, G. A. Rechnitz, SP5/9, pp. 525-532 (Apr. 1979).

Recent developments in homogeneous immunoassay techniques, D. S. Kabakeff, SP519, pp. 533-539 (Apr. 1979).

Analytical systems for trace organic analysis, H. M. MCNair, SP519, pp. 541-546 (Apr. 1979).

Selective detection in chromatographic analysis, L. S. Ettre, SP519, pp. 547-585 (Apr. 1979).

Automation of trace organic analysis, D. A. Burns, SPS/9, pp. 587-600 (Apr. 1979).

Electron capture negative ion chemical ionization mass spectrometry, D. F. Hunt and F. W. Crow. SP5/9. pp. 601-607 (Apr. 1979).

Mixture analysis by mass spectrometry, R. G. Cooks, SP519, pp. 609-625 (Apr. 1979).

Organic secondary ion mass spectrometry. A Benninghoven, SP519, pp. 627-635 (Apr. 1979).

The wire transport LC/MS system, R. P. W. Scott, SP5/9. pp. 637-645 (Apr. 1979).

Techniques for combined liquid chromatography-mass spectrometry, M. L. Vestal, SP519. pp. 647-654 (Apr. 1979).

Atmospheric pressure ionization mass spectrometry, D. 1 Carroll. 1. Dzidic R. N. Stillwell. and E. C. Horning. SP519. pp. 655-671 (Apr. 1979).

:52:Cf-plasma desorption mass spectrometry (PDMS) of antibiotic molecules, R. D. Macfarlane, SP5/9. pp. 673-677 (Apr. 1979).

Recent advances in symchronous luminescence spectroscopy for trace organic analysis, T. Vo-Dinh. R. B. Gammage, A R. Hawthorne, and J. H. Thorngate, SP5l9, pp. 679-684 (Apr. 1979). 
Analysis of individual polychlorinated biphenyls (PCBs) and their hepatic microsomal metabolites by HPLC-MS, P. Dymerski, M. Kennedy, and L. Kaminsky, SP519, pp. 68569) (Apr. 1979).

Suh-part-per-trillion detection of arganics in aqueous solution hy laser induced molecular fluorescence, J. H. Richardson. S. M. George, and M. E. Ando, SP5 19, pp. 691-696 (Apr. 1979).

Analysis of polymer autgassing as studied by plasma chro. matugraphy-mass spectroscopy, T. W. Carr, SP5/9, pp. 69770.3 (Apr. 1979).

Liquid chromatography with electrochemical detection. State of the art and future directions, P. T. Kissinger, C. S. Bruntlett, K. Bratin, and J. R. Rice, SP5 /9, pp. 705-712 (Apr. 1979).

Modification of conventional gas chromatographic inlets for the use of glass capillary columns, L. S. Ramos, D. W. Brown, R. G. Jenkins, and W. D. MacLeod, Jr., SP5 /9, pp. 713-718 (Apr. 1979).

Trace organic analysis using second-derivative uv-absorption spectroscopy, A. R. Hawthorne, J. H. Thorngate, R. B. Gammage, and T. Vo-Dinh, SP519, pp. $719-722$ (Apr. 1979).

On the analytical potential of micro-Raman spectroscopy in the trace characterization of polynuclear aromatic hydrocarbons, E. S. Etz, S. A. Wise, and K. F. J. Heinrich, SP519, pp. 723-729 (Apr. 1979).

Comhined glass capillary-column gas chromatography and mixed charge exchange-chemical ionization mass spectrometry of isomeric polycylic aromatic hydrocarbons, M. L. Lee, D. L. Vassilaros, W. S. Pipkin, and W. L. Sorensen, SP519, pp. 731-738 (Apr. 1979).

New concepts of quantitation in headspace gas analysis by stripping and trapping components in a closed circuit, J. Novak, J. Janak, and J. Golias, SP5 19, pp. $739-746$ (Apr. 1979).

Error estimates in total organic elemental content passive personal samplers, J. G. Montalvo, Jr., SP519, pp. 747-752 (Apr. 1979).

Concerted trace organic analysis in industrial research, $S$. A. Liebman and E. J. Levy, SP519, pp. 753.760 (Apr. 1979).

Diffusion tubes as a primary standard for OSHA-type calibration, F. J. Debbrecht, D. T. Daugherty, and E. M. Neel, SP519, pp. 761-769 (Apr. 1979).

Methods for the organic analysis of the Mighei; a reputedly contaminated meteorite, P. H. Buhl, SP519, pp. 771-775 (Apr. 1979).

The use of a novel gas chromatographic detection system for the analysis of trace halo-organics, J. D. Lupton, S. C. Havlicek, and P. R. Loy, SP5 19, pp. $777-782$ (Apr. 1979).

Use of polymer supported functional groups for the selective concentration of organic compounds, R. J. Kostyla, T. H. Mourey, R. Cohen, M. E. Merritt, K. Simmons, R. LaFaucia, G. Limentani, D. N. Washburn, and S. Siggia, SP5/9, pp. 783-787 (Apr. 1979).

A proposal for implementing a reference collection of humic and fulvic acids, R. L. Malcolm and P. MacCarthy, SP519. pp. $789-792$ (Apr. 1979).

The need to establish a reference collection of humic substances, P. MacCarthy and R. L. Malcolm, SP519, pp. $793-$ 796 (Apr. 1979).

Analysis of $4.5 \mathrm{~mol} / \mathrm{L}$ sulfuric acid for organic compounds leached from battery separators, E. C. Laird and S. B. Hanna, SP519, pp. 797-802 (Apr. 1979).

Analysis of trace plant constituents, N. Mandava, SP5 19 , pp. 803-807 (Apr. 1979).

GC-ECD assay after sample work-up: Nomenclature for standards, and some points of practice, E. Reid, SP5 19, pp. 809-810 (Apr. 1979).
TN1106. Frame C: A compact procedure for quantitative energy-dispersive electron probe $\mathrm{x}$-ray analysis, $\mathrm{R}$. L. Myklebust, C. E. Fiori, and K. F. J. Heinrich, Nat. Bur. Stand. (U.S.), Tech. Note 1106, 111 pages (Sept. 1979) SN003-003-021130 .

NBSIR 79-1740. The influence of polymer membrane properties on the performance of dissolved oxygen sensors, J. D. Barnes, 33 pages (June 1979). Order from NT1S as PB296299.

U.S. Patent 4,148,586. Apparatus for galvanic detection of optical absorptions, R. B. Green, R. A. Keller, G. G. Luther, P. C. Schenck, and J. C. Travis, 7 pages (A pr. 10, 1979).

18325. Blanchard, D. B., Harrison, S. H., Trace element profiles and ratios determined by instrumental neutron activation analysis for fine paper identification, J. Firrensic Sci. 23, No. 4, 679-686 (1978).

18334. Durst, R. A., Sources of error in ion-selective electrode potentiometry, Chapter 5 in Ion-Selective Electrodes in Analyrical Chemistry, H. Freiser, Ed., Vol. 1, 311-338 (Plenum Publishing Corp., New York, NY, 1978).

18338. Lindstrom, R. M., Fleming, R. F., Optimized measurement of aluminum in high-purity silicon, Proc. Nuclear Methods in Environmental and Energy Research, Columbia, MO, Oct. 10-13, 1977, pp. 90-98 (Technical Information Center, U.S. Department of Energy, Washington, DC, 1978).

18344. Schenck, P. K., Mallard, W. G. Travis, J. C., Smyth, K. C., Absorption spectra of metal oxides using optogalvanic spectroscopy, J. Chem. Phys. 69, No. 11,5147-5150 (Dec. 1, 1978).

18350. Becker, D. A., LaFleur, P. D., Le Roy, A., Spontaneous deposition radiochemical separation for platinum determination in biological materials, Proc. Int. Nuclear and Atumic Activation Analysis Conf. and Nineteenth Annual Meeting on Analytical Chemistry in Nuclear Technology, Garlinhurg. TN, Oct. 14-16, 1975, 1 page (American Nuclear Society, Hinsdale, IL. 1976).

18362. Durst, R. A., Potential pitfalls in the use of ion-selective electrode-reference electrode pairs, Puper in Theory, Design, and Biomedical Applications of Solid State Chemical Sensors, pp. 155-163 (CRC Press, Inc., West Palm Beach, FL, 1978).

18375. Breiter, D. N., Roush, M. L., Trace element characterization of thin polymer films by proton-induced $x$-ray emission spectrometry, Macromolecules 10, No. 4, 868-870 (Aug. 1977).

18379. Durst, R. A., Cali, J. P., Recommended reference materials for realization of physicochemical properties, Pure Appl. Chem. 50, E. F. G. Herington, Ed., 1485-1517 (1978).

18433. Howell, B. F., McCune, S., Schaffer, R., Lactate-topyruvate or pyruvate-to-lactate assay for lactate dehydrogenase: A re-examination, C/in. Chem. 25, No. 2 , 269-272 (1979).

18478. Greenberg, R. R., Gallorini, M., Gills, T. E., Cadmium analysis by radiochemical neutron activation analysis, Environ. Health Perspec. 28, 1-4 (Feb. 1979).

18568. Newbury, D. E., Microanalysis in the scanning electron microscope: Progress and prospects, (Proc. Ann. Intl. Scanning Electron Microscopy Conf., Washington, DC, Apr. 16-20, 1979), Scanning Electron Microsc. 11, 1-20 (Scanning Electron Microscopy, Inc., O'Hare, IL, 1979).

18580. Cascaval, C. N., Florin, R. E., Pyrolysis gas chromatography of some fluorine-containing polymers, J. Fluorine Chem. 13, 65-70 ( 1979).

18582. Brown, L. D., Ibers, J. A., Siedle, A. R., Iridium (1) and rhodium (1) complexes of benzotriazole. Structure of bis(triphenylphosphine) carbonyl (benzot riazenido) iridium (1), lnorg. Chem. 17, No. 11, 3026-3030 (1978).

18589. Newhury, D. E., Myklebust, R. L., Monte Carlo electron trajectory simulation of beam spreading in thin foil targets, (Proc. 2d Cornell Meeting on Analytical Electron Microscopy, Ithaca, NY, July 24-26, 1978), Uthramicrosc: 3, 391-395 
(North-Holland Publ. Co., Amsterdam. The Netherlands. $1979)$.

18626. Chabay, 1., Rosasco, G. J.. Kashiwagi, T., Speciesspecific Raman spectroscopic measurements of concentration fluctuations in unsteady flow, $J$. Chu'm. Plys. 70, No. 9, 4149 4154 (May 1. 1974).

18635. Schreiher, B. Pella. P. A., Application of anionexchange resin-loaded filters to the $x$-ray fluorescence determination of sulfate, Anal. Cho'm. 51, No. 6, 783-784 (May 1979).

18643. Blaha, J. J., Etz, E. S., Cunningham. W. C., Molecular analysis of microscopic samples with a Raman microprobe: Applications to particle characterization, (Proc. Ann. Intl. Scanning Electron Microscopy Conf., Washington, DC, Apr. 16-20, 1979), Scanning Electron Microse: 11, 93-102 (Scanning Electron Microscopy, Inc., O'Hare, IL, 1979),

18768. Cummings, A. L., Coxon, B., Layer, H. P., Hocken, R. J., Improved $100^{\circ} \mathrm{S}$ point and pol, Proc. 1978 Technical Se'ssion on Cane Sugar Refining Rescarch, Washington, DC, Sipt. 17-19, 1978. pp. 191-204 (U.S. Dept. of Agriculture, P.O. Box 19687, New Orleans, LA, 1979)

18794. Franklin, A. D., Young, K. F., Discussion-on the paper lonic conductivity of some lithium silicates and aluminosilicates, by 1 . D. Raistrick, C. Ho, and R. A. Huggins, J. Electrochem. Sioc. 124, No. 6, 871-872 (June 1977).

18840. Brill, R. H., Yamasaki, K., Barnes, I. L., Rosman, K. J R., Diaz, M., Lead isotopes in some Japanese and Chinese glasses, Ars Oric'ntulis 11, 87-109 (1979).

18889. Koch, W. F., Complication in the determination of nitrite by ion chromatography, Anal. Chem. 31. No. 9, 15711573 (Aug. 1979).

18970. Myklebust, R. L. Newhury, D. E., The use and abuse of a quantitative analysis procedure for energy-dispersive $x$ ray microanalysis, Proc. Fonrteenth Ann. Microbeam Analysis Society/1979 Conf., San Antonio, TX. Altg. 13-17. 1979, pp. 231-237 (San Francisco) Press, Inc., San Francisco, CA, 1979).

18971. Etz. E. S., Blahi, J. J.. Investigations into the critical measurement aspects of Raman microprobe analysis, Proc. Fonrteenth Ann. Microbeam Analisis Society/1979 Conf., San Antonio, TX, Aug. 13-17. 1979. pp. 173-184 (San Francisco Press, Inc., San Francisco, CA, 1979).

18972. Misra, D. N., Bowen, R. L., Reaction of anthranilic acid with cupric ion-containing hydroxyapatite surface, Paper in Surface Contamination, K. L. Mittal, Ed., 2, 983-991 (Plenum Publ. Corp., New York. NY, 1979)

18976. Small. J. A., Newhury, D. E., Myklebust, R. L., Analysis of particles and rough samples by FRAME P, a ZAF method incorporating peak-to-background measurements, Proc. Fourteenth Ann. Microbeam Analysis Sinciety/1979 Conf.. San Antonio, TX, Aug. 13-17. 1979. pp. 243-246 (San Francisco Press, Inc., San Francisco. CA. 1979).

18978. Newhury, D. E. Myklebust, R. L., Monte Carlo calculations of absolute $x$-ray generation from solid targets, Proc. Fourcenth Ann. Microheam Analysis Society/1979 Conf. San Antonio, TX, Aleg. 13-17. 1979, pp. 51-53 (San Francisco Press, Inc., San Francisco. CA. 1974).

18979. Newhury. D. E. The influence of instrumental sensitivity variations on quantitative analysis by secondary ion mass spectrometry. Proc. Fouricenti Ann: Microbeam Analysis Society/1979 Conf., San Antonio. TX. Aug. 13-17. 1979. pp. 335-337 (San Francisco Press. Inc., San Francisco. CA. 1979 ).

18984. Loebenstein. $W$. V., How to balance chemical equations, J. Wash. Acad. Sci. 69, No. 1. 7-11(1979).

\section{Atomic and Molecular Studies}

Theory of flow-induced fibril formation in polymer solutions, J. D. Hotfman, I. Re's. Nat. Bur. Stand. (U.S.), 84, No, 5, 359. 384 (Sept.Oct. 1979)

18331. Ausloos, P., Lias. S. G., Proton affinity of dichlorocarbene, J. Am. Chem. Sex. 100, No. 14,4594-4595 (July 5. 19781.

18332. Ausloos, P., Lias, S. G., Reactions of NO.2 ${ }^{+}$and solvated $\mathrm{NO}_{2}{ }^{+}$ions with aromatic compounds and alkanes, Int. $J$. Chem. Kinet. X, 657-667(1978)

18337. Lias, S. G., Ausloos, P., lonization energies of organic compounds hy equilihrium measurements, $\mathrm{J}$. Am. Chem. Sis. 100. No. 19, pp. 6027-60)34(1978).

18340. Shold, D. M., Rebhert, R. E., The photochemistry of methyl chloride, J. Photuchem. 9, $499-517$ (1978).

18359. Callcott, T. A., Arakawa, E. T., Ederer, D. L., Emission and absorption x-ray edges of $1, i$, Phys. Rev. $B$ 16, No. 12 , 5185-5192 (Dec. 15, 1977).

18366. Younger, S. M., Wiese, W. L., Systematic trends for the oscillator strengths of resonance transitions in the $\mathrm{Cu}$ and $\mathrm{Zn}$ isoelectronic sequences, Phys. Rov. $A$ 18, No, 5, 2366-2368 (Nov. 1978).

18369. Kaufman, V., Sugar, J., Analysis of the spectrum of four-times-ionized lutetium (1,u v), J. Opt. Sic. Am, 68. No. $11,1529-1541$ ( Nov. 1978).

18388. Horwitz, A. B., Leone, S. R., Laser-excited resonant isotopic $V \rightarrow V$ energy transfer: $\mathbf{H}^{35} \mathrm{Cl}-\mathrm{H}^{37} \mathrm{Cl}, \mathrm{H}^{73} \mathrm{Br}-\mathrm{H}^{41} \mathrm{Br}$, $\mathrm{D}^{35} \mathrm{Cl}-\mathrm{D}^{37} \mathrm{Cl}$, and $\mathrm{D}^{73} \mathrm{Br}-\mathrm{D}^{41} \mathrm{Br}, J$. Chem. Phys. 69, No. 12, $5319-5328$ (Dec. 15, 1978).

18389. McCann, K. J., Flannery, M. R., Elastic scattering and rotational excitation in ion-molecule collisions. $11 . \mathrm{Li}^{+}-\mathrm{H}_{2}$ and $\mathrm{H}^{+}-\mathrm{H}_{2}$ collisions, J. Chem. Plys. 69, No. 12, 5275-5287 (Dec. $15,1978)$.

18392. Celotta, R. J., Swanson, N., Kurepa, M., Electron scattering from ozone, Proc. Int. Conf. on the Physics of Electronic and Atomic Collisions, Paris, France, Juty 21-27, 1977, pp. 656-657 (Commissariat a L'Energie Atomique. Paris, France, 1978).

18409. Braun, W., Herron, J. T., Tsang, W., Churney, K., High intensity infrared laser irradiation calorimetry: Direct-deter. mination of heat input to chlorodifluoromethane and ethyl acetate, Chem. Phys. Lett. 59, No. 3, $492-497$ (Dec. I, 1978).

18412. Tsang, W., Walker, J. A., Braun, W., Herron, J. T., Mechanisms of decomposition of mixtures of ethyl acetate and isopropyl bromide subjected to pulsed infrared laser irradiation, Chem. Phys. Lett. 59, No. 3,487-491 (Dec. 1, 1978).

18413. Callcott, T. A.. Arakawa, E. T., Ederer, D. L., $\mathbf{L}_{2: 1}$ soft$\mathrm{x}$-ray emission and absorption spectra of $\mathrm{Na}$, Phys. Rev. $B$ 18, No. 12,6622-6630 (Dec. 15, 1978).

18435. Van Blerkom, D.. Castor, J. I., A simple estimate of the effect of a thick circumstellar dust shell on photospheric line profiles, Astrophy. J. 227, No. 2, 543-547 (Jan. 15, 1979).

18439. Ackerhalt, J. R.. Eherly, J. H., Shore, B. W., Statistical broadening and population loss in strongly excited three-level systems, Phys. Rev. A 19. No. 1. 248-263 (Jan. 1979).

18444. November, L. J.. Toomre, J., Gebbie, K. B.. Simon, G. W.. The height variation of supergranular velocity fields determined from simultaneous $O . S O$ ) 8 satellite and groundbased observations, Astrophys. J. 227, No. 2, 600-613 (Jan. 15. 1979)

18446. McCann, K. J.. Flannery. M. R., Multistate semiclassical orbital treatment of $\mathrm{Li}^{+}-\mathrm{H}_{2}$ and $\mathrm{H}^{+}-\mathrm{H}_{2}$ collisions, Chem. Phys. Lett. 60, No. 3. 523-527 (Jan. 15, 1979 ).

18448. Schroeder, L. W., Mathew, M., Cation ordering in $\mathrm{Ca}_{2} \mathrm{La}_{4}\left(\mathrm{SiO}_{4}\right)_{6} \mathrm{O}_{2}$, J. Solid State Chem. 26, 383-387 (1978).

18449. Smyth, K. C., Bentz. B. L.. Bruhn. C. G., Harrison, W. $W$., The role of penning ionization of the minor species in a 
neon hollow cathode discharge, J. Am. Chem. Soc. 101, No. 4, 797-799 (Feb. 14, 1979).

18473. Flannery, M. R., McCann, K. J., Systematic trends in the inelastic cross sections and form factors for $n l \rightarrow n^{\prime} l^{\prime}$ direct collisional transitions, J. Phys. B 12, No. 3, 427-445 (1979).

18474. Gallagher, A., Far-wing line broadening, Acta Phys. Pol. A54, No. 6, 761-765 (1978)

18485. Kaufman, V., Hagan, L., Spectrum and energy levels of singly ionized aluminum (Al II), J. Opt. Sóc. Am. 69, No. 2, 232-238 (Feb. 1979).

18498. Raymer, M. G., Carlsten, J. L., Pichler, G., Comparison of collisional redistribution and emission line shapes, $J$. Phys. $B$ Lett. to Ed. 12, No. 4, L119-L124 (1979).

18499. Reader, J., Acquista, N., Spectrum and energy levels of four-times ionized zirconium ( $\mathrm{Zr} \mathrm{V}), J$. Opt. Soc. Am. 69, No. 2, 239-253 (Feb. 1979).

18500. Reader, J., Luther, G., Acquista, N., Spectrum and energy levels of thirteen-times ionized molybdenum (Mo XIV), J. Opt. Soc. Am. 69, No. 1, 144-149 (Jan. 1979).

18502. Rowan, W. L., Roberts, J. R., Electron-impact ionization-rate coefficients for lithiumlike nitrogen and oxygen, Phys. Rev. A 19, No. 1, 90-98 (Jan. 1979).

18504. Siedle, A. R., Velapoldi, R. A., Erickson, N., Surface formation of cuprous benzotriazole, Inorg. Nucl. Chem. Lett. 15, No. 14, 33-36 (1979).

18506. Sugar, J., Kaufman, V., Identification of $5 g$ and $6 g$ terms and revised ionization energies in the $Y b$ II $4 f^{14} n l$ isoelectronic sequence, J. Opt. Soc. Am. 69, No. 1, 141-143 (Jan. 1979).

18507. Sugar, J., Lucatorto, T. B., Mcllrath, T. J., Weiss, A. W., Even-parity autoionizing states in neutral sodium (350400 A), Opt. Lett. 4, No. 4, 109-1 11 (Apr. 1979).

18508. Wiese, W. L., Younger, S. M., Theoretical simulation of beam foil decay curves for resonance transitions of heavy ions, J. Phys. 2, No. 40, Cl-146-Cl-148 (Feb. 1979).

18515. Castor, J. 1., Lamers, H. J. G., An atlas of theoretical P Cygni profiles, Astrophys. J. Suppl. Ser. 39, No. 4, 481-511 (Apr. 1979).

18516. Collins, L. A., Norcross, D. W., Schmid, G. B., Electron collisions with highly polar molecules: Integrated and momentum transfer cross sections and conductivity integrals for KOH and CsOH, J. Phys. B 12, No. 6, 1019-1030 (1979).

18526. LaVilla, R. E., Double-vacancy transitions in the copper $K \beta_{1,3}$ emission spectrum, Phys. Rev. A 19, No. 2, 717-720 (Feb. 1979)

18527. Klose, J. Z., Mean life of the $4 s^{2} S_{1 / 2}$ resonance level in Al 1, Phys. Rev. A 19, No. 2, 678-681 (Feb. 1979).

18528. Linsky, J. L., Haisch, B. M., Outer atmospheres of cool stars. I. The sharp division into solar-type and non-solar-type stars, Astrophys. J. 229, No. 1, L27-L32 (Apr. 1, 1979).

18534. Schubert, E., Schuck, A., Jung, K., Geltman, S., Triple differential cross sections for the electron impact ionization of helium at $35 \mathrm{eV}$ collision energy, J. Phys. B 12, No. 6, 967 978 ( 1979 ).

18542. Brown, D. W., Lowry, R. E., Molecular weight standards from sulfonation of polystyrene, J. Polym. Sci., Polym. Chem. Ed. 17, 1039-1046 (1979).

18545. Akcasu, A. Z., Han, C. C., Molecular weight and temperature dependence of polymer dimensions in solution, Macromolecules 12, No. 2, 276-280 (Mar.-Apr. 1979).

18546. Brugel, E. W., Wallerstein, G., Separate spectra of the visual components of MWC 349, Astrophys. J. 229, No. 1 , L23-L25 (Apr. 1, 1979).

18572. Wiese, W. L., Atomic transition probabilities and lifetimes, Chapter 25 in Progress in Atomic Spectroscopy, Part B, W. Hanle and H. Kleinpoppen, Eds., pp. 1101-1155 (Plenum Publ, Corp., New York, NY, 1979).
18576. Demkov, Y. N., Kunasz, C. V., Ostrovskii, V. N., United-atom approximation in the problem of $\Sigma$-Il transitions during close atomic collisions, Phys. Rev. A 18, No. 5, $2097-$ 2106 (Nov. 1978).

18577. Daywitt, W. C., An error analysis for the measurement of satellite EIRP using a calibrated radio star, IEEE Trans. Instrum. Meas. IM-27, No. 3, 253-258 (Sept. 1978).

18592. Murat, K., Katriel, J., The lowest triplet state of the biexciton may be bound, Phys. Lett. 71A, No. 1, 143-145 (Apr. 16, 1979).

18593. Wiese, W. L., Atomic processes for magnetic fusion research and their data status, (Proc. IX Int. Symp. on Physics of Ionized Gases, Dubrovnik, Yugoslavia, Aug. 28Sept. 2, 1978), Paper in The Physics of lonized Gases, R. K. Janev, Ed., pp. 661-696 (Institute of Physics, Beograd, Yugoslavia, 1979).

18595. Warner, B., Apsidal motion and evolution of cataclysmic variables, Acta Astron. 28, No. 3, 303-326 (1978).

18598. Harter, W. G., Galbraith, H. W., Patterson, C. W., Energy level cluster analysis for $E\left(\nu_{2}\right)$ vibration rotation spectrum of spherical top molecules, J. Chem. Phys. 69, No. 11 , 4888-4895 (Dec. 1, 1978).

18599. Harter, W. G., Patterson, C. W., Galbraith, H. W., Centrifugal and Coriolis effects on level cluster patterns for $T\left(\nu_{3}\right)$ rovibrational bands in spherical top molecules, J. Chem. Phys. 69, No. 1, 4896-4907 (Dec. 1, 1978).

18606. Pasachoff, J. M., Linsky, J. L., Haisch, B. M., Boggess, A., IUE and the search for a lukewarm corona, Sky and Telescope 57, No. 5, 438-443 (May 1979).

18609. Harter, W. G., Patterson, C. W., Theory of hyperfine and superfine levels in symmetric polyatomic molecules. Trigonal and tetrahedral molecules: Elementary spin-1/2 cases in vibronic ground states, Phys. Rev. A 19, No. 6, 2277-2303 (June 1979).

18632. Penn, D. R., Effect of bound hole pairs on the $d$-band photoemission spectrum of Ni, Phys. Rev. Lett. 42, No. 14, 921-925 (Apr. 2, 1979).

18641. Atkinson, G. H., Parmenter, C. S., Tang, K. Y., Modeto-mode vibrational energy flow in $S_{1}$ benzene. $V$ - $V$ resonant energy transfer, microscopic reversibility, and the role of level degeneracies, J. Chem. Phys. 71, No. 1, 68-72 (July 1, 1979).

18677. Parmenter, C. S., Seaver, M., A method to estimate intermolecular potential well depths for species in both ground and excited electronic states, J. Chem. Phys. 70, No. 12 , 5458-5462 (June 15, 1979).

18689. Smith, E. W., Giraud, M., Temperature dependence of rotational linewidths in $\mathrm{HCl}$ perturbed by argon, J. Chem. Phys. Lett. to Ed., 70, No. 4, 2027-2028 (Feb. 15, 1979).

18707. Gregory, D., Dunn, G. H., Phaneuf, R. A., Crandall, D. $H$., Absolute cross sections for $2 s-2 p$ excitation of $\mathrm{N}^{4+}$ by electron impact, Phys. Rev. A 20, No. 2, $410-420$ (Aug. 1979).

18715. Hoffman, J. D., On the formation of polymer fibrils by flow-induced crystallization, Polymer 20, No. 9, 1071-1077 (Sept. 1979).

18726. Florin, R. E., Electron spin resonance spectra of polymers during fluorination, J. Fluorine Chem. 14, 253-262 (1979).

18731. Clark, F. O., Lovas, F. J., Johnson, D. R., Dimethyl ether in orion, Astrophys. J. 229, 553-559 (Apr. 15, 1979).

18736. Wiese, W. L., Martin, G. A., Atomic transition probabilities, Section D. General Chemical in CRC Handbook of Chemistry and Physics, 59th Edition, R. C. Weast, Ed., pp. D1 12-D1 40 (CRC Press, Inc., 2255 Palm Beach Lakes Blvd., West Palm Beach, FL, 1978-1979).

18737. Wiese, W. L., Konjevic, N., Regularities in plasmabroadened line widths, (Proc. IX Int. Symp. on Physics of lonized Gases, Dubrovnik, Yugoslavia, Aug. 28-Sept. 2, 1978), Paper in The Physics of lonized Gases, R. K. Janev, Ed., pp. 257-260 (Institute of Physics, Beograd, Yugoslavia, 1978). 
18742. Sweeting, L. M., Coxon, B., Varma, R., Conformational analysis of peracetylated hexononitriles, Carbolivdr. Res. 72, 43-55 (1979).

18747. Atkinson, G. H., Parmenter, C. S., The $260 \mathrm{~nm}$ absorption spectrum of benzene: Vibronic analysis, $J$. Mol. Spectrosi: 73, 52-95 (1978)

18749. Atkinson, G. H., Parmenter, C. S., The $260 \mathrm{~nm}$ absorption spectrum of benzene: Remeasured band positions and refined assignments, $J$. Mol. Spectrosc. 73, 20-30 (1978).

18750. Atkinson, G. H., Parmenter, C. S., The $260 \mathrm{~nm}$ absorption spectrum of benzene: Selection rules and band contours of vibrational angular momentum components, $J$. Mol. Spectrosc. 73, $31-51$ ( 1978).

18753. Anderson, R. C., Henry, R. C., Moos, H. W., Linsky, J. L., Ultraviolet observations of cool stars. ViIl. Interstellar matter toward procyon, Astrophys. J. 226, No. 3, 883-887 (Dec. 15, 1978)

18764. Coxon, B., Hough, L., Revision, by proton, carbon-13, and nitrogen-15 n.m.r. spectroscopy, of the structure assigned a bis(hexopyranosyl)-amine derivative, Carbohydr. Res. 73, 47-57 (1979).

18782. Epstein, G. L., Reader, J., Spectrum and energy levels of triply ionized lanthanum (La IV), J. Opt. Soc. Am. 69, No 4, $511-520$ (Apr. 1979)

18786. Birnbaum, G., Bose, T. K., Comparison of dielectric and refractive virial coefficients and collision induced absorption bands, J. Chem. Phys. 71, No. 1, 17-19 (July 1, 1979).

18787. Farmer, B. L., Eby, R. K., Energetics of methyl branches in hydrocarbon crystals, Polym. 20, 363-366 (Mar. 1979).

18801. Levenson, M. D., Coherent optical transients observed by polarization switching, Chem. Pliys. Letl. 64, No. 3, 495498 (July 15,1979 ).

18808. Lucatorto, T. B., Mcllrath, T. J., Roberts, J. R., Capillary array: A new type of window for the vacuum ultraviolet, Appl. Opt. 18, No. 14, 2505-2509 (July 15, 1979).

18811. Lucatorto, T. B., Mcllrath, T. J., Mehlman, G., Timeresolved measurements of the far UV output of a BRV source, Appl. Opt. 18, No. 17, $2916-2917$ (Sept. 1, 1979).

18824. Kusch, P., Hessel, M. M., An analysis of the $B^{\prime} \Pi_{u^{-}} X^{\prime} \Sigma^{+}$ band system of $\mathrm{Na}_{2}, \mathrm{~J}$. Chem. Plivs. 68, No. 6, 2591-2606 (Mar. 15, 1978).

18828. Hagan, L., Atomic spectra reports, reports of observatories of Astronomical Society, Bull. Am. Astron. Soc. 7, No. 1 165-169 (1975); 8, No. 1, 210-214 (1976); 9, No. 1, 189 193 ( 1977 )

18832. Gutman, D., Braun. W., Tsang, W., Comparison of the thermal and infrared laser induced unimolecular decompositions of allylmethylether, ethylacetate, and isopropylbromide, J. Chem. Phys. 67. No. 9, 4291-4296 (Nov. 1, 1977).

18839. Ayres, T. R., Linsky, J. L., Garmire, G., Cordova, F., A search for coronal soft $x$-ray emission from cool stars with HEAO 1, Astrophys. J. 232, No. 2, L117-L120 (Sept. 1 1979).

18842. Jacox, M. E., Matrix isolation study of the vacuum ultraviolet photolysis of methyl cyanide. Vibrational and electronic spectra of the $\mathrm{CNC}$ free radical, $J$. Mol. Spectrosc. 71, $369-385$ ( 1978 ).

18847. Jacox, M. E., The stabilization and spectra of free radicals and molecular ions in rare gas matrices, Rev. Chem. Intermediates 2, 1-36 (1978).

18853. Linsky, J. L., Worden, S. P., McClintock, W.. Robertson, R. M., Stellar model chromospheres. X. High-resolution, absolute flux profiles of the $\mathrm{Ca} \| \mathrm{H}$ and $\mathrm{K}$ lines in stars of spectral types FO-M2, Astrophys. J. Suppl. Ser. 41, No. 1, 47-74 (Sept. 1979)

18855. Hagan, L., Modelling ultraviolet radiation sources and the upper atmosphere-Critical data needs, Proc. $6 / \mathrm{h}$ Intl Conf. on CODATA, Santa Flavia, Italy, May 22-25, 1978, B Dreyfus, Ed., pp. 73-76 (Pergamon Press, New York, NY. 1979).
8864. Wells, J. S., Sams. R. L., Lafterty, W. J., The high resolution infrared spectrum of the $\nu_{1}$ band of $\mathrm{HOCl}, J . \mathrm{Mol}$. Spectrosc: 77, 349-364 (1979).

18867. Hessel, M. M., Vidal, C. R., The $B^{\prime} \Pi_{n}-X^{\prime} \Sigma_{n}{ }^{+}$band system of the 'Li.: molecule, $J$. Che'm. Plivs. 70, No. 10, 4439 4459 (May 15, 1979).

18868. Reader, J., Acquista, N., Spectrum and energy levels of ten-times ionized yttrium (Y xi),J. Opt. Soc. Am. 69, No. 9, 1285-1288 (Sept. 1979).

18869. Jacox, M. E., The reaction of $F$ atoms with methane in an argon matrix, Cliem. Phys. 42, 133-148 (1979).

18870. Reader, J., Corliss, C. H., Line spectra of the elements, Section E. General Physical Constants in CRC Handhook of Chemistry and Physics, 60th Edition, R. C. Weast, Ed., pp E217-E349 (CRC Press, Inc., 2255 Palm Beach Lakes Blvd. West Palm Beach, FL, 1978-1979).

18874. Armstrong, L., Jr., Eberly, J. H., Laser bandwidth effect on two-photon two-channel ionisation in caesium, J. Phys. B. Lett. to Ed. 12, No. 10, L291-L296 (1979).

18876. Basri, G. S., Linsky, J. L., Bartoe, J. D. F., Brueckner, G., Van Hoosier, M. E., Lyman-alpha rucket spectra and models of the quiet and active solar chromosphere based on partial redistribution diagnostics, Astrophys. J. 230, No. 3 , 924-949 (June 15, 1979).

18877. Gallagher, A., Metal vapor excimers, Chapter 5 in Topics in Applied Physics, C. K. Rhodes, Ed., 30, 135-174 (Springer-Verlag, Berlin, Germany, 1979).

18879. Jacox, M. E., Matrix isolation study of the interaction of excited argon atoms with methyl cyanide. Vibrational and electronic spectra of ketenimine, Chem. Phys. 43, 157-172 (1979)

18880. Turk, G. C., Travis, J. C., DeVoe, J. R., O’Haver, T. C., Laser enhanced ionizaton spectrometry in analytical flames, Anal. Chem. 51, No. 12, 1890-1896 (Oct. 1979).

18886. Birnbaum, G., The shape of collision broadened lines from resonance to the far wings, J. Quant. Spectrosc. Radiat. Tranfer 21, 597-607 (1979).

18892. Eberly, J. H., Extended two-level theory of the exponential index of multiphoton processes, Phys. Rev. Lett. 42, No. 16, 1049-1052 (Apr. 16, 1979).

18893. Eberly, J. H., ONeil, S. V., Coherence versus incoherence: Time-independent rates for resonant two-photon ionization, Phys. Rev. A 19, No. 3, 1161-1168 (Mar. 1979).

18912. Ederer, D. L., Lucatorto, T. B., Mehlman, G., Photoabsorption spectrum of $\mathrm{Mg} \mathrm{I}$ in the range 226-170 A (54-70 eV), J. Opt. Soc. Am. 69, No. 4, 520-524 (Apr. 1979).

18913. Harris, H., Olszewski, E. W., Wallerstein, G., The binary cepheid AU Peg, Astron. J. 84, No. 10. 1598-1602 (Oct. 1979).

18917. Saykally, R. J., Evertson, K. M., Observation of pure rotational transitions in the $\mathrm{HBr}^{+}$molecular ion by laser magnetic resonance, Phys. Rer. Lett. 43, No. 7, 515-518 (Aug. 13, 1979).

18919. Saykally, R. J., Evenson, K. M., Laser magnetic resonance measurement of the $2^{3} P_{2}-2^{3} P_{1}$ splitting in atomic oxygen, J. Chem. Phys. 71, No. 4, 1564-1566 (Aug. 15, 1979).

18920. Schneeberger. T. J., Linsky, J. L.. McClintock, W. Worden, S. P.. Chromospheric emission lines in the red spectrum of AD leonis. 11. Physical conditions in flares, Astrophys. J. 231, No. 1, 148-151 (July 1, 1979).

18921. Patterson, C. W.. Galbraith, H. W., Krohn, B. J.. Harter, W. G., Energy level clusters for $\nu_{2}+\nu_{3}$ type combination bands of tetrahedrall molecules, $J$. Mol. Spectrosc. 77, No. 3, 457-473 (1979).

18922. Mango. S. A.. Bohlin, J. D., Glackin. D. L., Linsky, J. L., The solar XUV He 1 and He " emission lines. 1. Intensities and gross center-to-limb behavior, Astroplys. J. 220, No. 2, 683-691 (Mar. 1, 1978)

18923. Norcross, D. W., Addendum to "Photoabsorption by cesium," Phys. Rev. A 20, No. 3, 1285-1286 (Sept. 1979). 
18925. Tachibana, K., Phelps, A. V., Excitation of the $\mathbf{C}^{3} \Pi_{u}$ state of $\mathrm{N}_{2}$ by low energy electrons, J. Chem. Phys. 71, No. 8, 3544-3546 (Oct. 15, 1979).

18926. Kelch, W. L., Linsky, J. L., Worden, S. P., Stellar modei chromospheres. IX. Chromospheric activity in dwarf stars, Astrophys. J. 229, No. 2, $700-712$ (Apr. 15, 1979).

18927. Theodosiou, C. E., Armstrong, L., Jr., Two-photon ionisation of caesium, J. Phys. B Lett. to Ed. 12, No. 3, L87L91 (1979).

18928. Harter, W. G., Layer, H. P., Petersen, F. R., Evidence of tumbling multiplets in saturation absorption spectra of SiF 4 , Opt. Lett. 4, No. 3, 90-92 (Mar. 1979).

18929. Horwitz, A. B., Leone, S. R., Temperature dependence of resonant isotopic vibrational energy transfer in $\mathrm{H}^{35} \mathrm{Ci}$ $\mathrm{H}^{37} \mathrm{Cl}$, J. Chem. Phys. 70, No. 11, $4916-4923$ (June 1, 1979).

18933. Krauss, M., Neumann, D. B., Charge overlap effects in dispersion energies, J. Chem. Phys. 71, No. 1, 107-112 (July 1, 1979).

18934. Krauss, M., Neumann, D., Variational calculation of dynamic polarizabilities, Chem. Phys. Lett. 52, No. 3, 600602 (Dec. 15, 1977).

18935. Krauss, M., Neumann, D. B., The ${ }^{5} \Pi_{u}{ }^{5} \Sigma_{g}{ }^{+}$transition in $\mathbf{N}_{2}$, Mol. Phys. 37, No. 6, 1661-1671 (1979).

18936. Krauss, M., Mies, F. H., Electronic structure and radiative transitions of excimer systems, Chapter 2 in Topics in Applied Physics, C. K. Rhodes, Ed., 30, 5-46 (Springer-Verlag, Berlin, Germany, 1979).

18939. Henningsen, J. O., Petersen, J. C., Petersen, F. R., Jennings, D. A., Evenson, K. M., High resolution spectroscopy of vibrationally excited ${ }^{13} \mathrm{CH}_{3} \mathrm{OH}$ by frequency measurement of FIR iaser emission, J. Mol. Spectrosc. 77, 298-309 (1979).

18944. King, D. S., Schenck, P. K., Laser-excited galvanic spectroscopy, Laser Focus, pp. 50, 52, 54, 56, and 57 (Mar. 1978).

18948. Kelleher, D. E., Konjevic, N., Wiese, W. L., Test for ion dynamic dependence of plasma red shifts in neutral hydrogen, Phys. Rev. A 20, No. 3, $1195-1196$ (Sept. 1979).

18949. Roszman, L. J., Dielectronic recombination rate of Mo xxxiI, Phys. Rev. A 20, No. 3, 673-676 (Sept. 1979).

18950. Victor, G. A., Constantinides, E. R., Double photoionization and doubiy charged ions in the thermosphere, Geophys. Res. Lett. 6, No. 6, $519-522$ (June 1979).

18953. Leuchs, G., Smith, S. J., Walther, H., High resolution spectroscopy of Rydberg states, Proc. Fourth Int. Conf. on Laser Spectroscopy, Rottach-Egern, Germany, June 11-15, 1979, H. Walther, K. W. Rothe, Eds., pp. 255-263 (SpringerVerlag, New York, NY, Oct. 1979).

18960. Han, C. C., Molecular weight and temperature dependence of intrinsic viscosity of polymer solutions, Polymer 20, 1083-1086 (Sept. 1979).

18961. Scalabrin, A., Evenson, K. M., Additionai cw FIR iaser lines from optically pumped $\mathrm{CH}_{2} \mathrm{~F}_{2}$, Opt. Lett. 4, No. 9, 277 279 (Sept. 1979).

18974. Laufer, A. H., Photochemistry of bromoacetyiene. Formation of $\mathrm{HBr}$ and quenching of excited $\mathrm{Br}\left(4^{2} \mathrm{P}^{0}{ }_{1 / 2}\right), J$. Phys. Chem. 83, No. 21, 2683-2686 (1979).

18995. Martin, W. C., Working Group 4: Structure of atomic spectra. A. Compilations and bibliographies on energy ievels, wavelengths, and line classifications, Trans. of the International Astronomical Union Vol. XV11A-Part 1. Reports on Astronomy, E. A. Muller, Ed., Commission 14, Fundamental Spectroscopic Data, pp. 56-60 (D. Reidel Publ. Co., Dordrecht, Holland, 1979).

18996. Younger, S. M., Collision strengths and Gaunt factors for highly ionized atoms of the copper isoelectronic sequency, J. Quant. Spectrosc. Radiat. Transfer 22, 155-159 (1979).

18997. Younger, S. M., Wiese, W. L., An assessment of the effectlve Gaunt factor approximation, J. Quant. Spectrosc. Radiat. Transfer 22, 161-170 (1979).
8998. Younger, S. M., Diagrammatic many-body perturbation theory appiled to highiy ionized atoms of the copper isoelectronic sequence, Phys. Rev. A 20, No. 3, $951-963$ (Sept. 1979).

19007. Giampapa, M. S., Linsky, J. L., Schneeberger, T. J., Worden, S. P., Chromospheric emission lines in the red spectrum of AD Leonis, I. The nonflare spectrum, Astrophys. J. 226, No. 1, 144-150 (Nov. 15, 1978).

19019. Lee, S. A., Helmcke, J., Hall, J. L., High resolution twophoton spectroscopy of Rb Rydberg levels, (Proc. Fourth Int. Conf. on Laser Spectroscopy, Rottach-Egern, Federal Republic of Germany, June 11-15, 1979), Paper in Laser Spectroscopy, H. Walther, K. W. Rothe, Eds., IV, 130-141 (Springer-Verlag, New York, NY, Oct. 1979).

19028. Zajonc, A., Gallagher, A., Electron excitation of Li $S$ and $D$ states, Phys. Rev. A 20, No. 4, 1393-1397 (Ǫ̧t. 1979).

19042. Bialkowski, S. E., King, D. S., Stephenson, J. C., The gas phase iaser induced fluorescence spectroscopy of chiorofluoromethylene, J. Chem. Phys. 71, No. 10, 4010-4014 (Nov. 15, 1979).

\section{Building Technology}

SP439-1. Center for building technology: A perspective-1979, M. Olmert, Nat. Bur. Stand. (U.S.), Spec. Publ. 439-1, 31 pages (May 1979) SN003-003-02056-7.

SP446-2. Building technoiogy project summaries 1977-1978, $M$. Olmert and N. Raufaste, Eds., Nat. Bur. Stand. (U.S.),'Spec. Publ. 446-2, 108 pages (Jan. 1979) SN003-003-02021-4.

SP457-3. Building technoiogy publications 1978-Supplement 3, J. R. Debelius, Ed., Nat. Bur. Stand. (U.S.), Spec. Publ. 4573, 106 pages (July 1979) SN003-003-02096-6.

SP536. Seiected papers deaiing with regulatory concerns of building rehabilitation, P. W. Cooke, Ed., Nat. Bur. Stand. (U.S.), Spec. Publ. 536, 93 pages (Feb. 1979) SN003-00302032-0.

Bullding codes: Preservation and rehabilitation, R. J. Kapsch, SPS36, pp. 1-16 (Feb. 1979).

Information structure of building codes and standards for the needs of existing buildings, B. Smith, SP536, pp. 17-53 (Feb. 1979).

Contractor understand Ing relative to rehab costs, R. S. Harrington, SP536, pp. 55-6I (Feb. 1979).

The roie of fire prevention and controi in building construction and regulations, W. H. McLain, SP536, pp. 63-74 (Feb. 1979).

Rehabilitation as an instrument in meeting housing need: Can it really work?, J. Heron, SP536, pp. 75-81 (Feb. 1979).

Building codes and hlstoric preservation in Savannah Georgia, M. Rosentha1, SP536, pp. 83-93 (Feb. 1979).

SP549. Proceedings of the National Conference on Regulatory Aspects of Building Rehabilitation. Proceedings of a Conference held at the National-Bureau of Standards, Gaithersburg, MD, Oct. 30, 1978 , S. A. Berry, Ed., Nat. Bur. Stand. (U.S.), Spec. Publ. 549, 220 pages (Aug. 1979) SN003-00302107-5.

Pubiic programs for housing rehabilitation, A. Rechler, SP549, pp. 19-21 (Aug. 1979).

HUD rehabiiitation guidellnes, R. J. Kapsch, SP549, pp. 2327 (Aug. 1979).

Appilication of Article 22 of the Massachusetts State Building Code, P. Folkins, SP549, pp. 33-38 (Aug. 1979).

Impact of new construction oriented codes on building rehabilitation, R. P. Kuchnicki, SP549, pp. 39-42 (Aug. 1979).

Code requirements for existing bulldings: $A$ new approach, K. M. Schoonover, SP549, pp. 4,3-50 (Aug. 1979).

A "professional practice" approach to the rehabilitation process, W. E. Lewis, SP549, pp. 71-84 (Aug. 1979). 
A fire evaluation system for health care facilities, H. E. Nelson, if 549, pp. 85-102 (Aug. 1979).

Rehahilitation standards: What are they? Who is in develop, maintain, and enforce them?, B. A. Cummings, SP549, pp. 103-106 (Aug. 1979).

Rehabilitation, performance and the 'real world' of the code official, J. Stein, SP549, pp. 119-123 (Aug. 1979).

An architect's view of rehabilitation regulation, F. A. Stahl, SP549, pp. 125-129 (Aug. 1979).

Administration of a rehabilitation code in a major city, $\mathrm{C}$. C. Lederer, SP549, pp. 131-134 (Aug. 1979).

SP552. Research and innovation in the building regulatory process. Proceedings of the $3 d$ Annual NBS/NCSBCS Joint Conference held in Annapolis, MD, Sept. 12, 1978, in conjunction with the Eleventh Annual Meeting of the National Conference of States on Building Codes and Standards, Inc. (NCSBCS), P. W. Cooke, Ed., Nat. Bur. Stand. (U.S.), Spec. Publ. 552, 358 pages (July 1979) SN003-003-02091-5.

A defensible technique for determining code equivalency in buildings, G. N. Berlin, SP552, pp. 13-27 (July 1979).

The liability of municipalities and municipal officials for negligence in the regulation of buildings, $V$. Brannigan, SP552, pp. 29-37 (July 1979).

Buildings engineer emergency response team, S. S. Koren, SP552, pp. 39-44 (July 1979).

The development and implementation of building standards in Erance, I. Martinez, SP552, pp. 45-56 (July 1979).

A case history of the integrity of the National Electrical Code, D. J. MacFadyen, SP552, pp. 57-78 (July 1979).

Federal Government activities relative to the development of voluntary consensus standards, D. R. Mackay, SP552, pp. 79 93 (July 1979).

The formulation of sensible regulations for accessible rehabilitation housing, A. E. Osterberg, SP552, pp. 95-100 (July 1979).

Designing for access to, movement within, and egress frosm building and sites: Effective research for more reasonable regulation, F. I. Stah1, SP552, pp. 101-113 (July 1979).

Commanication techniques in building code implementation, T. J. Rosenberg, SP552, pp. 115-120 (July 1979).

A summary of Kentucky's experience in implementing a statewide energy code, J. R. Groves, Jr., SP552, pp. 121-130 (July 1979).

Energy conservation in building codes and standards, R. W. Lisle, SP552, pp. 131-140 (July 1979).

Implementation of energy conservation standards, $J . T$. Quinn, SP552, pp. 141-151 (July 1979).

The uses of an integrated data base in municipal computer assisted regubiary systems, N. S. Remmer, SP552, pp. 153 165 (July 1979).

Exploiting the computer to control the application of design criteria ts construction, R. E. Larson, SP552, pp. 167-183 (July 1979).

Construction labor demand system: An overview, W. F. Hahn, SP5 52, pp. 185-196 (July 1979).

Proposed criteria for establishing energy consumption standards for existing buildings, R. R. Somers $11, T$. C. Scott, and L. S. Fletcher, SP552, pp. 197-209 (July 1979).

Proposed solar energy legislation likely to affect the building regulatory process, R. J. Smith, SP552, pp. 211-216 (July 1979).

Critical performance standards for passive solar buildings, J. K. Holton, SP552, pp. 217-224 (July 1979).

A.case for more rational and explicit building regulations, H. M. Markman, SP552, pp. 225-247 (July 1979 ).

Formulation and expression analysis of standards and regulations, J. W. Melin and R. L. Tavis, SP552, pp. 249-266 (July 1979).

Life-cycle benefit-cost analysis of housing safety regulations, J. L. Walters, SP552, pp. 267-282 (July 1979).
Regulatory implications of adopting a metric building code for the Province of Alberta, Canada, A. J. M. Aikman, SP552, pp. 283-291 (July 1979).

An approach to third party approval for industrialized housing, C. M. Edwards, SP552, pp. 293-309 (July 1979).

Structural inspection of complex structures, C. G. Cooper and G. P. Berson, SP552, pp. $311-320$ (July 1979).

Lighting and building codes for energy conservation, $M$. S. Millet, J. R. Bedrick, G. S. Spencer, and G. B. Varey, SP552, pp. $321-335$ (July 1979).

Tax shelter in construction: Puhlic objectives and private incentives, U. P. Gauchat, SP552, pp. 337-346 (July 1979).

Resource zoning and land use planning: An examination of urban infrastructures, U. P. Gauchat and D. L. Schodek, SP552, pp. 347-360) (July 1979).

SP553. Water supply and drainage in buildings. Proceedings of an International Symposium, National Academy of Sciences, Washington, DC, Sept. 28-30, 1976, L. S. Galowin and J. R. Debelius, Eds., Nat. Bur. Stand. (U.S.), Spec. Publ. 553, 232 pages (Aug. 1979) SN003-003-02101-6.

Water requirements and procedures for estimating the demand for water in buildings, R. V. Benazzi, L. Guss, R. Orend, R. S. Wyly, and T. P. Konen, SP553, pp. 3-13 (Aug. 1979).

Protecting water quality in buildings, G. Williams, T. P. Konen, F. Liposki, J. R. Myers, L. Nielsen, W. Mikucki, and W. Staton, SP553, pp. 15-19 (Aug. 1979).

Water and water-related conservation in buildings, A. J. Fowell, A. Bransdorfer, P. Fletcher, R. J. Orend, H. J. Pavel, and G. H. Williams, SP553, pp. 21-31 (Aug. 1979).

Hydraulics of gravity drainage systems, R. S. Wyly, R. V. Benazzi, T. P. Konen, R. R. Manfredi, and L. S. Nielsen, SP553, pp. 35-51 (Aug. 1979).

Performance concepts for water supply and drainage systems in buildings, L. S. Galowin, W. J. Downing, L. S. Nielsen, M. J. Orloski, and R. S. Wyly, SP553, pp. 53-70 (Aug. 1979)

Alternative concepts for transporting and treating wastes within buildings, T. P. Konen, R. S. Bevans, W. J. Boegly, D. Savitsky, and C. Cole, SP553, pp. 71-77 (Aug. 1979).

CIB W-62 purpose, methodology and fields of work, $K$. Ovesen, SP553, pp. $81-88$ (Aug. 1979).

Standardization structure in Europe, F. Perrier, SP553, pp. 89-99 (Aug. 1979).

Certification and agreement system in Europe, D. Trinkler, SP553, pp. $101-108$ (Aug. 1979).

Research laboratories with CIB interest, R. Hanslin, C. D. J. Webster, and V. Nielsen, SP553, pp. 109-128 (Aug. $1979)$.

Cost benefit of plumbing: Large fringe benefits for sanitary installations by thorough analysis of system, T. Rosrud, SP553, pp. 131-135 (Aug. 1979).

Economic water supply design based on performance requirements, E. Olsson, SP553, pp. 137-159 (Aug. 1979).

Production, transport and use of hot water, F. Perrier, SP553, pp. 161-173 (Aug. 1979).

Performance requirements for taps: A consensus from Scandinavia, V. Nielsen, SP5 53, pp. 175-192 (Aug. 1979).

Code structure and standardization in the United States, M. Snyder, SP553; pp. 193-205 (Aug. 1979).

Potential savings from using reduced-size venting in the United States, H. Marshall, R. Ruegg, and R. Wyly, SP553. pp. 207-225 (Aug. 1979).

BSS75. Building research at the National Bureau of Standards 1968-1974, N. Gallagher, Ed., Nat. Bur. Stand. (U.S.), Bldg. Sci. Ser. 75, 126 pages ( Mar. 1979) SN003-003-02029-0.

BSS95. The development of an improved compression test method for wall panels, C. W. C. Yancey and L. E. Cattaneo, Nat. Bur. Stand. (U.S.), Bldg. Sci. Ser. 95, 108 pages (Feb. 1979) SN003-003-01697-7. 
BSSI(1)7. Soil and rock anchors for mobile homes-A state-ofthe-art report, W. D. Kovacs and F. Y. Yokel, Nat. Bur. Stund. (U.S.), Bldg. Sici. Ser. 107, 164 pages (Oct. 1979, SN()(1)3-()(0)-02121-1.

B.SII IX. Extreme wind speeds at 129 stations in the contiguous United States, E. Simiu, M. J. Changery, and J. J. Filliben, Nat. Bur. Sitund. (U.S.), Bldg. Sci. Ser. 118, 318 pages (Mar. 1974, SN003-003-(02041-9.

BSS 119. Economic evaluation of windows in buildings: Methodology, R. T. Ruegg and R. E. Chapman, Nat. Bur. Sitund. (U.S.), Bldg. Sici. Ser. 119, 118 pages (Apr. 1979) $\mathrm{SNO03-00)3-02042-7.}$

TN979. Lead paint abatement costs: Some technical and theoretical considerations, R. E. Chapman and J. G. Kowalski, Nat. Bur. Stand. (U.S.), Teclt. Note 979, 153 pages (Feb. 1979) SN()03-00)3-02022-2.

TN996. Mechanical properties of adobe, J. R. Clifton and F. L. Davis, Nat. Bur. Stand. (U.S.), Tech. Note 996, 45 pages (May 1479) SNo()3-003-02066-4.

TN998. Impact of building regulations on rehabilitation-Status and technical needs, J. G. Gross, J. H. Pielert, and P. W. Cooke, Nat. Bur. Stand. (U.S.), Tech. Note 998,50 pages (May 1979) SN003-003-02062-1.

TNII00. Analysis of tentative seismic design provisions for buildings, J. R. Harris, S. J. Fenves, and R. N. Wright, Nat. Bur. Siand. (U.S.), Tech. Note 1100, 599 pages (July 1979) SN()03-0)3-()2084-2.

NBSIR 77-1289. The measurement of wind loads on a full-scale mobile home, R. D. Marshall, 132 pages (Sept. 1977). Order from NTIS as PB297463.

NBSIR 78-1521. French schools-A report of the U.S. team visit to France from November 13 to 23, 1977, P. Driscoll, Coordinator, 42 pages (Mar. 1979). Order from NTIS as PB296148.

NBSIR 79-1729. Pedestrian movement on ramps-A preliminary investigation, G. E. Turner and B. L. Collins, 62 pages (Mar. 1979). Order from NTIS as PB294856.

NBSIR 79-1730. Protecting adobe walls from ground water, J. R. Clifton and F. Davis, 29 pages (Mar. 1979). Order from NTIS as PB295041.

BSIR 79-1736. Evaluation of hand-held infrared thermometers for wall thermal resistance determinations, S. J. Treado and D. M. Burch, 26 pages (July 1979). Order from NTIS as PB298057.

NBSIR 79-1780. Post-occupancy evaluation: A case study of the evaluation process, J. Elder, G. E. Turner, and A. I. Ruhin, 67 pages (Aug. 1979). Order from NTIS as PB80-119712.

NBSIR 79-1789. Economic analysis of insulation in selected masonry and wood-frame walls, S. R. Petersen, 137 pages (Sept. 1979). Order from NTIS as PB80-101967.

NBS-GCR-78-153. The architect's access to information, C. H. Burnette, 97 pages (Mar. 1979). Order from NTIS as PB294855.

NBS-GCR-78-154. Making information useful to architects, C. H. Burnette, 101 pages (Dec. 1978). Order from NTIS as PB292782.

18324. Yokel, F. Y., Guidelines for housing construction in mine subsidence areas, Prox. Int. Conf. on Evaluation and Prediction of Subsidence. Pensacola Beach, FL, Jan, 1978, S. K. Saxena, Ed., pp. 129-139 (American Society of Civil Engineers, New York, NY, 1978)

18351. Bietry, J., Sacre, C., Simiu, E., Mean wind profiles and change of terrain roughness, J. Siruct. Div., Am. Soc. Civ. Eng. 104, No. ST10, Proc. Paper 14099, 1585-1593 (Oct. 1978).

18415. Ellingwood, B., Leyendecker, E. V., Approaches for design against progressive collapse, J. Struct. Div., Proc. Am. Six. Civ. Eng. 104, No. ST3, Proc. Paper 13610, 413-423 (Mar. 1978).
18429. Raufaste, N. J., Jr., Olmert, K. M., Case study: NBS' Center for Building Technology, Words 7, No. 3, 34-37 (Feh.Mar. 1979).

18493. Milton, H. J., Our metric future. A n analysis of metrication's impact upon construction specifications, Constr. Specifi(er 32, No. 2, 36-47 (Feb. 1979).

185\%. McNall, P. E., Jr., The relation of thermal comfort to learning and performance: $A$ state-of-tbe-art report, (Proc. ASHRAE Semiannual Meeting on HVAC-Human Factors, Philadelphia, PA, Jan. 28-Feh. 2, 1979), Paper PH-79-9, No. 2 in ASHRAE Trans. 85, Pt. 1, $759-767$ (June 1979).

18688. Simiu, E., Scanlan, R. H., Flutter of a plate-like member in horizontal fluctuating flow, Eng. Siruct. 1, No. 4, 207-210 (July 1979).

18887. Knab, L. I., Moody, R. C., Glulam design criteria for temporary structures, J. Struct. Div., Am. Soc. Civ. Eng. 104, No. ST9, Proc. Paper 14031, 1485-1494 (Sept. 1978).

18977. Reinhold, T. A., Wind interaction of meighhoring tall buildings, Proc. ASCE Third Engineering Mechanics Division Specialty Conf., Sept. 17-19, 1979, Austin, TX, pp. 179-182 (American Society of Civil Engineers, New York, NY, 1979 ).

\section{Computer Science and Technology}

Enhancing Fortran to aid manipulation of large structured matrices, H. J. Greenherg and J. E. Kalan, J. Res. Nat. Bur. Stand. (U.S.), 84, No. 1, 21-47 (Jan.-Feh. 1979).

SP500-38. Computer science \& technology: Findings of the standard benchmark library-Study group, D. M. Conti, Nat. Bur. Sland. (U.S.), Spec. Publ. 500-38, 57 pages (Jan. 1979) SN003-003-02009-5.

SP500-39. Computer science \& technology: Computer model documentation: A review and an approach, S. I. Gass, Nat. Bur. Stand. (U.S.), Spec. Publ. 500-39, 89 pages (Feh. 1979) SN003-003-02020-6.

SP500-42. Computer science \& technology: A survey of remote monitoring, G. J. Nutt, Nat. Bur. Stand. (U.S.), Spec. Publ. 500-42, 34 pages (Jan. 1979) SNO03-003-02013-3.

SP500-44. Computer science \& technology: A methodology for the selection of interactive computer services, S. A. Mamrak and P. D. Amer, Nat. Bur. Stand. (U.S.), Spec. Publ. 500-44, 82 pages (Jan. 1979) SN003-003-02018.

SP500-45. Computer science \& technology: Computer peripheral memory system forecast, R. B. J. Warnar, P. J. Calomeris, and S. A. Recicar, Nat. Bur. Stand. (U.S.), Spec. Publ. 500-45, 147 pages (Apr. 1979) SN003-003-02039-7.

SP500-46. Computer science \& technology: Computers in the Federal Government: A compilation of statistics-1978, M. M. Gray, Nat. Bur. Stand. (U.S.), Spec. Publ. 500-46, 95 pages (Apr. 1979) SNO03-003-02037-1.

SP500-47. Computer science \& technology: Data base reorganization-Principles and practice, G. H. Sockut and R. P. Goldberg, Nat. Bur. Stand. (U.S.), Spec. Publ. 500-47, 51 pages (Apr. 1979) SN003-003-02055-9.

SP500-48. Computer science \& technology: Measurement of interactive computing: Methodology and application, I. W. Cotton, Nat. Bur. Stand. (U.S.), Spec. Publ. 500-48, 111 pages (June 1979). SN003-003-02081-8.

SP500-49. Computer science \& technology: Modeling and measurement techniques for evaluation of design alternatives in the implementation of database management software, D. R. Deutsch, Nat. Bur. Stand. (U.S.), Spec. Publ. 500-49, 244 pages (July 1979) SN003-003-02088-5.

SP500-50. Computer science \& technology: Computers, personnel administration, and citizen rights, A. F. Westin, Nat, Bur. Stand. (U.S.), Spec. Publ. 500-50, 465 pages (July 1979) SNO03-003-02087-7. 
SPS()0-52. Computer science \& technology: Computer performance evaluation users group (CPEUG). Proceedings of the Fifteenth Meeting held at San Diego, CA, Oct. 15-18, 1479. J. E. Weatherbee, Ed.. Nat. Bur. Stand. (U.S.), Spece. Publ. 50()-52, 240) pages (Oct. 1979) SN0(13-()03-()2118-1.

Data processing information utilization-An audit perspective, M. J. Thibault, SP5()()-52, pp. 3-8 (Oct. 1974).

Auditing an IMS system. C. L. Gausche and W. J. Schwinden. SP5()0-52, pp. 9-14 (Oct. 1979).

Applications and limitations of the cost-value technique for competitive computer selection, R. E. Barbour. Jr.. J. O. Holcombe, C. S. Harris, and W. C. Moncrief, $\$ P 50(1)-52, \mathrm{pp} .25-$ 36 (Oct. 1979).

Computer selection: To measure or not to measure, S. A. Mamrak, SP5(J)-52, pp. 37-52 (Oct. 1979)

Benchmarking interactive systems: Modeling the application, C. R. Spooner, SP50)-52, pp. 53-64 (Oct. 1979).

Methodology for establishing a computer performance management system: A case study, G. H. Goodman, SP50052, pp. 69-77 (Oct. 1979).

Naval laboratories' quality of service standards, J. S Dodds, SP500-52, pp. 79-86 (Oct. 1979).

Computer system migration planning through benchmark performance evaluation, A. Mukherjee, A. K. Jain, and B. A Ketchledge, SP500-52, pp. 89-104 (Oct. 1979).

An optimal sample size allocation scheme for benchmark design, S. K. Tripathi, K. D. Gordon, and A. K. Agrawala, SP50()-52, pp. 105-111 (Oct. 1979).

Computer workload forecasting, J. E. McNeece, SP500-52, pp. 113-120 (Oct. 1979),

A simulation model of JES output processing, H. P. Artis, SP5(0)-52, pp. 123-127 (Oct. 1979)

Design for performance, M. J. Kirrene and M. G. Spiegel, SP500-52, pp. 129-140) (Oct. 1979).

Quantitative methods in computer performance evaluation,

A. K. Jain, SP500-52, pp. 143-145 (Oct. 1979).

The application of clustering techniques to computer performance modeling, T. C. Hartrum and J. W. Thompson, SP500-52, pp. 147-161 (Oct. 1979).

Performance comparison measures for computer systems, I Drelzgalvis, SP500-52, pp. 163-176 (Oct. 1979).

Event driven capacity planning, S. W. Cox, SP500-52, pp 179-192 (Oct. 1979),

A FORTRAN synthetic program for benchmarking, $P$. $M$ Fleming and A. C. Rucks, SP500-52, pp. 193-199 (Oct 1979).

The NBS Network Measurement Instrument, M. D. Abrams and D. C. Neiman, SP5OO-52, pp. 201-211 (Oct. 1979).

Performance analysis of a saturated system-A case study, N. Lennon and W. P. Bond, Jr., SP500-52, pp. 215-218 (Oct. 1979).

Teleprocessing transaction thruput performance, B. Irwin, SP5OO-52, pp. 219-226 (Oct. 1979).

Methodology for performance evaluation and capacity planning, A. O. Allen, SP500-52, p. 227 (Oct. 1979).

Benchmarking with remote terminal emulation, $T$. F Wyrick and R. E. Youstra, SP500-52, pp. 229-230 (Oct 1979).

Planning and implementing remote teleprocessing services: Management perspectives of the TSP, R. L. DeMichiell and G. L. Underwood, SP500-52, pp. 231-232 (Oct. 1979).

Selection and evaluation of instructional time-sharing services-(A tutorial outline), R. T. Close and R. A. Kambeitz, SP50O-52, pp. 233-234 (Oct. 1979).

Tutorial on benchmark construction, H. Letmanyi, SP5OO52. pp. 235-240 (Oct. 1979 ).

Using accounting log data in performance reporting, $J$. P Bouhana, SP500-52, pp. 241-243 (Oct. 1979).
SP500-53. Computer science \& technology: Technology assessment: $A D P$ installation performance measurement and reporting. C. B. Wilson, Nat. Bur. Stand. (U.S.), Spec. Puhl. 500)53. 37 pages (Sept. 1979 ) SN(0)3-(903-02123-7.

SP50()-54. Computer science \& technology: A key notarization system for computer networks, M. E. Smid, Nat. Bur. Stand. (U.S.), Spece. Puhl. 500-54. 35 pages (Oct. 1979) SN003-()03$02130-0$

SP5(0)-55. Computer science \& technology: Selection of data entry equipment, S. A. Recicar, Nat. Bur. Stand. (U.S.), Spec. Puhl. 500-55. 77 pages ( Nov. 1974) SN003-(003-(02133-4.

FIPS PUB 64. Guidelines for documentation of computer programs and automated data systems for the initiation phase, $B$. Leong-Hong, Standards Coordinator, Nat. Bur. Stand. (U.S.), Fed. Info. Process. Siand. Puhl. (FIPS PUB) 64, 54 pages (Aug. 1974),

FIPS PUB 67. Guideline for selection of data entry equipment, Nat. Bur. Stand. (U.S.), Fed. Info. Prociess. Stand. Publ. (FIPS PUB) 67, 23 pages (Sept. 1979).

TN1108. SPEED2, a computer program for the reduction of data from automatic data acquisition systems, R. D. Peacock and J. M. Smith, Nat. Bur. Stand. (U.S.), Tech. Note IIOS, 153 pages (Sept. 1979) SNO03-003-02112-1.

NBSIR $78-1478$. A universal set of test data for computer implementations of elementary mathematical functions, $D$. W. Lozier, 29 pages (May 1978). Order from NTIS as PB291961.

NBSIR 79-1725. Phase II final report. Computerized site security monitor and response system, R. T. Moore, R. J. Carpenter, A. W. Holt, A. L. Koenig, and R. B. J. Warnar, 118 pages (Mar. 1979). Order from NTIS as PB294343.

NBSIR 79-1734. Guide to technical services and information sources for ADP managers and users, S. M. Radack, 50 pages (Apr. 1979). Order from NTIS as PB294845.

NBSIR 79-1927. Recovery from soft errors in triplicated computer systems operating in lock-step, A. L. Koenig and A. W Holt, 28 pages (Nov. 1979). Order from NTIS as PBS0-12693

NBS-GCR-78-127. Comparison of tape drive interface characteristics, Auerbach Associates, Inc., 75 pages (June 15, 1978). Order from NTIS as PB282291.

NBS-GCR-78-148. Effectiveness of program validation methods for scientific programs, W. E. Howden, 110 pages (Dec. 1978). Order from NTIS as PB289930.

NBS-GCR-79-182. Comparison of high speed printer interface characteristics, Calculon Corp, 144 pages (July 31, 1979). Order from NTIS as PB298943

18445. Dickens, B., Computer program to implement automated factor-jump thermogravimetry, Thermochim. Acta 29, 57-85 (1979).

18488. Kimbleton, S. R., Data sharing protocols: Structure, requirements and interrelationships, Proc. COMPSAC 78, IEEE Computer Societv"s Second Int. Computer Sofiware and Application Conf., Chicago, IL, Now. 13-16, 1978, pp. 270276 (IEEE Service Center, Piscataway, NJ, Nov. 1978).

18597. Molino, B. B., Hilsenrath, J., Beyond data retrieval: An outline of the unique data analysis feat ures of the NBS Omnidata system, Proc. Eighteenth Annual Tech. Simp. on Information Sistems-Effectiveness for the User, Gaithershurg, MD, June 21, 1979, pp. 159-165 (The Washington DC Chapter of the Association for Computing Machinery, Washington, DC, June 1979).

18760. Carpenter, R. J., Sokol, J., Jr., Rosenthal, R., A microprocessor-based local network node, (Proc. Seventeenth IEEE Computer Society lnt. Conf. COMPCON Fall 78, Washington, DC, Sept. 5-8, 1978), IEEE Catalog No. 78CH 1388-8C, pp. 104-110 (Institute of Electrical and Electronics Engineers, Inc.. New York. NY, 1978).

18777. Jeffery, S., Fife, D.. Deutsch, D., Sockut, G., Architectural considerations for federal database standards, (Proc. Eighteenth IEEE Computer Society Int. Conf. COMPCON 
Spring 79, San Francisco, CA, Feb. 26-Mar. 1, 1979), IEEE Cutrlog No. 79 CH1393-8C. pp. $139-143$ (Institute of Electrical and Electronics Engineers, Inc., New York, NY, 1979).

18891. Kimbleton. S. R., Data sharing protocols: Structure, requirements and interrelationships, (Proc. Second IEEE Computer Society Int. Cont. COMPSAC 78, Chicago, IL, Nov. 13-16, 1978), IEEE Catalog No. 78CHI338-3C, pp. 27()-276 (Institute of Electrical and Electronics Engineers, Inc., New York, NY, 1978).

18954. Hoghen, D., Peavy, S. T., OMNITAB 78 plotting capability, Prox: Computer Science and Statistic:s: 12th Ann. Symp. (In the Interface, University of Waterloo, Ontario, Canada, May 10-11, 1979, J. F. Gentleman, Ed., pp. 413-417 (1979). 18975. lstvan, E. J., New issues confronting the information systems planner, Infosystems 26, No. 6, 54, 58, 60, 62 and 67 (June 1979).

19009. Wood, H. M., Kimbleton, S. R., Access control mechanisms for a network operating system, Proc. $1979 \mathrm{Nat}$. Computer Conf., New York, NY, June 6, 1979, pp. 821-829 (June 1979).

19039. Smid, M. E., A key notarization system for computer networks, (Proc. National Telecommunications Conf., Washington, DC, Nov. 27-29, 1979), Paper in NTC 1979 Conference Record 3, 43.3.1-43.3.5 (Available from IEEE Publishing Services, New York, NY, as IEEE Catalog Number 79CH1514-9, 1979).

19041. Wood, H. M., Women and minorities in the computer professions, Proc: 1979 Nat. Computer Conf., New York, NY, June 6, 1979, pp. 419-424 (June 1979).

\section{Consumer Information and Protection}

CIS4, Revised 1978. Corrosion, E. L. R. Corliss, Nat. Bur. Stand. (U.S.), Consum. Inf. Ser. 4, 31 pages (Revised 1978) SNO03-003-02024-9.

CIS9, Revised 1979. Facts about hearing and hearing aids, J. Kruger and S. Halpin, Eds, Nat. Bur. Stand. (U.S.), Consum. Inf. Ser. 9, 12 pages (Revised June 1979) SN003-003-01947().

NBSIR 77-1298. Power lawn mowers: Ease of pull, V. J. Pezoldt and J. J. Persensky, 32 pages (June 1977). Order from NTIS as PB271974.

18793. Fowell, A. J., Clothes dryer air exchange, Proc. Conf. on Major Home Appliance Teclinology for Energy Conservation, West Lafayette, IN, Feb. 27-Mar. 1, 1978, D. R. Tree, G. E. Courville, V. O. Haynes, H. Phillips, Eds., pp. 168-170 (Available as Conf-780238 from the National Technical Information Service, Springfield, VA, 1978).

18862. Fechter, J. V., Jr., Generic approaches to product improvement research, $C P$ News 4, No. 1, 12-20 (Oct. 1978).

\section{Electromagnetic Metrology}

Monogr. 164. Electromagnetic boundary-value problems based upon a modification of residue calculus and function theoretic techniques, J. P. Montgomery and D. C. Chang, Nat. Bur. Stund. (U.S.), Monogr. 164, 183 pages (June 1979) SN003003-02075-3.

SP551. Proceedings of the $\mathbf{1 9 7 8}$ Electromagnetic Interference Workshop. Proceedings of a Workshop held at the National Bureau of Standards, Gaithersburg, MD, Nov. 2-3, 1978, M. G. Arthur, Ed., Nat. Bur. Stand. (U.S.), Spec. Publ. 551, 57 pages (July 1979) SN003-003-02099-1.

The extent of today's EMI problems and prioritizing EMI problems, C. M. Kendall, SP551, pp. 3-4 (July 1979).

Biological electro-magnetic interference (BEMI), D. R Justesen, SP5 51, pp. 5-6 (July 1979).

FCC activities regulating electromagnetic interference, $A$ W. Paul and J. Krauss, SP55I, pp. 7-9 (July 1979).
EMI/EMC legislation in the 95th and 96th Congresses, $C$ L. Jackson, SP551, pp. 10-11 (July 1979).

Voluntary standardization for electromagnetic compatibility, R. M. Showers, SP551, pp. 12-19 (July 1979).

What is needed for progress in EMC?, H. M. Schlicke, SP551, pp. 20-22 (July 1979).

Communications working group summary, J. P. Murray, SP55I, pp. 23-26 (July 1979).

Transportation working group summary, R. J. Wasko, SP551, pp. 27-28 (July 1979).

Consumer products working group summary, W. T. Collins, SP551, pp. 29-31 (July 1979).

Industrial working group summary, G. H. Hagn, SP55I, pp. 32.37 ( July 1979).

Medical working group summary, J. C. Toler, SP55I, pp. 38-41 (July 1979).

Plenary session IV summary "The Last, Last Word," M. G. Arthur, SP551, pp. 42-44 (July 1979).

TN1008. Antennas and the assuciated time domain range for the measurement of impulsive fields, $R$. A. Lawton and A. R. Ondrejka, Nat. Bur. Stand. (U.S.), Tech. Note 1)(1)8, 68 pages (Nov. 1978) SNO03-003-()1998-4.

TN 1011 . Construction of a large transverse electromagnetic cell, W. F. Decker, W. A. Wilson, and M. L. Crawtord, Nat. Bur. Stand. (U.S.), Tech. Note 11)11, 92 pages (Feb. 1979) $\mathrm{SNO} 03-003-02034-6$.

TN1012. Calibrating a six-port reflectometer with four impedance standards, C. A. Hoer, Nat. Bur. Stand. (U.S.), Tech. Note 1012, 24 pages (Mar. 1979) SN003-003-02036-2.

TN1013. Using a TEM cell for EMC measurements of electronic equipment, M. L. Craw ford and J. L. Workman, Nat. Bur. Stand. (U.S.), Tech. Note 1013, 72 pages (Apr. 1979) SN003-003-02053-2.

TN1014. Electromagnetic interference (EMI) radiative measurements for automotive applications, J. W. Adams, H. E. Taggart, M. Kanda, and J. Shafer, Nat. Bur. Stand. (U.S.), Tec/h. Note 1014, 48 pages (June 1979) SN003-003-02086-9.

TN1016. A standard for rf modulation factor, M. G. Arthur and G. R. Reeve, Nat. Bur. Stand. (U.S.), Tech. Note 1016, 92 pages (Sept. 1979 ) SN003-003-02125-3.

NBSIR 79-1605. A theoretical study of unbalanced ground effects on receiving dipoles, $M$. T. Ma, 15 pages (May 1979): Order from NT1S as PB296207.

NBSIR 79-1606. A variational expression for the scattering matrix of a coaxial line step discontinuity and its application to an over moded coaxial TEM cell, I. Sreenivasiah and D. C. Chang, 47 pages (May 1979). Order from NTIS as PB296324.

NBSIR 79-1608. Attenuation measurements on optical fiber waveguides: An interlaboratory comparison among manufacturers, G. W. Day and G. E. Chamberlain, 35 pages (May 1979 ). Order from NTIS as PB296951.

NBSIR 79-1613. Radar absorber measurement techniques at frequencies above $20 \mathrm{GHz}, \mathrm{N}$. S. Nahman, C. M. Allred, J. R. Andrews, C. A. Hoer, and R. A. Lawton, 70 pages (Aug. 1979 ). Order from NTIS as PB299576.

NBSIR 79-1615. Dispersion and attenuation characteristics of modes in a TEM-cell with a lossy dielectric slab, J. C. Tippet and D. C. Chang, 37 pages (Aug. 1979). Order from NTIS as PB80-105141.

NBSIR 79-1620. Time domain pulse measurements and computed frequency responses of optical communications components, J. R. Andrews and M. Young. 35 pages (Sept. 1979). Order from NTIS as PB80-120066.

U.S. Patent 4,146,848. Frequency stabilizing system and method for beam type device, H. W. Hellwig, S. Jarvis, Jr., and D J. Wineland, 10 pages ( $M$ ar. 27, 1979 ).

U.S. Patent 4,168,441. Picosecond pulse generator utilizing a Josephson junction, D. G. McDonald and R. L. Peterson, 6 pages (Sept. 18, 1979). 
18320. Miller, C, K. S. Millimeter wave metrology capabilities at NBS, Proc. 1974 Millimeter Waves Techniques Conf., San l)icho, ( 4, Mar. 26-28, 1974, 11 pages (Naval Electronics Laboratory Center, San Diego, CA, 1974).

18345. Tippet, J. C., Chang, D. C., A new approximation for the capacitance of a rectangular-coaxial-strip transmission line, IEEE Trans. Microwale Theory Tech., pp. 6012-6014 (Sept. 1976).

18365. Tewkshury, S. K., Meyer, F. C., Rollenhagen, D. C., Schoenwetter, H. K., Souders, T. M., Terminology related to the performance of $\mathbf{S} / \mathrm{H}, \mathrm{A} / \mathrm{D}$, and $\mathrm{D} / \mathrm{A}$ circuits, IEEE Trans. Circuits Sist. CAS-25, No. 7, 419-426 (July 1978).

18398. Taggart, H. E., Shafer, J. F., Testing of electronic industries association land-mobile communication antenna gain standards at the National Bureau of Standards, IEEE Trans. Veh. Technol. VT-27, No. 4, 259-264 (Nov. 1978).

18475. Garvey, R. M., Hellwig, H. W., Jarvis, S., Jr., Wineland, D. J., Two-frequency separated oscillating fields technique for atomic and molecular beam spectroscopy, IEEE Trans. Instrum. Mcas. IM-27, No. 4, 349-354 (Dec. 1978).

18486. Kautz, R. L., Attenuation in superconducting striplines, IEEE Trans. Magn. 15, No. 1, 566-569 (Jan. I979).

18529. McAuliff, R. C., Lentner, K. J., Moore, W. J. M., Schuster, G., An international comparison of power measurements at $120 \mathrm{~V}, 5 \mathrm{~A}$, and $60 \mathrm{~Hz}, 1 E E E$ Trans. Instrum. Meas. 27, No. 4, 445-449 (Dec. 1978).

18547. Danielson, B. L., Optical fiber phase discriminator, Appl. Opt. 17, No. 22, 3665-3668 (Nov. 15, 1978).

18557. Bussey, H. E., Dielectric measurements of lunar soil, (Proc. Tenth Lunar and Planetary Science Conf., National Aeronautics and Space Administration, Lyndon B. Johnson Space Center, Houston, TX, Mar. 19-23, 1979), Abstract in Lunar and Planetary Science, Part 1, 140-142 (Lunar and Planetary Institute, Houston, TX, 1979).

18563. Ellerbruch, D. A., Jesch, R. L., Jones, R. N., Bussey, H. E., Boyne, H. S., Electromagnetic scattering properties of soils and snow, Proc. 12th Int. Symp. on Remote Sensing of Environment, Ann Arbor, M1, Apr. 20-26, 1978, 1I, 957-974 (Environmental Research Institute of Michigan, Ann Arhor, M1, 1978)

18566. Bussey, H. E., Open circuited coaxial resonator for high sensitivity dielectric measurements, application to lunar soil 70051-20, (Proc. 10th Lunar and Planetary Science Conf., National Aeronautics and Space Administration, Lyndon B. Johnson Space Center, Houston, TX, Mar. 19-23, 1979), Abstract in Linar and Planetary Science, Part 1, 169-171 (Lunar and Planetary Institute, Houston, TX, 1979).

18578. Crawford, M. L., Workman, J. L., Asymmetric versus symmetric TEM cells for EMl measurements, Proc. 1978 IEEE Int. Simp. on Electromagnetic Compatibility, Atlanta, GA. June 20-22, 1978, pp, 204-210 (The Institute of Electrical and Electronics Engineers, Piscataway, NJ, 1979).

18579. Crawford, M. L., Comparison and selection of techniques for measuring $E M$ radiated emissions and susceptibility of large equipment, (Proc. $3 \mathrm{~d}$ Symp. and Technical Exhibition on Electromagnetic Compatibility, Rotterdam, The Netherlands, May 1-3, 1979), Paper in Electromagnetic Comparibility 1979, T. Dvorak, Ed., pp. 115-122 (May 1979).

18600 . Hoer, C. A., Calibrating two six-port reflectometers with an unknown length of precision transmission line, Proc. 1978 IEEE MTT-S Int. Microwate Symp. Digest, Ottawa, Canada, June 27-29, 1978, pp. 176-178 (The Institute of Electrical and Electronics Engineers, Piscataway, NJ, 1978).

18601. Hoer, C. A., Performance of a dual six-port automatic network analyzer, Proc. IEEE MTT-S 1979 Int. Microwave Sirmp. Digest: The World of Microwaves, Orlando, FL, Apr. 30-May 2, 1979, IEEE Cat. No. 79CHI439-9 MTT-S, 3 pages (The Institute of Electrical and Electronics Engineers, Piscataway, NJ, 1979).
18624. Kahler, R. L., An electronic ratio error set for current transformer calibrations, IEEE Trans. on Instrum. Meas. Short Papers IM-28, No. 2, 162-164 (June 1979).

18628. Dougherty, H. T., Estin, A. J., Morgan, W. L., Woodruff, J. J., The orbiting standards platform, Proc. 1978 Antenna Applications Symp., Univ. of IL. Urbana-Champaign, IL, Sept. 20-22, 1978, pp. 1-9 (Sept. 1978).

18640. Andrews, J. R., Measurements on pulses and pulse transmission media, circuits and components. Time-domain measurements, Paper in Review of Radio Science 1975-1977, p. 9 (Aeronomy Laboratory, Department of Electrical Engineering, University of Illinois, Urbana, IL, 1978).

18647. Danielson, B. L., Day, G. W., Franzen, D. L., Propagation measurements in multimode optical waveguides, Proc. First Fiber Optics and Communications Exposition, Chicago, IL, Sept. 6-8, 1978, pp. 205-207 (Information Gatekeepers, Inc., Brookline, MA, 1978).

18648. Day, G. W., Measurement problems in multimode optical waveguides, Proc. 1978 Intl. Conf. on Communications. Toronto, Canada, June 4-7, 1978, 1, 6.6.1 (Institute of Electrical and Electronics Engineers, New York, NY, 1978).

18650. Engen, G. F., An overview of the six-port measurement technique, Proc. 1978 IEEE MTT-S Intl. Microwave Symp. Digest, Ottawa, Canada, June 27-29, 1978, J. Y. Wong, Ed., pp. 174-175 (Institute of Electrical and Electronics, New York, NY, 1978).

18651. Engen, G. F., Calibrating the six-port reflectometer, Proc. 1978 IEEE MTT-S Intl. Microwave Symp. Digest, Ottawa, Canada, June 27-29, 1978, J. Y. Wong, Ed., pp. $182-$ 183 (Institute of Electrical and Electronics Engineers, New York, NY, 1978).

18652. Engen, G. F., Calibrating the six-port reflectometer by means of sliding terminations, IEEE Trans. Microwave Theory Tech. MTT-26, No. 12, 951-957 (Dec. 1978).

18653. Engen, G. F., Hoer, C. A., Speciale, R. A., The application of "thru-short-delay" to the calibration of the dual sixport, Proc. 1978 IEEE MTT-S Intl. Microwave Symp. Digest, Ottawa, Canada, June 27-29, 1978, J. Y. Wong, Ed., pp. $184-$ 185 (Institute of Electrical and Electronics Engineers, New York, NY, 1978).

18670. Komarek, E. L., Advantages of the six-port reflectometer for $\mathbf{r} /$ microwave power measurement in operational systems, (Proc. Government Microcircuit Applications Conf., Monterey, CA, Nov. 14-16, 1978), I978 GOMAC Digest of Papers VII, 39-42 (Nov. 1978).

18691. Stein, S. R., Manney, C. M., Jr., Walls, F. L., Gray, J. E., Besson, R. J., A systems approach to high performance oscillators, Proc. 32d Ann. Symp. on Frequency Control, Atlantic City, NJ, May 3I-June 2, 1978, pp. 527-530 (U.S. Army Electronics Research \& Development Command, Washington, DC, 1978).

18693. Stein, S. R., Walls, F. L., Composite oscillator systems for meeting user needs for time and frequency, Proc. $10 \mathrm{th}$ Ann. Precise Time and Time Interval Applications \& Planning Meeting, Washington, DC, Nov. 28, 1978, pp. 22-28 (Naval Research Laboratory, W ashington, DC, 1978).

18694. Tippet, J. C., Chang, D. C., Characteristic impedance of a rectangular coaxial line with offset in ner conductor, IEEE Trans. Microwave Theory Tech. MTT-26, No. 11, 876-883 (Nov. 1978).

18697. Walls, F. L., Wineland, D. J., Drullinger, R. E., New possibilities for frequency standards using laser cooling and detection of stored ions, Proc: 32d Ann. Symp. on Frequency Control, Atlantic City, NJ, May 3I-June 2, 1978, pp. 453-459 (U.S. Army Electronics Research \& Development Command, Washington, DC, 1978).

18698. Wineland, D. J., Howe, D. A., Mohler, M. B., Hellwig, H. W., Special purpose ammonia frequency standard-A feasibility study, IEEE Truns. Instrum. Meas. 28, No. 2, 122 132 (June 1979). 
18699. Wineland. D. J.. Walls, F. L., Drullinger, R. E., Highresolution spectroscopy hy radiative cooling of bound resonant absorbers, (Proc. I0th Ann. Ouantum Electronics Conf.. Atlanta, GA, May 30. 1978). J. Opt. Sici. Am. 68, 648 (1978).

18814. Larsen. E. B., Techniques for producing standard EM fields from $10 \mathrm{kH} \%$ to $10 \mathrm{GH}$. for evaluating radiation monitors, Proc. 1978 Simp. on Electromagnetic Ficlds in Biological Sistems, Ottawa, Canada, June 28-30, 1978, pp. 96-112 (1979).

18818. Stubenrauch, C. F., Some recent near-field measurements at NBS, Proc. 1979 Antona Applications. Sỵmp., Urhana-Champaign, IL, S'Pt. 26-28, 1979, pp. 1-25 (Sept. 1979).

18820. Boyne, H. S., Ellerbruch, D. A., Microwave measurements of snow stratigraphy and water equivalence, Proc $47 \mathrm{th}$ Annual Western Snow Conf.. Sparks, NV, Apr. 18-20, 1979, pp. 20-26 (1979).

18849. Engen, G. F., Hoer, C. A., "Thru-load delay": An improved technique for calibrating the dual six-port, (Proc. Conf. The World of Microwaves, Orlando, FL, Apr. 30-May 2, 1979), IEEE MTT-S 1979 International Micrinave Sumposium Digest, p. 53 (Available as IEEE Cat. No. $79 \mathrm{CH} 1439$ 9 MTT-S from Institute of Electrical and Electronics Engineers, New York, NY, 1979).

18856. Kanda, M., A "TEM" horn with continuously tapered resistive loading for picosecond pulse measurements, Proc. $3 d$ Symp. \& Tech. Exhibition on Electromagnetic Compatihility, Rotterdam, The Netherlands, May 1-3, 1979, pp. 67-70 (1979).

18895. Ware, R. H., Bender, P. L., Noise reduction techniques for use in determining local geomagnetic field changes, $J$. Geomag. Geoelectr. 30, 533-537 (1978).

18908. Hellwig, H., Microwave time and frequency standards, Radio Science 14, No. 4, 561-572 (July-Aug. 1979).

19033. Bennett, W. S., Taggart, H. E., Characterization of a CISPR/VDE far-field EMI test site with ground screen, Proc. Electromagnetic Compatihility Symp., Rotterdam, The Netherlands, May 1979, pp. 507-5i 3 (1979).

19034. Kanda, M., A braodband, isotropic, real-time, electricfield sensor (BIRES) using resistively loaded dipoles for EMI measurements, Proc. I979 IEEE Int. Symp. on Electromagnetic Compatibility, San Diego, CA, Oct. 9-11, 1979, pp. 423428 (Institute of Electrical and Electronics Engineers, Inc., New York, NY, 1979).

19035. Kanda, M., The characteristics of a traveling-wave linear antenna with a nonlinear load, Proc. Symp. Int. Union of Radio Science National Radio Science Meet., Seattle, WA, June 18-22, 1979, pp. 314 (University of Washington, Seattle, WA, 1979).

\section{Electronic Technology}

SP400-14. Semiconductor measurement technology: Thermal resistance measurements on power transistors, $S$. Rubin and $F$. F. Oettinger, Nat. Bur. Stand. (U.S.), Spec. Publ. 400-14, 69 pages (Apr. 1979) SNO03-003-02050-8.

SP400-38. Semiconductor measurement technology: Progress report, October 1, 1976 to March 31, 1977, W. M. Bullis, Ed., Nat. Bur. Stund. (U.S.), Spec. Publ. 400-38, 95 pages (Nov. 1979) SNOO3-003-02139-3.

SP400-47. Semiconductor measurement technology: The theoretical and experimental study of the temperature and dopant density dependence of hole mobility, effective mass, and resistivity in boron-doped silicon, S. S. Li, Nat. Bur. Stand. (U.S.), Spec. Publ. 400-47, 50 puges (Nov. 1979) SN003003-02 140-7.

SP400-48. Semiconductor measurement technology: Spreading resistance analysis for silicon layers with nonuniform resistivity, D. H. Dickey and J. R. Ehrstein, Nat. Bur. Stand. (U.S.),
Sper: Publ. 40(1)-48, 72 pages (May 1979) SN003-003-020613.

SP400)-51. Semiconductor measurement technology: A production-compatible microelectronic test pattern for evaluating photomask misalignment, T. J. Russell and D. A. Maxwell, Nat. Bur. Stand. (U.S.), Spec. Publ. 400)-51, 32 pages (Apr. 1979) SN()03-003-(02035-4.

SP400-52. Semiconductor measurement technology: An automated photovoltaic system for the measurement of resistivity variations in high-resistivity circular silicon slices, D. L. Blackburn, Nat. Bur. Stund. (U.S.), Spece. Puhl. 400-52, 41 pages (Nov. 1979) SN(0)3-()03-02138-5.

SP4(0)-54. Semiconductor measurement technology: A reversebias safe operating area transistor tester, D. W. Berning, Nat. Bur. Siand. (U.S.), Spec. Publ. 400)-54, 43 pages (Mar. 1979) SN(0)3-00)3-02(046-0.

SP40()-55. Semiconductor measurement technology: A wafer chuck for use between -196 and $350{ }^{\circ} \mathrm{C}, \mathrm{R}$. Y. Koyama and M. G. Buehler, Nat. Bur. Stand. (U.S.), Spe'c. Puhl. 400-55, 24 pages (Jan. 1979) SN()1)3-1)03-()2017-6.

SP40)-56. Semiconductor measurement technology: Comprehensive test pattern and approach for characterizing sOS technology, W. E. Ham, Nat. Bur. Stand. (U.S.), Spec. Publ. 400-56, 370 pages ( Dec. 1979) SN003-003-02144-6.

SP400-57. Semiconductor measurement technology: DISTRIB I, an impurity redistribution computer program, D. Gilsinn and R. Kraft, Nat. Bur. Stand. (U.S.), Spec. Publ. 400-57, 130) pages (Feb. 1979) SNOO3-003-02030-3.

SP400-58. Semiconductor measurement technology: NBS/DOE workshop, stability of (thin film) solar cells and materials, D. E. Sawyer and H. A. Schafft, Eds., Nat. Bur. Stand. (U.S.), Spec. Publ. 400-58, 181 pages (Aug. 1979) SNO03-003$02100-8$.

The importance of thin film solar cell stability, D. L. Feucht, SP4OO-58, p. 12 (Aug. 1979).

Status of the DOE photovoltaic performance criteria and standards project, L. M. Magid, SP40O-58, p. 13 (Aug. 1979).

The stability and reliability of $\mathrm{CdS} / \mathrm{Cu} \mathrm{u}_{2} \mathrm{~S}$ solar cells, J. D. Meakin and J. E. Phillips, SP4O0-58, pp. 17-29 (Aug. 1979).

Stability and ternary chalcopyrite photovoltaic devices, L. L. Kazmerski, SP400-58, pp. 30-40 (Aug. 1979).

Stability of thin film polycrystalline silicon solar cells, T. L. Chu, S. S. Chu, E. D. Stokes, C. L. Lin, and R. Abderrassoul, SP400-58, pp. 41.47 (Aug. 1979).

Reliability studies on MIS and transparent oxide-Si solar cells, W. A. Anderson and J. K. Kim, SP400-58, pp. 48-56 (Aug. 1979).

Stability of conducting oxide/Si heterostructure solar cells, S. L. Frank, M. L. Andren, and R. L. Anderson, SP4OO-5\&, pp. 57-62 (Aug. 1979).

Unique problem areas in M-I-S solar cell structures, S. J. Fonash, G. Fishkorn, and T. E. Sullivan, $S P 400-58$, pp. 6368 (Aug. 1979).

Reliability testing of GaAs AMOS solar cells, R. J. Stirn, SP4OO-58, pp. 69-75 (Aug. 1979).

Stability of thin film gallium arsenide solar cells, S. S. Chu, T. L. Chu, H. T. Yang, and E. D. Stokes, SP400-58, pp. 7681 (Aug. 1979).

Stability studies of amorphous silicon solar cells, D. E. Carlson, SP400-58, pp. 82-85 (Aug. 1979).

Silicon cell space program experience, P. A. Iles, SP400-58, pp. 86-94 (Aug. 1979).

Reliability concerns and life test procedures for concentrator solar cells, W. V. McLevige, SP400-58, pp. 95-101 (Aug. 1979).

Some reliability problems in integrated circuits-Their detection, definition, and remedy, J. W. Adolphsen, SP4OO-58, pp. 102-109 (Aug. 1979). 
Tests for instabilities in silicon integrated circuits, C. W. Circen, SP4(0)-5\&, pp. 110 -125 (Aug. 1979)

Real-time controls for reliability assurance, S. Kukunaris, sps())-5\&, pp. 126-127 (Aug. 1979).

Interdiffusion and interface problems relating to thin film photovoltaic devices, L. L. Kazmerski, .\$P4()()-58, pp. 128-143 (Aug. 1979).

Corrosion and its control, R. P. Frankenthal, SP4()()-58, pp. 144-145 (Aug. 1979),

Terrestrial silicon array field and test experience, $R$. G Ross, Jr., SP4O()-58, pp. 146-149 (Aug. 1979).

Methodology for designing accelerated aging tests for predicting life of photovoltaic arrays, R. E. Thomas and G. B. Gaines, SP4()()-58, pp. 15()-159 (Aug. 1979).

SP4())-59. Semiconductor measurement technology: Nondestructive tests used to insure the integrity of semiconductor devices, with emphasis on acoustic emission techniques, G. G. Harman, Nat. Bur. Stand. (U.S.), Spec. Publ. 40()-59, 72 pages (Sept. 1979) SN003-003-02 $116-4$.

TNI102. Large scale integration digital testing-Annotated biblingraphy, 1969-1978, T. F. Leedy, Nat. Bur. Stand. (U.S.), Tech. Note 1102, 44 pages (Aug. 1979) SN003-003()2097-4.

NBSIR 78-1444-3. Semiconductor technology program-Progress brief́s, W. M. Bullis, Ed., 16 pages (Oct. 1978). Order from NTIS as PB292681.

NBSIR 78-1558. Development of hydrogen and hydroxyl contamination in thin silicon dioxide thermal films, S. Mayo and W. H. Evans, 39 pages (Mar. 1979). Order from NTIS as PB293556.

NBSIR 78-1564. Tabulation of published data on electron devices of the U.S.S.R. Through December 1976, C. P. Marsden, 137 pages (Dec. 1978). Order from NTIS as PB291959.

NBSIR 78-1590 (NASA). Loose-particle detection in microelectronic devices, J. S. Hilten, P. S. Lederer, J. F. Mayo-Wells, and C. F. Vezzetti, 73 pages (Jan. 1979). Order from NTIS as PB290679.

NBSIR 79-1591. Semiconductor technology program-Progress briefs, W. M. Bullis, Ed., 12 pages (Jan. 1979). Order from NTIS as PB294846.

NBSIR 79-1591-2. Semiconductor technology program-Progress briefs, W. M. Bullis, Ed., 12 pages (Mar. 1979). Order from NTIS as PB298063.

NBSIR 79-1591-3. Semiconductor technology program-Progress briefs, W. M. Bullis, Ed., 12 pages (June 1979). Order from NTIS as PB298064.

NBSIR 79-1595. CMOS/SOS test patterns for process evaluation and control: Annual report, March 1 to November 1, 1978, L. W. Linholm, 53 pages (Jan. 1979). Order from NTIS as PB293487.

NBSIR 79-1723. Standard procedure for use of thermoluminescence dosimetry in radiation-hardness testing of electronic devices, J. C. Humphreys and S. E. Chappell, 74 pages (Mar. 1979). Order from NTIS as PB297518.

NBSIR 79-1744. The development of test structures for characterization of the fabrication and performance of radiationhardened CCD imagers, G. P. Carver and M. G. Buehler, 54 pages (May 1979). Order from NTIS as PB296167

NBSIR 79-1748. Detection of phosphorus in epitaxial silicon by. EPR, T. T. Chang, 16 pages (May 1979). Order from NTIS as $P B 296166$

NBSIR 79-1756. Measurement techniques for high power semiconductor materials and devices: Annual report, October 1, 1977 to September 30, 1978, F. F. Oettinger, Ed., 144 pages (June 1979). Order from NTIS as PB298574.

NBSIR 79-1909. Measurement techniques for solar cells, Quarterly Report: Aprill 1 to June 30, 1978, D. E. Sawyer, H. K. Kessler, and H. A. Schafft, 27 pages (Oct. 1979). Order from NTIS as PB301309.
NBS-GCR-78-134. Development of measurement techniques for monitoring chemical purity of materials used in digital IC processing, J. Stach, M. B. Das, and R. E. Tressler, 88 pages (Sept. 1978). Order from NTIS as PB291427.

NBS-GCR-78-155. Extended range MIS C(V) measurement: A technique for monitoring semiconductor device processing, $A$. M. Goodman, 18 pages (Jan. 1979). Order from NTIS as PB291011.

NBS-GCR-79-158. Techniques for the preparation and analysis of standard silicon semiconductor specimens for the ion microprobe mass analyzer, G. Larrabee and R. Dobrott, 62 pages (Jan. 1979). Order from NTIS as PB292806.

NBS-GCR-79-170. Investigation of moisture measurements, failure rate and leak rate and a study of moisture infusion, $R$. L. Sulouff, 57 pages (Aug. 1979). Order from NTIS as PB299172.

NBS-GCR-ETIP 78-49. The influence of defense procurement and sponsorship of research and development on the development of the civilian electronics ind ustry, J. M. Utterhack and A. E. Murray, 56 pages (Jan. 1979). Order from NTIS as PB290164.

18322. Sawyer, D. E., Solar cell measurement technique development and other services, Proc. Photovoltaics Program Semi-Annual Review Advanced Materials R\&D Branch, Golden, CO, Oct. 4-6, 1977, pp. $708-713$ (Available as Dept. of Energy CONF-77105I from National Technical Information Service, Springfield, VA 22161, 1978).

18356. Nyyssonen, D., Optical linewidth measurements on wafers, SPIE Semin. Proc. 135, $115-119$ (1978).

18451. Galloway, K. F., VLSI processing, radiation, and hardening, IEEE Trans. Nucl. Sci. NS-25, No. 6, 1469-1472 (Dec. 1978).

18458. Koyama, R. Y., Phillips, W. E., Myers, D. R., Liu, Y. M., Dietrich, H. B., The energy levels and the defect signature of sulfur-implanted silicon by thermally stimulated measureuments, Solid-State Electron. 21, No. 7, 953-955 (July 1978).

18460. Blackburn, D. L., Larrabee, R. D., Automated photovoltaic technique for nondestructively measuring resistivity variations of high resistivity silicon slices, (Proc. Topical Conf. on Characterization Techniques for Semiconductor Materials and Devices, Seattle, WA, May 21-26, 1978), Chapter in Electrochemical Sociery, P. A. Barnes and G. A. Rozgonyi, Eds., 78-3, 168-179 (Electrochemical Society, Princeton, NJ, 1978 ).

18463. Buehler, M. G., Microelectronic test patterns for use in procuring LSICs, Proc. Industry/Joint Services Automatic Test Conf. and Workshop on Advanced Test Technology Management Acquisition Support, San Diego, CA, Apr. 5, 1978, pp. 233-235 (American Electronics Association, Palo Alto, CA, Apr. 1978).

18533. Russell, T. J., Maxwell, D. B., Reimann, C. T., Buehler, M. G., A microelectronic test pattern for measuring uniformity of an integrated circuit fabrication technology, (Proc. Government Microcircuit Application Conf., Monterey, CA, Nov. 1978), Solid State Tech. 22, No. 2, pp. 71-74 (Feb. 1979).

18623. Myers, D. R., Roitman, P., Mayo, S., Electrical characterization of low-dose ion-implanted silicon annealed with microsecond laser pulses, (AIP Conf. Proc. No. 50, Materials Research Society, Boston, MA, Nov. 27-Dec. 1, 1978, Series Editor: H. C. Wolfe), Paper in Laser-Solid Interactions and Laser Processing-1978, S. D. Ferris, H. J. Leamy, J. M. Poate, Eds., pp. 563-568 (American Institute of Physics, New York, NY, 1979).

18629. Nyyssonen, D., Jerke, J. M., Optical linewidth measurement-A basic understanding, Proc. Microelectronics Measurement Teclinology Seminar, San Jose, CA, Feh. 6-7, 1979, pp. 251-266 (1979). 
18633. Sawyer, D. E., Kessler, H. K., Schafft, H. A., Solar cell measurement technique development and other services, Proc. Plotonoltaics Advanced Materials Review Meeting, Vail, CO, (). 24-26, 1978, pp. 41-50 ( Jan. 1979).

18634. Schafft, H. A., Performance criteria for photovoltaic power conditioning, control, and storage, Proc: U.S. DOE Ploseswoltaics Teclinology Development and Applications Program Review Conf. Arlingus, VA, Nov. 7-9, 1978, pp. 2$39-2-51$ ( 1978$)$

18738. Blackburn, D. L., Berning. D. W., Some effects of base current on transistor switching and reverse-bias second breakdown, (Proc. Intl. Electron Devices Meeting, Washington, DC, Dec. 4-6, 1978), Tec/lnical Digest 1978, pp. 671-675 (Institute of Electrical and Electronics Engineers, New York, NY, 1978)

18757. Buehler, M. G., Limitations and applications of the dc MOSFET dopant profile method, (Proc. Topical Conf. on Characterization Techniques for Semiconductor Materials and Devices, Seattle, WA, May 1978), Paper in Semiconducur Claracterization Techniques, P. A. Barnes, G. A. Rozgonyi, Eds., 78-3, 241-252 (The Electrochemical Society, Inc., Princeton, NJ, 1978).

\section{Energy Conservation and Production}

SP542. Possible contributions of cement and concrete technology to energy conservation, G. Frohnsdorff, P. W. Brown, and J. R. Clifton, Nat. Bur. Stand. (U.S.), Spec. Publ. 542, 76 pages (May 1979) SN003-003-02059-1.

SP548. Summer attic and whole-house ventilation. Proceedings of a Workshop held at the National Bureau of Standards, Gaithershurg, MD, July 13, 1978, M. H. Reppert, Ed., Nat. Bur. Stund. (U.S.), Spec. Publ. 548, 153 pages (July 1979) SN003-003-02089-3.

Solar reflectivity of common roofing materials and its influence on the roof heat gain of typical southwestern residences, J. A. Reagan and D. M. Acklam, SP548, Pp. 1-13 (July 1979).

Measurement of attic temperatures in Florida, T. I. Wetherington, Jr., SP548, pp. 15-24 (July 1979).

Forced ventilation for cooling attics in summer, G. S. Dutt and D. T. Harrje, SP548, Pp. 25-38 (July 1979).

Effect of powered attic ventilation on ceiling heat transfer and cooling load in two townhouses, R. A. Grot and C. I. Siu, SP548, pp. 39-56 (July 1979).

Attic ventilation research conducted by Arkansas Power and Light Company, F. B. Clark, SP548, pp. 57-72 (July 1979).

Ventilating residences and their attics for energy conservation-An experimental study, D. M. Burch and S. J. Treado, SP548, pp. 73-104 (July 1979).

Analysis of attic ventilation test, D. Brewster and T. Arkfeld, SP548, pp. 105-117 (July 1979).

A model for predicting the thermal performance of ventilated attic-ceiling-roof combinations, B. A. Peavy, SP548, pp. 119-149 (July 1979).

BSS 1 17. Experimental verification of a standard test procedure for solar collectors, J. E. Hill, J. P. Jenkins, and D. E. Jones, Nat. Bur. Stand. (U.S.), Bldg. Sci. Ser. 117,126 pages (Jan. 1979) SN003-003-02008-7.

TN992. An investigation of air-infiltration characteristics and mechanisms for a townhouse, S. J. Treado, D. M. Burch, and C. M. Hunt, Nat. Bur. Stund. (U.S.), Tech. Note 992, 36 pages (Aug. 1979) SN003-003-02090-7.

TN999. A study of the dynamic flue-gas temperature and offperiod mass flow rate of a residential gas-fired furnace, $C$. Park, W. J. Mulroy, and G. E. Kelly, Nat. Bur. Siand. (U.S.), Tech. Note 999, 41 pages (July 1979) SN003-003-02092-3.

TN1107. The use of aerial infrared thermography to compare the thermal resistances of roofs, D. M. Burch, Nat. Bur.
Stand. (U.S.), Tech. Note 1107, 38 pages (Aug. 1979) SN003-003-02102-4.

NBSIR 78-887. Development and evaluation of an LNG sampling measurement system, W. R. Parrish, J. M. Arvidson, and J. F. LaBrecque, 200 pages (July 1978). Order from NTIS as PB289938.

NBSIR 78-1494. Test procedures for the determination of the gross calorific value of refuse and refuse-derived-fuels by oxygen bomb calorimetry. Summary of the 1977 fiscal year results, D. R. Kirklin, D. J. Mitchell, J. Cohen, E. S. Domalski, and S. Abramowitz, 35 pages (Dec. 1978). Order from NTIS as PB290160.

NBSIR 78-1496. Preliminary data on the field performance of storage-type residential water heaters, R. A. Grot and L. S. Galowin, 27 pages (Apr. 1979). Order from NTIS as PB295431.

NBSIR 78-1501. Quantified occupant-use factors affecting energy consumption in residences, $R$. E. Clark and S. R. Hastings, 143 pages (July 1979). Order from NTIS as PB298052.

NBSIR 78-1509. An algorithm and basic computer program for calculating simple coal gasification equilibria, W. S. Horton, 83 pages (Aug. 1978;. Order from NTIS as PB291241.

NBSIR 78-1556. Kitchen range energy consumption, J. V. Fechter and L. G. Porter, 68 pages (Mar. 1979). Order from NTIS as PB294880.

NBSIR 79-1609. Materials studies for magnetic fusion energy applications at low temperatures-II, F. R. Fickett and R. P. Reed, Eds., 495 pages (June 1979). Order from NTIS as PB299288.

NBSIR 79-1618. Helium research in support of superconducting power transmission, D. E. Daney, 61 pages (Oct. 1979). Order from NTIS as PB80-116502,

NBSIR 79-1705. State solar energy legislation of 1977: A review of statutes relating to buildings, R. M. Eisenhard and L. A. Santucci, 396 pages (Feb. 1979). Order from NTIS as PB295642.

NBSIR 79-1709. Description of the data acquisition and instrumentation systems: Jersey City total energy project, C. Bulik, W. G. Rippey, C. W. Hurley, and D. E. Rorrer, 160 pages (Mar. 1979). Order from NTIS as PB294926.

NBSIR 79-1728. A low-cost method for measuring air infiltration rates in a large sample of dwellings, R. A. Grot, 14 pages (Apr. 1979). Order from NTIS as PB295444.

NBSIR 79-1732. Computer analysis of energy requirements in single-family residences: $A$ limited case study of the effects of envelope design, W. L. Carroll and J. P. Barnett, 31 pages (July 1979). Order from NTIS as PB299448.

NBSIR 79-1737. Testing of pebble-bed and phase-change thermal energy storage devices according to ASHRAE Standard 94-77, D. E. Jones and J. E. Hill, 48 pages (May 1979). Order from NTIS as PB295898.

NBSIR 79-1743. Standards for photovoltaic energy conversion systems, H. A. Schafft, 18 pages (May 1979). Order from NTIS as PB296274.

NBSIR 79-1751. Custody transfer systems for LNG ships: Tank survey techniques and sounding tables, R. H. F. Jackson, R. S. Collier, S. Haber, and P. V. Tryon, 85 pages (May 1979). Order from NTIS as PB295941.

NBSIR 79-1757. Data reduction processes for the Jersey City total energy project, D. E. Rorrer, W. G. Rippey, and Y. L. Chang, 117 pages (May 1979). Order from NTIS as PB296482.

NBSIR 79-1762. Residential solar data center-Data resources and reports, P. M. Christopher and J. E. Krzewick, 68 pages (June 1979). Ordẹr from NT1S as PB297582.

NBSIR 79-1770. The potential for energy savings with water conservation devices, R. L. Palla, J'r., 32 pages (Sept. 1979). Order from NTIS as PB80-127202. 
NBSIR 79-1771. An investigation of preferences for various types ofi energy cast feedhack, A. Ramey-Smith and J. L. Gaignon, 72 pages (Aug. 1979). Order from NTIS as PB300314.

NBSIR 79-1778. A perspective of a workshop on stability of (thin filom) Sollar cells and materials, H. A. Schafft and D. E. Sawyer, 16 pages (July 1979). Order from NTIS as PB297396.

NBSIR 79-1781. Field performance of residential refrigerators and combination refrigerator-freezers, Y. M. L. Chang and R. A. Grot, 46 pages (July 1979). Order from NTIS as PB299058

NBSIR 79-1799. Performance of a packaged solar space-heating system used with a mobile horne, D. E. Jones and J. E. Hill, 44 pages (Sept. 1979). Order from NTIS as PB300890.

NBSIR 79-1917. Solar energy systemas-Standards for rubber hose, R. D. Stiehler and J. L. Michalak, 36 pages (Nov. 1979). Order from NTIS as PB80-129828,

NBSIR 79-1923. Residential solar data center grant reports, $P$. M. Christopher and M. J. Aronoff, 74 pages (Oct. 1979). Order from NTIS as PB80-119928.

NBS-GCR-78-141-1. Solar building regulatory study. Volume I, J. Greenberg, 93 pages (Nov. 1978). Order from NTIS as PB289823.

NBS-GCR-78-141-2. Solar building regulatory stady. Volume II, J. Greenberg, 385 pages (Nov. 1978). Order from NTIS as PB289824.

NBS-GCR-79-181. Snow and ice accumulation at solar collector installations in the Chicago metropolitan area, R. B. Corotis, C. H. Dowding, and E. C. Rossow, 109 pages (Oct. 1979). Order from NTIS as PB80-1 \3749.

18336. Kusuda, T., Use of simulation models of buildings in assessing energy conservation strategies, Proc. Symp. Energy Conservation Sirategies in Buildings: Comfort, Acceptability, and Health, New Haven, CT, Jan. 25, 1978, J. A. J. Stolwijk, Ed., pp. 143-156 (J. B. Pierce Foundation Laboratories, Hartford, CT, 1978).

18339. Peavy, B. A., A note on response factors and conduction transfer functions, (Proc. Symp. American Society of Heating and Air-Conditioning Engineers Annual Meeting, Atlanta, GA, Jan. 29-Feb. 2, 1978), ASHRAE Trans. 84, Pt. 1, 688$690(1978)$.

18363. Holton, J. K., Interfacing building design and solar energy research and standards, Proc. Joint Conf. 1976 of the American Section of the Int. Solar Energy Society and the Solar Energy Society of Canada, Winnipeg, Canada, Aug. 15 20, 1978, pp. 74-82 (American Section of the Int. Solar Energy Society, Cape Canaveral, FL, 1978).

18385. Chi, J., Kelly, G. E., A method for estimating the seasonal performance of residential gas and oil-fired heating systems, ASHRAE Trans. 84, Part 1, 405-420 (1978).

18394. Hord, J., Hydrogen safety: An annotated bibliography of regulations, standards and guidelines, Proc. World Hydrogen Energy Conf., Zurich, Switzerland, Aug. 21-24, 1978, T. N. Veziroglu and W. Seifritz, Eds., pp. 2247-2248 (Pergamon Press Inc., Elmsford, NY, 1978).

18395. Parrish, W. R., Arvidson, J. M., LaBrecque, J. F., Evaluation of LNG samplimg-measurement systems for custody transfer, Proc. American Gas Association Operating Section Transmission Conf., Montreal, Quebec, Canada, May 8-10, 1978 and Distribution Conf., Denver, CO, May 22-24, 1978, pp. T-236-T-242 (American Gas Association, Arlington, VA, 1978).

18396. Parrish, W. R., Brennan, J. A., Siegwarth, J. D., LNG custody transfer research at National Bureau of Standards, Proc. American Gas Association Operating Section Transmission Conf., Monireal, Quehec, Canada, May 8-10, 1978 and Distribution Conf., Denver, CO, May 22-24, 1978, pp. T243-T-249 (American Gas Association, Arlington, VA, 1978).
18425. Hunt, B. J., Richtmyer, T. E., Hill, J. E., Franklin, E. A., Testing of water tanks for thermal storage according to ASHRAE Standard 94.77, A.SHRAE Trans. 85, Part 1, PH79-5, No. 1, 20 pages (1979).

18428. Liu, S. T., Hill, J. E., A proposed technique for correlating the performance of solar domestic water heating systems, ASHRAE Trans. 85, Part 1, No. 2516, 13 pages (1979).

18501. Richmond, J. C., Evaluation of solar absorbers, reflectors and transmitters-Physical reflectance standards, Proc. 1979 Conf. of the 25th Annual Tech. Meeting Learning to Use Our Environment, Seattle, WA, Apr. 30-May 2, 1979, pp. 26 (Institute of Environmental Sciences, Mt. Prospect, IL, 1979).

18703. Didion, D. A., Kelly, G. E., New testing and rating procedures for seasonal performance of heat pumps, ASHRAE J., pp. 40-44 (Sept. 1979).

18733. Harrje, D. T., Grot, R. A., Instrumentation for monitoring energy usage in buildings at twin rivers, Paper in Energy and Buildings, 1, 293-299 (Elsevier Sequoia S. A., Lausanne-The Netherlands, 1977/1978).

18770. Jenkins, J. P., Hill, J. E., Testing of water-heating collectors according to ASHRAE Standard 93-77, (Proc. Int. Solar Energy Society 1978 Meeting, New Delhi, India, Jan. 16-21, 1978), Paper in SUN: Mankind's Future Source of Energy, F. deWinter, M. Cox, Eds., 2, 1021-1028 (Pergamon Press, New York, NY, 1978).

18778. Didion, D. A., New testing and rating procedures for seasonal performance of heat pumps, Proc. Carrier Int. Symp. on Heat Pumps and Space Conditioning in the 1990's, Syracuse, NY, Feb. 2-3, 1979, pp. 37-47 (Carrier Corp., Syracuse, NY, Sept. 1979).

18784. Stahl, F. 1., Conway, D., Goglia, M. R., Human behavioral considerations in the planning and design of passive solar systems for commercial facilities: An exploratory study of the effects of sun and shade, Proc. 4th National Passive Solar Conference, Kansas City, MO, Oct. 3-5, 1979, pp. 26-29 (Oct. 1979).

18812. Hord, J., Parrish, W. R., Economics of hydrogen, Chapter 1 in Hydrogen: Its Technology and Implications, $\mathrm{K}$. E. Cox, K. D. Williamson, Jr., Eds., 5, 3-48 (CRC Press, Boca Raton, FL, 1979).

18829. Grot, R. A., Field performance of gas and electric water heaters, Proc. Major Home Appliance Technology for Energy Conservation, West Lafayette, IN, Feb. 27-Mar. 1, 1978, pp. $110-120$ (Available as CONF-780238 from the National Technical Information Service, Springfield, VA 22161 , 1978).

18836. Howard, C. P., Utensil interface for electric ranges, Proc. Major Home Appliance Teclinology for Energy Conservation. West Lafayette, IN, Feb. 27-Mar. I, 1978, pp. 9-10 (Available as CONF-780238 from the National Technical lnformation Service, Springfield, VA 22161, 1978).

18837. Howard, C. P., Instrumentation opportunities in appliance energy conservation, Proc. Major Home Appliance Technology for Energy Conservation, West Lafayette, IN, Feb. 27-Mar. 1, 1978, pp. 196-197 (Available as CONF-780238 from the National Technical Information Service, Springfield, VA 22161,1978 ).

18863. Hastings, S. R., Daylighting-Conflicts and synergies of architectural solutions, Proc. 1979 Topical Solar Glazing Conf., Pomona, NJ, June 22-23, 1979, pp. F-21 - F-24 (June 1979).

18888. Marshall, H. E., Petersen, S. R., Economics and the selection and development of energy sta ndards for buildings, Energy and Buildings 2, 89-99 (1979).

18894. Hastings, S. R., Passive solar design for urban commercial environments, (Proc. 4th Nat. Passive Solar Conf., Kansas City, MO, Oct. 3-5, 1979), Paper in Proceedings of the 4th National Passive Solar Conference, G. Franta, Ed., 4, Sec- 
tion 3. 303-306 (American Section of the International Solar Energy Society, Inc., Newark, DE, 1979).

18964. Powell, J. W., Economic evaluation of passive solar designs for urban environments, Proc. 4 th Nat. Passive Soltsr Conf.. Kansas City, MO, Oct. 3-5, 1979, pp. 1-5 (American Section of the International Solar Energy Society. Newark, DE, 1979).

18986. Jenkins, J. P., Hill, J. E., A comparison of test results for flat-plate water-heating solar collectors using the BSE and ASHRAE procedures, Proc: ASME Winter Ann. Meeting, New York, NY, Dec: 2-7, 1979, 79-WA/Sol-4, pp. 1-13 (American Society of Mechanical Engineers, New York, NY, 1979).

19003. Kusuda, T., Bean, J. W., Comparison between a simplified daylighting calculation procedure and a comprehensive interreflection model calculation procedure, (Proc. Third int. Symp. Use of Computers for Environmental Engineering $\mathrm{Re}$ lated to Buildings, Alberta, Canada, May 10-12, 1978), CNRC Publ. I7376, pp. 569-578 (National Research Council of Canada, Ottawa K1 A OR6, Canada, 1978).

19018. Krause, R. F., Jr., Fuller, E. R., Jr., Compressive, tensile, pipe-bonding strengths, and permeability of selected cementing-materials for hot-dry-rock wells, Progress Report No. 10. Cementing of Gesthermal Wells, July-Sept. I978, BNL 50943 UC-66c (Geothermal Energy, Drilling Tec/tnols)gy-TID-4500), pp. 139-147 (Brookhaven National Laboratory, Upton, NY, 1978 ).

19043. Marshall, H. E., Ruegg, R. T., Life-cycle costing guide for energy conservation in buildings, Chapter 9 in Energy Conservation Through Building Design, pp. 162-181 (McGraw Hill Book Co., New York, NY, 1979).

19044. Weber, S. F., Cost effectiveness of energy conservation investments in new United States residences, Proc. Second Int. CIB Symp. on Energy Conservation in the Built Environment, Copenhagen, Denmark, May 28-June 1, 1979, pp. 1-10 (May 1979).

\section{Engineering, Product and Information Standards}

H44, 1979 Edition. Specifications, tolerances, and other technical requirements for weighing and measuring devices, $H$. F. Wollin, Ed., Nat. Bur. Stand. (U.S.), Handb. 44, 1979 Edition, 213 pages' (Dec. 1979) SN003-003-021 43-1.

H105-3. Specifications and tolerances for reference standards and field standard weights and measures. 3. Specifications and tolerances for graduated neck type volumetric field standards, B. C. Keysar, Nat. Bur. Stand. (U.S.), Handb. I05-3 Revised, 23 pages (Mar. 1979) SN003-003-02044-3.

HI07, Revised. American National Standard N43.1; Radiological safety in the design and operation of particle accelerators. (ANSI N43.I-1978), E. H. Eisenhower, Chairman, ANSl Subcommittee N43, Nat. Bur. Stand. (U.S.), Handb. 107 Revised, 24 pages (May 1979) SN003-003-02064-8.

H129. American National Standard N538; Classification of industrial ionizing radiation gauging devices. (ANSI N5381979), E. H. Eisenhower, ANSI Subcommittee N43-3.2, Nat. Bur. Stand. (U.S.), Mandb. I29, 29 pages (Oct. 1979) SN003-003-02 135-1..

SP500-51. Computer science \& technology: Recommendations for database management system standards, J. Berg, Chairman, Nat. Bur. Stand. (U.S.) Spec. Publ. 500-5I, 99 pages (Aug. 1979) SN003-003-02095-8.

SP532. Report of the 63d National Conference on Weights and Measures 1978, H. F. Wollin, L. E. Barbrow, and A. P. Heffernan, Nat. Bur. Stand. (U.S.), Spec. Publ. 532, 323 pages (Feb. 1979) SN003-003-02045-1.

Electromagnetic interference-A problem of growing concern, C. K. S. Miller, SP532, pp. 1-12 (Feb. 1979).

A practical approach to the EMI-RF1 problem in the field, F. L. Platt, SP532, pp. 13-16 (Feb. 1979).
Laboratory metrology-lts goals and needs, R. C. Egnew, SP532, pp. $17-19$ (Feb. 1979).

National Food Processors Association solid content weight labeling program, A. W. Matthys, SP532, pp. 20-23 (Feb. (979).

An industry perspective on packaging regulations, R. W Miller, SP532, pp. 24-28 (Feb. 1979).

Measurements in the United Kingdon market place, F. L. N. Samuels, SP532, pp. 29-41 (Feb. 1979).

Food labeling-The next step, E. Williams, SP532, pp. 42. 47 (Feb. 1979).

Measurement assurance-The future of legal metrology, A. O. McCoubrey, SP532, pp. 48-54 (Feb. 1979).

Experience in program evaluation, D. Guensler, SP532, pp. 55-58 (Feb. 1979).

Cost-benefit performance auditing $-A$ tool for weights and measures program improvement, C. H. Vincent, SP532, pp. 59-60 (Feb. 1979).

Cost-benefit performance auditing-A tool for weights and measures program improvement, $R$. Lockridge, SP532, pp. 61-65 (Feb. 1979).

Application of quantity of contents requirements to packaged seafoods, 1. D. Sackett, Jr., SP532, pp. 66-7I (Feb. 1979).

Pressure measurement-A new activity for weights and measures, C. R. Tilford, SP532, pp. 72-77 (Feb. 1979).

Net weight assurance-A responsibility for both government and industry, S. J. Butler, SP532, pp. 118-124 (Feb. 1979).

FIPS PUB 58. Representations of local time of the day for information interchange, $H$. McEwen, Standards Coordinator, Nat. Bur. Stand. (U.S.), Fed. Info. Process. Sland. Publ. (FIPS $P U B$ ) 58,4 pages (Feb. 1979)

FIPS PUB 59. Representations of universal time, local time differentials, and United States time zone references for information interchange, H. McEwen, Standards Coordinator, Nat. Bur. Stand. (U.S.), Fed. Info. Process. Stand. Publ. (FIPS $P U_{B}$ ) 59, 4 pages (Feb. 1979).

FIPS PUB 65. Guideline for automatic data processing risk analysis, S. K. Reed, Standards Coordinator, Nat. Bur. Stand. (U.S.), Fed. Info. Process. Stand. Publ. (FIPS PUB) 65, 27 pages (Aug. 1979).

FiPS PUB 66. Standard Industrial Classification (S1C) codes, $\mathbf{H}$. McEwen, Standards Coordinator, Nat. Bur. Stand. (U.S.), Fed. Info. Process. Stand. Publ. (FIPS PUB) 66, 23 pages (Aug. 1979).

NBSIR 79-1900. Bibliography on the voluntary standards system and product certification, C. Chapman, 28 pages (Oct. 1979). Order from NTIS as PB80-117922.

NBS-GCR-79-172. Standards systems in Canada, the UK, West Germany, and Denmark: An overview, D. Hemenway, 195 pages (Apr. 1979). Order from NTIS as PB296912.

18440. Natrella, M. G.; Statistics in specifications, ASTM Stand. News 7, No. 1, 10-11, 40 (Jan. 1979).

18779. Eisenhower, E. H., Report of the National Bureau of Standards' survey of state measurement needs, (Proc. 9th Ann. Nat. Conf. on Radiation Control-Meeting Today's Challenges, Seattle, WA, June 19-23, 1977), HEW Publicalion ( $F D A$ ) 78-8054, pp. $117-126$ (U.S. Department of Health, Education, and Welfare, Public Health Service, Food and Drug Administration. Bureau of Radiological Health, Rockville, MD, Apr. 1978).

\section{Environmental Studies: Pollution Measurement}

SP556. Measurements and standards for recycled oil-11. Proceedings of a Conference held at the National Bureau of Standards, Gaithersburg, MD, Nov. 29-30, 1977, D. A. Becker and H. A. Hurd, Eds., Nat. Bur. Stand. (U.S.), Spec. Publ. 556, 212 pages (Sept. 1979) SN003-003-02I08-3. 
Conference ubjectives and the NBS recycled oil program, D. Becker, SP556, pp. 5-8 (Sept. 1979).

The current status of the re-refining industry, D. Ekedahl, SP556, pp. 9-13 (Sept. 1979).

A limited integrated assessment of the waste oil re-refining industry, S. Liroff, SP556, pp. 15-20 (Sept. 1979).

A survey of metals in oil: Occurrence and significance for reuse of spent automotive lubricating oils, T. Coyle and $A$. Siedle, SP556, p. 23 (Sept. 1979).

Speciation of metals in used oils: Recent progress and environmental implications of molecular lead compounds in used crankcase oils, F. Brinckman and W. Blair, ,SP556, pp. 25-38 (Sept. 1979).

The analysis of some residual fuel and waste lubricating oils by a high-performance liquid chromatographic procedure, $W$. May and J. Brown, SP556, pp. 39-44 (Sept. 1979).

Current EPA views on ambient air lead standards, J. Cooper, SP556, p. 47 (Sept. 1979).

An updated look at the fuel potential of waste automotive oil, P. Spawn and P. Fennelly, SP556, pp. 49-55 (Sept. 1979).

The burning of used oil as a fuel in cement manufacture, J. Armstrong and L. MacDonald, SP556, pp. 57-64 (Sept. 1979).

Industrial oils used as fuel, J. Swain, Jr., SP556, pp. 65-70 (Sept. 1979)

Runoff of oils from rural roads treated to suppress dust, $F$. Freestone, SP556, pp. 71-86 (Sept. 1979).

Test procedures for recycled oil used as burner fuel, J. Comeford, SP556, pp. 87-92 (Sept. 1979).

Recent Federal and State legislative developments in used oil recycling, W. Irwin and K. Heimann, SP556, pp. 95-100 (Sept. 1979).

EPA activities in waste oil management, $H$. Kaufman, SP556, pp. 101-104 (Sept. 1979).

The role of the FTC in recycled oil labeling, C. Aldhizer, SP556, pp. 105-106 (Sept. 1979).

Used oil recycling program issues: The Department of Energy, D. Ellerbe, SP556, pp. 107-108 (Sept. 1979).

Utilization of used oil: Energy conservation aspects, G. Mascetti, SP556, pp. 109-113 (Sept. 1979).

The EPA/DOD investigation of re-refined engine oil, $T$. Bowen, SP556, pp. 117-122 (Sept. 1979).

lowa re-refined oil fleet test, D. Ulrichson and D. Yake, SP556, pp. 123-132 (Sept. 1979).

Phillips recycled oil program, R. Linnard, SP556, pp: 133137 (Sept. 1979).

The system of used oil regulation in the Federal Republic of Germany, F. Irouschek, SP556, pp. 139-140 (Sept. 1979).

Testing and use of re-refined engine oils in Europe, D. Becker, SP556, pp. 141-144 (Sept. 1979).

Waste oil recycling utilizing solvent pretreatment, $C$. Thompson and W. Whisman, SP556, pp. 147-151 (Sept. 1979).

APl activities in used oil, B. Hutchings, SP556, pp. 153-155 (Sept. 1979).

Voluntary test method and specification standards (ASTM) for petroleum products from waste (used) oil, P. Strigner, SP556, pp. 157-158 (Sept. 1979).

Establishing substantial equivalency for motor oils, J. Comeford, SP556, pp. 161-163 (Sept. 1979).

Activities of the SAE Fuel and Lubricants Technical Committee, C. Schwarz, SP556, pp. 165-166 (Sept. 1979).

Some views on substantial equivalency, J. Creedon, SP556, pp. 167-170 (Sept. 1979).

Field experiences with re-refined motor oils, R. Pedall, SP556, pp. 171-173 (Sept. 1979).

An approach to qualification of re-refined engine oil under military specifications, T. Bowen, SP556, pp. 175-177 (Sept. 1979).
Performance testing is the key to engine oil quality, D. Stehouwer, SP556, pp. 179-182 (Sept. 1979).

Re-refined oil in our future, R. Bjorndal, SP556, pp. 183184 (Sept. 1979).

SP557. Chemical kinetic data needs for modeling the lower troposphere. Proceedings of a Workshop held at Reston, VA, May 15-17, 1978, J. T. Herron, R. E. Huie, and J. A. Hodgeson, Eds., Nat. Bur. Stand. (U.S.), Spec. Publ. 557, 105 pages (Aug. 1979) SNO03-003-02111-3.

An evaluation of chemical kinetic data needs for modeling the lower troposphere: Reactions of olefins with hydroxyl radical and with ozone, H. Niki, SP557, pp. 7-14 (Aug. 1979).

Tropospheric chemistry of aldehydes, A. C. Lloyd, SP557, pp. 27-46 (Aug. 1979).

Organic free radicals, D. M. Golden, SP557, pp. 51-61 (Aug. 1979).

Tropospheric chemistry of nitrogen oxides-A summary of the status of chemical kinetic data, R. A. Cox, SP557, pp. $71-79$ (Aug. 1979).

Reactions of aromatic compounds in the atmosphere, D. G. Hendry, SP557, pp. 85-91 (Aug. 1979).

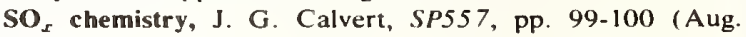
1979).

18342. Carpenter, B. S., Mapping and detecting elements selectively by the Nuclear Trace Technique, Proc. Int. Conf. on Nuclear Methods in Environmental and Energy Research, Columbia, MO, Oct. 10-13, 1977, pp. 136-143 (Available as Department of Energy CONF-771072 from National Technical Information Service, Springfield, VA 22161, 1978).

18343. Gills, T. E., Gallorini, M., Greenberg, R. R., The determination of selected toxic elements in biological matrices using radiochemical activation analysis, Proc. $3 d \operatorname{lnt}$. Conf. on Nuclear Methods in Environmental and Energy Research, Columbia, MO, Oct. 10-13, 1977, pp. 597-609 (Available as Department of Energy CONF.771072 from National Technical Information Service, Springfield, VA 22161, 1978).

18349. Becker, D. A., Environmental sample banking-research and methodology, Proc. Symp. on Trace Substances in Environmental Health-X, Columbia, MO, June 8-10, 1976, D. D. Hemphill, Ed., pp. 353-359 (University of Missouri, Columbia, MO, 1976).

18400. Coursey, B. M., Hutchinson, J. M. R., Lucas, L. L., Mann, W. B., Matsumura, T., Noyce, J. R., Radioactivity standards for environmental monitoring, J. Radioanal. Chem. 43, $451-460$ ( 1978$)$.

18402. Kingston, H. M., Barnes, I. L., Brady, T. J., Rains, T. C., Champ, M. A., Separation of eight transition elements from alkali and alkaline earth elements in estuarine and seawater with chelating resin and their determination by graphite furnace atomic absorption spectrometry, Anal. Chem. 50, No. 14, 2064-2070 (Dec. 1978 )

18405. Currie, L. A., Environmental radiocarbon measurements, Proc. of the First Conf. on Radiocarbon Dating with Accelerators, Rochester, NY, Apr. 20-21, 1978, H. E. Gove, Ed., pp. 372-390 (University of Rochester, Rochester, NY, 1978 ).

18420. MacCrehan, W. A., Durst, R. A., Measurement of organomercury species in biological samples by liquid chromatography with differential pulse electrochemical detection, Anal. Chem. 50, No. 14, 2108-2112 (Dec. 1978).

18484. Jewett, K. L., Brinckman, F. E., Bellama, J. M., Influence of environmental parameters on transmethylation between aquated metal ions, Chapter 11 in Organometals and Organometalloids. Occurrence and Fate in the Environment, ACS Symposium Series No. 82, pp. 158-187 (SIS/ACS, Washington, DC, 1978).

18538. Sweger, D. M., Travis, J. C., An application of infrared lasers to the selective detection of trace organic gases, Appl. Spectrosc. 33, No. 1, 46-51 (1979). 
18587. Kusuda, T., Hunt, C. M., McNall, P. E., Radioactivity (radon and daughter products) as a potential factor in building ventilation, $A S H R A E J .21$, No. 7, 30-34 (July 1979).

18607. Kilmer, R. D., Cadoff, M. A., Mathews, D. E: Shoemaker, C. O., Jr., Effects of load, inflation pressure and tire deflection on truck tire noise levels, DOT HS 803874,48 pages (Department of Transportation, National Highway Traffic Safety Administration, Washington, DC, Jan. 1979).

18783. Epstein, M. S., Zander, A. T., Direct determination of barium in sea and estuarine water by graphite furnace atomic spectrometry, Anal. Chem. 51, No. 7, 915-918 (June 1979).

18860. Iverson, W. P., Brinckman, F. E., Microbial metabolism of heavy metals, Chapter 8 in Water Pollution Microbiology, R. Mitchell, Ed., 2, 201-232 (John Wiley \& Sons, Inc., New York, NY, 1978).

18966. Etz, E. S., Blaha, J. J., Laser-Raman microprobe analysis of particles in pollution studies, (Proc. American Nuclear Society 1979 Winter Meeting, San Francisco, CA, Nov. 1115, 1979), Trans. Am. Nucl. Soc. 33, $241-242$ (Nov. 1979).

18980. Bright, D., Chabay, I., Measuring aerosol particles, Chemtech, pp. 694-699 (Nov. 1979).

\section{Failure Analysis}

A preliminary study of the fluid mechanics of liquid penetrant testing, S. Deutsch, J. Res. Nat. Bur. Stand. (U.S.), 84, No. 4, 287-292 (July-Aug. 1979).

SP547. MFPG-Detection, diagnosis, and prognosis. Proceedings of the 28th Meeting of the Mechanical Failures Prevention Group, held at San Antonio, TX, Nov. 28-30, 1978, T. R. Shives and W. A. Willard, Eds., Nat. Bur. Stand. (U.S.), Spec. Publ. 547, 368 pages (July 1979) SN003-00302083-4.

Space shuttle diagnostics, D. J. Webb, SP547, pp. 3-16 (July 1979).

Multispectral scanner on LANDSAT, S. M. Gritton and A. B. Marchant, SP547, pp. 17-30 (July 1979).

Drivetrain bearing analysis, T. C. Belrose and D. Board, SP547, pp. 31 -35 (July 1979).

Light helicopter detection, diagnosis and prognosis objectives and applications, H. G. Smith and R. E. Rohtert, SP547, pp. 36-57 (July 1979).

Gas turbines and millimeter-wave radar, N. B. Kramer, SP547, pp. 58-62 (July 1979).

Improving vehicle life-cycle reliability by prognostic maintenance management through geriometry, R. G. Salter, SP547, pp. 65-77 (July 1979).

Motor vehicle fault detection and diagnosis, J. J. Innes, SP547, pp. $78-97$ (July 1979).

Diagnosis of combat vehicle systems using simplified test equipment, T. E. Fitzpatrick, R. E. Hanson, and F. W. Hohn, SP547, pp. 98-110 (July 1979).

Automated vehicular test equipment, L. T. Carter, SP547, pp. 111-126 (July 1979).

The acoustic valve leak detector-A new tool for fluid systems maintenance, J. G. Dimmick and J. W. Dickey, SP547, pp. 129-152 (July 1979).

Pielstick engine diagnostics, A. Genot, SP547, pp. 153-166 (July 1979).

Machinery condition analysis for maintenance planning-The aircraft carrier experience, M. D. Dougherty, SP547, pp. 167-175 (July 1979).

Diesel engine analyzer: Past experience and future plans, $H$. W. Rethmann, SP547, pp. 176-190 (July 1979).

Fiber optics for bearing performance monitoring, G. J. Philips, SP547, pp. 191-199 (July 1979).

Statistical techniques for automating the detection of anomalous performance in rotating machinery, $K$. $R$. Piety and T. E. Magette, SP547, pp. 203-231 (July 1979).
Vibration analysis method for detection of abnormal movement of material in a rotary dissolver, C. M. Smith, D. N. Fry, and W. T. King, SP547, pp. 232-249 (July 1979).

Monitoring inlet steam valves of PWR $900 \mathrm{MW}$ turbogemerators, A. Jaudet and J. C. Sol, SP547, pp. 250-279 (July 1979).

An approach to monitoring existing utility turbogenerators, S. Doughiy, SP547, pp. 280-285 (July 1979).

Enhancing machinery protection through automated diagnostics, J. L. Frarey, SP547, pp. 286-295 (July 1979).

Report on industry/joint services project task group 1-d, J. P. Wright, SP547, pp. 299-302 (July 1979).

A polymer sensor for monitoring ball-bearing condition, $\mathrm{S}$. Edelman, J. M. Kenney, J. F. Mayo-Wells, and S. C. Roth, SP547, pp. 303-314 (July 1979).

An instrumentation technique to evaluate spectra for engine diagnostics, T. Carolan, SP547, pp. 315-322 (July 1979).

The direct reading ferrograph, D. P. Anderson, SP547, pp. 323-329 (July 1979).

An advanced real-time oil debris monitor, T. E. Tauber, SP547, pp. 33()-344 (July 1979).

A practical approach to aircraft system component malfunction diagnosis, F. E. Bishop, SP547, pp. 345-357 (July 1979).

NBSIR 78-1581. Annual Report 1978. Office of nondestructive evaluation, H. Berger and L. Mordfin, Eds., 58 pages (Jan. 1979). Order from NTIS as PB291946.

NBSIR 79-1790. A comparison of American and European ultrasonic testing standards, S. Golan, 73 pages (Aug. 1979). Order from NTIS as PB298809.

18368. Christ, B. W., Smith, J. H., Brady, C. H., Analyzing fire extinguisher failures, Met. Prog. 114, No. 8, 28-32 (Dec. 1978 ).

18378. Cohen, J., Methodology of product life testing, Proc. $27 t h$ Meeting of the Mechanical Failures Prevention Group, Gaithersburg, MD, Nov. 1-3, 1977, T. R. Shives and W. A. Willard, Eds., pp. 31-41 (National Bureau of Standards, Gaithersburg, MD, May 1978).

18391. Sachse, W., Golan, S., The scattering of elastic pulses and the non-destructive evaluation of materials, Proc. American Society of Mechanical Engineers Winter Annual Meeting. San Francisco, CA, Dec. 10-15, 1978, pp. 11-31 (American Society of Mechanical Engineers, New York, NY, 1979).

18525. Kaiserlik, J., Berger, H., McGogney, C., Timber pilings: Maintenance and inspection summary of a panel discussion, Proc. 4th Nondestructive Testing of Wood Symp., Vancouver, WA, Aug. 28-30, 1978, pp. 155-159 (Washington State Univ., Engineering Extension Service, Pullman, WA, 1979).

18612. McHenry, H. I., Read, D. T., Begley, J. A., Fracture mechanics analysis of pipeline girthwelds, Am. Soc. Test. Mater. Spec. Tech. Publ. 668, pp. 632-642 (1979).

18744. Chwirut, D. J., Eitzen, D. G., Toward the development of improved reference fatigue cracks for use in ultrasonic gondestructive evaluation, Int. Adv. Nondestruct. Test 6, 179-197 (1979).

18802. McHenry, H. I., Fitness for purpose evaluation of defects in pipeline girthwelds, Proc. Structural Integrity Technology Conf., Washington, DC, May 9-11, 1979, J. P. Gallagher, T. W. Crooker, Eds., pp. 39-44 (American Society of Mechanical Engineers, New York, NY, 1979).

18830. Hoffman, J. D., Materials failure and materials research policy, (Proc. Symp. 176th Meeting of the American Chemical Society, Miami, FL, Sept. 11-14, 1978), ACS Symp. Series 95, Durability of Macromolecular Materials, R. K. Eby, Ed., Paper 1, 1-10 (American Chemical Society, Washington, DC, 1979).

18831. Gubernatis, J. E., Krumhansl, J. A., Thomson, R. M., Interpretation of elastic-wave scattering theory for analysis and design of flaw-characterization experiments: The longwavelength limit, J. Appl. Phys. 50, No. 5, 3338-3345 (May 1979). 
18878. Hsu, N. N., Hardy, S. C., Experiments in acoustic emission waveform analysis for characterization of $\mathrm{AE}$ sources, sensurs and structures, (Proc. Winter Annual Meeting of the American Society of Mechanical Engineers, San Francisco. CA, Dec. 10-15, 1978), Paper in Elastic Waves and NonDestructite Testing of Materials, Y. H. Pao, Ed., AMD-29, 8.5-l1)6 (American Society of Mechanical Engineers, New York, NY, 1978).

\section{Fire Research}

SP540. Fire research and safety. Proceedings of the Third Joint Panel Conference of the U.S.-Japan Cooperative Program in Natural Resources held at the National Bureau of Standards, Gaithersburg, MD, Mar. 13-17, 1978, M. A. Sherald, Ed., Nat. Bur. Stand. (U.S.), Spec. Publ. 540, 729 pages (Nov. 1979) SN003-003-02141-5.

Smoke detector design and smoke properties, R. W. Bukowski and G. W. Mulholland, SP540, pp. I-45 (Nov. 1979).

False alarm of smoke detectors, J. Miyama and A. Watanabe, SP540, pp. $46-53$ (Nov. 1979).

Researches in smoke properties in Japan, F. Saito, Chairman, SP540, pp. 54-101 (Nov. 1979).

Human behavior, J. L. Bryan, SP540, pp. 115-133 (Nov. 1979).

Human Behavior, S. Horiuchi and T. Jin, SP540, pp. 134 137 (Nov. 1979).

Current U.S. systems activities in fire safety design, H. E. Nelson, SP540, pp. 138-147 (Nov. 1979).

Present status of research on fire safety systems for buildings, K. Kawagoe and Y. Morishita, SP540, pp. 148-161 (Nov. 1979).

Smoke control, I. Benjamin, SP540, pp. 162-165 (Nov. 1979).

Smoke control, T. Wakamatsu, SP540, pp. 166-169 (Nov. 1979).

Subprograms: A state-of-the-art review, J. de Ris, SP54O, pp. 110-208 (Nov. 1979).

Mathematical modeling of enclosed fires-A review of current U.S. research, C. D. MacArthur, SP540, pp. 209-232 (Nov. 1979).

Basic problems in physical understanding of compartment fire, Y. Hasemi, SP540, pp. 233-263 (Nov. 1979).

A model on fire spread in small scale building, T. Tanaka, SP540, pp. 264-355 (Nov. 1979).

Statistical analysis of fire spread process in houses, $Y$ Morishita, SP540, pp. 356-381 (Nov. 1979).

Experimental study of compartment fires using model boxes, F. Saito, SP54O, pp. 382-447 (Nov. 1979).

Research on evaluation of relative toxicities of combustion products of various materials, K. Kishitani and S. Yusa, SP540, pp. 453-484 (Nov. 1979).

Research on evaluation of toxicities of combustion gases generated during fires, K. Kishitani and K. Nakamura, SP54O, pp. 485-519 (Nov. 1979).

On the acute toxicities of the combustion products of various fibers, with special reference to blood cyanide and $\mathbf{P o}_{2}$ values, K. Yamamoto, SP540, pp. 520-527 (Nov. 1979).

Factors accelerating the gas toxicity in a fire, $F$. Saito, SP540, pp. 528-548 (Nov. 1979).

Biological testing in fire toxicology, P. W. Smith and C. R Crane, SP540, pp. 549-565 (Nov. 1979).

Recent test results from the FAA/NAFEC cabin fire safety program, C. P. Sarkos, SP54O, pp. 589-623 (Nov. 1979).

Brief comments on fire research at the U.S. Bureau of Mines, R. F. Chainen, SP540, pp. 624-625 (Nov. 1979).

Instrumentation for the size determination of submicron particulates systems by sideway light scattering method and the characteristics of smokes from polymerized materials in fire, T. Handa, K. Suda, T. Nagashima, K. Kaneko, T. Yamamura, Y. Takahashi, H. Suzuki, and F. Saito, SP540, pp. 626-711 (Nov. 1979).

Technical session on detection and smoke properties, J. Miyama, SP540, p. 713 (Nov. 1979).

Progress report session on human behavior, building systems and smoke control, G. Bates, Jr., SP54O, pp. 714-715 (Nov. 1979)

Technical session on fire modeling, H. Emmons, SP540, p. 716 (Nov. 1979).

Technical session on toxicity, A. Watanabe, SP540, p. 717 (Nov. 1979)

BSS115. Fire safety for high-rise buildings: The role of communications, R. A. Glass and A. I. Rubin, Nat. Bur. Stand. (U.S.), Bldg. Sci. Ser. 1l 5, 47 pages (Apr. 1979) SN003-00302016-8

TN985. Fire effects on reinforced concrete members, B. Ellingwood and J. Shaver, Nat. Bur. Stand. (U.S.), Tech. Note 985 , 42 pages (Aug. 1979) SN(003-003-02104-1.

TN991. COMPF2-A program for calculating post-flashover fire temperatures, V. Babrauskas, Nat. Bur. Stand. (U.S.), Tech. Note 991, 76 pages (June 1979) SN003-003-02080-0.

TN1101. Decision analysis of strategies for reducing upholstered furniture fire losses, S. G. Helzer, B. Buchbinder, and F. L. Offensend, Nat. Bur. Stand. (U.S.), Tech. Note 1101, 155 pages (June 1979) SN003-003-02078-8.

TN1103. Full-scale burnlng behavior of upholstered chairs, V. Babrauskas, Nat. Bur. Stand. (U.S.), Tech. Note 1103, 86 pages (Aug. 1979) SN003-003-02110-5.

TN1 109. Characterizatlon of electrical Ignition sources within television receivers, G. J. Rogers and D. D. Evans, Nat. Bur. Stand. (U.S.), Tech. Note 1109, 60 pages (Oct. 1979) SN003-003-02119-9.

NBSIR 78-1526. Annual conference on fire research, C. Huggett, Ed., 217 pages (Dec. 1978). Order from NTIS as PB291930.

NBSIR 78-1555. A system for fire safety evaluation of health care facilities, H. E. Nelson and A. J. Shibe, 146 pages (Nov. 1978). Order from NTIS as PB292273.

NBSIR 78-1571. Sprinkler-vent and spray mozzle systems for fire protection of openings in fire resistive walls and ceilings-The state-of-the-art and a plan for future research work, J. G. O'Neill, 29 pages (Jan. 1979). Order from NTIS as PB291889.

NBSIR 78-1584. Submarine compartment fire-Study-fire performance evaluation of hull insulation, B. T. Lee and J. N. Breese, 49 pages (May 1979). Order from NTIS as PB298264.

NBSIR 79-1588. Interlaboratory evaluation of the attic floor radiant panel test and smoldering combustion test for cellulose thermal insulation, J. R. Lawson, 38 pages (Feb. 1979). Order from NT1S as PB293159.

NBSIR 79-1596. Studies of flammability test procedures for curtains and drapes, D. E. Hopkins and J. F. Krasny, 25 pages (Mar. 1979). Order from NTIS as PB29 5039.

NBSIR 79-1700. Fire performance guidelines for shipboard interior finish, B. T. Lee and W. J. Parker, 24 pages (June 1979). Order from NT1S as PB297765.

NBSIR 79-1713. Final report on the "BFIRES/Version 1" computer simulation of emergency egress behavior during fires: Calibration and analysis, F. I. Stahl, 179 pages (Mar. 1979). Order from NTIS as PB295063.

NBSIR 79-1714. Fire buildup in shipboard compartments-Characterization of some vulne rable spaces and the status of prediction analysis, B. T. Lee and W. J. Parker, 45 pages (May 1979). Order from NTIS as PB297631.

NBSIR 79-1720. Mobile home fire studies: Summary and recommendations, E. K. Budnick and D. P. Klein, 94 pages (Mar. 1979). Order from NTIS as PB293527. 
VBSIR 79-1727. Group homes for the developmentally disabled: Case histories of demographics, household activities, and room use, A. M. Ramey-Smith and J. V. Fechter, 66 pages (Apr. (474). Order from NTIS as PB295037.

NBSIR 79-1731. A review of fire incidents, model building codes, and standards related to wond-burning appliances, $R$. D. Peacock, 60) pages (May 1979). Order from NTIS as PB298289

NBSIR 79-1739. Tests on the performance of automatic fire detectors in health care occupancies-A preliminary report, $R$. W. Bukowski, 29 pages (Apr. 1979). Order from NTIS as PB297150.

NBSIR 79-1745. Fire research publications, 1978, N. H. Jason, 17 pages (Apr. 1979). Order from NT1S as PB295395.

NBSIR 79-1747. Stairwell pressurization systems, I. A Benjamin and $\mathbf{J}$. H. Klote, 31 pages (June 1979). Order from NTIS as PB297479.

NBSIR 79-1749. Full-scale fire tests with automatic sprinklers in a patient room, J. G. O Neill and W. D. Hayes, Jr., 52 pages (June 1979). Order from NTIS as PB297417.

NBSIR 79-1754. A linearized finite difference computation of fluid heating in an enclosure, R. G. Rehm. M. R. Cordes, H. R. Buum, and J. Lewis, 76 puges (May 3, 1979). Order from NTIS as PB298053.

NBSIR 79-1755. Fire accident simulations with apparel fabrics, A. W. Meierhoefer, E. Braun, J. F. Krasny, and R. D. Peacock, 31 pages (June 1979). Order from NTIS as PB297815.

NBSIR 79-1796. Preliminary findings concerning the validity of "BFIRES": A comparison of simulated with actual fire events, F. I. Stahl, 22 pages (Aug. 1979). Order from NTIS as PB299451.

NBSIR 79-1902. Economic aspects of fire safety in health care facilities: Guidelines for cost-effective retrofits, $R$. E. Chapman, P. T. Chen, and W. G. Hall, 118 pages (Nov. 1979). Order from NTIS as PB\&()-120165.

NBSIR 79-1906. The evacuation of non-ambulatory patients from hospital and nursing home fires: A framework for a model, J. Archea and S. T. Margulis, Ed., 65 pages (Nov. 1979). Order from NTIS as PB80-119530.

NBSIR 79-1910. Purely buoyant diffusion flames: Some experimental results, B. J. McCaffrey, 51 pages (Oct. 1979). Order from NTIS as PB80-112113.

NBSIR 79-1912. Temperature measurement on operating surface mounted lighting fixtures, P. M. Fulcomer, 24 pages (Sept. 1979). Order from NTIS as PB80-103682.

NBSIR 79-1913. Temperature measurement on operating recessed lighting fixtures, P. M. Fulcomer, 23 pages (Sept. 1979). Order from NTIS as PB80-104722.

NBSIR 79-1915. Investigation of the effects of heating and air conditioning on the performance of smoke detectors in mobile homes, R. W. Bukowski, 181 pages (Oct. 1979). Order from NTIS as PB80-100001

NBSIR 79-1916. Thisd annual conference on fire research, I. M. Martinez, Ed., 188 pages (Oct. 1979). Order from NTIS as PB80-1 10240.

NBS-GCR-78-12x. Environments of fire detectors-Phase II: Effect of ceiling configuration. Volume 1 . Measurements, G. Heskestad and M. A. Delichatsios, 180 pages (June 1978). Order from NTIS as PB290951.

NBS-GCR-78-129. Environments of fire detectors-Phase II: Effect of ceiling configuration. Volume II. Analysis, G. Heskestad and M. A. Delichatsios, 112 pages (June 1978). Order from NTIS as PB284042.

NBS-GCR-78-135. An exploration of non-sampling error in fire incident surveys, M. A. McDaniel, L. Bickman, P. Edelman, and E. Herz, 24 pages (Dec. 1977). Order from NTIS as PB284849.
NBS-GCR-78-138. Human behavior in fire-A bibliography, J. L. Bryan, 23 piges (Aug. 1978). Order from NTIS as PB287412

NBS-GCR-78-140. An examination and analysis of the dynamics of the human behavior in the fire incident at St. Joseph's Hospital, Philadelphia, PA, on August 10, 1977, J L. Bryan and P. J. DiNenno, 62 pages (May 31, 1978). Order from NTIS as PB287935.

NBS-GCR-78-147. Review of smoke particulate properties data for burning natural and synthetic materials, C. P. Bankston, R. A. Cassanova, E. A. Powell, and B. T. Zinn, 61 pages (May 1978). Order from NTIS as PB292066.

NBS-GCR-78-149. Analysis of fire reports on file in the Massachusetts State Fire Marshal's Office relating to wood and coal heating equipment, J. W. Shelton, 9 puges (Nov. 1978). Order from NTIS as PB292521.

NBS-GCR-78-150. UNDSAFE-II-A computer code for buoyant turbulent flow in an enclosure with thermal radiation, $K . V$. Liu and K. T. Yang, 172 pages (July 15, 1978). Order from NTIS as PB291516.

NBS-GCR-78-151. One dimensional radiation model for surfaces and non-homogeneous gases and soot, V. K. Liu and J. R. Lloyd, 96 pages (Mar. 6, 1978). Order from NTIS as PB291099.

NBS-GCR-79-157. The psychology of firesetting: $A$ review and appraisal, R. G. Vreeland and M. B. Waller, 58 pages (Dec. 1978). Order from NTIS as PB290821.

NBS-GCR-79-159. An examination and analysis of the dynamics of the human behavior in the fire incident at the Kensington Gardens Nursing Home on January I, I978, J. L. Bryan and P. J. DiNenno, 67 pages (June 30, 1978). Order from NTIS as PB290892.

NBS-GCR-79-160. Reliability modeling of smoke detectors, H C. Rickers, 110 pages (Mar. 1979). Order from NTIS as PB295176.

NBS-GCR-79-161. Residential smoke detector reliability handbook. Section 1: Parts stress analysis, H. C. Rickers, 226 pages (Feb. 1979). Order from NTIS as PB295178.

NBS-GCR-79-162. Residential smoke detector reliability handbook. Section 2: System reliability evaluation techniques. Section 3: Component screening/test techniques, H. C. Rickers, 103 pages (Mar. 1979). Order from NTIS as PB295177.

NBS-GCR-79-163. A theoretical rationalization of a goaloriented systems approach to building fire safety, J. Watts, 266 pages (Feb. 28, 1978). Order from NTIS as PB294684.

NBS-GCR-79-168. Human fatalities from unwanted fires, W. G. Berl and B. M. Halpin, 64 pages (Dec. 1978). Order from NTIS as PB295411.

NBS-GCR-79-176. Fire protection design standards for buildings and construction, Nat. Committee of the Council of Ministers USSR on Building Construction (GOSSTROY USSR), 36 pages (Sept. 1970). Order from NTIS as PB298901.

NBS-GCR-79-179. An evaluation of planning and training for fire safety in health care facilities-Phase two, L. Bickman, E. Herz, P. Edelman, and D. Rivers, 179 pages (Aug. 1979) Order from NTIS as PB299023.

18514. Bright, R. G., Technical developments of domestic fire detectors, (Proc. Int. Fire, Security and Safety Exhibition and Conf., London, England, Apr. 24-28, 1978), Fire Surveyor Mag. 74, 9-16 (Aug. 1978 ).

18517. Divis, S., Assessment of fire hazards from furniture, Proc. Int. Fire, Security and Safery Exhibition and Conf., IFSSEC 78, London, England, Apr. 24-28, 1978, 30 pages (Victor Green Publ. Ltd., London, England, 1978).

18537. Peacock, R. D., A review of fire incidents related to wood-burning appliances, Proc. Wood-Heating Seminar IV. Portland. OR, Mar. 2I-24. 1979, pp. 43-66 (Wood Energy Institute, Camden, ME, 1979). 
185\%8. Paabo, M., Birky, M. M., Womble, S. E., Analysis of hydrogen cyanide in fire environments, J. Combnst. Toxicol. 6 , 99-108 (May 1979).

18625. Bukowski, R. W., Custer, R. L. P., Bright, R. G., Fire alarm communications, Chapter 19 in Handhosk of Building Se'urity Planning and Design, P. S. Hopt, Ed., pp. 19-1-1927 (McGraw-Hill Book Co., New York, NY, 1979).

18708. Braun, E., Krasny, J. F., Peacock, R. D., Stratton, A., NBS activities in apparel flammability, Proc. Ninth Annual Meeting of the Information Council on Fabric Flammahility, Ne'w York, NY, Dec. 11, 1975, pp. 263-271 (Dec. 1975)

18721 . Benjamin, 1. A., A firesafety evaluation system for health care facilities, (Proc. Intl. Fire Safety in Hospitals Symp., Paris, France, Apr, 4-5, 1978 ), Fire J. 73, No. 2, 52-55, 95 96 (Mar. 1979).

18991. Krasny, J. F., Braun, E., Peacock, R., Synthesis of a general apparel flammability standard, Proc. IOth Annual Information Council on Fabric Flammability Meering, New York, NY, De' 8-9, 1976, pp. $171-184$ (1976).

19045. Chapman, R. E., Cost-effective methods for achieving compliance to fire safety codes, Fire J. 73, No. 5, 30-39, 123 (Sept. 1979).

\section{Fluids: Liquids, Gases and Plasmas}

Molecular dynamics study of liquid rubidium and the LennardJones fluid, R. D. Mountain and S. W. Haan, J. Res. Nat. Bur. Sitand. (U.S.), 84, No. 6, 439-446 (Nov.-Dec. 1979).

TN989. A low-velocity airflow calibration and research facility, L. P. Purtell and P. S. Klehanoff, Nat. Bur. Stand. (U.S.), Tech. Note 989, 21 pages (Mar. 1979) SN003-003-02038-9.

18367. Chang, S. J., Zapas, L. J., Several relations for comparison of a general rate fluid and the BKZ fluid, Proc. VIlth Int. Congress of Rheology, Gothenburg, Sweden, Aug. 23-27, 1976, C. Klason and J. Kubát, Eds., pp. 566-567 (Tages-Anzeiger/Regina-Druck, Zurich, Switzerland, 1976).

18410. Davis, R. W., Moore, E. F., Mattingly, G. E., Miller, R. W., Numerical solutions for turbulent, swirling flow through target flowmeters, Proc. American Sociery of Mechanical Engineers 1978 Winter Annual Meeting, San Francisco, CA, Dec. $10-15,1978,78-W A / F M-4,1-11$ (American Society of Mechanical Engineers, New York, NY, 1978).

18457. Sengers, J. V., Moldover, M. R., Critical phenomena experiments in space?, Z. Flugwiss. Weltraumforsch 2, 371-379 (1978).

18481. Hardy, S. C., The motion of bubbles in a vertical temperature gradient, J. Colloid Interface Sci. 69, No. 1, 157-162 (Mar. 15, 1979).

18509. Piermarini, G. J., Forman, R. A., Block, S., Viscosity measurements in the diamond-anvil pressure cell, Proc. 6th AIRAPT Int. Hight Pressure Conf., Boulder, CO, July 25-29, 1977, pp. 860-864 (Plenum Press, New York, NY, 1979).

18541. Moldover, M. R., Sengers, J. V., Gammon, R. W., Hocken, R. J., Gravity effects in fluids near the gas-liquid critical point, Rev. Mod. Phys. 51, No. 1, 79-99 (Jan. 1979).

18567. Daney, D. E., Ludtke, P. R., Jones, M. C., An experimental study of thermally-induced flow oscillations in supercritical helium, J. Heat. Transfer 101, No. 1, 9-14 (Feb. $1979)$.

18752. Ackerson, B. J., Hanley, H. J. M., Transport properties of a binary mixture at the gas-liquid critical point, Am. Phys. Sis. Bull. 23, 315 ( 1978 ).

18821. Frenkiel, F. N., Klebanoff, P. S., Huang, T. T., Grid turbulence in air and water, Phys. Fluids 22, No, 9, 16061617 (Sept. 1979).

18825. Greer, S. C., Liquid-liquid critical phenomena, Acc. Clem. Res. 11,427-432 (Nov. 1978).

18930. Saylor, C. P., Refractometry of fluids in microscopic tubes, Appl. Opi. 18, No. 6, 802-808 (Mar. 15, 1979).
18937. Sengers, J. V., Dielectric constant of water and steam, Mech. Eng. 101, 44-45 (Sept. 1979).

19004. Kayser, R. F., Jr., Raveché, H. J., Equivalence of integral equations in the molecular theory of fluids, Physica 97A, 399-409 (1979).

19022. Olien, N. A., Present and future sources of fluid property data, Proc. American Society of Mechanical Engineers Winter Annual Meering, New York, NY, Dec. 2-7, 1979, Paper No. 79-WA/HT-19, 7 pages (American Socieiy of Mechanical Engineers, New York, NY, 1979).

\section{General Theoretical Chemistry and Physics}

18432. Fishbane, P. M., Horn, D., Meshkov, S., Spin forces in charmonium spectroscopy, Phys. Rev. D 19, No, 1, 288-290) (Jan. 1, 1979).

18483. Hunter, C., Stellar hydrodynamics of thin disk galaxies, Astrophys. J. 227, 73-92 (Jan. 1, 1979).

18565. Danos, M., Development of approaches and present status of the giant multipole resonance theory, Proc. 4th Seminar on Electromagnetic Interactions of Nuclei at Low and Medium Energies, Moscow, USSR, Dec. 13-15, 1977, pp. 321 (Nauka, Moscow, 1979).

18575. Demkov, Y. N., Ostrovskii, V. N., Solov'ev, E. A., Twostate approximation in the adiabatic and sudden-perturbation limits, Phys. Rev. A 18, No. 5, 2089-2096 (Nov. 1978).

18605. Kventsel, G. F., Katriel, J., Exact solutions for infiniterange spin Hamiltonians, J. Appl. Phys. 50, No. 3, 1820-1821 (Mar. 1979).

18614. Cahn, J. W., Kikuchi, R., Ground state of f.c.c. alloys with multiatom interactions, Acra Met. 27, 1329-1336 (1979).

18661. Katriel, J., On the divergence of perturbation theory for anharmonic oscillators, Phys. Lert. 72A, No. 2, 94-96 (June $25,1979)$.

18706. Harter, W. G., Patterson, C. W., Asymptotic eigensolutions of fourth and sixth rank octahedral tensor operators, $J$. Math. Phys. 20, No. 7, 1453-1459 (July 1979).

18732. Danos, M., Rafelski, J., Singularities in quantum field theory, II Nuovo Cimento 49A, No. 3, 326-367 (Feb. I, 1979).

18885. Katriel, J., Explicit expressions for the coefficients in Boson series expansions of arbitrary spin operators, Pllys. Status Solidi Short Notes B93, K177-K179 (1979).

19010. Meshkov, S., Introductory remarks-Quark flavors, Paper in New Frontiers in High-Energy Pliyscis 14, Studies in the Natural Sciences, A. Perlmutter, L. F. Scott, Eds., pp. 221-226 (Plenum Press, New York, NY, 1978).

\section{Health and Safety}

System for assessing eye injury potential of propelled objects, $R$. E. Berger, J. Res. Nat. Bur. Stand. (U.S.), 84, No. 1, 9-19 (Jan.-Feb. 1979).

Isoionic isotope exchange with hydroxylapatite and the dilution effect, D. N. Misra, J. Res. Nat. Bur. Stand. (U.S.), 84, No. 5, 395-406 (Sept.-Oct.'1979).

SP260-63. Standard reference materials: A reference method for the determination of potassium in serum, R. A. Velapoldi, R. C. Paule, R. Schaffer, J. Mandel, L. A. Machlan, and J. W. Gramlich, Nat. Bur. Stand. (U.S.), Spec. Publ. 260-63, 104 pages ( May 1979) SN003-003-02068-1.

SP260-67. Standard reference materials: A reference method for the determination of chloride in serum, $R$. A. Velapoldi, R. C. Paule, R. Schaffer, J. Mandel, T. J. Murphy, and J. W. Gramlich, Nat. Bur. Stand. (U.S.), Spec. Publ. 260-67, 97 pages (Nov. 1979) SN003-003-02136-9.

SP400-50. Semiconductor measurement technology: Reliability technology for cardiac pacemakers 111-A workshop report. 
Report of a Workshop held at the National Bureau of Standards, Gaithersburg, MD, Oct. 19-20, 1977, H. A. Schafft, Ed., Nat. Bur. Siand. (U.S.), Spec. Publ. 400-50, 134 pages (June 1979) SN(003-()(1)3-()2076-1.

SP48()-12. Communication systems guide, W. W. Scott, Jr., Nat. Bur. Siand. (U.S.), Spec. Publ. 480-12, 36 pages (Jan. 1979) $\mathrm{SN}()() 3-()() 3-0) 2012-5$

SP48()-14. Selection and application guide to commercial intrusion alarm systems, A. H. Sher and G. N. Stenbakken, Nat Bur. Stand. (U.S.), Spec. Publ. 480-14, 40 pages (Aug. 1979) SN(0)3-003-02098-2.

SP480-3(). Juror response to prerecorded videotape trials, E. M. Robertson, Nat. Bur. Stand. (U.S.), Spec. Publ. 480-30, 28 pages (June 1979) SNO03-003-02071-1.

SP480-33. Guide to high speed patrol car tires, A. C. Lewis and E. Lewis, Jr., Nat. Bur. Stand. (U.S.), Spec. Publ. 480-33, 42 pages (1979) SNO03-003-02073-7.

SP480-36. Some psychophysical tests of the conspicuities of emergency vehicle warning lights, G. L. Howett, Nat. Bur. Siand. (U.S.), Spec. Publ. 480-36, 24 pages (July 1979) SNO03-00 3-02085-1

SP480-38. The role of behavioral science in physical security. Proceedings of the Third Annual Symposium, May 2-4, 1978, J. J. Kramer, Ed., Nat. Bur. Stand. (U.S.), Spec. Publ. 480 38, 110 pages (Dec. 1979) SN003-003-02149-1

Biosensor for assessment of defender performance capability, T. E. Bevan, SP480-38, pp. 1-6 (Dec. 1979).

Neurophysiological operant and classical condition methods in rats in the detection of explosives, S. Weinstein, C. Weinstein, and R. Nolan, SP480-38, pp. 7-16 (Dec. 1979).

Link analysis of threats and physical safeguards, D. H. Harris, SP480-38, pp. 17-22 (Dec. 1979).

An overview of the M.A.I.T. analysis system (machine analysis of the internal threat), J. R. NiCastro, B. Woolson, and J. Glancy, SP480-38, pp. 23-28 (Dec. 1979).

Strategies of counter-nuclear terrorism: Theory and decision on the frontiers of law enforcement and criminal justice, L. R. Beres, SP480-38, pp. 29-46 (Dec. 1979).

Potential application of computer-based crisis management aids to problems of physical security, S. J. Andriole and J. A Daly, SP480-38, pp. $47-74$ (Dec. 1979).

Brain wave and biochemical research findings, $K$. Montor and D. Afdahl, SP480-38, pp. 75-80 (Dec. 1979).

Psychological deterrence in robberies of banks and its application to other institutions, W. D. Tiffany and J. M. Ketchel, SP480-38, pp. $81-88$ (Dec. 1979).

SP525. Ultrasonic tissue characterization II. A collection of reviewed papers based on talks presented at the Second 1nternational Symposium on Ultrasonic Tissue Characterization held at the National Bureau of Standards, Gaithersburg, MD, June 13-15, 1977, M. Linzer, Ed., Nat. Bur. Stand. (U.S.), Spec. Publ. 525, 339 pages (Apr. 1979) SN003-003-020583.

Elements of tissue characterization. Part I. Ultrasonic propagation properties, R. L. Johnston, S. A. Goss, V. Maynard, J. K. Brady, L. A. Frizzell, W. D. O'Brien, Jr., and F. Dunn, SP525, pp. 19-27 (Apr. 1979).

Absorption of sound in tissues, E. L. Carstensen, SP525, pp. 29-36 (Apr. 1979).

Mechanisms of ultrasonic attenuation in soft tissue, $M$ O'Donnell and J. G. Miller, SP525, pp. 37-40 (Apr. 1979).

Elements of tissue characterization. Part II. Ultrasonic propagation parameter measurements, S. A. Goss, R. L. Johnston, V. Maynard, L. Nider, L. A. Frizzell, W. D. O'Brien, Jr., and F. Dunn, SP525, pp. 43-51 (Apr. 1979).

A device for measuring ultrasonic propagation vefocity in tissue, B. D. Sollish, SP525, pp. 53-56 (Apr. 1979).

Measurement of the temperature dependence of the velocity of ultrasound in soft tissues, T. Bowen, W. G. Connor, R. L.
Nasoni, A. E. Pifer, and R. R. Sholes, SP525, pp. 57-61 (Apr. 1979)

Ultrasonic attenuation in normal and ischemic myocardium, M. O'Donnell, J. W. Mimbs, B. E. Sobel, and J. G. Miller, SP525, pp. 63-71 (Apr. 1979).

Acoustic microscopic analysis of myocardium, D. E. Yuhas and L. W. Kessler, SP52 5, pp. 73-79 (Apr. 1979).

Acoustic properties of normal and abnormal human brain, F. W. Kremkau, C. P. McGraw, and R. W. Barnes, SP525, pp. $81-84$ (Apr. 1979).

Frequency dependent attenuation of malignant breast tumors studied by the Fast Fuurier transform technique, E. K. Fry, N. T. Sanghvi, F. J. Fry, and H. S. Gallager, SP525, pp. 85-91 (Apr. 1979).

Correlation of ultrasonic attenuation with connective tissue content in breast cancers, T. Kobayashi, SP525, pp. 93-99 (Apr. 1979).

The attenuation of selected soft tissue as a function of frequency, D. H. Le Croissette, R. C. Heyser, P. M. Gammell, J. A. Roseboro, and R. L. Wilson, SP525, pp. 101-108 (Apr. 1979).

Clinical spectrum analysis techniques for tissue characterization, F. L. Lizzi and M. E. Elbaum, SP525, pp. 111-119 (Apr. 1979).

Tissue characterization in vivo by differential attenuation measurements, S. Levi and J. Keuwez, SP525, pp. 121-124 (Apr. 1979).

Statistical estimation of the acoustic attenuation coefficient slope for liver tissue from reflected ultrasonic signals, $R$. Kuc, M. Schwartz, N. Finby, and F. Dain, SP525, pp. 125-132 (Apr. 1979).

An ultrasonic tissue signature for the lung surface, T. L. Rhyne, SP525, pp. 135-141 (Apr. 1979).

Angle scan and frequency-swept ultrasonic scattering characterization of tissue, R. C. Waag, P. P. K. Lee, R. M. Lerner, L. P. Hunter, R. Gramiak, and E. A. Schenk, SP525, pp. 143-152 (Apr. 1979).

Quantitative measurements of scattering of ultrasound by heart and liver, J. M. Reid and K. K. Shung, SP525, pp. 153156 (Apr. 1979).

Dependence of ultrasound backscatter from human liver tissue on frequency and protein/lipid composition, $M$. Freese and E. A. Lyons, SP525, pp. 157-163 (Apr. 1979).

Ultrasound backscattering from blood: Hematocrit and erythrocyte aggregation dependence, $M$. Hanss and $M$. Boynard, SP525, pp. 165-169 (Apr. 1979).

Tumour detection by ultrasonic Doppler blood-flow signals, P. N. T. Wells, M. Halliwell, R. A. Mountford, R. Skidmore, A. J. Webb, and J. P. Woodcock, SP525, pp. 173-176 (Apr. 1979).

A theory relating sonic velocity to mineral content in bone, S. Lees and C. L. Davidson, SP525, pp. 179-187 (Apr. 1979).

Ultrasonic properties and microtexture of human cortical bone, H. S. Yoon and J. L. Katz, SP525, pp. 189-196 (Apr. 1979).

Attenuation and dispersion of ultrasound in cancellous bone, J. E. Barger, SP525, pp. 197-201 (Apr. 1979).

Transkull transmission of axisymmetric focused ultrasonic beams in the 0.5 to $1 \mathrm{MHz}$ frequency range: Implications for brain tissue visualization, interrogation, and therapy, F. J. Fry, SP525, pp. 203-208 (Apr. 1979).

Some advarces in acoustic imaging through skull, S. W. Smith, D. J. Phillips, O. T. von Ramm, and F. L. Thurstone, SP525, pp. 209-218 (Apr. 1979).

Characterization of in vivo breast tissue by ultrasonic timeof-flight computer tomography, G. H. Glover, SP525, pp. 221-225 (Apr. 1979). 
Variation of acoustic speed with temperature in various ex cised human tissues studied by ultrasound computerized tumography, B. Rajagopalan, J. F. Greenleaf, P. J. Thomas, S. A. Johnson, and R. C. Bahn, SP525, pp. 227-233 (Apr. 1979).

High spatial resolution ultrasonic measurement techniques for characterization of static and moving tissues, S. A. Johnson, J. F. Greenleaf, B. Rajagopalan, R. C. Bahn, B. Baxter, and D. Christensen, SP525, pp. 235-246 (Apr. 1979).

A comprehensive ultrasonic tissue analysis system, $M$. Linzer, S. 1. Parks, S. J. Norton, F. P. Higgins, D. R. Dietz, R. W. Shideler, T. H. Shawker, and J. L. Doppman, SP525, pp. 255-259 (Apr. 1979).

Theoretical analysis of instantaneous power spectra as applied to spectra-color ultrasonography, W. D. Jennings, E. Holasek, and E. W. Purnell, SP525, pp. 261-266 (Apr. 1979).

Identification of tissue parameters by digital processing of real-time ultrasonic clinical cardiac data, L. Joynt, D. Boyle, H. Rakowski, R. Popp, and W. Beaver, SP525, pp. 267-273 (Apr. 1979).

Dynamic autocorrelation analysis of A-scans in vivo, J. C. Gore, S. Leeman, C. Metreweli, N. J. Plessner, and K. Willson, SP525, pp. 275-280 (Apr. 1979).

Computer spectral analysis of ultrasonic $A$ mode echoes, $D$. E. Robinson, SP525, pp. 281-286 (Apr. 1979).

Cepstral signal processing for tissue signature analysis, J. Fraser, G. S. Kino, and J. Birnholz, SP525, pp. 287-295 (Apr. 1979).

Recognition of patterns in ultrasonic sectional pictures of the prostate for tumor diagnosis, W. von Seelen, A. Gaca, E. Loch, W. Scheiding, and G. Wessels, SP525, pp. 297-302 (Apr. 1979)

Recent developments in obtaining histopathological information from ultrasound tissue signatures, K. Preston, Jr., M. J. Czerwinski, M. L. Skolnik, and D. E. Leb, SP525, pp. 303 3 I3 (Apr. 1979).

Damage and death in tissues and associated changes is their mechanical. properties, L. Weiss, SP525, pp. 317-322 (Apr. 1979).

A human abdominal tissue phantom, P. D. Edmonds, Z. Reyes, D. B. Parkinson, R. A. Filly, and H. Busey, SP525, pp. 323-326 (Apr. 1979),

Tissue simulators for diagnostic ultrasound, R. C. Eggleton and J. A. Whitcomb, SP525, pp. 327-336 (A pr. 1979).

Tissue equivalent test objects for comparison of ultrasound transmission tomography by reconstruction with pulse echo ultrasound imaging, P. L. Carson, L. Shabason, D. E. Dick, and W. Clayman, SP525, pp. 337-340 (Apr. 1979).

Data of the velocity and attenuation of ultrasound in mammalian tissues-A survey, R. J. Parry and R. C. Chivers, SP525, pp. 343-360 (Apr. 1979).

SP565. A history of walkway slip-resistance research at the National Bureau of Standards, S. C. Adler and B. C. Pierman, Nat. Bur. Stand. (U.S.), Spec. Publ. 565, 36 pages (Dec. 1979) SN003-003-02142-3.

BSS120. Guidelines for stair safety, J. Archea, B. L. Collins, and F. I. Stahl, Nat. Bur. Stand. (U.S.), Bldg. Sci. Ser. 120, 129 pages (May 1979) SN003-003-02063-0.

TN971. Guidelines for cost-effective lead paint abatement, R. E Chapman and J. G. Kowalski, Nat. Bur. Stand. (U.S.), Tech. Note 971, 88 pages (Jan. 1979) SN003-003-02014-1.

NBSIR 77-1299. Power lawn mowers: Time-to-binde access, A M. Ramey and J. J. Persensky, 22 pages (May 1977). Order from NT1S as PB297641.

NBSIR 77-1401. Processing and characterization of NBS standard polyethylene for use as a megative control material, A. J. Bur, 32 pages (Jan. 1978). Order from NTIS as PB297464.
NBSIR 78-1507. Some thoughts on electrical connections, J. Rabinow, 35 pages (Aug. 1978). Order from NTIS as PB290491.

NBSIR 78-1547. Methodology for choosing test parameters to evaluate protective headgear, R. E. Berger and N. J. Calvano, 77 pages (Nov. 1978). Order from NTIS as PB292284.

NBSIR 78-1573. Properties and interactions of oral structures and restorative materials, J. M. Cassel, 94 pages (Dec. 1978). Order from NTIS as PB289913.

NBSIR 78-1586. Fire safety guidelines for vehicles in a Downtown People Mover system, R. D. Peacock, 57 pages (Jan. 1979). Order from NTIS as PB292600.

NBSIR 79-1707. Impact attenuation performance of surfaces installed under playground equipment, B. M. Mahajan and W. B. Beine, 53 pages (Feb. 1979). Order from NTIS as PB292743.

NBSIR 79-17!0. Electrical injuries-A literature review, Y. C Wu, 36 pages (Feb. 1979). Order from NTIS as PB298622.

NBSIR 79-1716. Possible fire and electric shock hazards from hot lamps in miniature Christras tree light strings and decorations, P. M. Fulcomer, 34 pages (Mar. 1979). Order from NTIS as PB295357.

NBSIR 79-1738. EVACNET; Prototype network optimization models for builiding evacuatioa, R. L. Francis and P. B. Saunders, 164 pages (Oct. 1979). Order from NTIS as PB80113780 .

NBSIR 79-1741. Physical testing of polymers for use in circulatory assist devices, R. W. Penn and G. B. McKenna, 45 pages (July 1978). Order from NTIS as PB295085.

NBSIR 79-1760. Evaluation of safety symbols, B. L. Collins and B. C. Pierman, 38 pages (June 1979). Order from NTIS as PB298175.

NBSIR 79-1768. Performance of plastic packaging for hazardous materials tramsportation. Part IV. Standardizing permeation measurements, J. D. Barnes, G. M. Martin, and F. L. McCrackin, 48 pages (June 1979). Order from NTIS as PB298047.

NBSIR 79-1784. Interaction of blood proteins with solid surfaces, R. E. Deh! and W. H. Grant, 47 pages (Aug. 1979). Order from NTIS as PB299447.

NBS-GCR-78-156. Home safety guidelines for architects and builders, D. Alessi and M. Brill, 126 pages (Dec. 1978). Order from NTIS as PB292928.

NBS-GCR-79-167. Behavioral and physical characteristics of developmentally disabled individuals, C. J. Overboe and Y. Y. Wang, 109 pages (Mar. 1979). Order from NTIS as PB294970.

U.S. Patent 4,158,944. Rotary blade coupling for lawn mower, J. Rabinow, 9 pages (June 26, 1979).

18381. Treado, M. J., Diamond, J. J., Taggart, H. E., Jones, R. N., Saulsbury, L. F., Workman, J. L., NILECJ standard for body-worn FM transmitters, NILECJ-STD-0214.00, 20 pages (U.S. Department of Justice, Law Enforcement Assistance Administration, National Institute of Law Enforcement and Criminal Justice, Washington, DC, Dec. 1978).

18397. Reite, M., Edrich, J., Zimmerman, J. T., Zimmerman, J. E., Human magnetic auditory evolied fields, Electroencepinalogr. Clin. Neurophysiol. 45, 114-1 17 (1978).

18411. Misra, D. N., Bowen, R. L., Mattamal, G. J., Surface area of dental enamel, bone, and hydroxyapatite: Chemisorption from solution, Calcif. Tiss. Res. 26, I 39-142 (1978).

18430. Stahl, F. 1., Exit emergency: A bhueprint for design stamdards research, The Consiruction Specifier, pp. 65-77 (Feb. 1979).

18441. Dick, C: E., Soares, C. G., Motz, J. W., X-ray scatter data for diagnostic radiology, Phys. Med. Biol. 23, No. 6, 1076-1085 (1978).

18461. Bowen, R. L., Adhesive bonding of various materials to hard tooth tissues XVII: Synthesis of a polyfunctional sur- 
face-active comonomer, J. Dent. Res. 58, No. 3, 1101-1107 (Mar. 1979).

$18 \$ 64$. Burnett, E. D., NBS hearing aid test procedures and test results of FY 78 hearing aids, Paper in Handhesk of Hearing Aid Me'usurement 1979, IB /1-69, 324 pages (Veterans Administration, Washington, DC, Mar. 1979).

18465. Calvano, N. J., Wakamiya. S., Dohbyn, R. C., Technical Coordinators, The ballistic resistance of police body armor, NILECJ-STD-()101.01, 17 palges (U.S. Department of Justicc, Law Enforcement Assistance Administration, National Institute of Law Enforcement and Criminal Justice, Washington, DC, Dec. 1978).

18492. Mills, R., Velapoldi, R. A., Technical Coordinators, Chemical spot test kits for preliminary identification of drugs of abuse, NILECJ-STD-0604.00, 19 pages (U.S. Depurtment of Justice, Law Enforcement Assistance Administration, National Institute of Law Enforcement and Criminal Justice, Washington, DC, Dec. 1978).

18497. Paffenbarger, G. C., The contributions to dental science of Robert J. Nelsen (Introductory remarks), (Callahan Memorial Award of the Ohio Dental Association, Columhus, Ohio, Sept. 23, 1978), J. Am. Coll. Dent. 46, No. 1, 57-59 (Jan. 1979).

18569. Brauer, G. M., Termini, D. J., Jackson, J. A., Durability of the bond between mineralized tissues and potential adhesives, (Proc. 176th National Meeting of the American Chemical Society, Miami, FL, Sept. 11-14, 1978), ACS Symp. Series 95, Durability of Macromolecular Materials, R. K. Ehy, Ed., Paper 27, 393-410 (American Chemical Society, Washington, DC, 1979).

18571. Dulik, D. M., Evaluation of commercial and newlysynthesized amine accelerators for dental composites, $J$. Dent. Res. 58, No. 4, 1308-1316 (Apr. 1979).

18586. Paffenharger, G. C., Rupp, N. W., Patel, P. R., Dimensional change of dental amalgam and a suggested correlation between marginal integrity and creep, J. Am. Dent. Assec. 99 , 31-37 (July 1979).

18638. Brauer, G. M., Kumpula, J. W., Termini, D. J., Davidson, K. M., Durability of the bond between bone and various 2-cyanoacrylates in an aqueous environment, $J$. Birmed. Muter. Res. 13, 593-606 (1979).

18644. Bowen, R. L., Compatibility of various materials with oral tissues. I: The components in composite restorations, (Proc. Composites in Dentistry Symp. Celebrating the 50th Anniv. of Cooperation Between the ADA and NBS in Dental Research 1928-1978, held in conjunction with the $56 \mathrm{th}$ General Session of the Int. Assoc. for Dental Rcsearch, Washington, DC, Mar. 15, 1978, W. E. Brown, R. L. Bowen, G. C. Paffenharger, and D. F. Taylor, Eds.), J. Dent. Res. 58, No. 5, 1493-1503 (May 1979).

18649. Dickson, G., Physical and chemical properties and wear, (Proc. Composites in Dentistry Symp. Celebrating the 50th Anniv. of Cooperation Between the ADA and NBS in Dental Research 1928-1978, held in conjunction with the 56th General Session of the Int. Assoc. for Dental Research, Washington, DC, Mar. 15, 1978, W. E. Brown, R. L. Bowen, G. C. Paffenbarger, and D. F. Taylor, Eds.), J. Dent. Res. 58, No. 5, 1535-1543 (May 1979)

18676. Paffenbarger, G. C., Fifty years of cooperative research between the American Dental Association and the National Bureau of Standards: A historical perspective 1928-1978, (Proc. Composites in Dentistry Symp. Celebrating the 50th Anniv. of Cooperation Between the ADA and NBS in Dental Research 1928-1978, held in conjunction with the 56th General Session of the Int. Assoc. for Dental Research, Washington, DC, Mar: 15, 1978, W. E. Brown, R. L. Bowen, G. C. Paffenharger, and D. F. Taylor, Eds.), J. Dent. Res. 58, No. 5, 1486-1492 (May 1979).
8684. Rupp, N. W., Clinical placement and performance of composite resin restorations, (Proc. Composites in Dentistry Symp. Celehrating the 50th Anniv. of Cooperation Between the ADA and NBS in Dental Research 1928-1978, held in conjunction with the 56 th General Session of the Int. Assoc. for Dental Research, Washington, DC, Mar. 15, 1978, W. E. Brown, R. L. Bowen, G. C. Patfenbarger, and D. F. Taylor, Eds. ), J. Dent. Res. 58, No. 5, 1551-1557 (May 1979).

18690. Stanley, H. R., Bowen, R. L., Folio, J., Compatibility of various materials with oral tissues. II: Pulp responses to composite ingredients, (Proc. Composites in Dentistry Symp. Celehrating the 50th Anniv. of Cooperation Between the ADA and NBS in Dental Research 1928-1978, held in conjunction with the 56th General Session of the Int. Assoc. for Dcntal Research, Washington, DC, Mar. 15, 1978, W. E. Brown, R. L. Bowen, G. C. Paffenharger, and D. F. Taylor, Eds.), J. Dent. Res. 58, No. 5, 1507-1517 (May 1979).

18729. Paffenbarger, G. C., Rupp, N. W., Patel, P. R., Linear dimensional change of copper-rich dertal amalgam, J. Am. Dent. Assoc. 99, 468-47I (Sept. 1979).

18735. Goodwin, K. E., Schleter, J. C., Maltese, M. D. K., Diversion Path Analysis Handbook Vol. 1, Methodology; Vol. 2, Example; Vol. 3, Computer Program 1; Vol. 4, Computer Program 2, DOE HCP/D60/0-(01/1, 157 pages; DOE HCP/D6010-0l/2, 287 pages; DOE HCP/D60l0-0l/3, 194 pages; $D O E H C P / D 6010-01 / 4,123$ pages (Available from the National Technical Information Service, Springfield, VA 22161, Nov. 1978)

18761. Cavallo, L. M., Golas, D. B., Mann, W. B., The traceability program for radiopharmaceuticals at the United States National Bureau of Standards, A. N. Z. Nucleur Medicine Newsletter, pp. 15-16 (1979).

18809. Brauer, G. M., Petrianyk, N., Termini, D. J., Storage stability of dental composites, J. Dent. Res. 58, No. 8, 1791 1800 ( Aug. 1979).

18834. Wagner, H. L., Dillon, J. G., A specification method for ultra high molecular weight polyethylene for implant use, $J$. Biomed. Mater. Res. 13, $821-824$ (1979).

18882. Katzke, S. W., Software certification-Fact or fancy?, Proc. Seventh Antual Conf. of The Society for Computer Medicine on Effective Performance in the Dynamic Health Care Environment, Las Vegas, NV, Nov. 9-11, 1977, Invited Paper 3.4, N. S. Hill, Ed., pp. I-1I (The Society for Computer Medicine, Minneapolis, MN, Dec. 1977).

18890. Knab, L. 1., Numerical aid to reduce construction injury losses, J. Consir. Div., Am. Soc. Civ. Eng. 104, No. C04, Proc. Paper 14213, 437-445 (Dec. 1978).

18985. Brauer, G. M., Jackson, J. A., Termini, D. J., Bonding of acrylic resins to dentin with 2-cyanoacrylate esters, $J$. Dent. Res. 58, No. 9, 1900-1907 (Sept. 1979).

19038. Collard, J. J., The search for a safe police tire, The $P_{(y-}$ lice Chief XLVI, No. 12, 30-34 (Dec. 1979).

\section{Instrumentation and Experimental Methods}

A high precision load cell mass comparator, R. M. Schoonover, J. Res. Nat. Bur. Stund. (U.S.), 84, No. 5, 347-351 (Sept.Oct. 1979).

TN987. A servo controlled electro-optic modulator for $\mathrm{cw}$ laser power stabilization and control, J. B. Fowler, M. A. Lind, and E. F. Zalewski, Nat. Bur. Stand. (U.S.), Tech. Note 987, 16 pages (Apr. 1979) SN003-003-02049-4.

TN1110. NBS interagency transducer project 1951-1979-An overview. P. S. Lederer, Nat. Bur. Stand. (U.S.), Tech. Note 1110,45 pages (Aug. 1979) SN003-003-02109-1

NBSIR 79-1604. A comparison of centrifuge and freezing calorimeter methods for measuring free water in snow, R. N Jones, 43 pages (May 1979). Order from NTIS as PB296321. 
1).S. Patent 4,139,933. Method for fabricating a scanning electrom microscope micrometer scale, D. B. Bullurd, F. Oghurn, and J. P. Young, 6 pages (Feb. 20, 1979).

18318 . Hartman, A. W.. Piezoelectric inchworm operation in a vacuum, (1pt. Eng. 17, No. 6, 645-646 (Nov.-Dec. 1978).

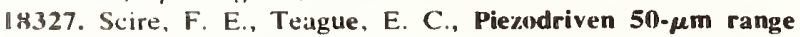
stage with subnanometer resolution, Rev. Sit. Instrum. 49, No) 12,1735-1740) (Dec. 1978)

18376. Chang, S. S., Automated adiabatic calorimetric system for heat capacity measurement, Proc. $7 t h$ Symp. on Thermophysical Properties, Gaithershurg, MD, May 10-12, 1977, pp. 75-82 (The American Society of Mechanical Engineers, New York, NY, 1977).

18399. Boettinger, W. J., Burdette, H. E., Kuriyama, M., X-ray magnifier, Rev. Sici. Instrum. 50, No. 1, 26-30 (Jan. 1979).

18447. Dickens, B., Experiences in developing an automated factor-jump method of thermogravimetry, Thermochim. Acta 29, $87-113(1979)$.

18450. Dickens, B., Automation of factor-jump thermogravimetry for active computer control, Thermochim. Acta 29, $41-56(1979)$.

18503. Schoenwetter, H. K., A high-speed low-noise 18-bit digital-to-analog converter, IEEE Trans. Instrum. Meas. IM27. No. 4, 413-417 (Dec. 1978).

18505. Souders, T. M., A bridge circuit for the dynamic characterization of sample/hold amplifiers, IEEE Trans. Instrum. Meus. IM-27, No. 4, 409-413 (Dec. 1978).

18590. Linsky, J. L., High resolution spectrograph for the space Ielescope, (Proc. Society of Photo-Optical Instrumentation Engineers, Tucson, AR, Jan. 29-Feb. 1, 1979), SPIE I72 Insirumentation in Astronomy III, 254-263 (1979).

18663. Giffard, R. P., Michelson, P. F., Soulen, R. J., Jr., Low frequency impedance and noise properties of an $r f$ biased resistive SQU1D, (Proc. 1978 Applied Superconductivity Conf., Pittsburgh, PA, Sept. 25-28, 1978), IEEE Trans. Mag. 15, No. 1, 276-279 (Jan. 1979).

18678 . Peterson, R. L., Analog-to-digital conversion with a SQU1D: Conditions for a countable pulse train, J. Appl. Phys. 50, No, 6, 4231-4239 (June 1979).

18846. Holdeman, L. B., Trapped-flux spin-down torques on a spherical superconducting gyroscope, J. Appl. P/tys. 49, No. 3, 951-954 (Mar. 1978).

18962. Frederick, N. V., Haynes, W. M., Differential capacitance sensor as position detector for a magnetic suspension densimeter, Rev. Sci. Instrum. 50, No. 9, 1154-1155 (Sept. 1979).

18987. Straty, G C., Younglove, B. A., Compact capacitor for wide-range dielectric constant measurements on small amounts of fluids, Rev. Sci. Instrum. 50, No. 10, 1309-1310 (Oct. 1979 ).

19000. Yin, L. I., Seltzer, S. M., The Lixiscope: A pocket-size x-ray imaging system, Plys. Med. Biol. 23, No. 5, 993-997 $\{1978\}$

\section{Lasers and Their Applications}

SP541. Laser induced dasmage in optical materials: 1978. Proceedings of a Symposium Sponsored by: National Bureau of Siandards, American Society for Testing and Materials, Office of Naval Research, Department of Energy, Defense Advanced Research Project Agency, NBS Boulder, CO, Sept. 12-14, 1978, A. J. Glass and A. H. Guenther, Eds., Nat. Bur. Siturd. (U.S.), Spec. Puhl. 54I, 362 pages (Dec. 1978) SNO()3-003-02052-4

Discussion of a theory of analysis of rate calorimetry which includes coating absorption, N. C. Fernelius and G. T. Johnston, SP541, pp. 7-12 (Dec. 1978).

Absorption coefficient of $\mathrm{NaF}$ by attenuated total reflection spectroscopy, D. L. Burdick, SP54I, pp. 13-18 (Dec. 1978).
Laser calorimetric measurement of two photon absorption, M. Bass, E. W. Van Stryland, and A. F. Stewart, SP541, pp. 19-23 (Dec. 1978)

A comparison of bulk and surface absorptions in $\mathrm{NaCl}$ and KCl between 9.2 and $10.8 \mu \mathrm{m}, \mathrm{H}$. Vora, M. C. Ohmer, and T. G. Stoebe, SP541, pp. 24-32 (Dec. 1978).

A $1.06 \mu \mathrm{m}$ laser absorption calorimeter for optical coatings, T. H. Allen, J. H. Apfel, and C. K. Carniglia, SP54I, pp. 33-36 (Dec. 1978).

Measured thin film absorption at the air-film interface, the film bulk, and the film-substrate interface, P. A. Temple, D. L. Decker, T. M. Donovan, and J. W. Bethke, SP54 I, pp. 37-42 (Dec. 1978).

Photoacoustic spectroscopy studies of thin film coatings on laser windows, N. C. Fernelius and D. A. Walsh, SP541, pp. 43-49 (Dec. 1978).

Piezo-optic coefficients of some neodymium doped laser glasses and single crystals of $\mathrm{CaF}_{2}, \mathrm{BaF}_{2}$ and $\mathrm{SrF}_{2}, \mathrm{R} . \mathrm{M}$. Waxler, A. Feldman, and D. Horowitz, SP54/, pp. 50-54 (Dec. 1978).

Refractive index of strontium fluoride, M. J. Dodge, SP54I, pp. 55-58 (Dec. 1978).

The development of fluorides for high power laser optics, $J$. F. Ready, H. Vora, R. A. Skogman, K. M. Leung, and E. Bernal, SP541, pp. 59-64 (Dec. 1978).

Optical properties of $\mathrm{KCl}$ forged between optically polished dies, R. H. Anderson and J. M. Bennett, SP54l, pp. 65-69 (Dec. 1978).

Bulk optical properties of fine grained forged calcium fluoride, R. H. Anderson, R. A. Skogman, J. F. Ready, and J. M. Bennett, SP541, pp. $70-77$ (Dec. 1978).

CW laser damage in $A R$ coated alkaline earth fluorides at $3.8 \mu \mathrm{m}$, J. A. Detrio and R. D. Petty, SP54/, pp. 78-85 (Dec. 1978 ).

Lattice absorption, phonon assignments, and image spoiling properties of CVD $\mathrm{ZmS}$ in the infrared, C. Klein, $\mathrm{B}$. diBenedetto, R. Donadio, T. Kohane, and J. Pappis, SP54I, pp. 86-97 (Dec. 1978).

Laser induced damage in fluoride glasses: A status report, S. E. Stokowski, D. Milam, and M. J. Weber, SP54I, pp. 99-108 (Dec. 1978).

Liquids for high repetition rate glass laser systems, J. M. Rinefierd, S. D. Jacobs, D. C. Brown. J. A. Abate, O. Lewis, and H. Appelbaum, SP54I, pp. 109-121 (Dec. 1978).

Physical and optical properties of surfaces generated by diamond-turning on an advanced machine, D. L. Decker and D. J. Grandjean, SP541, pp. 122-130 (Dec. 1978).

Optical and metallurgical characterization of molybdenum laser mirrors, S. M. Wong, G. Krauss, and J. M. Bennett, SP54I, pp. 132-163 (Dec. 1978)

1064-nm laser damage thresholds of polished glass surfaces as a function of pulse duration and surface roughness, D. Milam, SP54I, pp. 164-167 (Dec. 1978)

Large giant and free-running laser pulse energy and power densities through optical fibers, M. J. Landry, SP54/, pp. 168-189 (Dec. 1978).

Ultraviolet damage resistance of laser coatings, B. E. Newnam and D. H. Gill, SP541, pp. 190-202 (Dec. 1978).

Multithreshold evaluation of 100 -nsec pulsed laser damage to coating materials at $2.7-$ and $3.8-\mu \mathrm{m}$ wavelengths, $J . O$. Porteus, T. M. Donovan, J. L. Jernigan, and W. N. Faith, SP54I, pp. 202-211 (Dec. 1978)

Multithreshold damage measurements on $A s_{2} S_{3}, A s_{2} S_{3}$, and NaF at $\mathrm{HF}$ and $\mathrm{DF}$ wavelengths, T. $\mathrm{M}$. Donovan, J. O. Porteus, J. L. Jernigan, and E. J. Ashley, SP54/, pp. 212-217 (Dec. 1978).

TEM investigation of effects of a barrier layer on damage to $1.064 \mu$ Ar coatings, C. K. Carniglia, J. H. Apfel, G. B. Carrier, and D. Milam, SP54l, pp. 218-225 (Dec. 1978 ). 
Optical techniques for the determination of pulsed laser damage in thin films, T. W. Walker, A. H. Guenther, and P. E. Nielsen, SP54l, pp. 226-234 (Dec. 1978).

A statistical analysis of absorptive laser damage in dielectric thin films, A. B. Budgor and K. F. Luria-Budgor, SP541, pp. 235-248 (Dec. 1978).

New coating materials for $I R$ laser optical components, $R$. C. Pastor, J. A. Harrington, L. E. Gorre, and R. K. Chew, SP541, pp. 249-256 (Dec. 1978).

Improved $\mathrm{PbF}_{2}$ coatings for the infrared, $P$. Baumeister, $G$ P. Arnold, and D. F. Edwards, SP541, pp. 257-258 (Dec. 1978).

Graded index coatings of cubic thallium iodide (TII) and lead fluoride $\left(\mathbf{P b F}_{2}\right), \mathrm{T}$. J. Moravec and R. A. Skogman, SP541, pp. 259-265 (Dec. 1978).

Simple expressions for calculating the effect of volume or interface absorption in thin films on the performance of high reflectance or antireflectance multilayer coatings, H. E. Bennett and D. K. Burge, SP541, pp. 266-277 (Dec. 1978).

Simplified description of dielectric reflectors, $M$. Sparks and M. Flannery, SP541, pp. 278-287 (Dec. 1978).

Electric fields near coated surfaces: Application to damage protection, H. B. Rosenstock, SP541, pp. 288-295 (Dec. 1978).

Computer simulation of laser damage morphology in the alkali-halides, P. Kelly, D. Ritchie, P. Braunlich, and A. Schmid, SP541, pp. 296-298 (Dec. 1978).

The relative role of impact and multiphoton ionization mechanisms in laser induced damage of transparent dielectrics, B. G. Gorshkov, A. S. Epifanov, and A. A. Manenkov, SP541, Pp. 299-302 (Dec. 1978).

Theory of laser damage in dielectric solids, S. Brawer and W. L. Smith, SP541, pp. 303-304 (Dec. 1978).

Laser-induced damage in semiconductors, Y. K. Danileiko, A. A. Manenkov, and A. V. Sidorin, SP54I, pp. 305-308 (Dec. 1978).

Frequency dependence of breakdown fields in single-crystal $\mathrm{NaCl}$ and $\mathrm{KCl}, \mathrm{M}$. J. Soileau, M. Bass, and E. W. Van Stryland, SP541, pp. 309-317 (Dec. 1978).

Investigation of surface breakdown mechanism in 1R-optical materials, V. I. Kovalev and F. S. Faizullov, SP541, pp. 318 326 (Dec. 1978).

TN1009. Laser beam profile measurements using spatial sampling, Fourier optics, and holography, E. G. Johnson, Jr., Nat. Bur. Stand. (U.S.), Tech. Note 1009, 96 pages (Jan. 1979) SN003-003-02019-2.

TN1010. Measurement of pulsed-laser power, $M$. Young and R. A. Lawton, Nat. Bur. Stand. (U.S.), Tech. Note 1010, 40 pages (Feb. 1979) SN003-003-02028-1.

TN1015. Design of a reflection apparatus for laser beam profile measurements, E. G. Johnson, Jr., Nat. Bur. Stand. (U.S.), Tech. Note 1015, 124 pages (July 1979) SN003-003-021032.

NBSIR 79-1619. Quality assurance program for the NBS C, K, and $\mathbf{Q}$ laser calibration systems, W. E. Case, 101 pages (Aug 1979). Order from NTIS as PB80-1 18508

18319. McNeil, J. R., Johnson, W. L.. Collins, G. J., Persson, K. B., Franzen, D. L., Laser action in sputtered metal vapors, Proc. IXth Int. Conf. on Quantum Electronics, Amsterdam, The Netherlands, June 14-18, 1976, pp. 162-163 (North-Holland Publishing Co., Amsterdam, The Netherlands, 1976).

18364. Keller, R. A., Travis, J. C., Recent advances in analytical laser spectroscopy, Paper in Analytical Laser Spectroscopy', N. Omenetto, Ed., Chapter 8, 493-538 (John Wiley \& Sons, Inc., New York, NY, 1979).

18426. Inguscio, M., Strumia, F., Evenson, K. M., Jennings, D A., Scalabrin, A., Stein, S. R., Far-infrared $\mathbf{C H}_{3}$ F Stark laser, Opt. Lett. 4, No. 1, 9-11 (Jan. 1979).
18476. Geist, J., Applications of absolute radiometers, Proc 10th Annual Electro-Optics Laser 78 Conf., Boston, MA, Sept 19-21, 1978, pp. 277-284 (Industrial and Scientific Conference Management, Inc., Chicago, IL, 1978).

18551. Streit, G. E., Wells, J. S., Fehsenfeld, F. C., Howard, C. J., A tunable diode laser study of the reactions of nitric and nitrous acids: $\mathrm{HNO}_{3}+\mathrm{NO}$ and $\mathrm{HNO}_{2}+\mathrm{O}_{3}$, J. Chem. Phys. 70, No. 7, 3439-3443 (Apr. 1979).

18558. Levenson, M. D., Eesley, G. L., Polarization selective optical heterodyne detection for dramatically improved sensitivity in laser spectroscopy, Appl. Phys. 19, No. 1, 1-17, (1979).

18573. Baughcum, S. L., Leone, S. R., Free radical studies by excimer laser ultraviolet photolysis, (Proc. 22d Int. Tech. Symp. and Instrument Display, University of Arizona, Tucson, AZ, Aug. 4-5, 1978), Luser Spectrosc. 158, 29-32 (1978).

18662. Franzen, D. L., Danielson, B. L., Day, G. W., A simple first positive system nitrogen laser for use in optical fiber measurements, IEEE J. Quantum Electron. QE-14, No. 6, 402404 (June 1978).

18667. Horwitz, A. B., Leone, S. R., Versatile, isotopically specific hydrogen halide TEA pin laser, Rev. Sici. Instrum. 50, No. 7, 811-816 (July 1979).

18686. Schaefer, J. C., Chabay, I., Generation of enhanced coherent anti-Stokes Raman spectroscopy signals in liquidfilled waveguides, Opt. Lett. 4, No. 8, 227-229 (Aug. 1979).

18709. Braun, W., Herron, J. T., Tsang, W., Churney, K., High intensity infrared laser irradiation calorimetry: Direct-determination of heat input to chlorodifluoromethane and ethyl acetate, Chem. Phys. Lett. 59, No. 3, $492-497$ (Dec. 1, 1978 ).

18710. Rosenberg, L., Coulomb scattering in a laser field, Phys. Rev. A 20, No. 2, 457-464 (Aug. 1979).

18711. Rosenberg, L., Generalized low-frequency approximation for scattering in a laser field. 1I, Phys. Rev. A 20, No. 1, 275 280 (July 1979).

18712. Tsang, W., Walker, J. A., Braun, W., Herron, J. T., Mechanisms of decomposition of mixtures of ethyl acetate and isopropyl bromide subjected to pulsed infrared laser irradiation, Chem. Phys. Lett. 59, No. 3, 487-491 (Dec. 1, 1978).

18799. Lam, L. K., Schearer, L. D., Laser initiated afterglow in a high pressure $\mathrm{K}-\mathrm{Kr}$ mixture, Chem. Phys. Lett. 60, No. 1, 130-134 (Dec. 15, 1978).

18806. Travis, J. C., Schenck, P. K., Turk, G. C., Mallard, W. G., Effect of selective laser excitation on the ionization of atomic species in flames, Anal. Chem. 51, No. 9, 1516-1520 (Aug. 1979).

18914. Sanders, A. A., National standards of a powerful sort, Opt. Spectra, pp. 45-49 (Aug. 1979).

18915. Day, G. W., Fiber measurements: Quality and cost, (Proc. Intl. Conf. on Communications, Boston, MA, June 10 14, 1979), Paper in $I C C \cdot 79$ Conference Record 1, 10.4.1$10.4 .3(1979)$.

18952. Brillet, A., Hall, J. L., An improved test of the isotropy of space using laser techniques, Proc. Fourth Int. Conf. on Laser Spectroscopy, Rottach-Egern, Germany, June 11-15, 1979, H. Walther, K. W. Rothe, Eds., pp. 12-20 (SpringerVerlag, New York, NY, Oct. 1979).

18955. Smith, S. J., Hogan, P. B., Laser bandwidth and intensity effects in multiphoton ionization of sodium, Proc. Fourth Int. Conf. on Laser Spectroscopy, Rottach-Egern, Germany, June 11-15, 1979, H. Walther, K. W. Rothe, E.ds., pp. 360367 (Springer-Verlag, New York, NY, Oct. 1979)

18958. Abraham, J. L., Etz, E. S., Molecular microanalysis of pathological specimens in situ with a laser-Raman microprobe, Sci. 206, 716-718 (Nov. 9, 1979).

18963. Etz, E. S., Raman microprobe analysis: Principles and applications, Scanning Electron Microsc. Pt. I, pp. 67-82 and 92 (1979). 
1 8968. Warner, B. E., Persson, K. B., Collins, G. J., Metalvapor production by sputtering in a hollow-cathode discharge: Theory and experiment, J. Appl. Phys. 50, No. 9, 5694-5703 (Sept. 1979).

18982. Casciani, F. S., Etz, E. S., Raman microprobe study of hiological mineralization in situ: Enamel of the rat incisor, Proc. Fourlecenth Ann. Microbeam Analysis Society/1979 Conf., Sian Antonio, TX, Aug. 13-17, 1979, pp. 169-172 (San Francisco Press, Inc., San Francisco, CA, 1979 ).

18983. Turk, G. C., Mallard, W. G., Schenck, P. K., Smyth, K C., Improved sensitivity for laser enhanced ionization spectrometry in flames by stepwise excitation, Anal. Chem. 51, No. 14, 2408-2410 (Dec. 1979).

19008. Casciani, F. S., Etz, E. S., Newbury, D. E., Doty, S. B., Raman microprobe studies of two mineralizing tissues: Enamel of the rat incisor and the embryonic chick tibia, Sicunning Electron Microsc. Pt. II, pp. 383-391 (1979).

19021. Young, M., Continuous-wave (mode-locked) dye laser with unfolded cavity, Appl. Ope. 18, No. 19, 3212 (Oct. 1, 1979).

\section{Low Temperature Science and Engineering}

NBSIR 79-1607. Producing slush oxygen with an auger and measuring the storage characteristics of slush hydrogen, $R$. $O$. Voth and P. R. Ludtke, 41 pages (Mar. 1979). Order from NTIS as PB298555.

U.S. Patent 4,143,520. Cryogenic refrigeration system, J. E. Zimmerman, 8 pages (Mar. 13, 1979).

18419. Ho, J. C., King, G. B., Fickett, F. R., Low temperature specific heat of two stainless steels, Cryogenics 18, No. 5, 296298 (May 1978).

18548. Van Degrift, C. T., Bowers, W. J., Jr., Wildes, D. G., Pipes, P. B., A small gas thermometer for use at low temperatures, (Proc. 15th Int. Conf. on Low Temperature Physics, Grenoble, France, Aug. 23-29, 1978), J. Phys. 6, Suppl 8, No. 39, C6-1173-C6-1174 (Aug. 1978).

18553. Rainwater, J. C., Evaluation of frequency sums for the free energy of superfluid ' ${ }^{3} \mathrm{He}$, Phys. Rev. B 18, No. 7, 37283729 (Oct. 1, 1978).

18560. Kasen, M. B., Composite laminate applications in magnetic fusion energy superconducting magnet systems, ICCM/2 Proc. Int. Conf. on Composite Materials, 2d, Toronto, Ontario, Canada, Apr. I6-20, 1978, B. R. Norton, R. A. Signorelli, K. N. Street, and L. N. Phillips, Eds., pp. 1493-1507 (Metallurgical Society of the AIME, Warrendale, PA, 1978).

18564. Diller, D. E., LNG thermophysical properties data and custody transfer, GASTECH 78, Proc. Int. LNG/LPG Conf. and Exhibition, 6th, Monte-Carlo, Monaco, Nov. 7-10, 1978, 1, Session 2A, Presentation 1, 1-16 (GASTECH Exhibitions, Ltd., Rickmansworth, England, 1978).

18610. McHenry, H. I., Naranjo, S. E., Read, D. T., Reed, R. P., Low-temperature fracture properties of a USSR aluminum-6\% magnesium alloy, (Proc. $2 \mathrm{~d}$ Int. Cryogenic Materials Conf., Boulder, CO, Aug. 3-5, 1977), Paper K-3 in Advances in Cryogenic Engineering, K. D. Timmerhaus, R. P. Reed, and A. F. Clark, Eds., 24, 519-528 (Plenum Press, New York, NY, 1978).

18611. Tobler, R. L., Low temperature fracture behavior of a Ti-6Al-4V alloy and its electron beam welds, Am. Soc. Test. Mater. Spec. Tech. Publ. 651, pp. 267-294 (1978).

18617. Johnson, W. W., Jones, M. C., Measurements of axial heat transport in helium II with forced convection, (Proc. 2d Int. Cryogenic Materials Conf,, Boulder, CO, Aug. 3-5, 1977), Paper G-6 in Advances in Cryogenic Engineering, K. D. Timmerhaus, R. P. Reed, and A. F. Clark, Eds., 24, 363370 (Plenum Press, New York, NY, 1978).

18622. Ekin, J. W., Fatigue and stress effects in NbTi and $\mathrm{Nb}_{\sharp} \mathrm{Sn}$ multifilamentary superconductors, (Proc. 2d Int.
Cryogenic Materials Conf., Boulder, CO, Aug. 3-5, 1977), Paper F-1 in Advances in Cryogenic Engineering, K. D. Timmerhaus, R. P. Reed, and A. F. Clark, Eds., 24, 306-316 (Plenum Press, New York, NY, 1978).

18627. Haynes, W. M., Measurements of the orthobaric tiquid densities of argon (100-120 K) and ethylene (105-200 K), Cryogenics 18, No. 10, 621-623 (Oct. 1978).

18630. Ledbetter, H. M., Elastic constants at low temperatures: Recent measurements on technological materials at NBS, (Proc. 2d Int. Cryogenic Materials Conf., Boulder, CO, Aug. 3-5, 1977), Paper A-9 in Advances in Cryogenic Engineering, K. D. Timmerhaus, R. P. Reed, and A. F. Clark, Eds., 24, 103-119 (Plenum Press, New York, NY, 1978).

18631. Kasen, M. B., Composite materials for cryogenic structures, (Proc. 2d Int. Cryogenic Materials Conf., Boulder, CO, Aug. 3-5, 1977), Puper A-5 in Advances in Cryogenic Engineering, K. D. Timmerhaus, R. P. Reed, and A. F. Clark, Eds., 24, 63-73 (Plenum Press, New York, NY, 1978).

18655. Fickett, F. R., Investigation of a practical superconductor with a copper matrix, INCRA Project No. 255 Annual Report, 44 pages (International Copper Research Association, lnc., New York, NY, Jan. 1978).

18656. Fickett, F. R., Investigation of a practical superconductor with a copper matrix, INCRA Project No. 255A Annual Report, 64 pages (International Copper Research Association, Inc., New York, NY, Dec. 1978).

18679. Radebaugh, R., Ultralow-temperature physics In Japan, Off. Nav. Res. (Tokyo) Sci. Bull. 3, No. 2, 1-6 (Apr.-June 1978).

18680. Radebaugh, R., Lawless, W. N., Siegwarth, J. D., Morrow, A. J., Feaslbillty of electrocaloric refrigeration for the 4-15 K temperature range, Cryogenics 19, No. 4, 187-208 (Apr. 1979).

18681. Read, D. T., Ekin, J. W., Powell, R. L., Clark, A. F., Definitions of terms for practical superconductors. 3 . Fabrication, stabilization and transient losses, Cryogencis 19, No. 6, 327-332 (June 1979).

18700. Zimmerman, J. E., Cryocoolers for superconductive electronics, (AlP Conf. Proc. No. 44, Conf. on Future Trends in Superconductive Electronics, Charlottesville, VA, Mar. 2325, 1978, Series Editor: H. C. Wolfe), Paper in Future Trends in Superconductive Electronics, B. S. Deaver, Jr., C. M. Falco, J. H. Harris, S. A. Wolf, Eds., Sec. 7, pp. 412-420 (American Institute of Physics, New York, NY, 1979).

18701. Zimmerman, J. E., Sullivan, D. B., Superconducting devices, Paper in McGraw-Hill Yearbook of Science and Technology, pp. 378-380 (McGraw-Hill Book Company, New York, NY, 1979).

18713. Mopsik, F. 1., Khoury, F., Kryder, S. J., Bolz, L. H., The dielectric loss of polypropylene films and polypropylene-polyurethane laminates at cryogenic temperatures, (Proc. ICMC Symp. on Nonmetallic Materials and Composites at Low Temperatures, Munich, W. Germany, July 10-11, 1978), Paper in Nonmetallic Materials and Composites at Low Temperatures, A. F. Clark, R. P. Reed, G. Hartwig, Eds., pp. 8596 (Plenum Press, New York, NY, 1979).

18716. Ledbetter, H. M., Dynamic elastic modulus and internal friction in fibrous composites, (Proc. ICMC Symp. on Nonmetallic Materials and Composites at Low Temperatures, Munich, W. Germany, July 10-11, 1978), Paper in Nonmetallic Materials and Composites at Low Temperatures, A. F. Clark, R. P. Reed, G. Hartwig, Eds., pp. 267-281 (Plenum Press, New York, NY, 1979).

18717. Kasen, M. B., Cryogenic applications of composite technology, (Proc. ICMC Symp. on Nonmetallic Materials and Composites at Low Temperatures, Munich, W. Germany, July 10-11, 1978), Paper in Nonmetallic Materials and Composices at Low Temperatures, A. F. Clark, R. P. Reed, G. Hartwig, Eds., pp. 317-337 (Plenum Press, New York, NY, 1979). 
18718. F.kin. J. W. Schramm, R. F.. ('lirk. A. F. Fffect of strain on epoxy-impregnated superconducting composites, (Proc. IC 'MC Symp. on Nonmetallic Mitterials and Compusites alt l.ow Temperattures. Mutich, W. Ciermany. July I011. 1974). Paper in Nommetallic Malerials and (omposites at Isw Timpratures. A. F. ('lark, R. P'. Reed, G. Hartwig. Eds. pp. 301-308 (Plenum Press, New York. NY. 1979)

18719. Sparhs. L. L.. Cryogenic foam insulations: Polyurethane and polystyrene. (Proc. ICMC Symp. oII Nonmetallic Materials and composites at Low Temperatures, Munich, W. Germatny. July I(1)-11, 1978). Paper in Nommetallic Moterials and (immpusiles al Low Temperature's, A. F. Clark, R. P. Reed, G. H:artwig. Fils., pp. 165-205 (Plenum Press. New York. NY. 1979).

18762. Clark, A. F., Ekin, J. W., Radebaugh, R., Read, D. T., The development of standards for practical superconductors, IEEE Trans. Mas. 15, No. 1. 224-227 (Jan. 1979).

18771. Kasen, M. B., High-pressure industrial laminates for cryogenic applications, Compess. Tech. Rev'. Rese'ard/ Briefs, 1, No. 3. 17 (1979).

18775. Haynes. W. M. McCarty, R. D., The density of liquefied natural gas, Proc. 5sth Gus Processors Association Ann. Convintion. Demer. C(), Mar, 19-21, 1979, pp. 10-16 (Gas Processors Assoc., Tulsa, OK, 1979)

18776. Hord. J.. How safe is hydrogen?, Proc: Hydroge'n for Energy Distrihution Symp., Clicago, IL, July 24-28, I978, pp. n1.3-64.3 (Institute of Gas Technology, Chicago, IL, Jan. 1979).

18780. F.kin, J. W., Strain dependence of the critical current and critical field in multifilamentary $\mathrm{Nb}_{:} \mathrm{Sn}$ composites, IEEE Trans. Magn. 15. No. 1. 197-200 (Jan. 1979).

18781. Ekin. J. W.. Braginski, A. I., Effect of strain on the critical current of $\mathrm{Nb}_{3} \mathrm{Ge}$, IEEE Trants. Magn. 15, No. 1, 509-51 1 (Jiın. 1979).

18805. Siegwarth, J. D., LaBrecque, J. F., Younglove, B. A., Test of densimeters for use in the custody transfer of LNG, Proc. $53 \mathrm{~d} \mathrm{Int}$. Sihool of Hydrecarbon Measurement. Norman, ()K. Apr. II-13, 1978, pp. 385-390) (1978).

18813. Arp. V., Computer analysis of quench transients in forced-flow cooled superconductors for large MHD magnets, Proc: Supercomdusting MHI) Magnet Design Conf., Massaclussetts Inst. of Tech., Cambridge. MA, OCt. 18-19, 1978. pp. $411-4.32$ (May 1979).

18\&22. Jones. M. C.. Arp. V. D.. Review of hydrodynamics and heat transfer for large helium cooling systems, Cryogenic:s I8, No. 8. 483-490 (Aug. 1978).

18838. Diller. D. E.. NBS research on LNG thermophysical properties data and custody transfer measurement methods, Proc. Sitorage and Transfer of LNG Conf. Boumerdes, Algeria. Apr. 4-5. 197\%. pp. 125-130) (Institute of Gas Technology, Chicago, IL, 1978).

18859. Harris, R. E., Hamilton. C. A.. Fast superconducting instruments, (Proc, 44th AIP Conf. on Future Trends in Superconductive Electronics. Charlottesville, VA, Mar. 23-25. 1978). Paper in Future Trends in Superconductive Electronics, B. S. Deaver, Jr., C. M. Falco, J. H. Harris, S. A. Wolf, Eds., Pp. $448-458$ (American Institute of Physics. New York. NY, 1978).

18865. Reed. R. P., Yushchenko, K. A., Low temperature US/USSR material and weld properties for LNG applications-Part 1. Proc. 7th Int. Cryogenic Engineering Conf.. Londom. England. July 4-7. 197x, pp. 474-486 (IPC Science and Technology Press. Surrey. England, 1978).

18871. Sullivan. D. B., Holdeman, L. B.. Soulen, R. J.. Jr., The future of superconducting instruments in metrology, (Proc. 44th AIP Conf. on Future Trends in Superconductive Electronics. Charlottesville, VA, Mar. 23-25, I978), Paper in $F u$ ture Trends in Supereendurtive Electromics, B. S. Deaver. Jr.. C. M. Falco, J. H. Harris, S. A. Wolf. Eds., pp. 171-181 (American Institute of Physics. New York. NY. 1978).
18943. Tobler. R. L.. Reed. R. P.. Tensile and fracture hehavior of a nitrogen-strengthened, chromium-nickel-manganese stainless steel at cryogenic temperatures, $.4 \mathrm{~m}$. Sis. Test. Mater. Siper. Tiell. Publ. 665', pp. 537-552 (1979).

18957. Reid. D. T., Reed. R. P., Toughness, fatigue crack growth, and tensile properties of three nitrogen-strengthened stainless steels at cryogenic temperatures, (Proc. Symp. 11)7th AlME Ann. Meeting, Denver. CO. Mar. 2, 1978). Paper in The Mefal Sicience of Siainless sicels, E. W. Collings, H. W. King. Eds., pp. 92-121 (Metallurgical Society of the American Institute of Mechanical Engineers, Warrendale, PA, 19791 .

\section{Mathematical and Statistical Methods}

Cutting the d-cuhe, J. Lawrence, J. Re's. Nat. Bur. Stand. (U.S.), 84, No. 1, 49-53 (Jan.-Feb. 1979)

Non-free groups generated hy two parabolic matrices, R. J. Evans, J. Re's. Nat, Bur. Sturd. (U.S.), 84, No. 2, 179-180 (Mar.-Apr. 1979).

Exact coefficients of the limit cycle in Van der Pol's equation, A. Deprit and D. S. Schmidt, I. Res. Nat. Bur. Silund. (U.S.), 84, No. 4, 293-297 (July-Aug. 1979).

A class of double integrals involving Gaussian and trigonometric factors, D. M. Fradkin, J. Res. Nat. Bur. Stand. (U.S.), 84, No. 4. $319-326$ (July-Aug. 1979).

Generators for discrete polynomial $L_{1}$ approximation problems, P. Domich, J. Lawrence, and D. Shier, J. Re's. Nat. Bur. Sland. (U.S.), 84, No, 6. 455-488 (Nov.-Dec. 1979).

A graph coloring algorithm for large scheduling problems, $F$. T. Leighton, J. Re's. Nat. Bur. Sitand. (U.S.), 84, No. 6, 480-506 (Nov.-Dec. 1979).

SP534. Utility and use of large-scale mathematical models. Proceedings of at Workshop held at the National Bureau of Standards, Gathersburg. MD, Apr. 28-29, 1977, S. I. Gass, Ed., Nat. Bur. Stand. (U.S.), Spec, Publ. 534, 217 pages ( May 1979) SN003-003-02060-5.

The workshop issues, S. I. Gass, SP534, pp. 3-7 (May 1979).

Review of the DOD modeling effort and modeling as a profession, G. D. Brewer, SP534, pp. 9-14 (Mary 1979).

Review of the non-DOD modeling effort, G. Fromm, SP534, pp. 15-21 (May 1979).

Issues facing model de velopers 1, S. Bonder, SP534, pp. 2344 ( Mary 1979).

Issues facing model developers II, D. Meadows, SP534, pp. 45-50 ( May 1979)

Issues facing model developers III, D. Maxim, SP534, pp. 51-55 (May 1979).

Issues facing model developers IV, A. Pugh III, SP534, pp 57-59 (May 1979).

Model implementation, R. Larson. SP534, pp. 61-92 (May 1979).

Implementation of emergency service deployment models in operating agencies, J. M. Chaiken. SP534,pp. 93-106 (Mary 1979).

The PTI experience, J. Barrett, SP534, PP. 107-110 (May 1979).

The FEA project independence model experience, $H$. Greenberg, SP534, pp. 111-122 (May 1979).

The EPR1/NBER energy model assessment project, D. Kresge. SP534, pp. 123-135 (May 1979).

The energy modeling forum, W. Hogan, SP534, pp. 137 161 (May 1979).

Models in the policy process: A framework, B. Crissey, SP534,pp. 163-175 (May 1979).

Strategies in the model management, J. Mulvey, SP534.pp. 177-193 (May 1979). 
Software requirements for an improvement in transfer and adaptability of models, S. Dickhoven, SP534, pp. 195-203 (Maly 1979).

18427. Ku, H. H., Treatment of counting data, Chapter 7 in $A$ Houdhosk of Redionetivity Measurements Procedures, National Commil on Radiation Protection and Me'asurements, Report No. 58, 271-298 (NCRP, Washington, DC, Nov. 1, 1978).

18489 . Kraft, R., Finite difference techniques for diffusion and redistribution problems with segregation-type houndary conditions, ( Proc. AICA Int. Symp. on Computer Methods for Partial Differential Equations, Lehigh University, Bethlehem, PA, June 17-19, 1975), Paper in Advances in Computer Methods for Partial Differential Equations, R. Vichnevetsky, Ed., pp. 328-333 (AIC, Department of Computer Science. Rutgers University, New Brunswick, NJ, 1975).

18519. Filliben, J. J., Dataplast-An interactive system for graphics, Fortran function evaluation, and linear/non-linear fitting. Proc. 1978 Statistical Computing Section of the American Statistical Association, San Diego, CA, Aug. 14-17, 1978, pp. 344-353 (American Statistical Association. Washington, DC, 1978 )

18524. Johnson, C. R., Leighton, F. T., Rohinson, H. A., Sign patterns of inverse-positive matrices, Linear Algebra and Appl. 24, 75-83 (1979).

18543. Eisenhart, C., On the transition from "Student's" : to "Student's" t, Am. Situt. 33, No. 1, 6-10 (Feb. 1979).

I8602. Johnson, C. R., Beine, W. B., Wang, T. J., Right-left asymmetry in an eigenvector ranking procedure, J. Math. Psychol. 19, No. 1, 61-64 (Feb. 1979).

18788. Feinberg, R. B., Characterization of incidence algebras, Discrete Math. 17, 47-70) (1977).

18789. Feinberg, R. B., Faithful distributive modules over incidence algebras, Pac. J. Math. 65, No. 1, 35-45 (1976).

18903. Hogben, D., OMNITAB 78, (Proc. Intl. Assoc. for Statistical Computing Exhibition held at the $41 \mathrm{st}$ Session of the International Statistical Institute, New Delhi, India, 1977), Chapter 11 in A Comparative Review of Statistical Soffware, 1. Francis, Ed., pp. 197-208 (1979).

18909. Johnson, C. R., Hadamard products of matrices, Lineur and Multilinear Algehra I, 295-307 (1974).

18941. Johnson, C. R., An inclusion region for the field of values of a doubly stochastic matrix based on its graph, Aequationes Math. 17, 305-310 (1978).

18990. Ku, H. H., A biography of "Youden, W. J.," Internutional Encyclopedia of Statistics, W. H. Kruskal, J. M. Tanur, Eds., pp. 1257-1261 (The Free Press, Division of MacMillan Publ. Co., Inc., New York, NY, 1978).

\section{Measurement Science and Technology:}

\section{Policy and State-of-the-Art Surveys}

Monogr. 165. An institutional plan for deyeloping national standards with special reference to environment, safety, and health, B. W. Steiner, Nat. Bur. Stand. (U.S.), Monogr. 165, 24 pages (Sept. 1979) SN003-003-02094-0, \$4.00.

SP538. National Bureau of Standards: A national resource for science and technology, M. Heyman, Nat. Bur. Stand. (U.S.), Spec. Publ. 538, 86 pages (July 1979) SNO(03-(0)3-02093-1.

SP539. Metrology in industry and government: How to find out who needs what services. Proceedings of a Regional Seminar held at the Korea Standards, Research Institute, Dae Jeon, Korea, Sept. 27-28, 1978, H. S. Peiser, R. C. Sangster, and W. Jung, Eds., Nat. Bur. Stand. (U.S.), Spec. Puhl. 539, 165 pages (Apr. 1979) SN003-003-02040-1.

Quantitative measurement is the basis for all science and technology-But are we aware of the need for metrology?, $H$. S. Peiser, SP539, p. 17 (Apr. 1979).
Quantitative measurement, the basis for all science and technology, H. S. Peiser. SP539, pp. 19-22 (Apr. 1979).

Importance of national capahility in metrology for industrial development-The Indian experience, A. R. Verma, SP539, pp. 23-28 (Apr. 1979).

Quantitative measurement as a hasic framework for science and technology. S. Takiata, SP539. pp. 29-32 (Apr. 1979).

The need for quantitative measurement in Hong Kong. $H$. K. Lam, SP539. pp. 33-34 (Apr, 1979).

National measurement capabilities for industrial development in Korea, J. W. Choi, SP539, pp. 37-41 (Apr. 1979).

Development of metrology capabilities in step with industry needs-A New Zealand experience, M. C. Probine, SP539, pp. 43-66 (Apr. 1979).

Implementing metrology for developing industrialization, $\mathrm{H}$. Kartowisastro, SP539, pp. 67-78 (Apr. 1979).

Assessment of the requirement of industries/institutions for services in the field of standards, A. Ghani, SP539, pp. 7490 (Apr. 1979)

A national capability in metrology is essential to industrial development, M. Z. Hashim, SP539, pp. 91-93 (Apr. 1979).

The National Measurement Laboratory and Australian manufacturing industry, W. R. Blevin, SP539, pp. 97-100 (Apr. 1979).

A study of the National Measurement System in Korea-An interim report: How we approached it and what we found, $W$. Jung, SP539, pp. 101-112 (Apr. 1979).

But is industry aware of its dependence on metrology?, $H$. L. K. Goonetilleke, SP539, pp. 113-116 (Apr. 1979).

The National Metrology and Calibration Service for Industry in Thailand, C. Vashrangsi, SP539, pp. 117-124 (Apr. 1979).

SP543. The technological knowledge base for industrializing countries. Proceedings of the NBS/AID UNCSTD Seminar held at the National Bureau of Standards, Gaithersburg, MD, Oct. 16-17, 1978, R. C. Sangster, Ed., Nat. Bur. Stand. (U.S.), Spec. Puhl. 543, 239 pages (Apr. 1979) SN003-003()2057-5.

Expanding horizons: Technological knowledge for industrial takeoff, H. 1. Fusfeld, SP543, pp. 24-28 (Apr. 1979).

Korean measurement capabilities: Past and present, J. W Choi, SP543, pp. 34-39 (Apr. 1979).

On the National Standards System in Korea, D. H. Kim, SP543, pp. 41-44 (Apr. 1979).

Experience of a major U.S. firm in a newly industrializing country, R. Coria, SP543, pp. 46-50 (A pr. 1979).

Electronics metrology in Argentina, H. F. Mazza, SP543, pp. 53-54 (Apr. 1979).

Programs of IPT, J. C. Waeny, SP543, pp. 55-57 (Apr. 1979).

Standardization and measurement services in Indonesia, $M$. E. E. Gandhi, SP543, pp. 58-61 (Apr. 1979).

Present status of electronic measurement standards and calibration services in India, K. Chandra, SP543, pp. 62-63 (Apr. 1979).

Standardization in the developing nations, $A$. Fadlalla, SP543, pp. 65-72 (Apr. 1979).

The international standards picture, R. B. Belford, SP543, pp. 73-76 (Apr. 1979).

Towards standardization in Guyana, L. Lawrence, SP543, pp. 78-86 (Apr. 1979).

Standardization in Panama, M. F. de Chan, SP543, pp. 8788 (Apr. 1979).

Standardization as seen in Tanzania, T. Rajuraman, SP543, pp. 89.93 (Apr. 1979).

Views on standardization, J. E. Owino-Okwero, SP543, pp 94-98 (Apr. 1979).

Progress of standardization in the Sudan, A. G. Suliman, SP543, pp. 99-100 (Apr. 1979). 
Standardization in Tunisia, R. Bouhalila, SP543, pp. 10110.5 (Apr. 1979).

Standardization in Saudi Arahia, K. Y. Al-Khalat, SP543, pp. $106-107$ (Apr. 1979).

Standardization in Jordan, R. B. Halteh, SP543, pp. 108 (11) (Apr. 1979).

Estahlishing a quality control system in an industrializing country, K. S. Stephens, SP543, pp. 113-132 (Apr. 1979).

High technology quality control in a newly industrializing society, L. K. Tatt, SP543, pp. 134-141 (Apr. 1979).

On providing the technological knowledge base for industrializing Barhados, J. L. Tudor, SP543, pp. 144-147 (Apr. $1979)$.

Certification and quality control problems in Ghana, A. O. Ntiforo, SP543, pp. 148-149 (Apr. 1979).

United States preparations for the United Nations conference on science and technology for development, J. Wilkowski, SP543.pp. 151-155 (Apr. 1979)

A survey of development efforts in Turkey. T. G. Somer, SP543, pp. 163-172 (Apr. 1979).

Experience of an industrializing nation in deployment of technical knowledge to meet national needs, M. M. Qurashi, SP543, pp. 173-190 (Apr. 1979).

Management principles in industrialization, J. A. Slater, SP543, pp. 192-193 (Apr. 1979).

Remarks prepared for the NBS/AID UNCSTD seminar: The technological knowledge base for industrializing countries, 1. S. Djermakioye, SP543, pp. 196-198 (Apr. 1979).

Knowledge required to enable a country to acquire commercial industrial technology-Experience of a country with an intermediate economy, A. P. de Castro, SP543, pp. 199-208 (Apr. 1979).

The role of technology negotiators, R. J. Radway, SP543, pp. 209-214 (Apr. 1979).

A public interest point of view of science and technology for development, J. Gudaitis, SP543, pp. 216-217 (A pr. 1979).

SP558. Efficient allocation of research funds: Economic evaluation methods with case studies in building technology, H. E. Marshall and R. T, Ruegg. Nat. Bur. Stand. (U.S.), Spec. Publ. 55., 56 pages (Dec. 1979) SN003-003-02132-6.

TN995. NBS Reactor: Summary of activities-July 1977 to June 1978, F. J. Shorten, Ed., Nat. Bur. Stand. (U.S.), Tech. Note 995, 147 pages (May 1979) SNO03-003-02070-2

NBSIR 75-935. The National Measurement System for electricity, N. B. Belecki, B. L. Dunfee, and O. Petersons, 86 pages (Sept. 1978). Order from NTIS as PB299158.

NBSIR 78-1712. Report to A1D on an NBS/A1D workshop on standardization and measurement services, H. S. Peiser, C. C. Raley, and P. M. Odar, Eds., 156 pages (May 1979). Order from NTIS as PB296326.

NBSIR 79-1703. The timely development of environmental, safety, and health standards for energy technologies, B. W. Steiner, 40 pages (Jan. 1979). Order from NTIS as PB292753.

NBSIR 79-1721. Report to AID on an NBS/AID course on weights and measures services, H. S. Peiser, C. C. Raley, and A. D. Tholen, Eds., 64 pages (Apr. 1979). Order from NTIS as PB295838.b

NBSIR 79-1792. International activities-The fiscal year 1978 survey of international programs at NEL, S. Kramer and $\mathbf{M}$. Olmert, Ed., 121 pages (Aug. 1979). Order from NTIS as PB30)491

18354. Belanger, B. C.. The role of NBS in traceability to national standards for advanced measurement systems, Proc: Industry/Joint Siervices Automatic Test Conf. and Workshop on Adianced Test Technology Management and Support, San Dieg(, CA, Apr. 3-7, I978, pp. 295-296 (National Security Industrial Association, Washington, DC, 1978).

18482. Hudion, R. P., The 1978 Nobel Prize in Physics, Science 202, 960-962 (Dec. I, 1978)
18584. Bender, P. L., Some U.S. views on scientific opportunities in ocean and earth dynamics, European Space Agency Workshop, Silloss Elmau, Germany, Jan. I6-21, 1974, S. Hieher and T. D. Gueyene, Eds., pp. 19-23 (European Space Agency, Paris, France, 1978).

18685. Sangster, R. C., R\&D for developing countries: I-The role of industrial R\&D, Res. Manage. XXII, No. 3, 34-38 (May 1979).

18720. Belanger, B. C.. Kieffer, L. J., The NBS role in quality assurance for physical measurements, Proc. Nat. Conft. on Quality Assurance of Environmental Measurements, Denver. Co, Nov. 27-29, 1978, pp. 18-22 (1979).

\section{Measurement Science and Technology:}

\section{Physical Standards and Fundamental Constants}

NBS-GCR-ETIP 79-67. Impacts of government regulations on the iron and steel industry, 1. Gutmanis, 210 pages (Aug. 1978). Order from NTIS as PB289352.

18346. Hellwig, H., Evenson, K. M., Wineland, D. J., Time, frequency and physical measurement, Phys. Today, pp. 23-30) (Dec. 1978).

18469. Deslattes, R. D., Rydberg values for $x$ - and $\boldsymbol{\gamma}$-rays, (Proc. Int. Conf. on X-ray and XUV Spectroscopy, Sendai, Japan, Aug. 28-Sept. 1, 1978), Jap. J. Appl. Phys. Suppl. 17. Part 2, 1-6 (1978)

18472. Faller, J. E., Rinker, R. L., Zumberge, M. A., Plans for the development of a portable absolute gravimeter with a few parts in $10^{\circ}$ accuracy, (Proc. 1977 Symp. on Recent Crustal Movements, Trieste, Italy, June 20-24, 1977), Paper in Tectonophysics, C. A. Whitten, R. Green, and B. K. Meade, Eds., 52, 107-116 (Elsevier Scientific Publ. Co., Amsterdam, The Netherlands, 1979).

18487. Kessler, E. G., Jr., Deslattes, R. D., Henins, A., Wavelength of the $W K \alpha_{1} x$-ray line, Phys. Rev. A 19, No. 1, $215-218$ (Jan. 1979).

18510. Kess'-r, E. G., Jr., Jacobs, L., Schwitz, W., Deslattes, R. D., Precise $\gamma$-ray energies from the radioactive decay of ${ }^{171} \mathrm{Tm}$ and ${ }^{169} \mathrm{Yb}$, Nucl. Instrum. Methods 160, 435-437 (1979).

18549. Soulen, R. J., Jr., A superconductive device to provide reference temperatures below $0.5 \mathrm{~K}$, (Proc. 15 th Int. Conf. on Low Temperature Physics, Grenoble, France, Aug. 23-29, 1978), J. Phys. 6, Suppl. 8, No. 39, C6-1166-C6-1168 (Aug. 1978).

18550. Schooley, J. F., Superconductive fixed points for temperatures above $0.5 \mathrm{~K}$, (Proc. 15th Int. Conf. on Low Temperature Physics, Grenoble, France, Aug. 23-29, 1978), J. Phys. 6, Suppl. 8, No. 39, C6-1169-C6-1170 (Aug. 1978).

18562. Jennings, D. A., Petersen, F. R., Evenson, K. M., Frequency measurement of the $260-\mathrm{THz}(1.15-\mu \mathrm{m}) \mathrm{He}-\mathrm{Ne}$ laser, Optics Lett. 4, 129-130 (May 1979).

18608. Wineland, D. J., Laser-to-microwave frequency division using synchrotron radiation, J. Appl. Phys. 50, No. 4, 25282532 (Apr. 1979).

18642. Barger, R. L., Bergquist, J. C., English, T. C., Glaze, D. J., Resolution of photon-recoil structure of the 6573-A calcium line in an atomic beam with optical Ramsey fringes, Appl. Phys. Lett. 34, No. 12, 850-852 (June 15, 1979 ).

18692. Stein, S. R., Turneaure, J. P., Superconducting resonators: High stability oscillators and applications to fundamental physics and metrology, Proc. Conf. on Future Trends in Superconductive Electronics, San Diego, CA, Mar. 27-28, 1979, pp. 192-213 (Apr. 1979).

18696. Walls, F. L., Howe, D. A., A passive hydrogen maser frequency standard, Proc. $32 d$ Ann. Symp. on Frequency Control, Atlantic City, NJ, May 3I-June 2, I978, pp. 492-498 
(1I.S. Army Electronics Research \& Development Command. Washingum. DC, 1978).

18702. Williams, E. R., Olscul. P. T., New measurement of the protan gyranugnefic ratio and a derived value of the fine-

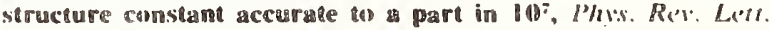
42. No. 24, 1575-1579) (Junc 11, 1979).

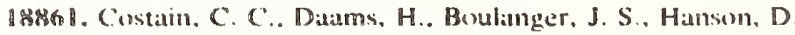
W., Kelpcrynski, W. J., Twob-way time transfers between NHC/PBS B

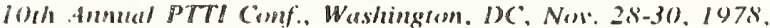
pp. $58.5-6000(1978)$

18875. Brillet, A., Hall, J. L., Improved laser test of the isotropy of space. Phys. Re'v. Lott. \$2, No, 9, 549-552 (Fub. 26, 1979).

18916. Baird, K. M., Evenson, K. M., Hanes, G. R., Jennings, D. A., Petersen, F. R., Extension of absolute-frequency measarements to the visible: Frequencies of ten hyperfine companents of iodine, (Opt. Le't. 4, No. 9, 263-264 (Sept. 1979).

18947. Fuller, J. E., Rinker, R. L., Zumberge, M. A., Progress on the development of a portable absolute gravimeter, (Proc. Conf. Bureau Gravimetriyute International, Paris, France, May 1979), Bull. d'lnf. A4, I-B-4-1-B-11 (Universite P. et M. Curi, 75230 Paris Cedex 05. France, 1979).

18993. Ashby, N., Allan, D. W.. Practical implications of relativity for a global comrdinate dime scale, (Proc. 1 9 th General Assembly of URSI, Helsinki, Finland, Aug. 1-4, 1978), Radie) Science 18, No. 4, 649-669 (American Geophysical Union, Washington, DC. July/Aug. 1979),

\section{Mechanics: Design, Testing and Measurement}

H128. Vibration isolation: Use and characterization, J. C. Snowdon, Nas. Bur. Stand. (U.S.), Handh. 128, 129 pages (May (979) SNO03-(003-1)2065-6.

NBSIR 78-1433. Low velocity performance of a bronze bearing vare anemometer, L. P. Purtell, 23 palges (Feb. 1978 ). Order from NTIS as PB291366.

NBSIR 78-1505. Characteristics of helicoid anemometers, J. M. McMichael and W. G. Cleveland, 17 pages (Aug. 1978). Order from NTIS as PB291987.

NBSIR 78-1545. Low velocity performance of a high speed vane anemameter, L. P. Purtell, 23 pages (Sept. 1978). Order from NTIS as PB291409.

NBSIR 78-1576. Final Report-Proximity-vision system for protoflight manipulator arm, J. S. Albus, 22 pages (Aug. 1978). Order from NTIS as PB291335.

NBSIR 79-1764. Image pattern recognition in industrial inspection, G. J. Vanderbrug and R. N. Nagel, 48 pages (Sept. 1979). Order from NTIS as PB8()-108871.

U.S. Patent 4,166,229. Piezoelectric poslymer menbrane stress gage, A. S. DeReggi and S. Edelman, 5 pages (Aug. 28. 1979).

18326. Fong, J. T., Uncertainties in fatigue life prediction and a rational definition of safety factors, Nuc\%. Eng. De's. 51,45$54(1978)$

18466. Colwell, J. H., A solid-dielectric capacitive pressure transducer, (Proc. 6th AlRAPT Conf., Boulder, CO, July 2529. 1977), Paper R-8 in Migh-Pressure Sichere and Technology. K. D. Timmerhaus and M. S. Barber. Eds., 1. 798-804 (Plenum Press, New York, NY, 1979).

18705. Brungraber, R. J.. Adler, S. C., Technical support for a slip-resistance standard, (Proc. American Society for Tenting and Materials Symp. on Walkway Surfaces: Measurement of Slip Resistance, Denver, CO. June 30, 1977). Am. Six. Test. Mater. Spec. Teeh. Publ. 649, pp. 40-48 (1978).

\section{Metrology: Physical Measurements}

Psychrometric wet elements as a basis for precise physico-chemical measurements. R. G. Wylie. J. Res. Nat. Bur. Stand. (U.S.), 84. No. 2.161-177 (Mar.-Apr. 1979).

Monogr. 163. Measurement assurance for gage bloxks, $C$. Croarkin, J. Beers, and C. Tucker, Nat. Bur. Sitund. (U/S.), Menengr. 163. 78 pages (Feh. 1979) SN0013-00)3-()2023-1.

SP545. Confribetions io color science, D. B. Judd and D. L MalcAdam, Ed., Nat. Bur. Siand. (U.S.), Spece. Publ. 54.5, 760 parges (Sept. 1979) SN(00.3-(00)3-02126-1.

SP546, 1979 Edition. Catalog of Federal metrology and calibration capabilities, K. O. Leedy, Nut. Bur. Stund. (U.S.), Sipec. Publ. 546, 1979 Edition, 52 pages (June 1979) SN00.3-003(1)2082-6

SP559. Time and frequency users' manual, G. Kamas and S. L. Howe, Eds., Nat. Bur. Stand. (U.S.), Spex: Puhl. $5.59,256$ panges ( Nov. 1979) SN()(1)3-(0)3-02137-1.

TNY1()-4. Self-study manual on optical radiation measurements: Part I-Concepts, chapters 7, 8, and \%, F. E. Nicodemus, Ed., Nat. Bur. Siand. (U.S.), Te'h. Note 910-4, 1.34 pages (June 1979) SN0(13-(0)3-(12067-2.

TN1105. A 20 bit + sign, relay switched D/A converter, T. M Souders and D. R. Flach. Nut. Bur. Stund. (U.S.), Tech. Nots 1105,21 pages (Oct. 1979) SN(0)3-(1)3-0)2129-6.

NBSIR 79-1742. Recent improvements to the ASTM-type ultrasonic reference block system, D. J. Chwirut, 54 pages (Apr. 1979). Order from NTIS as PB296044.

NBSIR 79-1758. The calibration of a roundness standard, C. P. Reeve, 22 pages (June 1979). Order from NTIS as PB297708.

NBSIR 79-1933. Evaluation of a multimegavolt impulse measurement system. R. E. Hebner, Jr., D. L. Hillhouse, and R. A. Bulluck, 102 pages (Nov. 1979). Order from NTIS as PB80-119720.

U.S. Patent 4,140,393. Birefrimgent crystal thermometer, T. C. Cetas, 4 pages (Feb. 20, 1979)

U.S. Patent 4.152,074. Inverse fourth power photumetric calibrator, D. A. Swyt, 6 pages (May 1, 1979).

U.S. Putent 4,165,183. Fringe counting interferometric system for high accuracy measurements, J. L. Hall and S. A. Lee, 15 pages (Aug. 21, 1979).

U.S. Patent 4,173,442. Apparatus and method for determination of wavelength, J. J. Snyder, 14 pages (Nov. 6, 1979).

18335. Hudson, R. P. NBS standards for pressure, temperature, and thumidity, (Proc. Air Quality Meteorology and Atmospheric Ozone. Boulder, CO, July 31-Aug. 6, 1977), Am. Sirc. Testing Mater. spece. Tech. Publ. 653, A. L. Morris, R. C. Barras, Eds., pp: 13-26 (1978).

18393. Hanson, D. W., Davis, D. D.. Cateora, J. V. Microprocessor-based sateltite-contralled clock, Proc. of the NBS-lEEE Microsompurer-Based Instrumentation Conf., Gaithershurg, MD, Jun' 12-13,1978, pp. 83-86 (Institute of Electrical and Electronics Engineers, Silver Spring. MD, 1978).

18401. Heydemann, P. L. M., Generation and measurement of pressure, Proc. N.ATO Summer Schosl for Migh Pressure. Corfu, Greece, Sept. 26-Oct. 7, 1977, H. Kelm, Ed.. PP. 1-49 (D. Reidel Publishing Company. Boston, MA, 1978)

18403. Mielenz, K. D., Refrection correction for fluorescence spectra of aqueous solutions, Appl. Opt. 17, No. 18. 2875 2876 (Sept. 15. 1978).

18434. Turgel, R. S., Oldham, N. M., High-precision audiofreqaency phase calibration standard, IEEE Truns. Instrum. Meas. IM-27, N17. 4, 460-464 (Dec. 1978).

18437. Williams, E. R., Olsen, P. T., A method to measure magnetic fields accurately using Ampere's law, IEEE Trans. Instrum. Mous. BM-27, No. 4, 467-469 (Dec. 1978). 
I8452. Cutkosky, R. D., A new switching technique for hinary resistive dividers, IEEE. Trans. Instrum. Meas. IM-27, No. 4. 421-422 (Dec. 1978).

18453. Cutkosky, R. D., A programmahle phase-sensitive detector for automatic hridge applications, IEEE Truns. Instrum. Mo's. IM-27, No. 4, 401-4012 (Dec. 1978).

18454. Shields, J. O.. Absolute measurement of loss angle using a toroidal cross capacitor, IEEE Trans. Instrum. Meas. IM-27, Ni). 4. 464-466 (Dec. 1978).

18455. Field. B. F., A fast response low-frequency voltmeter, IEEE Truns: Instrim. Mias. IM-27, No. 4, 368-372 (Dec. $1978)$.

18459. Bender, P. L., Faller, J. E., Levine, J., Moody, S., Pearlman. M. R., Silverberg, E. C., Possihle high-mohility LAGEOS ranging station, (Proc. 1977 Symp. on Recent Crustal Movements, Trieste, Italy, June 2()-24, 1977), Paper in Tectomophysics, C. A. Whitten, R. Green, and B. K. Meade. Eds., 52, 69-73 (Elsevier Scientific Publ. Co., Amsterdam. The Netherlands, 1979).

18477. Geist, J., Quantum efficiency of the $p-n$ junction in silicon as an absolute radiometric standard, $A p P /$. Opt. 18, No. 6. 760)-762 (Mar. 15, 1979).

18490. Lindstrom, R. M., Harrison, S. H., Harris, J. M., Accurate calibration of gold film standards by neutron activation and gravimetry, J. Appl. Phys. 49, No. 12, 5903-5908 (Dec. 1978).

18494. Misakian, M., Kotter, F. R., Discussion of F 78 169-5, "Analysis of the proximity effects in electric field measurements," IEEE Trans. Power Appar. Syst. PAS-97, No. 6. 2175-2176 (Nov./Dec. 1978).

18511. Han, C. C.. McCrackin. F. L.. Molecular weight and polydispersity measurements of polystyrene by quasielastic light scattering, Polym. 20, 427-432 (1979).

I85I3. Anderson, W. E.. Davis, R. S., Petersons, O., Moore, W. J. M.. An international comparison of high voltage capacitor calihrations, IEEE Truns. Power Appar. Syst. PAS-97, No. 4, 1217-1223 (July/Aug. 1978).

18554. Masters, L. W., Seiler, J. F., Roberts, W. E., Development of standards for evaluating solar absorptive coatings, (Proc. Division of Organic Coatings and Plastics Chemistry at the American Chemical Society/Chemical Society of Japan Chemical Congress, Honolulu, Hawaii, Apr. 1-6. 1979), Paper in Organic Cortings and Plastics Chemistry 40, 507-510 (American Chemical Society, Washington, DC, 1979).

18555. Marsbak. H., Soulen, R. J., Jr., Measurement of thermodynamic temperatures using noise and nuclear orientation thermometers, (Proc. I 5th Int. Conf. on Low Temperature Physics, Grenoble, France, Aug. 23-29, 1978). J. Phys. 6, Suppl. 8. No. 39. C6-1162-C6-1163 (Aug. 1978).

18561. Kamper, R. A., Status of RF and microwave calibration services at NBS, NCSL Newstenter 18, No. 3, 40 (Dec. 1978).

18574. Bender, P. L., Geodesy-Trends and prospects, Proc: Conf. I7th IEEE Conf. an Precision and Control Inchuding Simp. on Adaptive Processes, San Diego. CA, Jan. 10-12, 1978. PP. 455-457 (The Institute of Electrical and Electronics Engineers, Piscataway, NJ, 1978,.

18594. Weidner, V. R.. Hsia. J J.. NBS reference hazemeter: Its development and testing, Appl. (Opt. 18, No, 10, 1619. 1626 (May 15. 1979).

18603. Soulen. R. J., Jr., Noise thermometry using Josephson junctions, (Proc. 5th Int. Conf. on Noise, Bad Naubeim. Fed. Rep. of Germany. Mar. 13-16, 1978). Paper in Norise in Physical sistrms. D. Wolf, Ed., pp. 249-25y (Springer-Verlag. Berlin. Germany, 1478).

18654. Fuller. J. E., Rinker. R. L.. Zumberge. M. A.. Plans for the development of a portable absolute gravimeter: A tool for studying non-tidal variations in gravity, (Proc. Non-Tidal Variations in Gravity and Methods of Their Study Conf.. Trieste. Italy. June 20-24. 1977, Br,ll. Geofis. Teorr. App/. 20, Vo. 80 ). 355-361 (Dec. 1978 ).
18664. Grohmann, K., Zapt, T. L., An international costeparisoan of inductive voltage divider calihration methods between 10 kHz and $100 \mathrm{kH} \%$, Me't. 15, 69-75 (1979).

18665. Guildner, L. A.. Kostkowski, H. J., Evans, J. P., Appraisal of interpolation instruments for the International Practical Temperature Scale from 6.30.74 to $1064.43{ }^{\circ} \mathrm{C}$, Metrologia 15, 1-4 (1979).

18683. Richards, P. L., Shen, T. M., Harris, R. E., Lloyd, F. L., Quasiparticle heterodyne mixing in SIS tunnel junctions, Appl. Phys. Letl. 34, No. 5, 345-347 (Mar. 1, 1979).

18727. Hehner, R. E., Jr., Annestrand, S., Evaluation of calihration techniques for multimegavolt impulse dividers, Proc. Third Intl. Symp. on High Voltage Engineering, Milan, Italy, Aug. 28-3/, 1979, pp. 42.18, 1-4 (Associazione Elettrotecnica ed Elettronica ltaliana, Milan, Italy, Aug. 1979).

18773. Geist, J., Lind, M. A., Schaefer, A. R., Zulewski, E. F., A laser based characterization facility for silicon photocell studies, Proc. Workshop Terrestrial Plotovoltaic Measurements-II, Buton Rouge, LA, Nov. 1(1)-12, 1976, pp. 223-231 (Available as NASA CP-2010 from the National Tecbuical Information Service, Springtield, VA, 1976).

18774. Geist, J., Lind, M. A., Schaefer, A. R., Zalewski, E. F., A new approach to spectral radiometry hased on opto-electronics, Proc. $7 t h$ Int. Symp. of the Technical Committee on Photon-Detectors, Braunschweig, Federal Repuhlic of Germany, May 17-21, 1976, pp. 149-167 (1976).

18790. Fiori, C. E., Newhury, D. E., Artifacts observed in energy-dispersive $x$-ray spectrometry in the scanning electron microscopy, (Proc. 11 th Annual Scanning Electron Microscopy Conf., Los Angeles, CA, Apr. 17-21, 1978), Scanning Electron Microsc. 1, 401-422 (1978).

18796. Geist, J., Frontiers in optical radiation measurements, Proc. Electro-Optical Systems Design Conf.-1976 Int. Laser Exposition, New York, NY, Sept. 14-16, 1976, pp. 281-284 (1976)

18816. Moody, S. E., Levine, J., Design of an extended-range, three-wavelength distance-measuring instrument, Tec(onophysics 52, 77-82 (1979).

18826. Hellwig, H., Stein, S. R., Walls, F. L., Kahan, A., Relationships between the performance of time/frequency standards and navigation/communication systems, Proc. $10 \mathrm{th}$ Precision Time and Time Interval Planning Mecting, Washing1on, DC, Non. 28, 1978, pp. 37-51 (1979).

18833. Hillhouse, D. L., Portable system calibrates CCVTs, Electr. World 189, No. 12, 44.46 (June 15, 1978 ).

18844. Hsia, J. J., Venable, W. H., Jr., NBS capabilities for reflectance and transmittance measurements. Proc. Seminur on Testing Solar Energy. Materials and Systems, Gaithershurg. MD, May. 22-24, 1978, pp. 258-260 (1978).

18848. Franzen, D. L., Day, G. W., LED source for determining optical detector time response at $1.06 \mathrm{\mu m}$, Rev. Sci. Instrum. 50. No. 8, 1029-1031 (A ug. 1979).

18872. Hebner, R. E., Hillhouse, D. L., Kotter, F. R., Discussion on $F 77$ 696-8 "Transient measurement techniques in EHV systems," by R. Malewski' and G. R. Nourse, IEEE Trans. Power Appar. Syst. 97. No. 3, 901 (May/June 1978).

18899. Allan, D. W., Hellwig. H.. Time deviation and time prediction error for clock specification, characterization, and application, Proc. IEEE 1978 Position Location and Vavigation Symp., San Diego, CA, Nor. 6-9, 1978, pp. $29-36$ (Institute of Electrical and Electronics Engineers, Inc.. New York, NY. 1978).

18900. Schaefer. A. R.. Geist. J.. Spatial uniformity of quantum efficiency of a silicon photovoltaic detector, Appl. Opt. 18, No. 12. 1933-1936 (June 15, 1979).

18911. Spal, R.. Kahn, A. H., Eddy currents in a conducting cylinder with a crack, J. App/. Ply.s. 50. No. 10.6135-6138 (Oct. 1979). 
18938. Hillhouse, D. L., Petersons, O., Sze, W. C., A prototype system for on-site calibration of coupling capacitor voltage transformers (CVVTs), (Proc. IEEE Power Engineering Society Summer Meeting, Los Angeles, CA, July 16-21, 1978), IEEL Trans. Pow'er Appar. Syst. PAS-98, No. 3, 1026 10)36 (May/June 1979).

18940. Allan, D. W., A review of flicker noise frequency instabilities in precision frequency standards, Proc. Syrnp. on $1 / f$ Fluctuations, Tokyo, Japan, July //-13, 1977, pp. 158-172 (Institute of Electrical Engineers of Japan, Tokyo, Japan, $1977)$.

18999. Young, M., Conference on optical scattering standards, (Proc. Standards for Scattering from Optical Surtaces Conf., Boulder, CO, Feb. 6-7, 1979), SPIE J. 181, 133-134 (1979).

19005. Hellwig. H., Precise time and frequency, (Proc. Symp. 19th General Assembly of URSI on Time and Frequency, Helsinki, Finland, Aug. 1-4, 1978), Phys. Technol. 9, 266-267 (1978).

19029. Hanson, D. W., Davis, D. D., Cateora, J. V., NBS time to the Western Hemisphere by satellite, Rudio S. $i .14, \mathrm{No} .4$, 731-740 (July-Aug. 1979).

19032. Brenner, D., Modified multimeter measures precise voltage ratios, Electron. Design 27, No. 21, 162-163, 165 (Oct. 11, 1979).

19040. Plumb, H. H., Besley, L. M., Stabilities of germanium thermometers at $20 \mathrm{~K}$ and below, Proc. ISSA-78 Nut. Conf. and Ex/ribit, Philadelphia, PA, Oct. I5-19, I978, pp. 19-25 (Instrument Society of America, Pittsburgh, PA, 1978).

\section{Nuclear Physics and Radiation Technology}

SP554. Proceedings of a conference on neutrons from electron medical accelerators. Proceedings of a Conference held at the National Bureau of Standards, Gaithersburg, MD, Apr. 9-10, 1979, H. T. Heaton II and R. Jacobs, Eds., Nut. Bur. Stund. (U.S.), Spec. Publ. 554, 172 pages (Sept. 1979) SN003-003()2115-6

Unwanted neutron contribution to megavoltage $x$-ray and electron therapy, J. S. Laughlin, A. Reid, L. Zeitz, and J. Ding, SP554, pp. 1-14 (Sept. 1979).

Advantages and properties of high energy photon beams, $H$. E. Johns, SP554, pp. 15-21 (Sept. 1979).

Scattered radiation relative to leakage radiation in high energy $x$-ray beams, J. A. Rawlinson, SP554, pp. 25-28 (Sept. 1979).

International standards for medical accelerators, G. R. Higson, SP554, pp. 29-32 (Sept. 1979).

State regulations for medical accelerators, C. H. Smith, SP554, pp. 33-35 (Sept. 1979).

The RBE of neutrons, H. H. Rossi, SP554, pp. 37-40 (Sept. 1979).

Risk of cancer based on promotion from cytotoxicity, T. D. Jones, D. G. Jacobs, J. A. Auxier, and G. D. Kerr, SP554, pp. 41-56 (Sept. 1979).

Clinical tradeoff: The maximum probability of uncomplicated cure, L. Cohen, SP554, pp. 57-61 (Sept. 1979).

Dependence of radiation-induced neoplastic transformation in vitro upon radiation quality and repair, $A$. Han and $M$. M. Elkind, SP554,pp. 63-73 (Sept. 1979).

Neutron sources and their characteristics, R. C. McCall and W. P. Swanson, SP554, pp. 75-86 (Sept. 1979).

Mixed photon-neutron field measurements, R. Nath, K. W. Price, and G. R. Holeman, SP554, pp. $87-97$ (Sept. 1979).

Neutron contamination in the primary beam, P. H. McGinley and M. Sohrabi, SP554, pp. 99-107 (Sept. 1979).

Neutron production from electron accelerators used for medical purposes, E. J. Axton and A. G. Bardell, SP554, pp. 109-123 (Sept. 1979).
Survey of European measurements on photoneutron production from electron accelerators used for medical purposes, $E$. J. Axton and A. G. Bardell, SP554, pp. 125-127 (Sept. 1979).

Neutron leakage from current machines, $P$. R. Almond, SP5.54, pp. 129-138 (Sept. 1979).

Design criteria for photon beam exits on high energy medical accelerators to minimize neutron production, L. Taumann, SP554, pp. 139-144 (Sept. 1979).

Neutron leakage characteristics related to room shielding, $E$. Tochilin and P. D. LaRiviere, SP554, pp. 145-154 (Sept. 1979).

18355. Ehrlich, M., Soares, C. G., Jackson, B., Lanoue, P., Influence of source configuration on spectral composition of gamma-ray heams from "Co teletherapy units, Int. J. Appl. Rudiat. Isot. 29, 741-747 (1978).

18358. Berger, M. J., Planned compilation of stopping power and range data, Proc. Sixth Symp. on Microdosimetry, Brussels, Belgium, May 22-26, 1978, J. Borm and H. G. Ebert, Eds., 1, 639-649 (Harwood Academic Publishers, Ltd., London, England, 1978).

18360. Caswell, R. S., Coyne, J. J., Influence of nuclear data on calculations of neutron energy deposition, Proc. Third Symp. on Neutron Dosimetry in Biology and Medicinc, Nouherberg/Munchen, Federal Republic of Girmany, May 23-27. 1977 , G. Burger and H. G. Ehert, Eds., pp. 29-43 (Commission of the European Communities, DirectorateGeneral, Scientific and Technical Information Management, Batiment Jean Monnet, Luxembourg, 1978).

18361. Cavallo, L., Ehrlich, M., Hutchinson, J. M. R., Traceability in ionizing radiation measurements systems, Proc: Int. Symp. on National and International Standardization of Radiatiom Dosimetry, Atlanta, GA, De'C. 5-9, 1977, IAEA-SM$222 / 18,1,65-87$ (International Atomic Energy Agency, Vienna, Austria, 1978).

18370. Olsen, H. A., Maximon, L. C., High-frequency limit of bremsstrahlung, Phys. Re'. A 18, No. 6, 2517-2522 (Dec. 1978).

18371. Seltzer, S. M., Hubbell, J. H., Berger, M. J., Some theoretical aspects of electron and photon dosimetry, Proc: National and International Standardization of Radiation Dosimetry, Atlanta, GA, Dee. 5-9, 1977. IAEA-.SM-222/05, 11, 3-43 (International Atomic Energy Agency, Vienna, Austria, 19781.

18407. Cooper, J. W., Aberg, T.. Shaking processes in $\beta$-decay, Nucl. Phys. A 298. 239-252 (1978).

18416. Ehrlich, M.. Seltzer, S. M., Bielefeld, M. J.. Trombka, J. I., Spectrometry of a "Co gamma-ray beam used for instrument calibration, Metrol. 12,169-179 (1976).

18423. Danos, M., SU4 in nuclear structure, Pros. $3 d \mathrm{lnt}$. Conft. on Clustering Aspects of Nuclear Siructure and Nuctear Reacison, Winnipe'g, Manirsha, Canada, June 19-23. 1978, pp. 4868 (Américan Institute of Physics, New York, NY. 1978).

18442. MacDonald, W. M., Dressler, E. T., O'Connell, J. S., Photopion production in the Fermi-gas model, Phys. Ro' $C$ 19. No. 2, 455-464 (Feb. 1979).

18462. Bowman, C. D., Eisenhauer, C. M., Gilliam, D. M.. Photofission effects in reactor pressure vessel dosimetry. Proc. Siecond ASTM-EUR.ATOM Simp. on Reactor Dosimeiry, Pulo Allo. C.4. Oct. 3-7, 1977, pp. 575-582 (Available as NUREG/CP-0004 from National Technical Information Service, Springficld, VA 22161,1978)

18495. O Connell. J. S.. Electroproduction and decay of giant resonances, Comments Nuc\%. Part. Phys. 8, No. 5, 151-156 (1979).

18496. O Connell, J. S. MacDonald. W. M.. Dressler. E. T.. Photopion production in the Fermi gas model, (Proc. Int. Symp. on Photopion Nuclear Physics. Rensselaer Polytechnic Inst. Troy. NY, Aug. 10-12, 1978). Paper in Photopion 
Nuclear Plysics, P. Stoler. Ed.. pp. 381-384 (Plenum Publishing Corp., New York, NY, 1979).

18518. Dodge, W. R., Hayward, E., Moscati, G., Wolynec, E. Electrodisintegration of ${ }^{2: 3 \times} \mathrm{U}$, Plyss. Rer. C 18, No, 5, 2435 2437 ( Nov. 1978).

18520. Hayward, E., The electrodisintegration of ix Ni, $\operatorname{Proc}: 4 / 1$ Seminar on Electromagnetic Interartions of Nuclei at Low and Medium Energies, Moscow, USSR, Dec. 13-15, 1977, pp. 125 $139(1979)$.a

18521. Hayward, E., Nuclear elastic scattering of photons, Prox: 4th Seminar on Elestromagnetic Interactions of Nurlei at Low and Medium Energies, Moscow, USSS, Ded. 13-15, 1977, pp. 185-199 (1979).

18522. Hayward, E., Dodge, W. R., Patrick, B. H., Some experiences using a positron annihilation beam. Nucl. Insirum. Methods 159, 289-299 (1979).

18532. Olsen, H. A., Maximon, L. C., Effect of resonance scattering in the high frequency limit of bremsstrahlung, Pliys. Lett. 69A, No. 2, 90-92 (Nov. 27, 1978).

18535. Wolynec, E., Dodge, W. R., Hayward, E., Decay modes of giant resonances in ${ }^{5 \mu} \mathrm{Ni},{ }^{\text {HNI }} \mathrm{Ni}$, and ${ }^{\mathrm{A} 2} \mathrm{Ni}$, Pliys. Rev. Letl. 42, No. 1, 27-30 (Jan. 1, 1979).

18570. Bowman, C. D., Research applications of a high power induction linac, (Proc. Fifth Conf, on the Applications of Small Accelerators in Research and Industry, North Texas State Univ., Denton, TX, Nov, 6-8, 1978, J. L. Duggan, I. L. Morgan, Eds. ), IEEE Trans. on Nucl. Sci. NS-26, No. 1, Part 2 of Two Parts, 1426-1431 (IEEE Nuclear and Plasma Sciences Society, New York, NY, Feb. 1979).

18581. Carlson, A. D., Patrick, B. H., Measurements of the ${ }^{235} \mathbf{U}$ fission cross section in the $\mathrm{MeV}$ energy region, Proc. Int. Conf. on Neutron Physics and Nuclear Data for Reactors and Otleer Applied Purpuses, Harwell, Uniced Kingdom, Sept. 25-29. 1978, pp. 880-886 (Publications de LOCDE, Paris, France. 1979).

18585. Bowman, C. D., Schrack, R. A., The influence of vibrations of gas molecules on neutron reaction cross sections, Proc. Int. Conf. on Neutron Physics and Nuclear Data for Reactors and Oiher Applied Purposes, Harwell, United Kingdom, Sept. 25-29, 1978, pp. 736-741 (Publications de L'OCDE, Puris, France, 1979).

18591. Behrens, J. W., Schrack, R. A., Bowman, C. D., Resonance neutron radiography using a position-sensitive proportional counter, (Proc. Am. Nuclear Society Annual Meeting. Atlanta, GA, June 3-7, 1979), Trans. Am. Nuct. Sicc. 32, 207-208 (American Nuclear Society, Hinsdale, IL, 1979).

18658. Caswell, R. S., Coyne, J. J., Energy deposition spectra for neutrons based on recent cross section evaluations, Proc. Sixth Symp. on Microdosimeiry, Brussels, Belgium, May 22 26, 1978 , J. Booz and H. G. Ebert, Eds., II, 1159-1171 (Harwood Academic Publishers, Ltd., London, England, 1978).

18659. Paretzke, H. G., Berger, M. J., Stopping power and energy degradation for electrons in water vapor, Proc. Si.v/l Symp. on Microdosimetry, Brussels, Belgium, May 22-26, 1978, J. Booz and H. G. Ebert, Eds., II, 749-758 (Harwood Academic Publishers, Lid., London, England, 1978).

18660. Coyne, J. J., $\overline{\mathbf{W}}_{n}$, computed from recent nuclear data and $\mathbf{W}$ measurements, Proc. Sixth symp. on Microdosimetry, Brussels, Belgium, May 22-26, 1978, J. Booz and H. G. Ebert, Eds., II, 699-706 (Harwood Academic Publishers, Ltd., London, England, 1978).

18675. O'Connell, J. S., Schoch, B., Electromagnetic coincidence experiments, Proc: June Workshop in Intermediate Energy Electromagnetic Interactions With Nuclei, Cambridge, MA, June 13-24, 1977, 34 pages (1979).

18687. Schrack, R. A., Bowman, C. D., Chemical and temperature effects on thermal 2:ss $\mathrm{U}$ fission, Proc. Inıl. Conf. in Neutron Physics and Nuclear Data for Reactors and Oilier Ap- pliced Purposess. Harwell, United Kingdem, Sipt. 25-29, 1975 pp. $742-745$ (Publications De LOcde, Paris, France. 1979).

18704. Bickford, N. A., Fleming. R. F., Silicon irradiation facilities at the NBS reactor. (Proc. Neutron Transmutation Conf.. Columbia, MO, Apr. 23-26, 1978). Paper in Veatrom Trunsmulution Doping in Simicondurturs. J. M. Meese. Ed. pp. 165-170 (Plenum Publ. Corp.. New York. NY. 1979).

18769. Danos, M.. Gillet, V.. Relativistic field theory of nuclei. Chapter 21 in Mosenss in Nurlei. M. Rho. D. Wilkinson. Eds. III, 841-865 (North-Holland Publ. Co., Amsterdam. The Netherlands, (979).

18792. Fleming, R., Spiegel, V., Measurement of threshold reaction cross section ratios in fission neutron fields, Pros. $2 d$ ASTM-EURATOM Simp. (') Reater Dosimetry: Desimetry Methods for Fiuels, Cladding, and Siructural Materials, Pals Alto, CA, Ort. 3-7. 1977, 2, pp. 953-457 (Available as NUREG/CP-()o()4 from the National Technicial Information Service, Springlield, VA, O(t. 1977).

18798. Dressler, E., Single nucleon operators in pion photoproduction from nuclei, Pros. June Works/us) in Intermediate Energy Elertromagnetic Interations will Nuclei, MIT, Bessum, MA, June 13-24, 1977, Re'purt No. C()()-30h9. 677, pp. 147-154 (William H. Bates Linear Accelerator Laboratory and the Laboratory for Nuclear Science, Massachusetts Institute of Technology. B'ston, MA. 1977).

18800. Eisenhower, E. H., NBS radiation measurement assurance activities, (Proc. Xth Ann. Nat. Cont, on Radiation Control-Radiation Benelits and Risks: Facts, lssues, and Options, Springfield, 1L, May 2-7, 1976), HEW Puhlication (FDA) 77-8(121, pp. $391-397$ (U.S. Department of Health. Education, and Wellare, Public Health Service, Food and Drug Administration, Bureau of Radiological Health, Rockville, MD, Apr. 1977)

18841. Hutchinson, J. M. R., Schima, F. J., Coursey, B. M., Decay of ${ }^{12} \mathrm{Sn}^{\mathrm{m}}$, Plịs. Rev. C 18, No. 1, 408-413 (July (478).

18883. Spiegel, V., Eisenhauer, C. M., Grundl, J. A., Martin, G. C., Jr., Reaction rate measurements and integral cross sections using the NBS ${ }^{252} \mathrm{CF}$ fission neutron indoor irradiation facility, Proc. 2d ASTM-EURATOM Simp. "'n Reacur Dosimetry: Dosimeiry Melhods for Fuels, Cladding, and Sirurtural Materials, Palo Allo, CA, Oct. 3-7, 1977, 2, 959-967 (Available as NUREG/CP-()(0)4 from the National Technical Information Service, Springfield, VA, Oct. 1977).

18884. Gilliam, D. M., Helmer, R. G., Greenword, R. C., Rogers, J. W., Heinrich, R. R., Popek, R. J., Kellogg, L. S., Lippincott, E. P., Hansen, G. E., Zimmer, W. H., "Reference and standard benchmark field consensus fussion yields for U.S. reactor dosimetry programs," Proc, $2 d$ A.STMEURATOM Symp. on Reacuer Desimeary: Desimeary Meiluds for Fuels, Cladding, and Sirutural Materials, Pals Allo, CA, Oct. 3-7, 1977, 3, 1284-1306 (Available as NUREG/CP-0)(1)4 from the National Technical Information Service, Springtield, VA, Oct. 1977).

18901. Eisenhauer, C. M., Gilliam, D. M., Grundl, J. A.. Spiegel, $V$., Utilization of standard and reference neutron fields at NBS, Prox. 2d ASTM-EURATOM Simp. on Reacior Dosimetry: Dosimetry Methods for Fuels, Cladding, and Sirnctural Materials, Pale Alı, CA, Ort. 3-7, 1977. 3,1177-1191 (Available as NUREG/CP-())(1)4 from the National Technical Information Service, Springlield, VA, Oct. 1977).

18906. Penner, S., High duty-cycle accelerators and new experimental possibilities, (Proc. Nuclear Physics with Electromagnetic Interactions, Mainz, Germany, June 5-9, 1979), Paper in Lecture Nole's in Plisics, J. Ehlers, K. Hepp, R. Kippenhahn, H. A. Weidenmuller, J. Zittartz, Eds., 108, 99-113 (Springer-Verlag, Berlin, Germany, 1979).

18932. Penner, S., Galejs, A., Transport calculations for very high current beams, (Proc. 1979 Purticle Accelerator En- 
guncerang and Fechnology, San Francisen, CA. Mar, 12-14. |197), IIEEE Trans. Val. Sit. NS-26, No. 3. P(. I. 30863(184) (June 1979)

18451. Diım, M.. Ratilhhi, J.. Migher-order effects in fermitype charged current theory of weak interactions: Semi-leptomic neutral currents, P/1ss. L(16. 73B. No, 3. 313-316 (Feh. 27. 14781 .

18965 . Fincuhauer. (.. Model for diffusion of a pencil heam of clectrons: Angular distrihution. Trans. Am. Nal. Six. 32. $649-6.51)$ (June 1479).

18981. Hutchinson, J. M. R.. International Committee for Radionuclide Metrology ICRM Newsletter: Report of the Wonds Hole Conference on the Development of Naturally Contaminated Radioactivity Standards. (Proc. Symp. Int. ('smmittec on Radionuclide Metrolongy (ICRM). Woods Hole. MA. Oct. 1977). Paper in Environment Internatiumal 2. No. 1. 49.50 (Pergamon Press, Oxtord. England, 1979).

18484. Suares. C. G., Ehrlich. M.. Concerning 1, $\mathrm{B}_{4}()_{-}$thermoluminescence dosimeters, Mod. Phys. Commun. 6. No. 4. 312 (July/Aug. 1974).

18942 . Fhrlich. M. Criteria for testing personnel dosimetry performance, (Proc: Annual Meeting American Nuclear Society. Atlanta, GA. June 4-7, 1979). Trans. Am. Nucl. Six. 32,657$6.5 \times(1979)$.

191001. Sultzer. S. M.. X-ray source characteristics and detection efficiencies of prototype lixiscopes, (Proc. Lixiscope Cont.. NASA Guddard Space Flight Center. Greenbelt, MD. July 27-28. 1978). N.45.4 Comf. Puhl. 2/12, Preliminar! .4pplicaIums ared Evaluarion Re'sults. pp. 11-14 (NASA Goddard Space Flight Center. Greenhelt, MD, 1978).

190012. Lutvinger, R., Dose equivalent unit, Healt/ Plyss. Lett. (1) Ed. 37, 6(1)-60)3 (Oct. 1479)

19011. Dyer, C. S., Trombka, J. I., Seltzer, S. M.. Calculation of radioactivity induced in scintillator materials during spaceflight. (Proc. 1977 Winter Meeting American Nuclear Suciety. San Franciuco, CA. Nov. 27-Dec. 2, 1977). Trans. Am. Nucl Six. 27. 195-196 (1977).

19012. MeElroy. W. N.. Doran, D. G.. Guld, R.. Lippincott. E. P.. Schittgens, J. O.. Simons, R. L.. Morgan. W. C., Grundl. J. A. McGarry, E. D., Kam, F. B. K., Swank. J. H., Odette. G. R.. Standardization of dosimetry and damage analysis work for U.S. I,WR. FBR and MFR development programs. Proc 2d ASTM-EURATOM Simp. in Redier Dosimeiry:

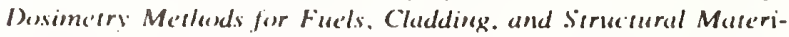
als, Pals .4lo), C.4. ().1. 3-7, 1977, 1, 17-60) (Available as NUREC;/CP-(0)(1) trom the National Technical Intormation Service, Springtield, VA. Oct. 1977).

14013. Fabry, A., Grundl, J. A.. McElroy. W. N.. Lippincott. E. P.. Farrar, H. IV. Status report on dosimetry benchmark neutron field development, characterization and application. Prox 2d ASTM-EURATOM Symp. on Reacer Dosime'ty: Desumetry Mothods for Fucls. Cladding. and Siructural Materi-

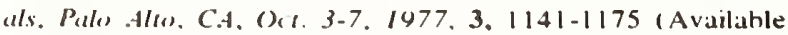
a) NUREG/CP-(1)(1) irom the National Technical Informa(iiun Service, Springtield, VA. Oct. 1977).

19014. Rahn. F. J., Serpan, C. Z., Fabry, A., McElruy, W. N. Grundl, J A.. Dehrue, J.. Trends in light water reactor dosimetry programs, Pros. 2d ASTM-EUR.4TOM Simp. in Redelor Desime'try: Dosimetry Medhods for Finels. Cladding. and Siructural Malerials. Pals .4lls, C.A. O)t. 3-7. 1977. 3. I1)64-1041 (Availahle as NUREG/CP-(100)4 from the National Technical Information Service. Springtiald. VA. Oct. 1977).

19015. Lapides, J. R.. Crannell. C. J., Crannell, H., Hornyak, W. F. Seltzer, S. M., Trombka, J. I., Wall, N. S., Measurements of $15.11-\mathrm{MeV} \gamma$-ray flux produced in the reactions

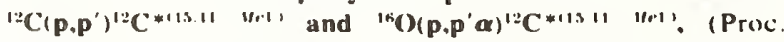
Symp. on Gamma Ray Spectroscopy in Astrophysics. NASAConddard Space Flight Center. Greenhelt, MD. Apr. 28-24. 1978). N.t.S.4 Terlinical Memorardum 79.560. 13 pages
A A railable from the National Technical Information Service. Springtield, VA, June 1978 ).

19(124. Grundl. J.. DeLeeuw-Gierts, G.. Workshop Chairmen's Report "Utilization of Benchmark Neutron Fields." Proc. 2d .45TM-EUR.ATOM Simp. on Reactor Dosimetry Dosimetry Metheds for Fuels. Cladding, and Sinuchural Materials. Palo Alo1, C.t, Oct. 3-7. 1977, 2, 981-982 1.Available as NUREG/CP-(0)(1) from the National Technical Intormation Service, Springtield, VA. Oct. 1977 ).

\section{Operations Analysis and Applications}

NBSIR 78-1539. Mathematical models for selecting catalogs of standard-sized items, D. R. Shier, 81) pages (Sept. 1978). Order from N'riS as PB2848()3.

\section{Processing and Performance of Materials}

Tensile behavior of some mathematical models of paper networks, J. C. Smith. J. Re's. Nat. Bur. Stand. (U.S.). 84, N(). 4. 299-31X (July-Aug. 1979).

SP550. A bibliography on the corrosion and protection of steel in concrete, E. Excialante and S. Ito. Nat. Bur. Stand. I U.S.). Spec. Publ. 550, 24 pages (Aug. 1979) SNo(1)3-(1)(03-(1)2106-7.

SP561. Vols. I and 2. Characterization of high temperature vapors and gases. Proceedings of the 10 th Materials Research Symposium held at the National Bureau of Standards. Gaithershurg. MD. Sept. 18-22. 1978. J. W. Hastie. Ed.. Nat. Bur. Siund. (U.S.). Spe'c. Puhl. 561/l. 800) pages: $561 / 3.901$ palges (Sept. 1979) SN()03-()03-()2124-5

The effusion method at age 69: Current state of the art, E. D. Cater. SP56//I. pp. 3-38 (Sept. 1979).

General theoretical angular number distribution functions of Knudsen flow through the following single and double-slit orifice geometries: Circular, rectangular, and cylindrical. F. Miller. SP561/1. pp. 39-65 (Sept. 1979).

Automatic data acquisition by the torsion-effusion method, J. G. Edwards, SP56//I. pp. 67-81 (Sept. 1979).

Application of laser pulse heating for the study of high temperature vapors, phase transitions and equation of state, $R$. W. Ohse. J. F. Bahelot, L. Cercignani. P. R. Kinsman, K. A. Long. J. Magill, and A. Scotti. SP56//1, pp. 83-109 (Sept. 1979).

A high temperature transpiration apparatus for the study of the atmosphere above viscous incongruently vaporizing melts, D. M. Sanders and W. K. Haller, SP561/1, pp. $111-123$ (Sept. 1979).

Vaporization thermodynamics and kinetics of hexagonal silicon carbide, R. G. Behrens and G. H. Rinehart, SPS6l/l. pp. 125-141 (Sept. 1979).

A very accurate pyrometer for general laboratory use, $E$. K. Storms and B. A. Mueller, SP561/1, pp. 143-151 (Sept. 1979).

Operation of near ideal heat pipes, L. A. Melton, SP5 I/I. pp. 153-16h (Sept. 1979 ).

Attainment of chemical equilibrium in effusive beam sources of the heterogeneous reaction type, D. L. Hildenhrand. IPSG1/1. Pp. 171-179 (Sept. 1979).

Thermodynamic and physico-chemical behavior of the interactions between Knudsen-effusion-cells and the systems under investigation. Analysis by high temperature mass spectrometry, C. Chatillori. M. Allibert, and A. Pattoret, SP561/l. pp. $181-210$ (Sept. 1979).

Characterization of high temperature vapors by angular dis. tribution mass spectrometry, R. T. Grimley and J. A. Forsman. $515561 / 1$, pp. $211-229$ (Sept. 1979 ). 
The high temperature vaporization and thermodynamics of the titanium oxides. XIV. Relative ionization cross-sections of Ti, TiO, and TiO, R. I. Sheldon and P. W. Gilles, SP56//I, pp. 231-2.34 (Sept. 1979).

Congruent vaporization and thermodynamics in the praseodymium-sulfur system, E. D. Cater, B. H. Mueller, and J. A. Fries, SP'561/1, pp. 237-262 (Sept. 1979).

Vapor pressure measurements of potassium over $\mathrm{K}_{2} \mathrm{O}-\mathrm{SiO}$. solutions hy a Knudsen effusion mass spectrometric method, E. R. Plante, S1356//I, pp. 265-281 (Sept. 1979).

Mass spectrometric investigation of vapor species over liquid germanium dioxide, T. Sasamoto, M. Kobayashi, and T. Sata, SP56//I, pp. 283-286 (Sept. 1979).

Mass spectrometric determination of atomization energies of inorganic molecules and their correlation by empirical models of bonding, K. A. Gingerich, SP56//I, pp. 289-300 (Sept. $1979)$.

High pressure molecular beam mass spectrometric sampling of high temperature molecules, C. A. Stearns, F. J. Kohl, G. C. Fryburg, and R. A. Miller, SP561/1, pp. 303-354 (Sept. 1979).

Transpiration mass spectrometry of high temperature vapors, D. W. Bonnell and J. W. Hastie, SP56I/l, pp. 357. 408 (Sept. 1979).

In situ analysis of minor gaseous species in crystal growth ambients using molecular beam mass spectrometry, $H$. Dun, B. L. Mattes, and D. A. Stevenson, SP56//1, pp. 411-428 (Sept. 1979).

Molecular beam mass spectrometric sampling of minor species from coal dust-air flames, F. T. Greene, J. E. Beachey, and T. A. Milne, SP561/1, pp. 431-442 (Sept. 1979).

The use of flames as media for the study of ion-molecule thermochemistry, W. J. Miller, SP56I/I, pp. 443-456 (Sept. 1979).

Mass spectrometric determination of negative and positive ion concentrations in coal-fired MHD plasmas, J. Wormhoudt and C. E. Kolb, SP56I/I, pp. 457-476 (Sept. 1979).

Mass spectrometric sampling of condensed system flames, O. P. Korobeinichev and A. G. Tereshenko, SP561/1, pp. 479-491 (Sept. 1979).

Matrix isolation studies of high temperature species, $R, H$. Hauge and J. L. Margrave, SP56I/I, pp. 495-509 (Sept. 1979).

The characterization of high temperature molecules using matrix isolation and isotope fine structure, J. S. Ogden, SP561/1, pp. $511-520$ (Sept. 1979).

Matrix isolation of high temperature species and matrix perturbation effects, F. W. Froben, SP56I/I, pp. 523-527 (Sept. 1979).

Matrix isolation study of the vibrational and electronic spectra of PO and HPO, M. Larzilliere and M. E. Jacox, SP561/I, pp. 529-543 (Sept. 1979).

ESR matrix isolation of $\mathrm{AlH}^{+}$formed during the high temperature vaporization of $\mathrm{Al}_{2} \mathbf{O}_{3}$, L. B. Knight, Jr., R. L. Martin, and E. R. Davidson, SP561/1, pp. 545-555 (Sept. 1979).

Matrix isolation studies of magnesium and iron atom reac. tions with water, R. H. Hauge, S. E. Gransden, J. W. Kauffman, and J. L. Margrave, SP56I/1, pp. 557-566 (Sept. 1979).

Photoselective bimetallic aggregation: A new route to bimetallic clusters, W. E. Klotzbucher and G. A. Ozin, SP561/1, pp. 567-585 (Sept. 1979).

Transition-metal molecules and Walsh's rules-Rationalization of optical and ESR data, W. Weltner, Jr., SP561/I, pp. 587-594 (Sept. 1979).

The determination of the molecular shapes of "high temperature' species, I. Beattie and D. A. Greenhalgh, SP56I/I. pp. 597-606 (Sept. 1979).
Raman spectroscopy in high temperature chemistry, M. C. Drake and G. M. Rosenblat, SP56//I, pp. 609-646 (Sept. 19791.

Resonance Raman spectra of metal halide vapor complexes, G. N. Papatheodorou, SP561/1, pp. 647-678 (Sept. 1979).

Infrared spectral measurements of species in a high temperature flow tube, M. E. Gersh and C. E. Kolb, SP561/l, pp. 679-693 (Sept. 1979).

Rotational spectroscopy of high temperature molecules, $T$. Torring and E. Tiemann, SP56//1, pp. 695-709 (Sept. 1979).

Modern high-temperature electron diffraction, $V$. P. Spiridonov and E. Z. Zasorin, SP561/1, pp. $711-755$ (Sept. 19791.

Photoionization mass spectrometry and photoelectron spectroscopy of high temperature vapors, J. Berkowitz, SP561/l, pp. $757-769$ (Sept. 1979).

The photoelectron spectroscopic characterization of vapors over heated inorganic solids, R. A. Bowling, T. W. Lassiter, D. O. Vick, and G. K. Schweitzer, SP561/1, pp. 771-789 (Sept. 1979).

Ab initio molecular orbital studies of some high temperature metal halide complexes, L. A. Curtiss, SP56//1, pp. 791-801 (Sept. 1979).

New optical diagnostic techniques for temperature and species concentration measurements in flames, J. R. McDonald, A. P. Baronavski, L. Pasternack, S. Lamont, and A. B. Harvey, SP561/2, pp. 817-831 (Sept. 1979).

Laser-absorption methods for characterizing high temperature gases, W. C. Gardiner, Jr., SP561/2, pp. 835-846 (Sept. 1979 ).

Near-resonance Rayleigh scattering and atomic flame fluorescence spectroscopy, C. Chan and J. W. Daily, SP56I/2, pp. 847-853 (Sept. 1979 ).

Laser induced reactions of lithium in flames, $\mathrm{C}$. $\mathrm{H}$. Muller III, K. Schofield, and M. Steinberg, SP561/2, pp. 855-864 (Sept. 1979).

Opto-galvanic spectroscopy: A new look at atoms and molecules, K. C. Smyth, P. K. Schenck, W. G. Mallard, and J. C. Travis, SP561/2, pp. 865-882 (Sept. 1979).

$\mathrm{SiCl}_{2}$ fluorescence as a chemical vapor deposition reactor probe, T. O. Sedgwick and G. U. Arbach, SP561/2, pp. 885896 (Sept. 1979)

Raman scattering of the gaseous phase at high temperature, R. Hillel, J. Bouix, and A. Machaelides, SP561/2, pp. 899911 (Sept. 1979).

Diagnostic techniques in combustion MHD flows, S. A. Self, SP561/2, pp. 915-941 (Sept. 1979).

CARS diagnostic investigations of flames, A. C. Eckbreth and R. J. Hall, SP561/2, pp. 943-972 (Sept. 1979).

Comparison of thermocouple, gas sampling and Raman measured temperatures in an afterburning turbojet engine plume, W. M. Roquemore and P. O. Yaney, SP561/2, pp. 973-1023 (Sept. 1979).

Use of thermocouples for gas temperature measurements in gas turbine combustors, R. R. Dils and P. S. Follansbee, SP56I/2,pp. 1027-1070 (Sept. 1979).

Moving thermocouple measurements of heat transfer in hot gases, L. W. Hunter, C. H. Hoshall, C. Grunfelder, and R. M. Fristrom, SP561/2,pp. 1071-1078 (Sept. 1979).

Application of the two line atomic fluorescence technique to the temporal measurement of small volume flame temperatures, J. Bradshaw, J. Bower, S. Weeks, K. Fujiwara, N. Omenetto, H. Haraguchi, and J. D. Winefordner, SP561/2, pp. 1079-1102 (Sept. 1979).

A comparison of spectroscopic flame temperature measurements: Na-D line reversal, rotational and vibrational Raman, and $\mathrm{OH}$ absorption spectroscopy, M. C. Drake, L. $\mathrm{H}$. Grabner, and J. W. Hastie, SP56I/2, pp. 1105-1134 (Sept. 1979 ). 
()ptical diagnostics in CVD reactors, G. H. Miller, A. J. Mulat, and P. J. Hargis, Jr., SPShI/2, pp. 1135-1151 (Sept. $1979)$.

Laser-generated opto-acoustic pulses in an atmospheric pressure flame, W. R. Anderson, J. E. Allen, Jr., T. D. Fansler, and D. R. Crosley, S1'561/2, pp. 1153-1167 (Sept. 19791.

Measurement of rotational distributions within $0 H\left(A^{2} \Sigma+, v^{\prime}\right.$ = (0) in flames, M. A. DeWilde and D. R. Crosley, S1P561/2, pp. 1171-1179 (Sept. 1979).

Rotational dependence of transition probahilities in the $O H$ A-X band system, 1. L. Chidsey and D. R. Crosley, SP561/2, pp. 1181-1191 (Sept. 1979).

Chemical processes in high Reynolds number turbulent diffusion flames, D. E. Jensen, SP561/2, pp. 1195-1220 (Sept. 1979).

Modeling study of flame structure in low-pressure, laminar, pre-mixed methane flames, J. R. Creighton and C. M. Lund, SP561/2, pp. 1223-1244 (Sept. 1979).

Predictive modeling of diborane oxidation, W. M. Shaub and M. C. Lin, SP56//2, pp. 1249-1261 (Sept. 1979).

New computational algorithms for chemical kinetics, D. T. Pratt, SP561/2, pp. 1265-1279 (Sept. 1979).

Measures of effectiveness and mechanisms for chemical and physical inhibition of quenched and adiabatic premixed flames, J. J. Reuther, SP561/2, pp. 1281-1312 (Sept. 1979).

Influence of water vapor on hydrogen combustion, $A$. Feugier, SP561/2, pp. 1315-1325 (Sept. 1979).

Inhibition on the propagation of flame, $T$. Inomata, S. Okazaki, T. Moriwaki, and M. Suzuki, SP561/2, pp. 13271337 (Sept. 1979).

Measurements of some elementary hydrocarbon reactions at high temperatures, $\mathbf{P}$. Roth and T. H. Just, SP561/2, pp. 1339-1352 (Sept. 1979).

The wall-less reactor. A technique for the study of gas phase oxidations and pyrolyses of hydrocarbons, J. E. Taylor, SP561/2, pp. 1353-1358 (Sept. 1979).

Studies of the elementary reaction kinetics of high-temperature species using optical measurement techniques, A. Fontijn, SP561/2, pp. 1359-1370 (Sept. 1979).

Diffusion of carbon dioxide at high temperatures, J. R. Ferron, D. L. Kerr, and A. U. Chatwani, SP561/2, pp. 13731402 (Sept. 1979).

The combustion of pulverized coals-An assessment of research needs, D. R. Hardesty and J. H. Pohl, SP561/2, pp. 1407-1449 (Sept. 1979).

Transport, thermodymamic and kinetic aspects of salt/ash deposition rates from combustion gases, D. E. Rosner, K. Seshadri, J. Fernandez de la Mora, G. Fryburg, F. Kohl, C. Stearns, and G. Santorn, SP561/2, pp. 1451-1474 (Sept. 1979).

The modeling of modern high pressure arc lamps, R. J Zollweg, SP561/2, pp. 1477-1494 (Șept. 1979).

The future of gas transport reactions, V. P. Orlovskii, SP561/2, pp. 1497-1506 (Sept. 1979).

New molecules involved in chemical transport reactions: Gaseous halide complexes, H. Schafer, SP561/2, pp. 1507 1515 (Sept. 1979).

Metal halide-Group IIl halide vapor complexes with emphasis on aluminum chloride, H. A. $९$ ye and D. M. Gruen, SP561/2, pp. 1517-1537 (Sept. 1979).

Formation of chromates from the reaction of alkali chlorides with $\mathrm{Cr}_{2} \mathrm{O}_{3}$ and oxygen, $\mathrm{C}$. Hirayama and $\mathrm{C}$. Y. Lin, SP56I/2, pp. 1539-1547 (Sept. 1979).

Catalytic reactions studies by a matrix isolation technique: Decomposition of HCOOH on Pt, D. Tevault and M. C. Lin, SP56//2, pp. 1551-1568 (Sept. 1979).

Reference data for high temperature systems, L. N. Gevantman, H. J. White, Jr., and D. R. Lide, Jr., SP561/2. pp. 1571-1579 (Sept. 1979).
Evaluation and compilation of the thermodynamic properties of high temperature species, M. W. Chase, J. R. Downey, and A. N. Syverud, SP561/2, pp. 1581-1594 (Sept. 1979).

Dimensional analysis of partition functions for ionic molecules: Thermodynamic properties of vapors, D. J. Frurip and M. Blander, SP561/2, pp. 1597-1609 (Sept. 1979).

Thermodynamics of non-rigid molecules at high temperature, P. Ip and H. L. Strauss, SP561/2, pp. 1611-1618 (Sept. 1979).

Graph theory prediction of the pressure second virial coefficients of some hydrocarbons, fluorocarbons, and their mixtures, W. Brostow, SP561/2, pp. 1619-1638 (Sept. 1979).

Mechanisms of oxidation and hot corrosion of metals and alloys at temperatures of 1150 to $1450 \mathrm{~K}$ under flow, E. A. Gulbransen and G. H. Meier, SP561/2, pp. 1639-1682 (Sept. 1979).

Potassium seed activities in open cycle MHD systems: Predictions using a multiphase multicomponent solution model, $C$. C. Hsu and C. E. Johnson, SP56//2, pp. 1683-17(14 (Sept. 19791.

Computer modeling of gas-condensed phase equilibria: Present status and some future needs in science and technolo. gy, M. Blander, SP561/2, pp. 1707-1715 (Sept. 1979).

SP562. The science of ceramic machining and surface flinishing II. Proceedings of a Symposium held at the National Bureau of Standards, Gaithersburg, MD, Nov. 13-15, 1978, B. J. Hockey and R. W. Rice, Eds., Nat. Bur. Stand. (U.S.), Spec. Publ. 562, 524 pages (Oct. 1979) SNO0)3-003-02122-9.

Abrasive wear in ceramics: An assessment, A. G. Evans, SP562, pp. 1-13 (Oct. 1979).

Nucleation of median and lateral cracks around Vickers indentations in soda-lime glass, J. T. Hagan, M. V. Swain, and J. E. Field, SP562, pp. 15-20 (Oct. 1979).

Fragmentation and damage penetration during abrasive machining of ceramics, H. P. Kirchner, R. M. Gruver, and D. M. Richard, SP562, pp. 23-42 (Oct. 1979).

Single-point scratches as a basis for understanding grinding and lapping, A. Broese van Groenou, N. Maan, and J. B. D. Veldkamp, SP562, pp. 43-59 (Oct. 1979).

Experiments on high-speed grinding of ferrites and glasses, A. Broese van Groenou and R. Brehm, SP562, pp. 61-74 (Oct. 1979).

Effect of workpiece properties on grinding forces in polycrystalline ceramics, B. G. Koepke and R. J. Stokes, SP562, pp. 75-91 (Oct. 1979).

Glass grinding mechanisms and influence on the finished surface and strength, S. Malkin and M. Huerta, SP562, pp. 93-106 (Oct. 1979).

The fine grinding of glass and ceramic material using conventional grinding wheels, E. D. Doyle and S. K. Dean, SP562, pp. 107-114 (Oct. 1979).

Some observations on environmental effects when diamond drilling, G. A . Cooper, SP562, pp. 115-137 (Oct. 1979).

The effect of chemical environments on the fracture of ceramic surfaces, R. E. Cuthrell, SP562, pp. 139-145 (Oct. 1979).

Some results on the wear of a bronze-bonded grinding wheel, A. Broese van Groenou, SP562, pp. 147-155 (Oct. 1979).

New concepts on surface finishing and its application to ceramics-Recent progress in ultra-fine finishing in Japan, $O$. Imanaka and M. Okutomi, SP562, pp. 157-169 (Oct. 1979).

Mechanism and application of the "mechanochemical polishing method using soft powder," N. Yasunaga, N. Tarumi, A. Obara, and O. Imanaka, SP562, pp. 171-182 (Oct. 1979).

Extended discussion: Hardness and its relation to machining, R. W. Rice and A. G. Evans, SP562, pp. 185-188 (Oct. 1979). 
Optimization of multistage grinding operations: The choice of consecutive removal rates, A. Broese van Groenou, SP562, pp. 191-199 (Oct. 1979).

Grinding stone, concrete and ceramics with coated abrasives, R. C. Lokken and E. J. Duwell, SP562, pp. 201-207 (Oct. 1979).

Turbine component machining development, D. W. Richerson and M. W. Rohare, SP562, pp. 209-220) (Oct. 1979).

Machinability studies on MACOR ${ }^{m}$ glass-ceramic, D. G. Grossman and D. L. Tuylor, SP562, pp. 221-229 (Oct. $1979)$.

Effects of various polishing media and techniques on the surface finish and behavior of laser glasses, R. L. Landingham, A. W. Casey, and R. O. Lindahl, SF562, pp. 231244 (Oct. 1979).

The fabrication of alumina tooth roots by diamond contour grinding, G. L. Messing, L. G. McCoy, and C. R. Hassler, SP562, pp. 247-254 (Oct. 1979).

Simultaneous finishing of both surfaces of hemispherical domes, R. Gentilman, F. Cooke, and P. Miles, SP562, pp. 255-260 (Oct. 1979).

Abrasionless machining methods for ceramics, R. F. Firestone, SP562, pp. 261-281 (Oct. 1979).

Shaping silicon compound ceramics with a continuous wave carbon dioxide laser, S. M. Copley, M. Bass, and R. G. Wallace, SP562, pp. 283-292 (Oct. 1979).

Optical and surface physical characteristics of diamondmachined infrared windows, D. L. Decker, D. J. Grandjean, and J. M. Bennett, SP562, pp. 293-303 (Oct. 1979).

Electrochemical grinding and surface damage for cemented carbides, S. Malkin and R. Levinger, SP562, pp. 305-315 (Oct. 1979).

A new ultra-fine polishing technique for sapphire, T. Sugita, S. Kawakami, and O. Imanaka, SP562, pp. $317-323$ (Oct. 1979).

Fine polishing of sapphire crystals, M. Ikeda, A. Yamada, Y. Kokaji, and S. Kimura, SP562, pp. 325-333 (Oct. 1979).

Surface characterization of optical materials, H. E. Bennett, SP562, pp. 337-350 (Oct. 1979).

The nature of strength controlling machining flaws in ceramics, R. W. Rice and J. J. Mecholsky, Jr., SP562, pp. $351-378$ (Oct. 1979).

Acoustic surface wave measurements of surface cracks in ceramics, B. T. Khuri-Yakub, A. G. Evans, and G. S. Kino, SP562, pp. 379-392 (Oct. 1979).

Characterization of surface damage in ceramics using selected area electron channeling, J. Lankford and D. L. Davidson, SP562, pp. 395-404 (Oct. 1979).

$Y$-deflection modulated secondary electron images in the evaluation of ceramic surface finish, L. P. Cook, E. N. Farabaugh, and C. D. Olson, SP562, pp. 407,415 (Oct. 1979).

Latent scratches on optical glasses that appear after cleaning, T. Izumitani, E. Miyade, S. Adachi, and S. Harada, SP562, pp. $417-425$ (Oct. 1979).

Machining flaws and the strength grain size behavior of ceramics, R. W. Rice, SP562, pp. 429-452 (Oct. 1979).

Surface machining effects on the strength distributions of aluminas, T. E. Easler, T. A. Countermine, R. E. Tressler, and R. C. Bradt, SP562, pp. $455-462$ (Oct. 1979).

Effect of surface finish on the strength of hot pressed silicon nitride, C. A. Andersson and R. J. Bratton, SP562, pp. 463474 (Oct. 1979).

The effect of surface finishing on the strength of commerclal hot pressed $\mathrm{Si}_{3} \mathbf{N}_{4}, \mathrm{C}$. C. Wu and K: R. McKinney, SP562, pp. 477-481 (Oct. 1979).

Surface condition and strength of silicon carbide-Silicon materials, T. J. Whalen and L. L. Terner, SP562, pp. 483488 (Oct. 1979).
The effect of grinding and polishing on the strength of annealed soda-lime-silica glass, R. Bowles, SP562, pp. 489-500) (Oct. 1979).

Surface flaw effects on crack propagation from subsonic water drop impact, Y. M. Ito and M. Rosenblatt, .\$P562. pp. 50) $1-511$ (Oct. 1979).

Surface characteristics of diamond-machined ceramic surfaces evaluated by high fluence diagnostics, M. J. Soileau, J. O. Porteus, and D. L. Decker, SP562, pp. 513-518 (Oct. $1979)$.

SP563. MFPG - Advanced composites: Design and applications. Proceedings of the 29th Meeting of the Mechanical Failures Prevention Group, held at the National Bureau of Standards. Gaithersburg, MD, May 23-25, 1979, T. R. Shives and W. A. Willard, Eds., Nat. Bur. Stand. (U.S.), Spec. Puhl. 563, 304 pages (Oct. 1979) SN()()3-()()3-()2 120-2.

Characterization and application of advanced composite materials, M. Waddoups, SP563, p. 3 (Oct. 1979).

Physical and mechanical response of graphite/polyimide materials to long term exposure in a space environment; material preparation and control testing, J. H. Powell, SP563, pp. 4-16 (Oct. 1979).

Effects of room-temperature aging on composite prepregs, H. C. Nash, C. F. Poranski, Jr., and R. Y. Ting, SP563, pp. 17-21 (Oct. 1979).

Application of instrumental techniques to the study of the cure of phthalocyanine/graphite composites, R. Y. Ting, SP563, pp. 25-31 (Oct. 1979).

Moisture dlffuslon analysis for composite microdamage, $C$. L. Leung and D. H. Kaelble, SP563, pp. 32-46 (Oct. 1979).

Recent work on technlgues and applications of moisture barriers to graphite epoxy composites, J. F. Haskins, SP563, pp. 47-56 (Oct. 1979).

In-service ultrasonic inspection system for composites, F. H. Chang, J. R. Bell, A. H. Gardner, C. P. Fisher, and G. P. Handley, SP563, p. 59 (Oct. 1979).

Design considerations for graphite-epoxy laminates of low thermal expansivity, D. D. Smith, SP563, pp. 60-71 (Oct. 1979).

Aircraft composite materials selection and application, V. L. Reneau, SP563, pp. 72-79 (Oct. 1979).

Composite structures in rotors and propellers, D. F Thompson, SP563, pp. 80-88 (Oct. 1979).

Development of a library module for the analysis of advanced composite materials, K. T. Knoll, SP563, pp. 91-107 (Oct. 1979).

Structural SMC-Material, process and performance review, R. B. Jutte, SP563, pp. 108-129 (Oct. 1979).

Development of a graphite-epoxy spacecraft precision mounting platform, K. S. Budlong and A. W. Sheffler, SP563, p. 130 (Oct. 1979).

Design analysis of automotive composite structures, $M . F$. Kowalski, D. S. Fine, and R. K. Herrman, SP563, p. 133 (Oct. 1979).

Fiberglass reinforced plastics use in transportation vehicles, R. D. Pistole, SP563. p. 134 (Oct. 1979).

Designing automotive components with continuous fiber composites, H. T. Kulkarni and P. Beardmore, SP563, pp 135-151 (Oct. 1979).

Fabrication of large composite spars and blades, $O$. Weingart, SP563, pp. 155-172 (Oct. 1979).

The effect of flber orlentation on the design parameters of reinforced and fllled thermoplastic compounds, P. J. Cloud and R. T. Alvord, SP563, p. 173 (Oct. 1979 ).

Quallty assurance of manufactured components, R. D. Margolis, SP563, p. 174 (Oct. 1979).

Degradatlon data of Kevlar pressure vessels, W. D. Humphrey, SP563, pp. 177-197 (Oct. 1979 ). 
Design assurance of a leak failure mode for composite overwrapped metal tankage, W. W. Schmidt, SP563, pp. 198-207 10 (1. 1979).

Composite materials in recreational equipment, $D$. Ratchlord, SP563, p. 208 (Oct. 1979).

Holographic nondestructive evaluation of spherical kevlar/epoxy pressure vessels, D. M. Boyd and B. W. Maxlield. \$1563, pp. 211-212 (Oct. 1979).

The Air Force "Manufacturing Cost/Design Guide (MC/DG)," B. R. Noton and D. L. Shunk, SP563, pp. 226227 (Oct. 1979).

Tensile strength and failure modes of boron-epoxy composite with a notch, C. E. S. Ueng, SP563, pp. 228-238 (Oct. 19791.

Failure criteria for composites under complex loading, P. W. Mast, L. A. Beaubien, D. R. Mulville, S. A. Sutton, R. W. Thomas, J. Tirosh, and 1. Wolock, SP563, p. 241 (Oct. 1979).

Failure analysis of an idealized composite damage zone, $C$. T. Herakovich and D. A. O'Brien, SP563, pp. 242-254 (Oct. 1979).

Interlamimar failure in epoxy based composite laminates, $A$. S. Wang, F. W. Crossman, and G. E. Law, Jr., SP563, pp. 255-264 (Oct. 1979).

Current developments in advanced composites for naval ship application, J. J. Kelly and H. H. Vanderveldt, SP563, pp. 267-275 (Oct. 1979).

Environmental effects on fiber reinforced organic matrix composites, M. Silvergleit, A. B. Macander, F. A. Brauer, and H. P. Edelstein, SP563, pp. 276-285 (Oct. 1979).

Composite technology for marine application, W. P. Couch, SP563, pp. 286-298 (Oct. 1979).

NBSIR 78-1575. Erosion by solid particle impact, A. W. Ruff and S. M. Wiederhorn, 103 pages (Jan. 1979). Order from NTIS as PB291988.

NBSIR 79-1746. Mathematical modefing and new experiments on durability of paper: A progress report, J. T. Fong, I. K. Fong, E. E. Toth, and E. L. Graminski, 83 pages (Apr. 11, 1979). Order from NTIS as PB295789.

NBSIR 79-1766. Studies on the photodegradation of poly (methyl methacrylate), M. Abouelezz and P. F. Waters, 52 pages ( June 1979). Order from NTIS as PB281828.

NBSIR 79-1767. NBS: Properties of electronic materials, J. R. Manning, 137 pages (June 1979). Order from NTIS as PB297465.

NBSIR 79-1914. Assessment of the quality of pulp fibers by short span tensile analysis, E. L. Graminski and K. Bonin, 22 pages (Oct. 1979). Order from NTIS as PB80-101918.

18348. Barnes, J. D., Assessing permeation performance of industrial plastic shipping containers, Proc. 36th Annual Technial Conf. Society of Plastics Engineers, Washington, DC, Apr. 24-27, 1978, pp. 824-826 (Society of Plastics Engineers, Greenwich, CT, 1978).

18418. Escalante, E., Iverson, W. P., The protection of steel piles by nonmetallic coatings in sea water, Mater. Perform. 17, No. 10, 9-15 (Oct. 1978).

18424. Escalante, E., Iverson, W. P., The protection of steel piles by selected coatings in a natural sea water environment, Proc. 10th Annual Offshore Technology Conf., Houston, TX, May 8-11, 1978, OTC 3190, pp. 1215-1222 (OTC, Houston, TX, 1978).

18639. Barnes, J. D., Martin, G. M., McCrackin, F. L., Performance of plastic packaging for hazardous materials transportation, DOT Report No. DOT/MTB/OHMO-77/5, 48 pages (Available from the National Technical Information Service, Springfield, VA 22161, June 1979).

18725. Bertocci, U., Mullen, J. L., Laboratory corrosion studies on tinned copper concentric neutral wires, Mater. Perform. 18, No. 6, 24-31 (June 1979).
8756. Bertocci, U., Mullen, J. L., Corrosion induced by an alternating voltage. A comparison between theoretical predictions and experimental results, (Proc. Int. Corrosion Forum Devoted Exclusively to the Protection and Performance of Materials, Atlanta, GA, Mar. 12-16, 1979), Paper 242 in Corrosion/79, pp. 242/1-242/11 (NACE, Publications Dept., P.O. Box 986, Katy, TX, 1979).

18854. Frohnsdorf,, G., Clifton, J. R., Brown, P. W., History and status of standards relating to alkalies in hydraulic cements, (Proc. American Society for Testing and Materials Symp. on Cement Standards-Evolution and Trends, St. Louis, MO, Dec. 7, 1977), Am. Soc. Test. Mater. Spec. Tech. Publ. 663, pp. 16-34 (1978).

18858. Ruff, A. W., Wiederhorn, S. M., Erosion by solid particle impact, Treatise Mater. Sci. Technol. 16, 69-126 (1979).

18945. Mauer, F. A., Robbins, C. R., X-ray powder diffraction measurements in reactive atmospheres at $1000{ }^{\circ} \mathrm{C}$ and $7 \mathrm{MPa}$ (1000 PSIG), Paper in Advances in X-ray Analysis, G. J. McCarthy, Ed., 22, 19-30 (Plenum Publ. Corp., New York, NY, 1979).

18946. Kruger, J., Fundamental aspects of the corrosion of metallic implants, Am. Soc. Test. Mater. Spec. Tech. Publ. 684, pp. 107-127 (1979).

18967. Reno, R. C., Swartzendruber, L. J., Bennett, L. H., Positron annihilation study of defects in titanium, NDT Int., pp. 224-227 (Oct. 1979).

19017. Wilson, W. K., Parks, E. J., An analysis of the aging of paper: Possible reactions and their effects on measurable properties, Restaurator 3, 37-61 (1979).

\section{Properties of Materials:}

\section{Electronic, Magnetic and Optical}

Room temperature poling of poly(vinylidene fluoride) with deposited metal electrodes, J. M. Kenney and S. C. Roth, J. Res. Nat. Bur. Stand. (U.S.), 84, No. 6, 447-453 (Nov.-Dec. 1979).

TN993. Optical materials characterization-Final technical report, February 1, 1978-September 30, 1978, A. Feldman, D. Horowitz, R. M. Waxler, and M. J. Dodge, Nat. Bur. Stand. (U.S.), Tech. Note 993, 71 pages (Feb. 1979) SN003-003$02031-1$

NBS-GCR-79-177. Investigations of surface flashover mechanisms, J. E. Thompson, 18 pages (June 1979). Order from NTIS as PB297193.

18328. Siedle, A. R., Bodner, G. M., Garber, A. R., Wright, R. F., Todd, L. J., A high-resolution ${ }^{11} \mathbf{B}$ NMR study of the $\left[\left(\mathbb{B}_{10} \mathrm{H}_{12}\right)_{2} \mathrm{Ni}\right]^{2-}$ ion, J. Magn. Reson. 31, 203-206 (1978).

18329. Abbundi, R., Rhyne, J. J., Sweger, D. M., Segnan, R., Magnetic relaxation phenomena in Dy-Sc alloys, Phys. Rev. B 18, No. 7, 3313-3317 (Oct. 1, 1978).

18372. Alperin, H. A., Pickart, S. J., Rhyne, J. J., Small-angle neutron scattering from rare-earth iron alloys (Extended $A$ bstract), J. Appl. Cryst. 11, 648-649 (1978).

18383. Watson, R. E., Bennett, L. H., A Mulliken electronegativity scale and the structural stability of simple compounds, J. Phys. Chem. Solids 39, 1235-1242 (1978).

18384. Anderson, W. E., Davis, R. S., Dissipation factor measurements on dielectric materials at liquid helium temperaiures, Proc. Conf. on Electrical Insulation and Dielectric Phenomena, Gaithersburg, MD, Nov. 3-6, 1975, pp. 151-156 (National Academy of Sciences, Washington, DC, 1978).

18404. Barnes, J., Fanconi, B., Critical review of vibrational data and force field constants for polyethylene, J. Phys. Chem. Ref. Data 7, No. 4, $1309-1321$ (1978).

18408. Davis, G. T., DeR eggi, A. S., Broadhurst, M. G.; Nonuniform poling and pyroelectric response in a PVDF-TFE 
copolymer, Proc. 1977 Annual Report Comf. on Electrical Insulation and Diclectric Phenomena, Colomic, NY, Oct. 17-20, 1977, pp. 209-213 (National Academy of Sciences, Washington, DC, 1979).

18421. Watson, R. E., Bennett, L. H., Transition metals: d-band hyhridization, electronegativities and structural stability of intermetallic compounds, Plys. Rev. B 18, No. 12, 6439-6449 (Dec. 15, 1978).

18540. Holdeman, L. B., Soulen, R. J., Jr., Finnegan, T. F., Peters, P. N., Superconducting properties of iridium thin films, J. Phys. Collonq. C6, Suppl. 8, Pt. 39, C6-608-C6-609 (Aug. 1978).

18556. Mangum, B. W., Bowers, W. J., Jr., Two practical magnetic thermometers for use below $30 \mathrm{~K}$, (Proc. 15th Int. Conf. on Low Temperature Physics, Grenoble, France, Aug. 23-29, 1978), J. Pliys. 6, Suppl. 8, No. 39, C6-1175-C6-1176 (Aug. 1978).

18604. Marshak, H., Turrell, B. G., $\gamma$-ray emission from oriented nuclei in a multiaxis nuclear spin system: ${ }^{100} \mathrm{Ho}^{165}$ Ho, Solid State Commun. 30, No. 11, 677-681 (1979).

18657. Fish, G. E., Rhyne, J. J., Sankar, S. G., Wallace, W. E., Effect of hydrogen on sublattice magnetization of Laves-phase rare earth iron compounds, (Proc. 24th Conf. on Magnetism \& Magnetic Materials, Cleveland, OH, Nov. 14-17, 1978), J. Appl. Pliys. 50, No. 3, 2003-2005 (Mar. 1979 ).

18674. Mountain, R. D., Model study of fluctuations and switching in amorphous semiconductors, J. Non-Cryst. Solids 33, 149-1 57 (1979).

18682. Rhyne, J. J., Fish, G. E., Sankar, S. G., Wallace, W. E., Magnetic properties of Laves-phase rare earth hydrides, (Proc. Conf. Physics of Metallic Rare-Earths, Saint-Pierre-deChartreuse, France, Sept. 4-7, 1978), J. Phys. 40, No. C-5, C5-209-C5-210 (May 1979).

18723. Bagozzi, R. P., lves, W. R., Nahman, N. S., Determination of the dielectric relaxation time in a Debye binary liquid by pulse measurements, (Proc. XV1 General Assembly of the Intl. Union of Radio Science, Ottawa, Canada, Aug. 26, 1969), Paper in Progress in Radio Science, 1966-1969, J. A. Lane, J. W. Findlay, C. E. White, Eds., 2, 257-265 (International Union of Radio Science, Brussels, Belgium, $1971)$.

18724. Bertocci, U., Photopotentials on copper and copper alloy electrodes, J. Electrochem. Soc. 125, No. 10, 1598-1602 (Oct. 1978).

18741. Callcott, T. A., Arakawa, E. T., Ederer, D. L., The soft x-ray emission and absorption spectra of simple metals, (Proc. Intl. Conf. on X-Ray and XUV Spectroscopy, Sendai, Japan, 1978), Jpn. J. Appl. Pliys. 17, Suppl. 17-2, 149-153 (1978).

18745. Eurl, W. L., VanderHart, D. L., Observations in solid polyethylenes by carbon-13 nuclear magnetic resonance with magic angle sample spinning, Macromolecules 12, No. 4, 762767 (July-Aug. 1979).

18746. Candela, G. A., Haines, R. A., A method for determining the region of superparamagnetism, Appl. Plys. Lett. 34, No. 12, 868-870 (June 15, 1979).

18754. Anderson, R. J. M., Kohler, B. E., Stevenson, J. M., The effects of strong excitation-phonon coupling on mixed crystal spectra: Diphenylmethylene in benzophenone, J. Chem. Phys. 71, No. 4, 1559-1563 (Aug. 15, 1979).

18804. Rosenbaum, J., Larson, E., Hoblitt, R., Fickett, F. R., A convenient standard for low-field susceptibility calibration, Re'. Sici. Instrum. 50, No. 8, 1027-1029 (Aug. 1979).

18819. Hebner, R. E., Jr., Misakian, M., Temperature dependence of the electro-optic Kerr coefficient of nitrobenzene, $J$. Appl. Physs. 50, No. 9, 6016-6017 (Sept. 1979).

18843. Kelley, E. F., Hebner, R. E., Jr., Time evolution of the electric field associated with breakdown phenomena in liquids, (Proc. Conf. on Electrical Insulation and Dielectric Phenomena, White Haven, PA, Oct. 1979), 1979 Annual Re- port of Conf. on Electrical Instation and Dielectric Phenomena, pp. 203-211 (1979).

18850. Lynn, J. W., Shelton, R. N., Neutron scattering studies of crystal field excitations in (RE)Ma $\mathrm{He}_{t}, J$. Appl. Phys. 50, No. 3, 1984-1986 (Mar. 1979).

18852. Shaulov, A., Bell, M. 1., Smith, W. A., Direct measurement of pyroelectric figures of merit of proper and improper ferroelectrics, J. Appl. Pliys. 50, No. 7, 4913-4919 (July 1979 ).

18881. Rhyne, J. J., Fish, G. E., Sankar, S. G., Wallace, W. E., Magnetic properties of ILaves-phase rare earth hydrides, $J$. Phys. C5, 40, Suppl. 5, C5-209-C5-210 (May 1979).

18897. Forester, D. W., Koon, N. C., Schelleng, J. H., Rhyne, J. J., Spin-glass and magnetic blocking transitions in amorphous YFe. Solid State Commun. 30, No. 4, 177-180 (1979).

18898. Rhyne, J. J., Lynn, J. W., Luborsky, F. E., Walter, J. L., Spin excitations in amorphous transition-metal boron glasses, J. Appl. Phys. 50, No. 3, I583-1585 (Mar. 1979).

18904. Layer, H. P., Acoustroptic modulator intensity servo, Appl. Opt. 18, No. 17, 2947-2949 (Sept. 1, 1979).

18910. Jednacak-Biscan, J., Mikac-Dadić, V., Pravdic,, V., Haller, W., Surface conductivity of glass at the solid/liquid interface, J. Colloid Interface Sci. 70, No. 1, 18-27 (1979).

18969. Hudson, R. P., Note on the dependence of $\mathrm{AC}$ magnetic susceptibility on the magnitude of the measuring field, $J$. Low Temp. Phys. 36, Nos. 5/6, 511-519 (1979).

19025. Trevino, S. F., An observation of one-dimensional reorientation and tunnel splitting of the ground and first excited state in a low barrier system: Solid witromethane, $J$. Chem. Phys. 71, No. 4, 1973-1974 (Aug. 15, 1979).

19026. Rush, J. J., Quasielastic neutron scattering and high resolution spectroscopy, NSF Worksliop Present Needs and Future Trends in Neutron Crystallography and Spectroscopy, Argonne National Laboratory, Argonne, IL, Nov. 15-17, 1978, Paper 14, pp. 71-75 (National Science Foundation, Washington, DC, 1979).

19030. Glinka, C. J., Rowe, J. M., Libowitz, G. G., Maeland, A., Neutron crystal-field spectroscopy of $\mathrm{CeD}_{2.12}$, J. Phys. C 12, 4229-4236 (1979).

19031. Koon, N. C., Rhyne, J. J., Excited state spin waves in $\mathrm{ErFe}_{2}$, Solid State Commun. 26, 537-540 (1978).

19046. Romanov, V. P., Candela, G. A., Roth, R. S., Swartzendruber, L. J., Magnetic properties and hyperfine interactions in the $\boldsymbol{\beta}^{\prime \prime \prime}$ phase of potassium ferrite, J. Appl. Phys. 50, No. 10, 6455-6458 (Oct. 1979).

19047. Watson, R. E., Bennett, L. H., Heats of formation of transition-metal alloys, Phys. Rev. Lett. 43, No. 15, 11301134 (Oct. 8, 1979).

\section{Properties of Materials:}

\section{Structural and Mechanical}

Molecular interpretations of modulus and swelling relations in natural rubber cross-linked by dicumyl peroxide, L. A. Wood, J. Res. Nat. Bur. Stand. (U.S.), 84, No. 5, 353-358 (Sept.Oct. 1979).

Monogr. 25, Section 16. Standard x-ray diffraction powder patterns. Section 16-Data for 86 substances, M. C. Morris, $H$. F. McMurdie, E. H. Evans, B. Paretzkin, J. H. de Groot, C. R. Hubbard, and S. J. Carmel, Nat. Bur. Stand. (U.S.), Monogr. 25, Sec. 16, 190 pages (Oct. 1979) SN003-00302128-8. 
NBSIR 78-1569. End-of-year-report. Micromechanical properties of beryllium and other instrument materials, $B$. W. Christ, R. S. Polvani, and R. J. Hocken, 42 pages (Oct. 1978). Order from NTIS as PB299654.

18341. Armstrong, R. W., Wu, C. C., Farabaugh, E. N., Crystal' subgrain misorientations vial $x$-ray diffraction microscopy, Adv. X-Ray Anal. 20, 201-206 (1977).

18347. Himes, V. L., Hubbard, C. R., Mighell, A. D., 3a,6adimethylglycouril \{3a,6a-dihydro-3a,6a-dimethylimidazo [4,5dlimidazole-2.5( $1 H, 6 H)$-dione $\}$, Acta Cryst. B34, 3102-3104 (1978).

18357. Watson, R. E., Bennett, L. H., Electron factors in the occurrence of sigma and structurally related transition metal alloy phases, Scr. Metall. 12, 1165-1170 (1978).

18373. Cahn, J. W., Allen, S. M., A microscopic theory for domain wall motion and its experimental verification in Fe-Al alloy domain growth kinetics, J. Phys. (Paris), Colloq. C7, 38, No. 12, C7-51-C7-54 (Dec. 1977).

18374. Steenbergen, C., Rush, J. J., Neutron scattering study of the methyl-group reorientations and the low temperature phase transition in $\left(\mathrm{CH}_{3}\right)_{2} \mathrm{SnF}_{2}, J$. Chem. Phys. 70, No. 1, 5056 (Jan. I, 1979 ).

18382. Wang, F. E., Mitchell, M. A., Sutula, R. A., Holden, J R., Bennett, L. H., Crystal structure study of a new compound $\mathbf{L i}_{5} \mathbf{B}_{4}$, J. Less-Common Met. 61, 237-251 (1978).

18422. Cahn, J. W., Monotectic composite growth, Metall Trans. A 10A, 119-121 (Jan. 1979).

18467. Crissman, J. M., Internal friction study of polycrystalline $n$-paraffins, J. Appl. Phys. 45, No, 10, $4190-4203$ (Oct. 1974 ).

18468. Crissman, J. M., Zapas, L. J., Dynamic mechanical behavior of polyethylene during creep to failure in uniaxial extension, J. Appl. Phys. 48, No. 10, 4049-4051 (Oct. 1977).

18491. Mathew, M., Schroeder, L. W., Crystal structure of a struvite analogue, $\mathrm{MgKPO}_{4} \cdot 6 \mathrm{H}_{2} \mathrm{O}$, Acta. Cryst. B35, 11-13 (1979)

18512. Brown, D. W., Lowry, R. E., The radiation-induced copolymerization of tetrafluoroethylene and styrene at high pressure, J. Polym. Sci. 17, 759-768 (1979).

18523. Horton, W. S., An examination of five preferred orientation functions, Carbon 17, 153-155 (1979).

18530. McCrackin, F. L., Monte Carlo calculations of the number of ways to pack nonoverlapping rods on a square lattice, J. Chem. Phys. 69, No, 12, 5419-5423 (Dec. 15, 1978).

18531. Naegele, D., Yoon, D. Y., Broadhurst, M. G., Formation of a new crystal form $\left(\alpha_{p}\right)$ of poly(vinylidene fluoride) under electric field, Macromolecules 11, No. 6, 1297-1298 (Dec. 1978).

18552. Read, D. T., Metallurgical "effects in niobium-titanium - alloys, Cryogenics 18, No. 10, 579-584 (Oct. 1978),

18583. Brown, W. E., Schroeder, L. W., Ferris, J. S., Interlayering of crystalline octacalcium phosphate and hydroxylapatite, J. Phys. Chem, 83, No. 11, 1385-1388 (1979).

18613. Allen, S. M., Cahn, J. W., A microscopic theory for antiphase boundary motion and its application to antiphase domain coarsening, Acta Met. 27, 1085-1095 (1979).

18618. Verdier, P. H., Monte Carlo studies of lattice-model polymer chains. 1V. Equilibrium dimensions and distributions in Rouse coordinates, $J$. Chem. Phys. 70, No. 12,5708-5713 (June 15, 1979).

18620. Flynn, J. H., Dickens, B., Application of new kinetic techniques to the lifetime prediction of polymers from weightloss data, (Proc. Symp. 176th National Meeting of the American Chemical Society, Miami, FL, Sept. 11-14, 1978), ACS Symp. Series 95, Durability of Macromolecular Materials, R. K. Eby, Ed., Paper 7, 97-115 (American Chemical Society, Washington, DC, 1979).

18636. Stalick, J. K., Siedle, A. R., Mighell, A. D., Hubbard, C. R., A novel bimetallic sulfur cluster. Crystal and molecular structure of a dimer of bis[methyldiphenylphosphinesil ver|tetrathiotungsten, $\left[\left(\mathrm{C}_{4 i} \mathrm{H}_{5}\right)_{2} \mathrm{PCH}_{3} \mathrm{l}_{4} \mathrm{Ag}_{4} \mathrm{~W}_{2} \mathrm{~S}_{4}, \mathrm{~J} . \mathrm{Am}\right.$. Chem. Soc. 101, No. I 1, 2903-2907 (May 23, 1979 ).

18637. Swartzendruber, L. J., Carter, G. C., Kahan, D. J. Read, M. E., Manning, J. R., Numerical physical property data for metal hydrides utilized for hydrogen storage, (Proc. 2d World Hydrogen Energy Conf., Zurich, Switzerland, Aug. 21-24, 1978), Paper in Hydrogen Energy System, T. N. Veziroglu and W. Seifritz, Eds., 4, 1973-2011 (Pergamon Press, Oxford, England, 1978)

18645. Carter, G. C., Bennett, L. H., Kahan, D. J., Cuthill, J. R., Chafe, H. D., Gray, A. G., Langer, E. L., Baker, H., The American Society for Metals and National Bureau of Standards Alloy Data Center's joint program for compilation of alloy phase diagrams, Proc. Sixth Intl. Codata Conf., Sicily, Italy, May 22-25, 1978, B. Dreyfus, Ed., pp. 235-237 (Pergamon Press, New York, NY, 1979).

18646. Cava, R. J., Roth, R. S., Characterization of modulated structures in $\mathbf{A B O}_{4+\boldsymbol{x}}$ phases, (AlP Conf. Proc. No. 53, Symp. on Modulated Structures, Kailua Kona, HI, Mar. 26-30, 1979. Series Editor: H. C. Wolfe), Paper in Modulated Structures-1979, J. M. Cowley, J. B. Cohen, M. B. Salamon, B. J. Wuensch, Eds., Sec. 7, pp. 361-363 (American Institute of Physics, New York, NY, 1979).

18669. Kikuchi, R., Cahn, J. W., Theory of interphase and antiphase boundaries in f.c.c. alloys, Acta Met. 27, 1337-1353 (1979).

18672. Mighell, A. D., Hubbard, C. R., Cohen, A., 2-ethoxy1,7,9-triethyl-7,9-dihydro-1H-purine-6,8-dione; a tetraethyl derivative of uric acid, Acta. Cryst. B35, 1280-1282 (1979).

18673. Mighell, A. D., Hubbard, C. R., Harris, J., Staffa, J. A., Zervos, C., S-carboxymethyl-L-cysteine, Acta Cryst. B35, $1258-1261$ (1979)

18734. Waterstrat, R. M., Haenssler, F., Muller, J., Nb-Si A 15 compounds produced by liquid quenching, J. Appl. Phys. 50, No. 7, 4763-4766 (July 1979)

18739. Cuthill, J. R., Kahan, D. J., Bennett, L. H., Chafe, H. D., Gray, A. G., Langer, E. L., Baker, H., Joint program of American Society for Metals and National Bureau of Standards for compilation of alloy phase diagrams, Proc. Vih Interamerican Conf. on Materials Technology, Sas Paulo, Brazil, Nov. 6-10,1978, pp. 149-152 (Southwest Research Institute, San Antonio, TX, 1979)

18765. Crissman, J. M., Zapas, L. J., Creep failure and fracture of polyethylene in uniaxial extension, Polym. Eng. Sci. 19, No. 2, 99-103 (Mid-Feb. 1979)

18766. Crissman, J. M., Zapas, L. J., Lifetime behavior of polyethylene bars in uniaxial extension in various chemical environments, (Proc. Symp. 176th Meeting of the American Chemical Society, Miami, FL, Sept. 11-14, 1978), ACS Symp. Series 95, Durability of Macromolecular Materials, R. K. Eby, Ed., Puper 20, 289-299 (American Chemical Society, Washington, DC, 1979).

18767. Crissman, J. M., Zapas, L. J., Mechanical behavior of a highly oriented polyethylene rod, J. Polym. Sci. 15, 1685 1693 (1977).

18772. Kranbuehl, D. E., Verdier, P. H., Simulation of the relaxation of random-coil polymer chains by lattice models with excluded volume: The effect of bead movement rules, $J$. Chem. Phys. 71, No. 6, 2662-2670 (Sept. 15, 1979).

18807. Zapas, L. J., Crissman, J. M., Stress-strain-time diagrams, including failure envelopes, for high-density polyethylenes of different molecular weight, (Proc. Symp. 176th Meeting of the American Chemical Society, Miami, FL, Sept. 11-14, 1978), ACS Symp. Series 95, Durability of Macromolecular Materials, R. K. Eby, Ed., Paper 21, 301-309 (American Chemical Society, Washington, DC, 1979).

18827. Hinkley, J. A., Han, C. C., Mozer, B., Yu, H., Chain deformations in rubber. Macromolecules 11, No. 4, 836-838 (July-Aug. 1978). 
18835. Alperin, H. A., Gillmor, W. R., Pickart, S. J., Rhyne, J. J., Magnetization and neutron scattering measurements on amorphous $\mathrm{NdFe}_{2}, J$. Appl. Phys. 50, No. 3, 1958-1960 (Mar. 1979).

18851. Wlodawer, A., Segrest, J. P., Chung, B. H., Chiovetti, R., Jr., Weinstein, J. N., High-density lipoprotein recombinants: Evidence for a bicycle tire micelle structure obtained by neutron scattering and electron microscopy, FEBS Lett. 104, No. 2, 231-235 (Aug. 1979).

18857. Jenkins, R., Hubbard, C. R., A preliminary report on the design and results of the second round robin to evaluate search/match methods for qualitative powder diff ractometry, (Proc. Twenty-Seventh Ann. Conf. on Applications of X-ray analysis, Denver, CO, Aug. 1-4, 1978), Paper in Advances in X-ray Analysis, G. J. McCarthy, C. S. Barrett, D. E. Leyden, J. B. Newkirk, C. O. Ruud, Eds., 22, 133-142 (Plenum Press, New York, NY, 1979).

18873. Choi, C. S., Prince, E., 1,2,3-triaminoguanidinium nitrate by neutron diffraction, Acta Cryst. B35, 761-763 (1979).

18896. Early, J., Discussion on the paper "A mechanism of intergranular fracture during high-temperature fatigue," by $B$. Min and R. Raj, (Proc. American Society for Testing and Materials Symp. on Fatigue Mechanisms, Kansas City, MO, May 22-24, 1978), Am. Soc. Test. Mater. Spec. Tech. Publ. 675, pp. 585-587 (1979).

18956. Wacker, P. F., Plane-radial scanning techniques with probe correction; natural orthogonalities with respect to summation on planar measurement lattices, (Proc. 1979 Int. IEEE/AP-S Symp., Seattle, W A, June 18-22, 1979), Paper in 1979 International Symposium Digest: Antennas and Propagation, 79 CHI456-3 AP, 2, 561-564 (IEEE Antennas and Propagation Society, University of Washington, Seattle, WA, 1979).

19023. Sanchez, I. C., Phase transition behavior of the isolated polymer chain, Macromolecules 12, 980-988 (Sept.-Oct. 1979).

19027. Choi, C. S., Prask, H. J., Trevino, S. F., Nondestructive investigation of texture by neutron diffraction, J. Appl. Cryst. 12, 327-331 (1979).

19036. Rowe, J. M., Rush, J. J., Hinks, D. G., Susman, S., Neutron scattering study of the dynamics of $(\mathrm{KCN})_{0.5}(\mathrm{KBr})_{0.5}$, Phys. Rev. Lett. 43, No. 16, $1158-1161$ (Oct. 15, 1979).

19037. Santoro, A., Roth, R. S., Minor, D., Neutron powder diffraction study of tantalum tungstate, $\mathrm{Ta}_{2} \mathbf{W O}_{\mathrm{H}}$, Acta Cryst. B35, 1202-1205 (1979).

\section{Properties of Materials:}

\section{Thermodynamic and Transport}

Diffusion coefficients of the 455 and 505 states of the large ribosomal subunit of $E$. coli by quasielastic light scattering, $C$. C. Han, I. N. Serdyuk, and H. Yu, J. Res. Nat. Bur. Stand. (U.S.), 84, No. 1, 1-8 (Jan.-Feb. 1979).

18352. Bowman, R. C., Jr., Carter, G. C., Chabre, Y., Nuclear magnetic resonance studies of diffusion in $\mathrm{FeTiH}_{s}$, Proc. $2 d$ Int. Congress on Hydrogen in Metals, Paris, France, June 6$11,1977,8$ pages (Pergamon Press, Paris, France, 1977).

18431. Wang, F. W., Dynamic flow birefringence and flow dichroism of block-copolymer molecules in solution with application to the free-draining limit, Macromolecules 11, No. 6, 1198-1205 (Nov.-Dec. 1978 ).

18480. Han, C. C., Concentration dependence of the diffusion coefficient of polystyrene at theta-condition, Polymer Notes 20 , 259-261 (Feb. 1979).

18730. deGraaf, L. A., Rush, J. J., Livingston, R. C., Flotow, H. E., Rowe, J. M., Study of hydrogen diffusion in vanadium and tantalum hydride by quasielastic thermal neutron scattering, Proc. Intl. Meet. on Hydrogen in Metals, Kernforsctungsanlage Julich, Germany, Mar. 20-24, 1972, pp. 301-312 (Mar. 1972).

18758. Cahn, J. W., Balluffi, R. W., On diffusional mass transport in polycrystals containing stationary or migrating grain boundaries, Scr. Metall. 13, No. 6, 499-502 (1979).

18759. Cahn, J. W., Pan, J. D., Balluffi, R. W., Diffusion induced grain boundary migration, Scr. Metall. 13, No. 6, 503 509 (1979).

\section{Standard Reference Data}

Energy levels of titanium, Ti I through Ti xxI, C. Corliss and J. Sugar, J. Pltys. Chem. Ref. Data 8, No. 1, 1-62 (1979).

The spectrum and energy levels of the neutral atom of boron ( $B$ 1), G. A. Odintzova and A. R. Striganov, J. Phys. Chem. Ref. Duta 8, No. 1, 63-68 (1979).

Relativistic atomic form factors and photon coherent scattering cross sections, J. H. Hubbell and I. Overbo, J. P/hys. Chem. Ref. Data 8, No. 1, 69-106 (1979).

Microwave spectra of molecules of astrophysical interest. XIV. Vinyl cyanide (Acrylonitrile), M. C. L. Gerry, K. Yamada, and G. Winnewisser, J. Phys. Chem. Ref. Data 8, No. 1, 107124 (1979).

Molten salts: Volume 4, Part 4. Mixed halide melts, G. J. Janz, R. P. T. Tomkins, and C. B. Allen, J. Phys. Chem. Ref. Data 8, No. 1, 125-302 (1979).

Atomic radiative and radiationless yields for $K$ and $L$ shells, $M$. O. Krause, J. Phys. Chem. Ref. Data 8, No. 2, 307-328 (1979).

Natural widths of atomic $K$ and $L$ levels, $K \alpha$-ray lines and several $K L L$ Auger lines, M. O. Krause and J. H. Oliver, $J$. Phys. Chem. Ref. Data 8, No. 2, 329-338 (1979).

Electrical resistivity of alkali elements, T. C. Chi, J. Phys. Chem. Ref. Data 8, No. 2, 339-438 (1979).

Electrical resistivity of alkaline earth elements, T. C. Chi, J. Phys. Chem. Ref. Data 8, No. 2, 439-498 (1979).

Vapor pressures and boiling points of selected halomethanes, $A$. P. Kudchadker, S. A. Kudchadker, R. P. Shukla, and P. R. Patnaik, J. Phys. Chem. Ref. Data 8, No. 2, 499-5 18 (1979).

Ideal gas thermodynamic properties of selected bromoethanes and iodoethane, S. A. Kudchadker and A. P. Kudchadker, J. Phys. Chem. Ref. Data 8, No. 2, $519-526$ (1979).

Thermodynamic properties of normal and deuterated naphthalenes, S. S. Chen, S. A. Kudchadker, and R. C. Wilhoit, J. Phys. Chem. Ref. Data 8, No. 2, 527-536 (1979).

Microwave spectra of molecules of astrophysical interest. XV. Propyne, A. Bauer, D. Boucher, J. Burie, J. Demaison, and A. Dubrulle, J. Phys. Chem. Ref. Data 8, No. 2, 537-558 (1979).

A correlation of the viscosity and thermal conductivity data of gaseous and liquid propane, P. M. Holland and H. J. M. Hanley, J. Phys. Chem. Ref. Data 8, No. 2, $559: 576$ (1979).

Microwave spectra of molecules of astrophysical interest. XVI. Methyl formate, A. Bauder, J. Phys. Chem. Ref. Data 8, No. 3, 583-618 (1979).

Molecular structures of gas-phase polyatomic molecules determined by spectroscopic methods, M. D. Harmony, V. W. Laurie, R. L. Kuczkowski, R. H. Schwendeman, D. A. Ramsay, F. J.' Lovas, W. J. Lafferty, and A. G. Maki, J. Phys. Chem. Ref. Data 8, No. 3, 619-722 (1979).

Critically evaluated rate constants for gaseous reactions of several electronically excited species, K. Schofield, J. Phys. Chem. Ref. Data 8, No. 3, 723-798 (1979).

A review, evaluation, and correlation of the phase equilibria, heat of mixing, and change in volume on mixing for liquid mixtures of methane + ethane, M. J. Hiza, R. C. Miller, and A. J. Kidnay, J. Phys. Chem. Ref. Daıa 8, No. 3, 799-816 (1979). 
Energy levels of aluminum, Al I through Al xıl, W. C. Martin and R. Zalubas, J. Phys. Chem. Ref. Data 8, No. 3, 817-864 (1979).

Energy levels of calcium, Ca 1 through Ca $x x, J$. Sugar and C. Corliss, J. Phys. Chem. Ref. Data 8, No. 3, 865-916 (1979).

Simplification of thermodynamic calculations through dimensionless entropies, K. S. Pitzer and L. Brewer, J. Phys. Chem. Ref. Duta 8, No. 3, 917-920 (1979).

Evaluated activity and osmotic coefficients for aqueous solutions: Iron chloride and the bi-univalent compounds of nickel and cobalt, R. N. Goldberg, R. L. Nuttall, and B. R. Staples, J. Pliys. Chem. Ref. Data 8, No, 4, 923-1004 (1979).

Evaluated activity and osmotic coefficients for aqueous solutions: Bi-univalent compounds of lead, copper, manganese, and uranium, R. N. Goldberg, J. Phys. Chem. Ref. Duta 8, No. 4, $1005-1050$ (1979).

Microwave spectra of molecules of astrophysical interest. XVII. Dimethyl ether, F. J. Lovas, H. Lutz, and H. Dreizler, J. Phys. Chem. Ref. Data 8, No. 4, $1051-1108$ (1979).

Energy levels of potassium, $K \mathbb{1}$ through $K \mathrm{xix}, \mathrm{C}$. Corliss and J. Sugar, J. Phys. Chem. Ref. Data 8, No. 4, $1109-1146$ (1979)

Electrical resistivity of copper, gold, palladium, and silver, R. A. Matula, J. Phys. Chem. Ref. Data 8, No. 4, 1147-1298 (1979).

SP426. Supplement 1. Bibliography of low energy electron and photon cross section data (January 1975 through December 1977), J. W. Gallagher, J. R. Rumble, Jr., and E. C. Beaty, Nat. Bur. Stand. (U.S.), Spec. Publ. 426, Suppl. I, 115 pages (June 1979) SN003-003-02074-5.

NSRDS-NBS61, Part 11. Physical properties data compilations relevant to energy storage. II. Molten salts: Data on single and multi-component salt systems, G. J. Janz, C. B. Allen, N. P. Bansal, R. M. Murphy, and R. P. T. Tomkins, Nat. Stand. Ref. Data Ser., Nat. Bur. Stand. (U.S.), 6I, Part II, 442 pages (Apr. 1979) SN003-003-02051-6.

NSRDS-NBS61, Part III. Physical properties data compilations relevant to energy storage. III. Engineering properties of single and polycrystalline sodium beta and beta"-alumina, G. R. Miller and D. G. Paquette, Nat. Bur. Stand. Ref. Data Ser., Nat. Bur. Stund. (U.S.), 61, Part III, 19 pages (June 1979) SNO03-003-02079-6.

NSRDS-NBS64. Rate coefficients for ion-molecule reactions. Organic ions other than those containing only $\mathbf{C}$ and $\mathbf{H}, \mathrm{L}$. W. Sieck, Nat. Stand. Ref. Data Ser., Nat. Bur. Stand. (U.S.), 64, 27 pages (Feb. 1979) SN003-003-02027-3.

18615. Hust, J. G., Kirby, R. K., Standard reference materials for thermophysical properties, (Proc. 2d lnt. Cryogenic Materials Conf., Boulder, CO, Aug. 3-5, 1977), Paper D-3 in Advances in Cryogenic Engineering, K. D. Timmerhaus, R. P. Reed, and A. F. Clark, Eds., 24, 232-239 (Plenum Press, New York, NY, 1978).

18616. Schramm, R. E., Kasen, M. B., Fiberglass-epoxy in a conical superconducting field magnet support, (Proc. $2 \mathrm{~d}$ Int. Cryogenic Materials Conf., Boulder, CO, Aug. 3-5, 1977), Paper E-3 in Advances in Cryogenic Engineering, K. D. Timmerhaus, R. P. Reed, and A. F. Clark, Eds., 24, 271-278 (Plenum Press, New York, NY, 1978).

18619. Sparks, L. L., Magnetic field effect on thermal conductivity of selected metals, (Proc. 2d 1nt. Cryogenic Materials Conf., Boulder, CO, Aug. 3-5, 1977), Paper D-2 in Advances in Cryogenic Engineering, K. D. Timmerhaus, R. P. Reed, and A. F. Clark, Eds., 24, 224-231 (Plenum Press, New York, NY, 1978)

18621. Tobler, R. L., McHenry, H. 1., Reed, R. P., Fracture mechanics parameters for an iron-13\% chromium-19\% manganese stainless steel and its welds at cryogenic temperatures, (Proc. 2d Int. Cryogenic Materials Conf., Boulder, CO, Aug. 3-5, 1977), Paper K-7 in Advances in Cryogenic Engineering,
K. D. Timmerhaus, R. P. Reed, and A. F. Clark, Eds., 24, 560-572 (Plenum Press, New York, NY, 1978).

18666. Hamilton, C. A., Harris, R. E., Sullivan, D. B., Highspeed superconducting electronics, (Proc. Government Microcircuit Applications Conf., Monterey, CA, Nov. 14-16, 1978), GOMAC 1978 Digest of Papers VII, 29-32 (1979).

18695. Tobler, R. L., Reed, R. P., Fatigue crack growth resistance of structural alloys at cryogenic temperatures, (Proc. 2d lnt. Cryogenic Materials Conf., Boulder, CO, Aug. 3-5, 1977), Paper A-7 in Advances in Cryogenic Engineering, K. D. Timmerhaus, R. P. Reed, and A. F. Clark, Eds., 24, 8290 (Plenum Press, New York, NY, 1978).

\section{Standard Reference Materials}

SP260, 1979-80 Edition. NBS Standard Reference Materials Catalog-1979-80 Edition, R. W. Seward, Nat. Bur. Stand. (U.S.), Spec. Publ. 260, 1979-80 edition, 107 pages (Apr. 1979) SN003-003-02048-6.

SP260-58. Standard reference materials: SRM 1470: Polyester film for oxygen gas transmission measurements, J. D. Barnes and G. M. Martin, Nat. Bur. Stand. (U.S.), Spec. Publ. 26058,43 pages (June 1979) SNO03-003-02077-0.

SP260-62. Standard reference materials: SRM 768: Temperature reference standard for use below $0.5 \mathrm{~K}, \mathrm{R}$. J. Soulen, Jr. and R. B. Dove, Nat. Bur. Stand. (U.S.), Spec. Publ. 260-62, 47 pages (Apr. 1979) SN003-003-02047-8.

SP260-65. Standard reference materials: Micro-homogeneity studies of NBS standard reference materials, NBS research materials, and other related samples, R. B. Marinenko, K. F. J. Heinrich, and F. C. Ruegg, Nat. Bur. Stand. (U.S.), Spec. Publ. 260-65, 84 pages (Sept. 1979) SN003-003-02114-1.

SP260-66. Standard reference materials: Didymium glass filters for calibrating the wavelength scale of spectrophotometers-SRM 2009, 2010, 2013, and 2014, W. H. Venable, Jr. and K. L. Eckerle, Nat. Bur. Stand. (U.S.), Spec. Publ. 26066, 85 pages (Oct. 1979) SNO03-003-02 127-0.

NSRDS-NBS3, Section 8. Selected tables of atomic spectra. A: Atomic energy levels-Second edition. B: Multiplet tables. $O$ vi, O vil, O viı,, C. E. Moore, Nat. Stand. Ref. Data Ser., Nat. Bur. Stand. (U.S.), 3, Sec. 8, 31 pages (Jan. 1979) SN003-003-01964-0.

18414. Cumbo, J. E., Michaelis, R. E., Production, characterization, and certification of NBS-SRM 64c, high-carbon fer: rochromium, Electr. Furn. Conf., Proc. 35, 52-56 (1977).

18470. Durst, R. A., Reference materials for $\mathrm{pH}$ and blood gases, (Proc. Workshop on Blood pH and gases, Utrecht, The Netherlands, June 5-6, 1978), Paper in Blood $p H$ and Gases, A. H. J. Maas, Ed., Session III, pp. 81-87 (University Press, Utrecht, The Netherlands, Mar. 1979).

18536. Cali, J. P., Measurement compatibility in clinical chemistry, CAMLT/Newsline 4, No. 6, 4-5 (The California Association for Medical Laboratory Technology, Oakland, CA, June 1978).

18539. Cali, J. P., NBS nuclear medicine and clinical chemistry-Standard reference materials, (Proc. Symp. on Standardization, Performance and Quality Control in Nuclear Medicine, Gaithersburg, MD, June 12-14, 1975), Paper in Chapter 16 in Quality Control in Nuclear Medicine, Radiopharmaceuticals, Instrumentation, and in Vitro Assays, B. A. Rhodes, Ed., pp. 150-153 (The C. V. Mosby Company, St. Louis, MO, 1977).

18668. Hust, J. G., Graphite as a standard reference material, (Proc. 15th Intl. Thermal Conductivity Conf., Ottawa, On- $i$ tario, Canada, Aug. 24-26, 1977), Paper in Thermal Conduclivity 15, V. V. Mirkovich, Ed., pp. $161-167$ (Plenum Press, New York, NY, 1978).

18748. Cali, J. P., The role of reference $m$ aterials in the analyti-! cal laboratory, Fresenius Z. Anal. Chem. No. 297, pp. 1-3 (1979). 
I8866. Greenberg. R. R., Trace element characterization of the NBS urban particulate matter Standard Reference Material by instrumental neutron activation analysis, Anal. Cluem. 51, No. 12, 2004-2006 (Oct. 1979).

18905. Kirby, R. K., Standard reference materials for thermophysical properties, Proce $7 t h$ Simp. on Thermophtysical Properties, Gaithershurg, MD, May 10-12, 1977, A. Cezairliyan, Ed., pp. 949-965 (The American Society of Mechanical Engineers, New York, NY, 1977).

18973. Marinenko, R. B., Heinrich, K. F. J., Ruegg, F. C., Microhomogeneity studies of NBS standards, Proc. Folurtecntl Ann. Microheam Analysis Society/1979 Conf., San Antonio, TX, Aug. 13-17, 1979, pp. 221-226 (San Francisco Press Inc., San Francisco, CA, 1979).

\section{Surfaces and Interfaces}

Observations of surface changes in platinum crucibles, $C$. P Saylor, E. Wichers, and J. 1. Hoffman, J. Res. Nat. Bur. Stand. (U.S.), 84, No. 5, 385-394 (Sept.-Oct. 1979).

18323. Waclawski, B. J., Gadzuk, J. W., Herbst-J. F., uv photoemission for rare gases implanted in Ge, P/rys. Rev. Lett. 41, No. 8, 583-586 (Aug. 21, 1978).

18406. Cuthill, J. R., ASTM Committee E-42 on surface analysis: Its history, scope, activities, and objectives, Am. Soc: Test. Mater., Stand. News, 6, No. 2, 8-11, 59-60 (Feb. 1978)

18417. Ericksion, N. E., ESCA studies of the clean Si (111) surface, Phys. Scr. 16, 462-465 (1977).

18791. Fisher, G. B., Madey, T. E., Yates, J. T., Jr., Ultraviolet photoemission studies of formaldehyde and related molecules adsorbed on Ru(110), J. Vac. Sci. Technol. 15, No. 2, 543547 (Mar./Apr. 1978).

18810. Greiner, G., Menzel, D., Klein, R., Field-induced redistribution processes in adsorption layers of hydrogen on ruthenium, Surf. Sci. 84, 129-140 (1979).

18924. Powell, C. J., Erickson, N. E., Madey, T. E., Results of a joint Auger/ESCA round robin sponsored by ASTM Committee E-42 on surface analysis, Part I. ESCA results, J. Electron Spectrosc. Relat. Phenom. 17, 361-403 (1979).

\section{Thermodynamics and Chemical Kinetics}

Enthalpies of solution of the nucleic acid bases. 5. Adenine in aqueous hydrochloric acid, aqueous sodium hydroxide, methanol, and ethanol, M. V. Kilday, J. Res. Nat. Bur. Stand. (U.S.), 84, No. 3, 231-240 (May-June 1979).

Sample preparation in ion-chromatography, W. F. Koch, J. Res Nat. Bur. Stand. (U.S.), 84, No. 3, 241-246 (May-June 1979).

Miniaturization of normal-state and superconducting striplines, 'R. L. Kautz, J. Res. Nat. Bur. Stand. (U.S.), 84, No. 3, 247 259 (May-June 1979).

Enthalpies of solution of $\mathrm{KBr}, \mathrm{KI}, \mathrm{KIO}_{3}$, and $\mathrm{KIO}_{4}$ in $\mathrm{H}_{2} \mathrm{O}, \mathrm{M}$ E. Efimov, G. N. Klevaichuk, V. A. Medvedev, and M. V Kilday, J. Res. Nat: Bur. Stand. (U.S.), 84, No. 4, 273-286 (July-Aug. 1979)

SP537. A bibliography of sources of experimental data leading to thermal properties of binary aqueous electrolyte solutions, D. Smith-Magowan and R. N. Goldberg, Nat. Bur. Stand. (U.S.), Spec. Puhl. 537, 89 pages (Mar. 1979) SN003-00302033-8.

NSRDS-NBS65. Rate constants for reactions of inorganic radicals in aqueous solution, A. B. Ross and P. Neta, Nat. Stand. Ref. Datu. Ser., Nut. Bur. Siand. (U.S.), 65, 62 pages (June 1979) SN003-003-02072-9.

NBSIR 78-1432. Automation of the ion energetics data center, R. Thompson, W. Webb, and H. M. Rosenstock, 84 pages (Dec. 1977). Order from NT1S as PB293918.
NBSIR 79-1612. Isobutane: Provisional thermodynamic functions from 114 to $700 \mathrm{~K}$ at pressures to 700 bar, R. D. Goodwin, 191 pages (July 1979). Order from NTIS as PB299361.

NBSIR 79-1621. Normal butane: Provisional thermodynamic functions from 135 to $700 \mathrm{~K}$ at pressures to $700 \mathrm{bar}, \mathrm{R}$. D. Goodwin. 171 pages (Sept. 1979). Order from NTIS as PB80- 118193 .

NBSIR 79-1777. A compendium of gas phase basicity and proton affinity measurements, K. N. Hartman, S. Lias, P. Ausloos, H. M. Rosenstock, S. S. Schroyer, C. Schmidt, D. Martinsen, and G. W. A. Milne, 563 pages (July 1979). Order from NT1S as PB299289.

NBSIR 79-1941. Table of recommended rate constants for chemical reactions occurring in combustion, F. Westley, 169 page: (Nov. 1979). Order from NT1S as PB80-128531,

18321. Robertson, B., Application of maximum entropy to nonequilibrium statistical mechanics, Proc. Maximum Entropy Furmalism Conf., Cambridge, MA, May 2-4, 1978, R. D. Levine and M. Tribus, Eds., pp. 289-320) (The MIT Press, Cambridge, MA, 1978).

18377. Chang, S. S., Heat capacity and thermodynamic properties of solid synthetic sapphire, $\alpha-\mathbf{A l}_{2} \mathbf{O}_{3,}$, Proc. $7 t h$ Symp. on Thermophysical Properties, Gaithershurg, MD, May I0-I2, 1977, pp. 83-90 (The American Society of Mechanical Engineers, New York, NY, 1977).

18380. Joseph, J. T., Hybl, A., Flynn, J. H., Differential scanning calorimetry studies of some analogs for the lipid component of biological membranes, Chem. Phys, Lipids 22. 239-243 (1978).

18436. Kurylo, M. J., Laufer, A. H., Evidence for atom exchange in $\mathrm{OH}$ reactions with carbonyl compounds: ${ }^{\mathrm{H}} \mathrm{OH}+$ $\mathrm{CO} .{ }^{1 \mathrm{H}} \mathrm{OCO}+\mathrm{OH} ; \quad{ }^{1 \mathrm{H}} \mathrm{OH}+\mathrm{CO} \rightarrow{ }^{1 \mathrm{H}} \mathrm{OC}+\mathrm{OH}, \quad J$. Chem Phys. Lett. to Ed. 70, No. 4, 2032-2033 (Feb. 15, 1979 ).

18443. Laufer, A. H., Bass, A. M., Photochemistry of acetylene. Biomolecular rate constant for the formation of butadiyne and reactions of ethynyl radicals, J. Phys. Chem. 83, No. 3, 310313 (1979)

18456. Tsai, D. H., The virial theorem and stress calculation in molecular dynamics, J. Chem. Phys. 70, No, 3, 1375-1382 (Feb. 1, 1979)

18671. Lin, H. M., Seaver, M., Tang, K. Y., Knight, A. E. W., Parmenter, C. S., The role of intermolecular potential well depths in collision-induced state changes, J. Chem. Plivs. 70, No, 12, 5442-5457 (June 15, 1979).

18743. Walker, J. A., Tsang, W., Thermal decomposition of hexamethylethane in a flow system, Intl. J. Chem. Kinet. XI, $867-882$ (1979).

18755. Armstrong, G. T., King, R. C., Fluorine flame calorimetry, Chapter 15 in Combustion Culorimetry, S. Sunner, M. Mansson, Eds., 1, 333-359 (Pergamon Press, Oxford, England, 1979)

18797. Domalski, E. S., From the history of combustion calorimetry, Chapter 18 in Combustion Calorimetry, S Sunner, M. Mansson, Eds., 1, 401-428 (Pergamon Press, Oxford, England, 1979)

18803. Mosselman, C., Churney, K. L., Calibration of combustion calorimeters, Chapter 3 in Combustion Culorimetry, $\mathrm{S}$ Sunner, M. Mansson, Eds., 1, 35-55 (Pergamon Press, Oxford, England, 1979)

18815. Younglove, B. A., Thermodynamic properties of nitrogen gas from sound velocity measurements, Proc. Ist Int. Symp. in Cryogenic Wind Tunnels, Southampton, England, Apr. 3-5. 1979, pp. 16.1-16.6 (1979).

19020 . Krause, R. F., Jr., Thermodynamics of vaporization of molybdenum pentafluoride, Proc. Simp. on High Temperature Metal Halide Chemistry, The Electrochemical Society Meeting, Princeton, NJ, Oct, 9-14, 1977, Proceedings Volume 78-1, 199-209 (1978). 


\section{Technology Incentives}

SP527. Footwear technology symposium-Manufacturing a competitive advantage. Proceedings of the Footwear Technology Symposium held at the National Bureau of Standards, Gaithersburg, MD, June 1-2, 1978, M. H. King, Ed., Nat. Bur. Siand. (U.S.), Sper. Puhl. 527, 348 pages (Feb. 1979) SN(1).3-()0.3-(0)2025-7.

Manufacturing a competitive advaneage, J. Baruch, SP527, pp. 3-6 (Feb. 1979).

General accounting office perspective, F. Haynes, SP527, pp. 7-10) (Feb. 1979).

Fitting technology into the picture, M. King, SP527, pp. 1320 (Feb. 1979).

Technology reviews, A. D. Little, S1'527, pp. 21-50 (Feh. 19791.

The potential of new technology, F. Daley, SP527, pp. 5159 (Feh. 1979).

A matter of trust, S. Harman, SP527, pp. 73-77 (Feh. 1979).

Industry response, R. M. Ansin, SP527, pp. 79-80 (Feh. 1979).

Industry view, F. A. Meister, SP527, pp. 83-86 (Feh. 1979).

Relating technologies to the marketplace, B. Levine, SP527, pp. 87-91 (Feh. 1979).

Symposium integration and future directions, J. Baruch, SP527, pp. 95-97 (Feb. 1979).

TN1104, Vols. 1 and 2. The FCC public message services policy change: An ETIP evaluability assessment report, J. Bell, S. Kirhy, R. G. Weiss, and S. Watson, Nat. Bur. Stand. (U.S.), Tech. Note 1104/1, 232 pages, 1104/2, 110 pages (Sept. $1979) \mathrm{SN}(003-(003-02117-2$.

NBSIR 79-1706. CSA weatherization demonstration project plan, R. Crenshaw, R. Clark, R. Chapman, R. Grot, and M. Godette, 81 pages (Mar. 1979). Order from NTIS as PB293498.

NBS-GCR-ETIP 78-40. Subsidies, capital formation, and technological change: Municipal watewater treatment facilities. Volume I, Charles River Associates Inc., 150 pages (Sept. 1978). Order from NTIS as PB285288

NBS-GCR-ETIP 78-41. Subsidies, capital formation, and technological change: Mass transit. Volume 2, Charles River Associates Inc., 196 pages (Sept. 1978). Order from NTIS as PB285289.

NBS-GCR-ETIP 78-42. Subsidies, capital formation, and technological change: First generation nuclear power plants. Volume 3, Churles River Associates Inc., 97 pages (Sept. 1978). Order from NTIS as PB285290.

NBS-GCR-ETIP 78-43. Subsidies, capital formation, and technological change: Maritime transport. Volume 4 , Charles River Associates Inc., 86 pages (Sept. 1978). Order from NTIS as PB285291

NBS-GCR-ETIP 78-44. Subsidies, capital formation, and technological change: Primary scientific and technical journal publishing. Volume 5, Charles River Associates Inc., 172 pages (Sept. 1978). Order from NTIS as PB285292.

NBS-GCR-ETIP 78-45. Subsidies, capital formation, and technological change: Health facilities. Volume 6, Charles River Associates Inc., 212 pages (Sept. 1978). Order from NTIS as PB285293.

NBS-GCR-ETIP 78-46. Subsidies, capital formation, and technological change: Local air transport. Volume 7, Charles River Associates Inc., 171 pages (Sept. 1978). Order from NTIS as PB285294.

NBS-GCR-ETIP 78-47. Subsidies, capital formation, and technological change: Summary and conclusions. Volume $\$$, Charles River Associates Inc., 114 pages (Sept. 1978). Order from NTIS as PB285295.
NBS-GCR-ETIP 78-50. Assessing the results of the portable oxygen gemerator experiment, N. B. McEachron and E. G. Woodward, 79 pages (Oct. 1977). Order from NTIS as PB289886.

NBS-GCR-ETIP 78-51. Assessing the results of the LCC water heater experiment. Volume I: Main report, N. B. McEachron, D. C. Hall, and L. F. Lewis, 50) pages (Sept. 1977). Order from NTIS as PB291826.

NBS-GCR-ETIP 78-52. Assessing the results of the LCC water heater experiment. Volume III: Appendices, N. B. McEachron, D. C. Hall, and L. F. Lewis, 139 pages (Sept. 1977). Order from NTIS as PB291827.

NBS-GCR-ETIP 78-53. Taxonomy of incentive approaches for stimulating inmovation, J. Booth, Z. Cook, and A. R. Ferguson, 103 pages (Aug. 1978). Order from NTIS as PB287932.

NBS-GCR-ETIP 78-57. Management of Federal R\&D for commercialization-Executive summary, N. B. McEachron, H. S. Javitz, D. S. Green, J. D. Logsdon, and E. Milhergs, 19 pages (Sept. 1978). Order from NTIS as PB292851.

NBS-GCR-ETIP 78-58. Management of Federal R\&D for commercialization-Final report, N. B. McEachron, H. S. Javity, D. S. Green, J. D. Logsdon, and E. Milhergs, 143 pages (Sept. 1978). Order from NTIS as PB292852.

NBS-GCR-ETIP 78-58A. Management of Federal R\&D for commercialization-Appendices: Supporting documentation, N. B. McEachron, H. S. Javitz, D. S. Green, J. D. Logsdon, and E. Milhergs, 175 pages (Dec. 1978). Order from NTIS as PB292853.

NBS-GCR-ETIP 78-59. A real-time case history of ETIP Project 67-Integrated utility system application, J. G. Taylor and L. Q. C. Lamar 111, 151 pages (Mar. 1978). Order from NTIS as PB292770.

NBS-GCR-ETIP 78-60). An international study of economic benefits attributable to $R \& D$, by source and sector of performance, R. U. Ayres, J. Lewis, and S. D. Collier, 71 pages (June 1978). Order from NTIS as PB292783.

NBS-GCR-ETIP 79-62. Balancing the objectives of clean air and economic growth: Regulated markets in emission reductions, W. A. Foskett, D. M. Klaus, and J. Haberle, 103 pages (June 1979). Order from NTIS as PB300835.

NBS-GCR-ETIP 79-63. Environmental regulation in theory and practice: EPA's process of setting best practicable control technology standards, W. A. Magat, L. P. Gianessi, and W. Harrington, 175 pages (Dec. 1978). Order from NTIS as PB297499.

NBS-GCR-ETIP 79-64. Regulatory administrative experiment manual, J. N. Nay and J. Waller, 114 pages (June 1979). Order from NTIS as PB298446.

NBS-GCR-ETIP 79-65. The regulatory processes and effects project, J. N. Nay and W. Frederick, 183 pages (June 1979). Order from NT1S as PB298631.

NBS-GCR-ETIP 79-66. An exploration of regulatory incentives for innovation: Six case studies, J. Booth and Z. Cook, 110 pages (Aug. 1979). Order from NTIS as PB299006.

NBS-GCR-ETIP 79-70. Overview report: Experiment in computer applicatio ns for regulatory agencies, Temple, Barker \& Sloane, Inc. (NBS contact: Darlene Carver), 115 pages (Sept. 1979). Order from NTIS as PB300770.

NBS-GCR-ETIP 79-71. An evaluation design concept for regulatory reform: The waiver of efficacy data, $H$. D. Ojha, T. V. Renda, J. E. Harrison, and J. H. Perwak, 182 pages (Sept. 1979). Order from NTIS as PB300846.

18722. Berlin, V. N., Administrative experimentation: A methodology for more rigorous "muddling through," Manage. Sci. 24, No. 8, 789-799 (Apr. 1978 ). 


\section{Other Subjects of General Interest}

SP305. Supplement 10. Publications of the National Bureau of Standards 1978 Catalog. A compilation of abstracts and key word and author indexes, B. L. Burris and R. J. Morehouse, Eds.. Nat. Bur. Stand. (U.S.), Spec. Publ. 305, Suppl. 10, 679 pages (June 1979) SN(0)3-()03-(1)2069-9.

SP376. Ruler: $15 \mathrm{~cm} / 6$ in, with metric-customary units and equivalent, Nat. Bur. Stand. (U.S.), Spec. Puhl. 376, both sides (Reissued Jan. 1979) SN()()3-()()3-()108()-4.

TN980. Historic preservation incentives of the 1976 Tax Reform Act: An economic analysis, S. F. Weber, Nat. Bur. Stand. (U.S.), Tech. Note 980, 32 pages (Feb. 1979) SN(0)3-()03(02015-0.

NBSIR 78-1577. Data bases available at the National Bureau of Standards Library, D. Cunningham, 53 pages (Mar. 1979). Order from NTIS as PB293170.

NBSIR 79-1793. Privacy as information management: A social psychological and environmental framework, S. T. Margulis, 28 pages (Sept. 1979). Order from NTIS as PB300986.

NBSIR 79-1928 (NBS). NBS library handbook for NBS staff, N. H. Knight, 76 pages (1979). Order from NTIS as PB80106420.

NBS-GCR-79-169. Critical evaluation of data for a standard ergonomics reference data system (SERDS), W. H. Teichner and E. Williams, 37 pages (Jan. 1979). Order from NTIS as PB295088.

18387. Goldman, D. T., Managing research, Plys. Today, Letter ti) the Editor 32, No. 1, 94-95 (Jan. 1979).

18471. Eisenhart, C., Contribution to invited discussion of "Francis Ysidro Edgeworth, Statistician," by Stephen M. Stigler, J. Roy. Stat. Soc. Ser. A (General) 141, Pt. 3, 317-318 (1978).

18714. Albus, J. S., Mechanisms of planning and problem solving in the brain, Math. Biosci. 45, 247-293 (1979).

18817. McGehan, F. P., Interpreting the scientific paper for the trade press, Proc. 26th Int. Tectinical Communication Conf., Los Angeles, CA, May 16-19, 1979, pp. M-115-M-117 (May 1979).

18823. Levine, J., Strain-tide spectroscopy, Geophys. J. R. Asiron. Soc. 54, 27.41 (1978).

18942. Henderson, M. M., Technology's help in putting information to work, Bull. Am. Soc. Inf. Sci. 6, No. 1, 32-35 (Oct. 1979).

19016. Weber, S. F., Tax incentives for historic preservation: An economic analysis, J. Real Estate Tax. 7, No. 1, 31-49 (Fall 1979).

19048. Berger, P. W., Sprague, P. A., Zurkowski, P., Library and information services for improving organizations and professions, Proc. White House Conf. on Library and Information Services-Dialogues on the Future of Library and Information Services, Washington, DC, Nov. 15-19, 1979, Cassette 2 Side 1 ( Staff of the White Howse Conference on Library and Information Services, Washington, DC, 1979).

18330. Armstrong, G. T., Cezairliyan, A., Calorimetry, Chapter in Kirk-Othmer Encycl. Cliem. Tec/lnol., 3d Ed. 4, 449-474 (John Wiley and Sons, Inc.. New York, NY, 1978). 


\subsection{AUTHOR INDEX}

A

Abate, J. A., Lewis, O., Appelbaum, H., Rinefierd, J. M., Jacobs, S. D., Brown, D. C., SP541, pp. 109-121 (Dec. 1978).

Abaundi, R., Rhyne, J. J., Sweger, D. M., Segnan, R., 18329.

Agderrassoul, R., Chu, T. L., Chu, S. S., Stokes, E. D., Lin, C. L., SP400-58, pp. 41.47 (Aug. 1979).

Aberg, T., Cooper, J. W., 18407.

AbouelezZ, M., Waters, P. F., NBSIR 79-1766.

ABRAhAM, J. L., ETZ, E. S., 18958.

Abramowitz, S., Kirklin, D. R., Mitchell, D. J., Cohen, J., DOMALSKI, E. S., NBSIR 78-1494.

Abrams, M. D.. Neiman, D. C., SP500-52, pp. 201-211 (Oct. 1979).

Ackerhalt, J. R., Eberly, J. H., Shore, B. W., 18439.

Ackerson, B. J., Hanley, H. J. M., 18752.

ACKLAM, D. M., ReAGAN, J. A., SP548, pp. 1 -1 3 (July 1979).

ACQUiSTA, N., READER, J., 18499.

ACQuista, N., ReAder, J., 18868 .

Acquista, N., Reader, J., Luther, G., 18500.

Adachi, S., Harada, S., lzumitani, 'T., MiYade, E., SP562, pp. 417-425 (Oct. 1979)

Adams, J. W., Taggart, H. E., Kanda, M., Shafer, J., TN1014.

Adler, S. C., Brungraber, R. J., 18705.

Adler, S. C., Pierman, B. C., SP565.

AdOlplisen, J. W., SP400-58, pp. 102-109 (Aug. 1979).

AFDAML, D., MONTOR, K., SP480-38, pp. $75-80$ (Dec. 1979)

Agrawala, A. K., Tripathi, S. K., Gordon, K. D., SP500-52, pp. 105-111 (Oct. 1979).

AIKMAN, A. J. M., SP552, pp. 283-291 (July 1979).

AKcasu, A. Z., Han, C. C., 18545.

Algus, J. S., NBS1R 78-1576.

Albus, J. S., 18714.

Aldhizer, C., SP556, pp. $105-106$ (Sept. 1979).

Alessi, D., Brill, M., NBS-GCR-78-156.

Alford, A. L., Doll, C. K., Garrison, A. W., Pope, J. D., SP5 19, pp. 65-78 (Apr. 1979).

Al-Khalaf, K. Y., SP543, pp. 106-107 (Apr. 1979).

Allan, D. W., 18940.

Allan, D. W., Ashby, N., 18993

Allan, D. W., Hellwig, H., 18899.

Allen, A. O., SP500-52, p. 227 (Oct. 1979).

Allen, C. B., Bansal, N. P., Murphy, R. M., Tomkins, R. P. T., JANZ, G. J., NSRDS-NBS61, Part II.

Allen, C. B., Janz, G. J., Tomkins, R. P. T., JPCRD 8, No. 1, 125-302 (1979).

Allen, J. E., Jr., Fansler, T. D., Crosley, D. R., Anderson, W. R., SP561/2, pp. 1153-1167 (Sept. 1979).

Allen, S. M., Cahn, J. W., 18373.

Allen, S. M., Cahn, J. W., 18613.

Allen, T. H., Apfel, J. H., Carniglia, C. K., SP541, pp. 3336 (Dec. 1978).

Allibert, M., Pattoret, A., Chatlllon, C., SP561/1, pp. 181 210 (Sept. 1979).

Allred, C. M., Andrews, J. R., Hoer, C. A., Lawton, R. A., NAHMAN, N. S., NBSIR 79-1613.

Almond, P. R., SP554, pp. $129-138$ (Sept. 1979).

Alperin, H. A., Gillmor, W. R., Pickart, S. J., Rhyne, J. J., 18835.

Alperin, H. A., Pickart, S. J., Rhyne, J. J., 18372.

Alvord, R. T., Cloud, P. J., SP563, p. 173 (Oct. 1979).

AMER, P. D.. MAMrak, S. A., SP500-44.

AMORE, F., SP519, Pp. 191-203 (Apr. 1979).

Amsel, L. P., Giering, J. E., Leaders, F. E., Jr., O'Brien, J. E., Hinsvark, O. N., Newman, W. R., SP519, pp. 481-485 (Apr. 1979).

ANderson, D. P., SP547, pp. 323-329 (July 1979).
Anderson, G. M., Purdy, W. C., Young, S. N., SP519, pp. 411-418 (Apr. 1979).

Anderson, R. C., Henry, R. C., Moos, H. W., Linsky, J. L., 18753.

Anderson, R. H., Bennett, J. M., SP541, pp. $65-69$ (Dec. 1978 ).

Anderson, R. H., Skogman, R. A., Ready, J. F., Bennett, J. M., SP541, pp. 70-77 (Dec. 1978).

Anderson, R. J. M., Kohler, B. E., Stevenson, J. M., 18754.

Anderson, R. L., Frank, S. L., ANDren, M. L., SP400-58, pp. 57-62 (Aug. 1979).

ANDerson, W. A., KiM, J. K., SP400-58, pp. $48-56$ (Aug. 1979).

Anderson, W. E., DAvis, R. S., 18384.

Anderson, W. E., Davis, R. S., Petersons, O., Moorte, W. J. M., 18513.

Anderson, W. R., Allen, J. E., Jr., Fansler, T. D., Crosley, D. R., SP561/2, pp. $1153-1167$ (Sept. 1979).

Andersson, C. A., Bratton, R. J., SP562, pp. $463-474$ (Oct. 1979).

Ando, M. E., Richardson, J. H., George, S. M., SP519, pp. 691-696 (Apr. 1979).

Andren, M. L., Anderson, R. L., Frank, S. L., SP4OO-58, Pp. 57.62 (Aug. 1979).

ANDREWS, J. R., 18640.

Andrews, J. R., Hoer, C. A., Lawton, R. A., Nahman, N. S., Allred, C. M., NBSIR 79-1613.

ANDREWS, J. R., YOUNG, M., NBSIR 79-1620.

ANDRiole, S. J., Daly, J. A., SP480-38, pp. $47-74$ (Dec. 1979).

Annestrand, S., Hebner, R. E., JR., 18727.

ANSIN, R. M., SP527, PP. 79-80 (Feb. 1979).

Apfel, J. H., Carniglia, C. K., Allen, T. H., SP541, pp. 33 36 (Dec. 1978).

A pfel, J. H., Carrier, G. B., Milam, D., Carniglia, C. K., SP541, Pp. $218-225$ (Dec. 1978).

Appel, B. R., Hoffer, E. M., Kothny, E. L., Wall, S. M., HAK, M., KNIGHTS, R. L., SP519, pp. $121-129$ (Apr. 1979).

Appelbaum, H., Rinefierd, J. M., Jacobs, S. D., Brown, D. C., AвATe, J. A., Lewis, O., SP541, Pp. 109-121 (Dec. 1978).

Arakawa, E. T., Ederer, D. L., Callcott, T. A., 18359.

Arakawa, E. T., Ederer, D. L., Callcott, T. A., 18413.

Arakawa, E. T., Ederer, D. L., Callcott, T. A., 18741 .

Arbach, G. U., Sedgwick, T. O., SP561/2, pp. 885-896 (Sept. 1979).

Archea, J., Collins, B. L., Stahl, F. I., BSS120.

Archea, J., MARgulis, S. T., NBSIR 79-1906.

Arkfeld, T., BrewSter, D., SP548, pp. $105-117$ (July 1979).

Armstrong, G. T., Cezairliyan, A., 18330.

Armstrong, G. T., KING, R. C., 18755.

Armstrong, J., MacDonald, L., SP556, pp. 57-64 (Sept. 1979 ).

Armstrong, L., JR., Eberly, J. H., 18874.

Armstrong, L., JR., Theodosiou, C. E., 18927.

Armstrong, R. W., Wu, C. C., Farabaugh, E. N., 18341 .

Arnold, G. P., Edwards, D. F., Baumeister, P., SP541, pp. 257-258 (Dec. 1978).

Aronoff, M. J., Christo Pher, P. M., NBSIIR 79-1923.

ARP, V., 18813 .

ARP, V. D., JONES, M. C., 18822 .

ARThUR, M. G., SP55I.

Arthur, M. G., SP551, pp. 42-44 (July 1979).

Arthur, M. G., Reeve, G. R., TNIOI6.

ARTIS, H. P., SP500-52, Pp. 123-127 (Oct. 1979).

Arvidson, J. M., Labrecque, J. F., Parrish, W. R., NBSIR $78-887$.

Arvidson, J. M., Labrecque, J. F., Parrish, W. R., 18395.

Ashby, N., Allan, D. W., 18993. 
Ashley, E. J., Donovan, T. M., Porteus, J. O., Jernigan, J. L., SP541, Pp. 212-217 (Dec. 1978).

Atkinson, G. H., Parmenter, C. S., Tang, K. Y., 18641.

Atkinson, G. H., Parmenter, C. S., 18747.

Atkinson, G. H., Parmenter, C. S., 18749.

Atxinson, G. H., Parmenter, C. S., 18750.

Ausloos, P., Lias. S. G., 18331 .

Ausloos, P., Lias, S. G., 18332 .

Ausloos, P., Lias, S. G., 18337.

Aúsloos, P., Rosenstock, H. M., Schroyer, S. S., Schmidt, C., Martinsen, D., Milne, G. W. A., hartman, K. N., lias, S., NBSIR 79-1777.

Auxier, J. A., KerR, G. D., Jones, T. D., Jacobs, D. G., SP554, Pp. $41-56$ (Sept. 1979).

Axton, E. J., Bardell, A. G., SP554, pp. $109-123$ (Sept. 1979).

Axton, E. J., Bardell, A. G., SP554, pp. 125-127 (Sept. 1979).

Ayres, R. U., Lewis, J., Colller, S. D., NBS-GCR-ETIP 7860.

Ayres, T. R., Linsky, J. L., Garmire, G., Cordova, F., /8839.

\section{B}

Babelot, J. F., Cercignani, L., Kinsman, P. R., Long, K. A., Magill, J., Scotti, A., OhSE, R. W., SP561/I, pp. 83-109 (Sept. 1979).

Babrauskas, V., TN/103.

BabraUSKaS, V., TN99I.

Bagozzl, R. P., Ives, W. R., Nahman, N. S., 18723 .

Bahn, R. C., Baxter, B., Christensen, D., Johnson, S. A., Greenleaf, J. F., Rajagopalan, B., SP525, pp. 235-246 (Apr. 1979).

Bahn, R. C., Rajagopalan, B., Greenleaf, J. F., Thomas, P. J., JoHnson, S. A., SP525, pp. 227-233 (Apr. 1979).

Baird, K. M., Evenson, K. M., Hanes, G. R., Jennings, D. A., Petersen, F. R., 18916 .

Baker, H., Carter, G. C., Bennett, L. H., Kahan, D. J., Cuthill, J. R., Chafe, H. D., Gray, A. G., Langer, E. L., 18645.

Baker, H., Cuthill, J. R., Kahan, D. J., Bennett, L. H., Chafe, H. D., Gray, A. G., Langer, E. L., 18739.

Ballard, D. B., Ogburn, F., Young, J. P., U.S. Patent $4,139,933$.

Balluffi, R. W., Cahn, J. W., 18758.

Balluffi, R. W., Cahn, J. W., Pan, J. D., 18759.

Bankston, C. P., Cassanova, R. A., Powell, E. A., Zinn, B. T., NBS-GCR-78-147.

Bansal, N. P., Murphy, R. M., Tomkins, R. P. T., Janz, G. J., Allen, C. B., NSRDS-NBS6I, Part II.

Barbour, R. E., Jr., Holcombe, J. O., Harris, C. S., MonCRIEF, W. C., SP500-52, pp. 25-36 (Oct. 1979).

Barbrow, L. E., Heffernan, A. P., Wollin, H. F., SP532.

Bardell, A. G., Axton, E. J., SP554, pp. 109-123 (Sept. 1979).

Bardell, A. G., Axton, E. J., SP554, pp. 125-127 (Sept. 1979).

Barger, J. E., SP525, pp. 197-201 (Apr. 1979).

Barger, R. L., Bergquist, J. C., English, T. C., Glaze, D. J., 18642.

Barnes, I. L., Brady, T. J., Rains, T. C., Champ, M. A., KingSTON, H. M., 18402 .

Barnes, I. L., Rosman, K. J. R., Diaz, M., Brill, R. H., YAMASAKI, K., 18840.

Barnes, J., FANCONI, B., 18404

BARNES, J. D., NBSIR 79-1740.

BARNES, J. D., 18348.

Barnes, J. D., Martin, G. M., SP260-58.

Barnes, J. D., Martin, G. M., MCCrackin, F. L., NBSIR 79 1768.
Barnes, J. D., Martin, G. M., McCrackin, F. L., 18639.

Barnes, R. W., Kremkau, F. W., McGraw, C. P., SP525, pp. 81-84 (Apr. 1979).

Barnett, J. P., Carroll, W. L., NBSIR 79-1732.

Baronavisi, A. P., Pasternack, L., Lamont, S., Harvey, A. B., MCDonald, J. R., SP561/2, pp. $817-831$ (Sept. 1979).

BARRETT, J., SP534, pp. 107-110 (May 1979).

Bartoe, J. D. F., Brueckner, G., Van Hoosier, M. E., Baski, G. S., LINSKY, J. L., 18876 .

BARUCH, J., SP527, pp. 3-6 (Feb. 1979).

BARUCH, J., SP527, pp. 95-97 (Feb. 1979).

BasRi, G. S., Linsky, J. L., Bartoe, J. D. F., Brueckner, G., VAN Hoosier, M. E., 18876 .

Bass, A. M., Laufer, A. H., 18443.

Bass, M., Van Stryland, E. W., Solleau, M. J., SP541, pp. 309-317 (Dec. 1978).

Bass, M., Van Stryland, E. W., Stewart, A. F., SP54I, pp. 19-23 (Dec. 1978).

Bass, M., Wallace, R. G., Copley, S. M., SP562, pp. 283-292 (Oct. 1979).

BATES, G., JR., SP540, pp. 714-715 (Nov. 1979).

BAUDER, A., JPCRD 8, No. 3, 583-618 (1979).

Bauer, A., Boucher, D., Burie, J., Demaison, J., Dubrulle, A., JPCRD 8, No. 2, $537-558$ (1979).

Baughcum, S. L., LeONe, S. R., $/ 8573$.

Baum, H. R., Lewis, J., ReHM, R. G., Cordes, M. R., NBSIR 79-1754.

Baumeister, P., Arnold, G. P., Edwards, D. F., SP54I, pp. 257-258 (Dec. 1978).

Baxter, B., Christensen, D., Johnson, S. A., Greenleap, J. F., Rajagopalan, B., Bahn, R. C., SP525, pp. 235-246 (Apr. 1979).

Beachey, J. E., Milne, T. A., Greene, F. T., SP561/1, pp. 431 442 (Sept. 1979).

BEAN, J. W., KuSUda, T., 19003.

BEAN, R. M., RiLeY, R. G., SP5/9, pp. 33-40 (Apr. 1979).

Beardmore, P., KulKarni, H. T., SP563, pp. 135-151 (Oct. 1979).

Beattie, I., Greenhalgh, D. A., SP561/1, pp. 597-606 (Sept. 1979).

Beaty, E. C., Gallagher, J. W., Rumble, J. R., JR., SP426. Supplement 1 .

Beaunien, L. A., Mulville, D. R., Sutton, S. A., Thomas, R. W., Tirosh, J., Wolock, I., Mast, P. W., SP563, p. 241 (Oct. 1979).

Beaver, W., Joynt, L., Boyle, D., Rakowski, H., Popp, R., SP525, Pp. 267-273 (Apr. 1979).

BECKER, D., SP556, pp. 141 -144 (Sept. 1979 ).

BeCKER, D., SP556, Pp. 5-8 (Sept. 1979).

BeCKER, D. A., 18349.

Becker, D. A., Hurd, H. A., SP556.

Becker, D. A., Lafleur, P. D., LeRoy, A., 18350.

Bedrick, J. R., Spencer, G. S., Varey, G. B., Millet, M. S., SP552, pp. 321-335 (July 1979).

Beers, J., Tucker, C., Croarkin, C., Monogr. 163.

BEGGS, D., SP519, pp. 169-173 (Apr. 1979).

Begley, J. A., McHenry, H. I., ReAd, D. T., 18612 .

Behrens, J. W., Schrack, R. A., Bowman, C. D., 18591

Bemiens, R. G., Rinehart, G. H., SP561/1, pp. $125-141$ (Sept. 1979).

BeIne, W. B., Mahajan, B. M., NBSIR 79-1707.

BEINE, W. B., WANG, T. J., JOHNSON, C. R., 18602 .

Belanger, B. C., 18354 .

Belanger, B. C., Kieffer, L. J., 18720 .

Belecki, N. B., Dunfee, B. L., Petersons, O., NBSIR 75-935.

BELFORd, R. B., SP543, pP. 73-76 (Apr. 1979).

Bell, J., Kirgy, S., Weiss, R. G., WatSon, S., TN1104, Vols. 1 and 2.

Bell, J. R., Gardner, A. H., Fisher, C. P., Handley, G. P., Chang, F. H., SP563, p. 59 (Oct. 1979). 
Bell, M. I., Smith, W. A., Shaulov, A., 18852.

Bellama, J. M., JeWetT, K. L., Brinckman, F. E., 18484.

Bellama, J. M., MacCrehan, W. A., Durst, R. A., SP519, pp. 57-63 (Apr. 1979).

Belrose, T. C., BoARd, D., SP547, pp. 31 -35 (July 1979).

Benazzi, R. V., Guss, L., Orend, R., Wyly, R. S., Konen, T. P., SPSS3, pp. 3-13 (Aug. 1979).

Benazzl, R. V., Konen, T. P., Manfredi, R. R., Nielsen, L. S., WYLY, R. S., SP553, Pp. 35-51 (Aug. 1979).

BENDER, P. L., 18574.

BENDER, P. L., 18584.

Bender, P. L., Faller, J. E., Levine, J., Moody, S., PearlMan, M. R., Silverberg, E. C., 18459.

BENDER, P. L., WARE, R. H., $/ 8895$.

BENJAMIN, I., SP540, pp. 162-165 (Nov. 1979).

Benjamin, I. A., 18721 .

BENJAMIN, I. A., KLote, J. H., NBSIR 79-1747.

BENNETT, H. E., SP562, pp. 337-350 (Oct. 1979).

Bennett, H. E., Burge, D. K., SP541, pp. 266-277 (Dec. 1978).

Bennett, J. M., Anderson, R. H., SP54I, pp. $65-69$ (Dec 1978).

Bennett, J. M., Anderson, R. H., Skogman, R. A., Ready, J. F., SP541, Pp. $70-77$ (Dec. 1978).

Bennett, J. M., Decker, D. L., Grandjean, D. J., SP562, pp. 293-303 (Oct. 1979).

Bennett, J. M., Wong, S. M., Krauss, G., SP541, pp. 132-163 (Dec. 1978).

Bennett, L. H., Chafe, H. D., Gray, A. G., langer, E. L., Baker, H., Cuthill, J. R., Kahan, D. J., 18739.

Bennett, L. H., Kahan, D. J., Cuthill, J. R., Chafe, H. D., Gray, A. G., Langer, E. L., Baker, H., Carter, G. C., 18645.

Bennett, L. H., Reno, R. C., Swartzendruber, L. J., 18967.

Bennett, L. H., Wang, F. E., Mitchell, M. A., Sutula, R. A., Holden, J. R., 18382 .

BenNetT, L. H., Watson, R. E., 18357.

BenNetT, L. H., Watson, R. E., 18383 .

BENNETT, L. H., WATSON, R. E., 18421 .

BENNETT, L. H., WATSON, R. E., 19047.

BennetT, W. S., TAgGaRT, H. E., 19033

Benninghoven, A., SP519, pp. 627-635 (Apr. 1979).

Bentz, B. L., Bruhn, C. G., Harrison, W. W., SMyth, K. C., 18449.

BERES, L. R., SP480-38, pp. 29-46 (Dec. 1979).

BERG, J., SPSO0-51.

Berger, H., MCGogney, C., Kaiserlik, J., 18525.

Berger, H., Mordfin, L., NBSIR 78-1581.

Berger, M. J., 18358.

Berger, M. J., Paretzke, H. G., 18659.

Berger, M. J., Seltzer, S. M., Hubbell, J. H., 18371 .

Berger, P. W., Sprague, P. A., Zurkowski, P., 19048.

Bergek, R. E., J. Res. 84, No. 1, 9-19 (1979).

Berger, R. E., Calvano, N. J., NBSIR 78-1547.

Brrgquist, J. C., English, T. C., Glaze, D. J., Barger, R. L. 18642.

BERKOWITZ, J., SP561/1, pp. 757-769 (Sept. 1979).

Berl, W. G., HALPIN, B. M., NBS-GCR-79-168.

BERLIN, G. N., SP552, Pp. 13-27 (July 1979).

BerLIN, V. N., 18722.

Bernal, E., Ready, J. F., Vora, H., Skogman, R. A., Leung, K. M., SP541, PP. 59-64 (Dec. 1978).

BERNING, D. W., SP400-54.

Berning, D. W., Blackburn, D. L., 18738.

BERRY, S. A., SP549.

Berson, G. P., Cooper, C. G., SP552, pp. 311-320 (Jully 1979).

BERTOCCI, U., 18724.

Bertocci, U., Mullen, J. L., $/ 8725$.

Bertocci, U., Mullen, J. L., 18756.

Besley, L. M., Plumb, H. H., 19040.
Besson, R. J., Stein, S. R., Manney, C. M., JR., Walls, F. L., GraY, J. E., 18691 .

Bethke, J. W., Temple, P. A., Decker, D. L., Donovan, T. M., SP541, pp. $37-42$ (Dec. 1978).

Bevan, T. E., SP480-38, pp. 1-6 (Dec. 1979).

Bevans, R. S., Boegly, W. J., Savitsky, D., Cole, C., Konen, T. P., SP553, pp. 71-77 (Aug. 1979).

Bialkowski, S. E., King, D. S., Stephenson, J. C., 19042.

Bickford, N. A., Fleming, R. F., 18704.

Bickman, L., Edelman, P., Herz, E., McDaniel, M. A., NBSGCR-78.135.

Bickman, L., Herz, E., Edelman, P., Rivers, D., NBS-GCR-79I79.

Bielefeld, M. J., Trombia, J. I., Ehrlich, M., Seltzer, S. M., 18416.

Bietry, J., SACre, C., Simiu, E., /835I.

Birky, M. M., Womble, S. E., PAabo, M., 18588.

Birnbaum, G., 18886 .

Birnbaum, G., Bose, T. K., 18786.

Birnholz, J., Fraser, J., Kino, G. S., SP525, pp. 287-295 (Apr. 1979).

Bishop, F. E., SP547, pp. 345-357 (July 1979).

BJORNDAL, R., SP556, Pp. 183-184 (Sept. 1979).

BlackBurn, D. L., SP400-52.

Blackburn, D. L., Berning, D. W., 18738.

BlackBurn, D. L., LARRABEe, R. D., 18460 .

Blaha, J. J., ETZ, E. S., 18966.

Blaha, J. J., ETZ, E. S., 18971.

Blaha, J. J., ETz, E. S., CunNingham, W. C., 18643.

Blair, W., Brinckman, F., SP556, pp. 25-38 (Sept. 1979).

Blanchard, D. B., Harrison, S. H., 18325.

Blander, M., SP561/2, pp. 1707-1715 (Sept. 1979).

Blander, M., FruriP, D. J., SP561/2, pp. $1597-1609$ (Sept. 1979).

BleVin, W. R., SP539, pp. 97-100 (Apr. 1979).

Block, S., Piermarini, G. J., Forman, R. A., 18509.

Board, D., Belrose, T. C., SP547, pp. 31 -35 (July 1979).

Bodner, G. M., Garber, A. R., Wright, R. F., Todd, L. J., SiEdle, A. R., 18328 .

Boegly, W. J., Savitsky, D., Cole, C., Konen, T. P., Bevans, R. S., SP553, pp. 71-77 (Aug. 1979).

Boettinger, W. J., Burdftte, H. E., Kuriyama, M., 18399.

Boggess, A., Pasachoff, J. M., Linsky, J. L., Haisch, B. M., 18606.

Bohlin, J. D., Glackin, D. L., Linsky, J. L., Mango, S. A., 18922.

Bolz, L. H., Mopsik, F. I., Khoury, F., KRYder, S. J., 18713.

BOND, W. P., JR., LENNON, N., SP500-52, pp. $215-218$ (Oct. 1979).

BONDER, S., SP534, Pp. 23-44 (May 1979).

Bonin, K., Graminski, E. L., NBSIR 79-1914.

Bonnell, D. W., Hastie, J. W., SP561/1, pp:357-408 (Sept. 1979).

Booth, J., Cook, Z., NBS-GCR-ETIP 79-66.

Booth, J., Cook, Z., Ferguson, A. R., NBS-GCR-ETIP 78-53.

Bose, T. K., Birnbaum, G., 18786.

Boucher, D., Burie, J., Demaison, J., Dubrulle, A., Bauer, A., JPCRD 8, No. 2, 537-558 (1979).

Bouhalila, R., SP543, pp. 101-105 (Apr. 1979).

Bouhana, J. P., SP500-52, pp. 241-243 (Oct. 1979).

Bouix, J., Machaelides, A., Hillel, R., SP561/2, pp. 899-911 (Sept. 1979).

Boulanger, J. S., Hanson, D. W., Kelpczynski, W. J., Costain, C. C., DaAms, H., 18861 .

BOWEN, R. L., I846I.

BOWEN, R. L., 18644.

Bowen, R. L., Folio, J., Stanley, H. R., 18690.

Bowen, R. L., Mattama L, G. J., MisRa, D. N., 18411 .

Bowen, R. L., MisRa, D. N., 18972.

BOWEN, T., SP556, pp. 117-122 (Sept. 1979).

BOWEN, T., SP556, pp. 175-177 (Sept. 1979). 
Bowen, T., Connor, W. G., Nason!, R. L., Pifer, A. E., SHOLES, R. R., SP525, Pp. 57-61 (Apr. 1979).

Bower, J., Weeks, S., Fujiwara, K., Omenetto, N., Haraguchi, H., Winefordner, J. D., Bradshaw, J., SPS61/2, pp. 1079-1102 (Sept. 1979).

Bower, V. E., Davis, R. S., J. Res. 84, No. 2, 157-160 (1979). Bowers, W. J., JR., Mangum, B. W., 18556 .

Bowers, W. J., JR., Wildes, D. G., Pipes, P. B., Van Degrift, C. T., 18548 .

BOWLES, R., SP562, pp. $489-500$ (Oct. 1979).

Bowling, R. A., Lassiter, T. W., Vick, D. O., Schweitzer, G. K., SP561/1, pp. 771-789 (Sept. 1979).

BOWMAN, C. D., 18570 .

Bowman, C. D., Behrens, J. W., Schrack, R. A., 18591 .

Bowman, C. D., Eisenhauer, C. M., Gilliam, D. M., 18462.

Bowman, C. D., Schrack, R. A., 18585.

Bowman, C. D., Schrack, R. A., 18687.

Bowman, R. C., JR., Carter, G. C., Chabre, Y., 18352.

BOYD, D. M., MAXFIELD, B. W., SP563, pp. $211-212$ (Oct. 1979).

Boyle, D., Rakowski, H., Popp, R., Beaver, W., Joynt, L., SPS25, Pp. 267-273 (Apr. 1979).

BOYNARD, M., Hanss, M., SP525, pp. 165-169 (Apr. 1979).

Boyne, H. S., Ellerbruch, D. A., 18820.

Boyne, H. S., Ellerbruch, D. A., Jesch, R. L., Jones, R. N., BusSEY, H. E., 18563 .

Bradshaw, J., Bower, J., Weeks, S., fujiwara, K., Omenetto, N., Haraguchi, H., Winefordner, J. D., SPS61/2, pp. 10791102 (Sept. 1979).

Bradt, R. C., Easler, T. E., Countermine, T. A., Tressler, R. E., SPS62, pp. 455-462 (Oct. 1979).

BrAdy, C. H., ChRIST, B. W., SMITH, J. H., 18368.

Brady, J. K., Frizzell, L. A., O'Brien, W. D., JR., Dunn, F., Johnston, R. L., Goss, S. A., MAYnARD, V., SP525, pp. 1927 (Apr. 1979).

Brady, T. J., Rains, T. C., Champ, M. A., Kingston, H. M., BARnes, I. L., 18402.

Braginski, A. I., EKIN, J. W., 18781 .

BranNigAN, V., SPS52, Pp. 29-37 (July 1979).

Bransdorfer, A., Fletcher, P., Orend, R. J., Pavel, H. J., Williams, G. H., Fowell, A. J., SP553, pp. 21-31 (Aug. 1979).

Bratin, K., Rice, J. R., Kissinger, P. T., Bruntlett, C. S., SP519, Pp. $705-712$ (Apr. 1979).

Bratton, R. J., Andersson, C. A., SP562, pp. 463-474 (Oct. 1979).

Brauer, F. A., Edelstein, H. P., Silvergleit, M., Macander, A. B., SP563, pp. 276-285 (Oct. 1979).

Brauer, G. M., Jackson, J. A., Termini, D. J., 18985.

Brauer, G. M., Kumpula, J. W., Termini, D. J., Davidson, K. M., 18638.

Brauer, G. M., Petrianyk, N., Termini, D. J., 18809.

Brauer, G. M., Termini, D. J., Jackson, J. A., 18569.

Braun, E., Krasny, J. F., Peacock, R. D., Meierhoefer, A. W., NBSIR 79-1755.

Braun, E., Krasny, J. F., Peacock, R. D., Stratton, A., 18708.

Braun, E., Peacock, R., Krasny, J. F., 18991.

Braun, W., herron, J. T., Tsang, W., Churney, K., 18709.

Braun, W., Herron, J. T., Tsang, W., Walker, J. A., 18712 .

Braun, W., Tsang, W., Gutman, D., 18832.

Braunlich, P., Schmid, A., Kelly, P., Ritchie, D., SP54 I, PP. 296-298 (Dec. 1978).

BraWer, S., SMITH, W. L., SP541, Pp. 303-304 (Dec. 1978).

BreEse, J. N., LEE, B. T., NBSIR 78-1584.

Brehm, R., Broese van Groenou, A., SP562, pp. $61-74$ (Oct. 1979).

Breiter, D. N., Roush, M. L., 18375.
Brennan, J. A., Siegwarth, J. D., Parrish, W. R., 18396.

BrenNer, D., 19032.

BREWER, G. D., SPS34, pp. 9-14 (May 1979).

Brewer, L., Pitzer, K. S., JPCRD 8, No. 3, 917.920 (1979).

Brewster, D., ARKFeld, T., SPS48, pp. $105-117$ (July 1979).

Bright, D., Chabay, I., 18980.

BrIGHT, R. G., 18514 .

Bright, R. G., Bukowski, R. W., Custer, R. L. P., 18625.

Brill, M., Alessi, D., NBS-GCR-78-156.

Brill, R. H., YamaSaK!, K., Barnes, 1. L., Rosman, K. J. R., DIAZ, M., 18840 .

Brillet, A., Hall, J. L., 18875 .

Brillet, A., Hall, J. L., 18952.

BrinckMan, F., Blair, W., SPS56, pp. $25-38$ (Sept. 1979).

Brinckman, F. E., Bellama, J. M., Jewett, K. L., 18484.

BrinckMAN, F. E., IVerson, W. P., 18860 .

Broadhurst, M. G., Davis, G. T., DeReggi, A. S., 18408.

Broadhurst, M. G., Nazgele, D., Yoon, D. Y., 18531 .

Broese van Groenou, A., SPS62, pp. 147-155 (Oct. 1979).

Broese van Groenou, A., SPS62, pp. $191-199$ (Oct. 1979).

Broese van Groenou, A., Brehm, R., SPS62, pp. $61-74$ (Oct. 1979).

Broese van Groenou, A., Maan, N., Veldkamp, J. B. D., SPS62, PP. 43-59 (Oct. 1979).

Brostow, W., SPS61/2, pp. $1619-1638$ (Sept. 1979).

Brown, D. C., Abate, J. A., Lewis, O., Appelbaum, H., Rinefierd, J. M., JaCOBS, S. D., SPS41, pp. 109-121 (Dec. 1978).

Brown, D. W., Jenkins, R. G., Macleod, W. D., JR., Ramos, L. S., SP519, Pp. $713-718$ (Apr. 1979).

BROWN, D. W., LOWRY, R. E., 18512 .

BROWN, D. W., LOWRY, R. E., 18542.

Brown, D. W., Ramos, L. S., Friedman, A. J., Macleod, W. D., JR., SP519, pp. 161-167 (Apr. 1979).

BROWN, J., MAY, W., SP556, pp. 39-44 (Sept. 1979).

Brown, J. M., Chesler, S. N., Guenther, F., Hilpert, L. R., HER TZ, H. S., WISE, S. A., MAY, W. E., SP519, pp. 219-224 (Apr. 1979).

Brown, L. D., IBERS, J. A., Siedle, A. R., 18582.

Brown, P. W., Clifton, J. R., FrohnsdorfF, G., SP542.

Brown, P. W., FrohnsdorfF, G., Clifton, J. R., 18854 :

Brown, R. A., McElroy, F. C., Searl, T. D., SPS19, pp. 7. 18 (Apr. 1979).

Brown, W. E., Schroeder, L. W., Ferris, J. S., 18583.

Brozowski, G., Burkitt, D., Gabriel, M., hanrahan, J., MCCarthy, E., SMITH, J., SP519, pp. 175-179 (Apr. 1979).

Brueckner, G., Van Hoosier, M. E., B asri, G. S., Linsky, J. L., Bartoe, J. D. F., 18876.

Brugel, E. W., Wallerstein, G., 18546.

Bruhn, C. G., Harrison, W. W., Smyth, K. C., Bentz, B. L., 18449.

Brungraber, R. J., Adler, S. C., 18705.

Brunnemann, K. D., Hoffmann, D., Schmeltz, I., SP519, pp. 297-309 (Apr. 1979).

Brunnemann, K. D., SchmeltZ, I., Wynder,. E. L., Hoffmann, D., SP519, pp. 131-141 (Apr. 1979).

Bruntlett, C. S., Bratin, K., Rice, J. R., Kissinger, P. T., SP519, Pp. 705-712 (Apr. 1979).

Bruntlett, C. S., Shoup, R. E., Kissinger, P. T., Felice, L. J., SP519, pp. 391 -397 (Apr. 1979).

BRYAN, J. L., NBS-GCR-78-138.

BRYAN, J. L., SP540, Pp. 115-133 (Nov. 1979).

Bryan, J. L., DiNenno, P. J., NBS-GCR-78-140.

Bryan, J. L., DiNenNo, P. J., NBS-GCR-79-159.

Buchbinder, B., Offensend, F. L., Helzer, S. G., TN1101.

Budgor, A. B., LuRIA-BudGor, K. F., SP541, pp. 235-248 (Dec. 1978).

Budlong, K. S., Sheffler, A. W., SP563, p. 130 (Oct. 1979). BUDNICK, E. K., KLEIN, D. P., NBSIR 79-1720.

Buehler, M. G., 18463. 
BUEHLER, M. G., 18757 .

Buehler, M. G., Carver, G. P., NBSIR 79-1744.

Buehler, M. G., Koyama, R. Y., SP400-5S.

Buehler, M. G., Russell, T. J., Maxwell, D. B., ReimanN, C. T., 18533.

BuHL, P. H., SP519, pp. $771-775$ (Apr. 1979).

Buxer, I., Scheulen, B., Telin, B., Durbeck, H. W., FrischKorn, C. G. B., SP5/9, pp. 437-445 (Apr. 1979).

Bukowski, R. W., NBSIR 79-1739.

BukowsKi, R. W., NBSIR 79-1915.

Bukowski, R. W., Custer, R. L. P., Bright, R. G., 18625.

Buxowski, R. W., Mulholland, G. W., SP540, pp. $1-45$ (Nov. 1979).

Bulu, C., Rippey, W. G., Hurley, C. W., Rorrer, D. E., NBSIR 79-1709.

BULLIS, W. M., NBSIR 78-1444-3.

Bullis, W. M., NBSIR 79-1591.

Bullis, W. M., NBSIR 79-1591-2.

Bullis, W. M., NBSIR 79-1591-3.

Bullis, W. M., SP400-38.

Bullock, R. A., Hegner, R. E., JR., Hillhouse, D. L., NBSIR 79.1933.

BUR, A. J., NBSIR 77-1401.

BURCH, D. M., TN1107.

Burch, D. M., Hunt, C. M., Treado, S. J., TN992.

BURCh, D. M., TREADO, S. J., NBSIR 79-1736.

Burch, D. M., Treado, S. J., SP548, pp. 73-104 (July 1979).

Burdette, H. E., Kuriyama, M., Boettinger, W. J., 18399.

BURdICK, D. L., SP54l, pp. 13-18 (Dec. 1978).

BuRge, D. K., BenNett, H. E., SP54/, pp. 266-277 (Dec. 19.78).

Burie, J., Demaison, J., Dubrulle, A., Bauer, A., Boucher, D., JPCRD 8, No. 2, 537-558 (1979).

Burkitt, D., Gabriel, M., Hanrahan, J., McCarthy, E., SMitr, J., Brozowski, G., SPS 19, pp. 175-179 (Apr. 1979).

BURNETT, E. D., 18464.

BuRNetTe, C. H., NBS-GCR-78-153.

BURNETTE, C. H., NBS-GCR-78-154.

BURNS, D. A., SPS19, pp. 587-600 (Apr. 1979).

BurRis, B. L., MOREhOUSE, R. J., SP305. Supplement 10.

Busey, H., Edmonds, P. D., Reyes, Z., PARKinson, D. B.,

Filly, R. A., SP525, pp. 323-326 (Apr. 1979).

BUSSEY, H. E., 18557.

Bussey, H. E., 18566.

Bussey, H. E., Boyne, H. S., Ellerbruch, D. A., Jesch, R. L., JONES, R. N., 18563.

BUTLER, S. J., SP532, pp. 118-124 (Feb. 1979).

\section{C}

Cadoff, M. A., Mathews, D. E., Shoemaker, C. O., JR., KILMER, R. D., 18607.

CAKN, J. W., 18422 .

Cahn, J. W., Allen, S. M., 18373.

Cahn, J. W., Allen, S. M., 18613.

Cahn, J. W., Balluffi, R. W., 18758.

CAHN, J. W., KIKUCHI, R., $186 / 4$.

CAHN, J. W., KIxUChI, R., 18669.

Cahn, J. W., Pan, J. D., Ballufi, R. W., 18759.

CALI, J. P., 18536.

CAli, J. P., 18539.

CALI, J. P., 18748.

CAli, J. P., DURst, R. A., 18379.

Callcott, T. A., Arakawa, E. T., Ederer, D. L., 18359.

Callcott, T. A., Arakawa, E. T., Ederer, D. L., 18413.

Callcott, T. A., Arakawa, E. T., Ederer, D. L., 1874 l.

Calomeris, P. J., Recicar, S. A., Warnar, R. B. J., SP500-45.

Calvano, N. J., Berger, R. E., NBSIR 78-1547.

Calvano, N. J., Wakamiya, S., Dobbyn, R. C., 18465.

Calvert, J. G., SP557, pp. 99-100 (Aug. 1979).
Candela, G. A., Haines, R. A., 18746.

Candela, G. A., Roth, R. S., Swartzendruber, L. J., Romanov, V. P., 19046.

Carlson, A. D., Patrick, B. H., 18581 .

Carlson, D. E., SP400-58, pp. 82-85 (Aug. 1979).

Carlsten, J. L., Pichler, G., Raymer, M. G., 18498.

Carmel, S. J., Morris, M. C., McMurdie, H. F., Evans, E. H., Paretzin, B., de Groot, J. H., Hubbard, C. R., Monogr. 25, Section 16.

Carniglia, C. K., Allen, T. H., Apfel, J. H., SP541, pp. 33 36 (Dec. 1978).

Carniglia, C. K., Apfel, J. H., Carrier, G. B., Milam, D., SP541, pp. $218-225$ (Dec. 1978).

Carolan, T., SP547, pp. $315-322$ (July 1979).

CARPENTER, B. S., 18342 .

Carpenter, R. J., Holt, A. W., Koenig, A. L., Warnar, R. B. J., MOORE, R. T., NBSIR 79-1725.

CARPenter, R. J., SoKol, J., JR., Rosenthal, R., 18760.

CARR, T. W., SP519, pp. 697-703 (Apr. 1979).

Carrier, G. B., Milam, D., Carniglia, C. K., Apfel, J. H., SP541, Pp. $218-225$ (Dec. 1978).

Carrole, D. 1., Dzidic, I., Stillwell, R. N., Horning, E. C., SP519, pp. 655-671 (Apr. 1979).

Carroll, W. L., Barnett, J. P., NBSIR 79-1732.

Carson, P. L., Shabason, L., Dick, D. E., Clayman, W., SP525, pp. $337-340$ (Apr. 1979).

Carstensen, E. L., SP525, pp. 29-36 (Apr. 1979).

Carter, G. C., Bennett, L. H., Kahan, D. J., Cuthill, J. R., Chafe, H. D., Gray, A. G., Langer, E. L., Baker, H., 18645.

Carter, G. C., Chabre, Y., Bowman, R. C., JR., 18352.

Carter, G. C., Kahan, D. J., Read, M. E., Mánning, J. R., SWARTZENDRUBER, L. J., 18637.

CARTER, L. T., SP547, pp. 111 -126 (July 1979).

Carver, G. P., Buehler, M. G., NBSIR 79-1744.

Cascaval, C. N., Florin, R. E., 18580.

Casciani, F. S., Etz, E. S., 18982.

Casciani, F. S., Etz, E. S., Newbury, D. E., Doty, S. B., 19008.

CASE, W. E., NBSIR 79-1619.

CASEY, A. W., Lindahl, R. O., LANDinghaM, R. L., SP562, pp. 231-244 (Oct. 1979).

Cassanova, R. A., Powell, E. A., Zinn, B. T., Bankston, C. P., NBS-GCR-78-147.

CASSEl, J. M., NBSIR 78-1573.

Castor, J. I., LAmers, H. J. G., 18515.

CASTOR, J. I., VAN BleRKOM, D., 18435.

CAswell, R. S., CoYne, J. J., 18360.

CAswell, R. S., CoYne, J. J., 18658.

Cateora, J. V., Hanson, D. W., Davis, D. D., 18393.

Cateora, J. V., hanson, D. W., Davis, D. D., 19029.

Cater, E. D., SP561/1, pp. 3-38 (Sept. 1979).

Cater, E. D., Mueller, B. H., Fries, J. A., SP561/1, pp. 237. 262 (Sept. 1979).

Cattaneo, L. E., Yancey, C. W. C., BSS95.

CAva, R. J., Roth, R. S., 18646.

Cavallo, L., Ehrlich, M., Hutchinson, J. M. R., 18361.

Cavallo, L. M., Golas, D. B., ManN, W. B., 18761 .

Celotta, R. J., Swanson, N., Kurepa, M., 18392.

Cercignani, L., Kinsman, P. R., Long, K. A., Maglll, J., Scotti, A., OhSE, R. W., Babelot, J. F., SP561/1, pp. 83109 (Sept. 1979).

Cetas, T. C., U.S. Patent 4,140,393.

Cezairliyan, A., Armstrong, G. T., 18330.

Chabay, I., Bright, D., 18980.

Chabay, I., Rosasco, G. J., Kashiwagi, T., 18626.

Chabay, I., Schaefer, J. C., 18686.

Chabre, Y., Bowman, R. C., Jr., Carter, G. C., 18352.

Chafe, H. D., Gray, A. G., langer, E. L., Baker, H., Carter, G. C., Bennett, L. H., Kahan, D. J., Cuthill, J. R., 18645. 
Chafe, H. D., Gray, A. G., Langer, E. L., Baker, H., Cuthill, J. R., Kahan, D. J., Bennett, L. H., 18739.

Chalken, J. M., SP534, pp. 93-106 (May 1979).

Chainen, R. F., SP540, pp. 624-625 (Nov. 1979).

Chamberlain, G. E., Day, G. W., NBSIR 79-1608.

Champ, M. A., Kingston, H. M., Barnes, I. L., Brady, T. J., RAINS, T. C., 18402.

Chan, C., DaIly, J. W., SP561/2, pp. 847-853 (Sept. 1979).

Chandra, K., SP543, pp. 62-63 (Apr. 1979).

Chang, D. C., Montgomery, J. P., Monogr. 164.

Chang, D. C., Sreenivasiah, 1., NBSIR 79-1606.

Chang, D. C., Tippet, J. C., NBSIR 79-1615.

Chang, D. C., Tippet, J. C., 18345.

Chang, D. C., Tippet, J. C., 18694.

Chang, F. H., Bell, J. R., Gardner, A. H., Fisher, C. P.,

HANDley, G. P., SP563, p. 59 (Oct. 1979).

Chang, S. J., Zapas, L. J., 18367.

Chang, S. S., 18376.

Chang, S. S., 18377.

Chang, S. Y., Chvapil, T., Chvapil, M., Eskelson, C. D., SP519, pp. 469-476 (Apr. 1979).

Chang, T. T., NBSIR 79-1748.

Chang, Y. L., Rorrer, D. E., RIPPey, W. G., NBSIR 79-1757.

Chang, Y. M. L., Grot, R. A., NBSIR 79-1781.

Changery, M. J., Filliben, J. J., Simiu, E., BSSII8.

ChapMan, C., NBSIR 79-1900.

Chapman, R., Grot, R., Godette, M., Crenshaw, R., Clark, R., NBSIR 79-1706.

ChAPMAN, R. E., 19045.

Chapman, R. E., Chen, P. T., Hall, W. G., NBSIR 79-1902.

Chapman, R. E., Kowalski, J. G., TN971.

Chapman, R. E., Kowalski, J. G., TN979.

Chapman, R. E., Ruegg, R. T., BSSI19.

Chappell, S. E., Humphreys, J. C., NBSIR 79-1723.

Chase, M. W., Downey, J. R., Syverud, A. N., SP561/2, pp. 1581-1594 (Sept. 1979).

Chatillon, C., Allibert, M., Pattoret, A., SP561/1, pp. 181 210 (Sept. 1979).

Chatwani, A. U., Ferron, J. R., Kerr, D. L., SP561/2, pp. 1373-1402 (Sept. 1979).

Chen, M., Mclntyre, P. A., SP519, pp. 257-265 (Apr. 1979).

Chen, P. T., HALl, W. G., Cha PMAN, R. E., NBSIR 79-1902.

Chen, S. S., Kudchadker, S. A., Wilhoit, R. C., JPCRD \&, No. 2, 527-536 (1979).

Chesler, S. N., Guenther, F., Hilpert, L. R., Hertz, H. S., WISE, S. A., MAY, W. E., BroWn, J. M., SP5 19, pp. 219-224 (Apr. 1979).

Chesler, S. N., Hertz, H. S., SPS19.

Chew, R. K., Pastor, R. C., Harrington, J. A., Gorre, L. E., SP541, pp. 249-256 (Dec. 1978).

Chi, J., Kelly, G. E., 18385 .

CHI, T. C., JPCRD 8, No. 2, $339-438$ (1979).

Снı, T. C., JPCRD 8, No. 2, 439-498 (1979).

Chidsey, I. L., Crosley, D. R., SP561/2, pp. $1181-1191$ (Sept. 1979).

Chiovett, R., Jr., Weinstein, J. N., Wlodawer, A., Segrest, J. P., Chung, B. H., 18851 .

Chivers, R. C., PARry, R. J., SP525, pp. 343-360 (Apr. 1979).

Choi, C. S., Prask, H. J., Trevino, S. F., 19027.

Choi, C. S., Prince, E., 18873.

Cног, J. W., SP539, pp. 37-41 (Apr. 1979).

Chol, J. W., SP543, pp. 34-39 (Apr. 1979).

Christ, B. W., Polvani, R. S., Hocken, R. J., NBSIR 78-1569.

Christ, B. W., SMith, J. H., Brady, C. H., 18368.

Christensen, D., Johnson, S. A., Greenleaf, J. F., Rajagopalan, B., Bahn, R. C., BaXter, B., SP525, pp. 235246 (Apr. 1979).

Christensen, R. G., Schaffer, R., Reeder, D. J., Enagonio, D. P., SP519, pp. 447-453 (Apr. 1979).

Christopher, P. M., Aronoff, M. J., NBSIR 79-1923.
Christopher, P. M., Krzewick, J. E., NBSIR 79-1762.

Chu, S. S., Chu, T. L., Y ANG, H. T., Stokes, E. D., SP40058, pp. 76-81 (Aug. 1979).

Chu, S. S., Stokes, E. D., Lin, C. L., Abderrassoul, R., Chu, T. L., SP400-58, pp. 41-47 (Aug. 1979).

Chu, T. L., Chu, S. S., Stokes, E. D., Lin, C. L., AbderrasSOuL, R., SP400-58, pp. 41-47 (Aug. 1979).

Chu, T. L., Yang, H. T., Stokes, E. D., Chu, S. S., SP40058, pp. 76-81 (Aug. 1979).

Chung, B. H., Chlovetti, R., Jr., Weinstein, J. N., Wlodawer, A., Segrest, J. P., 18851 .

Churney, K., Braun, W., Herron, J. T., Tsang, W., 18709.

Churney, K. L., Mosselman, C., 18803.

Chvapil, M., Eskelson, C. D., Chang, S. Y., Chvapil, T., SP519, pp. $469-476$ (Apr. 1979).

Chvapil, T., Chvapil, M., Eskelson, C. D., Chang, S. Y., SP519, pp. $469-476$ (Apr. 1979).

ChWIRUT, D. J., NBSIR 79-1742.

Chwirut, D. J., EITZEN, D. G., 18744.

Clark, A. F., Ekin, J. W., Radebaugh, R., Read, D. T., 18762.

Clark, A. F., Ekin, J. W., Schramm, R. E., 18718.

Clark, A. F., Read, D. T., Exin, J. W., Powell, R. L., 18681 .

Clark, F. B., SP548, pp. 57-72 (July 1979).

Clark, F. O., Lovas, F. J., Johnson, D. R., 18731 .

Clark, R., Chapman, R., Grot, R., Godette, M., Crenshaw, R., NBSIR 79-1706.

Clark, R. E., hastings, S. R., NBSIR 78-1501.

Clayman, W., Carson, P. L., Shabason, L., Dick, D. E., SP525, Pp. $337-340$ (Apr. 1979).

Cleveland, W. G., McMichael, J. M., NBSIR 78-1505.

Clifton, J. R., Brown, P. W., Frohnsdorff, G., 18854.

Clifton, J. R., Davis, F., NBSIR 79-1730.

Clifton, J. R., Davis, F. L., TN996.

Clifton, J. R., Frohnsdorff, G., Brown, P. W., SP542.

Close, R. T., Kambeitz, R. A., SP500-52, pp. 233-234 (Oct. 1979).

Cloud, P. J., Alvord, R. T., SP563, p. 173 (Oct. 1979).

Cohen, A., Mighell, A. D., Hubbard, C. R., 18672.

Cohen, A., Schaffer, R., White V, E., Sniegoski, L. T., SP519, pP. 405-410 (Apr. 1979).

COHEN, J., 18378.

Cohen, J., Domalski, E. S., Abramowitz, S., Kirklin, D. R., MITCHELL, D. J., NBSIR 78-1494.

COHEN, L., SP554, pp. 57-61 (Sept. 1979).

Cohen, R., Merritt, M. E., Simmons, K., LaFaucia, R., Llmentani, G., Washburn, D. N., Siggia, S., Kostyla, R. J., MOUREY, T. H., SP519, pp. 783-787 (Apr. 1979).

Cole, C., Konen, T. P., Bevans, R. S., Boegly, W. J., SavitSKY, D., SP553, pp. $71-77$ (Aug. 1979).

Collard, J. J., 19038.

Collier, R. S., Haber, S., Tryon, P. V., Jackson, R. H. F., NBSIR 79-1751.

Collier, S. D., Ayres, R. U., Lewis, J., NBS-GCR-ETIP 78 60.

Collings, E. W., Ledbetter, H. M., 18763.

Collins, B. L., Pierman, B. C., NBSIR 79-1760.

Collins, B. L., Stahl, F. I., Archea, J., BSS120.

Collins, B. L., Turner, G. E., NBSIR 79-1729.

Collins, G. J., Persson, K. B., Franzen, D. L., McNeil, J. R., JOHNSON, W. L., 18319 .

Collins, G. J., Warner, B. E., Persson, K. B., 18968.

Collins, L. A., Norcross, D. W., Schmid, G. B., 18516.

Collins, W. T., SP551, pp. 29-31 (July 1979).

Colwell, J. H., 18466.

CoMeford, J., SP556, pp. 161-163 (Sept. 1979).

CoMeford, J., SP556, pp. 87-92 (Sept. 1979).

Connor, W. G., Nasoni, R. L., Pifer, A. E., Sholes, R. R., BoWEN, T., SP525, pp. 57-61 (Apr. 1979). 
CONSTANTINIDES, E. R., VictoR, G. A., 18950.

CONTI, D. M., SP500-38.

Conway, D., Goglia, M. R., Stahl, F. I., 18784.

Cook, L. P., Farabaugh, E. N., Olson, C. D., SP562, pp. 407. 415 (Oct. 1979).

COOK, R. K., Proctor, T. M., 18728.

Coox, Z., Booth, J., NBS-GCR-ETIP 79-66.

COOK, Z., Ferguson, A. R., BOoth, J., NBS-GCR-ETIP 78-53.

CoOke, F., Miles, P., Gentilman, R., SP562, pp. 255-260 (Oct. 1979).

COOKE, P. W., SP536.

COOKE, P. W., SP552.

Cooke, P. W., Gross, J. G., Pielert, J. H., TN998.

CoOKs, R. G., SP519, pp. 609-625 (Apr. 1979).

Cooper, C. G., Berson, G. P., SP552, pp. $311-320$ (July 1979).

COOPER, G. A., SP562, pp. $115-137$ (Oct. 1979).

COOPER, J., SP556, p. 47 (Sept. 1979).

COOPER, J. W., ABERG, T., 18407.

COPLey, S. M., Bass, M., Wallace, R. G., SP562, pp. 283-292 (Oct. 1979).

CoRdes, M. R., BAum, H. R., Lewis, J., RehM, R. G., NBSIR 79-1754.

Cordova, F., Ayres, T. R., Linsky, J. L., Garmire, G., 18839.

CORIA, R., SP543, pp. 46-50 (Apr. 1979).

Corliss, C., Sugar, I., JPCRD 8, No. 1, 1-62 (1979).

Corliss, C., SUGAR, J., JPCRD 8, No. 3, 865-916 (1979).

Corliss, C., Sugar, J., JPCRD 8, No. 4, $1109-1146$ (1979).

Corliss, C. H., ReAder, J., 18870.

Corliss, E. L. R., CIS4, Revised 1978.

Corotis, R. B., Dowding, C. H., Rossow, E. C., NBS-GCR79-181.

Costain, C. C., Daams, H., Boulanger, J. S., Hanson, D. W., KelpCZYNSX1, W. J., 18861 .

Cotter, R. L., Edwards, R. W., NonnemaxeR, K. A., SP519, pp. $87-94$ (Apr. 1979).

COTTON, I. W., SP500-48.

Couch, W. P., SP563, Pp. 286-298 (Oct. 1979).

Countermine, T. A., Tressler, R. E., Bradt, R. C., Easler, T. E., SP562, pp. $455-462$ (Oct. 1979).

Coursey, B. M., Hutchinson, J. M. R., Lucas, L. L., Mann, W. B., Matsumura, T., Noyce, J. R., 18400.

Coursey, B. M., Hutchinson, J. M. R., Schima, F. J., 18841.

Cox, R. A., SP557, pp. $71-79$ (Aug. 1979).

Cox, S. W., SP500-52, pp. 179-192 (Oct. 1979).

Coxon, B., Hough, L., 18764.

Coxon, B., Layer, H. P., Hocken, R. J., Cummings, A. L., 18768.

Coxon, B., VARMa, R., SWeEting, L. M., 18742.

Coyle, T., Siedle, A., SP556, p. 23 (Sept. 1979).

COYNE, J. J., 18660.

COYNe, J. J., CASWEll, R. S., 18360.

COYNE, J. J., CASWELl, R. S., 18658.

Crandall, D. H., Gregory, D., Dunn, G. H., Phaneuf, R. A., 18707.

CRANE, C. R., SMith, P. W., SP540, pp. $549-565$ (Nov. 1979).

Crannell, C. J., Crannell, H., Hornyak, W. F., Seltzer, S. M., Trombra, J. I., WALl, N. S., LAPIDES, J. R., 19015.

Crannell, H., Hornyak, W. F., Seltzer, S. M., Trombka, J. I., WAll, N. S., LAPIDES, J. R., CRANnEll, C. J., 19015.

CRAWford, M. L., 18579.

Crawford, M. L., Decker, W. F., WILSON, W. A., TN1011.

CRAWford, M. L., WORKMaN, J. L., TN1013.

Crawford, M. L., WORKMAN, J. L., 18578.

Creedon, J., SP556, pp. 167-170 (Sept. 1979).

Creighton, J. R., Lund, C. M., SP561/2, pp. 1223-1244 (Sept. 1979).

Crenshaw, R., Clark, R., Chapman, R., Grot, R., Godette, M., NBSIR 79-1706.

CrisseY, B., SP534, pp. 163-175 (May 1979).
CRissman, J. M., 18467.

Crissman, J. M., ZaPAs, L. J., 18468.

Crissman, J. M., ZaPas, L. J., 18765.

Crissman, J. M., Zapas, L. J., 18766.

Crissman, J. M., Zapas, L. J., 18767.

Crissman, J. M., ZaPAS, L. J., 18807.

Croarkin, C., Beers, J., Tucker, C., Monogr. 163.

Crosley, D. R., Anderson, W. R., Allen, J. E., JR., Fansler, T. D., SPS61/2, pp. $1153-1167$ (Sept. 1979).

Crosley, D. R., Chidsey, 1. L., SP561/2, pp. 1181-1191 (Sept. 1979).

Crosley, D. R., DeWilde, M. A., SP561/2, pp. 1171-1179 (Sept. 1979).

Crossman, F. W., Law, G. E., JR., Wang, A. S., SP563, pp. 255-264 (Oct. 1979).

Crow, F. W., Hunt, D. F., SP519, pp. 601-607 (Apr. 1979).

Cumbo, J. E., Michaelis, R. E., $184 / 4$.

Cummings, A. L., Coxon, B., Layer, H. P., Hocken, R. J., 18768.

Cummings, B. A., SP549, pp. 103-106 (Aug. 1979).

Cunningham, D., NBSIR 78-1577.

Cunningham, W. C., Blahia, J. J., Etz, E. S., 18643.

Currie, L. A., 18405 .

CURTISS, L. A., SP561/l, pp. 791-801 (Sept. 1979).

Custer, R. L. P., Bright, R. G., Bukowski, R. W., 18625.

Cuthill, J. R., 18406.

Cuthile, J. R., Chafe, H. D., Gray, A. G., langer, E. L., Baker, H., Carter, G. C., Bennett, L. H., Kahan, D. J., 18645.

Cuthill, J. R., Kahan, D. J., Bennett, L. H., Chafe, H. D., Gray, A. G., LANGer, E. L., Baker, H., 18739.

Cuthrell, R. E., SP562, pp. 139-145 (Oct. 1979).

CutKoskY, R. D., 18452 .

CutKosky, R. D., 18453.

Czerwinski, M. I., Skolnik, M. L., Leb, D. E., Preston, K., JR., SP525, pp. 303-313 (Apr. 1979).

\section{D}

Daams, H., Boulanger, J. S., Hanson, D. W., Kelpczynski, W. J., Costain, C. C., 18861 .

Dally, J. W., Chan, C., SP561/2, pp. $847-853$ (Sept. 1979).

DaIn, F., KUc, R., SchwartZ, M., FinBy, N., SP525, pp. $125-$ 132 (Apr. 1979).

DALEY, F., SP527, pp. $51-59$ (Feb. 1979).

Daly, J. A., ANDriole, S. J., SP480-38, pp. 47-74 (Dec. 1979).

DANEY, D. E., NBSIR 79-1618.

DANEY, D. E., LudTKe, P. R., Jones, M. C., 18567.

Danielson, B. L., 18547.

Danielson, B. L., Day, G. W., Franzen, D. L., 18647.

Danielson, B. L., Day, G. W., Franzen, D. L., 18662.

Danileiko, Y. K., Manenkov, A. A., Sidorin, A. V., SP541, pp. 305-308 (Dec. 1978).

Danos, M., 18423.

Danos, M., 18565 .

Danos, M., Glllet, V., 18769.

Danos, M., Rafelsiki, J., 18732.

DanOS, M., RafelsKi, J., 18951 .

Das, B. S., ThOMAs, G. H., SP519, pp. 41-56 (Apr. 1979).

DAs, M. B., TrESSLER, R. E., STACH, J., NBS-GCR-78-134.

Daugherty, D. T., Neel, E. M., Debbrecht, F. J., SP5 19, pp. 761-769 (Apr. 1979).

Davidson, C. L., LeEs, S., SP525, pp. 179-187 (Apr. 1979).

DAVIDSON, D. L., LANKFORD, J., SP562, pp. 395-404 (Oct. 1979).

Davidson, E. R., KNIGHT, L. B., IR., MarTin, R. L., SP561/1, pp. 545-555 (Sept. 1979).

Davidson, K. M., Brauer, G. M., Kumpula, J. W., Termini, D. J., 18638 . 
Davis, D. D., Cateora, J. V., Hanson, D. W., 18393.

Davis, D. D., Cateora, J. V., Hanson, D. W., 19029.

Davis, F., Clifton, J. R., NBSIR 79-1730.

Davis, F. L., Clifton, J. R., TN996.

DAvis, G. T., DeReggi, A. S., Broadhurst, M. G., 18408.

DAvis, R. S., ANDERSON, W. E., 18384.

DAvis, R. S., Bower, V. E., J. Res. 84, No. 2, 157.160 (1979).

Davis, R. S., Petersons, O., Moore, W. J. M., Anderson, W. E., 18513.

Davis, R. W., Moore, E. F., Mattingly, G. E., Miller, R. W., 18410 .

Davis, S., 18517.

DAY, G. W., 18648.

DAY, G. W., 18915 .

Day, G. W., Chamberlain, G. E., NBSIR 79-1608.

Day, G. W., Franzen, D. L., 18848 .

DaY, G. W., Franzen, D. L., Danielson, B. L., 18647.

DAY, G. W., Franzen, D. L., Danielson, B. L., 18662 .

DAYWITT, W. C., 18577.

de CAstro, A. P., SP543, pp. 199-208 (Apr. 1979).

de ChAN, M. F., SP543, pp. 87-88 (Apr. 1979).

de Groot, J. H., Hubbard, C. R., Carmel, S. J., Morris, M. C., McMurdie, H. F., Evans; E. H., Paretzkin, B., Monogr. 25 , Section 16.

DE RIS, J., SP540, Pp. 11 0-208 (Nov. 1979).

Dean, S. K., Doyle, E. D., SP562, pp. $107-114$ (Oct. 1979).

Debbrecht, F. J., Daugherty, D. T., Neel, E. M., SP519, pP. 761-769 (Apr. 1979).

Debelius, J. R., SP457-3.

Debelius, J. R., Galowin, L. S., SP553.

Debrue, J., Rahn, F. J., Serpan, C. Z., Fabry, A., McElroy, W. N., GRUNDL, J. A., 19014.

Decker, D. L., Donovan, T. M., Bethke, J. W., Temple, P. A., SP541, pp. 37-42 (Dec. 1978).

Decker, D. L., Grandjean, D. J., SP54I, pp. 122-130 (Dec. 1978).

Decker, D. L., Grandjean, D. J., Bennett, J. M., SP562, pp. 293-303 (Oct. 1979).

Decker, D. L., Solleau, M. J., Porteus, J. O., SP562, pp. 513. 518 (Oct. 1979).

Decker, W. F., Wilson, W. A., Crawford, M. L., TNIOII.

DeCorpo, J. J., SaAlfeld, F. E., Smith, D. E., King, T. L., Eaton, H. G., Williams, F. W., Wyatt, J. R., SP519, pp. 213-218 (Apr. 1979).

deGraaf, L. A., Rush, J. J., Livingston, R. C., Flotow, H. E., Rowe, J. M., 18730 .

Dehl, R. E., Grant, W. H., NBSIR 79-1784.

Deleeuw-Gilerts, G., Grundl, J., 19024.

Delichatsios, M. A., Heskestad, G., NBS-GCR-78-128.

Delichatsios, M. A., Heskestad, G., NBS-GCR-78-129.

Demaison, J., Dubrulle, A., Bauer, A., Boucher, D., Burie, J., JPCRD 8, No. 2, 537-558 (1979).

DeMichiell, R. L., UNdeRWoOd, G. L., SP500-52, pp. 231-232 (Oct. 1979).

Demkov, Y. N., Kunasz, C. V., Ostrovski1, V. N., 18576.

Demkov, Y. N., Ostrovski,, V. N., Solov'Ev, E. A., 18575.

Denyszyn, R. B., HARden, J. M., HaRdison, D. L., McGaughey, J. F., Sykes, A. L., SP519, pp. 153-159 (Apr. 1979).

DePrit, A., Sснмidt, D. S., J. Res. 84, No. 4, 293-297 (1979).

DeReggi, A. S., Broadhurst, M. G., Davis, G. T., 18408.

DeReggi, A. S., Edelman, S., U.S. Patent 4,166,229.

Deslattes, R. D., 18469.

Deslattes, R. D., Henins, A., Kessler, E. G., JR., 18487.

Deslattes, R. D., Kessler, E. G., JR., Jacobs, L., Schwitz, W., 18510 .

Detrio, J. A., Petty, R. D., SP54I, pp. $78-85$ (Dec. 1978).

Deutsch, D., Sockut, G., JefFery, S., Fife, D., 18777.

DEUTSCH, D. R., SP500-49.

Deutsch, S., J. Res. 84, No. 4, 287-292 (1979).
DeVoe, J. R., O'Haver, T. C., Turk, G. C., Travis, J. C., 18880 .

DeWilde, M. A., Crosley, D. R., SP561/2, pp. 1171-1179 (Sept. 1979).

Diamond, J. J., Taggart, H. E., Jones, R. N., Saulsbury, L. F., Workman, J. L., Treado, M. J., 18381 .

Diaz, M., Brill, R. H., Yamasaki, K., Barnes, I. L., Rosman, K. J. R., 18840 .

diBenedetto, B., Donadio, R., Kohane, T., Pappis, J., Klein, C., SP541, pp. 86-97 (Dec. 1978).

Dick, C. E., Soares, C. G., Motz, J. W., 18441.

Dick, D. E., Clayman, W., Carson, P. L., Shabason, L., SP525, pp. 337-340 (Apr. 1979).

Dickens, B., 18445.

Dickens, B., 18447 .

Dickens, B., 18450.

Dickens, B., FlynN, J. H., 18620.

DickeY, D. H., EHRSTEIN, J. R., SP400-48.

Dickey, J. W., Dimmick, J. G., SP547, pp. $129-152$ (July 1979).

Dickhoven, S., SP534, pp. 195-203 (May 1979).

Dickson, G., 18649.

Didion, D. A., 18778 .

Didion, D. A., Kelly, G. E., 18703.

Dietrich, H. B., Koyama, R. Y., Phillips, W. E., Myers, D. R., LiU, Y. M., 18458.

Dietz, D. R., Shideler, R. W., Shawker, T. H., Doppman, J. L., Linzer, M., Parks, S. I., Norton, S. J., Higgins, F. P., SP525, pp. 255-259 (Apr. 1979).

Diller, D. E., 18564 .

Diller, D. E., 18838 .

Dillon, J. G., Wagner, H. L., 18834.

Dils, R. R., Follansbee, P. S., SP561/2, pp. 1027-1070 (Sept. 1979 ).

Dimmick, J. G., DickeY, J. W., SP547, pp. $129-152$ (July 1979).

DiNenno, P. J., BRYAN, J. L., NBS-GCR-78-140.

DiNenno, P. J., BRYAN, J. L., NBS-GCR-79-159.

Ding, J., Laughlin, J. S., Reid, A., Zeitz, L., SP554, Pp. 1 14 (Sept. 1979).

DJeRMaKoye, I. S., SP543, pp. 196-198 (Apr. 1979).

Dobbyn, R. C., Calvano, N. J., Wakamiya, S., 18465.

DobrotT, R., LARRABEE, G., NBS-GCR-79-158.

DODDS, J. S., SP500-52, pp. 79-86 (Oct. 1979).

DODGE, M. J., SP541, pp. 55-58 (Dec. 1978 ).

Dodge, M. J., Feldman, A., Horowitz, D., WaXler, R. M., TN993.

Dodge, W. R., Hayward, E., Moscati, G., Wolynec, E., 18518.

DOdGe, W. R., HAYWARD, E., Wolynec, E., 18535.

Dodge, W. R., Patrick, B. H., Hayward, E., 18522.

Doll, C. K., Garrison, A. W., Pope, J. D., Alford, A. L., SP519, pp. 65-78 (Apr. 1979).

Domalski, E. S., 18797.

Domalski, E. S., Abramowitz, S., Kirklin, D. R., Mitchell, D. J., COHEN, J., NBSIR 78-1494.

Domich, P., Lawrence, J., Shier, D., J. Res. 84, No. 6, 455 488 (1979).

Donadio, R., Kohane, T., Pappis, J., Klein, C., diBenedetto, B., SP54I, Pp. 86-97 (Dec. 1978).

Donahe, S. M., Janauer, G. E., Zucconi, T. D., Lewkowicz, C., SP519, pp. $455-459$ (Apr. 1979).

Donavan, P. R., Hosier, R. N., NBSIR 79-1599.

Donovan, T. M., Bethke, J. W., Temple, P. A., Decker, D. L., SP541, pp. 37-42 (Dec. 1978).

Donovan, T. M., Jernigan, J. L., Faith, W. N., Porteus, J. O., SP541, Pp. 202-211 (Dec. 1978).

Donovan, T. M., Porte Us, J. O., Jernigan, J. L., Ashley, E. J., SP54I, pp. $212-217$ (Dec. 1978). 
Doppman, J. L., Linzer, M., Parks, S. I., Norton, S. J., HigGins, F. P., Dietz, D. R., Shideler, R. W., Shawker, T. H., SPS2S, pp. 255.259 (Apr. 1979).

Doran, D. G., Gold, R., Lippincott, E. P., Schiffgens, J. O., Simons, R. L., Morgan, W. C., Grundl, J. A., McGarry, E. D., KaM, F. B. K., SWANK, J. H., OdetTe, G. R., McElROY, W. N., 19012 .

Doty, S. B., Casciani, F. S., Etz, E. S., Newbury, D. E., 19008.

Dougherty, H. T., Estin, A. J., Morgan, W. L., Woodruff, J. J., 18628.

Dougherty, M. D., SP547, pp. 167-175 (July 1979).

DoughtY, S., SP547, pp. 280-285 (July 1979).

Dove, R. B., Soulen, R. J., JR., SP260-62.

Dowding, C. H., Rossow, E. C., Corotis, R. B., NBS-GCR79.181

Downey, J. R., Syverud, A. N., Chase, M. W., SP561/2, pp. 1581-1594 (Sept. 1979).

Downing, W. J., Nielsen, L. S., Orloski, M. J., Wyly, R. S., Galowin, L. S., SP553, pp. 53-70 (Aug. 1979).

Doyle, E. D., DeAn, S. K., SP562, pp. $107-114$ (Oct. 1979).

Drake, M. C., Grabner, L. H., Hastie, J. W., SP561/2, pp. 1105-1134 (Sept. 1979).

Drake, M. C., Rosenblatt, G. M., SP561/1, pp. 609-646 (Sept. 1979).

Dreizler, H., Lovas, F. J., Lutz, H., JPCRD 8, No. 4, 1051 1108 (1979).

Dressler, E., 18798.

Dressler, E. T., O'Connell, J. S., MacDonald, W. M., 18442 .

Dressler, E. T., O'Connell, J. S., MacDonald, W. M., 18496.

DRISCOLL, P., NBSIR 78-1521.

Drullinger, R. E., Walls, F. L., Wineland, D. J., 18697.

Drullinger, R. E., Wineland, D. J., Walls, F. L., 18699.

Dubrulle, A., Bauer, A., Boucher, D., Burie, J., Demaison, J., JPCRD 8, No. 2, 537-558 (1979).

DudLeY, K. H., SP5/9, pp. $381-390$ (Apr. 1979).

DuliK, D. M., 18571 .

Dun, H., Mattes, B. L., Stevenson, D. A., SP561/1, pp. 411 428 (Sept. 1979).

Dunfee, B. L., Petersons, O., Belecki, N. B., NBSiR 75-935.

Dunn, F., Goss, S. A., Johnston, R. L., Maynard, V., Nider, L., Frizzell, L. A., O'Brien, W. D., JR., SP525, pp. 43-5 I (Apr. 1979).

Dunn, F., Johnston, R. L., Goss, S. A., Maynard, V., Brady, J. K., Frizzell, L. A., O'Brien, W. D., JR., SP525, pp. $19-$ 27 (Apr. 1979).

Dunn, G. H., Phaneuf, R. A., Crandall, D. H., Gregory, D., 18707.

Durbeck, H. W., Frischiorn, C. G. B., Buker, I., Scheulen, B., Telin, B., SP519, pp. 437.445 (Apr. 1979).

DURST, R. A., 18334.

DURST, R. A., 18362.

DURST, R. A., 18470.

Durst, R. A., Bellama, J. M., MacCrehan, W. A., SP519, pp. 57-63 (Apr. 1979).

Durst, R. A., Cali, J. P., 18379.

Durst, R. A., MACCREHAN, W. A., 18420.

DUTT, G. S., HARRJE, D. T., SP548, pP. 25-38 (July 1979).

Duwell, E. J., LoKken, R. C., SP562, pp. 201-207 (Oct. 1979).

Dyer, C. S., TrombKa, 3. I., Seltzer, S. M., 19011 .

DYMERSKI, P., KENNEDY, M., KAMINSKY, L., SP519, PP. 685-690 (Apr. 1979).

Dzelzgalvis, I., SP500-52, pp. 163-176 (Oct. 1979).

Dzidic, I., Stillweli, R. M., Horning, E. C., Carrold, D. I., SP519, pp. 655-67! (Apr. 1979).
EARL, W. L., VANDERHART, D. L., 18745

EARLY, J., 18896.

Easler, T. E., Countermine, T. A., Tressler, R. E., Bradt, R. C., SP562, pp. $455-462$ (Oct. 1979 ).

Eaton, H. G., Williams, F. W., Wyatt, J. R., DeCorpo, J. J., SAALFELD, F. E., SMITH, D. E., KING, T. L., SPS19, pp. $213-$ 218 (Apr. 1979).

EBerLy, J. H., 18892.

Eberly, J. H., ARMStrong, L., JR., 18874.

EberLy, J. H., ONeIL, S. V., 18893.

Eberly, J. H., SHORe, B. W., Ackerhalt, J. R., 18439.

EBY, R. K., FARMER, B. L., 18787.

Eckbreth, A. C., Hall, R. J., SP561/2, pp. $943-972$ (Sept. 1979).

Eckerle, K. L., Venable, W. H., JR., SP260-66.

Edelman, P., Herz, E., McDaniel, M. A., Bickman, L., NBSGCR-78-135.

Edelman, P., Rivers, D., Bickman, L., Herz, E., NBS-GCR-79179.

Edelman, S., DeReggi, A. S., U.S. Patent 4,166,229.

Edelman, S., Kenney, J. M., Mayo-Wells, J. F., Roth, S. C., SP547, pp. 303-314 (July 1979).

Edelstein, H. P., Silvergleit, M., Macander, A. B., Brauer, F. A., SP563, pp. 276-285 (Oct. 1979).

Ederer, D. L., Callcott, T. A., Araka wa, E. T., 18359.

Ederer, D. L., Callcott, T. A., Araka wa, E. T., 18413.

Ederer, D. L., Callcott, T. A., Arakawa, E. T., 18741.

Ederer, D. L., Lucatorto, T. B., Mehlman, G., 18912.

Edmonds, P. D., Reyes, Z., Parkinson, D. B., Filly, R. A., BUSEY, H., SP525, Pp. 323-326 (Apr. 1979).

EdRICH, J., Zimmerman, J. T., Zimmerman, J. E., Reite, M., 18397.

EDWARDS, C. M., SP552, Pp. 293-309 (July 1979).

Edwards, D. F., Baumeister, P., ARnOld, G. P., SP541, pp. 257-258 (Dec. 1978).

EDWARDS, J. G., SPS61/1, pp. 67-81 (Sept. 1979).

Edwards, R. W., Nonnemaker, K. A., Cotter, R. L., SP519, Pp. 87-94 (Apr. 1979).

Eesley, G. L., Levenson, M. D., 18558.

Efimov, M. E., Klevaichuk, G. N., Medvedev, V. A., Kilday, M. V., J. Res. 84, No. 4, 273-286 (1979).

EgGleton, R. C., Whitcome, I. A., SP525, pp. 327-336 (Apr. 1979).

EGNEW, R. C., SP532, Pp. $17-19$ (Feb. 1979).

EHRLSCH, M., 18992.

Ehrlich, M., Hutchinson, J. M. R., Ca vallo, L., 18361 .

Ehrlich, M., Seltzer, S. M., Bielefeld, M. J., TrombKa, J. I., 18416.

EHRLich, M., Soares, C. G., 18989.

Ehrlich, M., Soares, C. G., Jackson, B., Lanoue, P., 18355.

Ehrstein, J. R., DiCKey, D. H., SP400-48.

Eiceman, G. A., Walton, H. F., SP519, pp. $185-190$ (Apr. 1979).

Eisenhard, R. M., Santu CCI, L. A., NBSIR 79-1705.

EISENHART, C., 18471 .

EISENHART, C., 18543.

EISENhauer, C., 18965 .

Eisenhauer, C. M., Gilliam, D. M., Bowman, C. D., 18462 .

Eisenhaulr, C. M., Gilliam, D. M., Grunde, J. A., Spiegel, V., 18901 .

Eisenhauer, C. M., Grundl, J. A., Martin, G. C., Jr., SPIEGEL, V., 18883 .

EISENHOWER, E. H., H107, Revised.

EISENHOWER, E. Hi., H129.

EISENHOWER, E. H., 18779 .

EISENHOWER, E. H., 18800 .

Eitzen, D. G., Chwirut, D. J., 18744.

Eitzen, D. G., Miller, E. B., 18438 . 
EKEDAHL, D., SP556, pp. 9-13 (Sept. 1979).

EKIN, J. W., 18622.

EKIN, J. W., 18780.

Ekin, J. W., Braginski, A. I., 18781 .

Ekin, J. W., Powell, R. L., Clark, A. F., Read, D. T., 18681.

Ekin, J. W., Radebaugh, R., Read, D. T., Clark, A. F., 18762.

Ekin, J. W., Schramm, R. E., Clark, A. F., $187 / 8$.

Elbaum, M. E., Lizzi, F. L., SP525, pp. $111-119$ (Apr. 1979).

Elder, J., TURner, G. E., RUBin, A. I., NBSIR 79-1780.

ElKIND, M. M., HAN, A., SP554, pp. 63-73 (Sept. 1979).

Ellerbe, D., SP556, pp. 107-108 (Sept. 1979).

Ellerbruch, D. A., Boyne, H. S., 18820.

Ellerbruch, D. A., Jesch, R. L., Jones, R. N., Bussey, H. E., BOYNE, H. S., 18563.

Ellingwood, B., Leyendecker, E. V., 18415.

Ellingwood, B., Shaver, J., TN985.

EMMONS, H., SP540, p. 716 (Nov. 1979).

Enagonio, D. P., Christensen, R. G., Schaffer, R., Reeder, D. J., SP5I9, pp. 447-453 (A pr. 1979).

ENGEN, G. F., 18650 .

ENGEN, G. F., 18651 .

ENGEN, G. F., $/ 8652$.

ENGeN, G. F., HOER, C. A., 18849 .

Engen, G. F., Hoer, C. A., Speciale, R. A., 18653.

English, T. C., Glaze, D. J., Barger, R. L. Bergquist, J. C., 18642.

Epifanov, A. S., Manenkov, A. A., Gorshkov, B. G., SP541, pp. 299-302 (Dec. 1978).

Epstein, G. L., ReAder, J., 18782.

Epstein, M. S., ZANDER, A. T., 18783.

Ercegovich, C. D., Vallejo, R. P., SP519, pp. 333-340 (Apr. 1979).

Erickson, N., Siedle, A. R., Velapoldi, R. A., 18504.

ERICKSON, N. E., 18417.

Erickson, N. E., Madey, T. E., Powell, C. J., 18924.

Escalante, E., Ito, S., SP550.

Escalante, E., IVerson, W. P., 18418.

Escalante, E., Iverson, W. P., 18424.

Eskelson, C. D., Chang, S. Y., Chvapil, T., Chvapil, M., SP519, pp. 469-476 (Apr. 1979).

Estin, A. J., Morgan, W. L., Woodruff, J. J., Dougherty, H. T., 18628 .

ETTRE, L. S., SP519, pp. 547-585 (Apr. 1979).

ETZ, E. S., 18963.

ETZ, E. S., Aвraham, J. L., 18958.

ETZ, E. S., BLAHA, J. J., 18966.

ETZ, E. S., BLAHA, J. J., 18971 .

Etz, E. S., Casciani, F. S., 18982.

Etz, E. S., Cunningham, W. C., Blaha, J. J., 18643.

Etz, E. S., Newbury, D. E., Doty, S. B., Casciani, F. S., 19008.

Etz, E. S., WiSe, S. A., Heinrich, K. F. J., SP519, pp. 723729 (Apr. 1979).

Evans, A. G., SP562, pp. 1-13 (Oct. 1979).

Evans, A. G., Kino, G. S., Khuri-Yakub, B. T., SP562, pp. 379-392 (Oct. 1979).

Evans, A. G., Rice, R. W., SP562, pp. $185-188$ (Oct. 1979).

EVANS, D. D., Rogers, G. J., TN1109.

Evans, E. H., Paretzkin, B., de Groot, J. H., Hubbard, C. R., Carmel, S. J., Morris, M. C., McMurdie, H. F., Monogr. 25, Section 16.

Evans, J. P., Guildner, L. A., Kostkowski, H. J., 18665.

Evans, R. J., J. Res. 84, No. 2, 179-180 (1979).

Evans, W. H., MaYo, S., NBSIR 78-1558.

Evenson, K. M., Hanes, G. R., Jennings, D. A., Petersen, F. R., BAIRD, K. M., 18916 .

Evenson, K. M., Henningsen, J. O., Petersen, J. C., PeterSEn, F. R., Jennings, D. A., 18939.

Evenson, K. M., Jennings, D. A., Petersen, F. R., 18562.
Evenson, K. M., Jennings, D. A., Scalabrin, A., Stein, S. R., Inguscio, M., Strumia, F., 18426.

Evenson, K. M., SAYkally, R. J., $/ 8917$.

EVENSON, K. M., SAYKallY, R. J., $189 / 9$.

Evenson, K. M., Scalabrin, A., 1896 I.

Evenson, K. M., Wineland, D. J., Hellwig, H., 18346.

\section{F}

Fabry, A.. Grundl, J. A., McElroy, W. N., Lippincott, E. P., FARRAR,H., 19013.

Fabry, A., McElroy, W. N., Grundl, J. A., Debrue, J., RahN, F. J., SERPAN, C. Z., 19014.

Fadlalla, A., SP543, pp. 65-72 (Apr. 1979).

Faith, W. N., Porteus, J. O., Donovan, T. M., Jernigan, J. L., SP541, pp. 202-211 (Dec. 1978).

Faizullov, F. S., Kovalev, V. I., SP54I, pp. 318-326 (Dec. 1978).

Faller, J. E., Levine, J., Moody, S., Pearlman, M. R., Silverberg, E. C., Bender, P. L., 18459.

Faller, J. E., Rinker, R. L., Zumberge, M. A., $/ 8472$.

FAlleR, J. E., Rinker, R. L., Zumberge, M. A., 18654.

Faller, J. E., Rinker, R. L., Zumberge, M. A., 18947.

FANCONI, B., BARNeS, J., 18404 .

Fansler, T. D., Croslex, D. R., Anderson, W. R., Allen, J. E., JR., SP561/2, pp. $1153-1167$ (Sept. 1979).

Farabaugh, E. N., Armstrong, R. W., Wu, C. C., 18341.

Farabaugh, E. N., Olson, C. D., CoOK, L. P., SP562, pp. 407415 (Oct. 1979).

FARMER, B. L., EBY, R. K., 18787.

Farrar. H., FAbry, A., GRUNdL, 8. A.. McElRoY, W. N., LipPINCOTt, E. P.. 19013.

Fechter, J. V., Porter, L. G., NBSIR 78-1556.

FeChtER, J. V., RAMEY-SMITH, A. M., NBSIR 79-I727.

FEChTER, J. V., JR., 18862.

Fehsenfeld, F. C., How ard, C. J., Streit, G. E., Wells, J. S., $1855 \mathrm{~J}$

Feinberg, R. B., 18788 .

Feinberg, R. B., 18789 .

Feldman, A., Horowitz, D., Waxler, R. M., SP541, pp. 5054 (Dec. 1978).

Feldman, A., Horowitz, D., Waxler, R. M., Dodge, M. J., TN993.

Felice, L. I., Bruntlett, C. S., Shoup, R. E., Kissinger, P. T., SP519, pp. 391-397 (Apr. 1979).

Fennelly, P., SPawn, P., SP556, pp. $49-55$ (Sept. 1979).

Fenves, S. I., WRIGHT, R. N., HARRIS, I. R., TN1100.

Ferguson, A. R., BoOTh, J., COOK, Z., NBS-GCR-ETIP 78-53.

Fernandez de la Mora, J., Fryburg, G., Kohl, F., Stearns, C., Santoro, G., Rosner, D. E., Seshadri, K., SP561/2, pp. 1451-1474 (Sept. 1979).

Fernelius, N. C., Johnston, G. T., SP541, pp. 7-12 (Dec. 1978).

Fernelius, N. C., Walsh, D. A., SP541, pp. $43-49$ (Dec. 1978).

Ferris, J. S., Brown, W. E., Schroeder, L. W., 18583.

Ferron, J. R., KerR, D. L., Chatwani, A. U., SP561/2, pp. 1373-1402 (Sept. 1979).

FEucht, D. L., SP400-58, p. 12 (Aug. 1979).

Feugier, A., SP561/2, pp. $1315-1325$ (Sept. 1979).

FICKETT, F. R., 18655.

FICKeTT, F. R., 18656.

Fickett, F. R., Ho, J. C., King, G. B., 18419 .

FICKETT, F. R., REED, R. P., NBSIR 79-1609.

Fickett, F. R., Rosenbaum, J., Larson, E., Hoblitt, R., 18804.

FIELD, B. F., 18455.

Field, J. E., Hagan, J. T., Swain, M. V., SP562, pp. 15-20 (Oct. 1979).

Fife, D., Deutsch, D., Sockut, G., JefFery, S., 18777.

Filliben, J. J., 18519.

Filliben, J. J., Simiu, E., Changery, M. J., BSS 118 . 
Filly, R. A., Busey, H., Edmonds, P. D., Reyes, Z., ParkinSON, D. B., SP525, pp. 323-326 (Apr. 1979).

Fingy, N., Dain, F., KUC, R., Schwartz, M., SP525, pp. 125 132 (Apr. 1979).

Fine, D. S., Herrman, R. K., Kowalski, M. F., SP563, p. 133 (Oct. 1979).

Finnegan, T. F., Peters, P. N., Holdeman, L. B., Soulen, R. $J_{\text {., JR , } 18540 .}$

Fiori, C. E., Heinrich, K. F. J., MYKLebust, R. L., TNIIO6.

FIori, C. E., NEwBury, D. E., 18790.

Firestone, R. F., SP562, pp. 261-281 (Oct. 1979).

Fish, G. E., Rhyne, J. J., Sankar, S. G., Wallace, W. E., 18657.

Fish, G. E., Sankar, S. G., Wallace, W. E., Rhyne, J. J., 18682 .

Fish, G. E., Sankar, S. G., Wallace, W. E., Rhyne, J. J., $1888 i$.

Fishbane, P. M., Horn, D., Meshkov, S., 18432.

Fisher, C. P., Handley, G. P., Chang, F. H., Bell, J. R., GARDNER, A. H., SP563, p. 59 (Oct. 1979).

Fisher, G. B., MAdey, T. E., YATES, J. T., JR., $1879 /$.

Fisher, G. L., RaAbe, O. G., Olechno, J., Sucre, L., Jennings, W., SP519, pp. 109-120 (Apr. 1979).

Fishiorn, G., Sullivan, T. E., Fonash, S. J., SP400-58, pp. 63-68 (Aug. 1979).

Fitzpatrick, T. E., Hanson, R. E., Hohn, F. W., SP547, pp. 98-110 (July 1979).

FLACH, D. R., Souders, T. M., TNII05.

Flannery, M., Sparks, M., SP541, pp. $278-287$ (Dec. 1978).

Flannery, M. R., McCann, K. J., 18389.

Flannery, M. R., MCCann, K. J., 18446.

Flannery, M. R., MCCann, K. J., 18473.

Fleming, P. M., Rucks, A. C., SP500-52, pp. 193-199 (Oct. 1979).

Fleming, R., Spiegel, V., 18792.

Fleming, R. F., Bickford, N. A., 18704.

FLEMING, R. F., LINDSTROM, R. M., 18338.

Fletcher, L. S., Somers, R. R. II., Scott, T. C., SP552, pp. 197-209 (July 1979).

Fletcher, P., Orend, R. J., Pavel, H. J., Williams, G. H., Fowell, A. J., Bransdorfer, A., SP553, pp. 21-31 (Aug. 1979).

Florin, R. E., 18726 .

Florin, R. E., Cascaval, C. N., 18580.

Flotow, H. E., Rowe, J. M., DeGraAf, L. A., Rush, J. J., LiVingston, R. C., 18730.

FLYNN, D. R., 18785 .

FLyn,, J. H., Dickens, B., 18620.

Flynn, J. H., JOSEPH, J. T., HYBL, A., 18380.

Fulio, J., Stanley, H. R., Bowen, R. L., 18690.

FOLKINS, P., SP549, pp. 33-38 (Aug. 1979).

Follansbee, P. S., Dils, R. R., SP56/12, pp. 1027-1070 (Sept. 1979).

Fonash, S. J., Fishkorn, G., Sullivan, T. E., SP400-58, pp. 63-68 (Aug. 1979).

Fong, 1. K., Toth, E. E., Graminski, E. L., Fong, J. T., NBSIR 79-1746

FONG, I. T., 18326

Fong, J. T., Fong, I. K., Toth, E. E., Graminskı, E. L., NBSIR $79-1746$

Fontun, A., SP561/2, pp. $1359-1370$ (Sept. 1979).

Forester, D. W., Koon, N. C., Schelleng, J. H., Rhyne, J. J., 18897 .

Forman, R. A., Block, S., Piermarini, G. J., 18509.

Forsman, J. A., Grimley, R. T., SP56I/l, Pp. $211-229$ (Sept. 1979).

Foskett, W. A., Klaus, D. M., Haberle, J., NBS-GCR-ETIP 79-62.

Fowell, A. J., 18793.
Fowell, A. J., Bransdorfer, A., Fletcher, P., Orend, R. J., Pavel, H. J., Williams, G. H., SP553, pp. 21-31 (Aug. 1979).

Fowler, J. B., Lind, M. A., ZALEwSki, E. F., TN987.

Fradkin, D. M., J. Res. 84, No. 4, 319-326 (1979).

Francis, R. L., Saunders, P. B., NBSIR 79-1738.

Frank, S. L., Andren, M. L., Anderson, R. L., SP400-58, pp. 57.62 (Aug. 1979).

Frankenthal, R. P., SP400-58, pp. 144-145 (Aug. 1979).

FrankLin, A. D., Young, K. F., 18794.

Franklin, E. A., Hunt, B. J., Richtmyer, T. E., Hill, J. E., 18425.

Franzen, D. L., Danielson, B. L., Day, G. W., 18647.

Franzen, D. L., Danielson, B. L., Day, G. W., 18662.

Franzen, D. L., DAY, G. W., 18848 .

Franzen, D. L., McNeil, J. R., Johnson, W. L., Collins, G. J., Persson, K. B., $183 / 9$.

FraRey, J. L., SP547, pp. 286-295 (July 1979).

Fraser, J., Kino, G. S., Birnholz, J., SP525, pp. 287-295 (Apr. 1979).

Frederick, N. V., Haynes, W. M., 18962.

Frederick, W., NAY, J. N., NBS-GCR-ETIP 79-65.

FrEED, D. J., SP5 19, pp. 95-99 (Apr. 1979).

Freese, M., Lyons, E. A., SP525, pp. 157-163 (Apr. 1979).

FREESTONE, F., SP556, pp. $71-86$ (Sept. 1979).

Frenkiel, F. N., Klebanoff, P. S., Húang, T. T., 18821 .

Friedman, A. J., Macleod, W. D., JR., Brown, D. W., Ramos, L. S., SP519, pp. 161-167 (Apr. 1979).

Fries, J. A., Cater, E. D., Mueller, B. H., SP561/1, pp. 237 262 (Sept. 1979).

Frischiorn, C. G. B., Buker, I., Scheulen, B., Telin, B., DURBECK, H. W., SPS/9, pp. 437-445 (Apr. 1979).

Fristrom, R. M., Hunter, L. W., Hoshall, C. H., GrunFELDER, C., SP561/2, pp. $1071-1078$ (Sept. 1979).

Frizzell, L. A., O’Brien, W. D., Jr., Dunn, F., Johnston, R. L., Goss, S. A., Maynard, V., Brady, J. K., SP525, pp. 19 27 (Apr. 1979).

Frizzele, L. A., O'Brien, W. D., Jr., Dunn, F., Goss, S. A., Johnston, R. L., MAYNARD, V., NidER, L., SP525, pp. 4351 (Apr. 1979).

Froben, F. W., SP561/l, pp. 523-527 (Sept. 1979).

Frohnsdorf, G., Brown, P. W., Clifton, J. R., SP542.

Frohnsdorf, G., Clifton, J. R., Brown, P. W., 18854.

FroMM, G., SP534, pp. 1 5-21 (May 1979).

Frurip, D. J., Blander, M., SP561/2, pp. 1597-1609 (Sept. 1979).

FRY, D. N., KING, W. T., SмITH, C. M., SP547, pp. $232-249$ (July 1979).

Fry, E. K., Sanghvi, N. T., Fry, F. J., Gallager, H. S., SP525, Pp. 85-91 (Apr. 1979).

FRY, F. J., SP525, pp. 203-208 (Apr. 1979).

Fry, F. J., Gallager, H. S., Fry, E. K., Sanghvi, N. T., SP525, Pp. 85-91 (Apr. 1979).

Fryburg, G., Kohl, F.; Stearns, C., Santoro, G., Rosner, D. E., Seshadri, K., Fernandez de la Mora, J., SP561/2, pp. $1451 \cdot 1474$ (Sept. 1979).

Fryburg, G. C., Miller, R. A., Stearns, C. A., Kohl, F. J., SP561/l, PP. 303-354 (Sept. 1979).

Fujiwara, K., Omenetto, N., Haraguchi, H., Winefordner, J. D., Bradshaw, J., Bower, J., WeEks, S., SP56l/2, pp. 1079-1102 (Sept. 1979).

FULCOMER, P. M., NBSIR 79-17/6.

FulCOMER, P. M., NBSIR 79-19I2.

Fulcomer, P. M., NBSIR 79-1913.

Fuller, E. R., Jr., Krause, R. F., JR., 19018.

Fusfeld, H. I., SP543, pp. 24-28 (Apr. 1979). 
$\mathrm{G}$

Gabriel, M., Hanrahan, J., McCarthy, E., Smith, J., Brozowsk,, G., BurkitT, D., SP519, pp. 175-179 (Apr. 1979).

Gaca, A., Loch, E., Scheiding, W., Wessels, G., von Seelen, W., SP525, pp. 297-302 (Apr. 1979).

Gadzuk, J. W., Herbst, J. F., WaClawski, B. J., 18323 .

Gagnon, J. L., RAMEY-Smith, A., NBSIR 79-1771.

Gaines, G. B., Thomas, R. E., SP400-58, pp. $150-159$ (Aug. 1979).

Galbraith, H. W., Harter, W. G., Patterson, C. W., 18599.

Galbraith, H. W., Krohn, B. J., Harter, W. G., Patterson, C. W., 18921 .

Galbraith, H. W., Patterson, C. W., Harter, W. G., 18598.

Galejs, A., Penner, S., 18932.

Gallager, H. S., Fry, E. K., Sanghvi, N. T., Fry, F. J., SP525, Pp. 85-91 (Apr. 1979).

Gallagher, A., 18474 .

Gallagher, A., 18877 .

Gallagher, A., Zajonc, A., 19028.

Gallagher, J. W., Rumble, J. R., JR., BeAty, E. C., SP426. Supplement 1 .

Gallagher, N., BSS75.

Gallorini, M., Gills, T. E., Greenberg, R. R., 18478.

Gallorini, M., Greenberg, R. R., Gills, T. E., 18343.

GaLlowaY, K. F., 18451 .

Galowin, L. S., Debelius, J. R., SP553.

Galowin, L. S., Downing, W. J., Nielsen, L. S., Orloski, M. J., WYLY, R. S., SP553, pp. 53-70 (Aug. 1979).

GAlowin, L. S., GROT, R. A., NBSIR 78-1496.

Gammage, R. B., Hawthorne, A. R., Thorngate, J. H., VoDiNH, T., SP519, pp. 679-684 (Apr. 1979).

Gammage, R. B., Vo-Dinh, T., Hawthorne, A. R., ThornGATE, J. H., SP519, pp. $719-722$ (Apr. 1979).

Gammell, P. M., Roseboro, J. A., Wilson, R. L., Le CroisSETTE, D. H., Heyser, R. C., SP525, pp. $101-108$ (Apr. 1979).

Gammon, R. W., Hocken, R. J., Moldover, M. R., Sengers, J. V., 18541 .

GANDHI, M. E. E., SP543, pp. 58-61 (Apr. 1979).

Garber, A. R., Wright, R. F., Todd, L. J., Siedle, A. R., BODNER, G. M., 18328 .

GARDINER, W. C., JR., SP561/2, pp. 835-846 (Sept. 1979).

Gardner, A. H., Fisher, C. P., Handley, G. P., Chang, F. H., BELL, J. R., SP563, p. 59 (Oct. 1979).

Garmire, G., Cordova, F., Ayres, T. R., Linsky, J. L., 18839.

Garrison, A. W., Pope, J. D., Alford, A. L., Doll, C. K., SP519, Pp. 65-78 (Apr. 1979).

Garvey, R. M., Hellwig, H. W., Jarvis, S., JR., Wineland, D. J., 18475.

GASS, S. I., SP500-39.

GASS, S. 1., SP534.

GASS, S. I., SP534, pp. 3-7 (May 1979).

GAUChAT, U. P., SP552, Pp. 337-346 (July 1979).

Gauchat, U. P., SChODEK, D. L., SP552, pp. 347-360 (July 1979).

Gausche, C. L., Schwinden, W. J., SP500-52, pp. 9-19 (Oct. 1979).

Gebrie, K. B., Simon, G. W., November, L. J., ToOmre, J., 18444.

GEIST, J., 18476.

GEIST, J., 18477

GeIST, J., 18796.

Geist, J., Lind, M. A., Schaefer, A. R., Zalewski, E. F., 18773.

Geist, J., Lind, M. A., Schaefer, A. R., Zalewsi, E. F., 18774.

Geist, J., Schaefer, A. R., 18900.

Geltman, S., Schubert, E., Schuck, A., Jung, K., 18534.

GeNOT, A., SP547, pp. 153-166 (July 1979).
Gentilman, R., Cooke, F., Miles, P., SP562, pp. 255-260 (Oct. 1979).

George, S. M., Ando, M. E., Richardson, J. H., SPS19, pp. 691-696 (Apr. 1979).

GerRy, M. C. L., Yamada, K., Winnewisser, G., JPCRD 8, No. 1, 107-124 (1979).

Gersh, M. E., Kolb, C. E., SPS61/I, pp. 679-693 (Sept. 1979).

Getz, M. E., Hanes, G. W., Hill, K. R., SP519, pp. 345-353 (Apr. 1979).

Gevantman, L. N., White, H. J., JR., Lide, D. R., JR., SP561/2, Pp. 1571-1579 (Sept. 1979).

Ghani, A., SP539, pp. 79-90 (Apr. 1979).

Giampapa, M. S., Linsky, J. L., SchNeEberger, T. J., Worden, S. P., 19007.

Gianessi, L. P., Harrington, W., Magat, W. A., NBS-GCRETIP 79-63.

Giering, J. E., Leaders, F. E., JR,, O'Brien, J. E., Hinsvark, O. N., Newman, W. R., AmSEl, L. P., SP519, pp. 481-485 (Apr. 1979).

Giffard, R. P., Michelson, P. F., Soule,N, R. J., JR., 18663.

Gill, D. H., NewnaM, B. E., SPS4I, pp. 190-202 (Dec. 1978).

Gilles, P. W., Sheldon, R. I., SP561/1, pp. 231-234 (Sept. 1979).

Gillet, V., Danos, M., 18769.

Gilliam, D. M., Bowman, C. D., Eisenhauer, C. M., 18462.

Gilliam, D. M., Grundl, J. A., Spiegel, V., Eisenhauer, C. M., 18901 .

Gilliam, D. M., Helmer, R. G., Greenwood, R. C., Rogers, J. W., Heinrich, R. R., POPek, R. J., Kellogd, L. S., LippinCOTt, E. P., HANSEN, G. E., ZIMMER, W. H., 18884.

Glllmor, W. R., Pickart, S. J., Rhyne, J. J., Alperin, H. A., 18835.

Gills, T. E., Gallorini, M., Greenberg, R. R., 18343.

Gills, T. E., Greenberg, R. R., Gallorini, M., 18478 .

GILsinN, D., KRAFT, R., SP400-57.

GINGERICh, K. A., SP561/1, pp. 289-300 (Sept. 1979).

GiraUd, M., SMith, E. W., 18689.

Glackin, D. L., Linsky, J. L., Mango, S. A., Bohlin, J. D., 18922.

Glancy, J., NiCastro, J. R., Woolson, B., SP480-38, pp. 23 28 (Dec. 1979).

Glass, A. J., Guenther, A. H., SPS41.

Glass, R. A., Rubin, A. I., BSS115.

Glaze, D. J., Barger, R. L., Bergquist, J. C., English, T. C., 18642.

Glinka, C. J., Rowe, J. M., Libowitz, G. G., Maeland, A., 19030.

Glover, G. H., SP525, pp. 221-225 (Apr. 1979).

Godette, M., Crenshaw, R., Clark, R., Chapman, R., Grot, R., NBSIR 79-1706.

Goglia, M. R., Stahl, F. 1., Conway, D., 18784.

GOLAN, S., NBSIR 79-1790.

Golan, S., SAChSE, W., 18391 .

Golas, D. B., Mann, W. B., Cavallo, L. M., 18761 .

Gold, R., Lippincott, E. P., Schiffgens, J. O., Simons, R. L., Morgan, W. C., GrundL, J. A., McGarry, E. D., Kam, F. B. K., Swank, J. H., Odette, G. R., McElroy, W. N., DORAN, D. G., 19012.

GOLDBERG, R. N., JPCRD 8, No. 4, $1005-1050$ (1979).

Goldberg, R. N., Nuttall, R. L., STA Ples, B. R., JPCRD 8 , No. 4, 923-1004 (1979).

Goldberg, R. N., SMITH-Magowan, D., SP537.

Goldberg, R. P., SOCKUT, G. H., SP500 47.

Golden, D. M., SP557, pp. 51-61 (Aug. 1979).

GOLDMAN, D. T., 18387.

Golias, J., NovaK, J., JaNAK, 'J., SPS 19, pp. $739-746$ (Apr. 1979).

GOOdMAN, A. M., NBS-GCR-78-155.

GOODMAN, G. H., SP5O0-52, pp. 69-77 (Oct. 1979).

Goodwin, K. E., Schleter, J. C., Maltese, M. D. K., 18735. 
GoodwIN, R. D., NBSIR 79-16/2.

GOODWIN, R. D., NBSIR 79-1621.

GoONETILLEKE, H. L. K., SP539, pp. 113-116 (Apr. 1979).

Gordon, K. D., Agrawala, A. K., Tripathi, S. K., SP500-52, pp. 105-111 (Oct. 1979).

Gore, J. C., Leeman, S., Metrewell, C., Plessner, N. J., WILlSON, K., SP525, pp. 275-280 (Apr. 1979).

Gorre, L. E., Chew, R. K., Pastor, R. C., Harrington, J. A., SP541, PP. 249-256 (Dec. 1978).

Gorshiov, B. G., Epifanov, A. S., Manenkov, A. A., SP54I, pp. 299-302 (Dec. 1978).

Goss, S. A., Johnston, R. L., Maynard, V., Nider, L., FrizZELl, L. A., O'Brien, W. D., JR., DUNN, F., SP525, pp. 43. 51 (Apr. 1979).

Goss, S. A., Maynard, V., Brady, J. K., Frizzell, L. A., O'Brien, W. D., JR., Dunn, F., Johnston, R. L., SP525, pp. 19-27 (Apr. 1979).

Grabner, L. H., Hastie, J. W., Drake, M. C.; SP561/2, pp. 1105-1134 (Sept. 1979).

Gramiak, R., Schenk, E. A., WaAg, R. C., Lee, P. P. K., Lerner, R. M., Hunter, L. P., SP525, pp. 143-152 (Apr. 1979).

GraminsKi, E. L., BONIN, K., NBSIR 79-1914.

Graminski, E. L., Fong, J. T., Fong, I. K., Toth, E. E., NBSIR 79-1746.

Gramlich, J. W., Velapoldi, R. A., Paule, R. C., Schaffer, R., Mandel, J., Machlan, L. A., SP260-63.

Gramlich, J. W., Velapoldi, R. A., Paule, R. C., Schaffer, R., MANDEl, J., MURPHY, T. J., SP260-67.

Grandjean, D. J., Bennett, J. M., Decker, D. L., SP562, pp. 293-303 (Oct. 1979).

Grandjean, D. J., Decker, D. L., SP541, pp. $122-130$ (Dec. 1978).

Gransden, S. E., Kauffman, J. W., Margrave, J. L., Hauge, R. H., SP561/I, Pp. 557.566 (Sept. 1979).

Grant, W. H., Dehl, R. E., NBSIR 79-1784.

Gray, A. G., langer, E. L., Baker, H., Carter, G. C., Bennett, L. H., Kahan, D. J., Cuthill, J. R., Chafe, H. D., 18645.

Gray, A. G., Langer, E. L., Baker, H., Cuthill, J. R., Kahan, D. J., Bennett, L. H., Chafe, H. D., 18739.

Gray, J. E., Besson, R. J., Stein, S. R., Manney, C. M., JR., WALLS, F. L., 18691 .

GRAY, M. M., SP500-46.

GREEN, C. W., SP400-58, pp. $110-125$ (Aug. 1979).

Green, D. S., Logsdon, J. D., Milbergs, E., McEachron, N. B., JAVITZ, H. S., NBS-GCR-ETIP 78-57.

Green, D. S., Logsdon, J. D., Milbergs, E., McEachron, N. B., JAVITZ, H. S., NBS-GCR-ETIP 78-58.

Green, D. S., Logsdon, J. D., Milbergs, E., McEachron, N. B., JAVITZ, H. S., NBS-GCR-ETIP 78-58A.

Green, R. B., Keller, R. A., Luther, G. G., Schenck, P. C., Travis, J. C., U.S. Patent 4,148,586.

GreenberG, H., SP534, pp. 111-122 (May 1979).

Greenberg, H. J., Kalan, J. E., J. Res. 84, No. 1, 21-47 (1979).

GREENBERG, J., NBS-GCR-78-14I-I.

GREenBERG, J., NBS-GCR-78-141-2.

GreENBERG, R. R., 18866 .

Greenberg, R. R., Gallorini, M., Gills, T. E., 18478 .

Greenberg, R. R., Gills, T. E., Gallorini, M., 18343.

Greene, F. T., Beachey, J. E., Milne, T. A., SP561/1, pp. 431 442 (Sept. 1979).

Greenhalgh, D. A., Beattie, I., SP561/1, pp. 597-606 (Sept. 1979).

Greenleaf, J. F., Rajagopalan, B., Bahn, R. C., Baxter, B., Christensen, D., Johnson, S. A., SP525, pp. 235.246 (Apt. 1979).

Greenleaf, J. F., Thomas, P. J., Johnson, S. A., Bahn, R. C., Rajagopalan, B., SP525, pp. 227-233 (Apr. 1979).
Greenspan, M., 18479.

GreensPan, M., TSChIEgG, C. E., NBSIR 79.1753.

Greenwood, R. C., Rogers, J. W., Heinrich, R. R., Popek, R. J., Kellogg, L. S., Lippincott, E. P., hansen, G. E., Zimmer, W. H., Gilliam, D. M., Helmer, R. G., 18884.

GREer, S. C., 18825.

Gregory, D., Dunn, G. H., Phaneuf, R. A., Crandall, D. H., 18707.

Greiner, G., Menzel, D., Klein, R., 18810 .

Grimley, R. T., Forsman, J. A., SP561/1, pp. $211-229$ (Sept. 1979).

Grimsrud, E. P., Miller, D. A., SP5 19, pp. 143-151 (Apr. 1979).

Gritton, S. M., Marchant, A. B., SP547, pp. 17-30 (July 1979).

Grohmann, K., ZaPf, T. L., 18664.

Gross, J. G., Pielert, J. H., CoOke, P. W., TN998.

Grossman, D. G., Taylor, D. L., SPS62, pp. $221-229$ (Oct. 1979).

Grot, R., Godette, M., Crenshaw, R., Clark, R., Chapman, R., NBSIR 79.1706.

Grot, R. A., NBSIR 79-1728.

Grot, R. A., 18829 .

Grot, R. A., Chang, Y. M. L., NBSIR 79-1781.

Grot, R. A., Galowin, L. S., NBSIR 78-1496.

Grot, R. A., HARRJe, D. T., 18733.

Grot, R. A., Siu, C. I., SPS48, pp. 39.56 (July 1979).

Groves, J. R., JR., SP552, pp. $121-130$ (July 1979).

Gruen, D. M., OYe, H. A., SP561/2, pp. $1517-1537$ (Sept. 1979).

Grundl, J., Deleeuw-Gierts, G., 19024.

Grundl, J. A., Debrue, J., Rahn, F. J., Serpan, C. Z., Fabry, A., McElroy, W. N., 19014 .

Grundl, J. A., Martin, G. C., Jr., Spiegel, V., Eisenhauer, C. M., 18883 .

Grundl, J. A., McElroy, W. N., Lippincott, E. P., Fabry, A., 19013.

Grundl, J. A., McGarky, E. D., Kam, F. B. K., SWank, J. H., Odette, G. R., McElroy, W. N., Doran, D. G., Gold, R., Lippincott, E. P., Schiffgens, J. O., Simons, R. L., MorGAN, W. C., 19012 .

Grundl, J. A., Spiegel, V., Eisenhauer, C. M., Gilliam, D. M., 18901 .

Grunfelder, C., Fristrom, R. M., Hunter, L. W., hoshall, C. H., SPS61/2, pp. 1071-1078 (Sept. 1979).

Gruver, R. M., Richard, D. M., Kirchner, H. P., SP562, pp. $23-42$ (Oct. 1979).

Gubernatis, J. E., Krumhansl, J. A., Thomson, R. M., 18831 . GUdAITIS, J., SP543, pp. 216-217 (Apr. 1979).

GuensLeR, D., SP532, pp. 55-58 (Feb. 1979).

Guenther, A. H., Glass, A. J., SP54I.

Guenther, A. H., Nielsen, P. E., Walker, T. W., SP541, pp. 226-234 (Dec. 1978).

Guenther, F., Hilpert, L. R., Hertz, H. S., Wise, S. A., May, W. E., Briown, J. M., Chesler, S. N., SP519, pp. $219-224$ (Apr. 1979).

Guildner, L. A., Kostkowski, H. J., Evans, J. P., 18665.

Gulbransen, E. A., Meier, G. H., SPS6I/2, pp. 1639-1682 (Sept. 1979).

Guss, L., Orend, R., Wyly, R. S., Konen, T. P., Benazzi, R. V., SP553, pp. 3-13 (Aug. 1979).

Gutman, D., Braun, W., Tsang, W., 18832.

GuTMANIS, I., NBS-GCR-ETIP 79-67.

\section{H}

HaAn, S. W., Mountain, R. D., J. Res. 84, No. 6, 439-446 (1979).

haber, S., Tryon, P. V., Jackson, R. H. F., Collier, R. S., NBSIR 79-175I. 
Haberle, J., Foskett, W. A., Klaus, D. M., NBS-GCR-ETIP 79-62.

Haenssler, F., Muller, J., Waterstrat, R. M., 18734 .

Hagan, J. T., Swain, M. V., Field, J. E., SP562, pp. 15-20 (Oct. 1979).

HAGAN, L., 18828 .

Hagan, L., 18855 .

Hagan, L., KaUfman, V., 18485.

HAGN, G. H., SP551, pp. $32-37$ (July 1979)

HAHN, W. F., SPS52, pp. 185-196 (July 1979).

Haik, M., KNights, R. L., ApPel, B. R., Hoffer, E. M., Kothny, E. L., Wall, S. M., SP519, pp. $121-129$ (Apr. 1979).

Haines, R. A., Candela, G. A., 18746 .

Haisch, B. M., Boggess, A., Pasachoff, J. M., Linsky, J. L., 18606.

HAISCH, B. M., LINSKY, J. L., 18528 .

Hall, D. C., Lewis, L. F., McEAChron, N. B., NBS-GCR-ETIP 78-5I.

Hall, D. C., Lewis, L. F., McEachron, N. B., NBS-GCR-ETIP 78-52.

HAll, J. L., Brillet, A., 18875.

HAll, J. L., BRILlet, A., 18952.

Hall, J. L., Lee, S. A., U.S. Patent 4,165,183.

Hall, J. L., Lee, S. A., HelmCKe, J., 19019.

Hall, R. J., Eckbreth, A. C., SP561/2, pp. $943-972$ (Sept. 1979).

Hall, W. G., Chapman, R. E., Chen, P. T., NBSIR 79-1902.

Haller, W., Jednacak-Biscan, J., Mikac-Dadic, V., Pravdic, V., 18910 .

Haller, W. K., Sanders, D. M., SP561/1, pp. $111-123$ (Sept. 1979).

Halliwell, M., Mountford, R. A., Skidmore, R., Webb, A. J., WoOdCock, J. P., Wells, P. N. T., SP525, pp. 173-176 (Apr. 1979).

HALPERN, B., SPS19, pp. 373-379 (Apr. 1979).

HalPIN, B. M., BeRL, W. G., NBS-GCR-79-168

Halpin, S., Kruger, J., ClS9, Revised 1979.

HALTEH, R. B., SP543, pp. 108-1 10 (Apr. 1979).

HAM, W. E., SP400-56.

Hamilton, C. A., Harris, R. E., 18859.

Hamilton, C. A., Harris, R. E., Sullivan, D. B., 18666.

HaN, A., Elkind, M. M., SP554, pp. 63-73 (Sept. 1979).

HAN, C. C., 18480 .

HAN, C. C., 18960 .

Han, C. C., Akcasu, A. Z., 18545.

Han, C. C., McCrackin, F. L., 18511 .

han, C. C., Mozer, B., Yu, H., Hinkley, J. A., 18827.

Han, C. C., Serdyuk, I. N., Yu, H., J. Res. 84, No. 1, 1-8 (1979).

Handa, T., Suda, K., Nagashima, T., Kaneko, K., Yamamura, T., Takahashi, Y., Suzuki, H., Saito, F., SP54O, pp. 626-711 (Nov. 1979).

Handley, G. P., Chang, F. H., Bell, J. R., Gardner, A. H., FISHER, C. P., SP563, p. 59 (Oct. 1979).

Hanes, G. R., Jennings, D. A., Petersen, F. R., Baird, K. M., Evenson, K. M., 18916 .

Hanes, G. W., Hill, K. R., Getz, M. E., SP5 19, pp. 345-353 (Apr. 1979).

Hanley, H. J. M., Ackerson, B. J., 18752.

Hanley, H. J. M., Holland, P. M., JPCRD 8, No. 2, 559-576 (1979).

HANNA, S. B., LAIRD, E. C., SP5 19, pp. $797-802$ (Apr. 1979).

Hanrahan, J., McCarthy, E., Smith, J., Brozowski, G., BurKITT, D., GABRIEL, M., SP519, pp. 175-179 (Apr. 1979).

HANSEN, E. H., RuZICKA, J., SP519, pp. $501-507$ (Apr. 1979).

Hansen, G. E., Zimmer, W. H., Gilliam, D. M., Helmer, R. G., Greenwood, R. C., Rogers, J. W., Heinrich, R. R., Popek, R. J., Kellogg, L. S., Lippincott, E. P., 18884.
Hanslin, R., Webster, C. D. J., Nielsen, V., SP553, pp. 109 128 (Aug. 1979).

Hanson, D. W., Davis, D. D., Cateora, J. V., 18393.

Hanson, D. W., Davis, D. D., Cateora, J. V., 19029.

Hanson, D. W., Kelpczynski, W. J., Costain, C. C., DaAms, H., Boulanger, J. S., 18861 .

Hanson, R. E., Hohn, F. W., Fitzpatrick, T. E., SP547, pp. 98-110 (July 1979).

HANSS, M., BoYNARD, M., SP525, pp. 165-169 (Apr. 1979).

Harada, S., Izumitani, T., MiYade, E., Adachi, S., SP562, pp. 417.425 (Oct. 1979).

Haraguchi, H., Winefordner, J. D., Bradshaw, J., Bower, J., Weeks, S., FujiWara, K., OMenetto, N., SPS61/2, pp. 1079-1102 (Sept. 1979).

Harden, J. M., Hardison, D. L., McGaughey, J. F., Sykes, A. L., DenYSZYN, R. B., SPS19, pp. 153-159 (Apr. 1979).

Hardesty, D. R., Pohl, J. H., SP561/2, pp. 1407-1449 (Sept. 1979).

Hardison, D. L., McGaughey, J. F., Sykes, A. L., Denyszyn, R. B., Harden, J. M., SP519, pp. 153-159 (Apr. 1979).

HARDY, S. C., 18481 .

HaRDY, S. C., Hsu, N. N., 18878 .

Hargis, P. J., Jr., Miller, G. H., Mulac, A. J., SP561/2, pp. 1135-1151 (Sept. 1979).

Harman, G. G., SP400-59.

HARMAN, S., SP5 27, pp. 73-77 (Feb. 1979).

Harmony, M. D., Laurie, V. W., Kuczkowski, R. L., SchWendeman, R. H., Ramsay, D. A., Lovas, F. J., Lafferty, W. J., MAKI, A. G., JPCRD 8, No. 3, 619-722 (1979).

harrington, J. A., Gorre, L. E., Chew, R. K., Pastor, R. C., SP541, pp. 249-256 (Dec. 1978).

HARRINGTON, R. S., SP536, pp. 55-61 (Feb. 1979).

Harrington, W., Magat, W. A., Gianessi, L. P., NBS-GCRETIP 79-63.

Harris, C. S., Moncrief, W. C., Barbour, R. E., JR., HolCOMBE, J. O., SP500-52, pp. 25-36 (Oct. 1979)

HARRIS, D. H., SP480-38, pp. 17-22 (Dec. 1979).

Harris, H., Olszewsi, E. W., Wallerstein, G., 18913 .

Harris, J., Staffa, J. A., Zervos, C., Mighell, A. D., HubBARD, C. R., 18673 .

Harris, J. M., Lindstrom, R. M., Harrison, S. H., 18490.

Harris, J. R., Fenves, S. J., Wright, R. N., TNI100.

Harris, R. E., Hamilton, C. A., 18859.

Harris, R. E., Lloyd, F. L., Richards, P. L., Shen, T. M., 18683.

Harris, R. E., Sullivan, D. B., Hamilton, C. A., 18666.

harrison, J. E., Perwak, J. H., Oyha, H. D., Renda, T. V., NBS-GCR-ETIP 79-7I

HARRISON, S. H., BLANCHARD, D. B., 18325

Harrison, S. H., Harris, J. M., Lindstrom, R. M., 18490.

harrison, W. W., Smyth, K. C., Bentz, B. L., Bruhn, C. G., 18449 .

HARRJe, D. T., DUTt, G. S., SP548, pp. 25-38 (July 1979).

HARrJe, D. T., Grot, R. A., 18733.

Harter, W. G., Galbraith, H. W., Patterson, C. W., 18598.

Harter, W. G., Layer, H. P., Petersen, F. R., 18928.

Harter, W. G., Patterson, C. W., 18609.

Harter, W. G., Patterson, C. W., 18706.

harter, W. G., Patterson, C. W., Galbraith, H. W., 18599.

Harter, W. G., Patterson, C. W., Galbraith, H. W., Krohn, B. J., $I 8921$.

HARTMAN, A. W., 18318

Hartman, K. N., Lias, S., Ausloos, P., Rosenstock, H. M. Schroyer, S. S., Schmidt, C., Martinsen, D., Milne, G. W. A., NBSIR 79-1777.

HARTRUM, T. C., ThOMPSON, J. W., SP500-52, pp. 147-161 (Oct. 1979).

Harvey, A. B., McDona ld, J. R., Baronaviki, A. P., PasterNACK, L., LAMONT, S., SP561/2, pp. 817-831 (Sept. 1979).

HASEMI, Y., SP540, pp. 233-263 (Nov. 1979 ). 
HASHIM, M. Z., SP539, pp. $91-93$ (Apr. 1979).

HASKINS, J. F., SP563, pp. 47-56 (Oct. 1979).

Hassler, C. R., Messing, G. L., McCoy, L. G., SP562, pp. 247-254 (Oct. 1979).

HASTIE, J. W., SP56I, Vols. I and 2.

Hastie, J. W., Bonnele, D. W., SP56I/I, pp. 357-408 (Sept. 1979).

Hastie, J. W., Drake, M. C., Grabner, L. H., SPS61/2, pp. 1105-1134 (Sept. 1979).

Hastings, S. R., 18863.

Hastings, S. R., 18894 .

Hastings, S. R., Clark, R. E., NBSIR 78-1501.

Hatina, G., Maxwell, W. B., Thompson, J. N., SP519, pp. 279-288 (Apr. 1979).

Hauge, R. H., Gransden, S. E., Kauffman, J. W., Margrave, J. L., SP56I/I, pp. $557-566$ (Sept. 1979).

Hauge, R. H., Margrave, J. L., SP56//I, pp. $495-509$ (Sept. 1979).

Havlicek, S. C., Loy, P. R., Lupton, J. D., SP5/9, pp. 777. 782 (Apr. 1979).

Hawthorne, A. R., Thorngate, J. H., Vo-Dinh, T., GAMMAGE, R. B., SPS19, pp. 679-684 (Apr. 1979).

Hawthorne, A. R., Thorngate, J. H., Gammage, R. B., VoDiNH, T., SP5 19, pp. 719-722 (Apr. 1979).

HAYES, W. D., JR., O'NeILl, J. G., NBSIR 79-1749.

HAYNES, F., SPS27, pp. 7-10 (Feb. 1979).

HAYNes, W. M., 18627.

Haynes, W. M., Frederick, N. V., $/ 8962$.

Haynes, W. M., MCCARTY, R. D., 18775.

HAYWARD, E., 18520 .

HAYWARD, E., 18521 .

Hayward, E., Dodge, W. R., Patrick, B. H., $/ 8522$.

Hayward, E., Moscati, G., Wolynec, E., Dodge, W. R., $185 / 8$.

Hayward, E., Wolynec, E., Dodge, W. R., 18535.

Heaton, H. T. Il., Jacobs, R., SP554.

Hebner, R. E., Hillhouse, D. L., Kotter, F. R., $/ 8872$.

Hebner, R. E., JR., Annestrand, S., 18727.

Hebner, R. E., JR., Hillhouse, D. L., Bullock, R. A., NBSIR 79-1933.

Hebner, R. E., Jr., Kelley, E. F., $/ 8843$.

Hebner, R. E., JR., Misakian, M., 18819 .

Heffernan, A. P., Wollin, H. F., Barbrow, L. E., SP532.

Heimann, K., Irwin, W., SP556, pp. 95-100 (Sept. 1979).

HeINRICh, K. F. J., ETZ, E. S., WiSE, S. A., SP519, pp. 723. 729 (Apr. 1979).

Heinrich, K. F. J., Mrklebust, R. L., Fiori, C. E., TNIJ06.

Heinrich, K. F. J., Ruegg, F. C., Marinenko, R. B., SP26065.

Heinrich, K. F. J., Ruegg, F. C., Marinenko, R. B., 18973.

Heinrich, R. R., Popek, R. J., Kellogg, L. S., Lippincott, E. P., Hansen, G. E., Zimmer, W. H., Gilliam, D. M., Helmer,

R. G., GreenwoOd, R. C., Rogers, J. W., 18884 .

Hellwig, H., 18908.

Hellwig, H., 19005 .

Hellwig, H., Allan, D. W., 18899.

Hellwig, H., Evenson, K. M., Wineland, D. J., 18346 .

Hellwig, H., Stein, S. R., Walls, F. L., Kahan, A., 18826.

Hellwig, H. W., Jarvis, S., JR., Wineland, D. J., U.S. Patent $4,146,848$.

Hellwig, H. W., Jarvis, S., Jr., Wineland, D. J., Garvey, R. M., 18475 .

Hellwig, H. W., Wineland, D. J., Howe, D. A., Mohler, M. B., 18698.

Helmcke, J., Hall, J. L., Lee, S. A., 19019.

Helmer, R. G., Greenwood, R. C., Rogers, J. W., Heinrich, R. R., Popek, R. J., Kellogg, L. S., Lippincot, E. P., HaNSEN, G. E., ZimMer, W. H., Gilliam, D. M., $I 8884$.

Helzer, S. G., Buchbinder, B., Offensend, F. L., TNII0I.

Hemenway, D., NBS-GCR-79-I 72 .
Henderson, M. M., 18942.

HENDRY, D. G., SP557, pp. 85-91 (Aug. 1979).

Henins, A., Kessler, E. G., JR., Deslattes, R. D., 18487.

Henningsen, J. O., Petersen, J. C., Petersen, F. R., Jennings, D. A., Evenson, K. M., 18939.

Henry, R. C., Moos, H. W., Linsky, J. L., Anderson, R. C., 18753.

Herakovich, C. T., O'Brien, D. A., SP563, pp. 242-254 (Oct. 1979).

Herbst, J. F., Wacla wski, B. J., Gadzuk, J. W., $/ 8323$.

Heron, J., SPS36, pp. $75-81$ (Feb. 1979).

Herrman, R. K., Kowalski, M. F., Fine, D. S., SP563, p. 133 (Oct. 1979).

Herron, J. T., Hute, R. E., Hodgeson, J. A., SP557.

Merron, J. T., Tsang, W., Churney, K., Braun, W., 18709.

Herron, J. T., Tsang, W., Walker, J. A., Braun, W., /87/2.

Hertz, H. S., Chesler, S. N., SPS 19.

Hertz, H. S., Wise, S. A., May, W. E., Brown, J. M., Chesler, S. N., Guenther, F., Hilpert, L. R., SPS19, pp. 219-224 (Apr. 1979).

Herz, E., Edelman, P., Rivers, D., Bickman, L., NBS-GCR-79179.

Herz, E., McDaniel, M. A., Bickman, L., Edelman, P., NBSGCR-78-135.

Heskestad, G., Delichatsios, M. A., NBS-GCR-78-128.

Heskestad, G., Delichatsios, M. A., NBS-GCR-78-129.

HeSSE, C., SP519, pp. $461-468$ (Apr. 1979).

Hessel, M. M., KusCh, P., 18824 .

Hessel, M. M., Vidal, C. R., 18867.

HeydemanN, P. L. M., 18401 .

HEYMAN, M., SPS38.

Heyser, R. C., Gammell, P. M., Roseboro, J. A., Wilson, R. L., Le CroissetTe, D. H., SP525, pp. 101-108 (Apr. 1979).

Higgins, F. P., Dietz, D. R., Shideler, R. W., Shawker, T. H., Doppman, J. L., Linzer, M., Parks, S. I., Norton, S. J., SP525, pp. 255-259 (Apr. 1979).

Higson, G. R., SP554, pp. 29-32 (Sept. 1979).

Hildenarand, D. L., SP561/I, pp. $171-179$ (Sept. 1979).

Hile, J. E., Franklin, E. A., Hunt, B. J., Richtmyer, T. E., 18425.

Hile, J. E., Jenkins, J. P., 18770.

Hill, J. E., Jenkins, J. P., 18986.

Hill, J. E., Jenkins, J. P., Jones, D. E., BSS 117.

HILL, J. E., JONES, D. E., NBSIR 79-1737.

HILL, J. E., JONES, D. E., NBSIR 79-I799.

HILl, J. E., LIU, S. T., I8428.

Hill, K. R., GetZ, M. E., Hanes, G. W., SP519, pp. 345-353 (Apr. 1979).

Hillel, R., Bouix, J., Machaelides, A., SP56//2, pp. 899-911 (Sept. 1979).

Hilemouse, D. L., 18833 .

Hillhouse, D. L., Bullock, R. A., Hebner, R. E., JR., NBSIR 79-1933.

Hillhouse, D. L., Kotter, F. R., Hebne R, R. E., 18872.

Hillhouse, D. L., Petersons, O., Sze, W. C., 18938.

Hilpert, L. R., Hertz, H. S., Wise, S. A., May, W. E., Brown, J. M., Chesler, S. N., Guenther, F., SP5 19, pp. 219-224 (Apr. 1979).

Hilsenrath, J., Molino, B. B., 18597.

Hilten, J. S., Lederer, P. S., Mayo-Wells, J. F., Vezzetti, C. F., NBSIR 78-1590 (NASA).

Himes, V. L., Hubbard, C. R., Mighell, A. D., 18347.

Hinkley, J. A., HaN, C. C., Mozer, B., Yu, H., 18827.

Hinks, D. G., Susman, S., Rowe, J. M., Rush, J. J., 19036.

Hinsvark, O. N., Newman, W. R., Amsel, L. P., Giering, J. E., Leaders, F. E., JR., O'Brien, J. E., SP519, pp. 481-485 (Apr. 1979). 
Hirayama, C., Lin, C. Y., SP561/2, pp. $1539-1547$ (Sept. 1979).

HizA, M. J., MilleR, R. C., Kidnay, A. J., JPCRD 8, No. 3 , 799-816 (1979).

Ho, J. C., KING, G. B., Fickett, F. R., 18419.

Hoblitt, R., Fickett, F. R., Rosenbaum, J., Larson, E., 18804.

Hocken, R. J., Christ, B. W., Polvani, R. S., NBSIR 78-1569.

Hocken, R. J., Cummings, A. L., Coxon, B., Layer, H. P., 18768.

Hocken, R. J., Moldover, M. R., Sengers, J. V., Gammon, R. W., $1854 I$.

HOCKEY, B. J., RiCE, R. W., SP562.

Hodgeson, J. A., Herron, J. T., Her..e, R. E., SP557.

HOER, C. A., TNIOI2.

HOER, C. A., 18600 .

HOER, C. A., 18601 .

Hoer, C. A., ENGen, G. F., 18849.

Hoer, C. A., Lawton, R. A., Nahman, N. S., Allred, C. M., ANDREWS, J. R., NBSIR 79-1613.

Hoer, C. A., Speciale, R. A., Engen, G. F., 18653.

Hoffer, E. M., Kothin, E. L., Wall, S. M., Haik, M., KNIGHTS, R. L., APPEL, B. R., SP519, pp. $121-129$ (Apr. 1979).

Hoffman, J. D., J. Res. 84, No. 5, 359-384 (1979).

HofFMAN, J. D., 18715 .

HOfFman, J. D., 18830.

Hoffman, J. I., Saylor, C. P., Wichers, E., J. Res. 84, No. 5, 385-394 (1979).

Hoffman, M. K., Macias, E. S., Kumar, K. S., SP519, pp. 101 107 (Apr. 1979).

Hoffmann, D., Brunnemann, K. D., Schmeltz, I., Wynder, E. L., SP519, Pp. 131-141 (Apr. 1979).

Hoffmann, D., Schmeltz, I., Brunnemann, K. D., SP519, pp. 297-309 (Apr. 1979).

HoGAN, P. B., SMITH, S. J., 18955.

HOGAN, W., SP534, pp. 137-161 (May 1979).

HOGBEN, D., 18903.

Hogben, D., Peavy, S. T., 18954.

Hohn, F. W., Fitzpatrick, T. E., Hanson, R. E., SP547, pp. 98-110 (July 1979).

Holasek, E., Purnell, E. W., Jennings, W. D., SP525, pp. 261-266 (Apr. 1979).

Holcombe, J. O., Harris, C. S., Moncrief, W. C., Barbour, R. E., JR., SP5O0-52, pp. 25-36 (Oct. 1979).

Holdeman, L. B., 18846 .

Holdeman, L. B., Soulen, R. J., Jr., Finnegan, T. F., Peters, P. N., 18540 .

Holdeman, L. B., Soulen, R. J., JR., Sullivan, D. B., 18871 .

Holden, J. R., Bennett, L. H., Wang, F. E., Mitchell, M. A., SUtula, R. A., 18382 .

Holeman, G. R., Nath, R., Price, K. W., SP554, pp. 87-97 (Sept. 1979).

Holland, P. M., Hanley, H. J. M., JPCRD 8, No. 2, 559-576 (1979).

Holt, A. W., Koenig, A. L., NBSIR 79-1927.

Holt, A. W., Koenig, A. L., Warnar, R. B. J., Moore, R. T., CARPENTER, R. J., NBSIR 79-1725.

Holton, J. K., SP552, pp. 217-224 (July 1979).

Holton, J. K., 18363.

Hopkins, D. E., KRASNy, J. F., NBSIR 79-1596.

HORD, J., 18394.

HORD, J., 18776.

HORD, J., PARRISH, W. R., 18812.

HORIUCHI, S., JiN, T., SP540, Pp. 134-137 (Nov. 1979).

Horn, D., Meshkov, S., Fishbane, P. M., 18432.

Horning, E. C., Carroll, D. I., Dzidic, I., Stillwell, R. N., SP519, pp. 655-671 (Apr. 1979).

Hornyak, W. F., Seltzer, S. M., TrombKa, J. I., Wall, N. S., lapides, J. R., Crannell, C. J., Crannell, H., 19015.
Horowitz, D., Waxler, R. M., Dodge, M. J., Feldman, A., TN993.

Horowitz, D., Waxler, R. M., Feldman, A., SP54l, pp. 5054 (Dec. 1978).

HORTON, W. S., NBSIR 78-1509.

Horton, W. S., 18523.

HORWITZ, A. B., LEONE, S. R., 18388.

HORWITZ, A. B., LEONE, S. R., 18667.

Horwitz, A. B., LEONE, S. R., 18929.

HoRwitz, W., HowaRd, J. W., SP519, pp. 231.242 (Apr. 1979).

Hoshall, C. H., Grunfelder, C., Fristrom, R. M., Hunter, L. W., SP561/2, pp. 1071-1078 (Sept. 1979).

Hosier, R. N., Donavan, P. R., NBSIR 79-1599.

Hough, L., Coxon, B., 18764.

Howard, C. J., Streit, G. E., Wells, J. S., Fehsenfeld, F. C., 18551 .

HOWARD, C. P., 18836.

Howard, C. P., 18837.

Howard, J. W., Horwitz, W., SP519, pp. 231-242 (Apr. 1979).

HOWDEN, W. E., NBS-GCR-78-148.

Howe, D. A., Mohler, M. B., Hellwig, H. W., Wineland, D. J., 18698.

Howe, D. A., Walls, F. L., 18696.

Howe, S. L., Kamas, G., SP559.

Howell, B. F., McCune, S., Schaffer, R., 18433.

HOWETT, G. L., SP480-36.

Hsia, J. J., Venable, W. H., Jr., 18844.

HSIA, J. J., WEIDNER, V. R., 18594.

Hsu, C. C., Johnson, C. E., SP561/2, pp. -1683-1704 (Sept. 1979).

Hsu, N. N., Hardy, S. C., 18878.

Hsu, N. N., Sachse, W., 18907.

Huang, T. T., Frenkiel, F. N., Klebanoff, P. S., 18821

hubbard, C. R., Carmel, S. J., Morris, M. C., McMurdie, H. F., Evans, E. H., Paretzkin, B., de Groot, J. H., Monogr. 25 , Section 16.

Hubbard, C. R., Cohen, A., Mighell, A. D., 18672.

Hubbard, C. R., Harris, J., Staffa, J. A., Zervos, C., Mighell, A. D., 18673.

Hubbard, C. R., Jenkins, R., 18857.

Hubbard, C. R., Mighell, A. D., Himes, V. L., 18347.

Hubbard, C. R., Stalick, J. K., Siedle, A. R., Mighell, A. D., 18636.

Hubbard, W. D., ShePpard, A. J., SP5 19, pp. $267-269$ (Apr. 1979).

Hubbard, W. D., Sheppard, A. J., SP5 19, pp. 289-295 (Apr. 1979).

Hubbell, J. H., Berger, M. J., Seltzer, S. M., 18371 .

Hubbell, J. H., OVerbo, I., JPCRD 8, No. 1, 69-106 (1979).

Hudson, R. P., 18335.

Hudson, R. P., 18482.

Hudson, R. P., 18969.

Huerta, M., Malkin, S., SP562, pp. 93-106 (Oct. 1979).

HUGGETT, C., NBSIR 78-1526.

Huie, R. E., Hodgeson, J. A., Herron, J. T., SP557.

HuMphreY, W. D., SP563, pp. $177-197$ (Oct. 1979).

Humphreys, J. C., Chappell, S. E., NBSIR 79-1723.

Hung, A., Thenot, J. P., SP519, pp. $419-427$ (Apr. 1979).

Hunt, B. J., Richtmyer, T. E., Hill, J. E., Franklin, E. A., 18425.

Hunt, C. M., McNall, P. E., Kusuda, T., 18587.

Hunt, C. M., Treado, S. J., BurCh, D. M., TN992.

Hunt, D. F., Crow, F. W., SP51,9, pp. 601-607 (Apr. 1979).

Hunter, C., 18483.

Hunter, L. P., Gramiak, R., Schenk, E. A., WaAg, R. C., Lee, P. P. K., Lerner, R. M., SP525, Pp. 143-152 (Apr. 1979).

Hunter, L. W., Hoshall, C. H., Grunfelder, C., Fristrom, R. M., SP561/2, pp. 1071-1078 (Sept. 1979). 
HuRd, H. A., BeCKer, D. A., SPS56.

Hurley, C. W., Rorrer, D. E., Bulik, C., Rippey, W. G., NBSIR 79.1709.

Hust, J. G., 18668.

Hust, J. G., KiRBY, R. K., 18615.

Hutchings, B., SP556, Pp. 153-155 (Sept. 1979).

Hutchinson, J. M. R., 18981.

Hutchinson, J. M. R., Cavallo, L., Ehrlich, M., 18361.

Hutchinson, J. M. R., Lucas, L. L., ManN, W. B., Matsumu-

RA, T., NoYCE, J. R., CourseY, B. M., 18400.

Hutchinson, J. M. R., Schima, F. J., Coursey, B. M., 1884 I.

Hybl, A., Flynn, J. H., Joseph, J. T., 18380.

\section{I}

Ibers, J. A., Siedle, A. R., Brown, L. D., 18582.

IKEDA, M., YAMADA, A., KOKAJI, Y., KIMURA, S., SP562, pp. 325-333 (Oct. 1979).

ILES, P. A., SP400-58, Pp. 86-94 (Aug. 1979).

IMANAKA, O., OKUTOMI, M., SP562, pp. $157-169^{\circ}$ (Oct. 1979).

IMANaKa, O., SUgiTA, T., KaWAKaMI, S., SP562, pp. 317-323 (Oct. 1979).

Imanaka, O., Yasunaga, N., Tarumi, N., Obara, A., SP562, Pp. 171-182 (Oct. 1979).

inguscio, M., Strumia, F., Evenson, K. M., Jennings, D. A., SCalabrin, A., Stein, S. R., 18426 .

INNES, J. J., SP547, PP. 78-97 (July 1979).

INOMata, T., OKazaki, S., MoriWaki, T., Suzuki, M., SP561/2, pp. 1327-1337 (Sept. 1979).

IP, P., Strauss, H. L., SP56I/2, pp. $1611-1618$ (Sept. 1979).

IROUSCHEK, F., SP5S6, PP. $139-140$ (Sept. 1979).

InWIN, B., SP500-52, pp. 219-226 (Oct. 1979).

IRWIN, W., HeIMANN, K., SP556, pp. 95-100 (Sept. 1979).

ISTVAN, E. J., 18975.

Ito, S., Escalante, E., SP550.

ITO, Y. M., RosenglatT, M., SP562, pp. $501-511$ (Oct. 1979).

IVERSON, W. P., BRINCKMAN, F. E., 18860.

IVERSON, W. P., ESCALANTE, E., 18418

IVERSON, W. P., Escalante, E., 18424

IVES, W. R., NAHMAN, N. S., BagozzI, R. P., 18723.

lzumitani, T., MiYade, E., Adachi, S., Harada, S., SP562, pp. 417-425 (Oct. 1979).

\section{J}

Jackson, B., Lanoue, P., Ehrlich, M., Soares, C. G., 18355.

JACKSON, C. L., SP551, pp. 10-11 (July 1979).

Jackson, J. A., Brauer, G. M., Termini, D. J., 18569.

Jackson, J. A., Termini, D. J., Brauer, G. M., 18985.

Jackson, R. H. F., Collier, R. S., Haber, S., Tryon, P. V., NBSIR 79-1751.

JaCors, D. G., Auxier, J. A., KerR, G. D., Jones, T. D., SP554, PP. $41-56$ (Sept. 1979).

Jacoss, L., Schwitz, W., Deslattes, R. D., KessleR, E. G., JR., 18510 .

JaCOas, R., HeATON, H. T. 11 ., SP554.

Ja Cobs, S. D., Brown, D. C., Abate, J. A., LeWIS, O., AppelBAUM, H., Rinefierd, J. M., SP541, Pp. 109-121 (Dec. 1978).

JACOX, M. E., 18842.

JACox, M. E., 18847.

JACOX, M. E., 18869 .

JACOX, M. E., $/ 8879$.

Jacox, M. E., Larzilliere, M., SP561/1, pp. $529-543$ (Sept. 1979).

JAIN, A. K., SPSO0-52, Pp. 143.145 (Oct. 1979).

Jain, A. K., KetchledGe, B. A., Mukheruee, A., SP500-52, pp. 89-104 (Oct. 1979).

Janak, J., Golias, J., Novak, J., SP5 19, pp. $739-746$ (Apr. 1979).
Janauer, G. E., Zucconi, T. D., Lewkowicz, C., Donahe, S. M., SP519, pp. $455-459$ (Apr. 1979).

Janz, G. J., Allen, C. B., Bansal, N. P., Murphy, R. M., TOMKINS, R. P. T., NSRDS-NBS6I, Part $I I$.

Janz, G. J., TOMkins, R. P. T., Allen, C. B., JPCRD 8, No. $1,125-302$ (1979).

Jarvis, S., JR., Wineland, D. J., Garvey, R. M., Hellwig, H. W., 18475

Jarvis, S., JR., Wineland, D. J., Hellwig, H. W., U.S. Patent $4,146,848$.

JASON, N. H., NBSIR 79-1745.

JAUdeT, A., SOL, J. C., SP547, pp. 250-279 (July 1979).

Javitz, H. S., Green, D. S., Logsion, J. D., Mllbergs, E., MCEACHRON, N. B., NBS-GCR-ETIP 78.57.

Javitz, H. S., Green, D. S., Logsdon, J. D., Milbergs, E., MCEACHRON, N. B., NBS-GCR-ETIP 78-58.

Javitz, H. S., Green, D. S., Logsdon, J. D., Milbergs, E., MCEACHRON, N. B., NBS-GCR-ETIP 78-58A.

Jednacak-Biscan, J., Mikac-Dadic, V., Pravdic, V., Haller, W., 18910.

JefFery, S., Fife, D., Deutsch, D., Sockut, G., 18777.

JeNkins, J. P., HILL, J. E., 18770.

Jenkins, J. P., Hill, J. E., $/ 8986$.

Jenkins, J. P., Jones, D. E., Hill, J. E., BSS 117.

Jenkins, R., Hubbard, C. R., 18857.

Jenkins, R. G., Macleod, W. D., J R., Ramos, L. S., Brown, D. W., SP519, PP. 713-718 (Apr. 1979).

Jennings, D. A., Evenson, K. M., Henningsen, J. O., PeterSen, J. C., Petersen, F. R., 18939.

Jennings, D. A., Petersen, F. R., Evenson, K. M., 18562.

Jennings, D. A., Petersen, F. R., Baird, K. M., Evenson, K. M., HANES, G. R., 18916 .

Jennings, D. A., Scalabrin, A., Stein, S. R., Inguscio, M., Strumia, F., Evenson, K. M., 18426.

Jennings, W., Fisher, G. L., RaAbe, O. G., Olechno, J., SUCRE, L., SPS19, pp. 109-120 (Apr. 1979).

Jennings, W. D., Holasek, E., Purnell, E. W., SP525, pp. 261-266 (Apr. 1979).

JENSEN, D. E., SP56I/2, Pp. $1195-1220$ (Sept. 1979).

JERKE, J. M., NYYSSONEN, D., 18629.

Jernigan, J. L., Ashley, E. J., Donovan, T. M., Porteus, J. O., SP541, Pp. $212-217$ (Dec. 1978).

Jernigan, J. L., Faith, W. N., Porteus, J. O., Donovan, T. M., SPS4I, Pp. 202-211 (Dec. 1978).

Jesch, R. L., Jones, R. N., Bussey, H. E., Boyne, H. S., EllerBRUCH, D. A., 18563.

Jewett, K. L., Brinckman, F. E., Bellama, J. M., 18484.

JiN, T., HoRIUCHI, S., SP540, pp. 134-137 (Nov. 1979).

JoHNS, H. E., SP554, pp. 15-21 (Sept. 1979).

Johnson, C. E., Hsu, C. C., SP561/2, pp. 1683-1704 (Sept. 1979).

JOHNSON, C. R., 18909.

JOHNSON, C. R., 18941 .

JoHnson, C. R., BeINe, W. B., WANG, T. J., 18602 .

Johnson, C. R., Leighton, F. T., Robinson, H. A., 18524.

Johnson, D. R., Clark, F. O., Lovas, F. J., 18731 .

JOHNSON, E. G., JR., TN1009.

JOHNSON, E. G., JR., TNIOIS.

Johnson, S. A., Bahn, R. C., Rajagopalan. B., Greenleaf, J. F., ThOMAS, P. J., SPS 25, pp. $227-233$ (Apr. 1979).

Johnson, S. A., Greenleaf, J. F., Rajagopalan, B., Bahn, R. C., BaXter, B., Christensen, D., SP5 25, Pp. 235-246 (Apr. 1979).

Johnson, W. L., Collins, G. J., Persson, K. B., Franzen, D. L., MCNELL, J. R., 18319.

JOHNSON, W. W., JONES, M. C., 18617 .

Johnston, G. T., Fernelius, N. C., SP541, pp. 7-12 (Dec. 1978). 
Johnston, R. L., Goss, S. A., Maynard, V., Brady, J. K., Frizzell, L. A., O'Brien, W. D., Jr., Dunn, F., SP525, pp. 19-27 (Apr. 1979).

Johnston, R. L., Maynard, V., Nider, L., Frizzell, L. A., O'Brien, W. D., JR., DunN, F., Goss, S. A., SP525, pp. 4351 (Apr. 1979).

JONES, D. E., HiLl, J. E., NBSIR 79-1737.

JONES, D. E., HILL, J. E., NBSIR 79.1799.

Jones, D. E., Hill, J. E., JeNkins, J. P., BSSI 17.

JONES, M. C., ARP, V. D., 18822 .

Jones, M. C., DANey, D. E., Ludtke, P. R., 18567.

JONES, M. C., JOHNSON, W. W., 18617.

JONES, R. N., NBSIR 79-1604.

Jones, R. N., Bussey, H. E., Boyne, H. S., Ellerbruch, D. A., ЈESCH, R. L., 18563.

Jones, R. N., Saulsbury, L. F., Workman, J. L., Treado, M. J., Diamond, J. J., TAggart, H. E., 18381 .

Jones, T. D., Jacobs, D. G., Auxier, J. A., KerR, G. D., SP554, pp. 41-56 (Sept. 1979).

Jorgenson, J. W., Novotny, M., Smith, S. L., SP519, pp. 429436 (Apr. 1979).

Joseph, J. T., Hybl, A., Flynn, J. H., 18380.

Joynt, L., Boyle, D., Rakowski, H., Popp, R., Beaver, W., SP525, pp. 267-273 (Apr. 1979).

JUdD, D. B., MACAdAM, D. L., SP545.

Jung, K., Geltman, S., Schubert, E., Schuck, A., 18534.

JUNG, W., SP539, pp. 101-112 (Apr. 1979).

Jung, W., Peiser, H. S., Sangster, R. C., SP539.

JUST, T. H., ROTH, P., SP561/2, pp. 1339-1352 (Sept. 1979).

JUSTESEN, D. R., SPSSI, pp. 5-6 (July 1979).

JUTTE, R. B., SP563, pp. 108-129 (Oct. 1979).

\section{$\mathbf{K}$}

KABAKOFF, D. S., SP519, pp. 533-539 (Apr. 1979).

Kaelble, D. H., Leung, C. L., SP563, pp. 32-46 (Oct. 1979).

Kahan, A., Hellwig, H., Stein, S. R., Walls, F. L., 18826.

Kahan, D. J., Bennett, L. H., Chafe, H. D., Gray, A. G., Langer, E. L., Baker, H., Cuthill, J. R., 18739.

Kahan, D. J., Cuthill, J. R., Chafe, H. D., Gray, A. G., Langer, E. L., Baker, H., Carter, G. C., Bennett, L. H., 18645.

Kahan, D. J., Read, M. E., Manning, J. R.,Swartzendruber, L. J., Carter, G. C., 18637.

KAHLER, R. L., 18624.

KAHN, A. H., Spal, R., 18911 .

Kaiserlik, J., Berger, H., McGogney, C., 18525.

Kalan, J. E., Oreenberg, H. J., J. Res. 84, No. 1, $21-47$ (1979).

Kam, F. B. K., Swank, J. H., Odette, G. R., McElroy, W. N., Doran, D. G., Gold, R., Lippincott, E. P., Schiffgens, J. O., Simons, R. L., Morgan, W. C., Grundl, J. A., McGarRY, E. D., 19012.

Kamas, G., Howe, S. L., SP559.

Kambeitz, R. A., Close, R. T., SP500-52, pp. 233-234 (Oct. 1979).

Kaminsky, L., Dymersk1, P., Kennedy, M., SP519, pp. 685-690 (Apr. 1979).

KAMPER, R. A., 18561 .

KANDA, M., 18856.

KANDA, M., 19034.

KANDA, M., 19035.

Kanda, M., Shafer, J., Adams, J. W., TAggart, H. E., TN1014.

Kaneko, K., Yamamura, T., Takahashi, Y., SuzUki, H., Saito, F., Handa, T., Suda, K., Nagashima, T., SP540, pp. 626-711 (Nov. 1979).

KAPSCH, R. J., SP536, pp. 1-16 (Feb. 1979).

KAPSCH, R. J., SP549, pp. 23-27 (Aug. 1979).

KARTOWISAstro, H., SP539, pp. 67-78 (Apr. 1979).
KASEN, M. B., 18560.

KASEN, M. B., $/ 8631$.

KASEN, M. B., 18717 .

KASEN, M. B., 18771 .

Kasen, M. B., Schramm, R. E., 18616 .

Kashiwagi, T., Chabay, I., Rosasco, G. J., 18626.

KATRIEL, J., 18661 .

KATRIEL, J., 18885.

KATRiel, J., KVentsel, G. F., 18605.

KATRIEL, J., MURAT, K., 18592.

KATZ, J. L., YOON, H. S., SP525, pp. 189-196 (Apr. 1979).

KATZKE, S. W., 18882.

Kauffman, J. W., Margrave, J. L., Hauge, R. H., Gransden, S. E., SP561/1, Pp. $557-566$ (Sept. 1979).

KaUfMaN, H., SP556, pp. 101-104 (Sept. 1979).

Kaufman, V., Hagan, L., 18485.

Kaufman, V., Sugar, J., 18369.

KaUfman, V., SUgAR, J., 18506.

Kautz, R. L., J. Res. 84, No. 3, 247-259 (1979).

KAUTZ, R. L., 18486.

Kawagoe, K., Morishita, Y., SP540, Pp. $148-161$ (Nov. 1979).

Ka WaKam1, S., Imanaka, O., SugITA, T., SPS62, pp. 317-323 (Oct. 1979).

Kayser, R. F., JR., RAVEche, H. J., 19004.

KAZMERSKI, L. L., SP400-58, pp. 128.143 (Aug. 1979).

KAZMERSKI, L. L., SP400-58, Pp. 30.40 (Aug. 1979).

KelCh, W. L., Linsky, J. L., WORden, S. P., 18926.

Kelleher, D. E., Konjevic, N., Wiese, W. L., 18948.

Keller, R. A., Luther, G. G., Schenck, P. C., Travis, J. C., Green, R. B., U.S. Patent 4,148,586.

Keller, R. A., Travis, J. C., 18364 .

Kelley, E. F., Hebner, R. E., JR., 18843.

Kellogg, L. S., Lippincott, E. P., Hansen, G. E., Zimmer, W. H., Gilliam, D. M., Helmer, R. G., Greenwood, R. C., Rogers, J. W., Heinrich, R. R., Popek, R. J., 18884.

Kelly, G. E., Сhi, J., 18385.

Kelly, G. E., Didion, D. A., 18703.

Kelly, G. E., Park, C., Mulroy, W. J., TN999.

Kelly, J. J., Vanderveldt, H. H., SP563, pp. 267-275 (Oct. 1979).

Kelly, P., Ritchie, D., Braunlich, P., Schmid, A., SP541, pp. 296-298 (Dec. 1978 ).

Kelpczynski, W. J., Costain, C. C., DaAms, H., Boulanger, J. S., Hanson, D. W., 18861 .

Kemmer, A. M., Metcalfe, L., Toy, H. D., Parris, G. E., SherMan, P. L., SP519, pp. 205-212 (Apr. 1979).

KeNDALL, C. M., SP551, pp. 3-4 (July 1979).

Kennedy, M., Kaminsky, L., Dymerski, P., SP519, pp. 685.690 (Apr. 1979).

Kenney, J. M., Mayo-Wells, J. F., Roth, S. C., Edelman, S., SP547, pp. 303-314 (July 1979).

Kenney, J. M., Roth, S. C., J. Res. \&4, No. 6, $447-453$ (1979).

Kerr, D. L., Chatwani, A. U., Ferron, J. R., SP561/2, pp. 1373-1402 (Sept. 1979).

Kerr, G. D., Jones, T. D., Jacobs, D. G., Auxier, J. A., SP554, pp. 41-56 (Sept. 1979).

Kessler, E. G., JR., Deslattes, R. D., Henins, A., 18487.

Kessler, E. G., JR., Jacobs, L., Schwitz, W., Deslattes, R. D., 18510 .

Kessler, H. K., Schafft, H. A., SAwyer, D. E., NBSIR 79 1909.

Kessler, H. K., Schafft, H. A., Sa Wyer, D. E., 18633.

Kessler, L. W., Yuhas, D. E., SP525, pp. 73-79 (Apr. 1979).

Ketchel, J. M., Tiffany, W. D., SP480-38, pp. $81-88$ (Dec. 1979).

Ketchledge, B. A., Mukheriee, A., Jain, A. K., SPS00-52, pp. 89-104 (Oct. 1979).

KeuWeZ, J., LeVI, S., SP525, pp. 121-124 (Apr. 1979).

KEYSAR, B. C., HIOS-3. 
Khoury, F., Kryder, S. J., BOLz, L. H., MopsiK, F. I., 18713.

Khurt-Yakub, B. T., Evans, A. G., Kino, G. S., SP562, pp. 379-392 (Oct. 1979).

Kidnay, A. J., Hiza, M. J., Miller, R. C., JPCRD 8, No. 3, 799-816 ( I979).

Kieffer, L. J., Belanger, B. C., 18720.

KIKUCHI, R., CAHN, J. W., 18614.

KIKUCHI, R., CAHN, J. W., 18669.

Kilday, M. V.,J. Res. 84, No. 3, 231-240 (I979).

Kilday, M. V., Efimov, M. E., Klevaichuk, G. N., Medvedev, V. A., J. Res. 84, No. 4, 273-286 (1979).

Kilmer, R. D., Cadoff, M. A., Mathews, D. E., Shoemaker, C. O., JR., 18607.

KIM, D. H., SP543, pp. 41-44 (Apr. 1979).

KIM, J. K., ANDERSON, W. A., SP400-58, pp. 48-56 (Aug. 1979).

KimBleton, S. R., 18488.

Kimbleton, S. R., 18891 .

Kimbleton, S. R., WOOD, H. M., 19009.

Kimura, S., IKeda, M., Yamada, A., KoKaJi, Y., SP562, pp. 325-333 (Oct. 1979).

King, D. S., SChenCK, P. K., 18944.

King, D. S., Stephenson, J. C., Bialkowski, S. E., 19042.

KING, G. B., FicketT, F. R., Ho, J. C., 18419.

KING, M., SP527, pp. 13-20 (Feb. 1979).

KING, M. H., SP527.

KING, R. C., ARMStrong, G. T., 18755.

King, T. L., EATON, H. G., Williams, F. W., Wyatt, J. R., DeCorpo, J. J., SaAlfeld, F. E., Smith, D. E., SP519, pp. 213-218 (Apr. 1979).

KING, W. T., SMith, C. M., FRY, D. N., SP547, pp. 232-249 (July 1979).

Kingston, H. M., Barnes, I. L., Brady, T. J., Rains, T. C., Champ, M. A., 18402 .

Kino, G. S., Birnholz, J., Fraser, J., SP525, pp. 287-295 (Apr. 1979).

Kino, G. S., Khuri-Yakub, B. T., Evans, A. G., SP562, pp. 379-392 (Oct. 1979).

Kinsman, P. R., Long, K. A., Maglll, J., Scotti, A., Ohse, R. W., Babelot, J. F., Cercignani, L., SP561/1, pp. 83-109 (Sept. 1979).

KIRBY, R. K., 18905.

KIRBY, R. K., Hust, J. G., 18615.

KirbY, S., Weiss, R. G., WAtSon, S., Bell, J., TNI104, Vols. 1 and 2.

Kirchner, H. P., Gruver, R. M., Richard, D. M., SP562, pp. 23-42 (Oct. 1979).

Kirklin, D. R., Mitchell, D. J., Cohen, J., Domalski, E. S., ABRAMOWITZ, S., NBSIR 78-1494.

Kirrene, M. J., Spiegel, M. G., SP500-52, pp. $129-140$ (Oct. 1979).

Kishitani, K., Nakamura, K., SP540, pp. $485-519$ (Nov. 1979).

Kishitani, K., Yusa, S., SP540, pp. 453-484 (Nov. 1979).

Kissinger, P. T., Bruntlett, C. S., Bratin, K., Rice, J. R., SP519, pp. $705-712$ (Apr. 1979).

Kissinger, P. T., Felice, L. J., Bruntlett, C. S., Shoup, R. E., SP519, pp. 391-397 (Apr. 1979).

Klassen, R., Stavric, B., Stoltz, D. R., SP519, pp. 311-319 (Apr. 1979).

Klaus, D. M., Haberle, J., Foskett, W. A., NBS-GCR-EtiP 79-62.

Klebanoff, P. S., Huang, T. T., Frenkiel, F. N., 18821 .

Klebanoff, P. S., Purtell, L. P., TN989.

Klein, C., diBenedetto, B., Donadio, R., Kohane, T., Pappis, J., SP54I, pp. 86-97 (Dec. 1978).

Klein, D. P., Budnick, E. K., NBSIR 79-1720.

Klein, R., Greiner, G., Menzel, D., 18810.

Klevaichuk, G. N., Medvedev, V. A., Kilday, M. V., Efimov, M. E., J. Res. 84, No. 4, 273-286 (1979).
KLOSE, J. Z., 18527.

KLote, J. H., BeNJAMIN, I. A., NBSIR 79-1747.

Klotzbucher, W. E., Ozin, G. A., SP561/1, pp. 567.585 (Sept. 1979 ).

KNAB, L. I., 18890 .

KNAB, L. I., MOODY, R. C., $l 8887$.

Knight, A. E. W., Parmenter, C. S., Lin, H. M., Seaver, M., TANG, K. Y., 18671 .

Knight, L. B., JR., Martin, R. L., Davidson, E. R., SP561/1, pp. 545-555 (Sept. 1979).

KNIGHT, N. H., NBSIR 79-1928 (NBS).

KNights, R. L., APPel, B. R., Hoffer, E. M., Kothny, E. L. WALL, S. M., HaIK, M., SP519, pp. 121-129 (Apr. 1979).

KNOLL, K. T., SP563, pp. 91-107 (Oct. 1979).

Kobayashi, M., Sata, T., Sasamoto, T., SP561/1, pp. 283-286 (Sept. 1979).

KobaYashi, T., SP525, pp. 93-99 (Apr. 1979 ).

Kосн, W. F., J. Res. 84, No. 3, $241-246$ (1979).

КОсн, W. F., 18889.

KoENIG, A. L., HOLT, A. W., NBSIR 79-1927.

Koenig, A. L., Warnar, R. B. J., Moore, R. T., Carpenter, R. J., Holt, A. W., NBSIR 79-1725.

KOEPKE, B. G., STOKES, R. §., SP562, pp. $75-91$ (Oct. 1979).

Kohane, T., Pappis, J., Klein, C., diBenedetto, B., Donadio, R., SP541, pp. 86-97 (Dec. 1978).

Kohl, F., Stearns, C., Santoro, G., Rosner, D. E., Seshadri, K., Fernandez de la Mora, J., Fryburg, G., SP561/2, pp. 1451-1474 (Sept. 1979).

Kohl, F. J., Fryburg, G. C., Miller, R. A., Stearns, C. A., SP561/1, pp. 303-354 (Sept. 1979).

Kohler, B. E., Stevenson, J. M., Anderson, R. J. M., 18754.

KOKAJI, Y., KIMURA, S., IKedA, M., YAMADA, A., SP562, pp. 325-333 (Oct. 1979).

Kolb, C. E., Gersh, M. E., SP561/1, pp. 679-693 (Sept. 1979).

Kole, C. E., WormhoudT, J., SP561/1, pp. $457-476$ (Sept. 1979).

KOMAREK, E. L., 18670.

Konen, T. P., Benazzi, R. V., Guss, L., Orend, R., Wyly, R. S., SP553, pp. 3-13 (Aug. 1979).

Konen, T. P., Bevans, R. S., Boegly, W. J., Savitsky, D., COLE, C., SP553, pp. 71-77 (Aug. 1979).

Konen, T. P., Liposki, F., Myers, J. R., Niel.sen, L., Mikucki, W., Staton, W., Williams, G., SP553, pp. $15-19$ (Aug. 1979).

Konen, T. P., Manfredi, 'R. R., Nielsen, L. S., Wyly, R. S., BENAZZI, R. V., SP553, pp. 35-51 (Aug. 1979).

Konjevic, N., Wiese, W. L., 18737.

Konjevic, N., Wiese, W. L., Kelleher, D. E., 18948.

KoON, N. C., Rhyne, J. J., 19031.

Koon, N. C., Schelleng, J. H., Rhyne, J. J., Forester, D. W., 18897.

KOREN, S. S., SP552, pp. 39-44 (July 1979).

Korobeinichev, O. P., Tereshenko, A. G., SP561/1, pp. 479. 491 (Sept. 1979).

Kostkowski, H. J., Evans, J. P., Guildner, L. A., 18665.

Kostyla, R. J., Mourey, T. H., Cohen, R., Merritt, M. E., Simmons, K., LaFaucia, R., Limentani, G., Washburn, D. N., Siggia, S., SP519, pp. 783-787 (Apr. 1979).

Kothny, E. L., Wall, S. M., HaIk, M., Knights, R. L., Appel, B. R., HOFFER, E. M., SP519, pp. 121-129 (Apr. 1979).

Kotter, F. R., Hebner, R. E., Hillhouse, D. L., 18872.

KOTTER, F. R., MiSAKIAN, M., 18494.

Kovacs, W. D., YoKel, F. Y., BSS107.

Kovalev, V. I., Faizullov, F. S., SP541, pp. 318-326 (Dec. 1978).

Kowalski, J. G., Chapman, R. E., TN971.

Kowalski, J. G., Chapman, R. E., TN979.

Kowalski, M. F., Fine, D. S., Herrman, R. K., SP563, p. 133 (Oct. 1979).

Koyama, R. Y., Buehler, M. G., SP400-55. 
Koyama, R. Y., Phill.jps, W. E., Myers, D. R., LiU, Y. M., DIETRICH, H. B., 18458 .

KRAFT, R., 18489.

Kraft, R., GILSINN, D., SP400-57.

KRAMER, J. J., SP480-38.

KRAMER, N. B., SP547, pp. 58-62 (July 1979).

KRAMER, S., OlMERT, M., NBSIR 79-1792.

Kranbuehl, D. E., Verdier, P. H., 18772.

krasny, J. F., Braun, E., Peacock, R., 18991.

Krasny, J. F., Hopkins, D. E., NBSIR 79-1596.

Krasny, J. F., Peacock, R. D., Meierhoefer, A. W., Braun, E., NBSIR 79-1755.

Krasny, J. F., Peacock, R. D., Stratton, A., Braun, E., 18708.

Krause, M. O., JPCRD 8, No. 2, 307-328 (1979).

Krause, M. O., Oliver, J. H., JPCRD 8, No. 2, 329-338 (1979).

Krause, R. F., JR., 19020.

Krause, R. F., JR., Fuller, E. R., JR., 19018.

Krauss, G., Bennett, J. M., Wong, S. M., SP541, pp. 132-163 (Dec. 1978).

Krauss, J., Paul, A. W., SP551, pp. 7-9 (July 1979).

Krauss, M., Mies, F. H., 18936.

Krauss, M., Neumann, D., 18934.

Krauss, M., NeumanN, D. B., 18933.

Krauss, M., NeumanN, D. B., 18935.

Kremkau, F. W., McGraw, C. P., Barnes, R. W., SP525, pp. 81-84 (Apr. 1979).

Kresge, D., SP534, pp. 123-135 (May 1979).

Krohn, B. J., Harter, W. G., Patterson, C. W., Galbraith, H. W., 18921 .

KRUGER, J., 18946.

Kruger, J., Halpin, S., CIS9, Revised 1979.

Krumhansl, J. A., Thomson, R. M., Gubernatis, J. E., 18831. Kryder, S. J., Bolz, L. H., Mopsik, F. 1., Khoury, F., 18713.

Krzewick, J. E., Christopher, P. M., NBSIR 79.1762.

Ku, H. H., SP519, pp. 1-6 (Apr. 1979).

KU, H. H., 18427.

KU, H. H., 18990.

Kuc, R., Schwartz, M., Finby, N., Dain, F., SP525, pp. 125 132 (Apr. 1979).

KuснNicki, R. P., SP549, pp. 39-42 (Aug. 1979).

Kuczkowski, R. L., Schwendeman, R. H., Ramsay, D. A., Lovas, F. J., Lafferty, W. J., Makj, A. G., Harmony, M. D., LAUrie, V. W., JPCRD 8, No. 3, 619-722 (1979).

Kudchadker, A. P., Kudchadker, S. A., Shukla, R. P., PATNAIK, P. R., JPCRD 8, No. 2, $499-518$ (1979).

KudChadKer, A. P., KudChadKer, S. A., JPCRD 8, No. 2, 519-526 (1979).

KUdChADKer, S. A., KUdChAdKER, A. P., JPCRD 8, No. 2, 519-526 (1979).

Kudchadker, S. A., Shukla, R. P., Patnaik, P. R., KUDCHADKER, A. P., JPCRD 8, No. 2, $499-518$ (1979).

KudChadker, S. A., Wilhoit, R. C., Chen, S. S., JPCRD 8, No. 2, 527-536 (1979).

KuKUNARIS, S., SP400-58, pp. 126-127 (Aug. 1979).

Kulkarni, H. T., Beardmore, P., SP563, pp. $135-151$ (Oct. 1979).

Kumar, K. S., Hoffman, M. K., Macias, E. S., SP519, pp. 101 107 (Apr. 1979).

Kumpula, J. W., Termini, D. J., Davidson, K. M., Brauer, G. M., 18638.

Kunasz, C. V., Ostrovski, V. N., Demkov, Y. N., $/ 8576$.

Kurepa, M., Celotta, R. J., Swanson, N., 18392.

Kuriyama, M., Boettinger, W. J., Burdette, H. E., 18399.

KurTZ, D. A., SP519, pp. 19-32 (Apr. 1979).

Kurylo, M. J., Laufer, A. H., 18436.

Kusch, P., Hessel, M. M., 18824.

KusudA, T., $/ 8336$.

Kusuda, T., BeAN, J. W., 19003.
Kusuda, T., Hunt, C. M., McNall, P. E., 18587.

KVentsel, G. F., Katriel, J., 18605.

\section{$\mathbf{L}$}

LaBrecque, J. F., Parrish, W. R., Arvidson, J. M., NBSiR 78-887.

Labrecque, J. F., Parrish, W. R., Arvidson, J. M., 18395.

Labrecque, J. F., Younglove, B. A., Siegwarth, J. D., 18805.

Lafaucia, R., Limentani, G., Washburn, D. N., Siggia, S., Kostyla, R. J., Mourey, T. H., Cohen, R., Merritt, M. E., SimMONS, K., SP519, pp. 783-787 (Apr. 1979).

Lafferty, W. J., Maki, A. G., Harmony, M. D., Laurie, V. W., Kuczkowski, R. L., Schwendeman, R. H., Ramsay, D. A., Lovas, F. J., JPCRD 8, No. 3, 619-722 (1979).

LAFFerTy, W. J., Wells, J. S., SAMS, R. L., 18864.

LaFleur, P. D., LeRoy, A., Becker, D. A., 18350.

LAIRd, E. C., HANNA, S. B., SPS19, pp. 797-802 (Apr. 1979).

LAM, H. K., SP539, pp. 33-34 (Apr. 1979).

LAM, L. K., SChEARER, L. D., 18799.

LAmar, L. Q. C. III., TAylor, J. G., NBS-GCR-ETIP 78-59.

Lamers, H. J. G., Castor, J. 1., 18515.

Lamont, S., Harvey, A. B., McDonald, J. R., Baronavski, A. P., Pasternack, L., SP561/2, pp. 817-831 (Sept. 1979).

Landingham, R. L., Casey, A. W., Lindahl, R. O., SP562, pp. 231-244 (Oct. 1979).

LANDRY, M. J., SP541, Pp. $168-189$ (Dec. 1978).

Langer, E. L., Baker, H., Carter, G. C., Bennett, L. H., Kahan, D. J., Cuthill. J. R., Chafe, H. D., Gray, A. G., 18645.

Langer, E. L., Baker, H., Cuthill, J. R., Kahan, D. J., Bennett, L. H., Chafe, H. D., Gray, A. G., 18739.

LANKFord, J., DAvidSON, D. L., SP562, pp. $395-404$ (Oct. 1979).

Lanoue, P., Ehrlich, M., Soares, C. G., Jackson, B., 18355.

lapides, J. R., Crannell, C. J., Crannell, H., Hornyak, W. F., Seltzer, S. M., TrombKa, J. I., WAll, N. S., 19015.

LaRiviere, P. D., Tochilin, E., SP554, pp. 145-154 (Sept. 1979).

LARrabee, G., Dobrott, R., NBS-GCR-79-158.

Larrabee, R. D., Blackburn, D. L., 18460.

LARSEN, E. B., 18814.

Larson, E., Hoblitt, R., Fickett, F. R., Rosenbaum, J., 18804.

LARSON, R., SP534, pp. 61-92 (May 1979).

LARSON, R. E., SP552, Pp. 167-183 (July 1979).

Larzilliere, M., JacoX, M. E., SP561/1, pp. $529-543$ (Sept. 1979).

Lassiter, T. W., Vick, D. O., SChWeitzer, G. K., Bowling, R. A., SP561/1, pp. 771-789 (Sept. 1979).

LAUFER, A. H., 18974.

Laufer, A. H., BAss, A. M., 18443.

LAUfeR, A. H., KURYLO, M. J., 18436.

Laughlin, J. S., Reid, A., Zeitz, L., Ding, J., SP554, pp. 1 14 (Sept. 1979).

Laurie, V. W., Kuczkowski, R. L., Schwendeman, R. H., Ramsay, D. A., Lovas, F. J., Lafferty, W.. J., Maki, A. G., HARMONY, M. D., JPCRD 8, No. 3, $619-722$ (1979).

LAVILLA, R. E., 18526.

Law, G. E.,.Jr., Wang, A. S., Crossman, F. W., SP563, pp. 255-264 (Oct. 1979).

Lawless, W. N., Siegwarth, J. D., Morrow, A. J., RADEBAUgh, R., 18680 .

LAWRENCE, J., J. Res. 84, No. 1; 49-53 (1979).

Lawrence, J., Shier, D., Domich, P., J. Res. 84, No. 6, 455 488 (1979).

LAWRENCE, L., SP543, pp. 78-86 (Apr. 1979).

LAWSON, J. R., NBSIR 79-1588. 
Lawton, R. A., Nahman, N. S., Allred, C. M., Andrews, J. R., HOER, C. A., NBSIR 79-1613.

LAWTON, R. A., ONDREJKa, A. R., TNI008.

LAWTON, R. A., YoUng, M., TN1010.

LAYER, H. P., 18904.

Layer, H. P., Hocken, R. J., Cummings, A. L., Coxon, B., 18768.

Layer, H. P., Petersen, F. R., Harter, W. G., 18928.

le Croissette, D. H., Heyser, R. C., Gammell, P. M., ROSEboro, J. A., WILSON, R. L., SP525, pP. 101-108 (Apr. 1979).

Leaders, F. E., Jr., O'Brien, J. E., Hinsvark, O. N., Newman, W. R., Amsel, L. P., Giering, J. E., SP519, pp. 481-485 (Apr. 1979).

Leb, D. E., Preston, K., Jr., Czerwinski, M. J., Skolnik, M. L., SP525, pp. 303-313 (Apr. 1979).

LEDBETTER, H. M., 18630.

LeDBeTter, H. M., 18716 .

Ledbetter, H. M., Collings, E. W., 18763.

LeDERER, C. C., SP549, pp. 131-134 (Aug. 1979).

LEDERER, P. S., TNIIIO.

Lederer, P. S., Mayo-Wells, J. F., Vezzetti, C. F., Hilten, J. S., NBSIR $78-1590$ (NASA).

LEE, B. T., BREeSE, J. N., NBSIR 78-1584.

Lee, B. T., PARKer, W. J., NBSIR 79-1700.

LeE, B. T., PARKer, W. J., NBSIR 79-1714.

Lee, M. L., Vassilaros, D. L., Pipkin, W. S., Sorensen, W. L., SP519, pp. 731-738 (Apr. 1979).

Lee, P. P. K., Lerner, R. M., Hunter, L. P., Gramiak, R., SCHENK, E. A., WAAG, R. C., SP525, pp. 143-152 (Apr. 1979).

Lee, S. A., Hall, J. L., U.S. Patent $4,165,183$.

Lee, S. A., Helmcke, J., Hall, J. L., 19019.

LEEDY, K. O., SP546, 1979 Edition.

LEEDY, T. F., TNI102.

leeman, S., Metrewel, C., Plessner, N. J., Willson, K., GORE, J. C., SP525, pp. 275-280 (Apr. 1979).

Lees, S., Davidson, C. L., SP525, pp. 179-187 (Apr. 1979).

Leighton, F. T., J. Res. 84, No. 6, 489-506 (1979).

Leighton, F. T., Robinson, H. A., Johnson, C. R., 18524.

LENNON, N., Bond, W. P., JR., SP500-52, pp. $215-218$ (Oct. 1979).

Lentner, K. J., Moore, W. J. M., Schuster, G., McAuliff, R. C., 18529.

LENTO, H. G., SPSI9, pp. 243-248 (Apr. 1979).

LeONe, S. R., BAUghCUM, S. L., 18573.

LEONE, S. R., HORWITZ, A. B., 18388.

LEONE, S. R., HORWITZ, A. B., 18667.

LEONE, S. R., HORWITZ, A. B., 18929.

LEONG-HONG, B., FIPS PUB 64.

Lerner, R. M., Hunter, L. P., Gramiak, R., Schenk, E. A., WAAG, R. C., LEE, P. P. K., SP525, pp. 143-152 (Apr. 1979).

LeRoy, A., Becker, D. A., LAFleur, P. D., 18350.

LETMANYI, H., SPSO0-52, pp. 235-240 (Oct. 1979).

LeUChS, G., SMith, S. J., Walther, H., 18953.

Leung, C. L., Kaelale, D. H., SPS63, pp. 32.46 (Oct. 1979).

Leung, K. M., Bernal, E., Ready, J. F., Vora, H., Skogman, R. A., SP54I, pp. 59-64 (Dec. 1978).

LEVENSON, M. D., 18801 .

LeVenson, M. D., Eesley, G. L., 18558.

LEVINE, B., SP527, pp. 87-91 (Feb. 1979).

LEVINE, J., 18823.

Levine, J., Moody, S., Pearlman, M. R., Silverberg, E. C., Bender, P. L., Faller, J. E., 18459.

LeVINe, J., MoOdy, S. E., 18816.

Levinger, R., Malkin, S., SP562, pp. 305-315 (Oct. 1979).

Levy, E. J., Liebman, S. A., SP519, pp. 753-760 (Apr. 1979).

LEWIS, A. C., LEWIS, E., JR., SP480-33.

LEWIS, E., JR., LEWIS, A. C., SP480-33.
Lewis, J., Collier, S. D., Ayres, R. U., NBS-GCR-ETIP 7860.

Lewis, J., Rehm, R. G., Cordes, M. R., Baum, H. R., NBSIR 79-1754.

Lewis, L. F., McEachron, N. B., HaLl, D. C., NBS-GCR-ETIP 78.51 .

Lewis, L. F., McEAchron, N. B., Hall, D. C., NBS-GCR-ETIP 78-52.

Lewis, O., Appelbaum, H., Rinefierd, J. M., Jacobs, S. D., Brown, D. C., Arate, J. A., SPS41, pp. 109-121 (Dec. 1978).

LEWIS, W. E., SP549, pp. $71-84$ (Aug. 1979).

Lewkowicz, C., Donahe, S. M., Janauer, G. E., Zucconi, T. D., SPS19, pp. $455-459$ (Apr. 1979).

LeWy, A. J., MARKeY, S. P., SP519, pp. $399-404$ (Apr. 1979).

Leyendecker, E. V., EllingWOOD, B., 18415.

Li, B. W., SteWART, K. K., SP519, pp. 271-278 (Apr. 1979).

LI, S. S., $S P 400-47$.

Lias. S. G., Ausloos, P., 18331.

Lias, S., Ausloos, P., Rosenstock, H. M., Schroyer, S. S., Schmidt, C., Martinsen, D., Milne, G. W. A., Hartman, K. N., NBSIR 79-1777.

Lias, S. G., Ausloos, P., 18332.

Lias, S. G., Ausloos, P., 18337.

Libowitz, G. G., Maeland, A., Glinka, C. J., Rowe, J. M., 19030.

Lide, D. R., JR., Gevantman, L. N., White, H. J., JR., SP561/2, Pp. $1571-1579$ (Sept. 1979).

Liebman, S. A., Levy, E. J., SP519, pp. $753-760$ (Apr. 1979).

Limentani, G., Washburn, D. N., Siggia, S., Kostrla, R. J., Mourey, T. H., Cohen, R., Merritt, M. E., Simmons, K., LaFAUCiA, R., SP519, pp. $783-787$ (Apr. 1979).

Lin, C. L., Abderrassoul, R., Chu, T. L., Chu, S. S., Stokes, E. D., SP400-58, pp. $41-47$ (Aug. 1979).

Lin, C. Y., HiRAYAMA, C.; SPS61/2, pp. $1539-1547$ (Sept. 1979).

Lin, H. M., Seaver, M., Tang, K. Y., Knight, A. E. W., ParMENTER, C. S., 18671 .

Lin, M. C., Shaub, W. M., SP561/2, Pp. 1249-1261 (Sept. 1979).

Lin, M. C., Tevault, D., SP561/2, pp. 1551-1568 (Sept. 1979).

Lind, M. A., Schaefer, A. R., Zalewski, E. F., Geist, J., 18773 .

Lind, M. A., Schaefer, A. R., Zalewski, E. F., Geist, J., 18774.

Lind, M. A., Zalewsiki, E. F., Fowler, J. B., TN987.

Lindahl, R. O., Landingham, R. L., Casey, A. W., SP562, pp. 231-244 (Oct. 1979).

Lindstrom, R. M., Fleming, R. F., 18338.

Lindstrom, R. M., HARRison, S. H., HARRIS, J. M., 18490.

LINHOLM, L. W., NBSIR 79-1595.

LINNARD, R., SPS56, pp. 133-137 (Sept. 1979).

LINSKY, J. L., 18590.

Linsky, J. L., Anderson, R. C., Henry, R. C., Moos, H. W., 18753.

Linsky, J. L., Bartoe, J. D. F., Brueckner, G., Van Hoosier, M. E., BASRI, G. S., 18876 .

Linsky, J. L., Garmire, G., Cordova, F., Ayres, T. R., 18839.

LINSKY, J. L., HAISCH, B. M., 18528.

Linsky, J. L., Haisch, B. M., Boggess, A., Pasachoff, J. M., 18606.

Linsky, J. L., Mango, S. A., Bohlin, J. D., Glackin, D. L., 18922.

Linsky, J. L., McClintock, W., Worden, S. P., SCHNEEBERGER, T. J., 18920.

Linsky, J. L., Schneeber ger, T. J., Worden, S. P., Giampapa, M. S., 19007.

Linsky, J. L., Worden, S. P., Kelch, W. L., 18926. 
Linsky, J. L., Worden, S. P., McClintock, W., Robertson, R. M., 18853.

LINZER, M., SP525.

Linzer, M., Parks, S. I., Norton, S. J., Higgins, F. P., Dietz, D. R., Shideler, R. W., Shawker, T. H., Doppman, J. L., SP525, pp. 255-259 (Apr. 1979).

LiPOSKI; F., Myers, J. R., Nielsen, L., Mikucki, W., Staton, W., Williams, G., Konen, T. P., SP553, pp. 15-19 (Aug. 1979).

Lippincott, E. P., FAbry, A., Grundl, J. A., McElroy, W. N., 19013.

Lippincott, E. P., Hansen, G. E., Zimmer, W. H., Gilliam, D. M., Helmer, R. G., Greenwood, R. C., Rogers, J. W., Heinrich, R. R., Popek, R. J., KellogG, L. S., I 8884.

Lippincott, E. P., Schiffgens, J. O., Simons, R. L., Morgan, W. C., Grundl, J. A., McGarry, E. D., Kam, F. B. K., Swank, J. H., Odette, G. R., McElroy, W. N., Doran, D. G., Gold, R., 19012 .

LiROFF, S., SP556, pp. 15-20 (Sept. 1979).

LiSLE, R. W., SP552, pp. 131-140 (July 1979).

LitTLE, A. D., SP527, pp. 21-50 (Feb. 1979).

LIU, K. V., YANG, K. T., NBS-GCR-78-150.

LIU, S. T., HiLl, J. E., 18428.

LiU, V. K., Lloyd, J. R., NBS-GCR-78-151

LiU, Y. M., Dietrich, H. B., Koyama, R. Y., Phillips, W. E., MYeRS, D. R., 18458.

Livingston, R. C., Flotow, H. E., Rowe, J. M., deGraAf, L. A., Rush, J. J., 18730.

Lizzı, F. L., Elbaum, M. E., SP525, pp. $111-119$ (Apr. 1979).

LLOYd, A. C., SP557, pp. 27-46 (Aug. 1979).

Lloyd, F. L., Richards, P. L., Shen, T. M., HaRris, R. E., 18683.

LLOYD, J. R., LIU, V. K., NBS-GCR-78-151.

Loch, E., Scheiding, W., Wessels, G., von Seelen, W., Gaca, A., SP525, pp. 297-302 (Apr. 1979).

LOCKRIDGE, R., SP532, pp. 61-65 (Feb. 1979)

LOEBENSTEIN, W. V., 18984.

LOEVINGER, R., 19002.

Logsdon, J. D., Milbergs, E., McEachron, N. B., Javitz, H. S., GREEN, D. S., NBS-GCR-ETIP 78-57.

Logsdon, J. D., Milbergs, E., McEachron, N. B., Javitz, H. S., GREEN, D. S., NBS-GCR-ETIP 78-58.

Logsdon, J. D., Milbergs, E., McEachron, N. B., Javitz, H. S., GREEN, D. S., NBS-GCR-ETIP 78-58A.

LOKKEN, R. C., DUWell, E. J., SP562, pp. 201-207 (Oct. 1979).

Long, K. A., Magill, J., Scotti, A., Ohse, R. W., Babelot, J. F., Cercignani, L., Kinsman, P. R., SP561/1, pp. 83-109 (Sept. 1979).

Lovas, F. J., Johnson, D. R., Clark, F. O., 18731 .

Lovas, F. J., Lafferty, W. J., Makı, A. G., Harmony, M. D., Laurie, V. W., Kuczkowski, R. L., Schwendeman, R. H., RAMSAY, D. A., JPCRD 8, No. 3, 619-722 (1979).

Lovas, F. J., Lutz, H., Dreizler, H., JPCRD 8, No. 4, 10511108 (1979).

LOWRY, R. E., BROWN, D. W., 18512 .

LOWRY, R. E., BROWN, D. W., 18542.

Loy, P. R., Lupton, J. D., Havlicek, S. C., SP519, pp. 777. 782 (Apr. 1979).

LOZIER, D. W., NBSIR 78-1478.

Luborsky, F. E., Walter, J. L., RhyNe, J. J., LYNN, J. W., 18898.

Lucas, L. L., Mann, W. B., Matsumura, T., Noyce, J. R., Coursey, B. M., Hutchinson, J. M. R., 18400 .

LUCATORTo, T. B., MCIlrath, T. J., WeisS, A. W., Sugar, J., 18507.

Lucatorto, T. B., McIlrath, T. J., Roberts, J. R., 18808

Lucatorto, T. B., Mcllrath, T. J., Mehlman, G., 18811 .

Lucatorto, T. B., MehlMan, G., Ederer, D. L., 18912.

LudtKe, P. R., Jones, M. C., DANey, D. E., 18567.
LUDTKE, P. R., Voth, R. O., NBSIR 79-1607.

LUnd, C. M., Creighton, J. R., SP561/2, pp. 1223-1244 (Sept. 1979).

Lupton, J. D., Havlicek, S. C., Loy, P. R., SPS19, pp. $777-$ 782 (Apr. 1979).

LURIA-BUdGOR, K. F., BUDGOR, A. B., SP541, pp. 235-248 (Dec. 1978).

Lither, G., Acquista, N., Reader, J., 18500 .

Luther, G. G., Schenck, P. C., Travis, J. C., Green, R. B., Keller, R. A., U.S. Patent 4,148,586.

Lutz, H., Dreizler, H., Lovas, F. J., JPCRD 8, No. 4, 1051 1108 (1979).

LyNN, J. W., Luborsky, F. E., WALTER, J. L., RhyNe, J. J., 18898

LynN, J. W., Shelton, R. N., 18850 .

Lyons, E. A., FreESE, M., SP525, pp. $157-163$ (Apr. 1979).

\section{$\mathbf{M}$}

' IA, M. T., NBSIR 79-1605.

laAn, N., Veldkamp, J. B. D., Broese van Groenou, A., SP562, pp. 43-59 (Oct. 1979).

MACADAM, D. L., JUDD, D. B., SP545.

Macander, A. B., Brauer, F. A., Edelstein, H. P., SilverGLEIT, M., SP563, pp. 276-285 (Oct. 1979).

MacArthur, C. D., SP5 40, pp. 209-232 (Nov. 1979).

MacCarthy, P., Malcolm, R. L., SP5 19, pp. 789-792 (Apr. 1979).

MacCarthy, P., Malcolm, R. L., SP519, pp. 793-796 (Apr. 1979).

MacCrehan, W. A., Durst, R. A., 18420.

MacCrehan, W. A., Durst, R. A., Bellama, J. M., SP519, pp. 57-63 (Apr. 1979).

MacDonald, L., Armstrong, J., SP556, pp. 57-64 (Sept. 1979).

MacDonald, W. M., Dressler, E. T., O'Connell, J. S., 18442.

MacDonald, W. M., Dressler, E. T., O'Connell, J. S., 18496.

MacFadyen, D. J., SP552, pp. 57-78 (July 1979).

Macfarlane, R. D., SP5 19, pp. 673-677 (Apr. 1979).

Machaelides, A., Hillel, R., Bouix, J., SP561/2, pp. 899-911 (Sept. 1979).

Machlan, L. A., Gramlich, J. W., Velapoldi, R. A., Paule, R. C., Schaffer, R., MANDEL, J., SP260-63.

Macias, E. S., Kumar, K. S., Hoffman, M. K., SP519, pp. 101107 (Apr. 1979).

MACKAY, D. R., SP552, pp. 79-93 (July 1979).

MACLEOD, W. D., JR., Brown, D. W., RAMOS, L. S., Friedman, A. J., SP519, pp. 161-167 (Apr. 1979).

Macleod, W. D., JR., Malins, D. C., Thomas, L. C., SP519, pp. 79-86 (Apr. 1979).

MACLeOD, W. D., JR., Ramos, L. S., Brown, D. W., Jenkins, R. G., SP519, pp. 713-718 (Apr. 1979).

Madey, T. E., Powell, C. J., Erickson, N. E., 18924.

Madey, T. E., Yates, J. T., JR., Fisher, G. B., 18791.

MAdY, N., SMIth, D., SMITh, J., WeZwick, C., SP519, pp. 341 343 (Apr. 1979).

Maeland, A., Glinka, C. J., Rowe, J. M., Libowitz, G. G., 19030.

Magat, W. A., Gianessi, L. P., Harrington, W., NBS-GCRETIP 79-63

Magette, T. E., Piety, K. R., SP547, pp. 203-231 (July 1979).

MAGID, L. M., SP400-58, p. 13 (Aug. 1979).

Magile, J., Scotti, A., Ohse, R. W., Babelot, J. F., CerCignani, L., Kinsman, P. R., Long, K. A., SP56I/1, pp. 83109 (Sept. 1979).

MahaJAN, B. M., Beine, W. B., NBSIR 79-I707. 
Maki, A. G., harmony, M. D., Laurie, V. W., Kuczkowski, R. L., Schwendeman, R. H., Ramsay, D. A., Lovas, F. J., LAFFERTY, W. J., JPCRD 8, No. 3, 619-722 (1979).

Malcolm, R. L., MacCarthy, P., SP519, pp. $789-792$ (Apr. 1979).

Malcolm, R. L., MacCarthy, P., SP519, pp. 793-796 (Apt. 1979).

Malins, D. C., Thomas, L. C., Macleod, W. D., JR., SP519, pp. 79-86 (Apr. 1979).

Malkin, S., Huerta, M., SP562, pp. 93-106 (Oct. 1979).

MALKIN, S., LeVINGeR, R., SP562, pp. 305-315 (Oct. 1979).

Mallard, W. G., Schenck, P. K., SMyth, K. C., Turk, G. C., 18983.

Mallard, W. G., Travis, J. C., Schenck, P. K., Turk, G. C., 18806.

Mallard, W. G., Travis, J. C., Smyth, K. C., Schenck, P. K., SP561/2, pp. 865-882 (Sept. 1979).

Mallard, W. G., Travis, J. C., Smyth, K. C., Schenck, P. K., 18344.

Maltese, M. D. K., Goodwin, K. E., Schleter, J. C., 18735.

Mamrak, S. A., SP500-52, pp. 37-52 (Oct. 1979).

Mamrak, S. A., Amer, P. D., SP500-44.

MANDAVA, N., SP519, pp. 803-807 (Apr. 1979).

Mandel, J., Machlan, L. A., Gramlich, J. W., Velapoldi, R. A., Paule, R. C., Schaffer, R., SP260-63.

Mandel, J., Murphy, T. J., Gramlich, J. W., Velapoldi, R. A., Paule, R. C., Schaffer, R., SP260-67.

Manenkov, A. A., Gorshkov, B. G., Epifanov, A. S., SP541, Pp. 299-302 (Dec. 1978).

Manenkov, A. A., Sidorin, A. V., Danileiko, Y. K., SP54I, pp. 305-308 (Dec. 1978 ).

Manfredi, R. R., Nielsen, L. S., Wyly, R. S., Benazzi, R. V., KONEN, T. P., SP553, pp. 35-51 (Aug. 1979).

Mango, S. A., Bohlin, J. D., Glackin, D. L., Linsky, J. L., 18922.

Mangum, B. W., Bowers, W. J., JR., 18556.

Mann, W. B., Cavallo, L. M., Golas, D. B., 18761 .

Mann, W. B., Matsumura, T., Noyce, J. R., Coursey, B. M., Hutchinson, J. M. R., Lucas, L. L., 18400.

Manney, C. M., Jr., Walls, F. L., Gray, J. E., Besson, R. J., STEIN, S. R., 18691 .

MANNing, J. R., NBSIR 79-1767.

Manning, J. R., Swartzendruber, L. J., Carter, G. C., KAhAN, D. J., READ, M. E., 18637.

Marchant, A. B., Gritton, S. M., SP5.47, pp. 17-30 (July 1979).

MARGOLIS, R. D., SP563, p. 174 (Oct. 1979).

Margrave, J. L., Hauge, R. H., SP561/1, pp. $495-509$ (Sept. 1979).

Margrave, J. L., hauge, R. H., Gransden, S. E., Kauffman, J. W., SP561/1, pp. 557-566 (Sept. 1979).

Margulis, S. T., NBSIR 79-1 793.

MArgulis, S. T., Archea, J., NBSIR 79-1906.

Marinenko, R. B., Heinrich, K. F. J., Ruegg, F. C., SP26065.

Marinenko, R. B., Heinrich, K. F. J., Ruegg, F. C., 18973.

MARKeY, S. P., LEWY, A. J., SP519, pp. 399-404 (Apr. 1979).

MARKMAN, H. M., SP552, pp. 225-247 (July 1979).

Marsden, C. P., NBSIR 78-1564.

Marshak, H., Soulen, R. J., JR., 18555.

Marshak, H., Turrell, B. G., 18604.

Marshall, H., Ruegg, R., Wyly, R., SP553, pp. 207-225 (Aug. 1979).

Marshall, H. E., Petersen, S. R., 18888.

Marshall, H. E., Ruegg, R. T., SP558.

Marshall, H. E., Ruegg, R. T., 19043.

Marshall, R. D., NBSIR 77-1289.

Martin, G. A., Wiese, W. L., 18736.

Martin, G. C., Jr., Spiegel, V., Eisenhauer, C. M., Grundl, J. A., 18883 .
Martin, G. M., Barnes, J. D., SP260-58.

Martin, G. M., McCrackin, F. L., Barnes, J. D., NBSIR 791768.

Martin, G. M., McCrackin, F. L., Barnes, J. D., 18639.

Martin, R. L., Davidson, E. R., KNiGht, L. B., JR., SP561/1, Pp. 545-555 (Sept. 1979).

Martin, W. C., 18995.

Martin, W. C., Zalubas, R., JPCRD 8, No. 3, 817-864 (1979).

MARTINEZ, I., SP552, pp. $45-56$ (July 1979).

MARTINEZ, I. M., NBSIR 79-1916.

Martinsen, D., Milne, G. W. A., hartman, K. N., Lias, S., Ausloos, P., Rosenstock, H. M., SCH royer, S. S., SCHMidT, C., NBSIR 79-1777.

MASCETTI, G., SP556, pp. 109-113 (Sept. 1979).

Mast, P. W., Beaubien, L. A., Mulville, D. R., Sutton, S. A., Thomas, R. W., Tirosh, J., Wolock, I., SP563, p. 241 (Oct. 1979).

Masters, L. W., Seiler, J. F., Roberts, W. E., 18554.

MAthew, M., Schroeder, L. W., 18448.

MATHEW, M., SChroeder, L. W., 18491 .

Mathews, D. E., Shoemaker, C. O., JR., Kilmer, R. D., CADOFF, M. A., 18607.

Matsumura, T., Noyce, J. R., Coursey, B. M., hutchinson, J. M. R., LuCAS, L. L., MANN, W. B., 18400.

Mattamal, G. J., Misra, D. N., Bowen, R. L., /841/.

Mattes, B. L., Stevenson, D. A., Dun, H., SP561/1, pp. 411 428 (Sept. 1979).

MatThyS, A. W., SP532, pp. 20-23 (Feb. 1979).

Mattingly, G. E., Miller, R. W., Davis, R. W., Moore, E. F., 18410 .

Matula, R. A., JPCRD 8, No. 4, $1147-1298$ (1979).

Mauer, F. A., Robbins, C. R., 18945.

MAXfield, B. W., Boyd, D. M., SP563, pp. $211-212$ (Oct. 1979).

MAXIM, D., SP534, pp. $51-55$ (May 1979).

Maximon, L. C., Olsen, H. A., 18370.

MAXimon, L. C., Olsen, H. A., 18532.

MAXWell, D. A., RusSell, T. J., SP400-51.

Maxwell, D. B., Reimann, C. T., Buehler, M. G., Russell, T. J., 18533.

Maxwell, W. B., Thompson, J. N., Hatina, G., SP519, pp. 279-288 (Apr. 1979).

MAY, W., Brown, J., SP556, pp. 39-44 (Sept. 1979).

May, W. E., Brown, J. M., Chesler, S. N., Guenther, F., Hilpert, L. R., HertZ, H. S., WiSe, S. A., SP519, pp. 219. 224 (Apr. 1979).

Maynard, V., Brady, J. K., Frizzell, L. A., O'Brien, W. D., JR., Dunn, F., Johnston, R. L., Goss, S. A., SP525, pp. 1927 (Apr. 1979).

Maynard, V., Nider, L., Frizzell, L. A., O'Brien, W. D., Jr., Dunn, F., Goss, S. A., Johnston, R. L., SP525, pp. 43-51 (Apr. 1979).

MAYO, S., Evans, W. H., NBSIR 78-1558.

Mayo, S., Myers, D. R., RoItMan, P., 18623.

Mayo-Wells, J. F., Roth, S. C., Edelman, S., Kenney, J. M., SP547, pp. 303-314 (July 1979).

Mayo-Wells, J. F., Vezzett, C. F., Hilten, J. S., Lederer, P. S., NBSIR 78-1590 (NASA).

MAZZA, H. F., SP543, pp. 53-54 (Apr. 1979).

McAuliff, R. C., Lentner, K. J., MoOre, W. J. M., Schuster, G., 18529 .

MCCAFFREY, B. J., NBSIR 79-1910.

MCCall, R. C., Swanson, W. P., SP554, pp. $75-86$ (Sept. 1979).

MCCann, K. J., Flannery, M. R., 18389.

MCCANn, K. J., Flannery, M. R., 18446 .

MCCANn, K. J., Flannery, M. R., 18473. 
McCarthy, E., SMith, J., Brozowski, G., Burkitt, D. Gabriel, M., Hanrahan, J., SP519, pp. $175-179$ (Apr. 1979).

MCCARTY, R. D., HAYNES, W. M., 18775.

McClintock, W., Robertson, R. M., Linsky, J. L., Worden, S. P., 18853.

McClintock, W., Worden, S. P., Schneeberger, T. J., LiNSKY, J. L., 18920.

McCoubrey, A. O., SP532, pp. 48-54 (Feb. 1979).

McCoy, L. G., Hassler, C. R., Messing, G. L., SP562, pp. 247-254 (Oct. 1979).

MCCrackin, F. L., 18530.

McCrackin, F. L., Barnes, J. D., Martin, G. M., NBSIR 79. 1768.

McCrackin, F. L., Barnes, J. D., Martin, G. M., 18639.

McCrackin, F. L., HAN, C. C., 18511 .

McCune, S., Schaffer, R., Howell, B. F., 18433.

McDaniel, M. A., Bickman, L., Edelman, P., Herz, E., NBSGCR-78-135.

McDonald, D. G., Peterson, R. L., U.S. Patent 4,168,441.

McDonald, J. R., Baronavski, A. P., Pasternack, L., Lamont, S., Harvey, A. B., SP561/2, pp. 817-831 (Sept. 1979).

McEAChron, N. B., HALL, D. C., LEwIS, L. F., NBS-GCR-ETIP 78.51 .

McEAChron, N. B., HALl, D. C., LEWIS, L. F., NBS-GCR-ETIP 78.52.

McEachron, N. B., Javitz, H. S., Green, D. S., Logsdon, J. D., Milbergs, E., NBS-GCR-ETIP 78-57.

McEachron, N. B., Javitz, H. S., Green, D. S., Logsdon, J. D., Milbergs, E., NBS-GCR-ETIP 78-58.

McEachron, N. B., Javitz, H. S., Green, D. S., Logsdon, J. D., Milbergs, E., NBS-GCR-ETIP 78-58A.

MCEACHRON, N. B., WoodWARD, E. G., NBS-GCR-ETIP 78-50. McElroy, F. C., SeArl, T. D., Brown, R. A., SPS 19, pp. 7 18 (Apr. 1979).

McElroy, W. N., Doran, D. G., Gold, R., Lippincott, E. P., Schiffgens, J. O., Simons, R. L., Morgan, W. C., Grundl, J. A., McGarry, E. D., Kam, F. B. K., SWANK, J. H., OdeTte, G. R., 19012.

McElroy, W. N., Grundl, J. A., Debrue, J., Rahn, F. J., SerPAN, C. Z., FABRY, A., 19014.

McElroy, W. N., Lippincott, E. P., FAbry, A., Grundl, J. A., 19013.

MCEWEN, H., FIPS PUB 58.

MCEWEN, H., FIPS PUB 59.

MCEWEN, H., FIPS PUB 66.

MCGARRY, E. D., KaM, F. B. K., SWank, J. H., OdetTe, G. R., McElroy, W. N., Doran, D. G., Gold, R., Lippincott, E. P., Schiffgens, J. O., Simons, R. L., Morgan, W. C., Grundl, J. A., 19012 .

McGaughey, J. F., Sykes, A. L., Denyszyn, R. B., Harden, J. M., HARdison, D. L., SP519, pp. 153-159 (Apr. 1979).

McGehan, F. P., 18817 .

McGinley, P. H., Sohrabi, M., SP554, pp. 99-107 (Sept. 1979).

McGogney, C., Kaiserlik, J., Berger, H., 18525.

McGraw, C. P., Barnes, R. W., Kremkau, F. W., SP525, pp. 81-84 (Apr. 1979).

MCHENRY, H. I., 18802 .

Mchenry, H. I., Naranjo, S. E., Read, D. T., Reed, R. P., 18610.

MCHenRy, H. I., ReAD, D. T., Begley, J. A., 18612 .

MCHenRy, H. I., ReED, R. P., TOBleR, R. L., $1862 \mathrm{I}$.

McIlrath, T. J., Mehlman, G., Lucatorto, T. B., $/ 8811$.

McIlrath, T. J., Roberts, J. R., Lucatorto, T. B., 18808.

McIlrath, T. J., Weiss, A. W., Sugar, J., Lucatorto, T. B., 18507.

MClNTYRe, P. A., Chen, M., SP519, pp. 257-265 (Apr. 1979).

MCKenna, G. B., PEnN, R. W., NBSIR 79-1741.
MCKINNEY, K. R., Wu, C. C., SP562, pp. 477-481 (Oct. 1979).

MCLAIN, W. H., SP536, pp. 63-74 (Feb. 1979).

MCLeVige, W. V., SP400-58, pp. 95-101 (Aug. 1979).

McMichael, J. M., Cleveland, W. G., NBSIR 78-1505.

McMurdie, H. F., Evans, E. H., Paretzkin, B., de Groot, J.

H., Hubbard, C. R., Carmel, S. J., Morris, M. C., Monogr. 25 , Section 16.

MCNAIR, H. M., SP519, pp. $541-546$ (Apr. 1979).

McNall, P. E., Kusuda, T., Hunt, C. M., 18587.

MCNALL, P. E., JR., 18596.

MCNeECE, J. E., SPSOO-52, Pp. 113-120 (Oct. 1979).

McNeil, J. R., Johnson, W. L., Collins, G. J., Persson, K. B., Franzen, D. L., 18319.

MEADOWS, D., SP534, pp. 45-50 (May 1979).

Meakin, J. D., Phillips, J. E., SP400-58, pp. 17-29 (Aug. 1979).

Mecholsky, J. J., JR., Rice, R. W., SP562, pp. $351-378$ (Oct. 1979).

Medvedev, V. A., Kil.day, M. V., Efimov, M. E., Klevaichuk, G. N., J. Res. 84, No. 4, 273-286 (1979).

Mehlman, G., Ederer, D. L., Lucatorto, T. B., 18912.

Mehlman, G., Lucatorto, T. B., Mcilrath, T. J., 18811 .

Meier, G. H., Gulbransen, E. A., SP561/2, pp. 1639-1682 (Sept. 1979).

Meierhoefer, A. W., Braun, E., Krasny, J. F., Peacock, R. D., NBSIR 79-1755.

Meister, F. A., SP527, pp. 83-86 (Feb. 1979).

Melin, J. W., TAVIS, R. L., SP552, pp. 249-266 (July 1979).

Melton, L. A., SP561/1, pp. 153-166 (Sept. 1979).

Menzel, D., Klein, R., Greiner, G., 18810 .

Merritt, M. E., Simmons, K., LaFaucia, R., Limentani, G., Washburn, D. N., Siggia, S., Kostyla, R. J., Mourey, T. H., Cohen, R., SP519, pp. 783-787 (Apr. 1979).

Meshkov, S., 19010.

Meshkov, S., Fishbane, P. M., HoRn, D., 18432.

Messing, G. L., McCoy, L. G., Hassler, C. R., SP562, pp 247-254 (Oct. 1979).

Metcalfe, L., Toy, H. D., Parris, G. E., Sherman; P. L., KeMMER, A. M., SPS 19, pp. 205-212 (Apr. 1979).

Metreweli, C., Plessner, N. J., Willson, K., Gore, J. C., LeEMAN, S., SP525, pp. 275-280 (Apr. 1979).

Meyer, F. C., Rollenhagen, D. C., Schoenwetter, H. K., SOUders, T. M., TEWKsBury, S. K., 18365.

Michaelis, R. E., Cumbo, J. E., 18414.

Michalak, J. L., Stiehle R, R. D., NBSIR 79-1917.

Michelson, P. F., SOulen, R. J., JR., Giffard, R. P., 18663

Mielenz, K. D., 18403.

Mies, F. H., Krauss, M., 18936.

Mighell, A. D., Himes, V. L., Hubbard, C. R., 18347.

Mighell, A. D., Hubbar d, C. R., Cohen, A., 18672.

Mighell, A. D., Hubbard, C. R., Harris, J., Staffa, J. A., ZERVOS, C., 18673.

Mighell, A. D., Hubbard, C. R., Stalick, J. K., Siedle, A. R., 18636.

Mikac-Dadic, V., Pravdic, V., Haller, W., Jednacak-Biscan, J., 18910 .

Mikucki, W., Staton, W., Williams, G., Konen, T. P., LiPoski, F., MYerS, J. R., Nielsen, L., SP553, pp. 15-19 (Aug. 1979).

MILAM, D., SP541, pp. 164-167 (Dec. 1978).

Milam, D., Carniglia, C. K., Apfel, J. H., Carrier, G. B. SP541, pp. $218-225$ (Dec. 1978).

Milam, D., Weber, M. J., Stokowski, S. E., SP54I, pp. 99-108 (Dec. 1978).

Milbergs, E., McEachron, N. B., Javitz, H. S., Green, D. S., LOGSDON, J. D., NBS-GCR-ETIP 78-57.

Milbergs, E., McEachron, N. B., Javitz, H. S., Green, D. S., LOGSDON, J. D., NBS-GCR-ETIP 78-58.

Milbergs, E., McEachron, N. B., Javitz, H. S., Green, D. S., LOGSDON, J. D., NBS-GCR-ETIP 78-58A. 
Miles, P., Gentilman, R., Cooke, F., SP562, pp. 255-260 (Oct. 1979).

Miller, C. K. S., SP532, pp. 1-12 (Feb. 1979).

Miller, C. K. S., 18320.

Miller, D. A., Grimsrud, E. P., SP519, pp. 143-151 (Apr. 1979).

Miller, E. B., Eitzen, D. G., 18438 .

Milleq, F.o SP561/l, pp. 39-65 (Sept. 1979).

Miller, G. H., Mulac, A. J., Hargis, P. J., JR., SP561/2, pp. 1135-1151 (Sept. 1979).

Miller, G. R., Paquette, D. G., NSRDS-NBS6I, Parl III.

Miller, J. G., O'Donnell, M., SP525, pp. 37-40 (Apr. 1979).

Miller, J. G., O'Donnell, M., Mimbs, J. W., Sobel, B. E., SP525, pp. 63-71 (Apr. 1979).

Miller, R. A., Stearns, C. A., Kohl, F. J., Fryburg, G. C., SP561/l, pp. 303-354 (Sept. 1979).

Miller, R. C., Kidnay, A. J., Hiza, M. J., JPCRD 8, No. 3, 799-816 (1979).

Miller, R. W., SP532, pp. 24-28 (Feb. 1979).

Miller, R. W., Davis, R. W., Moore, E. F., Mattingly, G. E., 18410 .

Miller, W. J., SP561/1, pp. 443-456 (Sept. 1979).

Millet, M. S., Bedrick, J. R., Spencer, G. S., Varey, G. B., SPS52, pp. 321-335 (July 1979).

Mills, R., Velapoldi, R. A., 18492.

Milne, G. W. A., hartman, K. N., lias, S., Ausloos, P., Rosenstock, H. M., Schroyer, S. S., Schmidt, C., MartinSEN, D., NBSIR 79-1777.

Milne, T. A., Greene, F. T., Beachey, J. E., SP56 I/1, pp. 431 442 (Sept. 1979).

Milton, H. J., 18493.

Mimes, J. W., Sobel, B. E., Miller, J. G., O'Donnell, M., SP525, pp. 63-71 (Apr. 1979).

Mindrup, R., JR., SP519; pp. 225-229 (Apr. 1979).

Minor, D., SANTORO, A., Roth, R. S., 19037.

Misakian, M., Hebner, R. E., JR., 18819 .

Misakian, M., Kotter, F. R., 18494.

Misra, D. N., J. Res. 84, No. 5, 395-406 (1979).

MisRA, D. N., Bowen, R. L., 18972.

Miska, D. N., Bowen, R. L., Mattamal, G. J., 18411 .

Mitchell, D. J., Cohen, J., Domalski, E. S., Abramowitz, S., KIRILLIN, D. R., NBSIR 78-1494.

Mitchell, M. A., Sutula, R. A., Holden, J. R., Bennett, L. H., WANG, F. E., 18382 .

Miyade, E., Adachi, S., Harada, S., Izumitani, T., SP562, pp. 417-425 (Oct. 1979).

MiYama, J.。SP540, D. 713 (Nov. 1979).

MiYama, J., WaTANabe, A., SP5 40, pp. $46-53$ (Nov. 1979).

Mohler, M. B., Hellwig, H. W., Wineland, D. J., Howe, D. A., 18698 .

Moldover, M. R., Sengers, J. V., 18457.

Moldover, M. R., Sengers, J. V., Gammon, R. W., Hocken, R. J., 18541 .

Molino, B. B., Hilsenrath, J., 18597.

Moncrief, W. C., Barbour, R. E., Jr., Holcombe, J. O., HarRIS, C. S., SP500-52, pp. 25-36 (.Oct. 1979).

Montalvo, J. G., JR., SP519, pp. $747-752$ (Apr. 1979).

Montgomery, J. P., Chang, D. C., Monogr. 164.

MontoR, K., AFDAhL, D., SP480-38, Pp. $75-80$ (Dec. 1979).

MoOdy, R. C., KNAB, L. I., 18887 .

Moody, S., Pearlman, M. R., Silverberg, E. C., Bender, P. L., Faller, J. E., Levine, J., 18459.

Moody, S. E., LeVine, J., 18816.

MOORE, C. E., NSRDS-NBS3, Section 8.

Moore, E. F., Mattingly, G. E., Miller, R. W., Davis, R. W., 18410 .

Moore, R. T., Carpenter, R. J., Holt, A. W., Koenig, A. L., WARNAR, R. B. J., NBSIR 79-1725.

Moore, W. J. M., Anderson, W. E., Davis, R. S., Petersons, O., 18513 .
Moore, W. J. M., Schuster, G., McAuliff, R. C., Lentner, K. J., 18529 .

Moos, H. W., Linsky, J. L., Anderson, R. C., Henry, R. C., 18753.

Mopsik, F. 1., Khoury, F., Kryder, S. J., Bolz, L. H., 18713.

Moravec, T. J., Skogman, R. A., SP541, pp. 259-265 (Dec. 1978).

MORDFIN, L., BERGER, H., NBSIR 78-1581.

Morehouse, R. J., BURRis, B. L., SP305. Supplement 10.

Morgan, W. C., Grundl, J. A., McGarry, E. D., Kam, F. B. K., Swank, J. H., Odette, G. R., McElroy, W. N., Doran, D. G., Gold, R., Lippincotr, E. P., Schiffgens, J. O., Simons, R. L., 19012 .

Morgan, W. L., Woodruff, J. J., Dougherty, H. T., Estin, A. J., 18628 .

Morishita, Y., SP540, pp. 356-381 (Nov. 1979).

MORISHITA, Y., KAWAGOE, K., SP540, pp. 148-161 (Nov. 1979).

Moriwaki, T., Suzuki, M., INOMata, T., OKaZaKi, S., SP561/2, pp. 1327-1337 (Sept. 1979).

Morris, M. C., McMurdie, h. F., Evans, E. H., Paretzkin, B., de Groot, J. H., Hubbard, C. R., Carmel, S. J., Monogr. 25, Section 16.

Morrow, A. J., Radebaugh, R., Lawless, W. N., Siegwarth, J. D., 18680 .

Moscati, G., Wolynec, E., Dodge, W. R., Hayward, E., 18518.

Mosselman, C., Churney, K. L., 18803.

Motz, J. W., Dick, C. E., Soares, C. G., 18441 .

Mountain, R. D., 18674.

Mountain, R. D., HaAn, S. W., J. Res. 84, No. 6, 439-446 (1979).

Mountford, R. A., Skidmore, R., Web b, A. J., Woodcock, J. P., Wells, P. N. T., Halliwell, M., SP525, pp. 173-176 (Apr. 1979).

Mourey, T. H., Cohen, R., Merritt, M. E., Simmons, K., LaFaucia, R., Limentani, G., Washburn, D. N., Siggia, S., KosTYLA, R. J., SPS19, pp. $783-787$ (Apr. 1979).

Mozer, B., Yu, H., Hinkley, J. A., Han, C. C., 18827.

Mueller, B. A., StormS, E. K., SP561/1, pp. 143-151 (Sept. 1979).

Mueller, B. H., Fries, J. A., Cater, E. D., SP561/1, pp. 237 262 (Sept. 1979).

Mukherjee, A., Jain, A. K., Ketchledge, B. A., SP500-52, pp. 89-104 (Oct. 1979).

Mulac, A. J., Hargis, P. J., JR., Miller, G. H., SP561/2, pp. 1135-1151 (Sept. 1979).

Mulholland, G. W., Bukowski, R. W., SP540, pp. 1.45 (Nov. 1979).

Mullen, J. L., Bertocci, U., 18725.

MUllen, J. L., BerTOCCI, U., 18756.

Muller, C. H. III., Schofield, K., Steinberg, M., SP561/2, pp. 855-864 (Sept. 1979)

Muller, J., Waterstrat, R. M., Haenssler, F., 18734.

Mulroy, W. J., Kelly, G. E., Park, C., TN999.

MulveY, J., SP534, pp. 177-193 (May 1979).

Mulville, D. R., Sutton, S. A., Thomas, $\mathbb{R}$. W., Tirosh, J., Wolock, I., MASt, P. W., BEAubien, L. A., SP563, p. 241 (Oct. 1979).

MuRat, K., KATRiel, J., 18592.

Murphy, R. M., Tomkins, R. P. T., Janz, G. J., Allen, C. B., Bansal, N. P., NSRDS-NBS6l, Part II.

Murphy, T. J., Gramlich, J. W., Velapoldi, R. A., Paule, R. C., SChaffer, R., MAN del, J., SP260-67.

Murray, A. E., UtTerback, J. M., NBS-GCR-ETIP 78-49.

Murray, J. P., SP551, pp. 23-26 (July 1979).

Myers, D. R., LiU, Y. M., Dietrich, H. B., Koyama, R. Y., Phillips, W. E., 18458 .

Myers, D. R., RoITMAN, P., Mayo, S., I 8623. 
Myers, J. R., Nielsen, L., Mikucki, W., Staton, W., WilLiAMS, G., Konen, T. P., Liposki, F., SP553, pp. 15-19 (Aug. 1979).

Myklebust, R. L., FIORI, C. E., HeINRICH, K. F. J., TNI 106.

MyKLebust, R. L., NewBury, D. E., 18589.

Myklebust, R. L.. Newbury, D. E., 18970.

Myklebust, R. L., Newbury, D. E., 18978.

Myklebust, R. L., Small, J. A., Newbury, D. E., 18976.

\section{$\mathbf{N}$}

Naegele, D., Yoon, D. Y., Broadhurst, M. G., 18531 .

Nagashima, T., Kaneko, K., Yamamura, T., Takahashi, Y., Suzuki, H., Salto, F., Handa, T., SUda, K., SP540, pp. 626711 (Nov. 1979).

NAGEL, R. N., VANDERBrUg, G. J., NBSIR 79-1764.

Nahman, N. S., Allred, C. M., Andrews, J. R., Hoer, C. A., LAWTON, R. A., NBSIR 79-1613.

Nahman, N. S., Bagozzi, R. P., IVES, W. R., 18723.

NaKamURA, K., Kishitani, K., SP540, pp. 485.519 (Nov. 1979).

Naranjo, S. E., Read, D. T., Reed, R. P., McHenry, H. I., 18610.

Nash, H. C., Poranski, C. F., JR., Ting, R. Y., SP563, pp. 17-21 (Oct. 1979).

Nasoni, R. L., Pifer, A. E., Sholes, R. R., Bowen, T., ConNOR, W. G., SP525, pp. 57-61 (Apr. 1979).

Nath, R., Price, K. W., Holeman, G. R., SP554, pp. 87.97 (Sept. 1979).

NATRELla, M. G., 18440 .

NAY, J. N., Frederick, W., NBS-GCR-ETIP 79-65.

NAY, J. N., WALLER, J., NBS-GCR-ETIP 79-64.

Neel, E. M., Debbrecht, F. J., Daugherty, D. T., SP5/9, pp. 761-769 (Apr. 1979).

Neiman, D. C., Abrams, M. D., SP500-52, pp. 201-211 (Oct. 1979).

Nelson, H. E., SP540, pp. $138-147$ (Nov. 1979).

Nelson, H. E., SP549, pp. 85-102 (Aug. 1979).

Nelson, H. E., Shibe, A. J., NBSIR 78-1555.

NESHEIM, S., SP519, pp. 355-372 (Apr. 1979).

NetA, P., Ross, A. B., NSRDS-NBS65.

Neumann, D., Krauss, M., 18934.

Neumann, D. B., Krauss, M., 18933.

Neumann, D. B., Krauss, M., 18935.

NeWBURY, D. E., 18568.

NeWBURY, D. E., 18979.

Newbury, D. E., Doty, S. B., Casciani, F. S., Etz, E. S., 19008.

Newbury, D. E., FIori, C. E., 18790.

Newbury, D. E., Myklebust, R. L., 18589.

Newbury, D. E., Myklebust, R. L., 18970 .

Newbury, D. E., MYklebust, R. L., Small, J. A., 18976.

Newbury, D. E., Myklebust, R. L., 18978.

Newman, W. R., Amsel, L. P., Giering, J. E., Leaders, .F. E., Jr., O'Brien, J. E., Hinsvark, O. N., SP519, pp. 481-485 (Apr. 1979).

Newnam, B. E., Gill, D. H., SP54I, pp. $190-202$ (Dec. 1978).

NiCastro, J. R., Woolson, B., Glancy, J., SP480-38, pp. 2328 (Dec. 1979).

Nicodemus, F. E., TN910-4.

Nider, L., Frizzell, L. A., O'Brien, W. D., Jr., Dunn, F., Goss, S. A., Johnston, R. L., MaYnaRd, V., SP525, pp. 4351 (Apr. 1979).

Nielsen, L., Mikucki, W., Staton, W., Williams, G., Konen, T. P., Liposki, F., Myers, J. R., SP553, pp. 1 5-19 (Aug. 1979).

Nielsen, L. S., Orloski, M. J., Wyly, R. S., Galowin, L. S., Downing, W. J., SP553, pp. 53-70 (Aug. 1979).

Nielsen, L. S., Wyly, R. S., Benazzi, R. V., Konen, T. P., MANFREd, R. R., SP553, pp. 35-51 (Aug. 1979).
Nielsen, P. E., Walker, T. W., Guenther, A. H., SP541, pp. 226-234 (Dec. 1978).

NiELSEN, V., SP553, pp. 175-192 (Aug. 1979).

Nielsen, V., Hanslin, R., Webster, C. D. J., SP553, pp. 109128 (Aug. 1979).

Nikı, H., SP557, pp. 7-14 (Aug. 1979).

Nolan, R., Weinstein, S., Weinstein, C., SP480-38, pp. 7-16 (Dec. 1979).

Nonnemaker, K. A., Cotter, R. L., Edwards, R. W., SP519, pp. 87.94 (Apr. 1979).

Norcross, D. W., 18923.

Norcross, D. W., Schmid, G. B., Collins, L. A., 18516.

Norton, S. J., Higgins, F. P., Dietz, D. R., Shideler, R. W., Shawker, T. H., Doppman, J. L., Linzer, M., Parks, S. I., SP525, pp. 255-259 (Apr. 1979).

Noton, B. R., Shunk, D. L., SP563, pp. $226-227$ (Oct. 1979).

NovaK, J., Janak, J., Golias, J., SP519, pp. $739-746$ (Apr. 1979).

November, L. J., Toomre, J., Gebbie, K. B., Simon, G. W., I 8444 .

NovotnY, M., SP519, pp. 487.499 (Apr. 1979).

Novotny, M., Smith, S. L., Jorgenson, J. W., SP519, pp. 429 436 (Apr. 1979).

Noyce, J. R., Coursey, B. M., Hutchinson, J. M. R., Lucas, L. L., MANN, W. B., Matsumura, T., 18400.

NTIForo, A. O., SP543, pp. $148-149$ (Apr. 1979).

NUTT, G. J., SP500-42.

Nuttall, R. L., Staples, B. R., Goldberg, R. N., JPCRD 8, No. 4, 923-1004 (1979).

NYYSSONEN, D., 18356.

NYYSSONEN, D., JERKE, J. M., 18629.

\section{O}

Obara, A., Imanaka, O., Yasunaga, N., Tarumi, N., SP562, pp. $171-182$ (Oct. 1979).

O'Brien, D. A., Herakovich, C. T., SP563, pp. $242-254$ (Oct. 1979).

O'Brien, J. E., Hinsvark, O. N., Newman, W. R., Amsel, L. P., Giering, J. E., Leaders, F. E., JR., SP519, pp. 481-485 (Apr. 1979).

O'Brien, W. D., JR., Dunn, F., Goss, S. A., Johnston, R. L., Maynard, V., Nider, L., Frizzell, L. A., SP525, pp. 43-51 (Apr. 1979).

O'Brien, W. D., Jr., Dunn, F., Johnston, R. L., Goss, S. A., Maynard, V., Brady, J. K., Frizzell, L. A., SP525, pp. 1927 (Apr. 1979).

O'Connell, J. S., 18495.

o'Connell, J. S., Mac Donald, W. M., Dressler, E. T., 18442 .

O'Connell, J. S., MacDonald, W. M., Dressler, E. T., 18496.

O'Connell, J. S., SCHOCH, B., 18675.

Odar, P. M., Peiser, H. S., Raley, C. C., NBSIR 78-1712.

Odette, G. R., McElroy, W. N., Doran, D. G., Gold, R., Lippincott, E. P., Schiffgens, J. O., Simons, R. L., MorGan, W. C., Grunde, J. A., MCGarky, E. D., Kam, F. B. K., SWANK, J. H., 19012 .

Odintzova, G. A., Striganov, A. R., JPCRD 8, No. 1, 63-68 (1979).

O'Donnell, M., Miller, J. G., SP525, pp. $37-40$ (Apr. 1979).

O'Donnell, M., Mimbs, J. W., Sobel, B. E., Miller, J. G., SP525, pp. 63-71 (Apr. 1979).

Oettinger, F. F., NBSIR 79-1756.

Oettinger, F. F., Rubin, S., SP400-I4.

Offensend, F. L., Helzer, S. G., Buchi Inder, B., TN1 101.

Ogburn, F., Young, J. P., Ballard, D. B., U.S. Palent 4,139,933.

OGden, J. S., SP561/1, pp. $511-520$ (Sept. 1979). 
O'Haver, T. C., Turk, G. C., Travis, J. C., DeVoe, J. R., 18880.

Ohmer, M. C., Stoebe, T. G., Vora, H., SP541, pp. 24-32 (Dec. 1978).

Ohse, R. W., Babelot, J. F., Cercignani, L., Kinsman, P. R., LoNG, K. A., MAgill, J., Scottl, A., SP56//1, pp. 83-109 (Sept. 1979).

Ojha, H. D., Renda, T. V., Harrison, J. E., Perwak, J. H., NBS-GCR-ETIP 79-7I.

OKazakı, S., Moriwakı, T., Suzuki, M., Inomata, T., SP561/2, pp. 1327-1337 (Sept. 1979).

OKUTOM1, M., ImanaKa, O., SP562, pp. $157-169$ (Oct. 1979).

Oldham, N. M., Turgel, R. S., 18434.

Olechno, J., Sucre, L., Jennings, W., Fisher, G. L., RaAbe, O. G., SP519, pp. 109-120 (Apr. 1979).

Olien, N. A., 19022.

Oliver, J. H., Krause, M. O., JPCRD 8, No. 2, 329-338 (1979).

Olmert, K. M., Raufaste, N. J., JR., 18429.

OLMERT, M., SP439-I.

Olmert, M., Kramer, S., NBSIR 79-1792.

Olmert, M., Raufaste, N., SP446-2.

Olsen, H. A., MAXIMON, L. C., 18370 .

Olsen, H. A., Maximon, L. C., 18532.

Olsen, P. T., Williams, E. R., 18437.

Olsen, P. T., Williams, E. R., 18702 .

Olson, C. D., Cook, L. P., Farabaugh, E. N., SP562, pp. 407 415 (Oct. 1979).

Olsson, E., SP553, pp. 137-159 (Aug. 1979).

Olszewski, E. W., Wallerstein, G., Harris, H., 18913.

OMenetto, N., Haraguchi, H., Winefordner, J. D., Bradshaw, J., Bower, J., WeEks, S., Fujiwara, K., SPS6I/2, pp. 1079-1102 (Sept. 1979).

ONDREJKA, A. R., LAWTON, R. A., TN1008.

ONEIL, S. V., EBERLy, J. H., $/ 8893$.

O'NelLL, J. G., NBSIR 78-1571.

O'Neill, J. G., Hayes, W. D., JR., NBSIR 79-1749.

Orend, R., Wyly, R. S., Konen, T. P., Benazzi, R. V., Guss, L., SP553, pp. 3-13 (Aug. 1979).

Orend, R. J., Pavel, H. J., Williams, G. H., Fowell, A. J., Bransdorfer, A., Fletcher, P., SP553, pp. $21-31$ (Aug. 1979).

Orloski, M. J., Wyly, R. S., Galowin, L. S., Downing, W. J., Nielsen, L. S., SP553, pp. 53-70 (Aug. 1979).

OrLovskil, V. P., SP561/2, pp. 1497-1506 (Sept. 1979).

OSTERBERG, A. E., SP552, pp. 95-100 (July 1979).

Ostrovskil, V. N., Demkov, Y. N., Kunasz, C. V., 18576.

Ostrovskil, V. N., Solov'ev, E. A., Demkov, Y. N., 18575.

OVerbo, I., HubBell, J. H., JPCRD 8, No. 1, 69-106 (1979).

OVERBOE, C. J., WANG, Y. Y., NBS-GCR-79-167.

OVESEN, K., SP553, pp. 81-88 (Aug. 1979).

OWINO-OKWERO, J. E., SP543, pp. 94-98 (Apr. 1979).

Oye, H. A., Gruen, D. M., SP561/2, pp. 1517-1537 (Sept. 1979).

Ozin, G. A., Klotzbucher, W. E., SP561/1, pp. 567-585 (Sept. 1979 ).

\section{$\mathbf{P}$}

PaAbo, M., Birky, M. M., Womble, S. E., 18588 .

Paffentarger, G. C., 18497.

Paffentarger, G. C., 18676.

Paffenbarger, G. C., Rupp, N. W., Patel, P. R., 18586.

Paffenbarger, G. C., Rupp, N. W., Patel, P. R., 18729.

PALla, R. L., JR., NBSIR 79-1770.

Pan, J. D., Balluffi, R. W., Cahn, J. W., 18759.

Papatheodorou, G. N., SP561/I, pp. 647-678 (Sept. 1979).

Pappis, J., Klein, C., diBenedetto, B., Donadio, R., Kohane, T., SP541, pp. 86-97 (Dec. 1978).

Paquette, D. G., Miller, G. R., NSRDS-NBS6I, Part 11 .
Paretzke, H. G., Berger, M. J., 18659.

Paretzkin, B., de Groot, J. H., Hubbard, C. R., Carmel, S. J., Morris, M. C., McMurdie, H. F., Evans, E. H., Monogr. 25, Section 16.

Park, C., Mulroy, W. J., Kelly, G. E., TN999.

Park, D. L., Pohland, A. E., SP519, pp. 321 -331 (Apr. 1979).

Parker, W. J., Lee, B. T., NBSIR 79-1700.

Parker, W. J., LeE, B. T., NBSIR 79-17/4.

Parkinson, D. B., Filly, R. A., Busey, H., Edmonds, P. D., REYes, Z., SP525, pp. 323-326 (Apr. 1979).

PARKs, E. J., WILSON, W. K., 19017.

Parks, S. I., Norton, S. J., Higgins, F. P., Dietz, D. R., Shideler, R. W., Shawker, T. H., Doppman, J. L., Linzer, M., SP525, pp. 255-259 (Apr. 1979).

Parmenter, C. S., AtKinson, G. H., 18747.

Parmenter, C. S., AtKinson, G. H., 18749.

Parmenter, C. S., Atkinson, G. H., 18750.

Parmenter, C. S., Lin, H. M., Seaver, M., Tang, K. Y., KNIGHt, A. E. W., 18671 .

Parmenter, C. S., Seaver, M., 18677.

Parmenter, C. S., Tang, K. Y., Atkinson, G. H., $1864 I$.

Parris, G. E., Sherman, P. L., Kemmer, A. M., Metcalfe, L., TOY, H. D., SP519, pp. 205-212 (Apr. 1979).

Parrish, W. R., Arvidson, J. M., LaBrecque, J. F., NBSIR 78-887.

Parrish, W. R., Arvidson, J. M., LaBrecque, J. F., 18395.

Parrish, W. R., Brennan, J. A., Siegwarth, J. D., 18396.

PARRISH, W. R., HORD, J., 18812.

PARry, R. J., Chivers, R. C., SP525, pp. 343-360 (Apr. 1979).

Pasachoff, J. M., Linsky, J. L., Haisch, B. M., Boggess, A., 18606.

Pasternack, L., Lamont, S., Harvey, A. B., McDonald, J. R., BaronaVsKI, A. P., SP561/2, pp. 817-831.(Sept. 1979).

Pastor, R. C., harrington, J. A., Gorre, L. E., Chew, R. K., SP541, pp. 249-256 (Dec. 1978).

Patel, P. R., Paffenbarger, G. C., Rupp, N. W., 18586.

Patel, P. R., Paffenbarger, G. C., Rupp, N. W., 18729.

PatnalK, P. R., KudchadKer, A. P., KudchadKer, S. A., SHUKLA, R. P., JPCRD 8, No. 2, 499-5 18 (1979).

Patrick, B. H., Carlson, A. D., 18581 .

Patrick, B. H., Hayward, E., Dodge, W. R., 18522.

Patterson, C. W., Galbraith, H. W., Harter, W. G., 18599.

Patterson, C. W., Galbraith, H. W., Krohn, B. J., Harter, W. G., 18921 .

Patterson, C. W., harter; W. G., 18609.

Patterson, C. W., Harter, W. G., 18706.

Patterson, C. W., Harter, W. G., Galbraith, H. W., 18598.

Pattoret, A., Chatillon, C., Allibert, M., SP561/1, pp. 181 210 (Sept. 1979).

Paul, A. W., Krauss, J., SP55I, pp. 7-9 (July 1979).

Paule, R. C., Schaffer, R., Mandel, J., Machlan, L. A., Gramlich, J. W., Vela poldi, R. A., SP260-63.

Paule, R. C., Schaffer, R., Mandel, J., Murphy, T. J., GramLiCh, J. W., Velapoldi, R. A., SP260-67.

Pavel, H. J., Williams, G. H., Fowell, A. J., Bransdorfer, A., Fletcher, P., Orend, R. J., SP553, pp. 21-31 (Aug. 1979).

Peacock, R., krasny, J. F., Braun, E., 18991.

PEACOCK, R. D., NBSIR 78-1586.

PEACOCK, R. D., NBSIR 79-173l.

PEACOCK, R. D., 18537.

PeAcock, R. D., SMIth, J., TNII08.

Peacock, R. D., Meierhoefer, A. W., Braun, E., Krasny, J. F., NBSIR 79-1755.

Peacock, R. D., Stratton, A., Braun, E., Krasny, J. F., 18708 .

Pearlman, M. R., Silverberg, E. C., Bender, P. L., Faller, J. E., LeVine, J., MOODY, S., 18459.

PeAvy, B. A., SP548, pp. 119-149 (July 1979).

Peavy, B. A., 18339. 
Peavy, S. T., Hogben, D., 18954.

PEDALL, R., SP556, pp. $171-173$ (Sept. 1979).

PEISER, H. S., SP539, p. 17 (Apr. 1979).

Peiser, H. S., SP539, pp. 19-22 (Apr. 1979).

Peiser, H. S., Raley, C. C., Odar, P. M., NBSIR 78-1712.

Peiser, H. S., Raley, C. C., Tholen, A. D., NBSIR 79-1721.

Peiser, H. S., Sangster, R. C., Jung, W., SP539.

Pella, P. A., Schreiber, B., 18635.

PENN, D. R., 18632.

Penn, R. W., MCKenna, G. B., NBSIR 79-1741.

PENner, S., 18906.

Penner, S., Galejs, A., 18932.

Perrier, F., SP553, pp. 161-173 (Aug. 1979).

Perrier, F., SP553, pp. 89-99 (Aug. 1979).

Persensky, J. J., Pezoldt, V. J., NBSIR 77-1298.

Persensky, J. J., RAMEY, A. M., NBSIR 77-1299.

Persson, K. B., Collins, G. J., Warner, B. E., 18968.

Persson, K. B., Franzen, D. L., McNeil, J. R., Johnson, W. L., Collins, G. J., 18319 .

Perwak, J. H., Ojha, H. D., Renda, T. V., Harrison, J. E., NBS-GCR-ETIP 79-7I.

Peters, P. N., Holdeman, L. B., Soulen, R. J., Jr., Finnegan, T. F., 18540 .

Petersen, F. R., Baird, K. M., Evenson, K. M., Hanes, G. R., JenNings, D. A., 18916 .

Petersen, F. R., Evenson, K. M., Jennings, D. A., 18562.

Petersen, F. R., Harter, W. G., Layer, H. P., 18928.

Petersen, F. R., Jennings, D. A., Evenson, K. M., HenningSen, J. O., Petersen, J. C., 18939.

Petersen, J. C., Petersen, F. R., Jennings, D. A., Evenson, K. M., Henningsen, J. O., 18939.

Petersen, S. R., NBSIR 79-1789.

Petersen, S. R., Marshall, H. E., 18888 .

Peterson, R. L., 18678.

Peterson, R. L., McDonald, D. G., U.S. Patent 4,168,441.

Petersons, O., Belecki, N. B., Dunfee, B. L., NBSIR 75-935.

Petersons, O., Moore, W. J. M., Anderson, W. E., Davis, R. S., 18513.

Petersons, O., Sze, W. C., Hillhouse, D. L., 18938.

Petrianyk, N., Termini, D. J., Brauer, G. M., 18809.

Petty, R. D., Detrio, J. A., SP54I, pp. 78.85 (Dec. 1978).

Pezoldt, V. J., Persensky, J. J., NBSIR 77-1298.

Phaneuf, R. A., Crandall, D. H., Gregory, D., Dunn, G. H., 18707.

Phelps, A. V., Tachibana, K., $/ 8925$.

PhiLIPS, G: J., SP547, pp. $191-199$ (July 1979).

Phillips, D. J., von Ramm, O. T., Thurstone, F. L., Smith, S. W., SP525, pp. 209-218 (Apr. 1979).

Phillips, J. E., MEAKIN, J. D., SP400-58, pp. 17-29 (Aug. 1979).

Phillips, W. E., Myers, D. R., Liu, Y. M., Dietrich, H. B., KOYAMA, R. Y., 18458.

Pichler, G., Raymer, M. G., Carlsten, J. L., 18498.

Pickart, S. J., Rhyne, J. J., Alperin, H. A., 18372.

Pickart, S. J., Rhyne, J. J., Alperin, H. A., Gillmor, W. R., 18835.

Pielert, J. H., CoOke, P. W., Gross, J. G., TN998.

Pierman, B. C., Adler, S. C., SPS65.

Pierman, B. C., Collins, B. L., NBSIR 79-1760.

Piermarini, G. J., Forman, R. A., Block, S., 18509.

Piety, K. R., MAgetTe, T. E., SP547, pp. 203-231 (July 1979).

Pifer, A. E., Sholes, R. R., Bowen, T., Connor, W. G., NASONI, R. L., SP525, pp. 57-61 (Apr. 1979).

Pipes, P. B., Van Degrift, C. T., Bowers, W. J., JR., Wildes, D. G., 18548 .

Pipkin, W. S., Sorensen, W. L., Lee, M. L., Vassilaros, D L., SP519, pp. 731-738 (Apr. 1979).

Pistole, R. D., SP563, p. 134 (Oct. 1979).

Pitzer, K. S., Brewer, L., JPCRD 8, No. 3, 91 7-920 (1979).

Plante, E. R., SP56I/I, pp. 265-281 (Sept. 1979).
PLATT, F. L., SP532, PP. 13-16 (Feb. 1979).

Plessner, N. J., Willson, K., Gore, J. C., Leeman, S., Metrewell, C., SP525, pp. 275-280 (Apr. 1979).

Plumb, H. H., Besley, L. M., 19040.

POHL, J. H., HaRdesty, D. R., SP561/2, pp. 1407-1449 (Sept. 1979).

Pohland, A. E., PARK, D. L., SPS19, pp. 321 -331 (Apr. 1979).

Polvani, R. S., Hocken, R. J., Christ, B. W., NBSIR 78-1569.

Pope, J. D., Alford, A. L., Doll, C. K., GARrison, A. W:, SP519, pp. 65.78 (Apr. 1979).

Popek, R. J., Kellogg, L. S., Lippincott, E. P., Hansen, G. E., Zimmer, W. H., Gilliam, D. M., Helmer, R. G., GreenWOOd, R. C., ROGers, J. W., HEINRICH, R. R., 18884.

Popp, R., Beaver, W., Joynt, L., Boyle, D., Rakow Ski; H., SP525, PP. 267.273 (Apr. 1979).

Poranski, C. F., JR., Ting, R. Y., Nash, H. C., SPS63, pp. 17-21 (Oct. 1979).

Porter, L. G., FeChTER, J. V., NBSIR 78-1556.

Porteus, J. O., Decker, D. L., Solleau, M. J., SP562, Pp. 513 518 (Oct. 1979).

Porteus, I. O., Donovan, T. M., Jernigan, J. L., Faith, W. N., SP541, pp. 202-211 (Dec. 1978).

Porteus, J. O., Jernigan, J. L., Ashley, E. J., Donovan, T. M., SP541, pp. 212.217 (Dec. 1978).

Powell, C. J., Erickson, N. E., Madey, T. E., 18924.

Powell, E. A., Zinn, B. T., Bankston, C. P., Cassanova, R. A., NBS-GCR-78-147.

Powell, J. H., SPS63, pp. 4-16 (Oct. 1979).

POWELL, J. W., 18964.

Powell, R. L., Clark, A. F., Read, D. T., Ekin, J. W., 18681 .

Prask, H. J., Trevino, S. F., Chol, C. S., 19027.

Pratt, D. T., SP561/2, pp. $1265-1279$ (Sept. 1979).

Pravdic, V., Haller, W., Jednacak-Biscan, J., Mikac-Dadic, $\mathrm{V} ., 18910$.

Preston, K., Jr., Czerwinski, M. J., Skolnik, M. L., Leb, D. E., SP525, PP. 303-313 (Apr. 1979).

Price, K. W., Holeman, G. R., Nath, R., SP554, Pp. 87-97 (Sept. 1979).

Prince, E., Chol, C. S., 18873 .

Probine, M. C., SP539, pp. 43-66 (Apr. 1979).

Proctor, T. M., CoOK, R. K., 18728.

Pugh, A. ll1., SP534, pp. 57-59 (May 1979).

Purdy, W. C., Young, S. N., Anderson, G. M., SP519, Pp. $411-418$ (Apr. 1979).

Purnell, E. W., Jennings, W. D., Holasek, E., SP525, pp. 261-266 (Apr. 1979).

Purtell, L. P., NBSIR 78-1433.

Purtell, L. P., NBSIR 78-1545.

Purtell, L. P., Klebanoff, P. S., TN989.

QUINN, J. T., SP552, pp. 141-151 (July 1979).

QuRashi, M. M., SP543, pp. 173-190 (Apr. 1979).

$\mathbb{R}$

RaAbe, O. G., Olechno, J., Sucre, l., Jennings, W., Fisher, G. L., SPS19, pp. 109-120 (Apr. 1979).

RABINOW, J., NBSIR 78-1507.

Rabinow, J., U.S. Patent 4,158,944.

RADACK, S. M., NBSIR 79-1734.

RADEBAUgh, 'R., 18679.

Radebaugh, R., lawless, W. N., Siegwarth, J. D., Morrow, A. J., 18680 .

Radebaugh, R., Read, D. T., Clark, A. F., Ekin, J. W., 18762.

RADWAY, R. J., SP543, pp. 209-2 14 (Apr. 1979).

RAFELSKI, J., DANOS, M., 18732.

RafelsKi, J., Danos, M., 18951 . 
Rahn, F. J., Serpan, C. Z., Fabry, A., McElroy, W. N., Grundl, J. A., Debrue, J., 19014.

Rains, T. C., Champ, M. A., Kingston, H. M., Barnes, I. L., BRADY, T. J., 18402.

Rainwater, J. C., 18553.

Rajagopalan, B., Bahn, R. C., Baxter, B., Christensen, D., Johnson, S. A., Greenleaf, J. F., SP525, pp. $235-246$ (Apr. 1979).

Rajagopalan, B., Greenleaf, J. F., Thomas, P. J., Johnson, S. A., BAHN, R. C., SP525, pp. 227.233 (Apr. 1979).

Rajaraman, T., SP543, pp. 89-93 (Apr. 1979).

Rakowski, H., Popp, R., Beaver, W., Joynt, L., Boyle, D., SP525, Pp. 267-273 (Apr. 1979).

Raley, C. C., Odar, P. M., Peiser, H. S., NBSIR 78-17/2.

Raley, C. C., Tholen, A. D., Peiser, H. S., NBSIR 79-172I.

Ramey, A. M., Persensky, J. J., NBSIR 77-1299.

RAMEY-SmIth, A., GagnON, J. L., NBSIR 79-1771.

RAMEY-Smith, A. M., Fechter, J. V., NBSIR 79-1727.

Ramos, L. S., Brown, D. W., Jenkins, R. G., Macleod, W. D., JR., SP519, pp. $713-718$ (Apr. 1979).

Ramos, L. S., Friedman, A. J., Macleod, W. D., Jr., Brown, D. W., SP519, pp. 161-167 (Apr. 1979).

Ramsay, D. A., Lovas, F. J., Lafferty, W. J., Maki, A. G., Harmony, M. D., Laurie, V. W., Kuczkowsi, R. L., SCHWENDEMAN, R. H., JPCRD 8, No. 3, 619-722 (1979).

RATCHFORD, D., SP563, p. 208 (Oct. 1979).

Raufaste, N., Olmert, M., SP446-2.

Raufaste, N. J., JR., Olmert, K. M., 18429.

RAVeché, H. J., KAYSER, R. F., JR., 19004.

Raylinson, J. A., SP554, pp. 25-28 (Sept. 1979).

Raymer, M. G., Carlsten, J. L., Pichler, G., $/ 8498$.

READ, D. T., /8552.

ReAd, D. T., Begley, J. A., MCHenry, H. I., $186 / 2$.

Read, D. T., Clark, A. F., Ekin, J. W., Radebaugh, R., 18762.

Read, D. T., Ekin, J. W., Powell, R. L., Clark, A. F., 18681 .

ReAD, D. T., REED, R. P., 18957.

Read, D. T., Reed, R. P., Mchenry, H. I., Naranjo, S. E., $186 / 0$.

Read, M. E., Manning, J. R., Swartzendruber, L. J., Carter, G. C., KAHAN, D. J., $/ 8637$.

Reader, J., Acquista, N., 18499.

Reader, J., Acquista, N., 18868 .

Reader, J., Corliss, C. H., 18870 .

Reader, J., Epstein, G. L., /8782.

Reader, J., Luther, G., Acquista, N., 18500.

Ready, J. F., Bennett, J. M., Anderson, R. H., Skogman, R. A., SP541, pp. $70-77$ (Dec. 1978).

Ready, J. F., Vora, H., Skogman, R. A., Leung, K. M., BERNAL, E., SP541, pp. 59-64 (Dec. 1978).

Reagan, J. A., Acklam, D. M., SP548, pp. l-13 (July 1979).

Rebbert, R. E., Shold, D. M., 18340.

RECHLER, A., SP549, pp. 19-21 (Aug. 1979).

ReChNitZ, G. A., SP519, pp. 525-532 (Apr. 1979).

Recicar, S. A., SP500-55.

Recicar, S. A., Warnar, R. B. J., Calomeris, P. J., SP500-45.

REED, R. P., FICKETT, F. R., NBSIR 79-1609.

ReEd, R. P., Mchenry, H. I., Naranjo, S. E., Read, D. T., $186 / 0$.

ReEd, R. P., ReAD, D. T., 18957.

Reed, R. P., Tobler, R. L., $/ 8695$.

REed, R. P., TOBleR, R. L., 18943.

Reed, R. P., Tobler, R. L., MCHenry, H. I., /862I.

REED, R. P., YUSHCHENKo, K. A., 18865.

REED, S. K., FIPS PUB 65.

Reeder, D. J., Enagonio, D. P., Christensen, R. G., SChAFFER, R., SP519, pp. 447-453 (Apr. 1979).

REEVE, C. P., NBSIR 79-1758.

Reeve, G. R., Arthur, M. G., TNI0I6.
Rehm, R. G., Cordes, M. R., Baum, H. R., Lewis, J., NBSIR 79-1754.

Reid, A., Zeitz, L., Ding, J., Laughlin, J. S., SP554, pp. I14 (Sept. 1979).

REID, E., SPS19, pp. 809-810 (Apr. 1979).

ReID, J. M., Shung, K. K., SP525, pp. 153-156 (Apr. 1979).

Reimann, C. T., Buehler, M. G., Russell, T. J., Maxwell, D. B., 18533.

ReINHOLd, T. A., 18977.

Reite, M., Edrich, J., Zimmerman, J. T., Zimmerman, J. E., 18397.

REMMER, N. S., SP552, pp. 153-165 (July 1979).

Renda, T. V., harrison, J. E., Perwak, J. H., Ojha, H. D., NBS-GCR-ETIP 79-7I.

RENEAU, V. L., SP563, pp. $72-79$ (Oct. 1979).

Reno, R. C., SWartzendruber, L. J., Bennett, L. H., 18967.

REPPERT, M. H., SP548.

Rethmann, H. W., SP547, pp. 176-190 (July 1979).

Reuther, J. J., SP561/2, pp. $1281-1312$ (Sept. 1979).

Reyes, Z., Parkinson, D. B., Filly, R. A., Busey, H., EdMONDS, P. D., SP525, pp. 323-326 (Apr. 1979).

Rhyne, J. J., Alperin, H. A., Glllmor, W. R., Pickart, S. J., 18835.

Rhyne, J. J., Alperin, H. A., Pickart, S. J., 18372.

RhYNe, J. J., Fish, G. E., Sankar, S. G., Wallace, W. E., 18682 .

Rhyne, J. J., Fish, G. E., Sankar, S. G., Wallace, W. E., 18881 .

Rhyne, J. J., Forester, D. W., Koon, N. C., Schelleng, J. H., 18897.

Rhyne, J. J., KoON, N. C., 19031 .

RhYNe, J. J., LYNN, J. W., Luborsiky, F. E., Walter, J. L., 18898.

Rhyne, J. J., Sankar, S. G., Wallace, W. E., Fish, G. E., 18657.

Rhyne, J. J., Sweger, D. M., Segnan, R., Abbundi, R., 18329.

RHYNE, T. L., SP525, pp. 135-141 (Apr. 1979).

Rice, J. R., Kissinger, P. T., Bruntlett, C. S., Bratin, K., SP519, pp. $705-712$ (A.pr. 1979).

RJCE, R. W., SP562, pp. 429-452 (Oct. 1979).

Rice, R. W., Evans, A. G., SP562, pp. 185-188 (Oct. 1979).

RICE, R. W., HOCKEY, B. J., SP562.

Rice, R. W., Mecholsky, J. J., JR., SP562, pp. $351-378$ (Oct. 1979).

Richard, D. M., Kirchner, H. P., Gruver, R. M., SP562, pp. 23-42 (Oct. 1979).

Richards, P. L., Shen, T. M., Harris, R. E., Lloyd, F. L., 18683.

Richardson, J. H., George, S. M., Ando, M. E., SP519, pp. 691-696 (Apr. 1979).

Richerson, D. W., Robare, M. W., SP562, pp. 209-220 (Oct. 1979).

RICHMOND, J. C., /850I.

Richtmyer, T. E., Hill, J. E., Franklin, E. A., Hunt, B. J., 18425.

Richton, D., Scott, J., Smith, J. S., Weston, A. F., Wezwick, C., SP5 19, pp. 181-184 (Apr. 1979).

RICKERS, H. C., NBS-GCR-79-160.

RICKERS, H. C., NBS-GCR-79-I6I.

RICKERS, H. C., NBS-GCR-79-162.

Riley, R. G., BeAN, R. M., SP5 19, pp. 33-40 (Apr. 1979).

Rinefierd, J. M., Jacobs, S. D., Brown, D. C., Abate, J. A., Lewis, O., Appelbaum, H., SP54I, pp. 109-121 (Dec. 1978).

Rinehart, G. H., Behrens, R. G., SP56I/I, pp. $125-141$ (Sept. 1979).

Rinker, R. L., Zumberge, M. A., Faller, J. E., 18472.

Rinker, R. L., Zumberge, M. A., Faller, J. E., 18654.

Rinker, R. L., Zumberge, M. A., FAller, J. E., $/ 8947$.

RipPey, W. G., Chang, Y. L., Rorrer, D. E., NBSIR 79-I 757 . 
Rippey, W. G., Hurley, C. W., Rorrer, D. E., Bulik, C. NBSIR 79-1709.

Ritchie, D., Braunlich, P., Schmid, A., Kelly, P., SP541, pp. 296-298 (Dec. 1978).

Rivers, D., Bickman, L., Herz, E., Edelman, P., NBS-GCR-79. 179.

Robare, M. W., Richerson, D. W., SP562, pp. 209-220 (Oct. 1979).

Robbins, C. R., MAuer, F, A., 18945.

Roberts, J. R., LuCATORto, T. B., McIllath, T. J., 18808.

Roberts, J. R., Rowan, W. L., 18502.

Roberts, W. E., Masters, L. W., Seiler, J. F., 18554.

ROBERTSON, B., 18321.

ROBERTSON, E. M., SP480-30.

Robertson, R. M., LinSky, J. L., WORden, S. P., MCClintock, W., 18853 .

RoBINSON, D. E., SP525, pp. 281-286 (Apr. 1979).

Robinson, H. A., Johnson, C. R., Leighton, F. T., 18524.

ROGERS, G. J., EVANS, D. D., TN1109.

Rogers, J. W., Heinrich, R. R., Popek, R. J., Kellogg, L. S., Lippincott, E. P., Hansen, G. E., Zimmer, W. H., Gilliam, D. M., Helmer, R. G., GREENWOOD, R. C., $/ 8884$

ROHTERT, R. E., SMItH, H. G., SP547, pp. 36-57 (July 1979).

RoItMAN, P., MAYo, S., MYers, D. R., 18623.

Rollenhagen, D. C., Schoenwetter, H. K., Souders, T. M., Tewksbury, S. K., Meyer, F. C., 18365.

Romanov, V. P., Candela, G. A., Roth, R. S., SwartzenDRUBER, L. J., 19046.

ROQUEMORE, W. M., YANEY, P. O., SP561/2, pp. 973-1023 (Sept. 1979).

Rorrer, D. E., Bulik, C., Rippey, W. G., Hurley, C. W., NBSIR 79-1709.

RORRer, D. E., RIPPey, W. G., Chang, Y. L., NBSIR 79-1757.

Rosasco, G. J., Kashiwagi, T., Chabay, I., 18626.

Roseboro, J. A., Wilson, R. L., Le Croissette, D. H., Heyser, R. C., Gammell, P. M., SP525, pp. 101-108 (Apr. 1979).

Rosenbaum, J., Larson, E., Hoblitt, R., Fickett, F. R., 18804

ROSENBERG, L., 18710 .

ROSENBERG, L., 18711 .

RosenberG, T. J., SP552, pp. $115-120$ (July 1979).

Rosenblatt, G. M., Drake, M. C., SP56//I, pp. 609-646 (Sept. 1979).

Rosenblatt, M., ITO, Y. M., SP562, pp. $501-511$ (Oct. 1979).

ROSENSTOCK, H. B., SP541, pp. 288-295 (Dec. 1978).

Rosenstock, H. M., Schroyer, S. S., Schmidt, C., Martinsen, D., Milne, G. W. A., hartman, K. N., Lias, S., Ausloos, P., NBSIR 79-1777.

Rosenstock, H. M., ThOMpson, R., WeBB, W., NBSIR 781432.

RoSenthal, M., SP536, pp. 83-93 (Feb. 1979).

Rosenthal, R., Carpenter, R. J., Sokol, J., JR., 18760.

Rosman, K. J. R., Diaz, M., Brill, R. H., YAMASAKi, K., BARNES, I. L., $/ 8840$.

Rosner, D. E., Seshadri, K., Fernandez de la Mora, J., Fryburg, G., Kohl, F., Stearns, C., Santoro, G., SP561/2, pp. $1451-1474$ (Sept. 1979).

ROSRUD, T., SP553, pp. 131-135 (Aug. 1979).

Ross, A. B., NETA, P., NSRDS-NBS65.

Ross, R. G., JR., SP400-58, pp. 146-149 (Aug. 1979).

Rossi, H. H., SP554, pp. 37-40 (Sept. 1979).

Rossow, E. C., Corotis, R. B., Dowding, C. H., NBS-GCR79-181.

Roszman, L. J., 18949.

Roth, P., JUst, T. H., SP561/2, pp. 1339-1352 (Sept. 1979).

ROTH, R. S., CAVA, R. J., 18646.

Roth, R. S., MiNOR, D., SANTORO, A., 19037.

Roth, R. S., Swartzendruber, L. J., Romanov, V. P., CanDELA, G. A., 19046.
Roth, S. C., Edelman, S., Kenney, J. M., Mayo-Wells, J. F., SP547, pp. 303-314 (July 1979).

Roth, S. C., KenNeY, J. M., J. Res. 84, No. 6, 447.453 (1979).

Roush, M. L., Breiter, D. N., 18375.

ROWAN, W. L., ROBERTS, J. R., 18502.

Rowe, J. M., deGraAf, L. A., Rush, J. J., Livingston, R. C., FLOTOW, H. E., 18730

Rowe, J. M., Libowitz, G. G., Maeland, A., Glinka, C. J., 19030.

Rowe, J. M., Rush, J. J., Hinks, D. G., Susiman, S., 19036.

Rubin, A. 1., Elder, J., Turner, G. E., NBSIR 79-1780.

RUbin, A. 1., Glass, R. A., BSSII5.

Rubin, S., OetTinger, F. F., SP400-14.

Rucks, A. C., Fleming, P. M., SP500-52, pp. $193-199$ (Oct. 1979).

Ruegg, F. C., Marinenko, R. B., Heinrich, K. F. J., SP26065.

Ruegg, F. C., MARinenko, R. B., Heinrich, K. F. J., $/ 8973$.

Ruegg, R., Wyly, R., Marshall, H., SP553, pp. 207-225 (Aug. 1979).

RUegg, R. T., Chapman, R. E., BSSI/9.

Ruegg, R. T., Marshall, H. E., SP558.

Ruegg, R. T., Marshall, H. E., 19043.

RUfF, A. W., WIEDERHORN, S. M., NBSIR 78-1575.

RUfF, A. W., WIEDERHORN, S. M., 18858.

Rumble, J. R., Jr., Beaty, E. C., Gallagher, J. W., SP426. Supplement 1.

RUPP, N. W., 18684

Rupp, N. W., Patel, P. R., Paffenbarger, G. C., 18586.

Rupp, N. W., Patel, P. R., Paffenbarger, G. C., 18729.

Rush, J. J., 19026.

Rush, J. J., Hinks, D. G., Susman, S., Rowe, J. M., 19036.

Rush, J. J., Livingston, R. C., Flotow, H. E., Rowe, J. M., DEGRAAF, L. A., 18730 .

RUSh, J. J., SteEnbergen, C., 18374.

Russell, T. J., Maxwell, D. A., SP400-5I.

Russell, T. J., Maxwell, D. B., Reimann, C. T., Buehler, M. G., $/ 8533$.

Ruzicka, J., HaNSEN, E. H., SP519, pp. 501-507 (Apr. 1979).

SaAlfeld, F. E., Smith, D. E., King, T. L., Eaton, H. G., Williams, F. W., WyatT, J. R., DeCorpo, J. J., SP5/9, pp. 213 218 (Apr. 1979).

Sachse, W., Golan, S., 18391.

SAChSE, W., Hsu, N. N., 18907.

SACKETT, I. D., JR., SP532, pp. 66.71 (Feb. 1979).

SACre, C., SimiU, E.,Bietry, J., 18351 .

SAITO, F., SP540, Pp. 382-447 (Nov. 1979).

SAITO, F., SP540, pp. 528-548 (Nov. 1979).

SAITO, F., SP540, Pp. 54-101 (Nov. 1979).

Saito, F., Handa, T., Suda, K., Nagashima, T., Kaneko, K., Yamamura, T., Takahashi, Y., Suzuki, H., SP540, pp. 626711 (Nov. 1979).

SALTER, R. G., SP547, pp. 65-77 (July 1979).

SAMS, R. L., LAFFerty, W. J., Wells, J. S., 18864.

SAMUELS, F. L. N., SP532, pp. 29-41 (Feb. 1979).

SANCHEZ, I. C., 19023.

SANDERS, A. A., 18914 .

Sanders, D. M., HAller, W. K., SP561/1, pp. 111 -123 (Sept. 1979).

Sanghyi, N. T., Fry, F. J., Gallager, H. S., Fry, E. K., SP525, pp. 85-91 (Apr. 1979).

SANGSTER, R. C., SP543.

SANGSTER, R. C., 18685.

Sangster, R. C., Jung, W., Peiser, H. S., SP539.

Sankar, S. G., Wallace, W. E., Fish, G. E., Rhyne, J. J., 18657. 
Sankar, S. G., Wallace, W. E., Rhyne, J. J., Fish, G. E., 18682.

Sankar, S. G., Wallace, W. E., Rhyne, J. J., Fish, G. E., 18881 .

Santoro, A., Roth, R. S., Minor, D., 19037.

Santoro, G., Rosner, D. E., Seshadri, K., Fernandez de la Mora, J., Fryburg, G., Kohl, F., STEarns, C., SPS61/2, pp. 1451-1474 (Sept. 1979).

Santuccl, L. A., Eisenhard, R. M., NBSIR 79-1705.

SARKOS, C. P., SP540, pp. 589-623 (Nov. 1979).

SASamoto, T., Kobayashi, M., Sata, T., SPS61/1, pp. 283-286 (Sept. 1979).

Sata, T., Sasamoto, T., Kobayashi, M., SP561/1, pp. 283-286 (Sept. 1979).

Saulsbury, L. F., Workman, J. L., Treado, M. J., Diamond, J. J., TAggart, H. E., Jones, R. N., 18381 .

Saunders, P. B., Francis, R. L., NBSIR 79.1738.

Savitsky, D., Cole, C., Konen, T. P., Bevans, R. S., Boegly, W. J., SP553, pp. $71-77$ (Aug. 1979).

SAWYER, D. E., 18322.

SAwyer, D. E., Kessler, H. K., Schafft, H. A., NBSIR 79. 1909.

SAwyer, D. E., Kessler, H. K., Schafft, H. A., 18633.

SAWYER, D. E., SCHAFFT, H. A., NBSIR 79-1778.

SAWYER, D. E., SCHAFFT, H. A., SP400-58.

SAykAlly, R. J., EvenSON, K. M., 18917.

Saykally, R. J., EvenSON, K. M., 18919.

SAylor, C. P., 18930.

Saylor, C. P., Wichers, E., Hoffman, J. I., J. Res. 84, No. 5, 385-394 (1979).

Scalabrin, A., Evenson, K. M., 18961.

Scalabrin, A., Stein, S. R., Inguscio, M., Strumia, F., EvenSON, K. M., Jennings, D. A., 18426.

SCANLAN, R. H., Simiu, E., 18688.

SChaefer, A. R., Geist, J., 18900.

Schaefer, A. R., Zalewsiki, E. F., Geist, J., Lind, M. A., 18773.

Schaefer, A. R., Zalewski, E. F., Geist, J., Lind, M. A., 18774.

Schaefer, J. C., Chabay, 1., 18686.

SCHAFER, H., SPS61/2, pp. 1507-1515 (Sept. 1979).

Schaffer, R., Howel, B. F., MCCune, S., 18433.

Schaffer, R., Mandel, J., Machlan, L. A., Gramlich, J. W., Velapoldi, R. A., Paule, R. C., SP260-63.

Schaffer, R., Mandel, J., Murphy, T. J., Gramlich, J. W., Velapoldi, R. A., Paule, R. C., SP260-67.

Schaffer, R., Reeder, D. J., Enagonio, D. P., Christensen, R. G., SP519, pp. 447-453 (Apr. 1979).

Schaffer, R., White V, E., Sniegoski, L. T., Cohen, A., SP519, pp. 405-410 (Apr. 1979).

SCHAFF, H. A., NBSIR 79.1743.

SCHAFFT, H. A., SP400-50.

SСHAFFT, Н. А., 18634.

SCHAFFt, H. A., SAWYER, D. E., NBSIR 79-1778.

SChAFF, H. A., SAWYer, D. E., SP400-58.

SChafft, H. A., Sawyer, D. E., Kessler, H. K., NBSIR 79. 1909.

Schafft, H. A., SAwyer, D. E., Kessler, H. K., 18633.

SCHEARER, L. D., LAM, L. K., 18799.

Scheiding, W., Wessels, G., von Seelen, W., Gaca, A., Loch, E., SP525, pp. 297-302 (Apr. 1979).

Schelleng, J. H., Rhyne, J. J., Forester, D. W., Koon, N. C., 18897.

Schenck, P. C., Travis, J. C., Green, R. B., Keller, R. A., LUther, G. G., U.S. Patent 4,148,586.

SChencK, P. K., KING, D. S., 18944.

Schenck, P. K., Mallard, W. G., Travis, J. C., Smyth, K. C., SP561/2, pp. $865-882$ (Sept. 1979).

Schenck, P. K., Mallard, W. G., Travis, J. C., SMyth, K. C., 18344.
Schenck, P. K., Smyth, K. C., Turk, G. C., Mallard, W. G., 18983.

Schenck, P. K., Turk, G. C., Mallard, W. G., Travis, J. C., 18806.

Schenk, E. A., WAag, R. C., Lee, P. P. K., Lerner, R. M., Hunter, L. P., Gramiak, R., SP525, pp. 143.152 (Apr. 1979).

Scheulen, B., Telin, B., Durbeck, H. W., Frischkorn, C. G. B., BukER, 1., SP5/9, pp. $437-445$ (Apr. 1979).

Schiffgens, J. O., Simons, R. L., Morgan, W. C., Grundl, J. A., McGarry, E. D., KaM, F. B. K., Swank, J. H., Odette, G. R., McElroy, W. N., Doran, D. G., Gold, R., LippinCOTT, E. P., 19012.

Schill, G., Wahlund, K. G., SPS19, pp. $509-523$ (Apr. 1979).

SChima, F. J., Coursey, B. M., Hutchinson, J. M. R., 18841 .

Schleter, J. C., Maltese, M. D. K., Goodwin, K. E., 18735.

SCHLICKE, H. M., SPS5I, pp. 20-22 (July 1979).

Schmeltz, 1., Brunnemann, K. D., Hoffmann, D., SP519, pp. 297.309 (Apr. 1979).

Schmeltz, I., Wynder, E. L., Hoffmann, D., Brunnemann, K. D., SPS19, PP. 131-141 (Apr. 1979).

Schmid, A., Kelly, P., Ritchie, D., Braunlich, P., SP54I, pp. 296-298 (Dec. 1978).

Schmid, G. B., Collins, L. A., Norcross, D. W., 18516.

Schmidt, C., Martinsen, D., Milne, G. W. A., hartman, K. N., Lias, S., Ausloos, P., Rosenstock, H. M., Schroyer, S. S., NBSIR 79-1777.

Schmidt, D. S., DePRit, A., J. Res. 84, No. 4, 293-297 (1979).

SCHMIDT, W. W., SP563, pp. 198-207 (Oct. 1979).

Schneeberger, T. J., Linsky, J. L., McClintock, W., WorDEN, S. P., 18920.

Schneegerger, T. J., Worden, S. P., Giampapa, M. S., Linsky, J. L., 19007.

SСHосн, В., O'CONNEll, J. S., 18675.

Schodek, D. L., GaUchat, U. P., SPS52, pp. $347-360$ (July 1979).

SCHOENWETTER, H. K., 18503.

Schoenwetter, H. K., Souders, T. M., Tewksbury, S. K., Meyer, F. C., Rollenhagen, D. C., 18365.

SCHOFIELD, K., JPCRD \&, No. 3, $723-798$ (1979).

Schofteld, K., Steinberg, M., Muller, C. H. 111., SP56i/2, pp. 855-864 (Sept. 1979).

Schooley, J. F., 18550.

SChoONOVER, K. M., SPS49, pp. 43-50 (Aug. 1979).

Schoonover, R. M., J. Res. 84, No. 5, 347-351 (1979).

SChrack, R. A., Bowman, C. D., 18585.

SChrack, R. A., Bowman, C. D., 18687.

Schrack, R. A., Bowman, C. D., Behrens, J. W., 18591.

Schramm, R. E., Clark, A. F., Ekin, J. W., 18718.

Schramm, R. E., KASEN, M. B., 18616.

Schrelber, B., Pella, P. A., 18635.

Schroeder, L. W., Ferris, J. S., Brown, W. E., 18583.

SChroeder, L. W., MAThew, M., 18448.

Schroeder, L. W., MAthew, M., 18491 .

Schroyer, S. S., Schmidt, C., Martinsen, D., Milne, G. W. A., Hartman, K. N., Lias, S., Ausloos, P., Rosenstock, H. M., NBS/R 79-1777.

Schubert, E., Schuck, A., Jung, K., Geltman, S., 18534.

Schucx, A., Jung, K., Geltman, S., Schubert, E., 18534.

Schuster, G., McAuliff, R. C., Lentner, K. J., Moore, W. J. M., 18529 .

SChwartz, M., Finby, N., Dain, F., Kuc, R., SP525, pp. 125 132 (Apr. 1979).

SCHWARZ, C., SPS56, pp. $165-166$ (Sept. 1979).

SChWeitzer, G. K., BOW LiNG, R. A., LASSiter, T. W., Vick, D. O., SP561/1, pp. 771-789 (Sept. 1979).

Schwendeman, R. H., Ramsay, D. A., Lovas, F. J., Lafferty. W. J., MAKl, A. G., HaRMONY, M. D., LAuRie, V. W., KUCZ Kowski, R. L., JPCRD 8, No. 3, 619-722 (1979). 
Schwinden, W. J., Gausche, C. L., SP500-52, pp. 9-19 (Oct. 1979).

Schwitz, W., Deslattes, R. D., Kessler, E. G., JR., Jacobs, L., 18510 .

Scire, F. E., Teague, E. C., 18327.

SCott, J., Smith, J. S., Weston, A. F., Wezwick, C., Richton, D., SPS19, pp. 181-184 (Apr. 1979).

ScoTT, R. P. W., SP519, pp. 637-645 (Apr. 1979).

SCOTt, T. C., Fletcher, L. S., SOMERS, R. R. II., SP552, pp. 197-209 (July 1979).

SCOTT, W. W., JR., SP480-12.

Scotti, A., Ohse, R. W., Babelot, J. F., Cercignani, L., Kinsman, P. R., Long, K. A., Magill, J., SP561/1, pp. 83109 (Sept. 1979).

Searl, T. D., Brown, R. A., McElroy, F. C., SP519, pp. 718 (Apr. 1979).

Seaver, M., Parmenter, C. S., 18677.

Seaver, M., Tang, K. Y., Knight, A. E. W., Parmenter, C. S., LiN, H. M., 18671 .

Sedgwick, T. O., Arbach, G. U., SP561/2, pp. 885-896 (Sept. 1979)

Segnan, R., Abbundi, R., Rhyne, J. J., Sweger, D. M., 18329.

Segrest, J. P., Chung, B. H., Chiovett, R., JR., Weinstein, J. N., WLODAWER, A., 18851 .

Seiler, J. F., Roberts, W. E., Masters, L. W., 18554.

Self, S. A., SP561/2, pp. $915-941$ (Sept. 1979).

Seltzer, S. M., 19001 .

Seltzer, S. M., Bielefeld, M. J., TrombKa, J. I., Ehrlich, M., 18416.

Seltzer, S. M., Dyer, C. S., Trombka, J. I., 19011.

Seltzer, S. M., Hubbell, J. H., Berger, M. J., 18371 .

Seltzer, S. M., Trombka, J. I., Wall, N. S., Lapides, J. R., Crannell, C. J., Crannell, H., Hornyak, W. F., 19015.

Seltzer, S. M., Yin, L. I., 19000.

Sengers, J. V., 18937.

Sengers, J. V., Gammon, R. W., Hocken, R. J., Moldover, M. R., 18541 .

Sengers, J. V., Moldover, M. R., 18457.

Serdyuk, 1. N., Yu, H., HAN, C. C., J. Res. 84, No. 1, 1-8 (1979).

Serpan, C. Z., Fabry, A., McElroy, w. N., Grundl, J. A., Debrue, J., RAhN, F. J., 19014.

Sertie, J. A. A., Sved, S., SP519, pp. $477-480$ (Apr. 1979).

Seshadri, K., Fernandez de la Mora, J., Fryburg, G., Kohl, F., Stearns, C., Santoro, G., Rosner, D. E., SP561/2, pp. $1451-1474$ (Sept. 1979).

SEWARD, R. W., SP260, 1979-80 Edition.

Shabason, L., Dick, D. E., Clayman, W., Carson, P. L., SP525, pp. 337-340 (Apr. 1979).

Shafer, J., AdAms, J. W., TAggart, H. E., Kanda, M., TN1014.

ShafER, J. F., TAGgART, H. E., 18398.

Shaub, W. M., LiN, M. C., SP561/2, pp. $1249-1261$ (Sept. 1979).

Shaulov, A., Bell, M. I., Smith, W. A., 18852 .

Shaver, J., EllingwOOd, B., TN985.

Shawker, T. H., Doppman, J. L., Linzer, M., Parks, S. 1., Norton, S. J., Higgins, F. P., Dietz, D. R., Shideler, R. W., SP525, pp. 255-259 (Apr. 1979).

Sheffler, A. W., Budlong, K. S., SP563, p. 130 (Oct. 1979).

Sheldon, R. I., Gllles, P. W., SPS61/1, pp. $231-234$ (Sept. 1979).

Shelton, J. W., NBS-GCR-78-149.

Shelton, R. N., LYNN, J. W., 18850.

Shen, T. M., Harris, R. E., Lloyd, F. L., Richards, P. L., 18683.

Sheppard, A. J., HubBard, W. D., SP519, pp. 267-269 (Apr. 1979).

Sheppard, A. J., Hubbard, W. D., SP519, pp. 289-295 (Apr. 1979).
Sher, A. H., Stenbakken, G. N., SP480-14.

SHeRALd, M. A., SPS40:

Sherman, P. L., Kemmer, A. M., Metcalfe, L., Toy, H. D., PARRIS, G. E., SPS19, pp. 205-212 (Apr. 1979).

Shibe, A. J., Nelson, H. E., NBSIR 78-1555.

Shideler, R. W., Shawker, T. H., Doppman, J. L., Linzer, M., Parks, S. I., Norton, S. J., Higgins, F. P., Dietz, D. R., SP525, pp. 255.259 (Apr. 1979).

SHIELDS, J. Q., 18454.

Shier, D., Domich, P., LAWrence, J., J. Res. 84, No. 6, 455 488 ( 1979 ).

SHIER, D. R., NBSIR 78-1539.

SHIVES, T. R., WILLARd, W. A., SP547.

Shives, T. R., Willard, W. A., SP563.

Shoemaker, C. O., JR., Kilmer, R. D., Cadoff, M. A., MATHEWS, D. E., 18607.

ShOLd, D. M., RebBert, R. E., 18340.

Sholes, R. R., Bowen, T., Connor, W. G., Nasoni, R. L., Pifer, A. E., SP525, pp. 57-61 (Apr. 1979).

Shore, B. W., ACKerhalt, J. R., Eberly, J. H., 18439

SHORTEN, F. J., TN995.

Shoup, R. E., Kissinger, P. T., Felice, L. J., Bruntlett, C. S., SPS19, pp. 391.397 (Apr. 1979).

ShOWERS, R. M., SP5SI, pp. $12-19$ (July 1979).

Shukla, R. P., Patnalk, P. R., Kudchadker, A. P., KudChadKeR, S. A., JPCRD 8, No. 2, 499.518 (1979).

Shung, K. K., ReID, J. M., SP525, pp. $153-156$ (Apr. 1979).

Shunk, D. L., Noton, B. R., SP563, pp. 226-227 (Oct. 1979).

Sidorin, A. V., Danileiko, Y. K., Manenkov, A. A., SP541, pp. 305-308 (Dec. 1978).

SIECK, L. W., NSRDS-NBS64.

Siedle, A., Coyle, T., SP556, p. 23 (Sept. 1979).

Siedle, A. R., Bodner, G. M., Garber, A. R., Wright, R. F., TODD, L. J., 18328.

Siedle, A. R., Brown, L. D., lbers, J. A., 18582.

Siedle, A. R., Mighell, A. D., Hubbard, C. R., Stalick, J. K., 18636.

Siedle, A. R., Velapoldi, R. A., ERicikson, N., 18504.

Siegwarth, J. D., LaBrecque, J. F., Younglove, B. A., 18805.

Siegwarth, J. D., Morrow, A. J., Radebaugh, R., Lawless, W. N., 18680.

Siegwarth, J. D., Parrish, W. R., Brennan, J. A., 18396.

Siggia, S., Kostyla, R. J., Mourey, T. H., Cohen, R., MerRitt, M. E., Simmons, K., LaFaucia, R., Limentani, G., WASHBURN, D. N., SP5 19, pp. $783-787$ (Apr. 1979).

Silverberg, E. C., Bender, P. L., Faller, J. E., Levine, J., Moody, S., Pearlman, M. R., 18459.

Silvergleit, M., Macander, A. B., Brauer, F. A., Edelstein, H. P., SPS63, pp. 276-285 (Oct. 1979).

Simiu, E., Changery, M. J., Filliben, J. J., BSSII8.

Simiu, E., Scanlan, R. H., 18688.

Simiu, E., Biétry, J., SACre, C., 18351 .

Simmons, K., LAFAucia, R., Limentani, G., Washburn, D. N., Siggia, S., Kostyla, R. J., Mourey, T. H., Cohen, R., MeRRITT, M. E., SPS19, pp. $783-787$ (Apr. 1979).

Simon, G. W., November, L. J., TOOmRe, J., Gebile, K. B., 18444.

Simons, R. L., Morgan, W. C., Grundl, J. A., McGarry, E. D., Kam, F. B. K., Swank, J. H., Odette, G. R., McElroy, W. N., Doran, D. G., Gold, R., Lippincott, E. P., SchiffGENS, J. O., 19012.

Siu, C. I., Grot, R. A., SP548, pp. 39.56 (July 1979).

Skidmore, R., Webe, A. J., WoOdcock, J. P., Wells, P. N. T., Halliwell, M., Mountford, R. A., SP525, pp. 173-176 (Apr. 1979).

Skogman, R. A., Leung, K. M., Bernal, E., Ready, J. F., VORA, H., SP541, pp. 59-64 (Dec. 1978).

Skogman, R. A., Mora vec, T. J., SP541, pp. 259-265 (Dec. 1978). 
Skogman, R. A., Ready, J. F., Bennett, J. M., Anderson, R. H. SPS41, pp. $70-77$ (Dec. 1978).

Skolnik, M. L., Leb, D. E., Preston, K., JR., Czerwinski, M. J., SP525, pp. 303-313 (Apr. 1979).

SLATER, J. A., SP543, pp. 192-193 (Apr. 1979).

Small, J. A., Newgury, D. E., Myklebust, R. L., 18976.

SMID, M. E., SPSO0-54

SMID, M. E., 19039.

SMITH, B., SP536, pp. 17-53 (Feb. 1979).

SMITH, C. H., SPS54, pp. 33-35 (Sept. 1979),

SMITh, C. M., FRY, D. N., KING, W. T., SPS47, pp. 232-249 ( July 1979).

Smith, D., Smith, J., WezWICK, C., MadY, N., SP5/9, pp. 341 343 (Apr. 1979).

SMITH, D. D., SP563, pp. 60-71 (Oct. 1979).

SMith, D. E., King, T. L., EAton, H. G., Williams, F. W., W'YATt, J. R., DECORPO, J. J., SAALFELD, F. E., SPS19, pp. 213-218 (Apr. 1979).

SMITH, E. W., GiRAUd, M., 18689.

SMith, H. G., RohteRT, R. E., SP547, pp. 36-57 (July 1979).

Smith, J., Brozowski, G., Burkitt, D., Gabriel, M., HainRAHAN, J., MCCARTHY, E., SP519, pp. 175-179 (Apr. 1979).

SMith, J., WeZWICK, C., MADY, N., SMITh, D., SP519, pp. 341 343 (Apr. 1979).

SмITh, J. C., J. Res. 84, No. 4, 299-318 (1979).

Smith, J. H., Brady, C. H., Christ, B. W., 18368

SMITh, J. M.. PEACOCK, R. D., TNI 108.

SMith, J. S., Weston, A. F., WezWICK, C., Richton, D., SCOTT, J., SPS19, pp. 181-184 (Apr. 1979).

SMith, P. W., Crane, C. R., SP540, pp. $549-565$ (Nov. 1979).

SMITH, R. J., SPS52, pp. $211-216$ (July 1979).

SмITh, S. J., HOGAN, P. B., 18955.

SMith, S. J., WALTHER, H., LEUChS, G., 18953.

SMITH, S. L., JORGENSON, J. W., NOVOTNY, M., SP519, pp. 429. 436 (Apr. 1979).

Smith, S. W., Phillips, D. J., von RAmm, O. T., Thurstone, F. L., SPS2S, pp. 209-218 (Apr. 1979).

Smith, W. A., Shaulov, A., Bell, M. I., 18852.

SMITH, W. L., BRAWER, S., SPS 41, pp. 303-304 (Dec. 1978).

Smith-Magowan, D., Goldberg, R. N., SPS 37.

Smyth, K. C., Bentz, B. L., Bruhn, C. G., harrison, W. W., 18449.

Smyth, K. C., Schenck, P. K., Mallard, W. G., Travis, J. C., SP561/2, pp. 865-882 (Sept. 1979).

Smyth, K. C., Schenck, P. K., Mallard, W. G., Travis, J. C., 18344.

Smyth, K. C., Turk, G. C., Mallard, W. G., Schenck, P. K., 18983.

Sniegoski, L. T., Cohen, A., Schaffer, R., White V, E., SPS19, pp. 405-410 (Apr. 1979).

SNOWDON, J. C., HI28.

SNyder, J. J., U.S. Patent 4,173,442.

SNYDER, M., SP553, pp. 193-205 (Aug. 1979).

SoAres, C. G., EHrLich, M., 18989.

Soares, C. G., Jackson, B., Lanoue, P., Ehrlich, M., 18355.

SoAres, C. G., Motz, J. W., Dick, C. E., 1844 l.

Sobel, B. E., Miller, J. G., O'Donnell, M., Mimbs, J. W., SP525, pp. 63-71 (Apr. 1979).

Sockut, G., Jeffery, S., Fife, D., Deutsch, D., 18777.

Sockut, G. H., Goldgerg, R. P., SPS00-47.

Sohrabi, M., MCGinley, P. H., SP554, pp. 99-107 (Sept. 1979).

Solleau, M. J., Bass, M., Van Stryland, E. W., SP541, pp. 309-317 (Dec. 1978).

Solleau, M. J., Porteus, J. O., Decker, D. L., SP562, pp. 513 518 (Oct. 1979).

Sokol, J., JR., Rosenthal, R., Carpenter, R. J., 18760.

SOL, J. C., JAUDET, A., SP547, pp. $250-279$ (July 1979).

Sollish, B. D., SP525, pp. 53-56 (Apr. 1979).

Solov'ev, E. A., Demkov, Y. N., Ostrovsku, V. N., 18575.

SOMER, T. G., SP543, pp. 163-172 (Apr. 1979).
Somers, R. R. II., Scott, T. C., Fletcher, L. S., SP552, pp. 197-209 (July 1979).

Sorensen, W. L., Lee, M. L., Vassilaros, D. L., Pipkin, W. S., SP519, pp. $731-738$ (Apr. 1979).

SOUdERS, T. M., 18505 .

SOUdERS, T. M., FlACH, D. R., TNIIOS.

Souders, T. M., Tewksbury, S. K., Meyer, F. C., RolLenhagen, D. C., SChoenwetter, H. K., 18365 .

SOULEN, R. J., JR., 18549.

SOULEN, R. J., JR., 18603.

SOUlen, R. J., JR., Dove, R. B., SP260-62.

Soulen, R. J., JR., finnegan, T. F., Peters, P. N., Holdeman, L. B., 18540 .

Soulen, R. J., JR., Giffard, R. P., Michelson, P. F., 18663.

SOUlen, R. J., JR., MARShaK, H., 18555.

Soulen, R. J., JR., Sullivan, D. B., Holdeman, L. B., 18871 .

SPAL, R., KAHN, A. H., 18911 .

SPARKS, L. L., 18619 .

SPARKS, L. L., 18719 .

SPARKS, M., FlANNERY, M., SPS41, pp. 278-287 (Dec. 1978).

SPawn, P., Fennelly, P., SPS56, pp. 49-55 (Sept. 1979).

Speciale, R. A., Engen, G. F., Hoer, C. A., 18653.

Spencer, G. S., Varey, G. B., Millet, M. S., Bedrick, J. R., SPS52, pp. $321-335$ (July 1979).

SpIEGel, M. G., KirRene, M. J., SPSO0-S2, pp. $129-140$ (Oct. 1979).

Spiegel, V., Eisenhauer, C. M., Gilliam, D. M., Grundl, J. A., 18901 .

Spiegel, V., Eisenhauer, C. M., Grundl, J. A.,'Martin, G. C., JR., 18883.

SPIEGEl, V., Fleming, R., 18792.

SPIRIDONOV, V. P., ZASORIN, E. Z., SP561/l, pp. 711-75S (Sept. 1979).

SPOONER, C. R., SPSO0-5 2, pp. 53-64 (Oct. 1979).

Sprague, P. A., Zurkowski, P., Berger, P. W., 19048.

Sreenivasiah, I., Chang, D. C., NBSIR 79-1606.

STACH, J., DAS, M. B., TRESSLeR, R. E., NBS-GCR-78-134.

Staffa, J. A., Zervos, C., Mighell, A. D., Hubbard, C. R., HARRIS, J., 18673.

STAHL, F. A., SP549, pp. $125-129$ (Aug. 1979).

STAKL, F. I., NBSIR 79-1713.

STAHL, F. I., NBSIR 79-I 796.

STAHL, F. I., SP552, pp. 101-113 (July 1979).

STAHL, F. I., 18430 .

Stahl, F. I., Archea, J., Collins, B. L., BSS120.

Stahl, F. I., Conway, D., Goglia, M. R., 18784.

Stalick, J. K., Siedle, A. R., Mighell, A. D., Hubbard, C. R., 18636.

STANLEY, H. R., BOWEN, R. L., Folio, J., 18690.

Staples, B. R., Goldae Rg, R. N., Nuttall, R. L., JPCRD 8 , No. 4, 923-1004 (1979).

Staton, W., Williams, G., Konen, T. P., Liposki, F., Myers, J. R., Nielsen, L., Mikucki, W., SPS53, pp. $15-19$ (Aug. 1979).

Stavric, B., Stoltz, D. R., KLASSEN, R., SP519, pp. 311-319 (Apr. 1979).

Stearns, C., Santoro, G., Rosner, D. E., Seshadri, K., FerNANDEZ dE la MORA, J., Fryburg, G., Kohl, F., SPS61/2, Pp. 1451-1474 (Sept. 1979).

Stearns, C. A., Kohl, F. J., Fryburg, G. C., Miller, R. A., SPS61/1, pP. 303-354 (Sept. 1979).

Steengergen, C., Rush, J. J., 18374.

STEHOUWER, D., SPS 56, pp. 179-182 (Sept. 1979).

STEIN, J., SP549, Pp. $119-123$ (Aug. 1979).

Stein, S. R., Inguscio, M., Strumia, F., Evenson, K. M., Jennings, D. A., Scalabrin, A., 18426.

Stein, S. R., Manney, C. M., Jr., Walls, F. L., Gray, J. E., BESSON, R. J., 18691 .

Stein, S. R., TuRneAure, J. P., 18692.

Stein, S. R., WAlls, F. L., 18693. 
Stein, S. R., Walls, F. L., Kahan, A., Hellwig, H., 18826.

Steinberg, M., Muller, C. H. III., Schofield, K., SP561/2, pp. 855-864 (Sept. 1979).

STEINER, B. W., Monogr. 165.

STEINER, B. W., NBSIR 79-1703.

Stenbakken, G. N., SheR, A. H., SP480-14.

STEPHENS, K. S., SP543, pp. 113.132 (Apr. 1979 ).

StEPHENSON, J. C., BIALXOWSKI, S. E., KING, D. S., 19042.

Stevenson, D. A., Dun, H., Mattes, B. L., SP561/1, pp. 411 428 (Sept. 1979).

Stevenson, J. M., Anderson, R. J. M., Kohler, B. E., 18754.

Stewart, A. F., Bass, M., VAN Stryland, E. W., SP54I, pp. 19-23 (Dec. 1978).

STEWART, K. K., SP519, pp. 249-255 (Apr. 1979).

Stewart, K. K., LI, B. W., SP519, pp. 271-278 (Apr. 1979).

STIEHLeR, R. D., Michalak, J. L., NBSIR 79-1917.

Stillwell, R. N., Horning, E. C., Carroll, D. 1., Dzidic, 1., SP519, pp. 655-671 (Apr. 1979).

STIRN, R. J., SP400-58, pp. 69-75 (Aug. 1979).

StOebe, T. G., VORA, H., OHMER, M. C., SP54I, pp. 24-32 (Dec. 1978).

Stokes, E. D., Chu, S. S., Chu, T. L., YaNG, H. T., SP40058, pp. 76-81 (Aug. 1979).

Stokes, E. D., Lin, C. L., Abderrassoul, R., Chu, T. L., Chu, S. S., SP400-58, pp. 41-47 (Aug. 1979).

STOKES, R. J., KOEPKE, B. G., SP562, pp. $75-91$ (OCt. 1979).

STOKowski, S. E., MILAM, D., Weber, M. J., SP54I, pp. 99-108 (Dec. 1978).

Stoltz, D. R., Klassen, R., Stavric, B., SP5/9, pp. 311-319 (Apr. 1979).

Storms, E. K., Mueller, B. A., SP56I/I, pp. 143-151 (Sept. 1979).

Stratton, A., Braun, E., Krasny, J. F., Peacock, R. D., 18708.

Straty, G. C., Younglove, B. A., 18987.

Strauss, H. L., IP, P., SP56I/2, pp. 1611 -1618 (Sept. 1979).

Streit, G. E., Wells, J. S., Fehsenfeld, F. C., Howard, C. J., 18551 .

Striganov, A. R., Odintzova, G. A., JPCRD 8, No. 1, 63-68 (1979).

STRIGNER, P SP556, pp. 157-158 (Sept. 1979).

Strumia, F., Evenson, K. M., Jennings, D. A., Scalabrin, A., Stein, S. R., INGUSCio, M., 18426 .

STUBENRAUCh, C. F., $/ 8818$.

Sucre, L., Jennings, W., Fisher, G. L., RaAbe, O. G., Olechno, J., SP519, pp. 109-120 (Apr. 1979).

Suda, K., Nagashima, T., Kaneko, K., Yamamura, T., Takahashi, Y., Suzuki, H., Saito, F., Handa, T., SP540, pp. 626-711 (Nov. 1979).

Sugar, J., Corliss, C., JPCRD 8, No. 1, 1-62 (1979).

SUGAR, J., Corliss, C.,JPCRD 8, No. 3, 865-916 (1979).

Sugar, J., Corliss, C., JPCRD 8, No. 4, $1109-1146$ (1979).

SUgar, J., KaUfman, V., 18369.

Sugar, J., KaUfman, V., 18506.

Sugar, J., Lucatorto, T. B., Mcllrath, T. J., Weiss, A. W., 18507.

Sugita, T., Ka Wakami, S., ImanaKa, O., SP562, pp. 317-323 (Oct. 1979).

Suliman, A. G., SP543, pp. 99-100 (Apr. 1979).

Sullivan, D. B., Hamilton, C. A., HaRris, R. E., 18666.

Sullivan, D. B., Holdeman, L. B., Soulen, R. J., JR., 18871 .

Sullivan, D. B., Zimmerman, J. E., 18701.

Sullivan, T. E., Fonash, S. J., FishKorn, G., SP400-58, pp. 63-68 (Aug. 1979).

SuloufF, R. L., NBS-GCR-79-170.

Susman, S., Rowe, J. M., Rush, J. J., Hinks, D. G., 19036.

Sutton, S. A., Thomas, R. W., Tirosh, J., Wolock, 1., Mast, P. W., Beaubien, L. A., Mulville, D. R., SP563, p. 241 (Oct. 1979).
Sutula, R. A., Holden, J. R., Bennett, L. H., Wang, F. E., MitChell, M. A., 18382 .

Suzuki, H., Saito, F., Handa, T., Suda, K., Nagashima, T., KaNEKo, K., YaMaMURA, T., TAKahashi, Y., SP540, pp. 626$7 ! 1$ (Nov. 1979).

Suzuki, M., Inomata, T., OKazaki, S., Moriwaki, T., SP561/2, pp. 1327-1337 (Sept. 1979).

SVED, S., SERTIE, J. A. A., SPS19, pp. 477-480 (Apr. 1979).

SWAIN, J., JR., SP556, pp. 65.70 (Sept. 1979 ).

Swain, M. V., Field, J. E., Hagan, J. T., SP562, pp. $15-20$ (Oct. 1979).

Swank, J. H., Odette, G. R., McElroy, W. N., Doran, D. G., Gold, R., Lippincott, E. P., Schiffiens, J. O., Simons, R. L., Morgan, W. C., Grundl, J. A., McGarry, E. D., Kam, F. B. K., 19012

Swanson, N., Kurepa, M., Celotta, R. J., 18392.

SWanson, W. P., MCCall, R. C., SP554, pp. $75-86$ (Sept. 1979).

SWARtzendruber, L. J., Bennett, L. H., Reno, R. C., 18967.

SWartzendruber, L. J., Carter, G. C., Kahan, D. J., Read, M. E., ManNing, J. R., I8637.

Swartzendruber, L. J., Romanov, V. P., Candela, G. A., ROTH, R. S., 19046.

SWEETING, L. M., CoXon, B., VARMA, R., 18742.

Sweger, D. M., Segnan, R., Abbundi, R., Rhyne, J. J., 18329.

SWeger, D. M., Travis, J. C., 18538 .

Swyt, D. A., U.S. Patent 4,152,074.

Sykes, A. L., Denyszyn, R. B., Harden, J. M., Hardison, D. L., McGaughey, J. F., SP519, pp. 153-159 (Apr. 1979).

Syverud, A. N., Chase, M. W., Downey, J. R., SP56I/2, pp. 1581-1594 (Sept. 1979).

Sze, W. C., Hillhouse, D. L., Petersons, O., 18938.

$\mathbf{T}$

Tachibana, K., Phelps, A. V., 18925.

TAggart, H. E., Bennett, W. S., 19033.

Taggart, H. E., Jones, R. N., Saulsbury, L. F., Workman, J. L., Treado, M. J., Diamond, J. J., 18381 .

Taggart, H. E., Kanda, M., Shafer, J., Adams, J. W., TNIOI4.

TAgGart, H. E., Shafer, J. F., 18398.

Takahashi, Y., Suzuki, H., Saito, F., Handa, T., Suda, K., NAGASHima, T., KanEKO, K., YaMaMURA, T., SP540, pp. 626711 (Nov. 1979).

TAKATA, S., SP539, pp. 29-32 (Apr. 1979).

TANAKA, T., SP540, pp. 264-355 (Nov. 1979).

TAng, K. Y., Atkinson, G. H., Parmenter, C. S., 1864 I.

Tang, K. Y., Knight, A. E. W., Parmenter, C. S., Lin, H. M., SEAVER, M., $/ 867 I$.

Tarumi, N., Obara, A., Imanaka, O., Yasunaga, N., SP562, pp. 171-182 (Oct. 1979).

TATT, L. K., SP543, pp. 134-141 (Apr. 1979).

TAuber, T. E., SP547, pp. 330-344 (July 1979).

TAUMANN, L., SP554, pp. 139-144 (Sept. 1979).

Tavis, R. L., MElin, J. W., SP552, pp. 249-266 (July 1979).

TAYlor, D. L., Grossman, D. G., SP562, pp. $221-229$ (Oct. 1979).

TAYLOR, J. E., SP561/2, pp. 1353-1358 (Sept. 1979).

TAYLOR, J. G., Lamar, L. Q. C. 1II., NBS-GCR-ETIP 78-59.

Teague, E. C., Scire, F. E., 18327.

TeichneR, W. H., Williams, E., NBS-GCR-79-I69.

Telin, B., Durbeck, H. W., Frischkorn, C. G. B., Buker, I., SCheulen, B., SP519, pp. 437-445 (Apr. 1979).

Temple, P. A., Decker, D. L., Donovan, T. M., Bethke, J. W., SP541, pp. 37-42 (Dec. 1978).

Tereshenko, A. G., Korobeinichev, O. P., SP56I/I, pp. 479 491 (Sept. 1979).

Termini, D. J., Brauer, G. M., Jackson, J. A., 18985.

Termini, D. J., Brauer, G. M., Petrianyk, N., 18809. 
Termini, D. J., Davidson, K. M., Brauer, G. M., Kumpula, J. W., 18638.

Termini, D. J., Jackson, J. A., Brauer, G. M., 18569.

Terner, L. L., Whalen, T. J., SP562, pp. 483-488 (Oct. 1979).

Tevault, D., Lin, M. C., SP561/2, pp. 1551-1568 (Sept. 1979).

Tewisbury, S. K., Meyer, F. C., Rollenhagen, D. C., SChOENWETTER, H. K., SOUders, T. M., 18365.

Thenot, J. P., Hung, A., SPS 19, pp. $419-427$ (Apr. 1979).

Theodosiou, C. E., Armstrong, L., Jr., 18927.

Thibault, M. J., SP500-52, pp. 3-8 (Oct. 1979).

Tholen, A. D., Peiser, H. S., Raley, C. C., NBSIR 79-1721.

Thomas, G. H., DAs, B. S., SP519, pp. 41.56 (Apr. 1979).

Thomas, L. C., Macleod, W. D., JR., Malins, D. C., SP519, pp. $79-86$ (Apr. 1979).

Thomas, P. J., Johnson, S. A., Bahn, R. C., Rajagopalan, B., Greenleaf, J. F., SPS 25, pp. 227-233 (Apr. 1979).

Thomas, R. E., Gaines, G. B., SP400-58, pp. $150-159$ (Aug. 1979).

Thomas, R. W., Tirosh, J., Wolock, I., Mast, P. W., BeauBien, L. A., Mulville, D. R., Sutron, S. A., SP563, p. 241 (Oct. 1979).

Thompson, C., Whisman, W., SP556, pp. 147-151 (Sept. 1979).

ThOMPSON, D. F., SP563, pp. 80-88 (Oct. 1979).

Thompson, J. E., NBS-GCR-79-177.

Thompson, J. N., Hatina, G., Maxwell, W. B., SP519, pp. 279-288 (Apr. 1979).

ThOMPSON, J. W., HARTRum, T. C., SP500-52, pp. 147-161 (Oct. 1979).

Thompson, R., WeBb, W., Rosenstock, H. M., NBSIR 781432.

Thomson, R. M., Gubernatis, J. E., Krumhansl, J. A., 18831 .

Thorngate, J. H., Gammage, R. B., Vo-Dinh, T., HaWThORNe, A. R., SP519, pp. $719-722$ (Apr. 1979).

Thorngate, J. H., Vo-Dinh, T., Gammage, R. B., Hawthorne, A. R., SPS19, pp. 679-684 (Apr. 1979).

Thurstone, F. L., Smith, S. W., Phillips, D. J., von Ramm, O. T., SP525, pp. 209-218 (Apr. 1979).

Tiemann, E., Torring, T., SP561/1, pp. $695-709$ (Sept. 1979).

Tiffany, W. D., Ketchel, J. M., SP480-38, pp. $81-88$ (Dec. 1979).

TILFORD, C. R., SP532, pp. $72-77$ (Feb. 1979).

TING, R. Y., SP563, pp. 25-31 (Oct. 1979).

Ting, R. Y., Nash, H. C., Poranski, C. F., JR., SP563, pp. 17-21 (Oct. 1979).

TIPPET, J. C., ChanG, D. C., NBSIR 79-1615.

Tippet, J. C., Chang, D. C., 18345.

Tippet, J. C., Chang, D. C., 18694.

Tirosh, J., Wolock, I., Mast, P. W., Beaubien, L. A., Mulville, D. R., Sutton, S. A., Thomas, R. W., SP563, p. 241 (Oct. 1979).

TOBLER, R. L., 18611 .

Tobler, R. L., McHenry, H. I., Reed, R. P., 18621 .

TOBler, R. L., REed, R. P., 18695.

TOBler, R. L., REed, R. P., 18943.

Tochilin, E., LaRiviere, P. D., SP554, pp. $145-154$ (Sept. 1979).

Todd, L. J., Siedle, A. R., Bodner, G. M., Garber, A. R., WRIGHT, R. F., 18328 .

TOLER, J. C., SP55I, pp. 38-41 (July 1979).

Tomkins, R. P. T., Allen, C. B., Janz, G. J., JPCRD 8, No. 1, 125-302 (1979).

Tomkins, R. P. T., Janz, G. J., Allen, C. B., Bansal, N. P., MURPhY, R. M., NSRDS-NBS6I, Part III.

ToOmre, J., Gebbie, K. B., Simon, G. W., November, L. J., 18444 .

Torring, T., Tiemann, E., SP561/1, pp. $695-709$ (Sept. 1979).
Toth, E. E., Graminski, E. L., Fong, J. T., Fong, I. K., NBSIR $79-1746$.

Toy, H. D., Parris, G. E., Sherman, P. L., Kemmer, A. M., MetCalfe, L., SPS19, pp. 205-212 (Apr. 1979).

Travis, J. C., DeVoe, J. R., O'Haver, T. C., Turk, G. C., 18880 .

Travis, J. C., Green, R. B., Keller, R. A., luther, G. G., SChenck, P. C., U.S. Patent 4,148,586.

Travis, J. C., Keller, R. A., 18364.

Travis, J. C., Schenck, P. K., Turk, G. C., Mallard, W. G., 18806.

Travis, J. C., Smyth, K. C., Schenck, P. K., Mallard, W. G., SP561/2, pp. 865-882 (Sept. 1979).

Travis, J. C., Smyth, K. C., Schenck, P. K., Mallard, W. G., 18344.

Travis, J. C., Sweger, D. M., $/ 8538$.

Treado, M. J., Diamond, J. J., Taggart, H. E., Jones, R. N., Saulsbury, L. F., WORKMan, J. L., 18381 .

Treado, S. J., BURCh, D. M., NBSIR 79.1736.

Treado, S. J., BurCh, D. M., SP548, pp. 73-104 (July 1979).

Treado, S. J., Burch, D. M., Hunt, C. M., TN992.

Tressler, R. E., Bradt, R. C., Easler, T. E., Countermine, T. A., SP562, pp. $455-462$ (Oct. 1979).

Tressler, R. E., STACh, J., DAS, M. B., NBS-GCR-78-134.

TREVINO, S. F., 19025.

Trevino, S. F., Chol, C. S., Prask, H. J., 19027.

TrinkLer, D., SP553, pp. 101-108 (Aug. 1979).

Tripathi, S. K., Gordon, K. D., Agrawala, A. K., SP500-52, pp. 105-111 (Oct. 1979).

Trombia, J. I., Ehrlich, M., Seltzer, S. M., Bielefeld, M. J., 18416.

Trombka, J. I., Seltzer, S. M., Dyer, C. S., 19011 .

Trombia, J. I., Wall, N. S., Lapides, J. R., Crannell, C. J., Crannell, H., Hornyak, W. F., Seltzer, S. M., 19015.

Tryon, P. V., Jackson, R. H. F., Collier, R. S., Haber, S., NBSIR 79-175I.

TSAI, D. H., 18456 .

Tsang, W., Churney, K., Braun, W., Herron, J. T., 18709.

Tsang, W., Gutman, D., Braun, W., 18832.

TSANG, W., WALKER, J. A., 18743 .

Tsang, W., Walker, J. A., Braun, W., Merron, J. T., 18712.

TSChiegg, C. E., Greenspan, M., NBSIR 79-1753.

Tucker, C., Croarkin, C., Beers, J., Monogr. 163.

TUDOR, J. L., SP543, pp. 144-147 (Apr. 1979).

TURgel, R. S., Oldham, N. M., 18434.

Turk, G. C., Mallard, W. G., Schenck, P. K., Smyth, K. C., 18983.

Turk, G. C., Mallard, W. G., Travis, J. C., Schenck, P. K., 18806.

Turk, G. C., Travis, J. C., DeVoe, J. R., O'Haver, T. C., 18880 .

Turneaure, J. P., Stein, S. R., 18692.

Turner, G. E., Collins, B. L., NBSIR 79-1729.

TURner, G. E., RUbin, A. I., Elder, J., NBSIR 79-1780.

TUrRell, B. G., Marsha K, H., 18604.

\section{$\mathbf{U}$}

UENG, C. E. S., SP563, pp. 228-238 (Oct. 1979).

UlRICHSON, D., YAKE, D., SP556, pp. 123-132 (Sept. 1979).

UNDERWOOD, G. L., DEMICHIELL, R. L., SP500-52, pp. 231-232 (Oct. 1979).

UtTERback, J. M., MURRAY, A. E., NBS-GCR-ETIP 78-49.

$$
\text { V }
$$

Vallejo, R. P., Ercegovich, C. D., SPS19, pp. 333-340 (Apr. 1979). 
Van Blerkom, D., Castor, J. I., 18435.

Van Degrift, C. T., Bowers, W. J., JR., Wildes, D. G., Pipes, P. B., 18548 .

Van Hoosier, M. E., Basri, G. S., Linsky, J. L., Bartoe, J. D. F., BRUeckner, G., 18876 .

Van Stryland, E. W., Solleau, M. J., Bass, M., SP54I, pp. 309-317 (Dec. 1978).

Van Stryland, E. W., Stewart, A. F., Bass, M., SP54I, pp. 19-23 (Dec. 1978).

Vanderbrug, G. J., NAGel, R. N., NBSIR 79-I 764.

VANDERHART, D. L., EARL, W. L., 18745.

VANDeRVeldt, H. H., Kelly, J. J., SP563, pp. 267-275 (Oct. 1979).

Varey, G. B., Mlllet, M. S., Bedrick, J. R., Spencer, G. S., SP552, pp. 321-335 (July 1979).

VARMa, R., SWeeting, L. M., CoXon, B., $/ 8742$.

VAshrangsi, C., SP539, pp. 117-124 (Apr. 1979).

Vassilaros, D. L., Pipkin, W. S., Sorensen, W. L., Lee, M. L., SPS19, Pp. 731-738 (Apr. 1979).

Velapoldi, R. A., Erickson, N., Siedle, A. R., 18504.

Velapoldi, R. A., Mills, R., 18492.

Velapoldi, R. A., Paule, R. C., Schaffer, R., Mandel, J., Machlan, L. A., Gramlich, J. W., SP260-63.

Velapoldi, R. A., Paule, R. C., Schaffer, R., Mandel, J., MURPhy, T. J., GRAMLich, J. W., SP260-67.

Veldkamp, J. B. D., Broese van Groenou, A., MaAn, N., SPS62, PP. $43-59$ (Oct. 1979).

Venable, W. H., JR., Eckerle, K. L., SP260-66.

Venable, W. H., JR., Hsia, J. J., $/ 8844$.

VERDIER, P. H., 18618.

Verdier, P. H., KRanauehl, D. E., 18772.

VERMA, A. R., SP539, PP. 23-28 (Apr. 1979).

VESTAL, M. L., SPS19, pp. 647-654 (Apr. 1979).

Vezzetti, C. F., Hilten, J. S., Lederer, P. S., Mayo-Wells, J. F., NBSIR $78-1590$ (NASA).

Vick, D. O., Schweitzer, G. K., Bowling, R. A., Lassiter, T. W., SP56I/I, Pp. $771-789$ (Sept. 1979).

Victor, G. A., CONSTANTINides, E. R., 18950.

VIDAL, C. R., HESSEL, M. M., $/ 8867$.

VINCENT, C. H., SP532, pp. $59-60$ (Feb. 1979).

Vo-Dinh, T., Gammage, R. B., Hawthorne, A. R., ThornGATE, J. H., SPSI9, pp. 679-684 (Apr. 1979).

Vo-Dinh, T., Hawthorne, A. R., Thorngate, J. H., GAMMAGE, R. B., SP519, pp. $719-722$ (Apr. 1979).

von Ramm, O. T., Thurstone, F. L., Smith, S. W., Phillips, D. J., SPS25, Pp. 209-218 (Apr. 1979).

von Seelen, W., Gaca, A., Loch, E., Scheiding, W., Wessels, G., SP525, pp. 297-302 (Apr. 1979).

Vora, H., Ohmer, M. C., Stoebe, T. G., SP54I, pp. 24-32 (Dec. 1978).

Vora, H., Skogman, R. A., Leung, K. M., Bernal, E., Ready, J. F., SPS41, pp. 59-64 (Dec. 1978).

VOTH, R. O., LUDTKE, P. R., NBSIR 79-1607.

VREeland, R. G., WALler, M. B., NBS-GCR-79-157.

\section{$\mathbf{W}$}

WAag, R. C., Lee, P. P. K., Lerner, R. M., hunter, L. P., Gramiak, R., Schenk, E. A., SP525, Pp. $143-152$ (Apt. 1979).

WACKER, P. F., 18956.

Waclawski, B. J., Gadzuk, J. W., Herbst, J. F., 18323.

WADDOUPS, M., SP563, p. 3 (Oct. 1979).

WAENY, J. C., SPS43, pp. 55-57 (Apr. 1979).

WAGner, H. L., Dillon, J. G., 18834.

Wahlund, K. G., SChill, G., SPS19, pp. $509-523$ (Apr. 1979).

WAKaMATSU, T., SP540, pp. 166-169 (Nov. 1979).

Wakamiya, S., Dobbyn, R. C., Calvano. N. J., 18465.

Walker, J. A., Braun, W., Herron, J. T., Tsang, W., /87/2.
WALKER, J. A., TSANG, W., 18743.

Walker, T. W., Guenther, A. H., Nielsen, P. E., SP54 I, Pp. 226-234 (Dec. 1978).

Wall, N. S., Lapides, J. R., Crannell, C. J., Crannell, H., Hornyak, W. F., Seltzer, S. M., TrombKa, J. I., 19015.

Wall, S. M., Halk, M., KNights, R. L., Appel, B. R., Hoffer, E. M., KothNY, E. L., SPS19, pp. $121-129$ (Apr. 1979).

Wallace, R. G., Copley, S. M., Bass, M., SP562, pp. 283-292 (Oct. 1979).

Wallace, W. E., Fish, G. E., Rhyne, J. J., Sankar, S. G., 18657.

Wallace, W. E., Rhyne, J. J., Fish, G. E., Sankar, S. G., 18682.

Wallace, W. E., Rhyne, J. J., Fish, G. E., Sankar, S. G., 18881 .

WALLER, J., NAY, I. N., NBS-GCR-ETIP 79-64.

WALler, M. B., VREELAND, R. G., NBS-GCR-79-157.

Wallerstein, G., Brugel, E. W., 18546.

Wallerstein, G., Harris, H., Olszewski, E. W., 18913.

Walls, F. L., Drullinger, R. E., Wineland, D. J., $/ 8699$.

Walls, F. L., Gray, J. E., Besson, R. J., Stein, S. R., Manney, C. M., JR., $/ 8691$.

WALLS, F. L., HOWE, D. A., 18696.

Walls, F. L., Kahan, A., Hellwig, H., Stein, S. R., $/ 8826$.

WAlls, F. L., Stein, S. R., 18693.

Walls, F. L., Wineland, D. J., DRullinger, R. E., $/ 8697$.

WAlsh, D. A., Fernelius, N. C., SP54I, Pp. $43-49$ (Dec. 1978).

Walter, J. L., RHYNe, J. J., LYNN, J. W., LUbORSKY, F. E., 18898.

WALTERS, J. L., SP552, pp. 267-282 (July 1979).

Walther, H., Leuchs, G., Smith, S. J., 18953.

Walton, H. F., Elceman, G. A., SP519, pp. 185-190 (Apr. 1979).

Wang, A. S., Crossman, F. W., Law, G. E., JR., SP563, Pp. 255-264 (Oct. 1979).

Wang, F. E., Mitcheli, M. A., Sutula, R. A., Holden, J. R., BenNett, L. H., 18382 .

W ANG, F. W., 18431 .

W ANG, T. J., JohnSon, C. R., Beine, W. B., 18602.

WANG, Y. Y., OVERBOE, C. J., NBS-GCR-79-167.

WARE, R. H., BENDER, P. L., 18895.

Warnar, R. B. J., Calomeris, P. J., Recicar, S. A., SP500-45.

Warnar, R. B. J., Moore, R. T., Carpenter, R. J., Holt, A. W., KOENIG, A. L., NBSIR 79-I725.

WARNER, B., 18595 .

Warner, B. E., Persson, K. B., Collins, G. J., 18968.

Washbur n, D. N., Siggla, S., Kostyla, R. J., Mourey, T. H., Cohen, R., Merritt, M. E., Simmons, K., LaFaucia, R., LiMENTANI, G., SP5/9, pp. 783-787 (Apr. 1979).

WASKO, R. J., SP55I, PP. 27-28 (July 1979).

WATANABE, A., SP540, p. 717 (Nov. 1979).

Watanabe, A., MiYama, J., SP540, Pp. 46-53 (Nov. 1979).

Waters, P. F., Abouelezz, M., NBSIR 79-1766.

Waterstrat, R. M., Haenssler, F., Muller, J., $/ 8734$.

WATSON, R. E., BENNETT, L. H., 18357 .

Watson, R. E., BENNETT, L. H., 18383 .

WATSON, R. E., BENNETt, L. H., 18421 .

WAtSON, R. E., BENneTt, L. H., 19047.

Watson, S., Bell, J., Kirby, S., Weiss, R. G., TNII04, Vols. $I$ and 2.

WATTS, J., NBS-GCR-79-163.

Waxler, R. M., Dodge, M. J., Feldman, A., Horowitz, D., TN993.

WaXler, R. M., Feldman, A., Horowitz, D., SP54I, pp. 5054 (Dec. 1978).

WEATHERBEe, J. E., SPSO0-52. 
Webb, A. J., Woodcock, J. P., Wells, P. N. T., Halliwell, M., Mountford, R. A., Skidmore, R., SP525, pp. 173-176 (Apr. 1979).

WEBB, D. J., SP547, Pp. 3-16 (July 1979).

WebB, W., Rosenstock, H. M., Thompson, R., NBSIR 781432.

Weber, M. J., Stokowski, S. E., Milam, D., SP54I, pp. 99-108 (Dec. 1978 ).

WEBER, S. F., TN980.

WEBER, S. F., 19016.

Weber, S. F., 19044.

Webster, C. D. J., Nielsen, V., Hanslin, R., SPS53, pp. 109 128 (Aug. 1979).

Weeks, S., Fujiwara, K., Omenetto, N., Haraguchi, H., Winefordner, J. D., BradshaW, J., Bower, J., SP561/2, pp. 1079-1102 (Sept. 1979).

WeIdNer, V. R., Hsia, J. J., 18594.

WEINGART, O., SP563, pp. $155-172$ (Oct. 1979).

Weinstein, C., Nolan, R., Weinstein, S., SP480-38, pp. 7-16 (Dec. 1979).

Weinstein, J. N., Wlodawer, A., Segrest, J. P., Chung, B. H., Chiovetti, R., JR., 18851 .

Weinstein, S., Weinstein, C., Nolan, R., SP480-38, pp. 7-16 (Dec. 1979).

Weiss, A. W., Sugar, J., Lucatorto, T. B., McIllath, T. J., 18507.

WEISS, L., SPS25, pp. 317-322 (Apr. 1979).

Weiss, R. G., WATSON, S., Bell, J., KirBY, S., TNI104, Vols. $I$ and 2.

Wells, J. S., Fehsenfeld, F. C., Howard, C. J., Streit, G. E., 18551 .

Wells, J. S., SAMS, R. L., LAFFerty, W. J., 18864 .

Wells, P. N. T., Halliwell, M., Mountford, R. A., SkidMORE, R., WEBB, A. J., WOODCOCK, J. P., SP525, pp. 173176 (Apr. 1979).

WELTNER, W., JR., SP561/l, pp. 587-594 (Sept. 1979).

Wessels, G., von Seelen, W., Gaca, A., Loch, E., Scheiding, W., SP525, pp. 297-302 (Apr. 1979).

WESTIN, A. F., SP500-50.

WESTLEY, F., NBSIR 79-1941.

Weston, A. F., Wezwick, C., Richton, D., Scott, J., Smith, J. S., SPS19, pp. 181-184 (Apr. 1979).

WETHERINGTON, T. I., JR., SP548, pp. 15-24 (July 1979).

WeZWick, C., MadY, N., SMith, D., SMith, J., SP519, pp. 341 343 (Apr. 1979).

WezWick, C., Richton, D., SCOtT, J., SMith, J. S., Weston, A. F., SPS19, pp. 181-184 (Apr. 1979).

Whalen, T. J., Terner, L. L., SP562, pp. 483-488 (Oct. 1979).

Whisman, W., Thompson, C., SP556, pp. 147-151 (Sept. 1979).

Whitcomb, J. A., Eggleton, R. C., SP525, pp. 327-336 (Apr. 1979).

White, H. J., JR., Lide, D. R., JR., Gevantman, L. N., SP561/2, Pp. 1571-1579 (Sept. 1979).

White V, E., Sniegoski, L. T., Cohen, A., Schaffer, R., SP519, Pp. $405-410$ (Apr. 1979).

Wichers, E., Hoffman, J. I., Saylor, C. P., J. Res. 84, No. 5, 385-394 (1979).

WiederhorN, S. M., RUfF, A. W., NBSIR 78-1575.

WIEDERHORN, S. M., RUFF, A. W., 18858.

WIESE, W. L., 18572 .

WIESE, W. L., 18593.

Wiese, W. L., Kelleher, D. E., Konjevic, N., 18948.

WIESE, W. L., KONJEVIC, N., 18737.

Wiese, W. L., MARTin, G. A., 18736.

Wiese, W. L., YOUNGER, S. M., 18366.

WIESE, W. L., YOUNGER, S. M., 18508.

WIESE, W. L., YOUNGER, S. M., 18997.
WILdes, D. G., Pipes, P. B., Van Degrift, C. T., Bowers, W. J., JR., 18548 .

Wilhoit, R. C., Chen, S. S., KudChadker, S. A., JPCRD 8, No. 2, 527-536 (1979).

WILKowsKi, J., SP543, pp. 151-155 (Apr. 1979).

WILlard, W. A., Shives, T. R., SP547.

WILla Rd, W. A., Shives, T. R., SP563.

Williams, E., SP532, pp. $42-47$ (Feb. 1979).

Williams, E., TeichNER, W. H., NBS-GCR-79-169.

Williams, E. R., Olsen, P. T., 18437.

Williams, E. R., Olsen, P. T., 18702.

Williams, F. W., Wyatt, J. R., DeCorpo, J. J., Saalfeld, F, E., Sмith, D. E., King, T. L., Eaton, H. G., SP5 19, pp. 213 218 (Apr. 1979).

Williams, G., Konen, T. P., Liposki, F., Myers, J. R., NielSen, L., Mikucki, W., Staton, W., SP553, pp. 15-19 .(Aug. 1979).

Williams, G. H., Fowell, A. J., Bransdorfer, A., Fletcher, P., Orend, R. J., PAvel, H. J., SP553, pp. $21-31$ (Aug. 1979).

Willson, K., Gore, J. C., leeman, S., Metreweli, C., Plessner, N. J., SP525, pp. $275-280$ (Apr. 1979).

WILSON, C. B., SP500-53.

Wilson, R. L., Le Croissette, D. H., Heyser, R. C., GamMELL, P. M., Roseboro, J. A., SP525, pp. 101-108 (Apr. 1979).

Wilson, W. A., Crawford, M. L., Decker, W. F., TNIOII.

Wilson, W. K., Parks, E. J., 19017.

Winefordner, J. D., Bradshaw, J., Bower, J., Weeks, S., FuJiwara, K., Omenetto, N., Haraguchi, H., SP56I/2, pp. 1079-1102 (Sept. 1979).

WiNeland, D. J., $l 8608$.

Wineland, D. J., Drullinger, R. E., W al.l., F. L., 18697.

Wineland, D. J., Garvey, R. M., Hell wig, H. W., Jarvis, S., JR., 18475 .

Wineland, D. J., Hellwig, H., Evenson, K. M., 18346.

Wineland, D. J., Hellwig, H. W., Jarvis, S., JR., U.S. Patent $4,146,848$.

Wineland, D. J., Howe, D. A., Mohler, M. B., Hellwig, M. W., 18698.

Wineland, D. J., Walls, F. L., Drullinger, R. E., 18699.

WinNeWisSer, G., GerRY, M. C. L., Y AMADA, K., JPCRD 8, No. 1, 107-124 (1979).

Wise, S. A., Heinrich, K. F. J., Etz, E. S., SP5/9, pp. 723729 (Apr. 1979).

Wise, S. A., May, W. E., Brown, J. M., Chesler, S. N., Guenther, F., Hilpert, L. R., Hertz, H. S., SP519, pp. 219. 224 (Apr. 1979).

Wlodawer, A., Segrest, J. P., Chung, B. H., Chiovetti, R., JR., WEINSTEIN, J. N., 18851 .

Wollin, H. F., H44, 1979 Edition.

Wollin, H. F., Barbrow, L. E., Heffernan, A. P., SP5 32.

Wolock, I., Mast, P. W., Beaubien, L. A., Mulville, D. R., Sutton, S. A., Thomas, R. W., TiRosh, J., SP563, p. 241 (Oct. 1979).

Wolynec, E., Dodge, W. R., Hayward, E., Moscati, G., 18518.

Wolynec, E., Dodge, W. R., Hayward, E., 18535 .

Womble, S. E., PaAbo, M., Birky, M. M., 18588.

Wong, S. M., KRAuss, G., Bennett, J. M., SP541, pp. 132-163 (Dec. 1978).

Wood, H. M., 19041 .

WoOd, H. M., KIMBleton, S. R., 19009.

Wood, L. A., J. Res. 84, No. 5, 353-358 (1979).

Woodcock, J. P., Wells, P. N. T., Halliwell, M., MountFORD, R. A., SKIDMORE, R., WEBB, A. J., SP525, pp. 173-176 (Apr. 1979).

Woodruff, J. J., Dougherty, H. T., Estin, A. J., Morgan, W. L., 18628.

WOODWARD, E. G., McEACHRON, N. B., NBS-GCR-ETIP 78-50. 
Woolson, B., Glancy, J., NiCastro, J. R., SP480-38, pp. 2328 (Dec. 1979).

Worden, S. P., Giampapa, M. S., Linsky, J. L., Schneeberger, T. J., 19007.

Worden, S. P., Kelch, W. L., LinsKy, J. L., 18926.

Worden, S. P., McClintock, W., Robertson, R. M., Linsky, J. L., 18853 .

Worden, S. P., Schneeberger, T. J., Linsky, J. L., McClinTOCK, W., 18920 .

WORKMAN, J. L., CraWFORD, M. L., TNI013.

WORKMAN, J. L., CraWford, M. L., 18578.

Workman, J. L., Treado, M. J., Diamond, J. J., Taggart, H. E., Jones, R. N., SA ulsbury, L. F., 18381 .

Wormhoudt, J., Kolв, C. E., SP561/1, pp. 457-476 (Sept. 1979).

Wright, J. P., SP547, pp. 299-302 (July 1979).

Wright, R. F., TOdD, L. J., Siedle, A. R., Bodner, G. M., GARber, A. R., 18328 .

Wright, R. N., HARRIS, J. R., FENVES, S. J., TNI100.

Wu, C. C., Farabaugh, E. N., Armstrong, R. W., 18341 .

WU, C. C., MCKINNEY, K. R., SP562, pp. 477-481 (Oct. 1979).

WU, Y.C., NBSIR 79-1710.

Wyatt, J. R., DeCorpo, J. J., SaAlfeld, F. E., Smith, D. E., King, T. L., Eaton, H. G., Williams, F. W., SP519, pp. 213 218 (Apr. 1979).

Wylie, R. G., J. Res. 84, No. 2, 161-177 (1979).

Wyly, R., Marshall, H., Ruegg, R., SP553, pp. 207-225 (Aug. 1979).

Wyly, R. S., Benazzi, R. V., Konen, T. P., Manfredi, R. R., Nielsen, L. S., SP553, pp. 35-51 (Aug. 1979).

Wyly, R. S., Galowin, L. S., Downing, W. J., Nielsen, L. S., Orlosk1, M. J., SP553, pp. 53-70 (Aug. 1979).

Wyly, R. S., Konen, T. P., Benazzi, R. V., Guss, L., Orend, R., SP553, pp. 3-13 (Aug. 1979).

Wynder, E. L., Hoffmann, D., Brunnemann, K. D., SCHMELTZ, I., SP519, pp. 131-141 (Apr. 1979).

WYrick, T. F., YousTrA, R. E., SP500-52, pp. 229-230 (Oct. 1979).

\section{$\mathbf{X}$ \\ $\mathbf{Y}$}

YAKe, D., Ulrichson, D., SP556, pp. 123-132 (Sept. 1979).

Yamada, A., KoKaJi, Y., Kimura, S., IKEDA, M., SP562, pp. 325-333 (Oct. 1979).

Yamada, K., Winnewisser, G., Gerry, M. C. L., JPCRD 8, No. 1, 107-124 (1979).

YаMAMOTO, K., SP540, pp. $520-527$ (Nov. 1979).

Yamamura, T., Takahashi, Y., SuzUkı, H., Saito, F., Handa, T., Suda, K., Nagashima, T., Kaneko, K., SP540, pp. 626711 (Nov. 1979).

Yamasaki, K., Barnes, 1. L., Rosman, K. J. R., Diaz, M., BRILL, R. H., 18840 .

Yancey, C. W. C., Cattaneo, L. E., BSS95.

YANEY, P. O., ROQUEMORE, W. M., SP561/2, pp. 973-1023 (Sept. 1979).

Yang, H. T., Stokes, E. D., Chu, S. S., Chu, T. L., SP40058, pp. 76-81 (Aug. 1979).

YANG, K. T., LIU, K. V., NBS-GCR-78-150.

Yasunaga, N., Tarumi, N., Obara, A., Imanaka, O., SP562, Pp. $171-182$ (Oct. 1979).

YATES, J. T., JR., Fisher, G. B., MAdEy, T. E., 18791 .

YiN, L. I., Seltzer, S. M., 19000.

YOKEL, F. Y., 18324.

YoKel, F. Y., Kovacs, W. D., BSSIO7.

Yoon, D. Y., Broadhurst, M. G., NaEgele, D!, 18531 .

YOON, H. S., KATZ, J. L., SP525, pp. 189-196 (Apr. 1979).
Young, J. P., Ballard, D. B., Ogburn, F., U.S. Patent $4,139,933$.

Young, K. F., Franklin, A. D., 18794.

YouNG, M., 18999.

YOUNG, M., 19021 .

Young, M., ANDREwS, J. R., NBSIR 79.1620.

YOUNG, M., LAWTON, R. A., TNIOIO.

Young, S. N., Anderson, G. M., Purdy, W. C., SP5/9, pp. 411-418 (Apr. 1979).

YOUNGER, S. M., 18996.

YOUNGER, S. M., 18998.

YOUNGER, S. M., WIESE, W. L., 18366.

YOUNGER, S. M., WIESE, W. L., 18508.

YOUNGER, S. M., WIESE, W. L., 18997.

Younglove, B. A., 18815 .

Younglove, B. A., Siegwarth, J. D., LaBrecque, J. F., 18805.

Younglove, B. A., Straty, G. C., 18987.

Youstra, R. E., WYRICK, T. F., SP500-52, pp. 229-230 (Oct. 1979).

Yu, H., Han, C. C., Serdyuk, I. N., J. Res. 84, No. 1, 1-8 (1979).

Yu, H., Hinkley, J. A., Han, C. C., Mozer, B., 18827.

YuHAS, D. E., KeSSler, L. W., SP525, pp. 73-79 (Apr. 1979).

YuSA, S., Kishitani, K., SP540, pp. 453-484 (Nov. 1979).

Yushchenko, K. A., ReED, R. P., 18865.

\section{$\mathbf{Z}$}

Zajonc, A., Gallagher, A., 19028.

Zalewski, E. F., Fowler, J. B., LiND, M. A., TN987.

Zalewski, E. F., Geist, J., Lind, M. A., Schaefer, A. R., 18773.

Zalewski, E. F., Geist, J., Lind, M. A., Schaefer, A. R., 18774.

Zalubas, R., Martin, W. C., JPCRD 8, No. 3, 817-864 (1979).

ZANDER, A. T., Epstein, M. S., 18783 .

ZaPAS, L. J., Chang, S. J., 18367.

ZaPAS, L. J., Crissman, J. M., 18468.

Zapas, L. J., Crissman, J. M., 18765.

Zapas, L. J., Crissman, J. M., 18766.

Zapas, L. J., Crissman, J. M., 18767.

Zapas, L. J., Crissman, J. M., 18807.

Zapf, T. L., GrohmanN, K., 18664.

Zasorin, E. Z., SPIRIDONOV, V. P., SP561/1, pp. 711-755 (Sept. 1979).

Zeitz, L., Ding, J., Laughlin, J. S., Reid, A., SP554, pp. 114 (Sept. 1979).

Zervos, C., Mighell, A. D., Hubbard, C. R., Harris, J., StafFA, J. A., 18673 .

Zimmer, W. H., Gilliam, D. M., Helmer, R. G., Greenwood, R. C., Rogers, J. W., Heinrich, R. R., Popek, R. J., KelLogG, L. S., Lippincott, E. P., Hansen, G. E., 18884.

Zimmerman, J. E., U.S. Patent 4,143,520.

ZIMMERMAN, J. E., 18700 .

Zimmerman, J. E., Reite, M., Edrich, J., Zimmerman, J. T., 18397.

Zimmerman, J. E., Sullivan, D. B., 18701 .

Zimmerman, J. T., Zimmerman, J. E., Reite, M., Edrich, J., 18397.

Zinn, B. T., Bankston, C. P., Cassanova, R. A., Powell, E. A., NBS-GCR-78-147.

ZOLLWEG, R. J., SP561/2, pp. 1477-1494 (Sept. 1979).

Zucconi, T. D., Lewkowicz, C., Donahe, S. M., Janauer, G. E., SP519, pp. 455-459 (Apr. 1979).

Zumberge, M. A., Faller, J. E., Rinker, R. L., 18472.

Zumberge, M. A., Faller, J. E., Rinker, R. L., 18654.

Zumberge, M. A., Faller, J. E., Rinker, R. L., 18947.

Zurkowski, P., Berger, P. W., Sprague, P. A., 19048. 


\subsection{KEY WORD INDEX}

A

$\alpha$ phase: phase change piezoclectric polymers; polarization; polyvinylidene lluoride; $x$-ray diffraction; 18531

a phase; $485 \mathrm{~K}$; diffusion; quasiclastic scattering; tantalum hydride; vanadium hydride; 18730 ).

Abatement; building economics; building materials; economic analysis; housing; lead-based paint; lead poisoning; TN971.

Abatcment; building economics; building materials; cost estimation; econometric models; economic analysis; housing; leadbased paint; lead poisoning; TN979.

Abbe value; coolants, $\mathrm{dn} / \mathrm{dT}$; index matching liquids; neodymium glass lasers; nonlinear refractive index; thermal conductivity; viscosity; SP541, pp. 109.121 (Dec. 1978).

Abiotic synthesis; carbonaceous chondrite; chemical evolution; meteorite; Mighei; S1'5/9, pp. $771-775$ (Apr. 1979).

Abnormal loads; buildings (codes); probability theory; progressive collapse; reliability; structural engineering; $184 / 5$.

Abnormal psychology; arson; arsonists; firesetters; human behavior; literature reviews; pyromaniacs; NBS-GCR-79-157.

Abrasion; ceramic machining; ceramics; effects of machining on ceramic properties; hardness; surface characterizations; surface finishing; SP562.

Abrasive machining; ceramics; contact stress; damage penetration; fracture mechanics; fragmentation; glass; grinding; impact; silicon nitride; strength; stress intensity factor; SP562, pp. 23.42 (Oct. 1979).

Abrasive machining; chip formation; fine grinding; glass; ceramics; material removal; SP562, pp. 107-114 (Oct. 1979).

Abrasive wear; ceramics; fracture; plastic penetration; thermal stresses; SP562, pp. 1 -13 (Oct. 1979).

Abrasives; ceramics; coated abrasives; grinding; stone; SP562, pp. 201-207 (Oct. 1979).

Abrasives; ceramics; erosion; impact; metals; particle erosion; wear; NBSIR 78-1575.

Abrasives; ceramics; erosion; impact; metals; particle erosion; wear; 18858 .

Abscisic acid; gas chromatography; liquid chromatography; plant constituents; SP5 19, pp. 803-807 (Apr. 1979).

Ahsolutc detector; absorption coefficient; dead layer model; external; internal quantum efficiency; silicon; 18477 .

Absolute radiometers; blackbody measurements; chemical actinometry; second harmonic generation; solar radiation measurements; 18476 .

Absolute radiometry; dctector; electrically calibrated detectors; lascr power measurements; pyroelectric detectors; radiometry; silicon cell; silicon detector; silicon photodetector; 18773 .

Absolute radiometry; detector; electrically calibrated detectors; laser power measurements; pyroelectric detectors; radiometry; silicon cell; silicon dctector; silicon photodetector; 18774 .

Absolute sound power source; particle velocity; plane wave; sound intensity; sound power; standing wave tube; $l 8728$.

Absorbed dose; attenuation coefficient; detector response functions; dosimetry; electrons; foil transmission; photons; stopping power; transport theory: 18371 .

Absorbcd dose; dose equivalent; gray; sievcrt; unit; 19002 .

Absorption; amino acids; attenuation; frequency; mammalian tissues; polypeptidcs; proteins; tissuc characterization; ultrasonics; velocity; SP525, pp. 19-27 (Apr. 1979).

Absorption; antireflectance coatings; high reflectance coatings; interface absorption; multilayer films; scattering; SP541, pp. 266-277 (Dec. 1978).

Ahsorption; antireflection coatings; damage thresholds; impurities; laser-induced damage; thermal damage; SP541, pp. 202211 (Dec. 1978).

Absorption; arsenic selenide; arsenic trisulfide; defects; laser damage; sodium fluoride; SP541, pp. 212-217 (Dec. 1978).
Ahsorption; attenuation; computerized tomography; Doppler; impedance; medical diagnosis; microscopy; pattern recognition; scattering; signal processing; tissue characterization; tissue parameters; ultrasound; velocity; SP525.

Absorption; attenuation; heart; liver; scattering; scattering cross-section; Sl'525, pp. 153-156 (Apr. 1979).

Absorption; calorimetry; optical coatings; SP54l, pp. 33-36 (Dec. 1978).

Absorption; cesium; exponential index; ionization; multiphoton; Rabi frequency; Star shift; two-level model; 18892 .

Absorption; diamond-turning; scattered light; surface roughness; SP54I, pp. 122-130 (Dec. 1978).

Absorption; $\mathrm{KCl}$; $\mathrm{NaCl}$; tuneable laser calorimetry; 9.2 to 10.6

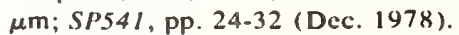

Absorption analysis; absorption spectrum; benzene; rotational contours of absorption bands; 18747 .

Absorption analysis; absorption spectrum; benzene; 18749 .

Absorption coefficient; adiabatic calorimetry; $\mathrm{As}_{2} \mathrm{Se}_{3}$; interface absorption; laser calorimetry: NaF; thin film absorption; water absorption; wedged film; SP54I, pp. 37-42 (Dec. 1978).

Absorption coefficient; dead layer model; external; internal quantum efficiency; silicon; absolute detector; 18477 .

Absorption coefficient; sodium fluoride film; total internal reflection; 0.65 to 3.0 microns; SP54l, pp. 13.18 (Dec. 1978).

Absorption edge; $\mathrm{CaF}_{2} ; \mathrm{KCl}$; optical absorption coefficient; optoacoustic spectroscopy; $\mathrm{PbF}_{2}$; photoacoustic spectroscopy; TII; ZnSe; SP541, pp. 43-49 (Dec. 1978).

Absorption of ultrasound; macromolecular relaxation; relaxation phenomenon; ultrasonic tissue absorption; SP525, pp. 29-36 (Apr. 1979).

Absorption selection rules; benzene; Herzberg-Teller theory; rotational contours of absorption bands; vibrational angular momentum; 18750.

Absorption spectra; core excitation; emission spectra; lattice relaxation; many body effects; sodium; 18413

Absorption spectroscopy; derivative spectroscopy; PNA analysis; trace organic analysis; SP519, pp. $719-722$ (Apr. 1979).

Absorption spectrum; benzene; absorption analysis; $l 8749$.

Absorption spectrum; benzene; rotational contours of absorption bands; absorption analysis; 18747 .

Absorptive coatings; accelerated laboratory tests; durability; outdoor exposure; solar collectors; standard test methods; 18554

Abstract; appearance potential; archival tape; computer program; data base; data base management; cmpirical molecular formula; GPSDC; ion energetics; ionization potential; NBSIR $78-1432$.

Abstracts; Center for Building Technology; key words; publications; SP457-3.

Abstracts, NBS publications; key words; publications; SP305. Supplement 10.

Ac current; high frequency oscillator; Josephson junction; picosecond pulse generator; U.S. Patent 4,168,44l.

A-c detector; automatic bridge; detector; high resolution detector; phase sensitive detector; programmable detector; 18453.

Ac generators; heat transfer; helium; hydrodynamics; large magnets; power transmission; review; superconductors; 18822 .

Ac Stark effect; double optica! resonance; laser bandwidth effects; multiphoton ionization; 18955 .

Ac voltage measurement; low frequency; microcomputer; 18455.

Accelerated aging; aging; aging of cellulose; aging of paper; cellulose; cellulose aging; natural aging; paper; paper aging; tests for paper; 19017 .

Accelerated laboratory tests; durability; outdoor exposure; solar collectors; standard test methods; absorptive coatings; 18554 . 
Acclerated stress test; capillary leaks; corrosion failure; hermeticity; moisture infusion; oxide moisture sensors; NBSGCR-79-170.

Accelerated tests; failure mechanisms; failure modes; photovoltaics; reliability; semiconductors; solar cells; stability; testing; thin films; $S P 400-58$.

Accelerated tests; failure mechanisms; failure modes; photovoltaics; reliability; semiconductors; solar cells; stability; testing; thin films; NBSIR 79-1778.

Acceleration insensitive oscillator; ammonia microwave absorption; atomic clock; cavity frequency stabilization; digital demodulator; frequency-lock servo; frequency standard; inversion transition in ammonia; precision; 18698 .

Accelerator; alloy; base metal; casting; composite; cyanoacrylate; dental alloy; initiator; resin; wear; NBSIR 78-1573.

Accelerator; neutron fluence; photoneutrons; SP554, pp. 75-86 (Sept. 1979).

Accelerator design; accelerator operation; health physics; particle accelerators; radiation measurements; radiation protection; standard; H107, Revised.

Accelerator mass spectrometry; anthropogenic and natural carbonaceous species; atmospheric gases and particles; environmental pollutants; fossil fuels; low-level counting; radiocarbon; 18405 .

Accelerator operation; health physics; particle accelerators; radiation measurements; radiation protection; standard; accelerator design; H107, Revised.

Accelerators; betatrons; electrons; megavoltage; neutrons; therapy; $x$ rays; SP554, pp. 1-14 (Sept. 1979).

Accelerators; IEC; interlocks; leakage; radiation; safety; standards; SP554, pp. 29-32 (Sept. 1979).

Accelerators; leakage radiation; regulations; SSRCR; state; SP554, pp. 33-35 (Sept. 1979).

Access control; computer networking; computer security; network operating systems; 19009

Access to information; architect; information format; information sources; technical information; technology application; NBS-GCR-78-153.

Access to information; architect; information format; information sources; technical information; technology application; NBS-GCR-78-154.

Accessibility standards; building codes; code administration; communication; physically handicapped; public awareness; public relations; SP552, pp. 115-120 (July 1979).

Accessible; disabled; housing; regulations; SP552, pp. 95-100 (July 1979).

Accident; apparel; burn injury; clothing; fabric flammability; fabrics; fire; garments; heat transfer; injury potential; simulation; NBSIR 79.1755.

Accident avoidance; accidents in the home; door accidents; home accidents; home safety; safety in the home; stair accidents; stair safety; window accidents; window safety; NBSGCR-78-156

Accident investigations; chimneys; coal; creosote; fire departments; fire safety; heating equipment; maintenance; stoves; wood; NBSIR 79-1731.

Accident investigations; chimneys; coal; creosote; fire departments; fire safety; heating equipment; maintenance; stoves; wood; NBS-GCR-78-149.

Accident investigations; chimneys; coal; creosote; fire departments; fire safety; heating equipment; maintenance; stoves; wood; 18537.

Accidents; architectural design; architectural psychology; architectural research; building codes; building design; building regulatory standards; floor coverings; home safety; safety standards; stair safety; stairway design; BSSI 20

Accidents in the home; door accidents; home accidents; home safety; safety in the home; stair accidents; stair safety; window accidents; window safety; accident avoidance; NBSGCR-78-156.
Accounting logs; performance evaluation; workload characterization; SP500-52, pp. 241-243 (Oct. 1979).

Accumulator; analog; centralized; check-out system; dessicant; discrete; displacement; fiber optics; filters; flight critical; flow; fluid; go-no-go; ground readout; hydraulic; IMACS; instantaneous diagnosis and analysis; level; SP547, pp. 345-357 (July 1979).

Accumulators; analysis of organics in water; automatic sampler; master analytical scheme; non-purgeable organics; organic pollutant; purgeable organics; WaterDROP; SP519, pp. 65-78 (Apr. 1979).

Accuracy; compatibility; radioactivity reference materials; standard reference materials; 18539 .

Accuracy; cryogenic; error estimation; liquefied natural gas; LNG; marine; mathematical modeling; measurement; photogrammetric; precision; ship cargo; statistical analysis; strapping; survey; NBSIR 79-175I.

Accuracy and precision; gold films; gravimetry; neutron activation analysis; Rutherford backscattering; standards; 18490 .

Acetylene; butadiyne; ethynyl; hydrogen; mechanism; photochemistry; radicals; rate constant; 18443 .

Acid-base status of blood; blood gases; blood $\mathrm{pH}$; carbon dioxide; oxygen; $\mathrm{pH} ; 18470$.

Acoustic; annual report; eddy currents; inspection; magnetic particles; nondestructive evaluation; penetrants; radiography; statistics; ultrasonics; visual-optical tests; NBSIR 78-158I.

Acoustic; computer processing; digital acquisition; digital signal processing; pulse-echo techniques; spectrum analysis; ultrasonics; SP525, pp. 281-286 (Apr. 1979).

Acoustic; crack; defects; elastic solid; pulses; scattering; ultrasonic; 18391 .

Acoustic cavitation; cavitation; cavitation threshold vs temperature; radiation-induced cavitation; temperature dependence of cavitation threshold; threshold; NBSIR 79-1753.

Acoustic emission; beam lead devices; electronic devices; hermeticity; hybrids; nondestructive tests; semiconductor; tapebonded devices; SP4OO-59.

Acoustic emission; capacitive transducer; signal analysis; simulated acoustic emission; time-domain deconvolution; transient elastic wave propagation; 18878 .

Acoustic emission; chemomechanical effects; environmental effects; fracture of brittle materials; hydrogen embrittlement; Rehbinder effects; Westwood effects; SP562, pp. 139-145 (Oct. 1979).

Acoustic emission; co-shock; couplant; detection; electronic package; impact noise; microcircuit device; particle detection; particle impact noise detection; PIND; pre-shock; seeded specimens; transducer; NBSIR 78-1590 (NASA).

Acoustic emission; failure detection; preventive maintenance; SP547, pp. 129-152 (July 1979).

Acoustic microscopy; anisotropy; attenuation; elastic microstructure; infarct; interferogram; myocardium; phase cancellation; velocity; SP525, pp. 73-79 (Apr. 1979).

Acoustic surface wave; ceramic; surface characterization; surface crack; turbine blade; SP562, pp. 379-392 (Oct. 1979).

Acoustic theory; calorimetry; electroacoustic method; medical applications; metrology; NDE; radiation force; transducer characterization; ultrasonics; 18438 .

Acoustic waves; piezoelectric polymer; preset tensile stress; pressure variations; U.S. Patent 4,166,229.

Acoustics; bridges; creosote; harbor facilities; inspection; maintenance; marine borers; nondestructive testing; pilings; timber; 18525 .

Acoustics; environmental noise; noise; noise emission; regulations; sound; 18785 .

Acoustics; flow; insertion loss; microphone; porous sphere; sphere; spheres; wind noise; windscreen; windscreen performance; windscreens; NBSIR 79-1599.

Acoustics; noise measurement; noise (sound); tire noise; transportation noise; truck; 18607 . 
Acoustooptic; intensity; laser; modulator; noise; servo control; 18904

Acrylatcs; adhesion, dental; bonding; coupling agent; dental; monomers; resins; surface-active comonomers; 18461 .

Activation; detcctors; dose; fast; neutrons; track; SP554, pp. 99-107 (Sept. 1979).

Activation analysis; benchmark fields; dosimetry; fission yields; measurements; neutrons; Np-237; Pu-239; U-235; U-238; 18884 .

Activation analysis; cadmium ratio; east neutron reactions; intcrfering nuclear reactions; optimization of analysis; silicon; trace analysis; 18338 .

Activation analysis; crystal structure; diffraction; isotopes; molecular dynamics; neutron; neutron radiography; nondestructive evaluation; nuclear reactor; radiation; TN995.

Activation analysis; electron beams; induction accelerator; ion acceleration; nuclear research; radiation processing; 18570 .

Activation energies; electronically excited states; evaluation; gaseous interactions; molecular correlations; quenching; radiative lifetimes; rate constants; reactive channels; recommended data; relaxation processes; review; JPCRD 8, No. 3, 723-798 (1979).

Activation energy; $A$-factor; comparative rate; flow system; heat of formation; hexylmethylethane; $t$-butyl radical; unimolecular decomposition; 18743

Activation energy; automated thermogravimetry; computer automated thermogravimeter; factor-jump thermogravimetry; polymer degradation; thermogravimetry; 18447 .

Activation energy; computer automation; computerized thermogravimetry; computer program; polymer degradation; polymer oxidation; thermogravimetry; 18445 .

Activation energy; degradation apparatus; factor-jump thermogravimetry; polymer degradation; polymer oxidation; programmed temperature control; thermogravimetry; 18450 .

Activation energy; methyl group; neutron scattering; potential barrier; quasielastic scattering; reorientation; residence time; tunneling; 18374

Activation parameters; aqueous transmethylation; chloride complexes; environment; formation constants; ionic mechanisms; kinetics; methylmercury; methyltin; NMR; primary salt effect; speciation; 18484 .

Activity coefficient; cobalt; critical evaluation; electrolyte; excess Gibbs energy: iron; nickel; osmotic coefficients; solutions; thermodynamic properties; JPCRD 8, No. 4, 923-1004 (1979).

Activity coefficient; copper; critical evaluation; electrolyte; excess Gibbs energy; lead; manganese; osmotic coefficients; solutions; thermodynamic properties; uranium; JPCRD 8 , No. 4, 1005-d050 (1979).

Activity coefficient; hydrogen ion activity; ionic activity; ionic activity scales; $\mathrm{pD} ; \mathrm{pD}$ scale; $\mathrm{pH} ; \mathrm{pH}$ scales; potentiometric ion activity; 18379 .

Acyclic sugars; chemical shifts; conformation; coupling constants; hexononitriles; iterative analysis; proton $\mathrm{nmr}$ spectroscopy; shift reagents; 18742 .

Adaptive reuse; architecture; building codss; building regulations; building safety; construction; performance; preservation; rehabilitation; renovation; SP536, pp. 1-16 (Feb. 1979).

Adaptive reuse; building codes; buildings; building safety; code enforcement; construction; fire safety; housing; preservation; regulations; rehabilitation; SPS 36.

Adaptive reuse: buildings; demolition; economics; historic preservation; lifc-cycle costing; redevelopment; rehabilitation; tax incentives; TN980

Adaptive rcuse; buildings; demolition; economics; historic preservation; life-cycle costing; redevelopment; rehabilitation; tax incentives; 19016

Additive damage; biaxial fatigue; biomaterials; circulatory assist devices; fatigue of polymers; mechanical testing; NBSIR 79 . 1741
Additivity of damage; cold drawn; crack growth; fracture; molecular weight distribution; necking; polyethylene; uniaxial creep; 18765 .

Adenine; enthalpy of dissociation; enthalpy of protonation; enthalpy of reaction; enthalpy of solution; nucleic acid bases; solution calorimetry; thermochemistry; J. Res. 84, No. 3 , 231.240 (1979).

Adhesion; bioadhesive bond strength; bone; cyanoacrylate; hydrolytic stability; 18638 .

Adhesion; bonding to mineralized tissues; bone; dentin; hydrolytic stability of bonds; isobutyl 2-cyanoacrylate; mineralized tissue; 2-cyanoacrylate esters; 18569 .

Adhesion, dental; bonding; coupling agent; dental; monomers; resins; surface-active comonomers; acrylates; 18461 .

Adhesive; bonding to dentin; dental adhesive; dentin; durability of dentin acrylic bond; isobutyl 2-cyanoacrylate; pretreatment of dentin; 2-cyanoacrylate esters; 18985.

Adhesive bond integrity; control testing; sonic testing device; SP563, p. 174 (Oct. 1979).

Adiabatic calorimetry; $\mathrm{As}_{2} \mathrm{Se}_{3}$; interface absorption; laser calorimetry; NaF; thin film absorption; water absorption; wedged film; absorption coefficient; SP541, pp. 37-42 (Dec. 1978).

Adiabatic calorimetry; automated calorimetry; calorimetry; heat capacity; measurement automation; p-Terphenyl; thermodynamic properties; $\lambda$-type transition; 18376

Adiabatic heating; $\mathrm{As}_{2} \mathrm{~S}_{3}$; automatic bridge; $\mathrm{Bi}_{12} \mathrm{GeO}_{20} ; \mathrm{CaCO}_{3}$; $\mathrm{CaF}_{2}$; capacitance measurement; evaporated electrodes; pressure transducer; temperature dependence; 18466 .

Adiabatic limit; atomic collisions; quasimolecule terms; sudden perturbation limit; transition probability; unified atom approximation; $\mathbf{\Sigma}-\Pi$ transition; 18576.

Adiabatic perturbation theory; elastic scattering phase shifts; pseudocrossing; sudden-perturbation limit; transition probability; $\mathbf{\Sigma}-\Pi$ transitions; 18575 .

Administrative experiment; anti-trust regulation; economic incentive; environmental regulation; innovation; regulatory reform; technological changes; NBS-GCR-ETIP 79-66.

Administrative experimentation; best practicable technology; clean water regulation; Environmental Protection Agency; evaluability assessment; evaluation; Experimental Technology Incentives Program; regulatory experimentation; regulatory policy; NBS-GCR-ETIP 79-63.

Administrative experimentation; econom ic deregulation; evaluability assessment; evaluation; Experimental Technology Incentives Program; Federal Communications Commission; regulatory experimentation; regulatory policy; techmology innovation; TN1104, Vols. I and 2.

Administrative experimentation; Environmental Protection Agency; evaluability assessment; Experimental Technology Incentives Program; industrial pollution regulation; market mechanism; offset policy; regulatory policy; technological innovation; NBS-GCR-ETIP 79-62.

Administrative experimentation; Environmental Protection Agency; evaluability assessment; evaluation; Experimental Technology Incentives Program; Federal Communications Conımission; Federal Trade Commission; NBS-GCR-ETIP 79. 65 .

Administrative experimentation; Environmental Protection Agency; evaluation design; Experimental Technology Incentives Program; pesticide policy; regulatory policy; regulatory reform; technological inrovation; NBS-GCR-ETIP 79-71.

Administrative experimentation; evaluability assessment; evaluation; experimental methods; Experimental Technology Incentives Program; regulation; regulatory oversight; regulatory processes and regulatory effects; regulatory reform; social science; NBS-GCR-ETIP 79-64.

Administrative experimentation; managerial decision-making; methodology; 18722 . 
Administrative procedures; building codes; building regulations, buildings; construction; economic impacts; environmental considerations; innovative practices; rcgulatory research; standards development; SP552.

Adobe; adobe soil; compressive strength; creep; flexural strength; mechanical properties; moisture; non-destructive testing: preservation; TN996.

Adobe building materials; chemical grouts; damp course membrane; metallic membrane; permeability; preservation technology; NBSIR 79-1730.

Adobe soil; compressive strength; crecp; flexural strength; mechanical properties; moisture; non-destructive testing; preservation; adobe; TN996.

ADP auditors; audit; data center; data processing; information utilization; SPSO0-52, pp. 3-8 (Oct. 1979).

ADP availability; annual loss exposure; application system vulnerability; computer security; data confidentiality; data integrity; data security; physical security; procedural security; risk analysis; risk assessment; systems security; FIPS PUB 65.

ADP costs; Federal acquisition dates; Federal ADP statistics; Federal ADP work-years; Federal Government computers; Federal minicomputers; statistics; SP500-46.

ADP information sources; ADP management; ADP policies; ADP services; automatic data processing; computer services; Federal Information Processing Standards; Federal standards; NBSIR 79-1734.

ADP management; ADP policies; ADP services; automatic data processing; computer services; Federal Information Processing Standards; Federal standards; ADP information sources; NBSIR 79-1734.

ADP policies; ADP services; automatic data processing; computer services; Federal Information Processing Standards; Federal standards; ADP information sources; ADP management; NBSIR 79-1734.

ADP services; automatic data processing; computer services; Federal Information Processing Standards; Federal standards; ADP information sources; ADP management; ADP policies; NBSIR 79-1734.

Adsorbed water; breakdown mechanism; frequency and time dependence of breakdown thresholds; IR window materials; $\mathrm{NaCl}$; pressure; pulsed TEA $\mathrm{CO}_{2}$ laser surface breakdown; spot size; surface absorption; transmitted pulse; SP54I, pp. 318-326 (Dec. 1978)

Adsorption; biomaterials; blood proteins; ellipsometry; polymer adsorption; protein adsorption; protein chromatography; radiolabeled proteins; NBSIR 79-1784.

Adsorption; chemisorption; formaldehyde; ruthenium; surface chemistry; ultraviolet photoemission spectroscopy; 18791

Adsorption; field emission; field-induced redistribution; hydrogen; ruthenium; 18810 .

Advanced composite materials; composite materials analysis; orthotropic materials; programmable calculators; solid state software; SP563, pp. 91-107 (Oct. 1979).

Advanced composite materials; graphite-epoxy laminate design; laminate design sensitivities; thermal expansion; SP563, pp. 60-71 (Oct. 1979).

Advanced composites; advanced ships; elastic properties; fatigue tests; nondestructive tests; structural analysis; ultimate strength; SP563, pp. 286-298 (Oct. 1979).

Advanced composites; applications of composites; composites; composite structures; design using composites; fiber composites; fiber glass; filament wound composites; SP563.

Advanced composites; cavitation erosion; extended immersion; flammability; glass reinforced plastics; graphite epoxy; impact; marine environment; SP563, pp. 276-285 (Oct. 1979).

Advanced composites; composite materials; cryogenics; industrial laminates; magnctic fusion energy; superconducting magnets; 18560 .
Advanced composites; dimensional stability; eutectic coating; graphite/epoxy; moisture barrier; space optics; SP563, pp. 47-56 (Oct. 1979).

Advanced sensors; Doppler millimeter radar; gas turbine monitoring; remote motion detection; static displacement measurement; vibration measurement; SP547, pp. 58-62 (July 1979).

Advanced ships; elastic properties; fatigue tests; nondestructive tests; structural analysis; ultimate strength; advanced composites; SP563, pp. 286-298 (Oct. 1979).

Advanced-fiber composites; cryogenics; industrial laminates; low-pressure laminates; metal-matrix composites; polymer matrices; 18631 .

Adversary characteristics; animal research; behavioral science; biosensors; computer analysis; ergonomics; human engineering; human factors; human motivation; human reliability; personnel selection; physical security; physiological psychology: sensory capability, terrorism; $S P 480-38$.

Aerial flyovers; aerial infrared thermography; energy conservation; roof heat-loss survey; TN/107.

Aerial infrared thermography; energy conservation; roof heatloss survey; aerial flyovers; TNI 107 .

Aerodynamic stability; aeroelasticity; fluctuating flow; flutter; suspended-span structures; time-dependent loads; 18688 .

Aerodynamics; boundary layer; loads (forces); roughness; structural analysis; tall buildings; wind pressure; 18351 .

Aerodynamics; boundary layers; dynamic response; interference effects; tall buildings; wind loads; wind tunnels; 18977.

Aerodynamics; building; codes and standards; full-scale testing; mobile homes; wind loads; NBSIR 77-1289.

Aeroelasticity; fluctuating flow; flutter; suspended-span structures; time-dependent loads; aerodynamic stability; 18688 .

Aerosol size measurement; calibration of particle sizing instruments; Doppler shift spectrometer; light scattering; optical particle sizing; particle size standards; 18980.

$A$-factor; comparative rate; flow system; heat of formation; hexylmethylethane; $t$-butyl radical; unimolecular decomposition; activation energy; 18743.

Affine network; neutron scattering; phantom nictwork; polybutadiene; rubber elasticity; uniform network; 18827 .

Affinity chromatography; environmental analysis; functional group analysis; SP519, pp. 783-787 (A pr. 1979).

Aflatoxin analysis; food and feed analysis; methods; preparation; sampling; SP519, pp. 355-372 (Apr. 1979).

Africa; Asia; developing countries; industrialization; Latin America; management; measurement; metrology; quality control; standards; technology transfer; UN Conference on Science and Technology for Development (UNCSTD); SP543.

Agencies; approval process; evaluation; industrialized housing products; inspection; regulation; third party; SP552, pp. 293309 (July 1979).

Aging; aging of cellulose; aging of paper; cellulose; cellulose aging; natural aging; paper; paper aging; tests for paper; accelerated aging; 19017.

Aging; analysis; atmosphere; sampling; SP519, pp. 213-218 (Apr. 1979)

Aging of cellulose; aging of paper; cellulose; cellulose aging; natural aging; paper; paper aging; tests for paper; accelerated aging; aging; 19017.

Aging of paper; cellulose; cellulose aging; natural aging; paper; paper aging; tests for paper; accelerated aging; aging; aging of cellulose; 19017.

Aging of polymer; composite; fiber; mechanical properties; moisture; prepreg; SP563, pp. 17-21 (Oct. 1979).

Aging of polymers; degradation of polymers; error propagation; factor-jump method; heating rate; lifetime prediction; polystyrene; polyurethane; thermogravimetry; weight-loss kinetics; 18620 . 
AID; assistance; developing economies; forcign rclations; industrializing nations; international relations; LDC's; measurement services; standardization; NBSIR 78-1712.

AID; assistance; developing cconomics; forcign rclations; industrializing nations; international rclations; measures; weights; wcights and measures; NBSIR 79-I72I.

Air; anemometer; helicoid anemometcr; lag; overspceding error; rotary anemomcter; unsteady flow; NBSIR 78-1505.

A ir; environment; gas chromatography/mass spectrometry; sampling; sediment; tracc analysis; water; $\beta$-chloroethers; SP5 19, pp. 205-212 (Apr. 1979).

Air bubbles; bubbles, air; viscous silicon oil; 18481 .

Air infiltration; air sample bags; energy conservation; retrofit; sulfur hexafluoride; tracer gas; weatherization; NBSIR 791728 .

Air infiltration; buildings; data acquisition; energy; instrumentation; measurcment; thermography; Twin Rivers Project; weather station; 18733 .

Air infiltration, residential; air permeability of houses; energy conscrvation; pressurization technique; tracer-gas technique; TN 992

Air permeability of houscs; energy conservation; pressurization technique; tracer-gas technique; air infiltration, residential; TN992.

Air pollutants; chlorine sink; high resolution IR spectra; hypochlorous acid; large A-value molecules; stratospheric $\mathrm{HOCl} ; 18864$

Air pollution; ambient acrosols; computer controlled gas chromutography/mass spectrometry; GRALE; organic analysis; reflectance; SP519, pp. I01-107 (Apr. 1979).

Air pollution-regulatory policy; economic incentives; Federal funding of civilian $R \& D$; regulatory policy; subsidy policy; technological innovation; NBS-GCR-ETIP 78-53.

Air sample bags; energy conservation; retrofit; sulfur hexafluoride; tracer gas; wcatherization; air infiltration; NBSIR $79-1728$

Air sampling; co-condensation; gas chromatography; trapping; SP519, pp. $95-99$ (Apr. 1979).

Air-conditioning; comfort; education; environment; human factors; research; school; 18596 .

Aircraft; compositcs; design allowables; SP563, pp. $72-79$ (Oct. 1979).

Aircraft carrier; condition analysis; machinery; maintenance; monitoring; repairs; vibration; SP547, pp. 167-175 (July 1979).

Aircraft component failurc; condition monitoring; debris monitoring; diagnostic techniques; failure detection; lubrication system monitoring; SP547, pp. 330-344 (July 1979).

Aircraft diagnostics; bearing; condition monitoring; diagnostic equipment; shock pulsc; SP547, pp. 31-35 (July 1979).

Aircraft structural components; composite materials; linear elastic matcrials; tensile fracture; SP563, p. 3 (Oct. 1979).

Airflow; anemometer; lascr velocimeter; low velocity; performance; vane anemometer; wind tunnel; NBSIR 78-1433.

Airflow; anemometer; laser velocimeter; low velocity; performance; vanc anemometer; wind tunnel; NBSIR 78-1545.

Airflow; calibration; facility; laser optics; low velocity; mine ventilation; velocity standard; TN989.

Airframe structure; cost-trade comparisons; manufacturing technologies; structural performance/cost trade-offs; SP563, pp. 226-227 (Oct. 1979)

Al 1 ; aluminum; delayed coincidence; $f$-value; imprisonment; laser; lifetime; mean life; oscillator strength; 18527 .

Alarm; burglar alarm; guidelines holdup alarm; intrusion alarm; SP480-14.

Alaskan pipeline; computers; corrosion; fire safety; gyromagnetic ratio; paper; photometric calibrator; safety tips; solar energy; toxic chemicals; ultra-black coating; DIM/NBS 63 , No. 11, 1-36 (1979).
Alcohol intoxication; autopsy; building fires; cigarettes; death; fire invcstigations; fire statistics; pathology; toxic gases; NBS. GCR-79-168

Aldehyde; free radical; photolysis; reactions; review; troposphere; SP557, pp. 27-46 (Aug. 1979).

Aldehydes; aromatics; chemical kinetics; data needs; free radicals; modcling; $\mathrm{NO}_{r}$; olefins; $\mathrm{SO}_{\boldsymbol{r}}$; troposphere; SP557.

Algebra by computer; differential equations; mathematical software; non-linear oscillations; J. Res. 84, No. 4, 293-297 (1979).

Algebraic method; balancing equations; chemical equations; equation balancing; 18984

Algorithm; chromatic number; color function; graph; graph coloring; heuristic; interchange; random test graphs; scheduling; time complexity; J. Res. 84, No. 6, 489-506 (1979).

Algorithm, finite-difference; finite-difference; integral form, eonservation of mass principle; mass principle; 18489 .

Algorithm testing; approximation; computational experiment; least absolute deviation; polynomial approximation; test problems; J. Res. 84, No. 6, 455-488 (1979).

Aliasing; Bravais lattices; Fast Fourier "Transform"; near-field scanning; orthogonalities; plane-radial scanning; probe correction; space groups; 18956 .

Aligned sheet polarizer; birefringent crystal; optical analyzer; polarized light; probe thermometer; temperature sensitive parameter; U.S. Patent 4,140,393.

Alkali elements; cesium; eleetrical resistivity; francium; lithium; magnetic flux density dependence; potassium; pressure dependence; rubidium; sodium; temperature dependence; JPCRD 8, No. 2, 339-438 (1979)

Alkali halides; backward scattering; forward scattering; grain boundaries; isostatic forging; optical figure; optical homogeneity; single crystal; Talystep traces; SP54I, pp. 6569 (Dec. 1978).

Alkalies; cement; history; standards; 18854.

Alkali-halides; laser pulse; pico-second; pico-second laser pulse; SP54I, pp. 296-298 (Dec. 1978).

Alkaline earth elements; barium; beryllium; calcium; electrical resistivity; magnesium; radium; strontium; temperature dependence; JPCRD 8, No. 2, 439-498 (1979).

Alkaline earth fluorides; refractive index; strontium fluoride; SP541, pp. 55-58 (Dec. 1978).

Alkoxyl; kinetics; radicals; review; troposphere; SP557, pp. 5161 (Aug. 1979)

Alloy; base metal; casting; composite; cyanoacrylate; dental alloy; initiator; resin; wear; accelerator; NBSIR 78-1573.

Alloy; copper; electrical property; niobium; superconductor; tin; 18656 .

Alloy; copper; low temperatures; niobium; precipitate; superconductor; tin; $/ 8655$.

Alloy data center; alloy phase diagrams; American Society for Metals; data compilation; phase diagrams; 18645.

Alloy phase diagrams; American Society for Metals; data compilation; phase diagrams; alloy data center; 18645 .

Alloy phase diagrams; applications; ASM/NBS data program; compilations; computer data bank; computer display; 18739 .

Alloy phases; electronegativity; electron factors; electron vacancies; Laves phase; sigma phase; transition metal; 18357.

Alloys; antiphase domains; critical behavior; domain growth; domain walls; ordering; surface mobility; 18373 .

Alloys; antiphase domains; eritical behavior; domain growth; domain walls; ordering; surface mobility; 18613.

Alloys; electronegativity; electronic configuration; $s-p$ binding; structural stability; 18383 .

Alloys; fiberglass; mechanical properties; nonmetallics; physical properties; stainless steel; NBSIR 79-1609.

Allylmethylether; bromide; ethylacetate; isopropyl; laser; nonequilibrium; pyrolysis; relaxation; thermal decomposition; 18832 . 
Alpha particle; dipole giant resonance; electroproduction; nickel; photon; photoproduction; quadrupole giant resonance; 18495 .

Alpha tracks; biomedical; boron; fission tracks; geochronology; geology; lithium; nitrogen; silicon devices; trace analysis; uranium; 18342 .

Alpha-particles; correlations; mass formula; nuclear; quartets; reactions; spectroscopy; SU4; 18423.

Alternating current; alternating voltage; comparison between theoretical and experimental results; copper; corrosion; hydrogen evolution; 18756 .

Alternating voltage; comparison between theoretical and experimental results; copper; corrosion; hydrogen evolution; alternating current; 18756 .

Alumina; aluminum oxide; calorimetry; corundum; enthalpy; heat capacity; sapphire; specific heat; standard reference materials; thermodynamic properties; 18377.

Alumina; diamond contour grinding; flexure strength; prosthetic device; serrated surface design; tooth roots; SP562, pp. 247. 254 (Oct. 1979).

Aluminum; atomic energy levels; atomic spectra; electron configurations; ionization potentials; JPCRD 8, No. 3, 817-864 (1979).

Aluminum; beryllium; core hole lifetime; lattice relaxation; lithium; magnesium; sodium; soft $\mathrm{x}$-ray absorption spectra; soft $\mathrm{x}$-ray emission spectra; 18741 .

Aluminum; copper; copper alloys; nickel; oxide films; photopotentials; 18724.

Aluminum; delayed coincidence; $f$-value; imprisonment; laser; lifetime; mean life; oscillator strength; $\mathbf{A l ~ 1 ; ~} 18527$.

Aluminum; energy levels; ionization energy; wavelengths; 18485 .

Aluminum alloy; copper; low temperature; magnetothermal conductivity; nickel alloy; stainless steel; thermal conductivity; 18619.

Aluminum alloys; copper alloys; elastic constants; iron alloys; nickel alloys; stainless steels; Young's modulus; 18630 .

Aluminum alloys; crack propagation; cryogenics; fatigue; fracture; low temperature tests; mechanical properties; 18610 .

Aluminum alloys; ferrous alloys; fracture mechanics; LNG; low temperature; mechanical properties; $\mathbf{l} 8865$.

Aluminum oxide; calorimetry; corundum; enthalpy; heat capacity; sapphire; specific heat; standard reference materials; thermodynamic properties; alumina; 18377 .

Aluminum SRM's; computer systems; electron microscopy; group decisions; properties of steam; space; stirling refrigerators; DIM/NBS 63, No. 5, 1-28 (1979).

Aluminum wiring; electrical connections; pressure terminals; wire creep; NBSIR 78-1507.

$\mathrm{Al}_{2} \mathrm{O}_{3} ; \mathrm{As}_{2} \mathrm{~S}_{3}$ glass; $\mathrm{BaF}_{2} ; \mathrm{CaF}_{2} ; \mathrm{CdF}_{2}$; chalcogenide glass; elastic compliances; elastic constants; elasto-optic constants; fused silica; $\mathrm{Ge}$; hot forged; $\mathrm{KBr} ; \mathrm{KCl}$; TN993.

$\mathrm{Al}_{2} \mathrm{O}_{3}$; Berg-Barrett; Lang; misorientation contrast; $\mathrm{x}$-ray topography; Zn; 18341 .

Amalgam; composites; dental materials; dimensional changes; physical properties; thermal expansion; wear; wear tests; 18649.

Amalgam; creep; dental; dimensional change; dispersion type alloy; high copper; single alloy; 18729.

Amaranth; Ames test; criteria for purity; food additives; mutagenicity; naphthylamines; saccharin; saccharin impurities; Salmonella typhimurium; SP519, pp. 311-319 (Apr. 1979).

Ambient aerosols; computer controlled gas chromatography/mass spectrometry; GRALE; organic analysis; reflectance; air pollution; SP519, pp. 101-107 (Apr. 1979).

Ambient concentration; compute and limit; error; sampler response factors; total elemental content passive personal samplers; total organic chlorine; weighted diffusion coefficient; SP519, pp. 747-752 (A pr. 1979).
Ambulatory people; autism; cerebral palsy; deafness; developmentally disabled; epilepsy; fire safety; group homes; handicapped; mental retardation; NBS-GCR-79-167.

American Dental Association; dental history; dental instruments; dental materials; dental research; National Bureau of Standards; 18676

American National Standard Representation for Calendar Date and Ordinal Date for Information Interchange; meridian designators; separators; sequencing; time elements; timekeeping systems; time representations; FIPS PUB 58.

American National Standard Representation for Calendar Date and Ordinal Date for Information Interchange; local time differentials; meridian designator; time differential factor; time zone references; Uniform Time Act of 1966; universal time; FIPS PUB 59.

American National Standards Institute; Health Physics Society Standards Committee; mandatory testing program; peer review; personnel dosimetry; processors; standard; trial use and comment; 18992.

American Society for Metals; data compilation; phase diagrams; alloy data center; alloy phase diagrams; 18645.

American Society of Information Science; computer technology library science; information science; 18942 .

Ames test; criteria for purity; food additives; mutagenicity; naphthylamines; saccharin; saccharin impurities; Salmonella typhimurium; Amaranth; SP519, pp. 311 -319 (Apr. 1979).

Amine accelerators; composite restorative resin; dimethylaminoglutethimide; dimethylaminophenylacetic acid and esters; properties of composites; tertiary 'aromatic amines; 18571 .

Amine accelerators; degradation of benzoyl peroxide; dental composites; restorative dental resins; shelf-life of composites; storage stability; 18809 .

Amino acid derivative; crystal structure; S-carboxymethyl$\mathrm{L}$-cysteine; single crystal; $\mathrm{x}$ ray; zwitterion; 18673 .

Amino acids; attenuation; frequency; mammalian tissues; polypeptides; proteins; tissue characterization; ultrasonics; velocity; absorption; SP525, pp. 19-27 (Apr. 1979).

Amino acids; barbiturates; carboxylic acids; catecholamines; conjugates; detection sensitivity; dipeptides; drugs; HPLC; ion-pair adsorption; ion-pair chromatography; ion-pair partition; metabolites; psychotropic amines; selectivity; SP519, PP. 509-523 (Apr. 1979).

Amino acids; drugs; nonvolatile organic compounds; organic trace detection; peptides; pharmaceuticals; secondary ion mass spectrometry; sputtering; structural information; vitamins; SP519, pp. 627-635 (Apr. 1979).

Ammonia microwave absorption; atomic clock; cavity frequency stabilization; digital demodulator; frequency-lock servo; frequency standard; inversion transition in ammonia; precision; acceleration insen sitive oscillator; 18698 .

Amorphous alloys; magn etic partides; magnetism; neutron scattering; rare earths; small angle scattering; 18372 .

Amorphous alloys; magnetic properties; neutron scattering; spin waves; transition-metal glasses; 18898 .

Amorphous germanium; binding energy shifts; extra-atomic screening; implants; ion bombardment; rare-gases; relaxation energy; ultraviolet photoelectron spect roscopy; 18323 .

Amorphous magnetism; Mossbauer effect; rare earths; spin freezing; spin glasses; susceptibility; 18897 .

Amorphous materials; domains; magnetism; "phase transitions; rare earths; small angle neutron scattering; 18835 .

Ampere's law; dimensional metrology; fundamental constants; gyromagnetic ratio of proton; magnetic fields; Maxwell's equations; solenoids; 18437 .

Amperometry; - chloride analysis; clinical analysis; clinical chemistry; coulometry; definitive method; electrolytes; reference method; serum chloride analysis; statistical analysis; SP260-67. 
Amplificr, sample/hold; bridge circuit; circuit bridge; dynamic characterization of sample/hold amplifier; 18505.

Amplitude; beam profilc; cross correlation; digital sampling; Fourier optics; holography; laser; laser parametcrs; laser pulse; optical processing; phase; precision measurements; wave front; TN1009.

Amplitude modulation; cavity pulling; cavity servo; dielectrically loaded cavity; frequency stability; second-order Doppler shift phase modulation; spin exchange; temperature coefficient; time dispersion; wall shift; 18696 .

Amplitude modulation; instrument landing system (ILS); measurement instrumentation; measurement standard; modulation; modulation factor; modulation meter; Newton-Raphson method; pcrcent modulation; signal generator; vhf omnidirectional radio range (VOR); TN1016.

Anabolic steroids; clean-up; contamination; dianabol; gas chromatography-mass spectrometry $(\mathrm{gc} / \mathrm{ms})$; gas liquid chromatography ( $g l c) ; \mathrm{gc} / \mathrm{ms}$ interface; high performance liquid chromatography (hplc); inert columns; metabolism; SP519, pp. 437-445 (Apr. 1979).

Analog; centralized; check-out system; dessicant; discrete; displacement; fiber optics; filters; flight critical; flow; fluid; gono-go; ground readout; hydraulic; 1MACS; instantaneous diagnosis and analysis; level; maintenance oriented; SP547, pp. 345-357 (July 1979).

Analog-to-digital converter; digital-to-analog converter; IEEE subcommittee; performance specifications; sample/hold circuit; standards; terminology; 18365.

Analysis; analytical food chemistry; errors; sampling; SP519, pp. 231-242 (Apr. 1979).

Analysis; atmosphere; sampling; aging; SP519, pp. 213-218 (Apr. 1979).

Analysis; biological; gas chromatography; Kepone ${ }^{R}$; partition chromatography; parts per billion; SP519, pp. 341-343 (Apr. 1979).

Analysis; certification; characterization; composition; properties; research materials; special reference materials; standard reference materials; SP260, 1979-80 Edition.

Analysis; clay; forensic; INAA; paper; trace elements; 18325.

Analysis; diversion of nuclear materials; diversion path analysis; material accounting; material control; nuclear material safeguards; safeguards; 18735 .

Analysis of organics in water; automatic sampler; master analytical scheme; non-purgeable organics; organic pollutant; purgeable organics; WaterDROP; accumulators; SP519, pp. 65-78 (Apr. 1979).

Analytic models; database management; model validation; performance evaluation; performance measurement; predictive modeling; set-processing; simulation; software design; SP5OO49.

Analytic queueing theory models; capacity planning; performance evaluation; SP5OO-52, p. 227 (Oct. 1979).

Analytical chemistry; ion-chromatography; law enforcement standards; materials properties; measurement science; science students; SRM; titanium alloy; DIM/NBS 63, No. 1/2, 1-28 (1979).

Analytical electron microscopy; microanalysis; Monte Carlo electron trajectory simulation; spatial resolution; thin foils; $x$ rays; 18589 .

Analytical flame spectroscopy; flame ionization; flame spectroscopy; laser enhanced ionization; laser spectroscopy; optogalvanic effect; trace metal analysis; tunable dye laser; 18880.

Analytical food chemistry; errors; sampling; analysis; SP519, pp. 231-242 (Apr. 1979).

Analytical laboratory; certified reference materials; measurement; measurement compatibility; reference materials; standard reference materials; 18748 .
Analytical systems; atomic absorption; gas chromatography; liquid chromatography; mass spectrometry; trace organic analysis; SP519, pp. $541-546$ (Apr. 1979).

Analytical techniques; contamination; environment; retrospective; sample storage; trace analysis; 18349.

Anchors; mobile home foundations; soil anchors; soil mechanics; wind upset; BSS107.

Ancillary methods; bonded phases; chromatographic preconcentration; detector sensitivity; gas chromatography; glass capillary columns; high-performance liquid chromatography; LC microcapillary columns; selective detectors; SP5/9, pp. 487-499 (Apr. 1979).

Anemometer; helicoid anemometer; lag; overspeeding error; rotary anemometer; unsteady flow; air; NBSIR 78-1505.

Anemometer; laser velocimeter; low velocity; performance; vane anemometer; wind tunnel; airflow; NBSIR 78-1433.

Anemometer; laser velocimeter; low velocity; performance; vane anemometer; wind tunnel; airflow; NBSIR 78-1545.

Angular; Born approximation; correlations; electron impact; electrons; helium; ionization; secondary; 18534.

Angular distributions; field ionization; laser spectroscopy; multiphoton processes; photoionization; quantum beats; sodium atom; 18953.

Angular scattering; characterization of tissue; optical correlation; scattering; swept-frequency diffraction; SPS25, pp. 143152 (Apr. 1979).

Angular study; electron spectroscopy for chemical analysis (ESCA); silicon; surface; XPS; 18417

Anharmonic oscillators; singular perturbation theory; 18661 .

Animal research; behavioral science; biosensors; computer analysis; ergonomics; human engineering; human factors; human motivation; human reliability; personnel selection; physical security; physiological psychology; sensory capability; terrorism; threat analysis; training; $S P 480-38$.

Anion exchange; filter paper; fuel oil; spectrometry; sulfate; $x$ ray; $l 8635$.

Anisotropy; attenuation; elastic microstructure; infarct; interferogram; myocardium; phase cancellation; velocity; acoustic microscopy; SP525, pp. 73-79 (Apr. 1979).

Anisotropy; dispersion; elasticity; human bone; microhardness; microstructure; piezoelectricity; thermodynamics; ultrasound; viscoelasticity; wave propagation; SPS25, pp. 189-196 (Apr. 1979).

Annual loss exposure; application system vulnerability; computer security; data confidentiality; data integrity; data security; physical security; procedural security; risk analysis; risk assessment; systems security; ADP availability; FIPS PUB 65.

Annual report; eddy currents; inspection; magnetic particles; nondestructive evaluation; penetrants; radiography; statistics; ultrasonics; visual-optical tests; acoustic; NBSIR 78-1581.

Annular array; breast cancer; chirp signals; imaging; optoacoustic; pulse compression; sensitivity; signal averaging; signal processing; tissue characterization; tomography; transducers; ultrasonics; SP525, pp. 255-259 (Apr. 1979).

Antenna; communications; land-mobile; standards; 18398 .

Antenna; conical transmission line; impulse response; impulsive fields; standards; TEM horn antenna; TN1008.

Antenna gain; antenna pattern; antenna polarization; large aperture antenna metrology; satellite communications metrology; 18628 .

Antenna gain; broadband antenna; directivity; FFT; method of measurements; non-dispersive; resistive loading; TEM horn; time domain measurement; 18856.

Antcnna gain calculation; field strength calibration; pyramidal horn antenna; if radiation monitor; st andard electromagnetic field; 18814 .

Antenna measurements; cylindrical scanning; far field; near field; planar scanning; 18818 . 
Antcnna pattern; antenna polarization; large apcrture antenna metrology; satellite communications mctrology; antenna gain; 18628 .

Antenna polarization; large aperture antenna metrology; satellite communications metrology; antenna gain; antenna pattern; 18628 .

Antennas; CISPR; ground screen; measurements; standards; VDE; 19033.

Anthranilic acid; chemisorption; cupric anthranilate; cupric ioncontaining hydroxyapatite; reaction kinetics; surface reaction; 18972.

Anthropogenic and natural carbonaceous species; atmosphcric gases and particles; environmental pollutants; fossil fuels; low-level counting; radiocarbon; accelerator mass spectrometry; 18405 .

Anthropometric manikin; free-field measurements; hearing aids; hearing aid tests; orthotelephonic response; 18464 .

Anthropometry; data base; engineering psychology; ergonomics; evaluation; human engineering; human factors; human performance; standard reference data; NBS-GCR-79-169.

Antiepilepsy drugs in serum; serum matrix; standard reference material (SRM); SP5 19, pp. 447-453 (Apr. 1979).

Antiphase domains; critical behavior; domain growth; domain walls; ordering; surface mobility; alloys; 18373 .

Antiphase domains; critical behavior; domain growth; domain walls; ordering; surface mobility; alloys; 18613

Antireflectance coatings; high reflectance coatings; interface absorption; multilayer films; scattering; absorption; SP541, pp. 266-277 (Dec. 1978).

Antireflection coatings; calcium fluoride; cw laser damage; DF laser; fusion cast; laser damage; laser window; single crystal; strontium fluoride; SP541, pp. 78-85 (Dec. 1978).

Antireflection coatings; CdSe; coating substrate; damage resistant; Ge; $\mathrm{PbF}_{2}$; pulsed HF laser; SP541, pp. 257-258 (Dec. 1978 ).

Antireflection coatings; damage thresholds; impurities; laser-induced damage; thermal damage; absorption; SP54I, pp. 202 211 (Dec. 1978).

Antireflection coatings; electron microscopy; laser damage; optical coatings; thin films; SP541, pp. 218-225 (Dec. 1978).

Antitrust; Canada; certification; Denmark; economics of standards; government policy; international standards; laboratory accreditation; standards systems; United Kingdom; West Germany; NBS-GCR-79-172.

Anti-trust regulation; economic incentive; environmental regulation; innovation; regulatory reform; technological changes; administrative experiment; NBS-GCR-ETIP 79-66.

Antitussive; dextromethorphan; gas-liquid chromatography; human plasma; nitrogen-sensitive detector; SP5I9, pp. 481485 (Apr. 1979).

Antivibration mounting; damping; dynamic properties; industrial engineering; isolation; machinery and equipment; mechanical impedance; mechanical vibrations; noise control; transmissibility; vibration isolation; vibrations; $H 128$.

Antoine equation; enthalpy of vaporization; halomethanes; vapor pressure-boiling point data; Wagner equation; JPCRD 8, No. 2, 499-518 (1979).

$\alpha$-particles; $\alpha$-spectrum; ${ }^{23 \mu} \mathrm{U}$; electrodisintegration; proton spectrum; ternary fission; 18518 .

$\alpha$-particles; electrons; heavy ions; international commission on radiation units and measurements; protons; stopping power; 18358.

Aperture pair; calibration; convolution; deconvolution; geometrical-optics radiometry; inversion; measurement-beam geometry; relative spectral responsivity; slit-scattering function; slit-scattering function corrections; spectral line radiometry; TN910-4.

Aperture synthesis; computed tomography; Doppler; fluid flow; high resolution; reconstruction; temperature reconstruction; ultrasound; SP525, pp. 227-233 (Apr. 1979).
Aperture synthcsis; computed tomography; Doppler; fluid flow; high resolution; reconstruction; temperature reconstruction; ultrasound; SP525, pp. 235-246 (Apr. 1979).

Aperture/aperture-image pair; aperture pair; calibration; convolution; deconvolution; geometrical-optics radiometry; inversion; measurement-beam geometry; relative spectral responsivity; slit-scattering function; slit-scattering function corrections; TN910-4.

Apparel; burn injury; clothing; fabric flammability; fabrics; fire; garments; heat transfer; injury potential; simulation; accident; NBSIR 79-1755.

Apparel; burn injury; ease of ignition; fabrics; fire; flammability tests; garments; heat transfer; standards; 18991 .

Apparel; extinguishability; fabrics; flammability; garments; hazard; heat transfer; ignitability; standard; test; 18708 .

Apparent molal heat capacity; aqueous systems; bibliography; electrochemistry; electrolytes; enthalpy of dilution; heat capacity; relative apparent molal enthalpy; salt solutions; thermochemistry; vapor pressure; SP5 37.

Appeals process; consensus standards; electrical distribution systems; flat conductor cable; National Electrical Code; technological innovation; SP552, pp. 57-78 (July 1979).

Appearance potential; archival tape; computer program; data base; data base management; empirical molecular formula; GPSDC; ion energetics; ionization potential; abstract; NBSIR $78-1432$

Appliance; clothes dryer; efficiency; energy conservation; heat recovery; lint; performance; venting; 18793.

Appliance; cooking; efficiency; energy; human factors; kitchen ranges; labeling; stoves; test methods; NBSIR 78-1556.

Appliance energy consumption; energy consumption of residences; lighting energy consumption; occupant factors; residential air conditioning; service hot water; space heating; ventilation; NBSIR 78-1501

Appliances; cooking utensils; energy conservation; energy efficiency; ranges and ovens; 18836.

Appliances; energy conservation; energy instrumentation; energy rate; energy use; 18837 .

Application; buildings; commercial; daylighting; energy; environments; heating; passive; solar; suburban; urban; 18894 .

Application; character set; computer interface; cost; data entry; edit; operator speed; record size; transaction volume; transfer speed; validate; verify; SP500-55.

Application system vulnerability; computer security; data confidentiality; data integrity; data security; physical security; procedural security; risk analysis; risk assessment; systems security; ADP availability; annual loss exposure; FIPS PUB 65.

Applications; ASM/NBS data program; compilations; computer data bank; computer display; alloy phase diagrams; 18739 .

Applications of composites; composites; composite structures; design using composites; fiber composites; fiber glass; filament wound composites; advanced composites; SP563.

Applied economics; building codes; building economics; economic analysis; fire safety; health care facilities; hospitals; life safety; mathematical programming; nursing homes; renovation; NBSIR 79-1902.

Applied economics; building codes; building economics; economic analysis; fire safety; health care facilities; hospitals; life safety; mathematical programming; nursing homes; renovation; 19045.

Appropriate technology; industrialization; industrial R\&D; LDC's; less developed countries; light capital technology; science and technology for development; U.N. Conference on Science and Technology for Development; UNCSTD; 18685.

Appropriations; fusion diagnostics; gravity waves; laser-interferometer; microwave measurements; non-destructive evaluation; pipe welds; standard; x-ray image; DIM/NBS 63, No. 3, 1-28 (1979). 
Approval process; cvaluation; industrialized housing products; inspcction; regulation; third party; agcncies; SP552, pp. 293. 309 (July 1979).

Approximation; computational cxpcriment; least absolute deviation; polynomial approximation; test problems; algorithm testing; J. Res. 84, No. 6, 455-488 (1979).

Aquatic humus; fulvic acid; humic acid; humic substances; reference collection of humic substances; reference samples; soil organic matter; SP519, pp. $789-792$ (Apr. 1979).

Aqucous organics; phenols; volatile organics, Carbopack C/0.2\% Carbowax 1500; SP5 19, pp. 225-229 (Apr. 1979).

Aqueous solution; carbonate radical; chemical kinetics; halogen radical anions; nitrate radical; oxyanion radicals; phosphate radical; photolysis; radiolysis; rates; selenium radicals; sulfate radical; thiocyanate radical anion; NSRDS-NBS65.

Aqueous solutions; fluorescence spectra; refractive index, uv, visible and ir; water; 18403.

Aqueous systems; bibliography; electrochemistry; electrolytes; enthalpy of dilution; heat capacity; rclative apparent molal enthalpy; salt solutions; thermochemistry; vapor pressure; apparent molal heat capacity; SP537.

Aqueous transmethylation; chloride complexes; environment; formation constants; ionic mechanisms; kinetics; methylmercury; methyltin; NMR; primary salt effect; speciation; activation parameters; 18484 .

Aramid fiber; composite applications; composites; concrete; cryogenics; epoxy resins; glass fiber; graphite fiber; 18717 .

Aramid-epoxy; boron-aluminum; boron-epoxy; composites; elastic constants glass-epoxy; internal friction; Young's modulus, 18716

Arc burn; contact burn; current threshold; electrical injury; electrolyte shift; heat effect; injury mechanism; injury statistics; mouth burn; specific electrical effect; NBSIR 79. 1710 .

Architect; information format; information sources; technical information; technology application; access to information; NBS - GCR-78-153.

Architect; information format; information sources; technical information; technology application; access to information; NBS-GCR-78-154.

Architectural barriers; building design; building site planning; environmental psychology; evaluation; fire escape; human research; measurement; pedestrian movement; regulation; safcty; standards; SP552, pp. 101-113 (July 1979).

Architectural barriers; building design; building site planning; environmental psychology; evaluation; fire escape; human research; measurement; pedestrian movement; regulation; safety; standards; 18430

Architectural design; architectural psychology; architecturaì research; building codes; building design; building regulatory standards; floor coverings; home safety; safety standards; stair safety; stairway design; accidents; BSS120.

Architectural psychology; architectural research; building codes; building design; building regulatory standards; floor coverings; home safety; safety standards; stair safety; stairway design; accidents; architectural design; BSS 120.

Architectural psychology; bibliography; buildings; communication; cost; human characteristics; personal control; physical environment; privacy; NBSIR 79-1793.

Architectural research; building codes; building design; building regulatory standards; floor coverings; home safety; safety standards; stair safety; stairway design; accidents; architectural design; architectural psychology; BSS120.

Architectural research; building fires; computer-aided design; environmental psychology; fire research; fire safety; human perfornance; modeling technique; programming; sensitivity analysis; simulation; NBSIR 79-1713.

Architectural research; building fires; computcr-aided design; computer simulation; environmental psychology; fire rescarch; fire safety; human performance; modeling techniquc; simulation; NBSIR 79-1796.

Architecture; building codes; building regulations; building safety; construction; performance; preservation; rehabilitation; renovation; adaptive reuse; SP536, pp. 1-16 (Feb. 1979).

Archival tape; computer program; data base; data base management; empirical molecular formula; GPSDC; ion energetics; ionization potential; abstract; appearance potential; NBSIR 78-1432.

Argon; comparisons; correlation; ethylene; experimental; magnetic suspension; orthobaric liquid density; tables; $/ 8627$.

Armor, body; ballistic deformation; ballistic penetration; body armor; bullet proof vests; 18465 .

Aromatic compound; charge transfer equilibria; entropy change; ion cyclotron resonance; ionization energy; 18337.

Aromatic substitution; association ions; charge transfer; ethyl nitrate; ion-molecule reactions; 18332 .

Aromatics; chemical kinetics; data needs; free radicals; modeling; $\mathrm{NO}_{x}$; olefins; $\mathrm{SO}_{x}$; troposphere; aldehydes; SP557.

Aromatics; free radicals; mechanism; reactions; tropospheric chemistry; SP557, pp. 85-91 (Aug. 1979).

Arrhenius parameters; combustion; decomposition; free radicals; hydrocarbons; hydrogen; nitrogen; organic compounds; oxidation; oxygen; oxygenated; rate constant; sulfur; NBSIR 79-194I.

Arsenic; bio-transformation; cadmium; food chain; lead; mercury; metal; methylation; microbial tolerance; microorganism; plasmid; tin; 18860 .

Arsenic selenide; arsenic trisulfide; defects; laser damage; sodium fluoride; absorption; SP541, pp. 212-217 (Dec. 1978).

Arsenic trisulfide; defects; laser damage; sodium fluoride; absorption; arsenic selenide; SP54I, pp. $212-217$ (Dec. 1978).

Arson; arsonists; firesetters; human behavior; literature reviews; pyromaniacs; abnormal psychology; NBS-GCR-79-157.

Arson; bibliographies; building fires; compartment fires; fabric flammability; fire detection systems; fire tests; flammability tests; human behavior; plastics; polymers; smoke; smoke detectors; subway fires; toxicity; upholstered furniture; NBSIR $79-1745$.

Arsonists; firesetters; human behavior; literature reviews; pyromaniacs; abnormal psychology; arson; NBS-GCR-79-157.

Artifacts; electron probe microanalysis; energy-dispersive $\mathrm{x}$-ray spectrometry; microanalysis; qualitative analysis; scanning electron microscopc; 18790 .

A-scan; correlation analysis; temporal changes; SP525, pp. 275 280 (Apr. 1979).

ASHRAE Standard 93-77; solar collectors; water-heating collectors; 18770 .

ASHRAE Standard 94-77; Glauber's salt; latent heat storage; pebble bed; phase-change unit; solar energy storage; thermal energy storage device; NBSIR 79-1737.

ASHRAE Standards; evaluation of test procedure; solar heating components; standard test procedure; thermal storage tests; water tank thermal storage; 18425

Asia; developing countries; industrialization; Latin America; management; measurement; metrology; quality control; standards; technology transfer; UN Conference on Science and Technology for Development (UNCSTD); Africa; SP5 43.

As-machined material strength; dimensional tolerances; profile grinding; silicon nitride; ultrasonic machining; SP562, pp. 209-220 (Oct. 1979)

ASM/NBS data program; compilations; computer data bank; computer display; alloy phase diagrams; applications; 18739 .

$\alpha$-spectrum; ${ }^{238} \mathrm{U}$; electrodisintegration; proton spectrum; ternary fission; $\alpha$-particles; 18518 .

Assistance; developing economies; foreign relations; industrializing nations; international relations; LDC's; measurement services; standardization; AID; NBSIR 78-1712. 
Assistance; developing economies; foreign relations; industrializing nations; international relations; measures; weights; weights and measures; A1D; NBSIR 79-1721.

Association ions; charge transfer; ethyl nitrate; ion-molecule reactions; aromatic substitution; 18332 .

ASTM; bathtubs; CPSC; performance test; showers; slip-resistance; 18705.

ASTM Committee E-42; Auger electron spectroscopy; electron spectroscopy; ESCA; secondary ion mass spectroscopy; surface analysis; 18406 .

ASTM E-84 Tunnel Test; construction standard; fire growth; fire tests; flame spread; flashover; impact assessment; interior finish; kitchen fires; life safety; mobile homes; room fires; NBSIR 79-1720.

Astrophysical spectra; atomic data compilations; atomic energy levels; atomic spectroscopy; atomic wavelengths; 18995 .

Asymmetric absorptance; damage thresholds; dielectric reflectors; electric-field distribution; high-power; reflectance; spectral absorptance; theory; SP541, pp. 278-287 (Dec. 1978).

Asymmetric diffraction; dynamical diffraction; microradiography; radiography; radiology; real-time radiography; resolution; X-ray image magnifier; 18399.

Asymptotic eigensolutions; high resolution spectra; spectral clusters; spherical top molecules; 4 th and 6 th rank octahedral tensor; 18706

$\mathrm{As}_{2} \mathrm{Se}_{3}$; interface absorption; laser calorimetry; $\mathrm{NaF}$; thin film absorption; water absorption; wedged film; absorption coefficient; adiabatic calorimetry; SP541, pp. $37-42$ (Dec. 1978).

$\mathrm{As}_{2} \mathrm{~S}_{3}$; automatic bridge; $\mathrm{Bi}_{12} \mathrm{GeO}_{20} ; \mathrm{CaCO}_{3} ; \mathrm{CaF}_{2}$; capacitance measurement; evaporated electrodes; pressure transducer; temperature dependence; adiabatic heating; 18466 .

$\mathrm{As}_{2} \mathrm{~S}_{3}$ glass; $\mathrm{BaF}_{2} ; \mathrm{CaF}_{2} ; \mathrm{CdF}_{2}$; chalcogenide glass; elastic compliances; elastic constants; elasto-optic constants; fused silica; $\mathrm{Ge}$; hot forged; $\mathrm{KBr}$; $\mathrm{KCl}$; $\mathrm{KCl}: \mathrm{KI}$; LiF; TN993.

Atmosphere; sampling; aging; analysis; SP519, pp. 213-218 (Apr. 1979). '

Atmospheric gases and particles; environmental pollutants; fossil fuels; low-level counting; radiocarbon; accelerator mass spectrometry; anthropogenic and natural carbonaceous species; 18405 .

Atmospheric pressure ionization; bioanalytical systems; mass spectrometry; negative ions; positive ions; SP519, pp. 655 671 (Apr. 1979).

Atmospheric properties; distance measurement; geodesy; instrumentation; multiwavelength techniques; tectonics; 18816 .

Atom; collision cross section; detachment; dissociation; elastic scattering; electron; excitation; ion; ionization; molecule; photon; positron; SP426. Supplement 1 .

Atomic absorption; atomic emission; barium; graphite furnace; seawater; wavelength modulation; 18783 .

Atomic absorption; gas chromatography; liquid chromatography; mass spectrometry; trace organic analysis; analytical systems; SP519, pp. 541-546 (Apr. 1979).

Atomic beams; atomic frequency standards; cavity phase shift; Ramsey envelope; Ramsey separated oscillating fields; two frequency separated oscillating fields; 18475 .

Atomic clock; cavity frequency stabilization; digital demodulator; frequency-lock servo; frequency standard; inversion transition in ammonia; precision; acceleration insensitive oscillator; ammonia microwave absorption; 18698.

Atomic clocks; cesium standards; crystal oscillators; frequency standards; hydrogen standards; rubidium standards; time and frequency; timekeeping; 18908.

Atomic clocks; frequency standards; frequency synthesis; fundamental constants; length standards; physical measurement systems; review article; speed of light; time standards; 18346 .

Atomic collisions; quasimolecule terms; sudden perturbation limit; transition probability; unified atom approximation; $\Sigma$-ח transition; adiabatic limit; 18576 .
Atomic data; data availability; dielectronic recombination rates; excitation rate coefficients; ionization rate coefficients; magnetic fusion research; transition probabilities; wavelengths; 18593.

Atomic data compilations; atomic energy levels; atomic spectroscopy; atomic wavelengths; astrophysical spectra; 18995.

Atomic decay curve simulation; atomic transition probabilities; beam-foil spectroscopy; cascades in atomic decay; exponential fitting; $\mathrm{Kr}$ VIII; 18508.

Atomic emission; barium; graphite furnace; seawater; wavelength modulation; atomic absorption; 18783 .

Atomic energy levels; atomic spectra; atomic transition probabilities; electron cross sections; fusion plasmas; lasers; molecular bands; molecular spectra; reaction rate constants; upper atmosphere; 18855 .

Atomic energy levels; atomic spectra; boron; JPCRD 8, No. 1, 63-68 (1979).

Atomic energy levels; atomic spectra; calcium energy levels; JPCRD 8, No. 3, 865-916 (1979).

Atomic energy levels; atomic spectra; electron configurations; ionization potentials; aluminum; JPCRD 8, No. 3, 817-864 (1979).

Atomic energy levels; atomic spectra; potassium energy levels; JPCRD 8, No. 4, 1109-1146 (1979).

Atomic energy levels; atomic spectra; titanium; JPCRD 8 , No 1, 1-62 (1979).

Atomic energy levels; atomic spectroscopy; atomic wavelengths; astrophysical spectra; atomic data compilations; 18995.

Atomic energy levels, O v1-O vuli; atomic spectra, O v1-O vill; multiplet tables, O vi-O vili; oxygen, spectra, O vi-O vili; NSRDS-NBS3, Section 8.

Atomic flame fluorescence; intracavity absorption; isotope analysis; laser analysis; laser fluorescence; laser spectroscopy; microfluorescence; saturation spectroscopy; tunable laser; 18364.

Atomic form factor; coherent scattering; cross sections; gamma rays; photons; Rayleigh scattering; tabulations; $\mathrm{x}$ rays; JPCRD 8, No. 1, 69-106 (1979).

Atomic frequency standards; cavity phase shift; Ramsey envelope; Ramsey separated oscillating fields; two frequency separated oscillating fields; atomic beams; 18475 .

Atomic line shapes; atomic spectra; atomic transition probabilities; bands, molecular; energy levels; energy levels, atomic; line shapes, atomic; molecular bands; molecular spectra; rotational constants; 18828 .

Atomic magnetic structures; conical spin structure; decay of ${ }^{166 m} \mathrm{Ho}$; nuclear orientation; nuclear spin system; ${ }^{166} \mathrm{Ho}^{165} \mathrm{Ho}$ 18604.

Atomic number; cobalt- 60 photons; configuration; plug; scattered photons; sleeve; source capsule; source pellets; spacer; spectra; spectrometry; 18355.

Atomic oxygen; glow discharge; laser magnetic resonance; 18919.

Atomic parity mixing; charged currents; fermi theory; neutral currents; neutrino scattering; weak interaction; 18951 .

Atomic physics; dielectronic recombination; highly ionized; impurity; molybdenum; plasma; 18949

Atomic properties; Auger yield; Coster-Kronig yield; effective fluorescence yield; fluorescence yield; $K$ shell; $L$ shell; nonradiative yield; partial level width; radiative yield; JPCRD 8 , No. 2, 307-328 (1979).

Atomic screening effects; bremsstrahlung high frequency limit; bremsstrahlung spectrum tip; continuum x rays; Coulomb field; non-relativistic bremsstrahlung; 18370 .

Atomic screening effects; bremsstrahlung high frequence limit; bremsstrahlung spectrum tip; continuum $x$ rays; Coulomb field; non-relativistic bremsstrahlung; 18532 . 
Atomic spectra; atomic transition probabilities; bands, molecular; energy levels; energy levels, atomic; line shapes, atomic; molecular bands; molecular spectra; rotational constants; atomic line shapes; 18828 .

Atomic spectra; atomic transition probabilities; electron cross sections; fusion plasmas; lasers; molecular bands; molecuiar spectra; reaction rate constants; upper atmosphere; atomic energy levels; 18855 .

Atomic spectra; boron; atomic energy levels; JPCRD 8, No. 1 , 63-68 (1979).

Atomic spectra; calcium energy levels; atomic energy levels; JPCRD 8, No. 3, 865-916 (1979).

Atomic spectra; electron configurations; ionization potentials; aluminum; atomic energy levels; JPCRD 8, No. 3, 817-864 (1979).

Atomic spectra; nitrogen; oxygen; plasma-broadening; singly ionized oxygen; stark broadening; 18737 .

Atomic spectra; potassium energy levels; atomic energy levels; JPCRD 8, No. 4, 1109-1146 (1979).

Atomic spectra; titanium; atomic energy levels; JPCRD 8, No. $1,1-62(1979)$.

Atomic spectra, O vi-O viu; multiplet tables, O vi-O viti; oxygen, spectra, O vi-O vin; spectra, O vi-O vili; NSRDSNBS3, Section 8.

Atomic spectroscopy; atomic wavelengths; astrophysical spectra; atomic data compilations; atomic energy levels; 18995 .

Atomic transition probabilities; bands, molecular; energy levels; energy levels, atomic; line shapes, atomic; molecular bands; molecular spectra; rotational constants; atomic line shapes; atomic spectra; 18828 .

Atomic transition probabilities; beam-foil spectroscopy; cascades in atomic decay; exponential fitting; Kr VI11; atomic decay curve simulation; 18508 .

Atomic transition probabilities; electric dipole lines; multiplets; singly ionized spectra; 18736

Atomic transition probabilities; electron cross sections; fusion plasmas; lasers; molecular bands; molecular spectra; reaction rate constants; upper atmosphere; atomic energy levels; atomic spectra; $\mathbf{I} 8 \mathbf{8 5 5}$.

Atomic transition probabilities; literature survey; oscillator strengths; 18572.

Atomic wavelengths; astrophysical spectra; atomic data compilations; atomic energy levels; atomic spectroscopy; $/ 8995$.

Atomospheric aerosols; materials sampling; mineralogy; molecular analysis; particle analysis; power plant emissions; Raman microprobe; Raman spectroscopy; urban dusts; vibrational analysis; $I 8643$.

Attenuation; brain tumor; clot; hemorrhage; hydrocephalus; impedance; infarct; speed; altrasonic; SP525, pp. 81-84 (Apr. 1979).

Attenuation; breast cancer; cancer; connective tissue; differential diagnosis; medullary carcinoma; papillary carcinoma; scirrhous carcinoma; shadowing; ultrasound; SPS2S, pp. 93-99 (Apr. 1979).

Attenuation; B-scan;cepstrum; computer; convolution; de-convolution; liver; power spectrum; signal processing; tissue characterization; tissue parameters; ultrasound; SP525, pp. 287-295 (Apr. 1979).

Attenuation; computerized tomography; Doppler; impedance; medical diagnosis; microscopy; pattern recognition; scattering; signal processing; tissue characterization; tissue parameters; ultrasound; velocity; absorption; SP525.

Attenuation; coupled integral equations; dispersion; lossy dielectric slab; modes considerations; TEM-cell; NBSIR 791615 .

Attenuation; dispersion; skull bone; sound speed; ultrasourd; SPS25, pp. 197-201 (Apr. 1979).

Attenuation; elastic microstructure; infarct; interferogram; myocardium; phase cancellation; velocity; acoustic microscopy; anisotropy; SP525, pp. 73-79 (Apr. 1979).
Attenuation; fiber optics; frequency response; measurements; 18915 .

Attenuation; fiber optics; interlaboratory comparison; measurements; optical communications; quality control; NBSIR 79 . 1608.

Attenuation; frequency; mammalian tissues; polypeptides; proteins; tissue characterization; ultrasonics; velocity; absorption; amino acids; SP525, pp. 19-27 (Apr. 1979).

Attenuation; heart; liver; scattering; scattering cross-section; absorption; SP525, pp. 153-156 (Apr. 1979).

Attenuation; mammalian tissues; ultrasound; velocity; SPS25, pp. 343-360 (Apr. 1979).

Attenuation; tissue properties; transmission; ultrasound; SP525, pp. 101-108 (Apr. 1979).

Attenuation coefficient; detector response functions; dosimetry; electrons; foil transmission; photons; stopping power; transport theory; absorbed dose; 18371 .

Attenuation measurements; fiber optics; frequency response measurements; measurements; review; 18647.

Attenuation of areola; attenuation of breast tissue; attenuation of malignant tumors; breast cancer detection; breast carcinoma; breast examination techniques; FFT techniques for breast; histology of breast tumors; SP525, pp. 85-91 (Apr. 1979).

Attenuation of breast tissue; attenuation of malignant tumors; breast cancer detection; breast carcinoma; breast examination techniques; FFT techniques for breast; histology of breast tumors; signal processing for tissue; SP525, pp. 85-91 (Apr. 1979).

Attenuation of malignant tumors; breast cancer detection; breast carcinoma; breast examination techniques; FFT techniques for breast; histology of breast tumors; signal processing for tissue; $x$-ray examination of breast; SP525, Pp. 85-91 (Apr. 1979).

Attenuators; calibration; laser; neodymium laser; peak power; power meter; pulsed laser; Q-switched; risetime; speckle; waveform; TNIO10.

Attic floor radiant panel; cellulose thermal insulation; critical radiant flux; flame spread; smoldering combustion; test methods; NBSIR 79-1588.

Attic ventilation; energy conservation; solar absorptance of roofing materials; whole-house ventilation; SP548.

Attitudes; consumer preference; energy; energy cost; feedback; feedback meters; NBSIR 79-177I.

AU Peg; binary cepheids; cepheids; population 11 cepheids; 18913.

$\mathrm{AuAl}_{2} ; \mathrm{Auln}_{2}$; Be; cryoge nic temperature scale; fixed points; 1r; superconductivity; thermometry; W; SP260-62.

$\mathrm{AuAl}_{2} ; \mathrm{Auln}_{2} ; \mathrm{Be}$; Ir; superconductivity; supercooling; temperature fixed points; $\mathbf{W} ; \mathbf{l} 8549$.

Audience; feature article; news release; publication announcement; scientist-author; technical communicator; technical paper; trade press; 18817.

Audio frequencies; impurities; internal friction; isomers; low temperatures; $n$-paraffins; polycrystals; relaxation process; Young's modulus; 18467.

Audit; capacity planning; financial applications; long-range planning; management control; measurement; modeling; online system design; performance evaluation; performance management; prototyping; remote terminal emulation; system testing; SPS00-52, pp. 129-140 (Oct. 1979).

Audit; data center; data processing; information utilization; ADP auditors; SP500-52, pp. 3-8 (Oct. 1979).

Auditing; capacity planning; computer performance evaluation; Information Management System (IMS); management reporting; performance analysis; structured approach; SP500-52, pp. 9-19 (Oct. 1979).

Audition; communications; hearing; hearing aids; selection of hearing aids; speech communication; CIS4, Revised 1978. 
Auditory evoked response; magnetoencephalography; SQUID magnetometer; 18397.

Auger effect; Auger line width; $K$ shell; level width; line width; $L$ shell; natural width; x-ray line width; JPCRD 8, No. 2, 329 338 ( 1979 ).

Auger electron spectroscopy; cathodoluminescence; ion scattering spectrometry; laser microprobe mass analyzer; laser Raman microprobe; microanalysis; secondary ion mass spectrometry; x-ray microanalysis; 18568 .

Auger electron spectroscopy; die attachment; electrical properties; electronics; hermeticity; indium-doped silicon; infrared reflectance; integrated circuits; line-width measurements; oxidation; photolithography; photovoltaic method; power-device grade silicon; SP4O0-38.

Auger electron spectroscopy; electron spectroscopy; ESCA; secondary ion mass spectroscopy; surface analysis; ASTM Committee E-42; 18406.

Auger line width; $K$ shell; level width; line width; $L$ shell; natural width; $x$-ray line width; Auger effect; JPCRD 8, No. 2, 329-338 (1979).

Auger spectroscopy; corrosion films; ESCA; impurities; microroughness; optical microscopy; polishing defects; scattered light; SIMS; stylus instruments; SP562, pp. 337-350 (Oct. 1979).

Auger yield; Coster-Kronig yield; effective fluorescence yield; fluorescence yield; $K$ shell; $L$ shell; non-radiative yield; partial level width; radiative yield; atomic properties; JPCRD 8 , No. 2, 307-328 (1979).

Auln $n_{2}$, Be; cryogenic temperature scale; fixed points; Ir; superconductivity; thermometry; W; $\mathrm{AuAl}_{2} ; S P 260-62$.

Auln $_{2}$; Be; Ir; superconductivity; supercooling; temperature fixed points; W; $\mathrm{AuAl}_{2} ; 18549$.

Autism; cerebral palsy; deafness; developmentally disabled; epilepsy; fire safety; group homes; handicapped; mental retardation; ambulatory people; NBS-GCR-79-167.

Autoionization; core-excited states; magnesium; photoabsorption-spectrum; synchrotron radiation; 18912.

Autoionizing states; laser-excitation technique; neutral sodium; sodium, neutral; 18507.

Automated calorimetry; calorimetry; heat capacity; measurement automation; p-Terphenyl; thermodynamic properties; $\lambda$ -type transition; adiabatic calorimetry; 18376 .

Automated data systems; computer programs; cost/benefit analysis; documentation; documentation content guidelines; feasibility study; FIPS guidelines; initiation phase; project request; software; FIPS PUB 64.

Automated surveillance; rotating machinery monitoring; statistical detection algorithm; vibrational signatures; SP547, pp. 203-231 (July 1979).

Automated test and diagnostics; automotive test and diagnostics; vehicle test and diagnostics; SP547, pp. 111-126 (July 1979).

Automated test equipment; measurement assurance; traceability; 18354 .

Automated testing; batteries; cardiac pacemakers; contamination; corrosion; electrostatic-induced damage; hermeticity; hybrid devices; leak testing; measurement technology; microcalorimetry; moisture; nondestructive testing; pacemaker leads; process control; reliability; SP400-50.

Automated thermogravimetry; computer automated thermogravimeter; factor-jump thermogravimetry; polymer degradation; thermogravimetry; activation energy; 18447.

Automatic bridge; $\mathrm{Bi}_{12} \mathrm{GeO}_{20} ; \mathrm{CaCO}_{3} ; \mathrm{CaF}_{2}$; capacitance measurement; evaporated electrodes; pressure transducer; temperature dependence; adiabatic heating; $\mathrm{As}_{2} \mathrm{~S}_{3} ; 18466$.

Automatic bridge; detector; high resolution detector; phase sensitive detector; programmable detector; a-c detector; 18453 .

Automatic data processing; computer reports; grant data; residential buildings; solar database; solar energy system; solar heating and cooling; NBSIR 79-1923.
Automatic data processing; computer services; Federal Information Processing Standards; Federal standards; ADP information sources; ADP management; ADP policies; ADP services; NBSIR 79-1734.

Automatic data processing; data base; residential buildings; solar data center; solar energy systems; solar heating and cooling; NBSIR 79-1762.

Automatic diagnostics; digitized data; spectrum analyzers; steady state mode; tolerance vibration levels; SP547, pp. 286295 (July 1979).

Automatic monitoring; failure annunciation; malfunction procedures; manned spaceflight failures; redundancy management; training for diagnosis; SP547, pp. 3-16 (July 1979).

Automatic network analyzer; calibration; microwave measurement; six-port; 18849.

Automatic network analyzer; microwave; microwave measurement; six-port; 18650.

Automatic network analyzer; microwave; microwave measurement; six-port; 18653.

Automatic sampler; master analytical scheme; non-purgeable organics; organic pollutant; purgeable organics; WaterDROP; accumulators; analysis of organics in water; SP519, pp. 6578 (Apr. 1979).

Automatic sprinkler; building code; smoke movement; spray nozzle; stairway protection; ventilated stair; NBSIR 78-1571.

Automatic sprinklers; building codes; building construction; Delphi Method; fire safety; health care facilities; hospitals; interior finishes; Life Safety Code; nursing homes; risk analysis; safety equivalency; safety evaluation; smoke detection; NBSIR 78-1555.

Automatic stack damper; flue-gas temperature profile; gas-fired furnace; off-period mass flow rate; part-load performance; seasonal efficiency; TN999.

Automatic test system; diesel engine analyzer; SP547, pp. 176 . 190 (July 1979).

Automation; bulk photovoltaic effect; computer control; homogeneity; measurement method; nondestructive testing; photoconductivity; power devices; resistivity variation; SP400-52.

Automation; clinical chemistry; environmental chemistry; gas chromatography; liquid chromatography; SP519, pp. 587-600 (Apr. 1979).

Automation; continuous analysis; controlled dispersion; flow injection analysis; SP519, pp. 501-507 (Apr. 1979).

Automation; image processing; inspection; manufacturing; pattern recognition; robotics; vision systems; NBSIR 79-1764.

Automation; laser; oscilloscope; picosecond; pulse; pulse measurement; time domain measurement; 18640 .

Automation; microwave; microwave measurements; reflectometer; six-port; 18652.

Automorphism; cyclic module; faithful distributive module; incidence algebra; multiplicative function; quasi-ordered set; topological algebra; 18789 .

Automotive component design; continuous fiber composite materials; fabrication; finite element stress analysis; front end; graphite; part integration; wheel; SP563, pp. 135-151 (Oct. 1979).

Automotive structures; composite material; composite material analysis program; Tsai-Wu tensor polynomial lamina strength failure criterion; SP563, p. 133 (Oct. 1979).

Automotive test and diagnostics; vehicle test and diagnostics; automated test and diagnostics; SP547, pp. 111-126 (July 1979).

Autopsy; building fires; cigarettes; death; fire investigations; fire statistics; pathology; toxic gases; alcohol intoxication; NBSGCR-79-168.

Availability standards; batch processing; calibration programs; computer standards; interactive processing; quality of service; response time; turnaround time; SP500-52, pp. $79-86$ (Oct. 1979). 
Avalanche photodiode; FFT; fiber optics; frequency response; impulse response; laser; photodiode; NBSIR 79-1620.

Axial heat transport; forced convection; heat transmission; helium II; mutual friction; 18617 .

Axisymmetric; beams; focal thermal flaw; skull transmission; ultrasound; SP525, pp. 203-208 (Apr. 1979).

Aza-arenes; hydrazines; nitroalkanes; nitrosamines; sidestream smoke; thermal energy analyzer; tobacco smoke; vinyl chloride; SP519, pp. 131-141 (Apr. 1979).

A/D converter; Josephson junction; SQUID; superconducting electronics; superconductivity; 18678.

A/D converters; D/A converters; data acquisition; data converters; dynamic measurements; settling time; 18503 .

\section{B}

Ba ions; frequency stability; frequency standard; ion temperature; laser induced cooling; $\mathrm{Mg}$ ions; optical \& microwave double resonance; stored ions; systematic effects; 18697.

Backscatter frequency dependence; cirrhosis; composition-dependent scattering; fatty liver; stochastic scattering; tissue characterization; ultrasonic tissue scattering; ultrasound attenuation; ultrasound diagnosis; SP525, pp. 157-163 (Apr. 1979).

Backward scattering; forward scattering; grain boundaries; isostatic forging; optical figure; optical homogeneity; single crystal; Talystep traces; alkali halides; SP541, pp. 65-69 (Dec. 1978).

Bacon function; Bragg function; Ergun function; graphite materials; Lorentz function; preferred orientation function; pyrolitic graphite; Ruland function; x-ray diffraction; 18523 .

Baffled piston radiator; piston radiator; radiation of sound; ultrasonic radiator; 18479 .

$\mathrm{BaF}_{2} ; \mathrm{CaF}_{2} ; \mathrm{CdF}_{2} ;$ chalcogenide glass; elastic compliances; elastic constants; elasto-optic constants; fused silica; Ge; hot forged; $\mathrm{KBr}$; $\mathrm{KCl}$; $\mathrm{KCl}: \mathrm{KI}$; $\mathrm{LiF} ; \mathrm{MgF}_{2} ; \mathrm{NaCl}$; $\mathrm{NaF}$; TN993.

$\mathrm{BaF}_{-}$; $\mathrm{CaF}_{2}$; laser glass; photoelasticity; piezo-birefringence; piezo-optic constants; SrF; stress-optical coefficient; SP541, pp. $50-54$ (Dec. 1978).

Balancing equations; chemical equations; equation balancing; algebraic method; 18984.

Ballistic deformation; ballistic penetration; body armor; bullet proof vests; armor, body; 18465 .

Ballistic penetration; body armor; bullet proof vests; armor, body; ballistic deformation; 18465 .

Bands, molecular; energy levels; energy levels, atomic; line shapes, atomic; molecular bands; molecular spectra; rotational constants; atomic line shapes; atomic spectra; atomic transition probabilities; 18828 .

Bandwidth; coherence; dynamic rate; incoherence; ionization; linear rate; multiphoton; rate approximation; saturable rate; 18893.

Bandwidth; didymium glass filter; passband centroid; spectrophotometer; transmittance; wavelength standard; SP26066.

Barbiturates; carboxylic acids; catecholamines; conjugates; detection sensitivity; dipeptides; drugs; HPLC; ion-pair adsorption; ion-pair chromatography; ion-pair partition; metabolites; psychotropic amines; selectivity; sulphonamides; SP519, pp. 509-523 (Apr. 1979).

Barium; beryllium; calcium; electrical resistivity; magnesium; radium; strontium; temperature dependence; alkaline earth elements; JPCRD 8, No. 2, 439-498 (1979).

Barium; graphite fumace; seawater; wavelength modulation; atomic absorption; atomic emission; 18783.

Barrier analysis; compartment fires; compartments; fault tree analysis; fire models; fire protection engineering; probability statistics; systems analysis; systems safety; walls; NBS-GCR79-163.
Barriers; building codes; code enforcement; historic district; historic preservation; regulations; rehabilitation; safety; SP536, pp. 83-93 (Feb. 1979).

Base drive circuit; electronic circuits; inductive load; nondestructive; protection circuit; reverse bias; safe operating area; second breakdown; switching power transistor; tester; transistor; SP4OO-54.

Base metal; casting; composite; cyanoacrylate; dental alloy; initiator; resin; wear; accelerator; alloy; NBSIR 78-1573.

BASIC; carbon dioxide; carbon monoxide; coal gasification; COLGAS; hydrogen; interactive computer program; methane; minimization of Gibbs energy; phase rule; simultaneous chemical equilibria; water; NBSIR 78-1509.

Basic research; computer; energy conservation; environmental quality; industrial productivity; materials utilization; measurement capabilities; medical aids; product safety; public health and safety; science and technology transfer; standards; SP538.

Batch processing; calibration programs; computer standards; interactive processing; quality of service; response time; turnaround time; availability standards; SPSO0-52, pp. 79-86 (Oct. 1979)

Bathtubs; CPSC; performance test; showers; slip-resistance; ASTM; 18705.

Batteries; cardiac pacemakers; contamination; corrosion; electrostatic-induced damage; hermeticity; hybrid devices; leak testing; measurement technology; microcalorimetry; moisture; nondestructive testing; pacemaker leads; process control; reliability; SP40O-5O.

Batteries; photovoltaic energy conversion; power conditioning; power systems; solar cells; standards; test methods; NBSIR 79-1743.

Battery; chromatography; sulfuric acid; trace organics; SP519, pp. 797-802 (Apr. 1979).

Battery application; engineering properties data; evaluated data; polycrystalline; single crystal; sodium beta alumina; sodium beta double prime alumina; NSRDS-NBS61, Part 111.

BBGKY; correlation functions; Kirkwood-Salsburg; MayerMontroll; 19004.

Be; cryogenic temperature scale; fixed points; Ir; superconductivity; thermometry; W; $\mathrm{AuAl}_{2} ; \mathrm{AuIn}_{2} ; \mathrm{SP260-62.}$

$\mathrm{Be}$; dispersion; excited states; He; interaction energy; overlap; 18933.

Be; Ir; superconductivity; supercooling; temperature fixed points; W; $\mathrm{AuAl}_{2} ; \mathrm{AuIn}_{2} ; 18549$.

Bead-spring model; block copolymer; flow birefringence; flow dichroism; polymer dynamics; Rouse-Zimm theory; solution properties; 18431 .

Beam lead devices; electronic devices; hermeticity; hybrids; nondestructive tests; semiconductor; tape-bonded devices; acoustic emission; SP400-59.

Beam profile; calibrated system; holography; irradiance; laser diagnostics; phase front; TN1015.

Beam profile; cross correlation; digital sampling; Fourier optics; holography; laser; laser parameters; laser pulse; optical processing; phase; precision measurements; wave front; amplitude; TNIOO9.

Beam quality; neutron production; photon beam exit; SP554, pp. 139-144 (Sept. 1979).

Beam transport; high current beams; numerical simulation; particle accelerators; space charge forces; 18932 .

Beam type device; frequency stabilizing system; microwave interaction regions; microwave signals; U.S. Patent 4,146,848.

Beam-addressables; cartridges; cassettes; core memories; disks; drums; floppy disks; laser beams; magnetic bubbles; masstapes; solid state memories; video disks; SP500-45.

Beam-foil spectroscopy; cascades in atomic decay; exponential fitting; Kr VIII; atomic decay curve simulation; atomic transition probabilities; 18508 . 
Beams; ceiling height; detectors; fire detectors; fire growth; heat detectors; room fires; smoke detectors; spacing; velocity; NBS-GCR-78-128.

Beams; ceiling height; detectors; fire detectors; fire growth; heat detectors; room fires; smoke detectors; spacing; velocity; NBS-GCR-78-129.

Beams; focal thermal flaw; skull transmission; ultrasound; axisymmetric; SP525, pp. 203-208 (Apr. 1979).

Bearing; condition monitoring; diagnostic equipment; shock pulse; aircraft diagnostics; SP547, pp. 31-35 (July 1979).

Bearing analysis; condition monitoring; engine diagnosis; failure detection; failure diagnosis; failure prevention; maintenance; performance monitoring; SP547.

Bearing noise; failure prevention; machinery noise; noise signature; non-destructive evaluation; piezoelectric polymer; spectrum analysis; strain gage; SP547, pp. 303-314 (July 1979).

Bedding; beds; compartment fires; firesafety engineering; fire tests; health care facilities; hospitals; mattresses; prisons; 18517.

Beds; compartment fires; firesafety engineering; fire tests; health care facilities; hospitals; mattresses; prisons; bedding; 18517.

Behavioral science; biosensors; computer analysis; ergonomics; human engineering; human factors; human motivation; human reliability; personnel selection; physical security; physiological psychology; sensory capability; terrorism; threat analysis; training; $S P 480-38$

Benchmark; fission spectrum; foils; neutron fields; scattering corrections; sensitivity; 18901 .

Benchmark construction process; benchmark validation; competitive evaluation; tutorial; vendor systems; workload requirements; SP500-52, pp. 235-240 (Oct. 1979).

Benchmark fields; benchmark testing; neutron fields; nuclear data; reactor dosimetry; 19024.

Benchmark fields; dosimetry; fission yields; measurements; neutrons; Np-237; Pu-239; U-235; U-238; activation analysis; 18884 .

Benchmark library; selection of ADP systems; standard benchmarks; synthetic benchmarks; workload characterization; workload definition; benchmarking; SP500-38.

Benchmark neutron field development; dosimetry methods; fission cross sections; reactor dosimetry; 19013.

Benchmark performance data; empirical models; IBM 168-3; IBM 3033; migration guidelines; migration planning; SP50052, pp. 89-104 (Oct. 1979).

Benchmark testing; neutron fields; nuclear data; reactor dosimetry; benchmark fields; 19024.

Benchmark validation; competitive evaluation; tutorial; vendor systems; workload requirements; benchmark construction process; SP500-52, pp. 235-240 (Oct. 1979).

Benchmarking; benchmark library; selection of ADP systems; standard benchmarks; synthetic benchmarks; workload characterization; workload definition; SP500-38.

Benchmarking; clustering; performance evaluation; stratified sampling; SP500-52, pp. 105-111 (Oct. 1979).

Benchmarking; computer performance measurement; distributed processing; interactive systems; kernels; modeling; real-time; simulation; synthetic programs; SP500-52, pp. 53 . 64 (Oct. 1979).

Benchmarking; cost analysis; evaluation; procurement; technical analysis; time-sharing; TSP; SP500-52, pp. 233-234 (Oct. 1979).

Benchmarking; performance evaluation; synthetic program; workload mapping; SPSO0-52, pp. 193-199 (Oct. 1979).

Benefit-cost analysis; building technology; economic impacts; economics; efficiency; payback; plumbing; roofing; shingles; venting; SP5 58.

Benzene; absorption analysis; absorption spectrum; 18749 .

Benzene; energy transfer; vibrational energy transfer; 18641 .
Benzene; Herzberg-Teller theory; rotational contours of absorption bands; vibrational angular momentum; absorption selection rules; 18750 .

Benzene; rotational contours of absorption bands; absorption analysis; absorption spectrum; 18747.

Benzodiazepines; clinical use; derivatization; quaternary twophase systems; serum; uv-detection; tricyclic antidepressives; SP519, pp. $461-468$ (Apr. 1979).

Benzoic acid; calibration; combustion bombs; combustion calorimetry; historical survey; prominent calorimetrists; 18797.

Benzotriazenides; iridium (1) complexes; organometallic benzotriazenides; rhodium (I) complexes; thallium benzotriazenide; 18582 .

Benzotriazole; charge transfer; copper; luminescence; microspectrofluorimetry; photoluminescence; spectrofluorimetry; surface analysis; tetrazole; 18504 .

Benzoyl peroxide; composite resins; dental materials; glass compositions; methacrylate monomers; polymerization accelerators; reinforcing fillers; silane coupling agents; 18644 .

Benzyl substituted diglycerides; differential scanning calorimetry; heat of fusion; lecithins; lipids; melting temperature; metastable states; phenyl substituted diglycerides; phospholipids; polymorphism; recrystallization temperature; I 8380 .

Berg-Barrett; Lang; misorientation contrast; $\mathrm{x}$-ray topography; $\mathrm{Zn} ; \mathrm{Al}_{3} \mathrm{O}_{3} ; 18341$.

Beryllium; calcium; electrical resistivity; magnesium; radium; strontium; temperature dependence; alkaline earth elements; barium; JPCRD 8, No. 2, 439-498 (1979).

Beryllium; ceramics; cryogenics; dielectric-constant; electrets; electrocaloric effect; entropy; ferroelectrics; glass-ceramics; heat switches; magneto-thermal conductivity; polarization; potassium tantalate; refrigeration; specific heat; strontium titanate; 18680 .

Beryllium; core hole lifetime; lattice relaxation; lithium; magnesium; sodium; soft $x$-ray absorption spectra; soft $x$-ray emission spectra; aluminum; 18741 .

Beryllium; differential cross section; Fermi gas; lithium; optical potentials; photopion; pion; 18442 .

Beryllium; differential cross section; Fermi gas; lithium; optical potentials; photopion; pion; 18496.

Beryllium; dimensional stability; gyroscope; instrument materials; microcreep; micromechanical properties; NBSIR 781569.

Best practicable technology; clean water regulation; Environmental Protection Agency; evaluability assessment; evaluation; Experimental Technology Incentives Program; regulatory experimentation; regulatory policy; rulemaking; $N B S-G C R$ ETIP 79-63.

Beta decay; rearrangement; shake-off; shake-up; 18407.

Betatrons; cobalt units; dose buildup; linacs; patient survival; SP554, pp. 15-21 (Sept. 1979).

Betatrons; detectors; dosimetry; leakage; linear accelerators; neutrons; SP554, pp. 1 29-138 (Sept. 1979).

Betatrons; electrons; megavoltage; neutrons; therapy; $x$ rays; accelerators; SP554, pp. 1-14 (Sept. 1979).

Biaxial fatigue; biomaterials; circulatory assist devices; fatigue of polymers; mechanical testing; additive damage; NBSIR 79. I74I.

Bibliographic data bases; computerized data bases; information storage and retrieval systems; libraries-automation; machinereadable-bibliographic data; NBSIR 78-I577.

Bibliographies; building fires; compartment fires; fabric flammability; fire detection systems; fire tests; flammability tests; human behavior; plastics; polymers; smoke; smoke detectors; subway fires; toxicity; upholstered furniture; arson; NBSIR 79-1745. 
Bibliographies; building fires; escape; evacuation; fires; high rise buildings; hospitals; human behavior; nursing homes; NBSGCR-78-138.

Bibliography; buildings; certification; economics of standards; legal aspects of standards; product certification; product liability; regulation; standards system; voluntary standards; NBSIR 79-1900.

Bibliography; buildings; communication; cost; human characteristics; personal control; physical environment; privacy; architectural psychology; NBSIR 79-1793.

Bibliography; electrochemistry; electrolytes; enthalpy of dilution; heat capacity; relative apparent molal enthalpy; salt solutions; thermochemistry; vapor pressure; apparent molal heat capacity; aqueous systems; SP5 37.

Biexcitons; Haken's Hamiltonian; polar crystals; 18592.

Binary cepheids; cepheids; population II cepheids; AU Peg; 18913.

Binary divider; divider network; guarded divider; resistive divider; self calibration; voltage divider; 18452.

Binary mixture at the gas-liquid critical point; gas-liquid critical point; Rayleigh light scattering; 18752 .

Binary mixtures; data correlation; excess volumes; heat of mixing; liquid-vapor equilibria; methane + ethane; JPCRD 8, No. 3, 799-816 (1979).

Binary stars; cataclysmic variables; 18595 .

Binary-liquid mixture; consolute point; critical exponent; critical phenomena; critical solution point; liquid-liquid critical point; renormalization group theory; scaling theory; universality hypothesis; 18825 .

Binding energies; copper; ESCA; gold; relative intensities; round robin; $x$-ray photoelectron spectroscopy; 18924 .

Binding energy shifts; extra-atomic screening; implants; ion bombardment; rare-gases; relaxation energy; ultraviolet photoelectron spectroscopy; amorphous germanium; 18323.

Binomial test; chi-squared test; Francis Ysidro Edgeworth (1845-1926); goodness of fit; Sir Francis Beaufort (1774$1857) ; / 8471$.

Bioadhesive bond strength; bone; cyanoacrylate; hydrolytic stability; adhesion; 18638 .

Bioanalytical systems; mass spectrometry; negative ions; positive ions; atmospheric pressure ionization; SP519, pp. 655671 (Apr. 1979).

Biological; gas chromatography; Kepone ${ }^{R}$; partition chromatography; parts per billion; analysis; SP519, pp. 341-343 (Apr. 1979).

Biological assay; crystal structure; single crystal; uric acid derivative; uric acid determination; x-ray diffraction; 18672 .

Biological materials analysis; environmental materials analysis; neutron activation analysis; noble metals analysis; platinum determination; radiochemical separation; spontaneous deposition technique; 18350 .

Biological microanalysis; biological mineralization; bone; dental studies; dentin; enamel; microanalysis; mineralizing tissue; Raman microprobe; Raman spectroscopy; 19008.

Biological microanalysis; biological tissue; foreign bodies; histological sections; implant materials; microanalysis; molecular microanalysis; pathological tissue; Raman microprobe; Raman spectra; Raman spectroscopy; 18958.

Biological microanalysis; biological tissue; dental studies; enamel; mineralizing tissue; Raman microprobe; Raman spectra; Raman spectroscopy; tissue sections; tooth; 18982 .

Biological microanalysis; microanalysis; micromineralogy; microsampling; molecular analysis; organic microanalysis; Raman microprobe; Raman spectra; Raman spectroscopy; 18963.

Biological mineralization; bone; dental studies; dentin; enamel; microanalysis; mineralizing tissue; Raman microprobe; Raman spectroscopy; biological microanalysis; 19008 .

Biological samples; electrochemical detection; liquid chromatography; metal speciation; organomercury cations; 18420 .
Biological tissue; dental studies; enamel; mineralizing tissue; Raman microprobe; Raman spectra; Raman spectroscopy; tissue sections; tooth; biological microanalysis; 18982 .

Biological tissue; foreign bodies; histological sections; implant materials; microanalysis; molecular microanalysis; pathological tissue; Raman microprobe; Raman spectra; Raman spectroscopy; biological microanalysis; 18958 .

Biomaterials; blood proteins; ellipsometry; polymer adsorption; protein adsorption; protein chromatography; radiolabeled proteins; adsorption; NBSIR 79-1784.

Biomaterials; circulatory assist devices; fatigue of polymers; mechanical testing; additive damage; biaxial fatigue; NBSIR 79-1741.

Biomaterials; negative control; polyethylene; processing sheets and rods; surface characterization; surface contamination; NBSIR 77-1401.

Biomedical; boron; fission tracks; geochronology; geology; lithium; nitrogen; silicon devices; trace analysis; uranium; alpha tracks; 18342 .

Biomedical standard; diacetylurea; molecular structure; urea; urea determination; x-ray diffraction; 18347.

Bio-selective membrane electrodes; bio-sensors; enzymes; immunoelectrodes; trace organic electrochemistry; SP519, pp. 525-532 (Apr. 1979).

Biosensors; computer analysis; ergonomics; human engineering; human factors; human motivation; human reliability; personnel selection; physical security; physiological psychology; sensory capability; terrosim; threat analysis; training; adversary characteristics; SP480-38.

Bio-sensors; enzymes; immunoelectrodes; trace organic electrochemistry; bio-selective membrane electrodes; SP519, pp. 525-532 (Apr. 1979).

Bio-transformation; cadmium; food chain; lẹad mercury; metal; methylation; microbial tolerance; microorganism; plasmid; tin; arsenic; 18860.

Bipolar process; contact resistor; cross bridge sheet resistor; electrical alignment resistor; integrated circuits; linewidth; photolithography; sheet resistance; silicon; test pattern; test structure; TTL; 18533 .

Birefringent crystal; optical analyzer; polarized light; probe thermometer; temperature sensitive parameter; aligned sheet polarizer; U.S. Patent 4,140,393.

Bis(hexopyranosyl)amine; carbon-13; conformational analysis; nitrogen-15 coupling constants; nitrogen-15 n.m.r. spectroscopy; proton; proton coupling; structural analysis; 18764 .

$\mathrm{Bi}_{12} \mathrm{GeO}_{20} ; \mathrm{CaCO}_{3} ; \mathrm{CaF}_{2}$; capacitance measurement; evaporated electrodes; pressure transducer; temperature dependence; adiabatic heating; $\mathrm{As}_{2} \mathrm{~S}_{3}$; automatic bridge; 18466 .

BKZ fluid; constitutive equation; non-linear flow histories; rate fluid; simple shear; 18367.

BK-7 glass; fused silica; laser damage; polished surfaces; pulse duration dependence of damage; surface roughness; SP54I. pp. 164-167 (Dec. 1978).

Blackbody measurements; chemical actinometry; second harmonic generation; solar radiation measurements; absolute radiometers; 18476 .

Blade aeroelastic behaviour; blade manufacture and quality control; composite propellers and rotors; failsafe blade design; propeller fatigue behaviour; propeller materials requirements; SP563, pp. 80-88 (Oct. 1979).

Blade manufacture and quality control; composite propellers and rotors; failsafe blade design; propeller fatigue behaviour; propeller materials requirements; blade aeroelastic behaviour; SP563, pp. 80-88 (Oct. 1979).

Block copolymer; flow birefringence; flow dichroism; polymer dynamics; Rouse-Zimm theory; solution properties; beadspring model; 18431 .

Blocking electrode; charge motion; polarization; poly(vinylchloride); poly(vinylidenefluoride); pyroelectric 
response; thermal pulse; tetrafluoroethylene copolymer; 18408

vinylidenefluoride-

Blocking temperature; magnetic; particles; superparamagnetic particles; 18746.

Blood erythrocytes aggregation; blood hcmatocrit; ultrasound backscattering from blood; SP525, pp. 165-169.(Apr. 1979).

Blood flow; breast cancer; diagnosis; Doppler; screening; ultrasonics; SP525, pp. 173-176 (Apr. 1979).

Blood gases; blood $\mathrm{pH}$; carbon dioxide; oxygen; $\mathrm{pH}$; acid-basc status of blood; 18470 .

Blood hematocrit; ultrasound backscattering from blood; blood erythrocytes aggregation; SP525, pp. 165-169 (Apr. 1979).

Blood $\mathrm{pH}$; carbon dioxide; oxygen; $\mathrm{pH}$; acid-base status of blood; blood gases; 18470 .

Blood proteins; ellipsometry; polymer adsorption; protein adsorption; protein chromatography; radiolabeled proteins; adsorption; biomaterials; NBSIR 79-1784.

Blood samples; clinical sampling of infants; clinical trace organic sampling; Guthrie blotters; SP519, pp. 373-379 (Apr. 1979).

Body armor; bullet proof vests; armor, body; ballistic deformation; ballistic penetration; 18465 .

Body-worn transmitters; communications equipment; FM transmitters; law enforcement equipment; standards; surveillance; undercover equipment; 18381 .

Boiler; combustion; energy; furnace; gas-fired; heating; oil-fired; rating; space-heating; testing; 18385 .

Bomb calorimetry; drop ealorimetry; electromagnetic power calorimetry; energy measurement; enthalpy measurement; entropy measurement; fuels, heating values; gas-flow calorimetry; heat capacity measurement; heat measurements; levitation calorimetry; microcalorimetry; 18330.

Bomb calorimetry; gross calorific values; refuse-derived-fuels; sample characterization; test procedures; NBSIR 78-1494.

Bond angles; bond distances; gas-phase polyatomic molecules; gas-phase spectroscopy; microwave spectroscopy; molecular conformation; molecular spectroscopy; molecular structure; molecules; structure; JPCRD 8, No. 3,619-722 (1979).

Bond distances; gas-phase polyatomic molecules; gas-phase spectroscopy; microwave spectroscopy; molecular conformation; molecular spectroscopy; molecular structure; molecules; structure; bond angles; JPCRD 8, No. 3, 619-722 (1979).

Bonded joints; composites; failure criteria; in-plane loads; SP563, p. 241 (Oct. 1979).

Bonded phases; chromatographic preconcentration; detector sensitivity: gas chromatography; glass capillary columns; highperformance liquid chromatography; LC microcapillary columns; selective detectors; ancillary methods; SPS19, pp. 487-499 (Apr. 1979).

Bonding; coupling agent; dental; monomers; resins; surface-active comonomers; acrylates; adhesion, dental; 18461 .

Bonding to dentin; dental adhesive; dentin; durability of dentin acrylic bond; isobutyl 2-cyanoacrylate; pretreatment of dentin; 2-eyanoacrylate esters; adhesive; 18985.

Bonding to mineralized tissues; bone; dentin; hydrolytic stability of bonds; isobutyl 2-cyanoacrylate; mineralized tissue; 2cyanoacrylate esters; adhesion; 18569.

Bone; chemisorption; enamel; hydroxyapatite; surface area; 18411 .

Bone; collagen; crosslinking modification; curvelinking; hydroxyapatite; sonic velocity; SP525, pp. 179-187 (Apr. 1979).

Bone; cyanoacrylate; hydrolytic stability; adhesion; bioadhesive bond strength; 18638 .

Bone; dental studies; dentin; enamel; microanalysis; mineralizing tissue; Raman microprobe; Raman spectroscopy; biological microanalysis; biological mineralization; 19008 .

Bone; dentin; hydrolytic stability of bonds; isobutyl 2cyanoacrylate; mineralized tissue; 2-cyanoacrylate esters; adhesion; bonding to mineralized tissues; 18569 .
Bonc; hydroxylapatitc; intcrlayering; octacalcium phosphatc; tooth; $x$-ray diffraction; 18583.

Boolcan scarch systcm; computcr programs; curve fitting; data analysis; data base management; data retrieval; file handling; graphic analysis; IMS information retrieval; KWOC indexing; lcast-squares; lincar regression; MIS; plotting; statistical analysis; 18597.

Born approximation; copper isoelectronic sequence; CoulombBorn approximation; distorted wave approximation; effective Gaunt factor; electron impact cxcitation collision strength; 18996.

Born approximation; correlations; electron impact; electrons; helium; ionization; secondary; angular; 18534.

Born-Oppenheimer approximation; centrifugal; Coriolis; frame transformation relations; level cluster; spherical tops; symmetry analysis; 18599.

Born-Oppenheimer approximation; high-resolution spectra; level clusters; Raman spectra; rotation-vibration spectra; symmetry analysis; 18598 .

Boron; atomic energy levels; atomic spectra; JPCRD 8, No. 1, 63-68 ( 1979 ).

Boron; fission tracks; geochronology; geology; lithium; nitrogen; silicon devices; trace analysis; uranium; alpha tracks; biomedical; 18342

Boron hydride; metalloborane; nickelaborane; nuclear magnetic resonance; 18328 .

Boron nitride; Cl-doped glasses; diffusion in silicon; integrated circuit processing; kinetics of oxide growth; oxidation of silicon; semiconductor processing; silicon; silicon dioxide; thermally stimulated measurement; thermal oxidation; Zn-doped glasses; NBS-GCR-78-134.

Boron-aluminum; boron-epoxy; composites; elastic constants glass-epoxy; internal friction; Young's modulus; aramidepoxy; 18716.

Boron-doped silicon; dopant density; effective mass; hole mobility; ionized impurity scattering mobility; lattice scattering mobility; neutral impurity; resistivity; scattering mechanisms; scattering mobility; $\rho$-type silicon; SP400-47.

Boron-epoxy; composites; elastic constants glass-epoxy; internal friction; Young's modulus; aramid-epoxy; boron-aluminum; 18716.

Boron-epoxy; edge cracks; failure modes; finite element method; tensile strength; SP563, pp. 228-238 (Oct. 1979).

Boson expansions; Holstein-Primakoff representation; spin operators; 18885 .

Bottom injection; multiple injection; smoke candle test; smoke control; stairwell pressurization; top injection; tracer gas test; NBSIR 79-1747.

Bottom loading; field standard provers; field standards; field standard test measures; provers; specifications; standards; test measures; tolerances; vapor recovery; H105-3.

Boundary layer; loads (forces); roughness; structural analysis; tall buildings; wind pressure; aerodynamics; 18351 .

Boundary layers; dynamic response; interference effects; tall buildings; wind loads; wind tunnels; aerodynamics; 18977.

Box plots; CALCOMP; computing system; confidence ellipse; OMNITAB 78; plots; portability plots; residuals; statistical plots; statistics; stem-and-leaf displays; 18954.

Bragg function; Ergun function; graphite materials; Lorentz function; preferred orientation function; pyrolitic graphite; Ruland function; x-ray diffraction; Bacon function; 18523 .

Brain; cerebrospinal fluid; fluorescence flow cell; liquid chromatography; tryptophan metabolites; SPS19, pp. 411-418 (Apr. 1979).

Brain mechanisms; cognition; goal seeking; intelligence; motor behavior; neural modeling; perception; planning; problem solving; robot control; 18714

Brain scanning; echoencephalography; neurology; phase compensation; SPS25, pp. 209-218 (Apr. 1979). 
Brain tumor; clot; hemorrhage; hydrocephalus; impedance; infarct; specd; ultrasonic; attenuation; SP525, pp. $81-84$ (Apr. 1979).

Brake; coupling dcvicc; cutting blade; dcad-man's handle; disconnect element; lawnmowcr; motor shaft; U.S. l'at'nt $4,1.58,944$.

Braking traction; corncring traction; driving traction; endurance; maintenance; operation; purchasing; pursuit tircs; safety; tread wear; Sl'48()-33.

Branch circuit wiring; electrical junction box; hazardous temperatures; load current; overlamping; surface mounted incandescent lighting fixture; thcrmal insulation; thermocouple; NBSIR 79-19/2.

Branch circuit wiring; electrical junction box; hazardous temperatures; load current; protective barrier; recessed incandescent lighting fixture; thermal insulation; thermocouple; NBSIR 79-1913.

Bravais lattices; Fast Fourier "Transform"; near-field scanning; orthogonalities; plane-radial scanning; probe correction; space groups; aliasing; 18956.

Breakdown; electro-optics; gas-solid interface; KDP; Pockels effcct; space charge; NBS-GCR-79-177.

Breakdown ficlds; $\mathrm{KCl}$; $\mathrm{NaCl}$; spot-sizc dependence; SP54I, pp. 309-317 (Dec. 1978).

Brcakdown mechanism; frequency and time dependence of brcakdown thresholds; IR window materials; $\mathrm{NaCl}$; prcssure; pulsed TEA $\mathrm{CO}_{2}$ lascr surface breakdown; spot size; surface absorption; transmitted pulse; adsorbed water; SP54I, pp. 318.326 (Dec. 1978).

Breast cancer; cancer; connective tissue; differential diagnosis; medullary carcinoma; papillary carcinoma; scirrhous carcinoma; shadowing; ultrasound; attenuation; SP525, pp. 93. 99 (Apr. 1979).

Breast cancer; chirp signals; imaging; opto-acoustic; pulse comprcssion; sensitivity; signal averaging; signal processing; tissue characterization; tomography; transducers; ultrasonics; annular array; SP525, pp. 255-259 (Apr. 1979).

Breast cancer; computerized tomography; mammography; timeof-flight; tissue characterization; ultrasonic imaging; ultrasound; SP525, pp. 221-225 (Apr. 1979).

Breast cancer; diagnosis; Doppler; screening; ultrasonics; blood flow; SP525, pp. 173-176 (Apr. 1979).

Breast cancer detection; breast carcinoma; breast examination techniques; FFT techniques for breast; histology of breast tumors; signal processing for tissue; $x$-ray examination of breast; attenuation of areola; attenuation of breast tissue; SP525, pp. 85-91 (Apr. 1979).

Breast carcinoma; brcast examination techniques; FFT techniques for breast; histology of breast tumors; signal processing for tissue; $x$-ray examination of breast; attenuation of arcola; attenuation of breast tissue; SP525, pp. 85-91 (Apr. 1979).

Breast examination techniques; FFT techniques for breast; histology of breast tumors; signal processing for tissue; $x$-ray examination of breast; attenuation of areola; attenuation of breast tissue; attenuation of malignant tumors; SP525, pp. 85-91 (Apr. 1979).

Brcathing apparatus; death; evacuation; fires; flashover; hospitals; human behavior; nursing staff; patients; room fires; NBS-GCR-78-140

Bremsstrahlung high frequence limit; bremsstrahlung spectrum tip; continuum $x$ rays; Coulomb field; non-relativistic bremsstrahlung; atomic screening effects; 18532 .

Bremsstrahlung high frequency limit; bremsstrahlung spectrum tip; continuum $x$ rays; Coulomb field; non-relativistic bremsstrahlung; atomic screening effects; 18370 .

Bremsstrahlung spectrum tip; continuum $x$ rays; Coulomb field; non-relativistic bremsstrahlung; atomic screening effects; bremsstrahlung high frequency limit; 18370 .
Bremsstrahlung spectrum tip; continuum x rays; Coulomb ficld; non-relativistic bremsstrahlung; atomic screening effccts; bremsstrahlung high frequence limit; 18532 .

Bridge circuit; circuit bridge; dynamic charactcrization of sample/hold amplificr; amplifier, samplc/hold; 18505 .

Bridge deck; concrete; corrosion; corrosion of stecl; rebar corrosion; reinfored concretc; SP550.

Bridgcs; buildings; design criteria; glucd-laminatcd timber; safcty; tcmporary structures; wood; 18887.

Bridgcs; crcosotc; harbor facilities; inspcction; maintenance; marine borcrs; nondestructive tcsting; pilings; timber; acoustics; 18525 .

Brittlc failure; flaw populations; flaws; fractography; fracture origins; grinding; machining; polishing; sanding; strength-size effects; SP562, pp. $351-378$ (Oct. 1979).

Brittlc failurc; flaw sizcs; grain sizc depcndence of strength; strength; SP562, pp. $429-452$ (Oct. 1979).

Broadband; dynamic rangc; Hcrmitian magnitude; isotropicity; isotropic, real-timc, elcctric-ficld scnsor (IRES); resistively loadcd dipole; tangential sensitivity; 19034 .

Broadband antenna; dircctivity; FFT; method of measurements; non-dispersive; resistivc loading; TEM horn; time domain measurement; antenna gain; 18856 .

Broadcast; coaxial; communication; contention; data; digital; cthernet; local; microproccssor; network; serial; 18760 .

Broadcast; coordinated universal time; synchronous satellite; time code; Westcrn Hemispherc; 19029.

Bromide; ethylacetatc; isopropyl; laser; non-equilibrium; pyrolysis; relaxation; thermal decomposition; allylmethylether; 18832 .

Bromides; chlorides; data compilation; density; elcctrical conductance; fluorides; halides; iodides; molten salt mixtures; standard refercnce data; surface tension; viscosity; JPCRD 8 , No. 1, 125-302 (1979).

Bromine atoms; bromoacetylene; excited statc; hydrogen bromide; photochcmistry mechanism; the rmochemistry; 18974 .

Bromoacetylene; excited statc; hydrogen bromide; photochemistry mechanism; thermochemistry; bromine atoms; 18974.

Bromoethanes; ideal gas thermodynamic properties; internal rotation; iodoethane; potential barrier heights; symmetric top; torsional frequencies; JPCRD 8, No. 2, 519.526 (1979).

Bronze binder; diamonds; erosion; grinding; wear; SP562, pp. 147-155 (Oct. 1979).

B-scan;cepstrum; computer; convolution; de-convolution; liver; power spectrum; signal processing; tissue characterization; tissue parameters; ultrasound; attenuation; SP525, pp. 287. 295 (Apr. 1979).

Bubbles, air; viscous silicon oil; air bubbles; 18481 .

Building design; buildings; construction matcrials; evacuation; exits; fire endurance; fire protection; stairways; standards; NBS-GCR-79-176.

Building; code administration; codes; evaluation; existing buildings; performance standard; SP549.

Building; codes and standards; full-scale testing; mobile homes; wind loads; aerodynamics; NBSIR 77-1289.

Building; ice; load; roof; roof load; snow; solar collector; structural engineering: NBS-GCR-79-181.

Building; private interests; public objectives; taxation; tax incentives; SP552, pp. $337-346$ (July 1979).

Building circulation; building ramps; pedestrian circulation; pedestrian flow; pedestrian movement; pedestrian ramps: ramps; NBSIR 79-1729.

Building code; building research; code administration; existing buildings; model codes; preservation; regulation; rehabilita tion; renovation; TN998.

Building code; smoke movement; spray nozzle; stairway protec tion; ventilated stair; automatic sprinkler; NBSIR $78-1571$. 
Building code structure; existing buildings; historic preservation; performance attributes; performance evaluation; building codes and standards; SP536, pp. $17-53$ (Feb. 1979).

Building codes; building construction; Delphi Method; fire safety; health care facilities; hospitals; interior finishes; Life Safety Code; nursing homes; risk analysis; safety equivalency; safety evaluation; smoke detection; automatic sprinklers; NBSIR 78-I555.

Building codes; building design; building regulatory standards; floor coverings; home safety; safety standards; stair safety; stairway design; accidents; architectural design; architectural psychology; architectural research; BSSI2O.

Building codes; building economics; economic analysis; fire safety; health care facilities; hospitals; life safety; mathematical programming; nursing homes; renovation; applied economics; NBSIR 79-1902.

Building codes; building economics; economic analysis; fire safety; health care facilities; hospitals; life safety; mathematical programming; nursing homes; renovation; applied economics; 19045.

Building codes; building evaluation; elderly; fire safety; handicapped occupants; health care facilities; nursing homes; user needs; NBSIR 79-1906.

Building codes; building performance simulation; computer applications; energy conservation; illumination standards; lighting distribution simulation; visual performance; SP552, pp. 321-335 (July 1979).

Building codes; building regulations; building safety; construction; performance; preservation; rehabilitation; renovation; adaptive reuse; architecture; SP536, pp. 1-16 (Feb. 1979).

Building codes; building regulations; buildings; construction; economic impacts; environmental considerations; innovative practices; regulatory research; standards development; administrative procedures; SP552.

Building codes; building regulations; cost-benefit analysis; lifecycle analysis; safety regulations; SP552, pp. 267-282 (July 1979).

Building codes; buildings; building safety; code enforcement; construction; fire safety; housing; preservation; regulations; rehabilitation; adaptive reuse; SP536.

Building codes; buildings; building standards; classification; decision tables; earthquake-resistant design; information networks; network; seismic design; systems analysis; TN1100.

Building codes; code administration; communication; physically handicapped; public awareness; public relations; accessibility standards; SP552, pp. 115-120 (July 1979).

Building codes; code enforcement; fire prevention codes; fire safety; master planning; regulation; standards; SP552, pp. 225-247 (July 1979).

Building codes; code enforcement; historic district; historic preservation; regulations; rehabilitation; safety; barriers; SP536, pp. 83-93 (Feb. 1979).

Building codes; community development; construction costs; contractors; housing; rehabilitation; standards; SP536, pp. 55 61 (Feb. 1979).

Building codes; construction; metric; SP552, pp. 283-29I (July 1979).

Building codes; control measures; fire codes; fire safety; governmental actions; life safety; regulation; risk assessment; societal goals; SP536, pp. 63-74 (Feb. 1979).

Building codes and standards; building code structure; existing buildings; historic preservation; performance attributes; performance evaluation; SP536, pp. 17-53 (Feb. 1979).

Building construction; Delphi Method; fire safety; health care facilities; hospitals; interior finishes; Life Safety Code; nursing homes; risk analysis; safety equivalency; safety evaluation; smoke detection; automatic sprinklers; building codes; NBSIR 78-I555.
Building design; building regulatory standards; floor coverings; home safety; safety standards; stair safety; stairway design; accidents; architectural design; architectural psychology; architectural research; building codes; BSS 120.

Building design; building site planning; environmental psychology; evaluation; fire escape; human research; measurement; pedestrian movement; regulation; safety; standards; architectural barriers; SP552, pp. 101-113 (July 1979).

Building design; building site planning; environmental psychology; evaluation; fire escape; human research; measurement; pedestrian movement; regulation; safety; standards; architectural barriers; 18430 .

Building design; cost; energy conservation; energy standards; fenestration; life-cycle costing; retrofitting; solar; 19043.

Building economics; building materials; cost estimation; econometric models; economic analysis; housing; lead-based paint; lead poisoning; abatement; TN979

Building economics; building materials; economic analysis; housing; lead-based paint; lead poisoning; abatement; TN97I.

Building economics; daylighting; economic analysis; energy conservation; engineering economics; life-cycle costs; solar heat gain; thermal efficiency; window; window management; BSS 119.

Building economics; economic analysis; fire safety; health care facilities; hospitals; life safety; mathematical programming; nursing homes; renovation; applied economics; building codes; NBSIR 79-1902.

Building economics; economic analysis; fire safety; health care facilities; hospitals; life safety; mathematical programming; nursing homes; renovation; applied economics; building codes; 19045 .

Building economics; energy conservation; insulation; life-cycle cost analysis; masonry construction; space heating and cooling requirements; thermal mass; NBSIR $79-1789$.

Building energy consumption analysis; computerized building energy analysis; cooling load calculation; energy conservation; heating load calculation; NBSLD analysis of residences; residential energy conservation; thermal mass effect in buildings; NBSIR 79-1 732 .

Building envelope; cost effectiveness; economics; energy conservation; internal rate of return; life-cycle costing; marginal analysis; optimal design; residential buildings; space cooling; space heating; 19044 .

Building evacuation; high-rise building design; network flow; NBSIR 79-1738.

Building evaluation; design process; man/environment research; post-occupancy evaluation; questionnaire; user needs; NBSIR 79.1780 .

Building evaluation; elderly; fire safety; handicapped occupants; health care facilities; nursing homes; user needs; building codes; NBSIR 79-1906.

Building fires; cigarettes; death; fire investigations; fire statistics; pathology; toxic gases; alcohol intoxication; autopsy; NBS-GCR-79-168.

Building fires; compartment fires; fabric flammability; fire detection systems; fire tests; flammability tests; human behavior; plastics; polymers; smoke; smoke detectors; subway fires; toxicity; upholstered furniture; arson; bibliographies; NBSIR 79-1745.

Building fires; computer-aided design; computer simulation; environmental psychology; fire research; fire safety; human performance; modeling technique; simulation; architectural research; NBSIR 79-1796.

Building fires; computer-aided design; environmental psychology; fire research; fire safety; human performance; modeling technique; programming; sensitivity analysis; simulation; architectural research; NBSIR 79-1713.

Building fires; conferences; fire detection; fire investigations; fire models; fire research; fire retardants; flame retardants; human behavior; smoke; toxic gases; toxicity; SP54O. 
Building fires; cost-benefit analysis; costs; decision analysis; fire losses; furniture; hazard analysis; probability; residential buildings; sensitivity analysis; smoke detectors; standards; upholstered furniture; $T N 1101$.

Building fires; equivalency; evaluation; fire safety; models; research; standards; systematic procedure; SP552, pp. 13-27 (July 1979).

Building fires; escape; evacuation; fires; high rise buildings; hospitais; human behavior; nursing homes; bibliographies; NB.S-(;CR-78-138.

Building materials; cost estimation; econometric models; economic analysis; housing; lead-based paint; lead poisoning; abatement; building economics; TN979.

Building materials; economic analysis; housing; lead-based paint; lead poisoning; abatement; building economics; TN971.

Building official; energy code; energy efficient; enforcement; implementation and effective $U$ value; on-site construction; SP552, pp. $131-140$ (July 1979).

Building performance simulation; computer applications; energy conservation; illumination standards; lighting distribution simulation; visual performance; building codes; SP552, pp. 32 l-335 (July 1979).

Building ramps; pedestrian circulation; pedestrian flow; pedestrian movement; pedestrian ramps; ramps; building circulation; NBSIR 79-1729.

Building regulation; energy conservation; legislation; solar energy; SP552, pp. 211-216 (July 1979).

Building regulations; building safety; construction; performance; preservation; rehabilitation; renovation; adaptive reuse; architecture; building codes; SP536, pp. 1-16 (Feb. 1979).

Building regulations; buildings; construction; economic impacts; environmental considerations; innovative practices; regulatory research; standards development; administrative procedures; building codes; SP552.

Building regulations; cost-benefit analysis; life-cycle analysis; safety regulations; building codes; SP552, pp. $267-282$ (July 1979).

Building regulatory standards; floor coverings; home safety; safety standards; stair safety; stairway design; accidents; architectural design; architectural psychology; architectural research; building codes; building design; BSSI 20 .

Building rehabilitation; energy measurements; energy-related inventions; environment; precision power; radioactivity; Raman microprobe; solar energy; toxic substances; DIM/NBS 63 , No. 6, 1-32 (June 1979).

Building research; building technology; codes; criteria; project summaries; standards; technical bases; SP446-2.

Building research; code administration; existing buildings; model codes; preservation; regulation; rehabilitation; renovation; building code; TN998.

Building rescarch; criteria; energy; engineering; industry construction; measurement techniques; standards; SP439.I.

Building research; NBS solar standards projects; solar energy; 18363

Building safety; code enforcement; construction; fire safety; housing; preservation; regulations; rehabilitation; adaptive reuse; building codes; buildings; SP536.

Building safety; construction; performance; preservation; rehabilitation; renovation; adaptive reuse; architecture; building codes; building regulations; SP536, pp. I-16 (Feb. 1979).

Building site planning; environmental psychology; evaluation; fire escape; human research; measurement; pedestrian movement; regulation; safety; standards; architectural barriers; building design; SP552, pp. 101-113 (July 1979).

Building site planning; environmental psychology; evaluation; fire escape; human research; measurement; pedestrian movement; regulation; safety; standards; architectural barriers; building design; $/ 8430$.
Building standards; classification; decision tables; earthquakeresistant design; information neiworks; network; seismic design; systems analysis; building codes; buildings; TNIIOO.

Building standards; foreign building standards; French building standards; French standards system; marking and certification; types of French standards; SP552, pp. 45-56 (July 1979).

Building technology; Center for Building Technology; history of building research; BSS75.

Building technology; codes; criteria; project summaries; standards; technical bases; building research; SP446-2.

Building technology; economic impacts; economics; efficiency; payback; plumbing; roofing: shingles; venting; benefit-cost analysis; SP558.

Building technology; France/NBS cooperative program; French schools; NBSIR 78-152I.

Building trades; construction industry; forecasting; labor information systems; manpower projections; modelling; SP552. pp. 185-196 (July 1979).

Building water systems; CIB; international plumbing research; plumbing and drainage; U.S. research in plumbing; SP553.

Building (codes); probability distribution functions; statistical analysis; storms; structural engineering; wind pressure; wind speeds; BSS118.

Buildings; building safety; code enforcement; construction; fire safety; housing; preservation; regulations; rehabilitation; adaptive reuse; building codes; SP536.

Buildings; building standards; classification; decision tables; earthquake-resistant design; information networks; network; seismic design; systems analysis; building codes; TNII00.

Buildings; certification; economics of standards; legal aspects of standards; product certification; product liability; regulation; standards system; voluntary standards; bibliography; NBSIR 79-1900.

Buildings; commercial; daylighting; energy; environments; heating: passive; solar; suburban; urban; application; 18894.

Buildings; communication; cost; human characteristics; personal control; physical environment; privacy; architectural psychology; bibliography; NBSIR 79-1 793.

Buildings; communications systems; fire safety; high-rise; model codes; people movement; systems design; BSSI 15.

Buildings; conservation; criteria; design; economics; efficiency; energy: energy budget; equity; life-cycle cost; optimal; standard; 18888 .

Buildings; construction; economic impacts; environmental considerations; innovative practices; regulatory research; standards development; administrative procedures; building codes; building regulations; SP552.

Buildings; construction materials; evacuation; exits; fire endurance; fire protection; stairways; standards; buiding design; NBS-GCR-79-176.

Buildings; data acquisition; energy; instrumentation; measurement; thermography; Twin Rivers Project; weather station; air infiltration; 18733 .

Buildings; demolition; economics; historic preservation; lifecycle costing; redevelopment; rehabilitation; tax incentives; adaptive reuse; TN980.

Buildings; demolition; economics; historic preservation; lifecycle costing; redevelopment; rehabilitation; tax incentives; adaptive reuse; 19016 .

Buildings: design; energy; legislation; solar; standards; State; NBSIR 79-1705.

Buildings; design criteria; glued-laminated timber; safety; temporary structures; wood; bridges; 18887 .

Buildings (codes); probability theory; progressi \%e collapse; reliability; structural engineering; abnormal loads; 18415 .

Bulk photovoltaic effect; computer control; homogeneity; measurement method; nondestructive testing; photoconductivity; power devices; resistivity variation; au tomation; SP400-52. 
Bullct proof vests; armor, body; ballistic deformation; ballistic penetration; body armor; 18465 .

Buoyancy; diffusion flames; fire entrainment; flame oscillations; plume; scaling; NBSIR 79-1910.

Buoyant convection; finite-difference computations; fire in an enclosure; heat addition; hyperbolic, elliptic equations; initial, boundary-value problem; linearized equations; partial differential equations; NBSIR 79-1754

Buoyant flow; compartment fires; computer programs; corridor fires; fire models; fire spread; room fires; thermal radiation; turbulence; NBS-GCR-78-150.

Burglar alarm; guidelines holdup alarm; intrusion alarm; alarm; SP480-14.

Burn injury; clothing; fabric flammability; fabrics; fire; garments; heat transfer; injury potential; simulation; accident; apparel; NBSIR 79-1755.

Burn injury; ease of ignition; fabrics; fire; flammability tests; garments; heat transfer; standards; apparel; 18991

Butadiyne; ethynyl; hydrogen; mechanism; photochemistry; radicals; rate constant; acetylene; 18443 .

Butylamine; collagen sponge; contraceptive device; gas chromatography: mass spectrometry; propylamine; SP519, pp. 469-476 (Apr. 1979).

\section{C}

Ca II emission, stars; chromospheres, stars; circumstellar shells; emission line, stars; late-type stars; 18853.

Ca II emission, stars; chromospheres, stars; emission line, star; late-type, ultraviolet; spectra; 18926.

Cable cool-down; cool-down helium; liquid helium; superconducting power transmission; thermal cycling; thermal stress; NBSIR 79-1618.

Cable interface; computer; controller; control units; hammer drive; input/output bus; interface; interface signals; $1 / O$ interface bus; line printer; print controller; printer; NBS-GCR-79. 182.

$\mathrm{CaCO}_{3} ; \mathrm{CaF}_{2}$; capacitance measurement; evaporated electrodes; pressure transducer; temperature dependence; adiabatic heating; $\mathrm{As}_{2} \mathrm{~S}_{3}$; automatic bridge; $\mathrm{Bi}_{12} \mathrm{GeO}_{20} ; 18466$.

Cadmium; food chain; lead; mercury; metal; methylation; microbial tolerance; microorganism; plasmid; tin; arsenic; bio-transformation; 18860 .

Cadmium; neutron activation; radiochemistry; 18478 .

Cadmium ratio; east neutron reactions; interfering nuclear reactions; optimization of analysis; silicon; trace analysis; activation analysis; 18338 .

$\mathrm{CaF}_{2}$; capacitance measurement; evaporated electrodes; pressure transducer; temperature dependence; adiabatic heating; $\mathrm{As}_{2} \mathrm{~S}_{3}$; automatic bridge; $\mathrm{Bi}_{12} \mathrm{GeO}_{20} ; \mathrm{CaCO}_{3} ; 18466$.

$\mathrm{CaF}_{2}$; $\mathrm{CdF}_{2}$; chalcogenide glass; elastic compliances; elastic constants; elasto-optic constants; fused silica; $\mathrm{Ge}$; hot forged; $\mathrm{KBr}$; $\mathrm{KCl}$; $\mathrm{KCl}: \mathrm{KI}$; LiF; $\mathrm{MgF}_{2} ; \mathrm{NaCl}$; $\mathrm{NaF}$; piezo-optic constants; refractive index; TN993.

$\mathrm{CaF}_{2} ; \mathrm{KCl}$; optical absorption coefficient; optoacoustic spectroscopy; $\mathrm{PbF}_{2}$; photoacoustic spectroscopy; TII; ZnSe; absorption edge; SP541, pp. 43-49 (Dec. 1978).

$\mathrm{CaF}_{2}$; laser glass; photoelasticity; piezo-birefringence; piezooptic constants; $\mathrm{SrF}_{2}$; stress-optical coefficient; $\mathrm{BaF}_{2} ;$ SP541, pp. 50-54 (Dec. 1978).

Calcium; electrical resistivity; magnesium; radium; strontium; temperature dependence; alkaline earth elements; barium; beryllium; JPCRD 8, No. 2, 439-498 (1979).

Calcium; optical Ramsey fringes; photon-recoil structure; saturated absorption; 18642 .

Calcium energy levels; atomic energy levels; atomic spectra; JPCRD 8, No. 3, 865-916 (1979).

Calcium fluoride; cw laser damage; DF laser; fusion cast; laser damage; laser window; single crystal; strontium fluoride; antireflection coatings; SP541, pp. $78-85$ (Dec. 1978).
Calcium fluoride; forging; laser windows; optical propcrties; scattering; SP541, pp. $70-77$ (Dec. 1978).

CALCOMP; computing system; confidencc ellipse; OMNITAB 78; plots; portability plots; residuals; statistical plots; statistics; stem-and-leaf displays; box plots; 18954 .

Calculations; cell dimensions; crystal; defect; energy; hydrocarbon; methyl-branch; structure; 18787

Calibrated system; holography; irradiance; laser diagnostics: phase front; beam profile; TN1015.

Calibration; Clausius-Mossotti equation; compressed-gas capacitor; high voltage; standards; sulfur-hexafluoride; 18513

Calibration; combustion bombs; combustion calorimetry; historical survey; prominent calorimetrists; benzoic acid; 18797.

Calibration; convolution; deconvolution; geometrical-optics radiometry; inversion; measurement-beam geometry; relative spectral responsivity; slit-scattering function; slit-scattering function corrections; spectral line radiometry; spectroradiometer characterizations; TN910-4

Calibration; current; impedance; network analyzer; power; reflection coefficient; reflectometer; scattering parameters; six-port; voltage; 18600.

Calibration; current; impedance; network analyzer; power; reflection coefficient; reflectometer; scattering parameters; six-port; voltage; 18601 .

Calibration; diffusion bonding; measurement assurance program; reference blocks; standards; ultrasonics; variability; NBSIR $79-1742$

Calibration; digital waveform synthesis; phase angle; phase measurement; phasc meter; waveform generator; 18434 .

Calibration; facility; lase $r$ optics; low velocity; mine ventilation velocity standard; airflow; TN989.

Calibration; Federal Government; laboratory; measurement; metrology; precision; test equipment; SP546, 1979 Edition.

Calibration; gage blocks; length; measurement assurance; measurement process control; systematic error; uncertainty: Monogr. 163.

Calibration; high pressure; high pressure chemistry; pressure generator; 18401 .

Calibration; impedance; reflection coefficient; reflectometer; six-port; TN1012.

Calibration; iron oxide; magnetic property; magnetometer; powders; susceptibility; 18804.

Calibration; laser; ncodymium laser; peak power; power meter; pulsed laser; Q-switched; risetime; speckle; wavcform; attenuators; TNIO1O.

Calibration; microwave measurement; six-port; automatic network analyzer; 18849 .

Calibration; microwave measurements; reflectometer; six-port; 18651

Calibration of particle sizing instruments; Doppler shift spectrometer; light scattering; optical particle sizing; particle size standards; aerosol size measurement; 18980 .

Calibration programs; computer standards; interactive processing; quality of service; response time; turnaround time; availability standards; batch processing; SP500-52, pp. 79-86 (Oct. 1979).

Calibration source; collimation system; data-reduction technique; low-activity replacement source; measurement technique; scatter contribution; source capsule; source housing; spectrometry results; ${ }^{60} \mathrm{CO}$ gamma-ray beam; 18416.

Calibrations; dissemination of units; electrical measurements; electric power measurements; electrotechnology; impact of measurements; measurement technology assessment; National Measurement System; standards; NBSIR 75-935.

Calibrations; energy; fluid mixtures; light; liquefied natural gas; measurements; microwaves; super spring; ultraviolet radiation; DIM/NBS 63, No. 9, 1-32 (1979).

Calibrations; inductive voltage dividers; international comparison; measurements; voltage dividers; voltage ratio; 18664. 
Calibrations; measurements; microwaves; radiofrequency; standards; 18.561 .

Calibrations; measurements; radiation; radiation control; radia(ion measurements; radiation protection; radiation safety; standirrls; states; 18779.

Californium; cross scetions; fission spectrum; neutron; threshold reaction; uraninu; 18792 .

Calilornium; dosimetry; tission ntutrons; iron cross section; nickel cross section; reaction rates; 18883

Cillathin Memorial Award; dental handpiece; dental materials: dental radiograpliy; dental research; Nelsen, Robert $\mathbf{1 ;} 18497$.

Calorimeter; laser; lascr MAP; laser mcasurements; laser power and encrgy; NBS standards; stand:urds; 18914

Calorimeters; combustion; combustion calorimeters; electrical calibration equipment; 18803.

Calorimetry; cormadum; enthalpy; heat capacity; sapphire: specific heat; standard reference matcrials; thermodynamic propertics; alumina; aluminum oxide; 18377.

Calorimetry; elasticity; electrical resistivity; emittance; measurement system; standard reference materials; temperature; thermal conductivity; thermal expansion; thermal properties; vapor pressure; viscosity; 18905

Calorimetry; electroacoustic method; medical applications; metrology; NDE; radiation force; transducer characterization; ultrasonics; acoustic theory; 18438 .

Calorimetry; heat capacity; measurement automation; pTeiphenyl; thermodynamic properties; $\lambda$-type transition; adiabatic calorimetry; antomated calorimetry; 18376

Calorimetry; infrared; kinetics; laser chemistry; mechanisms; multiphoton; thermochemistry; unimolecular dissociation; 18709

Calorimetry; laser beamsplitter system; laser calibration system; laser measurements; laser power calibration; NBSIR 79-16/9.

Calorimetry; optical coatings; absorption; SP54/, pp. 33-36 (Dec. 1978)

Calorimetry, gas flow; chlorine thermochemistry; flame calorimetry; fluorinaceous; oxidizer; thermochemistry of fluorine compounds; 18755

Canada; certification; Denmark; economics of standards government policy; international standards; laboratory accreditation; standards systems; United Kingdom; West Germany; antitrust; NBS-GCR-79-172

Cancer; connective tissue; differential diagnosis; medullary carcinoma; papillary carcinoma; scirrhous carcinoma; shadowing; ultrasound; attenuation; breast canccr; SP525, pp. 93-99 (Apr. 1979).

Capabilities; ease of learning and using; installation; language; maintenance; numerical analysis; OMNITAB 78; portability; poster; reliability; statistical computing section; worksheet; 18903

Capabilities; methodology; needs; Performance Management System (PMS); SP500-52, pp. 69-77 (Oct. 1979).

Capacitance; rectangular coaxial line; transmission lines; 18694.

Capacitance measurement; evaporated electrodes; pressure transducer; temperature depcndence; adiabatic heating; A $s_{2} \mathrm{~S}_{31}$; automalic bridge; $\mathrm{Bi}_{12} \mathrm{GcO}_{211} ; \mathrm{CaCO}_{3} ; \mathrm{CaF}_{2} ; 18466$.

Capacitance scnsor; densimeter; magnetic suspension; position detector; 18962

Capacitive transducer; signal analysis; simulated acoustic emission; time-domain deconvolution; transient elastic wave propatgation; acoustic emission; 18878 .

Capacitor; cross capacitor; dielectric; dissipation factor; loss angle; microphonic coupling; phase angle; surfacc films: 18454

Capacitor; density; dielectric constant; oxygen; 18987 .
Capacity planning; computer performance evaluation; Information Management System (IMS); management reporting; performance analysis; structured approach; auditing; SP500-52, pp. 9-19 (Oct. 1979)

Capacity planning; financial applications; long-range planning; manigement control; measurement; modeling; on-line system design; performance evaluation; performance management; prototyping; remote terminal cmulation; system testing; audit; SP500-52, pp. 129-140 (Oct. 1979).

Capacity planning; hardware monitors; modeling; performance cvaluation; performance prediction; simulation; validation; workload characterization; workload management; SPSOO-52. pp. 179-192 (Oct. 1979).

Capacity planning; performance evaluation; analytic queueing theory models; SPSO()-52, p. 227 (Oct. 1979).

Capillary columns; gas chromatography; hydrocarbons; SP5/9. pp. $713-718$ (Apr. 1979)

Capilary leaks; corrosion failure; hermeticity; moisture infu sion; oxide moisture sensors; accelerated stress test; NBSGCR-79-170.

Capillary-column; charge exchange; chemical ionization; gas chromatography; mass spectrometry; polycyclic aromatic hydrocarbons; SP519, pp. 731-738 (Apr. 1979).

Capital formation; economic growth; health facilities; public sector efficiency; subsidies; technological change; NBS-GCRETIP $78-45$

Capital formation; economic growth; journal publishing; public sector efficiency; subsidies; technological change; NBS-GCRETIP 78.44

Capital formation; economic growth; local air transport; public sector efficiency; subsidies; technological change; $N B S-G C R$ ETIP 78-46

Capital formation; economic growth; maritime transport; public scctor efficiency; subsidies; technological change; NBS-GCRETIP 78-43.

Capital formation; economic growth; mass transit; public sector efficiency; subsidies; technological change; NBS-GCR-ETIP $78-41$

Capital formation; economic growth; municipal wastewater treatment facilities; public sector efficiency; subsidies; technological change; NBS-GCR-ETIP 78-40.

Capital formation; economic growth; nuclear power plants; public sector cfficicncy; subsidies; technological change; NBS-GCR-ETIP $78-42$

Capital formation; economic growth; public sector efficiency; subsidies; technological change; NBS-GCR-ETIP 78-47.

Capital formation; Experimental Technology Incentives Program; regulatory impact; research and development; steel industry; technology; NBS-GCR-ETIP $79-67$

Carbamates; chemical ionization; electron-capture; hydrazines; maleic hydrazide; mass spectroscopy; nitrosamines; nitrosodiethanolamine; silylation; thermal energy analyzer (TEA): tobacco; SP5/9, pp. $297-309$ (Apr. 1979).

Carbamates; gas chromatography; organochloridcs; pesticides; sediment and water; SP519, pp. 191-203 (Apr. 1979).

Carbohydrates; fructose; galactose; gas-liquid chromatography; glucose; lactose; liquid chromatography; maltose; raffinose; ribosc; stachyose; sucrose; sugar analysis; SP5/9, pp. 271-278 (Apr. 1979)

Carbon; copper; hollow cathodes; mass spectrometry; neon; nitrogen; Penning effect; 18449.

Carbon dioxide; carbon monoxide; carbonyl; exchange; hydroxyl; kinetics; mechanism; photochemistry; 18436 .

Carbon dioxide; carbon monoxide; coal gasification; COLGAS; hydrogen; interactive computer program; methane; minimization of Gibbs energy; phase rule; simultaneous chemical equilibria; watcr; BASIC; NBSIR 78-I509

Carbon dioxide; oxygen; $\mathrm{pH}$; acid-base status of blood; blood gases; blood $\mathrm{pH} ; 18470$ 
Carbon monoxide; carbonyl; exchange; hydroxyl; kinetics; mechanism; photochemistry; carbon dioxide; 18436 .

Carbon monoxide; coal gasification; COLGAS; hydrogen; interactive computer program; methane; minimization of Gibbs energy; phase rule; simultaneous chemical equilibria; water; BASIC; carbon dioxide; NBSIR 78-1509.

Carbon tetrachloride; chloroform; drinking water analysis; gas chromatography; parts per billion; SP519, pp. 175.179 (Apr. 1979).

Carbonaceous chondrite; chemical evolution; meteorite; Mighei; abiotic synthesis; SP519, pp. 771-775 (Apr. 1979).

Carbonate radical; chemical kinetics; halogen radical anions; nitrate radical; oxyanion radicals; phosphate radical; photolysis; radiolysis; rates; selenium radicals; sulfate radical; thiocyanate radical anion; aqueous solution; NSRDS-NBS65.

Carbon-manganese steel; fatigue; fatigue cracks; fracture mechanics; fracture toughness; pipeline; weld flaws; weldments; 18802 .

Carbon-manganese steel; fracture mechanics; fracture toughness; pipeline; weld flaws; weldments; 18612 .

Carbonyl; exchange; hydroxyl; kinetics; mechanism; photochemistry; carbon dioxide; carbon monoxide; 18436 .

Carbon-13; conformational analysis; nitrogen-15 coupling constants; nitrogen-15 n.m.r. spectroscopy; proton; proton coupling; structural analysis; bis(hexopyranosyl)amine; 18764.

Carboxylic acids; catecholamines; conjugates; detection sensitivity; dipeptides; drugs; HPLC; ion-pair adsorption; ion-pair chromatography; ion-pair partition; metabolites; psychotropic amines; selectivity; sulphonamides; amino acids; SP519, pp. 509-523 (Apr. 1979).

Carcinogenesis; neutron; repair; survival; transformation; $x$ ray; SP554, pp. 63-73 (Sept. 1979 ).

Cardiac pacemakers; computer standards; fire safety; molybdenum; network measurement; semiconductors; SRM's; standards; DIM/NBS 63, No. 10, 1-36 (1979).

Cardiac pacemakers; contamination; corrosion; electrostatic-induced damage; hermeticity; hybrid devices; leak testing; measurement technology; microcalorimetry; moisture; nondestructive testing; pacemaker leads; process control; reliability; semiconductor devices; welding; SP400-50.

Carrier gas doping; electron capture detector; methyl chloride; monochlorinated organics; SP519, pp. 143-151 (Apr. 1979).

Cartridges; cassettes; core memories; disks; drums; floppy disks; laser beams; magnetic bubbles; masstapes; solid state memories; video disks; beam-addressables; SP500-45.

Cascades in atomic decay; exponential fitting; Kr VIII; atomic decay curve simulation; atomic transition probabilities; beamfoil spectroscopy; 18508 .

Case study; cogeneration; demonstration project; ETIP; evaluation; information intervention; integrated utility systems; NBS-GCR-ETIP 78-59.

Cassettes; core memories; disks; drums; floppy disks; laser beams; magnetic bubbles; masstapes; solid state memories; video disks; beam-addressables; cartridges; SP500-45.

Casting; composite; cyanoacrylate; dental alloy; initiator; resin; wear; accelerator; alloy; base metal; NBSIR 78-1573.

Cataclysmic variables; binary stars; 18595 .

Catalog; dynamic programming; iterative procedure; models; optimization; stability; standards; NBSIR 78-1539.

Catecholamines; conjugates; detection sensitivity; dipeptides; drugs; HPLC; ion-pair adsorption; ion-pair chromatography; ion-pair partition; metabolites; psychotropic amines; selectivity; sulphonamides; amino acids; barbiturates; SP519, pp. 509. 523 (Apr. 1979).

Catecholamines; electrochemical detection; liquid chromatography; phenolic metabolites; SPS19, pp. 391-397 (Apr. 1979).
Cathodoluminescence; ion scattering spectrometry; laser microprobe mass analyzer; laser Raman microprobe; microanalysis; secondary ion mass spectrometry; $\mathrm{x}$-ray microanalysis; Auger electron spectroscopy; 18568 .

Cation distribution; cation ordering; impurities; oxyapatite; I8448.

Cation ordering; impurities; oxyapatite; cation distribution; 18448 .

Cavitation; cavitation threshold vs temperature; radiation-induced cavitation; temperature dependence of cavitation threshold; threshold; acoustic cavitation; NBSIR 79-1753.

Cavitation erosion; extended immersion; flammability; glass reinforced plastics; graphite epoxy; impact; marine environment; advanced composites; SP563, pp. 276-285 (Oct. 1979).

Cavitation threshold vs temperature; radiation-induced cavitation; temperature dependence of cavitation threshold; threshold; acoustic cavitation; cavitation; NBSIR 79-1753.

Cavity frequency stabilization; digital demodulator; frequencylock servo; frequency standard; inversion transition in ammonia; precision; acceleration insensitive oscillator; ammonia microwave absorption; atomic clock; 18698.

Cavity phase shift; Ramsey envelope; Ramsey separated oscillating fields; two frequency separated oscillating fields; atomic beams; atomic frequency standards; 18475 .

Cavity pulling; cavity servo; dielectrically loaded cavity; frequency stability; second-order Doppler shift phase modulation; spin exchange; temperature coefficient; time dispersion; wall shift; amplitude modulation; 18696.

Cavity resonance; coaxial line resonator; dielectric constant; dielectric loss; lunar sample; temperature variation of dielectric parameters of soil; 18566 .

Cavity servo; dielectrically loaded cavity; frequency stability; second-order Doppler shift phase modulation; spin exchange; temperature coefficient; time dispersion; wall shift; amplitude modulation; cavity pulling; 18696 .

CCD; electrical test structure; gated diode; generation lifetime; integrated gated-diode electrometer; in tegrated test structure; leakage current; MOSFET dc profiler; surface recombination; NBSIR 79-1 744.

CCN; CNC; far infrared spectrum; HCCN; infrared spectrum; interferometer; matrix isolation; methyl cyanide; ultraviolet spectrum; vacuum ultraviolet photolysis; 18842 .

CCVT; compact; field calibration; high accuracy; modular capacitive divider; portable system; truck-mounted; 18833 .

CCVT; compact; field calibration; high accuracy; portable system; truck-mounted; 18938.

$\mathrm{CdF}_{2}$; chalcogenide glass; elastic compliances; elastic constants; elasto-optic constants; fused silica; $\mathrm{Ge}$; hot forged; $\mathrm{KBr} ; \mathrm{KCl}$; $\mathrm{KCl}: \mathrm{KI}$; LiF; $\mathrm{MgF}_{2}$; $\mathrm{NaCl}$; NaF; piezo-optic constants; refractive index; $\mathrm{SiO}_{2} ;$ TN993.

CdSe; CdTe; internal reflections; laser calorimeter; linear absorption; Nd:YAG laser; two photon absorption; SP541, pp. 19-23 (Dec. 1978).

CdSe; coating substrate; damage resistant; $\mathrm{Ge}$; $\mathrm{PbF}_{2}$; pulsed HF laser; antireflection coatings; SP54I, pp. 257-258 (Dec. 1978 ).

CdTe; internal reflections; laser calorimeter; linear absorption; Nd:YAG laser; two photon absorption; CdSe; SP54I, pp. 19. 23 (Dec. 1978).

Ceiling height; detectors; fire detectors; fire growth; heat detectors; room fires; smoke detectors; spacing; velocity; beams; NBS-GCR-78-128.

Ceiling height; detectors; fire detectors; fire growth; heat detectors; room fires; smoke detectors; spacing; velocity; beams; NBS-GCR-78-129.

Cell design; electrochemical detection; liquid chromatography; oxidation; reduction; SP519, pp. 705-712 (Apr. 1979).

Cell detachment; mechanical properties; tissue damage; tissue death; SP525, pp. 317-322 (Apr. 1979). 
Cell dimensions; crystal; defect; energy; hydrocarbon; methylbranch; structure; calculations; 18787 .

Ccll-proliferation; cell-turnover; cytotoxicity; homeostasis; promotion; RBE; risk; SP554, pp. 41-56 (Sept. 1979).

Cell-turnover; cytotoxicity; homeostasis; promotion; RBE; risk; cell-proliferation; SP554, pp. 41-56 (Sept. 1979).

Cellular plastic; low temperature; mechanical properties; polystyrene; polyurethane; thermal insulation; thermal properties; 18719

Cellulose; cellulose aging; natural aging; paper; paper aging; tcsts for paper; accelerated aging; aging; aging of cellulose; aging of paper; 19017.

Cellulose aging; natural aging; paper; paper aging; tests for paper; acceleratcd aging; aging; aging of cellulose; aging of paper; cellulose; 19017.

Ccllulose thermal insulation; critical radiant flux; flame spread; smoldering combustion; test methods; attic floor radiant panel; NBSIR 79-1588.

Cellulose triacetate filters; gas chromatography; pesticide residues; sampling; SP519, pp. 19-32 (Apr. 1979).

Cement; concrete; energy saving opportunities; research needs; SP5 42 .

Cement; history; standards; alkalies; 18854 .

Cemented carbides; electrochemical grinding; grinding; tungsten carbide; SP562, pp. 305-315 (Oct. 1979).

Cementing-materials; compressive strength; hot-dry-rock well; permeability to water; pipe-bonding strength; tensile strength; 19018.

Center for Building Technology; history of building research; building technology; BSS75.

Center for Building Technology; key words; publications; abstracts; SP457-3.

Center for Building Technology; manuscripts; word processing center; word processing equipment; 18429.

Centimeter; conversion; customary units; inch; metric units; SP376.

Central unit; computerized; detection; electronic lock; exclusion area; forced entry deterrent systems; guard control station; higher headquarters; perimeter station; remote unit; response force; triply redundant central computer; NBSIR 79.1725 .

Centralized; check-out system; dessicant; discrete; displacement; fiber optics; filters; flight critical; flow; fluid; go-no-go; ground readout; hydraulic; IMACS; instantaneous diagnosis and analysis; level; maintenance oriented; SP547, pp. 345 . 357 (July 1979).

Centrifugal; Coriolis; frame transformation relations; level cluster; spherical tops; symmetry analysis; Born-Oppenheimer approximation; 18599 .

Centrifuge; comparison of measurement methods; free water; freezing calorimeter; hydrology forecasting; microwave remote sensing; snow; NBSIR 79-1604.

Cepheids; population 11 cepheids; AU Peg; binary cepheids; 18913.

Cepstrum; computer; convolution; de-convolution; liver; power spectrum; signal processing; tissue characterization; tissue parameters; ultrasound; attenuation; B-san; SP525, pp. 287 295 (Apr. 1979).

Ceramic; scanning electron microscope; secondary electron emission; silicon; surface roughness; y-deflection modulation; SP562, pp. 407-415 (Oct. 1979).

Ceramic; surface characterization; surface crack; turbine blade; acoustic surface wave; SP562, pp. 379-392 (Oct. 1979).

Ceramic machining; ceramics; effects of machining on ceramic properties; hardness; surface characterizations; surface finishing; abrasion; SP562.

Ceramic surfaces; diamond single-point machining; high fluence; laser irradiation; SP562, pp. 513-518 (Oct. 1979).
Ceramics; chemical milling; electric discharge machining; electron beam machining; glass; hydrodynamic machining; ion beam machining; water jet cutting; SP562, pp. 261-281 (Oct. 1979).

Ceramics; chipping; crack formation; fracture toughness; friction; hardness; liquid softening; oxides; scratching; size effect; specific energy; SPS62, pp. 43-59 (Oct. 1979).

Ceramics; coated abrasives; grinding; stone; abrasives; SP562, pp. 20l-207 (Oct. 1979).

Ceramics; contact stress; damage penetration; fracture mechanics; fragmentation; glass; grinding; impact; silicon nitride; strength; stress intensity factor; abrasive machining; SP562, pp. 23-42 (Oct. 1979).

Ceramics; cryogenics; dielectric-constant; electrets; electrocaloric effect; entropy; ferroelectrics; glass-ceramics; heat switches; magneto-thermal conductivity; polarization; potassium tantalate; refrigeration; specific heat; strontium titanate; beryllium; 18680 .

Ceramics; effects of machining on ceramic properties; hardness; surface characterizations; surface finishing; abrasion; ceramic machining; SP562.

Ceramics; erosion; impact; metals; particle erosion; wear; abrasives; NBSIR 78-1575.

Ceramics; erosion; impact; metals; particle erosion; wear; abrasives; 18858 .

Ceramics; fracture; plastic penetration; thermal stresses; abrasive wear; SP562, pp. 1-13 (Oct. 1979).

Ceramics; material removal; abrasive machining; chip formation; fine grinding; glass; SP562, pp. 107-114 (Oct. 1979).

Cerebral palsy; deafness; developmentally disabled; epilepsy; fire safety; group homes; handicapped; mental retardation; ambulatory people; autism; NBS-GCR-79-167.

Cerebrospinal fluid; detector; high-performance liquid chromatography; light-scattering; lipids; nephelometry; oils; reversed-phase; serum; SP519, pp. 429-436 (Apr. 1979).

Cerebrospinal fluid; fluorescence flow cell; liquid chromatography; tryptophan metabolites; brain; SP519, pp. 411-418 (Apr. 1979).

Cerium dihydride; crystal-field splitting; inelastic neutron scattering; magnetic properties of rare earth alloys; metal hydrides; rare-earth hydrides; 19030.

Certification; characterization; composition; properties; research materials; special reference materials; standard reference materials; analysis; SP260, $1979-80$ Edition.

Certification; Denmark; economics of standards; government policy; international standards; laboratory accreditation; standards systems; United Kingdom; West Germany; antitrust; Canada; NBS-GCR-79- 172 .

Certification; economics of standards; legal aspects of standards; product certification; product liability; regulation; standards system; voluntary standards; bibliography; buildings; NBSIR 79-1900.

Certified reference materials; measurement; measurement compatibility; reference materials; standard reference materials; analytical laboratory; 18748 .

Cesium; electrical resistivity; francium; lithium; magnetic flux density dependence; potassium; pressure dependence; rubidium; sodium; temperature dependence; alkali elements; JPCRD 8, No. 2, 339-438 (1979).

Cesium; exponential index; ionization; multiphoton; Rabi frequency; Star shift; two-level model; absorption; 18892 .

Cesium; ionization; perturbation theory; second-order perturbation theory; two-photon ionization; 18927.

Cesium; laser bandwidth; lasers; multiph oton ionisation; 18874 .

Cesium standards; crystal oscillators; frequency standards; hydrogen standards; rubidium standards; time and frequency; timekeeping; atomic clocks; 18908 .

Chairs; compartment fires; fire tests; flammability; furnishings; upholstered furniture; TNIIO3. 
Chairs; doors; evacuation; fire departments; fire fighters; nursing homes; patients; room fircs; smoke; upholstered furniture; NBS-GCR-79-159.

Chalcogenide glass; elastic compliances; elastic constants; elasto-optic constants; fused silica; $\mathrm{Ge}$; hot forged; $\mathrm{KBr} ; \mathrm{KCl}$; $\mathrm{KCl}: \mathrm{KI}$; LiF; $\mathrm{MgF}_{2} ; \mathrm{NaCl}$; $\mathrm{NaF}$; piezo-optic constants; refractive index; $\mathrm{SiO}_{2} ; \mathrm{SrF}_{2} ;$ TN993.

Character set; computer interface; cost; data entry; edit; operator speed; record size; transaction volume; transfer speed; validate; verify; application; SP500-55.

Characteristic phonons; chemical-vapor deposition; image spoiling; infrared imaging; lattice absorption; zinc sulfide; SP541, pp. 86-97 (Dec. 1978).

Characteristic $\mathrm{x}$-ray yield; electron probe microanalysis; inner shell ionization cross section; Monte Carlo electron trajectory simulation; scanning electron microscopy; x-ray yield; 18978 .

Characterization; composition; properties; research materials; special reference materials; standard reference materials; analysis; certification; SP260, 1979-80 Edition.

Characterization; density; electrical resistivity; graphite; Lorenz ratio; reference materials; thermal conductivity; 18668

Characterization; differential attenuation; tumor; ultrasound; SP525, pp. 121-124 (Apr. 1979).

Characterization of tissue; optical correlation; scattering; sweptfrequency diffraction; angular scattering; SP525, pp. 143-152 (Apr. 1979).

Characterization, transducers; propagating, bulk waves; transducers, angle beam; transducers, contact; transducers, immersion; transducers, ultrasonic; transduction, ultrasonic; ultrasonic; ultrasound; 18907 .

Charge exchange; chemical ionization; gas chromatography; mass spectrometry; polycyclic aromatic hydrocarbons; capillary-column; SP519, pp. $731-738$ (Apr. 1979).

Charge motion; polarization; poly(vinylchloride); poly(vinylidenefluoride); pyroelectric response; thermal pulse; vinylidenefluoride-tetrafluoroethylene copolymer; blocking electrode; 18408 .

Charge transfer; chlorophyll; erythromycin; fast reactions; fission track; ion-dipole; $\beta$-endorphin; ${ }^{252} \mathrm{Cf}$; SP519, pp. 673677 (Apr. 1979).

Charge transfer; copper; luminescence; microspectrofluorimetry; photoluminescence; spectrofluorimetry; surface analysis; tetrazole; benzotriazole; 18504 .

Charge transfer; cyanomethyl radical; excited argon atoms; force constants; infrared spectrum; ketenimine; matrix isolation; methyl cyanide; ultraviolet spectrum; vacuum ultraviolet photolysis; 18879 .

Charge transfer; ethyl nitrate; ion-molecule reactions; aromatic substitution; association ions; 18332.

Charge transfer; excited argon atoms; free radicals; infrared spectra; matrix isolation; molecular ions; photochemistry; ultraviolet spectra; 18847 .

Charge transfer; hollow cathode discharge; metal vapor production; sputtering; 18968 .

Charge transfer equilibria; entropy change; ion cyclotron resonance; ionization energy; aromatic compound; 18337.

Charged currents; fermi theory; neutral currents; neutrino scattering; weak interaction; atomic parity mixing; 18951 .

Charged particle; electron; energy deposition; Monte Carlo; multiple scatter; tracklength; 18965 .

Charmonium; particle spectroscopy; quarks; selection rules; spin forces; tensor force; 18432.

Check-out system; dessicant; discrete; displacement; fiber optics; filters; flight critical; flow; fluid; go-no-go; ground readout; hydraulic; IMACS; instantaneous diagnosis and analysis; level; maintenance oriented; malfunction detection; SP547, pp. 345-357 (July 1979).

Chelating resin; graphite furnace atomic absorption; sea water; separation; trace element analysis; water analysis; 18402 .
Chemical actinometry; second harmonic generation; solar radiation measurements; absolute radiomcters; blackbody measurcments; 18476 .

Chemical composition; composite resins; dental materials; primates; pulp response; toxicology; 18690.

Chemical degradation; coal conversion; coal gasifier; computers; data; metric; refractory concrete; resource conservation and recovery; DIMINBS 63, No. 12, 1-32 (1979).

Chemical durability; glass surface; latent scratch; optical glass; polishing; cleaning; SP562, pp. 417-425 (Oct. 1979).

Chemical effects; delayed neutrons; Einstein model; fission; tempcrature effects; thermal; ${ }^{235} \mathrm{U} ; 18687$.

Chemical equations; equation balancing; algebraic method; balancing equations; 18984 .

Chemical evolution; meteorite; Mighei; abiotic synthesis; carbonaceous chondrite; SP519, pp. $771-775$ (Apr. 1979).

Chemical grouts; damp course membrane; metallic membrane; permeability; prcservation technology; adobe building materials; NBSIR 79-1730.

Chemical ionization; electron capture; gas chromatographymass spectrometry; negative ions; SP519, pp. 60I-607 (Apr. 1979).

Chemical ionization; electron-capture; hydrazines; maleic hydrazide; mass spectroscopy; nitrosamines; nitrosodiethanolamine; silylation; thermal energy analyzer (TEA); tobacco; carbamates; SP519, pp. 297-309 (Apr. 1979 ).

Chemical ionization; gas chromatography; mass spectrometry; polycyclic aromatic hydrocarbons; capillary-column; charge exchange; SP519, pp. 731-738 (Apr. 1979).

Chemical kinetics; data evaluation; gas phase ion-molecule reactions; mass spectrometry; organic molecules; rate coefficients; NSRDS-NBS64.

Chemical kinetics; data needs; free radicals; modeling; $\mathrm{NO}_{s}$; olefins; $\mathrm{SO}_{r}$; troposphere; aldehydes; a romatics; SP557.

Chemical kinetics; environmental measurements; nitric acid; nitrous acid; ozone; rate constants; 18551 .

Chemical kinetics; halogen radical anions; nitrate radical; oxyanion radicals; phosphate radical; photolysis; radiolysis; rates; selenium radicals; sulfate radical; thiocyanate radical anion; aqueous solution; carbonate radical; NSRDS-NBS65.

Chemical milling; electric discharge machining; electron beam machining; glass; hydrodynamic machining; ion beam machining; water jet cutting; ceramics; SP562, pp. 26I-281 (Oct. 1979).

Chemical processing; engineering calculations; equation of state; fluid properties; prediction; standard reference data; synthetic gas; 19022 .

Chemical shifts; conformation; coupling constants; hexononitriles; iterative analysis; proton $\mathrm{nmr}$ spectroscopy; shift reagents; acyclic sugars; 18742 .

Chemical spot tests; color tests; drugs of abuse; field test kits; sensitivity; specificity; 18492 .

Chemical-vapor deposition; image spoiling; infrared imaging; lattice absorption; zinc sulfide; characteristic phonons; SP541, pp. 86-97 (Dec. 1978).

Chemisorption; cupric anthranilate; cupric ion-containing hydroxyapatite; reaction kinetics; surface reaction; anthranilic acid; 18972

Chemisorption; enamel; hydroxyapatite; surface area; bone; 18411 .

Chemisorption; formaldehyde; ruthenium; surface chemistry; ultraviolet photoemission spectroscopy; adsorption; 18791 .

Chemistry of fire; combustion products; fire hazards; fire modeling; fire research; human behavior in fires; physics of fire; toxicity of combustion products; NBSIR 79-1916.

Chemomechanical effects; environmental effects; fracture of brittle materials; hydrogen embrittlement; Rehbinder effects; Westwood effects; acoustic emission; SP562, pp. 139-145 (Oct. 1979). 
Chevrcl-phase; cocxistence; crystal field; magnctic superconductor; neutron scattering; rarc carth; 18850.

Chimncys; coal; creosotc; fire departments; fire safety; heating cquipment; maintcnance; stoves; wood; accident investigations; NBSIR 79-1731

Chimncys; coal; creosote; fire departments; fire safety; heating equipment; maintenancc; stoves; wood; accidcnt investigations; NBS-GCR-78-149.

Chimncys; coal; creosote; fire departments; fire safcty; heating cquipment; maintenance; stoves; wood; accident investigations: 18537.

Chinese glass; galena ores; glass; Japanese glass; lead; lead isotopes; 18840 .

Chip formation; fine grinding; glass; ceramics; material removal; abrasive machining; SP562, pp. 107-114 (Oct. 1979 ).

Chip formation; grinding forces; surface condition; surface grinding; SP562, pp. 75-91 (Oct. 1979).

Chipping; crack formation; fracture toughness; friction; hardness; liquid softening; oxides; scratching; size effect; specific energy; ceramics; SP562, pp. 43-59 (Oct. 1979).

Chipping; ferrites; glass melting; grinding; grinding model; highspeed grinding; pyrex; size effect; SP562, pp. 61-74 (Oct. 1979).

Chirp signals; imaging; opto-acoustic; pulse compression; sensitivity; signal averaging; signal processing; tissue characterization; tomography; transducers; ultrasonics; annular array; breast cancer; SP525, pp. 255-259 (Apr. 1979).

Chi-squared test; Francis Ysidro Edgeworth (1845-1926); goodness of fit; Sir Francis Beaufort (1774-1857); binomial test; 18471

Chloride; methyl; methyl chloride; photochemistry; 18340

Chloride analysis; clinical analysis; clinical chemistry; coulometry; definitive method; electrolytes; reference method; serum chloride analysis; statistical analysis; amperometry; SP260-67.

Chloride complexes; environment; formation constants; ionic mechanisms; kinetics; methylmercury; methyltin; NMR; primary salt effect; speciation; activation parameters; aqueous transmethylation; 18484

Chlorides; data compilation; density; electrical conductance; fluorides: halides; iodides; molten salt mixtures; standard reference data; surface tension; viscosity; bromides; JPCRD 8, No. 1, 125-302 (1979).

Chlorine sink; high resolution IR spectra; hypochlorous acid; large A-value molecules; stratospheric $\mathrm{HOCl}$; air pollutants; 18864.

Chlorine thermochemistry; flame calorimetry; fluorinaceous; oxidizer; thermochemistry of fluorine compounds: calorimetry, gas flow; 18755 .

Chlorofluoromethylene; fluorescence; laser spectroscopy; multiphoton dissociation; radicals; vibronic spectroscopy; 19042.

Chloroform; drinking water analysis; gas chromatography; parts per billion; carbon tetrachloride; SP519, pp. 175-179 (Apr. 1979).

Chlorophyll; erythromycin; fast reactions; fission track; iondipole; $\beta$-endorphin; ${ }^{252} \mathrm{Cf}$; charge transfer; SP519, pp. 673. 677 (Apr. 1979).

Cholesterol; gas chromatography/mass spectrometry; isotope dilution; serum; SP519, pp. 405-410 (Apr. 1979).

Chromatic number; color function; graph; graph coloring; heuristic; interchange; random test graphs; scheduling; time complexity; algorithm; J. Res. 84, No. 6, 489-506 (1979).

Chromatographic preconcentration; detector sensitivity; gas chromatography; glass capillary columns; high-performance liquid chromatography; LC microcapillary columns; selective detectors; ancillary methods; bonded phases; SP519, pp. 487 499 (Apr. 1979).

Chromatography; sulfuric acid; trace organics; battery; SP519, pp. 797-802 (Apr. 1979).
Chromatography/column packings (GC); electron-capture detection; evaporation; nomenclature; sample work-up; standards; SP519, pp. 809-810 (Apr. 1979).

Chromospheres, stars; circumstellar shells; emission linc, stars; late-type stars; Ca 11 emission, stars; 18853.

Chromospheres, stars; emission line, star; late-type, ultraviolet; spectra; Ca II emission, stars; 18926.

$\mathrm{CH}_{2} \mathrm{~F}_{2}$; FIR; optically pumped; wavelength; $/ 896 I$.

$\mathrm{CH}_{4}$; collision induced bands; $\mathrm{CO}_{2} ; \mathrm{C}_{2} \mathrm{H}_{4} ;$ dielectric virial coefficients; refractive virial coefficients; $\mathrm{SF}_{6} ; 18786$.

$\mathrm{ClB}$; international plumbing research; plumbing and drainage; U.S. research in plumbing; building water systems; SP553.

Cigarettes; death; fire investigations; fire statistics; pathology; toxic gases; alcohol intoxication; autopsy; building fires; NBSGCR-79-I68.

Circuit bridge; dynamic characterization of sample/hold amplifier; amplifier, sample/hold; bridge circuit; 18505 .

Circulatory assist dcvices; fatigue of polymers; mechanical testing; additive damage; biaxial fatigue; biomaterials; NBSIR 79 . 1741 .

Circumferential tearing; fire extinguisher; hydrostatic pressure testing; intergranular cracking stainless steel; sensitized mctal; 18368.

Circumstellar dust; line formation; radiation transfer; stellar atmospheres; 18435.

Circumstellar shells; emission line, stars; late-type stars; Ca " emission, stars; chromospheres, stars; 18853.

Cirrhosis; composition-dependent scattering: fatty liver; stochastic scattering; tissue characterization; ultrasonic tissue scattering; ultrasound attenuation; ultrasound diagnosis; backscatter frequency dependence; SP525, pp. 157-163 (Apr. 1979).

CISPR; ground screen; measurements; standards; VDE; antennas; 19033.

Citizen rights; computers; computer utilization; confidentiality; data systems; personnel administration; personnel practices; personnel records; privacy; record-keeping practices; relevant information; security; SP5OO-5O.

Civil trials; courtroom procedures; juror attitudes; prerecorded videotaped trials; PRVTT; trials, PRVTT; videotaped trials; SP480-30.

Classification; decision tables; earthquake-resistant design; information networks; network; seismic design; systems analysis; building codes; buildings; building standards; TN1100.

Clausius-Mossotti equation; compressed-gas capacitor; high voltage; standards; sulfur-hexafluoride; calibration; 18513 .

Clay; forensic; INAA; paper; trace elements; analysis; 18325.

Cl-doped glasses; diffusion in silicon; integrated circuit processing; kinetics of oxide growth; oxidation of silicon; semiconductor processing; silicon; silicon dioxide; thermally stimulated measurement; thermal oxidation; Zn-doped glasses; boron nitride; NBS-GCR-78-134.

Clean water regulation; Environmental Protection Agency; evaluability assessment; evaluation; Experimental Technology Incentives Program; regulatory experimentation; regulatory policy; rulemaking; technological innovation; NBS-GCR-ETIP $79-63$.

Cleaning; chemical durability; glass surface; latent scratch; optical glass; polishing; SP562, pp. 417-425 (Oct. 1979).

Clean-up; contamination; dianabol; gas chromatography-mass spectrometry ( $\mathrm{gc} / \mathrm{ms}$ ); gas liquid chromatography (glc); $\mathrm{gc} / \mathrm{ms}$ interface; high performance liquid chromatography (hplc); inert columns; metabolism; methandienone; urine; SP5 19, pp. 437-445 (A pr. 1979).

Clinical analysis; clinical chemistry; coulometry; definitive method; electrolytes; reference method; serum chloride anàlysis; statistical analysis; amperometry; chloride analysis; SP260-67. 
Clinical analysis; clinical chemistry; definitive method; electrolytes; flame atomic emission spectroscopy; reference method; semiautomated pipetting; serum potassium analysis; statistical analysis; SP260-63.

Clinical analysis; fluorescence detection; liquid chromatography; triamterene assay; SP5 19, pp. 477-480 (Apr. 1979).

Clinical cardiac data; digital processing; Fast Fourier Transform; frequency spectra; in vivo; microprocessor-controlled data acquisition; myocardial infarction; real-time; tissue characterization; ultrasound diagnosis; SP525, pp. 267-273 (Apr. 1979).

Clinical chemistry; coulometry; definitive method; electrolytes; reference method; serum chloride analysis; statistical analysis; amperometry; chloride analysis; clinical analysis; SP260-67.

Clinical chemistry; definitive method; electrolytes; flame atomic emission spectroscopy; reference method; semiautomated pipetting; serum potassium analysis; statistical analysis; clinical analysis; SP260-63.

Clinical chemistry; drug analysis; gas chromatography; internal standards; methylation; sample preparation; SP519, pp. 381 390 (Apr. 1979).

Clinical chemistry; environmental chemistry; gas chromatography; liquid chromatography; automation; SP519, pp. 587600 (Apr. 1979).

Clinical chemistry; ion selective electrodes; penicillamine; potentiometric titration; SP519, pp. 455-459 (Apr. 1979).

Clinical chemistry; reference material; 18536 .

Clinical sampling of infants; clinical trace organic sampling; Guthrie blotters; blood samples; SP519, pp. 373-379 (Apr. 1979).

Clinical trace organic sampling; Guthrie blotters; blood samples; clinical sampling of infants; SP519, pp. 373-379 (Apr. 1979).

Clinical ultrasound; ocular tumor; power spectra; Rayleigh scattering; ultrasonic spectrum analysis; SP525, pp. 111-119 (Apr. 1979).

Clinical use; derivatization; quaternary two-phase systems; serum; uv-detection; tricyclic antidepressives; benzodiazepines; SP519, pp. 461-468 (Apr. 1979).

Clock; GOES; microprocessors; satellite; synchronization; time; 18393.

Clocks; communication; frequency standards; navigation; stability; time; 18826 .

Clocks; frequency drift; frequency stability; navigation; oscillator; position location; time dispersion; time error; time error measure; time prediction error; 18899.

Clock's rms time errors; flicker noise; frequency modulation; frequency reference; precision oscillators; 18940 .

Closed systems; electromagnetic problems; functional theoretic techniques; modified residue calculus; open systems; remote sensing; Monogr. 164.

Closure; $D$-stability; diagonal matrix; field of values; Hadamard product; inclusion theorem; Kronecker product; numerical radius; spectrum; stable matrix; 18909 .

Clot; hemorrhage; hydrocephalus; impedance; infarct; speed; ultrasonic; attenuation; brain tumor; SP525, pp. $81-84$ (Apr. 1979).

Clothes dryer; efficiency; energy conservation; heat recovery; lint; perform ance; venting; appliance; 18793.

Clothing; fabric flammability; fabrics; fire; garments; heat transfer; injury potential; simulation; accident; apparel; burn injury; NBSIR 79-1755.

Cluster analysis; computer modeling; computer performance; empirical models; modeling; performance modeling; workload characterization; SP500-52, pp. 147-161 (Oct. 1979).

Clustering; performance evaluation; stratified sampling; benchmarking; SP500-52, pp. 105-111 (Oct. 1979).

CMOS/SOS; process control; process metrology; silicon gate; test patterns; test structures; NBSIR 79-1595.
CNC; far infrared spectrum; HCCN; infrared spectrum; interferometer; matrix isolation; methyl cyanide; ultraviolet spectrum; vacuum ultraviolet photolysis; $\mathrm{CCN} ; 18842$.

Coal; creosote; fire departments; fire safety; heating equipment; maintenance; stoves; wood; accident investigations; chimneys; NBSIR 79-1731.

Coal; creosote; fire departments; fire safety; heating equipment; maintenance; stoves; wood; accident investigations; chimneys; NBS-GCR-78-149.

Coal; creosote; fire departments; fire safety; heating equipment; maintenance; stoves; wood; accident investigations; chimneys; 18537.

Coal combustion products; glass capillary gas chromatography; high pressure extraction; polynuclear aromatic hydrocarbon; SP519, pp. 109-120 (Apr. 1979).

Coal conversion; coal gasifier; computers; data; metric; refractory concrete; resource conservation and recovery; chemical degradation; DIM/NBS 63, No. 12, 1-32 (1979).

Coal gasification; COLGAS; hydrogen; interactive computer program; methane; minimization of Gibbs energy; phase rule; simultaneous chemical equilibria; water; BASIC; carbon dioxide; carbon monoxide; NBSIR 78-1509.

Coal gasification; high pressure; high temperature; measurement method; powder diffraction; reactive atmosphere; 18945 .

Coal gasifier; computers; data; metric; refractory concrete; resource conservation and recovery; chemical degradation; coal conversion; DIM/NBS 63, No. 12, 1-32 (1979).

Coalgebra; direct limit; faithful distributive module; generating function; incidence algebra; inverse limit; orthogonal idempotents; quasi-order; topological algebra; 18788 .

Coated abrasives; grinding; stone; abrasives; ceramics; SP562, pp. 201-207 (Oct. 1979).

Coating optical absorption; laser calorimetry theory; optical calorimetry theory; surface optical absorption; SP541, pp. 7 12 (Dec. 1978).

Coating protection; pile corrosion; protection of steel; salt water corrosion; sea water corrosion; s teel corrosion; 18424.

Coating substrate; damage resistant; $\mathrm{Ge}$; $\mathrm{PbF}_{2}$; pulsed HF laser; antireflection coatings; CdSe; SP541, pp. 257-258 (Dec. 1978).

Coatings; SiC; strength; surfaces; SP562, pp. 483-488 (Oct. 1979).

Coaxial; communication; contention; data; digital; ethernet; local; microprocessor; network; serial; broadcast; 18760 .

Coaxial line resonator; dielectric constant; dielectric loss; lunar sample; temperature variation of dielectric parameters of soil; cavity resonance; 18566 .

Coaxial transmission line; cut-off frequency; equivalent circuit; modal analysis; scattering matrix; step discontinuity; TEMcell; variational formulation; NBSIR 79-1606.

Cobalt; critical evaluation; electrolyte; excess Gibbs energy; iron; nickel; osmotic coefficients; solutions; thermodynamic properties; activity coefficient; JPCRD 8, No. 4, 923-1004 (1979).

Cobalt units; dose buildup; linacs; patient survival; betatrons; SP554, pp. 15-21 (Sept. 1979).

Cobalt-60 photons; configuration; plug; scattered photons; sleeve; source capsule; source pellets; spacer; spectra; spectrometry; atomic number; 18355 .

Co-condensation; gas chromatography; trapping; air sampling; SP519, pp. 95-99 (Apr. 1979).

Cocured and precured laminates; exoatmospheric exposure of composites; Long Duration Exposure Facility (LDEF); polyimide composite stability in space; polyimide/graphite mechanical properties; ultrasonic inspection; SP563, pp. 4-16 (Oct. 1979).

Code administration; codes; evaluation; existing buildings; performance standard; building; SP549. 
Code administration; communication; physically handicapped; public awareness; public relations; accessibility standards; huilding codes; SP552, pp. 115-120 (July 1979).

Code administration; existing buildings: model codcs; preservation; rcgulation: rehabilitation; renovation; building code; huilding research; TN998.

Codc cnforcement; construction; fire safety; housing; prescrvation; regulations; rchabilitation; adaptivc reuse; building codes; buildings; building safety; SP536

Code enforcement; county building codc; critical structures program; expense; inspeetion requirements; pre-construction confercnce; SP552, pp. 31 i-320 (July 1979).

Code cnforcement; fire prevention codcs; fire safety; master planning; rcgulation; standards; building codes; SP552, pp. 225-247 (July 1979).

Codc cnforcement; historic district; historic preservation; regulations; rehabilitation; safety; barriers; building codes; SP536, pp. 83-93 (Feb. 1979).

Codcs; criteria; project summaries; standards; technical bases; building research; building technology; SP446-2.

Codes; evaluation; existing buildings; performance standard; building; code administration; SP549

Codes; guidelines; hydrogen; regulations; safety; standards; 18394

Codes and standards; full-scale testing; mobile homes; wind loads; aerodynamics; building; NBSIR 77-1289

Codes and standards; solar energy; solar heating and cooling; solar model code; solar regulatory provisions; solar regulatory requirements; NBS-GCR-78-14l-1.

Codes and standards; solar energy; solar heating and cooling; solar model code; solar regulatory provisions; solar regulatory requirements; NBS-GCR-78-14I-2.

Cocxistence; crystal field; magnetic superconductor; neutron scattering; rare earth; Chevrel-phase; 18850

Cogeneration; demonstration project; ETIP; evaluation; information intcrvention; integrated utility systems; case study; NBS-GCR-ETIP 78-59.

Cognition; goal seeking; intelligence; motor behavior; neural modeling; perception; planning; problem solving; robot control; brain mechanisms; 18714

Coherence; dynamic rate; incoherence; ionization; linear rate; multiphoton; rate approximation; saturable rate; bandwidth; 18893.

Coherent anti-Stokes Raman spectroscopy (CARS); liquid-filled dielectric waveguide; optical waveguide; phase-matched propagation in waveguidc; Raman spectroscopy of liquids; signai enhancement of coherent Raman process; 18686 .

Coherent excitation; dressed atoms; inhomogeneous broadening; intense laser; multiphoton dissociation; multiphoton ionization; Rabi frequency; statistical broadening; three-level system; 18439 .

Coherent optical transients; $\mathrm{t}_{2}$; polarization switching; $/ 880 \mathrm{I}$.

Coherent scattering; cross sections; gamma rays; photons; Rayleigh scattering; tabulations; $x$ rays; atomic form factor; JPCRD 8, No. 1, 69-106 (1979).

Coherent scattering; Delbruck scattering; elastic scattering; giant resonance; tensor polarizability; Thomson scattering; 18521 .

Coincidence counting; decay probability; isomeric transition; liquid scintillation counting; photon counting; radioactivity; ${ }^{12}{ }^{\prime} \mathrm{Sn}^{m}$ decay scheme; 18841 .

Coincidence experiments; correlations in nuclei; cw accelerators; electronuclear physics; high duty-cycle; 18906 .

Coincidence experiments; electromagnetic; neutrons; photons; pions; protons; 18675.

Cold drawn; crack growth; fracture; molecular weight distribution; necking; polyethylene; uniaxial creep; additivity of damage; 18765 .
COLGAS; hydrogen; interactive computer program; methane; minimization of Gibbs energy; phase rule; simultaneous chemical equilibria; water; BASIC; carbon dioxide; carbon monoxidc; coal gasification; NBSIR 78-1509.

Collagen; crosslinking modification; curvelinking; hydroxyapatite; sonic velocity; bone; SP525, pp. 179-187 (Apr. 1979).

Collagen sponge; contraceptivc device; gas chromatography; mass spectrometry; propylamine; butylamine; SP519, pp. 469-476 (Apr. 1979).

Collapse transition; fluctuations; mean field approximation; ternary interactions; theta point; virial coefficients; 19023 .

Collector efficiency; comparison German BSE vs ASHRAE 93. 77 procedures; flat-plate solar collectors; German Bundesverband Solarenergie; solar collector testing; water-heating solar coliectors; 18986 .

Collimation; haze; hazemeter; integrating sphere; linearity; scattering; 18594.

Collimation system; data-reduction technique; low-activity replacement source; measurement technique; scatter contribution; source capsule; source housing; spectrometry results; ${ }^{60} \mathrm{CO}$ gamma-ray beam; calibration source; 18416 .

Collision cross section; detachment; dissociation; elastic scattering; electron; excitation; ion; ionization; molecule; photon; positron; atom; SP426. Supplement $I$.

Collision induced bands; $\mathrm{CO}_{2} ; \mathrm{C}_{2} \mathrm{H}_{4}$; dielectric virial coefficients; refractive virial coefficients; $\mathrm{SF}_{6} ; \mathrm{CH}_{4} ; 18786$.

Collisional excitation; collisional radiative recombination; laser induced plasma; optical emission; photoionization; PotassiumKrypton mixtures; resonant multiphoton ionizations; 18799.

Collisional excitation; dissociation energy; Dunham coefficients; Franck-Condon factors; laser fluorescence; molecular sodium; potential curves; 18824 .

Collisional line broadening; collisional redistribution; resonance fluorescence; 18498.

Collisional radiative recombination; laser induced plasma; optical emission; photoionization; Potassium-Krypton mixtures; rcsonant multiphoton ionizations; collisional excitation; 18799.

Collisional redistribution; resonancc fluorescence; collisional line broadening; 18498 .

Collisional transitions; highly excited Rydberg states; population of angular momentum states; 18473.

Collisions; cross sections; intermolecular potential; state changes; welì depths; 18671 .

Color; colorimetry; color spacing; color vision; Deane Judd; selected writings; spectrophotometry; SP545.

Color function; graph; graph coloring; heuristic; interchange; random test graphs; scheduling; time complexity; algorithm; chromatic number; J. Res. 84, No. 6, $489-506$ (1979).

Color, lights; conspicuity, lights; effective intensity; emergency lights; intensity, effective; lights, flashing; lights, warning; perception, visual; peripherai vision; vehicles, emergency; visibility, lights; visual perception; SP480-36.

Color spacing; color vision; Deane Judd; selected writings; spectrophotometry; color; colorimetry; SP545.

Color tests; drugs of abuse; field test kits; sensitivity; specificity; chemical spot tests; 18492 .

Color vision; Deane Judd; selected writings; spectrophotometry; color; colorimctry; color spacing; SP545.

Color-coded B-scan; spectra-color ultrasonography (SCU); spectrum analysis; ultrasonic spcctroscopy; instantaneous power spectra; SP525, pp. 261-266 (Apr. 1979).

Colorimetry; color spacing; color vision; Deane Judd; selected writings; spectrophotometry; color; SP 545.

Combat vehicies; diagnostic connector assembly; fighting vehicle systems; generic DCA; Hull systems; simplified test equipment for internal combustion engines; turret systems; vehicle maintenance; SP547, p p. 98-110 (July 1979). 
Combination bands; high resolution spectroscopy; lcvel clusters; spherical top molceules; 18921 .

Combination refrigerator-freezer field data; daily load profiles; energy consumption; field mcasurments; hourly load profiles; refrigerator field data; usage profiles; NBSIR 79-178I.

Combustion; combustion calorimeters; electrical calibration cquipment; culorimeters; 18803 .

Combustion; decomposition; free radicals; hydrocarbons; hydrogen; nitrogen; organic compounds; oxidation; oxygen; oxygenated; rate constant; sulfur; Arrhenius parametcrs; NBSIR 79-1941.

Combustion; energy; furnace; gas-fired; heating; oil-fired; rating; space-heating; testing; boiler; 18385 .

Combustion; equilibrium; high temperature; isolation; lasers; mass spectrometry; matrix; modeling; vapors; SP56I, Vols. I and 2 .

Combustion; flaming combustion; flexible foams; optical density; particle size; polypropylene; polyurethane foams; polyvinyl ehloride; pyrolysis; rigid foams; smokc; smoldering; weight loss; wood; NBS-GCR-78-147.

Combustion bombs; combustion calorimetry; historical survey; prominent calorimetrists; benzoic acid; calibration; 18797.

Combustion calorimeters; electrical calibration equipment; calorimeters; combustion; 18803.

Combustion calorimetry; historical survey; prominent calorimetrists; benzoic acid; calibration; combustion bombs; 18797.

Combustion products; fire barrier coatings; fire growth; flame spread; foam insulation; heat release; interior finish; laboratory fire tests; material ignitability; submarine compartment; NBSIR 78-I584.

Combustion products; fire hazards; fire modeling; fire researeh; human behavior in fires; NBSIR 78-1526.

Combustion products; fire hazards; fire modeling; fire research; human behavior in fires; physics of fire; toxicity of combustion products; chemistry of fire; NBSIR 79-19I6.

Combustion products; gas analysis; gas chromatography; hydrogen cyanide; 18588 .

Comfort; education; environment; human factors; research; school; air-conditioning; 18596.

Commercial; daylighting; energy; environments; heating; passive; solar; suburban; urban; application; buildings; 18894 .

Commercial; economics; evaluation; feasibility; passive; rehabilitation; retrofit; solar; 18964 .

Commercial impacts; Experimental Teehnology Incentives Program; Federal Supply Service; life cycle costing; procurement of water heaters; technological change; NBS-GCR-ETIP 7851.

Commercial impacts; Experimental Technology Incentives Program; Federal Supply Service; life eycle costing; procurement of water heaters; technological change; NBS-GCR-ETIP 78 52.

Commercialization; empirical investigation; ETIP; Federal civilian R\&D; implementing; management practices; technological ehange; NBS-GCR-ETIP 78-57.

Commercialization; empirical investigation; ETIP; Federal civilian R\&D; implementing; management practices; technological change: NBS-GCR-ETIP 78-58.

Commercialization; empirical investigation; ETIP; Federal civilian R\&D; implementing; NBS-GCR-ETIP 78-58A.

Communication; contention; data; digital; ethernet; local; microproeessor; network; serial; broadcast; coaxial; 18760 .

Communication; cost; human characteristics; personal control; physical environment; privacy; arehitectural psychology; bibliography; buildings; NBSIR 79-1793.

Communication; evaluation methods; fire safety; hazard warnings; pictograms; safety information; standardization; symbols; NBSIR 79-I760.

Communication; frequeney; frequency standards; navigation; time; time dissemination; 19005 .
Communication; frequency standards; navigation; stability; time; clocks; 18826.

Communication; physically handicapped; public awareness: public relations; accessibility standards; building codes; codc administration; SP552, pp. 115-120 (July 1979).

Communication systems; equipment selection; law enforement; public safety; $S P 480-12$

Communication systems; fiber opties; measurcment; optical communications; review; 18648 .

Communications; computcrs; data bases; networks; operating systems; protocols; 18488 .

Communications; computers; databases; networks; operating systems; protocols; 18891.

Communications; hearing; hearing aids; selection of hearing aids; speech communication; audition; CIS4, Revised 1978.

Communications; land-mobile; standards; antenna; 18398.

Communications equipment; FM transmitters; law enforcement equipment; standards; surveillance; undercover cquipment; body-worn transmitters; 18381 .

Communications systems; fire safety; high-rise; model codes; people movement; systems design; buildings; BSS 115 .

Community development; construction costs; contractors; housing; rehabilitation; standards; building codes; SP536, pp. 5561 (Feb. 1979).

Community Services Administration; heating balance point analysis; low-ineome residences; marginal cost/benefit analysis in weatherization; optimum weatherization retrofit combinations; thermal analysis of residences; NBSIR 79-I 706.

Compact; field calibration; high accuracy; modular capacitive divider; portable system; truck-mounted; CCVT; 18833.

Compact; field calibration; high accuracy; portable system; truck-mounted; CCVT; 18938.

Compact tension specimen; erack; crack, well-characterized; destructive evaluation; fatigue flaw evaluation; fracture mechanics; standards; technique development; 18744 .

Comparative rate; flow system; heat of formation; hexylmethylethane; $t$-butyl radical; unimolecular decomposition; activation energy; $A$-factor; 18743 .

Comparison between theoretical and expcrimental results; copper; corrosion; hydrogen evolution; alternating current; alternating voltage; 18756 .

Comparison German BSE vs ASHRAE 93-77 procedures; flatplate solar collectors; German Bundesverband Solarenergie; solar collector testing; water-heating solar collectors; collector efficiency; 18986.

Comparison measurements; Germanium resistance thermometer; Josephson junction noise thermometer; low temperature seale; ${ }^{3} \mathrm{He} /{ }^{4} \mathrm{He}$ dilution refrigerator; ${ }^{60} \mathrm{CO} \gamma$-ray thermometer; 18555.

Comparison measures; evaluation process; performance measures; performance ratings; response time; system design tradeoffs; thruput measures; SPSO0-52, pp. 163-176 (Oct. 1979).

Comparison of computers; computer measurement; computer selection; computer se rvices; ranking and selection; selection methodology; SP5OO-44.

Comparison of measurement methods; free water; freezing calorimeter; hydrology forecasting; microwave remote sensing; snow; centrifuge; NBSIR 79-1604.

Comparisons; correlation; custody transfer; density; experimental; extended corresponding states method; hard sphere model; Klosek-McKinley method; liquefied natural gas (LNG); magnetic suspension densimeter; 18775.

Comparisons; correlation; ethylene; experimental; magnetic suspension; orthobaric liquid density; tables; argon; 18627.

Compartment fires; compartments; fault tree analysis; fire models; fire protection engineering; probability statistics; systems analysis; systems safety; walls; barrier analysis; NBSGCR-79-163. 
Compartment fires; computer programs; corridor fires; fire models; fire spread; room fires; thermal radiation; turbulence; buoyant flow; NBS-GCR-78-150.

Compartment fires; fabric flammability; fire detection systems; fire tests; flammability tests; human behavior; plastics; polymers; smoke; smoke detectors; subway fires; toxicity; upholstered furniture; arson; bibliographies; building fires; NBSIR 79-1745.

Compartment fires; fire tests; flame spread; heat release rate; ignition; interior finish; passive fire protection; potential heat; smoke; NBSIR 79-1700.

Compartment fires; fire tests; flammability; furnishings; upholstered furniture; chairs; TNIIO3.

Compartment fires; firesafety engineering; fire tests; health care facilities; hospitals; mattresses; prisons; bedding; beds; 18517 .

Compartments; fault tree analysis; fire models; fire protection engineering; probability statistics; systems analysis; systems safety; walls; barrier analysis; compartment fires; NBS-GCR79-163.

Compatibility; permachor; permeation; plastic containers; polyethylene; standards; 18348 .

Compatibility; radioactivity reference materials; standard reference materials; accuracy; 18539.

Competitive evaluation; tutorial; vendor systems; workload requirements; benchmark construction process; benchmark validation; SP500-52, pp. 235-240 (Oct. 1979).

Competitive negotiated procurement; computer management; remote teleprocessing; statement of work; teleprocessing services program; timesharing; SP500-52, pp. 231-232 (Oct. 1979).

Compilation; energy storage; intermetallic compound; phase diagrams; physical properties; 18637.

Compilations; computer data bank; computer display; alloy phase diagrams; applications; ASM/NBS data program; 18739.

Complete analysis scheme; gas chromatography; hydrocarbons; permanent gas analysis; trace organics in air; SP519, pp. 153. 159 (Apr. 1979).

Component screening; electronic component reliability; failure analysis; failure models; failure rates; reliability; residential buildings; smoke detectors; NBS-GCR-79-160.

Component screening; electronic component reliability; failure analysis; failure models; failure rates; reliability; residential buildings; smoke detectors; NBS-GCR-79-161.

Component screening; electronic component reliability; failure analysis; failure models; failure rates; reliability; residential buildings; smoke detectors; NBS-GCR-79-162.

Composite; cyanoacrylate; dental alloy; initiator; resin; wear; accelerator; alloy; base metal; casting; NBSIR 78.1573.

Composite; fiber; mechanical properties; moisture; prepreg; aging of polymer; SP563, pp. 17-21 (Oct. 1979).

Composite applications; composites; concrete; cryogenics; epoxy resins; glass fiber; graphite fiber; aramid fiber; 18717 .

Composite design; graphite-epoxy; Precision Mounting Platform; resonant frequency; SP563, p. 130 (Oct. 1979).

Composite growth; contact angle; disjoining pressure; monotectic; multicomponent; wetting; 18422 .

Composite material; composite material analysis program; TsaiWu tensor polynomial lamina strength failure criterion; automotive structures; SP563, p. 133 (Oct. 1979).

Composite material analysis program; Tsai-Wu tensor polynomial lamina strength failure criterion; automotive structures; composite material; SP563, p. 133 (Oct. 1979).

Composite materials; critical flaw size; cyclic fatigue life; filament wound tankage; leakage failure mode; linear elastic fracture mechanics; metal liner; SP563, pp. 198-207 (Oct. 1979).

Composite materials; cryogenics; industrial laminates; magnetic fusion energy; superconducting magnets; advanced composites; 18560 .
Composite materials; filament winding; large composite structures; rotor blades; wind turbine; SP563, pp. $155-172$ (Oct. 1979).

Composite materials; linear elastic materials; tensile fracture; aircraft structural components; SP563, p. 3 (Oct. 1979).

Composite materials analysis; orthotropic materials; programmable calculators; solid state software; advanced composite materials; SP563, pp. 91-107 (Oct. 1979).

Composite propellers and rotors; failsafe blade design; propeller fatigue behaviour; propeller materials requirements; blade aeroelastic behaviour; blade manufacture and quality control; SP563, pp. 80-88 (Oct. 1979).

Composite resins; dental materials; glass compositions; methacrylate monomers; polymerization accelerators; reinforcing fillers; silane coupling agents; benzoyl peroxide; 18644 .

Composite resins; dental materials; primates; pulp response; toxicology; chemical composition; 18690 .

Composite restorative resin; dimethylaminoglutethimide; dimethylaminophenylacetic acid and esters; properties of composites; tertiary aromatic amines; amine accelerators; 18571 .

Composite sampling; nutritional analysis; nutritional labeling; sample preparation; SP519, pp. 243-248 (Apr. 1979).

Composite structures; design using composites; fiber composites; fiber glass; filament wound composites; advanced composites; applications of composites; composites; SP563.

Composite structures; flaw simulation; semi-automated ultrasonic inspection; ultrasonic inspection system; SP563, p. 59 (Oct. 1979).

Composite system; field quantization; interacting quantum fields; relativistic field theory; relativistic hamiltonian; relativistic stationary states; 18769 .

Composites; composite structures; design using composites; fiber composites; fiber glass; filament wound composites; advanced composites; applications of composites; SPS63.

Composites; concrete; cryogenics; epoxy resins; glass fiber; graphite fiber; aramid fiber; composite applications; 18717 .

Composites; dental materials; dimensional changes; physical properties; thermal expansion; wear; wear tests; amalgam; 18649.

Composites; design allowables; aircraft; SP563, pp. $72-79$ (Oct. 1979).

Composites; durability; flexural characteristics; recreational equipment; strength-to-weight ratio; SP563, p. 208 (Oct. 1979).

Composites; elastic constants glass-epoxy; internal friction; Young's modulus; aramid-epoxy; boron-aluminum; boronepoxy; 18716 .

Composites; failure criteria; in-plane loads; bonded joints; SP563, p. 241 (Oct. 1979).

Composites; fiberglass; mechanical porperties; modulus; strength; superconducting motor; 18616 .

Composites; holography; interferometers; matrix crazing; nondestructive testing; pressure vessels; SP563, pp. 211-212 (Oct. 1979).

Composites; hydrofoils; maintenance requirements; naval ship application; SP563, pp. 267-275 (Oct. 1979).

Composition; custody transfer; density; flow rate; LNG; mixtures; specific heating value; tank capacity tables; thermophysical properties; total heating value; 18564 .

Composition; custody transfer; density; flow rate; LNG; mathematical models; mixtures; specific heating value; tank capacity tables; thermophysical properties data; total heating value; 18838 .

Composition; high-carbon ferrochromium; homogeneity testing; preparation; processing; standard reference material; 18414 .

Composition; properties; research materials; special reference materials; standard reference materials; analysis; certification; characterization; SP260, 1979-80 Edition. 
Composition-dependent scattering; fatty liver; stochastic scattering; tissue characterization; ultrasonic tissue scattering; ultrasound attenuation; ultrasound diagnosis; backscatter lrequency depcndence; cirrhosis; SP525, pp. 157-163 (Apr. 1979).

Comprehensive process characterization; design rules; intradie parametric integrity; LSI circuits; mask alignment tolerances; modular test programs; parametric yield limitations; performance limitations; photomask performance; process control; test patterns; SP4()0-56.

Compressed-gas capacitor; high voltage; standards; sulfur-hcxafluoride; calibration; Clausius-Mossotti equation; 18513 .

Compression; eccentric loading; flat-end; kern; loading rate; pin-end; test method; wall panels; walls; BSS95.

Compression; failure; finite elements; graphite-epoxy; interlaminar stresses; laminated composites; stress concentrations; tension; tensor polynomial; SP563, pp. 242-254 (Oct. 1979).

Compressive strength; creep; flexural strength; mechanical properties; moisture; non-destructive testing; preservation; adobe; adobe soil; TN996

Compressive strength; hot-dry-rock well; permeability to water; pipe-bonding strength; tensile strength; cementing-materials; 19018 .

Computational experiment; least absolute deviation; polynomial approximation; test problems; algorithm testing; approximation; J. Res. 84, No. 6, $455-488$ (1979).

Compute and limit; error; sampler response factors; total elemental content passive personal samplers; total organic chlorine; weighted diffusion coefficient; ambient concentration; SP519, pp. 747-752 (Apr. 1979)

Computed tomography; Doppler; fluid flow; high resolution; reconstruction; temperature reconstruction; ultrasound; aperture synthesis; SP525, pp. 227-233 (Apr. 1979).

Computed tomography; Doppler; fluid flow; high resolution; reconstruction; temperature reconstruction; ultrasound; aperturc synthesis; SP525, pp. 235-246 (Apr. 1979).

Computed tomography-ultrasonic; diagnosis-ultrasonic; tissue equivalent test objects and phantoms; ultrasonic tissue characterization; ultrasound imaging; SP525, pp. 337-340 (Apr. 1979).

Computer; computer communications; computer performance measurement; data measurement; measurement; performance measurement; SP500-52, pp. 201-211 (Oct. 1979).

Computer; computer model; documentation; documentation procedures; model; model documentation; SP500-39.

Computer; controller; control units; hammer drive; input/output bus; interface; interface signals; $1 / O$ interface bus; line printer; print controller; printer; cable interface; NBS-GCR$79-182$.

Computer; convolution; de-convolution; liver; power spectrum; signal processing; tissue characterization; tissue parameters; ultrasound; attenuation; B-san; cepstrum; SP525, pp. 287-295 (Apr. 1979).

Computer; energy conservation; environmental quality; industrial productivity; materials utilization; measurement capabilities; medical aids; product safety; public health and safety; science and technology transfer; standards; basic research; SP538.

Computer; hot water; measurement; rating; solar; standards; testing; 18428 .

Computer analysis; ergonomics; human engincering; human factors; human motivation; human reliability; personnel selection; physical security; physiological psychology; sensory capability; terrosim; threat analysis; training; adversary characteristics; animal research; $S P 480-38$.

Computer applications; energy conservation; illumination standards; lighting distribution simulation; visual performance; building codes; building performance simulation; SP552, pp $321-335$ (July 1979).
Computer automated thermogravimeter; factor-jump thermogravimetry; polymer degradation; thermogravimetry; activation energy; automated thermogravimetry; 18447.

Computer automation; computerized thermogravimetry; computer program; polymer degradation; polymer oxidation; thermogravimetry; activation energy; 18445 .

Computer communications; computer performance measurement; data measurcment; measurement; performance measurement; computer; SP5OO-52, pp. 201-211 (Oct. 1979).

Computer control; homogeneity; measurement method; nondestructive testing; photoconductivity; power devices; resistivity variation; automation; bulk photovoltaic effect; SP40O-52.

Computer controlled gas chromatography/mass spectrometry; GRALE; organic analysis; reflectance; air pollution; ambient aerosols; SP519, pp. 101-107 (Apr. 1979).

Computer data bank; computer display; alloy phase diagrams; applications; ASM/NBS data program; compilations; 18739.

Computer display; alloy phase diagrams; applications: ASM/NBS data program; compilations; computer data bank; 18739.

Computer evaluation; computer performance; computer procurement; computers; computer selection; cost-value; cost-value technique; EDP selection; evaluation methodology; performance evaluation; procurement; SP500-52, pp. 25-36 (Oct. 1979).

Computer facilities; integrated data base; municipal governments; regulatory; SP552, pp. 153-165 (July 1979).

Computer graphics; data base management; data retrieval; durability; fatigue; interactive system; mathematical modeling; paper; paper fiber; report retrieval; scientific data; NBSIR 79-1746.

Computer interface; cost; data entry; edit; operator speed; record size; transaction volume; transfer speed; validate; verify; application; character set; SP500-5 5.

Computer interface standards; computers; cryogenic temperature; energy; energy savings; industrial robots; network services; SRM's; DIM/NBS 63, No. 4, 1-24 (1979).

Computer magnetic tape drives; computer tape controllers; group coded recording; interface electrical characteristics; interface functional characteristics; magnetic tape drives; NRZI recording; phase encoded recording; tape drive characteristics; NBS-GCR-78-127.

Computer management; remote teleprocessing; statement of work; teleprocessing services program; timesharing; competitive negotiated procurement; SP500-52, pp. 231-232 (Oct. 1979).

Computer measurement; computer procurement; computer selection; decision theory; SP500-52, pp. 37-52 (Oct. 1979).

Computer measurement; computer selection; computer services; ranking and selection; selection methodology; comparison of computers; SP5OO-44.

Computer model; documentation; documentation procedures; model; model documentation; computer; SP50O-39.

Computer modeling; computer performance; empirical models; modeling; performance modeling; workload characterization; cluster analysis; SP50O-52, pp. 147-161 (Oct. 1979).

Computer network; computer standards; fire safety; gamma-ray spectroscopy; matrix-isolation; metric conversion; satellite system; DIM/NBS 63, No. 7/8, 1-28 (1979).

Computer networking; computer security; network operating systems; access control; 19009.

Computer performance; computer procurement; computers; computer selection; cost-value; cost-value technique; EDP selection; evaluation methodology; performance evaluation; procurement; computer evaluation; SP500-52, pp. 25-36 (Oct. 1979).

Computer performance; empirical models; modeling; performance modeling; workload characterization; cluster analysis; computer modeling; SP500-52, pp. 147-161 (Oct. 1979). 
Computcr performancc cvaluation; computer performance measurement; computcr performance prediction; computer systcm acquisition; conference proceedings; CPE in auditing; hardware monitoring; CPEUG; installation management; onlinc systcm evaluation; prediction mcthods; SP5OO-52.

Computer performance evaluation; human factors; interactive computing; man-machine interaction; performance measurement; timcsharing; SP500-48.

Computer performance evaluation; Information Management System (IMS); management reporting; pcrformance analysis; structured approach; auditing; capacity planning; SP500-52, pp. 9-19 (Oct. 1979).

Computer performance evaluation (CPE); computer performance management (CPM); installation management; installation performance management; performance measurement and reporting; rcsource management; standard performance mcasures; SP5OO-53.

Computer performance management (CPM); installation management; installation performance management; performance measurement and reporting; resource management; standard performance measures; computer performance evaluation (CPE); SP500-53.

Computer performance measurement; computer performance prediction; computer system acquisition; conference proceedings; CPE in auditing; hardware monitoring; CPEUG; installation management; on-line system evaluation; prediction methods; queuing models; simulation; SP500-52.

Computer performance measurement; data measurement; measurement; performance measurement; computer; computer communications; SP50O-52, pp. 201-211 (Oct. 1979).

Computer performance measurement; distributed processing; interactive systems; kernels; modeling; real-time; simulation; synthetic programs; benchmarking; SP500-52, pp. 53-64 (Oct. 1979).

Computer performance prediction; computer system acquisition; conference proceedings; $\mathrm{CPE}$ in auditing; hardware monitoring; CPEUG; installation management; on-line system evaluation; prediction methods; queuing models; simulation; software monitoring; SP500-52.

Computer processing; digital acquisition; digital signal processing; pulse-echo techniques; spectrum analysis; ultrasonics; acoustic; SP525, pp. 281-286 (Apr. 1979).

Computer processing; estimation theory; liver attenuation; spectral analysis; statistical modeling; ultrasonic tissue characterization; SP525, pp. 125-132 (Apr. 1979).

Computer procurement; computer selection; decision theory; computer measurement; SP500-52, pp. 37-52 (Oct. 1979).

Computer procurement; computers; computer selection; costvalue; cost-value technique; EDP selection; evaluation methodology; performance evaluation; procurement; computer evaluation; computer performance; SP500-52, pp. 25 36 (Oct. 1979).

Computer program; data acquisition systems; data reduction; plotting; TNl 108 .

Computer program; data base; data base management; empirical molecular formula; GPSDC; ion energetics; ionization potential; abstract; appearance potential; archival tape; NBSIR 78-1432.

Computer program; economic performance; electric utilities; Experimental Technology Incentives Program; productivity; regulatory commission; regulatory policy; technological innovation; NBS-GCR-ETIP 79-70.

Computer program; energy dispersive detector; multichannel analyzer; peak overlap; quantitative electron probe microanalysis; x-ray continuum; x-ray spectrum; TNI106.

Computer program; polymer degradation; polymer oxidation; thermogravimetry; activation energy; computer automation; computerized thermogravimetry; 18445 .
Computer programs; corridor fires; fire models; fire spread; room fires; thermal radiation; turbulence; buoyant flow; compartment fires; NBS-GCR-78-I50.

Computer programs; cost/benefit analysis; documentation; documentation content guidelines; feasibility study; FIPS guidelines; initiation phase; project request; software; automated data systems; FIPS PUB 64.

Computer programs; curve fitting; data analysis; data base management; data retrieval; file handling; graphic analysis; IMS information retrieval; KWOC indexing; least-squares; linear regression; MIS; plotting; statistical analysis; Boolean search system; 18597.

Computer programs, fire protection; fire protection; fire resistance; fire tests; fire walls; safety engineering, fires; TN99I.

Computer reports; grant data; residential buildings; solar database; solar energy system; solar heating and cooling; automatic data processing; NBSIR 79-1923.

Computer security; data confidentiality; data integrity; data security; physical security; procedural security; risk analysis; risk assessment; systems security; ADP availability; annual loss exposure; application system vulnerability; FIPS PUB 65.

Computer security; network operating systems; access control; computer networking; 19009 .

Computer selection; computer services; ranking and selection; selection methodology; eomparison of computers; computer measurement; SPSOO-44

Computer selection; cost-value; cost-value technique; EDP selection; evaluation methodology; performance evaluation; procurement; computer evaluation; computer performance; computer procurement; computers; SPS00-52, pp. $25-36$ (Oct. 1979).

Computer selection; decision theory; computer measurement; computer procurement; SP500-52, pp. 37-52 (Oct. 1979).

Computer services; Federal Information Processing Standards; Federal standards; ADP information sources; ADP management; ADP policies; ADP services; automatic data processing; NBSIR 79-I734.

Computer services; ranking and selection; selection methodology; comparison of computers; computer measurement; computer selection; SP5OO-44.

Computer simulation; end-to-end length; entanglement effects; excluded volume effects; lattice-model polymer chains; polymer chain dynamics; random-coil polymer chains; relaxation times; self-entanglement effects; 18772.

Computer simulation; environmental psychology; fire research; fire safety; human performance; modeling technique; simulation; architectural research; building fires; computer-aided design; NBSIR 79-I796.

Computer standards; fire safety; gamma-ray spectroscopy; matrix-isolation; metric conversion; satellite system; computer network; DIM/NBS 63, No. 7/8, 1-28 (1979).

Computer standards; fire safety; molybdenum; network measurement; semiconductors; SRM's; standards; cardiac pacemakers; DIM/NBS 63, No. 10, 1-36 (1979).

Computer standards; interactive processing; quality of service; response time; turnaround time; availability standards; batch processing; calibration programs; SP500-52, pp. $79-86$ (Oct. 1979).

Computer system acquisition; conference proceedings; CPE in auditing; hardware monitoring; CPEUG; installation management; on-line system evaluation; prediction methods; queuing models; simulation; sof tware monitoring; workload definition; SP500-52.

Computer systems; electron microscopy; group decisions; properties of steam; space; stirling refrigerators; aluminum SRM's; DIM/NBS 63, No. 5, 1-28 (1979).

Computer tape controllers; group coded recording; interface electrical characteristics; interface functional characteristics; magnetic tape drives; NRZI recording; phase encoded 
recording; tape drive characteristics; computer magnetic tape drives; NBS-GCR-78-127.

Computer technology library science; information science; American Society of Information Science; 18942.

Computer time; conduction-transfer functions; dynamic heat transfer; thermal response factors; 18339 .

Computer trends; information age; information as a resource; information revolution; social issues in information; telecommunication trends; transborder data flows; computertelecommunications convergence; 18975 .

Computer utilization; confidentiality; data systems; personnel administration; personnel practices; personnel records; privacy; record-keeping practices; relevant information; security; citizen rights; computers; SP50O-50.

Computer workload; data requirements; documentation cycle; forecast; projections; sensitivity analysis; SP500-52, pp. 113120 (Oct. 1979).

Computer-aided design; computer simulation; environmental psychology; fire research; fire safety; human performance; modeling technique; simulation; architectural research; building fires; $N B S I R 79.1796$.

Computer-aided design; environmental psychology; fire research; fire safety; human performance; modeling technique; programming; sensitivity analysis; simulation; architectural research; building fires; NBSIR 79-1713.

Computer-aided design and manufacture (CAD/CAM); footwear industry; fragmented industries; government-industry cooperation; imports; innovation; leather; manufacturing technology; materials development; shoes; technology transfer; SP527.

Computer-Aided Engineering and Architectural Design System (CAEADS); design criteria; guide specifications; habitability criteria; SP552, pp. 167-183 (July 1979).

Computerized; detection; electronic lock; exclusion area; forced entry deterrent systems; guard control station; higher headquarters; perimeter station; remote unit; response force; triply redundant central computer; central unit; NBSIR 79. 1725.

Computerized building energy analysis; cooling load calculation; energy conservation; heating load calculation; NBSLD analysis of residences; residential energy conservation; thermal mass effect in buildings; building energy consumption analysis; NBSIR 79-1732.

Computerized data bases; information storage and retrieval systems; libraries-automation; machine-readable-bibliographic data; bibliographic data bases; NBSIR 78-1577.

Computerized processing; data editing; data flow; data processing; data reductions; raw data conversion to engineering units; total energy; total energy data flow; NBSIR 79. 1757.

Computerized thermogravimetry; computer program; polymer degradation; polymer oxidation; thermogravimetry; activation energy; computer automation; 18445 .

Computerized tomography; Doppler; impedance; medical diagnosis; microscopy; pattern recognition; scattering; signal processing; tissue characterization; tissue parameters; ultrasound; velocity; absorption; attenuation; SP5 25.

Computerized tomography; mammography; time-of-flight; tissue characterization; ultrasonic imaging; ultrasound; breast cancer; SP525, pp. 221-225 (Apr. 1979).

Computers; computer selection; cost-value; cost-value technique; EDP selection; evaluation methodology; performance evaluation; procurement; computer evaluation; computer performance; computer procurement; SP500-52, pp. 25-36 (Oct. 1979).

Computers; computer utilization; confidentiality; data systems; personnel administration; personnel practices; personnel records; privacy; record-keeping practices; relevant information; security; citizen rights; SP5OO-5O.
Computers; corrosion; fire safety; gyromagnetic ratio; paper; photometric calibrator; safety tips; solar energy; toxic chemicals; ultra-black coating; Alaskan pipeline; DIM/NBS 63, No. 11, 1-36 (1979).

Computers; cryogenic temperature; energy; energy savings; industrial robots; network services; SRM's; computer interface standards; DIM/NBS 63, No. 4, 1-24 (1979).

Computers; data; metric; refractory concrete; resource conservation and recovery; chemical degradation; coal conversion; coal gasifier; DIM/NBS 63, No. 12, 1.32 (1979).

Computers; data bases; networks; operating systems; protocols; communications; 18488 .

Computers; data processing; Federal Information Processing Standards Publication; industries; representations and codes; Standard Industrial Classification; FIPS PUB 66.

Computers; databases; networks; operating systems; protocols; communications; 18891 .

Computer-telecommunications convergence; computer trends; information age; information as a resource; information revolution; social issues in information; telecommunication trends; transborder data flows; 18975.

Computing system; confidence ellipse; OMN1TAB 78; plots; portability plots; residuals; statistical plots; statistics; stemand-leaf displays; box plots; CALCOMP; 18954.

Computing system; dataplot; fitting; graphics; interactive graphics; regression; software; transformation; 18519 .

Concentration fluctuations; fast Fourier transforms; Fourier transform analysis; mixing in turbulent flow; noise spectrum; Raman spectroscopy; turbulence; 18626.

Concrete; corrosion; corrosion of steel; rebar corrosion; reinforced concrete; bridge deck; SP550.

Concrete; cryogenics; epoxy resins; glass fiber; graphite fiber; aramid fiber; composite applications; composites; 18717.

Concrete; energy saving opportunities; research needs; cement; SP542.

Concrete (reinforced); fire load; fire resistance; fire tests structural engineering: temperature; thermal analysis; TN985.

Condensed phases; diffusion mechanisms; inelastic scattering; neutron scattering; orientational disorder; rotational dynamics; 19026 .

Condition analysis; machinery; maintenance; monitoring; repairs; vibration; aircraft carrier; SP547, pp. 167-175 (July 1979).

Condition monitoring; debris monitoring; diagnostic techniques; failure detection; lubrication system monitoring; aircraft component failure; SP547, pp. 330-344 (July 1979).

Condition monitoring; diagnostic equipment; shock pulse; aircraft diagnostics; bearing; SP547, pp. 31-35 (July 1979).

Condition monitoring; engine diagnosis; failure detection; failure diagnosis; failure prevention; maintenance; performance monitoring; bearing analysis; SP547.

Conduction band (CB) electrons; dielectric solids; electrons, conduction band (CB); laser damage; SP541, pp. 303-304 (Dec. 1978).

Conduction-transfer functions; dynamic heat transfer; thermal response factors; computer time; 18339.

Conductivity; electric conductivity; electrokinetics; glass-surface; surface conductivity; 18910 .

Conductivity; exchange interaction; ferrite; hyperfine field; magnetism; phase diagram; potassium; 19046.

Conductivity; ion-chromatography; ion-exchange; liquid chromatography; oil; oyster; J. Res. 84, No. 3, 241-246 (1979).

Conductivity anomalies; earthquake prediction; geomagnetism; induced currents; magnetometers; 18895.

Conference proceedings; CPE in auditing; hardware monitoring; CPEUG; installation management; on-line system evaluation; prediction methods; queuing models; simulation; software monitoring; workload definition; computer performance evaluation; SP500-52. 
Confercnces; firc detcction; fire investigations; fire models; fire research; firc rctardants; flamc rctardants; human behavior; smokc; toxic gases; toxicity; building fires; SP54O.

Confidence ellipse; OMNITAB 78; plots; portability plots; rcsiduals; statistical plots; statistics; stem-and-leaf displays; box plots; CALCOMP; computing systcm; 18954

Confidentiality; data systcms; pcrsonnel administration; personnel practices; pcrsonncl records; privacy; record-kceping practices; relevant information; sccurity; citizen rights; computers; computcr utilization; SP5OO-50.

Configuration; plug; scattercd photons; slceve; source capsule; source pcllcts; spacer; spectra; spectrometry; atomic number; cobalt -60 photons; 18355.

Configurations of rods; Monte Carlo; orientation entropy; packing of rods; square latticc; theories of liquid crystals; 18530.

Conformance; sampling; specifications; statistical methods; statistics; 18440 .

Conformation; coupling constants; hexononitriles; iterative analysis; proton nmr spectroscopy; shift reagents; acyclic sugars; chemical shifts; 18742 .

Conformation; crystallinity; NMR; polyethylenc; resolution; samplc spinning; solids; $13, \therefore 18745$.

Conformational analysis; nitrogen-15 coupling constants; nitrogen-15 n.m.r. spectroscopy; proton; proton coupling; structural analysis; bis(hexopyranosyl)amine; carbon-13; 18764.

Conical spin structure; decay of ${ }^{116 m} \mathrm{Ho}$; nuclear orientation; nuclcar spin system; ${ }^{164} \mathrm{Ho}^{165} \mathrm{Ho}$; atomic magnetic structures; 18604.

Conical transmission line; impulse response; impulsive fields; standards; TEM horn antenna; antenna; TNI008.

Conjugates; detection sensitivity; dipeptides; drugs; HPLC; ionpair adsorption; ion-pair chromatography; ion-pair partition; metabolites; psychotropic amines; selectivity; sulphonamides; amino acids; barbiturates; carboxylic acids; SP5 19, pp. 509 523 (Apr. 1979).

Connective tissue; differential diagnosis; mcdullary carcinoma; papillary carcinoma; scirrhous carcinoma; shadowing; ultrasound; attenuation; breast cancer; cancer; SP525, pp. 9399 (Apr. 1979).

Conscnsus standards; clectrical distribution systems; flat conductor cable; National Electrical Code; technological innovation; appeals process; SP552, pp. 57-78 (July 1979).

Consensus standards; Federal policies; Fedcral voluntary standards policy; voluntary standards; voluntary standards system; SP552, pp. 79-93 (July 1979).

Conservation; criteria; design; economics; efficicncy; energy; energy budget; equity; life-cycle cost; optimal; standard; buildings; $/ 8888$.

Conservation; energy cost; existing buildings; regulation; retrofit; standards; SP552, pp. 197-209 (July 1979).

Consolute point; critical exponent; critical phenomena; critical solution point; liquid-liquid critical point; rcnormalization group theory; scaling theory; universality hypothesis; binaryliquid mixture; 18825 .

Conspicuity, lights; effective intensity; emergency lights; intensity, effective; lights, flashing; lights, warning; perception, visual; peripheral vision; vehicles, emergency; visibility, lights; visual perccption; color, lights; SP480-36.

Constant loading; force; high precision; high-precision weighing; load cell; mass; mass comparator; mass difference; strain-gage; substitution weighing; weighing; weights; J. Res. 84, No. 5, 347-351 (1979).

Constitutive equation; non-linear flow histories; rate fluid; simple shear; BKZ fluid; $/ 8367$.

Construction; cost effectiveness; hazard; injuries; loss prevention; risk; safety; 18890 .
Construction; economic impacts; environmental considerations; innovative practices; regulatory research; standards developmcnt; administrative procedures; building codes; building regulations; buildings; SP552.

Construction; fire safety; housing; prescrvation; regulations; rehabilitation; adaptive reuse; building codes; buildings; building safety; code enforcement; SP536.

Construction; metric; building codes; SP552, pp. 283-291 (July 1979).

Construction; performance; preservation; rehabilitation; renovation; adaptive reuse; architecture; building codes; building regulations; building safety; SP536, pp. 1-16 (Feb. 1979).

Construction costs; contractors; housing; rehabilitation; standards; building codes; community development; SP536, pp. 55-61 (Feb. 1979).

Construction industry; forecasting; labor information systems; manpower projections; modelling; building trades; SP552, pp. 185-196 (July 1979).

Construction materials; evacuation; exits; fire endurance; fire protection; stairways; standards; buiding design; buildings; NBS-GCR-79-176.

Construction specifications; conversion approaches; dimensional coordination; metrication; SI; stages in metrication; 18493.

Construction standard; fire growth; fire tests; flame spread; flashover; impact assessment; interior finish; kitchen fires; life safety; mobile homes; room fires; ASTM E-84 Tunnel Test; NBSIR 79-1720.

Consumer affairs; education; electromagnetic interference; electronic devices; International Organization of Legal Metrology; measurement assurance; metrication; model laws and regulations; national type approval; packaging and labeling; specifications and tolerances; SP5 32.

Consumer preference; energy; energy cost; feedback; feedback meters; attitudes; NBSIR $79-177 I$.

Consumer product; human factors; lawn mowers; reaction time; safety; standards; NBSIR 77-1299.

Consumer products; hum an factors; human performance; lawn mowers; psychophysics; safety; standards; NBSIR 77-1298.

Consumer products; reliability engineering; testing methodology; useful life; 18378 .

Contact angle; disjoining pressure; monotectic; multicomponent; wetting; composite growth; 18422 .

Contact burn; current threshold; electrical injury; electrolyte shift; heat effect; injury mechanism; injury statistics; mouth burn; specific clectrical effect; arc burn; NBSIR 79-I IIO.

Contact resistor; cross bridge sheet resistor; electrical alignment resistor; semiconductor; silicon; test pattern; test structures; visual alignment; SP4OO-5I

Contact resistor; cross bridge sheet resistor; electrical alignment resistor; integrated circuits; lincwidth; photolithography; sheet resistance; silicon; test pattern; test structure; TTL; bipolar process; $/ 8533$.

Contact stress; damage penetration; fracture mechanics; fragmentation; glass; grinding; impact; silicon nitride; strength; stress intensity factor; abrasive machining; ceramics; SP562, pp. 23-42 (Oct. 1979).

Contamination; corrosion; electrostatic-induced damage; hermeticity; hybrid devices; leak testing; measurement technology; microcalorimetry; moisture; nondestructive testing; pacemaker leads; process control; reliability; semiconductor devices; welding; autom ated testing; SP4OO-5O.

Contamination; dianabol; gas chromatography-mass spectrometry ( $\mathrm{gc} / \mathrm{ms}$ ); gas liquid chromatography (glc); gc/ms interface; high performance liquid chromatography (hplc); inert columns; metabolism; methandie none; urine; SP519, pp. 437-445 (Apr. 1979).

Contamination; environment; retrospective; sample storage; trace analysis; analytical techniques; $l 8349$. 
Contention; data; digital; ethernet; local; microprocessor; network; serial; broadcast; coaxial; communication; 18760 .

Continental drift; distortion-of-plate; geophysics; ranging; tectonic motions; 18459 .

Continuous analysis; controlled dispersion; flow injection analysis; iutomation; SP519, pp. 501-507 (Apr. 1979).

Continuous fiber composite materials; fabrication; finite element stress analysis; front end; graphite; part integration; wheel: automotive component design; SP563, Pp. 135-151 (Oct. 1979).

Continuous flow system; environmental analysis; pesticides; synthetic carbonaceous resins; SP519, pp. 345-353 (Apr. 1979).

Continuum $x$ rays; Coulomb field; non-relativistic bremsstrahlung; atomic screening effects; bremsstrahlung high frequency limit; bremsstrahlung spectrum tip; 18370 .

Continuum $x$ rays; Coulomb field; non-relativistic bremsstrahlung; atomic screening effects; bremsstrahlung high frequence limit; bremsstrahlung spectrum tip; 18532 .

Contraceptive device; gas chromatography; mass spectrometry; propylamine; butylamine; collagen sponge; SP519, pp. 469476 (Apr. 1979).

Contractors; housing; rehabilitation; standards; building codes; community development; construction costs; SP536, pp. 5561 (Feb. 1979).

Contrast augmentation of reflecting surfaces; doublediaphragm; faces (crystal) on platinum crucibles; hematite forming on platinum; iron as alloy in platinum; platinum ware; surface of platinum influenced by method heating; $J$. Res. 84, No. 5, 385-394 (1979).

Control measures; fire codes; fire safety; governmental actions; life safety; regulation; risk assessment; societal goals; building codes; SP536, pp. 63-74 (Feb. 1979).

Control testing; sonic testing device; adhesive bond integrity; SP563, p. 174 (Oct. 1979).

Control units; fire alarm systems; fire detectors; high-rise communication systems; multiplex systems; NFPA standards; residential fire detector; sprinkler supervisory devices; 18625 .

Control units; hammer drive; input/output bus; interface; interface signals; $1 / O$ interface bus; line printer; print controller; printer; cable interface; computer; controller; NBS-GCR-79182.

Controlled dispersion; flow injection analysis; automation; continuous analysis; SP519, pp. 501-507 (Apr. 1979).

Controlled potential; coulometry; electrochemical equivalent of silver; electrochemistry; Faraday; potentiostat; silver; silver analysis; J. Res. 84, No. 2, 157-160 (1979).

Controller; control units; hammer drive; input/output bus; interface; interface signals; I/O interface bus; line printer; print controller; printer; cable interface; computer; NBS-GCR-79. 182 .

Convection; heat capacity measurement; $\mathrm{Pb}-\mathrm{Sn}$ off-eutectic alloys; phase diagram of $\mathrm{K}_{2} \mathrm{O}-\mathrm{Fe}_{2} \mathrm{O}_{3}$ system; solidification; surface tension of liquid gallium; thermodynamic properties; NBSIR 79-1767.

Convection; solar; solar atmospheric motions; supergranules; 18444

Convective heat transfer; convective mass transfer; emissivity of water; evaporation coefficient; humidity measurement; monomolecular film; psychrometer; psychrometry; radiative heat transfer; temperature depression; J. Res. 84, No. 2, 161 $177(1979)$.

Convective mass transfer; emissivity of water; evaporation coefficient; humidity measurement; monomolecular film; psychrometer; psychrometry; radiative heat transfer; temperature depression; water vapor measurement; wet bulb; $J$. Res. 84, No. 2, 161-177 (1979).

Conversion; customary units; inch; metric units; centimeter; SP376.
Conversion approaches; dimensional coordination; metrication; Sl; stages in metrication; construction specifications; 18493.

Convolution; deconvolution; geometrical-optics radiometry; inversion; measurement-beam geometry; relative spectral responsivity; slit-scattering function; slit-scattering function corrections; spectral line radiometry; spectroradiometer characterizations; spectroradiometry; TN910-4.

Convolution; de-convolution; liver; power spectrum; signal processing; tissue characterization; tissue parameters; ultrasound; attenuation; B-san; cepstrum; computer; SP525, PP. 287-295 (Apr. 1979).

Cooking; efficiency; energy; human factors; kitchen ranges; labeling; stoves; test methods; appliance; NBSIR 78-1556.

Cooking utensils; energy conservation; energy efficiency; ranges and ovens; appliances; 18836.

Coolants, dn/dT; index matching liquids; neodymium glass lasers; nonlinear refractive index; thermal conductivity; viscosity; Abbe value; SP541, pp. 109-121 (Dec. 1978).

Cool-down helium; liquid helium; superconducting power transmission; thermal cycling; thermal stress; cable cool-down; NBSIR 79.1618 .

Cooling load calculation; energy conservation; heating load calculation; NBSLD analysis of residences; residential energy conservation; thermal mass effect in buildings; building energy consumption analysis; computerized building energy analysis; NBSIR 79-1732.

Coordinate time; portable clocks; relativity; synchronization; time scales; 18993 .

Coordinated universal time; synchronous satellite; time code; Western Hemisphere; broadcast; 19029.

Copolymerization; polymerization; pressure; radiation; styrene; tetrafluoroethylene; 18512 .

Copper; copper alloys; nickel; oxide films; photopotentials; aluminum; 18724.

Copper; corrosion; hydrogen evolution; alternating current; alternating voltage; comparison between theoretical and experimental results; 18756 .

Copper; critical evaluation; data analysis; data compilation; data evaluation; data extraction; data synthesis; electrical resistivity; elements; gold; metals; molten metals; palladium; precious metals; reference data; silver; JPCRD 8, No. 4, $1147-1298$ (1979).

Copper; critical evaluation; electrolyte; excess Gibbs energy; lead; manganese; osmotic coefficients; solutions; thermodynamic properties; uranium; activity coefficient; JPCRD 8, No. 4, 1005-1050 (1979).

Copper; electrical property; niobium; superconductor; tin; alloy; 18656.

Copper; ESCA; gold; relative intensities; round robin; $\mathrm{x}$-ray photoelectron spectroscopy; binding energies; 18924 .

Copper; hollow cathodes; mass spectrometry; neon; nitrogen; Penning effect; carbon; 18449

Copper; iron; plastic; polymer; proton-induced $x$-ray fluorescence; thin films; trace element analysis; trace element concentrations; zinc; 18375 .

Copper; low temperature; magnetothermal conductivity; nickel alloy; stainless steel; thermal conductivity; aluminum alloy; 18619

Copper; low temperatures; niobium; precipitate; superconductor; tin; alloy; 18655 .

Copper; luminescence; microspectrofluorimetry; photoluminescence; spectrofluorimetry; surface analysis; tetrazole; benzotriazole; charge transfer; 18504 .

Copper; niobium; stripline; superconductivity; surface impedance; J. Res. 84, No. 3, 247-259 (1979).

Copper alloys; elastic constants; iron alloys; nickel alloys; stainless steels; Young's modulus; aluminum alloys; 18630.

Copper alloys; nickel; oxide films; photopotentials; aluminum; copper; 18724. 
Copper concentric neutrals; corrosion; corrosion tests; elec. trochemical measurements; potentiodynamic scans; 18725 .

Copper isoelectronic sequence; Coulomb-Born approximation; distorted wave approximation; effective Gaunt factor; electron impact excitation collision strength; Born approximation; 18996.

Copper isolectronic sequence; diagrammatic perturbation theory; electron correlation; ionization energies; line strengths; many-body interaction; many-body perturbation theory; oscillator strengths; 18998 .

Copper $K \beta$; double vacancy; emission spectrum; Hartree-Fock calculations; $\mathrm{x}$-ray emission; 18526 .

Core excitation; emission spectra; lattice relaxation; many body effects; sodium; absorption spectra; 184/3.

Core fibril; cumulative stress; flow-induced crystallization; nucleation theory; polyethylene; polymer fiber; shish; volume strain; J. Res. 84, No. 5, 359-384 (1979).

Core hole lifetime; core hole relaxation; $K$ x-ray absorption spectrum; $K$ x-ray emission spectrum; many body effects; rhonon interactions; 18359 .

Core hole lifetime; lattice relaxation; lithium; magnesium; sodium; soft $x$-ray absorption spectra; soft $x$-ray emission spectra; aluminum; beryllium; 18741 .

Core hole relaxation; $K$ x-ray absorption spectrum; $K$ x-ray emission spectrum; many body effects; rhonon interactions; core hole lifetime; 18359 .

Core memories; disks; drums; floppy disks; laser beams; magnetic bubbles; masstapes; solid state memories; video disks; beam-addressables; cartridges; cassettes; SP500-45.

Core resonance; free wobble; laser strainmeter; ocean load; preferred frame; spatial anisotropy; strain tides; 18823 .

Core-excited states; magnesium; photoabsorption-spectrum; synchrotron radiation; autoionization; 18912 .

Coriolis; frame transformation relations; level cluster; spherical tops; symmetry analysis; Born-Oppenheimer approximation; centrifugal; 18599.

Cornering traction; driving traction; endurance; maintenance; operation; purchasing; pursuit tires; safety; tread wear; braking traction; SP480-33.

Corning code 9658; glass-ceramic; machinable; MACOR $^{T M}$; SP562, pp. 221-229 (Oct. 1979).

Correlated data; critical point enhancement; data evaluation; propane; thermal conductivity; viscosity; JPCRD 8, No. 2 , 559-576 (1979).

Correlation; custody transfer; density; experimental; extended corresponding states method; hard sphere model; KlosekMcKinley method; liquefied natural gas (LNG); magnetic suspension densimeter; comparisons; 18775.

Correlation; ethylene; experimental; magnetic suspension; orthobaric liquid density; tables; argon; comparisons; 18627.

Correlation analysis; temporal changes; A-scan; SP525, pp. 275-280 (Apr. 1979).

Correlation functions; equations of motion; maximum entropy; nonequilibrium statistical mechanics; nonequilibrium thermodynamics; projection operator; 18321 .

Correlation functions; Kirkwood-Salsburg; Mayer-Montroll; BBGKY; 19004.

Correlations; electron impact; electrons; helium; ionization; secondary; angular; Born approximation; 18534.

Correlations; grid-turbulence; higher-order moments; hot-wire anemometry; probability distributions; small-scale turbulence; 18821 .

Correlations; mass formula; nuclear; quartets; reactions; spectroscopy; SU4; alpha-particles; 18423.

Correlations in nuclei; cw accelerators; electronuclear physics; high duty-cycle; coincidence experiments; 18906.

Corridor fires; fire models; fire spread; room fires; thermal radiation; turbulence; buoyant flow; compartment fires; computer programs; NBS-GCR-78-150.
Corridors; escape; fire detectors; full-scale tests; heat detectors; hospitals; ionizaton detectors; mattresses; nursing homes; photoelectric detectors; NBSIR 79-1739.

Corrosion; corrosion of steel; rebar corrosion; reinforced concrete; bridge deck; concrete; SP5SO.

Corrosion; corrosion tests; electrochemical measurements; potentiodynamic scans; copper concentric neutrals; 18725 .

Corrosion; crevice corrosion; galvanic corrosion; inhibitors; pitting corrosion; rust; stress corrosion; CIS9, Revised 1979.

Corrosion; crevice corrosion; galvanic corrosion; implants; im. plants passivity; 18946

Corrosion; data compilation; electrochemical energy storage materials; molten salts; physical properties; safety and hazards; thermal energy storage materials; thermal properties; thermodynamic properties; transport properties; NSRDSNBS61, Part 11 .

Corrosion; electrostatic-induced damage; hermeticity; hybrid devices; leak testing; measurement technology; microcalorimetry; moisture; nondestructive testing; pacemaker leads; process control; reliability; semiconductor devices; welding; automated testing; batteries; SP400-50.

Corrosion; fire safety; gyromagnetic ratio; paper; photometric calibrator; safety tips; solar energy; toxic chemicals; ultrablack coating; Alaskan pipeline; computers; DIM/NBS 63 , No. 11, 1-36 (1979).

Corrosion; hydrogen evolution; alternating current; alternating voltage; comparison between theoretical and experimental results; copper; 18756 .

Corrosion failure; hermeticity; moisture infusion; oxide moisture sensors; accelerated stress test; capillary leaks; NBSGCR-79-170.

Corrosion fatigue; design; engineering judgment; factor of safety; fatigue; mathematical modeling; nuclear engineering; reliability; risk; safety factor; sampling; Weibull distribution; 18326.

Corrosion films; ESCA; impurities; microroughness; optical microscopy; polishing defects; scattered light; SIMS; stylus instruments; Auger spectroscopy; SP562, pp. 337-350 (Oct. 1979).

Corrosion of steel; corrosion protection; nonmetallic coatings; offshore corrosion; saltwater corrosion; seawater corrosion; 18418

Corrosion of steel; rebar corrosion; reinforced concrete; bridge deck; concrete; corrosion; SP55O.

Corrosion protection; nonmetallic coatings; offshore corrosion; saltwater corrosion; seawater corrosion; corrosion of steel; 18418

Corrosion tests; electrochemical measurements; potentiodynamic scans; copper concentric neutrals; corrosion; 18725.

Corundum; enthalpy; heat capacity; sapphire; specific heat; standard reference materials; thermodynamic properties; alumina; aluminum oxide; calorimetry; 18377.

Co-shock; couplant; detection; electronic package; impact noise; microcircuit device; particle detection; particle impact noise detection; PIND; pre-shock; seeded specimens; transducer; acoustic emission; NBSIR 78-1590 (NASA).

Cosmic source; preliminary; proton interactions; relative measurements; ${ }^{12} \mathrm{C} \gamma$-rays; ${ }^{16} \mathrm{O} \gamma$-rays; 19015.

Cost; data entry; edit; operator speed; record size; transaction volume; transfer speed; validate; verify; application; character set; computer interface; SP500..55.

Cost; economics; hydrogen; production; storage; transmission; 18812

Cost; energy conservation; energy standards; fenestration; lifecycle costing; retrofitting; solar; building design; 19043 .

Cost; human characteristics; personal control; physical environment; privacy; architectural psychology; bibliography; buildings; communication; NBSIR 79-1793. 
Cost analysis; evaluation; procurement; technical analysis; timesharing; TSP; benchmarking; SP500-52, pp. 233-234 (Oct. 1979).

Cost effectiveness; economics; energy conservation; internal rate of return; life-cycle costing; marginal analysis; optimal design; residential buildings; space cooling; space heating; building envelope; 19044 .

Cost effectiveness; hazard; injuries; loss prevention; risk; safety; construction; 18890.

Cost estimation; econometric models; economic analysis; housing; lead-based paint; lead poisoning; abatement; building economics; building materials; TN979.

Cost-benefit analysis; costs; decision analysis; fire losses; furniture; hazard analysis; probability; residential buildings; sensitivity analysis; smoke detectors; standards; upholstered furniture; building fires; TNI 101 .

Cost-benefit analysis; life-cycle analysis; safety regulations; building codes; building regulations; SP552, pp. 267-282 (July 1979).

Coster-Kronig yield; effective fluorescence yield; fluorescence yield; $K$ shell; $L$ shell; non-radiative yield; partial level width; radiative yield; atomic properties; Auger yield; JPCRD 8, No. 2, 307-328 (1979).

Costs; decision analysis; fire losses; furniture; hazard analysis; probability; residential buildings; sensitivity analysis; smoke detectors; standards; upholstered furniture; building fires; cost-benefit analysis; TNI101.

Cost-trade comparisons; manufacturing technologies; structural performance/cost trade-offs; airframe structure; SP563, pp. 226-227 (Oct. 1979).

Cost-value; cost-value technique; EDP selection; evaluation methodology; performance evaluation; procurement; computer evaluation; computer performance; computer procurement; computers; computer selection; SP500-52, pp. 25-36 (Oct. 1979).

Cost-value technique; EDP selection; evaluation methodology; performance evaluation; procurement; computer evaluation; computer performance; computer procurement; computers; computer selection; cost-value; SP500-52, pp. 25-36 (Oct. 1979).

Cost/benefit analysis; documentation; documentation content guidelines; feasibility study; FIPS guidelines; initiation phase; project request; software; automated data systems; computer programs; FIPS PUB 64.

Coulomb field; non-relativistic bremsstrahlung; atomic screening effects; bremsstrahlung high frequency limit; bremsstrahlung spectrum tip; continuum $\mathrm{x}$ rays; 18370 .

Coulomb field; non-relativistic bremsstrahlung; atomic screening effects; bremsstrahlung high frequence limit; bremsstrahlung spectrum tip; continuum $\mathrm{x}$ rays; 18532 .

Coulomb-Born approximation; distorted wave approximation; effective Gaunt factor; electron impact excitation collision strength; Born approximation; copper isoelectronic sequence; 18996.

Coulometry; definitive method; electrolytes; reference method; serum chloride analysis; statistical analysis; amperometry; chloride analysis; clinical analysis; clinical chemistry; SP26067.

Coulometry; electrochemical equivalent of silver; electrochemistry; Faraday; potentiostat; silver; silver analysis; controlled potential; J. Res. 84, No. 2, 157-160 (1979).

Counting and control circuitry; fringe counting interferometric method and apparatus; Michelson interferometer; phase locked oscillators; retroreflectors; U.S. Patent 4,165,183.

County building code; critical structures program; expense; inspection requirements; pre-construction conference; code enforcement; SP552, pp. 311-320 (July 1979).

Couplant; detection: electronic package; impact noise; microcircuit device; particle detection; particle impact noise detection; PIND; pre-shock; seeded specimens; transducer; acoustic emission; co-shock; NBSIR 78-1590 (NASA).

Coupled integral equations; dispersion; lossy dielectric slab; modes considerations; TEM-cell; attenuation; NBSIR 79. 1615.

Coupled modes; dynamics; $\mathrm{KCN}-\mathrm{KBr}$; neutron scattering; phase transition; rotation-translation coupling; 19036.

Coupling agent; dental; monomers; resins; surface-active comonomers; acrylates; adhesion, dental; bonding; 18461 .

Coupling constants; hexononitriles; iterative analysis; proton nmr spectroscopy; shift reagents; acyclic sugars; chemical shifts; conformation; 18742 .

Coupling device; cutting blade; dead-man's handle; disconnect element; lawnmower; motor shaft; brake; U.S. Patent $4,158,944$.

Courtroom procedures; juror attitudes; prerecorded videotaped trials; PRVTT; trials, PRVTT; videotaped trials; civil trials; SP480-30.

$\mathrm{CO}_{2} ; \mathrm{C}_{2} \mathrm{H}_{4}$; dielectric virial coefficients; refractive virial coefficients; $\mathrm{SF}_{6} ; \mathrm{CH}_{4}$; collision induced bands; 18786 .

$\mathrm{CO}_{2}$; far wings; infrared wings; line shape; model correlation function; pressure broadening; 18886 .

$\mathrm{CO}_{2}$ laser; derivative spectra; infrared analysis; spectral coincidences; Stark modulation; Stark spectroscopy; trace gas analysis; 18538 .

$\mathrm{CO}_{2}$ laser; frequency comparison; frequency multiplication; frequency synthesis; laser frequency measurement; Penning trap; speed of light; 18608 .

CPE in auditing; hardware monitoring; CPEUG; installation management; on-line system evaluation; prediction methods; queuing models; simulation; software monitoring; workload definition; computer performance evaluation; computer performance measurement; SP5OO-52.

CPEUG; installation management; on-line system evaluation; prediction methods; queuing models; simulation; software monitoring; workload definition; computer performance evaluation; computer performance measurement; computer performance prediction; SP500-52.

CPSC; performance test; showers; slip-resistance; ASTM; bathtubs; 18705 .

Crack; crack, well-characterized; destructive evaluation; fatigue flaw evaluation; fracture mechanics; standards; technique development; compact tension specimen; 18744 .

Crack; defects; elastic solid; pulses; scattering; ultrasonic; acoustic; 18391 .

Crack activation; numerical simulation; subsonic water drop impact; surface flaws; SP562, pp. 501-511 (Oct. 1979).

Crack detection; eddy currents; non-destructive evaluation; $189 I I$.

Crack formation; fracture toughness; friction; hardness; liquid softening; oxides; scratching; size effect; specific snergy; ceramics; chipping; SP562, pp. 43-59 (Oct. 1979).

Crack growth; failure; polyethylene; solvent; stress-cracking agent; uniaxial creep; 18766 .

Crack growth; fracture; molecular weight distribution; necking; polyethylene; uniaxial creep; additivity of damage; cold drawn; 18765 .

Crack nucleation; fracture; median, radial and lateral cracks; plastic indentations; residual stresscs; shear flow lines; SP562, pp. 15-20 (Oct. 1979).

Crack propagation; cryogenics; fatigue; fracture; low tenperature tests; mechanical properties; aluminum alloys; 18610 .

Crack propagation; cryogenics; fracture; low temperature tests; martensitic transformations; mechanical properties; stainless steel alloys; 18943.

Crack propagation; fatigue; fracture resistance; low temperature tests; mechanical porperties; stain less steel; 18621 .

Crack propagation; fatigue; low temperature tests; nickel alloys; stainless steels; steels; superalloys; titanium alloys; $/ 8695$. 
Crack, well-characterized; destructive evaluation; fatigue flaw evaluation; fracture mechanics; standards; technique development; compact tension specimen; crack; 18744 .

Crankshaft displacement; medium speed diesel engine; piston ring wear; turbocharging monitoring; SP547, pp. 153.166 (July 1979).

Creep; dental; dimensional change; dispersion type alloy; high copper; single alloy; amalgam; 18729.

Creep; dental amalgam; dimensional changes; extrusion of restorations; marginal fracture; zinc effect; $I 8586$.

Creep; flexural strength; mechanical properties; moisture; nondestructive testing; preservation; adobe; adobe soil; compressive strength; TN996.

Creep; instability; polyethylene; viscoelastic; 18807 .

Creosote; fire departments; fire safety; heating equipment; maintenance; stoves; wood; accident investigations; chimneys; coal; NBSIR 79-I731.

Creosote; fire departments; fire safety; heating equipment; maintenance; stoves; wood; accident investigations; chimneys; coal; NBS-GCR-78-149.

Creosote; fire departments; fire safety; heating equipment; maintenance; stoves; wood; accident investigations; chimneys; coal; 18537 .

Creosote; härbor facilities; inspection; maintenance; marine borers; nondestructive testing; pilings; timber; acoustics; bridges; 18525 .

Cresol; luminescence spectrometry; organic pollutants monitoring; synchronous excitation spectroscopy; SP519, pp. 679. 684 ( Apr. 1979).

Crevice corrosion; galvanic corrosion; implants; implants passivity; corrosion; 18946 .

Crevice corrosion; galvanic corrosion; inhibitors; pitting corrosion; rust; stress corrosion; corrosion; CIS9, Revised 1979.

Crisis; flood recovery effort; missing link; rebuilding; SP552, pp. 39-44 ( July 1979).

Criteria; design; economics; efficiency; energy; energy budget; equity; life-cycle cost; optimal; standard; buildings; conservation; 18888 .

Criteria; energy; engineering; industry construction; measurement techniques; standards; building research; SP439-I.

Criteria; project summaries; standards; technical bases; building research; building technology; codes; SP446-2.

Criteria for purity; food additives; mutagenicity; naphthylamines; saccharin; saccharin impurities; Salmonella typhimurium; Amaranth; Ames test; SPS 19, pp. 311-319 (Apr. 1979).

Critical behavior; domain growth; domain walls; ordering; surface mobility; alloys; antiphase domains; 18373 .

Critical behavior; domain growth; domain walls; ordering; surface mobility; alloys; antiphase domains; 18613 .

Critical current; critical current degradation; multifilamentary $\mathrm{Nb}_{3} \mathrm{Sn}$; multifilamentary $\mathrm{NbTi}$; superconductors; $/ 8622$.

Critical current; definitions of terms; measurement techniques; standards; superconductors; 18762 .

Critical current degradation; multifilamentary $\mathrm{Nb}_{3} \mathrm{Sn}$; multifilamentary NbTi; superconductors; critical current; 18622 .

Critical evaluation; data analysis; data compilation; data evaluation; data extraction; data synthesis; electrical resistivity; elements; gold; metals; molten metals; palladium; precious metals; reference data; silver; JPCRD 8, No. 4, 1147.1298 (1979).

Critical evaluation; electrolyte; excess Gibbs energy; iron; nickel; osmotic coefficients; solutions; thermodynamic properties; activity coefficient; cobalt; JPCRD 8, No. 4, 9231004 (1979).

Critical evaluation; electrolyte; excess Gibbs energy; lead; manganese; osmotic coefficients; solutions; thermodynamic properties; uranium; activity coefficient; copper; JPCRD 8, No. 4, 1005-1050 (1979).
Critical exponent; critical phenomena; critical solution point; liquid-liquid critical point; renormalization group theory; scaling theory; universality hypothesis; binary-liquid mixture; consolute point; 18825 .

Critical flaw size; cyclic fatigue life; filament wound tankage; leakage failure mode; linear elastic fracture mechanics; metal liner; composite materials; SP563, pp. 198-207 (Oct. 1979).

Critical parameters; definitions; flux phenomena; Josephson phenomena; stabilization; superconductors; terminology; I868I.

Critical phenomena; critical solution point; liquid-liquid critical point; renormalization group theory; scaling theory; universality hypothesis; binary-liquid mixture; consolute point; critical exponent; 18825 .

Critical phenomena; critical-point universality; fluids; gravity effects; materials science; spacelab; 18457.

Critical point; gravity effects; phase transition; $I 8541$.

Critical point enhancement; data evaluation; propane; thermal conductivity; viscosity; correlated data; JPCRD 8, No. 2, 559-576 ( 1979 ).

Critical radiant flux; flame spread; smoldering combustion; test methods; attic floor radiant panel; cellulose thermal insulation; NBSIR 79-1588.

Critical solution point; liquid-liquid critical point; renormalization group theory; scaling theory; universality hypothesis; binary-liquid mixture; consolute point; critical exponent; critical phenomena; 18825 .

Critical strain rate; fatigue; grain boundary sliding; high temperature; intergranular fracture; stainless steel; $I 8896$.

Critical structures program; expense; inspection requirements; pre-construction conference; code enforcement; county building code; SP552, pp. 311-320 (July 1979).

Critical-current; critical-field; degradation; multifilamentary strain; $\mathrm{Nb}_{3} \mathrm{Sn}$; stress; superconductor; 18780 .

Critical-current; degradation; $\mathrm{Nb}_{3} \mathrm{Ge}$; strain; stress; superconductor; 18781 .

Critical-field; degradation; multifilamentary strain; $\mathrm{Nb}_{3} \mathrm{Sn}$; stress; superconductor; critical-current; 18780.

Critical-point universality; fluids; gravity effects; materials science; spacelab; critical phenomena; 18457 .

Cross bridge sheet resistor; electrical alignment resistor; semiconductor; silicon; test pattern; test structures; visual alignment; contact resistor; SP4OO-5I

Cross bridge sheet resistor; electrical alignment resistor; integrated circuits; linewidth; photolithography; sheet resistance; silicon; test pattern; test structure; TTL; bipolar process; contact resistor; 18533.

Cross capacitor; dielectric; dissipation factor; loss angle; microphonic coupling; phase angle; surface films; capacitor; I 8454 .

Cross correlation; digital sampling; Fourier optics; holography; laser; laser parameters; laser pulse; optical processing; phase; precision measurements; wave front; amplitude; beam profile; TNIO09.

Cross sections; electron collisions; molecules; momentumtransfer; polar molecules; scattering theory; 18516 .

Cross sections; electron impact; excitation, $2 s-2 p ; \mathrm{N}^{4+}$; crossed beams; 18707.

Cross sections; fission spectrum; neutron; threshold reaction; uranium; Californium; 18792.

Cross sections; gamma rays; photons; Rayleigh scattering; tabulations; $x$ rays; atomic form factor; coherent scattering; JPCRD 8, No. 1, 69-106 (1979).

Cross sections; intermolecular potential; state changes; well depths; collisions; 18671 .

Crossed beams; cross sections; electron impact; excitation, $2 s$ $2 p ; \mathrm{N}^{4+} ; 18707$.

Crosslinking modification; curvelinking; hydroxyapatite; sonic velocity; bone; collagen; SP525, pp. 179-187 (Apr. 1979). 
Cross-linking of rubber; dicumyl peroxide; elasticity theory of rubber; modulus of rubber; Mooney-Rivlin constants; rubber elasticity theory; rubber, natural; swelling of rubber network; J. Res. 84, No. 5, 353-358 (1979).

Crosstrack scan; earth imagery; ERTS; LANDSAT; multispectral scanner; reflective optics; SP547, pp. 17-30 (July 1979).

Crustal movements; earth rotation; geodynamics; gravity field; ocean current; plate tectonics; polar motion; 18584 .

Cryocoolers; Josephson devices; refrigeration; SQUID; superconductive electronics; 18700 .

Cryogenic; densimeters; density reference system; liquid methane; LNG; 18805.

Cryogenic; dielectric loss; dissipation factor; high voltage; low temperature polymer; 18384

Cryogenic; error estimation; liquefied natural gas; LNG; marine; mathematical modeling; measurement; photogrammetric; precision; ship cargo; statistical analysis; strapping; survey; accuracy; NBSIR 79-1751.

Cryogenic; fatigue; fracture; high-strength; low-temperature; mechanical properties; nitrogen; nitrogen-strengthened; stainless steel; tensile properties; toughness; 18957.

Cryogenic; hydrogen; oxygen; scraping auger; slush; slush production; slush storage; NBSIR 79-1607.

Cryogenic densimeter; custody transfer; density; flowmetering; liquefied natural gas; sampling; 18396.

Cryogenic temperature; dielectric loss; polymer films; polymers; polypropylene; polyurethane; superconducting power cable; $\tan 8 ; 18713$.

Cryogenic temperature; energy; energy savings; industrial robots; network services; SRM's; computer interface standards; computers; DIM/NBS 63, No. 4, I-24 (1979).

Cryogenic temperature scale; fixed points; Ir; superconductivity; thermometry; W; AuAl ; AuIn $_{2} ; \mathrm{Be} ; \mathrm{SP260-62.}$

Cryogenics; dielectric-constant; electrets; electrocaloric effect; entropy; ferroelectrics; glass-ceramics; heat switches; magneto-thermal conductivity; polarization; potassium tantalate; refrigeration; specific heat; strontium titanate; beryllium; ceramics; 18680 .

Cryogenics; dilution refrigerators; helium 3; Japan; millikelvin research; nuclear cooling; Pomeranchuk refrigerators; solid $\mathrm{He}^{3}$; superfluid $\mathrm{He}^{3}$; symposium; 18679.

Cryogenics; epoxy resins; glass fiber; graphite fiber; aramid fiber; composite applications; composites; concrete; 18717 .

Cryogenics; fatigue; fracture; low temperature tests; mechanical properties; aluminum alloys; crack propagation; 18610 .

Cryogenics; fixed points; pure materials; superconductivity; temperature scale; thermometry; 18550.

Cryogenics; fracture; low temperature tests; martensitic transformations; mechanical properties; stainless steel alloys; crack propagation; 18943.

Cryogenics; glass-epoxy; industrial laminates; mechanical properties; physical properties; radiation properties; 18771 .

Cryogenics; industrial laminates; low-pressure laminates; metalmatrix composites; polymer matrices; advanced-fiber composites; 18631 .

Cryogenics; industrial laminates; magnetic fusion energy; superconducting magnets; advanced composites; composite materials; 18560 .

Cryptography; digital signatures; encryption; identifiers; key management; key notarization; SPSO0-54.

Cryptography; digital signatures; encryption; identifiers; key management; key notarization; 19039.

Crystal; defect; energy; hydrocarbon; methyl-branch; structure; calculations; cell dimensions; 18787 .

Crystal; diffraction; $\mathrm{Li}_{5} \mathrm{~B}_{4}$; neutron powder; structure; $x$ ray; 18382 .

Crystal diffraction; gamma-ray energies; thulium; ytterbium; 18510.

Crystal field; magnetic superconductor; neutron scattering; rare earth; Chevrel-phase; coexistence; 18850.
Crystal fields; Laves phase; magnetic materials; neutron scattering; rare earths; spin waves; 19031 .

Crystal oscillators; frequency standards; hydrogen standards; rubidium standards; time and frequency; timekeeping; atomic clocks; cesium standards; 18908.

Crystal structure; diffraction; isotopes; molecular dynamics; neutron; neutron radiography; nondestructive evaluation; nuclear reactor; radiation; activation a nalysis; TN995.

Crystal structure; hydrogen bond; neutron diffraction; rigid body motion; triaminoguanidinium nitrate; $/ 8873$

Crystal structure; integrated intensities; lattice constants; peak intensities; powder patterns; reference intensities; standard; $\mathrm{x}$-ray diffraction; Monogr. 25, Section 16.

Crystal structure; magnesium phosphate; potassium phosphate; struvite analogue; 18491 .

Crystal structure; mechanism of formation; molecular compound; silver-sulfur-tungsten cluster; synthesis; $x$-ray diffraction; 18636.

Crystal structure; neutron scattering; nitromethane; rotation; tunneling; 19025 .

Crystal structure; $S$-carboxymethyl-L=cysteine; single crystal; $x$ ray; zwitterion; amino acid derivative; 18673

Crystal structure; single crystal; uric acid derivative; uric acid determination; $x$-ray diffraction; biological assay; 18672 .

Crystal-field splitting; inelastic neutron scattering; magnetic properties of rare earth alloys; metal hydrides; rare-earth hydrides; cerium dihydride; 19030.

Crystallinity; NMR; polyethylene; resolution; sample spinning; solids; $13 \mathrm{c}$; conformation; 18745.

Crystallization theory; extended chain fibrils; flow-induced crystallization; polymer crystallization; shish kebabs; 18715.

Crystallographic integrity; electron diffraction images; hydrated layer; ion microprobe mass spectrometer; roughness; phire; ultra-fine polishing; water; $x$-ray photoelectron trometer; SP562, pp. 3 17-323 (Oct. 1979).

CsI; detection efficiency; Lixiscope; radioactive $x$-ray source; rare-earth scintillator screen; ${ }^{125} \mathrm{I} ;{ }^{153} \mathrm{GD} ; 19001$.

Cu III; cw laser action; 18319 .

$\mathrm{Cu}$ sequence; oscillator stength; $\mathrm{Zn}$ sequence; 18366 .

Cube; geometry; hyperplane; J. Res. 84, No. 1, 49-53 (1979).

Cumulative stress; flow-induced crystallization; nucleation theory; polyethylene; polymer fiber; shish; volume strain; core fibril; J. Res. 84, No. 5, 359-384 (1979).

Cupric anthranilate; cupric ion-containing hydroxyapatite; reaction kinetics; surface reaction; anthranilic acid; chemisorption; 18972 .

Cupric ion-containing hydroxyapatite; reaction kinetics; surface reaction; anthranilic acid; chemisorption; cupric anthranilate; 18972.

Cure; dielectric analysis; DSC; graphite-fiber; polyphthalocyanine; prepreg; TGA; V/STOL; SP563, pp. 25-31 (Oct. 1979).

Curing shrinkage; glaze; margin staining; roughness; wear; 18684.

Current; impedance; network analyzer; power; reflection coefficient; reflectometer; scattering parameters; six-port; voltage; calibration; 18600 .

Current; impedance; netw ork analyzer; power; reflection coefficient; reflectometer; scattering parameters; six-port; voltage; calibration; 18601 .

Current comparators; current ratios; current transformers; current transformer testing; electronic ratio error set; transformer calibrations; 18624 .

Current crowding; die at tachment evaluation; junction temperature; measurement technology; power transistors; semiconductor devices; thermal characterization; thermal resistance; transistors; SP4OO-14.

Current measurement; electric transmission; electro-optic systems; high voltage; pulse measurement; voltage measurement; 18872 . 
Current ratios; current transformers; current transformer testing; electronic ratio error set; transformer calibrations; current comparators; 18624 .

Current threshold; electrical injury; electrolyte shift; heat effect; injury mechanism; injury statistics; mouth burn; specific electrical effect; arc burn; contact burn; NBSIR 79-1710.

Current transformer testing; electronic ratio error set; transformer calibrations; current comparators; current ratios; current transformers; 18624 .

Current transformers; current transformer testing; electronic ratio error set; transformer calibrations; current comparators; current ratios; 18624.

Curtains; drapes; fabrics; fire; flammability; international; selfextinguishment; ships; standards; NBSIR 79-1596.

Curve fitting; data analysis; data base management; data retrieval; file handling; graphic analysis; IMS information retrieval; KWOC indexing; least-squares; linear regression; M1S; plotting; statistical analysis; Boolean search system; computer programs; 18597.

Curvelinking; hydroxyapatite; sonic velocity; bone; collagen; crosslinking modification; SP525, pp. 179-187 (Apr. 1979).

Custody transfer; density; experimental; extended corresponding states method; hard sphere model; Klosek-McKinley method; liquefied natural gas (LNG); magnetic suspension densimeter; comparisons; correlation; 18775.

Custody transfer; density; flow rate; LNG; mixtures; specific heating value; tank capacity tables; thermophysical properties; total heating value; composition; 18564 .

Custody transfer; density; flow rate; LNG; mathematical models; mixtures; specific heating value; tank capacity tables; thermophysical properties data; total heating value; composition; 18838 .

Custody transfer; density; flowmetering; liquefied natural gas; sampling; cryogenic densimeter; 18396.

Custody transfer; density; gas analysis; gas chromatography; heating value; hydrocarbon; liquefied natural gas; phase equilibrium; pipelines; sampling; NBSIR 78-887.

Custody transfer; density; gas analysis; gas chromatography; heating value; liquefied natural gas; sampling; 18395 .

Customary units; inch; metric units; centimeter; conversion; SP376.

Cut-off frequency; equivalent circuit; modal analysis; scattering matrix; step discontinuity; TEM-cell; variational formulation; coaxial transmission line; NBSIR 79-1606.

Cutting blade; dead-man's handle; disconnect element; lawnmower; motor shaft; brake; coupling device; U.S. Patent $4,158,944$.

$\mathrm{Cw}$ accelerators; electronuclear physics; high duty-cycle; coincidence experiments; correlations in nuclei; 18906.

$\mathrm{Cw}$ laser action; $\mathrm{Cu} \mathbf{I 1} ; 18319$.

$\mathrm{Cw}$ laser damage; DF laser; fusion cast; laser damage; laser window; single crystal; strontium fluoride; antireflection coatings; calcium fluoride; SP541, pp. 78-85 (Dec. 1978).

Cyanoacrylate; dental alloy; initiator; resin; wear; accelerator; alloy; base metal; casting; composite; NBSIR 78-1573.

Cyanoacrylate; hydrolytic stability; adhesion; bioadhesive bond strength; bone; 18638.

Cyanomethyl radical; excited argon atoms; force constants; infrared spectrum; ketenimine; matrix isolation; methyl cyanide; ultraviolet spectrum; vacuum ultraviolet photolysis; charge transfer; 18879 .

Cyclic fatigue life; filament wound tankage; leakage failure mode; linear elastic fracture mechanics; metal liner; composite materials; critical flaw size; SP563, pp. 198-207 (Oct. 1979).

Cyclic module; faithful distributive module; incidence algebra; multiplicative function; quasi-ordered set; topological algebra; automorphism; 18789.

Cylindrical scanning; far field; near field; planar scanning; antenna measurements; 18818 .
Cytochrome P-450; liquid chromatography-mass spectrometry; PCB metabolism; polychlorinated biphenyls; SPS19, pp. 685690 (Apr. 1979).

Cytotoxicity; homeostasis; promotion; RBE; risk; cell-proliferation; cell-turnover; SP554, pp. 41-56 (Sept. 1979).

$\mathrm{C}^{13}$ methanol; FIR laser; laser frequency measurements; 18939.

$\mathrm{C}_{2} \mathrm{H}_{4}$; dielectric virial coefficients; refractive virial coefficients; $\mathrm{SF}_{6} ; \mathrm{CH}_{4}$; collision induced bands; $\mathrm{CO}_{2} ; 18786$.

\section{D}

Daily load profiles; energy consumption; field measurments; hourly load profiles; refrigerator field data; usage profiles; combination refrigerator-freezer field data; NBSIR 79-1781.

Damage analysis; dosimetry standardization; fast breeder reactors; light water reactors; 19012.

Damage penetration; fracture mechanics; fragmentation; glass; grinding; impact; silicon nitride; strength; stress intensity factor; abrasive machining; ceramics; contact stress; SP562, pp. 23-42 (Oct. 1979).

Damage resistant; $\mathrm{Ge}$; $\mathrm{PbF}_{2}$; pulsed $\mathrm{HF}$ laser; antireflection coatings; CdSe; coating substrate; SP541, pp. 257-258 (Dec. 1978).

Damage threshold; electric fields; internal reflection; protective coatings; SP541, pp. 288-295 (Dec. 1978).

Damage threshold; electron avalanche; frequency and pulse width dependencies of the critical field; multiphoton ionization; SPS41, pp. 299-302 (Dec. 1978).

Damage thresholds; dielectric reflectors; electric-field distribution; high-power; reflectance; spectral absorptance; theory; asymmetric absorptance; SP541, pp. 278-287 (Dec. 1978).

Damage thresholds; electric fields; laser damage; nanosecond pulses; pulsewidth dependence; standing waves; thin-film coatings; two-photon absorption; ultraviolet wavelength scaling; SP541, pp. 190-202 (Dec. 1978).

Damage thresholds; fluoroberyllate glass; fluorophosphate glass; inclusions; pulse duration; SP541, pp. 99-108 (Dec. 1978).

Damage thresholds; impurities; laser-induced damage; thermal damage; absorption; antireflection coatings; SP541, pp. 202 211 (Dec. 1978).

Damaged layer; elastic emission machining; environmental effect; hydrate; hydration polishing; mechanochemical polishing with soft powder; pre-existing defect; sapphire; solid state reaction; water vapor; working unit; SP562, pp. 157-169 (Oct. 1979).

Damaged layer; fine polishing; sapphire; silicon; solid state reaction; wear debris; SP562, pp. 325-333 (Oct. 1979).

Damp course membrane; metallic membrane; permeability; preservation technology; adobe building materials; chemical grouts; NBSIR 79-1730.

Damping; dynamic properties; industrial engineering; isolation; machinery and equipment; mechanical impedance; mechanical vibrations; noise control; transmissibility; vibration isolation; vibrations; antivibration mounting; $\mathrm{H} 128$.

Data; digital; ethernet; local; microprocessor; network; serial; broadcast; coaxial; communication; contention; 18760 .

Data; metric; refractory concrete; resource conservation and recovery; chemical degradation; coal conversion; coal gasifier; computers; DIM/NBS 63, No. 12, 1-32 (1979).

Data acquisition; data converters; dynamic measurements; settling time; A/D converters; D/A converters; 18503.

Data acquisition; energy; instrumentation; measurement; thermography; Twin Rivers Project; weather station; air infiltration; buildings; 18733 .

Data acquisition system; digital tape recorder; fuel measurement; instrumentation; total energy; transducers; weather station; NBSIR 79-1709.

Data acquisition systems; data reduction; plotting; computer program; TNI108. 
Data analysis; data basc management; data retricval; filc handling; graphic analysis; IMS information retrieval; KWOC indexing: least-squares; lincar regression; MIS; plotting; statistical analysis; Boolcan scarch system; computcr programs; curve fitting; 18597 .

Data analysis; data compilation; data cvaluation; data cxtraction; data synthcsis; clcctrical resistivity; elcments; gold; metals; molten metals; palladium; precious metals; reference data; silver; solid state physics; JPCRD 8, No. 4, 1147-1298 (1979).

Data availability; dielectronic recombination ratcs; excitation rate coefficients; ionization rate coefficients; magnetic fusion research; transition probabilities; wavelengths; atomic data; 18593.

Data banks; data bases; ergonomics; human factors; product research; 18862 .

Data base; data base management; empirical molecular formula; GPSDC; ion cnergetics; ionization potential; abstract; appearance potcntial; archival tape; computer program; NBSIR $78-1432$

Data base; data base management; file maintenance; reformatting; reorganization; restructuring; SP5OO-47.

Data base; engineering psychology; ergonomics; evaluation; human engineering; human factors; human performance; standard reference data; anthropometry; NBS-GCR-79-169.

Data base; residential buildings; solar data center; solar energy systems; solar heating and cooling; automatic data processing; NBSIR 79-1762.

Data base management; data retrieval; durability; fatigue; interactive system; mathematical modeling; paper; paper fiber; report retrieval; scientific data; computer graphics; NBSIR 79-1746.

Data base management; data retrieval; file handling; graphic analysis; IMS information retrieval; KWOC indexing; leastsquares; linear regression; MIS; plotting; statistical analysis; Boolean search system; computer programs; curve fitting; data analysis; 18597

Data base management; empirical molecular formula; GPSDC ion energetics; ionization potential; abstract; appearance potential; archival tape; computer program; data base; NBSIR 78-1432.

Data base management; file maintenance; reformatting; reorganization; restructuring; data base; $S P 500-47$.

Data bases; ergonomics; human factors; product research; data banks; 18862 .

Data bases; networks; operating systems; protocols; communications; computers; 18488 .

Data center; data processing; information utilization; ADP auditors; audit; SP500-52, pp. 3-8 (Oct. 1979).

Data collection; JES output; job entry subsystem; model design; model selection; remote work stations; simulation model; SP500-52, pp. 123-127 (Oct. 1979).

Data compilation; data evaluation; data extraction; data synthesis; electrical resistivity; elements; gold; metals; molten metals; palladium; precious metals; reference data; silver; solid state physics; transport properties; JPCRD 8, No. 4 , 1147-1298 (1979).

Data compilation; density; electrical conductance; fluorides; halides; iodides; molten salt mixtures; standard reference data; surface tension; viscosity; bromides; chlorides; JPCRD 8, No. 1, 125-302 (1979).

Data compilation; electrochemical energy storage materials; molten salts; physical properties; safety and hazards; thermal energy storage materials; thermal properties; thermodynamic properties; transport properties; corrosion; NSRDS-NBS6I, Part II.

Data compilation; ion thermochemistry; proton affinity; proton transfer equilibrium; NBSIR 79-1777.

Data compilation; phase diagrams; alloy data center; alloy phase diagrams; American Society for Metals; 18645.
Data confidentiality; data integrity; data security; physical security; procedural sccurity; risk analysis; risk assessment; systcms sccurity; ADP availability; annual loss cxposure; application system vulncrability; computer security; FIPS $P U B$ 65

Data converters; dynamic mcasurcments; scttling timc; A/D converters; D/A converters; data acquisition; 18503

Data corrclation; excess volumes; heat of mixing; liquid-vapor cquilibria; methanc + cthanc; binary mixtures; JI'CRD $8, \mathrm{No}_{0}$. 3, $799-816$ (1979).

Data cditing; data flow; data processing; data reductions; raw data conversion to cngincering units; total cncrgy; total cncrgy data flow; computerizcd processing; NBSIR 79.1757.

Data entry; economic considcrations; keyboard; kcypunch; optical character rccognition; optical mark sensing; source data cntry; FIPS PUB 67

Data entry; edit; operator specd; record sizc; transaction volume; transfer speed; validate; verify; application; character set; computer interface; cost; SP50(0-55.

Data evaluation; data extraction; data synthesis; elcctrical resistivity; elements; gold; metals; molten metals; palladium precious metals; reference data; silver; solid state physics; transport properties; copper; JPCRD 8, No. 4, 1147-1298 (1979).

Data evaluation; gas phase ion-molecule reactions; mass spectrometry; organic molecules; rate coefficients; chemical kinetics; NSRDS-NBS64.

Data evaluation; propane; thermal conductivity; viscosity; correlated data; critical point enhancement; JPCRD 8, No. 2 , 559-576 (1979)

Data extraction; data synthesis; elcctrical resistivity; elements; gold; metals; molten metals; palladium; precious metals; reference data; silver; solid state physics; transport properties; copper; critical evaluation; JPCRD 8, No. 4, 1 \47-1298 (1979).

Data flow; data processing; data reductions; raw data conversion to engineering units; total energy; total energy data flow; computerized processing; data editing; NBSIR 79-1757.

Data integrity; data security; physical security; procedural security; risk analysis; risk assessment; systems security; ADP availability; annual loss exposure; application system vulnerability; computer security; data confidentiality; FIPS PUB 65.

Data measurement; measurement; performance measurement; computer; computer communications; computer performance measurement; SP500-52, pp. 201-211 (Oct. 1979).

Data needs; free radicals; modeling; $\mathrm{NO}_{s}$; olefins; $\mathrm{SO}_{s}$; troposphere; aldehydes; aromatics; chemical kinetics; SP557.

Data pooling; data struetures; mathematical programming; matrices; name generation; operations research; programming languages; sparse matrices; J. Res. 84, No. 1, 21-47 (1979).

Data processing; data reductions; raw data conversion to engineering units; total energy; total energy data flow; computerized processing; data editing; data flow; NBSIR 79- 1757.

Data processing; Federal Information Processing Standards Publication; industries; representations and codes; Standard Industrial Classification; computers; FIPS PUB 66.

Data processing; information utilization; ADP auditors; audit; data center; SP500-52, pp. 3-8 (Oct. 1979).

Data reduction; plotting; computer program; data acquisition systems; TNIIO8.

Data reductions; raw data conversion to engineering units; total energy; total energy data flow; computerized processing; data editing; data flow; data processing; NBSIR 79-I757.

Data requirements; documentation cycle; forecast; projeetions; sensitivity analysis; computer workload; SP500-52, pp. 113 120 (Oct. 1979).

Data retrieval; durability; fatigue; interactive system; mathematical modeling; paper; paper fiber; report retrieval; seientific data; computer graphics; data base management; NBSIR 79- 1746 
Data retrieval; file handling; graphic analysis; IMS information retrieval; KWOC indexing; least-squares; linear regression; MIS; plotting; statistical analysis; Boolean search system; computer programs; curve fitting; data analysis; data base management; 18597.

Data security; physical security; procedural security; risk analysis; risk assessment; systems security; ADP availability; annual loss exposure; application system vulnerability; computer security; data confidentiality; data integrity; FIPS PUB 65.

Data structures; mathematical programming; matrices; name generation; operations research; programming languages; sparse matrices; data pooling; J. Res. 84, No. 1, 21-47 (1979).

Data synthesis; electrical resistivity; elements; gold; metals; molten metals; palladium; precious metals; reference data; silver; solid state physics; transport properties; copper; critical evaluation; data analysis; JPCRD 8, No. 4, 1147-1298 (1979).

Data systems; personnel administration; personnel practices; personnel recotds; privacy; record-keeping practices; relevant information; security; citizen rights; computers; computer utilization; confidentiality; SP500-50.

Database; data-description; data-dictionary; data-directory; data-manipulation; DBMS; languages; query; standards; SP500-51.

Database management; model validation; performance evaluation; performance measurement; predictive modeling; setprocessing; simulation; software design; analytic models; SPSO0-49.

Database management; standardization; 18777.

Databases; networks; operating systems; protocols; communications; computers; 18891 .

Data-description; data-dictionary; data-directory; data-manipulation; DBMS; languages; query; standards; database; SP50O51 .

Data-dictionary; data-directory; data-manipulation; DBMS; languages; query; standards; database; data-description; SP50051 .

Data-directory; data-manipulation; DBMS; languages; query; standards; database; data-description; data-dictionary; SPSOO51 .

Data-manipulation; DBMS; languages; query; standards; database; data-description; data-dictionary; data-directory; SPSO0-5I

Dataplot; fitting; graphics; interactive graphics; regression; software; transformation; computing system; 18519 .

Data-reduction technique; low-activity replacement source; measurement technique; scatter contribution; source capsule; source housing; spectrometry results; ${ }^{60} \mathrm{CO}$ gamma-ray beam; calibration source; collimation system; 18416 .

Daylighting; economic analysis; energy conservation; engineering economics; life-cycle costs; solar heat gain; thermal efficiency; window; window management; building economics; BSSI19.

Daylighting; energy; environments; heating; passive; solar; suburban; urban; application; buildings; commercial; 18894 .

Daylighting; energy calculation; energy consumption; fenestration; heating and cooling load; solar heat gain; 19003.

Daylighting; energy conservation; fenestration; solar energy; windows; 18863 .

d-band of $\mathrm{Ni}$; excitons; photoemission; satellite and band narrowing; 18632 .

DBMS; languages; query; standards; database; data-description; data-dictionary; data-directory; data-manipulation; SP500-51.

D-c transmission; deep level measurements; energy conservation; measurement methods; power-device grade silicon; resistivity variations; silicon; spreading resistance measurements; thermally stimulated measurements; thyristor materials measurements; NBSIR 79-1756.
Dc voltage ratio measurement; digital voltage ratio instrument errors; digital voltmeter for ratio measurement; voltage ratio measurement; 19032 .

Dead layer model; external; internal; quantum efficiency; reflectance; response; silicon detector; spatial position dependence; 18900.

Dead layer model; external; internal quantum efficiency; silicon; absolute detector; absorption coefficient; 18477.

Dead-man's handle; disconnect element; lawnmower; motor shaft; brake; coupling device; cutting blade; U.S. Patent $4,158,944$.

Deafness; developmentally disabled; epilepsy; fire safety; group homes; handicapped; mental retardation; ambulatory people; autism; cerebral palsy; NBS-GCR-79-167.

Deane Judd; selected writings; spectrophotometry; color; colorimetry; color spacing; color vision; SP545.

Death; evacuation; fires; flashover; hospitals; human behavior; nursing staff; patients; room fires; breathing apparatus; NBSGCR-78-140.

Death; fire investigations; fire statistics; pathology; toxic gases; alcohol intoxication; autopsy; building fires; cigarettes; NBSGCR-79-168.

Debris monitoring; diagnostic techniques; failure detection; lubrication system monitoring; aircraft component failure; condition monitoring; SP547, pp. 330-344 (July 1979).

Debye temperature; iron alloy; magnetic susceptibility; spinglass, sound velocity; 18763 .

Decay of ${ }^{186 m} \mathrm{Ho}$; nuclear orientation; nuclear spin system; ${ }^{168} \mathrm{Ho}^{165} \mathrm{Ho}$; atomic magnetic structures; conical spin structure; 18604 .

Decay probability; isomeric transition; liquid scintillation counting; photon counting; radioactivity; ${ }^{12} \mathrm{Sn}^{m}$ decay scheme; coincidence counting; 18841 .

Decision analysis; decisions; eigenvectors; management; multiple-attribute decisions; ordering; paired comparisons; prioritization; project selection; ranking; resource allocation; weighting multiple criteria; 18602 .

Decision analysis; fire losses; furniture; hazard analysis; probability; residential buildings; sensitivity analysis; smoke detectors; standards; upholstered furniture; building fires; costbenefit analysis; costs; TNI10I.

Decision criteria; demolition; housing needs; physical condition rehablitation; SP536, pp. 75-81 (Feb. 1979).

Decision tables; earthquake-resistant design; information networks; network; seismic design; systems analysis; building codes; buildings; building standards; classification; TNI 100 .

Decision tables; formulation analysis; information networks; regulations; standards; SP552, pp. 249-266 (July 1979).

Decision theory; computer measurement; computer procurement; computer selection; SP500-52, pp. 37-52 (Oct. 1979).

Decisions; eigenvectors; management; multiple-attribute decisions; ordering; paired comparisons; prioritization; project selection; ranking; resource allocation; weighting multiple criteria; decision analysis; 18602 .

Decomposition; free radicals; hydrocarbons; hydrogen; nitrogen; organic compounds; oxidation; oxygen; oxygenated; rate constant; sulfur; Arrhenius parameters; combustion; NBSIR 79-1941.

Deconvolution; geometrical-optics radiometry; inversion; measurement-beam geometry; relative spectral responsivity; slitscattering function; slit-scattering function corrections; spectral line radiometry; spectroradiometer characterizations; spectroradiometry; vignetting; TN9/0-4.

De-convolution; liver; power spectrum; signal processing; tissue characterization; tissue parameters; ultrasound; attenuation; B-san; cepstrum; computer; convolution; SP525, pp. 287-295 (Apr. 1979).

Deep level measurements; defect center characterization; defect density; ion implantation; silicon; sulfur; sulfur energy 
level in silicon; thermally stimulated eapacitance; thermally stimulated current; 18458 .

Deep level measurements; defect mapping; hot/cold wafer chuck: thermally stimulated measurements; thermal wafer chuck; variahle temperature; wafer chuck; SP400-55.

Deep level measurements; energy conservation; measurement methods; power-device grade silicon; resistivity variations; silicon; spreading resistance measurements; thermally stimulated measurements; thyristor materials measurements; thyristor measurements; NBSIR 79-1756.

Defect: energy; hydrocarbon; methyl-hranch; structure; calculations; cell dimensions; crystal; 18787 .

Defect center characterization; defect density; ion implantation; silicon; sulfur; sulfur encrgy level in silicon; thermally stimulated capacitancc; thermally stimulated current; deep level measurements; 18458 .

Defect density; ion implantation; silicon; sulfur; sulfur energy level in silicon; thermally stimulated capacitance; thermally stimulated current; deep level measurements; defect center characterization: 18458 .

Defect geometry; fluid elasticity; liquid penetrant testing; Rideal-Washhurn equation; surface tension; J. Res. 84, No. 4, 287-292 (1979).

Defect mapping; hot/cold wafer chuck; thermally stimulated measurements; thermal wafer chuck; variable temperature; wafer chuck; deep level measurements; SP400-55.

Defects; Doppler broadening; hardness; positron annihilation; titanium; 18967.

Defects; elastic solid; pulses; scattering; ultrasonic; acoustic; crack; 18391 .

Defects; etching; glass; grinding; polishing; strength; SP562, pp 489-50) (Oct. 1979).

Defects; laser damage; sodium fluoride; absorption; arsenic selenide; arsenic trisulfide; SP541, pp. 212-217 (Dec. 1978).

Definitc integrals; double integrals; error functions; Fourier transforms; radiation reaction; J. Res. 84, No. 4, 319-326 (1979).

Definitions; flux phenomena; Josephson phenomena; stabilization; superconductors; terminology; critical parameters; 18681 .

Definitions of terms; measurement techniques; standards; superconductors; critical current; 18762 .

Definitive method; electrolytes; flame atomic emission spectroscopy; reference method; semiautomated pipetting; serum potassium analysis; statistical analysis; clinical analysis; clinical chemistry; $S P 260-63$.

Definitive method; electrolytes; reference method; serum chloride analysis; statistical analysis; amperometry; chloride analysis; clinical analysis; clinical chemistry; coulometry; SP26()-67.

Degradation; epoxy resins; Kevlar 49; moisture; one-tenth scale motor case; S-glass; temperature effects; water boil; SP563, pp. 177-197 (Oct. 1979)

Degradation: IR; photodegradation; poly (methyl methacrylate); UV; visible; NBSIR 79-1766.

Degradation; multifilamentary strain; $\mathrm{Nb}_{3} \mathrm{Sn}$; stress; superconductor; critical-current; critical-field; 18780 .

Degradation; $\mathrm{Nb}_{3} \mathrm{Ge}$; strain; stress; superconductor; critical-current; 18781 .

Degradation apparatus; factor-jump thermogravimetry; polymer dcgradation; polymer oxidation; programmed temperature control; thermogravimetry; activation energy; 18450 .

Degradation of benzoyl peroxide; dental composites; restorative dental resins; shelf-life of composites; storage stability; amine accelerators; 18809 .

Degradation of polymers; error propagation; factor-jump method; heating rate; lifetime prediction; polystyrene; polyurethane; thermogravimetry; weight-loss kinetics; aging of polymers; 18620 .
Delamination mechanisms; energy relcase rate; finite element method; free-cdge stresses; graphitc epoxy composites; interlaminar cracks; stability of cracks; virtual crack closure; SP563, pp. 255-264 (Oct. 1979).

Delay linc; discriminator; fiber optics; phase discriminator; 18547.

Delayed coincidence; $f$-value; imprisonment; laser; lifetime; mcan life; oscillator strength; Al r; aluminum; 18527.

Delayed ncutrons; Einstein model: fission; temperature effects; thermal; ${ }^{23} \mathrm{U}$; chemical effects; 18687

Delbruck scattcring; elastic scattering; giant resonance; tensor polarizahility; Thomson scattering; cohcrent scattering; 18521 .

$d$-electron energy band parameters; $d$-electron transfer; heats of formation; transition metal alloys; 19047.

$d$-electron transfer; heats of formation; transition metal alloys; $d$-electron energy band parameters; 19047

Delphi Method; fire safety; health care facilities; hospitals; interior finishes; Life Safety Code; nursing homes; risk analysis; safety equivalency; safety evaluation; smoke detection; automatic sprinklers; building codes; building construction; NBSIR $78-1555$

Demographics; developmental disabilities; fire protection; group homes; household activities; room use; NBSIR 79-1727.

Demolition; economics; historic preservation; life-cycle costing; redevelopment; rehabilitation; tax incentives; adaptive reuse; buildings; TN980.

Demolition; economics; historic preservation; life-cycle costing; redevelopment; rehabilitation; tax incentives; adaptive reuse; buildings; 19016.

Demolition; housing needs; physical condition rehablitation; decision criteria; SP536, pp. 75-81 (Feb. 1979).

Demonstration project; ETIP; evaluation; information intervention; integrated utility systems; case study; cogeneration; NBS-GCR-ETIP 78-59

Denmark; economics of standards; government policy; international standards; laboratory accreditation; standards systems; United Kingdom; West Germany; antitrust; Canada; certification; NBS-GCR-79-172.

Densimeter; magnetic suspension; position detector; capacitance sensor; 18962

Densimeters; density reference system; liquid methane; LNG; cryogenic; 18805 .

Densities; enthalpies; entropies; equation of state; internal energies; isobars; isobutane; isochores; isotherms; Joule-Thomson inversion; latent heats of vaporization; melting line; orthobaric densities; specific heats; speeds of sound; vapor pressures; NBSIR 79-1612.

Densities; enthalpies; entropies; equation of state; internal energies; isobars; isochores; isotherms; Joule-Thomson inversion; latent heats of vaporization; melting line; n-butane; orthobaric densities; specific heats; speeds of sound; vapor pressures; NBSIR 79-1621.

Density; dielectric constant; oxygen; capacitor; 18987 .

Density; electrical conductance; fluorides; halides; iodides; molten salt mixtures; standard reference data; surface tension; viscosity; bromides; chlorides; data compilation; JPCRD $\mathbf{8}$, No. 1, 125-302 (1979).

Density; electrical resistivity; graphite; Lorenz ratio; reference materials; thermal conductivity; characterization; 18668 .

Density; experimental; extended corresponding states method; hard sphere model; Klosek-McKinley method; liquefied natural gas (LNG); magnetic suspension densimeter; comparisons; correlation; custody transfer; 18775 . 
Density; flow rate; LNG; mathematical models; mixtures; specific heating value; tank capacity tables; thermophysical properties data; total heating value; composition; custody transfer; 18838 .

Dcnsity; flow rate; LNG; mixtures; specific heating value; tank capacity tables; thermophysical properties; total heating value; composition; custody transfer; /8564.

Density; flowmetering; liquefied natural gas; sampling; cryogenic densimeter; custody iransfer; $/ 8396$.

Density; gas; nitrogen; sound velocity; thermodynamic properties; virial coefficients; $\mathbf{I 8 8} / 5$.

Densify; gas analysis; gas chromatography; heating value; hydrocarbon; liquefied natural gas; phase equilibrium; pipelines; sampling; custody transfer; NBSIR 78-887.

Density; gas analysis; gas chromatography; heating value; liquefied natural gas; sampling; custody transfer; $/ 8395$.

Density reference system; liquid methane; LNG; cryogenic; densimeters; 18805 .

Density wave oscillations; flow oscillations; flow stability; liquid helium; superconducting power transmission lines; supercritical helium; 18567.

Dental; dimensional change; dispersion type alloy; high copper; single alloy; amalgam; creep; 18729 .

Dental; monomers; resins; surface-active comonomers; acrylates; adhesion, dental; bonding; coupling agent; /8461.

Dental adhesive; dentin; durability of dentin acrylic bond; isobutyl 2-cyanoacrylate; pretreatment of dentin; 2cyanoacrylate esters; adhesive; bonding to dentin; 18985 .

Dental alloy; initiator; resin; wear; accelerator; alloy; base metal; casting; composite; cyanoacrylate; NBSIR 78-1573.

Dental analgam; dimensional changes; extrusion of restorations; marginal fracture; zinc effect; creep; 18586 .

Dental composites; restorative dental resins; shelf-tife of composites; storage stability; amine accelerators; degradation of benzoyl peroxide; 18809 .

Dental handpiece; dental materials; dental radiography; dental research; Nelsen, Robert is Callahan Memorial Award; 18497.

Dental history; dental instruments; dental materials; dental research; National Bureau of Standards; American Dental Association; 18676.

Dental instruments; dental materials; dental research; National Bureau of Standards; American Dental Association; dental history; 18676.

Dental materials; dental radiography; dental research; Nelsen, Robert L; Callahan Memorial Award; dental handpiece; 18497.

Dental materials; dental research; National Bureau of Standards; American Dental Association; dental history; dental instruments; 18676.

Dental materials; dimensional changes; physical properties; thermal expansion; wear; wear tests; amalgam; composites; 18649.

Dental materials; glass compositions; methacrylate monomers; polymerization accelerators; reinforcing fillers; silane coupling agents; benzoyl peroxide; composite resins; 18644 .

Dental materials; primates; pulp response; toxicology; chemical composition; composite resins; 18690.

Dental radiography; dental research; Nelsen, Robert 1: Callahan Memorial Award; dental handpiece; dental materials; 18497.

Dental research; National Bureau of Standards; American Dental Association; dental history; dental instruments; dental materials; $/ 8676$.

Dental research; Nelsen, Robert \&. Callahan Memorial Award; dental handpiece; dental materials; dental radiography; 18497.

Dental studies; dentin; enamel; microanalysis; mineralizing tissue; Raman inicroprobe; Raman spectroscopy; biological microanalysis; biological mineralization; bone; 19008 .
Dental studies; enamel; mineralizing tissue; Raman microprobe; Raman spectra; Raman spectroscopy; tissue sections; tooth; biological microanalysis; biological tissue; 18982 .

Dentin; durability of dentin acrylic bond; isobutyl 2-cyanoacrylate; pretreatment of dentin; 2-cyanoacrylate esters; adhesive; bonding to dentin; dental adhesive; 18985 .

Dentin; enamel; microanalysis; mineralizing tissue; Raman microprobe; Raman spectroscopy; biological microanalysis; biological mineralization; bone; denta! studies; $/ 9008$.

Dentin; hydrolytic stability of bonds; isobutyl 2-cyanoacrylate; mineralized tissue; 2-cyanoacrylate esters; adhesion; bonding to mineralized tissues; bone; 18569 .

Depth image; proximity sensor; robot vision; teleoperator vision; wrist-mounted TV; NBSIR 78-1576.

Derivative spectra; infrared analysis; spectral coincidences; Stark modulation; Stark spectroscopy; trace gas analysis; $\mathrm{CO}_{2}$ lascr; 18538 .

Derivative spectroscopy; PNA analysis; trace organic analysis; absorption spectroscopy; SP519, pp. $719-722$ (Apr. 1979).

Derivatization; quaternary two-phase systems; serum; uv-detection; tricyclic antidepressives; benzodiazepines; clinical use; SP519, pp. 461.468 (Apr. 1979).

Design; economics; efficiency; energy; energy budget; equity; life-cycle cost; optimal; standard; buildings; conservation; criteria; 18888 .

Design; energy; legislation; solar; standards; State; buildings; NBSIR 79-1705.

Design; engineering judgment; factor of safety; fatigue; mathematical modeling; nuclear engineering; reliability; risk; safety factor; sampling; Weibull distribution; corrosion fatigue; 18326.

Design allowables; aircraft; composites; SP563, pp. $72-79$ (Oct. 1979).

Design criteria; glued-laminated timber; safety; temporary structures; wood; bridges; buildings; 18887 .

Design criteria; guide specifications; habitability criteria; Computer-Aided Engineering and Architectural Design System (CAEADS); SP552, pp. 167-183 (July 1979).

Design process; man/environment research; post-occupancy evaluation; questionnaire; user needs; building evaluation; NBSIR 79-1780.

Design professionals; energy audits; energy codes; Kentucky Fire Marshal's office; lighting and thermal efficiency standards; local governments; new construction plans review; training and education; SP552, pp. 121-130 (July 1979).

Design rules; intradie parametric integrity; LSI circuits; mask alignment tolerances; modular test programs; parametric yield limitations; performance limitations; photomask performance; process control; test patterns; test structures; total process integration; SP400-56.

Design specifications; requirements definition; software certification; software development; software reliability; software validation; 18882 .

Design using composites; fiber composites; fiber glass; filament wound corrsposites; advanced composites; applications of composites; composites; composite structures; SP563.

Dessicant; discrete; displacement; fiber optics; filters; flight critical; flow; fluid; go-no-go; ground readout; hydraulic; IMACS; instantaneous diagnosis and analysis; level; maintenance oriented; malfunction detection; monitoring; SP547. pp. 345-357 (July 1979).

Destructive evaluation; fatigue flaw evaluation; fracture mechanics; standards; technique development; compact tension specimen; crack; crack, well-characterized; 18744 .

Detachment; dissociation; elastic scattering; electron; excitation; ion; ionization; molecule; photon; positron; atom; collision cross section; SP426. Supplement 1.

Detection; diagnosis; prognosis; SP547, pp. 36-57 (July 1979). 
Detection; electronic lock; exclusion area; forced entry deterrent systems; guard control station; higher headquarters; pcrimeter station; remote unit; response force; triply redundant central computer; central unit; computerized; NBSIR 79-1725.

Dctection; electronic package; impact noise; microcircuit device; particle detection; particle impact noise detection; PIND; pre-shock; seeded specimens; transducer; acoustic emission; co-shock; couplant; NBSIR 78-1590 (NASA).

Detection; fires; home fires; residential smoke detectors; smoke detectors; 18514

Detection efficiency; Lixiscope; radioactive $x$-ray source; rareearth scintillator screen; ${ }^{125} 1$; ${ }^{153} \mathrm{GD}$; Csl; 19001 .

Detection of lung disease; frequency signature; statistical scattering; tissue signature; ultrasonic scattering; ultrasound; SP525, pp. 135-141 (Apr. 1979).

Detection procedures; mechanical failures; steam-valves; turbine operational safety; turbogenerators; SP547, pp. 250-279 (July 1979).

Detection sensitivity; dipeptides; drugs; HPLC; ion-pair adsorption; ion-pair chromatography; ion-pair partition; metabolites; psychotropic amines; selectivity; sulphonamides; amino acids; barbiturates; carboxylic acids; catecholamines; SP519, pp. 509-523 (Apr. 1979).

Detection time; detector location; fire tests; gas detectors; kitchen fires; mobile homes; smoke detectors; tenability limits; upholstered furniture; NBSIR 79-1915.

Detector; electrically calibrated detectors; laser power measurements; pyroelectric detectors; radiometry; silicon cell; silicon detector; silicon photodetector; absolute radiometry; 18773 .

Detector; electrically calibrated detectors; laser power measurements; pyroelectric detectors; radiometry; silicon cell; silicon detector; silicon photodetector; absolute radiometry; 18774 .

Detector; high resolution detector; phase sensitive detector; programmable detector; a-c detector; automatic bridge; 18453.

Detector; high-performance liquid chromatography; light-scattering; lipids; nephelometry; oils; reversed-phase; serum; cerebrospinal fluid; SP519, pp. 429-436 (Apr. 1979).

Detector design; gas chromatography; liquid chromatography; selective detection; SP519, pp. 547-585 (Apr. 1979).

Detector location; fire tests; gas detectors; kitchen fires; mobile homes; smoke detectors; tenability limits; upholstered furniture; detection time; NBSIR 79-1915.

Detector response functions; dosimetry; electrons; foil transmission; photons; stopping power; transport theory; absorbed dose; attenuation coefficient; 18371 .

Detector sensitivity; gas chromatography; glass capillary columns; high-performance liquid chromatography; LC microcapillary columns; selective detectors; ancillary methods; bonded phases; chromatographic preconcentration; SP519, pp. 487-499 (Apr. 1979).

Detectors; dose; fast; neutrons; track; activation; SP554, pP. 99-107 (Sept. 1979).

Detectors; dosimetry; leakage; linear accelerators; neutrons; betatrons; SP554, pp. 129-138 (Sept. 1979).

Detectors; fire detectors; fire growth; heat detectors; room fires; smoke detectors; spacing; velocity; beams; ceiling height; NBS-GCR-78-128.

Detectors; fire detectors; fire growth; heat detectors; room fires; smoke detectors; spacing; velocity; beams; ceiling height; NBS-GCR-78-129.

Detectors; light emitting diode; 18848 .

Deuterium; hydrogen; ion dynamic effect; plasma line shift; spectral lines; Stark broadening; 18948.

Deuterium; interstellar medium; Lyman-alpha; 18753.

Developing countries; industrialization; Latin America; management; measurement; metrology; quality control; standards; technology transfer; UN Conference on Science and
Technology for Development (UNCSTD); Africa; Asia; SP543.

Developing countries; industrializing countries; Korea; measurements; metrology; physical standards; seminar; South Asia; SP539.

Developing economies; foreign relations; industrializing nations; international relations; LDC's; measurement services; standardization; AID; assistance; NBSIR 78-17/2.

Developing economies; foreign relations; industrializing nations; international relations; measures; weights; weights and measures; AID; assistance; NBSIR 79-1721.

Developmental disabilities; fire protection; group homes; household activities; room use; demographics; NBSIR 791727.

Developmentally disabled; epilepsy; fire safety; group homes; handicapped; mental retardation; ambulatory people; autism; cerebral palsy; deafness; NBS-GCR-79-167.

Device characterization; nondestructive testing; safe operating area, reverse-bias; second-breakdown, reverse-bias; transistors, power switching; 18738 .

Device measurements; laser scanning; light-biasing; metallization; ohmic contacts; reliability; semiconductor measurements; sheet resistance; solar cells; solar cell stability; NBSIR 79-1909.

Device measurements; laser scanning; metallization; ohmic contacts; reliability; semiconductor measurements; solar cells; solar cell stability; workshops; 18633 .

Device safety performance classification; gauges; gauging devices; ionizing radiation; radiation measurements; radiation safety; standard; HI29.

Dextromethorphan; gas-liquid chromatography; human plasma; nitrogen-sensitive detector; antitussive; SP5/9, pp. 481-485 (Apr. 1979).

DF laser; fusion cast; laser damage; laser window; single crystal; strontium fluoride; antireflection coatings; calcium fluoride; cw laser damage; SP541, pp. 78-85 (Dec. 1978).

Diacetylurea; molecular structure; urea; urea determination; $\mathrm{x}$ ray diffraction; biomedical standard; 18347 .

Diagnosis; Doppler; screening; ultrasonics; blood flow; brcast cancer; SP525, pp. 173-176 (Apr. 1979).

Diagnosis; emissions inspections; fault detection; fuel economy; motor vehicle; SP547, pp. 78-97 (July 1979).

Diagnosis; prognosis; detection; SP547, pp. 36-57 (July 1979).

Diagnosis-ultrasonic; tissue equivalent test objects and phantoms; ultrasonic tissue characterization; ultrasound imaging; computed tomography-ultrasonic; SP525, pp. 337-340 (Apr. 1979 ).

Diagnostic connector assembly; fighting vehicle systems; generic DCA; Hull systems; simplified test equipment for internal combustion engines; turret systems; vehicle maintenance; combat vehicles; SP547, pp. 98-110 (July 1979).

Diagnostic equipment; shock pulse; aircraft diagnostics; bcaring; condition monitoring; SP547, pp. 31-35 (July 1979).

Diagnostic radiology; scatterer thickness; scatterer to image plane separation; tissue equivalent phantoms; $x$-ray beam diameter; $x$-ray energies of 30 to $70 \mathrm{keV}$; $x$-ray scatter; $1844 I$.

Diagnostic techniques; failure detection; lubrication system monitoring; aircraft component failure; condition monitoring; debris monitoring; SP547, pP. 330-344 (July 1979).

Diagnostic testing; performance assurance; performance evaluation; remote monitoring; system sccurity testing; SP500-42.

Diagonal matrix; field of values; Hadamard product; inclusion theorem; Kronecker product; numerical radius; spectrum; stable matrix; closure; D-stability; 18909.

Diagrammatic perturbation theory; electron correlation; ionization energies; line strengths; many-body interaction; manybody perturbation theory; oscillator strengths; copper isolectronic sequence; 18998 . 
Diamond contour grinding; flexure strength; prosthetic device; serrated surface design; tooth roots; alumina; SP562, pp. 247-254 (Oct. 1979).

Diamond drilling; drilling; drilling additives; Rehbinder effect; rock fracture; surface chemistry; wear; SP562, pp. 115-137 (Oct. 1979).

Diamond single-point machining; dielectrics; infrared optical components; laser damage; optical properties; SP562, pp. 293-303 (Oct. 1979).

Diamond single-point machining; high fluence; laser irradiation; ceramic surfaces; SP562, pp. 513-518 (Oct. 1979).

Diamond-anvil; glass transition; high pressure; hydrostaticity; liquids; pressure cell; viscosity; 18509 .

Diamonds; erosion; grinding; wear; bronze binder; SP562, pp. 147-155 (Oct. 1979).

Diamond-turning; scattered light; surface roughness; absorption; SP541, pp. 122-130 (Dec. 1978).

Dianabol; gas chromatography-mass spectrometry (gc/ms); gas liquid chromatography (glc); $\mathrm{gc} / \mathrm{ms}$ interface; high performance liquid - chromatography (hplc); inert columns; metabolism; methandienone; urine; anabolic steroids; SP519, pp. 437-445 (Apr. 1979).

Dichlorocarbene; heat of formation; ion-molecule reactions; proton affinity; proton transfer reaction; 18331 .

Dicumyl peroxide; elasticity theory of rubber; modulus of rubber; Mooney-Rivlin constants; rubber elasticity theory; rubber, natural; swelling of rubber network; cross-linking of rubber; J. Res. 84, No. 5, 353-358 (1979).

Didymium glass filter; passband centroid; spectrophotometer; transmittance; wavelength standard; bandwidth; SP260-66.

Die attachment; electrical properties; electronics; hermeticity; indium-doped silicon; infrared reflectance; in tegrated circuits; line-width measurements; oxidation; photolithography; photovoltaic method; power-device grade silicon; radioisotope leak test; $S P 4 O O-38$.

Die attachment evaluation; junction temperature; measurement technology; power transistors; semiconductor devices; thermal characterization; thermal resistance; transistors; current crowding; SP4OO-14.

Dielectric; dissipation factor; loss angle; microphonic coupling; phase angle; surface films; capacitor; cross capacitor; 18454.

Dielectric analysis; DSC; graphite-fiber; polyphthalocyanine; prepreg; TGA; V/STOL; cure; SPS63, pp. 25-3I (Oct. 1979).

Dielectric constant; dielectric loss; lunar soil; microwave; profile effect on permittivity; temperature variation of permittivity; 18557 .

Dielectric constant; dielectric loss; lunar sample; temperature variation of dielectric parameters of soil; cavity resonance; coaxial line resonator; 18566 .

Dielectric constant; oxygen; capacitor; density; $l 8987$.

Dielectric constant of water; interpolating equation dielectric; steam; table-dielectric constant of water; thermophysical properties of water; water; 18937.

Dielectric loss; dissipation factor; high voltage; low temperature polymer; cryogenic; 18384 .

Dielectric loss; lunar sample; temperature variation of dielectric parameters of soil; cavity resonance; coaxial line resonator; dielectric constant; 18566 .

Dielectric loss; lunar soil; microwave; profile effect on permittivity; temperature variation of permittivity; dielectric constant; 18557.

Dielectric loss; polymer films; polymers; polypropylene; polyurethane; superconducting power cable; tan $\delta$; cryogenic temperature; 18713 .

Dielectric losses; superconducting losses; superconducting microcircuit; superconducting striplines; 18486 .

Dielectric measurements; dielectric relaxation time; timedomain; transmission lines; 18723
Dielectric reflectors; electric-field distribution; high-power; reflectance; spectral absorptance; theory; asymmetric absorptance; damage thresholds; SP541, pp. 278-287 (Dec. 1978).

Dielectric relaxation time; time-domain; transmission lines; dielectric measurements; 18723 .

Dielectric solids; electrons, conduction band (CB); laser damage; conduction band (CB) electrons; SP541, pp. 303304 (Dec. 1978).

Dielectric strength; electrets; piezoelectricity; polarization; poling procedures; polymers; poly(vinylidene fluoride); pyroelectricity; transducers; J. Res. 84, No. 6, 447-453 (1979).

Dielectric virial coefficients; refractive virial coefficients; $\mathrm{SF}_{\mathrm{H}}$; $\mathrm{CH}_{4}$; collision induced bands; $\mathrm{CO}_{2} ; \mathrm{C}_{2} \mathrm{H}_{4} ; 18786$.

Dielectrically loaded cavity; frequency stability; second-order Doppler shift phase modulation; spin exchange; temperature coefficient; time dispersion; wall shift; amplitude modulation; cavity pulling; cavity servo; 18696 .

Dielectric-constant; electrets; electrocaloric effect; entropy; ferroelectrics; glass-ceramics; heat switches; magneto-thermal conductivity; polarization; potassium tantalate; refrigeration; specific heat; strontium titanate; beryllium; ceramics; cryogenics; 18680 .

Dielectrics; frequency-domain measurements; magnetic materials; microwaves; millimeter waves; permeability measurements; permittivity measurements; radar absorbers; timedomain measurements; NBSIR 79-1613.

Dielectrics; infrared optical components; laser damage; optical properties; diamond single-point machining; SP562, pp. 293303 (Oct. 1979).

Dielectronic recombination; highly ionized; impurity; molybdenum; plasma; atomic physics; 18949.

Dielectronic recombination rates; excitation rate coefficients; ionization rate coefficients; magnetic fusion research; transition probabilities; wavelengths; atomic data; data availability; 18593.

Diesel engine analyzer; automatic test system; SP547, pp. 176 190 (July 1979).

Differential attenuation; tumor; ultrasound; characterization; SP525, pp. $121-124$ (Apr. 1979).

Differential cross section; Fermi gas; lithium; optical potentials; photopion; pion; beryllium; 18442 .

Differential cross section; Fermi gas; lithium; optical potentials; photopion; pion; beryllium; 18496 .

Differential diagnosis; medullary carcinoma; papillary carcinoma; scirrhous carcinoma; shadowing; ultrasound; attenuation; breast cancer; cancer; connective tissue; SP525, pp. 9399 (Apr. 1979).

Differential equations; mathematical software; non-linear oscillations; algebra by computer; J. Res. 84, No. 4, 293-297 (1979).

Differential pumping across capillary arrays; focused vacuum ultraviolet; heat-pipe oven use in the vacuum ultraviolet; multichannel capillary arrays; vacuum ultraviolet spectroscopy; vacuum ultraviolet windows; 18808 .

Differential scanning calorimetry; heat of fusion; lecithins; lipids; melting temperature; metastable states; phenyl substituted diglycerides; phospholipids; polymorphism; recrystallization temperature; benzyl substituted diglycerides; 18380 .

Diffraction; isotopes; molecular dynamics; neutron; neutron radiography; nondestructive evaluation; nuclear reactor; radiation; activation analysis; crystal structure; TN995.

Diffraction; $\mathrm{Li}_{5} \mathrm{~B}_{4}$; neutron powder; structure; $\mathrm{x}$ ray; crystal; 18382 .

Diffuse reflectance standards; solar absorptance; solar optical properties; solar reflectance; solar transmittance; spectral reflectance standards; terrestrial solar irradiance; 18501 . 
Diffusion; diffusion coefficient; light scattering; polydisperse; polydispersity; polystyrene; quasielastic light scattering; SRM706; standard reference material; 18511 .

Diffusion; dissolved oxygen; mathematical model; oxygen; oxygen sensor; permeation; polarographic sensor; polymer membrane; NBSIR 79-1740.

Diffusion; electronic technology; impurity distribution; material transport; segregation; semiconductor technology; SP400-57.

Diffusion; energy; hydrides; hydrogen storage; nuclear magnetic resonance; nuclear spin relaxation; 18352

Diffusion; grain boundaries; Harrison classification; lattice diffusion; migrating boundaries; polycrystals; thin films; 18758 .

Diffusion; grain boundaries; Harrison classification; lattice diffusion; migrating boundaries; polycrystals; thin films; 18759 .

Diffusion; quasielastic scattering; tantalum hydride; vanadium hydride; $\alpha$ phase; $485 \mathrm{~K} ; 18730$.

Diffusion bonding; measurement assurance program; reference blocks; standards; ultrasonics; variability; calibration; NBSIR 79-1742.

Diffusion coefficents; iteration; moisture profile modeling; nondestructive evaluation; statistical estimation; SP563, Pp. 32 46 (Oct. 1979).

Diffusion coefficient; $E$. coli ribosomal subunit; quasielastic light scattering; 45 S and 50S; J. Res. 84, No. 1, 1-8 (1979).

Diffusion coefficient; light scattering; polydisperse; polydispersity; polystyrene; quasielastic light scattering; SRM-706; standard reference material; diffusion; 18511 .

Diffusion flames; fire entrainment; flame oscillations; plume; scaling; buoyancy; NBSIR 79-1910.

Diffusion in silicon; integrated circuit processing; kinetics of oxide growth; oxidation of silicon; semiconductor processing; silicon; silicon dioxide; thermally stimulated measurement; thermal oxidation; $\mathrm{Zn}$-doped glasses; boron nitride; $\mathrm{Cl}$-doped glasses; NBS-GCR-78-134.

Diffusion mechanisms; inelastic scattering; neutron scattering; orientational disorder; rotational dynamics; condensed phases; 19026.

Diffusion tubes; OSHA; primary standards; SP519, pp. 761-769 (Apr. 1979).

Digital; ethernet; local; microprocessor; network; serial; broadcast; coaxial; communication; contention; data; 18760 .

Digital acquisition; digital signal processing; pulse-echo techniques; spectrum analysis; ultrasonics; acoustic; computer processing; SP525, pp. 281-286 (Apr. 1979).

Digital demodulator; frequency-lock servo; frequency standard; inversion transition in ammonia; precision; acceleration insensitive oscillator; ammonia microwave absorption; atomic clock; cavity frequency stabilization; 18698 .

Digital electronics; magnetometry; quantum interference; superconductivity; 18701 .

Digital periodic integrator; electron microprobe; homogeneity; standard reference materials; steel; SP260-65.

Digital periodic integrator; electron microprobe; homogeneity: standard reference materials; standards; 18973.

Digital processing; Fast Fourier Transform; frequency spectra; in vivo; microprocessor-controlled data acquisition; myocardial infarction; real-time; tissue characterization; ultrasound diagnosis; clinical cardiac data; SP525, pp. 267-273 (Apr. 1979).

Digital sampling; Fourier optics; holography; laser; laser parameters; laser pulse; optical processing; phase; precision measurements; wave front; amplitude; beam profile; cross correlation; TN1009.

Digital signal processing; pulse-echo techniques; spectrum analysis; ultrasonics; acoustic; computer processing; digital acquisition; SP525, pp. 281-286 (Apr. 1979).

Digital signatures; encryption; identifiers; key management; key notarization; cryptography; SP500-54.

Digital signatures; encryption; identifiers; key management; key notarization; cryptography; 19039.
Digital tape recorder; fuel measurement; instrumentation; total energy; transducers; weather station; data acquisition system; NBSIR 79.1709.

Digital voltage ratio instrument errors; digital voltmeter for ratio measurement; voltage ratio measurement; dc voltage ratio measurement; 19032 .

Digital voltmeter for ratio measurement; voltage ratio measurement; dc voltage ratio measurement; digital voltage ratio instrument errors; 19032.

Digital waveform synthesis; phase angle; phase measurement; phase meter; waveform generator; calibration; 18434 .

Digital-to-analog converter; high resolution; multirange; $\mathbf{R}-2 \mathbf{R}$ ladder; relay switching; self-calibration; twenty bits + sign; voltage output; TN1105

Digital-to-analog converter; IEEE subcommittee; performance specifications; sample/hold circuit; standards; terminology; analog-to-digital converter; 18365 .

Digitized data; spectrum analyzers; steady state mode; tolerance vibration levels; automatic diagnostics; SP547, pp. 286-295 (July 1979).

Dilution effect, at same $\mathrm{pH}$ and concentration; hydration shell, role of; hydroxylapatite, at different $\mathrm{pHs}$; isotopic exchange, isoionic; recrystallization, role of; surface layer, role of; $J$. Res. 84, No. 5, 395-406 (1979).

Dilution refrigerators; helium 3; Japan; millikelvin research; nuclear cooling; Pomeranchuk refrigerators; solid $\mathrm{He}^{3}$; superfluid $\mathrm{He}^{\mathrm{a}}$; symposium; cryogenics; 18679.

Dimensional change; dispersion type alloy; high copper; single alloy; amalgam; creep; dental; 18729 .

Dimensional changes; extrusion of restorations; marginal fracture; zinc effect; creep; dental amalgam; 18586.

Dimensional changes; physical properties; thermal expansion; wear; wear tests; amalgam; composites; dental materials; 18649.

Dimensional coordination; metrication; SI; stages in metrication; construction specifications; conversion approaches; 18493.

Dimensional metrology; fundamental constants; gyromagnetic ratio of proton; magnetic fields; Maxwell's equations; solenoids; Ampere's law; 18437.

Dimensional stability; eutectic coating; graphite/epoxy; moisture barrier; space optics; advanced composites; SP563, pp. 47-56 (Oct. 1979).

Dimensional stability; gyroscope; instrument materials; microcreep; micromechanical properties; beryllium; NBSIR 78-1569.

Dimensional tolerances; profile grinding; silicon nitride; ultrasonic machining; as-machined material strength; SP562, pp. 209-220 (Oct. 1979 ).

Dimensionless entropies; thermodynamic functions; JPCRD 8 , No. 3, 917-920 (1979).

Dimethyl ether; internal rotation; interstellar molecules; microwave spectrum; radio astronomy; rotational transitions; JPCRD 8, No. 4, $1051-1108$ (1979).

Dimethyl ether transitions; high-resolution spectra; Orion Nebula; 18731 .

Dimethylaminoglutethimide; dimethylaminophenylacetic acid and esters; properties of composites; tertiary aromatic amines; amine accelerators; composite restorative resin; 18571 .

Dimethylaminophenylacetic acid and esters; properties of composites; tertiary aromatic amines; amine accelerators; composite restorative resin; dimethylaminoglutethimide; 18571 .

Dipeptides; drugs; HPLC; ion-pair adsorption; ion-pair chromatography; ion-pair partition; metabolites; psychotropic amines; selectivity; sulphonamides; amino acids; barbiturates; carboxylic acids; catecholamines; conjugates; SP5 19, pp. 509-523 (Apr. 1979).

Diphenylmethylene; lineshape; low temperature; mixed crystal optical spectra; 18754 . 
Dipole antenna; ground effect; unbalanced system; NBSIR 79 1605.

Dipole giant resonance; electroproduction; nickel; photon; photoproduction; quadrupole giant resonance; alpha particle; 18495.

Direct limit; faithful distributive module; generating function; incidence algebra; inverse limit; orthogonal idempotents; quasi-order; topological algebra; coalgebra; 18788 .

Directivity; FFT; method of measurements; non-dispersive; resistive loading; TEM horn; time domain measurement; antenna gain; broadband antenna; 18856 .

Disabled; housing; regulations; accessible; SP552, pp. 95-100 (July 1979).

Disconnect element; lawnmower; motor shaft; brake; coupling device; cutting blade; dead-man's handle; U.S. Patent $4,158,944$.

Discrete; displacement; fiber optics; filters; flight critical; flow; fluid; go-no-go; ground readout; hydraulic; IMACS; instantaneous diagnosis and analysis; level; maintenance oriented; malfunction detection; monitoring; onboard; SP547, pp. 345357 (July 1979).

Discriminator; fiber optics; phase discriminator; delay line; 18547.

Disjoining pressure; monotectic; multicomponent; wetting; composite growth; contact angle; 18422 .

Disks; drums; floppy disks; laser beams; magnetic bubbles; masstapes; solid state memories; video disks; beam-addressables; cartridges; cassettes; core memories; SPSO0-45.

Dispersion; elasticity; human bone; microhardness; microstructure; piezoelectricity; thermodynamics; ultrasound; viscoelasticity; wave propagation; anisotropy; SP525, pp. 189-196 (Apr. 1979).

Dispersion; excited states; He; interaction energy; overlap; Be; 18933.

Dispersion; lossy dielectric slab; modes considerations; TEMcell; attenuation; coupled integral equations; NBSIR 79-1615.

Dispersion; skull bone; sound speed; ultrasound; attenuation; SP525, pp. 197-201 (Apr. 1979).

Dispersion type alloy; high copper; single alloy; amalgam; creep; dental; dimensional change; 18729.

Displacement; fiber optics; filters; flight critical; flow; fluid; gono-go; ground readout; hydraulic; IMACS; instantaneous diagnosis and analysis; level; maintenance oriented; malfunction detection; monitoring; onboard; patented; SP547, pp. 345-357 (July 1979).

Dissemination of units; electrical measurements; electric power measurements; electrotechnology; impact of measurements; measurement technology assessment; National Measurement System; standards; calibrations; NBSIR 75-935.

Dissipation factor; high voltage; low temperature polymer; cryogenic; dielectric loss; 18384.

Dissipation factor; loss angle; microphonic coupling; phase angle; surface films; capacitor; cross capacitor; dielectric; 18454 .

Dissociation; elastic scattering; electron; excitation; ion; ionization; molecule; photon; positron; atom; collision cross section; detachment; SP426. Supplement I.

Dissociation energy; Dunham coefficients; Franck-Condon factors; laser fluorescence; molecular sodium; potential curves; collisional excitation; 18824 .

Dissociation energy; Franck-Condon factors; laser spectroscopy; lithium molecule; molecular spectroscopy; potential curves; 18867.

Dissolved oxygen; mathematical model; oxygen; oxygen sensor; permeation; polarographic sensor; polymer membrane; diffusion; NBSIR 79-1740.

Distance measurement; geodesy; instrumentation; multiwavelength techniques; tectonics; atmospheric properties; 18816 .
Distance measurements; earthquakes; geodesy; geophysics; instrumentation; satellites; tectonics; 18574 .

Distorted wave approximation; effective Gaunt factor; electron impact excitation collision strength; Born approximation; copper isoelectronic sequence; Coulomb-Born approximation; 18996.

Distortion-of-plate; geophysics; ranging; tectonic motions; continental drift; 18459.

Distributed processing; interactive systems; kernels; modeling; real-time; simulation; synthetic programs; benchmarking; computer performance measurement; SP500-52, pp. 53-64 (Oct. 1979).

Distribution of regression coefficients; R. A. Fisher; Student's $\iota$; Student's $z$; Student (W. S. Gosset, 1876-1937; t-transformation of correlation coefficient; 18543.

Distributions in chain dimensions; equilibrium chain dimensions; excluded volume; lattice-model chains; polymer chain dimensions; random-coil chain dimensions; Rouse coordinates; 18618 .

Diurnal variations; elemental carbon; mass spectroscopy; organic aerosol constituents; primary organic carbon; sampling errors; secondary organic carbon; solvent extraction; spatial variations; SP519, pp. 121-129 (Apr. 1979).

Diversion of nuclear materials; diversion path analysis; material accounting; material control; nuclear material safeguards; safeguards; analysis; 18735 .

Diversion path analysis; material accounting; material control; nuclear material safeguards; safeguards; analysis; diversion of nuclear materials; 18735 .

Divider; Duhamel's integral; high voltage; impulse; pulse measurements; response time; step response; transients; NBSIR 79-1933.

Divider; high voltage; impulse; lightning impulse; pulse calibration; ramp response; step response; 18727 .

Divider network; guarded divider; resistive divider; self calibration; voltage divider; binary divider; 18452 .

Documentation; documentation content guidelines; feasibility study; FIPS guidelines; initiation phase; project request; software; automated data systems; computer programs; cost/benefit analysis; FIPS PUB 64.

Documentation; documentation procedures; model; model documentation; computer; computer model; SP500-39.

Documentation; energy; evaluation; guidelines; implementation; large-scale; management; mathematical models; policy analysis; software; standards; transfer; SPS34.

Documentation content guidelines; feasibility study; FIPS guidelines; initiation phase; project request; software; automated data systems; computer programs; cost/benefit analysis; documentation; FIPS PUB 64.

Documentation cycle; forecast; projections; sensitivity analysis; computer workload; data requirements; SP500-52, pp. 113 120 (Oct. 1979).

Documentation procedures; model; model documentation; computer; computer model; documentation; SP500-39.

Domain growth; domain walls; ordering; surface mobility; alloys; antiphase domains; critical behavior; 18373 .

Domain growth; domain walls; ordering; surface mobility; alloys; antiphase domains; critical behavior; 18613 .

Domain walls; ordering; surface mobility; alloys; antiphase domains; critical behavior; domain growth; 18373 .

Domain walls; ordering; surface mobility; alloys; antiphase domains; critical behavior; domain growth; 18613 .

Domains; magnetism; phase transitions; rare earths; small angle neutron scattering; amorphous materials; 18835 .

Dome finishing; finishing technique; hemispherical domes; oxides; sapphire; two-surface lapping; two-surface polishing; SP562, pp. 255-260 (Oct. 1979).

Door accidents; home accidents; home safety; safety in the home; stair accidents; stair safety; window accidents; window 
safcty; accident avoidance; accidents in the home; NBS-GCR$78-156$.

Doors; evacuation; fire departments; fire fighters; nursing homes; patients; room fires; smoke; upholstered furniture; chairs; NBS-GCR-79-159.

Dopant analysis; impurity analysis; ion microprobe mass analyzer (1MMA); microdot reference specimens; secondary ion mass spectroscopy (SIMS); silicon sputtering; NBS-GCR79-158.

Dopant density; effective mass; hole mobility; ionized impurity scattering mobility; lattice scattering mobility; neutral impurity; resistivity; scattering mechanisms; scattering mobility; $\rho$ type silicon; boron-doped silicon; SP400-47.

Dopant profiles; resistivity; resistivity profiles; semiconductor; silicon; spreading resistance; $S P 400-48$.

Doppler; fluid flow; high resolution; reconstruction; temperature reconstruction; ultrasound; aperture synthesis; computed tomography; SP525, pp. 227-233 (Apr. 1979).

Doppler; fluid flow; high resolution; reconstruction; temperature reconstruction; ultrasound; aperture synthesis; computed tomography; SP525, pp. 235-246 (Apr. 1979).

Doppler; impedance; medical diagnosis; microscopy; pattern recognition; scattering; signal processing; tissue characterization; tissue parameters; ultrasound; velocity; absorption; attenuation; computerized tomography; SP525.

Doppler; screening; ultrasonics; blood flow; breast cancer; diag. nosis; SP525, pp. 173-176 (Apr. 1979).

Doppler broadening; hardness; positron annihilation; titanium; defects; 18967.

Doppler effect; fission; gas target; molecular vibrations; neutron reactions; ${ }^{238} \mathrm{U} ; 18585$.

Doppler millimeter radar; gas turbine monitoring; remote motion detection; static displacement measurement; vibration measurement; advanced sensors; SP547, pp. 58-62 (July 1979).

Doppler shift spectrometer; light scattering; optical particle sizing; particle size standards; aerosol size measurement; calibration of particle sizing instruments; 18980 .

Doppler-free spectroscopy; frequency standard; high resolution spectroscopy; ion storage; laser spectroscopy; Mossbauer effect; optical pumping; optical spectroscopy; radiation pressure; radiative cooling; 18699 .

Dose; fast; neutrons; track; activation; detectors; SP554, pp. 99-107 (Sept. 1979).

Dose; ionizing; radioactivity; standards; testing; traceability; 18361 .

Dose; leakage; medical accelerator; neutrons; scatter; $\mathrm{x}$ rays; SP554, pp. 25-28 (Sept. 1979).

Dose buildup; linacs; patient survival; betatrons; cobalt units; SP554, pp. 15-21 (Sept. 1979).

Dose equivalent; gray; sievert; unit; absorbed dose; 19002

Dose-equivalent; electrons; kerma; multisphere; photon; photoneutrons; radiotherapy; spectrometry; SP554, pp. 109. 123 (Sept. 1979).

Dose-equivalent; electrons; kerma; multispheres; photoneutrons; photons; radiotherapy; spectrometry; SP554, pp. 125-127 (Sept. 1979).

Dosimetry; electrons; foil transmission; photons; stopping power; transport theory; absorbed dose; attenuation coefficient; detector response functions; 18371 .

Dosimetry; fast neutrons; photofission; photoneutrons; pressure vessel; reactor; threshold detectors; 18462 .

Dosimetry; fission neutrons; iron cross section; nickel cross section; reaction rates; Californium; 18883 .

Dosimetry; fission yields; measurements; neutrons; Np-237; Pu239; U-235; U-238; activation analysis; benchmark fields; 18884

Dosimetry; high energy radiotherapy beams; leakage; measurement techniques; medical accelerators; neutrons; relative biological effect; shielding techniques; standards; SP554.
Dosimetry; leakage; linear accelerators; neutrons; betatrons; detectors; SP554, pp. 129-138 (Sept. 1979).

Dosimetry methods; fission cross sections; reactor dosimetry; benchmark neutron field development; 19013

Dosimetry programs; light water reactors; nuclear reactors; reactor dosimetry; 19014

Dosimetry standardization; fast breeder reactors; light water reactors; damage analysis; 19012

Double integrals; error functions; Fourier transforms; radiation reaction; definite integrals; $J$. Res. $\mathbf{8 4}$, No. 4, 319-326 (1979).

Double optical resonance; laser bandwidth effects; multiphoton ionization; ac Stark effect; 18955.

Double photoionization; doubly charged ions; ionosphere; $\mathrm{O}^{++}$; photoionization; thermosphere; 18950 .

Double vacancy; emission spectrum; Hartree-Fock calculations; $\mathrm{x}$-ray emission; copper $K \boldsymbol{K} ; \mathbf{1 8 5 2 6}$

Double-diaphragm; faces (crystal) on platinum crucibles; hematite forming on platinum; iron as alloy in platinum; platinum ware; surface of platinum influenced by method heating; contrast augmentation of reflecting surfaces; J. Res. 84, No. 5, 385-394 (1979).

Doubly charged ions; ionosphere; $\mathrm{O}^{++}$; photoionization; thermosphere; double photoionization; 18950 .

Doubly stochastic matrix; eigenvalues; field of values; graph; longest circuit; permutation matrix; 18941

Drapes; fabrics; fire; flammability; international; self-extinguishment; ships; standards; curtains; NBSIR 79-1596.

Dressed atoms; inhomogeneous broadening; intense laser; multiphoton dissociation; multiphoton ionization; Rabi frequency; statistical broadening; three-level system; coherent excitation; 18439.

Drift tube; electrons; excitation; low energy; nitrogen; rate coefficients; 18925

Drilling; drilling additives; Rehbinder effect; rock fracture; surface chemistry; wear; diamond drilling; SP562, pp. 115-137 (Oct. 1979).

Drilling additives; Rehbinder effect; rock fracture; surface chemistry; wear; diamond drilling; drilling; SP562, pP. 115. 137 (Oct. 1979).

Drinking water analysis; gas chromatography; parts per billion; carbon tetrachloride; chloroform; SP5 19, pp. 175-179 (Apr. 1979).

Driving traction; endurance; maintenance; operation; purchasing; pursuit tires; safety; tread wear; braking traction; cornering traction; $S P 480-33$.

Drop calorimetry; electromagnetic power calorimetry; energy measurement; enthalpy measurement; entropy measurement; fuels, heating values; gas-flow calorimetry; heat capacity measurement; heat measurements; levitation calorimetry; microcalorimetry; radiation calorimetry; 18330 .

Drug analysis; food toxicants; hormones; neurotransmitters; nutrients; organic pollutants; trace organic analysis; SP519.

Drug analysis; gas chrom atography; internal standards; methylation; sample preparation; clinical chemistry; SP519, pp. 381 . 390 (A pr. 1979).

Drug assay; EMIT ${ }^{R}$ fluoroimmunoassay; fluorescence immunoassay; homogeneous enzyme immunoassay; immunoassay; SP519, pp. 533-539 (A pr. 1979).

Drugs; HPLC; ion-pair adsorption; ion-pair chromatography; ion-pair partition; metabolites; psychotropic amines; selectivity; sulphonamides; amino acids; barbiturates; carboxylic acids; catecholamines; conjugates; detection sensitivity; SP519, pp. $509-523$ (A.pr. 1979).

Drugs; nonvolatile organic compounds; organic trace detection; peptides; pharmaceuticals; secondary ion mass spectrometry; sputtering; structural information; vitamins; amino acids; SP519, pp. 627-635 (Apr. 1979).

Drugs of abuse; field test kits; sensitivity; specificity; chemical spot tests; color tests; 18492 . 
Drums; floppy disks; laser beams; magnetic bubbles; masstapes: solid state memories; video disks; beam-addressables; cartridges; cassettes; core memories; disks; SP5OO-45.

Dry oxidation of silicon; hydrogen contamination; hydroxyl contamination; semiconductor device fabrication; silicon; silicon dioxide; thermal oxidation of silicon; NBSIR 78-1558.

DSC; graphite-fiber; polyphthalocyanine; prepreg; TGA; V/STOL; cure; dielectric analysis; SP563, pp. 25-31 (Oct. 1979).

$D$-stability; diagonal matrix; field of values; Hadamard product; inclusion theorem; Kronecker product; numerical radius; spectrum; stable matrix; closure; 18909.

Duhamel's integral; high voltage; impulse; pulse measurements; response time; step response; transients; divider; NBSIR 79 1933.

Dunham coefficients; Franck-Condon factors; laser fluorescence; molecular sodium; potential curves; collisional excitation; dissociation energy; 18824 .

Durability; fatigue; interactive system; mathematical modeling; paper; paper fiber; report retrieval; scientific data; computer graphics; data base management; data retrieval; NBSIR 79. 1746.

Durability; flexural characteristics; recreational equipment; strength-to-weight ratio; composites; SP563, p. 208 (Oct. 1979).

Durability; outdoor exposure; solar collectors; standard test methods; absorptive coatings; accelerated laboratory tests; 18554 .

Durability of dentin acrylic bond; isobutyl 2-cyanoacrylate; pretreatment of dentin; 2-cyanoacrylate esters; adhesive; bonding to dentin; dental adhesive; dentin; 18985 .

Duty; liability; municipal corporations; negligence; sovereign immunity; tort; SP552, pp. 29-37 (July 1979).

Dye laser; laser cavity; mode locked dye laser; passive mode locking; picosecond pulses; Rhodamine 6G; 19021 .

Dynamic calibration; evaluation; interagency transducer project; performance characteristics; telemetry; transducer; TNIIIO.

Dynamic characterization of sample/hold amplifier; amplifier, sample/hold; bridge circuit; circuit bridge; 18505 .

Dynamic coupled-column liquid chromatography; extractor column; generator column; polynuclear aromatic hydrocarbon; standard reference material; SP519, pp. 219-224 (Apr. 1979).

Dynamic heat transfer; thermal response factors; computer time; conduction-transfer functions; 18339.

Dynamic measurements; settling time; A/D converters; D/A converters; data acquisition; data converters; 18503.

Dynamic mechanical; high pressure extrusion; oriented polyethylene; relaxation process; stress relaxation; torsion pendulum; 18767.

Dynamic programming; iterative procedure; models; optimization; stability; standards; catalog; NBSIR 78-1539.

Dynamic properties; industrial engineering; isolation; machinery and equipment; mechanical impedance; mechanical vibrations; noise control; transmissibility; vibration isolation; vibrations; antivibration mounting; damping; $H 128$

Dynamic range; Hermitian magnitude; isotropicity; isotropic, real-time, electric-field sensor (IRES); resistively loaded dipole; tangential sensitivity; broadband; 19034 .

Dynamic rate; incoherence; ionization; linear rate; multiphoton; rate approximation; saturable rate; bandwidth; coherence; 18893.

Dynamic response; interference effects; tall buildings; wind loads; wind tunnels; aerodynamics; boundary layers; $I 8977$.

Dynamical diffraction; microradiography; radiography; radiology; real-time radiography; resolution; $x$-ray image magnifier; asymmetric diffraction; 18399 .

Dynamics; KCN-KBr; neutron scattering; phase transition; rotation-translation coupling; coupled modes; 19036.
D/A converters; data acquisition; data converters; dynamic measurements; settling time; A/D converters; 18503.

\section{$\mathbf{E}$}

$E$. coli ribosomal subunit; quasielastic light scattering; $45 \mathrm{~S}$ and 50S; diffusion coefficient; J. Res. 84, No. 1, 1-8 (1979).

Earth imagery; ERTS; LANDSAT; multispectral scanner; reflective optics; crosstrack scan; SP547, pp. 17-30 (July 1979).

Earth rotation; geodynamics; gravity field; ocean current; plate tectonics; polar motion; crustal movements; 18584 .

Earthquake; fundamental "constant"; geophysics precision measurement; gravity; 18472 .

Earthquake; fundamental constant; geophysics; gravity; precision measurement; 18654 .

Earthquake prediction; geomagnetism; induced currents; magnetometers; conductivity anomalies; 18895 .

Earthquake-resistant design; information networks; network; seismic design; systems analysis; building codes; buildings; building standards; classification; decision tables; TNIIO0.

Earthqúakes; geodesy; geophysics; instrumentation; satellites; tectonics; distance measurements; 18574 .

Ease of ignition; fabrics; fire; flammability tests; garments; heat transfer; standards; apparel; burn injury; 18991.

Ease of learning and using; installation; language; maintenance; numerical analysis; OMNITAB 78; portability; poster; reliability; statistical computing section; worksheet; capabilities; 18903.

East neutron reactions; interfering nuclear reactions; optimization of analysis; silicon; trace analysis; activation analysis; cadmium ratio; 18338 .

E-beam lithography; integrated circuits; ion implantation; plasma etching; radiation damage; radiation hardening; VLSI processing; x-ray lithography; 18451 .

Eccentric loading; flat-end; kern; loading rate; pin-end; test method; wall panels; walls; compression; BSS95.

Echoencephalography; neurology; phase compensation; brain scanning; SP525, pp. 209-218 (Apr. 1979).

Econometric models; economic analysis; housing; lead-based paint; lead poisoning; abatement; building economics; building materials; cost estimation; TN979.

Economic analysis; energy conservation; engineering economics; life-cycle costs; solar heat gain; thermal efficiency; window; window management; building economics; daylighting; BSSI 19.

Economic analysis; fire safety; health care facilities; hospitals; life safety; mathematical programming; nursing homes; renovation; applied economics; building codes; building economics; NBSIR 79.1902.

Economic analysis; fire safety; health care facilities; hospitals; life safety; mathematical programming; nursing homes; renovation; applied economics; building codes; building economics; 19045.

Economic analysis; housing; lead-based paint; lead poisoning; abatement; building economics; building materials; TN97I.

Economic analysis; housing; lead-based paint; lead poisoning; abatement; building economics; building materials; cost estimation; econometric models; TN979.

Economic considerations; keyboard; keypunch; optical character recognition; optical mark sensing; source data entry; data entry; FIPS PUB 67.

Economic deregulation; evaluability assessment; evaluation; Experimental Technology Incentives Program; Federal Communications Commission; regulatory experimentation; regulatory policy; technology innovation; telecommunications; TNI104, Vols. $I$ and 2.

Economic growth; health facilities; public sector efficiency; subsidies; technological change; capital formation; NBS-GCRETIP 78-45. 
Economic growth; journal publishing; public sector efficiency; subsidies; technological change; capital formation; NBS-GCRETIP 78-44.

Economic growth; local air transport; public sector efficiency; subsidies; technological change; capital formation; NBS-GCRETIP 78-46.

Economic growth; maritime transport; public sector efficiency; subsidies; technological change; capital formation; NBS-GCRETIP $78-43$.

Economic growth; mass transit; public sector efficiency; subsidies; technological change; capital formation; NBS-GCRETIP $78-41$.

Economic growth; municipal wastewater treatment facilities; public sector efficiency; subsidies; technological change; capital formation; NBS-GCR-ETIP $78-40$.

Economic growth; nuclear power plants; public sector efficiency; subsidies; technological change; capital formation; NBSGCR-ETIP 78-42.

Economic growth; public sector efficiency; subsidies; technological change; capital formation; NBS-GCR-ETIP 78 47.

Economic impacts; economics; efficiency; payback; plumbing; roofing; shingles; venting; benefit-cost analysis; building technology; SP558.

Economic impacts; environmental considerations; innovative practices; regulatory research; standards development; administrative procedures; building codes; building regulations; buildings; construction; SP552.

Economic incentive; environmental regulation; innovation; regulatory reform; technological changes; administrative experiment; anti-trust regulation; NBS-GCR-ETIP 79-66.

Economic incentives; Federal funding of civilian R\&D; regulatory policy; subsidy policy; technological innovation; air pollution-regulatory policy; NBS-GCR-ETIP 78-53.

Economic performance; electric utilities; Experimental Technology Incentives Program; productivity; regulatory commission; regulatory policy; technological innovation; computer program; NBS-GCR-ETIP 79-70.

Economic performance; production/consumption; public and private R\&D; NBS-GCR-ETIP 78-60.

Economics; efficiency; energy; energy budget; equity; life-cycle cost; optimal; standard; buildings; conservation; criteria; design; 18888 .

Economics; efficiency; payback; plumbing; roofing; shingles; venting; benefit-cost analysis; building technology; economic impacts; SPS58.

Economics; energy conservation; internal rate of return; lifecycle costing; marginal analysis; optimal design; residential buildings; space cooling; space heating; building envelope; cost effectiveness; 19044 .

Economics; evaluation; feasibility; passive; rehabilitation; retrofit; solar; commercial; 18964.

Economics; historic preservation; life-cycle costing; redevelopment; rehabilitation; tax incentives; adaptive reuse; buildings; demolition; TN980.

Economics; historic preservation; life-cycle costing; redevelopment; rehabilitation; tax incentives; adaptive reuse; buildings; demolition; 19016.

Economics; hydrogen; production; storage; transmission; cost; 18812.

Economics of standards; government policy; international standards; laboratory accreditation; standards systems; United Kingdom; West Germany; antitrust; Canada; certification; Denmark; NBS-GCR-79-172.

Economics of standards; legal aspects of standards; product certification; product liability; regulation; standards system; voluntary standards; bibliography; buildings; certification; NBSIR 79.1900.
Eddy currents; inspection; magnetic particles; nondestructive evaluation; penetrants; radiography; statistics; ultrasonics; visual-optical tests; acoustic; annual report; NBSIR 78-1581.

Eddy currents; non-destructive evaluation; crack detection: 18911.

Edge cracks; failure modes; finite element method; tensile strength; boron-epoxy; SP563, pp. 228-238 (Oct. 1979).

Edit; operator speed; record size; transaction volume; transfer speed; validate; verify; application; character set; computer interface; cost; data entry; SPSOO-SS.

EDP selection; evaluation methodology; performance evaluation; procurement; computer evaluation; computer performance; computer procurement; computers; computer selection; cost-value; cost-value technique; SPSO0-52, pp. 25 36 (Oct. 1979).

Education; electromagnetic interference; electronic devices; International Organization of Legal Metrology; measurement assurance; metrication; model laws and regulations; national type approval; packaging and labeling; specifications and tolerances; vapor recovery; SP532.

Education; energy utilization codes; illustrated handbook; legislation; thermal envelope criteria; thermal performance criteria; SPS52, pp. 141-151 (July 1979).

Education; environment; human factors; research; school; airconditioning; comfort; 18596.

Effective carbon atom number; hazardous materials; packaging; plastics; standardization; transportation; NBSIR 79-1768.

Effective carbon atom number; hazardous materials; packaging; plastics; standardization; trans portation; 18639.

Effective fluorescence yieid; fluorescence yield; $K$ shell; $L$ shell; non-radiative yield; partial level width; radiative yield; atomic properties; Auger yield; Coster-Kronig yield; JPCRD 8, No. 2, 307-328 (1979).

Effective Gaunt factor; electron collision theory; electron correlation; electron excitation collision strength; electron excitation cross section; highly ionized atoms; 18997.

Effective Gaunt factor; electron impact excitation collision strength; Born approximation; copper isoelectronic sequence; Coulomb-Born approximation; distorted wave approximation; 18996.

Effective intensity; emergency lights; intensity, effective; lights, flashing; lights, warning; perception, visual; peripheral vision; vehicles, emergency; visibility, lights; visual perception; color, lights; conspicuity, lights; SP480-36.

Effective mass; hole mobility; ionized impurity scattering mobility; lattice scattering mobility; neutral impurity; resistivity; scattering mechanisms; scattering mobility; $\rho$-type silicon; boron-doped silicon; dopant density; SP4OO-47.

Effects of machining on ceramic properties; hardness; surface characterizations; surface finishing; abrasion; ceramic machining; ceramics; SP562.

Efficiency; energy; energy budget; equity; life-cycle cost; optimal; standard; buildings; conservation; criteria; design; economics; 18888 .

Efficiency; energy; human factors; kitchen ranges; labeling; stoves; test methods; appliance; cooking; NBSIR 78-1556.

Efficiency; energy conservation; heat recovery; lint; performance; venting; appliance; clothes dryer; 18793.

Efficiency; payback; plumbing; roofing; shingles; venting; benefit-cost analysis; building technology; economic impacts; economics; SPS58.

Eigenvalues; field of values; graph; longest circuit; permutation matrix; doubly stochastic matrix; 18941 .

Eigenvectors; management; multiple-attribute decisions; ordering; paired comparisons; prioritization; project selection; ranking; resource allocation; weighting multiple criteria; decision analysis; decisions; 18602 .

Einstein model; fission; temperature effects; thermal; ${ }^{235} \mathrm{U}$; chemical effects; delayed neutrons; 18687 . 
Elastic compliances; elastic constants; elasto-optic constants; fused silica; $\mathrm{Ge}$; hot forged; $\mathrm{KBr} ; \mathrm{KCl} ; \mathrm{KCl}: \mathrm{Kl}$; LiF; $\mathrm{MgF}_{2}$; $\mathrm{NaCl}$; $\mathrm{NaF}$; piezo-optic constants; refractive index; $\mathrm{SiO}_{2}$; $\mathrm{SrF}_{2} ;$ TN993.

Elastic constants; elasto-optic constants; fused silica; $\mathrm{Ge}$; hot forged; $\mathrm{KBr}$; $\mathrm{KCl} ; \mathrm{KCl}: \mathrm{Kl}$; $\mathrm{LiF} ; \mathrm{MgF}_{2} ; \mathrm{NaCl} ; \mathrm{NaF}$; piezo-optic constants; refractive index; $\mathrm{SiO}_{2} ; \mathrm{SrF}_{2} ;$ thermal expansion coefficient; TN993.

Elastic constants; iron alloys; nickel alloys; stainless steels; Young's modulus; aluminum alloys; copper alloys; 18630 .

Elastic constants glass-epoxy; internal friction; Young's modulus; aramid-epoxy; boron-aluminum; boron-epoxy; composites; 18716.

Elastic emission machining; environmental effect; hydrate; hydration polishing; mechanochemical polishing with soft powder; pre-existing defect; sapphire; solid state reaction; water vapor; working unit; damaged layer; SP562, pp. 157 169 (Oct. 1979).

Elastic microstructure; infarct; interferogram; myocardium; phase cancellation; velocity; acoustic microscopy; anisotropy; atienuation; SP525, pp. 73-79 (Apr. 1979).

Elastic properties; fatigue tests; nondestructive tests; structural analysis; ultimate strength; advanced composites; advanced ships; SP563, pp. 286-298 (Oct. 1979).

Elastic scattering; electron; excitation; ion; ionization; molecule; photon; positron; atom; collision cross section; detachment; dissociation; SP426. Supplement 1 .

Elastic scattering; giant resonance: tensor polarizability; Thomson scattering; coherent scattering; Delbruck scattering; I852I.

Elastic scattering; i on-molecule collisions; rotational excitation; semiclassical orbital; theory; 18446.

Elastic scattering phase shifts; pseudocrossing; sudden-perturbation limit; transition probability; $\Sigma-\Pi$ transitions; adiabatic perturbation theory; 18575 .

Elastic solid; pulses; scattering; ultrasonic; acoustic; crack; defects; 18391 .

Elasticity; electrical resistivity; emittance; measurement system; standard reference materials; temperature; thermal conductivity; thermal expansion; thermal properties; vapor pressure; viscosity; calorimetry; 18905 .

Elasticity; human bone; microhardness; microstructure; piezoelectricity; thermodynamics; ultrasound; viscoelasticity; wave propagation; anisotropy; dispersion; SP525, pp. 189. 196 (Apr. 1979).

Elasticity theory of rubber; modulus of rubber; Mooney-Rivlin constants; rubber elasticity theory; rubber, natural; swelling of rubber network; cross-linking of rubber; dicumyl peroxide; J. Res. 84, No. 5, 353-358 (1979).

Elasto-optic constants; fused silica; Ge; hot forged; $\mathrm{KBr}$; $\mathbf{K C l}$; $\mathrm{KCl}: \mathrm{KI}$; $\mathrm{LiF} ; \mathrm{MgF}_{2}$; $\mathrm{NaCl}$; $\mathrm{NaF}$; piezo-optic constants; refractive index; $\mathrm{SiO}_{2} ; \mathrm{SrF}_{2}$; thermal expansion coefficient; thermooptic constant; TN993.

Elderly; fire safety; handicapped occupants; health care facilities; nursing homes; user needs; building codes; building evaluation; NBSIR 79-1906.

Electrets; electrocaloric effect; entropy; ferroelectrics; glassceramics; heat switches; magneto-thermal conductivity; polarization; potassium tantalate; refrigeration; specific heat; strontium -titanate; beryllium; ceramics; cryogenics; dielectricconstant; 18680 .

Electrets; piezoelectricity; polarization; poling procedures; polymers; poly(vinylidene fluoride); pyroelectricity; transducers; dielectric strength; J. Res. 84, No. 6, 447-453 (1979).

Electric conductivity; electrokinetics; glass-surface; surface conductivity; conductivity; 18910 .

Electric dipole lines; multiplets; singly ionized spectra; atomic transition probabilities; 18736
Electric discharge machining; electron beam machining; glass; hydrodynamic machining; ion beam machining; water jet cutting; ceramics; chemical milling; SP562, pp. 261-281 (Oct. 1979).

Electric field measurements; instrumentation; measurement procedures; observer proximity effects; power transmission lines; Russian measurement technique; 18494 .

Electric fields; internal reflection; protective coatings; damage threshold; SP541, pp. 288-295 (Dec. 1978).

Electric fields; laser damage; nanosecond pulses; pulsewidth dependence; standing waves; thin-film coatings; two-photon absorption; ultraviolet wavelength scaling; damage thresholds; SP541, pp. 190-202 (Dec. 1978).

Electric power measurements; electrotechnology; impact of measurements; measurement technology assessment; National Measurement System; standards; calibrations; dissemination of units; electrical measurements; NBSIR 75-935.

Electric quadrupole; electrodisintegration; electron energy; giant resonance; virtual photons; ${ }^{58} \mathrm{Ni} ; 18520$.

Electric quadrupole; electrodisintegration; giant resonance; nickel isotopes; virtual photons; 18535 .

Electric shock; fire; flaming ignition; glowing ignition; hazard; ignition temperature; lamp surface temperature; melting temperature; miniature $\mathrm{Christmas}$ lights; plastic insulating material; polyethylene; series-constructed; NBSIR 79-I7I6.

Electric transmission; electro-optic systems; high voltage; pulse measurement; voltage measurement; current measurement; 18872 .

Electric utilities; Experimental Technology Incentives Program; productivity; regulatory commission; regulatory policy; technological innovation; computer program; economic performance; NBS-GCR-ETIP 79-70.

Electrical alignment resistor; integrated circuits; linewidth; photolithography; sheet resistance; silicon; test pattern; test structure; TTL; bipolar process; contact resistor; cross bridge sheet resistor; 18533 .

Electrical alignment resistor; semiconductor; silicon; test pattern; test structures; visual alignment; contact resistor; cross bridge sheet resistor; SP400-51.

Electrical breakdown; high speed photography; Kerr effect; liquid breakdown; nitrobenzene; partial discharges; streamers; transient phenomena; $I 8843$.

Electrical calibration equipment; calorimeters; combustion; combustion calorimeters; 18803 .

Electrical conductance; fluorides; halides; iodides; molten salt mixtures; standard reference data; surface tension; viscosity; bromides; chlorides; data compilation; density; JPCRD 8, No. 1, 125-302 (1979).

Electrical connections; pressure terminals; wire creep; aluminum wiring; NBSIR 78-1507.

Electrical distribution systems; flat conductor cable; National Electrical Code; technological innovation; appeals process; consensus standards; SP552, pp. 57-78 (July 1979).

Electrical failure; fire containment; ignition; television fire; TNI109.

Electrical injury; electrolyte shift; heat effect; injury mechanism; injury statistics; mouth burn; specific electrical effect; arc burn; contact burn; current threshold; NBSIR 79 1710 .

Electrical junction box; hazardous temperatures; load current; overlamping; surface mounted incandescent lighting fixture; thermal insulation; thermocouple; branch circuit wiring; NBSIR 79-1912.

Electrical junction box; hazardous temperatures; load current protective barrier; recessed incandescent lighting fixture thermal insulation; thermocouple; branch circuit wiring NBSIR 79-1913.

Electrical measurements; electric power measurements; elec trotechnology; impact of measurements; measuremen 
technology assessment; National Measurement System; standards; calibrations; dissemination of units; NBSIR 75-935.

Electrical measurements; electro-optics; Kerr coefficient; Kerr effect; nitrobenzene; pulse measurement; 18819

Electrical measurements; profiles; semiconductors; silicon; 18757.

Electrical measurements; resistivity; semiconductors; silicon; 18460.

Electrical properties; electronics; hermeticity; indium-doped silicon; infrared reflectance; integrated circuits; line-width measurements; oxidation; photolithography; photovoltaic method; power-device grade silicon; radioisotope leak test; resistivity variations; SP400-38.

Electrical properties; low temperatures; mechanical properties; metallurgical properties; niobium-titanium; physical properties; superconductors; 18552 .

Electrical property; niobium; superconductor; tin; alloy; copper; 18656.

Electrical resistivity; elements; gold; metals; molten metals; palladium; precious metals; reference data; silver; solid state physics; transport properties; copper; critical evaluation; data analysis; data compilation; JPCRD 8, No. 4, 1147-1298 (1979)

Electrical resistivity; emittance; measurement system; standard reference materials; temperature; thermal conductivity; thermal expansion; thermal properties; vapor pressure; viscosity; calorimetry; elasticity; 18905.

Electrical resistivity; enthalpy; specific heat; standard reference materials; thermal conductivity; thermophysical properties; 18615.

Electrical resistivity; francium; lithium; magnetic flux density dependence; potassium; pressure dependence; rubidium; sodium; temperature dependence; alkali elements; cesium; JPCRD 8, No. 2, 339-438 (1979).

Electrical resistivity; graphite; Lorenz ratio; reference materials; thermal conductivity; characterization; density; 18668 .

Electrical resistivity; magnesium; radium; strontium; temperature dependence; alkaline earth elements; barium; beryllium; calcium; JPCRD 8, No. 2, 439-498 (1979).

Electrical test structure; gated diode; generation lifetime; integrated gated-diode electrometer; integrated test structure; leakage current; MOSFET dc profiler; surface recombination; CCD; NBSIR 79-1744.

Electrically calibrated detector; optical radiation measurements; primary standards; standard source; 18796.

Electrically calibrated detectors; laser power measurements; pyroelectric detectors; radiometry; silicon cell; silicon detector; silicon photodetector; absolute radiometry; detector; 18773.

Electrically calibrated detectors; laser power measurements; pyroelectric detectors; radiometry; silicon cell; silicon detector; silicon photodetector; absolute radiometry; detector; 18774

Electric-field distribution; high-power; reflectance; spectral absorptance; theory; asymmetric absorptance; damage thresholds; dielectric reflectors; SP541, pp. 278-287 (Dec. 1978 ).

Electroacoustic method; medical applications; metrology; NDE; radiation force; transducer characterization; ultrasonics; acoustic theory; calorimetry; 18438 .

Electrocaloric effect; entropy; ferroelectrics; glass-ceramics; heat switches; magneto-thermal conductivity; polarization; potassium tantalate; refrigeration; specific heat; strontium titanate; beryllium; ceramics; cryogenics; dielectric-constant; electrets; 18680 .

Electrochemical detection; liquid chromatography; methylmercury; organometals; water preconcentration; SP519, pp. 57 63 (Apr. 1979).
Electrochemical detection; liquid chromatography; phenolic metabolites; catecholamines; SP519, pp. 391-397 (Apr. 1979 ).

Electrochemical detection; liquid chromatography; oxidation; reduction; cell design; SP519, pp. 705-712 (Apr. 1979).

Electrochemical detection; liquid chromatography; metal speciation; organomercury cations; biological samples; 18420 .

Electrochemical energy storage materials; molten salts; physical properties; safety and hazards; thermal energy storage materials; thermal properties; thermodynamic properties; transport properties; corrosion; data compilation; NSRDS-NBS61, Part II.

Electrochemical equivalent of silver; electrochemistry; Faraday; potentiostat; silver; silver analysis; controlled potential; coulometry; J. Res. 84, No. 2, 157-160 (1979).

Electrochemical grinding; grinding; tungsten carbide; cemented carbides; SP562, pp. 305-315 (Oct. 1979).

Electrochemical measurements; potentiodynamic scans; copper concentric neutrals; corrosion; corrosion tests; 18725 .

Electrochemistry; electrolytes; enthalpy of dilution; heat capacity; relative apparent molal enthalpy; salt solutions; thermochemistry; vapor pressure; apparent molal heat capacity; aqueous systems; bibliography; SP537.

Electrochemistry; Faraday; potentiostat; silver; silver analysis; controlled potential; coulometry; electrochemical equivalent of silver; J. Res. 84, No. 2, 157-160 (1979).

Electrode polarization; equivalent circuits; ionic conduction; lithium aluminosilicates; lithium silicate; 18794 .

Electrodeposited metal layers; gold-nickel layers; micrometer scale; scanning electron microscope scale; U.S. Patent $4,139,933$.

Electrodes; electrodes, ion-selective; electrodes, reference; errors; ion-selective electrodes; sensors, chemical; standards; 18334.

Electrodes, errors; electrodes, ion-selective; electrodes, reference; ion-selective electrodes; reference electrodes; sensors, chemical; 18362 .

Electrodes, ion-selective; electrodes, reference; errors; ionselective electrodes; sensors, chemical; standards; electrodes; 18334

Electrodes, ion-selective; electrodes, reference; ion-selective electrodes; reference electrodes; sensors, chemical; electrodes, errors; 18362 .

Electrodes, reference; errors; ion-selective electrodes; sensors, chemical; standards; electrodes; electrodes, ion-selective; 18334.

Electrodes, reference; ion-selective electrodes; reference electrodes; sensors, chemical; electrodes, errors; electrodes, ionselective; 18362 .

Electrodisintegration; electron energy; giant resonance; virtual photons; ${ }^{58} \mathrm{Ni}$; electric quadrupole; 18520.

Electrodisintegration; giant resonance; nickel isotopes; virtual photons; electric quadrupole; 18535.

Electrodisintegration; proton spectrum; ternary fission; $\alpha$-particles; $\alpha$-spectrum; ${ }^{238} \mathrm{U} ; 18518$.

Electro-dynamic wattmeters; energy measurements; energy standards; international comparisons; metrology; power measurements; precise electrical measurements; TDM wattmeters; thermal wattmeters; transfer standards; 18529.

Electrokinetics; glass-surface; surface conductivity; conductivity; electric conductivity; 18910 .

Electrolyte; excess Gibbs energy; iron; nickel; osmotic coefficients; solutions; thermodynamic properties; activity coefficient; cobalt; critical evaluation; JPCRD 8, No. 4, 923-1004 (1979).

Electrolyte; excess Gibbs energy; lead; manganese; osmotic coefficients; solutions; thermodynamic properties; uranium; activity coefficient; copper; critical evaluation; JPCRD 8 , No. 4, 1005-1050 (1979). 
Electrolyte shift; heat effect; injury mechanism; injury statistics; mouth burn; specific electrical effect; arc burn; contact burn; current threshold; electrical injury; NBSIR 79-1710.

Electrolytes; enthalpy of dilution; heat capacity; relative apparent molal enthalpy; salt solutions; thermochemistry; vapor pressure; apparent molal heat capacity; aqueous systems; bibliography; electrochemistry; SP537.

Electrolytes; flame atomic emission spectroscopy; reference method; semiautomated pipetting; serum potassium analysis; statistical analysis; clinical analysis; clinical chemistry; definitive method; SP260-63.

Electrolytes; reference method; serum chloride analysis; statistical analysis; amperometry; chloride analysis; clinical analysis; clinical chemistry; coulometry; definitive method; SP260-67.

Electromagnetic; neutrons; photons; pions; protons; coincidence experiments; 18675 .

Electromagnetic; radiated emissions; susceptibility measurements; 18579 .

Electromagnetic bioeffects; electromagnetic compatibility; electromagnetic immunity; electromagnetic interference; electromagnetic radiation; electromagnetic susceptibility; electronic smog; home entertainment electronics; industrial electronics; medical‘electronics; SP551.

Electromagnetic compatibility; electromagnetic immunity; electromagnetic interference; electromagnetic radiation; electromagnetic susceptibility; electronic smog; home entertainment electronics; industrial electronics; medical electronics; microwave electronics; SP55I.

Electromagnetic compatibility; measurements; transverse elèctromagnetic transmission cells; 18578 .

Electromagnetic immunity; electromagnetic interference; electromagnetic radiation; electromagnetic susceptibility; electronic smog; home entertainment electronics; industrial electronics; medical electronics; microwave electronics; nonionizing radiation; radiation hazards; SP551.

Electromagnetic interference; electromagnetic radiation; electromagnetic susceptibility; electronic smog; home entertainment electronics; industrial electronics; medical electronics; microwave electronics; nonionizing radiation; radiation hazards; radio regulations; SP551.

Electromagnetic interference; electronic'devices; International Organization of Legal Metrology; measurement assurance; metrication; model laws and regulations; national type approval; packaging and labeling; specifications and tolerances; vapor recovery; SP532.

Electromagnetic measurement; snow depth; soil moisture; 18563.

Electromagnetic power calorimetry; energy measurement; enthalpy measurement; entropy measurement; fuels, heating values; gas-flow calorimetry; heat capacity measurement; heat measurements; levitation calorimetry; microcalorimetry; radiation calorimetry; solution calorimetry; 18330 .

Electromagnetic problems; functional theoretic techniques; modified residue calculus; open systems; remote sensing; closed systems; Monogr. 164.

Electromagnetic radiation; electromagnetic susceptibility; electronic smog; home entertainment electronics; industrial electronics; medical electronics; microwave electronics; nonionizing radiation; radiation hazards; radio regulations; radio standards; RFI; SP551.

Electromagnetic susceptibility; electronic smog; home entertainment electronics; industrial electronics; medical electronics; microwave electronics; nonionizing radiation; radiation hazards; radio regulations; radio standards; $R F$; spectrum management; SP551.

Electromagnetic susceptibility testing; structural design and fabrication procedures; transverse electromagnetic (TEM) cell; TNIOII.

Electron; energy deposition; Monte Carlo; multiple scatter; tracklength; charged particle; 18965.
Electron; excitation; ion; ionization; molecule; photon; positron; atom; collision cross section; detachment; dissociation; elastic scattering; SP426. Supplement 1.

Electron anomalous moment; fine-structure constant; fundamental constant; magnetic fields; proton gyromagnetic ratio; quantum electrodynamic theory; 18702 .

Electron avalanche; frequency and pulse width dependencies of the critical field; multiphoton ionization; damage threshold; SP541, pp. 299-302 (Dec. 1978).

Electron beam machining; glass; hydrodynamic machining; ion beam machining; water jet cutting; ceramics; chemical milling; electric discharge machining; SP562, pp. 261-281 (Oct. 1979).

Electron beam welding; fatigue (materials); fracture properties; low temperature tests; mechanical properties; titanium; titanium alloys; 18611 .

Electron beams; induction accelerator; ion acceleration; nuclear research; radiation processing; activation analysis; 18570.

Electron capture; gas chromatography-mass spectrometry; negative ions; chemical ionization; SP519, pp. 601-607 (Apr. $1979)$.

Electron capture detector; gas chromatography; halo-organics; ionization detector; porous anode; SP519, pp. 777-782 (Apr. 1979).

Electron capture detector; methyl chloride; monochlorinated organics; carrier gas doping; SP519, pp. 143-151 (Apr. 1979).

Electron channeling; plasticity; subsurface damage; surface damage; SP562, pp. 395-404 (Oct. 1979).

Electron collision theory; electron correlation; electron excitation collision strength; electron excitation cross section; highly ionized atoms; effective Gaunt factor; 18997.

Electron collisions; molecules; momentum-transfer; polar molecules; scattering theory; cross sections; 18516 .

Electron configurations; ionization potentials; aluminum; atomic energy levels; atomic spectra; JPCRD 8, No. 3, 817 . 864 (1979).

Electron correlation; electron excitation collision strength; electron excitation cross section; highly ionized atoms; effective Gaunt factor; electron collision theory; $l 8997$.

Electron correlation; ionization energies; line strengths; manybody interaction; many-body perturbation theory; oscillator strengths; copper isolectronic sequence; diagrammatic perturbation theory; 18998 .

Electron cross sections; fusion plasmas; lasers; molecular bands; molecular spectra; reaction rate constants; upper atmosphere; atomic energy levels; atomic spectra; atomic transition probabilities; 18855 .

Electron devices; electron tubes; semiconductors; U.S.S.R; NBSIR 78-1564.

Electron diffraction images; hydrated layer; ion microprobe mass spectrometer; roughness; sapphire; ultra-fine polishing; water; x-ray photoelectron spectrometer; crystallographic integrity; SP562, pp. 317-323 (Oct. 1979).

Electron energy; giant resonance; virtual photons; ${ }^{58} \mathrm{Ni}$; electric quadrupole; electrodisintegration; 18520.

Electron energy loss; energy degradation; low-energy stopping power; 18659.

Electron excitation; lithium; 19028.

Electron excitation collision strength; electron excitation cross section; highly ionized atoms; effective Gaunt factor; electron collision theory; electron correlation; 18997.

Electron excitation cross section; highly ionized atoms; effective Gaunt factor; electron collision theory; electron correlation; electron excitation collision strength; 18997 .

Electron factors; electron vacancies; Laves phase; sigma phase; transition metal; alloy phases; electronegativity; 18357 .

Electron impact; electrons; helium; ionization; secondary; angular; Born approximation; correlations; 18534 . 
Electron impact; excitation, $2 s-2 p ; \mathrm{N}^{4+}$; crossed beams; cross sections; 18707.

Electron impact excitation collision strength; Born approximation; copper isoelectronic sequence; Coulomb-Born approximation; distorted wave approximation; effective Gaunt factor; 18996.

Electron impact ionization; ionization cross section; ionization rate coefficient; lithiumlike ions, ionization of; $\mathrm{N}^{+4} ; \mathrm{O}^{+5}$; rate coefficient; $/ 8502$.

Electron microprobe; homogeneity; standard reference materials; steel; digital periodic integrator; SP260-65.

Electron microprobe; homogeneity; standard reference materials; standards; digital periodic integrator; 18973 .

Electron microscopy; group decisions; properties of steam; space; stirling refrigerators; aluminum SRM's; computer systems; DIM/NBS 63, No. 5, 1.28 (1979).

Electron microscopy; high-density lipoproteins; neutron scattering; 18851 .

Electron microscopy; laser damage; optical coatings; thin films; antireflection coatings; SPS4I, pp. 218-225 (Dec. 1978).

Electron paramagnetic resonance; epitaxial silicon; Hall-effect measurements; phosphorus in silicon; NBSIR 79-1748.

Electron probe analysis; peak-to-background ratios; quantitative analysis; rough surfaces; x-ray microanalysis; 18976 .

Electron probe microanalysis; energy dispersive $x$-ray microanalysis; energy dispersive $x$-ray spectrometry; quantitative analysis; scanning electron microscopy; $x$-ray microanalysis; 18970.

Electron probe microanalysis; energy-dispersive $x$-ray spectrometry; microanalysis; qualitative analysis; scanning electron microscope; artifacts; 18790.

Electron probe microanalysis; inner shell ionization cross section; Monte Carlo electron trajectory simulation; scanning electron microscopy; $x$-ray yield; characteristic $x$-ray yield; 18978.

Electron scattering; energy loss; excited states; negative ions; ozone; resonances; 18392.

Electron spectroscopy; ESCA; secondary ion mass spectroscopy; surface analysis; ASTM Committee E-42; Auger electron spectroscopy; 18406.

Electron spectroscopy for chemical analysis (ESCA); silicon; surface; XPS; angular study; 18417.

Electron spin resonance; fluorination of polymers; free radicals; peroxy radicals; transition metal fluorides; $I 8726$.

Electron tubes; semiconductors; U.S.S.R; electron devices; NBSIR 78-1564.

Electron vacancies; Laves phase; sigma phase; transition metal; alloy phases; electronegativity; electron factors; $/ 8357$.

Electron-capture; hydrazines; maleic hydrazide; mass spectroscopy; nitrosamines; nitrosodiethanolamine; silylation; thermal energy analyzer (TEA); tobacco; carbamates; chemical ionization; SP519, pp. 297-309 (Apr. 1979).

Electron-capture detection; evaporation; nomenclature; sample work-up; standards; chromatography/column packings (GC); SP519, pp. 809-810 (Apr. 1979).

Electronegativities; hybridization; structural stability; transition elements; 18421 .

Electronegativity; electron factors; electron vacancies; Laves phase; sigma phase; transition metal; alloy phases; $/ 8357$.

Electronegativity; electronic configuration; $s-p$ binding; structural stability; alloys; 18383 .

Electronic circuits; inductive load; nondestructive; protection circuit; reverse bias; safe operating area; second breakdown; switching power transistor; tester; transistor; base drive circuit; SP400-54.

Electronic component reliability; failure analysis; failure models; failure rates; reliability; residential buildings; smoke detectors; component screening; NBS-GCR-79-160.
Electronic component reliability; failure analysis; failure models; failure rates; reliability; residential buildings; smoke detectors; component screening; NBS-GCR-79-16I.

Electronic component reliability; failure analysis; failure models; failure rates; reliability; residential buildings; smoke detectors; component screening; NBS-GCR-79-162.

Electronic configuration; $s-p$ binding; structural stability; alloys; electronegativity; $/ 8383$

Electronic devices; electrons; photons; radiation hardness; standard practice; thermoluminescence dosimeters; NBSIR 79. 1723.

Electronic devices; hermeticity; hybrids; nondestructive tests; semiconductor; tape-bonded devices; acoustic emission; beam lead devices; SP400-59.

Electronic devices; International Organization of Legal Metrology; measurement assurance; metrication; model laws and regulations; national type approval; packaging and labeling; specifications and tolerances; vapor recovery; weights and measures; consumer affairs; SP532.

Electronic discharge; hydrogen halides; isotopes; laser; TEA laser; 18667

Electronic lock; exclusion area; forced entry deterrent systems; guard control station; higher headquarters; perimeter station; remote unit; response force; triply redundant central computer; central unit; computerized; detection; NBSIR 79.1725.

Electronic package; impact noise; microcircuit device; particle detection; particle impact noise detection; PIND; pre-shock; seeded specimens; transducer; acoustic emission; co-shock; couplant; detection; NBSIR 78-1590 (NASA).

Electronic ratio error set; transformer calibrations; current comparators; current ratios; current transformers; current transformer testing; 18624 .

Electronic smog; home entertainment electronics; industrial electronics; medical electronics; microwave electronics; nonionizing radiation; radiation hazards; radio regulations; radio standards; $R$ FII; spectrum management; standardization organizations; telecommunications; SP551.

Electronic structure; energy curves; excimer; gain; radiative transition; 18936.

Electronic technology; impurity distribution; material transport; segregation; semiconductor technology; diffusion; SP400-57.

Electronically excited states; evaluation; gaseous interactions; molecular correlations; quenching; radiative lifetimes; rate constants; reactive channels; recommended data; relaxation processes; review; activation energies; JPCRD 8, No. 3, 723 . 798 (1979).

Electronics; hermeticity; indium-doped silicon; infrared reflectance; integrated circuits; line-width measurements; oxidation; photolithography; photovoltaic method; power-device grade silicon; radioisotope leak test; resistivity variations; re. sistors, sheet; $S P 400-38$.

Electronics; instruments; integrated circuits; Josephson junctions; measurements; superconductivity; $/ 8859$.

Electronics; integrated circuit; large scale integration; memory; microprocessor; testing; TNIIO2.

Electronics; integrated circuits; measurement technology; microelectronics; semiconductor devices; semiconductor materials; semiconductor process control; silicon; NBSIR 78 . 1444-3.

Electronics; integrated circuits; measurement technology; microelectronics; semiconductor devices; semiconductor materials; semiconductor process control; silicon; NBSIR 79. $159 I$.

Electronics; integrated circuits; measurement teehnology; microelectronics; semiconductor devices; semiconductor materials; semiconductor process control; silicon; NBSIR 79. I59I-2.

Electronics; integrated circuits; measurement technology; microelectronics; semiconductor devices; semiconductor 
materials; semiconductor process control; silicon; NBSIR 79 1591-3.

Electrons; excitation; low energy; nitrogen; rate coefficients; drift tube; 18925

Electrons; foil transmission; photons; stopping power; transport theory; absorbed dose; attenuation coefficient; detector response functions; dosimetry; 18371 .

Electrons; heavy ions; international commission on radiation units and measurements; protons; stopping power; $\alpha$-particles; 18358 .

Electrons; helium; ionization; secondary; angular; Born approximation; correlations; electron impact; 18534.

Electrons; kerma; multisphere; photon; photoneutrons; radiotherapy; spectrometry; dose-equivalent; SP554, pp. 109 123 (Sept. 1979).

Electrons; kerma; multispheres; photoneutrons; photons; radiotherapy; spectrometry; dose-equivalent; SP554, pp. 125127 (Sept. 1979).

Electrons; megavoltage; neutrons; therapy; $x$ rays; accelerators; betatrons; SP554, pp. 1-14 (Sept. 1979).

Electrons; photons; radiation hardness; standard practice; thermoluminescence dosimeters; electronic devices; NBSIR 791723.

Electrons, conduction band ( $\mathrm{CB}$ ); laser damage; conduction band (CB) electrons; dielectric solids; SP541, pp. 303-304 (Dec. 1978).

Electronuclear physics; high duty-cycle; coincidence experiments; correlations in nuclei; cw accelerators; 18906.

Electro-optic systems; high voltage; pulse measurement; voltage measurement; current measurement; electric transmission; 18872.

Electro-optics; gas-solid interface; KDP; Pockels effect; space charge; breakdown; NBS-GCR-79-177.

Electro-optics; Kerr coefficient; Kerr effect; nitrobenzene; pulse measurement; electrical measurements; 18819 .

Electroproduction; nickel; photon; photoproduction; quadrupole giant resonance; alpha particle; dipole giant resonance; 18495.

Electroproduction; nonrelativistic operators; nuclear photoproduction; photoproduction; pions; pseudovector coupling; 18798 .

Electrostatic-induced damage; hermeticity; hybrid devices; leak testing; measurement technology; microcalorimetry; moisture; nondestructive testing; pacemaker leads; process control; reliability; semiconductor devices; welding; automated testing; batteries; SP400-50.

Electrotechnology; impact of measurements; measurement technology assessment; National Measurement System; standards; calibrations; dissemination of units; electrical measurements; electric power measurements; NBSIR 75-935.

Elemental analysis; ion microprobe mass analyzer; local thermal equilibrium model; microanalysis; secondary ion mass spectrometry; surface analysis; 18979.

Elemental carbon; mass spectroscopy; organic aerosol constituents; primary organic carbon; sampling errors; secondary organic carbon; solvent extraction; spatial variations; diurnal variations; SP519, pp. 121-129 (Apr. 1979).

Elementary function testing; Fortran library test data; Fortran library testing; mathematical function testing; test data for elementary functions; test data for mathematical functions; NBSIR.78-1478.

Elements; emission; spectra; 18870 .

Elements; gold; metals; molten metals; palladium; precious metals; reference data; silver; solid state physics; transport properties; copper; critical evaluation; data analysis; data compilation; data evaluation; data extraction; JPCRD 8, No. 4, 1147-1298 (1979).

Ellipsometry; polymer adsorption; protein adsorption; protein chromatography; radiolabeled proteins; adsorption; biomaterials; blood proteins; NBSIR 79.1784.
EMC measurements; radiation resistance; rectangular coax; shielded strip line; TEM cell; 18345 .

Emergency communications; emergency evacuation; fire detection; fire safety; fire suppression; mass transportation; material flammability; people movers; smoke; NBSIR 78-1586.

Emergency evacuation; fire detection; fire safety; fire suppression; mass transportation; material flammability; people movers; smoke; emergency communications; NBSIR 78 . 1586.

Emergency lights; intensity, effective; lights, flashing; lights, warning; perception, visual; peripheral vision; vehicles, emergency; visibility, lights; visual perception; color, lights; conspicuity, lights; effective intensity; SP480-36.

Emission; spectra; elements; 18870 .

Emission line, star; late-type, ultraviolet; spectra; Ca II emission, stars; chromospheres, stars; 18926.

Emission line stars; emission nebulae; star formation; 18546.

Emission line stars; flare stars; late-type stars; stellar chromospheres; stellar coronae; 18920.

Emission line, stars; late-type stars; Ca II emission, stars; chromospheres, stars; circumstellar shells; 18853 .

Emission lines, stars; late-type stars; stellar chromospheres; stellar coronae; stellar winds; ultraviolet spectra; 18528 .

Emission nebulae; star formation; emission line stars; 18546.

Emission spectra; lattice relaxation; many body effects; sodium; absorption spectra; core excitation; 18413 .

Emission spectrum; Hartree-Fock calculations; x-ray emission; copper $K \beta$; double vacancy; 18526 .

Emissions; gas chromatography; tensilization; thermogravimetric analysis; tire cord; tire cord dip; tire cord finish; SP519, pp. 181-184 (Apr. 1979).

Emissions inspections; fault detection; fuel economy; motor vehicle; diagnosis; SP5 47, pp. 78-97 (July 1979).

Emissivity of water; evaporation coefficient; humidity measurement; monomolecular film; psychrometer; psychrometry; radiative heat transfer; temperature depression; water vapor measurement; wet bulb; wet element; J. Res. 84, No. 2, 161 177 ( 1979).

$\mathrm{EMIT}^{R}$ fluoroimmunoassay; fluorescence immunoassay; homogeneous enzyme immunoassay; immunoassay; drug assay; SP519, pp. 533-539 (Apr. 1979).

Emittance; measurement system; standard reference materials; temperature; thermal conductivity; thermal expansion; thermal properties; vapor pressure; viscosity; calorimetry; elasticity; electrical resistivity; 18905 .

Empirical investigation; ETIP; Federal civilian R\&D; implementing; management practices; technological change; commercialization; NBS-GCR-ETIP 78-5 ?.

Empirical investigation; ETIP; Federal civilian R\&D; implementing; management practices; technological change; commercialization; NBS-GCR-ETIP 78-58.

Empirical investigation; ETIP; Federal civilian R\&D; implementing; commercialization; NBS-GCR-ETIP 78-58A.

Empirical models; IBM 168-3; IBM 3033; migration guidelines; migration planning; benchmark performance data; SP500-52, pp. 89-104 (Oct. 1979).

Empirical models; modeling; performance modeling; workload characterization; cluster analysis; computer modeling; computer performance; SP5OO-52, pp. 147-161 (Oct. 1979).

Empirical molecular formula; GPSDC; ion energetics; ionization potential; abstract; appearance potential; archival tape; computer program; data base; data base management; NBSIR 78.1432 .

Employment; equal employment opportunity; labor force; minorities in computing; women in computing; 19041 .

Enamel; hydroxyapatite; surface area; bone; chemisorption; 18411 .

Enamel; microanalysis; mineralizing tissue; Raman microprobe; Raman spectroscopy; biological microanalysis; biological mineralization; bone; dental studies; dentin; 19008 . 
Enamel; mineralizing tissue; Raman microprobe; Raman spectra; Raman spectroscopy; tissue sections; tooth; biological microanalysis; biological tissue; dental studies; 18982

Encryption; identifiers; key management; key notarization; cryptography; digital signatures; SP500-54.

Encryption; identifiers; key management; key notarization; cryptography; digital signatures; 19039.

Endothermic solution reactions; enthalpy of solution; $\mathrm{KBr}, \mathrm{KI}$, $\mathrm{KIO}_{3}, \quad \mathrm{KIO}_{4}$; solution calorimetry; thermochemistry; tris(hydroxymethyl) aminomethane; J. Res. 84, No. 4, 273286 (1979).

End-to-end length; entanglement effects; excluded volume effects; lattice-model polymer chains; polymer chain dynamics; random-coil polymer chains; relaxation times; self-entanglement effects; computer simulation; 18772 .

Endurance; maintenance; operation; purchasing; pursuit tires; safety; tread wear; braking traction; cornering traction; driving traction; SP480-33.

Energy; energy budget; equity; life-cycle cost; optimal; standard; buildings; conservation; criteria; design; economics; efficiency; 18888 .

Energy; energy consumption; grey water; heat recovery; recycling; residential; wastewater treatment; water; water conservation; water heating; water usage; NBSIR 79-1770.

Energy; energy cost; feedback; feedback meters; attitudes; consumer preference; NBSIR 79-1771.

Energy; energy savings; industrial robots; network services; SRM's; computer interface standards; computers; cryogenic temperature; DIM/NBS 63, No. 4, 1-24 (1979).

Energy; engineering; industry construction; measurement techniques; standards; building research; criteria; SP439-I.

Energy; environments; heating; passive; solar; suburban; urban; application; buildings; commercial; daylighting; 18894 .

Energy; evaluation; guidelines; implementation; large-scale; management; mathematical models; policy analysis; software; standards; transfer; documentation; SP534.

Energy; fluid mixtures; light; liquefied natural gas; measurements; microwaves; super spring; ultraviolet radiation; calibrations; DIM/NBS 63, No. 9, 1-32 (1979).

Energy; furnace; gas-fired; heating; oil-fired; rating; space-heating; testing; boiler; combustion; 18385 .

Energy; human factors; kitchen ranges; labeling; stoves; test methods; appliance; cooking; efficiency; NBSIR 78-1556.

Energy; hydrides; hydrogen storage; nuclear magnetic resonance; nuclear spin relaxation; diffusion; 18352 .

Energy; hydrocarbon; methyl-branch; structure; calculations; cell dimensions; crystal; defect; 18787

Energy; instrumentation; measurement; thermography; Twin Rivers Project; weather station; air infiltration; buildings; data acquisition; 18733 .

Energy; legislation; solar; standards; State; buildings; design; NBSIR 79-1705.

Energy audits; energy codes; Kentucky Fire Marshal's office; lighting and thermal efficiency standards; local governments; new construction plans review; training and education; design professionals; SP552, pp. 121-130 (July 1979).

Energy budget; equity; life-cycle cost; optimal; standard; buildings; conservation; criteria; design; economics; efficiency; energy; 18888.

Energy calculation; energy consumption; fenestration; heating and cooling load; solar heat gain; daylighting; 19003 .

Energy code; energy efficient; enforcement; implementation and effective $U$ value; on-site construction; building official; SP552, pp. 131-140 (July 1979).

Energy codes; Kentucky Fire Marshal's office; lighting and thermal efficiency standards; local governments; new construction plans review; training and education; design professionals; energy audits; SP552, pp. I21-130 (July 1979).

Energy conservation; energy efficiency; ranges and ovens; appliances; cooking utensils; 18836 .
Energy conservation; energy instrumentation; energy rate; energy use; appliances; 18837

Energy conservation; energy standards; fenestration; life-cycle costing; retrofitting; solar; building design; cost; 19043.

Energy conservation; engineering economics; life-cycle costs; solar heat gain; thermal efficiency; window; window management; building economics; daylighting; economic analysis; BSS119.

Energy conservation; environmental quality; industrial productivity; materials utilization; measurement capabilities; medical aids; product safety; public health and safety; science and technology transfer; standards; basic research; computer; SP538.

Energy conservation; fenestration; solar energy; windows; daylighting; 18863 .

Energy conservation; heat recovery; lint; performance; venting; appliance; clothes dryer; efficiency; 18793

Energy conservation; heating load calculation; NBSLD analysis of residences; residential energy conservation; thermal mass effect in buildings; building energy consumption analysis; computerized building energy analysis; cooling load calculation; NBSIR 79-I732.

Energy conservation; illumination standards; lighting distribution simulation; visual performance; building codes; building performance simulation; computer applications; SP552, pp. 321-335 (July 1979).

Energy conservation; insulation; life-cycle cost analysis; masonry construction; space heating and cooling requirements; thermal mass; building economics; NBSIR 79-I789.

Energy conservation; internal rate of return; life-cycle costing; marginal analysis; optimal design; residential buildings; space cooling; space heating; building envelope; cost effectiveness; economics; 19044.

Energy conservation; legislation; solar energy; building regulation; SPS52, pp. 211-216 (July 1979).

Energy conservation; measurement methods; power-device grade silicon; resistivity variations; silicon; spreading resistance measurements; thermally stimulated measurements; thyristor materials measurements; thyristor measurements; dc transmission; NBSIR 79-1756.

Energy conservation; pressurization technique; tracer-gas technique; air infiltration, residential; air permeability of houses; TN992.

Energy conservation; retrofit; sulfur hexafluoride; tracer gas; weatherization; air infiltration; air sample bags; NBSIR 791728

Energy conservation; roof heat-loss survey; aerial flyovers; aerial infrared thermography; TNII07.

Energy conservation; solar absorptance of roofing materials; whole-house ventilation; attic ventilation; SP548.

Energy conservation design; indoor radiation; radon in buildings; ventilation and radon concentration; 18587.

Energy consumption; fenestration; heating and cooling load; solar heat gain; daylighting; energy calculation; 19003.

Energy consumption; field measurments; hourly load profiles; refrigerator field data; usage profiles; combination refrigerator-freezer field data; daily load profiles; NBSIR 79-1781.

Energy consumption; grey water; heat recovery; recycling; residential; wastewater treatment; water; water conservation; water heating; water usage; energy; NBSIR 79-I770.

Energy consumption of residences; lighting energy consumption; occupant factors; residential air conditioning; service hot water; space heating; ventilation; appliance energy consumption; NBSIR 78-1501.

Energy cost; existing buildings; regulation; retrofit; standards; conservation; SP552, pp. 197-209 (July 1979).

Energy cost; feedback; feedback meters; attitudes; consumer preference; energy; NBSIR 79-I77I.

Energy curve; excited state; $\mathrm{N}_{2}$; radiative transition; ${ }^{5} \Pi_{u} ;{ }^{5} \Sigma_{g}{ }^{+}$; 18935 . 
Energy curves; excimer; gain; radiative transition; electronic structure; 18936 .

Energy degradation; low-energy stopping power; electron energy loss; 18659.

Energy densities; ion-implanted silicon; laser pulses; power densities; thermal anneals; 18623 .

Energy deposition; Monte Carlo; multiple scatter; tracklength; charged particle; electron; 18965.

Energy deposition spectra; microdosimetry parameters; neutron cross section evaluations; single-event energy; 18658 .

Energy dispersive detector; multichannel analyzer; peak overlap; quantitative electron probe microanalysis; $x$-ray continuum; x-ray spectrum; computer program; TNIIO6.

Energy dispersive $\mathrm{x}$-ray microanalysis; energy dispersive $\mathrm{x}$-ray spectrometry; quantitative analysis; scanning electron microscopy; x-ray microanalysis; electron probe microanalysis; 18970 .

Energy dispersive $x$-ray spectrometry; quantitative analysis; scanning electron microscopy; $x$-ray microanalysis; electron probe microanalysis; energy dispersive $x$-ray microanalysis; 18970 .

Energy efficiency; ranges and ovens; appliances; cooking utensils; energy conservation; 18836 .

Energy efficient; enforcement; implementation and effective $U$ value; on-site construction; building official; energy code; SP552, pp. 131-140 (July 1979).

Energy field measurements; hot water heaters; hot water usage; residential water use; 18829 .

Energy gap; iridium; Josephson junction; low- $\mathrm{T}_{\boldsymbol{c}}$; microwaves; thin-film; tunneling; 18540.

Energy instrumentation; energy rate; energy use; appliances; energy conservation; 18837 .

Energy levels; energy levels, atomic; line shapes, atomic; molecular bands; molecular spectra; rotational constants; atomic line shapes; atomic spectra; atomic transition probabilities; bands, molecular; 18828 .

Energy levels; exotic atoms; interferometry; $x$ rays; 18469 .

Energy levels; hafnium; ionization energies; lutetium; osmium; rhenium; tantalum; tungsten; wavelengths; ytterbium; 18506 .

Energy levels; ion; ionization energy; spectrum; wavelengths; yttrium; 18868 .

Energy levels; ionization energy; wavelengths; aluminum; 18485 .

Energy levels; ions; molybdenum; pulsed laser; spectra; wavelengths; 18500 .

Energy levels; lanthanum; spectra; spectroscopy; triply-ionized; ultravioler; wavelengths; 18782 .

Energy levels; lutetium; spectrum; wavelengths; 18369 .

Energy levels, atomic; line shapes, atomic; molecular bands; molecular spectra; rotational constants; atomic line shapes; atomic spectra; atomic transition probabilities; bands, molecular; energy levels; 18828 .

Energy loss; excited states; negative ions; ozone; resonances; electron scattering; 18392 .

Energy measurement; enthalpy measurement; entropy measurement; fuels, heating values; gas-flow calorimetry; heat capacity measurement; heat measurements; levitation calorimetry; microcalorimetry; radiation calorimetry; solution calorimetry; bomb calorimetry; drop calorimetry; 18330 .

Energy measurements; energy standards; international comparisons; metrology; power measurements; precisc electrical measurements; TDM wattmeters; thermal wattmeters; transfer standards; electro-dynamic wattmeters; 18529.

Energy measurements; energy-related inventions; environment; precision power; radioactivity; Raman microprobe; solar energy; toxic substances; building rehabilitation; DIM/NBS 63, No. 6, 1-32 (June 1979).

Energy rate; energy use; appliances; energy conservation; energy instrumentation; 18837 .
Energy release rate; finite element method; free-edge stresses; graphite epoxy composites; intcrlaminar cracks; stability of cracks; virtual crack closure; delamination mechanisms; SP563, pp. 255-264 (Oct. 1979).

Energy saving-opportunities; rcsearch needs; cement; concrete; SP542.

Energy savings; industrial robots; network services; SRM's; computer interface standards; computers; cryogenic temperature; energy; DIM/NBS 63, No. 4, 1-24 (1979).

Energy standards; environmental standards; safety and health standards; standards de velopment; Monogr. 165.

Energy standards; environmental standards; safety and health standards; standards development; NBSIR 79-1703.

Energy standards; fenestration; life-cycle costing; retrofitting; solar; building design; cost; energy conservation; 19043.

Energy standards; international comparisons; metrology; power measurements; precise electrical measurements; TDM wattmeters; thermal wattmeters; transfer standards; electrodynamic wattmeters; energy measurements; 18529 .

Energy storage; intermetallic compound; phase diagrams; physical properties; compilation; 18637 .

Energy transfer; vibrational energy transfer; benzene; 18641 .

Energy usage; load profiles; water heaters; NBSIR 78-1496.

Energy use; appliances; energy conservation; energy instrumentation; energy rate; 18837 .

Energy utilization codes; illustrated handbook; legislation; thermal envelope criteria; thermal performance criteria; education; SP552, pp. 141-151 (July 1979).

Energy-dispersive $x$-ray spectrometry; microanalysis; qualitative analysis; scanning electron microscope; artifacts; electron probe microanalysis; 18790 .

Energy-related inventions; environment; precision power; radioactivity; Raman microprobe; solar energy; toxic substances; building rehabilitation; energy measurements; DIM/NBS 63, No. 6, 1-32 (June 1979).

Enforcement; implementation and effective $U$ value; on-site construction; building official; energy code; energy efficient; SP552, Pp. 131-140 (July 1979).

Engine diagnosis; failure detection; failure diagnosis; failure prevention; maintenance; performance monitoring; bearing analysis; condition monitoring; SP547.

Engine oil; fuel oil; hydraulic oil; industrial oil; lubricating oil; oil specifications; petroleum standards; petroleum test methods; recycled oil; re-refined oil; used oil; waste oil; SP556.

Engineering; industry construction; measurement techniques; standards; building research; criteria; energy; SP439-I.

Engineering; international cooperation; international research; international standards; National Bureau of Standards (NBS); National Engineering Laboratory (NEL); technology transfer; NBSIR 79.1792.

Engineering calculations; equation of state; fluid properties; prediction; standard reference data; synthetic gas; chemical processing; 19022.

Engineering economics; life-cycle costs; solar heat gain; thermal efficiency; window; window management; building economics; daylighting; economic analysis; energy conservation; $B S S 119$.

Engineering judgment; factor of safety; fatigue; mathematical modeling; nuclear engineering; reliability; risk; safety factor; sampling; Weibull distribution; corrosion fatigue; design; 18326

Enginecring properties data; evaluated data; polycrystalline; single crystal; sodium beta alumina; sodium beta double prime alumina; battery application; NSRDS-NBS6I, Part III.

Engineering psychology; ergonomics; evaluation; human engineering; human factors; human performance; standard reference data; anthropometry; data base; NBS-GCR-79-169.

Enhanced ionization; ionization spectrometry; LEI; stepwise excitation; tunable dye lasers; 18983 . 
Enhanced ionization theory; flame spectroscopy; ion production; laser enhanced ionization; laser spectroscopy; optogalvanic effect; 18806.

Entanglement effects; excluded volume effects; lattice-model polymer chains; polymer chain dynamics; random-coil polymer chains; relaxation times; self-entanglement effects; computer simulation; end-to-end length; 18772 .

Enthalpies; entropies; equation of state; internal energies; isobars; isobutane; isochores; isotherms; Joule-Thomson inversion; latent heats of vaporization; melting line; orthobaric densities; specific heats; speeds of sound; vapor pressures; densities; NBSIR 79-1612.

Enthalpies; entropies; equation of state; internal energies; isobars; isochores; isotherms; Joule-Thomson inversion; latent heats of vaporization; melting line; n-butane; orthobaric densities; specific heats; speeds of sound; vapor pressures; densities; NBSIR 79-1621.

Enthalpy; heat capacity; sapphire; specific heat; standard reference materials; thermodynamic properties; alumina; aluminum oxide; calorimetry; corundum; 18377.

Enthalpy; specific heat; standard reference materials; thermal conductivity; thermophysical properties; electrical resistivity; 18615.

Enthalpy and entropy of vaporization; entrainment method; melting temperature; molybdenum pentafluoride; vapor density; vapor pressure; 19020 .

Enthalpy measurement; entropy measurement; fuels, heating values; gas-flow calorimetry; heat capacity measurement; heat measurements; levitation calorimetry; microcalorimetry; radiation calorimetry; solution calorimetry; bomb calorimetry; drop calorimetry; 18330 .

Enthalpy of dilution; heat capacity; relative apparent molal enthalpy; salt solutions; thermochemistry; vapor pressure; apparent molal heat capacity; aqueous systems; bibliography; electrochemistry; electrolytes; SP537.

Enthalpy of dissociation; enthalpy of protonation; enthalpy of reaction; enthalpy of solution; nucleic acid bases; solution calorimetry; thermochemistry; adenine; J. Res. 84, No. 3, 231-240 (1979).

Enthalpy of formation; ideal gas thermodynamic properties; molecular structure; normal and deuterated naphthalenes; vibrational assignments; JPCRD 8, No. 2, $527-536$ (1979).

Enthalpy of protonation; enthalpy of reaction; enthalpy of solution; nucleic acid bases; solution calorimetry; thermochemistry; adenine; enthalpy of dissociation; J. Res. 84, No. 3, 231 240 (1979).

Enthalpy of reaction; enthalpy of solution; nucleic acid bases; solution calorimetry; thermochemistry; adenine; enthalpy of dissociation; enthalpy of protonation; J. Res. 84, No. 3, 231 240 (1979).

Enthalpy of solution; $\mathrm{KBr}, \mathrm{Kl}, \mathrm{KlO}_{3}, \mathrm{KlO}_{4}$; solution calorimetry; thermochemistry; tris(hydroxymethyl)aminomethane; endothermic solution reactions; J. Res. 84, No. 4, 273-286 (1979).

Enthalpy of solution; nucleic acid bases; solution calorimetry; thermochemistry; adenine; enthalpy of dissociation; enthalpy of protonation; enthalpy of reaction; J. Res. 84, No. 3, 231240 (1979).

Enthalpy of vaporization; halomethanes; vapor pressure-boiling point data; Wagner equation; Antoine equation; JPCRD 8, No. 2, 499-518 (1979).

Entrainment method; melting temperature; molybdenum pentafluoride; vapor density; vapor pressure; enthalpy and entropy of vaporization; 19020 .

Entropies; equation of state; internal energies; isobars; isobutane; isochores; isotherms; Joule-Thomson inversion; latent heats of vaporization; melting line; orthobaric densities; specific heats; speeds of sound; vapor pressures; densities; enthalpies; NBSIR 79-1612.
Entropies; equation of state; internal energies; isobars; isochores; isotherms; Joule-Thomson inversion; latent heats of vaporization; melting line; n-butane; orthobaric densities; specific heats; speeds of sound; vapor pressures; densities; enthalpies; NBSIR 79-1621.

Entropy; ferroelectrics; glass-ceramics; heat switches; magnetothermal conductivity; polarization; potassium tantalate; refrigeration; specific heat; strontium titanate; beryllium; ceramics; cryogenics; dielectric-constant; electrets; electrocaloric effect; 18680 .

Entropy change; ion cyclotron resonance; ionization energy; aromatic compound; charge transfer equilibria; 18337.

Entropy measurement; fuels, heating values; gas-flow calorimetry; heat capacity measurement; heat measurements; levitation calorimetry; microcalorimetry; radiation calorimetry; solution calorimetry; bomb calorimetry; drop calorimetry; electromagnetic power calorimetry; 18330 .

Environment; formation constants; ionic mechanisms; kinetics; methylmercury; methyltin; NMR; primary salt effect; speciation; activation parameters; aqueous transmethylation; chloride complexes; 18484 .

Environment; gas chromatography/mass spectrometry; sampling; sediment; trace analysis; water; $\beta$-chloroethers; air; SP519, pp. 205-212 (Apr. 1979).

Environment; human factors; research; school; air-conditioning; comfort; education; 18596.

Environment; ICRM; natural matrix; radioactivity; standards; Woods Hole; 18981 .

Environment; precision power; radioactivity; Raman microprobe; solar energy; toxic substances; building rehabilitation; energy measurements; energy-related inventions; DIMINBS 63, No. 6, 1-32 (June 1979).

Environment; retrospective; sample storage; trace analysis; analytical techniques; contamination; 18349.

Environmental analysis; functional group analysis; affinity chromatography; SP519, pp. 783-787 (Apr. 1979).

Environmental analysis; pesticides; synthetic carbonaceous resins; continuous flow system; SP519, pp. 345-353 (Apr. 1979).

Environmental chemistry; gas chromatography; liquid chromatography; automation; clinical chemistry; SP519, pP. 587600 (Apr. 1979).

Environmental considerations; innovative practices; regulatory research; standards development; administrative procedures; building codes; building regulations; buildings; construction; economic impacts; SP5 52.

Environmental effect; hydrate; hydration polishing; mechanochemical polishing with soft powder; pre-existing defect; sapphire; solid state reaction; water vapor; working unit; damaged layer; elastic emission machining; SP562, pp. 157169 (Oct. 1979).

Environmental effects; fracture of brittle materials; hydrogen embrittlement; Rehbinder effects; Westwood effects; acoustic emission; chemomechanical effects; SP562, pp. 139-145 (Oct. 1979).

Environmental materials analysis; neutron activation analysis; noble metals analysis; platinum determination; radiochemical separation; spontaneous deposition technique; biological materials analysis; 18350 .

Environmental measurements; Measurement Assurance Programs; quality assurance; 18720 .

Environmental measurements; modeling; sampling schemes; statistical sampling; SP519, pp. 1-6 (A pr. 1979).

Environmental measurements; nitric acid; nitrous acid; ozone; rate constants; chemic al kinetics; 18551 .

Environmental noise; noise; noise emission; regulations; sound; acoustics; 18785 .

Environmental pollutants; fossil fuels; low-level counting; radiocarbon; accelerat or mass spectrometry; anthropogenic 
and natural carbonaceous species; atmospheric gases and particles; 18405

Environmental pollution; fluorescence; high performance liquid chromatography; occupational health; picogram; polycyclic aromatic hydrocarbons; selectivity; sensitivity; specificity; trace analysis; SP519, pp. 41-56 (Apr. 1979).

Environmental Protection Agency; evaluability assessment; Experimental Technology Incentives Program; industrial pollution regulation; market mechanism; offset policy; regulatory policy; technological innovation; administrative experimentation; NBS-GCR-ETIP 79-62.

Environmental Protection Agency; evaluability assessment; evaluation; Experimental Technology Incentives Program; regulatory experimentation; regulatory policy; rulemaking; technological innovation; administrative experimentation; NBS-GCR-ETIP 79-63.

Environmental Protection Agency; evaluability assessment; evaluation; Experimental Technology Incentives Program; Federal Communications Commission; Federal Trade Commission; Food and Drug Administration; NBS-GCR-ETIP 7965.

Environmental Protection Agency; evaluation design; Experimental Technology Incentives Program; pesticide policy; regulatory policy; regulatory reform; technological innovation; administrative experimentation; NBS-GCR-ETAP 79-71.

Environmental psychology; evaluation; fire escape; human research; measurement; pedestrian movement; regulation; safety; standards; architectural barriers; building design; building site planning; SP552,pp. 101-113 (July 1979).

Environmental psychology; evaluation; fire escape; human research; measurement; pedestrian movement; regulation; safety; standards; architectural barriers; building design; building site planning; 18430 .

Environmental psychology; field methodology; passive solar systems; pedestrian behavior; psychology of rctailing; retail facilities; 18784 .

Environmental psychology; fire research; fire safety; human performance; modeling technique; programming; sensitivity analysis; simulation; architectural research; building fires; computer-aided design; NBSIR 79-1713.

Environmental psychology; fire research; fire safety; human performance; modeling technique; simulation; architectural research; building fires; computer-aided design; computer simulation; NBSIR 79-1796

Environmental quality; industrial productivity; materials utilization; measurement capabilities; medical aids; product safety; public health and safety; science and technology transfer; standards; basic research; computer; energy conservation; SP538.

Environmental regulation; innovation; regulatory reform; technological changes; administrative experiment; anti-trust regulation; economic incentive; NBS-GCR-ETIP 79-66.

Environmental standards; safety and health standards; standards development; energy standards; Monogr. 165.

Environmental standards; safety and health standards; standards development; energy standards; NBSIR 79-1703.

Environments; heating; passive; solar; suburban; urban; application; buildings; commercial; daylighting; energy; 18894 .

Enzyme assay; influence of inhibitor on lactate dehydrogenase assay; lactate dehydrogenase assay; lactate to pyruvate reaction; pyruvate to lactate reaction; spectrophotometric enzyme assay; 18433 .

Enzymes; immunoelectrodes; trace organic electrochemistry; bio-selective membrane electrodes; bio-sensors; SP519, pp. 525-532 (Apr. 1979).

Epilepsy; fire safety; group homes; handicapped; mental retardation; ambulatory people; autism; cerebral palsy; deafness; developmentally disabled; NBS-GCR-79-167.

Epitaxial silicon; Hall-effect measurements; phosphorus in silicon; electron paramagnetic resonance; NBS/R 79-1748.
Epoxy; epoxy-impregnated magncts; superconductor; training superconducting magnet; 18718 .

Epoxy polymer; plasma chromatography-mass spectroscopy; polymer outgassing; SP519, pp. 697-703 (Apr. 1979).

Epoxy resins; glass fiber; graphite fiber; aramid fiber; composite applications; composites; concrete; cryogenics; $187 / 7$.

Epoxy resins; Kevlar 49; moisture; one-tenth scale motor case; S-glass; temperature effects; water boil; degradation; SP563, pp. 177-197 (Oct. 1979).

Epoxy-impregnated magnets; superconductor; training superconducting magnet; epoxy; 18718 .

Equal employment opportunity; labor force; minorities in computing; women in computing; employment; 19041 .

Equation balancing; algebraic method; balancing equations; chemical equations; 18984 .

Equation of state; fluid properties; prediction; standard refercnce data; synthetic gas; chemical processing; engineering calculations; 19022

Equation of state; internal energies; isobars; isobutane; isochores; isotherms; Joule-Thomson inversion; latent heats of vaporization; melting line; orthobaric densities; specific heats; speeds of sound; vapor pressures; densities; enthalpies; entropies; NBSIR 79-1612.

Equation of state; internal energies; isobars; isochores; isotherms; Joule-Thomson inversion; latent heats of vaporization; melting line; $\mathbf{n}$-butane; orthobaric densities; specific heats; speeds of sound; vapor pressures; densities; enthalpies; entropies; NBSIR 79-1621.

Equations of motion; maximum entropy; nonequilibrium statistical mechanics; nonequilibrium thermodynamics; projection operator; correlation functions; 18321 .

Equilibration trapping; gas chromatography; headspace gas stripping; standard-addition calibration; trace analysis; trapping column; SP519, pp. 739-746 (Apr. 1979).

Equilibrium; high temperature; isolation; lasers; mass spectrometry; matrix; modeling; vapors; combustion; SP561, Vols. 1 and 2 .

Equilibrium; homogeneous system; hydrostatic pressure; internal stress; internal virial; molecular dynamics; Monte Carlo method; periodic boundaries; pressure; stress calculation; virial theorem of Clausius; 18456.

Equilibrium antiphase domain (APB) boundaries; f.c.c. alloys; interphase (IPB) boundaries; second-order transitions; 18669.

Equilibrium chain dimensions; excluded volume; lattice-model chains; polymer chain dimensions; random-coil chain dimensions; Rouse coordinates; distributions in chain dimensions; 18618 .

Equipment selection; law enforcement; public safety; communication systems; SP480-12.

Equity; life-cycle cost; optimal; standard; buildings; conscrvation; criteria; design; economics; efficiency; energy; energy budget; 18888 .

Equivalency; evaluation; fire safcty; models; research; standards; systematic procedure; building fires; SP552, pp. 13-27 (July 1979).

Equivalent circuit; modal analysis; scattering matrix; step discontinuity; TEM-cell; variational formulation; coaxial transmission line; cut-off frequency; NBSIR 79-1606.

Equivalent circuits; ionic conduction; lithium aluminosilicates; lithium silicate; electrode polarization; 18794 .

Ergonomics; evaluation; human engineering; human factors; human performance; standard reference data; anthropometry; data base; engineering psychology; NBS-GCR-79-169.

Ergonomics; human engineering; human factors; human motivation; human reliability; personnel selection; physical security; physiological psychology; sensory capability; terrosim; threat analysis; training; adversary characteristics; animal research; behavioral science; $S P 480-38$.

Ergonomics; human factors; product research; data banks; data bases; 18862 . 
Ergun function; graphite materials; Lorentz function; preferred orientation function; pyrolitic graphite; Ruland function; $x$ ray diffraction; Bacon function; Bragg function; 18523 .

Erosion; grinding; wear; bronze binder; diamonds; SP562, pp. I47-I 55 (Oct. I979).

Erosion; impact; metals; particle erosion; wear; abrasives; ceramics; NBSIR 78-1575.

Erosion; impact; metals; particle erosion; wear; abrasives; ceramics; 18858 .

Error; sampler response factors; total elemental content passive personal samplers; total organic chlorine; weighted diffusion coefficient; ambient concentration; compute and limit; SP519, pp. 747-752 (Apr. 1979).

Error analysis; G/kT, EIRP; G/T, precision measurements; radio star; satellite communications; 18577.

Error analysis; instrumental analysis; multielement analysis; neutron activation analysis; SRM; trace elements; urban particulate; 18866 .

Error estimation; liquefied natural gas; LNG; marine; mathematical modeling; measurement; photogrammetric; precision; ship cargo; statistical analysis; strapping; survey; accuracy; cryogenic; NBSIR 79-1751.

Error functions; Fourier transforms; radiation reaction; definite integrals; double integrals; J. Res. 84, No. 4, 319-326 (1979).

Error propagation; factor-jump method; heating rate; lifetime prediction; polystyrene; polyurethane; thermogravimetry; weight-loss kinetics; aging of polymers; degradation of polymers; 18620 .

Errors; ion-selective electrodes; sensors, chemical; standards; electrodes; electrodes, ion-selective; electrodes, reference; 18334.

Errors; sampling; analysis; analytical food chemistry; SP519, pp. 23I-242 (Apr. I979).

ERTS; LANDSAT; multispectral scanner; reflective optics; crosstrack scan; earth imagery; SP547, pp. I7-30 (July (979).

Erythromycin; fast reactions; fission track; ion-dipole; $\beta$-endorphin; ${ }^{252} \mathrm{Cf}$; charge transfer; chlorophylI; SP5 19, pp. 673-677 (Apr. 1979).

ESCA; gold; relative intensities; round robin; $x$-ray photoelectron spectroscopy; binding energies; copper; 18924.

ESCA; impurities; microroughness; optical microscopy; polishing defects; scattered light; SIMS; stylus instruments; Auger spectroscopy; corrosion films; SP562, pp. 337-350 (Oct. 1979).

ESCA; secondary ion mass spectroscopy; surface analysis; ASTM Committee E-42; Auger electron spectroscopy; electron spectroscopy; 18406.

Escape; evacuation; fires; high rise buildings; hospitals; human behavior; nursing homes; bibliographies; building fires; NBSGCR-78-138.

Escape; fire detectors; full-scale tests; heat detectors; hospitals; ionizaton detectors; mattresses; nursing homes; photoelectric detectors; corridors; NBSIR 79-1739.

Estimation theory; liver attenuation; spectral analysis; statistical modeling; ultrasonic tissue characterization; computer processing; SP525, pp. 125-132 (Apr. 1979).

Etching; glass; grinding; polishing; strength; defects; SP562, pp. 489-500 (Oct. 1979).

Ethernet; Iocal; microprocessor; network; serial; broadcast; coaxial; communication; contention; data; digital; 18760 .

Ethyl nitrate; ion-molecule reactions; aromatic substitution; association ions; charge transfer; 18332.

Ethylacetate; isopropyl; laser; non-equilibrium; pyrolysis; relaxation; thermal decomposition; allylmethylether; bromide; 18832 .

Ethylene; experimental; magnetic suspension; orthobaric liquid density; tables; argon; comparisons; correlation; 18627.

Ethynyl; hydrogen; mechanism; photochemistry; radicals; rate constant; acetylene; butadiyne; 18443 .
ETIP; evaluation; information intervention; integrated utility systems; case study; cogeneration; demonstration project; NBS-GCR-ETIP 78-59.

ETIP; Federal civilian R\&D; implementing; commercialization; empirical investigation; NBS-GCR-ETIP 78-58A.

ETIP; Federal civilian R\&D; implementing; management practices; technological change; commercialization; empirical investigation; NBS-GCR-ETIP 78-57.

ETIP; Federal civilian R\&D; implementing; management practices; technological change; commercialization; empirical investigation; NBS-GCR-ETIP 78-58.

Eutectic coating; graphite/epoxy; moisture barrier; space optics; advanced composites; dimensional stability; SP563, pp. 47-56 (Oct. 1979).

Evacuation; exits; fire endurance; fire protection; stairways; standards; buiding design; buildings; construction materials; NBS-GCR-79-176

Evacuation; fire departments; fire fighters; nursing homes; patients; room fires; smoke; upholstered furniture; chairs; doors; NBS-GCR-79-159.

Evacuation; fire doors; fire drills; fire extinguishers; fire safety; health care facilities; hospitals; human behavior; nursing homes; nursing staff; training; NBS-GCR-79-179.

Evacuation; fires; flashover; hospitals; human behavior; nursing staff; patients; room fires; breathing apparatus; death; NBS. GCR-78-140.

Evacuation; fires; high rise buildings; hospitals; human behavior; nursing homes; bibliographies; building fires; escape; NBS-GCR-78-138.

Evaluability assessment; evaluation; Experimental Technology Incentives Program; Federal Communications Commission; regulatory experimentation; regulatory policy; technology innovation; telecommunications; administrative experimentation; TNI I04, Vols. I and 2.

Evaluability assessment; evaluation; Experimental Technology Incentives Program; regulatory experimentation; regulatory policy; rulemaking; technological innovation; administrative experimentation; best practicable technology; clean water regulation; NBS-GCR-ETIP 79-63.

Evaluability assessment; evaluation; experimental methods; Experimental Technology Incentives Program; regulation; regulatory oversight; regulatory processes and regulatory effects; regulatory reform; social science; technological innovation; NBS-GCR-ETIP 79-64

Evaluability assessment; evaluation; Experimental Technology Incentives Program; Federal Communications Commission; Federal Trade Commission; Food and Drug Administration; Interstate Commerce Commission; regulation; NBS-GCRETIP 79-65.

Evaluability assessment; Experimental Technology Incentives Program; industrial pollution regulation; market mechanism; offset policy; regulatory policy; technological innovation; administrative experimentation; Environmental Protection Agency; NBS-GCR-ETIP 79-62.

Evaluated data; polycrystalline; single crystal; sodium beta alumina; sodium beta double prime alumina; battery application; engineering properties data; NSRDS-NBS6I, Part III.

Evaluation; existing buildings; performance standard; building; code administration; codes; SP549.

Evaluation; experimental methods; Experimental Technology Incentives Program; regulation; regulatory oversight; regulatory processes and regulatory effects; regulatory reform; social science; technological innovation; administrative experimentation; NBS-GCR-ETIP 79-64.

Evaluation; Experimental Technology Incentives Program; Federal Communications Commission; regulatory experimentation; regulatory policy; technology innovation; telecommunications; administrative experimentation; economic deregulation; TNI 104, Vols. 1 and 2. 
Evaluation; Experimental Technology Incentives Program; regulatory experimentation; regulatory policy; rulemaking; technological innovation; administrative experimentation; best practicable technology; clean water regulation; NBSGCR-ETIP 79-63.

Evaluation; Experimental Technology Incentives Program; Federal Communications Commission; Federal Trade Commission; Food and Drug Administration; Interstate Commerce Commission; regulation; NBS-GCR-ETIP 79-65.

Evaluation; feasibility; passive; rehabilitation; retrofit; solar; commercial; economics; 18964 .

Evaluation; fire escape; human research; measurement; pedestrian movement; regulation; safety; standards; architectural barriers; building design; building site planning; environmental psychology; SP552, pp. 101-113 (July 1979).

Evaluation; fire escape; human research; measurement; pedestrian movement; regulation; safety; standards; architectural barriers; building design; building site planning; environmental psychology; 18430 .

Evaluation; fire safety; models; research; standards; systematic procedure; building fires; equivalency; SP552, pp. 13-27 (July 1979).

Evaluation; gaseous interactions; molecular correlations; quenching; radiative lifetimes; rate constants; reactive channels; recommended data; relaxation processes; review; activation energies; electronically excited states; JPCRD 8, No. 3 , 723.798 (1979).

Evaluation; guidelines; implementation; large-scale; management; mathematical models; policy analysis; software; standards; transfer; documentation; energy; SP534.

Evaluation; human engineering; human factors; human performance; standard reference data; anthropometry; data base; engineering psychology; ergonomics; NBS-GCR-79-169.

Evaluation; industrialized housing products; inspection; regulation; third party; agencies; approval process; SP552, pp. 293. 309 (July 1979).

Evaluation; information intervention; integrated utility systems; case study; cogeneration; demonstration project; ETIP; NBSGCR-ETIP 78-59.

Evaluation; interagency transducer project; performance characteristics; telemetry; transducer; dynamic calibration; TN1110.

Evaluation; international; standardization; standard recommended practice; synopsis; ultrasonic standards; ultrasonic testing; NBSIR 79-1790.

Evaluation; procurement; technical analysis; time-sharing; TSP; benchmarking; cost analysis; SP500-52, pp. 233-234 (Oct. 1979).

Evaluation design; Experimental Technology Incentives Program; pesticide policy; regulatory policy; regulatory reform; technological innovation; administrative experimentation; Environmental Protection Agency; NBS-GCR-ETIP 79-7I.

Evaluation methodology; performance evaluation; procurement; computer evaluation; computer performance; computer procurement; computers; computer selection; cost-value; cost-value technique; EDP selection; SP500-52, pp. 25-36 (Oct. 1979).

Evaluation methods; fire safety; hazard warnings; pictograms; safety information; standardization; symbols; communication; NBSIR 79.1760

Evaluation of test procedure; solar heating components; standard test procedure; thermal storage tests; water tank thermal storage; ASHRAE Standards; 18425.

Evaluation process; performance measures; performance ratings; response time; system design tradeoffs; thruput measures; comparison measures; SP500-52, pp. $163-176$ (Oct. 1979).

Evaporated electrodes; pressure transducer; temperature dependence; adiabatic heating; $\mathbf{A s}_{2} \mathrm{~S}_{3}$; automatic bridge; $\mathrm{Bi}_{12} \mathbf{G e O}_{20}$; $\mathrm{CaCO}_{3} ; \mathrm{CaF}_{2}$; capacitance measurement; 18466 .
Evaporation; nomenclature; sample work-up; standards; chromatography/column packings (GC); electron-capture detection; SP519, pp. 809-810 (Apr. 1979).

Evaporation coefficient; humidity measurement; monomolecular film; psychrometer; psychrometry; radiative heat transfer; temperature depression; water vapor measurement; wet bulb; wet element; convective heat transfer; J. Res. 84, No. 2, 161177 (1979).

Excess Gibbs energy; iron; nickel; osmotic coefficients; solutions; thermodynamic properties; activity coefficient; cobalt; critical evaluation; electrolyte; JPCRD 8, No. 4, 923-1004 (1979).

Excess Gibbs energy; lead; manganese; osmotic coefficients; solutions; thermodynamic properties; uranium; activity coefficient; copper; critical evaluation; electrolyte; JPCRD 8, No. 4, 1005-1050 (1979).

Excess volumes; heat of mixing; liquid-vapor equilibria; methane + ethane; binary mixtures; data correlation; JPCRD 8, No. 3, 799-816 (1979)

Exchange; hydroxyl; kinetics; mechanism; photochemistry; carbon dioxide; carbon monoxide; carbonyl; 18436 .

Exchange interaction; ferrite; hyperfine field; magnetism; phase diagram; potassium; conductivity; 19046.

Excimer; gain; radiative transition; electronic structure; energy curves; 18936.

Excimer lasers; excimer molecules; metal atoms; 18877.

Excimer molecules; metal atoms; excimer lasers; 18877.

Excitation; ion; ionization; molecule; photon; positron; atom; collision cross section; detachment; dissociation; elastic scattering; electron; SP426. Supplement 1.

Excitation; low energy; nitrogen; rate coefficients; drift tube; electrons; 18925.

Excitation rate coefficients; ionization rate coefficients; magnetic fusion research; transition probabilities; wavelengths; atomic data; data availability; dielectronic recombination rates; 18593.

Excitation, $2 s-2 p ; \mathrm{N}^{4+}$; crossed beams; cross sections; electron impact; 18707 .

Excited argon atoms; force constants; infrared spectrum; ketenimine; matrix isolation; methyl cyanide; ultraviolet spectrum; vacuum ultraviolet photolysis; charge transfer; cyanomethyl radical; 18879 .

Excited argon atoms; free radicals; infrared spectra; matrix isolation; molecular ions; photochemistry; ultraviolet spectra; charge transfer; 18847.

Excited state; hydrogen bromide; photochemistry mechanism; thermochemistry; bromine atoms; bromoacetylene; 18974 .

Excited state; $\mathrm{N}_{2}$; radiative transition; ${ }^{5} \Pi_{4} ;{ }^{5} \Sigma_{y}{ }^{+}$; energy curve; 18935.

Excited states; ground state; intermolecular potential; molecules; well depths; 18677.

Excited states; He; inter action energy; overlap; Be; dispersion; 18933.

Excited states; negative ions; ozone; resonances; electron scattering; energy loss; 18392.

Excitons; photoemission; satellite and band narrowing; $d$-band of $\mathrm{Ni} ; 18632$.

Excluded volume; lattice-model chains; polymer chain dimensions; random-coil chain dimensions; Rouse coordinates; distributions in chain dimensions; equilibrium chain dimensions; 18618.

Excluded volume effects; lattice-model polymer chains; polymer chain dynamics; random-coil polymer chains; relaxation times; self-entanglement effects; computer simulation; end-to-end length; entanglement effects; 18772.

Exclusion area; forced entry deterrent systems; guard control station; higher headquarters; perimeter station; remote unit; response force; triply redundant central computer; central unit; computerized; detection; electronic lock; NBSIR 79. 1725 . 
Existing buildings; historic preservation; performance attributes; performance evaluation; building codes and standards; building code structure; SP536, pp. 17-53 (Feb. 1979).

Existing buildings; model codes; preservation; regulation; rehabilitation; renovation; building code; building research; code administration; TN998.

Existing buildings; performance standard; building; code administration; codes; evaluation; SP549.

Existing buildings; regulation; retrofit; standards; conservation; energy cost; SP552, pp. 197-209 (July 1979).

Exits; fire endurance; fire protection; stairways; standards; buiding design; buildings; construction materials; evacuation; NBS-GCR-79-176.

Exoatmospheric exposure of composites; Long Duration Exposure Facility (LDEF); polyimide composite stability in space; polyimide/graphite mechanical properties; ultrasonic inspection; cocured and precured laminates; SP563, pp. 4.16 (Oct. 1979).

Exotic atoms; interferometry; x rays; energy levels; 18469 .

Expense; inspection requirements; pre-construction conference; code enforcement; county building code; critical structures program; SPS52, pp. 31 I-320 (July 1979).

Experimental; extended corresponding states method; hard sphere model; Klosek-McKinley method; liquefied natural gas (LNG); magnetic suspension densimeter; comparisons; correlation; custody transfer; density; $\mathbf{1 8 7 7 5}$.

Experimental; magnetic suspension; orthobaric liquid density; tables; argon; comparisons; correlation; ethylene; 18627.

Experimental methods; Experimental Technology Incentives Program; regulation; regulatory oversight; regulatory processes and regulatory effects; regulatory reform; social science; technological innovation; administrative experimentation; NBS-GCR-ETIP 79-64.

Experimental Technology Incentives Program; Federal Communications Commission; regulatory experimentation; regulatory policy; technology innovation; telecommunications; administrative experimentation; economic deregulation; TN/104, Vols. $l$ and 2.

Experimental Technology Incentives Program; impact of government on industry; procurement experiments; procurement policy; research and development policy; technological change; NBS-GCR-ETIP 78-49.

Experimental Technology Incentives Program; portable oxygen generator experiment; procurement policy; two-step prototype procurement; Veteran's Administration; NBS-GCR-ETIP 78-50.

Experimental Technology Incentives Program; Federal Supply Service; life cycle costing; procurement of water heaters; technological change; commercial impacts; NBS-GCR-ETIP $78-51$.

Experimental Technology Incentives Program; Federal Supply Service; life cycle costing; procurement of water heaters; technological change; commercial impacts; NBS-GCR-ETIP 78-52.

Experimental Technology Incentives Program; industrial pollution regulation; market mechanism; offset policy; regulatory policy; technological innovation; administrative experimentation; Environmental Protection Agency; evaluability assessment; NBS-GCR-ETIP 79-62.

Experimental Technology Incentives Program; regulatory experimentation; regulatory policy; rulemaking; technological innovation; administrative experimentation; best practicable technology; clean water regulation; Environmental Protection Agency; NBS-GCR-ETIP 79-63.

Experimental Technology Incentives Program; regulation; regulatory oversight; regulatory processes and regulatory effects; regulatory reform; social science; technological innovation; administrative experimentation; evaluability assessment; evaluation; NBS-GCR-ETIP 79-64.
Experimental Technology Incentives Program; Federal Communications Commission; Federal Trade Commission; Food and Drug Administration; Interstate Commerce Commission; regulation; regulatory processes and regulatory effects; NBSGCR-ETIP 79-65.

Experimental Technology Incentives Program; regulatory impact; research and development; steel industry; technology; capital formation; NBS-GCR-ETIP 79-67.

Experimental Technology Incentives Program; productivity; regulatory commission; regulatory policy; technological innovation; computer program; economic performance; electric utilities; NBS-GCR-ETIP 79-70.

Experimental Technology Incentives Program; pesticide policy; regulatory policy; regulatory reform; technological innovation; administrative experimentation; Environmental Protection Agency; evaluation design; NBS-GCR-ETIP 79-71.

Explosion; fire; hydrogen; procedures; regulations; research needs; safety; standards; 18776.

Exponential fitting; $\mathrm{Kr}$ VIII; atomic decay curve simulation; atomic transition probabilities; beam-foil spectroscopy; cascades in atomic decay; 18508 .

Exponential index; ionization; multiphoton; Rabi frequency; Star shift; two-level model; absorption; cesium; 18892.

Extended chain fibrils; flow-induced crystallization; polymer crystallization; shish kebabs; crystallization theory; 18715 .

Extended corresponding states method; hard sphere model; Klosek-McKinley method; liquefied natural gas (LNG); magnetic suspension densimeter; comparisons; correlation; custody transfer; density; experimental; $/ 8775$.

Extended immersion; flammability; glass reinforced plastics; graphite epoxy; impact; marine environment; advanced composites; cavitation erosion; SP563, pp. 276-285 (Oct. 1979).

Extended-range capacitance and conductance measurements; high-voltage $C(V)$ and $G(V)$ measurements; semiconductor device measurements; silicon-on-sapphire measurements; NBS-GCR-78-155.

External; internal; quantum efficiency; reflectance; response; silicon detector; spatial position dependence; dead layer model; 18900 .

External; internal quantum efficiency; silicon; absolute detector; absorption coefficient; dead layer model; 18477.

Extinguishability; fabrics; flammability; garments; hazard; heat transfer; ignitability; standard; test; apparel; 18708 .

Extra-atomic screening; implants; ion bombardment; rare-gases; relaxation energy; ultraviolet photoelectron spectroscopy; amorphous germanium; binding energy shifts; 18323 .

Extraction; herbicides; high pressure liquid chromatography; organics in water; pesticides; SP519, pp. 87-94 (Apr. 1979).

Extraction; hydrocarbons; marine; petroleum; sediments; SP519, Pp. 161-167 (Apr. 1979).

Extractor column; generator column; polynuclear aromatic hydrocarbon; standard reference material; dynamic coupledcolumn liquid chromatography; SPS19, pp. 219-224 (Apr. 1979).

Extrusion of restorations; marginal fracture; zinc effect; creep; dental amalgam; dimensional changes; 18586 .

Eye injury; impact; ocular contusion; projectiles; propelled objects; test methods; toy safety; J. Res. 84, No. I, 9-19 (1979).

\section{$\mathbb{F}$}

Fabric flammability; fabrics; fire; garments; heat transfer; injury potential; simulation; accident; apparel; burn injury; clothing; NBSIR 79-1755.

Fabric flammability; fire detection systems; fire tests; flammability tests; humari behavior; plastics; polymers; smoke; smoke detectors; subway fires; toxicity; upholstered furniture; arson; bibliographies; building fires; compartment fires; NBSIR 79-1745. 
Fabrication; finite element stress analysis; front end; graphite; part integration; wheel; automotive component design; continuous fiber composite materials; SP563, pp. 135-151 (Oct. 1979).

Fabrics; fire; flammability; international; self-extinguishment; ships; standards; curtains; drapes; NBSIR 79-1596.

Fabrics; fire; flammability tests; garments; heat transfer; standards; apparel; burn injury; ease of ignition; 18991.

Fabrics; fire; garments; heat transfer; injury potential; simulation; accident; apparel; burn injury; clothing; fabric flammability; NBSIR 79-1755.

Fabrics; flammability; garments; hazard; heat transfer; ignitability; standard; test; apparel; extinguishability; 18708.

Face centered cubic; ground state; interfaces; multi-ion interactions; ordered alloys; statistical mechanics; 18614 .

Faces (crystal) on platinum crucibles; hematite forming on platinum; iron as alloy in platinum; platinum ware; surface of platinum influenced by method heating; contrast augmentation of reflecting surfaces; double-diaphragm; J. Res. 84, No. 5, 385-394 (1979).

Facility; laser optics; low velocity; mine ventilation; velocity standard; airflow; calibration; TN989.

Factor of safety; fatigue; mathematical modeling; nuclear engineering; reliability; risk; safety factor; sampling; Weibull distribution; corrosion fatigue; design; engineering judgment; 18326.

Factor-jump method; heating rate; lifetime prediction; polystyrene; polyurethane; thermogravimetry; weight-loss kinetics; aging of polymers; degradation of polymers; error propagation; 18620 .

Factor-jump thermogravimetry; polymer degradation; thermogravimetry; activation energy; automated thermogravimetry; computer automated thermogravimeter; 18447.

Factor-jump thermogravimetry; polymer degradation; polymer oxidation; programmed temperature control; thermogravimetry; activation energy; degradation apparatus; 18450 .

Fading; Harshaw Chemical Company; relative humidity; storage; Studsvik AB Atomenergi, Sweden; thermoluminescence dosimeters; 18989.

Failsafe blade design; propeller fatigue behaviour; propeller materials requirements; blade aeroelastic behaviour; blade manufacture and quality control; composite propellers and rotors; SP563, pp. 80-88 (Oct. 1979).

Failure; finite elements; graphite-epoxy; interlaminar stresses; laminated composites; stress concentrations; tension; tensor polynomial; compression; SP563, pp. 242-254 (Oct. 1979).

Failure; polyethylene; solvent; stress-cracking agent; uniaxial creep; crack growth; 18766 .

Failure analysis; failure models; failure rates; reliability; residential buildings; smoke detectors; component screening; electronic component reliability; NBS-GCR-79-160.

Failure analysis; failure models; failure rates; reliability; residential buildings; smoke detectors; component screening; electronic component reliability; NBS-GCR-79-161.

Failure analysis; failure models; failure rates; reliability; residential buildings; smoke detectors; component screening; electronic component reliability; NBS-GCR-79-162.

Failure annunciation; malfunction procedures; manned spaceflight failures; redundancy management; training for diagnosis; automatic monitoring; SPS47, pp. 3-16 (July 1979).

Failure criteria; in-plane loads; bonded joints; composites; SP563, p. 241 (Oct. 1979).

Failure criteria; loss factor; nonlinear creep; polyethylene; 18468.

Failure detection; failure diagnosis; failure prevention; maintenance; performance monitoring; bearing analysis; condition monitoring; engine diagnosis; SP547.
Failure detection; lubrication system monitoring; aircraft component failure; condition monitoring; debris monitoring; diagnostic techniques; SP547, pp. 330-344 (July 1979).

Failure detection; preventive maintenance; acoustic emission; SP547, pp. 129-152 (July 1979).

Failure diagnosis; failure prevention; maintenance; performance monitoring; bearing analysis; condition monitoring; engine diagnosis; failure detection; SP547.

Failure mechanisms; failure modes; photovoltaics; reliability; semiconductors; solar cells; stability; testing; thin films; accelerated tests; SP4OO-58.

Failure mechanisms; failure modes; photovoltaics; reliability; semiconductors; solar cells; stability; testing; thin films; accelerated tests; NBSIR 79-1778.

Failure models; failure rates; reliability; residential buildings; smoke detectors; component screening; electronic component reliability; failure analysis; NBS-GCR-79-160.

Failure models; failure rates; reliability; residential buildings; smoke detectors; component screening; electronic component reliability; failure analysis; NBS-GCR-79-161.

Failure models; failure rates; reliability; residential buildings; smoke detectors; component screening; electronic component reliability; failure analysis; NBS-GCR-79-162.

Failure modes; finite element method; tensile strength; boronepoxy; edge cracks; SP563, pp. 228-238 (Oct. 1979).

Failure modes; photovol taics; reliability; semiconductors; solar cells; stability; testing; thin films; accelerated tests; failure mechanisms; SP4OO-58.

Failure modes; photovoltaics; reliability; semiconductors; solar cells; stability; testing; thin films; accelerated tests; failure mechanisms; NBSIR 79-1778.

Failure prevention; machinery noise; noise signature; nondestructive evaluation; piezoelectric polymer; spectrum analysis; strain gage; bearing noise; SP547, pp. 303-314 (July 1979).

Failure prevention; maintenance; performance monitoring; bearing analysis; condition monitoring; engine diagnosis; failure detection; failure diagnosis; SP5 47.

Failure rates; reliability; residential buildings; smoke detectors; component screening; electronic component reliability; failure analysis; failure models; NBS-GCR-79-160.

Failure rates; reliability; residential buildings; smoke detectors; component screening; electronic component reliability; failure analysis; failure models; NBS-GCR-79-161.

Failure rates; reliability; residential buildings; smoke detectors; component screening; electronic component reliability; failure analysis; failure models; NBS-GCR-79-162.

Faithful distributive module; generating function; incidence algebra; inverse limit; orthogonal idempotents; quasi-order; topological algebra; coalgebra; direct limit; 18788 .

Faithful distributive module; incidence algebra; multiplicative function; quasi-ordered set; topological algebra; automorphism; cyclic module; 18789 .

Far field; near field; planar scanning; antenna measurements; cylindrical scanning; 18818 .

Far infrared spectrum; HCCN; infrared spectrum; interferometer; matrix isolation; methyl cyanide; ultraviolet spectrum; vacuum ultraviolet photolysis; CCN; CNC; 18842 .

Far ultraviolet; light pulse shape; vacuum spark; 18811 .

Far wings; infrared wings; line shape; model correlation function; pressure broadening; $\mathrm{CO}_{2} ; 18886$.

Faraday; potentiostat; silver; silver analysis; controlled potential; coulometry; electrochemical equivalent of silver; electrochemistry; J. Res. 84, No. 2, 157-160 (1979).

Far-infrared; laser; methyl fluoride; Stark; 18426.

Fast; neutrons; track; activation; detectors; dose; SP554, pp. 99-107 (Sept. 1979).

Fast breeder reactors; light water reactors; damage analysis; dosimetry standardization; 19012 . 
Fust Fourier Transform; frequency spectra; in vivo; microprocessor-controlled data acquisition; myocardial infarction; real-time; tissue characterization; ultrasound diagnosis; clinical cardiac data; digital processing; SP525, pp. 267. 273 (Apr. 1979).

Fast Fourier transform; linear load; Newton-Raphson interation methods; nonlinear load; time-domain measurements; timestepping finite-difference technique; transient; traveling-wave antenna; 19035.

Fast Fourier "Transform"; near-field scanning; orthogonalities; plane-radial scanning; probe correction; space groups; aliasing; Bravais lattices; 18956.

Fast Fourier transforms; Fourier transform analysis; mixing in turbulent flow; noise spectrum; Raman spectroscopy; turbulence; concentration fluctuations; 18626.

Fast neutrons; photofission; photoneutrons; pressure vessel; reactor; threshold detectors; dosimetry; 18462.

Fast reactions; fission track; ion-dipole; $\beta$-endorphin; ${ }^{252} \mathrm{Cf}$; charge transfer; chlorophyll; erythromycin; SP519, pp. 673677 (Apr. 1979).

Fatigue; fatigue cracks; fracture mechanics; fracture toughness; pipeline; weld flaws; weldments; carbon-manganese steel; 18802 .

Fatigue; fracture; high-strength; low-temperature; mechanical properties; nitrogen; nitrogen-strengthened; stainless steel; tensile properties; toughness; cryogenic; 18957.

Fatigue; fracture; low temperature tests; mechanical properties; aluminum alloys; crack propagation; cryogenics; 18610 .

Fatigue; fracture resistance; low temperature tests; mechanical porperties; stainless steel; crack propagation; 18621 .

Fatigue; grain boundary sliding; high temperature; intergranular fracture; stainless steel; critical strain rate; $I 8896$.

Fatigue; interactive system; mathematical modeling; paper; paper fiber; report retrieval; scientific data; computer graphics; data base management; data retrieval; durability; NBSIR 79-I746.

Fatigue; low temperature tests; nickel alloys; stainless steels; steels; superalloys; titanium alloys; crack propagation; 18695 .

Fatigue; mathematical modeling; nuclear engineering; reliability; risk; safety factor; sampling; Weibull distribution; corrosion fatigue; design; engineering judgment; factor of safety; 18326.

Fatigue cracks; fracture mechanics; fracture toughness; pipeline; weld flaws; weldments; carbon-manganese steel; fatigue; 18802 .

Fatigue flaw evaluation; fracture mechanics; standards; technique development; compact tension specimen; crack; crack, well-characterized; destructive evaluation; 18744 .

Fatigue of polymers; mechanical testing; additive damage; biaxial fatigue; biomaterials; circulatory assist devices; NBSIR 79. 1741 .

Fatigue tests; nondestructive tests; structural analysis; ultimate strength; advanced composites; advanced ships; elastic properties; SP563, pp. 286-298 (Oct. 1979).

Fatigue (materials); fracture properties; low temperature tests; mechanical properties; titanium; titanium alloys; electron beam welding; 18611 .

F-atom production; F-atom reactions; $\mathrm{H}$-atom abstraction; hydrogen bonding; hydrogen fluoride; infrared spectrum; matrix isolation; methane; methyl fluoride; methyl radical; 18869.

F-atom reactions; $\mathbf{H}$-atom abstraction; hydrogen bonding; hydrogen fluoride; infrared spectrum; matrix isolation; methane; methyl fluoride; methyl radical; F-atom production; 18869.

Fats; lipoxidase; oils; PUFA; 9,12-di-cis-polyunsaturated fatty acids; SP5 19, pp. 289-295 (Apr. 1979).

Fatty liver; stochastic scattering; tissue characterization; ultrasonic tissue scattering; ultrasound attenuation; ultrasound diagnosis; backscatter frequency dependence; cirrhosis; composition-dependent scattering; SP525, pp. 157-163 (Apr. 1979).

Fault detection; fuel economy; motor vehicle; diagnosis; emissions inspections; SP547, pp. 78-97 (July 1979).

Fault tolerant computer; soft errors; TMR; triply modular redundant; NBSIR 79-1927.

Fault tree analysis; fire models; fire protection engineering; probability statistics; systems analysis; systems safety; walls; barrier analysis; compartment fires; compartments; NBSGCR-79-163.

F.c.c. alloys; interphase (IPB) boundaries; second-order transitions; equilibrium antiphase domain (APB) boundaries; 18669 .

Feasibility; passive; rehabilitation; retrofit; solar; commercial; economics; evaluation; 18964.

Feasibility study; FIPS guidelines; initiation phase; project request; software; automated data systems; computer programs; cost/benefit analysis; documentation; documentation content guidelines; FIPS PUB 64.

Feature article; news release; publication announcement; scientist-author; technical communicator; technical paper; trade press; audience; 18817 .

Federal acquisition dates; Federal ADP statistics; Federal ADP work-years; Federal Government computers; Federal minicomputers; statistics; ADP costs; SP500-46.

Federal ADP statistics; Federal ADP work-years; Federal Government computers; Federal minicomputers; statistics; ADP costs; Federal acquisition dates; SP500-46.

Federal ADP work-years; Federal Government computers; Federal minicomputers; statistics; ADP costs; Federal acquisition dates; Federal ADP statistics; SP500-46.

Federal civilian R\&D; implementing; commercialization; empirical investigation; ETIP; NBS-GCR-ETIP 78-58A.

Federal civilian R\&D; implementing; management practices; technological change; commercialization; empirical investigation; ETIP; NBS-GCR-ETIP 78-57.

Federal civilian R\&D; implementing; management practices; technological change; commercialization; empirical investigation; ETIP; NBS-GCR-ETIP 78-58.

Federal Communications Commission; Federal Trade Commission; Food and Drug Administration; Interstate Commerce Commission; regulation; regulatory processes and regulatory effects; administrative experimentation; NBS-GCR-ETIP 79 65.

Federal Communications Commission; regulatory experimentation; regulatory policy; technology innovation; telecommunications; administrative experimentation; economic deregulation; evaluability assessment; evaluation; TNIIO4, Vols. I and 2.

Federal funding of civilian R\&D; regulatory policy; subsidy policy; technological innovation; air pollution-regulatory policy; economic incentives; NBS-GCR-ETIP 78-53.

Federal Government; laboratory; measurement; metrology; precision; test equipment; calibration; SP546, 1979 Edition.

Federal Government computers; Federal minicomputers; statistics; ADP costs; Federal acquisition dates; Federal ADP statistics; Federal ADP work-years; SP500-46.

Federal Information Processing Standards; Federal standards; ADP information sources; ADP management; ADP policies; ADP services; automatic data processing; computer services; NBSIR 79.1734.

Federal Information Processing Standards Publication; industries; representations and codes; Standard Industrial Classification; computers; dat a processing; FIPS PUB 66.

Federal minicomputers; statistics; ADP costs; Federal acquisition dates; Federal ADP statistics; Federal ADP work-years; Federal Government computers; SP500-46. 
Fedcral policies; Federal voluntary standards policy; voluntary standards; voluntary standards system; consensus standards; SP552, pp. 79-93 (July 1979).

Fcderal standards; ADP information sources; ADP management; ADP policies; ADP services; automatic data processing; computer services; Federal Information Processing Standards; NBSIR 79-I734.

Fedcral Supply Service; life cycle costing; procurement of water heaters; technological change; commercial impacts; Experimental Technology Incentives Program; NBS-GCR-ETIP $78-51$

Federal Supply Service; life cyclc costing; procurement of water heaters; technological change; commercial impacts; Experimental Technology Incentives Program; NBS-GCR-ETIP $78-52$.

Federal Trade Commission; Food and Drug Administration; Interstate Commerce Commission; regulation; regulatory processes and regulatory effects; administrative experimentation; Environmental Protection Agency; evaluability assessment; NBS-GCR-ETIP 79-65.

Federal voluntary standards policy; voluntary standards; voluntary standards system; consensus standards; Federal policies; SP552, pp. $79-93$ (July 1979).

Feedback; feedback meters; attitudes; consumer preference; energy; energy cost; NBSIR 79-177I.

Feedback meters; attitudes; consumer preference; energy; energy cost; feedback; NBSIR 79-I77I.

Fenestration; heating and cooling load; solar heat gain; daylighting; energy calculation; energy consumption; 19003.

Fenestration; life-cycle costing; retrofitting; solar; building design; cost; energy conservation; energy standards; 19043.

Fenestration; solar energy; windows; daylighting; energy conservation; 18863 .

Fermi gas; lithium; optical potentials; photopion; pion; beryllium; differential cross section; 18442 .

Fermi gas; lithium; optical potentials; photopion; pion; beryllium; differential cross section; 18496 .

Fermi theory; neutral currents; neutrino scattering; weak interaction; atomic parity mixing; charged currents; 1895 I.

Ferrite; hyperfine field; magnetism; phase diagram; potassium; conductivity; exchange interaction; 19046.

Ferrites; glass melting; grinding; grinding model; high-speed grinding; pyrex; size effect; chipping; SP562, pp. 61-74 (Oct. 1979).

Ferroelectrics; figures of merit; improper ferroelectrics; pyroelectric detectors; pyroelectric vidicons; terbium molybdate; triglycine sulfate; $I 8852$.

Ferroelcctrics; glass-ceramics; heat switches; magneto-thermal conductivity; polarization; potassium tantalate; refrigeration; specific heat; strontium titanate; beryllium; ceramics; cryogenics; dielectric-constant; electrets; electrocaloric effect; entropy; 18680.

Ferrography; machine condition monitoring; oil analysis; oil sampling; wear; wear particles; SP547, pp. 323-329 (July 1979).

Ferromagnetism; magnetization equation; spin Hamiltonians; spinodal point; spin-phonon coupling; 18605 .

Ferrous alloys; fracture mechanics; LNG; low temperature; mechanical properties; aluminum alloys; 18865 .

Feynman integrals; quantum field theory; singularities; $S$-matrix; 18732.

FFT; fiber optics; frequency response; impulse response; laser; photodiode; avalanche photodiode; NBSIR 79-1620.

FFT; method of measurements; non-dispersive; resistive loading; TEM horn; time domain measurement; antenna gain; broadband antenna; directivity; $\mathbf{I 8 8 5 6}$.

rFT techniques for breast; histology of breast tumors; signal processing for tissue; $x$-ray examination of breast; attenuation of areola; attenuation of breast tissue; attenuation of malignant tumors; breast cancer detection; breast carcinoma; SP525, pp. 85-91 (Apr. 1979).

Fiber; mcchanical properties; moisture; prepreg; aging of polymer; composite; SP563, pp. 17-21 (Oct. 1979).

Fiber composites; fiber glass; filament wound composites; advanced composites; applications of composites; composites; composite structures; design using composites; SP563.

Fiber glass; filament wound composites; advanced composites; applications of composites; composites; composite structures; design using composites; fibcr composites; SP563.

Fiber length distribution; fiber strength; interfiber bonding; recycled pulps; short span tensile analysis; zero span tensile; NBSIR 79-1914.

Fiber optics; filters; flight critical; flow; fluid; go-no-go; ground readout; hydraulic; IMACS; instantaneous diagnosis and analysis; level; maintenance oriented; malfunction detection; monitoring; onboard; patented; pressure; pumps; SP547, pp. 345-357 (July 1979).

Fiber optics; frequency response; impulse response; laser; photodiode; avalanche photodiode; FFT; NBSIR 79-1620.

Fiber optics; frequency response; measurements; attenuation; 18915.

Fiber optics; frequency response measurements; measurements; review; attenuation measurements; 18647

Fiber optics; interlaboratory comparison; measurements; optical communications; quality control; attenuation; NBSIR 79. 1608.

Fiber optics; measurement; optical communications; review; communication systems; 18648 .

Fiber optics; phase discriminator; delay line; discriminator; I8547.

Fiber reinforced; thermoplastics; SP563, p. 173 (Oct. 1979).

Fiber strength; interfiber bonding; recycled pulps; short span tensile analysis; zero span tensile; fiber length distribution; NBSIR 79-1914.

Fiberglass; mechanical porperties; modulus; strength; superconducting motor; composites; 18616 .

Fiberglass; mechanical properties; nonmetallics; physical properties; stainless steel; alloys; NBSIR 79-1609.

Fiberglass composites; fiberglass reinforced plastics; SP563, p. 134 (Oct. 1979).

Fiberglass reinforced plastics; fiberglass composites; SP563, p. 134 (Oct. 1979).

Field calibration; high accuracy; modular capacitive divider; portable system; truck-mounted; CCVT; compact; 18833.

Field calibration; high accuracy; portable system; truckmounted; CCVT; compact; 18938.

Field emission; field-induced redistribution; hydrogen; ruthenium; adsorption; 18810 .

Field ionization; laser spectroscopy; multiphoton processes; photoionization; quantum beats; sodium atom; angular distributions; 18953.

Field measurments; hourly load profiles; refrigerator field data; usage profiles; combination refrigerator-freezer field data; daily load profiles; energy consumption; NBSIR 79-I 781 .

Field methodology; passive solar systems; pedestrian behavior; psychology of retailing; retail facilities; environmental psychology; 18784 .

Field of values; graph; longest circuit; permutation matrix; doubly stochastic matrix; eigenvalues; 1894 I.

Field of values; Hadamard product; inclusion theorem; Kronecker product; numerical radius; spectrum; stable matrix; closure; $D$-stability; diagonal matrix; 18909 .

Field quantization; interacting quantum fields; relativistic field theory; relativistic hamiltonian; relativistic stationary states; composite system; 18769 .

Field standard provers; field standards; field standard test measures; provers; specifications; standards; test measures; tolerances; vapor recovery; bottom loading; HIO5-3. 
Ficld standard test measures; provers; specifications; standards; test measures; tolerances; vapor recovery; bottom loading; field standard provers; field standards; H105-3.

Field standards; field standard test measures; provers; specifications; standards; test measures; tolerances; vapor recovery; bottom loading; field standard provers; H105-3.

Field strength calibration; pyramidal horn antenna; rf radiation monitor; standard electromagnetic field; antenna gain calculation; 18814 .

Field test kits; sensitivity; specificity; chemical spot tests; color tests; drugs of abuse; 18492 .

Field-induced redistribution; hydrogen; ruthenium; adsorption; field emission; 18810 .

Fighting vehicle systems; generic DCA; Hull systems; simplified test equipment for internal combustion engines; turret systems; vehicle maintenance; combat vehicles; diagnostic connector assembly; SP547, pp. 98-110 (July 1979).

Figures of merit; improper ferroelectrics; pyroelectric detectors; pyroelectric vidicons; terbium molybdate; triglycine sulfate; ferroelectrics; 18852 .

Filament winding; large composite structures; rotor blades; wind turbine; composite materials; SP563, pp. $155-172$ (Oct. 1979).

Filament wound composites; advanced composites; applications of composites; composites; composite structures; design using composites; fiber composites; fiber glass; SP563.

Filament wound tankage; leakage failure mode; linear elastic fracture mechanics; metal liner; composite materials; critical flaw size; cyclic fatigue life; SP563, pp. 198-207 (Oct. 1979).

File handling; graphic analysis; IMS information retrieval; KWOC indexing; least-squares; linear regression; MIS; plotting; statistical analysis; Boolean search system; computer programs; curve fitting; data analysis; data base management; data retrieval; 18597.

File maintenance; reformatting; reorganization; restructuring; data base; data base management; SP500-47.

Filter paper; fuel oil; spectrometry; sulfate; $x$ ray; anion exchange; 18635 .

Filters; flight critical; flow; fluid; go-no-go; ground readout; hydraulic; IMACS; instantaneous diagnosis and analysis; level; maintenance oriented; malfunction detection; monitoring; onboard; patented; pressure; pumps; reservoirs; SP547, pp. 345-357 (July 1979).

Financial applications; long-range planning; management control; measurement; modeling; on-line system design; performance evaluation; performance management; prototyping; remote terminal emulation; system testing; audit; capacity planning; SP500-52, pp. 129-140 (Oct. 1979).

Fine grinding; glass; ceramics; material removal; abrasive machining; chip formation; SP562, pp. 107-114 (Oct. 1979).

Fine polishing; sapphire; silicon; solid state reaction; wear debris; damaged layer; SP562, pp. 325-333 (Oct. 1979).

Fine-structure constant; fundamental constant; magnetic fields; proton gyromagnetic ratio; quantum electrodynamic theory; electron anomalous moment; 18702 .

Finishes; flexure; fracture; fracture mechanics; grinding; silicon nitride; strength; surface; SP562, pp. 463-474 (Oct. 1979).

Finishing technique; hemispherical domes; oxides; sapphire; two-surface lapping; two-surface polishing; dome finishing; SP562, pp. 255-260 (Oct. 1979).

Finite element method; free-edge stresses; graphite epoxy composites; interlaminar cracks; stability of cracks; virtual crack closure; delamination mechanisms; energy release rate; SP563, pp. 255-264 (Oct. 1979).

Finite element method; tensile strength; boron-epoxy; edge cracks; failure modes; SP563, pp. 228-238 (Oct. 1979).

Finite element stress analysis; front end; graphite; part integration; wheel; automotive component design; continuous fiber composite materials; fabrication; SP563, pp. 135-151 (Oct. 1979).
Finite elements; graphite-epoxy; interlaminar stresses; laminated composites; stress concentrations; tension; tensor polynomial; compression; failure; SP563, pp. 242-254 (Oct. 1979).

Finite-difference; integral form, conservation of mass principle; mass principle; algorithm, finite-difference; 18489 .

Finite-difference computations; fire in an enclosure; heat addition; hyperbolic, elliptic equations; initial, boundary-value problem; linearized equations; partial differential equations; buoyant convection; NBSIR 79-1754.

FIPS guidelines; initiation phase; project request; software; automated data systems; computer programs; cost/benefit analysis; documentation; documentation content guidelines; feasibility study; FIPS PUB 64.

FIR; optically pumped; wavelength; $\mathrm{CH}_{2} \mathrm{~F}_{2} ; 18961$.

FIR laser; laser frequency measurements; $\mathrm{C}^{13}$ methanol; 18939.

Fire; flaming ignition; glowing ignition; hazard; ignition temperature; lamp surface temperature; melting temperature; miniature Christmas lights; plastic insulating material; polyethylene; series-constructed; electric shock; NBSIR 79. 1716.

Fire; flammability; international; self-extinguishment; ships; standards; curtains; drapes; fabrics; NBSIR 79-1596.

Fire; flammability tests; garments; heat transfer; standards; apparel; burn injury; ease of ignition; fabrics; 18991 .

Fire; garments; heat transfer; injury potential; simulation; accident; apparel; burn injury; clothing; fabric flammability; fabrics; NBSIR 79-1755.

Fire; hydrogen; procedures; regulations; research needs; safety; standards; explosion; 18776 .

Fire alarm systems; fire detectors; high-rise communication systems; multiplex systems; NFPA standards; residential fire detector; sprinkler supervisory devices; control units; 18625 .

Fire barrier coatings; fire growth; flame spread; foam insulation; heat release; interior finish; laboratory fire tests; material ignitability; submarine compartment; combustion products; NBSIR 78-1584.

Fire codes; fire safety; governmental actions; life safety; regulation; risk assessment; societal goals; building codes; control measures; SP536, pp. 63-74 (Feb. 1979).

Fire containment; ignition; television fire; electrical failure; TN1109.

Fire departments; fire fighters; nursing homes; patients; room fires; smoke; upholstered furniture; chairs; doors; evacuation; NBS-GCR-79-159.

Fire departments; fire incidence; fire reporting; fire victims; human behavior; statistical sampling; surveys; NBS-GCR-78135.

Fire departments; fire safety; heating equipment; maintenance; stoves; wood; accident investigations; chimneys; coal; creosote; NBSIR 79-1731.

Fire departments; fire safety; heating equipment; maintenance; stoves; wood; accident investigations; chimneys; coal; creosote; NBS-GCR-78-149.

Fire departments; fire safety; heating equipment; maintenance; stoves; wood; accident investigations; chimneys; coal; creosote; 18537.

Fire detection; fire investigations; fire models; fire research; fire retardants; flame retardants; human behavior; smoke; toxic gases; toxicity; building fires; conferences; SP540.

Fire detection; fire safety; fire suppression; mass transportation; material flammability; people movers; smoke; emergency communications; emergency evacuation; NBSIR 78-1586.

Fire detection systems; fire tests; flammability tests; human behavior; plastics; polymers; smoke; smoke detectors; subway fires; toxicity; upholstered furniture; arson; bibliographies; building fires; compartment fires; fabric flammability; NBSIR $79-1745$.

Fire detectors; fire growth; heat detectors; room fires; smoke detectors; spacing; velocity; beams; ceiling height; detectors; NBS-GCR-78-128. 
Fire detectors; fire growth; heat detectors; room fires; smoke detectors; spacing; velocity; beams; ceiling height; detectors; NBS-GCR-78-129.

Fire dctectors; full-scale tests; heat dctcctors; hospitals; ionizaton detectors; mattresses; nursing homes; photoelectric detectors; corridors; escape; NBSIR 79-1739.

Fire detectors; high-rise communication systems; multiplex systems; NFPA standards; residential fire detcctor; sprinkler supervisory devices; control units; fire alarm systems; 18625 .

Fire doors; fire drills; fire extinguishers; fire safety; health care facilities; hospitals; human behavior; nursing homes; nursing staff; training; evacuation; NBS-GCR-79-179.

Firc drills; fire extinguishers; fire safety; health care facilities; hospitals; human behavior; nursing homes; nursing staff; training; evacuation; fire doors; NBS-GCR-79-I79.

Fire endurance; fire protection; stairways; standards; buiding design; buildings; construction materials; evacuation; exits; NBS-GCR-79-176.

Fire entrainment; flamc oscillations; plume; scaling; buoyancy; diffusion flames; NBSIR 79.19/0.

Fire escape; human research; measurement; pedestrian movement; regulation; safety; standards; architectural barriers; building design; building site planning; environmental psychology; evaluation; SP552, pp. 101-113 (July 1979).

Fire escape; human research; measurement; pedestrian movement; regulation; safety; standards; architectural barriers; building design; building site planning; environmental psychology; evaluation; 18430.

Fire extinguisher; hydrostatic pressure testing; intergranular cracking stainless steel; sensitized metal; circumferential tearing; 18368 .

Fire extinguishers; fire safety; health care facilities; hospitals; human behavior; nursing homes; nursing staff; training; evacuation; fire doors; fire drills; NBS-GCR-79-179.

Fire fighters; nursing homes; patients; room fires; smoke; upholstered furniture; chairs; doors; evacuation; fire departments; NBS-GCR-79-159.

Fire growth; fire statistics; flame spread; fuel load survey; heat release; interior finish; laboratory fire tests; material ignitability; prediction model; shipboard spaces; NBSIR 79-17/4.

Fire growth; fire tests; flame spread; flashover; impact assessment; interior finish; kitchen fires; life safety; mobile homes; room fires; ASTM E-84 Tunnel Test; construction standard; NBSIR 79-1720.

Fire growth; flame spread; foam insulation; heat release; interior finish; laboratory fire tests; material ignitability; submarine compartment; combustion products; fire barrier coatings; NBSIR 78-1584.

Fire growth; heat detectors; room fires; smoke detectors; spacing; velocity; beams; ceiling height; detectors; fire detectors; NBS-GCR-78- $/ 28$.

Fire growth; heat detectors; room fires; smoke detectors; spacing; velocity; beams; ceiling height; detectors; fire detectors; NBS-GCR-78-129.

Fire hazards; fire modeling; fire research; human behavior in fires; combustion products; NBSIR 78-I526.

Fire hazards; fire modeling; fire research; human behavior in fires; physics of fire; toxicity of combustion products; chennistry of fire; combustion products; NBSIR 79-1916.

Fire hazards; fire protection; fire safety; health care facility; smoke development; 18721 .

Fire in an enclosure; heat addition; hyperbolic, elliptic equations; initial, boundary-value problem; linearized equations; partial differential equations; buoyant convection; finite-difference computations; NBSIR 79.1754.

Fire incidence; fire reporting; fire victims; human behavior; statistical sampling; surveys; fire departments; NBS-GCR-78135 .
Fire investigations; fire models; fire research; fire retardants; flame retardants; human behavior; smoke; toxic gases; toxicity; building fires; conferences; fire detection; SPS4O.

Fire investigations; fire statistics; pathology; toxic gases; alcohol intoxication; autopsy; building fires; cigarettes; death; NBSGCR-79-168.

Fire load; fire resistance; fire tests structural engineering; temperature; thermal analysis; concrete (reinforced); TN985.

Fire losses; furniture; hazard analysis; probability; residential buildings; sensitivity analysis; smoke detectors; standards; upholstered furniture; building fires; cost-benefit analysis; costs; decision analysis; TNIIO1.

Fire modeling; fire research; human behavior in fires; combustion products; fire hazards; NBSIR 78-I526.

Fire modeling; fire research; human behavior in fires; physics of fire; toxicity of combustion products; chemistry of fire; combustion products; fire hazards; NBSIR 79-19/6.

Fire models; fire protection engineering; probability statistics; systems analysis; systems safety; walls; barrier analysis; compartment fires; compartments; fault tree analysis; NBS-GCR$79-163$.

Fire models; fire research; fire retardants; flame retardants; human behavior; smoke; toxic gases; toxicity; building fires; conferences; fire detection; fire investigations; SP540.

Fire models; fire spread; room fires; thermal radiation; turbulence; buoyant flow; compartment fires; computer programs; corridor fires; $N B S-G C R-78-150$.

Fire models; heat transfer; room fires; smoke; soot; thermal radiation; NBS-GCR-78-151.

Fire prevention codes; fire safety; master planning; regulation; standards; building codes; code enforcement; SP552, pp. 225-247 (July 1979).

Fire protection; fire resistance; fire tests; fire walls; safety engineering, fires; computer programs, fire protection; TN991.

Fire protection; fire safety; health care facility; smoke development; fire hazards; 18721 .

Fire protection; group homes; household activities; room use; demographics; developmental disabilities; NBSIR 79-I 727.

Fire protection; stairways; standards; buiding design; buildings; construction materials; evacuation; exits; fire endurance; NBS-GCR-79-176.

Fire protection engineering; probability statistics; systems analysis; systems safety; walls; barrier analysis; compartment fires; compartments; fault tree analysis; fire models; NBS-GCR-79163.

Fire reporting; fire victims; human behavior; statistical sampling; surveys; fire departments; fire incidence; NBS-GCR-78135.

Fire research; fire retardants; flame retardants; human behavior; smoke; toxic gases; toxicity; building fires; conferences; fire detection; fire investigations; fire models; SP540.

Fire research; fire safety; human performance; modeling technique; programming; sensitivity analysis; simulation; architectural research; building fires; computer-aided design; environmental psychology; NBSIR 79-1713.

Fire research; fire safety; human performance; modeling technique; simulation; architectural research; building fires; computer-aided design; computer simulation; environmental psychology; NBSIR 79-1796.

Fire research; human behavior in fires; combustion products; fire hazards; fire modeling; NBSIR 78-/526.

Fire research; human behavior in fires; physics of fire; toxicity of combustion products; chemistry of fire; combustion products; fire hazards; fire modeling; NBSIR 79-1916.

Fire resistance; fire tests; fire walls; safety engineering, fircs; computer programs, fire protection; fire protection; TN99l.

Fire resistance; fire tests structural engineering; temperature; thermal analysis; concrete (reinforced); fire load; TN985. 
Fire retardants; flame retardants; human behavior; smoke; toxic gases; toxicity; building fires; conferences; fire detection; fire investigations; fire models; fire research; SP540.

Fire safety; fire suppression; mass transportation; material flammability; people movers; smoke; emergency communications; emergency evacuation; fire detection; NBSIR 78-1586.

Fire safety; gamma-ray spectroscopy; matrix-isolation; metric conversion; satellitc system; computer network; computer standards; DIM/NBS 63, No. 7/8, 1-28 (1979).

Fire safety; governmental actions; life safety; regulation; risk assessment; societal goals; building codes; control measures; fire codes; SP536, pp. 63-74 (Feb. 1979).

Fire safety; group homes; handicapped; mental retardation; ambulatory people; autism; cerebral palsy; deafness; developmentally disabled; epilepsy; NBS-GCR-79-167.

Fire safety; gyromagnetic ratio; paper; photometric calibrator; safety tips; solar energy; toxic chemicals; ultra-black coating; Alaskan pipeline; computers; corrosion; DIM/NBS 63, No. 1 1, 1-36 (1979).

Fire safety; handicapped occupants; health care facilities; nursing homes; user needs; building codes; building evaluation; elderly; NBSIR 79-1906.

Fire safety; hazard warnings; pictograms; safety information; standardization; symbols; communication; evaluation methods; NBSIR 79-1760.

Fire safety; health care facilities; hospitals; interior finishes; Life Safety Code; nursing homes; risk analysis; safety equivalency; safety evaluation; smoke detection; automatic sprinklers; building codes; building construction; Delphi Method; NBSIR 78-1555.

Fire safety; health care facilities; hospitals; life safety; mathematical programming; nursing homes; renovation; applied economics; building codes; building economics; economic analysis; NBSIR 79-1902.

Fire safety; health care facilities; hospitals; human behavior; nursing homes; nursing staff; training; evacuation; fire doors; fire drills; fire extinguishers; NBS-GCR-79-179.

Fire safety; health care facilities; hospitals; life safety; mathematical programming; nursing homes; renovation; applied economics; building codes; building economics; economic analysis; 19045.

Fire safety; health care facility; smoke development; fire hazards; fire protection; 18721 .

Fire safety; heating equipment; maintenance; stoves; wood; accident investigations; chimneys; coal; creosote; fire departments; NBSIR 79-1731.

Fire safety; heating equipment; maintenance; stoves; wood; accident investigations; chimneys; coal; creosote; fire departments; NBS-GCR-78-149.

Fire safety; heating equipment; maintenance; stoves; wood; accident investigations; chimneys; coal; creosote; firc departments; 18537.

Fire safety; high-rise; model codes; people movement; systems design; buildings; communications systems; BSSII5.

Fire safety; housing; preservation; regulations; rehabilitation; adaptive reuse; building codes; buildings; building safety; code enforcement; construction; SP536.

Fire safety; human performance; modeling technique; programming; sensitivity analysis; simulation; architectural research; building fires; computer-aided design; environmental psychology; fire research; NBSIR 79-1713.

Fire safety; human performance; modeling technique; simulation; architectural research; building fires; computer-aided design; computer simulation; environmental psychology; fire research; NBSIR 79-1796.

Fire safety; master planning; regulation; standards; building codes; code enforcement; fire prevention codes; SP552, pp. 225-247 (July 1979).
Fire safety; models; research; standards; systematic procedure; building fires; equivalency; evaluation; SP552, pp. 13-27 (July 1979).

Fire safety; molybdenum; network measurement; semiconductors; SRM's; standards; cardiac pacemakers; computer standards; DIMINBS 63, No. 10, 1-36 (1979).

Fire spread; room fires; thermal radiation; turbulence; buoyant flow; compartment fires; computer programs; corridor fires; fire models; NBS-GCR-78-150.

Fire statistics; flame spread; fuel load survey; heat release; interior finish; laboratory fire tests; material ignitability; prediction model; shipboard spaces; fire growth; NBSIR 79-1714.

Fire statistics; pathology; toxic gases; alcohol intoxication; autopsy; building fires; cigarettes; death; fire investigations; NBS-GCR-79-I68.

Fire suppression; mass transportation; material flammability; people movers; smoke; emergency communications; emergency evacuation; fire detection; fire safety; NBSIR 78-1586.

Fire tests; fire walls; safety engineering, fires; computer programs, fire protection; fire protection; fire resistance; TN99I.

Fire tests; flame spread; flashover; impact assessment; interior finish; kitchen fires; life safety; mobile homes; room fires; ASTM E-84 Tunnel Test; construction standard; fire growth; NBSIR 79-1720.

Fire tests; flame spread; heat release rate; ignition; interior finish; passive fire protection; potential heat; smoke; compartment fires; NBSIR 79-1700.

Fire tests; flammability; furnishings; upholstered furniture; chairs; compartment fires; TN1 103.

Fire tests; flammability tests; human behavior; plastics; polymers; smoke; smoke detectors; subway fires; toxicity; upholstered furniture; arson; bibliographies; building fires; compartment fires; fabric flammability; fire detection systems; NBSIR 79-1745.

Fire tests; gas detcctors; kitchen fires; mobile homes; smoke detectors; tenability limits; upholstered furniture; detection time; detector location; NBSIR 79-1915.

Fire tests; health care facilities; hospitals; mattresses; prisons; bedding; beds; compartment fires; firesafety engineering; 18517.

Fire tests structural engineering; temperaturc; thermal analysis; concrete (reinforced); fire load; fire resistance; TN985.

Fire victims; human behavior; statistical sampling; surveys; fire departments; fire incidence; fire reporting; NBS-GCR-78-135.

Fire walls; safety engineering, fires; computer programs, fire protection; fire protection; fire resistance; fire tests; TN991.

Fires; flashover; hospitals; human behavior; nursing staff; patients; room fires; breathing apparatus; death; evacuation; NBS-GCR-78-140.

Fires; high rise buildings; hospitals; human behavior; nursing homes; bibliographies; building fires; escape; evacuation; NBS-GCR-78-138.

Fires; home fires; residential smoke detectors; smoke detectors; detection; 18514.

Firesafety engineering; fire tests; health care facilities; hospitals; mattresses; prisons; bedding; beds; compartment fires; 18517.

Firesetters; human behavior; literature reviews; pyromaniacs; abnormal psychology; arson; arsonists; NBS-GCR-79-157.

Fission; gas target; molecular vibrations; neutron reactions; 23*U; Doppler effect; 18585.

Fission; temperature effects; thermal; ${ }^{235} \mathrm{U}$; chemical effects; delayed neutrons; Einstein model; 18687.

Fission cross section; linac; neutron flux determination; proton telescope; standard cross section; ${ }^{235} \mathrm{U}(\mathrm{n}, \mathrm{f}) ; 18581$.

Fission cross sections; reactor dosimetry; benchmark neutron field development; dosimetry methods; 19013.

Fission neutrons; iron cross section; nickel cross section; reaction rates; Californium; dosimetry; 18883 .

Fission spectrum; foils; neutron fields; scattering corrections; sensitivity; benchmark; 18901 . 
Fission spectrum; neutron; threshold reaction; uranium; Californium; cross sections; 18792 .

Fission track; ion-dipole; $\beta$-endorphin; ${ }^{252} \mathrm{Cf}$; charge transfer; chlorophyll; erythromycin; fast reactions; SP519, pp. 673-677 (Apr. 1979).

Fission tracks; geochronology; geology; lithium; nitrogen; silicon devices; trace analysis; uranium; alpha tracks; biomedical; boron; 18342 .

Fission yields; measurements; neutrons; Np-237; Pu-239; U235; U-238; activation analysis; benchmark fields; dosimetry; 18884

Fitting; graphics; interactive graphics; regression; software; transformation; computing system; dataplot; 18519 .

Fixed points; $1 r$; superconductivity; thermometry; W; $\mathrm{AuAl}_{2}$; Auln $_{2}$; Be; cryogenic temperature scale; SP260-62.

Fixed points; pure materials; superconductivity; temperature scale; thermometry; cryogenics; 18550.

Fizeau-type interferometer; fringe pattern; spatial period; wavelength of light; U.S. Patent 4,I73,442.

Flame atomic emission spectroscopy; reference method; semiautomated pipetting; serum potassium analysis; statistical analysis; clinical analysis; clinical chemistry; definitive method; electrolytes; SP260-63.

Flame calorimetry; fluorinaceous; oxidizer; thermochemistry of fluorine compounds; calorimetry, gas flow; chlorine thermochemistry; 18755 .

Flame ionization; flame spectroscopy; laser enhanced ionization; laser spectroscopy; opto-galvanic effect; trace metal analysis; tunable dye laser; analytical flame spectroscopy; 18880 .

Flame oscillations; plume; scaling; buoyancy; diffusion flames; fire entrainment; NBSIR 79-1910.

Flame retardants; human behavior; smoke; toxic gases; toxicity; building fires; conferences; fire detection; fire investigations; fire models; fire research; fire retardants; SP54O.

Flame spectroscopy; ion production; laser enhanced ionization; laser spectroscopy; optogalvanic effect; enhanced ionization theory; 18806

Flame spectroscopy; laser enhanced ionization; laser spectroscopy; opto-galvanic effect; trace metal analysis; tunable dye laser; analytical flame spectroscopy; flame ionization; 18880

Flame spread; flashover; impact assessment; interior finish; kitchen fires; life safety; mobile homes; room fires; ASTM E-84 Tunnel Test; construction standard; fire growth; fire tests; NBSIR 79-I 720 .

Flame spread; foam insulation; heat release; interior finish; laboratory fire tests; material ignitability; submarine compartment; combustion products; fire barrier coatings; fire growth; NBSIR 78-1584.

Flame spread; fuel load survey; heat release; interior finish: laboratory fire tests; material ignitability; prediction model; shipboard spaces; fire growth; fire statistics; NBSIR 79-17/4.

Flame spread; heat release rate; ignition; interior finish; passive fire protection; potential heat; smoke; compartment fires; fire tests; NBSIR 79-1700.

Flame spread; smoldering combustion; test methods; attic floor radiant panel; cellulose thermal insulation; critical radiant flux; NBSIR 79-1588.

Flaming combustion; flexible foams; optical density; particle size; polypropylene; polyurethane foams; polyvinyl chloride; pyrolysis; rigid foams; smoke; smoldering; weight loss; wood; combustion; NBS-GCR-78-147.

Flaming ignition; glowing ignition; hazard; ignition temperature; lamp surface temperature; melting temperature; miniature Christmas lights; plastic insulating material; polyethylene; series-constructed; electric shock; fire; NBSIR 79-1716.

Flammability; furnishings; upholstered furniture; chairs; compartment fires; fire tests; TNI 103 .
Flammability; garments; hazard; heat transfer; ignitability; standard; test; apparel; extinguishability; fabrics; 18708 .

Flammability; glass reinforced plastics; graphite epoxy; impact; marine environment; advanced composites; cavitation erosion; extended immersion; SP563, pp. 276-285 (Oct. 1979).

Flammability; international; self-extinguishment; ships; standards; curtains; drapes; fabrics; fire; NBSIR 79-1596.

Flammability tests; garments; heat transfer; standards; apparel; burn injury; ease of ignition; fabrics; fire; 18991

Flammability tests; human behavior; plastics; polymers; smoke; smoke detectors; subway fires; toxicity; upholstered furniture; arson; bibliographies; building fires; compartment fires; fabric flammability; fire detection systems; fire tests; NBSIR 79 . 1745.

Flare stars; helium; x-ray emission; 19007.

Flare stars; late-type stars; stellar chromospheres; stellar coronae; emission line stars; 18920.

Flashover; hospitals; human behavior; nursing staff; patients; room fires; breathing apparatus; death; evacuation; fires; NBS-GCR-78-140.

Flashover; impact assessment; interior finish; kitchen fires; life safety; mobile homes; room fires; ASTM E-84 Tunnel Test; construction standard; fire growth; fire tests; flame spread; NBSIR 79-1720.

Flat conductor cable; National Electrical Code; technological innovation; appeals process; consensus standards; electrical distribution systems; SP552, pp. 57-78 (July 1979).

Flat-end; kern; loading rate; pin-end; test method; wall panels; walls; compression; eccentric loading; BSS95.

Flat-plate solar collectors; German Bundesverband Solarenergie; solar collector testing; water-heating solar collectors; collector efficiency; comparison German BSE vs ASHRAE 9377 procedures; 18986.

Flavor; hadron; quark; spectroscopy; spectrum; structure; 19010.

Flaw populations; flaws; fractography; fracture origins; grinding; machining; polishing; sanding; strength-size effects; brittle failure; SP562, pp. 351-378 (Oct. 1979).

Flaw simulation; semi-automated ultrasonic inspection; ultrasonic inspection system; composite structures; SP563, p. 59 (Oct. 1979).

Flaw sizes; grain size dependence of strength; strength; brittle failure; SP562, pp. $429-452$ (Oct. 1979).

Flaws; fractography; fracture origins; grinding; machining; polishing; sanding; strength-size effects; brittle failure; flaw populations; SP562, pp. 351-378 (Oct. 1979).

Flaws in crystals; NDE; ultrasonic scattering; 18831.

Flexible foams; optical density; particle size; polypropylene; polyurethane foams; polyvinyl chloride; pyrolysis; rigid foams; smoke; smoldering; weight loss; wood; combustion; flaming combustion; NBS-GCR-78-147.

Flexural characteristics; recreational equipment; strength-toweight ratio; composites; durability; SP563, p. 208 (Oct. 1979).

Flexural strength; mechanical properties; moisture; non-destructive testing; preservation; adobe; adobe soil; compressive strength; creep; TN996.

Flexure; fracture; fracture mechanics; grinding; silicon nitride; strength; surface; finishes; SP562, pp. 463-474 (Oct. 1979).

Flexure pivots; linear positioning; micromanipulator; optical microscope stage; piezoelectric drives; scanning stage; SEM microscope stage; submicrometer positioning instrumentation; TEM microscope stage; 18327.

Flexure strength; prosthetic device; serrated surface design; tooth roots; alumina; diamond contour grinding; SP562, pp. 247-254 (Oct. [ 979 ).

Flicker noise; frequency modulation; frequency reference; precision oscillators; clock's rms time errors; 18940 . 
Flight critical; flow; fluid; go-no-go; ground readout; hydraulic; IMACS; instantaneous diagnosis and analysis; level; maintenance oriented; malfunction detection; monitoring; onboard; patented; pressure; pumps; reservoirs; sensors; SP547, pp. 345-357 (July 1979).

Flood recovery effort; missing link; rebuilding; crisis; SP552, pp. $39-44$ (July 1979).

Floor coverings; home safety; safety standards; stair safety; stairway design; accidents; architectural design; architectural psychology; architectural research; building codes; building design; building regulatory standards; BSSI 20.

Floppy disks; laser beams; magnetic bubbles; masstapes; solid state memories; video disks; beam-addressables; cartridges; cassettes; core memories; disks; drums; SP500-45.

Flow; fluid; go-no-go; ground readout; hydraulic; IMACS; instantaneous diagnosis and analysis; level; maintenance oriented; malfunction detection; monitoring; onboard; patented; pressure; pumps; reservoirs; sensors; tailorable; temperature; SP547, pp. 345-357 (July 1979).

Flow; insertion loss; microphone; porous sphere; sphere; spheres; wind noise; windscreen; windscreen performance; windscreens; acoustics; NBSIR 79-1599.

Flow birefringence; flow dichroism; polymer dynamics; RouseZimm theory; solution properties; bead-spring model; block copolymer; 18431 .

Flow dichroism; polymer dynamics; Rouse-Zimm theory; solution properties; bead-spring model; block copolymer; flow birefringence; 18431 .

Flow injection analysis; automation; continuous analysis; controlled dispersion; SP519, pp. $501-507$ (Apr. 1979).

Flow oscillations; flow stability; liquid helium; superconducting power transmission lines; supercritical helium; density wave oscillations; 18567.

Flow rate; LNG; mathematical models; mixtures; specific heating value; tank capacity tables; thermophysical properties data; total heating value; composition; custody transfer; density; 18838 .

Flow rate; LNG; mixtures; specific heating value; tank capacity tables; thermophysical properties; total heating value; composition; custody transfer; density; 18564 .

Flow stability; liquid helium; superconducting power transmission lines; supercritical helium; density wave oscillations; flow oscillations; 18567.

Flow system; heat of formation; hexylmethylethane; $t$-butyl radical; unimolecular decomposition; activation energy; $A$ factor; comparative rate; 18743 .

Flow-induced crystallization; polymer crystallization; shish kebabs; crystallization theory; extended chain fibrils; 18715 .

Flow-induced crystallization; nucleation theory; polyethylene; polymer fiber; shish; volume strain; core fibril; cumulative stress; J. Res. 84, No. 5, 359-384 (1979).

Flowmeter; fluid dynamics; mathematical modeling; numerical modeling; pipe flows; turbulence modeling; 18410 .

Flowmetering; liquefied natural gas; sampling; cryogenic densimeter; custody transfer; density; 18396.

Fluctuating flow; flutter; suspended-span structures; time-dependent loads; aerodynamic stability; aeroelasticity; 18688.

Fluctuation; master equation; noise spectrum; nonequilibrium; stationary states; switching; threshold switching; 18674 .

Fluctuations; mean field approximation; ternary interactions; theta point; virial coefficients; collapse transition; 19023 .

Flue-gas temperature profile; gas-fired furnace; off-period mass flow rate; part-load performance; seasonal efficiency; automatic stack damper; TN999.

Fluid; go-no-go; ground readout; hydraulic; IMACS; instantaneous diagnosis and analysis; level; maintenance oriented; malfunction detection; monitoring; onboard; patented; pressure; pumps; reservoirs; sensors; tailorable; temperature; SP547. pp. 345-357 (July 1979).
Fluid dynamics; mathematical modeling; numerical modeling; pipe flows; turbulence modeling; flowmeter; 18410 .

Fluid elasticity; liquid penetrant testing; Rideal-Washburn equation; surface tension; defect geometry; J. Res. 84, No. 4, $287-$ 292 (1979).

Fluid flow; high resolution; reconstruction; temperature reconstruction; ultrasound; aperture synthesis; computed tomography; Doppler; SP525, pp. 227-233 (Apr. 1979).

Fluid flow; high resolution; reconstruction; temperature reconstruction; ultrasound; aperture synthesis; computed tomography; Doppler; SP525, pp. 235-246 (Apr. 1979).

Fluid mixtures; light; liquefied natural gas; measurements; microwaves; super spring; ultraviolet radiation; calibrations; energy; DIM/NBS 63, No. 9, 1-32 (1979).

Fluid properties; prediction; standard reference data; synthetic gas; chemical processing; engineering calculations; equation of state; 19022 .

Fluids; gravity effects; materials science; spacelab; critical phenomena; critical-point universality; 18457.

Fluids; noxious fluids; refractive index; refractive index tubes; 18930.

Fluorescence; high performance liquid chromatography; occupational health; picogram; polycyclic aromatic hydrocarbons; selectivity; sensitivity; specificity; trace analysis; environmental pollution; SP519, pp. 41-56 (Apr. 1979).

Fluorescence; laser spectroscopy; multiphoton dissociation; radicals; vibronic spectroscopy; chlorofluoromethylene; 19042.

Fluorescence; organics in water; pulsed laser; SP519, pp. 691696 (Apr. 1979).

Fluorescence detection; liquid chromatography; triamterene assay; clinical analysis; SP519, pp. 477-480 (Apr. 1979).

Fluorescence flow cell; liquid chromatography; tryptophan metabolites; brain; cerebrospinal fluid; SPS19, pp. 411-418 (Apr. 1979).

Fluorescence immunoassay; homogeneous enzyme immunoassay; immunoassay; drug assay; $\mathrm{EMIT}^{R}$ fluoroimmunoassay; SP519, pp. 533-539 (A pr. 1979).

Fluorescence spectra; ref ractive index, uv, visible and ir; water; aqueous solutions; 18403 .

Fluorescence yield; $K$ shell; $L$ shell; non-radiative yield; partial level width; radiative yield; atomic properties; Auger yield; Coster-Kronig yield; effective fluorescence yield; JPCRD 8 , No. 2, 307-328 (1979).

Fluorides; forging; laser windows; lithium fluoride; mechanical properties; optical properties; ultraviolet transmission; SP541, pp. 59-64 (Dec. 1978).

Fluorides; halides; iodides; molten salt mixtures; standard reference data; surface tension; viscosity; bromides; chlorides; data compilation; density; electrical conductance; JPCRD 8, No. 1, 125-302 (1979).

Fluorinaceous; oxidizer; thermochemistry of fluorine compounds; calorimetry, gas flow; chlorine thermochemistry; flame calorimetry; 18755 .

Fluorination of polymers; free radicals; peroxy radicals; transition metal fluorides; electron spin resonance; 18726.

Fluoroberyllate glass; fluorophosphate glass; inclusions; pulse duration; damage thresholds; SP54I, pp. 99-108 (Dec 1978).

Fluorophosphate glass; inclusions; pulse duration; damage thresholds; fluoroberyllate glass; SP541, pp. 99-108 (Dec 1978).

Flutter; suspended-span structures; time-dependent loads; aerodynamic stability; aeroelasticity; fluctuating flow; 18688 .

Flux phenomena; Josephson phenomena; stabilization; superconductors; terminology; critical parameters; definitions; I868I.

FM transmitters; law enforcement equipment; standards; surveillance; undercover equipment; body-worn transmitters; communications equipment; 18381 . 
Foam insulation; hcat releasc; interior finish; laboratory fire tcsts; material ignitability; submarine compartment; combustion products; fire barrier coatings; fire growth; flame spread; NBSIR 78-1584

Focal thermal flaw; skull transmission; ultrasound; axisymmetric; beams; SP525, pp. 203-208 (Apr. 1979).

Focuscd vacuum ultraviolet; heat-pipe oven use in the vacuum ultraviolet; multichannel capillary arrays; vacuum ultraviolet spectroscopy; vacuum ultraviolet windows; differential pumping across capillary arrays; 18808 .

Foil transmission; photons; stopping power; transport theory; absorbed dose; attenuation coefficient; detector response functions; dosimetry; electrons; $/ 837 I$.

Foils; neutron fields; scattering corrections; sensitivity; benchmark; fission spectrum; /890I.

Food additives; mutagenicity; naphthylamines; saccharin; saccharin impurities; Salmonella typhimurium; Amaranth; Ames test; criteria for purity; SP519, pp. 311-319 (Apr. 1979).

Food and Drug Administration; Interstate Commerce Commission; regulation; rcgulatory processes and regulatory effects; administrative experimentation; Environmental Protection Agency; evaluability assessment; evaluation; NBS-GCR-ETIP $79-65$.

Food and fced analysis; methods; preparation; sampling; aflatoxin analysis; SP5/9, pp. 355-372 (Apr. 1979)

Food chain; lcad; mercury; metal; methylation; microbial tolerance; microorganism; plasmid; tin; arsenic; bio-transformation; cadmium; $/ 8860$.

Food toxicants; hormones; neurotransmitters; nutrients; organic pollutants; trace organic analysis; drug analysis; SPS I 9.

Food toxicants; mycotoxins; review; seafood toxins; SP5 I9, pp. 321-331 (Apr. 1979).

Foods; radiometric microbiological assay; vitamin $\mathbf{B}_{12} ;$ SP5/9, pp. 257-265 (Apr. 1979).

Footwear industry; fragmented industries; government-industry cooperation; imports; innovation; leather; manufacturing technology; materials development; shoes; technology transfer; computer-aided design and manufacture (CAD/CAM); SP527

Force; high precision; high-precision weighing; load cell; mass; mass comparator; mass difference; strain-gage; substitution weighing; weighing; weights; constant loading; J. Res. 84, No. 5, 347-351 (1979).

Force constants; infrared spectrum; ketenimine; matrix isolation; methyl cyanide; ultraviolet spectrum; vacuum ultraviolet photolysis; charge transfer; cyanomethyl radical; excited argon atoms; 18879

Force field refinement; lattice dynamics; $n$-alkanes; non-bonded potential functions; polyethylene; vibrational data; $/ 8404$

Forced convection; heat transmission; helium 11; mutual friction; axial heat transport; $I 86 I 7$.

Forced entry deterrent systems; guard control station; higher headquarters; perimeter station; remote unit; response force; triply redundant central computer; central unit; computerized; detection; electronic lock; exclusion area; NBSIR 79. 1725 .

Forced flow; helium; stability; superconductor; transient flow; transient heat transfer; 18813 .

Forecast; projections; sensitivity analysis; computer workload; data requirements; documentation cycle; SP50O-52, pp. 113120 (Oct. 1979).

Forecasting; labor information systems; manpower projections; modelling; building trades; construction industry; SP552, pp 185-196 (July 1979).

Foreign bodies; histological sections; implant materials; microanalysis; molecular microanalysis; pathological tissue; Raman microprobe; Raman spectra; Raman spectroscopy; biological microanalysis; biological tissue; 18958 .
Forcign building standards; French building standards; French standards system; marking and certification; types of French standards; building standards; SP552, pp. 45-56 (July 1979).

Foreign relations; industrializing nations; international relations; LDC's; measurement services; standardization; AlD; assistance; dcveloping economies; NBSIR 78-I7II2.

Foreign relations; industrializing nations; international relations; measures; weights; weights and measures; AID; assistance; dcveloping economies; NBSIR 79-I72I.

Forensic; INAA; paper; trace elements; analysis; clay; $I 8325$.

Forging; laser windows; lithium fluoride; mechanical properties; optical properties; ultraviolet transmission; fluorides; SP54I, pp. 59-64 (Dec. 1978).

Forging; laser windows; optical properties; scattering; calcium fluoride; SP54I, pp. $70-77$ (Dec. 1978).

Formaldehyde; ruthenium; surface chemistry; ultraviolet photoemission spectroscopy; adsorption; chemisorption; I879I

Formation constants; ionic mechanisms; kinetics; methylmercury; methyltin; NMR; primary salt effect; speciation; activation parameters; aqueous transmethylation; chloride complexes; environment; 18484

Formulation analysis; information networks; regulations; standards; decision tables; SP552, pp. 249-266 (July 1979).

Fortran library test data; Fortran library testing; mathematical function testing; test data for elementary functions; test data for mathematical functions; elementary function testing; NBSIR 78- 1478

Fortran library testing; mathematical function testing; test data for elementary functions; test data for mathematical functions; elementary function testing; Fortran library test data; NBSIR 78- $/ 478$.

Forward scattering; grain boundaries; isostatic forging; optical figure; optical homogeneity; single crystal; Talystep traces; alkali halides; backward scattering; SPS4I, pp. $65-69$ (Dec. 1978).

Fossil fuels; low-level counting; radiocarbon; accelerator mass spectrometry; anthropogenic and natural carbonaceous species; atmospheric gases and particles; environmental pollutants; 18405 .

Foundation design; geotechnical engineering; housing construction; mine subsidence; mining; site development; standards; structural design; $/ 8324$.

Fourier optics; holography; laser; laser parameters; laser pulse; optical processing; phase; precision measurements; wave front; amplitude; beam profile; cross correlation; digital sampling; TNIOO9.

Fourier transform analysis; mixing in turbulent flow; noise spectrum; Raman spectroscopy; turbulence; concentration fluctuations; fast Fourier transforms; 18626.

Fourier transform infrared; gas chromatography; modular organic analysis system; pyrolysis; trace organic analysis; SP5/9, pp. 753-760 (Apr. 1979).

Fourier transforms; radiation reaction; definite integrals; double integrals; error functions; J. Res. 84, No. 4, 319-326 (1979).

Fractography; fracture origins; grinding; machining; polishing; sanding; strength-size effects; brittle failure; flaw populations; flaws; SP562, pp. $351-378$ (Oct. 1979).

Fracture; fracture mechanics; grinding; silicon nitride; strength; surface; finishes; flexure; SP562, pp. 463-474 (Oct. 1979).

Fracture; high-strength; low-temperature; mechanical properties; nitrogen; nitrogen-strengthened; stainless steel; tensile properties; toughness; cryogenic; fatigue; 18957.

Fracture; low temperature tests; martensitic transformations; mechanical properties; stainless steel alloys; crack propagation; cryogenics; $/ 8943$.

Fracture; low temperature tests; mechanical properties; aluminum alloys; crack propagation; cryogenics; fatigue; $186 \mathrm{IO}$. 
Fracture; median, radial and lateral cracks; plastic indentations; residual stresses; shear flow lines; crack nucleation; SP562, pp. 15s20 (Oct. 1979).

Fracture; molecular weight distribution; necking; polyethylene; uniaxial creep; additivity of damage; cold drawn; crack growth; 18765 .

Fracture; plastic penetration; thermal stresses; abrasive wear; ceramics; SP562, pp. 1-13 (Oct. 1979).

Fracture mechanics; fracture toughness; pipeline; weld flaws; weldments; carbon-manganese steel; 18612 .

Fracture mechanics; fracture toughness; pipeline; weld flaws; weldments; carbon-manganese steel; fatigue; fatigue cracks; 18802.

Fracture mechanics; fragmentation; glass; grinding; impact; silicon nitride; strength; stress intensity factor; abrasive machining; ceramics; contact stress; damage penetration; SP562, pp. 23-42 (Oct. 1979).

Fracture mechanics; grinding; silicon nitride; strength; surface; finishes; flexure; fracture; SP562, pp. 463-474 (Oct. 1979).

Fracture mechanics; LNG; low temperature; mechanical properties; aluminum alloys; ferrous alloys; 18865 .

Fracture mechanics; standards; technique development; compact tension specimen; crack; crack, well-characterized; destructive evaluation; fatigue flaw evaluation; 18744 .

Fracture of brittle materials; hydrogen embrittlement; Rehbinder effects; Westwood effects; acoustic emission; chemomechanical effects; environmental effects; SP562, pp. 139-145 (Oct. 1979)

Fracture origin; fracture strength; machining of ceramics; oxidation and degradation; silicon-nitride; SP562, pp. 477.481 (Oct. 1979).

Fracture origins; grinding; machining; polishing; sanding; strength-size effects; brittle failure; flaw populations; flaws; fractography; SP562, pp. $351-378$ (Oct. 1979).

Fracture properties; low temperature tests; mechanical properties; titanium; titanium alloys; electron beam welding; fatigue (materials); 18611 .

Fracture resistance; low temperature tests; mechanical porperties; stainless steel; crack propagation; fatigue; 18621 .

Fracture strength; machining of ceramics; oxidation and degradation; silicon-nitride; fracture origin; SP562, pp. 477481 (Oct. 1979).

Fracture toughness; friction; hardness; liquid softening; oxides; scratching; size effect; specific energy; ceramics; chipping; crack formation; SP562, pp. 43-59 (Oct. 1979).

Fracture toughness; pipeline; weld flaws; weldments; carbonmanganese steel; fracture mechanics; 18612.

Fracture toughness; pipeline; weld flaws; weldments; carbonmanganese steel; fatigue; fatigue cracks; fracture mechanics; 18802.

Fragmentation; glass; grinding; impact; silicon nitride; strength; stress intensity factor; abrasive machining; ceramics; contact stress; damage penetration; fracture mechanics; SP562, pp. 23-42 (Oct. 1979).

Fragmented industries; government-industry cooperation; imports; innovation; leather; manufacturing technology; materials development; shoes; technology transfer; computer-aided design and manufacture (CAD/CAM); footwear industry; SP527.

Frame transformation relations; level cluster; spherical tops; symmetry analysis; Born-Oppenheimer approximation; centrifugal; Coriolis; 18599.

France/NBS cooperative program; French schools; building technology; NBSIR 78-1521.

Francis Ysidro Edgeworth (1845-1926); goodness of fit; Sir Francis Beaufort (1774-1857); binomial test; chi-squared test; 18471 .

Francium; lithium; magnetic flux density dependence; potassium; pressure dependence; rubidium; sodium; temperature de- pendence; alkali elements; cesium; electrical resistivity; JPCRD 8, No. 2, 339-438 (1979).

Franck-Condon factors; laser fluorescence; molecular sodium; potential curves; collisional excitation; cissociation energy; Dunham coefficients; 18824 .

Franck-Condon factors; laser spectroscopy; lithium molecule; molecular spectroscopy; potential curves; dissociation energy; 18867.

Free groups; matrix groups; roots of unity; J. Res. 84, No. 2, 179-180 (1979).

Free radical; photolysis; reactions; review; troposphere; aldehyde; SP557, pp. 27-46 (Aug. 1979).

Free radicals; hydrocarbons; hydrogen; nitrogen; organic compounds; oxidation; oxygen; oxygenated; rate constant; sulfur; Arrhenius parameters; combustion; decomposition; NBSIR 79-1941.

Free radicals; infrared spectra; matrix isolation; molecular ions; photochemistry; ultraviolet spectra; charge transfer; excited argon atoms; 18847 .

Free radicals; mechanism; reactions; tropospheric chemistry; aromatics; SP557, pp. 85-91 (Aug. 1979).

Free radicals; modeling; $\mathrm{NO}_{x}$; olefins; $\mathrm{SO}_{x}$; troposphere; aldehydes; aromatics; chemical kinetics; data needs; SP557.

Free radicals; peroxy radicals; transition metal fluorides; electron spin resonance; fluorination of polymers; 18726 .

Free water; freezing calorimeter; hydrology forecasting; microwave remote sensing; snow; centrifuge; comparison of measurement methods; NBSIR 79-1604.

Free wobble; laser strainmeter; ocean load; preferred frame; spatial anisotropy; strain tides; core resonance; 18823

Free-edge stresses; graphite epoxy composites; interlaminar cracks; stability of cracks; virtual crack closure; delamination mechanisms; energy release rate; finite element method; SP563, pp. 255-264 (Oct. 1979).

Free-field measurements; hearing aids; hearing aid tests; orthotelephonic response; anthropometric manikin; 18464.

Free-free transitions; low-frequency approximation; multiphoton effects; scattering in laser field; 18711 .

Free-running laser pulses; giant laser pulse; optical fiber damage; pulsed $\mathrm{Nd}^{3+}$ laser damage; single and multiple element fibers; surface threshold damage; SP541, pp. 168-189 (Dec. 1978).

Freezing calorimeter; hydrology forecasting; microwave remote sensing; snow; centrifuge; comparison of measurement methods; free water; NBSIR 79-1604.

French building standards; French standards system; marking and certification; types of French standards; building standards; foreign building standards; SP552, pp. $45-56$ (July 1979).

French schools; building technology; France/NBS cooperative program; NBSIR 78-1521.

French standards system; marking and certification; types of French standards; building standards; foreign building standards; French building standards; SP552, pp. $45-56$ (July 1979).

Frequency; frequency standards; navigation; time; time dissemination; communic ation; 19005 .

Frequency; He-Ne laser; nonlinear optics; $1.15 \theta \mathrm{m} ; 18562$.

Frequency; mammalian tissues; polypeptides; proteins; tissue characterization; ultrasonics; velocity; absorption; amino acids; attenuation; SP5 25, pp. 19-27 (Apr. 1979).

Frequency and pulse width dependencies of the critical field; multiphoton ionization; damage threshold; electron avalanche; SP541, pp. 299-302 (Dec. 1978).

Frequency and time dependence of breakdown thresholds; IR window materials; $\mathrm{NaCl}$; pressure; pulsed $\mathrm{TEA} \mathrm{CO}_{2}$ laser surface breakdown; spot size; surface absorption; transmitted pulse; adsorbed water; breakdown mechanism; SP541, pp. 318-326 (Dec. 1978). 
Frequency calibration; high frequency; Loran-C; low frequency; radio broadcasts; satellite broadcasts; standard frequencies; television color subcarrier; time and frequency calibration methods; time calibration; time signals; SP559.

Frequency comparison; frequency multiplication; frequency synthesis; laser frequcncy measurement; Penning trap; speed of light; $\mathrm{CO}_{2}$ lascr; 18608 .

Frequency dependent polarizability; helium ' $S$ state; molecular electronic structure; van der Waals cocfficient; 18934 .

Frequency drift; frequency stability; navigation; oscillator; position location; time dispersion; timc error; timc error measure; time prediction error; clocks; 18899.

Frequency lock loop; frequency stability; navigation; oscillator systems; phase lock loop; position location; spectral purity; 18693.

Frequency measurements; iodine; laser; visible; 18916.

Frequency modulation; frequency reference; precision oscillators; clock's rms time errors; flicker noise; 18940 .

Frequency multiplication; frequency synthesis; laser frequency measurement; Penning trap; speed of light; $\mathrm{CO}_{2}$ laser; frequency comparison; 18608 .

Frequency reference; precision oscillators; clock's rms time errors; flicker noise; frequency modulation; 18940 .

Frequency response; impulse response; laser; photodiode; avalanche photodiode; FFT; fiber optics; NBSIR 79-1620.

Frequency response; measurements; attenuation; fiber optics; 18915.

Frequency response measurements; measurements; review; attenuation measurements; fiber optics; 18647.

Freouency signature; statistical scattering; tissue signature; ultrasonic scattering; ultrasound; detection of lung disease; SP525, pp. 135-141 (Apr. 1979).

Frequency spectra; in vivo; microprocessor-controlled data acquisition; myocardial infarction; real-time; tissue characterization; ultrasound diagnosis; clinical cardiac data; digital processing; Fast Fourier Transform; SP525, pp. 267-273 (Apr. 1979).

Frequency stability; frequency standard; ion temperature; laser induced cooling; $\mathbf{M g}$ ions; optical \& microwave double resonance; stored ions; systematic effects; Ba ions; $/ 8697$.

Frequency stability; navigation; oscillator; position location; time dispersion; time error; time error measure; time prediction error; clocks; frequency drift; $\mathbf{1 8 8 9 9}$.

Frequency stability; navigation; oscillator systems; phase lock loop; position location; spectral purity; frequency lock loop; 18693.

Frequency stability; second-order Doppler shift phase modulation; spin exchange; temperature coefficient; time dispersion; wall shift; amplitude modulation; cavity pulling; cavity servo; dielectrically loaded cavity; 18696.

Frequency stabilizing system; microwave interaction regions; microwave signals; beam type device; U.S. Patent 4,I46,848.

Frequency standard; high resolution spectroscopy; ion storage; laser spectroscopy; Mossbauer effect; optical pumping; optical spectroscopy; radiation pressure; radiative cooling; Doppler-free spectroscopy; 18699 .

Frequency standard; inversion transition in ammonia; precision; acceleration insensitive oscillator; ammonia microwave absorption; atomic clock; cavity frequency stabilization; digital demodulator; frequency-lock servo; 18698.

Frequency standard; ion temperature; laser induced cooling; Mg ions; optical \& microwave double resonance; stored ions; systematic effects; Ba ions; frequency stability; 18697 .

Frequency standards; frequency synthesis; fundamental constants; length standards; physical measurement systems; review article; speed of light; time standards; atomic clocks; 18346.

Frequency standards; hydrogen standards; rubidium standards; time and frequency; timekeeping; atomic clocks; cesium standards; crystal oscillators; 18908
Frequency standards; navigation; stability; time; clocks; communication; 18826

Frequency standards; navigation; time; time dissemination; communication; frequency; 19005 .

Frequency sums; Rainer and Serene; superfluid ${ }^{3} \mathrm{He} ; 18553$.

Frequency synthesis; fundamental constants; length standards; physical measurement systems; revicw article; speed of light; time standards; atomic clocks; frequency standards; 18346 .

Frequency synthesis; laser frequency measurement; Penning trap; speed of light; $\mathrm{CO}_{2}$ laser; frequency comparison; frequency multiplication; 18608 .

Frequency-domain measurements; magnetic materials; microwaves; millimeter waves; permeability measurements; permittivity measurements; radar absorbers; time-domain measurements; dielectrics; NBSIR 79-16/3.

Frequency-lock servo; frequency standard; inversion transition in ammonia; precision; acceleration insensitive oscillator; ammonia microwave absorption; atomic clock; cavity frequency stabilization; digital demodulator; 18698 .

Friction; hardness; liquid softening; oxides; scratching; size effect; specific energy; ceramics; chipping; crack formation; fracture toughness; SP562, pp. 43-59 (Oct. 1979).

Friction; measurement; reference standards; safety research; walkway slip-resistance; SP565.

Fringe counting interferometric method and apparatus; Michelson interferometer; phase locked oscillators; retroreflectors; counting and control circuitry; U.S. Patent $4,165,183$.

Fringe pattern; spatial period; wavelength of light; Fizeau-type interferometer; U.S. Patent 4,173,442.

Front end; graphite; part integration; wheel; automotive component design; continuous fiber composite materials; fabrication; finite element stress analysis; SP563, pp. 135-151 (Oct. 1979).

Fructose; galactose; gas-liquid chromatography; glucose; lactose; liquid chromatography; maltose; raffinose; ribose; stachyose; sucrose; sugar analysis; carbohydrates; SP5 19, pp. 271-278 (Apr. 1979).

Fuel economy; motor vehicle; diagnosis; emissions inspections; fault detection; SP547, pp. 78-97 (July 1979).

Fuel load survey; heat release; interior finish; laboratory fire tests; material ignitability; prediction model; shipboard spaces; fire growth; fire statistics; flame spread; NBSIR 79 . 1714 .

Fuel measurement; instrumentation; total energy; transducers; weather station; data acquisition system; digital tapc recorder; NBSIR 79-1709.

Fuel oil; hydraulic oil; industrial oil; lubricating oil; oil specifications; petroleum standards; petroleum test methods; recycled oil; re-refined oil; used oil; waste oil; engine oil; SP556.

Fuel oil; spectrometry; sulfate; $x$ ray; anion exchange; filter paper; 18635 .

Fuels, heating values; gas-flow calorimetry; heat capacity measurement; heat measurements; levitation calorimetry; microcalorimetry; radiation calorimetry; solution calorimetry; bomb calorimetry; drop calorimetry; electromagnetic power calorimetry; energy measurement; 18330 .

Full-scale testing; mobile homes; wind loads; aerodynamics; building; codes and standards; NBSIR 77-1289.

Full-scale tests; heat detectors; hospitals; ionizaton detectors; mattresses; nursing homes; photoelectric detectors; corridors; escape; fire detectors; NBSIR 79-I739.

Fulvic acid; humic acid; humic substances; reference collection of humic substances; rcference samples; soil organic matter; aquatic humus; SP519, pp. 789-792 (Apr. 1979).

Fulvic acid; humic acid; humic substances; reference collection of humic substances; soil organic matter; standard humic materials; SP5 19, pp. 793-796 (Apr. 1979).

Functional group analysis; affinity chromatography; environmental analysis; SP5/9, pp. 783-787 (Apr. 1979). 
Functional theoretic techniques; modified residue calculus; open systems; remote sensing; closed systems; electromagnctic problems; Monogr. 164.

Fundamental constant; geophysics; gravity; precision measurement; earthquake; 18654 .

Fundamental "constant"; geophysics precision measurement; gravity; earthquake; 18472 .

Fundamental constant; magnetic fields; proton gyromagnetic ratio; quantum electrodynamic theory; electron anomalous moment; fine-structure constant; 18702 .

Fundamental constants; geodynamics; geophysics; instrumentation; 18947.

Fundamental constants; gyromagnetic ratio of proton; magnetic fields; Maxwell's equations; solenoids; Ampere's law; dimensional metrology; 18437.

Fundamental constants; length standards; physical measurement systems; review article; speed of light; time standards; atomic clocks; frequency standards; frequency synthesis; 18346 .

Furnace; gas-fired; heating; oil-fired; rating; space-heating; testing; boiler; combustion; energy; 18385 .

Furnishings; upholstered furniture; chairs; compartment fires; fire tests; flammability; TN/ 103 .

Furniture; hazard analysis; probability; residential buildings; sensitivity analysis; smoke detectors; standards; upholstered furniture; building fires; cost-benefit analysis; costs; decision analysis; fire losses; TNIIOI.

Fused silica; Ge; hot forged; $\mathrm{KBr} ; \mathrm{KCl}$; $\mathrm{KCl}: \mathrm{KI}$; $\mathbf{L i F}$; $\mathrm{MgF}_{2}$; $\mathrm{NaCl} ; \mathrm{NaF}$; piezo-optic constants; refractive index; $\mathrm{SiO}_{2}$; $\mathrm{SrF}_{2}$; thermal expansion coefficient; thermo-optic constant; ZnS; ZnSe; TN993.

Fused silica; laser damage; polished surfaces; pulse duration dependence of damage; surface roughness; BK-7 glass; SP541, pp. 164-167 (Dec. 1978).

Fusion cast; laser damage; laser window; single crystal; strontium fluoride; antireflection coatings; calcium fluoride; $\mathrm{cw}$ laser damage; DF laser; SP54I, pp. 78-85 (Dec. 1978).

Fusion diagnostics; gravity waves; laser-interferometer; microwave measurements; non-destructive evaluation; pipe welds; standard; x-ray image; appropriations; DIM/NBS 63, No. 3, 1-28 (1979).

Fusion plasmas; lasers; molecular bands; molecular spectra; reaction rate constants; upper atmosphere; atomic energy levels; atomic spectra; atomic transition probabilities; electron cross sections; 18855 .

$f$-value; imprisonment; laser; lifetime; mean life; oscillator strength; Al ı; aluminum; delayed coincidence; 18527.

\section{G}

Gage blocks; length; measurement assurance; measurement process control; systematic error; uncertainty; calibration; Monogr. 163.

Gain; radiative transition; electronic structure; energy curves; excimer; 18936.

Galactic astronomy; space astronomy; stellar astronomy; ultraviolet spectroscopy; 18590 .

Galactose; gas-liquid chromatography; glucose; lactose; liquid chromatography; maltose; raffinose; ribose; stachyose; sucrose; sugar analysis; carbohydrates; fructose; SP519, pp. 271-278 (Apr. 1979).

Galaxies; stellar dynamics; structure-hydrodynamics; 18483 .

Galena ores; glass; Japanese glass; lead; lead isotopes; Chinese glass; 18840 .

Galvanic corrosion; implants; implants passivity; corrosion; crevice corrosion; 18946.

Galvanic corrosion; inhibitors; pitting corrosion; rust; stress corrosion; corrosion; crevice corrosion; CIS9, Revised 1979.

Gamma rays; neutron leakage rates; SP554, pp. 145-154 (Sept. 1979).
Gamma rays; photons; Rayleigh scattering; tabulations; $x$ rays; atomic form factor; coherent scattering; cross sections; JPCRD 8, No. 1, 69-106 (1979).

Gamma rays; precision wavelength; silicon lattice spacing; tungsten $x$ rays; $x$-ray wavelength ratios; 18487 .

Gamma-ray energies; thulium; ytterbium; crystal diffraction; 18510.

Gamma-ray spectroscopy; matrix-isolation; metric conversion; satellite system; computer network; computer standards; fire safety; DIM/NBS 63, No. 7/8, 1-28 (1979).

Garments; hazard; heat transfer; ignitability; standard; test; apparel; extinguishability; fabrics; flammability; 18708 .

Garments; heat transfer; injury potential; simulation; accident; apparel; burn injury; clothing; fabric flammability; fabrics; fire; NBSIR 79-1755.

Garments; heat transfer; standards; apparel; burn injury; ease of ignition; fabrics; fire; flammability tests; 18991 .

Gas; nitrogen; sound velocity; thermodynamic properties; virial coefficients; density; $/ 8815$.

Gas analysis; gas chromatography; heating value; hydrocarbon; liquefied natural gas; phase equilibrium; pipelines; sampling; custody transfer; density; NBSIR 78-887.

Gas analysis; gas chromatography; heating value; liquefied natural gas; sampling; custody transfer; density; 18395 .

Gas analysis; gas chromatography; hydrogen cyanide; combustion products; 18588 .

Gas chromatography; gas chromatography/mass spectrometry; preconcentration techniques; sample preparation; ultraviolet spectrometry; SP519, pp. 7-18 (Apr. 1979).

Gas chromatography; glass capillary columns; high-performance liquid chromatography; LC microcapillary columns; selective detectors; ancillary methods; bonded phases; chromatographic preconcentration; detector sensitivity; SP519, pp. 487-499 (Apr. 1979).

Gas chromatography; halo-organics; ionization detector; porous anode; electron capture detector; SP5 19, pp. 777-782 (Apr. 1979).

Gas chromatography; he adspace gas stripping; standard-addition calibration; trace analysis; trapping column; equilibration trapping; SP5/9, pp. $739-746$ (Apr. 1979).

Gas chromatography; heating value; hydrocarbon; liquefied natural gas; phase equilibrium; pipelines; sampling; custody transfer; density; gas analysis; NBSIR 78.887.

Gas chromatography; heating value; liquefied natural gas; sampling; custody transfer; density; gas analysis; $\mathbf{l} 8395$.

Gas chromatography; hydrocarbons; capillary columns; SP519. pp. 713-718 (Apr. 1979).

Gas chromatography; hydrocarbons; permanent gas analysis; trace organics in air; complete analysis scheme; SPS 19, pp. 153-159 (Apr. 1979).

Gas chromatography; hydrogen cyanide; combustion products; gas analysis; 18588 .

Gas chromatography; internal standards; methylation; sample preparation; clinical chemistry; drug analysis; SP5 19, pp. 381-390 (Apr. 1979).

Gas chromatography; $\operatorname{Kepone}^{R}$; partition chromatography; parts per billion; analysis; biological; SP519, pp. 341-343 (Apr. 1979).

Gas chromatography; liquid chromatography; automation; clinical chemistry; environmental chemistry; SP519, pp. 587-600 (Apr. 1979).

Gas chromatography; liquid chromatography; mass spectrometry; trace organic analysis; analytical systems; atomic absorption; SP519, pp. 541-546 (Apr. 1979).

Gas chromatography; liquid chromatography; plant constituents; abscisic acid; SP519, pp. 803-807 (Apr. 1979).

Gas chromatography; liquid chromatography; selective detection; detector design; SPS19, pp. 547-585 (Apr. 1979). 
Gas chromatography; mass spectrometry; polycyclic aromatic hydrocarbons; capillary-column; charge exchange; chemical ionization; SP519, pp. $731-738$ (Apr. 1979).

Gas chromatography; mass spectrometry; propylamine; buiylamine; collagen sponge; contraceptive device; SP519, pp. 469-476 (Apr. 1979).

Gas chromatography; modular organic analysis system; pyrolysis; tracc organic analysis; Fourier transform infrared; SP519, pp. 753-760) (Apr. 1979).

Gas chromatography; nitrogen-phosphorus; selective detection; steroid hormones; SP5 19, pp. $419-427$ (Apr. 1979).

Gas chromatography; organochlorides; pesticides; sediment and water; carbamates; SP519, pp. 191-203 (Apr. 1979).

Gas chromatography; parts per billion; carbon tetrachloride; chloroform; drinking water analysis; SP519, pp. 175-179 (Apr. 1979).

Gas chromatography; pesticide residues; sampling; cellulose triacetate filters; SP519, pp. 19-32 (Apr. 1979).

Gas chromatography; tensilization; thermogravimetric analysis; tire cord; tire cord dip; tire cord finish; emissions; SP5 19, pp. 181-184 (Apr. 1979).

Gas chromatography; trapping; air sampling; co-condensation; SP519, pp. 95-99 (Apr. 1979).

Gas chromatography-mass spectrometry; negative ions; chemical ionization; electron capture; SP519, pp. 601-607 (Apr. 1979).

Gas chromatography-mass spectrometry ( $\mathrm{gc} / \mathrm{ms}$ ); gas liquid chromatography (glc); gc/ms interface; high performance liquid chromatography (hplc); inert columns; metabolism; methandienone; urine; anabolic steroids; clean-up; SP519, pp. 437-445 (Apr. 1979).

Gas chromatography/mass spectrometry; isotope dilution; serum; cholesterol; SP519, pp. 405-410 (Apr. 1979).

Gas chromatography/mass spectrometry; microcomputer; routine analysis; trace organics in water; SP519, pp. 169-173 (Apr. 1979).

Gas chromatography/mass spectrometry; preconcentration techniques; sample preparation; ultraviolet spectrometry; gas chromatography; SP519, pp. 7-18 (Apr. 1979).

Gas chromatography/mass spectrometry; sampling; sediment; trace analysis; water; $\beta$-chloroethers; air; environment; SP519, pp. 205-212 (Apr. 1979).

Gas chromatography-mass spectrometry; glass capillary chromatography; high pressure liquid chromatography; hydrocarbon persistence; infrared spectroscopy; petroleum hydrocarbons; sediment analysis; SP519, pp. 33-40 (Apr. 1979).

Gas detectors; kitchen fires; mobile homes; smoke detectors; tenability limits; upholstered furniture; detection time; detector location; fire tests; NBSIR 79-1915.

Gas liquid chromatography (glc); gc/ms interface; high performance liquid chromatography (hplc); inert columns; metabolism; methandienone; urine; anabolic steroids; cleanup; contamination; dianabol; SP519, pp. $437-445$ (Apr. 1979).

Gas phase ion-molecule reactions; mass spectrometry; organic molecules; rate coefficients; chemical kinetics; data evaluation; NSRDS-NBS64.

Gas target; molecular vibrations; neutron reactions; ${ }^{23 \mu} \mathrm{U}$; Doppler effect; fission; 18585 .

Gas thermometer; low temperature; temperature scale; thermometry; tunnel diode oscillator; 18548.

Gas transmission rate; manometric technique; oxygen; permeability; poly(ethylene terephthalate); standard reference material; temperature coefficient; time-lag; SP260-58.

Gas turbine monitoring; remore motion detection; static displacement measurement; vibration measurement; advanced sensors; Doppler millimeter radar; SP547, pp. 58-62 (July 1979).
Gaseous interactions; molecular correlations; quenching; radiative lifetimes; rate constants; reactive channels; recommended data; relaxation processes; review; activation energies; electronically excited states; evaluation; JPCRD 8, No. 3, 723-798 (1979).

Gas-fired; heating; oil-fired; rating; space-heating; testing; boiler; combustion; energy; furnace; 18385 .

Gas-fired furnace; off-period mass flow rate; part-load performance; seasonal efficiency; automatic stack damper; fluegas temperature profile; TN999.

Gas-flow calorimetry; heat capacity measurement; heat measurements; levitation calorimetry; microcalorimetry; radiation calorimetry; solution calorimetry; bomb calorimetry; drop calorimetry; electromagnetic power calorimetry; energy measurement; enthalpy measurement; 18330.

Gas-liquid chromatography; glucose; lactose; liquid chromatography; maltose; raffinose; ribose; stachyose; sucrose; sugar analysis; carbohydrates; fructose; galactose; SP519, pp. 271 278 (Apr. 1979).

Gas-liquid chromatography; human plasma; nitrogen-sensitive detector; antitussive; dextromethorphan; SP519, pp. 481-485 (Apr. 1979).

Gas-liquid critical point; Rayleigh light scattering; binary mixture at the gas-liquid critical point; 18752 .

Gas-phase polyatomic molecules; gas-phase spectroscopy; microwave spectroscopy; molecular conformation; molecular spectroscopy; molecular structure; molecules; structure; bond angles; bond distances; JPCRD 8, No. 3, 619-722 (1979).

Gas-phase spectroscopy; microwave spectroscopy; molecular conformation; molecular spectroscopy; molecular structure; molecules; structure; bond angles; bond distances; gas-phase polyatomic molecules; JPCRD 8, No. 3, 619-722 (1979).

Gas-solid interface; KDP; Pockels effect; space charge; breakdown; electro-optics; NBS-GCR-79-177.

Gas/liquid chromatography; panthenol; pantothenates; pharmaceutical preparations; SP519, pp. 267-269 (Apr. 1979).

Gated diode; generation lifetime; integrated gated-diode electrometer; integrated test structure; leakage current; MOSFET dc profiler; surface recombination; CCD; electrical test structure; NBSIR 79-1744.

Gated frequency analysis; Gaussian window; impulsive complex signals; linear averaging; reciprocating; records after trigger; tape loop; time signal; time window; SP547, pp. 315-322 (July 1979).

Gauges; gauging devices; ionizing radiation; radiation measurements; radiation safety; standard; device safety performance classification; $H 129$.

Gauging devices; ionizing radiation; radiation measurements; radiation safety; standard; device safety performance classification; gauges; $H I 29$.

Gaussian window; impulsive complex signals; linear averaging; reciprocating; records after trigger; tape loop; time signal; time window; gated frequency analysis; SP547, pp. 315-322 (July 1979).

$\mathrm{Gc/ms}$ interface; high performance liquid chromatography (hplc); inert columns; metabolism; methandienone; urine; anabolic steroids; clean-up; contamination; dianabol; gas chromatography-mass spectrometry (gc/ms); SP519, pp. 437 445 ( Аpr. 1979).

$\mathrm{Gd}\left(\mathrm{PO}_{3}\right)_{3}$; low temperature thermometry; magnetic susceptibility; magnetic thermometers; $\mathrm{Nd}\left(\mathrm{C}_{2} \mathrm{H}_{5} \mathrm{SO}_{4}\right)_{3} \cdot 9 \mathrm{H}_{2} \mathrm{O}$; thermometry; 18556.

$\mathrm{Ge}$; hot forged; $\mathrm{KBr} ; \mathrm{KCl}$; $\mathrm{KCl}: \mathrm{KI}$; $\mathrm{LiF} ; \mathrm{MgF}_{2} ; \mathrm{NaCl} ; \mathrm{NaF}$; piezo-optic constants; refractive index; $\mathrm{SiO}_{2} ; \mathrm{SrF}_{2}$; thermal expansion coefficient; thermo-optic constant; $\mathrm{ZnS}$; $\mathrm{ZnSe}$; TN993.

Ge; $\mathrm{PbF}_{2}$; pulsed HF laser; antireflection coatings; CdSe; coating substrate; damage resistant; SP541, pp. 257-258 (Dec. 1978). 
Gclatin; human abdominal tissues; phantom; SP525, pp. 323. 326 (Apr. 1979).

Gcncrating function; incidence algebra; inverse limit; orthogonal idempotents; quasi-order; topological algcbra; coalgcbra; direct limit; faithful distributive module; 18788 .

Generation lifetime; integrated gated-diode electrometer; integrated test structure; leakage current; MOSFET dc profiler; surface recombination; $C C D$; electrical test structure; gated diode; NBSIR 79-1744

Generator column; polynuclear aromatic hydrocarbon; standard reference material; dynamic coupled-column liquid chromatography; extractor column; SP519, pp. 219-224 (Apr. 1979).

Generic DCA; Hull systems; simplified test equipment for internal combustion engines; turret systems; vehicle maintenance; combat vehicles; diagnostic connector assembly; fighting vehicle systems; SP547, pp. 98-110 (July 1979).

Geochronology; geology; lithium; nitrogen; silicon devices; trace analysis; uranium; alpha tracks; biomedical; boron; fission tracks; 18342

Geodesy; geophysics; instrumentation; satellites; tectonics; distance measurements; earthquakes; 18574 .

Geodesy; instrumentation; multiwavelength techniques; tectonics; atmospheric properties; distance measuremcnt; 18816 .

Geodynamics; geophysics; instrumentation; fundamental constants; 18947.

Geodynamics; gravity field; ocean current; plate tectonics; polar motion; crustal movements; earth rotation; 18584 .

Geology; lithium; nitrogen; silicon devices; trace analysis; uranium; alpha tracks; biomedical; boron; fission tracks; geochronology; 18342 .

Geomagnetism; induced currents; magnetometers; conductivity anomalies; earthquake prediction; 18895.

Geometrical-optics radiometry; inversion; measurement-beam geometry; relative spectral responsivity; slit-scattering function; slit-scattering function corrections; spectral line radiometry; spectroradiometer characterizations; spectroradiometry; vignetting; TN910-4

Geometry; hyperplane; cube; J. Res. 84, No. 1, 49-53 (1979).

Geophysics; gravity; precision measurement; earthquake; fundamental constant; 18654 .

Geophysics; instrumentation; fundamental constants: geodynamics; 18947.

Geophysics; instrumentation; satellites; tectonics; distance measurements; earthquakes; geodesy; 18574.

Geophysics; ranging; tectonic motions; continental drift; distortion-of-plate; 18459.

Geophysics precision measurement; gravity; earthquake; fundamental "constant"; 18472 .

Geotechnical engineering; housing construction; mine subsidence; mining; site development; standards; structural design; foundation design; 18324 .

Geriometry; life cycle reliability; on-vehicle computing instrumentation; prognostic maintenance management; SP547, pP. 65-77 (July 1979).

German Bundesverband Solarenergie; solar collector testing; water-heating solar collectors; collector efficiency; comparison German BSE vs ASHRAE 93-77 procedures; flatplate solar collectors; 18986 .

Germanium resistance thermometer; Josephson junction noise thermometer; low temperature scale; ${ }^{3} \mathrm{He} /{ }^{4} \mathrm{He}$ dilution refrigerator; ${ }^{n} \mathrm{CO} \gamma$-ray thermometer; comparison measurements; 18555.

Germanium thermometers; low temperature; rhodium-iron thermometry; thermal cycles to low temperatures; 19040 .

Giant laser pulse; optical fiber damage; pulsed $\mathrm{Nd}^{3+}$ laser damage; single and multiple element fibers; surface threshold damage; free-running laser pulses; SP541, pp. 168-189 (Dec. 1978).
Giant resonancc; nickel isotopcs; virtual photons; electric quadrupolc; clcctrodisintegration; 18535.

Giant rcsonance; tensor polarizability; Thomson scattcring; coherent scattering; Delbruck scattering; elastic scattering; 18521 .

Giant resonancc; virtual photons; ${ }^{5 \pi} \mathrm{Ni}$; electric quadrupolc; electrodisintegration; electron energy; 18520 .

Giant resonances; hydrodynamic modcl; isoscalar resonances; isovector resonances; photonuclear physics; shell model; 18565.

Glass; ceramics; material removal; abrasive machining; chip formation; fine grinding; SP562, pp. 107-114 (Oct. 1979).

Glass; grinding; impact; silicon nitridc; strength; stress intensity factor; abrasive machining; ceramics; contact stress; damage penetration; fracture mechanics; fragmentation; SP562, pP. 23-42 (Oct. 1979).

Glass; grinding; polishing; strength; defects; etching; SP562, pp. 489-500 (Oct. 1979).

Glass; hydrodynamic machining; ion beam machining; watcr jet cutting; ceramics; chemical milling; electric discharge machining; electron beam machining; SP562, pp. 261-281 (Oct. 1979).

Glass; Japanese glass; lead; lead isotopes; Chinese glass; galena ores; 18840 .

Glass capillary chromatography; high pressure liquid chromatography; hydrocarbon persistence; infrared spectroscopy; petroleum hydrocarbons; sediment analysis; gas chromatography-mass spectrometry; SP519, pp. 33-40 (Apr. 1979).

Glass capillary columns; high-performance liquid chromatography; LC microcapillary columns; selective detectors; ancillary methods; bonded phases; chromatographic preconcentration; detector sensitivity; gas chromatography; SP519, pp. 487-499 (Apr. 1979).

Glass capillary gas chromatography; high pressure extraction; polynuclear aromatic hydrocarbon; coal combustion products; SP519, pp. 109-120 (Apr. 1979).

Glass compositions; methacrylate monomers; polymerization accelerators; reinforcing fillers; silane coupling agents; benzoyl peroxide; composite resins; de ntal materials; 18644 .

Glass fiber; graphite fiber; aramid fiber; composite applications; composites; concrete; cryogenics; cpoxy resins; 18717

Glass fiber reinforcement; polyester resin; structural sheet molding compound; SP563, pp. 108-129 (Oct. 1979).

Glass, grinding; strength; surface damage; SP562, pp. 93-106 (Oct. 1979).

Glass melting; grinding; grinding model; high-speed grinding; pyrex; size effect; chipping; ferrites; SP562, pp. $61-74$ (Oct. 1979).

Glass reinforced plastics; graphite epoxy; impact; marine environment; advanced composites; cavitation erosion; extended immersion; flammability; SP563, pp. 276-285 (Oct. 1979)

Glass surface; latent scratch; optical glass; polishing; cleaning; chemical durability; SP562, pp. 417-425 (Oct. 1979).

Glass transition; high pressure; hydrostaticity; liquids; pressure cell; viscosity; diamond-anvil; 18509

Glass-ceramic; machinable; MACOR ${ }^{T M}$; Corning code 9658; SP562, pp. $221-229$ (Oct. 1979).

Glass-ceramics; heat switches; magneto-thermal conductivity; polarization; potassium tantalate; refrigeration; specific heat; strontium titanate; beryllium; ceramics; cryogenics; dielectricconstant; electrets; electrocaloric effect; entropy; ferroelectrics; 18680 .

Glass-epoxy; industrial laminates; mechanical properties; physical properties; radiation properties; cryogenics; 18771

Glass-surface; surface conductivity; conductivity; electric conductivity; electrokinetics; 18910 .

Glauber's salt; latent heat storage; pebble bed; phase-change unit; solar energy storage; thermal energy storage device; ASHRAE Standard 94-77; NBSIR 79-1737. 
Glazc; margin staining; roughness; wear; curing shrinkagc; 18684 .

Glow discharge; lascr magnctic resonance; atomic oxygen; 18919

Glowing ignition; hazard; ignition temperature; lamp surface temperaturc; melting tcmperaturc; miniature Christmas lights; plastic insulating material; polycthylene; series-constructed; elcctric shock; fire; flaming ignition; NBSIR 79-1716.

Glucose; lactose; liquid chromatography; maltosc; raffinose; ribose; stachyose; sucrose; sugar analysis; carbohydratcs; fructose; galactosc; gas-liquid chromatography; SP519, pp. 271-278 (Apr. 1979).

Glued-laminated timber; safety; temporary structures; wood; bridges; buildings; design criteria; 18887.

Goal seeking; intelligence; motor behavior; neural modeling; perception; planning; problem solving; robot control; brain mechanisms; cognition; 18714 .

GOES; microprocessors; satellite; synchronization; time; clock; 18393.

Gold; metals; molten metals; palladium; precious metals; reference data; silver; solid state physics; transport properties; copper; critical evaluation; data analysis; data compilation; data evaluation; data extraction; JPCRD 8, No. 4, 1147 1298 (1979).

Gold; relative intensities; round robin; $\mathrm{x}$-ray photoelectron spectroscopy; binding energies; copper; ESCA; 18924.

Gold films; gravimetry; neutron activation analysis; Rutherford backscattering; standards; accuracy and precision; 18490 .

Gold-nickel layers; micrometer scale; scanning electron microscope scale; electrodeposited metal layers; U.S. Patent $4,139,933$.

Go-no-go; ground readout; hydraulic; IMACS; instantaneous diagnosis and analysis; level; maintenance oriented; malfunction detection; monitoring; onboard; patented; pressure; pumps; reservoirs; sensors; tailorable; temperature; accumulator; SP547, pp. 345-357 (July 1979).

Goodness of fit; Sir Francis Beaufort (1774-1857); binomial test; chi-squared test; Francis Ysidro Edgeworth (1845$1926) ; 18471$.

Government policy; international standards; laboratory accreditation; standards systems; United Kingdom; West Germany; antitrust; Canada; certification; Denmark; economics of standards; NBS-GCR-79-172.

Governmental actions; life safety; regulation; risk assessment; societal goals; building codes; control measures; fire codes; fire safety; SP536, pp. 63-74 (Feb. 1979).

Government-industry cooperation; imports; innovation; leather; manufacturing technology; materials development; shoes; technology transfer; computer-aided design and manufacture $(\mathrm{CAD} / \mathrm{CAM})$; footwear industry; fragmented industries; SP527.

GPSDC; ion energetics; ionization potential; abstract; appearance potential; archival tape; computer program; data base; data base management; empirical molecular formula; NBSIR $78-1432$.

Graded index; lead fluoride; polymorphism; thallium iodide; thin films; SP541, pp. 259-265 (Dec. 1978).

Grain boundaries; Harrison classification; lattice diffusion; migrating boundaries; polycrystals; thin films; diffusion; 18758 .

Grain boundaries; Harrison classification; lattice diffusion; migrating boundaries; polycrystals; thin films; diffusion; 18759.

Grain boundaries; isostatic forging; optical figure; optical homogeneity; single crystal; Talystep traces; alkali halides; backward scattering; forward scattering; SP54I, pp. 65-69 (Dec. 1978).

Grain boundary sliding; high temperature; intergranular fracture; stainless steel; critical strain rate; fatigue; 18896 .
Grain size dependence of strength; strength; brittle failure; flaw sizes; SP562, pp. 429-452 (Oct. 1979).

GRALE; organic analysis; reflectance; air pollution; ambient aerosols; computer controllcd gas chromatography/mass spectrometry; SP519, pp. 101-107 (Apr. 1979).

Grant data; residential buildings; solar database; solar energy system; solar heating and cooling; automatic data processing; computer reports; NBSIR 79-1923.

Graph; graph coloring; heuristic; interchange; random tcst graphs; scheduling; time complexity; algorithm; chromatic number; color function; J. Res. 84, No. 6, 489-506 (1979).

Graph; longest circuit; permutation matrix; doubly stochastic matrix; eigenvalues; field of values; 18941 .

Graph coloring; heuristic; interchange; random test graphs; scheduling; time complexity; algorithm; chromatic number; color function; graph; J. Res. 84, No. 6, 489-506 (1979).

Graphic analysis; IMS information retrieval; KWOC indexing; least-squares; linear regression; MIS; plotting; statistical analysis; Boolean search system; computer programs; curve fitting; data analysis; data base management; data retrieval; file handling; 18597.

Graphics; interactive graphics; regression; software; transformation; computing system; dataplot; fitting; 18519 .

Graphite; Lorenz ratio; reference materials; thermal conductivity; characterization; density; electrical resistivity; 18668 .

Graphite; part integration; wheel; automotive component design; continuous fiber composite materials; fabrication; finite clement stress analysis; front end; SP563, pp. 135-151 (Oct. 1979).

Graphite epoxy; impact; marine environment; advanced composites; cavitation erosion; extended immersion; flammability; glass reinforced plastics; SP563, pp. 276-285 (Oct. 1979).

Graphite epoxy composites; interlaminar cracks; stability of cracks; virtual crack closure; delamination mechanisms; energy release rate; finite element method; free-edge stresses; SP563, pp. 255-264 (Oct. 1979).

Graphite fiber; aramid fiber; composite applications; composites; concrete; cryogenics; epoxy resins; glass fiber; 18717 .

Graphite furnace; seawater; wavelength modulation; atomic absorption; atomic emission; barium; 18783 .

Graphite furnace atomic absorption; sea water; separation; trace element analysis; water analysis; chelating resin; 18402 .

Graphite materials; Lorentz function; preferred orientation function; pyrolitic graphite; Ruland function; x-ray diffraction; Bacon function; Bragg function; Ergun function; 18523.

Graphite-epoxy; interlaminar stresses; laminated composites; stress concentrations; tension; tensor polynomial; compression; failure; finite elements; SP563, pp. 242-254 (Oct. 1979).

Graphite-epoxy; Precision Mounting Platform; resonant frequency; composite design; SP563,p. 130 (Oct. 1979).

Graphite-epoxy laminate design; laminate design sensitivities; thermal expansion; advanced composite materials; SP563, pp. 60-71 (Oct. 1979).

Graphite-fiber; polyphthalocyanine; prepreg; TGA; V/STOL; cure; dielectric analysis; DSC; SP563, pp. 25-31 (Oct. 1979).

Graphite/epoxy; moisture barrier; space optics; advanced composites; dimensional stability; eutectic coating; SP563, pp. 47-56 (Oct. 1979).

Gravimetry; neutron activation analysis; Rutherford backscattering; standards; accuracy and precision; gold films; 18490.

Gravity; earthquake; fundamental "constant"; geophysics precision measurement; 18472 .

Gravity; precision measurement; earthquake; fundamental constant; geophysics; 18654 .

Gravity effects; materials science; spacelab; critical phenomena; critical-point universality; fluids; 18457 .

Gravity effects; phase transition; critical point; 18541 .

Gravity field; ocean current; plate tectonics; polar motion; crustal movements; earth rotation; geodynamics; 18584 . 
Gravity waves; laser-interfcrometer; microwavc measurements non-destructive evaluation; pipe welds; standard; $x$-ray image; appropriations; fusion diagnostics; DIM/NBS 63, No. 3, 1-28 (1979).

Gray; sievert; unit; absorbed dose; dose equivalent; 19002.

Grey water; heat recovery; recycling; residential; wastewater treatment; water; water conservation; water heating; water usage; energy; energy consumption; NBSIR 79-1770.

Grid-turbulence; higher-order moments; hot-wire anemometry; probability distributions; small-scale turbulence; correlations; I 8821 .

Grinding; grinding damage; lapping; polishing; polishing times; SP562, pp. 191-199 (Oct. 1979).

Grinding; grinding model; high-speed grinding; pyrex; size effect; chipping; ferrites; glass melting; SP562, pp. $61-74$ (Oct. 1979).

Grinding: impact; silicon nitride; strength; stress intensity factor; abrasive machining; ceramics; contact stress; damage penetration; fracture mechanics; fragmentation; glass; SPS62, pp. 23-42 (Oct. 1979).

Grinding; machining; polishing; sanding; strength-size effects; brittle failure; flaw populations; flaws; fractography; fracture origins; SP562, pp. $351-378$ (Oct. 1979).

Grinding; polishing; strength; defects; etching; glass; SPS62, pp. 489-500 (Oct. 1979).

Grinding; silicon nitride; strength; surface; finishes; flexure; fracture; fracture mechanics; SP562, pp. $463-474$ (Oct. 1979).

Grinding; stone; abrasives; ceramics; coated abrasives; SPS62, pp. 201-207 (Oct. 1979).

Grinding; tungsten carbide; cemented carbides; electrochemical grinding; SPS62, pp. 305-315 (Oct. 1979).

Grinding; wear; bronze binder; diamonds; erosion; SP562, pp. 147-155 (Oct. 1979).

Grinding damage; lapping; polishing; polishing times; grinding; SP562, pp. 191-199 (Oct. 1979).

Grinding forces; surface condition; surface grinding; chip formation; SPS62, pp. 75-91 (Oct. 1979).

Grinding model; high-speed grinding; pyrex; size effect; chipping; ferrites; glass melting; grinding; SP562, pp. 61-74 (Oct. 1979).

Gross calorific values; refuse-derived-fuels; sample characterization; test procedures; bomb calorimetry; NBSIR 78-1494.

Ground effect; unbalanced system; dipole antenna; NBSIR 79. 1605.

Ground readout; hydraulic; IMACS; instantaneous diagnosis and analysis; level; maintenance oriented; malfunction detection; monitoring; onboard; patented; pressure; pumps; reservoirs; sensors; tailorable; temperature; accumulator; analog; SP547, pp. 345-357 (July 1979).

Ground screen; measurements; standards; VDE; antennas; CISPR; 19033.

Ground state; interfaces; multi-ion interactions; ordered alloys; statistical mechanics; face centered cubic; 18614 .

Ground state; intermolecular potential; molecules; well depths; excited states; 18677 .

Group coded recording; interface electrical characteristics; interface functional characteristics; magnetic tape drives; NRZI recording; phase encoded recording; tape drive characteristics; computer magnetic tape drives; computer tape controllers; NBS-GCR-78-127.

Group decisions; properties of steam; space; stirling refrigerators; aluminum SRM's; computer systems; electron microscopy; DIM/NBS 63, No. 5, 1-28 (1979).

Group homes; handicapped; mental retardation; ambulatory people; autism; cerebral palsy; deafness; developmentally disabled; epilepsy; fire safety; NBS-GCR-79-167.

Group homes; household activities; room use; demographics; developmental disabilities; fire protection; NBSIR 79-1727.
Guard control station; higher headquarters; perimeter station; remote unit; response force; triply redundant central computer; central unit; computerizcd; detection; electronic lock; exclusion area; forced entry deterrent systems, NBSIR 79 . 1725 .

Guarded divider; resistive divider; self calibration; voltage divider; binary divider; divider network; 18452 .

Guide specifications; habitability criteria; Computer-Aided Engineering and Architectural Design System (CAEADS); design criteria; SP552, pp. 167-183 (July 1979).

Guidelines; hydrogen; regulations; safety; standards; codes; 18394 .

Guidelines; implementation; large-scale; management; mathematical models; policy analysis; software; standards; transfer; documentation; energy; evaluation; SPS34.

Guidelines holdup alarm; intrusion alarm; alarm; burglar alarm; SP480-14.

Guthrie blotters; blood samples; clinical sampling of infants; clinical trace organic sampling; SPS19, pp. 373-379 (Apr. 1979).

Gyromagnetic ratio; paper; photometric calibrator; safety tips; solar energy; toxic chemicals; ultra-black coating; Alaskan pipeline; computers; corrosion; fire safety; DIMINBS 63, No. 11, 1-36 (1979).

Gyromagnetic ratio of proton; magnetic fields; Maxwell's equations; solenoids; Ampere's law; dimensional metrology; fundamental constants; $/ 8437$.

Gyroscope; instrument materials; microcreep; micromechanical properties; beryllium; dimensional stability; NBSIR 78-1569.

Gyroscope; ralativity; space; superconducting; torque; trapped flux; 18846 .

G/kT, EIRP; G/T, precision measurements; radio star; satellite communications; error analysis; 18577 .

G/T, precision measurements; radio star; satellite communications; error analysis; G/kT, EIRP; 18577 .

\section{$\mathbf{H}$}

Habitability criteria; Computer-Aided Engineering and Architectural Design System (CAEADS); design criteria; guide specifications; SP552, pp. 167-183 (July 1979).

Hadamard product; inclusion theorem; Kronecker product; numerical radius; spectrum; stable matrix; closure; $D$-stability; diagonal matrix; field of values; 18909 .

Hadamard product; inverse-positive matrix; matrix sign patterns; positive matrix; 18524 .

Hadron; quark; spectroscopy; spectrum; structure; flavor; 19010.

Hafnium; ionization energies; lutetium; osmium; rhenium; tantalum; tungsten; wavelengths; ytterbium; energy levels; 18506.

Haken's Hamiltonian; polar crystals; biexcitons; 18592.

Halides; iodides; molten salt mixtures; standard reference data; surface tension; viscosity; bromides; chlorides; data compilation; density; electrical conductance; fluorides; JPCRD 8, No. 1, 125-302 (1979).

Hall-effect measurements; phosphorus in silicon; electron paramagnetic resonance; epitaxial silicon; NBSIR 79-I748.

Halogen radical anions; nitrate radical; oxyanion radicals; phosphate radical; photolysis; radiolysis; rates; selenium radicals; sulfate radical; thiocyanate radical anion; aqueous solution; carbonate radical; chemical kinetics; NSRDS-NBS65.

Halomethanes; vapor pressure-boiling point data; Wagner equation; Antoine equation; enthalpy of vaporization; JPCRD 8, No. 2, $499-518$ (1979).

Halo-organics; ionization detector; porous anode; electron capture detector; gas chromatography; SPS19, pp. 777-782 (Apr. 1979). 
Hammer drivc; input/output bus; interface; interface signals; 1/O interfacc bus; line printer; print controller; printer; cable interfacc; computcr; controller; control units; NBS-GCR-79182.

Handicapped; mental retardation; ambulatory people; autism; cerebral palsy; deafness; developmentally disablcd; epilepsy; fire safety; group homes; NBS-GCR-79-167

Handicapped occupants; health care facilities; nursing homes; user needs; building codes; building evaluation; elderly; fire safety; NBSIR 79-1906.

Harbor facilities; inspection; maintenance; marine borers; nondestructive testing; pilings; timber; acoustics; bridgcs; creosote; 18525 .

Hard sphere model; Klosek-McKinley method; liquefied natural gas (LNG); magnetic suspension densimeter; comparisons; correlation; custody transfer; density; experimental; extended corresponding states method; 18775 .

Hardness; liquid softening; oxides; scratching; size effect; specific energy; ceramics; chipping; crack formation; fracture toughness; friction; SP562, pp. 43-59 (Oct. 1979).

Hardness; positron annihilation; titanium; defects; Doppler broadening; 18967.

Hardness; surface characterizations; surface finishing; abrasion; ceramic machining; ceramics; effects of machining on ceramic properties; SP562.

Hardware monitoring; CPEUG; installation management; online system evaluation; prediction methods; queuing models; simulation; software monitoring; workload definition; computer performance evaluation; computer performance measurement; computer performance prediction; SP5OO-52.

Hardware monitors; modeling; performance evaluation; performance prediction; simulation; validation; workload characterization; workload management; capacity planning; SP5OO52, pp. 179-192 (Oct. 1979).

Harrison classification; lattice diffusion; migrating boundaries; polycrystals; thin films; diffusion; grain boundaries; 18758 .

Harrison classification; lattice diffusion; migrating boundaries; polycrystals; thin films; diffusion; grain boundaries; 18759 .

Harshaw Chemical Company; relative humidity; storage; Studsvik AB Atomenergi, Sweden; thermoluminescence dosimeters; fading; 18989.

Hartree-Fock calculations; $x$-ray emission; copper $K \beta$; double vacancy; emission spectrum; 18526.

H-atom abstraction; hydrogen bonding; hydrogen fluoride; infrared spectrum; matrix isolation; methane; methyl fluoride; methyl radical; F-atom production; F-atom reactions; 18869 .

Hazard; heat transfer; ignitability; standard; test; apparel; extinguishability; fabrics; flammability; garments; 18708 .

Hazard; ignition temperature; lamp surface temperature; melting temperature; miniature Christmas lights; plastic insulating material; polyethylene; series-constructed; electric shock; fire; flaming ignition; glowing ignition; NBSIR 79-1716.

Hazard; injuries; loss prevention; risk; safety; construction; cost effectiveness; 18890 .

Hazard analysis; probability; residential buildings; sensitivity analysis; smoke detectors; standards; upholstered furniture; building fires; cost-benefit analysis; costs; decision analysis; fire losses; furniture; TN1101.

Hazard warnings; pictograms; safety information; standardization; symbols; communication; evaluation methods; fire safety; NBSIR 79-1760.

Hazardous materials; packaging; plastics; standardization; transportation; effective carbon atom number; NBSIR 79-1768.

Hazardous materials; packaging; plastics; standardization; transportation; effective carbon atom number; 18639.

Hazardous temperatures; load current; overlamping; surface mounted incandescent lighting fixture; thermal insulation; thermocouple; branch circuit wiring; electrical junction box; NBSIR 79.1912.
Hazardous temperatures; load current; protective barrier: recessed incandescent lighting fixture; thermal insulation; thermocouple; branch circuit wiring; electrical junction box; NBSIR 79-1913.

Haze; hazemeter; integrating sphere; linearity; scattering; collimation; 18594 .

Hazemeter; integrating sphere; linearity; scattering; collimation; haze; 18594 .

$\mathrm{HBr}^{+}$laser magnetic resonance; molecular ions; 18917 .

HCCN; infrared spectrum; interferometer; matrix isolation; methyl cyanide; ultraviolet spectrum; vacuum ultraviolet photolysis; CCN; CNC; far infrared spectrum; 18842.

$\mathrm{HCl}-\mathrm{Ar}$; rotational linewidths; temperature dependence; theoretical and experimental comparison; vibrational effect; 18689 .

He; interaction energy; overlap; Be; dispersion; excited states; 18933.

Head injury; helmet; impact; test method; headform; headgear; NBSIR 78-1547.

Head injury criterion; impact; peak acceleration; performance; playground surfaces; test method; NBSIR 79-1707.

Headform; headgear; head injury; helmet; impact; test method; NBSIR 78-1547.

Headgear; head injury; helmet; impact; test method; headform; NBSIR 78-1547.

Headspace gas stripping; standard-addition calibration; trace analysis; trapping column; equilibration trapping; gas chromatography; SP519, pp. 739-746 (Apr. 1979).

Health care facilities; hospitals; human behavior; nursing homes; nursing staff; training; evacuation; fire doors; fire drills; fire extinguishers; fire safety; NBS-GCR-79-179.

Health care facilities; hospitals; interior finishes; Life Safety Code; nursing homes; risk analysis; safety equivalency; safety evaluation; smoke detection; automatic sprinklers; building codes; building construction; Delphi Method; fire safety; NBSIR 78-1555.

Health care facilities; hospitals; life safety; mathematical programming; nursing homes; renovation; applied economics; building codes; building economics; economic analysis; fire safety; NBSIR 79-1902.

Health care facilities; hospitals; life safety; mathematical programming; nursing homes; renovation; applied economics; building codes; building economics; economic analysis; fire safety; 19045.

Health care facilities; hospitals; mattresses; smoke movement; sprinkler systems; NBSIR 79-1749.

Health care facilities; hospitals; mattresses; prisons; bedding; beds; compartment fires; firesafety engineering; fire tests; 18517.

Health care facilities; nursing homes; user needs; building codes; building evaluation; elderly; fire safety; handicapped occupants; NBSIR 79-1906.

Health care facility; smoke development; fire hazards; fire protection; fire safety; 18721 .

Health facilities; public sector efficiency; subsidies; technological change; capital formation; economic growth; NBS-GCRETIP 78-45.

Health physics; particle accelerators; radiation measurements; radiation protection; standard; accelerator design; accelerator operation; H107, Revised.

Health Physics Society Standards Committee; mandatory testing program; peer review; personnel dosimetry; processors; standard; trial use and comment; American National Standards Institute; 18992.

Hearing; hearing aids; selection of hearing aids; speech communication; audition; communications; CIS4, Revised 1978.

Hearing aid tests; orthotelephonic response; anthropometric manikin; free-field measurements; hearing aids; 18464 .

Hearing aids; hearing aid tests; orthotelephonic response; anthropometric manikin; free-field measurements; 18464. 
Hcaring aids; selection of hearing aids; speech communication; audition; communications; hearing; CIS4, Revised 1978.

Heart; liver; scattering; scattering cross-section; absorption; attenuation; SP525, pp. 153-156 (Apr. 1979).

Heat addition; hyperbolic, elliptic equations; initial, boundaryvalue problem; linearized equations; partial differential equations; buoyant convection; finite-difference computations; fire in an enclosure; NBSIR 79-1754.

Heat capacity; low temperature alloy; specific heat; stainless steel; 18419 .

Heat capacity; measurement automation; p-Terphenyl; thermodynamic properties; $\lambda$-type transition; adiabatic calorimetry; automated calorimetry; calorimetry; 18376 .

Heat capacity; relative apparent molal enthalpy; salt solutions; thermochemistry; vapor pressure; apparent molal heat capacity; aqueous systems; bibliography; electrochemistry; electrolytes; enthalpy of dilution; SP537.

Heat capacity; sapphire; specific heat; standard reference materials; thermodynamic properties; alumina; aluminum oxide; calorimetry; corundum; enthalpy; 18377

Heat capacity measurement; heat measurements; levitation calorimetry; microcalorimetry; radiation calorimetry; solution calorimetry; bomb calorimetry; drop calorimetry; electromagnetic power calorimetry; energy measurement; enthalpy measurement; entropy measurement; 18330 .

Heat capacity measurement; $\mathrm{Pb}-\mathrm{Sn}$ off-eutectic alloys; phase diagram of $\mathrm{K}_{2} \mathrm{O}-\mathrm{Fe}_{2} \mathrm{O}_{3}$ system; solidification; surface tension of liquid gallium; thermodynamic properties; convection; NBSIR 79-1767.

Heat detectors; hospitals; ionizaton detectors; mattresses; nursing homes; photoelectric detectors; corridors; escape; fire detectors; full-scale tests; NBSIR 79-1739.

Heat detectors; room fires; smoke detectors; spacing; velocity; beams; ceiling height; detectors; fire detectors; fire growth; NBS-GCR-78-I28.

Heat detectors; room fires; smoke detectors; spacing; velocity; beams; ceiling height; detectors; fire detectors; fire growth; NBS-GCR-78-129.

Heat effect; injury mechanism; injury statistics; mouth burn; specific electrical effect; arc burn; contact burn; current threshold; electrical injury; electrolyte shift; NBSIR 79-17IO.

Heat measurements; levitation calorimetry; microcalorimetry; radiation calorimetry; solution calorimetry; bomb calorimetry; drop calorimetry; electromagnetic power calorimetry; energy measurement; enthalpy measurement; entropy measurement; fuels, heating values; 18330 .

Heat of formation; hexylmethylethane; $t$-butyl radical; unimolecular decomposition; activation energy; $A$-factor; comparative rate; flow system; 18743 .

Heat of formation; ion-molecule reactions; proton affinity; proton transfer reaction; dichlorocarbene; 18331

Heat of fusion; lecithins; lipids; melting temperature; metastable states; phenyl substituted diglycerides; phospholipids; polymorphism; recrystallization temperature; benzyl substituted diglycerides; differential scanning calorimetry; 18380 .

Heat of mixing; liquid-vapor equilibria; methane + ethane; binary mixtures; data correlation; excess volumes; JPCRD 8 , No. 3, 799-816 (1979).

Heat pumps; part-load evaluation; standards for heat pumps; testing procedures for heat pumps; 18703 .

Heat pumps; part-load evaluation; standards for heat pumps; testing procedures for heat pumps; 18778 .

Heat recovery; lint; performance; venting; appliance; clothes dryer; efficiency; energy conservation; 18793 .

Heat recovery; recycling; residential; wastewater treatment; water; water conservation; water heating; water usage; energy; energy consumption; grey water; NBSIR 79-1770.

Heat release; interior finish; laboratory fire tests; material ignitability; submarine compartment; combustion products; fire barrier coatings; fire growth; flame spread; foam insulation; NBSIR 78-1584.

Heat release; interior finish; laboratory fire tests; material ignitability; prediction model; shipboard spaces; fire growth; fire statistics; flame spread; fuel load survey; NBSIR 79-1714.

Heat release rate; ignition; interior finish; passive fire protection; potential heat; smoke; compartment fires; fire tests; flame spread; NBSIR 79- 1700 .

Heat switches; magneto-thermal conductivity; polarization; potassium tantalate; refrigeration; specific heat; strontium titanate; beryllium; ceramics; cryogenics; dielectric-constant; electrets; electrocaloric effect; entropy; ferroelectrics; glassceramics; 18680 .

Heat transfer; helium; hydrodynamics; large magnets; power transmission; review; superconductors; ac generators; 18822 .

Heat transfer; ignitability; standard; test; apparel; extinguishability; fabrics; flammability; garments; hazard; 18708 .

Heat transfer; injury potential; simulation; accident; apparel; burn injury; clothing; fabric flammability: fabrics; fire; garments; NBSIR 79-1755.

Heat transfer; room fires; smoke; soot; thermal radiation; fire models; NBS-GCR-78-151.

Heat transfer; standards; apparel; burn injury; ease of ignition; fabrics; fire; flammability tests; garments; 18991 .

Heat transmission; helium II; mutual friction; axial heat transport; forced convection; 18617 .

Heating; oil-fired; rating; space-heating; testing; boiler; combustion; energy; furnace; gas-fired; 18385 .

Heating; passive; solar; suburban; urban; application; buildings; commercial; daylighting; energy; environments; 18894 .

Heating and cooling load; hybrid computer; NBSLD; thermal comfort; 18336 .

Heating and cooling load; solar heat gain; daylighting; energy calculation; energy consumption; fenestration; 19003 .

Heating balance point analysis; low-income residences; marginal cost/benefit analysis in weatherization; optimum weatherization retrofit combinations; thermal analysis of residences; Community Services Administration; NBSIR 79 . 1706 .

Heating equipment; maintenance; stoves; wood; accident investigations; chimneys; coal; creosote; fire departments; fire safety; NBSIR 79-1731

Heating equipment; maintenance; stoves; wood; accident investigations; chimneys; coal; creosote; fire departments; fire safety; NBS-GCR-78-149.

Heating equipment; maintenance; stoves; wood; accident investigations; chimneys; coal; creosote; fire departments; fire safety; 18537 .

Heating load calculation; NBSLD analysis of residences; residential energy conservation; thermal mass effect in buildings; building energy consumption analysis; computerized building energy analysis; cooling load calculation; energy conservation; NBSIR 79-1732.

Heating rate; lifetime prediction; polystyrene; polyurethane; thermogravimetry; weight-loss kinetics; aging of polymers; degradation of polymers; error propagation; factor-jump method; 18620 .

Heating value; hydrocarbon; liquefied natural gas; phase equilibrium; pipelines; sampling; custody transfer; density; gas analysis; gas chromatography; NBSIR 78-887.

Heating value; liquefied natural gas; sampling; custody transfer; density; gas analysis; gas chromatography; 18395 .

Heat-pipe oven use in the vacuum ultraviolet; multichannel capillary arrays; vacuum ultraviolet spectroscopy; vacuum ultraviolet windows; differential pumping across capillary arrays; focused vacuum ultraviolet; 18808 .

Heats of formation; transition metal alloys; $d$-electron energy band parameters; $d$-electron transfer; 19047 . 
Heavy ions; international commission on radiation units and measurements; protons; stopping power; $\alpha$-particles; electrons; 18358 .

Helicoid anemometer; lag; overspeeding error; rotary anemometer; unsteady flow; air; anemometer; NBSIR 781505.

Helium; hydrodynamics; large magnets; power transmission; review; superconductors; ac generators; heat transfer; 18822 .

Helium; ionization; secondary; angular; Born approximation; correlations; elcctron impact; electrons; 18534

Helium; stability; superconductor; transient flow; transient heat transfer; forced flow; 18813 .

Helium; x-ray emission; flare stars; 19007.

Helium II; mutual friction; axial heat transport; forced convection; heat transmission; 18617

Helium 'S state; molecular electronic structure; van der Waals coefficient; frequency dependent polarizability; 18934 .

Helium 3; Japan; millikelvin research; nuclear cooling; Pomeranchuk refrigerators; solid $\mathrm{He}^{3}$; superfluid $\mathrm{He}^{3}$; symposium; cryogenics; dilution refrigerators; 18679.

Helmet; impact; test method; headform; headgear; head injury; NBSIR 78-1547.

Hematite forming on platinum; iron as alloy in platinum; platinum ware; surface of platinum influenced by method heating; contrast augmentation of reflecting surfaces; doublediaphragm; faces (crystal) on platinum crucibles; J. Res. 84, No. 5, 385-394 (1979).

Hemispherical domes; oxides; sapphire; two-surface lapping; two-surface polishing; dome finishing; finishing technique; SP562, pp. 255-260 (Oct. 1979).

Hensorrhage; hydrocephalus; impedance; infarct; speed; ultrasonic; attenuation; brain tumor; clot; SPS25, pp. 81-84 (Apr. 1979).

He-Ne laser; nonlinear optics; $1.15 \mathrm{\theta m}$; frequency; 18562.

Herbicides; high pressure liquid chromatography; organics in water; pesticides; extraction; SP519, pp. 87-94 (Apr. 1979).

Hermes/CTS; international time comparison; precise time transfer; satellite; time; time scales; 18861 .

Hermeticity; hybrid devices; leak testing; measurement technology; microcalorimetry; moisture; nondestructive testing; pacemaker leads; process control; reliability; semiconductor devices; welding; automated testing; batteries; cardiac pacemakers; contamination; corrosion; SP400-50.

Hermeticity; hybrids; nondestructive tests; semiconductor; tapebonded devices; acoustic emission; beam lead devices; electronic devices; SP400-59.

Hermeticity; indium-doped silicon; infrared reflectance; integrated circuits; linc-width measurements; oxidation; photolithography; photovoltaic method; power-device grade silicon; radioisotope leak test; resistivity variations; resistors, sheet; SP400-38

Hermeticity; moisture infusion; oxide moisture sensors; accelerated stress test; capillary leaks; corrosion failure; NBSGCR-79-170.

Hermitian magnitude; isotropicity; isotropic, real-time, electricfield sensor (IRES); resistively loaded dipole; tangential sensitivity; broadband; dynamic range; 19034.

Herzberg-Teller theory; rotational contours of absorption bands; vibrational angular momentum; absorption selection rules; benzene; 18750 .

Heuristic; interchange; random test graphs; scheduling; time complexity; algorithm; chromatic number; color function; graph; graph coloring; J. Res. 84, No. 6, $489-506$ (1979).

Hexononitriles; iterative analysis; proton $\mathrm{nmr}$ spectroscopy; shift rcagents; acyclic sugars; chemical shifts; conformation; coupling constants; 18742 .

Hexylmethylethane; $\ell$-butyl radical; unimolecular decomposition; activation energy; $A$-factor; comparative rate; flow system; heat of formation; 18743
High accuracy; modular capacitive divider; portable system; truck-mounted; CCVT; compact; field calibration; 18833 .

High accuracy; portable system; truck-mounted; CCVT; compact; field calibration; 18938 .

High copper; single alloy; amalgam; creep; dental; dimensional change; dispersion type alloy; 18729 .

High current beams; numerical simulation; particle accelerators; space charge forces; beam transport; 18932 .

High duty-cycle; coincidence experiments; cotrelations in nuclei; cw accelerators; electronuclear physics; 18906 .

High energy radiotherapy beams; leakage; measurement techniques; medical accelerators; neutrons; relative biological effect; shielding techniques; standards; dosimetry; SP554.

High energy $x$-ray radiotherapy machine; mixed photon-neutron field dosimetry; neutron leakage; SP554, pp. $87-97$ (Sept. 1979).

High fluence; laser irradiation; ceramic surfaces; diamond single-point machining; SP562, pp. 513-518 (Oct. 1979).

High frequency; Loran-C; low frequency; radio broadcasts; satellite broadcasts; standard frequencies; television color subcarrier; time and frequency calibration methods; time calibration; time signals; frequency calibration; SP559.

High frequency oscillator; Josephson junction; picosecond pulse generator; ac current; U.S. Patent 4,168,44l.

High performance liquid chromatography; occupational health; picogram; polycyclic aromatic hydrocarbons; selectivity; sensitivity; specificity; trace analysis; environmental pollution; fluorescence; SP519, pp. 41-56 (Apr. 1979).

High performance liquid chromatography; phylloquinone; tocopherols; tocotrienols; vitamin $\mathrm{E}$; vitamin $\mathrm{K}$; SPS19, pp. 279-288 (Apr. 1979)

High performance liquid chromatography (hplc); inert columns; metabolism; methandienone; urine; anabolic steroids; cleanup; contamination; dianabol; gas chromatography-mass spectrometry (gc/ms); gas liquid chromatography (glc); SP5/9, pp. 437-445 (Apr. 1979).

High precision; high-precision weighing; load cell; mass; mass comparator; mass difference; strain-gage; substitution weighing; weighing; weights; constant loading; force; J. Res. 84, No. 5, 347-35I (1979).

High pressure; high pressure chemistry; pressure generator; calibration; 18401

High pressure; high temperature; measurement method; powder diffraction; reactive atmosphere; coal gasification; 18945 .

High pressure; high temperature; mechanochemical polishing; quartz crystal; sapphire; Si single crystal; SP562, pp. 171-182 (Oct. 1979)

High pressure; hydrostaticity; liquids; pressure cell; viscosity; diamond-anvil; glass transition; 18509 .

High pressure chemistry; pressure generator; calibration; high pressure; 18401 .

High pressure extraction; polynuclear aromatic hydrocarbon; coal combustion products; glass capillary gas chromatography; SP519, pp. 109-120 (Apr. 1979).

High pressure extrusion; oriented polyethylene; relaxation process; stress relaxation; torsion pendulum; dynamic mechanical; 18767 .

High pressure liquid chromatography; hydrocarbon persistence; infrared spectroscopy; petroleum hydrocarbons; sediment analysis; gas chromatography-mass specirometry; glass capillary chromatography; SP519, pp. 33-40 (Apr. 1979).

High pressure liquid chromatography; organics in water; pesticides; extraction; herbicides; SP519, pp. $87-94$ (Apr. 1979).

High reflectance coatings; interface absorption; multilayer films; scattering; absorption; antireflectance coatings; SP541, pp. 266-277 (Dec. 1978).

High resolution; multirange; R-2R ladder; relay switching; selfcalibration; twenty bits + sign; voltage output; digital-toanalog converter; TNI 105. 
High resolution; reconstruetion; temperature reconstruction; ultrasound; aperture synthesis; computed tomography; Doppler; tluid flow; SP525, pp. 227-233 (Apr. 1979).

High resolution; reconstruction; temperature reconstruction; ultrasound; aperture synthesis; computed tomography; Doppler; fluid flow: SP525, pp. 235-246 (Apr. 1979).

High resolution detector; phase sensitive detector; programmablc detector; a-c detector; automatic bridge; detector; 18453 .

High resolution IR spectra; hypochlorous acid; large A-value molecules; stratospheric $\mathrm{HOCl}$; air pollutants; chlorine sink; 18864 .

High resolution spectra; spectral clusters; spherical top molecules; 4 th and 6 th rank octahedral tensor; asymptotic eigensolutions: 18706 .

High resolution spectroscopy; hyperfine structure; level clusters; saturation absorption spectra; superfine structure; symmetry analysis; tableau calculus; 18609.

High resolution spectroscopy; ion storage; laser spectroscopy; Mossbauer effect; optical pumping; optical spectroscopy; radiation pressure; radiative cooling; Doppler-free spectroscopy; frequency standard: 18699.

High resolution spectroscopy; level clusters; spherical top molecules; combination bands; 18921

High resolution spectroscopy; level clusters; saturation absorption spectroscopy; spherical top molecules; 18928 .

High rise buildings; hospitals; human behavior; nursing homes; bibliographies; building fires; escape; evacuation; fires; NBSGCR-78-138.

High speed logic; Josephson computer; Josephson junction: microstriplines; superconductivity; 18666.

High speed performance; high speed tires; police tires; pursuit tires; tire maintenance; traction performance; tread wear; 19038.

High speed photography; Kerr effect; liquid breakdown; nitrobenzene; partial discharges; streamers; transient phenomena; electrical breakdown; 18843.

High speed tires; police tires; pursuit tires; tire maintenance; traction performance; tread wear; high speed performance; 19038.

High stability oscillators; superconducting cavity stabilized oscillator; superconducting oscillators; superconducting resonators; 18692.

High temperature; intergranular fracture; stainless steel; critical strain rate; fatigue; grain boundary sliding; 18896 .

High temperature; isolation; lasers; mass spectrometry; matrix; modeling; vapors; combustion; equilibrium; SP561, Vols. I and 2 .

High temperature; measurement method; powder diffraction; reactive atmosphere; coal gasification; high pressure; 18945.

High temperature; mechanochemical polishing; quartz crystal; sapphire; Si single crystal; high pressure; SP562, pp. 171-182 (Oct. 1979).

High vacuum; interferometry; piezo-electric positioner; 18318 .

High voltage; impulse; lightning impulse; pulse calibration; ramp response; step response; divider; 18727.

High voltage; impulse; pulse measurements; response time; step response; transients; divider; Duhamel's integral; NBSIR 79. 1933.

High voltage; low temperature polymer; cryogenic; dielectric loss; dissipation factor; 18384 .

High voltage; pulse measurement; voltage measurement; current measurement; electric transmission; electro-optic systems; 18872 .

High voltage; standards; sulfur-hexafluoride; calibration; Clausius-Mossotti equation; compressed-gas capacitor; 18513.

High-carbon ferrochromium; homogeneity testing; preparation; processing; standard reference material; composition; 18414 .

High-density lipoproteins; neutron scattering; electron microscopy; 18851 .
Higher headquarters; perimeter station; remotc unit; response force; triply redundant central computer; central unit; computerized; detection; electronic lock; exclusion area; forced entry deterrent systems; guard control station; NBSIR 791725 .

Higher-order moments; hot-wire anemometry; probability distributions; small-scale turbulence; correlations; grid-turbulence; 18821 .

Highly excited Rydberg states; population of angular momentum states; collisional transitions; 18473 .

Highly ionized; impurity; molybdenum; plasma; atomic physies; dielectronic recombination; 18949.

Highly ionized atoms; effective Gaunt factor; electron collision theory; electron correlation; electron excitation collision strength; electron excitation cross section; 18997.

High-performance liquid chromatography; LC microcapillary columns; selective detectors; ancillary methods; bonded phases; chromatographic preconcentration; detector sensitivity; gas chromatography; glass capillary columns; SP519, pp 487.499 (Apr. 1979).

High-performance liquid chromatography; light-scattering; lipids; nephelometry; oils; reversed-phase; serum; cerebrospinal fluid; detector; SP519, pp. $429-436$ (Apr 1979).

High-power; reflectance; spectral absorptance; theory; asymmetric absorptance; damage thresholds; dielectric reflectors; electric-field distribution; SP541, pp. 278-287 (Dec. 1978).

High-precision weighing; load cell; mass; mass comparator; mass difference; strain-gage; substitution weighing; weighing; weights; constant loading; force; high precision; J. Res. 84 , No. 5, 347-351 (1979).

High-pressure liquid chromatography; marine biota; metabolites; polynuclear aromatic hydrocarbons; SP519, pp. 79.86 (Apr. 1979).

High-resolution spectra; level clusters; Raman spectra; rotationvibration spectra; symmetry analysis; Born-Oppenheimer approximation; 18598.

High-resolution spectra; Orion Nebula; dimcthyl ether transitions; 18731 .

High-rise; model codes; people movement; systems design; buildings; communications systems; fire safety; BSSI1 15 .

High-rise building design; network flow; building evacuation; NBSIR 79.1738.

High-rise communication systems; multiplex systems; NFPA standards; residential fire detector; sprinkler supervisory devices; control units; fire alarm systems; fire detectors 18625 .

High-speed grinding; pyrex; size effect; chipping; ferrites; glass melting; grinding; grinding model; SP562, pp. $61-74$ (Oct 1979).

High-strength; low-temperature; mechanical properties; nitrogen; nitrogen-strengthened; stainless steel; tensile properties; toughness; cryogenic; fatigue; fracture; 18957

High-voltage $\mathbf{C}(\mathrm{V})$ and $\mathrm{G}(\mathrm{V})$ measurements; semiconductor device measurements; silicon-on-sapphire measurements; extended-range capacitance and conductance measurements NBS-GCR-78-155.

Histological sections; implant materials; microanalysis; molccular microanalysis; pathological tissue; Raman microprobe; Raman spectra; Raman spectroscopy; biological microanalysis; biological tissue; foreign bodies; 18958 .

Histology of breast tumors; signal processing for tissue; $x$-ray examination of breast; attenuation of areola; attenuation of breast tissue; attenuation of malignant tumors; breast cancer detection; breast carcinoma; SP525, pp. 85-91 (Apr. 1979).

Historic district; historic preservation; regulations; rehabilitation; safety; barriers; building codes; code enforcement; SP536, pp. 83-93 (Feb. 1979). 
Historic preservation; life-cycle costing; redevelopment; rehabilitation; tax incentives; adaptive reuse; buildings; demolition; economics; TN980.

Historic preservation; life-cycle costing; redevelopment; rehabilitation; tax incentives; adaptive reuse; buildings; demolition: economics; 19016

Historic preservation; performance attributes; performance evaluation; building codes and standards; building code structure; existing buildings; SP536, pp. 17-53 (Feb. 1979).

Historic preservation; regulations; rehabilitation; safety; barriers; building codes; code enforcement; historic district; SP536, pp. 83-93 (Feb. 1979).

Historical survey; prominent calorimetrists; benzoic acid; calibration; combustion bombs; combustion calorimetry; 18797.

History; standards; alkalies; cement; 18854 .

History of building research; building technology; Center for Building Technology; BSS75.

Hole mobility; ionized impurity scattering mobility; lattice scattering mobility; neutral impurity; resistivity; scattering mechanisms; scattering mobility; $\rho$-type silicon; boron-doped silicon; dopant density; effective mass; SP400-47.

Hollow cathode discharge; metal vapor production; sputtering; charge transfer; 18968 .

Hollow cathodes; mass spectrometry; neon; nitrogen; Penning effect; carbon; copper; 18449.

Holography; interferometers; matrix crazing; nondestructive testing; pressure vessels; composites; SP563, pp. 211-212 (Oct. 1979).

Holography; irradiance; laser diagnostics; phase front; beam profilc; calibrated system; TNI015.

Holography; laser; laser parameters; laser pulse; optical processing; phase; precision measurements; wave front; amplitude; beam profile; cross correlation; digital sampling; Fourier optics; TN1009.

Holstein-Primakoff reprcsentation; spin operators; Boson expansions; 18885 .

Home accidents; home safety; safety in the home; stair accidents; stair safety; window accidents; window safety; accident avoidance; accidents in the home; door accidents; NBS-GCR-78-156.

Home entertainment electronics; industrial electronics; medical electronics; microwave electronics; nonionizing radiation; radiation hazards; radio regulations; radio standards; $\mathbb{R F I}$; spectrum management; standardization organizations; telecommunications; TVI; SP55I.

Home fires; residential smoke detectors; smoke detectors; detection; fires; 18514 .

Home safety; safety in the home; stair accidents; stair safety; window accidents; window safety; accident avoidance; accidents in the home; door accidents; home accidents; NBSGCR-78-156.

Home safety; safety standards; stair safety; stairway design; accidents; architectural design; architcctural psychology; architectural research; building codes; building design; building regulatory standards; floor coverings; BSS 120.

Homeostasis; promotion; RBE; risk; cell-proliferation; cell-turnover; cytotoxicity; SP554, pp. 41-56 (Sept. 1979).

Homogeneity; measurement method; nondestructive testing; photoconductivity; power devices; resistivity variation; automation; bulk photovoltaic effect; computer control; SP4OO52.

Homogeneity; standard reference materials; steel; digital periodic integrator; electron microprobe; SP260-65.

Homogeneity; standard reference materials; standards; digital periodic integrator; electron microprobe; 18973.

Homogeneity testing; preparation; processing; standard reference material; composition; high-carbon ferrochromium; 18414.
Homogeneous enzyme immunoassay; immunoassay; drug assay; EMIT $^{*}$ fluoroimmunoassay; fluorescence immunoassay; SP519, pp. 533-539 (Apr. 1979).

Homogeneous system; hydrostatic pressure; internal stress; internal virial; molecular dynamics; Monte Carlo method; periodic boundaries; pressure; stress calculation; virial theorem of Clausius; equilibrium; 18456.

Hormones; neurotransmitters; nutrients; organic pollutants; trace organic analysis; drug analysis; food toxicants; SP5 19.

Hose; hose specifications; rubber hose; solar energy systems; NBSIR 79-1917.

Hose specifications; rubber hose; solar energy systems; hose; NBSIR 79-1917

Hospitals; human behavior; nursing homes; bibliographies; building fires; escape; evacuation; fires; high rise buildings; NBS-GCR-78-138.

Hospitals; human behavior; nursing homes; nursing staff; training; evacuation; fire doors; fire drills; fire extinguishers; fire safety; health care facilities; NBS-GCR-79-179.

Hospitals; human behavior; nursing staff; patients; room fires; breathing apparatus; death; evacuation; fires; flashover; NBSGCR $-78-140$.

Hospitals; interior finishes; Life Safety Code; nursing homes; risk analysis; safety equivalency; safety evaluation; smoke detection; automatic sprinklers; building codes; building construction; Delphi Method; fire safety; health care facilities; NBSIR 78-1555.

Hospitals; ionizaton detectors; mattresses; nursing homes; photoelectric detectors; corridors; escape; fire detectors; fullscale tests; heat detectors; NBSIR 79-I 739.

Hospitals; life safety; mathematical programming; nursing homes; renovation; applied economics; building codes; building economics; economic analysis; fire safety; health care facilities; NBSIR 79-1902.

Hospitals; life safety; mathematical programming; nursing homes; renovation; applied economics; building codes; building economics; economic analysis; fire safety; health care facilities: 19045 .

Hospitals; mattresses; prisons; bedding; beds; compartment fires; firesafety engineering; fire tests; health care facilities; 18517.

Hospitals; mattresses; smoke movement; sprinkler systems; health care facilities; NBSIR 79-1749.

Hot forged; $\mathrm{KBr}$; $\mathrm{KCl} ; \mathrm{KCl}: \mathrm{KI}$; $\mathrm{LiF} ; \mathrm{MgF}_{2} ; \mathrm{NaCl}$; $\mathrm{NaF}$; piezooptic constants; refractive index; $\mathrm{SiO}_{2} ; \mathrm{SrF}_{2}$; thermal expansion coefficient; thermo-optic constant; ZnS; ZnSe; TN993.

Hot water; measurement; rating; solar; standards; testing; computer; 18428 .

Hot water heaters; hot water usage; residential water use; energy field measurements; 18829 .

Hot water usage; residential water use; energy field measurements; hot water heaters; 18829.

Hot-dry-rock well; permeability to water; pipe-bonding strength; tensile strength; cementing-materials; compressive strength; 19018 .

Hot-wire anemometry; probability distributions; small-scale turbulence; correlations; grid-turbulence; higher-order moments; I882I.

Hot/cold wafer chuck; thermally stimulated measurements; thermal wafer chuck; variable temperature; wafer chuck; deep level measurements; defect mapping; SP4OO-55.

Hourly load profiles; refrigerator field data; usage profiles; combination refrigerator-freezer field data; daily load profiles; energy consumption; field measurments; NBSIR 791781 .

Household activities; room use; demographics; developmental disabilities; fire protection; group homes; NBSIR 79-1727.

Housing; lead-based paint; lead poisoning; abatement; building economics; building materials; economic analysis; TN97I. 
Housing; lead-based paint; lead poisoning; abatement; building economics; building materials; cost estimation; econometric models; economic analysis; TN979.

Housing; preservation; regulations; rehabilitation; adaptive rcuse; building codes; buildings; building safety; code enforcement; construction; fire safety; SP536.

Housing; regulations; accessible; disabled; SP552, pp. 95-100 (July 1979).

Housing; rehabilitation; standards; building codes; community development; construction costs; contractors; SP536, pp. 55 61 (Feb. 1979).

Housing construction; mine subsidence; mining; site development; standards; structural design; foundation design; geotechnical engineering; 18324.

Housing needs; physical condition rehablitation; decision criteria; demolition; SP536, pp. 75-81 (Feb. 1979).

HPLC; ion-pair adsorption; ion-pair chromatography; ion-pair partition; metabolites; psychotropic amines; selectivity; sulphonamides; amino acids; barbiturates; carboxylic acids; catecholamines; conjugates; detection sensitivity; SP519, pp. 509-523 (Apr. 1979).

Hull systems; simplified test equipment for internal combustion engines; turret systems; vehicle maintenance; combat vehicles; diagnostic connector assembly; fighting vehicle systems; generic DCA; SP547, pp. 98-110 (July 1979).

Human abdominal tissues; phantom; gelatin; SP525, pp. 323 326 (Apr. 1979).

Human behavior; literature reviews; pyromaniacs; abnormal psychology; arson; arsonists; firesetters; NBS-GCR-79-157.

Human behavior; nursing homes; bibliographies; building fires; escape; evacuation; fires; high rise buildings; hospitals; NBS. GCR-78-138.

Human behavior; nursing homes; nursing staff; training; evacuation; fire doors; fire drills; fire extinguishers; fire safety; health care facilities; hospitals; NBS-GCR-79-179.

Human behavior; nursing staff; patients; room fires; breathing apparatus; death; evacuation; fires; flashover; hospitals; NBS. GCR-78-140.

Human behavior; plastics; polymers; smoke; smoke detectors; subway fires; toxicity; upholstered furniture; arson; bibliographies; building fires; compartment fires; fabric flammability; fire detection systems; fire tests; flammability tests; NBSIR $79-1745$.

Human behavior; smoke; toxic gases; toxicity; building fires; conferences; fire detection; fire investigations; fire models; fire research; fire retardants; flame retardants; SP54O.

Human behavior; statistical sampling; surveys; fire departments; fire incidence; fire reporting; fire victims; NBS-GCR-78-135.

Human behavior in fires; combustion products; fire hazards; fire modeling; fire research; NBSIR 78-1526.

Human behavior in fires; physics of fire; toxicity of combustion products; chemistry of fire; combustion products; fire hazards; fire modeling; fire research; NBSIR 79-1916.

Human bone; microhardness; microstructure; piezoelectricity; thermodynamics; ultrasound; viscoelasticity; wave propagation; anisotropy; dispersion; elasticity; SP525, pp. 189-196 (Apr. 1979).

Human characteristics; personal control; physical environment; privacy; architectural psychology; bibliography; buildings; communication; cost; NBSIR 79-1793.

Human engineering; human factors; human motivation; human reliability; personnel selection; physical security; physiological psychology; sensory capability; terrorism;threat analysis; training; adversary characteristics; animal research; behavioral science; biosensors; SP480-38.

Human engineering; human factors; human performance; standard reference data; anthropometry; data base; engineering psychology; ergonomics; evaluation; NBS-GCR-79-169.
Human factors; human motivation; human reliability; personnel selection; physical security; physiological psychology; sensory capability; terrosim; threat analysis; training; adversary characteristics; animal research; behavioral science; biosensors; computer analysis; $S P 480-38$.

Human factors; human performance; lawn mowers; psychophysics; safety; standards; consumer products; NBSIR $77-1298$

Human factors; human performance; standard reference data; anthropometry; data base; engineering psychology; ergonomics; evaluation; human engineering; NBS-GCR-79-169.

Human factors; interactive computing; man-machine interaction; performance measurement; timesharing; computer performance evaluation; SP5O0-48

Human factors; kitchen ranges; labeling; stoves; test methods; appliance; cooking; efficiency; energy; NBSIR 78-1556.

Human factors; lawn mowers; reaction time; safety; standards; consumer product; NBSIR 77-1299.

Human factors; product research; data banks; data bases; ergonomics; 18862 .

Human factors; research; school; air-conditioning; comfort; education; environment; 18596.

Human motivation; human reliability; personnel selection; physical security; physiological psychology; sensory capability; terrosim; threat analysis; training; adversary characteristics; animal research; behavioral science; biosensors; computer analysis; ergonomics; $S P 480-38$.

Human performance; lawn mowers; psychophysics; safety; standards; consumer products; human factors; NBSIR 77-1298.

Human performance; modeling technique; programming; sensitivity analysis; simulation; architectural research; building fires; computer-aided design; environmental psychology; fire research; fire safety; NBSIR 79-1713.

Human performance; modeling technique; simulation; architectural research; building fires; computer-aided design; computer simulation; environmental psychology; fire research; fire safety; NBSIR 79-1796.

Human performance; standard reference data; anthropometry; data base; engineering psychology; ergonomics; evaluation; human engineering; human factors; NBS-GCR-79-169.

Human plasma; melatonin; negative chemical ionization mass spectrometry; SP519, pp. 399.404 (Apr. 1979).

Human plasma; nitrogen-sensitive detector; antitussive; dextromethorphan; gas-liquid chromatography; SP519, pp. 481-485 (Apr. 1979).

Human reliability; personnel selection; physical security; physiological psychology; sensory capability; terrosim; threat analysis; training; adversary characteristics; animal research; behavioral science; biosensors; computer analysis; ergonomics; human engineering; SP480-38.

Human research; measurement; pedestrian movement; regulation; safety; standards; architectural barriers; building design; building site planning; environmental psychology; evaluation; fire escape; SP552, pp. 101-113 (July 1979).

Human research; measurement; pedestrian movement; regulation; safety; standards; architectural barriers; building design; building site planning; environmental psychology; evaluation; fire escape; 18430.

Humic acid; humic substances; reference collection of humic substances; reference samples; soil organic matter; aquatic humus; fulvic acid; SP519, pp. $789-792$ (Apr. 1979).

Humic acid; humic substances; reference collection of humic substances; soil organic matter; standard humic materials; fulvic acid; SP519, pp. 793-796 (Apr. 1979).

Humic substances; reference collection of humic substances; reference samples; soil organic matter; aquatic humus; fulvic acid; humic acid; SP519, pp. 789-792 (Apr. 1979).

Humic substances; reference collection of humic substances; soil organic matter; standard humic materials; fulvic acid; humic acid; SP519, pp. 793-796 (Apr. 1979). 
Humidity; ozone; pressure; standards; temperature; vacuum; 18335.

Humidity measurement; monomolecular film; psychrometer; psychrometry; radiative heat transfer; temperature depression; water vapor measurement; wet bulb; wet element; convective heat transfer; convective mass transfer; J. Res. 84, No. 2, 161-177 (1979).

Hybrid computer; NBSLD; thermal comfort; heating and cooling load; 18336.

Hybrid devices; leak testing; measurement technology; microcalorimetry; moisture; nondestructive testing; pacemaker leads; process control; reliability; semiconductor devices; welding; automated testing; batteries; cardiac pacemakers; contamination; corrosion; SP400-50.

Hybridization; structural stability; transition elements; electronegativities; 18421 .

Hybrids; nondestructive tests; semiconductor; tape-bonded devices; acoustic emission; beam lead devices; electronic devices; hermeticity; SP400-59.

Hydrate; hydration polishing; mechanochemical polishing with soft powder; pre-existing defect; sapphire; solid state reaction; water vapor; working unit; damaged layer; elastic emission machining; environmental effect; SP562, pp. 157-169 (Oct. 1979).

Hydrated layer; ion microprobe mass spectrometer; roughness; sapphire; ultra-fine polishing; water; $x$-ray photoelectron spectrometer; crystallographic integrity; electron diffraction images; SP562, pp. 317-323 (Oct. 1979).

Hydration polishing; mechanochemical polishing with soft powder; pre-existing defect; sapphire; solid state reaction; water vapor; working unit; damaged layer; elastic emission machining; environmental effect; hydrate; SP562, pp. 157 169 (Oct. 1979).

Hydration shell, role of; hydroxylapatite, at different $\mathrm{pHs}$; isotopic exchange, isoionic; recrystallization, role of; surface layer, role of; dilution effect, at same $\mathrm{pH}$ and concentration; J. Res. 84, No. 5, 395-406 (1979).

Hydraulic; IMACS; instantaneous diagnosis and analysis; level; maintenance oriented; malfunction detection; monitoring; onboard; patented; pressure; pumps; reservoirs; sensors; tailorable; temperature; accumulator; analog; centralized; SP547, pp. 345-357 (July 1979).

Hydraulic oil; industrial oil; lubricating oil; oil specifications; petroleum standards; petroleum test methods; recycled oil; re-refined oil; used oil; waste oil; engine oil; fuel oil; SP556.

Hydrazines; maleic hydrazide; mass spectroscopy; nitrosamines; nitrosodiethanolamine; silylation; thermal energy analyzer (TEA); tobacco; carbamates; chemical ionization; electroncapture; SP519, pp. 297-309 (Apr. 1979).

Hydrazines; nitroalkanes; nitrosamines; sidestream smoke; thermal energy analyzer; tobacco smoke; vinyl chloride; azaarenes; SP519, pp. 131-141 (Apr. 1979).

Hydrides; hydrogen storage; nuclear magnetic resonance; nuclear spin relaxation; diffusion; energy; 18352 .

Hydrides; intermetallic compounds; Laves phase; magnetism; neutron scattering; rare earths; 18682 .

Hydrides; intermetallic compounds; Laves phase; magnetism; neutron scattering; rare earths; 18881 .

Hydrides; Laves phase; magnetic properties; neutron scattering; rare earth compounds; 18657.

Hydrocarbon; liquefied natural gas; phase equilibrium; pipelines; sampling; custody transfer; density; gas analysis; gas chromatography; heating value; NBSIR 78-887.

Hydrocarbon; methyl-branch; structure; calculations; cell dimensions; crystal; defect; energy; 18787.

Hydrocarbon persistence; infrared spectroscopy; petroleum hydrocarbons; sediment analysis; gas chromatography-mass spectrometry; glass capillary chromatography; high pressure liquid chromatography; SP519, pp. 33-40 (A pr. 1979).
Hydrocarbons; capillary columns; gas chromatography; SP519, pp. 713-718 (Apr. 1979).

Hydrocarbons; hydrogen; nitrogen; organic compounds; oxidation; oxygen; oxygenated; rate constant; sulfur; Arrhenius parameters; combustion; decomposition; free radicals; NBSIR 79-1941.

Hydrocarbons; marine; petroleum; sediments; extraction; SP519, pp. 161-167 (Apr. 1979).

Hydrocarbons; permanent gas analysis; trace organics in air; complete analysis scheme; gas chromatography; SP519, pp. 153-159 (Apr. 1979).

Hydrocephalus; impedance; infarct; speed; ultrasonic; attenuation; brain tumor; clot; hemorrhage; SP525, pp. $81-84$ (Apr. 1979).

Hydrodynamic machining; ion beam machining; water jet cutting; ceramics; chemical milling; electric discharge machining; electron beam machining; glass; SP562, pp. 261281 (Oct. 1979).

Hydrodynamic model; isoscalar resonances; isovector resonances; photonuclear physics; shell model; giant resonances; 18565 .

Hydrodynamic radius; intrinsic viscosity; polymer dimensions in solution; polystyrene; radius of gyration; temperature and molecular weight dependence; 18960 .

Hydrodynamic radius; light scattering; molecular weight dependence; polystyrene; radius of gyration; temperature dependence; 18545 .

Hydrodynamics; large magnets; power transmission; review; superconductors; ac generators; heat transfer; helium; 18822.

Hydrofoils; maintenance requirements; naval ship application; composites; SP563, pp. 267-275 (Oct. 1979).

Hydrogen; interactive computer program; methane; minimization of Gibbs energy; phase rule; simultaneous chemical equilibria; water; BASIC; carbon dioxide; carbon monoxide; coal gasification; COLGAS; NBSIR 78-1509.

Hydrogen; ion dynamic effect; plasma line shift; spectral lines; Stark broadening; deuterium; 18948.

Hydrogen; mechanism; photochemistry; radicals; rate constant; acetylene; butadiyne; ethynyl; 18443 .

Hydrogen; nitrogen; organic compounds; oxidation; oxygen; oxygenated; rate constant; sulfur; Arrhenius parameters; combustion; decomposition; free radicals; hydrocarbons; NBSIR 79-1941.

Hydrogen; oxygen; scraping auger; slush; slush production; slush storage; cryogenic; NBSIR 79-1607.

Hydrogen; procedures; regulations; research needs; safety; standards; explosion; fire; 18776.

Hydrogen; production; storage; transmission; cost; economics; 18812 .

Hydrogen; regulations; safety; standards; codes; guidelines; 18394.

Hydrogen; ruthenium; adsorption; field emission; field-induced redistribution; 18810 .

Hydrogen bond; neutron diffraction; rigid body motion; triaminoguanidinium nitrate; crystal structure; 18873 .

Hydrogen bonding; hydrogen fluoride; infrared spectrum; matrix isolation; methane; methyl fluoride; methyl radical; Fatom production; $\mathbf{F}$-atom reactions; $\mathbf{H}$-atom abstraction; 18869 .

Hydrogen bromide; photochemistry mechanism; thermochemistry; bromine atoms; bromoacetylene; excited state; 18974.

Hydrogen contamination; hydroxyl contamination; semiconductor device fabrication; silicon; silicon dioxide; thermal oxidation of silicon; dry oxidation of silicon; NBSIR 78-1558.

Hydrogen cyanide; combustion products; gas analysis; gas chromatography; 18588 .

Hydrogen embrittlement; Rehbinder effects; Westwood effects; acoustic emission; chemomechanical effects; environmental effects; fracture of brittle materials; SP562, pp. 139-145 (Oct. 1979). 
Hydrogen cvolution; altcrnating current; alternating voltage; comparison between theoretical and experimental results; copper; corrosion; 18756.

Hydrogen fluoride; infrared spectrum; matrix isolation; methanc; methyl fluoride; methyl radical; F-atom production; F-atom reactions; $\mathbf{H}$-atom abstraction; hydrogen bonding; 18869.

Hydrogen halides; isotopes; laser; TEA laser; electronic discharge; 18667 .

Hydrogen halides; isotopes; laser; vibrational encrgy transfer; 18388.

Hydrogen halides; isotopes; temperature dependence; vibrational energy transfer; 18929 .

Hydrogen ion activity; ionic activity; ionic activity scales; pD; $\mathrm{pD}$ scale; $\mathrm{pH}$; $\mathrm{pH}$ scales; potentiometric ion activity; activity coefficient; 18379 .

Hydrogen standards; rubidium standards; time and frequency; timekeeping; atomic clocks; cesium standards; crystal oscillators; frequency standards; 18908 .

Hydrogen storage; nuclear magnetic resonance; nuclear spin relaxation; diffusion; energy; hydrides; 18352 .

Hydrology forecasting; microwave remote sensing; snow; centrifuge; comparison of measurement methods; -free water; freezing calorimeter; NBSIR 79-1604.

Hydrolytic stability; adhesion; bioadhesive bond strength; bone; cyanoacrylate; 18638 .

Hydrolytic stability of bonds; isobutyl 2-cyanoacrylate; mineralized tissue; 2-cyanoacrylate esters; adhesion; bonding to mineralized tissues; bone; dentin; 18569 .

Hydrostatic pressure; internal stress; internal virial; molecular dynamics; Monte Carlo method; periodic boundaries; pressure; stress calculation; virial theorem of Clausius; equilibrium; homogeneous system; 18456.

Hydrostatic pressure testing; intergranular cracking stainless steel; sensitized metal; circumferential tearing; fire extinguisher; 18368 .

Hydrostaticity; liquids; pressure cell; viscosity; diamond-anvil; glass transition; high pressure; 18509.

Hydroxyapatite; sonic velocity; bone; collagen; crosslinking modification; curvelinking; SP525, pp. 179-187 (Apr. I979).

Hydroxyapatite; surface area; bone; chemisorption; enamel; 18411 .

Hydroxyl; kinetics; mechanism; photochemistry; carbon dioxide; carbon monoxide; carbonyl; exchange; 18436 .

Hydroxyl; kinetics; olefin; ozone; review; troposphere; SP557, pp. 7-14 (Aug. 1979).

Hydroxyl contamination; semiconductor device fabrication; silicon; silicon dioxide; thermal oxidation of silicon; dry oxidation of silicon; hydrogen contamination; NBSIR 78-1558.

Hydroxylapatite; interlayering; octacalcium phosphate; tooth; $x$ ray diffraction; bone; 18583 .

Hydroxylapatite, at different pHs; isotopic exchange, isoionic; recrystallization, role of; surface layer, role of; dilution effect, at same $\mathrm{pH}$ and concentration; hydration shell, role of; $J$. Res. 84, No. 5, 395-406 (1979).

Hyperbolic, elliptic equations; initial, boundary-value problem; linearized equations; partial differential equations; buoyant convection; finite-difference computations; fire in an enclosure; heat addition; NBSIR 79-1754.

Hyperfine field; magnetism; phase diagram; potassium; conductivity; exchange interaction; ferrite; 19046.

Hyperfine fields; magnetic relaxation; magnetism; Mossbauer; rare earths; spin glass; 18329 .

Hyperfine structure; level clusters; saturation absorption spectra; superfine structure; symmetry analysis; tableau calculus; high resolution spectroscopy; 18609 .

Hyperplane; cube; geometry; J. Res. 84, No. 1, $49-53$ ( 1979 ).

Hypochlorous acid; large A-value molecules; stratospheric $\mathrm{HOCl}$; air pollutants; chlorine sink; high resolution IR spectra; $l 8864$.

\section{I}

IBM I68-3; IBM 3033; migration guidelines; migration planning; benchmark performance data; cmpirical models; SP500-52, pp. 89-104 (Oct. 1979).

IBM 3033; migration guidelincs; migration planning; benchmark performance data; empirical models; IBM 168-3; SP500-52, pp. 89-104 (Oct. 1979).

Ice; load; roof; roof load; snow; solar collector; structural engineering; building; NBS-GCR-79-181.

ICRM; natural matrix; radioactivity; standards; Woods Hole; environment; 18981 .

Ideal gas thermodynamic properties; internal rotation; iodoethane; potential barrier heights; symmetric top; torsional frequencies; bromoethanes; JPCRD 8, No. 2, $519-526$ (1979).

Ideal gas thermodynamic properties; molecular structure; normal and deuterated naphthalenes; vibrational assignments; enthalpy of formation; JPCRD 8, No. 2, 527-536 (1979).

Identifiers; key management; key notarization; cryptography; digital signatures; encryption; SP500-54.

Identifiers; key management; key notarization; cryptography; digital signatures; encryption; 19039.

IEC; interlocks; leakage; radiation; safety; standards; accelerators; SP554, pp. 29-32 (Sept. 1979).

IEEE subcommittee; performance specifications; sample/hold circuit; standards; terminology; analog-to-digital converter; digital-to-analog converter; 18365 .

Ignitability; standard; test; apparel; extinguishability; fabrics; flammability; garments; hazard; heat transfer; 18708.

Ignition; interior finish; passive fire protection; potential heat; smoke; compartment fires; fire tests; flame spread; heat release rate; NBSIR 79-1700.

Ignition; television fire; electrical failure; fire containment; TN1109.

Ignition temperature; lamp surface temperature; melting temperature; miniature Christmas lights; plastic insulating material; polyethylene; series-constructed; electric shock; fire; flaming ignition; glowing ignition; hazard; NBSIR 79-1716.

Illumination standards; lighting distribution simulation; visual performance; building codes; building performance simulation; computer applications; energy conservation; SP552, pP. 321-335 (July 1979).

Illustrated handbook; legislation; thermal envelope criteria; thermal performance criteria; education; energy utilization codes; SP552, pp. 14I-15I (July 1979).

IMACS; instantaneous diagnosis and analysis; level; maintenance oriented; malfunction detection; monitoring; onboard; patented; pressure; pumps; reservoirs; sensors; tailorable; temperature; accumulator; analog; centralized; SP547, pp. 345-357 (July 1979).

Image processing; inspection; manufacturing; pattern recognition; robotics; vision systems; automation; NBSIR 79-1764.

Image spoiling; infrared imaging; lattice absorption; zinc sulfide; characteristic phonons; chemical-vapor deposition; SP54I, pp. 86-97 (Dec. 1978).

Imaging; low-dose; low-intensity; microchannel plate; radiography; $\mathrm{x}$ ray; 19000 .

Imaging; opto-acoustic; pulse compression; sensitivity; signal averaging; signal processing; tissue characterization; tomography; transducers; ultrasonics; annular array; breast cancer; chirp signals; SP525, pp. 255-259 (Apr. 1979).

Immunoassay; drug assay; EMIT $^{R}$ fluoroimmunoassay; fluorescence immunoassay; homogeneous enzyme immunoassay; SP5 19, pp. 533-539 (Apr. 1979).

Immunoelectrodes; trace organic electrochemistry; bio-selective membrane electrodes; bio-sensors; enzymes; SP5 19, pp. 525 532 (Apr. 1979). 
Impact; marine cnvironment; advanced composites; cavitation crosion; extended immersion; flammability; glass reinforced plastics; graphite epoxy; SP563, pp. 276-285 (Oct. 1979).

Impact; mctals; particle erosion; wear; abrasives; ceramics; erosion; NBSIR 78-1575.

Impact; mctals; particle erosion; wear; abrasives; ceramics; erosion; 18858 .

Impact; ocular contusion; projectiles; propelled objects; test methods; toy safety; cye injury; J. Res. 84, No. 1, 9-19 (1979).

Impact; peak acceleration; performance; playground surfaces; test method; head injury criterion; NBSIR 79-1707.

Impact; silicon nitride; strength; stress intensity factor; abrasive machining; ceramics; contact stress; damage penetration; fracture mechanics; fragmentation; glass; grinding; SP562, pp. 23-42 (Oct. 1979).

Impact; test method; headform; headgear; head injury; helmet; NBSIR 78-1547.

Impact assessment; interior finish; kitchen fires; life safety; mobile homes; room fires; ASTM E-84 Tunnel Test; construction standard; fire growth; fire tests; flame spread; flashover; NBSIR 79-1720.

Impact noise; microcircuit device; particle detection; particle impact noise detection; PIND; pre-shock; seeded specimens; transducer; acoustic emission; co-shock; couplant; detection; electronic package; NBSIR 78-1590 (NASA).

Impact of government on industry; procurement experiments; procurement policy; research and development policy; technological change; Experimental Technology Incentives Program; NBS-GCR-ETIP 78-49.

Impact of measurements; measurement technology assessment; National Measurement System; standards; calibrations; dissemination of units; electrical measurements; electric power measurements; electrotechnology; NBSIR 75-935.

Impedance; infarct; speed; ultrasonic; attenuation; brain tumor; clot; hemorrhage; hydrocephalus; SPS25, pp. 81-84 (Apr. 1979).

Impedance; medical diagnosis; microscopy; pattern recognition; scattering; signal processing; tissue characterization; tissue parameters; ultrasound; velocity; absorption; attenuation; computerized tomography; Doppler; SP525.

Impedance; network analyzer; power; reflection coefficient; reflectometer; scattering parameters; six-port; voltage; calibration; current; 18600.

Impedance; network analyzer; power; reflection coefficient; reflectometer; scattering parameters; six-port; voltage; calibration; current; 18601 .

Impedance; reflection coefficient; reflectometer; six-port; calibration; TN1OI2.

Implant materials; microanalysis; molecular microanalysis; pathological tissue; Raman microprobe; Raman spectra; Raman spectroscopy; biological microanalysis; biological tissue; foreign bodies; histological sections; 18958.

Implants; implants passivity; corrosion; crevice corrosion; galvanic corrosion; 18946 .

Implants; ion bombardment; rare-gases; relaxation energy; ultraviolet photoelectron spectroscopy; amorphous germanium; binding energy shifts; extra-atomic screening; 18323 .

Implants passivity; corrosion; crevice corrosion; galvanic corrosion; implants; 18946 .

Implementation; large-scale; management; mathematical models; policy analysis; software; standards; transfer; documentation; energy; evaluation; guidelines; SP534.

Implementation and effective $\mathbf{U}$ value; on-site construction; building official; energy code; energy efficient; enforcement; SP552, pp. 131-140 (July 1979).

Implementing; commercialization; empirical investigation; ETIP; Federal civilian R\&D; NBS-GCR-ETIP 78-58A.
Implementing; management practices; technological changc; commcrcialization; empirical investigation; ETIP; Fedcral civilian R\&D; NBS-GCR-ETIP $78-57$.

Implemcnting; management practiccs; technologıcal change; commercialization; empirical investigation; ETIP; Federal civilian R\&D; NBS-GCR-ETIP 78-58.

Imports; innovation; leather; manufacturing technology; materials development; shoes; technology transfer; computer-aided design and manufacture (CAD/CAM); footwear industry; fragmented industrics; government-industry cooperation; SPS27.

Imprisonment; laser; lifetime; mean life; oscillator strength; Al 1; aluminum; delayed coincidence; $f$-value; 18527 .

Improper fcrroelectrics; pyroelectric detectors; pyroelectric vidicons; terbium molybdate; triglycine sulfate; ferroelectrics; figures of merit; 18852 .

Impulse; lightning impulse; pulse calibration; ramp response; step response; divider; high voltage; 18727

Impulse; pulse measurements; response time; step response; transients; divider; Duhamel's integral; high voltage; NBSIR 79-1933.

Impulse response; impulsive fields; standards; TEM horn antenna; antenna; conical transmission line; TNIOOS.

Impulse response; laser; photodiode; avalanche photodiode; FFT; fiber optics; frequency response; NBSIR 79-1620.

Impulsive complex signals; linear averaging; reciprocating; records after trigger; tape loop; time signal; time window; gated frequency analysis; Gaussian window; SP547, pp. $315-$ 322 (July 1979).

Impulsive fields; standards; TEM horn antenna; antenna; conical transmission line; impulse response; TNIOOS.

Impurities; internal friction; isomers; low temperatures; n-paraffins; polycrystals; relaxation process; Y oung's modulus; audio frequencies; 18467.

Impurities; laser-induced damage; thermal damage; absorption; antireflection coatings; damage thresholds; SP541, pp. 202211 (Dec. 1978)

Impurities; microroughness; optical microscopy; polishing defects; scattered light; SIMS; stylus instruments; Auger spectroscopy; corrosion films; ESCA; SP562, pp. 337-350 (Oct. $1979)$.

Impurities; oxyapatite; cation distribution; cation ordering; 18448.

Impurity; molybdenum; plasma; atomic physics; dielectronic recombination; highly ionized; $I 8949$.

Impurity analysis; ion microprobe mass analyzer (IMMA); microdor reference specimens; secondary ion mass spectroscopy (SIMS); silicon sputtering; dopant analysis; NBSGCR-79-158.

Impurity distribution; material transport; segregation; semiconductor technology; diffusion; electronic technology; SP4OO57.

IMS information retrieval; KWOC indexing; least-squares; linear regression; MIS; plotting; statistical analysis; Boolean search system; computer programs; curve fitting; data analysis; data base management; data retrieval; file handling; graphic analysis; 18597.

In situ evaluation of insulation; R-value measurement by spot radiometer; thermal resistance of walls; infrared thermometers; NBSIR 79-1736.

In vivo; microprocessor-controlled data acquisition; myocardial infarction; real-time; tissue characterization; ultrasound diagnosis; clinical cardiac data; digital processing; Fast Fourier Transform; frequency spectra; SP525, pp. 267-273 (Apr. 1979).

INAA; paper; trace elements; analysis; clay; forensic; 18325.

Inch; metric units; centimcter; conversion; customary units; SP376. 
Incidence algebra; inverse limit; orthogonal idempotents; quasiorder; topological algebra; coalgebra; direct limit; faithful distributive module; generating function; 18788 .

Incidence algebra; multiplicative function; quasi-ordered set; topological algebra; automorphism; cyclic module; faithful distributive module; 18789 .

Inclusion theorem; Kronecker product; numerical radius; spectrum; stable matrix; closure; $D$-stability; diagonal matrix; field of values; Hadamard product; 18909 .

Inclusions; pulse duration; damage thresholds; fluoroberyllate glass; fluorophosphate glass; SP54I, pp. 99-I 08 (Dec. 1978).

Incoherence; ionization; linear rate; multiphoton; rate approximation; saturable rate; bandwidth; coherence; dynamic rate; 18893 .

Incommensurate lattice; lanthanum niobate; modulated structure; nonstoichiometry; two-dimensional modulated structure; 18646 .

Index matching liquids; neodymium glass lasers; nonlinear refractive index; thermal conductivity; viscosity; Abbe value; coolants, dn/dT; SP541, pp. I09-12I (Dec. 1978).

Indium-doped silicon; infrared reflectance; integrated circuits: line-width measurements; oxidation; photolithography; photovoltaic method; power-device grade silicon; radioisotope leak test; resistivity variations; resistors, sheet; scanning acoustic microscope; SP4OO-38.

Indoor radiation; radon in buildings; ventilation and radon concentration; energy conservation design; 18587 .

Induced currents; magnetometers; conductivity anomalies; earthquake prediction; geomagnetism; 18895 .

Induction accelerator; ion acceleration; nuclear research; radiation processing; activation analysis; electron beams; 18570 .

Inductive load; nondestructive; protection circuit; reverse bias; safe operating area; second breakdown; switching power transistor; tester; transistor; base drive circuit; electronic circuits; SP4OO-54.

Inductive voltage dividers; international comparison; measurements; voltage dividers; voltage ratio; calibrations; 18664 .

Industrial electronics; medical electronics; microwave electronics; nonionizing radiation; radiation hazards; radio regulations; radio standards; RFI; spectrum management; standardization organizations; telecommunications; TVI; vehicular electronics; SP55I.

Industrial engineering; isolation; machinery and equipment; mechanical impedance; mechanical vibrations; noise control; transmissibility; vibration isolation; vibrations; antivibration mounting; damping; dynamic properties; HI28.

Industrial laminates; low-pressure laminates; metal-matrix composites; polymer matrices; advanced-fiber composites; cryogenics; /863I

Industrial laminates; magnetic fusion energy; superconducting magnets; advanced composites; composite materials; cryogenics; 18560 .

Industrial laminates; mechanical properties; physical properties; radiation properties; cryogenics; glass-epoxy; 18771 .

Industrial oil; lubricating oil; oil specifications; petroleum standards; petroleum test methods; recycled oil; re-refined oil; used oil; waste oil; engine oil; fuel oil; hydraulic oil; SP556.

Industrial pollution regulation; market mechanism; offset policy; regulatory policy; technological innovation; administrative experimentation; Environmental Protection Agency; evaluability assessment; Experimental Technology Incentives Program; NBS-GCR-ETIP 79-62.

Industrial productivity; materials utilization; measurement capabilities; medical aids; product safety; public health and safety; science and technology transfer; standards; basic research; computer; energy conservation; environmental quality; SP538.

Industrial robots; network services; SRM's; computer interface standards; computers; cryogenic temperature; energy; energy savings; DIM/NBS 63, No. 4, 1-24 (1979).
Industrial R\&D; LDC's; less dcvcloped countries; light capital technology; science and technology for development; U.N. Conference on Science and Technology for Development; UNCSTD; appropriate technology; industrialization; 18685.

Industrialization; industrial R\&D; LDC's; less developed countries; light capital technology; science and technology for development; U.N. Conference on Science and Technology for Development; UNCSTD; appropriate technology; $/ 8685$.

Industrialization; Latin America; management; measurement; metrology; quality control; standards; technology transfer; UN Conference on Science and Technology for Development (UNCSTD); Africa; A sia; developing countries; SP543.

Industrialized housing products; inspection; regulation; third party; agencies; approval process; evaluation; SP552, pp. 293-309 (July 1979).

Industrializing countries; Korea; measurements; metrology; physical standards; seminar; South Asia; developing countries; SP539.

Industrializing nations; international relations; LDC's; measurement services; standardization; AID; assistance; developing economies; foreign relations; NBSIR 78-1712.

Industrializing nations; international relations; measures; weights; weights and measures; AID; assistance; developing economies; foreign relations; NBSIR 79-I72I.

Industries; representations and codes; Standard Industrial Classification; computers; data processing; Federal Information Processing Standards Publication; FIPS PUB 66.

Industry construction; measurement techniques; standards; building research; criteria; energy; engineering; SP439-I.

Inelastic neutron scattering; magnetic properties of rare earth alloys; metal hydrides; rare-earth hydrides; cerium dihydride; crystal-field splitting; 19030 .

Inelastic scattering; neutron scattering; orientational disorder; rotational dynamics; condensed phases; diffusion mechanisms; 19026.

Inert columns; metabolism; methandienone; urine; anabolic steroids; clean-up; contamination; dianabol; gas chromatography-mass spectrometry ( $\mathrm{gc} / \mathrm{ms}$ ); gas liquid chromatography (glc); gc/ms interface; SP519, pp. 437-445 (Apr. 1979).

Infarct; interferogram; myocardium; phase cancellation; velocity; acoustic microscopy; anisotropy; attenuation; elastic microstructure; SP525, pp. 73-79 (Apr. 1979).

Infarct; speed; ultrasonic; attenuation; brain tumor; clot; hemorrhage; hydrocephalus; impedance; SP525, pp. 81-84 (Apr. 1979).

Influence of inhibitor on lactate dehydrogenase assay; lactate dehydrogenase assay; lactate to pyruvate reaction; pyruvate to lactate reaction; spectrophotometric enzyme assay; enzyme assay; 18433.

Information age; information as a resource; information revolution; social issues in information; telecommunication trends; transborder data flows; computer-telecommunications convergence; computer trends; 18975.

Information as a resource; information revolution; social issues in information; telecommunication trends; transborder data flows; computer-telecommunications convergence; computer trends; information age; 18975 .

Information format; information sources; technical information; technology application; access to information; architect; NBS-GCR-78-153.

Information format; information sources; technical information; technology application; access to information; architect; NBS-GCR-78-154.

Information intervention; integrated utility systems; case study; cogeneration; demonstration project; ETIP; evaluation; NBSGCR-ETIP 78-59.

Information Management System (IMS); management reporting; performance analysis; structured approach; auditing: capacity planning; computer performance evaluation; SP5OO52, pp. 9-19 (Oct. 1979). 
Information networks; network; seismic design; systcms analysis; building codes; buildings; building standards; classification; decision tables; earthquake-rcsistant design; TN//0O.

Information networks: regulations: standards: decision tables; formulation analysis: SP552, pp. 249-266 (July 1979).

Information revolution; social issues in information; telecommunication trends; transborder data flows; computer-telecommunications convergence; computer trends; information agc; information as a resource; $l 8975$.

Information science; American Society of Information Sciencc; computer technology library science; 18942

Information services; librarics. OF1 OF2 : 19048.

Information sources; technical information; technology application; access to information; architect; information format; NBS-GCR-78-153.

Information sources; technical information; technology application; access to information; architect; information format; NBS-GCR-78-154.

Information storage and retrieval systems; libraries-automation; machine-readable-bibliographic data; bibliographic data bases; computerized data bases; NBSIR 78-1577.

Information utilization; ADP auditors; audit; data center; data processing; SP500-52, pp. 3.8 (Oct. 1979).

Infrared; kinetics; laser chemistry; mechanisms; multiphoton; thermochemistry; unimolecular dissociation; calorimetry; 18709 .

Infrared analysis; spectral coincidences; Stark modulation; Stark spectroscopy; trace gas analysis; $\mathrm{CO}_{2}$ laser; derivative spectra; 18538 .

Infrared emission; laser; methylene iodiode; methyl iodiode; photodissociation; radical; $l 8573$.

Infrared imaging; lattice absorption; zinc sulfide; characteristic phonons; chemical-vapor deposition; image spoiling; SP54l, pp. $86-97$ (Dec. 1978).

Infrared laser; kinetics; mechanisms; modeling; multiphoton; unimolecular dissociation; 18712 .

Infrared laser windows; materials purification; reactive atmosphere process (RAP) chemistry; thin film coating materials; SP541, pp. 249-256 (Dec. 1978).

Infrared optical components; laser damage; optical properties; diamond single-point machining; dielectrics; SP562, pp. 293 303 (Oct. 1979).

Infrared reflectance; integrated circuits; line-width measurements; oxidation; photolithography; photovoltaic method; power-device grade silicon; radioisotope leak test; resistivity variations; resistors, sheet; scanning acoustic microscope; semiconductor matcrials; $S P 400-38$.

Infrared spectra; matrix isolation; molecular ions; photochemistry; ultraviolet spectra; charge transfer; excited argon atoms; free radicals; $l 8847$.

Infrared spectroscopy; petroleum hydrocarbons; sediment analysis; gas chromatography-mass spectrometry; glass capillary chromatography; high pressure liquid chromatography; hydrocarbon persistence; SP5 19. pp. 33-40 (Apr. 1979).

Infrared spectrum; interferometer; matrix isolation; methyl cyanide; ultraviolet spectrum; vacuum ultraviolet phoiolysis; CCN; CNC; far infrared spectrum; HCCN; 18842.

Infrared spectrum; ketenimine; matrix isolation; methyl cyanide; ultraviolet spectrum; vacuum ultraviolet photolysis; charge transfer; cyanomethyl radical; excited argon atoms; force constants; 18879 .

Infrared spectrum; matrix isolation; methane; methyl fluoride; methyl radical; $\mathbf{F}$-atom production; $\mathbf{F}$-atom rcactions; $\mathbf{H}$-atom abstraction; hydrogen bonding; hydrogen fluoridc; 18869 .
Infrared thermomctcrs; in situ cvaluation of insulation; R-value measurcment by spot radiometer; thermal resistance of walls; NBSIR 79.1736.

Infrared wings: line shape: model correlation function; pressurc broadening: $\mathrm{CO}_{2}$; far wings; 18886 .

Infrastructurc; land usc; resource zoning; urban; zoning regulations; SP552, pp. 347-360 (July 1979).

Inhibitors; pitting corrosion; rust; stress corrosion; corrosion; crevice corrosion; galvanic corrosion: CIS9, Revised 1979.

Inhomogeneitics; inhomogeneity thermal losses; mechanisms; viscous relative motion; SP525, pp. 37-40 (Apr. 1979).

Inhomogeneity thermal losses; mechanisms; viscous relative motion; inhomogeneities; SP525, pp. 37-40) (Apr. 1979).

Inhomogeneous broadening; intense laser; multiphoton dissociation; multiphoton ionization; Rabi frequency: statistical broadening; thrce-level system; coherent excitation; dressed atoms; 18439.

Initial, boundary-value problem; linearized equations; partial differential equations; buoyant convection; finite-difference computations; fire in an enclosure; heat addition; hyperbolic, elliptic equations; NBSIR 79-1754.

Initial spectra; ion pair energy; nuclear data; secondary charged particles; 18660 .

Initiation phase; project request; software; automated data systems; computer programs; cost/benefit analysis; documentation; documentation content guidelines; feasibility study: FIPS guidelines; FIPS PUB 64.

Initiator; resin; wear; accelerator; alloy; base metal; casting; composite; cyanoacrylate; dental alloy: NBSIR 78-1573.

Injuries; loss prevention; risk: safety: construction; cost effectiveness; hazard; 18890 .

Injury mechanism; injury statistics; mouth burn; specific electrical effect; arc burn; contact burn; current threshold; electrical injury; electrolyte shift; heat effect; NBSIR 79-17IO.

Injury potcntial; simulation; accident; apparel; burn injury: clothing; fabric flammability; fabrics; fire; garments; heat transfer; NBSIR 79-1755.

Injury statistics; mouth burn; specific electrical effect; arc burn; contact burn; current threshold; electrical injury; electrolyte shift; heat effect; injury mechanism; NBSIR 79-1710.

Inner shell ionization cross section; Monte Carlo electron trajectory simulation; scanning electron microscopy; x-ray yield; characteristic $x$-ray yield; electron probe microanalysis; 18978 .

Innovation; leather; manufacturing technology; materials development; shoes; technology transfer; computer-aided design and manufacture ( $C A D / C A M)$; footwear industry; fragmented industries; government-industry cooperation; imports; SP527.

Innovation; regulatory reform; technological changes; administrative experiment; anti-trust regulation; economic incentive; environmental regulation; NBS-GCR-ETIP 79-66.

Innovative practices; regulatory research; standards development; administrative procedures; building codes; building regulations; buildings; construction; economic impacts; environmental considerations; SP5S2.

In-plane loads; bonded joints; composites; failure criteria; SP563, p. 241 (Oct. 1979).

Input lockout; mathematical modeling; queuing models; race conditions: TCAM data flow: teleprocessing; SP50O-52, pp. 219-226 (Oct. 1979).

Input/output bus; interface; interface signals; $1 / O$ interface bus; line printer; print controller; printer; cable intcrface; computer; controller; control units; hammer drive; NBS-GCR-79. 182.

Insertion loss; microphone; porous sphere; sphere; spheres; wind noise; windscreen; windscreen performance; windscreens; acoustics; flow; NBSIR 79-1599. 
Inspcction; magnctic particles; nondestructive evaluation penctrants; radiography; statistics; ultrasonics; visual-optical tcsts; acoustic; annual report; eddy currents; NBSIR 78-1581. Inspection; maintenance; marine borers; nondestructive testing: pilings; timber; acoustics; bridges; creosote; harbor facilities; 18525.

Inspection; manufacturing; pattern recognition; robotics; vision systems; automation; image processing; NBSIR 79-1764.

Inspection; regulation; third party; agencies; approval process; evaluation; industrialized housing products; SP552, pp. 293 309 (July 1979).

Inspection requirements; pre-construction conference; code enforcement; county building code; critical structures program; expense; SP552, pp. 311-320 (July 1979).

Instability; polyethylene; viscoelastic; creep; 18807 .

Installation; language; maintenance; numerical analysis; $O M$ NITAB 78; portability; poster; reliability; statistical computing section; worksheet; capabilities; ease of learning and using: 18903 .

Installation management; installation performance management; performance measurement and reporting; resource management; standard performance measures; computer performance evaluation (CPE); computer performance management (CPM); SP500-53.

Installation management; on-line system evaluation; prediction methods; queuing models; simulation; software monitoring: workload definition; computer performance evaluation; computer performance measurement: computer performance prediction; computer system acquisition; SP5OO-52.

Installation performance management; performance measurement and reporting; resource management; standard performance measures; computer performance evaluation (CPE); computer performance management (CPM); installation management; SP5OO-53.

Instantaneous diagnosis and analysis; level; maintenance oriented; malfunction detection; monitoring; onboard; patented; pressure; pumps; reservoirs; sensors; tailorable; temperature; accumulator; analog; centralized; check-out system; SP547, pp. 345-357 (July 1979).

Instantaneous optimization; radiation therapy; uncomplicated cure; SP554, pp. 57-61 (Sept. 1979).

Instantaneous power spectra; color-coded B-scan; spectra-color ultrasonography (SCU); spectrum analysis; ultrasonic spectroscopy; SP525, pp. 261-266 (Apr. 1979).

Instrument landing system (ILS); measurement instrumentation; measurement standard; modulation: modulation factor; modulation meter; Newton-Raphson method; percent modulation; signal generator; vhf omnidirectional radio range (VOR); amplitude modulation; TNIOI6

Instrument materials; microcreep; micromechanical properties; beryllium; dimensional stability; gyroscope; NBSIR 78-1569.

Instrumental analysis; multielement analysis; neutron activation analysis; SRM; trace elements; urban particulate; error analysis; 18866 .

Instrumentation; fundamental constants; geodynamics; geophysics; 18947 .

Instrumentation; measurement; thermography; Twin Rivers Project; weather station; air infiltration; buildings; data acquisition; energy: 18733 .

Instrumentation; measurement procedures; observer proximity effects; power transmission lines; Russian measurement technique; electric field measurements; $/ 8494$.

Instrumentation; multiwavelength techniques; tectonics; atmospheric properties; distance measurement; geodesy; 18816.

Instrumentation; satellites; tectonics; distance measurements; earthquakes; geodesy; geophysics; 18574 .

Instrumentation; total energy; transducers; weather station; data acquisition system; digital tape recorder; fuel measurement; NBSIR 79-1709. instruments; integrated circuits; Josephson junctions; measurements; superconductivity; electronics; 18859.

Instruments; International Practical Temperature Scale; interpolation; interpolation instruments; temperature scale from 630.74 to $1064.43{ }^{\circ} \mathrm{C}$; 18665

Insulation; life-cycle cost analysis; masonry construction; space heating and cooling requirements; thermal mass; building economics; energy conservation; NBSIR 79-1789.

Integral form, conservation of mass principle; mass principle; algorithm, finite-difference; finite-difference; 18489

Integrated circuit; large scale integration; memory; microprocessor; testing; electronics; TN/102.

Integrated circuit; process validation wafer (PVW); reliability; silicon; test pattern; transistor gain; 18463 .

Integrated circuit processing; kinetics of oxide growth; oxidation of silicon; semiconductor processing; silicon; silicon dioxide; thermally stimulated measurement; thermal oxidation; Zn-doped glasses; boron nitride; Cl-doped glasses; diffusion in silicon; NBS-GCR-78-134.

Integrated circuits; ion implantation; plasma etching; radiation damage; radiation hardening; VLSI processing; $x$-ray lithography; E-beam lithography; 18451

Integrated circuits; Josephson junctions; measurements; superconductivity; electronics; instruments; 18859

Integrated circuits; linewidth; photolithography; sheet resistance; silicon; test pattern; test structure; TTL; bipolar process; contact resistor; cross bridge sheet resistor; electrical alignment resistor; 18533

Integrated circuits; line-width measurements; oxidation; photolithography; photovoltaic method; power-device grade silicon; radioisotope leak test; resistivity variations; resistors sheet; scanning acoustic microscope; semiconductor materials; $S P 400-38$.

Integrated circuits; measurement technology; microelectronics; semiconductor devices; semiconductor materials; semiconductor process control; silicon; electronics; NBSIR 78-14443

Integrated circuits; measurement technology; microelectronics semiconductor devices; semiconductor materials; semiconductor process control; silicon; electronics; NBSIR 79-I59I.

Integrated circuits; measurement technology; microelectronics: semiconductor devices; semiconductor materials; semiconductor process control; silicon; electronics; NBSIR 79-I59I. 2 .

Integrated circuits; measurement technology; microelectronics; semiconductor devices; semiconductor materials; semiconductor process control; silicon; electronics; NBSIR 79-159I3.

Integrated data base; municipal governments; regulatory; computer facilities; SP552, pp. 153-165 (July 1979).

Integrated gated-diode electrometer; integrated test structure; leakage current; MOSFET dc profiler; surface recombination; CCD; electrical test structure; gated diode; generation lifetime; NBSIR 79-1744.

Integrated intensities; lattice constants; peak intensities; powder patterns; reference intensities; standard; x-ray diffraction; crystal structure; Monogr. 25, Section 16.

Integrated test structure; leakage current; MOSFET dc profiler; surface recombination; CCD; electrical test structure; gated diode; generation lifetime; integrated gated-diode electrometer; NBSIR 79-1744.

Integrated utility systems; case study; cogeneration; demonstration project; ETIP; evaluation; information intervention; NBS-GCR-ETIP 78-59.

Integrating sphere; linearity; scattering; collimation; haze; hazemeter; $I 8594$.

Intelligence; motor behavior; neural modeling; perception; planning; problem solving; robot control; brain mechanisms; cognition; goal seeking; 18714 
Intense laser; multiphoton dissociation; multiphoton ionization; Rabi frequency; statistical broadening; three-level system; coherent excitation; dressed atoms; inhomogeneous broadening; 18439 .

Intensity; laser; modulator; noise; servo control; acoustooptic; 18904 .

Intensity, effective; lights, flashing; lights, warning; perception, visual; peripheral vision; vehicles, emergency; visibility, lights; visual perception; color, lights; conspicuity, lights; effective intensity; emergency lights; SP480-36.

Interacting quantum fields; relativistic field theory; rclativistic hamiltonian; relativistic stationary states; composite system; field quantization; 18769 .

Interaction energy; overlap; Be; dispersion; excited states; He; 18933.

Interactive computer program; methane; minimization of Gibbs energy; phase rule; simultaneous chemical equilibria; water; BASIC; carbon dioxide; carbon monoxide; coal gasification; COLGAS; hydrogen; NBSIR 78-1509.

Interactive computing; man-machine interaction; performance measurement; timesharing; computer performance evaluation; human factors; SP5OO-48.

Interactive graphics; regression; software; transformation; computing system; dataplot; fitting; graphics; 18519

Interactive processing; quality of service; response time; turnaround time; availability standards; batch processing; calibration programs; computer standards; SP5OO-52, pp. 7986 (Oct. 1979).

Interactive system; mathematical modeling; paper; paper fiber; report retrieval; scientific data; computer graphics; data base management; data retrieval; durability; fatigue; NBSIR 79. 1746.

Interactive systems; kernels; modeling; real-time; simulation; synthetic programs; benchmarking; computer performance measurement; distributed processing; SP5OO-52, pp. 53-64 (Oct. 1979).

Interagency transducer project; performance characteristics; telemetry; transducer; dynamic calibration; evaluation; TNIIIO.

Interchange; random test graphs; scheduling; time complexity; algorithm; chromatic number; color function; graph; graph coloring: heuristic; J. Res. 84, No. 6, 489-506 (1979).

Interface; interface signals; $1 / O$ interface bus; line printer; print controller; printer; cable interface; computer; controller; control units; hammer drive; input/output bus; NBS-GCR-79. 182 .

Interface absorption; laser calorimetry; $\mathrm{NaF}$; thin film absorption; water absorption; wedged film; absorption coefficient; adiabatic calorimetry; $\mathrm{As}_{2} \mathrm{Se}_{3}$; SP541, pp. $37-42$ (Dec. 1978).

Interface absorption; multilayer films; scattering; absorption; antireflectance coatings; high reflectance coatings; SP54I, pp. 266-277 (Dec. 1978)

Interface electrical characteristics; interface functional characteristics; magnetic tape drives; NRZI recording; phase encoded recording; tape drive characteristics; computer magnetic tape drives; computer tape controllers; group coded recording; NBS-GCR-78-127.

Interface functional characteristics; magnetic tape drives; NRZI recording; phase encoded recording; tape drive characteristics; computer magnetic tape drives; computer tape controllers; group coded recording; interface electrical characteristics; NBS-GCR-78-127.

Interface signals; $\mathbb{1} / O$ interface bus; line printer; print controller; printer; cable interface; computer; controller; control units; hammer drive; input/output bus; interface; NBS-GCR-79-182.

Interfaces; multi-ion interactions; ordered alloys; statistical mechanics; face centered cubic; ground state; 18614 .

Interference effects; tall buildings; wind loads; wind tunnels; aerodynamics; boundary layers; dynamic response; 18977 .
Interfering nuclear reactions; optimization of analysis; silicon; trace analysis; activation analysis; cadmium ratio; east neutron reactions; 18338 .

Interferogram; myocardium; phase cancellation; velocity; acoustic microscopy; anisotropy; attenuation; elastic microstructure; infarct; SP525, pp. 73-79 (A pr. 1979).

Interferometer; matrix isolation; methyl cyanide; ultraviolet spectrum; vacuum ultraviolet photolysis; CCN; CNC; far infrared spectrum; HCCN; infrared spectrum; 18842 .

Interferometers; matrix crazing; nondestructive testing; pressurc vessels; composites; holography; SP563, pp. 211-212 (Oct. 1979).

Interferometry; piezo-electric positioner; high vacuum; 18318 . Interferometry; x rays; energy levels; exotic atoms; 18469.

Interfiber bonding; recycled pulps; short span tensile analysis; zero span tensile; fiber length distribution; fiber strength; NBSIR 79-1914.

Intergranular cracking stainless steel; sensitized metal; circumferential tearing; fire extinguisher; hydrostatic pressure testing; 18368 .

Intergranular fracture; stainless steel; critical strain rate; fatigue; grain boundary sliding; high temperature; 18896 .

Interior finish; kitchen fires; life safety; mobile homes; room fires; ASTM E-84 Tunne! Test; construction standard; fire growth; fire tests; flame spread; flashover; impact assessment; NBSIR 79-1720.

Interior finish; laboratory fire tests; material ignitability; submarine compartment; combustion products; fire barrier coatings; fire growth; flame spread; foam insulation; heat release; NBSIR 78-1584.

Interior finish; laboratory fire tests; material ignitability; prediction model; shipboard spaces; fire growth; fire statistics; flame spread; fuel load survey; heat release; NBSIR 79-1714.

Interior finish; passive fire protection; potential heat; smoke; compartment fires; fire tests; flame spread; heat release rate; ignition; NBSIR 79-1700.

Interior finishes; Life Safety Code; nursing homes; risk analysis; safety equivalency; safety evaluation; smoke detection; automatic sprinklers; building codes; building construction; Delphi Method; fire safety; health care facilities; hospitals; NBSIR 78-1555.

Interlaboratory comparison; measurements; optical communications; quality control; attenuation; fiber optics; NBSIR 791608 .

Interlaminar cracks; stability of cracks; virtual crack closure; delamination mechanisms; energy release rate; finite element method; free-edge stresses; graphite epoxy composites; SP563, pp. 255-264 (Oct. 1979).

Interlaminar stresses; laminated composites; stress concentrations; tension; tensor polynomial; compression; failure; finite elements; graphite-epoxy; SP563, pp. 242-254 (Oct. 1979).

Interlayering; octacalcium phosphate; tooth; $x$-ray diffraction; bone; hydroxylapatite; 18583 .

Interlocks; leakage; radiation; safety; standards; accelerators; IEC; SP554, pp. 29-32 (Sept. 1979).

Intermediate scattering function; Lennard-Jones liquid; liquid rubidium; molecular dynamics; radial distribution function; transverse current correlation function; velocity autocorrelation function; J. Res. 84, No. 6, 439-446 (1979).

Intermetallic compound; phase diagrams; physical properties; compilation; energy storage; 18637 .

Intermetallic compounds; Laves phase; magnetism; neutron scattering; rare earths; hydrides; 18682 .

Intermetallic compounds; Laves phase; magnetism; neutron scattering; rare earths; hydrides; 18881 .

Intermetallic compounds; liquid quenching; metastable phases; niobium-silicon alloys; . splat-cooling; superconductivity; 18734.

Intermolccular potential; molecules; well depths; excited states; ground state; 18677 
Intermolecular potential; statc changcs; well depths; collisions; cross sections; 18671 .

Internal; quantum efficiency; reflectance; response; silicon detector; spatial position dependence; dead layer model; external; 18900 .

Intcrnal energies; isobars; isobutane; isochores; isotherms; Joule-Thomson inversion; latent heats of vaporization; melting line; orthobaric densities; specific heats; speeds of sound; vapor pressurcs; densities; enthalpies; entropies; equation of state; NBSIR 79-16/2.

Intcrnal energies; isobars; isochores; isotherms; Joule-Thomson inversion; latent heats of vaporization; melting line; n-butane; orthobaric densities; specific heats; speeds of sound; vapor pressures; densities; enthalpies; entropies; cquation of state; NBSIR 79-1621.

Intcrnal friction; isomers; low temperatures; n-paraffins; polycrystals; relaxation process; Young's modulus; audio frequencies; impurities; 18467.

Intcrnal friction; Young's modulus; aramid-epoxy; boron-aluminum; boron-epoxy; composites; elastic constants glassepoxy: 18716 .

Internal quantum efficiency; silicon; absolute detector; absorption coefficient; dead layer model; external; 18477.

Intcrnal rate of return; life-cycle costing; marginal analysis; optimal design; residential buildings; space cooling; space heating; building envelope; cost effectiveness; economics; energy conservation; 19044.

Internal reflection; protective coatings; damage threshold; electric fields; SP541, pp. 288-295 (Dec. 1978).

Internal reflections; laser calorimeter; linear absorption; Nd:YAG laser; two photon absorption; CdSe; CdTe; SP54I, pp. 19-23 (Dec. 1978).

Internal rotation; interstellar molecules; line strengths; methyl formate; microwave spectrum; radio astronomy; rotational transitions; JPCRD 8, No. 3, 583-618 ( 1979).

Internal rotation; interstellar molecules; microwave spectrum; radio astronomy; rotational transitions; dimethyl ether; JPCRD 8, No. 4, 1051-1108 (1979).

Internal rotation; iodoethane; potential barrier heights; symmetric top; torsional frequencies; bromoethanes; ideal gas thermodynamic properties; JPCRD 8, No. 2, 5[9-526 (1979).

Internal standards; methylation; sample preparation; clinical chemistry; drug analysis; gas chromatography; SP519, pp. 381-390 (Apr. 1979).

Intcrnal stress; internal virial; molecular dynamics; Monte Carlo method; periodic boundaries; pressure; stress calculation; virial theorem of Clausius; equilibrium; homogeneous system; hydrostatic pressure; 18456

Intcrnal virial; molecular dynamics; Monte Carlo method: periodic boundaries; pressure; stress calculation; virial theorem of Clausius; equilibrium; homogeneous system; hydrostatic pressure; internal stress; 18456 .

International; self-extinguishment; ships; standards; curtains; drapcs; fabrics; fire; flammability: NBSIR 79-1596.

Intcrnational; standardization; standard recommended practice; synopsis; ultrasonic standards; ultrasonic testing; evaluation; NBSIR 79-1790.

International commission on radiation units and measurements; protons; stopping power; $\alpha$-particles; electrons; heavy ions; 18358

International comparison; measurements; voltage dividers; voltage ratio; calibrations; inductive voltage dividers; 18664

International comparisons; metrology; power measurements; precise electrical measurements; TDM wattmeters; thermal wattmeters; transfer standards; electro-dynamic wattmeters; energy measurements; energy standards; 18529.

Intcrnational cooperation; international research; international standards; National Bureau of Standards (NBS); National Engineering Laboratory (NEL); technology transfer; engineering: NBSIR 79-1792.
International Organization of Legal Mctrology; measurement assurance; metrication; model laws and regulations; national type approval; packaging and labeling; specifications and tolerances; vapor recovery; weights and measures; consumer affairs; education; SP532.

International plumbing research; plumbing and drainage; U.S. rcsearch in plumbing; building water systems; CIB: SP553.

International Practical Temperature Scale; interpolation; interpolation instruments; temperature scale from 630.74 to $1064.43{ }^{\circ} \mathrm{C}$; instruments; 18665 .

International relations; LDC's: measurement services; standardization; AID; assistance; developing economies; foreign relations; industrializing nations; NBSIR 78-1712.

International relations; measures; weights; weights and measures; AID; assistance; developing economies; foreign relations; industrializing nations; NBS1R 79-1721.

International research; international standards; National Bureau of Standards (NBS); National Engineering Laboratory (NEL); technology transfer; engineering; international cooperation; NBSIR 79-1792.

International standards; laboratory accreditation; standards systems; United Kingdom; West Germany: antitrust; Canada; certification; Denmark; economics of standards; government policy; NBS-GCR-79-1 72 .

International standards; National Bureau of Standards (NBS); National Engineering Laboratory (NEL); technology transfer; engineering; international cooperation; international research NBSIR 79-1792.

International time comparison; precise time transfer; satellite; time; time scales; Hermes/CTS; 18861

Interphase (IPB) boundaries; second-order transitions; equilibrium antiphase domain (APB) boundaries; f.c.c. alloys; 18669 .

Interpolating equation dielectric; steam; table-dielectric constant of water; thermophysical properties of water; water; dielectric constant of water; 18937.

Interpolation; interpolation instruments; temperature scale from 630.74 to I064.43 ${ }^{\circ} \mathrm{C}$; instruments; International Practical Temperature Scale; 18665 .

Interpolation instruments; temperature scale from 630.74 to $1064.43{ }^{\circ} \mathrm{C}$; instruments; International Practical Temperature Scale; interpolation; 18665.

Interstate Commerce Commission; regulation; regulatory processes and regulatory effects; administrative experimentation; Environmental Protection Agency; evaluability assessment; evaluation; Experimental Technology Incentives Program; NBS-GCR-ETIP 79-65.

Interstellar medium; Lym an-alpha; deuterium; 18753.

Interstellar molecules; line strengths; methyl formate; microwave spectrum; radio astronomy; rotational transitions; internal rotation; JPCRD 8, No. 3, 583-618 (1979).

Interstellar molecules; line strengths; microwave spectra; molecular constants; propyne; radio astronomy; rotational transitions; JPCRD 8, No. 2, 537-558 (1979).

Interstellar molecules; microwave spectra; molccular parameters; radio astronomy; rotational transitions; vinyl cyanide; JPCRD 8, No. 1, 107-124 (1979).

Interstellar molecules; microwave spectrum; radio astronomy; rotational transitions; dimethyl ether; internal rotation: JPCRD 8, No. 4, 1051 -I108 (1979).

Intracavity absorption; isotope analysis; laser analysis; laser fluorescence; laser spectroscopy: microfluorescence; saturation spectroscopy; tunable laser; atomic flame fluorescence; 18364.

Intradie parametric integrity; LSI circuits; mask alignment tolerances; modular test programs; parametric yield limitations; performance limitations; photomask performance; process control; test patterns; test structures; total process integration; SP4OO-56. 
Intrinsic viscosity; molecular weight; polyethylene; shear rate; ultra high molecular weight polyethylene; viscosity number; 18834

Intrinsic viscosity; polymer dimensions in solution; polystyrene; radius of gyration; temperature and molecular weight dependence; hydrodynamic radius; 18960.

Intrusion alarm; alarm; burglar alarm; guidelines holdup alarm; SP480-14.

Inventory management; on-line; performance; response time; saturated system; transaction processor; SP500-52, pp. $215-$ 218 (Oct. 1979).

Inverse fourth power; light flux; photometric calibrator; U.S. Patent 4,152,074.

Inverse limit; orthogonal idempotents; quasi-order; topological algebra; coalgebra; direct limit; faithful distributive module; generating function; incidence algebra; 18788 .

Inverse-positive matrix; matrix sign patterns; positive matrix; Hadamard product; 18524 .

Inversion; measurement-beam geometry; relative spectral responsivity; slit-scattering function; slit-scattering function corrections; spectral line radiometry; spectroradiometer characterizations; spectroradiometry; vignetting; aperture/aperture-image pair; aperture pair; TN910-4.

Inversion transition in ammonia; precision; acceleration insensitive oscillator; ammonia microwave absorption; atomic clock; cavity frequency stabilization; digital demodulator; frequency-lock servo; frequency standard; 18698 .

lodides; molten salt mixtures; standard reference data; surface tension; viscosity; bromides; chlorides; data compilation; density; electrical conductance; fluorides; halides; JPCRD 8 , No. I, $125-302$ (1979).

lodine; laser; visible; frequency measurements; 18916.

lodoethane; potential barrier heights; symmetric top; torsional frequencies; bromoethanes; ideal gas thermodynamic properties; internal rotation; JPCRD 8, No. 2, 519-526 (1979).

Ion; ionization; molecule; photon; positron; atom; collision cross section; detachment; dissociation; elastic scattering; electron; excitation; SP426. Supplement 1.

Ion; ionization energy; spectrum; wavelengths; yttrium; energy levels; 18868 .

Ion acceleration; nuclear research; radiation processing; activation analysis; electron beams; induction accelerator; 18570 .

lon beam machining; water jet cutting; ceramics; chemical milling; electric discharge machining; electron beam machining; glass; hydrodynamic machining; SP562, pp. 261-281 (Oct. 1979).

Ion bombardment; rare-gases; relaxation energy; ultraviolet photoelectron spectroscopy; amorphous germanium; binding energy shifts; extra-atomic screening; implants; 18323 .

Ion cyclotron resonance; ionization energy; aromatic compound; charge transfer equilibria; entropy change; 18337.

Ion dynamic effect; plasma line shift; spectral lines; Stark broadening; deuterium; hydrogen; 18948

Ion energetics; ionization potential; abstract; appearance potential; archival tape; computer program; data base; data base management; empirical molecular formula; GPSDC; NBSIR $78-1432$.

Ion implantation; plasma etching; radiation damage; radiation hardening; VLSI processing; $x$-ray lithography; E-beam lithography; integrated circuits; 18451 .

Ion implantation; silicon; sulfur; sulfur energy level in silicon; thermally stimulated capacitance; thermally stimulated current; deep level measurements; defect center characterization; defect density; 18458 .

Ion microprobe mass analyzer; local thermal equilibrium model; microanalysis; secondary ion mass spectrometry; surface analysis; elemental analysis; 18979 .

Ion microprobe mass analyzer (IMMA); microdot reference specimens; secondary ion mass spectroscopy (SIMS); silicon sputtering; dopant analysis; impurity analysis; NBS-GCR-79158.

Ion microprobe mass spectrometer; roughness; sapphire; ultrafine polishing; water; $x$-ray photoelectron spectrometer; crystallographic integrity; electron diffraction images; hydrated layer; SP562, pp. 317 323 (Oct. 1979).

Ion pair energy; nuclear data; secondary charged particles; initial spectra; 18660 .

Ion production; laser enhanced ionization; laser spectroscopy; optogalvanic effect; enhanced ionization theory; flame spectroscopy; 18806 .

Ion scattering spectrometry; laser microprobe mass analyzer; laser Raman microprobe; microanalysis; secondary ion mass spectrometry; $x$-ray microanalysis; Auger electron spectroscopy; cathodoluminescence; 18568 .

Ion selective electrodes; penicillamine; potentiometric titration; clinical chemistry; SP5 19, pp. 455-459 (Apr. 1979).

Ion storage; laser spectroscopy; Mossbauer effect; optical pumping; optical spectroscopy; radiation pressure; radiative cooling; Doppler-free spectroscopy; frequency standard; high resolution spectroscopy; 18699.

Ion temperature; laser induced cooling; $\mathrm{Mg}$ ions; optical \& microwave double resonance; stored ions; systematic effects; $\mathrm{Ba}$ ions; frequency stability; frequency standard; $l 8697$.

Ion thermochemistry; proton affinity; proton transfer equilibrium; data compilation; NBSIR 79-1777.

lon-chromatography; ion-exchange; liquid chromatography; oil; oyster; conductivity; J. Res. 84, No. 3, 241-246 (1979).

lon-chromatography; law enforcement standards; materials properties; measurement science; science students; SRM; titanium alloy; analytical chemistry; DIM/NBS 63, No. 1/2, 1-28 (1979).

Ion-chromatography; nitrite; nitrite solutions; oxidation; 18889 .

Ion-dipole; $\beta$-endorphin; ${ }^{252} \mathrm{Cf}$; charge transfer; chlorophyll; erythromycin; fast reactions; fission track; SP519, pp. 673. 677 (Apr. 1979).

Ion-exchange; liquid chromatography; oil; oyster; conductivity; ion-chromatography; J. Res. 84, No. 3, 241-246 (1979).

Ionic activity; ionic activity scales; $\mathrm{pD} ; \mathrm{pD}$ scale; $\mathrm{pH} ; \mathrm{pH}$ scales; potentiometric ion activity; activity coefficient; hydrogen ion activity; 18379 .

Ionic activity scales; $\mathrm{pD} ; \mathrm{pD}$ scale; $\mathrm{pH} ; \mathrm{pH}$ scales; potentiometric ion activity; activity coefficient; hydrogen ion activity; ionic activity; 18379 .

Ionic conduction; lithium aluminosilicates; lithium silicate; electrode polarization; equivalent circuits; 18794.

Ionic conductors; neutron diffraction; powder method; profile refinement; tantalum tungstate; thermal expansion; 19037.

Ionic mechanisms; kinetics; methylmercury; methyltin; NMR; primary salt effect; speciation; activation parameters; aqueous transmethylation; chloride complexes; environment; formation constants; 18484 .

Ion-implanted silicon; laser pulses; power densities; thermal anneals; energy densities; 18623 .

Ionization; linear rate; multiphoton; rate approximation; saturable rate; bandwidth; coherence; dynamic rate; incoherence; 18893.

Ionization; molecule; photon; positron; atom; collision cross section; detachment; dissociation; elastic scattering; electron; excitation; ion; SP426. Supplement 1.

Ionization; multiphoton; Rabi frequency; Star shift; two-level model; absorption; cesium; exponential index; 18892 .

Ionization; perturbation theory; second-order perturbation theory; two-photon ionization; cesium; 18927.

Ionization; secondary; angular; Born approximation; correlations; electron impact; electrons; helium; $I 8534$.

lonization cross section; ionization rate coefficient; lithiumlike ions, ionization of; $\mathrm{N}^{+4} ; \mathrm{O}^{+5}$; rate coefficient; electron impact ionization; 18502 . 
Ionization detector; porous anode; electron capture detector; gas chromatography; halo-organics; SP5/9, pp. 777-782 (Apr. 1979).

lonization energies; line strengths; many-body interaction; many-body perturbation theory; oscillator strengths; copper isolectronic sequence; diagrammatic perturbation theory; electron correlation; 18998 .

Ionization energies; lutetium; osmium; rhenium; tantalum; tungsten; wavelengths; yttcrbium; energy levels; hafnium; 18506 .

lonization energy; aromatic compound; charge transfer equilibria; entropy change; ion cyclotron resonancc; 18337.

Ionization energy; spectrum; wavelengths; yttrium; energy levels; ion; 18868 .

lonization energy; wavelengths; aluminum; energy levels; 18485.

Ionization potential; abstract; appearance potential; archival tape; computer program; data base; data base management; empirical molecular formula; GPSDC; ion energetics; NBSIR $78-1432$

Ionization potentials; aluminum; atomic energy levels; atomic spectra; electron configurations; JPCRD 8, No. 3, 817.864 (1979).

lonization rate coefficient; lithiumlike ions, ionization of; $\mathrm{N}^{+4}$; $\mathrm{O}^{+3}$; rate coefficient; electron impact ionization; ionization cross section; 18502

Ionization rate coefficients; magnetic fusion research; transition probabilities; wavelengths; atomic data; data availability; dielectronic recombination rates; excitation rate coefficients; 18593.

lonization spectrometry; LEl; stepwise excitation; tunable dye lasers; enhanced ionization; 18983.

lonizaton detectors; mattresses; nursing homes; photoelectric detectors; corridors; escape; fire detectors; full-scale tests; heat detectors; hospitals; NBSIR 79-1739.

lonized impurity scattering mobility; lattice scattering mobility; neutral impurity; resistivity; scattering mechanisms; scattering mobility; $\rho$-type silicon; boron-doped silicon; dopant density; effective mass; hole mobility; SP4OO-47.

lonizing; radioactivity; standards; testing; traceability; dose; 18361 .

Ionizing radiation; radiation measurements; radiation safety; standard; device safety performance classification; gauges; gauging devices; $\boldsymbol{H} / 29$.

Ion-molecule collisions; rotational excitation; semiclassical treatment; 18389 .

lon-molecule collisions; rotational excitation; semiclassical orbital; theory; elastic scattering; 18446 .

lon-molecule reactions; aromatic substitution; association ions; charge transfer; ethyl nitrate; 18332.

lon-molecule reactions; proton affinity; proton transfer reaction; dichlorocarbene; heat of formation; 18331 .

lonosphere; $\mathrm{O}^{++}$; photoionization; thermosphere; double photoionization; doubly charged ions; 18950

Ion-pair adsorption; ion-pair chromatography; ion-pair partition; metabolites; psychotropic amines; selectivity; sulphonamides; amino acids; barbiturates; carboxylic acids; catecholamines; conjugates; detection sensitivity; dipeptides; drugs; SP519, pp. 509-523 (Apr. 1979).

Ion-pair chromatography; ion-pair partition; metabolites; psychotropic amines; selectivity; sulphonamides; amino acids; barbiturates; carboxylic acids; catecholamines; conjugates; detection sensitivity; dipeptides; drugs; HPLC; SP519, pp. 509-523 (Apr. 1979).

lon-pair partition; metabolites; psychotropic amines; selectivity; sulphonamides; amino acids; barbiturates; carboxylic acids; catecholamines; conjugates; detection sensitivity; dipeptides; drugs; HPLC; ion-pair adsorption; SP519, pp. 509-523 (Apr. 1979).

Ions; molybdenum; pulsed laser; spectra; wavelengths; energy Icvels; 18500 . lon-selective electrodes; reference electrodes; sensors, chcmical; electrodes, errors; electrodes, ion-selective; electrodes, reference; 18362 .

lon-selective electrodes; sensors, chemical; standards; electrodes; electrodes, ion-sclective; electrodes, reference; errors; 18334

IR; photodegradation; poly (methyl methacrylate); UV; visible; degradation; NBSIR 79-1766.

Ir; superconductivity; supercooling; temperature fixed points; W; $\mathrm{AuAl}_{2} ; \mathrm{AuIn}_{2} ; \mathrm{Be} ; 18549$.

Ir; superconductivity; thermometry; W; $\mathrm{AuAl}_{2} ; \mathrm{AuIn}_{2} ; \mathrm{Be}$; cryogenic temperature scale; fixed points; SP260-62.

IR window materials; $\mathrm{NaCl}$; pressure; pulsed TEA $\mathrm{CO}_{2}$ laser surface breakdown; spot size; surface absorption; transmitted pulse; adsorbed water; breakdown mechanism; frequency and time dependence of breakdown thresholds; SP54I, pp. 318. 326 (Dec. 1978).

Iridium; Josephson junction; low- $\mathrm{T}_{c}$; microwaves; thin-film; tunneling; energy gap; 18540 .

Iridium (1) complexes; organometallic benzotriazenides; rhodium (1) complexes; thallium benzotriazenide; benzotriazenides: 18582

Iron; nickel; osmotic coefficients; solutions; thermodynamic properties; activity coefficient; cobalt; critical evaluation; electrolyte; excess Gibbs energy; JPCRD 8, No. 4, 923-1004 (1979).

Iron; plastic; polymer; proton-induced $x$-ray fluorescence; thin films; trace element analysis; trace element concentrations; zinc; copper; 18375 .

Iron alloy; magnetic susceptibility; spin-glass, sound velocity; Debye temperature; $/ 87063$.

Iron alloys; nickel alloys; stainless steels; Young's modulus; aluminum alloys; copper alloys; elastic constants; 18630 .

Iron as alloy in platinum; platinum ware; surface of platinum influenced by method heating; contrast augmentation of reflecting surfaces; double-diaphragm; faces (crystal) on platinum crucibles; hematite forming on platinum; J. Res. 84, No. 5, 385-394 (1979).

Iron cross section; nickel cross section; reaction rates; Californium; dosimetry; fission neutrons; 18883 .

Iron oxide; magnetic property; magnetometer; powders; susceptibility; calibration; 18804 .

Irradiance; laser diagnostics; phase front; beam profile; calibrated system; holography; TNIOIS.

Ischemic injury; myocardial infarction; ultrasonic attenuation; SP525, pp. 63-71 (Apr. 1979).

Isobars; isobutane; isochores; isotherms; Joule-Thomson inversion; latent heats of vaporization; melting line; orthobaric densities; specific heats; speeds of sound; vapor pressures; densities; enthalpies; entropies; equation of state; internal energies; NBSIR 79.1612.

Isobars; isochores; isotherms; Joule-Thomson inversion; latent heats of vaporization; melting line; $n$-butane; orthobaric densities; specific heats; speeds of sound; vapor pressures; densities; enthalpies; entropies; equation of state; internal energies; NBSIR 79-1621.

Isobutane; isochores; isotherms; Joule-Thomson inversion; latent heats of vaporization; melting line; orthobaric densities; specific heats; speeds of sound; vapor pressures; densities; enthalpies; entropies; equation of state; internal energies; isobars; NBSIR 79-1612.

Isobutene copolymers; pyrolysis gas chromatography; random scission; tetrafluoroethylene copolymers; 1,3,3,3tetrafluoropropene polymer; 3,3,3-trifluoropropene copolymers; $3,3,4,4,5,5,5$-heptafluoropentene-I polymer; 18580 .

Isobutyl 2-cyanoacrylate; mineralized tissue; 2-cyanoacrylate esters; adhesion; bonding to mineralized tissues; bone; dentin; hydrolytic stability of bonds; 18569 . 
Isobutyl 2-cyanoacrylate; pretreatment of dentin; 2-cyanoacrylate esters; adhesive; bonding to dentin; dental adhesive; dentin; durability of dentin acrylic bond; 18985 .

Isochores; isotherms; Joule-Thomson inversion; latcnt heats of vaporization; melting line; orthobaric densities; specific heats; speeds of sound; vapor pressures; densities; enthalpies; entropies; equation of state; internal energies; isobars; isobutane; NBSIR 79-16I2.

Isochores; isotherms; Joule-Thomson inversion; latcnt heats of vaporization; melting line; n-butane; orthobaric densities; specific heats; speeds of sound; vapor pressures; densities; enthalpies; entropies; equation of state; internal energies; isobars; NBSIR 79-1621.

Isolation; lasers; mass spectrometry; matrix; modeling; vapors; combustion; equilibrium; high temperature; SP561, Vols. 1 and 2 .

Isolation; machinery and equipment; mechanical impedance; mechanical vibrations; noise control; transmissibility; vibration isolation; vibrations; antivibration mounting; damping; dynamic properties; industrial engineering; $H / 28$.

1someric transition; liquid scintillation counting; photon counting; radioactivity; ${ }^{21} \mathrm{Sn}^{m}$ decay scheme; coincidence counting; decay probability; 18841 .

Isomers; low temperatures; $n$-paraffins; polycrystals; relaxation process; Young's modulus; audio frequencies; impurities; internal friction; 18467 .

Isopropyl; laser; non-equilibrium; pyrolysis; relaxation; thermal decomposition; allylmethylether; bromide; ethylacetate; 18832.

Isoscalar resonances; isovector resonances; photonuclear physics; shell model; giant resonances; hydrodynamic model; 18565 .

Isostatic forging; optical figure; optical homogeneity; single crystal; Talystep traces; alkali halides; backward scattering; forward scattering; grain boundaries; SP54l, pp. 65-69 (Dec. 1978).

Isotherms; Joule-Thomson inversion; latent heats of vaporization; melting line; orthobaric densities; specific heats; speeds of sound; vapor pressures; densities; enthalpies; entropies; equation of state; internal energies; isobars; isobutane; isochores; NBSIR 79-1612.

Isotherms; Joule-Thomson inversion; latent heats of vaporization; melting line; n-butane; orthobaric densities; specific heats; speeds of sound; vapor pressures; densities; enthalpies; entropies; equation of state; internal energies; isobars; isochores; NBSIR 79-1621.

Isotope analysis; laser analysis; laser fluorescence; laser spectroscopy; microfluorescence; saturation spectroscopy; tunable laser; atomic flame fluorescence; intracavity absorption; 18364 .

Isotope dilution; serum; cholesterol; gas chromatography/mass spectrometry; SP519, pp. 405-410 (Apr. !979).

Isotopes; laser; TEA laser; electronic discharge; hydrogen halides; 18667.

Isotopes; laser; vibrational energy transfer; hydrogen halides; 18388 .

Isotopes; molecular dynamics; neutron; neutron radiography; nondestructive evaluation; nuclear reactor; radiation; activation analysis; crystal structure; diffraction; TN995.

Isotopes; temperature dependence; vibrational energy transfer; hydrogen halides; 18929 .

Isotopic exchange, isoionic; recrystallization, role of; surface layer, role of; dilution effect, at same $\mathrm{pH}$ and concentration; hydration shell, role of; hydroxylapatite, at different $\mathrm{pHs}$; $J$. Res. 84, No. 5, 395-406 (1979).

Isotropic, real-time, electric-field sensor (IRES); resistively loaded dipole; tangential sensitivity; broadband; dynamic range; Hermitian magnitude; isotropicity; 19034
Isotropicity; isotropic, real-time, electric-field sensor (IRES); resistively loaded dipole; tangential sensitivity; broadband; dynamic range; Hermitian magnitude; 19034.

Isotropy of space; Michelson-Morley experiment; special relativity; stabilized lasers; 18875 .

Isotropy of space; Michelson-Morley experiment; special relativity; stabilized lasers; $I 8952$.

Isovector resonances; photonuclear physics; shell model; giant resonances; hydrodynamic model; isoscalar resonances; 18565 .

Iteration; moisture profile modeling; nondestructive evaluation; statistical estimation; diffusion coefficents; SP563, pp. 32-46 (Oct. 1979).

Iterative analysis; proton nmr spectroscopy; shift reagents; acyclic sugars; chemical shifts; conformation; coupling constants; hexononitriles; 18742 .

Iterative procedure; models; optimization; stability; standards; catalog; dynamic programming; NBSIR 78-1539.

$\mathrm{I}_{2}$; polarization switching; coherent optical transients: 18801 .

$1 / O$ interface bus; line printer; print controller; printer; cable interface; computer; controller; control units; hammer drive; input/output bus; interface; interface signals; NBS-GCR-79. 182 .

\section{J}

Japan; millikelvin research; nuclear cooling; Pomeranchuk refrigerators; solid $\mathrm{He}^{3}$; superfluid $\mathrm{He}^{3}$; symposium; cryogenics; dilution refrigerators; helium $3 ; 18679$.

Japanese glass; lead; lead isotopes; Chinese glass; galena ores; glass; 18840 .

JES output; job entry subsystem; model design; model selection; remote work stations; simulation model; data collection; SP500-52, pp. 123-127 (Oct. 1979).

Job entry subsystem; model design; model selection; remote work stations; simulation model; data collection; JES output; SP500-52, pp. 123-127 (Oct. 1979).

Johnson noise; Josephson junctions; noise thermometry; resistive SQUIDS; temperature measurement; 18603 .

Josephson computer; Josephson junction; microstriplines; superconductivity; high speed logic; 18666 .

Josephson devices; refrigeration; SQUID; superconductive electronics; cryocoolers; 18700 .

Josephson effect; metrology; noise thermometry; SQUID's; standards; superconductivity; $l 8871$.

Josephson junction; low- $T_{c}$; microwaves; thin-film; tunneling; energy gap; iridium; 18540 .

Josephson junction; microstriplines; superconductivity; high speed logic; Josephson computer; 18666.

Josephson junction; noise; point contacts; SQUID; 18663.

Josephson junction; picosecond pulse generator; ac current; high frequency oscillator; U.S. Patent 4,168,441.

Josephson junction; SQUID; superconducting electronics; superconductivity; A/D converter; 18678 .

Josephson junction noise thermometer; low temperature scale; ${ }^{3} \mathrm{He} /{ }^{4} \mathrm{He}$ dilution refrigerator; ${ }^{60} \mathrm{CO} \gamma$-ray thermometer; comparison measurements; Germanium resistance thermometer; 18555.

Josephson junctions; measurements; superconductivity; electronics; instruments; in tegrated circuits; 18859.

Josephson junctions; microwave receivers; microwaves; mixers; superconductivity; tunnel junctions; 18683 .

Josephson junctions; noise thermometry; resistive SQUIDS; temperature measurement; Johnson noise; $l 8603$.

Josephson phenomena; stabilization; superconductors; terminology; critical parameters; definitions; flux phenomena; 18681

Joule-Thomson inversion; latent heats of vaporization; melting line; orthobaric densities; specific heats; speeds of sound; 
Vupor pressures; densitics; cnthalpies; entropies; equation of statc; internal cnergics; isobars; isobutanc; isochores; isotherms; NBSIR 79-16I2.

Joulc-Thomson inversion; latent hcats of vaporization; melting linc; n-butanc; orthobaric densitics; spccific hcats; speeds of sound; vapor pressurcs; densitics; cnthalpies; entropies; equation of state; internal cncrgics; isobars; isochores; isotherms; NBSIR 79-1621.

Journal publishing; public scctor cfficiency; subsidies; technological change; capital formation; economic growth; NBS-GCR-ETIP 78-44.

Junction temperature; measurement technology; power transistors; semiconductor devices; thermal characterization; thermal resistance; transistors; current crowding; die attachment evaluation; SP4OO-14.

Juror attitudes; prerecorded videotaped trials; PRVTT; trials, PRVTT; videotaped trials; civil trials; courtroom procedures; SP480-30.

\section{$\mathbf{K}$}

$K$ shell; $L$ shell; non-radiative yield; partial level width; radiative yield; atomic properties; Auger yield; Coster-Kronig yield; effective fluorescence yield; fluorescence yield; JPCRD 8, No. 2, 307-328 (1979).

$K$ shell; level width; line width; $L$ shell; natural width; $x$-ray line width; Auger effect; Auger line width; JPCRD 8, No. 2, 329338 ( 1979).

$K$ x-ray absorption spectrum; $K$ x-ray emission spectrum; many body effects; rhonon interactions; core hole lifetime; core hole relaxation; 18359 .

$K$ x-ray emission spectrum; many body effects; rhonon interactions; core hole lifetime; core hole relaxation; $K$ x-ray absorption spectrum; 18359.

$\mathrm{KBr} ; \mathrm{KCl} ; \mathrm{KCl}: \mathrm{Kl}$; LiF; $\mathrm{MgF}_{2} ; \mathrm{NaCl}$; $\mathrm{NaF}$; piezo-optic constants; refractive index; $\mathrm{SiO}_{2} ; \mathrm{SrF}_{2}$; thermal expansion coefficient; thermo-optic constant; $\mathrm{ZnS} ; \mathrm{ZnSe} ; \mathrm{Al}_{2} \mathrm{O}_{3} ;$ TN993.

$\mathrm{KBr}, \mathrm{KI}, \mathrm{KIO}_{3}, \mathrm{KIO}_{4}$; solution calorimetry; thermochemistry; tris(hydroxymethyl)aminomethane; endothermic solution reactions; enthalpy of solution; J. Res. 84, No. 4, 273-286 (1979).

$\mathrm{KCl}$; $\mathrm{KCl}: \mathrm{KI}$; LiF; $\mathrm{MgF}_{2} ; \mathrm{NaCl}$; NaF; piezo-optic constants; refractive index; $\mathrm{SiO}_{2} ; \mathrm{SrF}_{2}$; thermal expansion coefficient; thermo-optic constant; $\mathrm{ZnS} ; \mathrm{ZnSe} \mathrm{Al}_{2} \mathrm{O}_{3} ;$ TN993.

$\mathrm{KCl}$; $\mathrm{NaCl}$; spot-size dependence; breakdown fields; SP541, pp. 309-317 (Dec. 1978).

$\mathrm{KCl} ; \mathrm{NaCl}$; tuneable laser calorimetry; 9.2 to $10.6 \mu \mathrm{m}$; absorption; SP541, pp. 24-32 (Dec. 1978).

$\mathrm{KCl}$; optical absorption coefficient; optoacoustic spectroscopy; $\mathrm{PbF}_{2}$; photoacoustic spectroscopy; TII; ZnSe; absorption edge; $\mathrm{CaF}_{2}$; SP541, pp. 43-49 (Dec. 1978).

$\mathrm{KCl}: \mathrm{KI} ; \mathrm{LiF} ; \mathrm{MgF}_{2} ; \mathrm{NaCl} ; \mathrm{NaF}$; piezo-optic constants; ref ractive index: $\mathrm{SiO}_{2}: \mathrm{SrF}_{2}$; thermal expansion coefficient; thermo-optic constant; $\mathrm{ZnS} ; \mathrm{ZnSe}_{\mathrm{n}} \mathrm{Al}_{2} \mathrm{O}_{3 ;} ;$ TN993.

$\mathrm{KCN}-\mathrm{KBr}$; neutron scattering; phase transition; rotation-translation coupling; coupled modes; dynamics; 19036.

KDP; Pockels effect; space charge; breakdown; electro-optics; gas-solid interface; NBS-GCR-79-177.

Kentucky Fire Marshal's office; lighting and thermal efficiency standards; local governments; new construction plans review; training and education; design professionals; energy audits; energy codes; SP552, pp. 121-130 (July 1979).

Kepone $^{H}$; partition chromatography; parts per billion; analysis; biological; gas chromatography; SP519, pp. 34l-343 (Apr. 1979).

Kerma; multisphere; photon; photoneutrons; radiotherapy; spcctrometry; dose-equivalent; electrons; SP554, pp. 109-123 (Sept. 1979).
Kerma; multispheres; photoneutrons; photons; radiotherapy; spectrometry; dose-equivalent; electrons; SP554, pp. 125-127 (Sept. 1979).

Kerma factors; neutron cross section; neutron energy deposition; nuclcar data; nuclear reactions; secondary particle spectra; 18360 .

Kern; loading rate; pin-end; test method; wall panels; walls; compression; eccentric loading; flat-end; BSS95.

Kernels; modeling; real-time; simulation; synthetic programs; benchmarking; computer performance measurement; distributed processing; interactive systems; SP500-52, pp. 53-64 (Oct. 1979).

Kerr coefficient; Kerr effect; nitrobenzene; pulse measurement; electrical measurements; electro-optics; 18819 .

Kerr effect; liquid breakdown; nitrobenzene; partial discharges; streamers; transient phenomena; electrical breakdown; high speed photography; 18843 .

Kerr effect; nitrobenzene; pulse measurement; electrical measurements; electro-optics; Kerr coefficient; 18819 .

Ketenimine; matrix isolation; methyl cyanide; ultraviolet spectrum; vacuum ultraviolet photolysis; charge transfer; cyanomethyl radical; excited argon atoms; force constants; infrared spectrum; 18879.

Kevlar 49; moisture; one-tenth scale motor case; S-glass; temperature effects; water boil; degradation; epoxy resins; SP563, pp. 177-197 (Oct. 1979).

Key management; key notarization; cryptography; digital signatures; encryption; identifiers; SP50O-54.

Key management; key notarization; cryptography; digital signatures; encryption; identifiers; 19039.

Key notarization; cryptography; digital signatures; encryption; identifiers; key manage ment; SP500-54.

Key notarization; cryptography; digital signatures; encryption; identifiers; key manage ment; 19039.

Key words; publications; abstracts; Center for Building Technology; SP457-3.

Key words; publications; abstracts, NBS publications; SP305. Supplement 10.

Keyboard; keypunch; optical character recognition; optical mark sensing; source data entry; data entry; economic considerations; FIPS PUB 67.

Keypunch; optical character recognition; optical mark sensing; source data entry; data entry; economic considerations; keyboard; FIPS PUB 67.

$\mathrm{Ki}$; LiF; $\mathrm{MgF}_{2} ; \mathrm{NaCl} ; \mathrm{NaF}$; piezo-optic constants; refractive index; $\mathrm{SiO}_{2} ; \mathrm{SrF}_{2}$; thermal expansion coefficient; thermo-optic constant; $\mathrm{ZnS} ; \mathrm{ZnSe} ; \mathrm{Al}_{2} \mathrm{O}_{3} ;$ TN993.

Kinetics; laser chemistry; mechanisms; multiphoton; thermochemistry; unimolecular dissociation; calorimetry; infrared; 18709 .

Kinetics; mechanism; photochemistry; carbon dioxide; carbon monoxide; carbonyl; exchange; hydroxyl; 18436 .

Kinetics; mechanisms; modeling; multiphoton; unimolecular dissociation; infrared lase $\mathrm{r} ; 18712$.

Kinetics; methylmercury; methyltin; NMR; primary salt effect; speciation; activation parameters; aqueous transmethylation; chloride complexes; environment; formation constants; ionic mechanisms; 18484 .

Kinetics; olefin; ozone; review; troposphere; hydroxyl; SP557, pp. 7-14 (Aug. 1979).

Kinetics; photochemistry; review; sulfur dioxide; troposphere; SP557, pp. 99-100 (Aug. 1979).

Kinetics; radicals; review; tropospherc; alkoxyl; SP557, pp. 5161 (Aug. 1979). 
Kinetics of oxidc growth; oxidation of silicon; semiconductor processing; silicon; silicon dioxide; thermally stimulated mcasurement; thermal oxidation; Zn-doped glasses; boron nitride; Cl-doped glasses; diffusion in silicon; integrated circuit processing; NBS-GCR-78-134.

Kirkwood-Salsburg; Mayer-Montroll; BBGKY; correlation functions; 19004

Kitchen fircs; life safety; mobile homes; room fires; ASTM E84 Tunnel Test; construction standard; fire growth; fire tests; flame spread; flashover; impact assessment; interior finish; NBSIR 79-1720.

Kitchen fires; mobilc homes; smoke detectors; tenability limits; upholstered furniture; detection time; detector location; fire tcsts; gas detectors; NBSIR 79-1915.

Kitchen ranges; labeling; stoves; test methods; appliance; cooking; efficiency; energy; human factors; NBSIR 78-1556.

Klosek-McKinley method; liquefied natural gas (LNG); magnetic suspension densimeter; comparisons; correlation; custody transfer; density; cxperimental; extended corresponding states method; hard sphere model; 18775.

Korca; measurements; metrology; physical standards; seminar; South Asia; developing countries; industrializing countries; SP539.

$\mathrm{Kr}$ VIII; atomic decay curve simulation; atomic transition probabilities; beam-foil spectroscopy; cascades in atomic decay; exponential fitting; 18508 .

Kronecker product; numerical radius; spectrum; stable matrix; closure; $D$-stability; diagonal matrix; field of values; Hadamard product; inclusion theorem; 18909.

KWOC indexing; least-squares; lincar regression; MIS; plotting; statistical analysis; Boolean search system; computer programs; curve fitting; data analysis; data base management; data retrieval; file handling; graphic analysis; IMS information retrieval; 18597 .

\section{$\mathbb{L}$}

$L$ shell; natural width; x-ray line width; Auger effect; Auger line width; $K$ shell; level width; line width; JPCRD 8, No. 2, 329 338 ( 1979 ).

$L$ shell; non-radiative yield; partial level width; radiative yield; atomic properties; Auger yield; Coster-Kronig yield; effective fluorescence yield; fluorescence yield; $K$ shell; JPCRD 8, No. 2, 307-328 (1979).

L $\alpha$ emission; sun, atmosphere; sun, chromosphere; sun, plage; ultraviolet, spectra; 18876

Labeling; stoves; test methods; appliance; cooking; efficiency; energy; human factors; kitchen ranges; NBSIR 78-1556.

Labor force; minorities in computing; women in computing; employment; equal employment opportunity; 19041 .

Labor information systems; manpower projections; modelling; building trades; construction industry; forecasting; SP552, pp. 185-196 (July 1979).

Laboratory; measurement; metrology; precision; test equipment; calibration; Federal Government; SP546, 1979 Edition.

Laboratory accreditation; standards systems; United Kingdom; West Germany; antitrust; Canada; certification; Denmark; economics of standards; government policy; international standards; NBS-GCR-79-172.

Laboratory fire tests; Inatcrial ignitability; submarine compartment; combustion products; fire barrier coatings; fire growth: flame spread; foam insulation; heat release; interior finish; NBSIR 78-1584.

Laboratory fire tests; material ignitability; prediction model; shipboard spaces; fire growth; fire statistics; flame spread; fuel load survey; heat release; interior finish; NBSIR 79. 1714 .

Lactate dehydrogenase assay; lactate to pyruvate reaction; pyruvate to lactate reaction; spectrophotometric enzyme assay; enzyme assay; influence of inhibitor on lactate dehydrogenase assay; 18433.

Lactate to pyruvatc reaction; pyruvate to lactate rcaction; spectrophotometric enzyme assay; enzyme assay; influcnce of inhibitor on lactate dchydrogenase assay; lactate dehydrogenase assay; 18433 .

Lactose; liquid chromatography; maltose; raffinosc; ribosc; stachyose; sucrose; sugar analysis; carbohydrates; fructose; galactose; gas-liquid chromatography; glucosc; SP519. pp. 271-278 (Apr. 1979).

Lag; overspeeding error; rotary anemometcr; unsteady flow; air; anemometer; helicoid anemometer; NBSIR 78-1505.

Laminate design sensitivities; thermal expansion; advanced composite materials; graphite-epoxy laminate design; SP563, pp. 60-71 (Oct. 1979).

Laminated composites; stress concentrations; tension; tensor polynomial; compression; failure; finite elements; graphiteepoxy; interlaminar stresses; SP563, pp. 242-254 (Oct. 1979).

Lamp surface temperature; melting temperaturc; miniature Christmas lights; plastic insulating material; polyethylene; series-constructed; electric shock; fire; flaming ignition; glowing ignition; hazard; ignition temperature; NBSIR 79-1716.

Land use; resource zoning; urban; zoning regulations; infrastructure; SP552, pp. 347-360 (July. 1979).

Land-mobile; standards; antenna; communications; 18398 .

LANDSAT; multispectral scanner; reflective optics; crosstrack scan; earth imagery; ERTS; SP547, pp. 17-30 (July 1979).

Lang; misorientation contrast; $\mathrm{x}$-ray topography; $\mathrm{Zn;} \mathbf{A l}_{\mathbf{2}} \mathbf{O}_{\mathbf{3}}$; Berg-Barrett; l834l.

Language; maintenance; numerical analysis; OMNITAB 78; portability; poster; reliability; statistical computing section; worksheet; capabilities; ease of learning and using; installation; 18903 .

Languages; query; standards; database; data-description; datadictionary; data-directory; data-manipulation; DBMS; SP500$5 l$.

Lanthanum; spectra; spectroscopy; triply-ionized; ultraviolet; wavelengths; energy levels; 18782 .

Lanthanum niobate; modulated structure; nonstoichiometry; two-dimensional modulated structure; incommensurate lattice; 18646 .

Lapping; polishing; polishing times; grinding; grinding damage; SP562, pp. $191-199$ (Oct. 1979).

Large aperture antenna metrology; satellite communications metrology; antenna gain; antenna pattern; antenna polarization; 18628.

Large A-value molecules; stratospheric $\mathrm{HOCl}$; air pollutants; chlorine sink; high resolution IR spectra; hypochlorous acid; 18864 .

Large composite structures; rotor blades; wind turbine; composite materials; filament winding; SP563, pp. $155-172$ (Oct. 1979).

Large magnets; power transmission; review; superconductors; ac generators; heat transfer; helium; hydrodynamics; 18822 .

Large scale integration; memory; microprocessor; testing; electronics; integrated circuit; TN/ 102.

Large-scale; management; mathematical models; policy analysis; software; standards; transfer; documcntation; energy: evaluation; guidelines; implementation; SP534.

Laser; laser MAP; laser measurements; laser power and energy; NBS standards; standards; calorimeter; 18914.

Laser; laser parameters; laser pulse; optical processing; phase; precision measurements; wave front; amplitude; beam profile; cross correlation; digital sampling; Fourier optics; holography; TN1009.

Laser; lifetime; mean life; oscillator strength; Al 1; aluminum; delayed coincidence; $f$-value; imprisonment; 18527.

Laser; methyl fluoride; Stark; far-infrared; $/ 8426$. 
Laser; methylenc iodiode; methyl iodiode; photodissociation; radical; infrarcd emission; 18573 .

Laser; modulator; noisc; servo control; acoustooptic; intensity; 18904.

Lascr; ncodymium lascr; peak power; power meter; pulsed lascr; Q-switchcd; risetime; speckle; waveform; attenuators; calibration; TNIOIO).

Lascr; non-equilibrium; pyrolysis; relaxation; thermal decomposition; allylmcthylether; bromide; ethylacetate; isopropyl; 18832 .

Laser; optical fibers; 18662 .

Laser; oscilloscope; picosecond; pulse; pulse measurement; time domain measurement; automation; 18640 .

Luser; photodiode; avalanche photodiode; FFT; fiber optics; frequency response; impulse response; NBSIR 79-1620.

Lascr; shaping; silicon compound ceramics; SP562, pp. 283-292 (Oct. 1979).

Laser; TEA laser; electronic discharge; hydrogen halides; isotopes; 18667.

Laser; vibrational energy transfer; hydrogen halides; isotopes; 18388.

Laser; visible; frequency measurements; iodine; 18916 .

Laser analysis; laser fluorescence; laser spectroscopy; microfluorescence; saturation spectroscopy; tunable laser; atomic flame fluorescence; intracavity absorption; isotope analysis; 18364 .

Laser application; pol; polarimetry; saccharimetry; sugar analysis; sugar scale; wavelength; 18768 .

Laser bandwidth; lasers; multiphoton ionisation; cesium; 18874 .

Laser bandwidth effects; multiphoton ionization; ac Stark effect; double optical resonance; 18955 .

Laser beams; magnetic bubbles; masstapes; solid state memories; video disks; beam-addressables; cartridges; cassettes; core memories; disks; drums; floppy disks; SP500-45.

Laser beamsplitter system; laser calibration system; laser measurements; laser power calibration; calorimetry; NBSIR 79 1619.

Laser calibration system; laser measurements; laser power calibration; calorimetry; laser beamsplitter system; NBSIR $79-1619$

Laser calorimeter; linear absorption; Nd:YAG laser; two photon absorption; CdSe; CdTe; internal reflections; SP54I, pp. 19-23 (Dec. 1978).

Laser calorimetry; NaF; thin film absorption; water absorption; wedged film; absorption coefficient; adiabatic calorimetry; $\mathrm{As}_{2} \mathrm{Se}_{3}$; interface absorption; SP541, pp. 37-42 (Dec. 1978).

Laser calorimetry theory; optical calorimetry theory; surface optical absorption; coating optical absorption; SP541, pp. 712 (Dec. 1978).

Laser cavity; mode locked dye laser; passive mode locking; picosecond pulses; Rhodamine 6G; dye laser; 19021 .

Laser chemistry; mechanisms; multiphoton; thermochemistry; unimolecular dissociation; calorimetry; infrared; kinetics; 18709.

Laser damage; conduction band (CB) electrons; dielectric solids; electrons, conduction band (CB); SP54I/ Pp. 303-304 (Dec. 1978 ).

Laser damage; laser interaction; optical components; optical fabrication; optical materials and properties; thin film coatings; SP541.

Laser damage; laser window; single crystal; strontium fluoride; antireflection coatings; calcium fluoride; $\mathrm{cw}$ laser damage; DF laser; fusion cast; SP541, pp. 78-85 (Dec. 1978).

Laser damage; nanosecond pulses; pulsewidth dependence; standing waves; thin-film coatings; two-photon absorption; ultraviolet wavelength scaling; damage thresholds; electric fields; SP541, pp. 190-202 (Dec. 1978).
Laser damage; optical coatings; thin films; antireflection coatings; electron microscopy; SP541, pp. 218-225 (Dec. 1978).

Laser damage; optical probe technique; radiation scattering; thin films; SP541, pp. 226-234 (Dec. 1978).

Laser damage; optical properties; diamond single-point machining; dielectrics; infrared optical components; SP562, pp. 293303 (Oct. 1979).

Laser damage; polished surfaces; pulse duration dependence of damage; surface roughness; BK-7 glass; fused silica; SP54I, pp. 164-167 (Dec. 1978).

Laser damage; probability; statistical analysis; thin films; Weibull distribution; SP54I, pp. 235-248 (Dec. 1978).

Laser damage; sodium fluoride; absorption; arsenic selenide; arsenic trisulfide; defects; SP54I, pp. 212-217 (Dec. 1978).

Laser diagnostics; phase front; beam profile; calibrated system; holography; irradiance; TNI015.

Laser enhanced ionization; laser spectroscopy; optogalvanic effect; enhanced ionization theory; flame spectroscopy; ion production; 18806 .

Laser enhanced ionization; laser spectroscopy; opto-galvanic effect; trace metal analysis; tunable dye laser; analytical flame spectroscopy; flame ionization; flame spectroscopy; 18880 .

Laser excitation; microanalysis; microparticle analysis; microprobe resolution; microsample heating; optical detection; Raman microprobe; Raman spectra; Raman spectroscopy; 18971 .

Laser excited galvanic spectroscopy; lasers, bandwidth determination of; lasers, frequency locking of; lasers, wavelength calibration of; optogalvanic effect; trace metal detection; 18944.

Laser fluorescence; laser spectroscopy; microfluorescence; saturation spectroscopy; tunable laser; atomic flame fluorescence; intracavity absorption; isotope analysis; laser analysis; 18364 .

Laser fluorescence; molecular sodium; potential curves; collisional excitation; dissociation energy; Dunham coefficients; Franck-Condon factors; 18824 .

Laser frequency measurement; Penning trap; speed of light; $\mathrm{CO}_{2}$ laser; frequency comparison; frequency multiplication; frequency synthesis; 18608 .

Laser frequency measurements; $\mathrm{C}^{13}$ methanol; FIR laser; 18939.

Laser glass; particle characterization; polishing compounds; subsurface defects; surface contamination; surface preparation; SP562, pp. 231-244 (Oct. 1979).

Laser glass; photoelasticity; piezo-birefringence; piezo-optic constants; $\mathrm{SrF}_{2}$; stress-optical coefficient; $\mathrm{BaF}_{2} ; \mathrm{CaF}_{2} ; \mathrm{SP541}$, pp. 50-54 (Dec. 1978).

Laser induced breakdown; laser-induced damage threshold; nonequilibrium carriers; semiconductors, Ge, Si, GaAs; SP541, pp. 305-308 (Dec. 1978).

Laser induced cooling; $\mathrm{Mg}$ ions; optical \& microwave double resonance; stored ions; systematic effects; Ba ions; frequency stability; frequency standard; ion temperature; 18697.

Laser induced plasma; optical emission; photoionization; Potassium-Krypton mixtures; resonant multiphoton ionizations; collisional excitation; collisional radiative recombination; 18799 .

Laser interaction; optical components; optical fabrication; optical materials and properties; thin film coatings; laser damage; SP541.

Laser ionization; laser vaporization; liquid chromatography; liquid chromatography/mass spectrometry; SP519, pp. 647654 (Apr. 1979).

Laser irradiation; ceramic surfaces; diamond single-point machining; high fluence; SP562, pp. 513-518 (Oct: 1979).

Laser magnetic resonance; atomic oxygen; glow discharge; 18919.

Laser MAP; laser measurements; laser power and energy; NBS standards; standards; calorimeter; lase r; 18914. 
Laser mcasurcments; laser power and energy; NBS standards: standards; calorimcter; lascr; laser MAP; 18914.

Lascr measuremcnts; laser power calibration; calorimetry; laser beamsplittcr systcm; laser calibration systcm; NBSIR 79. 1619 .

Laser microprobe mass analyzer; laser Raman microprobe; microanalysis; secondary ion mass spectrometry; $\mathrm{x}$-ray microanalysis; Auger electron spectroscopy; cathodoluminescencc; ion scattcring spectromctry; 18568 .

Laser mirror; metallurgical characterization; microstructures; molybdenum; optical characterization; SP54I, pp. 132-163 (Dec. 1978)

Laser optics; low velocity; mine ventilation; velocity standard; airflow; calibration; facility; TN989.

Laser parameters; laser pulse; optical processing; phase; precision measurements; wave front; amplitude; beam profile; cross correlation; digital sampling; Fourier optics; holography; laser; TNIOOO

Laser power and energy; NBS standards; standards: calorimeter; laser; laser MAP; laser measurements; 18914 .

Laser power calibration; calorimetry; laser beamsplitter systcm; laser calibration system; laser measurements; NBSIR 79. 1619 .

Laser power measurements; pyroelectric detectors; radiometry; silicon cell; silicon detector; silicon photodetector; absolute radiometry; detector; electrically calibrated detectors; 18773 .

Laser power measurements; pyroelectric detectors; radiometry; silicon ccll; silicon detector; silicon photodetector; absolute radiometry; detector; electrically calibrated detectors; 18774 .

Laser power modulator; laser power stabilizer; photodetector characterization; radiometric instrumentation; TN987.

Laser power stabilizer; photodetector characterization; radiometric instrumentation; laser power modulator; TN987.

Laser pulse; optical processing; phase; precision measurements; wave front; amplitude; beam profile; cross correlation; digital sampling; Fourier optics; holography; laser; laser parameters; TN1009

Laser pulse; pico-second; pico-second lascr pulse; alkali-halides; SP541, pp. 296-298 (Dec. 1978).

Laser pulses; power densities; thermal anneals; energy densities; ion-implanted silicon; / 8623

Laser Raman microprobe; microanalysis; secondary ion mass spectrometry; x-ray microanalysis; Auger electron spectroscopy; cathodoluminescence; ion scattering spectrometry; laser microprobe mass analyzer; 18568 .

Laser scanner: measurement development; photovoltaics; reliability; solar arrays; solar cells; workshops; 18322 .

Laser scanning; light-biasing; metallization; ohmic contacts; reliability; semiconductor measurements; sheet resistance; solar cells; solar cell stability; device measurements; NBSIR 79. 1909

Laser scanning; metallization; ohmic contacts; reliability; semiconductor measurements; solar cclls; solar cell stability; workshops; device measurements; 18633 .

Laser spectroscopy; lithium molecule; molecular spectroscopy; potential curves; dissociation energy; Franck-Condon factors; 18867.

Laser spectroscopy; microfluorescence; saturation spectroscopy; tunable laser; atomic flame fluorescence; intracavity absorption; isotope analysis; laser analysis; laser fluorescence; 18364

Lascr spectroscopy; Mossbauer effect; optical pumping; optical spectroscopy; radiation pressure; radiative cooling; Dopplerfree spectroscopy; frequency standard; high resolution spectroscopy; ion storage; 18699 .

Laser spectroscopy; multiphoton dissociation; radicals; vibronic spectroscopy; chlorofluoromethylene; fluorescence; 19042.

Laser spectroscopy; multiphoton processes; photoionization; quantum beats; sodium atom; angular distributions; field ionization: 18953 .
Laser spectroscopy; noise, lascr sources; nonlincar spectroscopy; optical heterodync; spcctroscopy, laser; 18558 .

Laser spcctroscopy; optical Ramsey effect; rcsonancc linc shape analysis; Rydberg atoms; two photon spectroscopy; 19019.

Laser spectroscopy; optogalvanic effect; enhanced ionization theory; flame spectroscopy; ion production; laser enhanced ionization: 18806

Laser spectroscopy; opto-galvanic effect; trace metal analysis; tunable dye laser; analytical flame spectroscopy; flame ionization; flame spectroscopy; laser enhanced ionization; 18880 .

Laser strainmeter; ocean load; preferred frame; spatial anisotropy; strain tides; core resonance; free wobblc; 18823.

Laser vaporization; liquid chromatography; liquid chromatography/mass spectrometry; laser ionization; SP519, pp. 647. 654 (Apr. 1979).

Laser velocimeter; low velocity; performance; vane anemometer; wind tunnel; airflow; anemometer: NBSIR 78-1433.

Laser velocimeter; low velocity; performance; vane anemometer; wind tunnel; airflow; anemometer; NBSIR 78-1545.

Laser window: single crystal; strontium fluoride; antireflection coatings; calcium fluoride; cw laser damage; DF laser; fusion cast; laser damage; SP541, pp. 78-85 (Dec. 1978).

Laser windows; lithium fluoride; mechanical properties; optical properties; ultraviolet transmission; fluorides; forging; SP54I, pp. 59-64 (Dec. 1978).

Laser windows; optical propertics; scattering; calcium fluoride; forging; SP54I, pp. $70-77$ (Dec. 1978).

Laser-excitation technique; neutral sodium; sodium, neutral; autoionizing states; 18507 .

Laser-induced damage; thermal damage; absorption; antireflection coatings; damage thresholds; impurities; SP54I, pp. 202211 (Dec. 1978).

Laser-induced damage threshold; noncquilibrium carriers; semiconductors, Ge, Si, GaAs; laser induced breakdown; SP54I, pp. 305-308 (Dec. 1978 ).

Laser-interferometer; microwave measurements; non-destructive evaluation; pipe welds; standard; $x$-ray image; appropriations; fusion diagnostics; gravity waves; DIM/NBS 63, No. 3, $1.28(1979)$.

Laser-Raman microprobe; liquid chromatograph-Raman spectrometer interface; micro-Raman spectroscopy; organic microanalysis; PAH microsamples; (PAHs); polynuclear aromatic hydrocarbons; Raman spectra; trace organic analysis; SP519, pp. 723-729 (Apr. 1979).

Lasers; mass spectrometry; matrix; modeling; vapors; combustion; equilibrium; high temperature; isolation; SP56I, Vols. I and 2

Lasers; molecular bands; molecular spectra; reaction rate constants; upper atmosphere; atomic energy levels; atomic spectra; atomic transition probabilities; electron cross sections; fusion plasmas; 18855 .

Lasers; multiphoton ionisation; cesium; laser bandwidth; 18874 .

Lasers, bandwidth determination of; lasers, frequency locking of; lasers, wavelength calibration of; optogalvanic effect; trace metal detection; laser excited galvanic spectroscopy; 18944

Lasers, frequency locking of; lasers, wavelength calibration of; optogalvanic effect; trace metal detection; laser excited galvanic spectroscopy; lasers, bandwidth determination of; I 8944

Lasers, wavelength calibration of; optogalvanic effect; trace metal detcction; laser excited galvanic spcctroscopy; lasers, bandwidth determination of; lasers, frequency locking of; 18944

Latent heat storage; pebble bed; phase-change unit; solar energy storage; thermal energy storage device; ASHRAE Standard 94-77; Glauber's salt; NBSIR 79-1737. 
Latent heats of vaporization; melting line; orthobaric densitics; specific heats; specds of sound; vapor pressures; densitics; enthalpics: entropics; cquation of statc; internal energics; isohars; isobutanc; isochorcs; isotherms; Joulc-Thomson inversion; NBSIR 79-1612.

Latcnt hcats of vaporization; mclting line; n-butanc; orthobaric densitics; spccific heats; spceds of sound; vapor pressures; densitics; cnthalpies; entropies; cquation of state; internal cnergics; isobars; isochores; isothcrms; Joulc-Thomson inversion; NBSIR 79-162I.

Lutcnt scratch; optical glass; polishing; cleaning; chemical durability; glass surface; SP562, pp. 417-425 (Oct. 1979).

Latc-type stars; Ca $11 \mathrm{cmission,} \mathrm{stars;} \mathrm{chromospheres,} \mathrm{stars;} \mathrm{cir-}$ cumstcllar shells; emission line, stars; 18853

Latc-type stars; stellar chromospheres; stellar coronae; stellar winds; ultraviolet spectra; emission lincs, stars; $/ 8528$.

Latc-type stars; stellar chromospheres; stellar coronae; emission line stars; flare stars; 18920

Latc-type, ultraviolet; spectra; Ca il emission, stars; chromosphcres, stars; emission line, star; 18926.

Latin America; management; measurement; metrology; quality control; standards; technology transfer; UN Conference on Scicnce and Technology for Development (UNCSTD); Africa; Asia; developing countries; industrialization; SP543.

Latticc absorption; zinc sulfide; characteristic phonons; chemical-vapor deposition; image spoiling; infrared imaging; SP541, pp. 86-97 (Dec. 1978).

Luttice constants; peak intensities; powder patterns; reference intcnsities; standard; $x$-ray diffraction; crystal structure; intcgrated intensities; Monogr. 25, Section 16.

Lattice diffusion; migrating boundaries; polycrystals; thin films; diffusion; grain boundaries; Harrison classification; 18758 .

Lattice diffusion; migrating boundaries; polycrystals; thin films; diffusion; grain boundaries; Harrison classification; 18759.

Latticc dynamics; $n$-alkanes; non-bonded potential functions; polyethylene; vibrational data; force field refinement; 18404 .

Latticc relaxation; lithium; magnesium; sodium; soft $x$-ray absorption spectra; soft $x$-ray emission spectra; aluminum; beryllium; core hole lifetime; 18741 .

Lattice relaxation; many body effects; sodium; absorption spectra; core excitation; emission spectra; 18413.

Lattice scattering mobility; neutral impurity; resistivity; scattering mechanisms; scattering mobility; $\rho$-type silicon; borondoped silicon; dopant density; effective mass; hole mobility; ionized impurity scattering mobility; $S P 400-47$.

Lattice-model chains; polymer chain dimensions; random-coil chain dimensions; Rouse coordinates; distributions in chain dimensions; equilibrium chain dimensions; excluded volume; 18618 .

Lattice-model polymer chains; polymer chain dynamics; random-coil polymer chains; relaxation times; self-entanglement effccts; computer simulation; end-to-end length; entanglemont effects; excluded volume effects; 18772 .

Luves phase; magnetic materials; ncutron scattering; rare earths; spin waves; crystal fields; 19031 .

Laves phase; magnetic properties; neutron scattering; rare earth compounds; hydrides; 18657.

Laves phase; magnetism; neutron scattering; rare earths; hydrides; intermetallic compounds; 18682 .

Laves phase; magnetism; neutron scattering; rare earths; hydrides; intermetallic compounds; 18881 .

Laves phase; sigma phase; transition metal; alloy phases; electroncgativity; electron factors; electron vacancies; 18357 .

Law enforcement; public safety; communication systems; equipment selection; SP480-12.

Law enforcement equipment; standards; surveillance; undercover equipment; body-worn transmitters; communications equipment; FM transmitters; 18381 .
Law cnforecment standards; materials propertics; measurement science; scicnce students; SRM; titanium alloy; analytical chemistry; ion-chromatography; DIM/NBS 63 , No. 1/2, 1-28 (1979).

Lawn mowcrs; psychophysics; safcty; standards; consumer products; human factors; human performance; NBSIR 77 1298.

Lawn mowers; rcaction timc; safety; standards; consumer product; human factors; NBSIR 77-1299.

Lawnmowcr; motor shaft; brakc; coupling device; cutting blade; dead-man's handle; disconnect element; U.S. Patent 4,158,944.

LC microcapillary columns; selective detectors; ancillary methods; bonded phases; chromatographic preconcentration; detector sensitivity; gas chromatography; glass capillary columns; high-performance liquid chromatography; SP519, pp. 487-499 (Apr. 1979).

LDC's; less developed countries; light capital technology; science and technology for development; U.N. Conference on Science and Technology for Development; UNCSTD; appropriate technology; industrialization; industrial R\&D; 18685.

LDC's; measurement services; standardization; AID; assistance; developing economies; foreign relations; industrializing nations; international relations; NBSIR $78-1712$.

Lead; lead isotopes; Chinese glass; galena ores; glass; Japanese glass; 18840 .

Lead; manganese; osmotic coefficients; solutions; thermodynamic properties; uranium; activity coefficient; copper; critical evaluation; electrolyte; excess Gibbs energy; JPCRD 8, No. 4, 1005-1050 (1979).

Lead; mercury; metal; methylation; microbial tolerance; microorganism; plasmid; tin; arsenic; bio-transformation; cadmium; food chain; 18860 .

Lead fluoride; polymorphism; thallium iodide; thin films; graded index; SP541, pp. 259-265 (Dec. 1978).

Lead isotopes; Chinesc glass; galena ores; glass; Japanese glass; lead; 18840 .

Lead poisoning; abatemcnt; building economics; building materials; economic analysis; housing; lead-based paint; TN97I.

Lead poisoning; abatement; building economics; building materials; cost estimation; econometric models; economic analysis; housing; lead-based paint; TN979.

Lead-based paint; lead poisoning; abatement; building economics; building materials; economic analysis; housing; TN97I

Lead-based paint; lead poisoning; abatement; building economics; building materials; cost estimation; econometric models; economic analysis; housing: TN979.

Leak testing; measurement technology; microcalorimetry; moisture; nondestructive testing; pacemaker leads; process control; reliability; semiconductor devices; welding; automated testing; batteries; cardiac pace makers; contamination; corrosion; electrostatic-induced damage; SP40O-50.

Leakage; linear accelerators; neutrons; betatrons; detectors; dosimetry; SP554, pp. 129-138 (Sept. 1979).

Leakage; measurement techniques; medical accelerators; neutrons; relative biological effect; shielding techniques; standards; dosimetry; high energy radiothe rapy beams; SP554.

Leakage; medical accelerator; neutrons; scatter; $x$ rays; dose; SP554, pp. 25-28 (Sept. 1979).

Leakage; radiation; safe ty; standards; accelerators; IEC; interlocks; SP554, pp. 29-32 (Sept. 1979).

Leakage current; MOSFET dc profiler; surface recombination; CCD; electrical test structure; gated diode; generation lifetime; integrated gated-diode electrometer; integrated test structure; NBSIR 79-1 744 . 
Leakagc failurc mode; linear elastic fracture mechanics; metal lincr; compositc matcrials; critical flaw size; cyclic fatigue lifc; filament wound tankagc; SP563, pp. 198-207 (Oct. 1979).

Leakagc radiation; regulations; SSRCR; state; accelerators; SP554, pp. 33-35 (Sept. 1979).

Lcast absolutc deviation; polynomial approximation; test problems; algorithm testing; approximation; computational cxpcriment; J. Res. 84, No. 6, 455-488 (1979).

Lcast squares circle; least squares estimation; polar graph; restraints; roundness standard; spindle error; standard deviation; stylus; NBSIR 79-1758.

Least squares estimation; polar graph; restraints; roundness standard; spindle error; standard deviation; stylus; least squares circle; NBSIR 79-1758

Least-squares; linear regression; MIS; plotting; statistical analysis; Boolean search system; computer programs; curve fitting; data analysis; data base management; data retrieval; file handling; graphic analysis; IMS information retrieval; KWOC indexing; 18597.

Lcather; manufacturing technology; materials development; shoes; tcchnology transfer; computer-aided design and manufacture (CAD/CAM); footwear industry; fragmented industrics; government-industry cooperation; imports; innovation; SP527.

Lecithins; lipids; melting temperature; metastable states; phenyl substituted diglyccrides; phospholipids; polymorphism; rccrystallization temperature; benzyl substitured diglycerides; differential scanning calorimetry; heat of fusion; 18380 .

Legal aspects of standards; product certification; product liability; regulation; standards system; voluntary standards; bibliography; buildings; certification; economics of standards; NBSIR 79-1900

Legislation; solar; standards; State; buildings; design; energy; NBSIR 79-1705

Legislation; solar energy; building regulation; energy conservation; SP552, pp. $211-216$ (July 1979).

Legislation; thermal envelope criteria; thermal performance criteria; education; energy utilization codes; illustrated handbook; SP552, pp. 141-151 (July 1979).

LEI; stcpwise excitation; tunable dye lasers; enhanced ionization; ionization spectrometry; 18983.

Length; mcasurement assurance; measurement process control; systematic crror; uncertainty; calibration; gage blocks; Monogr. 163.

Length standards; physical measurement systems; review article; speed of light; time standards; atomic clocks; frequency standards; frequency synthesis; fundamental constants; 18346 .

Length-mcasuring devices; liquid-measuring devices; measures; scales; specifications; taximeters; tolerances; volume-measuring deviccs; weighing devices; weights; H44, 1979 Edition.

Lennard-Jones liquid; liquid rubidium; molecular dynamics; radial distribution function; transverse current correlation function; velocity autocorrelation function; intermediate scattering function; J. Res. 84, No. 6, 439-446 (1979).

Less developed countries; light capital technology; science and technology for development; U.N. Conference on Science and Technology for Development; UNCSTD; appropriate tcchnology; industrialization; industrial R\&D; LDC's; 18685.

Level; maintenance oriented; malfunction detection; monitoring; onboard; patented; pressure; pumps; reservoirs; sensors; tailorable; temperature; accumulator; analog; centralized; check-out system; dessicant; discrete; displacement; SP547, pp. 345-357 (July 1979).

Level cluster; spherical tops; symmetry analysis; Born-Oppenheimer approximation; centrifugal; Coriolis; frame transformation relations; 18599.
Level clusters; Raman spectra; rotation-vibration spectra; symmetry analysis; Born-Oppenheimer approximation; highresolution spectra; 18598 .

Level clusters; saturation absorption spectra; superfine structure; symmetry analysis; tableau calculus; high resolution spectroscopy; hyperfine structure; 18609 .

Level clusters; saturation absorption spectroscopy; spherical top molecules; high rcsolution spectroscopy; 18928 .

Level clusters; spherical top molecules; combination bands; high resolution spectroscopy; 18921 .

Level width; line width; $L$ shell; natural width; $x$-ray line width; Auger effect; Auger line width; $K$ shell; JPCRD 8, No. 2, 329-338 (1979).

Levitation calorimetry; microcalorimetry; radiation calorimetry; solution calorimetry; bomb calorimetry; drop calorimetry; electromagnetic power calorimetry; energy measurement; enthalpy measurement; entropy measurement; fuels, heating values; gas-flow calorimetry; 18330 .

Liability; municipal corporations; negligence; sovereign immunity; tort; duty; SP552, pp. 29-37 (July 1979).

Libraries. OF1 OF2 ; information services; 19048.

Libraries-automation; machine-readable-bibliographic data; bibliographic data bases; computerized data bases; information storage and retrieval systems; NBSIR 78-1577.

Library policy; library procedures; library services; NBSIR 791928 (NBS).

Library procedures; library services; library policy; NBSIR 791928 ( NBS).

Library services; library policy; library procedures; NBSIR 79. 1928 ( NBS).

LiF; $\mathrm{MgF}_{2} ; \mathrm{NaCl}, \mathrm{NaF}$; piezo-optic constants; refractive index; $\mathrm{SiO}_{2} ; \mathrm{SrF}_{2}$; thermal expansion coefficient; thermo-optic constant; $\mathrm{ZnS} ; \mathrm{ZnSe} ; \mathrm{Al}_{2} \mathrm{O}_{3} ;$ TN993.

Life cycle costing: procurement of water heaters; technological change; commercial impacts; Experimental Technology Incentives Program; Federal Supply Service; NBS-GCR-ETIP $78-51$.

Life cycle costing; procurement of wate $r$ heaters; technological change; commercial impacts; Experimental Technology Incentives Program; Federal Supply Service; NBS-GCR-ETIP $78-52$.

Life cycle reliability; on-vehicle computing instrumentation; prognostic maintenance management; geriometry; SP 547, pp. 65-77 (July 1979).

Life safety; mathematical programming; nursing homes; renovation; applied economics; building codes; building economics; economic analysis; fire safety; health care facilities; hospitals; NBSIR 79-I 902

Life safety; mathematical programming; nursing homes; renovation; applied economics; building codes; building economics: economic analysis; fire safety; health care facilities; hospitals; 19045.

Life safety; mobile homes; room fires; ASTM E-84 Tunnel Test; construction standard; fire growth; fire tests; flame spread; flashover; impact assessment; interior finish; kitchen fires; NBSIR 79-1720.

Life safety; regulation; risk assessment; societal goals; building codes; control measures; fire codes; fire safety; governmental actions; SP536, pp. 63-74 (Feb. 1979).

Life Safety Code; nursing homes; risk an alysis; safety equivalency; safety evaluation; smoke detection; automatic sprinklers; building codes; building construction; Delphi Method; fire safety; health care facilities; hospitals; interior finishes; NBSIR 78-1555.

Life-cycle analysis; safety regulations; building codes; building regulations; cost-benefit analysis; SP5 52, pp. 267-282 (July 1979).

Life-cycle cost; optimal; standard; buildings; conservation; criteria; design; economics; efficiency; energy; energy budget; equity; 18888 . 
Lifi-cyclc cost analysis; masonry construction; space heating and cooling rcquirements; thermal mass; building economics; energy conscrvation; insulation; NBSIR 79-1789.

Life-cycle costing; marginal analysis; optimal design; residential buildings; space cooling; space heating; building envelope; cost effectiveness; economics; energy conservation; internal rate of return; 19044 .

Lifc-cycle costing; redevelopment; rehabilitation; tax incentives; adaptive reuse; buildings; demolition; economics; historic preservation; TN980.

Life-cycle costing; redevelopment; rchabilitation; tax incentives; adaptive reuse; buildings; demolition; economics; historic preservation; 19016.

Life-cycle costing; retrofitting; solar; building design; cost; energy conservation; energy standards; fenestration; 19043.

Life-cycle costs; solar heat gain; thermal efficiency; window; window management; building economics; daylighting; economic analysis; energy conservation; engineering economics; BSSI19.

Lifetime; mean life; oscillator strength; Al r; aluminum; delayed coincidence; $f$-value; imprisonment; laser; 18527.

Lifetime prediction; materials durability; materials failure; 18830.

Lifetime prediction; polystyrene; polyurethane; thermogravimetry; weight-loss kinetics; aging of polymers; degradation of polymers; error propagation; factor-jump method; heating rate; 18620 .

Light; liquefied natural gas; measurements; microwaves; super spring; ultraviolet radiation; calibrations; energy; fluid mixtures; DIMINBS 63, No. 9, 1-32 (1979).

Light absorption; metal oxides; molecular absorption; opto-galvanic spectroscopy; uv irradiation; 18344 .

Light capital technology; science and technology for development; U.N. Conference on Science and Technology for Development; UNCSTD; appropriate technology; industrialization; industrial R\&D; LDC's; less developed countries; 18685 .

Light emitting diode; detectors; 18848 .

Light flux; photometric calibrator; inverse fourth power; U.S. Patent 4,152,074.

Light pulse shape; vacuum spark; far ultraviolet; 18811 .

Light scattering; molecular weight dependence; polystyrene; radius of gyration; temperature dependence; hydrodynamic radius; 18545 .

Light scattering; optical particle sizing; particle size standards; aerosol size measurement; calibration of particle sizing instruments; Doppler shift spectrometer; 18980.

Light scattering; polydisperse; polydispersity; polystyrene; quasielastic light scattering; SRM-706; standard reference material; diffusion; diffusion coefficient; 18511 .

Light water reactors; damage analysis; dosimetry standardization; fast breeder reactors; 19012 .

Light water reactors; nuclear reactors; reactor dosimetry; dosimetry programs; 19014.

Light-biasing; metallization; ohmic contacts; reliability; semiconductor measurements; sheet resistance; solar cells; solar cell stability; device measurements; laser scanning; NBSIR 79-1909.

Lighting and thermal efficiency standards; local governments; new construction plans review; training and education; design professionals; energy audits; energy codes; Kentucky Fire Marshal's office; SP552, pp. 121-130 (July 1979).

Lighting distribution simulation; visual performance; building codes; building performance simulation; computer applications; energy conservation; illumination standards; SP552, pp. 321-335 (July 1979).

Lighting energy consumption; occupant factors; residential air conditioning; service hot water; space heating; ventilation; appliance energy consumption; energy consumption of residences; NBSIR 78-1501.
Lightning impulse; pulse calibration; ramp response; step response; divider; high 'voltage; impulse; 18727.

Lights, flashing; lights, warning; perception, visual; peripheral vision; vehicles, emergency; visibility, lights; visual perception; color, lights; conspicuity, lights; effective intensity emergency lights; intensity, effective; SP480-36.

Lights, warning; perception, visual; peripheral vision; vehicles, emergency; visibility, lights; visual perception; color, lights; conspicuity, lights; effective intensity; emergency lights; intensity, effective; lights, flashing; SP480-36.

Light-scattering; lipids; nephelometry; oils; reversed-phase; serum; cerebrospinal fluid; detector; high-performance liquid chromatography; SP519, pp. $429-436$ (Apr. 1979).

Linac; neutron flux determination; proton telescope; standard cross section; ${ }^{235} \mathrm{U}(\mathrm{n}, \mathrm{f})$; fission cross section; 18581 .

Linac; neutrons; position-sensitive detector; radiography; timeof-flight technique; 18591 .

Linacs; patient survival; betatrons; cobalt units; dose buildup; SP554, pp. 15-21 (Sept. 1979).

Line broadening; line shapes; 18474 .

Line formation; radiation transfer; stellar atmospheres; circumstellar dust; 18435 .

Line printer; print controller; printer; cable interface; computer; controller; control units; hammer drive; input/output bus; interface; interface signals; $1 / O$ interface bus; NBS-GCR79-182.

Line profiles; P-Cygni lines; radiative transfer; resonance lines; stars; stellar winds; 18515 .

Line shape; model correlation function; pressure broadening; $\mathrm{CO}_{2}$; far wings; infrared wings; 18886

Line shapes; line broadening; 18474.

Line shapes, atomic; molecular bands; molecular spectra; rotational constants; atomic line shapes; atomic spectra; atomic transition probabilities; bands, molecular; energy levels; energy levels, atomic; 18828 .

Line strengths; many-body interaction; many-body perturbation theory; oscillator strengths; copper isolectronic sequence; diagrammatic perturbation theory; electron correlation; ionization energies; 18998 .

Line strengths; methyl formate; microwave spectrum; radio astronomy; rotational transitions; internal rotation; interstellar molecules; JPCRD 8, No. 3, 583-618 (1979).

Line strengths; microwave spectra; molecular constants; propyne; radio astronomy; rotational transitions; interstellar molecules; JPCRD 8, No. 2, 537-558 ( 1979).

Line width; $L$ shell; natural width; $x$-ray line width; Auger effect; A uger line width; $K$ shell; level width; JPCRD 8, No. 2 , 329-338 (1979).

Linear absorption; Nd:YAG laser; two photon absorption; CdSe; CdTe; internal reflections; laser calorimeter; SP54I, pp. 19-23 (Dec. 1978).

Linear accelerators; neutrons; betatrons; detectors; dosimetry; leakage; SP554, pp. 129-138 (Sept. 1979).

Linear averaging; reciprocating; records after trigger; tape loop; time signal; time window; gated frequency analysis; Gaussian window; impulsive complex signals; SP547, pp. $315-322$ (July 1979 ).

Linear elastic fracture mechanics; metal liner; composite materials; critical flaw size; cyclic fatigue life; filament wound tankage; leakage failure mode; SP563, pp. 198-207 (Oct. 1979).

Linear elastic materials; tensile fracture; aircraft structural components; composite materials; SP563, p. 3 (Oct. 1979).

Linear load; Newton-Raphson interation methods; nonlinear load; time-domain measurements; time-stepping finite-difference technique; transient; traveling-wave antenna; Fast Fourier transform; 19035

Linear positioning; micromanipulator; optical microscope stage; piezoelectric drives; scanning stage; SEM microscope stage; 
submicrometer positioning instrumentation; TEM microscope stage; flexurc pivots; 18327.

Linear ratc; multiphoton; rate approximation; saturable rate; bandwidth; coherence; dynamic rate; incoherence; ionization; 18893.

Linear regression; M1S; plotting; statistical analysis; Boolean search systcm; computer programs; curve fitting; data analysis; data base management; data retrieval; file handling; graphic analysis; IMS information retrieval; KWOC indexing; least-squarcs; 18597.

Linearity; scattering; collimation; haze; hazemeter; integrating sphere; 18594.

Linearized equations; partial differential equations; buoyant convection; finite-difference computations; fire in an enclosure; heat addition; hyperbolic, elliptic equations; initial, boundary-value problem; NBSIR 79-1754.

Lineshape; low temperature; mixed crystal optical spectra; diphenylmethylene; 18754 .

Linewidth; photolithography; sheet resistance; silicon; test pattern; test structure; TTL; bipolar process; contact resistor; cross bridge sheet resistor; electrical alignmont resistor; integrated circuits; 18533

Linewidth measurcment; microlithography; micrometrology; optical microscopy; 18629

Line-width measurements; oxidation; photolithography; photovoltaic method; power-device grade silicon; radioisotope leak test; resistivity variations; resistors, sheet; scanning acoustic microscope; semiconductor materials; semiconductor process control; silicon; SP400-38.

Lint; performance; venting; appliance; clothes dryer; efficiency; energy conservation; heat recovery; 18793 .

Lipids; melting temperature; metastable states; phenyl substituted diglycerides; phospholipids; polymorphism; recrystallization temperature; benzyl substituted diglycerides; differential scanning calorimetry; heat of fusion; lecithins; 18380

Lipids; ncphelometry; oils; reversed-phase; serum; cerebrospinal fluid; detector; high-performance liquid chromatography; light-scattering; SP519, pp. 429-436 (Apr. 1979).

Lipoxidase; oils; PUFA; 9,12-di-cis-polyunsaturated fatty acids; fats; SP519, pp. 289-295 (Apr. 1979)

Liquefied natural gas; LNG; marine; mathematical modeling; measurement; photogrammetric; precision; ship cargo; statistical analysis; strapping; survey; accuracy; cryogenic; error estimation; NBSIR 79-175I

Liquefied natural gas; measurements; microwaves; super spring; ultraviolet radiation; calibrations; energy; fluid mixtures; light; DIM/NBS 63, No. 9, 1-32 (1979).

Liquefied natural gas; phase equilibrium; pipelines; sampling; custody transfer; density; gas analysis; gas chromatography; heating value; hydrocarbon; NBSIR $78-887$

Liquefied natural gas; sampling; cryogenic densimeter; custody transfer; density; flowmetering; 18396

Liquefied natural gas; sampling; custody transfer; density; gas analysis; gas chromatography; heating value; 18395 .

Liquefied natural gas (LNG); magnetic suspension densimeter; comparisons; correlation; custody transfer; density; experimental; extended corresponding states method; hard sphere model; Klosek-McKinley method; 18775.

Liquid breakdown; nitrobenzcne; partial discharges; streamers; transient phenomena; electrical breakdown; high speed photography; Kerr effect; 18843.

Liquid chromatograph-Raman spectrometer interface; microRaman spectroscopy; organic microanalysis; PAH microsamples; (PAHs); polynuclear aromatic hydrocarbons; Raman spectra; trace organic analysis; laser-Raman microprobe; SP519, pp. 723-729 (Apr. 1979)

Liquid chromatography; automation; clinical chemistry; environmental chemistry; gas chromatography; SP519, pp. 587. 600 (Apr. 1979).
Liquid chromatography; liquid chromatography/mass spectrometry; laser ionization; laser vaporization; SP5/9, pp. 647 654 (Apr. 1979).

Liquid chromatography; maltose; raffinose; ribose; stachyose; sucrose; sugar analysis; carbohydrates; fructose; galactose; gas-liquid chromatography; glucose; lactose; SP519, pp. 271278 (Apr. 1979).

Liquid chromatography; mass spectrometry; trace organic analysis; analytical systems; atomic absorption; gas chromatography; SP519, pp. 541-546 (Apr. 1979).

Liquid chromatography; metal speciation; organomercury cations; biological samples; electrochemical deteetion; 18420 .

Liquid chromatography; methylmercury; organometals; water preconcentration; electrochemical detection; SP5/9, pp. 57 63 (Apr. 1979).

Liquid chromatography; oil; oyster; conductivity; ion-chromatography; ion-exchange; J. Res. 84, No. 3, 241-246 (1979).

Liquid chromatography; oxidation; reduction; cell design; electrochemical detection; SP519, pp. $705-712$ (Apr. 1979).

Liquid chromatography; phenolic metabolites; catecholamines; electrochemical detection; SP519, pp. $391-397$ (Apr. 1979).

Liquid chromatography; plant constituents; abscisic acid; gas chromatography; SP519, pp. 803-807 (Apr. 1979).

Liquid chromatography; selective detection; detector design; gas chromatography; SP519, pp. 547-585 (Apr. 1979).

Liquid chromatography; trace enrichment; wastewater analysis; SP519, pp. 185-190 (Apr. 1979).

Liquid chromatography; triamterene assay; clinical analysis; fluorescence detection; SP519, pp. 477-480 (Apr. 1979).

Liquid chromatography; tryptophan metabolites; brain; cerebrospinal fluid; fluorescence flow cell; SP5/9, pp. 411418 (Apr. 1979).

Liquid chromatography-mass spectrometry; PCB metabolism; polychlorinated biphenyls; cytochrome P-450; SP519, pp. 685-690 (Apr. 1979).

Liquid chromatography/mass spectrometry; laser ionization; laser vaporization; liquid chromatography; SPSI9, pp. 647 654 (Apr. 1979).

Liquid chromatography/mass spectrometry; pesticides; vitamin A; wire transport; SP5 19, pp. 637-645 (Apr. 1979).

Liquid helium; superconducting power transmission; thermal cycling; thermal stress; cable cool-down; cool-down helium; NBSIR 79-1618.

Liquid helium; superconducting power transmission lines; supercritical helium; density wave oscillations; flow oscillations; flow stability; 18567 .

Liquid methane; LNG; cryogenic; densimeters; density reference system; 18805 .

Liquid penetrant testing; Rideal-Washburn equation; surface tension; defect geometry; fluid elasticity; J. Res. 84, No. 4, 287-292 (1979).

Liquid quenching; metastable phases; niobium-silicon alloys; splat-cooling; superconductivity; intermetallic compounds; 18734.

Liquid rubidium; molecular dynamics; radial distribution function; transverse current correlation function; velocity autocorrelation function; intermediate scattering function; Lennard-Jones liquid; J. Res. 84, No. 6, 439-446 (1979).

Liquid scintillation counting; photon counting; radioactivity; ${ }^{12}{ }^{\prime} \mathrm{Sn}^{m}$ decay scheme; coincidence counting; decay probability; isomeric transition; 18841 .

Liquid softening; oxides; scratching; size effect; specific energy; ceramics; chipping; crack formation; fracture toughness; friction; hardness; SP562, pp. 43-59 (Oct. 1979).

Liquid-filled dielectric waveguide; optical waveguide; phasematched propagation in waveguide; Raman spectroscopy of liquids; signal enhancement of coherent Raman process; coherent anti-Stokes Raman spcctroscopy (CARS); 18686. 
Liquid-liquid critical point; rcnormalization group theory; scaling thcory; univcrsality hypothcsis; binary-liquid mixture; consolutc point; critical cxponent; critical phenomena; critical solution point; 18825 .

Liquid-mcasuring devices; mcasurcs; scalcs; specifications; taximetcrs; tolerances; volumc-mcasuring devices; weighing devices; weights; length-measuring devices; H44, 1979 Edition.

Liquids; pressure ccll; viscosity; diamond-anvil; glass transition; high pressure; hydrostaticity; 18509.

Liquid-vapor equilibria; methane + ethane; binary mixtures; data correlation; excess volumes; heat of mixing; JPCRD 8 , No. 3, 799-816 (1979).

Literature reviews; pyromaniacs; abnormal psychology; arson; arsonists; firesetters; human behavior; NBS-GCR-79-157.

Litcrature survey; oscillator strengths; atomic transition probabilities; 18572 .

Lithium; electron excitation; 19028 .

Lithium; magnesium; sodium; soft $x$-ray absorption spectra; soft $\mathrm{x}$-ray emission spectra; aluminum; beryllium; core hole lifetime; lattice relaxation; 18741 .

Lithium; magnetic flux density dependence; potassium; pressure dependence; rubidium; sodium; temperature dependence; alkali elements; cesium; electrical resistivity; francium; JPCRD 8, No. 2, $339-438$ (1979).

Lithium; nitrogen; silicon devices; trace analysis; uranium; alpha tracks; biomedical; boron; fission tracks; geochronology; geology; 18342 .

Lithium; optical potentials; photopion; pion; beryllium; differential cross section; Fermi gas; 18442 .

Lithium; optical potentials; photopion; pion; beryllium; differential cross section; Fermi gas; 18496

Lithium aluminosilicates; lithium silicate; electrode polarization; equivalent circuits; ionic conduction; 18794 .

Lithium fluoride; mechanical properties; optical properties; ultraviolet transmission; fluorides; forging; laser windows; SP541, pp. 59-64 (Dec. 1978).

Lithium molecule; molecular spectroscopy; potential curves; dissociation energy; Franck-Condon factors; laser spectroscopy; 18867.

Lithium silicate; electrode polarization; equivalent circuits; ionic conduction; lithium aluminosilicates; 18794 .

Lithiumlike ions, ionization of; $\mathrm{N}^{+4} ; \mathrm{O}^{+5}$; rate coefficient; electron impact ionization; ionization cross section; ionization rate coefficient; 18502 .

Liver; power spectrum; signal processing; tissue characterization; tissue parameters; ultrasound; attenuation; B-san; cepstrum; computer; convolution; de-convolution; SP525, pp. 287-295 (Apr. 1979).

Liver; scattering; scattering cross-section; absorption; attenuation; heart; SP525, pp. 153-156 (Apr. 1979).

Liver attenuation; spectral analysis; statistical modeling; ultrasonic tissue characterization; computer processing; estimation theory; SP525, pp. 125-132 (Apr. 1979).

Lixiscope; radioactive $x$-ray source; rare-earth scintillator screen; ${ }^{125} \mathrm{I} ;{ }^{153} \mathrm{GD}$; CsI; detection efficiency; 19001 .

$\mathrm{Li}_{5} \mathrm{~B}_{4}$; neutron powder; structure; $\mathrm{x}$ ray; crystal; diffraction; 18382.

LNG; cryogenic; densimeters; density reference system; liquid methane; 18805 .

LNG; low temperature; mechanical properties; aluminum alloys; ferrous alloys; fracture mechanics; 18865 .

LNG; marine; mathematical modeling; measurement; photogrammetric; precision; ship cargo; statistical analysis; strapping; survey; accuracy; cryogenic; error estimation; liquefied natural gas; NBSIR 79-1751.

LNG; mathematical models; mixtures; specific heating value; tank capacity tables; thermophysical properties data; total heating value; composition; custody transfer; density; flow rate; 18838 .
LNG; mixtures; specific heating value; tank capacity tables; thermophysical properties; total heating value; composition; custody transfer; density; flow rate; 18564 .

Load; roof; roof load; snow; solar collector; structural engineering; building; ice; NBS-GCR-79-181.

Load application factors; load hardness; load rate; machining; translational motion; SP562, pp. 185-188 (Oct. 1979).

Load cell; mass; mass comparator; mass difference; strain-gage; substitution weighing; weighing; weights; constant loading; force; high precision; high-precision weighing; J. Res. 84, No. 5, 347-351 (1979).

Load current; overlamping; surface mounted incandescent lighting fixture; thermal insulation; thermocouple; branch circuit wiring; electrical junction box; hazardous temperatures; NBSIR 79-1912

Load current; protective barrier; recessed incandescent lighting fixture; thermal insulation; thermocouple; branch circuit wiring; electrical junction box; hazardous temperatures; NBSIR $79-1913$

Load hardness; load rate; machining; translational motion; load application factors; SP562, pp. 185-188 (Oct. 1979).

Load profiles; water heaters; energy usage; NBSIR 78-1496.

Load rate; machining; translational motion; load application factors; load hardness; SP562, pp. $185-188$ (Oct. 1979).

Loading rate; pin-end; test method; wall panels; walls; compression; eccentric loading; flat-end; kern; BSS95.

Loads (forces); roughness; structural analysis; tall buildings; wind pressure; aerodynamics; boundary layer; 18351 .

Local; microprocessor; network; serial; broadcast; coaxial; communication; contention; data; digital; e thernet; 18760 .

Local air transport; public sector efficiency; subsidies; technological change; capital formation; economic growth; NBS-GCR-ETIP 78-46.

Local governments; new construction plans review; training and education; design professionals; energy audits; energy codes; Kentucky Fire Marshal's office; lighting and thermal efficiency standards; SP552, pp. 121-130 (July 1979).

Local thermal equilibrium model; microanalysis; secondary ion mass spectrometry; surface analysis; elemental analysis; ion microprobe mass analyzer; 18979 .

Local time differentials; meridian designator; time differential factor; time zone references; Uniform Time Act of 1966; universal time; American National Standard Representation for Calendar Date and Ordinal Date for Information Interchange; FIPS PUB 59.

Long Duration Exposure Facility (LDEF); polyimide composite stability in space; polyimide/graphite mechanical properties; ultrasonic inspection; cocured and precured laminates; exoatmospheric exposure of composites; SP563, pp. 4-16 (Oct. 1979).

Long term frequency stability; oscillator systems; quartz crystal oscillator; short term frequency stability; 18691 .

Longest circuit; permutation matrix; doubly stochastic matrix; eigenvalues; field of values; graph; 18941 .

Long-range planning; management control; measurement; modeling; on-line system design; performance evaluation: performance management; prototyping; remote terminal emulation; system testing; audit; capacity planning; financial applications; SP500-52, pp. 129-140 (Oct. 1979).

Loran-C; low frequency; radio broadcasts; satellite broadcasts; standard frequencies; television color subcarrier; time and frequency calibration methods; time calibration; time signals; frequency calibration; high frequency; SP559.

Lorentz function; preferred orientation function; pyrolitic graphite; Ruland function; x-ray diffraction; Bacon function; Bragg function; Ergun function; graphite materials; 18523.

Lorenz ratio; reference materials; thermal conductivity; characterization; density; electrical resistivity; graphite; 18668 . 
Loss angle; microphonic coupling; phasc angle; surface films; capacitor; cross capacitor; dielcctric; dissipation factor; 18454.

Loss factor; nonlincar creep; polycthylene; failure criteria; 18468.

Loss prevention; risk; safety; construction; cost effectiveness; hazard; injuries; 18890 .

Lossy dielectric slab; modes considerations; TEM-cell; attcnuation; coupled integral equations; dispersion; NBSIR 79-1615.

Low energy; nitrogen; ratc coefficients; drift tube; electrons; excitation; 18925 .

Low frequency; microcomputer; ac voltage measurement; 18455.

Low frequency; radio broadcasts; satellite broadcasts; standard frequencies; television color subcarrier; time and frequency calibration methods; time calibration; time signals; frequency calibration; high frequency; Loran-C; SP559.

Low input power cyclic cryogenic refrigerator; multi-stage displacer; Stirling machine; superconducting quantum interfering devices (SQUID); U.S. Patent 4,143,520.

Low temperature; magnetotnermal conductivity; nickel alloy; stainless steel; thermal conductivity; aluminum alloy; copper; 18619 .

Low temperature; mechanical properties; aluminum alloys; ferrous alloys; fracture mechanics; LNG; 18865.

Low temperature; mechanical properties; polystyrene; polyurethane; thermal insulation; thermal properties; cellular plastic; $187 / 9$.

Low temperature; mixed crystal optical spectra; diphenylmethylene; lineshape; 18754.

Low temperature; rhodium-iron thermometry; thermal cycles to low temperatures; germanium thermometers; 19040.

Low temperature; temperature scale; thermometry; tunnel diode oscillator; gas thermometer; 18548 .

Low temperature alloy; specific heat; stainless steel; heat capacity; 18419 .

Low temperature physics; Nobel Prize; 18482 .

Low temperature polymer; cryogenic; dielectric loss; dissipation factor; high voltage; 18384 .

Low temperature scale; ${ }^{3} \mathrm{He} /{ }^{4} \mathrm{He}$ dilution refrigerator; ${ }^{60} \mathrm{CO} \gamma$ ray thermometer; comparison measurements; Germanium resistance thermometer; Josephson junction noise thermometer; 18555.

Low temperature tests; martensitic transformations; mechanical properties; stainless steel alloys; crack propagation; cryogenics; fracture; 18943 .

Low temperature tests; mechanical porperties; stainless steel; crack propagation; fatigue; fracture resistance; 18621 .

Low temperature tests; mechanical properties; aluminum alloys; crack propagation; cryogenics; fatigue; fracture; 18610 .

Low temperature tests; mechanical properties; titanium; titanium alloys; electron beam welding; fatigue (materials); fracture properties; $1861 /$.

Low temperature tests; nickel alloys; stainless steels; steels; superalloys; titanium alloys; crack propagation; fatigue; 18695 .

Low temperature thermometry; magnetic susceptibility; magnetic thermometers; $\mathrm{Nd}\left(\mathrm{C}_{2} \mathrm{H}_{5} \mathrm{SO}_{4}\right)_{3} \cdot 9 \mathrm{H}_{2} \mathrm{O}$; thermometry; $\mathrm{Gd}\left(\mathrm{PO}_{3}\right)_{3} ; 18556$.

Low temperatures; magnetic susceptibility; magnetic thermometry; paramagnetic relaxation; 18969 .

Low temperatures; mechanical properties; metallurgical properties; niobium-titanium; physical properties; superconductors; electrical properties; 18552 .

Low temperatures; niobium; precipitate; superconductor; tin; alloy; copper; 18655.

Low temperatures; $n$-paraffins; polycrystals; relaxation process; Young's modulus; audio frequencies; impurities; internal friction; isomers; 18467.

Low velocity; mine ventilation; velocity standard; airflow; calibration; facility; laser optics; TN989.
Low velocity; performance; vane anemometer; wind tunnel; airflow; anemometer; laser velocimeter; NBSIR 78-1433.

Low velocity; performance; vane anemometer; wind tunnel; airflow; anemometer; laser velocimeter; NBSIR 78-1545.

Low-activity replacement source; measurement technique; scatter contribution; source capsule; source housing; spectromctry results; ${ }^{\circ 0} \mathrm{CO}$ gamma-ray beam; calibration source; collimation system; data-reduction techniquc; 18416 .

Low-dose; low-intensity; microchannel plate; radiography; $\mathbf{x}$ ray; imaging: 19000 .

Low-energy stopping power; electron energy loss; energy degradation; 18659 .

Low-frequency approximation; multiphoton effects; scattering in laser field; free-free transitions; 18711 .

Low-income residences; marginal cost/benefit analysis in weatherization; optimum weatherization retrofit combinations; thermal analysis of residences; Community Services Administration; heating balance point analysis; NBSIR 79 1706.

Low-intensity; microchannel plate; radiography; $\mathrm{x}$ ray; imaging; low-dose; 19000.

Low-level; measurements; radioactivity; standards; traceability; 18400.

Low-level counting; radiocarbon; accelerator mass spectrometry; anthropogenic and natural carbonaceous species; atmospheric gases and particles; environmental pollutants; fossil fuels; 18405 .

Low-pressure laminates; metal-matrix composites; polymer matrices; advanced-fiber composites; cryogenics; industrial laminates; 18631 .

Low- $T_{r}$; microwaves; thin-film; tunneling; energy gap; iridium; Josephson junction; 18540.

Low-temperature; mechanical properties; nitrogen; nitrogenstrengthened; stainless steel; tensile properties; toughness; cryogenic; fatigue; fracture; high-strength; 18957.

LSI circuits; mask alignment tolerances; modular test programs; parametric yield limitations; performance limitations; photomask performance; process control; test patterns; test structures; total process integration; comprehensive process characterization; design rules; $S P 400-56$.

Lubricating oil; oil specifications; petroleum standards; petroleum test methods; recycled oil; re-refined oil; used oil; waste oil; engine oil; fuel oil; hydraulic oil; industrial oil; SP556.

Lubrication system monitoring; aircraft component failure; condition monitoring; debris monitoring; diagnostic techniques; failure detection; SP547, pp. 330-344 (July 1979).

Luminescence; microspectrofluorimetry; photoluminescence; spectrofluorimetry; surface analysis; tetrazole; benzotriazole; charge transfer; copper; 18504.

Luminescence spectrometry; organic pollutants monitoring; synchronous excitation spectroscopy; cresol; SP519, pp. 679 684 (Apr. 1979).

Lunar sample; temperature variation of dielectric parameters of soil; cavity resonance; coaxial line resonator; dielectric constant; dielectric loss; 18566 .

Lunar soil; microwave; profile effect on permittivity: temperature variation of permittivity; dielectric constant; dielectric loss: 18557.

Lutetium; osmium; rhcnium; tantalum; tungsten; wavelengths; ytterbium; energy levels; hafnium; ionization energies; 18506 .

Lutetium; spectrum; wavelengths; energy levels; 18369.

Lyman-alpha; deuterium; interstellar medium; $/ 8753$.

\section{$\mathbf{M}$}

Machinable; MACOR ${ }^{\text {MM }}$; Corning code 9658; glass-ccramic; SP562, pp. 221-229 (Oct. 1979).

Machine condition monitoring; oil analysis; oil sampling; wear; wear particles; ferrography; SP547, pp. 323-329 (July 1979). 
Machinc-rcadablc-bibliographic data; bibliographic data bases; computcrizcd data bases; information storage and retrieval systems; librarics-automation; NBS1R 78-1577.

Machincry; maintenance; monitoring; repairs; vibration; aircraft carricr; condition analysis; SP547, pp. 167-175 (July 1979).

Machinery and cquipment; mechanical impedance; mechanical vibrations; noisc control; transmissibility; vibration isolation; vibrations; antivibration mounting; damping; dynamic propertics; industrial engineering; isolation; $H 128$.

Machincry noise; noise signature; non-destructive evaluation; piczoclectric polymer; spectrum analysis; strain gage; bearing noise; failure prevention; SP547, pp. 303-314 (July 1979).

Machining; polishing; sanding; strength-size effects; brittle failure; flaw populations; flaws; fractography; fracture origins; grinding; SP562, pp. $351-378$ (Oct. 1979).

Machining; translational motion; load application factors; load hardness; load rate; SP562, pp. 185-188 (Oct. 1979).

Machining of ceramics; oxidation and degradation; siliconnitride; fracture origin; fracture strength; SP562, pp. 477-481 (Oct. 1979).

MACOR $^{\text {rM }}$; Corning code 9658; glass-ceramic; machinable; SP562, pp. $221-229$ (Oct. 1979).

Macromolecular relaxation; relaxation phenomenon; ultrasonic tissue absorption; absorption of ultrasound; SP525, pp. 29-36 (Apr. 1979).

Magnesium; photoabsorption-spectrum; synchrotron radiation; autoionization; core-excited states; 18912 .

Magnesium; radium; strontium; temperature dependence; alkaline earth elements; barium; beryllium; calcium; electrical resistivity; JPCRD 8, No. 2, 439-498 (1979).

Magnesium; sodium; soft $\mathrm{x}$-ray absorption spectra; soft $\mathrm{x}$-ray emission spectra; aluminum; beryllium; core hole lifetime; lattice relaxation; lithium; 18741 .

Magnesium phosphate; potassium phosphate; struvite analogue; crystal structure; 18491 .

Magnetic; particles; superparamagnetic particles; blocking temperature; 18746.

Magnetic bubbles; masstapes; solid state memories; video disks; beam-addressables; cartridges; cassettes; core memories; disks; drums; floppy disks; laser beams; SP500-45.

Magnetic fields; Maxwell's equations; solenoids; Ampere's law; dimensional metrology; fundamental constants; gyromagnetic ratio of proton; 18437 .

Magnetic fields; proton gyromagnetic ratio; quantum electrodynamic theory; electron anomalous moment; fine-structure constant; fundamental constant; 18702

Magnetic flux density dependence; potassium; pressure dependence; rubidium; sodium; temperature dependence; alkali elements; cesium; electrical resistivity; francium; lithium; JPCRD 8, No. 2, 339-438 (1979).

Magnetic fusion energy; superconducting magnets; advanced composites; composite materials; cryogenics; industrial laminates; 18560 .

Magnetic fusion research; transition probabilities; wavelengths; atomic data; data availability; dielectronic recombination rates; excitation rate coefficients; ionization rate coefficients; 18593.

Magnetic materials; microwaves; millimeter waves; permeability measurements; permittivity measurements; radar absorbers; time-domain measurements; dielectrics; frequency-domain measurements; NBSIR 79-1613.

Magnetic materials; neutron scattering; rare earths; spin waves; crystal fields; Laves phase; 19031 .

Magnetic particles; nondestructive evaluation; penetrants; radiography; statistics; ultrasonics; visual-optical tests; acoustic; annual report; eddy currents; inspection; NBSIR 78 1581 .

Magnetic partides; magnetism; neutron scattering; rare earths; small angle scattering; amorphous alloys; 18372 .
Magnetic properties; neutron scattering; rare earth compounds; hydrides; Laves phase; 18657.

Magnetic properties; neutron scattering; spin waves; transitionmetal glasses; amorphous alloys; 18898 .

Magnetic properties of rare earth alloys; metal hydrides; rareearth hydrides; cerium dihydride; crystal-field splitting; inelastic neutron scattering; 19030.

Magnetic property; magnetometer; powders; susceptibility; calibration; iron oxide; 18804

Magnetic relaxation; magnetism; Mossbauer; rare earths; spin glass; hyperfine fields; 18329 .

Magnetic superconductor; neutron scattering; rare earth; Chevrel-phase; coexistence; crystal field; 18850 .

Magnetic susceptibility; magnetic thermometers; $\mathrm{Nd}\left(\mathrm{C}_{2} \mathrm{H}_{5}\right.$ $\left.\mathrm{SO}_{4}\right)_{3} \cdot 9 \mathrm{H}_{2} \mathrm{O}$ : thermometry; $\mathrm{Gd}\left(\mathrm{PO}_{3}\right)_{3}$; low temperature thermometry; 18556 .

Magnetic susceptibility; magnetic thermometry; paramagnetic relaxation; low temperatures; 18969

Magnetic susceptibility; spin-glass, sound velocity; Debye temperature; iron alloy; 18763

Magnetic suspension; orthobaric liquid density; tables; argon; comparisons; correlation; ethylene; experimental; 18627.

Magnetic suspension; position detector; capacitance sensor; densimeter; 18962.

Magnetic suspension densimeter; comparisons; corrclation; custody transfer; density; experimental; extended corresponding states method; hard sphere model; Klosek-McKinley method; liquefied natural gas (LNG); 18775 .

Magnetic tape drives; NRZI recording; phase encoded recording; tape drive characteristics; computer magnetic tape drives; computer tape controllers; group coded recording; interface electrical characteristics; interface functional characteristics; NBS-GCR-78-127.

Magnetic thermometers; $\mathrm{Nd}\left(\mathrm{C}_{2} \mathrm{H}_{5} \mathrm{SO}_{4}\right)_{3} \cdot 9 \mathrm{H}_{2} \mathrm{O}$; thermometry; $\mathrm{Gd}\left(\mathrm{PO}_{3}\right)_{3}$; low temperature thermometry; magnetic susceptibility; 18556 .

Magnetic thermometry; paramagnetic relaxation; low temperatures; magnetic susceptibility; 18969.

Magnetism; Mossbauer; rare earths; spin glass; hyperfine fields; magnetic relaxation; 18329 .

Magnetism; neutron scattering; rare earths; small angle scattering; amorphous alloys; magnetic partides; 18372 .

Magnetism; neutron scattering; rare earths; hydrides; intermetallic compounds; Laves phase; 18682 .

Magnetism; neutron scattering; rare earths; hydrides; intermetallic compounds; Laves phase; 18881 .

Magnetism; phase diagram; potassium; conductivity; exchange interaction; ferrite; hyperfine field; 19046.

Magnetism; phase transitions; rare earths; small angle neutron scattering; amorphous materials; domains; 18835 .

Magnetization equation; spin Hamiltonians; spinodal point; spin-phonon coupling; ferromagnetism; 18605 .

Magnetoencephalography; SOUID magnetometer; auditory evoked response; 18397

Magnetometer; powders; susceptibility; calibration; iron oxide; magnetic property; 18804 .

Magnetometers; conductivity anomalies; earthquake prediction; geomagnetism; induced currents; 18895.

Magnetometry; quantum interference; superconductivity; digital electronics; 18701 .

Magnetothermal conductivity; nickel alloy; stainless steel; thermal conductivity; aluminum alloy; copper; low temperature; 18619 .

Magneto-thermal conductivity; polarization; potassium tantalate; refrigeration; specific heat; strontium titanate; beryllium; ceramics; cryogenics; dielectric-constant; electrets; electrocaloric effect; entropy; ferroelectrics; glass-ceramics; heat switches; 18680 . 
Maintenance; marine borers; nondestructive testing; pilings; timber; acoustics; bridges; creosote; harbor facilities; inspection; 18525.

Maintenance; monitoring; repairs; vibration; aircraft carrier; condition analysis; machinery; SPS47, pp. 167-175 (July 1979).

Maintenance; numerical analysis; OMNITAB 78; portability; poster; reliability; statistical computing scetion; worksheet; capabilities; ease of learning and using; installation; language; 18903.

Maintenance; operation; purchasing; pursuit tircs; safety; tread wear; braking traction; cornering traction; driving traction; endurance; SP480-33.

Maintenance; performance monitoring; bearing analysis; condition monitoring; engine diagnosis; failure detection; failurc diagnosis; failure prevention; SP547.

Maintenance; stoves; wood; accident investigations; chimneys; coal; creosote; fire departments; fire safcty; heating equipment; NBSIR 79-1731.

Maintenance; stoves; wood; accident investigations; chimneys; coal; creosote; fire departments; firc safety; heating equipment; NBS-GCR-78-149.

Maintenance; stoves; wood; accident investigations; chimneys; coal; creosote; fire departments; fire safety; heating equipment; 18537.

Maintenance oriented; malfunction detection: monitoring; onboard; patented; pressure; pumps; reservoirs; sensors; tailorable; temperature; accumulator; analog; centralized; check-out system; dessicant; discrete; displacement; fiber optics; SP547. pp. 345-357 (July 1979).

Maintenance requirements; naval ship application; composites; hydrofoils; SP563, pp. 267-275 (Oct. 1979).

Maleic hydrazide; mass spectroscopy; nitrosamines; nitrosodiethanolamine; silylation; thermal energy analyzer (TEA); tobacco; carbamates; chemical ionization; electroncapture; hydrazines; SP519, pp. 297-309 (Apr. 1979).

Malfunction detection; monitoring; onboard; patented; pressure; pumps; reservoirs; sensors; tailorablc; temperature; accumulator; analog; centralized; check-out system; dessicant; discrete; displacement; fiber optics; filters; SP547, pp. 345357 ( July 1979).

Malfunction procedures; manned spaceflight failures; redundancy management; training for diagnosis; automatic monitoring; failure annunciation; SP547, pp. 3-16 (July 1979).

Maltose; raffinose; ribose; stachyose; sucrose; sugar analysis; carbohydrates; fructose; galactose; gas-liquid chromatography; glucose; lactose; liquid chromatography; SP5/9, pp. 271-278 (Apr. 1979).

Mammalian tissues; polypeptides; proteins; tissue characterization; ultrasonics; velocity; absorption; amino acids; attenuation; frequency; SP525, pp. 19-27 (Apr. 1979).

Mammalian tissues; ultrasound; velocity; attenuation; SP525, pp. 343-360 (Apr. 1979).

Mammography; time-of-flight; tissue characterization; ultrasonic imaging; ultrasound; breast cancer, computerized tomography; SP525, pp. 221-225 (Apr. 1979).

Management; mathematical models; policy analysis; software; standards; transfer; documentation; energy; evaluation; guidelines; implementation; large-scale; SP534.

Management; measurement; metrology; quality control; standards; technology transfer; UN Conference on Science and Technology for Development (UNCSTD); Africa; Asia; developing countries; industrialization; Latin America; SP543.

Management; multiple-attribute decisions; ordering; paired comparisons; prioritization; project selection; ranking; resource allocation; weighting multiple criteria; decision analysis; decisions; eigenvectors; 18602 .

Management; research; 18387.
Management control; measurement; modeling; on-line system design; performance evaluation; performance management; prototyping; remote terminal emulation; system testing; audit; capacity planning; financial applications; long-range planning; SP500-52, pp. 129-140 (Oct. 1979).

Management practices; technological change; commercialization; empirical investigation; ETIP; Federal civilian R\&D; implementing; NBS-GCR-ETIP $78-57$.

Management practices; technological change; commercialization; empirical investigation; ETIP; Federal civilian R\&D; implementing; NBS-GCR-ETIP 78-58.

Management reporting; performance analysis; structured approach; auditing; capacity planning; computer performance evaluation; Information Management System (IMS); SP50O52, pp. 9-19 (Oct. 1979).

Managerial decision-making; methodology; administrative experimentation; 18722

Mandatory testing program; peer review; personnel dosimetry; processors; standard; trial use and comment; American $\mathrm{Na}$ tional Standards Institute; Health Physics Society Standards Committee; 18992 .

Manganese; osmotic coefficients; solutions; thermodynamic properties; uranium; activity coefficient; copper; critical evaluation; electrolyte; excess Gibbs energy; lead; JPCRD 8, No. 4, $1005-1050$ (1979).

Man-machine interaction; performance measurement; timesharing; computer performance evaluation; human factors; interactive computing; $S P 500-48$.

Manned spaceflight failures; redundancy management; training for diagnosis; automatic monitoring; failure annunciation; malfunction procedures; SP547, pp. 3-16 (July 1979).

Manometric technique; oxygen; permeability; poly(ethylene terephthalate); standard reference material; temperature coefficient; time-lag; gas transmission rate; SP260-58.

Manpower projections; modelling; building trades; construction industry; forecasting; labor information systems; SP552, pp. 185-196 (July 1979).

Manufacturing; pattern recognition; robotics; vision systems; automation; image processing; inspection; NBSIR 79-1 764.

Manufacturing technologies; structural performance/cost tradeoffs; airframe structure; cost-trade comparisons; SP563, pp. 226-227 (Oct. 1979).

Manufacturing technology; materials development; shoes; technology transfer; computer-aided design and manufacture (CAD/CAM); footwear industry; fragmented industries; government-industry cooperation; imports; innovation; leather; SP527.

Manuscripts; word processing center; word processing equipment; Center for Building Technology; 18429.

Many body effects; rhonon interactions; core hole lifetime; core hole relaxation; $K$ x-ray absorption spectrum; $K$ x-ray emission spectrum; 18359.

Many body effects; sodium; absorption spectra; core excitation; emission spectra; lattice relaxation; 18413 .

Many-body interaction; many-body perturbation thcory; oscillator strengths; copper isolectronic sequence; diagrammatic perturbation theory; electron correlation; ionization energies; line strengths; 18998 .

Many-body perturbation theory; oscillator strengths; copper isolectronic sequence; diagrammatic perturbation theory; electron correlation; ionization energies; line strengths; manybody interaction; 18998 .

Man/environment research; post-occupancy evaluation; questionnaire; user needs; building evaluation; design process: NBSIR 79-1780.

Margin staining; roughness; wear; curing shrinkage; glaze; 18684 .

Marginal analysis; optinial design; residential buildings; space cooling; space heating; building cnvelope; cost effectiveness; 
economics; cncrgy conscrvation; internal ratc of return; lifecyclc costing: 19044

Marginal cost/bencfit analysis in weatherization; optimum weatherization retrofit combinations; thermal analysis of residences; Community Services Administration; heating balance point analysis; low-income residences; NBSIR 79 1706.

Marginal fracturc; zinc cffect; creep; dental amalgam; dimensional changes; extrusion of restorations; 18586.

Marine; mathematical modeling; measurement; photogrammetric; precision; ship cargo; statistical analysis; strapping; survey; accuracy; cryogenic; error estimation; liquefied natural gas; LNG; NBSIR 79-1751.

Marine; petroleum: sediments; extraction; hydrocarbons; SP519, pp. 161-167 (Apr. 1979).

Marinc biota; metabolites; polynuclear aromatic hydrocarbons; high-pressure liquid chromatography; SP519, pp. $79-86$ (Apr. 1979).

Murine borers; nondestructive testing; pilings; timber; acoustics; bridges; creosote; harbor facilities; inspection; maintenance; 18525.

Marinc environment; advanced composites; cavitation erosıon; cxtcnded immersion; flammability; glass reinforced plastics; graphite epoxy; impact; SP563, pp. 276-285 (Oct. 1979).

Maritime transport; public sector efficiency; subsidies; tcchnological change; capital formation; economic growth; NBS-GCR-ETIP 78-43.

Market mechanism; offset policy; regulatory policy; technological innovation; administrative experimentation; Environmental Protection Agency; evaluability assessment; Experimental Tcchnology Incentives Program; industrial pollution regulation; NBS-GCR-ETIP 79-62.

Marking and certification; types of French standards; building standards; foreign building standards; French building standards; French standards system; SP552, pp. $45-56$ (July 1979).

Martensitic transformations; mechanical properties; stainless steel alloys; crack propagation; cryogenics; fracture; low tempcrature tests; 18943.

Mask alignment tolerances; modular test programs; parametric yield limitations; performance limitations; photomask performance; process control; test patterns; test structures; total process integration; comprehensive process characterization; design rules; SP400-56.

Masonry construction; space heating and cooling requirements; thermal mass; building economics; energy conservation; insulation; life-cycle cost analysis; NBSIR 79-1789.

Mass; mass comparator; mass difference; strain-gage; substitution weighing; weighing: weights; constant loading: force; high precision; high-precision weighing; load cell; J. Res. 84 , No. 5, 347-351 (1979).

Mass comparator; mass difference; strain-gage; substitution weighing; weighing; weights; constant loading; force; high precision; high-precision weighing; load cell; mass; J. Res. 84 , No. 5, 347-351 (1979).

Mass difference; strain-gage; substitution weighing; weighing; weights; constant loading; force; high precision; high-precision weighing; load cell; mass; mass comparator; J. Res. 84 , No. 5, 347-351 (1979).

Mass formula; nuclear; quartets; reactions; spectroscopy; SU4; alpha-particles; correlations; 18423 .

Mass principle; algorithm, finite-difference; finite-difference; integral form, conservation of mass principle: 18489 .

Mass spectrometry; matrix; modeling; vapors; combustion; equilibrium; high temperature; isolation; lasers; SP561, Vols. 1 and 2.

Mass spectrometry; negative ions: positive ions; atmospheric pressure ionization; bioanalytical systems; SP519, pp. 655671 (Apr. 1979).
Mass spectrometry; neon; nitrogen; Penning effect; carbon; copper; hollow cathodes: 18449.

Mass spectrometry; organic molecules; rate coefficients; chemical kinetics; data cvaluation; gas phase ion-molecule reactions: NSRDS-NBS64

Mass spectromctry; polycyclic aromatic hydrocarbons; capillary-column; charge exchange: chemical ionization; gas chromatography; SP519, pp. $731-738$ (Apr. 1979).

Mass spectrometry; propylamine; butylamine; collagen sponge; contraceptive device; gas chromatography; SP519, pp. 469. 476 (Apr. 1979).

Mass spectromctry; trace organic analysis; analytical systems; atomic absorption; gas chromatography; liquid chromatography; SP519, pp. 541-546 (Apr. 1979).

Mass spectroscopy; nitrosamines; nitrosodiethanolamine; silylation; thermal energy analyzer (TEA); tobacco; carbamates; chemical ionization; electron-capture; hydrazines; maleic hydrazide; SP519, pp. 297-309 (Apr. 1979).

Mass spectroscopy: organic aerosol constituents; primary organic carbon; sampling errors; secondary organic carbon; solvent extraction; spatial variations; diurnal variations; elemental carbon; SP519, pp. 121-129 (Apr. 1979).

Mass transit; public sector efficiency; subsidies; technological change: capital formation; economic growth; NBS-GCR-ETIP $78-41$.

Mass transportation; material flammability; people movers; smoke; emergency communications; emergency evacuation; fire detection; fire safety; fire suppression; NBSIR 78-1586.

Mass-analyzed ion kinetic energy spectrometry; MIKES; mixture analysis; trace analysis; SP519, pp. 609-625 (Apr. 1979).

Masstapes; solid state memories; video disks; beam-addressables; cartridges; cassettes; core memories; disks; drums; floppy disks; laser beams; magnetic bubbles; SP50O-45.

Master analytical scheme; non-purgeable organics; organic pollutant: purgeable organics; WaterDROP; accumulators; analysis of organics in water; automatic sampler; SP519, pp. 6578 (Apr. 1979).

Master equation; noise spectrum; non equilibrium; stationary states; switching; threshold switching; fluctuation; 18674 .

Master planning; regulation; standards; building codes; code enforcement; fire prevention codes; fire safety; SP552, pp. 225247 (July 1979).

Material accounting; material control; nuclear material safeguards; safeguards; analysis; diversion of nuclear materials; diversion path analysis; 18735 .

Material control; nuclear material safeguards; safeguards; analysis; diversion of nuclear materials; diversion path analysis; material accounting; 18735 .

Material flammability; people movers; smoke; emergency communications; emergency evacuation; fire detection; fire safety; fire suppression; mass transportation; NBSIR 78-1586.

Material ignitability; prediction model; shipboard spaces; fire growth; fire statistics; flame spread; fuel load survey; heat release; interior finish; laboratory fire tests; NBSIR 79-1714.

Material ignitability; submarine compartment; combustion products; fire barrier coatings; fire growth; flame spread; foam insulation; heat release; interior finish; laboratory fire tests; NBSIR 78-1584.

Material removal; abrasive machining; chip formation: fine grinding; glass; ceramics; SP562, pp. 107-114 (Oct. 1979).

Material transport; segregation; semiconductor technology; diffusion; electronic technology; impurity distribution; SP40057.

Materials development; shoes; technology transfer; computeraided design and manufacture (CAD/CAM); footwear industry; fragmented industries; government-industry cooperation; imports; innovation; leather; manufacturing technology; SP527. 
Materials durability; materials failure; lifetime prediction; 18830.

Materials failure; lifctime prediction; materials durability; 18830 .

Materials propertics; measurement science; science students; SRM; titanium alloy; analytical chemistry; ion-chromatography; law enforcement standards; DIM/NBS 63, No. 1/2, I28 (1979).

Materials purification; reactive atmosphere process (RAP) chemistry; thin film coating materials; infrared laser windows; SP541, pp. 249-256 (Dec. 1978).

Materials sampling; mineralogy; molecular analysis; particle analysis; power plant emissions; Raman microprobe; Raman spectroscopy; urban dusts; vibrational analysis; atomospheric aerosols; 18643.

Materials science; spacelab; critical phenomena; critical-point universality; fluids; gravity effects; 18457.

Materials utilization; measurement capabilities; medical aids; product safety; public health and safety; science and technology transfer; standards; basic research; computer; energy conservation; environmental quality; industrial productivity; SP538.

Mathematical function testing; test data for elementary functions; test data for mathematical functions; elementary function testing; Fortran library test data; Fortran library testing; NBSIR $78-1478$.

Mathematical model; oxygen; oxygen sensor; permeation; polarographic sensor; polymer membrane; diffusion; dissolved oxygen; NBSIR 79-1740.

Mathematical modeling; measurement; photogrammetric; precision; ship cargo; statistical analysis; strapping; survey; accuracy; cryogenic; error estimation; liquefied natural gas; LNG; marine; NBSIR 79-175I.

Mathematical modeling; nuclear engineering; reliability; risk; safety factor; sampling; Weibull distribution; corrosion fatigue; design; engineering judgment; factor of safety; fatigue; 18326 .

Mathematical modeling; numerical modeling; pipe flows; turbulence modeling; flowmeter; fluid dynamics; 18410 .

Mathematical modeling; paper; paper fiber; report retrieval; scientific data; computer graphics; data base management; data retrieval; durability; fatigue; interactive system; NBSIR 79-1746.

Mathematical modeling; queuing models; race conditions; TCAM data flow; teleprocessing; input lockout; SP5OO-52, pp. $219-226$ (Oct. 1979).

Mathematical modeling, network; network, tensile properties; paper, interfiber bonding; paper, low-density handsheets; paper, pulp characterization; paper, tensile testing; J. Res. 84, No. 4, 299-318 (1979).

Mathematical models; mixtures; specific heating value; tank capacity tables; thermophysical properties data; total heating value; composition; custody transfer; density; flow rate; $L N G$; 18838 .

Mathematical models; policy analysis; software; standards; transfer; documentation; energy; evaluation; guidelines; implementation; large-scale; management; SP534.

Mathematical programming; matrices; name generation; operations research; programming languages; sparse matrices; data pooling; data structures; J. Res. 84, No. 1, 21-47 (1979).

Mathematical programming; nursing homes; renovation; applied economics; building codes; building economics; economic analysis; fire safety; health care facilities; hospitals; life safety; NBSIR 79-1902.

Mathematical programming; nursing homes; renovation; applied economics; building codes; building economics; economic analysis; fire safety; health care facilities; hospitals; life safety; 19045 .
Mathematical software: non-linear oscillations; algebra by computer; differential equations; J. Res. 84. No. 4, 293-297 (1979).

Matrices; name generation; operations research; programming languages; sparse matrices; data pooling; data structures; mathematical programming; J. Res. 84, No. 1, $21-47$ (1979).

Matrix; modeling; vapors; combustion; equilibrium; high temperature; isolation; lasers; mass spectrometry; SP56I, Vols. I and 2 .

Matrix crazing; nondestructive testing; pressure vessels; composites; holography; interferometers; SP563, pp. 211-212 (Oct. 1979).

Matrix groups; roots of unity; free groups; J. Res. 84, No. 2, $179-180(1979)$.

Matrix isolation; methane; methyl fluoride; methyl radical; $F$ atom production; $\mathrm{F}$-atom reactions; $\mathrm{H}$-atom abstraction; hydrogen bonding; hydrogen fluoride; infrared spectrum; 18869 .

Matrix isolation; methyl cyanide; ultraviolet spectrum; vacuum ultraviolet photolysis; CCN; CNC; far infrared spectrum; HCCN; infrared spectrum; interferometer; 18842 .

Matrix isolation; methyl cyanide; ultraviolet spectrum; vacuum ultraviolet photolysis; charge transfer; cyanomethyl radical; excited argon atoms; force constants; infrared spectrum; ketenimine; 18879 .

Matrix isolation; molecular ions; photochemistry; ultraviolet spectra; charge transfer; excited argon atoms; free radicals; infrared spectra; 18847 .

Matrix sign patterns; positive matrix; Hadamard product; inverse-positive matrix; 18524 .

Matrix-isolation; metric conversion; satellite system; computer network; computer standards; fire safety; gamma-ray spectroscopy; DIM/NBS 63, No. 7/8, 1-28 (1979).

Mattresses; nursing homes; photoelectric detectors; corridors; escape; fire detectors; full-scale tests; heat detectors; hospitals; ionizaton detectors; NBSIR 79-1739.

Mattresses; prisons; bedding; beds; compartment fires; firesafety engineering; fire tests; health care facilities; hospitals; 18517.

Mattresses; smoke movement; sprinkler systems; health care facilities; hospitals; NBSIR 79-1749.

Maximum entropy; nonequilibrium statistical mechanics; nonequilibrium thermodynamics; projection operator; correlation functions; equations of motion; 18321 .

Maxwell's equations; solenoids; Ampere's law; dimensional metrology; fundamental constants; gyromagnetic ratio of proton; magnetic fields; $l 8437$.

Mayer-Montroll; BBGKY; correlation functions; Kirkwood-Salsburg: 19004 .

Mean field approximation; ternary interactions; theta point; virial coefficients; collapse transition; fluctuations; 19023.

Mean life; oscillator strength; Al 1; aluminum; delayed coincidence; $f$-value; imprisonment; laser; lifetime; 18527 .

Measurement; measurement compatibility; reference materials; standard reference materials; analytical laboratory; certified reference materials; 18748 .

Measurement; metrology; precision; test equipment; calibration; Federal Government; laboratory; SP546, 1979 Edition.

Measurement; metrology; quality control; standards; technology transfer; UN Conference on Science and Technology for Development (UNCSTD); Africa; Asia; developing countries; industrialization; Latin America; management; SP543.

Measurement; modeling; on-line system design; performance evaluation; performance management; prototyping; remote terminal emulation; system testing; audit; capacity planning; financial applications; long-range planning; management control; SP500-52, pp. 129-140 (Oct. 1979).

Measurement; optical communications; review; communication systems; fiber optics; 18648 . 
Measurcment; pedestrian movement; rcgulation; safcty; standards: architectural barriers; building design; building sitc planning; cnvironmental psychology; evaluation; fire cscape; human rcscarch: SP552, pp. 101.113 (July 1979).

Meusurement; pedestrian movement; regulation; safcty; standards; architcctural barricrs; building design; building site planning; cnvironmental psychology; evaluation; fire escape; human rescarch; 18430 .

Mcasurcment; performancc measuremcnt; computer; computer communications; computer performance measurement; data measurcment; SP500-52, pp. 201-211 (Oct. 1979).

Measurcment; photogrammetric; precision; ship cargo; statistical analysis; strapping; survey; accuracy; cryogenic; error estimation; liquefied natural gas; LNG; marine; mathematical modcling; NBSIR 79-175I.

Mcasurcment; rating; solar; standards; testing; computer; hot watcr; 18428 .

Measurement; reference standards; safety research; walkway slip-rcsistance; friction; SP565.

Measurement; solar collector; solar energy; solar radiation; standards; standard test; testing; BSS 117.

Measurement; thermography; Twin Rivers Project; weather station; air infiltration; buildings; data acquisition; energy; instrumentation; 18733 .

Mcasurement assurance; measurement consistency; measurement system; national standards; radiation; radiation control; radiation measurements; traceability; 18800 .

Measurement assurance; measurement process control; systematic error; uncertainty; calibration; gage blocks; length; Monogr. 163.

Measurement assurance; metrication; model laws and regulations; national type approval; packaging and labeling; specifications and tolerances; vapor recovery: weights and measures; consumer affairs; education; electromagnetic interference; electronic devices; SP532.

Measurement assurance; traceability; automated test equipment; 18354 .

Measurement assurance program; reference blocks; standards; ultrasonics; variability; calibration; diffusion bonding; NBSIR 79.1742 .

Measurement Assurance Programs; quality assurance; environmental measurements; 18720 .

Measurement automation; p-Terphenyl; thermodynamic properties; $\lambda$-type transition; adiabatic calorimetry; automated calorimetry; calorimetry; heat capacity; 18376.

Mcasurement capabilities; medical aids; product safety; public health and safety; science and technology transfer; standards: basic research; computer; energy conservation; environmental quality; industrial productivity; materials utilization; SP538.

Measurement compatibility; reference materials; standard reference materials; analytical laboratory; certified reference materials; measurement; 18748 .

Measurement consistency; measurement system; national standards; radiation; radiation control; radiation measurements; traceability: measurement assurance; 18800 .

Measurement development; photovoltaics; reliability; solar arrays; solar cells; workshops; laser scanner; 18322

Measurement instrumentation; measurement standard; modulation; modulation factor; modulation meter; Newton-Raphson method; percent modulation; signal generator; vhf omnidirectional radio range (VOR); amplitude modulation; instrument landing system (ILS); TN1016.

Measurement method; nondestructive testing; photoconductivity; power devices; resistivity variation; automation; bulk photovoltaic effect; computer control; homogeneity; SP4OO52.

Measurement method; powder diffaction; reactive atmosphere; coal gasification; high pressure; high temperature; 18945 .
Measurement methods; power-device grade silicon; resistivity variations; silicon; spreading resistance measurements; thermally stimulated measurements; thyristor materials measurements; thyristor measurements; d-c transmission; deep level measurcments; NBSIR 79-1756.

Measurement procedures; observer proximity effects; power transmission lines; Russian measurement technique; electric field measurements; instrumentation; 18494 .

Measurement procedures; susceptibility and emission measurements; transverse electromagnetic cell; TN1O13.

Measurement process control; systematic error; uncertainty; calibration; gage blocks; length; measurement assurance; Monogr. 163.

Measurement science; science students; SRM; titanium alloy; analytical chemistry; ion-chromatography; law enforcement standards; materials properties; DIM/NBS 63 , No. 1/2, 1-28 (1979).

Measurement services; standardization: AlD; assistance; developing economies; foreign relations; industrializing nations; international relations; LDC's; NBSIR 78-1712.

Measurement standard; modulation; modulation factor; modulation metcr; Newton-Raphson method; percent modulation; signal generator; vhf omnidirectional radio range (VOR); amplitude modulation; instrument landing system (ILS); measurement instrumentation: TNI016.

Measurement system; national standards; radiation; radiation control; radiation measurements; traceability; measurement assurance; measurement consistency; 18800 .

Measurement system; standard reference materials; temperature; thermal conductivity; thermal expansion; thermal properties; vapor pressure; viscosity; calorimetry; elasticity; electrical resistivity; emittance; $\mathbf{l} 8905$.

Measurement technique; scatter contribution; source capsule; source housing; spectrometry results; ${ }^{60} \mathrm{CO}$ gamma-ray beam; calibration source; collimation system; data-rcduction technique; low-activity replacement source; 18416 .

Measurement techniques; medical accelerators; neutrons; relative biological effect; shielding techniques; standards; dosimetry; high energy radiotherapy beams; leakage; SP554.

Measurement techniques; standards; building research; criteria; energy; engineering; industry construction: SP439-1.

Measurement techniques; standards; superconductors; critical current; definitions of terms; 18762 .

Measurement technology; microcalorimetry; moisture; nondestructive testing; pacemaker leads; process control; reliability; semiconductor devices; welding; automated testing; batteries: cardiac pacemakers; contamination; corrosion; electrostatic-induced damage; hermeticity; SP4OO-5O.

Measurement technology; microelectronics; semiconductor devices; semiconductor materials; semiconductor process control; sílicon; electronics; integrated circuits; NBSIR 78 1444-3.

Measurement technology: microelectronics; semiconductor devices; semiconduct or materials; semiconductor process control; silicon; electronics; integrated circuits; NBSIR 79. 1591 .

Measurement technology: microelectronics; semiconductor devices; semiconductor materials; semiconductor process control; silicon; electronics: integrated circuits; NBSIR 79 . 1591-2.

Measurement technology; microelectronics; semiconductor devices; semiconductor materials; semiconductor process control; silicon: electronics; integrated circuits; NBSIR 79. 1591-3.

Measurement technology: power transistors; semiconductor devices; thermal characterization; thermal resistance; transistors; current crowding; die attachment evaluation; junction temperature; $S P 400-14$. 
Mcasurement tcchnology assessment; National Measurement Systcm; standards; calibrations; dissemination of units; electrical mcasurcments; electric power measurements; electrotechnology; impact of mcasurements; NBSIR 75-935.

Mcasurcment-bcam gcometry; relative spectral responsivity; slit-scattcring function; slit-scattering function corrections; spectral linc radiometry; spectroradiometer characterizations; spectroradiometry; vignetting; aperture/aperture-image pair; aperturc pair; TN9/O-4.

Measurcments; attenuation; fiber optics; frequency response; 18915

Measurements; metrology; physical standards; seminar; South Asia; developing countries; industrializing countries; Korea; SP5 39.

Measurements; microwaves; radiofrequency; standards; calibrations; $1856 I$

Measurements; microwaves; super spring; ultraviolet radiation; calibrations; energy; fluid mixtures; light; liquefied natural gas; DIM/NBS 63, No. 9, 1-32 (1979).

Mcasurements; ncutrons; Np-237; Pu-239; U-235; U-238; activation analysis; benchmark fields; dosimetry; fission yields; 18884

Measurements; optical communications; quality control; attenuation; fiber optics; interlaboratory comparison; NBSIR $79-1608$.

Measurements; radiation; radiation control; radiation measurements; radiation protection; radiation safety; standards; states; calibrations; $/ 8779$

Measurements; radioactivity; standards; traceability; low-level; 18400 .

Measurements; review; attenuation measurements; fiber optics; frequency response measurements; / 8647 .

Measurements; standards; VDE; antennas; CISPR; ground screen; $/ 9033$.

Measurements; superconductivity; electronics; instruments; integrated circuits; Josephson junctions; $/ 8859$.

Measurements; transverse electromagnetic transmission cells; electromagnetic compatibility; 18578

Measurements; voltage dividers; voltage ratio; calibrations; inductive voltage dividers; international comparison; $/ 8664$.

Measures; scales; specifications; taximeters; tolerances; volumemeasuring devices; weighing devices; weights; length-measuring devices; liquid-measuring devices; H44, 1979 Edition.

Measures; weights; weights and measures; AID; assistance; developing economies; foreign relations; industrializing nations; international relations; NBSIR 79-I72I

Mechanical failures; steam-valves; turbine operational safety; turbogcnerators; detection procedures; SP547, pp. 250-279 (July 1979).

Mechanical impedance; mechanical vibrations; noise control; transmissibility; vibration isolation; vibrations; antivibration mounting; damping; dynamic properties; industrial engineering; isolation; machinery and equipment; $H I 28$.

Mechanical porperties; modulus; strength; superconducting motor; composites; fiberglass; 18616 .

Mechanical porperties; stainless steel; crack propagation; fatigue; fracture resistance; low temperature tests; $1862 I$.

Mechanical properties; aluminum alloys; crack propagation; cryogenics; fatigue; fracture; low temperature tests; 18610 .

Mechanical properties; aluminum alloys; ferrous alloys; fracture mechanics; LNG; low temperature; 18865

Mechanical properties; metallurgical properties; niobium-titanium; physical properties; superconductors; electrical properties; low temperatures; 18552 .

Mechanical properties; moisture; non-destructive testing; preservation; adobe; adobe soil; compressive strength; creep; flexural strength; TN996.

Mechanical properties; moisture; prepreg; aging of polymer; composite; fiber; SP563, pp. 17-21 (Oct. 1979).
Mechanical properties; nitrogen; nitrogen-strengthened; stainless steel; tensile properties; toughness; cryogenic; fatiguc: fracture; high-strength; low-temperature; 18957.

Mechanical properties; nonmetallics; physical properties; stainless steel; alloys; fiberglass; NBSIR 79-I609.

Mechanical properties; optical properties; ultraviolet transmission; fluorides; forging; laser windows; lithium fluoridc; SP54I, pp. 59-64 (Dec. 1978).

Mechanical properties; physical properties; radiation properties; cryogenics; glass-epoxy; industrial laminates; 18771 .

Mechanical properties; polystyrene; polyurethane; thermal insulation; thermal properties; cellular plastic; low temperature; 18719.

Mechanical properties; stainless steel alloys; crack propagation; cryogenics; fracture; low temperature tests; martensitic transformations; / 8943

Mechanical properties; tissue damage; tissue death; cell detachment; SP525, pp. 317-322 (Apr. 1979).

Mechanical properties; titanium; titanium alloys; electron beam welding; fatigue (materials); fracture properties; low temperature tests; $186 I I$.

Mechanical testing; additive damage; biaxial fatigue; biomaterials; circulatory assist devices; fatigue of polymers; NBSIR 79 . I74I.

Mechanical vibrations; noise control; transmissibility; vibration isolation; vibrations; antivibration mounting; damping; dynamic properties; industrial engineering; isolation; machinery and equipment; mechanical impedance; $H I 28$.

Mechanism; photochemistry; carbon dioxide; carbon monoxide; carbonyl; exchange; hydroxyl; kinetics; 18436 .

Mechanism; photochemistry; radicals; rate constant; acetylene; butadiyne; ethynyl; hydrogen; 18443 .

Mechanism; reactions; tropospheric chemistry; aromatics; free radicals; SP557, pp. 85-91 (Aug. 1979).

Mechanism of formation; molecular compound; silver-sulfurtungsten cluster; synthesis; $x$-ray diffaction; crystal structure; 18636.

Mechanisms; modeling; multiphoton; unimolecular dissociation; infrared laser; kinetics; $/ 87 / 2$

Mechanisms; multiphoton; thermochemistry; unimolecular dissociation; calorimetry; infrared; kinetics; laser chemistry; I 8709 .

Mechanisms; viscous relative motion; inhomogeneities; inhomogeneity thermal losses; SP525, pp. 37-40 (Apr. 1979).

Mechanochemical polishing; quartz crystal; sapphire; Si single crystal; high pressure; high temperature; SP562, pp. 171.182 (Oct. 1979).

Mechanochemical polishing with soft powder; pre-existing defect; sapphire; solid state reaction; water vapor; working unit; damaged layer; elastic emission machining; environmental effect; hydrate; hydration polishing; SP562, pp. 157-169 (Oct. 1979)

Median, radial and lateral cracks; plastic indentations; residual stresses; shear flow lines; crack nucleation; fracture; SP562, pp. 15-20 (Oct. 1979).

Medical accelerator; neutrons; scatter; $x$ rays; dose; leakage; SP554, pp. 25-28 (Sept. 1979).

Medical accelerators; neutrons; relative biological effect; shielding techniques; standards; dosimetry; high energy radiotherapy beams; leakage; measurement techniques; SP554.

Medical aids; product safety; public health and safety; science and technology transfer; standards; basic research; computer; energy conservation; environmental quality; industrial 
productivity; materials utilization; measurcment capabilities; SP538.

Medical applications; mctrology; NDE; radiation force; transduccr charactcrization; ultrasonics; acoustic theory; calorimetry; elcctroacoustic method; 18438 .

Medical diagnosis; microscopy; pattern rccognition; scattering; signal processing; tissue characterization; tissue parameters; ultrasound; velocity; absorption; attcnuation; computerized tomography; Doppler; impedance; SP525.

Medical electronics; microwave electronics; nonionizing radiation; radiation hazards; radio regulations; radio standards; RFl; spectrum management; standardization organizations; telccommunications; TVI; vehicular electronics; electromagnetic bioeffects; SP55I

Medium speed diesel engine; piston ring wear; turbocharging monitoring; crankshaft displacement; SP547, pp. 153-166 (July 1979).

Medullary carcinoma; papillary carcinoma; scirrhous carcinoma; shadowing; ultrasound; attenuation; breast cancer; cancer; connective tissue; differential diagnosis; SP525, pp. 93-99 (Apr. 1979)

Megavoltage; neutrons; therapy; $x$ rays; accelerators; betatrons; electrons; SP554, pp. 1-14 (Sept. 1979).

Melatonin; negative chemical ionization mass spectrometry; human plasma; SP519, pp. 399-404 (Apr. 1979).

Melting line; n-butane; orthobaric densities; specific heats; speeds of sound; vapor pressures; densities; enthalpies; entropies; equation of state; internal energies; isobars; isochores; isotherms; Joule-Thomson inversion; latent heats of vaporization; NBSIR 79-I62I.

Melting line; orthobaric densities; specific heats; speeds of sound; vapor pressures; densities; enthalpies; entropies; equation of state; internal energies; isobars; isobutane; isochores; isotherms; Joule-Thomson inversion; latent heats of vaporization; NBSIR 79-16I2.

Melting temperature; metastable states; phenyl substituted diglycerides; phospholipids; polymorphism; recrystallization temperature; benzyl substituted diglycerides; differential scanning calorimetry; heat of fusion; lecithins; lipids; $I 8380$.

Melting temperature; miniature Christmas lights; plastic insulating material; polyethylene; series-constructed; electric shock; fire; flaming ignition; glowing ignition; hazard; ignition temperature; lamp surface temperature; NBSIR 79-1716.

Melting temperature; molybdenum pentafluoride; vapor density; vapor pressure; enthalpy and entropy of vaporization; entrainment method; 19020 .

Memory; microprocessor; testing; electronics; integrated circuit; large scale integration; TNIIO2.

Mensuration; microdensitometry; microlithography; micrometrology; microscopy; partially coherent imaging; I8356.

Mental retardation; ambulatory people; autism; cerebral palsy; deafness; developmentally disabled; epilepsy; fire safety; group homes; handicapped; NBS-GCR-79-167.

Mercury; metal; methylation; microbial tolerance; microorganism; plasmid; tin; arsenic; bio-transformation; cadmium; food chain; lead; 18860 .

Meridian designator; time differential factor; time zone references; Uniform Time Act of 1966; universal time; American National Standard Representation for Calendar Date and Ordinal Date for Information Interchange; local time differentials; FIPS PUB 59.

Meridian designators; separators; sequencing; time elements; timekeeping systems; time representations; American $\mathrm{Na}$ tional Standard Representation for Calendar Date and Ordinal Date for Information Interchange; FIPS PUB 58.

Metabolism; methandienone; urine; anabolic steroids; clean-up; contamination; dianabol; gas chromatography-mass spectrometry ( $\mathrm{gc} / \mathrm{ms})$; gas liquid chromatography ( $\mathrm{glc}) ; \mathrm{gc} / \mathrm{ms}$ interface; SP519, pp. 437-445 (Apr. 1979).
Metabolites; polynuclear aromatic hydrocarbons; high-pressure liquid chromatography; marine biota; SP519, pp. 79-86 (Apr. 1979).

Metabolites; psychotropic amines; selectivity; sulphonamides; amino acids; barbiturates; carboxylic acids; catecholamines; conjugates; detection sensitivity; dipeptides; drugs; HPLC; ion-pair adsorption; ion-pair chromatography; SP5/9, pp. 509-523 (Apr. 1979).

Metal; methylation; microbial tolerance; microorganism; plasmid; tin; arsenic; bio-transformation; cadmium; food chain; lead; mercury; 18860 .

Metal atoms; excimer lasers; excimer molecules; 18877 .

Metal hydrides; rare-earth hydrides; cerium dihydride; crystalfield splitting; inelastic neutron scattering; magnetic properties of rare earth alloys; 19030 .

Metal liner; composite materials; critical flaw size; cyclic fatigue life; filament wound tankage; leakage failure mode; linear elastic fracture mechanics; SP563, pp. 198-207 (Oct. 1979).

Metal oxides; molecular absorption; opto-galvanic spectroscopy; uv irradiation; light absorption; 18344 .

Metal speciation; organomercury cations; biological samples; electrochemical detection; liquid chromatography; 18420 .

Metal texture; neutron diffraction; nondestructive testing; pole figure; texture of copper shaped charge liner; texture of $\mathrm{Ni}$ W alloy; 19027 .

Metal vapor production; sputtering; charge transfer; hollow cathode discharge; 18968 .

Metallic membrane; permeability; preservation technology; adobe building materials; chemical grouts; damp course membrane; NBSIR 79-I730.

Metallization; ohmic contacts; reliability; semiconductor measurements; sheet resistance; solar cells; solar cell stability; device measurements; laser scanning; light-biasing; NBSIR 79. 1909 .

Metallization; ohmic contacts; reliability; semiconductor measurements; solar cells; solar cell stability; workshops; device measurements; laser scanning; $/ 8633$.

Metalloborane; nickelaborane; nuclear magnetic resonance; boron hydride; 18328 .

Metallurgical characterization; microstructures; molybdenum; optical characterization; laser mirror; SP54I, pp. 132-163 (Dec. 1978).

Metallurgical properties; niobium-titanium; physical properties; superconductors; electrical properties; low temperatures; mechanical properties; 18552 .

Metal-matrix composites; polymer matrices; advanced-fiber composites; cryogenics; industrial laminates; low-pressure laminates; 18631 .

Metals; molten metals; palladium; precious metals; reference data; silver; solid state physics; transport properties; copper; critical evaluation; data analysis; data compilation; data evaluation; data extraction; data synthesis; JPCRD 8, No. 4, $1147-1298$ (1979).

Metals; particle erosion; wear; abrasives; ceramics; erosion; impact; NBSIR 78-1575.

Metals; particle erosion; wear; abrasives; ceramics; erosion; impact; 18858 .

Metastable phases; niobium-silicon alloys; splat-cooling; superconductivity; intermetallic compounds; liquid quenching; 18734 .

Metastable states; phenyl substituted diglycerides; phospholipids; polymorphism; recrystallization temperature; benzyl substituted diglycerides; differential scanning calorimetry; heat of fusion; lecithins; lipids; melting temperature; 18380 .

Meteorite; Mighei; abiotic synthesis; carbonaceous chondrite; chemical evolution; SP519, pp. 771-775 (Apr. 1979). 
Methacrylate monomcrs; polymcrization accclerators; reinforcing fillers; silanc coupling agents; benzoyl pcroxide; compositc resins; dental matcrials; glass compositions; 18644

Methandienone; urinc; anabolic stcroids; clcan-up; contamination; dianabol; gas chromatography-mass spectromctry ( $\mathrm{gc} / \mathrm{ms})$; gas liquid chromatography ( $\mathrm{glc}) ; \mathrm{gc} / \mathrm{ms}$ interface; high pcrformance liquid chromatography (hplc); SP5/9, pp. 437-445 (Apr. 1979).

Methane; methyl fluoride; methyl radical; F-atom production; F-atom reactions; $\mathrm{H}$-atom abstraction; hydrogen bonding; hydrogen fluoride; infrared spectrum; matrix isolation; 18869.

Methane; minimization of Gibbs energy; phase rule; simultaneous chemical equilibria; water; BASIC; carbon dioxide; carbon monoxide; coal gasification; COLGAS; hydrogen; interactive computer program; NBSIR 78-1509.

Methane + ethane; binary mixtures; data correlation; excess volumes; heat of mixing; liquid-vapor equilibria; JPCRD $\mathbf{8}$, No. 3, 799-816 (1979).

Method of measurements; non-dispersive; resistive loading; TEM horn; time domain measurement; antenna gain; broadband antenna; directivity; FFT; 18856 .

Methodology; administrative experimentation; managerial decision-making; 18722

Methodology; needs; Performance Management System (PMS); capabilities; SP500-52, pp. 69-77 (Oct. 1979).

Methods; preparation; sampling; aflatoxin analysis; food and feed analysis; SP519, pp. 355-372 (Apr. 1979).

Methyl; methyl chloride; photochemistry; chloride; 18340.

Methyl chloride; monochlorinated organics; carrier gas doping; electron capture detector; SP519, pp. 143-151 (Apr. 1979).

Methyl chloride; photochemistry; chloride; methyl; 18340 .

Methyl cyanide; ultraviolet spectrum; vacuum ultraviolet photolysis; CCN; CNC; far infrared spectrum; HCCN; infrared spectrum; interferometer; matrix isolation; 18842.

Methyl cyanide; ultraviolet spectrum; vacuum ultraviolet photolysis; charge transfer; cyanomethyl radical; excited argon atoms; force constants; infrared spectrum; ketenimine; matrix isolation; 18879 .

Methyl fluoride; methyl radical; F-atom production; F-atom reactions; $\mathrm{H}$-atom abstraction; hydrogen bonding; hydrogen fluoridc; infrared spectrum; matrix isolation; methane; $/ 8869$.

Mcthyl fluoride; Stark; far-infrared; laser; 18426 .

Mcthyl formate; microwave spectrum; radio astronomy; rotational transitions; internal rotation; interstellar molecules; line strengths; JPCRD 8, No. 3, 583-618 (1979).

Methyl group; neutron scattering; potential barrier; quasielastic scattering; reorientation; residence time; tunneling; activation energy; 18374.

Methyl iodiode; photodissociation; radical; infrared emission; laser; methylene iodiode; 18573.

Methyl radical; F-atom production; F-atom reactions; $\mathrm{H}$-atom abstraction; hydrogen bonding; hydrogen fluoride; infrared spectrum; matrix isolation; methane; methyl fluoride; 18869 .

Methylation; microbial tolerance; microorganism; plasmid; tin; arsenic; bio-transformation; cadmium; food chain; lead; mercury; metal; 18860 .

Methylation; sample preparation; clinical chemistry; drug analysis; gas chromatography; internal standards; SP519, pp. 381 390 (Apr. 1979).

Methyl-branch; structure; calculations; cell dimensions; crystal; defect; energy; hydrocarbon; 18787

Methylene iodiode; methyl iodiode; photodissociation; radical; infrared emission; laser; 18573

Methylmercury; methyltin; NMR; primary salt effect; speciation; activation parameters; aqueous transmethylation: chloride complexes; environment; formation constants; ionic mechanisms; kinetics; 18484 .
Methylmercury; organometals; water preconcentration; electrochemical detection; liquid chromatography; SP5/9, pp. 57-63 (Apr. 1979).

Methyltin; NMR; primary salt cffcct; speciation; activation parameters; aqueous transmethylation; chloride complexes; environment; formation constants; ionic mechanisms; kinetics; methylmercury; 18484 .

Metric; building codes; construction; SP552, pp. 283-291 (July 1979).

Metric; refractory concrete; resource conservation and recovery; chemical degradation; coal conversion; coal gasifier; computers; data; DIM/NBS 63, No. 12, 1-32 (1979).

Metric conversion; satellite system; computer network; computer standards; fire safety; gamma-ray spectroscopy; matrixisolation; DIM/NBS 63, No. 7/8, 1-28 (1979).

Metric units; centimeter; conversion; customary units; inch; SP376.

Metrication; model laws and regulations; national type approval; packaging and labeling; specifications and tolerances; vapor recovery; weights and measures; consumer affairs; education; electromagnetic interference; electronic devices; SP532.

Metrication; SI; stages in metrication; construction specifications; conversion approaches; dimensional coordination; 18493.

Metrology; NDE; radiation force; transducer characterization; ultrasonics; acoustic theory; calorimetry; electroacoustic method; medical applications; 18438 .

Metrology; noise thermometry; SQUID's; standards; superconductivity; Josephson effect; 18871 .

Metrology; physical standards; seminar; South Asia; developing countries; industrializing countries; Korea; measurements; SP539.

Metrology; power measurements; precise electrical measure.ments; TDM wattmeters; thermal wattmeters; transfer standards; electro-dynamic wattmeters; energy measurements; energy standards; international comparisons; 18529 .

Metrology; precision; test equipment; calibration; Federal Government; laboratory; measurement; SP546, 1979 Edition.

Metrology; quality control; standards; technology transfer; UN Conference on Science and Technology for Development (UNCSTD); Africa; Asia; developing countries; industrialization; Latin America; management; measurement: SP543.

$\mathrm{Mg}$ ions; optical \& microwave double resonance; stored ions; systematic effects; Ba ions; frequency stability; frequency standard; ion temperature; laser induced cooling; 18697.

$\mathrm{MgF}_{2} ; \mathrm{NaCl} ; \mathrm{NaF}$; piezo-optic constants; refractive index; $\mathrm{SiO}_{2}$; $\mathrm{SrF}_{2}$; thermal expansion coefficient; thermo-optic constant; $\mathrm{ZnS} ; \mathrm{ZnSe} ; \mathrm{Al}_{2} \mathrm{O}_{3} ; \mathrm{As}_{2} \mathrm{~S}_{3}$ glass; TN993.

Michelson interferometer; phase locked oscillators; retroreflectors; counting and control circuitry; fringe counting interferometric method and apparatus; U.S. Patent 4,165,183.

Michelson-Morley experiment; special relativity; stabilized lasers; isotropy of space; 18875

Michelson-Morley experiment; special relativity; stabilized lasers; isotropy of space; 18952.

Microanalysis; micromineralogy; microsampling; molecular analysis; organic microanalysis; Raman microprobe; Raman spectra; Raman spectroscopy; biological microanalysis; 18963.

Microanalysis; microparticle analysis; microprobe resolution: microsample heating; optical detection; Raman microprobe; Raman spectra; Raman spectroscopy; laser excitation; 18971 .

Microanalysis; mineralizing tissue; Raman microprobe; Raman spectroscopy; biological microanalysis; biological mineralization; bone; dental studies; dentin; enamel; 19008.

Microanalysis; molecular microanalysis; pathological tissue; Raman microprobe; Raman spectra; Raman spectroscopy; biological microanalysis; biological tissue; foreign bodies; histological sections; implant materials; 18958. 
Microanalysis; Monte Carlo electron trajectory simulation; spatial resolution; thin foils; $x$ rays; analytical electron microscopy: 18589.

Microanalysis; particle analysis; pollution studies; power plants; Raman microprobe; Raman spectroscopy; vibrational spectra; 18966.

Microanalysis; qualitative analysis; scanning electron microscope; artifacts; electron probe microanalysis; energydispersive $x$-ray spectrometry; 18790 .

Microanalysis; secondary ion mass spectrometry; $x$-ray microanalysis; Auger electron spectroscopy; cathodoluminescence; ion scattering spectrometry; laser microprobe mass analyzer; laser Raman microprobe; 18568.

Microanalysis; secondary ion mass spectrometry; surface analysis; elemental analysis; ion microprobe mass analyzer; local thermal equilibrium model; 18979.

Microbial tolerance; microorganism; plasmid; tin; arsenic; biotransformation; cadmium; food chain; lead; mercury; metal; methylation; 18860 .

Microcalorimetry; moisture; nondestructive testing; pacemaker leads; process control; reliability; semiconductor devices; welding; automated testing; batteries; cardiac pacemakers; contamination; corrosion; electrostatic-induced damage; hermeticity; hybrid devices; SP4OO-5O.

Microcalorimetry; radiation calorimetry; solution calorimetry; bomb calorimetry; drop calorimetry; electromagnetic power calorimetry; energy measurement; enthalpy measurement; entropy measurement; fuels, heating values; gas-flow calorimetry; heat capacity measurement; 18330 .

Microchannel plate; radiography; x ray; imaging; low-dose; lowintensity; 19000 .

Microcircuit device; particle detection; particle impact noise detection; PIND; pre-shock; seeded specimens; transducer; acoustic emission; co-shock: couplant; detection; electronic package; impact noise; NBSIR $78-1590$ (NASA).

Microcomputer; ac voltage measurement; low frequency; 18455.

Microcomputer; routine analysis; trace organics in water; gas chromatography/mass spectrometry; SP519, pp. 169.173 (Apr. 1979).

Microcreep; micromechanical properties; beryllium; dimensional stability; gyroscope; instrument materials; NBSIR 78 1569.

Microdensitometry; microlithography; micrometrology: microscopy; partially coherent imaging; mensuration; $\mathbf{1 8 3 5 6}$.

Microdosimetry parameters; neutron cross section evaluations; single-event energy; energy deposition spectra; 18658 .

Microdot reference specimens; secondary ion mass spectroscopy (SIMS); silicon sputtering; dopant analysis; impurity analysis; ion microprobe mass analyzer (IMMA); NBS-GCR-79. 158.

Microelectronics; semiconductor devices; semiconductor materials: semiconductor process control; silicon; electronics; integrated circuits; measurement technology; NBSIR 781444-3.

Microelectronics; semiconductor devices; semiconductor materials; semiconductor process control; silicon; electronics; integrated circuits; measurement technology; NBSIR 79 . 1591 .

Microelectronics; semiconductor devices; semiconductor materials; semiconductor process control; silicon; electronics; integrated circuits; measurement technology; NBSIR 79. 1591-2.

Microelectronics; semiconductor devices: semiconductor materials; semiconductor process control; silicon; electronics; integrated circuits; measurement technology; NBSIR 79. 1591-3.

Microfluorescence; saturation spectroscopy; tunable laser; atomic flame fluorescence; intracavity absorption; isotope analysis; laser analysis; laser fluorescence; laser spectroscopy; 18364.

Microhardness; microstructure; piezoelectricity; thermodynamics; ultrasound; viscoelasticity; wave propagation; anisotropy dispersion; elasticity; human bone; SP525, pp. 189-196 (Apr. 1979 ).

Microlithography; micrometrology; microscopy; partially coherent imaging; mensuration; microdensitometry; 18356

Microlithography: micrometrology; optical microscopy; linewidth measurement; 18629.

Micromanipulator; optical microscope stage; piezoelectric drives; scanning stage; SEM microscope stage; submicrometer positioning instrumentation; TEM microscope stage; flexure pivots; linear positioning; 18327.

Micromechanical properties; beryllium; dimensional stability; gyroscope; instrument materials; microcreep; NBSIR $788_{-i}$ 1569.

Micrometer scale; scanning electron microscope scale; electrodeposited metal layers; gold-nickel layers; U.S. Patent 4,139,933.

Micrometrology; microscopy; partially coherent imaging; mensuration; microdensitometry; microlithography; 18356 .

Micrometrology: optical microscopy; linewidth measurement; microlithography; 18629.

Micromineralogy; microsampling; molecular analysis; organic microanalysis; Raman microprobe; Raman spectra; Raman spectroscopy; biological microanalysis; microanalysis; 18963 .

Microorganism; plasmid; tin; arsenic; bio-transformation; cadmium; food chain; lead; mercury; metal; methylation; microbial tolerance; 18860 .

Microparticle analysis; microprobe resolution; microsample heating; optical detection; Raman microprobe; Raman spectra; Raman spectroscopy; laser excitation; microanalysis; 18971

Microphone; porous sphere; sphere; spheres; wind noise; windscreen; windscreen performance; windscreens; acoustics; flow; insertion loss; NBSIR 79-1599.

Microphonic coupling; phase angle; surface films; capacitor; cross capacitor; dielectric; dissipation factor; loss angle; 18454.

Microprobe resolution; microsample heating; optical detection; Raman microprobe; Raman spectra; Raman spectroscopy; laser excitation; microanalysis; microparticle analysis; 18971 .

Microprocessor; network; serial; broadcast; coaxial; communication; contention; data; digital; ethernet; local; 18760 .

Microprocessor; testing; electronics; integrated circuit; large scale integration; memory: TNI 102 .

Microprocessor-controlled data acquisition; myocardial infarction; real-time; tissue characterization; ultrasound diagnosis; clinical cardiac data; digital processing; Fast Fourier Transform; frequency spectra; in vivo; SP525, pp. 267-273 (Apr. 1979).

Microprocessors; satellite; synchronization; time; clock; GOES; 18393

Microradiography; radiography; radiology; real-time radiography; resolution; $x$-ray image magnifier; asymmetric diffraction; dynamical diffraction; 18399 .

Micro-Raman spectroscopy; organic microanalysis; PAH microsamples; (PAHs); polynuclear aromatic hydrocarbons; Raman spectra; trace organic analysis; laser-Raman microprobe; liquid chromatograph-Raman spectrometer interface; SP519, pp. 723-729 (Apr. 1979).

Microroughness; optical microscopy; polishing defects; scattered light; SIMS; stylus instruments; Auger spectroscopy: corrosion films; ESCA; impurities; SP562, pp. 337-350 (Oct. 1979).

Microsample heating; optical detection; Raman microprobe; Raman spectra: Raman spectroscopy; laser excitation; microanalysis: microparticle analysis; microprobe resolution; 18971. 
Microsampling; molecular analysis; organic microanalysis; Raman microprobe; Raman spectra; Raman spectroscopy; biological microanalysis; microanalysis; micromineralogy; 18963.

Microscopy; partially coherent imaging; mensuration; micrudensitometry; microlithography; micrometrology; 18356.

Microscopy; pattern recognition; scattering; signal processing; tissuc characterization; tissue parameters; ultrasound; velocity; absorption; attenuation; computerized tomography; Doppler; impedance; medical diagnosis; SP525.

Microspectrofluorimetry; photoluminescence; spectrofluorimetry; surfacc analysis; tetrazolc; benzotriazole; charge transfer; copper; luminescence; 18504.

Microstriplines; superconductivity; high spced logic; Josephson computer; Josephson junction; 18666 .

Microstructure; piezoelectricity; thermodynamics; ultrasound; viscoelasticity; wave propagation; anisotropy; dispersion; elasticity; human bone; microhardness; SP525, pp. 189-196 (Apr. 1979).

Microstructures; molybdenum; optical characterization; laser mirror; metallurgical characterization; SP541, pp. 132-163 (Dec. 1978).

Microwave; microwave measurement; six-port; automatic network analyzer; 18650 .

Microwave; microwave measurement; six-port; automatic network analyzer; 18653.

Microwave; microwave measurements; reflectometer; six-port; automation; 18652.

Microwave; profile effect on permittivity; temperature variation of permittivity; dielectric constant; dielectric loss; lunar soil; 18557.

Microwave electronics; nonionizing radiation; radiation hazards; radio regulations; radio standards; RFI; spectrum management; standardization organizations; telecommunications; TVI; vehicular electronics; electromagnetic bioeffects; electromagnetic compatibility; SP55I.

Microwave interaction regions; microwave signals; beam type device; frequency stabilizing system; U.S. Patent 4,146,848

Microwave measurement; six-port; automatic network analyzer; microwave; 18650 .

Microwave measurement; six-port; automatic network analyzer; microwave; 18653.

Microwave measurement; six-port; automatic network analyzer; calibration; 18849

Microwave measurements; microwave power; microwave systems; power monitor; reflectometers; six-port reflectometers; 18670 .

Microwave measurements; non-destructive evaluation; pipe welds; standard; $\mathrm{x}$-ray image; appropriations; fusion diagnostics; gravity waves; laser-interferometer; DIM/NBS 63, No. 3, 1-28 (1979).

Microwave measurements; reflectomcter; six-port; calibration; 18651.

Microwave measurements; reflectometer; six-port; automation; microwave; 18652 .

Microwave power; microwave systems; power monitor; reflectometers; six-port reflectometers; microwave measurements; 18670 .

Microwave receivers; microwavcs; mixers; superconductivity; tunnel junctions; Josephson junctions; 18683 .

Microwave remote scnsing; snow; centrifuge; comparison of measurement methods; free water; freezing calorimeter; hydrology forccasting; NBSIR 79-1604.

Microwave remote sensing; snowpack-water equivalence; snow stratigraphy; 18820 .

Microwave signals; beam type device; frequency stabilizing system; microwave interaction regions; U.S. Patent $4,146,848$
Microwave spectra; molecular constants; propyne; radio astronomy; rotational transitions; interstcllar molcculcs; line strengths; JPCRD 8, No. 2, 537-558 (1979).

Microwavc spectra; molecular parameters; radio astronomy; rotational transitions; vinyl cyanide; intcrstellar moleculcs; JPCRD 8, No. 1, 107-124 (1979).

Microwave spectroscopy; molecular conformation; molecular spectroscopy; molecular structure; molccules; structure; bond angles; bond distances; gas-phase polyatomic molecules; gasphase spectroscopy; JPCRD 8, No. 3, 619-722 (1979).

Microwave spectrum; radio astronomy; rotational transitions; internal rotation; interstellar molecules; line strengths; methyl formate; JPCRD 8, No. 3, 583-618 (1979).

Microwave spectrum; radio astronomy; rotational transitions; dimethyl ether; intcrnal rotation; interstellar molecules; JPCRD 8, No. 4, 1051-1108 (1979).

Microwave systems; power monitor; reflectometers; six-port reflectometers; microwave measurements; microwave power; 18670.

Microwaves; millimeter waves; permeability measurements; permittivity measurements; radar absorbers; time-domain measurements; dielectrics; frequency-domain measurements; magnetic materials; NBSIR 79-1613.

Microwaves; mixers; superconductivity; tunnel junctions; Josephson junctions; microwave receivers; 18683 .

Microwaves; radiofrequency; standards; calibrations; measurements; 18561 .

Microwaves; super spring; ultraviolet radiation; calibrations; energy; fluid mixtures; light; liquefied natural gas; measurements; DIM/NBS 63, No. 9, 1-32 (1979).

Microwaves; thin-film; tunneling; energy gap; iridium; Josephson junction; low- $\mathrm{T}_{c} ; 18540$.

Mighei; abiotic synthesis; carbonaceous chondrite; chemical evolution; meteorite; SP519, pp. $771-775$ (Apr. 1979).

Migrating boundaries; polycrystals; thin films; diffusion; grain boundaries; Harrison classification; lattice diffusion; 18758 .

Migrating boundaries; polycrystals; thin films; diffusion; grain boundaries; Harrison classification; lattice diffusion; 18759 .

Migration guidelines; migration planning; benchmark performance data; empirical models; IBM 168-3; IBM 3033; SP500-52, pp. 89-104 (Oct. 1979).

Migration planning; benchmark performance data; empirical models; IBM 168-3; IBM 3033; migration guidelines; SP50O52, pp. 89-104 (Oct. 1979).

MIKES; mixture analysis; trace analysis; mass-analyzed ion kinetic energy spectrometry; SP519, pp. 609-625 (Apr. 1979).

Military systems; non-electronic equipment; testing; SP547, pp. 299-302 (July 1979).

Millikelvin research; nuclear cooling; Pomeranchuk refrigerators; solid $\mathrm{He}^{3}$; superfluid $\mathrm{He}^{3}$; symposium; cryogenics; dilution refrigerators; helium 3; Japan; 18679.

Millimeter waves; permeability measurem ents; permittivity mea. surements; radar absorbers; time-domain measurements: dielectrics; frequency-domain measurements; magnetic materials; microwaves; NBSIR 79-1613.

Millimeter waves; standards; 18320 .

Mine subsidence; mining; site development; standards; struc tural design; foundation design; geotechnical engineering housing construction; 18324 .

Mine ventilation; velocity standard; airflow; calibration; facility laser optics; low velocity; TN989.

Mineralized tissue; 2-cyanoacrylate esters; adhesion; bonding tc mineralized tissues; bone; dentin; hydrolytic stability o bonds; isobutyl 2-cyanoactylate; 18569 .

Mineralizing tissue; Raman microprobe; Raman spectra; Ramat, spectroscopy; tissue sections; tooth; biological microanalysis biological tissue; dental studies; enamel; 18982 . 
Mineralizing tissuc; Raman microprobc; Raman spectroscopy; biological microanalysis; biological mineralization; bone; dental studics; dentin; enamcl; microanalysis; 19008 .

Mineralogy; molecular analysis; particlc analysis; power plant cmissions; Raman microprobc; Raman spectroscopy; urban dusts: vibrational analysis; atomosphcric aerosols; materials sampling: 18643 .

Miniature Christmas lights; plastic insulating material; polycthylene; series-constructcd; electric shock; fire; flaming ignition; glowing ignition; hazard; ignition temperature; lamp surface temperature; melting temperature; NBSIR 79-1716.

Minimization of Gibbs energy; phase rule; simultaneous chemical equilibria; water; BASIC; carbon dioxide; carbon monoxide; coal gasification; COLGAS; hydrogen; interactive computer program; methane; NBSIR $78-1509$

Mining; site development; standards; structural design; foundation design; geotechnical engineering; housing construction; mine subsidence; 18324 .

Minorities in computing; women in computing; employment: equal employment opportunity; labor force; 19041 .

MIS; plotting; statistical analysis; Boolean search system; computer programs; curve fitting; data analysis; data base management; data retrieval; file handling; graphic analysis; IMS information retrieval; KWOC indexing; least-squares; linear regression; 18597.

Misorientation contrast; x-ray topography; $\mathrm{Zn} ; \mathrm{Al}_{2} \mathrm{O}_{3}$; Berg-Barrett; Lang; $1834 I$.

Missing link; rebuilding; crisis; flood recovery effort; SP552, pp. 39-44 (July 1979).

Mixed crystal optical spectra; diphenylmethylene; lineshape; low temperature; 18754.

Mixed photon-neutron field dosimetry: neutron leakagc; high energy x-ray radiotherapy machine; SP554, pp. 87-97 (Sept. 1979).

Mixers; superconductivity; tunnel junctions; Josephson junctions; microwave receivers; microwaves; 18683.

Mixing in turbulent flow; noise spectrum; Raman spectroscopy; turbulence; concentration fluctuations; fast Fourier transforms; Fourier transform analysis; 18626

Mixture analysis; trace analysis; mass-analyzed ion kinetic energy spectrometry; MIKES; SP5 19, pp. 609-625 (Apr. 1979).

Mixtures; specific heating value; tank capacity tables; thermophysical properties; total heating value; composition; custody transfer; density; flow rate; LNG; 18564 .

Mixtures; specific heating value; tank capacity tables; thermophysical properties data; total heating value; composition; custody transfer; density; flow rate; LNG; mathematical models; 18838 .

Mobile home; packaged solar space-heating system; rating; standards; testing; NBSIR 79-1799.

Mobile home foundations; soil anchors; soil mechanics; wind upset; anchors; BSS107.

Mobile homes; room fires; ASTM E-84 Tunnel Test; construction standard; fire growth; fire tests; flame spread; flashover; impact assessment; interior finish; kitchen fires; life safety; NBSIR 79-1720.

Mobile homes; smoke detcctors; tenability limits; upholstered furniture; detection time; detector location; fire tests; gas detectors; kitchen fires; NBSIR 79-1915

Mobile homes; wind loads; aerodynamics; building; codes and standards; full-scale testing; NBSIR 77-1289.

Mobile-radio; near-field strength levels; vehicular electromagnetic environment; vehicular near-zone electric fields; vehicular near-zone magnetic ficlds; worst-case EM fields; TN1014.

Modal analysis; scattering matrix; step discontinuity; TEM-cell; variational formulation; coaxial transmission line; cut-off frequency; equivalent circuit; NBSIR 79-1606.

Mode locked dye laser; passive mode locking; picosecond pulses; Rhodamine 6G; dye laser; laser cavity; 19021 .
Modcl; model documentation; computer; computer model; documentation; documentation procedures; SPSOO-39.

Model codes; people movement; systems design; buildings; communications systems; fire safcty; high-risc; BSS115.

Model codes; preservation; regulation; rehabilitation; renovation; building code; building research; code administration; existing buildings; $r N 998$

Model correlation function; pressure broadcning: $\mathrm{CO}_{2}$; far wings; infrarcd wings: line shape; 18886 .

Model design; model selcction; remote work stations; simulation model; data collection; JES output; job entry subsystem; SP500-52, pp. 123-127 (Oct. 1979).

Model documentation; computer; computer model; documentation; documentation procedures; model; SP500-39.

Model laws and regulations; national type approval; packaging and labeling; specifications and tolerances; vapor recovery; weights and measures; consumer affairs; education; electromagnetic interference; electronic devices; SP532.

Model selection; remote work stations; simulation model; data collection; JES output; job entry subsystem; model design; SP50O-52, pp. 123-127 (Oct. 1979).

Model validation; performance evaluation; performance measurement; predictive modeling; set-processing; simulation; software design; analytic models; database management; SP5O0-49.

Modeling; multiphoton; unimolecular dissociation; infrared laser; kinetics; mechanisms; 18712 .

Modeling; $\mathrm{NO}_{x}$; olefins; $\mathrm{SO}_{x}$; troposphere; aldehydes; aromatics; chemical kinetics; data needs; free radicals; SP557.

Modeling; on-line system design; performance evaluation; performance management; prototyping; remote terminal emulation; system testing; audit; capacity planning; financial applications; long-range planning; management control; measurcment; SP500-52, pp. 129-140 (Oct. 1979).

Modeling; performance evaluation; performance prediction; simulation; validation; workload characterization; workload management; capacity planning; hardware monitors; SP50O52, pp. 179-192 (Oct. 1979).

Modeling; performance modeling; workload characterization; cluster analysis; computer modeling; computer performance; empirical models; SPSOO-52, pp. 147-161 (Oct. 1979).

Modeling; real-time; simulation; synthetic programs; benchmarking; computer performance measurement; distributed processing; interactive systems; kernels; SP500-52, pp. 53-64 (Oct. 1979)

Modeling; sampling schemes; statistical sampling; environmental measurements; SP5 19, pp. 1-6 (Apr. 1979).

Modeling; vapors; combustion; equilibrium; high temperature; isolation; lasers; mass spectrometry; matrix; SP56I, Vols. I and 2 .

Modeling technique; programming; sensitivity analysis; simulation; architectural research; building fires; computer-aided design; environmental psychology; fire research; fire safety; human performance; NBSIR 79-17i3.

Modeling technique; simulation; architectural research; building fires; computer-aided design; computer simulation; environmental psychology; fire research; fire safety; human performance; NBSIR 79-1796.

Modelling; building trades; eonstruction industry; forecasting; labor information systems; manpower projections; SP552, pp. 185-196 (July 1979).

Models; optimization; stability; standards; catalog; dynamic programming; iterative procedure; NBSIR 78-1539.

Models; research; standards; systematic procedure; building fires; equivalency; evaluation; fire safety; SP552, pp. 13-27 (July 1979).

Modes considerations; TEM-cell; attenuation; coupled integral equations; dispersion; lossy dielectric slab; NBSIR 79-1615. 
Modified rcsiduc calculus; opcn systems; remote sensing; closed systcms; electromagnctic problems; functional theoretic tcchniques; Monogr. 164.

Modular capacitivc divider; portable system; truck-mounted; CCVT; compact; field calibration; high accuracy; 18833 .

Modular organic analysis system; pyrolysis; trace organic analysis; Fourier transform infrared; gas chromatography; SP519, pp. 753-760 (Apr. 1979).

Modular test programs; parametric yield limitations; performance limitations; photomask performance; process control; test patterns; test structures; total process integration; comprehensive process characterization; design rules; intradie parametric integrity; SP400-56.

Modulated structure; nonstoichiometry: two-dimensional modulated structure; incommensurate lattice; lanthanum niobate; 18646.

Modulation; modulation factor; modulation meter; NewtonRaphson method; percent modulation; signal generator; vhf omnidirectional radio range (VOR); amplitude modulation; instrument landing system (ILS); measurement instrumentation; measurement standard; TN 1016

Modulation factor; modulation meter; Newton-Raphson method; percent modulation; signal generator; vhf omnidirectional radio range (VOR); amplitude modulation; instrument landing system (ILS); measurement instrumentation; measurement standard; modulation; TN1016.

Modulation meter; Newton-Raphson method; percent modulation; signal generator; vhf omnidirectional radio range (VOR); amplitude modulation; instrument landing system (ILS); measurement instrumentation; measurement standard; modulation; modulation factor; TN1016.

Modulator; noise; servo control; acoustooptic; intensity; laser; 18904

Modulus; strength; superconducting motor; composites; fiberglass; mechanical porperties; 18616 .

Modulus of rubber; Mooney-Rivlin constants; rubber elasticity theory; rubber, natural; swelling of rubber network; crosslinking of rubber; dicumyl peroxide; elasticity theory of rubber; J. Res. 84, No. 5, 353-358 (1979).

Moisture; nondestructive testing; pacemaker leads; process control; reliability; semiconductor devices; welding; automated testing; batteries; cardiac pacemakers; contamination; corrosion; electrostatic-induced damage; hermeticity; hybrid devices; leak testing; SP4OO-5O.

Moisture; non-destructive testing; preservation; adobe; adobe soil; compressive strength; creep; flexural strength; mechanical properties; TN996.

Moisture; one-tenth scale motor case; S-glass; temperature effects; water boil; degradation; epoxy resins; Kevlar 49; SP563, pp. 177-197 (Oct. 1979).

Moisture; prepreg; aging of polymer; composite; fiber; mechanical properties; SP563, pp. 17-21 (Oct. 1979)

Moisture barrier; space optics; advanced composites; dimensional stability; eutectic coating; graphite/epoxy; SP563, pp. 47-56 (Oct. 1979).

Moisture infusion; oxide moisture sensors; accelerated stress test; capillary leaks; corrosion failure; hermeticity; NBS-GCR$79-170$

Moisture profile modeling; nondestructive evaluation; statistical estimation; diffusion coefficents; iteration; SP563, pp. 32-46 (Oct. 1979).

Molecular absorption; opto-galvanic spectroscopy; uv irradiation; light absorption; metal oxides; 18344 .

Molecular analysis; organic microanalysis; Raman microprobe; Raman spectra; Raman spectroscopy; biological microanalysis; microanalysis; micromineralogy; microsampling; 18963.

Molecular analysis; particle analysis; power plant emissions; Raman microprobe; Raman spectroscopy; urban dusts; vibrational analysis; atomospheric aerosols; materials sampling: mineralogy; 18643 .
Molecular bands; molecular spectra; reaction rate constants; upper atmospherc; atomic energy levels; atomic spcctra; atomic transition probabilitics; electron cross sections; fusion plasmas; lasers; 18855.

Molecular bands; molecular spectra; rotational constants; atomic line shapes; atomic spectra; atomic transition probabilities; bands, molecular; energy levels; cnergy levels, atomic; linc shapes, atomic; 18828 .

Molecular compound; silver-sulfur-tungsten cluster; synthesis; $x$-ray diffraction; crystal structure; mechanism of formation; 18636.

Molecular conformation; molecular spectroscopy; molecular structure; molecules; structure; bond angles; bond distances; gas-phase polyatomic molecules; gas-phase spectroscopy; microwave spectroscopy; JPCRD 8, No. 3, 619-722 (1979).

Molecular constants; propyne; radio astronomy; rotational transitions; interstellar molecules; line strengths; microwave spectra; JPCRD 8, No. 2, 537-558 (1979).

Molecular correlations; quenching; radiative lifetimes; ratc constants; reactive channels; recommended data; relaxation processes; review; activation energies; electronically excited states; evaluation; gaseous interactions; JPCRD 8, No. 3, 723-798 (1979).

Molecular dynamics; Monte Carlo method; periodic boundaries; pressure; stress calculation; virial theorem of Clausius; equilibrium; homogeneous system; hydrostatic pressure; internal stress; internal virial; 18456 .

Molecular dynamics; neutron; neutron radiography; nondestructive evaluation; nuclear reactor; radiation; activation analysis; crystal structure; diffraction; isotopes; TN995.

Molecular dynamics; radial distribution function; transverse current correlation function; velocity autocorrelation function; intermediate scattering function; Lennard-Jones liquid; liquid rubidium; J. Res. 84, No. 6, 439-446 (1979).

Molecular electronic structure; van der Waals coefficient; frequency dependent polarizability; helium 'S state; 18934 .

Molecular ions; $\mathrm{HBr}^{+}$laser magnetic resonance; 18917 .

Molecular ions; photochemistry; ultraviolet spectra; charge transfer; excited argon atoms; free radicals; infrared spectra; matrix isolation; 18847 .

Molecular microanalysis; pathological tissue; Raman microprobe; Raman spectra; Raman spectroscopy; biological microanalysis; biological tissue; foreign bodies; histological sections; implant materials; microanalysis; 18958.

Molecular parameters; radio astronomy; rotational transitions; vinyl cyanide; interstellar molecules; microwave spectra; JPCRD 8, No. 1, 107-124 (1979).

Molecular sodium; potential curves; collisional excitation; dissociation energy; Dunham coefricients; Franck-Condon factors; laser fluorescence; 18824

Molecular spectra; reaction rate constants; upper atmosphere; atomic energy levels; a tomic spectra; atomic transition probabilities; electron cross sections; fusion plasmas; lasers; molecular bands; 18855

Molecular spectra; rotational constants; atomic line shapes; atomic spectra; atomic transition probabilities; bands, molecular; energy lcvels; energy levels, atomic; line shapes, atomic; molecular bands; 18828 .

Molecular spectroscopy; molecular structure; molecules; structure; bond angles; bond distances; gas-phase polyatomic molecules; gas-phase spectroscopy; microwave spectroscopy; molecular conformation; JPCRD 8, No. 3, 619-722 (1979).

Molecular spectroscopy; potential curves; dissociation encrgy: Franck-Condon factors; laser spectroscopy; lithium molecule: 18867.

Molecular structure; molecules; structure; bond angles; bond distances; gas-phase polyatomic molccules; gas-phase spectroscopy; microwave speciroscopy; molecular conformation; molecular spectroscopy; JPCRD 8, No. 3, 619-722 (1979). 
Molccular structurc: normal and deuteratcd naphthalenes; vibrational assignments; enthalpy of formation; ideal gas thermodynamic propertics; JPCRD 8, No. 2, 527-536 (1979).

Molccular structurc; urea; urea detcrmination; x-ray diffraction: biomcdical standard; diacetylurea; 18347 .

Molccular vibrations; neutron reactions; ${ }^{23 *} \mathrm{U}$; Doppler effect; fission; gas target; 18585 .

Molccular weight; polyethylene; shear rate; ultra high molecular weight polyethylene; viscosity number; intrinsic viscosity; 18834 .

Molecular weight dependence; polystyrene; radius of gyration; tcmperature dependence; hydrodynamic radius; light scattering: 18545 .

Molecular weight distribution; necking; polyethylene; uniaxial creep; additivity of damage; cold drawn; crack growth; fracture; 18765 .

Molecule; photon; positron; atom; collision cross section; detachment; dissociation; elastic scattering; electron; excitation; ion; ionization; SP426. Supplement I.

Molecules; momentum-transfer; polar molecules; scattering theory; cross sections; electron collisions; 18516 .

Molecules; structure; bond angles; bond distances; gas-phase polyatomic molecules; gas-phase spectroscopy; microwave spectroscopy; molecular conformation; molecular spectroscopy; molecular structure; JPCRD 8, No. 3, 619-722 (1979).

Molecules; well depths; excited states; ground state; intermolecular potential; 18677

Molten metals; palladium; precious metals; reference data; silver; solid state physics; transport properties; copper; critical evaluation; data analysis; data compilation; data evaluation; data extraction; data synthesis; JPCRD 8, No. 4, 1147 1298 (1979).

Molten salt mixtures; standard reference data; surface tension; viscosity; bromides; chlorides; data compilation; density; electrical conductance; fluorides; halides; iodides; JPCRD 8, No. 1, 125-302 (1979).

Molten salts; physical properties; safety and hazards; thermal energy storage materials; thermal properties; thermodynamic properties; transport properties; corrosion; data compilation; electrochemical energy storage materials; NSRDS-NBS6I, Part II.

Molybdenum; network measurement; semiconductors; SRM's; standards; cardiac pacemakers; computer standards; fire safety; DIM/NBS 63, No. 10, 1-36 (1979).

Molybdenum; optical characterization; laser mirror; metallurgical characterization; microstructures; SP541, pp. 132-163 (Dec. 1978).

Molybdenum; plasma; atomic physics; dielectronic recombination; highly ionized; impurity; 18949.

Molybdenum; pulsed laser; spectra; wavelengths; energy levels; ions; 18500 .

Molybdenum pentafluoride; vapor density; vapor pressure; enthalpy and entropy of vaporization; entrainment method; melting temperature; 19020 .

Momentum-transfer; polar molecules; scattering theory; cross sections; electron collisions; molecules; 18516 .

Monitor system; rotary dissolver; signature analysis; vibration analysis; SP547, pp. 232-249 (July 1979).

Monitoring; onboard; patented; pressure; pumps; reservoirs; sensors; tailorable; temperature; accumulator; analog; centralized; check-out system; dessicant; discrete; displacement; fiber optics; filters; flight critical; flow; fluid; SP547, pp. 345 357 (July 1979).

Monitoring; repairs; vibration; aircraft carrier; condition analysis; machinery; maintenance; SP547, pp. 167-175 (July 1979).

Monochlorinated organics; carrier gas doping; electron capture detector; methyl chloride; SP519, pp. 143-151 (Apr. 1979).

Monomers; resins; surface-active comonomers; acrylates; adhesion, dental; bonding; coupling agent; dental; 18461 .
Monomolecular film; psychrometer; psychrometry; radiative heat transfer; temperature deprcssion; water vapor measurcment; wet bulb; wet element; convective heat transfer; convective mass transfer; emissivity of water; J. Res. 84, No. 2 , $161-177$ (1979).

Monotectic; multicomponent; wetting; composite growth; contact angle; disjoining pressure; 18422 .

Monte Carlo; multiple scatter; tracklength; charged particle; electron; energy deposition; 18965 .

Monte Carlo; orientation entropy; packing of rods; square lattice; theories of liquid crystals; configurations of rods; 18530 .

Monte Carlo electron trajectory simulation; spatial resolution; thin foils; $x$ rays; analytical electron microscopy; microanalysis: 18589 .

Monte Carlo electron trajectory simulation; scanning electron microscopy; $x$-ray yield; characteristic $x$-ray yield; electron probe microanalysis; inner shell ionization cross section; 18978 .

Monte Carlo method; periodic boundaries; pressure; stress calculation; virial theorem of Clausius; equilibrium; homogeneous system; hydrostatic pressure; internal stress; internal virial; molecular dynamics; 18456 .

Mooney-Rivlin constants; rubber elasticity theory; rubber, natural; swelling of rubber network; cross-linking of rubber; dicumyl peroxide; elasticity theory of rubber; modulus of rubber; J. Res. 84, No. 5, 353-358 (1979).

MOSFET dc profiler; surface recombination; CCD; electrical test structure; gated diode; generation lifetime; integrated gated-diode electrometer; integrated test structure; leakage current; NBSIR 79-I744.

Mossbauer; rare earths; spin glass; hyperfine fields; magnetic relaxation; magnetism; 18329 .

Mossbauer effect; optical pumping; optical spectroscopy; radiation pressure; radiative cooling; Doppler-free spectroscopy; frequency standard; high resolution spectroscopy; ion storage; laser spectroscopy; 18699.

Mossbauer effect; rare earths; spin freezing; spin glasses; susceptibility; amorphous magnetism; 18897.

Motor behavior; neural modeling; perceptien; planning; problem solving; robot control; brain mechanisms; cognition; goal seeking; intelligence; 18714 .

Motor shaft; brake; coupling device; cutting blade; dead-man's handle; disconnect element; lawnmower; U.S. Patent 4,158,944.

Motor vehicle; diagnosis; emissions inspections; fault detection; fuel economy; SP547, pp. $78-97$ (July 1979).

Mouth burn; specific electrical effect; arc burn; contact burn; current threshold; electrical injury; electrolyte shift; heat effect; injury mechanism; injury statistics; NBSIR 79-1710.

Multichannel analyzer; peak overlap; quantitative electron probe microanalysis; $x$-ray continuum; $x$-ray spectrum; computer program; energy dispersive detector; TNII06.

Multichannel capillary arrays; vacuum ultraviolet spectroscopy; vacuum ultraviolet windows; differential pumping across capillary arrays; focused vacuum ultraviolet; heat-pipe oven use in the vacuum ultraviolet; 18808 .

Multicomponent; wetting; composite growth: contact angle; disjoining pressure; monotectic; 18422 .

Multielement analysis; neutron activation analysis; SRM; trace elements; urban particulate; error analysis; instrumental analysis; 18866 .

Multifilamentary NbTi; superconductors; critical current; critical current degradation; multifilamentary $\mathrm{Nb}_{3} \mathrm{Sn} ; 18622$.

Multifilamentary $\mathrm{Nb}_{3} \mathrm{Sn}$; multifilamentary $\mathrm{NbTi}$; superconductors; critical current; critical current degradation; 18622 .

Multifilamentary strain; $\mathrm{Nb}_{3} \mathrm{Sn}$; stress; superconductor; criticalcurrent; critical-field; degradation; 18780 .

Multi-ion interactions; ordered alloys; statistical mechanics; face centered cubic; ground state; interfaces; 18614 . 
Multilayer films; scattering; absorption; antireflectance coatings; high reflectance coatings; interface absorption; SP541, pp. 266-277 (Dec. 1978).

Multiphoton; Rabi frequency; Star shift; two-level model; absorption; cesium; exponential index; ionization; 18892 .

Multiphoton; rate approximation; saturable rate; bandwidth; coherence; dynamic rate; incoherence; ionization; linear rate; 18893.

Multiphoton; thermochemistry; unimolecular dissociation; calorimetry; infrared; kinetics; laser chemistry; mechanisms; 18709.

Multiphoton; unimolecular dissociation; infrared laser; kinetics; mechanisms; modeling; 187/2.

Multiphoton dissociation; multiphoton ionization; Rabi frequency; statistical broadening; three-level system; coherent excitation; dressed atoms; inhomogeneous broadening; intense laser; 18439.

Multiphoton dissociation; radicals; vibronic spectroscopy; chlorofluoromethylene; fluorescence; laser spectroscopy; 19042.

Multiphoton effects; scattering in laser field; free-free transitions; low-frequency approximation; 18711 .

Multiphoton ionisation; cesium; laser bandwidth; lasers; 18874 .

Muitiphoton ionization; ac Stark effect; double optical resonance; laser bandwidth effects; 18955 .

Multiphoton ionization; damage threshold; electron avalanche; frequency and pulse width dependencies of the critical field; SP541, pp. 299-302 (Dec. 1978).

Multiphoton ionization; Rabi frequency; statistical broadening; three-level system; coherent excitation; dressed atoms; inhomogeneous broadening; intense laser; multiphoton dissociation; 18439 .

Multiphoton processes; photoionization; quantum beats; sodium atom; angular distributions; field ionization; laser spectroscopy; 18953 .

Multiphoton transitions; scattering in an external field; stimulated bremsstrahlung; 18710 .

Multiple injection; smoke candle test; smoke control; stairwell pressurization; top injection; tracer gas test; bottom injection; NBSIR 79-I747.

Multiple scatter; tracklength; charged particle; electron; energy deposition; Monte Carlo; 18965.

Multiple-attribute decisions; ordering; paired comparisons; prioritization; project selection; ranking; resource allocation; weighting multiple criteria; decision analysis; decisions; eigenvectors; management; 18602 .

Multiplet tables, O vi-O vili; oxygen, spectra, O vI-O vIII; spectra, O vi-O vili; wavelengths, O vi-O vIII; NSRDS-NBS3, Section 8.

Multiplets; singly ionized spectra; atomic transition probabilities; electric dipole lines; 18736 .

Multiplex systems; NFPA standards; residential fire detector; sprinkler supervisory devices; control units; fire alarm systems; fire detectors; high-rise communication systems; 18625.

Multiplicative function; quasi-ordered set; topological algebra; automorphism; cyclic module; faithful distributive module; incidence algebra; 18789 .

Multirange; R-2R ladder; relay switching; self-calibration; iwenty bits + sign; voltage output; digital-to-analog converter; high resolution; TNIIOS.

Multispectral scanner; reflective optics; crosstrack scan; earth imagery; ERTS; LANDSAT; SP547, pp. 17-30 (July 1979).
Multisphere; photon; photoneutrons; radiotherapy; spectrometry; dose-equivalent; electrons; kerma; SP554, pp. 109123 (Sept. 1979).

Multispheres; photoneutrons; photons; radiotherapy; spectrometry; dose-equivalent; electrons; kerma; SP554, pp. 125127 (Sept. 1979).

Multi-stage displacer; Stirling machine; superconducting quantum interfering devices (SQUID); low input power cyclic cryogenic refrigerator; U.S. Patent 4,143,520.

Multiwavelength techniques; tectonics; atmospheric properties; distance measurement; geodesy; instrumentation; 18816 .

Municipal corporations; negligence; sovereign immunity; tort; duty; liability; SP552, pp. 29-37 (July 1979).

Municipal governments; regulatory; computer facilities; integrated data base; SP5 52, pp. 153-165 (July 1979).

Municipal wastewater treatment facilities; public sector efficiency; subsidies; technological change; capital formation; economic growth; NBS-GCR-ETIP 78-40.

Mutagenicity; naphthylamines; saccharin; saccharin impurities; Salmonella typhimurium; Amaranth; Ames test; criteria for purity; food additives; SP519, pp. 311 -319 (Apr. 1979).

Mutual friction; axial heat transport; forced convection; heat transmission; helium $11 ; 18617$.

$\Sigma-\Pi$ transition; adiabatic limit; atomic collisions; quasimolecule terms; sudden perturbation limit; transition probability; unified atom approximation; 18576 .

$\Sigma-\Pi$ transitions; adiabatic perturbation theory; elastic scattering phase shifts; pseudocrossing; sudden-perturbation limit; transition probability; 18575 .

Mycotoxins; review; seafood toxins; food toxicants; SP5 19, pp. 321-331 (Apr. 1979).

Myocardial infarction; real-time; tissue characterization; ultrasound diagnosis; clinical cardiac data; digital processing; Fast Fourier Transform; frequency spectra; in vivo; microprocessor-controlled data acquisition; SP525, pp. 267. 273 (Apr. 1979).

Myocardial infarction; ultrasonic attenuation; ischemic injury; SP525, pp. 63-7I (Apr. 1979).

Myocardium; phase cancellation; velocity; acoustic microscopy; anisotropy; attenuation; elastic microstructure; infarct; interferogram; SP525, pp. 73-79 (Apr. 1979).

\section{$\mathbf{N}$}

$\mathrm{NaCl} ; \mathrm{NaF}$; piezo-optic constants; refractive index; $\mathrm{SiO}_{2} ; \mathrm{SrF}_{2}$; thermal expansion coefficient; thermo-optic constant; ZnS; $\mathrm{ZnSe} ; \mathrm{Al}_{2} \mathrm{O}_{3} ; \mathrm{As}_{2} \mathrm{~S}_{3}$ glass; $\mathrm{BaF}_{2} ;$ TN993.

$\mathrm{NaCl}$; pressure; pulsed TEA $\mathrm{CO}_{2}$ laser surface breakdown; spot size; surface absorption; transmitted pulse; adsorbed water; breakdown mechanism; frequency and time dependence of breakdown thresholds; IR window materials; SPS4I, pp. 318326 (Dec. 1978).

$\mathrm{NaCl}$; spot-size dependence; breakdown fields; KCl; SP541, pp. 309-317 (Dec. 1978).

$\mathrm{NaCl}$; tuneable laser calorimetry; 9.2 to $10.6 \mu \mathrm{m}$; absorption; KCl; SP541, pp. 24-32 (Dec. 1978).

$\mathrm{NaF}$; piezo-optic constants; refractive index; $\mathrm{SiO}_{2} ; \mathrm{SrF}_{2}$; thermal expansion coefficient; thermo-optic constant; ZnS; ZnSe; $\mathrm{Al}_{2} \mathrm{O}_{3} ; \mathrm{As}_{2} \mathrm{~S}_{3}$ glass; $\mathrm{BaF}_{2} ;$ TN993.

$\mathrm{NaF}$; thin film absorption; water absorption; wedged film; absorption coefficient; adiabatic calorimetry; $\mathrm{As}_{2} \mathrm{Se}_{3}$; interface absorption; laser calorimetry; SP541, pp. $37-42$ (Dec. 1978).

$n$-alkanes; non-bonded potential functions; polyethylene; vibrational data; force field refinement; lattice dynamics; 18404.

Name generation; operations research; programming languages; sparse matrices; data pooling; data structures; mathematical programming; matrices; J. Res. 84, No. 1, $21-47$ (1979).

Nanosecond pulses; pulsewidth dependence; standing waves; thin-film coatings; two-photon absorption; ultraviolet 
wavelength scaling; damage thrcsholds; electric fields; laser damage; SP54l, pp. 190-202 (Dec. 1978).

Naphthylamines; saccharin; saccharin impurities; Salmonella typhimurium; Amaranth; Ames test; critcria for purity; food additives; mutagenicity; SP519, pp. 311-319 (Apr. 1979).

National Bureau of Standards; American Dental Association; dental history; dental instruments; dental materials; dental research; 18676.

National Bureau of Standards (NBS); National Engineering Laboratory (NEL); technology transfer; engineering; international cooperation; international research; international standards; NBSIR 79-1792.

National Electrical Code; technological innovation; appeals process; consensus standards; electrical distribution systems; flat conductor cable; SP552, pp. 57-78 (July 1979).

National Engineering Laboratory (NEL); technology transfer; engineering; international cooperation; international research; international standards; National Bureau of Standards (NBS); NBSIR 79-1792.

National Measurement System; standards; calibrations; dissemination of units; electrical measurements; electric power measurements; electrotechnology; impact of measurements; measurement technology assessment; NBSIR 75-935.

National standards; radiation; radiation control; radiation measurements; traceability; measurement assurance; measurement consistency; measurement system; 18800 .

National type approval; packaging and labeling; specifications and tolerances; vapor recovery; weights and measures; consumer affairs; education; electromagnetic interference; electronic devices; International Organization of Legal Metrology; measurement assurance; SP532.

Natural aging; paper; paper aging; tests for paper; accelerated aging; aging; aging of cellulose; aging of paper; cellulose; cellulose aging; 19017.

Natural matrix; radioactivity; standards; Woods Hole; environment; ICRM; 18981 .

Natural width; x-ray line width; Auger effect; Auger line width; $K$ shell; level width; line width; $L$ shell; JPCRD 8, No. 2 , 329-338 (1979).

Naval ship application; composites; hydrofoils; maintenance requirements; SP563, pp. 267-275 (Oct. 1979).

Navigation; oscillator; position location; time dispersion; time error; time error measure; time prediction error; clocks; frequency drift; frequency stability; 18899 .

Navigation; oscillator systems; phase lock loop; position location; spectral purity; frequency lock loop; frequency stability; 18693.

Navigation; stability; time; clocks; communication; frequency standards; 18826 .

Navigation; time; time dissemination; communication; frequency; frequency standards; 19005.

NBS reactor; neutrons; silicon irradiation; thermal fluxes; 18704.

NBS solar standards projects; solar energy; building research; 18363.

NBS standards; standards; calorimeter; laser; laser MAP; laser measurements; laser power and energy; 18914

NBSLD; thermal comfort; heating and cooling load; hybrid computer; 18336.

NBSLD analysis of residences; residential energy conservation; thermal mass effect in buildings; building energy consumption analysis; computerized building energy analysis; cooling load calculation; energy conservation; heating load calculation; NBSIR 79-1732.

N-butane; orthobaric densities; specific heats; speeds of sound; vapor pressures; densities; enthalpies; entropies; equation of state; internal energies; isobars; isochores; isotherms; JouleThomson inversion; latent heats of vaporization; melting line; NBSIR 79.1621.
$\mathrm{Nb}_{3} \mathrm{Ge}$; strain; stress; superconductor; critical-current; degradation; 18781

$\mathrm{Nb}_{3} \mathrm{Sn}$; stress; superconductor; critical-current; critical-field; degradation; multifilamentary strain; 18780 .

Nd:YAG laser; two photon absorption; CdSe; CdTe; internal reflections; laser calorimeter; linear absorption; SP541, pp. 19.23 (Dec. 1978).

NDE; radiation force; transducer characterization; ultrasonics; acoustic theory; calorimetry; electroacoustic method; medical applications; metrology; 18438 .

NDE; ultrasonic scattering; flaws in crystals; 18831 .

$\mathrm{Nd}\left(\mathrm{C}_{2} \mathrm{H}_{5} \mathrm{SO}_{4}\right)_{3} \cdot 9 \mathrm{H}_{2} \mathrm{O}$; the rmometry; $\mathrm{Gd}\left(\mathrm{PO}_{3}\right)_{3}$; low temperature thermometry; magnetic susceptibility; magnetic thermometers; 18556.

Near field; planar scanning; antenna measurements; cylindrical scanning; far field; 18818 .

Near-field scanning; orthogonalities; plane-radial scanning; probe correction; space groups; aliasing; Bravais lattices; Fast Fourier "Transform"; 18956.

Near-field strength levels; vehicular electromagnetic environment; vehicular near-zone electric fields; vehicular near-zone magnetic fields; worst-case EM fields; mobile-radio; TNIO/4.

Necking; polyethylene; uniaxial creep; additivity of damage; cold drawn; crack growth; fracture; molecular weight distribution; 18765 .

Needs; Performance Management System (PMS); capabilities; methodology; SP500-52, pp. 69-77 (Oct. 1979).

Negative chemical ionization mass spectrometry; human plasma; melatonin; SP519, pp. $399-404$ (Apr. 1979).

Negative control; polyethylene; processing sheets and rods; surface characterization; surface contamination; biomaterials; NBSIR 77-1401.

Negative ions; chemical ionization; electron capture; gas chromatography-mass spectrometry; SP519, pp. 601-607 (Apr. 1979).

Negative ions; ozone; resonances; electron scattering; energy loss; excited states; 18392 .

Negative ions; positive ions; atmospheric pressure ionization; bioanalytical systems; mass spectrometry; SP519, pp. 655671 (Apr. 1979).

Negligence; sovereign immunity; tort; duty; liability; municipal corporations; SP552, pp. 29-37 (July 1979).

Nelsen, Robert J; Callahan Memorial Award; dental handpiece; dental materials; dental radiography; dental research; 18497.

Neodymium glass lasers; nonlinear refractive index; thermal conductivity; viscosity; Abbe value; coolants, dn/dT; index matching liquids; SP541, pp. 109-121 (Dec. 1978).

Neodymium laser; peak power; power meter; pulsed laser; $Q$ switched; risetime; speckle; waveform; attenuators; calibration; laser; TNIOIO.

Neon; nitrogen; Penning effect; carbon; copper; hollow cathodes; mass spectrometry; 18449 .

Nephelometry; oils; reversed-phase; serum; cerebrospinal fluid; detector; high-performance liquid chromatography; light-scattering; lipids; SP519, pp. 429-436 (Apr. 1979).

Network; seismic design; systems analysis; building codes; buildings; building standards; classification; decision tables; earthquake-resistant design; information networks; TN1100.

Network; serial; broadcast; coaxial; communication; contention; data; digital; ethernet; local; microprocessor; 18760 .

Network analyzer; power; reflection coefficient; reflectometer; scattering parameters; six-port; voltage; calibration; current; impedance; 18600 .

Network analyzer; power; reflection coefficient; reflectometer; scattering parameters; six-port; voltage; calibration; current; impedance; 18601 .

Network flow; building evacuation; high-rise building design; NBSIR 79-1738. 
Network measurement; semiconductors; SRM's; standards; cardiac pacemakers; computer standards; fire safety; molybdcnum; DIM/NBS 63, No. 10, 1-36 (1979).

Network operating systems; access control; computer networking; computer security; 19009 .

Network services; SRM's; computer interface standards; computers; cryogenic temperature; energy; energy savings; industrial robots; DIM/NBS 63, No. 4, I-24 (1979).

Network, tensile properties; paper, interfiber bonding; paper. low-density handsheets; paper, pulp characterization; paper, tensile testing; mathematical modeling, network; J. Res. 84, No. 4, 299-318 (1979).

Networks; operating systems; protocols; communications; computers; data bases; 18488 .

Networks; operating systems; protocols; communications; computers; databases; 18891 .

Neural modeling; perception; planning; problem solving; robot control; brain mechanisms; cognition; goal seeking; intelligence; motor behavior; 18714 .

Neurology; phase compensation; brain scanning; echoencephalography; SP525, pp. 209-218 (Apr. 1979).

Neurotransmitters; nutrients; organic pollutants; trace organic analysis; drug analysis; food toxicants; hormones; SP519.

Neutral currents; neutrino scattering; weak interaction; atomic parity mixing; charged currents; fermi theory; 18951 .

Neutral impurity; resistivity; scattering mechanisms; scattering mobility; $\rho$-type silicon; boron-doped silicon; dopant density; cffective mass; hole mobility; ionized impurity scattering mobility: lattice scattering mobility; SP400.47.

Neutral sodium; sodium, neutral; autoionizing states; laser-excitation technique; 18507.

Neutrino scattering; weak interaction; atomic parity mixing; charged currents; fermi theory; neutral currents; 18951 .

Neutron; neutron radiography; nondestructive evaluation; nuclear reactor; radiation; activation analysis; crystal structure; diffraction; isotopes; molecular dynamics; TN995.

Neutron; repair; survival; transformation; $x$ ray; carcinogenesis; SP554, pp. 63-73 (Sept. 1979).

Neutron; threshold reaction; uranium; Californium; cross sections; fission spectrum; 18792 .

Neutron activation; radiochemistry; cadmium; 18478 .

Neutron activation analysis; noble metals analysis; platinum determination; radiochemical separation; spontaneous deposition technique; biological materials analysis; environmental materials analysis; 18350 .

Neutron activation analysis; Rutherford backscattering; standards; accuracy and precision; gold films; gravimetry; 18490 .

Neutron activation analysis; SRM; trace elements; urban particulate: error analysis; instrumental analysis; multielement analysis: 18866 .

Neutron cross section; neutron energy dcposition; nuclear data; nuclear reactions; secondary particle spectra; kerma factors; 18360 .

Neutron cross section evaluations; single-event energy; energy deposition spectra; microdosimetry parameters; 18658 .

Neutron diffraction; nondestructive testing; pole figure; texture of copper shaped charge liner; texture of $\mathrm{Ni}-\mathrm{W}$ alloy; metal texture; 19027.

Neutron diffraction; powder method; profile refinement; tantalum tungstate; thermal expansion; ionic conductors; 19037.

Neutron diffraction; rigid body motion; triaminoguanidinium nitrate; crystal structure; hydrogen bond; 18873 .

Neutron energy deposition; nuclear data; nuclear reactions; secondary particle spectra; kerma factors; neutron cross section; 18360 .

Neutron fields; nuclear data; reactor dosimetry; benchmark fields; benchmark testing; 19024 .

Neutron fields; scattering corrections; sensitivity; benchmark; fission spectrum; foils; 18901 .
Neutron fluence; photoneutrons; accelerator; SP554, pp. 75-86 (Sept. 1979).

Neutron flux determination; proton telescope; standard cross section; ${ }^{235} \mathrm{U}(\mathrm{n}, \mathrm{f})$; fission cross section; linac; 18581 .

Neutron leakage; high energy $x$-ray radiotherapy machine; mixed photon-neutron field dosimetry; SP554, pp. 87-97 (Sept. 1979).

Neutron leakage rates; gamma rays; SP554, pp. 145-154 (Sept. 1979).

Neutron powder; structure; $x$ ray; crystal; diffraction; $\mathrm{Li}_{5} \mathrm{~B}_{4}$; 18382

Neutron production; photon beam exit; beam quality; SP554, pp. 139-144 (Sept. 1979).

Neutron radiography; nondestructive evaluation; nuclear reactor; radiation; activation analysis; crystal structure; diffraction; isotopes; molecular dynamics; neutron; TN995.

Neutron reactions; ${ }^{238} \mathrm{U}$; Doppler effect; fission; gas target: molecular vibrations; 18585 .

Neutron scattering; electron microscopy; high-density lipoproteins; 18851 .

Neutron scattering; nitrornethane; rotation; tunneling; crystal structure; 19025 .

Neutron scattering; orientational disorder; rotational dynamics; condensed phases; diffusion mechanisms; inelastic scattering; 19026.

Neutron scattering; phantom network; polybutadiene; rubber elasticity; uniform network; affine network; 18827 .

Neutron scattering; phase transition; rotation-translation coupling; coupled modes; dynamics; KCN-KBr; 19036 .

Neutron scattering; potential barrier; quasielastic scattering; reorientation; residence time; tunneling; activation energy; methyl group; 18374 .

Neutron scattering; rare earth; Chevrel-phase; coexistence; crystal field; magnetic superconductor; 18850 .

Neutron scattering; rare earth compounds; hydrides; Laves phase; magnetic properties; 18657 .

Neutron scattering; rare earths; hydrides; intermetallic compounds; Laves phase: magnetism; 18682 .

Neutron scattering; rare earths; hydrides; intermetallic compounds; Laves phase; magnetism; 18881 .

Neutron scattering; rare earths; small angle scattering; amorphous alloys; magnetic partides; magnetism; 18372 .

Neutron scattering; rare earths; spin waves; crystal fields; Laves phase; magnetic materials; 19031 .

Neutron scattering; spin waves; transition-metal glasses; amorphous alloys; magnetic properties; 18898 .

Neutrons; betatrons; detectors; dosimetry; leakage; linear accelerators; SP554, pp. 129-138 (Sept. 1979).

Neutrons; Np-237; Pu-239; U-235; U-238; activation analysis; benchmark fields; dosimetry; fission yields; measurements; 18884 .

Neutrons; photons; pions; protons; coincidence experiments; elcctromagnetic: 18675 .

Neutrons; position-sensitive detector; radiography; time-of-flight technique; linac; 18591 .

Neutrons; radiotherapy; RBE; SP554, pp. 37-40 (Sept. 1979).

Neutrons; relative biological effect; shielding techniques; stan- $i$ dards; dosimetry; high energy radiotherapy beams; leakage; measurement techniques; medical accelerators; SP554.

Neutrons; scatter; $x$ rays; dose; leakage; medical accelerator; SP554, pp. 25-28 (Sept. 1979).

Neutrons; silicon irradiation; thermal fluxes; NBS reactor; 18704 .

Neutrons; therapy; $x$ rays; accclerators; betatrons; electrons megavoltage; SP554, pp. 1-14 (Sept. 1979).

Neutrons; track; activation; detectors; dose; fast; SP5 54, pp 99-107 (Sept. 1979).

New construction plans review; training and education; desigr professionals; energy audits; energy codes; Kentucky Fire 
Marshal's office; lighting and thermal efficiency standards; local governments; SP552, pp. 121-130 (July 1979).

Ncws release; publication announcement; scientist-author; tcchnical communicator; technical paper; trade press; audience; fcature article; 18817 .

Newton-Raphson interation methods; nonlinear load; timedomain measurements; time-stepping finite-difference technique; transient; traveling-wave antenna; Fast Fourier transform; linear load; 19035.

Newton-Raphson method; percent modulation; signal generator; vhf omnidirectional radio range (VOR); amplitude modulation; instrument landing system (ILS); measurement instrumentation; measurement standard; modulation; modulation factor; modulation meter; TN1016.

NFPA standards; residential fire detector; sprinkler supervisory devices; control units; fire alarm systems; fire detectors; highrise communication systems; multiplex systems; 18625 .

Nickel; osmotic coefficients; solutions; thermodynamic properties; activity coefficient; cobalt; critical evaluation; electrolyte; excess Gibbs energy; iron; JPCRD 8, No. 4, 923-1004 (1979).

Nickel; oxide films; photopotentials; aluminum; copper; copper alloys; 18724 .

Nickel; photon; photoproduction; quadrupole giant resonance; alpha particle; dipole giant resonance; electroproduction; 18495.

Nickel alloy; stainless steel; thermal conductivity; aluminum alloy; copper; low temperature; magnetothermal conductivity; 18619.

Nickel alloys; stainless steels; steels; superalloys; titanium alloys; crack propagation; fatigue; low temperature tests; 18695 .

Nickel alloys; stainless steels; Young's modulus; aluminum alloys; copper alloys; elastic constants; iron alloys; 18630 .

Nickel cross section; reaction rates; Californium; dosimetry; fission neutrons; iron cross section; 18883 .

Nickel isotopes; virtual photons; electric quadrupole; electrodisintegration; giant resonance; $\mathbf{1 8 5 3 5}$.

Nickelaborane; nuclear magnetic resonance; boron hydride; metalloborane; 18328 .

Niobium; precipitate; superconductor; tin; alloy; copper; low temperatures; 18655 .

Niobium; stripline; superconductivity; surface impedance; copper; J. Res. 84, No. 3, 247-259 (1979).

Niobium; superconductor; tin; alloy; copper; electrical property; 18656 .

Niobium-silicon alloys; splat-cooling; superconductivity; intermetallic compounds; liquid quenching; metastable phases; 18734.

Niobium-titanium; physical properties; superconductors; electrical properties; low temperatures; mechanical properties; metallurgical properties; 18552

Nitrate radical; oxyanion radicals; phosphate radical; photolysis; radiolysis; rates; selenium radicals; sulfate radical; thiocyanate radical anion; aqueous solution; carbonate radical; chemical kinetics; halogen radical anions; NSRDS-NBS65.

Nitrates; nitrites; nitrogen oxides; photdlysis; reactions; review; tropospheric chemistry; SP557, pp. $71-79$ (Aug. 1979).

Nitric acid; nitrous acid; ozone; rate constants; chemical kinetics; environmental measurements; 18551 .

Nitrite; nitrite solutions; oxidation; ion-chromatography; 18889 .

Nitrite solutions; oxidation; ion-chromatography; nitrite; 18889 .

Nitrites; nitrogen oxides; photolysis; reactions; review; tropospheric chemistry; nitrates; SP557, pp. $71-79$ (Aug. 1979).

Nitroalkanes; nitrosamines; sidestream smoke; thermal energy analyzer; tobacco smoke; vinyl chloride; aza-arenes; hydrazines; SPS19, pp. 131-141 (Apr. 1979).

Nitrobenzene; partial discharges; streamers; transient phenomena; electrical breakdown; high speed photography; Kerr effect; liquid breakdown; 18843.
Nitrobenzene; pulse measurement; electrical measurements; electro-optics; Kerr coefficient; Kerr effect; 18819 .

Nitrogen; nitrogen-strengthened; stainless steel; tensile properties; toughness; cryogenic; fatigue; fracture; high-strength; low-temperature; mechanical properties; 18957.

Nitrogen; organic compounds; oxidation; oxygen; oxygenated; rate constant; sulfur; Arrhenius parameters; combustion; decomposition; free radicals; hydrocarbons; hydrogen; NBSIR 79-194I.

Nitrogen; oxygen; plasma-broadening; singly ionized oxygen; stark broadening; atomic spectra; 18737 .

Nitrogen; Penning effect; carbon; copper; hollow cathodes; mass spectrometry; ncon; 18449.

Nitrogen; rate coefficients; drift tube; electrons; excitation; low energy; 18925 .

Nitrogen; silicon devices; trace analysis; uranium; alpha tracks; biomedical; boron; fission tracks; geochronology; geology; lithium; 18342 .

Nitrogen; sound velocity; thermodynamic properties; virial coefficients; density; gas; 18815 .

Nitrogen oxides; photolysis; reactions; review; tropospheric chemistry; nitrates; nitrites; SP557, pp. $71-79$ (Aug. 1979).

Nitrogen-phosphorus; selective detection; steroid hormones; gas chromatography; SP519, pp. $419-427$ (Apr. 1979).

Nitrogen-sensitive detector; antitussive; dextromethorphan; gasliquid chromatography; human plasma; SPS19, pp. 481-485 (Apr. 1979).

Nitrogen-strengthened; stainless steel; tensile properties; toughness; cryogenic; fatigue; fracture; high-strength; lowtemperature; mechanical properties; nitrogen; 18957.

Nitrogen-15 coupling constants; nitrogen-15 n.m.r. spectroscopy; proton; proton coupling; structural analysis; bis(hexopyranosyl)amine; carbon-13; conformational analysis; 18764 .

Nitrogen-15 n.m.r. spectroscopy; proton; proton coupling; structural analysis; bis( hexopyranosyl)amine; carbon-1 3; conformational analysis; nitrogen-15 coupling constants; 18764 .

Nitromethane; rotation; tunneling; crystal structure; neutron scattering; 19025 .

Nitrosamines; nitrosodiethanolamine; silylation; thermal energy analyzer (TEA); tobacco; carbamates; chemical ionization; electron-capture; hydrazines; maleic hydrazide; mass spectroscopy; SP519, pp. 297-309 (Apr. 1979).

Nitrosamines; sidestream smoke; thermal energy analyzer; tobacco smoke; vinyl chloride; aza-arenes; hydrazines; nitroalkanes; SP519, pp. 131-141 (Apr. 1979).

Nitrosodiethanolamine; silylation; thermal energy analyzer (TEA); tobacco; carbamates; chemical ionization; electroncapture; hydrazines; maleic hydrazide; mass spectroscopy; nitrosamines; SP519, pp. 297-309 (Apr. 1979).

Nitrous acid; ozone; rate constants; chemical kinetics; environmental measurements; nitric acid; 18551 .

NMR; polyethylene; resolution; sample spinning; solids; 13 ; conformation; crystallinity; 18745 .

NMR; primary salt effect; speciation; activation parameters; aqueous transmethylation; chloride complexes; environment; formation constants; ionic mechanisms; kinetics; methylmercury; methyltin; 18484 .

Nobel Prize; low temperature physics; 18482 .

Noble metals analysis; platinum determination; radiochemical separation; spontaneous deposition technique; biological materials analysis; environmental materials analysis; neutror. activation analysis; 18350 .

Noise; noise emission; regulations; sound; acoustics; environmental noise; 18785 .

Noise; point contacts; SQUID; Josephson junction; 18663 .

Noise; servo control; acoustooptic; intensity; laser; modulator; 18904. 
Noise control; transmissibility; vibration isolation; vibrations; antivibration mounting; damping; dynamic properties; industrial engineering; isolation; machinery and equipment; mechanical impedance; mechanical vibrations; $H 128$.

Noise emission; regulations; sound; acoustics; environmental noise; noise; 18785 .

Noise, laser sources; nonlinear spectroscopy; optical heterodyne; spectroscopy, laser; laser spectroscopy; $/ 8558$.

Noise measurement; noise (sound); tire noise; transportation noise; truck; acoustics; 18607.

Noise signature; non-destructive evaluation; piezoelcctric polymer; spectrum analysis; strain gage; bearing noise; failure prevention; machinery noise; SP547, pp. 303-314 (July 1979).

Noise spectrum; nonequilibrium; stationary states; switching; threshold switching; fluctuation; master equation; 18674 .

Noise spectrum; Raman spectroscopy; turbulence; concentration fluctuations; fast Fourier transforms; Fourier transform analysis; mixing in turbulent flow; 18626.

Noise thermometry; resistive SQUIDS; temperature measurement; Johnson noise; Josephson junctions; 18603 .

Noise thermometry; SQUID's; standards; superconductivity; Josephson effect; metrology; 18871 .

Noise (sound); tire noise; transportation noise; truck; acoustics; noise measurement; 18607 .

Nomenclature; sample work-up; standards; chromatography/column packings (GC); electron-capture detection; evaporation; SP519, pp. 809-810 (Apr. 1979).

Non-bonded potential functions; polyethylene; vibrational data; force field refinement; lattice dynamics; $n$-alkanes; 18404 .

Nondestructive; protection circuit; reverse bias; safe operating area; second breakdown; switching power transistor; tester: transistor; base drive circuit; electronic circuits; inductive load; SP4OO-54.

Non-destructive evaluation; crack detection; eddy currents; 18911 .

Nondestructive evaluation; nuclear reactor; radiation; activation analysis; crystal structure; diffraction; isotopes; molecular dynamics; neutron; neutron radiography; TN995.

Nondestructive evaluation; penetrants; radiography; statistics; ultrasonics; visual-optical tests; acoustic; annual report; eddy currents; inspection; magnetic particles; NBSIR 78-1581.

Non-destructive evaluation; piezoelectric polymer; spectrum analysis; strain gage; bearing noise; failure prevention; machinery noise; noise signature; SP547, pp. 303-314 (July 1979).

Non-destructive evaluation; pipe welds; standard; $x$-ray image; appropriations; fusion diagnostics; gravity waves; laser-interferometer; microwave measurements; DIM/NBS 63, No. 3 , 1-28 (1979).

Nondestructive evaluation; statistical estimation; diffusion coefficents; iteration; moisture profile modeling; SP563, pp. 3246 (Oct. 1979).

Nondestructive testing; pacemaker leads; process control; reliability; semiconductor devices; welding; automated testing; batteries; cardiac pacemakers; contamination; corrosion; electrostatic-induced damage; hermeticity; hybrid devices; leak testing; SP400-50.

Nondestructive testing; photoconductivity; power devices; resistivity variation; automation; bulk photovoltaic effect; computer control; homogeneity; measurement method; SP4OO-52.

Nondestructive testing; pilings; timber; acoustics; bridges: creosote; harbor facilities; inspection; maintenance; marine borers; 18525 .

Nondestructive testing; pole figure; texture of copper shaped charge liner; texture of $\mathrm{Ni}-\mathrm{W}$ alloy; metal texture; neutron diffraction; 19027 .

Non-destructive testing; preservation; adobe; adobe soil; compressive strcngth; creep; flexural strength; mechanical properties; moisture; TN996.
Nondestructive testing; pressure vessels; composites; holography; interferometers; matrix crazing; SP563, pp. $211-212$ (Oct. 1979).

Nondestructive testing; safe operating area, reverse-bias; second-breakdown, reverse-bias; transistors, power switching; device characterization; 18738 .

Nondestructive tests; semiconductor; tape-bonded devices; acoustic emission; beam lead devices; electronic devices; hermeticity; hybrids; SP4OO-59.

Nondestructive tests; structural analysis; ultimate strength; advanced composites; advanced ships; elastic properties; fatigue tests: SP563, pp. 286-298 (Oct. 1979).

Non-dispersive; resistive loading; TEM horn; time domain measurement; antenna gain; broadband antenna; directivity; FFT; method of measurements; 18856 .

Non-electronic equipment; testing; military systems; SP547, pp. 299-302 (July 1979)

Non-equilibrium; pyrolysis; relaxation; thermal decomposition; allylmethylether; bromide; ethylacetate; isopropyl; laser; 18832.

Nonequilibrium; stationary states; switching; threshold switching; fluctuation; master equation; noise spectrum; 18674.

Nonequilibrium carriers; semiconductors, Ge, Si, GaAs; laser induced breakdown; laser-induced damage threshold; SP54I, pp. 305-308 (Dec. 1978).

Nonequilibrium statistical mechanics; nonequilibrium thermodynamics; projection operator; correlation functions; equations of motion; maximum entropy; 18321 .

Nonequilibrium thermodynamics; projection operator; correlation functions; equations of motion; maximum entropy; nonequilibrium statistical mechanics; 18321 .

Non-invasive temperature monitoring; soft tissue; temperature dependence; ultrasound velocity; zero crossing detection; SP525, pp. 57-61 (Apr. 1979).

Nonionizing radiation; radiation hazards; radio regulations; radio standards; $\mathrm{RFI}$; spectrum management; standardization organizations; telecommunications; TVI; vehicular electronics; electromagnetic bioeffects; electromagnetic compatibility; electromagnetic immunity; SP55I.

Nonlinear creep; polyethylene; failure criteria; loss factor; 18468.

Non-linear flow histories; rate fluid; simple shear; BKZ fluid; constitutive equation; $/ 8367$.

Nonlinear load; time-domain measurements; time-stepping finite-difference technique; transient; traveling-wave antenna; Fast Fourier transform; linear load; Newton-Raphson interation methods; 19035.

Nonlinear optics; $1.15 \mathrm{\theta m}$; frequency; He-Ne laser; 18562 .

Non-linear oscillations; algebra by computer; differential equations; mathematical software; J. Res. 84, No. 4, 293-297 (1979).

Nonlinear refractive index; thermal conductivity; viscosity; Abbe value; coolants, $\mathrm{dn} / \mathrm{dT}$; index matching liquids; neodymium glass lasers; SP541, pp. 109-121 (Dec. 1978).

Nonlinear spectroscopy; optical heterodyne; spectroscopy, laser; laser spectroscopy; noise, laser sources; 18558 .

Nonmetallic coatings; offshore corrosion; saltwater corrosion; seawater corrosion; corrosion of steel; corrosion protection; 18418 .

Nonmetallics; physical properties; stainless steel; alloys; fiberglass; mechanical properties; NBSIR 79-I609.

Non-purgeable organics; organic pollutant; purgeable organics; WaterDROP; accumulators; analysis of organics in water; automatic sampler; master analytical scheme; SP519, pp. 65-78 (Apr. 1979).

Non-radiative yield; partial level width; radiative yield; atomic properties; Auger yield; Coster-Kronig yield; effective fluorescence yield; fluorescence yield; $K$ shell; $L$ shell; JPCRD 8, No. 2, 307-328 (1979). 
Non-rclativistic bremsstrahlung; atomic screening effects; bremsstrahlung high frequency limit; bremsstrahlung spectrum tip; continuum $x$ rays; Coulomb field; 18370 .

Non-relativistic bremsstrahlung; atomic screening effects; bremsstrahlung high frequence limit; bremsstrahlung spectrum tip; continuum $x$ rays; Coulomb field; 18532 .

Nonrelativistic operators; nuclear photoproduction; photoproduction; pions; pseudovector coupling; electroproduction; 18798.

Nonstoichiometry; two-dimensional modulated structure; incommensurate lattice; lanthanum niobate; modulated structure; 18646.

Nonvolatile organic compounds; organic trace detection; peptides; pharmaceuticals; sccondary ion mass spectrometry; sputtering; structural information; vitamins; amino acids; drugs; SP519, pp. 627-635 (Apr. 1979).

Normal and deuterated naphthalenes; vibrational assignments; enthalpy of formation; ideal gas thermodynamic properties; molecular structure; JPCRD 8, No. 2, 527-536 (1979).

$\mathrm{NO}_{s}$; olefins; $\mathrm{SO}_{s}$; troposphere; aldehydes; aromatics; chemical kinetics; data needs; free radicals; modeling; SP557.

Noxious fluids; refractive index; refractive index tubes; fluids; 18930.

n-paraffins; polycrystals; relaxation process; Young's modulus; audio frequencies; impurities; internal friction; isomers; low temperatures; 18467.

Np-237; Pu-239; U-235; U-238; activation analysis; benchmark fields; dosimetry; fission yields; measurements; neutrons; 18884.

NRZI recording; phase encoded recording; tape drive characteristics; computer magnetic tape drives; computer tape controllers; group coded recording; interface electrical characteristics; interface functional characteristics; magnetic tape drives; NBS-GCR-78-127.

$\rho$-type silicon; boron-doped silicon; dopant density; effective mass; hole mobility; ionized impurity scattering mobility; lattice scattering mobility; neutral impurity; resistivity; scattering mechanisms; scattering mobility; SP400-47.

Nuclear; quartets; reactions; spectroscopy; SU4; alpha-particles; correlations; mass formula; 18423 .

Nuclear cooling; Pomeranchuk refrigerators; solid $\mathrm{He}^{3}$; superfluid $\mathrm{He}^{3}$; symposium; cryogenics; dilution refrigerators; helium 3; Japan; millikelvin research; 18679.

Nuclear data; nuclear reactions; secondary particle spectra; kerma factors; neutron cross section; neutron energy deposition; 18360 .

Nuclear data; reactor dosimetry; benchmark fields; benchmark testing; neutron fields; 19024 .

Nuclear data; secondary charged particles; initial spectra; ion pair energy; 18660 .

Nuclear engineering; reliability; risk; safety factor; sampling; Weibull distribution; corrosion fatigue; design; engineering judgment; factor of safety; fatigue; mathematical modeling; 18326.

Nuclear magnetic resonance; boron hydride; metalloborane; nickelaborane; 18328 .

Nuclear magnetic resonance; nuclear spin relaxation; diffusion; energy; hydrides; hydrogen storage; 18352 .

Nuclear material safeguards; safeguards; analysis; diversion of nuclear materials; diversion path analysis; material accounting; material control; 18735.

Nuclear orientation; nuclear spin system; ${ }^{166} \mathrm{Ho}^{165} \mathrm{Ho}$; atomic magnetic structures; conical spin structure; decay of ${ }^{166 m} \mathrm{Ho}$; 18604.

Nuclear photoproduction; photoproduction; pions; pseudovector coupling; electroproduction; nonrelativistic operators; 18798.

Nuclear power plants; public sector efficiency; subsidies; technological change; capital formation; economic growth; NBS-GCR-ETIP 78-42.
Nuclear reactions; secondary particle spectra; kerma factors; neutron cross section; neutron energy deposition; nuclear data; 18360 .

Nuclear reactor; radiation; activation analysis; crystal structure; diffraction; isotopes; molecular dynamics; ncutron; neutron radiography; nondestructive evaluation; TN995.

Nuclear reactors; reactor dosimetry; dosimetry programs; light water reactors; 19014 .

Nuclear, research; radiation processing; activation analysis; electron beams; induction accelerator; ion acceleration; 18570 .

Nuclear spin relaxation; diffusion; energy; hydrides; hydrogen storage; nuclear magnctic resonance; $\mathbf{8 3 5 2}$.

Nuclear spin system; ${ }^{166} \mathrm{Ho}^{165} \mathrm{Ho}$; atomic magnetic structures; conical spin structure; decay of ${ }^{1}{ }^{6} \mathrm{~m} H \mathrm{Ho}$; nuclear orientation; 18604.

Nucleation theory; polye thylene; polymer fiber; shish; volume strain; core fibril; cumulative stress; flow-induced crystallization; J. Res. 84, No. 5, 359-384 (1979).

Nucleic acid bases; solution calorimetry; thermochemistry; adenine; enthalpy of dissociation; enthalpy of protonation; enthalpy of reaction; enthalpy of solution; J. Res. 84, No. 3, 231 -240 (1979).

Numerical analysis; OMNITAB 78; portability; poster; reliability; statistical computing section; worksheet; capabilities; ease of learning and using; installation; language; maintenance; 18903.

Numerical modeling; pipe flows; turbulence modeling; flowmeter; fluid dynamics; mathematical modeling; 18410 .

Numerical radius; spectrum; stable matrix; closure; $D$-stability; diagonal matrix; field ô values; Hadamard product; inclusion theorem; Kronecker product; 18909.

Numerical simulation; particle accelerators; space charge forces; beam transport; high current beams; 18932 .

Numerical simulation; subsonic water drop impact; surface flaws; crack activation; SP562, pp. $501-511$ (Oct. 1979).

Nursing homes; bibliographies; building fires; escape; evacuation; fires; high rise buildings; hospitals; human behavior; NBS-GCR-78-138.

Nursing homes; nursing staff; training; evacuation; fire doors; fire drills; fire extinguishers; fire safety; health care facilities; hospitals; human behavior; NBS-GCR-79-179.

Nursing homes; patients; room fires; smoke; upholstered furniture; chairs; doors; evacuation; fire de partments; fire fighters; NBS-GCR-79-159.

Nursing homes; photoelectric detectors; corridors; escape; fire detectors; full-scale tests; heat detectors; hospitals; ionizaton detectors; mattresses; NBSIR 79-1739.

Nursing homes; renovation; applied economics; building codes; building economics; economic analysis; fire safety; health care facilities; hospitals; life safety; mathematical programming; NBSIR 79-1902.

Nursing homes; renovation; applied economics; building codes; building economics; economic analysis; fire safety; health care facilities; hospitals; life safety; mathematical programming; 19045.

Nursing homes; risk analysis; safety equivalency; safery evaluation; smoke detection; automatic sprinklers; building codes; building construction; Delphi Method; fire safety; health care facilities; hospitals; interior finishes; Life Safety Code; NBSIR $78-1555$.

Nursing homes; user needs; building codes; building evaluation; elderly; fire safety; handicapped occupants; health care facilities; NBSIR 79-1906.

Nursing staff; patients; room fires; breathing apparatus; death; evacuation; fires; flashover; hospitals; human behavior; NBSGCR-78-140.

Nursing staff; training; evacuation; fire doors; fire drills; fire extinguishers; fire safety; health care facilities; hospitals; human behavior; nursing homes; NBS-GCR-79-179. 
Nutricnt analysis; nutrition; standard reference materials; SP519, pp. 249-255 (Apr. 1979).

Nutrients; organic pollutants; trace organic analysis; drug analysis; food toxicants; hormones; neurotransmitters; SPS19.

Nutrition; standard reference materials; nutrient analysis; SP519, pp. 249-255 (Apr. 1979).

Nutritional analysis; nutritional labeling; sample preparation; composite sampling; SP519, pp. 243-248 (Apr. 1979).

Nutritional labeling; sample preparation; composite sampling; nutritional analysis; SPS 19, pp. 243-248 (Apr. 1979).

$\mathrm{N}^{+4}$; $\mathrm{O}^{+5}$; rate coefficient; electron impact ionization; ionization cross section; ionization rate coefficient; lithiumlike ions, ionization of; 18502 .

$\mathrm{N}_{2}$; radiative transition; ${ }^{5} \Pi_{u} ;{ }^{5} \Sigma_{u}{ }^{+}$; energy curve; excited state; 18935.

$\mathrm{N}^{4+}$; crossed beams; cross sections; electron impact; excitation, $2 s-2 p ; 18707$.

\section{O}

Observer proximity effects; power transmission lines; Russian measurement technique; electric field measurements; instrumentation; measurement procedures; 18494.

Occupant factors; residential air conditioning; service hot water; space heating; ventilation; appliance energy consumption; energy consumption of residences; lighting energy consumption; NBSIR $78-1501$.

Occupational health; picogram; polycyclic aromatic hydrocarbens; selectivity; sensitivity; specificity; trace analysis; environmental pollution; fluorescence; high performance liquid chromatography; SP519, pp. 41.56 (Apr. 1979).

Ocean current; plate tectonics; polar motion; crustal movements; earth rotation; geodynamics; gravity field; 18584 .

Ocean load; preferred frame; spatial anisotropy; strain tides; core resonance; free wobble; laser strainmeter; 18823 .

Octacalcium phosphate; tooth; x-ray diffraction; bone; hydroxylapatite; interlayering; 18583 .

Ocular contusion; projectiles; propelled objects; test methods; toy safety; eye injury; impact; J. Res. 84, No. 1, 9-19 (1979).

Ocular tumor; power spectra; Rayleigh scattering; ultrasonic spectrum analysis; clinical ultrasound; SP525, pp. 111-119 (Apr. 1979).

Off-period mass flow rate; part-load performance; seasonal efficiency; automatic stack damper; flue-gas temperature profile; gas-fired furnace; TN999.

Offset policy; regulatory policy; technological innovation; administrative experimentation; Environmental Protection Agency; evaluability assessment; Experimental Technology Incentives Program; industrial pollution regulation; market mechanism; NBS-GCR-ETIP 79-62.

Offshore corrosion; saltwater corrosion; seawater corrosion; corrosion of steel; corrosion protection; nonmetallic coatings; 18418.

Ohmic contacts; reliability; semiconductor measurements; sheet resistance; solar cells; solar cell stability; device measurements; laser scanning; light-biasing; metallization; NBSIR 79. 1909.

Ohmic contacts; reliability; semiconductor measurements; solar cells; solar cell stability; workshops; device measurements; laser scanning; metallization; 18633 .

Oil; oyster; conductivity; ion-chromatography; ion-exchange; liquid chromatography; J. Res. 84, No. 3, 241-246 (1979).

Oil analysis; oil sampling; wear; wear particles; ferrography; machine condition monitoring; SP547, pp. 323-329 (July 1979).

Oil sampling; wear; wear particles; ferrography; machine condition monitoring; oil analysis; SPS47, pp. 323-329 (July 1979).
Oil specifications; petroleum standards; petroleum test methods; recycled oil; re-refined oil; used oil; waste oil; engine oil; fuel oil; hydraulic oil; industrial oil; lubricating oil; SPS56.

Oil-fired; rating; space-heating; testing; boiler; combustion; energy; furnace; gas-fired; heating; 18385 .

Oils; PUFA; 9,12-di-cis-polyunsaturated fatty acids; fats; lipoxidase; SP519, pp. 289-295 (Apr. 1979).

Oils; reversed-phase; serum; cerebrospinal fluid; detector; highperformance liquid chromatography; light-scattering; lipids; nephelometry; SP519, pp. 429.436 (Apr. 1979).

Olefin; ozone; review; troposphere; hydroxyl; kinetics; SP557, pp. 7-14 (Aug. 1979).

Olefins; $\mathrm{SO}_{s} ;$ troposphere; aldehydes; aromatics; chemical kinetics; data needs; free radicals; modeling; NOr; SP557.

OMNITAB 78; plots; portability plots; residuals; statistical plots; statistics; stem-and-leaf displays; box plots; CALCOMP; computing system; confidence ellipse; 18954 .

OMNITAB 78; portability; poster; reliability; statistical computing section; worksheet; capabilities; ease of learning and using; installation; language; maintenance; numerical analysis; 18903.

Onboard; patented; pressure; pumps; reservoirs; sensors; tailorable; temperature; accumulator; analog; centralized; check-out system; dessicant; discrete; displacement; fiber optics; filters; flight critical; flow; fluid; go-no-go; SP547, pp. 345-357 (July 1979).

One-tenth scale motor case; S-glass; temperature effects; water boil; degradation; epoxy resins; Kevlar 49; moisture; SP563, pp. 177-197 (Oct. 1979).

On-line; performance; response time; saturated system; transaction processor; inventory management; SPSOO-52, pp. 215 218 (Oct. 1979).

On-line system design; performance evaluation; performance management; prototyping; remote terminal emulation; system testing; audit; capacity planning; financial applications; longrange planning; management control; measurement; modeling; SPSOO-52, pp. $129-140$ (Oct. 1979).

On-line system evaluation; prediction methods; queuing models; simulation; software monitoring; workload definition; computer performance evaluation; computer performance measurement; computer performance prediction; computer system acquisition; conference proceedings; SP500-52.

On-site construction; building official; energy code; energy efficient; enforcement; implementation and effective $U$ value; SP552, pp. 131-140 (July 1979).

On-vehicle computing instrumentation; prognostic maintenance management; geriometry; life cycle reliability; SP547, pp. 6577 (July 1979).

Open systems; remote sensing; closed systems; electromagnetic problems; functional theoretic techniques; modified residue calculus; Monogr. 164.

Operating systems; protocols; communications; computers; data bases; networks; 18488 .

Operating systems; protocols; communications; computers; databases; networks; 18891 .

Operation; purchasing; pursuit tires; safety; tread wear; braking traction; cornering traction; driving traction; endurance; maintenance; SP480-33.

Operations research; programming languages; sparse matrices; data pooling; data structures; mathematical programming; matrices; name generation; J. Res. 84, No. 1, 21-47 (1979).

Operator speed; record size; transaction volume; transfer speed; validate; verify; application; character set; computer interface; cost; data entry; edit; SP5OO-55.

Optical absorption coefficient; optoacoustic spectroscopy; $\mathrm{PbF}_{2}$; photoacoustic spectroscopy; Tll; ZnSe; absorption edge; $\mathrm{CaF}_{2}$; KCl; SPS4I, pp. 43-49 (Dec. 1978). 
Optical analyzer; polarized light; probe thermometer; temperature sensitive parameter; aligned sheet polarizer; birefringent crystal; U.S. Patent 4,140,393.

Optical calorimetry theory; surface optical absorption; coating optical absorption; laser calorimetry theory; SP541, pp. 7-12 (Dec. 1978 ).

Optical character recognition; optical mark sensing; source data entry; data entry; economic considerations; keyboard; keypunch; FIPS PUB 67.

Optical characterization; laser mirror; metallurgical characterization; microstructures; molybdenum; SP54I, pp. 132-163 (Dec. 1978).

Optical coatings; absorption; calorimetry; SP541, pp. 33-36 (Dec. 1978).

Optical coatings; thin films; antireflection coatings; electron microscopy; laser damage; SP541, pp. $218-225$ (Dec. 1978).

Optical communications; quality control; attenuation; fiber optics; interlaboratory comparison; measurements; NBSIR 79. 1608.

Optical communications; review; communication systems; fiber optics; measurement; 18648.

Optical components; optical fabrication; optical materials and properties; thin film coatings; laser damage; laser interaction; SP541.

Optical correlation; scattering; swept-frequency diffraction; angular scattering; characterization of tissue; SP525, pp. 143152 (Apr. 1979).

Optical density; particle size; polypropylene; polyurethane foams; polyvinyl chloride; pyrolysis; rigid foams; smoke; smoldering; weight loss; wood; combustion; flaming combustion; flexible foams; NBS-GCR-78-147.

Optical detection; Raman microprobe; Raman spectra; Raman spectroscopy; laser excitation; microanalysis; microparticle analysis; microprobe resolution; microsample heating; 18971 .

Optical emission; photoionization; Potassium-Krypton mixtures; resonant multiphoton ionizations; collisional excitation; collisional radiative recombination; laser induced plasma; 18799 .

Optical fabrication; optical materials and properties; thin film coatings; laser damage; laser interaction; optical components; SP54l.

Optical fiber damage; pulsed $\mathrm{Nd}^{3+}$ laser damage; single and multiple element fibers; surface threshold damage; freerunning laser pulses; giant laser pulse; SP54I, pp. 168-189 (Dec. 1978).

Optical fibers; laser; 18662 .

Optical figure; optical homogeneity; single crystal; Talystep traces; alkali halides; backward scattering; forward scattering; grain boundaries; isostatic forging; SP54I, pp. $65-69$ (Dec. 1978).

Optical glass; polishing; cleaning; chemical durability; glass surface; latent scratch; SP562, pp. $417-425$ (Oct. 1979).

Optical heterodyne; spectroscopy, laser; laser spectroscopy; noise, laser sources; nonlinear spectroscopy; 18558 .

Optical homogeneity; single crystal; Talystep traces; alkali halides; backward scattering; forward scattering; grain boundaries; isostatic forging; optical figure; SP541, pp. $65-69$ (Dec. 1978).

Optical mark sensing; source data entry; data entry; economic considerations; keyboard; keypunch; optical character recognition; FIPS PUB 67.

Optical materials and properties; thin film coatings; laser damage; laser interaction; optical components; optical fabrication; SP54I.

Optical microscope stage; piezoelectric drives; scanning stage; SEM microscope stage; submicrometer positioning instrumentation; TEM microscope stage; flexure pivots; linear positioning; micromanipulator; 18327.

Optical microscopy; linewidth measurement; microlithography; micrometrology; 18629.
Optical microscopy; polishing defects; scattered light; S1MS; stylus instruments; Auger spectroscopy; corrosion films; ESCA; impurities; microroughness; SP562, pp. 337-350 (Oct. 1979).

Optical particle sizing; particle size standards; aerosol size measurement; calibration of particle sizing instruments; Doppler shift spectrometer; light scattering; 18980 .

Optical potentials; photopion; pion; beryllium; differential cross section; Fermi gas; lithium; 18442.

Optical potentials; photopion; pion; beryllium; differential cross section; Fermi gas; lithium; 18496.

Optical probe technique; radiation scattering; thin films; laser damage; SP541, pp. 226-234 (Dec. 1978).

Optical processing; phase; precision measurements; wave front; amplitude; beam profile; cross correlation; digital sampling; Fourier optics; holography; laser; laser parameters; laser pulse; TN1009

Optical properties; diamond single-point machining; dielectrics; infrared optical components; laser damage; SP562, pp. 293303 (Oct. 1979).

Optical properties; scattering; calcium fluoride; forging; laser windows; SP541, pp. $70-77$ (Dec. 1978).

Optical properties; ultraviolet transmission; fluorides; forging; laser windows; lithium fluoride; mechanical properties; SP541, pp. 59-64 (Dec. 1978).

Optical pumping; optical spectroscopy; radiation pressure; radiative cooling; Doppler-free spectroscopy; frequency standard; high resolution spectroscopy; ion storage; laser spectroscopy; Mossbauer effect; 18699 .

Optical radiation measurements; primary standards; standard source; electrically calibrated detector; 18796 .

Optical Ramsey effect; resonance line shape analysis; Rydberg atoms; two photon spectroscopy; laser spectroscopy; 19019.

Optical Ramsey fringes; photon-recoil structure; saturated absorption; calcium; 18642.

Optical scattering; optical surface quality; scartering; standards; surface roughness; 18999.

Optical spectroscopy; radiation pressure; radiative cooling; Doppler-free spectroscopy; frequency standard; high resolution spectroscopy; ion storage; laser spectroscopy; Mossbauer effect; optical pumping; 18699.

Optical surface quality; scattering; standards; surface roughness; optical scattering; 18999 .

Optical waveguide; phase-matched propagation in waveguide; Raman spectroscopy of liquids; signal enhancement of coherent Raman process; coherent anti-Stokes Raman spectroscopy (CARS); liquid-filled dielectric waveguide; $I 8686$.

Optical \& microwave double resonance; stored ions; systematic effects; Ba ions; frequency stability; frequency standard; ion temperature; laser induced cooling; $\mathbf{M g}$ ions; 18697.

Optically pumped; wavelength; $\mathrm{CH}_{2} \mathrm{~F}_{2} ; \mathrm{FIR} ; \mathrm{I} 961$.

Optimal; standard; buildings; conservation; criteria; design; economics; efficiency; energy; energy budget; equity; lifecycle cost; 18888 .

Optimal design; residential buildings; space cooling; space heating; building envelope; cost effectiveness; economics; energy conservation; internal rate of return; life-cycle costing; marginal analysis; 19044 .

Optimization; stability; standards; catalog; dynamic programming; iterative procedure; models; NBSIR 78-1539.

Optimization of analysis; silicon; trace analysis; activation analysis; cadmium ratio; east neutron reactions; interfering nuclear reactions; 18338 .

Optimum weatherization retrofit combinations; thermal analysis of residences; Community Services Administration; heating balance point analysis; low-income residences; marginal $\cos$ /benefit analysis in weatherization; NBSIR 79-1706.

Opto-acoustic; pulse compression; sensitivity; signal averaging; signal processing; tissue characterization; tomography; trans- 
ducers; ultrasonics; annular array; breast cancer; chirp signals; imaging; SP525, pp. 255-259 (Apr. 1979).

Optoacoustic spectroscopy; $\mathrm{PbF}_{2}$; photoacoustic spectroscopy; Tl1; ZnSe; absorption edge; $\mathrm{CaF}_{2} ; \mathrm{KCl}$; optical absorption coefficient; SP541, pp. 43-49 (Dec. 1978).

Optogalvanic effect; enhanced ionization theory; flame spectroscopy; ion production; laser enhanced ionization; laser spectroscopy; 18806 .

Opto-galvanic effect; predetermined frequency; spectroscopic and analytic determinations; variable wavelength monochromatic light; U.S. Patent 4,148,586.

Opto-galvanic effect; trace metal analysis; tunable dye laser; analytical flame spectroscopy; flame ionization; flame spectroscopy; laser enhanced ionization; laser spectroscopy; 18880 .

Optogalvanic effect; trace metal detection; laser excited galvanic spectroscopy; lasers, bandwidth determination of; lasers, frequency locking of; lasers, wavelength calibration of; 18944.

Opto-galvanic spectroscopy; uv irradiation; light absorption; metal oxides; molecular absorption; 18344

Ordered alloys; statistical mechanics; face centered cubic; ground state; interfaces; multi-ion interactions; 18614 .

Ordering; paired comparisons; prioritization; project selection; ranking; resource allocation; weighting multiple criteria; decision analysis; decisions; eigenvectors; management; multipleattribute decisions; 18602 .

Ordering; surface mobility; alloys; antiphase domains; critical behavior; domain growth; domain walls; 18373 .

Ordering; surface mobility; alloys; antiphase domains; critical behavior; domain growth; domain walls; 18613 .

Organic aerosol constituents; primary organic carbon; sampling errors; secondary organic carbon; solvent extraction; spatial variations; diurnal variations; elemental carbon; mass spectroscopy; SP519, pp. 121-129 (Apr. 1979).

Organic analysis; reflectance; air pollution; ambient aerosols; computer controlled gas chromatography/mass spectrometry; GRALE; SP519,pp. 101-107 (Apr. 1979).

Organic compounds; oxidation; oxygen; oxygenated; rate constant; sulfur; Arrhenius parameters; combustion; decomposition; free radicals; hydrocarbons; hydrogen; nitrogen; NBSIR 79-1941.

Organic microanalysis; PAH microsamples; (PAHs); polynuclear aromatic hydrocarbons; Raman spectra; trace organic analysis; laser-Raman microprobe; liquid chromatograph-Raman spectrometer interface; micro-Raman spectroscopy; SP519, pp. 723-729 (Apr. 1979).

Organic microanalysis; Raman microprobe; Raman spectra; Raman spectroscopy; biological microanalysis; microanalysis; micromineralogy; microsampling; molecular analysis; 18963.

Organic molecules; rate coefficients; chemical kinetics; data evaluation; gas phase ion-molecule reactions; mass spectrometry; NSRDS-NBS64.

Organic pollutant; purgeable organics; WaterDROP; accumulators; analysis of organics in water; automatic sampler; master analytical scheme; non-purgeable organics; SP519, pp. 65-78 (Apr. 1979).

Organic pollutants; trace organic analysis; drug analysis; food toxicants; hormones; neurotransmitters; nutrients; SP519.

Organic pollutants monitoring; synchronous excitation spectroscopy; cresol; luminescence spectrometry; SP519, pp. 679684 (Apr. 1979).

Organic trace detection; peptides; pharmaceuticals; secondary ion mass spectrometry; sputtering; structural information; vitamins; amino acids; drugs; nonvolatile organic compounds; SP519, pp. 627-635 (Apr. 1979).

Organics in water; pesticides; extraction; herbicides; high pressure liquid chromatography; SP519, pp. 87-94 (Apr. 1979).

Organics in water; pulsed laser; fluorescence; SP519, pp. 691696 (Apr. 1979).
Organochlorides; pesticides; sediment and water; carbamates; gas chromatography; SP519, pp. 191-203 (Apr. 1979).

Organomercury cations; biological samples; electrochemical detection; liquid chromatography; metal speciation; 18420.

Organometallic benzotriazenides; rhodium (1) complexes; thallium benzotriazenide; benzotriazenides; iridium (I) complexes; 18582 .

Organometals; water preconcentration; electrochemical detection; liquid chromatography; methylmercury; SP519, pp. 57 63 (Apr. 1979).

Orientation entropy; packing of rods; square lattice; theories of liquid crystals; configurations of rods; Monte Carlo; 18530.

Orientational disorder; rotational dynamics; condensed phases; diffusion mechanisms; inelastic scattering; neutron scattering; 19026.

Oriented polyethylene; relaxation process; stress relaxation; torsion pendulum; dynamic mechanical; high pressure extrusion; 18767.

Orion Nebula; dimethyl ether transitions; high-resolution spectra; 18731 .

Orthobaric densities; specific heats; speeds of sound; vapor pressures; densities; enthalpies; entropies; equation of state; internal energies; isobars; isobutane; isochores; isotherms; Joule-Thomson inversion; latent heats of vaporization; melting line; NBSIR 79-1612.

Orthobaric densities; specific heats; speeds of sound; vapor pressures; densities; enthalpies; entropies; equation of state; internal energies; isobars; isochores; isotherms; Joule-Thomson inversion; latent heats of vaporization; melting line; $n$-butane; NBSIR 79-1621.

Orthobaric liquid density; tables; argon; comparisons; correlation; ethylene; experimental; magnetic suspension; 18627 .

Orthogonal idempotents; quasi-order; topological algebra; coalgebra; direct limit; faithful distributive module; generating function; incidence algebra; inverse limit; 18788 .

Orthogonalities; plane-radial scanning; probe correction; space groups; aliasing; Bravais lattices; Fast Fourier "Transform"; near-field scanning; 18956.

Orthotelephonic response; anthropometric manikin; free-field measurements; hearing aids; hearing aid tests; 18464 .

Orthotropic materials; programmable calculators; solid state sof tware; advanced composite materials; composite materials analysis; SP563, pp. 91-107 (Oct. 1979).

Oscillator; position location; time dispersion; time error; time error measure; time prediction error; clocks; frequency drift; frequency stability; navigation; 18899 .

Oscillator stength; $\mathrm{Zn}$ sequence; Cu sequence; 18366 .

Oscillator strength; Al 1 ; aluminum; delayed coincidence; $f$ value; imprisonment; laser; lifetime; mean life; 18527.

Oscillator strengths; atomic transition probabilities; literature survey; 18572 .

Oscillator strengths; copper isolectronic sequence; diagrammatic perturbation theory; electron correlation; ionization energies; line strengths; many-body interaction; many-body perturbation theory; 18998 .

Oscillator strengths; photoabsorption; 18923.

Oscillator systems; phase lock loop; position location; spectral purity; frequency lock loop; frequency stability; navigation; 18693.

Oscillator systems; quartz crystal oscillator; short term frequency stability; long term frequency stability; 18691 .

Oscilloscope; picosecond; puise; pulse measurement; time domain measurement; automation; laser; 18640.

OSHA; primary standards; diffusion tubes; SP519, pp. 761-769 (Apr. 1979).

Osmium; rhenium; tantalum; tungsten; wavelengths; ytterbium; energy levels; hafnium; ionization energies; lutetium; 18506.

Osmotic coefficients; solutions; thermodynamic properties; activity coefficient; cobalt; critical evaluation; electrolyte; ex- 
cess Gibbs energy; iron; nickel; JPCRD 8, No. 4, 923-1004 (1979).

Osmotic coefficients; solutions; thermodynamic properties; uranium; activity coefficient; copper; critical evaluation; electrolyte; excess Gibbs energy; lead; manganese; JPCRD 8, No. 4, $1005-1050(1979)$.

Outdoor exposure; solar collectors; standard test methods; absorptive coatings; accelerated laboratory tests; durability; 18554.

Overlamping; surface mounted incandescent lighting fixture; thermal insulation; thermocouple; branch circuit wiring; electrical junction box; hazardous temperatures; load current; NBSIR 79-1912.

Overlap; Be; dispersion; excited states; He; interaction energy; 18933.

Overspeeding error; rotary anemometer; unsteady flow; air; anemometer; helicoid anemometer; lag; NBSIR 78+1505.

Oxidation; ion-chromatography; nitrite; nitrite solutions; 18889 .

Oxidation; oxygen; oxygenated; rate constant; sulfur; Arrhenius parameters; combustion; decomposition; free radicals; hydrocarbons; hydrogen; nitrogen; organic compounds; NBSIR 79-194I.

Oxidation; photolithography; photovoltaic method; powerdevice grade silicon; radioisotope leak test; resistivity variations; resistors, sheet; scanning acoustic microscope; semiconductor materials; semiconductor process control; silicon; silicon dioxide; SP4OO-38.

Oxidation; reduction; cell design; electrochemical detection; liquid chromatography; SP5/9, pp. 705-712 (Apr. 1979).

Oxidation and degradation; silicon-nitride; fracture origin; fracture strength; machining of ceramics; SP562, pp. 477-481 (Oct. 1979).

Oxidation of silicon; semiconductor processing; silicon; silicon dioxide; thermally stimulated measurement; thermal oxidation; Zn-doped glasses; boron nitride; Cl-doped glasses; diffusion in silicon; integrated circuit processing; kinetics of oxide growth; NBS-GCR-78-134.

Oxide films; photopotentials; aluminum; copper; copper alloys; nickel; 18724 .

Oxide moisture sensors; accelerated stress test; capillary leaks; corrosion failure; hermeticity; moisture infusion; NBS-GCR79-170.

Oxides; sapphire; two-surface lapping; two-surface polishing; dome finishing; finishing technique; hemispherical domes; SP562, pp. 255-260 (Oct. 1979).

Oxides; scratching; size effect; specific energy; ceramics; chipping; crack formation; fracture toughness; friction; hardness; liquid softening; SPS62, pp. 43-59 (Oct. 1979).

Oxidizer; thermochemistry of fluorine compounds; calorimetry, gas flow; chlorine thermochemistry; flame calorimetry; fluorinaceous; 18755 .

Oxyanion radicals; phosphate radical; photolysis; radiolysis; rates; selenium radicals; sulfate radical; thiocyanate radical anion; aqueous solution; carbonate radical; chemical kinetics; halogen radical anions; nitrate radical; NSRDS-NBS65.

Oxyapatite; cation distribution; cation ordering; impurities; 18448 .

Oxygen; capacitor; density; dielectric constant; 18987 .

Oxygen; oxygen sensor; permeation; polarographic sensor; polymer membrane; diffusion; dissolved oxygen; mathematical model; NBSIR 79. 1740 .

Oxygen; oxygenated; rate constant; sulfur; Arrhenius parameters; combustion; decomposition; free radicals; hydrocarbons; hydrogen; nitrogen; organic compounds; oxidation; NBSIR $79-1941$.

Oxygen; permeability; poly(ethylene terephthalate); standard reference material; temperature coefficient; time-lag; gas transmission rate; manometric technique; $S P 260-58$.

Oxygen; pH; acid-base status of blood; blood gases; blood $\mathrm{pH}$; carbon dioxide; 18470 .
Oxygen; plasma-broadening; singly ionized oxygen; stark broadening; atomic spectra; nitrogen; 18737 .

Oxygen; scraping auger; slush; slush production; slush storage; cryogenic; hydrogen; NBSIR 79-1607.

Oxygen sensor; permeation; polarographic sensor; polymer membrane; diffusion; dissolved oxygen; mathematical model; oxygen; NBSIR 79-I740.

Oxygen, spectra, O vi-O vili; spectra, O vi-O vili; wavelengths, O v1-O vili; atomic energy levels, O v1-O vili; NSRDS-NBS3, Secrion 8.

Oxygenated; rate constant; sulfur; Arrhenius parameters; combustion; decomposition; free radicals; hydrocarbons; hydrogen; nitrogen; organic compounds; oxidation; oxygen; NBSIR 79-1941.

Oyster; conductivity; ion-chromatography; ion-exchange; liquid chromatography; oil; J. Res. 84, No. 3, 241-246 (1979).

Ozone; pressure; standards; temperature; vacuum; humidity; 18335.

Ozone; rate constants; chemical kinetics; environmental measurements; nitric acid; nitrous acid; 18551 .

Ozone; resonances; electron scattering; energy loss; excited states; negative ions; 18392 .

Ozone; review; troposphere; hydroxyl; kinetics; olefin; SP557. pp. $7-14$ (Aug. 1979).

$\mathrm{O}^{++}$; photoionization; thermosphere; double photoionization; doubly charged ions; ionosphere; 18950.

$\mathrm{O}^{+5}$; rate coefficient; electron impact ionization; ionization cross section; ionization rate coefficient; lithiumlike ions, ionization of; $\mathrm{N}^{+4} ; 18502$.

\section{$\mathbf{P}$}

Pacemaker leads; process control; reliability; semiconductor devices; welding; automated testing; batteries; cardiac pacemakers; contamination; corrosion; electrostatic-induced damage; hermeticity; hybrid devices; leak testing; measurement technology; microcalorimetry; SP400-50.

Packaged solar space-heating system; rating; standards; testing; mobile home; NBSIR 79-I 799.

Packaging; plastics; standardization; transportation; effective carbon atom number; hazardous materials; NBSIR 79-I 768 .

Packaging; plastics; standardization; transportation; effective carbon atom number; hazardous mate rials; 18639 .

Packaging and labeling; specifications and tolerances; vapor recovery; weights and measures; consumer affairs; education; electromagnetic interference; electronic devices; International Organization of Legal Metrology; measurement assurance; metrication; SP532.

Packing of rods; square lattice; theories of liquid crystals; configurations of rods; Monte Carlo; orientation entropy; 18530 .

PAH microsamples; (PAHs); polynuclear aromatic hydrocarbons; Raman spectra; trace organic analysis; laser-Raman microprobe; liquid chromatograph-Raman spectrometer interface; micro-Raman spectroscopy; organic microanalysis; SP519, pp. 723-729 (Apr. 1979).

Paired comparisons; prioritization; project selection; ranking; resource allocation; weighting multiple criteria; decision analysis; decisions; eigenvectors; management; multiple-attribute decisions; ordering; 18602 .

Palladium; precious metals; reference data; silver; solid state physics; transport properties; copper; critical evaluation; data analysis; data compilation; data evaluation; data extraction; data synthesis; electrical resistivity; JPCRD 8, No. 4, 1147 1298 (1979).

Panthenol; pantothenates; pharmaceutical preparations; gas/liquid chromatography; SP519, pp. 267-269 (Apr. 1979).

Pantothenates; pharmaceutical preparations; gas/liquid chromatography; panthenol; SPS19, pp. $267-269$ (Apr. 1979). 
Paper; papcr aging; tcsts for papcr; accelcrated aging; aging; aging of cellulosc; aging of paper; ccllulose; cellulose aging; natural aging: 19017 .

Paper; paper fibcr; report retrieval; scientific data; computcr graphics; data base management; data retrieval; durability; fatiguc; interactive system; mathematical modeling; NBSIR 79.1746.

Paper; photometric calibrator; safety tips; solar cnergy; toxic chemicals; ultra-black coating; Alaskan pipeline; computers; corrosion; fire safety; gyromagnetic ratio; DIM/NBS 63, No. $11,1-36$ (1979).

Paper; trace elements; analysis; clay; forensic; INAA; / 8325.

Paper aging; tests for paper; accelerated aging; aging; aging of cellulose; aging of paper; cellulose; cellulose aging; natural aging; paper; 19017 .

Paper fiber; report retrieval; scientific data; computer graphics; data base management; data retrieval; durability; fatigue; interactive system; mathematical modeling; paper; NBSIR 79 . 1746.

Paper, interfiber bonding; paper, low-density handsheets; paper, pulp characterization; paper, tensile testing; mathematical modeling, network; network, tensile properties; J. Res. 84, No. 4, 299-318 (1979).

Paper, low-density handsheets; paper, pulp characterization; paper, tensile testing; mathematical modeling, network; network, tensile properties; paper, interfiber bonding; J. Res. 84, No. 4, 299-318 (1979).

Paper, pulp charaeterization; paper, tensile testing; mathematical modeling, network; network, tensile properties; paper, interfiber bonding; paper, low-density handsheets; J. Res. 84, No. 4, 299-318 (1979)

Paper, tensile testing; mathematical modeling, network; network, tensile properties; paper, interfiber bonding; paper, low-density handsheets; paper, pulp characterization; J. Res. 84, No. 4, 299-318 (1979).

Papillary carcinoma; scirrhous carcinoma; shadowing; ultrasound; attenuation; breast cancer; cancer; connective tissue; differential diagnosis; medullary carcinoma; SP525, pp. 93-99 (Apr. 1979).

Paramagnetic relaxation; low temperatures; magnetic susceptibility; magnetic thermometry; 18969 .

Parametric yield limitations; performance limitations; photomask performance; process control; test patterns; test structures; total process integration; comprehensive process characterization; design rules; intradie parametric integrity; LSI circuits; SP4OO-56.

Part integration; wheel; automotive component design; continuous fiber composite materials; fabrication; finite element stress analysis; front end; graphite; SP563, pp. 135-151 (Oct. 1979).

Partial differential equations; buoyant convection; finite-differcnce computations; firc in an enclosure; heat addition; hyperbolic, elliptic equations; initial, boundary-value problem; linearized equations; NBSIR 79-1754.

Partial discharges; streamers; transient phenomena; electrical breakdown; high speed photography; Kerr effect; liquid breakdown; nitrobenzene; 18843 .

Partial level width; radiative yield; atomic properties; Auger yield; Coster-Kronig yield; effective fluorescence yield; fluorescence yield; $K$ shell; $L$ shell; non-radiative yield; JPCRD 8, No. 2, 307-328 (1979).

Partially coherent imaging; mensuration; microdensitometry; microlithography; micrometrology; microscopy; 18356.

Particle accelerators; radiation measurements; radiation protection; standard; accelerator design; accelerator operation; health physics; H107, Revised.

Particle accelerators; space charge forces; beam transport; high current beams; numerical simulation; 18932 .
Particlc analysis; pollution studies; power plants; Raman microprobc; Raman spectroscopy; vibrational spcctra; microanalysis; 18966.

Particle analysis; power plant emissions; Raman microprobe; Raman spectroscopy; urban dusts; vibrational analysis; atomospheric aerosols; materials sampling; mineralogy; molecular analysis; 18643 .

Particle characterization; polishing compounds; subsurface defects; surface contamination; surface preparation; laser glass; SP562, pp. 231-244 (Oct. 1979).

Particle detection; particle impact noise detection; PIND; preshock; seeded specimens; transducer; acoustic emission; coshock; couplant; detection; electronic package; impact noise; microcircuit device; NBSIR 78-1590 (NASA).

Particle erosion; wear; abrasives; ceramics; erosion; impact; metals; NBSIR 78-1575.

Particle erosion; wear; abrasives; ceramics; erosion; impact; metals; 18858 .

Particle impact noise detection; PIND; pre-shock; seeded specimens; transducer; acoustic emission; co-shock; couplant; detection; electronic package; impact noise; microcircuit device; particle detection; NBSIR 78-1590 (NASA).

Particle size; polypropylene; polyurethane foams; polyvinyl chloride; pyrolysis; rigid foams; smoke; smoldering; weight loss; wood; combustion; flaming combustion; flexible foams; optical density; NBS-GCR-78-147.

Particle size standards; aerosol size measurement; calibration of particle sizing instruments; Doppler shift spectrometer; light scattering; optieal particle sizing; 18980 .

Particle spectroscopy; quarks; selection rules; spin forces; tensor force; charmonium; 18432 .

Particle velocity; plane wave; sound intensity; sound power; standing wave tube; absolute sound power source; 18728 .

Particles; superparamagnetic particles; blocking temperature; magnetic; 18746 .

Partition chromatography; parts per billion; analysis; biological; gas chromatography; Kepone ${ }^{R}$; SP519, pp. 341-343 (Apr. 1979).

Part-load evaluation; standards for heat pumps; testing procedures for heat pumps; heat pumps; 18703 .

Part-load evaluation; standards for heat pumps; testing procedures for heat pumps; heat pumps; 18778 .

Part-load performance; seasonal efficiency; automatic stack damper; flue-gas temperature profile; gas-fired furnace; offperiod mass flow rate; TN999.

Parts per billion; analysis; biological; gas chromatography; Kepone $^{R}$; partition chromatography; SP5/9, pp. 341-343 (Apr. 1979).

Parts per billion; carbon tetrachloride; chloroform; drinking water analysis; gas chromatography; SP5/9, pp. 175-179 (Apr. 1979).

Passband ccntroid; spectrophotometer; transmittance; wavelength standard; bandwidth; didymium glass filter; SP260-66.

Passive; rehabilitation; retrofit; solar; commercial; economics; evaluation; feasibility; 18964 .

Passive; solar; suburban; urban; application; buildings; commercial; daylighting; energy; environments; heating; $/ 8894$.

Passive fire protection; potential heat; smoke; compartment fires; fire tests; flame spread; heat release rate; ignition; interior finish; NBSIR 79-I700.

Passive mode locking; picosecond pulses; Rhodamine 6G; dye laser; laser cavity; mode locked dye laser; 19021 .

Passive solar systems; pedestrian behavior; psychology of retailing; retail facilities; environmental psychology; field methodology; 18784 .

Passive solar systems; performance standards; system classification; SP552, pp. 217-224 (July 1979). 
Putcntcd; prcssurc; pumps; reservoirs; scnsors; tailorable; tempcraturc; accumulator; analog; centralized; check-out system; dessicant; discretc; displaccment; fiber optics; filters; flight critical; flow; fluid; go-no-go; ground readout; SP547, pp. 345-357 (July 1979).

Pathological tissuc; Raman microprobe; Raman spectra; Raman spectroscopy; biological microanalysis; biological tissue; forcign bodics; histological sections; implant materials; microanalysis; molecular microanalysis; 18958 .

Pathology; toxic gases; alcohol intoxication; autopsy; building fircs; cigarettes; death; fire investigations; fire statistics; NBSGCR-79-168.

Patient survival; betatrons; cobalt units; dose buildup; linacs; SP554, pp. 15-21 (Sept. 1979).

Patients; room fires; breathing apparatus; death; evacuation; fires; flashover; hospitals; human behavior; nursing staff; NBS-GCR-78-140.

Patients; room fires; smoke; upholstered furniture; chairs; doors; evacuation; fire departments; fire fighters; nursing homes; NBS-GCR-79-159.

Pattern recognition; prostate tumors; ultrasound; SP525, pp. 297-302 (Apr. 1979).

Pattern recognition; robotics; vision systems; automation; image processing; inspection; manufacturing; NBSIR 79-1764.

Pattern recognition; scattering; signal processing; tissue characterization; tissue parameters; ultrasound; velocity; absorption; attcnuation; computerized tomography; Doppler; impedance; medical diagnosis; microscopy; SP525.

Payback; plumbing; roofing; shingles; venting; benefit-cost analysis; building technology; economic impacts; economics; efficiency; SP5 58.

$\mathrm{PbF}_{2}$; photoacoustic spectroscopy; TII; ZnSe; absorption edge; $\mathrm{CaF}_{2} ; \mathrm{KCl}$; optical absorption coefficient; optoacoustic spectroscopy; SP541, pp. 43-49 (Dec. 1978).

$\mathrm{PbF}_{2}$; pulsed HF laser; antireflection coatings; CdSe; coating substrate; damage resistant; Ge; SP541, pp. 257-258 (Dec. 1978).

$\mathrm{Pb}-\mathrm{Sn}$ off-eutectic alloys; phase diagram of $\mathrm{K}_{2} \mathrm{O}-\mathrm{Fe}_{2} \mathrm{O}_{3}$ system; solidification; surface tension of liquid gallium; thermodynamic properties; convection; heat capacity measurement; NBSIR 79-1767.

PCB metabolism; polychlorinated biphenyls; cytochrome P-450; liquid chromatography-mass spectrometry; SP519, pp. 685690 (Apr. 1979).

P-Cygni lines; radiative transfer; resonance lines; stars; stellar winds; line profiles; 18515

PD; pD scale; $\mathrm{pH}$; pH scales; potentiometric ion activity; activity coefficient; hydrogen ion activity; ionic activity; ionic activity scales; 18379 .

PD scale; $\mathrm{pH} ; \mathrm{pH}$ scales; potentiometric ion activity; activity coefficient; hydrogen ion activity; ionic activity; ionic activity scales; pD; 18379 .

Peak acceleration; performance; playground surfaces; test method; head injury criterion; impact; NBSIR 79-1707.

Peak intensities; powder patterns; reference intensities; standard; $x$-ray diffraction; crystal structure; integrated intensities; lattice constants; Monogr. 25, Section 16.

Peak overlap; quantitative electron probe microanalysis; $x$-ray continuum; $x$-ray spectrum; computer program; energy dispersive detector; multichannel analyzer; TN1106.

Peak power; power meter; pulsed laser; Q-switched; risetime; speckle; waveform; attenuators; calibration; laser; neodymium laser; TN1010.

Peak-to-background ratios; quantitative analysis; rough surfaces; x-ray microanalysis; electron probe analysis; 18976.

Pebble bed; phase-changc unit; solar energy storage; thermal energy storage device; ASHRAE Standard 94-77; Glauber's salt; latent heat storage; NBSIR 79-1737.
Pedestrian behavior; psychology of retailing; retail facilities; cnvironmental psychology; field methodology; passive solar systems; 18784 .

Pedestrian circulation; pedestrian flow; pedestrian movement; pedestrian ramps; ramps; building circulation; building ramps; NBSIR 79-1729.

Pedestrian flow; pedestrian movement; pedestrian ramps; ramps; building circulation; building ramps; pedestrian circulation; NBSIR 79-1729.

Pedestrian movement; pedestrian ramps; ramps; building circulation; building ramps; pedestrian circulation; pedestrian flow; NBSIR 79-1729.

Pedestrian movement; regulation; safety; standards; architectural barriers; building design; building site planning; environmental psychology; evaluation; fire escape; human research; measurement; SP552, pp. 101-113 (July 1979).

Pedestrian movement; regulation; safety; standards; architectural barriers; building design; building site planning; environmental psychology; evaluation; fire escape; human research; measurement; 18430 .

Pedestrian ramps; ramps; building circulation; building ramps; pedestrian circulation; pedestrian flow; pedestrian movement; NBSIR 79-1729.

Peer review; personnel dosimetry; processors; standard; trial use and comment; American National Standards Institute; Health Physics Society Standards Committee; mandatory testing program; 18992.

Penetrants; radiography; statistics; ultrasonics; visual-optical tests; acoustic; annual report; eddy currents; inspection; magnetic particles; nondestructive evaluation; NBSIR 78-1581.

Penicillamine; potentiometric titration; clinical chemistry; ion selective electrodes; SP519, pp. $455-459$ (Apr. 1979).

Penning effect; carbon; copper; hollow cathodes; mass spectrometry; neon; nitrogen; 18449.

Penning trap; speed of light; $\mathrm{CO}_{2}$ laser; frequency comparison; frequency multiplication; frequency synthesis; laser frequency measurement; 18608 .

People movement; systems design; buildings; communications systems; fire safety; high-rise; model codes; BSS 115.

People movers; smoke; emergency communications; emergency evacuation; fire detection; fire safety; fire suppression; mass transportation; material flammability; NBSIR 78-1586.

Peptides; pharmaceuticals; secondary ion mass spectrometry; sputtering; structural information; vitamins; amino acids; drugs; nonvolatile organic compounds; organic trace detection; SP5!9, pp. 627-635 (Apr. 1979).

Percent modulation; signal generator; vh $f$ omnidirectional radio range (VOR); amplitude modulation; instrument landing system (ILS); measurement instrumentation; measurement standard; modulation; modulation factor; modulation meter; Newton-Raphson method; TN1016.

Perception; planning; problem solving; robot control; brain mechanisms; cognition; goal seeking; intelligence; motor behavior; neural modeling; 18714 .

Perception, visual; peripheral vision; vehicles, emergency; visibility, lights; visual perception; color, lights; conspicuity, lights; effective intensity; emergency lights; intensity, effective; lights, flashing; lights, warning; $S P 480-36$.

Performance; playground surfaces; test method; head injury criterion; impact; peak acceleration; NBSIR 79-1707.

Performance; preservation; rehabilitation; renovation; adaptive reuse; architecture; building codes; building regulations; building safety; construction; SP536, pp. 1-16 (Feb. 1979).

Performance; response time; saturated system; transaction processor; inventory management; on-line; SP500-52, pp. 215-218 (Oct. 1979).

Performance; vane anemometer; wind tunnel; airflow; anemometer; laser velocimeter; low velocity; NBSIR 781433. 
Performance; vanc ancmometer; wind tunnel; airflow; anemometcr; laser velocimetcr; low velocity; NBSIR 781545.

Performancc; venting; appliance; clothes dryer; efficiency; energy conservation; heat recovery; lint; 18793.

Pcrformance analysis; structured approach; auditing; capacity planning; computcr performance evaluation; Information Management System (IMS); management reporting; SP50O52, pp. 9-19 (Oct. 1979).

Performance assurance; performance evaluation; remote monitoring; system security testing; diagnostic testing; SP500-42.

Performance attributes; performance evaluation; building codes and standards; building code structure; existing buildings; historic preservation; SP536, pp. $17-53$ (Feb. 1979).

Pcrformancc characteristics; telemetry; transducer; dynamic calibration; evaluation; interagency transducer project; TNIIIO.

Pcrformance criteria; photovoltaics; pồer conditioning; power control; solar energy; storage; 18634.

Performance evaluation; analytic queueing theory models; capacity planning; SP500-52, p. 227 (Oct. 1979).

Performance evaluation; building codes and standards; building code structure; existing buildings; historic preservation; performance attributes; SP536, pp. $17-53$ (Feb. 1979).

Performance evaluation; performance management; prototyping; remote terminal emulation; system testing; audit; capacity planning; financial applications; long-range planning; management control; measurement; modeling; on-line system design; SP50O-52, pp. 129-140 (Oct. 1979).

Performance evaluation; performance measurement; predictive modeling; set-processing; simulation; software design; analytic models; database management; model validation; SP5OO-49.

Performance evaluation; performance prediction; simulation; validation; workload characterization; workload management; capacity planning; hardware monitors; modeling; SP5OO-52, pp. 179-192 (Oct. 1979).

Performance evaluation; procurement; computer evaluation; computer performance; computer procurement; computers; computer selection; cost-value; cost-value technique; EDP selection; evaluation methodology; SP500-52, pp. 25-36 (Oct. 1979).

Performance evaluation; remote monitoring; system security testing; diagnostic testing; performance assurance; SP500-42.

Performance evaluation; stratified sampling; benchmarking; clustering; SP500-52, pp. 105-111 (Oct. 1979).

Performance evaluation; synthetic program; workload mapping; benchmarking; SP5OO-52, pp. 193-199 (Oct. 1979).

Performance evaluation; workload characterization; accounting logs; SP500-52, pp. 241-243 (Oct. 1979).

Performance limitations; photomask performance; process control; test patterns; test structures; total process integration; comprehensive process characterization; design rules; intradie parametric integrity; LSI circuits; mask alignment tolerances; modular test programs; SP4OO-56.

Performance management; prototyping; remote terminal emulation; system testing; audit; capacity planning; financial applications; long-range planning; management control; measurcment; modeling; on-linc system design; performance evaluation; SP500-52, pp. 129-140 (Oct. 1979).

Performance Management System (PMS); capabilities; methodology; needs; SP500-52, pp. 69-77 (Oct. 1979).

Performance measurement; computer; computer communications; computer performance measurement; data measurement; measurement; SP5OO-52, pp. 201-211 (Oct. 1979).

Performance measurement; predictive modeling; set-processing; simulation; software design; analytic models; database management; model validation; performance evaluation; SP5O0-49.
Performance measurement; timesharing; computer performance evaluation; human factors; interactive computing; manmachine intcraction; SP5O0-48.

Performance measurement and reporting; resource management; standard performance measures; computer pcrformance evaluation (CPE); computcr performancc management (CPM); installation management; installation pcrformancc management; SP5OO-53.

Pcrformance measures; performance ratings; responsc time; system design tradeoffs; thruput mcasurcs; comparison measures; evaluation process; SP500-52, pp. 163-176 (Oct. 1979).

Pcrformance modeling; workload characterization; clustcr analysis; computer modeling; computer performance; empirical models; modeling; SP50O-52, pp. 147-161 (Oct. 1979).

Performance monitoring; bearing analysis; condition monitoring; engine diagnosis; failure detection; failure diagnosis; failure prevention; maintenance; SP547.

Performance prediction; simulation; validation; workload characterization; workload management; capacity planning; hardware monitors; modeling; performance evaluation; SP500-52, pp. $179-192$ (Oct. 1979).

Performance ratings; response time; system design tradeoffs; thruput measures; comparison measures; evaluation process; performance measurcs; SP500-52, pp. 163-176 (Oct. 1979).

Performance specifications; sample/hold circuit; standards; terminology; analog-to-digital converter; digital-to-analog converter; IEEE subcommittee; 18365 .

Performance standard; building; code administration; codes; evaluation; existing buildings; SP549.

Performance standards; system classification; passive solar systems; SP552, pp. 217-224 (July 1979).

Performance test; showers; slip-resistance; ASTM; bathtubs; CPSC; 18705.

Perimeter station; remote unit; response force; triply redundant central computer; central unit; computerized; detection; electronic lock; exclusion area; forced entry deterrent systems; guard control station; higher headquarters; NBSIR 79-1725.

Periodic boundaries; pressure; stress calculation; virial theorem of Clausius; equilibrium; homogeneous system; hydrostatic pressure; internal stress; internal virial; molecular dynamics; Monte Carlo method; 18456.

Peripheral vision; vehicles, emergency; visibility, lights; visual perception; color, lights; conspicuity, lights; effectivc intensity; emergency lights; intensity, effective; lights, flashing; lights, warning; perception, visual; $S P 480-36$.

Permachor; permeation; plastic containers; polyethylene; standards; compatibility; $/ 8348$.

Permanent gas analysis; trace organics in air; complete analysis scheme; gas chromatography; hydrocarbons; SP519. pp. 153159 (Apr. 1979).

Permeability; poly(ethylene terephthalate); standard reference material; temperature coefficient; time-lag; gas transmission rate; manometric technique; oxygen; SP260-58.

Permeability; preservation technology; adobe building materials; chcmical grouts; damp course membrane; metallic membrane; NBSIR 79-1730.

Permeability measurements; permittivity measurements; radar absorbers; time-domain measurements; dielectrics; frequencydomain measurements; magnetic materials; microwaves; millimeter waves; NBSIR 79-1613.

Permeability to water; pipe-bonding strength; tensile strength; cementing-materials; compressive strength; hot-dry-rock well; 19018.

Permeation; plastic containers; polyethylene; standards; compatibility; permachor; 18348 .

Permeation; polarographic sensor; polymer membranc; diffusion; dissolved oxygen; mathematical model; oxygen; oxygen scnsor; NBSIR 79-174O. 
Purmittivity measurements; radar absorbers; time-domain measurements; dielectrics; frequency-domain measurements; magnetic materials; microwaves; millimeter waves; permeability measurements; NBSIR 79-1613.

Permutation matrix; doubly stochastic matrix; eigenvalues; field of values; graph; longest circuit; 18941 .

Peroxy radicals; transition metal fluorides; electron spin resonance; fluorination of polymers; free radicals; 18726 .

Personal control; physical environment; privacy; architectural psychology; bibliography; buildings; communication; cost; human characteristics; NBSIR 79-1793.

Personnel administration; personnel practices; personnel records; privacy; record-keeping practices; relevant information; security; citizen rights; computers; computer utilization; confidentiality; data systems; SP5O0-50.

Personnel dosimetry; processors; standard; trial use and comment: American National Standards Institute; Health Physics Society Standards Committee; mandatory testing program; peer review; 18992.

Personnel practices; personnel records; privacy; record-keeping practices; relevant information; security; citizen rights; computers; computer utilization; confidentiality; data systems; personnel administration; SP500-50.

Personnel records; privacy; record-keeping practices; relevant information; security; citizen rights; computers; computer utilization; confidentiality; data systems; personnel administration; personnel practices; SP5OO-5O

Personnel selection; physical security; physiological psychology; sensory capability; terrosim; threat analysis; training; adversary characteristics; animal research; behavioral science; biosensors; computer analysis; ergonomics; human engineering; human factors; SP480-38.

Perturbation theory; second-order perturbation theory; twophoton ionization; cesium; ionization; 18927.

Pesticide policy; regulatory policy; regulatory reform; technological innovation; administrative experimentation; Environmental Protection Agency; evaluation design; Experimental Technology Incentives Program; NBS-GCR-ETIP 79. 71.

Pesticide residues; sampling; cellulose triacetate filters; gas chromatography: SP519, pp. 19-32 (Apr. 1979).

Pesticides; extraction; herbicides; high pressure liquid chromatography; organics in water; SP519, pp. 87-94 (Apr. $1979)$.

Pesticides; sediment and water; carbamates; gas chromatography; organochlorides; SP5/9, pp. 191-203 (Apr. 1979).

Pesticides; synthetic carbonaceous resins; continuous flow system; environmental analysis; SP519, pp. 345-353 (Apr. 1979).

Pesticides; vitamin A; wire transport; liquid chromatography/mass spectrometry; SP519, pp. 637-645 (Apr. 1979).

Petroleum; sediments; extraction; hydrocarbons; marine; SP519, pp. 161-167 (Apr. 1979).

Petroleum hydrocarbons; sediment analysis; gas chromatography-mass spectrometry; glass capillary chromatography; high pressure liquid chromatography; hydrocarbon persistence; infrared spectroscopy; SPS/9, pp. 33-40 (Apr. 1979).

Petroleum standards; petroleum test methods; recycled oil; rerefined oil; used oil; waste oil; engine oil; fuel oil; hydraulic oil; industrial oil; lubricating oil; oil specifications; SP556.

Petroleum test methods; recycled oil; re-refined oil; used oil; waste oil; engine oil; fuel oil; hydraulic oil; industrial oil; lubricating oil; oil specifications; petroleum standards; SP556.

$\mathrm{PH}$; acid-base status of blond; blood gases; blood $\mathrm{pH}$; carbon dioxide; oxygen; 18470

$\mathrm{PH}$; pH scales; potentiometric ion activity; activity coefficient; hydrogen ion activity; ionic activity; ionic activity scales; $p D$; pD scale; 18379 .
PH scales; potentiometric ion activity; activity coefficient; hydrogen ion activity; ionic activity; ionic activity scales; $\mathrm{pD}$; pD scale; $\mathrm{pH} ; 18379$.

Phantom; gelatin; human abdominal tissues; SP525, pp. 323 326 (Apr. 1979)

Phantom network; polybutadiene; rubber elasticity; uniform network; affine network; neutron scattering; 18827

Pharmaceutical preparations; gas/liquid chromatography; panthenol; pantothenates; SP519, pp. 267-269 (Apr. 1979).

Pharmaceuticals; secondary ion mass spectrometry; sputtering; structural information; vitamins; amino acids; drugs; nonvolatile organic compounds; organic trace detection; peptides; SP519, pp. 627-635 (Apr. 1979).

Phase; precision measurements; wave front; amplitude; beam profile; cross correlation; digital sampling; Fourier optics; holography; laser; laser parameters; laser pulse; optical processing; $T N 1009$.

Phase angle; phase measurement; phase mcter; waveform generator; calibration; digital waveform synthesis; 18434 .

Phase angle; surface films; capacitor; cross capacitor; dielectric; dissipation factor; loss angle; microphonic coupling; 18454 .

Phase cancellation; velocity; acoustic microscopy; anisotropy; attenuation; elastic microstructure; infarct; interferogram; myocardium; SP525, pp. 73-79 (Apr. 1979).

Phase change piezoelectric polymers; polarization; polyvinylidene fluoride; $x$-ray diffraction; $\alpha$ phase; 18531

Phase compensation; brain scanning; echoencephalography; neurology; SP525, pp. 209-218 (Apr. 1979).

Phase diagram; potassium; conductivity; exchange interaction; ferrite; hyperfine field; magnetism; 19046.

Phase diagram of $\mathrm{K}_{2} \mathrm{O}-\mathrm{Fe}_{2} \mathrm{O}_{3}$ system; solidification; surface tension of liquid gallium; thermodynamic properties; convection; heat capacity measurement; $\mathrm{Pb}$-Sn off-cutectic alloys; NBSIR $79-1767$.

Phase diagrams; alloy data center; alloy phase diagrams; American Society for Metals; data compilation; 18645.

Phase diagrams; physical properties; compilation; energy storage; intermetallic compound; 18637 .

Phase discriminator; delay line; discriminator; fiber optics; 18547.

Phase encoded recording; tape drive characteristics; computer magnetic tape drives; computer tape controllers; group coded recording; interface electrical characteristics; interface functional characteristics; magnetic tape drives; NRZI recording; NBS-GCR-78-127.

Phase equilibrium; pipelines; sampling; custody transfer; density; gas analysis; gas chromatography; heating value; hydrocarbon; liquefied natural gas; NBSIR 78-887.

Phase front; beam profile; calibrated system; holograplıy; irradiance; laser diagnostics; 7 N1015.

Phase lock loop; position location; spectral purity; frequency lock loop; frequency stability; navigation; oscillator systems; 18693.

Phasc locked oscillators; retroreflectors: counting and control circuitry; fringe counting interferometric method and apparatus; Michelson interferometer; U.S. Patent 4,165,183.

Phase measurement; phase meter; waveform generator; calibration; digital waveform synthesis; phase angle; 18434 .

Phase meter; waveform generator; calibration; digital waveform synthesis; phase angle; phase measurement; 18434 .

Phase rule; simultaneous chemical equilibria; water; BASIC; carbon dioxide; carbon monoxide; coal gasification; COLGAS; hydrogen; interactive computer program; methane; minimization of Gibbs energy: NBSIR 78-1509.

Phase sensitive detector; programmable detector; a-c detector; automatic bridge; detector; high resolution detector; 18453 .

Phase transition; critical point; gravity effects; 18541 .

Phase transition; rotation-translation coupling; coupled modes; dynamics; KCN-KBr; neutron scattcring; $1903 \mathrm{~h}$ 
Phasc transitions; rarc carths; small anglc ncutron scattcring; amorphous matcrials; domains; magnctism; 18835 .

Phasc-change unit; solar encrgy storage; thermal cncrgy storage dcvice; ASHRAF Standard 94-77; Glauber's salt; latent hcat storagc; pebblc bcd; NBSIR 79-1737.

Phasc-matched propagation in waveguide: Raman spectroscopy of liquids; signal cnhancement of coherent Raman process; coherent anti-Stokes Raman spectroscopy (CARS); liquidfillcd dielectric waveguide; optical wavcguidc: 18686 .

Phenolic mctabolites: catccholamines; electrochcmical detcction; liquid chromatography; SPS19, pp. 391.397 (Apr. 1979).

Phenols; volatile organics, Carbopack C/0.2\% Carbowax 1500; aqueous organics; SP519, pp. 225-229 (Apr. 1979).

Phenyl substituted diglycerides; phospholipids; polymorphism; recrystallization temperature; benzyl substituted diglyceridcs; differential scanning calorimetry: heat of fusion; lecithins; lipids; melting temperature; metastable states; 18380 .

Phosphatc radical; photolysis; radiolysis; rates; selenium radicals; sulfate radical; thiocyanate radical anion; aqueous solution; carbonate radical; chemical kinetics; halogen radical anions; nitrate radical; oxyanion radicals; NSRDS-NBS65.

Phospholipids; polymorphism; recrystallization temperature; benzyl substituted diglycerides; differential scanning calorimetry; heat of fusion; lecithins; lipids; melting temperature; metastable states; phenyl substituted diglycerides; 18380.

Phosphorus in silicon; electron paramagnetic resonance; epitaxial silicon; Hall-effect measurements; NBSIR 79-1748.

Photoabsorption; oscillator strengths; 18923 .

Photoabsorption-spectrum; synchrotron radiation; autoionization; corc-excited states; magnesium; 18912.

Photoacoustic spectroscopy; TII; ZnSe; absorption edge; $\mathrm{CaF}_{2}$; $\mathrm{KCl}$; optical absorption coefficient; optoacoustic spectroscopy: $\mathrm{PbF}_{2}$; SPS41, pp. $43-49$ (Dec. 1978 ).

Photochemistry; carbon dioxide; carbon monoxide; carbonyl; exchange; hydroxyl; kinetics; mechanism; 18436.

Photochemistry; chloride; methyl; methyl chloride; 18340 .

Photochemistry; radicals; rate constant; acetylene; butadiyne; ethynyl; hydrogen; mechanism; 18443 .

Photochemistry; review; sulfur dioxide; troposphere; kinetics; SP557, pp. 99-100 (Aug. 1979).

Photochemistry; ultraviolet spectra; charge transfer; excited argon atoms; free radicals; infrared spectra; matrix isolation; molecular ions; 18847 .

Photochemistry mechanism; thermochemistry; bromine atoms; bromoacctylene; excited state; hydrogen bromide; 18974 .

Photoconductivity; power devices; resistivity variation; automation; bulk photovoltaic effect; computer control; homogeneity: measurement method; nondestructive testing: SP4OO-52.

Photodegradation; poly (methyl methacrylate); UV; visible; degradation; IR; NBSIR 79-1766.

Photodetector characterization; radiometric instrumentation; laser power modulator; laser power stabilizer; TN987.

Photodiode; avalanche photodiode; FFT; fiber optics; frequency response; impulse response; laser: NBSIR 79.1620.

Photodissociation; radical; infrared emission; laser; methylene iodiode; methyl iodiode; 18573 .

Photoelasticity; piezo-birefringence; piczo-optic constants; $\mathrm{SrF}_{2}$; stress-optical coefficient; $\mathrm{BaF}_{2} ; \mathrm{CaF}_{2}$; laser glass; SP54I, pp. 50-54 (Dec. 1978).

Photoelectric detectors; corridors; escape; fire detectors; fullscale tests; heat detectors; hospitals; ionizaton detectors; mattresses; nursing homes; NBSIR 79-1739.

Photoemission; satellite and band narrowing; $d$-band of $\mathrm{Ni}$; excitons; 18632 .

Photofission; photoneutrons; pressure vessel; rcactor; threshold detectors; dosimetry; fast neutrons; 18462 .
Photogrammctric; precision; ship cargo: statistical analysis; strapping; survey; accuracy; cryogenic; error cstimation; liqueficd natural gas; LNG; marine; mathcmatical modcling; measurement; NBSIR 79-1751.

Photoionization; Potassium-Krypton mixtures; resonant multiphoton ionizations; collisional excitation; collisional radiative recombination; laser induced plasma; optical cmission; 18799.

Photoionization; quantum beats; sodium atom; angular distributions; field ionization; laser spectroscopy; imultiphoton processes; 18953.

Photoionization; thermosphere; double photoionization; doubly charged ions; ionosphere; $\mathrm{O}^{++}: 18950$.

Photolithography; photovoltaic method; power-device grade silicon; radioisotope leak test; resistivity variations; resistors, sheet; scanning acoustic microscope; semiconductor materials; semiconductor process control; silicon; silicon dioxide; silicon-on-sapphire; $S P 40 O-38$.

Photolithography; sheet resistance; silicon; test pattern; test structure; TTL; bipolar process; contact resistor; cross bridge sheet resistor; electrical alignment resistor; integrated circuits; linewidth; 18533 .

Photoluminescence; spectrofluorimetry; surface analysis; tetrazole; benzotriazole; charge transfer; copper; luminescence; microspcctrofluorimetry; 18504 .

Photolysis; radiolysis; rates; selenium radicals; sulfate radical; thiocyanate radical anion; aqueous solution; carbonate radical; chemical kinetics; halogen radical anions; nitrate radical; oxyanion radicals; phosphate radical; NSRDS-NBS65.

Photolysis; reactions; review; troposphere; aldehyde; free radical; SP557, pp. 27-46 (Aug. 1979).

Photolysis; reactions; review; tropospheric chemistry; nitrates; nitrites; nitrogen oxides; SP557, pp. 71-79 (Aug. 1979).

Photomask performance; process control; test patterns; test structures; total process integration; comprehensive process characterization; design rules; intradie parametric integrity; LSI circuits; mask alignment tolerances; modular test programs; SP400-56.

Photometric calibrator; inverse fourth power; light flux; U.S. Patent 4,152,074.

Photometric calibrator; safety tips; solar energy; toxic chemicals; ultra-black coating; Alaskan pipeline; computers; corrosion: fire safety; gyromagnetic ratio; paper; DIM/NBS 63 , No. 11, 1-36 (1979).

Photon; photoneutrons; radiotherapy; spectrometry; doseequivalent; electrons; kerma; multisphere; SP554, pp. 109123 (Sept. 1979).

Photon; photoproduction; quadrupole giant resonance; alpha particle; dipole giant resonance; electroproduction; nickel; 18495.

Photon; positron; atom; collision cross section; detachment; dissociation; elastic scattering; electron; excitation; ion; ionization; molecule: SP426. Supplement I.

Photon beam exit; beam quality; neutron production; SP554, pp. 139-144 (Sept. 1979).

Photon counting; radioactivity; ${ }^{12} \mathrm{Sn}^{m}$ decay scheme; coincidence counting; decay probability; isomeric transition; liquid scintillation counting; 18841 .

Photoneutrons; accelerator; neutron fluence; SP554, pp. 75-86 (Sept. 1979).

Photoneutrons; pressure vesscl; reactor; threshold detectors: dosimetry; fast neutrons; photofission; $\mathbf{1 8 4 6 2}$.

Photoneutrons; radiotherapy; spectrometry; dose-equivalent; electrons; kerma; multisphere; photon; SP554, pp. 109-123 (Sept. 1979).

Photon-recoil structure; saturated absorption; calcium; optical Ramsey fringes; 18642 .

Photons; pions; protons; coincidence experiments; electromagnetic; neutrons; 18675 . 
Photons; radiation hardness; standard practice; thermolumincscence dosimeters; electronic devices; electrons; NBSIR 79.1723 .

Photons; radiotherapy; spectrometry; dose-equivalent; electrons; kerma; multispheres; photoneutrons; SP554, pp. 125 127 (Sept. 1979).

Photons; Rayleigh scattering; tabulations; $x$ rays; atomic form factor; coherent scattering; cross sections; gamma rays; JPCRD 8, No. 1, 69-106 (1979).

Photons; stopping power; transport theory; absorbed dose; attenuation coefficient; detector response functions; dosimetry; electrons; foil transmission; 18371 .

Photonuclear physics; shell model; giant resonances; hydrodynamic model; isoscalar resonances; isovector resonances; 18565 .

Photopion; pion; beryllium; differential cross section; Fermi gas; lithium; optical potentials; 18442 .

Photopion; pion; beryllium; differential cross section; Fermi gas; lithium; optical potentials; 18496 .

Photopotentials; aluminum; copper; copper alloys; nickel; oxide films; 18724.

Photoproduction; pions; pseudovector coupling; electroproduction; nonrelativistic operators; nuclear photoproduction; 18798.

Photoproduction; quadrupole giant resonance; alpha particle; dipole giant resonance; electroproduction; níckel; photon; 18495.

Photovoltaic energy conversion; power conditioning; power systems; solar cells; standards; test methods; batteries; NBSIR 79.1743.

Photovoltaic method; power-device grade silicon; radioisotope leak test; resistivity variations; resistors, sheet; scanning acoustic microscope; semiconductor materials; semiconductor process control; silicon; silicon dioxide; silicon-on-sapphire; sodium contamination; SP4O0-38.

Photovoltaics; power conditioning; power control; solar energy; storage; performance criteria; 18634 .

Photovoltaics; reliability; semiconductors; solar cells; stability; testing; thin films; accelerated tests; failure mechanisms; failure modes; SP400.58.

Photovoltaics; reliability; semiconductors; solar cells; stability; testing; thin films; accelerated tests; failure mechanisms; failure modes; NBSIR 79-1778.

Photovoltaics; reliability; solar arrays; solar cells; workshops; laser scanner; measurement development; 18322

Phylloquinone; tocopherols; tocotrienols; vitamin E; vitamin K; high performance liquid chromatography; SPS19, pp. 279 288 (Apr. 1979).

Physical condition rehablitation; decision criteria; demolition; housing needs; SP536, pp. 75-81 (Feb. 1979).

Physical environment; privacy; architectural psychology; bibliography; buildings; communication; cost; human characteristics; personal control; NBSIR 79-1793.

Physical measurement systems; review article; speed of light; time standards; atomic clocks; frequency standards; frequency synthesis; fundamental constants; length standards; 18346 .

Physical properties; compilation; energy storage; intermetallic compound; phase diagrams; 18637.

Physical properties; radiation properties; cryogenics; glassepoxy; industrial laminates; mechanical properties; 18771 .

Physical properties; safety and hazards; thermal energy storage materials; thermal properties; thermodynamic properties; transport properties; corrosion; data compilation; electrochemical energy storage materials; molten salts; NSRDSNBS6I, Part 11 .

Physical properties; stainless steel; alloys; fiberglass; mechanical properties; nonmetallics; NBSIR 79-1609.

Physical properties; superconductors; electrical properties; low temperatures; mechanical properties; metallurgical properties; niobium-titanium; 18552 .
Physical properties; thermal expansion; wear; wear tests; amalgam; composites; dental materials; dimensional changes; l8649.

Physical security; physiological psychology; sensory capability; terrosim; threat analysis; training; adversary characteristics; animal research; behavioral science; biosensors; computer analysis; ergonomics; human engineering; human factors; human motivation; SP480-38.

Physical security; procedural security; risk analysis; risk assessment; systems security; ADP availability; annual loss exposure; application system vulnerability; computer security; data confidentiality; data integrity; data security; FIPS PUB 65.

Physical standards; seminar; South Asia; developing countries; industrializing countries; Korea; measurements; metrology; SP539.

Physically handicapped; public awareness; public relations; accessibility standards; building codes; code administration; communication; SP552, pp. $115-120$ (July 1979).

Physics of fire; toxicity of combustion products; chemistry of fire; combustion products; fire hazards; fire modeling; fire research; human behavior in fires; NBSIR 79-1916.

Physiological psychology; sensory capability; terrosim; threat analysis; training; adversary characteristics; animal research; behavioral science; biosensors; computer analysis; ergonomics; human engineering; human factors; human motivation; human reliability; SP480-38.

Picogram; polycyclic aromatic hydrocarbons; selectivity; sensitivity; specificity; trace analysis; environmental pollution; fluorescence; high perfermance liquid chromatography; occupational health; SP519, pp. 41-56 (Apr. 1979).

Pico-second; pico-second laser pulse; alkali-halides; laser pulse; SPS41, pp. 296-298 (Dec. 1978).

Picosecond; pulse; pulse measurement; time domain measurement; automation; laser; oscilloscope; 18640.

Pico-second laser pulse; alkali-halides; laser pulse; pico-second; SP541, pp. 296-298 (Dec. 1978).

Picosecond pulse generator; ac current; high frequency oscillator; Josephson junction; U.S. Patent 4,168,44I.

Picosecond pulses; Rhodamine 6G; dye laser; laser cavity; mode locked dye laser; passive mode locking; 19021 .

Pictograms; safety information; standardization; symbols; communication; evaluation methods; fire safety; hazard warnings; NBSIR 79-1760.

Picture processing; signal analysis; ultrasound; SP525, pp. 303313 (Apr. 1979).

Piezo-birefringence; piezo-optic constants; $\mathrm{SrF}_{2}$; stress-optical coefficient; $\mathrm{BaF}_{2} ; \mathrm{CaF}_{2}$; laser glass; photoelasticity; SP54I, pp. 50-54 (Dec. 1978).

Piezoelectric drives; scanning stage; SEM microscope stage; submicrometer positioning instrumentation; TEM microscope stage; flexure pivots; linear positioning; micromanipulator; optical microscope stage; 18327.

Piezoelectric polymer; preset tensile stress; pressure variations; acoustic waves; U.S. Patent 4,166,229.

Piezoelectric polymer; spectrum analysis; strain gage; bearing noise; failure prevention; machinery noise; noise signature; non-destructive evaluation; SP547, pp. 303-314 (July 1979).

Piezo-electric positioner; high vacuum; interferometry; I83 I8.

Piezoelectricity; polarization; poling procedures; polymers; poly(vinylidene fluoride); pyroelectricity; transducers; dielectric strength; electrets; J. Res. 84, No. 6, $447-453$ (1979).

Piezoelectricity; thermodynamics; ultrasound; viscoelasticity; wave propagation; anisotropy; dispersion; elasticity; human bone; microhardness; microstructure; SP525, pp. 189-196 (Apr. 1979).

Piezo-optic constants; refractive index; $\mathrm{SiO}_{2} ; \mathrm{SrF}_{2}$; thermal expansion coefficient; thermo-optic constant; $\mathrm{ZnS} ; \mathrm{ZnSe} ; \mathrm{Al}_{2} \mathrm{O}_{3}$; $\mathrm{As}_{2} \mathrm{~S}_{3}$ glass; $\mathrm{BaF}_{2} ; \mathrm{CaF}_{2} ;$ TN993. 
Piczo-optic constants; $\mathrm{SrF}_{2} ;$ stress-optical coefficient; $\mathrm{BaF}_{2}$; $\mathrm{CaF}_{2}$; laser glass; photoelasticity; piezo-birefringence; SP54I, pp. $5($ ) -54 (Dcc. 1978).

Pile corrosion; protection of steel; salt water corrosion; sea watcr corrosion; steel corrosion; coating protection; 18424 .

Pilings; timbcr; acoustics; bridges; creosote; harbor facilities; inspection; maintenancc; marine borers; nondestructive testing; 18525.

PIND; pre-shock; seeded specimens; transducer; acoustic emission; co-shock; couplant; detection; electronic package; impact noise; microcircuit device; particle detection; particle impact noise detection; NBSIR 78-1590 (NASA).

Pin-end; test method; wall panels; walls; compression; eccentric loading; flat-end; kern; loading rate; BSS9S.

Pion; beryllium; differential cross section; Fermi gas; lithium; optical potentials; photopion; 18442.

Pion; beryllium; differential cross section; Fermi gas; lithium; optical potentials; photopion; 18496.

Pions; protons; coincidence experiments; electromagnetic; neutrons; photons; 18675.

Pions; pseudovector coupling; electroproduction; nonrelativistic operators; nuclear photoproduction; photoproduction; 18798 .

Pipe flows; turbulence modeling; flowmeter; fluid dynamics; mathematical modeling; numerical modeling; 18410 .

Pipe welds; standard; x-ray image; appropriations; fusion diagnostics; gravity waves; laser-interferometer; microwave measurements; non-destructive evaluation; DIM/NBS 63, No. 3, $1-28$ (1979).

Pipe-bonding strength; tensile strength; cementing-materials; compressive strength; hot-dry-rock well; permeability to water; 19018.

Pipeline; weld flaws; weldments; carbon-manganese steel; fracture mechanics; fracture toughness; 18612 .

Pipeline; weld flaws; -weldments; carbon-manganese steel; fatigue; fatigue cracks; fracture mechanics; fracture toughness; 18802

Pipelines; sampling; custody transfer; density; gas analysis; gas chromatography; heating value; hydrocarbon; liquefied natural gas; phase equilibrium; NBSIR 78-887.

Piston radiator; radiation of sound; ultrasonic radiator; baffled piston radiator; 18479 .

Piston ring wear; turbocharging monitoring; crankshaft displacement; medium speed diesel engine; SP547, pp. 153-166 (July 1979).

Pitting corrosion; rust; stress corrosion; corrosion; crevice corrosion; galvanic corrosion; inhibitors; C1S9, Revised 1979.

Planar scanning; antenna measurements; cylindrical scanning; far field; near field; 18818

Plane wave; sound intensity; sound power; standing wave tube; absolute sound power source; particle velocity; 18728 .

Plane-radial scanning; probe correction; space groups; aliasing; Bravais lattices; Fast Fourier "Transform"; near-field scanning; orthogonalities; 18956.

Planning; problem solving; robot control; brain mechanisms; cognition; goal seeking; intelligence; motor behavior; neural modeling; perception; 18714 .

Plant constituents; abscisic acid; gas chromatography; liquid chromatography; SP519, pp. 803-807 (Apr. 1979).

Plasma; atomic physics; dielectronic recombination; highly ionized; impurity; molybdenum; 18949.

Plasma chromatography-mass spectroscopy; polymer outgassing; epoxy polymer; SP519, pp. 697-703 (Apr. 1979).

Plasma etching; radiation damage; radiation hardening; VLSI processing; $x$-ray lithography; E-beam lithography; integrated circuits; ion implantation; 18451 .

Plasma line shift; spectral lines; Stark broadening; deuterium; hydrogen; ion dynamic effect; 18948

Plasma-broadening; singly ionized oxygen; stark broadening; atomic spectra; nitrogen; oxygen; 18737.
Plasmid; tin; arsenic; bio-transformation; cadmium; food chain; lead; mercury; metal; methylation; microbial tolcrancc; microorganism; 18860 .

Plastic; polymer; proton-induced $x$-ray fluorcscence; thin films; trace element analysis; trace element concentrations; zinc; copper; iron; 18375 .

Plastic containers; polyethylene; standards; compatibility; permachor; permeation; 18348 .

Plastic indentations; residual stresses; shcar flow lincs; crack nucleation; fracture; median, radial and lateral cracks; SP562, pp. 15-20 (Oct. 1979).

Plastic insulating material; polyethylene; series-constructed; electric shock; fire; flaming ignition; glowing ignition; hazard; ignition temperature; lamp surface temperature; melting tcmperature; miniature Christmas lights; NBSIR 79-1716.

Plastic penetration; thermal stresses; abrasive wear; ceramics; fracture; SP562,pp. 1-13 (Oct. 1979).

Plasticity; subsurface damage; surface damage; electron channeling; SP562, pp. $395-404$ (Oct. 1979).

Plastics; polymers; smoke; smoke detectors; subway fires; toxicity; upholstered furniture; arson; bibliographies; building fires; compartment fires; fabric flammability; fire detection systems; fire tests; flammability tests; human behavior; NBSIR 79-1745.

Plastics; standardization; transportation; effective carbon atom number; hazardous materials; packaging; NBSIR 79-1768.

Plastics; standardization; transportation; effective carbon atom number; hazardous materials; packaging; 18639.

Plate tectonics; polar motion; crustal movements; earth rotation; geodynamics; gravity field; ocean current; 18584 .

Platinum determination; radiochemical separation; spontaneous deposition technique; biological materials analysis; environmental materials analysis; neutron activation analysis; noble metals analysis; 18350 .

Platinum ware; surface of platinum influenced by method heating; contrast augmentation of reflecting surfaces; doublediaphragm; faces (crystal) on platinum crucibles; hematite forming on platinum; iron as alloy in platinum; J. Res. 84, No. 5, 385-394 (1979).

Playground surfaces; test method; head injury criterion; impact; peak acceleration; performance; NBSIR 79-1707.

Plots; portability plots; residuals; statistical plots; statistics; stem-and-leaf displays; box plots; CALCOMP; computing system; confidence ellipse; OMNITAB 78; 18954.

Plotting; computer program; data acquisition systems; data reduction; TNI108.

Plotting; statistical analysis; Boolean search system; computer programs; curve fitting; data analysis; data base management; data retrieval; file handling; graphic analysis; IMS information retrieval; KWOC indexing; least-squares; linear regression; MIS; 18597.

Plug; scattered photons; sleeve; source capsule; source pellets; spacer; spectra; spectrometry; atomic number; cobalt 60 photons; configuration; 18355 .

Plumbing; roofing; shingles; venting; benefit-cost analysis; building technology; economic impacts; economics; efficiency; payback; SP558.

Plumbing and drainage; U.S. research in plumbing; building water systems; CIB; international plumbing research; SP553.

Plume; scaling; buoyancy; diffusion flames; fire entrainment; flame oscillations; NBSIR 79-1910.

PNA analysis; trace organic analysis; absorption spectroscopy; derivative spectroscopy; SPS19, pp. $719-722$ (Apr. 1979).

Pockels effect; space charge; breakdown; electro-optics; gassolid interface; KDP; NBS-GCR-79-177.

Point contacts; SQUID; Josephson junction; noise; $/ 8663$.

Pol; polarimetry; saccharimetry; sugar analysis; sugar scale; wavelength; laser application; 18768 .

Polar crystals; biexcitons; Haken's Hamiltonian; 18592. 
Polar graph; restraints; roundness standard; spindle error; standard deviation; stylus; least squares circle; least squares estimation; NBSIR 79.1758.

Polar molecules; scattering theory; cross sections; electron collisions; molecules; momentum-transfer; 18516.

Polar motion; crustal movements; earth rotation; geodynamics; gravity field; ocean current; plate tectonics; 18584 .

Polarimetry; saccharimetry; sugar analysis; sugar scale; wavelength; laser application; pol; 18768 .

Polarization; poling procedures; polymers; poly(vinylidene fluoride); pyroelectricity; transducers; dielectric strength; electrets; piezoelectricity; J. Res. 84, No. 6, 447-453 (1979).

Polarization; polyvinylidene fluoride; $x$-ray diffraction; $\alpha$ phase; phase change piezoelectric polymers; 18531 .

Polarization; poly(vinylchloride); poly(vinylidenefluoride); pyroelectric response; thermal pulse; vinylidenefluoridetetrafluoroethylene copolymer; blocking electrode; charge motion; 18408 .

Polarization; potassium tartalate; refrigeration; specific heat; strontium titanate; beryllium; ceramics; cryogenics; dielectricconstant; electrets; electrocaloric effect; entropy; ferroelectrics; glass-ceramics; heat switches; magneto-thermal conductivity; 18680 .

Polarization switching; coherent optical transients; $1_{2} ; 18801$.

Polarized light; probe thermometer; temperature sensitive parameter; aligned sheet polarizer; birefringent crystal; optical analyzer; U.S. Patent 4,140,393.

Polarographic sensor; polymer membrane; diffusion; dissolved oxygen; mathematical model; oxygen; oxygen sensor; permeation; NBSIR 79-1740.

Pole figure; texture of copper shaped charge liner; texture of Ni-W alloy; metal texture; neutron diffraction; nondestructive testing; 19027.

Police tires; pursuit tires; tire maintenance; traction performance; tread wear; high speed performance; high speed tires; 19038.

Policy analysis; software; standards; transfer; documentation; energy; evaluation; guidelines; implementation; large-scale; management; mathematical models; SP534.

Poling procedures; polymers; poly(vinylidene fluoride); pyroelectricity; transducers; dielectric strength; electrets; piezoelectricity; polarization; J. Res. 84, No. 6, 447-453 (1979).

Polished surfaces; pulse duration dependence of damage; surface roughness; BK-7 glass; fused silica; laser damage; SP54I, pp. 164-167 (Dec. 1978).

Polishing; cleaning; chemical durability; glass surface; latent scratch; optical glass; SP562, pp. $417-425$ (Oct. 1979).

Polishing; polishing times; grinding; grinding damage; lapping; SP562, pp. 191-199 (Oct. 1979).

Polishing; sanding; strength-size effects; brittle failure; flaw populations; flaws; fractography; fracture origins; grinding; machining; SP562, pp. 351.378 (Oct. 1979).

Polishing; strength; defects; etching; glass; grinding; SP562, pp. 489-500 (Oct. 1979).

Polishing compounds; subsurface defects; surface contamination; surface preparation; laser glass; particle characterization; SP562, pp. 231-244 (Oct. 1979).

Polishing defects; scattered light; SIMS; stylus instruments; Auger spectroscopy; corrosion films; ESCA; impurities; microroughness; optical microscopy; SP562, pp. 337-350 (Oct. 1979).

Polishing times; grinding; grinding damage; lapping; polishing; SP562, pp. 191-199 (Oct. 1979).

Pollution studies; power plants; Raman microprobe; Raman spectroscopy; vibrational spectra; microanalysis; particle analysis; 18966 .

Poly (methyl methacrylate); UV; visible; degradation; IR; photodegradation; NBSIR 79-1766.
Polybutadiene; rubber elasticity; uniform network; affine network; neutron scattering; phantom network; 18827 .

Polychlorinated biphenyls; cytochrome P-450; liquid chromatography-mass spectrometry; PCB metabolism; SP519, pp. 685-690 (Apr. 1979).

Polycrystalline; single crystal; sodium beta alumina; sodium beta double prime alumina; battery application; engineering properties data; evaluated data; NSRDS-NBS61, Part III.

Polycrystals; relaxation process; Young's modulus; audio frequencies; impurities; internal friction; isomers; low temperatures; $n$-paraffins; 18467.

Polycrystals; thin films; diffusion; grain boundaries; Harrison classification; lattice diffusion; migrating boundaries; 18758 .

Polycrystals; thin films; diffusion; grain boundaries; Harrison classification; lattice diffusion; migrating boundaries; 18759 .

Polycyclic aromatic hydrocarbons; capillary-column; charge exchange; chemical ionization; gas chromatography; mass spectrometry; SP519, pp. 731-738 (Apr. 1979).

Polycyclic aromatic hydrocarbons; selectivity; sensitivity; specificity; trace analysis; environmental pollution; fluorescence; high performance liquid chromatography; occupational health; picogram; SP519, pp. 41-56 (Apr. 1979).

Polydisperse; polydispersity; polystyrene; quasielastic light scattering; SRM-706; standard reference material; diffusion; diffusion coefficient; light scattering; 18511 .

Polydispersity; polystyrene; quasielastic light scattering; SRM706; standard reference material; diffusion; diffusion coefficient; light scattering; polydisperse; 18511 .

Polyester resin; structural sheet molding compound; glass fiber reinforcement; SP563, pp. 108-129 (Oct. 1979).

Polyethylene; failure criteria; loss factor; nonlinear creep; 18468.

Polyethylene; polymer fiber; shish; volume strain; core fibril; cumulative stress; flow-induced crystallization; nucleation theory; J. Res. 84, No. 5, 359-384 (1979).

Polyethylene; processing sheets and rods; surface characterization; surface contamination; biomaterials; negative control; NBSIR 77-140I.

Polyethylene; resolution; sample spinning; solids; $13_{c}$; conformation; crystallinity; NMR; 18745.

Polyethylene; series-constructed; electric shock; fire; flaming ignition; glowing ignition; hazard; ignition temperature; lamp surface temperature; melting temperature; miniature Christmas lights; plastic insulating material; NBSIR 79-1716.

Polyethylene; shear rate; ultra high molecular weight polyethylene; viscosity number; intrinsic viscosity; molecular weight; 18834.

Polyethylene; solvent; stress-cracking agent; uniaxial creep; crack growth; failure; 18766 .

Polyethylene; standards; compatibility; permachor; permeation; plastic containers; 18348 .

Polyethylene; uniaxial creep; additivity of damage; cold drawn; crack growth; fracture; molecular weight distribution; necking; 18765

Polyethylene; vibrational data; force field refinement; lattice dynamics; $n$-alkanes; non-bonded potential functions; 18404 .

Polyethylene; viscoelastic; creep; instability; 18807

Polyimide composite stability in space; polyimide/graphite mechanical properties; ultrasonic inspection; cocured and precured laminates; exoatmospheric exposure of composites; Long Duration Exposure Facility (LDEF); SP563, pp. 4-16 (Oct. 1979).

Polyimide/graphite mechanical properties; ultrasonic inspection; cocured and precured laminates; exoatmospheric exposure of composites; Long Duration Exposure Facility (LDEF); polyimide composite stability in space; SP563, pp. 4-16 (Oct: 1979).

Polymer; proton-induced $x$-ray fluorescence; thin films; trace element analysis; trace element concentrations; zinc; copper; iron; plastic; 18375 . 
Polymer adsorption; protein adsorption; protein chromatography; radiolabeled proteins; adsorption; biomaterials; blood proteins; ellipsometry; NBSIR 79-1784.

Polymer chain dimensions; random-coil chain dimensions; Rouse coordinates; distributions in chain dimensions; equilibrium chain dimensions; excluded volume; lattice-model chains; 18618 .

Polymer chain dynamics; random-coil polymer chains; relaxation times; self-entanglement effects; computer simulaton; end-to-end length; entanglement effects; excluded volume effects; lattice-model polymer chains; 18772.

Polymer crystallization; shish kebabs; crystallization theory; extended chain fibrils; flow-induced crystallization; 18715 .

Polymer degradation; polymer oxidation; programmed temperature control; thermogravimetry; activation energy; degradation apparatus; factor-jump thermogravimetry; 18450 .

Polymer degradation; polymer oxidation; thermogravimetry; activation energy; computer automation; computerized thermogravimetry; computer program; 18445.

Polymer degradation; thermogravimetry; activation energy; automated thermogravimetry; computer automated thermogravimeter; factor-jump thermogravimetry; $/ 8447$.

Polymer dimensions in solution; polystyrene; radius of gyration; temperature and molecular weight dependence; hydrodynamic radius; intrinsic viscosity; 18960 .

Polymer dynamics; Rouse-Zimm theory; solution properties; bead-spring model; block copolymer; flow birefringence; flow dichroism; 18431 .

Polymer fiber; shish; volume strain; core fibril; cumulative stress; flow-induced crystallization; nucleation theory; polyethylene; J. Res. 84, No. 5, 359-384 (1979).

Polymer films; polymers; polypropylene; polyurethane; superconducting power cable; tan $\delta$; cryogenic temperature; dielectric loss; 18713 .

Polymer matrices; advanced-fiber composites; cryogenics; industrial laminates; low-pressure laminates; metal-matrix composites; 18631 .

Polymer membrane; diffusion; dissolved oxygen; mathematical model; oxygen; oxygen sensor; permeation; polarographic sensor; NBSIR 79-I740.

Polymer outgassing; epoxy polymer; plasma chromatographymass spectroscopy; SP519, pp. 697-703 (Apr. 1979).

Polymer oxidation; programmed temperature control; thermogravimetry; activation energy; degradation apparatus; factor-jump thermogravimetry; polymer degradation; 18450 .

Polymer oxidation; thermogravimetry; activation energy; computer automation; computerized thermogravimetry; computer program; polymer degradation; 18445 .

Polymerization; pressure; radiation;

styrene; tetrafluoroethylene; copolymerization; 18512 .

Polymerization accelerators; reinforcing fillers; silane coupling agents; benzoyl peroxide; composite resins; dental materials; glass compositions; methacrylate monomers; 18644 .

Polymers; polypropylene; polyurethane; superconducting power cable; $\tan \delta$; cryogenic temperature; dielectric loss; polymer films; 18713 .

Polymers; polystyrene at theta-condition; theta temperature; 18480 .

Polymers; poly(vinylidene fluoride); pyroelectricity; transducers; dielectric strength; electrets; piezoelectricity; polarization; poling procedures; J. Res. 84, No. 6, $447-453$ (1979).

Polymers; smoke; smoke detectors; subway fires; toxicity: upholstered furniture; arson; bibliographies; building fires; compartment fires; fabric flammability; fire detection systems; fire tests; flammability tests; human behavior; plastics; NBSIR 79-1745.

Polymorphism; recrystallization temperature; benzyl substituted diglycerides; differential scanning calorimetry; heat of fusion; lecithins; lipids; melting temperature; metastable states; phenyl substituted diglycerides; phospholipids; 18380 .
Polymorphism; thallium iodide; thin films; graded index; lead fluoride; SP54I, pp. 259-265 (Dec. 1978).

Polynomial approximation; test problems; algorithm testing; approximation; computational experiment; least absolute deviation; J. Res. 84, No. 6, $455-488$ ( 1979 ).

Polynuclear aromatic hydrocarbon; coal combustion products; glass capillary gas chromatography; high pressure extraction; SP519, pp. I09-120 (Apr. 1979).

Polynuclear aromatic hydrocarbon; standard referẹnce material; dynamic coupled-column liquid chromatography; extractor column; generator column; SP519, pp. 219-224 (Apr. 1979).

Polynuclear aromatic hydrocarbons; high-pressure liquid chromatography; marine biota; metabolites; SP519, pp. 79-86 (Apr. 1979).

Polynuclear aromatic hydrocarbons; Raman spectra; trace organic analysis; laser-Raman microprobe; liquid chromatograph-Raman spectrometer interface; micro-Raman spectroscopy; organic microanalysis; PAH microsamples; (PAHs); SP519, pp. 723-729 (Apr. 1979).

Polypeptides; proteins; tissue characterization; ultrasonics; velocity; absorption; amino acids; attenuation; frequency; mammalian tissues; SP525, pp. 19-27 (Apr. 1979).

Polyphthalocyanine; prepreg; TGA; V/STOL; cure; dielectric analysis; DSC; graphite-fiber; SP563, pp. 25-31 (Oct. 1979).

Polypropylene; polyurethane; superconducting power cable; tan $\delta$; cryogenic temperature; dielectric loss; polymer films; polymers; 18713.

Polypropylene; polyurethane foams; polyvinyl chloride; pyrolysis; rigid foams; smoke; smoldering; weight loss; wood; combustion; flaming combustion; flexible foams; optical density; particle size; NBS-GCR-78-147.

Polystyrene; polyurethane; thermal insulation; thermal properties; cellular plastic; low temperature; mechanical properties; 18719.

Polystyrene; polyurethane; thermogravimetry; weight-loss kinetics; aging of polymers; degradation of polymers; error propagation; factor-jump method; heating rate; lifetime prediction; 18620 .

Polystyrene; quasielastic light scattering; SRM-706; standard reference material; diffusion; diffusion coefficient; light scattering; polydisperse; polydispersity; 18511 .

Polystyrene; radius of gyration; temperature dependence; hydrodynamic radius; light scattering; molecular weight dependence; 18545 .

Polystyrene; radius of gyration; temperature and molecular weight dependence; hydrodynamic radius; intrinsic viscosity; polymer dimensions in solution; 18960 .

Polystyrene; sodium (polystyrene sulfonate); sulfonation; sulfur trioxide; triethyl phosphate; 18542 .

Polystyrene at theta-condition; theta temperature; polymers; 18480.

Polyurethane; superconducting power cable; tan $\delta$; cryogenic temperature; 'dielectric loss; polymer films; polymers; polypropylene; 18713 .

Polyurethane; thermal insulation; thermal properties; cellular plastic; low temperature; mechanical properties; polystyrene; 18719.

Polyurethane; thermogravimetry; weight-loss kinetics; aging of polymers; degradation of polymers; error propagation; factorjump method; heating rate; lifetime prediction; polystyrene; 18620 .

Polyurethane foams; polyvinyl chloride; pyrolysis; rigid foams; smoke; smoldering; weight loss; wood; combustion; flaming combustion; flexible foams; optical density; particle size; polypropylene; NBS-GCR-78-147.

Polyvinyl chloride; pyrolysis; rigid foams; smoke; smoldering; weight loss; wood; combustion; flaming combustion; flexible foams; optical density; particle size; polypropylene; polyurethane foams; NBS-GCR-78-147. 
Polyvinylidene fluoride; $x$-ray diffraction; $\alpha$ phase; phase change piezoelectric polymers; polarization; 18531 .

Poly(ethylene terephthalate); standard reference material; temperature coefficient; time-lag; gas transmission rate; manometric technique; oxygen; permeability; SP260-58.

Poly(vinylchloride); poly(vinylidenefluoride); pyroelectric response; thcrmal pulse; vinylidenefluoridetetrafluoroethylene copolymer; blocking electrode; charge motion; polarization; 18408 .

Poly(vinylidene fluoride); pyroelectricity; transducers; dielectric strength; electrets; piezoelectricity; polarization; poling procedures; polymers; J. Res. 84, No. 6, 447-453 (1979).

Poly(vinylidenefluoride); pyroelectric response; thermal pulse; vinylidenefluoride-tetrafluoroethylene copolymer; blocking electrode; charge motion; polarization; poly(vinylchloride); 18408.

Pomeranchuk refrigerators; solid $\mathrm{He}^{3}$; superfluid $\mathrm{He}^{3}$; symposium; cryogenics; dilution refrigerators; helium 3; Japan; millikelvin research; nuclear cooling; 18679.

Population 11 cepheids; AU Peg; binary cepheids; cepheids; 18913.

Population of angular momentum states; collisional transitions; highly excited Rydberg states; 18473 .

Porous anode; electron capture detector; gas chromatography; halo-organics; ionization detector; SP519, pp. 777-782 (Apr. 1979).

Porous sphere; sphere; spheres; wind noise; windscreen; windscreen performance; windscreens; acoustics; flow; insertion loss; microphone; NBSIR 79-1599.

Portability; poster; reliability; statistical computing section; worksheet; capabilities; ease of learning and using; installation; language; maintenance; numerical analysis; OMNITAB $78 ; 18903$

Portability plots; residuals; statistical plots; statistics; stem-andleaf displays; box plots; CALCOMP; computing system; confidence ellipse; OMNITAB 78; plots; 18954.

Portable clocks; relativity; synchronization; time scales; coordinate time; 18993.

Portable oxygen generator experiment; procurement policy; two-step prototype procurement; Veteran's Administration; Experimental Technology Incentives Program; NBS-GCRETIP 78-50.

Portable system; truck-mounted; CCVT; compact; field calibration; high accuracy; modular capacitive divider; 18833.

Portable system; truck-mounted; CCVT; compact; field calibration; high accuracy; 18938.

Position detector; capacitance sensor; densimeter; magnetic suspension; 18962.

Position location; spectral purity; frequency lock loop; frequency stability; navigation; oscillator systems; phase lock loop; 18693.

Position location; time dispersion; time error; time error measure; time prediction error; clocks; frequency drift; frequency stability; navigation; oscillator; 18899.

Position-sensitive detector; radiography; time-of-flight technique; linac; neutrons; 18591 .

Positive ions; atmospheric pressure ionizłtion; bioanalytical systems; mass spectrometry; negative ions; SP519, pp. 655671 (Apr.. 1979).

Positive matrix; Hadamard product; inverse-positive matrix; matrix sign patterns; 18524 .

Positron; atom; collision cross section; detachment; dissociation; elastic scattering; electron; excitation; ion; ionization; molecule; photon; SP426. Supplement 1.

Positron annihilation; titanium; defects; Doppler broadening; hardness; 18967.

Positron annihilation-in-flight; quasi-monoenergetic photons; sodium iodide spectrometer; $15.1 \mathrm{MeV}$ branching ratio; 18522.
Poster; reliability; statistical computing section; worksheet; capabilities; ease of learning and using; installation; language; maintenance; numerical analysis; OMNITAB 78; portability; 18903.

Post-occupancy evaluation; questionnaire; user needs; building evaluation; dessign - process; man/environment research; NBSIR 79.1780.

Potassium; conductivity; exchange interaction; ferrite; hyperfine field; magnetism; phase diagram; 19046.

Potassium; pressure dependence; rubidium; sodium; temperature dependence; alkali elements; cesium; electrical resistivity; francium; lithium; magnetic flux density dependence; JPCRD 8, No. 2, 339-438 (1979).

Potassium energy levels; atomic energy levels; atomic spectra; JPCRD 8, No. 4, 1109-1146 (1979).

Potassium phosphate; struvite analogue; crystal structure; magnesium phosphate; 18491 .

Potassium tantalate; refrigeration; specific heat; strontium titanate; beryllium; ceramics; cryogenics; dielectric-constant; electrets; electrocaloric effect; entropy; ferroelectrics; glassceramics; heat switches; magneto-thermal conductivity; polarization; 18680 .

Potassium-Krypton mixtures; resonant multiphoton ionizations; collisional excitation; collisional radiative recombination; laser induced plasma; optical emission; photoionization; 18799.

Potato alkaloids; radioimmunoassay; solanidine; solanine; SP519, pp. 333-340 (Apr. 1979).

Potential barrier; quasielastic scattering; reorientation; residence time; tunneling; activation energy; methyl group; neutron scattering; 18374 .

Potential barrier heights; symmetric top; torsional frequencies; bromoethanes; ideal gas thermodynamic properties; internal rotation; iodoethane; JPCRD 8, No. 2, $519-526$ (1979).

Potential curves; collisional excitation; dissociation energy; Dunham coefficients; Franck-Condon factors; laser fluorescence; molecular sodium; 18824.

Potential curves; dissociation energy; Franck-Condon factors; laser spectroscopy; lithium molecule; molecular spectroscopy; 18867.

Potential heat; smoke; compartment fires; fire tests; flame spread; heat release rate; ignition; interior finish; passive fire protection; NBSIR 79-I700.

Potentiodynamic scans; copper concentric neutrals; corrosion; corrosion tests; electrochemical measurements; 18725 .

Potentiometric ion activity; activity coefficient; hydrogen ion activity; ionic activity; ionic activity scales; pD; $\mathrm{pD}$ scale; $\mathrm{pH}$; pH scales; 18379 .

Potentiometric titration; clinical chemistry; ion selective electrodes; penicillamine; SP519, pp. $455-459$ (Apr. 1979).

Potentiostat; silver; silver analysis; controlled potential; coulometry; electrochemical equivalent of silver; electrochemistry; Faraday; J. Res. 84, No. 2, 157-160 (1979).

Powder diffraction; reactive atmosphere; coal gasification; high pressure; high temperature; measurement method; 18945.

Powder method; profile refinement; tantalum tungstate; thermal expansion; ionic conductors; neutron diffraction; 19037.

Powder patterns; reference intensities; standard; $x$-ray diffraction; crystal structure; integrated intensities; lattice constants; peak in tensities; Monogr. 25, Section 16.

Powders; susceptibility; calibration; iron oxide; magnetic property; magnetometer; 18804 .

Power; reflection coefficient; reflectometer; scattering parameters; six-port; voltage; calibration; current; impedance; network analyzer; 18600.

Power; reflection coefficient; reflectometer; scattering parameters; six-port; voltage; calibration; current; impedance; network analyzer; 18601 .

Power conditioning; power control; solar energy; storage; performance criteria; photovoltaics; 18634 . 
Power conditioning; power systems; solar cells; standards; test methods; batteries; photovoltaic energy conversion; NBSIR 79-1743.

Power control; solar energy; storage; performance criteria; photovoltaics; power conditioning; 18634 .

Power densities; thermal anneals; energy densities; ion-implanted silicon; laser pulses; 18623.

Power devices; resistivity variation; automation; bulk photovoltaic effect; computer control; homogeneity; measurement method; nondestructive testing; photoconductivity; SP400-52.

Power measurements; precise electrical measurements; TDM wattmeters; thermal wattmeters; transfer standards; electrodynamic wattmeters; energy measurements; energy standards; international comparisons; metrology; 18529.

Power metcr; pulsed laser; Q-switched; risetime; speckle; waveform; attenuators; calibration; laser; neodymium laser; peak power; TN1010.

Power monitor; rcflectometers; six-port reflectometers; microwave measurements; microwave power; microwave systems; 18670.

Power plant emissions; Raman microprobe; Raman spectroscopy; urban dusts; vibrational analysis; atomospheric aerosols; materials sampling; mineralogy; molecular analysis; particle analysis; 18643 .

Power plants; Raman microprobe; Raman spectroscopy; vibrational spectra; microanalysis; particle analysis; pollution studies; 18966.

Power spectra; Rayleigh scattering; ultrasonic spectrum analysis; clinical ultrasound; ocular tumor; SP525, pp. 111-119 (Apr. 1979).

Power spectrum; signal processing; tissue characterization; tissue parameters; ultrasound; attenuation; B-san; cepstrum; computer; convolution; de-convolution; liver; SP525, pp. 287-295 (Apr. 1979).

Power systems; solar cells; standards; test methods; batteries; photovoltaic energy conversion; power conditioning; NBSIR 79-1743.

Power transistors; semiconductor devices; thermal characterization; thermal resistance; transistors; current crowding; die attachment evaluation; junction temperature; measurement technology; SP400-14.

Power transmission; review; superconductors; ac generators; heat transfer; helium; hydrodynamics; large magnets; 18822.

Power transmission lines; Russian measurement technique; electric field measurements; instrumentation; measurement procedures; observer proximity effects; 18494 .

Power-device grade silicon; radioisotope leak test; resistivity variations; resistors, sheet; scanning acoustic microscope; semiconductor materials; semiconductor process control; silicon; silicon dioxíde; silicon-on-sapphire; sodium contamination; test patterns; SP400-38.

Power-device grade silicon; resistivity variations; silicon; spreading resistance measurements; thermally stimulated measurements; thyristor materials measurements; thyristor measurements; d-c transmission; deep level measurements; energy conservation; NBSIR 79-1756.

Precious metals; reference data; silver; solid state physics; transport properties; copper; critical evaluation; data analysis; data compilation; data evaluation; data extraction; data synthesis; electrical resistivity; elements; JPCRD 8, No. 4, $1147-1298$ ( 1979$)$.

Precipitate; superconductor; tin; alloy; copper; low temperatures; niobium; 18655 .

Precise electrical measurements; TDM wattmeters; thermal wattmeters; transfer standards; electro-dynamic wattmeters; energy measurements; energy standards; international comparisons; metrology; power measurements; 18529.

Precise timc transfer; satellite; time; time scales; Hermes/CTS; international time comparison; 18861 .
Precision; acceleration insensitive oscillator; ammonia microwave absorption; atomic clock; cavity frequency stabilization; digital demodulator; frequency-lock servo; frequency standard; inversion transition in ammonia; 18698 .

Precision; radioactivity measurements; statistical design of experiment; statistical terms and formulas; statistics; systematic error; uncertainty; 18427.

Precision; ship cargo; statistical analysis; strapping; survey; accuracy; cryogenic; error estimation; liquefied natural gas; LNG; marine; mathematical modeling; measurement; photogrammetric; NBSIR 79-1751.

Precision; test equipment; calibration; Federal Government; laboratory; measurement; metrology; SP546, 1979 Edition.

Precision measurement; earthquake; fundamental constant; geophysics; gravity; 18654 .

Precision measurements; wave front; amplitude; beam profile; cross correlation; digital sampling; Fourier optics; holography; laser; laser parameters; laser pulse; optical processing; phase; TN1009.

Precision Mounting Platform; resonant frequency; composite design; graphite-epoxy; SP563, p. 130 (Oct. 1979).

Precision oscillators; clock's rms time errors; flicker noise; frequency modulation; frequency referencc; 18940 .

Precision power; radioactivity; Raman microprobe; solar energy; toxic substances; building rehabilitation; energy measurements; energy-related inventions; environment; DIMINBS 63 , No. 6, 1-32 (June 1979).

Precision wavelength; silicon lattice spacing; tungsten $\mathrm{x}$ rays; $\mathrm{x}$-ray wavelength ratios; gamma rays; 18487 .

Preconcentration techniques; sample preparation; ultraviolet spectrometry; gas chromatography; gas chromatography/mass spectrometry; SP519, pp. 7-18 (Apr. 1979).

Pre-construction conference; code enforcement; county building code; critical structures program; expense; inspection requirements; SP552, pp. 311-320 (July 1979).

Predetermined frequency; spectroscopic and analytic determinations; variable wavelength monochromatic light; optogalvanic effect; U.S. Patent 4,148,586.

Prediction; standard reference data; synthetic gas; chemical processing; engineering calculations; equation of state; fluid properties; 19022 .

Prediction methods; queuing models; simulation; software monitoring; workload definition; computer performance evaluation; computer performance measurement; computer performance prediction; computer system acquisition; conference proceedings; CPE in auditing; SP500-52.

Prediction model; shipboard spaces; fire growth; fire statistics; flame spread; fuel load survey; heat release; interior finish; laboratory fire tests; material ignitability; NBSIR 79-1714.

Predictive modeling; set-processing; simulation; software design; analytic models; database management; model validation; performance evaluation; performance measurement; SP50O49.

Pre-existing defect; sapphire; solid state reaction; water vapor; working unit; damaged layer; elastic emission machining; environmental effect; hydrate; hydration polishing; mechanochemical polishing with soft powder; SP562, pp. 157-169 (Oct. 1979).

Preferred frame; spatial anisotropy; strain tides; core resonance; free wobble; laser strainmeter; ocean load; 18823 .

Preferred orientation function; pyrolitic graphite; Ruland function; $x$-ray diffraction; Bacon function; Bragg function; Ergun function; graphite materials; Lorentz function; 18523 .

Preliminary; proton interactions; relative measurements; ${ }^{12} \mathrm{C} \boldsymbol{\gamma}$ rays; ${ }^{16} \mathrm{O} \gamma$-rays; cosmic source; 19015.

Preparation; processing; standard reference material; composition; high-carbon ferrochromium; homogeneity testing; 18414.

Preparation; sampling; aflatoxin analysis; food and feed analysis; methods; SP519, pp. 355-372 (Apr. 1979). 
Preprcg; aging of polymer; composite; fiber; mechanical properties; moisture; SP563, pp. 17-21 (Oct. 1979).

Prepreg; TGA; V/STOL; cure; dielectric analysis; DSC; graphite-fibcr; polyphthalocyanine; SP563, pp. 25-31 (Oct. 1979).

Prerecorded videotaped trials; PRVTT; trials, PRVTT; videotaped trials; civil trials; courtroom procedures; juror attitudes; 5 P480-30.

Preservation; adobe; adobe soil; compressive strength; creep; flexural strength; mechanical properties; moisture; nondestructive testing; TN996.

Preservation; regulation; rehabilitation; renovation; building code; building research; code administration; existing buildings; model codes; TN998.

Preservation; regulations; rehabilitation; adaptive reuse; building codes; buildings; building safety; code enforcement; construction; fire safety; housing; SP536.

Preservation; rehabilitation; renovation; adaptive reuse; architecture; building codes; building regulations; building safety; construction; performance; SP536, pp. 1-16 (Feb. 1979).

Preservation technology; adobe building materials; chemical grouts; damp course membrane; metallic membrane; permeability; NBSIR 79-1730.

Preset tensile stress; pressure variations; acoustic waves; piezoelectric polymer; U.S. Patent 4,166,229.

Pre-shock; seeded specimens; transducer; acoustic emission; coshock; couplant; detection; electronic package; impact noise; microcircuit device; particle detection; particle impact noise detection; PIND; NBSIR 78-1590 (NASA).

Pressure; pulsed TEA $\mathrm{CO}_{2}$ laser surface breakdown; spot size; surface absorption; transmitted pulse; adsorbed water; breakdown mechanism; frequency and time dependence of breakdown thresholds; IR window materials; $\mathrm{NaCl}$; SP54I, pp. 318.326 (Dec. 1978).

Pressure; pumps; reservoirs; sensors; tailorable; temperature; accumulator; analog; centralized; check-out system; dessicant; discrete; displacement; fiber optics; filters; flight critical; flow; fluid; go-no-go; ground readout; hydraulic; SP547, pp. 345-357 (July 1979).

Pressure; radiation; styrene; tetrafluoroethylene; copolymerization; polymerization; 18512 .

Pressure; standards; temperature; vacuum; humidity; ozone; 18335.

Pressure; stress calculation; virial theorem of Clausius; equilibrium; homogeneous system; hydrostatic pressure; internal stress; internal virial; molecular dynamics; Monte Carlo method; periodic boundaries; 18456 .

Pressure broadening; $\mathrm{CO}_{2}$; far wings; infrared wings; line shape; model correlation function; 18886 .

Pressure cell; viscosity; diamond-anvil; glass transition; high pressure; hydrostaticity; liquids; 18509.

Pressure dependence; rubidium; sodium; temperature dependence; alkali elements; cesium; electrical resistivity; francium; lithium; magnetic flux density dependence; potassium; JPCRD 8, No. 2, 339-438 (1979).

Pressure generator; calibration; high pressure; high pressure chemistry; 18401 .

Pressure terminals; wire creep; aluminum wiring; electrical connections; NBSIR 78-1507.

Pressure transducer; temperature dependence; adiabatic heating; $\mathrm{As}_{2} \mathrm{~S}_{3} ;$ automatic bridge; $\mathrm{Bi}_{12} \mathrm{GeO}_{20} ; \mathrm{CaCO}_{3} ; \mathrm{CaF}_{2}$; capacitance measurement; evaporated electrodes; 18466.

Pressure variations; acoustic waves; piezoelectric polymer; preset tensile stress; U.S. Patent 4,166,229.

Pressure vessel; reactor; threshold detectors; dosimetry; fast neutrons; photofission; photoneutrons; 18462 .

Pressure vessels; composites; holography; interferometers; matrix crazing; nondestructive testing; SP563, pp. 211-212 (Oct. 1979).
Pressurization technique; tracer-gas technique; air infiltration, residential; air permeability of houses; energy conservation; TN992.

Pretreatment of dentin; 2-cyanoacrylate esters; adhesive; bonding to dentin; dental adhesive; dentin; durability of dentin acrylic bond; isobutyl 2-cyanoacrylate; 18985 .

Preventive maintenance; acoustic emission; failure detection; SP547, pp. 129-IS2 (July 1979).

Primary organic carbon; sampling errors; secondary organic carbon; solvent extraction; spatial variations; diurnal variations; elemental carbon; mass spectroscopy; organic aerosol constituents; SP519, pp. 121-129 (Apr. 1979).

Primary salt effect; speciation; activation parameters; aqueous transmethylation; chloride complexes; environment; formation constants; ionic mechanisms; kinetics; methylmercury; methyltin; NMR; 18484 .

Primary standards; diffusion tubes; OSHA; SP519, pp. 761-769 (Apr. 1979).

Primary standards; standard source; electrically calibrated detector; optical radiation measurements; 18796 .

Primates; pulp response; toxicology; chemical composition; composite resins; dental materials; 18690 .

Print controller; printer; cable interface; computer; controller; control units; hammer drive; input/output bus; interface; interface signals; $1 / O$ interface bus; line printer; NBS-GCR-79. 182.

Printer; cable interface; computer; controller; control units; hammer drive; input/output bus; interface; interface signals; 1/O interface bus; line printer; print controller; NBS-GCR-79. 182 .

Prioritization; project selection; ranking; resource allocation; weighting multiple criteria; decision analysis; decisions; eigenvectors; management; multiple-attribute decisions; ordering; paired comparisons; 18602 .

Prisons; bedding; beds; compartment fires; firesafety engineering; fire tests; health care facilities; hospitals; mattresses; 18517.

Privacy; architectural psychology; bibliography; buildings; communication; cost; human characteristics; personal control; physical environment; NBSIR 79-1793.

Privacy; record-keeping practices; relevant information; security; citizen rights; computers; computer utilization; confidentiality; data systems; personnel administration; personnel practices; personnel records; SP500-50.

Private interests; public objectives; taxation; tax incentives; building; SP552, pp. 337-346 (July 1979).

Probability; residential buildings; sensitivity analysis; smoke dctectors; standards; upholstered furniture; building fires; costbenefit analysis; costs; decision analysis; fire losses; furniture; hazard analysis; TNI 101 .

Probability; statistical analysis; thin films; Weibull distribution; laser damage; SP54I, pp. 235-248 (Dec. 1978).

Probability distribution functions; statistical analysis; storms; structural engineering; wind pressure; wind speeds; building (codes); BSSII8.

Probability distributions; small-scale turbulence; correlations; grid-turbulence; higher-order moments; hot-wire anemometry; 18821 .

Probability statistics; systems analysis; systems safety; walls; barrier analysis; compartment fires; compartments; fault trcc analysis; fire models; fire protection engineering; NBS-GCR79-163.

Probability theory; progressive collapse; reliability; structural engineering; abnormal loads; buildings (codes); 18415 .

Probe correction; space groups; aliasing; Bravais lattices; Fast Fourier "Transform"; near-field scanning; orthogonalities; plane-radial scanning; 18956.

Probe thermometer; temperature sensitive parameter; aligned sheet polarizer; birefringent crystal; optical analyzer; polarized light; U.S. Patent 4,140,393. 
Problem solving; robot control; brain mechanisms; cognition; goal seeking; intelligence; motor behavior; neural modeling; perception; planning; 18714 .

Procedural security; risk analysis; risk assessment; systems security; ADP availability; annual loss exposure; application system vulnerability; computer security; data confidentiality; data integrity; data security; physical security; FIPS PUB 65.

Procedures; regulations; research needs; safety; standards; explosion; fire; hydrogen; 18776.

Process control; process metrology; silicon gate; test patterns; test structures; CMOS/SOS; NBSIR 79-1595.

Process control; reliability; semiconductor devices; welding; automated testing; batteries; cardiac pacemakers; contamination; corrosion; electrostatic-induced damage; hermeticity; hybrid devices; leak testing; measurement technology; microcalorimetry; moisture; SP4OO-5O.

Process control; test patterns; test structures; total process integration; comprehensive process characterization; design rules; intradie parametric integrity; LSI circuits; mask alignment tolerances; modular test programs; parametric yield limitations; SP4OO-56.

Process metrology; silicon gate; test patterns; test structures; CMOS/SOS; process control; NBSIR 79-1595.

Process validation wafer ( $P V W$ ); reliability; silicon; test pattern; transistor gain; integrated circuit; 18463 .

Processing; standard reference material; composition; high-carbon ferrochromium; homogeneity testing; preparation; 18414

Processing sheets and rods; surface characterization; surface contamination; bioınaterials: negative control; polyethylene; NBSIR 77-1401.

Processors; standard; trial use and comment; American National Standards Institute; Health Physics Society Standards Committee; mandatory testing program; peer review; personnel dosimetry; 18992

Procurement; computer evaluation; computer performance; computer procurement; computers; computer selection; costvalue; cost-value technique; EDP selection; evaluation methodology; performance evaluation; SP500-52, pp. 25-36 (Oct. 1979).

Procurement; technical analysis; time-sharing; TSP; benchmarking; cost analysis; evaluation; SP500-52, pp. 233-234 (Oct. 1979).

Procurement experiments; procurement policy; research and development policy; technological change; Experimental Technology Incentives Program; impact of government on industry; NBS-GCR-ETIP 78-49.

Procurement of water heaters; technological change; commercial impacts; Experimental Technology Incentives Program; Federal Supply Service; life cycle costing; NBS-GCR-ETIP 78-51.

Procurement of water heaters; technological change; commercial impacts; Experimental Technology Incentives Program; Federal Supply Service; life cycle costing; NBS-GCR-ETIP $78-52$

Procurement policy; research and development policy; technological change; Experimental Technology Incentives Program; impact of government on industry; procurement experiments; NBS-GCR-ETIP 78-49.

Procurement policy; two-step prototype procurement; Veteran's Administration; Experimental Technology Incentives Program; portable oxygen generator experiment; NBS-GCR-ETIP 78-50.

Product certification; product liability; regulation; standards system; voluntary standards; bibliography; buildings; certification; economics of standards; legal aspects of standards; NBSIR 79-1900.

Product liability; regulation; standards system; voluntary standards; bibliography; buildings; certification; economics of standards; legal aspects of standards; product certification; NBSIR 79-1900.

Product research; data banks; data bases; ergonomics; human factors; 18862

Product safety; public health and safety; science and technology transfer; standards; basic research; computer; energy conservation; environmental quality; industrial productivity; materials utilization; measurement capabilities; medical aids; SP538.

Production; storage; transmission; cost; economics; hydrogen; 18812.

Production/consumption; public and private R\&D; economic performance; NBS-GCR-ETIP 78-60.

Productivity; regulatory commission; regulatory policy; technological innovation; computer program; economic performance; electric utilities; Experimental Technology Incentives Program; NBS-GCR-ETIP 79-70.

Profile effect on permittivity; temperature variation of permittivity; dielectric constant; dielectric loss; lunar soil; microwave; 18557 .

Profile grinding; silicon nitride; ultrasonic machining; asmachined material strength; dimensional tolerances; SP562, pp. 209-220 (Oct. 1979).

Profile refinement; tantalum tungstate; thermal expansion; ionic conductors; neutron diffraction; powder method; 19037.

Profiles; semiconductors; silicon; electrical measurements; 18757.

Prognosis; detection; diagnosis; SP547, pp. 36-57 (July 1979).

Prognostic maintenance management; geriometry; life cycle reliability; on-vehicle computing instrumentation; SP547, pp. 65-77 (July 1979).

Program testing; scientific programs; software errors; software validations; NBS-GCR-78-148

Programmable calculators; solid state software; advanced composite materials; composite materials analysis; orthotropic materials; SP563, pp. $91-107$ (Oct. 1979).

Programmable detector; a-c detector; automatic bridge; detector; high resolution detector; phase sensitive detector; 18453 .

Programmed temperature control; thermogravimetry; activation energy; degradation apparatus; factor-jump thermogravimetry; polymer degradation; polymer oxidation; 18450 .

Programming; sensitivity analysis; simulation; architectural research; building fires; computer-aided design; environmental psychology; fire research; fire safety; human performance; modeling technique; NBSIR 79-1713.

Programming languages; sparse matrices; data pooling; data structures; mathematical programming; matrices; name generation; operations research; J. Res. 84, No. 1, $21-47$ (1979).

Progressive collapse; reliability; structural engineering; abnormal loads; buildings (codes); probability theory; 18415 .

Project request; software; automated data systems; computer programs; cost/benefit analysis; documentation; documentation content guidelines; feasibility study; FIPS guidelines; initiation phase; FIPS PUB 64

Project selection; ranking; resource allocation; weighting multiple criteria; decision analysis; decisions; eigenvectors; management; multiple-attribute decisions; ordering; paired comparisons; prioritization; 18602.

Project summaries; standards; technical bases; building research; building technology; codes; criteria; SP446-2 .

Projectiles; propelled objects; test methods; toy safety; eye injury; impact; ocular contusion; J. Res. 84, No. 1, 9-19 (1979).

Projection operator; correlation functions; equations of motion; maximum entropy; nonequilibrium statistical mechanics; nonequilibrium thermodynamics; 18321 .

Projections; sensitivity analysis; computer workload; data requirements; documentation cycle; forecast; SP50O-52, pp. 113-120 (Oct. 1979). 
Prominent calorimetrists; benzoic acid; calibration; combustion bombs; combustion calorimetry; historical survey; 18797 .

Promotion; RBE; risk; cell-proliferation; cell-turnover; cytotoxicity; homeostasis; SP554, pp. 41-56 (Sept. 1979).

Propagating, bulk waves: transducers, angle beam; transducers, contact; transducers, immersion; transducers, ultrasonic; transduction, ultrasonic; ultrasonic; ultrasound; characterization, transducers; 18907

Propagation velocity; reflection technique; solids; tissue; ultrasound; SP525, pp. 53-56 (Apr. 1979).

Propane; thermal conductivity; viscosity; correlated data; critical point enhancement; data evaluation: JPCRD 8, No. 2, 559-576 (1979).

Propelled objects; test methods; toy safety; eye injury; impact; ocular contusion; projectiles; J. Res. 84, No. 1, 9-19 (1979).

Propeller fatigue behaviour; propeller materials requirements; blade aeroelastic behaviour; blade manufacture and quality control; composite propellers and rotors; failsafe blade design; SP563, pp. 80-88 (Oct. 1979).

Propeller materials requirements; blade aeroelastic behaviour; blade manufacture and quality control; composite propellers and rotors; failsafe blade design; propeller fatigue behaviour; SP563, pp. 80-88 (Oct. 1979).

Properties; research materials; special reference materials; standard reference materials; analysis; certification; characterization; composition; SP260, 1979-80 Edition.

Properties of composites; tertiary aromatic amines; amine accelerators; composite restorative resin; dimethylaminoglutethimide; dimethylaminophenylacetic acid and esters; 18571 .

Properties of steam; space; stirling refrigerators; aluminum SRM's; computer systems; electron microscopy; group decisions; DIM/NBS 63, No. 5, 1-28 (1979).

Propylamine; butylamine; collagen sponge; contraceptive device; gas chromatography; mass spectrometry; SP519, Pp. 469-476 (Apr. 1979).

Propyne; radio astronomy; rotational transitions; interstellar molecules; line strengths; microwave spectra; molecular constants; JPCRD 8, No. 2, 537-558 (1979).

Prostate tumors; ultrasound; pattern recognition; SP525, pp. 297-302 (Apr. 1979).

Prosthetic device; serrated surface design; tooth roots; alumina; diamond contour grinding; flexure strength; SP562, pp. 247 254 (Oct. 1979).

Protection circuit; reverse bias; safe operating area; second breakdown; switching power transistor; tester; transistor; base drive circuit; electronic circuits; inductive load; nondestructive; SP4OO-54.

Protection of steel; salt water corrosion; sea water corrosion; steel corrosion; coating protection; pile corrosion; 18424 .

Protective barrier; recessed incandescent lighting fixture; thermal insulation; thermocouple; branch circuit wiring; electrical junction box; hazardous temperatures; load current; NBSIR 79-1913.

Protective coatings; damage threshold; electric fields; internal reflection; SP541, pp. 288-295 (Dec. 1978 ).

Protein adsorption; protein chromatography; radiolabeled proteins; adsorption; biomaterials; blood proteins; ellipsometry; polymer adsorption; NBSIR 79-1784.

Protein chromatography; radiolabeled proteins; adsorption; biomaterials; blood proteins; ellipsometry; polymer adsorption; protein adsorption; NBSIR 79-1784.

Proteins; tissue characterization; ultrasonics; velocity; absorption; amino acids; attenuation; frequency; mammalian tissues; polypeptides; SP525, pp. 19-27 (Apr. 1979).

Protocols; communications; computers; data bases; networks; operating systems: 18488 .

Protocols; communications; computers; databases; networks; operating systems; $I 8891$.
Proton; proton coupling; structural analysis; bis(hexopyranosyl)amine; carbon-13; conformational analysis; nitrogen-15 coupling constants; nitrogen-15 n.m.r. spectroscopy; 18764 .

Proton affinity; proton transfer equilibrium; data compilation; ion thermochemistry: NBSIR 79-1777.

Proton affinity; proton transfer reaction; dichlorocarbene; heat of formation; ion-molecule reactions; 18331 .

Proton coupling; structural analysis; bis(hexopyranosyl)amine; carbon-13; conformational analysis; nitrogen-15 coupling constants; nitrogen-15 n.m.r. spectroscopy; proton; 18764 .

Proton gyromagnetic ratio; quantum electrodynamic theory; electron anomalous moment; fine-structure constant; fundamental constant; magnetic fields; 18702 .

Proton interactions; relative measurements; ${ }^{12} \mathrm{C} \gamma$-rays; ${ }^{18} \mathrm{O} \gamma$ rays; cosmic source; preliminary; 19015 .

Proton nmr spectroscopy; shift reagents; acyclic sugars; chemical shifts; conformation; coupling constants; hexononitriles; iterative analysis; 18742 .

Proton spectrum; ternary fission; $\alpha$-particles; $\alpha$-spectrum; ${ }^{239} U$; electrodisintegration; 18518 .

Proton telescope; standard cross section; ${ }^{235} \mathrm{U}(\mathrm{n}, \mathrm{f})$; fission cross section; linac; neutron flux determination; 18581 .

Proton transfer equilibrium; data compilation; ion thermochemistry; proton affinity; NBSIR 79-1777.

Proton transfer reaction; dichlorocarbene; heat of formation; ion-molecule reactions; proton affinity; 18331 .

Proton-induced x-ray fluorescence; thin films; trace element analysis: trace element concentrations; zinc; copper; iron; plastic; polymer; 18375 .

Protons; coincidence experiments; electromagnetic; neutrons; photons; pions; 18675 .

Protons; stopping power; $\alpha$-particles; electrons; heavy ions; international commission on radiation units and measurements; 18358.

Prototyping; remote terminal emulation; system testing; audit; capacity planning; financial applications; long-range planning; management control; measurement; modeling; on-line system design; performance evaluation; performance management; SPS00-52, Pp. 129-140 (Oct. 1979).

Provers; specifications; standards; test measures; tolerances; vapor recovery; bottom loading; field standard provers; field standards; field standard test measures; HIO5-3.

Proximity sensor; robot vision; teleoperator vision; wristmounted TV; depth image; NBSIR 78-1576.

PRVTT; trials, PRVTT; videotaped trials; civil trials; courtroom procedures; juror attitudes; prerecorded videotaped trials; SP480-30.

Pseudocrossing; sudden-perturbation limit; transition probability; $\Sigma-\Pi$ transitions; adiabatic perturbation theory; elastic scattering phase shifts; 18575 .

Pseudovector coupling; electroproduction; nonrelativistic operators; nuclear photoproduction; photoproduction; pions; 18798.

Psychology of retailing; retail facilities; environmental psychology; field methodology; passive solar systems; pedestrian behavior; 18784 .

Psychophysics; safety; standards; consumer products; human factors; human perform ance; lawn mowers; NBSIR 77-1298.

Psychotropic amines; selectivity; sulphonamides; amino acids; barbiturates; carboxylic acids; catecholamines; conjugates; detection sensitivity; dipeptides; drugs; HPLC; ion-pair adsorption; ion-pair chromatography; ion-pair partition; SP519. pp. 509-523 (Apr. 1979).

Psychrometer; psychrometry; radiative heat transfer; temperature depression; water vapor measurement; wet bulb; wet element; convective heat transfer; convective mass transfer; emissivity of water; evaporation coefficient; J. Res. 84, No. 2. 161-177 (1979). 
Psychrometry; radiative heat transfer; temperature depression; water vapor measurement; wet bulb; wet element; convective heat transfer; convective mass transfer; emissivity of water; evaporation coefficient; J. Res. 84, No. 2, $161-177$ (1979).

P-Terphenyl; thermodynamic properties; $\lambda$-type transition; adiabatic calorimetry; automated calorimetry; calorimetry; heat capacity; measurement automation; 18376 .

Public and private R\&D; economic performance; production/consumption; NBS-GCR-ETIP 78-60.

Public awareness; public relations; accessibility standards; building codes; code administration; communication; physically handicapped; SP552, pp. 115-120 (July 1979).

Public health and safety; science and technology transfer; standards; basic research; computer; energy conservation; environmental quality; industrial productivity; materials utilization; measurement capabilities; medical aids; product safety; SP538.

Public objectives; taxation; tax incentives; building; private interests; SP552, pp. 337-346 (July 1979)

Public relations; accessibility standards; building codes; code administration; communication; physically handicapped; public awareness; SP552, pp. 115-120 (July 1979).

Public safety; communication systems; equipment selection; law enforcement; SP480-12.

Public sector efficiency; subsidies; technological change; capital formation; economic growth; municipal wastewater treatment facilities; NBS-GCR-ETIP $78-40$.

Public sector efficiency; subsidies; technological change; capital formation; economic growth; mass transit; NBS-GCR-ETIP $78-41$.

Public sector efficiency; subsidies; technological change; capital formation; economic growth; nuclear power plants; NBSGCR-ETIP 78-42.

Public sector efficiency; subsidies; technological change; capital formation; economic growth; maritime transport; NBS-GCRETIP 78.43 .

Public sector efficiency; subsidies; technological change; capital formation; economic growth; journal publishing; NBS-GCRETIP 78-44.

Public sector efficiency; subsidies; technological change; capital formation; economic growth; health facilities; NBS-GCRETIP 78.45 .

Public sector efficiency; subsidies; technological change; capital formation; economic growth; local air transport; NBS-GCRETIP 78-46.

Public sector efficiency; subsidies; technological change; capital formation; economic growth; NBS-GCR-ETIP 78-47.

Publication announcement; scientist-author; technical communicator; technical paper; trade press; audience; feature article; news release; 18817 .

Publications; abstracts; Center for Building Technology; key words; SP457-3.

Publications; abstracts, NBS publications; key words; SP305. Supplement 10.

PUFA; 9,12-di-cis-polyunsaturated fatty acids; fats; lipoxidase; oils; SP519, pp. 289-295 (Apr. 1979).

Pulp response; toxicology; chemical composition; composite resins; dental materials; primates; 18690.

Pulse; pulse measurement; time domain measurement; automation; laser; oscilloscope; picosecond; 18640.

Pulse calibration; ramp response; step response; divider; high voltage; impulse; lightning impulse; 18727.

Pulse compression; sensitivity; signal averaging; signal processing; tissue characterization; tomography; transducers; ultrasonics; annular array; breast cancer; chirp signals; imaging; opto-acoustic; SP525, pp. 255-259 (Apr. 1979).

Pulse duration; damage thresholds; fluoroberyllate glass; fluorophosphate glass; inclusions; SP541, pp. 99-108 (Dec. 1978).
Pulse duration dependence of damage; surface roughness; BK7 glass; fused silica; laser damage; polished surfaces; SP54I, pp. 164-167 (Dec. 1978).

Pulse measurement; electrical measurements; electro-optics; Kerr coefficient; Kerr effect; nitrobenzene; 18819.

Pulse measurement; time domain measurement; automation; laser; oscilloscope; picosecond; pulse; 18640.

Pulse measurement; voltage measurement; current measurement; electric transmission; electro-optic systems; high voltage; 18872 .

Pulse measurements; response time; step response; transients; divider; Duhamel's integral; high voltage; impulse; NBSIR 79. 1933.

Pulsed HF laser; antireflection coatings; CdSe; coating substrate; damage resistant; Ge; $\mathrm{PbF}_{2} ;$ SP 54I, pp. $257-258$ (Dec. 1978).

Pulsed laser; fluorescence; organics in water; SP519, pp. 691. 696 (Apr. 1979).

Pulsed laser; Q-switched; risetime; speckle; waveform; attenuators; calibration; laser; neodymium laser; peak power; power meter; TNIOIO.

Pulsed laser; spectra; wavelengths; energy levels; ions; molybdenum; 18500 .

Pulsed $\mathrm{Nd}^{3+}$ laser damage; single and multiple element fibers; surface threshold damage; free-running laser pulses; giant laser pulse; optical fiber damage; SP541, pp. 168-189 (Dec. 1978).

Pulsed TEA $\mathrm{CO}_{2}$ laser surface breakdown; spot size; surface absorption; transmitted pulse; adsorbed water; breakdown mechanism; frequency and time dependence of breakdown thresholds; IR window materials; $\mathrm{NaCl}$; pressure; SP54I, pp. 318-326 (Dec. 1978).

Pulse-echo techniques; spectrum analysis; ultrasonics; acoustic; computer processing; digital acquisition; digital signal processing; SP525, pp. 281-286 (Apr. 1979).

Pulses; scattering; ultrasonic; acoustic; crack; defects; elastic solid; 18391 .

Pulsewidth dependence; standing waves; thin-film coatings; twophoton absorption; ultraviolet wavelength scaling; damage thresholds; electric fields; laser damage; nanosecond pulses; SP541, pp. 190-202 (Dec. 1978).

Pumps; reservoirs; sensors; tailorable; temperature; accumulator; analog; centralized; check-out system; dessicant; discrete; displacement; fiber optics; filters; flight critical; flow; fluid; go-no-go; ground readout; hydraulic; IMACS; SP547, pp. 345-357 (July 1979).

Purchasing; pursuit tires; safety; tread wear; braking traction; cornering traction; driving traction; endurance; maintenance; operation; SP480-33.

Pure materials; superconductivity; temperature scale; thermometry; cryogenics; fixed points; 18550 .

Purgeable organics; WaterDROP; accumulators; analysis of organics in water; automatic sampler; master analytical scheme; non-purgeable organics; organic pollutant; SPS19, pp. $65-78$ (Apr. 1979).

Pursuit tires; safety; tread wear; braking traction; cornering traction; driving traction; endurance; maintenance; operation; purchasing; SP480-33.

Pursuit tires; tire maintenance; traction performance; tread wear; high speed performance; high speed tires; police tires; 19038.

Pu-239; U-235; U-238; activation analysis; benchmark fields; dosimetry; fission yields; measurements; neutrons; Np-237; 18884.

Pyramidal horn antenna; rf radiation monitor; standard electromagnetic field; antenna gain calculation; field strength calibration; 18814 .

Pyrex; size effect; chipping; ferrites; glass melting; grinding; grinding model; high-speed grinding; SP562, pp. 61-74 (Oct. 1979). 
Pyroelectric detectors; pyroelectric vidicons; terbium molybdate; triglycine sulfate; ferroelectrics; figures of merit; improper ferroelectrics; 18852 .

Pyroelectric detectors; radiometry; silicon cell; silicon detector; silicon photodetector; absolute radiometry; detector; electrically calibrated detectors; laser power measurements; 18773 .

Pyroelectric detectors; radiometry; silicon cell; silicon detector; silicon photodetector; absolute radiometry; detector; electrically calibrated detectors; laser power measurements; 18774 .

Pyroelectric response; thermal pulse; vinylidenefluoridetetrafluoroethylene copolymer; blocking electrode; charge motion; polarization; poly (vinylchloride); poly (vinylidenefluoride); 18408 .

Pyroelectric vidicons; terbium molybdate; triglycine sulfate; ferroelectrics; figures of merit; improper ferroelectrics; pyroelectric detectors; 18852 .

Pyroelectricity; transducers; dielectric strength; electrets; piezoelectricity; polarization; poling procedures; polymers; poly(vinylidene fluoride); J. Res. 84, No. 6, 447-453 (1979).

Pyrolitic graphite; Ruland function; $x$-ray diffraction; Bacon function; Bragg function; Ergun function; graphite materials; Lorentz function; preferred orientation function; 18523 .

Pyrolysis; relaxation; thermal decomposition; allylmethylether; bromide; ethylacetate; isopropyl; laser; non-equilibrium; 18832.

Pyrolysis; rigid foams; smoke; smoldering; weight loss; wood; combustion; flaming combustion; flexible foams; optical density; particle size; polypropylene; polyurethane foams; polyvinyl chloride; NBS-GCR-78-147.

Pyrolysis; trace organic analysis; Fourier transform infrared; gas chromatography; modular organic analysis system; SP519, pp. 753-760 (Apr. 1979).

Pyrolysis gas chromatography; random scission; tetrafluoroethylene copolymers; 1,3,3,3-tetrafluoropropene polymer; 3,3,3-trifluoropropene copolymers; 3,3,4,4,5,5,5heptafluoropentene-1 polymer; isobutene copolymers; 18580 .

Pyromaniacs; abnormal psychology; arson; arsonists; firesetters; human behavior; literature reviews; NBS-GCR-79-157.

Pyruvate to lactate reaction; spectrophotometric enzyme assay; enzyme assay; influence of inhibitor on lactate dehydrogenase assay; lactate dehydrogenase assay; lactate to pyruvate reaction: 18433 .

\section{Q}

Q-switched; risetime; speckle; waveform; attenuators; calibration; laser; neodymium laser; peak power; power meter; pulsed laser; TNIOIO.

Quadrupole giant resonance; alpha particle; dipole giant resonance; electroproduction; nickel; photon; photoproduction; 18495.

Qualitative analysis; scanning electron microscope; artifacts; electron probe microanalysis; energy-dispersive $x$-ray spectrometry; microanalysis; 18790 .

Qualitative x-ray powder diffractometry; round robin; search/match methods; 18857.

Quality assurance; environmental measurements; Measurement Assurance Programs; 18720.

Quality control; attenuation; fiber optics; interlaboratory comparison; measurements; optical communications; NBSIR 79 1608.

Quality control; standards; technology transfer; UN Conference on Science and Technology for Development (UNCSTD); Africa; Asia; developing countries; industrialization; Latin America; management; measurement; metrology; SP543.

Quality of service; response time; turnaround time; availability standards; batch processing; calibration programs; computer standards; interactive processing; SP50O-52, pp. 79-86 (Oct. 1979).
Quantitative analysis; rough surfaces; x-ray microanalysis; electron probe analysis; peak-to-background ratios; 18976.

Quantitative analysis; scanning electron microscopy; $\mathrm{x}$-ray microanalysis; electron probe microanalysis; energy dispersive $\mathrm{x}$-ray microanalysis; energy dispersive $\mathrm{x}$-ray spectrometry; 18970.

Quantitative electron probe microanalysis; x-ray continuum; xray spectrum; computer program; energy dispersive detector; multichannel analyzer; peak overlap; TN1106.

Quantum beats; sodium atom; angular distributions; field ionization; laser spectroscopy; multiphoton processes; photoionization; 18953.

Quantum efficiency; reflectance; response; silicon detector; spatial position dependence; dead layer model; external; internal; 18900 .

Quantum electrodynamic theory; electron anomalous moment; fine-structure constant; fundamental constant; magnetic fields; proton gyromagnetic ratio; 18702 .

Quantum field theory; singularities; $S$-matrix; Feynman integrals; 18732 .

Quantum interference; superconductivity; digital electronics; magnetometry; 18701 .

Quark; spectroscopy; spectrum; structure; flavor; hadron; 19010.

Quarks; selection rules; spin forces; tensor force; charmonium; particle spectroscopy; 18432 .

Quartets; reactions; spectroscopy; SU4; alpha-particles; correlations; mass formula; nuclear; 18423 .

Quartz crystal; sapphire; Si single crystal; high pressure; high temperature; mechanochemical polishing; SP562, pp. 171. 182 (Oct. 1979).

Quartz crystal oscillator; short term frequency stability; long term frequency stability; oscillator systems; 18691 .

Quasielastic light scattering; SRM-706; standard reference material; diffusion; diffusion coefficient; light scattering; polydisperse; polydispersity; polystyrene; 18511 .

Quasielastic light scattering; $45 \mathrm{~S}$ and $50 \mathrm{~S}$; diffusion coefficient; E. coli ribosomal subunit; J. Res. 84, No. 1, 1-8 (1979).

Quasielastic scattering; reorientation; residence time; tunneling; activation energy; methyl group; neutron scattering; potential barrier; 18374 .

Quasielastic scattering; tantalum hydride; vanadium hydride; $\alpha$ phase; $485 \mathrm{~K}$; diffusion; 18730.

Quasimolecule terms; sudden perturbation limit; transition probability; unified atom approximation; $\Sigma-\Pi$ transition; adiabatic limit; atomic collisions; 18576.

Quasi-monoenergetic photons; sodium iodide spectrometer: 15.1 MeV branching ratio; positron annihilation-in-flight; 18522.

Quasi-order; topological algebra; coalgebra; direct limit; faithful distributive module; generating function; incidence algebra; inverse limit; orthogonal idempotents; 18788 .

Quasi-ordered set; topological algebra; automorphism; cyclic module; faithful distributive module; incidence algebra; multiplicative function; 18789 .

Quaternary two-phase systems; serum; uv-detection; tricyclic antidepressives; benzodiazepines; clinical use; derivatization; SP519, pp. $461-468$ (Apr. 1979).

Quenching; radiative lifetimes; rate constants; reactive channels; recommended data; relaxation processes; review; activation energies; electronically excited states; evaluation; gaseous interactions; molecular correlations; JPCRD 8, No. 3, 723-798 (1979).

Query; standards; database; data-description; data-dictionary; data-directory; data-manipulation; DBMS; languages; SP5OO51 .

Questionnaire; user needs; building evaluation; design process; man/environment research; post-occupancy evaluation; NBSIR 79-1780. 
Queuing models; race conditions; TCAM data flow; teleprocessing; input lockout; mathematical modeling; SP50O. 52, pp. 219-226 (Oct. 1979).

Queuing models; simulation; software monitoring; workload definition; computer performance evaluation; computer performance measurement; computer performance prediction; computer system acquisition; conference proceedings; CPE in auditing; hardware monitoring; CPEUG; SP500-52.

R. A. Fisher; Student's $t$; Student's $z$; Student (W. S. Gosset, 1876-1937; t-transformation of correlation coefficient; distribution of regression coefficients; 18543 .

\section{$\mathbf{R}$}

Rabi frequency; Star shift; two-level model; absorption; cesium; exponential index; ionization; multiphoton; 18892 .

Rabi frequency; statistical broadening; three-level system; coherent excitation; dressed atoms; inhomogeneous broadening; intense laser; multiphoton dissociation; multiphoton ionization; 18439.

Race conditions; TCAM data flow; teleprocessing; input lockout; mathematical modeling; queuing models; SP5OO-52, pp. 219-226 (Oct. 1979).

Radar absorbers; time-domain measurements; dielectrics; frequency-domain measurements; magnetic materials; microwaves; millimeter waves; permeability measurements; permittivity measurements; NBSIR 79-1613.

Radial distribution function; transverse current correlation function; velocity autocorrelation function; intermediate scattering function; Lennard-Jones liquid; liquid rubidium; molecular dy namics; J. Res. 84, No. 6, 439-446 (1979).

Radiated emissions; susceptibility measurements; electromagnetic; 18579 .

Radiation; activation analysis; crystal structure; diffraction; isotopes; molecular dynamics; neutron; neutron radiography; nondestructive evaluation; nuclear reactor; TN995.

Radiation; radiation control; radiation measurements; radiation protection; radiation safety; standards; states; calibrations; measurements; 18779.

Radiation; radiation control; radiation measurements; traceability; measurement assurance; measurement consistency; measurement system; national standards; 18800 .

Radiation; safety; standards; accelerators; IEC; interlocks; leakage; SP5 54, pp. 29-32 (Sept. 1979).

Radiation; styrene; tetrafluoroethylene; copolymerization; polymerization; pressure; 18512 .

Radiation calorimetry; solution calorimetry; bomb calorimetry; drop calorimetry; electromagnetic power calorimetry; energy measurement; enthalpy measurement; entropy measurement; fuels, heating values; gas-flow calorimetry; heat capacity measurement; heat measurements; 18330.

Radiation control; radiation measurements; radiation protection; radiation safety; standards; states; calibrations; measurements; radiation; 18779 .

Radiation control; radiation measurements; traceability; measurement assurance; measurement consistency; measurement system; national standards; radiation; 18800 .

Radiation damage; radiation hardening; VLSI processing; $x$-ray lithography; E-beam lithography; integrated circuits; ion implantation; plasma etching; 18451 .

Radiation force; transducer characterization; ultrasonics; acoustic theory; calorimetry; electroacoustic method; medical applications; metrology; NDE; 18438.

Radiation hardening; VLSI processing; x-ray lithography; Ebeam lithography; integrated circuits; ion implantation; plasma etching; radiation damage; 18451 .

Radiation hardness; standard practice; thermoluminescence dosimeters; electronic devices; electrons; photons; NBSIR 79. 1723.
Radiation hazards; radio regulations; radio standards; RFI; spectrum management; standardization organizations; telecommunications; TVI; vehicular electronics; electromagnetic bioeffects; electromagnetic compatibility; electromagnetic immunity; SP55I.

Radiation measurements; radiation protection; standard; accelerator design; accelerator operation; health physics; particle accelerators; HIO7, Revised.

Radiation measurements; radiation protection; radiation safety; standards; states; calibrations; measurements;. radiation; radiation control; 18779.

Radiation measurements; radiation safety; standard; device safety performance classification; gauges; gauging devices; ionizing radiation; $H / 29$.

Radiation measurements; traceability; measurement assurance; measurement consistency; measurement system; national standards; radiation; radiation control; 18800 .

Radiation of sound; ultrasonic radiator; baffled piston radiator; piston radiator; 18479 .

Radiation pressure; radiative cooling; Doppler-free spectroscopy; frequency standard; high resolution spectroscopy; ion storage; laser spectroscopy; Mossbauer effect; optical pumping; optical spectroscopy; 18699.

Radiation processing; activation analysis; electron beams; induction accelerator; ion acceleration; nuclear research; 18570 .

Radiation properties; cryogenics; glass-epoxy; industrial laminates; mechanical properties; physical properties; 18771 .

Radiation protection; radiation safety; standards; states; calibrations; measurements; radiation; radiation control; radiation measurements; 18779 .

Radiation protection; standard; accelerator design; accelerator operation; health physics; particle accelerators; radiation measurements; H107, Revised.

Radiation reaction; definite integrals; double integrals; error functions; Fourier transforms; J. Res. 84, No. 4, 319-326 ( 1979 ).

Radiation resistance; rectangular coax; shielded strip line; TEM cell; EMC measurements; 18345 .

Radiation safety; standard; device safety performance classification; gauges; gauging devices; ionizing radiation; radiation measurements; $H I 29$.

Radiation safety; standards; states; calibrations; measurements; radiation; radiation control; radiation measurements; radiation protection; 18779 .

Radiation scattering; thin films; laser damage; optical probe technique; SP54I, pp. 226-234 (Dec. 1978).

Radiation therapy; uncomplicated cure; instantaneous optimization; SP554, pp. 57-61 (Sept. 1979).

Radiation transfer; stellar atmospheres; circumstellar dust; line formation; 18435 .

Radiation-induced cavitation; temperature dependence of cavitation threshold; threshold; acoustic cavitation; cavitation; cavitation threshold vs temperature; NBSIR 79-1753.

Radiative cooling; Doppler-free spectroscopy; frequency standard; high resolution spectroscopy; ion storage; laser spectroscopy; Mossbauer effect; optical pumping; optical spectroscopy; radiation pressure; 18699 .

Radiative heat transfer; temperature depression; water vapor measurement; wet bulb; wet element; convective heat transfer; convective mass transfer; emissivity of water; evaporation coefficient; humidity measurement; J. Res. 84, No. 2, 161-177 (1979).

Radiative lifetimes; rate constants; reactive channels; recommended data; relaxation processes; review; activation energies; electronically excited states; evaluation; gaseous interactions; molecular correlations; quenching; JPCRD 8, No. 3, 723-798 (1979).

Radiative transfer; resonance lines; stars; stellar winds; line profiles; P-Cygni lines; 18515. 
Radiative transition; electronic structure; energy curves; excimer; gain; 18936 .

Radiative transition; ${ }^{5} \Pi_{u} ;{ }^{5} \Sigma_{u}{ }^{+}$; energy curve; excited state; $N_{2}$; 18935.

Radiative yield; atomic properties; Auger yield; Coster-Kronig yield; effective fluorescence yield; fluorescence yield; $K$ shell; $L$ shell; non-radiative yield; partial level width; JPCRD 8, No. 2, 307-328 (1979).

Radical; infrared emission; laser; methylene iodiode; methyl iodiode; photodissociation; 18573 .

Radicals; rate constant; acetylene; butadiyne; ethynyl; hydrogen; mechanism; photochemistry; 18443.

Radicals; review; troposphere; alkoxyl; kinetics; SP557, pp. 51 61 (Aug. 1979).

Radicals; vibronic 'spectroscopy; chlorofluoromethylene; fluorescence; laser spectroscopy; multiphoton dissociation; 19042.

Radio astronomy; rotational transitions; dimethyl ether; internal rotation; interstellar molecules; microwave spectrum; JPCRD 8, No. 4, $1051-1108$ (1979).

Radio astronomy; rotational transitions; interstellar molecules; line strengths; microwave spectra; molecular constants; propyne; JPCRD 8, No. 2, 537-558 (1979).

Radio astronomy; rotational transitions; internal rotation; interstellar molecules; line strengths; męthyl formate; microwave spectrum; JPCRD 8, No. 3, 583-618 (1979).

Radio astronomy; rotational transitions; vinyl cyanide; interstellar molecules; microwave spectra; molecular parameters: JPCRD 8, No. 1, 107-124 (1979).

Radio broadcasts; satellite broadcasts; standard frequencies; television color subcarrier; time and frequency calibration methods; time calibration; time signals; frequency calibration; high frequency; Loran-C; low frequency; SP5 59.

Radio regulations; radio standards; RFI; spectrum management; standardization organizations; telecommunications; TVI; vehicular electronics; electromagnetic bioeffects; electromagnetic compatibility; electromagnetic immunity; electromagnetic interference; SP55 1.

Radio standards; $R$ FI; spectrum management; standardization organizations; telecommunications; TVI; vehicular electronics; electromagnetic bioeffects; electromagnetic compatibility; electromagnetic immunity; electromagnetic interference; electromagnetic radiation; SP551.

Radio star; satellite communications; error analysis; $G / k T$, EIRP; G/T, precision measurements; 18577

Radioactive $\mathrm{X}$-ray source; rare-earth scintillator screen; ${ }^{128} \mathbf{1}$; ${ }^{153} \mathrm{GD}$; Csl; detection efficiency; Lixiscope; 19001 .

Radioactivity; radiopharmaceuticals; traceability; 18761 .

Radioactivity; Raman microprobe; solar energy; toxic substances; building rehabilitation; energy measurements; energy-related inventions; environment; precision power; DIM/NBS 63, No. 6, 1-32 (June 1979).

Radioactivity; scintillator materials during spacenight; spaceflight; 19011 .

Radioactivity; standards; testing; traceability 7 , dose; ionizing: 18361.

Radioactivity: ștandards; traceability; low-level; measurements; 18400.

Radioactivity: standards; Woods Hole; environment; ICRM; natural matrix; 18981 .

Radioactivity; ${ }^{121} \mathrm{Sn}$ " decay scheme; coincidence counting: decay probability; isomeric transition; liquid scintillation counting: photon counting; 18841 .

Radioactivity measurements; statistical design of experiment; statistical terms and formulas; statistics; systematic error; uncertainty: precision; $\mathbf{1 8 4 2 7}$.

Radioactivity reference materials; standard reference materials; accuracy; compatibility; 18539 .
Radiocarbon; accelerator mass spectrometry; anthropogenic and natural carbonaceous species; atmospheric gases and particles; environmental pollutants; fossil fuels; low-level counting: 18405 .

Radiochemical; selectivity; sensitivity; toxic elements; 18343 .

Radiochemical separation; spontaneous deposition technique; biological materials analysis; environmental materials analysis; neutron activation analysis; noble metals analysis; platinum determination; 18350 .

Radiochemistry; cadmium; neutron activation; 18478 .

Radiofrequency; standards; calibrations; measurements; microwaves; 18561 .

Radiography: radiology; real-time radiography; resolution; $x$-ray image magnifier; asymmetric diffraction; dynamical diffraction; microradiography: $\mathbf{8 3 9 9}$.

Radiography; statistics; ultrasonics; visual-optical tests; acoustic; annual report; eddy currents; inspection; magnetic particles; nondestructive evaluation; penetrants; NBSIR 78-1581.

Radiography; time-of-flight technique; linac; neutrons; positionsensitive detector; 18591 .

Radiography; $x$ ray; imaging; low-dose; low-intensity; microchannel plate; 19000 .

Radioimmunoassay; solanidine; solanine; potato alkaloids; SP519, pp. 333-340 (Apr. 1979).

Radioisotope leak test; resistivity variations; resistors, sheet; scanning acoustic microscope; semiconductor materials; semiconductor process control; silicon; silicon dioxide; silicon-on-sapphire; sodium contamination; test patterns; test structures; $S \mathbf{P} 400-38$.

Radiolabeled proteins; adsorption; biomaterials; blood proteins; ellipsometry; polymer adsorption; protein adsorption; protein chromatography: NBSIR 79-1784.

Radiology; real-time radiography; resolution; $x$-ray image magnifier; asymmetric diffraction; dynamical diffraction; microradiography; radiography; $\mathbf{l} 8399$.

Radiolysis; rates; selenium radicals; sulfate radical; thiocyanate radical anion; aqueous solution; carbonate radical; chemical kinetics; halogen radical anions; nitrate radical; oxyanion radicals; phosphate radical; photolysis; NSRDS-NBS65.

Radiometric instrumentation; laser power modulator; laser power stabilizer; photodetector characterization; TN987.

Radiometric microbiological assay; vitamin $\mathrm{B}_{12}$; foods; SP519. pp. 257-265 (Apr. 1979).

Radiometry; silicon cell; silicon detector; silicon photodetector; absolute radiometry; detector; electrically calibrated detectors; laser power measurements; pyroelectric detectors; 18773.

Radiometry; silicon cell; silicon detector; silicon photodetector; absolute radiometry; detector; electrically calibrated detectors; laser power measurements; pyroelectric detectors; 18774.

Radiopharmaceuticals; traceability; radioactivity; 18761 .

Radiotherapy: RBE; neutrons; SP554, pp. $37-40$ (Sept. 1979).

Radiotherapy; spectrometry; dose-equivalent; electrons; kerma; multisphere; photon; photoneutrons; SP554, pp. 109-123 (Sept. 1979).

Radiotherapy; spectrometry; dose-equivalent; electrons; kerma; multispheres; photoneutrons; photons; SP554, pp. 125-127 (Sept. 1979).

Radium; strontium; temperature dependence; alkaline earth elements; barium; beryllium; calcium; electrical resistivity; magnesium; JPCRD 8, No. 2, $439-498$ (1979).

Radius of gyration; temperature and molecular weight dependence: hydrodynamic radius; intrinsic viscosity: polymer dimensions in solution; polystyrene; $\mathbf{1 8 9 6 0}$.

Radius of syration; temperature dependence; hydrodynamic radius; light scattering: molecular weight dependence; polystyrene; 18545 .

Radon in buildings; ventilation and radon concentration; energy conservation design; indoor radiation; 18587. 
Raffinosc; ribose; stachyose: sucrose; sugar analysis; carbohydrates; fructose; galactose; gas-liquid chromatography; glucose; lactose; liquid chromatography; maltose; SP519, pp. 271-278 (Apr. 1979).

Rainer and Serene; superfluid ${ }^{3} \mathrm{He}$; frequency sums; 18553.

Ralativity; space; superconducting; torque: trapped flux; gyroscope; 18846 .

Raman microprobc; Raman spectra; Raman spectroscopy; biological microanalysis; biological tissue; foreign bodies; histological sections; implant materials; microanalysis; molccular microanalysis; pathological tissue; 18958 .

Raman microprobe; Raman spectra; Raman spectroscopy; biological microanalysis; microanalysis; micromineralogy; microsampling; molecular analysis; organic microanalysis; 18963.

Raman microprobe; Raman spectra; Raman spectroscopy; laser excitation; microanalysis; microparticle analysis; microprobe resolution; microsample heating; optical detection; 18971 .

Raman microprobe; Raman spectra; Raman spectroscopy; tissue sections; tooth; biological microanalysis; biological tissue; dental studies; enamel; mineralizing tissue; 18982 .

Raman microprobe; Raman spectroscopy; biological microanalysis; biological mineralization; bone; dental studies; dentin; enamel; microanalysis; mineralizing tissue; 19008

Raman microprobe; Raman spectroscopy; urban dusts; vibrational analysis; atomospheric aerosols; materials sampling; mineralogy: molecular analysis; particle analysis; power plant emissions; 18643.

Raman microprobe; Raman spectroscopy; vibrational spectra; microanalysis; particlc analysis; pollution studies; power plants; 18966 .

Raman microprobe; solar energy; toxic substances; building rehabilitation; energy measurements; energy-related inventions; environment; precision power; radioactivity; DIM/NBS 63, No. 6, 1-32 (June 1979).

Raman spectra; Raman spectroscopy; biological microanalysis; biological tissue; foreign bodies; histological sections; implant matcrials; microanalysis; molecular microanalysis; pathological tissuc; Raman microprobe; 18958 .

Raman spectra; Raman spectroscopy; biological microanalysis; microanalysis; micromineralogy; microsampling; molecular analysis; organic microanalysis; Raman microprobe; 18963.

Raman spectra; Raman spectroscopy; laser excitation; microanalysis; microparticle analysis; microprobe resolution; microsample heating; optical detection; Raman microprobe; 18971 .

Raman spectra; Raman spectroscopy; tissue sections; tooth; biological microanalysis; biological tissue; dental studies; enamel; mineralizing tissuc; Raman microprobe; 18982 .

Raman spectra; rotation-vibration spectra; symmetry analysis; Born-Oppenheimer approximation; high-resolution spectra; level clusters; 18598 .

Raman spectra; trace organic analysis; laser-Raman microprobe; liquid chromatograph-Raman spectrometer interface; micro-Raman spectroscopy; organic microanalysis; PAH microsamples; (PAHs); polynuclear aromatic hydrocarbons; SP519. pp. 723.729 (Apr. 1979).

Raman spectroscopy; biological microanalysis; biological tissue; foreign bodies; histological sections; implant materials; microanalysis; molecular microanalysis; pathological tissue; Raman microprobe; Raman spectra; 18958.

Raman spectroscopy; biological microanalysis; microanalysis; micromineralogy; microsampling; molecular analysis; organic microanalysis; Raman microprobe; Raman spectra; 18963.

Raman spectroscopy; biological microanalysis; biological mineralization; bone; dental studies; dentin; enamel; microanalysis; mineralizing tissue; Raman microprobe; 19008.
Raman spcctroscopy; laser excitation; microanalysis; microparticle analysis; microprobe resolution; microsample heating; optical detection; Raman microprobe: Raman spectra; 18971 .

Raman spectroscopy; tissue sections; tooth; biological microanalysis; biological tissue; dental studies; enamel; mineralizing tissue; Raman microprobe; Raman spectra; 18982.

Raman spectroscopy; turbulence; concentration fluctuations; fast Fourier transforms; Fourier transform analysis; mixing in turbulent flow; noise spectrum; 18626

Raman spectroscopy; urban dusts; vibrational analysis; atomospheric aerosols; materials sampling; mineralogy; molecular analysis; particle analysis; power plant emissions; Raman microprobe; 18643.

Raman spectroscopy; vibrational spectra; microanalysis; particle analysis; pollution studies; power plants; Raman microprobe; 18966.

Raman spectroscopy of liquids; signal enhancement of coherent Raman process; coherent anti-Stokes Raman spectroscopy (CARS); liquid-filled dielectric waveguide; optical waveguide; phase-matched propagation in waveguide; 18686 .

Ramp response; step response; divider; high voltage; impulse; lightning impulse; pulse calibration; 18727 .

Ramps; building circulation; building ramps; pedestrian circulation; pedestrian flow; pedestrian movement; pedestrian ramps; NBSIR 79-1729.

Ramsey envelope; Ramsey separated oscillating fields; two frequency separated oscillating fields; atomic beams; atomic frequency standards; cavity phase shift; 18475 .

Ramsey separated oscillating fields; two frequency separated oscillating fields; atomic beams; atomic frequency standards; cavity phase shift; Ramsey envelope; 18475 .

Random scission; tetrafluoroethylene copolymers; 1,3,3,3tetrafluoropropene polymer; 3,3,3-trifluoropropene copolymers; $3,3,4,4,5,5,5$-heptafluoropentene-1 polymer; isobutene copolymers; pyrolysis gas ch romatography; 18580 .

Random test graphs; scheduling; time complexity; algorithm; chromatic number; color function; graph; graph coloring; heuristic; interchange; J. Res. 84, No. 6, 489-506 (1979).

Random-coil chain dimensions; Rouse coordinates; distributions in chain dimensions; equilibrium chain dimensions; excluded volume; latticc-model chains; polymer chain dimensions; 18618.

Random-coil polymer chains; relaxation times; self-entanglement effects; computer simulation; end-to-end length; entanglement effects; excluded volume effects; lattice-model polymer chains; polymer chain dynamics; 18772 .

Ranges and ovens; appliances; cooking utensils; energy conservation; energy efficiency; 18836.

Ranging; tectonic motions; continental drift; distortion-of-plate; geophysics; 18459.

Ranking; resource allocation; weighting multiple criteria; decision analysis; decisions; eigenvectors; management; multipleattribute decisions; ordering; paired comparisons; prioritization; project selection; 18602 .

Ranking and selection; selection methodology; comparison of computers; computer measurement; computer selection; computer services; SP50O-44.

Rare earth; Chevrel-phase; coexistence; crystal field; magnetic superconductor; neutron scattering; 18850.

Rare earth compounds; hydrides; Laves phase; magnetic propcrties; neutron scattering; 18657.

Rare earths; hydrides; intermetallic compounds; Laves phase; magnetism; neutron scattering; 18682 .

Rare earths; hydrides; intermetallic compounds; Laves phase magnetism; neutron scattering; 18881 .

Rare earths; small angle neutron scattering; amorphous materi: als; domains; magnetism; phase transitions; 18835 .

Rare earths; small angle scattering; amorphous alloys; magnetic partides; magnetism; neutron scattering; 18372 . 
Rure earths; spin freezing; spin glasses; susceptibility; amorphous magnetism; Mossbauer effect; 18897.

Rare earths; spin glass; hyperfine fields; magnetic relaxation; magnetism; Mossbauer; 18329.

Rare earths; spin waves; crystal fields; Laves phase; magnetic materials; neutron scattering; 19031 .

Rare-earth hydrides; cerium dihydride; crystal-field splitting; inelastic neutron scattering; magnetic properties of rare earth alloys; metal hydrides; 19030 .

Rare-earth scintillator screen; ${ }^{125} \mathrm{I}$; ${ }^{153} \mathrm{GD}$; CsI; detection efficiency; Lixiscope; radioactive x-ray source; 19001 .

Rare-gases: relaxation energy; ultraviolet photoelectron spectroscopy; amorphous germanium; binding energy shifts; extraatomic screening; implants; ion bombardment; 18323 .

Rate approximation; saturable rate; bandwidth; coherence; dynamic rate; incoherence; ionization; linear rate; multiphoton; 18893 .

Rate coefficient; electron impact ionization; ionization cross section; ionization rate coefficient; lithiumlike ions, ionization of; $\mathrm{N}^{+4} ; \mathrm{O}^{+5} ; 18502$.

Rate coefficients; chemical kinetics; data evaluation; gas phase ion-molecule reactions; mass spectrometry; organic molecules; NSRDS-NBS64.

Rate coefficients; drift tube; electrons; excitation; low energy; nitrogen; 18925 .

Rate constant; acetylene; butadiyne; ethynyl; hydrogen; mechanism; photochemistry; radicals; 18443 .

Rate constant; sulfur; Arrhenius parameters; combustion; decomposition; free radicals; hydrocarbons; hydrogen; nitrogen; organic compounds; oxidation; oxygen; oxygenated; NBSIR 79-1941.

Rate constants; chemical kinetics; environmental measurements; nitric acid; nitrous acid; ozone; 18551 .

Rate constants; reactive channels; recommended data; relaxation processes; review; activation energies; electronically excited states; evaluation; gaseous interactions; molecular correlations; quenching; radiative lifetimes; JPCRD 8, No. 3, 723-798 (1979).

Rate fluid; simple shear; BKZ fluid; constitutive equation; nonlinear flow histories; 18367 .

Rates; selenium radicals; sulfate radical; thiocyanate radical anion; aqueous solution; carbonate radical; chemical kinetics; halogen radical anions; nitrate radical; oxyanion radicals; phosphate radical; photolysis; radiolysis; NSRDS-NBS65.

Rating; solar; standards; testing; computer; hot water; measurement; 18428 .

Rating; space-heating; testing; boiler; combustion; energy; furnace; gas-fired; heating; oil-fired; 18385 .

Rating; standards; testing; mobile home; packaged solar spaceheating system; NBSIR 79-1799.

Raw data conversion to engineering units; total energy; total energy data flow; computerized processing; data editing; data flow; data processing; data reductions; NBSIR 79-1757.

Rayleigh light scattering; binary mixture at the gas-liquid critical point; gas-liquid critical point; $\mathbf{1 8 7 5 2}$.

Rayleigh scattering; tabulations; $x$ rays; atomic form factor; coherent scattering; cross sections; gamma rays; photons; JPCRD 8, No. 1, 69-106 (1979).

Rayleigh scattering; ultrasonic spectrum analysis; clinical ultrasound; ocular tumor; power spectra; SP525, Pp. 111-119 (Apr. 1979).

RBE; neutrons; radiotherapy; SP554, pp. $37-40$ (Sept. 1979).

RBE; risk; cell-proliferation; cell-turnover; cytotoxicity; homeostasis; promotion; SP554, pp. 41-56 (Sept. 1979).

Reaction kinetics; surface reaction; anthranilic acid; chemisorption; cupric anthranilate; cupric ion-containing hydroxyapatite; 18972 .

Reaction rate constants; upper atmosphere; atomic energy levels; atomic spectra; atomic transition probabilities; elec- tron cross sections; fusion plasmas; lasers; molecular bands; molecular spectra; 18855 .

Reaction rates; Californium; dosimetry; fission neutrons; iron cross section; nickel cross section; 18883

Reaction time; safety; standards; consumer product; human factors; lawn mowers; NBSIR 77-1299.

Reactions; review; troposphere; aldehyde; free radical; photolysis; SP557, pp. $27-46$ (Aug. 1979).

Reactions; review; tropospheric chemistry; nitrates; nitrites; nitrogen oxides; photolysis; SP557, pp. $71-79$ (Aug. 1979).

Reactions; spectroscopy; SU4; alpha-particles; correlations; mass formula; nuclear; quartets; 18423 .

Reactions; tropospheric chemistry; aromatics; free radicals; mechanism; SP5 57, pp. 85-91 (Aug. 1979).

Reactive atmosphere; coal gasification; high pressure; high temperature; measurement method; powder diffraction; 18945 .

Reactive atmosphere process (RAP) chemistry; thin film coating materials; infrared laser windows; materials purification; SP541, pp. 249-256 (Dec. 1978).

Reactive channels; recommended data; relaxation processes; review; activation energies; electronically excited states; evaluation; gaseous interactions; molecular correlations; quenching; radiative lifetimes; rate constants; JPCRD 8 , No. 3, $723-798$ ( 1979).

Reactor; threshold detectors; dosimetry; fast neutrons; photofission; photoneutrons; pressure vessel; 18462 .

Reactor dosimetry; benchmark fields; benchmark testing; neutron fields; nuclear data; 19024.

Reactor dosimetry; benchmark neutron field development; dosimetry methods; fission cross sections; 19013 .

Reactor dosimetry; dosimetry programs; light water reactors; nuclear reactors; 19014.

Real-time; simulation; synthetic programs; benchmarking; computer performance measurement; distributed processing; interactive systems; kernels; modeling; SP500-52, pp. 53-64 (Oct. 1979).

Real-time; tissue characterization; ultrasound diagnosis; clinical cardiac data; digital processing; Fast Fourier Transform; frequency spectra; in vivo; microprocessor-controlled data acquisition; myocardial infarction; SP525, pp. 267-273 (Apr. 1979).

Real-time radiography; resolution; $x$-ray image magnifier; asymmetric diffraction; dynamical diffraction; microradiography; radiography; radiology; 18399 .

Rearrangement; shake-off; shake-up; beta decay; 18407.

Rebar corrosion; reinforced concrete; bridge deck; concrete; corrosion; corrosion of steel; SP55O.

Rebuilding; crisis; flood recovery effort; missing link; SP552, Pp. 39-44 (July 1979).

Recessed incandescent lighting fixture; thermal insulation; thermocouple; branch circuit wiring; electrical junction box; hazardous temperatures; load current; protective barrier; NBSIR 79-1913.

Reciprocating; records after trigger; tape loop; time signal; time window; gated frequency analysis; Gaussian window; impulsive complex signals; linear averaging; SP547, pp. 315-322 (July 1979).

Recommended data; relaxation processes; review; activation energies; electronically excited states; evaluation; gaseous interactions; molecular correlations; quenching; radiative lifetimes; rate constants; reactive channels; JPCRD 8, No. 3, 723-798 (1979).

Reconstruction; temperature reconstruction; ultrasound; aperture synthesis; computed tomography; Doppler; fluid flow; high resolution; SP525, pp. 227-233 (A pr. 1979).

Reconstruction; temperature reconstruction; ultrasound; aperture synthesis; computed tomography; Doppler; fluid flow; high resolution; SP525, pp. 235-246 (A pr. 1979). 
Record size; transaction volume; transfer speed; validate; verify; application; character set; computer interface; cost; data entry; edit; operator speed; SP5O0-55.

Record-keeping practices; relevant information; security; citizen rights; computers; computer utilization; confidentiality; data systems; personnel administration; personnel practices; personnel records; privacy; SP50O-50.

Records after trigger; tape loop; time signal; time window; gated frequency analysis; Gaussian window; impulsive complex signals; linear averaging; reciprocating; SP547, pp. 315322 (July 1979).

Recreational equipment; strength-to-weight ratio; composites; durability; flexural characteristics; SP563, p. 208 (Oct. 1979).

Recrystallization, role of; surface layer, role of; dilution effect, at same $\mathrm{pH}$ and concentration; hydration shell, role of; hydroxylapatite, at different pHs; isotopic exchange, isoionic; J. Res. 84, No. 5, 395-406 (1979).

Recrystallization temperature; benzyl substituted diglycerides; differential scanning calorimetry; heat of fusion; lecithins; lipids; melting temperature; metastable states; phenyl substituted diglycerides; phospholipids; polymorphism; 18380.

Rectangular coax; shielded strip line; TEM cell; EMC measurements; radiation resistance; 18345 .

Rectangular coaxial line; transmission lines; capacitance; 18694.

Recycled oil; re-refined oil; used oil; waste oil; engine oil; fuel oil; hydraulic oil; industrial oil; lubricating oil; oil specifications; petroleum standards; petroleum test methods; SP556.

Recycled pulps; short span tensile analysis; zero span tensile; fiber length distribution; fiber strength; interfiber bonding; NBSIR 79-1914.

Recycling; residential; wastewater treatment; water; water conservation; water heating; water usage; energy; energy consumption; grey water; heat recovery; NBSIR 79-1770.

Redevelopment; rehabilitation; tax incentives; adaptive reuse; buildings; demolition; economics; historic preservation; lifecycle costing; TN980.

Redevelopment; rehabilitation; tax incentives; adaptive reuse; buildings; demolition; economics; historic preservation; lifecycle costing: 19016 .

Reduction; cell design; electrochemical detection; liquid chromatography; oxidation; SP519, pp. 705-7I2 (Apr. 1979).

Redundancy management; training for diagnosis; automatic monitoring; failure annunciation; malfunction procedures; manned spaceflight failures; SP547, pp. 3-16 (July 1979).

Reference blocks; standards; ultrasonics; variability; calibration; diffusion bonding; measurement assurance program; NBSIR 79-1742.

Reference collection of humic substances; reference samples; soil organic matter; aquatic humus; fulvic acid; humic acid; humic substances; SP519, pp. 789-792 (Apr. 1979).

Reference collection of humic substances; soil organic matter; standard humic materials; fulvic acid; humic acid; humic substances; SP519, pp. 793-796 (Apr. 1979).

Reference data; silver; solid state physics; transport properties; copper; critical evaluation; data analysis; data compilation; data evaluation; data extraction; data synthesis; electrical resistivity; elements; gold; metals; JPCRD 8, No. 4, 1147-1298 (1979).

Reference electrodes; sensors, chemical; electrodes, errors; electrodes, ion-selective; electrodes, reference; ion-selective electrodes; 18362.

Reference intensities; standard; $x$-ray diffraction; crystal structure; integrated intensities; lattice constants; peak intensities; powder patterns; Monogr. 25, Section 16.

Reference material; clinical chemistry; 18536.

Reference materials; standard reference materials; analytical laboratory; certified reference materials; measurement; measurement compatibility; 18748 .
Reference materials; thermal conductivity; characterization; density; electrical resistivity; graphite; Lorenz ratio; 18668 .

Reference method; semiautomated pipetting; serum potassium analysis; statistical analysis; clinical analysis; clinical chemistry; definitive method; electrolytes; flame atomic emission spectroscopy; SP260-63.

Reference method; serum chloride analysis; statistical analysis; amperometry; chloride analysis; clinical analysis; clinical chemistry; coulometry; definitive method; electrolytes; SP260-67.

Reference samples; soil organic matter; aquatic humus; fulvic acid; humic acid; humic substances; reference collection of humic substances; SP519, pp. 789-792 (Apr. 1979).

Reference standards; safety research; walkway slip-resistance; friction; measurement; SP565.

Reflectance; air pollution; ambient aerosols; computer controlled gas chromatography/mass spectrometry; GRALE; organic analysis; SP519, pp. 101-107 (Apr. 1979).

Reflectance; response; silicon detector; spatial position dependence; dead layer model; external; internal; quantum efficiency; 18900 .

Reflectance; spectral absorptance; theory; asymmetric absorptance; damage thresholds; dielectric reflectors; electricfield distribution; high-power; SP541, pp. 278-287 (Dec. 1978).

Reflectance; standard reference materials; transmittance; 18844.

Reflection coefficient; reflectometer; scattering parameters; sixport; voltage; calibration; current; impedance; network analyzer; power; 18600 .

Reflection coefficient; reflectometer; scattering parameters; sixport; voltage; calibration; current; impedance; network analyzer; power; 18601 .

Reflection coefficient; reflectometer; six-port; calibration; impedance; TNIOI2.

Reflection technique; solids; tissue; ultrasound; propagation velocity; SP525, pp. 53 -56 (Apr. 1979).

Reflective optics; crosstrack scan; earth imagery; ERTS; LANDSAT; multispectral scanner; SP547, pp. 17-30 (July 1979).

Reflectometer; scattering parameters; six-port; voltage; calibration; current; impedance; network analyzer; power; reflection coefficient; 18600 .

Reflectometer; scattering parameters; six-port; voltage; calibration; current; impedance; network analyzer; power; reflection coefficient: 18601 .

Reflectometer; six-port; automation; microwave; microwave measurements; 18652

Reflectometer; six-port; calibration; impedance; reflection coefficient; TNIOI2.

Reflectometer; six-port; calibration; microwave measurements; 18651 .

Reflectometers; six-port reflectometers; microwave measurements; microwave power; microwave systems; power monitor; 18670.

Reformatting; reorganization; restructuring; data base; data base management; file maintenance; $S P 500-47$.

Refractive index; refractive index tubes; fluids; noxious fluids; 18930.

Refractive index; $\mathrm{SiO}_{2} ; \mathrm{SrF}_{2}$; thermal expansion coefficient; thermo-optic constant; $\mathrm{ZnS} ; \mathrm{ZnSe} ; \mathrm{Al}_{2} \mathrm{O}_{3} ; \mathrm{As}_{2} \mathrm{~S}_{3}$ glass; $\mathrm{BaF}_{2}$; $\mathrm{CaF}_{2} ; \mathrm{CdF}_{2} ;$ TN993.

Refractive index; strontium fluoride; alkaline earth fluorides; SP541, pp. 55-58 (Dec. 1978 ).

Refractive index tubes; fluids; noxious fluids; refractive index; 18930.

Refractive index, uv, visible and ir; water; aqueous solutions fluorescence spectra; 18403 .

Refractive virial coefficients; $\mathrm{SF}_{6} ; \mathrm{CH}_{4}$; collision induced bands $\mathrm{CO}_{2} ; \mathrm{C}_{2} \mathrm{H}_{4}$; dielectric virial coefficients; 18786 . 
Refractory concrete; resource conservation and recovery: chemical degradation; coal conversion; coal gasifier; computers; data; metric; DIM/NBS 63, No. 12, 1-32 (1979).

Refrigeration; specific heat; strontium titanate; beryllium; ceramics; cryogenics; dielectric-constant; electrets; electrocaloric effect; entropy; ferroelectrics; glass-ceramics; heat switches; magneto-thermal conductivity; polarization; potassium tantalate; 18680 .

Refrigeration; SQUID; superconductive electronics; cryocoolers; Josephson devices; 18700.

Refrigerator field data; usage profiles; combination refrigeratorfreezer field data; daily load profiles; energy consumption; field measurments; hourly load profiles; NBSIR 79-1781.

Refuse-derived-fuels; sample characterization; test procedures; bomb calorimetry; gross calorific values; NBSIR 78-1494.

Regression; software; transformation; computing system; dataplot; fitting; graphics; interactive graphics; 18519 .

Regulation; regulatory oversight; regulatory processes and regulatory effects; regulatory reform; social science; technological innovation; administrative experimentation; evaluability assessment; evaluation; experimental methods; NBS-GCR-ETIP 79.64.

Regulation; regulatory processes and regulatory effects; administrative experimentation; Environmental Protection Agency; evaluability assessment; evaluation; Experimental Technology Incentives Program; Federal Communications Commission; NBS-GCR-ETIP 79-65.

Regulation; rehabilitation; renovation; building code; building research; code administration; existing buildings; model codes; preservation; TN998.

Regulation; retrofit; standards; conservation; energy cost; existing buildings; SP552, pp. 197-209 (July 1979).

Regulation; risk assessment; societal goals; building codes; control measures; fire codes; fire safety; governmental actions; life safety; SP536, pp. 63-74 (Feb. 1979).

Regulation; safety; standards; architectural barriers; building design; building site planning; environmental psychology; evaluation; fire escape; human research; measurement; pedestrian movement; SP552, pp. $101-113$ (July 1979).

Regulation; safety; standards; architectural barriers; building design; building site planning; environmental psychology; evaluation; fire escape; human research; measurement; pedestrian movement; 18430 .

Regulation; standards; building codes; code enforcement; fire prevention codes; fire safety; master planning; SP552, pp. 225-247 (July 1979).

Regulation; standards system; voluntary standards; bibliography; buildings; certification; economics of standards; legal aspects of standards; product certification; product liability; NBSIR 79-1900.

Regulation; third party; agencies; approval process; evaluation; industrialized housing products; inspection; SP552, pp. 293309 (July 1979).

Regulations; accessible; disabled; housing; SP552, pp. 95-100 (July 1979).

Regulations; rehabilitation; adaptive reuse; building codes; buildings; building safety; code enforcement; construction; fire safety; housing; preservation; SP536.

Regulations; rehabilitation; safety; barriers; building codes; code enforcement; historic district; historic preservation; SP536, pp. 83-93 (Feb. 1979).

Regulations; research needs; safety; standards; explosion; fire; hydrogen; procedures; 18776.

Regulations; safety; standards; codes; guidelines; hydrogen; 18394.

Regulations; sound; acoustics; environmental noise; noise; noise emission; 18785 .

Regulations; SSRCR; state; accelerators; leakage radiation; SP554, pp. 33-35 (Sept. 1979).
Regulations; standards; decision tables; formulation analysis; information networks; SP552, pp. 249-266 (July 1979).

Regulatory: computer facilities; integrated data base; municipal governments; SP552, pp. 153-165 (July 1979).

Regulatory commission; regulatory policy; technological innovation; computer program; economic performance; electric utilities; Experimental Technology Incentives Program; productivity; NBS-GCR-ETIP 79-70.

Regulatory experimentation; regulatory policy; technology innovation; telecommunications; administrative experimentation; economic deregulation; evaluability assessment; evaluation; Experimental Technology Incentives Program; TN1104, Vols. 1 and 2 .

Regulatory experimentation; regulatory policy; rulemaking; technological innovation; administrative experimentation; best practicable technology; clean water regulation; Environmental Protection Agency; evaluability assessment; evaluation; NBS-GCR-ETIP 79-63.

Regulatory impact; research and development; steel industry; technology; capital formation; Experimental Technology Incentives Program; NBS-GCR-ETIP 79-67.

Regulatory oversight; regulatory processes and regulatory effects; regulatory reform; social science; technological innovation; administrative experimentation; evaluability assessment; evaluation; experimental me thods; NBS-GCR-ETIP 79-64.

Regulatory policy; regulatory reform; technological innovation; administrative experimentation; Environmental Protection Agency; evaluation design; Experimental Technology Incentives Program; pesticide policy; NBS-GCR-ETIP 79-71.

Regulatory policy; rulemaking; technological innovation; administrative experimentation; best practicable technology; clean water regulation; Environmental Protection Agency; evaluability assessment; evaluation; NBS-GCR-ETIP 79-63.

Regulatory policy; subsidy policy; technological innovation; air pollution-regulatory policy; economic incentives; Federal funding of civilian R\&D; NBS-GCR-ETIP 78-53.

Regulatory policy; technological innovation; administrative experimentation; Environmental Protection Agency; evaluability assessment; Experimental Technology Incentives Program; industrial pollution regulation; market mechanism; offset policy; NBS-GCR-ETIP 79-62.

Regulatory policy; technological innovation; computer program; economic performance; electric utilities; Experimental Technology Incentives Program; productivity; regulatory commission: NBS-GCR-ETIP 79-70.

Regulatory policy; technology innovation; telecommunications; administrative experimentation; economic deregulation; evaluability assessment; evaluation; Experimental Technology Incentives Program; Federal Communications Commission; TN1104, Vols. 1 and 2.

Regulatory processes and regulatory effects; regulatory reform; social science; technological innovation; administrative experimentation; evaluability assessment; evaluation; experimental methods; Experimental Technology Incentives Program; regulation; NBS-GCR-ETIP 79-64.

Regulatory processes and regulatory effects; administrative experimentation; Environmental Protection Agency; evaluability assessment; evaluation; Experimental Technology Incentives Program; Federal Communications Commission; NBSGCR-ETIP 79-65.

Regulatory reform; social science; technological innovation; administrative experimentation; evaluability assessment; evaluation; experimental methods; Experimental Technology Incentives Program; regulation; regulatory oversight; NBS-GCRETIP 79-64.

Regulatory reform; technological changes; administrative experiment; anti-trust regulation; economic incentive; environmental regulation; innovation; NBS-GCR-ETIP 79-66. 
Regulatory reform; technological innovation; administrative experimentation; Environmental Protection Agency; evaluation design; Experimental Technology Incentives Program; pesticide policy; regulatory policy; NBS-GCR-ETIP 79-71.

Regulatory research; standards development; administrative procedures; building codes; building regulations; buildings; construction; economic impacts; environmental considerations; innovative practices; SP552.

Rehabilitation; adaptive reuse; building codes; buildings; building safety; code enforcement; construction; fire safety; housing; preservation; regulations; SP536.

Rehabilitation; renovation; adaptive reuse; architecture; building codes; building regulations; building safety; construction; performance; preservation; SP536, pp. 1-16 (Feb. 1979).

Rehabilitation; renovation; building code; building research; code administration; existing buildings; model codes; preservation; regulation; TN998.

Rehabilitation; retrofit; solar; commercial; economics; evaluation; feasibility; passive; 18964.

Rehabilitation; safety; barriers; building codes; code enforcement; historic district; historic preservation; regulations; SP536, pp. 83-93 (Feb. 1979).

Rehabilitation; standards; building codes; community development; construction costs; contractors; housing; SP536, pp. 55-61 (Feb. 1979).

Rehabilitation; tax incentives; adaptive reuse; buildings; demolition; economics; historic preservation; life-cycle costing; redevelopment; TN980.

Rehabilitation; tax incentives; adaptive reuse; buildings; demolition; economics; historic preservation; life-cycle costing; redevelopment; 19016

Rehbinder effect; rock fracture; surface chemistry; wear; diamond drilling; drilling; drilling additives; SP562, pp. 115 137 (Oct. 1979).

Rehbinder effects; Westwood effects; acoustic emission; chemomechanical effects; environmental effects; fracture of brittle materials; hydrogen embrittlement; SP562, pp. 139145 (Oct. 1979).

Reinforced concrete; bridge deck; concrete; corrosion; corrosion of steel; rebar corrosion; SP550.

Reinforcing fillers; silane coupling agents; benzoyl peroxide; composite resins; dental materials; glass compositions; methacrylate monomers; polymerization accelerators; 18644 .

Relative apparent molal enthalpy; salt solutions; thermochemistry; vapor pressure; apparent molal heat capacity; aqueous systems; bibliography; electrochemistry; electrolytes; enthalpy of dilution; heat capacity; SP537.

Relative biological effect; shielding techniques; standards; dosimetry; high energy radiotherapy beams; leakage; measurement techniques; medical accelerators; neutrons; SP554.

Relative humidity; storage; Studsvik AB Atomenergi, Sweden; thermoluminescence dosimeters; fading; Harshaw Chemical Company; 18989.

Relative intensities; round robin; $x$-ray photoelectron spectroscopy; binding energies; copper; ESCA; gold; 18924 .

Relative measurements; ${ }^{12} \mathrm{C} \gamma$-rays; ${ }^{16} \mathrm{O} \gamma$-rays; cosmic source; preliminary; proton interactions; 19015 .

Relative spectral responsivity; slit-scattering function; slit-scattering function corrections; spectral line radiometry; spectroradiometer characterizations; spectroradiometry; vignetting; aperture/aperture-image pair; aperture pair; calibration; convolution; TN9 10-4

Relativistic field theory; relativistic hamiltonian; relativistic stationary states; composite system; field quantization; interacting quantum fields; 18769 .

Relativistic hamiltonian; relativistic stationary states; composite system; field quantization; interacting quantum fields; relativistic field theory; 18769 .
Relativistic stationary states; composite system; field quantization; interacting quantum fields; relativistic field theory; relativistic hamiltonian; 18769 .

Relativity; synchronization; time scales; coordinate time; portable clocks; 18993

Relaxation; thermal decomposition; allylmethylether; bromide; ethylacetate; isopropyl; laser; non-equilibrium; pyrolysis; 18832 .

Relaxation energy; ultraviolet photoelectron spectroscopy; amorphous germanium; binding energy shifts; extra-atomic screening; implants; ion bombardment; rare-gases; 18323 .

Relaxation phenomenon; ultrasonic tissue absorption; absorption of ultrasound; macromolecular relaxation; SP525, pp. 29-36 (Apr. 1979).

Relaxation process; stress relaxation; torsion pendulum; dynamic mechanical; high pressure extrusion; oriented polyethylene; 18767.

Relaxation process; Young's modulus; audio frequencies; impurities; internal friction; isomers; low temperatures; $n$-paraffins; polycrystals; 18467 .

Relaxation processes; review; activation energies; electronically excited states; evaluation; gaseous interactions; molecular correlations; quenching; radiative lifetimes; rate constants; reactive channels; recommended data; JPCRD 8, No. 3, 723 798 ( 1979).

Relaxation times; self-entanglement effects; computer simulation; end-to-end length; entanglement effects; excluded volume effects; lattice-model polymer chains; polymer chain dynamics; random-coil polymer chains; 18772 .

Relay switching; self-calibration; twenty bits + sign; voltage output; digital-to-analog converter; high resolution; multirange; R-2R ladder; TN1105.

Relevant information; security; citizen rights; computers; computer utilization; confidentiality; data systems; personnel administration; personnel practices; personnel records; privacy; record-keeping practices; SP500-50.

Reliability; residential buildings; smoke detectors; component screening; electronic component reliability; failure analysis; failure models; failure rates; NBS-GCR-79-160.

Reliability; residential buildings; smoke detectors; component screening; electronic component reliability; failure analysis; failure models; failure rates; NBS-GCR-79-16I.

Reliability; residential buildings; smoke detectors; component screening; electronic component reliability; failure analysis; failure models; failure rates; NBS-GCR-79-162.

Reliability; risk; safety factor; sampling; Weibull distribution; corrosion fatigue; design; engineering judgment; factor of safety; fatigue; mathematical modeling; nuclear engineering; 18326.

Reliability; semiconductor devices; welding; automated testing; batteries; cardiac pacemakers; contamination; corrosion; electrostatic-induced damage; hermeticity; hybrid devices; leak testing; measurement technology; microcalorimetry; moisture; nondestructive testing; SP4OO-5O.

Reliability; semiconductor measurements; sheet resistance; solar cells; solar cell stability; device measu rements; laser scanning; light-biasing; metallization; ohmic contacts; NBSIR 79-1909.

Reliability; semiconductor measurements; solar cells; solar cell stability; workshops; device measurements; laser scanning; metallization; ohmic contacts; 18633 .

Reliability; semiconductors; solar cells; stability; testing; thin films; accelerated tests; failure mechanisms; failure modes; photovoltaics; SP4OO-58.

Reliability; semiconductors; solar cells; stability; testing; thin films; accelerated tests; failure mechanisms; failure modes; photovoltaics; NBSIR 79-1778.

Reliability; silicon; test pattern; transistor gain; integrated circuit; process validation wafer (PVW); 18463 .

Reliability; solar arrays; solar cells; workshops; laser scanner; measurement development; photovoltaics; 18322 . 
Reliability; statistical computing section; worksheet; capabilities; ease of learning and using; installation; language; maintenance; numerical analysis; OMNITAB 78; portability; poster; 18903 .

Reliability; structural engineering; abnormal loads; buildings (codes); probability theory; progressive collapse; 18415

Reliability engineering; testing methodology; useful life; consumer products; 18378 .

Remote monitoring; system security testing; diagnostic testing; performance assurance; performance evaluation; SP500-42.

Remote motion detection; static displacement measurement; vibration measurement; advanced sensors; Doppler millimeter radar; gas turbine monitoring; SP547, pp. 58-62 (July 1979).

Remote sensing; closed systems; electromagnetic problems; functional theoretic techniques; modified residue calculus; open systems; Monogr. 164.

Remote teleprocessing; statement of work; teleprocessing services program; timesharing; competitive negotiated procurement; computer management; SP500-52, pp. 231-232 (Oct. 1979).

Remote terminal emulation; system testing; audit; capacity planning; financial applications; long-range planning; mảnagement control; measurement; modeling; on-line system design; performance evaluation; performance management; prototyping; SP500-52, pp. 129-140 (Oct. 1979).

Remote unit; response force; triply redundant central computer; central unit; computerized; detection; electronic lock; exclusion area; forced entry deterrent systems; guard control station; higher headquarters; perimeter station; NBSIR 791725.

Remote work stations; simulation model; data collection; JES output; job entry subsystem; model design; model selection; SP500-52, pp. 123-127 (Oct. 1979).

Renormalization group theory; scaling theory; universality hypothesis; binary-liquid mixture; consolute point; critical exponent; critical phenomena; critical solution point; liquidliquid critical point; 18825 .

Renovation; adaptive reuse; architecture; building codes; building regulations; building safety; construction; performance; preservation; rehabilitation; SP536, pp. 1-16 (Feb. 1979).

Renovation; applied economics; building codes; building economics; economic analysis; fire safety; health care facilities; hospitals; life safety; mathematical programming; nursing homes; NBSIR 79-1902.

Renovation; applied economics; building codes; building economics; economic analysis; fire safety; health care facilities; hospitals; life safety; mathematical programming; nursing homes; 19045.

Renovation; building code; building research; code administration; existing buildings; model codes; preservation; regulation; rehabilitation; TN998.

Reorganization; restructuring; data base; data base management; file maintenance; reformatting; SP500-47.

Reorientation; residence time; tunneling; activation energy; methyl group; neutron scattering; potential barrier; quasielastic scattering; 18374 .

Repair; survival; transformation; $x$ ray; carcinogenesis; neutron; SP554, pp. 63-73 (Sept. 1979).

Repairs; vibration; aircraft carrier; condition analysis; machinery; maintenance; monitoring; SP547, pp. 167-175 (Juiy 1979).

Report retrieval; scientific data; computer graphics; data base management; data retrieval; durability; fatigue; interactive system; mathematical modeling; paper; paper fiber; NBSIR 79-1746.

Representations and codes; Standard Industrial Classification; computers; data processing; Federal Information Processing Standards Publication; industries; FIPS PUB 66.
Requirements definition; software certification; software development; software reliability; software validation; design specifications; 18882 .

Re-refined oil; used oil; waste oil; engine oil; fuel oil; hydraulic oil; industrial oil; lubricating oil; oil specifications; petroleum standards; petroleum test methods; recycled oil; SP556.

Research; management; 18387 .

Research; school; air-conditioning; comfort; education; environment; human factors; 18596.

Research; standards; systematic procedure; building fires; equivalency; evaluation; fire safety; models; SP552, pp. 1327 (July 1979).

Research and development; steel industry; technology; capital formation; Experimental Technology Incentives Program; regulatory impact; NBS-GCR-ETIP 79-67.

Research and development policy; technological change; Experimental Technology lncentives Program; impact of government on industry; procurement experiments; procurement policy; NBS-GCR-ETIP 78-49.

Research materials; special reference materials; standard reference materials; analysis; certification; characterization; composition; properties; SP260, 1979-80 Edition.

Research needs; cement; concrete; energy saving-opportunities; SP5 42.

Research needs; safety; standards; explosion; fire; hydrogen; procedures; regulations; 18776 .

Reservoirs; sensors; tailorable; temperature; accumulator; analog; centralized; check-out system; dessicant; discrete; displacement; fiber optics; filters; flight critical; flow; fluid; gono-go; ground readout; hydraulic; IMACS; SP547, pp. 345 357 (July 1979).

Residence time; tunneling; activation energy; methyl group; neutron scattering; potential barrier; quasielastic scattering; reorientation; 18374.

Residential; wastewater treatment; water; water conservation; water heating; water usage; energy; energy consumption; grey water; heat recovery; recycling; NBSIR 79-1770.

Residential air conditioning; service hot water; space heating; ventilation; appliance energy consumption; energy consumption of residences; lighting energy consumption; occupant factors; NBSIR 78-1501.

Residential buildings; sensitivity analysis; smoke detectors; standards; upholstered furniture; building fires; cost-benefit analysis; costs; decision analysis; fire losses; furniture; hazard analysis; probability; TNIIOI

Residential buildings; smoke detectors; component screening; electronic component reliability; failure analysis; failure models; failure rates; reliability; NBS-GCR-79-160.

Residential buildings; smoke detectors; component screening; electronic component reliability; failure analysis; failure models; failure rates; reliability; NBS-GCR-79-161.

Residential buildings; smoke detectors; component screening; electronic component reliability; failure analysis; failure models; failure rates; reliability; NBS-GCR-79-162.

Residential buildings; solar data center; solar energy systems; solar heating and cooling; automatic data processing; data base; NBSIR 79-1762.

Residential buildings; solar database; solar energy system; solar heating and cooling; automatic data processing; computer reports; grant data; NBSIR 79-1923.

Residential buildings; space cooling; space heating; building envelope; cost effectiveness; economics; energy conservation; internal rate of return; life-cycle costing; marginal analysis; optimal design; 19044.

Residential energy conservation; thermal mass effect in buildings; building energy consumption analysis; computerized building energy analysis; cooling load calculation; energy conservation; heating load calculation; NBSLD analysis of residences; NBSIR 79.1732 . 
Residential fire detector; sprinkler supervisory devices; control units; fire alarm systems; fire detectors; high-rise communication systems; multiplex systems; NFPA standards; 18625.

Residential smoke detectors; smoke detectors; detection; fires; home fires; 18514 .

Residential water use; energy field measurements; hot water heaters; hot water usage; 18829 .

Residual stresses; shear flow lines; crack nucleation; fracture; median, radial and lateral cracks; plastic indentations; SP562, pp. 15-20 (Oct. 1979).

Residuals; statistical plots; statistics; stem-and-leaf displays; box plots; CALCOMP; computing system; confidence ellipse; OMNITAB 78; plots; portability plots; 18954.

Resin; wear; accelerator; alloy; base metal; casting; composite; cyanoacrylate; dental alloy; initiator; NBSIR 78-1573.

Resins; surface-active comonomers; acrylates; adhesion, dental; bonding; coupling agent; dental; monomers; 18461 .

Resistive divider; self calibration; voltage divider; binary divider; divider network; guarded divider; 18452.

Resistive loading; TEM horn; time domain measurement; antenna gain; broadband antenna; directivity; FFT; method of measurements; non-dispersive; $/ 8856$.

Resistive SQUIDS; temperature measurement; Johnson noise; Josephson junctions; noise thermometry; 18603 .

Resistively loaded dipole; tangential sensitivity; broadband; dynamic range; Hermitian magnitude: isotropicity; isotropic, real-time, electric-field sensor (IRES); 19034.

Resistivity; resistivity profiles; semiconductor; silicon; spreading resistance; dopant profiles; SP4OO-48.

Resistivity; scattering mechanisms; scattering mobility; $\rho$-type silicon; boron-doped silicon; dopant density; effective mass; hole mobility; ionized impurity scattering mobility; lattice scattering mobility; neutral impurity; SP $400-47$.

Resistivity; semiconductors; silicon; electrical measurements; 18460.

Resistivity profiles; semiconductor; silicon; spreading resistance; dopant profiles; resistivity; SP4OO-48.

Resistivity variation; automation; bulk photovoltaic effect; computer control; homogeneity; measurement method; nondestructive testing; photoconductivity; power devices; SP4OO52.

Resistivity variations; resistors, sheet; scanning acoustic microscope; semiconductor materials; semiconductor process control; silicon; silicon dioxide; silicon-on-sapphire; sodium contamination; test patterns; test structures; thermally stimulated current and capacitance; SP4OO-38.

Resistivity variations; silicon; spreading resistance measurements; thermally stimulated measurements; thyristor materials measurements; thyristor measurements; d-c transmission; deep level measurements; energy conservation; measurement methods; NBSIR 79-I756.

Resistors, sheet; scanning acoustic microscope; semiconductor materials; semiconductor process control; silicon; silicon dioxide; silicon-on-sapphire; sodium contamination; test patterns; test structures; thermally stimulated current and capacitance; transistors; $S P 4 O O-38$.

Resolution; sample spinning; solids; 13 ; conformation; crystallinity; NMR; polyethylene; 18745 .

Resolution; $x$-ray image magnifier; asymmetric diffraction; dynamical diffraction; microradiography; radiography; radiology; real-time radiography; 18399.

Resonance fluorescence; collisional line broadening; collisional redistribution; 18498 .

Resonance line shape analysis; Rydberg atoms; two photon spectroscopy; laser spectroscopy; optical Ramsey effect; 19019.

Resonance lines; stars; stellar winds; line profiles; P-Cygni lines; radiative transfer; 18515 .

Resonances; electron scattering; energy loss; excited states; negative ions; ozone; 18392 .
Resonant frequency; composite design; graphite-epoxy; Precision Mounting Platform; SP563, p. 130 (Oct. 1979).

Resonant multiphoton ionizations; collisional excitation; collisional radiative recombination; laser induced plasma; optical emission; photoionization; Potassium-Krypton mixtures; 18799.

Resource allocation; weighting multiple criteria; decision analysis; decisions; eigenvectors; management; multiple-attribute decisions; ordering; paired comparisons; prioritization; project selection; ranking; 18602 .

Resource conservation and recovery; chemical degradation; coal conversion; coal gasifier; computers; data; metric; refractory concrete; DIM/NBS 63, No. 12, 1-32 (1979).

Resource management; standard performance measures; computer performance evaluation (CPE); computer performance management (CPM); installation management; installation performance management; performance measurement and reporting; SP5O0-53.

Resource zoning; urban; zoning regulations; infrastructure; land use; SP552, pp. 347-360 (July 1979).

Response; silicon detector; spatial position dependence; dead layer model; external; internal; quantum efficiency; reflectance; 18900.

Response force; triply redundant central computer; central unit; computerized; detection; electronic lock; exclusion area; forced entry deterrent systems; guard control station; higher headquarters; perimeter station; remote unit; NBSIR 791725 .

Response time; saturated system; transaction processor; inventory management; on-line; performance; SP500-52, pp. 215 218 (Oct. 1979).

Response time; step response; transients; divider; Duhamel's integral; high voltage; im pulse; pulse measurements; NBSIR 79 1933.

Response time; system design tradeoff; thruput measures; comparison measures; evaluation process; performance measures; performance ratings; SP5OO-52, pp. 163-176 (Oct. 1979).

Response time; turnaround time; availability standards; batch processing; calibration programs; computer standards; interactive processing; quality of service; SPSOO-52, pp. 79.86 (Oct. 1979).

Restorative dental resins; shelf-life of composites; storage stability; amine accelerators; degradation of benzoyl peroxide; dental composites; 18809 .

Restraints; roundness standard; spindle error; standard deviation; stylus; least squares circle; least squares estimation; polar graph; NBSIR 79-I 758.

Restructuring; data base; data base management; file maintenance; reformatting; reorganization; SP500-47.

Retail facilities; environmental psychology; field methodology; passive solar systems; pedestrian behavior; psychology of retailing; 18784 .

Retrofit; solar; commercial; economics; evaluation; feasibility; passive; rehabilitation; 18964 .

Retrofit; standards; conservation; energy cost; existing buildings; regulation; SP552, pp. 197-209 (July 1979).

Retrofit; sulfur hexafluoride; tracer gas; weatherization; air infiltration; air sample bags; energy conservation; NBSIR 79. 1728 .

Retrofitting; solar; building design; cost; energy conservation: energy standards; fenestration; life-cycle costing; 19043.

Retroreflectors; counting and control circuitry; fringe counting interferometric method and apparatus; Michelson interferometer; phase locked oscillators; U.S. Patent 4,165,183.

Retrospective; sample storage; trace analysis; analytical techniques; contamination; environment: 18349.

Reverse bias; safe operating area; second breakdown; switching power transistor; tester; transistor; base drive circuit; electronic circuits; inductive load; nondestructive; protection circuit; SP400-54. 
Reversed-phase; serum; cerebrospinal fluid; detector; high-performance liquid chromatography; light-scattering; lipids; nephelometry; oils; SP519, pp. 429-436 (Apr. 1979).

Review; activation energies; electronically excited states; evaluation; gaseous interactions; molecular correlations; quenching; radiative lifetimes; rate constants; reactive channels; recommended data; relaxation processes; JPCRD 8, No. 3, 723-798 (1979).

Review; attenuation measurements; fiber optics; frequency response measurements; measurements; 18647 .

Review; communication systems; fiber optics; measurement; optical communications; 18648 .

Review; seafood toxins; food toxicants; mycotoxins; SP519, pp. 321-331 (Apr. 1979).

Review; sulfur dioxide; troposphere; kinetics; photochemistry; SP557, pp. 99.100 (Aug. 1979).

Review; superconductors; ac generators; heat transfer; helium; hydrodynamics; large magnets; power transmission; $\mathbf{l 8 8 2 2}$.

Review; troposphere; aldehyde; free radical; photolysis; reactions; SP557, pp. 27-46 (Aug. 1979).

Review; troposphere; alkoxyl; kinetics; radicals; SP557, pp. 51 . 61 (Aug. 1979).

Review; troposphere; hydroxyl; kinetics; olefin; ozone; SP557, pp. 7-14 (Aug. 1979).

Review; tropospheric chemistry; nitrates; nitrites; nitrogen oxides; photolysis; reactions; SP557, pp. $71-79$ (Aug. 1979).

Review article; speed of light; time standards; atomic clocks; frequency standards; frequency synthesis; fundamental constants; length standards; physical measurement systems; 18346.

Rf radiation monitor; standard electromagnetic field; antenna gain calculation; field strength calibration; pyramidal horn antenna; 18814 .

RFI; spectrum management; standardization organizations; telecommunications; TVI; vehicular electronics; electromagnetic bioeffects; electromagnetic compatibility; electromagnetic immunity; electromagnetic interference; electromagnetic radiation; SP5 51 .

Rhenium; tantalum; tungsten; wavelengths; ytterbium; energy levels; hafnium; ionization energies; lutetium; osmium; 18506.

Rhodamine 6G; dye laser; laser cavity; mode locked dye laser; passive mode locking; picosecond pulses; 19021 .

Rhodium (I) complexes; thallium benzotriazenide; benzotriazenides; iridium (I) complexes; organometallic benzotriazenides; 18582 .

Rhodium-iron thermometry; thermal cycles to low temperatures; germanium thermometers; low temperature; 19040.

Rhonon interactions; core hole lifetime; core hole relaxation; $\boldsymbol{K}$ $\mathbf{x}$-ray absorption spectrum; $\boldsymbol{K}$ x-ray emission spectrum; many body effects; 18359 .

Ribose; stachyose; sucrose; sugar analysis; carbohydrates; fructose; galactose; gas-liquid chromatography; glucose; lactose; liquid chromatography; maltose; raffinose; SP519, pp. 271 . 278 (Apr. 1979).

Rideal-Washburn equation; surface tension; defect geometry; fluid elasticity; liquid penetrant testing; $\mu$, Res. 84, No. 4, 287-292 (1979).

Rigid body motion; triaminoguanidinium nitrate; crystal structure; hydrogen bond; neutron diffraction; 18873 .

Rigid foams; smoke; smoldering; weight loss; wood; combustion; flaming combustion; flexible foams; optical density; particle size; polypropylene; polyurethane foams; polyvinyl chloride; pyrolysis; NBS-GCR-78-147.

Risetime; speckle; waveform; attenuators; calibration; laser; neodymium laser; peak power; power meter; pulsed laser; $Q$ switched; TN1010.

Risk; cell-proliferation; cell-turnover; cytotoxicity; homeostasis; promotion; RBE; SP554, pp. $41-56$ (Sept. 1979).
Risk; safety; construction; cost effectiveness; hazard; injuries; loss prevention; 18890 .

Risk; safety factor; sampling; Weibull distribution; corrosion fatigue; design; engineering judgment; factor of safety; fatigue; mathematical modeling; nuclear engineering; reliability; 18326.

Risk analysis; risk assessment; systems security; ADP availability; annual loss exposure; application system vulnerability; computer security; data confidentiality; data integrity; data security; physical security; procedural security; FIPS PUB 65.

Risk analysis; safety equivalency; safety evaluation; smoke detection; automatic sprinklers; building codes; building construction; Delphi Method; fire safety; health care facilities; hospitals; interior finishes; Life Safety Code; nursing homes; NBSIR 78-1555.

Risk assessment; societal goals; building codes; control measures; fire codes; fire safety; governmental actions; life safety; regulation; SP536, pp. 63-74 (Feb. 1979).

Risk assessment; systems security; ADP availability; annual loss exposure; application system vulnerability; computer security; data confidentiality; data integrity; data security; physical security; procedural security; risk analysis; FIPS PUB 65.

Robot control; brain mechanisms; cognition; goal seeking; intelligence; motor behavior; neural modeling; perception; planning; problem solving; 18714 .

Robot vision; teleoperator vision; wrist-mounted TV; depth image; proximity sensor; NBSIR 78-1576.

Robotics; vision systems; automation; image processing; inspection; manufacturing; pattern recognition; NBSIR 79-1764.

Rock fracture; surface chemistry; wear; diamond drilling; drilling; drilling additives; Rehbinder effect; SP562, pp. 115 137 (Oct. 1979).

Roof; roof load; snow; solar collector; structural engineering; building; ice; load; NBS-GCR-79-181.

Roof heat-loss survey; aerial flyovers; aerial infrared thermography; energy conservation; TN/107.

Roof load; snow; solar collector; structural engineering; building; ice; load; roof; NBS-GCR-79-181.

Roofing; shingles; venting; benefit-cost analysis; building technology; economic impacts; economics; efficiency; payback; plumbing; SP558.

Room fires; ASTM E-84 Tunnel Test; construction standard; fire growth; fire tests; flame spread; flashover; impact assessment; interior finish; kitchen fires; life safety; mobile homes; NBSIR 79-1720.

Room fires; breathing apparatus; death; evacuation; fires; flashover; hospitals; human behavior; nursing staff; patients; NBS-GCR-78-140.

Room fires; smoke; soot; thermal radiation; fire models; heat transfer; NBS-GCR-78-151.

Room fires; smoke; upholstered furniture; chairs; doors; evacuation; fire departments; fire fighters; nursing homes; patients; NBS-GCR-79-159.

Room fires; smoke detectors; spacing; velocity; beams; ceiling height; detectors; fire detectors; fire growth; heat detectors; NBS-GCR-78-128.

Room fires; smoke detectors; spacing; velocity; beams; ceiling height; detectors; fire detectors; fire growth; heat detectors; NBS-GCR-78-129.

Room fires; thermal radiation; turbulence; buoyant flow; compartment fires; computer programs; corridor fires; fire models; fire spread; NBS-GCR-78-150.

Room use; demographics; developmental disabilities; fire protection; group homes; household activities; NBSIR 79-1727.

Roots of unity; free groups; matrix groups; J. Res. 84, No. 2, 179-180 (1979).

Rotary anemometer; unsteady flow; air; anemometer; helicoid anemometer; lag; overspeeding error; NBSIR 78-1505.

Rotary dissolver; signature analysis; vibration analysis; monitor system; SP547, pp. 232-249 (July 1979). 
Rotating equipment; vibration monitoring; vibration signal processing; SP547, pp. 280-285 (July 1979).

Rotating machinery monitoring; statistical detection algorithm; vibrational signatures; automated surveillance; SP547, pp. 203-231 (July 1979).

Rotation; tunneling; crystal structure; neutron scattering; nitromethane; 19025.

Rotational constants; atomic line shapes; atomic spectra; atomic transition probabilities; bands, molecular; energy levels; energy levels, atomic; line shapes, atomic; molecular bands; molecular spectra; 18828 .

Rotational contours of absorption bands; absorption analysis; absorption spectrum; benzene; 18747 .

Rotational contours of absorption bands; vibrational angular momentum; absorption selection rules; benzene; HerzbergTeller theory; 18750 .

Rotational dynamics; condensed phases; diffusion mechanisms; inelastic scattering; neutron scattering; orientational disorder; 19026.

Rotational excitation; semiclassical orbital; theory; elastic scattering; ion-molecule collisions; 18446.

Rotational excitation; semiclassical treatment; ion-molecule collisions; 18389.

Rotational linewidths; temperature dependence; theoretical and experimental comparison; vibrational effect; $\mathrm{HCl}-\mathrm{Ar} ; 18689$.

Rotational transitions; dimethyl ether; internal rotation; interstellar molecules; microwave spectrum; radio astronomy; JPCRD 8, No. 4, 1051-1108 (1979).

Rotational transitions; internal rotation; interstellar molecules; line strengths; methyl formate; microwave spectrum; radio astronomy; JPCRD 8, No. 3, 583-618 (1979).

Rotational transitions; interstellar molecules; line strengths; microwave spectra; molecular constants; propyne; radio astronomy; JPCRD 8, No. 2, 537-558 (1979).

Rotational transitions; vinyl cyanide; interstellar molecules; microwave spectra; molecular parameters; radio astronomy; JPCRD 8, No. 1, 107-124 (1979).

Rotation-translation coupling; coupled modes; dynamics; $\mathrm{KCN}$ $\mathrm{KBr}$; neutron scattering; phase transition; 19036 .

Rotation-vibration spectra; symmetry analysis; Born-Oppenheimer approximation; high-resolution spectra; level clusters; Raman spectra; 18598.

Rotor blades; wind turbine; composite materials; filament winding; large composite structures; SP563, pp. $155-172$ (Oct. 1979).

Rough surfaces; $x$-ray microanalysis; electron probe analysis; peak-to-background ratios; quantitative analysis; 18976 .

Roughness; sapphire; ultra-fine polishing; water; $x$-ray photoelectron spectrometer; crystallographic integrity; electron diffraction images; hydrated layer; ion microprobe mass spectrometer; SP562, pp. 317-323 (Oct. 1979).

Roughness; structural analysis; tall buildings; wind pressure; aerodynamics; boundary layer; loads (forces); 18351 .

Roughness; wear; curing shrinkage; glaze; margin staining; 18684.

Round robin; search/match methods; qualitative $x$-ray powder diffractometry; 18857 .

Round robin; $x$-ray photoelectron spectroscopy; binding energies; copper; ESCA; gold; relative intensities; 18924.

Roundness standard; spindle error; standard deviation; stylus; least squares circle; least squares estimation; polar graph; restraints; NBSIR 79-1 758 .

Rouse coordinates; distributions in chain dimensions; equilibrium chain dimensions; excluded volume; lattice-model chains; polymer chain dimensions; random-coil chain dimensions; 18618.

Rouse-Zimm theory; solution properties; bead-spring model; block copolymer; flow birefringence; flow dichroism; polymer dynamics; 18431 .
Routine analysis; trace organics in water; gas chromatography/mass spectrometry; microcomputer; SP519, pp. 169173 (Apr. 1979).

Rubber elasticity; uniform network; affine network; neutron scattering; phantom network; polybutadiene; 18827 .

Rubber elasticity theory; rubber, natural; swelling of rubber network; cross-linking of rubber; dicumyl peroxide; elasticity theory of rubber; modulus of rubber; Mooney-Rivlin constants; J. Res. 84, No. 5, 353-358 (1979).

Rubber hose; soalr energy systems; hose; hose specifications; NBSIR 79-1917.

Rubber, natural; swelling of rubber network; cross-linking of rubber; dicumyl peroxide; elasticity theory of rubber; modulus of rubber; Mooney-Rivlin constants; rubber elasticity theory; J. Res. 84, No. 5, 353-358 (1979).

Rubidium; sodium; temperature dependence; alkali elements; cesium; electrical resistivity; francium; lithium; magnetic flux density dependence; potassium; pressure dependence; JPCRD 8, No. 2, $339-438$ (1979).

Rubidium standards; time and frequency; timekeeping; atomic clocks; cesium standards; crystal oscillators; frequency standards; hydrogen standards; 18908 .

Ruland function; $x$-ray diffraction; Bacon function; Bragg function; Ergun function; graphite materials; Lorentz function; preferred orientation function; pyrolitic graphite; 18523 .

Rulemaking; technological innovation; administrative experimentation; best practicable technology; clean water regulation; Environmental Protection Agency; evaluability assessment; evaluation; Experimental Technology Incentives Program; NBS-GCR-ETIP 79-63.

Russian measurement technique; electric field measurements; instrumentation; measurement procedures; observer proximity effects; power transmission lines; 18494 .

Rust; stress corrosion; corrosion; crevice corrosion; galvanic corrosion; inhibitors; pitting corrosion; CIS9, Revised 1979.

Ruthenium; adsorption; field emission; field-induced redistribution; hydrogen; 18810 .

Ruthenium; surface chemistry; ultraviolet photoemission spectroscopy; adsorption; chemisorption; formaldehyde; 18791 .

Rutherford backscattering; standards; accuracy and precision; gold films; gravimetry; neutron activation analysis; 18490 .

$\mathbf{R}$-value measurement by spot radiometer; thermal resistance of walls; infrared thermometers; in situ evaluation of insulation; NBSIR 79-1736.

Rydberg atoms; two photon spectroscopy; laser spectroscopy; optical Ramsey effect; resonance line shape analysis; 19019 .

R-2R ladder; relay switching; self-calibration; twenty bits + sign; voltage output; digital-to-analog converter; high resolution; multirange; TNIIOS.

\section{$\mathbf{S}$}

Saccharimetry; sugar analysis; sugar scale; wavelength; laser application; pol; polarimetry; 18768 .

Saccharin; saccharin impurities; Salmonella typhimurium; Amaranth; Ames test; criteria for purity; food additives; mutagenicity; naphthylamines; SP519, pp. 311-319 (Apr. 1979).

Saccharin impurities; Salmonella typhimurium; Amaranth; Ames test; criteria for purity; food additives; mutagenicity; naphthylamines; saccharin; SP519, pp. $311-319$ (Apr. 1979).

Safe operating area; second breakdown; switching power transistor; tester; transistor; base drive circuit; electronic circuits; inductive load; nondestructive; protection circuit; reverse bias; SP4OO-54.

Safe operating area, reverse-bias; second-breakdown, reversebias; transistors, power switching; device characterization; nondestructive testing; 18738 .

Safeguards; analysis; diversion of nuclear materials; diversion path analysis; material accounting; material control; nuclear material safeguards; 18735 . 
Safety; barriers; building codes; code enforcement; historic district; historic preservation; regulations; rehabilitation; SP536, pp. 83-93 (Feb. 1979).

Safety; construction; cost effectiveness; hazard; injuries; loss prevention; risk; 18890 .

Safety; standards; accelerators; IEC; interlocks; leakage; radiation; SP554, pp. 29-32 (Sept. 1979).

Safety; standards; architectural barriers; building design; building site planning; environmental psychology; evaluation; fire escape; human research; measurement; pedestrian movement; regulation; SPS52, pp. 101-113 (July 1979).

Safety; standards; architectural barriers; building design; building site planning; environmental psychology; evaluation; fire escape; human research; measurement; pedestrian movement; regulation; 18430 .

Safety; standards; codes; guidelines; hydrogen; regulations; 18394.

Safety; standards; consumer product; human factors; lawn mowers; reaction time; NBSIR 77-1299.

Safety; standards; consumer products; human factors; human performance; lawn mowers; psychophysics; NBSIR 77-1298.

Safety; standards; explosion; fire; hydrogen; procedures; regulations; research needs; 18776 .

Safety; temporary structures; wood; bridges; buildings; design criteria; glued-laminated timber; 18887

Safety; tread wear; braking traction; cornering traction; driving traction; endurance; maintenance; operation; purchasing; pursuit tires; SP480-33.

Safety and hazards; thermal energy storage materials; thermal properties; thermodynamic properties; transport properties; corrosion; data compilation; electrochemical energy storage materials; molten salts; physical properties; NSRDS-NBS6I, Part 11 .

Safety and health standards; standards development; energy standards; environmental standards; Monogr. 165.

Safety and health standards; standards development; energy standards; environmental standards; NBSIR 79-1703.

Safety engineering, fires; computer programs, fire protection; fire protection; fire resistance; fire tests; fire walls; TN991.

Safety equivalency; safety evaluation; smoke detection; automatic sprinklers; building codes; building construction; Delphi Method; fire safety; health care facilities; hospitals; interior finishes; Life Safety Code; nursing homes; risk analysis; NBSIR 78-1555.

Safety evaluation; smoke detection; automatic sprinklers; building codes; building construction; Delphi Method; fire safety; health care facilities; hospitals; interior finishes; Life Safety Code; nursing homes; risk analysis; safety equivalency; NBSIR 78-1555.

Safety factor; sampling; Weibull distribution; corrosion fatigue; design; engineering judgment; factor of safety; fatigue; mathematical modeling; nuclear engineering; reliability; risk; 18326.

Safety in the home; stair accidents; stair safety; window accidents; window safety; accident avoidance; accidents in the home; door accidents; home accidents; home safety; NBS. GCR-78-156.

Safety information; standardization; symbols; communication; evaluation methods; fire safety; hazard warnings; pictograms; NBSIR 79-1760.

Safety regulations; building codes; building regulations; costbenefit analysis; life-cycle analysis; SP552, pp. 267-282 (July 1979).

Safety research; walkway slip-resistance; friction; measurement; reference standards; SP565.

Safety standards; stair safety; stairway design; accidents; architectural design; architectural psychology; architectural research; building codes; building design; building regulatory standards; floor coverings; home safety; BSS 120.
Safety tips; solar energy; toxic chemicals; ultra-black coating; Alaskan pipeline; computers; corrosion; fire safety; gyromagnetic ratio; paper; photometric calibrator; DIM/NBS 63, No. 11, 1-36 (1979).

Salmonella typhimurium; Amaranth; Ames test; criteria for purity; food additives; mutagenicity; naphthylamines; saccharin; saccharin impurities; SP519, pp. 311 -319 (Apr. 1979).

Salt solutions; thermochemistry; vapor pressure; apparent molal heat capacity; aqueous systems; bibliography; electrochemistry; electrolytes; enthalpy of dilution; heat capacity; relative apparent molal enthalpy; SPS37.

Salt water corrosion; sea water corrosion; steel corrosion; coating protection; pile corrosion; protection of steel; 18424 .

Saltwater corrosion; seawater corrosion; corrosion of steel; corrosion protection; nonmetallic coatings; offshore corrosion; 18418.

Sample characterization; test procedures; bomb calorimetry; gross calorific values; refuse-derived-fuels; NBSIR 78-1494.

Sample preparation; clinical chemistry; drug analysis; gas chromatography; internal standards; methylation; SP5 19, pp. 381 390 (Apr. 1979).

Sample preparation; composite sampling; nutritional analysis; nutritional labeling; SP519, pp. 243-248 (Apr. 1979).

Sample preparation; ultraviolet spectrometry; gas chromatography; gas chromatography/mass spectrometry; preconcentration techniques; SP519, pp. 7-18 (Apr. 1979).

Sample spinning; solids; $13_{c}$; confornation; crystallinity; NMR; polyethylene; resolution; 18745 .

Sample storage; trace analysis; analytical techniques; contamination; environment: retrospective; 18349 .

Sample work-up; standards; chromatography/column packings (GC); electron-capture detection; evaporation; nomenclature; SP519, pp. 809-810 (Apr. 1979).

Sampler response factors; total elemental content passive personal samplers; total organic chlorine; weighted diffusion coefficient; ambient concentration; compute and limit; error; SP519, pp. 747-752 (Apr. 1979).

Sample/hold circuit; standards; terminology; analog-to-digital converter; digital-to-analog converter; IEEE subcommittee; performance specifications; 18365 .

Sampling; aflatoxin analysis; food and feed analysis; methods; preparation; SP519, pp. 355-372 (Apr. 1979).

Sampling; aging; analysis; atmosphere; SPS19, pp. 213-218 (Apr. 1979).

Sampling; analysis; analytical food chemistry; errors; SP519, pp. 231-242 (Apr. 1979).

Sampling; cellulose triacetate filters; gas chromatography; pesticide residues; SP519, pp. 19-32 (Apr. 1979).

Sampling; cryogenic densimeter; custody transfer; density; flowmetering; liquefied natural gas; 18396 .

Sampling; custody transfer; density; gas analysis; gas chromatography; heating value; hydrocarbon; liquefied natural gas; phase equilibrium; pipelines; NBSIR 78-887.

Sampling; custody transfer; density; gas analysis; gas chromatography; heating value; liquefied natural gas; 18395 .

Sampling; sediment; trace analysis; water; $\boldsymbol{\beta}$-chloroethers; air; environment; gas chromatography/mass spectrometry; SP519, pp. 205.212 (Apr. 1979).

Sampling; specifications; statistical methods; statistics; conformance; 18440 .

Sampling; Weibull distribution; corrosion fatigue; design; engineering judgment; factor of safety; fatigue; mathematical modeling; nuclear engineering; reliability; risk; safety factor; 18326.

Sampling errors; secondary organic carbon; solvent extraction; spatial variations; diurnal variations; elemental carbon; mass spectroscopy; organic aerosol constituents; primary organic carbon; SP519, pp. 121-129 (Apr. 1979).

Sampling schemes; statistical sampling; environmental measurements; modeling; SP519, pp. 1-6 (Apr. 1979). 
Sanding; strength-size effects; brittle failure; flaw populations; flaws; fractography; fracture origins; grinding; machining; polishing; SP562, pp. $351-378$ (Oct. 1979).

Sapphire; Si single crystal; high pressure; high temperature; mechanochemical polishing; quartz crystal; SP562, pp. 171 182 (Oct. 1979).

Sapphire; silicon; solid state reaction; wear debris; damaged layer; fine polishing; SP562, pp. 325-333 (Oct. 1979).

Sapphire; solid state reaction; water vapor; working unit; damaged layer; elastic emission machining; environmental effect; hydrate; hydration polishing; mechanochemical polishing with soft powder; pre-existing defect; SP562, pp. 157-169 (Oct. 1979).

Sapphire; specific heat; standard reference materials; thermodynamic properties; alumina; aluminum oxide; calorimetry; corundum; enthalpy; heat capacity; 18377 .

Sapphire; two-surface lapping; two-surface polishing; dome finishing; finishing technique; hemispherical domes; oxides; SP562, pp. 255-260 (Oct. 1979).

Sapphire; ultra-fine polishing; water; $x$-ray photoelectron spectrometer; crystallographic integrity; electron diffraction images; hydrated layer; ion microprobe mass spectrometer; roughness; SP562, pp. 317-323 (Oct. 1979).

Satellite; synchronization; time; clock; GOES; microprocessors; 18393.

Satellite; time; time scales; Hermes/CTS; international time comparison; precise time transfer; 18861 .

Satellite and band narrowing; $d$-band of $\mathrm{Ni}$; excitons; photoemission; 18632 .

Satellite broadcasts; standard frequencies; television color subcarrier; time and frequency calibration methods; time calibration; time signals; frequency calibration; high frequency; Loran-C; low frequency; radio broadcasts; SP559.

Satellite communications; error analysis; G/kT, EIRP; G/T, precision measurements; radio star; 18577.

Satellite communications metrology; antenna gain; antenna pattern; antenna polarization; large aperture antenna metrology; 18628 .

Satellite system; computer network; computer standards; fire safety; gamma-ray spectroscopy; matrix-isolation; metric conversion; DIM/NBS 63, No. 7/8, 1-28 (1979).

Satellites; space astronomy; stars, chromospheres; stars, coronae; stars, late-type; stars, winds; ultraviolet spectra; 18606.

Satellites; tectonics; distance measurements; earthquakes; geodesy; geophysics; instrumentation; 18574 .

Saturable rate; bandwidth; coherence; dynamic rate; incoherence; ionization; linear rate; multiphoton; rate approximation; 18893.

Saturated absorption; calcium; optical Ramsey fringes; photonrecoil structure; 18642 .

Saturated system; transaction processor; inventory management; on-line; performance; response time; SP500-52, pp. 215-218 (Oct. 1979).

Saturation absorption spectra; superfine structure; symmetry analysis; tableau calculus; high resolution spectroscopy; hyperfine structure; level clusters; 18609.

Saturation absorption spectroscopy; spherical top molecules; high resolution spectroscopy; level clusters; 18928 .

Saturation spectroscopy; tunable laser; atomic flame fluorescence; intracavity absorption; isotope analysis; laser analysis; laser fluorescence; laser spectroscopy; microfluorescence; 18364 .

Scales; specifications; taximeters; tolerances; volume-measuring devices; weighing devices; weights; length-measuring devices; liquid-measuring devices; measures; $\mathrm{H44}, 1979$ Edition.

Scaling; buoyancy; diffusion flames; fire entrainment; flame oscillations; plume; NBSIR 79-1910.
Scaling theory; universality hypothesis; binary-liquid mixture; consolute point; critical exponent; critical phenomena; critical solution point; liquid-liquid critical point; renormalization group theory; 18825 .

Scanning acoustic microscope; semiconductor materials; semiconductor process control; silicon; silicon dioxide; silicon-on-sapphire; sodium contamination; test patterns; test structures; thermally stimulated current and capacitance; transistors; ultraviolet reflectance; SP4OO-38.

Scanning electron microscope; artifacts; electron probe microanalysis; energy-dispersive $x$-ray spectrometry; microanalysis; qualitative analysis; 18790 .

Scanning electron microscope; secondary electron emission; silicon; surface roughness; y-deflection modulation; ceramic; SP562, pp. 407-415 (Oct. 1979).

Scanning electron microscope scale; electrodeposited metal layers; gold-nickel layers; micrometer scale; U.S. Patent 4,139,933.

Scanning electron microscopy; $x$-ray microanalysis; electron probe microanalysis; energy dispersive $x$-ray microanalysis; energy dispersive $x$-ray spectrometry; quantitative analysis; 18970.

Scanning electron microscopy; x-ray yield; characteristic $x$-ray yield; electron probe microanalysis; inner shell ionization cross section; Monte Carlo electron trajectory simulation; 18978.

Scanning stage; SEM microscope stage; submicrometer positioning instrumentation; TEM microscope stage; flexure pivots; linear positioning; micromanipulator; optical microscope stage; piezoelectric drives; 18327.

$S$-carboxymethyl-L=cysteine; single crystal; $\mathrm{x}$ ray; zwitterion; amino acid derivative; crystal structure; $/ 8673$.

Scatter; $x$ rays; dose; leakage; medical accelerator; neutrons; SP554, pp. 25-28 (Sept. 1979).

Scatter contribution; source capsule; source housing; spectrometry results; ${ }^{60} \mathrm{CO}$ gamma-ray beam; calibration source; collimation system; data-reduction technique; low-activity replacement source; measurement tech nique; 18416 .

Scattered light; SIMS; stylus instruments; Auger spectroscopy; corrosion films; ESCA; impurities; microroughness; optical microscopy; polishing defects; SP562, pp. 337-350 (Oct. 1979).

Scattered light; surface roughness; absorption; diamond-turning; SP541, pp. 122-130 (Dec. 1978).

Scattered photons; sleeve; source capsule; source pellets; spacer; spectra; spectrometry; atomic number; cobalt -60 photons; configuration; plug; /8355.

Scatterer thickness; scatterer to image plane separation; tissue equivalent phantoms; $x$-ray beam diameter; $x$-ray energies of 30 to $70 \mathrm{keV}$; $\mathrm{x}$-ray scatter; diagnostic radiology; $1844 \mathrm{l}$.

Scatterer to image plane separation; tissue equivalent phantoms; $x$-ray beam diameter; $x$-ray energies of 30 to $70 \mathrm{keV}$; $\mathrm{x}$-ray scatter; diagnostic radiology; scatterer thickness; 1844 l.

Scattering; absorption; antireflectance coatings; high reflectance coatings; interface absorption; multilayer films; SP541, pp. 266-277 (Dec. 1978 ).

Scattering; calcium fluoride; forging; laser windows; optical properties; SP541, pp. $70-77$ (Dec. 1978).

Scattering; collimation; haze; hazemeter; integrating sphere; linearity; 18594.

Scattering; scattering cross-section; absorption; attenuation; heart; liver; SP525, pp. 153-156 (Apr. 1979).

Scattering; signal processing; tissue characterization; tissue parameters; ultrasound; velocity; absorption; attenuation; computerized tomography; Doppler; impedance; medical diagnosis; microscopy; pattern recognition; SP525.

Scattering; standards; su rface roughness; optical scattering; optical surface quality; 18999 . 
Scattering; swept-frequency diffraction; angular scattering; characterization of tissue; optical correlation; SP525, pp. 143-152 (Apr. 1979).

Scattering; ultrasonic; acoustic; crack; defects; elastic solid; pulses; 18391 .

Scattering corrections; sensitivity; benchmark; fission spectrum; foils; neutron fields; 18901 .

Scattering cross-section; absorption; attenuation; heart; liver; scattering; SP525, pp. 153-156 (Apr. 1979).

Scattering in an external field; stimulated bremsstrahlung; multiphoton transitions; 18710 .

Scattering in laser field; free-free transitions; low-frequency approximation; multiphoton effects; 18711 .

Scattering matrix; step discontinuity; TEM-cell; variational formulation; coaxial transmission line; cut-off frequency; equivalent circuit; modal analysis; NBSIR 79-1606.

Scattering mechanisms; scattering mobility; $\rho$-type silicon; boron-doped silicon; dopant density; effective mass; hole mobility; ionized impurity scattering mobility; lattice scattering mobility; neutral impurity; resistivity; $S P 400-47$.

Scattering mobility; $\rho$-type silicon; boron-doped silicon; dopant density; effective mass; hole mobility; ionized impurity scattering mobility; lattice scattering mobility; neutral impurity; resistivity; scattering mechanisms; SP400-47.

Scattering parameters; six-port; voltage; calibration; current; impedance; network analyzer; power; reflection coefficient; reflectometer; 18600 .

Scattering parameters; six-port; voltage; calibration; current; impedance; network analyzer; power; reflection coefficient; reflectometer; 18601 .

Scattering theory; cross sections; electron collisions; molecules; momentum-transfer; polar molecules; 18516 .

Scheduling; time complexity; algorithm; chromatic number; color function; graph; graph coloring; heuristic; interchange; random test graphs; J. Res. 84, No. 6, $489-506$ (1979).

$\beta$-chloroethers; air; environment; gas chromatography/mass spectrometry; sampling; sediment; trace analysis; water; SP519, pp. 205-212 (Apr. 1979).

School; air-conditioning; comfort; education; environment; human factors; research; 18596.

Science and technology for development; U.N. Conference on Science and Technology for Development; UNCSTD; appropriate technology; industrialization; industrial R\&D; LDC's; less developed countries; light capital technology; 18685 .

Science and technology transfer; standards; basic research; computer; energy conservation; environmental quality; industrial productivity; materials utilization; measurement capabilities; medical aids; product safety; public health and safety; SP538.

Science students; SRM; titanium alloy; analytical chemistry; ion-chromatography; law enforcement standards; materials properties; measurement science; DIM/NBS 63, No. 1/2, 1 28 (1979).

Scientific data; computer graphics; data base management; data retrieval;-durability; fatigue; interactive system; mathematical modeling; paper; paper fiber; report retrieval; NBSIR 79. 1746.

Scientific programs; software errors; software validations; program testing; NBS-GCR-78-148.

Scientist-author; technical communicator; technical paper; trade press; audience; feature article; news release; publication announcement; 18817 .

Scintillator materials during spaceflight; spaceflight; radioactivity; 19011 .

Scirrhous carcinoma; shadowing; ultrasound; attenuation; breast cancer; cancer; connective tissue; differential diagnosis; medullary carcinoma; papillary carcinoma; SP525, pp. 93-99 (Apr. 1979).
Scraping auger; slush; slush production; slush storage; cryogenic; hydrogen; oxygen; NBSIR 79-1607.

Scratching; size effect; specific energy; ceramics; chipping; crack formation; fracture toughness; friction; hardness; liquid softening; oxides; SP562, pp. 43-59 (Oct. 1979).

Screening; ultrasonics; blood flow; breast cancer; diagnosis; Doppler; SP525, pp. 173-176 (Apr. 1979).

Sea water; separation; trace element analysis; water analysis; chelating resin; graphite furnace atomic absorption; 18402 .

Sea water corrosion; steel corrosion; coating protection; pile corrosion; protection of steel; salt water corrosion; 18424 .

Seafood toxins; food toxicants; mycotoxins; review; SP519, pp. 321-331 (Apr. 1979).

Search/match methods; qualitative $\mathrm{x}$-ray powder diffractometry; round robin; 18857 .

Seasonal efficiency; automatic stack damper; flue-gas temperature profile; gas-fired furnace; off-period mass flow rate; partload performance; TN999.

Seawater; wavelength modulation; atomic absorption; atomic emission; barium; graphite furnace; 18783 .

Seawater corrosion; corrosion of steel; corrosion protection; nonmetallic coatings; offshore corrosion; saltwater corrosion; 18418 ,

Second breakdown; switching power transistor; tester; transistor; base drive circuit; electronic circuits; inductive load; nondestructive; protection circuit; reverse bias; safe operating area; SP400-54.

Second harmonic generation; solar radiation measurements; absolute radiometers; blackbody measurements; chemical actinometry; 18476.

Secondary; angular; Born approximation; correlations; electron impact; electrons; helium; ionization; 18534 .

Secondary charged particles; initial spectra; ion pair energy; nuclear data; 18660 .

Secondary electron emission; silicon; surface roughness; ydeflection modulation; ceramic; scanning electron microscope; SP562, pp. 407-415 (Oct. 1979).

Secondary ion mass spectrometry; sputtering; structural information; vitamins; amino acids; drugs; nonvolatile organic compounds; organic trace detection; peptides; pharmaceuticals; SP519, pp. 627-635 (Apr. 1979).

Secondary ion mass spectrometry; surface analysis; elemental analysis; ion microprobe mass analyzer; local thermal equilibrium model; microanalysis; 18979.

Secondary ion mass spectrometry; $x$-ray microanalysis; Auger electron spectroscopy; cathodoluminescence; ion scattering spectrometry; laser microprobe mass analyzer; laser Raman microprobe; microanal ysis; 18568 .

Secondary ion mass spectroscopy; surface analysis; ASTM Committee E-42; Auger electron spectroscopy; electron spectroscopy; ESCA; 18406.

Secondary ion mass spectroscopy (S1MS); silicon sputtering; dopant analysis; impurity analysis; ion microprobe mass analyzer (IMMA); microdot reference specimens; NBS-GCR79-158.

Secondary organic carbon; solvent extraction; spatial variations; diumal variations; elemental carbon; mass spectroscopy; organic aerosol constituents; primary organic carbon; sampling errors; SP519, pp. $121-129$ (Apr. 1979).

Secondary particle spectra; kerma factors; neutron cross section; neutron energy deposition; nuclear data; nuclear reactions; $l 8360$.

Second-breakdown, reverse-bias; transistors, power switching; device characterization; nondestructive testing; safe operating area, reverse-bias; 18738 .

Second-order Doppler shift phase modulation; spin exchange; temperature coefficient; time dispersion; wall shift; amplitude modulation; cavity pulling; cavity servo; dielectrically loaded cavity; frequency stability; 18696 . 
Second-order perturbation theory; two-photon ionization; cesium; ionization; perturbation theory; 18927 .

Second-order transitions; equilibrium antiphase domain (APB) boundaries; f.c.c. alloys; interphase (IPB) boundaries; 18669 .

Security; citizen rights; computers; computer utilization; confidentiality; data systems; personnel administration; personnel practices; personnel records; privacy; record-keeping practices; relevant information; $S P 500-50$.

Sediment; trace analysis; water; $\beta$-chloroethers; air; environment; gas chromatography/mass spectrometry; sampling; SP5 19, pp. 205-212 (Apr. 1979).

Sediment analysis; gas chromatography-mass spectrometry; glass capillary chromatography; high pressure liquid chromatography; hydrocarbon persistence; infrared spectroscopy; petroleum hydrocarbons; SP5 19, pp. 33-40 (Apr. 1979).

Sediment and water; carbamates; gas chromatography; organochlorides; pesticides; SP519, pp. 191-203 (Apr. 1979).

Sediments; extraction; hydrocarbons; marine; petroleum; SP5 19, pp. 161-167 (Apr. 1979).

Seeded specimens; transducer; acoustic emission; co-shock; couplant; detection; electronic package; impact noise; microcircuit device; particle detection; particle impact noise detection; P1ND; pre-shock; NBSIR 78-1590 (NASA).

Segregation; semiconductor technology; diffusion; electronic technology; impurity distribution; material transport; SP4OO57.

Seismic design; systems analysis; building codes; buildings; building standards; classification; decision tables; earthquakeresistant design; information networks; network; TN1100.

Selected writings; spectrophotometry; color; colorimetry; color spacing; color vision; Deane Judd; SP545.

Selection methodology; comparison of computers; computer measurement; computer selection; computer services; ranking and selection; SP500-44.

Selection of ADP systems; standard benchmarks; synthetic benchmarks; workload characterization; workload definition; benchmarking; benchmark library; SP5OO-38.

Selection of hearing aids; speech communication; audition; communications; hearing; hearing aids; CIS4, Revised 1978.

Selection rules; spin forces; tensor force; charmonium; particle spectroscopy; quarks; 18432 .

Selective detection; detector design; gas chromatography; liquid chromatography; SP519, pp. 547-585 (Apr. 1979).

Selective detection; steroid hormones; gas chromatography; nitrogen-phosphorus; SP519, pp. 419-427 (Apr. 1979).

Selective detectors; ancillary methods; bonded phases; chromatographic preconcentration; detector sensitivity; gas chromatography; glass capillary columns; high-performance liquid chromatography; LC microcapillary columns; SP519, pp. 487-499 (Apr. 1979).

Selectivity; sensitivity; specificity; trace analysis; environmental pollution; fluorescence; high performance liquid chromatography; occupational health; picogram; polycyclic aromatic hydrocarbons; SP519, pp. 41-56 (Apr. 1979).

Selectivity; sensitivity; toxic elements; radiochemical; 18343 .

Selectivity; sulphonamides; amino acids; barbiturates; carboxylic acids; catecholamines; conjugates; detection sensitivity; dipeptides; drugs; HPLC; ion-pair adsorption; ion-pair chromatography; ion-pair partition; metabolites; SP519, pp. 509 523 (Apr. 1979).

Selenium radicals; sulfate radical; thiocyanate radical anion; aqueous solution; carbonate radical; chemical kinetics; halogen radical anions; nitrate radical; oxyanion radicals; phosphate radical; photolysis; radiolysis; rates; NSRDSNBS65.

Self calibration; voltage divider; binary divider; divider network; guarded divider; resistive divider; 18452.

Self-calibration; twenty bits + sign; voltage output; digital-toanalog converter; high resolution; multirange; $\mathbf{R}-2 \mathbf{R}$ ladder; relay switching; TN1105.
Self-entanglement effects; computer simulation; end-to-end length; entanglement effects; excluded volume effects; latticemodel polymer chains; polymer chain dynamics; random-coil polymer chains; relaxation times; 18772 .

Self-extinguishment; ships; standards; curtains; drapes; fabrics; fire; flammability; international; NBSIR 79-1596.

SEM microscope stage; submicrometer positioning instrumentation; TEM microscope stage; flexure pivots; linear positioning; micromanipulator; optical microscope stage; piezoelectric drives; scanning stage; 18327.

Semiautomated pipetting; serum potassium analysis; statistical analysis; clinical analysis; clinical chemistry; definitive method; electrolytes; flame atomic emission spectroscopy; reference method; SP260-63.

Semi-automated ultrasonic inspection; ultrasonic inspection system; composite structures; flaw simulation; SP563, p. 59 (Oct. 1979).

Semiclassical orbital; theory; elastic scattering; ion-molecule collisions; rotational excitation; 18446.

Semiclassical treatment; ion-molecule collisions; rotational excitation; 18389 .

Semiconductor; silicon; spreading resistance; dopant profiles; resistivity; resistivity profiles; SP400-48.

Semiconductor; silicon; test pattern; test structures; visual alignment; contact resistor; cross bridge sheet resistor; electrical alignment resistor; SP4OO-51.

Semiconductor; tape-bonded devices; acoustic emission; beam lead devices; electronic devices; hermeticity; hybrids; nondestructive tests; SP4OO-59.

Semiconductor device fabrication; silicon; silicon dioxide; thermal oxidation of silicon; dry oxidation of silicon; hydrogen contamination; hydroxyl contamination; NBSIR 78-1558.

Semiconductor device measurements; silicon-on-sapphire measurements; extended-range capacitance and conductance measurements; high-voltage $C(V)$ and $G(V)$ measurements; NBS-GCR-78-155.

Semiconductor devices; semiconductor materials; semiconductor process control; silicon; electronics; integrated circuits; measurement technology; microelectronics; NBSIR 78-14443.

Semiconductor devices; semiconductor materials; semiconductor process control; silicon; electronics; integrated circuits; measurement technology; microelectronics; NBSIR 79-1591.

Semiconductor devices; semiconductor materials; semiconductor process control; silicon; electronics; integrated circuits; measurement technology; microelectronics; NBSIR 79-15912.

Semiconductor devices; semiconductor materials; semiconductor process control; silicon; electronics; integrated circuits; measurement technology; microelectronics; NBSIR 79-15913.

Semiconductor devices; thermal characterization; thermal resistance; transistors; current crowding; die attachment evaluation; junction temperature; measurement technology; power transistors; SP400-14

Semiconductor devices; welding; automated testing; batteries; cardiac pacemakers; contamination; corrosion; electrostaticinduced damage; hermeticity; hybrid devices; leak testing; measurement technology; microcalorimetry; moisture; nondestructive testing; pacemaker leads; SP4OO-5O.

Semiconductor materials; semiconductor process control; silicon; silicon dioxide; silicon-on-sapphire; sodium contamination; test patterns; test structures; thermally stimulated current and capacitance; transistors; ultraviolet reflectance; VCE(SAT); SP4O0-38.

Semiconductor materials; semiconductor process control; silicon; electronics; integrated circuits; measurement technology; microelectronics; semiconductor devices; NBSIR 781444-3. 
Semiconductor materials; semiconductor process control; silicon; electronics; integrated circuits; measurement technology; microelectronics; semiconductor devices; NBSIR 791591 .

Semiconductor materials; semiconductor process control; silicon; electronics; integrated circuits; measurement technology; microelectronics; semiconductor devices; NBSIR 79I59I-2.

Semiconductor materials; semiconductor process control; silicon; electronics; integrated circuits; measurement technology; microelectronics; semiconductor devices; NBSIR 791591-3.

Semiconductor measurements; sheet resistance; solar cells; solar cell stability; device measurements; laser scanning; light-biasing; metallization; ohmic contacts; reliability; NBSIR 79-1909.

Semiconductor measurements; solar cells; solar cell stability; workshops; device measurements; laser scanning; metallization; ohmic contacts; reliability; 18633 .

Semiconductor process control; silicon; electronics; integrated circuits; measurement technology; microelectronics; semiconductor devices; semiconductor materials; NBSIR 78-1444-3.

Semiconductor process control; silicon; electronics; integrated circuits; measurement technology; microelectronics; semiconductor devices; semiconductor materials; NBSIR 79-1591.

Semiconductor process control; silicon; electronics; integrated circuits; measurement technology; microelectronics; semiconductor devices; semiconductor materials; NBSIR 79-1591-2.

Semiconductor process control; silicon; electronics; integrated circuits; measurement technology; microelectronics; semiconductor devices; semiconductor materials; NBSIR 79-1591-3.

Semiconductor process control; silicon; silicon dioxide; siliconon-sapphire; sodium contamination; test patterns; test structures; thermally stimulated current and capacitance; transistors; ultraviolet reflectance; VCE(SAT); x-ray photoelectron spectroscopy; SP4OO-38.

Semiconductor processing; silicon; silicon dioxide; thermally stimulated measurement; thermal oxidation; Zn-doped glasses; boron nitride; Cl-doped glasses; diffusion in silicon; integrated circuit processing; kinetics of oxide growth; oxidation of silicon; NBS-GCR-78-134.

Semiconductor technology; diffusion; electronic technology; impurity distribution; material transport; segregation; SP4O0-57.

Semiconductors; silicon; electrical measurements; resistivity; 18460 .

Semiconductors; silicon; electrical measurements; profiles; 18757.

Semiconductors; solar cells; stability; testing; thin films; accelerated tests; failure mechanisms; failure modes; photovoltaics; reliability; SP4OO-58.

Semiconductors; solar cells; stability; testing; thin films; accelerated tests; failure mechanisms; failure modes; photovoltaics; reliability; NBSIR 79-1778.

Semiconductors; SRM's; standards; cardiac pacemakers; computer standards; fire safety; molybdenum; network measurement; DIM/NBS 63, No. 10, 1-36 (1979).

Semiconductors; U.S.S.R; electron devices; electron tubes; NBSIR 78-1564.

Semiconductors, Ge, Si, GaAs; laser induced breakdown; laserinduced damage threshold; nonequilibrium carriers; SP54I, pp. 305-308 (Dec. 1978).

Seminar; South Asia; developing countries; industrializing countries; Korea; measurements; metrology; physical standards; SP539.

Sensitivity; benchmark; fission spectrum; foils; neutron fields; scattering corrections; 18901 .
Sensitivity; signal averaging; signal processing; tissue characterization; tomography; transducers; ultrasonics; annular array; breast cancer; chirp signals; imaging; opto-acoustic; pulse compression; SP5 25, pp. 255-259 (Apr. 1979).

Sensitivity; specificity; chemical spot tests; color tests; drugs of abuse; field test kits; 18492 .

Sensitivity; specificity; trace analysis; environmental pollution; fluorescence; high performance liquid chromatography; occupational health; picogram; polycyclic aromatic hydrocarbons; selectivity; SP519, pp. 41-56 (Apr. 1979).

Sensitivity; toxic elements; radiochemical; selectivity; 18343 .

Sensitivity analysis; computer workload; data requirements; documentation cycle; forecast; projections; SP500-52, pp. 113-120 (Oct. 1979).

Sensitivity analysis; simulation; architectural research; building fires; computer-aided design; environmental psychology; fire research; fire safety; human performance; modeling technique; programming; NBSIR 79-1713.

Sensitivity analysis; smoke detectors; standards; upholstered furniture; building fires; cost-benefit analysis; costs; decision analysis; fire losses; furniture; hazard analysis; probability; residential buildings; TN1101.

Sensitized metal; circumferential tearing; fire extinguisher; hydrostatic pressure testing; intergranular cracking stainless steel; 18368 .

Sensors; tailorable; temperature; accumulator; analog; centralized; check-out system; dessicant; discrete; displacement; fiber optics; filters; flight critical; flow; fluid; go-no-go; ground readout; hydraulic; IMACS; SP547, pp. 345-357 (July 1979).

Sensors, chemical; electrodes, errors; electrodes, ion-selective; electrodes, reference; ion-selective electrodes; reference electrodes; 18362 .

Sensors, chemical; standards; electrodes; electrodes, ion-selective; electrodes, reference; errors; ion-selective electrodes; 18334.

Sensory capability; terrosim; threat analysis; training; adversary characteristics; animal research; behavioral science; biosensors; computer analysis; ergonomics; human engineering; human factors; human motivation; human reliability; personnel selection; physical security; SP480-38.

Separation; trace element analysis; water analysis; chelating resin; graphite furnace atomic absorption; sea water; 18402 .

Separators; sequencing; time elements; timekeeping systems; time representations; American National Standard Representation for Calendar Date and Ordinal Date for Information Interchange; meridian designators; FIPS PUB 58.

Sequencing; time elements; timekeeping systems; time representations; American National Standard Representation for Calendar Date and Ordinal Date for Information Interchange; meridian designators; separators; FIPS PUB 58.

Serial; broadcast; coaxial; communication; contention; data; digital; ethernet; local; microprocessor; network; 18760 .

Series-constructed; electric shock; fire; flaming ignition; glowing ignition; hazard; ignition temperature; lamp surface temperature; melting temperature; miniature Christmas lights; plastic insulating material; polyethylene; NBSIR 79-1716.

Serrated surface design; tooth roots; alumina; diamond contour grinding; flexure strength; prosthetic device; SP562, pp. 247 254 (Oct. 1979).

Serum; cerebrospinal fluid; detector; high-performance liquid chromatography; light-scattering; lipids; nephelometry; oils; reversed-phase; SP519, pp. 429-436 (A pr. 1979).

Serum; cholesterol; gas chromatography/mass spectrometry; isotope dilution; SP519, pp. 405-410 (Apr. 1979).

Serum; uv-detection; tricyclic antidepressives; benzodiazepines; clinical use; derivatization; quaternary two-phase systems; SP519, pp. 461-468 (Apr. 1979). 
Serum chloride analysis; statistical analysis; amperometry; chloride analysis; clinical analysis; clinical chemistry; couIometry; definitive method; electrolytes; reference method; SP260-67.

Serum matrix; standard reference material (SRM); antiepilepsy drugs in serum; SP519, pp. $447-453$ (Apr. 1979).

Serum potassium analysis; statistical analysis; clinical analysis; clinical chemistry; definitive method; electrolytes; flame atomic emission spectroscopy; reference method; semiautomated pipetting; SP260-63.

Service hot water; space heating; ventilation; appliance energy consumption; energy consumption of residences; lighting energy consumption; occupant factors; residential air conditioning; NBSIR 78.1501.

Servo control; acoustooptic; intensity; laser; modulator; noise; 18904.

Set-processing; simulation; software design; analytic models; database management; model validation; performance evaluation; performance measurement; predictive modeling; SP50049.

Settling time; A/D converters; D/A converters; data acquisition; data converters; dynamic measurements; 18503 .

$\mathrm{SF}_{\mathrm{B}} ; \mathrm{CH}_{4}$; collision induced bands; $\mathrm{CO}_{2} ; \mathrm{C}_{2} \mathrm{H}_{4}$; dielectric virial coefficients; refractive virial coefficients; 18786 .

S-glass; temperature effects; water boil; degradation; epoxy resins; Kevlar 49; moisture; one-tenth scale motor case; SP563, pp. 177-197 (Oct. 1979).

Shadowing; ultrasound; attenuation; breast cancer; cancer; connective tissue; differential diagnosis; medullary carcinoma; papillary carcinoma; scirrhous carcinoma; SPS25, pp. 93-99 (Apr. 1979).

Shake-off; shake-up; beta decay; rearrangement; 18407.

Shake-up; beta decay; rearrangement; shake-off; 18407 .

Shaping; silicon compound ceramics; laser; SP562, pp. 283-292 (Oct. 1979).

Shear flow lines; crack nucleation; fracture; median, radial and lateral cracks; plastic indentations; residual stresses; SP562, pp. 15-20 (Oct. 1979).

Shear rate; ultra high molecular weight polyethylene; viscosity number; intrinsic viscosity; molecular weight; polyethylene; 18834 .

Sheet resistance; silicon; test pattern; test structure; TTL; bipolar process; contact resistor; cross bridge sheet resistor; electrical alignment resistor; integrated circuits; linewidth; photolithography; 18533 .

Sheet resistance; solar cells; solar cell stability; device measurements; laser scanning; light-biasing; metallization; ohmic contacts; reliability; semiconductor measurements; NBSIR 79 1909.

Shelf-life of composites; storage stability; amine accelerators; degradation of benzoyl peroxide; dental composites; restorative dental resins; 18809 .

Shell model; giant resonances; hydrodynamic model; isoscalar resonances; isovector resonances; photonuclear physics; 18565 .

Shielded strip line; TEM cell; EMC measurements; radiation resistance; rectangular coax; 18345 .

Shielding techniques; standards; dosimetry; high energy radiotherapy beams; leakage; measurement techniques; medical accelerators; neutrons; relative biological effect; SP554.

Shift reagents; acyclic sugars; chemical shifts; conformation; coupling constants; hexononitriles; iterative analysis; proton nmr spectroscopy; 18742 .

Shingles; venting; benefit-cost analysis; building technology; economic impacts; economics; efficiency; payback; plumbing; roofing; SP558.

Ship cargo; statistical analysis; strapping; survey; accuracy; cryogenic; error estimation; liquefied natural gas; LNG; marine; mathematical modeling; measurement; photogrammetric; precision; NBSIR 79.1751.
Shipboard spaces; fire growth; fire statistics; flame spread; fuel load survey; heat relcase; interior finish; laboratory fire tests; material ignitability; prediction model; NBSIR 79-1714.

Ships; standards; curtains; drapes; fabrics; fire; flammability; international; self-extinguishment; NBSIR 79-1596.

Shish; volume strain; core fibril; cumulative stress; flow-induced crystallization; nucleation theory; polyethylene; polymer fiber; J. Res. 84, No. 5, 359-384 (1979).

Shish kebabs; crystallization theory; extended chain fibrils; flow-induced crystallization; polymer crystallization; 18715 .

Shock pulse; aircraft diagnostics; bearing; condition monitoring; diagnostic equipment; SP547, pp. 31-35 (July 1979).

Shoes; technology transfer; computer-aided design and manufacture (CAD/CAM); footwear industry; fragmented industries; government-industry cooperation; imports; innovation; leather; manufacturing technology; materials development; SP527.

Short span tensile analysis; zero span tensile; fiber length distribution; fiber strength; interfiber bonding; recycled pulps; NBSIR 79.1914.

Short term frequency stability; long term frequency stability; oscillator systems; quartz crystal oscillator; 18691 .

Showers; slip-resistance; ASTM; bathtubs; CPSC; performance test; 18705 .

SI; stages in metrication; construction specifications; conversion approaches; dimensional coordination; metrication; 18493 .

Si single crystal; high pressure; high temperature; mechanochemical polishing; quartz crystal; sapphire; SP562, pp. 171-182 (Oct. 1979).

SiC; strength; surfaces; coatings; SP562, pp. $483-488$ (Oct. 1979 ).

Sidestream smoke; thermal energy analyzer; tobacco smoke; vinyl chloride; aza-arenes; hydrazines; nitroalkanes; nitrosamines; SP519, pp. 131-141 (Apr. 1979).

Sievert; unit; absorbed dose; dose equivalent; gray; 19002.

Sigma phase; transition metal; alloy phases; electronegativity; electron factors; electron vacancies; Laves phase; 18357 .

Signal analysis; simulated acoustic emission; time-domain deconvolution; transient elastic wave propagation; acoustic emission; capacitive transducer; 18878 .

Signal analysis; ultrasound; picture processing; SP525, pp. $303-$ 313 (Apr. 1979).

Signal averaging; signal processing; tissue characterization; tomography; transducers; ultrasonics; annular array; breast cancer; chirp signals; imaging; opto-acoustic; pulse compression; sensitivity; SP525, pp. 255-259 (Apr. 1979).

Signal enhancement of coherent Raman process; coherent antiStokes Raman spectroscopy (CARS); liquid-filled dielectric waveguide; optical waveguide; phase-matched propagation in waveguide; Raman spectroscopy of liquids; 18686.

Signal generator; vhf omnidirectional radio range (VOR); amplitude modulation; instrument landing system (ILS); measurement instrumentation; measurement standard; modulation; modulation factor; modulation meter; Newton-Raphson method; percent modulation; TN1016.

Signal processing; tissue characterization; tissue parameters; ultrasound; velocity; absorption; attenuation; computerized tomography; Doppler; impedance; medical diagnosis; microscopy; pattern recognition; scattering; SP525.

Signal processing; tissue characterization; tomography; transducers; ultrasonics; annular array; breast cancer; chirp signals; imaging; opto-acoustic; pulse compression; sensitivity; signal averaging; SP525, pp. 255-259 (Apr. 1979).

Signal processing; tissue characterization; tissue parameters; ultrasound; attenuation; B-san; cepstrum; computer; convolution; de-convolution; liver; power spectrum; SP525, pp. 287295 (Apr. 1979).

Signal processing for tissue; x-ray examination of breast; attenuation of areola; attenuation of breast tissue; attenuation 
of malignant tumors; breast cancer detection; breast carcinoma; breast examination techniques; SP525, pp. 85-91 (Apr. 1979).

Signature analysis; vibration analysis; monitor system; rotary dissolver; SP547, pp. 232-249 (July 1979).

Silane coupling agents; benzoyl peroxide; composite resins; dental materials; glass compositions; methacrylate monomers; polymerization accelerators; reinforcing fillers; 18644 .

Silicon; absolute detector; absorption coefficient; dead layer model; external; internal quantum efficiency; 18477 .

Silicon; electrical measurements; profiles; semiconductors; 18757.

Silicon; electrical measurements; resistivity; semiconductors; 18460 .

Silicon; electronics; integrated circuits; measurement technology; microelectronics; semiconductor devices; semiconductor materials; semiconductor process control; NBSIR 78-1444-3.

Silicon; electronics; integrated circuits; measurement technology; microelectronics; semiconductor devices; semiconductor materials; semiconductor process control; NBSIR 79-1591.

Silicon; electronics; integrated circuits; measurement technology; microelectronics; semiconductor devices; semiconductor materials; semiconductor process control; NBSIR 79-1591-2.

Silicon; electronics; integrated circuits; measurement technology; microelectronics; semiconductor devices; semiconductor materials; semiconductor process control; NBSIR 79-1591-3.

Silicon; silicon dioxide; silicon-on-sapphire; sodium contamination; test patterns; test structures; thermally stimulated current and capacitance; transistors; ultraviolet reflectance; VCE(SAT); x-ray photoelectron spectroscopy; auger electron spectroscopy; SP4OO-38.

Silicon; silicon dioxide; thermal oxidation of silicon; dry oxidation of silicon; hydrogen contamination; hydroxyl contamination; semiconductor device fabrication; NBSIR 78-1558.

Silicon; silicon dioxide; thermally stimulated measurement; thermal oxidation; $\mathrm{Zn}$-doped glasses; boron nitride; Cl-doped glasses; diffusion in silicon; integrated circuit processing; kinetics of oxide growth; oxidation of silicon; semiconductor processing; NBS-GCR-78-134.

Silicon; solid state reaction; wear debris; damaged layer; fine polishing; sapphire; SP562, pp. $325-333$ (Oct. 1979).

Silicon; spreading resistance; dopant profiles; resistivity; resistivity profiles; semiconductor; $S P 400-48$.

Silicon; spreading resistance measurements; thermally stimulated measurements; thyristor materials measurements; thyristor measurements; d-c transmission; deep level measurements; energy conservation; measurement methods; power-device grade silicon; NBSIR 79-1756.

Silicon; sulfur; sulfur energy level in silicon; thermally stimulated capacitance; thermally stimulated current; deep level measurements; defect center characterization; defect density; ion implantation; 18458 .

Silicon; surface; XPS; angular study; electron spectroscopy for chemical analysis (ESCA); 18417.

Silicon; surface roughness; y-deflection modulation; ceramic; scanning electron microscope; secondary electron emission; SP562, pp. 407-415 (Oct. 1979).

Silicon; test pattern; test structure; TTL; bipolar process; contact resistor; cross bridge sheet resistor; electrical alignment resistor; integrated circuits; linewidth; photolithography; sheet resistance; 18533 .

Silicon; test pattern; test structures; visual alignment; contact resistor; cross bridge sheet resistor; electrical alignment resistor; semiconductor; SP4OO-5I.

Silicon; test pattern; transistor gain; integrated circuit; process validation wafer ( $P V W$ ); reliability; 18463.

Silicon; trace analysis; activation analysis; cadmium ratio; east neutron reactions; interfering nuclear reactions; optimization of analysis; 18338 .
Silicon cell; silicon detector; silicon photodetector; absolute radiometry; detector; electrically calibrated detectors; laser power measurements; pyroelectric detectors; radiometry; 18773.

Silicon cell; silicon detector; silicon photodetector; absolute radiometry; detector; electrically calibrated detectors; laser power measurements; pyroelectric detectors; radiometry; I8774.

Silicon compound ceramics; laser; shaping; SP562, pp. 283-292 (Oct. 1979).

Silicon detector; silicon photodetector; absolute radiometry; detector; electrically calibrated detectors; laser power measurements; pyroelectric detectors; radiometry; silicon cell; 18773 .

Silicon detector; silicon photodetector; absolute radiometry; detector; electrically calibrated detectors; laser power measurements; pyroelectric detectors; radiometry; silicon cell; 18774 .

Silicon detector; spatial position dependence; dead layer model; external; internal; quantum efficiency; reflectance; response; 18900 .

Silicon devices; trace analysis; uranium; alpha tracks; biomedical; boron; fission tracks; geochronology; geology; lithium; nitrogen; 18342 .

Silicon dioxide; silicon-on-sapphire; sodium contamination; test patterns; test structures; thermally stimulated current and capacitance; transistors; ultraviolet reflectance; VCE(SAT); $\mathrm{x}$-ray photoelectron spectroscopy; auger electron spectroscopy; die attachment; SP4OO-38.

Silicon dioxide; thermal oxidation of silicon; dry oxidation of silicon; hydrogen contamination; hydroxyl contamination; semiconductor device fabrication; silicon; NBSIR 78-1558.

Silicon dioxide; thermally stimulated measurement; thermal oxidation; Zn-doped glasses; boron nitride; Cl-doped glasses; diffusion in silicon; integrated circuit processing; kinetics of oxide growth; oxidation of silicon; semiconductor processing; silicon; NBS-GCR-78-134.

Silicon gate; test patterns; test structures; CMOS/SOS; process control; process metrology; NBSIR 79-1595.

Silicon irradiation; thermal fluxes; NBS reactor; neutrons; 18704 .

Silicon lattice spacing; tungsten $\mathrm{x}$ rays; $\mathrm{x}$-ray wavelength ratios; gamma rays; precision wavelength; 18487 .

Silicon nitride; strength; stress intensity factor; abrasive machining; ceramics; contact stress; damage penetration; fracture mechanics; fragmentation; glass; grinding; impact; SP562, pp. 23-42 (Oct. 1979).

Silicon nitride; strength; surface; finishes; flexure; fracture; fracture mechanics; grinding; SP562, pp. 463-474 (Oct. 1979).

Silicon nitride; ultrasonic machining; as-machined material strength; dimensional tolerances; profile grinding; SP562, pp. 209-220 (Oct. 1979).

Silicon photodetector; absolute radiometry; detector; electrically calibrated detectors; laser power measurements; pyroelectric detectors; radiometry; silicon cell; silicon detector; 18773 .

Silicon photodetector; absolute radiometry; detector; electrically calibrated detectors; laser power measurements; pyroelectric detectors; radiometry; silicon cell; silicon detector; 18774 .

Silicon sputtering; dopant analysis; impurity analysis; ion microprobe mass analyzer (IMMA); microdot reference specimens; secondary ion mass spectroscopy (SIMS); NBSGCR-79-158.

Silicon-nitride; fracture origin; fracture strength; machining of ceramics; oxidation and degradation; SP562, pp. 477.481 (Oct. 1979).

Silicon-on-sapphire; sodium contamination; test patterns; test structures; thermally stimulated current and capacitance; transistors; ultraviolet reflectance; VCE(SAT); $x$-ray photoelectron spectroscopy; auger electron spectroscopy; die attachment; electrical properties; SP4OO-38. 
Silicon-on-sapphire measurements; extended-range capacitance and conductance measurements; high-voltage $C(V)$ and $G(V)$ measurements; semiconductor device measurements; NBS-GCR-78-155.

Silver; silver analysis; controlled potential; coulometry; electrochemical equivalent of silver; electrochemistry; Faraday; potentiostat; J. Res. 84, No. 2, 157+160 (1979).

Silver; solid state physics; transport properties; copper; critical evaluation; data analysis; data compilation; data evaluation; data extraction; data synthesis; electrical resistivity; elements; gold; metals; molten metals; JPCRD 8, No. 4, 1147-1298 (1979).

Silver analysis; controlled potential; coulometry; electrochemical equivalent of silver; electrochemistry; Faraday; potentiostat; silver; J. Res. 84, No. 2, 157-160 (1979).

Silver-sulfur-tungsten cluster; synthesis; x-ray diffraction; crystal structure; mechanism of formation; molecular compound; 18636.

Silylation; thermal energy analyzer (TEA); tobacco; carbamates; chemical ionization; electron-capture; hydrazines; maleic hydrazide; mass spectroscopy; nitrosamines; nitrosodiethanolamine; SP519, pp. 297-309 (Apr. 1979).

Simple shear; BKZ fluid; constitutive equation; non-linear flow histories; rate fluid; 18367

Simplified test equipment for internal combustion engines; turret systems; vehicle maintenance; combat vehicles; diagnostic connector assembly; fighting vehicle systems; generic DCA; Hull systems; SP547, pp. 98-110 (July 1979).

SIMS; stylus instruments; Auger spectroscopy; corrosion films; ESCA; impurities; microroughness; optical microscopy; polishing defects; scattered light; SP562, pp. 337-350 (Oct. 1979).

Simulated acoustic emission; time-domain deconvolution; transient elastic wave propagation; acoustic emission; capacitive transducer; signal aKalysis; 18878 .

Simulation; accident; apparel; burn injury; clothing; fabric flammability; fabrics; fire; garments; heat transfer; injury potentia!; NBSIR 79-1755.

Simulation; architectural research; building fires; computeraided design; environmental psychology; fire research; fire safety; human performance; modeling technique; programming; sensitivity analysis; NBSIR 79-1713.

Simulation; architectural research; building fires; computeraided design; computer simulation; environmental psychology; fire research; fire safety; human performance; modeling technique; NBSIR 79-1796.

Sirnulation; software design; analytic models; database management; model validation; performance evaluation; performance measurement; predictive modeling; set-processing; SP500-49.

Simulation; software monitoring; workload definition; computer performance evaluation; computer performance measurement; computer performance prediction; computer system acquisition; conference proceedings; CPE in auditing; hardware monitoring; CPEUG; SP500-52.

Simulation; synthetic programs; benchmarking; computer performance measurement; distributed processing; interactive systems; kernels; modeling; real-time; SPSO0-52, pp. 53-64 (Oct. 1979).

Simulation; validation; workload characterization; workload management; capacity planning; hardware monitors; modeling; performance evaluation; performance prediction; SPSOO52, pp. $179-192$ (Oct. 1979).

Simulation model; data collection; JES output; job entry subsystem; model design; model selection; remote work stations; SP500-52, Pp. 123-127 (Oct. 1979).

Simultaneous chemical equilibria; water; BASIC; carbon dioxide; carbon monoxide; coal gasification; COLGAS; hydrogen; interactive computer program; methane; minimization of Gibbs energy; phase rule; NBSIR 78-1509.
Single alloy; amalgam; creep; dental; dimensional change; dispersion type alloy; high copper; 18729.

Single and multiple element fibers; surface threshold damage; free-running laser pulses; giant laser pulse; optical fiber damage; pulsed $\mathrm{Nd}^{3+}$ laser damage; SP54I, pp. 168-189 (Dec. 1978 ).

Single crystal; sodium beta alumina; sodium beta double prime alumina; battery application; engineering properties data; evaluated data; polycrystalline; NSRDS-NBS61, Part 111.

Single crystal; strontium fluoride; antireflection coatings; calcium fluoride; cw laser damage; DF laser; fusion cast; laser damage; laser window; SP541, pp. 78-85 (Dec. 1978).

Single crystal; Talystep traces; alkali halides; backward scattering; forward scattering; grain boundaries; isostatic forging; optical figure; optical homogeneity; SP54l, pp. $65-69$ (Dec. 1978).

Single crystal; uric acid derivative; uric acid determination; $x$ ray diffraction; biological assay; crystal structure; 18672 .

Single crystal; $x$ ray; zwitterion; amino acid derivative; crystal structure; $S$-carboxymethyl-L=cysteine; 18673 .

Single-event energy; energy deposition spectra; microdosimetry parameters; neutron cross section evaluations; 18658 .

Singly ionized oxygen; stark broadening; atomic spectra; nitrogen; oxygen; plasma-broadening; 18737.

Singly ionized spectra; atomic transition probabilities; electric dipole lines; multiplets; 18736.

Singular perturbation the ory; anharmonic oscillators; 18661 .

Singularities; S-matrix; Feynman integrals; quantum field theory; 18732 .

$\mathrm{SiO}_{2}$; $\mathrm{SrF}_{2}$; thermal expansion coefficient; thermo-optic constant; $\mathrm{ZnS} ; \mathrm{ZnSe} ; \mathrm{Al}_{2} \mathrm{O}_{3} ; \mathrm{As}_{2} \mathrm{~S}_{3}$ glass; $\mathrm{BaF}_{2} ; \mathrm{CaF}_{2} ; \mathrm{CdF}_{2}$; TN993.

Sir Francis Beaufort (1774-1857); binomial test; chi-squared test; Francis Ysidro Edgeworth (1845-1926); goodness of fit; 18471 .

Site development; standards; structural design; foundation design; geotechnical engineering; housing construction; mine subsidence; mining; 18324 .

Six-port; automatic network analyzer; calibration; microwave measurement; 18849 .

Six-port; automatic network analyzer; microwave; microwave measurement; 18650 .

Six-port; automatic network analyzer; microwave; microwave measurement; 18653.

Six-port; automation; microwave; microwave measurements; reflectometer; 18652 .

Six-port; calibration; impedance; reflection coefficient; reflectometer; TNIOI2.

Six-port; calibration; microwave measurements; reflectometer; 18651 .

Six-port; voltage; calibration; current; impedance; network analyzer; power; reflection coefficient; reflectometer; scattering parameters; 18600.

Six-port; voltage; calibration; current; impedance; network analyzer; power; reflection coefficient; reflectometer; scattering parameters; 18601

Six-port reflectometers; microwave measurements; microwave power; microwave systems; power monitor; reflectometers; 18670 .

Size effect; chipping; ferrites; glass melting; grinding; grinding model; high-speed grinding; pyrex; SP562, pp. $61-74$ (Oct. 1979).

Size effect; specific energy; ceramics; chipping; crack formation; fracture toughness; friction; hardness; liquid softening; oxides; scratching; SP562, pp. 43-59 (Oct. 1979).

Skull bone; sound speed; ultrasound; attenuation; dispersion; SP525, pp. 197-201 (A pr. 1979).

Skull transmission; ultrasound; axisymmetric; beams; focal thermal flaw; SP525, pp. 203-208 (Apr. 1979). 
Slceve; source capsule; source pellets; spacer; spectra; spectrometry; atomic number; cobalt-60 photons; configuration; plug; scattered photons; 18355 .

Slip-resistance; ASTM; bathtubs; CPSC; performance test; showers; 18705 .

Slit-scattering function; slit-scattering function corrections; spectral line radiometry; spectroradiometer characterizations; spectroradiometry; vignetting; aperture/aperture-image pair; aperture pair; calibration; convolution; deconvolution; TN910-4.

Slit-scattering function corrections; spectral line radiometry; spectroradiometer characterizations; spectroradiometry; vignetting; aperture/aperture-image pair; aperture pair; calibration; convolution; deconvolution; geometrical-optics radiometry; inversion; TN910-4.

Slush; slush production; slush storage; cryogenic; hydrogen; oxygen; scraping auger; NBSIR 79-1607.

Slush production; slush storage; cryogenic; hydrogen; oxygen; scraping auger; slush; NBSIR 79-1607.

Slush storage; cryogenic; hydrogen; oxygen; scraping auger; slush; slush production; NBSIR 79-1607.

Small angle neutron scattering; amorphous materials; domains; magnetism; phase transitions; rare earths; 18835 .

Small angle scattering; amorphous alloys; magnetic partides; magnetism; neutron scattering; rare earths; 18372 .

Small-scale turbulence; correlations; grid-turbulence; higherorder moments; hot-wire anemometry; probability distributions; 18821 .

$S$-matrix; Feynman integrals; quantum field theory; singularities; 18732 .

Smoke; compartment fires; fire tests; flame spread; heat release rate; ignition; interior finish; passive fire protection; potential heat: NBSIR 79-1700.

Smoke; emergency communications; emergency evacuation; fire detection; fire safety; fire suppression; mass transportation; material flammability; people movers; NBSIR 78-1586.

Smoke; smoke detectors; subway fires; toxicity; upholstered furniture; arson; bibliographies; building fires; compartment fires; fabric flammability; fire detection systems; fire tests; flammability tests; human behavior; plastics; polymers; NBSIR 79-I745.

Smoke; smoldering; weight loss; wood; combustion; flaming combustion; flexible foams; optical density; particle size; polypropylene; polyurethane foams; polyvinyl chloride; pyrolysis; rigid foams; NBS-GCR-78-147.

Smoke; soot; thermal radiation; fire models; heat transfer; room fires; NBS-GCR-78-151.

Smoke; toxic gases; toxicity; building fires; conferences; fire detection; fire investigations: fire models; fire research; fire retardants; flame retardants; human behavior; SP540.

Smoke; upholstered furniture; chairs; doors; evacuation; fire departments; fire fighters; nursing homes; patients; room fires; NBS-GCR-79-159.

Smoke candle test; smoke control; stairwell pressurization; top injection; tracer gas test; bottom injection; multiple injection; NBSIR 79-I 747.

Smoke control; stairwell pressurizatioh; top injection; tracer gas test; bottom injection; multiple injection; smoke candle test; NBSIR 79-1747.

Smoke detection; automatic sprinklers; building codes; building construction; Delphi Method; fire safety; health care facilities; hospitals; interior finishes; Life Safety Code; nursing homes; risk analysis; safety equivalency; safety evaluation; NBSIR 78-1555.

Smoke detectors; component screening; electronic component reliability; failure analysis; failure models; failure rates; reliability; residential buildings; NBS-GCR-79-160.

Smoke detectors; component screening; electronic component reliability; failure analysis; failure models; failure rates; reliability; residential buildings; NBS-GCR-79-I6I .
Smoke detectors; component screening; electronic component reliability; failure analysis; failure models; failure rates; reliability; residential buildings; NBS-GCR-79-162.

Smoke detectors; detection; fires; home fires; residential smoke detectors; 18514 .

Smoke detectors; spacing; velocity; beams; ceiling height; detectors; fire detectors; fire growth; heat detectors; room fires; NBS-GCR-78-128.

Smoke detectors; spacing; velocity; beams; ceiling height; detectors; fire detectors; fire growth; heat detectors; room fires; NBS-GCR-78-I29.

Smoke detectors; standards; upholstered furniture; building fires; cost-benefit analysis; costs; decision analysis; fire losses; furniture; hazard analysis; probability; residential buildings; sensitivity analysis; TN1101.

Smoke detectors; subway fires; toxicity; upholstered furniture; arson; bibliographies; building fires; compartment fires; fabric flammability; fire detection systems; fire tests; flammability tests; human behavior; plastics; polymers; smoke; NBSIR 79 . 1745 .

Smoke detectors; tenability limits; upholstered furniture; detection time; detector location; fire tests; gas detectors; kitchen fires; mobile homes; NBSIR 79-1915.

Smoke development; fire hazards; fire protection; fire safety; health care facility; 18721 .

Smoke movement; spray nozzle; stairway protection; ventilated stair; automatic sprinkler; building code; NBSIR 78-1571.

Smoke movement; sprinkler systems: health care facilities; hospitals; mattresses; NBSIR 79-1749.

Smoldering; weight lose; wood; combustion; flaming combustion; flexible foams; optical density; particle size; polypropylene; polyurethane foams; polyvinyl chloride; pyrolysis; rigid foams; smoke; NBS-GCR-78-147.

Smoldering combustion; test methods; attic floor radiant panel; cellulose thermal insulation; critical radiant flux; flame spread; NBSIR 79-1588.

Snow; centrifuge; comparison of measurement methods; free water; freezing calorimeter; hydrology forecasting; microwave remote sensing; NBSIR 79-I604.

Snow; solar collector; structural engineering; building; ice; load; roof; roof load; NBS-GCR-79-181.

Snow depth; soil moisture; electromagnetic measurement; I8563.

Snow stratigraphy; microwave remote sensing; snowpack-water equivalence; $I 8820$.

Snowpack-water equivalence; snow stratigraphy; microwave remote sensing; 18820 .

Social issues in information; telecommunication trends; transborder data flows; computer-telecommunications convergence; computer trends; information age; information as a rcsource; information revolution; 18975.

Social science; technological innovation; administrative experimentation; evaluability assessment; evaluation; experimental methods; Experimental Technology Incentives Program; regulation; regulatory oversight; NBS-GCR-ETIP 79-64.

Societal goals; building codes; control measures; fire codes; fire safety; governmental actions; life safety; regulation; risk assessment; SP536, pp. 63-74 (Feb. 1979).

Sodium; absorption spectra; core excitation; emission spectra; lattice relaxation; many body effects; 18413 .

Sodium; soft x-ray absorption spectra; soft x-ray emission spectra; aluminum; beryllium; core hole lifetime; lattice relaxation; lithium; magnesiu m; 18741 .

Sodium; temperature dependence; alkali elements; cesium; electrical resistivity; francium; lithium; magnetic flux density dependence; potassium; pressure dependence; rubidium; JPCRD 8, No. 2, 339-438 ( I979). 
Sodium atom; angular distributions; field ionization; laser spectroscopy; multiphoton processes; photoionization; quantum beats; 18953

Sodium beta alumina; sodium beta double prime alumina; battery application; engineering properties data; evaluated data; polycrystalline; single crystal; NSRDS-NBS6I, Part III.

Sodium beta double prime alumina; battery application; engineering properties data; evaluated data; polycrystalline; single crystal; sodium beta alumina; NSRDS-NBS6I, Part III.

Sodium contamination; test patterns; test structures; thermally stimulated current and capacitance; transistors; ultraviolet reflectance; VCE(SAT); x-ray photoelectron spectroscopy; auger electron spectroscopy; die attachment; electrical properties; electronics; SP4O0-38.

Sodium fluoride; absorption; arsenic selenide; arsenic trisulfide; defects; laser damage; SP54I, pp. $212-217$ (Dec. 1978).

Sodium fluoride film; total internal reflection; 0.65 to 3.0 microns; absorption coefficient; SP541, pp. 13-18 (Dec. 1978).

Sodium iodide spectrometer; $15.1 \mathrm{MeV}$ branching ratio; positron annihilation-in-flight; quasi-monoenergetic photons; 18522.

Sodium, neutral; autoionizing states; laser-excitation technique; neutral sodium; 18507.

Sodium (polystyrene sulfonate); sulfonation; sulfur trioxide; triethyl phosphate; polystyrene; 18542.

Soft errors; TMR; triply modular redundant; fault tolerant computer; NBSIR 79-1927.

Soft tissue; temperature dependence; ultrasound velocity; zero crossing detection; non-invasive temperature monitoring; SP525, pp. 57-61 (Apr. 1979).

Soft $x$-ray absorption spectra; soft $x$-ray emission spectra; aluminum; beryllium; core hole lifetime; lattice relaxation; lithium; magnesium; sodium; 18741 .

Soft $x$-ray emission spectra; aluminum; beryllium; core hole lifetime; lattice relaxation; lithium; magnesium; sodium; soft x-ray absorption spectra; 18741 .

Software; automated data systems; computer programs; cost/benefit analysis; documentation; documentation content guidelines; feasibility study; FIPS guidelines; initiation phase; project request; FIPS PUB 64.

Software; standards; transfer; documentation; energy; evaluation; guidelines; implementation; large-scale; management; mathematical models; policy analysis; SP534.

Software; transformation; computing system; dataplot; fitting; graphics; interactive graphics; regression; 18519 .

Software certification; software development; software reliability; software validation; design specifications; requirements definition; 18882 .

Software design; analytic models; database management; model validation; performance evaluation; performance measurement; predictive modeling; set-processing; simulation; SP5OO. 49 .

Software development; software reliability; software validation; design specifications; requirements definition; software certification; 18882 .

Software errors; software validations; program testing; scientific programs; NBS-GCR-78-148.

Software monitoring; workload definition; computer performance evaluation; computer performance measurement; computer performance prediction; computer system acquisition; conference proceedings; CPE in auditing; hardware monitoring; CPEUG; installation management; SP500-52.

Software reliability; software validation; design specifications; requirements definition; software certification; software development; 18882 .

Software validation; design specifications; requirements definition; software certification; software development; software reliability; 18882 .
Software validations; program testing; scientific programs; software errors; NBS-GCR-78-148.

Soil anchors; soil mechanics; wind upset; anchors; mobile home foundations; BSS107.

Soil mechanics; wind upset; anchors; mobile home foundations; soil anchors; BSSI07.

Soil moisture; electromagnetic measurement; snow depth; 18563.

Soil organic matter; aquatic humus; fulvic acid; humic acid; humic substances; reference collection of humic substances; reference samples; SP5 19, pp. $789-792$ (Apr. 1979).

Soil organic matter; standard humic materials; fulvic acid; humic acid; humic substances; reference collection of humic substances; SP5 19, pp. 793-796 (Apr. 1979).

Solanidine; solanine; potato alkaloids; radioimmunoassay; SP5 19, pp. 333-340 (Apr. 1979).

Solanine; potato alkaloids; radioimmunoassay; solanidine; SP519, pp. 333-340 (Apr. 1979).

Solar; building design; cost; energy conservation; energy standards; fenestration; life-cycle costing; retrofitting; 19043.

Solar; commercial; economics; evaluation; feasibility; passive; rehabilitation; retrofit; 18964 .

Solar; solar atmospheric motions; supergranules; convection; 18444.

Solar; standards; State; buildings; design; energy; legislation; NBSIR 79-1705.

Solar; standards; testing; computer; hot water; measurement; rating; 18428 .

Solar; suburban; urban; application; buildings; commercial; daylighting; energy; environments; heating; passive; 18894 .

Solar absorptance; solar optical properties; solar reflectance; solar transmittance; spectral reflectance standards; terrestrial solar irradiance; diffuse reflectance standards; 18501 .

Solar absorptance of roofing materials; whole-house ventilation; attic ventilation; energy conservation; SP548.

Solar arrays; solar cells; workshops; laser scanner; measurement development; photovol taics; reliability; 18322 .

Solar atmospheric motions; supergranules; convection; solar; 18444.

Solar cell stability; device measurements; laser scanning; lightbiasing; metallization; ohmic contacts; reliability; semiconductor measurements; sheet resistance; solar cells; NBSIR 79-1909.

Solar cell stability; workshops; device measurements; laser scanning; metallization; ohmic contacts; reliability; semiconductor measurements; solar cells; 18633.

Solar cells; solar cell stability; device measurements; laser scanning; light-biasing; metallization; ohmic contacts; reliability; semiconductor measurements; sheet resistance: NBSIR 79-1909.

Solar cells; solar cell stability; workshops; device measurements; laser scanning; metallization; ohmic contacts; reliability; semiconductor measurements; 18633 .

Solar cells; stability; testing; thin films; accelerated tests; failure mechanisms; failure modes; photovoltaics; reliability; semiconductors; SP4OO-58.

Solar cells; stability; testing; thin films; accelerated tests; failure mechanisms; failure modes; photovoltaics; reliability; semiconductors; NBSIR 79-1778.

Solar cells; standards; test methods; batteries; photovoltaic energy conversion; power conditioning; power systems; NBSIR 79-1743.

Solar cells; workshops; laser scanner; measurement development; photovoltaics; reliability; solar arrays; 18322 .

Solar collector; solar energy; solar radiation; standards; standard test; testing; measurement; BSSII 7 .

Solar collector; structural engineering; building; ice; load; roof; roof load; snow; NBS-GCR-79-181. 
Solar collector testing; water-heating solar collcctors; collector efficiency; comparison German BSE vs ASHRAE 93-77 procedures; flatiplate solar collectors; German Bundesverband Solarenergie; 18986.

Solar collectors; standard test methods; absorptive coatings; accelerated laboratory tests; durability; outdoor exposure; 18554 .

Solar collectors; water-heating collectors; ASHRAE Standard 93-77; 18770 .

Solar data center; solar energy systems; solar heating and cooling; automatic data processing; data base; residential buildings; NBSIR 79-1762.

Solar database; solar energy system; solar heating and cooling; automatic data processing; computer reports; grant data; residential buildings; NBSIR 79-1923.

Solar energy; building regulation; energy conservation; legislation; SP552, pp. 211-216 (July 1979).

Solar energy; building research; NBS solar standards projects; 18363.

Solar energy; solar heating and cooling; solar model code; solar regulatory provisions; solar regulatory requirements; codes and standards; NBS-GCR-78-141-1.

Solar energy; solar heating and cooling; solar model code; solar regulatory provisions; solar regulatory requirements; codes and standards; NBS-GCR-78-141-2.

Solar energy; solar radiation; standards; standard test; testing; measurement; solar collector; BSSII7.

Solar energy; storage; performance criteria; photovoltaics; power conditioning; power control; 18634 .

Solar energy; toxic chemicals; ultra-black coating; Alaskan pipeline; computers; corrosion; fire safety; gyromagnetic ratio; paper; photometric calibrator; safety tips; DIM/NBS 63. No. 11, 1-36 (1979).

Solar energy; toxic substances; building rehabilitation; energy measurements; energy-related inventions; environment; precision power; radioactivity; Raman microprobe; DIMINBS 63 , No. 6, 1.32 (June 1979).

Solar energy; windows; daylighting; energy conservation; fenestration; 18863 .

Solar energy storage; thermal energy storage device; ASHRAE Standard 94-77; Glauber's salt; latent heat storage; pebble bed; phase-change unit; NBSIR 79-1737.

Solar energy system; solar heating and cooling; automatic data processing; computer reports; grant data; residential buildings; solar database; NBS1R 79-1923.

Solär energy systems; hose; hose specifications; rubber hose; NBSIR 79-1917.

Solar energy systems; solar heating and cooling; automatic data processing; data base; residential buildings; solar data center; NBSIR 79.1762 .

Solar heat gain; daylighting; energy calculation; energy consumption; fenestration; heating and cooling load; 19003.

Solar heat gain; thermal efficiency; window; window management; building economics; daylighting; economic analysis; energy conservation; engineering economics; life-cycle costs; BSS 119 .

Solar heating and cooling; automatic data processing; data base; residential buildings; solar data center; solar energy systems; NBSIR 79-1762.

Solar heating and cooling; automatic data processing; computer reports; grant data; residential buildings; solar database; solar energy system; NBSIR 79-1923.

Solar heating and cooling; solar model code; solar regulatory provisions; solar regulatory requirements; codes and standards; solar energy; NBS-GCR-78-141-1.

Solar heating and cooling; solar model code; solar regulatory provisions; solar regulatory requirements; codes and standards; solar energy; NBS-GCR-78-141-2.

Solar heating components; standard test procedure; thermal storage tests; water tank thermal storage; ASHRAE Standards; evaluation of test procedure; 18425 .
Solar model code; solar rcgulatory provisions; solar rcgulatory requirements; codes and standards; solar energy; solar heating and cooling; NBS-GCR-78-14l-I.

Solar model code; solar regulatory provisions; solar regulatory requiremcnts; codes and standards; solar energy; solar heating and cooling; NBS-GCR-78-141-2.

Solar optical properties; solar reflcctance; solar transmittance; spectral reflectance standards; terrestrial solar irradiance; diffuse reflectance standards; solar absorptance; 18.501 .

Solar radiation; standards; standard test; testing; measurement; solar collector; solar energy; BSS117.

Solar radiation measurements; absolute radiometers; blackbody measurements; chemical actinometry; second harmonic generation; 18476.

Solar reflectance; solar transmittance; spectral reflectance standards; terrestrial solar irradiance; diffuse reflectance standards; solar absorptance; solar optical properties; 18501 .

Solar regulatory provisions; solar regulatory requirements; codes and standards; solar energy; solar heating and cooling; solar model code; NBS-GCR-78-141-1.

Solar regulatory provisions; solar regulatory requirements; codes and standards; solar energy; solar heating and cooling; solar model code; NBS.GCR-78-141-2.

Solar regulatory requirements; codes and standards; solar energy; solar heating and cooling; solar model code; solar regulatory provisions; NBS-GCR-78-141-1.

Solar regulatory requirements; codes and standards; solar energy; solar heating and cooling; solar model code; solar regulatory provisions; NBS-GCR-78-141-2.

Solar transmittance; spectral reflectance standards; terrestrial solar irradiance; diffuse reflectance standards; solar absorptance; solar optical properties; solar reflectance; 18501 .

Solenoids; Ampere's law; dimensional metrology; fundamental constants; gyromagnetic ratio of proton; magnetic fields; Maxwell's equations; 18437.

Solid $\mathrm{He}^{3}$; superfluid $\mathrm{He}^{3}$; symposium; cryogenics; dilution refrigerators; helium 3; Japan; millikelvin research; nuclear cooling; Pomeranchuk refrigerators; 18679 .

Solid state memories; video disks; beam-addressables; cartridges; cassettes; core memories; disks; drums; floppy disks; laser beams; magnetic bubbles; masstapes; SP500-45.

Solid state physics; transport properties; copper; critical evaluation; data analysis; data compilation; data evaluation; data extraction; data synthesis; electrical resistivity; elements; gold; metals; molten metals; palladium; JPCRD 8, No. 4, $1147-1298$ (1979).

Solid state reaction; water vapor; working unit; damaged layer; elastic emission machining; environmental effect; hydrate; hydration polishing; mechanochemical polishing with soft powder; pre-existing defect; sapphire; SP562, pp. 157-169 (Oct. 1979).

Solid state reaction; wear debris; damaged layer; fine polishing; sapphire; silicon; SP562, pp. 325-333 (Oct. 1979).

Solid state software; advanced composite materials; composite materials analysis; orthotropic materials; programmable calculators; SP563, pp. $91-107$ (Oct. 1979).

Solidification; surface tension of liquid gallium; thermodynamic properties; convection; heat capacity measurement; $\mathrm{Pb}-\mathrm{Sn}$ off-eutectic alloys; phase diagram of $\mathrm{K}_{2} \mathrm{O}-\mathrm{Fe}_{2} \mathrm{O}_{3}$ system; NBSIR 79-1767.

Solids; tissue; ultrasound; propagation velocity; reflection technique; SP525, pp. 53-56 (Apr. 1979).

Solids; 13r; conformation; crystallinity; NMR; polyethylene; resolution; sample spinning; 18745 .

Solution calorimetry; bom b calorimetry; drop calorimetry; electromagnetic power calorimetry; energy measurement; enthalpy measurement; entropy measurement; fuels, heating values; gas-flow calorimetry; heat capacity measurement; heat measurements; levitation calorimetry; 18330 . 
Solution calorimetry; thermochemistry; adenine; enthalpy of dissociation; enthalpy of protonation; enthalpy of reaction; enthalpy of solution; nucleic acid bases; J. Res. 84, No. 3, 231-240 (1979).

Solution calorimetry: tris(hydroxymethyl)aminomethane; endothermic solution reactions; enthalpy of solution; $\mathrm{KBr}, \mathrm{Kl}, \mathrm{KlO}_{3}, \mathrm{KIO}_{4} ; J$. Res. 84, No. 4, 273-286 (1979).

Solution properties; bead-spring model; block copolymer; flow birefringence; flow dichroism; polymer dynamics; RouseZimm theory; 18431 .

Solutions; thermodynamic properties; activity coefficient; cobalt; critical evaluation; electrolyte; excess Gibbs energy; iron; nickel; osmotic coefficients; JPCRD 8, No. 4, 923-1004 (1979).

Solutions; thermodynamic properties; uranium; activity coefficient; copper; critical evaluation; electrolyte; excess Gibbs energy; lead; manganese; osmotic coefficients; JPCRD 8, No. 4, 1005-1050 (1979).

Solvent; stress-cracking agent; uniaxial creep; crack growth; failure; polyethylene; 18766 .

Solvent extraction; spatial variations; diurnal variations; elemental carbon; mass spectroscopy; organic aerosol constituents; primary organic carbon; sampling errors; secondary organic carbon; SP519, pp. 121-129 (Apr. 1979).

Sonic testing device; adhesive bond integrity; control testing; SP563, p. 174 (Oct. 1979).

Sonic velocity; bone; collagen; crosslinking modification; curvelinking; hydroxyapatite; SP525, pp. 179-187 (Apr. 1979).

Soot; thermal radiation; fire models; heat transfer; room fires; smoke; NBS-GCR-78-151.

Sound; acoustics; environmental noise; noise; noise emission; regulations; 18785 .

Sound intensity; sound power; standing wave tube; absolute sound power source; particle velocity; plane wave; 18728 .

Sound power; standing wave tube; absolute sound power source; particle velocity; plane wave; sound intensity; 18728 .

Sound speed; ultrasound; attenuation; dispersion; skull bone; SP525, pp. 197-201 (Apr. 1979).

Sound velocity; thermodynamic properties; virial coefficients; density; gas; nitrogen; 18815 .

Source capsule; source housing; spectrometry results; ${ }^{60} \mathrm{CO}$ gamma-ray beam; calibration source; collimation system; data-reduction technique; low-activity replacement source; measurement technique; scatter contribution; 18416 .

Source capsule; source pellets; spacer; spectra; spectrometry; atomic number; cobalt-60 photons; configuration; plug; scattered photons; sleeve; 18355 .

Source data entry; data entry; economic considerations; keyboard; keypunch; optical character recognition; optical mark sensing; FIPS PUB 67.

Source housing; spectrometry results; ${ }^{60} \mathrm{CO}$ gamma-ray beam; calibration source; collimation system; data-reduction technique; low-activity replacement source; measurement technique; scatter contribution; source capsule; /84/6.

Source pellets; spacer; spectra; specirometry; atomic number; cobalt-60 photons; configuration; plug; scattered photons; sleeve; source capsule; 18355.

South Asia; developing countries; industrializing countries; Korea; measurements; metrology; physical standards; seminar; SP539.

Sovereign immunity; tort; duty; liability; municipal corporations; negligence; SPS52, pp. 29-37 (July 1979).

$\mathrm{SO}_{x}$; troposphere; aldehydes; aromatics; chemical kinetics; data needs; free radicals; modeling; $\mathrm{NO}_{x}$; olefins; SP557.

$s-p$ binding; structural stability; alloys; electronegativity; electronic configuration; 18383 .

Space; stirling refrigerators; aluminum SRM's; computer systems; electron microscopy; group decisions; properties of steam; DIM/NBS 63, No. 5, 1-28 (1979).
Space; superconducting; torque; trapped flux; gyroscope; ralativity; 18846 .

Space astronomy; stars, chromospheres; stars, coronae; stars, late-type; stars, winds; ultraviolet spectra; satellites; 18606.

Space astronomy; stellar astronomy; ultraviolet spectroscopy; galactic astronomy; 18590 .

Space charge; breakdown; electro-optics; gas-solid interface; KDP; Pockels effect; NBS-GCR-79-177.

Space charge forces; beam transport; high current beams; numerical simulation; particle accelerators; 18932 .

Space cooling; space heating; building envelope; cost effectiveness; economics; energy conservation; internal rate of return; life-cycle costing; marginal analysis; optimal design; residential buildings; 19044 .

Space groups; aliasing; Bravais lattices; Fast Fourier "Transform"; near-field scanning; orthogonalities; plane-radial scanning; probe correction; 18956.

Space heating; building envelope; cost effectiveness; economics; energy conservation; internal rate of return; life-cycle costing; marginal analysis; optimal design; residential buildings; space cooling; 19044.

Space heating; ventilation; appliance energy consumption; energy consumption of residences; lighting energy consumption; occupant factors; residential air conditioning; service hot water; NBSIR 78-1501.

Space heating and cooling requirements; thermal mass; building economics; energy conservation; insulation; life-cycle cost analysis; masonry construction; NBSIR 79-1789.

Space optics; advanced composites; dimensional stability; eutectic coating; graphite/epoxy; moisture barrier; SP563, pp. 47-56 (Oct. 1979).

Spaceflight; radioactivity; scintillator materials during spaceflight; 19011 .

Space-heating; testing; boiler; combustion; energy; furnace; gasfired; heating; oil-fired; rating; 18385 .

Spacelab; critical phenomena; critical-point universality; fluids; gravity effects; materials science; 18457.

Spacer; spectra; spectrometry; atomic number; cobalt-60 photons; configuration; plug; scattered photons; sleeve; source capsule; source pellets; 18355 .

Spacing; velocity; beams; ceiling height; detectors; fire detectors; fire growth; heat detectors; room fires; smoke detectors; NBS-GCR-78-128.

Spacing; velocity; beams; ceiling height; detectors; fire detectors; fire growth; heat detectors; room fires; smoke detectors; NBS-GCR-78-129.

Sparse matrices; data pooling; data structures; mathematical programming; matrices; name generation; operations research; programming languages; J. Res. 84, No. 1, 21-47 (1979).

Spatial anisotropy; strain tides; core resonance; free wobble; laser strainmeter; ocean load; preferred frame; 18823 .

Spatial period; wavelength of light; Fizeau-type interferometer; fringe pattern; U.S. Patent 4,173,442.

Spatial position dependence; dead layer model; external; internal; quantum efficiency; reflectance; response; silicon detector; 18900 .

Spatial resolution; thin foils; $x$ rays; analytical electron microscopy; microanalysis; Monte Carlo electron trajectory simulation; 18589 .

Spatial variations; diurnal variations; elemental carbon; mass spectroscopy; organic aerosol constituents; primary organic carbon; sampling errors; secondary organic carbon; solvent extraction; SP519, pp. 121-129 (Apr. 1979).

Special reference materials; standard reterence materials; analysis; certification; characterization; composition; properties; research materials; SP2 60, 1979-80 Edition.

Special relativity; stabnized lasers; isotropy of space; Michelson-Morley experiment; $\mathbf{1 8 8 7 5}$. 
Special relativity; stabilized lasers; isotropy of space; Michelson-Morley experiment; 18952 .

Speciation; activation parameters; aqueous transmethylation; chloride complexes; environment; formation constants; ionic mechanisms; kinetics; methylmercury; methyltin; NMR; primary salt effect; $l 8484$.

Specific electrical effect; arc burn; contact burn; current threshold; electrical injury; electrolyte shift; heat effect; injury mechanism; injury statistics; mouth burn; NBSIR 79-1710.

Specific energy; ceramics; chipping; crack formation; fracture toughness; friction; hardness; liquid softening; oxides; scratching; size effect; SP562, pp. $43-59$ (Oct. 1979).

Specific heat; stainless steel; heat capacity; low temperature alloy: 18419 .

Specific heat; standard reference materials; thermodynamic properties; alumina; aluminum oxide; calorimetry; corundum; enthalpy; heat capacity; sapphire; 18377.

Specific heat; standard reference materials; thermal conductivity; thermophysical properties; electrical resistivity; enthalpy; 18615.

Specific heat; strontium titanate; beryllium; ceramics; cryogenics; dielectric-constant; electrets; electrocaloric effect; entropy; ferroelectrics; glass-ceramics; heat switches; magneto-thermal conductivity; polarization; potassium tantalate; refrigeration; 18680 .

Specific heating value; tank capacity tables; thermophysical properties; total heating value; composition; custody transfer; density; flow rate; LNG; mixtures; 18564.

Specific heating value; tank capacity tables; thermophysical properties data; total heating value; composition; custody transfer; density; flow rate; LNG; mathematical models; mixtures; 18838 .

Specific heats; speeds of sound; vapor pressures; densities; enthalpies; entropies; equation of state; internal energies; isobars; isobutane; isochores; isotherms; Joule-Thomson inversion; latent heats of vaporization; melting line; orthobaric densities; NBSIR 79-16I2.

Specific heats; speeds of sound; vapor pressures; densities; enthalpies; entropies; equation of state; internal energies; isobars; isochores; isotherms; Joule-Thomson inversion; latent heats of vaporization; melting line; n-butane; orthobaric densities; NBSIR 79-1621.

Specifications; standards; test measures; tolerances; vapor recovery; bottom loading; field standard provers; field standards; field standard test measures; provers; H105-3.

Specifications; statistical methods; statistics; conformance; sampling; 18440 .

Specifications; taximeters; tolerances; volume-measuring devices; weighing devices; weights; length-measuring devices; liquid-measuring devices; measures; scales; H44, 1979 Edition.

Specifications and tolerances; vapor recovery; weights and measures; consumer affairs; education; electromagnetic interference; electronic devices; International Organization of Legal Metrology; measurement assurance; metrication; model laws and regulations; SP532.

Specificity; chemical spot tests; color tests; drugs of abuse; field test kits; sensitivity; 18492 .

Specificity; trace analysis; environmental pollution; fluorescence; high performance liquid chromatography; occupational health; picogram; polycyclic aromatic hydrocarbons; selectivity; sensitivity; SP519, pp. 41-56 (Apr. 1979).

Speckle; waveform; attenuators; calibration; laser; neodymium laser; peak power; power meter; pulsed laser; Q-switched; risetime; TN1OIO.

Spectra; Ca " emission, stars; chromospheres, stars; emission line, star; late-type, ultraviolet; 18926.

Spectra; elements; emission; 18870 .
Spectra; spectrometry; atomic number; cobalt-60 photons; configuration; plug; scattered photons; sleeve; source capsule; source pellets; spacer; 18355 .

Spectra; spectroscopy; triply-ionized; ultraviolet; wavelengths; energy levels; lanthanum; 18782 .

Spectra; ultraviolet; wavelengths; zirconium; 18499.

Spectra; wavelengths; energy levels; ions; molybdenum; pulsed laser; 18500.

Spectra, O vi-O viı; wavelengths, O vi-O vıi; atomic energy levels, O v1-O vi11; atomic spectra, O vi-O vili; NSRDS-NBS3, Section 8.

Spectra-color ultrasonography (SCU); spectrum analysis; ultrasonic spectroscopy; instantaneous power spectra; colorcoded B-scan; SP525, pp. 261-266 (Apr. 1979).

Spectral absorptance; theory; asymmetric absorptance; damage thresholds; dielectric reflectors; electric-field distribution; high-power; reflectance; SP541, pp. 278-287 (Dec. 1978).

Spectral analysis; statistical modeling; ultrasonic tissue characterization; computer processing; estimation theory; liver attenuation; SP525, pp. 125-132 (Apr. 1979).

Spectral clusters; spherical top molecules; 4 th and 6 th rank octahedral tensor; asymptotic eigensolutions; high resolution spectra; 18706.

Spectral coincidences; Stark modulation; Stark spectroscopy; trace gas analysis; $\mathrm{CO}_{2}$ laser; derivative spectra; infrared analysis; 18538 .

Spectral line radiometry; spectroradiometer characterizations; spectroradiometry; vignetting; aperture/aperture-image pair; aperture pair; calibration; convolution; deconvolution; geometrical-optics radiometry; inversion; measurement-beam geometry; TN910-4.

Spectral lines; Stark broadening; deuterium; hydrogen; ion dynamic effect; plasma line shift; 18948 .

Spectral purity; frequency lock loop; frequency stability; navigation; oscillator systems; phase lock loop; position location; 18693.

Spectral reflectance standards; terrestrial solar irradiance; diffuse reflectance standards; solar absorptance; solar optical properties; solar reflectance; solar transmittance; 18501 .

Spectrofluorimetry; surface analysis; tetrazole; benzotriazole; charge transfer; copper; luminescence; microspectrofluorimetry; photoluminescence; 18504 .

Spectrometry; atomic number; cobalt-60 photons; configuration; plug; scattered photons; sleeve; source capsule; source pellets; spacer; spectra; 18355 .

Spectrometry; dose-equivalent; electrons; kerma; multisphere; photon; photoneutrons; radiotherapy; SP554, pp. 109-123 (Sept. 1979).

Spectrometry; dose-equivalent; electrons; kerma; multispheres; photoneutrons; photons; radiotherapy; SP554, pp. 125-127 (Sept. 1979).

Spectrometry; sulfate; $x$ ray; anion exchange; filter paper; fuel oil; 18635 .

Spectrometry results; ${ }^{60} \mathrm{CO}$ gamma-ray beam; calibration source; collimation system; data-reduction technique; low-activity replacement source; measurement technique; scatter contribution; source capsule; source housing; 18416 .

Spectrophotometer; transmittance; wavelength standard; bandwidth; didymium glass filter; passband centroid; SP260-66.

Spectrophotometric enzyme assay: enzyme assay; influence of inhibitor on lactate dehydrogenase assay; lactate dehydrogenase assay; lactate to pyruvate reaction; pyruvate to lactate reaction; 18433 .

Spectrophotometry; color; colorimetry; color spacing; color vision; Deane Judd; selected writings; SP545.

Spectroradiometer characterizations; spectroradiometry; vignetting; aperture/aperture-image pair; aperture pair; calibration; convolution; deconvolution; geometrical-optics radiometry; inversion; measurement-beam geometry; relative spectral responsivity; TN910-4. 
Spectroradiometry; vignetting; aperture/aperture-image pair; aperture pair; calibration; convolution; deconvolution; geometrical-optics radiometry; inversion; measurement-beam geometry; relative spectral responsivity; slit-scattering function; TN910-4.

Spectroscopic and analytic determinations; variable wavelength monochromatic light; opto-galvanic effect; predetermined frequency; U.S. Patent 4,148,586.

Spectroscopy; spectrum; structure; flavor; hadron; quark; 19010.

Spectroscopy; SU4; alpha-particles; correlations; mass formula; nuclear; quartets; reactions; 18423 .

Spectroscopy; triply-ionized; ultraviolet; wavelengths; energy levels; lanthanum; spectra; 18782 .

Spectroscopy, laser; laser spectroscopy; noise, laser sources; nonlinear spectroscopy; optical heterodyne; 18558 .

Spectrum; stable matrix; closure; $D$-stability; diagonal matrix; field of values; Hadamard product; inclusion theorem; Kronecker product; numerical radius; 18909.

Spectrum; structure; flavor; hadron; quark; spectroscopy; 19010.

Spectrum; wavelengths; energy levels; lutetium; 18369.

Spectrum; wavelengths; yttrium; energy levels; ion; ionization energy; 18868 .

Spectrum analysis; strain gage; bearing noise; failure prevention; machinery noise; noise signature; non-destructive evaluation; piezoelectric polymer; SP547, pp. 303-314 (July 1979).

Spectrum analysis; ultrasonic spectroscopy; instantaneous power spectra; color-coded B-scan; spectra-color ultrasonography (SCU); SP525, pp. 261-266 (Apr. 1979).

Spectrum analysis; ultrasonics; acoustic; computer processing; digital acquisition; digital signal processing; pulse-echo techniques; SP525, pp. 281-286 (Apr. 1979).

Spectrum analyzers; steady state mode; tolerance vibration levels; automatic diagnostics; digitized data; SP547, pp. 286295 (July 1979).

Spectrum management; standardization organizations; telecommunications; TVI; vehicular electronics; electromagnetic bioeffects; electromagnetic compatibility; electromagnetic immunity; electromagnetic interference; electromagnetic radiation; electromagnetic susceptibility; SP55I.

Speech communication; audition; communications; hearing; hearing aids; selection of hearing aids; CIS4, Revised 1978.

Speed; ultrasonic; attenuation; brain tumor; clot; hemorrhage; hydrocephalus; impedance; infarct; SP525, pp. 81-84 (Apr. 1979).

Speed of light; $\mathrm{CO}_{2}$ laser; frequency comparison; frequency multiplication; frequency synthesis; laser frequency measurement; Penning trap; 18608 .

Speed of light; time standards; atomic clocks; frequency standards; frequency synthesis; fundamental constants; length standards; physical measurement systems; review article; 18346.

Speeds of sound; vapor pressures; densities; enthalpies; entropies; equation of state; internal energies; isobars; isobutane; isochores; isotherms; Joule-Thomson inversion; latent heats of vaporization; melting line; orthobaric densities; specific heats; NBSIR 79-1612.

Speeds of sound; vapor pressures; densities; enthalpies; entropies; equation of state; internal energies; isobars; isochores; isotherms; Joule-Thomson inversion; latent heats of vaporization; melting line; n-butane; orthobaric densities; specific heats; NBSIR 79-1621.

Sphere; spheres; wind noise; windscreen; windscreen performance; windscreens; acoustics; flow; insertion loss; microphone; porous sphere; NBSIR 79-1599.

Spheres; wind noise; windscreen; windscreen performance; windscreens; acoustics; flow; insertion loss; microphone; porous sphere; sphere; NBSIR 79-1599.
Spherical top molecules; combination bands; high resolution spectroscopy; level clusters; 18921

Spherical top molecules; high resolution spectroscopy; level clusters; saturation absorption spectroscopy; 18928 .

Spherical top molecules; 4th and 6th rank octahedral tensor; asymptotic eigensolutions; high resolution spectra; spectral clusters; 18706.

Spherical tops; symmetry analysis; Born-Oppenheimer approximation; centrifugal; Coriolis; frame transformation relations; level cluster; 18599.

Spin exchange; temperature coefficient; time dispersion; wall shift; amplitude modulation; cavity pulling; cavity servo; dielectrically loaded cavity; frequency stability; second-order Doppler shift phase modulation; 18696.

Spin forces; tensor force; charmonium; particle spectroscopy; quarks; selection rules; 18432 .

Spin freezing; spin glasses; susceptibility; amorphous magnetism; Mossbauer effect; rare earths; 18897.

Spin glass; hyperfine fields; magnetic relaxation; magnetism; Mossbauer; rare earths; 18329.

Spin glasses; susceptibility; amorphous magnetism; Mossbauer effect; rare earths; spin freezing; 18897 .

Spin Hamiltonians; spinodal point; spin-phonon coupling; ferromagnetism; magnetization equation; 18605.

Spin operators; Boson expansions; Holstein-Primakoff representation; 18885 .

Spin waves; crystal fields; Laves phase; magnetic materials; neutron scattering; rare earths; 19031 .

Spin waves; transition-metal glasses; amorphous alloys; magnetic properties; neutron scattering; 18898 .

Spindle error; standard deviation; stylus; least squares circle; least squares estimation; polar graph; restraints; roundness standard; NBSIR 79-1758.

Spin-glass, sound velocity; Debye temperature; iron alloy; magnetic susceptibility; 18763 .

Spinodal point; spin-phonon coupling; ferromagnetism; magnetization equation; spin Hamiltonians; 18605.

Spin-phonon coupling; ferromagnetism; magnetization equation; spin Hamiltonians; spinodal point; 18605 .

Splat-cooling; superconductivity; intermetallic compounds; liquid quenching; metastable phases; niobium-silicon alloys; 18734.

Spontaneous deposition technique; biological materials analysis; environmental materials analysis; neutron activation analysis; noble metals analysis; platinum determination; radiochemical separation; 18350 .

Spot size; surface absorption; transmitted pulse; adsorbed water; breakdown mechanism; frequency and time dependence of breakdown thresholds; IR window materials; $\mathrm{NaCl}$; pressure; pulsed TEA $\mathrm{CO}_{2}$ laser surface breakdown; SP54I, pp. 318-326 (Dec. 1978).

Spot-size dependence; breakdown fields; $\mathrm{KCl} ; \mathrm{NaCl}$; SP4I, pp. 309-317 (Dec. 1978).

Spray nozzle; stairway protection; ventilated stair; automatic sprinkler; building code; smoke movement; NBSIR 78-157I.

Spreading resistance; dopant profiles; resistivity; resistivity profiles; semiconductor; silicon; SP4OO-48.

Spreading resistance measurements; thermally stimulated measurements; thyristor materials measurements; thyristor measurements; d-c transmission; deep level measurements; energy conservation; measurement methods; power-device grade si!icon; resistivity varjations; NBSIR 79-1756.

Sprinkler supervisory devices; control units; fire alarm systems; fire detectors; high-rise communication systems; multiplex systems; NFPA standards; residential fire detector; 18625.

Sprinkler systems; health care facilities; hospitals; mattresses; smoke movement; NBSIR 79-1749.

Sputtering; charge transfer; hollow cathode discharge; metal vapor production; 18968 . 
Sputtering; structural information; vitamins; amino acids; drugs; nonvolatile organic compounds; organic trace detection; peptides; pharmaceuticals; secondary ion mass spectrometry; SP519, pp. 627-635 (Apr. 1979).

Square lattice; theories of liquid crystals; configurations of rods; Monte Carlo; orientation entropy; packing of rods; 18530.

SQUID; Josephson junction; noise; point contacts; 18663 .

SQUID; superconducting electronics; superconductivity; A/D converter; Josephson junction; 18678 .

SQU1D; superconductive electronics; cryocoolers; Josephson devices; refrigeration; 18700 .

SQUID magnetometer; auditory evoked response; magnetoencephalography; 18397.

SQUID's; standards; superconductivity; Josephson effect; metrology; noise thermometry; 18871 .

$\mathrm{SrF}_{2} ;$ stress-optical coefficient; $\mathrm{BaF}_{2} ; \mathrm{CaF}_{2} ;$ laser glass; photoelasticity; piezo-birefringence; piezo-optic constants; SP541, pp. 50-54 (Dec. 1978).

$\mathrm{SrF}_{2}$; thermal expansion coefficient; thermo-optic constant; $\mathrm{ZnS} ; \mathrm{ZnSe} ; \mathrm{Al}_{2} \mathrm{O}_{3} ; \mathrm{As}_{2} \mathrm{~S}_{3}$ glass; $\mathrm{BaF}_{2} ; \mathrm{CaF}_{2} ; \mathrm{CdF}_{2}$; chalcogenide glass; elastic compliances; TN993.

SRM; titanium alloy; analytical chemistry; ion-chromatography; law enforcement standards; materials properties; measurement science; science students; DIM/NBS 63 , No. $1 / 2,1-28$ (1979).

SRM; trace elements; urban particulate; error analysis; instrumental analysis; multielement analysis; neutron activation analysis; 18866 .

SRM's; computer interface standards; computers; cryogenic temperature; energy; energy savings; industrial robots; network services; DIM/NBS 63, No. 4, 1-24 (1979).

SRM's; standards; cardiac pacemakers; computer standards; fire safety; molybdenum; network measurement; semiconductors; DIM/NBS 63, No. 10, 1-36 (1979).

SRM-706; standard reference material; diffusion; diffusion coefficient; light scattering; polydisperse; polydispersity; polystyrene; quasielastic light scattering; 18511 .

SSRCR; state; accelerators; leakage radiation; regulations; SP554, pp. 33-35 (Sept. 1979).

Stability; standards; catalog; dynamic programming; iterative procedure; models; optimization; NBSIR 78-1539.

Stability; superconductor; transient flow; transient heat transfer; forced flow; helium; 18813 .

Stability; testing; thin films; accelerated tests; failure mechanisms; failure modes; photovoltaics; reliability; semiconductors; solar cells; SP4O0-58.

Stability; testing; thin films; accelerated tests; failure mechanisms; failure modes; photovoltaics; reliability; semiconductors; solar cells; NBSIR 79-1778.

Stability; time; clocks; communication; frequency standards; navigation; 18826 .

Stability of cracks; virtual crack closure; delamination mechanisms; energy release rate; finite elempnt method; freeedge stresses; graphite epoxy composites; interlaminar cracks; SP563, pp. 255-264 (Oct. 1979).

Stabilization; superconductors; terminology; critical parameters; definitions; flux phenomena; Josephson phenomena; 18681 .

Stabilized lasers; isotropy of space; Michelson-Morley experiment; special relativity; $\mathbf{1 8 8 7 5}$.

Stabilized lasers; isotropy of space; Michelson-Morley experiment; special relativity; 18952 .

Stable matrix; closure; $D$-stability; diagonal matrix; field of values; Hadamard product; inclusion theorem; Kronecker product; numerical radius; spectrum; 18909.

Stachyose; sucrose; sugar analysis; carbohydrates; fructose; galactose; gas-liquid chromatography; glucose; lactose; liquid chromatography; maltose; raffinose; ribose; SP519, pp. 271 278 (Apr. 1979).
Stages in metrication; construction specifications; conversion approaches; dimensional coordination; metrication; Sl; 18493.

Stainless steel; alloys; fiberglass; mechanical properties; nonmetallics; physical properties; NBSIR 79-1609.

Stainless steel; crack propagation; fatigue; fracture resistance; low temperature tests; mechanical porperties; 18621 .

Stainless steel; critical strain rate; fatigue; grain boundary sliding; high temperature; intergranular fracture; 18896.

Stainless steel; heat capacity; low temperature alloy; specific heat; 18419 .

Stainless steel; tensile properties; toughness; cryogenic; fatigue; fracture; high-strength; low-temperature; mechanical properties; nitrogen; nitrogen-strengthened; 18957 .

Stainless steel; thermal conductivity; aluminum alloy; copper; low temperature; magnetothermal conductivity; nickel alloy; 18619 .

Stainless steel alloys; crack propagation; cryogenics; fracture; low temperature tests; martensitic transformations; mechanical properties; 18943.

Stainless steels; steels; superalloys; titanium alloys; crack propagation; fatigue; low temperature tests; nickel alloys; 18695.

Stainless steels; Young's modulus; aluminum alloys; copper alloys; elastic constants; iron alloys; nickel alloys; 18630 .

Stair accidents; stair safety; window accidents; window safety; accident avoidance; accidents in the home; door accidents; home accidents; home safety; safety in the home; NBS-GCR$78-156$.

Stair safety; stairway design; accidents; architectural design; architectural psychology; architectural research; building codes; building design; building regulatory standards; floor coverings; home safety; safety standards; BSS120.

Stair safety; window accidents; window safety; accident avoidance; accidents in the home; door accidents; home accidents; home safety; safety in the home; stair accidents; NBS-GCR-78-156.

Stairway design; accidents; architectural design; architectural psychology; architectural research; building codes; building design; building regulatory standards; floor coverings; home safety; safety standards; stair safety; BSSI2O.

Stairway protection; ventilated stair; automatic sprinkler; building code; smoke movement; spray nozzle; NBSIR 78-157I.

Stairways; standards; buiding design; buildings; construction materials; evacuation; exits; fire endurance; fire protection; NBS-GCR-79-176.

Stairwell pressurization; top injection; tracer gas test; bottom injection; multiple injection; smoke candle test; smoke control; NBSIR 79.1747.

Standard; accelerator design; accelerator operation; health physics; particle accelerators; radiation measurements; radiation protection; H107, Revised.

Standard; buildings; conservation; criteria; design; economics; efficiency; energy; ene rgy budget; equity; life-cycle cost; optimal; 18888 .

Standard; device safety performance classification; gauges; gauging devices; ionizing radiation; radiation measurements; radiation safety; $H 129$.

Standard; test; apparel; extinguishability; fabrics; flammability; garments; hazard; heat transfer; ignitability; 18708.

Standard; trial use and comment; American National Standards Institute; Health Physics Society Standards Committee; mandatory testing program; peer review; personnel dosimetry; processors; 18992.

Standard; $x$-ray diffraction; crystal structure; irtegrated intensities; lattice constants; peak intensities; powder patterns; reference intensities; Monogr. 25, Section 16.

Standard; x-ray image; a ppropriations; fusion diagnostics; gravity waves; laser-interferometer; microwave measurements; 
non-destructive evaluation; pipe welds; DIM/NBS 63, No. 3, 1.28 (1979).

Standard benchmarks; synthetic benchmarks; workload characterization; workload definition; benchmarking; benchmark library; selection of ADP systems; SP500-38.

Standard cross section; ${ }^{235} \mathrm{U}(\mathrm{n}, \mathrm{f})$; fission cross section; linac; neutron flux determination; proton telescope; 18581 .

Standard deviation; stylus; least squares circle; leasi squares estimation; polar graph; restraints; roundness standard; spindle error; NBSIR 79.1758.

Standard electromagnetic field; antenna gain calculation; field strength calibration; pyramidal horn antenna; if radiation monitor; 18814 .

Standard frequencies; television color subcarrier; time and frequency calibration methods; time calibration; time signals; frequency calibration; high frequency; Loran-C; low frequency; radio broadcasts; satellite broadcasts; SP559.

Standard humic materials; fulvic acid; humic acid; humic substances; reference collection of humic substances; soil organic matter; SP5 19, pp. $793-796$ (Apr. 1979).

Standard Industrial Classification; computers; data processing; Federal Information Processing Standards Publication; industries; representations and codes; FIPS PUB 66.

Standard performance measures; computer performance evaluation (CPE); computer performance management (CPM); installation management; installation performance management; performance measurement and reporting; resource management; SP500-53.

Standard practice; thermoluminescence dosimeters; electronic devices; electrons; photons; radiation hardness; NBSIR 79. 1723.

Standard recommended practice; synopsis; ultrasonic standards; ultrasonic testing; evaluation; international; standardization; NBSIR 79-1790.

Standard reference data; anthropometry; data base; engineering psychology; ergonomics; evaluation; human engineering; human factors; human performance; NBS-GCR-79-169.

Standard reference data; surface tension; viscosity; bromides; chlorides; data compilation; density; electrical conductance; fluorides; halides; iodides; molten salt mixtures; JPCRD 8, No. 1, 125-302 (1979).

Standard reference data; synthetic gas; chemical processing; engineering calculations; equation of state; fluid properties; prediction; 19022.

Standard reference material; composition; high-carbon ferrochromium; homogeneity testing; preparation; processing; 18414.

Standard reference material; diffusion; diffusion coefficient; light scattering; polydisperse; polydispersity; polystyrene; quasielastic light scattering; SRM-706; 18511 .

Standard reference material; dynamic coupled-column liquid chromatography; extractor column; generator column; polynuclear aromatic hydrocarbon; SP519. pp. 219-224 (Apr. 1979).

Standard reference material; temperature coefficient; time-lag; gas transmission rate; manometric technique; oxygen; permeability; poly(ethylene terephthalate); SP260-58.

Standard reference material (SRM); antiepilepsy drugs in serum; serum matrix; SP519, pp. $447-453$ (Apr. 1979).

Standard reference materials; accuracy; compatibility; radioactivity reference materials; $l 8539$.

Standard reference materials; analysis; certification; characterization; composition; properties; research materials; special reference materials; SP260, 1979-80 Edition.

Standard reference materials; analytical laboratory; certified reference materials; measurement; measurement compatibility; reference materials; 18748 .

Standard reference materials; nutrient analysis; nutrition; SP519, pp. 249-255 (Apr. 1979).
Standard reference materials; standards; digital periodic integrator; electron microprobe; homogeneity; 18973.

Standard reference materials; steel; digital periodic integrator; electron microprobe; homogeneity; SP260-65.

Standard reference materials; temperature; thermal conductivity; thermal expansion; thermal properties; vapor pressure; viscosity; calorimetry; elasticity; electrical resistivity; emittance; measurement system; 18905.

Standard reference materials; thermal conductivity; thermophysical properties; electrical resistivity; enthalpy; specific heat; 18615 .

Standard reference materials; thermodynamic properties; alumina; aluminum oxide; calorimetry; corundum; enthalpy; heat capacity; sapphire; specific heat; 18377.

Standard reference materials; transmittance; reflectance; 18844 .

Standard source; electrically calibrated detector; optical radiation measurements; primary standards; 18796 .

Standard test; testing; measurement; solar collector; solar energy; solar radiation; standards; BSS 117 .

Standard test methods; absorptive coatings; accelerated laboratory tests; durability; outdoor exposure; solar collectors; 18554.

Standard test procedure; thermal storage tests; water tank thermal storage; ASHRAE Standards; evaluation of test procedure; solar heating components; 18425 .

Standard-addition calibration; trace analysis; trapping column; equilibration trapping; gas chromatography; headspace gas stripping; SP519, pp. $739-746$ (Apr. 1979).

Standardization; AID; assistance; developing economies; foreign relations; industrializing nations; international relations; LDC's; measurement services; NBSIR 78-1712.

Standardization; database management; 18777.

Standardization; standard recommended practice; synopsis; ultrasonic standards; ultrasonic testing; evaluation; international; NBSIR 79-1790.

Standardization; symbols; communication; evaluation methods; fire safety; hazard warnings; pictograms; safety information; NBSIR 79-1760.

Standardization; transportation; effective carbon atom number; hazardous materials; packaging; plastics; NBSIR 79-I768.

Standardization; transportation; effective carbon atom number; hazardous materials; packaging; plastics; 18639.

Standardization organizations; telecommunications; TVl; vehicular electronics; electromagnetic bioeffects; electromagnetic compatibility; electromagnetic immunity; electromagnetic interference; electromagnetic radiation; electromagnetic susceptibility; electronic smog; SP551.

Standards; accelerators; $1 \mathrm{EC}$; interlocks; leakage; radiation; safety; SP554, pp. 29-32 (Sept. 1979).

Standards; accuracy and precision; gold films; gravimetry; neutron activation analysis; Rutherford backscattering; 18490.

Standards; alkalies; cement; history; 18854 .

Standards; antenna; communications; land-mobile; 18398.

Standards; apparel; burn injury; ease of ignition; fabrics; fire; flammability tests; garments; heat transfer; 18991 .

Standards; architectural barriers; building design; building site planning; environmental psychology; evaluation; fire escape; human research; measurement; pedestrian movement; regulation; safety; SP552, pp. 101-113 (July 1979).

Standards; architectural barriers; building design; building site planning; environmental psychology; evaluation; fire escape; human research; measurement; pedestrian movement; regulation; safety; 18430 .

Standards; basic research; computer; energy conservation; environmental quality; industrial productivity; materials utilization; measurement capabilities; medical aids; product safety; public health and safety; science and technology transfer; SP538. 
Standards; buiding design; buildings; construction materials; evacuation; exits; fire endurance; fire protection; stairways; NBS-GCR-79-176.

Standards; building codes; code enforcement; fire prevention codes; fire safety; master planning; regulation; SP552, pp. 225-247 (July 1979).

Standards; building codes; community development; construction costs; contractors; housing; rehabilitation; SP536, pp. 55-61 (Feb. 1979).

Standards; building research; criteria; energy; engineering; industry construction; measurement techniques; SP439-1.

Standards; calibrations; dissemination of units; electrical measurements; electric power measurements; electrotechnology; impact of measurements; measurement technology assessment; National Measurement System; NBSIR 75-935.

Standards; calibrations; measurements; microwaves: radiofrequency; 18561 .

Standards; calorimeter; laser; laser MAP; laser measurements: laser power and energy; NBS standards; 18914.

Standards; cardiac pacemakers; computer standards; fire safety; molybdenum; network measurement; semiconductors; SRM's; DIMINBS 63, No. 10, 1-36 (1979).

Standards; catalog; dynamic programming; iterative procedure; models; optimization; stability; NBSIR 78-1539.

Standards; chromatography/column packings (GC); electroncapture detection; evaporation; nomenclature; sample workup; SP519, pp. 809-810 (Apr. 1979).

Standards; codes; guidelines; hydrogen; regulations; safety; 18394.

Standards; compatibility; permachor; permeation; plastic containers; polyethylene; 18348 .

Standards; conservation; energy cost; existing buildings; regulation; retrofit; SP552, pp. 197-209 (July 1979).

Standards; consumer product; human factors; lawn mowers; reaction time; safety; NBSIR 77-1299.

Standards; consumer products; human factors; human performance; lawn mowers; psychophysics; safety; NBSIR 77. 1298.

Standards; curtains; drapes; fabrics; fire; flammability; international; self-extinguishment; ships; NBSIR 79-1596.

Standards; database; data-description; data-dictionary; datadirectory; data-manipulation; DBMS; languages; query; SP500-51.

Standards; decision tables; formulation analysis; information networks; regulations; SP552, pp. 249-266 (July 1979).

Standards; digital periodic integrator; electron microprobe; homogeneity; standard reference materials; 18973.

Standards; dosimetry; high energy radiotherapy beams; leakage; measurement techniques; medical accelerators; neutrons; relative biological effect; shielding techniques; SP554.

Standards; electrodes; electrodes, ion-selective; electrodes, reference; errors; ion-selective electrodes; sensors, chemical; 18334.

Standards; explosion; fire; hydrogen; procedures; regulations; research needs; safety; 18776 .

Standards; millimeter waves; 18320 .

Standards; standard test; testing; measurement; solar collector; solar energy; solar radiation; BSS 117.

Standards; State; buildings; design; energy; legislation; solar; NBSIR 79.1705.

Standards; states; calibrations; measurements; radiation; radiation control; radiation measurements; radiation protection; radiation safety; 18779 .

Standards; structural design; foundation design; geotechnical engineering; housing construction; mine subsidence; mining; site development; 18324.

Standards; sulfur-hexafluoride; calibration; Clausius-Mossotti equation; compressed-gas capacitor; high voltage; 18513 .

Standards; superconductivity; Josephson effect; metrology; noise thermometry; SQUID's; 18871 .
Standards; superconductors; critical current; definitions o terms; measurement techniques; 18762

Standards; surface roughness; optical scattering; optical surface quality; scattering; 18999 .

Standards; surveillance; undercover equipment; body-worn transmitters; communications equipment; FM transmitters; law enforcement equipment; 18381 .

Standards; systematic procedure; building fires; equivalency; evaluation; fire safety; models; research; SP552, pp. 13-27 (July 1979).

Standards; technical bases; building research; building technology; codes; criteria; project summaries; SP446-2.

Standards; technique development; compact tension specimen; crack; crack, well-characterized; destructive evaluation; fatigue flaw evaluation; fracture mechanics; 18744 .

Standards; technology transfer; UN Conference on Science and Technology for Development (UNCSTD); Africa; Asia; developing countries; industrialization; Latin America; management; measurement; metrology; quality control; SP543.

Standards; TEM horn antenna; antenna; conical transmission line; impulse response; impulsive fields; TN 1008.

Standards; temperature; vacuum; humidity; ozone; pressure; 18335

Standards; terminology; analog-to-digital converter; digital-toanalog converter; IEEE subcommittee; performance specifications; sample/hold circuit; 18365.

Standards; test measures; tolerances; vapor recovery; bottom loading; field standard provers; field standards; field standard test measures; provers; specifications; H105-3.

Standards; test methods; batteries; photovoltaic energy conversion; power conditioning; power systems; solar cells; NBSIR $79-1743$

Standards; testing; computer; hot water; measurement; rating; solar; 18428.

Standards; testing; mobile home; packaged solar space-heating system; rating; NBSIR 79-1799.

Standards; testing; traceability; dose; ionizing; radioactivity; 18361 .

Standards; traceability; low-level; measurements; radioactivity; 18400 .

Standards; transfer; documentation; energy; evaluation; guidelines; implementation; large-scale; management; mathematical models; policy analysis; software; SP534.

Standards; ultrasonics; variability; calibration; diffusion bonding; measurement assurance program; reference blocks; NBSIR 79-1742.

Standards; upholstered furniture; building fires; cost-benefit analysis; costs; decision analysis; fire losses; furniture; hazard analysis; probability; residential buildings; sensitivity analysis; smoke detectors; TNIIOI.

Standards; VDE; antennas; CISPR; ground screen; measurements; 19033.

Standards; Woods Hole; environment; ICRM; natural matrix; radioactivity; 18981

Standards development; administrative procedures; building codes; building regulations; buildings; construction; economic impacts; environmental considerations; innovative practices; regulatory research; SP552.

Standards development; energy standards; environmental standards; safety and health standards; Monogr. 165.

Standards development; energy standards; environmental standards; safety and health standards; NBSIR 79-1703.

Standards for heat pumps; testing procedures for heat pumps; heat pumps; part-load evaluation; 18703 .

Standards for heat pumps; testing procedures for heat pumps; heat pumps; part-load evaluation; 18778 .

Standards system; voluntary standards; bibliography; buildings; certification; economics of standards; legal aspects of stan- 
dards; product certification; product liability; regulation; NBSIR 79-1900.

Standards systems; United Kingdom; West Germany; antitrust; Canada; certification; Denmark; economics of standards; government policy; international standards; laboratory accreditation; NBS-GCR-79-172.

Standing wave tube; absolute sound power source; particle velocity; plane wave; sound intensity; sound power; 18728 .

Standing waves; thin-film coatings; two-photon absorption; ultraviolet wavelength scaling; damage thresholds; electric fields; laser damage; nanosecond pulses; pulsewidth dependence; SP541, pp. 190-202 (Dec. 1978).

Star formation; emission line stars; emission nebulae; $\mathbf{8 5 4 6 .}$

Star shift; two-level model; absorption; cesium; exponential index; ionization; multiphoton; Rabi frequency; 18892 .

Stark; far-infrared; laser; methyl fluoride; 18426 .

Stark broadening; atomic spectra; nitrogen; oxygen; plasmabroadening; singly ionized oxygen; 18737 .

Stark broadening; deuterium; hydrogen; ion dynamic effect; plasma line shift; spectral lines; 18948 .

Stark modulation; Stark spectroscopy; trace gas analysis; $\mathrm{CO}_{2}$ laser; derivative spectra; infrared analysis; spectral coincidences; 18538 .

Stark spectroscopy; trace gas analysis; $\mathrm{CO}_{2}$ laser; derivative spectra; infrared analysis; spectral coincidences; Stark modulation; 18538 .

Stars; stellar winds; line profiles; P-Cygni lines; radiative transfer; resonance lines; 18515 .

Stars, chromospheres; stars, coronae; stars, late-type; stars, winds; ultraviolet spectra; satellites; space astronomy; 18606.

Stars, coronae; stars, flare; stars, supergiants; x-ray, sources; 18839.

Stars, coronae; stars, late-type; stars, winds; ultraviolet spectra; satellites; space astronomy; stars, chromospheres; 18606.

Stars, flare; stars, supergiants; $\mathrm{x}$-ray, sources; stars, coronae; 18839.

Stars, late-type; stars, winds; ultraviolet spectra; satellites; space astronomy; stars, chromospheres; stars, coronae; 18606.

Stars, supergiants; x-ray, sources; stars, coronae; stars, flare; 18839.

Stars, winds; ultraviolet spectra; satellites; space astronomy; stars, chromospheres; stars, coronae; stars, late-type; 18606.

State; accelerators; leakage radiation; regulations; SSRCR; SP554, pp. 33-35 (Sept. 1979).

State; buildings; design; energy; legislation; solar; standards; NBSIR 79-1705.

State changes; well depths; collisions; cross sections; intermolecular potential; 18671 .

Statement of work; teleprocessing services program; timesharing; competitive negotiated procurement; computer management; remote teleprocessing; SP500-52, pp. 231-232 (Oct. 1979).

States; calibrations; measurements; radiation; radiation control; radiation measurements; radiation protection; radiation safety; standards; 18779.

Static displacement measurement; vibration measurement; advanced sensors; Doppler millimeter radar; gas turbine monitoring; remote motion detection; SP547, pp. 58-62 (July 1979).

Stationary states; switching; threshold switching; fluctuation; master equation; noise spectrum; nonequilibrium; 18674 .

Statistical analysis; amperometry; chloride analysis; clinical analysis; clinical chemistry; coulometry; definitive method; electrolytes; reference method; serum chloride analysis; SP260-67.

Statistical analysis; Boolean search system; computer programs; curve fitting; data analysis; data base management; data retrieval; file handling; graphic analysis; IMS information retrieval; KWOC indexing; least-squares; linear regression; MIS; plotting; 18597.
Statistical analysis; clinical analysis; clinical chemistry; definitive method; electrolytes; flame atomic emission spectroscopy; reference method; semiautomated pipetting; serum potassium analysis; $S P 260-63$.

Statistical analysis; storms; structural engineering; wind pressure; wind speeds; building (codes); probability distribution functions; $B S S I I 8$.

Statistical analysis; strapping; survey; accuracy; cryogenic; error estimation; liquefied natural gas; LNG; marine; mathematical modeling; measurement; photogrammetric; precision; ship cargo; NBSIR 79-175I.

Statistical analysis; thin films; Weibull distribution; laser damage; probability; SP54I, pp. 235-248 (Dec. 1978).

Statistical broadening; three-level system; coherent excitation; dressed atoms; inhomogeneous broadening; intense laser; multiphoton dissociation; multiphoton ionization; Rabi frequency; 18439 .

Statistical computing section; worksheet; capabilities; ease of learning and using; installation; language; maintenance; numerical analysis; OMNITAB 78; portability; poster; reliability; 18903 .

Statistical design of experiment; statistical terms and formulas; statistics; systematic error; uncertainty; precision; radioactivity measurements; 18427 .

Statistical detection algorithm; vibrational signatures; automated surveillance; rotating machinery monitoring; SP547, pp. 203-231 (July 1979).

Statistical estimation; diffusion coefficents; iteration; moisture profile modeling; nondestructive evaluation; SP563, pp. 3246 (Oct. 1979).

Statistical mechanics; face centered cubic; ground state; interfaces; multi-ion interactions; ordered alloys; 18614 .

Statistical methods; statistics; conformance; sampling; specifications; 18440 .

Statistical modeling; ultrasonic tissue characterization; computer processing; estimation theory; liver attenuation; spectral analysis; SP525, pp. 125-132 (Apr. 1979).

Statistical plots; statistics; stem-and-leaf displays; box plots; CALCOMP; computing system; confidence ellipse; OMNITAB 78; plots; portability plots; residuals; 18954.

Statistical sampling; environmental measurements; modeling; sampling schemes; SP519, pp. 1-6 (Apr. 1979).

Statistical sampling; surveys; fire departments; fire incidence; fire reporting; fire victims; human behavior; NBS-GCR-78135.

Statistical scattering; tissue signature; ultrasonic scattering; ultrasound; detection of lung disease; frequency signature; SP525, pp. 135-141 (Apr. 1979).

Statistical terms and formulas; statistics; systematic error; uncertainty; precision; radioactivity measurements; statistical design of experiment; 18427.

Statistics; ADP costs; Federal acquisition dates; Federal ADP statistics; Federal ADP work-years; Federal Government computers; Federal minicomputers; SP500-46.

Statistics; conformance; sampling; specifications; statistical methods; 18440 .

Statistics; stem-and-leaf displays; box plots; CALCOMP; computing system; confidence ellipse; OMNITAB 78; plots; portability plots; residuals; statistical plots; 18954 .

Statistics; systematic error; uncertainty; precision; radioactivity measurements; statistical design of experiment; statistical terms and formulas; 18427 .

Statistics; ultrasonics; visual-optical tests; acoustic; annual report; eddy currents; inspection; magnetic particles; nondestructive evaluation; penetrants; radiography; NBSIR 781581 .

Statistics; Youden plot; Youden ruggedness test; Youden squares; Youden, W. J; 18990. 
Stcady state mode; tolerance vibration levels; automatic diagnostics; digitized data; spectrum analyzers; SP547, pp. 286295 (July 1979).

Steam; table-dielectric constant of water; thermophysical properties of water; water; dielectric constant of water; interpolating equation dielectric; 18937.

Steam-valves; turbine operational safety; turbogenerators; detection procedures; mechanical failures; SP547, pp. 250-279 (July 1979).

Steel; digital periodic integrator; electron microprobe; homogeneity; standard reference materials; SP260-65.

Steel corrosion; coating protection; pile corrosion; protection of steel; salt water corrosion; sea water corrosion; 18424 .

Steel industry; technology; capital formation; Experimental Technology Incentives Program; regulatory impact; research and development; NBS-GCR-ETIP 79-67.

Steels; superalloys; titanium alloys; crack propagation; fatigue; low temperature tests; nickel alloys; stainless steels; 18695 .

Stellar astronomy; ultraviolet spectroscopy; galactic astronomy; space astronomy; 18590 .

Stellar atmospheres; circumstellar dust; line formation; radiation transfer; 18435.

Stellar chromospheres; stellar coronae; emission line stars; flare stars; late-type stars; 18920.

Stellar chromospheres; stellar coronae; stellar winds; ultraviolet spectra; emission lines, stars; late-type stars; 18528 .

Stellar coronae; emission line stars; flare stars; late-type stars; stellar chromospheres; 18920 .

Stellar coronae; stellar winds; ultraviolet spectra; emission lines, stars; late-type stars; stellar chromospheres; 18528 .

Stellar dynamics; structure-hydrodynamics; galaxies; 18483 .

Stellar winds; line profiles; P-Cygni lines; radiative transfer; resonance lines; stars; 18515 .

Stellar winds; ultraviolet spectra; emission lines, stars; late-type stars; stellar chromospheres; stellar coronae; 18528.

Stem-and-leaf displays; box plots; CALCOMP; computing system; confidence ellipse; OMNITAB 78; plots; portability plots; residuals; statistical plots; statistics; 18954 .

Step discontinuity; TEM-cell; variational formulation; coaxial transmission line; cut-off frequency; equivalent circuit; modal analysis; scattering matrix; NBSIR 79-1606.

Step response; divider; high voltage; impulse; lightning impulse; pulse calibration; ramp response; 18727.

Step response; transients; divider; Duhamel's integral; high voltage; impulse; pulse measurements; response time; NBSIR 79 1933.

Stepwise excitation; tunable dye lasers; enhanced ionization; ionization spectrometry; LEI; 18983.

Steroid hormones; gas chromatography; nitrogen-phosphorus; selective detection; SP519, pp. $419-427$ (Apr. 1979).

Stimulated bremsstrahlung; multiphoton transitions; scattering in an external field; 18710 .

Stirling machine; superconducting quantum ihterfering devices (SOUID); low input power cyclic cryogenic refrigerator; multi-stage displacer; U.S. Patent 4,143,520.

Stirling refrigerators; aluminum SRM's; computer systems; electron microscopy; group decisions; properties of steam; space; DIMINBS 63, No. 5, 1-28 (1979).

Stochastic scattering; tissue characterization; ultrasonic tissue scattering; ultrasound attenuation; ultrasound diagnosis; backscatter frequency dependence; cirrhosis; composition-dependent scattering; fatty liver; SP525, pp. 157-163 (Apr. 1979).

Stone; abrasives; ceramics; coated abrasives; grinding; SP562, pp. 201-207 (Oct. 1979).

Stopping power; $\alpha$-particles; electrons; heavy ions; international commission on radiation units and measurements; protons; 18358 .
Stopping power; transport theory; absorbed dose; attenuation coefficient; detector response functions; dosimetry; electrons; foil transmission; photons; 18371 .

Storage; performance criteria; photovoltaics; power conditioning; power control; solar energy; 18634.

Storage; Studsvik AB Atomenergi, Sweden; thermoluminescence dosimeters; fading; Harshaw Chemical Company; relative humidity; 18989 .

Storage; transmission; cost; economics; hydrogen; production; 18812 .

Storage stability; amine accelerators; degradation of benzoyl peroxide; dental composites; restorative dental resins; shelflife of composites; 18809 .

Stored ions; systematic effects; Ba ions; frequency stability; frequency standard; ion temperature; laser induced cooling; $\mathrm{Mg}$ ions; optical \& microwave double resonance; 18697.

Storms; structural engineering; wind pressure; wind speeds; building (codes); probability distribution functions; statistical analysis; $B S S I I 8$.

Stoves; test methods; appliance; cooking; efficiency; energy; human factors; kitchen ranges; labeling; NBSIR 78-1556.

Stoves; wood; accident investigations; chimneys; coal; creosote; fire departments; fire safety; heating equipment; maintenance; NBSIR 79-1731.

Stoves; wood; accident investigations; chimneys; coal; creosote; fire departments; fire safety; heating equipment; maintenance; NBS-GCR-78-149.

Stoves; wood; accident investigations; chimneys; coal; creosote; fire departments; fire safety; heating equipment; maintenance; 18537 .

Strain; stress; superconductor; critical-current; degradation; $\mathrm{Nb}_{3} \mathrm{Ge} ; 18781$.

Strain gage; bearing noise; failure prevention; machinery noise; noise signature; non-destructive evaluation; piezoelectric polymer; spectrum analysis; SP547, pp. 303-314 (July 1979).

Strain tides; core resonance; free wobble; laser strainmeter; ocean load; preferred frame; spatial anisotropy; 18823 .

Strain-gage; substitution weighing; weighing; weights; constant loading; force; high precision; high-precision weighing; load cell; mass; mass comparator; mass difference; J. Res. 84, No. 5, 347-351 (1979).

Strapping; survey; accuracy; cryogenic; error estimation; liquefied natural gas; LNG; marine; mathematical modeling; measurement; photogrammetric; precision; ship cargo; statistical analysis; NBSIR 79-175I.

Stratified sampling; benchmarking; clustering; performance evaluation; SP500-52, pp. 105-111 (Oct. 1979).

Stratospheric $\mathrm{HOCl}$; air pollutants; chlorine sink; high resolution IR spectra; hypochlorous acid; large A-value molecules; 18864 .

Streamers; transient phenomena; electrical breakdown; high speed photography; Kerr effect; liquid breakdown; nitrobenzene; partial discharges; 18843 .

Strength; brittle failure; flaw sizes; grain size dependence of strength; SP562, pp. $429-452$ (Oct. 1979).

Strength; defects; etching; glass; grinding; polishing; SP562, pp. 489-500 (Oct. 1979).

Strength; stress intensity factor; abrasive machining; ceramics; contact stress; damage penetration; fracture mechanics; fragmentation; glass; grinding; impact; silicon nitride; SP562, pp. 23-42 (Oct. 1979).

Strength; superconducting motor; composites; fiberglass; mechanical porperties; modulus; 18616 .

Strength; surface; finishes; flexure; fracture; fracture mechanics; grinding; silicon nitride; SP562, pp. 463-474 (Oct. 1979).

Strength; surface damage; glass, grinding; SP562, pp. 93-106 (Oct. 1979).

Strength; surfaces; coatings; SiC; SP562, pp. $483-488$ (Oct. 1979). 
Strength-size effects; brittle failure; flaw populations; flaws; fractography; fracture origins; grinding; machining; polishing; sanding; SP562, pp. 351-378 (Oct. 1979).

Strength-to-weight ratio; composites; durability; flexural characteristics; recreational equipment; SP563, p. 208 (Oct. 1979).

Stress; superconductor; critical-current; critical-field; degradation; multifilamentary strain; $\mathrm{Nb}_{3} \mathrm{Sn} ; 18780$.

Stress; superconductor; critical-current; degradation; $\mathrm{Nb}_{3} \mathrm{Ge}$; strain; 18781 .

Stress calculation; virial theorem of Clausius; equilibrium; homogeneous systèm; hydrostatic pressure; internal stress; internal virial; molecular dynamics; Monte Carlo method; periodic boundaries; pressure; 18456 .

Stress concentrations; tension; tensor polynomial; compression; failure; finite elements; graphite-epoxy; interlaminar stresses; laminated composites; SP563, pp. 242-254 (Oct. 1979).

Stress corrosion; corrosion; crevice corrosion; galvanic corrosion; inhibitors; pitting corrosion; rust; CIS9, Revised 1979.

Stress intensity factor; abrasive machining; ceramics; contact stress; damage penetration; fracture mechanics; fragmentation; glass; grinding; impact; silicon nitride; strength; SP562, pp. 23-42 (Oct. 1979 ).

Stress relaxation; torsion pendulum; dynamic mechanical; high pressure extrusion; oriented polyethylene; relaxation process; 18767.

Stress-cracking agent; uniaxial creep; crack growth; failure; polyethylene; solvent; 18766.

Stress-optical coefficient; $\mathrm{BaF}_{2} ; \mathrm{CaF}_{2}$; laser glass; photoelasticity; piezo-birefringence; piezo-optic constants; $\mathrm{SrF}_{2}$; SP54I, pp. $50-54$ (Dec. 1978).

Stripline; superconductivity; surface impedance; copper; niobium; J. Res. 84, No. 3, 247-259 (1979).

Strontium; temperature dependence; alkaline earth elements; barium; beryllium; calcium; electrical resistivity; magnesium; radium; JPCRD 8, No. 2, $439-498$ (1979).

Strontium fluoride; alkaline earth fluorides; refractive index; SP541, pp. 55.58 (Dec. 1978 ).

Strontium fluoride; antireflection coatings; calcium fluoride; $\mathrm{cw}$ laser damage; DF laser; fusion cast; laser damage; laser window; single crystal; SP541, pp. 78-85 (Dec. 1978).

Strontium titanate; beryllium; ceramics; cryogenics; dielectricconstant; electrets; electrocaloric effect; entropy; ferroelectrics; glass-ceramics; heat switches; magneto-thermal conductivity; polarization; potassium tantalate; refrigeration; specific heat; 18680 .

Structural analysis; bis(hexopyranosyl)amine; carbon-13; conformational analysis; nitrogen-15 coupling constants; nitrogen-15 n.m.r. spectroscopy; proton; proton coupling; 18764.

Structural analysis; tall buildings; wind pressure; aerodynamics; boundary layer; loads (forces); roughness; 18351 .

Structural analysis; ultimate strength; advanced composites; advanced ships; elastic properties; fatigue tests; nondestructive tests; SP563, pp. 286-298 (Oct. 1979).

Structural design; foundation design; geotechnical engineering; housing construction; mine subsidence; mining; site development; standards; 18324 .

Structural design and fabrication procedures; transverse electromagnetic (TEM) cell; electromagnetic susceptibility testing; TNIOII.

Structural engineering; abnormal loads; buildings (codes); probability theory; progressive collapse; reliability; 18415.

Structural engineering; building; ice; load; roof; roof load; snow; solar collector; NBS-GCR-79-181.

Structural engineering; wind pressure; wind speeds; building (codes); probability distribution functions; statistical analysis; storms; BSS118.

Structural information; vitamins; amino acids; drugs; nonvolatile organic compounds; organic trace detection; pep- tides; pharmaceuticals; secondary ion mass spectrometry; sputtering; SP519, pp. 627-635 (Apr. 1979).

Structural performance/cost trade-offs; airframe structure; costtrade comparisons; manufacturing technologies; SP563, pp. 226-227 (Oct. 1979).

Structural sheet molding compound; glass fiber reinforcement; polyester resin; SP563, pp. 108-129 (Oct. 1979).

Structural stability; alloys; electronegativity; electronic configuration; $s-p$ binding; 18383 .

Structural stability; transition elements; electronegativities; hybridization; 18421 .

Structure; bond angles; bond distances; gas-phase polyatomic molecules; gas-phase spectroscopy; microwave spectroscopy; molecular conformation; molecular spectroscopy; molecular structure; molecules; JPCRD 8, No. 3, 619-722 (1979).

Structure; calculations; cell dimensions; crystal; defect; energy; hydrocarbon; methyl-branch; 18787.

Structure; flavor; hadron; quark; spectroscopy; spectrum; 19010.

Structure; $x$ ray; crystal; diffraction; $L_{i_{5}} B_{4}$; neutron powder; 18382 .

Structured approach; auditing; capacity planning; computer performance evaluation; Information Management System (IMS); management reporting; performance analysis; SP5OO52, pp. 9-19 (Oct. 1979).

Structure-hydrodynamics; galaxies; stellar dynamics; 18483 .

Struvite analogue; crystal structure; magnesium phosphate; potassium phosphate; 18491 .

Student (W. S. Gosset, 1876-1937; t-transformation of correlation coefficient; distribution of regression coefficients; R. A. Fisher; Student's $t$; Student's z; 18543.

Student's $t$; Student's $z$; Student (W. S. Gosset, 1876-1937; ttransformation of correlation coefficient; distribution of regression coefficients; R. A. Fisher; 18543.

Student's z; Student (W. S. Gosset, 1876-1937; t-transformation of correlation coefficient; distribution of regression coefficients; R. A. Fisher; Student's $t ; 18543$.

Studsvik AB Atomenergi, Sweden; thermoluminescence dosimeters; fading; Harshaw Chemical Company; relative humidity; storage; 18989 .

Stylus; least squares circle; least squares estimation; polar graph; restraints; roundness standard; spindle error; standard deviation; NBSIR 79-1758.

Stylus instruments; Auger spectroscopy; corrosion films; ESCA; impurities; microroughness; optical microscopy; polishing defects; scattered light; SIMS; SP562, pp. 337-350 (Oct. 1979).

Styrene; tetrafluoroethylene; copolymerization; polymerization; pressure; radiation; 18512 .

Submarine compartment; combustion products; fire barrier coatings; fire growth; flame spread; foam insulation; heat release; interior finish; laboratory fire tests; material ignitability; NBSIR 78-1584.

Submicrometer positioning instrumentation; TEM microscope stage; flexure pivots; linear positioning; micromanipulator; optical microscope stage; piezoelectric drives; scanning stage; SEM microscope stage; 18327.

Subsidies; technological change; capital formation; economic growth; municipal wastewater treatment facilities; public sector efficiency; NBS-GCR-ETIP 78-4O.

Subsidies; technological change; capital formation; economic growth; mass transit; public sector efficiency; NRS-GCRETIP 78-4I.

Subsidies; technological change; capital formation; economic growth; nuclear power plants; public sector efficiency; NBSGCR-ETIP 78-42.

Subsidies; technological change; capital formation; economic growth; maritime transport; public sector efficiency; NBSGCR-ETIP 78-43. 
Subsidies; technological change; capital formation; economic growth; journal publishing; public sector efficiency; NBSGCR-ETIP $78-44$.

Subsidies; technological change; capital formation; economic growth; health facilities; public sector efficiency; NBS-GCRETIP $78-45$.

Subsidies; technological change; capital formation; economic growth; local air transport; public sector efficiency; NBSGCR-ETIP 78-46.

Subsidies; technological change; capital formation; economic growth; public sector efficiency; NBS-GCR-ETIP 78-47.

Subsidy policy; technological innovation; air pollution-regulatory policy; economic incentives; Federal funding of civilian R\&D; regulatory policy; NBS-GCR-ETIP 78-53.

Subsonic water drop impact; surface flaws; crack activation; numerical simulation; SP562, pp. 501-511 (Oct. 1979).

Substitution weighing; weighing; weights; constant loading; force; high precision; high-precision weighing; load cell; mass; mass comparator; mass difference; strain-gage; J. Res. 84, No. 5, 347-351 (1979).

Subsurface damage; surface damage; electron channeling; plasticity; SP562, pp. 395-404 (Oct. 1979).

Subsurface defects; surface contamination; surface preparation; laser glass; particle characterization; polishing compounds; SP562, pp. 231-244 (Oct. 1979).

Suburban; urban; application; buildings; commercial; daylighting; energy; environments; heating; passive; solar; 18894.

Subway fires; toxicity; upholstered furniture; arson; bibliographies; building fires; compartment fires; fabric flammability; fire detection systems; fire tests; flammability tests; human behavior; plastics; polymers; smoke; smoke detectors; NBSIR 79.1745

Sucrose; sugar analysis; carbohydrates; fructose; galactose; gasliquid chromatography; glucose; lactose; liquid chromatography; maltose; raffinose; ribose; stachyose; SP519, pp. 271 278 (Apr. 1979).

Sudden perturbation limit; transition probability; unified atom approximation; $\Sigma-\Pi$ transition; adiabatic limit; atomic collisions; quasimolecule terms; 18576.

Sudden-perturbation limit; transition probability; $\Sigma-\Pi$ transitions; adiabatic perturbation theory; elastic scattering phase shifts; pseudocrossing; 18575.

Sugar analysis; carbohydrates; fructose; galactose; gas-liquid chromatography; glucose; lactose; liquid chromatography; maltose; raffinose; ribose; stachyose; sucrose; SP519, pp. 271-278 (Apr. 1979).

Sugar analysis; sugar scale; wavelength; laser application; pol; polarimetry; saccharimetry; 18768 .

Sugar scale; wavelength; laser application; pol; polarimetry; saccharimetry; sugar analysis; 18768 .

Sulfate; $x$ ray; anion exchange; filter paper; fuel oil; spectrometry; 18635 .

Sulfate radical; thiocyanate radical anion; aqueous solution; carbonate radical; chemical kinetics; halogen radical anions; nitrate radical; oxyanion radicals; phosphate radical; photolysis; radiolysis; rates; selenium radicals; NSRDS-NBS65.

Sulfonation; sulfur trioxide; triethyl phosphate; polystyrene; sodium (polystyrene sulfonate); 18542 .

Sulfur; Arrhenius parameters; combustion; decomposition; free radicals; hydrocarbons; hydrogen; nitrogen; organic compounds; oxidation; oxygen; oxygenated; rate constant; NBSIR 79.1941

Sulfur; sulfur energy level in silicon; thermally stimulated capacitance; thermally stimulated current; deep level measurements; defect center characterization; defect density; ion implantation; silicon; 18458.

Sulfur dioxide; troposphere; kinetics; photochemistry; review; SP557, pp. 99-100 (Aug. 1979).
Sulfur energy level in silicon; thermally stimulated capacitance; thermally stimulated current; deep level measurements; defect center characterization; defect density; ion implantation; silicon; sulfur; 18458 .

Sulfur hexafluoride; tracer gas; weatherization; air infiltration; air sample bags; energy conservation; retrofit; NBSIR 79 1728 .

Sulfur trioxide; triethyl phosphate; polystyrene; sodium (polystyrene sulfonate); sulfonation; 18542.

Sulfur-hexafluoride; calibration; Clausius-Mossotti equation; compressed-gas capacitor; high voltage; standards; 18513 .

Sulfuric acid; trace organics; battery; chromatography; SPS19, pp. 797-802 (Apr. 1979).

Sulphonamides; amino acids; barbiturates; carboxylic acids; catecholamines; conjugates; detection sensitivity; dipeptides; drugs; HPLC; ion-pair adsorption; ion-pair chromatography; ion-pair partition; metabolites; psychotropic amines; SP519, pp. 509-523 (Apr. 1979).

Sun, atmosphere; sun, chromosphere; sun, plage; ultraviolet, spectra; L $\alpha$ emission; 18876.

Sun, chromosphere; sun, plage; ultraviolet, spectra; L $\alpha$ emission; sun, atmosphere; 18876.

Sun, chromosphere; sun, spectra; sun, transition region; ultraviolet, spectra; 18922 .

Sun, plage; ultraviolet, spectra; L $\alpha$ emission; sun, atmosphere; sun, chromosphere; 18876 .

Sun, spectra; sun, transition region; ultraviolet, spectra; sun, chromosphere; 18922.

Sun, transition region; ultraviolet, spectra; sun, chromosphere; sun, spectra; 18922.

Super spring; ultraviolet radiation; calibrations; energy; fluid mixtures; light; liquefied natural gas; measurements; microwaves; DIM/NBS 63, No. 9, 1-32 (1979).

Superalloys; titanium alloys; crack propagation; fatigue; low temperature tests; nickel alloys; stainless steels; steels; 18695.

Superconducting; torque; trapped flux; gyroscope; ralativity; space; 18846.

Superconducting cavity stabilized oscillator; superconducting oscillators; superconducting resonators; high stability oscillators; 18692 .

Superconducting electronics; superconductivity; A/D converter; Josephson junction; SQU1D; 18678 .

Superconducting losses; superconducting microcircuit; superconducting striplines; dielectric losses; 18486 .

Superconducting magnets; advanced composites; composite materials; cryogenics; industrial laminates; magnetic fusion energy; 18560

Superconducting microcircuit; superconducting striplines; dielectric losses; superconducting losses; 18486.

Superconducting motor; composites; fiberglass; mechanical porperties; modulus; strength; 18616 .

Superconducting oscillators; superconducting resonators; high stability oscillators; superconducting cavity stabilized oscillator; 18692 .

Superconducting power cable; tan $\delta$; cryogenic temperature; dielectric loss; polymer films; polymers; polypropylene; polyurethane; 18713 .

Superconducting power transmission; thermal cycling; thermal stress; cable cool-down; cool-down helium; liquid helium; NBSIR 79-1618.

Superconducting power transmission lines; supercritical helium; density wave oscillations; flow oscillations; flow stability; liquid helium; 18567.

Superconducting quantum interfering devices (SQU1D); low input power cyclic cryogenic refrigerator; multi-stage displacer; Stirling machine; U.S. Patent 4,143,520.

Superconducting resonators; high stability oscillators; superconducting cavity stabilized oscillator; superconducting oscillators; 18692 . 
Supcrconducting striplincs; diclcctric losses; superconducting losscs; superconducting microcircuit; 18486

Supcrconductive electronics; cryocoolers; Josephson devices; rcfrigeration; SQUID; 18700.

Supcrconductivity; A/D converter; Josephson junction; SQUID; superconducting electronics; 18678 .

Superconductivity; digital electronics; magnetometry; quantum interference; 18701 .

Superconductivity; electronics; instruments; integrated circuits; Josephson junctions; measurements; 18859.

Superconductivity; high speed logic; Josephson computer; Josephson junction; microstriplines; 18666 .

Superconductivity; intermetallic compounds; liquid quenching; metastable phases; niobium-silicon alloys; splat-cooling; 18734.

Superconductivity; Josephson effect; metrology; noise thermometry; SQUID's; standards; 18871 .

Superconductivity; supercooling; temperature fixed points; $W$; AuAl $;$; Auln $;$; Be; 1r; 18549.

Superconductivity; surface impedance; copper; niobium: stripline; J. Res. 84, No. 3, 247-259 (1979).

Superconductivity; temperature scale; thermometry; cryogenics; fixed points; pure materials; 18550 .

Superconductivity; thermometry; W; $\mathrm{AuAl}_{2} ; \mathrm{Auln}_{2} ; \mathrm{Be}$; cryogenic temperature scale; fixed points; $1 \mathrm{r} ; S P 260-62$.

Superconductivity; tunnel junctions; Josephson junctions; microwave receivers; microwaves; mixers; 18683 .

Superconductor; critical-current; critical-field; degradation; multifilamentary strain; $\mathrm{Nb}_{3} \mathrm{Sn}$; stress; 18780 .

Superconductor; critical-current; degradation; $\mathrm{Nb}_{3} \mathrm{Ge}$; strain; stress; 18781 .

Superconductor; tin; alloy; copper; electrical property; niobium; 18656.

Superconductor; tin; alloy; copper; low temperatures; niobium; precipitate; 18655 .

Superconductor; training superconducting magnet; epoxy; epoxy-impregnated magnets; 18718 .

Superconductor; transient flow; transient heat transfer; forced flow; helium; stability; 18813 .

Superconductors; ac generators; heat transfer; helium; hydrodynamics; largc magnets; power transmission; review; 18822 .

Superconductors; critical current; critical current degradation; multifilamentary $\mathrm{Nb}_{3} \mathrm{Sn}$; multifilamentary $\mathrm{NbTi} ; 18622$.

Superconductors; critical current; definitions of terms; measurement techniques; standards; 18762 .

Superconductors; electrical properties; low temperatures; mechanical properties; metallurgical properties; niobiumtitanium; physical properties; 18552 .

Superconductors; terminology; critical parameters; definitions; flux phenomena; Josephson phenomena; stabilization; 18681 .

Supercooling; temperature fixed points; W; $\mathrm{AuAl}_{2} ; \mathrm{Auln}_{2} ; \mathrm{Be}$; 1r; superconductivity; 18549 .

Supercritical helium; density wave oscillations; flow oscillations; flow stability; liquid helium; superconducting power transmission lines; 18567.

Superfine structure; symmetry analysis; tableau calculus; high resolution spectroscopy; hyperfine structure; level clusters; saturation absorption spectra; 18609.

Superfluid $\mathrm{He}^{3}$; symposium; cryogenics; dilution refrigerators; helium 3; Japan; millikelvin research; nuclear cooling; Pomeranchuk refrigerators; solid $\mathrm{He}^{3} ; 18679$.

Superfluid ${ }^{3} \mathrm{He}$; frequency sums; Rainer and Serene; 18553.

Supergranules; convection; solar; solar atmospheric motions; 18444.

Superparamagnetic particles; blocking temperature; magnetic; particles; 18746 .

Surface; finishcs; flexure; fracture; fracture mechanics; grinding; silicon nitride; strength; SP562, pp. 463-474 (Oct. 1979).
Surface; XPS; angular study; electron spectroscopy for chemical analysis (ESCA); silicon; 18417

Surface absorption; transmitted pulse; adsorbed water; breakdown mechanism; frequency and time dependence of breakdown thresholds; IR window materials; $\mathrm{NaCl}$; pressurc; pulsed TEA $\mathrm{CO}_{2}$ laser surface breakdown; spot size; SP541, pp. $318-326$ (Dec. 1978 ).

Surface analysis; ASTM Committee E-42; Auger electron spectroscopy; electron spectroscopy; ESCA; secondary ion mass spectroscopy; 18406 .

Surface analysis; elemental analysis; ion microprobe mass analyzer; local thermal equilibrium model; microanalysis; secondary ion mass spectrometry; 18979.

Surface analysis; tetrazole; benzotriazole; charge transfer; copper; luminescence; microspectrofluorimetry; photoluminescence; spectrofluorimetry; 18504 .

Surface area; bone; chemisorption; enamel; hydroxyapatite; 18411 .

Surface characterization; surface contamination; biomaterials; negative control; polyethylene; processing sheets and rods; NBSIR 77-1401.

Surface characterization; surface crack; turbine blade; acoustic surface wave; ceramic; SP562, pp. 379-392 (Oct. 1979).

Surface characterizations; surface finishing; abrasion; ceramic machining; ceramics; effects of machining on ceramic properties; hardness; SP562.

Surface chemistry; ultraviolet photoemission spectroscopy; adsorption; chemisorption; formaldehyde; ruthenium; 18791 .

Surface chemistry; wear; diamond drilling; drilling; drilling additives; Rehbinder effect; rock fracture; SP562, pp. 115-137 (Oct. 1979).

Surface condition; surface grinding; chip formation; grinding forces; SP562, pp. 75-91 (Oct. 1979).

Surface conductivity; conductivity; electric conductivity; electrokinetics; glass-surface; 18910 .

Surface contamination; biomaterials; negative control; polyethylene; processing sheets and rods; surface characterization; NBSIR 77-1401.

Surface contamination; surface preparation; laser glass; particle characterization; polishing compounds; subsurface defects; SP562, pp. 231-244 (Oct. 1979).

Surface crack; turbine blade; acoustic surface wave; ceramic; surface characterization; SP562, pp. 379-392 (Oct. 1979).

Surface damage; electron channeling; plasticity; subsurface damage; SP562, pp. $395-404$ (Oct. 1979).

Surface damage; glass, grinding; strength; SP562, pp. 93-106 (Oct. 1979).

Surface films; capacitor; cross capacitor; dielectric; dissipation factor; loss angle; microphonic coupling; phase angle; 18454 .

Surface finishing; abrasion; ceramic machining; ceramics; effects of machining on ceramic properties; hardness; surface characterizations; SP562.

Surface flaws; crack activation; numerical simulation; subsonic water drop impact; SP562, pp. 501-511 (Oct. 1979).

Surface grinding; chip formation; grinding forces; surface condition; SP562, pp. 75-91 (Oct. 1979).

Surface impedance; copper; niobium; stripline; superconductivity; J. Res. 84, No. 3, 247-259 (1979).

Surface layer, role of; dilution effect, at same $\mathrm{pH}$ and concentration; hydration shell, role of; hydroxylapatite, at different $\mathrm{pHs}$; isotopic exchange, isoionic; recrystallization, role of; $J$. Res. 84, No. 5, 395-406 (1979).

Surface mobility; alloys; antiphase domains; critical behavior; domain growth; domain walls; ordering; 18373 .

Surface mobility; alloys; antiphase domains; critical behavior; domain growth; domain walls; ordering; 18613 .

Surface mounted incandescent lighting fixture; thermal insulation; thermocouple; branch circuit wiring; electrical junction box; hazardous temperatures; load current; overlamping; NBSIR 79-1912. 
Surface of platinum influenced by method heating; contrast augmentation of reflecting surfaces; double-diaphragm; faces (crystal) on platinum crucibles; hematite forming on platinum; iron as alloy in platinum; platinum ware; J. Res. 84, No. 5, 385-394 (1979).

Surface optical absorption; coating optical absorption; laser calorimetry theory; optical calorimetry theory; SP541, pp. 712 (Dec. 1978).

Surface preparation; laser glass; particle characterization; polishing compounds; subsurface defects; surface contamination; SP562, pp. 231.244 (Oct. 1979).

Surface reaction; anthranilic acid; chemisorption; cupric anthranilate; cupric ion-containing hydroxyapatite; reaction kinetics; 18972.

Surface recombination; CCD; electrical test structure; gated diode; generation lifetime; integrated gated-diode electrometer; integrated test structure; leakage current; MOSFET dc profiler; NBSIR 79-1744.

Surface roughness; absorption; diamond-turning; scattered light; SP541, pp. 122-130 (Dec. 1978).

Surface roughness; BK-7 glass; fused silica; laser damage; polished surfaces; pulse duration dependence of damage; SP541, pp. 164-167 (Dec. 1978).

Surface roughness; optical scattering; optical surface quality; scattering; standards; 18999.

Surface roughness; y-deflection modulation; ceramic; scanning electron microscope; secondary electron emission; silicon; SP562, pp. 407-415 (Oct. 1979).

Surface tension; defect geometry; fluid elasticity; liquid penetrant testing; Rideal-Washburn equation; J. Res. 84, No. 4, 287-292 (1979).

Surface tension; viscosity; bromides; chlorides; data compilation; density; electrical conductance; fluorides; halides; iodides; molten salt mixtures; standard reference data; JPCRD 8, No. 1, 125-302 (1979).

Surface tension of liquid gallium; thermodynamic properties; convection; heat capacity measurement; $\mathrm{Pb}-\mathrm{Sn}$ off-eutectic alloys; phase diagram of $\mathrm{K}_{2} \mathrm{O}-\mathrm{Fe}_{2} \mathrm{O}_{3}$ system; solidification; NBSIR 79-1767.

Surface threshold damage; free-running laser pulses; giant laser pulse; optical fiber damage; pulsed $\mathrm{Nd}^{3+}$ laser damage; single and multiple element fibers; SP541, pp. 168-189 (Dec. 1978).

Surface-active comonomers; acrylates; adhesion, dental; bonding: coupling agent; dental; monomers; resins; 18461 .

Surfaces; coatings; SiC; strength; SP562, pp. 483-488 (Oct. 1979).

Surveillance; undercover equipment; body-worn transmitters; communications equipment; FM transmitters; law enforcement equipment; standards; 18381 .

Survey; accuracy; cryogenic; error estimation; liquefied natural gas; LNG; marine; mathematical modeling; measurement; photogrammetric; precision; ship cargo; statistical analysis; strapping; NBSIR 79-1751.

Surveys; fire departments; fire incidence; fire reporting; fire victims; human behavior; statistical sampling; NBS-GCR-78-135.

Survival; transformation; $x$ ray; carcinogenesis; neutron; repair; SP554, pp. 63-73 (Sept. 1979).

Susceptibility; amorphous magnetism; Mossbauer effect; rare earths; spin freezing; spin glasses; 18897.

Susceptibility; calibration; iron oxide; magnetic property; magnetometer; powders; 18804 .

Susceptibility and emission measurements; transverse electromagnetic cell; measurement procedures; TNIO13.

Susceptibility measurements; electromagnetic; radiated emissions; 18579.

Suspended-span structures; time-dependent loads; aerodynamic stability; aeroelasticity; fluctuating flow; flutter; 18688 .

SU4; alpha-particles; correlations; mass formula; nuclear; quartets; reactions; spectroscopy; 18423 .
Swelling of rubber network; cross-linking of rubber; dicumyl peroxide; elasticity theory of rubber; modulus of rubber; Mooney-Rivlin constants; rubber elasticity theory; rubber, natural; J. Res. 84, No. 5, 353-358 (1979).

Swept-frequency diffraction; angular scattering; characterization of tissue; optical correlation; scattering; SP525, pp. 143152 (Apr. 1979).

Switching; threshold switching; fluctuation; master equation; noise spectrum; nonequilibrium; stationary states; 18674 .

Switching power transistor; tester; transistor; base drive circuit; electronic circuits; inductive load; nondestructive; protection circuit; reverse bias; safe operating area; second breakdown; SP400-54.

Symbols; communication; evaluation methods; fire safety; hazard warnings; pictograms; safety information; standardization; NBSIR 79-1760.

Symmetric top; torsional frequencies; bromoethanes; ideal gas thermodynamic properties; internal rotation; iodoethane; potential barrier heights; JPCRD 8, No. 2, $519-526$ (1979).

Symmetry analysis; Born-Oppenheimer approximation; highresolution spectra; level clusters; Raman spectra; rotationvibration spectra; 18598 .

Symmetry analysis; Born-Oppenheimer approximation; centrifugal; Coriolis; frame transformation relations; level cluster; spherical tops; 18599.

Symmetry analysis; tableau calculus; high resolution spectroscopy: hyperfine structure; level clusters; saturation absorption spectra; superfine structure; 18609.

Symposium; cryogenics; dilution refrigerators; helium 3; Japan; millikelvin research; nuclear cooling; Pomeranchuk refrigerators; solid $\mathrm{He}^{3}$; superflu id $\mathrm{He}^{3} ; 18679$.

Synchronization; time; clock; GOES; microprocessors; satellite; 18393.

Synchronization; time scales; coordinate time; portable clocks; relativity; 18993.

Synchronous excitation spectroscopy; cresol; luminescence spectrometry; organic pollutants monitoring; SP519, pp. 679 684 (Apr. 1979).

Synchronous satellite; time code; Western Hemisphere; broadcast; coordinated universal time; 19029.

Synchrotron radiation; autoionization; core-excited states; magnesium; photoabsorption-spectrum; 18912.

Synopsis; ultrasonic standards; ultrasonic testing; evaluation; international; standardization; standard recommended practice; NBSIR 79-1790.

Synthesis; x-ray diffraction; crystal structure; mechanism of formation; molecular compound; silver-sulfur-tungsten cluster; 18636.

Synthetic benchmarks; workload characterization; workload definition; benchmarking; benchmark library; selection of ADP systems; standard benchmarks; SP500-38.

Synthetic carbonaceous resins; continuous flow system; environmental analysis; pesticides; SP5 19, pp. 345.353 (Apr. 1979).

Synthetic gas; chemical processing; engineering calculations; equation of state; fluid properties; prediction; standard reference data; 19022.

Synthetic program; workload mapping; benchmarking; performance evaluation; SPSO0-52, pp. 193-199 (Oct. 1979).

Synthetic programs; benchmarking; computer performance measurement; distributed processing; interactive systems; kernels; modeling; real-time; simulation; SP500-52, pp. 53-64 (Oct. 1979).

System classification; passive solar systems; performance standards; SP552, pp. 217-224 (July 1979 ).

System design tradeoffs; thruput measures; comparison measures; evaluation process; performance measures; performance ratings; response time; SP500-52, pp. 163-176 (Oct. 1979). 
Systcm sccurity testing; diagnostic testing; performance assurance; performance evaluation; remote monitoring; SP5OO42.

System testing; audit; capacity planning; financial applications; long-range planning; management control; measurement; modeling; on-line system design; performance evaluation; performance management; prototyping; remote terminal emulation; SP500-52, pp. 129-140 (Oct. 1979).

Systematic cffects; Ba ions; frequency stability; frequency standard; ion temperature; laser induced cooling; $\mathrm{Mg}$ ions; optical \& microwave double resonance; stored ions; 18697 .

Systematic error; uncertainty; calibration; gage blocks; length; measurement assurance; measurement process control; Monogr. 163.

Systematic error; uncertainty; precision; radioactivity measurements; statistical design of experiment; statistical terms and formulas; statistics; 18427.

Systematic procedure; building fires; equivalency; evaluation; fire safety; models; research; standards; SP552, pp. 13-27 (July 1979).

Systems analysis; building codes; buildings; building standards; classification; decision tables; earthquake-resistant design; information networks; network; seismic design; TN110O.

Systems analysis; systems safety; walls; barrier analysis; compartment fires; compartments; fault tree analysis; fire models; fire protection engineering; probability statistics; NBS-GCR79.163.

Systems design; buildings; communications systems; fire safety; high-rise; model codes; people movement; BSS115.

Systems safety; walls; barrier analysis; compartment fires; compartments; fault tree analysis; fire models; fire protection engineering; probability statistics; systems analysis; NBS-GCR79.163

Systems security; ADP availability; annual loss exposure; application system vulnerability; computer security; data confidentiality; data integrity; data security; physical security; procedural security; risk analysis; risk assessment; FIPS PUB 65 .

\section{$\mathrm{T}$}

Tableau calculus; high resolution spectroscopy; hyperfine structure; level clusters; saturation absorption spectra; superfine structure; symmetry analysis; 18609 .

Table-dielectric constant of water; thermophysical properties of water; water; dielectric constant of water; interpolating equation dielectric; steam; 18937.

Tables; argon; comparisons; correlation; ethylene; experimental; magnetic suspension; orthobaric liquid density; 18627 .

Tabulations; $x$ rays; atomic form factor; coherent scattering; cross sections; gamma rays; photons; Rayleigh scattering; JPCRD 8, No. 1, 69-106 (1979).

Tailorable; temperature; accumulator; analog; centralized; check-out system; dessicant; discrete; displacement; fiber optics; filters; flight critical; flow; fluid; go-no-go; ground readout; hydraulic; IMACS; SP547, pp. 345-357 (July 1979).

Tall buildings; wind loads; wind tunnels; aerodynamics; boundary layers; dynamic response; interference effects; 18977 .

Tall buildings; wind pressure; aerodynamics; boundary layer; loads (forces); roughness; structural analysis; 18351 .

Talystep traces; alkali halides; backward scattering; forward scattering; grain boundaries; isostatic forging; optical figure; optical homogeneity; single crystal; SP541, pp. 65-69 (Dec. 1978).

Tan 8; cryogenic temperature; dielectric loss; polymer films; polymers; polypropylene; polyurethane; superconducting power cable; 18713 .

Tangential sensitivity; broadband; dynamic range; Hermitian magnitude; isotropicity; isotropic, real-time, electric-field sensor (IRES); resistively loaded dipole; 19034.
Tank capacity tables; thermophysical properties; total heating value; composition; custody transfer; density; flow rate; LNG; mixtures; specific heating value; 18564 .

Tank capacity tables; thermophysical properties data; total heating value; composition; custody transfer; density; flow rate; $\mathrm{L} N G$; mathematical models; mixtures; specific heating value; 18838 .

Tantalum; tungsten; wavelengths; ytterbium; energy levels; hafnium; ionization energies; lutetium; osmium; rhenium; 18506.

Tantalum hydride; vanadium hydride; $\alpha$ phase; $485 \mathrm{~K}$; diffusion; quasielastic scattering; 18730 .

Tantalum tungstate; thermal expansion; ionic conductors; neutron diffraction; powder method; profile refinement; 19037.

Tape drive characteristics; computer magnetic tape drives; computer tape controllers; group coded recording; interface electrical characteristics; interface functional characteristics; magnetic tape drives; NRZI recording; phase encoded recording; NBS-GCR-78-127.

Tape loop; timc signal; timc window; gated frequency analysis; Gaussian window; impulsive complex signals; linear averaging; reciprocating; records after trigger; SP547, pp. 315-322 (July 1979).

Tape-bonded devices; acoustic emission; beam lead devices; electronic devices; hermeticity; hybrids; nondestructive tests; semiconductor; SP400-59.

Tax incentives; adaptive reuse; buildings; demolition; economics; historic preservation; life-cycle costing; redevelopment; rehabilitation; TN980.

Tax incentives; adaptive reuse; buildings; demolition; economics; historic preservation; life-cycle costing; redevelopment; rehabilitation; 19016.

Tax incentives; building; private interests; public objectives; taxation; SP552, pp. 337-346 (July 1979).

Taxation; tax incentives; building; private interests; public objectives; SP552, pp. 337.346 (July 1979).

Taximeters; tolerances; volume-measuring devices; weighing devices; weights; length-measuring devices; liquid-measuring devices; measures; scales; specifications; H44, 1979 Edition.

t-butyl radical; unimolecular decomposition; activation energy; $A$-factor; comparative rate; flow system; heat of formation; hexylmethylethane; 18743 .

TCAM data flow; teleprocessing; input lockout; mathematical modeling; queuing models; race conditions; SP500-52, pp. 219-226 (Oct. 1979).

TDM wattmeters; thermal wattmeters; transfer standards; electro-dynamic wattmeters; energy measurements; energy standards; international comparisons; metrology; power measurements; precise electrical measurements; 18529.

TEA laser; electronic discharge; hydrogen halides; isotopes; laser; 18667.

Technical analysis; time-sharing; TSP; benchmarking; cost analysis; evaluation; procurement; SP50O-52, pp. 233-234 (Oct. 1979).

Technical bases; building research; building technology; codes; criteria; project summaries; standards; SP446-2.

Technical communicator; technical paper; trade press; audience; feature article; news release; publication announcement; scientist-author; 18817 .

Technical information; technology application; access to information; architect; information format; information sources; NBS-GCR-78-153.

Technical information; technology application; access to information; architect; information format; information sources; NBS-GCR-78-154.

Technical paper; trade press; audience; feature article; news release; publication announcement; scientist-author; technical communicator; 18817 . 
Tcchnique development; compact tension specimen; crack; crack, well-characterized; destructive evaluation; fatigue flaw evaluation; fracture mechanics; standards; I8744.

Technological change; capital formation; economic growth; municipal wastewater treatment facilities; public sector efficiency; subsidies; NBS-GCR-ETIP 78-40.

Technological change; capital formation; economic growth; mass transit; public sector efficiency; subsidies; NBS-GCRETIP 78-4I.

Technological change; capital formation; economic growth; nuclear power plants; public sector efficiency; subsidies; NBS-GCR-ETIP 78-42.

Technological change; capital formation; economic growth; maritime transport; public sector efficiency; subsidies; NBS. GCR-ETIP 78-43.

Technological change; capital formation; economic growth; journal publishing; public sector efficiency; subsidies; NBSGCR-ETIP 78-44.

Technological change; capital formation; economic growth; health facilities; public sector efficiency; subsidies; NBSGCR-ETIP 78-45.

Technological change; capital formation; economic growth; local air transport; public sector efficiency; subsidies; NBSGCR-ETIP 78-46.

Technological change; capital formation; economic growth; public sector efficiency; subsidies; NBS-GCR-ETIP 78-47.

Technological change; commercial impacts; Experimental Technology Incentives Program; Federal Supply Service; life cycle costing; procurement of water heaters; NBS-GCR-ETIP $78-5 I$.

Technological change; commercial impacts; Experimental Technology Incentives Program; Federal Supply Service; life cycle costing; procurement of water heaters; NBS-GCR-ETIP 78.52 .

Technological change; commercialization; empirical investigation; ETIP; Federal civilian R\&D; implementing; management practices; NBS-GCR-ETIP 78-57.

Technological change; commercialization; empirical investigation; ETIP; Federal civilian R\&D; implementing; management practices; NBS-GCR-ETIP 78-58.

Technological change; Experimental Technology Incentives Program; impact of government on industry; procurement experiments; procurement policy; research and development policy; NBS-GCR-ETIP 78-49.

Technological changes; administrative experiment; anti-trust regulation; economic incentive; environmental regulation; innovation; regulatory reform; NBS-GCR-ETIP 79-66.

Technological innovation; administrative experimentation; Environmental Protection Agency; evaluability assessment; Experimental Technology Incentives Program; industrial pollution regulation; market mechanism; offset policy; regulatory policy; NBS-GCR-ETIP 79-62.

Technological innovation; administrative experimentation; best practicable technology; clean water regulation; Environmental Protection Agency; evaluability assessment; evaluation; Experimental Technology Incentives Program; NBS-GCRETIP 79-63.

Technological innovation; administrative experimentation; evaluability assessment; evaluation; experimental methods; Experimental Technology Incentives Program; regulation; regulatory oversight; regulatory processes and regulatory effects; NBS-GCR-ETIP 79-64.

Technological innovation; administrative experimentation; Environmental Protection Agency; evaluation design; Experimental Technology Incentives Program; pesticide policy; regulatory policy; regulatory reform; NBS-GCR-ETIP 79-7I.

Technological innovation; air pollution-regulatory policy: economic incentives; Federal funding of civilian R\&D; regulatory policy; subsidy policy; NBS-GCR-ETIP 78-53.
Technological innovation; appeals process; consensus standards; electrical distribution systems; flat conductor cable; National Electrical Code; SP552, pp. 57-78 (July 1979).

Technological innovation; computer program; economic performance; electric utilities; Experimental Technology Incentives Program; productivity; regulatory commission; regulatory policy; NBS-GCR-ETIP 79-70.

Technology; capital formation; Experimental Technology Incentives Program; regulatory impact; rese arch and development; steel industry; NBS-GCR-ETIP 79-67.

Technology application; access to information; architect; information format; information sources; technical information; NBS-GCR-78-153.

Technology application; access to information; architect; information format; information sources; technical information; NBS-GCR-78-I54.

Technology innovation; telecommunications; administrative experimentation; economic deregulation; evaluability assessment; evaluation; Experimental Technology Incentives Program; Federal Communications Commission; regulatory experimentation; TNIIO4, Vols. I and 2.

Technology transfer; computer-aided design and manufacture (CAD/CAM); footwear industry; fragmented industries; government-industry cooperation; imports; innovation; leather; manufacturing technology; materials development; shoes; SP527.

Technology transfer; engineering; international cooperation; international research; international standards; National Bureau of Standards (NBS); National Engineering Laboratory (NEL); NBSIR 79-I792.

Technology transfer; UN Conference on Science and Technology for Development (UNCSTD); Africa; Asia; developing countries; industrialization; Latin America; management; measurement; metrology; quality control; standards; SP543.

Tectonic motions; continental drift; distortion-of-plate; geophysics; ranging; $/ 8459$.

Tectonics; atmospheric properties; distance measurement; geodesy; instrumentation; multiwavelength techniques; 18816 .

Tectonics; distance measurements; earthquakes; geodesy; geophysics; instrumentation; satellites; 18574 .

Telecommunication trends; transborder data flows; computertelecommunications convergence; computer trends; information age; information as a resource; information revolution; social issues in information; $/ 8975$.

Telecommunications; administrative experimentation; economic deregulation; evaluability assessment; evaluation; Experimental Technology Incentives Program; Federal Communications Commission; regulatory experimentation; regulatory policy; TNII04, Vols. I and 2.

Telecommunications; TVI; vehicular electronics; electromagnetic bioeffects; electromagnetic compatibility; electromagnetic immunity; electromagnetic interference; electromagnetic radiation; electromagnetic susceptibility; electronic smog; home entertainment electronics; SP55I.

Telemetry; transducer; dynamic calibration; evaluation; interagency transducer project; performance characteristics; TNIIIO.

Teleoperator vision; wrist-mounted TV; depth image; proximity sensor; robot vision; NBSIR 78-1576.

Teleprocessing; input lockout; mathematical modeling; queuing models; race conditions; TCAM data flow; SP500-52, pp. 219-226 (Oct. 1979).

Teleprocessing services program; timesharing; competitive. negotiated procurement; computer management; remote teleprocessing; statement of work; SP500-52, pp. 231-232 (Oct. 1979).

Television color subcarrier; time and frequency calibration methods; time calibration; time signals; frequency calibration; 
high frequency; Loran- $C$; low frequency; radio broadcasts; satellite broadcasts; standard frequencies; SP559.

Television fire; electrical failure; fire containment; ignition; TN1109.

TEM cell; EMC measurements; radiation resistance; rectangular coax; shielded strip line: 18345 .

TEM horn; time domain measurement; antenna gain; broadband antenna; directivity; FFT; method of measurements; non-dispersive; resistive loading; 18856 .

TEM horn antenna; antenna; conical transmission line; impulse response; impulsive fields; standards; TN1008.

TEM microscope stage; flexure pivots; linear positioning; micromanipulator; optical microscope stage: piezoelectric drives; scanning stage; SEM microscope stage; submicrometer positioning instrumentation; 18327.

TEM-cell; attenuation; coupled integral equations; dispersion; lossy dielectric slab; modes considerations; NBSIR 79-1615.

TEM-cell; variational formulation; coaxial transmission line; cut-off frequency; equivalent circuit; modal analysis; scattering matrix; step discontinuity; NBSIR 79-1606.

Temperature; accumulator; analog; centralized; check-out system; dessicant; discrete; displacement; fiber optics; filters; flight critical; flow; fluid; go-no-go; ground readout; hydraulic; IMACS; instantaneous diagnosis and analysis; SP547, pp. 345-357 (July 1979).

Temperature; thermal analysis; concrete (reinforced); fire load; fire resistance; fire tests structural engineering; TN985.

Temperature; thermal conductivity; thermal expansion; thermal properties; vapor pressure; viscosity; calorimetry; elasticity; electrical resistivity; emittance; measurement system; standard reference materials; 18905 .

Temperature; vacuum; humidity; ozone; pressure; standards; 18335.

Temperature and molecular weight dependence; hydrodynamic radius; intrinsic viscosity; polymer dimensions in solution; polystyrene; radius of gyration; 18960 .

Temperature coefficient; time dispersion; wall shift; amplitude modulation; cavity pulling; cavity servo; dielectrically loaded cavity; frequency stability; second-order Doppler shift phase modulation; spin exchange; 18696 .

Temperature coefficient; time-lag; gas transmission rate; manometric technique; oxygen; permeability; poly(ethylene terephthalate); standard reference material; $S P 260-58$.

Temperature dependence; adiabatic heating; $\mathrm{As}_{2} \mathbf{S}_{3}$; automatic bridge: $\mathrm{Bi}_{12} \mathrm{GeO}_{20} ; \mathrm{CaCO}_{3} ; \mathrm{CaF}_{2}$; capacitance measurement; evaporated electrodes; pressure transducer; 18466 .

Temperature dependence; alkali elements; cesium; electrical resistivity; francium; lithium; magnetic flux density dependence; potassium; pressure dependence; rubidium; sodium; JPCRD 8, No. 2, $339-438$ (1979).

Temperature dependence; alkaline earth elements; barium; beryllium; calcium; electrical resistivity; magnesium; radium; strontium; JPCRD 8, No. 2, $439-498$ ( 1979).

Temperature dependence; hydrodynamic radius; light scattering; molecular weight dependence; polystyrene; radius of gyration; 18545.

Temperature dependence; theoretical and experimental comparison; vibrational effect; HCl-Ar; rotational linewidths; 18689

Temperature dependence; ultrasound velocity; zero crossing detection; non-invasive temperature monitoring; soft tissue; SP525, pp. 57-61 (Apr. 1979).

Temperature dependence; vibrational energy transfer; hydrogen halides; isotopes; 18929

Temperature dependence of cavitation threshold; threshold; acoustic cavitation; cavitation; cavitation threshold $v s$ temperature; radiation-induced cavitation; NBSIR 79-1753.

Temperature depression; water vapor measurement; wet bulb; wet element; convective heat transfer; convective mass transfer; emissivity of water; evaporation coefficient; humidity measurement; monomolecular film; psychrometer; J. Res. 84, No. 2, 161-177 (1979).

Temperature effects; thermal; ${ }^{235} \mathrm{U}$; chemical effects; delayed neutrons; Einstein model; fission; 18687.

Temperature effects; water boil; degradation; epoxy resins; Kevlar 49; moisture; one-tenth scale motor case; S-glass; SP563, pp. 177-197 (Oct. 1979).

Temperature fixed points; W; $\mathrm{AuAl}_{2} ; \mathrm{Auln}_{2} ; \mathrm{Be}$; Ir; superconductivity; supercooling; 18549 .

Temperature measurement; Johnson noise; Josephson junctions; noise thermometry; resistive SQUIDS; 18603.

Temperature reconstruction; ultrasound; aperture synthesis; computed tomography; Doppler; fluid flow; high resolution; reconstruction; SP525, pp. 227-233 (Apr. 1979).

Temperature reconstruction; ultrasound; aperture synthesis; computed tomography; Doppler; fluid flow; high resolution; reconstruction; SP525, pp. 235-246 (Apr. 1979).

Temperature scale; thermometry; cryogenics; fixed points; pure materials; superconductivity; 18550 .

Temperature scale; thermometry; tunnel diode oscillator; gas thermometer; low temperature; 18548 .

Temperature scale from 630.74 to $1064.43^{\circ} \mathrm{C}$; instruments; International Practical Temperature Scale; interpolation; interpolation instruments; 18665 .

Temperature sensitive parameter; aligned sheet polarizer; birefringent crystal; optical analyzer; polarized light; probe thermometer; U.S. Patent 4,140,393.

Temperature variation of dielectric parameters of soil; cavity resonance; coaxial line resonator; dielectric constant; dielectric loss; lunar sample; 18566.

Temperature variation of permittivity; dielectric constant; dielectric loss; lunar soil; microwave; profile effect on permittivity; 18557.

Temporal changes; A-scan; correlation analysis; SP525, pp. 275-280 (Apr. 1979).

Temporary structures; wood; bridges; buildings; design criteria; glued-laminated timber; safety; 18887 .

Tenability limits; upholstered furniture; detection time; detector location; fire tests; gas detectors; kitchen fires; mobile homes; smoke detectors; NBSIR 79-1915.

Tensile fracture; aircraft structural components; composite materials; linear elastic materials; SP563, p. 3 (Oct. 1979).

Tensile properties; toughness; cryogenic; fatigue; fracture; highstrength; low-temperature; mechanical properties; nitrogen; nitrogen-strengthened; stainless steel; 18957 .

Tensile strength; boron-epoxy; edge cracks; failure modes; finite element method; SP563, pp. 228-238 (Oct. 1979).

Tensile strength; cementing-materials; compressive strength; hot-dry-rock well; permeability to water; pipe-bonding strength; 19018.

Tensilization; thermogravimetric analysis; tire cord; tire cord dip; tire cord finish; emissions; gas chromatography; SP519. pp. 181-184 (Apr. 1979).

Tension; tensor polynomial; compression; failure; finite elements; graphite-epoxy; interlaminar stresses; laminated composites; stress concentrations; SP563, pp. 242-254 (Oct. 1979).

Tensor force; charmonium; particle spectroscopy; quarks; selection rules; spin forces; 18432 .

Tensor polarizability; Thomson scattering; coherent scattering; Delbruck scattering; elastic scattering; giant resonance; 18521.

Tensor polynomial; compression; failure; finite elements; graphite-epoxy; interlaminar stresses; laminated composites; stress concentrations; tension; SP563, pp. 242-254 (Oct. 1979).

Terbium molybdate; triglycine sulfate; ferroelectrics; figures of merit; improper ferroelectrics; pyroelectric detectors; pyroelectric vidicons; 18852 . 
Terminology; analog-to-digital converter; digital-to-analog converter; IEEE subcommittee; performance specifications; sample/hold circuit; standards; 18365 .

Terminology; critical parameters; definitions; flux phenomena; Josephson phenomena; stabilization; superconductors; 18681 .

Ternary fission; $\alpha$-particles; $\alpha$-spectrum; ${ }^{234} U$; electrodisintegration; proton spectrum; 18518 .

Ternary interactions; theta point; virial coefficients; collapse transition; fluctuations; mean field approximation; 19023.

Terrestrial solar irradiance; diffuse reflectance standards; solar absorptance; solar optical properties; solar reflectance; solar transmittance; spectral reflectance standards; 18501 .

Terrosim; threat analysis; training; adversary characteristics; animal research; behavioral science; biosensors; computer analysis; ergonomics; human engineering; human factors; human motivation; human reliability; personnel selection; physical security; SP480-38.

Tertiary aromatic amines; amine accelerators; composite restorative resin; dimethylaminoglutethimide; dimethylaminophenylacetic acid and esters; properties of composites; 18571 .

Test; apparel; extinguishability; fabrics; flammability; garments; hazard; heat transfer; ignitability; standard; 18708 .

Test data for elementary functions; test data for mathematical functions; elementary function testing; Fortran library test data; Fortran library testing; mathematical function testing; NBSIR 78-1478.

Test data for mathematical functions; elementary function testing; Fortran library test data; Fortran library testing; mathematical function testing; test data for elementary functions; NBSIR 78-1478.

Test equipment; calibration; Federal Government; laboratory; measurement; metrology; precision; SP546, 1979 Edition.

Test measures; tolerances; vapor recovery; bottom loading; field standard provers; field standards; field standard test measures; provers; specifications; standards; H105-3.

Test method; head injury criterion; impact; peak acceleration; performance; playground surfaces; NBSIR 79-1707.

Test method; headform; headgear; head injury; helmet; impact; NBSIR 78-1547.

Test method; wall panels; walls; compression; eccentric loading; flat-end; kern; loading rate; pin-end; BSS95.

Test methods; appliance; cooking; efficiency; energy; human factors; kitchen ranges; labeling; stoves; NBSIR 78-1556.

Test methods; attic floor radiant panel; cellulose thermal insulation; critical radiant flux; flame spread; smoldering combustion; NBSIR 79-1588.

Test methods; batteries; photovoltaic energy conversion; power conditioning; power systems; solar cells; standards; NBSIR 79-1743.

Test methods; toy safety; eye injury; impact; ocular contusion; projectiles; propelled objects; J. Res. 84, No. 1, 9-19 (1979).

Test pattern; test structure; TTL; bipolar process; contact resistor; cross bridge sheet resistor; electrlcal alignment resistor; integrated circuits; linewidth; photolithography; sheet resistance; silicon; 18533 .

Test pattern; test structures; visual alignment; contact resistor; cross bridge sheet resistor; electrical alignment resistor; semiconductor; silicon; SP400-51.

Test pattern; transistor gain; integrated circuit; process validation wafer (PVW); reliability; silicon; 18463

Test patterns; test structures; CMOS/SOS; process control; process metrology; silicon gate; NBSIR 79-1595.

Test patterns; test structures; thermally stimulated current and capacitance; transistors; ultraviolet reflectance; VCE(SAT); $\mathrm{x}$-ray photoelectron spectroscopy; auger electron spectroscopy; die attachment; electrical properties; electronics; hermeticity; SP400-38.
Test patterns; test structures; total process integration; comprehensive process characterization; design rules; intradie parametric integrity; LSI circuits; mask alignment tolerances; modular test programs; parametric yield limitations; performance limitations; SP400-56.

Test problems; algorithm testing; approximation; computational experiment; least absolute deviation; polynomial approximation; J. Res. 84, No. 6, 455-488 (1979).

Test procedures; bomb calorimetry; gross calorific values; refuse-derived-fuels; sample characterization; NBSIR 781494.

Test structure; TTL; bipolar process; contact resistor; cross bridge sheet resistor; electrical alignment resistor; integrated circuits; linewidth; photolithography; sheet resistance; silicon; test pattern; 18533.

Test structures; CMOS/SOS; process control; process metrology; silicon gate; test patterns; NBSIR 79-1595.

Test structures; thermally stimulated current and capacitance; transistors; ultraviolet reflectance; VCE(SAT); $x$-ray photoelectron spectroscopy; auger electron spectroscopy; die attachment; electrical properties; electronics; hermeticity; indium-doped silicon; SP400-38.

Test structures; total process integration; comprehensive process characterization; design rules; intradie parametric integrity; LSI circuits; mask alignment tolerances; modular test programs; parametric yield limitations; performance limitations; photomask performance; SP400-56.

Test structures; visual alignment; contact resistor; cross bridge sheet resistor; electrical alignment resistor; semiconductor; silicon; test pattern; SP400-5I.

Tester; transistor; base drive circuit; electronic circuits; inductive load; nondestructive; protection circuit; reverse bias; safe operating area; second breakdown; switching power transistor; SPAOO-54.

Testing; boiler; combustion; energy; furnace; gas-fired; heating; oil-fired; rating; space-heating; 18385 .

Testing; computer; hot water; measurement; rating; solar; standards; 18428 .

Testing; electronics; integrated circuit; large scale integration; memory; microprocessor; TN1 102.

Testing; measurement; solar collector; solar energy; solar radiation; standards; standard test; BSSI 17 .

Testing; military systems; non-electronic equipment; SP547, pp. 299-302 (July 1979).

Testing; mobile home; packaged solar space-heating system; rating; standards; NBSIR 79-1799.

Testing; thin films; accelerated tests; failure mechanisms; failure modes; photovoltaics; reliability; semiconductors; solar cells; stability; SP400-58.

Testing; thin films; accelerated tests; failure mechanisms; failure modes; photovoltaics; reliability; semiconductors; solar cells; stability; NBSIR 79-1778.

Testing; traceability; dose; ionizing; radioactivity; standards; 18361 .

Testing methodology; useful life; consumer products; reliability engineering; 18378 .

Testing procedures for heat pumps; heat pumps; part-load evaluation; standards for heat pumps; 18703 .

Testing procedures for heat pumps; heat pumps; part-load evaluation; standards for heat pumps; 18778 .

Tests for paper; accelerated aging; aging; aging of cellulose; aging of paper; cellulose; cellulose aging; natural aging; paper; paper aging; 19017.

Tetrafluoroethylene; copolymerization; polymerization; pressure; radiation; styrene; 18512 .

Tetrafluoroethylene copolymers; 1,3,3,3-tetrafluoropropene polymer; 3,3,3-trifluoropropene copolymers; 3,3,4,4,5,5,5heptafluoropentene-1 polymer; isobutene copolymers; pyrolysis gas chromatography; random scission; 18580. 
Tetrazole; benzotriazole; charge transfer; copper; luminescence; microspectrofluorimetry; photoluminescence; spectrofluorimetry; surface analysis; 18504.

Texture of copper shaped charge liner; texture of $\mathrm{Ni}-\mathrm{W}$ alloy; metal texture; neutron diffraction; nondestructive testing; pole figure; 19027 .

Texture of Ni-W alloy; metal texture; neutron diffraction; nondestructive testing; pole figure; texture of copper shaped charge liner; 19027

TGA; V/STOL; cure; dielectric analysis; DSC; graphite-fiber; polyphthalocyanine; prepreg; SP563, pp. 25-31 (Oct. 1979).

Thallium benzotriazenide; benzotriazenides; iridium (i) complexes; organometallic benzotriazenides; rhodium (1) complexes; 18582

Thallium iodide; thin films; graded index; lead fluoride; polymorphism; SP541, pp. 259-265 (Dec. 1978).

Theoretical and experimental comparison; vibrational effect; HCl-Ar; rotational linewidths; temperature dependence; 18689.

Theories of liquid crystals; configurations of rods; Monte Carlo; orientation entropy; packing of rods; square lattice; 18530.

Theory; asymmetric absorptance; damage thresholds; dielectric reflectors; electric-field distribution; high-power; reflectance; spectral absorptance; SP54I, pp. 278-287 (Dec. 1978).

Theory; elastic scattering; ion-molecule collisions; rotational excitation; semiclassical orbital; 18446 .

Therapy; $x$ rays; accelerators; betatrons; electrons; megavoltage; neutrons; SP554, pp. 1 -1 4 (Sept. 1979).

Thermal; ${ }^{235} \mathrm{U}$; chemical effects; delayed neutrons; Einstein model; fission; temperature effects; 18687.

Thermal analysis; concrete (reinforced); fire load; fire resistance; fire tests structural engineering; temperature; TN985.

Thermal analysis of residénces; Community Services Administration; heating balance point analysis; low-income residences; marginal cost/benefit analysis in weatherization; optimum weatherization retrofit combinations; NBSIR 79-I706.

Thermal anneals; energy densities; ion-implanted silicon; laser pulses; power densities; 18623 .

Thermal characterization; thermal resistance; transistors; current crowding; die attachment evaluation; junction temperature; measurement technology; power transistors; semiconductor devices; SP4OO-I4.

Thermal comfort; heating and cooling load; hybrid computer; NBSLD; 18336 .

Thermal conductivity; aluminum alloy; copper; low temperature; magnetothermal conductivity; nickel alloy; stainless steel; 18619 .

Thermal conductivity; characterization; density; electrical resistivity; graphite; Lorenz ratio; reference materials; 18668 .

Thermal conductivity; thermal expansion; thermal properties; vapor pressure; viscosity; calorimetry; elasticity; electrical resistivity; emittance; measurement system; standard reference materials; temperature; 18905.

Thermal conductivity; thermophysical properties; electrical resistivity; enthalpy; specific heat; standard reference materials; 18615 .

Thermal conductivity; viscosity; Abbe value; coolants, dn/dT; index matching liquids; neodymium glass lasers; nonlinear refractive index; SP54I, pp. 109-121 (Dec. 1978).

Thermal conductivity; viscosity; correlated data; critical point enhancement; data evaluation; propane; JPCRD 8, No. 2, 559-576 (1979).

Thermal cycles to low temperatures; germanium thermometers; low temperature; rhodium-iron thermometry; 19040.

Thermal cycling; thermal stress; cable cool-down; cool-down helium; liquid helium; superconducting power transmission; NBSIR 79-1618.
Thermal damage; absorption; antireflection coatings; damage thresholds; impurities; laser-induced damage; SP54I, pp. 202 211 (Dec. 1978).

Thermal decomposition; allylmethylether; bromide; ethylacetate; isopropyl; laser; non-equilibrium; pyrolysis; relaxation; 18832 .

Thermal efficiency; window; window management; building economics; daylighting; economic analysis; energy conservation; engineering economics; life-cycle costs; solar heat gain; BSS 119

Thermal energy analyzer; tobacco smoke; vinyl chloride; azaarenes; hydrazines; nitroalkanes; nitrosamines; sidestream smoke; SP519, pp. 131-141 (Apr. 1979).

Thermal energy analyzer (TEA); tobacco; carbamates; chemical ionization; electron-capture; hydrazines; maleic hydrazide; mass spectroscopy; nitrosamines; nitrosodiethanolamine; silylation; SP5 19, pp. 297-309 (Apr. 1979).

Thermal energy storage device; ASHRAE Standard 94-77; Glauber's salt; latent heat storage; pebble bed; phase-change unit; solar energy storage; NBSIR 79-1737.

Thermal energy storage materials; thermal properties; thermodynamic properties; transport properties; corrosion; data compilation; electrochemical energy storage materials; molten salts; physical properties; safety and hazards; NSRDSNBS6I, Part II.

Thermal envelope criteria; thermal performance criteria; education; energy utilization codes; illustrated handbook; legislation; SP552, pp. 141-15I (July 1979).

Thermal expansion; advanced composite materials; graphiteepoxy laminate design; laminate design sensitivities; SP563, pp. 60-71 (Oct. 1979).

Thermal expansion; ionic conductors; neutron diffraction; powder method; profile refinement; tantalum tungstate; 19037.

Thermal expansion; thermal properties; vapor pressure; viscosity; calorimetry; elasticity; electrical resistivity; emittance; measurement system; standard reference materials; temperature; thermal conductivity; 18905.

Thermal expansion; wear; wear tests; amalgam; composites; dental materials; dimensional changes; physical properties; 18649.

Thermal expansion coefficient; thermo-optic constant; ZnS; $\mathrm{ZnSe} ; \mathrm{Al}_{2} \mathrm{O}_{3} ; \mathrm{As}_{2} \mathrm{~S}_{3}$ glass; $\mathrm{BaF}_{2} ; \mathrm{CaF}_{2} ; \mathrm{CdF}_{2} ;$ chalcogenide glass; elastic compliances; elastic constants; TN993.

Thermal fluxes; NBS reactor; neutrons; silicon irradiation; 18704.

Thermal insulation; thermal properties; cellular plastic; low temperature; mechanical properties; polystyrene; polyurethane; 18719 .

Thermal insulation; thermocouple; branch circuit wiring; electrical junction box; hazardous temperatures; load current; overlamping; surface mounted incandescent lighting fixture; NBSIR 79-1912.

Thermal insulation; thermocouple; branch circuit wiring; electrical junction box; hazardous temperatures; load current; protective barrier; recessed incandescent lighting fixture; NBSIR 79-1913.

Thermal mass; building economics; energy conservation; insulation; life-cycle cost analysis; masonry construction; space heating and cooling requirements; NBSIR 79-1789.

Thermal mass effect in buildings; building energy consumption analysis; computerized building energy analysis; cooling load calculation; energy conservation; heating load calculation; NBSLD analysis of residences; residential energy conservation; NBSIR 79-1732.

Thermal oxidation; $\mathrm{Zn}$-doped glasses; boron nitride; $\mathrm{Cl}$-doped glasses; diffusion in silicon; integrated circuit processing; kinetics of oxide grow th; oxidation of silicon; semiconductor processing; silicon; silicon dioxide; the rmally stimulated measurement; $N B S-G C R-78-134$. 
Thermal oxidation of silicon; dry oxidation of silicon; hydrogen contamination; hydroxyl contamination; semiconductor device fabrication; silicon; silicon dioxide; NBSIR 78-1558.

Thermal performance criteria; education; energy utilization codes; illustrated handbook; legislation; thermal envelope criteria; SP552, pp. 141-151 (July 1979).

Thermal properties; cellular plastic; low temperature; mechanical properties; polystyrene; polyurethane; thermal insulation; 18719.

Thermal properties; thermodynamic properties; transport properties; corrosion; data compilation; electrochemical energy storage materials; molten salts; physical properties; safety and hazards; thermal energy storage materials; NSRDS-NBS61, Part II.

Thermal properties; vapor pressure; viscosity; calorimetry; elasticity; electrical resistivity; emittance; measurement system; standard reference materials; temperature; thermal conductivity; thermal expansion; 18905.

Thermal pulse; vinylidenefluoride-tetrafluoroethylene copolymer; blocking electrode; charge motion; polarization; poly(vinylchloride); poly(vinylidenefluoride); pyroelectric response; 18408 .

Thermal radiation; fire models; heat transfer; room fires; smoke; soot; NBS-GCR-78-151.

Thermal radiation; turbulence; buoyant flow; compartment fires; computer programs; corridor fires; fire models; fire spread; room fires; NBS-GCR-78-150.

Thermal resistance; transistors; current crowding; die attachment evaluation; junction temperature; measurement technology; power transistors; semiconductor devices; thermal characterization; $S P 400-14$.

Thermal resistance of walls; infrared thermometers; in situ evaluation of insulation; $R$-value measurement by spot radiometer; NBSIR 79-1736.

Thermal response factors; computer time; conduction-transfer functions; dynamic heat transfer; 18339.

Thermal storage tests; water tank thermal storage; ASHRAE Standards; evaluation of test procedure; solar heating components; standard test procedure; 18425 .

Thermal stress; cable cool-down; cool-down helium; liquid helium; superconducting power transmission; thermal cycling; NBSIR 79.1618.

Thermal stresses; abrasive wear; ceramics; fracture; plastic penetration; SP562, pp. 1-13 (Oct. 1979).

Thermal wafer chuck; variable temperature; wafer chuck; deep level measurements; defect mapping; hot/cold wafer chuck; thermally stimulated measurements; SP4OO-55.

Thermal wattmeters; transfer standards; electro-dynamic wattmeters; energy measurements; energy standards; international comparisons; metrology; power measurements; precise electrical measurements; TDM wattmeters; 18529.

Thermally stimulated capacitance; thermally stimulated current; deep level measurements; defect center characterization; defect density; ion implantation; silicon; sulfur; sulfur energy level in silicon; 18458 .

Thermally stimulated current; deep level measurements; defect center characterization; defect density; ion implantation; silicon; sulfur; sulfur energy level in silicon; thermally stimulated capacitance; 18458 .

Thermally stimulated current and capacitance; transistors; ultraviolet reflectance; VCE(SAT); $x$-ray photoelectron spectroscopy; auger electron spectroscopy; die attachment; electrical properties; electronics; hermeticity; indium-doped silicon; infrared reflectance; $S P 400-38$.

Thermally stimulated measurement; thermal oxidation; Zndoped glasses; boron nitride; $\mathrm{Cl}$-doped glasses; diffusion in silicon; integrated circuit processing; kinetics of oxide growth; oxidation of silicon; semiconductor processing; silicon; silicon dioxide; NBS.GCR-78-134.
Thermally stimulated measurements; thermal wafer chuck; variable temperature; wafer chuck; deep level measurements; defect mapping; hot/cold wafer chuck; SP4O0-55.

Thermally stimulated measurements; thyristor materials measurements; thyristor measurements; d-c transmission; deep level measurements; energy conservation; measurement methods; power-device grade silicon; resistivity variations; silicon; NBSIR 79-I 756.

Thermochemistry; adenine; enthalpy of dissociation; enthalpy of protonation; enthalpy of reaction; enthalpy of solution; nucleic acid bases; solution calorimetry; J. Res. 84, No. 3, 231-240 (1979).

Thermochemistry; bromine atoms; bromoacetylene; excited state; hydrogen bromide; photochemistry mechanism; 18974.

Thermochemistry; tris(hydroxymethyl)aminomethane; endothermic solution reactions; enthalpy of solution; $\mathbf{K B r}, \mathbf{K l}$, $\mathrm{KIO}_{3}, \mathrm{KIO}_{4}$; solution calorimetry; J. Res. 84, No. 4, 27.3-286 (1979).

Thermochemistry; unimolecular dissociation; calorimetry; infrared; kinetics; laser chemistry; mechanisms; multiphoton 18709

Thermochemistry; vapor pressure; apparent molal heat capacity; aqueous systems; bibliography; electrochemistry; electrolytes; enthalpy of dilution; heat capacity; relative apparent molal enthalpy; salt solutions; SP537.

Thermochemistry of fluorine compounds; calorimetry, gas flow; chlorine thermochemistry; flame calorimetry; fluorinaceous; oxidizer; 18755.

Thermocouple; branch circuit wiring; electrical junction box; hazardous temperatures; load current; overlamping; surface mounted incandescent lighting fixture; thermal insulation; NBSIR 79-1912.

Thermocouple; branch circuit wiring; electrical junction box; hazardous temperatures; load current; protective barrier; recessed incandescent lighting fixture; thermal insulation; NBSIR 79-1913

Thermodynamic functions; dimensionless entropies; JPCRD 8 , No. 3, $917-920$ (1979).

Thermodynamic properties; activity coefficient; cobalt; critical evaluation; electrolyte; excess Gibbs energy; iron; nickel; osmotic coefficients; solutions; JPCRD 8, No. 4, 923-1004 (1979).

Thermodynamic properties; alumina; aluminum oxide; calorimetry; corundum; enthalpy; heat capacity; sapphire; specific heat; standard reference materials; 18377 .

Thermodynamic properties; convection; heat capacity measurement; $\mathrm{Pb}$-Sn off-eutectic alloys; phase diagram of $\mathrm{K}_{2} \mathrm{O}-\mathrm{Fe}_{2} \mathrm{O}_{3}$ system; solidification; surface tension of liquid gallium; NBSIR 79-1767.

Thermodynamic properties; transport properties; corrosion; data compilation; electrochemical energy storage materials; molten salts; physical properties; safety and hazards; thermal energy storage materials; thermal properties; NSRDS-NBS6I, Part II.

Thermodynamic properties; $\lambda$-type transition; adiabatic calorimetry; automated calorimetry; calorimetry; heat capacity; measurement automation; p-Terphenyl; 18376 .

Thermodynamic properties; uranium; activity coefficient; copper; critical evaluation; electrolyte; excess Gibbs energy; lead; manganese; osmotic coefficients; solutions; JPCRD 8, No. 4, 1005-1050 (1979).

Thermodynamic properties; virial coefficients; density; gas; nitrogen; sound velocity; 18815 .

Thermodynamics; ultrasound; viscoelasticity; wave propagation; anisotropy; dispersion; elasticity; human bone; microhardness; microstructure; piezoelectricity; SP525, pp. 189-196 (Apr. 1979). 
Thermography; Twin Rivers Project; weather station; air infiltration; buildings; data acquisition; energy; instrumentation; measu rement; 18733 .

Thermogravimetric analysis; tire cord; tire cord dip; tire cord finish; emissions; gas chromatography; tensilization; SP519, pp. 181-184 (Apr. 1979).

Thermogravimetry; activation energy; automated thermogravimetry; computer automated thermogravimeter; factor-jump thermogravimetry; polymer degradation; 18447.

Thermogravimetry; activation energy; computer automation; computerized thermogravimetry; computer program; polymer degradation; polymer oxidation; 18445.

Thermogravimetry; activation energy; degradation apparatus; factor-jump thermogravimetry; polymer degradation; polymer oxidation; programmed temperature control; 18450.

Thermogravimetry; weight-loss kinetics; aging of polymers; degradation of polymers; error propagation; factor-jump method; heating rate; lifetime prediction; polystyrene; polyurethane; 18620 .

Thermoluminescence dosimeters; electronic devices; electrons; photons; radiation hardness; standard practice; NBSIR 79. 1723.

Thermoluminescence dosimeters; fading; Harshaw Chemical Company; relative humidity; storage; Studsvik AB Atomenergi, Sweden; 18989.

Thermometry; cryogenics; fixed points; pure materials; superconductivity; temperature scale; 18550 .

Thermometry; $\mathrm{Gd}\left(\mathrm{PO}_{3}\right)_{3}$; low temperature thermometry; magnetic susceptibility; magnetic thermometers; $\mathrm{Nd}\left(\mathrm{C}_{2} \mathrm{H}_{5} \mathrm{SO}_{4}\right)_{3}$. $9 \mathrm{H}_{2} \mathrm{O} ; 18556$.

Thermometry; tunnel diode oscillator; gas thermometer; low temperature; temperature scale; 18548 .

Thermometry; W; $\mathrm{AuAl}_{2} ; \mathrm{AuIn}_{2} ; \mathrm{Be}$; cryogenic temperature scale; fixed points; Ir; superconductivity; SP260-62

Thermo-optic constant; $\mathrm{ZnS} ; \mathrm{ZnSe} ; \mathrm{Al}_{2} \mathrm{O}_{3} ; \mathrm{As}_{2} \mathrm{~S}_{3}$ glass; $\mathrm{BaF}_{2}$; $\mathrm{CaF}_{2}$; $\mathrm{CdF}_{2}$; chalcogenide glass; elastic compliances; elastic constants; elasto-optic constants; TN993.

Thermophysical properties; electrical resistivity; enthalpy; specific heat; standard reference materials; thermal conductivity; 18615 .

Thermophysical properties; total heating value; composition; custody transfer; density; flow rate; LNG; mixtures; specific heating value; tank capacity tables; 18564 .

Thermophysical properties data; total heating value; composition; custody transfer; density; flow rate; LNG; mathematical models; mixtures; specific heating value; tank capacity tables; 18838.

Thermophysical properties of water; water; dielectric constant of water; interpolating equation dielectric; steam; tabledielectric constant of water; 18937 .

Thermoplastics; fiber reinforced; SP563, p. 173 (Oct. 1979).

Thermosphere; double photoionization; doubly charged ions; ionosphere; $\mathrm{O}^{++}$; photoionization; 18950.

Theta point; virial coefficients; collapse transition; fluctuations; mean field approximation; ternary interactions; 19023.

Theta temperature; polymers; polystyrene at theta-condition; 18480 .

Thin film absorption; water absorption; wedged film; absorption coefficient; adiabatic calorimetry; $\mathrm{As}_{2} \mathrm{Se}_{3}$; interface absorption; laser calorimetry; NaF; SP541, pp. $37-42$ (Dec. 1978).

Thin film coating materials; infrared laser windows; materials purification; reactive atmosphere process (RAP) chemistry; SP541, pp. 249-256 (Dec. 1978).

Thin film coatings; laser damage; laser interaction; optical components; optical fabrication; optical materials and properties; SPS41.

Thin films; accelerated tests; failure mechanisms; failure modes; photovoltaics; reliability; semiconductors; solar cells; stability; testing; SP400-58.
Thin films; accelerated tests; failure mechanisms; failure modes; photovoltaics; reliability; semiconductors; solar cells; stability; testing; NBSIR 79.1778.

Thin films; antireflection coatings; electron microscopy; laser damage; optical coatings; SP54I, pp. 218-225 (Dec. 1978).

Thin films; diffusion; grain boundaries; Harrison classification; lattice diffusion; migrating boundaries; polycrystals; 18758 .

Thin films; diffusion; grain boundaries; Harrison classification; lattice diffusion; migrating boundaries; polycrystals; 18759 .

Thin films; graded index; lead fluoride; polymorphism; thallium iodide; SP541, pp. 259-265 (Dec. 1978).

Thin films; laser damage; optical probe technique; radiation scattering; SP541, pp. 226-234 (Dec. 1978).

Thin films; trace element analysis; trace element concentrations; zinc; copper; iron; plastic; polymer; proton-induced $\mathrm{x}$ ray fluorescence; 18375 .

Thin films; Weibull distribution; laser damage; probability; statistical analysis; SP541, pp. 235-248 (Dec. 1978 ).

Thin foils; $x$ rays; analytical electron microscopy; microanalysis; Monte Carlo electron trajectory simulation; spatial resolution; 18589.

Thin-film; tunneling; energy gap; iridium; Josephson junction; low- $T_{c} ;$ microwaves; 18540 .

Thin-film coatings; two-photon absorption; ultraviolet wavelength scaling; damage thresholds; electric fields; laser damage; nanosecond pulses; pulsewidth dependence; standing waves; SP541, pp. 190-202 (Dec. 1978).

Thiocyanate radical anion; aqueous solution; carbonate radical; chemical kinetics; halogen radical anions; nitrate radical; oxyanion radicals; phosphate radical; photolysis; radiolysis; rates; selenium radicals; sulfate radical; NSRDS-NBS65.

Third party; agencies; approval process; evaluation; industrialized housing products; inspection; regulation; SP552, pp. 293-309 (July 1979).

Thomson scattering; coherent scattering; Delbruck scattering; elastic scattering; giant resonance; tensor polarizability; 18521 .

Threat analysis; training; adversary characteristics; animal research; behavioral science; biosensors; computer analysis; ergonomics; human engineering; human factors; human motivation; human reliability; personnel selection; physical security; physiological psychology; SP480-38.

Three-level system; coherent excitation; dressed atoms; inhomogeneous broadening; intense laser; multiphoton dissociation; multiphoton ionization; Rabi frequency; statistical broadening; 18439 .

Threshold; acoustic cavitation; cavitation; cavitation threshold $v s$ temperature; radiation-induced cavitation; temperature dependence of cavitation threshold; NBSIR 79-1753.

Threshold detectors; dosimetry; fast neutrons; photofission; photoneutrons; pressure vessel; reactor; 18462 .

Threshold reaction; uranium; Californium; cross sections; fission spectrum; neutron; 18792.

Threshold switching; fluctuation; master equation; noise spectrum; nonequilibrium; stationary states; switching; 18674 .

Thruput measures; comparison measures; evaluation process; performance measures; performance ratings; response time; system design tradeoffs; SP500-52, pp. 163-176 (Oct. 1979).

Thulium; ytterbium; crystal diffraction; gamma-ray energies; 18510.

Thyristor materials measurements; thyristor measurements; $d-c$ transmission; deep level measurements; energy conservation; measurement methods; power-device grade silicon; resistivity variations; silicon; spreading resistance measurements; NBSIR 79-1756.

Thyristor measurements; d-c transmission; deep level measurements; energy conservation; measurement methods; powerdevice grade silicon; resistivity variations; silicon; spreading resistance measurements; thermally stimulated measurements; NBSIR 79-I756. 
Timber; acoustics; bridges; creosote; harbor facilities; inspection; maintenance; marine borers; nondestructive testing; pilings; 18525 .

Time; clock; GOES; microprocessors; satellite; synchronization; 18393.

Time; clocks; communication; frequency standards; navigation; stability; 18826 .

Time; time dissemination; communication; frequency; frequency standards; navigation; 19005.

Time; time scales; Hermes/CTS; international time comparison; precise time transfer; satellite; 18861 .

Time and frequency; timekeeping; atomic clocks; cesium standards; crystal oscillators; frequency standards; hydrogen standards; rubidium standards; 18908 .

Time and frequency calibration methods; time calibration; time signals; frequency calibration; high frequency; Loran-C; low frequency; radio broadcasts; satellite broadcasts; standard frequencies; television color subcarrier; SP5 59.

Time calibration; time signals; frequency calibration; high frequency; Loran- $C$; low frequency; radio broadcasts; satellite broadcasts; standard frequencies; television color subcarrier; time and frequency calibration methods; SP559.

Time code; Western Hemisphere; broadcast; coordinated universal time; synchronous satellite; 19029.

Time complexity; algorithm; chromatic number; color function; graph; graph coloring; heuristic; interchange; random test graphs; scheduling; J. Res. 84, No. 6, 489-506 (1979).

Time differential factor; time zone references; Uniform Time Act of 1966; universal time; American National Standard Representation for Calendar Date and Ordinal Date for Information Interchange; local time differentials; meridian designator; FIPS PUB 59.

Time dispersion; time error; time error measure; time prediction error; clocks; frequency drift; frequency stability; navigation; oscillator; position location; 18899.

Time dispersion; wall shift; amplitude modulation; cavity pulling; cavity servo; dielectrically loaded cavity; frequency stability; second-order Doppler shift phase modulation; spin exchange; temperature coefficient; 18696 .

Time dissemination; communication; frequency; frequency standards; navigation; time; 19005

Time domain measurement; antenna gain; broadband antenna; directivity; FFT; method of measurements; non-dispersive; resistive loading; TEM horn; 18856 .

Time domain measurement; automation; laser; oscilloscope; picosecond; pulse; pulse measurement; 18640 .

Time elements; timekeeping systems; time representations; American National Standard Representation for Calendar Date and Ordinal Date for Information Interchange; meridian designators; separators; sequencing; FIPS PUB 58.

Time error; time error measure; time prediction error; clocks; frequency drift; frequency stability; navigation; oscillator; position location; time dispersion; 18899 .

Time error measure; time prediction error; clocks; frequency drift; frequency stability; navigation; oscillator; position location; time dispersion; time error; 18899 .

Time prediction error; clocks; frequency drift; frequency stability; navigation; oscillator; position location; time dispersion; time error; time error measure; 18899 .

Time representations; American National Standard Representation for Calendar Date and Ordinal Date for Information Interchange; meridian designators; separators; sequencing; time elements; timekeeping systems; FIPS PUB 58.

Time scales; coordinate time; portable clocks; relativity; synchronization; 18993 .

Time scales; Hermes/CTS; international time comparison; precise time transfer; satellite; time; 18861 .

Time signal; time window; gated frequency analysis; Gaussian window; impulsive complex signals; linear averaging; reciprocating; records after trigger; tape loop; SP547, pp. 315-322 (July 1979).

Time signals; frequency calibration; high frequency; Loran-C; low frequency; radio broadcasts; satellite broadcasts; standard frequencies; television color subcarrier; time and frequency calibration methods; time calibration; SP559.

Time standards; atomic clocks; frequency standards; frequency synthesis; fundamental constants; length standards; physical measurement systems; review article; speed of light; 18346 .

Time window; gated frequency analysis; Gaussian window; impulsive complex signals; linear averaging; reciprocating; records after trigger; tape loop; time signal; SP547, pp. 315 322 (July 1979).

Time zone references; Uniform Time Act of 1966; universal time; American National Standard Representation for Calendar Date and Ordinal Date for Information Interchange; local time differentials; meridian designator; time differential factor; FIPS PUB 59.

Time-dependent loads; aerodynamic stability; aeroelasticity; fluctuating flow; flutter; suspended-span structures; 18688 .

Time-domain; transmission lines; dielectric measurements; dielectric relaxation time; 18723 .

Time-domain deconvolution; transient elastic wave propagation; acoustic emission; capacitive transducer; signal analysis; simulated acoustic emission; 18878 .

Time-domain measurements; dielectrics; frequency-domain measurements; magnetic materials; microwaves; millimeter waves; permeability measurements; permittivity measurements; radar absorbers; NBSIR 79.1613.

Time-domain measurements; time-stepping finite-difference technique; transient; traveling-wave antenna; Fast Fourier transform; linear load; Newton-Raphson interation methods; nonlinear load; 19035.

Timekeeping; atomic clocks; cesium standards; crystal oscillators; frequency standards; hydrogen standards; rubidium standards; time and frequency; 18908 .

Timekeeping systems; time representations; American National Standard Representation for Calendar Date and Ordinal Date for Information Interchange; meridian designators; separators; sequencing; time elements; FIPS PUB 58.

Time-lag; gas transmission rate; manome tric technique; oxygen; permeability; poly(ethylene terephthalate); standard reference material; tem perature coefficient; SP260-58.

Time-of-flight; tissue characterization; ultrasonic imaging; ultrasound; breast cancer; computerized tomography; mammography; SP525, pp. 221-225 (Apr. 1979).

Time-of-flight technique; linac; neutrons; position-sensitive detector; radiography; 18591 .

Timesharing; competitive negotiated procurement; computer management; remote teleprocessing; statement of work; teleprocessing services program; SP500-52, pp. 231-232 (Oct. 1979).

Timesharing; computer performance evaluation; human factors; interactive computing; man-machine interaction; performance measurement; SP5OO-48.

Time-sharing; TSP; benchmarking; cost analysis; evaluation; procurement; technical analysis; SP500-52, pp. 233-234 (Oct. 1979).

Time-stepping finite-difference technique; transient; travelingwave antenna; Fast Fourier transform; linear load; NewtonRaphson interation methods; nonlinear load; time-domain measurements; 19035 .

Tin; alloy; copper; electrical property; niobium; superconductor; 18656 .

Tin; alloy; copper; low temperatures; niobium; precipitate; superconductor; 18655 .

Tin; arsenic; bio-transformation; cadmium; food chain; lead; mercury; metal; methylation; microbial tolerance; microorganism; plasmid; 18860 . 
Tire cord; tire cord dip; tire cord finish; emissions; gas chromatography; tensilization; thermogravimetric analysis; SP519, pp. 181-184 (Apr. 1979).

Tire cord dip; tire cord finish; emissions; gas chromatography; tensilization; thermogravimetric analysis; tire cord; SP519, pp. 181-184 (Apr. 1979).

Tire cord finish; emissions; gas chromatography; tensilization; thermogravimetric analysis; tire cord; tire cord dip; SP519, pp. 181-184 (Аpr. 1979).

Tire maintenance; traction performance; tread wear; high speed performance; high speed tires; police tires; pursuit tires 19038.

Tire noise; transportation noise; truck; acoustics; noise measurement; noise (sound); 18607.

Tissue; ultrasound; propagation velocity; reflection technique; solids; SP525, pp. 53-56 (Apr. 1979).

Tissue characterization; tissue parameters; ultrasound; velocity; absorption; attenuation; computerized tomography; Doppler; impedance; medical diagnosis; microscopy; pattern recognition; scattering; signal processing; SP525.

Tissue characterization; tissue parameters; ultrasound; attenuation; B-san; cepstrum; computer; convolution; de-convolution; liver; power spectrum; signal processing; SP525, pp. 287.295 (Apr. 1979).

Tissue characterization; tomography; transducers; ultrasonics; annular array; breast cancer; chirp signals; imaging; optoacoustic; pulse compression; sensitivity; signal averaging; signal processing; SP525, pp. 255-259 (Apr. 1979).

Tissue characterization; ultrasonic imaging; ultrasound; breast cancer; computerized tomography; mammography; time-offlight; SP525, pp. 221.225 (Apr. 1979).

Tissue characterization; ultrasonic tissue scattering; ultrasound attenuation; ultrasound diagnosis; backscatter frequency dependence; cirrhosis; composition-dependent scattering; fatty liver; stochastic scattering; SP525, pp. 157-163 (Apr. 1979).

Tissue characterization; ultrasonics; velocity; absorption; amino acids; attenuation; frequency; mammalian tissues; polypeptides; proteins; SP525, pp. 19-27 (Apr. 1979).

Tissue characterization; ultrasound diagnosis; clinical cardiac data; digital processing; Fast Fourier Transform; frequency spectra; in vivo; microprocessor-controlled data acquisition; myocardial infarction; real-time; SP525, pp. 267.273 (Apr. 1979).

Tissue damage; tissue death; cell detachment; mechanical properties; SP525, Pp. 317-322 (Apr. 1979).

Tissue death; cell detachment; mechanical properties; tissue damage; SP525, pp. 317.322 (Apr. 1979).

Tissue equivalent phantoms; $x$-ray beam diameter; $x$-ray energies of 30 to $70 \mathrm{keV}$; $x$-ray scatter; diagnostic radiology; scatterer thickness; scatterer to image plane separation; $1844 I$.

Tissue equivalent test objects and phantoms; ultrasonic tissue characterization; ultrasound imaging; computed tomographyultrasonic; diagnosis-ultrasonic; SP525, pp. 337-340 (Apr. 1979).

Tissue parameters; ultrasound; attenuation; B-san; cepstrum; computer; convolution; de-convolution; liver; power spectrum; signal processing; tissue characterization; SP525, pp. 287-295 (Apr. 1979).

Tissue parameters; ultrasound; velocity; absorption; attenuation; computerized tomography; Doppler; impedance; medical diagnosis; microscopy; pattern recognition; scattering; signal processing; tissue characterization; SP525.

Tissue properties; transmission; ultrasound; attenuation; SP525, Pp. 101-108 (Apr. 1979).

Tissue sections; tooth; biological microanalysis; biological tissue; dental studies; enamel; mineralizing tissue; Raman microprobe; Raman spectra; Raman spectroscopy; 18982.

Tissue signature; tissue simulators; training phantoms; ultrasonic phantoms; SP525, pp. 327.336 (Apr. 1979).
Tissue signature; ultrasonic scattering; ultrasound; detection of lung disease; frequency signature; statistical scattering; SP525, pp. 135-141 (Apr. 1979).

Tissue simulators; training phantoms; ultrasonic phantoms; tissue signature; SP525, pp. 327-336 (Apr. 1979).

Titanium; atomic energy levels; atomic spectra; JPCRD 8, No. $1,1-62(1979)$

Titanium; defects; Doppler broadening; hardness; positron annihilation; 18967.

Titanium; titanium alloys; electron beam welding; fatigue (materials); fracture properties; low temperature tests; mechanical properties; 18611 .

Titanium alloy; analytical chemistry; ion-chromatography; law enforcement standards; materials properties; measurement science; science students; SRM; DIM/NBS 63, No. 1/2, 1-28 (1979).

Titanium alloys; crack propagation; fatigue; low temperature tests; nickel alloys; stainless steels; steels; superalloys; $l 8695$.

Titanium alloys; electron beam welding; fatigue (materials); fracture properties; low temperature tests; mechanical properties; titanium; 18611 .

TII; ZnSe; absorption edge; $\mathrm{CaF}_{2} ; \mathrm{KCl}$; optical absorption coefficient; optoacoustic spectroscopy; $\mathrm{PbF}_{2}$; photoacoustic spec. troscopy; SP54I, pp. $43-49$ (Dec. 1978 ).

TMR; triply modular redundant; fault tolerant computer; soft errors; NBSIR 79-1927.

Tobacco; carbamates; chemical ionization; electron-capture; hydrazines; maleic hydrazide; mass spectroscopy; nitrosamines; nitrosodiethanolamine; silylation; thermal energy analyzer (TEA); SP5 19, pp. 297-309 (Apr. 1979).

Tobacco smoke; vinyl chloride; aza-arenes; hydrazines; nitroalkanes; nitrosamines; sidestream smoke; thermal energy analyzer; SP519, pp. 131-141 (Apr. 1979).

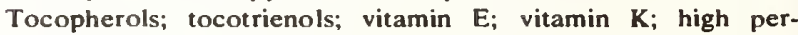
formance liquid chromatography; phylloquinone; SP519, Pp. 279-288 (Apr. 1979).

Tocotrienols; vitamin $\mathrm{E}$; vitamin $\mathrm{K}$; high performance liquid chromatography; phylloquinone; tocopherols; SP519, pp. 279-288 (Apr. 1979).

Tolerance vibration levels; automatic diagnostics; digitized data; spectrum analyzers; steady state mode; SP547, pp. 286-295 (July 1979).

Tolerances; vapor recovery; bottom loading; field standard provers; field standards; field standard test measures; provers; specifications; standards; test measures; HIO5-3.

Tolerances; volume-measuring devices; weighing devices; weights; length-measuring devices; liquid-measuring devices; measures; scales; specifications; taximeters; H44, 1979 Edition.

Tomography; transducers; ultrasonics; annular array; breast cancer; chirp signals; imaging; opto-acoustic; pulse compression; sensitivity; signal averaging; signal processing; tissue characterization; SP52 5, pp. 255-259 (Apr. 1979).

Tooth; biological microanalysis; biological tissue; dental studies; enamel; mineralizing tissue; Raman microprobe; Raman spectra; Raman spectroscopy; tissue sections; 18982.

Tooth; $x$-ray diffraction; bone; hydroxylapatite; interlayering; octacalcium phosphate; 18583 .

Tooth roots; alumina; diamond contour grinding; flexure strength; prosthetic device; serrated surface design; SP562, pp. 247-254 (Oct. 1979).

Top injection; tracer gas test; bottom injection; multiple injection; smoke candle test; smoke control; stairwell pressurization; NBSIR 79-1747.

Topological algebra; automorphism; cyclic module; faithful distributive module; incidence algebra; multiplicative function; quasi-ordered set; 18789 .

Topological algebra; coalgebra; direct limit; faithful distributive module; generating function; incidence algebra; inverse limit; orthogonal idempotents; quasi-order; 18788 . 
Torque; trapped flux; gyroscope; ralativity; space; superconducting; 18846 .

Torsion pendulum; dynamic mechanical; high pressure extrusion; oriented polyethylene; relaxation process; stress relaxation; 18767.

Torsional frequencies; bromoethanes; ideal gas thermodynamic properties; internal rotation; iodoethane; potential barrier heights; symmetric top; JPCRD 8, No. 2, $519-526$ (1979).

Tort; duty; liability; municipal corporations; negligence; sovereign immunity; SP552, pp. 29-37 (July 1979).

Total elemental content passive personal samplers; total organic chlorine; weighted diffusion coefficient; ambient concentration; compute and limit; error; sampler response factors; SP519, pp. 747-752 (Apr. 1979).

Total energy; total energy data flow; computerized processing; data editing; data flow; data processing; data reductions; raw data conversion to engineering units; NBSIR 79-1757.

Total energy; transducers; weather station; data acquisition system; digital tape recorder; fuel measurement; instrumentation; NBSIR 79-1709.

Total energy data flow; computerized processing; data editing; data flow; data processing; data reductions; raw data conversion to engineering units; total energy; NBSIR 79-1757.

Total heating value; composition; custody transfer; density; flow rate; LNG; mixtures; specific heating value; tank capacity tables; thermophysical properties; 18564 .

Total heating value; composition; custody transfer; density; flow rate; LNG; mathematical models; mixtures; specific heating value; tank capacity tables; thermophysical properties data; 18838.

Total internal reflection; 0.65 to 3.0 microns; absorption coefficient; sodium fluoride film; SP54I, pp. 13-18 (Dec. 1978).

Total organic chlorine; weighted diffusion coefficient; ambient concentration; compute and limit; error; sampler response factors; total elemental content passive personal samplers; SP519, pp. 747-752 (Apr. 1979).

Total process integration; comprehensive process characterization; design rules; intradie parametric integrity; LSI circuits; mask alignment tolerances; modular test programs; parametric yield limitations; performance limitations; photomask performance; process control; SP400-56.

Toughness; cryogenic; fatigue; fracture; high-strength; low-temperature; mechanical properties; nitrogen; nitrogenstrengthened; stainless steel; tensile properties; 18957.

Toxic chemicals; ultra-black coating; Alaskan pipeline; computers; corrosion; fire safety; gyromagnetic ratio; paper; photometric calibrator; safety tips; solar energy; $D / M / N B S$ 63, No. 11, 1-36 (1979).

Toxic elements; radiochemical; selectivity; sensitivity; 18343 .

Toxic gases; alcohol intoxication; autopsy; building fires; cigarettes; death; fire investigations; fire statistics; pathology; NBS-GCR-79-168.

Toxic gases; toxicity; building fires; conferences; fire detection; fire investigations; fire models; fire research; fire retardants; flame retardants; human behavior; smoke; SP54O.

Toxic substances; building rehabilitation; energy measurements; energy-related inventions; environment; precision power; radioactivity; Raman microprobe; solar energy; DIM/NBS 63 . No. 6, 1-32 (June 1979).

Toxicity; building fires; conferences; fire detection; fire investigations; fire models; fire research; fire retardants; flame retardants; human behavior; smoke; toxic gases; SP54O.

Toxicity; upholstered furniture; arson; bibliographies; building fires; compartment fires; fabric flammability; fire detection systems; fire tests; flammability tests; human behavior; plastics; polymers; smoke; smoke detectors; subway fires; NBSIR 79-1745.

Toxicity of combustion products; chemistry of fire; combustion products; fire hazards; fire modeling; fire research; human behavior in fires; physics of fire; NBSIR 79-1916.
Toxicology; chemical composition; composite resins; dental materials; primates; pulp response; 18690 .

Toy safety; eye injury; impact; ocular contusion; projectiles; propelled objects; test methods; J. Res. 84, No. 1, 9-19 ( 1979 ).

Trace analysis; activation analysis; cadmium ratio; east neutron reactions; interfering nuclear reactions; optimization of analysis; silicon; 18338 .

Trace analysis; analytical techniques; contamination; environment; retrospective; sample storage; 18349.

Trace analysis; environmental pollution; fluorescence; high performance liquid chromatography; occupational health; picogram; polycyclic aromatic hydrocarbons; selectivity; sensitivity; specificity; SP519, pp. 41-56 (Apr. 1979).

Trace analysis; mass-analyzed ion kinetic energy spectrometry; MIKES; mixture analysis; SP519, pp. 609-625 (Apr. 1979).

Trace analysis; trapping column; equilibration trapping; gas chromatography; headspace gas stripping; standard-addition calibration; SP519, pp. 739-746 (Apr. 1979).

Trace analysis; uranium; alpha tracks; biomedical; boron; fission tracks; geochronology; geology; lithium; nitrogen; silicon devices; 18342 .

Trace analysis; water; $\beta$-chloroethers; air; environment; gas chromatography/mass spectrometry; sampling; sediment; SP519, pp. 205-212 (Apr. 1979).

Trace element analysis; trace element concentrations; zinc; copper; iron; plastic; polymer; proton-induced $x$-ray fluorescence; thin films; 18375 .

Trace element analysis; water analysis; chelating resin; graphite furnace atomic absorption; sea water; separation; 18402 .

Trace element concentrations; zinc; copper; iron; plastic; polymer; proton-induced $x$-ray fluorescence; thin films; trace element analysis; 18375 .

Trace elements; analysis; clay; forensic; INAA; paper; 18325 .

Trace elements; urban particulate; error analysis; instrumental analysis; multielement analysis; neutron activation analysis; SRM; 18866 .

Trace enrichment; waste water analysis; liquid chromatography; SP519, pp. 185-190 (Apr. 1979).

Trace gas analysis; $\mathrm{CO}_{2}$ laser; derivative spectra; infrared analysis; spectral coincidences; Stark modulation; Stark spectroscopy; 18538.

Trace metal analysis; tunable dye laser; analytical flame spectroscopy; flame ionization; flame spectroscopy; laser enhanced ionization; laser spectroscopy; opto-galvanic effect; 18880 .

Trace metal detection; laser excited galvanic spectroscopy; lasers, bandwidth determination of; lasers, frequency locking of; lasers, wavelength calibration of; optogalvanic effect; 18944.

Trace organic analysis; absorption spectroscopy; derivative spectroscopy; PNA analysis; SP519, pp. $719-722$ (Apr. 1979 ).

Trace organic analysis; analytical systems; atomic absorption; gas chromatography; liquid chromatography; mass spectrometry; SP519, pp. $541-546$ (Apr. 1979).

Trace organic analysis; drug analysis; food toxicants; hormones; neurotransmitters; nutrients; organic pollutants; SP519.

Trace organic analysis; Fourier transform infrared; gas chromatography; modular organic analysis system; pyrolysis; SP519, pp. 753-760 (Apr. 1979).

Trace organic analysis; laser-Raman microprobe; liquid chromatograph-Raman spectrometer interface; micro-Raman spectroscopy; organic microanalysis; PAH microsamples; (PAHs); polynuclear aromatic hydrocarbons; Raman spectra; SP519, pp. 723-729 (Apr. 1979).

Trace organic electrochemistry; bio-selective membrane electrodes; bio-sensors; enzymes; immunoelectrodes; SP5 19, pp. 525-532 (Apr. 1979). 
Trace organics; battery; chromatography; sulfuric acid; SP519, pp. $797-802$ (Apr. 1979).

Trace organics in air; complete analysis scheme; gas chromatography; hydrocarbons; permanent gas analysis; SP519, pp. 153-159 (Apr. 1979).

Trace organics in water; gas chromatography/mass spectrometry; microcomputer; routine analysis; SP519, pp. 169. 173 (Apr. 1979).

Traceability; automated test equipment; measurement assurance; 18354 .

Traceability; dose; ionizing; radioactivity; standards; testing; I836I.

Traceability; low-level; measurements; radioactivity; standards; 18400 .

Traceability; measurement assurance; measurement consistency; measurement system; national standards; radiation; radiation control; radiation measurements; 18800 .

Traceability; radioactivity; radiopharmaceuticals; 18761 .

Tracer gas; weatherization; air infiltration; air sample bags; energy conservation; retrofit; sulfur hexafluoride; NBSIR 79. 1728 .

Tracer gas test; bottom injection; multiple injection; smoke candle test; smoke control; stairwell pressurization; top injection; NBSIR 79-1747.

Tracer-gas technique; air infiltration, residential; air permeability of houses; energy conservation; pressurization technique; TN992.

Track; activation; detectors; dose; fast; neutrons; SP554, pp. 99-107 (Sept. 1979).

Tracklength; "charged particle; electron; energy deposition; Monte Carlo; multiple scatter; 18965.

Traction performance; tread wear; high speed performance; high speed tires; police tires; pursuit tires; tire maintenance; 19038 .

Trade press; audience; feature article; news release; publication announcement; scientist-author; technical communicator; technical paper; 18817 .

Training; adversary characteristics; animal research; behavioral science; biosensors; computer analysis; ergonomics; human engineering; human factors; human motivation; human reliability; personnel selection; physical security; physiological psychology; sensory capability; SP480-38.

Training; evacuation; fire doors; fire drills; fire extinguishers; fire safety; health care facilities; hospitals; human behavior; nursing homes; nursing staff; NBS-GCR -79-I79.

Training and education; design professionals; energy audits; energy codes; Kentucky Fire Marshal's office; lighting and thermal efficiency standards; local governments; new construction plans review; SP552, pp. $121-130$ (July 1979).

Training for diagnosis; automatic monitoring; failure annunciation; malfunction procedures; manned spaceflight failures; redundancy management; SP547, pp. 3-16 (July 1979).

Training phantoms; ultrasonic phantoms; tissue signature; tissue simulators; SP525, pp. 327-336 (Apr. 1979).

Training superconducting magnet; epoxy; epoxy-impregnated magnets; superconductor; 18718 .

Transaction processor; inventory management; on-line; performance; response time; saturated system; SP500-52, pp. 215-218 (Oct. 1979).

Transaction volume; transfer speed; validate; verify; application; character set; computer interface; cost; data entry; edit; operator speed; record size; SP5O0-55.

Transborder data flows; computer-telecommunications convergence; computer trends; information age; information as a resource; information revolution; social issues in information; telecommunication trends; 18975 .

Transducer; acoustic emission; co-shock; couplant; detection; electronic package; impact noise; microcircuit device; particle detection; particle impact noise detection; PIND; preshock; seeded specimens; NBSIR 78-1590 (NASA).
Transducer; dynamic calibration; evaluation; interagency transducer project; performance characteristics; telemetry; TN1110.

Transducer characterization; ultrasonics; acoustic theory; calorimetry; electroacoustic method; medical applications; metrology; NDE; radiation force; 18438 .

Transducers; dielectric strength; electrets; piezoelectricity; polarization; poling procedures; polymers; poly(vinylidene fluoride); pyroelectricity; J. Res. 84, No. 6, 447-453 (1979).

Transducers; ultrasonics; annular array; breast cancer; chirp signals; imaging; opto-acoustic; pulse compression; sensitivity; signal averaging; signal processing; tissue characterization; tomography; SP525, pp. 255-259 (Apr. 1979).

Transducers; weather station; data acquisition system; digital tape recorder; fuel measurement; instrumentation; total energy; NBSIR 79-1709.

Transducers, angle beam; transducers, contact; transducers, immersion; transducers, ultrasonic; transduction, ultrasonic; ultrasonic; ultrasound; characterization, transducers; propagating, bulk waves; 18907 .

Transducers, contact; transducers, immersion; transducers, ultrasonic; transduction, ultrasonic; ultrasonic; ultrasound; characterization, transducers; propagating, bulk waves; transducers, angle beam; 18907.

Transducers, immersion; transducers, ultrasonic; transduction, ultrasonic; ultrasonic; ultrasound; characterization, transducers; propagating, bulk waves; transducers, angle beam; transducers, contact; 18907 .

Transducers, ultrasonic; transduction, ultrasonic; ultrasonic; ultrasound; characterization, transducers; propagating, bulk waves; transducers, angle beam; transducers, contact; transducers, immersion; 18907 .

Transduction, ultrasonic; ultrasonic; ultrasound; characterization, transducers; propagating, bulk waves; transducers, angle beam; transducers, contact; transducers, immersion; transducers, ultrasonic; 18907 .

Transfer; documentation; energy; evaluation; guidelines; implementation; large-scale; management; mathematical models; policy analysis; software; standards; SP534.

Transfer speed; validate; verify; application; character set; computer interface; cost; data entry; edit; operator speed; record size; transaction volume; SPSOO-55.

Transfer standards; electro-dynamic wattmeters; energy measurements; energy standards; international comparisons; metrology; power measurements; precise electrical measurements; TDM wattmeters; thermal wattmeters; 18529 .

Transformation; computing system; dataplot; fitting; graphics; interactive graphics; regression; software; 18519.

Transformation; $x$ ray; carcinogenesis; neutron; repair; survival; SP554, pp. 63-73 (Sept. 1979).

Transformer calibrations; current comparators; current ratios; current transformers; current transformer testing; electronic ratio error set; 18624 .

Transient; traveling-wave antenna; Fast Fourier transform; linear load; Newton-Raphson interation methods; nonlinear load; time-domain measurements; time-stepping finite-difference technique; 19035 .

Transient elastic wave propagation; acoustic emission; capacitive transducer; signal analysis; simulated acoustic emission; time-domain deconvolution; 18878 .

Transient flow; transient heat transfer; forced flow; helium; stability; superconductor; 18813 .

Transient heat transfer; forced flow; helium; stability; superconductor; transient flow; 18813 .

Transient phenomena; electrical breakdown; high speed photography; Kerr effect; liquid breakdown; nitrobenzene; partial discharges; streamers; 18843 .

Transients; divider; Duhamel's integral; high voltage; impulse; pulse measurements; response time; step response; NBSIR 79-1933. 
Transistor; base drive circuit; electronic circuits; inductive load; nondestructive; protection circuit; reverse bias; safe operating area; second breakdown; switching power transistor; tester; SP400-54.

Transistor gain; integrated circuit; process validation wafer (PVW); reliability; silicon; test pattern; 18463.

Transistors; current crowding; die attachment evaluation; junction temperature; measurement technology; power transistors; semiconductor devices; thermal characterization; thermal resistance; $S P 400-14$.

Transistors; ultraviolet reflectance; VCE(SAT); $x$-ray photoelectron spectroscopy; auger electron spectroscopy; die attachment; electrical properties; electronics; hermeticity; indium-doped silicon; infrared reflectance; integrated circuits; line-width measurements; SP400-38.

Transistors, power switching; device characterization; nondestructive testing; safe operating area, reverse-bias; secondbreakdown, reverse-bias; 18738 .

Transition elements; electronegativities; hybridization; structural stability; 18421 .

Transition metal; alloy phases; electronegativity; electron factors; electron vacancies; Laves phase; sigma phase; 18357.

Transition metal alloys; $d$-electron energy band parameters; $d$ electron transfer; heats of formation; 19047.

Transition metal fluorides; electron spin resonance; fluorination of polymers; free radicals; peroxy radicals; 18726 .

Transition probabilities; wavelengths; atomic data; data availability; dielectronic recombination rates; excitation rate coefficients; ionization rate coefficients; magnetic fusion research; 18593.

Transition probability; $\Sigma-\Pi$ transitions; adiabatic perturbation theory; elastic scattering phase shifts; pseudocrossing; sudden-perturbation limit; 18575 .

Transition probability; unified atom approximation; $\Sigma-\Pi$ transition; adiabatic limit; atomic collisions; quasimolecule terms; sudden perturbation limit; 18576 .

Transition-metal glasses; amorphous alloys; magnetic properties; neutron scattering; spin waves; 18898 .

Translational motion; load application factors; load hardness; load rate; machining; SP562, pp. $185-188$ (Oct. 1979).

Transmissibility; vibration isolation; vibrations; antivibration mounting; damping; dynamic properties; industrial engineering; isolation; machinery and equipment; mechanical impedance; mechanical vibrations; noise control; $H I 28$.

Transmission; cost; economics; hydrogen; production; storage; 18812.

Transmission; ultrasound; attenuation; tissue properties; SP525, pp. 101-108 (Apr. 1979).

Transmission lines; capacitance; rectangular coaxial line; 18694.

Transmission lines; dielectric measurements; dielectric relaxation time; time-domain; 18723 .

Transmittance; reflectance; standard reference materials; 18844.

Transmittance; wavelength standard; bandwidth; didymium glass filter; passband centroid; spectrophotometer; SP260-66.

Transmitted pulse; adsorbed water; breakdown mechanism; frequency and time dependence of breakdown thresholds; IR window materials; $\mathrm{NaCl}$; pressure; pulsed TEA $\mathrm{CO}_{2}$ laser surface breakdown; spot size; surface absorption; SP54I, pp. 318-326 (Dec. 1978).

Transport properties; copper; critical evaluation; data analysis; data compilation; data evaluation; data extraction; data synthesis; electrical resistivity; elements; gold; metals; molten metals; palladium; precious metals; JPCRD 8, No. 4, 11471298 (1979).
Transport properties; corrosion; data compilation; electrochemical energy storage materials; molten salts; physical properties; safety and hazards; thermal energy storage materials; thermal properties; thermodynamic properties; NSRDSNBS6 I, Part 11.

Transport theory; absorbed dose; attenuation coefficient; detector response functions; dosimetry; electrons; foil transmission; photons; stopping power; 18371 .

Transportation; effective carbon atom number; hazardous materials; packaging; plastics; standardization; NBSIR 791768.

Transportation; effective carbon atom number; hazardous materials; packaging; plastics; standardization; 18639 .

Transportation noise; truck; acoustics; noise measurement; noise (sound); tire noise; 18607.

Transverse current correlation function; velocity autocorrelation function; intermediate scattering function; LennardJones liquid; liquid rubidium; molecular dynamics; radial distribution function; J. Res. 84, No. 6, 439-446 (1979).

Transverse electromagnetic cell; measurement procedures; susceptibility and emission measurements; TN1013.

Transverse electromagnetic transmission cells; electromagnetic compatibility; measure ments; 18578 .

Transverse electromagnetic (TEM) cell; electromagnetic susceptibility testing; structural design and fabrication procedures; $T$ NIOII.

Trapped flux; gyroscope; ralativity; space; superconducting; torque; 18846 .

Trapping; air sampling; co-condensation; gas chromatography; SP519, pp. 95-99 (Apr. 1979).

Trapping column; equilibration trapping; gas chromatography; headspace gas stripping; standard-addition calibration; trace analysis; SPS 19, pp. 739-746 (Apr. 1979).

Traveling-wave antenna; Fast Fourier transform; linear load; Newton-Raphson interation methods; nonlinear load; timedomain measurements; time-stepping finite-difference technique; transient; 19035.

Tread wear; braking traction; cornering traction; driving traction; endurance; maintenance; operation; purchasing; pursuit tires; safety; SP480-33.

Tread wear; high speed performance; high speed tires; police tires; pursuit tires; tire maintenance; traction performance; 19038.

Trial use and comment; American National Standards Institute; Health Physics Society Standards Committee; mandatory testing program; peer review; personnel dosimetry; processors; standard; 18992.

Trials, PRVTT; videotaped trials; civil trials; courtroom procedures; juror attitudes; prerecorded videotaped trials; PRVTT; SP480-30.

Triaminoguanidinium nitrate; crystal structure; hydrogen bond; neutron diffraction; rigid body motion; 18873 .

Triamterene assay; clinical analysis; fluorescence detection; liquid chromatography; SP519, pp. 477-480 (Apr. 1979).

Tricyclic antidepressives; benzodiazepines; clinical use; derivatization; quaternary two-phase systems; serum; uv-detection; SP519, pp. $461-468$ (Apr. 1979).

Triethyl phosphate; polystyrene; sodium (polystyrene sulfonate ); sulfonation; sulfur trioxide; 18542 .

Triglycine sulfate; ferroelectrics; figures of merit; improper ferroelectrics; pyroelectric detectors; pyroelectric vidicons; terbium molybdate; 18852 .

Triply modular redundant; fault tolerant computer; soft errors; TMR; NBSIR 79-1927.

Triply redundant central computer; central unit; computerized; detection; electronic lock; exclusion area; forced entry deterrent systems; guard control station; higher headquarters; perimeter station; remote unit; response force; NBSIR 791725 . 
Triply-ionized; ultraviolet; wavelengths; energy levels; lanthanum; spectra; spectroscopy; 18782 .

Tris(hydroxymethyl)aminomethane; endothermic solution reactions; enthalpy of solution; $\mathrm{KBr}, \mathrm{KI}, \mathrm{KIO}_{3}, \mathrm{KlO}_{4}$; solution calorimetry; thermochemistry; J. Res. 84, No. 4, 273-286 (1979).

Troposphere; aldehyde; free radical; photolysis; reactions; review; SP557, pp. 27-46 (Aug. 1979).

Troposphere; aldehydes; aromatics; chemical kinetics; data needs; free radicals; modeling; $\mathrm{NO}_{5}$; olefins; $\mathrm{SO}_{s} ;$ SP557.

Troposphere; alkoxyl; kinetics; radicals; review; SP557, pp. 51 61 (Aug. 1979).

Troposphere; hydroxyl; kinetics; olefin; ozone; review; SP557, pp. 7-14 (Aug. 1979).

Troposphere; kinetics; photochemistry; review; sulfur dioxide; SP557, pp. 99-100 (Aug. 1979).

Tropospheric chemistry; aromatics; free radicals; mechanism; reactions; SP557, pp. 85-91 (Aug. 1979).

Tropospheric chemistry; nitrates; nitrites; nitrogen oxides; photolysis; reactions; review; SP557, pp. $71-79$ (Aug. 1979).

Truck; acoustics; noise measurement; noise (sound); tire noise; transportation noise; 18607 .

Truck-mounted; CCVT; compact; field calibration; high accuracy; modular capacitive divider; portable system; 18833 .

Truck-mounted; CCVT; compact; field calibration; high accuracy; portable system; 18938 .

Tryptophan metabolites; brain; cerebrospinal fluid; fluorescence flow cell; liquid chromatography; SP519, pp. 411-418 (Apr. 1979).

Tsai-Wu tensor polynomial lamina strength failure criterion; automotive structures; composite material; composite material analysis program; SP563, p. 133 (Oct. 1979).

TSP; benchmarking; cost analysis; evaluation; procurement; technical analysis; time-sharing; SP500-52, pp. 233-234 (Oct. 1979).

TTL; bipolar process; contact resistor; cross bridge sheet resistor; electrical alignment resistor; integrated circuits; linewidth; photolithography; sheet resistance; silicon; test pattern; test structure; 18533 .

T-transformation of correlation coefficient; distribution of regression coefficients; R. A. Fisher; Student's $t$; Student's $z$; Student (W. S. Gosset, 1876-1937; 18543.

Tumor; ultrasound; characterization; differential attenuation; SP525, pp. $121-124$ (Apr. 1979).

Tunable dye laser; analytical flame spectroscopy; flame ionization; flame spectroscopy; laser enhanced ionization; laser spectroscopy; opto-galvanic effect; trace metal analysis; 18880 .

Tunable dye lasers; enhanced ionization; ionization spectrometry; LEI; stepwise excitation; 18983.

Tunable laser; atomic flame fluorescence; intracavity absorption; isotope analysis; laser analysis; laser fluorescence; laser spectroscopy; microfluorescence; saturation spectroscopy; 18364.

Tuneable laser calorimetry; 9.2 to $10.6 \mu \mathrm{m}$; absorption; $\mathrm{KCl}$; NaCl; SP541, pp. 24-32 (Dec. 1978).

Tungsten; wavelengths; ytterbium; energy. levels; hafnium; ionization energies; lutetium; osmium; rhenium; tantalum; 18506 .

Tungsten carbide; cemented carbides; electrochemical grinding; grinding; SP562, pp. 305-315 (Oct. 1979).

Tungsten $\mathrm{x}$ rays; $\mathrm{x}$-ray wavelength ratios; gamma rays; precision wavelength; silicon lattice spacing; 18487 .

Tunnel diode oscillator; gas thermometer; low temperature; temperature scale; thermometry; 18548

Tunnel junctions; Josephson junctions; microwave receivers; microwaves; mixers; superconductivity; 18683 .

Tunneling; activation energy; methyl group; neutron scattering; potential barrier; quasielastic scattering; reorientation; residence time; 18374.
Tunneling; crystal structure; neutron scattering; nitromethane; rotation; 19025.

Tunneling; energy gap; iridium; Josephson junction; low- $\mathrm{T}_{c}$; microwaves; thin-film; 18540 .

Turbine blade; acoustic surface wave; ceramic; surface characterization; surface crack; SP562, pp. 379-392 (Oct. 1979).

Turbine operational safety; turbogenerators; detection procedures; mechanical failures; steam-valves; SP547, pp. 250-279 (July 1979).

Turbocharging monitoring; crankshaft displacement; medium speed diesel engine; piston ring wear; SP547, pp. 153-166 (July 1979).

Turbogenerators; detection procedures; mechanical failures; steam-valves; turbine operational safety; SP547, pp. 250-279 (July 1979).

Turbulence; buoyant flow; compartment fires; computer programs; corridor fires; fire models; fire spread; room fires; thermal radiation; NBS-GCR-78-150.

Turbulence; concentration fluctuations; fast Fourier transforms; Fourier transform analysis; mixing in turbulent flow; noise spectrum; Raman spectroscopy; 18626 .

Turbulence modeling; flowmeter; fluid dynamics; mathematical modeling; numerical modeling; pipe flows; 18410 .

Turnaround time; availability standards; batch processing; calibration programs; computer standards; interactive processing; quality of service; response time; SP5OO-52, pp. 79-86 (Oct. 1979).

Turret systems; vehicle maintenance; combat vehicles; diagnostic connector assembly; fighting vehicle systems; generic DCA; Hull systems; simplified test equipment for internal combustion engines; SP547, pp. 98-110 (July 1979).

Tutorial; vendor systems; workload requirements; benchmark construction process; benchmark validation; competitive evaluation; SP50O-52, pp. 235-240 (Oct. 1979).

TVI; vehicular electronics; electromagnetic bioeffects; electromagnetic compatibility; electromagnetic immunity; electromagnetic interference; electromagnetic radiation; electromagnetic susceptibility; electronic smog; home entertainment electronics; industrial electronics; SP55I.

Twenty bits + sign; voltage output; digital-to-analog converter; high resolution; multirange; $\mathbf{R}-2 \mathrm{R}$ ladder; relay switching; self-calibration; TN1105.

Twin Rivers Project; weather station; air infiltration; buildings; data acquisition; energy; instrumentation; measurement; thermography; 18733 .

Two frequency separated oscillating fields; atomic beams; atomic frequency standards; cavity phase shift; Ramsey envelope; Ramsey separated oscillating fields; 18475 .

Two photon absorption; CdSe; CdTe; internal reflections; laser calorimeter; linear absorption; Nd:YAG laser; SP54I, pp. 1923 (Dec. 1978).

Two photon spectroscopy; laser spectroscopy; optical Ramsey effect; resonance line shape analysis; Rydberg atoms; 19019.

Two-dimensional modulated structure; incommensurate lattice; lanthanum niobate; modulated structure; nonstoichiometry; 18646.

Two-level model; absorption; cesium; exponential index; ionization; multiphoton; Rabi frequency; Star shift; 18892.

Two-photon absorption; ultraviolet wavelength scaling; damage thresholds; electric fields; laser damage; nanosecond pulses; pulsewidth dependence; standing waves; thin-film coatings; SP541, pp. 190-202 (Dec. 1978).

Two-photon ionization; cesium; ionization; perturbation theory; second-order perturbation theory; 18927.

Two-step prototype procurement; Veteran's Administration; Experimental Technology Incentives Program; portable oxygen generator experiment; procurement policy; NBS-GCRETIP 78-50. 
Two-surface lapping; two-surface polishing; dome finishing; finishing technique; hemispherical domes; oxides; sapphire; SP562, pp. 255-260 (Oct. 1979).

Two-surface polishing; dome finishing; finishing technique; hemispherical domes; oxides; sapphire; two-surface lapping; SP562, pp. 255-260 (Oct. 1979).

Types of French standards; building standards; foreign building standards; French building standards; French standards system; marking and certification; SP552, pp. 45-56 (July 1979).

\section{U}

Ultimate strength; advanced composites; advanced ships; elastic properties; fatigue tests; nondestructive tests; structural analysis; SP563, pp. 286-298 (Oct. 1979).

Ultra high molecular weight polyethylene; viscosity number; intrinsic viscosity; molecular weight; polyethylene; shear rate; 18834.

Ultra-black coating; Alaskan pipeline; computers; corrosion; fire safety; gyromagnetic ratio; paper; photometric calibrator; safety tips; solar energy; toxic chemicals; DIM/NBS 63, No. 11, 1-36 (1979).

Ultra-fine polishing; water; $x$-ray photoelectron spectrometer; crystallographic integrity; electron diffraction images; hydrated layer; ion microprobe mass spectrometer; roughness; sapphire; SP562, pp. $317-323$ (Oct. 1979).

Ultrasonic; acoustic; crack; defects; elastic solid; pulses; scattering; 18391 .

Ultrasonic; attenuation; brain tumor; clot; hemorrhage; hydrocephalus; impedance; infarct; speed; SP525, pp. 81-84 (Apr. 1979).

Ultrasonic; ultrasound; characterization, transducers; propagating, bulk waves; transducers, angle beam; transducers, contact; transducers, immersion; transducers, ultrasonic; transduction, ultrasonic; 18907.

Ultrasonic absorption; ultrasonic attenuation; ultrasonic instrumentation; ultrasonic measurements; ultrasonic spectroscopy; ultrasonic tissue characterization; ultrasonic tissue parameters; ultrasonic tissue signature; ultrasonic velocity; SP525, pp. 43-51 (Apr. 1979).

Ultrasonic attenuation; ischemic injury; myocardial infarction; SP525, pp. 63-71 (Apr. 1979).

Ultrasonic attenuation; ultrasonic instrumentation; ultrasonic measurements; ultrasonic spectroscopy; ultrasonic tissue characterization; ultrasonic tissue parameters; ultrasonic tissue signature; ultrasonic velocity; ultrasonic absorption; SP525, pp. 43-51 (Apr. 1979).

Ultrasonic imaging; ultrasound; breast cancer; computerized tomography; mammography; time-of-flight; tissue characterization; SP525, pp. 221-225 (Apr. 1979).

Ultrasonic inspection; cocured and precured laminates; exoatmospheric exposure of composites; Long Duration Exposure Facility (LDEF); polyimide composite stability in space; polyimide/graphite mechanical properties; SP563, pp. 4-16 (Oct. 1979).

Ultrasonic inspection system; composite structures; flaw simulation; semi-automated ultrasonic inspection; SP563, p. 59 (Oct. 1979).

Ultrasonic instrumentation; ultrasonic measurements; ultrasonic spectroscopy; ultrasonic tissue characterization; ultrasonic tissue parameters; ultrasonic tissue signature; ultrasonic velocity; ultrasonic absorption; ultrasonic attenuation; SP525, pp. 43-51 (Apr. 1979).

Ultrasonic machining; as-machined material strength; dimensional tolerances; profile grinding; silicon nitride; SP562, pp. 209-220 (Oct. 1979).
Ultrasonic measurements; ultrasonic spectroscopy; ultrasonic tissue characterization; ultrasonic tissue parameters; ultrasonic tissue signature; ultrasonic velocity; ultrasonic absorption; ultrasonic attenuation; ultrasonic instrumentation; SP525, pp. 43-51 (Apr. 1979).

Ultrasonic phantoms; tissue signature; tissue simulators; training phantoms; SP525, pp. 327-336 (Apr. 1979).

Ultrasonic radiator; baffled piston radiator; piston radiator; radiation of sound; 18479 .

Ultrasonic scattering; flaws in crystals; NDE; 18831 .

Ultrasonic scattering; ultrasound; detection of lung disease; frequency signature; statistical scattering; tissue signature; SP525, pp. 135-141 (Apr. 1979).

Ultrasonic spectroscopy; instantaneous power spectra; colorcoded B-scan; spectra-color ultrasonography (SCU); spectrum analysis; SP525, pp. 261-266 (Apr. 1979).

Ultrasonic spectroscopy; ultrasonic tissue characterization; ultrasonic tissue parameters; ultrasonic tissue signature; ultrasonic velocity; ultrasonic absorption; ultrasonic attenuation; ultrasonic instrumentation; ultrasonic measurements; SP525, pp. 43-51 (Apr. 1979).

Ultrasonic spectrum analysis; clinical ultrasound; ocular tumor; power spectra; Rayleigh scattering; SP525, pp. $111-119$ (Apr. 1979).

Ultrasonic standards; ultrasonic testing; evaluation; international; standardization; standard recommended practice; synopsis; NBSIR 79.1790.

Ultrasonic testing; evaluation; international; standardization; standard recommended practice; synopsis; ultrasonic standards; NBSIR 79-1790.

Ultrasonic tissue absorption; absorption of ultrasound; macromolecular relaxation; relaxation phenomenon; SP525, pp. 29-36 (Apr. 1979).

Ultrasonic tissue characterization; computer processing; estimation theory; liver attenuation; spectral analysis; statistical modeling; SP525, pp. 125-132 (Apr. 1979).

Ultrasonic tissue characterization; ultrasonic tissue parameters; ultrasonic tissue signature; ultrasonic velocity; ultrasonic absorption; ultrasonic attenuation; ultrasonic instrumentation; ultrasonic measurements; ultrasonic spectroscopy; SP525, pp. 43-51 (Apr. 1979).

Ultrasonic tissue characterization; ultrasound imaging; computed tomography-ultrasonic; diagnosis-ultrasonic; tissue equivalent test objects and phantoms; SP525, pp. 337-340 (Apr. 1979).

Ultrasonic tissue parameters; ultrasonic tissue signature; ultrasonic velocity; ultrasonic absorption; ultrasonic attenuation; ultrasonic instrumentation; ultrasonic measurements; ultrasonic spectroscopy; ultrasonic tissue characterization; SP525, pp. 43-51 (Apr. 1979).

Ultrasonic tissue scattering; ultrasound attenuation; ultrasound diagnosis; backscatter frequency dependence; cirrhosis; composition-dependent scattering; fatty liver; stochastic scattering; tissue characterization; SP525, pp. 157-163 (Apr. 1979).

Ultrasonic tissue signature; ultrasonic velocity; ultrasonic absorption; ultrasonic attenuation; ultrasonic instrumentation; ultrasonic measurements; ultrasonic spectroscopy; ultrasonic tissue characterization; ultrasonic tissue parameters; SP525, pp. 43-51 (Apr. 1979).

Ultrasonic velocity; ultrasonic absorption; ultrasonic attenuation; ultrasonic instrumentation; ultrasonic measurements; ultrasonic spectroscopy; ultrasonic tissue characterization; ultrasonic tissue parameters; ultrasonic tissue signature; SP525, pp. 43-51 (Apr. 1979).

Ultrasonics; acoustic; computer processing; digital acquisition; digital signal processing; pulse-echo techniques; spectrum analysis; SP525, pp. 281-286 (Apr. 1979).

Ultrasonics; acoustic theory; calorimetry; electroacoustic method; medical applications; metrology; NDE; radiation force; transducer characterization; 18438. 
Ultrasonics; annular array; breast cancer; chirp signals; imaging; opto-acoustic; pulse compression; sensitivity; signal averaging; signal processing; tissue characterization; tomography; transducers; SP525, pp. 255-259 (Apr. 1979).

Ultrasonics; blood flow; breast cancer; diagnosis; Doppler; screening; SP525, pp. 173-176 (Apr. 1979).

Ultrasonics; variability; calibration; diffusion bonding; measurement assurance program; reference blocks; standards; NBSIR 79-1742.

Ultrasonics; velocity; absorption; amino acids; attenuation; frequency; mammalian tissues; polypeptides; proteins; tissue characterization; SP525, pp. 19-27 (Apr. 1979).

Ultrasonics; visual-optical tests; acoustic; annual report; eddy currents; inspection; magnetic particles; nondestructive evaluation; penetrants; radiography; statistics; NBSIR 781581 .

Ultrasound; aperture synthesis; computed tomography; Doppler; fluid flow; high resolution; reconstruction; temperature reconstruction; SP525, pp. 227-233 (Apr. 1979).

Ultrasound; aperture synthesis; computed tomography; Doppler; fluid flow; high resolution; reconstruction; temperature reconstruction; SP525, pp. 235-246 (Apr. 1979).

Ultrasound; attenuation; breast cancer; cancer; connective tissue; differential diagnosis; medullary carcinoma; papillary carcinoma; scirrhous carcinoma; shadowing; SPS25, pP. 9399 (Apr. 1979).

Ultrasound; attenuation; B-san; cepstrum; computer; convolution; de-convolution; liver; power spectrum; signal processing; tissue characterization; tissue parameters; SP525, pp. 287-295 (Apr. 1979).

Ultrasound; attenuation; dispersion; skull bone; sound speed; SP525, PP. 197-201 (Apr. 1979).

Ultrasound; attenuation; tissue properties; transmission; SP525, pp. 101-108 (Apr. 1979).

Ultrasound; axisymmetric; beams; focal thermal flaw; skull transmission; SPS25, pp. 203-208 (Apr. 1979).

Ultrasound; breast cancer; computerized tomography; mammography; time-of-flight; tissue characterization; ultrasonic imaging; SP525, pp. 221-225 (Apr. 1979).

Ultrasound; characterization; differential attenuation; tumor; SPS25, Pp. $121-124$ (Apr. 1979).

Ultrasound; characterization, transducers; propagating, bulk waves; transducers, angle beam; transducers, contact; transducers, immersion; transducers, ultrasonic; transduction, ultrasonic; ultrasonic; 18907.

Ultrasound; detection of lung disease; frequency signature; statistical scattering; tissue signature; ultrasonic scattering; SP525, pp. 135-141 (Apr. 1979).

Ultrasound; pattern recognition; prostate tumors; SP525, pp. 297-302 (Apr. 1979).

Ultrasound; picture processing; signal analysis; SP525, pp. 303313 (Apr. 1979).

Ultrasound; propagation velocity; reflection technique; solids; tissue; SP525, pp. 53-56 (Apr. 1979).

Ultrasound; velocity; absorption; attenuation; computerized tomography; Doppler; impedance; medical diagnosis; microscopy; pattern recognition; scattering; signal processing; tissue characterization; tissue parameters; SPS25.

Ultrasound; velocity; attenuation; mammalian tissues; SP525. pp. 343-360 (Apr. 1979).

Ultrasound; viscoelasticity; wave propagation; anisotropy; dispersion; elasticity; human bone; microhardness; microstructure; piezoelectricity; thermodynamics; SP525, PP. 189196 (Apr. 1979).

Ultrasound attenuation; ultrasound diagnosis; backscatter frequency dependence; cirrhosis; composition-dependent scattering; fatty liver; stochastic scattering; tissue characterization; ultrasonic tissue scattering; SP525, PP. 157-163 (Apr. 1979).
Ultrasound backscattering from blood; blood erythrocytes aggregation; blood hematocrit; SP525, pp. $165-169$ (Apr. 1979).

Ultrasound diagnosis; backscatter frequency dependence; cirrhosis; composition-dependent scattering; fatty liver; stochastic scattering; tissue characterization; ultrasonic tissue scattering; ultrasound attenuation; SP525, pp. 157-163 (Apr. 1979).

Uitrasound diagnosis; clinical cardiac data; digital processing; Fast Fourier Transform; frequency spectra; in vivo; microprocessor-controlled data acquisition; myocardial infarction; real-time; tissue characterization; SP525, pp. $267-$ 273 (Apr. 1979).

Ultrasound imaging; computed tomography-ultrasonic; diagnosis-ultrasonic; tissue equivalent test objects and phantoms; ultrasonic tissue characterization; SP525, pp. 337-340 (Apr. 1979).

Ultrasound velocity; zero crossing detection; non-invasive temperature monitoring; soft tissue; temperature dependence; SP525, pp. 57-6I (Apr. 1979).

Ultraviolet; wavelengths; energy levels; lanthanum; spectra; spectroscopy; triply-ionized; $/ 8782$.

Ultraviolet; wavelengths; zirconium; spectra; 18499.

Ultraviolet photoelectron spectroscopy; amorphous germanium; binding energy shifts; extra-atomic screening; implants; ion bombardment; rare-gases; relaxation energy; 18323.

Ultraviolet photoemission spectroscopy; adsorption; chemisorption; formaldehyde; ruthenium; surface chemistry; 18791 .

Ultraviolet radiation; calibrations; energy; fluid mixtures; light; liquefied natural gas; measurements; microwaves; super spring; DIMINBS 63, No. 9, 1-32 (1979).

Ultraviolet reflectance; VCE(SAT); $x$-ray photoelectron spectroscopy; auger electron spectroscopy; die attachment; electrical properties; electronics; hermeticity; indium-doped silicon; infrared reflectance; integrated circuits; line-width measurements; oxidation; SP4OO-38.

Ultraviolet spectra; charge transfer; excited argon atoms; free radicals; infrared spectra; matrix isolation; molecular ions; photochemistry; 18847 .

Ultraviolet spectra; emission lines, stars; late-type stars; stellar chromospheres; stellar coronae; stellar winds; /8528.

Ultraviolet, spectra; L $\alpha$ emission; sun, atmosphere; sun, chromosphere; sun, plage; 18876.

Ultraviolet spectra; satellites; space astronomy; stars, chromospheres; stars, coronae; stars, late-type; stars, winds; 18606.

Ultraviolet, spectra; sun, chromosphere; sun, spectra; sun, transition region; 18922 .

Ultraviolet spectrometry; gas chromatography; gas chromatography/mass spectrometry; preconcentration techniques; sample preparation; SP5 19, pp. 7-18 (Apr. 1979).

Ultraviolet spectroscopy; galactic astronomy; space astronomy; stellar astronomy; 18590 .

Ultraviolet spectrum; vacuum ultraviolet photolysis; $\mathrm{CCN}$; CNC; far infrared spectrum; HCCN; infrared spectrum; interferometer; matrix isolation; methyl cyanide; 18842 .

Ultraviolet spectrum; vacuum ultraviolet photolysis; charge transfer; cyanomethyl radical; excited argon atoms; force constants; infrared spectrum; ketenimine; matrix isolation; methyl cyanide; 18879 .

Ultraviolet transmission; fluorides; forging; laser windows; lithium fluoride; mechanical properties; optical properties; SP541, pp. 59-64 (Dec. 1978).

Ultraviolet wavelength scaling; damage thresholds; electric fields; laser damage; nanosecond pulses; pulsewidth dependence; standing waves; thin-film coatings; two-photon absorption; SP54I, pp. 190-202 (Dec. 1978).

UN Conference on Science and Technology for Development (UNCSTD); Africa; Asia; developing countries; industrialization; Latin America; management; measurement; metrology; quality control; standards; technology transfer; SPS43. 
U.N. Conference on Science and Technology for Development; UNCSTD; appropriate technology; industrialization; industrial R\&D; LDC's; less developed countries; light capital technology; science and technology for development; 18685 .

Uncertainty; calibration; gage blocks; length; measurement assurance; measurement process control; systematic error; Monogr. 163.

Uncertainty; precision; radioactivity measurements; statistical design of experiment; statistical terms and formulas; statistics; systematic error; 18427.

Uncomplicated cure; instantaneous optimization; radiation therapy; SP554, pp. 57-61 (Sept. 1979).

UNCSTD; appropriate technology; industrialization; industrial R\&D; LDC's; less developed countries; light capital technology; science and technology for development; U.N. Conference on Science and Technology for Development; 18685.

Undercover equipment; body-worn transmitters; communications equipment; FM transmitters; law enforcement equipment; standards; surveillance; 18381 .

Uniaxial creep; additivity of damage; cold drawn; crack growth; fracture; molecular weight distribution; necking; polyethylene; 18765 .

Uniaxial creep; crack growth; failure; polyethylene; solvent; stress-cracking agent; 18766 .

Unified atom approximation; $\Sigma-\Pi$ transition; adiabatic limit; atomic collisions; quasimolecule terms; sudden perturbation limit; transition probability; 18576 .

Uniform network; affine network; neutron scattering; phantom network; polybutadiene; rubber elasticity; 18827 .

Uniform Time Act of 1966; universal time; American National Standard Representation for Calendar Date and Ordinal Date for Information Interchange; local time differentials; meridian designator; time differential factor; time zone references; FIPS PUB 59.

Unimolecular decomposition; activation energy; $A$-factor; comparative rate; flow system; heat of formation; hexylmethylethane; $t$-butyl radical; 18743 .

Unimolecular dissociation; calorimetry; infrared; kinetics; laser chemistry; mechanisms; multiphoton; thermochemistry; 18709 .

Unimolecular dissociation; infrared laser; kinetics; mechanisms; modeling; multiphoton; 18712 .

Unit; absorbed dose; dose equivalent; gray; sievert; 19002 .

United Kingdom; West Germany; antitrust; Canada; certification; Denmark; economics of standards; government policy; international standards; laboratory accreditation; standards systems; NBS-GCR-79-172.

Universal time; American National Standard Representation for Calendar Date and Ordinal Date for Information Interchange; local time differentials; meridian designator; time differential factor; time zone references; Uniform Time Act of 1966; FIPS PUB 59.

Universality hypothesis; binary-liquid mixture; consolute point; critical exponent; critical phenomena; critical solution point; liquid-liquid critical point; renormalization group theory; scaling theory; 18825 .

Unsteady flow; air; anemometer; helicoid anemometer; lag; overspeeding error; rotary anemometer; NBSIR 78-1505.

Upholstered furniture; arson; bibliographies; building fires; compartment fires; fabric flammability; fire detection systems; fire tests; flammability tests; human behavior; plastics; polymers; smoke; smoke detectors; subway fires; toxicity; NBSIR 79-1745.
Upholstered furniture; building fires; cost-benefit analysis; costs; decision analysis; fire losses; furniture; hazard analysis; probability; residential buildings; sensitivity analysis; smoke detectors; standards; TN1101.

Upholstered furniture; chairs; compartment fires; fire tests; flammability; furnishings; TN1103.

Upholstered furniture; chairs; doors; evacuation; fire departments; fire fighters; nursing homes; patients; room fires; smoke; NBS-GCR-79-159.

Upholstered furniture; detection time; detector location; fire tests; gas detectors; kitchen fires; mobile homes; smoke detectors; tenability limits; NBSIR 79-1915.

Upper atmosphere; atomic energy levels; atomic spectra; atomic transition probabilities; electron cross sections; fusion plasmas; lasers; molecular bands; molecular spectra; reaction rate constants; 18855 .

Uranium; activity coefficient; copper; critical evaluation; electrolyte; excess Gibbs energy; lead; manganese; osmotic coefficients; solutions; thermodynamic properties; JPCRD 8, No. 4, 1005-1050 (1979).

Uranium; alpha tracks; biomedical; boron; fission tracks; geochronology; geology; lithium; nitrogen; silicon devices; trace analysis; 18342 .

Uranium; Californium; cross sections; fission spectrum; neutron; threshold reaction; 18792 .

Urban; application; buildings; commercial; daylighting; energy; environments; heating; passive; solar; suburban; 18894 .

Urban; zoning regulations; infrastructure; land use; resource zoning; SP552, pp. 347-360 (July 1979).

Urban dusts; vibrational analysis; atomospheric aerosols; materials sampling; mineralogy; molecular analysis; particle analysis; power plant emissions; Raman microprobe; Raman spectroscopy; 18643.

Urban particulate; error analysis; instrumental analysis; multielement analysis; neutron activation analysis; SRM; trace elements; 18866 .

Urea; urea determination; x-ray diffraction; biomedical standard; diacetylurea; molecular structure; 18347.

Urea determination; $x$-ray diffraction; biomedical standard; diacetylurea; molecular structure; urea; 18347.

Uric acid derivative; uric acid determination; x-ray diffraction; biological assay; crystal structure; single crystal; 18672 .

Uric acid determination; $x$-ray diffraction; biological assay; crystal structure; single crystal; uric acid derivative; 18672 .

Urine; anabolic steroids; clean-up; contamination; dianabol; gas chromatography-mass spectrometry $(\mathrm{gc} / \mathrm{ms})$; gas liquid chromatography (glc); gc/ms interface; high performance liquid chromatography (hplc); inert columns; SP519, pp. 437-445 (Apr. 1979).

U.S. research in plumbing; building water systems; $\mathrm{ClB}$; international plumbing research; plumbing and drainage; SPS53.

Usage profiles; combination refrigerator-freezer field data; daily load profiles; energy consumption; field measurments; hourly load profiles; refrigerat or field data; NBSIR 79-1781.

Used oil; waste oil; engine oil; fuel oil; hydraulic oil; industrial oil; lubricating oil; oil specifications; petroleum standards; petroleum test methods; recycled oil; re-refined oil; SP556.

Useful life; consumer products; reliability engineering; testing methodology; 18378 .

User needs; building codes; building evaluation; elderly; fire safety; handicapped occupants; health care facilities; nursing homes; NBSIR 79-1906.

User needs; building evaluation; design process; man/environment research; post-occupancy evaluation; questionnaire; NBSIR 79-1780.

U.S.S.R; electron devices; electron tubes; semiconductors; NBSIR 78-1564.

UV; visible; degradation; IR; photodegradation; poly (methyl methacrylate); NBSIR 79-1766. 
Uv irradiation; light absorption; metal oxides; molecular absorption; optoagalvanic spectroscopy; 18344 .

Uv-detection; tricyclic antidepressives; benzodiazepines; clinical use; derivatization; quaternary two-phase systems; serum; SP519, pp. $461-468$ (Apr. 1979).

U-235: U-238; activation analysis; benchmark fields; dosimetry; fission yields; measurements; neutrons; Np-237; Pu-239; 18884 .

U-238; activation analysis; benchmark fields; dosimetry; fission yields; measurements; neutrons; Np-237; Pu-239; U-235; 18884

\section{V}

Vacuum; humidity; ozone; pressure; standards; temperature; 18335.

Vacuum spark; far ultraviolet; light pulse shape; 18811 .

Vacuum ultraviolet photolysis; CCN; CNC; far infrared spectrum; HCCN; infrared spectrum; interferometer; matrix isolation; methyl cyanide; ultraviolet spectrum; 18842 .

Vacuum ultraviolet photolysis; charge transfer; cyanomethyl radical; excited argon atoms; force constants; infrared spectrum; ketenimine; matrix isolation; methyll cyanide; ultraviolet spectrum; 18879 .

Vacuum ultraviolet spectroscopy; vacuum ultraviolet windows; differential pumping across capillary arrays; focused vacuurn ultraviolet; heat-pipe oven use in the vacuum ultraviolet; multichannel capillary arrays; 18808 .

Vacuum ultraviolet windows; differential pumping across capillary arrays; focused vacuum ultraviolet; heat-pipe oven use in the vacuum ultraviolet; multichannel capillary arrays; vacuum ultraviolet spectroscopy; 18808 .

Validate; verify; application; character set; computer interface; cost; data entry; edit; operator speed; record size; transaction volume; transfer speed; SPSO0-55.

Validation; workload characterization; workload management; capacity planning; hardware monitors; modeling; performance evaluation; performance prediction; simulation; SP500-52, pp. 179-192 (Oct. 1979).

Van der Waals coefficient; frequency dependent polarizability; helium ' $S$ state; molecular electronic structure; 18934.

Vanadium hydride; $\alpha$ phase; $485 \mathrm{~K}$; diffusion; quasielastic scattering; tantalum hydride; 18730 .

Vane anemometer; wind tunnel; airflow; anemometer; lascr velocimeter; low velocity; performance; NBSIR 78-I433.

Vane anemometer; wind tunnel; airflow; anemometer; laser velocimeter; low velocity; performance; NBSIR 78-1545.

Vapor density; vapor pressure; enthalpy and entropy of vaporization; entrainment method; melting temperature; molybdenum pentafluoride; 19020 .

Vapor pressure; apparent molal heat capacity; aqueous systems; bibliography; electrochemistry; electrolytes; enthalpy of dilution; heat capacity; relative apparent molal enthalpy; salt solutions; thermochemistry; SP537.

Vapor pressure; enthalpy and entropy of vaporization; entrainment method; melting temperature; molybdenum pentafluoride; vapor density; 19020.

Vapor pressure; viscosity; calorimetry; elasticity; electrical resistivity; emittance; measurement system; standard reference materials; temperature; thermal conductivity; thermal expansion; thermal properties; 18905 .

Vapor pressures; densities; enthalpies; entropies; equation of state; internal energies; isobars; isobutane; isochores; isotherms; Joule-Thomson inversion; latent heats of vaporization; melting line; orthobaric densities; specific heats; speeds of sound; NBSIR 79-1612.

Vapor pressures; densities; enthalpies; entropies; equation of state; internal energies; isobars; isochores; isotherms; JouleThomson inversion; latent heats of vaporization; melting line; n-butane; orthobaric densities; specific heats; speeds of sound; NBSIR 79-1621.

Vapor pressure-boiling point data; Wagner equation; Antoine equation; enthalpy of vaporization; halomethanes; JPCRD 8 , No. 2, 499-518 (1979).

Vapor recovery; bottom loading; field standard provers; field standards; field standard test measures; provers; specifications; standards; test measures; tolerances; HIO5-3.

Vapor recovery; weights and measures; consumer affairs; education; electromagnetic interference; electronic devices; International Organization of Legal Metrology; measurement assurance; metrication; model laws and regulations; national type approval; SP532.

Vapors; combustion; equilibrium; high temperature; isolation; lasers; mass spectrometry; matrix; modeling; SP561, Vols. I and 2.

Variability; calibration; diffusion bonding; measurement assurance program; reference blocks; standards; ultrasonics; NBSIR 79-1742.

Variable temperature; wafer chuck; deep level measurements; defect mapping; hot/cold wafer chuck; thermally stimulated measurements; thermal wafer chuck; SP400-55.

Variable wavelength monochromatic light; opto-galvanic effect; predetermined frequency; spectroscopic and analytic determinations; U.S. Patent 4,148,586.

Variational formulation; coaxial transmission line; cut-off frequency; equivalent circuit; modal analysis; scattering matrix; step discontinuity; TEM-cell; NBSIR 79-1606.

VCE(SAT); $x$-ray photoelectron spectroscopy; auger electron spectroscopy; die attachment; electrical properties; electronics; hermeticity; indium-doped silicon; infrared reflectance; integrated circuits; line-width measurements; oxidation; photolithography; SP400-38.

VDE; antennas; CISPR; ground screen; measurements; standards; 19033.

Vehicle maintenance; combat vehicles; diagnostic connector assembly; fighting vehicle systems; generic DCA; Hull systems; simplified test equipment for internal combustion engines; turret systems; SP547, pp. 98-110 (July 1979).

Vehicle test and diagnostics; automated test and diagnostics; automotive test and diagnostics; SP547, pp. 11:-126 (July 1979).

Vehicles, emergency; visibility, lights; visual perception; color, lights; conspicuity, lights; effective intensity; emergency lights; intensity, effective; lights, flashing; lights, warning; perception, visual; peripheral vision; SP480-36.

Vehicular electromagnetic environment; vehicular near-zone electric fields; vehicular near-zone magnetic fields; worst-case EM fields; mobile-radio; near-field strength levels; TN1014.

Vehicular electronics; electromagnetic bioeffects; electromagnetic compatibility; electromagnetic immunity; electromagnetic interference; electromagnetic radiation; electromagnetic susceptibility; electronic smog; home entertainment electronics; industrial electronics; SP5SI.

Vehicular near-zone electric fields; vehicular near-zone magnetic fields; worst-case EM fields; mobile-radio; near-field strength levels; vehicular electromagnetic environment; TNIOI4.

Vehicular near-zone magnetic fields; worst-case EM fields; mobile-radio; near-field strength levels; vehicular electromagnetic environment; vehicular near-zone electric fields; TNIOI 4.

Velocity; absorption; amino acids; attenuation; frequency; mammalian tissues; polypeptides; proteins; tissue characterization; ultrasonics; SP525, pp. 19-27 (Apr. 1979).

Velocity; absorption; attenuation; computerized tomography; Doppler; impedance; medical diagnosis; microscopy; pattern recognition; scattering; signal processing; tissue characterization; tissue parameters; ultrasound; SP 525. 
Velocity; acoustic microscopy; anisotropy; attenuation; elastic microstructure; infarct; interferogram; myocardium; phase cancellation; SP525, pp. 73-79 (Apr. 1979).

Velocity; attenuation; mammalian tissues; ultrasound; SP525, pp. 343-360 (Apr. 1979).

Velocity; beams; ceiling height; detectors; fire detectors; fire growth; heat detectors; room fires; smoke detectors; spacing; NBS-GCR-78-128.

Velocity; beams; ceiling height; detectors; fire detectors; fire growth; heat detectors; room fires; smoke detectors; spacing; NBS-GCR-78-129.

Velocity autocorrelation function; intermediate scattering function; Lennard-Jones liquid; liquid rubidium; molecular dynamics; radial distribution function; transverse current correlation function; J. Res. 84, No. 6, 439-446 (1979).

Velocity standard; airflow; calibration; facility; laser optics; low velocity; mine ventilation; TN989.

Vendor systems; workload requirements; benchmark construction process; benchmark validation; competitive evaluation; tutorial; SPSO0-52, pp. 235-240 (Oct. 1979).

Ventilated stair; automatic sprinkler; building code; smoke movement; spray nozzle; stairway protection; NBSIR 781571.

Ventilation; appliance energy consumption; energy consumption of residences; lighting energy consumption; occupant factors; residential air conditioning; service hot water; space heating; NBSIR 78-1501.

Ventilation and radon concentration; energy conservation design; indoor radiation; radon in buildings; 18587 .

Venting; appliance; clothes dryer; efficiency; energy conservation; heat recovery; lint; performance; 18793.

Venting; benefit-cost analysis; building technology; economic impacts; economics; efficiency; payback; plumbing; roofing; shingles; SP558.

Verify; application; character set; computer interface; cost; data entry; edit; operator speed; record size; transaction volume; transfer speed; validate; SP500-55.

Veteran's Administration; Experimental Technology Incentives Program; portable oxygen generator experiment; procurement policy; two-step prototype procurement; NBS-GCRETIP 78-50.

Vhf omnidirectional radio range (VOR); amplitude modulation; instrument landing system (ILS); measurement instrumentation; measurement standard; modulation; modulation factor; modulation meter; Newton-Raphson method; percent modulation; signal generator; TN1016.

Vibration; aircraft carrier; condition analysis; machinery; maintenance; monitoring; repairs; SP547, Pp. 167-175 (July 1979).

Vibration analysis; monitor system; rotary dissolver; signature analysis; SP547, Pp. 232-249 (July 1979).

Vibration isolation; vibrations; antivibration mounting; damping; dynamic properties; industrial engineering; isolation; machinery and equipment; mechanical impedance; mechanical vibrations; noise control; transmissibility; H128.

Vibration measurement; advanced sensors; Doppler millimeter radar; gas turbine monitoring; remote motion detection; static displacement measurement; SP547, PP. 58-62 (July 1979).

Vibration monitoring; vibration signal processing; rotating equipment; SP547, pp. 280-285 (July 1979).

Vibration signal processing; rotating equipment; vibration monitoring; SP547, pp. 280-285 (July 1979).

Vibrational analysis; atomospheric aerosols; materials sampling; mineralogy; molecular analysis; particle analysis; power plant emissions; Raman microprobe; Raman spectroscopy; urban dusts; 18643

Vibrational angular momentum; absorption selection rules; benzene; Herzberg-Teller theory; rotational contours of absorption bands; 18750 .
Vibrational assignments; enthalpy of formation; ideal gas thermodynamic properties; molecular structure; normal and deuterated naphthalenes; JPCRD 8, No. 2, 527-536 (1979).

Vibrational data; force field refinement; lattice dynamics; $n$-alkanes; non-bonded potential functions; polyethylene; 18404 .

Vibrational effect; $\mathrm{HCl}-\mathrm{Ar}$; rotational linewidths; temperature dependence; theoretical and experimental comparison; 18689.

Vibrational energy transfer; benzene; energy transfer; 18641 .

Vibrational energy transfer; hydrogen halides; isotopes; laser; 18388.

Vibrational energy transfer; hydrogen halides; isotopes; temperature dependence; 18929.

Vibrational signatures; automated surveillance; rotating machinery monitoring; statistical detection algorithm; SP547, pp. 203-231 (July 1979).

Vibrational spectra; microanalysis; particle analysis; pollution studies; power plants; Raman microprobe; Raman spectroscopy; 18966.

Vibrations; antivibration mounting; damping; dynamic properties; industrial engineering; isolation; machinery and equipment; mechanical impedance; mechanical vibrations; noise control; transmissibility; vibration isolation; $H 128$.

Vibronic spectroscopy; chlorofluorometliylene; fluorescence; laser spectroscopy; multiphoton dissociation; radicals; 19042 .

Video disks; beam-addressables; cartridges; cassettes; core memories; disks; drums; floppy disks; laser beams; magnetic bubbles; masstapes; solid state memories; SP500-45.

Videotaped trials; civil trials; courtroom procedures; juror attitudes; prerecorded videotaped trials; PRVTT; trials, PRVTT; SP480-30.

Vignetting; aperture/aperture-image pair; aperture pair; calibration; convolution; deconvolution; geometrical-optics radiometry; inversion; measurement-beam geometry; relative spectral responsivity; slit-scattering function; slit-scảttering function corrections; TN910-4

Vinyl chloride; aza-arenes; hydrazines; nitroalkanes; nitrosamines; sidestream smoke; thermal energy analyzer; tobacco smoke; SP519, pp. 131-141 (Apr. 1979).

Vinyl cyanide; interstellar molecules; microwave spectra; molecular parameters; radio astronomy; rotational transitions; JPCRD 8, No. 1, 107-124 (1979).

Vinylidenefluoride-tetrafluoroethylene copolymer; blocking electrode; charge motion; polarization; poly(vinylchloride); poly(vinylidenefluoride); pyroelectric response; thermal pulse; 18408

Virial coefficients; collapse transition; fluctuations; mean field approximation; ternary interactions; theta point; 19023 .

Virial coefficients; density; gas; nitrogen; sound velocity; thermodynamic properties; 18815 .

Virial theorem of Clausius; equilibrium; homogeneous system; hydrostatic pressure; internal stress; internal virial; molecular dynamics; Monte Carlo method; periodic boundaries; pressure; stress calculation; 18456.

Virtual crack closure; delamination mechanisms; energy release rate; finite element ntethod; free-edge stresses; graphite epoxy composites; interlaminar cracks; stability of cracks; SP563, pp. 255-264 (Oct. 1979).

Virtual photons; electric quadrupole; electrodisintegration; giant resonance; nickel isotopes; 18535

Virtual photons; ${ }^{58} \mathrm{Ni}$; electric quadrupole; electrodisintegration; electron energy; giant resonance; 18520.

Viscoelastic; creep; instability; polyethylene; 18807.

Viscoelasticity; wave propagation; anisotropy; dispersion; elasticity; human bone; microhardness; microstructure; piezoelectricity; thermodynamics; ultrasound; SP525, $\mathrm{p} \dot{\mathrm{p}}$. 189-196 (Apr. 1979).

Viscosity; Abbe value; coolants, dn/dT; index matching liquids; neodymium glass lasers; nonlinear refractive index; thermal conductivity; SP541, PP. 109-121 (Dec. 1978). 
Viscosity; bromides; chlorides; data compilation; density; electrical conductance; fluorides; halides; iodides; molten salt mixtures; standard reference data; surface tension; JPCRD 8 , No. 1, 125-302 (1979).

Viscosity; calorimetry; elasticity; electrical resistivity; emittance; measurement system; standard reference materials; temperature; thermal conductivity; thermal expansion; thermal properties; vapor pressure; 18905 .

Viscosity; correlated data; critical point enhancement; data evaluation; propane; thermal conductivity; JPCRD 8, No. 2 , 559-576 (1979).

Viscosity; diamond-anvil; glass transition; high pressure; hydrostaticity; liquids; pressure cell; 18509 .

Viscosity number; intrinsic viscosity; molecular weight; polyethylene; shear rate; ultra high molecular weight polyethylene; 18834 .

Viscous relative motion; inhomogeneities; inhomogeneity thermal losses; mechanisms; SP525, pp. 37-40 (Apr. 1979).

Viscous silicon oil; air bubbles; bubbles, air; 18481 .

Visibility, lights; visual perception; color, lights; conspicuity, lights; effective intensity; emergency lights; intensity, effective; lights, flashing; lights, warning; perception, visual; peripheral vision; vehicles, emergency; $S P 480-36$.

Visible; degradation; IR; photodegradation; poly (methyl methacrylate); UV; NBSIR 79-1766.

Visible; frequency measurements; iodine; laser; 18916.

Vision systems; automation; image processing; inspection; manufacturing; pattern recognition; robotics; NBSIR 79. 1764 .

Visual alignment; contact resistor; cross bridge sheet resistor; electrical alignment resistor; semiconductor; silicon; test pattern; test structures; SP400-5I.

Visual perception; color, lights; conspicuity, lights; effective intensity; emergency lights; intensity, effective; lights, flashing; lights, warning; perception, visual; peripheral vision; vehicles, emergency; visibility, lights; SP480-36.

Visual performance; building codes; building performance simulation; computer applications; energy conservation; illumination standards; lighting distribution simulation; SP552, pp. $321-335$ (July 1979).

Visual-optical tests; acoustic; annual report; eddy currents; inspection; magnetic particles; nondestructive evaluation; penetrants; radiography; statistics; ultrasonics; NBSIR 78 1581 .

Vitamin A; wire transport; liquid chromatography/mass spectrometry; pesticides; SP5 19, pp. 637-645 (Apr. 1979).

Vitamin $\mathrm{B}_{12}$; foods; radiometric microbiological assay; SP519. pp. 257-265 (Apr. 1979).

Vitamin $E$; vitamin $K$; high performance liquid chromatography; phylloquinone; tocopherols; tocotrienols; SP519, pp. 279-288 (Apr. 1979).

Vitamin K; high performance liquid chromatography; phylloquinone; tocopherols; tocotrienols; vitamin E; SP5 19, pp. 279-288 (Apr. 1979).

Vitamins; amino acids; drugs; nonvolatile organic compounds; organic trace detection; peptides; pharmaceuticals; secondary ion mass spectrometry; sputtering; structural information; SP519, pp. 627-635 (Apr. 1979).

VLSI processing; x-ray lithography; E-beam lithography; integrated circuits; ion implantation; plasma etching; radiation damage; radiation hardening; 18451 .

Volatile organics, Carbopack C/0.2\% Carbowax 1500; aqueous organics; phenols; SP519, pp. 225-229 (Apr. 1979).

Voltage; calibration; current; impedance; network analyzer; power; reflection coefficient; reflectometer; scattering parameters; six-port; 18600.

Voltage; calibration; current; impedance; network analyzer; power; reflection coefficient; reflectometer; scattering parameters; six-port; 18601 .
Voltage divider; binary divider; divider network; guarded divider; resistive divider; self calibration; $\mathbf{1 8 4 5 2}$.

Voltage dividers; voltage ratio; calibrations; inductive voltage dividers; international comparison; measurements; /8664.

Voltage measurement; current measurement; electric transmission; electro-optic systems; high voltage; pulse measurement; 18872 .

Voltage output; digital-to-analog converter; high resolution; multirange; $R-2 R$ ladder; relay switching; self-calibration; twenty bits + sign; TN1105.

Voltage ratio; calibrations; inductive voltage dividers; international comparison; measurements; voltage dividers; 18664 .

Voltage ratio measurement; dc voltage ratio measurement; digital voltage ratio instrument errors; digital voltmeter for ratio measurement; 19032 .

Volume strain; core fibril; cumulative stress; flow-induced crystallization; nucleation theory; polyethylene; polymer fiber; shish; J. Res. 84, No. 5, 359-384 (1979).

Volume-measuring devices; weighing devices; weights; lengthmeasuring devices; liquid-measuring devices; measures; scales; specifications; taximeters; tole rances; H44, 1979 Edition.

Voluntary standards; bibliography; buildings; certification; economics of standards; legal aspects of standards; product certification; product liability; regulation; standards system; NBSIR 79-1900.

Voluntary standards; voluntary standards system; consensus standards; Federal policies; Federal voluntary standards policy; SP552, pp. $79-93$ (July 1979).

Voluntary standards system; consensus standards; Federal policies; Federal voluntary standards policy; voluntary standards; SP552, pp. 79-93 (July 1979).

V/STOL; cure; dielectric analysis; DSC; graphite-fiber; polyphthalocyanine; prepreg; TGA; SP563, pp. 25-31 (Oct. 1979).

\section{$\mathbf{W}$}

Wafer chuck; deep level measurements; defect mapping; hot/cold wafer chuck; thermally stimulated measurements; thermal wafer chuck; variable temperature; SP400-55.

Wagner equation; Antoine equation; enthalpy of vaporization; halomethanes; vapor pressure-boiling point data; JPCRD 8 , No. 2, 499-518 (1979).

Walkway slip-resistance; friction; measurement; reference standards; safety research; SP565.

Wall panels; walls; compression; eccentric loading; flat-end; kern; loading rate; pin-end; test method; BSS95.

Wall shift; amplitude modulation; cavity pulling; cavity servo; dielectrically loaded cavity; frequency stability; second-order Doppler shift phase modulation; spin exchange; temperature coefficient; time dispersion; 18696 .

Walls; barrier analysis; compartment fires; compartments; fault tree analysis; fire models; fire protection engineering; probability statistics; systems analysis; systems safety; NBS-GCR. 79.163 .

Walls; compression; eccentric loading; flat-end; kern; loading rate; pin-end; test method; wall panels; BSS95.

Waste oil; engine oil; fuel oil; hydraulic oil; industrial oil; lubricating. oil; oil specifications; petroleum standards; petroleum test methods; recycled oil; re-refined oil; used oil; SP556.

Wastewater analysis; liquid chromatography; trace enrichment; SP519, pp. 185-190 (Apr. 1979). 
Wastewater treatment; water; water conservation; water heating; water usage; energy; energy consumption; grey water; heat recovery; recycling; residential; NBSIR 79-1770.

Water; aqueous solutions; fluorescence spectra; refractive index, uv, visible and ir; 18403.

Water; BASIC; carbon dioxide; carbon monoxide; coal gasification; COLGAS; hydrogen; interactive computer program; methane; minimization of Gibbs energy; phase rule; simul. taneous chemical equilibria; NBSIR 78-1509.

Water; dielectric constant of water; interpolating equation dielectric; steam; table-dielectric constant of water; thermophysical properties of water; 18937.

Water; $\beta$-chlóroethers; air; environment; gas chromatography/mass spectrometry; sampling; sediment; trace analysis; SP519, pp. 205-212 (Apr. 1979).

Water; water conservation; water heating; water usage; energy; energy consumption; grey water; heat recovery; recycling; residential; wastewater treatment; NBSIR 79-1770.

Water; x-ray photoelectron spectrometer; crystallographic integrity; electron diffraction images; hydrated layer; ion microprobe mass spectrometer; roughness; sapphire; ultrafine polishing; SP562, pp. 317-323 (Oct. 1979).

Water absorption; wedged film; absorption coefficient; adiabatic calorimetry; $\mathrm{As}_{2} \mathrm{Se}_{3}$; interface absorption; laser calorimetry; NaF; thin film absorption; SP541, pp. 37-42 (Dec. 1978).

Water analysis; chelating resin; graphite furnace atomic absorption; sea water; separation; trace element analysis; 18402.

Water boil; degradation; epoxy resins; Kevlar 49; moisture; one-tenth scale motor case; S-glass; temperature effects; SP563, pp. 177-197 (Oct. 1979).

Water conservation; water heating; water usage; energy; energy consumption; grey water; heat recovery; recycling; residential; wastewater treatment; water; NBSIR 79-1770.

Water heaters; energy usage; load profiles; NBSIR 78-1496.

Water heating; water usage; energy; energy consumption; grey water; heat recovery; recycling; residential; wastewater treatment; water; water conservation; NBSIR 79-1 770.

Water jet cutting; ceramics; chemical milling; electric discharge machining; electron beam machining; glass; hydrodynamic machining; ion beam machining; SP562, pp. 261-281 (Oct. 1979).

Water preconcentration; electrochemical detection; liquid chromatography; methylmercury; organometals; SP519, pp. 57-63 (Apr. 1979).

Water tank thermal storage; ASHRAE Standards; evaluation of test procedure; solar heating components; standard test procedure; thermal storage tests; 18425 .

Water usage; energy; energy consumption; grey water; heat recovery; recycling; residential; wastewater treatment; water; water conservation; water heating; NBSIR 79-1770.

Water vapor; working unit; damaged layer; elastic emission machining; environmental effect; hydrate; hydration polishing; mechanochemical polishing with soft powder; pre-existing defect; sapphire; solid state reaction; SP562, pp. 157-169 (Oct. 1979).

Water vapor measurement; wet bulb; wet element; convective heat transfer; convective mass transfer; emissivity of water; evaporation coefficient; humidity measurement; monomolecular film; psychrometer; psychrometry; J. Res. 84, No. 2, 161-177 (1979).

WaterDROP; accumulators; analysis of organics in water; automatic sampler; master analytical scheme; non-purgeable organics; organic pollutant; purgeable organics; SP519, pp. 6578 (Apr. 1979).

Water-heating collectors; ASHRAE Standard 93-77; solar collectors; 18770 .

Water-heating solar collectors; collector efficiency; comparison German BSE vS ASHRAE 93-77 procedures; flat-plate solar collectors; German Bundesverband Solarenergie; solar collector testing; 18986 .

Wave front; amplitude; beam profile; cross correlation; digital sampling; Fourier optics; holography; laser; laser parameters; laser pulse; optical processing; phase; prccision measurements; TN1009.

Wave propagation; anisotropy; dispersion; elasticity; human bone; microhardness; microstructure; piezoelectricity; thermodynamics; ultrasound; viscoelasticity; SP525, pp, 189-196 (Apr. 1979).

Waveform; attenuators; calibration; laser; neodymium laser; peak power; power meter; pulsed laser; Q-switched; risetime; speckle; TNIOIO.

Waveform generator; calibration; digital waveform synthesis; phase angle; phase measurement; phase meter; 18434 .

W avelength; $\mathrm{CH}_{2} \mathrm{~F}_{2} ;$ FIR; optically pumped; 18961 .

Wavelength; laser application; pol; polarimetry; saccharimetry; sugar analysis; sugar scale; 18768 .

Wavelength modulation; atomic absorption; atomic emission; barium; graphite furnace; seawater; 18783 .

Wavelength of light; Fizeau-type interferometer; fringe pattern; spatial period; U.S. Patent 4,173,442.

Wavelength standard; bandwidth; didymium glass filter; passband centroid; spectro photometer; transmittance; SP260-66.

Wavelengths; aluminum; energy levels; ionization energy; 18485.

Wavelengths; atomic data; data availability; dielectronic recombination rates; excitation rate coefficients; ionization rate coefficients; magnetic fusion research; transition probabilities; 18593 .

Wavelengths; energy levels; ions; molybdenum; pulsed laser; spectra; 18500 .

Wavelengths; energy levels; lanthanum; spectra; spectroscopy; triply-ionized; ultraviolet; 18782 .

Wavelengths; energy levels; lutetium; spectrum; 18369.

Wavelengths; ytterbium; energy levels; hafnium; ionization energies; lutetium; osmium; rhenium; tantalum; tungsten; 18506.

Wavelengths; yttrium; energy levels; ion; ionization energy; spectrum; 18868 .

Wavelengths; zirconium; spectra; ultraviolet; 18499 .

Wavelengths, O vi-O vili; atomic energy levels, O vi-O vil; atomic spectra, O VI-O vili; multiplet tables, O vi-O vit; NSRDS-NBS3, Section 8.

Weak interaction; atomic parity mixing; charged currents; fermi theory; neutral currents; neutrino scat tering; 18951 .

Wear; abrasives; ceramics; erosion; impact; metals; particle erosion; NBSIR 78-1575.

Wear; abrasives; ceramics; erosion; impact; metals; particle erosion; 18858 .

Wear; accelerator; alloy; base metal; casting; composite; cyanoacrylate; dental alloy; initiator; resin; NBSIR 78-1573.

Wear; bronze binder; diamonds; erosion; grinding; SP562, pp. 147-155 (Oct. 1979).

Wear; curing shrinkage; glaze; margin staining; roughness; 18684.

Wear; diamond drilling; drilling; drilling additives; Rehbinder effect; rock fracture; surface chemistry; SP562, pp. 115-137 (Oct. 1979).

Wear; wear particles; ferrography; machine condition monitoring; oil analysis; oil sampling; SP547, pp. 323-329 (July 1979).

Wear; wear tests; amalgam; composites; dental materials; dimensional changes; physical properties; thermal expansion; 18649.

Wear debris; damaged layer; fine polishing; sapphire; silicon; solid state reaction; SP562, pp. 325-333 (Oct. 1979).

Wear particles; ferrography; machine condition monitoring; oil analysis; oil sampling; wear; SP547, pp. 323-329 (July 1979). 
Wear tests; amalgam; composites; dental materials; dimensional changes; physical properties; thermal expansion; wear; 18649 .

Weather station; air infiltration; buildings; data acquisition; energy; instrumentation; measurement; thermography; Twin Rivers Project; 18733.

Weather station; data acquisition system; digital tape recorder; fuel measurement; instrumentation; total energy; transducers; NBSIR 79+1709.

Weatherization; air infiltration; air sample bags; energy conservation; retrofit; sulfur hexafluoride; tracer gas; NBSIR 79. 1728 .

Wedged film; absorption coefficient; adiabatic calorimetry; $\mathrm{As}_{2} \mathrm{Se}_{3}$; interface absorption; laser calorimetry; $\mathrm{NaF}$; thin film absorption; water absorption; SP541, pp. $37-42$ (Dec. 1978).

Weibull distribution; corrosion fatigue; design; engineering judgment; factor of safety; fatigue; mathematical modeling; nuclear engineering; reliability; risk; safety factor; sampling; 18326.

Weibull distribution; laser damage; probability; statistical analysis; thin films; SP54I, pp. 235-248 (Dec. 1978). .

Weighing; weights; constant loading; force; high precision; highprecision weighing; load cell; mass; mass comparator; mass difference; strain-gage; substitution weighing; $J$. Res. 84, No. 5, 347-35I (1979).

Weighing devices; weights; length-measuring devices; liquidmeasuring devices; measures; scales; specifications; taximeters; tolerances; volume-measuring devices; H44, 1979 Edition.

Weight loss; wood; combustion; flaming combustion; flexible foams; optical density; particle size; polypropylene; polyurethane foams; polyvinyl chloride; pyrolysis; rigid foams; smoke; smoldering; NBS-GCR-78-147.

Weighted diffusion coefficient; ambient concentration; compute and limit; error; sampler response factors; total elemental content passive personal samplers; total organic chlorine; SP519, pp. $747-752$ (Apr. 1979).

Weighting multiple criteria; decision analysis; decisions; eigenvectors; management; multiple-attribute decisions; ordering; paired comparisons; prioritization; project selection; ranking; resource allocation; 18602.

Weight-loss kinetics; aging of polymers; degradation of polymers; error propagation; factor-jump method; heating rate; lifetime prediction; polystyrene; polyurethane; thermogravimetry; 18620 .

Weights; constant loading; force; high precision; high-precision weighing; load cell; mass; mass comparator; mass difference; strain-gage; substitution weighing; weighing; J. Res. 84, No. 5, 347-351 (1979).

Weights; length-measuring devices; liquid-measuring devices; measures; scales; specifications; taximeters; tolerances; volume-measuring devices; weighing devices; $\mathrm{H44}, 1979 \mathrm{Edi}$ tion.

Weights; weights and measures; AlD; assistance; developing economies; foreign relations; industrializing nations; international relations; measures; NBSIR 79-1721.

Weights and measures; AID; assistance; developing economies; foreign relations; industrializing nations; international relations; measures; weights; NBSIR 79-I $72 I$.

Weights and measures; consumer affairs; education; electromagnetic interference; electronic devices; International Organization of Legal Metrology; measurement assurance; metrication; model laws and regulations; national type approval; packaging and labeling; SP532.

Weld flaws; weldments; carbon-manganese steel; fracture mechanics; fracture toughness; pipeline; 18612.

Weld flaws; weldments; carbon-manganese steel; fatigue; fatigue cracks; fracture mechanics; fracture toughness; pipeline; 18802 .
Welding; automated testing; batteries; cardiac pacemakers; contamination; corrosion; electrostatic-induced damage; hermeticity; hybrid devices; leak testing; measurement technology; microcalorimetry; moisture; nondestructive testing; pacemaker leads; process control; SP4OO-5O.

Weldments; carbon-manganese steel; fatigue; fatigue cracks; fracture mechanics; fracturc toughness; pipeline; weld flaws; 18802 .

Weldments; carbon-manganese steel; fracture mechanics; fracture toughness; pipeline; weld flaws; $/ 8612$.

Well depths; collisions; cross sections; intermolecular potential; state changes; $/ 867 /$.

Well depths; excited states; ground state; intermolecular potential; molecules; 18677.

West Germany; antitrust; Canada; certification; Denmark; economics of standards; government policy; international standards; laboratory accreditation; standards systems; United Kingdom; NBS-GCR-79-172.

Western Hemisphere; broadcast; coordinated universal time; synchronous satellite; time code; 19029.

Westwood effects; acoustic emission; chemomechanical effects; environmental effects; fracture of brittle materials; hydrogen embrittlement; Rehbinder effects; SP562, pp. I39-145 (Oct. 1979).

Wet bulb; wet element; convective heat transfer; convective mass transfer; emissivity of water; evaporation coefficient; humidity measurement; monomolecular film; psychrometer; psychrometry; radiative heat transfer; J. Res. 84, No. 2, 161177 (1979).

Wet element; convective heat transfer; convective mass transfer; emissivity of water; evaporation coefficient; humidity measurement; monomolecular film; psychrometer; psychrometry; radiative heat transfer; temperature depression; J. Res. 84, No. 2, 16I-177 (1979).

Wetting; composite growth; contact angle; disjoining pressure; monotectic; multicomponent; 18422 .

Wheel; automotive component design; continuous fiber composite materials; fabrication; finite element stress analysis; front end; graphite; part integration; SP563, pp. 135-151 (Oct. 1979).

Whole-house ventilation; attic ventilation; energy conservation; solar absorptance of roofing materials; SP548.

Wind loads; aerodynamics; building; codes and standards; fullscale testing; mobile homes; NBSIR 77-1289.

Wind loads; wind tunnels; aerodynamics; boundary layers; dynamic response; interference effects; tall buildings; 18977 .

Wind noise; windscreen; windscreen performance; wind screens; acoustics; flow; insertion loss; microphone; porous sphere; sphere; spheres; NBSIR 79-1599.

Wind pressure; aerodynamics; boundary layer; loads (forces); roughness; structural analysis; tall buildings; 18351 .

Wind pressure; wind speeds; building ( codes); probability distribution functions; statistical analysis; storms; structural engineering; BSSII8.

Wind speeds; building (codes); probability distribution functions; statistical analysis; storms; structural engineering; wind pressure; $B S S I / 8$.

Wind tunnel; airflow; anemometer; laser velocimeter; low velocity; performance; vane anemometer; NBSIR 78-1433.

Wind tunnel; airflow; anemometer; laser velocimeter; low velocity; performance; vane anemometer; NBSIR 78-1545.

Wind tunnels; aerodynamics; boundary layers; dynamic response; interference effects; tall buildings; wind loads; 18977.

Wind turbine; composite materials; filament winding; large composite structures; rotor blades; SP563, pp. $155-172$ (Oct. 1979).

Wind upset; anchors; mobile home foundations; soil anchors; soil mechanics; BSS107. 
Window; window management; building economics; daylighting; economic analysis; energy conservation; engineering economics; life-cycle costs; solar heat gain; thermal efficiency; $B S S I 19$.

Window accidents; window safety; accident avoidance; accidents in the home; door accidents; home accidents; home safety; safety in the home; stair accidents; stair safety; NBSGCR-78-156.

Window management; building economics; daylighting; economic analysis; energy conservation; engineering economics; life-cycle costs; solar heat gain; thermal efficiency; window; BSS119.

Window safety; accident avoidance; accidents in the home; door accidents; home accidents; home safety; safety in the home; stair accidents; stair safety; window accidents; NBSGCR - 78-156.

Windows; daylighting; energy conservation; fenestration; solar energy; 18863 .

Windscreen; windscreen performance; windscreens; acoustics; flow; insertion loss; microphone; porous sphere; sphere; spheres; wind noise; NBSIR 79-1599.

Windscreen performance; windscreens; acoustics; flow; insertion loss; microphone; porous sphere; sphere; spheres; wind noise; windscreen; NBSIR 79-1599.

Windscreens; acoustics; flow; insertion loss; microphone; porous sphere; sphere; spheres; wind noise; windscreen; windscreen performance; NBSIR 79-1599.

Wire creep; aluminum wiring; electrical connections; pressure terminals; NBSIR 78-1507.

Wire transport; liquid chromatography/mass spectrometry; pesticides; vitamin A; SP519, pp. 637-645 (Apr. 1979).

Women in computing; employment; equal employment opportunity; labor force; minorities in computing; 19041 .

Wood; accident investigations; chimneys; coal; creosote; fire departments; fire safety; heating equipment; maintenance; stoves; NBSIR 79-1731.

Wood; accident investigations; chimneys; coal; creosote; fire departments; fire safety; heating equipment; maintenance; stoves; NBS-GCR-78-149.

Wood; accident investigations; chimneys; coal; creosote; fire departments; fire safety; heating equipment; maintenance; stoves; 18537.

Wood; bridges; buildings; design criteria; glued-laminated timber; safety; temporary structures; 18887 .

Wood; combustion; flaming combustion; flexible foams; optical density; particle size; polypropylene; polyurethane foams; polyvinyl chloride; pyrolysis; rigid foams; smoke; smoldering; weight loss; NBS-GCR-78-147.

Woods Hole; environment; ICRM; natural matrix; radioactivity; standards; 18981 .

Word processing center; word processing equipment; Center for Building Technology; manuscripts; 18429 .

Word processing equipment; Center for Building Technology; manuscripts; word processing center; 18429.

Working unit; damaged layer; elastic emission machining; environmental effect; hydrate; hydration polishing; mechanochemical polishing with soft powder; pre-existing defect; sapphire; solid state reaction; water vapor; SP562, pp. 157-169 (Oct. 1979).

Workload characterization; accounting logs; performance evaluation; SP500-52, pp. 241-243 (Oct. 1979).

Workload characterization; cluster analysis; computer modeling; computer performance; empirical models; modeling; performance modeling; SP500-52, pp. 147-161 (Oct. 1979).

Workload characterization; workload definition; benchmarking; benchmark library; selection of ADP systems; standard benchmarks; synthetic benchmarks; SP5O0-38.

Workload characterization; workload management; capacity planning; hardware monitors; modeling; performance evalua- tion; performance prediction; simulation; validation; SP50052, pp. 179-192 (Oct. 1979).

Workload definition; benchmarking; benchmark library; selection of ADP systems; standard benchmarks; synthetic benchmarks; workload characterization; SP500-38.

Workload definition; computer performance evaluation; computer performance measurement; computer performance prediction; computer system acquisition; conference proceedings; CPE in auditing; hardware monitoring; CPEUG; installation management; on-line system evaluation; SP50052.

Workload management; capacity planning; hardware monitors; modeling; performance evaluation; performance prediction; simulation; validation; workload characterization; SP500-52, pp. 179-192 (Oct. 1979).

Workload mapping; benchmarking; performance evaluation; synthetic program; SP500-52, pp. 193-199 (Oct. 1979).

Workload requirements; benchmark construction process; benchmark validation; competitive evaluation; tutorial; vendor systems; SP500-52, pp. 235-240 (Oct. 1979).

Worksheet; capabilities; ease of learning and using; installation; language; maintenance; numerical analysis; OMNITAB 78; portability; poster; reliability; statistical computing section; 18903.

Workshops; device measurements; laser scanning; metallization; ohmic contacts; reliability; semiconductor measurements; solar cells; solar cell stability; 18633 .

Workshops; laser scanner; measurement development; photovoltaics; reliability; solar arrays; solar cells; 18322 .

Worst-case EM fields; mobile-radio; near-field strength levels; vehicular electromagnetic environment; vehicular near-zone electric fields; vehicular near-zone magnetic fields; $T N 1014$.

Wrist-mounted TV; depth image; proximity sensor; robot vision; teleoperator vision; NBSIR 78-1576.

\section{$\mathbf{X}$}

$X$ ray; anion exchange; filter paper; fuel oil; spectrometry; sulfate; 18635 .

$\mathrm{X}$ ray; carcinogenesis; neutron; repair; survival; transformation; SP554, pp. 63-73 (Sept. 1979).

$\mathrm{X}$ ray; crystal; diffraction; $\mathrm{Li}_{5} \mathrm{~B}_{4}$; neutron powder; structure; 18382.

$X$ ray; imaging; low-dose; low-intensity; microchannel plate; radiography; 19000 .

$\mathrm{X}$ ray; zwitterion; amino acid derivative; crystal structure; $\boldsymbol{S}$ carboxymethyl-L=cysteine; single crystal; 18673 .

$X$ rays; accelerators; betatrons; electrons; megavoltage; neutrons; therapy; SP5 54, pp. 1-14 (Sept. 1979).

$\mathrm{X}$ rays; analytical electron microscopy; microanalysis; Monte Carlo electron trajectory simulation; spatial resolution; thin foils; 18589 .

$\mathrm{X}$ rays; atomic form factor; coherent scattering; cross sections; gamma rays; photons; Rayleigh scattering; tabulations JPCRD 8, No. 1, 69-106 (1979).

$X$ rays; dose; leakage; medical accelerator; neutrons; scatter; SP554, pp. 25-28 (Sept. 1979).

$\mathrm{X}$ rays; energy levels; exotic atoms; interferometry; 18469 .

XPS; angular study; electron spectroscopy for chemical analysis (ESCA); silicon; surface; 18417 .

$\mathrm{X}$-ray beam diameter; $\mathrm{x}$-ray energies of 30 to $70 \mathrm{keV}$; $\mathrm{x}$-ray scatter; diagnostic radiology; scatterer thickness; scatterer to image plane separation; tissue equivalent phantoms; 18441 .

$\mathrm{X}$-ray continuum; $\mathrm{X}$-ray spectrum; computer program; energy dispersive detector; multichannel analyzer; peak overlap; quantitative electron probe microanalysis; TN1 106.

$\mathrm{X}$-ray diffraction; $\alpha$ phase; phase change piezoelectric polymers; polarization; polyvinylidene fluoride; 18531 . 
X-ray diffraction; Bacon function; Bragg function; Ergun function; graphite materials; Lorentz function; preferred orientation function; pyrolitic graphite; Ruland function; 18523.

$\mathrm{X}$-ray diffraction; biological assay; crystal structure; single crystal; uric acid derivative; uric acid determination; 18672.

$\mathrm{X}$-ray diffraction; biomedical standard; diacetylurea; molecular structure; urea; urea determination; 18347.

$\mathrm{X}$-ray diffraction; bone; hydroxylapatite; interlayering; octacalcium phosphate; tooth; 18583.

$\mathrm{X}$-ray diffraction; crystal structure; integrated intensities; lattice constants; peak intensities; powder patterns; reference intensities; standard; Monogr. 25, Section 16.

$\mathrm{X}$-ray diffraction; crystal structure; mechanism of formation; molecular compound; silver-sulfur-tungsten cluster; synthesis; 18636.

$\mathrm{X}$-ray emission; copper $K \beta$; double vacancy; emission spectrum; Hartree-Fock calculations; 18526.

$\mathrm{X}$-ray emission; flare stars; helium; 19007.

$\mathrm{X}$-ray energies of 30 to $70 \mathrm{keV}$; $\mathrm{x}$-ray scatter; diagnostic radiology; scatterer thickness; scatterer to image plane separation; tissue equivalent phantoms; $x$-ray beam diameter; $1844 l$.

$\mathrm{X}$-ray examination of breast; attenuation of areola; attenuation of breast tissue; attenuation of malignant tumors; breast cancer detection; breast carcinoma; breast examination techniques; FFT techniques for breast; SP525, pp. 85-91 (Apr. 1979).

$\mathrm{X}$-ray image; appropriations; fusion diagnostics; gravity waves; laser-interferometer; microwave measurements; non-destructive evaluation; pipe welds; standard; DIM/NBS 63, No. 3, $1-28$ (1979).

$\mathrm{X}$-ray image magnifier; asymmctric diffraction; dynamical diffraction; microradiography; radiography; radiology; real-time radiography; resolution; 18399.

$X$-ray line width; Auger effect; Auger line width; $K$ shell; level width; line width; $L$ shell; natural width; JPCRD 8, No. 2, $329-338$ (1979).

X-ray lithography; E-beam lithography; integrated circuits; ion implantation; plasma etching; radiation damage; radiation hardening; VLSI processing; 18451 .

$\mathrm{X}$-ray microanalysis; Auger electron spectroscopy; cathodoluminescence; ion scattering spectrometry; laser microprobe mass analyzer; laser Raman microprobe; microanalysis; secondary ion mass spectrometry; 18568 .

$\mathrm{X}$-ray microanalysis; electron probe analysis; peak-tobackground ratios; quantitative analysis; rough surfaces; 18976.

$\mathrm{X}$-ray microanalysis; electron probe microanalysis; energy dispersive $x$-ray microanalysis; energy dispersive $x$-ray spectrometry; quantitative analysis; scanning electron microscopy; 18970.

$\mathrm{X}$-ray photoelectron spectrometer; crystallographic integrity; electron diffraction images; hydrated layer; ion microprobe mass spectrometer; roughness; sapphire; ultra-fine polishing; water; SP562, pp. $317-323$ (Oct. 1979).

$\mathrm{X}$-ray photoelectron spectroscopy; auger electron spectroscopy; die attachment; electrical properties; electronics; hermeticity; indium-doped silicon; infrared reflectance; integrated circuits; line-width measurements; oxidation; photolithography; photovoltaic method; SP400-38.

$\mathrm{X}$-ray photoelectron spectroscopy; binding energies; copper; ESCA; gold; relative intensities; round robin; 18924 .

$\mathrm{X}$-ray scatter; diagnostic radiology; scatterer thickness; scatterer to image plane separation; tissue equivalent phantoms; $\mathrm{x}$-ray beam diameter; $\mathrm{x}$-ray energies of 30 to $70 \mathrm{keV} ; 1844 I$.

$\mathrm{X}$-ray, suurces; stars, coronae; stars, flare; stars, supergiants; 18839.

$\mathrm{X}$-ray spectrum; computer program; energy dispersive detector; multichannel analyzer; peak overlap; quantitative electron probe microanalysis; $x$-ray continuum; TNI 106.
$\mathrm{X}$-ray topography; $\mathrm{Zn} ; \mathrm{Al}_{2} \mathrm{O}_{3}$; Berg-Barrett; Lang; misorientation contrast; 18341 .

$\mathrm{X}$-ray wavelength ratios; gamma rays; precision wavelength; silicon lattice spacing; tungsten $\mathrm{x}$ rays; 18487 .

$\mathrm{X}$-ray yield; characteristic $\mathrm{X}$-ray yield; electron probe microanalysis; inner shell ionization cross section; Monte Carlo electron trajectory simulation; scanning electron microscopy; 18978 .

\section{$\mathbf{Y}$}

Yag laser; two photon absorption; CdSe; CdTe; internal reflections; laser calorimeter; linear absorption; Nd:SP541, pp. 19. 23 (Dec. 1978 ).

Y-deflection modulation; ceramic; scanning electron microscope; secondary electron emission; silicon; surface roughness; SP562, pp. 407-415 (Oct. 1979).

Youden plot; Youden ruggedness test; Youden squares; Youden, W. Ji: statistics; 18990 .

Youden ruggedness test; Youden squares; Youden, W. L: statistics; Youden plot; 18990.

Youden squares; Youden, W. $\mathrm{J}_{\text {i }}$ statistics; Youden plot; Youden ruggedness test; 18990.

Youden, W. Ji statistics; Youden plot; Youden ruggedness test; Youden squares; 18990.

Young's modulus; aluminum alloys; copper alloys; elastic constants; iron alloys; nickel alloys; stainless steels; 18630 .

Young's modulus; aramid-epoxy; boron-aluminum; boronepoxy; composites; elastic constants glass-epoxy; internal friction; 18716 .

Young's modulus; audio frequencies; impurities; internal friction; isomers; low temperatures; n-paraffins; polycrystals; relaxation process; 18467 .

Ytterbium; crystal diffraction; gamma-ray energies; thulium; 18510.

Ytterbium; energy levels; hafnium; ionization energies; lutetium; osmium; rhenium; tantalum; tungsten; wavelengths; 18506.

Yttrium; energy levels; ion; ionization energy; spectrum; wavelengths; 18868 .

\section{$\mathbf{Z}$}

Zero crossing detection; non-invasive temperature monitoring; soft tissue; temperature dependence; ultrasound velocity; SP525, pp. 57-61 (Apr. 1979).

Zero span tensile; fiber length distribution; fiber strength; interfiber bonding; recycled pulps; short span tensile analysis; NBSIR 79-19I4.

Zinc; copper; iron; plastic; polymer; proton-induced $\mathrm{x}$-ray fluorescence; thin films; trace element analysis; tracc element concentrations; 18375 .

Zinc effect; creep; dental amalgam; dimensional changes; extrusion of restorations; marginal fracture; 18586 .

Zinc sulfide; characteristic phonons; chemical-vapor deposition; image spoiling; infrared imaging; lattice absorption; SP54I, pp. 86-97 (Dec. 1978).

Zirconium; spectra; ultra violet; wavelengths; 18499.

$\mathrm{Zn} ; \mathrm{Al}_{2} \mathrm{O}_{3}$; Berg-Barrett; Lang; misorientation contrast; $\mathrm{x}$-ray topography; 18341 .

$\mathrm{Zn}$ sequence; $\mathrm{Cu}$ sequence; oscillator stength; 18366 .

$\mathrm{Zn}$-doped glasses; boron nitride; Cl-dopcd glasses; diffusion in silicon; integrated circuit processing; kinetics of oxide growth; oxidation of silicon; semiconductor processing; silicon; silicon dioxide; thermally stimulated measurement; thermal oxidation; NBS-GCR-78-134.

$\mathrm{ZnS} ; \mathrm{ZnSe} ; \mathrm{Al}_{2} \mathrm{O}_{3} ; \mathrm{As}_{2} \mathrm{~S}_{3}$ glass; $\mathrm{BaF}_{2} ; \mathrm{CaF}_{2} ; \mathrm{CdF}_{2}$; chalcogenide glass; elastic compliances; clastic constants; elasto-optic constants; fused silica; Ge; hot forged; TN993. 
$\mathrm{ZnSe}$; absorption edge; $\mathrm{CaF}_{2} ; \mathrm{KCl}$; optical absorption coefficient; optoacoustic spectroscopy; $\mathrm{PbF}_{2}$; photoacoustic spectroscopy; TIl; SP541, pp. 43-49 (Dec. 1978).

$\mathrm{ZnSe} ; \mathrm{Al}_{2} \mathrm{O}_{3} ; \mathrm{As}_{2} \mathrm{~S}_{3}$ glass; $\mathrm{BaF}_{2} ; \mathrm{CaF}_{2} ; \mathrm{CdF}_{2}$; chalcogenide glass; elastic compliances; elastic constants; elasto-optic constants; fused silica; Ge; hot forged; KBr; TN993.

Zoning regulations; infrastructure; land use; resource zoning; urban; SP552, pp. 347-360 (July 1979).

Zwitterion; amino acid derivative; crystal structure; $S$-carboxymethyl-L=cysteine; single crystal; $x$ ray; 18673 .

0.65 to 3.0 microns; absorption coefficient; sodium fluoride film; total internal reflection; SP541, pp. 13-18 (Dec. 1978).

$1.15 \mathrm{\theta m}$; frequency; He-Ne laser; nonlinear optics; 18562.

${ }^{12} \mathrm{C} \gamma$-rays; ${ }^{16} \mathrm{O} \gamma$-rays; cosmic source; preliminary; proton interactions; relative measurements; 19015 .

${ }^{121} \mathrm{Sn}^{m}$ decay scheme; coincidence counting; decay probability; isomeric transition; liquid scintillation counting; photon counting; radioactivity; 18841 .

${ }^{125} \mathrm{I}$; ${ }^{153} \mathrm{GD}$; CsI; detection efficiency; Lixiscope; radioactive $\mathrm{x}$ ray source; rare-earth scintillator screen; 19001 .

13. $:$ conformation; crystallinity; NMR; polyethylene; resolution; sample spinning; solids; 18745 .

1,3,3,3-tetrafluoropropene polymer; 3,3,3-trifluoropropene copolymers; $3,3,4,4,5,5,5$-heptafluoropentene-1 polymer; isobutene copolymers; pyrolysis gas chromatography; random scission; tetrafluoroethylene copolymers; 18580 .

15.1 MeV branching ratio; positron annihilation-in-flight; quasimonoenergetic photons; sodium iodide spectrometer; 18522 .

${ }^{153} \mathrm{GD}$; Csl; detection efficiency; Lixiscope; radioactive $\mathrm{x}$-ray source; rare-earth scintillator screen; ${ }^{125} \mathrm{I} ; 19001$.

${ }^{16} \mathrm{O} \gamma$-rays; cosmic source; preliminary; proton interactions; relative measurements; ${ }^{12} \mathrm{C} \gamma$-rays; 19015 .

${ }^{166} \mathrm{Ho}^{185} \mathrm{Ho}$; atomic magnetic structures; conical spin structure; decay of ${ }^{188 \mathrm{~m}} \mathrm{Ho}$; nuclear orientation; nuclear spin system; 18604.

2-cyanoacrylate esters; adhesion; bonding to mineralized tissues; bone; dentin; hydrolytic stability of bonds; isobutyl 2 cyanoacrylate; mineralized tissue; 18569.

2-cyanoacrylate esters; adhesive; bonding to dentin; dental adhesive; dentin; durability of dentin acrylic bond; isobutyl 2cyanoacrylate; pretreatment of dentin; 18985 .

${ }^{235} \mathrm{U}$; chemical effects; delayed neutrons; Einstein model; fission; temperature effects; thermal; 18687.

${ }^{2235} \mathrm{U}(\mathrm{n}, \mathbf{f})$; fission cross section; linac; neutron flux determination; proton telescope; standard cross section; 18581 .

${ }^{238} \mathrm{U}$; Doppler effect; fission; gas target; molecular vibrations; neutron reactions; 18585 .

${ }^{238} \mathrm{U}$; electrodisintegration; proton spectrum; ternary fission; $\alpha$ particles; $\alpha$-spectrum; 18518.

${ }^{252} \mathrm{Cf}$; charge transfer; chlorophyll; erythromycin; fast reactions; fission track; ion-dipole; $\beta$-endorphin; SP519, pp. 673-677 (Apr. 1979).

${ }^{3} \mathrm{He} /{ }^{4} \mathrm{He}$ dilution refrigerator; ${ }^{80} \mathrm{CO} \gamma$-ray thermometer; comparison measurements; Germanium resistance thermometer; Josephson junction noise thermometer; low temperature scale; 18555

3,3,3-trifluoropropene copolymers; 3,3,4,4,5,5,5-heptafluoropentene-1 polymer; isobutene copolymers; pyrolysis gas chromatography; random scission; tetrafluoroethylene copolymers; 1,3,3,3-tetrafluoropropene polymer; 18580 .

3,3,4,4,5,5,5-heptafluoropentene-1 polymer; isobutene copolymers; pyrolysis gas chromatography; random scission; tetrafluoroethylene copolymers; 1,3,3,3-tetrafluoropropene polymer; 3,3,3-trifluoropropene copolymers; 18580 .

4th and 6th rank octahedral tensor; asymptotic eigensolutions; high resolution spectra; spectral clusters; spherical top molecules; 18706.

$45 S$ and 50S; diffusion coefficient; $E$. coli ribosomal subunit; quasielastic light scattering; J. Res. 84, No. 1, I-8 (1979).
$485 \mathrm{~K}$; diffusion; quasielastic scattering; tantalum hydride; vanadium hydride; $\alpha$ phase; 18730 .

${ }^{5} \Sigma_{n}{ }^{+}$; energy curve; excited state; $\mathrm{N}_{2}$; radiative transition; ${ }^{5} \Pi_{u}$; 18935.

${ }^{5} \Pi_{n} ;{ }^{5} \Sigma_{q}+$; energy curve; excited state; $\mathrm{N}_{2}$; radiative transition; 18935 .

${ }^{3} \mathrm{Ni}$; electric quadrupole; electrodisintegration; electron energy; giant resonance; virtual photons; 18520 .

${ }^{60} \mathrm{CO} \gamma$-ray thermometer; comparison measurements; Germanium resistance thermometer; Josephson junction noise thermometer; low temperature scale; ${ }^{3} \mathrm{He} /{ }^{4} \mathrm{He}$ dilution refrigerator; 18555 .

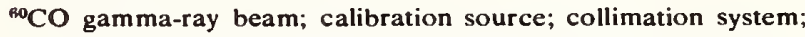
data-reduction technique; low-activity replacement source; measurement technique; scatter contribution; source capsule; source housing; spectrometry results; 18416 .

9,12-di-cis-polyunsaturated fatty acids; fats; lipoxidase; oils; PUFA; SP519, pp. 289-295 (Apr. 1979).

9.2 to $10.6 \mu \mathrm{m}$; absorption; $\mathrm{KCl}$; $\mathrm{NaCl}$; tuneable laser calorimetry; SP541, pp. 24-32 (Dec. 1978 ). 


\section{APPENDIX A. LIST OF DEPOSITORY LIBRARIES IN THE UNITED STATES}

\section{ALABAMA}

Alexander City: Alerander City State Junior College, Thomas D. Russell Library (1967).

Auburn: Auburn University, Ralph Brown Draughon Library (1907).

Birmingham:

Birmingham Public Library (1895).

Birmingham-Southern College Library (1932).

Jefferson State Junior College, James B. Allen Library (1970).

Samford University, Harwell G. Davis Library (1884).

Enterprise: Enterprise State Junior College, Learning Resource Center (1967).

Florence: University of North Alabama, Collier Library (1932).

Gadsden: Gadsden Public Library (1963).

Huntsville: University of Alabama, Huntsville Campus Library (1964).

Jacksonville: Jacksonville State University, Ramona Wood Library (1929).

Maswell A.F. Base: Air University Library (1963).

Mobile:

Mobile Public Library (1963).

Spring Hill College, Thomas Byrne Memorial Library (1937).

University of South Alabama Library (1968).

Montgomery:

Alabama State Department of Archives and History Library (1884).

Alabama Supreme Court and State Law Library (1884).

Auburn University at Montgomery Library (1971)-RE GIONAI.

Normal: Alabama Agricultural and Mechanical College, Drake Memorial Library (1963).

St. Bernard: St. Bernard College, Herman J. Heidrich Library (1962).

Troy: Troy State University, Lurleen $\mathbb{B}$. Wallace Educational Resources Center (1963).

Tuskegee Institute: Tuskegee Institute, Hollis Burke Frissell Library (1907).

University:

University of Alabama, School of Law Library (1967).

University of Alabama Library (1860)-REGIONA.L

\section{ALASRA}

Anchorage:

Supreme Court of Alaska Library (1973).

University of Alaska, Anchorage Library (1961).

College: University of Alaska, Elmer E. Rasmuson Library (1922).

Juneau: Alaska State Library (1964).

Ketchikan: Ketchikan Community College Library (1970).

\section{ARIZONA}

Coolidge: Central Arizona College, Instructional Materials Center (1973).

Flagstaff: Northern Arizona University Library (1937).
Phoeniz:

Department of Library and Archives (unknown)-REGION. AL.

Grand Canyon College, Fleming Library.

Phoenix Public Library (1917).

Prescott: Yavapai College Library (1976).

Tempe:

Arizona State University, Matthews Library (1944).

Arizona State University, College of Law Library (1977).

Thatcher: Eastern Arizona Junior College Library (1963).

Tucson:

Tucson Public Library (1970).

University of Arizona Library (1907)-REGIONAL.

Yuma: Yuma City-County Library (1963).

\section{ARKANSAS}

Arkadelphia: Ouachita Baptist University, Riley Library (1963).

Batesville: Arkansas College Library (1963).

Clarksville: College of the Ozarks Library (1925).

Conway: Hendrix College, O. C. Bailey Library (1903).

Fayetteville: University of Arkansas Library (1907).

Little Rock:

Arkansas Supreme Court Library (1962).

Little Rock Public Library (1953).

University of Arkansas at Little Rock Library (1973).

Magnolia: Southern Arkansas University, Mogale Library (1956).

Monticello: University of Arkansas at Monticello Library (1956).

Pine Bluff: University of Arkansas at Pine Bluff, Watson Memorial Library (1976).

Russellville: Arkansas Tech University, Tomlinson Library (1925).

Searcy: Harding College, Beaumont Memorial Library (1963).

State College: Arkansas State University, Dean B. Ellis Library (1913).

Walnut Ridge: Southeru Baptist College, Felix Goodson Library (1967).

\section{CALIFORNIA}

Anaheim: Anahein Public Library (1963).

Arcadia: Arcadia Public Library (1975).

Arcata: Humboldt State College Library (1963).

Bakersfield:

California State College, Bakersfield Library (1974).

Kern County Library System (1943).

Berkeley:

University of California, General Library (1907).

University of California, Law Library, Earl Warren Legal Center (1963).

Carson:

California State University, Dominguez Hills, Educational Resources Center (1973).

Carson Regional Library (1973).

Chico: Chico State University Library (1962).

Claremont: Pomona College Documents Collection, Honnold Library (1913).

Coalingo: West Hills Community College (1978). 
Compton: Compton Library (1972).

Culver City: Culver City Library (1966).

Davis:

University of California at Davis Library (1953).

University of California at Davis, School of Law Library (1972).

Downey: Downey City Library (1963).

Fresno:

California State University Library (1962).

Fresno County Free Library (1920).

Fullerton: California State University, Fullerton Library (1963).

Garden Grove: Garden Grove Regional Library (1963).

Gardena: Gardena Public Library (1966).

Hayward: California State College at Hayward Library (1963).

Huntington Park: Huntington Park Library, San Antonio Region (1970).

Inglewood: Inglewood Public Library (1963).

Irvine: University of California at Irvine Library (1963).

La Jolla: University of California, San Diego, University Library (1963).

Lakewood: Angelo Iacoboni Public Library (1970).

Lancaster: Lancaster Regional Library (1967).

Long Beach:

California State University at Long Beach Library (1962).

Long Beach Public Library (1933).

Los Angeles:

California State College at Los Angeles, John F. Kennedy Memorial Library (1956).

Los Angeles County Law Library (1963).

Los Angeles Public Library (1891).

Loyola University of Los Angeles Library (1933).

Occidental College, Mary Norton Clapp Library (1941).

Pepperdine University Library (1963).

Southwestern University, School of Law Library (1975).

University of California at Los Angeles Library (1932).

University of California at Los Angeles, Law Library (1958).

University of Southern California Library (1933).

Menlo Park: Department of the Interior, Geological Survey Library (1962).

Montebello: Montebello Library (1966).

Monterey: Naval Postgraduate School Library (1963).

Monterey Park: Bruggemeyer Memorial Library (1964).

Northridge: California State University at Northridge, Delmar T. Oviatt Library (1958).

Norwalk: Los Cerritos Regional Library (1973).

Oakland:

Mills College Library (1966).

Oakland Public Library (1923).

Ontario: Ontario City Library (1974).

Pasadena:

California Institute of Technology, Robert A. Millikan Memorial Library (1933).

Pasadena Public Library (1963).

Pleasant Hill: Contra Costa County Library (1964).

Redding: Shasta County Library (1956).

Redlands: University of Redlands, Armacost Library (1933).

Redwood City: Redwood City Public Library (1966).

Reseda: West Valley Regional Branch Library (1966).

Richmond: Richmond Public Library (1943).

Riverside:

Riverside Public Library (1947).

University of California at Riverside Library (1963).

Sacramento:

California State Library (1895)-REGIONAL.

Sacramento City-County Library (1880).

Sacramento County Law Library (1963).

Sacramento State University Library (1963).

San Bernardino: San Bernardino County Free Library (1964).
San Diego:

San Diego State University, Love Library (1962).

San Diego County Law Library (1973).

San Diego County Library (1966).

San Diego Public Library (1895).

University of San Diego Law Library (1967).

San Francisco:

Mechanics' Institute Library (1889).

San Francisco Public Library (1889).

San Francisco State College, Social Science and Business Library (1955).

Supreme Court of California Library (1972).

U.S. Court of Appeals for Ninth Circuit Library (1971).

University of San Francisco, Richard A. Gleeson Library (1963).

San Jose: San Jose State College Library (1962).

San Leandro: San Leandro Community Library Center (1961).

San Luis Obispo: California State Polytechnic University Lj. brary (1969).

San Rafael: Marin County Free Library (1975).

Santa Ana:

Orange County Law Library (1975).

Santa Ana Public Library (1959).

Santa Barbara: University of California at Santa Barbara Library (1960).

Santa Clara: University of Santa Clara, Orradre Library (1963).

Santa Cruz: University of California at Santa Cruz Library (1963).

Santa Rosa: Santa Rosa-Sonoma County Public Library (1896).

Stanford: Stanford University Libraries (1895).

Stockton: Public Library of Stockton and San Joaquin County (1884).

Thousand Oaks: California Lutheran College Library (1964).

Torrance: Torrance Civic Center Library (1969).

Turlock: Stanislaus State College Library (1964).

Valencia: Valencia Library (1972).

Ventura: Ventura County Library Services Agency (1975).

Visalia: Tulare County Free Library (1967).

Walnut: Mount San Antonio College Library (1966).

West Covina: West Covina Library (1966).

Whittier: Whittier College, Wardman Library (1963).

\section{CANAL ZONE}

Balboa Heights: Canal Zone Library-Museum (1963).

\section{COLORADO}

Alamosa: Adams State College, Learning Resources Center (1963)

Boulder: University of Colorado Libraries (1879)-REGIONAL.

Colorado Springs:

Colorado College, Charles Leaming Tutt Library (1880).

University of Colorado, Colorado Springs Library (1974).

Denver:

Auraria Libraries (1978).

Colorado State Library (unknown).

Denver Public Library (1884)-REGIONAL.

Department of Interior, Bureau of Reclamation Library (1962).

Regis College, Dayton Memorial Library (1915).

Supreme Court Library (1978).

University of Denver, Penrose Library (1909).

U.S. Court of Appeals for Tenth Circuit Library (1973).

Fort Collins: Colorado State University Library (1907).

Golden: Colorado School of Mines, Arthur Lakes Library (1939). 
Grand Junction: Mesa County Public Library (1975).

Greeley: University of Northern Colorado Library (1966).

Gunnison: Western State College, Leslie J. Savage Library (1932).

La Junta: Otero Junior College, Wheeler Library (1963).

Lakewood: Jefferson County Public Library, Lakewood Regional Library (1968).

Pueblo:

Pueblo Regional Library (1893).

University Southern Colorado Library, Learning Resources Center (1965).

U.S. Air Force Academy: Academy Library (1956).

\section{CONNECTICUT}

Bridgeport: Bridgeport Public Library (1884).

Danbury: Western Connecticut State College, Ruth A. Haas Library (1967).

Danielson: Quinebaug Valley Community College (1975).

Enfield: Enfield Public Library (1967).

Hartford:

Connecticut State Library (unknown)-REGIONAL.

Hartford Public Library (1945).

Trinity College Library (1895).

Middletown: Wesleyan University Library (1906).

Mystic: Marine Historical Association, Inc., G. W. Blunt White Library (1964).

New Britain: Central Connecticut State College, Elihu Burritt Library (1973).

New Haven:

Southern Connecticut State College Library (1968).

Yale University Library (1859).

New London:

Connecticut College Library (1926).

U.S. Coast Guard Academy Library (1939).

Stamford: Stamford Public Library (1973).

Storrs: University of Connecticut, Wilbur Cross Library (1907).

Waterbury:

Post College, Traurig Library (1977).

Silas Bronson Library (1869).

West Haven: University of New Haven Library (1971).

\section{DELAWARE}

Dover:

Delaware State College, William C. Jason Library (1962).

State Department of Community Affairs and Economic Development, Division of Libraries (1972).

State Law Library in Kent County (unknown).

Georgetown:

Delaware Technical and Community College, Southern Branch Library (1968).

Sussex County Law Library (1976).

Newark: University of Delaware, Morris Library (1907).

Wilmington:

Delaware Law School Library (1976).

New Castle County Law Library (1974).

Wilmington Institute and New Castle County Library (1861).

\section{DISTRICT OF COLUMBIA}

Washington:

Administrative Conference of U.S. Library (1977).

Advisory Commission on Intergovernmental Relations $\mathrm{Li}$. brary (1972).

Civil Aeronautics Board Library (1975).

Civil Service Commission Library (1963).

Department of Commerce Library (1955).
Department of Health, Education, and Welfare Library (1954).

Department of Housing and Urban Development Library (1969).

Department of the Interior Central Library (1895).

Department of Justice Main Library (1895).

Department of Labor Library (1976).

Department of State Library (1895).

Department of State, Office of Legal Advisor, Law Library (1966).

Department of Transportation, National Highway Traffic Safety Administration Library (1968).

District of Columbia Public Library (1943).

Federal City College Library (1970).

Federal Deposit Insurance Corporation Library (1972).

Federal Election Commission Library (1975).

Federal Reserve System Law Library (1976).

General Accounting Office Library (1975).

General Services Administration Library (1975).

Georgetown University Library (1969).

Indian Claims Commission Library (1968).

Library of Congress, Gift and Exchange Division (1977).

National Defense University Library (1895).

Navy Department Library (1895).

Navy Department, Office of Judge Advocate General Li. brary (1963).

Office of Management and Budget Library (1965).

Office of The Adjutant General, Department of Army Li. brary (1969).

Postal Service Library (1895).

Research Library, Board of Governors of the Federal Reserve System (1978).

Treasury Department Library (1895).

U.S. Court of Appeals, Judge's Library (1975).

U.S. Supreme Court Library (1978).

Veterans' Administration, Central Office Library (1976).

\section{FLORIDA}

Boca Raton: Florida Atlantic University Library (1963).

Clearwater: Clearwater Public Library (1972).

Coral Gables: University of Miami Library (1939).

Crestview: Robert F. L. Sikes Public Library (1978).

Daytona Beach: Volusia County Public Libraries (1963).

DeLand: Stetson University, duPont-Ball Library (1887).

Fort Lauderdale:

Broward County Library System (1967).

Nova University Law Library (1967).

Fort Pierce: Indian River Community College Library (1975).

Gainesville: University of Florida Libraries (1907)-REGION. AL.

Jacksonville:

Haydon Burns Library (1914).

Jacksonville University, Swisher Library (1962).

University of North Florida Library (1972).

Lakeland: Lakeland Public Library (1928).

Leesburg: Lake-Sumter Community College Library (1963).

Melbourne: Florida Institute of Technology Library (1963).

Miami:

Florida International University Library (1970).

Miami Public Library (1952).

North Miami: Florida International University, North Miami Campus Library (1977).

Opa Locka: Biscayne College Library (1966).

Orlando: Florida Technological University Library (1966).

Palatka: St. Johns River Junior College Library (1963).

Pensacola: University of West Florida, John C. Pace Library (1966).

Port Charlotte: Charlotte County Library System (1973). 


\section{St. Petersburg:}

St. Petersburg Public Library (1965).

Stetson University College Law Library (1975).

Sarasota: Selby Public Library (1970).

Tallahassee:

Florida Agricultural and Mechanical University, Coleman Memorial Library (1936).

Florida State University, R. M. Stozier Library (1941). (1941).

Florida Supreme Court Library (1974).

State Library of Florida (1929).

Tampa:

Tampa Public Library (1965).

University of South Florida Library (1962).

University of Tampa, Merle Kelce Library (1953).

Winter Park: Rollins College, Mills Memorial Library (1909).

\section{GEORGIA}

Albany: Albany Public Library (1964).

Americus: Georgia Southwestern College, James Earl Carter $\mathrm{Li}$ brary (1966).

Athens: University of Georgia Libraries (1907)-REGIONAL.

Atlanta:

Atlanta Public Library (1880).

Atlanta University, Trevor Arnett Library (1962).

Emory University, Robert W. Woodruff Library (1928).

Emory University, School of Law Library (1968).

Georgia Institute of Technology, Price Gilbert Memorial Li. brary (1963).

Georgia State Library (unknown).

Georgia State University Library (1970).

Augusta: Augusta College Library (1962).

Brunswick: Brunswick-Glyn County Regional Library (1965).

Carrollton: West Georgia College, Sanford Library (1962).

Columbus: Columbus College, Simon Schwob Memorial Library (1975).

Dahlonega: North Georgia College Library (1939).

Dalton: Dalton Junior College Library (1978).

Decatur: Dekalb Community College-South Campus, Learning Resources Center (1973).

Macon: Mercer University Library (1964).

Marietta: Kennesaw Junior College Library (1968).

Milledgeville: Georgia College at Milledgeville, Ina Dillard Russell Library (1950).

Mount Berry: Berry College, Memorial Library (1970).

Savannah: Savannah Public and Chatham-Efringham Liberty Regional Library (1857).

Statesboro: Georgia Southern College Library (1939).

Valdosta: Valdosta State College, Richard Holmes Powell Library (1956).

\section{GUAM}

Agana: Nieves M. Flores Memorial Library (1962).

\section{HAWAII}

Hilo: University of Hawaii, Hilo Campus Library (1962).

Honolulu:

Hawaii Medical Library, Inc. (1968).

Hawaii State Library (1929).

Municipal Reference Library of the City and County of Honolulu (1965).

Supreme Court Law Library (1973).

University of Hawaii Library (1907)-REGIONAL.

Laie: Church College of Hawaii, Woolley Library (1964).

Lihue: Kauai Public Library (1967).
Pearl City: Leeward Community College Library (1967).

Wailuku: Maui Public Library (1962).

\section{IDAHO}

Boise:

Boise State University Library (1966).

Boise Public Library and Information Center (1929).

Idaho State Law Library (unknown).

Idaho State Library (1971).

Caldwell: College of Idaho, Terteling Library (1930).

Moscow: University of Idaho Library (1907)-REGIONAL.

Pocatello: Idaho State University Library (1908).

Rexburg: Ricks College, David O. McKay Library (1946).

Twin Falls: College of Southern Idaho Library (1970).

\section{ILLINOIS}

Bloomington: Illinois Wesleyan University Libraries (1964).

Carbondale: Southern Illinois University Library (1932).

Carlinville: Blackburn College Library (1954).

Carterville: Shawnee Library System (1971).

Champaign: University of Illinois Law Library, College of Law (1965).

Charleston: Eastern Illinois University, Booth Library (1962).

Chicago:

Chicago Public Library (1876).

Chicago State University Library (1954).

DePaul University, Lincoln Park Campus Library (1975).

Field Museum of Natural History Library (1963).

John Crerar Library (1909).

Loyola University of Chicago, E. M. Cudahy Memorial Li. brary (1966).

Northeastern Illinois University Library (1961).

University of Chicago Law Library (1964).

University of Chicago Library (1897).

University of Illinois, Chicago Circle Campus Library (1957).

Decatur: Decatur Public Library (1954).

De Kalb: Northern Illinois University, Swen Franklin Parson Library (1960).

Edwardsville: Southern Illinois University, Lovejoy Memorial Library (1959).

Elsah: Principia College, Marshall Brooks Library (1957).

Evanston: Northwestern University Library (1876).

Freeport: Freeport Public Library (1905).

Galesburg: Galesburg Public Library (1896).

Jacksonville: MacMurray College, Henry Pfeiffer Library (1929).

Kankakee: Olivet Nazarene College, Benner Library and Resource Center (1946).

Lake Forest: Lake Forest College, Donnelley Library (1962).

Lebanon: McKendree College, Holman Library (1968).

Lisle: Illinois Benedictine College, Theodore F. Lownik Library (1911).

Lockport: Lewis University Library (1952).

Macomb: Western Illinois University Memorial Library (1962).

Moline: Black Hawk College, Learning Resources Center (1970).

Monmouth: Monmouth College Library (1860).

Morton Grove: Oakton Community College Library (1976).

Mt. Carmel: Wabash Valley College Library (1975).

Mt. Prospect: Mt. Prospect Public Library (1977).

Normal: Illinois State University, Milner Library (1877).

Oak Park: Oak Park Public Library (1963).

Oglesby: Illinois Valley Community College Library (1976).

Palos Hills: Moraine Valley Community College Library (1972).

Park Forest South: Governors State University Library (1974). 
Peoria:

Bradley University, Cullom Davis Library (1963).

Peoria Public Library (1883).

River Forest: Rosary College Library (1966).

Rockford: Rockford Public Library (unknown).

Springfield: Illinois State Library (unknown)-REGIONAL.

Urbana: University of Illinois Library (1907).

Wheaton: Wheaton College Library (1964).

Woodstock: Woodstock Public Library (1963).

\section{INDIANA}

Anderson: Anderson College, Charles E. Wilson Library (1959).

Bloomington: Indiana University Library (1881).

Crawfordsville: Wabash College, Lilly Library (1906).

Evansville:

Evansville and Vanderburgh County Public Library (1928).

Indiana State University, Evansville Campus Library (1969).

Fort Wayne:

Indiana-Purdue Universities, Waiter E. Helmke Library (1965).

Public Library of Fort Wayne and Allen County (1896).

Franklin: Franklin College Library (1976).

Gary:

Gary Public Library (1943).

Indiana University, Northwest Campus Library (1966).

Greencastle: De Pauw University, Roy O. West Library (1879).

Hammond: Hammond Public Library (1964).

Hanover: Hanover College Library (1892).

Huntington: Huntington College Library (1964).

Indianapolis:

Butler University, Irwin Library (1965).

Indiana State Library (unknown)-REGIONAL.

Indiana Supreme Court Law Library (1975).

Indiana University, Law Library (1967).

Indianapolis-Marion County Public Library (1906).

Kokomo: Indiana University, Kokomo Regional Campus Library (1969).

Lafayette: Purdue University Library (1907).

Muncie:

Ball State University Library (1959).

Muncie Public Library (1906).

New Albany: Indiana University, Southeastern Campus Library (1965).

Notre Dame: University of Notre Dame, Memorial Library (1883).

Rensselaer: St. Joseph's College Library (1964).

Richmond:

Earlham College, Lilly Library (1964).

Morrison-Reeves Library (1906).

South Bend: Indiana University at South Bend Library (1965).

Terre Haute: Indiana State University, Cunningham Memorial Library (1906).

Valparaiso: Valparaiso University, Moellering Memorial Líbrary (1930).

\section{IOWA}

Ames: Iowa State University of Science and Technology Library (1907).

Cedar Falls: University of Northern Iowa Library (1946).

Council Bluffs:

Free Public Library (1885).

Iowa Western Community College, Hoover Media Library (1972).

Davenport: Davenport Public Library (1973).

Des Moines:

Drake University, Cowles Library (1966).

Drake University Law Library (1972).
State Library Commission of Iowa (unknown).

Public Library of Des Moines (1888).

Dubuque:

Carnegie-Stout Public Library (unknown).

Loras College, Wahlert Memorial Library (1967).

Fayette: Upper Iowa College, Henderson-Wilder Library (1974).

Grinnell: Grinnell College, Burling Library (1874).

Iowa City:

University of Iowa, Law Library (1968).

University of Iowa Library (1884)-REGIONAL.

Lamoni: Graceland College, Frederick Madison Smith Library (1927).

Mason City: North Iowa Area Community College Library (1976).

Mount Vernon: Cornell College, Russell D. Cole Library (1896). Orange City: Northwestern University, Ramaker Library (1970).

Sioux City: Sioux City Public Library (1894).

\section{RANSAS}

Atchison: Benedictine College Library (1965).

Baldwin City: Baker University Library (1908).

Colby: Colby Community Junior College Library (1968).

Emporia: Emporia State University, William Allen White Library (1909).

Hays: Fort Hays Kansas State College, Forsyth Library (1926).

Hutchinson: Hutchinson Public Library (1963).

Lawrence:

University of Kansas, Watson Library (1869)-REGIONAL.

University of Kansas Law Library (1971).

Manhattan: Kansas State University, Farrell Library (1907).

Pittsburg: Pittsburg State University, Porter Library (1952).

Salina: Kansas Wesleyan University, Memorial Library (1930).

Topeka:

Kansas State Historical Society Library (1877).

Kansas State Library (unknown).

Kansas Supreme Court Law Library (1975).

Washburn University of Topeka, Law Library (1971).

Wichita: Wichita State University Library (1901).

\section{KENTUCKY}

Ashland: Ashland Public Library (1946).

Barbourville: Union College, Abigail E. Weeks Memorial Library (1958).

Bowling Green: Western Kentucky University, Cravens Graduate Center and Library (1934).

Covington: Thomas More College Library (1970).

Danville: Centre College, Grace Doherty Library (1884).

Frankfort:

Kentucky Department of Libraries (1967).

Kentucky State University, Blazer Library (1972).

State Law Library (unknown).

Highland Heights: Northern Kentucky University, W. Frank Steely Library (1973).

Hopkinsville: Hopkinsville Community College Library (1976).

Lexington:

University of Kentucky, Law Library (1968).

University of Kentucky, Margaret I. King Library (1907)REGIONAL.

Louisville:

Louisville Free Public Library (1904).

University of Louisville, Belknap Campus Library (1925).

University of Louisville Law Library (1975).

Morehead: Morehead State University, Johnson Camden Library (1955).

Murray: Murray State University Library (1924). 
Owensboro: Kentucky Wesleyan College Library (1966).

Richmond: Eastern Kentucky University, John Grant Crabbe Library (1966).

\section{LOUISIANA}

Baton Rouge:

Louisiana State Library (1976).

Louisiana State University Law Library (1929).

Louisiana State University Library (1907)-REGIONAL.

Southern University Library (1952).

Eunice: Louisiana State University at Eunice, Le Doux Library (1969).

Hammond: Southeastern Louisiana University, Sims Memorial Library (1966).

Lafayette: University of Southwestern Louisiana Library (1938).

Lake Charles: McNeese State University, Frazar Memorial Library (1941).

Monroe: Northeast Louisiana University, Sandel Library (1963).

Natchitoches: Northwestern State University, Watson Memorial Library (1887).

New Orleans:

Isaac Delgado Colle 3, Moss Technical Library (1968).

Law Library of Louisiana (unknown).

Loyola University Library (1942).

New Orleans Public Library (1883).

Southern University in New Orleans Library (1962).

Tulane University, Howard-Tilton Memorial Library (1942).

Tulane University Law Library (1976).

U.S. Court of Appeals, Fifth Circuit Library (1973).

University of New Orleans Library (1963).

Pineville: Louisiana College, Richard W. Norton Memorial Library (1969).

Ruston: Louisiana Technical University Library (1896)-RE. GIONAL.

Shreveport:

Louisiana State University at Shreveport Library (1967).

Shreve Memorial Library (1923).

Thibodaux: Francis T. Nicholls State University, Leonidas Polk Library (1962).

\section{MAINE}

Augusta:

Maine Law and Legislative Reference Library (1973).

Maine State Library (unknown).

Bangor: Bangor Public Library (1884).

Brunswick: Bowdoin College, Hawthorne-Longfellow Library (1884).

Castine: Maine Maritime Academy, Nutting Memorial Library (1969).

Lewiston: Bates College Library (1882).

Orono: University of Maine, Raymond H. Fogler Library (1907)-REGIONAL.

Portland:

Portland Public Library (1884).

University of Maine Law Library (1964).

Springvale: Nasson College Library (1961).

Waterville: Colby College Library (1884).

\section{MARYLAND}

Annapolis:

Maryland State Library (unknown).

U.S. Naval Academy, Nimitz Library (1895).

Baltimore:

Enoch Pratt Free Library (1887).

Johns Hopkins University, Milton S. Eisenhower Library (1882).
Morgan State College, Soper Library (1940).

University of Baltimore, Langsdale Library (1973).

University of Maryland, Baltimore County Library (1971).

University of Maryland, School of Law Library (1969).

Bel Air: Harford Community College Library (1967).

Beltsville: Department of Agriculture, National Agricultural Library (1895).

Bethesda: National Library of Medicine Library (1978).

Chestertown: Washington College, Chester M. Miller Library (1891).

College Park: University of Maryland, McKeldin Library (1925)-REGIONAL.

Cumberland: Allegany Community College Library (1974).

Frostburg: Frostburg State College Library (1967).

Germantown: Energy Research \& Development Adm. Library (1963).

Patuxent River: Naval Air Station Library (1968).

Rockville: Montgomery County Department of Public Libraries (1951).

Salisbury: Salisbury State College, Blackwell Library (1965).

Towson: Goucher College, Julia Rogers Library (1966).

Westminster: Western Maryland College Library (1896).

\section{MASSACHUSETTS}

Amherst:

Amherst College Library (1884).

University of Massachusetts, Godell Library (1907).

Belmont: Belmont Memorial Library (1968).

Boston:

Boston Athenaeum Library (unknown).

Boston College, Bapst Library (1963).

Boston Public Library (1859)-REGIONAL.

Northeastern University, Dodge Library (1962).

State Library of Massachusetts (unknown).

Brookline: Public Library of Brookline (1925).

Cambridge:

Harvard College Library (1860).

Massachusetts Institute of Technology Libraries (1946).

Middlesex County Law Library (1978).

Chicopee: Our Lady of the Elms College Library (1969).

Lowell: University of Lowell/North Campus, Alumni/Lydon Li. brary (1952).

Lynn: Lynn Public Library (1953).

Marlborough: Marlborough Public Library (1971).

Medford: Tufts University Library (1899).

Milton: Curry College Library (1972).

New Bedford: New Bedford Free Public Library (1858).

North Dartmouth: Southeastern Massachusetts University Li. brary (1965).

North Easton: Stonehill College, Cushing-Martin Library (1962).

Springfield: Springfield City Library (1966).

Waltham: Brandeis University, Goldfarb Library (1965).

Wellesley: Wellesley College Library (1943).

Wenham: Gordon College, Winn Library (1963).

Williamstown: Williams College Library (unknown).

Worcester:

American Antiquarian Society Library (1814).

University of Massachusetts, Medical Center Library (1972).

Worcester Public Library (1859).

\section{MICHIGAN}

Albion: Albion College, Stockwell Memorial Library (1966).

Allendale: Grand Valley State College Library (1963).

Alma: Alma College, Monteith Library (1963).

Ann Arbor:

Great Lakes Basin Commission Library (1971).

University of Michigan, Harlan Hatcher Library (1884).

Benton Harbor: Benton Harbor Public Library (1907). 
Bloomfieid Hills: Cranbrook Institute of Science Library (1940). Dearborn:

Henry Ford Centennial Library (1969).

Henry Ford Community College Library (1957).

Detroit:

Detroit Public Library (1868)-REGIONAL.

Marygrove College Library (1965).

Mercy College of Detroit Library (1965).

University of Detroit Library (1884).

Wayne State University Law Library (197i).

Wayne State University, G. Flint Purdy Library (1973).

Dowagiac: Southwestern Michigan College Library (1971).

East Lansing:

Michigan State University, Law Library (1971).

Michigan State University Library (1907).

Escanaba: Michigan State Library, Upper Peninsula Branch (1964).

Farmington: Martin Luther King Learning Resources Center, Oakland Community College (1968).

Flint:

Flint Public Library (1967).

University of Michigan, Flint Library (1959).

Grand Rapids:

Calvin College Library (1967).

Grand Rapids Public Library (1876).

Houghton: Michigan Technological University Library (1876).

Jackson: Jackson District Library (1965).

Kalamazoo:

Kalamazoo Library System (1907).

Western Michigan University, Dwight B. Waldo Library (1963).

Lansing: Michigan State Library (unknown)-REGIONAL.

Livonia: Schoolcraft College Library (1962).

Marquette: Northern Michigan University, Olsen Library (1963).

Monroe: Monroe County Library System (1974).

Mt. Clemens: Macomb County Library (1968).

Mt. Pleasant: Central Michigan University Library (1958).

Muskegon: Hackley Public Library (1894).

Olivet: Olivet College Library (1974).

Petoskey: North Central Michigan College Library (1962).

Port Huron: Saint Clair County Library System (1876).

Rochester: Oakland University, Kresge Library (1964).

Saginaw: Hoyt Public Library (1890).

Traverse City: Northwestern Michigan College, Mark Osterlin Library (1964).

University Center: Delta College Library (1963).

Warren: Warren Public Library, Arthur J. Miller Branch (1973).

Wayne: Wayne Oakland Federated Library System (1957).

Ypsilanti: Eastern Michigan University Library (1965).

\section{MINNESOTA}

Bemidji: Bemidji State University, A. C. Clark Library (1963).

Collegeville: St. John's University, Alcuin Library (1954).

Duluth: Duluth Public Library (1909).

Mankato: Mankato State University Memorial Library (1962).

Minneapolis:

Anoka County Library (1971).

Hennepin County Libraries (1971).

Minneapolis Public Library (1893).

University of Minnesota, Wilson Library (1907)-REGIONAL.

Moorhead: Moorhead State University Library (1956).

Morris: University of Minnesota at Morris Library (1963).

Northfield:

Carleton College Library (1930).

St. Olaf College, Rolvaag Memorial Library (1930).

St. Cloud: St. Cloud State University Library (1962).

St. Paul:

Minnesota Historical Society Library (1867).
Minnesota State Law Library (unknown).

St. Paul Public Library (1914).

University of Minnesota, St. Paul Campus Library (1974).

Saint Peter: Gustavus Adolphus College Library (1941).

Stillwater: Stillwater Public Library (1893).

Willmar: Crow River Regional Library (1958).

Winona: Winona State University, Maxwell Library (1969).

\section{MISSISSIPPI}

Cleveland: Delta State University, W. B. Roberts Library (1975). Clinton: Mississippi College School of Law Library (1977).

Columbus: Mississippi State University for Women, J. C. Fant Memorial Library (1920).

Hattiesburg: University of Southern Mississippi Library (1935).

Jackson:

Jackson State College Library (1968).

Millsaps College, Millsaps-Wilson Library (1963).

Mississippi Library Commission (1947).

Mississippi State Law Library (unknown).

Lorman: Alcorn Agricultural and Mechanical College Library (1970).

State College: Mississippi State University, Mitchell Memorial Li.

University: brary (1907).

University of Mississippi Library (1833)-REGIONAL.

University of Mississippi, School of Law Library (1967).

\section{MISSOURI}

Cape Girardeau: Southeast Missouri State University, Kent Library (1916).

Columbia: University of Missouri Library (1862).

Fayette: Central Methodist College Library (1962).

Fulton: Westminster College, Reeves Library (1875).

Jefferson City:

Lincoln University, Inman E. Page Library (1944).

Missouri State Library (1963).

Missouri Supreme Court Library (unknown).

Joplin: Missouri Southern State College Library (1966).

Kansas City:

Kansas City Public Library (1881).

Rockhurst College Library (1917).

University of Missouri at Kansas City, General Library (1938).

Kirksville: Northeast Missouri State Teachers College, Pickler Memorial Library (1966).

Liberty: William Jewell College Library (1900).

Rolla: University of Missouri at Rolla Library (1907).

St. Charles: Lindenwood College, Margaret Leggat Butler $\mathrm{Li}$ brary (1973).

St. Joseph: St. Joseph Public Library (1891).

St. Louis:

Maryville College Library (1976).

St. Louis County Library (1970).

St. Louis Public Library (1866).

St. Louis University, Law Library (1967).

St. Louis University, Pius XII Memorial Library (1866).

University of Missouri at St. Louis, Thomas Jefferson $\mathrm{Li}$ brary (1966).

U.S. Court of Appeals, Eighth Circuit Library (1972).

Washington University, John M. Olin Library (1906).

Springfield:

Drury College, Walker Library (1874).

Southwest Missouri State College Library (1963).

Warrensburg: Central Missouri State College, Ward Edwards Library (1914). 


\section{MONTANA}

Billings: Eastern Montana College Library (1924).

Bozeman: Montana State University Library (1907).

Butte: Montana College of Mineral Science and Technology Library (1901).

Helena:

Carroll College Library (1974).

Montana Historical Society Library (unknown).

Montana State Library (1966).

State Law Library of Montana (1977).

Missoula: University of Montana Library (1909)-REGIONAL.

\section{NEBRASKA}

Blair: Dana College, Dana-LIFE Library (1924).

Crete: Doane College, Whitin Library (1944).

Fremont: Midland Lutheran College Library (1924).

Kearney: Kearney State College, Calvin T. Ryan Library (1962).

Lincoln:

Nebraska Publications Clearinghouse, Nebraska Library Commission (1972)-REGIONAL.

Nebraska State Library (unknown).

University of Nebraska, Don L. Love Memorial Library (1907)-JOINT REGIONAL.

Omaha:

Creighton University, Alumni Library (1964).

Omaha Public Library (1880).

University of Nebraska at Omaha, University Library (1939).

Scottsbluff: Scottsbluff Public Library (1925).

Wayne: Wayne State College, U.S. Conn. Library (1970).

\section{NEVADA}

Carson City:

Nevada State Library (unknown).

Nevada Supreme Court Library (1973).

Las Vegas:

Clark County District Library (1974).

University of Nevada at Las Vegas, James R. Dickinson Library (1959).

Reno:

Nevada State Historical Society Library (1974).

University of Nevada Library (1907)-REGIONAL

\section{NEW HAMPSHIRE}

Concord:

Franklin Pierce Law Center Library (1973).

New Hampshire State Library (unknown).

Durham: University of New Hampshire Library (1907).

Pranconia: Pranconia College Library (1972).

Hanover: Dartmouth College, Baker Library (1884).

Henniker: New England College Library (1966).

Manchester:

Manchester City Library (1884).

New Hampshire College, H.A.B. Shapiro Memorial Library (1976).

St. Anselm's College, Geise Library (1963).

Nashua: Nashua Public Library (1971).

\section{NEW JERSEY}

Bayonne: Bayonne Free Public Library (1909).

Bloomfield: Free Public Library of Bloomfield (1965).

Bridgeton: Cumberland County Library (1966).

Camden: Rutgers University-Camden Library (1966).
Convent Station: College of St. Elizabeth, Mahoney Library (1938).

Dover: County College of Morris Library, Learning Resources Center (1975).

East Brunswick: East Brunswick Public Library (1977).

East Orange: East Orange Public Library (1966).

Elizabeth: Free Public Library of Elizabeth (1895).

Glassboro: Glassboro State College, Savitz Learning Resource Center (1963).

Hackensack: Johnson Free Public Library (1966).

Irvington: Free Public Library of Irvington (1966).

Jersey City:

Free Public Library of Jersey City (1879).

Jersey City State College, Forrest A. Irwin Library (1963).

Lawrenceville: Rider College Library (1975).

Madison: Drew University, Rose Memorial Library (1939).

Mahwah: Ramapo College Library (1971).

Mount Holly: Burlington County Library (1966).

New Brunswick:

Free Public Library (1908).

Rutgers University Library (1907).

Newark:

Newark Public Library (1906)-REGIONAL.

Rutgers-The State University, John Cotton Dana Library (1966).

Passaic: Passaic Public Library (1964).

Phillipsburg: Phillipsburg Free Public Library (1976).

Plainfield: Plainfield Public Library (1971).

Pomona: Stockton State College Library (1972).

Princeton: Princeton University Library (1884).

Rutherford: Fairleigh Dickinson University, Messler Library (1953).

Shrewsbury: Monmouth County Library (1968).

South Orange: Seton Hall University Library (1947).

Teaneck: Fairleigh Dickinson University, Teaneck Campus Library (1963).

Toms River: Ocean County College Learning Resources Center (1966).

Trenton:

New Jersey State Library, Law and Reference Bureau, Department of Education (unknown).

Trenton Free Public Library (1902).

Union: Kean College of New Jersey, Nancy Thompson Library (1973).

Upper Montclair: Montclair State College, Harry A. Sprague Library (1967).

Wayne: Wayne Public Library (1972).

West Long Branch: Monmouth College, Guggenheim Memorial Library (1963).

Woodbridge: Free Public Library of Woodbridge (1965).

\section{NEW MEXICO}

Albuquerque:

University of New Mexico, Medical Center Library (1973).

University of New Mexico, School of Law Library (1973).

University of New Mexico, Zimmerman Library (1896)-REGIONAL.

Hobbs: New Mexico Junior College, Pannell Library (1969).

Las Cruces: New Mexico State University Library (1907).

Las Vegas: New Mexico Highlands University, Donnelly Library (1913).

Portales: Eastern New Mexico University Library (1962).

Santa Fe:

New Mexico State Library (1960)-REGIONAL.

Supreme Court Law Library (unknown).

Silver City: Western New Mexico University, Miller Library (1972). 


\section{NEW YORK}

Albany:

New York State Library (unknown)-REGIONAL.

State University of New York at Albany Library (1964).

Auburn: Seymour Library (1972).

Bayside: Queensborough Community College Library (1972).

Binghamton: State University of New York at Binghamton Library (1962).

Brockport: State University of New York, Drake Memorial Library (1967).

Bronx:

Herbert H. Lehman College Library (1967).

New York Public Library, Mott Haven Branch (1973).

Bronxville: Sarah Lawrence College Library (1969).

Brooklyn:

Brooklyn College Library (1936).

Brooklyn Law School, Law Library (1974).

Brooklyn Public Library (1908).

Polytechnic Institute of Brooklyn, Spicer Library (1963).

Pratt Institute Library (1891).

State University of New York, Downstate Medical Center Library (1958).

Buffalo:

Buffalo and Erie County Public Library (1895).

State University of New York at Buffalo, Lockwood Memorial Library (1963).

Canton: St. Lawrence University, Owen D. Young Library (1920).

Cheektowago: Cheektowago Public Library (1978).

Corning: Corning Community College, Arthur A. Houghton, Jr. Library (1963).

Cortland: State University of New York, College at Cortland, Memorial Library (1964).

Delhi: State University Agricultural and Technical College Li. brary (1970).

Douglaston: Cathedral College Library (1971).

East Islip: East Islip Public Library (1974).

Elmira: Elmira College, Gannett-Tripp Learning Center (1956).

Farmingdale: State University Agricultural and Technical Institute at Farmingdale Library (1917).

Flushing: Queens College, Paul Klapper Library (1939).

Garden City: Adelphi University, Swirbul Library (1966).

Genesco: State University College, Milne Library (1967).

Greenvale: C. W. Post College, B. Davis Schwartz Memorial Library (1965).

Hamilton: Colgate University Library (1902).

Hempstẹd: Hofstra University Library (1964).

Ithaca:

Cornell University Library (1907).

New York State Colleges of Agriculture and Home Economics, Albert R. Mann Library (1943).

Jamaica:

Queens Borough Public Library (1926).

St. John's University Library (1956).

Kings Point: U.S. Merchant Marine Academy Library (1962).

Mount Vernon: Mount Vernon Public Library (1962).

New Paltz: State University College Sojourner Truth Library (1965).

New York City:

City University of New York, City College Library (1884).

College of Insurance, Ecker Library (1965).

Columbia University Libraries (1882).

Cooper Union Library (1930).

Fordham University Library (1937).

Medical Library Center of New York (1976).

New York Law Institute Library (1909).

New York Public Library (Astor Branch) (1907).

New York Public Library (Lenox Branch) (1884).

New York University Libraries (1967).

New York University, Law Library (1973).
State University of New York, Maritime College Library (1947).

U.S. Court of Appeals Library (1976).

Newburgh: Newburgh Free Library (1909).

Niagara Falls: Niagara Falls Public Library (1976).

Oakdale: Dowling College Library (1965).

Oneonta: State University College, James M. Milne Library (1966).

Oswego: State University College, Penfield Library (1966).

Plattsburgh: State University College, Benjamin F. Feinberg Li-

Potsdam: brary (1967).

Clarkson College of Technology, Harriet Call Burnap Memorial Library (1938).

State University College, Frederick W. Crumb Memorial Library (1964).

Poughkeepsie: Vassar College Library (1943).

Purchase: State University of New York, College at Purchase Library (1969).

Rochester:

Rochester Public Library (1963).

University of Rochester Library (1880).

St. Bonaventure: St. Bonaventure College, Friedsam Memorial Library (1938).

Saratoga Springs: Skidmore College Library (1964).

Schenectady: Union College, Schaffer Library (1901).

Southampton: Southampton College Library (1973).

Staten Island (Grymes Hill): Wagner College, Horrmann Library (1953).

Stony Brook: State University of New York at Stony Brook Library (1963).

Syracuse: Syracuse University Library (1878).

Troy: Troy Public Library (1869).

Uniondale: Nassau Library System (1965).

Utica:

Utica Public Library (1885).

Utica/Rome State University College Library (1977).

West Point: U.S. Military Academy Library (unknown).

Yonkers: Yonkers Public Library (1910).

Yorktown Heights: Mercy College at Fox Meadow Library.

\section{NORTH CAROLINA}

Asheville: University of North Carolina at Asheville, D. Hiden Ransey Library (1965).

Boiling Springs: Gardner-Webb College, Dover Memorial Library (1974).

Boone: Appalachian State University Library (1963).

Buies Creek: Campbell College, Carrie Rich Memorial Library (1965).

Chapel Hill: University of North Carolina Louis Round Wilson Library (1884)-REGIONAL.

Charlotte:

Public Library of Charlotte and Mecklenburg County (1964).

Queens College, Everette Library (1927).

University of North Carolina at Charlotte, Atkins Library (1964).

Cullowhee: Western Carolina University, Hunter Library (1953).

Davidson: Davidson College, Hugh A. \& Jane Grey Memorial Library (1893).

Durham:

Duke University, William R. Perkins Library (1890).

North Carolina Central University, James $\mathbb{E}$. Shepard Memorial Library (1973).

Elon College: Elon College Library (1971).

Fayetteville: Fayetteville State University, Chesnutt Library (1971). 
Greensboro:

North Carolina Agricultural and Technical State University, F. D. Bluford Library (1937).

University of North Carolina at Greensboro, Walter Clinton Jackson Library (1963).

Greenville: East Carolina University, J. Y. Joyner Library (1951).

Laurinburg: St. Andrews Presbyterian College, DeTamble Library (1969).

Lexington: Davidson County Public Library System (1971).

Mount Olive: Mount Olive College, Moye Library (1971).

Murfreesboro: Chowan College, Whitaker Library (1963).

Pembroke: Pembroke State University, Mary Livermore Library

Raleigh: (1965).

North Carolina State Library (unknown).

North Carolina State University, D. H. Hill Library (1923).

North Carolina Supreme Court Library (1972).

Wake County Public Libraries (1969).

Rocky Mount: North Carolina Wesleyan College Library (1969).

Salisbury: Catawba College Library (1925).

Wilmington: University of North Carolina at Wilmington, William M. Randall Library (1965).

Wilson: Atlantic Christian College, Clarence L. Hardy Library (1930).

Winston-Salem:

Forsyth County Public Library System (1954).

Wake Forest University, Z. Smith Reynolds Library (1902).

\section{NORTH DAKOTA}

Bismarck:

North Dakota State Law Library (unknown).

State Historical Society of North Dakota (1907).

State Library Commission Library (1971).

Veterans Memorial Public Library (1967).

Dickinson: Dickinson State College Library (1968).

Fargo:

Fargo Public Library (1964).

North Dakota State University Library (1907)-REGIONAL, in cooperation with University of North Dakota, Chester Fritz Library at Grand Forks.

Grand Forks: University of North Dakota, Chester Fritz Library (1890).

Minot: Minot State College, Memorial Library (1925).

Valley City: State College Library (1913).

\section{OHIO}

Ada: Ohio Northern University, J. P. Taggart Law Library (1965).

Akron:

Akron Public Library (1952).

University of Akron Library (1963).

Alliance: Mount Union College Library (1888).

Ashland: Ashland College Library (1938).

Athens: Ohio University Library (1886).

Batavia: Clermont General and Technical College Library (1973).

Bluffton: Bluffton College, Musselman Library (1951).

Bowling Green: Bowling Green State University Library (1933).

Canton: Malone College, Everett L. Cattell Library (1970).

Chardon: Geauga County Public Library (1971).

Cincinnati:

Public Library of Cincinnati and Hamilton County (1884).

University of Cincinnati Library (1929).

Cleveland:

Case Western Reserve University, Freiberger Library (1913).
Cleveland Heights-University Heights Public Library (1970).

Cleveland Public Library (1886).

Cleveland State University Library (1966).

John Carroll University, Grasselli Library (1963).

Municipal Reference Library (1970).

Columbus:

Capital University Library (1968).

Ohio State Library (unknown)-REGIONAL.

Ohio State University, William Oxley Thompson Memorial Library (1907).

Ohio Supreme Court Law Library (1973).

The Public Library of Columbus and Franklin County (1885).

Dayton:

Dayton and Montgomery County Public Library (1909).

University of Dayton, Albert Emanuel Library (1969).

Wright State University Library (1965).

Delaware: Ohio Wesleyan University, L. A. Beeghly Library (1845).

Elyria: Elyria Public Library (1966).

Findlay: Findlay College, Shafer Library (1969).

Gambier: Kenyon College, Gordon Keith Chalmers Memorial Library (1873).

Granville: Denison University, William Howard Doane Library (1884).

Hiram: Hiram College, Teachout-Price Memorial Library (1874).

Kent: Kent State University Library (1962).

Marietta: Marietta College, Dawes Memorial Library (1884).

Middletown: Miami University at Middletown, Gardner-Harvey Library (1970).

New Concord: Muskingum College Library (1960).

Oberlin: Oberlin College Library (1858).

Oxford: Miami University, Alumni Library (1909).

Portsmouth: Portsmouth Public Library (unknown).

Rio Grande: Rio Grande College, Jeanette Albiez Davis Library (1966).

Springfield: Warder Public Library (1884).

Steubenville:

College of Steubenville, Starvaggi Memorial Library (1971).

Public Library of Steubenville and Jefferson County (1950).

Tiffin: Heidelberg College, Leon A. Beeghly Library (1964).

Toledo:

Toledo-Lucas County Public Library (1884).

University of Toledo Library (1965).

Westerville: Otterbein College (1967).

Wooster: College of Wooster, the Andrews Library (1960).

Youngstown:

Public Library of Youngstown and Mahoning County (1923).

Youngstown State University, William F. Maag Library (1971).

\section{OKLAHOMA}

Ada: East Central Oklahoma State University, Linscheid Library (1914).

Alva: Northwestern Oklahoma State University Library (1907).

Bartlesville: United States ERDA.BERC Library (1962).

Bethany: Bethany Nazarene College, R. T. Williams Library (1971).

Durant: Southeastern Oklahoma State University Library (1929).

Edmond: Central State University Library (1934).

Enid: Public Library of Enid and Garfield County (1908).

Langston: Langston University, G. Lamar Harrison Library (1941).

Muskogee: Muskogee Public Library (1971).

Norman: University of Oklahoma Libraries (1893).

Oklahoma City:

Oklahoma County Libraries (1974). 
Oklahoma City University Library (1963).

Oklahoma Department of Libraries (1893)-REGIONAL.

Shawnee: Oklahoma Baptist University Library (1933).

Stillwater: Oklahoma State University Library (1907).

Tahlequah: Northeastern Oklahoma State University, John Vaughan Library (1923).

Tulsa:

Tulsa City-County Library Commission (1963).

University of Tulsa, McFarlin Library (1929).

Weatherford: Southwestern Oklahoma State University, Al Harris Library (1958).

\section{OREGON}

Ashland: Southern Oregon College Library (1953).

Corvallis: Oregon State University Library (1907).

Eugene: University of Oregon Library (1883).

Forest Grove: Pacific University Library (1897).

La Grande: Eastern Oregon College, Walter M. Pierce Library (1954).

McMinnville: Linfield College, Northup Library (1965).

Monmouth: Oregon College of Education Library (1967).

Portland:

Department of Energy, Bonneville Power Administration Library (1962).

Lewis and Clark College, Aubrey R. Watzek Library (1967).

Library Association of Portland (1884).

Portland State University Library (1963)-REGIONAL.

Salem:

Reed College Library (1912).

Oregon State Library (unknown).

Oregon Supreme Court Library (1974).

Willamette University Library (1969).

\section{PENNSYLVANIA}

Allentown: Muhlenberg College, Haas Library (1939).

Allegheny: Alleghany County Law Library (1977).

Altoona: Altoona Public Library (1969).

Bethlehem: Lehigh University, Linderman Library (1876).

Blue Bell: Montgomery County Community College, Learning Resources Center (1975).

Carlisle: Dickinson College, Boyd Lee Spahr Library (1947).

Cheyney: Cheyney State College, Leslie Pinckney Hill Library (1947).

Collegeville: Ursinus College, Myrin Library (1963).

Coraopolis: Robert Morris College Library (1978).

Doylestown: Bucks County Free Library, Center County $\mathrm{Li}$ brary (1970).

East Stroudsburg: East Stroudsburg State College, Kemp Library (1966).

Erie: Erie Public Library (1897).

Greenville: Thiel College, Langenheim Memorial Library (1963).

Harrisburg: State Library of Pennsylvania (unknown)-REGIONAL.

Haverford: Haverford College Library (1897).

Hazleton: Hazleton Area Public Library (1964).

Indiana: Indiana University of Pennsylvania, Rhodes R. Stabley Library (1962).

Johnstown: Cambria Public Library (1965).

Lancaster: Franklin and Marshall College, Fackenthal Library (1895).

Lewisburg: Bucknell University, Ellen Clarke Bertrand Library (1963).

Mansfield: Mansfield State College Library (1968).

Meadville: Allegheny College, Reis Library (1907).

Millersville: Millersville State College, Ganser Library (1966).

Monessen: Monessen Public Library-(1969).
New Castle: New Castle Free Public Library (1963).

Newtown: Bucks County Community College Library (1968).

Norristown: Montgomery County-Norristown Public Library (1969)

Philadelphia:

Drexel University Library (1963).

Free Library of Philadelphia (1897).

St. Joseph's College Library (1974).

Temple University, Samuel Paley Library (1947).

Thomas Jefferson University, Scott Memorial Library (1978).

U.S. Court of Appeals, Third Circuit (1973).

University of Pennsylvania, Biddle Law Library (1974).

University of Pennsylvania Library (1886).

Pittsburgh:

Bureau of Mines, Pittsburgh Research Center Library (1962).

Carnegie Library of Pittsburgh, Allegheny Regional Branch (1924).

Carnegie Library of Pittsburgh (1895).

La Roche College, John J. Wright Library (1974).

University of Pittsburgh, Hillman Library (1910).

Pottsville: Pottsville Free Public Library (1967).

Reading: Reading Public Library (1901).

Scranton: Scranton Public Library (1895).

Shippensburg: Shippensburg. State College, Ezra Lehman Memorial Library (1973).

Slippery Rock: Slippery Rock State College, Maltby Library (1965).

Swarthmore: Swarthmore College Library (1923).

University Park: Pennsylvania State University Library (1907).

Villanova: Villanova University, School of Law Library (1964).

Warren: Warren Library Association, Warren Public Library (1885).

Washington: Washington and Jefferson College, Memorial Library (1884).

Waynesburg: Waynesburg College Library (1964).

West Chester: West Chester State College, Francis Harvey Green Library (1967).

Wilkes-Barre: King's College, D. Leonard Corgan Library (1949).

Williamsport: Lycoming College Library (1970).

York: York Junior College Library (1963).

Youngwood: Westmoreland County Community College, Learning Resource Center (1972).

\section{PUERTO RICO}

Mayaguez: University of Puerto Rico, Mayaguez Campus Library (1928).

Ponce: Catholic University of Puerto Rico Library (1966).

Rio Piedras: University of Puerto Rico General Library (1928).

\section{RHODE ISLAND}

Kingston: University of Rhode Island Library (1907).

Newport: Naval War College Library (1963).

Providence:

Birown University, John D. Rockefeller, Jr. Library (unknown).

Providence College, Phillips Memorial Library (1969).

Providence Public Library (1884).

Rhode Island College Library (1965).

Rhode Island State Library (before 1895).

Warwick: Warwick Public Library (1966).

Westerly: Westerly Public Library (1909).

Woonsocket: Woonsocket Harris Public Library (1977). 


\section{SOUTH CAROLINA}

Charleston:

Baptist College at Charleston Library (1967).

College of Charleston, Robert Scott Small Library (1869).

The Citadel Memorial Library (1962).

Clemson: Clemson University Library (1893).

Columbia:

Benedict College, Learning Resources Center (1969).

Richland County Public Library (1978).

South Carolina State Library (before 1895).

University of South Carolina Undergraduate Library (1884).

Conway: University of South Carolina, Coastal Carolina Regional Campus Library (1974).

Due West: Erskine College, McCain Library (1968).

Florence:

Florence County Library (1967).

Francis Marion College, James A. Rogers Library (1970).

Greenville:

Furman University Library (1962).

Greenville County Library (1966).

Greenwood: Lander College Library (1967).

Orangeburg: South Carolina State College, Whittaker Library (1953).

Rock Hill: Winthrop College Library (1896).

Spartanburg: Spartanburg County Public Library (1967).

\section{SOUTH DAKOTA}

Aberdeen: Northern State College Library (1963).

Brookings: South Dakota State University, Hilton M. Briggs Library (1889).

Pierre: South Dakota State Library (1973).

Rapid City:

Rapid City Public Library (1963).

South Dakota School of Mines and Technology Library (1963).

Sioux Falls:

Augustana College, Mikkelsen Library and Learning Resources Center (1969).

Sioux Falls Public Library (1903).

Spearfish: Black Hills State College Library (1942).

Vermillion: University of South Dakota, I. D. Weeks Library (1889).

Yankton: Yankton College, Corliss Lay Library (1904).

\section{TENNESSEE}

Bristol: King College Library (1970).

Chattanooga:

Chattanooga-Hamilton County Bicentennial Library (1908).

TVA Technical Library (1976).

Clarksville: Austin Peay State University, Felix G. Woodward Library (1945).

Cleveland: Cleveland State Community College Library (1973).

Columbia: Columbia State Community College Library (1973).

Cookeville: Tennessee Technological University, Jere Whitson Memorial Library (1969).

Jackson: Lambuth College, Luther L. Gobbel Library (1967).

Jefferson City: Carson-Newman College Library (1964).

Johnson City: East Tennessee State Universith, Sherrod Library (1942).

Knoxville:

Public Library of Knoxville and Knox County, Lawson McGhee Library (1973).

University of Tennessee Law Library (1971).

University of Tennessee Library (1907).

Martin: University of Tennessee at Martin Library (1957).
Memphis:

Memphis and Shelby County Public Library and Information Center (1896).

Memphis State University, John W. Brister Library (1966).

Murfreesboro: Middle Tennessee State University, Andrew L. Todd Library (1912).

Nashville:

Fisk University Library (1965).

Joint University Libraries (1884).

Public Library of Nashville and Davidson County (1884).

Tennessee State Law Library (1976).

Tennessee State Library and Archives, State Library Division (unknown).

Tennessee State University, Martha M. Brown Memorial Li. brary (1972).

Vanderbilt University Law Library (1976).

Sewanee: University of the South, Jesse Ball duPont Library (1973).

\section{TEXAS}

Abilene: Hardin-Simmons University, Rupert and Pauline Richardson Library (1940).

Arlington:

Arlington Public Library (1970).

Austin:

University of Texas at Arlington Library (1963).

Tezas State Law Library (1972).

Texas State Library (unknown)-REGIONAL.

University of Texas at Austin Library (1884).

University of Texas, Lyndon B. Johnson School of Public Affairs Library (1966).

University of Tezas, School of Law Library (1965).

Baytown: Lee College Library (1970).

Bequmont: Lamar University Library (1957).

Brownwood: Howard Payne University, Walker Memorial Library (1964).

Canyon: West Tezas State University Library (1928).

College Station: Texas Agricultural and Mechanical University Library (1907).

Commerce: East Texas State University Library (1937).

Corpus Christi: Texas A\&II University at Corpus Christi Library (1976).

Corsicana: Navarro Junior College Library (1965).

Dallas:

Bishop College, Zale Library (1966).

Dallas Baptist College Library (1967).

Dallas Public Library (1900).

Southern Methodist University, Fondren Library (1925).

University of Texas Health Science Center Library at Dallas (1975).

Denton: Norih Texas State University Library (1948).

Edinburg: Pan American University Library (1959).

El Paso:

El Paso Public Library (1906).

University of Texas at El Paso Library (1966).

Fort Worth:

Fort Worth Public Library (1905).

Texas Christian University, Mary Couts Burnett Library (1916).

Galveston: Rosenberg Library (1909).

Houst in:

Houston Public Library (1884).

North Harris County College, Learning Resource Center (1974).

Rice University, Fondren Library (1967).

University of Houston Library (1957).

Huntsville: Sam Houston State University, Estill Library (1949).

Irving: Irving Municipal Library (1974). 
Kingsville: Texas Arts and Industries University Library (1944).

Lake Jackson: Brazosport College Library (1969).

Laredo: Laredo Junior College Library (1970).

Longview: Nicholson Memorial Public Library (1961).

Lubbock: Texas Tech University Library (1935)-REGIONAL

Marshall: Wiley College, Cole Library (1962).

Mesquite: Mesquite Public Library (1975).

Nacogdoches: Stephen F. Austin State University, Steen Library (1965).

Plainview: Wayland Baptist College, Van Howeling Memorial Library (1963).

Richardson: University of Texas at Dallas Library (1972).

San Angelo: Angelo State University, Porter Henderson Library (1964).

San Antonio:

San Antonio College Library (1972).

San Antonio Public Library, Business and Science Department (1899).

St. Mary's University Library (1964).

Trinity University Library (1964).

University of Texas at San Antonio Library (1973).

San Marcos: Southwest Texas State University Library (1955).

Seguin: Texas Lutheran College, Blumberg Memorial Library (1970).

Sherman: Austin College, Arthur Hopkins Library (1963).

Texarkana: Texarkana Community College, Palmer Memorial Library (1963).

Victoria: University of Houston, Victoria Campus Library (1973).

Waco: Baylor University Library (1905).

Wichita Falls: Midwestern University, Moffett Library (1963).

\section{UTAH}

Cedar City: Southern Utah State College Library (1964).

Ephraim: Snow College, Lucy A. Phillips Library (1963).

Logan: Utah State University, Merrill Library and Learning Resources Center (1907)-REGIONAL.

Ogden: Weber State College Library (1962).

Provo:

Brigham Young University, Lee Library (1908).

Brigham Young University Law Library (1972).

Salt Lake City:

University of Utah, Spencer S. Eccles Medical Sciences Library (1970).

University of Utah, Law Library (1966).

University of Utah, Marriott Library (1893).

Utah State Library Commission, Documents Library (unknown).

Utah State Supreme Court Law Library (1975).

\section{VERMONT}

Burlington: University of Vermont, Bailey Library (1907).

Castleton: Castleton State College, Calvin Coolidge Library (1969).

Johnson: Johnson State College, John Dewey Library (1955).

Lyndonville: Lyndon State College, Samuel Reed Hall Library (1969).

Middlebury: Middlebury College, Egbert Starr Library (1884).

Montpelier: Vermont Department of Libraries (before 1895).

Northfield: Norwich University Library (1908).

Putney: Windham College, Dorothy Culbertson Marvin Memorial Library (1965).

\section{VIRGIN ISLANDS}

Charlotte Amalie (St. Thomas):

College of the Virgin Islands, Raiph M. Paiewonsky Li . brary (1973).

St. Thomas Public Library (1968).

Christiansted (St. Croix): Florence Augusta Stephens Williams Public Library (1974).

\section{VIRGINIA}

Blacksburg: Virginia Polytechnic Institute, Newman Library (1907).

Bridgewater: Bridgewater College, Alexander Mack Memorial Library (1902).

Charlottesville:

University of Virginia, Alderman Library (1910)-REGIONAL.

University of Virginia Law Library (1964).

Chesapeake: Chesapeake Public Library System (1970).

Danville: Danville Community College Library (1969).

Emory: Emory and Henry College Library (1884).

Fairfax: George Mason University, Fenwick Library (1960).

Fredericksburg: Mary Washington College, E. Lee Trinkle Library (1940).

Hampden-Sydney: Hampden-Sydney College, Eggleston Library (1891).

Hampton: Hampton Institute, Huntington Memorial Library (1977).

Harrisonburg: James Madison University, Madison Memorial Library (1973).

Hollins College: Hollins College, Fishburn Library (1967).

Lexington:

Virginia Military Institute, Preston Library (1874).

Washington and Lee University, Cyrus Hall McCormick Library (1910).

Martinsville: Patrick Henry Community College Library (1971).

Norfolk:

Armed Forces Staff College Library (1963).

Norfolk Public Library (1895).

Old Dominion University Library (1963).

Petersburg: Virginia State College, Johnston Memorial Library (1907).

Quantico:

Federal Bureau of Investigation Academy Library (1970).

Marine Corps Schools, James Carson Breckinridge Library (1967).

Reston: Department of the Interior, Geological Survey Library (1962).

Richmond

State Law Library (1973).

University of Richmond, Boatwright Memorial Library (1900).

U.S. Court of Appeals, Fourth Circuit Library (1973).

Virginia Commonwealth University, James Branch Cabell Library (1971).

Virginia State Library (unknown).

Roanoke: Roanoke Public Library (1964).

Salem: Roanoke College Library (1886).

Williamsburg: William and Mary College Library (1936).

Wise: Clinch Valley College, John Cook Wyllie Library (1971).

\section{WASHINGTON}

Bellingham: Western Washington State College, Wilson Library (1963).

Cheney: Eastern Washington State College Library (1966).

Ellensburg: Central Washington University Library (1962).

Everett: Everett Public Library (1914). 
Kingsville: Texas Arts and Industries University Library (1944).

Lake Jackson: Brazosport College Library (1969).

Laredo: Laredo Junior College Library (1970).

Longview: Nicholson Memorial Public Library (1961).

Lubbock: Tezas Tech University Library (1935)-REGIONAL

Marshall: Wiley College, Cole Library (1962).

Mesquite: Mesquite Public Library (1975).

Nacogdoches: Stephen F. Austin State University, Steen Library (1965).

Plainview: Wayland Baptist College, Van Howeling Memorial Library (1963).

Richardson: University of Texas at Dallas Library (1972).

San Angelo: Angelo State University, Porter Henderson Library

San Antonio: (1964).

San Antonio College Library (1972).

San Antonio Public Library, Business and Science Department (1899).

St. Mary's University Library (1964).

Trinity University Library (1964).

University of Texas at San Antonio Library (1973).

San Marcos: Southwest Texas State University Library (1955).

Seguin: Texas Lutheran College, Blumberg Memorial Library (1970).

Sherman: Austin College, Arthur Hopkins Library (1963).

Texarkana: Texarkana Community College, Palmer Memorial Library (1963).

Victoria: University of Houston, Victoria Campus Library (1973).

Waco: Baylor University Library (1905).

Wichita Falls: Midwestern University, Moffett Library (1963).

\section{UTAH}

Cedar City: Southern Utah State College Library (1964).

Ephraim: Snow College, Lucy A. Phillips Library (1963).

Logan: Utah State University, Merrill Library and Learning Resources Center (1907)-REGIONAL.

Ogden: Weber State College Library (1962).

Provo:

Brigham Young University, Lee Library (1908).

Brigham Young University Law Library (1972).

Salt Lake City:

University of Utah, Spencer S. Eccles Medical Sciences Library (1970).

University of Utah, Law Library (1966).

University of Utah, Marriott Library (1893).

Utah State Library Commission, Documents Library (unknown).

Utah State Supreme Court Law Library (1975).

\section{VERMONT}

Burlington: University of Vermont, Bailey Library (1907).

Castleton: Castleton State College, Calvin Coolidge Library (1969).

Johnson: Johnson State College, John Dewey Library (1955).

Lyndonville: Lyndon State College, Samuel Reed Hall Library (1969).

Middlebury: Middlebury College, Egbert Starr Library (1884).

Montpelier: Vermont Department of Libraries (before 1895).

Northfield: Norwich University Library (1908).

Putney: Windham College, Dorothy Culbertson Marvin Memorial Library (1965).

\section{VIRGIN ISLANDS}

Charlotte Amalie (St. Thomas):

College of the Virgin Islands, Ralph M. Paiewonsky $\mathrm{Li}$. brary (1973).

St. Thomas Public Library (1968).

Christiansted (St. Croix): Florence Augusta Stephens Williams Public Library (1974).

\section{VIRGINIA}

Blacksburg: Virginia Polytechnic Institute, Newman Library (1907).

Bridgewater: Bridgewater College, Alexander Mack Memorial Library (1902).

Charlottesville:

University of Virginia, Alderman Library (1910)-REGION. AL.

University of Virginia Law Library (1964).

Chesapeake: Chesapeake Public Library System (1970).

Danville: Danville Community College Library (1969).

Emory: Emory and Henry College Library (1884).

Fairfax: George Mason University, Fenwick Library (1960).

Fredericksburg: Mary Washington College, E. Lee Trinkle Library (1940).

Hampden-Sydney: Hampden-Sydney College, Eggleston Library (1891).

Hampton: Hampton Institute, Huntington Memorial Library (1977).

Harrisonburg: James Madison University, Madison Memorial Library (1973).

Hollins College: Hollins College, Fishburn Library (1967).

Lexington:

Virginia Military Institute, Preston Library (1874).

Washington and Lee University, Cyrus Hall McCormick Li. brary (1910).

Martinsville: Patrick Henry Community College Library (1971).

Norfolk:

Armed Forces Staff College Library (1963).

Norfolk Public Library (1895).

Old Dominion University Library (1963).

Petersburg: Virginia State College, Johnston Memorial Library (1907).

Quantico:

Federal Bureau of Investigation Academy Library (1970).

Marine Corps Schools, James Carson Breckinridge Library (1967).

Reston: Department of the Interior, Geological Survey Library (1962).

Richmond:

State Law Library (1973).

University of Richmond, Boatwright Memorial Library (1900).

U.S. Court of Appeals, Fourth Circuit Library (1973).

Virginia Commonwealth University, James Branch Cabell Library (1971).

Virginia State Library (unknown).

Roanoke: Roanoke Public Library (1964).

Salem: Roanoke College Library (1886).

Williamsburg: William and Mary College Library (1936).

Wise: Clinch Valley College, John Cook Wyllie Library (1971).

\section{WASHINGTON}

Bellingham: Western Washington State College, Wilson Library (1963).

Cheney: Eastern Washington State College Library (1966).

Ellensburg: Central Washington University Library (1962).

Everett: Everett Public Library (1914). 


\section{APPENDIX B. LIST OF DISTRICT OFFICES OF THE U.S. DEPARTMENT OF COMMERCE}

ALABAMA

Birmingham-Gayle C. Shelton, Jr., Director, Suite 200-201, 908 South 20th Street, 35205, Area Code 205 Tel 254-1331, FTS 229-1331

\section{ALASKA}

Anchorage-Jack C. Wilburn, Director, 701 C Street, P.O. Box 32, 99513, Area Code 907 Tel 271-5041, FTS Dlal 8 399-0150, Ask for 2715041

\section{ARIZONA}

Phoenix-Donald W. Fry, Director, Sulte 2950 Valley Bank Center, 201 North Central Avenue 85073, Area Code 602 Tel 261-3285, FTS 2613285

\section{ARKANSAS}

- Little Rock-Robert E. Kistler, Director, Suite 635, Savers Federal Building, 320 W. Capitol Avenue, 72201, Area Code 501 Tel 378-5794, FTS 740-5794

- Jonesboro-P.O. Box 2525, ASU Stale University, Arkansas 72467, Area Code 501 Tel 792-4760, FTS 277-4760

\section{CALIFORNIA}

- Los Angeles-Paul W. Leinenbach, Director, Room 800, 11777 San Vicente Boulevard 90049, Area Code $213 \mathrm{Tel}$ 824-7591, FTS 799-7591

-San Diego-110 West C Street, 92101, Area Code 714 Tel 293-5395

San Francisco-Betty D. Neuhart, Director, Federal Building, Box 36013, 450 Golden Gate Avenue 94102, Area Code 415 Tele 5565860 , FTS $556-5868$

\section{COLORADO}

-Denver-Thomas F. Maguire, Room 165. New Customhouse, 19th \& Stout Street 80202, Area Code $303 \mathrm{Tel}$ 837-3246, FTS 327-3246

\section{CONNECTICUT}

Hartford-Richard C. Kilbourn, Director, Room 610-B, Federal Office Building, 450 Main Street 06103, Area Code 203 Tel 244-3530, FTS 2443530

\section{FLORIDA}

Miami-Roger J. LaRoche, Director, Room 821, City National Bank BuildIng, 25 West Flagler Street 33130 , Area Code 305 Tel 350-5267, FTS 350-5267

- Clearwater-128 North Osceola Avenue 33515 , Area Code 813 Tel 461-0011

-Jacksonville-815 S. Main Street, Suite 100,32207, Area Code 904 Tel 791-2796, FTS 946-2796

-Tallahassee-Collins Bldg., Rm. G-20 32304, Area Code 904 Tel 488-6469, FTS $946-4320$

\section{GEORGIA}

Atlanta-Director, (Vacant) Suite 600,1365 Peachtree Street, N.E. 30309, Area Code 404 Tel 881-7000, FTS $257-7000$

Savannah-James $W$. Mclntire, Director, 222 U.S. Courthouse \& P.O. Box 9746, 125-29 Bull Street, 31412, Area Code 912 Tel 232-4321, Ext. 204, FTS 248-4204

\section{HAWAII}

Honolulu-H. Tucker Gratz, Director, 4106 Federal Building, P.O. Box 50026, 300 Ala Moana Boulevard 96850, Area Code 808 Tel 546-8694, FTS Dial 8, 556-0220, Ask for 5468694

\section{ILLINOIS}

Chicago-Gerald M. Marks, Director, 1406 Mid Continental Plaza Building, 55 East Monroe Street 60603, Area Code 312 Tel $353-4450$, FTS 3534450

- Commerce Buslness Dally

Room 1304, 433 West Van Buren Street 60607, Area Code 312 Tel 353-2950

\section{INDIANA}

Indianapolis-Mel R. Sherar, Director, 357 U.S. Courthouse \& Federal Office Building, 46 East Ohio Street 46204. Area Code 317 Tel 269-6214, FTS 331-6214

\section{IOWA}

Des Moines-Jesse N. Durden, Director, 817 Federal Building, 210 Walnut Street 50309, Area Code 515 Tel 284-4222, FTS 862-4222

\section{KENTUCKY}

- Louisville-Donald R. Henderson, Director, Room 636, U.S. Post Office and Court House Building 40202, Area Code 502 Tel 582-5066, FTS 352-5066

\section{LOUISIANA}

New Orleans-Director (Vacant), 432 International Trade Mart, No. 2 Canal Street 70130 , Area Code 504 Tel 5896546, FTS 682-6546

\section{MAINE}

-Augusta (Boston, Massachusetts District -1 Memorial Circle, Casco Bank Bldg., Area Code 207 Tell 6232239, FTS 833-6249

\section{MARYLAND}

Baltimore-Carroll F. Hopkins, Director, 415 U.S. Cusstomhouse, Gay and Lombard Streets 21202, Area Code $301 \mathrm{Tel} 962-3560$, FTS $922-3560$

\section{MASSACHUSETTS}

Boston-Francis J. O'Connor, Director 10th Floor, 441 Stuart Street 02116. Area Code 617 Tel 223-2312, FTS 223-2312

\section{MICHIGAN}

-Detroit-Raymond R. Riesgo, Director, 445 Federal Building, 231 West Layfayette 48226 , Area Code 313 Tel 226-3650, FTS 226-3650

-Grand Rapids-350 Ottawa Street N.W. 49503, Area Code 616 Tel 456-2411/33 FTS 372-2411

\section{MINNESOTA}

Minneapolis-Glenn A. Matson, Director, 218 Federal Building, 110 South Fourth Street 55401, Area Code 612 Teil 725-2133, FTS 725-2133

\section{MISSISSIPPI}

- Jackson-Director (Vacant), Provldence Capitol, Suite 550, 200 East Pascagoula 39201, Area Code 601 Tel 969-4388, FTS 490-4388

\section{MISSOUR}

St. Louis-Donald R. Loso, Director, 120 South Central Avenue 63105, Area Code 314 Tel 425-3302-4, FTS 279-3302

- Kansas Clty-James D. Cook Director, Room 1840, 601 East 12th Street 64106, Area Code 816 Tel 374-3142, FTS 758-3142

\section{NEBRASKA}

Omaha-George H. Payne, Dlrector, Capitol Plaza, Suite 703A, 1815 Capitol Avenue 68102, Area Code 402 Tel 221-3665, FTS 864-3665

\section{NEVADA}

Reno-Joseph J. Jeremy, Director, 777 W. 2nd Street, Room 120, 89503 Area Code 702 Tel 784-5203, FTS 470-5203

\section{NEW JERSEY}

Newark-Thomas J. Murray, Dlrector, 4th Floor, Gateway Bullding, Market Street \& Penn Plaza 07102, Area Code 201 Tel 645-6214, FTS 341-6214

\section{NEW MEXICO}

Albuquerque-William E. Dwyer, DIrector, 505 Marquette Ave., NW, Sulte 1015, 87102, Area Code 505 Tel 7662386, FTS $474-2386$

\section{NEW YORK}

Buffalo-Robert F. Magee, Director, 1312 Federal Building, 111 West $\mathrm{Hu}$ ron Street 14202, Area Code 716 Tel 846-4191, FTS 437-4191

New York-Arthur C. Rutzen, Direcior, Room 3718, Federal Ófice Building, 26 Federal Plaza, Foley Square 10007. Area Code 212 Tel 264-0634, FTS 264-0600 


\section{NORTH CAROLINA}

Greensboro-Joel B. New, Director, 203 Federal Building, West Market Street, P.O. Box 1950 27402, Area Code 919 Tel 378-5345, FTS 699-5345

\section{OHIO}

Cincinnati-Gordon B. Thomas, Director, 10504 Federal Office Building, 550 Main Street 45202, Area Code 513 Tel 684-2944, FTS 684-2944

Cleveland-Charles B. Stebbins, Director, Room 600, 656 Euclid Avenue 44114, Area Code 216 Tel 522-4750, FTS 293-4750

\section{OKLAHOMA}

-Oklahoma City (Dallas, Texas District)-4024 Lincoln Boulevard 73105, Area Code $405 \mathrm{Tel} 231-5302$, FTS 736-5302

\section{OREGON}

Portland - Lloyd R. Porter, Director, Room 618, 1220 S.W. 3rd Avenue 97204, Area Code 503 Tel 221-3001, FTS 423-3001

\section{PENNSYLVANIA}

Philadelphia-Patrick P. McCabe, Director, 9448 Federal Building, 600 Arch Street 19106, Area Code 215 Tel 597-2850, FTS 597-2866

Pittsburgh-William M. Bradley, Director, 2002 Federal Building, 1000 Liberty Avenue 15222, Area Code 412 Tel $644-2850$, FTS $722-2850$

\section{PUERTO RICO}

San Juan (Hato Rey)-Enrique Vilella, Director, Room 659-Federal Building 00918, Area Code 809 Tel 753-4555, Ext. 555, FTS Dial 9 4726620 , Ask for $753-4555$

\section{RHODE ISLAND}

- Providence (Boston, Massachusetts District) -7 Jackson Walkway 02903 , Area Code 401 Tel 277-26J5, e::t. 22, FTS $838-4482$

\section{SOUTH CAROLINA}

Columbia-Margaret A. Patrick Director, Strom Thurmond Fed. Bldg., Suite 571, 1835 Assembly Street 29201 Area Code 803 Tel 765-5345 FTS 677-5345

- Charleston-505 Federal Building, 334 Meeting Street 29403, Area Code 803 Tel 677-4361, FTS 677-4361

\section{TENNESSEE}

Memphis-Bradford $\mathrm{H}$. Rice, Director, Room 710, 147 Jefferson Avenue 38103, Area Code 901 Tel 521-3213, FTS 222-3213

- Nashville-Room 1020, Andrew Jackson Office Building 37219 , Area Code 615 Tel 251-5161 FTS 852-5161

\section{TEXAS}

Dallas-C. Carmon Stiles, Director Room 7A5, 1100 Commerce Street 75242 Area Code 214 Tel 767-0542 FTS 729-0542

Houston-Felicito C. Guerrero, Director, 2625 Federal Bldg., Courthouse, 515 Rusk Street 77002, Area Code 713 Tel 226-4231, FTS 527-4231

\section{UTAH}

Salt Lake City-Director (Vacant) 1201 Federal Building, 125 South State Street 84138 , Area Code 801 Tel 524-5116, FTS 588-5116

\section{VIRGINIA}

Richmond-Philip A. Ouzts, Director, 8010 Federal Bldg., 400 North 8th Street, 23240, Area Code 804 Tel 771-2246, FTS 925-2246

- Fairfax-8550 Arlington Blvd. 22031, Area Code 703 Tel 560 6460, FTS 235-1519

\section{WASHINGTON}

Seattle-Judson S. Wonderly, Director, Room 706, Lake Union Building, 1700 Westlake Avenue North 98109, Area Code 206 Tel 442-5615, FTS 399-5615, FOMC 399-5910/11

\section{WEST VIRGINIA}

Charleston-Roger L. Fortner, Director, 3000 New Federal Building, 500 Quarrier Street 25301, Area Code 304 Tel 343-6181, ext. 375, FTS 9241375

\section{WISCONSIN}

Milwaukee-Russell H. Leitch, Director, Federal BIdg/U.S. Courthouse, 517 East Wisconsin Avenue 53202. Area Code 414 Tel. 291-3473, FTS 362-3473

\section{WYOMING}

Cheyenne-Lowell O. Burns, Director, 6022 O'Mahoney Federal Center, 2120 Capitol Avenue 82001, Area Code 307 Tel 778-2220, ext. 2151, FTS 3282151 
NBS JIAA (REV. Q-78)

\begin{tabular}{|c|c|}
\hline $\begin{array}{c}\text { U.S. DEPT. OF COMM. } \\
\text { BIBLIOGRAPHIC DATA } \\
\text { SHEET }\end{array}$ & $\begin{array}{l}\text { 1. PUBLICATION OR REPORT NO. } \\
\text { NBS SP305, SuMp1. 11 } 11\end{array}$ \\
\hline
\end{tabular}
26ovt. Accession No

4. TITLE AND SUBTITLE

Publications of the National Bureau of Standards 1979 Catalog

5. Pubication Date

February 1980

6. Performing Organization Code

8. Performing Organ. Report No.

7. AUTHOR(S)

Betty L. Burris and Rebecca J. Morehouse, Editors

9. PERFORMING ORGANIZATION NAME AND ADDRESS

10. Project/Task/Work Unit Ho.

NATIONAL BUREAU OF STANDARDS

DEPARTMENT OF COMMERCE

11. Contract/Grant No.

WASHINGTON, DC 20234

12. SPONSORING ORGANIZATION NAME AND COMPLETE ADDRESS (Street, City, State, zIP)

13. Type of Report \& Period Covered

Same as Item 9

January-December 1979

14. Spensoring Agency Code

15. SUPPLEMENTARY NOTES

Library of Congress Catalog Card No. 48-47112

$\square$ Document describes a computer program; SF-185, FIPS Software Summary, is attached.

16. ABSTRACT (A 200-word or less tactual summary of most significant information. If document includes a significant bibliography or literature survey, mention it here.)

This 1Ith supplement to Special Publication 305 of the National Bureau of Standards lists the publications of the Bureau issued between January 1 - December 31, 1979. It includes an abstract of each publication (plus some earlier papers omitted from Special Publication 305 Supplement 10), key-word and author indexes; and general information and instructions about NBS publications.

17. KEY WORDS (six to twelve entries; alphabotical order; capitalize only the first letter of the first key word unless a proper name; separated by semicolons)

Abstracts, NBS publications; key words; publications.

18. AVAILABILITY

[X. Unlimited

For Official Distribution. Do Plot Release to NTIS

X Order From Sup. of Doc., U.S. Government Printing Office, Washington, DC 20402, SD Stock No. SNÓ03-003-02194-6.

$\square$ Order From National Technical Information Service (NTIS), Springfield, VA. 22161

\begin{tabular}{|l|l|}
\hline $\begin{array}{l}\text { 19. SECURITY CLASS } \\
\text { (THIS REPORT) } \\
\text { UNCLASSIFIED }\end{array}$ & $\begin{array}{c}\text { 21. NO. OF } \\
\text { PRINTED PAGES }\end{array}$ \\
\hline $\begin{array}{l}\text { 20. SECURITY CLLASS } \\
\text { (THIS PAGE) }\end{array}$ & 615 \\
UNCLASSIFIED & 22. Price \\
\hline
\end{tabular}




\section{Announcement of New Publications \\ of the \\ National Bureau of Standards}

Superintendent of Documents, Government Printing Office, Washington, DC 20402

Dear Sir:

Please add my name to the announcement list of new publications as issued by the National Bureau of Standards.

Name.

Company.

Address.

City. State - Zip code.

(Notification Key N519) 
Superintendent of Documents

U.S. Government Printing Office

Washington, D.C. 20402

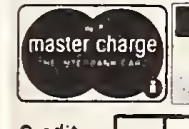

VSSA $^{\circ}$

Date

Card No.

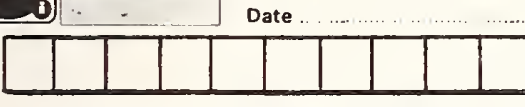

Customer's Name and Address

ZIP

Your Order Number

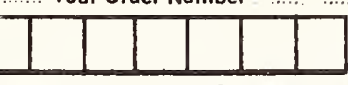

Expiration Date

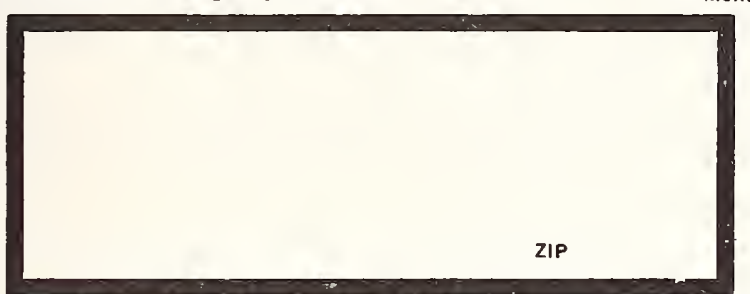
Month/Year
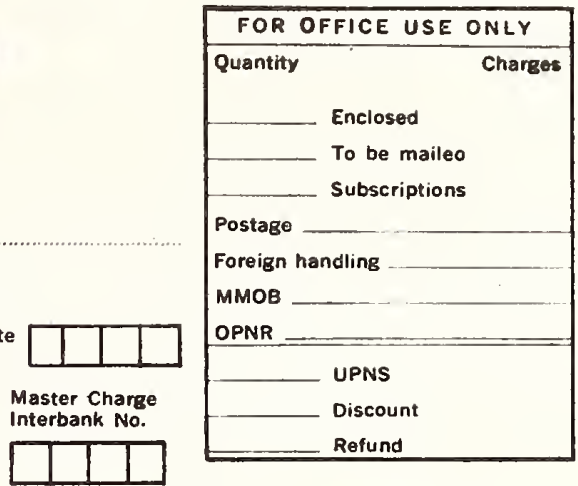

BEFORE USING THIS FORM, READ IMPORTANT INFORMATION ON REVERSE SIDE PLEASE PRINT OR TYPE ALL INFORMATION ON THIS FORM.

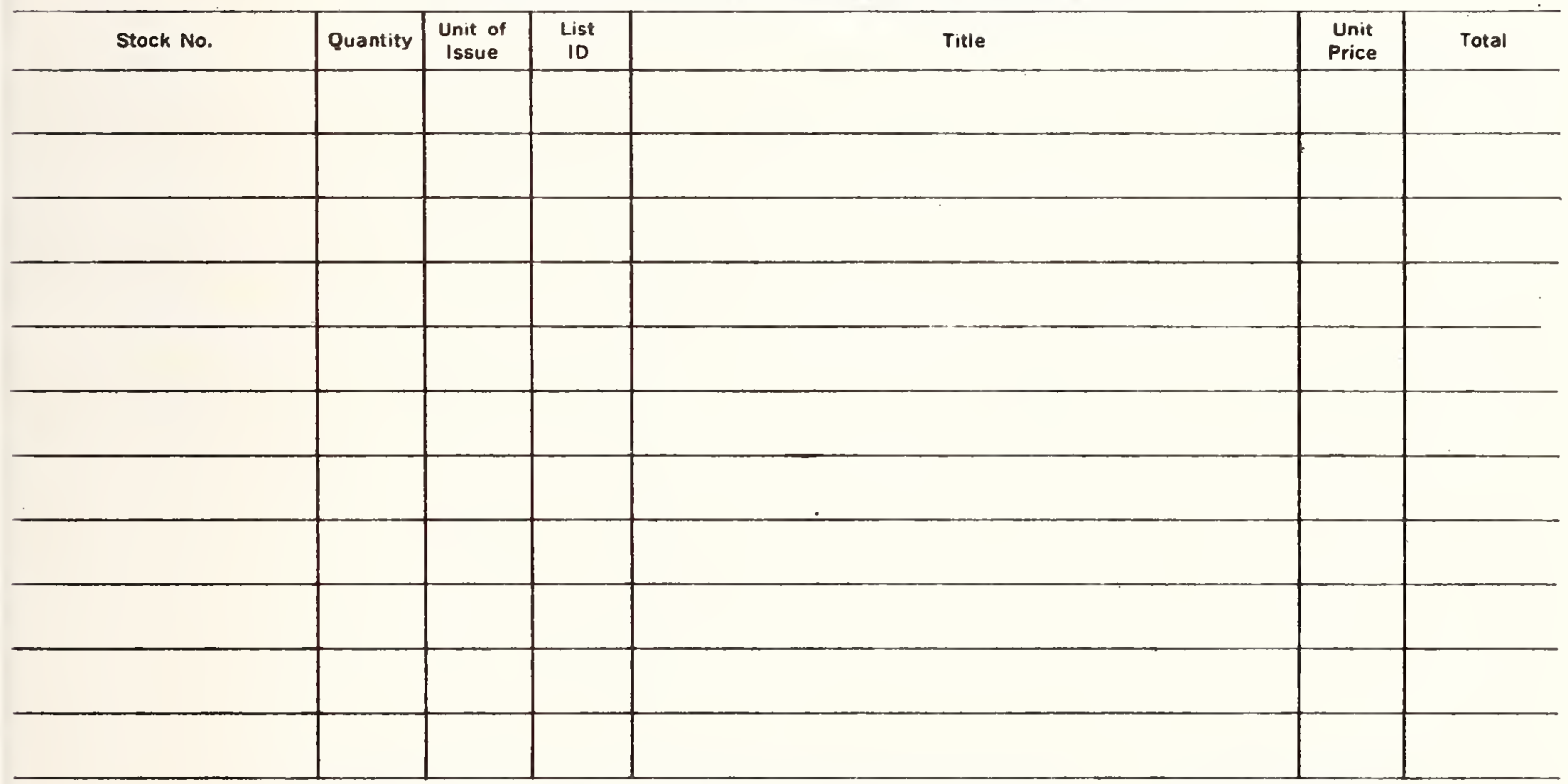

WE REQUEST THAT YOU ORDER A MINIMUM OF \$1.00 WORTH OF MATERIALS.

TOTAL ENCLOSED $\$$

SHIP TO: (II diferent from above)

Unit of Issue

PK

EA

PD

SE
Explanation

Package containlng multlple copies

Each-single copy

Pad containing multiple sheets

Sot of multiple items

Kit of multiple Items In a special conteiner 


\section{INFORMATION CONCERANRG YOUR ORDER OR INQUURY}

Thank you for your interest in U.S. Governmen? publications. If you have made a written inquiry, it is returned herewith for your reference. We have indicated the prices of publications currently available, or have provided the information requested to the best of our ability. Unless otherwise noted, prices are for single copies.

Regulations require payment in advance of shipment of publications. Please make checks or money orders payable to the Superintendent of Documents. You may charge your order using your Deposit Account, Master Charge, or Visa. Do not send currency (bills or coins) or postage stamps.

Shipping is by non-prionty mail or United Parcel Senvice. First class mailing is available at a higher rate. Contact us for rates if you desire this service. (202-783-3238)

With the exception of specially priced publications and subscriptions, a discount of 25 percent is allowed on quantity purchases (100 or more copies of a single publication). The same discount applies to orders from a bookdealer (any quantity) when the publications are malled to the dealer's normal place of business. No discount will be allowed when publications and subscriptions are mailed to a third party (umless in quantities of 100 or moré per title).

NON U.S. CUSTOMERS: International mailing regulations require special handling for which we charge an additional 25 percent of the total cost of your order. Remittance is required in advance of shipping by draft on a United States or Canadian bank, by UNESCO coupons, or by International Postal Money Order made payable to the Superintendent of Documents. These orders are mailed vla surface mall unless funds are sent to cover airmail postage. Foreign currency or checks will not be accepted. All orders must be in English.

\section{TO ORDER, USE FORM ON REVERSE SIDE}

\section{Follow Instructions Below}

1. Please use separate forms for ordering publications and subscriptions.

2. Type or print your complete name and address, your order number (if any), your Deposit Account number (if applicable), Visa or Master Charge number (if applicable), and date in proper places at the top of the form. If order is to be shipped to a third party, fill in address at bottom of form. We request you order a minimum of $\$ 1.00$ worth of materials. Please include office/home telephone no

3. When ordering publlcallons, type or print the stock number, unit of issue (see front), quantity, title, price, and total payment enclosed

4. When ordering subscriptlons, or single issues of subscriptions, type or print the stock number, quantity, title, price, List ID (when available), and total payment enclosed. Allow 2-6 weeks plus mailing time for processing. All subscriptions are for one year, unless otherwise noted. Subscribers will be notified in ample time to renew.

5. Mail Original of Form to Superintendent of Documents, U.S. Government Printing Office, Washıngton, D.C. 20402. Retain the copy for your records.

6. If shipment is incorrect, return the shipping documents for adjustment. DO NOT RETURN BOOKS UNTIL NOTIFIED TO DO SO. All claims must be submitted within six months.

7. Call 202-783-3238 for publication information or for placing your Deposit Account, Visa or Master Charge order

\section{THE FOLLOWING INFORMATION EXPPLANS HOW YOUR REQUEST WAS PROCESSED}

Circle . Indicates the quantity of publications enclosed or scheduleci for mailing.

B . . The publication is not available at this time but we have scheduled mailing for a later date. Charges have been included on your order.

C. . We are unable to identify the publication from the iniormation furnished.

1. . This publication is not currentiy in stock. Please inquire as to the availability and price in bo days. You may inquire and order by telephone (202-.783-3238) using your VISA, MASTER CHARGE. or Superintendent of Documents Deposit Account. This will expecitite sinpment of your publications.

L . . The publication is not currently sold by this Ofíice. We suggesi you cuntact your local library which can reter ycu to a Federal Depository Library in your area for further assistance.

S. . Publication has bean replaced by another wiŝli similar but more recent information and is vill be includad in your shipment.

T . . Publication has been replaced jy another with similar but more recent information. Because of a difference In price, we are noting new ordering information on your request.

2 . . Requested or pertinent information has been supplied. See attached. 

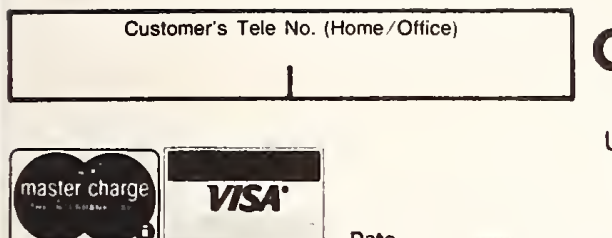

Credit Card No.
ORDER FORM

Superintendent of Documents

U.S. Government Printing Office Washington, D.C. 20402
Date ...................................... Your Order Number

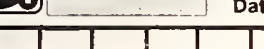

Customer's Name and Address
Explration Date Month/Year

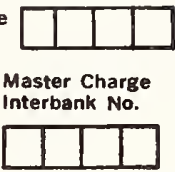

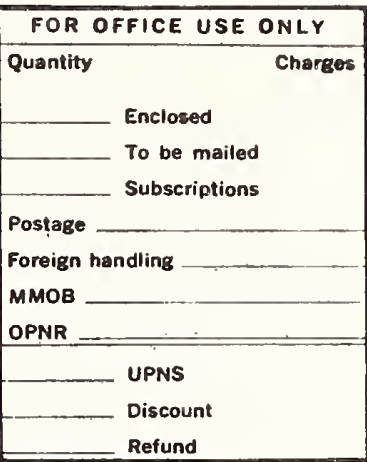

Deposit Account Number

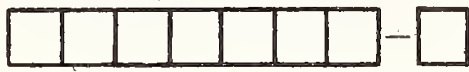

BEFORE USING THIS FORM, READ IMPORTANT INFORMATION ON REVERSE SIDE PLEASE PRINT OR TYPE ALL INFORMATION ON THIS FORM.

\begin{tabular}{|c|c|c|c|c|c|c|}
\hline Stock No. & Quantity & $\begin{array}{l}\text { Unit of } \\
\text { Issue }\end{array}$ & $\begin{array}{l}\text { List } \\
\text { ID }\end{array}$ & Title & $\begin{array}{c}\text { Unit } \\
\text { Price }\end{array}$ & Total \\
\hline & & & & & & \\
\hline & & & & & & \\
\hline & & & & & & \\
\hline & & & & & & \\
\hline & & & & & & \\
\hline & & & & & & \\
\hline & & & & & & \\
\hline & & & & & & \\
\hline & & & & & & \\
\hline & & & & & & \\
\hline
\end{tabular}

SHIP TO: (if difierent from above)

Unit of Issue

PK
EA
PD
SE
KT
Explanation

Peckage contalning multiole copies

Each-singie copy

Pad containing multiple sheets

Sot of multiple tems

Kit of muitiple Items In a epeeiel contalner 
Thank you for your interest in U.S. Government publications. If you have made a written inquiry, it is returned herewith for your reference. We have indicated the prices of publications currently available, or have provided the information requested to the best of our ability. Unless otherwise noted, prices are for single copies.

Regulations require payment in advance of shipment of publications. Please make checks or money orders payable to the Superintendent of Documents. You may charge your order using your Deposit Account, Master Charge, or Visa. Do not send. currency (bills or coins) or postage stamps.

Shipping is by non priority mail or United Parcel Service. First class mailing is available at a higher rate. Contact us for rates If you desire this service. (202-783-3238)

With the exception of specially priced publications and subscriptions, a discount of 25 percent is allowed on quantity purchases (100 or more copies of a single publication). The same discount applies to orders from a bookdealer (any quantity) when the publications are mailed to the dealer's normal place of business. No discount will be allowed when publications and subscriptions are mailed to a third party (unless in quantities of 100 or more per title).

NON U.S. CUSTOMERS: International mailing regulations require special handling for which we charge an additional 25 percent of the total cost of your order. Remittance is required in advance of shipping by draft on a United States or Canadian bank, by UNESCO coupons, or by International Postal Money Order made payable to the Superintendent of Documents. These orders are mailed via surface mail unless funds are sent to cover airmail postage. Foreign currency or checks will not be accepted. All orders must be in English.

\section{TO ORDER, USE FORM ON REVERSE SIDE}

\section{Follow Instructions Below}

1. Please use separate forms for ordering publications and subscriptions.

2. Type or print your complete name and address, your order number (if any), your Deposit Account number (if applicable), Visa or Master Charge number (if applicable), and date in proper places at the top of the form. If order is to be shipped to a third party, fill in address at bottom of form. We request you order a minimum of $\$ 1.00$ worth of materials. Please include office/home telephone no.

3. When ordering publications, type or print the stock number, unit of issue (see front), quantity, title, price, and total payment enclosed.

4. When ordering subscriptions, or single issues of subscriptions, type or print the stock number, quantity, title, price, List ID (when available), and total payment enclosed. Allow 2-6 weeks plus mailing time for processing. All subscriptions are for one year, untess otherwise noted. Subscribers will be notified in ample time to renew.

5. Mail Original of Form to Superintendent of Documents, U.3. Government Printing Office, Washington, D.C. 20402. Retain the copy for your records.

6. If shipment is incorrect, return the shipping documents for adjustment. DO NOT RETURN BOOKS UNTIL NOTIFIED TO DO SO. All claims must be submitted within six months.

7. Call 202-783-3238 for publication information or for placing your Deposit Account, Visa or Master Charge order.

\section{THE FOLLOWING INFORMATION EXPLAINS HOW YOUR REQUEST WAS PROCESSED}

Circle . Indicates the quantity of publications enclosed or scheduled for mailing.

e . . The publication is not available at this time but we have scheduled mailing for a later date. Charges have been included on your order.

C. . We are unable so identify the publication from the information furnished.

1. . . This publication is not currently in stock. Please inquire as to the availability and price in 60 days. You may inquire and order by telephone (202-783-3238) using your VISA, MASTER CHARGE, or Superintendent of Documents Deposit Account. This will expedite shipment of your publications.

L . . . The publication is not currently sold by this Office. We suggest you contact your local library which can refer you to a Federal Depository Library in your area for further assistance.

S. . Publication has been replaced by another with similar but more recent information and it will be included in your shipment.

$\gamma$. . Publication has been replaced by another with similar but more recent information. Because of a difference in price, we are noting new ordering information on your request.

2 . . Requested or pertinent information has been supplied. See attached. 


\section{ORDER FORM}

Superintendent of Documents

U.S. Government Printing Office Washington, D.C. 20402

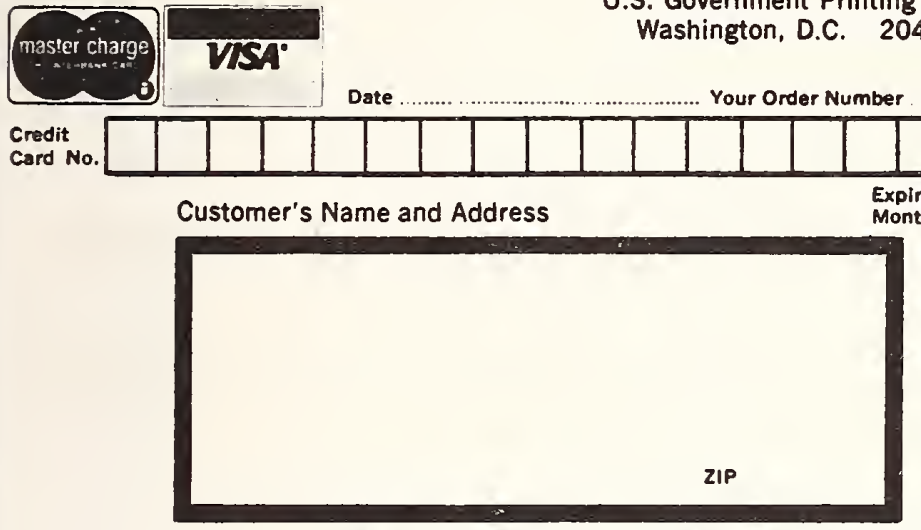

FOR OFFICE USE ONLY

Quantity

Charges

Enclosed

To be mailed

Subseriptions

Postage

Foreign handling

MMOB

OPNR

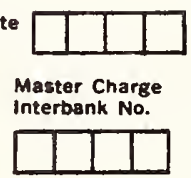

$\begin{array}{ll}\ldots & \text { UPNS } \\ & \text { Discount } \\ \text { Refund }\end{array}$

Deposit Account Number

BEFORE USING THIS FORM, READ IMPORTANT INFORMATION ON REYERSE SIDE PLEASE PRINT OR TYPE ALL INFORMATION ON THIS FORM.

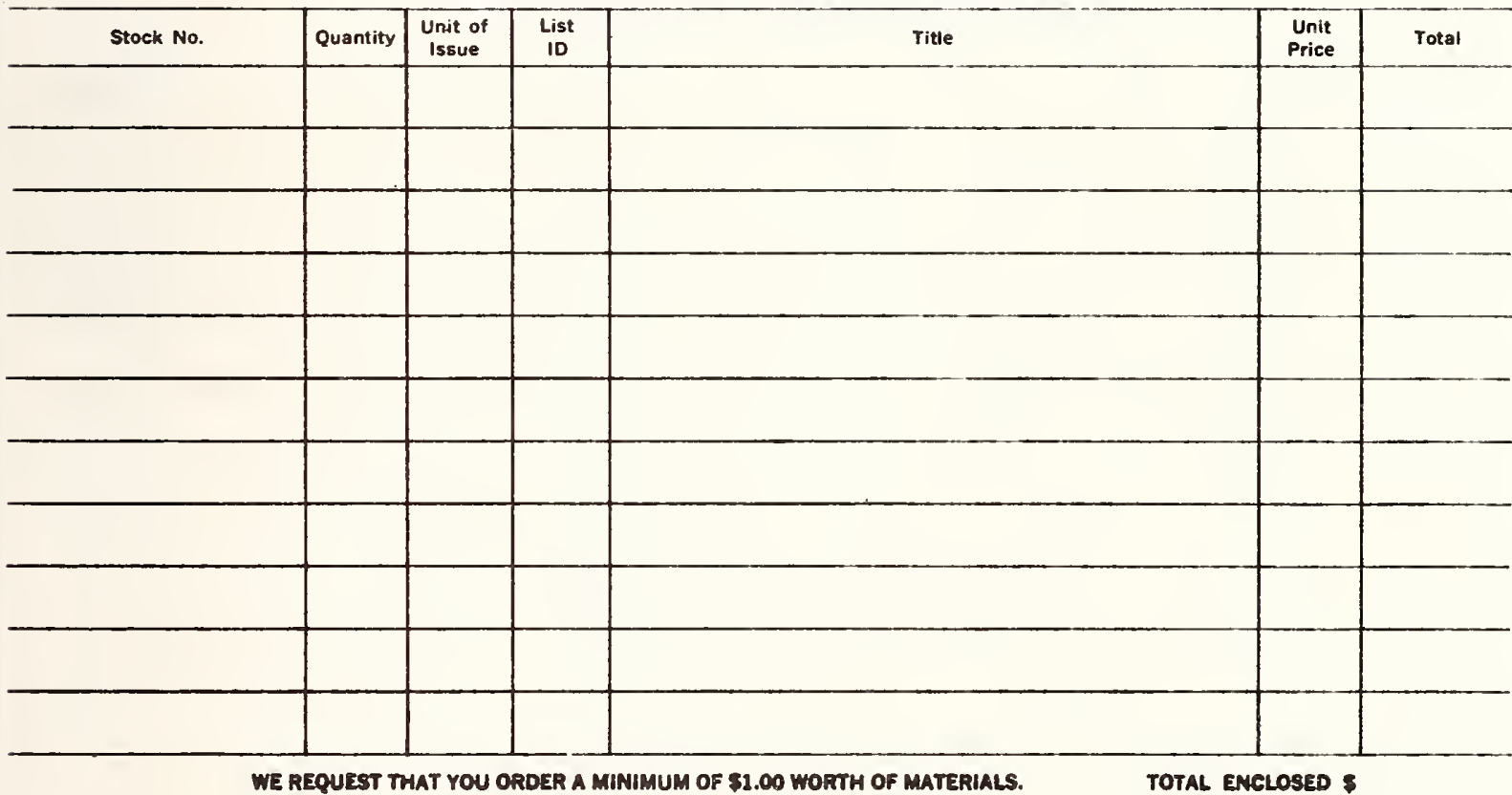

WE REQUEST THAT YOU ORDER A MINIMUM OF \$1.00 WORTH OF MATERIALS.

TOTAL ENCLOSED S

SHIP TO: (If difierent from abovo)

Unit of issue

PK

EA

PD

SE
Explanation

Package containing multiple copies

Eoch- ingie copy

Pad containing multiple sheets

Sot of multiple items

KIt of multiple ttems in a specisl containef 
Thank you for your intcrest in U.S. Government publications. If you have made a written inquiry, it is returned herewith for your reference. We have indicated the prices of publications currently available, or have provided the information requested to the best of our abillty. Uniess othenwise noted, prices ere for single copies.

Regulations require payment in edvance of shipment of publications. Please make checks or money orders payable to the Superintendent of Documents. You mey cherge your order using your Deposit Account, Master Charge, or Visa. Do not send currency (bills or colns) or postage stamps.

Shlpping is by non.priority mail or United Parcel Service. First class mailing is available at a higher rate. Contact us for rates if you desire this service. (202-783-3238)

With the exception of specially priced publications end subscriptions, a discount of 25 percent is allowed on quantity purcheses (100 or more copies of e single publication). The same discount applies to orders from a bookdealer (any quantity) when the publications are malled to the deeler's normel place of business. No discount will be allowed when publications and subscriptions ere meiled to a third party (unless in quantities of 100 or more per title).

NON U.S. CUSTOMERS: Iriternationel meiling regulations require special handling for which we charge an additional 25 percent of the total cost of your order. Remittance is required in advance of shipping by draft on a United States or Canadian bank, by UNESCO coupons, or by Internetional Postal Money Order made payable to the Superintendent of Documents. These orders are mailed via surface mail unless funds are sent to cover alrmail postage. Foreign currency or checks will not be accepted. All orders must be in English.

\section{TO ORDER, USE FORM ON REVERSE SIDE}

\section{Follow Instructions Below}

1. Pleese use separete forms for ordering publicetions and subscriptions.

2. Type or print your complete name and eddress, your order number (if any), your Deposit Account number (if applicable), Vise or Master Cherge number (if epplicable), and date in proper places at the top of the form. 11 order is to be shipped to a third party, fill in eddress et bottom of form. We request you order a minimum of $\$ 1.00$ worth of materials. Please include office/home telephone no

3. When ordering publlcetions, type or print the stock number, unit of issue (see front), quantity, title, price, and total payment enclosed.

4. When ordering subscriptions, or single Issues of subscriptions, type or print the stock number, quantity, title, price, List ID (when avelleble), end total payment enclosed. Allow 2-6 weeks plus mailing time for processing. All subscriptions are for one year, unless otherwise noted. Subscribers will be notified In ample time to renew.

5. Mail Originel of Form to Superintendent of Documents, U.S. Government Printing Office, Washington, D.C. 20402. Retain the copy for your records.

6. If shipment is incorrect, return the shlpping documents for adjustment. DO NOT RETURN BOOKS UNTIL NOTIFIED TO DO SO. All cleims must be submltted within six months.

7. Cail 202-783-3238 for publication information or for placing your Deposit Account, Visa or Master Charge order.

\section{THE FOLLOWING INFORMATION EXPLAINS HOW YOUR REQUEST WAS PROCESSED}

Circle . Indlcates the quantity of publications enclosed or scheduled for mailing.

a . . The publlcation is not aveliable et this time but we have scheduled mailing for a later date. Cherges have been included on your order.

C . . We ere uneble to identify the pubiication from the information furnished.

1 . . This publication is not currentiy in stock. Please Inquire as to the availability and price in 60 days. You may Inquire and order by telephone (202-783-3238) using your VISA, MASTER CHARGE, or Superintendent of Documents Deposit Account. This will expedite shipment of your publications.

L . . . The publicetion Is not currently sold by this Office. We suggest you contact your local library which can refer you to a Federal Depository Librery in your area for further assistance.

$\mathbf{S}$. . Publication hes been repleced by enother with similar but more recent information and it will be included In your shipment.

T . . Publlcation hes been repleced by enother with similar but more recent information. Because of a difference In price, we are noting new ordering Information on your request.

2 . - Requested or pertinent informetion has been supplied. See ettached. 

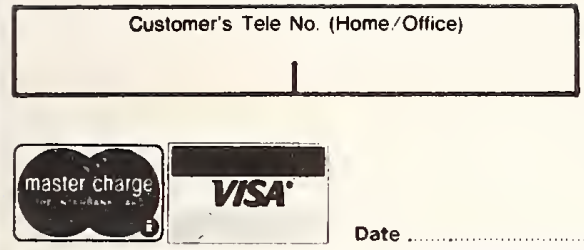

VSA $^{\circ}$

Date

Date ........................................ Your Order Number

Credit Card No.

\section{ORDER FORM}

Superintendent of Documents

U.S. Government Printing Offic Washington, D.C. 20402

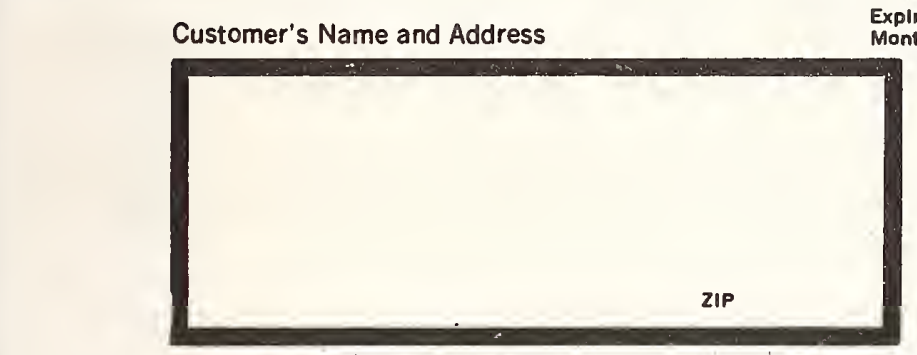

Explration Dat Month/Year

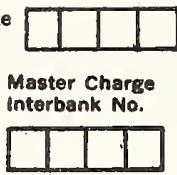

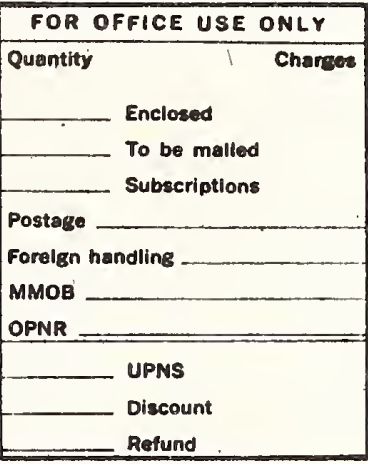

Deposit Account Number

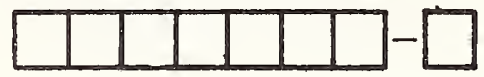

BEFORE USING THIS FORM, READ IMPORTANT IMFORMATION ON REVERSE SIDE PLEASE PRINT OR TYPE ALL INFORMATION ON THIS FORM.

\begin{tabular}{|c|c|c|c|c|c|c|}
\hline stock No. & Quantity & $\begin{array}{c}\text { Unit of } \\
\text { Issue }\end{array}$ & $\begin{array}{c}\text {. List } \\
\text { ID }\end{array}$ & Title & $\begin{array}{r}\text { Unlt } \\
\text { Price } \\
\end{array}$ & Total \\
\hline & & & & & & \\
\hline & & & & & & \\
\hline & & & & & & \\
\hline & & & & & & \\
\hline & & & & & & \\
\hline & & & & & & \\
\hline & & & & & & \\
\hline & & & & & & \\
\hline & & & & & & \\
\hline & & & & & & \\
\hline
\end{tabular}

WE REQUEST THAT YOU ORDER A MINIMUM OF \$1.00 WORTH OF MATERIALS.

TOTAL EMGLOSEO \$

SHIP TO: (if difierent from show)

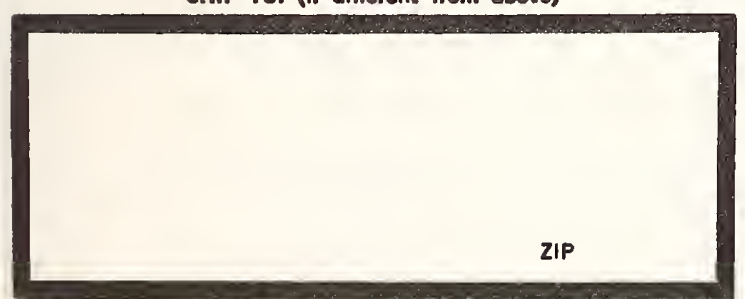

UnIt of Is
PK
EA
FD
SE
KT

\section{Explanation}

Package containing multiple coples

Each-single copy

Pad containing multiple shoers

Set of multiplo items

Kit of multiple items in - spocial container 


\section{INFORMATION CONCERNING YOUR ORDER OR INQUIRY}

Thank you for your interest in U.S. Government publications. If you have made a written inquiry, it is. returned herewith for your reference. We have indicated the prices of publications currently avallable, or have.provided the information requested to the best of our abillty. Unless otherwise noted, prices are for single copies.

Regulations require payment in advance of shipment of publications. Please make checks or money orders payable to the Superintendent of Documents. You may charge your order using your Deposit Account, Master Charge, or Visa. Do not send currency (bills or coins) ôr postage stamps.

Shipping is by non-priority mail or United Parcel Service. First class mailing is available at a higher rate. Contact us for rates if you desire this service. (202-783-3238)

With the exception of specially priced publications and subscriptions, a discount of 25 percent is allowed on quantity purchases (100 or more copies of a single publication). The same discount applies to orders from a bookdealer (any quantity) when the publications are malled to the dealer's normal place of business. No discount will be allowed when publications and subscriptions are mailed to a third party (unless in quantities of 100 or more per title).

NON U.S. CUSTOMERS: International mailing regulations require special handling for which we charge an addltional 25 percent of the total cost of your order. Remittance is required in advance of shipping by draft on a United States or Canadian bank, by UNESCO coupons, or by. International Postal Money Order made payable to the Superintendent of Documents. These orders are mailed vla surface mail unless funnts are sent to cover airmail postage. Foreign currency or checks will not be accepted. All orders must be in English.

\section{TO ORDER, USE FORM ON REVERSE SIDE}

\section{Follow Instructions Below}

1. Please use separate forms for ordering publications and subscriptions.

2. Type or print your complete name and address, your order number (if any), your Deposit Account number (if applicable), Visa or Master Charge number (if applicable), and date in proper places at the top of the form. If order is to be shipped to a third party, fill in address at bottom of form. We request you order a minimum of $\$ 1.00$ worth of materials. Please include office/home telephone no.

3. When ordering publications, type or print the stock number, unit of issue (see front), quantity, title, price, and total payment enclosed.

4. When ordering subscriptions, or single issues of subscriptions, type or print the stock number, quantity, title, price, LIst ID (when available), and total payment enclosed. Allow 2-6 weeks plus mailing time for processing. All subscriptions are for one year, unless otherwise noted. Subscribers will be notified in ample time to renew.

5. Mail Orıgınal of Fu.m to Superintendent of Documents, U.S. Government Printing Office, Washington, D.C. 20402. Retaln the copy for your records.

6. It shipment is incorrect, return the shipping documents for adjustment. DO NOT RETURN BOOKS UNTIL NOTIFIED TO DO SO. All claims must be submitted within six months.

7. Call 202-783-3238 for publication information or for placing your Deposil Account, Visa or Master Charge order.

\section{THE FOLLOWING INFORMATION EXPLAINS HOW YOUR REQUEST WAS PROCESSED}

Circle . . indicates the quantity of publications enclosed or scheduled for mailing.

B. . The publication is not available at this time but we have scheduled mailing for a later date. Charges have been included on your order.

c. . We are unable to identify the pubıcation from the information furnished.

i . . This publication is not currently in stock. Please inquire as to the availability and price in 60 days. You may inquire and order by telephone (202-783-3238) using your VISA, MASTER CHARGE, or Superintendent of Documents Deposit Account. This will expedite shipment of your publications.

L . . The publication is not currently sold by this office. We suggest you contact your local library which cen refer you to a Federal Depository Library in your area for further assistance.

$S:$. Publication has been replaced by another with similar but more recent information and it will be included in your shipment.

T. Publication has been replaced by another with similar but more, recent information. Because of a. difference In price, we are noting new ordering information on your request.

2. . Requested or pertinent Information has been suppileo. See attached. 


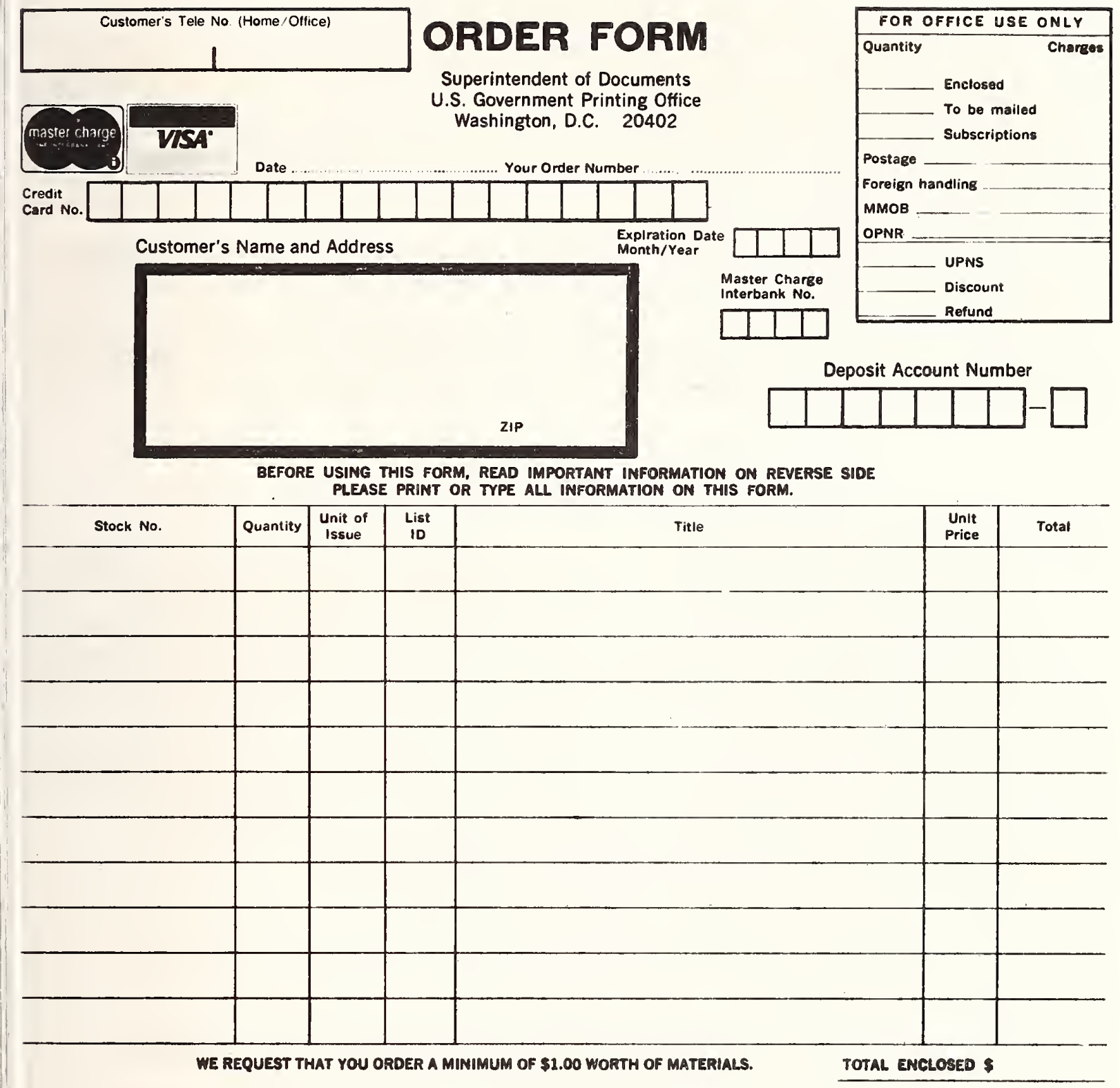

SHIP TO: (if different from abow)

Unit of issue

PK
EA
PD
SE
KT
Explanation

Packege containing multiple coples

Each-single copy

Pad containing muitiple sheets

Set of multipio items

Kit of multipia items in a special contanner 
Thank you for your interes: in U.S. Governmert publications. If you have made a written inquiry, it is returned herewith for your reference. We have indicated tine prices ol publications currently available, or have provided the information requested to the best of our ebllity. Uniess otherwise noted, prices are for single copies.

Reguiations require payment in advance of shipment of publications. Please make checks or money orders payabie to the Superintendent of Documents. You may charge your order using your Deposit Accoust, Master Charge, or Visa. Do not send currency (bills or coins) or postage stamps.

Shipping is by non-priority mail or United Parcel Service. First class mailing is available at a higher rete. Contact us for rates if you desire this service. (202-783-3238)

With the exception of specialiy priced publications end subscriptions, a discount of 25 percent is eliowed on quantity purchases (100 or more copies of e single pubiication). The same discount epplies to orders from a bookdealer (any quantity) when the publications ere meiled to the deaier's normal place of business. No discount wiil be eilowed when publications and subscriptions ere meiled to e third party (uniess in quantities of 100 or more per titie).

NON U.S. CUSTOMERS: internationel mailing regulations require speclai handing for which we cherge en edditionel 25 percent of the total cost of your order. Remittance is required in edvance of shipping by draft on e United States or Cenadian bank, by UNESCO coupons, or by Internetionel Postai Money Order made payabie to the Superintendent of Documents. These orders ere mailed vie surfece maii unless funds ere sent to cover eirmail postage. Foreign currency or checks will not be eccepted. All orders must be in English.

\section{TO ORDER, USE FORM ON REVERSE SIDE}

\section{Follow Instructions Below}

1. Please use separate forms for ordering publications and subscriptions.

2. Type or print your complete name and address, your order number (if any), your Deposit Account number (if applicabie), Visa or Master Charge number (if applicable), and date in proper places at the top ol the form. If order is to be shipped to e third party, fili in eddress et bottom of form. We request you order a minimum of $\$ 1.00$ worth of materiais. Please include office/home telephone no.

3. When ordering publlcatlons, type or print the stock number, unit of issue (see front), quantity, titie, price, and totel payment enclosed.

4. When ordering subscriptions, or single issues of subscriptions, type or print the stock number, quentity, title, price, List 10 (when eveilabie), end total payment enclosed. Allow 2-6 weeks plus mailing time for processing. Ali subscriptions ere for one year, unless otherwise noted. Subscribers wiil be notified in empie time to renew.

5. Meii Original of Form to Superintendent of Documents, U.S. Government Printing Office, Weshington, D.C. 20402. Retein the copy for your records.

6. If shipment is incorrect, return the shipping documents for edjustment. DO NOT RETURN BOOKS UNTIL NOTIFIED TO DO SO. All cleims must be submitted within six months.

7. Cell 202-783-3238 for publication information or for placing your Deposit Account, Visa or Master Cherge order.

\section{THE FOLLOWING INFORMATION EXPLAINS HOW YOUR REQUEST WAS PROCESSED}

Circle . Indicates the quantity of publications enclosed or scheduled for maiiing.

B . . The pubiication is not evailabie at this time but we have scheduied mailing for a later date. Cherges heve been inciuded on your order.

c. . We are unable to identify the publication from the information furnished.

I . . This publicetion is not currentiy in stock. Piease inquire as to the availability end price in 60 days. You may inquire end order by teiephone (202-783-3238) using your VISA, MASTER CHARGE, or Superintendent of Documents Deposit Account. Tiiss will expedite shipment of your pubiications.

ᄂ. . . The publication is not currentiy sold by this Oírice. We sugzesi you contasi your local library which can refer you to e Federei Depository Library in your area for further assistance.

s . . Publication has been repiaced by encther with similar but moro recent informetion and if will be inciuded in your shipment.

T . . Publicetion has been repiaced by another with similer but more recent informetion. Because of e difference in price, we ere noting new ordaring information on your request.

2 . . Requested or pertinent information has baen supplied. See attached. 
MAIL ORDER TO:

NIS

National Technical Information Service U.S. DEPARTMENT OF COMMERCE Springfield, Va. 22161

(703) $557-4650$ TELEX 89.9405

PURCHASER: Telephone:

\section{For DDC Users Only}

DDC User Code

Contract Number

(last 6 characters only)
Treasury Agency Location Code For Government Users

(who report on SF-224) (8 digit)

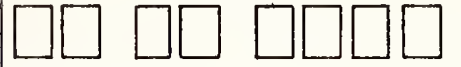

Date

SHIP TO:

(Enter if different from address at left)

Name

Organization

Address

City, State, ZIP

\section{Order Options}

\section{METHOD OF PAYMENT}

Charge my NTIS deposit account no.

Purchase order no.

Check enclosed for $\$$

Ship \& Bill. See reverse (not applicable outside North America).

Charge to my American Express Card account number

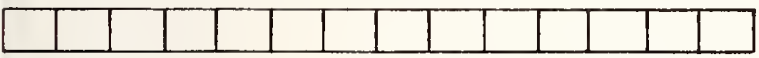

Card expiration date

Signature
It is vital that you order by number or your order wili be manually filled, causing a delay. You can opt for airmail/first class delivery as indicated below. Just check the Priority Mail Services box. If you're really pressed for time, cail the NTIS Rush Handling Service (703) $557-4700$. For a $\$ 10$ per item charge your order will be mailed within 8 working hours. Or, you can pick up your order in the Washington In. formation Center \& Bookstore or at our Springfield Operations Center within 24 hours for a $\$ 6$ per item charge.

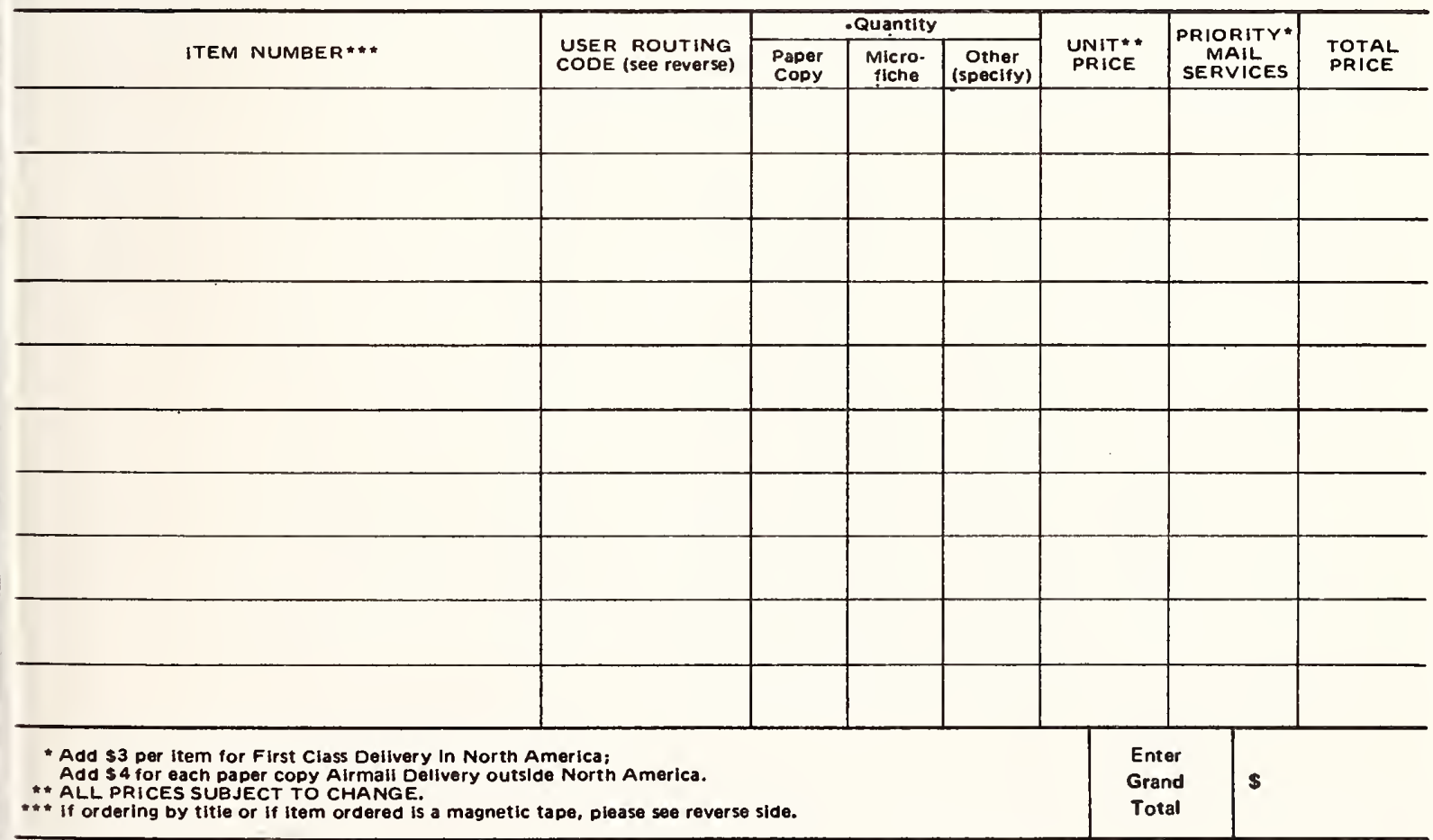


USER ROUTING CODE:

SHIP \& BILL SERYICE:

ORDERING MAGNETIC TAPE: (check mode)

ORDERING BY TITLE:
NTIS can label each item for routing within your organization. If you want this service put your routing code in the box marked USER ROUTING CODE (Limit eight characters).

Prepayment helps to expedite your order and can be accomplished through the use of an NTIS Deposit Account, check, money order, or American Express Card account number " For "Ship and Bill", NTIS charges \$5 extra for each order (regardless of the number of items); \$5 extra for each On-line NTISearch; • NTIS does not "Ship and Bill" for magnetic tapes, or for orders outside North America.

\section{TITLE \#1}

Sponsor's Series \# Contract or Grant Number of Report

Date Published

Originator (Give specific laboratory, or division and location.)

Turn to other side. Write " 1 " in the Item Number block and complete the rest of the line.

\section{TITLE \#2}

Sponsors Series \# Contract or Grant Number of Report

Originator (Give specific laboratory, or division and location.)

Turn to other side. Write " 2 " in the Item Number block and complete the rest of the line.

\section{TITLE \#3}

Sponsor's Series

Contract or Grant Number of Report

Originator (Give specific laboratory, or division and location.)

Turn to other side. Write " 3 " in the Item Number block and complete the rest of the line.

\section{TITLE \#4}

Sponsor's Series \# Contract or Grant Number of Report

Date Published

Originator (Give specific laboratory, or division and location.)

Turn to other side. Write "4" in the ltem Number block and complete the rest of the line.

\section{TITLE}

Sponsor's Series \# Contract or Grant Number of Report

Originator (Give specific laboratory, or division and location.) 
MAIL ORDER TO:

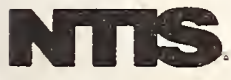

National Technical Information Service U.S. DEPARTMENT OF COMMERCE Springfield, Va. 22161

(703) 557-4650 TELEX $89-9405$

PURCHASER: Telephone:

\section{For DDC Users Only}

DDC User Code

Contract Number

(last 6 characters only)

SHIP TO:
Treasury Agancy Location Coda For Government Users

(who report on SF-224) (8 digit)

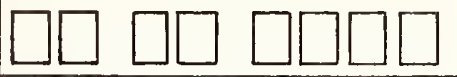

(Entar if different from address at laft)

Name

Organization

Address

City, State, ZIP

\section{Order Options}

\section{METHOD OF PAYMENT}

Charge my NTIS deposit account no.

Purchase order no.

Chack enclosed for $\$$

Ship \& Bill. See reverse (not applicable outside North America).

Charge to my Amarican Express Card account number

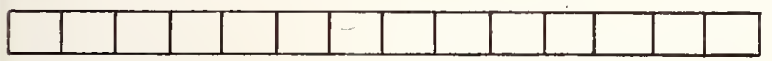

Card expiration date

Signature

It is vital that you order by number or your order will be manually filled, causing a delay. You can opt for airmail/first class delivery as indicated below. Just chack the Priority Mail Services box. If you're really pressed for time, call tha NTIS Rush Handling Service (703) $557-4700$. For a $\$ 10$ par item charge your order will be mailed within 8 working hours. Or, you can pick up your order in the Washington Information Center \& Bookstore or at our Springfiald Operations Center within 24 hours for a $\$ 6$ per item charge.

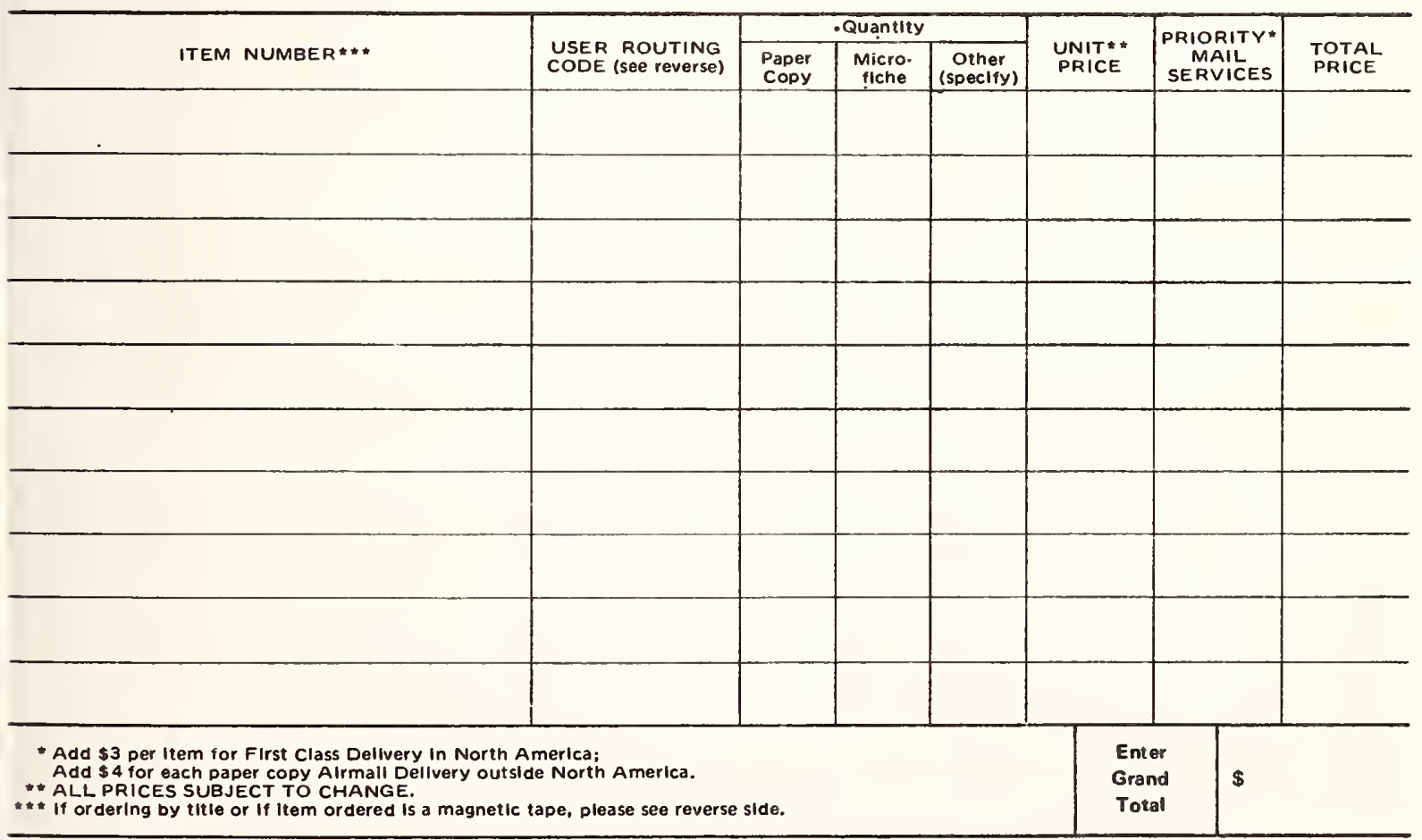


USER ROUTING CODE:

SHIP \& BILL SERVICE:

ORDERING MAGNETIC TAPE:

(check mode)

ORDERING BY TITLE:
NTIS can label each item for routing within your orgenizetion. If you want this service put your routing code in the box marked USER ROUTING CODE (Limit eight characters).

Prepayment helps to expedite your order and can be accomplished through the use of an NTIS Deposit Account, check, money order, or American Express Card account number - For "Ship and Bill". NTIS charges \$5 extra for each order (regardless of the number of items); \$5 extra for each On-line NTISearch; $\bullet$ NTIS does not "Ship and Bill" for magnetic tapes, or for orders outside North America.
$\square 7$ track
$\square 200 \mathrm{BPI}$
$\square 556 \mathrm{BPI}$
$\square 800 \mathrm{BPI}$
$\square$ odd parity
$\square$ even perity
$\square 9$ treck
$\square 1600 \mathrm{BPI}$
$\square 800 \mathrm{BPI}$

lodd parityl

\section{TITLE \#1}

Sponsor's Series \# Contract or Grent Number of Report

Originetor (Give specific laboratory, or division and location.)

Turn to other side. Write " 1 " in the Item Number block and complete the rest of tha line.

\section{TITLE \#2}

\begin{tabular}{|l|l}
\hline Sponsors Series \# & Contract or Grant Number of Report
\end{tabular}

Originator (Give specific laboratory, or division and location.)

Turn to other side. Write " 2 " in the Item Number block and complete the rest of the line.

\section{TITLE \#3}

Sponsor's Series \# Contract or Grant Number of Report

Originator (Give specific leboratory, or division and location.)

Turn to other side. Write " 3 " in the Item Number block and complete the rest of the line.

\section{TITLE \#4}

Sponsor's Series \#

Contract or Grant Number of Report

Originator (Give specific laboratory, or division and location.)

Personal Author

Turn to other side. Write " 4 " in the Item Number block and complete the rest of the line.

\section{TITLE \#5}

\begin{tabular}{|l|l|l|}
\hline Sponsor's Series \# & Contract or Grant Number of Report & Personal Author \\
\hline Originator (Give specific laboratory, or division and location.) & \\
\hline Turn to other side. Write " 5 " in the Item Number block and complete the rest of the line.
\end{tabular}

Turn to other side. Write " 5 " in the Item Number block and complete the rest of the line. 


\section{MAIL ORDER TO:}

\section{NISS}

National Tachnical Information Service U.S. DEPARTMENT OF COMMERCE Springfield, Va. 22161

(703) 557-4650 TELEX 89-9405

\section{For DDC Users Only}

DDC User Code

Contract Number

(last 6 characters only)
Treasury Agency Location Code For Government Users (who report on SF-224) (8 digit)
PURCHASER: Telaphone:

SHIP TO:

(Enter if different from address at left)

Name

Organization

Address

City, State, ZIP
Attention:

\section{METHOD OF PAYMENT}

Cherge my NTIS deposit account no.

Purchese ordar no.

Check enclosed for $\$$.

Ship \& Bill. See reverse (not applicable outside North America).

Charge to my American Express Card account number

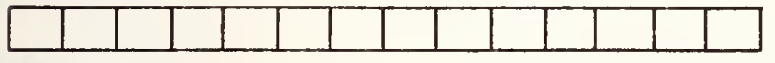

Card axpiration dete

Signeture

\section{Order Options}

It is vital that you order by number or your order will be manually filled, causing a deley. You can opt for airmail/first class delivery as indiceted below. Just check the Priority Moil Services box. If you're really pressed for time, cell tha NTIS Rush Handling Service (703) $557-4700$. For e $\$ 10$ per item charga your order will be meiled within 8 working hours. Or, you can pick up your order in the Washington Informetion Center \& Bookstore or et our Springfield Oparations Centar within 24 hours for e $\$ 6$ per itam charga.

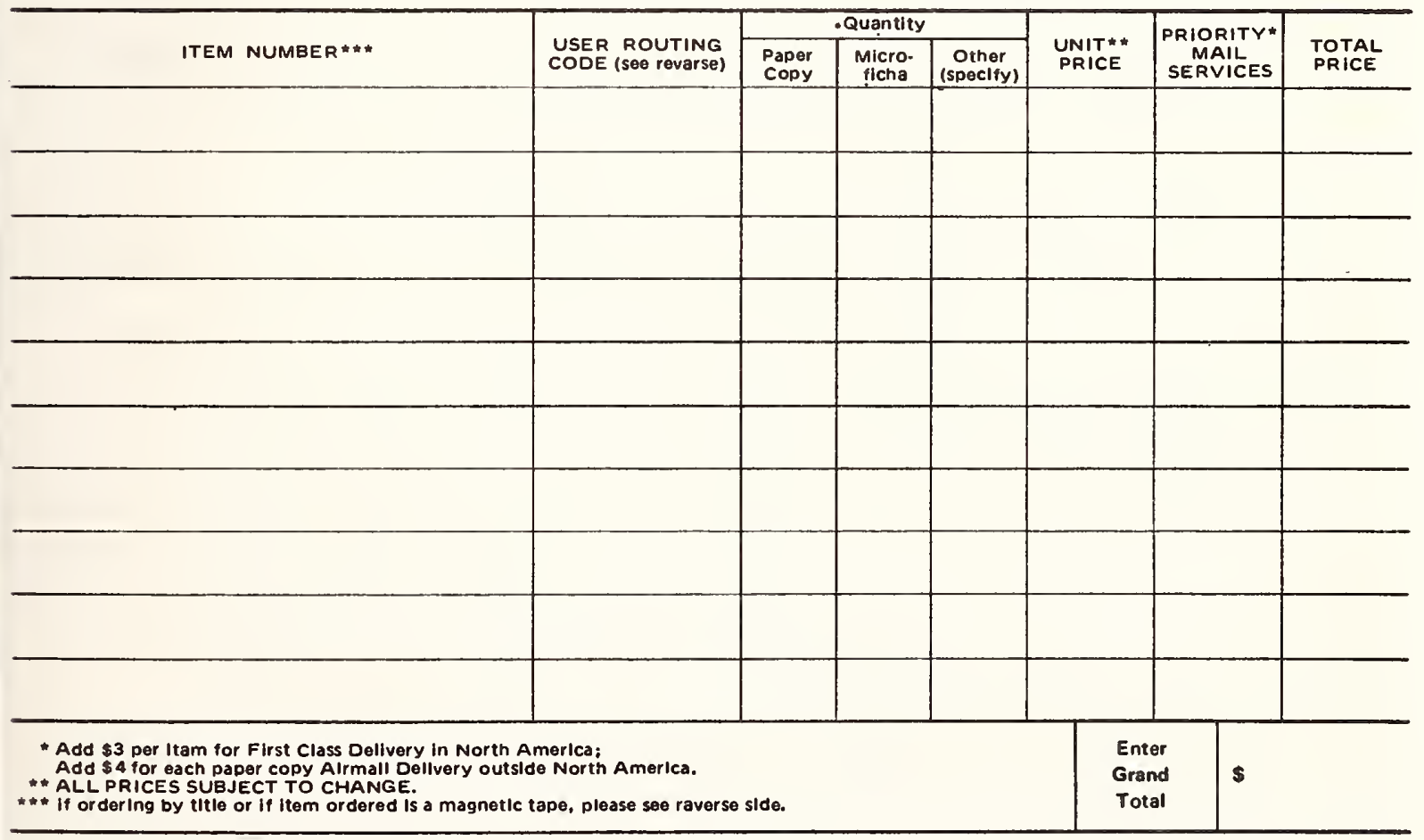


USER ROUTING CODE:

SHIP \& BILL SERVICE:

ORDERING MAGNETIC TAPE:

(check mode)

ORDERING BY TITLE:
NTIS can label each item for routing within your organization. If you want this service put your routing code in the box marked USER ROUTING CODE (Limit eight characters).

Prepayment helps to expedite your order and can be accomplished through the use of an NTIS Deposit Account, check, money order, or American Express Card account number • For "Ship and Bill", NTIS charges $\$ 5$ extra for each order (regardless of the number of items); $\$ 5$ extra for each On-line NTISearch; *

NTIS does not "Ship and Bill" for magnetic tapes, or for orders outside North America.

\section{TITLE \#1}

Sponsor's Series \#

Originator (Give specific laboratory, or division and location.) $\square 200 \mathrm{BPI}$

$\square 556 \mathrm{BPI}$

$\square 800 \mathrm{BPI}$ $\square$ odd parity

$\square$ even parity $\square 1600 \mathrm{BPI}$

$\square 9$ track

\section{$\square 800 \mathrm{BPI}$}

If ordering without an item number (by title only) allow an additional two weeks.

Personal Author

Date Published

Turn to other side. Write " $f$ " in the Item Number block and complete the rest of the line.

\section{TITLE \#2}

Sponsors Series

Contract or Grant Number of Report

Date Published

Originator (Give specific laboratory, or division and location.)

Personal Author

Turn to other side. Write " 2 " in the Item Number block and complete the rest of the line.

\section{TITLE \#3}

Sponsor's Series \#

Contract or Grant Number of Report

Date Published

Originator (Give specific laboratory, or division and location.)

Personal Author

Turn to other side. Write " 3 " in the Item Number block and complete the rest of the line.

\section{TITLE \#4}

Sponsor's Series \#

Originator (Give specific laboratory, or division and location.)

Turn to other side. Write " 4 " in the Item Number block and complete the rest of the line.

\section{TITLE $\# 5$}

Sponsor's Series \#

Originator (Give specific laboratory, or division and location.)

Turn to other side. Write " 5 " in the Item Number block and complete the rest of the line. 
MAIL ORDER TO:

\section{NIS}

National Technical Information Service U.S. DEPARTMENT OF COMMERCE Springfield, Va. 22161

(703) 557-4650 TELEX $89-9405$

\section{For DDC Users Only}

DDC User Code

Contract Number

(last 6 characters only)
Treasury Agency Location Code For Government Users (who report on SF-224) (8 digit)
PURCHASER: Telephone:

SHIP TO:

(Enter if different from address at left)

Name

Organization

Address

City, State, ZIP
Attention:

\section{METHOD OF PAYMENT}

Charge my NTIS deposit account no.

Purchase order no.

Check enclosed for $\$$

Ship \& Bill. See reverse (not applicable outside North America).

Charge to my American Express Card account number

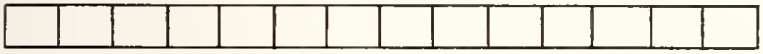

Card expiration date

Signature

\section{Order Options}

It is vital that you order by number or your order will be manually filled, causing a delay. You can opt for airmail/first class delivery as indicated below. Just check the Priority Mail Services box. If you're really pressed for time, call the NTIS Rush Handling Service (703) $557-4700$. For a $\$ 10$ per item charge your order will be mailed within 8 working hours. Or, you can pick up your order in the Washington Information Center \& Bookstore or at our Springfield Operations Center within 24 hours for a \$6 per item charge.

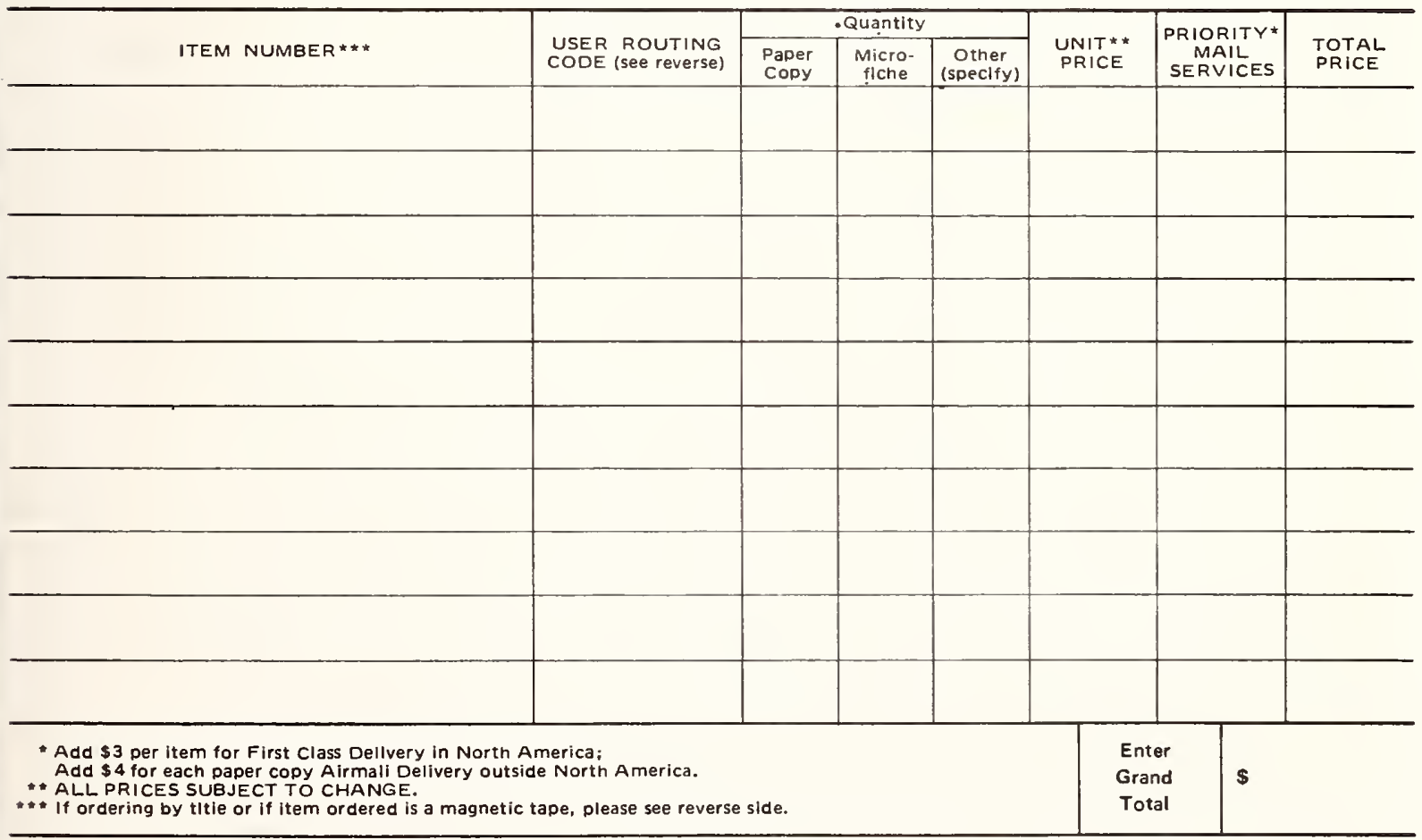

NT 15. $173(5 / 79)$ 
USER ROUTING CODE:

SHIP \& BILL SERVICE:

ORDERING MAGNETIC TAPE:

(check mode)

ORDERING BY TITLE:
NTIS can label each item for routing within your organization. If you want this service put your routing code in the box marked USER ROUTING CODE (Limit eight characters).

Prepayment helps to expedite vour order and can be accomplished through the use of an NTIS Deposit Account, check, money order, or American Express Card account number • For "Ship and Bill", NTIS charges $\$ 5$ extra for each order (regardless of the number of items); $\$ 5$ extra for each On-line NTISearch: • NTIS does not "Ship and Bill" for magnetic tapes, or for orders outside North America.
$\square 7$ track
$\square 200 \mathrm{BPI}$
$\square 556 \mathrm{BPI}$
$\square 800 \mathrm{BPI}$
$\square$ odd parity
$\square$ even parity
$\square 9$ track
$\square 1600 \mathrm{BPI}$
$\square 800 \mathrm{BPI}$

lodd parity

\section{TITLE \#1}

Sponsor's Series \# Contract or Grant Number of Report

Originator (Give specific laboratory, or division end location.)

Turn to other side. Write "1" in the Item Number block and complete the rest of the line.

\section{TITLE \#2}

\begin{tabular}{|c|c|c|c|}
\hline Sponsors Series \# & Contract or Grent Number of Report & & Date Published \\
\hline \multicolumn{2}{|c|}{ Originator (Give specific laboratory, or division and location.) } & \multicolumn{2}{|l|}{ Personal Author } \\
\hline
\end{tabular}

Turn to other side. Write " 2 " in the Item Number block and complete the rest of the line.

\section{TITLE \#3}

Sponsor's Series \#

Originator (Give specific laboratory, or division and location.)

Turn to other side. Write " 3 " in the Item Number block and complete the rest of the line.

\section{TITLE \#4}

Sponsor's Series \#

Turn to other side. Write " 4 " in the Item Number block and complete the rest of the line.

\section{TITLE \#5}

Sponsor's Series \# Contract or Grant Number of Report 
MAIL ORDER TO:

NIIS

National Technical Information Service U.S. DEPARTMENT OF COMMERCE Springfield, Va. 22161

(703) 557-4650 TELEX $89-9405$

PURCHASER: Telephone:

\section{For DDC Users Only}

DDC User Code

Contract Number

(last 6 characters only)
Treasury Agency Location Code For Governmant Usars

(who report on SF-224) (8 digit)

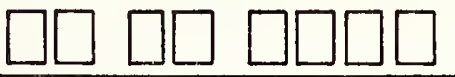

Date

SHIP TO:

(Enter if diffarant from addrass at laft)

Name

Orgenization

Address

City, Stete, ZIP

\section{Order Options}

\section{METHOD OF PAYMENT}

Charge my NTIS deposit account no.

Purchase order no.

Check enclosed for $\$$

Ship \& Bill. See reverse (not applicable outside North America).

Charge to my American Express Card account number

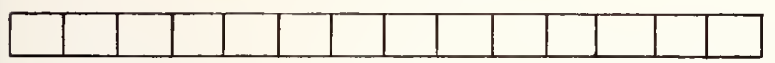

Card expiration date

Signature
It is vitel that you order by number or your order will be menually filled, causing a delay. You can opt for airmail/first class delivery es indicated below. Just check tha Priority Mail Services box. If you'ra really pressed for time, call tha NTIS Rush Hendling Service (703) $557-4700$. For e $\$ 10$ per item cherge your order will be mailed within 8 working hours. Or, you formation Centar \& Bookstore or at our Springfield Oparations Center within 24 hours for e $\$ 6$ per item charge. can pick up your order in the Washington In-

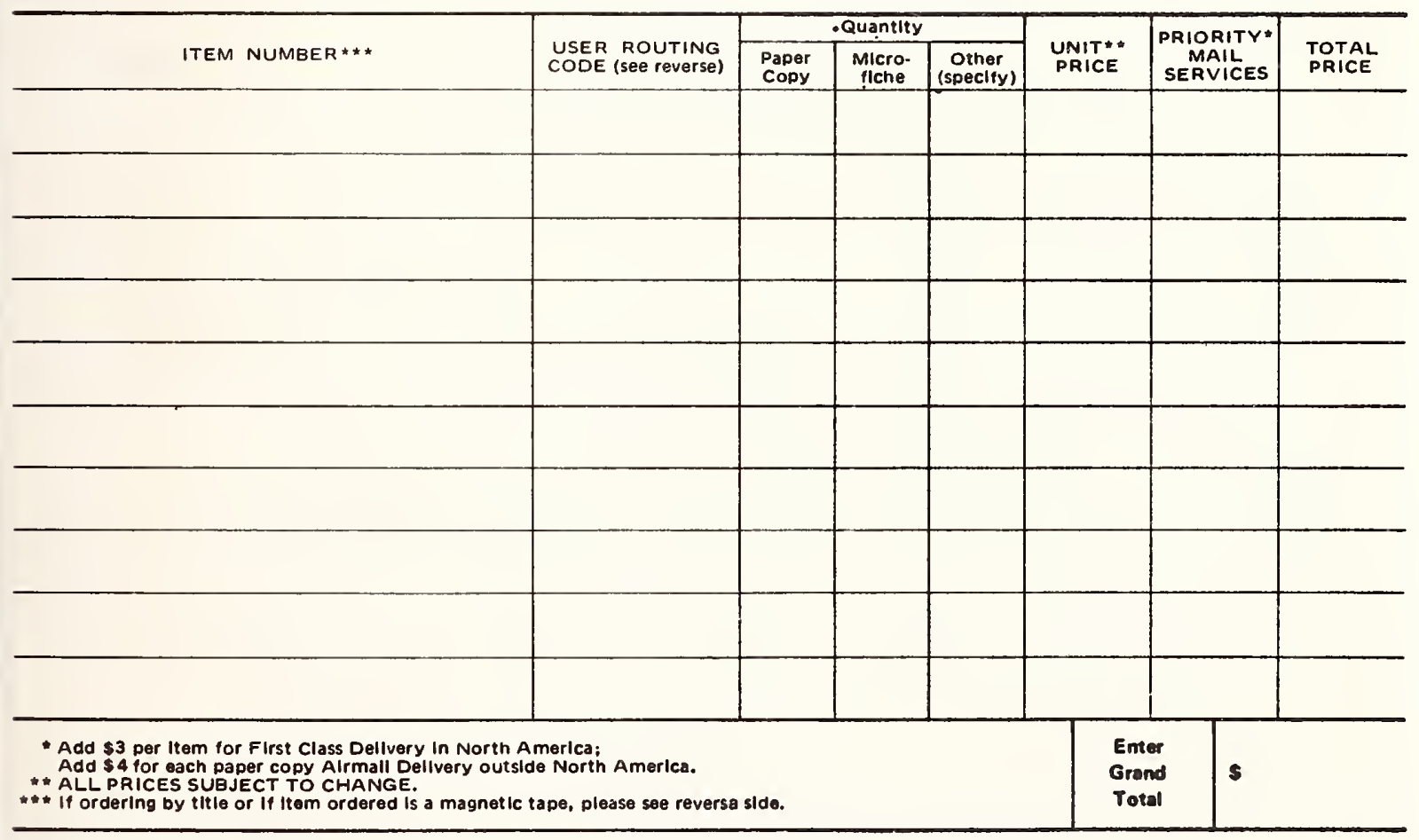

NTIS-173 (5/79) 
USEA ROUTING CODE:

SHIP \& BILL SERVICE:

ORDERING MAGNETIC TAPE:

(check mode)

ORDERING BY TITLE:
NTIS can label each item for routing within your organization. If you want this service put your routing code in the box marked USER ROUTING CODE (Limit eight characters).

Prepayment helps to expedite your order and can be accomplished through the use of an NTIS Deposit Account, check, money order, or American Express Card account number - For "Ship and Bill", NTIS charges $\$ 5$ extra for each order (regardless of the number of items): \$5 extra for each On-line NTISearch; NTIS does not "Ship and Bill" for magnetic tapes, or for orders outside North America.

\section{TITLE \#1}

Sponsor's Series \# Contract or Grant Number of Report

Date Published

Originator (Give specific laboratory, or division and location.)

Turn to other side. Write "1" in the Item Number block and complete the rest of the line.

\section{TITLE $\# 2$}

Sponsors Series \# Contract or Grant Number of Report

Originator (Give specific laboratory, or division and location.)

Turn to other side. Write " 2 " in the Item Number block and complete the rest of the line.

\section{TITLE \#3}

Sponsor's Series \#

Contract or Grant Number of Report

Originator (Give specific laboratory, or division and location.

Turn to other side. Write " 3 " in the Item Number block and complete the rest of the line.

\section{TITLE \#4}

Sponsor's Series

Turn to other side. Write " 4 " in the Item Number block and complete the rest of the line.

\section{TITLE \#5}

Sponsor's Series \# 
EDGP INDEX

A Guide to Users of This Publication

Descripive

NBS Periodical and Non-Periodical Publications

Purchase Procedures and Document Availability

Cisotions (index code is shown within parentheses)

Journal of Resecreh

Journal of Physical and Chemical Reference Data (JPCRD)

DIMENSIONS/NBS (DIM/NBS)

Monographs (Monogr.)

Handbooks (H)

Special Publications (SP)

Applied Mathematics Series (AMS)

National Standard Reference Data Series (NSRDS)

Building Science Series (BSS)

Federal Information Processing Standards Publications (FIPS PUBS)

Product Standards (PS)

Technical Notes (TN)

Consumer Information Series (CIS)

NBS Interagency Reports (NBSIR)

Grantee/Confractor Reports and Patents (GCR and/or NBS Patents)

NBS Papers Published in Non-NBS Media [5-digit arabic number]

Listing of NBS Papers by Major Subject Areas

Indexes

Author Index

Key Word Index

Depository Libraries in the United States

District Offices of the U.S. Department of Commerce 



